ESH-EMS--91-0090

DE93 006573

THE ENVIRONMENTAL PROTECTION DEPARTMENT ENVIRONMENTAL MONITORING SECTION

\title{
THE SAVANNAH RIVER SITE'S GROUNDWATER MONITORING PROGRAM
}

\section{FOURTH QUARTER 1991 (U)}

Environmental Protection Department

Westinghouse Savannah River Company

Aiken, SC

and

Exploration Resources, Inc.

Athens, GA

Publication Date: June 2, 1992

Westinghouse Savannah River Company

Savannah River Site

Aiken, SC 29808

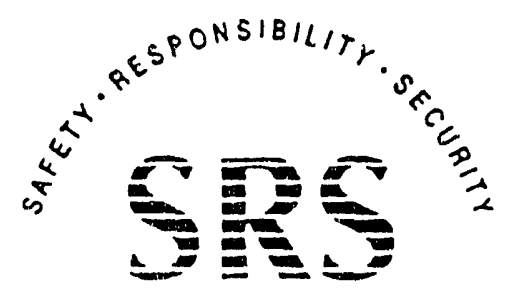

SAVANNAH RIVER SITE

Prepared for the U.S. Department of Energy under control contract No. AA46317P

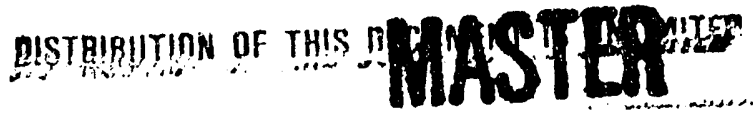


This page was left blank intentionally. 


\section{CONTENTS}

1. EXECUTIVE SUMMARY $\ldots \ldots \ldots \ldots \ldots \ldots \ldots \ldots \ldots \ldots \ldots \ldots \ldots \ldots$

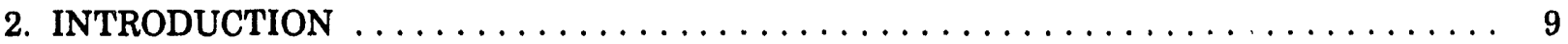

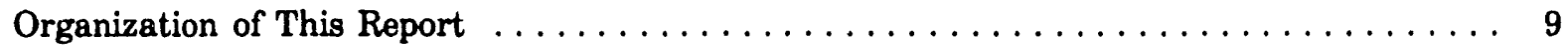

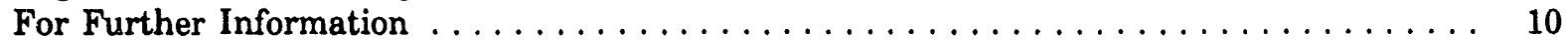

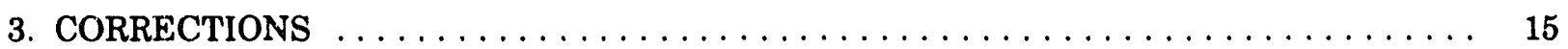

4. FLAGGING CRITERIA $\ldots \ldots \ldots \ldots \ldots \ldots \ldots \ldots \ldots \ldots \ldots \ldots \ldots \ldots \ldots$

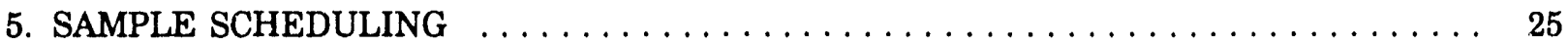

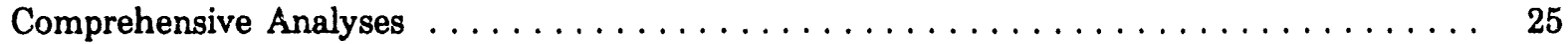

Scheduling Based on Flagging Levels $\ldots \ldots \ldots \ldots \ldots \ldots \ldots \ldots \ldots \ldots \ldots \ldots \ldots$

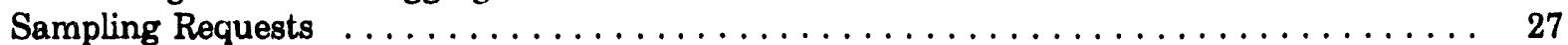

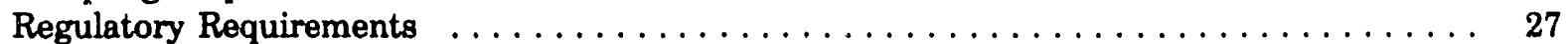

Purge-Water Containment Program $\ldots \ldots \ldots \ldots \ldots \ldots \ldots \ldots \ldots \ldots \ldots \ldots$

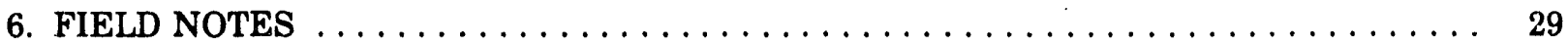

7. ANALYTICAL DATA REVIEW $\ldots \ldots \ldots \ldots \ldots \ldots \ldots \ldots \ldots \ldots \ldots \ldots \ldots \ldots \ldots$

Review of the Analytical Data for Errors $\ldots \ldots \ldots \ldots \ldots \ldots \ldots \ldots \ldots \ldots \ldots \ldots$

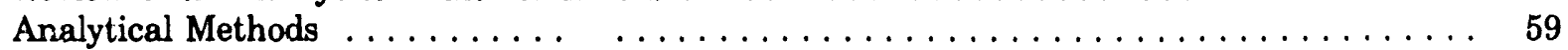

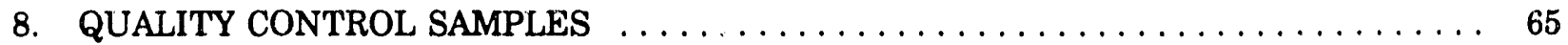

Replicate and Duplicate Analyses of Samples $\ldots \ldots \ldots \ldots \ldots \ldots \ldots \ldots \ldots \ldots \ldots \ldots$

Comments on the Replicate and Duplicate Analyses $\ldots \ldots \ldots \ldots \ldots \ldots \ldots \ldots \ldots \ldots$

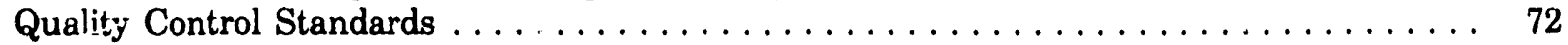

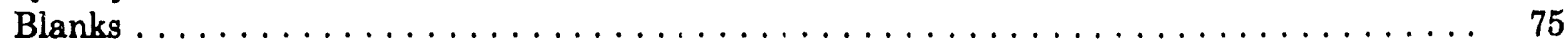

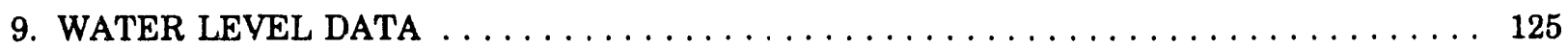

10. SITE INDEX BY WELL SERIES $\ldots \ldots \ldots \ldots \ldots \ldots \ldots \ldots \ldots \ldots \ldots \ldots \ldots$

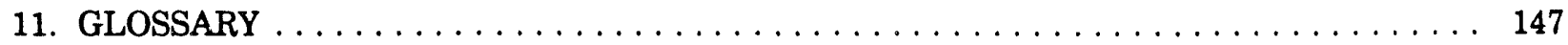

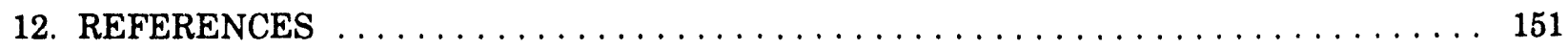

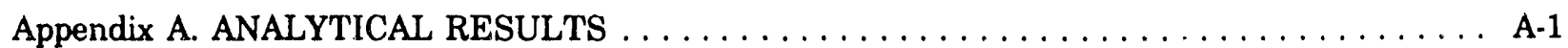

Appendix B. SECOND QUARTER RAUIONUCLIDE ANALYSES $\ldots \ldots \ldots \ldots \ldots \ldots \ldots$ B-1

Appendix C. THIRD QUARTER RAIIONUCLIDE ANALYSES $\ldots \ldots \ldots \ldots \ldots \ldots \ldots \ldots$ C-1 


\section{LIST OF FIGURES}

Figure 1. Areas and Locations Monitored for Groundwater Quality at the Savannah River Site . . . . . . . . . . . . . . . . . . . . . . 12

Figure 2. Separations and Waste Management Areas Monitored for Groundwater Quality .................................... 13

Figure 3. Two Types of Groundwater Monitoring Wellheads $\ldots \ldots \ldots \ldots \ldots \ldots \ldots \ldots$ 


\section{LIST OF TABLES}

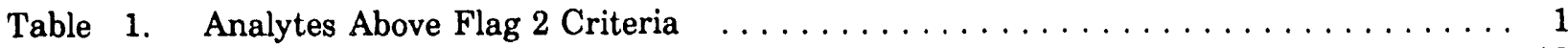

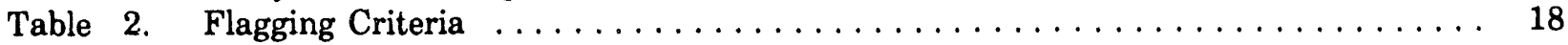

Table 3. Number of Analyses Performed During Fourth Quarter $1991 \ldots \ldots$

Table 4. Comprehensive Analyses Constituents $\ldots \ldots \ldots \ldots \ldots$

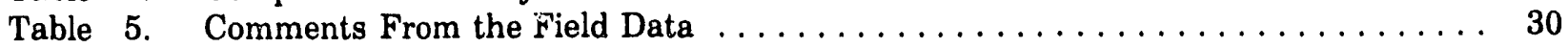

Table 6. General Engineering Laboratory Blanks With Elevated Results . . . . . . . . . . 46

Table 7. EPD/EMS Blind Blanks With Elevated Results . . . . . . . . . . . . . . 47

Table 8. General Engineering Samples With High Analytical Results as Compared

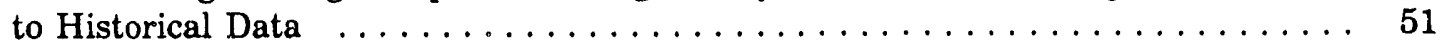

Table 9. General Engineering Samples With Low Analytical Results as Compared

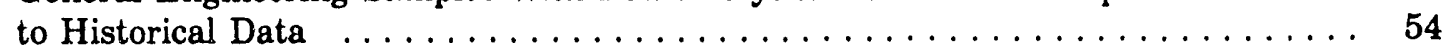

Table 10. Analyses Not Performed by General Engineering . . . . . . . . . . . . . 56

Table 11. M-Area Laboratory Samples With H.igh Analytical Results as Compared

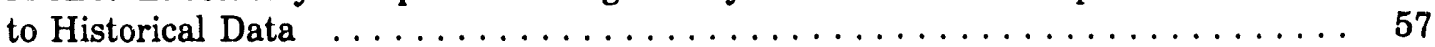

Table 12. EPD/EMS Laboratory Samples With Low Analytical Results as Compared

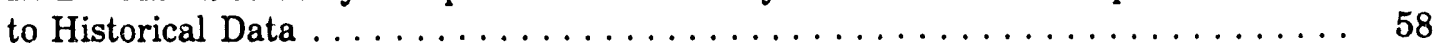

Table 13. Analyses Not Performed by the EPD/EMS Laboratory . . . . . . . . . . . . . . 58

Table 14. Teledyne Isotopes Samples With Low Analytical Results as Compared

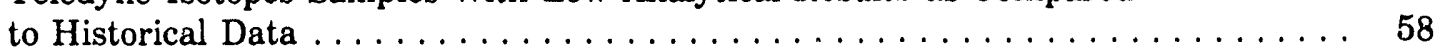

Table 15. Analyses Not Performed by Teledyne Isotopes . . . . . . . . . . . . . . . . . 59

Table 16. Methods and Detec cion Limits Used by General Engineering . . . . . . . . . . . . 59

Table 17. Methods and Dets..ction Limits Used by Teledyne Isotopes . . . . . . . . . . . . 63

Table 18. Wells Providing Blind Replicate Sampies . . . . . . . . . . . . . . . . . 65

Table 19. Analytes Not Detected in any Replicated or Duplicated Samples . . . . . . . . . . . 66

Table 20. Intralaboratory MRD Index for General Engineering . . . . . . . . . . . . . . 69

Table 21. Intralabr ratory MRD Index for Teledyne Isotopes . . . . . . . . . . . . . . . . . 70

Table 22. General Engineering Samples and Blind Replicates Yielding

Results Where One Is More Than Twice Another $\ldots \ldots \ldots \ldots \ldots \ldots$

Table 23. Teledyne Isotopes Samples and Blind Replicates Yielding Results Where One Is More Than Twice Another . . . . . . . . . . . . . . . 71

Table 24. Quality Control Standards for Common Analyses, Batch No. 2528 . . . . . . . . 72

Table 25. Quality Control Standards for Appendix IX Analyses, Batch No. 2602 . . . . . . 74

Table 26. Quality Control Standards for Inorganics Analyses, Batch No. $412 \ldots \ldots$. . . . . . 75

Table 27. Trip Blanks Associated With Laboratory Blanks High in Dichloromethane . . . . . 76

Table B-1. Radionuclides Above Flag 2 Criteria, Second Quarter $1991 \ldots \ldots$

Table B-2. Analytes Above Flag 2 Criteria, Second Quarter $1991 \ldots \ldots$

Table 1:-3. Second Quarter Radionuclide Samples With High Analytical Results

Compared to Historial Data . . . . . . . . . . . . . . . . . . . . B-8

Table B-4. Methods and Detection Limits Used by Eco'Tek for Radionuclide Analyses . . . . . B-9

Table C-1. Radionuclides Above Flag 2 Criteria During Third Quarter $1991 \ldots \ldots$

Table C-2. Analytes Above Flag 2 Criteria During Third Quarter $1991 \ldots \ldots$ 


\section{LIST OF TABLES}

Table C-3. Samples With High Analytical Results Compared to Historial Data . . . . . . . . . C-10

Table C-4. Samples With Low Analytical Results Compared to Historical Data . . . . . . . . C-10

Table C-5. Analyses Not Performed by Teledyne Isotopes $\ldots \ldots \ldots \ldots \ldots \ldots \ldots \ldots \ldots$ C-11

Table C-6. Methods and Detection Limits Used by Teledyne for Radionuclides . . . . . . . . . C-11 


\section{EXECUTIVE SUMMARY}

The Environmental Protection Department/ Environmental Monitoring Section (EPD/EMS) administers the Savannah River Site's (SRS) Groundwater Monitoring Program. During fourth quarter 1991, EPD/EMS conducted extensive sampling of monitoring wells.

EPD/EMS established two sets of flagging criteria in 1986 to assist in the management of sample results. The flagging criteria do not define contamination levels; instead, they aid personnel in sample scheduling, interpretation of data, and trend identification. Beginning in 1991, the flagging criteria are based on EPA drinking water standards and method detection limits. A detailed explanation of the current flagging criteria is presented in the Flagging Criteria section of this document.

Analytical results from fourth quarter 1991 are listed in this report, which is distributed to all

\section{Table 1. Analytes Above Flag 2 Criteria}

$\underline{\text { Site }}$

Well

Series

100 AREAS

\section{Area}

C-Area Disassembly Basin

$\mathrm{CDB}$ water above Flag 2 in fourth quarter 1991 are listed in Table 1 , organized by location and well series. Results from all laboratory analyses above Flag 2 are used to generate this table. Also, specific conductance and $\mathrm{pH}$ data

\section{K Area}

K-Area Acid/Caustic Basin

$\mathrm{KAC}$

Iron, total organic halogens

K-Area Disassembly Basin

$\mathrm{KDB}$
Analytes Above Flag 2 Criteria Fourth Quarter 1991

Those sites with constituents in the groundfrom the field are insl.

site custodians. Thirteen wells scheduled for analyses during fourth quarter 1991 were not sampled pending establishment of a purge-water containment program. For more information, see the Sample Scheduling section.

One or more analytes exceeded Flag 2 during fourth quarter 1991 in 61 monitoring well series. Analytes exceeded the current Flag 2 criteria for the first time since 1984 in 16 of the 61 monitoring well series.

ran

\footnotetext{
Krea Disassembly Basin
}

.

Note: Analytes in bold were detected at levels above the current Flag 2 criteria for the first time since 1984. 


\section{EXECUTIVE SUMMARY}

Table 1. Analytes Above Flag 2 Criteria (cont.)

$\underline{\text { Site }}$

100 AREAS (cont.)

K Area (cont.)

K-Area Reactor Seepage Basin

K-Area Retention Basin

\section{Area}

L-Area Acid/Caustic Basin

L-Area Disassembly Basin

L-Area Oil and Chemical Basin

L-Area Reactor Seepage Basin

L-Area Research Wells

\section{$P$ Area}

P-Area Acid/Caustic Basin

P-Area Burning/Rubble Pit

P-Area Coal Pile Runoff Containment Basin

P.Area Disassembly Basin

P.Area Reactor Seepage Basins

\section{R Area}

R-Area Acid/Caustic Basin
Well Analytes Above Flag 2 Criteria

Series Fourth Quarter 1991
KSB Tritiun

KRB Tritium

I, AC Iron, lead

LDB Tetrachloroethylene

LCO Manganese, nonvolatile beta, specific conductance, sulfate, tetrachloroethylene, total alpha-emitting radium, trichloroethylene,

trichlorofluoromethane, tritium

LSB Aluminum, tritium

LAW Iron, $\mathrm{pH}$, specific conductance

PAC Iron, manganese

PRP Lead, tetrachloroethylene, trichloroethylene, tritium

PCB Lead

PDB Lead, total organic halogens, tritium

PSB Lead, strontium-89/90, tritium

RAC. Iron, :ead

Note: Analytes in bold were detected at levels above the current Flag 2 criteria for the first time since 1984. 
Table 1. Analytes Above Flag 2 Criteria (cont.)

Site

Well Analytes Above Flag 2 Criteria

Series

Fourth Quarter 1991

\section{AREAS}

\section{Burial Grounds (E Area)}

Burial Grounds

Burial Gro inds Perimeter

E-Area Vaults Near the Burial Grounds

\section{F Area}

Burma Road Rubble Pit

F.Area Acid/Caustic Basin

F-Area A Line

F-Area Canyon Building

F-Area Coal Pile Runoff Containment Basin

FCB

F-Area Seepage Basins

FSB

F-Area Sludge Land Application Site

Old F-Area Seepage Basin

Between the F-Area Canyon Building and the Naval Fuel Material Facility

BG

BGO

BGX

BRR

FCA
FAC Gross alpha, manganese, tetrachloroethylene total organic halogens, total alpha-emitting radium, trichloroethylene

FAL Trichloroethylene

Gross alpha, nitrate as nitrogen, nonvolatile beta, total alpha-emitting radium, trichloroethylene

Total organic halogens

Aluminum, cadmium, cobalt, gross alpha, iron, lead, manganese, mercury, nickel, nitrate as nitrogen, nonvolatile beta, $\mathrm{pH}$, specific conductance, sulfate, total organic halogens, total alpha-emitting radium, trichloroethylene, tritium, uranium

FSS Lead, manganese, total organic halogens, tritium

FNB Gross alpha, manganese, nitrate as nitrogen, nonvolatile beta, tutal alpha-emitting radium, trichloroethyleie, tritium, uranium-233/234, uranium-238

NBG Nitrate as nitrogen, total alpha-emitting radium, trichloroethylene, tritium

Note: Analytes in bold were detected at levels above the current Flag 2 criteria for the first time since 1984. 


\section{EXECUTIVE SUMMARY}

Table 1. Analytes Above Flag 2 Criteria (cont.)

Site

\section{H Area}

H-Area Acid/Caustic Basin

H-Area Canyon Building

H-Area Seepage Basins

H-Area Tank Farm

\section{S Area}

S-Area Vitrification Building

\section{Y Area}

Y-Area Waste Solidification and Disposal Facili: y

\section{0/700 AREAS}

A-Area Burning/Rubble Pits

A-Area Metals Burning Pit

M-Area Hazardous Waste Management Facility (HWMF)

\begin{tabular}{ll} 
Well & Analytes Above Flag 2 Criteria \\
Series & Fourth Quarter 1991 \\
\hline
\end{tabular}

HAC Iron, manganese, specific conductance, tritium

HCA Total alpha-emitting radium, tritium

HSB Aluminum, arsenic, cadmium, cobalt, gross alpha, iron, lead, manganese, mercury, nickel, nitrate as nitrogen, nonvolatile beta, $\mathrm{pH}$, specific conductance, tetrachloroethylene, total organic halogens, total alpha-emitting radium, trichlorofluoromethane, tritium, vanadium

HTF Lead, total alpha-emitting radium

SCA Manganese, tritium

YSC

$\mathrm{pH}$, total organic halogens

ARP Trichloroethylene

ABP Lead, lithium, manganese, $\mathrm{pH}$, specific conductance, tetrachloroethylene, trichloroethylene, tritium

MSB Aluminum, barium, bromodichloromethane, cadium, chloroethene (vinyl chloride), chloroform, dibromochloromethane, dichlorodifluoromethane, 1,1-dichloroethylene, trans-1,2-dichloroethylene, gross alpha, iron, lead, manganese, mercury, nitrate as nitrogen, nonvolatile beta, $\mathrm{pH}$, specific conductance, 1,1,1,2-tetrachloroethane, tetrachloroethylene, total organic carbon, total organic halogens, total alpha-emitting radium, 1,1,1-trichloroethane, trichloroethylene, trichlorofluoromethane, tritium, uranium

Note: Analytes in bold were detected at levels above the current Flag 2 criteria for the first time since 1984. 
Table 1. Analytes Above Flag 2 Criteria (cont.)

$\underline{\text { Site }}$

300/700 AREAS (cont.)

M Area: Recovery Wells (also used for plume definition)

Metallurgical Laboratory Seepage Basin

Miscellaneous Chemical Basin

Motor Shop Oil Basin

Savannah River Laboratory (SRL)

Seepage Basins

Silverton Road Waste Site

400 AREA

\section{Area}

D-Area Coal Pile Runoff Containment Basin and Ash Basins

D-Area Oil Disposal Basin

DOB
Analytes Above Flag 2 Criteria

Fourth Quarter 1991
RWM Nitrate as nitrogen, tetrachloroethylene, 1,1,2-trichloroethane, trichloroethylene

AMB Aluminum, antimony, gross alpha, iron, manganese, $\mathrm{pH}$, specific conductance, tetrachloroethylene, total organic halogens, total alpha. emitting radium, trichloroethylene

MCB Carbon tetrachloride, lithium, manganese, nonvolatile beta, $\mathrm{pH}$, specific conductance, tetrachloroethylene, total organic halogens, total alpha-emitting radium, trichloroethylene, tritium

AOB

ASB

SRW carbons, trichloroethylene

Chromium, $\mathrm{pH}$, radium-228, specific conductance, tetrachloroethylene, total organic halogens, total alpha-emitting radium, trichloroethylene, tritium

Trichloroethylene

Trichloroethylene

Tetrachloroethylene, trichloroethylene

\section{AREAS}

\section{Central Shops Area}

Central Shops Burning/Rubble Pit South of the Ford Building Seepage Basin

CBR Total alpha-emitting radium

Ford Building Seepage Lasin

HXB Total organic halogens, tritium

Potential New Production Reactor

NPM $\quad$ pH, specific conductance, total organic Site Characterization Wells halogens

Note: Analytes in bold were detected at levels above the current Flag 2 criteria for the first time since 1984. 
Table 1. Analytes Above Flag 2 Criteria (cont.)

$\underline{\text { Site }}$

Well Analytes Above Flag 2 Criteria

600 AREAS (cont.)

\section{General Areas}

Adjacent to SRS Road E-2 near the Proposed Sanitary Landfill Site (P 14 Cluster)

B-Area Microbiolngy Wells (P 29 Cluster)

Chemicals, Metals, and Pesticides (CMP; Pits

Ha'yardous 'Waste/Mixed Waste Disposal Facility

Interim Waste Technology Site P, Characterization Wells

Interim Waste 'Technology Site P: Characterization Wells

Interim Waste Technology Site Q: Characterization Wells

Road A Chemical Basin (Baxley Road)

Sanitary Landfill

Sewage Sludge Application Sites

\section{$T N X$}

New 'INX Seepage Basin

Old 'TNX Seepage Basin

Aluminum, iron, specific conductance

Benzene

LFW

Total organic halogens, total alpha-emitting radium

XSB

Fourth Quarter 1991

CMP

Lead, tetrachloroethylene, trichloroethylene

Manganese, trichlorofluoromethane

Aluminum, iron, $\mathrm{pH}$, specific conductance, total carbon, total inorganic carbon

Aluminum, iron, $\mathrm{pH}$

Aluminum, iron, manganese, $\mathrm{pH}$, total carbon, total inorganic carbon

Lead, total organic halogens, total alpha-emitting radium

Benzene, chlorobenzene, chloroethane, chloroethene (vinyl chloride), 1,1-dichloroethane, 1,2-dichloroethane, 1,1-dichloroethylene, iron, lead, manganese, specific condurtance, tetrachloroethylene, total organic carbon, total organic halogens, total alpha-emitting radium, 1,1,1trichloroethane, trichloroethylene, trichlorofluoromethane, tritium

Gross alpha, iron, manganese. tolal organic carbon, total organic halogens, total alpha-emitting radium

Carbon tetrachloride, iron, manganese, nitrate as nitrogen, specific conductance, tetrachloroethylene, total organic halogens, total alpha-em:tting radium, trichloroethylene, tritium

Note: Analytes in bold were detected at levels above the current Flag 2 criteria for the first time since 1984. 


\section{Table 1. Analytes Above Flag 2 Criteria (cont.)}

Site

$\begin{array}{ll}\text { Well } & \text { Analytes Above Flag } 2 \text { Criteria } \\ \text { Series } & \text { Fourth Quarter 1991 }\end{array}$

600 AREAS (cont.)

TNX (cont.)

TNX Area: Assessment Wells

TNX Carbon tetrachloride, iron, manganese, nitrate as nitrogen, tetrachloroethylene, total organic halogens, total alpha-emitting radium, trichloroethylene

TNX Burying Grounds

TBG

Carbon tetrachloride, iron, manganese, nitrate as nitrogen, total organic halogens, total alphaemitting radium, trichloroethylene

Note: Analytes in bold were detected at levels above the current Flag 2 criteria for the first time since 1984. 


\section{NOTES}




\section{INTRODUCTION}

This report summarizes the SRS groundwater monitoring program conducted by EPD/EMS in the fourth quarter of 1991 . It includes the analytical data, field data, data review, quality control, and other documentation for this program; provides a record of the program's activities; and serves as an official document of the analytical results.

EPD/EMS is responsible for monitoring for constituents in the groundwater at approximately 135 waste sites in 16 areas at SRS (see Figures 1 and 2, pp. 12-13). The majority of this monitoring is required by U.S. Department of Energy (DOE) orders and by federal and state regulations administered by the U.S. Environmental Protection Agency (EPA) and the South Carolina Department of Health and Environmental Control (SCDHEC). The groundwater monitoring program includes the following activities:

- installation, maintenance, and abandonment of monitoring wells

- environmental soil borings

- development of sampling and analytical schedules

- collection and analyses of groundwater samples

- review of analytical and other data

- maintenance of the databases containing groundwater monitoring data

- quality assurance (QA) evaluations of laboratory performance
- reports of results to waste-site facility custodians and to the Environmental Protertion Section (EPS) of EPD

EPD/EMS is responsible for monitoring wells but not for the facilities that are monitored. It is the responsibility of the custodian of each waste site to ensure that EPD/EMS is informed of sampling requirements and special requests for the sampling schedule, to assist in reviewing the data, and to make any decisions regarding groundwater monitoring at the waste site.

Each custodian receives a copy of this report; also, each custodian receives site-specific data upon request, including the following:

- a computer printout of the analytical dala for the current quarter and for the previous seven quarters, designed to assist in identifying trends

- a computer printout of analytical values at or above Flag 1 and Flag 2 criteria for the quarter, designed to assist in identifying elevated analytical values

\section{ORGANIZATION OF THIS REPORT}

This report is divided into sections that focus on specific aspects of the SRS groundwater monitoring program. The Executive Summary section presents a tabular listing by waste site and well series of all analytes detected at or above Flag 2 criteria during the quarter. Analytes detected at or above Flag 2 criteria for the first time since 1984 are indicated in bold type. 


\section{INTRODUCTION}

The next five sections address sampling and assessment of groundwater quality at SKS.

The Flagging Criteria section lisis flagging criteria for analytes and provides a short description of how the criteria were derived. The Sample Scheduling section discusses the preparation of the sampling schedule and the criteria for analyte selection, including flagging.

During sample collection, samplers often write comments in the field log books that may be pertinent to the analysis of the sample. Many of the comments concern wells that went dry during saripling or the appearance of water that is colored, turbid, or aerated. These comments are given in the Field Notes section.

Samples are analyzed by the EPD/EMS and M-Area laboratories at SRS and by one or more off-site laboratories. During the fourth quarter, General Engineering was the primary off-site laboratory; radionuclide analyses were conducted by Teledyne Isotopes. The Analytical Data Review section contains two subsections. The Review of the Analytical Data for Errors subsection is a discussion of discrepancies in each laboratory's analytical data, including results that are considerably higher or lower than previous results, analyses that were omitted, and laboratory blanks that showed elevated results. The Analytical Methods subsection lists the methods the laboratories used for measuring concentrations of each analyte.

A select number of replicate samples are analyzed by the primary off-site laboratory as part of the EPD/EMS quality control program. The Quality Control Samples section contains four subsections. The Replicate and Duplicate Analyses of Samples subsection explains the replicate analysis program, gives the statistical methods used for comparison, and lists the results of the comparisons. The Comments on the Replicate and Duplicate Analyses subsection discusses the replicate and duplicate analyses comparison results and their meanings. The accuracy of analyses is tested using solutions with known analyte concentrations; the results and accuracy percentage are found in the Quality Control Standards subsection. The Blanks subsection lists analytical results of laboratory tests on samples of deionized water

to aid in determining if constituents were in the rinsewater, in sample containers, or introduced during analysis.

The Water Level Data section includes field data obtained on concurrent water elevations in the $\mathrm{A} / \mathrm{M}$ areas; these data are used by SRS personnel in hydrogeologic studies.

The Site Index by Well Series assists the reader in identifying the site assuciated with ec.ch well series. A list of terms, abbreviaiions, and acronyms used in this report can be found in the Glossary section. References cited are listed in the References section.

The Analytical Results section includes tables listing the analytical results from all the laboratories and field data for all wells sampled during the quarter. The tables appear in alphabetical order by well name.

\section{FOR FURTHER INFORMATION}

The following is a brief description of documents pertaining to the groundwater monitoring program.

\section{Quarterly Reports}

EPD/EMS has published a description of its groundwater monitoring program for each quarter since the beginning of 1986. A list of these quarterly reports follows.

\section{$\underline{\text { Report }}$}

Third Quarter 1991

Second Quarter 1991

First Quarter 1991

Fourth Quarter 1990

Third Quarter 1990

Second Quarter 1990

First Quarter 1990

Fourth Quarter 1989

Third Quarter 1989

Second Quarter 1989

First Quarter 1989

Fourth Quarter 1988

Third Quarter 1988

Second Quarter 1988

First Quarter 1988

Fourth Quarter 1987

Third Quarter 1987
Document Number

ESH-EMS-910089

ESH-EMS-910088

ESH-EMS-910087

ESH-EMS-900134

ESH-EMS-900133

ESH-EMS-900132

ESF'-EMS-90-0131

ESH-EMS-890046

ESH-EMS-890045

ESH-EMS-890044

ESH-EMS-890043

HPR-89-193

HPR-88-489

HPR $-88-300$

HPR-88-238

HPR-88-098

HPR-87-339 
Second Quarter 1987

HPR-87-286

First Quarter 1987

Fourth Quarter 1986

Third Quarter 1986

Second Quarter 1986

First Quarter 1986 (revised)

\section{Annual Reports}

The U.S. Department of Energy's Savannah River Site Environmental Report, which includes groundwater data for the year, site descriptions, and site maps, is a public document issued annually. A list of recent reports follows.

\section{Report Document Number}

1990 WSRC-IM-91-28 (Vols. 1 and 2)

1989 WSRC-IM-90-60 (Vols. 1 and 2)

1988 WSRC-RP-89-59-1 (Vols. 1 and 2)

1987 DPSPU-88-30-1 (Vols. 1 and 2)

1986 DPSPU-87-30-1 (Vols. 1 and 2)

1985 DPSPU-86-30-1 (Vols. 1 and 2)

\section{Inventory and Maps of Wells}

The Environmental Protection Department's Well Inventory provides an historical record of wells monitored by EPD/ENS, contains a list of wells currently in the EPD/EMS groundwater monitoring program, and provides pertinent information about all wells listed in EPD/EMS documents. The latest version is ESH-EMS910092, which includes site maps for active and abandoned wells.

\section{Other Data Reports}

The U.S. Department of Energy's Geoscience Implementation Plan and Geohydrology Program Report describe projects relating to the geohydrology program at SRS and their current status and administration.

Christensen and Gordon's Technical Summary of Groundwater Quality Protection Program at Savannah River Plant, Volume I-Site Geohydrology, and Solid and Hazardous Wastes, DPST-83-829, December 1983, describes SRS waste disposal sites and analytical monitoring data.

Stone and Christensen's Technical Summary of Groundwater Quality Protection Program at Savannah River Plant, Volume II-Radioactive Waste, DPST-83-829, December 1983, presents representative monitoring data for radioactivity in groundwater at SRS.

Full bibliographical listings of these and other documents can be found in the References section of this report. 


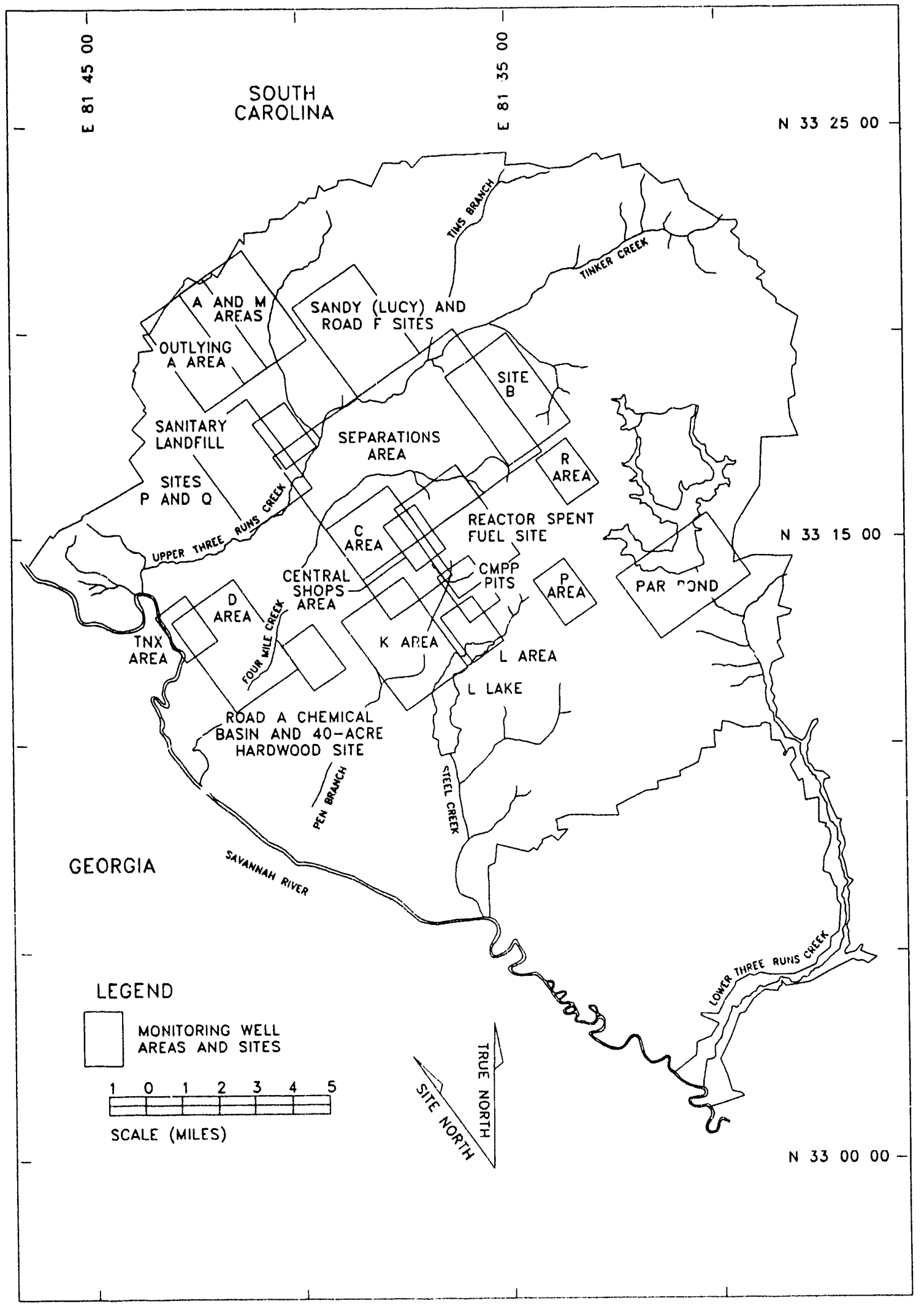

Figure 1. Areas and Locations Monitored for Groundwater Quality at the Savannah River Site 


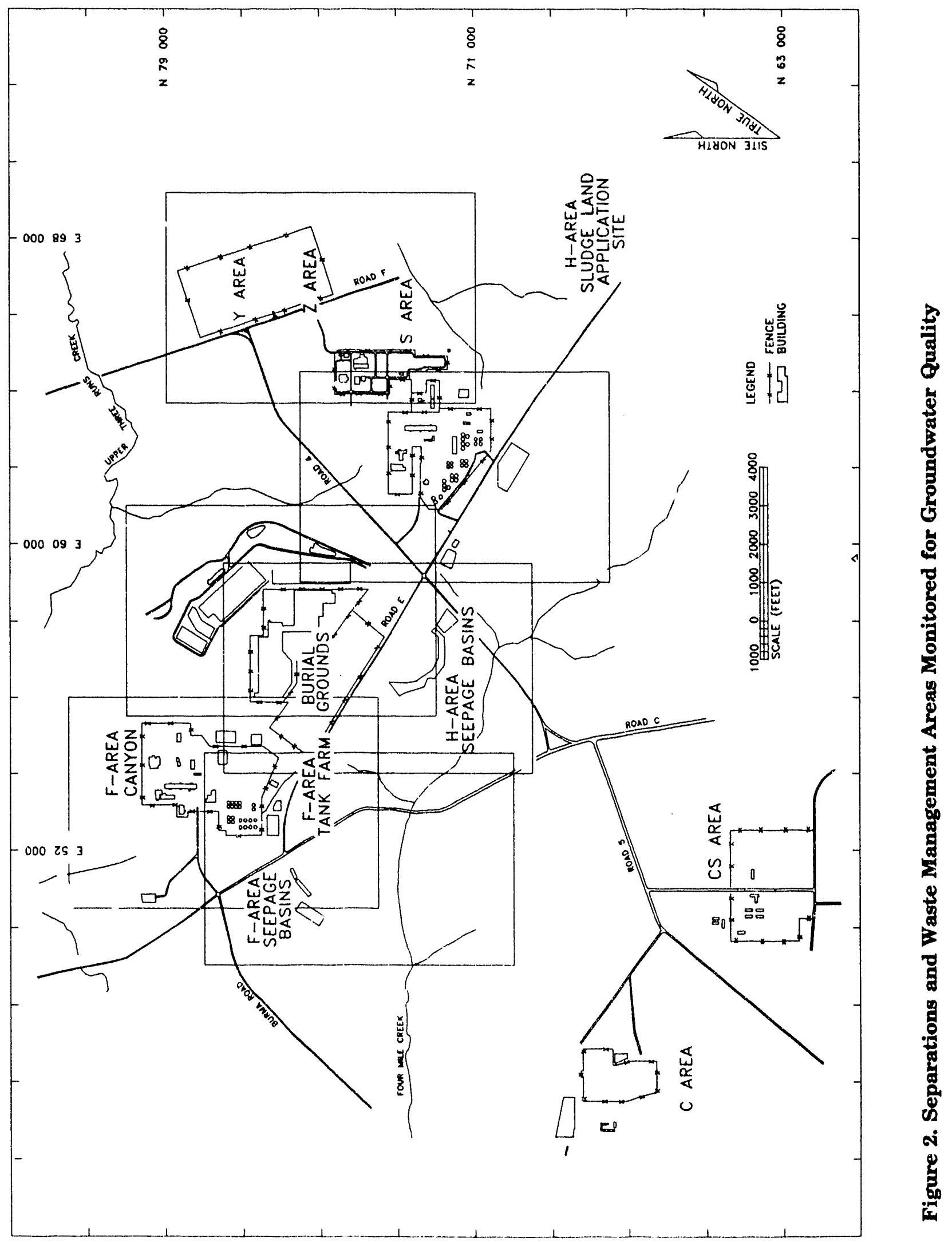


NOTES 


\section{CORRECTIONS}

\section{CORRECTION/CLARIFICATION FOR REPORTS DATING TO 1984}

The results of analyses performed using EPA Method 900.1 have been incorrectly referred to in the past as total radium results and have been inappropriately evaluated against the drinking water standard for combined radium226 and radium-228. EPA Method 900.1 should be considered a gross radium alpha screening procedure; it may be used to screen drinking water for the necessity of performing a specific radium-226 analysis, but it gives no indication of the presence or quantity of radium-228 in the sample. This analysis will be referred to in the future as total alpha-emitting radium. The tables in Appendix A of this report were prepared prior to clarification of this issue.

\section{ADDITION TO THE FOURTH QUARTER 1990 REPORT (ESH-EMS-900134)}

Benzene was detected in one of the P-series wells in B Area at $28 \mu \mathrm{g} / \mathrm{L}$. This information did not appear in the Executive Summary because, at the time the report was written, there was no Flag 2 criterion for benzene.

\section{CORRECTIONS TO THE FIRST QUARTER 1991 REPORT (ESH-EMS- 910087)}

In the Executive Summary, it was incorrectly reported that one or more $P$-series wells in $F$ Area contained the following analytes above Flag 2: benzene, americium-241, radium-226, thorium-232, and uranium-238. Instead, one or more P-series wells in B Area contained benzene and iron above Flag 2, and one or more P-series wells in TNX Area contained americium-241, radium-226, thorium-232, and uranium-238 in excess of Flag 2 criteria.

\section{CORRECTIONS TO T'AE SECOND QUARTER 1991 REF ORT (ESH-EMS- 910088)}

Field data for well HSB132C was inadvertently omitted from the analytical-resuits table. The table should have read:

WELL HSB132C

Sample date: $5 / 20 / 91$

Water elevation: 222.2

$\mathrm{pH}: 5.5$

Specific conductance: $32 \mu \mathrm{S} / \mathrm{cm}$

Alkalinity as $\mathrm{CaCO}_{3}: 4 \mathrm{mg} / \mathrm{L}$

Volu:ne purged before sampling: $141 \mathrm{gal}$

Radionuclide results were not available from the laboratory for the second quart_r report. Those results, along with a table compiling all the locations having analytes above Flag 2 for the quarter, the results of review of the radionuclide data, and a listing of the methods and detections limits used, may be found in Appendix $B$ of this report. The flagging criteria used were those in effect fourth quarter 1991 , which differ from those of second quarter for a few radionuclides. The only difference with any effect upon the reported results is that iodine-131 had no flag at the time of the second quarter report.

\section{CORRECTIONS TO THE THIRD QUARTER 1991 REPORT (ESH-EMS- 910089)}

The flagging criteria for xylenes were changed during the preparation of the third quarter report. The new criteria were listed in the Flagging Criteria section and used to flag data in the Analytical Results section, but the Executive Summary was prepared using tise older, much lower criteria. 


\section{CORRECTIONS}

Radionuclide results were not available from the laboratory in time for the third quarter report. Those results may be found in Appendix $\mathbf{C}$ of this report along with a table compiling all the locations having analytes above Flag 2 for the quarter, the results of review of the radionuclide data, and a listing of the methods and detection limits used. The flagging criteria used are those in effect fourth quarter 1991, which differ from those of third quarter for a few radionuclides. None of these differences has any effect on the reported results. 


\section{FLAGGING CRITERLA}

Analyses in the data tables are assigned a flag level $(0,1$, or 2$)$ depending on their concentration in a groundwater sample. Beginning in 1991, EPD/EMS modified its guidelines for setting flagging levels for the Groundwater Monitoring Program. The flagging criteria in Table 2 were determined as follows.

Flag 0: Analytical results below Flag 1 or: for a constituent having no flagging criteria are classified as Flag 0.

Flag 1: The Flag 1 criterion for a constituent was set as one-half of the Environmental Protection Agency (EPA) final primary drinking water standard, the EPA proposed primary drinking water standard, or the EPA secondary drinking water standard for that constituent. If a constituent does not have an EPA drinking water standard, the Flag 1 criterion was set as five times a recently published 90 th percentile detection limit obtained by one of the primary laboratories.

Flag 2: The Flag 2 criterion for a constituent was set as the EPA final primary drinking water standard, the EPA proposed primary drinking water standard, or the EPA secondary drinking water standard for that constituent. If a constituent does not have a drinking water standard, the Flag 2 criterion was set as 10 times a recently published 90th percentile detection limit obtained by one of the primary laboratories.

The following major cations, aesthetic analyses, and indicator parameters are not assigned flagging criteria: alkalinity, calcium, color, corrosivity, magnesium, odor, potassium, silica, sodium, total dissolved solids, total phosphorus, total phosphates (as P), and turbidity.

Common laboratory contaminants and cleaners, including ketones, methylene chloride, and phthalates, are not assigned flagging criteria.

The following acronyms are used as abbreviated sources in the flagging criteria table. Complete information concerning documents cited can be found in the References section of this document.

APHA Method - A specific analytical method for testing constituent levels in a sample as established by the American Public Health Association, American Water Works Association, and Water Pollution Control Federation. See American Public Health Association, et al., in References.

DWS-Drinking Water Standards.

EPA-Environmental Protection Agency.

EPA Method-A specific analytical method for testing constituent levels. Descriptions of these methods can be found in the EPA publications Methods for Chemical Analysis of Water and Wastes, Test Methods for Evaluating Solid Waste, and Code of Federal Regulations, Title 40, Section 136 (1991). See Environmental Protection Agency in References.

EPD/EMS - The Environmental Protection Department, Environmental Monitoring Section, at the Savannah River Site. 


\section{FLAGGING CRITERIA}

Table 2. Flagging Criteria

Analyte

Acenaphthene

Acenaphthylene

Acetone

Acetonitrile (Methyl cyanide)

Acetophenone

2-Acetylaminofluorene

Acrolein

Acrylonitrile

Aldrin

Allyl chloride

Aluminum

4-Aminobiphenyl

Ammonia

Ammonia nitrogen

Aniline

Anthracene

Antimony

Aramite

Arsenic

Azobenzene

Barium

Benzene

alpha-Benzene hexachloride

beta-Be.nzene hexachloride

delta-Benzene hexachloride

Benzidine

Benzo[a]anthracene

Benzo[b]fluoranthene

Benzo[ $k]$ fluoranthene

Benzoic acid

Benzo[g,h,i]perylene

Benzo[a]pyrene

1,4-Benzoquinone

Benzyl alcohol

Beryllium

Bis(2-chloroethoxy) methane

Bis(2-chloroethyl) ether

Bis(2-chloroisopropyl) ether

Bis(chloromethyl)ether

Bromide

Bromodichloromethane

Bromoform

Bromomethane (Methyl bromide)

4-Bromophenyl phenyl ether

2-sec-Butyl-4,6-dinitrophenol

Cadmium

Carbon disulfide

Carbon tetrachloride

Carbonate

Chlordane

\begin{tabular}{|c|c|c|c|}
\hline$\underline{\text { Unit }}$ & Flag 1 & Flag 2 & Source \\
\hline$\mu \mathrm{g} / \mathrm{L}$ & 50 & 100 & EPA Method 8270 \\
\hline$\mu \mathrm{g} / \mathrm{L}$ & 50 & 100 & EPA Method 8270 \\
\hline$\mu \mathrm{g} / \mathrm{L}$ & - & 100 & EPA Method $8240^{*}$ \\
\hline$\mu \mathrm{g} / \mathrm{L}$ & 500 & 1,000 & EPA Method 8240 \\
\hline$\mu \mathrm{g} / \mathrm{L}$ & 50 & 100 & EPA Method 8270 \\
\hline$\mu \mathrm{g} / \mathrm{L}$ & 50 & 100 & EPA Method 8270 \\
\hline$\mu \mathrm{g} / \mathrm{L}$ & 100 & 200 & EPA Method 8240 \\
\hline$\mu \mathrm{g} / \mathrm{L}$ & 100 & 200 & EPA Method 8240 \\
\hline$\mu \mathrm{g} / \mathrm{L}$ & 2.5 & 5 & EPA Method 8080 \\
\hline$\mu \mathrm{g} / \mathrm{L}$ & 250 & 500 & EPA Method 8240 \\
\hline$\mu \mathrm{g} / \mathrm{L}$ & 100 & 200 & EPA Method 6010 \\
\hline$\mu \mathrm{g} / \mathrm{L}$ & 50 & 100 & EPA Method 8270 \\
\hline$\mu \mathrm{g} / \mathrm{L}$ & 500 & 1,000 & APHA Method 417B \\
\hline$\mu \mathrm{g} / \mathrm{L}$ & 50 & 100 & EPA Method 350.1 \\
\hline$\mu \mathrm{g} / \mathrm{L}$ & 50 & 100 & EPA Method 8270 \\
\hline$\mu \mathrm{g} / \mathrm{L}$ & 50 & 100 & EPA Method 8270 \\
\hline$\mu \mathrm{g} / \mathrm{L}$ & 2.5 & 5 & Proposed DWS (EPA, 1990) \\
\hline$\mu \mathrm{g} / \mathrm{L}$ & 50 & 100 & EPA Method 8270 \\
\hline$\mu \mathrm{g} / \mathrm{L}$ & 25 & 50 & Final DWS (EPA, 1991a) \\
\hline$\mu \mathrm{g} / \mathrm{L}$ & 50 & 100 & EPA Method 625 \\
\hline$\mu \mathrm{g} / \mathrm{L}$ & 1,000 & 2,000 & Final DWS (EPA, 1991a) \\
\hline$\mu \mathrm{g} / \mathrm{L}$ & 2.5 & 5 & Final DWS (EPA, 1991a) \\
\hline$\mu \mathrm{g} / \mathrm{L}$ & 2.5 & 5 & EPA Method 8080 \\
\hline$\mu \mathrm{g} / \mathrm{L}$ & 2.5 & 5 & EPA Method 8080 \\
\hline$\mu \mathrm{g} / \mathrm{L}$ & 2.5 & 5 & EPA Method 8080 \\
\hline$\mu \mathrm{g} / \mathrm{L}$ & 250 & 500 & EPA Method 8270 \\
\hline$\mu \mathrm{g} / \mathrm{L}$ & 0.05 & 0.1 & Proposed DWS (EPA, 1990) \\
\hline$\mu \mathrm{g} / \mathrm{L}$ & 0.1 & 0.2 & Proposed DWS (EPA, 1990) \\
\hline$\mu \mathrm{g} / \mathrm{L}$ & 0.1 & 0.2 & Proposed DWS (EPA, 1990) \\
\hline$\mu \mathrm{g} / \mathrm{L}$ & 250 & 500 & EPA Method 8270 \\
\hline$\mu \mathrm{g} / \mathrm{L}$ & 50 & 100 & EPA Method 8270 \\
\hline$\mu \mathrm{g} / \mathrm{L}$ & 0.1 & 0.2 & Proposed DWS (EPA, 1990) \\
\hline$\mu \mathrm{g} / \mathrm{L}$ & 50 & 100 & EPA Method 8270 \\
\hline$\mu \mathrm{g} / \mathrm{L}$ & 100 & 200 & EPA Method 8270 \\
\hline$\mu \mathrm{g} / \mathrm{L}$ & 0.5 & 1 & Proposed DWS (EPA, 1990) \\
\hline$\mu \mathrm{g} / \mathrm{L}$ & 50 & 100 & EPA Method 8270 \\
\hline$\mu \mathrm{g} / \mathrm{L}$ & 50 & 100 & EPA Method 8270 \\
\hline$\mu \mathrm{g} / \mathrm{L}$ & 50 & 100 & EPA Method 8270 \\
\hline$\mu \mathrm{g} / \mathrm{L}$ & 50 & 100 & EPA Method 8270 \\
\hline$\mu \mathrm{g} / \mathrm{L}$ & 5,000 & 10,000 & EPA Method 300.0 \\
\hline$\mu \mathrm{g} / \mathrm{L}$ & 50 & 100 & Final DWS (EPA, 1991a) \\
\hline$\mu \mathrm{g} / \mathrm{L}$ & 50 & 100 & Final DWS (EPA, 1991a) \\
\hline$\mu \mathrm{g} / \mathrm{L}$ & 5 & 10 & EPA Method 8240 \\
\hline$\mu \mathrm{g} / \mathrm{L}$ & 50 & 100 & EPA Method 8270 \\
\hline$\mu \mathrm{g} / \mathrm{L}$ & 3.5 & 7 & Proposed DWS (EPA, 1990) \\
\hline$\mu \mathrm{g} / \mathrm{L}$ & 2.5 & 5 & Final DWS (EPA, 1991a) \\
\hline$\mu \mathrm{g} / \mathrm{L}$ & 5 & 10 & EPA Method 8240 \\
\hline$\mu \mathrm{g} / \mathrm{L}$ & 2.5 & 5 & Final DWS (EPA, 1991a) \\
\hline$\mu \mathrm{g} / \mathrm{L}$ & 500 & 1,000 & EPA Method 310.1 \\
\hline$\mu \mathrm{g} / \mathrm{L}$ & 1 & 2 & Final DWS (EPA, 1991a) \\
\hline
\end{tabular}

* The detection limit and Flag 2 criterion for acetone, a common laboratory contaminant, are set as $100 \mu \mathrm{g} / \mathrm{L}$. 
FLAGGING CRITERIA

Table 2. Flagging Criteria (cont.)

\begin{tabular}{|c|c|c|c|c|}
\hline Analyte & Urit & Flag 1 & Flag 2 & Source \\
\hline Chloride & $\mu \mathrm{g} / \mathrm{L}$ & 125,000 & 250,000 & Secondary DWS (EPA, 1991b) \\
\hline 4-Chloroaniline & $\mu \mathrm{g} / \mathrm{L}$ & 50 & 100 & EPA Method 8270 \\
\hline Chlorobenzene & $\mu \mathrm{g} / \mathrm{L}$ & 5 & 10 & EPA Method 8240 \\
\hline Chlorobenzilate & $\mu \mathrm{g} / \mathrm{L}$ & 50 & 100 & EPA Method 8270 \\
\hline Chloroethane & $\mu \mathrm{g} / \mathrm{L}$ & 5 & 10 & EPA Method 8240 \\
\hline Chloroethene (Vinyl chloride) & $\mu \mathrm{g} / \mathrm{L}$ & 1 & 2 & Final DWS (EPA, 1991a) \\
\hline Chloroethyl vinyl ether & $\mu \mathrm{g} / \mathrm{L}$ & 5 & 10 & EPA Method 8240 \\
\hline 2-Chloroethyl vinyl ether & $\mu \mathrm{g} / \mathrm{L}$ & 5 & 10 & EPA Method 8240 \\
\hline Chloroform & $\mu \mathrm{g} / \mathrm{L}$ & 50 & 100 & Final DWS (EPA, 1991a) \\
\hline para-Chloro-meta-cresn! & $\mu \mathrm{g} / \mathrm{L}$ & 50 & 100 & EPA Method 8270 \\
\hline Chloromethane (Methyl chloride) & $\mu \mathrm{g} / \mathrm{L}$ & 5 & 10 & EPA Method 8240 \\
\hline 2-Chloronaphthalene & $\mu \mathrm{g} / \mathrm{L}$ & 50 & 100 & EPA Method 8240 \\
\hline 2-Chlorophenol & $\mu \mathrm{g} / \mathrm{L}$ & 50 & 100 & EPA Method 8270 \\
\hline 4-Chlorophenyl phenyl ether & $\mu \mathrm{g} / \mathrm{L}$ & 50 & 100 & EPA Method 8270 \\
\hline Chloroprene & $\mu \mathrm{g} / \mathrm{L}$ & 1,000 & 2,000 & EPA Method 8240 \\
\hline Chromium & $\mu \mathrm{g} / \mathrm{L}$ & 50 & 100 & Final DWS (EPA, 1991a) \\
\hline Chrysene & $\mu \mathrm{g} / \mathrm{L}$ & 0.1 & 0.2 & Proposed DWS (EPA, 1990) \\
\hline Cobalt & $\mu \mathrm{g} / \mathrm{L}$ & 20 & 40 & EPA Method 6010 \\
\hline Copper & $\mu \mathrm{g} / \mathrm{L}$ & 650 & 1,300 & Final DWS (EPA, 1991a) \\
\hline m-Cresol (3-Methylphenol) & $\mu \mathrm{g} / \mathrm{L}$ & 50 & 100 & EPA Method 8270 \\
\hline o-Cresol (2-Methylphenol) & $\mu \mathrm{g} / \mathrm{L}$ & 50 & 100 & EPA Method 8270 \\
\hline p-Cresol (4-Methylphenol) & $\mu \mathrm{g} / \mathrm{L}$ & 50 & 100 & EPA Method 8270 \\
\hline Syanide & $\mu \mathrm{g} / \mathrm{L}$ & 100 & 200 & Proposed DWS (EPA, 1990) \\
\hline $\mathrm{p}, \mathrm{p}^{\prime}-\mathrm{L} \cap \mathrm{D}$ & $\mu \mathrm{g} / \mathrm{L}$ & 2.5 & 5 & EPA Method 8080 \\
\hline $\mathrm{p}, \mathrm{p}^{\prime}-\mathrm{DDE}$ & $\mu \mathrm{g} / \mathrm{L}$ & 2.5 & 5 & EPA Method 8080 \\
\hline $\mathrm{p}, \mathrm{p}^{\prime}-\mathrm{DDT}$ & $\mu \mathrm{g} / \mathrm{L}$ & 2.5 & 5 & EPA Method 8080 \\
\hline Diallate & $\mu \mathrm{g} / \mathrm{L}$ & 50 & 100 & EPA Method 8270 \\
\hline Dibenz $[a, h]$ anthracene & $\mu \mathrm{g} / \mathrm{L}$ & 0.15 & 0.3 & Proposed DWS (EPA, 1990) \\
\hline Dibenzofuran & $\mu \mathrm{g} / \mathrm{L}$ & 50 & 100 & EPA Method 8270 \\
\hline Dibromochloromethane & $\mu \mathrm{g} / \mathrm{L}$ & 50 & 100 & Final DWS (EPA, 1991a) \\
\hline Dibromochloropropane & $\mu \mathrm{g} / \mathrm{L}$ & 0.1 & 0.2 & Final DWS (EPA, 1991a) \\
\hline 1,2-Dibromo-3-chloropropane & $\mu \mathrm{g} / \mathrm{L}$ & 0.1 & 0.2 & Final DWS (EPA, 1991a) \\
\hline 1,2-Dibromoethane & $\mu \mathrm{g} / \mathrm{L}$ & 100 & 200 & EPA Method 8240 \\
\hline \multicolumn{5}{|l|}{ Dibromomethane } \\
\hline (Methylene bromide) & $\mu \mathrm{g} / \mathrm{L}$ & 5 & 10 & EPA Method 8240 \\
\hline 1,2-Dichlorobenzene & $\mu \mathrm{g} / \mathrm{L}$ & 300 & 600 & Final DWS (EPA, 1991a) \\
\hline 1,3-Dichlorobenzene & $\mu \mathrm{g} / \mathrm{L}$ & 50 & 100 & EPA Method 8270 \\
\hline 1,4-Dichlorobenzene & $\mu \mathrm{g} / \mathrm{L}$ & 37.5 & 75 & Final DWS (EPA, 1991a) \\
\hline 3,3'-Dichlorobenzidine & $\mu \mathrm{g} / \mathrm{L}$ & 50 & 100 & EPA Method 8270 \\
\hline trans-1,4-Dichloro-2-butene & $\mu \mathrm{g} / \mathrm{L}$ & 150 & 300 & EPA Method 8240 \\
\hline Dichlorodifluoromethane & $\mu \mathrm{g} / \mathrm{L}$ & 5 & 10 & EPA Method 8240 \\
\hline 1,1-Dichloroethane & $\mu \mathrm{g} / \mathrm{L}$ & 5 & 10 & EPA Method 8240 \\
\hline 1,2-Dichloroethane & $\mu \mathrm{g} / \mathrm{L}$ & 2.5 & 5 & Final DWS (EPA, 1991a) \\
\hline cis-1,2-Dichloroethene & $\mu \mathrm{g} / \mathrm{L}$ & 35 & 70 & Final DWS (EPA, 1991a) \\
\hline 1,1-Dichloroethylene & $\mu \mathrm{g} / \mathrm{L}$ & 3.5 & 7 & Final DWS (EPA, 1991a) \\
\hline 1,2-Dichloroethylene & $\mu \mathrm{g} / \mathrm{L}$ & 25 & 50 & EPA Method 8240 \\
\hline trans-1,2-Dichloroethylene & $\mu g / L$ & 50 & 100 & Final DWS (EPA, 1991a) \\
\hline 2,4-Dichlorophenol & $\mu \mathrm{g} / \mathrm{L}$ & 50 & 100 & EPA Method 8270 \\
\hline 2,6-Dichlorophenol & $\mu \mathrm{g} / \mathrm{L}$ & 50 & 100 & EPA Method 8270 \\
\hline 2,4-Dichlorophenoxyacetic acid & $\mu \mathrm{g} / \mathrm{L}$ & 35 & 70 & Final DWS (EPA, 1991a) \\
\hline 1,2-Dichloropropane & $\mu \mathrm{g} / \mathrm{L}$ & 2.5 & 5 & Final DWS (EPA, 1991a) \\
\hline cis-1,3-Dichloropropene & $\mu \mathrm{g} / \mathrm{L}$ & 5 & 10 & EPA Method 8240 \\
\hline trans-1,3-Dichloropropene & $\mu \mathrm{g} / \mathrm{L}$ & 5 & 10 & EPA Method 8240 \\
\hline Dieldrin & $\mu \mathrm{g} / \mathrm{L}$ & 2.5 & 5 & EPA Method 8080 \\
\hline
\end{tabular}


Table 2. Flagging Criteria (cont.)

Analyte

Dimethoate

p-Dimethylaminoazobenzene

p-(Dimethylamino)ethylbenzene

7,12-Dimethylbenz [a]anthracene

3,3'-Dimethylbenzidine

a,a-Dimethylphenethylamine

2,4-Dimethyl phenol

1,3-Dinitrobenzene

4,6-Dinitro-ortho-cresol

2,4-Dinitrophenol

2,4-Dinitrotoluene

2,6-Dinitrotoluene

1,4-Dioxane

Diphenylamine

1,2-Diphenylhydrazine

Dissolved organic carbon

Disulfoton

alpha-Endosulfan

beta-Endosulfan

Endosulfan I

Endosulfan II

Endosulfan sulfate

Endrin

Endrin aldehyde

Ethylbenzene

Ethyl methacrylate

Ethyl methanesulfonate

Famphur

Fluoranthene

Fluorene

Fluoride

Heptachlor

Heptachlor epoxide

Heptachlorodibenzo-p-dioxin

isomers

1,2,3,4,6,7,8-Heptachlorodibenzo-pdioxin

Heptachlorodibenzo-p-furan

isomers

1,2,3,4,6,7,8-Heptachlorodibenzo-pfuran

Hexachlorobenzene

Hexachlorobutadiene

Hexachlorocyclopentadiene

Hexachlorodibenzo-p-dioxin isomers

$1,2,3,4,7,8$-Hexachlorodibenzo-pdioxin

Hexachlorodibenzo-p-furan isomers

1,2,3,4,7,8-Hexachlorodibenzo-pfuran

Hexachloroethane

Hexachlorophene

Hexachloropropene

2-Hexanone
Unit Flag 1 Flag 2 Source

$\mu \mathrm{g} / \mathrm{L} \quad 50 \quad 100 \quad$ EPA Method 8270

$\mu \mathrm{g} / \mathrm{L} \quad 50 \quad 100 \quad$ EPA Method 8270

$\mu \mathrm{g} / \mathrm{L} \quad 50 \quad 100 \quad$ EPA Method 8270

$\mu \mathrm{g} / \mathrm{L} \quad 50 \quad 100 \quad$ EPA Method 8270

$\mu \mathrm{g} / \mathrm{L} \quad 50 \quad 100 \quad$ EPA Method 8270

$\mu \mathrm{g} / \mathrm{L} \quad 50 \quad 100 \quad$ EPA Method 8270

$\mu \mathrm{g} / \mathrm{L} \quad 50 \quad 100 \quad$ EPA Method 8270

$\mu \mathrm{g} / \mathrm{L} \quad 50 \quad 100 \quad$ EPA Method 8270

$\mu \mathrm{g} / \mathrm{L} \quad 250 \quad 500 \quad$ EPA Method 8270

$\mu \mathrm{g} / \mathrm{L} \quad 250 \quad 500 \quad$ EPA Method 8270

$\mu \mathrm{g} / \mathrm{L} \quad 50 \quad 100 \quad$ EPA Method 8270

$\mu \mathrm{g} / \mathrm{L} \quad 50 \quad 100 \quad$ EPA Method 8270

$\mu \mathrm{g} / \mathrm{L} \quad 50 \quad 100 \quad$ EPA Method 8270

$\mu \mathrm{g} / \mathrm{L} \quad 50 \quad 100 \quad$ EPA Method 8270

$\mu \mathrm{g} / \mathrm{L} \quad 50 \quad 100 \quad$ EPA Method 8270

$\mu \mathrm{g} / \mathrm{L} \quad 5,000 \quad 10,000 \quad$ EPA Method 9060

$\mu \mathrm{g} / \mathrm{L} \quad 50 \quad 100 \quad$ EPA Method 8270

$\mu \mathrm{g} / \mathrm{L} \quad 50 \quad 100 \quad$ EPA Method 8270

$\mu \mathrm{g} / \mathrm{L} \quad 50 \quad 100 \quad$ EPA Method 8270

$\mu \mathrm{g} / \mathrm{L} \quad 2.5 \quad 5 \quad$ EPA Method 8080

$\mu \mathrm{g} / \mathrm{L} \quad 2.5 \quad 5 \quad$ EPA Method 8080

$\mu \mathrm{g} / \mathrm{L} \quad 2.5 \quad 5 \quad$ EPA Method 8080

$\mu \mathrm{g} / \mathrm{L} \quad 0.1 \quad 0.2 \quad$ Final DWS (EPA, 1991a)

$\mu \mathrm{g} / \mathrm{L} \quad 2.5 \quad 5 \quad$ EPA Method 8080

$\mu \mathrm{g} / \mathrm{L} \quad 350 \quad 700$

$\mu \mathrm{g} / \mathrm{L} \quad 50 \quad 100$

$\mu \mathrm{g} / \mathrm{L} \quad 50 \quad 100$

$\mu \mathrm{g} / \mathrm{L} \quad 50 \quad 100$

$\mu \mathrm{g} / \mathrm{L} \quad 50 \quad 100$

$\mu \mathrm{g} / \mathrm{L} \quad 50 \quad 100$

$\mu \mathrm{g} / \mathrm{L} \quad 2,000 \quad 4,000$

$\mu \mathrm{g} / \mathrm{L} \quad 0.2 \quad 0.4$

$\mu \mathrm{g} / \mathrm{L} \quad 0.1 \quad 0.2$

$\mu \mathrm{g} / \mathrm{L} \quad 0.00325 \quad 0.0065$

Final DWS (EPA, 1991a)

EPA Melinod 8270

EPA Method 8270

EPA Method 8270

EPA Method 8270

EPA Method 8270

Final DWS (EPA, 1991a)

Final DWS (EPA, 1991a)

Final DWS (EPA, 1991a)

EPA Method 8280

$\mu \mathrm{g} / \mathrm{L} \quad 0.00325 \quad 0.0065$

EPA Method 8280

$\mu \mathrm{g} / \mathrm{L} \quad 0.00225 \quad 0.0045$

EPA Method 8280

$\mu \mathrm{g} / \mathrm{L} \quad 0.00225 \quad 0.0045$

EPA Method 8280

$\mu \mathrm{g} / \mathrm{L} \quad 0.5$

$\mu \mathrm{g} / \mathrm{L} \quad 50 \quad 100$

$\mu \mathrm{g} / \mathrm{L} \quad 25 \quad 50$

$\mu \mathrm{g} / \mathrm{L} \quad 0.00225 \quad 0.0045$

Proposed DWS (EPA, 1990)

EPA Method 8270

Proposed DWS (EPA, 1990)

EPA Method 8280

$\mu \mathrm{g} / \mathrm{L} \quad 0.00225 \quad 0.0045$

EPA Method 8280

$\mu \mathrm{g} / \mathrm{L} \quad 0.002 \quad 0.004$

EFA Method 8280

$\mu \mathrm{g} / \mathrm{L} \quad 0.002 \quad 0.004$

$\mu \mathrm{g} / \mathrm{L} \quad 50 \quad 100$

$\mu \mathrm{g} / \mathrm{L} \quad 250 \quad 500$

$\mu \mathrm{g} / \mathrm{L} \quad 50 \quad 100$

$\mu \mathrm{g} / \mathrm{L} \quad 100 \quad 200$
EPA Method 8270

EPA Method 8270

EPA Method 8270

EPA Method 8240
EPA Method 8280 
Table 2. Flagging Criteria (cont.)

\begin{tabular}{|c|c|c|c|c|}
\hline Analyte & Unit & Flag 1 & Flag 2 & Source \\
\hline Indeno $[1,2,3-c, d]$ pyrene & $\mu \mathrm{g} / \mathrm{L}$ & 50 & 100 & EPA Method 8270 \\
\hline Iodine & $\mu \mathrm{g} / \mathrm{L}$ & 500 & 1,000 & APHA Method 415 \\
\hline Iodomethane (Methyl iodide) & $\mu g / L$ & 75 & 150 & EPA Method 8240 \\
\hline Iron & $\mu g / L$ & 150 & 300 & Secondary DWS (EPA, 1991b) \\
\hline Isobutyl alcohol & $\mu g / L$ & 500 & 1,000 & EPA Method 8240 \\
\hline Isodrin & $\mu g / L$ & 50 & 100 & EPA Method 8270 \\
\hline Isophorone & $\mu g / L$ & 50 & 100 & EPA Method 8270 \\
\hline Isosafrole & $\mu g / L$ & 50 & 100 & EPA Method 8270 \\
\hline Kepone & $\mu \mathbf{g} / \mathrm{L}$ & 50 & 100 & EPA Method 8270 \\
\hline Lead & $\mu g / L$ & 7.5 & 15 & Final DWS (EPA, 1991a) \\
\hline Lindare & $\mu g / L$ & 0.1 & 0.2 & Final DWS (EPA, 1991a) \\
\hline Lithium & $\mu \mathrm{g} / \mathrm{L}$ & 25 & 50 & EPA Method 6010 \\
\hline Manganese & $\mu \mathrm{g} / \mathrm{L}$ & 25 & 50 & Secondary DWS (EPA, 1991b) \\
\hline Mercury & $\mu \mathrm{g} / \mathrm{L}$ & 1 & 2 & Final DWS (EPA, 1991a) \\
\hline Methacrylonitrile & $\mu \mathrm{g} / \mathrm{L}$ & 250 & 500 & EPA Method 8240 \\
\hline Methapyrilene & $\mu g / L$ & 50 & 100 & EPA Method 8270 \\
\hline Methoxychlor & $\mu g / L$ & 20 & 40 & Final DWS (EPA, 1991a) \\
\hline 3-Methylcholanthrene & $\mu g / L$ & 50 & 100 & EPA Method 8270 \\
\hline 2-Methyl-4,6-dinitrophenol & $\mu g / L$ & 250 & 500 & EPA Method 8270 \\
\hline Methyl methacrylate & $\mu g / L$ & 50 & 100 & EPA Method 8270 \\
\hline Methyl methanesulfonate & $\mu \mathrm{g} / \mathrm{L}$ & 50 & 100 & EPA Method 8270 \\
\hline 2-Methylnaphthalene & $\mu \mathrm{g} / \mathrm{L}$ & 50 & 100 & EPA Method 8270 \\
\hline Molybdenum & $\mu \mathrm{g} / \mathrm{L}$ & 250 & 500 & EPA Method 6010 \\
\hline Naphthalene & $\mu g / L$ & 50 & 100 & EPA Method 8270 \\
\hline 1,4-Naphthoquinone & $\mu \mathrm{g} / \mathrm{L}$ & 50 & 100 & EPA Method 8270 \\
\hline 1-Naphthylamine & $\mu \mathrm{g} / \mathrm{L}$ & 50 & 100 & EPA Method 8270 \\
\hline 2-Naphthylamine & $\mu \mathrm{g} / \mathrm{L}$ & 50 & 100 & EPA Method 8270 \\
\hline Nickel & $\mu g / L$ & 50 & 100 & Proposed DWS (EPA, 1990) \\
\hline Nitrate as nitrogen & $\mu \mathrm{g} / \mathrm{L}$ & 5,000 & 10,000 & Final DWS (EPA, 1991a) \\
\hline Nitrite as nitrogen & $\mu \mathrm{g} / \mathrm{L}$ & 500 & 1,000 & Final DWS (EPA, 1991a) \\
\hline 2-Nitroaniline & $\mu \mathrm{g} / \mathrm{L}$ & 50 & 100 & EPA Method 8270 \\
\hline 3-Nitroaniline & $\mu \mathrm{g} / \mathrm{L}$ & 50 & 100 & EPA Method 8270 \\
\hline 4-Nitroaniline & $\mu \mathrm{g} / \mathrm{L}$ & 50 & 100 & EPA Method 8270 \\
\hline Nitrobenzene & $\mu g / L$ & 50 & 100 & EPA Method 8270 \\
\hline Nitrogen by Kjeldahl method & $\mu g / L$ & 500 & 1,000 & EPA Method 351.2 \\
\hline 2-Nitrophenol & $\mu \mathrm{g} / \mathrm{L}$ & 50 & 100 & EPA Method 8270 \\
\hline 4-Nitrophenol & $\mu \mathrm{g} / \mathrm{L}$ & 50 & 100 & EPA Method 8270 \\
\hline 4-Nitroquinoline-1-oxide & $\mu \mathrm{g} / \mathrm{L}$ & 50 & 100 & EPA Method 8270 \\
\hline N-Nitrosodi-n-butylamine & $\mu \mathrm{g} / \mathrm{L}$ & 50 & 100 & EPA Method 8270 \\
\hline N-Nitrosodiethylamine & $\mu \mathrm{g} / \mathrm{L}$ & 50 & 100 & EPA Method 8270 \\
\hline N-Nitrosodimethylamine & $\mu g / L$ & 50 & 100 & EPA Method 8270 \\
\hline N-Nitrosodiphenylamine & $\mu g / L$ & 50 & 100 & EPA Method 8270 \\
\hline N-Nitrosodipropylamine & $\mu g / L$ & 50 & 100 & EPA Method 8270 \\
\hline N-Nitrosomethylethylamine & $\mu \mathrm{g} / \mathrm{L}$ & 50 & 100 & EPA Method 8270 \\
\hline N-Nitrosomorpholine & $\mu \mathrm{g} / \mathrm{L}$ & 50 & 100 & EPA Method 8270 \\
\hline N-Nitrosopiperidine & $\mu g / L$ & 50 & 100 & EPA Method 8270 \\
\hline N-Nitrosopyrrolidine & $\mu \mathrm{g} / \mathrm{L}$ & 50 & 100 & EPA Method 8270 \\
\hline 5-Nitro-0-toluidine & $\mu \mathrm{g} / \mathrm{L}$ & 50 & 100 & EPA Method 8270 \\
\hline Octachlorodibenzo-p-dioxin isomers & $\mu \mathrm{g} / \mathrm{L}$ & 0.005 & 0.01 & EPA Method 8280 \\
\hline Octachlorodibenzo-p-furan isomers & $\mu \mathrm{g} / \mathrm{L}$ & 0.005 & 0.01 & EPA Method 8280 \\
\hline Oil \& grease & $\mu \mathrm{g} / \mathrm{L}$ & 5,000 & 10,000 & EPA Method 413.1 \\
\hline Parathion & $\mu \mathrm{g} / \mathrm{L}$ & 2.5 & 5 & EPA Method 8080 \\
\hline Parathion methyl & $\mu g / L$ & 2.5 & 5 & EPA Method 8080 \\
\hline PCB 1016 & $\mu \mathrm{g} / \mathrm{L}$ & 0.25 & 0.5 & Final DWS (EPA, 1991a) \\
\hline
\end{tabular}


Table 2. Flagging Criteria (cont.)

\begin{tabular}{|c|c|c|c|c|}
\hline Analvte & $\underline{\text { Unit }}$ & Flag 1 & Flag 2 & Source \\
\hline РCB 1221 & $\mu \mathrm{g} / \mathrm{L}$ & 0.25 & 0.5 & Final DWS (EPA, 1991a) \\
\hline PCB 1232 & $\mu \mathrm{g} / \mathrm{L}$ & 0.25 & 0.5 & Final DWS (EPA, 1991a) \\
\hline PCB 1242 & $\mu \mathrm{g} / \mathrm{L}$ & 0.25 & 0.5 & Final DWS (EPA, 1991a) \\
\hline PCB 1248 & $\mu \mathrm{g} / \mathrm{L}$ & 0.25 & 0.5 & Final DWS (EPA, 1991a) \\
\hline PCB 1254 & $\mu \mathrm{g} / \mathrm{L}$ & 0.25 & 0.5 & Final DWS (EPA, 1991a) \\
\hline PCB 1260 & $\mu \mathrm{g} / \mathrm{L}$ & 0.25 & 0.5 & Final DWS (EPA, 1991a) \\
\hline PCB 1262 & $\mu \mathrm{g} / \mathrm{L}$ & 0.25 & 0.5 & Final DWS (EPA, 1991a) \\
\hline Pentachlorobenzene & $\mu g / L$ & 50 & 100 & EPA Method 8270 \\
\hline Pentachlorodibenzo-p-dioxin isomers & $\mu \mathrm{g} / \mathrm{L}$ & 0.00275 & 0.0055 & EPA Method 8280 \\
\hline $\begin{array}{l}\text { 1,2,3,7,8-Pentachlorodibenzo-p- } \\
\text { dioxin }\end{array}$ & & & & \\
\hline dioxin & $\mu \mathrm{g} / \mathrm{L}$ & 0.00275 & 0.0055 & EPA Method 8280 \\
\hline $\begin{array}{l}\text { Pentachlorodibenzo-p-furan isomers } \\
1,2,3,7,8 \text {-Pentachlorodibenzo-p- }\end{array}$ & $\mu \mathrm{g} / \mathrm{L}$ & 0.00275 & 0.0055 & EPA Method 8280 \\
\hline furan & $\mu \mathrm{g} / \mathrm{L}$ & 0.00275 & 0.0055 & EPA Method 8280 \\
\hline Pentachloroethane & $\mu \mathrm{g} / \mathrm{L}$ & 50 & 100 & EPA Method 8270 \\
\hline Pentachloronitrobenzene & $\mu \mathrm{g} / \mathrm{L}$ & 50 & 100 & EPA Method 8270 \\
\hline Pentachlorophenol & $\mu \mathrm{g} / \mathrm{L}$ & 0.5 & 1 & Final DWS (EPA, 1991a) \\
\hline $\mathrm{pH}$ & $\mathrm{pH}$ & 8 & 10 & Set by EPD/EMS* \\
\hline $\mathrm{pH}$ & $\mathrm{pH}$ & 4 & 3 & Set by EPD/EMS* \\
\hline Phenacetin & $\mu \mathrm{g} / \mathrm{L}$ & 50 & 100 & EPA Method 8270 \\
\hline Phenanthrene & $\mu \mathrm{g} / \mathrm{L}$ & 50 & 100 & EPA Method 8270 \\
\hline Phenol & $\mu \mathrm{g} / \mathrm{L}$ & 50 & 100 & EPA Method 8270 \\
\hline Phenols & $\mu \mathrm{g} / \mathrm{L}$ & 25 & 50 & EPA Method 420.1 \\
\hline p-Phenylenediamine & $\mu \mathrm{g} / \mathrm{L}$ & 50 & 100 & EPA Method 8270 \\
\hline Phorate & $\mu \mathrm{g} / \mathrm{L}$ & 2.5 & 5 & EPA Method 8080 \\
\hline 2-Picoline & $\mu \mathrm{g} / \mathrm{L}$ & 50 & 100 & EPA Method 8270 \\
\hline Pronamid & $\mu \mathrm{g} / \mathrm{L}$ & 50 & 100 & EPA Method 8270 \\
\hline Propionitrile & $\mu \mathrm{g} / \mathrm{L}$ & 1,000 & 2,000 & EPA Method 8240 \\
\hline Pyrene & $\mu \mathrm{g} / \mathrm{L}$ & 50 & 100 & EPA Method 8270 \\
\hline Pyridine & $\mu \mathrm{g} / \mathrm{L}$ & 50 & 100 & EPA Met'sod 8270 \\
\hline Safrole & $\mu \mathrm{g} / \mathrm{L}$ & 50 & 100 & EPA Method 8270 \\
\hline Selenium & $\mu \mathrm{g} / \mathrm{L}$ & 25 & 50 & Final DWS (EPA, 1991a) \\
\hline Silver & $\mu \mathrm{g} / \mathrm{L}$ & 25 & 50 & Final DWS (EPA, 1991a) \\
\hline Specific conductance & $\mu \mathrm{S} / \mathrm{cm}$ & 250 & 500 & Set by EPD/EMS* \\
\hline Styrene & $\mu \mathrm{g} / \mathrm{L}$ & 50 & 100 & Final DWS (EPA, 1991a) \\
\hline Sulfate & $\mu \mathrm{g} / \mathrm{L}$ & 200,000 & 400,000 & Proposed DWS (EPA, 1990) \\
\hline Sulfide & $\mu \mathrm{g} / \mathrm{L}$ & 5,000 & 10,000 & EPA Method 9030 \\
\hline Sulfotepp & $\mu \mathrm{g} / \mathrm{L}$ & 50 & 100 & EPA Method 8270 \\
\hline $2,3,7,8-\mathrm{TCDD}$ & $\mu \mathrm{g} / \mathrm{L}$ & 0.00225 & 0.0045 & EPA Method 8280 \\
\hline $2,3,7,8-\mathrm{TCDF}$ & $\mu \mathrm{g} / \mathrm{L}$ & 0.002 & 0.004 & EPA Method 8280 \\
\hline $1,2,4,5$-Tetrachlorobenzene & $\mu \mathrm{g} / \mathrm{L}$ & 50 & 100 & EPA Method 8270 \\
\hline $\begin{array}{l}\text { Tetrachlorodibenzo-p-dioxin } \\
\text { isomers }\end{array}$ & $\mu \mathrm{g} / \mathrm{L}$ & 0.00225 & 0.0045 & EPì Method 8280 \\
\hline $\begin{array}{l}\text { Tetrachlorodibenzo-p-furan } \\
\text { isomers }\end{array}$ & $\mu \mathrm{g} / \mathrm{L}$ & 0.002 & 0.004 & EPA Method 8280 \\
\hline 1,1,1,2-Tetrachloroethane & $\mu \mathrm{g} / \mathrm{L}$ & 5 & 10 & EPA Method 8240 \\
\hline 1,1,2,2-Tetrachloroethane & $\mu \mathrm{g} / \mathrm{L}$ & 5 & 10 & EPA Method 8240 \\
\hline Tetrachloroethylene & $\mu \mathrm{g} / \mathrm{L}$ & 2.5 & 5 & Final DWS (EPA, 1991a) \\
\hline 2,3,4,6-Tetrachlorophenol & $\mu \mathrm{g} / \mathrm{L}$ & 50 & 100 & EPA Melhod 8270 \\
\hline Tetraethyl dithiopyrophosphate & $\mu \mathrm{g} / \mathrm{L}$ & 50 & 100 & EPA Method 8270 \\
\hline Thallium & $\mu \mathrm{g} / \mathrm{L}$ & 0.5 & 1 & Proposed DWS (EPA, 1990) \\
\hline
\end{tabular}

* Will not trigger scheduling of samples. 
FLAGGING CRITERIA

Table 2. Flagging Criteria (cont.)

\begin{tabular}{|c|c|c|c|c|}
\hline Analyte & $\underline{\text { Unit }}$ & Flag 1 & Flag 2 & Source \\
\hline Thionazin & $\mu \mathrm{g} / \mathrm{L}$ & 50 & 100 & EPA Method 8270 \\
\hline Tin & $\mu \mathrm{g} / \mathrm{L}$ & 10 & 20 & EPA Method 282.2 \\
\hline Toluene & $\mu \mathrm{g} / \mathrm{L}$ & 500 & 1,000 & Final DWS (EPA, 1991a) $†$ \\
\hline o-Toluidine & $\mu \mathrm{g} / \mathrm{L}$ & 50 & 100 & EPA Method 8270 \\
\hline Total carbon & $\mu \mathrm{g} / \mathrm{L}$ & 5,000 & 10,000 & EPA Method 9060 \\
\hline Total hydrocarbons & $\mu \mathrm{g} / \mathrm{L}$ & 5,000 & 10,000 & EPA Method 418.1 \\
\hline Total inorganic carbon & $\mu \mathrm{g} / \mathrm{L}$ & 5,000 & 10,000 & EPA Method 9060 \\
\hline 'Total organic carbon & $\mu \mathrm{g} / \mathrm{L}$ & 5,000 & 10,000 & EPA Method 9060 \\
\hline Total organic halogens & $\mu \mathrm{g} / \mathrm{L}$ & 25 & 50 & EPA Method 9020 \\
\hline Total organic nitrogen & $\mu \mathrm{g} / \mathrm{L}$ & 500 & 1,000 & APHA Method 420 \\
\hline Total petroleum hydrocarbons & $\mu \mathrm{g} / \mathrm{L}$ & 5,000 & 10,000 & EPA Method 418.1 \\
\hline Total silica & $\mu \mathrm{g} / \mathrm{L}$ & 500 & 1,000 & EPA Method 6010 \\
\hline Toxaphene & $\mu \mathrm{g} / \mathrm{L}$ & 1.5 & 3 & Final DWS (EPA, 1991a) \\
\hline 2,4,5-TP (Silvex) & $\mu \mathrm{g} / \mathrm{L}$ & 25 & 50 & Final DWS (EPA, 1991a) \\
\hline Tributyl phosphate & $\mu \mathrm{g} / \mathrm{L}$ & 50 & 100 & EPA Method 8270 \\
\hline 1,2,4-Trichlorobenzene & $\mu g / L$ & 4.5 & 9 & Proposed DWS (EPA, 1990) \\
\hline $1,1,1$-Trichloroethane & $\mu \mathrm{g} / \mathrm{L}$ & 100 & 200 & Final DWS (EPA, 1991a) \\
\hline 1,1,2-Trichloroethane & $\mu \mathrm{g} / \mathrm{L}$ & 2.5 & 5 & Proposed DWS (EPA, 1990) \\
\hline Trichloroethylene & $\mu \mathrm{g} / \mathrm{L}$ & 2.5 & 5 & Final DWS (EPA, 1991a) \\
\hline Trichlorofluoromethane & $\mu \mathrm{g} / \mathrm{L}$ & 5 & 10 & EPA Method 8240 \\
\hline 2,4,5-Trichlorophenol & $\mu \mathrm{g} / \mathrm{L}$ & 50 & 100 & EPA Method 8270 \\
\hline 2,4,6-Trichlorophenol & $\mu \mathrm{g} / \mathrm{L}$ & 50 & 100 & EPA Method 8270 \\
\hline 2,4,5-Trichlorophenoxyacetic acid & $\mu \mathrm{g} / \mathrm{L}$ & 2.5 & 5 & EPA Method 8150 \\
\hline 1,2,3-Trichloropropane & $\mu \mathrm{g} / \mathrm{L}$ & 5 & 10 & EPA Method 8240 \\
\hline 0,0,0-Triethyl phosphorothioate & $\mu \mathrm{g} / \mathrm{L}$ & 50 & 100 & EPA Method 8270 \\
\hline 1,3,5-'Trinitrobenzene & $\mu \mathrm{g} / \mathrm{L}$ & 50 & 100 & EPA Method 8270 \\
\hline Uranium & $\mu \mathrm{g} / \mathrm{L}$ & 10 & 20 & Proposed DWS (EPA, 1991c) \\
\hline Vanadium & $\mu \mathrm{g} / \mathrm{L}$ & 50 & 100 & EPA Method 6010 \\
\hline Vinyl acetate & $\mu \mathrm{g} / \mathrm{L}$ & 5 & 10 & EPA Method 8240 \\
\hline Xylenes & $\mu \mathrm{g} / \mathrm{L}$ & 5,000 & 10,000 & Final DWS (EPA, 1991a) \\
\hline Zinc & $\mu \mathrm{g} / \mathrm{L}$ & 2,500 & 5,000 & Secondary DWS (EPA, 1991b) \\
\hline Americium-241 & $\mu \mathrm{Ci} / \mathrm{L}$ & $3.17 \mathrm{E}-09$ & $6.34 \mathrm{E}-09$ & Proposed DWS (EPA, 1991c) \\
\hline Americium-243 & $\mu \mathrm{Ci} / \mathrm{L}$ & $3.19 \mathrm{E}-09$ & $6.37 \mathrm{E}-09$ & Proposed DWS (EPA, 1991c) \\
\hline Antimony-125 & $\mu \mathrm{Ci} / \mathrm{mL}$ & $1.5 \mathrm{E}-07$ & $3 \mathrm{E}-07$ & Final DWS (EPA, 1977) \\
\hline Barium-140 & $\mu \mathrm{Ci} / \mathrm{mL}$ & $4.5 E-08$ & $9 E-08$ & Final DWS (EPA, 1977) \\
\hline Beryllium-7 & $\mu \mathrm{Ci} / \mathrm{mL}$ & $3 E-06$ & $6 \mathrm{E}-06$ & Final DWS (EPA, 1977) \\
\hline Carbon-14 & $\mu \mathrm{Ci} / \mathrm{mL}$ & $1 \mathrm{E}-06$ & $2 E-06$ & Final DWS (EPA, 1977) \\
\hline Cerium-141 & $\mu \mathrm{Ci} / \mathrm{mL}$ & $1.5 \mathrm{E}-07$ & $3 E-07$ & Final DWS (EPA, 1977) \\
\hline Cerium-144 & $\mu \mathrm{Ci} / \mathrm{mL}$ & $1.31 \mathrm{E}-07$ & $2.61 E-07$ & Proposed DWS (EPA, 1991c) \\
\hline Cesium-134 & $\mu \mathrm{Ci} / \mathrm{mL}$ & $4.07 \mathrm{E}-08$ & $8.13 E-08$ & Proposed DWS (EPA, 1991c)* \\
\hline Cesium-137 & $\mu \mathrm{Ci} / \mathrm{mL}$ & $1 \mathrm{E}-07$ & $2 \mathrm{E}-07$ & Final DWS (EPA, 1977) \\
\hline Chromium-51 & $\mu \mathrm{Ci} / \mathrm{mL}$ & $3 \mathrm{E}-06$ & $6 \mathrm{E}-06$ & Final DWS (EPA, 1977) \\
\hline Cobalt -57 & $\mu \mathrm{Ci} / \mathrm{mL}$ & $5 E-07$ & $1 \mathrm{E}-06$ & Final DWS (EPA, 1977) \\
\hline Cobalt -58 & $\mu \mathrm{Ci} / \mathrm{mL}$ & $4.5 \mathrm{E}-06$ & $9 \mathrm{E}-06$ & Final DWS (EPA, 1977) \\
\hline Cobalt -60 & $\mu \mathrm{Ci} / \mathrm{mL}$ & $5 \mathrm{E}-08$ & $1 E-07$ & Final DWS (EPA, 1977) \\
\hline Curium-242 & $\mu \mathrm{Ci} / \mathrm{mL}$ & $6.65 \mathrm{E}-08$ & $1.33 \mathrm{E}-07$ & Proposed DWS (EPA, 1991c) \\
\hline Curium-243 & $\mu \mathrm{Ci} / \mathrm{mL}$ & $4.15 \mathrm{E}-09$ & $8.3 E-09$ & Proposed DWS (EPA, 1991c) \\
\hline Curium-244 & $\mu \mathrm{Ci} / \mathrm{mL}$ & $4.92 \mathrm{E}-09$ & $9.84 E-09$ & Proposed DWS (EPA, 1991c) \\
\hline
\end{tabular}

† Will not trigger scheduling of saimples.

* EPD/EMS set this flagging criteria using the 1991 proposed DWS because the final DWS in 1977 may have been in error. 
Table 2. Flagging Criteria (cont.)

Analyte

Curium-246

Europium-154

Europium-155

Gross alpha

Iodine-129

Iodine-131

Iron-55

Iron-59

Lanthanum-140

Manganeséjas

Neptunium-237

Nickel-59

Nickel-63

Niobium-95

Nonvolatile beta

Plutonium-238

Plutonium-239

Plutonium-239/240

Plutonium-240

Plutoniumi-241

Plutonium-242

Potassium-40

Radium-226

Radium-228

Radon-222

Ruthenium-103

Ruthenium-106

Sodium-22

Strontium-89

Strontium-89/90

Strontium-90

Technetium-99

Thorium-228

Thorium-230

Thorium-232

Thorium-234

Tin-113

Total alpha-emitting radium

Tritium

Uranium alpha activity

Uranium-233/234

Uranium-234

Uranium-235

Uranium-238

Zinc-65

Zirconium-95

Zirconium/Niobium-95

\begin{tabular}{|c|c|c|c|}
\hline Unit & Flag 1 & Flag 2 & Source \\
\hline$\mu \mathrm{Ci} / \mathrm{mL}$ & $3.14 \mathrm{E}-09$ & $6.27 \mathrm{E}-09$ & Proposed DWS (EPA, 1991c) \\
\hline$\mu \mathrm{Ci} / \mathrm{mL}$ & $1 E-07$ & $2 \mathrm{E}-07$ & Final DWS (EPA, 1977) \\
\hline$\mu \mathrm{Ci} / \mathrm{mL}$ & $3 E-07$ & $6 \mathrm{E}-07$ & Final DWS (EPA, 1977) \\
\hline$\mu \mathrm{Ci} / \mathrm{mL}$ & $7.5 E-09$ & $1.5 \mathrm{E}-08$ & Final DWS (EPA, 1991a) \\
\hline$\mu \mathrm{Ci} / \mathrm{mL}$ & $5 E-10$ & $1 E-09$ & Final DWS (EPA, 1977) \\
\hline$\mu \mathrm{Ci} / \mathrm{mL}$ & $1.5 \mathrm{E}-09$ & $3 E-09$ & Final DWS (EPA, 1977) \\
\hline$\mu \mathrm{Ci} / \mathrm{mL}$ & $1 E-06$ & $2 E-06$ & Final DWS (EPA, 1977) \\
\hline$\mu \mathrm{Ci} / \mathrm{mL}$ & $1 \mathrm{E}-07$ & $2 E-07$ & Final DWS (EPA, 1977) \\
\hline$\mu \mathrm{Ci} / \mathrm{mL}$ & $3 E-08$ & $6 \mathrm{E}-08$ & Final DWS (EPA, 1977) \\
\hline$\mu \mathrm{Ci} / \mathrm{mL}$ & $1.5 \mathrm{E}-07$ & $3 E-07$ & Final DWS (EPA, 1977) \\
\hline$\mu \mathrm{Ci} / \mathrm{mL}$ & $3.53 \mathrm{E}-09$ & $7.06 \mathrm{E}-09$ & Proposed DWS (EPA, 1991c) \\
\hline$\mu \mathrm{Ci} / \mathrm{mL}$ & $1.5 \mathrm{E}-07$ & $3 E-07$ & Final DWS (EPA, 1977) \\
\hline$\mu \mathrm{Ci} / \mathrm{mL}$ & $2.5 E-08$ & $5 E-08$ & Final DWS (EPA, 1977) \\
\hline$\mu \mathrm{Ci} / \mathrm{mL}$ & $1.5 \mathrm{E}-07$ & 3.E-07 & Final DWS (EPA, 1977) \\
\hline$\mu \mathrm{Ci} / \mathrm{mL}$ & $2.5 E-08$ & $5 \mathrm{E}-08$ & Proposed DWS (EPA, 1986a) \\
\hline$\mu \mathrm{Ci} / \mathrm{mL}$ & $3.51 \mathrm{E}-09$ & $7.02 \mathrm{E}-09$ & Proposed DWS (EPA, 1991c) \\
\hline$\mu \mathrm{Ci} / \mathrm{mL}$ & $3.11 \mathrm{E}-08$ & $6.21 \mathrm{E}-08$ & Proposed DWS (EPA, 1991c) \\
\hline$\mu \mathrm{Ci} / \mathrm{mL}$ & $3.11 \mathrm{E}-08$ & $6.21 \mathrm{E}-08$ & Proposed DWS (EPA, 1991c)* \\
\hline$\mu \mathrm{Ci} / \mathrm{mL}$ & $3.11 \mathrm{E}-08$ & $6.22 \mathrm{E}-08$ & Proposed DWS (EPA, 1991c) \\
\hline$\mu \mathrm{Ci} / \mathrm{mL}$ & $3.13 E-08$ & $6.26 \mathrm{E}-08$ & Proposed DWS (EPA, 1991c) \\
\hline$\mu \mathrm{Ci} / \mathrm{mL}$ & $3.27 \mathrm{E}-08$ & $6.54 \mathrm{E}-08$ & Proposed DWS (EPA, 1991c) \\
\hline$\mu \mathrm{Ci} / \mathrm{mL}$ & $1.5 \mathrm{E}-07$ & $3 \mathrm{E}-07$ & Proposed DWS (EPA, 1986a) \\
\hline$\mu \mathrm{Ci} / \mathrm{mL}$ & $7.85 \mathrm{E}-09$ & $1.57 \mathrm{E}-08$ & Proposed DWS (EPA, 1991c) \\
\hline$\mu \mathrm{Ci} / \mathrm{mL}$ & $3.93 \mathrm{E}-09$ & $7.85 \mathrm{E}-09$ & Proposed DWS (EPA, 1991c) \\
\hline$\mu \mathrm{Ci} / \mathrm{mL}$ & $1.5 \mathrm{E}-07$ & $3 E-07$ & Proposed DWS (EPA, 1991c) \\
\hline$\mu \mathrm{Ci} / \mathrm{mL}$ & $1 \mathrm{E} \ldots 07$ & $2 \mathrm{E}-07$ & Final DWS (EPA, 1977) \\
\hline$\mu \mathrm{Ci} / \mathrm{mL}$ & $1.5 \mathrm{E}-08$ & $3 E-08$ & Final DWS (EPA, 1977) \\
\hline$\mu \mathrm{Ci} / \mathrm{mL}$ & $2.33 \mathrm{E}-07$ & $4.66 \mathrm{E}-07$ & Proposed DWS (EPA, 1991c) \\
\hline$\mu \mathrm{Ci} / \mathrm{mL}$ & $1 E-08$ & $2 \mathrm{E}-08$ & Final DWS (Eł A, 1977) \\
\hline$\mu \mathrm{Ci} / \mathrm{mL}$ & $4 E-09$ & $8 E-09$ & Final DWS (EPA, 1991a) \\
\hline$\mu \mathrm{Ci} / \mathrm{mL}$ & $4 \mathrm{E}-09$ & $8 E-09$ & Final DWS (EPA, 1991a) \\
\hline$\mu \mathrm{Ci} / \mathrm{mL}$ & $4.5 \mathrm{E}-07$ & $9 \mathrm{E}-07$ & Final DWS (EPA, 1977) \\
\hline$\mu \mathrm{Ci} / \mathrm{mL}$ & $6.25 \mathrm{E}-08$ & $1.25 \mathrm{E}-07$ & Pronnsed DWS (EPA, 1991c) \\
\hline$\mu \mathrm{Ci} / \mathrm{mL}$ & $3.96 \mathrm{E}-08$ & $7.92 \mathrm{E}-08$ & Prc, used DWS (EPA, 1991c) \\
\hline$\mu \mathrm{Ci} / \mathrm{mL}$ & $4.4 \mathrm{E}-08$ & $8.8 \mathrm{E}-08$ & Proposed DWS (EPA, 1991c) \\
\hline$\mu \mathrm{Ci} / \mathrm{mL}$ & $2 E-07$ & $4.01 \mathrm{E}-07$ & Proposed DWS (EPA, 1991c) \\
\hline$\mu \mathrm{Ci} / \mathrm{mL}$ & $1.5 \mathrm{E}-07$ & $3 E-07$ & Final DWS (EPA, 1977) \\
\hline$\mu \mathrm{Ci} / \mathrm{mL}$ & $2.5 \mathrm{E}-09$ & $5 E-09$ & $\begin{array}{l}\text { Final DWS for radium-226 plus } \\
-228 \text { (EPA, 1991a) }\end{array}$ \\
\hline$\mu \mathrm{Ci} / \mathrm{mL}$ & $1 E-05$ & $2 E-05$ & Final DWS (EPA, 1991a) \\
\hline$\mu \mathrm{Ci} / \mathrm{mL}$ & $1.5 \mathrm{E}-08$ & $3 E-08$ & Froposed DWS (EPA, 1991c) \\
\hline$\mu \mathrm{Ci} / \mathrm{mL}$ & $6.9 \mathrm{E}-09$ & $1.38 \mathrm{E}-08$ & Proposed DWS (EPA, 1991c)* \\
\hline$\mu \mathrm{Ci} / \mathrm{mL}$ & $6.95 E-09$ & $1.39 \mathrm{E}-08$ & Proposed DWS (EPA, 1991c) \\
\hline$\mu \mathrm{Ci} / \mathrm{mL}$ & $7.25 \mathrm{E}-09$ & $1.45 \mathrm{E}-08$ & Proposed DWS (EPA, 1991c) \\
\hline$\mu \mathrm{Ci} / \mathrm{mL}$ & $7.3 \mathrm{E}-09$ & $1.46 \mathrm{E}-08$ & Proposed DWS (EPA, 1991c) \\
\hline$\mu \mathrm{Ci} / \mathrm{mL}$ & $1.5 \mathrm{E}-07$ & $3 \mathrm{E}-07$ & Final DWS (EPA, 1977) \\
\hline$\mu \mathrm{Ci} / \mathrm{mL}$ & $1 \mathrm{E}-07$ & $2 \mathrm{E}-07$ & Final DWS (EPA, 1977) \\
\hline$\mu \mathrm{Ci} / \mathrm{mL}$ & $1 \mathrm{E}-07$ & $2 \mathrm{E}-07$ & Final DWS (EPA, 1977)* \\
\hline
\end{tabular}

* When radionuclide analyses are combined, the lower DWS of the two isotopes is used for flagging. 


\section{SAMPLE SCHEDULING}

Scheduling of analyses for the SRS groundwater monitoring program conducted by EPD/EMS is determined by several factors. Wells are sampled for comprehensive analyses on a regular basis. Other scheduling is based on flagging levels, regulatory requirements, and special requests that fall within the scope of the groundwater monitoring program. This information was used to generate The Savannah River Site's Groundwater Monitoring Program 1991 Sampling Schedule.

A breakdown by laboratory of the total number of analyses performed for fourth quarter 1991 is shown in Table 3.

Table 3. Number of Analyses Performed During Fourth Quarter 1991

Laboratory

EPD/EMS Laboratory

General Engineering

M-Area Laboratory

Teledyne

\section{COMPREHENSIVE ANALYSES}

New wells initially are scheduled for four quarters of comprehensive analyses, except that the herbicide/pesticide suite (see Table 4) is scheduled only during the first of the four quarters. Comprehensive analyses include indicator parameters, groundwater quality characteristics, and some drinking water characteristics. After the initial four quarters of analyses for new wells, comprehensive analyses including herbicides/ pesticides are scheduled once every two years. Wells sampled exclusively for radionuclide analyses are not included in these biennial comprehensive analyses.
Table 4. Comprehensive-Analyses Constituents

\author{
Arsenic \\ Barium \\ Cadmium \\ Chloride \\ Chromium \\ Fluoride \\ Herbicides/pesticides (suite) \\ 2,4-Dichlorophenoxyacetic acid \\ Endrin \\ Lindane \\ Methoxychlor \\ Toxaphene \\ 2,4,5-TP (Silvex) \\ Iron \\ Lead \\ Major ions (suite) \\ Alkalinity (field measurement) \\ Calcium \\ Magnesium \\ Potassium \\ Silica \\ Manganese \\ Mercury \\ Nitrate as nitrogen \\ $\mathrm{pH}$ \\ Phenols \\ Selenium \\ Silver \\ Sodium \\ Specific conductance \\ Sulfate \\ Total dissolved solids \\ Total organic carbon \\ Total organic halogens \\ Total phosphates (as P) \\ Gross alpha \\ Nonvolatile beta \\ Total alpha-emitting radium \\ Tritium
}




\section{SCHEDULING BASED ON FLAGGING LEVELS}

Wells are grouped for scheduling by monitoring site or by the investigation for which they are sampled. Specific criteria for Flag 1 and Flag 2 designations are found in the Flagging Criteria section of this report.

Constituents classified as Flag 0 in each well series are scheduled for analyses only by custodian request or as part of the biennial comprehensive analysis program. If an analytical result for a constituent in any well exceeds Flag 1, all wells in the same scheduling series will be sampled and analyzed for that constituent once a year. If a constituent falls below Flag 1 for three consecutive sampling episodes, the individual well's flag will be reduced from Flag 1 status to Flag 0 status and the flagging-based sampling will cease.

If an analytical result for a constituent exceeds Flag 2, all wells in the same scheduling series will be sampled and analyzed for that constituent twice a year. If a constituent falls below Flag 2 for three consecutive sampling episodes, the individual well's flag will be reduced from Flag 2 status to Flag 1 or Flag 0 status, depending on the results, and the well will be scheduled according to the lower flag.

If a constiiuent has ever been flagged in a well series, it is automatically flagged for all new wells of that series. For removal from a new well, a constituent's flag must follow the rules referred to earlier.

The following parameters or constituents are not scheduled according to flagging rules but will receive analyses by custodian request or during biennial comprehensive analyses:

- The indicator parameters specific conductance and $\mathrm{pH}$ and the common laburatory contaminant toluene have flagging criteria that do not trigger the scheduling mechanism.
- Thorium-234, which may be reported as part of the gamma PHA analysis, has flagging criteria that do not trigger sample collection in the scheduling program for gamma PHA or alpha spectroscopy.

Analyses for iodine-131, iron-55, iron-59, nickel63 , and plutonium-241 have been discontinued as part of the EPD/EMS Groundwater Monitoring Program, and historical data for these constituents will not trigger sample collection in the scheduling program. The low quantities of these constituents and the limited analytical capabilities at production-oriented laboratories have necessitated this program modification.

\section{Flagging-Based Scheduling of Suites}

When one of the six constituents of the herbicide/pesticide suite of comprehensives was flagged, the entire suite was flagged for analyses during fourth quarter 1991 following the conventional flagging scheme.

Certain wells in the $A / M$ Areas are analyzed for GC VOA by the M-Area Laboratory by request. If any of these wells yields an analytical result equal to or exceeding Flag 2, then GC VOA analysis is scheduled for verification by an offsite laboratory.

The GC VOA suite is a subset of the more extensive GCMS VOA suite. In general, the GC VOA and GCMS VOA suites follow the rule that if one compound is flagged, the whole suite is flagged. In an effort to avoid duplication of GC VOA analyses or unnecessary analyses of other GCMS VOA compounds, analyses are scheduled according to the following strategy. Following GCMS VOA analysis, if only GC VOA compounds equal or exceed Flag 1 or 2, only GC VOA is scheduled for analysis at the appropriate intervals. If GC VOA compounds exceed Flag 2 and other constituents of the GCMS VOA suite exceed Flag 1 only, GCMS VOA analysis is scheduled for one quarter and GC VOA analysis is scheduled for a different quarter. Thus, GC VOA compounds are analyzed twice, fulfilling the Flag 2 requirement for those constituents. 


\section{SAMPLE SCHEDULING}

GCMS VOA analysis is scheduled once for individual wells that have had two results for total organic halogens (TOH) greater than 10 $\mu \mathrm{g} / \mathrm{L}$ (excluding the first $\mathrm{TOH}$ analysis) and that have never received GCMS VOA analysis.

\section{SAMPLING REQUESTS}

Many analyses are scheduled at the request of various SRS groups. The person or group requesting the analyses must submit a formal sampling request form to EPD/EMS. If the request is within the scope of the groundwater monitoring program, and if provision for the analyses has been made in the current laboratory contract, the analyses are added to the sampling schedule. Likewise, if a sampling request needs to be deleted, the originator of the request must submit a deletion form.

\section{REGULATORY REQUIREMENTS}

All regulatory sampling requirements, such as those for the Resource Conservation and Recovery Act (RCRA), are scheduled by request.

\section{PURGE-WATER CONTAINMENT PROGRAM}

During fourth quarter, a purge-water containment program was partially implemented to containerize and properly dispose of the water purged from certain wells before sampling. However, pending full implementation of this program, the following wells that had been scheduled for analyses as part of the groundwater monitoring program during fourth quarter were not sampled:

BGO 26A

BGO 37C

CSB 1A

CSB 2A

CSB 6A

FSB 98A

LFW 7

$P \quad$ 28TC

RWM 12

TBG 3

TBG 4

TBG 5

TBG 6 
NOTES 


\section{FIELD NOTES}

Sample collection and field data measurements were performed by EPD/EMS personnel and Ge-Hy Environmental Sampling of New Ellenton, SC.

Each sampler maintained a field notebook. These field books are located in the fourth quarter 1991 section of the EPD/EMS Groundwater Monitoring Library. Field measurements may include alkalinity, $\mathrm{pH}$, temperature, specific conductance, air temperature, depth to the water prior to pumping, and volume of water purged prior to sampling.

All well visitations were routine during the fourth quarter of 1991, except as indicated in Table 5. The samplers' observations about water samples, well conditions, and any special collection methods are noted in the table. All wells were pumped except for those from the following series, which were bailed: the $F$ series; the FAC series except FAC 4; the FCA series except FCA 19D; the FTF series; the H series; the HTF series (except HTF 5, HTF 6, HTF 8, and HTF 34, in which pumps are installed but inoperable); the MGC series; the MGE series; the MGG series; the RSA series; the RSB series; the RSC series; the RSD series; the RSE series except RSE 24 and RSE 25; the SSS series; the Z series; and the ZW series. The following individual wells also were bailed, although the other wells in the series were pumped: BG 121, BG 125, CMP 16C, CSD 1D, IDP 3D, IDP 4, IDQ 1, K 301P, MSB 3B, MSB 3D, MSB 9A, MSB 9B, MSB 9C, MSB 10C, MSB 11C, MSB 11E, MSB 11F, MSB 15A, MSB 15C, MSB 16C, MSB 17C, MSB 24A, MSB 27A, MSB 31C, MSB 40D, MSB 42D, MSB 44C, MSB 45C, MSB 46C, SCA 3A, SCA 4A, YSC 1A, and ZBG $1 \mathrm{~A}$.

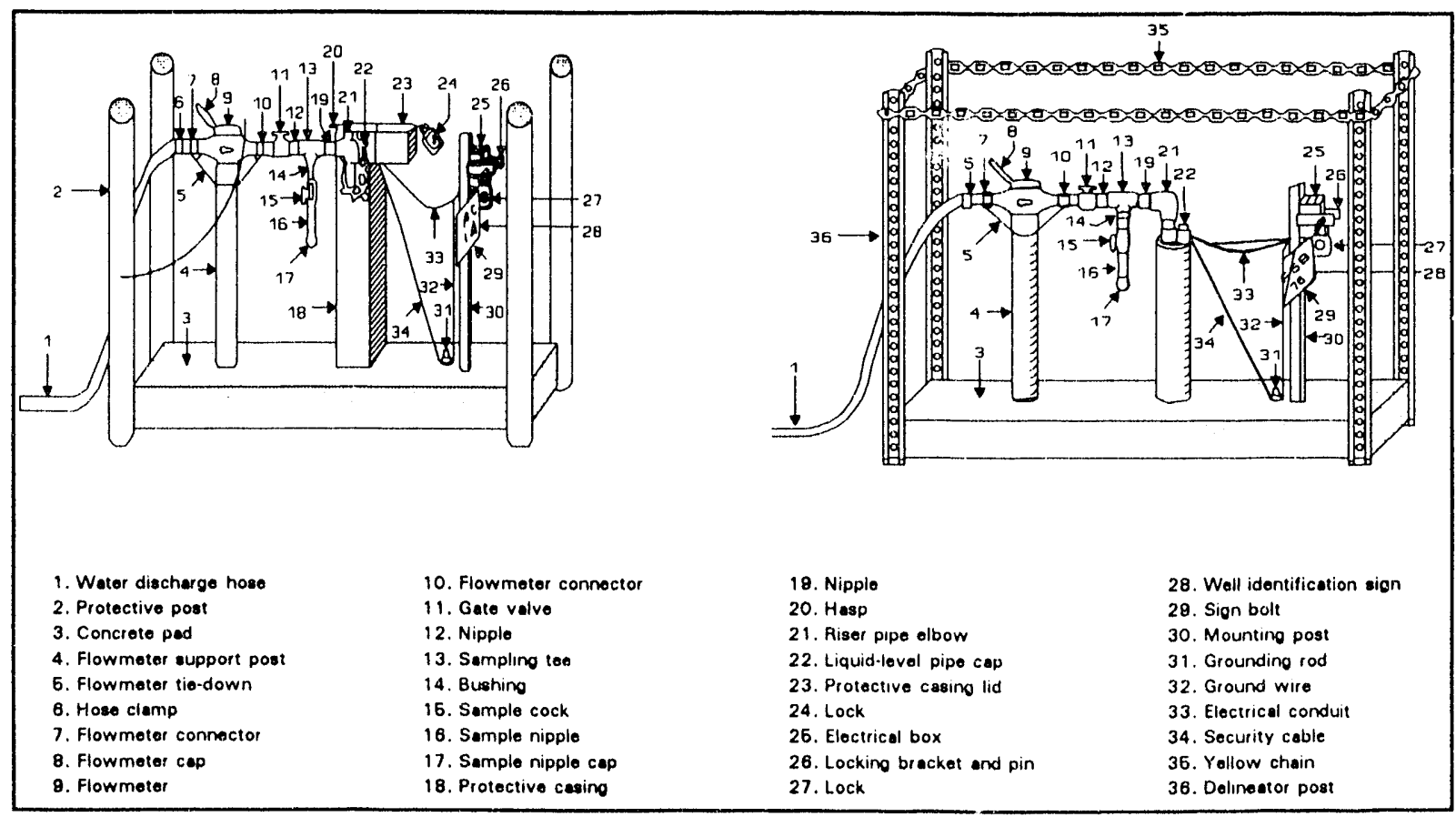

Figure 3. Two Types of Groundwater Monitoring Wellheads 
Among $\mathrm{Z}$ series wells, only wells $\mathrm{Z} 3$ and $\mathrm{Z} 9$ have casings large enough to allow sampling. All other $\mathrm{Z}$ wells have very narrow casings ( $3 / 4 ")$, making bailing impractical. Even if these other $\mathrm{Z}$ wells are scheduled, they are not sampled and water elevation measurements are not taken.

If a well runs dry during purging before a sample is collected and the well is revisited and sampled within 24 hours, this is considered one sampling event, yielding a single set of field and analytical data. For such wells, the volume purged before the well went dry during the first visitation is given in this section. The total amount of water purged from each well in one sampling event is given in the Analytical Results section.

Comments about dry wells, continuously pumping wells, and malfunctioning wells can be found in the Analytical Results section.

Table 5. Comments From the Field Data

\section{ABP Series}

\begin{tabular}{|c|c|c|}
\hline $\mathrm{ABP} 8 \mathrm{C}$ & $11 / 14 / 91$ & Dry after $2.4 \mathrm{gal}$ \\
\hline $\mathrm{ABP} \quad 8 \mathrm{D}$ & $11 / 15 / 91$ & $\begin{array}{l}\text { Unable to sample, wouldn't } \\
\text { pump water to surface }\end{array}$ \\
\hline
\end{tabular}

\begin{tabular}{|c|c|c|c|}
\hline \multicolumn{4}{|c|}{ AMB Series } \\
\hline $\mathrm{AMB}$ & 4 & $11 / 14 / 91$ & Well has been abandoned \\
\hline $\mathrm{AMB}$ & $4 \mathrm{~A}$ & $11 / 14 / 91$ & No discharge hose; surges \\
\hline AMB & $4 B$ & $11 / 14 / 91$ & No discharge hose \\
\hline AMB & $4 \mathrm{D}$ & $12 / 11 / 91$ & $\begin{array}{l}\text { No well identification sign, } \\
\text { handwritten identification } \\
\text { on electric box is } \\
\text { "AMB 4DR"; moderately } \\
\text { turbid; light brown }\end{array}$ \\
\hline AMB & 7 & $\begin{array}{l}11 / 14 / 91 \\
11 / 15 / 91\end{array}$ & $\begin{array}{l}\text { Dry after } 6.8 \mathrm{gal} \\
\text { Light turbidity; light beige }\end{array}$ \\
\hline A.MB & $7 \mathrm{~A}$ & $11 / 14 / 91$ & No discharge hose \\
\hline AMB & $7 \mathrm{~B}$ & $11 / 14 / 91$ & No discharge hose \\
\hline AMB & $10 \mathrm{~A}$ & $12 / 02 / 91$ & Dry after $81.0 \mathrm{gal}$ \\
\hline $\mathrm{AMB}$ & 10DD & $11 / 13 / 91$ & Strory sulfuric odor \\
\hline $\mathrm{AMB}$ & $11 \mathrm{~B}$ & $12 / 02 / 91$ & $\begin{array}{l}\text { Moderately turbid; light } \\
\text { brown }\end{array}$ \\
\hline AMB & $12 \mathrm{D}$ & $11 / 14 / 91$ & Light turbidity; light brown \\
\hline AMB & 13AR & $11 / 14 / 91$ & No discharge hose \\
\hline
\end{tabular}

\section{AOB Series}

AOB $1 \quad 11 / 13 / 91$ Light brown; highly aerated AUB $2 \quad 11 / 13 / 91$ Light brown; highly aerated

\section{Well Date $\underline{\text { Comments }}$ \\ AOB $3 \quad 11 / 14 / 91$ Dry after $8.8 \mathrm{gal}$}

\section{ARP Series}

ARP 1A 11/11/91 New fence with locked gate prevented access

$11 / 13 / 91$ No water in standpipe; aerated

ARP $3 \quad 12 / 06 / 91$ Weakly turbid; light brown
ASB 1A
$11 / 07 / 91$
$11 / 07 / 91$
ASB 2C
$12 / 06 / 91$
ASB 3C
$11 / 11 / 91$
$12 / 21 / 91$
ASB 6AA
$12 / 05 / 91$
ASB 6TA
$12 / 05 / 91$
ASB 10C
$12 / 06 / 91$

BG Series

\begin{tabular}{|c|c|c|}
\hline BG 91 & $10 / 21 / 91$ & $\begin{array}{l}\text { Dry after } \sim 14.2 \mathrm{gal} \\
\text { Turbidity yaried: brown }\end{array}$ \\
\hline & $\begin{array}{l}10 / 22 / 91 \\
10 / 21 / 91\end{array}$ & $\begin{array}{l}\text { Turbidity varied; brown } \\
\text { Dry after } \sim 17.7 \mathrm{gal}\end{array}$ \\
\hline BG 104 & $10 / 21 / 91$ & Dry after $\sim 5$ gal \\
\hline & $10 / 22 / 91$ & $\begin{array}{l}\text { No water in standpipe, } \\
\text { unable to sample; no } \\
\text { discharge hose; T-joint and } \\
\text { elbow leak }\end{array}$ \\
\hline BG 108 & $10 / 21 / 91$ & $\begin{array}{l}\text { Unable to sample, pump } \\
\text { would not start }\end{array}$ \\
\hline & $12 / 26 / 91$ & $\begin{array}{l}\text { Unable to sample, pump } \\
\text { would not start }\end{array}$ \\
\hline BG 110 & $10 / 21 / 91$ & Dry after -37 gal \\
\hline & $10 / 22 / 91$ & Weakly turbid; light brown \\
\hline & $10 / 21 / 91$ & Strongly turbid; brown \\
\hline & $10 / 16 / 91$ & No cap on well ca \\
\hline
\end{tabular}

BGO Series

$\begin{array}{llll}\text { BGO 1D } & 10 / 14 / 91 & \begin{array}{l}\text { Dry after }-7.3 \text { gal } \\ \text { Turbidity varied; clear to } \\ \text { light brown }\end{array} \\ \text { BGO 3D } & \begin{array}{l}10 / 15 / 91 \\ 10 / 15 / 91\end{array} & \begin{array}{l}\text { Dry after }-4 \text { gal } \\ \text { Turbidity varied; clear to } \\ \text { light brown }\end{array} \\ \text { BGO 4D } & 10 / 18 / 91 & \begin{array}{l}\text { Unable to sample, no access } \\ \text { BGO 5C }\end{array} 10 / 18 / 91 & \begin{array}{l}\text { Unable to sample, no access } \\ \text { BGO 5D }\end{array} \\ \text { BGO 6D } & 10 / 18 / 91 & \begin{array}{l}\text { Unable to sample, no access } \\ \text { Dry after }-5.1 \text { gal; well } \\ \text { pad covered with dirt }\end{array}\end{array}$


FIELD NOTES

Table 5. Comments From the Field Data (cont.)

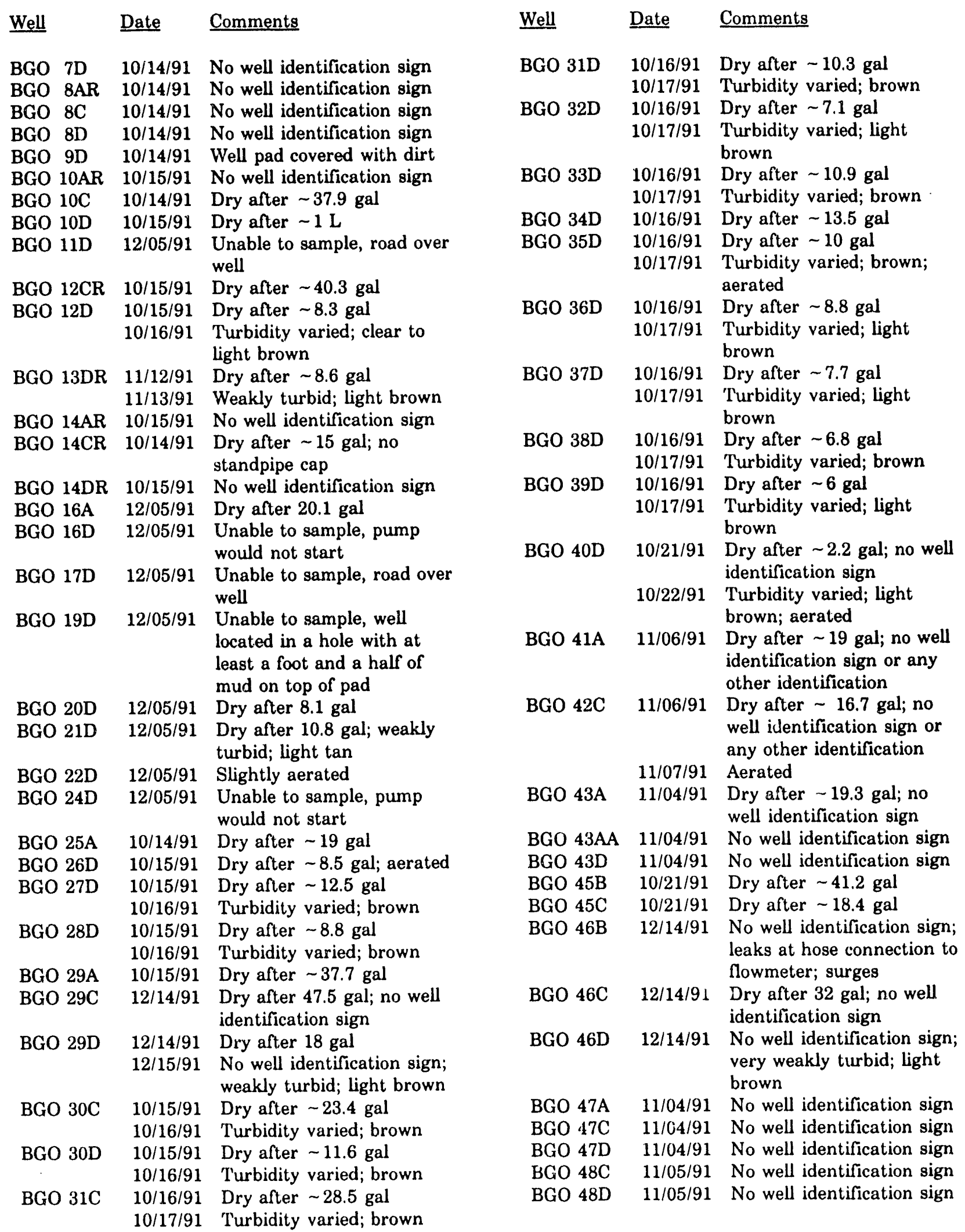


Table 5. Comments From the Field Data (cont.)

\begin{tabular}{|c|c|c|}
\hline Well & Date & Comments \\
\hline BGO 49A & $11 / 05 / 91$ & No well identification sign \\
\hline GO $49 \mathrm{C}$ & $11 / 05 / 91$ & No well identification sign \\
\hline & $11 / 05 / 91$ & $\begin{array}{l}\text { Dry afler } 16.3 \mathrm{gal} \text {; no well } \\
\text { identification sign }\end{array}$ \\
\hline & $11 / 06 / 91$ & $\begin{array}{l}\text { Very weakly turbid; very } \\
\text { light brown; aerated }\end{array}$ \\
\hline BGO 50A & $12 / 14 / 91$ & $\begin{array}{l}\text { Dry after pumping } 73 \mathrm{gal} \text {; } \\
\text { no well identification sign } \\
\text { and no handwritten identi- } \\
\text { fication }\end{array}$ \\
\hline $3 G 0$ 50C & $12 / 14 / 91$ & $\begin{array}{l}\text { Dry after pumping } 51.5 \text { gal; } \\
\text { no well identification sign } \\
\text { and no handwritten identi- } \\
\text { fication }\end{array}$ \\
\hline & $12 / 14 / 91$ & $\begin{array}{l}\text { No well identification sign; } \\
\text { weakly turbid; light brown; } \\
\text { surges }\end{array}$ \\
\hline
\end{tabular}

BGX Series

\begin{tabular}{|c|c|c|c|}
\hline BGX & $1 \mathrm{~A}$ & 10/21/91 & $\begin{array}{l}\text { Dry after } \sim 9.7 \mathrm{gal} \text {; no well } \\
\text { identification sign }\end{array}$ \\
\hline BGX & $1 \mathrm{C}$ & $10 / 21 / 91$ & $\begin{array}{l}\text { Dry after }-15 \text { gal; no well } \\
\text { identification sign }\end{array}$ \\
\hline \multirow[t]{2}{*}{ BGX } & 1D & $10 / 21 / 91$ & $\begin{array}{l}\text { Dry after } \sim 6 \text { gal; no well } \\
\text { identification sign }\end{array}$ \\
\hline & & $10 / 22 / 91$ & $\begin{array}{l}\text { Turbidity varied; light } \\
\text { brown }\end{array}$ \\
\hline $3 G X$ & $2 B$ & $10 / 17 / 91$ & $\begin{array}{l}\text { Dry after } \sim 47.6 \text { gal; no } \\
\text { well identification sign }\end{array}$ \\
\hline BGX & 2D & $10 / 17 / 91$ & $\begin{array}{l}\text { Dry after } 21 \text { gal; no well } \\
\text { identification sign }\end{array}$ \\
\hline G & 3D & $10 / 17 / 91$ & No well identification sign \\
\hline BGX & $4 \mathrm{~A}$ & $10 / 13 / 91$ & No well identification sign \\
\hline BGX & $4 \mathrm{C}$ & $10 / 18 / 91$ & No well identification sign \\
\hline BGX & $4 \mathrm{D}$ & $10 / 18 / 91$ & No well identification sign \\
\hline BG? & $5 \mathrm{D}$ & $10 / 18 / 91$ & No well identification sign \\
\hline & $6 \mathrm{D}$ & $10 / 17 / 91$ & $\begin{array}{l}\text { No well identification sign; } \\
\text { no standpipe cap }\end{array}$ \\
\hline & 7D & $11 / 06 / 91$ & No well identification sign \\
\hline & & $11 / 06 / 91$ & $\begin{array}{l}\text { No well identification sign } \\
\text { or any other identification }\end{array}$ \\
\hline & & $10 / 18 / 91$ & No well identification sign \\
\hline \multirow{2}{*}{\multicolumn{2}{|c|}{ BGX 10D }} & $10 / 17 / 91$ & Dry after $-4.1 \mathrm{gal}$ \\
\hline & & & $\begin{array}{l}\text { Turbidity varied; light } \\
\text { brown; aerated }\end{array}$ \\
\hline & & & No well identification sign \\
\hline & & $10 / 17 / 91$ & $\begin{array}{l}\text { Dry after } \sim 8.5 \text { gal; no well } \\
\text { identification sign }\end{array}$ \\
\hline
\end{tabular}

\section{BRD Series}

$\begin{array}{llll}\text { Well } & & \text { Date } & \text { Comments } \\ \text { BRD } & 2 & 11 / 12 / 91 & \text { Surges; turbid } \\ \text { BRD } & \text { 5D } & 11 / 12 / 91 & \text { Surges slightly; turbid }\end{array}$

\section{BRR Series}

$\begin{array}{llll}\text { BRR 1D } & 11 / 11 / 91 & \text { Dry after } 8.8 \mathrm{gal} \\ \text { BRR } & \text { 2D } & 11 / 11 / 91 & \text { Dry after } 11.5 \mathrm{gal} \\ \text { BRR } & 3 \mathrm{D} & 11 / 11 / 91 & \text { Dry after 10.0 gal } \\ \text { BRR } & \text { 4D } & 11 / 11 / 91 & \text { Dry after 10.2 gal } \\ & & 11 / 12 / 91 & \text { Turbid; aerated } \\ \text { BRR } & 5 D & 11 / 11 / 91 & \text { Dry after } 7.5 \mathrm{gal} \\ & & 11 / 12 / 91 & \text { Slight turbidity }\end{array}$

CBR Series
CBR ID 11/11/91 Surges badly
CBR 3D 11/11/91 Discharge hose split at meter

\section{CCB Series \\ CCB $211 / 27 / 91$ Discharge hose broken, about 3 feet left; sample valve handle broken off; strongly turbid; red color \\ CCB $3 \quad 11 / 27 / 91$ Very weakly turbid; light pink \\ CCB 4 11/27/91 Flowmeter stopped work- ing, estimated volume purged; very weakly turbid; very light pink}

\section{CDB Series}

$\begin{array}{ccl}\text { CDB 1 } & 12 / 11 / 91 & \begin{array}{l}\text { Dry after 15 gal; leaks at } \\ \text { gate valve and T-joint; } \\ \text { difficult to read flowmeter } \\ \text { due to condensation under } \\ \text { glass cover } \\ \text { Dry after 11 gal; small } \\ \text { amount of fine sand }\end{array} \\ \text { CDB 2 } & 12 / 11 / 91\end{array}$

CMP Series

$\begin{array}{lll}\text { CMP 8B } & 11 / 26 / 91 & \text { No discharge hose } \\ \text { CMP 9B } & 11 / 26 / 91 & \text { Flowmeter sticks } \\ \text { CMP 11 } & 12 / 02 / 91 & \text { Dry after 20.0 gal } \\ \text { CMP 12 } & 12 / 02 / 91 & \text { Dry after 21.2 gal } \\ \text { CMP 13 } & 12 / 02 / 91 & \text { Dry after 8.0 gal } \\ \text { CMP 15B } & 12 / 02 / 91 & \text { Dry after 22.5 gal } \\ \text { CMP 15C } & 12 / 02 / 91 & \text { Dry after 23.0 gal }\end{array}$

BRD $1 \quad 11 / 12 / 91$ Surges slightly 
FIELD NOTES

Table 5. Comments From the Field Data (cont.)

\begin{tabular}{|c|c|c|c|}
\hline Well & & Date & Comments \\
\hline \multicolumn{4}{|c|}{ CSA Series } \\
\hline CSA & 1 & $11 / 20 / 91$ & $\begin{array}{l}\text { Surges badly after third } \\
\text { well volume; very weakly } \\
\text { turbid; light pink }\end{array}$ \\
\hline CSA & 2 & $11 / 20 / 91$ & $\begin{array}{l}\text { Very weakly turbid; light } \\
\text { pink }\end{array}$ \\
\hline CSA & 3 & $11 / 20 / 91$ & $\begin{array}{l}\text { Very weakly turbid; very } \\
\text { pale pink }\end{array}$ \\
\hline \multicolumn{4}{|c|}{ CSB Series } \\
\hline CSB & $1 \mathrm{~A}$ & $12 / 10 / 91$ & Dry after $10 \mathrm{gal}$ \\
\hline CSB & $3 \mathrm{~A}$ & $\begin{array}{l}12 / 10 / 91 \\
12 / 11 / 91\end{array}$ & $\begin{array}{l}\text { Dry after } 18 \text { gal } \\
\text { Weakly turbid; light } \\
\text { pinkish-brown }\end{array}$ \\
\hline & $4 \mathrm{~A}$ & $12 / 11 / 91$ & Strongly turbid; red color \\
\hline C & $5 \mathrm{~A}$ & $\begin{array}{l}12 / 10 / 91 \\
12 / 11 / 91\end{array}$ & $\begin{array}{l}\text { Dry after } 9 \mathrm{gal} \\
\text { Weakly turbid; pink color }\end{array}$ \\
\hline
\end{tabular}

CSD Series
CSD 1D 11/08/91 No well identification sign; light turbidity
CSD 2D 11/08/91 Dry after 1.5 gal; no water in standpipe
CSD 4D 11/08/91 Dry after $16.4 \mathrm{ggl}$
CSD 8D 11/08/91 No well identíication sign
CSD 9D 11/08/91 No well identification sign
CSD 10D 11/08/91 No well identification sign
CSD 11D 11/08/91 Dry after $14.4 \mathrm{gal}$

CSO Series

CSO $1 \quad 11 / 26 / 91$ Very weakly turbid; dingy gray

\section{CSR Serie日}

$\begin{array}{llll}\text { CSR } 2 & 12 / 26 / 91 & \begin{array}{l}\text { Dry after } 8 \text { gal; moderately } \\ \text { turbid; orange }\end{array} \\ \text { CSR } 3 & 12 / 26 / 91 & \begin{array}{l}\text { Dry after } 30 \text { gal; weakly } \\ \text { turbid; orange }\end{array}\end{array}$

\section{DBP Series}
DBP 4
11/27/91 Standing water surrounds two sides of well pad

$\begin{array}{lrl}\text { Well } & \text { Date } & \text { Comments } \\ \text { DCB Series } & & \\ \text { DCB 6 } & 12 / 03 / 91 & \begin{array}{l}\text { No well identification sign; } \\ \text { no discharge hose; weakly } \\ \text { turbid; very light brown; } \\ \text { surges }\end{array} \\ \text { DCB } 7 & 12 / 03 / 91 & \begin{array}{l}\text { No well identification sign; } \\ \text { no discharge hose }\end{array} \\ \text { DCB 8 } & 11 / 27 / 91 & \begin{array}{l}\text { No well identification sign } \\ \text { DCB 9 }\end{array} \\ \text { DCB 11 } & 11 / 27 / 91 & \text { No well identification sign } \\ \text { DCB 12 } & 11 / 27 / 91 & \begin{array}{l}\text { Dry after }-9.7 \text { gal } \\ \text { DCB 13 }\end{array} \\ 11 / 27 / 91 & \begin{array}{l}\text { No well identification sign } \\ \text { Dry after } 4.2 \text { gal; } \\ \text { moderately turbid; brown }\end{array}\end{array}$

DOB Series

DOB $2 \quad 12 / 03 / 91 \quad$ Oil-like film on sample surface

\section{F Series}

\begin{tabular}{|c|c|c|c|}
\hline $\mathbf{F}$ & 14 & $12 / 22 / 91$ & $\begin{array}{l}\text { Strongly turbid; yellow- } \\
\text { brown }\end{array}$ \\
\hline $\mathbf{F}$ & 15 & $12 / 22 / 91$ & Moderately turbid; brown \\
\hline $\mathbf{F}$ & 16 & $12 / 22 / 91$ & $\begin{array}{l}\text { Strongly turbid; orange- } \\
\text { brown }\end{array}$ \\
\hline $\mathbf{F}$ & 17 & $12 / 22 / 91$ & $\begin{array}{l}\text { Dry after } 2.4 \text { gal; weakly } \\
\text { turbid; light brown }\end{array}$ \\
\hline & 25 & $12 / 22 / 91$ & $\begin{array}{l}\text { Moderately turbid; light } \\
\text { brown }\end{array}$ \\
\hline
\end{tabular}

FAC Series

\begin{tabular}{|c|c|c|}
\hline \multirow[t]{2}{*}{ FAC 3} & $11 / 06 / 91$ & Dry after $4.5 \mathrm{gal}$ \\
\hline & $11 / 07 / 91$ & Extremely turbid \\
\hline FAC 4 & $11 / 07 / 91$ & $\begin{array}{l}\text { Sample nipple will not shut } \\
\text { off when well is throttled } \\
\text { for sample }\end{array}$ \\
\hline \multirow[t]{2}{*}{ FAC 5} & $11 / 06 / 91$ & Dry after $14.75 \mathrm{gal}$ \\
\hline & $11 / 07 / 91$ & Moderately turbid \\
\hline \multirow[t]{2}{*}{ FAC 6} & $11 / 06 / 91$ & Dry after $6.25 \mathrm{gal}$ \\
\hline & $11 / 07 / 91$ & Moderately turbid \\
\hline $\mathrm{AC}$ & $11 / 06 / 91$ & Dry after $12.0 \mathrm{gal}$ \\
\hline 4 & $11 / 06 / 91$ & Dry after $35.5 \mathrm{gal}$ \\
\hline
\end{tabular}

FAl Series

FAL $1 \quad 11 / 13 / 91$ Dry after $\sim 9$ gal

FAL $211 / 13 / 91$ Dry after $\sim 4$ gal

11/14/91 Turbidity varied; light brown; T-joint leaks 
Table 5. Comments From the Field Data (cont.)

\begin{tabular}{|c|c|c|}
\hline Well & Date & Comments \\
\hline \multicolumn{3}{|c|}{ FBP Series } \\
\hline FBP $2 A$ & $12 / 14 / 91$ & Leaks at $\mathrm{T}$-joint \\
\hline FBP 4 & $12 / 14 / 91$ & Sample valve does not work \\
\hline \multicolumn{3}{|c|}{ FCA Series } \\
\hline FCA 2C & $11 / 13 / 91$ & Dry after $\sim 0.4 \mathrm{gal}$ \\
\hline & $11 / 14 / 91$ & Turbidity varied; brown \\
\hline FCA 2D & $\begin{array}{l}11 / 13 / 91 \\
11 / 14 / 91\end{array}$ & $\begin{array}{l}\text { Dry after } \sim 5.2 \mathrm{gal} \\
\text { Turbidity varied; brown }\end{array}$ \\
\hline FCA 9B & $11 / 13 / 91$ & No well identification sign \\
\hline FCA $9 \mathrm{C}$ & $11 / 13 / 91$ & $\begin{array}{l}\text { Unable to sample, trash } \\
\left(\sim 2^{\prime}\right) \text { in well prevented } \\
\text { access }\end{array}$ \\
\hline FCA 9D & $11 / 14 / 81$ & Turbid; orange \\
\hline FCA $10 \mathrm{~A}$ & $11 / 14 / 91$ & $\begin{array}{l}\text { No well identification sign; } \\
\text { turbid; orange }\end{array}$ \\
\hline FCA 10B & $11 / 13 / 91$ & No well identification sign \\
\hline FCA 10D & $\begin{array}{l}11 / 14 / 91 \\
11 / 15 / 91\end{array}$ & $\begin{array}{l}\text { Dry after } \sim 0.8 \mathrm{gal} \\
\text { Turbid; orange }\end{array}$ \\
\hline FCA $16 A$ & $11 / 15 / 91$ & $\begin{array}{l}\text { Dry after } \sim 10.5 \text { gal; turbid } \\
\text { orange }\end{array}$ \\
\hline FCA 16B & $11 / 14 / 91$ & No well identification sign \\
\hline FCA $16 \mathrm{D}$ & $11 / 13 / 91$ & $\begin{array}{l}\text { No well identification sign; } \\
\text { construction prevented } \\
\text { access, unable to sample }\end{array}$ \\
\hline & 11/14/91 & No well identification sign \\
\hline FCA 1 & $\begin{array}{l}11 / 13 / 91 \\
11 / 14 / 91\end{array}$ & $\begin{array}{l}\text { Dry after } \sim 5.4 \mathrm{gal} \\
\text { No well identification sign; } \\
\text { no discharge hose; aerated }\end{array}$ \\
\hline
\end{tabular}

FCB Series

\begin{tabular}{|c|c|c|}
\hline $\mathrm{CB} 4$ & $\begin{array}{l}11 / 13 / 91 \\
11 / 14 / 91\end{array}$ & $\begin{array}{l}\text { Dry after } \sim 14.4 \mathrm{gal} \\
\text { Turbidity varied; brown; }\end{array}$ \\
\hline & & $\begin{array}{l}\text { Drated after } 3.8 \mathrm{gal} \\
\text { Dry }\end{array}$ \\
\hline & $11 / 07 / 91$ & Dry after $1.8 \mathrm{gal}$ \\
\hline
\end{tabular}

FET Series

FET 1D $12 / 02 / 91 \quad$ Dry after $\sim 8.3 \mathrm{gal}$

\section{FNB Series}

FNB $2 \quad 10 / 31 / 91$ Weakly turbid; light brown

\section{FSB Series}

$\begin{array}{lll}\text { FSB 1TA } & 10 / 14 / 91 & \begin{array}{l}\text { No standpipe; no flowmeter, } \\ \text { estimated volume purged }\end{array} \\ \text { FSB 70C } & 10 / 15 / 91 & \text { Surges badly } \\ \text { FSB 70D } & 10 / 14 / 91 & \text { Dry after 7.5 gal }\end{array}$

$\begin{array}{lll}\text { Well } & \text { Date } & \text { Comments } \\ & & \\ \text { FSB 78C } & 10 / 14 / 91 & \text { Dry after 24.0 gal } \\ \text { FSB 88D } & 10 / 14 / 91 & \text { Dry after 8.3 gal } \\ \text { FSB 89C } & 10 / 15 / 91 & \text { Surges } \\ \text { FSB 89D } & 10 / 15 / 91 & \text { Surges } \\ \text { FSB 91C } & 10 / 16 / 91 & \text { Dry after 20.8 gal } \\ \text { FSB 93D } & 10 / 16 / 91 & \text { Dry after 6.4 gal } \\ \text { FSB 94C } & 10 / 16 / 91 & \text { Dry after 34.0 gal } \\ \text { FSB 97C } & 10 / 16 / 91 & \text { Dry after 30.2 gal } \\ \text { FSB 97D } & 10 / 16 / 91 & \text { Dry after 3.8 gal } \\ \text { FSB 98D } & 10 / 23 / 91 & \text { Dry after 8.8 gal } \\ \text { FSB 99D } & 10 / 16 / 91 & \text { Surges } \\ \text { FSB100A } & 10 / 16 / 91 & \text { No pad; surges badly } \\ \text { FSB104C } & 12 / 09 / 91 & \text { Well pad covered viitǐ } ~ \\ & & \text { foot of sand; surges } \\ \text { FSB104D } & 12 / 09 / 91 & \text { Well pad covered with } ~ \\ & & \text { foot of sand } \\ \text { FSB106D } & 10 / 21 / 91 & \text { Dry after 2.3 gal } \\ \text { FSB107C } & 10 / 22 / 91 & \text { Surges badly } \\ \text { FSB107D } & 10 / 22 / 91 & \text { Surges } \\ \text { FSB108D } & 10 / 21 / 91 & \text { Dry after 8.7 gal } \\ \text { FSB109D } & 10 / 21 / 91 & \text { Lry after after 9.5 gal } \\ \text { FSB110C } & 10 / 15 / 91 & \text { Surges } \\ \text { FSB111D } & 10 / 18 / 91 & \text { Surges badly } \\ \text { FSB112A } & 10 / 21 / 91 & \text { Well pad covered with sand } \\ & & \text { and debris } \\ \text { FSB112C } & 10 / 21 / 91 & \text { Surges badly; well pad } \\ & & \text { covered with sand } \\ \text { FSB112D } & 10 / 21 / 91 & \text { Throttle valve split and } \\ & & \text { spraying } \\ \text { FSB113C } & 10 / 23 / 91 & \text { Dry after 26.9 gal } \\ \text { FSB114A } & 10 / 18 / 91 & \text { Well pad covered with sand, } \\ & & \text { gravel and fallen tree } \\ \text { FSB114C } & 10 / 18 / 91 & \text { Well pad covered with sand } \\ & & \text { and gravel } \\ \text { FSB114D } & 10 / 18 / 91 & \text { Well pad covered with sand } \\ \text { FSB115C } & 10 / 21 / 91 & \text { Dry after 11.6 gal } \\ \text { FSB115D } & 10 / 22 / 91 & \text { Surges } \\ \text { FSB116C } & 10 / 22 / 91 & \text { Surges } \\ \text { FSB116D } & 10 / 21 / 91 & \text { Dry after } 2.3 \text { gal } \\ \text { FSB119D } & 10 / 22 / 91 & \text { Muddy; surges } \\ \text { FSB120D } & 10 / 21 / 91 & \text { Dry after 6.5 gal } \\ \text { FSB122C } & 12 / 09 / 91 & \text { Surges } \\ \text { FSB122D } & 12 / 09 / 91 & \text { Sprays from discharge hose } \\ & & \text { connection } \\ & & \end{array}$

\section{FSS Series}

\begin{tabular}{|c|c|c|}
\hline \multirow[t]{2}{*}{ FSS 1D } & $11 / 12 / 91$ & Dry after $\sim 7.9 \mathrm{gal}$ \\
\hline & $11 / 13 / 91$ & $\begin{array}{l}\text { Turbidity varied; brown; } \\
\text { aerated }\end{array}$ \\
\hline \multirow[t]{2}{*}{ FSS } & $11 / 12 / 91$ & Dry after $\sim 10.8$ gal \\
\hline & $11 / 13 / 91$ & Weakly turbid; light brown \\
\hline 3D & $11 / 12 / 4)$ & Dry after $\sim 10 \mathrm{gal}$ \\
\hline
\end{tabular}


FIELD NOTES

Table 5. Comments From the Field Data (cont.)

\begin{tabular}{|c|c|c|c|}
\hline \multicolumn{2}{|c|}{ Well } & Date & Comments \\
\hline \multicolumn{2}{|c|}{ FSS 4D } & $\begin{array}{l}11 / 12 / 91 \\
11 / 13 / 91\end{array}$ & $\begin{array}{l}\text { Dry after } \sim 11.4 \mathrm{gal} \\
\text { Turbidity varied; brown }\end{array}$ \\
\hline \multicolumn{4}{|c|}{ GBW Series } \\
\hline \multicolumn{2}{|c|}{ GBW } & $12 / 07 / 91$ & Dry after $15 \mathrm{gal}$ \\
\hline \multicolumn{4}{|c|}{ H Series } \\
\hline $\mathbf{H}$ & 14 & $12 / 22 / 91$ & $\begin{array}{l}\text { Moderately turbid; light } \\
\text { brown; sand }\end{array}$ \\
\hline $\mathrm{H}$ & 16 & $12 / 22 / 91$ & $\begin{array}{l}\text { Dry after } 8 \mathrm{~L} \text {; weakly } \\
\text { turbid; brown }\end{array}$ \\
\hline $\mathbf{H}$ & 17 & $12 / 22 / 91$ & $\begin{array}{l}\text { Dry after } \sim 1.1 \mathrm{~L} ; \text { strongly } \\
\text { turbid; orange; sand }\end{array}$ \\
\hline $\mathbf{H}$ & $18 \mathrm{~A}$ & $12 / 22 / 91$ & $\begin{array}{l}\text { Dry after } 4.5 \text { gal; well } \\
\text { wrongly identified as } \\
\text { "H 18"; moderately turbid; } \\
\text { light brown }\end{array}$ \\
\hline
\end{tabular}

\section{HAC Series}

$\begin{array}{lll}\text { HAC } 2 & 12 / 02 / 91 & \begin{array}{l}\text { Dry after }-5.2 \text { gal; } \\ \text { turbidity varied; light } \\ \text { brown }\end{array} \\ \text { HAC } 3 & 12 / 02 / 91 & \begin{array}{l}\text { Dry after } \sim 7.9 \text { gal; aerated } \\ \text { Hel }\end{array}\end{array}$

\section{HAP Serieo}

\begin{tabular}{|c|c|c|c|}
\hline HAP & 1 & $11 / 12 / 91$ & No standpipe cap \\
\hline \multicolumn{4}{|c|}{ HCA Series } \\
\hline HCA & 1 & $12 / 02 / 91$ & Dry after $\sim 14.8 \mathrm{gal}$ \\
\hline HCA & 2 & $12 / 02 / 91$ & $\begin{array}{l}\text { Very weakly turbid; very } \\
\text { light browı; aerated }\end{array}$ \\
\hline HCA & 3 & $12 / 02 / 91$ & Dry after $\sim 11.7 \mathrm{gal}$ \\
\hline $\mathrm{HCA}$ & 4 & $12 / 02 / 91$ & Dry after $\sim 19.8 \mathrm{gal}$ \\
\hline \multicolumn{4}{|c|}{ HCB Series } \\
\hline $\mathrm{HCB}$ & 1 & $11 / 12 / 91$ & $\begin{array}{l}\text { Standing water surrounds } \\
\text { well pad }\end{array}$ \\
\hline $\mathrm{HCB}$ & 2 & $11 / 12 / 91$ & $\begin{array}{l}\text { Standing water on two } \\
\text { sides of well pad }\end{array}$ \\
\hline
\end{tabular}

\section{HET Series}

\begin{tabular}{|c|c|c|}
\hline HET 1D & $12 / 02 / 91$ & Dry after $\sim 14.4 \mathrm{gal}$ \\
\hline HET 2D & $12 / 02 / 91$ & Dry after $\sim 9.2 \mathrm{gal}$ \\
\hline HET 3D & $12 / 02 / 91$ & Dry after $-10.4 \mathrm{gal}$ \\
\hline HE'T 4D & $\begin{array}{l}12 / 02 / 91 \\
12 / 03 / 91\end{array}$ & $\begin{array}{l}\text { Dry aftor } \sim 13.6 \mathrm{gal} \\
\text { Very weakly tıarbid; very } \\
\text { light brown }\end{array}$ \\
\hline
\end{tabular}

Well Date Cornments

HMD Series

HMD $1 D \quad 10 / 21 / 91$ Dry after $\sim 5.5$ gal; no well identification sign

10/22/91 Turbidity varied; light brown

HMD 2D 10/22/91 No well identification sign

HMD 3D 10/22/91 No well identification sign

HMD 4D 10/21/91 Dry after $\sim 7.4 \mathrm{gal}$

10/22/91 Turbidity varied; light brown

HR3 Series

HR3 $11 \quad 11 / 22 / 91$ Weakly turbid; light brown

HRs Series

HR8 14 11/22/91 Unable to sample, well locat $a x i$ insicle radiologically controlled area (RCA), no entry allowed at this time

HSB Series

FiSB 1TB 10i01/91 No well identification sign; no flowmeter; estimated volume purged; no standpipe, unable to measure water level

HSB $6610,01 / 91$ Weakly turbid; very light brown

HSB 68 10/01/91 Turbidity varied; very light brown

HSB 68B 10/01/91 Dry after $\sim 63 \mathrm{gal}$

10/02/91 Sample valve does not shut off water flow; discharge hose leaks; turbidity varied; light brown; aerated

HSB 68C 10/01/91 Dry after $\sim 19.8 \mathrm{gal}$

HSB 70C 10/01/91 Dry after $\sim 26$ gal

HSB 71C 10/07/91 Dry after $\sim 21.2$ gal; aerated

HSB 83A 10/03/91 Well pad covered with dirt

HSB 83B 10/03/91 Well pad covered with dirt

HSB 83C 10/03/91 Well pad covered with dirt

HSB 83D 10/03/91 Well pad covered with dirt

HSB 84C 10/02/91 Dry after $-14.5 \mathrm{gal}$

HSB 85B 10/01/91 Dry after $-47.1 \mathrm{gal}$

HSB102D 10/03/91 Dry after $\sim 5.7$ gal; weakly turbid; light brown

HSB110D 10/07/91 Weakly turbid; light brown

HSB112E 10/07/91 Dry after $\sim 2.3 \mathrm{gal}$

10/08/91 Turbidicy varied; light brown 
Table 5. Comments From the Field Data (cont.)

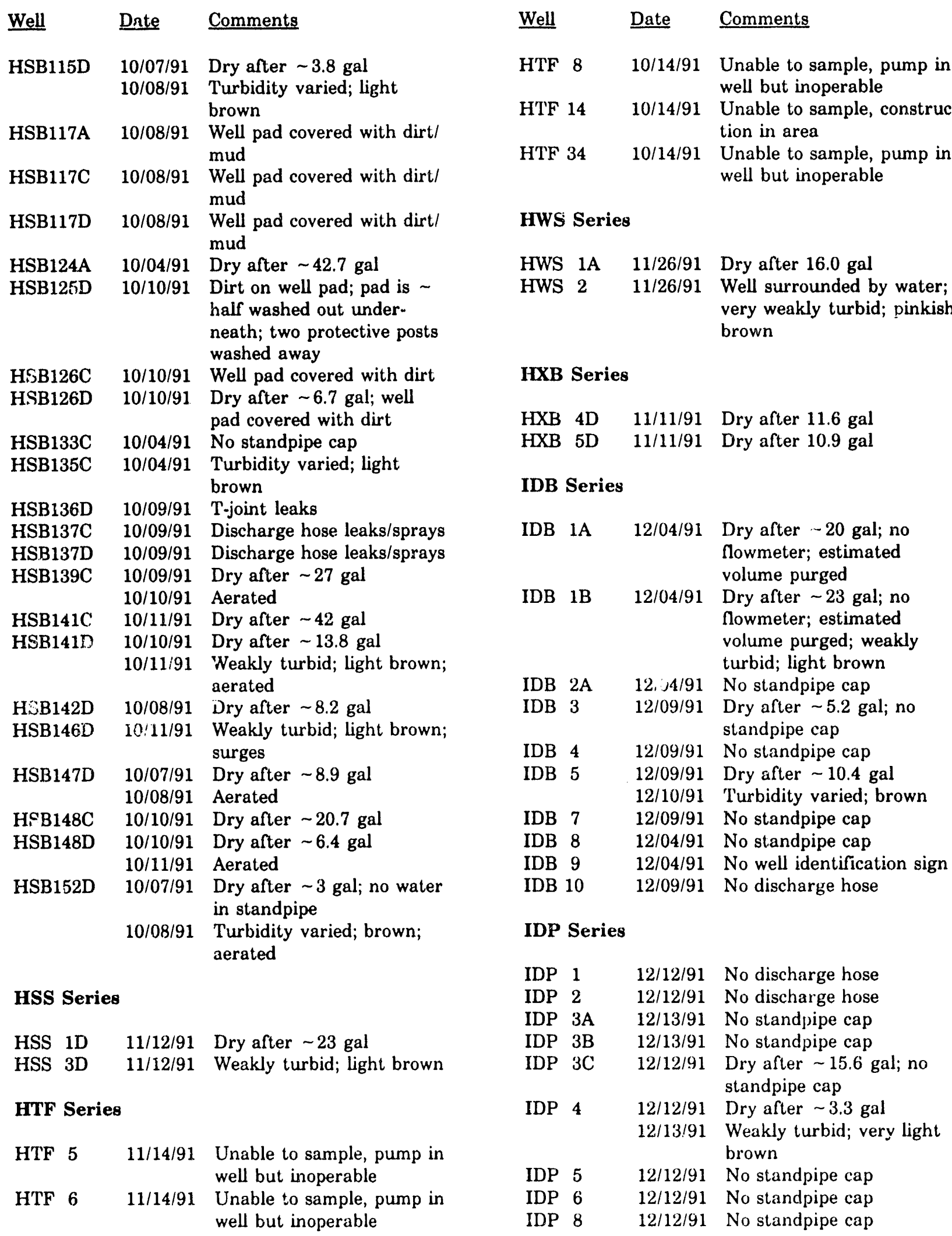


Table 5. Comments From the Field Data (cont.)

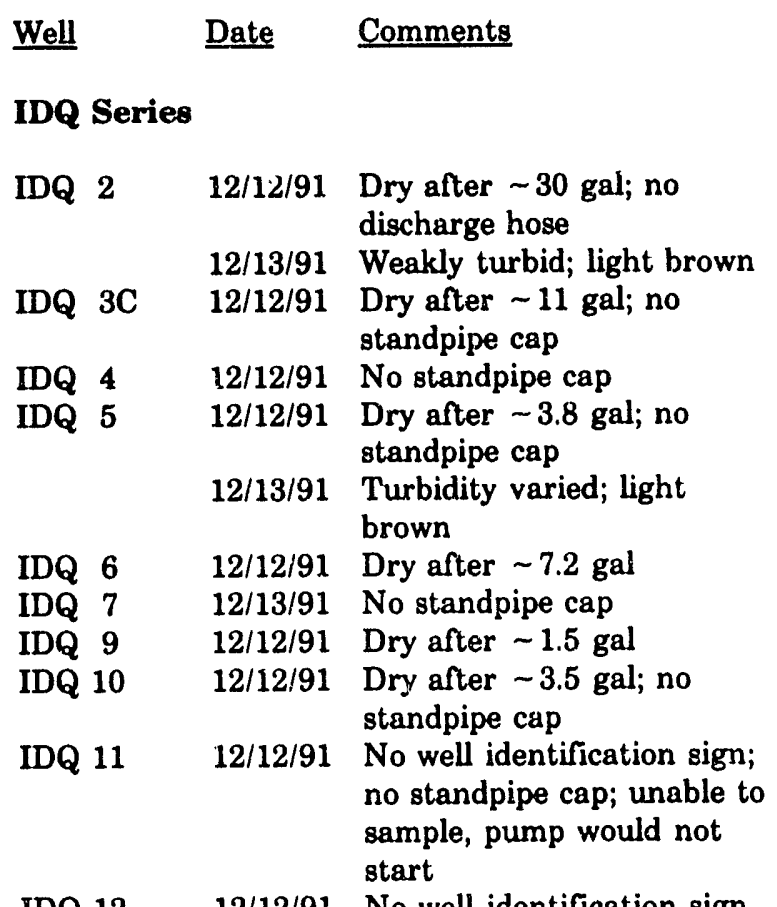

IDQ $1212 / 12 / 91$ No well identification sign

\section{KAB Series}

\begin{tabular}{|c|c|c|c|}
\hline KAB & 1 & $11 / 21 / 91$ & Dry after $\sim 20 \mathrm{gal}$ \\
\hline KAB & 2 & $11 / 21 / 91$ & No discharge hose \\
\hline KAB & 3 & $11 / 21 / 91$ & Discharge hose leaks/sprays \\
\hline $\mathrm{KAB}$ & 4 & $11 / 21 / 91$ & Discharge hose leaks/sprays \\
\hline \multicolumn{4}{|c|}{ KAC Series } \\
\hline $\mathrm{KAC}$ & 1 & $11 / 18 / 91$ & $\begin{array}{l}\text { Weakly turbid; very light } \\
\text { brown }\end{array}$ \\
\hline $\mathrm{KA}$ & 2 & $11 / 18 / 91$ & Weakly turbid; light brown \\
\hline \multirow[t]{2}{*}{$\mathrm{KAC}$} & 6 & $11 / 18 / 91$ & Dry after $\sim 8.2 \mathrm{gal}$ \\
\hline & & $11 / 19 / 91$ & $\begin{array}{l}\text { Weakly turbid; very light } \\
\text { brown }\end{array}$ \\
\hline \multirow[t]{2}{*}{$\mathrm{KAC}$} & 7 & $11 / 18 / 91$ & Dry after $8.1 \mathrm{gal}$ \\
\hline & & $11 / 19 / 91$ & $\begin{array}{l}\text { Turbidity varied; light } \\
\text { brown }\end{array}$ \\
\hline
\end{tabular}

KCB Serie日

$\begin{array}{llll}\text { KCB } 2 & 11 / 20 / 91 & \begin{array}{l}\text { Very weakly turbid; very } \\ \text { light brown }\end{array} \\ \text { KCB } 4 & 11 / 20 / 91 & \begin{array}{l}\text { Unable to sample, dirt road } \\ \text { cut through well location }\end{array}\end{array}$

Well Date Comments

\section{KDB Series}

$\begin{array}{lll}\text { KDB } 1 & 10 / 22 / 91 & \begin{array}{l}\text { Dry after 17 gal; no } \\ \text { discharge hose }\end{array} \\ & 11 / 22 / 91 & \begin{array}{l}\text { Dry after 18 gal; no } \\ \text { discharge hose }\end{array} \\ & 12 / 17 / 91 & \begin{array}{l}\text { Dry after } 18 \text { gal; no } \\ \text { discharge hose }\end{array} \\ \text { KDB } 2 & 10 / 22 / 91 & \begin{array}{l}\text { Sprays from T-joint; no } \\ \text { discharge hose }\end{array} \\ & 11 / 22 / 91 & \begin{array}{l}\text { T-joint leaks; no discharge } \\ \text { hose }\end{array} \\ & 12 / 17 / 91 & \begin{array}{l}\text { T-joint leaks; no discharge } \\ \text { hose }\end{array} \\ \text { KDB 3 } & 10 / 22 / 91 & \begin{array}{l}\text { Dry after 20 gal; weakly } \\ \text { turbid; light brown }\end{array} \\ & 11 / 22 / 91 & \begin{array}{l}\text { Dry after 20 gal; T-joint } \\ \text { leaks; weakly turbid; light } \\ \text { brown } \\ \text { Dry after 20 gal; T-joint } \\ \text { leaks; very weakly turbid; } \\ \text { light brown }\end{array} \\ & 12 / 17 / 91\end{array}$

KDT Series
KDT 1D 12/17/91 Dry after 12 gal; no discharge hose; turbidity varied while sampling; light brown

\section{KRB Series}

KRB 16D 12/10/91 No well identification sign, well not marked

KRB 17D 12/10/91 No well identification sign

KRB 18D 12/10/91 Dry after 12 gal

12/11/91 No well identification sign; moderately turbid; light brown

KRB 19D 12/10/91 Dry after 9 gal

12/11/91 No well identification sign; very weakly turbid; light brown

KRP Series

$\begin{array}{llll}\text { KRP } & 1 & 11 / 20 / 91 & \text { Surges } \\ \text { KRP } & 3 & 11 / 20 / 91 & \text { Surges }\end{array}$ 
Table 5. Comments From the Field Data (cont.)

Well Date Comments

KSB Series

K 301P 11/20/91 Heavily turbid; dark brown

12/13/91 Moderately turbid; light brown

KSB $1 \quad 11 / 19 / 91$ Moderately turbid; light brown

12/13/91 Weakly turbid; light brown

KSB 4A 11/19/91 Moderately turbid; light brown

12/13/91 Moderately turbid; brown

\section{KSS Serie日}

KSS 1D 11/18/91 Weakly turbid; light brown KSS 2D 11/18/91 Flowmeter not working, estimated volume purged

\section{LAW Series}

LAW 1D 12/14/91 No well identification sign; $\mathrm{T}$-joint leaks; no discharge hose; odor

LAW 2B 12/11/91 No well identification sign; missing discharge hose, sample nipple, and coupling

LAW 3B 12/14/91 No well identification sign, handwritten identification faded; when the pump was turned on, water discharged from the water level access pipe; no discharge hose, sample nipple, and coupling

12/30/91 No well identification sign, handwritten identification faded; no discharge hose

\section{LCO Series}

$\begin{array}{lll}\text { LCO } 1 & 11 / 19 / 91 & \begin{array}{l}\text { Surges badly } \\ \text { LCO } 4\end{array} \\ & 11 / 19 / 91 & \begin{array}{l}\text { Well incorrectly marked as } \\ \text { LOC 4; very light turbidity; } \\ \text { very pale pink }\end{array}\end{array}$

LDB Serie:

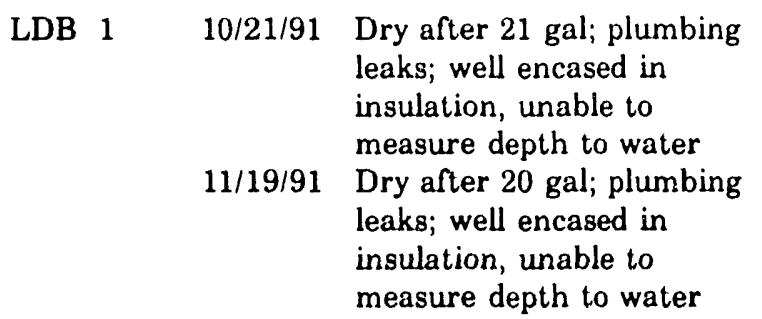

Well Date

LDB 2 10/21/91 Dry after 22 gal; plumbing leaks; well encased in insulation, unable to measure depth to water

11/19/91 Dry after 21 gal; plumbing leaks; well encased in insulation, unable to measure depth to water

12/16/91 Dry after 20 gal; plumbing leaks; well encased in insulation, unable to measure depth to water

\section{LFW Series}

\begin{tabular}{|c|c|c|}
\hline LFW 8 & $10 / 28 / 91$ & $\begin{array}{l}\text { Weakly turbid; light brown; } \\
\text { odor }\end{array}$ \\
\hline LFW 10A & $10 / 24 / 91$ & $\begin{array}{l}\text { Turbidity varied; light } \\
\text { brown; weak odor }\end{array}$ \\
\hline LFW 16 & $10 / 24 / 91$ & $\begin{array}{l}\text { Weakly turbid; light brown; } \\
\text { weak odor }\end{array}$ \\
\hline LFW 17 & $10 / 24 / 91$ & Odor \\
\hline LFW 18 & $10 / 24 / 91$ & Odor \\
\hline LFW 19 & $10 / 24 / 91$ & $\begin{array}{l}\text { Above-ground plumbing } \\
\text { broken }\end{array}$ \\
\hline & $12 / 16 / 91$ & No discharge hose \\
\hline LFW 21 & $10 / 25 / 91$ & Odor \\
\hline LFW 22 & $10 / 25 / 91$ & Odor \\
\hline LFW 28 & $10 / 28 / 91$ & Dry after $\sim 14.2 \mathrm{gal}$ \\
\hline LFW 36 & $10 / 24 / 91$ & $\begin{array}{l}\text { Well pad covered with dirt; } \\
\text { odor }\end{array}$ \\
\hline LFW 38 & $10 / 24 / 91$ & $\begin{array}{l}\text { Well pad covered with dirt; } \\
\text { no standpipe cap }\end{array}$ \\
\hline LFW 42 & $10 / 24 / 91$ & vered with dirt \\
\hline LFW 43B & $10 / 28 / 91$ & No well identification sign \\
\hline LFW 43C & $10 / 28 / 91$ & No well identification sign \\
\hline LFW 43D & $10 / 28 / 91$ & No well identification sign \\
\hline LFW 44D & $10 / 28 / 91$ & No well identific \\
\hline LFW 45D & $10 / 28 / 91$ & No well identification sign \\
\hline LFW 46D & $10 / 28 / 91$ & $\begin{array}{l}\text { No well identification sign; } \\
\text { turbidity varied; light } \\
\text { brown }\end{array}$ \\
\hline & $10 / 28 / 91$ & No well identification sign \\
\hline FW 47D & $10 / 28 / 91$ & No well \\
\hline LFW 48C & $10 / 29 / 91$ & No well identification sign \\
\hline LFW 48D & $10 / 29 / 91$ & $\begin{array}{l}\text { No well identification sign; } \\
\text { very weakly lurbid; very } \\
\text { light brown; odor }\end{array}$ \\
\hline LFW 550 & $10 / 29 / 91$ & $\begin{array}{l}\text { No well identification sign; } \\
\text { no discharge hose }\end{array}$ \\
\hline & 10125101 & No well identification sign \\
\hline & $10 / 29 / 91$ & No well identification sign \\
\hline & $10 / 29 / 91$ & No well identification sign \\
\hline & $10 / 29 / 91$ & No well identification sign \\
\hline
\end{tabular}


Table 5. Comments From the Field Data (cont.)

\begin{tabular}{|c|c|c|}
\hline Well & Date & Comments \\
\hline LFW 57D & 10/29/91 & No well identification sign \\
\hline LFW 58D & $10 / 29 / 91$ & No well identification sign \\
\hline LFW 59B & 10/31/91 & No well identification sign \\
\hline LFW $59 \mathrm{C}$ & $10 / 31 / 91$ & $\mathrm{~N} \cap$ well identification sign \\
\hline LFW 59D & 10/31/91 & No well identification sign \\
\hline \multirow[t]{2}{*}{ LFW 60D } & $10 / 28 / 91$ & $\begin{array}{l}\text { Dry after } \sim 8.7 \text { gal; no well } \\
\text { identification sign; no } \\
\text { discharge hose }\end{array}$ \\
\hline & 10/29/91 & Aerated \\
\hline LFW 61C & 10/31/91 & $\begin{array}{l}\text { No well identification sign; } \\
\text { no discharge hose }\end{array}$ \\
\hline L.FW 61D & 10/31/91 & $\begin{array}{l}\text { No well identification sign; } \\
\text { turbidity varied; brown }\end{array}$ \\
\hline LFW 62B & 10/31/91 & $\begin{array}{l}\text { No well identification sign; } \\
\text { moderately turbid; light } \\
\text { brown }\end{array}$ \\
\hline \multirow{3}{*}{$\begin{array}{l}\text { LFW 62C } \\
\text { LFW 62D }\end{array}$} & 10/29/91 & No well identification sign \\
\hline & & $\begin{array}{l}\text { Dry after } \sim 8.8 \mathrm{gal} \text {; no well } \\
\text { identification sign }\end{array}$ \\
\hline & $10 / 29 / 91$ & Aerated \\
\hline
\end{tabular}

\section{LRP Series}

LRP $2 \quad 11 / 25 / 91 \quad \begin{aligned} & \text { Throttle valve split and } \\ & \text { spraying }\end{aligned}$

\section{LSB Series}

$\begin{array}{llll}\text { LSB } 2 & 10 / 24 / 91 & \text { Surges } \\ & & 11 / 19 / 91 & \text { Surges badly } \\ \text { LSB } 4 & 10 / 24 / 91 & \text { Surges } \\ & & 11 / 19 / 91 & \text { Surges }\end{array}$

\section{MCB Series}

\begin{tabular}{|c|c|c|c|}
\hline MCB & 2 & $11 / 14 / 91$ & Dry after $8.0 \mathrm{gal}$ \\
\hline MCB & 4 & $11 / 14 / 91$ & Dry after 5.5 gal \\
\hline \multirow[t]{2}{*}{$\mathrm{MCB}$} & 5 & $12 / 05 / 91$ & Dry after $\sim 10 \mathrm{gal}$ \\
\hline & & $12 / 06 / 91$ & Aerated \\
\hline \multirow[t]{2}{*}{ MCB } & $5 \mathrm{C}$ & $12 / 05 / 91$ & Dry after $\sim 10 \mathrm{gal}$ \\
\hline & & $12 / 06 / 91$ & $\begin{array}{l}\text { Flowmeter did not register } \\
\text { first two gallons }\end{array}$ \\
\hline MCB & 6 & $11 / 14 / 91$ & Dry after $3.5 \mathrm{gal}$ \\
\hline \multirow[t]{2}{*}{ MCB } & $7 \mathrm{C}$ & $12 / 05 / 91$ & Dry after $~ 10.5 \mathrm{gal}$ \\
\hline & & $12 / 06 / 91$ & Turbidity varied; brown \\
\hline \multicolumn{4}{|c|}{ MSB Series } \\
\hline MSB & $1 \mathrm{C}$ & $10 / 02 / 91$ & Dry after $26.5 \mathrm{gal}$ \\
\hline MSB & $1 \mathrm{CC}$ & $10 / 02 / 91$ & Dry after $11.0 \mathrm{gal}$ \\
\hline \multirow[t]{2}{*}{ MSB } & $2 \mathrm{~B}$ & $11 / 21 / 91$ & Dry after $30.5 \mathrm{gal}$ \\
\hline & & $11 / 22 / 91$ & $\begin{array}{l}\text { Turbidity varied while } \\
\text { collecting samples; light } \\
\text { orange }\end{array}$ \\
\hline
\end{tabular}

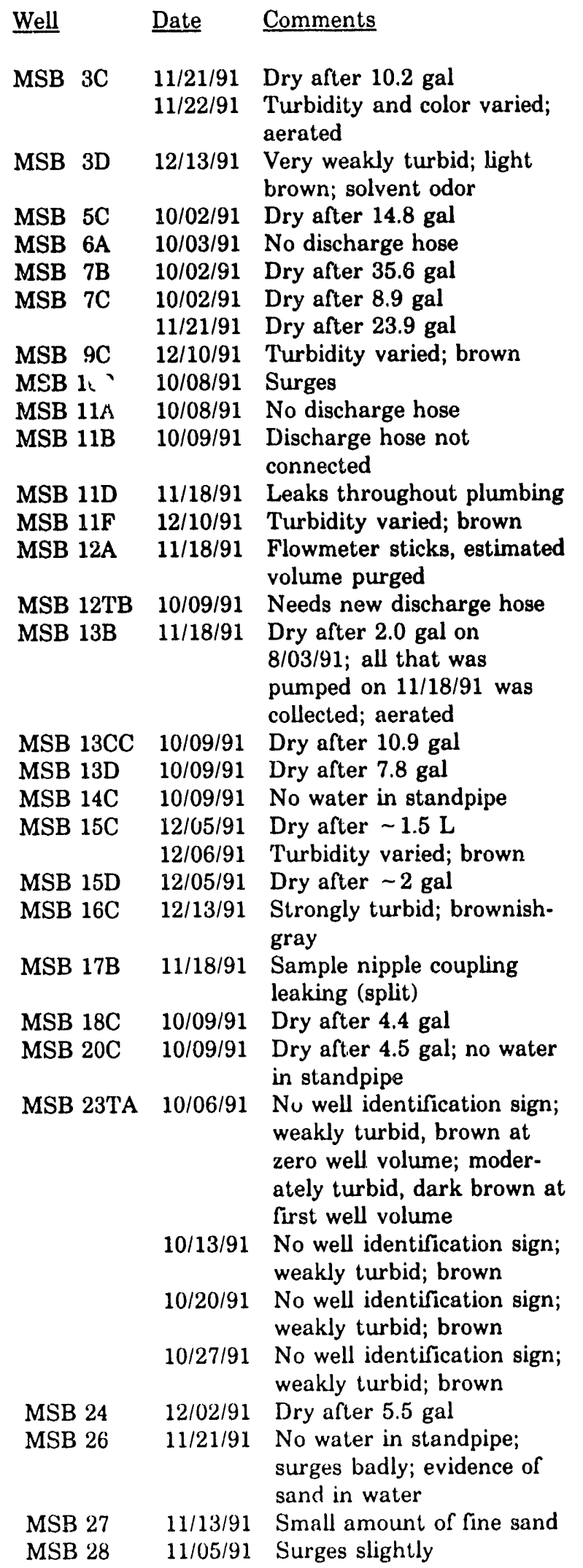


Table 5. Comments From the Field Data (cont.)

\begin{tabular}{|c|c|c|}
\hline Well & $\underline{\text { Date }}$ & Cornments \\
\hline MSB 30AA & $11 / 04 / 91$ & Dry after $67.0 \mathrm{gal}$ \\
\hline MSB 31A & $10 / 31 / 91$ & $\begin{array}{l}\text { Unable to sample, pump } \\
\text { has been removed and not } \\
\text { replaced }\end{array}$ \\
\hline MSB 34C & $10 / 25 / 91$ & No water in standpipe \\
\hline MSB 35A & $10 / 25 / 91$ & $\begin{array}{l}\text { Discharge hose split and } \\
\text { spraying at flowmeter }\end{array}$ \\
\hline MSB 36B & $11 / 22 / 91$ & Leaks throughout plumbing \\
\hline MSB 36D & $10 / 29 / 91$ & $\begin{array}{l}\text { Dry after } 3.0 \text { gal; no water } \\
\text { in standpipe }\end{array}$ \\
\hline \multirow[t]{2}{*}{ MSB 37A } & $11 / 05 / 91$ & Dry after $76.0 \mathrm{gal}$ \\
\hline & $11 / 06 / 91$ & $\begin{array}{l}\text { Flowmeter constantly } \\
\text { sticking; estimated volume } \\
\text { purged }\end{array}$ \\
\hline MSB 37D & $11 / 01 / 91$ & $\begin{array}{l}\text { Unable to sample, pump } \\
\text { has been removed and not } \\
\text { replaced }\end{array}$ \\
\hline MSB 39A & $10 / 07 / 91$ & Dry after $63.0 \mathrm{gal}$ \\
\hline MSB 39B & $10 / 08 / 91$ & $\begin{array}{l}\text { Discharge hose badly split } \\
\text { at flowmeter }\end{array}$ \\
\hline MSB 39C & $10 / 08 / 91$ & Discharge hose split \\
\hline MSB 39TA & $10 / 08 / 91$ & $\begin{array}{l}\text { Bad leaks throughout } \\
\text { plumbing }\end{array}$ \\
\hline MSB 40A & $10 / 30 / 91$ & $\begin{array}{l}\text { Flowmeter not working, } \\
\text { estimated volume purged }\end{array}$ \\
\hline MSB 40C & $10 / 30 / 91$ & No water in standpipe \\
\hline MSB 40TA & $10 / 30 / 91$ & Needs new discharge hose \\
\hline MSB 44C & $11 / 06 / 91$ & Strongly turbid \\
\hline MSB 46A & $10 / 30 / 91$ & Dry after $46.0 \mathrm{gal}$ \\
\hline MSB 46B & $10 / 31 / 91$ & No water in standpipe \\
\hline MSB 47TA & $11 / 26 / 91$ & Moderately turbid; brown \\
\hline MSB 48B & $11 / 27 / 91$ & Small amount of sand \\
\hline MSB 48D & $10 / 07 / 91$ & $\begin{array}{l}\text { Did not pump water to } \\
\text { surface }\end{array}$ \\
\hline MSB 49D & $10 / 10 / 91$ & Dry after 14.7 gal \\
\hline MSB 51D & $10 / 30 / 91$ & Dry after $7.5 \mathrm{gal}$ \\
\hline MSB 52D & $11 / 04 / 91$ & Dry after $4.5 \mathrm{gal}$ \\
\hline MSB 55D & $10 / 31 / 91$ & No water in standpipe \\
\hline MSB 55HC & $12 / 05 / 91$ & Dry after $\sim 7.5 \mathrm{gal}$ \\
\hline \multirow[t]{2}{*}{ MSB 57D } & $10 / 08 / 91$ & Dry after $12.8 \mathrm{gal}$ \\
\hline & $11 / 21 / 91$ & $\begin{array}{l}\text { Surges severely, cannot } \\
\text { even up flow }\end{array}$ \\
\hline MSB 58D & $11 / 21 / 91$ & Dry after 7.5 gal \\
\hline MSB 60D & $10 / 08 / 91$ & Surges badly \\
\hline MSB 61D & $10 / 28 / 91$ & $\begin{array}{l}\text { Dry after } 13.6 \text { gal; tens } \\
\text { column on flowmeter did } \\
\text { not turn while pumping dry }\end{array}$ \\
\hline MSB 62D & $10 / 10 / 91$ & Dry after $4.1 \mathrm{gal}$ \\
\hline MSB 63D & $10 / 10 / 91$ & Dry after 7.4 gal \\
\hline MSB 64B & $11 / 21 / 91$ & Weak turbidity; light tan \\
\hline MSB 65D & $11 / 04 / 91$ & Dry after $7.2 \mathrm{gal}$ \\
\hline MSB $66 \mathrm{C}$ & $11 / 04 / 91$ & $\begin{array}{l}\text { Discharge hose split at } \\
\text { flowmeter }\end{array}$ \\
\hline MSB $66 \mathrm{D}$ & $11 / 04 / 91$ & Pump did not work \\
\hline
\end{tabular}

\begin{tabular}{|c|c|c|}
\hline Well & Date & Comments \\
\hline MSB 68D & $12 / 05 / 91$ & $\begin{array}{l}\text { No well identification sign; } \\
\text { leaks at gate valve/T-joint } \\
\text { connection }\end{array}$ \\
\hline MSB $69 \mathrm{C}$ & $11 / 01 / 91$ & Dry after $28.4 \mathrm{gal}$ \\
\hline MSB 70D & $11 / 05 / 91$ & $\begin{array}{l}\text { Dry after } 5.3 \text { gal; no } \\
\text { discharge hose }\end{array}$ \\
\hline MSB 71B & $11 / 05 / 91$ & Dry after $42.0 \mathrm{gal}$ \\
\hline MSB 74B & $12 / 02 / 91$ & $\begin{array}{l}\text { Very weakly turbid; light } \\
\text { brown }\end{array}$ \\
\hline MSB $74 C$ & $10 / 29 / 91$ & Dry after $12.2 \mathrm{gal}$ \\
\hline MSB 74D & $10 / 29 / 91$ & Dry after 7.6 gal \\
\hline MSB 75B & $12 / 02 / 91$ & $\begin{array}{l}\text { No well identification sign; } \\
\text { very weakly turbid; light } \\
\text { brown }\end{array}$ \\
\hline MSB 75C & $10 / 29 / 91$ & Dry after $3.0 \mathrm{gal}$ \\
\hline MSB 76C & $11 / 21 / 91$ & $\begin{array}{l}\text { Surges very badly, cannot } \\
\text { even up flow; weakly } \\
\text { turbid; pale pinkish orange }\end{array}$ \\
\hline MSB 77B & $10 / 28 / 91$ & No discharge hose \\
\hline MSB 77C & $10 / 28 / 91$ & No discharge hose \\
\hline MSB 77D & $10 / 28 / 91$ & $\begin{array}{l}\text { Dry after } 10.3 \text { gal; no } \\
\text { discharge hose }\end{array}$ \\
\hline MSB 77TA & $10 / 28 / 91$ & $\begin{array}{l}\text { Dry after } 63.0 \text { gal; no } \\
\text { discharge hose }\end{array}$ \\
\hline MSB 78D & $11 / 13 / 91$ & $\begin{array}{l}\text { Unable to sample, pump } \\
\text { would not start }\end{array}$ \\
\hline MSB 79B & $10 / 01 / 91$ & Dry after 37.7 gal \\
\hline MSB $79 \mathrm{C}$ & $10 / 01 / 91$ & Dry after $5.8 \mathrm{gal}$ \\
\hline MSB $82 A$ & $10 / 01 / 91$ & Dry after $29.4 \mathrm{gal}$ \\
\hline MSB 82D & $10 / 02 / 91$ & Surges badly \\
\hline MSB 83D & $10 / 01 / 91$ & $\begin{array}{l}\text { Dry after } 7.8 \text { gal; well } \\
\text { surrounded by water }\end{array}$ \\
\hline & $10 / 01 / 91$ & Surges and slows \\
\hline MSB $85^{\prime} \mathrm{TA}$ & $10 / 01 / 91$ & Dry after $28.0 \mathrm{gal}$ \\
\hline
\end{tabular}

\section{MWD Series}

\begin{tabular}{|c|c|c|c|}
\hline MWD & $1 \mathrm{~A}$ & $12 / 30 / 91$ & $\begin{array}{l}\text { Unable to sample, well } \\
\text { installation incomplete-no } \\
\text { pump }\end{array}$ \\
\hline MWD & $1 \mathrm{~B}$ & $12 / 30 / 91$ & $\begin{array}{l}\text { Unable to sample, well } \\
\text { installation incomplete-no } \\
\text { pump }\end{array}$ \\
\hline MWD & $1 \mathrm{C}$ & $12 / 30 / 91$ & $\begin{array}{l}\text { Unable to sample, well } \\
\text { installation incomplete--no } \\
\text { pump }\end{array}$ \\
\hline MWD & 1D & $12 / 30 / 91$ & $\begin{array}{l}\text { Unable to sample, well } \\
\text { installation incomplete-no } \\
\text { pump }\end{array}$ \\
\hline MWD & $2 A$ & $12 / 30 / 91$ & $\begin{array}{l}\text { Unable to sample, well } \\
\text { installation incomplete-no } \\
\text { pump }\end{array}$ \\
\hline
\end{tabular}


Table 5. Comments From the Field Data (cont.)

\begin{tabular}{|c|c|c|c|c|c|c|}
\hline Well & & Date & Comments & $\underline{\text { Well }}$ & Date & Comments \\
\hline MWD & $2 \mathrm{C}$ & $12 / 30 / 91$ & $\begin{array}{l}\text { Unable to sample, well } \\
\text { installation incomplete-no } \\
\text { pump }\end{array}$ & NPM $1 \mathrm{~A}$ & $12 / 10 / 91$ & $\begin{array}{l}\text { Unable to sample, well } \\
\text { installation incomplete } \\
\text { no pump; no well identi- }\end{array}$ \\
\hline MWD & $2 \mathrm{D}$ & $12 / 30 / 91$ & $\begin{array}{l}\text { Unable to sample, well } \\
\text { installation incomplete-no }\end{array}$ & & & $\begin{array}{l}\text { fication sign, well marked } \\
\text { as "M12-1A" }\end{array}$ \\
\hline & & & pump & NPM 2 & $12 / 09 / 91$ & Dry after 26 gal \\
\hline MWD & $3 \mathrm{~A}$ & $12^{/ 30 / 91}$ & $\begin{array}{l}\text { Unable to sample, well } \\
\text { installation incomplete-no }\end{array}$ & & $12 / 10 / 91$ & $\begin{array}{l}\text { No well identification sign; } \\
\text { weakly turbid; light brown }\end{array}$ \\
\hline MWD & $5 \mathrm{~A}$ & $12 / 30 / 91$ & $\begin{array}{l}\text { pump } \\
\text { Unable to sample, well } \\
\text { installation incomplete-- no }\end{array}$ & NPM 3 & $12 / 09 / 91$ & $\begin{array}{l}\text { No well identification sign; } \\
\text { well marked as "NPM 3" } \\
\text { and "M12 \#3" }\end{array}$ \\
\hline MWD & $5 \mathrm{C}$ & $12 / 30 / 91$ & $\begin{array}{l}\text { pump } \\
\text { Unable to sample, well } \\
\text { installation incomplete-no }\end{array}$ & NPM 4 & $12 / 09 / 91$ & $\begin{array}{l}\text { No well identification sign; } \\
\text { moderately turbid; pinkish } \\
\text { brown }\end{array}$ \\
\hline & & $12 / 30 / 91$ & $\begin{array}{l}\text { pump } \\
\text { Unable to sample, well }\end{array}$ & NPM 4DD & $12 / 09 / 91$ & $\begin{array}{l}\text { Dry after } \sim 500 \mathrm{~mL} \text {; no well } \\
\text { identification sign }\end{array}$ \\
\hline MWD & ov & $12 / 30 / 91$ & $\begin{array}{l}\text { installation incomplete-no } \\
\text { pump }\end{array}$ & NPM 19A & $12 / 08 / 91$ & $\begin{array}{l}\text { No well identification sign; } \\
\text { well marked as "M12-19 }\end{array}$ \\
\hline MWD & 8 & $12 / 30 / 91$ & $\begin{array}{l}\text { Unable to sample, well } \\
\text { installation incomplete-no }\end{array}$ & & & $\begin{array}{l}\text { (5) A"; very weakly turbid; } \\
\text { light brown }\end{array}$ \\
\hline & & & pump & NPM 19B & $12 / 08 / 91$ & No well identification sign; \\
\hline MWD & 9 & $12 / 30 / 91$ & $\begin{array}{l}\text { Unable to sample, well } \\
\text { installation incomplete-no } \\
\text { pump }\end{array}$ & NPM 19C & $12 / 08 / 91$ & $\begin{array}{l}\text { well marked as "M12-19 (4)" } \\
\text { No well identification sign; } \\
\text { well marked as "M12-19 }\end{array}$ \\
\hline MWD & 10 & $12 / 30 / 91$ & $\begin{array}{l}\text { Unable to sample, well } \\
\text { installation incomplete-no } \\
\text { pump }\end{array}$ & NPM 19D & $12 / 08 / 91$ & $\begin{array}{l}\text { (3) } \mathrm{C} " \\
\text { No well identification sign; } \\
\text { well marked as "M12-19 }\end{array}$ \\
\hline MWD & 11 & $12 / 30 / 91$ & $\begin{array}{l}\text { Unable to sample, well } \\
\text { installation incomplete-no } \\
\text { pump }\end{array}$ & NPM 19E & $12 / 08 / 91$ & $\begin{array}{l}\text { (2) } \mathrm{D} \text { " } \\
\text { Dry after } 30 \text { gal; no well } \\
\text { identification sign; well } \\
\text { marked as "M12-19 (1) E" }\end{array}$ \\
\hline NBG & Series & & & NPM 34A & $12 / 08 / 91$ & $\begin{array}{l}\text { No well identification sign; } \\
\text { well marked as "M12-34 }\end{array}$ \\
\hline NBG & 1 & $11 / 13 / 91$ & Dry after $\sim 10.7 \mathrm{gal}$ & & & $5 \mathrm{~A}^{\prime \prime}$ \\
\hline NBG & 2 & $\begin{array}{l}11 / 13 / 91 \\
11 / 14 / 91\end{array}$ & $\begin{array}{l}\text { Dry after } \sim 14.1 \text { gal } \\
\text { Very weakly turbid; very } \\
\text { light brown }\end{array}$ & NPM 34B & $12 / 08 / 91$ & $\begin{array}{l}\text { Dry after } 29 \text { gal; no well } \\
\text { identification sign; well } \\
\text { marked as "M12-34 } 4 \text { B"; }\end{array}$ \\
\hline NBG & 3 & $\begin{array}{l}11 / 13 / 91 \\
11 / 14 / 91\end{array}$ & $\begin{array}{l}\text { Dry after } \sim 10 \text { gal } \\
\text { Weakly turbid; light brown }\end{array}$ & & & $\begin{array}{l}\text { moderately turbid; pinkish } \\
\text { brown }\end{array}$ \\
\hline NBG & 4 & $11 / 13 / 91$ & Dry after $-10.5 \mathrm{gal}$ & NPM $34 \mathrm{C}$ & $12 / 08 / 91$ & Very weakly turbid; light \\
\hline NBG & 5 & $\begin{array}{l}11 / 13 / 91 \\
11 / 14 / 91\end{array}$ & $\begin{array}{l}\text { Dry after }-15.2 \text { gal } \\
\text { Flowmeter leaks (bottom } \\
\text { plug) }\end{array}$ & & & $\begin{array}{l}\text { brown; no well identi- } \\
\text { fication sign; well marked } \\
\text { as "M12-34 (1) E" }\end{array}$ \\
\hline NPN & Series & & & NPM 34D & $12 / 08 / 91$ & $\begin{array}{l}\text { Dry after } 84.5 \text { gal; no well } \\
\text { identification sign; well } \\
\text { marked as "M12-34 2 D"; }\end{array}$ \\
\hline NPM & 1 & $12 / 10 / 91$ & $\begin{array}{l}\text { Unable to sample, well } \\
\text { installation incomplete-- } \\
\text { no pump; no well identi- } \\
\text { fication sign; well marked } \\
\text { as "M12-1" }\end{array}$ & NPM 34E & $12 / 08 / 91$ & $\begin{array}{l}\text { strongly turbid; brown; } \\
\text { leaks at gate valve } \\
\text { No well identification sign; } \\
\text { well marked as "M12-34 } \\
\text { (1) E" }\end{array}$ \\
\hline
\end{tabular}


Table 5. Comments From the Field Data (cont.)

\begin{tabular}{|c|c|c|c|}
\hline \multicolumn{2}{|c|}{ Well } & Date & Comments \\
\hline \multicolumn{4}{|c|}{ P Series } \\
\hline & $14 \mathrm{C}$ & $12 / 09 / 91$ & $\begin{array}{l}\text { Unable to sample, pump } \\
\text { would not start }\end{array}$ \\
\hline ? & $26 \mathrm{~A}$ & $12 / 04 / 91$ & $\begin{array}{l}\text { Unable to sample, pump } \\
\text { has been pulled }\end{array}$ \\
\hline P & $28 \mathrm{~A}$ & $11 / 08 / 91$ & No discharge hose \\
\hline $\mathrm{P}$ & $28 \mathrm{~TB}$ & $11 / 08 / 91$ & No discharge hose \\
\hline $\mathrm{P}$ & $29 \mathrm{C}$ & $11 / 18 / 91$ & $\begin{array}{l}\text { No discharge hose; } \\
\text { flowmeter disconnected, } \\
\text { estimated volume purged }\end{array}$ \\
\hline & $29 \mathrm{TA}$ & $11 / 18 / 91$ & No discharge hose \\
\hline $\mathrm{P}$ & $29 \mathrm{TC}$ & $11 / 18 / 91$ & No discharge hose \\
\hline
\end{tabular}

PAC Series

PAC $211 / 19 / 91$ Discharge hose leaks/ sprays; no standpipe cap; aerated; surges; well pad covered in dirt

PAC $3 \quad 11 / 20 / 91$ Discharge hose leaks/ sprays; weakly turbid; very light brown

PAC $5 \quad 11 / 19 / 91$ Dry after 11.5 gal

PAC $611 / 19 / 91$ Dry after $10.9 \mathrm{gal}$

$11 / 20 / 91$ Weak odor

\section{PDB Series}

\begin{tabular}{|c|c|c|}
\hline \multirow[t]{3}{*}{ PDB 2} & $10 / 21 / 91$ & $\begin{array}{l}\text { Leaks around T-joint; } \\
\text { aerated }\end{array}$ \\
\hline & $11 / 19 / 91$ & Leaks around 'T-joint \\
\hline & $12 / 16 / 91$ & Leaks around 'T'-joint \\
\hline \multirow[t]{3}{*}{ PDB 3} & $10 / 21 / 91$ & $\begin{array}{l}\text { PVC plumbing painter. } \\
\text { blue; no discharge hose }\end{array}$ \\
\hline & $11 / 19 / 91$ & $\begin{array}{l}\text { PVC plumbing painled } \\
\text { blue; no discharge hose }\end{array}$ \\
\hline & $12 / 16 / 91$ & $\begin{array}{l}\text { PVC plumbing painted } \\
\text { blue; no discharge hose; } \\
\text { surges }\end{array}$ \\
\hline
\end{tabular}

\section{PRP Series}

$\begin{array}{ll}\text { PRP 2 } 11 / 19 / 91 & \begin{array}{l}\text { Discharge hose leaks/ } \\ \text { sprays; no standpipe cap; } \\ \text { aerated; surges }\end{array}\end{array}$

PRP 4 11/20/91 Discharge hose leaks/sprays

\section{PSB Series}

PSB 3A 11/19/91 Discharge hose leaks/ sprays; lurbidity varied; light brown

12/16/91 Discharge hose leaks/sprays $\begin{array}{lll}\text { Well } & \text { Date } & \text { Comments } \\ \text { PSB 5A } & 10 / 23 / 91 & \text { Dry after } \sim 23 \text { gal } \\ & 11 / 19 / 91 & \text { Dry after }-22 \text { gal } \\ & 12 / 16 / 91 & \text { Dry after }-21 \text { gal }\end{array}$

PSS Series

PSS 1D 11/19/91 Turbidity varied; very light brown

PSS 3D 11/19/91 Dry after $\sim 8.6$ gal; moderately turbid; light brown

RAC Series
RAC $1 \quad 12 / 15 / 91$ Surges; leaks/sprays at sa'nple valve; weakly turbid; white
RAC $2 \quad 12 / 15 / 91$ Weakly turbid; white
RAC $3 \quad 12 / 15 / 91$ Weakly turbid; white
RAC $412 / 15 / 91$ Sample valve handle broken
RDB Series off

\author{
RDB $1 D \quad 12 / 06 / 91$ Surges \\ RDB 2D 12/06/91 Very weakly turbid; very \\ light tan; surges
}

\section{RRP Series}

RRP $212 / 15 / 91$ Leaks/sprays between Tjoint and sample valve

RRP $3 \quad 12 / 15 / 91$ Moderately turbid; pink

\section{RSE Series}

RSE $12 \quad 12 / 18 / 91$ Bucket stuck in well

RSE $24 \quad 12 / 06 / 91$ Surges badly

\section{RSF Series}

\begin{tabular}{|c|c|c|}
\hline RSF & $12 / 11 / 91$ & No well identification sign \\
\hline RSF & $12 / 11 / 91$ & $\begin{array}{l}\text { No well identification sign; } \\
\text { discharge hose leaks/sprays }\end{array}$ \\
\hline & $2 / 11 / 9$ & No well identification sign \\
\hline
\end{tabular}

\section{RWM Series}

RWM 1 10/11/91 Aerated

11/07/91 No water in standpipe; aerated

11/11/91 No water in standpipe; aerated

$12 / 12 / 91$ No water in standpipe; aerated 
FIELD NOTES

Table 5. Comments From the Field Data (cont.)

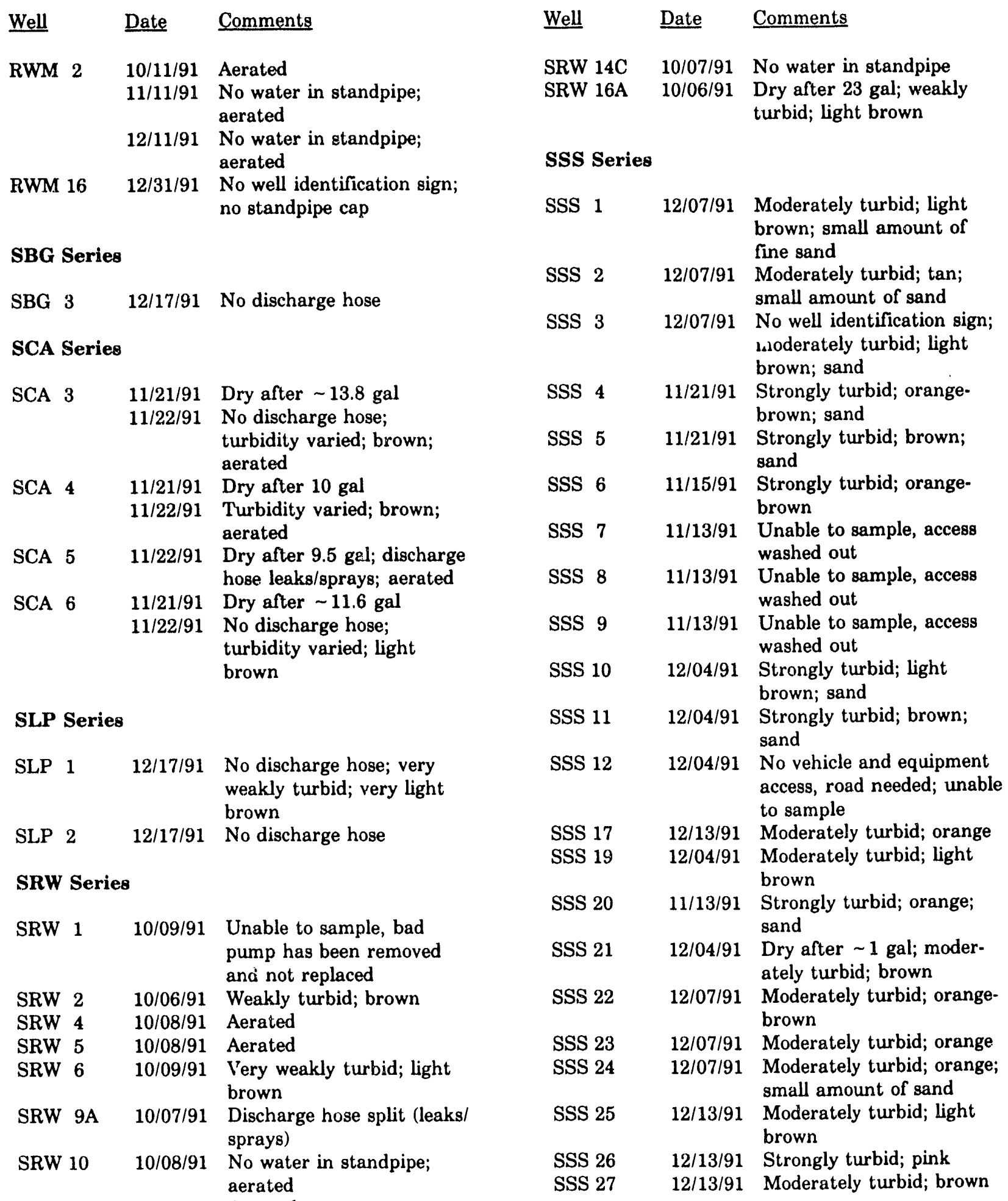

SRW $11 \quad$ 10/08/91 Aerated

SRW 13A 10/07/91 Discharge hose split (leaks/ sprays)

SRW 13B 10/07/91 Discharge hose split (leaks/ sprays) 
Table 5. Comments From the Field Data (cont.)

\begin{tabular}{|c|c|c|}
\hline Well & Date & Comments \\
\hline \multicolumn{3}{|c|}{ TBG Series } \\
\hline TBG 1 & $11 / 20 / 91$ & $\begin{array}{l}\text { Well wrongly identified as } \\
\text { TBG 1D on sign; sample } \\
\text { nipple broken off }\end{array}$ \\
\hline BG 7 & $11 / 20 / 91$ & $\begin{array}{l}\text { Well wrongly identified as } \\
\text { TBG 7D }\end{array}$ \\
\hline
\end{tabular}

TNX Serie日

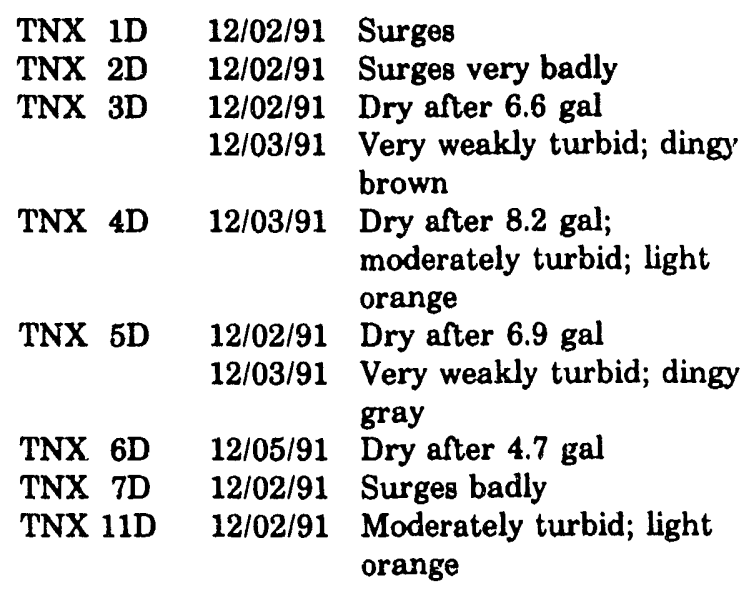

XSB Series

XSB 2D 12/04/91 Dry after 7.4 gal
Well Date Comments

YSB Series

YSB 1A 11/20/91 Weakly turbid; very light orange

YSB 3A 11/20/91 Weakly turbid; very light orange

YSB 4A 11/20/91 Moderately turbid; light tan

YSC Series

YSC 1A 11/21/91 No well identification sign; unable to sample, well hit by lightning

YSC 1C 11/21/91 No well identification sign

YSC 2D $11 / 21 / 91 \quad$ Dry after $\sim 13.7 \mathrm{gal}$

11/22/91 Turbidity varied; brown

YSC 4C 11/21/91 No well identification sign

YSC 5A 11/21/91 No well identification sign

Z Series

Z $312 / 10 / 91$ Puller stuck in well

ZDT Series

ZDT $1 \quad 11 / 12 / 91$ No standpipe cap

ZDT 2 11/12/91 No standpipe cap 


\section{ANALYTICAL DATA REVIEW}

Sample analyses performed for EPD/EMS during four 4 quarter 1991 were conducted by EPA-approved methods except as noted in Table 16 on page 59.

General Engineering (GE) of Charleston, SC, the primary SCDHEC-certified subcontracting laboratory for sample analysis, performed all analyses, with the following exceptions:

- The M-Area Laboratory (MA) at SRS performed chloroform, tetrachloroethylene, trans-1,2-dichloroethylene, 1,1-dichloroethylene, trichloroethylene, and 1,1,1trichloroethane analyses for certain wells in the $\mathrm{A} / \mathrm{M}$ Areas.

- The EPD/EMS Laboratory (EM) operated by EPD/EMS at SRS conducted totalactivity analyses of samples for shipping clearance. The EPD/EMS Laboratory also conducted tritium, gross alpha, nonvolatile beta, and selected radionuclide analyses of samples from specified well series.

- Teledyne Isotopes performed radionuclide analyses.

\section{REVIEW OF THE ANALYTICAL DATA FOR ERRORS}

Effective fourth quarter 1991, exceeded holding time is indicated by a notation of $Q$ in the analytical-results tables. See page A-2 for further information. (This information formerly was included in this section.)

EPD/EMS reviews analytical data from the laboratories for errors and unusual results before entering this information into the database. All suspect data are brought to the attention of the laboratories for review, corrections, and comments.
Typical errors corrected for entry into the database include incorrect sample dates, incorrect run dates, incorrect identifications for well samples, incorrectly entered analytical units or methods and corresponding detection limits, incorrect dilution factor calculations, and data entry errors.

Analytical results that appear different from historical data collected since 1988 are brought to the attention of the appropriate laboratory. Thus, the laboratory is able to identify problems with some of these analyses, including incorrect dilution factor calculations and data entry errors. Data files are corrected by EPD/EMS after receiving written notificetion from the laboratory.

Specific details concerning the corrections can be found in the EMS Groundwater Monitoring Program Changes to the Database Log Book, where the corrections are also recorded.

\section{Review of General Engineering Analytical Data}

Matrix interferences appear to be responsible for low mercury spike recoveries for MSB 43D and for low selenium spike recoveries for FSB 79 and $\mathrm{P}$ 14C.

Even though the laboratory blank was clean, contamination from the laboratory is suspected as the cause of the high dichloromethane (methylene chloride) results for the following samples: BGO 31C, BGO 33C, FSB112C, FSB117D, FSB119D, FSB120C.

The silvex results for samples from $\mathrm{BGO} 12 \mathrm{AR}$, HSB152C, LFW 6, LFW 10A, LFW 20, LFW 35, LFW 39, and LFW 40 should be treated as suspicious. The spiking solution for 
these samples was of poor quality, resulting in below-normal surrogate recovery.

The herbicide data for the following samples should be treated as suspicious due to poor spike recovery for the quality control samples: BGO 12D, FSB112D, LFW 16, LFW 17, LFW 57D, LFW 58D, LFW 59B, LFW 59C, LFW 59D, LFW 61C, LFW 61D, LFW 62C, and LFW 62D.

The surrogates for 2,4,5-TP (Silvex) and 2,4-dichlorophenoxyacetic acid for the following wells failed and, because of insufficient sample, the samples could not be re-extracted for reanalysis: LFW 16, LFW 17, and LFW 58D. The surrogates for herbicides also failed for FAC 5 , MCB 7C, and SSS 11. The results should be treated as suspicious.

Beginning fourth quarter 1991, GE uses the analytical modifier " $V$ " to flag sample results associated with internal laboratory blanks having elevated results. (See p. A-2.) Table 6 associates well samples with specific blanks having, for most analytes, results four times greater than detection limits; antimony is listed for any positive result in the associated blank.

\section{Table 6. General Engineering Laboratory Blanks With Elevated Results}

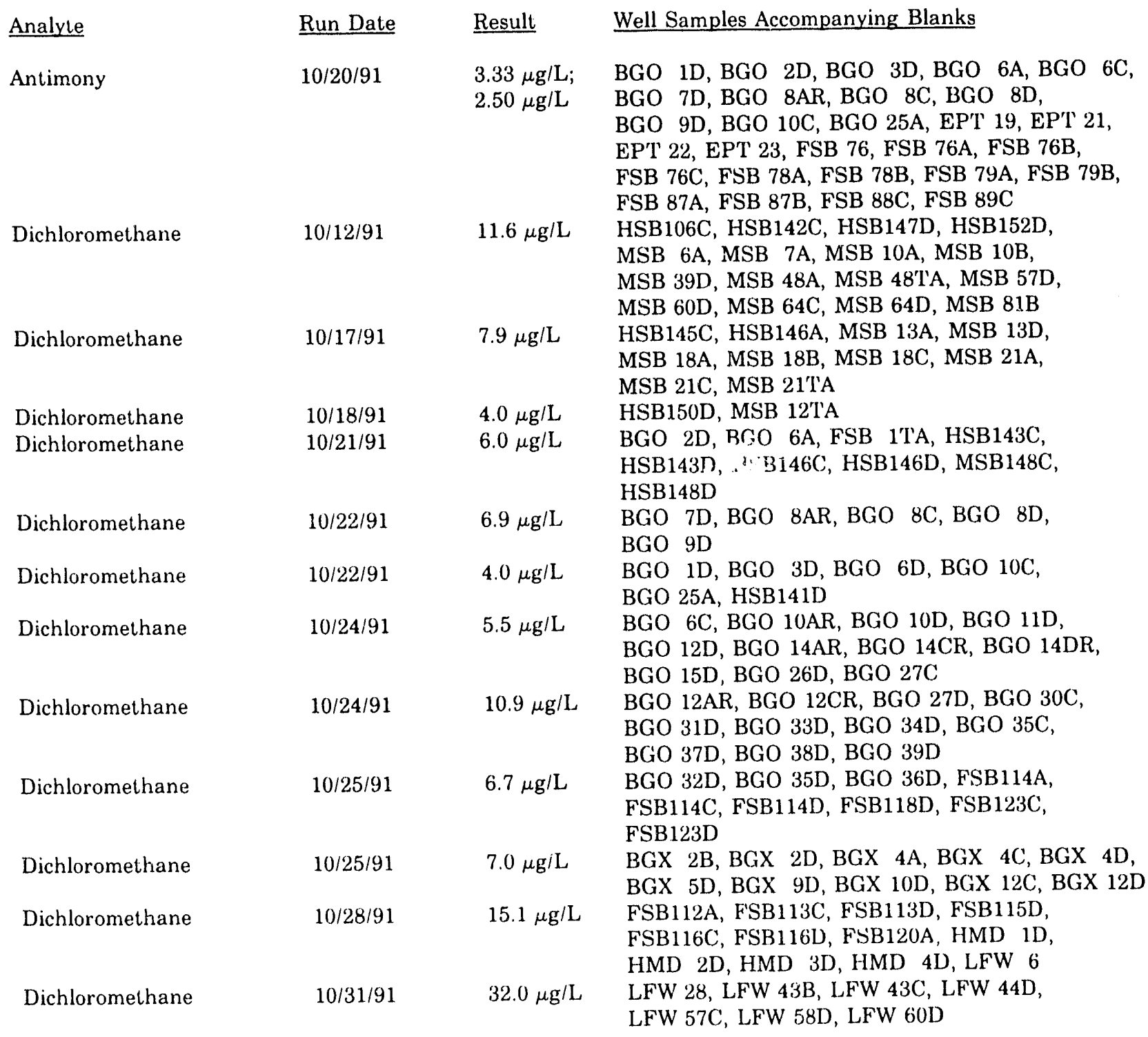


Table 6. General Engineering Laboratory Blanks With Elevated Results (cont.)

\begin{tabular}{|c|c|c|c|}
\hline Analyte & Run Date & $\underline{\text { Result }}$ & Well Samples Accompanying Blanks \\
\hline Dichloromethane & $10 / 31 / 91$ & $14.5 \mu \mathrm{g} / \mathrm{L}$ & $\begin{array}{l}\text { LFW 48C, LFW 48D, LFW 56D, LFW 57B, } \\
\text { LFW 57D, LFW 58D, LFW 62C, LFW 62D, } \\
\text { MSB 36D, MSB 36TA }\end{array}$ \\
\hline Dichloromethane & $11 / 01 / 91$ & $12.0 \mu \mathrm{g} / \mathrm{L}$ & $\begin{array}{l}\text { LFW 43D, MSB 36A, MSB 36C, MSB 74C, } \\
\text { MSB 74D }\end{array}$ \\
\hline Dichloromethane & $11 / 04 / 91$ & $11.0 \mu \mathrm{g} / \mathrm{L}$ & $\begin{array}{l}\text { LFW 59C, LFW 61C, MSB 31B, MSB 40A, } \\
\text { MSB 40C, MSB 40TA, MSB 75C }\end{array}$ \\
\hline Dichloromethane & $11 / 04 / 91$ & $10.3 \mu \mathrm{g} / \mathrm{L}$ & $\begin{array}{l}\text { FNB 2, FNB 3, FNB 4, LFW 59D, LFW 61D, } \\
\text { LFW 62B }\end{array}$ \\
\hline Sichloromethane & $11 / 08 / 91$ & $11.0 \mu \mathrm{g} / \mathrm{L}$ & $\begin{array}{l}\text { ABP } 1 \mathrm{~A}, \mathrm{ABP} 3, \mathrm{ABP} 3 \mathrm{C}, \mathrm{FNB} \quad 1, \mathrm{FNB} 3 \\
\mathrm{MSB} 47 \mathrm{BB}, \mathrm{MSB} 55 \mathrm{~B}, \mathrm{MSB} 55 \mathrm{TA}\end{array}$ \\
\hline Dichloromethane & $11 / 11 / 91$ & $10.0 \mu \mathrm{g} / \mathrm{L}$ & $\begin{array}{l}\text { ABP } 2 \mathrm{~A}, \mathrm{ABP} \quad 4, \mathrm{LFW} 27, \mathrm{LFW} 34, \mathrm{MSB} 19 \mathrm{~B} \text {, } \\
\text { MSB } 77 \mathrm{~B}, \mathrm{MSB} \quad 77 \mathrm{TA}\end{array}$ \\
\hline Dichloromethane & $11 / 13 / 91$ & $9.3 \mu \mathrm{g} / \mathrm{L}$ & $\begin{array}{l}\text { BGO 43A, BGO 43AA, BGO 43D, BGO 47A, } \\
\text { BGO 47C, BGO 47D, BGO 48C, BGO } 49 A \text {, } \\
\text { BGO 49C }\end{array}$ \\
\hline Dichloromethane & $11 / 15 / 91$ & $8.5 \mu \mathrm{g} / \mathrm{L}$ & $\begin{array}{l}\text { BGO 49D, BGX 7D, BGX 8D, FAC 3, FAC 4, } \\
\text { FAC 7, FCB 2, FCB 3, MSB 70D, RWM } 1\end{array}$ \\
\hline Dichloromethane & $11 / 21 / 91$ & $7.38 \mu \mathrm{g} / \mathrm{L}$ & $\begin{array}{l}\text { AMB } 4 \mathrm{~A}, \mathrm{AMB} 4 \mathrm{~B}, \mathrm{AMB} \text { 7A, AMB } 7 \mathrm{~B}, \mathrm{AOB} \\
\text { FCB 4, FSS 1D, FSS 3D, FSS 4D, MCB 6C }\end{array}$ \\
\hline Dichloromethane & $12 / 05 / 91$ & $4.0 \mu \mathrm{g} / \mathrm{L}$ & CMP 8, CMP 8A, MSB 48B, 2BG 2 \\
\hline Dichloromethane & $12 / 26 / 91$ & $4.96 \mu \mathrm{g} / \mathrm{L}$ & BGO 46D, BGO 50D, KDT 1D \\
\hline Methyl ethyl ketone & $11 / 25 / 91$ & $9.8 \mu \mathrm{g} / \mathrm{L}$ & $\begin{array}{l}\text { AOB 1, AOB 3, BRR 4D, LCO 1, MSB 13B, } \\
\text { MSB 64B }\end{array}$ \\
\hline Trichloroethylene & $10 / 24 / 91$ & $4.01 \mu \mathrm{g} / \mathrm{L}$ & BGX 3D, BGX 6D \\
\hline
\end{tabular}

GE found no errors upon review of the records of the EPD/EMS blind blanks having elevated results listed in Table 7, along with associated samples. In most cases, the blanks results are greater than four times the detection limit.

Results for sodium and total dissolved solids are 20 times detection limit. Sodium and silica, which have no flags, were detected at elevated levels in many blind blanks; the associated samples are not enumerated.

Table 7. EPD/EMS Blind Blanks With Elevated Results

$\begin{array}{lcc}\text { Analyte } & \text { Run Date } & \text { Result } \\ \text { Benzene } & 12 / 03 / 91 & 20 \mu \mathrm{g} / \mathrm{L} \\ \text { Chlorobenzene } & 12 / 03 / 91 & 20.2 \mu \mathrm{g} / \mathrm{L} \\ 1,1 \text {-Dichloroetislene } & 12 / 03 / 91 & 19.8 \mu \mathrm{g} / \mathrm{L} \\ \text { Mercury } & 10 / 31 / 91 & 1.1 \mu \mathrm{g} / \mathrm{L}\end{array}$

Associated Samples

MSB 2B, MSB 2C, MSB 3C, MSB 4C, MSB 6B, MSB 36B, MSB 58D

MSB 2B, MSB 2C, MSB 3C, MSB 4C, MSB 6B, MSB 36B, MSB 58D

MSB 2B, MSB 2C, MSB 3C, MSB 4C, MSB 6B, MSB 36B, MSB 58D

BGO 40D, BGO 45A, BGO 45B, BGO 45C, BGO 45D, BGX 1A, BGX 1C, BGX 1D, LFW 21, LFW 22, LFW 23, LFW 24, LFW 25, LFW 26, LFW 27, LFW 31, LFW 32, LFW 33, LFW 34 
Table 7. EPD/EMS Blind Blanks With Elevated Results (cont.)

Analyte

Nitrate as nitrogen

Nitrate as nitrogen

Nitrate as nitrogen $\underline{\text { Result }}$

$440 \mu \mathrm{g} / \mathrm{L}$

$10 / 16 / 91 \quad 310 \mu \mathrm{g} / \mathrm{L}$

$11 / 20 / 91 \quad 230 \mu \mathrm{g} / \mathrm{L}$

$\begin{array}{lcl}\text { Nitrate as nitrogen } & 12 / 02 / 91 & 1,380 \mu \mathrm{g} / \mathrm{L} \\ \text { Silica } & 10 / 11 / 91 & 10,600 \mu \mathrm{g} / \mathrm{L} \\ \text { Silica } & 10 / 16 / 91 & 10,900 \mu \mathrm{g} / \mathrm{L} \\ \text { Silica } & 10 / 18 / 91 & 11,000 \mu \mathrm{g} / \mathrm{L} \\ \text { Silica } & 10 / 18 / 91 & 14,900 \mu \mathrm{g} / \mathrm{L} \\ \text { Silica } & 10 / 10 / 91 & 10,200 \mu \mathrm{g} / \mathrm{L} \\ \text { Silica } & 10 / 21 / 91 & 10,600 \mu \mathrm{g} / \mathrm{L} \\ \text { Silica } & 10 / 21 / 91 & 10,700 \mu \mathrm{g} / \mathrm{L} \\ \text { Silica } & 10 / 21 / 91 & 10,400 \mu \mathrm{g} / \mathrm{L} \\ \text { Silica } & 10 / 23 / 91 & 9,640 \mu \mathrm{g} / \mathrm{L} \\ \text { Silica } & 10 / 23 / 91 & 9,470 \mu \mathrm{g} / \mathrm{L} \\ \text { Silica } & 10 / 25 / 91 & 10,100 \mu \mathrm{g} / \mathrm{L} \\ \text { Silica } & 10 / 28 / 91 & 9,120 \mu \mathrm{g} / \mathrm{L}\end{array}$

\section{Associated Samples}

HSB 68C, HSB 70C, HSB 83A, HSB 83B, HSB 83C, HSB 84C, HSB 84D, HSB100D, HSB101C, HSB102C, HSB103C, HSB104C, HSB105C, HSB106C, HSB106D, HSB107C, HSB108C, HSB109C, HSB110C, HSB118A, HSB120A, HSB121A, HSB122A, HSB123A, HSB124A, HSB132C, HSB132D, HSB133C, HSB133D, HSB135C, HSB135D, MSB 1C, MSB 1CC, MSB 2D, MSB 5B, MSB 5C, MSB 6A, MSB 6C, MSB 7A, MSB 7B, MSB 7C, MSB 29A, MSB 29B, MSB 29C, MSB 29D, MSB 29TA, MSB 43A, MSB 43B, MSB 43D, MSB 43TA, MSB 48A, MSB 48C, MSB 48TA, MS 54B, MSB 54C, MSB 54D, MSB 54TA, MSB 81B

BGO 2D, BGO 6A, BGO 7D, BGO 8C, BGO 8D, BGO 9D, FSB 1TA, FSB 76A, FSB 76C, FSB 78A, FSB 79A, FSB 79B, HSB 68B, HSB 71, HSB109D, HSB110D, HSB111E, HSB113C, HSB117C, HSB119A, HSB125C, HSB126C, HSB127C, HSB130C, HSB130D, HSB131C, HSB131D, HSB134C, HSB134D, HSB138D, HSB139A, HSB139D, HSB140A, HSB140C, HSB140D, HSB141A, HSB141C, HSB141D, HSB142D, HSB143C, HSB143D, HSB145C, HSB146A, HSB146C, HSB146D, HSB148C, HSB148D, HSB150D, HSB151C, HSB151D, HSB152C, MSB 5A, MSB 13A, MSB 13CC, MSB 13D, MSB 18A, MSB 18B, MSB 18C, MSB 21A, MSB 21C, MSB 21TA, MSB 49B, MSB 49D, MSB 56D, MSB 62B, MSB 62C, MSB 62D, MSB 63B, MSB 63C, MSB 82D

ABP 8C, AMB 4A, AMB 4B, AMB 7, AMB 7A, AMB 7B, AMB 12D, AMB 13AR, BGO 13DR, BRD 1, BRD 2, BRD 4, BRD 5D, FAL 1, FAL 2, FCA 2D, FCA 9D, FCA 10A, FCA 19D, FCB 4, FSS 2D, HSS 2D, HSS 3D, HXB 4D, HXB 5D, MCB 2, MCB 4, MCB 6, NBG 1, NBG 2, NBG 3, NBG 4, NBG 5 MSB 42A, MSB 45A, MSB 47B, MSB 47C, MSB 47TA, MSB 48B 
Table 7. EPD/EMS Blind Blanks With Elevated Results (cont.)

\begin{tabular}{|c|c|c|c|}
\hline Analyte & Run Date & $\underline{\text { Result }}$ & Associated Samples \\
\hline Silica & $10 / 30 / 91$ & $9,460 \mu \mathrm{g} / \mathrm{L}$ & \\
\hline Silica & $10 / 31 / 91$ & $9,590 \mu \mathrm{g} / \mathrm{L}$ & \\
\hline Silica & $10 / 31 / 91$ & $9,520 \mu \mathrm{g} / \mathrm{L}$ & \\
\hline Silica & $11 / 04 / 91$ & $9,970 \mu \mathrm{g} / \mathrm{L}$ & \\
\hline Silica & $11 / 04 / 91$ & $9,590 \mu \mathrm{g} / \mathrm{L}$ & \\
\hline Silica & $11 / 06 / 91$ & $9,410 \mu \mathrm{g} / \mathrm{L}$ & \\
\hline Silica & $11 / 06 / 91$ & $9,490 \mu \mathrm{g} / \mathrm{L}$ & \\
\hline Silica & $11 / 14 / 91$ & $9,490 \mu \mathrm{g} / \mathrm{L}$ & \\
\hline Silica & $11 / 18 / 91$ & $9,510 \mu \mathrm{g} / \mathrm{L}$ & \\
\hline Silica & $11 / 18 / 91$ & $8,850 \mu \mathrm{g} / \mathrm{L}$ & \\
\hline Silica & $11 / 18 / 91$ & $9,430 \mu \mathrm{g} / \mathrm{L}$ & \\
\hline Silica & $11 / 19 / 91$ & $9,340 \mu \mathrm{g} / \mathrm{L}$ & \\
\hline Silica & $11 / 20 / 91$ & $9,090 \mu \mathrm{g} / \mathrm{L}$ & \\
\hline Silica & $12 / 02 / 91$ & $10,400 \mu \mathrm{g} / \mathrm{L}$ & \\
\hline Silica & $12 / 30 / 91$ & $559 \mu \mathrm{g} / \mathrm{L}$ & \\
\hline Sodium & $10 / 31 / 91$ & $238, \quad 3 / \mathrm{L}$ & \\
\hline Sodium & $10 / 31 / 91$ & $214 \mu \mathrm{g} / \mathrm{L}$ & \\
\hline Sodium & $11 / 04 / 91$ & $440 \mu \mathrm{g} / \mathrm{L}$ & \\
\hline Sodium & $11 / 04 / 91$ & $1,200 \mu \mathrm{g} / \mathrm{L}$ & \\
\hline Sodium & $11 / 06 / 91$ & $467 \mu \mathrm{g} / \mathrm{L}$ & \\
\hline Sodium & $11 / 06 / 91$ & $798 \mu \mathrm{g} / \mathrm{L}$ & \\
\hline Sodium & $11 / 14 / 91$ & $955 \mu \mathrm{g} / \mathrm{L}$ & \\
\hline Sodium & $11 / 18 / 91$ & $652 \mu \mathrm{g} / \mathrm{L}$ & \\
\hline Sodium & $11 / 19 / 91$ & $876 \mu \mathrm{g} / \mathrm{L}$ & \\
\hline Sodium & $11 / 20 / 91$ & $1,100 \mu \mathrm{g} / \mathrm{L}$ & \\
\hline Sodium & $11 / 20 / 91$ & $1,160 \mu \mathrm{g} / \mathrm{L}$ & \\
\hline Sodium & $12 / 02 / 91$ & $2,240 \mu \mathrm{g} / \mathrm{L}$ & \\
\hline Specific conductance & $12 / 16 / 91$ & $50 \mu \mathrm{S} / \mathrm{cm}$ & 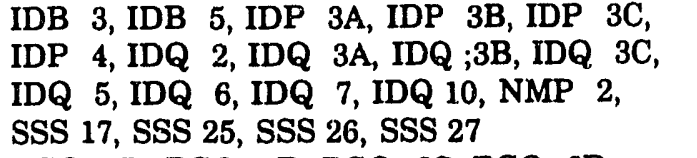 \\
\hline Total dissolved solid 3 & $10 / 21 / 91$ & $29,000 \mu \mathrm{g} / \mathrm{L}$ & $\begin{array}{l}\text { BGO 1D, BGO 3D, BGO 6C, BGO 6D, } \\
\text { BGO 8AR, BGO 10AR, BGO 10C, BGO 10D, } \\
\text { BGO 11D, BGO 12D, BGO 14AR, BGO 14CR, } \\
\text { BGO 14DR, BGO 15D, BGO 25A, BGO 26D, } \\
\text { BGO 27C, BGO 29A, FSB 76B, FSB 87B, } \\
\text { FSB 87C, FSB 88C, FSB 88D, FSB 89C, } \\
\text { FSB 89D, FSB 90C, FSB 90D, FSB 96AR, } \\
\text { FSB 99A, FSB 99D, FSB101A, FSB110C, } \\
\text { FSB117D, HSB142C, MSB 13CC, MSB 13D }\end{array}$ \\
\hline Total organic halogens & $11 / 04 / 91$ & $36 \mu \mathrm{g} / \mathrm{L}$ & $\begin{array}{l}\text { FNB 1, FNB 2, FNB 3, FNB 4, LFW 59B, } \\
\text { LFW 59C, LFW 59D, LFW 61C, LFW 61D, } \\
\text { LFW 62B, MSB 46A, MSB 46B, MSB 47BB, } \\
\text { MSB 47D, MSB 55B, MSB 55D, MSB 55TA }\end{array}$ \\
\hline Total organic halogens & $11 / 07 / 91$ & $87 \mu \mathrm{g} / \mathrm{L}$ & $\begin{array}{l}\text { MSB 42B, MSB 42C, MSB 42TA, MSB 52B, } \\
\text { MSB 52D }\end{array}$ \\
\hline Total organic halogens & $11 / 08 / 91$ & $38 \mu \mathrm{g} / \mathrm{L}$ & $\begin{array}{l}\text { BGO 43AA, BGO 43D, BGO 47A, BGO 47C, } \\
\text { BGO 47D, MSB 37A, MSB 44A, MSB 44B, } \\
\text { MSB 44C, MSB 70D }\end{array}$ \\
\hline $\begin{array}{l}\text { Total organic halogens } \\
\text { Total organic halogens }\end{array}$ & $\begin{array}{l}11 / 19 / 91 \\
11 / 20 / 91\end{array}$ & $147 \mu \mathrm{g} / \mathrm{L}$ & AMB 11D, BGO 13DR, FSS 2D, SSS 6 \\
\hline Total organic halogens & $1 i / 20 / 91$ & $22 \mu \mathrm{g} / \mathrm{L}$ & KAC 1, KAC 2, KAC 4, MSB 13B, MSB 16A \\
\hline
\end{tabular}


Table 7. EPD/EMS Blind Blanks With Elevated Results (cont.)

$\begin{array}{llll}\text { Analyte } & \text { Run Date } & \text { Result } \\ \text { Total organic halogens } & 11 / 27 / 91 & 30 \mu \mathrm{g} / \mathrm{L}\end{array}$

Total or ${ }_{\text {‘ }}$ anic halogens $12 / 02 / 91 \quad 20 \mu \mathrm{g} / \mathrm{L}$

Total organic halogens $12 / 05 / 91 \quad 18 \mu \mathrm{g} / \mathrm{L}$

Total organic halogens $12 / 09 / 91 \quad 59 \mu \mathrm{g} / \mathrm{L}$

Totai phosphates (as P) 11/22/91 $210 \mu \mathrm{g} / \mathrm{L}$

$\begin{array}{lll}\text { Trichloroethylene } & 12 / 03 / 91 & 17.9 \mu \mathrm{g} / \mathrm{L} \\ \text { Tritium } & 10 / 31 / 91 & \begin{array}{l}1.4 \mathrm{E}-05 \pm 1.1 \mathrm{E}-06 \\ \mu \mathrm{Ci} / \mathrm{mL}\end{array}\end{array}$

Tritium

$11 / 04 / 91$
Associated Samples

MSB 2B, MSB 2C, MSB 3C, MSB 4C, MSB 6B, MSB 26, MSB 34A, MSB 37TA, MSB 58D, MSB 59D, MSB 64B, MSB 76C, SCA 3, SCA 4, SCA 5, SCA 6, SSS 4, SSS 5, YSC 1C, YSC 2A, YSC 2D, YSC 4C, YSC 5A CMP 8, CMP 8A, CMP 8B, CMP 9B, CMP 10, CMP 10B, CMP 11B, CMP 13B, CMP 14B, CMP 14C, CMP 16B, MSB 42A, MSB 45A, MSB 47B, MSB 47C, MSB 47TA, MSB 48B, YSC 2A

HAC 1, IAC 2, HAC 3, MSB 23B, MSB 25A, MSB 74B, MSB 75B, TNX 1D, TNX 2D, TNX 7D, TNX 8D, TNX 9D, TNX 10D, I'NX 11D, TNX 12D

BGO 20D, BGO 21D, CMP 11, CMP 12, CMP 12A, CMP 12B, CMP 13, CMP 15A, CMP 15B, CMP 15C, P 26B, P 26D, SSS 10, SSS 11, SSS 19, SSS 21, TNX 3D, TNX 4D, TNX 5D, XSB 1A, XSB 1B, XSB 1D, XSB 2D, XSB 4D

ABP 1A, ABP 2A, ABP 3, ABP 3C, ABP 4, ASB 1A, ASB 2A, ASB 2C, ASB 3A, ASB 5A, ASB 6A, ASB 6C, ASB 7, ASB 8, ASB 8A, ASB 8TA, BGO 43A, BGO 43AA, BGO 43D, BGO 47A, BGO 47C, BGO 47D, BGO 48C, BGO 49D, BGX 7D, BGX 8D, CSD 1D, CSD 8D, CSD 9D, CSD 10D, FAC 3, FAC 4, FAC 7, FAC 8, FCB 2, FCB 3, FCB 5, FCB 6, FNB 1, FNB 2, FNB 3, LFW 59B, LFW 59C, LFW 59D, LFW 61C, LFW 61D, LFW 62B, MSB 19A, MSB 19B, MSB 19C, MSB 31B, MSB 32, MSB 37A, MSB 37B, MSB 38TA, MSB 42B, MSB 42C, MSB 42TA, MSB 44A, MSB 44B, MSB 44C, MSB 45B, MSB 47BB, MSB 52B, MSB 52D, MSB 55B, MSB 55TA, MSB 70D, RWM 1

MSB 2B, MSB 2C, MSB 3C, MSB 4C, MSB 6B, MSB 36B, MSB 58D

BGO 2D, BGO $6 \mathrm{~A}, \mathrm{BGO} 7 \mathrm{D}, \mathrm{BGO} 8 \mathrm{C}$, BGO 8D, BGO 9D, FSB 1TA, FSB 76A, FSB 76B, FSB 76C, FSB 78A, FSB 79A, FSB 79B, HSB140A, HSB140C, HSB140D, HSB141A, HSB141C, HSB141D, HSB143C, HSB143D, HSB145C, HSB146A, HSB146C, HSB146D, HSB148C, HSB148D, MSB 62B, MSB 63D

$1.2 \mathrm{E}-04 \pm 1.8 \mathrm{E}-06$ $\mu \mathrm{Ci} / \mathrm{mL}$
BGO 6D, BGO 10AR, BGO 10D, BGO 11D, BGO 12AR, BGO 12CR, BGO 12D, BGO 14AR, BGO 14CR, BGO 14DR, BGO 15D, BGO 26D, BGO 27C, BGO 27D, BGO 29A, BGO 30C, BGO 31D, BGO 33D, BGO 34D, BGO 35C, BGO 36D, BGO 37D, BGO 38D, BGO 39D, FSB 97A, FSB114A, FSB114C 
Table 7. EPD/EMS Blind Blanks With Elevated Results (cont.)

Analyte

$\underline{\text { Run Date }} \quad \underline{\text { Result }}$

Associated Samples

Tritium

$12 / 19 / 91$

$7.7 \mathrm{E}-06 \pm 8 \mathrm{E}-07$

$\mu \mathrm{Ci} / \mathrm{mL}$

\begin{abstract}
CDB 1, CDB 2, IDP 3A, IDP 3B, IDP 3C, IDP 4, IDQ 2, IDQ 3A, IDQ 3B, IDQ 3C, IDQ 5, IDQ 6, IDQ 7, IDQ 10, K 301P, KSB 2, KSB 3, NPM 2, PDB 2, PDB 3, RAC 1, RAC 2, RAC 3, RAC 4, SSS 25, SSS 26, SSS 27
\end{abstract}

A technical review of the quarter's analytical data identified at least one reported result for the analyses in Table 8 as high in comparison

to historical data. A review of the laboratory records did not reveal any problems with the analyses, except as noted previously.

Table 8. General Engineering Samples With High Analytical Results as Compared to Historical Data

Analyte
Acetone
Aluminum
Arsenic
Barium
Benzene
Bis(2-ethylhexyl)phthalate
Bromide
Bromodichloromethane
Calcium
Carbon tetrachloride
Chloride
Chlorobenzene
Chloroethane
Chloroethene (Vinyl chloride)
Chloroform
Chloromethane (Methyl chloride)
Chromium
Copper
Cyanide
Dichlorodifluoromethane
1,1-Dichloroethane
1,1-Dichloroethylene
Can

$\underline{\text { Wells }}$

MSB 29A, MSB 29B, MSB 29C, MSB 29D, MSB 43A, MSB 43TA

AMB 10A, AMB 11B, BGO 35D, BGO 45B, FSB 92D, FSB106D, FSB113D, FSB121C, MSB 2D, MSB 3B, MSB 6B, MSB 10C, MSB 15A, MSB 62D, MSB 64B

SSS 4

AMB 10A, AMB 11B, AMB 13AR, BGO 30D, BGO 45B, FSB121C, FSB122D, HSB141C, MSB 2B, MSB 3B, MSB 10C, MSB 15A, MSB 16A, TBG 1, XSB 2D

LFW 10A, LFW 37

MSB 29B

TNX 5D, XSB 2D, YSB 3A

MSB 15C

ABP 8C, AMB 10A, AMB 13AR, BGO 10D, BGO 45B, BGO 45C, FSB121C, HSB141C, IDP 3C, LFW 16, MSB 2B, MSB 2C, MSB 5C, MSB 6C, MSB 13B, MSB 16A, MSB 79B, SSS 19, XSB 2D

TBG 1, TNX 3D

BGX 1A, FSB 79, FSB 88D, FSB 94DR, FSB 95DR, FSB 97C, HSB116C, LFW 10A, SSS 4, SSS 19

LFW 17, LFW 18, LFW 36, LFW 48D, MSB 2B

LFW 36

BGO 28D, LFW 8, LFW 47C, LFW 55C, MSB 9B

MSB 3B, MSB 3D, MSB 15C, TNX 5D

AMB 11B

BGO 45B, MCB 7C, MSB 10C

BG 91, BG 104, BG 109, HSB152D, IDB 5, MSB 1D, MSB 10C, RWM 1, YSB 4A

FSB 94DR, MSB 6C

MSB 3D

LFW 16, LFW 57D, LFW 62C, LFW 62D, MSB 2B, MSB 5C, MSB 14A, MSB $31 \mathrm{C}$

LFW 39, LFW 40, LFW 62D, MSB 31C 
Table 8. General Engineering Samples With High Analytical Results as Compared to Historical Data (cont.)

Analyte

Dichloromethane (Methylene chloride)

Ethylbenzene

Fluoride

Iodine

Iron

Lead

Magnesium

Manganese

Mercury

Nickel

Nitrate as nitrogen

Phenols

Potassium

Silica

Sodium
Wells

ABP 1A, AMB 4B, AMB 7A, AMB 7B, AOB 1, BGO 6A, BGO 7D, BGO 8AR, BGO 8C, BGO 8D, BGO 9D, BGO 31C, BGO 37D, BGO 39D, BGO 45A, BGO 45B, BGO 45C, BGO 45D, BGX 4A, BGX 4C, CMP 8A, CMP 10B, CMP 11B, CMP 13B, FSB112C, FSB113C, FSB113D, FSB116D, FSB117D, FSB119D, FSB120C, FSB123C, FSB123D, HAC 2, HSB141D, HSB142C, HSB142D, HSB143D, HSB147D, LFW 10A, LFW 21, LFW 43B, LFW 43C, LFW 43D, LFW 44D, LFW 55C, LFW 55D, LFW 56D, LFW 57B, LFW 57D, LFW 62C, MCB 5, MCB 6C, MSB 3B, MSB 3D, MSB 6A, MSB 7A, MSB 7B, MSB 7C, MSB 9A, MSB 9B, MSB 9C, MSB 10A, MSB 10B, MSB 11C, MSB 11F, MSB 12TA, MSB 13B, MSB 14A, MSB 15A, MSB 15C, MSB 17A, MSB 17B, MSB 36A, MSB 36D, MSB 36TA, MSB 48A, MSB 48TA, MSB 55B, MSB 57D, MSB 64C, MSB 81B, PAC 5, TNX 7D

LFW 16

AMB 10A, BRD 2, FSB108D, MSB 6C, MSB 82A

BG $91, \mathrm{BG} 110$

AMB 8D, AMB 11D, BGO 35D, CBR 3D, FSB 1TA, FSB 99C, FSB116D, FSB118D, HAC 3, HSB113D, HSB131D, HSB147D, HSB150D, IDB 5, LAC 1, LFW 46D, LFW 47D, MSB 4D, MSB 7C, MSB 13CC, MSB 13D, MSB 16A, MSB 34TB, MSB 37A, MSB 54D, PAC 3, RAC 3, SSS 5, SSS 10, TNX 6D, YSC 2D ABP 8C, LFW 61D, MSB 2B, MSB 13CC, MSB 54D, MSB 55D, MSB 61C, XSB 2D

BGO 10D, BGO 12C, CBR 3D, CSD 10D, FSB113C, FSB122D, FSS 1D, HSB 70C, IDB 1B, IDP 3C, LFW 10A, LFW 16, MSB 3C, MSB 4C, MSB 5C, MSB 6C, MSB 7B, MSB 16A, SSS 19, TBG 1, XSB 2D, YSB 3A

AMB 4A, BGO 12C, FSB 1TA, FSB112A, HSB150D, LFW 10A, LFW 16, MCB 6, MSB 6C, MSB 16A, SSS 19, XSB 2D

AMB 5, AMB 6, AMB 8D, AMB 9D, BG 52, BGO 45A, FSB 77, FSB119D, LFW 27, LFW 39, LFW 59C, LFW 62C, MSB 34TB, MSB 35B, MSB 41B, MSB 81B

BGO 30D, FSB120D, LFW 20, MSB 6C, MSB 59D

AMB 6, BGO 8C, BGO 10D, CBR 3D, FAl 1, FCA 10A, FSB 87B, FSB 94DR, FSB 96AR, HSB 84C, HSB110D, HSB112C, HSB112D, HSB113D, HSB114C, HSB115C, HSB115D, HSB116C, HSB116D, HSB118A, HSB119A, HSB123A, HSB127C, HSB129D, HSB133C, HSB136C, HSB142D, HSB150D, HSB152D, HTF 7, IDP 4, IDQ 2, IDQ 3A, IDQ 3B, IDQ 3C; LFW 31, MSB 2B, MSB 2C, MSB 3C, MSB 3B, MSB 6B, MSB 7A, MSB 9A, MSB 13A, MSB 13D, MSB 18A, MSB 18B, MSB 21C, MSB 21TA, MSB 29A, MSB 43'TA, MSB 62B, MSB 79C, MSB 82A, SCA 4, SCA 6, SSS 19, TBG 1, TBG 5B, $\mathrm{XSB} 2 \mathrm{D}, \mathrm{YSC} 1 \mathrm{C}$

BRD 2, IDP 3C, IDQ 3C, MSB 9A, MSB 9B, MSB 9C, SSS 25

AMB 10A, AMB 13AR, BGO 14AR, BGO 45B, BGO 45C, FSB 88D, FSB117D, FSB119D, FSB121C, HSB110D, HSB141C, IDQ 7, MSB 2B, MSB 3B, MSB 3D, MSB 63C, MSB 76C, MSB 77C, SSS 4, YSC 2D BGO 10D, HXB 5B, MSB 7B, MSB 62D

AMB 10A, BGO 14AR, FAC 4, LFW 10A, LFW 16, LFW 21, MSB 9A, MSB 16A, MSB 39D, SSS 4, XSB 2D, YSC 2D 
Table 8. General Engineering Samples With High Analytical Results as Compared to Historical Data (cont.)

Analyte

Specific conductance

Sulfate

1,1,1,2-Tetrachloroethane 1,1,2,2-Tetrachloroethane Tetrachloroethylene

Toluene

Total dissolved solids

Total inorganic carbon

Total organic carbon

Total organic halogens

Total petroleum hydrocarbons Total phosphates (as P)

\section{1,1,1-Trichloroethane}

Trichloroethylene
Wells

AMB 10A, BGO 14AR, BGO 30D, BGO 45B, BGO 45C, BGX 1A, FSB118D, FSB120C, HSB141D, LFW 6, LFW 10A, LFW 16, MSB 3B, MSB 9A, MSB 10C, MSB 15A, MSB 37TA, MSB 42A, MSB 77B, SSS 4, SSS 19, XSB 2D, YSC 2D

ASB 6A, BGO 2D, BGO 3D, BGO 35D, BGX 1A, FNB 3, FSB 79, FSB 79C, FSB 92D, FSB 93D, FSB 97D, FSB 98C, FSB105DR, FSB110D, HSB 84D, HSB105D, HSB110D, HSB112D, HSB116D, IDB 7, LFW 16, LFW 24, LFW 25, LFW 55D, LFW 57B, MSB 14A, MSB 18C, MSB 33A, MSB 62D, YSC 2D

MSB 59D

MSB 12B

BGO 40D, DOB 4, FAC 3, LCO 4, LFW 41, LFW 62D, MCB 7C, MSB 2B, MSB 3B, MSB 3C, MSB 4C, MSB 6B, MSB 9A, MSB 9B, MSB 11B, MSB 11C, MSB 12B, MSB 15C, MSB 17B, MSB 31C, MSB 39D, MSB 76C, MSB 79B, MSB 83TA, TNX 1D

AMB 10A, LFW 10A, LFW 16, LFW 21, MCB 6C, MSB 2B, MSB 3B AC 1A, BGO 10D, BGO 30D, BGO 31, BGO 45C, BGO 45D, HSB103C, HSB131D, HSB147D, HSB149D, LFW 62D, MSB 3B, MSB 4B, MSB 26, MSB 37TA, MSB 41A, MSB 45A, MSB 50B, MSB 77C, SSS 4, SSS 6, SSS 27, XSB 2D, YSB 1A, YSB 2A, YSC $2 D$

IDB 1B

KAC 7, MSB 13B, SSS 1, SSS 4, SSS 6 , SSS 10, SSS 11

AC 3A, AMB 4B, AMB 7, AMB 7A, AMB 10D, AMB 11B, AMB 12D, AMB 13AR, ASB 2C, ASB 3A, ASB 8C, ASB 8TA, BGO 39D, BGO 45D, BGX 1A, BGX 2B, BGX 3D, BGX 6D, BRD 2, BRR 4D, CMP 14B, CMP 14C, FAC 3, FAC 4, FAC 5, FCB 4, FSB 89C, FSB 98C, FSB100A, FSB106C, FSB106D, FSB112D, FSB113D, FSB115C, FSB116C, FSB119D, FSB120C, FSS 1D, FSS 3D, FSS 4D, HSB 66, HSB 68A, HSB 68C, HSB 69A, HSB 84B, HSB 86A, HSB100C, HSB105D, HSB109C, HSB111D, HSB113C, HSB118A, HSB119A, HSB130C, HSB134C, HSB136C, HSB139A, KAC 7, LFW 10A, LFW 20, LFW 25, LFW 39, LFW 47D, LFW 55C, LFW 55D, LFW 59C, MCB 4, MCB 7C, MSB 2D, MSB 23B, MSB 37A, MSB 45A, MSB 47B, MSB 50B, MSB 50D, MSB 51B, MSB 51D, MSB 55TA, MSB 59D, MSB 75C, MSB 76C, MSB 77B, MSB 77D, MSB 82D, MSB 83D, MSB 85B, MSB 85C, PAC 4, PDB 3, SCA 4, SCA 5, SCA 6, SSS 6, SSS 20, SSS 22, XSB 4D, XSB 5A, YSB 3A, YSC 2D, YSC 4C CMP 11

AMB 13AR, ASB 3C, BG 94, BG 95, BG 96, BGO 31C, BGO 33C, FAC 3, FAC 5, FAC 6, FAC 7, FNB 2, FNB 3, FSB 76, FSB 94C, FSB111D, FSB113C, FSS 1D, FSS 2D, HSB 68B, HSB 71, HSB152D, IDB 2B, IDB 6, LFW 46D, LFW 62B, MSB 2B, MSB 3C, MSB 13D, MSB 14A, MSB 44C, MSB 47C, MSB 51D, MSB 55B, MSB 55TA, MSB 57D, MSB 63D, MSB 74D, MSB 77C, SCA 5, SSS 1 , SSS 3 , SSS 4 , SSS 5 , SSS 6 , SSS 10, SSS 11, SSS 19, SSS 20, SSS 22, SSS 23 , SSS 24, SSS 25, SSS 26, SSS 27

BGO 45B, FSB116D, HSB152D, LFW 62D, MSB 2D, MSB 14A, MSB 31C

AMB 7, AMB 7B, BGO 40D, FAC 3, FAC 4, FCB 2, FSB 99C, LCO 4, LFW 62D, MCB 7C, MSB 2B, MSB 3C, MSB 4C, MSB 9A, MSB 17B, MSB 21TA, MSB 31C, MSB 36A, MSB 39D, MSB 82A, MSB 85TA, TNX 1D, TNX 3D, ZBG 2 


\section{Table 8. General Engineering Samples With High Analytical Results as Compared to Historical Data (cont.)}

Analyte

Trichlorofluoromethane

Turbidity

Zinc

Gross alpha

Nonvolatile beta

Total alpha-emitting radium

Tritium

Uranium alpha activity $\underline{\text { Wells }}$

BGO 6D, RRR 3D, HSB143D, HSB146D, LFW 59D, LFW 62D, MSB 15C, MSB 55TA, MSB 82D, MSB 83D, MSB 85B, XSB 1B, ZBG 2 BGO 12AR, BGO 14DR, BGO 18A, BGO 27C, BGO 29A, BGO 31C, BGO 31D, BGO 33C, BGO 35C, BGO 45C, BGO 45D, FAC 3, FAC 4, FAC 6, FAC 7, HSB 65C, HSB 85A

BG 104, HSB 68B, IDQ 5, MSB 1D, MSB 10C, MSB 11C, MSB 13D, PAC 5

AMB 7, AMB 12D, AMB 13AR, ASB 6AA, BG 52, BGO 40D, FCA 2C, FSB 94DR, FSB 95CR, FSB 97C, FSB102C, FSB105DR, FSB112D, FSB117D, HCA 2, HSB 67, HSB 68, HSB 69, HSB 71C, HSB 84D, HSB 86C, HSB 86D, HSB102D, HSB103D, HSB104D, HSB105D, HSB106D, HSB107D, HSB108D, HSB109D, HSB111E, HSB113D, HSB114D, HSB115C, HSB115D, HSB116D, HSB127C, HSB129C, HSB129D, HSB136C, HSB136D, HSB137C, HSB145D, IDQ 2, LFW 19, LFW 57B, LFW 62B, MCB 6, MSB 6B, MSB 6C, MSB 7C, MSB 44C, MSB 47B, MSB 47C, MSB 47D, MSB 77D, MSB 79C, SSS 5, SSS 6, TBG 1, TNX 10D, XSB 2D AMB 10A, AMB 13AR, ASB 6TA, BG 59, FAL 2, FCB 4, FSS 3D, HAC 1, HSB127C, HSB142C, HSB143C, IDB 1A, IDB 2A, IDB 2C, IDP 3A, IDQ 4, LFW 62B, MCB 5C, MSB 3B, MSB 3D, MSB 64D, MSB 77D, SSS 22, SSS 23, XSB 2D ASB 8C, BGX 10D, BRD 2, CBR 2D, HSB 67, HSB 68, HSB 69, HSB 86D, HSB103D, HSB105D, HSB1.14D, HSB116D, LFW 19, LFW 20, LFW 44D, LFW 59D, MCB 7C, MSB 48B, YSB 3A, XSB 2D, YSB 4A ABP 8C, AMB 7A, AMB 10B, AMB 11B, AOB 2, BG 67, BGO 10AR, BGO 10D, BGO 12AR, BGO 12CR, BGO 12D, BGO 14AR, BGO 26D, BGO 29A, BGO 31C, BGO 35C, BGO 45D, FAL 1, FSB 76A, FSB114A, FSB114C, FSS 4D, HSB118A, HSB140A, HSB140C, HSB141A, HSB142D, HSB146A, HSB150D, HSB151D, HSB152D, IDB 1A, IDB 1C, IDB 2A, IDB 2B, IDB 2C, IDP $3 A$, IDP $3 B$, IDP $3 C$, IDP 4, IDQ 2, IDQ 3A, IDQ 3B, IDQ 3C, IDQ 5, IDQ 6, IDQ 7, KDB 1, LDB 1, LSB 2, MCB 5C, MCB 6C, MCB 7C, MSB 13B, MSB 37TA, MSB 62B, RAC 1, RAC 3, RAC 4, SSS 19, SSS 27, TBG 5B, XSB 3A

MSB 19B, MSB 21C, MSB 36A, MSB 40C, MSB 40TA

A technical review of the quarter's analytical data identified at least one result of the analyses in Table 9 as low in comparison to historical data. A review of the laboratory records did not reveal any problems with the analyses.

Table 9. General Engineering Samples With Low Analytical Results as Compared to Historical Data

Analyte $\quad$ Wells

Acetone $\quad$ MSB 58D

Aluminum MSB $11 \mathrm{~F}, \mathrm{MSB} 13 \mathrm{~B}$

Barium BGO 12C, IDQ 6

Calcium BGO 3D, BGO 12C, KAC 1

Carbon tetrachloride MCB 5

Chloride MSE 10C, MSB $15 \mathrm{C}$ 
Table 9. General Engineering Samples With Low Analytical Results as Compared to Historical Data (cont.)

Analyte
Chloroethane
Chloroform
Copper
1,1-Dichloroethane
Dichloromethane
(Methylene chloride)
Fluoride
Iron

Lead

Magnesium

Manganese

Mercury

Nickel

Nitrate as nitrogen

Phenols

Potassium

Sodium

Specific conductance

Sulfate

1,1,2,2-Tetrachloroethane

Tetrachloroethylene

Toluene

Total dissolved solids

Total organic carbon

Total organic halogens

Total phosphates (as P)

1,1,1-Trichloroethane

Trichloroethylene

Trichlorofluoromethane

Turbidity

Zinc

Gross alpha

Nonvolatile beta

Total alpha-emitting radium
Wells

LFW 59D, LFW 61C

ASB 6TA, BGO 33C, BGX 1D

HSB 65C, MSB 9C, MSB 11F, MSB 36D

LFW 10A, LFW 58D

AMB 4A, BRR 5D, LFW 61D, MSB 6B, MSB 77C

SSS 19

BG 104, BGO 3D, BGO 10D, BGO 21D, CBR 1D, DOB 1, FAC 5, FSB 95CR, FSB 98C, FSB104D, FSB115D, HSB 68C, HSB 69,

HSB111C, HSB135D, IDQ 5, KAC 1, LFW 59D, MCB 4, MCB 5, MSB 1CC, MSB 26, MSB 42A, MSB 45B, MSB 83B, RAC 1, SSS 19, SSS 20, SSS 22, SSS 23, SSS 27, XSB 1D

BGX 1A, FSB 88D, IDB 3, LFW 62B, MCB 5C, MSB 56D, SSS 6

AMB 10A, HSB124A, MSB 2B

AMB 10A, AOB 2, HSB141C

MSB 15C

BGO 45C, FSB116D

ABP 3C, BGX 2D, DOB 3, HSB105C, HSB126C, KAC 1, LFW 10A,

LFW 47D, MSB 9B, MSB 10C, MSB 11F, MSB 26, SSS 19

MSB 2C

BGO 12AR, BGO 12C, BGO 12CR, FSB 91C, FSB 94C, IDP $3 \mathrm{C}$

BGO 12C, FSB 91C

BGO 16A

FNB 4, HAC 1, MSB 15C, MSB 42A

MSB $10 \mathrm{C}$

CMP 12, MSB 2C, MSB 3D, MSB 7A, MSB 9C, MSB 10C, MSB 11F, MSB 14A, MSB 48B

AMB 4A, MSB 2C, MSB 77TA

BG 103, BGO 12C, BGO 34D, BGO 36D, BGO 37D, BGO 40D, BGX 9D, HSB130C, HSB134D, HSB135D, HSB140C, HSB140D, HSB146D,

IDP 4, IDQ 5, LFW 45D, MSB 34A, MSB 48TA, MSB 49D, MSB 56D,

MSB 75C, P 26D

MSB 77TA

ASB 6TA, ASB 8, BGO 12AR, BGX 1D, CMP 13, FSB122C, HSB141C, HSB141D, HXB 5D, LFW 43B, LFW 43C, LFW 43D, LFW 44D,

LFW 46D, LFW 48C, MCB 5, MSB 3D, MSB 8B, MSB 16A, MSB 26

BGO 40D, BGX 1C

BGO 10D, BGX 12D

BGO 12C, CMP 12, FCA 9D, FCA 19D, LFW 58D, MCB 5, MSB 2C,

MSB 9C, MSB 10C, MSB 11D, MSB 11F, MSB 15C, MSB 17A, MSB 76C

BGX 1A, LFW 10A, LFW 43D, LFW 47D, LFW 56D, LFW 58D, LFW $61 \mathrm{C}$

$\mathrm{KAC} 3$

AMB 13AR, FSB 88D, FSB116D, HSB117A, IDB 3, MSB 9A, MSB 15A, MSB 18C, MSB 19B, MSB 36D, MSB 62D

FSB 88D

BGO 12C, BGO 45B, BGX 1A, FCA 9D, MSB 3C, YSC 2A

BGO 40D, SSS 27 


\section{ANALYTICAL DATA REVIEW}

Table 9. General Engineering Samples With Low Analytical Results as Compared to Historical Data (cont.)

Analyte $\quad$ Wells

Tritium

ASB 6A, ASB 7, BG 92, BG 93, BG 94, BG 95, BG 96, BGO 32D, BGO 45B, BGX 4C, BGX 6D, FNB 4, FSB 88D, FSB111C, HMD 2D, HMD 3D, HSB111E, HSB134D, KSB 1, KSB 4A, LAC 1, LAC 3, LAC 4, LDB 1, LDB 2, LFW 6, LFW 18, LFW 21, LFW 34, LFW 39, LFW 47C, LFW 48C, LFW 55D, LFW 57C, LFW 59C, LFW 59D, LFW 61C, LFW 61D, LFW 62C, LSB 2, MSB 51D, MSB 61C, PSB 4A

Because alkalinity as $\mathrm{CaCO}_{3}$ was not on the current contract, General Engineering did not perform that analysis on se following wells for which it was scheduled: BG 91, BG 92, BG 93, BG 94, BG 95, BG 96, BG 101, BG 103, BG 104, BG 107, BG 109, BG 110, BG 121, BG 122, HSB140A, HSB140C, HSB140D, HSB141A, HSB141C, HSB141D, HSB142C, HSB142D, HSB143C, HSB143D, HSB144A, HSB145C, HSB145D, HSB146A, HSB146C, HSB146D, HSB147D, HSB148C, HSB148D, HSB149D, HSB150D, HSB151C, HSB151D, HSB152C, HSB152D, IDB 1A, IDB 1B, IDB 1C, IDB 2A, IDB 2B, IDB 2C, IDB 3, IDB 4, IDB 5, IDB 6, IDB 7, IDB 8, IDB 9, IDB 10, IDP 1, IDP 2, IDP 3A, IDP 3B, IDP 3C, IDP 4, IDP 5, IDP 6, IDP 7, IDP 8, IDP 9, IDQ 2, IDQ 3A, IDQ 3B, IDQ 3C, IDQ 4, IDQ 5, IDQ 6, IDQ 7, IDQ 8, IDQ 9, IDQ 10, IDQ 12, MSB 31C, MSB 36D, MSB 39D.

For the same reason, General Engineering did not perform analyses for tributyl phosphate for the following wells for which it was scheduled: BGO 8AR, BGO 10AR, BGO 12AR, BGO 12CR, BGO 13DR, BGO 14AR, BGO 14CR, BGO 14DR, BGO 26D, BGO 27C, BGO 27D, BGO 28D, BGO 29A, BGO 29C, BGO 29D, BGO 30C, BGO 30D, BGO 31C, BGO 31D, BGO 32D, BGO 33C, BGO 33D, BGO 34D, BGO 35C, BGO 35D, BGO 36D, BGO 37D, BGO 38D, BGO 39D, BGO 40D, BGO 41A, BGO 42C, BGO 43A, BGO 43AA, BGO 43D, BGO 45A, BGO 45B, BGO 45C, BGO 45D, BGO 46B, BGO 46C, BGO 46D, BGO 4'7A, BGO 47C, BGO 47D, BGO 48C, BGO 48D, BGO 49A, BGO 49C, BGO 49D, BGO 50A, BGO 50C, BGO 50D, FSB 79C, FSB 91D, FSB 97A, FSB 97C, FSB110D, HSB102D, HSB107D, HSB112D, HSB116C, HSB119A.

Table 10 lists the reasons General Engineering did not perform certain other analyses on samples from wells that could be sampled. See also the Sample Scheduling section of this report for a list of wells scheduled but not sampled this quarter.

Table 10. Analyses Not Performed by General Engineering

Wells

BGO 10D

FCA $2 \mathrm{C}$

FCA $10 D$

FSB103C, FSB104C, FSB104D, FSB113A, FSB122C, FSB122D, IDP 1 , IDP 2, IDP $3 A$, IDP $3 B$, IDP $3 \mathrm{C}$, IDP 4 , IDP 5 , IDP 6 , IDP 7, IDP 8, IDP 9, IDQ 2, IDQ 3A, IDQ 3B, IDQ 3C, IDQ 4, IDQ 5, IDQ 6, IDQ 7, IDQ 8, IDQ 9, IDQ 10, IDQ 12, MSB 3B, MSB 3D

\section{Analytes Reason}

Herbicides

All scheduled analyses except gross alpha, nonvolatile beta, total radium

GC VOA, nitrate as nitrogen, tritium

Uranium
Insufficient water for complete sample collection

Insuficient water for complete sample collection

Insufficient water for complete sample collection

Not in current contract 
Table 10. Analyses Not Performed by General Engineering (cont.)

\author{
Wells \\ FSB106D \\ FSB120D, LFW 57C, LFW 60D \\ HMD 2D \\ LFW 57C, LFW 60D \\ MSB 13B \\ MSB 31C, MSB 36D, MSB 39D \\ NPM 4DD \\ $P \quad 14 T A, P \quad 14 \mathrm{TC}$
}

SSS 21

Analytes
Herbicides/pesticici-s, gross alpha,
nonvolatile beta, total alpha-
emitting radium
Phenols
Herbicides
Total dissolved solids, total
phosphates
Appendix IX dioxins and furans,
herbicides, PCBs, and pesticides
Ammonia
All scheduled analyses other than
total organic carbon
All scheduled analyses

$\underline{\text { Reason }}$

Insufficient water for complete sample collection

Laboratory error

Extraction problems at the laboratory

Laboratory error

Insufficient water for complete sample collection

Not on current contract

Insufficient water for complete sample collection

No field log entries; chains of custody say "Generator not available for 5 horse[power] pump"

Insufficient water for complete sample collection

\section{Review of the M-Area Laboratory Analytical Data}

A technical review of the quarter's analytical data identified at least one result from the analyses in Table 11 as high in comparison to historical data. A review of the laboratory records did not reveal any problems with the analyses.

\section{Table 11. M-Area Laboratory Samples With High Analytical Results as Compared to Historical Data}

Analyte

Chloroform

T'etrachloroethylene

Trichloroethylene $\underline{\text { Wells }}$

MSB 67C

MSB 23TA, MSB 26A, MSB 34A, MSB 37A, MSB 37C

ARP 1A, ASB 4, MCB 7C, MSB 23TA, MSB 26A, MSB 37A, MSB 37C, MSB 45B, MSB 66TA

A technical review of the quarter's analytical data identified the analyses for tetrachloroethylene from MSB 26 and for trichloroethylene from ASB 3C, MCB 5, MSB 26, MSB 28A, MSB 34B, RWM 3, and RWM 9 as low in comparison to historical data. A review of the laboratory records did not reveal any problems with the analyses.

\section{Review of the EPD/EMS Laboratory Radioactive Analytical Data}

A technical review of the quarter's analytical data identified the analyses in Table 12 as high in comparison to historical data. A review of the laboratory records did not reveal any problems with the analyses. 


\section{ANALYTICAL DATA REVIEW}

Table 12. EPD/EMS Laboratory Samples With Low Analytical Results as Compared to Historical Data

Analyte

Strontium-89/90

Gross alpha

Tritium

\section{Wells}

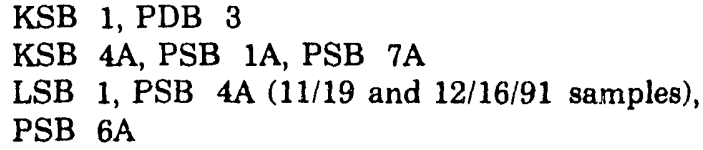

KSB 1, PDB 3

KSB 4A, PSB 1A, PSB 7A

LSB 1, PSB 4A (11/19 and 12/16/91 samples), PSB 6A

A technical review of the quarter's analytical data identified the analysis for gross alpha from the $11 / 22 / 91$ sample from well $\mathrm{KDB} 1$ as high in comparison to historical data. A review of the laboratory records did not reveal any problems with the analyses.

Table 13 lists analyses not performed by EM on wells that were not dry.

Table 13. Analyses Not Performed by the EPD/EMS Laboratory

Analyte

Gross alpha, nonvolatile beta

Gross alpha
Wells

K $301 \mathrm{P}$ (3 monthly samples),
KDB $3(11 / 22$ and $12 / 17$ sample),
KSB $2(10 / 24$ and $12 / 13$ sample),
KSB $3(10 / 24$ sample), LDB 2
(12/16 sample), LSB 2 (12/16
sample), LSB $3(12 / 16$ sample),
PDB 3 (12/16 sample), PSB 4A
(12/16 sample)
LDB 1 (12/16 sample)

$\underline{\text { Reason }}$

Samples misplaced by

laboratory

Samples misplaced by laboratory

\section{Review of the Teledyne Isotopes Analytical Data}

A technical review of the quarter's analytical data identified the analyses in Table 14 as low in comparison to historical data. A review of the laboratory records did not reveal any problems with the analyses.

Table 14. Teledyne Isotopes Samples With Low Analytical Results as Compared to Historical Data

Analyte

Americium-241

Radium-226

Uranium-233/234

Uranium-238 $\underline{\text { Wells }}$

ASB 6AA

ASB 6AA

BGO 18A, BGO 22D, BGO 45B

BGO 45B, MSB 13B

Table 15 lists the reasons Teledyne Isotopes did not perform certain analyses on samples from wells that were not dry. See also the Sample Scheduling section of this report for a list of wells scheduled but not sampled this quarter. 
Table 15. Analyses Not Performed by Teledyne Isotopes

$\begin{array}{ll}\text { Wells } & \text { Analytes } \\ \text { FCA 10D } & \text { Gamma PHA } \\ \text { NPM 4DD } & \text { Gamma PHA }\end{array}$

\section{ANALYTICAL METHODS}

GE performed most of the analyses conducted during fourth quarter 1991, using the methods listed in Table 16.

The M-Area Laboratory (MA) at SRS analyzed certain wells in the A/M Areas for chloroform, tetrachloroethylene, trans-1,2-dichloroethylene, 1,1-dichloroethylene, trichloroethylene, and 1,1,1-trichloroethane by EPA method 601 (Gas Chromatography). The undiluted sample detection limit varied among 1,5 , and $10 \mu \mathrm{g} / \mathrm{L}$.

The EPD/EMS Laboratory (EM) at SRS conducted selected radionuclide analyses of samples required by the groundwater monitoring program. The gross alpha and nonvolatile beta analytical methods used by the EPD/EMS Laboratory are in-house methods based on applicable EPA methods. Methods used by EPD/EMS for testing other radioisotopes also are in-house analytical methods. The EPD/EMS Laboratory radioactivity determinations are reported as the absolute concentrations calculated from the analytical tests.

Teledyne Isotopes performed most of the radionuclide analyses. Their in-house methods, based on applicable EPA and DOE procedures, and detection limits are listed in Table 17.

If the laboratories used more than one analytical method for one analyte, the methods are listed in the tables in descending order according to frequency of use. Generally, the method listed first was used for at least half of the analyses.
Reason

Well bailed dry before complete sample collection

Well pumped dry before sample could be collected

Table 16. Methods and Detection Limits Used by General Engineering

\begin{tabular}{|c|c|c|}
\hline Analyte & Method & Limit \\
\hline Acenaphthene & EPA8270 & $10 \mu \mathrm{g} / \mathrm{L}$ \\
\hline Acenaphthylene & EPA8270 & $10 \mu \mathrm{g} / \mathrm{L}$ \\
\hline Acetone & EPA8240 & $100 \mu \mathrm{g} / \mathrm{L}$ \\
\hline \multicolumn{3}{|l|}{ Acetonitrile } \\
\hline Acetophenone & EPA8270 & $10 \mu \mathrm{g} / \mathrm{L}$ \\
\hline \multicolumn{2}{|l|}{ 2-Acetylamino- } & $10 \mu \mathrm{g} / \mathrm{L}$ \\
\hline Acrolein & EPA8240 & $20 \mu \mathrm{g} / \mathrm{L}$ \\
\hline Acrylonitrile & EPA8240 & $20 \mu \mathrm{g} / \mathrm{L}$ \\
\hline Aldrin & EPA8080 & $0.05 \mu \mathrm{g} / \mathrm{L}$ \\
\hline Allyl chloride & $\begin{array}{l}\text { EPA8270 } \\
\text { EPA8240 }\end{array}$ & $\begin{array}{l}10 \mu \mathrm{g} / \mathrm{L} \\
50 \mu \mathrm{g} / \mathrm{L}\end{array}$ \\
\hline Aluminun & EPA6010 & $20 \mu \mathrm{g} / \mathrm{L}$ \\
\hline 4-Aminobiphenyl & EPA8270 & $10 \mu \mathrm{g} / \mathrm{L}$ \\
\hline Aniline & EPA8270 & $10 \mu \mathrm{g} / \mathrm{L}$ \\
\hline Anthracene & EPA8270 & $10 \mu \mathrm{g} / \mathrm{L}$ \\
\hline Antimony & EPA7041 & $2 \mu \mathrm{g} / \mathrm{L}$ \\
\hline Aramite & EPA8270 & $10 \mu \mathrm{g} / \mathrm{L}$ \\
\hline Arsenic & EPA7060 & $2 \mu \mathrm{g} / \mathrm{L}$ \\
\hline Barium & EPA6010 & $3 \mu \mathrm{g} / \mathrm{L}$ \\
\hline Benzene & EPA8240 & $1 \mu \mathrm{g} / \mathrm{L}$ \\
\hline hexachloride & $\begin{array}{l}\text { EPA8080 } \\
\text { EPA8270 }\end{array}$ & $\begin{array}{l}0.05 \mu \mathrm{g} / \mathrm{L} \\
10 \mu \mathrm{g} / \mathrm{L}\end{array}$ \\
\hline \multicolumn{3}{|l|}{ beta-Benzene } \\
\hline hexachloride & $\begin{array}{l}\text { EPA8080 } \\
\text { EPA8270 }\end{array}$ & $\begin{array}{l}0.05 \mu \mathrm{g} / \mathrm{L} \\
10 \mu \mathrm{g} / \mathrm{L}\end{array}$ \\
\hline \multicolumn{3}{|l|}{ delta-Benzene } \\
\hline hexachloride & $\begin{array}{l}\text { EPA8080 } \\
\text { EPA8270 }\end{array}$ & $\begin{array}{l}0.05 \mu \mathrm{g} / \mathrm{L} \\
10 \mu \mathrm{g} / \mathrm{L}\end{array}$ \\
\hline Benzidine & EPA8270 & $10 \mu \mathrm{g} / \mathrm{L}$ \\
\hline Benzo[a]anthracene & EPA8270 & $10 \mu \mathrm{g} / \mathrm{L}$ \\
\hline Benzo[b]fluoranthene & EPA8270 & $10 \mu \mathrm{g} / \mathrm{L}$ \\
\hline Benzo[k]fluoranthene & EPA8270 & $10 \mu \mathrm{g} / \mathrm{L}$ \\
\hline
\end{tabular}


Table 16.

Methods and Detection Limits Used by GE (cont.)

\begin{tabular}{|c|c|c|}
\hline Analyte & Method & $\begin{array}{l}\text { Detection } \\
\text { Limit }\end{array}$ \\
\hline Benzo[a]pyrene & EPA8270 & $10 \mu \mathrm{g} / \mathrm{L}$ \\
\hline Benzo[g,h,i]perylene & EPA8270 & $10 \mu \mathrm{g} / \mathrm{L}$ \\
\hline Benzyl alcohol & EPA8270 & $10 \mu \mathrm{g} / \mathrm{L}$ \\
\hline Beryllium & EPA6010 & $3 \mu \mathrm{g} / \mathrm{L}$ \\
\hline $\begin{array}{l}\text { Bis(2-chloroisopropyl) } \\
\text { ether }\end{array}$ & $\begin{array}{l}\text { EPA8270 } \\
\text { EPA8240 }\end{array}$ & $\begin{array}{l}10 \mu \mathrm{g} / \mathrm{L} \\
10 \mu \mathrm{g} / \mathrm{L}\end{array}$ \\
\hline $\begin{array}{l}\text { Bis(2-chloroethoxy) } \\
\text { methane }\end{array}$ & EPA8270 & $10 \mu \mathrm{g} / \mathrm{L}$ \\
\hline $\begin{array}{l}\text { Bis(2-chloroethyl) ether } \\
\text { Bis(2-ethylhexyl) }\end{array}$ & EPA8270 & $10 \mu \mathrm{g} / \mathrm{L}$ \\
\hline phthalate & EPA8270 & $10 \mu \mathrm{g} / \mathrm{L}$ \\
\hline Bromide & EPA300.0 & $1,000 \mu \mathrm{g} / \mathrm{I}$ \\
\hline Bromodichloromethane & EPA8240 & $1 \mu \mathrm{g} / \mathrm{L}$ \\
\hline Bromoform & EPA8240 & $1 \mu \mathrm{g} / \mathrm{L}$ \\
\hline $\begin{array}{l}\text { Bromomethane (Methyl } \\
\text { bromide) }\end{array}$ & EPA8240 & $1 \mu \mathrm{g} / \mathrm{L}$ \\
\hline $\begin{array}{l}\text { 4-Bromophenyl phenyl } \\
\text { ether }\end{array}$ & EPA8270 & $10 \mu \mathrm{g} / \mathrm{L}$ \\
\hline Butylbenzyl phthalate & EPA8270 & $10 \mu \mathrm{g} / \mathrm{L}$ \\
\hline $\begin{array}{l}\text { 2-sec-Butyl-4,6-dinitro- } \\
\text { phenol }\end{array}$ & EPA8270 & \\
\hline Cadmium & EPA6010 & $2 \mu \mathrm{g} / \mathrm{L}$ \\
\hline Calcium & EPA6010 & $10 \mu \mathrm{g} / \mathrm{L}$ \\
\hline Carbo & EPA8240 & $1 \mu \mathrm{g} / \mathrm{L}$ \\
\hline Carbon tetrachloride & $\begin{array}{l}\text { EPA8240 } \\
\text { EPA8010 }\end{array}$ & $\begin{array}{l}1 \mu \mathrm{g} / \mathrm{L} \\
1 \mu \mathrm{g} / \mathrm{L}\end{array}$ \\
\hline Chlordane & $\begin{array}{l}\text { EPA8080 } \\
\text { EPA8270 }\end{array}$ & $\begin{array}{l}0.5 \mu \mathrm{g} / \mathrm{L} \\
10 \mu \mathrm{g} / \mathrm{L}\end{array}$ \\
\hline Chloride & EPA300.0 & $250 \mu \mathrm{g} / \mathrm{L}$ \\
\hline 4-Ch & EPA8270 & $10 \mu \mathrm{g} / \mathrm{L}$ \\
\hline Chlorobenzene & EPA8240 & $1 \mu \mathrm{g} / \mathrm{L}$ \\
\hline Chlorobenzilate & EPA8270 & $10 \mu \mathrm{g} / \mathrm{L}$ \\
\hline para-Ch & EPA8270 & $10 \mu \mathrm{g} / \mathrm{L}$ \\
\hline Chloroethane & EPA8240 & $1 \mu \mathrm{g} / \mathrm{L}$ \\
\hline $\begin{array}{l}\text { Chloroethene (Vinyl } \\
\text { chloride) }\end{array}$ & EPA8240 & $1 \mu \mathrm{g} / \mathrm{L}$ \\
\hline 2-Chloroethyl vinyl ether & $\begin{array}{l}\text { EPA8240 } \\
\text { EPA8270 }\end{array}$ & $\begin{array}{l}1 \mu \mathrm{g} / \mathrm{L} \\
10 \mu \mathrm{g} / \mathrm{L}\end{array}$ \\
\hline Chloroform & $\begin{array}{l}\text { EPA8240 } \\
\text { EPA8010 }\end{array}$ & $\begin{array}{l}1 \mu \mathrm{g} / \mathrm{L} \\
1 \mu \mathrm{g} / \mathrm{L}\end{array}$ \\
\hline thane (Methyl & EPA8240 & $1 \mu \mathrm{g} / \mathrm{L}$ \\
\hline 2-Chloronaphthalene & EPA 8270 & $10 \mu \mathrm{g} / \mathrm{L}$ \\
\hline 2-Chlorophenol & EPA8270 & $10 \mu \mathrm{g} / \mathrm{L}$ \\
\hline $\begin{array}{l}\text { 4-Chlorophenyl phenyl } \\
\text { ether }\end{array}$ & EPA8270 & $10 \mu \mathrm{g} / \mathrm{L}$ \\
\hline Chloroprene & EPA8240 & $200 \mu \mathrm{g} / \mathrm{L}$ \\
\hline Chromium & EPA6010 & $4 \mu \mathrm{g} / \mathrm{L}$ \\
\hline Chrysene & EPA8270 & $10 \mu \mathrm{g} / \mathrm{L}$ \\
\hline Cobalt & EPA6010 & $4 \mu \mathrm{g} / \mathrm{L}$ \\
\hline Copper & EPA6010 & $4 \mu \mathrm{g} / \mathrm{L}$ \\
\hline
\end{tabular}

Analyte

Detection

m-Cresol

(3-Methylphenol)

o-Cresol

(2-Methylphenol)

p-Cresol

(4-Methylphenol)

Cyanide

p,p'-DDD

$p, p^{\prime}-D D E$

$p, p^{\prime}-D D T$

Diallate

Dibenz $[a, h]$ anthracene

Dibenzofuran

Dibromochloromethane

1,2-Dibromo-3-chloro-

propane

Dibromomethane (Methylene bromide)

1,2-Dibromoethane

Di-n-butyl phthalate

1,2-Dichlorobenzene

1,3-Dichlorobenzene

1,4-Dichlorobenzene

3,3'-Dichlorobenzidine

trans-1,4-Dichloro-2-

butene

Dichlorodifluoromethane

1,1-Dichloroethane

1,2-Dichloroethane

trans-1,2-Dichloroethylene

1,1-Dichloroethylene

Dichloromethane

(Methylene chloride)

2,4-Dichlorophenol

2,6-Dichlorophenol

2,4-Dichlorophenoxy-

acetic acid

1,2-Dichloropropane

cis-1,3-Dichloropropene

trans-1,3-Dichloropro-

pene

Dieldrin

Diethyl phthalate

Dimethoate

p-Dimethylaminoazo-

benzene

7,12- Dimethylbenz $[a]$ -

anthracene

3,3'-Dimethylbenzidine
Method Limit

$\begin{array}{ll}\text { EPA8270 } & 10 \mu \mathrm{g} / \mathrm{L} \\ & \\ \text { EPA8270 } & 10 \mu \mathrm{g} / \mathrm{L} \\ & \\ \text { EPA8270 } & 10 \mu \mathrm{g} / \mathrm{L} \\ \text { EPA9012 } & 5 \mu \mathrm{g} / \mathrm{L} \\ \text { EPA8080 } & 0.1 \mu \mathrm{g} / \mathrm{L} \\ \text { EPA8270 } & 10 \mu \mathrm{g} / \mathrm{L} \\ \text { EPA8080 } & 0.1 \mu \mathrm{g} / \mathrm{L} \\ \text { EPA8270 } & 10 \mu \mathrm{g} / \mathrm{L} \\ \text { EPA8080 } & 0.1 \mu \mathrm{g} / \mathrm{L} \\ \text { EPA8270 } & 10 \mu \mathrm{g} / \mathrm{L} \\ \text { EPA8270 } & 10 \mu \mathrm{g} / \mathrm{L} \\ \text { EPA8270 } & 10 \mu \mathrm{g} / \mathrm{L} \\ \text { EPA8270 } & 10 \mu \mathrm{g} / \mathrm{L} \\ \text { EPA8240 } & 1 \mu \mathrm{g} / \mathrm{L} \\ & \\ \text { EPA8240 } & 1.0 \mu \mathrm{g} / \mathrm{L} \\ & \\ \text { EPA8240 } & 1 \mu \mathrm{g} / \mathrm{L} \\ \text { EPA8240 } & 20 \mu \mathrm{g} / \mathrm{L} \\ \text { EPA8270 } & 10 \mu \mathrm{g} / \mathrm{L} \\ \text { EPA8270 } & 10 \mu \mathrm{g} / \mathrm{L} \\ \text { EPA8270 } & 10 \mu \mathrm{g} / \mathrm{L} \\ \text { EPA8270 } & 10 \mu \mathrm{g} / \mathrm{L} \\ \text { EPA8270 } & 10 \mu \mathrm{g} / \mathrm{L} \\ & \\ \text { EPA8240 } & 30 \mu \mathrm{g} / \mathrm{L} \\ \text { EPA8240 } & 1 \mu \mathrm{g} / \mathrm{L} \\ \text { EPA8240 } & 1 \mu \mathrm{g} / \mathrm{L} \\ \text { EPA8240 } & 1 \mu \mathrm{g} / \mathrm{L} \\ & \\ \text { EPA8240 } & 1, \mathrm{gg} / \mathrm{L} \\ \text { EPA8240 } & 1 \mu \mathrm{g} / \mathrm{L} \\ \text { EPA8240 } & 1 \mu \mathrm{g} / \mathrm{L} \\ \text { EPA8270 } & 10 \mu \mathrm{g} / \mathrm{L} \\ \text { EPA8270 } & 10 \mu \mathrm{g} / \mathrm{L} \\ & \\ \text { EPA8150 } & 0.3 \mu \mathrm{g} / \mathrm{L} \\ \text { EPA8240 } & 1 \mu \mathrm{g} / \mathrm{L} \\ \text { EPA8240 } & 1 \mu \mathrm{g} / \mathrm{L} \\ & \\ \text { EPA8240 } & 1 \mu \mathrm{g} / \mathrm{L} \\ \text { EPA8080 } & 0.5 \mu \mathrm{g} / \mathrm{L} \\ \text { EPA8270 } & 10 \mu \mathrm{g} / \mathrm{L} \\ \text { EPA8270 } & 10 \mu \mathrm{g} / \mathrm{L} \\ \text { EPA8270 } & 10 \mu \mathrm{g} / \mathrm{L} \\ \text { EPA8270 } & 10 \mu \mathrm{g} / \mathrm{L} \\ & \\ \text { EPA8270 } & 10 \mu \mathrm{g} / \mathrm{L} \\ \text { EPA8270 } & 10 \mu \mathrm{g} / \mathrm{L}\end{array}$


ANALYTICAL DATA REVIEW

\begin{tabular}{|c|c|c|c|c|c|}
\hline $\begin{array}{l}\text { Meth } \\
\text { Limi }\end{array}$ & $\begin{array}{l}\text { ods and } \\
\text { ts Used b }\end{array}$ & $\begin{array}{l}\text { Detection } \\
\text { y GE (cont.) }\end{array}$ & Analyte & Method & $\begin{array}{l}\text { Detection } \\
\underline{\text { Limit }}\end{array}$ \\
\hline & & Detection & Hexachlorophene & EPA8270 & $10 \mu \mathrm{g} / \mathrm{L}$ \\
\hline Analyte & Method & $\underline{\text { Limit }}$ & Hexachloropropene & EPA8270 & $10 \mu \mathrm{g} / \mathrm{L}$ \\
\hline $\mathrm{a}, \mathrm{a}$-Dimethylphenethyl- & & & 2-Hexanone & $\begin{array}{l}\text { EPA8240 } \\
\text { EPA8270 }\end{array}$ & $\begin{array}{l}1 \mu \mathrm{g} / \mathrm{L} \\
10 \mu \mathrm{g} / \mathrm{L}\end{array}$ \\
\hline $\begin{array}{l}\text { a,a-Dimethylphenethyl- } \\
\text { amine }\end{array}$ & EPA8270 & $10 \mu \mathrm{g} / \mathrm{L}$ & $\begin{array}{l}\text { Indeno }[1,2,3-c, d] \text { pyrene } \\
\text { Iodine }\end{array}$ & APHA415 & $50 \mu \mathrm{g} / \mathrm{L}$ \\
\hline 2,4-Dimethyl phenol & EPA8270 & $10 \mu \mathrm{g} / \mathrm{L}$ & Iodomethane (Methyl & & \\
\hline Dimethyl phthalate & EPA8270 & $10 \mu \mathrm{g} / \mathrm{L}$ & iodide) & EPA8240 & $15 \mu \mathrm{g} / \mathrm{L}$ \\
\hline 1,3-Dinitrobenzene & EPA8270 & $10 \mu \mathrm{g} / \mathrm{L}$ & Iron & EPA6010 & $4 \mu \mathrm{g} / \mathrm{L}$ \\
\hline 2,4-Dinitrophenol & EPA8270 & $45 \mu \mathrm{g} / \mathrm{L}$ & Isobutyl alcohol & EPA8240 & $100 \mu \mathrm{g} / \mathrm{L}$ \\
\hline 2,4-Dinitrotoluene & EPA8270 & $10 \mu \mathrm{g} / \mathrm{L}$ & Isodrin & EPA8270 & $10 \mu \mathrm{g} / \mathrm{L}$ \\
\hline 2,6-Dinitrotoluene & EPA8270 & $10 \mu \mathrm{g} / \mathrm{L}$ & Isophorone & EPA8270 & $10 \mu \mathrm{g} / \mathrm{L}$ \\
\hline Di-n-uctyl phthalate & EPA8270 & $10 \mu \mathrm{g} / \mathrm{L}$ & Isosafrole & EPA8270 & $10 \mu \mathrm{g} / \mathrm{L}$ \\
\hline 1,4-Dioxane & EPA8270 & $10 \mu \mathrm{g} / \mathrm{L}$ & Kepone & EPA8270 & $10 \mu \mathrm{g} / \mathrm{L}$ \\
\hline Diphenylamine & EPA8270 & $10 \mu \mathrm{g} / \mathrm{L}$ & Lead & EPA7421 & $3 \mu \mathrm{g} / \mathrm{L}$ \\
\hline 1,2-Diphenylhydrazine & EPA8270 & $10 \mu \mathrm{g} / \mathrm{L}$ & Lindane (gamma- & & \\
\hline Dissolved organic carbon & EPA9060 & $1,000 \mu \mathrm{g} / \mathrm{L}$ & Benzene hexachloride) & EPA8080 & $0.005 \mu \mathrm{g} / \mathrm{L}$ \\
\hline Disulfoton & EPA8270 & $10 \mu \mathrm{g} / \mathrm{L}$ & & EPA8270 & $10 \mu \mathrm{g} / \mathrm{L}$ \\
\hline Endosulfan I & EPA8080 & $0.1 \mu \mathrm{g} / \mathrm{L}$ & Lithium & EPA6010 & $5 \mu \mathrm{g} / \mathrm{L}$ \\
\hline & EPA8270 & $10 \mu \mathrm{g} / \mathrm{L}$ & Magnesium & EPA6010 & $2 \mu \mathrm{g} / \mathrm{L}$ \\
\hline Endosulfan II & EPA8080 & $0.1 \mu \mathrm{g} / \mathrm{L}$ & Manganese & EPA6010 & $2 \mu \mathrm{g} / \mathrm{L}$ \\
\hline & EPA8270 & $10 \mu \mathrm{g} / \mathrm{L}$ & Mercury & EPA7470 & $0.2 \mu \mathrm{g} / \mathrm{L}$ \\
\hline Endosulfan sulfate & EPA8080 & $0.1 \mu \mathrm{g} / \mathrm{L}$ & Methacrylonitrile & EPA8240 & $50 \mu \mathrm{g} / \mathrm{L}$ \\
\hline & EPA8270 & $10 \mu \mathrm{g} / \mathrm{L}$ & Methapyrilene & EPA8270 & $10 \mu \mathrm{g} / \mathrm{L}$ \\
\hline Endrin & EPA8080 & $0.006 \mu \mathrm{g} / \mathrm{L}$ & Methoxychlor & EPA8080 & $0.5 \mu \mathrm{g} / \mathrm{L}$ \\
\hline & EPA8270 & $10 \mu \mathrm{g} / \mathrm{L}$ & 3-Methylcholanthrene & EPA8270 & $10 \mu \mathrm{g} / \mathrm{L}$ \\
\hline Endrin aldehyde & EPA8080 & $0.1 \mu \mathrm{g} / \mathrm{L}$ & 2-Methyl-4,6-dinitro- & & \\
\hline & EPA8270 & $10 \mu \mathrm{g} / \mathrm{L}$ & phenol & EPA8270 & $10 \mu \mathrm{g} / \mathrm{L}$ \\
\hline Ethylbenzene & EPA8240 & $1 \mu \mathrm{g} / \mathrm{L}$ & Methyl ethyl ketone & EPA8240 & $1 \mu \mathrm{g} / \mathrm{L}$ \\
\hline Ethyl methacrylate & EPA8270 & $10 \mu \mathrm{g} / \mathrm{L}$ & Methyl isobutyl ketone & EPA8240 & $1 \mu \mathrm{g} / \mathrm{L}$ \\
\hline Ethyl methanesulfonate & EPA8270 & $10 \mu \mathrm{g} / \mathrm{L}$ & Methyl methacrylate & EPA8270 & $10 \mu \mathrm{g} / \mathrm{L}$ \\
\hline Famphur & EPA8270 & $10 \mu \mathrm{g} / \mathrm{L}$ & Methyl methanesulfonate & EPA8270 & $10 \mu \mathrm{g} / \mathrm{L}$ \\
\hline Fluoranthene & EPA8270 & $10 \mu \mathrm{g} / \mathrm{L}$ & 2-Methylnaphthalene & EPA8270 & $10 \mu \mathrm{g} / \mathrm{L}$ \\
\hline Fluorene & EPA8270 & $10 \mu \mathrm{g} / \mathrm{L}$ & Naphthalene & EPA8270 & $10 \mu \mathrm{g} / \mathrm{L}$ \\
\hline Fluoride & EPA340.2 & $100 \mu \mathrm{g} / \mathrm{L}$ & 1,4-Naphthoquinone & EPA8270 & $10 \mu \mathrm{g} / \mathrm{L}$ \\
\hline Heptachlor & EPA8080 & $0.05 \mu \mathrm{g} / \mathrm{L}$ & 1-Naphthylamine & EPA8270 & $10 \mu \mathrm{g} / \mathrm{L}$ \\
\hline & EPA8270 & $10 \mu \mathrm{g} / \mathrm{L}$ & 2-Naphthylamine & EPA8270 & $10 \mu \mathrm{g} / \mathrm{L}$ \\
\hline Heptachlor epoxide & EPA8080 & $0.05 \mu \mathrm{g} / \mathrm{L}$ & Nickel & EPA6010 & $4 \mu \mathrm{g} / \mathrm{L}$ \\
\hline & EPA8270 & $10 \mu \mathrm{g} / \mathrm{L}$ & Nitrate as nitrogen & EPA300.0 & $50 \mu \mathrm{g} / \mathrm{L}$ \\
\hline Heptachlorodibenzo-p- & & & & EPA353.3 & $50 \mu \mathrm{g} / \mathrm{L}$ \\
\hline dioxin isomers & EPA8280 & $6.5 \mathrm{E}-04 \mu \mathrm{g} / \mathrm{L}$ & Nitrite as nitrogen & EPA300.0 & $10 \mu \mathrm{g} / \mathrm{L}$ \\
\hline 1,2,3,4,6,7,8-HPCDD & EPA8280 & $6.5 \mathrm{E}-04 \mu \mathrm{g} / \mathrm{L}$ & 2-Nitroaniline & EPA8270 & $10 \mu \mathrm{g} / \mathrm{L}$ \\
\hline Heptachlorodibenzo-p- & & & 3-Nitroaniline & EPA8270 & $10 \mu \mathrm{g} / \mathrm{L}$ \\
\hline furan isomers & EPA8280 & $4.5 \mathrm{E}-04 \mu \mathrm{g} / \mathrm{L}$ & 4-Nitroaniline & EPA8270 & $10 \mu \mathrm{g} / \mathrm{L}$ \\
\hline $1,2,3,4,6,7,8-\mathrm{HPCDF}$ & EPA8280 & $4.5 \mathrm{E}-04 \mu \mathrm{g} / \mathrm{L}$ & Nitrobenzene & EPA8270 & $10 \mu \mathrm{g} / \mathrm{L}$ \\
\hline Hexachlorobenzene & EPA8270 & $10 \mu \mathrm{g} / \mathrm{L}$ & 2-Nitrophenol & EPA8270 & $10 \mu \mathrm{g} / \mathrm{L}$ \\
\hline Hexachlorobutadiene & EPA8270 & $10 \mu \mathrm{g} / \mathrm{L}$ & 4-Nitrophenol & EPA8270 & $10 \mu \mathrm{g} / \mathrm{L}$ \\
\hline Hexachlorocyclo- & & & 4-Nitroquinoline-1-oxide & EPA8270 & $10 \mu \mathrm{g} / \mathrm{L}$ \\
\hline nentadiene & EPA8270 & $10 \mu \mathrm{g} / \mathrm{L}$ & N-Nitrosodi-n-butylamine & EPA8270 & $10 \mu \mathrm{g} / \mathrm{L}$ \\
\hline Hexachlorodibenzo-p- & & & $\mathrm{N}$-Nitrosodiethylamine & EPA8270 & $10 \mu \mathrm{g} / \mathrm{L}$ \\
\hline dioxin isomers & EPA8280 & $4.5 \mathrm{E}-04 \mu \mathrm{g} / \mathrm{L}$ & $\mathrm{N}$-Nitrosodimethylamine & EPA8270 & $10 \mu \mathrm{g} / \mathrm{L}$ \\
\hline 1,2,3,4,7,8-HXCDD & EPA8280 & $4.5 \mathrm{E}-04 \mu \mathrm{g} / \mathrm{L}$ & N-Nitrosodiphenylamine & EPA8270 & $10 \mu \mathrm{g} / \mathrm{L}$ \\
\hline Hexachlorodibenzo-p- & & & N-Nitrosodi-propylamine & EPA8270 & $10 \mu \mathrm{g} / \mathrm{L}$ \\
\hline furan isomers & EPA8280 & $4.0 \mathrm{E}-04 \mu \mathrm{g} / \mathrm{L}$ & N-Nitrosomethylethyl- & & \\
\hline $1,2,3,4,7,8-\mathrm{HXCDF}$ & EPA8280 & $4.0 \mathrm{E}-04 \mu \mathrm{g} / \mathrm{L}$ & amine & EPA8270 & $10 \mu \mathrm{g} / \mathrm{L}$ \\
\hline Hexachloroethane & EPA8270 & $10 \mu \mathrm{g} / \mathrm{L}$ & N-Nitrosomorpholine & EPA8270 & $10 \mu \mathrm{g} / \mathrm{L}$ \\
\hline
\end{tabular}


Table 16. Methods and Detection Limits Used by GE (cont.)

\begin{tabular}{|c|c|c|}
\hline Analyte & Method & $\begin{array}{l}\text { Detection } \\
\text { Limit }\end{array}$ \\
\hline N-Nitrosopiperıdine & EPA8270 & $10 \mu \mathrm{g} / \mathrm{L}$ \\
\hline N-Nitrosopyrrolidine & EPA8270 & $10 \mu \mathrm{g} / \mathrm{L}$ \\
\hline 5-Nitro-o-toluidine & EPA8270 & $10 \mu \mathrm{g} / \mathrm{L}$ \\
\hline $\begin{array}{l}\text { Octachlorodibenzo-p- } \\
\text { dioxin isomers }\end{array}$ & EPA8280 & $0.001 \mu \mathrm{g} / \mathrm{L}$ \\
\hline $\begin{array}{l}\text { Octachlorodibenzo-p- } \\
\text { furan isomers }\end{array}$ & EPA8280 & $0.001 \mu \mathrm{g} / \mathrm{L}$ \\
\hline Oil \& grease & EPA413.1 & $1,000 \mu \mathrm{g} / \mathrm{L}$ \\
\hline Parathion & EPA8080 & $0.05 \mu \mathrm{g} / \mathrm{L}$ \\
\hline Parathion methyl & EPA8080 & $0.05 \mu \mathrm{g} / \mathrm{L}$ \\
\hline PCB 1016 & EPA8080 & $0.5 \mu \mathrm{g} / \mathrm{L}$ \\
\hline & EPA8270 & $150 \mu \mathrm{g} / \mathrm{L}$ \\
\hline PCB 1221 & EPA8080 & $0.5 \mu \mathrm{g} / \mathrm{L}$ \\
\hline & EPA8270 & $150 \mu \mathrm{g} / \mathrm{L}$ \\
\hline PCB 1232 & EPA8ᄂ30 & $0.5 \mu \mathrm{g} / \mathrm{L}$ \\
\hline & EPA8270 & $150 \mu \mathrm{g} / \mathrm{L}$ \\
\hline PCB 1242 & EPA8080 & $0.5 \mu \mathrm{g} / \mathrm{L}$ \\
\hline & EPA8270 & $150 \mu \mathrm{g} / \mathrm{L}$ \\
\hline PCB 1248 & EPA8080 & $0.5 \mu \mathrm{g} / \mathrm{L}$ \\
\hline & EPA8270 & $150 \mu \mathrm{g} / \mathrm{L}$ \\
\hline PCB 1254 & EPA8080 & $0.5 \mu \mathrm{g} / \mathrm{L}$ \\
\hline & EPA8270 & $150 \mu \mathrm{g} / \mathrm{L}$ \\
\hline PCB 1260 & EPA8080 & $0.5 \mu \mathrm{g} / \mathrm{L}$ \\
\hline & EPA8270 & $150 \mu \mathrm{g} / \mathrm{L}$ \\
\hline Pentachlorobenzene & EPA8270 & $10 \mu \mathrm{g} / \mathrm{L}$ \\
\hline $\begin{array}{l}\text { Pentachlorodibenzo-p- } \\
\text { dioxin isomers }\end{array}$ & EPA8280 & $5.5 \mathrm{E}-04 \mu \mathrm{g} / \mathrm{L}$ \\
\hline $1,2,3,7,8-\mathrm{PCDD}$ & EPA8280 & $5.5 \mathrm{E}-04 \mu \mathrm{g} / \mathrm{L}$ \\
\hline Pentachlorodibenzo-p- & & \\
\hline furan isomers & EPA8280 & $5.5 \mathrm{E}-04 \mu \mathrm{g} / \mathrm{L}$ \\
\hline $1,2,3,7,8-\mathrm{PCDF}$ & EPA8280 & $5.5 \mathrm{E}-04 \mu \mathrm{g} / \mathrm{L}$ \\
\hline Pentachloroethane & EPA8270 & $10 \mu \mathrm{g} / \mathrm{L}$ \\
\hline Pentachloronitrobenzene & EPA8270 & $10 \mu \mathrm{g} / \mathrm{L}$ \\
\hline Pentachlorophenol & EPA8270 & $10 \mu \mathrm{g} / \mathrm{L}$ \\
\hline $\mathrm{pH}$ & EPA150.1 & None \\
\hline Phenacetin & EPA8270 & $10 \mu \mathrm{g} / \mathrm{L}$ \\
\hline Phenanthrene & EPA8270 & $10 \mu \mathrm{g} / \mathrm{L}$ \\
\hline Phenol & EPA8270 & $10 \mu \mathrm{g} / \mathrm{L}$ \\
\hline Phenols & EPA420.2 & $5 \mu \mathrm{g} / \mathrm{L}$ \\
\hline p-Phenylenediamine & EPA8270 & $10 \mu \mathrm{g} / \mathrm{L}$ \\
\hline Phorate & EPA8080 & $0.1 \mu \mathrm{g} / \mathrm{L}$ \\
\hline 2-Picoline & EPA8270 & $10 \mu \mathrm{g} / \mathrm{L}$ \\
\hline Potassium & EPA6010 & $500 \mu \mathrm{g} / \mathrm{L}$ \\
\hline Pronamid & EPA8270 & $10 \mu \mathrm{g} / \mathrm{L}$ \\
\hline Propionitrile & EPA8240 & $200 \mu \mathrm{g} / \mathrm{L}$ \\
\hline Pyrene & EPA8270 & $10 \mu \mathrm{g} / \mathrm{L}$ \\
\hline Pyridine & EPA8270 & $10 \mu \mathrm{g} / \mathrm{L}$ \\
\hline Safrole & EPA8270 & $10 \mu \mathrm{g} / \mathrm{L}$ \\
\hline Selenium & EPA7740 & $2 \mu \mathrm{g} / \mathrm{L}$ \\
\hline Silica & EPA6010 & $100 \mu \mathrm{g} / \mathrm{L}$ \\
\hline Silver & EPA6010 & $2 \mu \mathrm{g} / \mathrm{L}$ \\
\hline Sodium & EPA6010 & $10 \mu \mathrm{g} / \mathrm{L}$ \\
\hline
\end{tabular}

Analyte

Specific conductance

Styrene

Sulfate

Sulfide

Sulfotepp

1,2,4,5-Tetrachlorobenzene

Tetrachlorodibenzo-pdioxin isomers

2,3,7,8-TCDD

Tetrachlorodibenzo-pfuran isomers

$2,3,7,8-\mathrm{TCDF}$

1,1,2,2-Tetrachloroethane

Tetrachloroethylene

2,3,4,6-Tetrachlorophenol

Thallium

Thionazin

Tin

Toluene

o-Toluidine

Total carbon

Total dissolved solids

Total inorganic carbon

Total organic carbon

Total organic halogens

Total petroleum hydrocarbons

Total phosphates (as P)

Toxaphene

2,4,5-TP (Silvex)

1,2,4-Trichlorobenzene

1,1,1-Trichloroethane

1,1,2-Trichloroethane

Trichloroethylene

Trichlorofluoromethane

2,4,5-Trichlorophenol

2,4,6-Trichlorophenol

2,4,5-Trichlorophenoxyacetic acid

1,2,3-Trichloropropane

0,0,0-Triethyl phospho-

$$
\text { rothioate }
$$

1,3,5-Trin:trobenzene

Turbidity

Uranium

Vanadium

Vinyl acetate

Xylenes

Zinc
Detection

Method $\underline{\text { Limit }}$

EPA120.1 $1 \mu \mathrm{S} / \mathrm{cm}$

EPA8240 $1 \mu \mathrm{g} / \mathrm{L}$

EPA300.0 $1,000 \mu \mathrm{g} / \mathrm{L}$

EPA9030 $1,000 \mu \mathrm{g} / \mathrm{L}$

EPA8270 $10 \mu \mathrm{g} / \mathrm{L}$

EPA8270 $10 \mu \mathrm{g} / \mathrm{L}$

EPA8280 4.5E-04 $\mu \mathrm{g} / \mathrm{L}$

EPA8280 4.5E-04 $\mu \mathrm{g} / \mathrm{L}$

EPA8280 4.0E-04 $\mu \mathrm{g} / \mathrm{L}$

EPA8280 4.0E-04 $\mu \mathrm{g} / \mathrm{L}$

$1 \mu \mathrm{g} / \mathrm{L}$

$1 \mu \mathrm{g} / \mathrm{L}$

$1 \mu g / L$

$10 \mu \mathrm{g} / \mathrm{L}$

$2 \mu \mathrm{g} / \mathrm{L}$

$10 \mu \mathrm{g} / \mathrm{L}$

$2 \mu \mathrm{g} / \mathrm{L}$

$1 \mu \mathrm{g} / \mathrm{L}$

$10 \mu \mathrm{g} / \mathrm{L}$

$1,000 \mu \mathrm{g} / \mathrm{L}$

$1,000 \mu \mathrm{g} / \mathrm{L}$

$1,000 \mu \mathrm{g} / \mathrm{L}$

$1,000 \mu \mathrm{g} / \mathrm{L}$

$5 \mu \mathrm{g} / \mathrm{L}$

EPA418.1 $1,000 \mu \mathrm{g} / \mathrm{L}$

EPA365.1 $50 \mu \mathrm{g} / \mathrm{L}$

EPA8080 $0.24 \mu \mathrm{g} / \mathrm{L}$

EPA8270 $10 \mu \mathrm{g} / \mathrm{L}$

EPA8150 $0.09 \mu \mathrm{g} / \mathrm{L}$

EPA8270 $10 \mu \mathrm{g} / \mathrm{L}$

EPA8240 $1 \mu \mathrm{g} / \mathrm{L}$

EPA8010 $1 \mu \mathrm{g} / \mathrm{L}$

EPA8240 $1 \mu \mathrm{g} / \mathrm{L}$

EPA8240 $1 \mu \mathrm{g} / \mathrm{L}$

EPA8010 $1 \mu \mathrm{g} / \mathrm{L}$

EPA8240 $1 \mu \mathrm{g} / \mathrm{L}$

EPA8270 $10 \mu \mathrm{g} / \mathrm{L}$

EPA8270 $10 \mu \mathrm{g} / \mathrm{L}$

EPA8150 $0.09 \mu \mathrm{g}$

EPA8240 $1 \mu \mathrm{g} / \mathrm{L}$

EPA8270 $10 \mu \mathrm{g} / \mathrm{L}$

EPA8270 $10 \mu \mathrm{g} / \mathrm{L}$

EPA180.1 $0.1 \mathrm{NTU}$

EPA6010 $20 \mu \mathrm{g} / \mathrm{L}$

EPA6010 $8 \mu \mathrm{g} / \mathrm{L}$

EPA8240 $1 \mu \mathrm{g} / \mathrm{L}$

EPA8240 $2 \mu \mathrm{g} / \mathrm{L}$

EPA6010 $2 \mu \mathrm{g} / \mathrm{L}$ 
Table 16. Methods and Detection Limits Used by GE (cont.)

$\begin{array}{lll}\text { Analyte } & \text { Method } & \begin{array}{l}\text { Detection } \\ \text { Limit }\end{array} \\ \begin{array}{lll}\text { Gross alpha } & \text { EPA900.0 } & 2.0 \mathrm{E}-09 \mu \mathrm{Ci} / \mathrm{mL} \\ \begin{array}{l}\text { Nonvolatile beta } \\ \text { Total radium }\end{array} & \text { EPA900.0 } & 2.0 \mathrm{E}-09 \mu \mathrm{Ci} / \mathrm{mL} \\ \begin{array}{l}\text { Tritium } \\ \begin{array}{l}\text { Uranium alpha } \\ \text { activity }\end{array}\end{array} & \text { EPA906.1 } & 1.0 \mathrm{E}-09 \mu \mathrm{Ci} / \mathrm{mL} \\ 7.0 \mathrm{E}-07 \mu \mathrm{Ci} / \mathrm{mL} \\ \end{array} & \text { EPA908.0 } & 1.0 \mathrm{E}-09 \mu \mathrm{Ci} / \mathrm{mL}\end{array}$

Table 17. Methods and Detection Limits Used by Teledyne Isotopes

\begin{tabular}{|c|c|c|}
\hline Arialyte & Method & $\begin{array}{l}\text { Detection } \\
\text { Limit }\end{array}$ \\
\hline Ame:icium-241 & PRO05232 & $1.0 \mathrm{E}-10 \mu \mathrm{Ci} / \mathrm{mL}$ \\
\hline Antinıony-125 & 'TIMLGS01 & $9.2 \mathrm{E}-09 \mu \mathrm{Ci} / \mathrm{mL}$ \\
\hline Cerium-144 & TIMLGS01 & 3.3E-08 $\mu \mathrm{Ci} / \mathrm{mL}$ \\
\hline Cesium-134 & TIMLGS01 & $6.4 \mathrm{E}-09 \mu \mathrm{Ci} / \mathrm{mL}$ \\
\hline Cesium-137 & TIMLGS01 & $3.4 \mathrm{E}-09 \mu \mathrm{Ci} / \mathrm{mL}$ \\
\hline Cobalt-57 & TIMLGS01 & 4.3E-09 $\mu \mathrm{Ci} / \mathrm{mL}$ \\
\hline Cobalt-60 & TIMLGS01 & $4.1 \mathrm{E}-09 \mu \mathrm{Ci} / \mathrm{mL}$ \\
\hline Europium-154 & TLMLGS01 & $1.2 \mathrm{E}-08 \mu \mathrm{Ci} / \mathrm{mL}$ \\
\hline Manganese-54 & TIMLGS01 & 4.3E-09 $\mu \mathrm{Ci} / \mathrm{mL}$ \\
\hline Plutonium-238 & TIMLPU01 & $6.0 \mathrm{E}-10 \mu \mathrm{Ci} / \mathrm{mL}$ \\
\hline Plutonium-242 & TIMLPU01 & $2.0 \mathrm{E}-10 \mu \mathrm{Ci} / \mathrm{mL}$ \\
\hline \multicolumn{3}{|l|}{ Plutonium- } \\
\hline Potassium-40 & TIMLGSO1 & $6.9 \mathrm{E}-08 \mu \mathrm{Ci} / \mathrm{mL}$ \\
\hline Radium-226 & TIMLTS94 & $5.1 \mathrm{E}-09 \mu \mathrm{Ci} / \mathrm{mL}$ \\
\hline Radium-228 & TIMLTS94 & $5.0 \mathrm{E}-10 \mu \mathrm{Ci} / \mathrm{mL}$ \\
\hline Ruthenium-103 & TIMLGS01 & $2.2 \mathrm{E}-08 \mu \mathrm{Ci} / \mathrm{mL}$ \\
\hline Sodium-22 & TIMLGS01 & $4.5 \mathrm{E}-09 \mu \mathrm{Ci} / \mathrm{mL}$ \\
\hline Strontium-89 & TIMLSR02 & $2.0 \mathrm{E}-09 \mu \mathrm{Ci} / \mathrm{mL}$ \\
\hline Strontium-90 & TLMLSR02 & $5.0 \mathrm{E}-10 \mu \mathrm{Ci} / \mathrm{mL}$ \\
\hline Technetium-99 & PRO03278 & $1.9 \mathrm{E}-08 \mu \mathrm{Ci} / \mathrm{mL}$ \\
\hline Thorium-228 & PRO05232 & $3.9 \mathrm{E}-09 \mu \mathrm{Ci} / \mathrm{mL}$ \\
\hline Thorium-230 & PRO05232 & $2.0 \mathrm{E}-10 \mu \mathrm{Ci} / \mathrm{mL}$ \\
\hline Thorium-232 & PRO05232 & $1.0 \mathrm{E}-10 \mu \mathrm{Ci} / \mathrm{mL}$ \\
\hline \multicolumn{3}{|l|}{ Uranium- } \\
\hline & PRO05232 & $1.0 \mathrm{E}-10 \mu \mathrm{Ci} / \mathrm{mL}$ \\
\hline Uranium-238 & PRO05232 & $1.0 \mathrm{E}-10 \mu \mathrm{Ci} / \mathrm{mL}$ \\
\hline Zinc-65 & TLMLGS01 & $1.1 \mathrm{E}-08 \mu \mathrm{Ci} / \mathrm{mL}$ \\
\hline
\end{tabular}




\section{NOTES}




\section{QUALITY CONTROL SAMPLES}

\section{REPLICATE AND DUPLICATE ANALYSES OF SAMPLES}

Blind replicate and duplicate samples are analyzed by the primary laboratory, General Engineering (GE), and the radiological laboratory, Teledyne Isotopes (TE), in order to satisfy quality assurance standards.

For intralaboratory comparisons, $10 \%$ of the samples generally are analyzed in duplicate. During 1991, however, GE replaced many duplicate analyses, specifically for metals and organic parameters, with duplicate matrix spike recovery determinations. The use of matrix spike duplicates provides the laboratory more data with which to assess analytical precision. Matrix spike duplicate results are not, however, reported or evaluated in this report.

For further intralaboratory comparisons, EPD/ EMS sends blind replicates of approximately 5\% of the total samples to the laboratories for analysis. The results of the duplicate and replicate analyses are included in the Analytical Results section (Appendix A) of this report.

The replicate and duplicate analytical results are used to generate Mean Relative Difference (MRD) indexes, which are used to evaluate a laboratory's performance.

Table 18 lists the names and sample dates of well samples sent to GE as blind replicates. Those marked with ${ }^{*}$ also were sent as blind replicates to Teledyne; those marked with + were sent to both $\mathrm{GE}$ and the M-Area Laboratory (MA).
Table 18. Wells Providing Blind Replicatc Samples

$\begin{array}{ll}\text { Well } & \text { Sainple Date } \\ \text { AMB 11D } & 11 / 17 / 91 \\ \text { AOB 1*+ } & 11 / 13 / 91 \\ \text { ASB 9B }{ }^{*}+ & 11 / 11 / 91 \\ \text { BGO 10AR } & 10 / 15 / 91 \\ \text { BGO 12AR }{ }^{*} & 10 / 16 / 91 \\ \text { BGX 12C* } & 10 / 18 / 91 \\ \text { CBR 2D } & 11 / 11 / 91 \\ \text { CSD 13D } & 11 / 11 / 91 \\ \text { DCB 7 } & 12 / 03 / 91 \\ \text { DOB 3* } & 12 / 03 / 91 \\ \text { FCB 2 } & 11 / 07 / 91 \\ \text { FNB 3* } & 10 / 31 / 91 \\ \text { FSB101A } & 10 / 17 / 91 \\ \text { FSB114D } & 10 / 18 / 91 \\ \text { FSB120A } & 10 / 21 / 91 \\ \text { HMD 3D } & 10 / 22 / 91 \\ \text { HSB118A } & 10 / 04 / 91 \\ \text { HSB130C } & 10 / 11 / 91 \\ \text { HSB150D } & 10 / 10 / 91 \\ \text { HSS 2D } & 11 / 12 / 91 \\ \text { IDP 3A* } & 12 / 13 / 91 \\ \text { IDQ 4* } & 12 / 12 / 91 \\ \text { KAC 1 } & 11 / 18 / 91 \\ \text { KSS 1D } & 11 / 18 / 91 \\ \text { LFW 27 } & 10 / 25 / 91 \\ \text { LFW 43B } & 10 / 28 / 91 \\ \text { LFW 58D } & 10 / 29 / 91 \\ \text { MSB 11B } & 10 / 09 / 91 \\ \text { MSB 13A* } & 10 / 10 / 91 \\ \text { MSB 38'TA+ } & 11 / 01 / 91 \\ \text { MSB 42C+ } & 11 / 04 / 91 \\ \text { MSB 43D } & 10 / 04 / 91 \\ \text { MSB 44A }+ & 11 / 06 / 91 \\ \text { MSB 53C+ } & 10 / 28 / 91 \\ \text { MSB 56D + } & 10 / 13 / 91 \\ \text { MSB 62B } & 10 / 11 / 91 \\ & \\ & \end{array}$


Table 18. Wells Providing Blind Replicate Samples (cont.)

$\begin{array}{ll}\text { Well } & \text { Sample Dat } \\ \text { P 26D* } & 12 / 04 / 91 \\ \text { P 28TB } & 11 / 08 / 91 \\ \text { P 29C } & 11 / 18 / 91 \\ \text { PAC 4 } & 11 / 20 / 91 \\ \text { PDB 2* } & 10 / 21 / 91 \\ \text { PRP 4 } & 11 / 20 / 91 \\ \text { PSB 3A } & 10 / 23 / 91 \\ \text { PSS 1D } & 11 / 19 / 91 \\ \text { RWM 8+ } & 11 / 11 / 91 \\ \text { SRW 2B+ } & 10 / 06 / 91 \\ \text { TBG 5A } & 11 / 20 / 91 \\ \text { TNX 2D* } & 12 / 02 / 91 \\ \text { XSB 4D* } & 12 / 04 / 91 \\ \text { YSC 2A } & 11 / 25 / 91 \\ \text { ZBG 2* } & 11 / 25 / 91\end{array}$

Certain analytes were not present in concentrations above detection limits in any well samples having replicates or duplicates. These analytes are not considered in further evaluation of replicate and duplicate analyses. They are listed in Table 19. (See Tables 16 and 17 on pages 59-63 for the detection limits that are effective this quarter.)

\section{Table 19. Analytes Not Detected in Any Replicated or Duplicated Samples}

Analyte

Number of Analyses

\section{General Engineering}

Acenaphthene

Acenaphthylene

Acetone

Acetonitrile (Methyl cyanide)

Acetophenone

2-Acetylaminofluorene

Acrolein

Acrylonitrile

Aldrin

Allyl chloride

4-Aminobiphenyl

Aniline

Anthracene

Aramite

alpha-Benzene hexachloride

beta-Benzene hexachloride

delta-Benzene hexachloride

Benzidine
Analyte

Number of Analyses

Benzola janthracene $\quad 12$

Benzolb] fluoranthene 12

Benzo[k]lluoranthene 12

Benzolg,h,i|perylene $\quad 12$

Benzola]pyrene $\quad 12$

Benzyl alcohol 4

Beryllium 22

Bis(2-chloroethoxy) methane 12

Bis(2-chloroethyl) ether $\quad 12$

Bis(2-chloroisopropyl) ether $\quad 12$

Bis(2-ethylhexyl) phthalate $\quad 12$

Bromodichloromethane 69

Bromoform $\quad 69$

Bromomethane (Methyl bromide) 69

4-Bromophenyl phenyl ether 12

Butylbenzyl phthalate 12

2-sec-Butyl-4,6-dinitrophenol 4

Cadmium $\quad 89$

Carbon disulfide 4

Chlordane 16

4-Chloroaniline 4

Chlorobenzene 69

Chlorobenzilate 4

para-Chloro-meta-cresol $\quad 12$

Chloroethane 69

Chloroethene (Vinyl chloride) $\quad 69$

2-Chloroethyl vinyl ether $\quad 69$

Chloromethane (Methyl chloride) 69

2-Chloronaphthalene 12

2-Chlorophenol 12

4-Chlorophenyl phenyl ether $\quad 12$

Chloroprene 4

Chrysene 12

Cobalt $\quad 32$

m-Cresol (3-Methylphenol) 4

o-Cresol (2-Methylphenol) 4

p-Cresol (4-Methylphenol) 4

$\mathrm{p}, \mathrm{p}^{\prime}$-DDD 12

$\mathrm{p}, \mathrm{p}^{\prime}-\mathrm{DDE} \quad 12$

$\mathrm{p}, \mathrm{p}^{\prime}$-DD'T 12

Diallate 4

Dibenz $\{a, h]$ anthracene $\quad 12$

Dibenzofuran 4

Dibromochloromethane 69

1,2-Dibromo-3-chloropropane 4

1,2-Dibromoethane 4

Dibromomethane (Methylene bromide) 4

Di-n-butyl phthalate 12

1,2-Dichlorobenzene 4

1,3-Dichlorobenzene 4

1,4-Dichlorobenzene 4

3,3'-Dichlorobenzidine $\quad 12$

trans-1,4-Dichloro-2-butene 4

Dichlorodifluoromethane 4

1,2-Dichloroethane $\quad 69$

trans-1,2-Dichloroethylene 69 


\section{Table 19. Analytes Not Detected in any Replicated or Duplicated Samples (cont.)}

Analyte

Number of Analyses

2,4-Dichlorophenol

2,6-Dichlorophenol

2,4-Dichlorophenoxyacetic acid

1,2-Dichloropropane

cis-1,3-Dichloropropene

trans-1,3-Dichloropropene

Dieldrin

Diethyl phthalate

Dimethoate

p-Dimethylaminoazobenzene

7,12-Dimethylbenz $[a]$ anthracene

3,3'-Dimethylbenzidine

a,a-Dimethylphenethylamine

2,4-Dimethyl phenol

Dimethyl phthalate

1,3-Dinitrobenzene

2,4-Dinitrophenol

2,4-Dinitrotoluene

2,6-Dinitrotoluene

Di-n-octyl phthalate

1,4-Dioxane

Diphenylamine

1,2-Diphenylhydrazine

Disulfoton

Endosulfan I

Endosulfan II

Endosulfan sulfate

Endrin

Endrin aldehyde

Ethylbenzene

Ethyl methacrylate

Ethyl methanesulfonate

Famphur

Fluoranthene

Fluorene

Heptachlor

Heptachlor epoxide

1,2,3,4,6,7,8-HPCDD

Heptachlorodibenzo-p-dioxin isomers

1,2,3,4,6,7,8-HPCDF

Heptachlorodibenzo-p-furan isomers

Hexachlorobenzene

Hexachlorobutadiene

Hexachlorocyclopentadiene

$1,2,3,4,7,8$-Hexachlorodibenzo-p-dioxin

Hexachlorodibenzo-p-dioxin isomers

1,2,3,4,7,8-Hexachlorodibenzo-p-furan

Hexachlorodibenzo-p-furan isom $\mathrm{s}$

Hexachloroethane

Hexachlorophene

Hexachloropropene

2-Hexanone
Analyte

Number of Analyses

Indeno $[1,2,3-c, d]$ pyrene

12

Iodomethane (Methyl iodide)

Isobutyl alcohol

Isodrin

Isophorone

Isosafrole

Kepone

Lindane

Lithium

Methacrylonitrile

Methapyrilene

Methoxychlor

3-Methylcholanthrene

2-Methyl-4,6-dinitrophenol

Methyl ethyl ketone

Methyl isobutyl ketone

Methyl methacrylate

Methyl methanesulfonate

2-Methylnaphthalene

Naphthalene

1,4-Naphthoquinone

1-Naphthylamine

2-Naphthylamine

2-Nitroaniline

3-Nitroaniline

4-Nitroaniline

Nitrobenzene

2-Nitrophenol

4-Nitrophenol

4-Nitroquinoline-1-oxide

N-Nitrosodi-n-butylamine

N-Nitrosodiethylamine

$\mathrm{N}$-Nitrosodimethylamine

N-Nitrosodiphenylamine

N-Nitrosodi-propylamine

N-Nitrosomethylethylamine

N-Nitrosomorpholine

N-Nitrosopiperidine

$\mathrm{N}$-Nitrosopyrrolidine

5-Nitro-o-toluidine

Octachlorodibenzo-p-dioxin isomers

Octachlorodibenzo-p-furan isomers

Parathion

Parathion methyl

PCB 1016

PCB 1221

PCB 1232

PCB 1242

PCB 1248

PCB 1254

PCB 1260

Pentachlorobenzene

1,2,3,7,8-Pentachlorodibenzo-p-dioxin

Pentachlorodibenzo-p-dioxin isomers

1,2,3,7,8-Pentachlorodibenzo-p-furan

Pentachlorodibenzo-p-furan isomers

Pentachloroethane
4

4

4

12

4

110

4

4

108

4

12

4

4

4

4

4

16

4

4

4

4

12

12

12

4

4

4

12

12

12

4

4

4

4

4

20

20

4

4

12 


\section{QUALITY CONTROL SAMPLES}

Table 19. Analytes Not Detected in any Replicated or Duplicated Samples (cont.)

Analyte

Number of Analyses

Pentachloronitrobenzene

Pentachlorophenol

Phenacetin

Phenanthrene

Phenol

p-Phenylenediamine

Phorate

2-Picoline

Pronamid

Propionitrile

Pyrene

Pyridine

Safrole

Silver

Styrene

Sulfide

Sulfotepp

1,2,4,5-Tetrachlorobenzene

$2,3,7,8$-Tetrachlorodibenzo-p-dioxin

Tetrachlorodibenzo-p-dioxin isomers

2,3,7,8-Tetrachlorodibenzo-p-furan

Tetrachlorodibenzo-p-furan isomers

1,1,1,2-Tetrachloroethane

1,1,2,2-'Tetrachloroethane

2,3,4,6-Tetrachlorophenol

Thallium

Thionazin

Tin

o-Toluidine

Total petroleum hydrocarbons

Toxaphene

1,2,4-Trichlorobenzene

1,1,2-Trichloroethane

2,4,5-Trichlorophenol

2,4,6-Trichlorophenol

2,4,5-Trichlorophenoxyacetic acid

1,2,3-'Trichloropropane

$\mathrm{O}, \mathrm{O}, \mathrm{O}$-Triethyl phosphorothioate

1,3,5-Trinitrobenzene

Uranium

Uranium alpha activity

Vanadium

Vinyl acetate

Xylenes

\section{Teledyne Isotopes}

Antimony-125

Cerium-144

Cobalt-57

Cobalt-60

Cesium-134
Analyte

Number of Analyses

Cesium-137

26

Europium-154

Manganese-54

Plutonium-238

Potassium-40

Radium-226

Ruthenium-103

Sodium-22

Strontium-89

Strontium-90

Technetium-99

Thorium-228

Thorium-232

Zinc- 65

\section{Intralaboratory Comparisons}

Intralaboratory comparisons are performed on two types of samples: in-house duplicates and blind replicates. To assess the reproducibility of identical chemical analyses on duplicates and replicates, EPD/EMS personnel developed the mean relative difference (MRD). For both types of intralaboratory comparisons, the MRD is defined as the average absolute difference between an original sample and its duplicate or blind replicate, expressed as a percentage of the mean of those two values. It is calculated as

$$
M R D=\left\{\frac{\sum_{i=1}^{n}\left(\left|x_{i}-y_{i}\right| /\left[\left(x_{i}+y_{i}\right) / 2\right]\right)}{n}\right\} \times 100,
$$

where

$x_{i}=$ an analyte's mean concentration in a water sample for the $i^{\text {th }}$ well,

$y_{i}=$ the analyte's mean concentration in the replicate or duplicate, and

$n=$ the number of pairs of observations.

For the in-house duplicate comparisons, the quantities $x_{i}$ and $y_{i}$ represent the results for the original sample and the in-house duplicate, respectively. For the blind replicate comparisons, $x_{i}$ and $y_{i}$ represent the resuits for the known sample and the EPD blind replicate, respectively.

Generally, the closer the original results and their replicate or duplicate results are to each other, the lower the MRD. 


\section{Normalizing Data to the RDL}

Because some detection limits may be anomalously high (due to dilution or other effects, for example), it is necessary to use a reference detection limit (RDL) in the MRD calculations. This is set as the 90th percentile value. All the results less than the RDL are adjusted up to that value. Results that are detection limit values above the RDL are eliminated from the MRD index calculations. By definition, fewer than $10 \%$ of the detection limit values are above the RDL.

The intralaboratory MRD index for General Engineering is listed in Table 20. Table 21 presents the index for Teledyne Isotopes.

Tabie 20. Intralaboratory MRD Index for General Engineering

\begin{tabular}{|c|c|c|c|c|c|}
\hline \multirow[b]{2}{*}{ Analyte } & \multirow[b]{2}{*}{$\underline{\mathrm{RDL}}$} & \multicolumn{2}{|c|}{ In-house Duplicates } & \multicolumn{2}{|c|}{ Blind Replicates } \\
\hline & & $\begin{array}{l}\text { Number of } \\
\text { Analyses }\end{array}$ & $\underline{\text { MRD }}$ & $\begin{array}{l}\text { Number of } \\
\text { Analyses }\end{array}$ & MRD \\
\hline Aluminum & $20 \mu \mathrm{g} / \mathrm{L}$ & 0 & - & 19 & 6.77 \\
\hline Antimony & $2.0 \mu \mathrm{g} / \mathrm{L}$ & 0 & - & 18 & 0.92 \\
\hline Arsenic & $2.0 \mu \mathrm{g} / \mathrm{L}$ & 0 & - & 38 & 0.27 \\
\hline Barium & $3.0 \mu \mathrm{g} / \mathrm{L}$ & 0 & - & 40 & 1.43 \\
\hline Benzene & $1.0 \mu \mathrm{g} / \mathrm{L}$ & 0 & - & 31 & 0.02 \\
\hline Bromide & $1,000 \mu \mathrm{g} / \mathrm{L}$ & 9 & 0.29 & 7 & - \\
\hline Calcium & $10 \mu \mathrm{g} / \mathrm{L}$ & 0 & - & 37 & 3.09 \\
\hline Carbon tetrachloride & $1.0 \mu \mathrm{g} / \mathrm{L}$ & 0 & - & 41 & 0.22 \\
\hline Chloride & $250 \mu \mathrm{g} / \mathrm{L}$ & 106 & 2.65 & 40 & 3.40 \\
\hline Chloroform & $1.0 \mu \mathrm{g} / \mathrm{L}$ & 0 & - & 41 & 1.26 \\
\hline Chromium & $4.0 \mu \mathrm{g} / \mathrm{L}$ & 0 & - & 42 & 0.10 \\
\hline Copper & $4.0 \mu \mathrm{g} / \mathrm{L}$ & 0 & - & 24 & 0.68 \\
\hline Cyanide & $5.0 \mu \mathrm{g} / \mathrm{L}$ & 27 & 1.52 & 17 & - \\
\hline 1,1-Dichloroethane & $1.0 \mu \mathrm{g} / \mathrm{L}$ & 0 & - & 31 & 5.94 \\
\hline 1,1-Dichloroethylene & $1.0 \mu \mathrm{g} / \mathrm{L}$ & 0 & - & 31 & 0.17 \\
\hline Dichloromethane & & & & & \\
\hline (Methylene chloride) & $1.0 \mu \mathrm{g} / \mathrm{L}$ & 0 & - & 31 & 36.05 \\
\hline Dissolved organic carbon & $1,000 \mu \mathrm{g} / \mathrm{L}$ & 2 & - & 4 & 16.67 \\
\hline Fluoride & $100 \mu \mathrm{g} / \mathrm{L}$ & 88 & 0.63 & 34 & 0.54 \\
\hline Iodine & $50 \mu \mathrm{g} / \mathrm{L}$ & 9 & 4.87 & 2 & 0.99 \\
\hline Iron & $4.0 \mu \mathrm{g} / \mathrm{L}$ & 0 & - & 33 & 11.04 \\
\hline Lead & $3.0 \mu \mathrm{g} / \mathrm{L}$ & 0 & - & 43 & 1.65 \\
\hline Magnesium & $2.0 \mu \mathrm{g} / \mathrm{L}$ & 0 & - & 37 & 2.53 \\
\hline Manganese & $2.0 \mu \mathrm{g} / \mathrm{L}$ & 0 & - & 34 & 3.29 \\
\hline Mercury & $0.2 \mu \mathrm{g}^{\prime} \mathrm{L}$ & 0 & - & 40 & 5.36 \\
\hline Nickel & $4.0 \mu \mathrm{g} / \mathrm{L}$ & 0 & - & 23 & 2.51 \\
\hline Nitrate as nitrogen & $50 \mu \mathrm{g} / \mathrm{L}$ & 117 & 1.85 & 41 & 18.16 \\
\hline Nitrite as nitrogen & $10 \mu \mathrm{g} / \mathrm{L}$ & 16 & 0.06 & 10 & - \\
\hline $\mathrm{pH}$ & $\mathrm{N} / \mathrm{A}$ & 0 & - & 39 & 1.38 \\
\hline Phenols & $5.0 \mu \mathrm{g} / \mathrm{L}$ & 74 & 0 & 32 & - \\
\hline Potassium & $500 \mu \mathrm{g} / \mathrm{L}$ & 0 & - & 37 & 2.35 \\
\hline Selenium & $2.0 \mu \mathrm{g} / \mathrm{L}$ & 0 & - & 38 & 0.23 \\
\hline Silica & $100 \mu \mathrm{g} / \mathrm{L}$ & 0 & - & 37 & 1.42 \\
\hline Sodium & $10 \mu \mathrm{g} / \mathrm{L}$ & 0 & - & 40 & 1.58 \\
\hline Specific conductance & $1 \mu \mathrm{S} / \mathrm{cm}$ & 5 & 1.03 & 39 & 3.78 \\
\hline Sulfate & $1,000 \mu \mathrm{g} / \mathrm{L}$ & 82 & 1.97 & 36 & 6.10 \\
\hline Tetrachloroethylene & $1.0 \mu \mathrm{g} / \mathrm{L}$ & 0 & - & 41 & 6.32 \\
\hline
\end{tabular}


Table 20. Intralaboratory MRD Index for General Engineering (cont.)

\begin{tabular}{|c|c|c|c|c|c|}
\hline \multirow[b]{2}{*}{ Analyte } & \multirow[b]{2}{*}{$\underline{\mathrm{RDL}}$} & \multicolumn{2}{|c|}{ In-house Duplicates } & \multicolumn{2}{|c|}{ Blind Replicates } \\
\hline & & $\begin{array}{l}\text { Number of } \\
\text { Analyses }\end{array}$ & $\underline{\text { MRD }}$ & $\begin{array}{l}\text { Number of } \\
\text { Analyses }\end{array}$ & $\underline{\text { MRD }}$ \\
\hline Toluene & $1.0 \mu \mathrm{g} / \mathrm{L}$ & 0 & - & 31 & 0.94 \\
\hline Total carbon & $1,000 \mu \mathrm{g} / \mathrm{L}$ & 9 & 5.64 & 2 & 41.56 \\
\hline Total dissolved solids & $1,000 \mu \mathrm{g} / \mathrm{L}$ & 73 & 12.49 & 33 & 28.43 \\
\hline Total inorganic carbon & $1,000 \mu \mathrm{g} / \mathrm{L}$ & 3 & 0 & 2 & 77.27 \\
\hline Total organic carbon & $1,000 \mu \mathrm{g} / \mathrm{L}$ & 76 & 1.63 & 33 & - \\
\hline Total organic halogens & $5.0 \mu \mathrm{g} / \mathrm{L}$ & 89 & 4.48 & 31 & 34.10 \\
\hline Total phosphates (as P) & $50 \mu \mathrm{g} / \mathrm{L}$ & 78 & 4.08 & 39 & 6.86 \\
\hline 2,4,5-TP (Silvex) & $0.09 \mu \mathrm{g} / \mathrm{L}$ & 0 & - & 18 & 3.83 \\
\hline 1,1,1-Trichloroethane & $1.0 \mu \mathrm{g} / \mathrm{L}$ & 0 & - & 41 & 3.71 \\
\hline Trichloroethylene & $1.0 \mu \mathrm{g} / \mathrm{L}$ & 0 & - & 41 & 9.76 \\
\hline Trichlorofluoromethane & $1.0 \mu \mathrm{g} / \mathrm{L}$ & 0 & - & 31 & 13.96 \\
\hline Turbidity & $0.1 \mathrm{NTU}$ & 7 & 3.56 & 4 & 48.40 \\
\hline Zinc & $2.0 \mu \mathrm{g} / \mathrm{L}$ & 0 & - & 19 & 8.44 \\
\hline Gross alpha & $2.0 \mathrm{E}-9 \mu \mathrm{Ci} / \mathrm{mL}$ & 0 & - & 37 & $12.25^{*}$ \\
\hline Nonvolatile beta & $2.0 \mathrm{E}-9 \mu \mathrm{Ci} / \mathrm{mL}$ & 0 & - & 36 & $37.56^{*}$ \\
\hline Total alpha-emitting radium & $1.0 \mathrm{E}-9 \mu \mathrm{Ci} / \mathrm{mL}$ & 0 & . & 36 & $31.19^{*}$ \\
\hline Tritium & $7.0 \mathrm{E}-10 \mu \mathrm{Ci} /-$ & 0 & - & 39 & $19.78^{*}$ \\
\hline
\end{tabular}

- No results were above reference detection limit.

* No allowance for accuracy was made.

Table 21. Intralaboratory MRD Index for Teledyne Isotopes

\begin{tabular}{|c|c|c|c|c|c|}
\hline \multirow[b]{2}{*}{ Analyte } & \multirow[b]{2}{*}{$\underline{\mathrm{RDL}}$} & \multicolumn{2}{|c|}{ In-house Duplicates } & \multicolumn{2}{|c|}{ Blind Replicates } \\
\hline & & $\begin{array}{l}\text { Number of } \\
\text { Analyses }\end{array}$ & $\underline{\text { MRD }}$ & $\begin{array}{l}\text { Number of } \\
\text { Analyses }\end{array}$ & $\underline{\mathrm{MRD}}$ \\
\hline Americium-241 & $1.0 \mathrm{E}-10 \mu \mathrm{Ci} / \mathrm{rnL}$ & 1 & - & 5 & 13.33 \\
\hline Plutonium-242 & $2.0 \mathrm{E} \cdot 10 \mu \mathrm{Ci} / \mathrm{mL}$ & 1 & - & 5 & 0 \\
\hline Plutonium-239/240 & $2.0 \mathrm{E}-10 \mu \mathrm{Ci} / \mathrm{mL}$ & 1 & - & 4 & 37.50 \\
\hline Radium-228 & $5.0 \mathrm{E}-10 \mu \mathrm{Ci} / \mathrm{mL}$ & 0 & - & 5 & 71.54 \\
\hline Thorium-230 & $1.0 \mathrm{E}-10 \mu \mathrm{Ci} / \mathrm{mL}$ & 1 & 66.67 & 4 & 68.01 \\
\hline Uranium-233/234 & $1.0 \mathrm{E}-10 \mu \mathrm{Ci} / \mathrm{mL}$ & 4 & 21.43 & 9 & 59.81 \\
\hline Uranium-238 & $1.0 \mathrm{E}-10 \mu \mathrm{Ci} / \mathrm{mL}$ & 4 & - & 9 & 37.43 \\
\hline
\end{tabular}

- No results were above reference detection limit.

No allowance for accuracy was made.

\section{COMMENTS ON THE REPLICATE AND DUPLICATE ANALYSES}

No high MRDs (greater than 20) were calculated for GE laboratory duplicates (see Table 20 above). Among all the pairs of values for GE samples and laboratory duplicates, only the analyses for total dissolved solids for HSB131D and its iahoratory duplicate yielded results where one was more than twice the other.
High MRDs (greater than 20) for blind replicates from GE (see Table 20 above) were calculated for dichloromethane (methylene chloride), total carbon, total dissolved solids, total inorganic carbon, total organic halogens, turbidity, nonvolatile beta, and total alphaemitting radium. 
Table 22 lists all the analytes and wells from which GE's results for samples and blind replicates were more than twice one another.

Two pairs of nonvolatile beta results were especially dissimilar: the blind replicate result for FSB120A is more than eight times the sample result, and the sample result for $\mathrm{KAC} 1$ is more than six times the detection limit result obtained for the blind replicate.
There were only two pairs of results for total carbon. Neither has one result as much as twice the other; the high MRD represents the effect of a small data set upon the calculation.

Dichloromethane is a common laboratory contaminant. It was detected in blanks associated sometimes with both a sample and its replicate and sometimes with only one or the other.

Table 22. General Engineering Samples and Blind Replicates Yielding Results Where One Is More Than Twice Another

\section{Analyte}

1,1-Dichloroethane

Dichloromethane (Methylene chloride)

Iron

Mercury

Nitrate as nitrogen

Tetrachloroethylene

Total dissolved solids

Total inorganic carbon

Total organic halogens

1,1,1-Trirhloroethane

Trichloroethylene

Trichloronuoromethane

Turbidity

Gross alpha

Nonvolatile beta

Tritium

Total radium
Wells

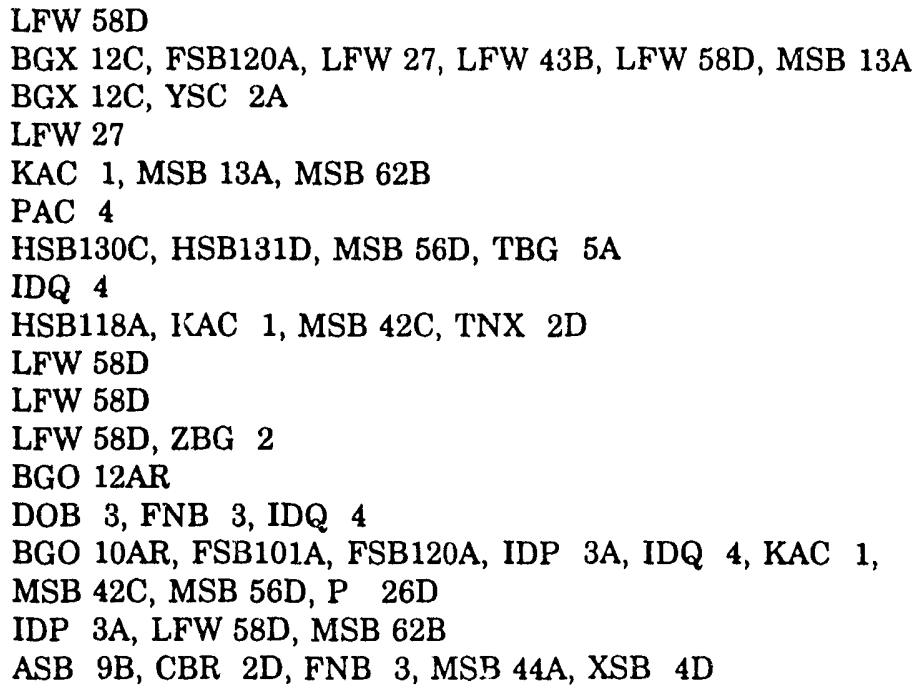

High MRDs (greater tha. _J) were calculated for laboratory duplicates from TE for thorium230 and uranium-233/234 (see Table 21 above). The thorium-230 result for the duplicate of sample XSB 1B was twice that for the sample itself; the uranium-233/234 result for sample $\mathrm{XSB} 1 \mathrm{~B}$ was two and one-half times that of the laboratory duplicate.

High MRDs (greater than 20 were calculated for blind replicates from TE for plutonium$239 / 240$, radium-228, thorium-230, uranium$233 / 234$, and uranium-238.

Table 23 lists all the analytes and wells from which Teledyne's results for samples and blind replicates were more than twice one another.

Table 23. Teledyne Isotopes Samples and Blind Replicates Yielding Results Where One Is More Than Twice Another

Analyte

Americium-241

Plutonium-239/240

Radium-228

Thorium-230

Uranium-233/234

Uranium-238 $\underline{\text { Wells }}$

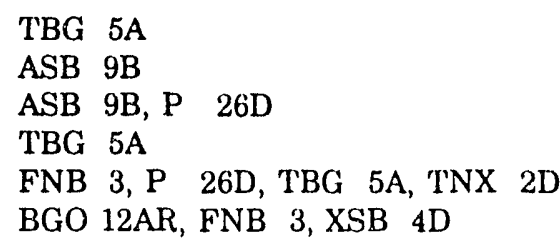




\section{QUALITY CONTROL STANDARDS}

During fourth quarter 1991, EPD/EMS conducted a quality assessment of General Engineering, the primary laboratory used for sample analysis. The laboratory was sent three sets of certified environmental quality control standards purchased from Environmental Resource Associates (ERA) of Arvada, CO (Batch Numbers 2528, 2602, and 412). The following analyses are listed: common analyses in Table 24, Appendix IX analyses in Table 25, and inorganics in Table 26.
General Engineering's results were compared with the ERA-certified values and advisory ranges. Of 99 analyses reported, four were eliminated from further consideration because the laboratory's contract detection limit was above the ERA advisory range. A fifth was eliminated because the laboratory reported results for the wrong constituent (hexachloropropene rather than hexachlorophene). Of the remaining 94 analyses, 87 , or $92.6 \%$, fell within the advisory range.

Table 24. Quality Control Standards for Common Analyses, Batch No. 2528

Analyte

Chlorine $(\mu \mathrm{g} / \mathrm{L})$

Turbidity (NTU)

\section{Inorganics}

Alkalinity' (as $\mathrm{CaCO}_{3}$ ) (mg/L)

Fluoride $(\mu \mathrm{g} / \mathrm{L})$

Nitrate as nitrogen $(\mu \mathrm{g} / \mathrm{L})$

$\mathrm{pH}$

Potassium ( $\mu \mathrm{g} / \mathrm{L})$

Sodium $(\mu \mathrm{g} / \mathrm{L})$

Sulfate $(\mu \mathrm{g} / \mathrm{L})$

Metals

Antimony $(\mu \mathrm{g} / \mathrm{L})$

Arstanic $(\mu \mathrm{g} / \mathrm{L})$

Baricin: $(\mu \mathrm{g} / \mathrm{L})$

Beryllin $(\mu \mathrm{g} / \mathrm{L})$

Cadmiura $(\mu \mathrm{g} / \mathrm{L})$

Calcium $(\mu \mathrm{g} / \mathrm{L})$

Chromium ( $\mu \mathrm{g} / \mathrm{L})$

Copper $(\mu \mathrm{g} / \mathrm{L})$

Hardness as $\mathrm{CaCO}_{3}(\mathrm{mg} / \mathrm{L})$

Iron $(\mu \mathrm{g} / \mathrm{L})$

Lead $(\mu \mathrm{g} / \mathrm{L})$

Manganese $(\mu \mathrm{g} / \mathrm{L})$

Mercury $(\mu \mathrm{g} / \mathrm{L})$

Nickel $(\mu \mathrm{g} / \mathrm{L})$

Selenium $(\mu \mathrm{g} / \mathrm{L})$

Silver $(\mu \mathrm{g} / \mathrm{L})$

Thallium $(\mu \mathrm{g} / \mathrm{L})$
Certified

Value

1,650

4.90

65.6

4,100

6,900

8.9

27,800

73,800

91,300

102

99.4

182

35.0

159

19,300

162

145

48.2

312

158

168

5.6

154

25.4

61.0

64.8
Advisory

Range

$1,400-1,900$

4.4-5.4

60-71

$3,700-4,500$

$6,200-7,700$

$8.7-9.1$

$24,000-32,000$

$63,000-85,000$

$79,000-104,000$
GE

Result

5.06

$-$

4,050

6,200

$9.26^{*}$

28,800

71,800

$74,100^{*}$

- Results not received.

* Results out of range. 
QUALITY CONTROL SAMPLES

Table 24. Quality Control Standards for Common Analyses, Batch No. 2528 (cont.)

Analyte

\section{Herbicides/Pesticides}

2,4-Dichlorophenoxyacetic acid $(\mu \mathrm{g} / \mathrm{L})$

Endrin $(\mu \mathrm{g} / \mathrm{L})$

Certified

Value

3.19

2.19

1.00

4.20

3.35

2.91

Halomethanes

Bromodichloromethane $(\mu \mathrm{g} / \mathrm{L})$

Bromoform $(\mu \mathrm{g} / \mathrm{L})$

Chloroform $(\mu \mathrm{g} / \mathrm{L})$

Dibromochloromethane $(\mu \mathrm{g} / \mathrm{L})$

\section{Volatiles}

Benzene $(\mu \mathrm{g} / \mathrm{L})$

Carbon tetrachloride $(\mu \mathrm{g} / \mathrm{L})$

Chloroethene (Vinyl chloride) ( $\mu \mathrm{g} / \mathrm{L}$ )

1,4-Dichlorobenzene ( $\mu \mathrm{g} / \mathrm{L})$

1,2-Dichloroethane $(\mu \mathrm{g} / \mathrm{L})$

1,1-Dichloroethylene $(\mu \mathrm{g} / \mathrm{L})$

1,1,1-Trichloroethane $(\mu \mathrm{g} / \mathrm{L})$

Trichloroethylene $(\mu \mathrm{g} / \mathrm{L})$

\section{Unregulated Volatiles}

Bromobenzene $(\mu \mathrm{g} / \mathrm{L})$

Chlorobenzene $(\mu \mathrm{g} / \mathrm{L})$

1,2-Dibromoethane $(\mu \mathrm{g} / \mathrm{L})$

Dibromomethane $(\mu \mathrm{g} / \mathrm{L})$

1,2-Dichlorobenzene ( $\mu \mathrm{g} / \mathrm{L})$

1,2-Dichloropropane ( $\mu \mathrm{g} / \mathrm{L})$

Ethyl benzene $(\mu \mathrm{g} / \mathrm{L})$

11.9

17.0

33.1

22.1

8.48

13.0

2.38

18.0

9.28

16.0

4.69

13.8

18.4

5.6

8.5

14.0

23.5

10.0

4.9

Dichloromethane (Methylene chloride) $(\mu \mathrm{g} / \mathrm{L})$

1,1,1,2-Tetrachloroethane $(\mu \mathrm{g} / \mathrm{L})$

Tetrachloroethylene $(\mu \mathrm{g} / \mathrm{L})$

Toluene $(\mu \mathrm{g} / \mathrm{L})$

1,1,2-Trichloroethane $(\mu \mathrm{g} / \mathrm{L})$
Advisory

Range

0.96-4.1

0.66-3.2

$0.29-1.4$

$1.3-6.7$

$1.4-4.2$

$0.87-3.8$

4.2-18

$7.6-29$

23-40

12-33

3.1-13

9.1-18

$0.36-6.0$

6.5-34

4.5-14

3.0-23

2.4-7.6

9.8-22

6.8-28

2.1-8.9

4.7-11

4.2-22

8.5-45

1.9-18

1.8-7.9

4.5-27

$7.3-25$

8.4-19

9.8-31

11-31
GE

Result

* Results out of range.

- Results not received.

$\dagger$ Results not considered in calculating percentage of analyses within advisory range. 
Table 25. Quality Control Standards for Appendix IX Analyses, Batch No. 2602

Analyte

Volatiles

Acetone $(\mu \mathrm{g} / \mathrm{L})$

Carbon tetrachloride $(\mu \mathrm{g} / \mathrm{L})$

1,2-Dibromoethane $(\mu \mathrm{g} / \mathrm{L})$

1,4-Dioxane $(\mu \mathrm{g} / \mathrm{L})$

Ethyl acetate $(\mu \mathrm{g} / \mathrm{L})$

Ethylbenzene $(\mu \mathrm{g} / \mathrm{L})$

1,1,1-Trichloroethane $(\mu \mathrm{g} / \mathrm{L})$

\section{Base/Neutrals}

Acenaphthene $(\mu \mathrm{g} / \mathrm{L}) \quad 29.8$

Aniline $(\mu \mathrm{g} / \mathrm{L})$

Bis(2-chloroethyl) ether $(\mu \mathrm{g} / \mathrm{L})$

Bis(2-ethylhexyl) phthalate $(\mu \mathrm{g} / \mathrm{L})$

1,4-Dichlorobenzene $(\mu \mathrm{g} / \mathrm{L})$

Hexachlorophene $(\mu \mathrm{g} / \mathrm{L})$

N-Nitrosodi-n-butylamine $(\mu \mathrm{g} / \mathrm{L})$

Phenanthrene $(\mu \mathrm{g} / \mathrm{L})$

1,3,5-Trinitrobenzene $(\mu \mathrm{g} / \mathrm{L})$

\section{Acids}

o-Cresol (2-Methylphenol) ( $\mu \mathrm{g} / \mathrm{L})$

2,6-Dichlorophenol $(\mu \mathrm{g} / \mathrm{L})$

2,4,6-Trichlorophenol $(\mu \mathrm{g} / \mathrm{L})$

\section{Pesticides}

Dieldrin $(\mu \mathrm{g} / \mathrm{L})$

Endrin $(\mu \mathrm{g} / \mathrm{L})$

Isodrin $(\mu \mathrm{g} / \mathrm{L})$

Kepone $(\mu \mathrm{g} / \mathrm{L})$

Parathion $(\mu \mathrm{g} / \mathrm{L})$

\section{PCBs}

Aroclor $1016(\mu \mathrm{g} / \mathrm{L})$

Aroclor $1260(\mu \mathrm{g} / \mathrm{L})$

\section{Certified \\ Value}

27.9

8.44

17.1

37.7

46.6

7.59

24.1

75.4

50.2

65.4

267

153

48.9

33.9

111

44.3

54.6

0.503

1.97

0.543

1.67

2.77

2.03

1.21
Advisory

Range

$7.5-47$

5.9-11

7.7-27

5.7-68

7.1-83

2.8-10

12-39

14-45

35-190

9.1-110

14-79

28-82

$80-430$

46-240

26-59

5. 1-61

33-140

14-71

20-79

0.21-0.92

$0.59-2.9$

0.13-0.98

0.25-3.1

$0.74-4.9$

1.1-2.3

0.39-1.5
GE

Result

$<100 \dagger$

8.23

$<20 \dagger$

$-$

6.21

23.1

26.3

83.4

52.7

47.4

51.2

-

161

43.1

11.9

70.3

42.0

47.2

$<0.50 t$

0.78

$1.15^{*}$

2.84

$\lcm{133}$

1.84

1.21

$\dagger$ Results not considered in calculating percentage of analyses within advisory range.

- Results not received.

* Results out of range. 
Table 26. Quality Control Standards for Inorganics Analyses, Batch No. 412

Analyte

Certified
Value

Trace Metals

Aluminum $(\mu \mathrm{g} / \mathrm{L})$

Antimony $(\mu \mathrm{g} / \mathrm{L})$

Arsenic $(\mu \mathrm{g} / \mathrm{L})$

Barium $(\mu \mathrm{g} / \mathrm{L})$

Beryllium $(\mu \mathrm{g} / \mathrm{L})$

Boron $(\mu \mathrm{g} / \mathrm{L})$

Cadmium $(\mu \mathrm{g} / \mathrm{L})$

Chromium $(\mu \mathrm{g} / \mathrm{L})$

Cobalt $(\mu \mathrm{g} / \mathrm{L})$

Copper $(\mu \mathrm{g} / \mathrm{L})$

Iron $(\mu \mathrm{g} / \mathrm{L})$

Lead $(\mu \mathrm{g} / \mathrm{L})$

Manganese $(\mu \mathrm{g} / \mathrm{L})$

Mercury ( $\mu \mathrm{g} / \mathrm{L})$

Mulybdenum $(\mu \mathrm{g} / \mathrm{L})$

Nickel $(\mu \mathrm{g} / \mathrm{L})$

Selenium $(\mu \mathrm{g} / \mathrm{L})$

Silver $(\mu \mathrm{g} / \mathrm{L})$

Strontium $(\mu \mathrm{g} / \mathrm{L})$

Thallium $(\mu \mathrm{g} / \mathrm{L})$

Vanadium $(\mu \mathrm{g} / \mathrm{L})$

Zinc $(\mu \mathrm{g} / \mathrm{L})$

\section{Cations}

Calcium $(\mu \mathrm{g} / \mathrm{L})$

Magnesium $(\mu \mathrm{g} / \mathrm{L})$

Potassium $(\mu \mathrm{g} / \mathrm{L})$

Sodium $(\mu \mathrm{g} / \mathrm{L})$

Cyanide and Phenol

Cyanide $(\mu \mathrm{g} / \mathrm{L})$

Phenol ( $\mu \mathrm{g} / \mathrm{L})$

- Results not received.

* Results out of range.

\section{BLANKS}

Blanks are among the quality control guidelines of the RCRA Ground-water Monitoring Technical Enforcement Guidance Document (EPA, 1986d). There are two general categories
418

108

92.7

223

97.2

200

113

141

212

115

327

170

166

1.94

212

175

103

91.8

249

95.0

148

234

80,800

90,400

61,900

31,900

453

181

$\begin{array}{ll}\text { Advisory } & \text { GE } \\ \text { Range } & \underline{\text { Result }}\end{array}$

$\begin{array}{ll}343-493 & 434 \\ 81-127 & 120 \\ 70-109 & 91.2 \\ 183-263 & 230 \\ 80-115 & 98.7 \\ 164-236 & - \\ 92-133 & 121 \\ 115-166 & 152 \\ 174-250 & 227 \\ 94-136 & 122 \\ 268-386 & 347 \\ 139-201 & 172 \\ 136-196 & 175 \\ 1.4-2.4 & 1.77 \\ 174-250 & - \\ 144-206 & 187 \\ 77-122 & 100 \\ 75-108 & 88.8 \\ 204-294 & - \\ 71-112 & 99.3 \\ 121-175 & 153 \\ 192-276 & 248\end{array}$

$\begin{array}{ll}69,000-92,000 & 78,600 \\ 77,000-103,000 & 91,400 \\ 52,000-71,000 & 67,500 \\ 27,000-37,000 & 34,000\end{array}$

$330-580$

$140-220$

$660^{*}$ $410^{*}$ of blanks: sampling blanks, which test the integrity of field sample collection methods and equipment, and laboratory quality control blanks, which test for contamination or other false positives when samples are analyzed in the laboratory. 


\section{Sampling Blanks}

Three types of sampling blanks were sent to the labos atories during fourth quarter. Trip blanks (denoted as WELL BLANK in the tables beginning on page 77) are sample containers of deionized water that are transported to the well sample location, left unopened, and sent to the laboratory for analysis. They are used to check for contamination resulting from transport, shipping, and site conditions. They also are used as blind blanks to test the laboratory's reliability. All trip blanks collected on a single day are reported under one heading in the tables beginning on page 77 .

Field blanks (FB) are generated by filling sample containers at the sample location with deionized water. They are treated as well samples, sent to the M-Area Laboratory for analysis, and used to check for possible contamination of the containers.

Equipment blanks (EPT) are samples of deionized water opened at the sampling location and poured or pumped through the sampling device or metals filter to test for equipment cuntamination. Results from these blanks are used to identify possible contaminants in the sampling equipment.

\section{Laboratory Quality Control Blanks}

Laboratory blanks, sometimes called internal blanks, are generated internally by a laboratory to test the integrity of its procedures and equipment.

\section{Analytical Results and Review}

During fourth quarter, one trip blank contained benzene, chlorobenzene, 1,1-dichloroethylene, and trichloroethylene above Flag 2 levels. Other results above Flag 2 criteria were tritium in another trip blank, total organic halogens in three trip blanks, and antimony in four equipment blanks.

A number of trip blanks were associated with laboratory blanks yielding elevated results for dichloromethane. The following table lists the sample dates for these blanks and the dichloromethane result for the associated laboratory blanks.

Table 27. Trip Blanks Associated With Laboratory Blanks High in Dichloromethane

Sample Date(s) Laboratory Blank Result

$\begin{array}{ll}10 / 10 / 91 & 4.0 \mu \mathrm{g} / \mathrm{L} \\ 10 / 15 / 91 & 4.0 \mu \mathrm{g} / \mathrm{L} \\ 10 / 16 / 91 & 5.5 \mu \mathrm{g} / \mathrm{L} \\ 10 / 18 / 91 & 6.7 \mu \mathrm{g} / \mathrm{L} \\ 10 / 18 / 91 ; 10 / 22 / 91 & 15.1 \mu \mathrm{g} / \mathrm{L} \\ 10 / 29 / 91 & 32.0 \mu \mathrm{g} / \mathrm{L} \\ 11 / 07 / 91 & 8.5 \mu \mathrm{g} / \mathrm{L} \\ 11 / 25 / 91 & 4.0 \mu \mathrm{g} / \mathrm{L}\end{array}$

The Analytical Data Review section lists fourth quarter laboratory blanks and EPD/EMS blind blanks with elevated results, along with the groundwater samples that accompanied them in their respective analytical batches.

The blanks tables that follow list the dates, field measurements, and analytical results for all three types of sampling blanks. See Appendix A for a key to abbreviations used in the tables. 
QUALITY CONTROL SAMPLES

WELL BLANK

MEASIJREMENTS CONDUCTED IN THE FIELD

Sample date: 10/04/91

Wopth to water: Not available

Water olevation: Not availablo
$\mathrm{Sp}$. conductance: $8 \mu \mathrm{s} / \mathrm{cm}$

LABORATORY ANALYSES

$\begin{array}{ll}\text { E } & \text { Analyte } \\ 0 & \text { pH } \\ 0 & \text { pH } \\ 0 & \text { Spocific conductance } \\ 0 & \text { Specific conductance } \\ 0 & \text { Acenaphthene } \\ 0 & \text { Acenaphthylene } \\ 0 & \text { Acetone }\end{array}$

Acelone

Acetophenone

2-Acetylaminofluorene

Acrolonitrlo

Acrlon

Allyl chloride

A-Aminobiphenyl

Aniline

Anthracene

Antimony

Antimony

Arsenic

Arsenic

Crarium

Garium

alpha-Benzene hexachioride

beta-Benzene hexachloride

deta-Benzene hexachloride

Benzola)anthracene

Benzo b] flucranthene

Benzol g, hil)porylene

Benzil alcohol

Beryllum

Bis 2-chloroisopropyl)ether

Bis 2-chloroethoxy) methane

Bis (2-chloroethyl) ether

Eis(2-ethylhexyl) phthalate

Bromodichlor

Bromomethane

4-8romophenyl phenyl ethe

Butylbenzyl phthalate

Cadmium

Cadmium

Carton disulfide

Carbon tetrach

Chlordan

Chloride

para-Chloro-mota-cresol

4-Chloroaniline

Chiorobenzilate

Chloroethane

Chloroethene Ninyl chloride)

2-Chloroethyl vinvl ether

Chloroform

Chloromethane
2-Chloronaphthajene

2-Chlorophenol

4-Chlorophenyl phenyl ether

Chloroprene

Chromium

Chromium

Cobalt

Cobat

0 Copper

C-Cresol (2-Methylphenol)

in-Cresol (3-Methylphenol

o p-Cresol (4-Methylphenol)

0 Cyanide

Cyanide

0 p., 0 -DDD

0
$0, p^{\prime}-D D T$

Di-ri-butyl phthalate

Diallate

Dibenz[a, h]anthracene

1,2-Dibromo-3-chloropropan

Dibromochloromethane

Result Mod Unit Lab

4.9
4.8

JQ JQ

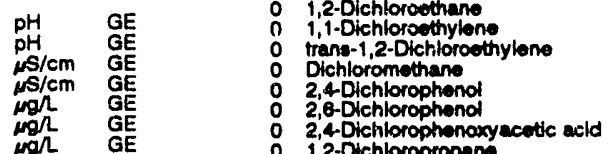

1,2-Dichloropropans

o cis-1,3-Dichloropropene

Diethyl phthalate

Dimethoate

2,4-Dimethyl pheno

p-Dinethylaminoezzobenzene

bimethylbenz[a]anthracene

3,3'-Dimethylbenzidine

a, a-Dimethylphenethy

1,3-Dinitrobenzene

2,4-Dinitrophenol

2,6-Dinltrotoluene

1,4-Dioxane

Diphonylar

Disulíoton

Endosulfan I

Endosulfan sulfate

Endosultar

Endrin aidohydo

Etyl methangationato

Ethylbenzone

Fluoranthen

Fluorene

Fluoride

Heptachlor epoxide

Heptachiorodibenzo-p-dioxins

1,2,3,4,6,7,8-HPCDF

Heptachlorodibenzo-p

Hexachlorobutadiene

Hexachlorocyclopentadiene

$1,2,3,4,7,8-H \times C D D$

Hexachlorodibenzo-p-dioxins

$1,2,3,4,7,8-4 \times C D F$

Hexachiorophene

Hexachloropropen

2. Hexanone

lindeno[1,2,3-c,d]pyrene
lodomethane (Mothyl lodide)

rocomo

liobutyl alcohol

teodin

lepesafiole

Kepone

o Loed

Lindan

o Magnesium

- Manganeso

O Morcury

Methacrylonitrile

Methapyrilen

Methyl thy keton

Mothyl ethyl kotone

Metyl inthection

Mothyl methan lut fonato

2-Methyl-4,8-dinitrophenol

3-Methylcholanthrene

2-Methyinaphthalene

N.Nitrosodiethylamine

N-Nitrosodimethylamine

N.Nitrosodi-n-butylamine

N-Nitrosodiphenylamine

N-Nitrosomethylethylamine

N-Nitrosomorpholine

N-Nitrosopipenidine

Naphthalane
Posult Mod Untt Lab

$<10$

$<30$
$<10$
$<10$
$<<10$

$\leq 10$

$<1.0$

$<1.0$

$<1.0$

$<10$
$<10$
$<10$

$<<<1.30$

$<1.0$

$<0.50$

$<10$

$<<$

$<10$

$<10$

$<10$

$<10$

$<<10$

$<10$

$<0.10$

$<0.10$

$\leqslant 0.0080$

$<10$

$<10$

$\leq 10$

$<10$

$<100$
$<100$

$<0.050$
$<0.050$

$<0.00085$

$<0.00065$

$<0.00045$

$<10$

$<<0$

$<0.00045$

$<0.00040$

$\leq 10$

$<10$

$<10$

$<10$

$<4.0$

$\leq 10$

$<10$

$<10$

$<3.0$

$<0.0050$

$<2.0$

$<0.20$

$<0.20$

$<50$
$<10$
$<50$

$<0.50$

$<1.0$
$<1.0$

$<10$
$<10$

$<10$

$<10$

$\leq 10$

$<10$

$<10$

$<10$

$<10$

$<10$
$<10$
$<10$
$<10$ 
QUALITY CONTROL SAMPLES

WELL BLANK collected on 10/04/91, laboratory analyses (cont)

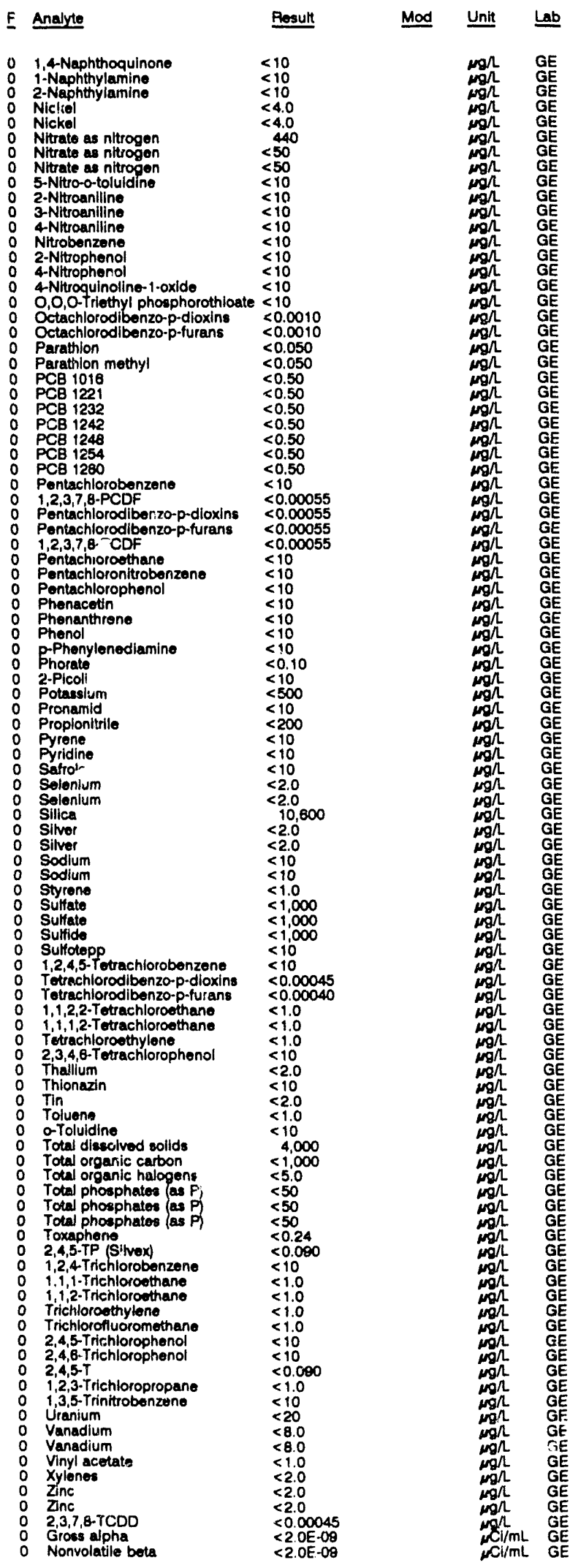

WELL BLANK colloctod on 10/04/91, laboratory analyoes (cont.)

\begin{tabular}{|c|c|c|c|}
\hline F Analyte & Result & Mod & Unit \\
\hline $\begin{array}{ll}0 & \text { Total radium } \\
0 & \text { Total radium } \\
0 & \text { Tritium }\end{array}$ & $\begin{array}{l}<1.0 E-09 \\
<1.0 E-09 \\
<7.0 E-07\end{array}$ & & $\begin{array}{c}\mathrm{Nl} / \mathrm{mL} \\
\mathrm{N} \mathrm{Cl} / \mathrm{mL} \\
\mathrm{NCl} / \mathrm{mL}\end{array}$ \\
\hline
\end{tabular}

\section{WELL BLANK}

MEASUREMENTS CONDUCTEN IN THE FIELU

Sample dato: 10/09/91

Depth to water: Not avaliable

Sp. conductance: $5 \mu \mathrm{S} / \mathrm{cm}$

Alkalinity: $0 \mathrm{mg} / \mathrm{L}$

LABOFATORY ANALYSES

0 pH

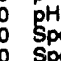

Specific conductance

Specific conductance

Aluminum

Areonic

Berium

Barium

Benzene

Benzene

Bromodichloromethane

Gromodichloromethane

Bromoform

Bromomethane

Bromomethan

Cadmlum

Carton totrachloride

Carbon tetrachloride

Chlorido

Chloride

Chlorobenzene

Chlorobenzene

Chloroethane

Chloroethane

Chloroethene Ninyl chloride)

Chloroethene Minyl chlor 2-Chloroethyl vinyl ether
2-Chloroethyl vinyl ether

Chloroform

Chloroform

Chloromethane

Chromium

Chromlum

Copper

- Copper

0 Cyanide

O Gyanide

Dibromochloromethan

1,1-Dichloroethane

1,2-Dichloroethane

1,2-Dichloroethane

1,1-Dichloroethylene

1,1-Dichloroethylone

trans-1,2-Dichloroethylene

Dichloromethane

D Dichloromethano

1,2-Dichloropropane

1,2-Dichloropropane

o cls-1,3-Dichloropropene

trans $-1,3$-Dichloropropene
trans-1,3-Dichloropropene

Ethylbenzene

Ethylbenzono

Load

0 Mercury

Morcuny

Nicke

O Nitrate as nitrogen

Nitrato as nitrogon

Phenols

Phenols

Solenium

O Solen

S Silver

Sodium

Sodium

0 Sulfate

1,1,2,2-Tetrachloroethane

Rosult Mod Unit Lab

${ }_{4.8}^{4.8} \quad$ Jo

PH GE

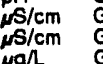

(1)

$<20$

(1)

$<1.0$

$<1.0$

$<1.0$

$<1.0$

$<1.0$

$<2.0$

$<1.0$

$<250$

$<1.0$

$\leq 1.0$

(1.0

$<1.0$

$<1.0$

$<1.0$

$\leq 1.0$

$<1.0$

$\leq 4.0$

$\leq 4.0$

$<5.0$

$<1.0$

$\leq 1.0$

$<1.0$

$<1.0$

$<1.0$

$<1.0$

$<1.0$

2.0
$<1.0$

$<1.0$
$<1.0$
$<1.0$

$<1.0$

$<1.0$

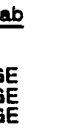


QUALITY CONTROL SAMPLES

\begin{tabular}{|c|c|c|c|}
\hline E Analyte & Result & Mod & Unit \\
\hline 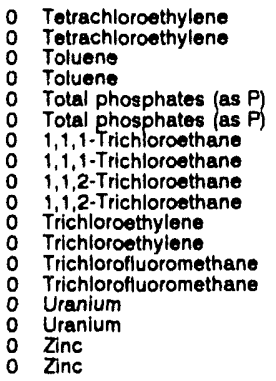 & $\begin{array}{l}<1.0 \\
<1.0 \\
<1.0 \\
<1.0 \\
<50 \\
<50 \\
<1.0 \\
<1.0 \\
<1.0 \\
<1.0 \\
<1.0 \\
<1.0 \\
<1.0 \\
<1.0 \\
<20 \\
<20 \\
<2.0 \\
<2.0\end{array}$ & & 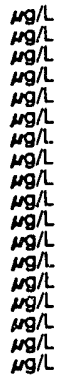 \\
\hline
\end{tabular}

\section{WELL BLANK}

MEASUREMENTS CONDUCTED IN THE FIELD

Sample date: 10/10/91
Depth to water: Not available
Water elevation: Not available
Sp. conductance: 7 wS/cm

LABORATORY ANALYSES

\begin{tabular}{|c|c|c|c|c|c|}
\hline$E$ & Analyte & Result & Mod & Unit & Lab \\
\hline & 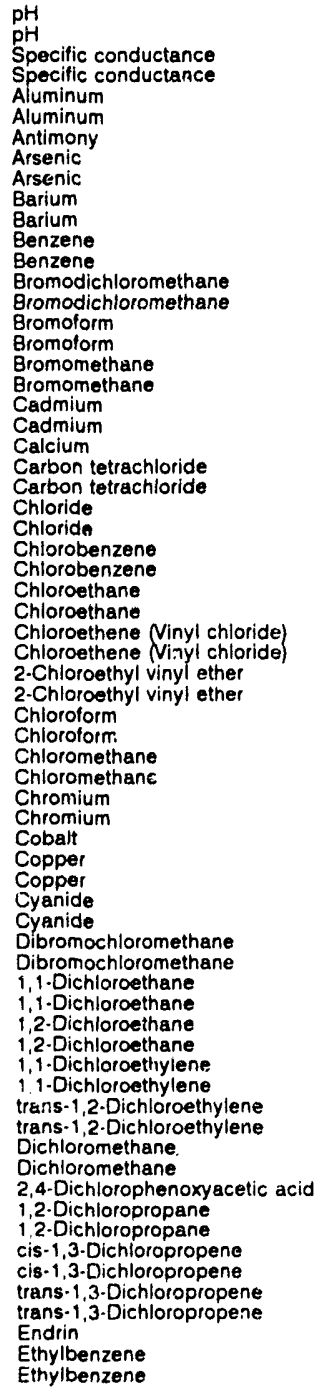 & $\begin{aligned} & 4.8 \\
& 4.9 \\
& 10 \\
& 10 \\
&<20 \\
&<20 \\
&<2.0 \\
&<2.0 \\
&<2.0 \\
&<3.0 \\
&<3.0 \\
&<1.0 \\
&<1.0 \\
&<1.0 \\
&<1.0 \\
&<1.0 \\
&<1.0 \\
&<1.0 \\
&<1.0 \\
&<2.0 \\
&<2.0 \\
&<10 \\
&<1.0 \\
&<1.0 \\
&<250 \\
&<250 \\
&<1.0 \\
&<1.0 \\
&<1.0 \\
&<1.0 \\
&<1.0 \\
&<1.0 \\
&<1.0 \\
&<1.0 \\
&<1.0 \\
&<1.0 \\
&<1.0 \\
&<1.0 \\
&<4.0 \\
&<4.0 \\
&<4.0 \\
&<4.0 \\
&<4.0 \\
&<5.0 \\
&<5.0 \\
&<1.0 \\
&<1.0 \\
&<1.0 \\
&<1.0 \\
&<1.0 \\
&<1.0 \\
&<1.0 \\
&<1.0 \\
&<1.0 \\
&<1.0 \\
& 7.0 \\
& 3.2 \\
&<0.3 n \\
&<1.0 \\
&<1.0 \\
&<1.0 \\
&<1.0 \\
&<1.0 \\
&<1.0 \\
&<0.0060 \\
&<1.0 \\
&<1.0\end{aligned}$ & $\begin{array}{l}\mathrm{J} 2 \mathrm{~V} \\
\mathrm{~J} 2 \mathrm{~V}\end{array}$ & 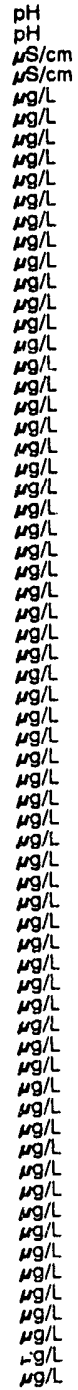 & $\begin{array}{l}G E \\
G E \\
G E \\
G E \\
G E \\
G E \\
G E \\
G E \\
G E \\
G E \\
G E \\
G E \\
G E \\
G E \\
G E \\
G E \\
G E \\
G E \\
G E \\
G E \\
G E \\
G E \\
G E \\
G E \\
G E \\
G E \\
G E \\
G E \\
G E \\
G E \\
G E \\
G E \\
G E \\
G E \\
G E \\
G E \\
G E \\
G E \\
G E \\
G E \\
G E \\
G E \\
G E \\
G E \\
G E \\
G E \\
G E \\
G E \\
G E \\
G E \\
G E \\
G E \\
G E \\
G E \\
G E \\
G E \\
G E \\
G E \\
G E \\
G E \\
G E \\
G E \\
G E \\
G E \\
G E \\
G E \\
G E\end{array}$ \\
\hline
\end{tabular}

WELL BLANK collectod on 10/10/81, laboratory analyses (cont.)

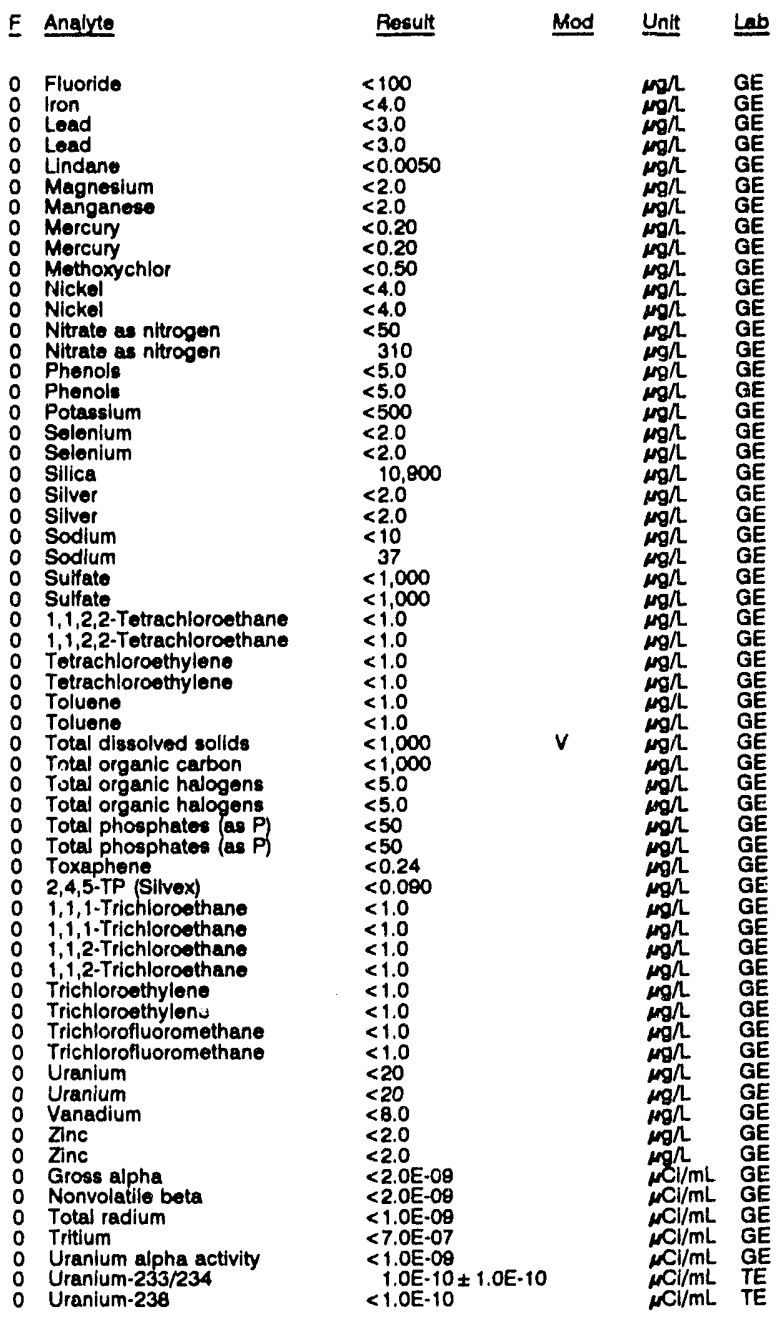

\section{WELL BLANK.}

MEASUREMENTS CONDUCTED IN THE FIELD

Sample date: $10 / 11 / 91$

Wepth to water: Not available

Water olevation: Not availab

LABORATORY ANALYSES

\begin{tabular}{|c|c|c|c|c|c|}
\hline$F$ & Analyte & Result & Mod & Unit & Lab \\
\hline & $\begin{array}{l}\mathrm{pH} \\
\text { pH } \\
\text { Specific conductance } \\
\text { Specific conductance } \\
\text { Aluminum } \\
\text { Aluminum } \\
\text { Antimony } \\
\text { Arsenic } \\
\text { Arsenic } \\
\text { Barlum } \\
\text { Barium } \\
\text { Benzene } \\
\text { Bromodichloromethane } \\
\text { Bromoform } \\
\text { Bromomethane } \\
\text { Cadmium } \\
\text { Cadmium } \\
\text { Calcium } \\
\text { Calcium } \\
\text { Carbon tetrachloride } \\
\text { Chloride } \\
\text { Chloride } \\
\text { Chlorobenzene } \\
\text { Chlorothane } \\
\text { Chloroethene Ninyl chioride) }\end{array}$ & $\begin{aligned} & 5.0 \\
& 4.9 \\
& 10 \\
& 10 \\
&<20 \\
&<20 \\
&<2.0 \\
&<2.0 \\
&<2.0 \\
&<3.0 \\
&<3.0 \\
&<1.0 \\
&<1.0 \\
&<1.0 \\
&<1.0 \\
&<2.0 \\
&<2.0 \\
& 12 \\
&<10 \\
&<1.0 \\
&<250 \\
&<250 \\
&<1.0 \\
&<1.0 \\
&<1.0\end{aligned}$ & $\begin{array}{l}\text { JQ } \\
\text { JQ }\end{array}$ & 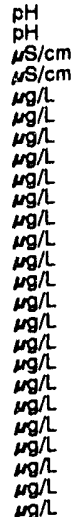 & $\begin{array}{l}\mathrm{GE} \\
\mathrm{GE} \\
\mathrm{GE} \\
\mathrm{GE} \\
\mathrm{GE} \\
\mathrm{GE} \\
\mathrm{GE} \\
\mathrm{GE} \\
\mathrm{GE} \\
\mathrm{GE} \\
\mathrm{GE} \\
\mathrm{GE} \\
\mathrm{GE} \\
\mathrm{GE} \\
\mathrm{GE} \\
\mathrm{GE} \\
\mathrm{GE} \\
\mathrm{GE} \\
\mathrm{GE} \\
\mathrm{GE} \\
\mathrm{GE} \\
\mathrm{GE} \\
\mathrm{GE} \\
\mathrm{GE} \\
\mathrm{GE}\end{array}$ \\
\hline
\end{tabular}

Time: $7: 25$

Alkalinity: $0 \mathrm{mg} / \mathrm{h}$

Alkalinity: $0 \mathrm{mg} / \mathrm{h}$ 


\section{QUALITY CONTROL SAMPLES}

WELL BLANK collected on 10/11/91, laboratory analyses (cont.)

\begin{tabular}{|c|c|c|c|c|}
\hline Analyce & Result & Mod & Unit & Lab \\
\hline 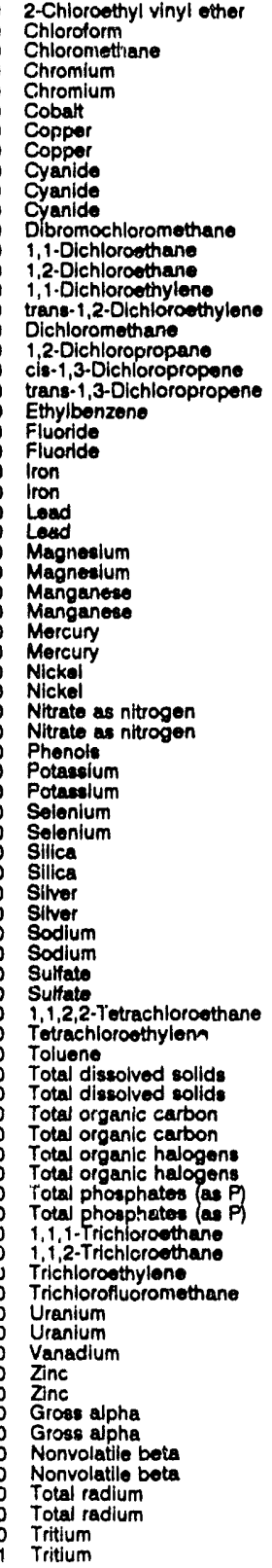 & $\begin{array}{l}<1.0 \\
1.1 \\
<1.0 \\
<4.0 \\
<4.0 \\
<4.0 \\
<4.0 \\
<4.0 \\
<5.0 \\
<5.0 \\
<5.0 \\
<1.0 \\
<1.0 \\
<1.0 \\
<1.0 \\
<1.0 \\
2.3 \\
<1.0 \\
<1.0 \\
<1.0 \\
<1.0 \\
<100 \\
<100 \\
<4.0 \\
<4.0 \\
<3.0 \\
<3.0 \\
<2.0 \\
<2.0 \\
<2.0 \\
<2.0 \\
<0.20 \\
<0.20 \\
<4.0 \\
<4.0 \\
60 \\
60 \\
<5.0 \\
<500 \\
<500 \\
<2.0 \\
<2.0 \\
11.000 \\
10.200 \\
<2.0 \\
<2.0 \\
<10 \\
14 \\
<1.000 \\
<1.000 \\
<1.0 \\
<1.0 \\
<1.0 \\
<1.000 \\
12.000 \\
<1.000 \\
<1.000 \\
7.2 \\
<5.0 \\
<50 \\
<50 \\
<1.0 \\
<1.0 \\
<1.0 \\
<1.0 \\
<20 \\
<20 \\
<8.0 \\
<2.0 \\
<2.0 \\
<2.0 \mathrm{E}-09 \\
<2.0 \mathrm{E}-09 \\
<2.0 \mathrm{E}-09 \\
<2.0 \mathrm{E}-09 \\
1.4 \mathrm{E}-09 \\
<1.0 \mathrm{E}-09 \\
<7.0 \mathrm{E}-07 \\
1.4 \mathrm{E}-05 \pm 1.0 \mathrm{E}-10 \\
\mathrm{E} \cdot 06\end{array}$ & J2V & 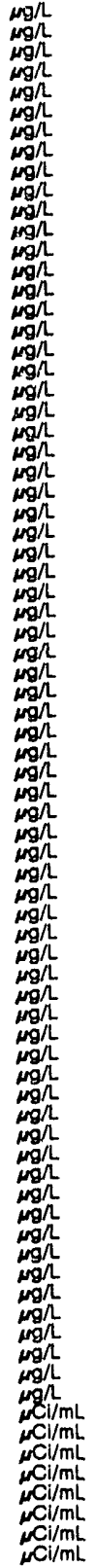 & $\begin{array}{l}G E \\
G E \\
G E \\
G E \\
G E \\
G E \\
G E \\
G E \\
G E \\
G E \\
G E \\
G E \\
G E \\
G E \\
G E \\
G E \\
G E \\
G E \\
G E \\
G E \\
G E \\
G E \\
G E \\
G E \\
G E \\
G E \\
G E \\
G E \\
G E \\
G E \\
G E \\
G E \\
G E \\
G E \\
G E \\
G E \\
G E \\
G E \\
G E \\
G E \\
G E \\
G E \\
G E \\
G E \\
G E \\
G E \\
G E \\
G E \\
G E \\
G E \\
G E \\
G E \\
G E \\
G E \\
G E \\
G E \\
G E \\
G E \\
G E \\
G E \\
G E \\
G E \\
G E \\
G E \\
G E \\
G E \\
G E \\
G E \\
G E \\
G E \\
G E \\
G E \\
G E \\
G E \\
G E \\
G E \\
G E \\
G E \\
G E \\
G E\end{array}$ \\
\hline
\end{tabular}

WELL BLANK

MEASUREMENTS CONDUCTED IN THE FIELD

Sample date: 10/13/81

Depth to water: Not available

Water elovation: Not availe

LABORATORY ANALYSES

\begin{tabular}{|c|c|c|c|c|}
\hline Analyte & Result & Mod & Unit & Lab \\
\hline $\begin{array}{ll}0 & \mathrm{pH} \\
0 & \text { Specific conductance } \\
0 & \text { Arsenic } \\
0 & \text { Barium } \\
0 & \text { Cadmium } \\
0 & \text { Cslcium } \\
0 & \text { Carbon tetrachloride }\end{array}$ & $\begin{array}{r}4.7 \\
10 \\
<2.0 \\
<3.0 \\
<2.0 \\
<10 \\
<1.0\end{array}$ & JQ & 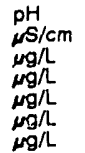 & $\begin{array}{l}\mathrm{GE} \\
\mathrm{GE} \\
\mathrm{GE} \\
\mathrm{GE} \\
\mathrm{GE} \\
\mathrm{GE} \\
\mathrm{GE}\end{array}$ \\
\hline
\end{tabular}

WELL. BLANK collocted on 10/13/91, laboratory analyses (cont.)

E Analyte

Pesult

Mod Unit Leb

o Chioride

o Chloroform

F Fluor

0 Lead

O Magnesium

O Manganese

O Mercury

Phenols

$\begin{array}{ll}0 & \text { Potassium } \\ 0 & \text { Selenium }\end{array}$

o Sillica

0 Silver

o sodium

- Tetrachloroethylene

- Total dissolved solids

- Total organic carbon

Total organic halogens

o Total phosphates as $\mathrm{P}$

0 Trichloroethylene

Gross alpha

Nonvolatile beta

0 Tritium
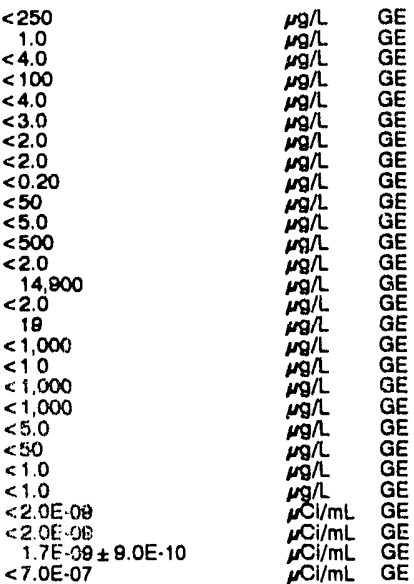

WELL BLANK

MEASUREMENTS CONDUCTED IN THE FIELD

Sample date: 10/15/9

Depth to water: Not available

Water elevation: Nof avalablo
$S p$. conductance: $10 \mathrm{pS} / \mathrm{cm}$

Alkallnity: $0 \mathrm{mg} / \mathrm{l}$

LABORATOAY ANALYSES

$:$ 品

Spreific conductance

Specilicanc

0

Acetophenone

Acetophem

Aluminum

Antimony

Arsenic

Arsenic

Barium

Benzeno

Bromodichloromethane

Bromodichloromethan

Bromoform
Bromoform

Bromomethane

Bromomethan

Cadmium

Calcium

Carbon tetrachloride

Carbon tetrachloride

Chioride

Chloride

Chlorids

Chlorobenzene

Chlorobenzene

Chloroethane

Chloroethane

Chloroethene Ninyl chloride)

2-Chloroethyl vinyl ether

Chloroform

Chloresorm

Chloromethane

Chromium

Chromium

Copper

Copper

Cyanido

Cyanide

Cyanide
0 Oibromochioromethane

1,1-Dichloroethane
Mod Unit Lab

Ja

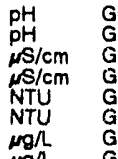

$\mu g /$ GE 
QUALITY CONTROL SAMPLES

WELL BLANK collocted on 10/15/91, laboratory analyses (cont)

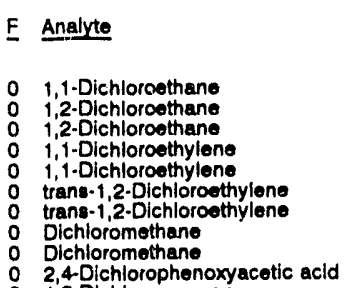

1,2-Dichloropropane

1,2-Dichloropropane

cis-1,3.Dichloropropene

trans-1,3-Dichloropropene

0 trans-

O Endrin

Ethylbenzene

0 Fluoride

0 Fluoride

0 Fluoride

0 Iron

0 lron

- Lead

Undane

Lindane

Magnesium

Manganose

Manganese

Mercury

Mercury

Methoxychlor

Naphthalene
Naphthalene

Nickel

Nitrate as nitrogen

Nitrato as nitrogen

Phenols

Phenols

Potassium

Selenium

Selenium

Silica

Silver

Silver

Sodium

Sodium

Sulfate Tetrachloroethane

i, 1,2 . Tetrachlorouthane

Tetrachloroethylene

Tetrachloroethylone

Tin

Toluene

Total dissolved solid

Total dissolved solids

Total organic carbon

Total organic carbon

Total organic halogens

Total phosphates las P

Total phospha

Toxaphene

Toxaphene

1,1,1-Trichloroethane

1,1,1-Trichloroethane

1,1,2-Trichloroethane

1,1,2-Trichloroethan

Trichloroethylene

Trichlorofluoromethane

Trichlorofluoromethan

Vanadium

Vanadium

Xylenes

Xylenes

Gross alpha

Total radium

Tritium

Uranium-233/234
Result

$<1.0$

$<1.0$

$<1.0$

$<1.0$

$<1.0$
3.0

3.0
3.0
$<0.30$

Mod Unit Lab

$<1.0$

$<1.0$
$<1.0$
$<1.0$
$<1.0$

$<1.0$

$<0.0060$

$<1.0$

$<1.0$

$<100$
$<100$

$<100$

$<100$

$<4.0$

$<3.0$

$<0.0050$

$<0.0050$

$<2.0$

$<2.0$

$<2.0$

$<0.20$

$<0.50$

$<10$

$<10$

$<4.0$

$<50$

$<50$

$<5.0$

$<500$

$<2.0$
$<2.0$

$<2.0$
10,400
10,400

10,400
$<2.0^{2}$

$<2.0$

25

$<1,000$

$<1,000$

$<1.0$

$<1.0$

$<1.0$

$<2.0$

$<1.0$

15,000
15,000

$<1,000$

$<1,000$

$<5.0$

$<50$

$<0.24$

$<0.24$

$<1.0$

$<1.0$

$<1.0$

$<1.0$

$<1.0$

$<1.0$
$<8.0$

$<8.0$

$<2.0$

$<2.0 E-09$
$<$. OF-09

3.7 $-08 \pm 1.5 \mathrm{E}-08$

$<7.0 \mathrm{E} \cdot 07$

$<1.0 E \cdot 10$
$<1.0 E \cdot 10$
WELL BLANK

MEASUREMENTS CONDUCTED IN THE FIELD

Sample date: 10/16/91

Depth to water: Not avallable

Water elovalloni Not avallab

LABORATORY ANALYSES

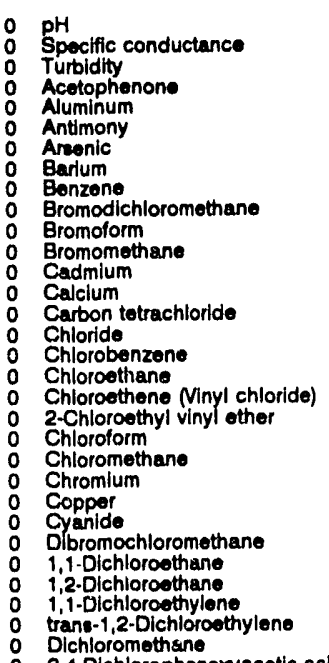

$\begin{array}{ll}\text { Dichloromethsine } & 4.6 \\ 2,4 \text {-Dichlorophenoxyacetic acid } & <0.30 \\ 1,2 \text {-Dichloropropane } & <1.0\end{array}$

cie-1,3-Dichlotopropeno

trans-1,3-Dichloropropen

Endrin

Ethylbenzene

Iron

Lead

Magnesium

Mercury

Methoxychlor

O Naphthalen

Nickel

Nitrate as nitrogen

Phenols

Potassium
Selenlum

Silica

Sodium

Sodium

1,1,2,2-Tetrachloroethane

Totrachloroethylene

Tin

Total dissoived solids

Toty organic carbon

Total organic halogens

Toxaphene

2,4,5-TP (Silvex)

1,1,1-Trichloroethan

Trichloroothy!on?

romethane

Vanadlum

Xylenes

Gross alpha

Total radium

2 Tritium

Uranium-233/234

Booult

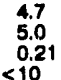

$<20$

$<2.0$

$<1.0$

$<1.0$

$<1.0$

$<1.0$

$<1.0$

$<1.0$

$<1.0$

1.0

$<4.0$

$<4.0$

$<1.0$

<1.0

$<1.0$

$<1.0$

$<0.0080$

$<1.0$

$<4.0$

$<3.0000$

$<2.0$

$<<0.20$

$<10$

$<4.0$
$<50$

$<50$
$<5.0$

$<5.0$
$<500$
$<2.0$
10.600

10,600

$<2.0$
25
$<1.000$

$<1,000$

$<1.0$

$<2.0$

28,000
$<1,000$

18
$<50$

$<0.24$
$<0.090$

$<1.0$

$<1.0$

$<1.0$

$<8.0$

$<2.0$

$<<2.08 .09$

$<1.0 \mathrm{E}-09$

1.2E-04 $+1.8 E-06$

$<2.0 \mathrm{E}-10$
$<2.0 \mathrm{E}-10$

Time: 7:30

Alkalinity: $0 \mathrm{mg} /$

Water temperature: $21.6^{\circ} \mathrm{C}$

Mod Unit Lab

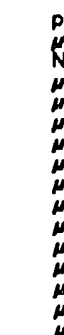

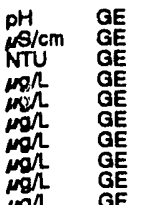

J2 


\section{QUALITY CONTROL SAŃPLES}

WELL BLANK

MEASUREMENTS CONDUCTED IN THE FIELD

Sample date: 10/17/8i

Depth to water: Not available

Sp. conductance: $? \mu \mathrm{s} / \mathrm{cm}$

LABORATORY ANALYSES

\begin{tabular}{|c|c|c|c|}
\hline Analute & Plesult & Mod & Unit \\
\hline 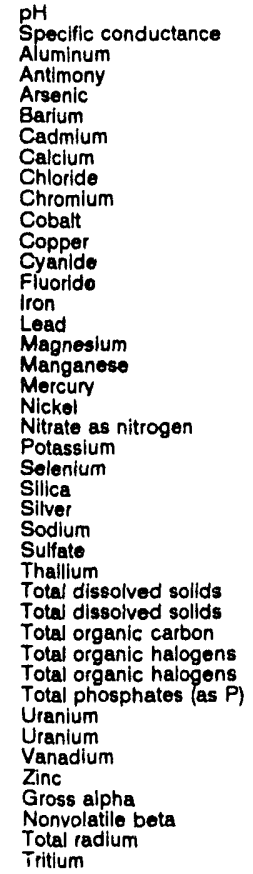 & $\begin{aligned} 5.1 \\
3.0 \\
<20 \\
<2.0 \\
<2.0 \\
<3.0 \\
<2.0 \\
11 \\
<250 \\
<4.0 \\
<4.0 \\
<4.0 \\
<5.0 \\
<100 \\
<4.0 \\
<3.0 \\
<2.0 \\
<2.0 \\
<0.20 \\
<4.0 \\
<50 \\
<500 \\
<2.0 \\
10.700 \\
<2.0 \\
2.1 \\
<1,1.1 \\
<2.1 \\
51.2 .0 \\
7.000 \\
<1,000 \\
<5.0 \\
<5.0 \\
<50 \\
<20 \\
<20 \\
<8.0 \\
<2.0 \\
<2.0 E-09 \\
<2.0 E-09 \\
<1.0 E-09 \\
<7.0 E-07\end{aligned}$ & $\stackrel{V}{V}$ & 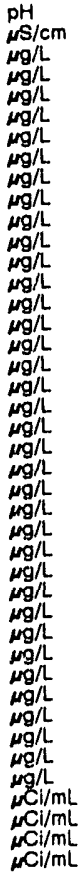 \\
\hline
\end{tabular}

WELL BLANK

MEASUREMENTS CONDLCTED IN THE FIELD

Sampie date: 10/18/61 Depth to water: Not available Water elevation: Not available
Sp. conductance: $8 \mu \mathrm{S} / \mathrm{cm}$

LABORATOAY ANALYSES
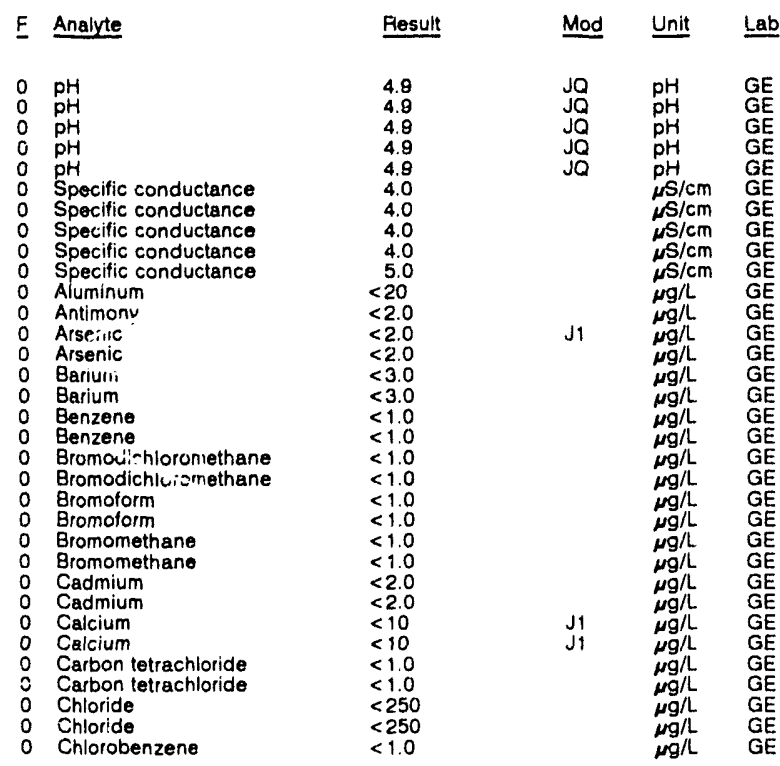

Time: $7: 45$

PH: 4.8 : $0 \mathrm{mg} / \mathrm{L}$

Water temperature: $18.2^{\circ} \mathrm{C}$
WELL BLANK collected on 10/18/91, laboratory analyses (cont.)

$E$ Analyte Result Mod Unit Lab

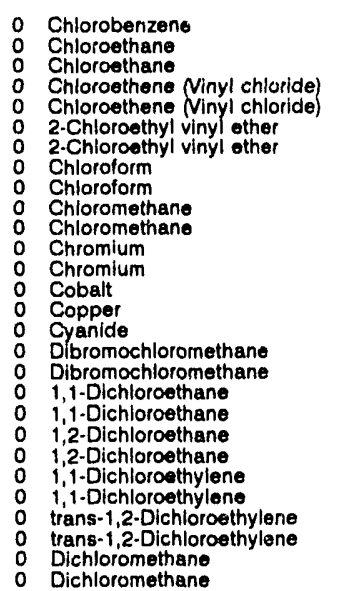

2,4-Dichlorof 'enoxyacetic acid < <0.30

2,4-Dichloroprienoxyacetic acid $<0.30$

1,2-Dichloropropane

1,2-Dichloropropane

$<1.0$

cis-1,3-Dichloropropene $<1.0$

trans-1,3-Dichloropropene

Endrin

Endrin

Ethylbenzene

Fluoride

Fluorid

Iron
Iron

0 lron

Lindane

Lindane

Magnesium

Magnesium

Manganeso

Mercury

Methoxychlor

Methoxychlor

Nickel

Nitrate as nitrogen

Nitrate as nitrogen

Phenols

Potassium

Potassium

Selenium

Selenium

Silica

o Silica

0 Silver

0 Sodium

Sodium

0 Sulfate

1,1,2,2-Tetrachloruethane

Tetrachicroethylene

0 Thallium

0 Toluene

o Toluene

Total dissolved solids

Total dissolved solids
0 Total organic carbon

Total organic carbon

Total organic carbon

Total organic carbon

- Total organic carbon

Total organic carbon

Total organic halogens

o Total organic halogens

- Total organic halogens

Total organic halogens

0
0
0 Total phosphates (as F)

- Toxaphiene

Toxaphene

$\begin{array}{lll}0 & 2,4,5-T P & \text { (Silvex) } \\ 0 & 2,4,5-T P & \text { (Silvex) }\end{array}$

$2,4,5-1 P($ Silvex
1,1,1-Trichloroethane

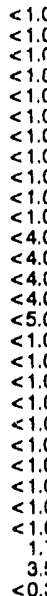

$\mu \mathrm{\mu g} / \mathrm{L} \quad \mathrm{GE}$

$\mathrm{GE}$
$\mathrm{GE}$
$\mathrm{GE}$

$<1.0$

$<0.0060$

$<1.0$

$<100$

$<100$

$<4.0$

$<3.0$
$<3.0$

$<0.0050$

$<2.00$

$<2.0$

$<<$

$<2.0$
$<0.20$
$<.20$

$<0.50$

$<0.50$

$<4.0$

$<5.0$

$<500$

$<500$
$<2.0$

8.070
8,840

$<2.0$
$<2.0$

15
15

$<1,000$

$<1.0$

$<1.0$
$<1.0$
$<1.0$

$<1.0$

$<2.0$
$<1.0$
$<1.0$

5,000

$<1,000$

$<1,000$

$<1,000$

$<1,000$

$<5.0$

$<5.0$

$<5.0$

$<50$

$<0.24$

$<0.24$

$<0.090$
$<0.080$

$<1.0$ 


\section{QUALITY CONTROL SAMPLES}

WELL BLANK collected on 10/18/91, laboratory analyses (cont.)

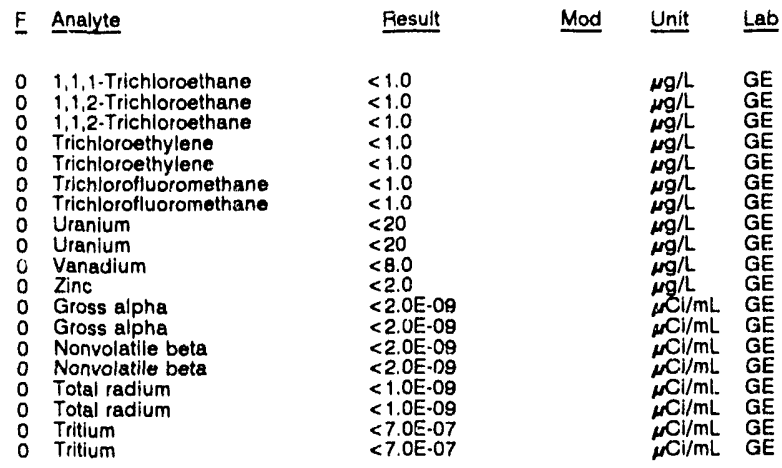

WELL BLANK

MEASUREMENTS CONDLUCTED IN THE FIELD

Sample date: 10/21/91

Depth to water: Not avallable

Water elevation: Not available

Sp. conductance: $6 \mu \mathrm{s} / \mathrm{cm}$

LABORATORY ANALYSES

F Analyte Result Mod Unit Lab

pH

Aluminum

Aluminum

Arsenic

0 Barium

B Bromone

Bromoform

Cadmium

Calcium

Chloride

Chlorobenzene

Chloroethane

Chloroethene Ninyl chloride)

2-Chloroothyl vinyl ether

Chloroform

Chloromethane

Chromium

0 Cobalt

O Copper

o Dibromochloromethane

1,1-Dichloroethane

1,2-Dichlororthane

1,1-Dichloroethylene

Dichloromethane

2,4-Dichlorophenoxyacetic acid

1,2-Dichloror ropane

cis-1,3-Dichluropropene

trans-1,3-Dichloropropene

Ethylbenzene

Fluoride

Iron

Lead

0 Lindane

Magnesium

Manganese

Mercury

Methoxychlor

Nickel

Nitrate as nitrogen

Nitrate as nitrộn

Potassium

Selenium

Silica

Silver

Sodium

Sulfate

Tetrachloroethylene

Tetrachloroethylene

Thallium

Total dissolved solids

Total organic caibon

Time: 9:05

pH: 4.7

Alkalinity: $0 \mathrm{mg} / \mathrm{L}$ : $18.9^{\circ} \mathrm{C}$

$<1,000$

$\begin{array}{llll}\text { Mod Unit Lab } & 0 & \text { Tritium } \\ & 0 & \text { Zinc-65 }\end{array}$

Jo $\quad \mathrm{pH} / \mathrm{GH}$ GE $\mathrm{GE}$ WELL BLANK

MEASUREMENTS CONDUCTED IN THE FIELD

Sample date: 10/22/91

Depth to water: Not available

LABORATORY ANALYSES

\begin{tabular}{|c|c|c|c|}
\hline Analyte & Result & Mod & Unit \\
\hline 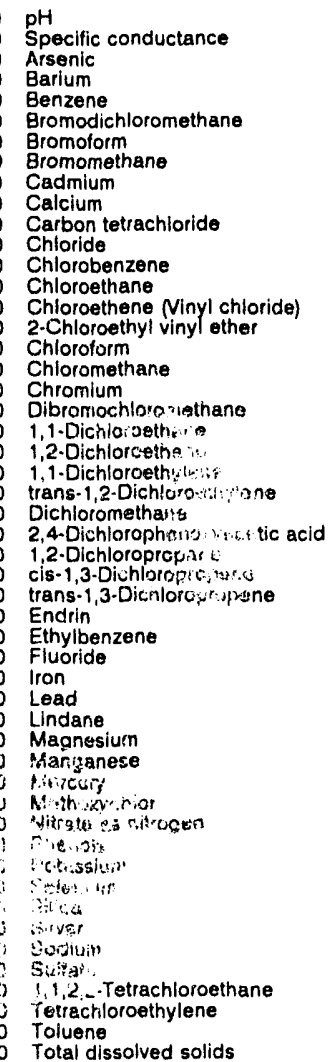 & $\begin{aligned} & 4.8 \\
& 10 \\
&<2.0 \\
&<3.0 \\
&<1.0 \\
&<1.0 \\
&<1.0 \\
&<1.0 \\
&<2.0 \\
&<10 \\
&<1.0 \\
&<250 \\
&<1.0 \\
&<1.0 \\
&<1.0 \\
&<1.0 \\
&<1.0 \\
&<1.0 \\
&<4.0 \\
&<1.0 \\
&<1.0 \\
&<1.0 \\
&<1.0 \\
&<1.0 \\
& 6.4 \\
&<0.30 \\
&<1.0 \\
&<1.0 \\
&<1.0 \\
&<0.0060 \\
&<1.0 \\
&<100 \\
&<4.0 \\
&<3.0 \\
&<0.0050 \\
&<2.0 \\
&<2.0 \\
&<0.20 \\
&<0.50 \\
&<50 \\
&<5.0 \\
&<500 \\
&<2.0 \\
& 9120 \\
&<2.0 \\
&>13 \\
&<1.000 \\
&<1.0 \\
&<1.0 \\
&<1.0 \\
& 6.000\end{aligned}$ & $\begin{array}{l}\text { J2V } \\
\text { JQ }\end{array}$ & 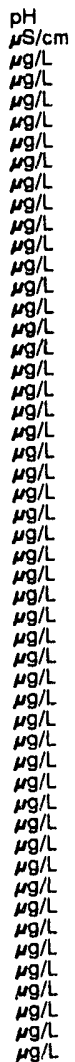 \\
\hline
\end{tabular}

Time: 7:40

pH. $4.6: 40.0 \mathrm{mg}$

Alkalinity: $0 \mathrm{mg} / \mathrm{L}$ : $212^{\circ} \mathrm{C}$
Sp. conductanco: $10 \mu \mathrm{s} / \mathrm{cm}$

\begin{tabular}{|c|c|c|c|}
\hline Analyte & Result & Mod & Unit \\
\hline $\begin{array}{l}\text { Total phosphates (as P) } \\
\text { Toxaphene } \\
2,4,5-T P \text { (Silvex) } \\
1,1,1-\text { Trichloroethane } \\
\text { 1,1,1-Trichloroethane } \\
\text { 1,1,2-Trichloroothane } \\
\text { Trichloroethylene } \\
\text { Trichioroethylene } \\
\text { Trichlorofluoromethane } \\
\text { Uranlum } \\
\text { Uranium } \\
\text { Vanadium } \\
\text { Zinc } \\
\text { Antimony-125 } \\
\text { Cerium-144 } \\
\text { Cesium-134 } \\
\text { Cesium-137 } \\
\text { Cobalt-57 } \\
\text { Cobalt-60 } \\
\text { Europlum-154 } \\
\text { Gross alpha } \\
\text { Manganese-54 } \\
\text { Nonvolatile beta } \\
\text { Potassium-40 } \\
\text { Radium-226 } \\
\text { Ruthenium-103 } \\
\text { Sodium-22 } \\
\text { Strontium-89 } \\
\text { Strontium-90 } \\
\text { Thorium-228 } \\
\text { Total radium } \\
\text { Tritium } \\
\text { Tritium } \\
\text { Zinc-65 }\end{array}$ & $\begin{array}{l}<50 \\
<0.24 \\
<0.090 \\
<1.0 \\
<1.0 \\
<1.0 \\
<1.0 \\
<1.0 \\
<1.0 \\
<20 \\
<20 \\
<8.0 \\
<2.0 \\
<7.2 \mathrm{E} \cdot 09 \\
<2.4 \mathrm{E} \cdot 08 \\
<4.1 \mathrm{E}-09 \\
<3.0 \mathrm{E}-08 \\
<3.3 \mathrm{E}-09 \\
<2.9 \mathrm{E}-09 \\
<1.2 \mathrm{E}-08 \\
<2.0 \mathrm{E} \cdot 09 \\
<4.2 \mathrm{E}-09 \\
<2.0 \mathrm{E}-09 \\
<4.6 \mathrm{E}-08 \\
<5.2 \mathrm{E} \cdot 09 \\
<2.2 \mathrm{E} \cdot 08 \\
<4.6 \mathrm{E} \cdot 09 \\
<2.0 \mathrm{E} \cdot 09 \\
<4.0 \mathrm{E} \cdot 10 \\
<3.4 \mathrm{E} \cdot 09 \\
1.0 \mathrm{E} \cdot 09 \pm 1.5 \mathrm{E} \cdot 09 \\
<7.0 \mathrm{E} \cdot 07 \\
<7.0 \mathrm{E} \cdot 07 \\
<1.0 \mathrm{E}-08\end{array}$ & JQ & 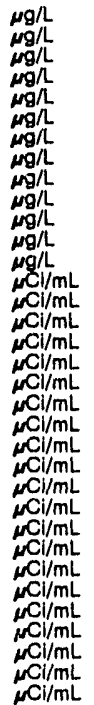 \\
\hline
\end{tabular}

(10/21/81, laboratory analysos (cont)

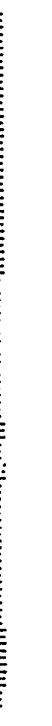




\section{QUALITY CONTROL SAMPLES}

WELL BLANK collected on 10/22/81, labotatory analyses (cont.)

\begin{tabular}{|c|c|c|c|}
\hline Analyte & Result & Mod & Unit \\
\hline $\begin{array}{l}\text { Total organic carbon } \\
\text { Total organic halogens } \\
\text { Total organic halogens } \\
\text { Total phosphates as P) } \\
\text { Total phosphates as P) } \\
\text { Toxaphene } \\
2,4,5-T P \text { (Sllvex) } \\
1,1,1-\text { Trichloroethane } \\
1,1,2 \text {-Trichloroethane } \\
\text { Trichloroethylene } \\
\text { Trichlorofluoromethane } \\
\text { Gross alpha } \\
\text { Nonvolatile beta } \\
\text { Total radium } \\
\text { Tritium }\end{array}$ & $\begin{array}{l}<1.000 \\
<5.0 \\
<5.0 \\
<50 \\
<50 \\
<0.24 \\
<0.090 \\
<1.0 \\
<1.0 \\
<1.0 \\
<1.0 \\
<2.0 \mathrm{E} \cdot 09 \\
<2.0 \mathrm{E} \cdot 09 \\
2.5 \mathrm{E}-09 \pm 1.0 \mathrm{E} \cdot 09 \\
<7.0 \mathrm{E} \cdot 07\end{array}$ & JQ & $\begin{array}{l}\mu g / L \\
\mu g / L \\
\mu g / L \\
\mu g / L \\
\mu g / L \\
\mu g / L \\
\mu g / L \\
\mu g / L \\
\mu g / L \\
\mu g / L \\
\mu g / L \\
\mu C i / m L \\
\mu C i / m L \\
\mu C l / m L \\
\mu C l / m L\end{array}$ \\
\hline
\end{tabular}

WELL BLANK

MEASUREMENTS CONDUCTED IN THE FIELD

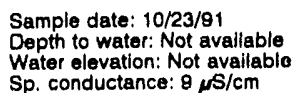

Time: $8: 20$

Alkalinity: $0 \mathrm{mg} / \mathrm{L}$

Water temperature: $22.5^{\circ} \mathrm{C}$

LABORATORY ANALYSES

\begin{tabular}{|c|c|c|c|}
\hline Analyte & Result & Mod & Unit \\
\hline $\begin{array}{l}\text { Aluminum } \\
\text { Carbon tetrachloride } \\
\text { Chloroform } \\
\text { Chromium } \\
\text { Copper } \\
\text { Lead } \\
\text { Tetrachloroethylene } \\
\text { 1,1,1-Trichloroethane } \\
\text { Trichioroethylene } \\
\text { Tritium }\end{array}$ & $\begin{array}{l}<20 \\
<1.0 \\
1.3 \\
<4.0 \\
<4.0 \\
<3.0 \\
<1.0 \\
<1.0 \\
<1.0 \\
<7.0 \mathrm{E}-07\end{array}$ & J1 & $\begin{array}{l}\mu g / L \\
\mu g / L \\
\mu g / L \\
\mu g / L \\
\mu g / L \\
\mu g / L \\
\mu g / L \\
\mu g / L \\
\mu g / L \\
\mu C l / m L\end{array}$ \\
\hline
\end{tabular}

WELL BLANK

MEASUREMENTS COIVDUCTED IN THE FIELD

Sample date: $10 / 25 / 91$

Depth to water: Not available

Water elevation: Not availa
Sp. conductance: $9 \mu \mathrm{s} / \mathrm{cm}$

Time: $7: 40$

Alkalinity: $0 \mathrm{mg} / \mathrm{h}$

Water temperature: $23.3^{\circ} \mathrm{C}$

LABORATORY ANALYSES

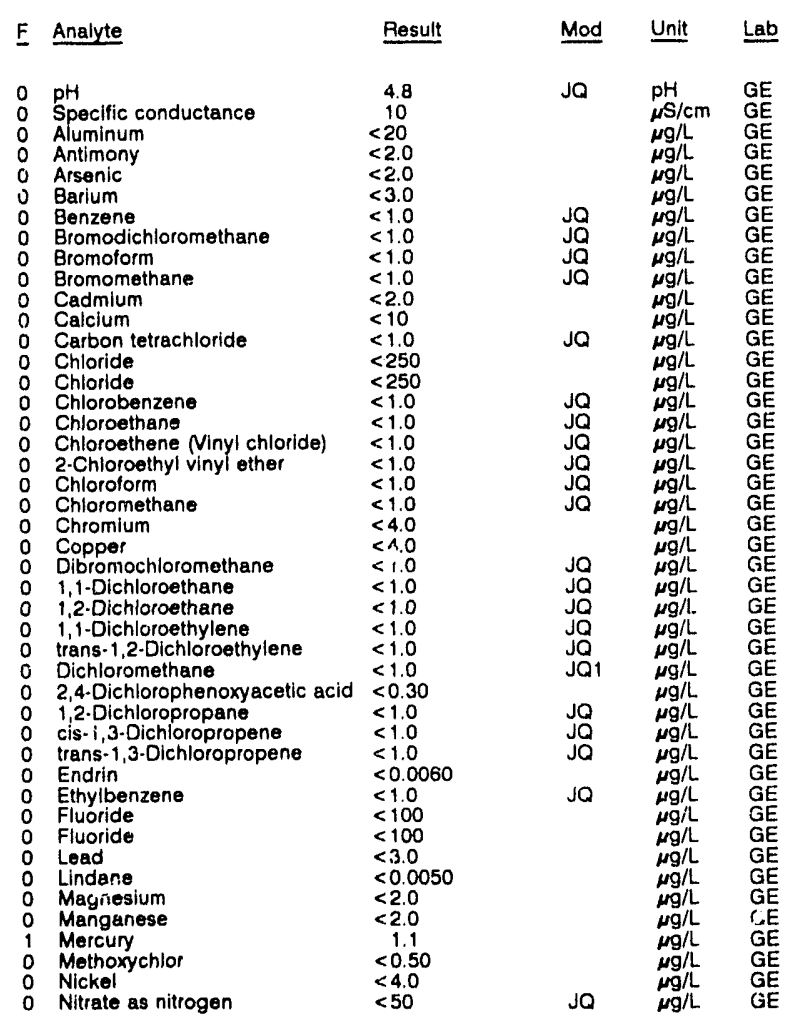

WELL BLANK collected on 10/25/91, laboratory analyses (cont.)

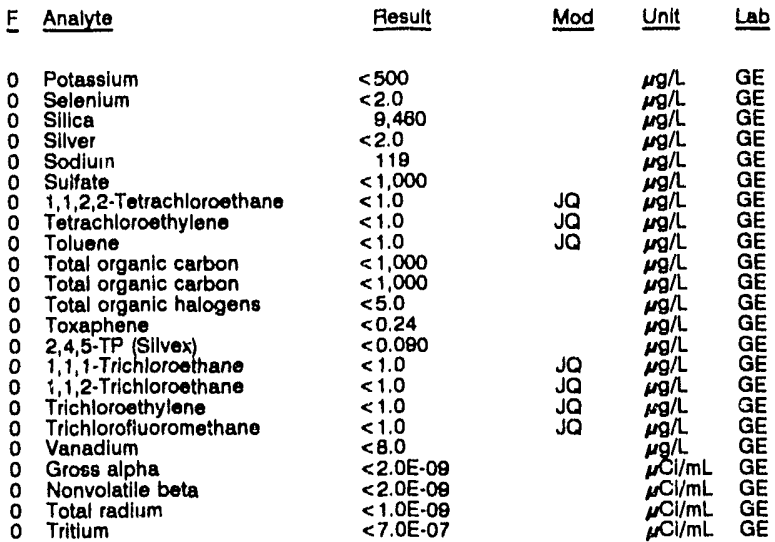

\section{WELL BLANK}

MEASUREMENTS CONDUCTED IN THE FIELD

Sample date: 10/28/81

Depth to water: Not available

Sp. conductance: $8 \mu \mathrm{S} / \mathrm{cm}$

LABORATORY ANALYSES

E Analyte Result Mod Unit Lab

$\stackrel{\mathrm{pH}}{0} \mathrm{pH}$

0 phecific conductance

Specific conductance

0 Arsenic

0 Arsenic

0 Barium

0 Barium

o Benzene

O Bromodichlor

0 Bromomethane

Cadmium

Cadmilum

0 Calcium

Carbon tetrachloride

Carbon tetrachloride

Chloride

Chlorobenzen

Chloroethane

Chioroethene (Vinyl chloride)

2-Chloroethyl vinyl ether

Chloroform

Chlorotorm

Chromium

Dibromochloromethane

1,1-Dichloroethane

1,2-Dichloroethane

trans. 1,2 -Dichloroethylene

Dichloromethane

$\operatorname{Time:~}_{\mathrm{pH}: 4.7}$

Alkalinity: $0 \mathrm{mg} / \mathrm{L}$

Water temperature: $21.3^{\circ} \mathrm{C}$

1,2-Dichloropropan

cis-1,3-Dichloropropene

trans-1,

Endrin

Ethylbenzene

Fluoride

Iron

0 Lean

Lead

Lindane

Magnesium

Magnesium

Manganese

Mercury

Mercury

Methoxychlor

Nitrate as nitrogen

Nitrate as nitrogen

Phenols
Phenols

4.9
4.9
410
10
$<2.0$
$<2.0$
$<3.0$
$<3.0$
$<1.0$
$<1.0$
$<1.0$
$<1.0$
$<2.0$
$<2.0$
$<10$
$<10$
$<1.0$
$<1.0$
$<250$
$<250$
$<1.0$
$<1.0$
$<1.0$
$<1.0$
$<1.0$
11.2
$<1.0$
$<4.0$
$<4.0$
$<1.0$
$<1.0$
$<1.0$
$<1.0$
$<1.0$
$<1.0$
$<0.30$
$<1.0$
$<1.0$
$<1.0$
$<0.0060$
$<0.0060$
$<1.0$
$<100$
$<100$
$<4.0$
$<4.0$
$<3.0$
$<3.0$
$<0.0050$
$<0.0050$
$<2.0$
$<2.0$
$<2.0$
$<2.0$
$<0.20$
0.35
$<0.50$
$<0.50$
$<50$
$<50$
$<5.0$
$<5.0$
$<1.0$

JO $\quad \mathrm{pH} \quad \mathrm{GE}$

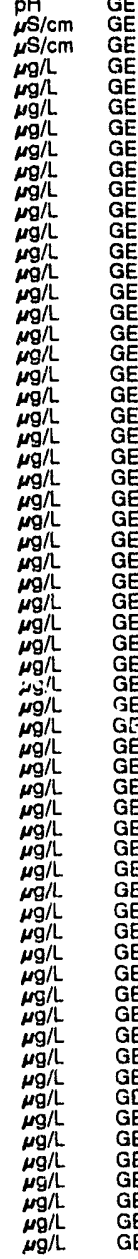


QUALITY CONTROL SAMPLES

WELL. BLANK collected on 10/28/91, laboratory analyses (cont.)

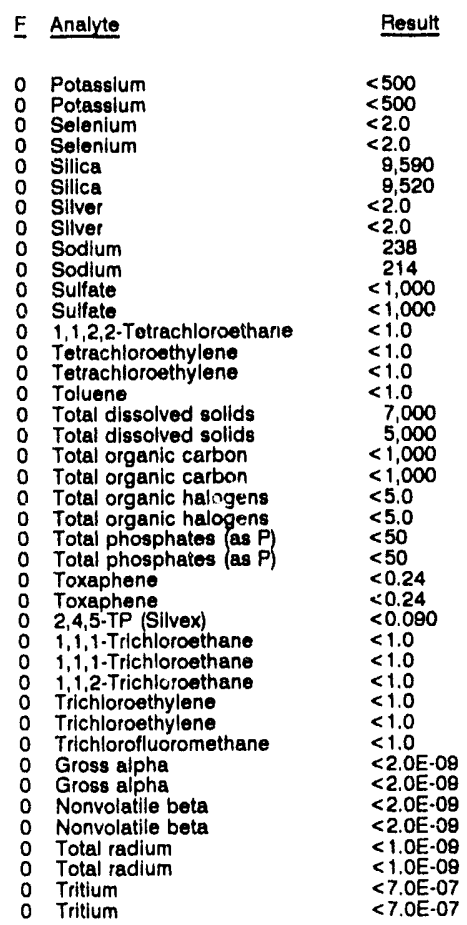

\section{WELL BLANK}

MEASUREMENTS CONDUCTED IN THE FIELD

Sample date: 10/29/91

Depth to water: Not avallable

$\mathrm{Sp}$. conductance: $\mathbf{9} \boldsymbol{\mu \mathrm { s } / \mathrm { cm }}$

LABORATORY ANALYYSES

F Analyte Result Mod Unit Lab

$0 \mathrm{pH}$

Specific conductance

0 Arsenic

Arsenic
Barlum

Benzene

Bromodich

Bromomethane

Cadmium

Calcium

Carbon

Chlorobenzene

Chloroethane

2-Chloroethyl vinyl ether

Chlorolorm

Chloromethane

D Chromium

o 1,1-Dichloroethane

o 1,2-Dichloroethane

1,1-Dichloroethylene

o trans-1,2-Dichloroethylene $<1$.

2,4-Dichlorophenaxyacetic asid $<0.30$

1,2-Dichloropropane

0 trans-1,3-Dichloropropene

0 Endrin

0 Endrin

0 Fluoride

0 Iron

0 Lead

0 Lindane

O Lindane

Manganese

0 Mercury

Methoxychlor
Methoxychlor

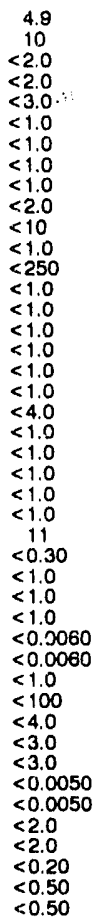

WELL BLANK collected on 10/\%9/91, laboratory analyees (cont.)

\begin{tabular}{|c|c|c|c|}
\hline Analyte & Result & Mod & Unit \\
\hline 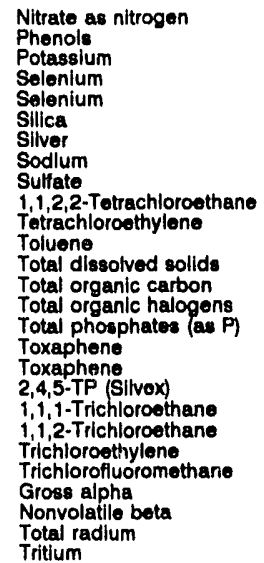 & $\begin{array}{l}<50 \\
<5.0 \\
<500 \\
<2.0 \\
<2.0 \\
99,870 \\
<2.0 \\
440 \\
<1,000 \\
<1.0 \\
<1.0 \\
<1.0 \\
5,000 \\
<1.000 \\
<5.0 \\
<50 \\
<0.24 \\
<0.24 \\
<0.090 \\
<1.0 \\
<1.0 \\
<1.0 \\
<1.0 \\
3.7 \mathrm{E} \cdot 09 \pm 5.7 \mathrm{E}-00 \\
<2.0 \mathrm{E} \cdot 00 \\
<1.0 \mathrm{E} \cdot 09 \\
<7.0 \mathrm{E} \cdot 07\end{array}$ & JOV & 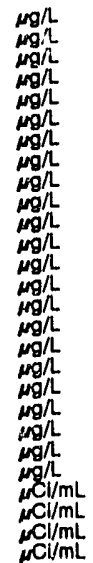 \\
\hline
\end{tabular}

WELL BLANK

MEASUREMENTS CONDUCTED IN THE FIELD

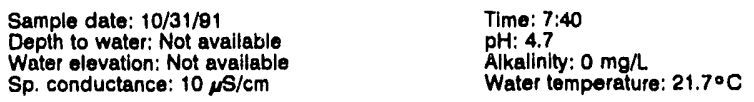

LABORATORY ANALYSES

F Analyte Result

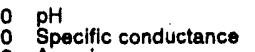

Arsenic

0 Barlum

B Benzene

0 Bromodichloromethane

Bromoform

Bromomethane

Cadmium

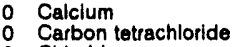

O Chloride

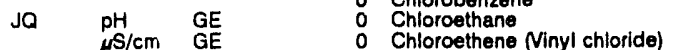

Chloroethene Ninyl chloride)
2-Chloroethyl vinyl ether

Chloroform

Chromium

O Chromium

D Dibromochloromethane

1,1-Dichloroethane

o 1,2-Dichloroethane

0 1,1-Dichloroethylene

trans-1,2-Dichlorooth

0
0
0

$\begin{array}{ll}0 & 1,2-\text {-Dichloropropane } \\ 0 & \text { cis-1,3-Dichloropropene }\end{array}$

trans-1,3-Dichloropropene

Ethylbenzene

0 lion

0 Iron

O Magnesium

Mercury

Nitrate 8.8 nittogen

Phenols

Potassium

Selenium

Silica

Sod'uin

Sulfate

Sulfate -Tetrachloroethane

Tetrachloroethylene

Toluen

Total dissolved solids

Total organic carton

Total organic halogens

Total phosphates (as P

1,1,2-Trichloroethan

Trichloroethylene
Trichlorofluoromethane

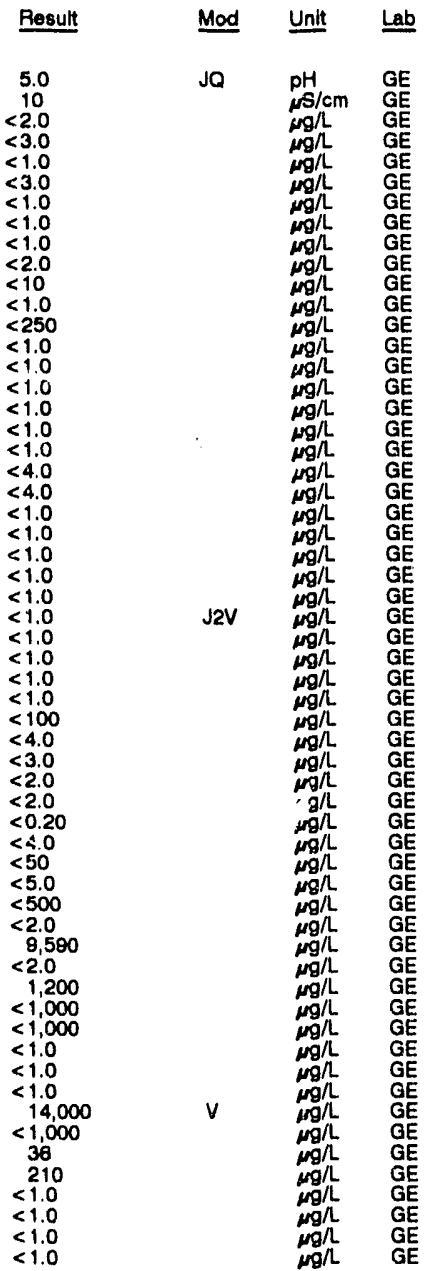




\section{QUALITY CONTROL SAMPLES}

WELL BLANK collected on 10/31/91, laboratory analyses (cont.)

\begin{tabular}{|c|c|c|c|}
\hline Analyte & Result & Mod & Unit \\
\hline $\begin{array}{l}\text { Zinc } \\
\text { Antimony-125 } \\
\text { Cerium-144 } \\
\text { Cesium-134 } \\
\text { Cesium-137 } \\
\text { Cobalt-57 } \\
\text { Cobalt-60 } \\
\text { Europium-154 } \\
\text { Gross alpha } \\
\text { Manganese-54 } \\
\text { Nonvolatile bota } \\
\text { Pottassium-40 } \\
\text { Radium-226 } \\
\text { Ruthenium-103 } \\
\text { Sodium-22 } \\
\text { Thotium-228 } \\
\text { Total radium } \\
\text { Tritium } \\
\text { Uranium-233/234 } \\
\text { Uranium-238 } \\
\text { Zinc-65 }\end{array}$ & $\begin{array}{l}<2.0 \\
<9.4 \mathrm{E}-09 \\
<3.6 \mathrm{E} \cdot 08 \\
<3.7 \mathrm{E} \cdot 09 \\
<3.4 \mathrm{E} \cdot 09 \\
<4.6 \mathrm{E} \cdot 09 \\
<3.7 \mathrm{E} \cdot 09 \\
<9.4 \mathrm{E}-09 \\
<2.0 \mathrm{E} \cdot 09 \\
<3.6 \mathrm{E}-08 \\
<2.0 \mathrm{E}-09 \\
<3.7 \mathrm{E}-08 \\
<6.4 \mathrm{E} \cdot 09 \\
<2.2 \mathrm{E}-08 \\
<3.5 \mathrm{E}-09 \\
<4.0 \mathrm{E} \cdot 09 \\
<1.0 \mathrm{E}-09 \\
<7.0 \mathrm{E} \cdot 07 \\
<1.0 \mathrm{CE} \cdot 10 \\
<1.0 \mathrm{E} \cdot 10 \\
<9.8 \mathrm{E} \cdot 09\end{array}$ & & $\begin{array}{l}\mu \mathrm{g} / \mathrm{L} \\
\mu \mathrm{Ci} / \mathrm{mL} \\
\mu \mathrm{Ci} / \mathrm{mL} \\
\mu \mathrm{Ci} / \mathrm{mL} \\
\mu \mathrm{Ci} / \mathrm{mL} \\
\mu \mathrm{Ci} / \mathrm{mL} \\
\mu \mathrm{Ci} / \mathrm{mL} \\
\mu \mathrm{Cl} / \mathrm{mL} \\
\mu \mathrm{Ci} / \mathrm{mL} \\
\mu \mathrm{Ci} / \mathrm{mL} \\
\mu \mathrm{Ci} / \mathrm{mL} \\
\mu \mathrm{Ci} / \mathrm{mL} \\
\mu \mathrm{Cl} / \mathrm{mL} \\
\mu \mathrm{Ci} / \mathrm{mL} \\
\mu \mathrm{Ci} / \mathrm{mL} \\
\mu \mathrm{Ci} / \mathrm{mL} \\
\mu \mathrm{Ci} / \mathrm{mL} \\
\mu \mathrm{Ci} / \mathrm{mL} \\
\mu \mathrm{Ci} / \mathrm{mL} \\
\mu \mathrm{Ci} / \mathrm{mL} \\
\mu \mathrm{Ci} / \mathrm{mL}\end{array}$ \\
\hline
\end{tabular}

WELL BLANK

MEASUREMENTS CONDUCTED IN THE FIELD

Sample date: 11/01/91

Depth to water: Not available

Water olevalion. Not available

$\mathrm{Sp}$. conductance: $9 \mu \mathrm{S} / \mathrm{cm}$

LABORATORY ANALYSES

F Allalyte

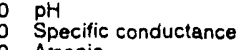

0 Arsenic

0 Barium

Cadmium
Calcium

Carbon tetrachloride

Chloride

Chloroform

Chromium

Fluoride

Iron

Magnesium

Manganese

Mercury

Nitrate as nitrogen

Nitrate as nitrogen

Potassium

Selenium

Silica

Sodium

Sodium

Sulfate

Tetrachloroethylene

Total dissolved solids

Total organic carbon

Total organic halogens

Total phosphates (as P)

$1,1,1$. Trichloroethan

Trichlorichoethane

- Gross alpha

Nonvolatile beta

Tritium

WELL BLANK

MEASUREMENTS CONDUCTED IN THE FIELD

Sample date: $11 / 0.4 / 01$

Depth to water: Not available

Water elevation: Not available

Sp. conductance: $10 \mu \mathrm{S} / \mathrm{cm}$

LABORATORY ANALYSES

\begin{tabular}{|c|c|c|c|}
\hline Analyte & Result & Mod & Unit \\
\hline $\begin{array}{l}\text { pH } \\
\text { Specific conductance } \\
\text { Arsenic } \\
\text { Barium } \\
\text { Cadmium } \\
\text { Calcium } \\
\text { :rrbon tetrachloride } \\
\text { C.nloride }\end{array}$ & $\begin{array}{r}5.2 \\
4.0 \\
<20 \\
<3.0 \\
<20 \\
<10 \\
<1.0 \\
300\end{array}$ & Jo & $\begin{array}{l}p r d \\
\mu \mathrm{S} / \mathrm{cli} \\
\mu g / L \\
\mu g / L \\
\mu g / L \\
\mu g / L \\
\mu g / L \\
\mu g / L\end{array}$ \\
\hline
\end{tabular}

Time: $4: 40$

Alkalinity: $0 \mathrm{mg}$

Water temperature: $20.9^{\circ} \mathrm{C}$
WELL BLANK collected on 11/04/81, laboratory analyses (cont.)
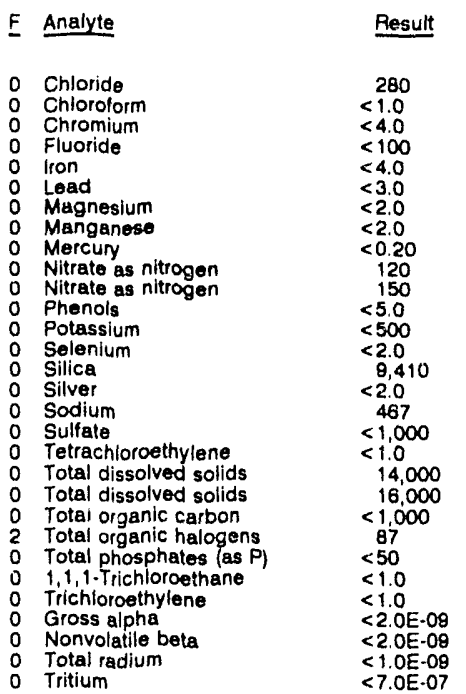

Mod Unit Lab

WELL BLANK

MEASUREMENTS CONDUCTED IN THE FIELD

Sample date: $11 / 06 / 91$

Depth to water: Not available

Sp. conduciance: 8 S $/ \mathrm{cm}$

LABORATORY ANALYSES

Time: $\theta: 15$

Alkalinity: $1 \mathrm{mg} / \mathrm{L}$

Water temperature: $176^{\circ} \mathrm{C}$

Pesult

pH

Acenaphthene
Acenaphthylene

Acenaph

o Aluminum

Anthracene

Arsenic

Arsenic

Barium

Barium

alpha-Benzene hexachlorid

beta-Benzeno hexachloride

delta

Benzidine

Benzo[a]anthracene

Benzolalpyrene

Benzo b) fluoranthene

Benzo $[g, h, i] p e r y$ !ene

Bis (2.chloroethoxy) methane

Bis (2.chloroethyl) ether

Bis (2-chloroisopropyl) ether
Bis(2-ethylhexyl) pinthalate

Bromide

Bromide

Bromodich

Bromolorm

4-Bromophenyl phenyl ether

Butylbenzyl phthalate

Cadmium

Cadmium

Carbon tetrachloride

Carbon tetrachloride

Chlordan

para-Chioro-meta-creso

Chlorobenzene

Chioroethene Ninyl chloride)

2. Chloroethyl vinyl ether
2hide

2.Chloroeth

Chloroform

Chloromethane

2-Chloronaphthalene

4-Chiorophenyl phenyl ether

Chromium

Chrysene

$5.3 \quad$ JQ

JQ $\quad \mathrm{PH} \quad \mathrm{GE}$

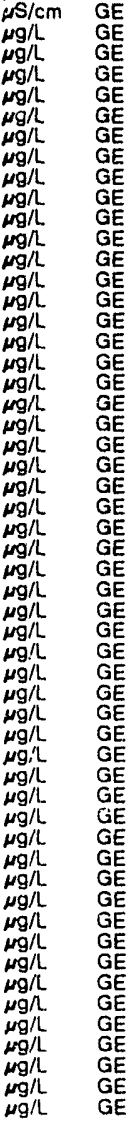




\section{QUALITY CONTROL SAMPLES}

WELL BLANK collected on 11/06/91, laboratory analyses (cont.)

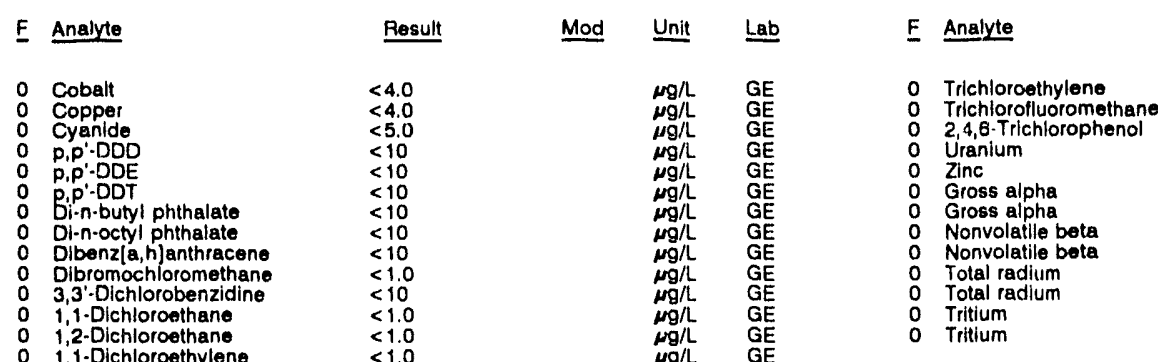

J2V

trans-1,2-Dichloroethylene

Dichloromethane

2,4-Dichlorophenol

cls-1,3-Oichloropropene

0 trans-1,3-D

Dieldrin

2,4-Dimethyl phenol

2,4-Dinitrophenol

2,4-Dinitrotoluene

1,2-Diphenylhydrazin

1,2-Diphenyl

Endosulifan II

Endosult

Endrin aldehyde

Ethylbenzene

Fiuoranthene

Fluoride

Heptachlor

Hexachiorobenzene

Hexachlorobutadiene

Hexachiorocyclopente

indeno $[1,2,3 \cdot c, d]$ pyrene

Iron

Iron

Lead

0 Lindane

Magnesium

Mercury

Methoxychlor

2-Methyl-4,6-dinitrophenol

N-Nitrosodimethylamine

N-Nitrosodiphenylamine
N-Nitrosodi-propylamine

Naphthalene

Nitrate as nitrogen

2-Nitropheno

PCB 1018

PCB 1232

PCB 1242

PCB 1248

Pentachlorophenol

Pentachlorophe

Phenol

Phenols

Potassium

Potassium

Syrene

Selenium

Sillica

$\begin{array}{ll}0 & \text { Silver } \\ 0 & \text { Silver }\end{array}$

Sodium

Sulfate

$1,1,2,2$. Tetrachloroethe

Tetrachloroethylene

0 Thallium

Toluene

Total organic carbon

1 Total organic halogens

o Total phosph

o 1,2,4-Ti: =hlorobenzene

o 1,1,1-Trichloroethane

0 i. 1,1-Trichloroethane

$1,1,2$-Trichloroetha
0 Trichloroethylene

Total dissolved solids

\section{WELL BLANK}

MEASUREMENTS CONDUCTED IN THE FIELD

Sample date: 11/07/81

Depth to water: Not available

Wp conductanco: $\theta$ a

LABORATORY ANALYSES

F Analyte

$\begin{array}{ll}\mathrm{pH} \\ 0 & \text { Specific conductance }\end{array}$

A Arsenic

Barium

B Bromodichloromethane

Bromoform

0 Cadmium

o Cadmium

0 Carbon tetiachloride

0 Chloride

o Chlorobenzene

Chloroethane

2.Chloroethyl vinyl ethes

Chloroform

o Chloromethane

Chromium

o Copper

1,1-Dichloroethane

1,1-Dichloroethane

o 1,1-Dichloroethylene

1,1-Dichloroethylene
0 trans-1,2-Dichloroethylene

Dichloromethane

2,4-Dichlorophenoxy

1,2-Dichloropropane
cls-1,3-Dichloropropene

trans-1,3-Dichloropropene

0 Endrin

Ethylbenzene

0 Iron

- Lead

- Lindane

Magnesium

Mangane

Mercury

Nitrate as nitrogen

Phenols

Potasslum

Silica

Silver

Sodium

Sulfate

Tetrachloroethylene

Total organic carbon

Total organic halogens

Total phos

2,4,5-TP (Silvex)

$1,1,1$-Trichioroethane

1,1,2-Trichloroethan

Trichlorofluoromethnne

Gross alpha

Nonvolatile beta

Total radium
Result

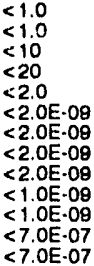

$\mu g / L \quad G E$

$<10$

$2.0 \mathrm{E} \cdot 0 \mathrm{O}$

$<2.0 \mathrm{E} \cdot 08$

$<1.0 \mathrm{E} \cdot 00$

$<7.0 E \cdot 07$
$<7.0 E \cdot 07$
Lat

$\mathrm{GE}$
$\mathrm{GE}$
$\mathrm{GE}$
$\mathrm{GE}$
$\mathrm{GE}$
$\mathrm{GE}$
$\mathrm{GE}$
$\mathrm{GE}$
$\mathrm{GE}$
$\mathrm{GE}$
$\mathrm{GE}$
$\mathrm{GE}$
$\mathrm{GE}$
Time: $4: 25$

Alkalinity: $0 \mathrm{mgh}$

Water tomperature: $17.9^{\circ} \mathrm{C}$

Result Mod Unit Lab

5.2

$<2.0$

$<1.0$

$<1.0$

$<1.0$

$<10$

$<250$

$<1.0$

$<1.0$

$<1.0$

$<1.0$

$<4.0$

$<1.0$

$<1.0$

$<1.0$

$<0.30$

$<1.0$
$<1.0$

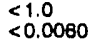

$<1.0$

$<100$

$<4.0$

$<2.005$

$<2.0$

$<0.20$

$<50$

$<5.0$

$<500$

8,510
$<2,0$

652

$<1,000$

$<1.0$

$<1.0$
$<1.0$

15,000

$<5.0$

$<5.0$

$<024$

$<1.0$

$<1.0$

$<1.0$

$<1.0$
$<2.0 \mathrm{E}-09$
$<2.0 \mathrm{E}-09$

$<2.0 E-09$
$<1.0 \mathrm{E}-09$

$<1.0 \mathrm{E}-09$
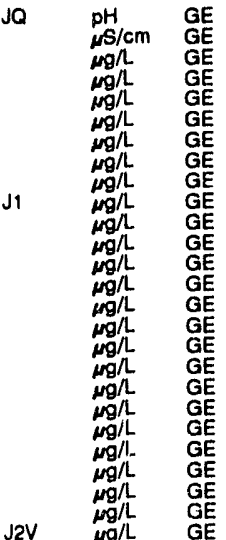
QUALITY CONTROL SAMPLES

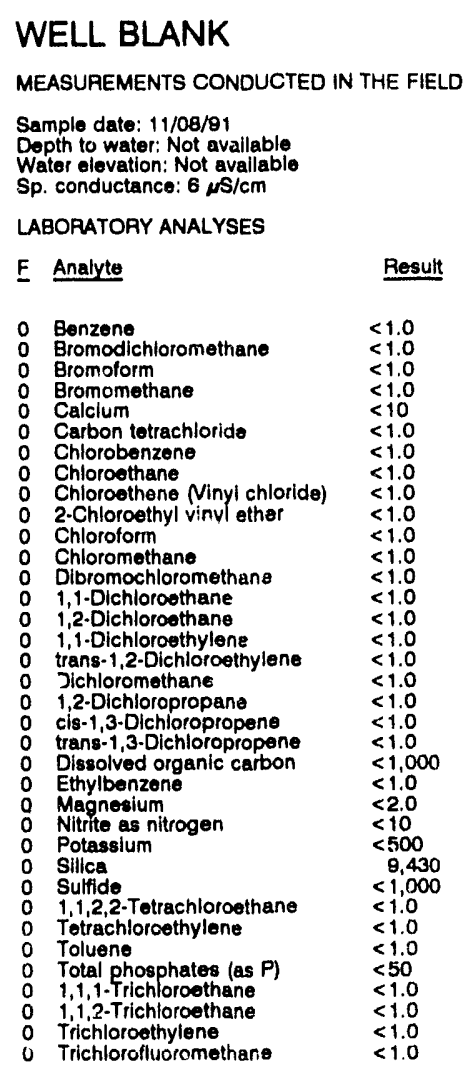

\section{WELL BLANK}

MEASUREMENTS CONDUCTED IN THE FIELD

Sample dats. $11 / 11 / 91$
Dopth to water: Not avallablo Water elevation: Not availablo

LABORATORY ANALYSES

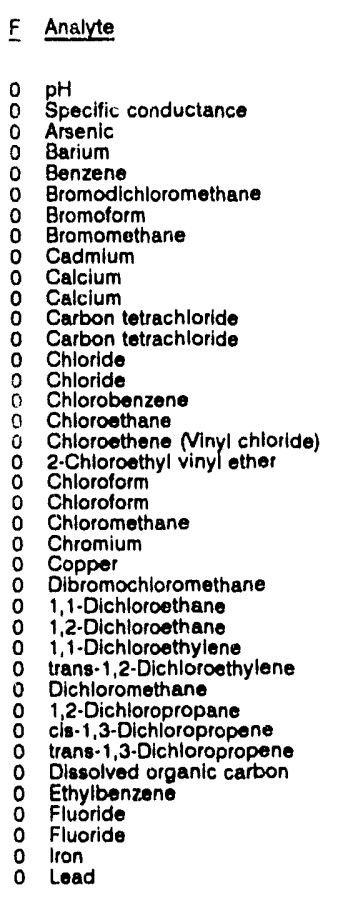

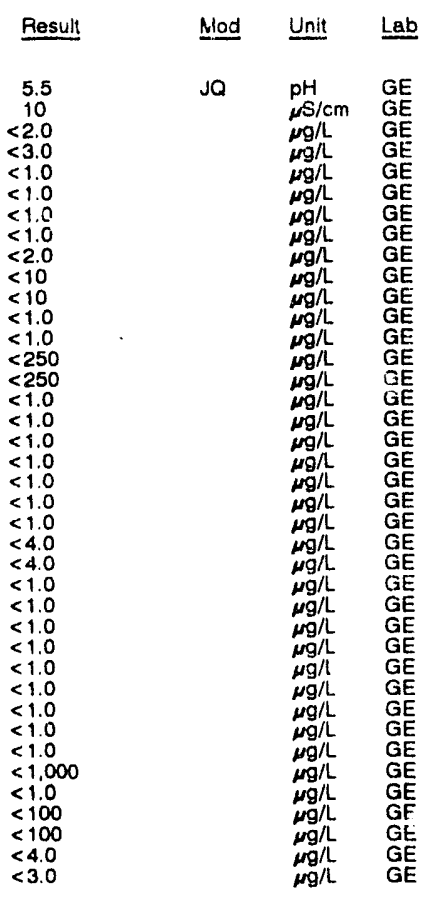

WELL. BLANK collected on 11/11/81, laboratory analyses (cont.)

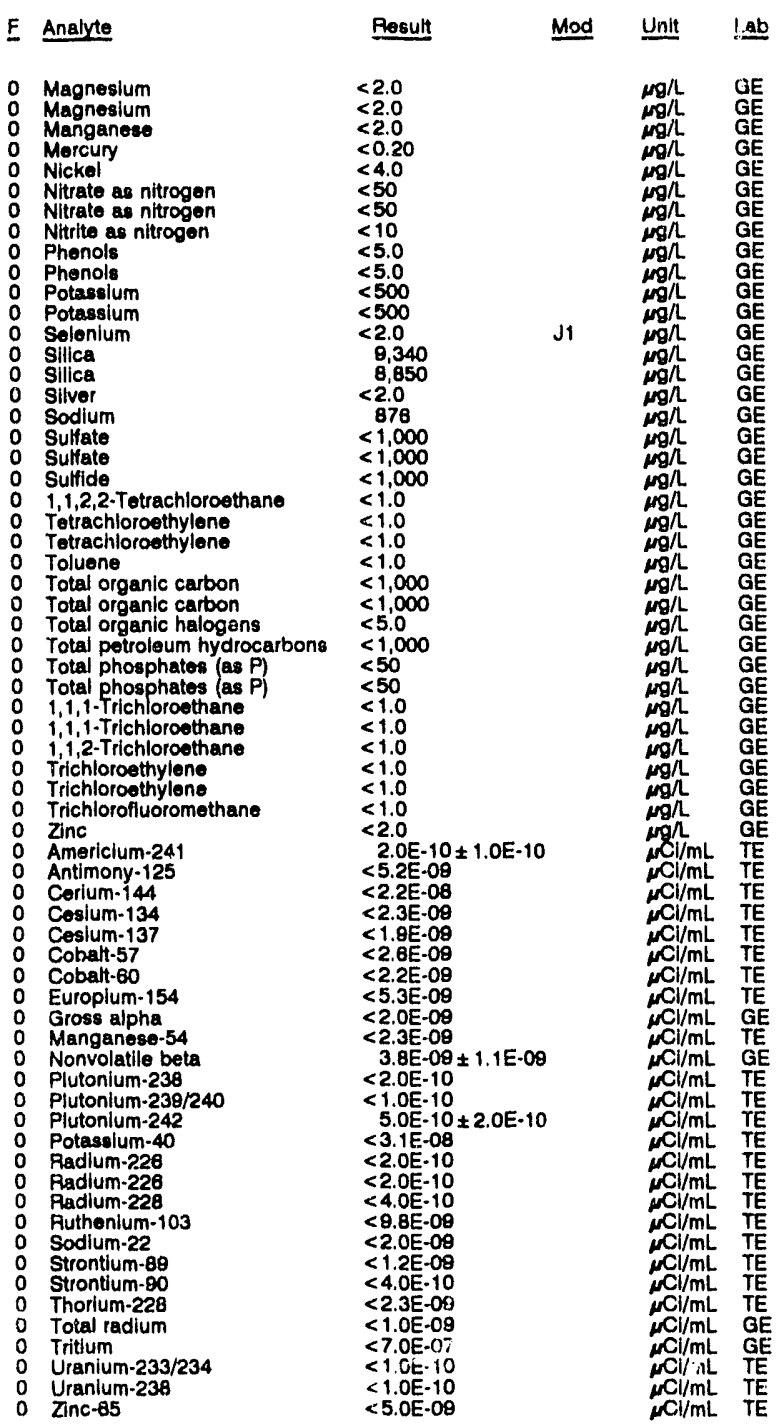

\section{WELL BLANK}

MEASUREMENTS CONDUCTED IN THE FIELD

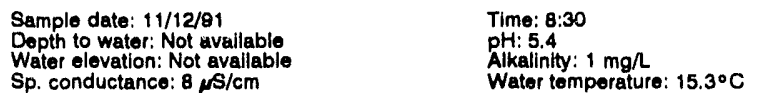

\section{LABORATORY ANALYSES}

Water temperature: $15.3^{\circ} \mathrm{C}$

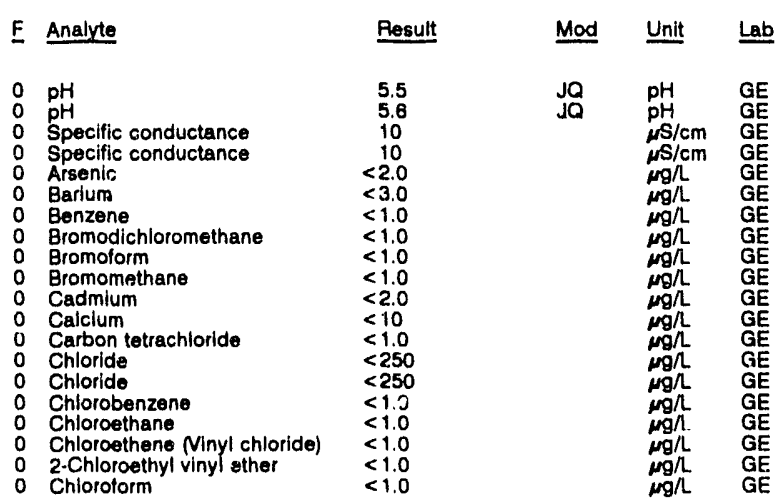


QUALITY CONTROL SAMPLES

WELL BLANK collected on 11/12/81, laboratory analyses (cont.)

\begin{tabular}{|c|c|c|c|c|c|}
\hline E & Analyte & Result & Mod & Unit & Lab \\
\hline 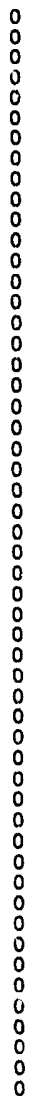 & 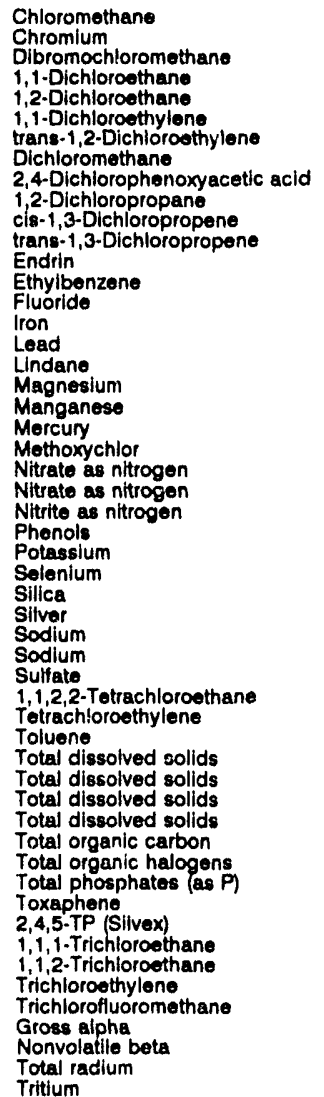 & $\begin{array}{l}<1.0 \\
<4.0 \\
<1.0 \\
<1.0 \\
<1.0 \\
<1.0 \\
<1.0 \\
<1.0 \\
<0.30 \\
<1.0 \\
<1.0 \\
<1.0 \\
<0.0060 \\
<1.0 \\
<100 \\
<4.0 \\
<3.0 \\
<0.0050 \\
<2.0 \\
<2.0 \\
0.21 \\
<0.50 \\
<50 \\
230 \\
<100 \\
<5.0 \\
<500 \\
<2.0 \\
8.090 \\
<2.0 \\
1,100 \\
1.160 \\
<1.000 \\
<1.0 \\
<1.0 \\
<1.0 \\
13.000 \\
11.000 \\
12,000 \\
11.000 \\
<1.000 \\
7.6 \\
<50 \\
<0.24 \\
<0.090 \\
<1.0 \\
<1.0 \\
<1.0 \\
<1.0 \\
<2.0 E-09 \\
<2.0 E \cdot 09 \\
<1.0 E-09 \\
<7.0 E-07\end{array}$ & $\begin{array}{l}\text { JQ } \\
\text { J1 }\end{array}$ & 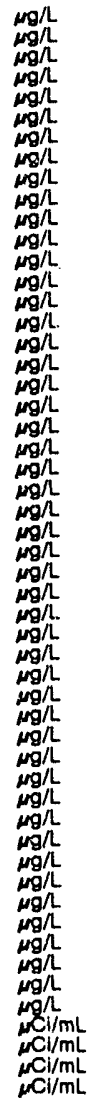 & $\begin{array}{l}\mathrm{GE} \\
\mathrm{GE} \\
\mathrm{GE} \\
\mathrm{GE} \\
\mathrm{GE} \\
\mathrm{GE} \\
\mathrm{GE} \\
\mathrm{GE} \\
\mathrm{GE} \\
\mathrm{GE} \\
\mathrm{GE} \\
\mathrm{GE} \\
\mathrm{GE} \\
\mathrm{GE} \\
\mathrm{GE} \\
\mathrm{GE} \\
\mathrm{GE} \\
\mathrm{GE} \\
\mathrm{GE} \\
\mathrm{GE} \\
\mathrm{GE} \\
\mathrm{GE} \\
\mathrm{GE} \\
\mathrm{GE} \\
\mathrm{GE} \\
\mathrm{GE} \\
\mathrm{GE} \\
\mathrm{GE} \\
\mathrm{GE} \\
\mathrm{GE} \\
\mathrm{GE} \\
\mathrm{GE} \\
\mathrm{GE} \\
\mathrm{GE} \\
\mathrm{GE} \\
\mathrm{GE} \\
\mathrm{GE} \\
\mathrm{GE} \\
\mathrm{GE} \\
\mathrm{GE} \\
\mathrm{GE} \\
\mathrm{GE} \\
\mathrm{GE} \\
\mathrm{GE} \\
\mathrm{GE} \\
\mathrm{GE} \\
\mathrm{GE} \\
\mathrm{GE} \\
\mathrm{GE} \\
\mathrm{GE} \\
\mathrm{GE} \\
\mathrm{GE} \\
\mathrm{GE}\end{array}$ \\
\hline
\end{tabular}

\section{WELL BLANK}

MEASUREMENTS CONDUCTED IN THE FIELD

Sample date: $11 / 13 / 91$
Depth to water: Not avallable
Water olevation: Not available

Water olovation: Not availabi

LABORATORY ANALYSES

\begin{tabular}{|c|c|c|c|}
\hline Analyte & Result & Mod & Unit \\
\hline 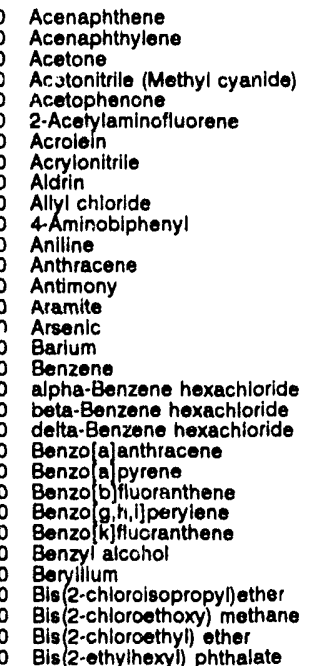 & $\begin{array}{l}<10 \\
<10 \\
<100 \\
<1.0 \\
<10 \\
<10 \\
<20 \\
<20 \\
<0.050 \\
<50 \\
<10 \\
<10 \\
<10 \\
<2.0 \\
<10 \\
<2.0 \\
<3.0 \\
<1.0 \\
<0.050 \\
<0.050 \\
<0.050 \\
<10 \\
<10 \\
<10 \\
<10 \\
<10 \\
<10 \\
<3.0 \\
<10 \\
<10 \\
<10 \\
<10\end{array}$ & & 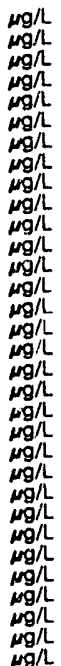 \\
\hline
\end{tabular}

Time: $4: 15$
WELL BLANK collocted on $11 / 13 / 81$, laboratory analyses (cont)

F Analyte Regult Mod Unit Lab

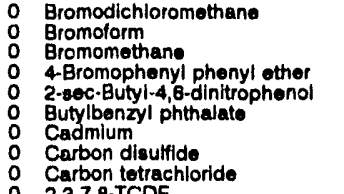

$<1.0$
$<1.0$
$<1.0$
$<10$
$<10$
$<10$
$<2.0$
$<1.0$
$<1.0$
$<0.00040$
$<0.50$

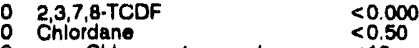

0 para-Chloro-meta-cresol $<10$

$\begin{array}{lll}0 & \text { 4-Chloroaniline } & <10 \\ 0 & \text { Chlorobenzene } & <1.0\end{array}$

Chlorobenzilate $<10$

o Chloroethane 1 Chloroethene Ninyl chloride) $<1.0$

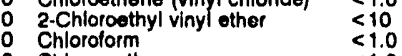

O Chloromethane $\quad<1$-Chloronaphthalene

$\begin{array}{lll}0 & 2 \text {-Chloronaphthalene } & <10 \\ 0 & \text { 2-Chlorophenol } & <10\end{array}$

0 4-Chlorophenyl phenyl ether $<10$

Chloroprene $<200$

O Chromium $<10$

O Cobalt

o Coppet (2-Methylphenol)

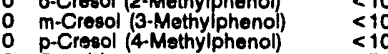

Cyanido

$\begin{array}{lll}0 & p, p^{\prime}-\mathrm{DDD} & <0.10 \\ 0 & \mathrm{p}, \mathrm{p}^{\prime}-\mathrm{DDE} & <0.10\end{array}$

0 p,p'DDT

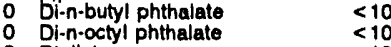

Diallate 10

$<10$

o 1,2-Dlbromo-3-chloropropane $<10$

o Dibromochloromethane $<1.0$

0 1,2-Dibromoethane $<20$

0 Dibromomethane $\quad<1.0$

0 trans-1,4-Dichloro-2-butene $<30$

o 1,3 Dichlorobenzene $\quad<10$

0 1,4-Dichlorobenzene $<10$

0 $3,3^{\prime}$-Dichlorobenzidine

Dichlorodif uoromethan

o 1,1-Dichloroethane

o 1,2-Dichlcroethane

trane-12-Dichlorosthylene

D Dichloromethane 5.8

0 2,4-Dichlorophenol

0 2,6-Dichlorophenol $<10$

0 2,4-Dichlorophenoxyacetic acid $<0.30$

1,2-Dichloropropane

Trans-1,3-Dichloroproper:

Deldrin

D $<10$

0 2,4-Dimethyl phenol $<10$

$<10$

o bimethylbenz[a]anthracene $<10$

0

0 a-Dimethylphenethylamine $<10$

0 1,3-Dinitrobenzene $<10$

2 2,4-Dinitrotoluene

2,6-Dinitrotoluen

Diphenylamin

Disulfoton

0 Endosulfan I

0 Endosulfan sulfate

0 Endosultar

O Endrin

O Endrin uldehyde

Ethyl methanesulfonate

Ethylbenzene

- Famphur

Fluoranthene

Fluorene

\begin{tabular}{ll}
$\quad<0.050$ \\
\hline Heptachlor epoxide & $<0.050$
\end{tabular}

$1,2,3,4,6,7,8-H P C D D \quad<0.00065$

Heptachlorodibenzo-p-dioxins $<0.00065$

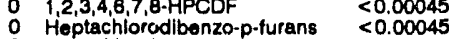

Heptachlorcdibenzo-p-furans $<10$

Hexachlorobutadiene $<10$

Hexachlorocyclopentadiene

Hexachlorodibenzo-p-dioxins

$<0.00045$

$<0.00045$ 
QUALITY CONTROL SAMPLES

WELL BLANK collected on 11/13/81, laboratory analyses (cont.)

E Analyte

o Hoxachlorodibenzo-p-furans

Hexachlorothanz-p-

Hexachlorophene

Hexachloropropene

2.Hexanone

indeno $1,2,3-c, d] p y r e n e$
lodomethane (Methyl lodide)

isobutyl alcohol

Isophoro

lsosafrole
Kepone

Kepon

0 Lindane

Methacrylonitrile

Methapyrilen

Methoxychlor

Methyl isobutyl ketone

Methyl methacrylate

2-Methyl-4,8-dinitrophenol

3-Methylcholanthrene

2.Mothylnaphthalene

N-Nitrosodiethylamine
N-Nitrosodimethylamine

N-Nitrosodi-n-butylamine

N-Nitrosodiphenylamine

N-Nitrosodi-propylamine
N-Nitrosomethylethylamine

N-Nitrosomorpholine

N-Nitrosopiperidine

N-Nitrosopyrro
Naphthalene

1,4-Naphthoquinone

1-Naphthylamine

2.Naphthylamine

5-Nitro-0.toluidine

2-Nitroaniline

3-Nitroaniline

4 Nitroaniline

2-Nitrophene

4-Nitrophenol

$0,0$. - triethyl phosphorothioat

Octachlorodibenzo-p-dioxins

Octachlorodibenzo-p-furans

Parathion

Parathion methyl

PCB 1016

PCB 1232

PCB 1242

PCB 1254

Pentachlorobenzene

Pentachloroben

Pentachlorodibenzo-p-dioxins

Pentachlorodibenzo-p.turans

1,2,3,7,8-PCDF

Pentachloroethane

o Pentachloronitrobenzentachlorophenol

Pentachloroph

o Phenanthrene

p-Phenylenediamine

Phorate

2.Picoline

Propionitrile

Pyrene

Safrole

- Selenium

Siver

0 Sulfide

Sulfide

Sulfotepp

Tetrachlorodibenzo-p-dioxins

Totrachlorodibenzo-p.turans

$1,1,1,2$. Tetrachlorothan

Tetrachloroethylene

2,3,4,6-Tetrachlorophenol

Thailium

Tin

Toluene

Total petroleum hydrocarbons

$2,4,5 \cdot$ TP (Silvex)

1,2,4-Trichlorobenzene

\section{Result}

$<0.00040$

$<10$

$<10$

$<10$

$<100$

$<10$

$<10$

$<10$

$<0.0050$

$<50$

$<10$

$<0.50$

$<1.0$

$<10$

$<10$

$<10$

$<10$

$<10$

$<10$

$<10$

$<10$

$<10$

$<10$

$<10$

$<4.0$

$<10$

$<10$

$<10$

$<10$

$<10$

$<0.0010$

$<<0.0010$

$<0.050$

$<0.50$

$<0.50$

$<0.50$

$<0.50$

$<0.00055$

$<0.00055$

$<10$

$<10$
$<10$
$<10$

$<10$

$<10$
$<10$

$<0.10$

$<10$
$<10$

$<200$

$<10$

$<10$

$<2.0$

$<1,000$

$<10$

$<0.00045$

$<1.0$

$<1.0$

$<1.0$

$<10$
$<20$

$<10$

$<2.0$

$<10$

$<1,000$
$<0.24$

$<0.24$
$<0.090$

$<10$
Mod
Unit L

i) $1,1,2$-Trichloroethan

Trichlorofluoromethane

2,4,5-Trichlorophenol

1,2,3-Trichloropropan

$1,3,5$-Trinitrobenzene

Vinyl acetate

0 Xylenes

2,3,7,8-TCDD

Antimony-125
Corium-144

Coslum-134

Cobalt-57

0 Cobalt-60

Europium-154

Gross ulpha

Nonvolatile beta

Potassium-40

Padium-226
Ruthenium-103

- Sodium-22

0 Total radium

- Tritium

WELL BLANK

MEASUREMENTS CONDUCTED IN THIE FIELD

Sample date: 11/17/91

Depth to water: Not available

Water elevation: Not availabie
Sp. conductance: $10 \mathrm{wS} / \mathrm{cm}$

LABORATORY ANALYSES

E Analyte Result Mod Unit Lab

: $\mathrm{gp}$

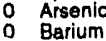

Barium

Cadmium

Carbon tetrachloride

Chloride

Chloroform

Chromium

Cyanide

2,4-Dichlorophenoxyeretic acid

Fluoride

Iron

Lead

Lindane

Manganese

Mercury

Methoxychlo

Nickel

Nitrate as nitrogen

Phenols

Potassium

Silica

Silica

Sodium

Sulfate

Tetrachlorcethylene

Total organic halogens
Total phosphates (as P)

Toxaphene

$2,4,5-1 P$ (Silvox)

1,1,1-Trichloroethe

Gross alpha

Nonvolatile be
Total radium
Result Mod Unit Lab

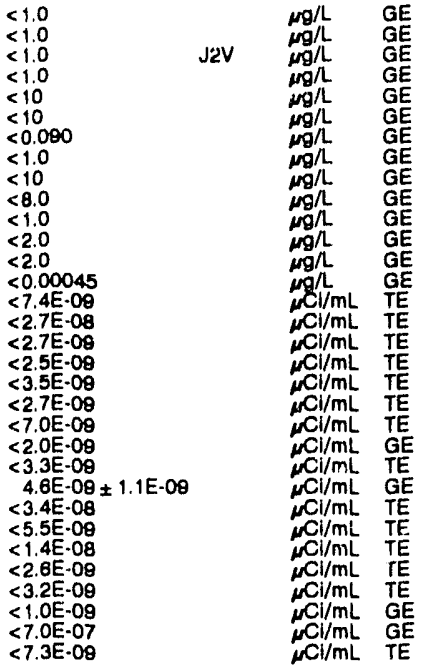

$E E$
$G E$
$G E$
$G E$
$G E$
$G E$
$T E$
$T E$
$T E$
$T E$
$T E$
$T E$
$T E$
$T E$
$T E$
$T E$
$T E$
$T E$
$T E$
$T E$
$T E$
$T E$
$T E$ 


\section{QUALITY CONTROL SAMPLES}

WELL BLANK

MEASUREMENTS CONDUCTED IN THE FIELD

Sample date: $11 / 18 / 91$

Wepth to water: Not available

Water olevation: Not available
Sp. conductance: $0 \mu \mathrm{s} / \mathrm{cm}$

LABORATORY ANALYSES

E Analyte

$0 \mathrm{pH}$

0 Turbidity

0 Acenaphthene

Aldrin

Aluminum

Anthracene

Arsenic

Barium

Benzene

alpha-Benzene hexachloride

beta.Benzene hexachloride

delta-Benzene hexachloride

Benzidine

Benzo alanthracene

Benzo a pyrene

Benzo[b]fluoranthene

Benzo[k fluoranthene

Beryllium

Bis 2-chloroethoxy) methane

Bis 2-chloroethyl) other

Bis(2-chloroisopropyl) ether
Bis (2-ethylhexyl) phithalate

Bromide

Bromodichioromethane

Bromodichloromethane

Bromoform

Bromomethane

4-Bromophenyl phenyl other

Butylbenzyl phthalate

Cadmium

Calcium

Carbon tetrachloride

Chlordane

para-Chloro-meta-cresol

Chlorobenzent

Chlorobenzene

Chloroethene

Chloroethene Ninyl chloride)

Chloroethiene Ninyl chitoride)

2-Chloroethyl vinyl ether
2-Chloroethyl vinyl ether

Chioroform

Chioroform

Chloromethane

2-Chioronaphthalene

2-Chlorophenol

4.Chlorophenyl phenyl ether

Chromium

Cobalt

Copper

o P.P'-DOD

0
0
0

O Di-n-butyl phthalate

Di-n-octy! phthalate

Dibenz[a,h]anthracene

Dibromochioromethane

3.3'-Dizhlorobenzidine

o 1,1-Dichloroethene

1,1-Dichloroethane

o 1,2-Dichloroethane

o 1,1-Dichloroethylene

trans. 1, Dichloroethyiene

trans-1,2.Dichioroethylene

Dichloromethane

Dichloromethane

2,4-Dichlorophenol

1,4 ichlorophenoxy

1,2-Dichloropropane

cis-1,3-Dichloropropene

cis-1,3-Dichioropropene

o trans-4,3-Dichloropropene

WELL BLANK collected on 11/18/91, laboratory analyses (cont)

F Analyte Mesult Mod Unit Lub

$\operatorname{Time:~}_{\mathrm{pH}: \mathrm{8}: 45}$

Alkalinity: $1 \mathrm{mgh}$

Water temperature: $18.1^{\circ} \mathrm{C}$

trans-1,3-Dichloropropene Diethyl phthalate

2,4Dimothyl phenol

Dimothyl phthalate

2,4-Dinitrophenal

2,6-Dinitrotoluene

Dissolved organic carbon

Endosulfan

0 Endosulfan sulfato

Endrin

Endrin aldehyde

Ethylbenzene

Fluoranthene

Fluorene

Fluoride

Heptachlor opoxtde

Hexachlorobenzene

Hexachlorocyclopentadiene

Hoxachloroethano

Indeno[1,2,3-c,d]pyrene

0 leophorone

Lead

Magnesium

Magnesium

Manganese

Mercuny

Methoxychlor

2-Methyl-4,5-dinitropheno

N-Nitrosodimothylamine

N-Nitrosodiphenylamine
N-Nitrosodi-propylamine

Naphthalen

Nickel

Nitrate as nitrogen

Nitrite as nitrogen

Nitrobenzene

2-Nitrophenol

4 Nitrophenol

PCB 1016

PCB 1221

PCB 1242

PCB 1248

PCB 1254

Pentachlorophenol

Phenanthrene

Phenol

- Potassium

O Polassium

0 Pyrene

Solenium

Silica

Silica

Silver
Sodium

Sulfide

Sulfid

1,1,2,2-Tetrachloroethane

1,1,2,2-Tetrachloroethan

Tetrachloroethyleno

Thallium

Tolvene

o Total dissolved solids

o Total organic carbon

Total organic carbon

Total organic halogens

Total phosphates (as P)

0 2,4,5.TP (Silvex)

1,2,4-Trichlorobenzene

1, 1,1-Trichlorosthane

1,1,2-Trichloroothane

1,1,2-Trichloroethane

o Trichloroethylene

o Trichloroethylene

o Trichlorofluoromethane

o Trichlorofluoromethane

2.4,6-Trichlorophenol

0 Zinc

- Gross alpha

- Nonvolatile beta

- Total radium
$<1.0$

$<10$
$<10$

$<10$

$<45$

$\leq<10$

$<10$

$<1,000$

$<10$
$<10$
$<10$

$<10$

$<1.0$

$<<10$

$\leq 100$

$<10$

$<10$

$<10$
$<10$

$<100$

$<4.0$

$<3.0$

$<10$
$<2.0$
$<2.0$

$<2.0$
$<020$
$<020$

$<0.50$

$<<10$

$<10$

$<10$
$<10$
$<$

$<4.0$
$<50$

$<50$
$\leq 10$
$\leq 10$

$<10$
$<10$
$<10$

$<10$

$<150$
$<150$

$<150$

$<150$

$<150$
$<150$

$<150$
$<10$
$<10$
$<10$

$<1.5$

$<500$
$<500$

$<<10$

$<2.0$
$<100$
$<100$

$<2.0$
$<10$
$<10$

$\leq 1,000$
$<1,000$
$<100$

$<1.0$

$<1.0$

$<<2.0$

$<1.0$

10,000

$<1,000$
$<1,000$

$<22$

$<50$

$<0.090$

$<10$

$<1.0$
$<1.0$

$<1.0$

$<1.0$

$<1.0$

$<1.0$

$<1.0$
$<20$

$<2.0 \mathrm{E}-08$

$<2.0 \mathrm{E}-00$

$<1.0 \mathrm{E}-09$
$<7.0 \mathrm{E}-07$ mg GE

mg G GE

m G



$m$ G $G$

gign G

GE

gen

mon GE

wor $a$

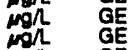

gen

mgn

$\operatorname{mgn}_{\mathrm{mg}} \mathrm{GE}$

gan G

gon a

$\mathrm{mgh}_{\mathrm{mgh}} \mathrm{GE}$

Jo

$\mu_{\mu h} \mathrm{GE}$
$\mathrm{Mg}$
$\mathrm{Gg}$
$\mathrm{GE}$

$\begin{array}{ll}\mu g \wedge & G E \\ \mu g \Lambda & G E \\ \mu g \Omega & G E \\ \mu g n & G E\end{array}$

${ }_{9 g \Omega} G E$

${ }_{\mu 9 \Omega} \mathrm{GE}$

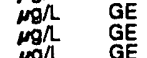

$\mu g \Omega$ GE

$\mu \mathrm{g} \Omega$

${ }_{\mu \rho} \mathrm{GE}$

${ }_{\mu g h} G E$

$\mu \mathrm{mg}$ GE

$\operatorname{mog}^{2} \mathrm{~g}$

g $G$

Mgn GE

G G

$\mu g$ GE

$\mathrm{mgh}$ GE

$\operatorname{mon}_{9 \Omega} G E$

$\mu \mathrm{gh}$ GE

Mgn GE

$\operatorname{mgg}_{\mathrm{gg}} \mathrm{GE}$
$\mathrm{Gg}$
$\mathrm{GE}$

Mgh GE

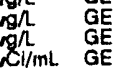

$\mu \mathrm{C} / \mathrm{mL} \mathrm{L}$

$\mu \mathrm{Cl} / \mathrm{mL} \mathrm{G}$ 
WELL BLANK

MEASUREMENTS CONOUCTED IN THE FIELD

Sample date: 11/18/91

Dopth to water: No avalleblo

Sp. conductanco: $1 \mathrm{~s} / \mathrm{sm}$

LABOFATOPY ANALYSES

\begin{tabular}{|c|c|c|c|}
\hline Analde & Reeult & Mod & Unit \\
\hline 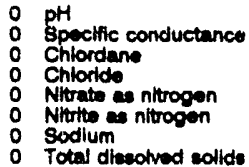 & $\begin{aligned} & 6.2 \\
& 5.0 \\
&<0.50 \\
&<250 \\
&<50 \\
&<10 \\
&<10 \\
&<1,000\end{aligned}$ & JO & 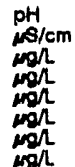 \\
\hline
\end{tabular}

\section{WELL BLANK}

MEASUREMENTS CONOUCTED IN THE FIELO

Sample dato: 11/20/91

Depth to water: Not avallable

Sp. conductance: $1 \mathrm{~ms} / \mathrm{cm}$

I MBORATORY ANALYSES

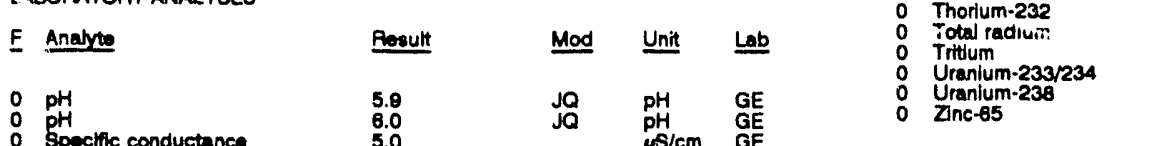

Specific conductance

Specific conductance

0 Arsonic

Barium

O Bromide

Bromide
0 Bromodlchloromethane
0

B Bromomethane

Cadmium

Cadcium

- Carton tetrachloride

o Chlordane

Chloride

Chloride

Chiorobenzene

Chloroethene Minyl chloride)

2-Chloroethyl vinyl other

2-Chloroethy

Chloroform

Chroromem

Dibromochloromethane

1,1-Dichloroethane

1,2-Dichloromenthe

1,t-Dlchlorothylene

Dichioromethane

$\begin{array}{ll}\text { Dichioromethane } & <1.0 \\ \text { 2,4-Dichlorophenoxyacetic acid }<0.30 & <0\end{array}$

1,2-Dichloropropane

cis-1,3-Oichloropropeno

trans-1,3-Dichloropropene

O Ethylbenzene

$\begin{array}{ll}0 & \text { Fluorido } \\ 0 & \text { Iron } \\ 0 & \text { Lead }\end{array}$

Undane

Magnesium

Manganete

Morcury

Nitrate niltrogen

Nitrate as nitrogen

Nitrate as nitrogen

Nitrite as nitrogen

Phonols

Silica

Siver

Sodium

Sexdium

Sul1,2,2-Tntrachiorcethane

Tetrachioroethylene

Tolueno

Total diseotved solids

Total diasotved sollids

Total organic halooens

Total phosphates (as P

Toxaphene
Timo: 7:40

Alkalinity: $1 \mathrm{mg} / \mathrm{l}$

Water temperature: $21.1^{\circ} \mathrm{C}$

Time: 7:45

Aikalinity: $0 \mathrm{mgh}$

Water temperature: $18.5^{\circ} \mathrm{C}$

$\underline{\text { Lab }}$

$G E$
$G E$
$G E$
$G E$
$G E$
$G E$
$G E$
$G E$
$G E$

$<1.000$
$<1.0$
$<1.0$

$<1.0$
$<1.0$
$<2.0$

$<2.0$
$<10$

$<1.0$

$<250$

$<250$
$<250$

$<1.0$

$<1.0$

$<1.0$

$<1.0$

$<1.0$

$<4.0$

$<1.0$

$<1.0$

$<1.0$

$<1.0$
$<1.0$

$<1.0$
$<0.0060$

$<0.0000$
$<1.0$

$<4.0$

$<0.0050$

$<2.0$

$<2.00$

$<0.50$

$<50$

$<50$

$<50$
$<10$
$<10$
$<5.0$

$<5.0$

$<2.0$

$<100$

$<2.0$

$<1,000$

$<1,000$
$<1.0$
$<1.0$

$<1.0$

12,000
10,000

$<1,000$

$<5.0$
$<50$

$<0.24$
WELL BLANK

Sample date: 11/21/81

Depth to water: Not avalable

Wath olovation: Not availablo

LABORATORY ANALYSES

WELL BLANK

Samplo date: 11/22/9;

Depth to water: Not avallable

Sp. conductance 1 astab

LABORATOPY ANALYSES

WELL BLANK collocted on 11/20/91, laboratory analyees (cont)

\begin{tabular}{|c|c|c|}
\hline Analyte & Pasult & Unit \\
\hline 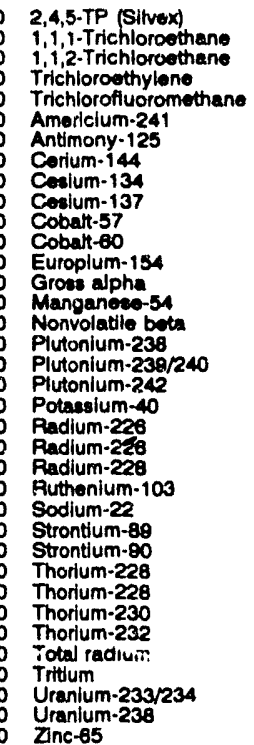 & $\begin{array}{l}<0.000 \\
<1.0 \\
<1.0 \\
<1.0 \\
<1.0 \\
<1.0 E-10 \\
<7.6 E-09 \\
<2.0 E-08 \\
<3.9 E-09 \\
<3.2 E-09 \\
<2.7 E-09 \\
<4.2 E-09 \\
<1.0 E-06 \\
2.2 E-09 \pm 1.3 E-09 \\
<3.5 E-09 \\
<2.0 E-09 \\
<4.0 E-10 \\
<1.0 E-10 \\
1.0 E-09 \pm 4.0 E-10 \\
<4.4 E-08 \\
<1.0 E-10 \\
<1.0 E-10 \\
1.0 E-09 \pm 7.0 E-10 \\
<8.8 E-09 \\
<3.8 E-09 \\
<1.0 E-09 \\
<4.0 E-10 \\
2.3 E-09 \pm 1.6 E-09 \\
2.3 E-09 \pm 1.6 E-09 \\
<1.0 E-10 \\
<1.0 E-10 \\
<1.0 E-09 \\
<7.0 E-07 \\
6.0 E-10 \pm 2.0 E-10 \\
<1.0 E-10 \\
<7.8 E-09\end{array}$ & 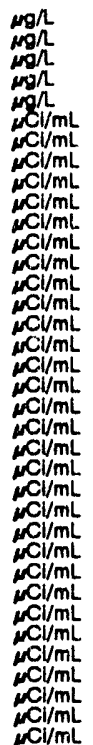 \\
\hline
\end{tabular}

MEASUREMENTS CONDUCTED IN THE FIELD

Time: 8:05

Alkelinity: $1 \mathrm{mon}$

Water tomporative: $19.8 \circ \mathrm{C}$

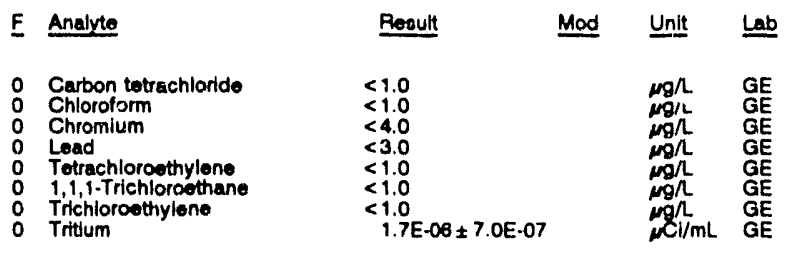

MEASUREMENTS CONOUCTED IN THE FIELD

PH: 5.5 .

Water temporature: $20.0 \circ \mathrm{C}$

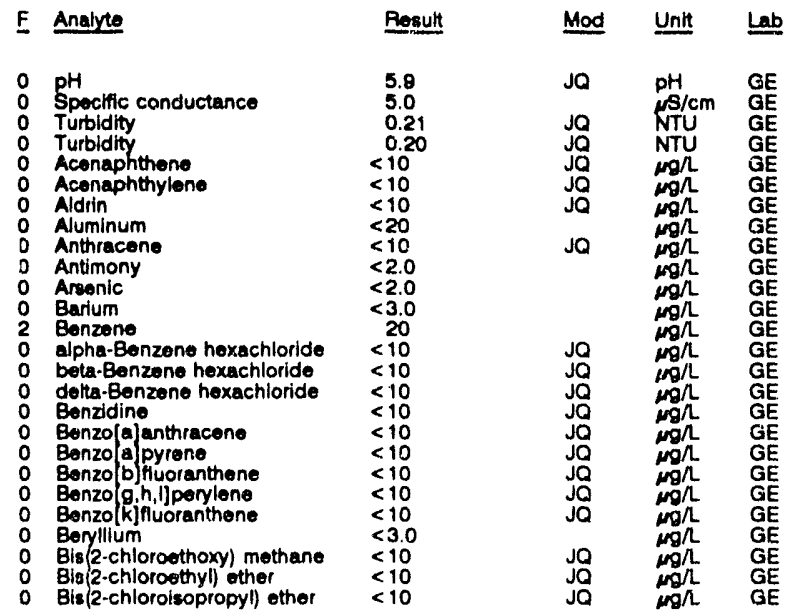


QUALITY CONTROL SAMPLES

WELL BLANK colloctod on 11/22/81, laboratory analyses (cont.)

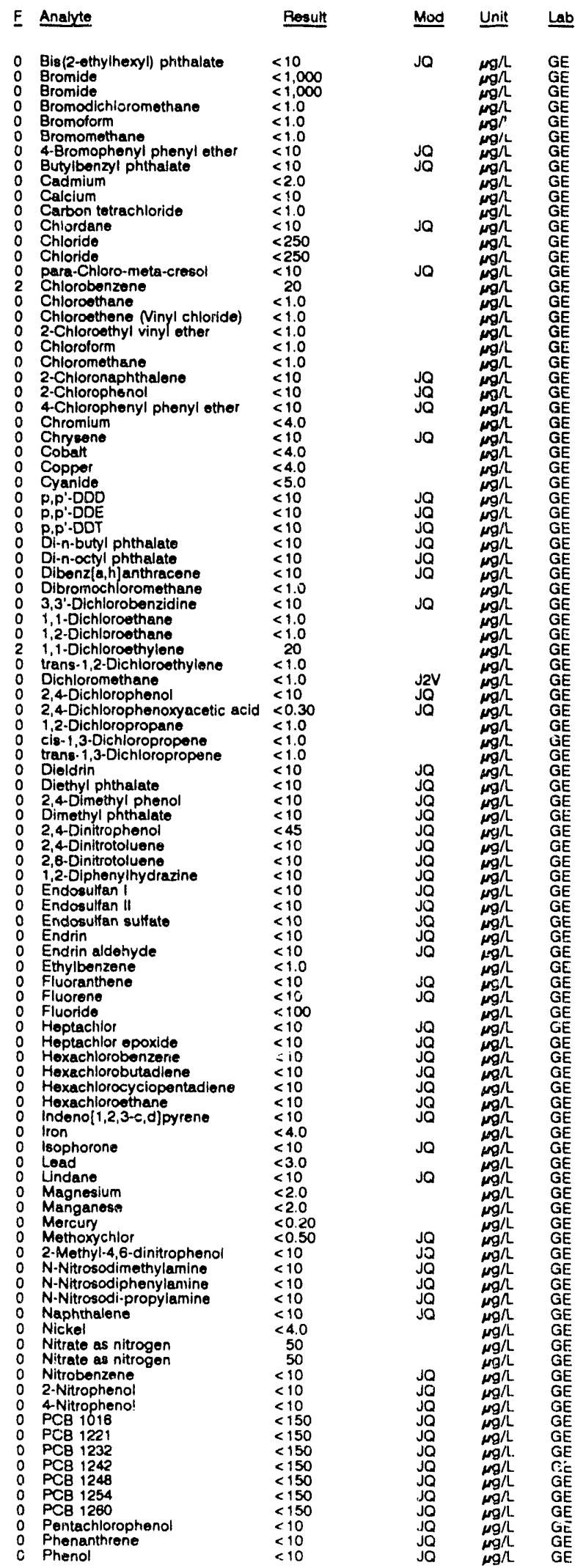

WELL BLANK collected on 11/22/91, laboratory analyese (cont)

\begin{tabular}{|c|c|c|c|}
\hline Analyte & Rosult & Mod & Unit \\
\hline 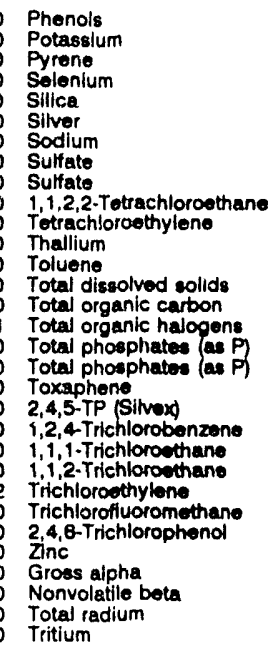 & $\begin{array}{l}<5.0 \\
<500 \\
<10 \\
<2.0 \\
<100 \\
<2.0 \\
<10 \\
<1.000 \\
<1.000 \\
<1.0 \\
<1.0 \\
<2.0 \\
21 \\
<1.000 \\
<1,000 \\
31 \\
<50 \\
<50 \\
<10 \\
<0.090 \\
<10 \\
<1.0 \\
<1.0 \\
18 \\
<1.0 \\
<10 \\
<2.0 \\
<2.0 E-09 \\
<2.0 E-09 \\
<1.0 E-09 \\
<7.0 E-07\end{array}$ & $\begin{array}{l}\mathrm{Ja} \\
\mathrm{J}\end{array}$ & 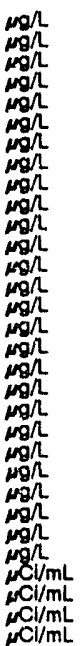 \\
\hline
\end{tabular}

WELL BLANK

MEASUREMENTS CONDUCTED IN THE FIELD

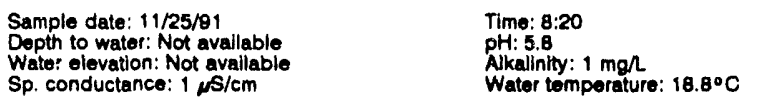

LABORATORY ANALYSES

\begin{tabular}{|c|c|c|c|}
\hline Analyte & Result & Mod & Unit \\
\hline 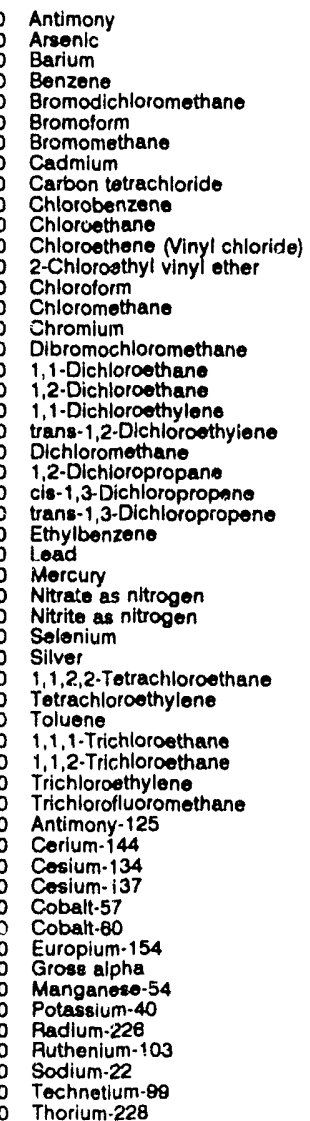 & 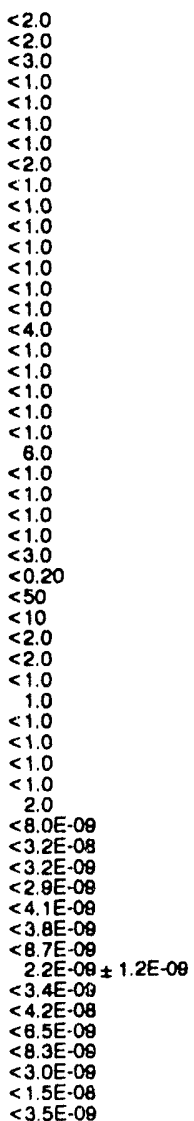 & $\sqrt{2} 2 \mathrm{~V}$ & 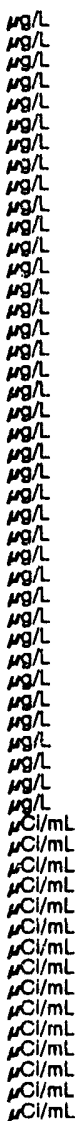 \\
\hline
\end{tabular}


WELL BLANK collected on 11/25/81, laboretory analyses (cont)

\begin{tabular}{|c|c|c|c|}
\hline Analyte & Result & Mod & Unit \\
\hline $\begin{array}{ll}0 & \text { Total radium } \\
0 & \text { Tritium } \\
0 & \text { Zinc-65 }\end{array}$ & $\begin{array}{l}<1.0 E-09 \\
<7.0 E-07 \\
<8.0 E-09\end{array}$ & & 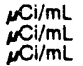 \\
\hline
\end{tabular}

WELL BLANK

MEASUREMENTS CONDUCTED IN THE FIELD
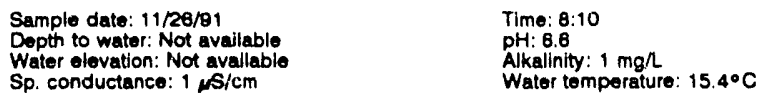

LABOPATOAY ANALYSES

\begin{tabular}{|c|c|c|c|c|}
\hline$\underline{F}$ & Analyte & Result & Mod & Unit \\
\hline $\begin{array}{l}0 \\
0 \\
0 \\
0 \\
0 \\
0 \\
0 \\
0 \\
0 \\
0 \\
0 \\
0 \\
0 \\
0 \\
0 \\
0 \\
0\end{array}$ & $\begin{array}{l}\text { pH } \\
\text { Specific conductance } \\
\text { Arsenic } \\
\text { Barium } \\
\text { Cadmium } \\
\text { Calcium } \\
\text { Chloride } \\
\text { Chromium } \\
\text { Fluoride } \\
\text { ton } \\
\text { Lead } \\
\text { Magnesium } \\
\text { Manganese } \\
\text { Mercury } \\
\text { Nitrate as nitrogen } \\
\text { Phenols } \\
\text { Potassium } \\
\text { Selenium } \\
\text { Sillica } \\
\text { Silver } \\
\text { Sodlum } \\
\text { Sulfate } \\
\text { Total dissotved solids } \\
\text { Total organic carton } \\
\text { Total organic halogens } \\
\text { Total phosphates (as P) } \\
\text { Growe alpha } \\
\text { Nonvolatile beta } \\
\text { Total radium } \\
\text { Tritium }\end{array}$ & $\begin{aligned} & 5.5 \\
& 5.0 \\
&<2.0 \\
&<3.0 \\
&<2.0 \\
&<10 \\
&<250 \\
&<4.0 \\
&<100 \\
&<4.0 \\
&<3.0 \\
&<2.0 \\
&<2.0 \\
&<0.20 \\
& 1.380 \\
&<5.0 \\
&<500 \\
&<2.0 \\
&<100 \\
&<2.0 \\
&<10 \\
&<1.000 \\
&<1,000 \\
&<1.000 \\
& 20 \\
&<50 \\
&<2.0 E-09 \\
&<2.0 \mathrm{E}-09 \\
&<1.0 \mathrm{E}-09 \\
&<7.0 \mathrm{E}-07\end{aligned}$ & JQ & 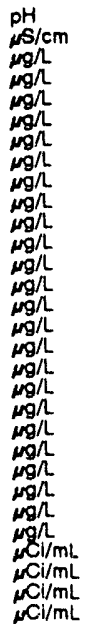 \\
\hline
\end{tabular}

\section{WELL BLANK}

MEASUREMENTS CONDUCTED IN THE FIELE

Sample date: 12/02/91

Depth to water: Not available

Water elevation: Not available

LABORATORY ANALYSES

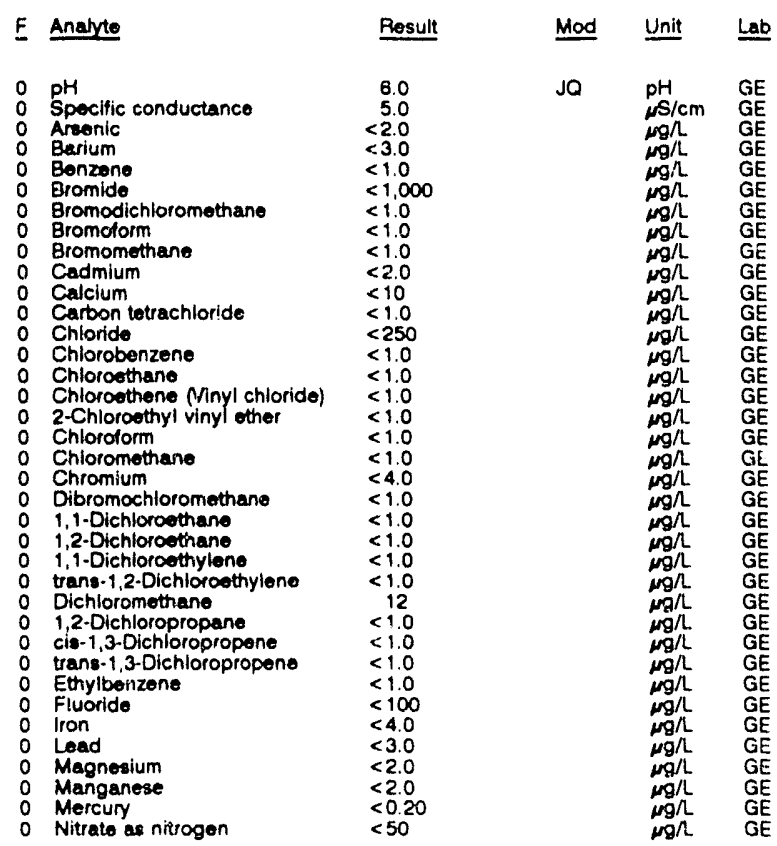

WELL BLANK collected on 12/02/91, laboratory analyses (cont.)

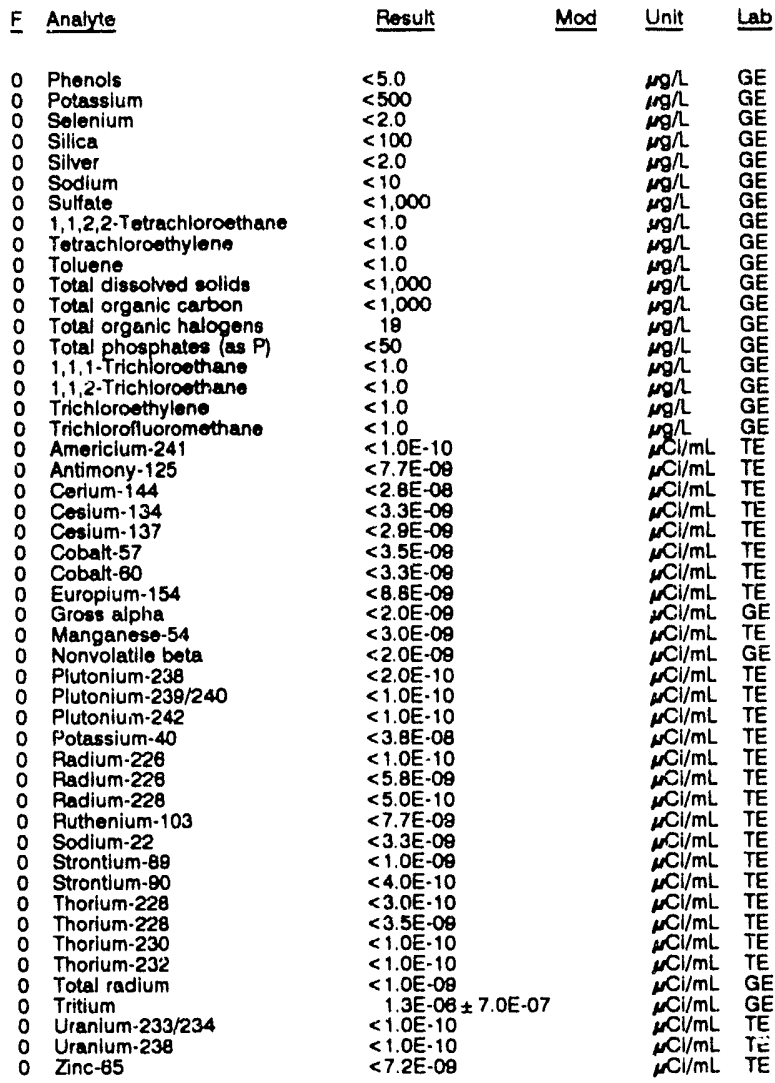

WELL BLANK

MEASUREMENTS CONDUCTED IN THE FIELD

Sample date: 12/03/81 Depth to water: Not avallable
Water elevation: Not avallable Sp. conductance: $1 \mathrm{\mu s} / \mathrm{cm}$

LABORATORY ANALYSES

E Analyte $\underline{\text { Result }} \underline{\text { Mod Unit Lab }}$

o Acenaphthylene

0 Aldrin

Anthracene

Arsenic

Barium

Benzeno

alpha-Benzene hexachloride

beta-Benzene hexachloride

delta-Benzene hexachloride

Benzidine

Benzo[a]anthracene

Benzo a) pyrone

Benzo b) fluoranthen

Benzo (g, hil) perylene

Benzolk]filium

Bis(2-chloroethoxy) methane

Bis 2-chloroethyl) other

Bis 2-chloroisopropyl) other

Bis(2-othylhexyl) phthalate

Bromodichloromethane

Bromoform

Bromomethane

4-Bromophenyl phenyl ethe
Butylbenzyl phthalate

Butylbenzyl phthalate
Cadmium

Carbon totrachloride

Chiordane

para-Chioro-meta-cresol

Chlorobenzene

Chloroethane

Chloroethene Ninyl chloride)

2-Chloroethyl vinyl ether
Time: 8:05

pH: 5.6

Water temperaturs: $21.0^{\circ} \mathrm{C}$

$<10$
$<10$

$<10$
$<10$
$<10$

$<10$
$<2.0$
$<2.0$

$<3.0$

$<1.0$
$<10$

$<10$

$<10$
$<10$
$<10$

$<10$
$<10$

$<10$
$<10$

$<10$
$<3.0$
$<10$

$<10$
$<10$
$<10$

$<10$
$<10$

$<10$
$<1.0$
$<1.0$

$<1.0$
$<10$

$<10$
$<2.0$

$<1.0$
$<10$

$<250$
$<10$

$<1.0$

$<1.0$
$<1.0$

$<1.0$
$<1.0$
Alkalinity: $1 \mathrm{mg} / \mathrm{L}$ 


\section{QUALITY CONTROL SAMPLES}

WELL BLANK collected on 12/03/81, laboratory analyses (cont.)

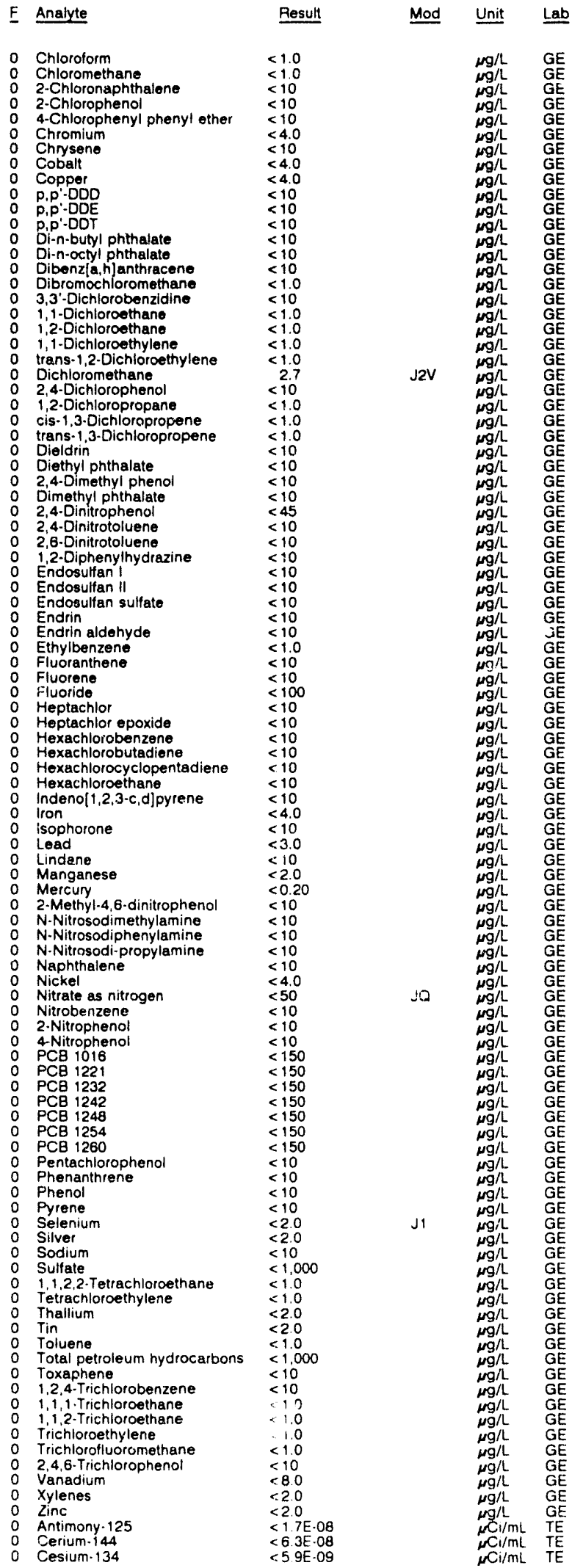

WELL BLANK collected on 12/03/91, iboratory aralyses (cont)

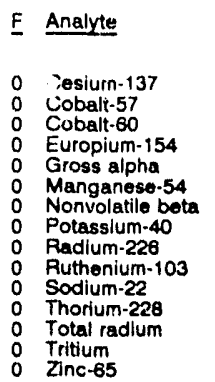

\begin{tabular}{|c|c|c|}
\hline Result & Mod & Unit \\
\hline $\begin{array}{l}<5.8 \mathrm{EE}-09 \\
<8.2 \mathrm{E}-09 \\
<6.8 \mathrm{E}-09 \\
<2.0 \mathrm{E}-09 \\
<2.0 \mathrm{E}-09 \\
<7.2 \mathrm{E}-09 \\
2.5 \mathrm{E}-09 \pm 18 \mathrm{BE}-09 \\
<8.2 \mathrm{E}-09 \\
<1.3 \mathrm{E}-08 \\
<1.4 \mathrm{E}-08 \\
<7.1 \mathrm{E}-09 \\
<7.6 \mathrm{E}-09 \\
<1.0 \mathrm{E}-09 \\
7.3 \mathrm{E}-09 \times 7.0 \mathrm{E}-07\end{array}$ & & $\begin{array}{l}\mu \mathrm{Cl} / \mathrm{mL} \\
\mu \mathrm{Cl} / \mathrm{mL} \\
\mu \mathrm{Cl} / \mathrm{mL} \\
\mu \mathrm{Cl} / \mathrm{mL} \\
\mu \mathrm{Cl} / \mathrm{mL} \\
\mu \mathrm{Cl} / \mathrm{mL} \\
\mu \mathrm{Cl} / \mathrm{LL} \\
\mu \mathrm{Cl} / \mathrm{mL} \\
\mu \mathrm{Cl} / \mathrm{mL} \\
\mu \mathrm{Cl} / \mathrm{mL} \\
\mu \mathrm{Cl} / \mathrm{mL} \\
\mu \mathrm{Cl} / \mathrm{mL} \\
\mu \mathrm{Cl} / \mathrm{mL} \\
\mu \mathrm{Cl} / \mathrm{mL}\end{array}$ \\
\hline
\end{tabular}

WELL BLANK

MEASUREMENTS CONDUCTED IN THE FIELD

Sample date: 12/04/81 Depth to water: Not avallable Sp. conductance: $1 \mathrm{\mu S} / \mathrm{cm}$

LABORATORY ANALYSES

E Analyte Result Mod Unit Lab

Time: $8: 05$
pH: 5.7
Alkalinity: $0 \mathrm{mg} /$.

Water temperature: $172^{\circ} \mathrm{C}$
8.0
5.0
52.0
$<3.9$
5

$\leq 3.0$

$<1,0$

$<10$

$<1.0$

$\leq<.0$

$<1.0$

$<1.0$

$<2.0$

$<100$

$<1.0$

$<1.0$
$<1.0$
$<1.0$

$<1.0$

$<1.0$

$<1.0$

$<1.0$

$<1.0$

$<1.0$

$<1.0$
$<1.0$

$<1.0$

1.0

$<1.0$

$<1.0$

$<1.0$

$<1.0$

$<1.0$

$<1.0$

$<1.0$
1.2

1.0

20.30
$<1.0$
$<1.0$
5

$<1.0$

$<1.0$

$<1.0$

1,000

$<1,000$

$=0.0060$

$<1.0$

$<100$
$<4.0$
$<3.0$
$<0050$

$<3.0$

$<2.0$
$<2.0$
$<2.0$
$<0.20$

$<0.20$

$<0.50$

$<50$
$<10$

$<5.0$

$<500$ 


\section{QUALITY CONTROL SAMPLES}

WELL BLANK colloctod on 12/04/81, laboratory analyser (cont.)

\begin{tabular}{|c|c|c|c|}
\hline Analyte & Rosult & Mod & Unit \\
\hline 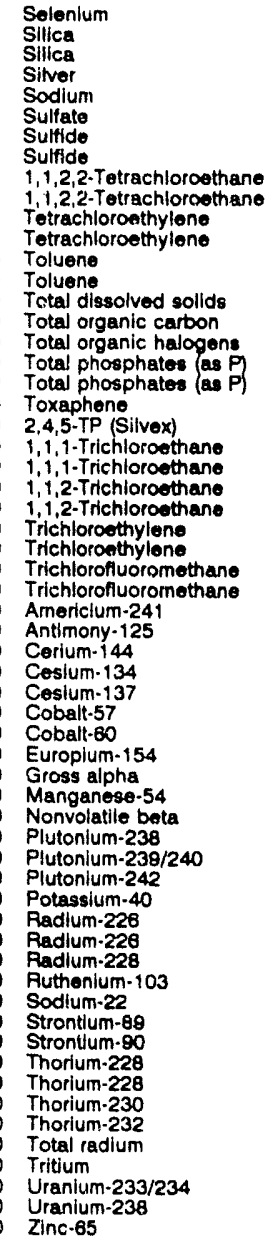 & $\begin{array}{l}<2.0 \\
<100 \\
<100 \\
<2.0 \\
<10 \\
<1.000 \\
<1.000 \\
<1.000 \\
<1.0 \\
<1.0 \\
<1.0 \\
<1.0 \\
<1.0 \\
<1.0 \\
<1.000 \\
<1.000 \\
<5.0 \\
<50 \\
<50 \\
<0.24 \\
<0.090 \\
<1.0 \\
<1.0 \\
<1.0 \\
<1.0 \\
<1.0 \\
<1.0 \\
<1.0 \\
<1.0 \\
<1.0 E-10 \\
<5.8 E-09 \\
<2.2 E-08 \\
<2.0 E-09 \\
<1.6 E-09 \\
<2.7 E-09 \\
<1.8 E-09 \\
<5.7 E-09 \\
<2.0 E-09 \\
<2.0 E-09 \\
6.3 E-09 \pm 1.8 E-09 \\
<4.0 E-10 \\
3.0 E-10 \pm 3.0 E-10 \\
<1.0 E-10 \\
<3.7 E-08 \\
<1.0 E-10 \\
<1.0 E-10 \\
<7.0 E-10 \\
<4.6 E-09 \\
<2.1 E-09 \\
<8.0 E-10 \\
6.0 E-10 \pm 8.0 E-10 \\
<5.0 E-10 \\
<5.0 E-10 \\
<1.0 E-10 \\
<1.0 E-10 \\
<10 E-09 \\
<7.0 E-07 \\
5.0 E-10 \pm 1.0 E-10 \\
<1.0 E-10 \\
<3.9 E-09 \\
\end{array}$ & ביבו & 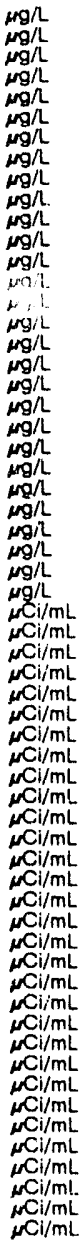 \\
\hline
\end{tabular}

\section{WELL BLANK}

MEASUREMENTS CONDUCTED IN THE FIELD

Sample date: $12 / 05 / 91$
Depth to water: Not avallable
Water elevation: Not avallable
Sp. Conductance: 1 s/cm
LABORATORY ANALYSES
F Analyte

0
0
0

Time: $4: 15$

pH: 5.8

Water temperature: $13.7^{\circ} \mathrm{C}$

Result Mod Unit Lab
WELL BLANK collectod cn 12/05/91, laboratory analyses (cont.)

E Analyte Result Mad Unit Lab

$\begin{array}{ll}0 & \text { trans-1,2-Dichloroethylene } \\ 0 & \text { Dichloromethane } \\ 0 & 1,2-\text { Dichloropropane } \\ 0 & \text { cis-1,3-Dichloropropene } \\ 0 & \text { trans-1,3-Dichloropropene } \\ 0 & \text { Ethylbenzene } \\ 0 & \text { Fluoride } \\ 0 & \text { Iron } \\ 0 & \text { Lead } \\ 0 & \text { Magnesium } \\ 0 & \text { Manganese } \\ 0 & \text { Mercury }\end{array}$

$<1.0$

4.4
$<1.0$
$<1.0$

$<1.0$

$<100$

$<4.0$
$<3.0$

$<2.0$

Nitrate as nitrogen

Phenols

Potassium

Selenlum

Silica

Sodium

Sulfate

1,1,2,2-Tetrachloroethane

Tetrachloroethylene

Tolvene

Total dissolved solids

2 Total organic halogens

1,12-Trichloroethen

Trichloroethylene

Trichlorofluoromethane

Americium-241

Antimony-125

Cerium-144

Ceslum-137

Cobalt-5

$\begin{array}{ll}0 & \text { Cobalt- } 60 \\ 0 & \text { Europium.154 }\end{array}$

Gross alpha

Nonvolatile beta

Plutonium.239/240

Plutonium.242

0 Potassium -40

0 Radium-226

0 Radium-228

$\begin{array}{ll}0 & \text { Radium-228 } \\ 0 & \text { Ruthenium-103 }\end{array}$

0 Sodium-22

O Strontium-88

Strontium-90

Thorium.228

Thorium-230

Thorium-232

Total radium

Tritium

Uranium-233/234

Uranium-238
Zinc-65

$<0.20$

$<5.0$

$<500$

$<100$

$<2.0$
$<10$

$<1,000$

$<1.0$
$<1.0$

3.7

$<1,000$
$<1,000$

$<1,000$

$<50$

$<1.0$

$<1.0$
$<10$

4. OE- $10 \pm 2.0 \mathrm{E}-10$

$<7.6 \mathrm{E}-09$

$<2.0 \mathrm{E}-08$
$<3.5 \mathrm{E}-09$

$<3.0 \mathrm{E}-09$

$<2.7 \mathrm{E}-09$

$<3.5 \mathrm{E}-09$

2.2E. $09 \pm 8.8 \mathrm{E} \cdot 10$

$<3.6 \mathrm{E}-09$

$<2.0 \mathrm{E}-09$
$<1.0 \mathrm{E}-10$

$<1.0 \mathrm{E} \cdot 10$

$<1.0 \mathrm{E}-10$

$<4.4 \mathrm{E} \cdot 08$

$3.0 \mathrm{E}-10 \pm 1.0 \mathrm{E}-10$

$3.0 \mathrm{E}-10 \pm 1.0 \mathrm{E}-10$

$2.8 \mathrm{E} \cdot 08 \pm 1.3 \mathrm{E} \cdot 08$

$<8.4 \mathrm{E} \cdot 0 \mathrm{O}$

$<8.0 \mathrm{E}-10$

$<8.0 E-10$
$<4.0 \mathrm{E}-10$

$<3.0 \mathrm{E}-10$

$<3.0 E \cdot 10$

$<1.0 E-10$
$<1.0 E-10$

$<1.0 \mathrm{OE}-09$

$3.0 \mathrm{E} \cdot 10 \pm 2.0 \mathrm{E} \cdot 10$

$<1.0 \mathrm{E}-10$
$<1,0 \mathrm{E}-09$

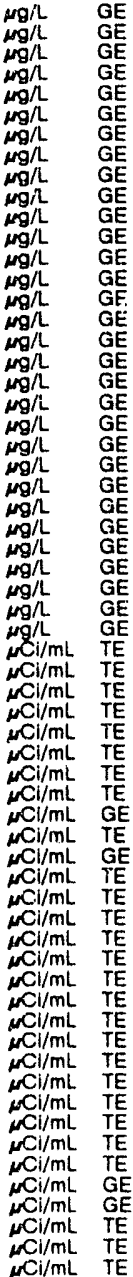

WELL BLANK

MEASUREMENTS CONDUCTED IN THE FIELD

Sample date: 12/12/81

Depth to water: Not available

Water elevation: Not ayailable

$\mathrm{Sp}$. conductance: $1 \mu \mathrm{s} / \mathrm{cm}$

LABORATORY ANALYSES

$\begin{array}{ll}\text { F } & \text { Analyte } \\ 0 & \text { pH } \\ 0 & \text { Specific conductance } \\ 0 & \text { Aluminum } \\ 0 & \text { Antimony } \\ 0 & \text { Barium } \\ 0 & \text { Beryllium } \\ 0 & \text { Cadmium } \\ 0 & \text { Calciun } \\ 0 & \text { Chloride } \\ 0 & \text { Chromium } \\ 0 & \text { Cobalt } \\ 0 & \text { Copper } \\ 0 & \text { Fluoride } \\ 0 & \text { lodine } \\ 0 & \text { Iron } \\ 0 & \text { Lead } \\ 0 & \text { Magnesium } \\ 0 & \text { Manganese } \\ 0 & \text { Mercury } \\ 0 & \text { Nickel } \\ 0 & \text { Nitrate as nitrogen } \\ 0 & \text { Nitrite as nitrogen } \\ 0 & \text { Phenols }\end{array}$

\begin{tabular}{|c|c|c|}
\hline Result & Mod & Unit \\
\hline $\begin{aligned} & 5.6 \\
& 5.0 \\
&<20 \\
&<2.0 \\
&<3.0 \\
&<3.0 \\
&<2.0 \\
&<10 \\
&<250 \\
&<4.0 \\
&<4.0 \\
&<4.0 \\
&<100 \\
&<50 \\
&<4.0 \\
&<3.0 \\
&<2.0 \\
&<2.0 \\
&<0.20 \\
&<4.0 \\
&<50 \\
&<10 \\
&<5.0\end{aligned}$ & JQ & 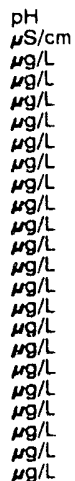 \\
\hline
\end{tabular}


QUALITY CONTROL SAMPLES

WELL BLANK collected on 12/12/91, laboratory analyses (cont.)

\begin{tabular}{|c|c|}
\hline Analyte & Result \\
\hline 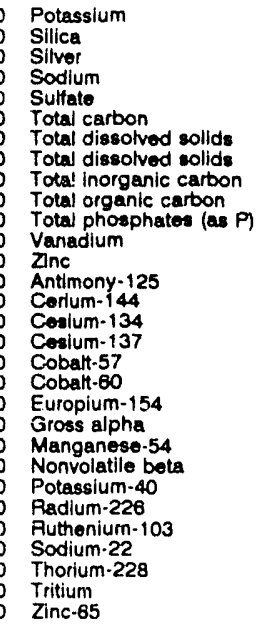 & $\begin{array}{l}<500 \\
386 \\
<2.0 \\
<10 \\
<1,000 \\
<1,000 \\
<1,000 \\
<1,000 \\
<1,000 \\
<1,000 \\
<50 \\
<8.0 \\
<2.0 \\
<6.6 \mathrm{E} \cdot 09 \\
<2.0 \mathrm{E}-08 \\
<2.8 \mathrm{E}-09 \\
<2.2 \mathrm{E}-09 \\
<2.7 \mathrm{E}-09 \\
<2.7 \mathrm{E}-09 \\
<7.4 \mathrm{E} \cdot 09 \\
<2.0 \mathrm{E}-09 \\
<2.5 \mathrm{E} \cdot 09 \\
<2.0 \mathrm{E}-09 \\
<4.6 \mathrm{E}-08 \\
<5.4 \mathrm{E}-09 \\
<6.1 \mathrm{E}-09 \\
<2.8 \mathrm{E}-09 \\
<2.9 \mathrm{E}-09 \\
<7.0 \mathrm{E} \cdot 07 \\
<4.7 \mathrm{E} \cdot 09\end{array}$ \\
\hline
\end{tabular}

WELL BLANK

MEASUREMENTS CONDUCTED IN THE FIELD

Sample date: $12 / 13 / 91$

Depth to water: Not available

Water elevation: Not availablo

LABORATORY ANALYSES

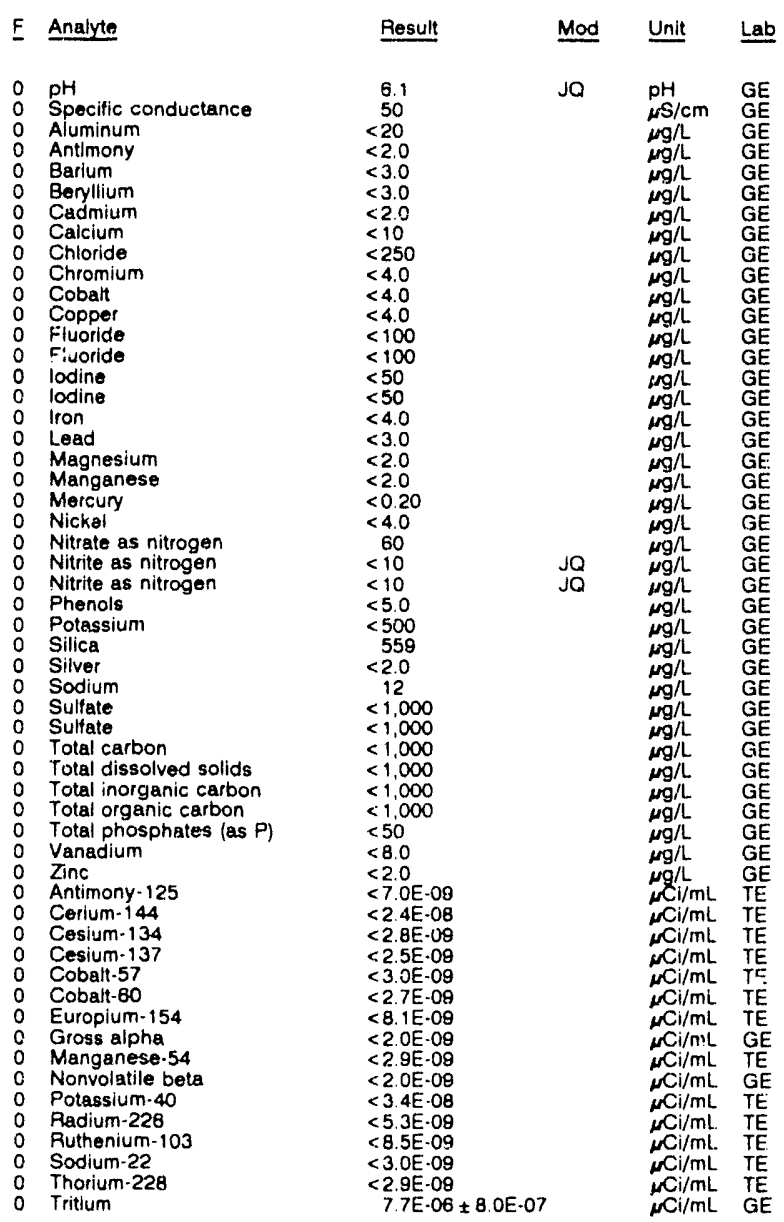

WELL BLANK collected on 12/13/91, laboratory analyeee (cont.)

$\begin{array}{llll}E \text { Analyto } & \text { Rosuit } & \text { Mod Unit Lab } \\ 0 \text { Znc-65 } & <7.0 E-99 & \mu \mathrm{Cl} / \mathrm{mL} T E\end{array}$

WELL EPT 1

MEASUREMENTS CONDUCTED IN THE FIELD

Sample date: 10/01/81

Depth to water: Not avallable

Water olevation: Not avallable
Sp. conductance: $B \mu \mathrm{s} / \mathrm{cm}$

LABORATORY ANALYSES

\begin{tabular}{|c|c|c|c|}
\hline Analyte & Peoult & Mod & Unit \\
\hline $\begin{array}{l}\text { Aluminum } \\
\text { Antimonny } \\
\text { Arsenic } \\
\text { Barium } \\
\text { Beryllium } \\
\text { Cadmium } \\
\text { Calcium } \\
\text { Chromium } \\
\text { Cobalt } \\
\text { Copper } \\
\text { lron } \\
\text { Lead } \\
\text { Lithlum } \\
\text { Magnesium } \\
\text { Manganese } \\
\text { Mercury } \\
\text { Nickel } \\
\text { Potassium } \\
\text { Selenium } \\
\text { Sillica } \\
\text { Silver } \\
\text { Sodium } \\
\text { Thallium } \\
\text { Tin } \\
\text { Uranium } \\
\text { Vanadlum } \\
\text { Zinc }\end{array}$ & $\begin{array}{l}<20 \\
<2.0 \\
<2.0 \\
<3.0 \\
<3.0 \\
<2.0 \\
17 \\
<4.0 \\
<4.0 \\
<4.0 \\
<4.0 \\
<3.0 \\
<5.0 \\
2.4 \\
<2.0 \\
<0.20 \\
<4.0 \\
<500 \\
<2.0 \\
19.800 \\
<2.0 \\
7.4 \\
<2.0 \\
4.5 \\
<20 \\
<8.0 \\
<2.0\end{array}$ & $\sqrt{ } 2$ & 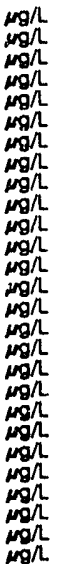 \\
\hline
\end{tabular}

WELL EPT 2

MEASUREMENTS CONDUCTED IN THE FIELD

Sample date: 10/01/91

Depth to water: Not avallable

$\mathrm{Sp}$. conductance: $7 \mathrm{~s} / \mathrm{cm}$

LABORATORY ANALYSES

Time: $6: 50$

Alkalinity: $0 \mathrm{mgh}$

Water temperature: $17.2^{\circ} \mathrm{C}$

E Analyte Result Mod Unit Lab

- Aluminum

Antimony

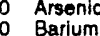

o Beryllium

Cadmium

Chromium

Cobalt

o Copper

0 Lron

o Lead

0 Magnesium

Manganese

Nickel

Potassium

Soleniuin

0 Silica

o Silver

o Sodium

0 Tin

0 Uranium

V Vanadium
0 Zinc

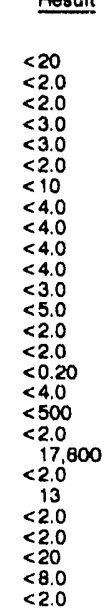

Time: 8:45

Time: $8: 45$
PH: 4.6
Akalinity: $0 \mathrm{mgr}$

Water iemperature: $17.1^{\circ} \mathrm{C}$

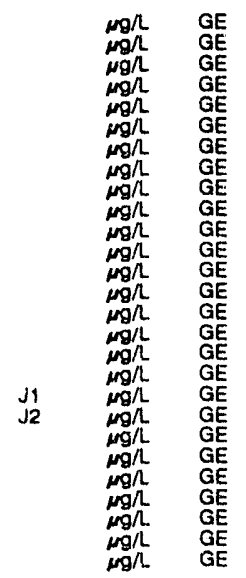




\section{QUALITY CONTROL SAMPLES}

\section{WELL EPT 3}

MEASUREMENTS CONDUCTED IN THE FIELD

Sample dare: 10/02/91

Water olovation: Not avallable

$\mathrm{Sp}$. conductance: $7 \mathrm{~ms} / \mathrm{cm}$

LABORATORY ANALYSES

E Analyte

0 Aluminum

$\therefore$ Antimony

0 Brsenic

Beryllium

Cadmium

0 Chromium

Cobalt

$\begin{array}{ll}0 \\ 0 \\ 0 & \text { Copper } \\ 0 & \text { Iron }\end{array}$

D Lead

0 Magnesium

Manganese

Morcury

Potasalum

0 Silica

Silver

Thallium

Tin

Uranium

Zinc

WELL EPT 4

MEASUREMENTS CONDUCTED IN THE FIELD

Sample date: 10/02/91

Depth to wate: Not avai!able
Water elevation: Not available
Sp. conductance: 8 S $/ \mathrm{cm}$

LABORATORY ANALYSES

$E$ Analyte

0 Aluminum

Antimony

Arsenit:

Beryllium

Calcium

Chromium

Cobalt

- Copper

- Lead

L Lithium

Magnesium

Mercuny

Potassium

Selenium

Silica

o Silver

Sodium

Tin

Uraniurn

Vanadium

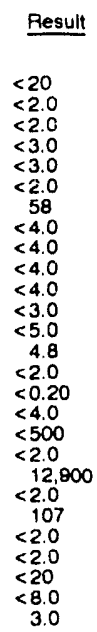

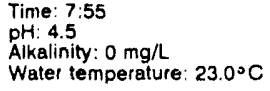

Water temperature: $23.0^{\circ} \mathrm{C}$

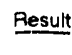

$<20$
$<2.0$

$<2.0$

$<3.0$
$<3.0$

$<2.0$

$<4.0$
$<4.0$

$<4.0$

$<4.0$

$<3.0$

$<5.0$
2.0
$<2.0$

$<2.0$

$<4.0$

$<500$

14,700

$<2.0$

17
$<2.0$
3.8

$<20$

$<8.0$
$<2.0$

WELL EPT 5

MEASUREMENTS CONDUCTED IN THE FIELO

Sample date: $10 / 03 / 91$ Depth to water: Not available Water elevation. Nol available

Sp. conductance: $\mathrm{s} / \mathrm{cm}$

LABORATORY ANALYSES

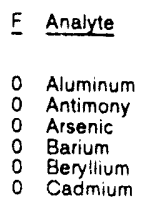

Result

$<20$

$<20$

$<2.0$
$<3.0$

$<20$

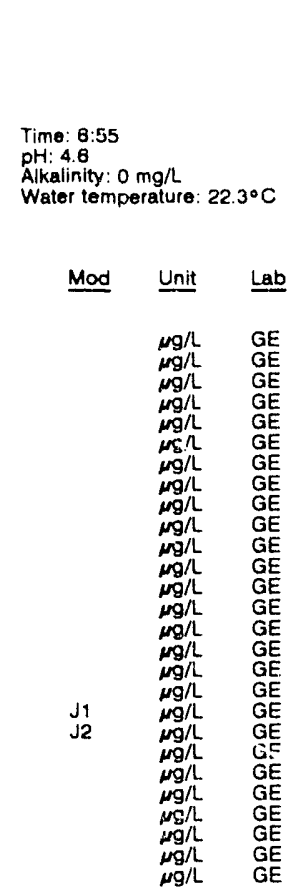

WELL EPT 5 collected on 10/03/81, laboratory analyses (cont.)

\begin{tabular}{|c|c|c|c|}
\hline Analyte & Rosult & Mod & Unit \\
\hline $\begin{array}{ll}0 & \text { Calcium } \\
0 & \text { Chromium } \\
0 & \text { Cobalt } \\
0 & \text { Copper } \\
0 & \text { iron } \\
0 & \text { Lead } \\
0 & \text { Lithium } \\
0 & \text { Magnesium } \\
0 & \text { Manganese } \\
0 & \text { Morcury } \\
0 & \text { Nickel } \\
0 & \text { Potassium } \\
0 & \text { Selenium } \\
0 & \text { Sillica } \\
0 & \text { Silver } \\
0 & \text { Sodium } \\
0 & \text { Thallium } \\
0 & \text { Tin } \\
0 & \text { Uranium } \\
0 & \text { Vanadium } \\
0 & \text { Zinc }\end{array}$ & $\begin{aligned} 28 \\
<4.0 \\
<4.0 \\
<4.0 \\
<4.0 \\
<3.0 \\
<5.0 \\
<2.0 \\
<2.0 \\
<0.20 \\
<4.0 \\
<500 \\
<2.0 \\
16.700 \\
<2.0 \\
<13 \\
<2.0 \\
3.4 \\
<20 \\
<8.0 \\
<2.0\end{aligned}$ & $\begin{array}{l}\mathrm{J} 1 \\
\mathrm{~J} 2\end{array}$ & 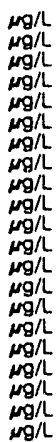 \\
\hline
\end{tabular}

WELL EPT 6

MEASUREMENTS CONDUCTED IN THE FIELD

Sample date: 10/03/91

Depth to water: Not available

$\mathrm{Sp}$. conductance: $8 \mathrm{sS} / \mathrm{cm}$

Time: $8: 15$

Alkallnity: $0 \mathrm{mg} / \mathrm{L}$

Water temperaive $21.5^{\circ} \mathrm{C}$

LABORATORY ANALYSES

\begin{tabular}{|c|c|c|c|}
\hline Analyte & Result & Mod & Unit \\
\hline $\begin{array}{l}\text { Aluminum } \\
\text { Antimony } \\
\text { Arsenic } \\
\text { Barium } \\
\text { Beryllium } \\
\text { Cadmium } \\
\text { Calcium } \\
\text { Chromium } \\
\text { Cobalt } \\
\text { Copper } \\
\text { lon } \\
\text { Lead } \\
\text { Lithium } \\
\text { Magnesium } \\
\text { Manganese } \\
\text { Mercury } \\
\text { Nickel } \\
\text { Potassium } \\
\text { Selenium } \\
\text { Silica } \\
\text { Silver } \\
\text { Sodium } \\
\text { Thallium } \\
\text { Tin } \\
\text { Uranium } \\
\text { Vanadium } \\
\text { Zinc }\end{array}$ & $\begin{array}{c}<20 \\
<2.0 \\
<2.0 \\
<3.0 \\
<3.0 \\
<2.0 \\
29 \\
<4.0 \\
<4.0 \\
<4.0 \\
<4.0 \\
<3.0 \\
<5.0 \\
2.3 \\
<2.0 \\
<0.20 \\
<4.0 \\
<500 \\
<2.0 \\
13.000 \\
<2.0 \\
40 \\
<2.0 \\
2.9 \\
<20 \\
<8.0 \\
2.5\end{array}$ & $\begin{array}{l}\mathrm{J} 1 \\
\mathrm{~J} 2\end{array}$ & $\begin{array}{l}\mu g / L \\
\mu g / L \\
\mu g / L \\
\mu g / L \\
\mu g / L \\
\mu g / L \\
\mu g / L \\
\mu g / L \\
\mu g / L \\
\mu g / L \\
\mu g / h \\
\mu g / L \\
\mu g / L \\
\mu g / L \\
\mu g / L \\
\mu g / L \\
\mu g / L \\
\mu g / L \\
\mu g / L \\
\mu g / L \\
\mu g / L \\
\mu g / L \\
\mu g / L \\
\mu g / L \\
\mu g / L \\
\mu g / L \\
\mu g / L\end{array}$ \\
\hline
\end{tabular}

WELI. EPT 7

MEASURE:MENTS CONDUCTED IN THE FIELD

Sample date: 10/04/91

Wepth to water: Not available

$\mathrm{Sp}$. conductance: $8 \mathrm{~s} / \mathrm{cm}$

LABOPATORY ANALYSES

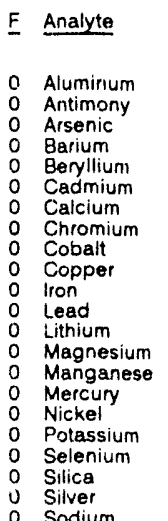

Time: $7: 55$

Alkalinity: $0 \mathrm{mg} / \mathrm{L}$

Water temperature: $22.1^{\circ} \mathrm{C}$

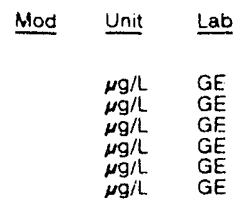

Time: $8: 40$

PH: 4.5 Alkalinity: O mg/L

Water temperature: $21.2^{\circ} \mathrm{C}$

\begin{tabular}{|c|c|c|}
\hline Result & Mod & Unit \\
\hline $\begin{array}{l}<20 \\
=2.0 \\
=2.0 \\
=3.0 \\
=3.0 \\
<2.0 \\
27 \\
=4.0 \\
=4.0 \\
=4.0 \\
=4.0 \\
=3.0 \\
=5.0 \\
2.7 \\
<2.0 \\
<0.20 \\
=4.0 \\
=500 \\
=2.0 \\
11.100 \\
<2.0 \\
13\end{array}$ & J1 & $\begin{array}{l}\mu g / L \\
\mu g / L \\
\mu g / L \\
\mu g / L \\
\mu g / L \\
\mu g / L \\
\mu g / L \\
\mu g / L \\
\mu g / L \\
\mu g / L \\
\mu g / L \\
\mu g / L \\
\mu g / L \\
\mu g / L \\
\mu g / L \\
\mu g / L \\
\mu g / L \\
\mu g / L \\
\mu g / L \\
\mu g / L \\
\mu g / L \\
\mu g / L\end{array}$ \\
\hline
\end{tabular}


WELL EPT 7 collected on 10/04/91, laboratory analyses (cont.)

\begin{tabular}{llllll} 
E Analyte & Result & Mod & Unit & Lab \\
\cline { 3 - 5 } & & & & \\
0 & Thallium & $<2.0$ & & & \\
0 & Tin & & $\mathrm{mg} / \mathrm{L}$ & $\mathrm{GE}$ \\
0 Uranium & $<20$ & $\mathrm{mg} / \mathrm{L}$ & $\mathrm{GE}$ \\
0 Vanadium & $<8.0$ & & $\mathrm{mg} / \mathrm{L}$ & $\mathrm{GE}$ \\
0 & Zinc & & & $\mathrm{mg} / \mathrm{L}$ & $\mathrm{GE}$ \\
$\mathrm{Ng} / \mathrm{L}$ & $\mathrm{GE}$
\end{tabular}

WELL EPT 8

MEASUREMENTS CONDUCTED IN THE FIELD

Sample date: 10/04/91

Depth to water: Not available

Water elevation. Not available

LABORATORY ANALYSES
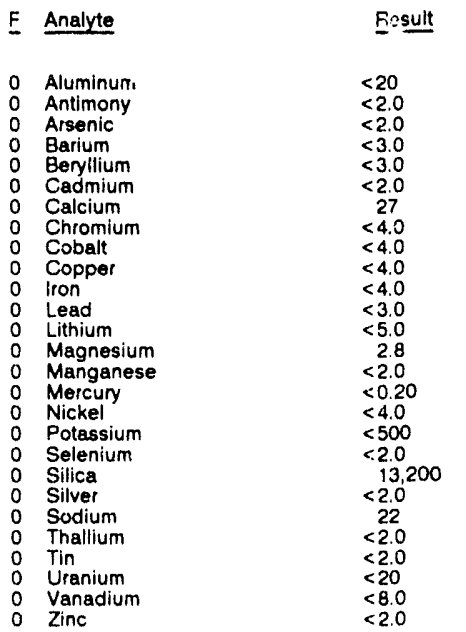

\section{WELL EPT 9}

MEASUAEMENTS CONDUCTED IN THE FIELD

Sample date: 10/07/91

Depth to water. Not available

Water elevation: Not available

LABORATORY ANALYSES

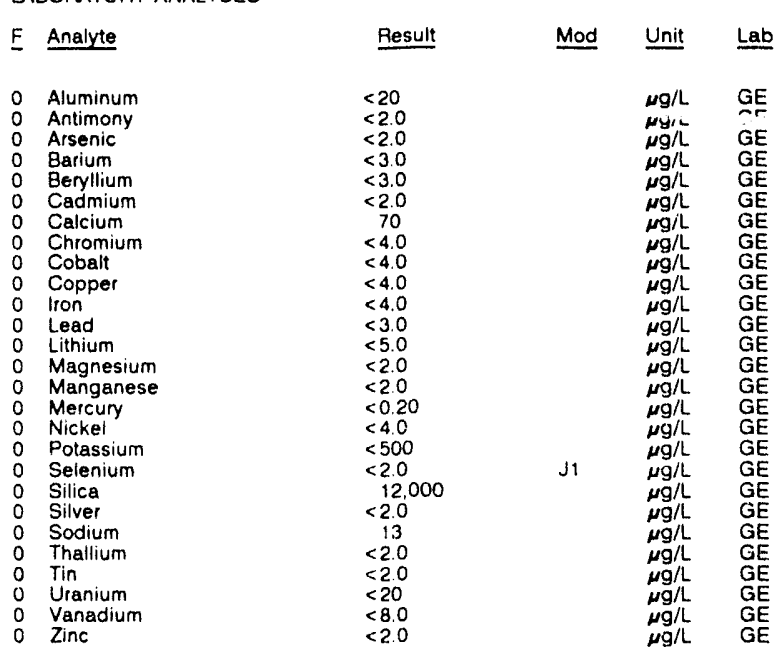

Time: $6: 45$

Alkalinity: $0 \mathrm{mg}$ '!

Water temperature: $20.3^{\circ} \mathrm{C}$

Mod Unit Lab

Time: $8: 45$

PH: 4.7

Water temperature: $18.2^{\circ} \mathrm{C}$

WELL EPT 10

MEASUREMENTS CONDUCTED IN THE FIELD

Sample date: 10/07/91

Depth to water: Not available

Water elevalion. Not avallable

LABORATORY ANALYSES

\begin{tabular}{|c|c|}
\hline E Analyte & Result \\
\hline $\begin{array}{ll}0 & \text { Aluminum } \\
0 & \text { Antimony } \\
0 & \text { Arsenic } \\
0 & \text { Barium } \\
0 & \text { Beryllium } \\
0 & \text { Cadmium } \\
0 & \text { Calcium } \\
0 & \text { Chromium } \\
0 & \text { Cobalt } \\
0 & \text { Copper } \\
0 & \text { Iron } \\
0 & \text { Lead } \\
0 & \text { Lithium } \\
0 & \text { Magnesium } \\
0 & \text { Manganese } \\
0 & \text { Mercury } \\
0 & \text { Nickel } \\
0 & \text { Potassium } \\
0 & \text { Selenium } \\
0 & \text { Silica } \\
0 & \text { Silver } \\
0 & \text { Sodium } \\
0 & \text { Thallium } \\
0 & \text { Tin } \\
0 & \text { Uranium } \\
0 & \text { Vanadium } \\
0 & \text { Zinc }\end{array}$ & $\begin{array}{l}<20 \\
<2.0 \\
<2.0 \\
<3.0 \\
<3.0 \\
<2.0 \\
16 \\
<4.0 \\
<4.0 \\
<4.0 \\
<4.0 \\
<3.0 \\
<5.0 \\
3.8 \\
<2.0 \\
<0.20 \\
<4.0 \\
<500 \\
<2.0 \\
14.100 \\
<2.0 \\
31.0 \\
<2.0 \\
<2.0 \\
<20 \\
<8.0 \\
<2.0\end{array}$ \\
\hline
\end{tabular}

Time: 8:50

pH: 3.9 .

Water temperature: $20.0^{\circ} \mathrm{C}$

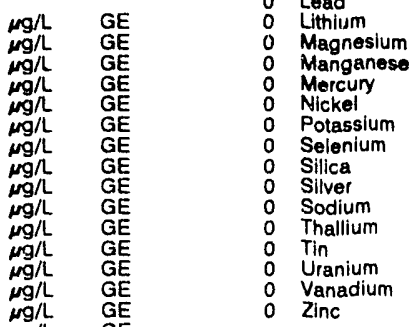

WELL EPT 11

MEASUREMENTS CONDUCTED IN THE FIELD

Sample date: $10 / 08 / 91$

Cepth to water: Not available

Sp. conductance: $8 \mu \mathrm{s} / \mathrm{cm}$

LABORATORY ANALYSES

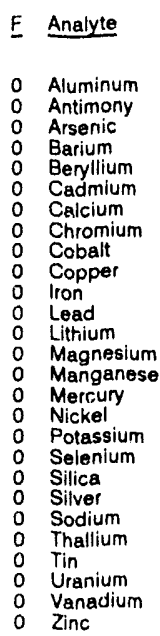

Result

Timi: : 8:10

PH: 4.7

Water temperalure: $15.8^{\circ} \mathrm{C}$

$<20$
$<2.0$
$<2.0$
$<3.0$
$<3.0$
$<2.0$
$<10$
$<4.0$
$<4.0$
$<4.0$
$<4.0$
$<3.0$
$<5.0$
$<2.0$
$<2.0$
$<0.20$
$<4.0$
$<500$
$<2.0$
14.400
$<2.0$
$<10$
$<2.0$
$<2.0$
$<20$
$<8.0$
$<2.0$

WELL EPT 12

MEASUREMENTS CONDUCTED IN THE FIELD

Sample date: 10/08/91

Depth to water: Not available

Water elevation: Not available

Sp. conductance: $7 \mu \mathrm{S} / \mathrm{cm}$

LABORATORY ANALYSES

\begin{tabular}{|c|c|}
\hline F Analyte & Result \\
\hline $\begin{array}{ll}0 & \text { Aluminum } \\
0 & \text { Antimony } \\
0 & \text { Arsenic } \\
0 & \text { Barium } \\
0 & \text { Beryllium } \\
0 & \text { Cadmium }\end{array}$ & $\begin{array}{l}<20 \\
<2.0 \\
<2.0 \\
<3.0 \\
<3.0 \\
<2.0\end{array}$ \\
\hline
\end{tabular}

Time: $6: 50$

Alkalinity: $0 \mathrm{mg} / \mathrm{L}$

Water temperature: $18.8^{\circ} \mathrm{C}$

Result

Mod Unit Lab

$\begin{array}{cc}\mu g / L & G E \\ \mu g / L & G E \\ \mu g / L & G E \\ \mu g / L & G E \\ \mu g / L & G E \\ \mu g / L & G E\end{array}$ 
WELL EPT 12 collected on 10/08/91, laboratory analyses (cont.)

\begin{tabular}{|c|c|c|c|}
\hline Analyte & Pesult & Mod & Unit \\
\hline $\begin{array}{l}\text { Calcium } \\
\text { Chromium } \\
\text { Cobalt } \\
\text { Coppor } \\
\text { Iron } \\
\text { Lead } \\
\text { Lithium } \\
\text { Magnesium } \\
\text { Manganese } \\
\text { Mercury } \\
\text { Nickol } \\
\text { Potassium } \\
\text { Selenium } \\
\text { Sllica } \\
\text { Silver } \\
\text { Sodium } \\
\text { Thallium } \\
\text { Tin } \\
\text { Uranium } \\
\text { Vanadium } \\
\text { Zine }\end{array}$ & $\begin{aligned} & 29 \\
&<4.0 \\
&<4.0 \\
&<4.0 \\
&<4.0 \\
&<3.0 \\
&<5.0 \\
& 2.5 \\
&<2.0 \\
&<0.20 \\
&<4.0 \\
&<500 \\
&<2.0 \\
& 12.800 \\
&<2.0 \\
& 31 \\
&<2.0 \\
&<2.0 \\
&<20 \\
&<8.0 \\
&<2.0\end{aligned}$ & J1 & 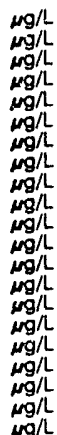 \\
\hline
\end{tabular}

WELL EPT 13

MEASUREMENTS CONDUCTED IN THE FIELD

Sample date: 10/09/81

Depth to water: Not avallable Water elevation: Not available
Sp. conductance: $7 \mathrm{~s} / \mathrm{cm}$

LABORATORY ANALYSES

\begin{tabular}{|c|c|c|c|}
\hline Analyte & Result & Mod & Unit \\
\hline $\begin{array}{ll}0 & \text { Aluminum } \\
0 & \text { Aluminum } \\
0 & \text { Antimony } \\
0 & \text { Antimony } \\
0 & \text { Arsenic } \\
0 & \text { Arsenic } \\
0 & \text { Barium } \\
0 & \text { Barium } \\
0 & \text { Beryllium } \\
0 & \text { Beryllium } \\
0 & \text { Cadmium } \\
0 & \text { Cadmium } \\
0 & \text { Calcium } \\
0 & \text { Calcium } \\
0 & \text { Chromium } \\
0 & \text { Chromium } \\
0 & \text { Cobalt } \\
0 & \text { Cobalt } \\
0 & \text { Copper } \\
0 & \text { Copper } \\
0 & \text { lron } \\
0 & \text { lron } \\
0 & \text { Lead } \\
0 & \text { Lead } \\
0 & \text { Lithium } \\
0 & \text { Lithlum } \\
0 & \text { Magnesium } \\
0 & \text { Magnesium } \\
0 & \text { Manganese } \\
0 & \text { Manganese } \\
0 & \text { Mercury } \\
0 & \text { Mercury } \\
0 & \text { Nickel } \\
0 & \text { Nickel } \\
0 & \text { Potassium } \\
0 & \text { Potassium } \\
0 & \text { Selenlum } \\
0 & \text { Selenium } \\
0 & \text { Silica } \\
0 & \text { Sillica } \\
0 & \text { Silver } \\
0 & \text { Silvet } \\
0 & \text { Sodium } \\
0 & \text { Sodium } \\
0 & \text { Thallium } \\
0 & \text { Thallium } \\
0 & \text { Tin } \\
0 & \text { Tin } \\
0 & \text { Uranium } \\
0 & \text { Vanadium } \\
0 & \text { Vanadium } \\
0 & \text { Zinc } \\
0 & \text { Zinc } \\
\text { and }\end{array}$ & $\begin{array}{l}<20 \\
<20 \\
<2.0 \\
<2.0 \\
<2.0 \\
<2.0 \\
<3.0 \\
<3.0 \\
<3.0 \\
<3.0 \\
<2.0 \\
<2.0 \\
449 \\
49 \\
<4.0 \\
<4.0 \\
<4.0 \\
<4.0 \\
<4.0 \\
<4.0 \\
<4.0 \\
<4.0 \\
<3.0 \\
<3.0 \\
<5.0 \\
<5.0 \\
3.8 \\
3.8 \\
<2.0 \\
<2.0 \\
<0.20 \\
<0.20 \\
<4.0 \\
<4.0 \\
<500 \\
<500 \\
<2.0 \\
<2.0 \\
12.100 \\
12.100 \\
<2.0 \\
<2.0 \\
<10 \\
<10 \\
<2.0 \\
<2.0 \\
<2.0 \\
<2.0 \\
<20 \\
<8.0 \\
<8.0 \\
<2.0 \\
<2.0\end{array}$ & $\begin{array}{l}\mathrm{J} 1 \\
\mathrm{~J} 1\end{array}$ & $\begin{array}{l}\mu g / L \\
\mu g / L \\
\mu g / L \\
\mu g / L \\
\mu g / L \\
\mu g / L \\
\mu g / L \\
\mu g / L \\
\mu g / L \\
\mu g / L \\
\mu g / L \\
\mu g / L \\
\mu g / L \\
\mu g / L \\
\mu g / L \\
\mu g / L \\
\mu g / L \\
\mu g / L \\
\mu g / L \\
\mu g / L \\
\mu g / L \\
\mu g / L \\
\mu g / L \\
\mu g / L \\
\mu g / L \\
\mu g / L \\
\mu g / L \\
\mu g / L \\
\mu g / L \\
\mu g / L \\
\mu g / L \\
\mu g / L \\
\mu g / L \\
\mu g / L \\
\mu g / L \\
\mu g / L \\
\mu g / L \\
\mu g / L \\
\mu g / L \\
\mu g / L \\
\mu g / L \\
\mu g / L \\
\mu g / L \\
\mu g / L \\
\mu g / L \\
\mu g / L \\
\mu g / L \\
\mu g / L \\
\mu g / L \\
\mu g / L \\
\mu g / L \\
\mu g / L \\
\mu g / L\end{array}$ \\
\hline
\end{tabular}

WELL EPT 14

MEASUREMENTS CONDUCTED IN THE FIELD

Sample date: 10/09/9

Depth to water: Not available

Water elevation: Not available
Sp. conductance: $7 \mathrm{ss} / \mathrm{cm}$

LABORATORY ANALYSES

F Analyte

- Aluminum

o Antimony

Antimony

Arsenic

Arsenic
Barium

Barium

Beryllium

Cadmium

Cadmium

Calcium

Chromium

Chromium

0 Cobalt

- Copper

o Copper

$\begin{array}{ll}0 & \text { Iron } \\ 0 & \text { Iron }\end{array}$

0 Lead

o Lead

- Lithium

Magnesium

Magnesium

Manganese

Mercury

O Mercury

0 Nickel

Potassium

Potassium

Selenium

Silica

Silica

Silver

Sodium

Sodium

Thallium

0 Tin

0 Tin

Uranium

Vanadium

0

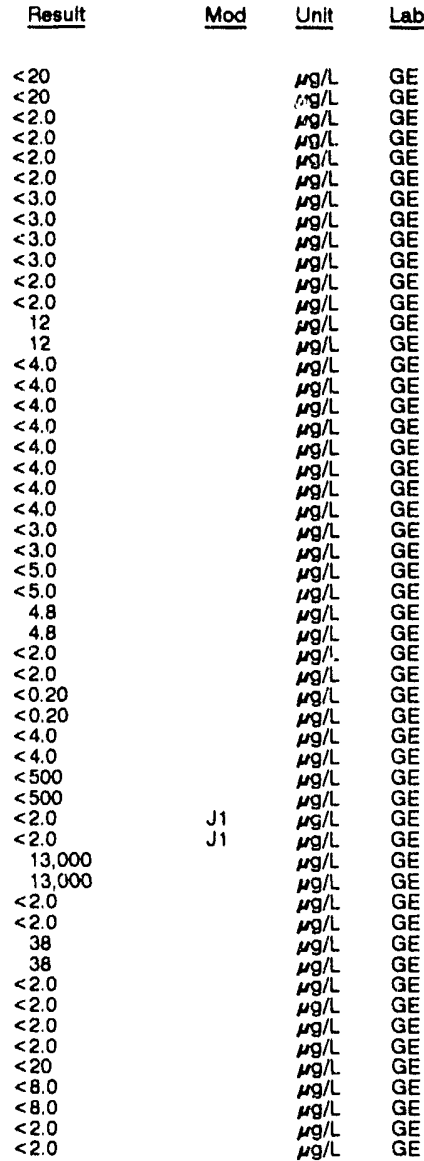

\section{WELL EPT 15}

MEASUREMENTS CONDUCTED IN THE FIELD

Sample date: 10/10/91

Depth to water: Not available

Walor elevation: Not availablo

Yp. conductance: B pS/cm

Time: $6: 45$

Al: 4.5

Water temperature: $23.3^{\circ} \mathrm{C}$

LABORATORY ANALYSES

\begin{tabular}{|c|c|c|c|c|}
\hline E & Analyte & Result & Mod & Unit \\
\hline $\begin{array}{l}0 \\
0 \\
0 \\
0 \\
0 \\
0 \\
0 \\
0 \\
0 \\
0 \\
0 \\
0 \\
0 \\
0 \\
0 \\
0 \\
0 \\
0 \\
0 \\
0 \\
0 \\
0\end{array}$ & $\begin{array}{l}\text { Aluminum } \\
\text { Antimony } \\
\text { Arsenic } \\
\text { Barium } \\
\text { Beryllium } \\
\text { Cadmium } \\
\text { Calcium } \\
\text { Chromium } \\
\text { Cobalt } \\
\text { Copper } \\
\text { lron } \\
\text { Lead } \\
\text { Lithium } \\
\text { Magnesium } \\
\text { Manganese } \\
\text { Mercury } \\
\text { Nickel } \\
\text { Potassiun } \\
\text { Selenium } \\
\text { Silica } \\
\text { Silver } \\
\text { Prdium }\end{array}$ & $\begin{array}{l}<20 \\
<2.0 \\
<2.0 \\
<3.0 \\
<3.0 \\
<2.0 \\
<10 \\
<4.0 \\
<4.0 \\
<4.0 \\
<4.0 \\
<3.0 \\
<5.0 \\
2.2 \\
<2.0 \\
<0.20 \\
<4.0 \\
<500 \\
<2.0 \\
11.900 \\
<2.0\end{array}$ & & $\begin{array}{l}\mu g / h \\
\mu g / L \\
\mu g / L \\
\mu g / L \\
\mu g / L \\
\mu g / L \\
\mu g / L \\
\mu g / L \\
\mu g / L \\
\mu g / L \\
\mu g / L \\
\mu g / L \\
\mu g / L \\
\mu g / h \\
\mu g / h \\
\mu g / L \\
\mu g / L \\
\mu g / L \\
\mu g / L \\
\mu g / L \\
\mu g / h\end{array}$ \\
\hline
\end{tabular}


WELL EPT 15 collected on 10/10/91, laboratory analyses (cont.)

\begin{tabular}{|c|c|c|c|}
\hline Analyte & Rescilt & Mod & Unit \\
\hline $\begin{array}{l}\text { Thallium } \\
\text { Tin } \\
\text { Uranium } \\
\text { Uranium } \\
\text { Vanadlum } \\
\text { Zinc }\end{array}$ & $\begin{array}{l}<2.0 \\
<2.0 \\
<20 \\
<20 \\
<8.0 \\
<2.0\end{array}$ & & $\begin{array}{l}\mu \mathrm{g} / \mathrm{h} \\
\mathrm{mg} / \mathrm{h} \\
\mathrm{mg} / \mathrm{h} \\
\mathrm{mg} / \mathrm{h} \\
\mu \mathrm{g} / \mathrm{h}\end{array}$ \\
\hline
\end{tabular}

\section{WELL EPT 16}

MEASUREMENTS CONDUCTED IN THE FIELD

Sample date: 10/10/91

Depth to water: Not available

Water elovallon: Not availa

LABORATORY ANALYSES
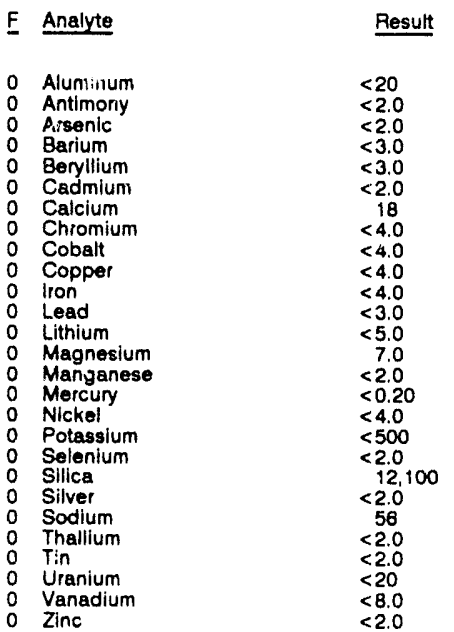

\section{WELLL EPT 17}

MEASUREMENTS CONDUCTED IN THE FIELD

Sample date: 10/11/81

Depth to water: Not available

Sp. conductance: $7 \mu \mathrm{S} / \mathrm{cm}$

LABORATORY ANALYSES

$\begin{array}{lll}\text { F Analyte } & \text { Result } \\ & \\ 0 & \text { Aluminum } & <20 \\ 0 & \text { Antimony } & <2.0 \\ 0 & \text { Arsenic } & <2.0 \\ 0 & \text { Barlum } & <3.0 \\ 0 & \text { Beryllium } & <3.0 \\ 0 & \text { Cadmium } & <2.0 \\ 0 & \text { Calcium } & <10 \\ 0 & \text { Chromium } & <4.0 \\ 0 & \text { Cobalt } & <4.0 \\ 0 & \text { Copper } & <4.0 \\ 0 & \text { lron } & <4.0 \\ 0 & \text { Lead } & <3.0 \\ 0 & \text { Lithium } & <5.0 \\ 0 & \text { Magnesium } & <2.0 \\ 0 & \text { Manganese } & <2.0 \\ 0 & \text { Mercury } & <0.20 \\ 0 & \text { Nickel } & <4.0 \\ 0 & \text { Potassium } & <500 \\ 0 & \text { Selenium } & 11.0 \\ 0 & \text { Silica } & <2.0 \\ 0 & \text { Silver } & 13 \\ 0 & \text { Sodium } & <2.0 \\ 0 & \text { Thallium } & <2.0 \\ 0 & \text { Tin } & <20 \\ 0 & \text { Uranium } & <.0 \\ 0 & \text { Uranium } & <2.0 \\ 0 & \text { Vanadium } & \\ 0 & \text { Zinc } & \end{array}$

Time: $8: 35$

Alkalinity: $0 \mathrm{mg} / \mathrm{h}$

Water temperature: $18.4^{\circ} \mathrm{C}$
WELL EPT 18

MEASUREMENTS CONDUCTED IN THE FIELD

Sample date: 10/11/81

Dapth to water: Not availablo

Sp. conductance: $8 \mu \mathrm{s} / \mathrm{cm}$

LABORATORY ANALYSES

F Analyte

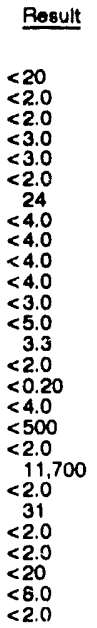

Time: $6: 50$

Alkalinity: $0 \mathrm{mg} / \mathrm{L}$

Water temperature: $22.0^{\circ} \mathrm{C}$

- Aluminum

- Antimony

0 Barium

o Beryllium

Calcium

0 Chromium

Cobalt

0 Iron

0 Lead

- Magneslum

Manganese

Nickel

Potassium

0 Selenium

o Silica

Sodium

0 Thallium

Uranium

Vanadium
Zlnc

Rosult

Mod Unit Lab

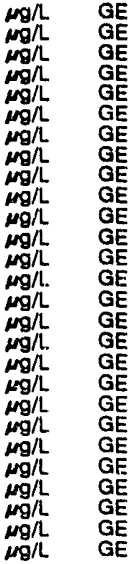

WELL EPT 19

MEASUREMENTS CONDUCTED IN THE FIELD

Sample date: 10/14/91

Depth to water: Not available

Water alevation: Not availabio

LABORATORY ANALYSES

E Analyte

Result

Time: $9: 15$

PH: 4.8 Alkalinity: $0 \mathrm{mg} / \mathrm{L}$

Water temperature: $16.3^{\circ} \mathrm{C}$
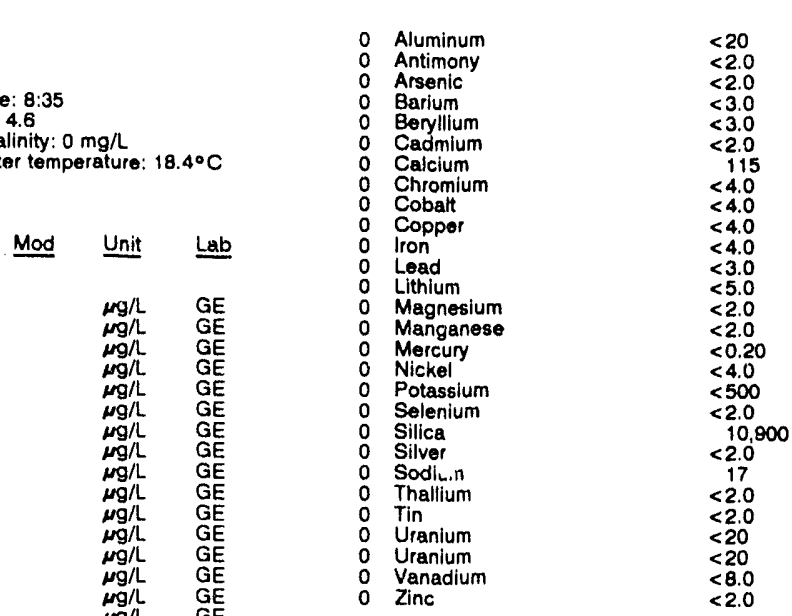

Mod Unit Lab

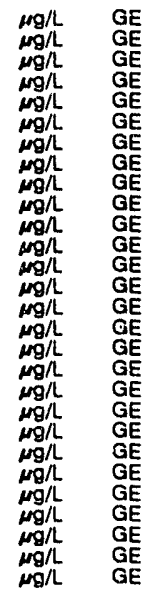

WELL EPT 20

MEASUREMENTS CONDUCTED IN THE FIELD

Sample date: $10 / 13 / \theta^{\circ}$

\begin{tabular}{|c|c|c|c|}
\hline Analyte & Result & Mod & Unit \\
\hline $\begin{array}{l}\text { Aluminum } \\
\text { Antimony } \\
\text { Arsenic } \\
\text { Barium } \\
\text { Beryllium }\end{array}$ & $\begin{array}{r}<20 \\
2.4 \\
<2.0 \\
<3.0 \\
<3.0\end{array}$ & & $\begin{array}{l}m g / L \\
\mu g / L \\
\mu g / L \\
\mu g / L \\
\mu g / L\end{array}$ \\
\hline
\end{tabular}

Depth to water: Not available

Sp. conductance: $6 \mu \mathrm{S} / \mathrm{cm}$

LABORATORY ANALYSES

Time: 13:30

Alk: 4.7 : 0

Water temperature: $25.0^{\circ} \mathrm{C}$

$\mu g / L$ GE 
QUALITY CONTROL SAMPLES

\begin{tabular}{|c|c|c|c|c|c|}
\hline E & Analyte & Result & Mod & Unit & tab \\
\hline $\begin{array}{l}0 \\
0 \\
0 \\
0 \\
0 \\
0 \\
0 \\
0 \\
0 \\
0 \\
0 \\
0 \\
0 \\
0 \\
0 \\
0 \\
0 \\
0 \\
0 \\
0 \\
0 \\
0 \\
0\end{array}$ & $\begin{array}{l}\text { Cadmium } \\
\text { Calcium } \\
\text { Chromium } \\
\text { Cobalt } \\
\text { Copper } \\
\text { lron } \\
\text { Lead } \\
\text { Lithium } \\
\text { Magnesium } \\
\text { Manganese } \\
\text { Mercury } \\
\text { Nickel } \\
\text { Potassium } \\
\text { Selenium } \\
\text { Silica } \\
\text { Sitver } \\
\text { Sodium } \\
\text { Thallium } \\
\text { Tin } \\
\text { Uranium } \\
\text { Uranium } \\
\text { Vanadium } \\
\text { Zinc }\end{array}$ & $\begin{array}{r}<2.0 \\
<11 \\
<4.0 \\
<4.0 \\
8.4 \\
<4.0 \\
<3.0 \\
<5.0 \\
10 \\
<2.0 \\
<0.20 \\
<4.0 \\
<500 \\
<2.0 \\
11.710 \\
<2.0 \\
15 \\
<20 \\
<2.0 \\
<20 \\
<20 \\
<80 \\
<2.0\end{array}$ & & $\begin{array}{l}\mu g / L \\
\mu g / L \\
\mu g / L \\
\mu g / L \\
\mu g / L \\
\mu g / L \\
\mu g / L \\
\mu g / L \\
\mu g / L \\
\mu g / L \\
\mu g / L \\
\mu g / L \\
\mu g / L \\
\mu g / L \\
\mu g / L \\
\mu g / L \\
\mu g / L \\
\mu g / L \\
\mu g / L \\
\mu g / L \\
\mu g / L \\
\mu g / L \\
\mu g / L\end{array}$ & $\begin{array}{l}\mathrm{GE} \\
\mathrm{GE} \\
\mathrm{GE} \\
\mathrm{GE} \\
\mathrm{GE} \\
\mathrm{GE} \\
\mathrm{GE} \\
\mathrm{GE} \\
\mathrm{GE} \\
\mathrm{GE} \\
\mathrm{GE} \\
\mathrm{GE} \\
\mathrm{GE} \\
\mathrm{GE} \\
\mathrm{GE} \\
\mathrm{GE} \\
\mathrm{GE} \\
\mathrm{GE} \\
\mathrm{GE} \\
\mathrm{GE} \\
\mathrm{GE} \\
\mathrm{GE} \\
\mathrm{GE}\end{array}$ \\
\hline
\end{tabular}

WE:.L. EPI 22 collected on 10/15/91, laboratory analyses (cont.)

\begin{tabular}{|c|c|c|c|}
\hline Analyte & Result & Mod & Unit \\
\hline $\begin{array}{l}\text { Silver } \\
\text { Sodium } \\
\text { Thallium } \\
\text { Tin } \\
\text { Uranium } \\
\text { Vanadium } \\
\text { Zinc }\end{array}$ & $\begin{array}{l}<2.0 \\
17 \\
<2.0 \\
<2.0 \\
<20 \\
<8.0 \\
<2.0\end{array}$ & & $\begin{array}{l}\mu g / L \\
\mu g / L \\
\mu g / L \\
\mu g / L \\
\mu g / L \\
\mu g / L \\
\mu g / L\end{array}$ \\
\hline
\end{tabular}

WELL EPT 23

MEASUREMENTS CONDUCTED IN THE FIELD

Sampie date: $10 / 15 / 91$

Depth to water: Not available

Watel elevation: Not available
Sp. conductance: $4 \mu \mathrm{S} / \mathrm{cm}$

Alkalinity: $0 \mathrm{mg} / \mathrm{h}$

Water temperature: $22.1^{\circ} \mathrm{C}$

LABORATORY ANALYSES

\begin{tabular}{|c|c|c|c|}
\hline Analyte & Resull & Mod & Unit \\
\hline $\begin{array}{l}\text { Aluminum } \\
\text { Antimony } \\
\text { Arsenic } \\
\text { Barium } \\
\text { Beryillum } \\
\text { Cadmium } \\
\text { Calcium } \\
\text { Chromium } \\
\text { Cobalt } \\
\text { Coppet } \\
\text { Iron } \\
\text { Lead } \\
\text { Lithium } \\
\text { Magnesium } \\
\text { Manganese } \\
\text { Mercury } \\
\text { Nicke! } \\
\text { Potassium } \\
\text { Selenium } \\
\text { Silica } \\
\text { Silver } \\
\text { Sodium } \\
\text { Thallium } \\
\text { Tin } \\
\text { Uranium } \\
\text { Uranium } \\
\text { Vanadium }\end{array}$ & $\begin{array}{l}<20 \\
<2.0 \\
<20 \\
<3.0 \\
<3.0 \\
<2.0 \\
<10 \\
<4.0 \\
<40 \\
<4.0 \\
<4.0 \\
<3.0 \\
<5.0 \\
<2.0 \\
<2.0 \\
<0.20 \\
<4.0 \\
<500 \\
<2.0 \\
10.300 \\
<2.0 \\
49 \\
<20 \\
<2.0 \\
<20 \\
<20 \\
<8.0 \\
<20\end{array}$ & & $\begin{array}{l}\mu g / L \\
\mu g / L \\
\mu g / L \\
\mu g / L \\
\mu g / L \\
\mu g / L \\
\mu g / L \\
\mu g / L \\
\mu g / L \\
\mu g / L \\
\mu g / L \\
\mu g / L \\
\mu g / L \\
\mu g / L \\
\mu g / L \\
\mu g / L \\
\mu g / L \\
\mu g / L \\
\mu g / L \\
\mu g / L \\
\mu g / L \\
\mu g / L \\
\mu g / L \\
\mu g / L \\
\mu g / L \\
\mu g / L \\
\mu g / L \\
\mu g / L\end{array}$ \\
\hline
\end{tabular}

WELL EPT 21

MEASUAEMENTS CONDUCTED IN THE FIELO

Sample date: $10 / 14 / 91$

Depth to water: Not available

Water elevation: Not availab

Sp. conductance : $2 \mu \mathrm{S} / \mathrm{cm}$

Time: $6: 15$

PH 4.2

Water temperature $19.8^{\circ} \mathrm{C}$

ABORATORY ANALYSES

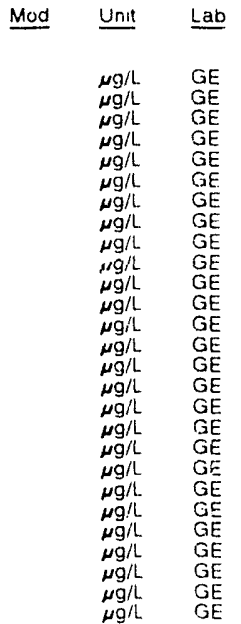

E Analyte
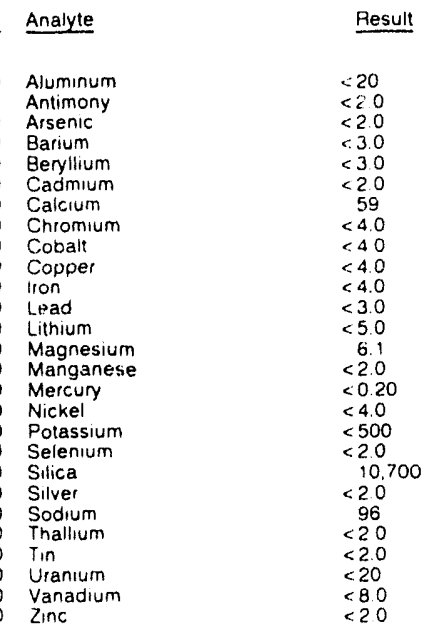

\section{WELL EPT 22}

MEASUREMENTS CONDUCTED IN THE FIELD

Sample date 10/15/91

Depth to water Not avallable

Water elevation Not availab

ABORATORY ANALYSES

\begin{tabular}{|c|c|c|c|}
\hline Analyte & Result & Mod & $\underline{\text { Ur, } 1}$ \\
\hline $\begin{array}{l}\text { Aluminum } \\
\text { Antimony } \\
\text { Alsenic } \\
\text { Barium } \\
\text { Beryllium } \\
\text { Cadmium } \\
\text { Calcium } \\
\text { Chromiurn } \\
\text { Cobalt } \\
\text { Copper } \\
\text { iron } \\
\text { Lead } \\
\text { Lithium } \\
5 \text { Magnesium } \\
0 \text { Manganese } \\
0 \text { Mercury } \\
0 \text { Nickel } \\
0 \text { Potassium } \\
0 \text { Selenium } \\
0 \text { Silica }\end{array}$ & $\begin{array}{l}<20 \\
<20 \\
<20 \\
<30 \\
<30 \\
<20 \\
24 \\
<40 \\
<40 \\
<40 \\
400 \\
<30 \\
<50 \\
<20 \\
<20 \\
<020 \\
<40 \\
<500 \\
<20 \\
9550\end{array}$ & & $\begin{array}{l}\mu g / h \\
\mu g / h \\
\mu g / h \\
\mu g / L \\
\mu g / L \\
\mu g / h \\
\mu g / L \\
\mu g / L \\
\mu g / L \\
\mu g / L \\
\mu g / h \\
\mu g / L \\
\mu g / L \\
\mu g / L \\
\mu g / h \\
\mu g / L \\
\mu g / h \\
\mu g / h \\
\mu g / L \\
\mu g / L\end{array}$ \\
\hline
\end{tabular}

\section{WELL EPT 24}

MEASUREMENTS UUNDUCTEO IN THE FIELD

Sample date 10/16/91

Depth 10 watel. Not available

Wa:er elevation: Not avaliable

LABORATORY ANALYSES

$\begin{array}{ll}\text { F } & \text { Analyte } \\ & \\ 0 & \text { Aluminum } \\ 0 & \text { Antimony } \\ 0 & \text { Arsenic } \\ 0 & \text { Barlum } \\ 0 & \text { Berylium } \\ 0 & \text { Cadmium } \\ 0 & \text { Calcium } \\ 0 & \text { Chromium } \\ 0 & \text { Cobalt } \\ 0 & \text { Copper } \\ 0 & \text { tron } \\ 0 & \text { Lead } \\ 0 & \text { Lithium } \\ 0 & \text { Magnesium } \\ 0 & \text { Manganese } \\ 0 & \text { Mercury } \\ 0 & \text { Yi.kel } \\ 0 & \text { Fotassium } \\ 0 & \text { Selenium } \\ 0 & \text { Silica } \\ 0 & \text { Silver } \\ 0 & \text { Sodium } \\ 0 & \text { Thallum } \\ 0 & \text { Tin } \\ 0 & \text { Uranium } \\ 0 & \text { Uranium } \\ 0 & \text { Variadium } \\ 0 & \text { Zinc } \\ & \end{array}$

Time 820

$\mathrm{pH} 46$

Water temperature $20.6^{\circ} \mathrm{C}$

Zinc
Time 8:40

pH: 4.2

Water temperature: $18.0^{\circ} \mathrm{C}$

Result Mod Unit Lab

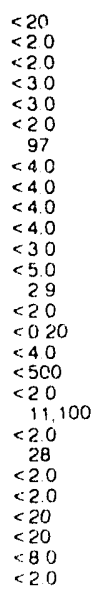

$\begin{array}{ll}\mu g / L & G E \\ \mu g / L & G E \\ \mu g / L & G E \\ \mu / L & G E \\ \mu g / L & G E \\ \mu g / L & G E \\ \mu g / L & G E \\ \mu g / L & G E \\ \mu / L & G E \\ \mu g / L & G E \\ \mu g / L & G E \\ \mu g / L & G E \\ \mu g / L & G E \\ \mu / L & G E \\ \mu g / L & G E \\ \mu g / L & G E \\ \mu g / L & G E \\ \mu g / L & G E \\ \mu g / L & G E \\ \mu g / L & G E \\ \mu g / L & G E \\ \mu g / L & G E \\ \mu g / L & G E \\ \mu g / L & G E \\ \mu g / L & G E \\ \mu g / L & G E \\ \mu g / L & G E \\ \mu g / L & G E\end{array}$ 
WELL EPT 25

MEASUREMENTS CONDUCTED IN THE FIELD

Sample dalo: 10/10101

Dopth to water: Not avilable

Sp. conductance: $5, \mathrm{~A} / \mathrm{cm}$

IABORATOFY ANULYSES

\begin{tabular}{|c|c|}
\hline E Analyte & Result \\
\hline 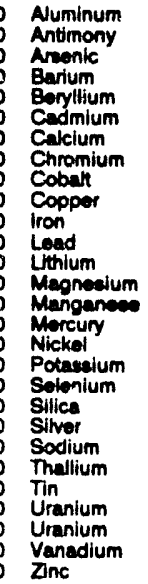 & $\begin{array}{l}<20 \\
<2.0 \\
<2.0 \\
<3.0 \\
<3.0 \\
<2.0 \\
30 \\
<4.0 \\
<4.0 \\
<4.0 \\
<4.0 \\
<3.0 \\
<5.0 \\
3.6 \\
<-.0 \\
<0.20 \\
<4.0 \\
<500 \\
<2.0 \\
11.000 \\
<2.0 \\
46 \\
<2.0 \\
<2.0 \\
<20 \\
<20 \\
<8.0 \\
5.6\end{array}$ \\
\hline
\end{tabular}

\section{WELL EPT 26}

MEASUAEMENTS CONDUCTED IN THE FIELD

Sample date: 10/17/81

Wepth to water: Not available

Sp. conductance: 7 $\mathrm{S} / \mathrm{cm}$

LABOFATORY ANALYSES

\begin{tabular}{|c|c|}
\hline Anayte & Rosult \\
\hline 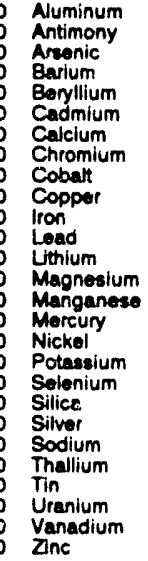 & $\begin{array}{l}<20 \\
<2.0 \\
<2.0 \\
<3.0 \\
<3.0 \\
<2.0 \\
38 \\
<4.0 \\
<4.0 \\
<4.0 \\
<4.0 \\
<3.0 \\
<5.0 \\
<2.0 \\
<2.0 \\
<0.20 \\
<4.0 \\
<500 \\
<2.0 \\
10.300 \\
<2.0 \\
24 \\
<2.0 \\
<2.0 \\
<20 \\
<8.0 \\
<2.0\end{array}$ \\
\hline
\end{tabular}

WELL EPT 27

MEASUREMENTS CONDUCTED IN THE FIELD

Semple date: 10/17/91

Depth to water: Not available

Water otevation: Nol available

Sp. conductance: 6 is $/ \mathrm{cm}$

LABORATORY ANALYSES

\begin{tabular}{|c|c|c|c|c|}
\hline E & Anabrte & Resul: & Mod & Unit \\
\hline $\begin{array}{l}0 \\
0 \\
0 \\
0 \\
0\end{array}$ & $\begin{array}{l}\text { Aluminum } \\
\text { Antimony } \\
\text { Arsenic } \\
\text { Barium } \\
\text { Beryllium }\end{array}$ & $\begin{array}{l}<20 \\
<2.0 \\
<2.0 \\
<3.0 \\
<3.0\end{array}$ & & $\begin{array}{l}m g h \\
\operatorname{mg} h \\
\operatorname{mg} h \\
\operatorname{mg} h\end{array}$ \\
\hline
\end{tabular}

Time: 6:50

PH: 4.3 Alkalinity: $0 \mathrm{mg}$

Alkalinity: $0 \mathrm{mg} / \mathrm{h}$ : $19.50 \mathrm{C}$

GE
WELL EPT 27 collected on 10/17/91, laboratory anaiywes (cont)

\begin{tabular}{|c|c|c|c|}
\hline Analyte & Result & Mod & Unit \\
\hline $\begin{array}{l}\text { Cadmium } \\
\text { Calcium } \\
\text { Chromium } \\
\text { Cobalt } \\
\text { Copper } \\
\text { Iron } \\
\text { Load } \\
\text { Lthium } \\
\text { Magnesium } \\
\text { Manganese } \\
\text { Mercury } \\
\text { Nickel } \\
\text { Potassium } \\
\text { Solonium } \\
\text { Silliea } \\
\text { Silver } \\
\text { Sodium } \\
\text { Thallium } \\
\text { Tin } \\
\text { Uranium } \\
\text { Uranium } \\
\text { Vanadium }\end{array}$ & $\begin{array}{l}<2.0 \\
74 \\
<4.0 \\
<4.0 \\
<4.0 \\
<4.0 \\
<3.0 \\
<5.0 \\
5.0 \\
<2.0 \\
<0.20 \\
<4.0 \\
<300 \\
<2.0 \\
11.200 \\
<2.0 \\
449 \\
<2.0 \\
<2.0 \\
<20 \\
<20 \\
<8.0 \\
<2.0\end{array}$ & $\sqrt{2}$ & 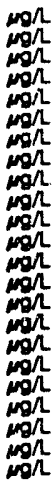 \\
\hline
\end{tabular}

WELL EPT 28

MEASUREMENTS CONDUCTED IN THE FIELD

Sample date: $10 / 18 / 91$

Depth to water: Not available Nepter olevation: Not avaliablo

Sp. conductance: $7 \mu \mathrm{s} / \mathrm{cm}$

PH: 4.5

Water temperature: $14.8^{\circ} \mathrm{C}$

ABORATORY ANALYSES

F Analyte

Result

Mod Unk Lab

- Aluminum

0 Antimony

0 Barium

o Beryllium

o Caicium

o) Chromium

o Cobalt

0 tron

0 Lead

o Lthlum

o Magnganese

o Nickel

O Potassium

o Selenium

o Silice

O Sodium

o Thallium

O $\operatorname{Tin}_{\text {Uranium }}$

o Uranium
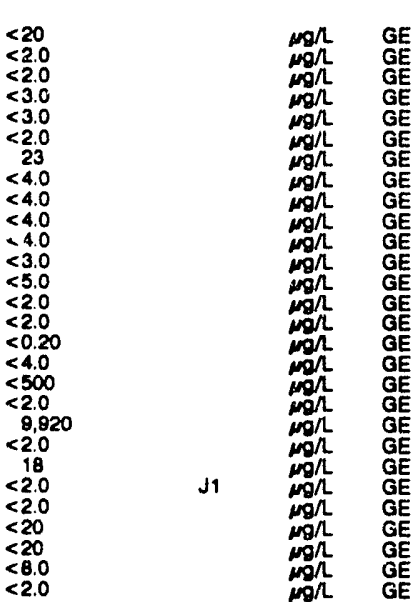

WELL EPT 29

MEASUAEMENTS CONDUCTED IN THE FIELD

Sample date: 10/18/91

Depth to water: Not availabie

Wp conductance: 2 availablo

ABORATORY ANALYSES

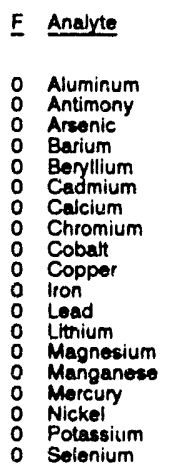

\begin{tabular}{l} 
Result \\
\multicolumn{2}{r}{} \\
$<20$ \\
$<2.0$ \\
$<2.0$ \\
$<3.0$ \\
$<3.0$ \\
$<2.0$ \\
68 \\
$<4.0$ \\
$<4.0$ \\
$<4.0$ \\
$<4.0$ \\
$<3.0$ \\
$<5.0$ \\
2.3 \\
$<2.0$ \\
$<0.20$ \\
$<4.0$ \\
$<500$ \\
$<2.0$
\end{tabular}

Time: 6.50

$\mathrm{PH}: 4.2$

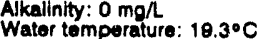


QUALITY CONTROL SAMPLES

WELL EPT 29 collected on 10/18/91, laboratory analyees (cont)

\begin{tabular}{|c|c|c|c|}
\hline F Analyte & Roesult & Mod & Unit \\
\hline $\begin{array}{ll}0 & \text { Sllica } \\
0 & \text { Silver } \\
0 & \text { Sodium } \\
0 & \text { Thallium } \\
0 & \text { Tn } \\
0 & \text { Uranium } \\
0 & \text { Vanadium } \\
0 & \text { Zinc }\end{array}$ & $\begin{array}{rl} & 10,100 \\
< & 2.0 \\
40 & 40 \\
<2.0 \\
<2.0 \\
<20 \\
<8.0 \\
<2.0\end{array}$ & J1 & 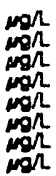 \\
\hline
\end{tabular}

\section{WELL EPT 30}

MEASUREMENTS CONDUCTED IN THE FIELD

Sample date: 10/21/81

Wepth to water: Not avaliable

Water olevation: Not avallablo
Sp. conductance: 5 p $\$ / \mathrm{cm}$

LABORATORY GRTMLYSF S

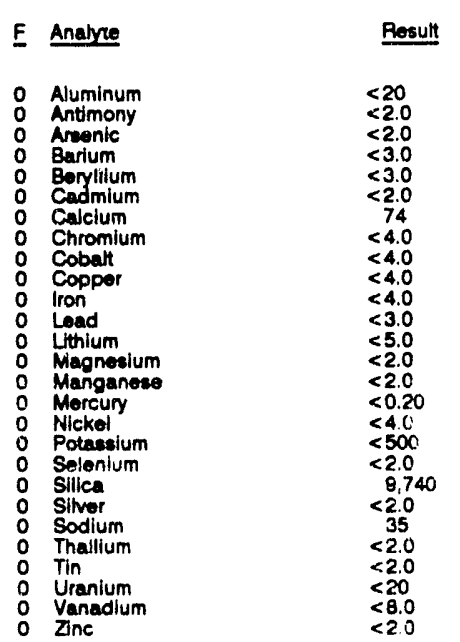

\section{WELL EPT 31}

RAEASURFMENTS CONDUCTEO IN THE FIELC

Sumple date: 10/21/91

Eopth to water Nol availat :

Water olevation: Nor availat

LABORATOAY ANALYSES

F Analyte

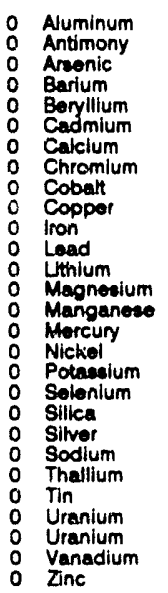

Timo: $6: 50$

PH: 4.5 .

Water tomperature: $21.0^{\circ} \mathrm{C}$

Tirre: 845

Alkalifity: $0 \mathrm{mgh}$

Weter cemperature: $17.6^{\circ} \mathrm{C}$

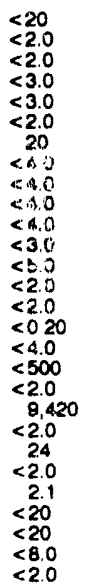

Mod Unit Lab

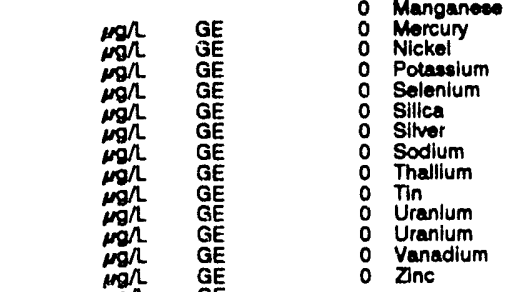

WELL EPT 33

MEASUREMENTS CONDUCTED IN THE FIELO

Sample date: 10/22/81

Dopth to water: Not avallable

Water olevatien: Not available
Sp. conductance: $10 \mathrm{~s} / \mathrm{cm}$

LABOPATORY ANALYSES

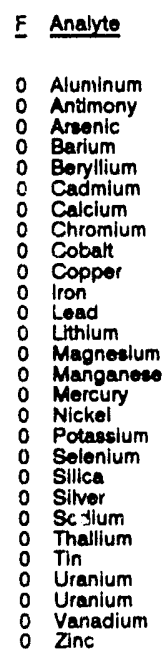

Rosuit Mod Unit Lيb

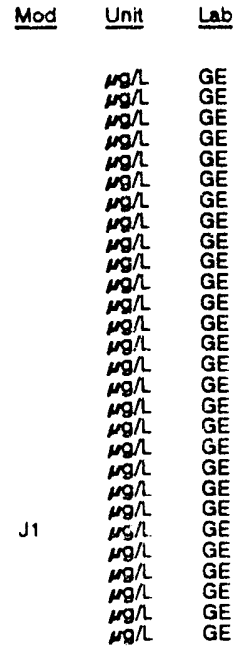

E Analyte

WELL EPT 34

MEASUREMENTS CONDUCTED IN THE FIELD

Semple date: 10/22/91

Depth to water: Not avaliable

Water olevation: Not availablo

LABORATORY ANALYSES
WELL EPT 32

MEASUREMENTS CONDUCTED IN THE FIELD

Sample date: 10/21/O1
Depth to water: Not avalable
Wator olovation: Not avallable
Sp. conductence: 6 S $/ \mathrm{cm}$

LABOFATORY ANALYSES

\begin{tabular}{|c|c|c|c|c|}
\hline Analyte & Ressult & Mod & Unit & Lab \\
\hline 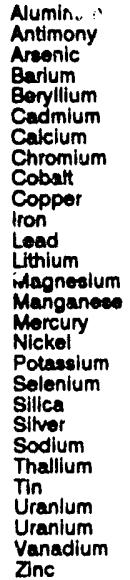 & $\begin{array}{l}<20 \\
<2.0 \\
<2.0 \\
<3.0 \\
<3.0 \\
<2.0 \\
35 \\
<4.0 \\
<4.0 \\
10 \\
<4.0 \\
<3.0 \\
<5.0 \\
5.8 \\
<2.0 \\
<0.20 \\
<4.0 \\
<500 \\
<2.0 \\
8.460 \\
<2.0 \\
344 \\
<2.0 \\
<2.0 \\
<20 \\
<20 \\
<8.0 \\
2.8\end{array}$ & J1 & 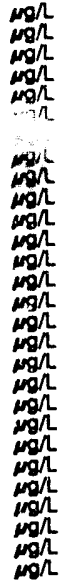 & $\begin{array}{l}\mathrm{GE} \\
\mathrm{GE} \\
\mathrm{GE} \\
\mathrm{GE} \\
\mathrm{GE} \\
\mathrm{GE} \\
\mathrm{GE} \\
\mathrm{GE} \\
\mathrm{GE} \\
\mathrm{GE} \\
\mathrm{GE} \\
\mathrm{GE} \\
\mathrm{GE} \\
\mathrm{GE} \\
\mathrm{GE} \\
\mathrm{GE} \\
\mathrm{GE} \\
\mathrm{GE} \\
\mathrm{GE} \\
\mathrm{GE} \\
\mathrm{GE} \\
\mathrm{GE} \\
\mathrm{GE} \\
\mathrm{GE} \\
\mathrm{GE} \\
\mathrm{GE} \\
\mathrm{GE} \\
\mathrm{GE}\end{array}$ \\
\hline
\end{tabular}

Time: 10:00

Akralinity: $0 \mathrm{mon}$

Water temperature: $18.8^{\circ} \mathrm{C}$

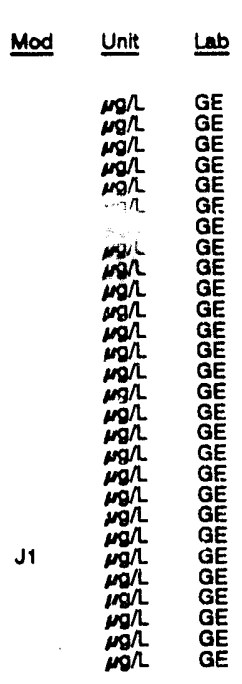

\section{Time: $8: 25$}

Nikalinity: 0 mor

Water tomporature: $19.5^{\circ} \mathrm{C}$

Mod Unit Lab

\begin{tabular}{|c|c|c|}
\hline Rosult & Mod & Unit \\
\hline $\begin{array}{l}<20 \\
<2.0 \\
2.8 \\
<3.0 \\
<3.0 \\
<2.0 \\
<10 \\
<4.0 \\
<4.0 \\
<4.0 \\
<4.0 \\
<3.0 \\
<5.0 \\
<2.0 \\
<2.0 \\
<0.20 \\
<4.0 \\
<500 \\
<2.0 \\
<.180 \\
<2.0 \\
75 \\
<2.0 \\
<2.0 \\
<20 \\
<20 \\
<8.0 \\
18\end{array}$ & & 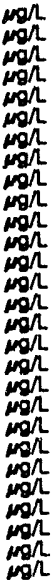 \\
\hline
\end{tabular}

Time: $6: 55$

PH: 4.1 . 0

Water temperature: $18.6^{\circ} \mathrm{C}$

\begin{tabular}{lllll} 
F Analyte & Result & Mod & Unit & Lab \\
\cline { 3 - 5 } & & $<20$ & & \\
0 & Aluminum & $<2.0$ & $\mathrm{mg} /$ & $\mathrm{GE}$ \\
0 & Antimony & $<2.0$ & $\mathrm{mgh}$ & $\mathrm{GE}$ \\
0 & Arsenic & $<3.0$ & $\mathrm{mgh}$ & $\mathrm{GE}$ \\
0. & Barium & $\mathrm{mgh}$ & $\mathrm{GE}$
\end{tabular}




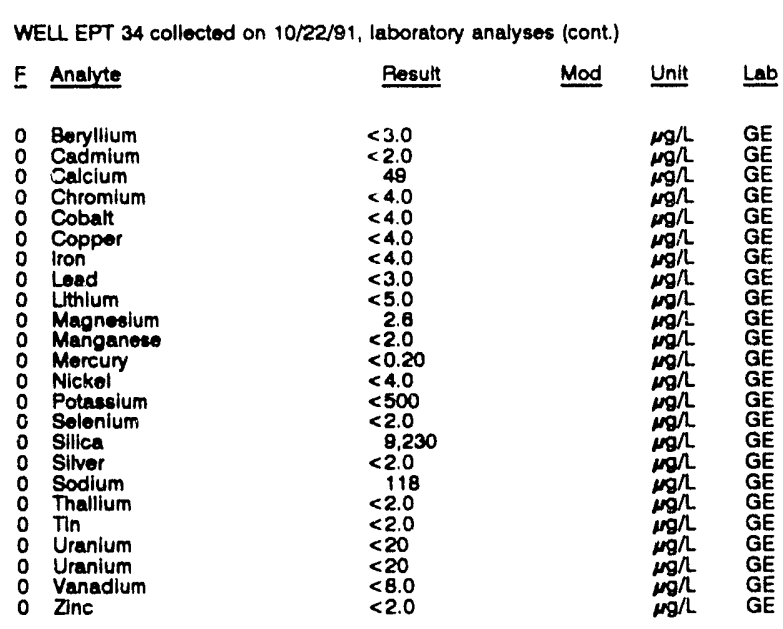

WELL EPT 36 collected on 10/23/91, laboratory analyeer (cont)

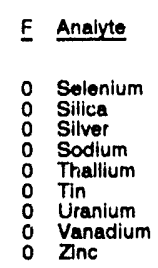

Pesult

$<2.0$
8,350
$<2.0$
113
$<2.0$
2.2
$<20$
$<8.0$
3.1

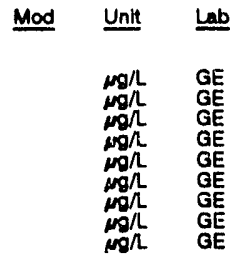

\section{WELL EPT 37}

MEASUREMENTS CONDUCTED IN THE FIELD

Sample date: 10/23/91

Depth to water: Not avalable

Water olovation: Not avaliablo

Sp. conductanco: O ps/cm

ABORATORY ANALYSES

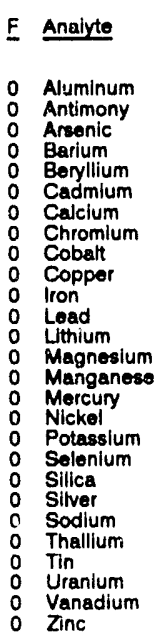

Time: 12:45

PH: 4.7 Alkalinity: $0 \mathrm{mgh}$

Alkalinity: $0 \mathrm{mgh}$, $25.1^{\circ} \mathrm{C}$

Depth to wator: Not availabie

Water olevation: Not availabie
Sp. conductence: $8 \mu \mathrm{s} / \mathrm{cm}$

LABORATORY ANALYSES

E Analyte

- Aluminum

0 Arsenic

0 Barium

Boryllium

Calcium

Cotralt

Copaper

$\lim n$

Load

Magnesium

Manganese

inercury

Potassium

Selenium

Sillice

Silver

Thallium

Tin

Uranium

0 Vanadium

Zinc
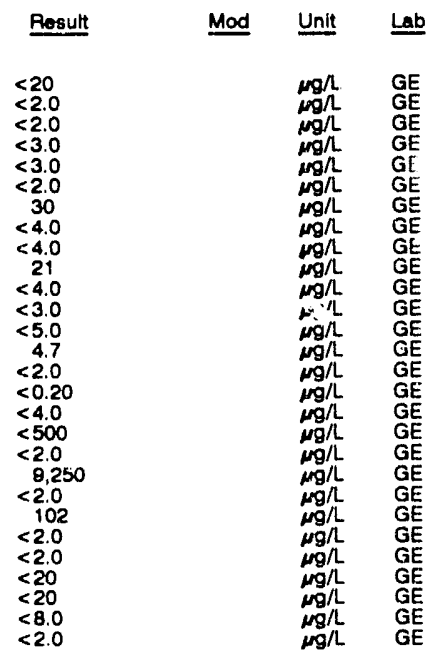

\section{WELL EPT 36}

MEASUREMENTS CONDUCTED IN THE FIELD

Sample date: 10/23/81

Depth to water: Not availabie

Water elevation: Not avallable

LABORATORY ANALYSES

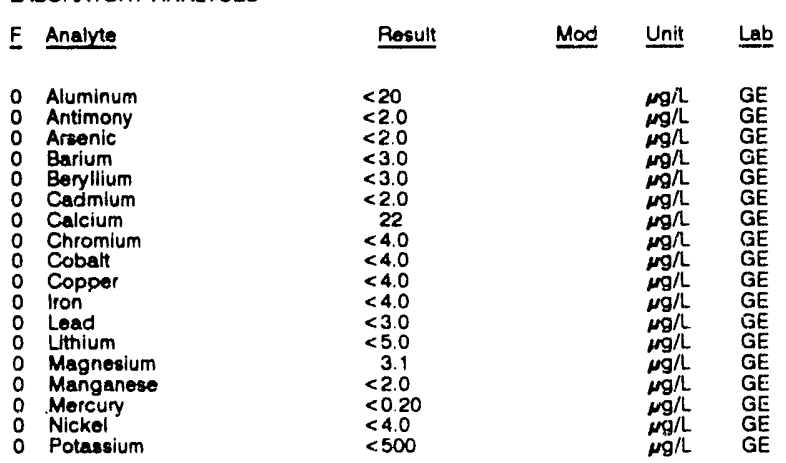

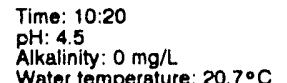

Water temperature: $20.7^{\circ} \mathrm{C}$

\section{WELL EPT 38}

MEASUREMENTS CONDUCTED IN THE FIELD

Sample date: 10/24/91

Depth to water: Not available

Wator elovation. Not availa

LABOPATORY ANALYSES

\section{F Analyte}

0 Aluminum

Antimony

Arsenic

Barium.

Cadmium

Calcium

Cobatt

Copper

0 lron

Lead

- Magnesium

0 Mercury

o Nickel

Potassium

O Selenium

S Silver

Sodium

Thallun

Tin

Vanadium
Manganese

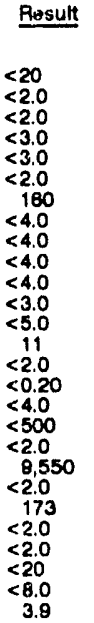

Time: 5:40

PH: 4.4 . $0 \mathrm{mon}$

Water tomperature: $20.8^{\circ} \mathrm{C}$

Mod Unit Lab

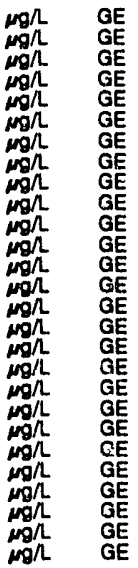

Time: 8:35

pH: 4.5

Water toinperature: $20.6^{\circ} \mathrm{C}$

Rosult Mad Unit Lab

$<20$
$<2.0$
$<2.0$
$<3.0$
$<3.0$
$<2.0$
$<10$
$<4.0$
$<4.0$
$<4.0$
$<4.0$
$<3.0$
$<5.0$
$<2.0$
$<2.0$
$<0.20$
$<4.0$
$<500$
$<2.0$
8,270
$<2.0$
128
$<2.0$
$<2.0$
$<20$
$<8.0$
$<2.0$ 


\section{QUALITY CONTROL SAMPLES}

WELL EPT 39

MEASUREMENTS CONDUCTED IN THE FIELD

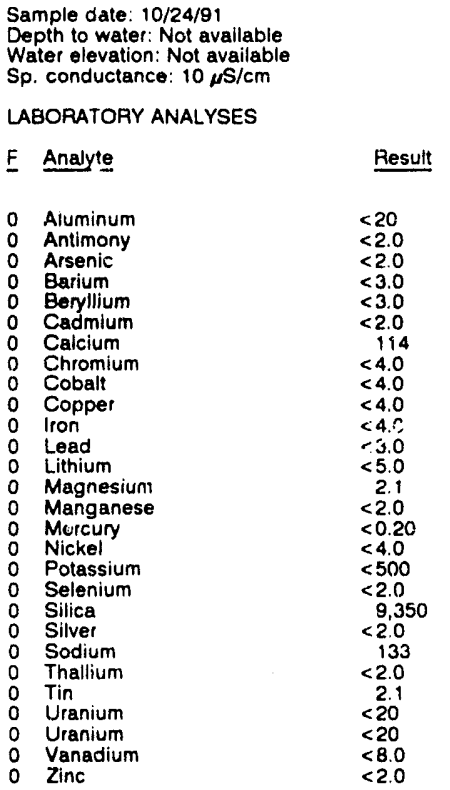

\section{WELL EPT 40}

MEASUREMENTS CONDUCTED IN THE FIELD

Sample date: 10/25/91

Depth to water: Not available

Water elevation: Not available

LABORATORY ANALYSES

$\begin{array}{lll}\text { E Analyte } & \text { Result } \\ & \text { Aluminum } & \\ 0 & \text { Alum } & <20 \\ 0 & \text { Antimony } & <2.0 \\ 0 & \text { Arsenic } & <2.0 \\ 0 & \text { Barium } & <3.0 \\ 0 & \text { Beryllium } & <3.0 \\ 0 & \text { Cadmium } & <2.0 \\ 0 & \text { Calcium } & <10 \\ 0 & \text { Chromium } & <4.0 \\ 0 & \text { Cobalt } & <4.0 \\ 0 & \text { Copper } & <4.0 \\ 0 & \text { lron } & <4.0 \\ 0 & \text { Lead } & <3.0 \\ 0 & \text { Lithium } & <5.0 \\ 0 & \text { Magnesium } & 3.4 \\ 0 & \text { Manganese } & <2.0 \\ 0 & \text { Mercury } & 0.40 \\ 0 & \text { Nickel } & <4.0 \\ 0 & \text { Potassium } & <500 \\ 0 & \text { Selenium } & <2.0 \\ 0 & \text { Silica } & 9.430 \\ 0 & \text { Silvet } & <2.0 \\ 0 & \text { Sodium } & 137 \\ 0 & \text { Thallium } & <2.0 \\ 0 & \text { Tin } & <2.0 \\ 0 & \text { Uranium } & <20 \\ 0 & \text { Vanadium } & <8.0 \\ 0 & \text { Zinc } & <2.0\end{array}$

WELL EPT 41

MEASUREMENTS CONDUCTED IN THE FIELD

Sample date: 10/25/81

Depth to water: Not available

Water elevation: Not available

Sp. conductance: $10 \mu \mathrm{S} / \mathrm{cm}$

LABORATORY ANALYSES

E Analyte

Result

Aluminum

Antimony

0 Arsenic

Beryllium
Time: $6: 45$
pH: 3.7

Alkalinity: $0 \mathrm{mg} / \mathrm{L}$

Water temperature: $22.5^{\circ} \mathrm{C}$

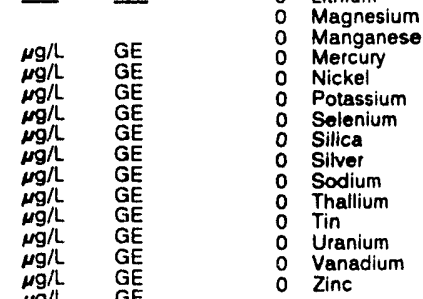

WELL EPT 42

MEASUREMENTS CONDUCTED IN THE FIELD

Sample date: 10/28/91

Depth to water: Not available

Water elevation: Not available
Sp. conductance: $8 \mu \mathrm{S} / \mathrm{cm}$

LABORATORY ANALYSES

F Analyte

- Aluminum

- Arsenic

Barium

Cadium

- Calcium

Chromium

Cobalt

o ron

0 Lead

Magnesium

Manganese

Mercury

Potassium

0 Selenium

Silica

Silver

Sodium

Thallium

Uranium

Vanadiu

Result

$<20$

$<2.0$
$<2.0$
$<3.0$

$<3.0$
$<2.0$

11
$<4.0$

$<4.0$

$<4.0$

$<4.0$
$<3.0$

$<2.0$

$<2.0$
$<0.20$

$<4.0$

$<500$
$<2.0$
8,690

$<2.0$

170
$<2.0$

$<2.0$

$<8.0$

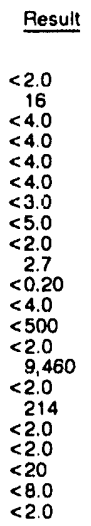

Mod Unit Lab

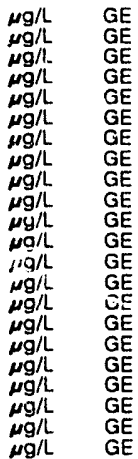

$G E$
$G E$
$G E$
$G E$
$G E$
$G E$
$G E$
$G E$
$G E$
$G E$
$G E$
$G E$
$G E$
$G E$
$G E$
$G E$
$G E$
$G E$
$G E$
$G E$
$G E$
$G E$
$G E$
$G E$

WELL EPT 43

MEASUREMENTS CONOUCTED IN THE FIELD

Sample date: 10/28/91 Depth to water: Not available Sp. conductance: $\theta$ uscm

Time: $6: 15$

PH: 4.5

Water temperature: $21.9^{\circ} \mathrm{C}$

ABOPATORY ANALYSES

Mod Unit Lab

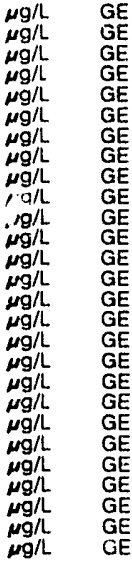

F Analyte

Time: $9: 00$

PH: 4.5

Alkalinity: $0 \mathrm{mg} / \mathrm{L}$ : $20.4^{\circ} \mathrm{C}$

- Aluminum

- Antimony

0 Arsenic

Beryllium

Cadmium

Chromium

Cobalt

0 Copper

- Iron

0 Lead

o Magnesium

- Manganese

0 Mercury

o Nickel

o Potassium

$\begin{array}{ll}0 & \text { Silica } \\ 0 & \text { Silver }\end{array}$
Result

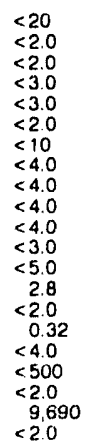

Mod Unit Lab

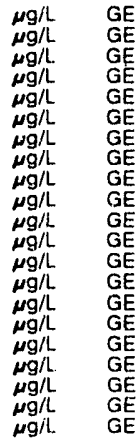


QUALITY CONTROL SAMPLES

WELL EPT 43 collected on 10/28/81, laboratory analyses (cont.)

\begin{tabular}{|c|c|c|c|}
\hline Analyte & Result & Mod & Unit \\
\hline $\begin{array}{l}\text { Sodium } \\
\text { Thallium } \\
\text { Tin } \\
\text { Uranium } \\
\text { Vanadium } \\
\text { Zinc }\end{array}$ & $\begin{aligned} & 149 \\
&<2.0 \\
&<2.0 \\
&<20 \\
&<8.0 \\
&<2.0\end{aligned}$ & & 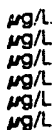 \\
\hline
\end{tabular}

\section{WELL EPT 44}

MEASUREMENTS CONDUCTED IN THE FIELD

Sample date: 10/28/91

Wapth to water: Not available

Water elevation: Not availablo

LABORATORY ANALYSES

$\begin{array}{lll}\text { F Analyte } & \text { Result } \\ & \\ 0 & \text { Aluminum } & <20 \\ 0 & \text { Antimony } & <2.0 \\ 0 & \text { Arsenic } & <2.0 \\ 0 & \text { Barium } & <3.0 \\ 0 & \text { Beryllium } & <3.0 \\ 0 & \text { Cadmium } & <2.0 \\ 0 & \text { Caicium } & <10 \\ 0 & \text { Chromium } & <4.0 \\ 0 & \text { Cobalt } & <4.0 \\ 0 & \text { Copper } & <4.0 \\ 0 & \text { lron } & <4.0 \\ 0 & \text { Lead } & <3.0 \\ 0 & \text { Utthium } & <5.0 \\ 0 & \text { Magnesium } & <2.0 \\ 0 & \text { Manganese } & <2.0 \\ 0 & \text { Mercury } & 0.24 \\ 0 & \text { Nickel } & <4.0 \\ 0 & \text { Potassium } & <500 \\ 0 & \text { Selienium } & <2.0 \\ 0 & \text { Silica } & 11,000 \\ 0 & \text { Silver } & <2.0 \\ 0 & \text { Sodium } & 275 \\ 0 & \text { Thallium } & <2.0 \\ 0 & \text { Tin } & <2.0 \\ 0 & \text { Uranium } & <20 \\ 0 & \text { Uranium } & <8.0 \\ 0 & \text { Vanadium } & <2.0 \\ 0 & \text { Zinc } & \end{array}$

WELL EPT 4?

MEASUREMENTS CONOUCTED IN THE FIELD

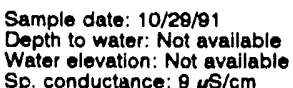

Water olevation: Not availabio

LABORATORY ANALYSES
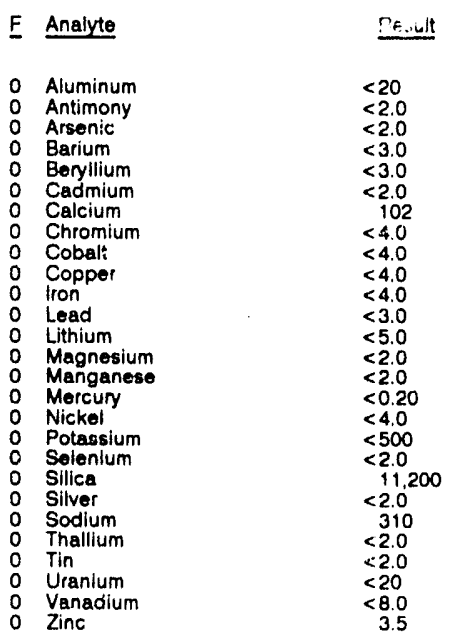

WELL EPT 46

MEASUREMENTS CONDUCTED IN THE FIELD

Sample date: 10/30/91

Depth to water: Not avallable

Sp.

LABORATORY ANALYSES

F Analyte

Result

0 Aluminum

0 Antimony

0 Barlum

O Cadmium

O Calclum

Chromium

Copalt

o Iron

L Lead

- Magnesium

- Manganes

Nickury

Potassium

Selenium

0 Silica

Sodium

Sodium

Thallun

O Uranium

0 Vanadium

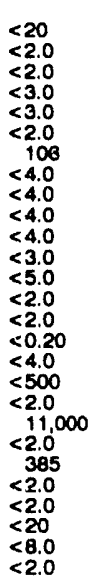

WELL EPT 47

MEASUREMENTS CONDUCTED IN THE FIELD

Sample date: 10/31/91

Depth to water: Not avallable

Sp. conductance: $9 \mu \mathrm{S} / \mathrm{cm}$

LABORATORY ANALYSES

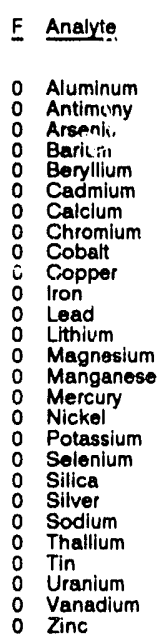

Result

Time: 5:00

PH: 4.4 : $0 \mathrm{mg}$

Water temperature: $20.4^{\circ} \mathrm{C}$

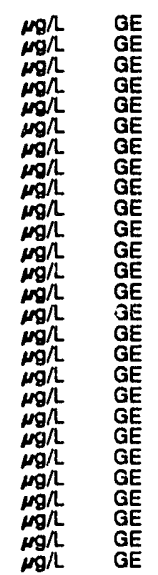

AH: 4.5

Water temperature: $21.7^{\circ} \mathrm{C}$

Mod Unit Lab

E

\section{WELL EPT 48}

MEASUAEMENTS CONDUCTED IN THE FIELD

Sarnple date: 10/31/91

Depth to water: Not avaliable

Water elevation: Not available

Sp. conductance: $10 \mathrm{ws} / \mathrm{cm}$
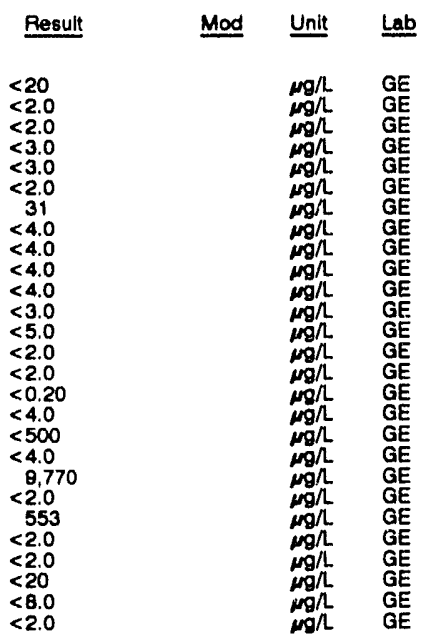

LABORATORY ANALYSES

\begin{tabular}{|c|c|c|c|}
\hline Analyte & Pesult & Mod & Unit \\
\hline $\begin{array}{ll}0 & \text { Aluminum } \\
0 & \text { Antimony } \\
0 & \text { Arsenic } \\
0 & \text { Barium } \\
0 & \text { Beryllium } \\
0 & \text { Cadmium }\end{array}$ & $\begin{array}{l}<20 \\
<2.0 \\
<2.0 \\
<3.0 \\
<3.0 \\
<2.0\end{array}$ & & $\begin{array}{l}\mu \mathrm{g} / \mathrm{L} \\
\mathrm{mg/L} \\
\mathrm{\mu g} / \mathrm{L} \\
\mathrm{\mu g} / \mathrm{L} \\
\mu \mathrm{g} / \mathrm{L} \\
\mu \mathrm{g} / \mathrm{L}\end{array}$ \\
\hline
\end{tabular}

\section{Time: 6:50}

Alkalinity: $0 \mathrm{mg} / \mathrm{h}$.

Water temporature: $18.1^{\circ} \mathrm{C}$

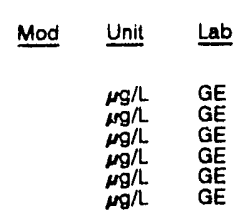




\section{QUALITY CONTROL SAMPLES}

\begin{tabular}{|c|c|c|c|c|}
\hline F Anajyte & Result & $\underline{M o d}$ & Unit & Lab \\
\hline 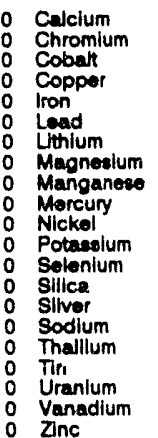 & $\begin{array}{l}<10 \\
<4.0 \\
<4.0 \\
<4.0 \\
<4.0 \\
<3.0 \\
<5.0 \\
3.5 \\
<2.0 \\
<0.20 \\
<4.0 \\
<500 \\
<4.0 \\
8.620 \\
<2.0 \\
707 \\
<2.0 \\
<2.0 \\
<20 \\
<8.0 \\
<2.0\end{array}$ & & 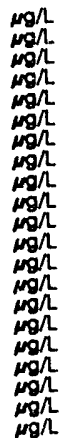 & $\begin{array}{l}\mathrm{GE} \\
\mathrm{GE} \\
\mathrm{GE} \\
\mathrm{GE} \\
\mathrm{GE} \\
\mathrm{GE} \\
\mathrm{GE} \\
\mathrm{GE} \\
\mathrm{GE} \\
\mathrm{GE} \\
\mathrm{GE} \\
\mathrm{GE} \\
\mathrm{GE} \\
\mathrm{GE} \\
\mathrm{GE} \\
\mathrm{GE} \\
\mathrm{GE} \\
\mathrm{GE} \\
\mathrm{GE} \\
\mathrm{GE} \\
\mathrm{GE}\end{array}$ \\
\hline
\end{tabular}

WELL EPT 49

MEASUREMENTS CONDUCTED IN THE FIELD

Sample date: 11/01/81

Depth to waiter: Not avallable

Water olevation: Not avaliable

conductance: $8 \mathrm{sS} / \mathrm{cm}$

LABCPPATORY ANALYSES

F Analyte

0 Aluminum

Arsonic

Barium

O Caryllium

- Calclum

o Chromium

Copper

iron

Lead

Magnesium

Manganore

Nickel

Potasslum

Solonlum

Silica

Sodium

Thallium

Tin

Uranium

Vanadium

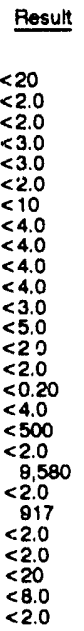

WELLL EPT 50

MEASUREMENTS CONDUCTED IN THE FIELD

Sample date: 11/01/91

Depth to water: Not avallable

Pp. conductance: $8 \mathrm{~s} / \mathrm{cm}$

LABOFATORY ANALYYSES

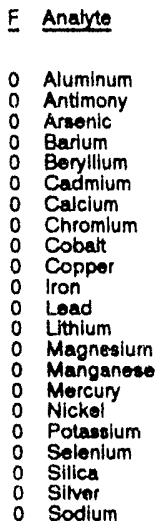

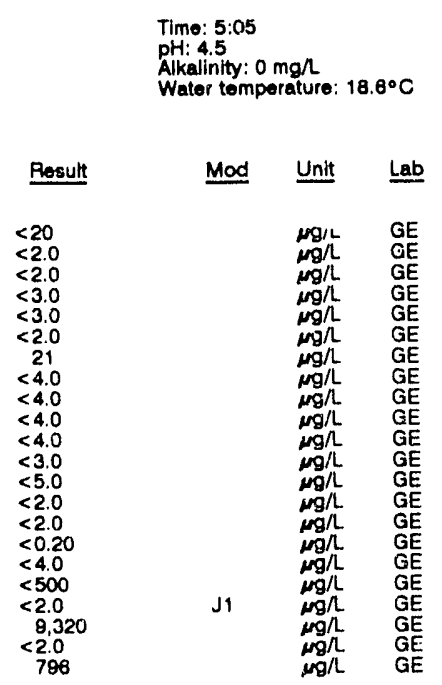

WELL EPT 50 collectod on 11/01/91, laboratory anulyses (cont.)

\begin{tabular}{|c|c|c|c|c|}
\hline$F$ & Analyte & Rosult & Mod & $\underline{\text { Unit }}$ \\
\hline $\begin{array}{l}0 \\
0 \\
0 \\
0\end{array}$ & $\begin{array}{l}\text { Thallium } \\
\text { Tin } \\
\text { Uranlum } \\
\text { Vanadium } \\
\text { Zine }\end{array}$ & $\begin{array}{l}<2.0 \\
<2.0 \\
<20 \\
<8.0 \\
<2.0\end{array}$ & & $\underset{\substack{m g / h \\
\operatorname{mg} / L}}{\mu g / L}$ \\
\hline
\end{tabular}

WELL EPT 51

MEASUREMENTS CONDUCTED IN THE FIELD

Sample date: 11/04/91

Depth to water: Not avaitable

Water elevation: Not avaliablo

$\mathrm{Sp}$. conductance: $8 \mu \mathrm{s} / \mathrm{cm}$

Time: 5:00

pH: 5.0

Water tomperature: $12.7^{\circ} \mathrm{C}$

LABORATORY ANALYSES

E Analyte

Bosult

Aluminum

Antimony

Arsonic

Beryllium

Cadcium

Chromium

Cobalt

0 iron

0 Lead

Magneslum

Magnesium

Mercury

- Potassium

o Selenium

0 Sillica

0 Sodlum

Thallium

o Tin

O Uranium

0 Vanadium

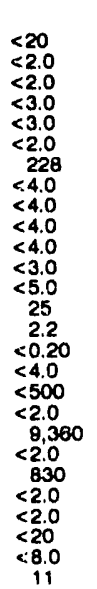

Mod Unit Lab

WELL EPT 52

MEASUREMENTS CONDUCTED IN THE FIELD

Sample date: 11/04/91

Depth to water: Not avallable

Water olevation: Nor avallable

Sp. conductance: 7 pS/cm

Time: $\theta: 35$

pH: 5.0 : $0 \mathrm{mg}$

Alkalinity: $0 \mathrm{mg} / \mathrm{h}$ : $0.2^{\circ} \mathrm{C}$

LABORATORY ANALYSES

E Analyte Rosult Mod Unit Lab

\begin{tabular}{|c|c|c|c|}
\hline $\begin{array}{ll}0 & \text { Aluminum } \\
0 & \text { Antimony } \\
0 & \text { Arsenic } \\
0 & \text { Barlum } \\
0 & \text { Beryillum } \\
0 & \text { Cadmium } \\
0 & \text { Calclum } \\
0 & \text { Chromium } \\
0 & \text { Cobalt } \\
0 & \text { Copper } \\
0 & \text { lron } \\
0 & \text { Lead } \\
0 & \text { Lthium } \\
0 & \text { Magnesium } \\
0 & \text { Manganese } \\
0 & \text { Mercury } \\
0 & \text { Nickel } \\
0 & \text { Potassium } \\
0 & \text { Solenium } \\
0 & \text { Silica } \\
0 & \text { Silver } \\
0 & \text { Sodium } \\
0 & \text { Thallium } \\
0 & \text { Tin } \\
0 & \text { Uranium } \\
0 & \text { Vanadium } \\
0 & \text { Zinc }\end{array}$ & $\begin{array}{l}<20 \\
<2.2 \\
<2.0 \\
<3.0 \\
<3.0 \\
<2.0 \\
<10 \\
<4.0 \\
<4.0 \\
<4.0 \\
<4.0 \\
<3.0 \\
<5.0 \\
<2.0 \\
<2.0 \\
<0.20 \\
<4.0 \\
<500 \\
<2.0 \\
9,340 \\
<2.0 \\
688 \\
<2.0 \\
<2.0 \\
<20 \\
<8.0 \\
<2.0\end{array}$ & J1 & 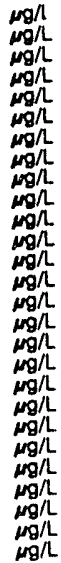 \\
\hline
\end{tabular}


QUALITY CONTROL SAMPLES

WELL EPT 53

MEASUAEMENTS CONDUCTED IN THE FIELD

Sample date: 11/05/91

Depth to water: Not available

Water elevation: Not avalablo

LABORATORY ANALYSES

E Anajyte

0 Aluminum

Antimony

Barium

Beryllium

Cadinium

Chromium

Cobalt

Copper

Iron

Lithium

Magnesium

Manganese

Nickel

Potassium

Selenium

Silica

Sodium

Thallium

Tin

Uranium

Zanadiu

\section{WELL EPT 54}

MEASUREMENTS CONDUCTED IN THE FIELD

Sample date: 11/05/91

Depth to water: Not avallable

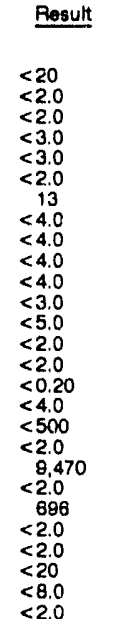

LABORATORY ANALYSES

E Analyte

\begin{tabular}{l} 
Result \\
\multicolumn{1}{r}{} \\
$<20$ \\
$<2.0$ \\
$<2.0$ \\
$<3.0$ \\
$<3.0$ \\
$<2.0$ \\
15 \\
$<4.0$ \\
$<4.0$ \\
$<4.0$ \\
$<4.0$ \\
$<3.0$ \\
$<57$ \\
$<2.0$ \\
$<2.0$ \\
$<0.20$ \\
$<4.0$ \\
$<500$ \\
$<2.0$ \\
8.120 \\
$<2.0$ \\
767 \\
$<2.0$ \\
$<2.0$ \\
$<20$ \\
$<8.0$ \\
$<2.0$
\end{tabular}

WELL EPT 55

MEASUREMENTS CONDUCTED IN THE FIELD

Sample date: 11/08/81

Depth to water: Not available

Water elevation: Not available
Sp. conductance: 8 s $/ \mathrm{cm}$

LABORATORY ANALYSES

\begin{tabular}{|c|c|c|c|}
\hline F Analyte & Result & Mod & $\underline{\text { Unit }}$ \\
\hline $\begin{array}{ll}0 & \text { Aluminum } \\
0 & \text { Antimony } \\
0 & \text { Arsenic } \\
0 & \text { Garium } \\
0 & \text { Beryllium } \\
0 & \text { Cadmium }\end{array}$ & $\begin{array}{l}<20 \\
<2.0 \\
<2.0 \\
<3.0 \\
<3.0 \\
<2.0\end{array}$ & & $\begin{array}{l}\mu g / L \\
\mu g / L \\
\mu g / L \\
\mu g / L \\
\mu g / L \\
\mu g / L\end{array}$ \\
\hline
\end{tabular}

Time: $9: 10$

pH: 5.1

Alkalinity: $0 \mathrm{mg} / \mathrm{h}$
WELL EPT 55 collected on 11/08/91, laboratory analyees (cont.)

\begin{tabular}{|c|c|c|c|}
\hline Analyte & Result & Mod & Unit \\
\hline $\begin{array}{l}\text { Calcium } \\
\text { Chromium } \\
\text { Cobalt } \\
\text { Copper } \\
\text { leon } \\
\text { Lead } \\
\text { Lithlum } \\
\text { Magnesium } \\
\text { Manganese } \\
\text { Morcury } \\
\text { Nickel } \\
\text { Potassium } \\
\text { Selenium } \\
\text { Sillca } \\
\text { Silver } \\
\text { Sodium } \\
\text { Thallium } \\
\text { Tin } \\
\text { Uranium } \\
\text { Vanadium }\end{array}$ & $\begin{array}{l}23 \\
<4.0 \\
<4.0 \\
<4.0 \\
<4.0 \\
<3.0 \\
<5.0 \\
<2.0 \\
<2.0 \\
<0.20 \\
<4.0 \\
<500 \\
<2.0 \\
\theta .480 \\
<2.0 \\
834 \\
<2.0 \\
<2.0 \\
<20 \\
<8.0 \\
<2.0\end{array}$ & J1 & 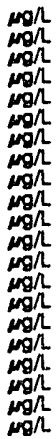 \\
\hline
\end{tabular}

WELL. EPT 56

MEASUREMENTS CONDUCTED IN THE FIELD

Sample date: 11/06/91

Depth to water: Not available Water olovation: Not avallablo

ABORATOPY ANALYSES

F Analyte

$\underline{\text { Result }}$

0 Aluminum

Antimiony

- Arsenic

0 Beryllium

o Cadmium

0 Chromium

0 Cotalt

o Copper

0 Lead

o Magnesium

- Manganeso

0 Morcury

o Nickel

Potassium

Selenium

Sodium

o $\quad$ Sodium

o Thallium

Uin

$\begin{array}{ll}0 & \text { Vanadium } \\ 0 & \text { Zinc }\end{array}$

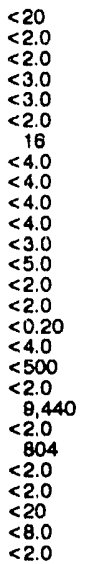

Time: $5: 00$
pH: 4.8

PH: 4.9

Water temperature: $13.7^{\circ} \mathrm{C}$

WELL EPT 57

MEASUREMENTS CONOUCTEO IN THE FIELD

Sample date: 11/07/91

Depth to water: Not available

Water elevation: Not availablo

Mod Unit Lab

LABORATORY ANALYSES
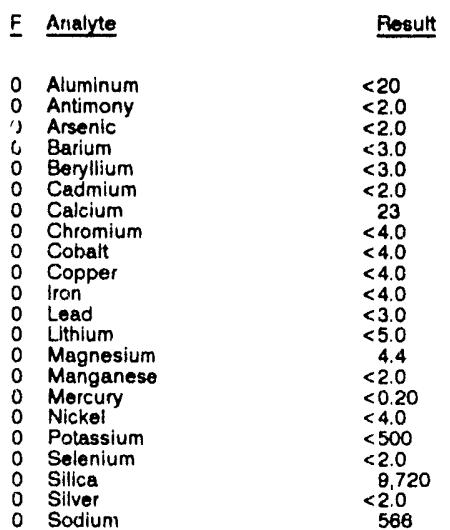

Time: 14:50

PH: 4.9

Alkalinity: $0 \mathrm{mg} / \mathrm{L}$
Water temperature: $20.8^{\circ} \mathrm{C}$

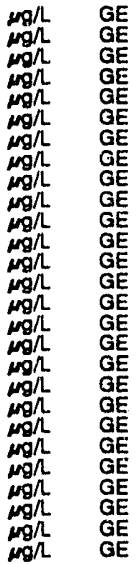

Mod Unit Lab

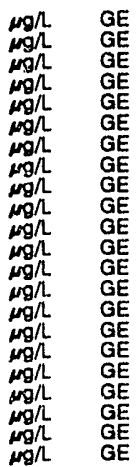




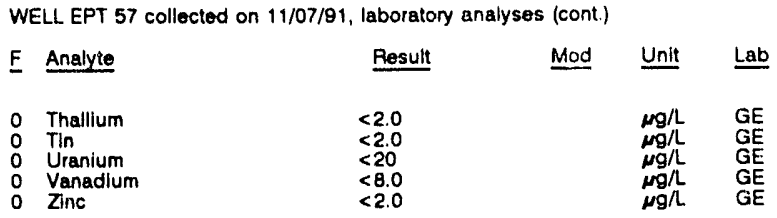

WELL EPT 58

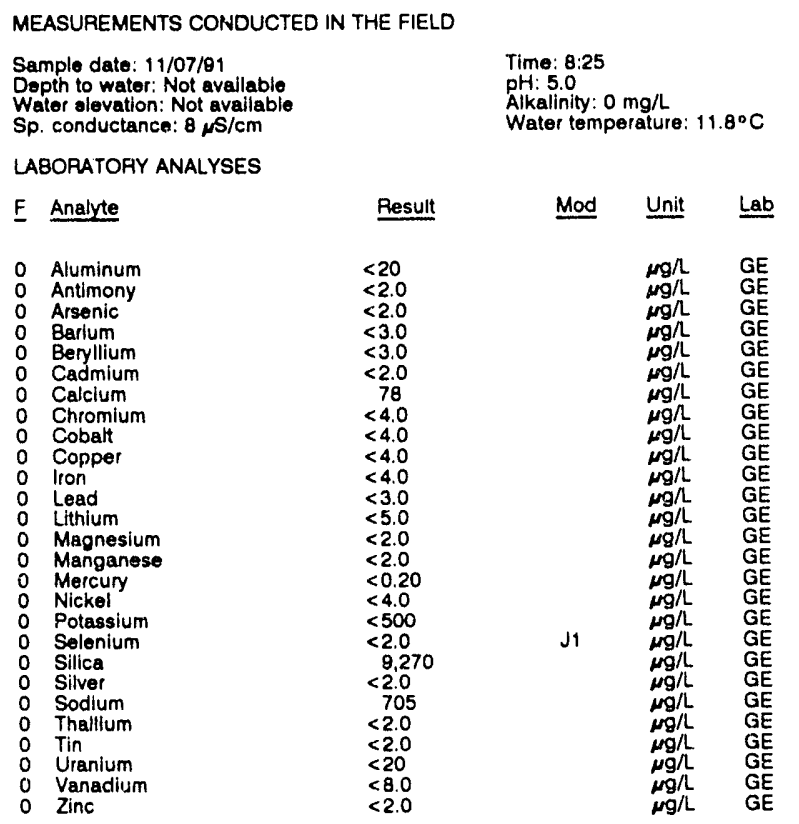

\section{WELL EPT 59}

MEASUREMENTS CONDUCTEO IN THE FIELD

Sample date: 11/07/91

Depth to water: Not available Water Glevation: Not availablo

LABORATORY ANALYSES

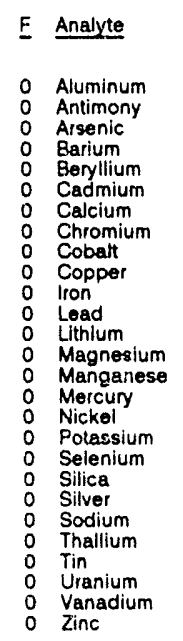

\begin{tabular}{l} 
Result \\
\hline \\
$<20$ \\
$<2.0$ \\
$<2.0$ \\
$<3.0$ \\
$<3.0$ \\
$<2.0$ \\
19 \\
$<4.0$ \\
$<4.0$ \\
$<4.0$ \\
$<4.0$ \\
$<3.0$ \\
$<5.0$ \\
3.4 \\
$<2.0$ \\
$<0.20$ \\
$<4.0$ \\
$<500$ \\
$<2.0$ \\
$>9.510$ \\
$<2.0$ \\
549 \\
$<2.0$ \\
$<2.0$ \\
$<20$ \\
$<5.0$ \\
$<2.0$
\end{tabular}

WELL EPT 60

MEASUREMENTS CONDUCTED IN THE FIELD

Sample date: $11 / 11 / 81$
Depth to water: Not uvallable
Water elevation: Not available

Sp. conductance: $7 \mu \mathrm{S} / \mathrm{cm}$

LABORATORY ANALYSES

\begin{tabular}{|c|c|c|c|c|c|}
\hline$\underline{F}$ & Analyte & Result & Mod & Unit & Lab \\
\hline $\begin{array}{l}0 \\
0 \\
0 \\
0 \\
0 \\
0 \\
0 \\
0 \\
0 \\
0 \\
0 \\
0 \\
0 \\
0 \\
0 \\
0 \\
0 \\
0 \\
0 \\
0 \\
0 \\
0 \\
0 \\
0 \\
0 \\
0 \\
0\end{array}$ & $\begin{array}{l}\text { Aluminum } \\
\text { Antimony } \\
\text { Arsenic } \\
\text { Barium } \\
\text { Beryllium } \\
\text { Cadmium } \\
\text { Calcium } \\
\text { Chromium } \\
\text { Cobalt } \\
\text { Copper } \\
\text { Iron } \\
\text { Lead } \\
\text { Lithium } \\
\text { Magnesium } \\
\text { Manganese } \\
\text { Mercury } \\
\text { Nickel } \\
\text { Potassium } \\
\text { Selenlum } \\
\text { Silica } \\
\text { Silver } \\
\text { Sodium } \\
\text { Thallium } \\
\text { Tin } \\
\text { Uraniuni } \\
\text { Variddium } \\
\text { Zinc }\end{array}$ & $\begin{array}{l}<20 \\
<2.0 \\
<2.0 \\
<3.0 \\
<3.0 \\
<2.0 \\
<10 \\
<4.0 \\
<4.0 \\
<4.0 \\
<4.0 \\
<3.0 \\
<5.0 \\
<2.0 \\
<2.0 \\
<0.20 \\
<4.0 \\
<500 \\
<2.0 \\
9,240 \\
<2.0 \\
8.55 \\
<2.0 \\
<2.0 \\
<20 \\
<8.0 \\
<2.0\end{array}$ & J1 & $\begin{array}{l}\mu g / L \\
\mu g / L \\
\mu g / L \\
\mu g / L \\
\mu g / L \\
\mu g / L \\
\mu g / L \\
\mu g / L \\
\mu g / L \\
\mu g / L \\
\mu g / L \\
\mu g / L \\
\mu g / L \\
\mu g / L \\
\mu g / L \\
\mu g / L \\
\mu g / L \\
\mu g / L \\
\mu g / L \\
\mu g / L \\
\mu g / h \\
\mu g / L \\
\mu g / L \\
\mu g / L \\
\mu g / L \\
\mu g / L \\
\mu g / L\end{array}$ & $\begin{array}{l}\mathrm{GE} \\
\mathrm{GE} \\
\mathrm{GE} \\
\mathrm{GE} \\
\mathrm{GE} \\
\mathrm{GE} \\
\mathrm{GE} \\
\mathrm{GE} \\
\mathrm{GE} \\
\mathrm{GE} \\
\mathrm{GE} \\
\mathrm{GE} \\
\mathrm{GE} \\
\mathrm{GE} \\
\mathrm{GE} \\
\mathrm{GE} \\
\mathrm{GE} \\
\mathrm{GE} \\
\mathrm{GE} \\
\mathrm{GE} \\
\mathrm{GE} \\
\mathrm{GE} \\
\mathrm{GE} \\
\mathrm{GE} \\
\mathrm{GE} \\
\mathrm{GE} \\
\mathrm{GE}\end{array}$ \\
\hline
\end{tabular}

\section{WELL EPT 61}

MEASUREMENTS CONDUCTED IN THE FIELD

Sp. conductance: $7 \mathrm{\mu S} / \mathrm{cm}$

LABORATORY ANALYSES

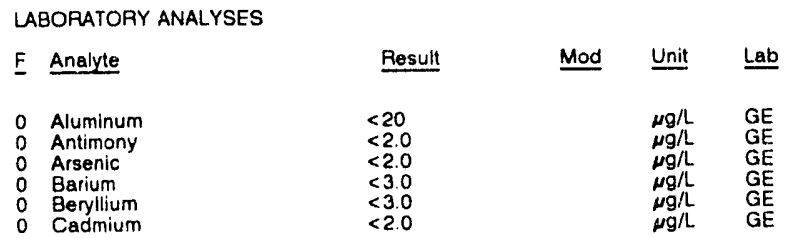

Time: $:: 35$

Alk: 4.9 : $1 \mathrm{mg} / \mathrm{h}$
Water temperature: $11.7{ }^{\circ} \mathrm{C}$

Ge
$G E$
$G E$
$G E$
$G E$
$G E$
$G E$
$G E$
$G E$
$G E$
$G E$
$G E$
$G E$
$G E$
$G E$
$G E$
$G E$
$G E$
$G E$
$G E$
$G E$
$G E$
$G E$
$G E$
$G E$
$G E$
Time: $4: 30$

pH: 4.7
Sample date: 11/08/91

Depth to water: Not available

LABORATORY ANALYSES

\begin{tabular}{|c|c|c|c|}
\hline F Analyte & Result & Mod & Unit \\
\hline $\begin{array}{ll}0 & \text { Aluminum } \\
0 & \text { Antimony } \\
0 & \text { Arsenic } \\
0 & \text { Barium } \\
0 & \text { Beryllium } \\
0 & \text { Cadmium } \\
0 & \text { Calcium } \\
0 & \text { Chromium } \\
0 & \text { Cobalt } \\
0 & \text { Copper } \\
0 & \text { tron } \\
0 & \text { Lead } \\
0 & \text { Litnium } \\
0 & \text { Magnesium } \\
0 & \text { Manganese } \\
0 & \text { Mercury } \\
0 & \text { Nickel } \\
0 & \text { Potassium } \\
0 & \text { Selenium } \\
0 & \text { Silica } \\
0 & \text { Silver } \\
0 & \text { Sodium } \\
0 & \text { Thallium } \\
0 & \text { Tin } \\
0 & \text { Uranlum } \\
0 & \text { Vanadium } \\
0 & \text { Zinc }\end{array}$ & $\begin{array}{l}<20 \\
<2.0 \\
<2.0 \\
<3.0 \\
<3.0 \\
<2.0 \\
30 \\
<4.0 \\
<4.0 \\
<4.0 \\
<4.0 \\
<3.0 \\
<5.0 \\
5.4 \\
<2.0 \\
<0.20 \\
<4.0 \\
<500 \\
<2.0 \\
8.430 \\
<2.0 \\
842 \\
<2.0 \\
<2.0 \\
<20 \\
<8.0 \\
<2.0\end{array}$ & J1 & $\begin{array}{l}\mu g / L \\
\mu g / L \\
\mu g / L \\
\mu g / L \\
\mu g / L \\
\mu g / L \\
\mu g / L \\
\mu g / L \\
\mu g / L \\
\mu g / L \\
\mu g / L \\
\mu g / L \\
\mu g / L \\
\mu g / L \\
\mu g / L \\
\mu g / L \\
\mu g / L \\
\mu g / L \\
\mu g / L \\
\mu g / L \\
\mu g / L \\
\mu g / L \\
\mu g / L \\
\mu g / L \\
\mu g / L \\
\mu g / L \\
\mu g / L\end{array}$ \\
\hline
\end{tabular}

WELL EPT 62

MEASUREMENTS CONDUCTED IN THE FIELD Sample date: $11 / 08 / 91$
Depth to water: Not available
Water elevation: Not available
Sp. conductance: $8 \mu \mathrm{s} / \mathrm{cm}$

\section{Time: $4: 45$}

PH: 4.8 . $0 \mathrm{mgl}$

Water iemperature: $14.7^{\circ} \mathrm{C}$

Mod Unit Lab

Time: $5: 00$

Alkalinity: $0 \mathrm{mg} / \mathrm{L}$

Mod Unit Lab

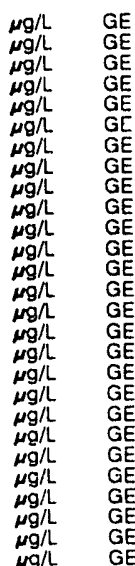

Alkalinity: $0 \mathrm{mg} / \mathrm{L}$
Water temperature: $17.1^{\circ} \mathrm{C}$ 
QUALITY CONTROL SAMPLES

\begin{tabular}{|c|c|c|c|c|}
\hline F Analyte & Result & Mod & Unit & Lab \\
\hline $\begin{array}{ll}0 & \text { Calcium } \\
0 & \text { Chromium } \\
0 & \text { Cobalt } \\
0 & \text { Copper } \\
0 & \text { Iron } \\
0 & \text { Lead } \\
0 & \text { Lithium } \\
0 & \text { Magnesium } \\
0 & \text { Manganese } \\
0 & \text { Mercury } \\
0 & \text { Nickel } \\
0 & \text { Potassium } \\
0 & \text { Selenium } \\
0 & \text { Sillca } \\
0 & \text { Silver } \\
0 & \text { Sodium } \\
0 & \text { Thallium } \\
0 & \text { Tin } \\
0 & \text { Uranium } \\
0 & \text { Vanadium } \\
0 & \text { Zinc }\end{array}$ & $\begin{aligned} & 13 \\
&<4.0 \\
&<4.0 \\
&<4.0 \\
& 7.1 \\
&<3.0 \\
&<5.0 \\
&<2.0 \\
&<2.0 \\
&<0.20 \\
&<4.0 \\
&<500 \\
&<2.0 \\
& 9.660 \\
&<2.0 \\
& 875 \\
&<2.0 \\
&<2.0 \\
&<20 \\
&<8.0 \\
&<2.0\end{aligned}$ & J1 & $\begin{array}{l}\mu g / L \\
\mu g / L \\
\mu g / L \\
\mu g / L \\
\mu g / L \\
\mu g / L \\
\mu g / L \\
\mu g / L \\
\mu g / L \\
\mu g / L \\
\mu g / L \\
\mu g / L \\
\mu g / L \\
\mu g / L \\
\mu g / L \\
\mu g / L \\
\mu g / L \\
\mu g / L \\
\mu g / L \\
\mu g / L \\
\mu g / L\end{array}$ & $\begin{array}{l}\mathrm{GE} \\
\mathrm{GE} \\
\mathrm{GE} \\
\mathrm{GE} \\
\mathrm{GE} \\
\mathrm{GE} \\
\mathrm{GE} \\
\mathrm{GE} \\
\mathrm{GE} \\
\mathrm{GE} \\
\mathrm{GE} \\
\mathrm{GE} \\
\mathrm{GE} \\
\mathrm{GE} \\
\mathrm{GE} \\
\mathrm{GE} \\
\mathrm{GE} \\
\mathrm{GE} \\
\mathrm{GE} \\
\mathrm{GE} \\
\mathrm{GE}\end{array}$ \\
\hline
\end{tabular}

WELL EPT 63

MEASUREMENTS CONDUCTED IN THE FIELD

Sample date: 11/11/91 Depth to water: Not available Water elevation: Not available
Sp. conductance: $7 \mu \mathrm{S} / \mathrm{cm}$

LAGORATORY ANALYSES

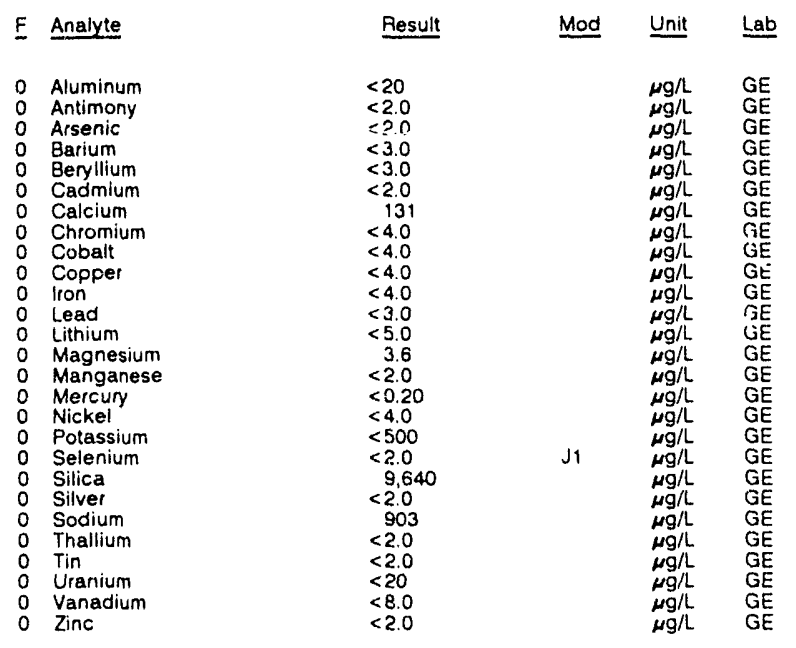

\section{WELL EPT 64}

MEASUREMENTS CONDUCTED IN THE FIELD

Sample date: 11/12/91

Depth to water: Not available

Water elevation: Not available

LABORATORY ANALYSES
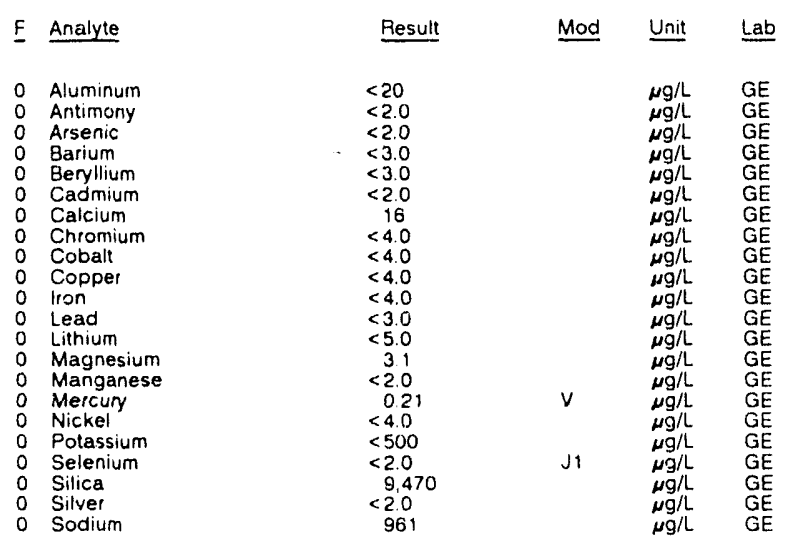

Time: $4: 50$

pH: 5.0

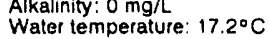

WELL EPT 64 collected on 11/12/91, laboratory analyses (cont.)

\begin{tabular}{|c|c|c|c|}
\hline E Analyte & Result & Mod & Unit \\
\hline $\begin{array}{ll}0 & \text { Thallium } \\
0 & \text { Tin } \\
0 & \text { Uranium } \\
0 & \text { Vanadium } \\
0 & \text { Zinc }\end{array}$ & $\begin{array}{l}<2.0 \\
<2.0 \\
<20 \\
<8.0 \\
<2.0\end{array}$ & & $\begin{array}{l}\mathrm{mg} / \mathrm{h} \\
\mathrm{mg} / \mathrm{h} \\
\mathrm{mgh} \\
\mathrm{Ng} / \mathrm{h} \\
\mathrm{mg} / \mathrm{L}\end{array}$ \\
\hline
\end{tabular}

\section{WELI. EPT 65}

MEASUREMENTS CONOUCTED IN THE FIELD

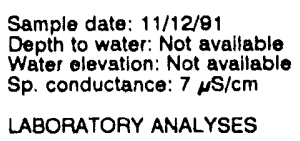

Time: $\because \cdots$

Alkalinity: $1 \mathrm{mgh}$

Water temperature: $11.2^{\circ} \mathrm{C}$

LABORATORY ANALYSES
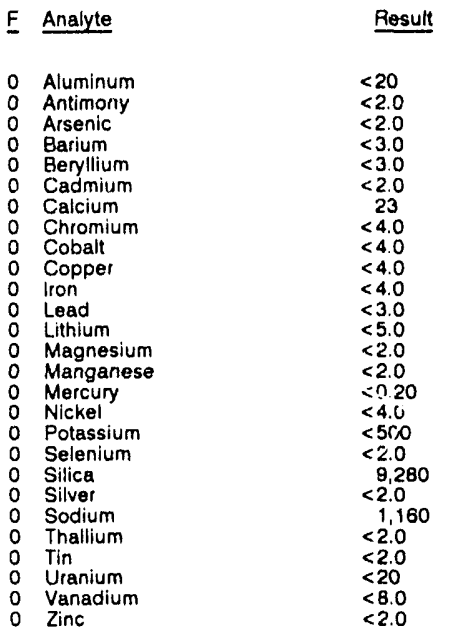

Mod Unit Lab

Zinc

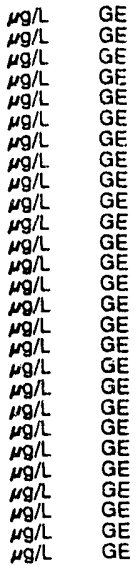

\section{WELL EPT 66}

MEASUREMENTS CONDUCTEO IN THE FIEL.D

Sample date: $11 / 13 / 91$

Depth to water: Not available

$\mathrm{Sp}$ conductance: $5 \mu \mathrm{S} / \mathrm{cm}$

LABORATORY ANALYSES

E Analyte

Time: $5: 05$

Alkalinity: $0 \mathrm{mg} / \mathrm{h}$

Water temperature: $13.5^{\circ} \mathrm{C}$

- Aluminum

Antimony

Arsenic

Beryllium

Cadmium
Calcium

Chromium

Cobalt

Coppe
0 iron

Iron

Lead

Magnesiun

Manganese

Mercury

Nickel

0 Potassium

Selien

o Silve

Sodium

0 Thallium

o Tin $_{0}$ Uranium

Vanadium

Zine
Result

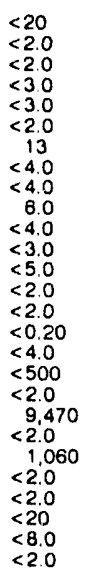

Mod Unit Lab

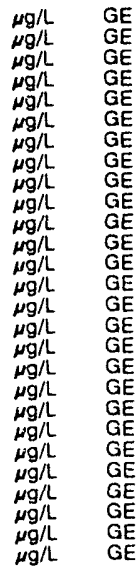




\section{QUALITY CONTROL SAMPLES}

WELL EPT 67

MEASUREMENTS CONOUCTED IN THE FIELD

Sample date: $11 / 13 / 91$

Depth to water: Not available

Water elevation: Not available
Sp. conductance: $10 \mu \mathrm{S} / \mathrm{cm}$

LABORATORY ANALYSES

\begin{tabular}{|c|c|}
\hline Analyte & Result \\
\hline $\begin{array}{l}\text { Aluminum } \\
\text { Antimony } \\
\text { Arsenic } \\
\text { Barium } \\
\text { Beryllium } \\
\text { Cadmium } \\
\text { Calcium } \\
\text { Chromium } \\
\text { Cobalt } \\
\text { Copper } \\
\text { lron } \\
\text { Lead } \\
\text { Lithium } \\
\text { Magnesium } \\
\text { Manganooe } \\
\text { Mercury } \\
\text { Nickel } \\
\text { Potusslum } \\
\text { Selenium } \\
\text { Silica } \\
\text { Sitver } \\
\text { Sodium } \\
\text { Thallium } \\
\text { Tin } \\
\text { Uranium } \\
\text { Vanidium } \\
\text { Zinc }\end{array}$ & $\begin{array}{l}<20 \\
<2.0 \\
<2.0 \\
<3.0 \\
<3.0 \\
<2.0 \\
28 \\
<4.0 \\
<4.0 \\
<4.0 \\
<4.0 \\
<3.0 \\
<5.0 \\
<2.0 \\
<2.0 \\
<0.20 \\
<4.0 \\
<500 \\
<2.0 \\
9.410 \\
<2.0 \\
1.810 \\
<2.0 \\
<2.0 \\
<20 \\
<8.0 \\
4.3\end{array}$ \\
\hline
\end{tabular}

WELL EPT 68

MEASUREMENTS CONDUCTED IN THE FIELD

Sample date: 11/13/91

Depth to water: Not available

Water elevation: Not availahle
Sp. conductance: $8, \mathrm{~S} / \mathrm{cm}$

LABORATC.RY ANALYSES

E Analyte

Aluminum

Antimony

Arsenic
Barium

Beryllium

Calclum

Chromiu

Cobait

lion

Lead

Magnesium

Mercury

Nickel

Potassium

Selenium
Silica

Silica

Sodium

Thallium

Uranium

Vanadium

Zinc

\section{WELL EPT 69}

MEASUREMENTS CONDUCTED IN THE FIELD

Sample date: $11 / 14 / 91$

Depth to water: Not available

Water elevation: Not available

Sp. conductance: $9 \mu \mathrm{s} / \mathrm{cm}$

LABORATORY ANALYSES

\begin{tabular}{|c|c|c|c|}
\hline Analyte & Result & Mod & Unit \\
\hline $\begin{array}{l}\text { Aluminum } \\
\text { Antimony } \\
\text { Arsenic } \\
\text { Barium } \\
\text { Beryllium } \\
\text { Cadmium }\end{array}$ & $\begin{array}{l}<20 \\
<20 \\
<20 \\
<30 \\
<30 \\
<20\end{array}$ & & $\begin{array}{l}\mu g / L \\
\mu g / L \\
\mu g / L \\
\mu g / L \\
\mu g / L \\
\mu g / L\end{array}$ \\
\hline
\end{tabular}

WELL. EPT 69 coliected on 11/14/91, laboratory analyses (cont.)

E Analyte

0 Calcium

0 Chromium

O Coppe

0 Iron

0 Lead

0 Lithlum

Manganes

Mercury

Potassium

Selenium

Silica

Silver

Sodium

Tin

Uranium

Vanadium
Zinc

WELL EPT 70

MEASUREMENTS CONDUCTED IN THE FIELD

Sampie date: 11/14/91

Depth to water: Not available

: $\mu$ S/cm

Result

22
$<4.0$

$<4.0$

$<4.0$

$<3.0$

$<20$

$<2.0$

$<0.20$
$<4.0$

$<500$
$<2.0$

$<.580$
$<2.0$

1,530

$<2.0$
$<2.0$

$<20$

$<8.0$
$<2.0$

ABORATORY ANAL.YSES

F Analyte

- Aluminum

- Arsenic

Barium

Beryllum

Calcium

- Chromium

0 Cobalt

O Copper

o Lead

o Magnesium

O Mercury

Nickel

Selenium

o Silica

o Silica

Sodium

Thallium

Tin

Vanadium
Zine

$<20$
$<2.0$

$<2.0$
$<3.0$

$<3.0$

$<10$

$<4.0$

$<4.0$

$<4.0$

$<5.0$

$<2.0$

$<2.0$

$<4.0$
$<500$

$<500$
$<2.0$

$<2.0$

$<.0$
1.630

$<2.0$

$<2.0$

$<8.0$
$<2.0$ o Mariganese

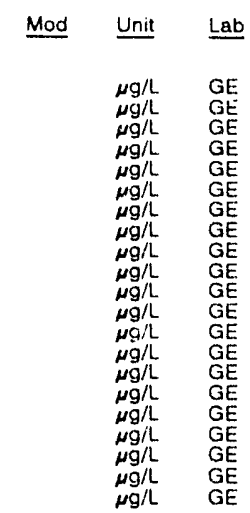

Time: $8: 50$

pH: 5.4

Water temperature: $16.2^{\circ} \mathrm{C}$

Result Mod Unit Lab

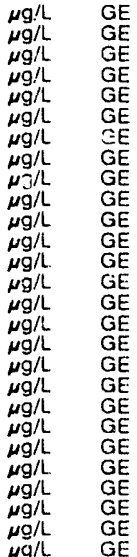

WELL EPT 71

MEASUREMENTS CONDUCTED IN THE FIELD

Sample date: 11/15/91

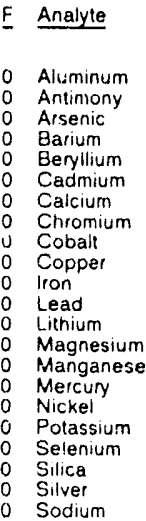

\begin{tabular}{l}
\multicolumn{1}{r}{ Resuit } \\
\hline \\
$<20$ \\
$<2.0$ \\
$<20$ \\
$<30$ \\
$<3.0$ \\
$<2.0$ \\
37 \\
$<40$ \\
$<4.0$ \\
$<4.0$ \\
$<40$ \\
$<3.0$ \\
$<5.0$ \\
$<2.0$ \\
$<2.0$ \\
$<0.20$ \\
$<4.0$ \\
$<500$ \\
$<2.0$ \\
9.330 \\
$<2.0$ \\
1.750
\end{tabular}

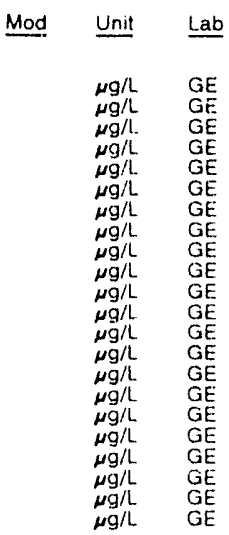

Depth to water: Not available

Water elevation. Not available

Sp. conductance: $8 \mu \mathrm{s} / \mathrm{cm}$

LABORATOFY ANALYSES

Time: $5: 05$

$\mathrm{pH}: 5.0$

Alkalinity: $0 \mathrm{mg} / \mathrm{L}$

Water temperature: $14.5^{\circ} \mathrm{C}$

Time: 4:20

Alkalinity: $0 \mathrm{mg} / \mathrm{L}$

Water temperature $17.6^{\circ} \mathrm{C}$ 


\begin{tabular}{|c|c|c|c|}
\hline E Analyte & Result & Mod & Unit \\
\hline $\begin{array}{ll}0 & \text { Thallium } \\
0 & \text { Tln } \\
0 & \text { Uranium } \\
0 & \text { Vanadiilm } \\
0 & \text { Zinc }\end{array}$ & $\begin{array}{l}<2.0 \\
<2.0 \\
<20 \\
<8.0 \\
<2.0\end{array}$ & & $\begin{array}{l}\mu g / L \\
\mu g / \Lambda \\
\mu g / L \\
\mu g / L \\
\mu g / h\end{array}$ \\
\hline
\end{tabular}

WELL. EPT 72

\begin{tabular}{|c|c|c|c|c|}
\hline \multicolumn{2}{|l|}{$\begin{array}{l}\text { Sample date: } 11 / 15 / 81 \\
\text { Depth to water: Not available } \\
\text { Water elevation: Not available } \\
\text { Sp. conductance: } 9 \mu \mathrm{S} / \mathrm{cm}\end{array}$} & \multicolumn{3}{|c|}{$\begin{array}{l}\text { Time: } 14: 30 \\
\text { PH: } 5.6: 3 \text { Alkalinity: } 3 \mathrm{mg} / \mathrm{L} \\
\text { Water temperature: } 24.0^{\circ} \mathrm{C}\end{array}$} \\
\hline \multicolumn{5}{|l|}{ LABORATORY ANALYSES } \\
\hline E Analyte & Result & Mod & Unit & Lab \\
\hline $\begin{array}{ll}0 & \text { Aluminum } \\
0 & \text { Antimony } \\
0 & \text { Arsenic } \\
0 & \text { Barlium } \\
0 & \text { Beryllium } \\
0 & \text { Cadmium } \\
0 & \text { Calcium } \\
0 & \text { Chromium } \\
0 & \text { Cobalt } \\
0 & \text { Copper } \\
0 & \text { lisit } \\
0 & \text { Lead } \\
0 & \text { Lithlum } \\
0 & \text { Magnesium } \\
0 & \text { Manganese } \\
0 & \text { Mercury } \\
0 & \text { Nickel } \\
0 & \text { Potassium } \\
0 & \text { Selenium } \\
0 & \text { Silica } \\
0 & \text { Siliver } \\
0 & \text { Sodium } \\
0 & \text { Thallium } \\
0 & \text { Tin } \\
0 & \text { Uranium } \\
0 & \text { Vanaadium } \\
0 & \text { Zinc }\end{array}$ & $\begin{array}{l}<20 \\
<2.0 \\
<2.0 \\
<3.0 \\
<3.0 \\
<2.0 \\
14 \\
<4.0 \\
<4.0 \\
<4.0 \\
<4.0 \\
<3.0 \\
<5.0 \\
6.6 \\
<2.0 \\
<0.20 \\
<4.0 \\
<500 \\
<2.0 \\
10.100 \\
<2.0 \\
1,860 \\
<2.0 \\
<2.0 \\
<20 \\
<8.0 \\
<2.0\end{array}$ & J1 & 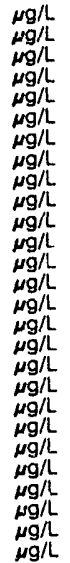 & $\begin{array}{l}G E \\
G E \\
G E \\
G E \\
G E \\
G E \\
G E \\
G E \\
G E \\
G E \\
G E \\
G E \\
G E \\
G E \\
G E \\
G E \\
G E \\
G E \\
G E \\
G E \\
G E \\
G E \\
G E \\
G E \\
G E \\
G E \\
G E\end{array}$ \\
\hline
\end{tabular}

\section{WELL EPT 73}

MEASUREMENTS CONDUCTED IN THE FIELD

Sample date: $11 / 17 / 91$

Depth to water: Not available Water elevation: Not available

LABORATORY ANALYSES

\begin{tabular}{|c|c|c|c|}
\hline Analyte & Result & Mod & Unit \\
\hline $\begin{array}{l}\text { Aluminum } \\
\text { Antimony } \\
\text { Arsenic } \\
\text { Barium } \\
\text { Beryllium } \\
\text { Cadmium } \\
\text { Calcium } \\
\text { Chromium } \\
\text { Cobalt } \\
\text { Copper } \\
\text { Iron } \\
\text { Lead } \\
\text { Lithium } \\
\text { Magnesium } \\
\text { Manganese } \\
\text { Mercury } \\
\text { Nickel } \\
\text { Potassium } \\
\text { Selenium } \\
\text { Silica } \\
\text { Silver } \\
\text { Sodium } \\
\text { Thallium } \\
0 \text { Tin } \\
0 \text { Uranium } \\
0 \text { Vanadium } \\
0 \text { Zinc }\end{array}$ & $\begin{array}{l}<20 \\
<2.0 \\
<2.0 \\
<3.0 \\
<3.0 \\
<2.0 \\
66 \\
<4.0 \\
<4.0 \\
<4.0 \\
8.3 \\
<3.0 \\
<5.0 \\
2.9 \\
<2.0 \\
<0.20 \\
<4.0 \\
<500 \\
<2.0 \\
9.810 \\
<2.0 \\
1.980 \\
<2.0 \\
<2.0 \\
<20 \\
<8.0 \\
2.0\end{array}$ & J1 & $\begin{array}{l}\mu g / L \\
\mu g / L \\
\mu g / L \\
\mu g / L \\
\mu g / L \\
\mu g / L \\
\mu g / L \\
\mu g / L \\
\mu g / L \\
\mu g / L \\
\mu g / L \\
\mu g / L \\
\mu g / L \\
\mu g / L \\
\mu g / L \\
\mu g / L \\
\mu g / L \\
\mu g / L \\
\mu g / L \\
\mu g / L \\
\mu g / L \\
\mu g / L \\
\mu g / L \\
\mu g / L \\
\mu g / L \\
\mu g / L \\
\mu g / L\end{array}$ \\
\hline
\end{tabular}

WELL EPT 74

MEASUREMENTS CONDUCTED IN THE FIELD

Sample date: $11 / 18 / 91$

Depth to water: Not available

Water olevation: Not avallab

LABORATORY ANALYSES
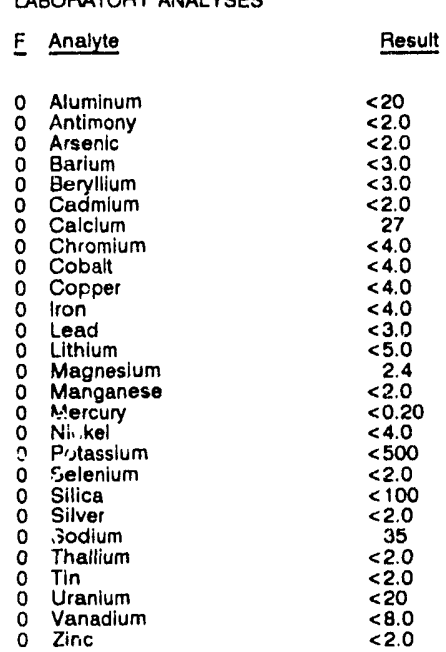

\author{
Time: 4:20 \\ pH: 5.2 \\ Water temperature: $15.6^{\circ} \mathrm{C}$
}

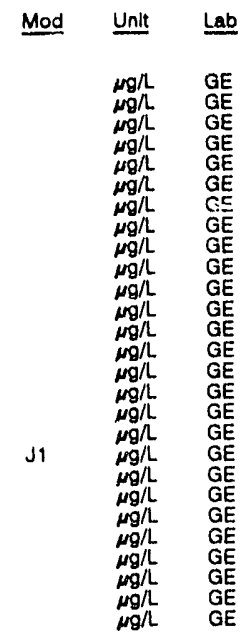

\section{WELL EPT 75}

MEASUREMENTS CONDUCTED IN THE FIELD

Sample date: 11/18/91

Wepth to watet: Not available

$\mathrm{Sp}$. conductance: $2 \mathrm{~s} / \mathrm{cm}$

LABORATORY ANALYSES

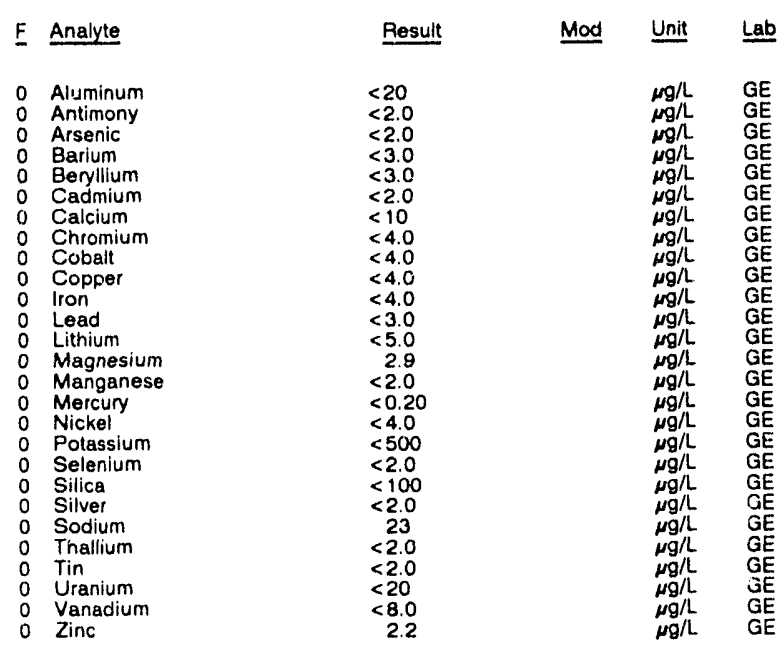

WELL EPT 76

MEASUREMENTS CONDUCTED IN THE FIELD

Sample date: $11 / 19 / 91$

Depth to water: Not available

Water elevation: Not available
Sp conductance: $3 \mu \mathrm{S} / \mathrm{cm}$

LABORATORY ANALYSES

\begin{tabular}{|c|c|c|c|}
\hline Analyte & Fiesult & Mod & Unit \\
\hline $\begin{array}{l}\text { Aluminium } \\
\text { Antimony } \\
\text { Atsenic } \\
\text { Barium } \\
\text { Geryllium } \\
\text { Cadmium }\end{array}$ & $\begin{array}{l}<20 \\
<2.0 \\
<2.0 \\
<3.0 \\
<3.0 \\
<2.0\end{array}$ & & $\begin{array}{l}\mu g / L \\
\mu g / L \\
\mu g / L \\
\mu g / L \\
\mu g / L \\
\mu g / L\end{array}$ \\
\hline
\end{tabular}

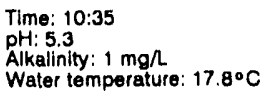

$\mathrm{pH}: 5.2$

Alkalinity: $0 \mathrm{mg} / \mathrm{L}$

Water temperature: $18.9^{\circ} \mathrm{C}$ 
QUALITY CONTROL SAMPLES

WELL EPT 76 collerted on 11/19/81, laboratory analyses (cont.)

F Analyte

Calcium

Cobalt

Iron

Lead

Lithium

Manganese

Mercury

Potasslum

Potassium

Sillica

Sorlium

Thallium

Tin

Uranium

Zinc

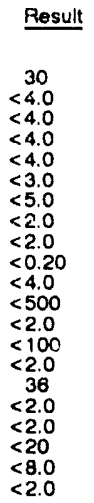

Mod

Unit Lab

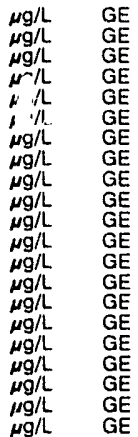

WELL EPT 77

MEASUREMENTS CONDUCTED IN THE FIELD

Sample date: $11 / 19 / 8$

Depth to water: Not available

Water elevation: Not avallable
Sp. conductance: $1 \mu \mathrm{S} / \mathrm{cm}$

LABORATORY ANALYSES

E Analyte

- Aluminum

Antimony

Barium

Beryllium

Cadmium

Chromium

Cobalt

Iron

Lead

Magnosium

Manganese

Mercury

Potassium

Selenium

Silica

Siver

Thallium

Tin

Uranium

Vanadiu

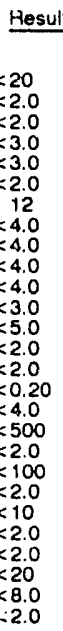

WELL EPT 78

MEASUREMENTS CONDUCTED IN THE FIELD

Sample date: 11/19/91

Depth to water: Not available

Water elovation: Not available

LABORATORY ANALYSES

\begin{tabular}{|c|c|c|c|}
\hline Analyte & Besult & Mod & Unit \\
\hline $\begin{array}{ll}0 & \text { Aluminum } \\
0 & \text { Antimony } \\
0 & \text { Arsenic } \\
0 & \text { Barium } \\
0 & \text { Beryllium } \\
0 & \text { Cadmium } \\
0 & \text { Calcium } \\
0 & \text { Chromium } \\
0 & \text { Cobalt } \\
0 & \text { Copper } \\
0 & \text { ron } \\
0 & \text { Lead } \\
0 & \text { Lithium } \\
0 & \text { Magnesium } \\
0 & \text { Manganese } \\
0 & \text { Mercury } \\
0 & \text { Nickel } \\
0 & \text { Potassium } \\
0 & \text { Selenium } \\
0 & \text { Silica } \\
0 & \text { Silver } \\
0 & \text { Sodium }\end{array}$ & $\begin{array}{l}<20 \\
<2.0 \\
<2.0 \\
<3.0 \\
<3.0 \\
<2.0 \\
12 \\
<4.0 \\
<4.0 \\
<4.0 \\
<4.0 \\
<3.0 \\
<5.0 \\
<2.0 \\
<2.0 \\
<0.20 \\
<4.0 \\
<500 \\
<2.0 \\
<100 \\
<2.0 \\
322\end{array}$ & $j 1$ & $\begin{array}{l}\mu g / L \\
\mu g / L \\
\mu g / L \\
\mu g / L \\
\mu g / L \\
\mu g / L \\
\mu g / L \\
\mu g / L \\
\mu g / L \\
\mu g / L \\
\mu g / L \\
\mu g / L \\
\mu g / L \\
\mu g / L \\
\mu g / L \\
\mu g / L \\
\mu g / L \\
\mu g / L \\
\mu g / L \\
\mu g / L \\
\mu g / L \\
\mu g / L\end{array}$ \\
\hline
\end{tabular}

WELL EPT 78 collected on 11/18/81, laboratory analyses (cont.)

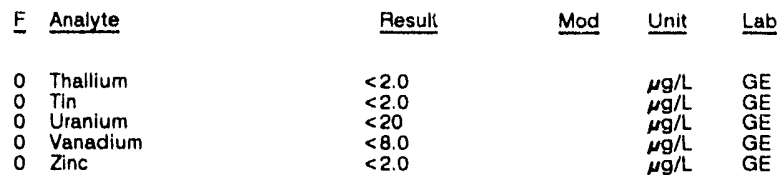

WELL EPT 79

MEASUREMENTS CONDUCTED IN THE FIELDD

Sample date: $11 / 2(1 / 91$

Depth to water: Not available

Watel elevation: Not available
Sp. conductance: $1, \mathrm{~S} / \mathrm{cm}$

Time: $8: 2$

Alkalinity: $1 \mathrm{mg} / \mathrm{L}$

AABORATORY ANALYSES

$E$ Analyte

Result

Mod Unit Lab

0 Aluminum

Antimony

0 Arsenic

Beryllium

Cadmium

Chromium

C Cobalt

O Coppe

o Iron

0 Lithium

O Magnesium

Manganese

0 Mercury

- Potassium

Selenium

Silica

0 Sodium

0 Thallium

Tin

Uranium

$\begin{array}{ll}0 & \text { Vanadiu } \\ 0 \text { Zinc } & \end{array}$

$<20$
$<2.0$
$<2.0$
$<3.0$
$<3.0$
$<2.0$
$<10$
$<4.0$
$<4.0$
$<4.0$
$<4.0$
$<3.0$
$<5.0$
$<2.0$
$<2.0$
$<0.20$
$<4.0$
$<500$
$<2.0$
$<100$
$<2.0$
$<10$
$<2.0$
$<2.0$
$<20$
$<8.0$
$<2.0$

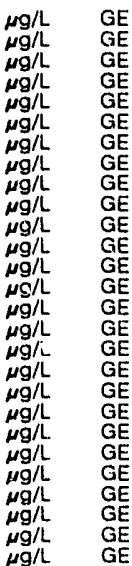

WELL EPT 80

MEASUREMENTS CONDUCTED IN THE FIELD

Sample date: 11/20/91

Depth to water: Not available

Water elevation: Not availab

p. conductance: $1 \mu \mathrm{S} / \mathrm{cm}$

Time: $4: 20$
pH: 5.2

ABORATORY ANALYSES

E Analyte

Result

Water temperature: $19.5^{\circ} \mathrm{C}$

0 Aluninum

Antimony

Barium

Beryllium

C Cadmium

0 Calcium

Chromium

o Copper

0 Iron

0 Lead

o Magnesium

${ }_{0}$ Mercury

$\begin{array}{lll}0 & \text { Mercury } \\ 0 & \text { Nickel }\end{array}$

0 Potassium

0 Selenium

$\begin{array}{ll}0 & \text { Silica } \\ 0 & \text { Silver }\end{array}$

0 Silver

Sodium

Thallium

Tin

Vanadium
Mod Unit Lab

$\mu g / L \quad G E$

$\mu g / L \quad G E$

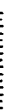


WELL EPT 81

MEASUREMENTS CONDUCTED IN THE FIELD

Sample date: $11 / 21 / 91$

Depth to water: Not available

Sp. conductance: $1 \mu \mathrm{S} / \mathrm{cm}$

LABORATORY ANALYSES

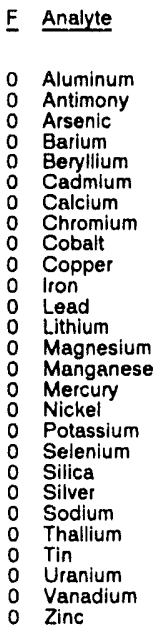

\begin{tabular}{l} 
Result \\
\multicolumn{1}{r}{} \\
$<20$ \\
$<2.0$ \\
$<2.0$ \\
$<3.0$ \\
$<3.0$ \\
$<2.0$ \\
$<10$ \\
$<4.0$ \\
$<4.0$ \\
$<4.0$ \\
$<4.0$ \\
$<3.0$ \\
$<5.0$ \\
$<2.0$ \\
$<2.0$ \\
$<0.20$ \\
$<4.0$ \\
$<500$ \\
$<2.0$ \\
$<100$ \\
$<2.0$ \\
$<10$ \\
$<2.0$ \\
$<2.0$ \\
$<20$ \\
$<8.0$ \\
$<2.0$
\end{tabular}

\section{WELL EPT 82}

MFASUREMENTS CONDUCTED IN THE FIELD

Sample date: 11/21/91

Depth to water: Not available

Water elevation: Not availablo

LABORATORY ANALYSES
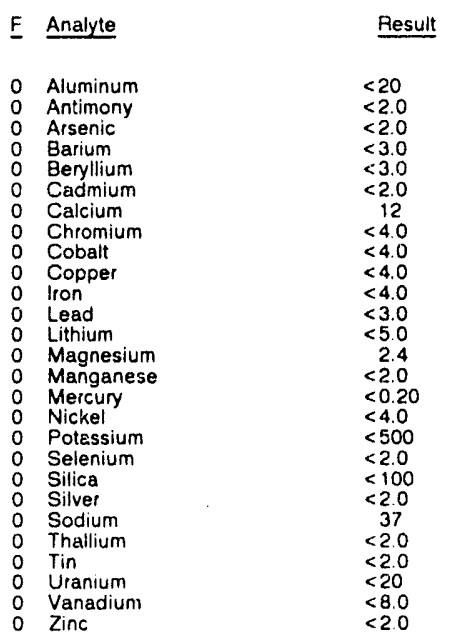

WELL EPT 83

MEASUREMENTS CONDUCTED IN THE FIELD

Sample date: 11/21/91

Depth to water: Not available

$\mathrm{Sp}$. conductance: $1 \mu \mathrm{S} / \mathrm{cm}$

LABORATORY ANALYSES

\begin{tabular}{|c|c|c|c|}
\hline Analyte & Result & Mod & Unit \\
\hline $\begin{array}{ll}0 & \text { Aluminum } \\
2 & \text { Antimony } \\
0 & \text { Arsenic } \\
0 & \text { Barium } \\
0 & \text { Beryllium } \\
0 & \text { Cadmium }\end{array}$ & $\begin{array}{l}<20 \\
11 \\
<2.0 \\
<3.0 \\
<3.0 \\
<2.0\end{array}$ & & $\begin{array}{l}\mu g / L \\
\mu g / L \\
\mu g / L \\
\mu g / L \\
\mu g / L \\
\mu g / L\end{array}$ \\
\hline
\end{tabular}

Time: 13:50

pH: 5.4

Alkalinity: $1 \mathrm{mg} / \mathrm{L}$

Water temperature: $24.7^{\circ} \mathrm{C}$
WELL EPT 83 collocted on 11/21/91, laboratory analyses (cont.)

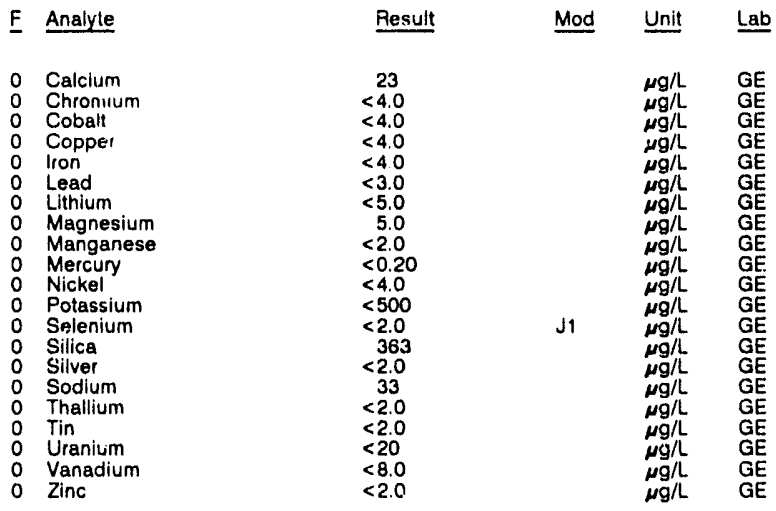

WELL EPT 84

MEASUREMENTS CONDUCTED IN THE FIELL

Sample date: 11/22/91

Depth to water: Not avallable

$\mathrm{Sp}$. conductance: $1 \mu \mathrm{S} / \mathrm{cm}$

pH: 4.8

PH: 4.8 : $1 \mathrm{ma} / \mathrm{h}$

Water temperature: $20.0^{\circ} \mathrm{C}$

LABORATORY ANALYSES

E Analyte
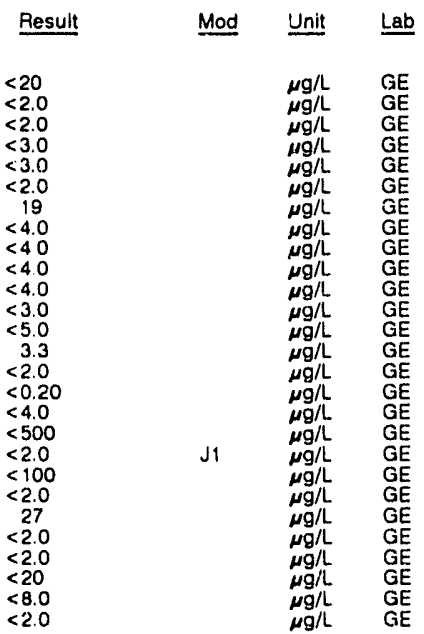

WELL EPT 85

MEASUREMENTS CONDUCTED IN THE FIELD

Sample date: 11/22/91

Depth to water: Not available

Water elevation: Not available

LABORATORY ANALYSES

$\begin{array}{ll}\text { F } & \text { Analyte } \\ 0 & \text { Aluminum } \\ 0 & \text { Antimony } \\ 0 & \text { Arsenic } \\ 0 & \text { Barium } \\ 0 & \text { Beryllium } \\ 0 & \text { Cadmium } \\ 0 & \text { Calcium } \\ 0 & \text { Chromium } \\ 0 & \text { Cobalt } \\ 0 & \text { Copper } \\ 0 & \text { Iron } \\ 0 & \text { LEad } \\ 0 & \text { Lithium } \\ 0 & \text { Magnesium } \\ 0 & \text { Manganese } \\ 0 & \text { Mercury } \\ 0 & \text { Nicikel } \\ 0 & \text { Potassium } \\ 0 & \text { Selenium } \\ 0 & \text { Silica } \\ 0 & \text { Silver } \\ 0 & \text { Sodium }\end{array}$

\begin{tabular}{l}
$\quad$ Pesult \\
\multicolumn{1}{r}{} \\
$<20$ \\
$<2.0$ \\
$<2.0$ \\
$<3.0$ \\
$<3.0$ \\
$<2.0$ \\
$<10$ \\
$<4.0$ \\
$<4.0$ \\
$<4.0$ \\
$<4.0$ \\
$<3.0$ \\
$<5.0$ \\
2.8 \\
$<2.0$ \\
$<0.20$ \\
$<4.0$ \\
$<500$ \\
$<2.0$ \\
$<100$ \\
$<2.0$ \\
$<10$
\end{tabular}

Time: 8:55

pH: 5.5

Alkaler temperature: $19.5^{\circ} \mathrm{C}$

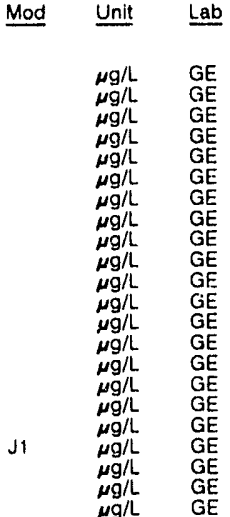


QUALITY CONTROL SAMPLES

WELL EPT 85 collected on 11/22/91, laboratory analyses (cont.)

\begin{tabular}{|c|c|c|c|}
\hline F Analyte & Result & Mod & Unit \\
\hline $\begin{array}{ll}0 & \text { Thallium } \\
0 & \text { Tin } \\
0 & \text { Uranium } \\
0 & \text { Vanadium } \\
0 & \text { Zinc }\end{array}$ & $\begin{array}{l}<2.0 \\
<2.0 \\
<20 \\
<8.0 \\
<2.0\end{array}$ & & 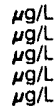 \\
\hline
\end{tabular}

WELLL EPT 86

MEASUREMENTS CONDUCTED IN THE FIELD

Sample date: 11/22/91

Depth to water: Not avallable

Sp. conductance: $1 \mu \mathrm{s} / \mathrm{cm}$

LABORATORY ANALYSES

\begin{tabular}{|c|c|c|c|}
\hline Analyte & Result & Mod & Unit \\
\hline 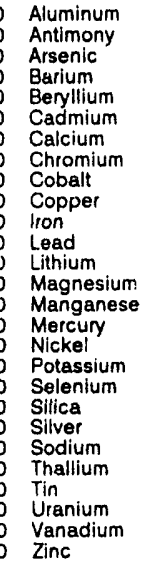 & $\begin{array}{l}<20 \\
<2.0 \\
<2.0 \\
<3.0 \\
<3.0 \\
<2.0 \\
<10 \\
<4.0 \\
<4.0 \\
<4.0 \\
<4.0 \\
<3.0 \\
<5.0 \\
<2.0 \\
<2.0 \\
<0.20 \\
<4.0 \\
<500 \\
<2.0 \\
<100 \\
<2.0 \\
27 \\
<2.0 \\
<2.0 \\
<20 \\
<8.0 \\
<2.0\end{array}$ & J1 & $\begin{array}{l}\mu \mathrm{g} / \mathrm{L} \\
\mu g / \mathrm{L} \\
\mu g / \mathrm{L} \\
\mu \mathrm{g} / \mathrm{L} \\
\mu \mathrm{g} / \mathrm{L} \\
\mu \mathrm{g} / \mathrm{L} \\
\mu \mathrm{g} / \mathrm{L} \\
\mu \mathrm{g} / \mathrm{L} \\
\mu \mathrm{g} / \mathrm{L} \\
\mu \mathrm{g} / \mathrm{L} \\
\mu \mathrm{g} / \mathrm{L} \\
\mu \mathrm{g} / \mathrm{L} \\
\mu g / \mathrm{L} \\
\mu \mathrm{g} / \mathrm{L} \\
\mu \mathrm{g} / \mathrm{L} \\
\mu \mathrm{g} / \mathrm{L} \\
\mu \mathrm{g} / \mathrm{L} \\
\mu \mathrm{g} / \mathrm{L} \\
\mu \mathrm{g} / \mathrm{L} \\
\mu \mathrm{g} / \mathrm{L} \\
\mu \mathrm{g} / \mathrm{L} \\
\mu \mathrm{g} / \mathrm{L} \\
\mu \mathrm{g} / \mathrm{L} \\
\mu \mathrm{g} / \mathrm{L} \\
\mu \mathrm{g} / \mathrm{L} \\
\mu \mathrm{g} / L \\
\mu g / L\end{array}$ \\
\hline
\end{tabular}

WELL EPT 87

MEASUREMENTS CONDUCTED IN THE FIELD

Sample date: $11 / 25 / 91$

Depth to water: Not available

Water elevation: Not available

LABORATORY ANALYSES

E Analyte

- Aluminum

0 Antimony

Arsenic
Barium

Beryllium

Cadmium

Calcium

Cobalt

Copper

Iron

0 Lead

Lithium

Manganese

Mercury

Potassium

0 Selenium

0 Silica

Silver

0 Thallium

0 Tin

- Uranium

O Vanadium
Time: 10:30

pH: 4.8

Water temperalure: $17.9^{\circ} \mathrm{C}$

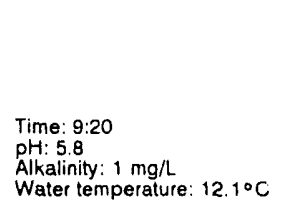

Water temperature: $12.1^{\circ} \mathrm{C}$

Mod Unit Lab

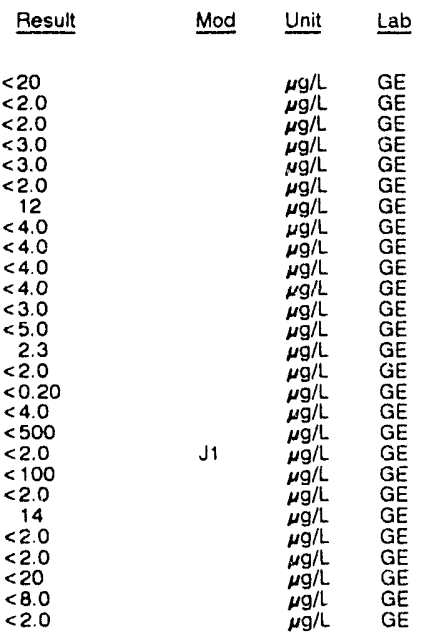

WELL EPT 88

MEASUREMENTS CONDUCTED IN THE FIELD

Sample date: $11 / 26 / 91$

Depth to water: Not available

Sp. conductance: 1 a $/ \mathrm{cm}$

LABORATORY ANALYSES

$\begin{array}{ll}\text { F } & \text { Analyte } \\ & \\ 0 & \text { Aluminum } \\ 0 & \text { Antimony } \\ 0 & \text { Arsenic } \\ 0 & \text { Barium } \\ 0 & \text { Beryllium } \\ 0 & \text { Cadmium } \\ 0 & \text { Calcium } \\ 0 & \text { Chromium } \\ 0 & \text { Cobalt } \\ 0 & \text { Copper } \\ 0 & \text { lron } \\ 0 & \text { Lead } \\ 0 & \text { Lithium } \\ 0 & \text { Magnesium } \\ 0 & \text { Manganese } \\ 0 & \text { Mercury } \\ 0 & \text { Nickel } \\ 0 & \text { Potassium } \\ 0 & \text { Selenium } \\ 0 & \text { Silica } \\ 0 & \text { Silver } \\ 0 & \text { Sodium } \\ 0 & \text { Thallium } \\ 0 & \text { Tin } \\ 0 & \text { Uranium } \\ 0 & \text { Vanadium } \\ 0 & \text { Zinc }\end{array}$

\begin{tabular}{l}
\multicolumn{1}{r}{ Pesult } \\
\hline \\
$<20$ \\
$<2.0$ \\
$<2.0$ \\
$<3.0$ \\
$<3.0$ \\
$<2.0$ \\
24 \\
$<4.0$ \\
$<4.0$ \\
$<4.0$ \\
11 \\
$<3.0$ \\
$<5.0$ \\
3.9 \\
$<2.0$ \\
$<0.20$ \\
$<4.0$ \\
$<500$ \\
$<2.0$ \\
$<100$ \\
$<2.0$ \\
42 \\
$<2.0$ \\
$<2.0$ \\
$<20$ \\
$<8.0$ \\
$<2.0$
\end{tabular}

Time: $8: 10$

Alkalinity: $1 \mathrm{mg} / \mathrm{L}$

Water temperature: $10.6^{\circ} \mathrm{C}$

\section{WELL EPT 89}

MEASUREMENTS CONDUCTED IN THE FIELD

Sample date: $11 / 26 / 91$

Depth to water: Not available

Water elevation: Not available
Sp. conductance: $1 \mu \mathrm{S} / \mathrm{cm}$

LABORATORY ANALYSES

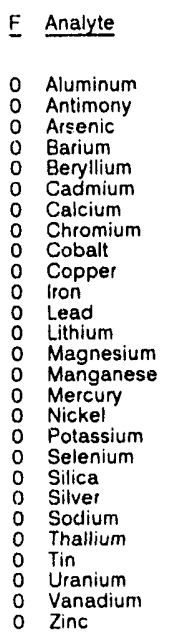

Result

Time: $8: 55$

Alkalinity: $1 \mathrm{mg} / \mathrm{h}$

Water temperature: $15.0^{\circ} \mathrm{C}$

Mod Unit Lab

$\mu \quad \mu / L \quad G E$

$\mu g / L \quad G E$

$\mu g / L \quad G E$

\section{J1}

$\begin{array}{ll}\mu g / \mathrm{L} & \mathrm{GE} \\ \mu \mathrm{g} / \mathrm{L} & \mathrm{GE} \\ \mu g / \mathrm{L} & \mathrm{GE} \\ \mu \mathrm{g} / \mathrm{L} & \mathrm{GE} \\ \mu \mathrm{g} / \mathrm{L} & \mathrm{GE} \\ \mu \mathrm{g} / \mathrm{L} & \mathrm{GE} \\ \mu \mathrm{g} / \mathrm{L} & \mathrm{GE} \\ \mu \mathrm{g} / \mathrm{L} & \mathrm{GE} \\ \mu \mathrm{G} / \mathrm{L} & \mathrm{GE} \\ \mu \mathrm{G} / \mathrm{L} & \mathrm{GE} \\ \mu \mathrm{g} / \mathrm{L} & \mathrm{GE} \\ \mu g / \mathrm{L} & \mathrm{GE} \\ \mu \mathrm{g} / \mathrm{L} & \mathrm{GE}\end{array}$

WELL EPT 90

MEASUREMENTS CONDUCTED IN THE FIELD

Sample date: 12/02/91

Depth to water: Not available

Water elevation: Not available

Sp. conductance: $1 \mu \mathrm{S} / \mathrm{cm}$

LABORATORY ANALYSES
E Analyte
- Aluminum
- Antimony
0 Barium
Beryllium

Result
Mod Unit Lab

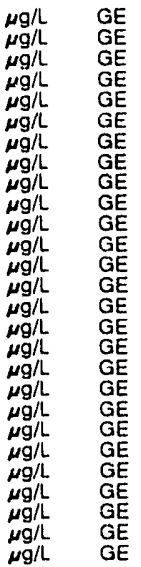

Time 8:35

pH: 5.6

Water temperature: $22.4^{\circ} \mathrm{C}$

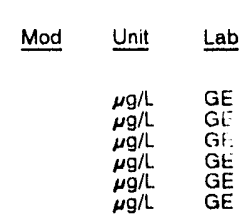


QUALITY CONTROL SAMPLES

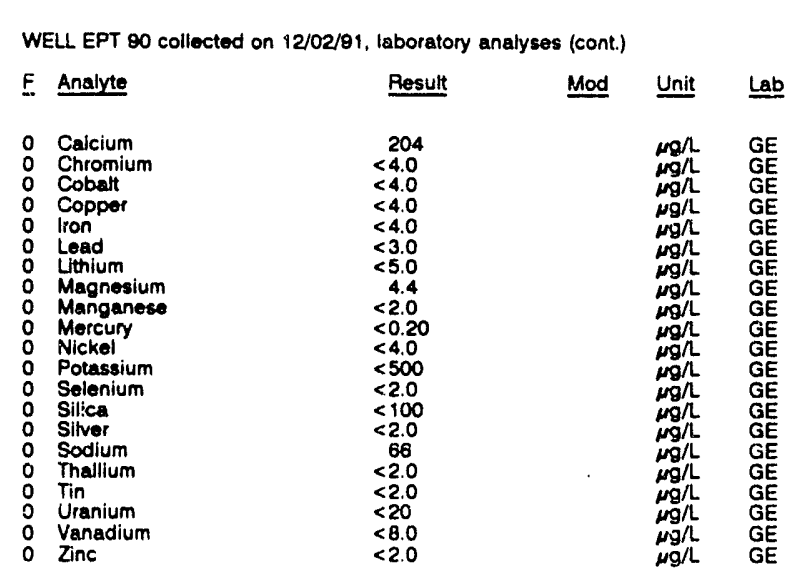

\section{WELL. EPT 91}

MEASUREMENTS CONOUCTED IN THE FIELD

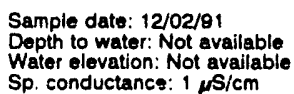

Sp. conductancs: $1 \mu \mathrm{S} / \mathrm{cm}$

LABORATORY ANIALYYSES

\begin{tabular}{|c|c|}
\hline Analyte & Result \\
\hline $\begin{array}{l}\text { Aluminum } \\
\text { Antimony } \\
\text { Arsenic } \\
\text { Barlum } \\
\text { Beryllium } \\
\text { Cadmium } \\
\text { Calcium } \\
\text { Chromium } \\
\text { Cobalt } \\
\text { Copper } \\
\text { Iron } \\
\text { Lead } \\
\text { Lithium } \\
\text { Magnesium } \\
\text { Manganese } \\
\text { Marcury } \\
\text { Nickel } \\
\text { Potassium } \\
\text { Selenium } \\
\text { Silica } \\
\text { Silver } \\
\text { Sodium } \\
\text { Thallium } \\
\text { Tin } \\
\text { Uranium } \\
\text { Vanadium } \\
\text { Zinc }\end{array}$ & $\begin{aligned}<20 \\
<2.0 \\
<2.0 \\
<3.0 \\
<3.0 \\
<2.0 \\
31 \\
<4.0 \\
<4.0 \\
<4.0 \\
<4.0 \\
<3.0 \\
<5.0 \\
<2.0 \\
<2.0 \\
<0.20 \\
<4.0 \\
<500 \\
<2.0 \\
<100 \\
<2.0 \\
<10 \\
<2.0 \\
<2.0 \\
<20 \\
<8.0 \\
<2.0\end{aligned}$ \\
\hline
\end{tabular}

WELL EPT 92

MEASUREMENTS CONDUCTED IN THE FIELD

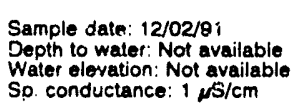

Sp. conductance: $1 \mathrm{\mu s} / \mathrm{cm}$

LABORATOAY ANALYSES

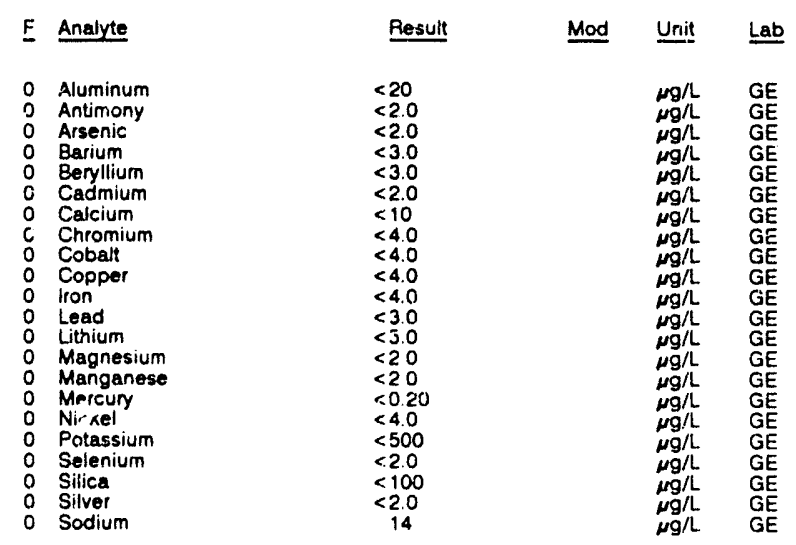

WELL EPT 92 collected on 12/02/81, laboratory analyses (cont.)

\begin{tabular}{|c|c|c|c|}
\hline E Arialyte & Result & Mod & Unit \\
\hline $\begin{array}{ll}0 & \text { Thallium } \\
0 & \text { Tin } \\
0 & \text { Uranium } \\
0 & \text { Vanadium } \\
0 & \text { Zinc }\end{array}$ & $\begin{array}{l}<2.0 \\
<2.0 \\
<20 \\
<8.0 \\
<2.0\end{array}$ & & $\begin{array}{l}\mu g / L \\
\mu g / L \\
\mu g / L \\
\mu g / L\end{array}$ \\
\hline
\end{tabular}

\section{WELL EPT 93}

MEASUREMENTS CONDUCTEO IN THE FIELD
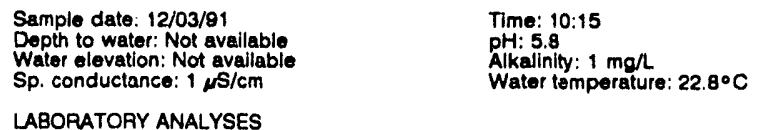

\begin{tabular}{|c|c|c|c|}
\hline Analyte & Result & Mod & Unit \\
\hline $\begin{array}{l}\text { Aluminum } \\
\text { Antimony } \\
\text { Arsenic } \\
\text { Barium } \\
\text { Beryllium } \\
\text { Cadmium } \\
\text { Caicium } \\
\text { Chromium } \\
\text { Cobalt } \\
\text { Copper } \\
\text { llon } \\
\text { Lead } \\
\text { Lithium } \\
\text { Magnesium } \\
\text { Manganese } \\
\text { Mercury } \\
\text { Nickel } \\
\text { Pctassiumi } \\
\text { Selenium } \\
\text { Silica } \\
\text { Silver } \\
\text { Sodium } \\
\text { Thaltium } \\
\text { Tin } \\
\text { Uranium } \\
\text { Vanadium } \\
\text { Zinc }\end{array}$ & $\begin{array}{l}<20 \\
<2.0 \\
<2.0 \\
<3.0 \\
<3.0 \\
<2.0 \\
<10 \\
<4.0 \\
<4.0 \\
<4.0 \\
<4.0 \\
<3.0 \\
<5.0 \\
<2.0 \\
<2.0 \\
<0.20 \\
<4.0 \\
<500 \\
<2.0 \\
<100 \\
<2.0 \\
<10 \\
<2.0 \\
<2.0 \\
<20 \\
<8.0 \\
<2.0\end{array}$ & J1 & $\begin{array}{l}\mu g / L \\
\mu g / L \\
\mu g / L \\
\mu g / h \\
\mu g / L \\
\mu g / L \\
\mu g / L \\
\mu g / L \\
\mu g / L \\
\mu g / L \\
\mu g / L \\
\mu g / L \\
\mu g h \\
\mu g / L \\
\mu g / L \\
\mu g / L \\
\mu g / L \\
\mu g / L \\
\mu g / L \\
\mu g / L \\
\mu g / L \\
\mu g / L \\
\mu g / L \\
\mu g / L \\
\mu g / L \\
\mu g / L \\
\mu g / L\end{array}$ \\
\hline
\end{tabular}

\section{WELI_ EPT 94}

MEASUREMENTS CONDUCTED IN THE FIELD

Sample date: 12/03/91

Depth io water: Not available

$\mathrm{Sp}$. conductance: $2 \mu \mathrm{S} / \mathrm{cm}$

LABORATORY ANALYSES

E Analyte

Result

Time: 8:10

PH: 5.5

Water temperature: $22.0^{\circ} \mathrm{C}$

- Aluminum

0 Antimony

O Arsenic

0 Beryllium

0 Cadmium

o Chromium

o Cobalt

o Iron

0 Lead

o Lithium

o Magnesium

o Mercury

O Nickel

o Selenium

O Silica

O Silver

o Sodium

0 Tha

o Uranium

0 Zinc

\begin{tabular}{|c|c|c|}
\hline Result & Mod & Unit \\
\hline $\begin{array}{l}<20 \\
<2.0 \\
<2.0 \\
<3.0 \\
<3.0 \\
<2.0 \\
41.0 \\
<4.0 \\
<4.0 \\
<4.0 \\
<4.0 \\
<3.0 \\
<5.0 \\
6.1 \\
<2.0 \\
<0.20 \\
<4.0 \\
<500 \\
<2.0 \\
<100 \\
<2.0 \\
84 \\
<2.0 \\
<2.0 \\
<20 \\
<8.0 \\
<20\end{array}$ & J1 & 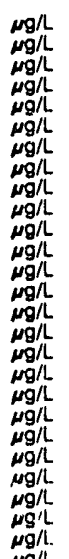 \\
\hline
\end{tabular}


QUALITY CONTROL SAMPLES

WELL EPT 95

MEASUREMENTS CONDUCTED IN THE FIELD

Sample date: 12/04/91

Depth to water: Not available

Sp. conductance: $1 \mu \mathrm{s} / \mathrm{cm}$

LABORATORY ANALYSES

E Analyte

- Aluminum

Antimony

Barium

Beryllium

Calcium

Chromium

Cobalt

0 Iron

0 Lead

Lithium

Manganese

Mercury

Potassium

Selenium

Silica

Silver

Sodium

Thallin

Uranium

Vanadium

WELL EPT 96

MEASUREMENTS CONDUCTED IN THE FIELD

Sample date: 12/04/81

Wepth to water: Not available

Sp. conductance: $1 \mu \mathrm{s} / \mathrm{cm}$

LABORATORY ANALYSES

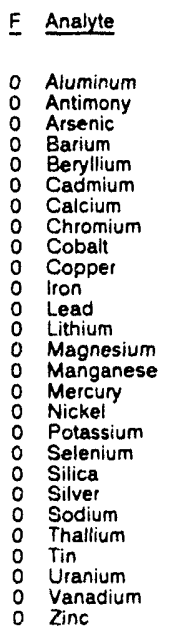

$\underline{\text { Result }}$

$<20$

$<2.0$

$<3.0$

$<2.0$

47
$<4.0$

$<4.0$

$<4.0$

$<3.0$
$<5.0$

2.5
$<2.0$
$<0.20$

$<500$

$<2.0$

$<100$
$<2.0$

15
$<2.0$

$<20$

$<8.0$

WELL EPT 97

MEASUREMENTS CONDUCTED IN THE FIELD

Sample date: 12/04/81

Water elevation: Not available

$\mathrm{Sp}$. conductance: $1 \mu \mathrm{S} / \mathrm{cm}$

LABORATORY ANALYSES

\begin{tabular}{|c|c|c|c|}
\hline F Analyte & Result & Mod & Unit \\
\hline $\begin{array}{ll}0 & \text { Aluminum } \\
0 & \text { Antimony } \\
0 & \text { Arsenic } \\
0 & \text { Barlum } \\
0 & \text { Beryllium } \\
0 & \text { Cadmium }\end{array}$ & $\begin{array}{r}32 \\
<2.0 \\
<2.0 \\
<3.0 \\
<3.0 \\
<2.0\end{array}$ & & $\begin{array}{l}\mu g / L \\
\mu g / L \\
\mu g / L \\
\mu g / L \\
\mu g / L \\
\mu g / L\end{array}$ \\
\hline
\end{tabular}

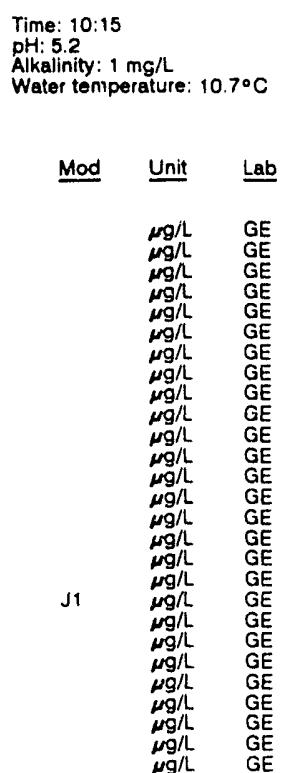

Time: $8: 30$

pH: 5.9

Water temperature $114^{\circ} \mathrm{C}$

Mod Unit Lab

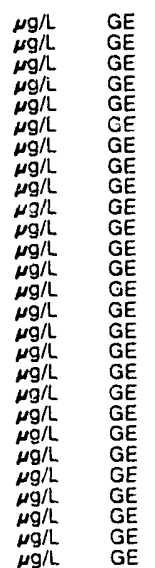

Time: 8:45

pH: 5.5

Nater temperature $10.6^{\circ} \mathrm{C}$

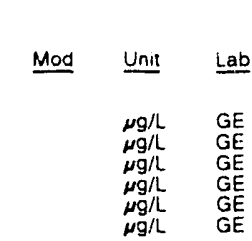

WELL EPT 97 collected on 12/04/81, laboratory analyses (cont.)

\begin{tabular}{|c|c|c|c|}
\hline Analyte & Result & Mod & Unit \\
\hline $\begin{array}{l}\text { Calcium } \\
\text { Chromium } \\
\text { Cobalt } \\
\text { Copper } \\
\text { lron } \\
\text { Lead } \\
\text { Lithium } \\
\text { Magnesium } \\
\text { Manganese } \\
\text { Mercury } \\
\text { Nickel } \\
\text { Potassium } \\
\text { Selenium } \\
\text { Silica } \\
\text { Sitver } \\
\text { Sodium } \\
\text { Thallium } \\
\text { Tin } \\
\text { Uranium } \\
\text { Vanadium } \\
\text { Zinc }\end{array}$ & $\begin{array}{r}36 \\
<4.0 \\
<4.0 \\
<4.0 \\
15 \\
<3.0 \\
<5.0 \\
21 \\
3.0 \\
<0.20 \\
<4.0 \\
<500 \\
<2.0 \\
<100 \\
<2.0 \\
<10 \\
<2.0 \\
<2.0 \\
<20 \\
<8.0 \\
<2.0\end{array}$ & J1 & 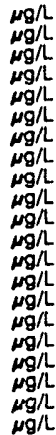 \\
\hline
\end{tabular}

WELL FPT 98

MEASUREMENTS CONDUCTED IN THE FIELO

Sample date: 12/05/91

Depth to water: Not available

Water elevation: Not ava

$\mu \mathrm{S} / \mathrm{cm}$

Time: $5: 15$

PH: 5.9

Water temperature: $12.3^{\circ} \mathrm{C}$

ABORATORY ANALYSES

E Analyte

Aluminum

Antimony

Arsenic

Beryllium

Cadmium

Chromium

Cobalt

Copper

lion

Lead

Magnesium

Manganese

Mercur

Nickol

Potassium

Selenium

Silica

Sodium

Thallium

Uranium

Vanadium

Result Mod Unit Lab

WELL EPT 99

MEASUREMENTS CONDUCTED IN THE FIELD

Sample date: 12/05/91

Depth to water: Not available

Sp conductance: $1 \mu \mathrm{S} / \mathrm{cm}$

LABORATORY ANAL.YSES
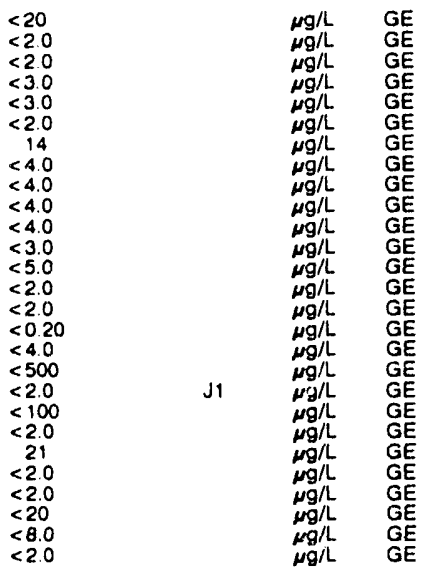

\begin{tabular}{|c|c|c|c|}
\hline Analyte & Result & Mod & Unit \\
\hline $\begin{array}{l}\text { Aluminum } \\
\text { Antimony } \\
\text { Arsenic } \\
\text { Barium } \\
\text { Beryltium } \\
\text { Cadmium } \\
\text { Calcium } \\
\text { Chromium } \\
\text { Cobalt } \\
\text { Copper } \\
\text { ron } \\
\text { Lead } \\
\text { Lithium } \\
\text { Magnesium } \\
\text { Manganese } \\
\text { Mereury } \\
\text { Nickel } \\
\text { Potassium } \\
\text { Selenium } \\
\text { Silica } \\
\text { Silver } \\
\text { Sodium }\end{array}$ & $\begin{array}{l}<20 \\
<2.0 \\
<20 \\
<3.0 \\
<30 \\
<2.0 \\
<10 \\
<4.0 \\
<4.0 \\
<4.0 \\
<40 \\
<3.0 \\
<5.0 \\
23 \\
<2.0 \\
<0.20 \\
<40 \\
<500 \\
<2.0 \\
524 \\
<2.0\end{array}$ & & $\begin{array}{l}\mu g / L \\
\mu g / L \\
\mu g / L \\
\mu g / L \\
\mu g / L \\
\mu g / L \\
\mu g / L \\
\mu g / L \\
\mu g / L \\
\mu g / L \\
\mu g, L \\
\mu g / L \\
\mu g / L \\
\mu g / L \\
\mu g / L \\
\mu g / L \\
\mu g / L \\
\mu g / L \\
\mu g / L \\
\mu g / L \\
\mu g / L \\
\mu g / L\end{array}$ \\
\hline
\end{tabular}


QUALITY CONTROL SAMPLES

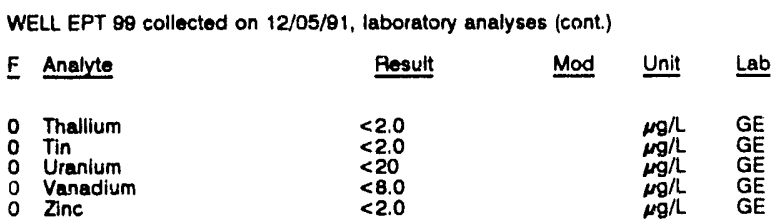

WELL EPT100

MEASUREMENTS CONDUCTED IN THE FIELD

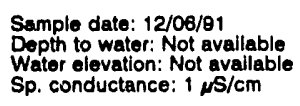

LABORATORY ANALYSES

\begin{tabular}{|c|c|c|c|}
\hline Analyte & Rosult & Mod & Unit \\
\hline 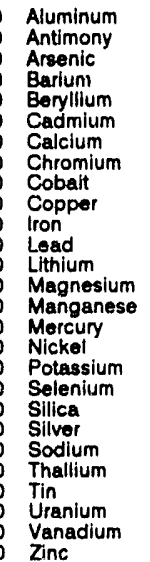 & $\begin{array}{l}<20 \\
<2.0 \\
<2.0 \\
<3.0 \\
<3.0 \\
<2.0 \\
24 \\
<4.0 \\
<4.0 \\
<4.0 \\
<4.0 \\
<3.0 \\
<5.0 \\
<2.0 \\
<2.0 \\
<0.20 \\
<4.0 \\
<500 \\
<2.0 \\
<100 \\
<2.0 \\
<10 \\
<2.0 \\
<2.0 \\
<20 \\
<8.0 \\
<2.0\end{array}$ & & 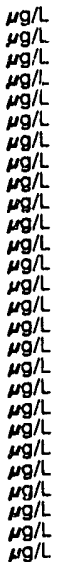 \\
\hline
\end{tabular}

WELL EPT101

MEASUREMENTS CONDUCTED IN THE FIELD

Sample date: 12/07/81

Depth to water: Not available

Water elevation: Not available
Sp. conductance: 2 s $\mathrm{S} / \mathrm{cm}$

LABORATORY ANALYSES

E Analyte

- Aluminum

2 Antimony

Arsenic

Barium

Beryllium

Calcium

Chromium

Cobalt

Iron

Load

Magnesium

Manganese

Mercury

Potassium

Selenium

Silica

Silver

Sodium

Tin

Uranium

Zine

\section{Time: $8: 40$ \\ Alkalinity: $1 \mathrm{mg} / \mathrm{L}$ \\ Water temperature: $14.9^{\circ} \mathrm{C}$}

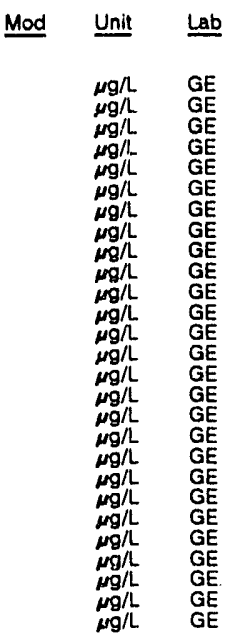

Time: $9: 45$

PH: 5.5

Alkalnity: $1 \mathrm{mg} / \mathrm{L}$ : $14.7^{\circ} \mathrm{C}$

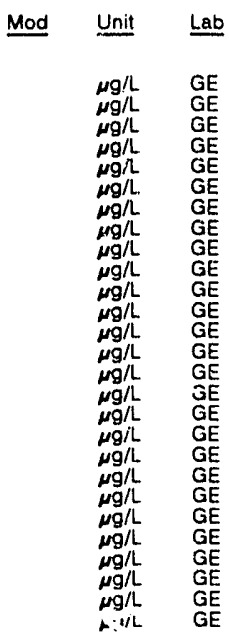

WELLL EPT102

MEASUREMENTS CONDUCTED IN THE FIELD

Sample date: 12/08/91

Depth to water: Not available

Water elevation: Not 8vailable
Sp. conductance: $1 \mu \mathrm{s} / \mathrm{cm}$

LABORATORY ANALYSES

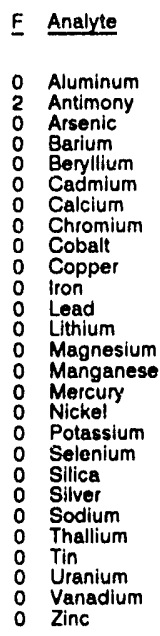

\begin{tabular}{l}
\multicolumn{1}{r}{ Result } \\
\hline \\
$<20$ \\
16 \\
$<2.0$ \\
$<3.0$ \\
$<3.0$ \\
$<2.0$ \\
14 \\
$<4.0$ \\
$<4.0$ \\
$<4.0$ \\
$<4.0$ \\
$<3.0$ \\
$<5.0$ \\
2.6 \\
$<2.0$ \\
$<0.20$ \\
$<4.0$ \\
$<500$ \\
$<2.0$ \\
150 \\
$<2.0$ \\
29 \\
$<2.0$ \\
$<2.0$ \\
$<20$ \\
$<8.0$ \\
$<2.0$
\end{tabular}

Time: $9: 55$

PH: 5.3 : $1 \mathrm{mg}$ inity: $1 \mathrm{mg}$

Water temperature: $18.0^{\circ} \mathrm{C}$

E Analyte

Mod Unit Lab

WELL EPT103

MEASIJREMENTS CONDUCTED IN THE FIELD

Sample date: 12/09/91

Depth to water: Not available

Sp. conductance: $1 \mu \mathrm{s} / \mathrm{cm}$

Alkalinity: $1 \mathrm{mg} / \mathrm{L}$

Water temperature: $24.8^{\circ} \mathrm{C}$

LABORATORY ANALYSES
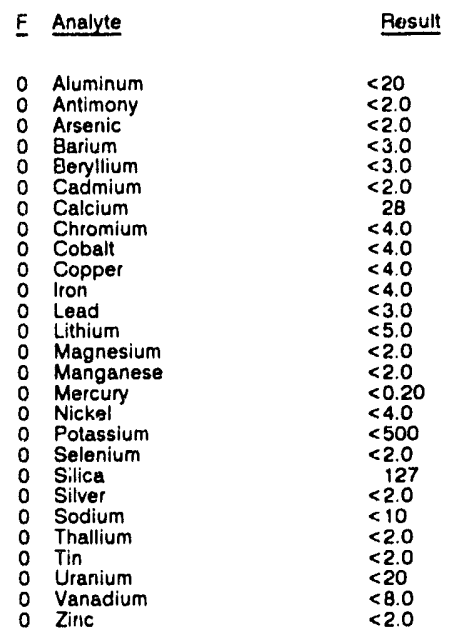

WELL EPT104

MEASUREMENTS CONDUCTED IN THE FIELD

Sample date: 12/08/81

Depth to water: Not available

Water elevation: Not available

LABORATORY ANALYSES

\begin{tabular}{|c|c|c|c|}
\hline Analyte & Result & Mod & Unit \\
\hline $\begin{array}{l}\text { Aluminum } \\
\text { Antimony } \\
\text { Arsenic } \\
\text { Earium } \\
\text { Beryllium } \\
\text { Cadmium }\end{array}$ & $\begin{array}{l}<20 \\
<2.0 \\
<2.0 \\
<3.0 \\
<3.0 \\
<2.0\end{array}$ & & $\begin{array}{l}\mu g / L \\
\mu g / L \\
\mu g / L \\
\mu g / L \\
\mu g / L \\
\mu g / L\end{array}$ \\
\hline
\end{tabular}




\section{QUALITY CONTROL SAMPLES}

\begin{tabular}{|c|c|c|c|}
\hline Analyte & Result & Mod & Unit \\
\hline 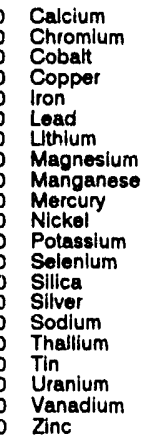 & $\begin{array}{l}<10 \\
<4.0 \\
<4.0 \\
<4.0 \\
<4.0 \\
<3.0 \\
<5.0 \\
<2.0 \\
<2.0 \\
<0.20 \\
<4.0 \\
<500 \\
<2.0 \\
13.8 \\
<2.0 \\
<10 \\
<2.0 \\
<2.0 \\
<20 \\
<8.0 \\
<2.0\end{array}$ & & 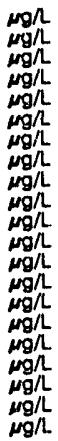 \\
\hline
\end{tabular}

\section{WELL EPT105}

MEASUREMENTS CONDUCTED IN THE FIELD

Sample date: 12/10/91

Depth to water: Not available

Sp. conductance: $1 \mu \mathrm{S} / \mathrm{cm}$

LABORATORY ANALYSES

\begin{tabular}{|c|c|c|c|}
\hline Analyte & Result & Mod & Unit \\
\hline $\begin{array}{l}\text { Aluminum } \\
\text { Antimony } \\
\text { Arsenic } \\
\text { Barium } \\
\text { Berillium } \\
\text { Cadmium } \\
\text { Calclum } \\
\text { Chromium } \\
\text { Cobalt } \\
\text { Copper } \\
\text { lon } \\
\text { Lead } \\
\text { Lead } \\
\text { Magium } \\
\text { Magnesium } \\
\text { Manganese } \\
\text { Merccury } \\
\text { Nickel } \\
\text { Potassium } \\
\text { Selenium } \\
\text { Sllica } \\
\text { Silver } \\
\text { Sodium } \\
\text { Thallium } \\
\text { Tin } \\
\text { Uranium } \\
\text { Vanadium } \\
\text { Zine }\end{array}$ & $\begin{array}{l}<20 \\
<2.0 \\
<2.0 \\
<3.0 \\
<3.0 \\
<2.0 \\
13 \\
<4.0 \\
<4.0 \\
<4.0 \\
<4.0 \\
<3.0 \\
<5.0 \\
<2.0 \\
<2.0 \\
<0.20 \\
<4.0 \\
<500 \\
<2.0 \\
156 \\
<2.0 \\
17 \\
<2.0 \\
<2.0 \\
<20 \\
<8.0 \\
<2.0\end{array}$ & & 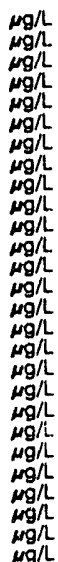 \\
\hline
\end{tabular}

WELL EPT106

MEASUAREMENTS CONDUCTED IN THE FIELD

Samplo date: 12/10/81

Depth to water: Not available

Water elevation: Not availablo
Sp. conductance: 1 S/cm

LABORATORY ANALYSES

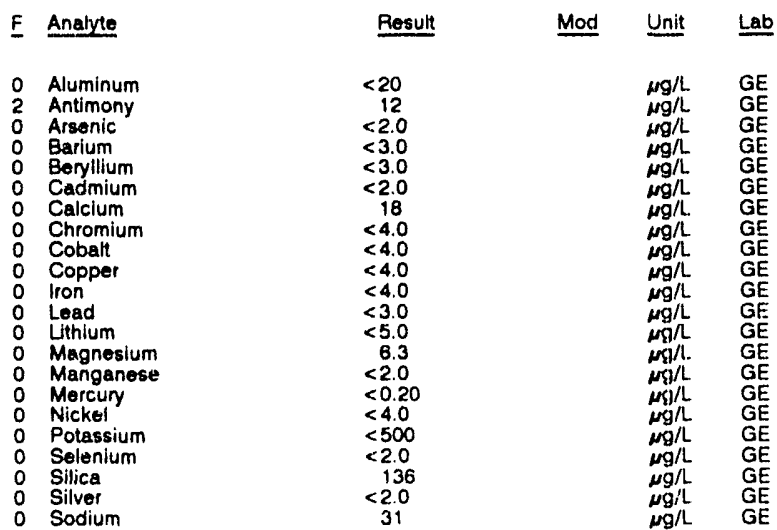

WELL EPT106 coliocted on 12/10/81, laboratory analyses (cont.)

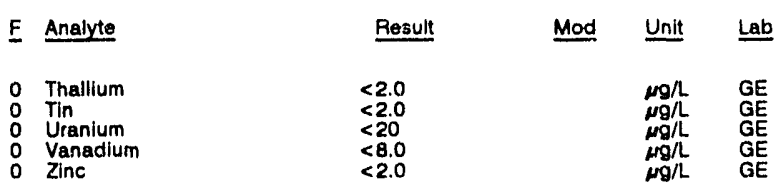

WELL. EPT107

MEASUREMENTS CONDUCTED IN THE FIELD

Sample date: 12/12/91

Depth to water: Not avallable

Sp. conductanco: $1 \mathrm{wS} / \mathrm{cm}$

LABORATORY ANALYSES

$E$ Analyte

Result

Time: $8: 55$

PH: 6.1 : 1 ilkalinity: 1 moll

Water temperature: $17.8^{\circ} \mathrm{C}$

- Aluminum

0 Antimony

Arsenic

Baryllium

Cadmium

Chromium

Cobalt

Copper

Lead

0 Lithium

Manganese

Mercury

Potassium

Potassium

Silica

Silver

Thallium

Tin

Vanadium

Presult Mod Unit Lab

WELL EPT108

MEASUREMENTS CONDUCTED IN THE FIELD

Sample date: 12/11/91

Depth to water: Not available

Water olevation: Not available

$<20$
$<2.0$
$<2.0$
$<3.0$
$<3.0$
$<2.0$
52
$<4.0$
$<4.0$
$<4.0$
$<4.0$
$<3.0$
$<5.0$
$<2.0$
$<2.0$
$<0.20$
$<4.0$
$<500$
$<2.0$
324
$<2.0$
25
$<2.0$
$<2.0$
$<8.0$
$<2.0$

LABORATORY ANALYSES

E Analyte

Result

- Aluminum

Antimony

0 Arsenic

Beryllium

Cadmium

Calcium

Chromium

O Coppe

0 Iron

Lead

Lithium

Magneslum

0 Mercury

o Nickel

o Potassium

0 Selenium

- Silica

O Silver

0 Thallium

Tin

Vanadium

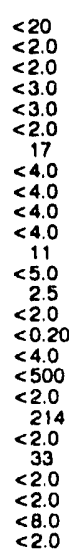

Time: $8: 35$

pH: 5.4

Alkalinity: $1 \mathrm{mg} / \mathrm{h}$

Water temperature: $14.7^{\circ} \mathrm{C}$

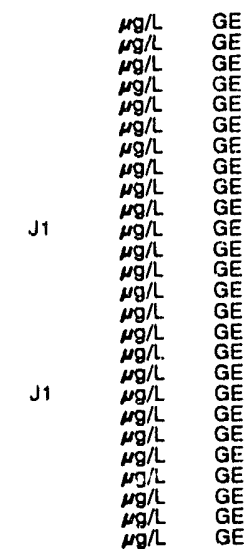

Mod Unit Lab

$\mu g / L \quad G E$

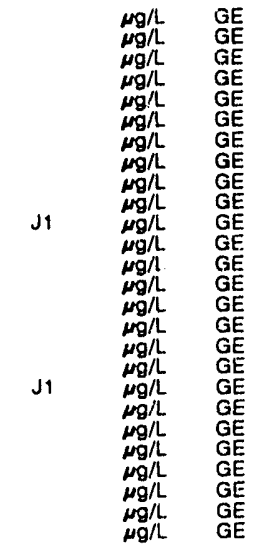




\section{QUALITY CONTROL SAMPLES}

WELL EPT109

MEASUREMENTS CONDUCTED .. T THE FIELD

L.mple dato: 12/13/91

Wepth to water: Not available Water elevation: Not availablo

LABORATORY ANALYSES
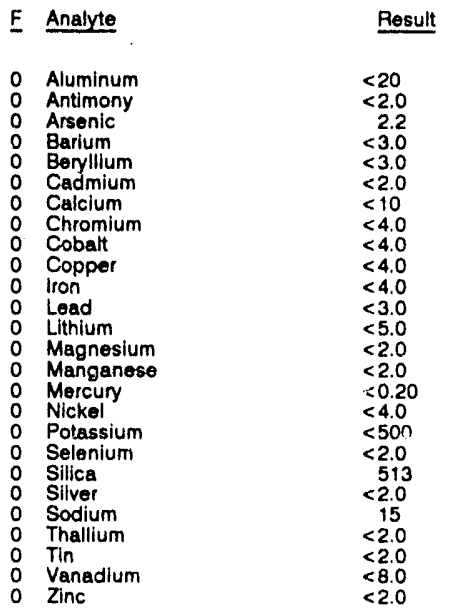

WELL EPT110

MEASUREMENTS CONDUCTED IN THE FIELD

Sample date: $12 / 13 / 91$

Depth to water: Not avallable Water elevation: Not available

LBORATORY ANALYSES
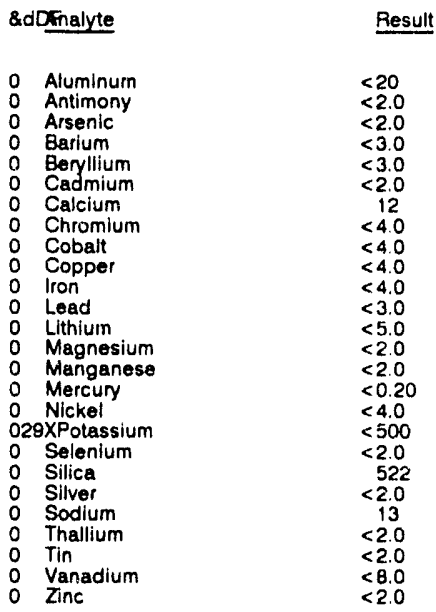

\section{WELL EPT111}

MEASUREMENTS CONDUCTED IN THE FIELD

Sample date: $12 / 14 / 01$

Depth to water: Not available

Sp. conductance: $1 \mu \mathrm{s} / \mathrm{cm}$

LABORATORY ANALYSES

\begin{tabular}{|c|c|c|c|c|}
\hline F Analyte & Result & Mod & Unit & $\underline{\text { Lab }}$ \\
\hline 0 Aluminum & $<20$ & & $\mu g / L$ & $\mathrm{GE}$ \\
\hline $\begin{array}{ll}0 & \text { Arsenic } \\
0 & \text { Barium } \\
0 & \text { Beryllium } \\
0 & \text { Cadmium } \\
0 & \text { Caicium } \\
0 & \text { Chromium }\end{array}$ & $\begin{array}{l}<2.0 \\
<3.0 \\
<3.0 \\
<2 . \\
<10 \\
<4.0\end{array}$ & & $\begin{array}{l}\mu g / L \\
\mu g / L \\
\mu g / L \\
\mu g / L \\
\mu g / L G E \\
\mu g / L\end{array}$ & $\begin{array}{l}G E \\
G E \\
G E \\
G E \\
G E\end{array}$ \\
\hline
\end{tabular}

Time: 9:25

PH: 4.8 . $1 \mathrm{mg}$

Alkalinity: $1 \mathrm{mg} / \mathrm{L}$

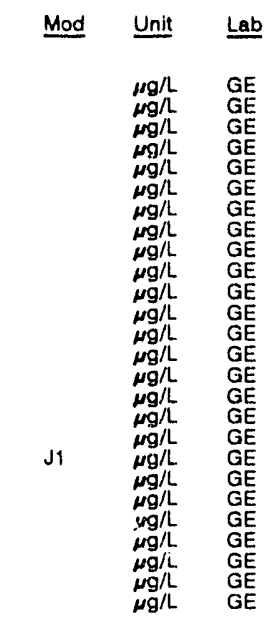

Time: $9: 15$

PH: 5.6

Water temperature: $20.5^{\circ} \mathrm{C}$

Mod Unit Lab

WELL EPTI11 collected on 12/14/91, laboratory analyses (cont.)

Mod Unit Lab

$\begin{array}{ll}\text { F } & \text { Analyte } \\ & \\ 0 & \text { Cobalt } \\ 0 & \text { Copper } \\ 0 & \text { Iron } \\ 0 & \text { Lead } \\ 0 & \text { Lithlum } \\ 0 & \text { Magnesium } \\ 0 & \text { Manganese } \\ 0 & \text { Mercury } \\ 0 & \text { Nickel } \\ 0 & \text { Potassium } \\ 0 & \text { Selenium } \\ 0 & \text { Silica } \\ 0 & \text { Silver } \\ 0 & \text { Sodium } \\ 0 & \text { Thallium } \\ 0 & \text { Tin } \\ 0 & \text { Vanadium } \\ 0 & \text { Zinc } \\ \end{array}$

\begin{tabular}{l} 
Pesult \\
\multicolumn{1}{r}{} \\
$<4.0$ \\
$<4.0$ \\
$<4.0$ \\
$<3.0$ \\
$<5.0$ \\
$<2.0$ \\
$<2.0$ \\
$<0.20$ \\
$<4.0$ \\
$<500$ \\
$<2.0$ \\
652 \\
$<2.0$ \\
$<10$ \\
$<2.0$ \\
$<2.0$ \\
$<8.0$ \\
$<2.0$
\end{tabular}

$\begin{array}{llll}\mu \mathrm{g} / \mathrm{L} & \mathrm{GE} & 0 & \text { Potassium } \\ \mu \mathrm{g} / \mathrm{L} & \mathrm{GE} & 0 & \text { Selenium } \\ \mu \mathrm{g} / \mathrm{L} & \mathrm{GE} & 0 & \text { Silica } \\ \mu \mathrm{g} / \mathrm{L} & \mathrm{GE} & 0 & \text { Silver } \\ \mu \mathrm{g} / \mathrm{L} & \mathrm{GE} & 0 & \text { Sodium } \\ \mu \mathrm{g} / \mathrm{L} & \mathrm{GE} & 0 & \text { Thallium } \\ \mu \mathrm{g} / \mathrm{L} & \mathrm{GE} & 0 & \text { Tin } \\ \mu \mathrm{g} / \mathrm{L} & \mathrm{GE} & 0 & \text { Vanadium } \\ \mu g / L & \mathrm{GE} & 0 & \text { Zinc }\end{array}$

WELL EPT113

MEASUREMENTS CONDUCTED IN THE FIELD

Sample datc. 12/16/91

Depth to water: Not available

Water elevation: Not available

LABORATORY ANALYSES

E Analyte

Aluminum

Antimon

0 Arsenic

Beryllium

Cadmium

Calciuin

Chromium

Cobalt

Coppe

Lead

Lithium

Magnesium

Mercury

Potassium

Selenium

0 Silica

Silver

Sodium

Thallium

Tin

Vanadium
Zinc

\begin{tabular}{l}
$r$ Result \\
\hline \\
$<20$ \\
$<2.0$ \\
$<2.0$ \\
$<3.0$ \\
$<3.0$ \\
$<2.0$ \\
$<10$ \\
$<4.0$ \\
$<4.0$ \\
$<4.0$ \\
$<4.0$ \\
$<3.0$ \\
$<5.0$ \\
$<2.0$ \\
$<2.0$ \\
$<0.20$ \\
$<4.0$ \\
$<500$ \\
$<2.0$ \\
832 \\
$<2.0$ \\
24 \\
$<2.0$ \\
$<2.0$ \\
$<8.0$ \\
3.3
\end{tabular}

Mod Unit Lab

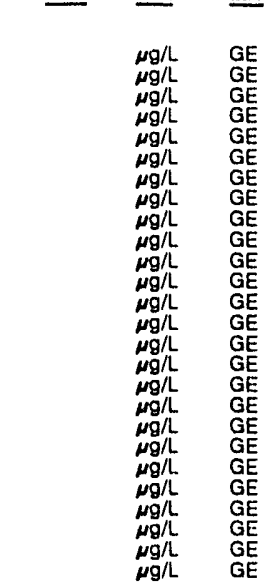

Time: $8: 45$

Alkalinity: $1 \mathrm{mg} / \mathrm{L}$

Water temperature: $27.7^{\circ} \mathrm{C}$

Time: : $: 50$

Alkalinity: $1 \mathrm{mg} / \mathrm{h}$.

Water temperature: $13.7^{\circ} \mathrm{C}$

Result Mod Unit Lab

\begin{tabular}{|c|c|c|}
\hline $\begin{array}{l}<20 \\
<2.0 \\
<2.0 \\
<3.0 \\
<3.0 \\
<2.0 \\
<10 \\
<4.0 \\
<4.0 \\
<4.0 \\
<4.0 \\
<3.0 \\
<5.0 \\
<2.0 \\
<2.0 \\
<0.20 \\
<4.0 \\
<500 \\
<2.0 \\
858 \\
<2.0 \\
<10 \\
<2.0 \\
<2.0 \\
<8.0 \\
<2.0\end{array}$ & J1 & $\begin{array}{l}\mu g / L \\
\mu g / L \\
\mu g / L \\
\mu g / L \\
\mu g / L \\
\mu g / L \\
\mu g / L \\
\mu g / L \\
\mu g / L \\
\mu g / L \\
\mu g / L \\
\mu g / L \\
\mu g / L \\
\mu g / L \\
\mu g / L \\
\mu g / L \\
\mu g / L \\
\mu g / L \\
\mu g / L \\
\mu g / L \\
\mu g / L \\
\mu g / L \\
\mu g / L \\
\mu g / L \\
\mu g / L\end{array}$ \\
\hline
\end{tabular}


QUALITY CONTROL SAMPLES

\section{WELL EPT114}

MEASUREMENTS CONDUCTED IN THE FIELD

Sample date: $12 / 16 / 91$ Depth to water: Not available Water olevation: Not available

Sp. conductance: $1 \mu \mathrm{S} / \mathrm{cm}$

\begin{tabular}{lll} 
E Analyte & Result \\
\hline 0 & Aluminum & \\
0 & Antimony & $<20$ \\
0 & Arsenic & $<2.0$ \\
0 & Esrlum & $<2.0$ \\
0 & Beryllium & $<3.0$ \\
0 & Cadmium & $<3.0$ \\
0 & Calcium & $<2.0$ \\
0 & Chromium & $<10$ \\
0 & Cobalt & $<4.0$ \\
0 & Copper & $<4.0$ \\
0 & lon & $<4.0$ \\
0 & Lead & $<4.0$ \\
0 & Lithium & $<3.0$ \\
0 & Magnesium & $<5.0$ \\
0 & Manganese & $<2.0$ \\
0 & Mercury & $<2.0$ \\
0 & Nickel & $<0.20$ \\
0 & Potassium & $<4.0$ \\
0 & Selenium & $<500$ \\
0 & Silica & $<2.0$ \\
0 & Silver & 1,200 \\
0 & Sodium & $<2.0$ \\
0 & Thallium & $<10$ \\
0 & Tin & $<2.0$ \\
0 & Vanadium & $<8.0$ \\
0 & Zinc & $<2.0$ \\
\end{tabular}

\section{WELL EPT115}

MEASUREMENTS CONDUCTED IN THE FIELD

Sample date: 12/17/81

Depth to water: Not available

Water elevation: Not available

LABORATORY ANALYSES

$\begin{array}{lll}\text { F Analyte } & \text { Result } \\ & \\ 0 \text { Aluminum } & <20 \\ 1 \text { Antimony } & 3.5 \\ 0 & \text { Arsenic } & <2.0 \\ 0 & \text { Barlum } & <3.0 \\ 0 & \text { Beryllium } & <3.0 \\ 0 & \text { Cadinum } & <2.0 \\ 0 & \text { Calcium } & <10 \\ 0 & \text { Chromium } & <4.0 \\ 0 & \text { Cobalt } & <4.0 \\ 0 & \text { Copper } & <4.0 \\ 0 & \text { Iron } & <4.0 \\ 0 & \text { Lead } & <3.0 \\ 0 & \text { Lithium } & <5.0 \\ 0 & \text { Magnesium } & <2.0 \\ 0 & \text { Manganese } & <2.0 \\ 0 & \text { Mercury } & <0.20 \\ 0 & \text { Nickel } & <4.0 \\ 0 & \text { Potassium } & <500 \\ 0 & \text { Selenium } & <2.0 \\ 0 & \text { Silica } & 2.970 \\ 0 & \text { Silver } & <2.0 \\ 0 & \text { Sodium } & 86 \\ 0 & \text { Thallium } & <2.0 \\ 0 & \text { Tin } & <2.0 \\ 0 & \text { Vanadium } & <.0 \\ 0 & \text { Zinc } & <2.0\end{array}$

\section{WELL EPT116}

MEASUREMENTS CONOUCTED IN THE FIELD

Sample date: 12/26/91

Depth to water: Not avaliable

Water elevation: Not available

LABORATORY ANALYSES

\begin{tabular}{|c|c|}
\hline Analyte & Result \\
\hline $\begin{array}{l}\text { Aluminum } \\
\text { Antimony } \\
\text { Arsenic } \\
\text { Barium } \\
\text { Beryllium } \\
\text { Cadmium } \\
\text { Calcium } \\
\text { Chromium }\end{array}$ & $\begin{array}{l}<20 \\
<2.0 \\
<2.0 \\
<3.0 \\
<3.0 \\
<2.0 \\
15 \\
<4.0\end{array}$ \\
\hline
\end{tabular}

WELL EPT 116 collected on 12/26/91, laboratory analyses (cont.)

\begin{tabular}{|c|c|c|c|}
\hline Analyte & Result & Mod & Unit \\
\hline $\begin{array}{ll}0 & \text { Cobalt } \\
0 & \text { Copper } \\
0 & \text { lron } \\
0 & \text { Lead } \\
0 & \text { Lithium } \\
0 & \text { Magnesium } \\
0 & \text { Manganese } \\
0 & \text { Mercury } \\
0 & \text { Nickel } \\
0 & \text { Potassium } \\
0 & \text { Selenium } \\
0 & \text { Silica } \\
0 & \text { Silver } \\
0 & \text { Sodium } \\
0 & \text { Thallium } \\
0 & \text { Tin } \\
0 & \text { Vanadium } \\
0 & \text { Zinc }\end{array}$ & $\begin{array}{l}<4.0 \\
<4.0 \\
<4.0 \\
<3.0 \\
<5.0 \\
<2.0 \\
<2.0 \\
<0.20 \\
<4.0 \\
<500 \\
<2.0 \\
8.640 \\
<2.0 \\
117 \\
<2.0 \\
<2.0 \\
<8.0 \\
3.4\end{array}$ & $J 1$ & $\begin{array}{l}\mu g / L \\
\mu g / L \\
\mu g / L \\
\mu g / L \\
\mu g / L \\
\mu g / L \\
\mu g / L \\
\mu g / L \\
\mu g / L \\
\mu g / L \\
\mu g / L \\
\mu g / L \\
\mu g / L \\
\mu g / L \\
\mu g / L \\
\mu g / L \\
\mu g / L \\
\mu g / L\end{array}$ \\
\hline
\end{tabular}

\section{WELL EPT117}

MEASUAEMENTS CONDUCTED IN THE FIELD

Sample date: $12 / 30 / 91$

Depth to water: Not avallable

Water elevation: Not available

$\mathrm{Sp}$. conductance: $2 \mu \mathrm{s} / \mathrm{cm}$

LABORATORY ANALYSES

\begin{tabular}{|c|c|c|c|}
\hline Analyte & Result & Mod & Unit \\
\hline 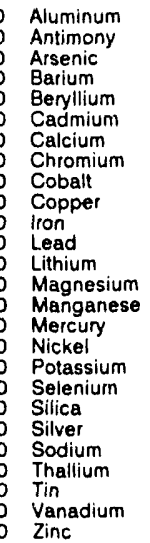 & $\begin{array}{l}<20 \\
<2.0 \\
<2.0 \\
<3.0 \\
<3.0 \\
<2.0 \\
<10 \\
<4.0 \\
<4.0 \\
<4.0 \\
<4.0 \\
<3.0 \\
<50 \\
2.2 \\
2.1 \\
<0.20 \\
<4.0 \\
<500 \\
<2.0 \\
7.650 \\
<2.0 \\
52 \\
<2.0 \\
<2.0 \\
<8.0 \\
<2.0\end{array}$ & $j 1$ & $\begin{array}{l}\mu g / L \\
\mu g / L \\
\mu g / L \\
\mu g / L \\
\mu g / L \\
\mu g / L \\
\mu g / L \\
\mu g / L \\
\mu g / L \\
\mu g / L \\
\mu g / L \\
\mu g / L \\
\mu g / L \\
\mu g / L \\
\mu g / L \\
\mu g / L \\
\mu g / L \\
\mu g / L \\
\mu g / L \\
\mu g / L \\
\mu g / L \\
\mu g / L \\
\mu g / L \\
\mu g / L \\
\mu g / L \\
\mu g / L\end{array}$ \\
\hline
\end{tabular}

WELL FB 31

MEASUREMENTS CONDUCTED IN THE FIELD

Sample date: $11 / 13 / 81$

Depth to water: Not available

Water elevation: Not available
$\mathrm{Sp}$. conductance: $6 \mu \mathrm{S} / \mathrm{cm}$

LABORATORY ANALYSES

\begin{tabular}{|c|c|c|c|}
\hline Analyte & Result & Mod & Unit \\
\hline $\begin{array}{l}\text { Chloroform } \\
1,1 \text {-Dichloroethylene } \\
\text { trans } 1,2 \text {-Dichloroethylene } \\
\text { Tetrachloroethylene } \\
1,1,1 \text {-Trichioroethane } \\
\text { irichloroethylene }\end{array}$ & $\begin{array}{l}<5.0 \\
<5.0 \\
<5.0 \\
<5.0 \\
<5.0 \\
<5.0\end{array}$ & & $\begin{array}{l}\mu g / L \\
\mu g / L \\
\mu g / L \\
\mu g / L \\
\mu g / L \\
\mu g / L\end{array}$ \\
\hline
\end{tabular}

WELL FB 32

Time: $:: 25$

PH: 5.3

Water temperature: $15.7^{\circ} \mathrm{C}$

MEASUREMENTS CONDUCTED IN THE FIELD

Sample date: $11 / 11 / 91$

Depth to wate! Not available

Water elevation: Not available

Time: $12: 50$

Alkalinity: $1 \mathrm{mg} / \mathrm{L}$

Water temperature: $16.4^{\circ} \mathrm{C}$

Mod Unit Lab

LABORATORY ANALYSES

\begin{tabular}{|c|c|c|c|}
\hline E Analyte & Result & Mod & Unit \\
\hline $\begin{array}{ll}\text { o } & \text { Chloruform } \\
0 & 1,1 \cdot \text { Dichloroethylene } \\
0 & \text { trans } 1,2 \cdot \text { Dichloroethylene } \\
0 & \text { Tetrachloroethylene }\end{array}$ & $\begin{array}{l}<5.0 \\
<5.0 \\
<5.0 \\
<5.0\end{array}$ & & $\begin{array}{l}\mu g / L \\
\mu g / L \\
\mu g / L \\
\mu g / L\end{array}$ \\
\hline
\end{tabular}


QUALITY CONTROL SAMPLES

WELL FB 32 collected on 11/11/91, laboratory analyses (cont)

\begin{tabular}{|c|c|c|c|}
\hline Analyte & Result & Mod & Unit \\
\hline $\begin{array}{l}\text { 1,1,1-Trichloroethane } \\
\text { Trichloroethylene }\end{array}$ & $\begin{array}{l}<5.0 \\
<5.0\end{array}$ & & $\begin{array}{l}\mu \mathrm{g} / \mathrm{h} \\
\mu \mathrm{g} / \mathrm{L}\end{array}$ \\
\hline
\end{tabular}

WELL FB 33

MEASUREMENTS CONDUCTED IN THE FIELD

Sample date: $11 / 01 / 9$

Depth to water: Not available

Sp. conductance: $8 \mu \mathrm{s} / \mathrm{cm}$

LABORATORY ANALYSES

\begin{tabular}{|c|c|c|c|c|}
\hline $\mathrm{F}$ & Analyte & Result & Mod & Unit \\
\hline & $\begin{array}{l}\text { Chloroform } \\
1,1 \cdot \text { Dichloroethylene } \\
\text { ttans-1,2-Dichloroethylene } \\
\text { Tetrachloroethylene } \\
1,1,1 \text {-Trichloroethane } \\
\text { Trichloroethylene }\end{array}$ & $\begin{array}{l}<5.0 \\
<5.0 \\
<5.0 \\
<5.0 \\
<5.0 \\
<5.0\end{array}$ & & $\begin{array}{l}\mu \mathrm{g} / \mathrm{h} \\
\mu \mathrm{g} / \mathrm{L} \\
\mu \mathrm{g} / \mathrm{h} \\
\mu \mathrm{g} / \mathrm{h} \\
\mu \mathrm{g} / \mathrm{h} \\
\mu \mathrm{g} / \mathrm{h}\end{array}$ \\
\hline
\end{tabular}

WELL FB 34

MEASUREMENTS CONDUCTED IN THE FIELD

Sample date: 11/04/81

Depth to water: Not available

Sp. conductance: $10 \mathrm{\mu S} / \mathrm{cm}$

LABORATORY ANALYSES

\begin{tabular}{|c|c|c|}
\hline & Analyte & Result \\
\hline & $\begin{array}{l}\text { Chloroform } \\
1,1 \cdot \text { Dichloroethylene } \\
\text { trans- } 1,2 \text {-Dichloroethylene } \\
\text { Tetrachloroethylene } \\
1,1,1 \text {-Trichloroethane } \\
\text { Trichloroethylene }\end{array}$ & $\begin{array}{l}<5.0 \\
<5.0 \\
<5.0 \\
<5.0 \\
<5.0 \\
<5.0\end{array}$ \\
\hline
\end{tabular}

WELL FB 35

MEASUREMENTS CONDUCTED IN THE FIELD

Sample date: $11 / 06 / 81$

Depth to water: Not available

Water olevation: Not availab

Sp. conductance: $7 \mu \mathrm{S} / \mathrm{cm}$

ABORATORY ANALYSES

\begin{tabular}{|c|c|c|}
\hline & Analyte & Result \\
\hline $\begin{array}{l}0 \\
0 \\
0 \\
0\end{array}$ & $\begin{array}{l}\text { Chloroform } \\
1,1-\text { Dichloroethylene } \\
\text { trans }-1,2 \text { Dichloroethylene } \\
\text { Tetrachloroethylene } \\
1,1,1-\text { Trichloroethane } \\
\text { Trichloroethylene }\end{array}$ & $\begin{array}{l}<5.0 \\
<5.0 \\
<5.0 \\
<5.0 \\
<5.0 \\
<5.0\end{array}$ \\
\hline
\end{tabular}

WELL FB 36

MEASUREMENTS CONDUCTED IN THE FIELD

Sample date: 10/28/91

Depth to water: Not available

Water elevation: Not availab

Sp. conductance: $8 \mu \mathrm{S} / \mathrm{cm}$

LABORATORY ANALYSES

\begin{tabular}{|c|c|c|c|c|}
\hline$\underline{F}$ & Analyte & Result & Mod & Unit \\
\hline $\begin{array}{l}0 \\
0 \\
0 \\
0 \\
0\end{array}$ & $\begin{array}{l}\text { Chloroform } \\
1,1 \text {-Dichloroethylene } \\
\text { trans-1,2-Dichloroethylene } \\
\text { Tetrachloroethylene } \\
1,1,1 \text {-Trichloroethane } \\
\text { Trichloroethylene }\end{array}$ & $\begin{array}{l}<1.0 \\
<1.0 \\
<1.0 \\
<1.0 \\
<1.0 \\
<10\end{array}$ & & $\begin{array}{l}\mu g / L \\
\mu g / L \\
\mu g / L \\
\mu g / L \\
\mu g / L \\
\mu g / L\end{array}$ \\
\hline
\end{tabular}

Time: $4: 20$

PH: 4.2200

Water temperature: $20.7^{\circ} \mathrm{C}$

Time: $4: 20$

pH: 5.0
Alkalinity: $0 \mathrm{mg} / \mathrm{h}$
Water temperature: $16.6^{\circ} \mathrm{C}$

Mod Unit Lab

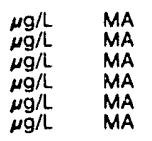

Time: $4: 20$

pH: 4.8 Alkalinity: $0 \mathrm{mg} / \mathrm{L}$

Alkalinity: $0 \mathrm{mg} / \mathrm{L}$ : $16.7^{\circ} \mathrm{C}$

Mod Unit Lab
WELL FB 37

MEASUREMENTS CONDUCTED IN THE FIELD

Sample date: $10 / 13 / 91$ Depth to water: Not available Water elevation: Not available
Sp. conductance: $7 \mathrm{~s} / \mathrm{cm}$

LABORATORY ANALYSES

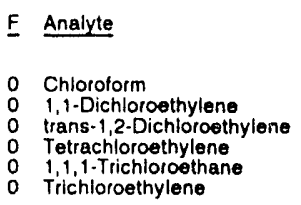

Result

Trichloroethylene

$<1.0$
$<1.0$
$<1.0$
$<1.0$
$<1.0$
$<1.0$

WELL FB 38

MEASUREMENTS CONDUCTED IN THE FIELD

Sample date: $11 / 11 / 81$

Depth to water: Not available

Water elevation: Not available

LABORATORY ANALYSES

F Analyte

Result

- Chloroform

1,1-Dichloroethylene

o trans-1,2-Dichloroethylene

Tetrachloroethylene

Trichloroethylene

$<5.0$
$<5.0$
$<5.0$

$<5.0$

WELL FB 39

MEASUREMENTS CONDUCTED IN THE FIELD

Sample date: 10/06/91

Depth to water: Not available

Water elevation: Not available

$\mathrm{Sp}$. conductance: $7 \mathrm{\mu S} / \mathrm{cm}$

LABORATORY ANALYSES

F Analyte

Pesult

- Chloroform

1,1-Dichloroethylene

trans-1,2-Dichloroethylene

o 1,1,1-Trichloroethane

D 1,1, 1 -Trichloroetha
o Trichloroethylene

$$
\begin{aligned}
& <1.0 \\
& <1.0 \\
& <5.0 \\
& <1.0 \\
& <1.0 \\
& <1.0
\end{aligned}
$$

WELL FB 40

MEASUREMENTS CONDUCTEO IN THE FIELD

Sample date: 11/06/91

Depth to water: Not available

Sp. conductance:

LABORATORY ANALYSES

ime: $10: 00$

pH: 4.7 Alkalinity: $0 \mathrm{mg} / \mathrm{h}$

Water temperature: $21.2^{\circ} \mathrm{C}$

\begin{tabular}{|c|c|}
\hline \multirow[t]{2}{*}{ Mod } & Unit \\
\hline & $\begin{array}{l}\mu g / L \\
\mu g / h \\
\mu g / L \\
\mu g / L \\
\mu g / L \\
\mu g / L\end{array}$ \\
\hline
\end{tabular}

Time: 13:25

$\mathrm{pH}: 5.6$

Alkalinity: $2 \mathrm{mg} / \mathrm{L}$

Water temperature: $18.6^{\circ} \mathrm{C}$

\begin{tabular}{|c|c|c|c|}
\hline Analyte & Result & Mod & Unit \\
\hline $\begin{array}{l}\text { Chloroform } \\
1,1 \text {-Dichloroethylene } \\
\text { trans-1,2-Dichloroethylene } \\
\text { Tetrachloroethylene } \\
1,1,1 \text {-Trichloroethane } \\
\text { Trichloroethylene }\end{array}$ & $\begin{array}{l}<5.0 \\
<5.0 \\
<5.0 \\
<5.0 \\
<5.0 \\
<5.0\end{array}$ & & $\begin{array}{l}\mu g / L \\
\mu g / L \\
\mu g / L \\
\mu g / L \\
\mu g / L \\
\mu g / L\end{array}$ \\
\hline
\end{tabular}


NOTES 


\section{WATER LEVEL DATA}

During iourth quarter 1991, water level measurements wre obtained for a continuing project in the $A / N_{1}$ areas. Site custodians use these data, obtained as concurrently as possible, in hydrogeologic interpretation. Some wells not routinely monitored for the EPD/EMS groundwater

WELL ABP $1 A$

MEASUREMENTS CONDUCTED IN THE FIELD

Sample date: $12: 19 / 91$

Depth to water: $138.32 \mathrm{ft}(42.16 \mathrm{~m})$ below TOC

Wa:er elevation: $221.68 \mathrm{t}(67.54 \mathrm{~m}) \mathrm{ms}$

WELL ABP 1DD

MEASUREMENTS CONDUCTED IN THE FIELD

Sample date: $12 / 19 / 91$
Depth to water: $137.93 \mathrm{ft}(42.04 \mathrm{~m})$ below TOC Water eievation: $222.17 \mathrm{ft}(67.72 \mathrm{~m}) \mathrm{msl}$

WELL ABP 2

MEASUREMENTS CONDUCTED IN THE FIELD

Sample date: $12 / 18 / 91$

Depth 10 water: 162.77 it $(46.56 \mathrm{~m})$ below TOC Water elevation: $219.13 \mathrm{it}(66.79 \mathrm{~m}) \mathrm{msl}$

WELL ABP 2DD

MEASUREMENTS CONDUCTED IN THE FIELD

Sample date: $12 / 19 / 91$

Depth to vrater: $151.90 \mathrm{fl}(46.30 \mathrm{~m})$ below TOC

Water elevation: $218.70 \mathrm{ft}(66.66 \mathrm{~m}) \mathrm{ms}$

WELL ABP 3

MEASUREMENTS CONDUCTED IN THE FIELD

Sarnole date: $12 / 19 / 91$
Depth to water: $131.98 \mathrm{ft}(40.23 \mathrm{~m})$ below TOC

Water elevation: $221.72 \mathrm{ft}(67.68 \mathrm{~m}) \mathrm{msl}$

WELL ABP $3 C$

MCASUREMENTS CONDUCTED IN THE FIELD

Sample date: $12 / 19 / 91$

Depth to water: $168.4111(48.28 \mathrm{~m})$ below TOC

Water elevation: 196.09 / $159.77 \mathrm{~m} / \mathrm{ms}$

WELL ABP 4

MEASUREMENTS CONDUCTED IN THE. FIELD

Sample date: $12 / 19 / 91$

Depth to water: $146.47 \mathrm{ft} 144.34 \mathrm{~m}$ below TOC

Water elevation: $218.83 \mathrm{it} 166.70 \mathrm{mi} \mathrm{msl}$

WELL ABP 4DD

MEASUREMENTS CONDUCTED IN THE FIELD

Sample date: $12 / 19 / 91$

Depth to water: $146.36 \mathrm{ft}(44.31 \mathrm{mi}$ below TOC

Water elevation: $219.64 \mathrm{ft}(66.95 \mathrm{~m}) \mathrm{msl}$

$$
\text { Time: } 11: 07
$$

Time: $11: 07$

Time: $10: 58$

Time: 10:67

Time: 11:01

Time: 11:01

Tune: $10: 43$

Time: 10:43 monitoring program, as well as some wells outside the $\mathrm{A} / \mathrm{M}$ areas, are included in these data. Only water levels were measured for this project; no field tests of water characteristics were done. Ge-Hy Environmental Sampling of New Ellenton, $\mathrm{SC}$, collected the data.

WELL ABP 6D

MEASUREMENTS CONDUCTED IN THE FIELD

Sample date: $12 / 19 / 91$



Water elevation: $218.88 \mathrm{ft}(66.76 \mathrm{~m} / \mathrm{ms}$

WELL ABP 7D

MEASUREMENTS CONDUCTED IN THE FIELD

Sample date: $12 / 19 / 81$

Depth to water: $144.42 \mathrm{ft}(44.02 \mathrm{~m})$ below TOC

Water elevation: $219.78 \mathrm{ft}(66.99 \mathrm{~m}) \mathrm{msl}$

WELL ABP $8 C$

MEASUREMENTS CONDUCTED IN THE FIELD

Sample dste: $12 / 18 / 81$
Depth to water: $175.76 \mathrm{ft}(63.57 \mathrm{~m})$ below TOC

Water elevation: $186.34 \mathrm{ft}(59.86 \mathrm{~m}) \mathrm{msl}$

WELL ABP 8D

MEASUREMENTS CONDUCTED IN THE FI:-

Sample date: $12 / 19 / 91$

Depth to water: $152.41+146.46 \mathrm{~m} /$ below TOC

Water elevation: $218.49 \mathrm{ft}(68.60 \mathrm{~m}) \mathrm{msl}$

WELL ABW 1

MEASUREMENTS CONDUCTED IN THE FIELD

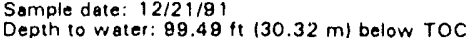
Water elevation: $226.31 \mathrm{ft}(68.68 \mathrm{~m}) \mathrm{ms}$

WELL AC $1 \mathrm{~A}$

MEASUREMENTS CONDUCTED IN THE FIELD

Sample date: $12 / 18 / 91$

Depth to water: $48.3411(14.73 \mathrm{~m})$ below TOC

Water elevation: $213.76 \mathrm{ft}(66.15 \mathrm{~m}) \mathrm{msl}$

WELL AC $1 \mathrm{~B}$

MEASUREMENTS CONDUCTED IN THE FIELD

Sample date: $12 / 18 / 91$

Depth to water: $48.28 \mathrm{ft}(14.72 \mathrm{~m})$ below TOC

Water elevation: $213.72 \mathrm{ft}(66.14 \mathrm{~m}) \mathrm{ms}$

WELL AC 2A

MEASUREMENTS CONDUCTED IN THE FIELD

Sample date: $12 / 19 / 91$

Depth to water: $124.78 \mathrm{ft}(38.03 \mathrm{~m})$ below TOC Water elevation: $219.92(t(67.03 \mathrm{~m}) \mathrm{msl}$
Time: 10:55

Timo: 10:47

Time: 10:52

Tirne: 10:62

Time: 11:09

Timo: 11:36

Time: $11: 37$

Time: $14: 48$ 


\section{WELL AC 2B}

MEASUREMENTS CONDUCTED IN THE FIELD

Semple dato: 12/18/81

Depth to water: $117.60 \mathrm{ft}(35.84 \mathrm{~m})$ below TOC Water slevation: $227.20 \% 169.26 \mathrm{ml}$ mai

WELL AC $3 A$

MEASUREMENTS CONDUCTED IN THE FIELD

Semple date: $12 / 18 / 81$

Depth to water: $83.72 \mathrm{ft}(28.67 \mathrm{~m})$ below TOC Water olevation: $208.68 \mathrm{H}(83.68 \mathrm{ml} \mathrm{msl}$

WELL AC 3B

MEASUREMENTS CONDUCTED IN THE FIELD

Somple date: $12 / 18 / 91$

Depth to water: $91.87 \mathrm{ft}(28.00 \mathrm{~m})$ below TOC Water olovetion. $210.63 \mathrm{ft} 184.20 \mathrm{ml} \mathrm{mal}$

WELL ACB $1 \mathrm{~A}$

MEASUREMENTS CONDUCTED IN THE FIELD

Sample date: $12 / 20 / 91$

Depth to water: $122.08 \mathrm{ft}(37.21 \mathrm{~m})$ below TOC Water olevation: $237.52 \mathrm{ft} 172.40 \mathrm{~m} / \mathrm{mol}$

WELL ACB $2 A$

MEAS IREMENTS CONOUCTED IN THE FIELD

Sampie dal - 12/20/81

Depth to wate: $110.80 \mathrm{ft}(33.77 \mathrm{~m})$ below TOC Water olevation: $239.00 \mathrm{ft}(72.86 \mathrm{~m}) \mathrm{msl}$

WELI. ACB $3 A$

MEASUREMENTS CONDUCTED IN THE FIELD

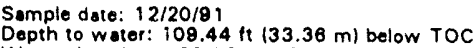
Water siovetion: $238.88 \mathrm{ft} 172.81 \mathrm{mi} \mathrm{ms}$

WELL ACB 4A

MEASUREMENTS CONDUCTED IN THE FIELD

Sanple date: $12 / 20 / 01$

Depth to water: $118.83 \mathrm{ft}(36.56 \mathrm{~m})$ below TOC Water alovation: $238.17 \mathrm{ft}(72.80 \mathrm{~m}) \mathrm{mol}$

WELL AMB 4A

MEASUREMENTS CONDUCTED IN THE FIELD

Sample date: $12 / 21 / 81$

Depth to weter: $182.22 \mathrm{ft}(49.46 \mathrm{~m})$ bolow TOC Water elevation: $218.28 \mathrm{ft}(66.53 \mathrm{~m}) \mathrm{mg}$

WELL AMB 4B

MEASUREMENTS CONDUCTED IN THE FIELD

Semple date: $12 / 21 / 81$ Dopth to water: $168.07 \mathrm{ft}(47.67 \mathrm{~m})$ below TOC
Wator olevation: $224.33 \mathrm{ft}(68.38 \mathrm{~m}) \mathrm{msi}$

WELL AMB 4D

MEASIJIIEMENTS CONDUCTED IN THE FIELD

Sample date: $12 / 21 / 8$

. Water elevation: $233.07 \mathrm{At} 17.04 \mathrm{ml} \mathrm{ms}$

WELL AMB 5

MEASUREMENTS CONDUCTED IN THE FIELL

Semplo date: $12 / 21 / 81$

(t) $144.68 \mathrm{~m} /$ below TOC Water olevation: $233.03 \mathrm{ft}(71.03 \mathrm{~m}) \mathrm{ms}$

WELL AMB 6

MEASUREMENTS CONDUCTED IN THE FIELD

Semple date: $12 / 21 / 9$ :

Depth to water: $143.60 \mathrm{ft}(43.77 \mathrm{~m})$ below TOC Wher olovation: $233.50 \mathrm{t}(71.20 \mathrm{~m}) \mathrm{mgl}$
Time: $14: 48$

Time: $11: 10$

Time: $11: 10$

Time: 16:43

Time: 16:46

Time: 16:39

Timo: 16:37

Time: 9:34

Time: 8:36

Timo: $8: 34$

Time: $8: 32$

Time: $8: 32$
WELL AMB 7

MEASUREMENTS CONDUCTED IN THE FIELD

Sampie date: $12 / 21 / 81$ ( $141.43 \mathrm{~m})$ below TOC Wuter elevation: $233.98 \mathrm{ft}(71.32 \mathrm{~m} / \mathrm{msl}$

WELL AMB $7 . A$

MEASUREMENTS CONDUCTED IN THE FIELO

Sample date: $12 / 21 / 81$ it $(47.34 \mathrm{~m} /$ below TOC Water olevation: $218.29 \mathrm{ft}(66.64 \mathrm{~m}) \mathrm{msl}$

WELL AMB 7B

MEASUREMENTS CONDUCTED IN THE FIELD

Sample date: $12 / 21 / 91$

Depth to water: 148.66 it $(46.28 \mathrm{~m})$ below TOC Water elevetion: $224.44 \mathrm{it}(88.41 \mathrm{~m}) \mathrm{mol}$

WELL AMB 8D

MEASUREMENTS CONDUCTED IN THE FIELD

Sample date: $12 / 21 / 91$

Depth to water: $136.04 \mathrm{ft}(41.47 \mathrm{~m})$ below TOC Water alovetion: $233.58 \mathrm{tt}(7,1.19 \mathrm{~m} / \mathrm{msl}$

WELL AMB 9D

MEASUREMENTS CONDUCTED IN THE FIELD

Somple date: $12 / 21 / 81$ Somple date: $12 / 21 / 81$
Depth to water: $134.18 \mathrm{ft}(40.90 \mathrm{~m})$ below TOC
Water elevation: $233.72 \mathrm{tt}(71.24 \mathrm{~m}) \mathrm{msl}$

WELL AMB $10 A$

MEASUREMENTS CONDUCTED IN THE FIELD

Sernple date: $12121 / 91$. $146.32 \mathrm{~m} /$ below TOC Depth to water: $148.68 \mathrm{ft}(46.32 \mathrm{~m} /$ below $T O C$ (t) $(66.39 \mathrm{~m}) \mathrm{ms}$

WELL AMB 10B

MEASUREMENTS CONDUCTED IN THE FIELD

Semple doto: 12/21/81

Dopth to weter: $143.70 \mathrm{ft}(43.80 \mathrm{~m})$ below TOC Weter olovation: $222.70 \mathrm{ft}(67.88 \mathrm{~m}) \mathrm{mal}$

WELL AMB 10D

MEASUREMENTS CONDUCTED IN THE FIELD

Sample date: $12 / 21 / 91$

Depth to water: $130.72 \mathrm{ft}(39.84 \mathrm{~m} /$ below TOC Water alevation: $234.78 \mathrm{ft}(71.56 \mathrm{~m}) \mathrm{ms}$

WELL AMB 10DD

MEASUREMENTS CONOUCTED IN THE FIELD

Somple dato: 12/21/91

Depth to water: $8.76 \mathrm{ft}(2.08 \mathrm{~m})$ bolow TOC Water elovation: $368.66 \mathrm{tt}(108.32 \mathrm{~m}) \mathrm{mst}$

WELL AMB 11B

MEASUREMENTS CONDUCTED IN THE FIELD

Somple dato: 12/21/81

Time: 9:16 Depth to water: $142.37 \mathrm{ft}(43.39 \mathrm{~m})$ below TOC

WELL AMB 110

MEASUREMENTS CONDUCTED IN THE FIELD

Sample date: $12 / 21 / 91$ i $138.91 \mathrm{~m}$ ) below TOC Water elevation: $236.33 \mathrm{ft}(72.03 \mathrm{~m}) \mathrm{msl}$

WELL AMB 12D

MEASUREMENTS CONDUCTED IN THE FIELD

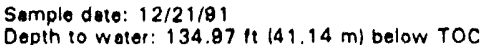
Water elevation: $234.83 \mathrm{ft}(71.58 \mathrm{~m}) \mathrm{mal}$
Time: 8:25

Time: 8:26

Time: 8:28

TIme: $9: 4$

Time: $8: 46$

Time: 8:50

Time: 8:62

Time: 8:64

Time: $8: 62$

Time: 8:16

Timo: $8: 21$ 
WELL AMB 13AR

MEASURLMENTS CONDUCTED IN THE FIELD

Sample date: $12 / 21 / 81$

Depth to water: $146.88 \mathrm{ft}(44.80 \mathrm{~m})$ below TOC Water elevation: $218.12 \mathrm{ft}(66.48 \mathrm{~m}) \mathrm{msl}$

WELL AOB 1

MEASUREMENTS CONDUCTED IN THE FIELD

Sample date: 12/20/91

Depth to water: $104.35 \mathrm{ft}(31.81 \mathrm{~m})$ below TOC Water elevation: $236.75 \mathrm{ft}(72.16 \mathrm{~m}) \mathrm{ms}$

WELL AOB 2

MEASUREMENTS CONDUCTED IN THE FIELD

Sample date: $12 / 20 / 91$

Depth to water: $108.04 \mathrm{ft}(32.93 \mathrm{~m})$ below TOC Water elevation: $237.36 \mathrm{ft}(72.36 \mathrm{~m}) \mathrm{msl}$

WELL AOB 3

MEASUREMENTS CONDUCTED IN THE FIELD

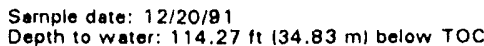
Water olevation: $238.33 \mathrm{ft}(72.64 \mathrm{~m} / \mathrm{msl}$

WELL ARP $1 \mathrm{~A}$

MEASUREMENTS CONDUCTED IN THE FIELD

Sarmple date: $12 / 19 / 91$

There was no water in stand pipe.

WELL ARP 2

MEASUREMENTS CONOUCTED IN THE FIELD

Sample date: $12 / 19 / 91$

Depth to water: $120.18 \mathrm{ft}(36.63 \mathrm{~m})$ below TOC Water elevation: $217.12 \mathrm{ft}(66.18 \mathrm{~m}) \mathrm{msl}$

\section{WELL ARP 3}

MEASUREMENTS CONDUCTED IN THE FIELD

Sample date: $12 / 19 / 91$

Depth to water: 11987 (1 $136.57 \mathrm{~m} /$ below TOC Water elevation: $219.83 \mathrm{~h}(67.00 \mathrm{~m} / \mathrm{ms}$

\section{WELL ARP 4}

MEASUREMENTS CONDUCTED IN THE FIELD

Sample date: $12 / 19 / 91$

Depth to water: $132.601(140.42 \mathrm{~m})$ below TOC Water elevation: $215.80 \mathrm{ft}(65.78 \mathrm{~m}) \mathrm{ms}$

WELL ASB $1 \mathrm{~A}$

MEASUREMENTS CONDUCTED IN THE FIELD

Sample date: $12 / 20 / 91$

There was no water in stand pipe.

WELL ASB 2A

MEASUREMENTS CONDUCTED IN THE FIELD

Sample date: $12 / 20 / 91$

Depth to water: $11: 1.22 \mathrm{ft}(33.90 \mathrm{~m})$ below TOC Water elevation: $237.78 \mathrm{ft}(72.48 \mathrm{~m}) \mathrm{ms}$

WELL ASB 2C

MEASUREMENTS CONDUCTED IN THE FIELD

Sample date: $12 / 20 / 91$

Depth to water: $126.34 \mathrm{ft}(38.61 \mathrm{~m})$ beiow TOC Water elevation: $223.06 \mathrm{ft}(67.99 \mathrm{~m}) \mathrm{ms}$

WELL ASB 3A

MEASUREMENTS CONDUCTED IN THE FIELD

Sample date: 12/20/91

Depth to water: $105.89 \mathrm{ft}(32.31 \mathrm{~m} /$ below TOC Water elevation: $238.01 \mathrm{ft}(72.86 \mathrm{~m}) \mathrm{ms}$
Time: 11:00

Time: 9:69

Tinre: 16:23

Tume: 15:26

Time: 16:29

TIme: 11:44

Time: 11:48

Time: 11:61

Tinie: $11: 42$

Time: 10:57

Time: 10:67

Time: 10:47
WELL ASB $3 C$

MEASUREMENTS CONDUCTED IN THE FIELD

Sample date: $12 / 20 / 91$

Depth to water: $123.93 \mathrm{ft}(37.77 \mathrm{~m})$ below TOC

Weter olevation: $222.07 \mathrm{tt}(67.69 \mathrm{~m}) \mathrm{ms}$

WELL ASB 4

MEASUREMENTS CONDUCTED IN THE FIELD

Somple date: $12 / 21 / 91$

inaccessibility prevented messurement.

WELL ASB 5A

MEASUREMENTS CONDUCTED IN THE FIELD

Sample date: $12 / 20 / 91$
Depth to water: $108.00 \mathrm{ft}(32.82 \mathrm{~m})$ below TOC Water elevation: $237.00 \mathrm{ft}(72.24 \mathrm{~m}) \mathrm{ms} /$

WELL ASB $6 A$

MEASUREMENTS CONDUCTED IN THE FIELD

Somple date: $12 / 20 / 91$
Depth to water: $111.09 \mathrm{ft}(33.86 \mathrm{~m})$ below TOC

Woter elevotion: $238.11 \mathrm{ft}(72.88 \mathrm{~m}) \mathrm{msl}$

WELL ASB 6AA

MEASUREMENTS CONDUCTED IN THE FIELD

Sample date: $12 / 20 / 91$

Depth to water: 136.56 ft $(41.62 \mathrm{~m})$ below TOC

Woter elevation: $217.64 \mathrm{ft}(66.34 \mathrm{~m}) \mathrm{ms}$

WELL ASB 6C

MEASUREMENTS CONDUCTED IN THE FIELD

Sample date: $12 / 20 / 91$

Depth to water: $133.39 \mathrm{ft}(40.66 \mathrm{~m})$ below TOC Depth to water: $133.39 \mathrm{ft}(40.66 \mathrm{~m})$ below
Water elevation: $220.21 \mathrm{tt}(67.12 \mathrm{~m}) \mathrm{msl}$

WELL ASB 6TA

MEASUREMENTS CONDUCTED IN THE FIELD

Sample date: $12 / 20 / 91$ f $142.49 \mathrm{~m}$ below TOC Depth to water: $139.39 \mathrm{ft}(42.49 \mathrm{~m})$ belor
Water elevation: $213.61 \mathrm{ft}(66.08 \mathrm{~m}) \mathrm{ms}$ )

WELL ASB 7

MEASUREMENTS CONDUCTED IN THE FIELD

Somple date: $12 / 20 / 91$ ( $136.25 \mathrm{~m})$ below TOC Depth to woter: $118.92 \mathrm{ft}(36.25 \mathrm{~m})$ below
Water elevation: $234.48 \mathrm{ft}(71.47 \mathrm{~m}) \mathrm{mgl}$

WELL ASB 8

MEASUREMENTS CONDUCTED IN THE FIELD

Sample date: $12 / 20 / 91$

Depth to water: $115.26 \mathrm{ft}(36.13 \mathrm{~m})$ below TOC Water elevation: $233.74 \mathrm{ft}(7,24 \mathrm{~m}) \mathrm{msl}$

WELL ASB 8A

MEASUREMENTS CONDUCTED IN THE FIELO

Sample date: $12 / 20 / 91$

Depth to water: $130.47 \mathrm{tt}(39.77 \mathrm{~m} /$ below TOC Water elevation: $218.83 \mathrm{ft}(66.70 \mathrm{~m}) \mathrm{msl}$

WELL ASB 8B

MEASUREMENTS CONDUCTED IN THE FIELD

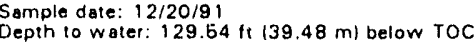
Water elevation: $220.26 \mathrm{ft}(67.14 \mathrm{~m}) \mathrm{msl}$

WELL ASB 8C

MEASUREMENTS CONDUCTED IN THE FIELD

Sample date: $12 / 20 / 9$

Dopth to water: $126.33 \mathrm{ft} 138.51 \mathrm{~m} /$ bolow TOC

Time. 11:17 


\section{WELL ASB 8TA}

meAsurements CONOUCTED IN THE Field

Sample date: $12 / 20 / 91$
Depth to water: 134.67 to $(41.06 \mathrm{~m} /$ below TOC Depth to water: $134.67 \mathrm{tt}(41.06 \mathrm{~m} /$ below
Water olevation: $214.83 \mathrm{ft}(66.61 \mathrm{~m} / \mathrm{msl}$

WELL ASB 9

MEASUREMENTS CONOUCTED IN THE FIELO

Sample date: $12 / 21 / 91$

Depth to water: $66.98 \mathrm{ft}(20.42 \mathrm{~m})$ below TOC Water elevation: $242.02 \mathrm{ft}(73.77 \mathrm{~m}) \mathrm{ms}$ |

WELL ASB 9B

MEASUREMENTS CONDUCTED IN THE FIELD

Somplo date: $12 / 21 / 91$

Depth to wate: $89.05 \mathrm{ft}(27.14 \mathrm{~m})$ below TOC Water elevation: $219.85 \mathrm{ft}(67.04 \mathrm{~m} / \mathrm{msl}$

WELL ASB $9 \mathrm{C}$

MEASUREMENTS CONDUCTED IN THE FIELD

Sample dote: $12 / 21 / 91$

Depth to water: $88.75 \mathrm{ft}(27.36 \mathrm{~m})$ below TOC

WELL ASB $10 \mathrm{C}$

MEASUREMENTS CONDUCTED IN THE GIELD

Sample date: $12 / 20 / 91$

Depth to water: $125.82 \mathrm{ft}(38.35 \mathrm{~m})$ below rOC Weter elevation: $223.08 \mathrm{ft}(68.00 \mathrm{~m}) \mathrm{ms}$ !

\section{WELL MCB 2}

MEASUREMENTS CONDUCTED IN THE FIELD

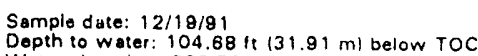
Water alevation: $223.72 \mathrm{ft}(68.19 \mathrm{~m}) \mathrm{msl}$

WELL MCB 4

MEASUREMENTS CONDUCTED IN THE FIELD

Sample date: $12 / 19 / 9$,

Depth 10 water: $127.70 \mathrm{ft}(38.92 \mathrm{~m})$ below TOC Water elevation: $222.70 \mathrm{ft}(67.88 \mathrm{~m} / \mathrm{msl}$

WELL MCB 5

MEASUREMENTS CONDUCTED IN THE FIELO

Sample date: $12 / 19 / 91$

Depth to water: $116.45 \mathrm{ft}(36.49 \mathrm{~m})$ below TOC Water elevation: $223.16 \mathrm{ft}(68.02 \mathrm{~m}) \mathrm{ms}$

WELL MCB $5 \mathrm{C}$

MEASUREMENTS CONDUCTED IN THE FIELD

Sample date: $12 / 19 / 91$

Depth to water: $144.73 \mathrm{ft}(44.11 \mathrm{~m})$ below TOC

Water elevation: $194.37 \mathrm{ft} 159.24 \mathrm{ml} \mathrm{ms}$

WELL MCB 6

MEASUREMENTS CONDUCTED IN THE FIELD

Sample date: $12 / 19 / 81$

Depth to water: $113.17 \mathrm{ft}(34.49 \mathrm{~m})$ below TOC
Water elevation: $218.93 \mathrm{ft}(66.73 \mathrm{~m}) \mathrm{msl}$

WELL MCB 6C

MEASUREMENTS CONDUCTED IN THE FIELD

Sample date: $12 / 19 / 91$

Depth to water: $137.35 \mathrm{ft}(41.86 \mathrm{~m})$ below TOC

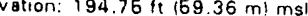

WELL MCB 7C

MEASUREMENTS CONDUCTED IN THE FIELD

Sample date: $12 / 19 / 9$ i

Depth to water: $144.46 \mathrm{ft}(44.03 \mathrm{~m})$ below TOC Water elevation: $193.24 \mathrm{fr} 168.90 \mathrm{~m} / \mathrm{ms}$ !
Tine: $9: 20$

Time: $11: 19$

Time: 10:31

Time: 10:29

Tine: 10:29

Time: 10:63

Time: $9: 26$

Time: 10:39

Time: 10:30

Time: 10:30

Time: 9.20

Time: 1034
WELL MCB 8D

MEASUREMENTS CONDUCTED IN THE FIELD

Sample date: 12:19/91

Depth to water: $11701 \mathrm{tt} 13667 \mathrm{~m} /$ below TOC

Time: 10:37 Water elevation: $223.69 \mathrm{it} 168.18 \mathrm{ml} \mathrm{ms}$

\section{WELL MCB 9D}

MEASUREMENTS CONDUCTED IN THE FIELD

Sample date: $12 / 19 / 91$

Depth 10 water: $121.29 \mathrm{ft}(36.97 \mathrm{~m})$ belove TOC Water elevation: $221.61 \mathrm{fs}(67.55 \mathrm{ml} \mathrm{msl}$

WELL MSB $1 \mathrm{~B}$

MEASUREMENTS CONDUCTEO IN THE FIELL

Sample date: $12 / 18 / 91$

Depth to water: $147.93 \mathrm{At} 146.09 \mathrm{~m}$ ! below TOC Water elevation: 206.87 it $163.06 \mathrm{~m} / \mathrm{mgl}$

WELL MSB $1 \mathrm{C}$

MEASUREMENTS CONDUCTED IN THE FIELO

Sample date: $12 / 18 / 91$

Depth 10 water: $140.08 \mathrm{ft}(42.70 \mathrm{~m})$ below TOC Water elevation: $215.02(1)(65.54 \mathrm{~m})$ ing

WELL MSB 1CC

MEASUREMENTS CONDUCTED IN THE FIELD

Sample date: $12 / 18 / 91$

Depth to vrater: $137.94 \mathrm{ft}(42.04 \mathrm{~m})$ below TO Water elevation: $216.96 \mathrm{tt}(66.13 \mathrm{ml}$ insl

WELL MSB 1D

MEASUREMENTS CONDUCTEDIN THE FIELD

Sample date: $12 / 18 / 91$

Depth to water: $126.2211138 .17 \mathrm{~m} /$ below TOC Water elevation: $229.68 \mathrm{ft}(70.01 \mathrm{~m} / \mathrm{ms}$

WELL MSB 2B

MEASUREMENTS CONDUCTED IN THE FIELD

Sample date: $12 / 18 / 91$

Depth to water: $145.43 \mathrm{ft}(44.33 \mathrm{~m})$ below TOC Water elevation: $209.17 \mathrm{ft}(63.76 \mathrm{~m}) \mathrm{mg} /$

WELL MSB 2C

MEASUREMENTS CONDUCTED IN THE FIELD

Sample date: $12 / 18 / 91$

D.pth to water: $138.75 \mathrm{ft}(42.29 \mathrm{~m})$ below TOC Water elevation: $215.95 \mathrm{ft}(65.82 \mathrm{~m} / \mathrm{ms}$

WELL MSB 2D

MEASUREMENTS CONDUCTED IN THE FIELD

Sample date: $12 / 18 / 91$

Depth to water: $123.07 / 1(37.61 \mathrm{~m} /$ below roc Watel elevation: 230.73 i: $(70.33 \mathrm{~m} / \mathrm{ms}$

WELL MSB 3B

MEASUREMENTS CONOUCTED IN THE FIELD

Sample dare: $12 / 18 / 91$ Depth to water: $162.17 \mathrm{ft}(46.38 \mathrm{~m})$ below TOC Water elevation: $208.83 \mathrm{ft}(63.65 \mathrm{~m}) \mathrm{ms}$

\section{WELL MSB 3C}

MEASUREMENTS CONDUCTED IN THE FIELD

Sample date: 12/18/91

Depth to water: 143.54 / $(43.75 \mathrm{~m})$ below TOC Water elevation: $217.26(1,166.22 \mathrm{~m}) \mathrm{ms}$

\section{WELL MSB 3D}

MEASUREMENTS CONDUCTED IN THE FIELO

Sample date: $12 / 18 / 91$

Depth to water: $130.281 t+59.71 \mathrm{~m} /$ below TOC Tirne: 16:42 
WELL MSB 4B

MEASUREMENTS CONDUCTED IN THE FIELD

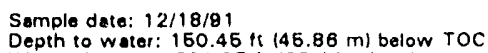
Depth to water: $160.46 \mathrm{ft}(46.86 \mathrm{~m})$ below
Water alevation: $204.86 \mathrm{ft}(62.44 \mathrm{~m}) \mathrm{ms} /$

WELL MSB 4C

MEASUREMENTS CONOUCTED IN THE FIELD

Sample date: $12 / 18 / 91$ if $(43.29 \mathrm{~m} /$ below TOC Water elovation: $213.18 \mathrm{tt}(64.98 \mathrm{~m} / \mathrm{ms}$

WELL MSB 4D

MEASUREMENTS CONOUCTED IN THE FIELD

Sample date: $12 / 18 / 91$ Depth to water: $126.73 \mathrm{Ht}(38.63 \mathrm{~m})$ below TOC
Water olevation: $228.87 \mathrm{tt}(69.76 \mathrm{~m}) \mathrm{msl}$

WELL MSB 5A

MEASUREMENTS CONOUCTEO IN THE FIELD

Sample date: $12 / 19 / 91$

Depth to water: 118.30 \&s $(36.06 \mathrm{~m})$ below TOC Water elevation: $228.30 \mathrm{ft}(68.98 \mathrm{~m}) \mathrm{ms}$

WELL MSB 5B

MEASUREMENTS CONDUCTED IN THE FIELD

Sample date: $12 / 19 / 81$

Dopth to water: $138.82 \mathrm{ft}(42.31 \mathrm{~m})$ below TOC Water elevation: $206.68 \mathrm{ft}(63.00 \mathrm{~m}) \mathrm{msl}$

WELL MSB 5C

MEASUREMENTS CONDUCTED IN THE FIELO

Sample date: $12 / 19 / 91$

Depth to water: $123.47 \mathrm{ft}(37.63 \mathrm{~m})$ below TOC Water elevation: $222.23 \mathrm{ft}(67.74 \mathrm{~m}) \mathrm{msl}$

\section{WELL MSB 6A}

MEASUREMENTS CONDUCTED IN THE FIELO

Sample date: 12/19/91

Depth to water: $1 \cdot=.14 \mathrm{ft}(36.01 \mathrm{~m})$ below TOC

Depth to water: $1.14 \mathrm{ft}(36.01 \mathrm{~m})$ beto
Water elevation: $226.76 \mathrm{ft}(68.81 \mathrm{~m}) \mathrm{ms}$ (

\section{WELL MSB 6B}

MEASUREMENTS CONDUCTED IN THE FIELD

Sample date: $12 / 19 / 91$

Depth 10 water: $138.66 \mathrm{ft}(42.26 \mathrm{~m})$ below TOC Water elevation: $206.64 \mathrm{tt}(62.98 \mathrm{~m}) \mathrm{ms}$

VVELL MSB 6C

MEASUREMENTS CONDUCTEO IN THE FIELD

Sample date: $12 / 19 / 91$

Depth to water: 121.36 th $(36.99 \mathrm{~m})$ below TOC Water elevation: $222.84 \mathrm{Ht}(67.92 \mathrm{ml} \mathrm{msl}$

WELL MSB 7A

MEASUREMENTS CONDUCTED IN THE FIELD

Sample date: $12 / 18 / 81$

Depth to water: $117.62 \mathrm{ft}(36.85 \mathrm{~m})$ below TOC Water elevation: $226.8811(69.16 \mathrm{~m}) \mathrm{ms}$

WELL MSB 7B

MEASUREMENTS CONDUCTED IN THE FIELD

Sample date: $12 / 18 / 91$

Depth to water: $139.42 \mathrm{ft}(42.60 \mathrm{~m})$ below TOC Wepth to water: $139.42 \mathrm{ft} / 42.60 \mathrm{~m} /$ below

WELL MSB 7C

MEASUREMENTS CONDUCTED IN THE FIELO

Sample date: $12 / 18 / 91$ Depth to water: $122.81 \mathrm{ft}(37.43 \mathrm{~m} /$ below TOC Water elevation: $221.79 \mathrm{ft}(67.60 \mathrm{~m}) \mathrm{msl}$
Time: 16:24

Time: 16:23

Time: 16:26

Time: 12:26

Time: $12: 28$

Time: 12:26

Time: 12:13

Time: 12:16

Time: $12: 13$

TIme: 16:12

Time: $16: 11$

Time: $16: 14$
WELL MSB 8A

MEASUREMENTS CONDUCTED IN THE FIELD

Somple date: $12 / 18 / 91$

There $w$ as no water in stand pipe.

Time: 16:06

WELL MSB 8B

MEASUREMENTS CONDUCTED IN THE FIELD

Semple dete: $12 / 18 / 81$

Depth to water: $136.78 \mathrm{ft}(41.68 \mathrm{~m})$ below TOC Wopth to water: $207.11 \mathrm{ft}(63.13 \mathrm{~m}) \mathrm{ms}$

WELL MSB 8C

MEASUREMENTS CONDUCTED IN THE FIELD

\section{Sample date: $12 / 18 / 91$}

Depth to water: $124.82 \mathrm{ft}(38.05 \mathrm{~m})$ below TOC Water elevation: $219.18 \mathrm{ft}(66.81 \mathrm{~m}) \mathrm{ms}$

WELL MSB $9 A$

MEASUREMENTS CONDUCTED IN THE FIELD

\section{Sample date: $12 / 18 / 91$}

Depth 10 water: $160.74 \mathrm{ft}(46.95 \mathrm{~m})$ below TOC Water elevation: $208.66 \mathrm{ft}(63.60 \mathrm{~m}) \mathrm{ms}$

\section{WELL MSB 9B}

MEASUREMENTS CONDUCTED IN THE FIELD

Sample dale: $12 / 18 / 91$

Depth to water: $130.26 \mathrm{ft}(39.70 \mathrm{~m})$ below TOC Water elevation: $229.36 \mathrm{ft}(68.91 \mathrm{~m}) \mathrm{msl}$

\section{WELL MSB 9C}

MEASUREMENTS CONDUCTEO IN THE FIELD

Sample date: $12 / 18 / 81$

Depth to water: $130.46 \mathrm{ft}(39.76 \mathrm{~m})$ below TOC Water elevation: $228.64 \mathrm{ft}(68.69 \mathrm{~m}) \mathrm{ms} \mid$

\section{WELL MSB 10A}

MEASUREMENTS CONDUCTED IN THE FIELD

Somple date: $12 / 19 / 91$

Depth to water: $148.02 \mathrm{ft}(46.12 \mathrm{~m})$ below TOC Wepth to water: $148.02 \mathrm{ft}(46.12 \mathrm{~m})$ below

\section{WELL MSB 10B}

MEASUREMENTS CONDUCTED IN THE FIELD

Sample date: $12 / 19 / 91$

Depth 10 water 146.02 ft $(44.51 \mathrm{~m})$ below TOC Depth to water: $146.02 \mathrm{ft}(44.61 \mathrm{~m})$ below

\section{WELL MSB 10C}

MEASUREMENTS CONDUCTED IN THE FIELD

Sample date: $12 / 19 / 91$

Depth to water: $128.68 \mathrm{ft}(39.22 \mathrm{~m})$ below TOC Water elevation: $227.32 \mathrm{tt}(69.29 \mathrm{~m} / \mathrm{msl}$

WELL MSB $11 \mathrm{~A}$

MEASUREMENTS CONDUCTED IN THE FIELD

Sample date: $12 / 18 / 91$

Depth to water: $164.95 \mathrm{ft}(47.23 \mathrm{~m})$ below TOC Water elevation: $209.95 \mathrm{ft}(63.99 \mathrm{~m}) \mathrm{ms}$

WELL MSB 11B

MEASUREMENTS CONDUCTED IN THE FIELD

Sample date: $12 / 18 / 91$

Depth to water: $160.01 \mathrm{ft}(46.72 \mathrm{~m})$ below TOC Water elevation: $214.79 \mathrm{ft}(66.47 \mathrm{~m}) \mathrm{msl}$

WELL MSB $11 \mathrm{C}$

MEASUREMENTS CONDUCTEO IN THE FIELD

Sample date: $12 / 19 / 9$ ? $36.12 \mathrm{~m}$ ) below TOC Depth to water: $148.03 \mathrm{ft}(46.12 \mathrm{~m})$ below
Water elevation: $216.87 \mathrm{tt}(66.10 \mathrm{~m} / \mathrm{msl}$
Time: 16:07

Time: 16:06

Time: 16:32

Time: 16:32

Time: 16:30

Time: 13:12

Time: 13:16

Time: 13:14

Time: 13:02

Time: 13:04

Time: 13:04 
WELL MSB $11 D$

MEASUREMENTS CONDUCTED IN THE FIELD

Sample date: $12 / 19 / 01$

Depth to water: $136.78 \mathrm{ft}(41.69 \mathrm{~m})$ below TOC Depth to water: $136.79 \mathrm{ft}(41.69 \mathrm{~m})$ below
Water elovation: $228.41 \mathrm{ft}(68.62 \mathrm{~m} / \mathrm{ms})$

WELL MSB $11 \mathrm{E}$

MEASUREMENTS CONDUCTED IN THE FIELD

Sample date: $12 / 19 / 81$
Depth to wator: $124.24 \mathrm{ft}(37.87 \mathrm{~m})$ below TOC Depth to water: $124.24 \mathrm{ft}(37.87 \mathrm{~m})$ below
Water elevation: $240.86 \mathrm{ft}(73.46 \mathrm{~m}) \mathrm{mg})$

WELL MSB $11 \mathrm{~F}$

MEASUREMENTS CONDUCTED IN THE FIELD

Sample date: $12 / 18 / 81$

Depth 10 water: $135.88 \mathrm{ft}(41.41 \mathrm{~m})$ below TOC Water elevation: $228.94 \mathrm{ft}(69.78 \mathrm{~m}) \mathrm{msl}$

WELL MSB 12A

MEASUREMENTS CONDUCTED IN THE FIELD

Sample date: $12 / 19 / 91$

Depth to water: $14: 2.17 \mathrm{ft}(43.33 \mathrm{~m})$ below TOC Water elevation: $205.63 \mathrm{ft}(62.68 \mathrm{~m}) \mathrm{ms}$

WELL MSB 12B

MEASUREMENTS CONDUCTED IN THE FIELD

Sample date: $12 / 19 / 81$

Depth to water: $13294 \mathrm{ft}(40.52 \mathrm{~m})$ below TOC Water olevetion: $21594 \mathrm{ft}(65.67 \mathrm{~m}) \mathrm{ms}$

WELL MSB 12C

MEASUREMENTS CONDUCTED IN THE FIELD

Sample date: $12 / 19 / 81$
Depth to water: $127.48 \mathrm{ft}(38.86 \mathrm{~m})$ below TOC Water elevation: $220.42 \mathrm{ft} 167.18 \mathrm{~m} / \mathrm{msl}$

WELL MSB 12D

MEASUREMENTS CONDUCTED IN THE FIELD

Sample date: $12 / 18 / 8$

There was no water in stand pipe.

WELL MSB 12TA

MEASUREMENTS CONDUCTED IN THE FIELD

Sample date: $12 / 19 / 81$

Depth to water: $166.64 \mathrm{ft}(47.74 \mathrm{~m})$ below TOC Water elevation: $191.86 \mathrm{ft}(68.48 \mathrm{~m} / \mathrm{ms}$

WELL MSB 12 TB

MEASUREMENTS CONDUCTED IN THE FIELD

Sample date: 12/19/91

Depth to water: $156.85 \mathrm{ft}(47.81 \mathrm{~m} /$ below TOC Water elevation: $192.05 \mathrm{ft}(68.54 \mathrm{~m}) \mathrm{ms}$

WELL MSB 13A

MEASUREMENTS CONDUCTED IN THE FIELD

Sample date: $12 / 19 / 91$

Depth to water: $14: 0.66 \mathrm{ft}(42.87 \mathrm{~m})$ below TOC Water elevation: $204.64 \mathrm{ft}(62.34 \mathrm{~m}) \mathrm{ms}$

WELL MSB 13B

MEASUREMENTS CONDUCTEO IN THE FIELD

Sample date: $12 / 19.91$

Depth to water: $163.19 \mathrm{ft}(46.69 \mathrm{~m})$ below TO' Water elevation: $192.41 \mathrm{ft} 158.65 \mathrm{~m} / \mathrm{ms} \mid$

WELL MSB 13CC

MEASUREMENTS CONDUCTED IN THE FIELDD

Sample date: $12 / 19181$

Depth to water: $123.93 \mathrm{ft}(37.77 \mathrm{~m} /$ below TOC

Depth to water: $123.93 \mathrm{ft}(37.77 \mathrm{~m} /$ below
Woter eievation: $222.97 \mathrm{ft}(67.96 \mathrm{~m} / \mathrm{ms}$.
Time: $13: 23$

Time: 12:48

Time: 13:06

Time: 13:08

Time: 13:02

Time: $13: 20$

Time: 13:24

Time: 13:22

Time: 13:21

Time: 13:23

Tine: $12: 46$

TIme: $12: 48$
WELL MSB 13D

MEASUREMENTS CONDUCTED IN THE FIELD

rime: $12: 46$

Depth tc water: $120.51 \mathrm{ft}(36.73 \mathrm{~m})$ below TOC Water elevation: $227.19 \mathrm{ft}(69.26 \mathrm{~m}) \mathrm{msl}$

WELL MSB 14:A

MEASUREMENTS CONDUCTEO IN THE FIELD

Sample date: $12 / 18 / 91$

Depth to water: 134.28 th $140.93 \mathrm{~m} /$ below TOC Water elevation: $214: .02 \mathrm{ft}(66.23 \mathrm{~m}) \mathrm{ms}$

WELL MSB 14:B

MEASUREMENTS CONDUCTED IN THE FIELD

Depth to water: 132.74 ft $(40.46 \mathrm{~m})$ below TOC Water elevation: $215.96 \mathrm{ft}(66.83 \mathrm{~m}) \mathrm{mgl}$

WELL MSB 14:C

MEASUREMENTS CONDUCTED IN THE FILLD

Sample date: $12 / 18 / 91$

There was no water in stand pipe.

Tune: $16: 08$

WELL MSB 15A

MEASUREMENTS CONDUCTED IN THE FIELO

Sample date: $12 / 19 / 91$

Depth to water: $14: 8.75 \mathrm{ft} 145.34 \mathrm{~m}$ below TOC Water elevation: $218.46 \mathrm{ft}(66.58 \mathrm{~m})$ mgl

WELL MSB 15AA

MEASUREMENTS CONOUCTED IN THE FIELD

Sample date: $12 / 19 / 91$

Depth to water: $157.20 \mathrm{ft}(47.92 \mathrm{~m} /$ below TOC

Water elevation: $212.30 \mathrm{ft} 164.71 \mathrm{~m} / \mathrm{msl}$

WELL MSB 15C

MEASUREMENTS CL..DUCTEO IN THE FIELD

Sample date: 12/19/91

Depth to water- $124.69 \mathrm{ft}(38.01 \mathrm{~m})$ below TOC Water elevation: $241.91 \mathrm{ft}(73.74 \mathrm{~m} / \mathrm{ms}$

WELL MSB 15D

MEASUREMENTS CONDUCTED IN THE FIELO

Sample date: $12 / 19 / 91$

Depth to " th mi $137.52 \mathrm{ft}(42.01 \mathrm{~m})$ below TOC Water ele $30.98 \mathrm{ft}(70.40 \mathrm{~m}) \mathrm{msl}$

WELL MSB 16A

MEASUREMENTS CONDUCTED IN THE FIELD

Sample date: $12 / 19,91$

Depth to water: $14: 8.34 \mathrm{ft}(46.52 \mathrm{~m})$ below toC Water elevation: $217.36 \mathrm{H}(66.25 \mathrm{~m}) \mathrm{ms}$

WELL MSB 16C

MEASUREMENTS CONDUCTED IN THE FIELD

Sample date: $12 / 19 / 91$

Depth to water: $13800 \mathrm{ft}(42.06 \mathrm{~m} /$ below TOC Water elevation: $226.60 \mathrm{ft}(69.63 \mathrm{~m}) \mathrm{ms})$

WELL MSB 17A

MEASUREMENTS CONDUCTED IN THE FIELD

Sample date: $12 / 19 / 91$

Depth to water: $14: 3.93$ ft $(43.87 \mathrm{~m})$ below TOC Water elevation: $214: .07 \mathrm{ft}(65.25 \mathrm{~m}) \mathrm{ms}$

\section{WELL. MSB 178}

MEASUREMENTS CONDUCTED IN THE FIE

Depth to water: 13499 (t $(41.15 \mathrm{~m})$ below 100

Time: $13: 30$ 
WELL MSB 17BB

MEASUREMENTS CONDUCTED IN THE FIELD

Somple date: $12 / 18 / 81$

Depth to water: $14: 8.87 \mathrm{ft}(46.41 \mathrm{~m})$ below TOC Water elevation: $210.33 \mathrm{ft}(64.11 \mathrm{~m}) \mathrm{ms}$

WELL MSB $17 \mathrm{C}$

MEASUREMENTS CONDUCTED IN THE FIELD

Somple date: $12 / 18 / 81$
The well wes dry.

WELL MSB 17D

MEASUREMENTS CONDUCTED IN THE FIELD

Sample date: $12 / 19 / 81$

Depth to water: $13+.20 \mathrm{ft}(40.90 \mathrm{~m})$ below TOC Water elevotion: $228.00 \mathrm{ft}(68.89 \mathrm{~m} / \mathrm{ms}$

WELL MSB 18A

MEASUREMENTS CONDUCTED IN THE FIELD

Sompin date: $12 / 19$ '91

Depth to water: $130.70 \mathrm{ft}(39.84 \mathrm{~m})$ below TOC Water elevation: $209.60 \mathrm{ft}(63.86 \mathrm{~m}) \mathrm{ms} /$

WELL MSB 18B

MEASUREMENTS CONDUCTED IN THE FIELD

Sample dete: $12 / 19 / 91$

Depth to water: $121.60 \mathrm{ft}(37.06 \mathrm{~m})$ below TOC Water elevation: $218.70 \mathrm{ft}(66.66 \mathrm{~m}) \mathrm{ms}$

WELLL MSB 18C

MEASUREMENTS CONDUCTED IN THE FIELD

Sample date: $12 / 19 / 91$

Depth to water: $116.21 \mathrm{ft}(35.42 \mathrm{~m})$ below TOC Water elevation: $224.39 \mathrm{ft}(68.39 \mathrm{~m} / \mathrm{msi}$

WELL MSB 19A

MEASUREMENTS CONDUCTED IN THE FIELD

Sample date: $12 / 2 \mathrm{~s} / 91$ Depth to water: $86.19 \mathrm{ft}(26.27 \mathrm{~m})$ below TOC

Water elevation: $213.31 \mathrm{ft}(66.02 \mathrm{~m} / \mathrm{ms} /$

WELL MSB 19B

MEASUREMENTS CONDUCTED IN THE FIELD

Somple dote: $12 / 20 / 81$

Depth to water: $83.96 \mathrm{ft}(25.69 \mathrm{~m})$ below TOC

Water elevation: $216.96 \mathrm{ft}(66.82 \mathrm{~m} / \mathrm{mis}$

WELL ivISB 19C

MEASUREMENTS CONDUCTED IN THE FIELD

Sample date: $121 \%$ ' 19

Depth to water: $61.68 \mathrm{ft}(18.80 \mathrm{~m})$ below
Water elevatio: $238.61 \mathrm{ft}(72.70 \mathrm{~m}) \mathrm{ms}$ !

WELL. MSB 20A

MEASUREMENTS CONDUCTED IN THE FIELD

Somple date: $12 / 19 / 91$

Cepth to water: $137.68 \mathrm{ft}(41.93 \mathrm{~m})$ below toc

Worter elevation: $218.42 \mathrm{ft} 165.97 \mathrm{ml} \mathrm{msl}$

WELL MSB 20C

MEASUAEMENTS CONDUCTED IN THE FIELD

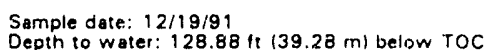
Water elevation: $224.42 \mathrm{tt}(68.40 \mathrm{~m} / \mathrm{ms}$ l

WELL MSB 21A

MEASUREMENTS CONDUCTED IN THE FIELD

Somple date: 12/18/81

Depth to woter: $134.74 \mathrm{ft}(41.07 \mathrm{~m})$ below TOC Water elevation: $218.66 \mathrm{ft}(66.65 \mathrm{~m} / \mathrm{ms}$
Time: 13:28

Time: 13:32

Time: 12:07

Time: 12:09

Tirne: 12:07

Time: 16:61

Time: 16:63

Time: 16:51

Tune: 14:16

T:me: 14:16

Time: $14: 23$
WELL MSB 21B

MEASUREMENTS CONDUCTED IN THE FIELD

Sample date: $12 / 19 / 81$

Depth to water: $136.13 \mathrm{tt}(41.49 \mathrm{~m})$ below TOC Water elevation: $219.17 \mathrm{ft}(66.80 \mathrm{~m}) \mathrm{msl}$

Time: 14:21

WELL MSB $21 \mathrm{C}$

MEASUREMENTS CONDUCTED IN THE FIELD

Sample date: $12 / 19 / 91$

Depth to water: $126.65 \mathrm{ft}(38.67 \mathrm{~m})$ below TOC Water elevation: $226.85 \mathrm{ft}(69.14: \mathrm{m} / \mathrm{msl}$

WELL MSB 21 TA

MEASUREMENTS CONOUCTED IN THE FIELD

Sample date: $12 / 19 / 81$

Depth to water: $160.93 \mathrm{ft}(49.05 \mathrm{~m})$ below TOC Water elevation: $193.77 \mathrm{ft}(69.06 \mathrm{~m}) \mathrm{ms}$

WELL MSB 22

MEASUREMENTS CONDUCTED IN THE FIELD

Sample date: 12/18/91

Depth to weter: $128.85 \mathrm{ft}(39.68 \mathrm{~m})$ bel دw TOC Water elevation: $228.16 \mathrm{ft}(69.86 \mathrm{~m}) \mathrm{ms}$

WELL MSB 23

MEASUREMENTS CONDUCTED IN THE FIELU

Sample date: $12 / 18 / 91$

There $w a s$ no water in stand pipe.

WF'LL MSB 23B

MEASUREM NTS CONDUCTED IN TRE FIELC

Somple date: $12 / 18 / 31$

Depth to water. $150.21 \mathrm{ft}(46.78 \mathrm{~m})$ beiow TOC Water elevatien: $221.39 \mathrm{ft}(67.48 \mathrm{~m}) \mathrm{msl}$

W'ELL MSB 23TA

MEASUREN:NATS CONOUCTED IN THE FIELD

Sarriple dat. 12/18/91 Time: 14:06 Water elevation: $200.59 \mathrm{i}:(61.14: \mathrm{m}) \mathrm{msl}$

WE! LL MSB 24

MEASUREMENTS CONDUCTED IN THE FIELD

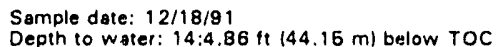
Depth to water: $14: 4.86 \mathrm{ft}(44.16 \mathrm{~m})$ below
Water elevetion: $236.34 \mathrm{ft}(71.73 \mathrm{~m}) \mathrm{ms}$

WELL MSB 24A

MEASUREMENTS CONDUCTED IN THE FIELD

Sample date: $\quad-118 / 91$ Water elevation: $224.34 \mathrm{ft}(68.38 \mathrm{~m}) \mathrm{msl}$

\section{WELL MSB 25}

MEASUREMENTS CONDUCTED IN THEE FIELO

Sample date: $12 / 18 / 91$

There was no water in stand pipe.

Time: $13: 26$

WELL MSB 25A

MEASUREMENTS CONOUCTED IN THE FIELD

Sample date: $12 / 18 / 91$

Depth to water: 151.40 \# $(46.15$ nil below TOC Water elevation: $216.00 \mathrm{it}(66.63 \mathrm{~m} / \mathrm{ms}$

WELL MSB 26

MEASUREMENTS CONDUCTED IN THE FIELD

Sample date: $12 / 19 / 91$

Time: $14: 69$ 
WELL MSB 26A

MEASUREMENTS CONDUCTED IN THE FIELD Semple date: $12 / 19 / 91$ (t $(42.32 \mathrm{~m})$ below TOC Water elevation: $222.06 \mathrm{ft}(67.68 \mathrm{~m}) \mathrm{ms}$ )

WELL MSB 26B

MEASUREMENTS CONDUCTED IN THE FIELD

Sample date: $12 / 19 / 9)$
Depth to water: $14: 6.86 \mathrm{ft}(44.46 \mathrm{~m} /$ below TOC Water elevation: $217.36 \mathrm{ft}(66.25 \mathrm{~m}) \mathrm{msl}$

WELL MSB 27

MEASUREMENTS CONOUCTED IN THE FIELD

Sample date: $12 / 18 / 91$
Depth to water: $137.78 \mathrm{ft}(42.00 \mathrm{~m})$ below TOC Water elevation: $237.71 \mathrm{ft}(72.46 \mathrm{~m}) \mathrm{mal}$

WELL MSB 27A

MEASUREMENTS CONIJUC TED IN THE FIELD

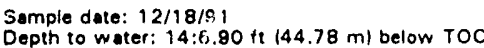
Wepter to water: $14: 62.90 \mathrm{ft}(64.78 \mathrm{~m})$ below

WELL MSB 27B

MEASUREMENTS CONDUCTED IN THE FIELD

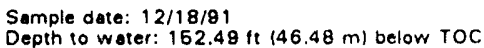
Water elsvation: $224.31 \mathrm{ft}(68.37 \mathrm{~m}) \mathrm{ms}$

WELL MSB 27TA

MEASU.REMENTS CONDUCTED IN THE FIELD

Somple date: $12 / 18 / 81$
Depth to water: $176.12 \mathrm{ft}(63.68 \mathrm{~m})$ below TOC Weter eisvation: $200.48 \mathrm{ft}(61.11 \mathrm{~m}) \mathrm{ms}$

WELL MSB 28

MEASUREMENTS CONDUCTED IN THE FIEL.D

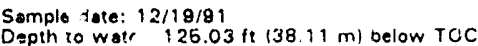
Whter elevaticu: 228 i7 $\mathrm{ft}(69.81 \mathrm{~m} / \mathrm{ms}$

WELL MSB 28A

MEASUREMENTS CONUU:TED IN THE FIELD

Sample date: $12 / 19 / 91$ th $140.40 \mathrm{~m}$ below TOC

Weth olevation: $221.6411,07.56$

WELL MSB 29A

MEASUREMENTS CONDUCTED IN THE FIELD

Sample date: $12 / 20 / 91$

Depth to water: 14:6.36 ft $144.31 \mathrm{~m} /$ below TOC Woter elevation: $220.04 \mathrm{ft} 167.07 \mathrm{ml} \mathrm{ms}$

WELL MSB 29B

MEASUREMENTS CONDUCTED IN THE FIELD

Sample date: $12 / 20 / 91$ f $143.05 \mathrm{~m}$ below TOC Weter elevetion: $223.25 \mathrm{ft}(68.26 \mathrm{~m}) \mathrm{ms}$

WELL MSB 29C

MEASUREMENTS CONDUCTED IN THE FIELD

Sample date: $12 / 20 / 91$

Depth to water: 134.82 ff $14109 \mathrm{~m} /$ betow TOC Wepth to water: $34.82 \mathrm{ft}(41.09 \mathrm{~m})$ below

WELL MSB 29D

MEASUREMENTS CONDUCTED IN THE FIELD

Semple date: $12 / 20 / 01$

Depth to water: $132.62 \mathrm{ft}(40.42 \mathrm{~m})$ below TOC

Water elevation: $232.48 \mathrm{ft} 170.86 \mathrm{mi} \mathrm{ms}$
Time: 14:68

Time: $14: 68$

Time: 13:49

Time: $13: 49$

Time: 13:47

Time: $13: 47$

Time: $14: 3$

Time: $14 \cdot 3$

Time: 13:10

Time: 13:10

Time: 13:08

Fime: 13:12
WELL MSB 29DD

MEASUREMENTS CONDUCTED IN THE FIELIO

Sample date: $12 / 20 / 81$ Depth to water: $132.38 \mathrm{ft}(40.35 \mathrm{~m})$ below TOC

WELL MSB 29TA

MEASUREMENTS CONDUCTED IN THE FIELD

Sample date: $12 / 20 / 91$ Depth to water: $152.98 \mathrm{ft} 146.63 \mathrm{~m} /$ below TOC Woter elevation: $212.21 \mathrm{ft}(64.68 \mathrm{~m} / \mathrm{ms}$ )

WELLL MSB 30A

MEASUREMENTS CONDUCTED IN THE FIELD

Sample date: $12 / 19 / 91$

Depth to water: $166.68 \mathrm{ft}(47.76 \mathrm{~m})$ below TOC Water elevation: $197.92 \mathrm{ft}(60.33 \mathrm{~m} ! \mathrm{ms}$

WELL MSB 30AA

MEASUREMENTS CONDUCTED IN THE FIELD

Sample date: $12 / 19 / 91$

Depth to water: $129.64 \mathrm{ft}(39.48 \mathrm{~m})$ below TOC Water elevation: $223.06 \mathrm{ft}(67.99 \mathrm{~m}) \mathrm{ms}$

WELL MSB 30B

MEASUREMENTS CONDUCTED IN THE FIELD

Sample date: $12 / 19 / 91$

Depth to water: $128.99 \mathrm{ft}(39.32 \mathrm{~m})$ below TOC Watet elevation: $224.11 \mathrm{ft} 168.31 \mathrm{~m} / \mathrm{msl}$

WELL MSB 30C

MEASUREMENTS CONDUCTED IN THE FIELD

Sample date: 12/19/81 Time: 14:38 Water elevation: $230.47 \mathrm{ft}(70.25 \mathrm{~m}) \mathrm{ms}$

WELL MSB 30CC

MEASUREMENTS CONDUCTED IN THE FIELD

Sample date: $12 / 18 / 91$ Time: $14: 38$ Depth to water: $129.39 \mathrm{ft}(39.44 \mathrm{~m})$ beluw TOC Woter clevation: $224.31 \mathrm{ft}(68.37 \mathrm{~m} / \mathrm{ms}$

WELL MSB $31 \mathrm{~A}$

MEASUREMENTS CONDUCTED IN THE FIELD

Sample date: 12/20/91 Time: 16:17 Depth to water: $160.48 \mathrm{ft}(45.87 \mathrm{~m} /$ below $T O C$ Water elevation: $196.72 \mathrm{ft} 169.96 \mathrm{ml} \mathrm{ms}$

WELL MSB 31B

MEASUREMENTS CONDUCTED IN THE FIELO

Sample date: $12 / 20191$

Time: 16:18

Depth to water: $128.80 \mathrm{ft}(39.26 \mathrm{~m})$ below TOC Water elevation: $218.70 \mathrm{ft}(66.66 \mathrm{~m}) \mathrm{ms}$

WELL MSB $31 \mathrm{C}$

MEASUREMENTS CONDUCTED IN THE FIELD

Sumple date: $12 / 20 / 91$

Depth to water: $113.38 \mathrm{ft}(34.66 \mathrm{~m} /$ below TOC Water elevation: $233.92 \mathrm{ft}(71.30 \mathrm{~m}) \mathrm{ms}$ !

WELL MSB $31 \mathrm{CC}$

MEASUREMENTS CONDUCTED IN THE FIELL

Sample date: $12 / 20 / 91$

Depth 10 ivater: 129.20 it $139.38 \mathrm{~m}$ below TOC Wrater elevation $21960 ! 166.93 \mathrm{~m} / \mathrm{ms})$

WELL MSB 32

MEASUREMENTS CONDUCTED IN THE FIELD

Sample date: $12 / 20 / 91$

Depth to water: $30.13 \mathrm{ft} 19.18 \mathrm{~m} /$ below TOC

Time: 16:02 
WELL MSB 33

MEASUREMENTS CONDUCTED IN THE FIELD

Sample date: $12 / 20 / 91$

Depth to water: $37.67 \mathrm{ft}(11.48 \mathrm{~m})$ below TOC Water elovation: $218.83 \mathrm{ft}(66.73 \mathrm{~m}) \mathrm{msl}$

WELL MSB 33A

MEASUREMENTS CONDUCTED IN THE FIELD

Sample date: $12 / 20 / 91$

Depth to water: $52.69 \mathrm{ft}(16.06 \mathrm{~m})$ below TOC Water elevation: $202.71 \mathrm{ft}(61.78 \mathrm{~m} / \mathrm{msl}$

WELL MSB 33B

MEASUREMENTS CONDUCTED IN THE FIELO

\section{Sample dete: 12,2010 ,}

Depth to water: $47.51 \mathrm{ft}(14: .48 \mathrm{~m})$ below TOC Water elovation: $207.69 \mathrm{ft}(63.30 \mathrm{~m} / \mathrm{msl}$

WELL MSB 33C

MEASUREMENTS CONDUCTED IN THE FIELD

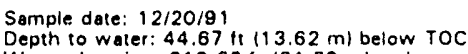
Water elevation: $210.63 \mathrm{ft}(64.20 \mathrm{~m}) \mathrm{msl}$

\section{WELL MSB 33TA}

MEASUREMENTS CONDUCTED IN THE FIELD

Sample date: $12 / 20 / 91$

Depth to water: $60.94 \mathrm{ft}(18.67 \mathrm{~m})$ below TOC Water olevation: $194.66 \mathrm{ft}(69.30 \mathrm{~m}) \mathrm{ms}$

\section{WELL MSB 34A}

MEASUREMENTS CONDUCTED IN THE FIELD

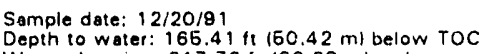
Water elevotion: $217.79 \mathrm{ft}(66.38 \mathrm{~m}) \mathrm{msl}$

WELL MSB 34B

MEASUREMENTS CONDUCTED IN THE FIELD

Somple date: $12 / 20 / \theta$

Depth to water: $166.65 \mathrm{ft}(47.44 \mathrm{~m})$ below TOC Water elevation: $227.46 \mathrm{ft}(69.33 \mathrm{~m}) \mathrm{ms}$

WELL MSB 34C

MEASUREMENTS CONDUCTED IN THE FIELD

Sample date: $12 / 20 / 9$

There was no water in stand pipe.

WELL MSB 34TA

MEASUREMENTS CONDUCTED IN THE FIELO

Sampie date: 12/20/8 1

Depth to water: 181.88 ft 155.44 mil below TOC Water elevation: $200.62 \mathrm{tt}(61.16 \mathrm{~m}) \mathrm{ms}$

WELL MSB 34TB

MEASUREMENTS CONDUCTED IN THE FIELD

Sample date: $12 / 20 / 91$

Depth to water: 180.67 it $156.07 \mathrm{~m}$ ) below TOC Water elevation: $202.13 \mathrm{ft}(61.61 \mathrm{~m} / \mathrm{ms} \mid$

WELL MSB 35A

MEASUREMENTS CONDUCTED IN THE FIELD

Sample date: $12 / 20 / 9$

Depth to water: $134.24 \mathrm{ft}(40.92 \mathrm{~m}$ ! below TOC Water elevation: $216.86 \mathrm{ft} 166.10 \mathrm{mi} \mathrm{ms}$

WELL MSB 35B

MEASUREMENTS CONDUCTED IN THE FIELD

Somple date: $12 / 20 / 91$

Depth to water: $132.01 \mathrm{ft}(40.24 \mathrm{~m})$ below TOC Water eievation: $219.79 \mathrm{ft}(66.99 \mathrm{~m}) \mathrm{msl}$
Time: 14:08

Time: 16:02

Time: 16:06

Time: 16:04

Time: 16:02

Time: 15:04

Time: 14:10

Time: 14:08

Time: 14.08

Time: 14:05

Time: $16: 32$

Time: $16: 32$
Time: 14:06
WELL MSB 35D

MEASUREMENTS CONDUCTED IN THE FIELD

Sample date: $12 / 20 / 91$

Time: 16:30

Was no water in stand pipe.

WELL MSB 35TA

MEASUREMENTS CONOUCTED IN THE FIELD

Sample date: $12 / 20 / 91$

Depth to Water: $160.46 \mathrm{ft}(46.86 \mathrm{~m})$ below TOC
Water elevation: $199.94 \mathrm{ft}(60.94 \mathrm{~m} / \mathrm{ms})$

WELL MSB 36A

MEASUREMENTS CONDUCTED IN THE FIELD

Sample date: $12 / 20 / 81$

Depth to water: $131.34 \mathrm{ft}(40.03 \mathrm{~m})$ betow TOC
Weter elevation: $208.26 \mathrm{ft}(63.78 \mathrm{~m}) \mathrm{ms}$

WELL MSB 36B

MEASUREMENTS CONDUCTED IN THE FIELD

Sample date: $12 / 20 / 91$

Depth to water: $126.76 \mathrm{ft}(38.63 \mathrm{~m} /$ below roc

Water elevation: $213.96 \mathrm{tt}(66.21 \mathrm{~m}) \mathrm{ms}$

WELL MSB 36C

MEASUREMENTS CONDUCTED IN THE FIELO

Sample date: $12 / 20 / 91$

Depth to water: $127.21 \mathrm{ft}(38.77 \mathrm{~m} /$ below TOC Water elevation: $213.69 \mathrm{ft}(65.10 \mathrm{~m}) \mathrm{msl}$

WELL MSB 36D

MEASUREMENTS CONDUCTED IN THE FIELD

Sample date: $12 / 20 / 91$

There was no water in stand pipe.

WELL MSB 36TA

MEASUREMENTS CONDUCTED IN THE FIELD

Sample date: $12 / 20 / 81$

Depth to water: $14: 6.14:$ : $(44.64 \mathrm{~m})$ below TOC Woter elevation: $194.46 \mathrm{ft}(69.27 \mathrm{~m} / \mathrm{ms}$

WELL MSB 37A

MEASUREMENTS CONDUCTED IN THE FIELO

Somple date: $12 / 20 / 91$

Depth to water: $176.46 \mathrm{ft}(63.78 \mathrm{~m})$ below TOC Water elevation: $206.66 \mathrm{ft}(62.99 \mathrm{~m}) \mathrm{ms}$

WELL MSB 37B

MEASUREMENTS CONDUCTED IN THE FIELD

Sample date: $12 / 20 / 91$

Depth to water: $164.18 \mathrm{ft}(60.04 \mathrm{~m})$ below TOC 'Nater alevation: $218.62 \mathrm{tt}(66.64 \mathrm{~m}) \mathrm{ms}$

WELL MSB 37C

MEASUREMENTS CONDUCTED IN THE FIELD

Sample date: $12 / 20 / 91$

Depth to water: $156.69 \mathrm{ft}(47.45 \mathrm{~m})$ below TOC Woter elevation: $227.41 \mathrm{ft}(69.32 \mathrm{~m}) \mathrm{ms} \mid$

WELL MSB 37D

MEASUREMENTS CONDUCTED IN THE FIELD

Sample date: $12 / 20 / 91$

Depth to water: $161.66 \mathrm{ft}(46.23 \mathrm{~m})$ below TOC Water elevation: $231.14: \mathrm{ft}(70.46 \mathrm{~m}) \mathrm{msl}$

WELL MSB 37TA

MEASUREMENTS CONDUCTED IN THE FIELD

Somple date: $12 / 20 / 91$

Depth to water: $176.32 \mathrm{ft}(63.44 \mathrm{~m})$ below TOC Woter elevation: $207.08 \mathrm{ft}(63.12 \mathrm{~m} / \mathrm{msl}$
Tıme: 14:38

Time: 16:28

Time: 14:34

Time: $14: 36$

Time: 14:36

Time: 14:34

Time: $9: 68$

Time: $9: 66$

Time: $9: 64$

Time: $9: 64$

Time: 8:67 


\section{WELL MSB 38B}

MEASUREMENTS CONDUCTED IN THE FIELD

Semple date: $12 / 20 / 91$

Depth to water: $14: 2.89 \mathrm{ft}(43.66 \mathrm{~m} /$ below TOC Water elevation: $213.71 \mathrm{ft}(65.14: \mathrm{m}) \mathrm{ms} !$

WELL MSB 38C

MEASUREMENTS CONDUCTED IN THE FIELD

Sample dete: $12 / 20 / 8$

Depth to water: $14: 0.32 \mathrm{ft}(42.77 \mathrm{~m})$ below TOC Depth to woter: $14: 0.32 \mathrm{ft}(42.77 \mathrm{~m})$ below

WELL MSB 38D

MEASUREMENTS CONDUCTED IN THE FIELD

Sample date: $12 / 20 / 91$

There was no water in stand pipe.

WELL MISB 38TA

MEASUREMENTS CONDUCTED IN THE FIELD

Sample date: $12 / 20 / 81$

Depth to water: 161.70 ft $(49.29 \mathrm{~m})$ below TOC Water elevation: $186.00 \mathrm{ft}(59.44 \mathrm{~m}) \mathrm{msl}$

WELL MSB 39A

MEASUREMENTS CONDUCTED IN THE FIELD

Sample date: $12 / 18 / 9)$ $140.85 \mathrm{~m} /$ below TOC Depth to water: $134.02 \mathrm{ft}(40.85 \mathrm{~m})$ below

WELL MSB 39B

MEASUREMENTS CONDUCTED IN THE FIELD

Sample date: $12 / 19 / 91$

Depth to water: $131.57(4)(40.10 \mathrm{~m})$ below TOC Water elevation: $210.23 \mathrm{ft}(64.0 \mathrm{Bm}) \mathrm{ms}$ )

WELL MSB 39C

MEASUREMENTS CONDUCTED IN THE FIELD

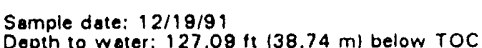
Water elevation: $214: .41 \mathrm{ft}(66.36 \mathrm{~m}) \mathrm{ms}$

WELL MSB 39D

MEASUREMENTS CONDUCTED IN THE FIELO

Sample date: $12 / 19 / 91$

Depth to water: $110.22 \mathrm{ft}(33.60 \mathrm{~m})$ below TOC Water elevation: $231.48(\mathrm{t}(70.66 \mathrm{~m}) \mathrm{ms}$ !

WELL MSB 39TA

MEASUREMENTS CONDUCTED IN THE FIELD

Somple date: $12 / 19 / 91$

Depth to water: $14: 9.25$ \& $(45.49 \mathrm{~m})$ below TOC Water elevation: $182.65 \mathrm{ft}(58.69 \mathrm{~m}) \mathrm{ms}$

WELL MSB 40A

MEASUREMENTS CONOUCTED IN THE FIELD

Sample date: $12 / 19 / 91$

Depth to water: $118.68 \mathrm{ft}(36.17 \mathrm{~m})$ below TOC Water elevation: $202.62 \mathrm{ft}(61.73 \mathrm{~m}$ ins

WELL MSB 40B

MEASUREMENTS CONDUCTED IN THE FIELD

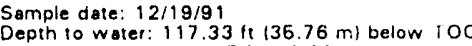
Water elevation: $204.37 \mathrm{ht}(62.29 \mathrm{~m}) \mathrm{msi}$

WELL MSB 40C

MEASUREMENTS CONDUCTED IN THE FIELD

Sample date: $12 / 19 / 91$

There was no water in stand pipe.
Time: $14: 23$

Time: $14: 26$

Time: 14:26

Time: $14: 23$

Time: 15:17

Time: 16:18

Time: 15:18

Time: 15:20

rıme: 15:17

Time: 16:36

Tıme: 15:38
WELL MSB 40D

MEASUREMENTS CONOUCTED IN THE FIELD

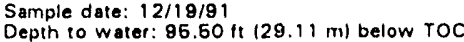

Time: $16: 34$ Water elevation: $227.40 \mathrm{ft}(68.31 \mathrm{~m}) \mathrm{ms}$

\section{WELL MSB 40TA}

MEASUREMENTS CONOUCTED IN THE FIELD

Sample date: $12 / 19 / 91$ Water elevation: $188.94 \mathrm{ft}(67.69 \mathrm{ml} \mathrm{msl}$

WELL MSB 41A

MEASUREMENTS CONDUCTED IN THE FIELD

Sample date: 12/21/81

Depth to water: $107.01 \mathrm{ft}(32.62 \mathrm{~m})$ below TOC Water elevation; $216.79 \mathrm{ft}(66.08 \mathrm{~m}) \mathrm{msl}$

\section{WELL MSE 418}

MEASUREMENTS CONDUCTED IN THE FIELD

Sample date: 12:21/9

Sample date: $12 / 21 / 9$ ) Water elevation: $216.96 \mathrm{ft}(66.13 \mathrm{~m}) \mathrm{msl}$

WELL MSB $41 \mathrm{C}$

MEASUREMENTS CONDUCTED IN THE FIELD

Sample date: $12 / 21 / 91$
Depth to Water: $107.36 \mathrm{ft}(32.72 \mathrm{~m})$ below TOC Depth to water: $107.36 \mathrm{ft}(32.72 \mathrm{~m} /$ below
Water elevation: $217.24 \mathrm{ft}(66.22 \mathrm{~m} / \mathrm{ms} \mid$

\section{WELL MSB 41D}

MEASUREMENTS CONDUCTED IN THE FIELD

Depth to water: 87.80 it $(26.76 \mathrm{~m})$ below TOC Water elevation: $237.20 \mathrm{ft}(72.30 \mathrm{~m}) \mathrm{msl}$

\section{WELL MSB 41TA}

MEASUREMENTS CONDUCTED IN THE FIELD

Depth 10 water: 117.64 (1) $(35.86 \mathrm{~m})$ below TOC Water elevation: $206.06 \mathrm{ft}(62.81 \mathrm{~m} / \mathrm{ms}$

WELL MSB 42A

MEASUREMENTS CONDUCTED IN THE FIELD

Sample date: $12 / 20 / 91$

Depth to water: $167.77 \mathrm{ft}(48.09 \mathrm{~m})$ below TOC Woter elevation: $218.83 \mathrm{ft}(66.70 \mathrm{~m}) \mathrm{msl}$

WELL MSB 42B

MEASUREMENTS CONDUCTED IN THE FIELD

Sample date: $12 / 20 / 9$ 1

Depth 10 water: $161.02 \mathrm{ft}(46.03 \mathrm{~m})$ below TOC Wepter io water: $51.02 \mathrm{ft}(46.03 \mathrm{~m})$ below

WELL MSB 42C

MEASUREMENTS CONDUCTED IN THE FIELD

Sample date: $12 / 20 / 91$
Depth to water: $14: 6.14:$ ft $(44.54 \mathrm{~m} /$ below TOC Water elevation: $230.36+170.21 \mathrm{ml} \mathrm{msl}$

WELL MSB 42D

MEASUREMENTS CONDUCTED IN THE FIELD

Sample date: $12 / 20 / 91$

The well was dry.

WELL MSB 42TA

MEASUREMENTS CONDUCTED IN THE FIELD

Sample date: $12 / 20 / 91$

Depth to water: $170.97 \mathrm{ft}(52.11 \mathrm{~m})$ below TOC

Time: $9: 42$ 


\section{WATER LEVEL DATA}

\section{WELL MSB 43A}

MEASUREMENTS CONDUCTED IN THE FIELD

Sample date: $12 / 20 / 81$

Depth to water: 128.87 \& $(39.28 \mathrm{~m})$ below TOC Wator elevation: $228.03 \mathrm{ft}(68.81 \mathrm{~m}) \mathrm{ms}$

WELL MSB 43B

MEASUREMENTS CONDUCTED IN THE FIELD

Somple dote: 12/20/81

Depth to water: 128.41 ft $139.14:$ m) below TOC Water elevetion: $228.68 \mathrm{ft} 169.98 \mathrm{ml} \mathrm{ms}$

WELL MSB 43D

MEASUREMENTS CONDUCTED IN THE FIELD

Sample date: 12/20/81

Depth to water: $128.33 \mathrm{ft}(38.61 \mathrm{~m})$ below TOC Water elevation: $231.17 \mathrm{ft} 170.46 \mathrm{ml} \mathrm{ms}$

WELLL MSB 43DD

MEASUREMENTS CONCUCTED IN THE FIELD

Sample date: $12 / 20 / 81$

Dopth to water: $125.98 \mathrm{ft}(38.40 \mathrm{~m})$ below TOC Woter olevation: $232.12 \mathrm{ft}(70.76 \mathrm{~m}) \mathrm{msl}$

WELL MSB 43TA

MEASUREMENTS CONDUCTED IN THE FIELD

Sample date: 12/20/81

Depth to water: $166.11 \mathrm{ft}(47.28 \mathrm{~m})$ below TOC Water elevation: $202.49 \mathrm{f}:(61.72 \mathrm{~m}) \mathrm{msl}$

WELL MSB 44A

MEASUREMENTS CONDUCTED IN THE FIELD

Semple date: $12 / 20 / 81$

Depth to weter: $158.48 \mathrm{ft}(48.61 \mathrm{~m})$ below TOC Weter elevation: $217.42 \mathrm{ft}(66.27 \mathrm{~m}) \cdot \mathrm{msl}$

WELL MSB 44B

MEASUREMENTS CONDUCTED IN THE FIELD

Sample date: $12 / 20 / 81$

Depth to water: 163.38 it $(46.75 \mathrm{~m})$ below TOC Water elevation: $223.72 \mathrm{ft}(68.18 \mathrm{~m}) \mathrm{msl}$

WELL MSB 44C

MEASUREMENTS CONDUCTED IN THE FIELD

Semple date: 12/20/91

Depth to wator: $14: 2.42 \mathrm{ft}(43.41 \mathrm{~m} /$ below TOC Water elevation: $236.48 \mathrm{ft}(71.78 \mathrm{~m} / \mathrm{msl}$

WELL MSB 45A

MEASUREMENTS CONDUCTED IN THE FIEI.D

Sample dato: 12/20/81

Depth io weter: $164.67 \mathrm{ft}(50.19 \mathrm{~m} /$ below TOC Woter elevetion: $216.43 \mathrm{ft}(66.97 \mathrm{~m}) \mathrm{ms}$

\section{WELL MSB 45B}

MEASUREMENTS CONDUCTED IN THE FIELD

Sample date: $12 / 20 / 91$

Depth 10 water: $154.724147 .16 \mathrm{~m}$ below TOC Weter elevation: $226.38 \mathrm{tt}(69.00 \mathrm{~m}) \mathrm{msl}$

WELL MSB 45C

MEASUREMENTS CONDUCTED IN THE FIELD

Somple date: $12 / 20 / 9$

\section{WELL MSB 46A}

MEASUREMENTS CONDUCTED IN THE FIELD

Sample date: $12 / 20 / 91$

Wepth 10 water: $158.50 \mathrm{tt}(4831 \mathrm{~m} /$ below $T O C$ Woter elevation: $214.20 \mathrm{ft}(66.29 \mathrm{~m}) \mathrm{ms}$
Time: 14:18
WELL MSB 46B

MEASUREMENTS CONDUCTED IN THE FIELD

Somple date: $12 / 20 / 91$

Depth to water: $14: 6.83 \mathrm{ft}(44.76 \mathrm{~m})$ below TOC Wotar elevation: $226.87 \mathrm{ft}(69.15 \mathrm{~m}) \mathrm{ms}$

WELL MSB 46C

MEASUREMENTS CONDUCTED IN THE FIELD

Sample date: $12 / 20 / 91$

Depth to water: $136.73 \mathrm{ft}(41.37 \mathrm{~m})$ below TOC Water elevation: $237.07 \mathrm{ft}(72.26 \mathrm{~m}) \mathrm{ms}$

WELL MSB 47B

MEASUREMENTS CONDUCTEO IN THE FIELD

Semple date: $12 / 18 / 91$

Depth to water: $14: 0.33 \mathrm{ft}(42.77 \mathrm{~m})$ below TOC Water elevetion: $228.67 \mathrm{ft}(69.70 \mathrm{~m}) \mathrm{msl}$

WELL MSB 4?BB

MEASUREMENTS CONDUCTED IN THE FIELD

Sample date: $12 / 18 / 91$

Depth to water: $14: 8.36 \mathrm{ft}(46.63 \mathrm{~m})$ below TOC Water elevstion: $218.74 \mathrm{ft}(66.98 \mathrm{~m}) \mathrm{msl}$

WELL MSB 47C

MEASUREMENTS CONDUCTED IN THE FIELD

Sample date: $12 / 18 / 91$

Depth to water: $136.6 E$ ' $(41.62 \mathrm{~m} /$ below TOC Water elevation: $232.76 \mathrm{ft} 170.94 \mathrm{~m}) \mathrm{msl}$

WELL MSB 470

MEASUREMENTS CONDUCTED IN THE FIELD

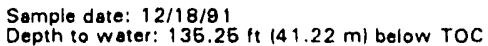
Wepth to water: $136.25 \mathrm{ft}(41.22 \mathrm{~m} / \mathrm{bel} / \mathrm{w}$

WELL MSB 47TA

MEASUREMENTS CONDUCTED IN THE FIELD

Sample date: $12 / 18 / 91$

Depth to water: 152.94 ft $(46.62 \mathrm{~m})$ below TOC Water elevation: $216.06 \mathrm{ft}(65.86 \mathrm{~m} / \mathrm{ms})$

WELL MSB 48A

MEASUREMENTS CONDUCTEO IN THE HIELD

Sample date: $12 / 20 / 91$

Depth to water: 139.42 th $(42.50 \mathrm{~m})$ below TOC W'ater elevation: $222.78 \mathrm{ft}(67.90 \mathrm{~m} / \mathrm{ms})$

WELL MSB 48B

MEASUREMENTS CONDUCTED IN THE FIELD

Somple date: $12 / 20 / 91$. $142.05 \mathrm{~m} /$ belovy TOC Depth to water: $137.87 \mathrm{ft}(42.06 \mathrm{~m})$ belov
Water elevation: $223.93 \mathrm{ft}(68.26 \mathrm{~m}) \mathrm{ms} /$

WELL MSB 48C

MEASUREMENTS CONDUCTED IN THE FIELD

Sample date: $12 / 20 / 91$

Depth to water: $138.72 \mathrm{ft}(42.28 \mathrm{~m})$ below TOC Water elevation: $224.18 \mathrm{tt}(68.33 \mathrm{~m}) \mathrm{ms}$

WELL MSB 48D

MEASUREMENTS CONDUCTED IN THE FIELD

Sample date: $12 / 20 / 91$

Depth to water: $130.14:$ ft $(39.67 \mathrm{~m})$ below TOC Water elevation: 233.06 : $(71.04 \mathrm{~m}) \mathrm{ms}$

WELL MSB 48TA

MEASUREMENTS CONDUCTED IN THE FIELD

Sample date: $12 / 20 / 91$

Depth to water: 14:0.54 ft $142.84 \mathrm{~m}$ ) below TOC Woter elevation: $221.86 \mathrm{ft}(67.62 \mathrm{~m}) \mathrm{ms} /$
Time: 9:23

Time: 14:60

ime: $11: 50$

Time: 11:52

Time: $11: 50$ 
WELL MSB 49A

MEASUREMENTS CONDUCTED IN THE FIELD

Semple date: 12/19/91

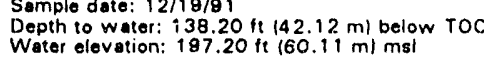

WELL MSB 49B

MEASUREMENTS CONDUCTED IN THE FIELD

Sample date: 12/19/8

Depth to water: $132.69 \mathrm{ft}(40.44 \mathrm{~m})$ below TOC Water olevation: $202.11 \mathrm{ft}(61.60 \mathrm{~m}) \mathrm{ms}$ |

WELL MSB 49D

MEASUREMENTS CONDUCTED IN THE FIELD

Somple date: $12 / 18 / 81$

Depth to water: $5.23 \mathrm{ft}(32.08 \mathrm{~m} /$ below TOC Weter elevstion: $228.82 \mathrm{ft}(69.78 \mathrm{~m}) \mathrm{msl}$

WELL MSB 50B

MEASUREMENTS CONDUCTED IN THE FIELD

Somple date: $12 / 21 / 91$

Depth to water: $21.45 \mathrm{ft} 16.54 \mathrm{ml}$ belon TOC Water elevation: $202.66 \mathrm{ft} 161.74 \mathrm{mi} \mathrm{msl}$

WELL MSB 500

MEASUREMENTS CONDUCTED IN THE FIELD

Sample date: $12 / 21 / 81$

Dopth to water: $20.71 \mathrm{ft} 16.31 \mathrm{~m} /$ below TOC

Water elevation: $202.78(\mathrm{ft}(61.81 \mathrm{~m}) \mathrm{ms}$

WELL MSB 51B

MEASUREMENTS CONDUCTED IN THE FIELD

Sample date: 12/21/81

Dopth to woter: 58.37 (t) $(17.78 \mathrm{~m})$ below TOC Water elevation: $206.13 \mathrm{ft}(62.52 \mathrm{~m}) \mathrm{msl}$

WELL MSB 510

MEASUREMENTS CONDUCTED IN THE FIELD

Somple dote: $12 / 21 / 91$

Depth to water: $51.63 \mathrm{ft}(15.71 \mathrm{~m})$ below TOC Vuater elevation: $210.97 \mathrm{ft}(64.30 \mathrm{ml} \mathrm{ms}$

WELL MSB 528

MEASUREMENTS CONDUCTED IN THE FIELD

Somple date: $12 / 21 / 81$

Depth to weter: $103.02 \mathrm{ft} 131.40 \mathrm{~m} /$ below TOC Water elevation: $218.88 \mathrm{ts}(66.72 \mathrm{~m}) \mathrm{msl}$

WELL MSB 52D

MEASUREMENTS CONDUCTED IN THE FIELD

Somple dato: $12 / 21 / 81$

Depth 10 water: $82.29 \mathrm{ht}(25.08 \mathrm{~m})$ below TOC Woter elevation: $239.61 \mathrm{ft}(73.00 \mathrm{~m} / \mathrm{ms}$

WELL MSB 53B

MEASUREMENTS CONDUCTED IN THE FIELD

Sample date: $12 / 21 / 91$
Depth to water: 122.36 tt $137.30 \mathrm{~m} /$ below TOC Water elevation: $222.24 \mathrm{ft}(67.74 \mathrm{~m}) \mathrm{ms}$

WELL MSB 53C

MEASUREMENTS CONDUCTED IN THE FIELO

Sample date: 12/21/81

Depth to water: $122.65 \mathrm{ft}(37.38 \mathrm{~m})$ below TOC Woter elevation: $222.86 \mathrm{ft}(67.93 \mathrm{~m}) \mathrm{msl}$

WELL MSB 53D

MEASUREMENTS CONDUCTED IN THE FIELD

Sample date: 12/21/81

Depth to water: $110.77 \mathrm{ft}(33.76 \mathrm{~m} /$ below $\mathrm{TOC}$

Water elevation: $234.33 \mathrm{ft}(71.42 \mathrm{~m} / \mathrm{msl}$
Time: 12:00

Time: 12:02

Time: 12:00

Time: $8: 4$

Time: $8: 41$

Time: 8:66

Time: $8: 66$

Time: 10:11

Time: 10:11

Time: 10:68

Time: 10:69

Tirne: $11: 00$
WELL MSB 54B

MEASUREMENTS CONDUCTED IN THE FIELD

Sample date: $12 / 20 / 81$

Dopth to water: $161.49 \mathrm{ft}(46.17 \mathrm{~m})$ velow TOC Water elevation: $222.21 \mathrm{ft}(67.73 \mathrm{~m}) \mathrm{ms}$

WELL MSB 54C

MEASUREMENTS CONDUCTED IN THE FIELD

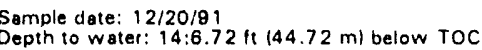
Water elevation: $226.98 \mathrm{ft} 169.18 \mathrm{~m} / \mathrm{msl}$

WELL MSB 54D

MEASUREMENTS CONDUCTED IN THE FIELO

Semple dete: $12 / 20 / 91$

Depth to water: $14: 0.48 \mathrm{ft}(42.82 \mathrm{~m})$ below TOC Water elevation: $233.62 \mathrm{ft}(71.18 \mathrm{~m}) \mathrm{ms}$

WELL MSB 54TA

MEASUREMENTS CONDUCTED IN THE FIELD

Sample date: $12 / 20 / 91$

Depth 10 water: $164.72 \mathrm{ft}(47.16 \mathrm{~m})$ below roC Water elevation: $219.08 \mathrm{ft}(66.78 \mathrm{~m}) \mathrm{ms}$

WELL MSB 55B

MEASUREMENTS CONDUCTED IN THE FIELD

Sample date: $12 / 20 / 81$ Sample date: $12 / 20 / 81$
Depth to water: $14: 7.69 \mathrm{ft}(46.02 \mathrm{~m})$ below TOC
Water elevation: $221.21 \mathrm{ft}(67.43 \mathrm{~m}) \mathrm{msl}$

WELL MSB 55C

MEASUREMENTS CONDUCTED IN THE FIELD

Sample date: $12 / 20 / 91$

Depth to wster: $139.80 \mathrm{ft}(42.61 \mathrm{~m})$ below TOC Water elevation: $228.70 \mathrm{ft} 170.01 \mathrm{ml} \mathrm{mgl}$

WELL MSB 55D

MEASUREMENTS CONDUCTED IN THE FIELD

Sample date: $12 / 20 / 91$

There was no woter in stand pipe.

Time: $12: 41$

WELL MSB $55 \mathrm{HC}$

MEASUREMENTS CONDUCTED IN THE FIELD

Sample date: $12 / 20 / 9$

Depth to water: $135.60 \mathrm{ft}(41.33 \mathrm{~m} /$ below TOC Water elevation: $233.20 \mathrm{fl} 171.08 \mathrm{~m} / \mathrm{ms}$

WELL MSB 55TA

MEASUREMENTS CONDUCTED IN THE FIELD

Sample date: $12 / 20 / 8$

Dopth to water: $165.39 \mathrm{ft} 147.36 \mathrm{~m} /$ below TOC Watel elevation: 213.4 it $166.05 \mathrm{~m} / \mathrm{ms}$ |

WELL. MSB 56D

MEASUREMENTS CONDUCTED IN THE FIELD

Sample date: $12 / 20 / 91$

Depth to water: $68.17 \mathrm{ft}(17.73 \mathrm{~m})$ below TOC Water elevation: $221.6311(67.66 \mathrm{~m}) \mathrm{msl}$

WELL MSB 57D

MEASUREMENTS CONDUCTED IN THE FIELD

Semple date: $12 / 18 / 81$
Depth to water: $126.26 \mathrm{ft}(38.18 \mathrm{~m})$ below TOC Water elevation: $23 \mathrm{C} .96 \mathrm{ft}(70.39 \mathrm{~m}) \mathrm{ms}$

WELL MSB 580

MEASUREMENTS CONDUCTED IN THE FIELD

Sample date: $12 / 18 / 91$

Depth to water: $127.36 \mathrm{ft} 138.82 \mathrm{~m} /$ below TOC

Time: 16:37 
WELL MSB 59D

MEASUREMENTS CONDUCTED IN THE FIELD

Sample date: $12 / 18 / 81$ Depth to water: $130.08 \mathrm{ft}(39.66 \mathrm{~m})$ beiow toc
Woter elevation: $228.22 \mathrm{ft}(69.87 \mathrm{~m}) \mathrm{ms}$ )

WELL MSB 60D

MEASUREMENTS CONDUCTED IN THE FIELD

Sample date: $12 / 18 / 81$

Depth to woter: $124.92 \mathrm{ft}(38.08 \mathrm{~m})$ below TOC Woter olovation: $228.68 \mathrm{tt} 169.98 \mathrm{~m} / \mathrm{ms}$

WELL MSB $61 \mathrm{C}$

MEASUREMENTS CONDUCTED IN THE FIELD

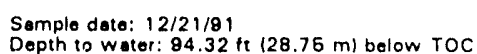
Depth to water: $94.32 \mathrm{ft}(28.75 \mathrm{~m})$ below
Water elevation: $223.28 \mathrm{ft}(68.06 \mathrm{~m}) \mathrm{ms}$ ।

WELL MSB 61D

MEASUREMENTS CONDUCTED IN THE FIELD

Somple dato: $12 / 21 / 81$

Depth to water: $92.60 \mathrm{ft}(28.19 \mathrm{~m})$ below TOC
Water elevation: $226.60 \mathrm{ft}(68.76 \mathrm{~m}) \mathrm{msl}$

WELL MSB 62B

MEASUREMENTS CONDUCTED IN THE FIELO

Sample date: $12 / 19 / 91$

Depth to water: $14: 2.46 \mathrm{ft}(43.42 \mathrm{~m})$ below TOC Depth to water: $14: 2.46 \mathrm{ft}(43.42 \mathrm{~m})$ below
Water olevation: $206.66 \mathrm{ft}(62.99 \mathrm{~m}) \mathrm{msl}$

WELL MSB 62C

MEASUREMENTS CONDUCTED IN THE FIELD

Sample date: $12 / 19 / 91$

Depth to water: $127.24 \mathrm{ft}(38.78 \mathrm{~m})$ below TOC Water elevation: $221.86 \mathrm{ft}\langle 67.62 \mathrm{~m} / \mathrm{ms}$

WELL MSB 62D

MEASUREMENTS CONDUCTED IN THE FIELD

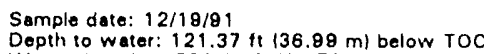

Water elevation: $228.13 \mathrm{ft}(69.63 \mathrm{~m}) \mathrm{ms}$ i

WELL. MSB 63B

MEASUREMENTS CONDUCTED IN THE FIELD

Sample date: $12 / 18 / 81$

Depth to water: $139.43 \mathrm{ft}(42.60 \mathrm{~m})$ below TOC

Depth to water: $139.43 \mathrm{ft}(42.60 \mathrm{~m})$ below
Water elevation: $207.67 \mathrm{tt}(63.27 \mathrm{~m} / \mathrm{ms})$

WELL MSB 63C

MEASUREMENTS CONDUCTED IN THE FIELD

Sample date: $12 / 18 / 91$

Depth to water: $127.73 \mathrm{tt}(38.93 \mathrm{~m})$ below $10 C$

(t $(66.86 \mathrm{~m}) \mathrm{ms}$

WELL MSB 63D

MEASUREMENTS CONDUCTED IN THE FIELD

Somple date: $12 / 18 / 91$

Depth to water: $117.88 \mathrm{ft}(36.96 \mathrm{~m})$ betow TOC Water elevation: $228.82 \mathrm{ft}(69.75 \mathrm{~m}) \mathrm{ms}$

WELL MSB 64B

MEASUREMENTS CONDUCTED IN THE FIELLO

Sample date: $12 / 19 / 91$

Depth to water: $14: 1.74$ ft $143.20 \mathrm{~m} /$ velow TOC Water elevation: $206.96 \mathrm{ft}(63.08 \mathrm{~m} / \mathrm{ms}$

WELL MSB $64 \mathrm{C}$

MEASUREMENTS CONDUCTED IN THE FIELO

Sample date: $12 / 18 / 81$

Depth to waler: $127.26 \mathrm{ft}(38.78 \mathrm{~m})$ below $\mathrm{rOC}$ Woter elevation: $221.44 \mathrm{ft}(67.60 \mathrm{~m}) \mathrm{ms})$
Time: $16: 29$

Time: $15: 20$

Time: $11: 06$

Time: 11:06

Time: 12:67

Time: 12:69

Time: 12:67

Time: $16: 68$

Time: 16:01

Time: 16:69

Time: 12:20

Time: $12: 20$
WELL MSB 64D

MEASUREMENTS CONDUCTED IN THE FIELO Sample date: $12 / 19 / 91$
Depth to water: $123.03 \mathrm{ft}(37.60 \mathrm{~m} /$ below TOC
Water elevatiois: $226.97 \mathrm{ft}(68.88 \mathrm{~m}) \mathrm{ms}$ !

Time: 12:22

WELL MSB 65D

MEASUREMENTS CONDUCTED IN THE FIELD

Somple date: $12 / 18 / 91$ Depth 10 wate: $116.83 \mathrm{ft}(36.31 \mathrm{~m})$ below TOC Water elevation: $233.67 \mathrm{tt}(71.22 \mathrm{~m} / \mathrm{msl}$

WELL MSB 66B

MEASUREMENTS CONDUCTED IN THE FIELD

Sample date: $12 / 20 / 81$

Depth to water: $164.43 \mathrm{ft}(60.12 \mathrm{~m})$ below TOC Water elevation: $219.07 \mathrm{ft}(66.77 \mathrm{~m} / \mathrm{ms}$

WELL MSB 66C

MEASUREMENTS CONDUCTED IN THE FIELD

Sample date: $12 / 20 / 91$

Depth to water: $165.63 \mathrm{ft}(47.44 \mathrm{~m})$ below TOC Water elevation: $227.87 \mathrm{ft}(69.46 \mathrm{~m} / \mathrm{msl}$

WELL MSB 66D

MEASUREMENTS CONDUCTED IN THE FIELD

Sample date: $12 / 20 / 91$

Depth to water: $163.31 \mathrm{ft}(46.73 \mathrm{~m})$ below TOC Water elevation: $228.99 \mathrm{ft}(70.10 \mathrm{~m}) \mathrm{ms} /$

\section{WELL MSB 66TA}

MEASUREMENTS CONDUCTED IN THE FIELD

Sample date: $12 / 20 / 91$

Depth to water: $176.69 \mathrm{ht}(53.83 \mathrm{~m})$ below TOC Water elevation: $206.21 \mathrm{ft}(62.86 \mathrm{~m}) \mathrm{msl}$

\section{WELL MSB 67B}

MEASUREMENTS CONDUCTED IN THE FIELD

Somple date: $12 / 20 / 91$
Depth to water: $14: 6.62 \mathrm{ft}(44.69 \mathrm{~m})$ below TOC Depth to water: $14: 6.62 \mathrm{ft}(44.69 \mathrm{~m})$ belo
Water elevation: $218.48 \mathrm{it}(66.59 \mathrm{~m} / \mathrm{ms} /$

\section{WELL MSB 67C}

MEASUREMENTS CONDUCTED IN THE FIELD

Sample date: $12 / 20 / 81$
Depth to water: 137.28 th $(41.84 \mathrm{~m} /$ below TOC Depth to water: $137.28 \mathrm{ft}(41.84 \mathrm{~m} /$ below
Water elevation: $227.62 \mathrm{ht} / 68.36 \mathrm{~m} / \mathrm{ms}$

\section{WELL MSB 67D}

MEASUREMENTS CONOUCTED IN THE FIELD

Sample date: 12/20/91

Depth to water: $132.47 \mathrm{H}(40.38 \mathrm{~m})$ below TOC Watel elevation: $232.63 \mathrm{ht} 170.88 \mathrm{~m} / \mathrm{msl}$

WELL MSB 68B

MEASUREMENTS CONDUCTED IN THE FIELD

Sample dote: 12:20/91

Depth to water: 138.18 th $(42.12 \mathrm{~m}$ ) below TOC Water elevation: $218.72 \mathrm{t}(66.67 \mathrm{~m} / \mathrm{msl}$

WELL MSB 68C

MEASUREMENTS CONDUCTED IN THE FIELD

Sample date: $12 / 20 / 91$

Depth to water: 130.18 \& $(39.68 \mathrm{~m} /$ below TOC Water elevation: $226.62 \mathrm{ft}(69.04 \mathrm{~m} / \mathrm{msl}$

WELL MSB 68D

MEASUREMENTS CONDUCTEO IN THE FELD

Sample date: $12 / 20 / 91$
Depth to water: $123.61 \mathrm{~h}(37.68 \mathrm{~m})$ below TOC Water elevation: $233.39 \mathrm{tt}(71.14: \mathrm{ml} \mathrm{msl}$
Time: 10:34

Tıme: 10:32

Time: 10:30

Time: 10:18

Time: 10:19

Tine: $10: 2^{\circ}$ 


\section{WELL MSB 69B}

MEASUREMENTS CONDUCTEO IN THE FIELD

Somple dote: $12 / 20 / 81$

Depth to water: 161.30 it $(49.16 \mathrm{~m})$ below TOC Water elevation: $220.40 \mathrm{ft}(67.18 \mathrm{~m}) \mathrm{ms}$

WELL MSB 69C

MEASUREMENTS CONDUCTED IN THE FIELD

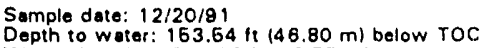
Water elevetion: 228.26 ft $169.57 \mathrm{mt}) \mathrm{ms}$

WELL MSB 69D

MEASUREMENTS CONDUCTED IN THE FIELD

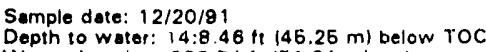
Water elevation: $233.74 \mathrm{ft}(71.24 \mathrm{~m}) \mathrm{ms}$

WELL MSB 69TA

MEASUREMENTS CONDUCTED IN THE FIELO

Semple date: $12 / 20 / 81$

Depth to water: $166.84 \mathrm{ft}(60.85 \mathrm{~m})$ below TOC Water elevation: $214: .66 \mathrm{ft}(66.43 \mathrm{~m}) \mathrm{ms}$ i

WELL MSB 70C

MEASUREMENTS CONDUCTED IN THE FIELD

Sample date: $12 / 19 / 91$
Depth to water: $14: 5.86 \mathrm{ft}(44.46 \mathrm{~m})$ below TOC Woter elevation: $216.34 \mathrm{ft}(66.94 \mathrm{~m}) / 1 \mathrm{~s})$

WELL MSB 7OD

MEASUREMENTS CONDUCTED IN THE FIELD

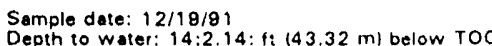
Water elevation: $220.36 \mathrm{ft}(67.17 \mathrm{~m}) \mathrm{ms}$ !

WELL MSB 71B

MEASUREMENTS CONDUCTED IN THE FIELD

Sample date: $12 / 19 / 91$

Depth to water: $128.17 \mathrm{ft}(39.07 \mathrm{~m})$ below TOC Water elevation: $216.93 \mathrm{ft}(66.12 \mathrm{~m}) \mathrm{msl}$

WELL MSB 72B

MEASUREMENTS CONDUCTED IN THE FIELD

Semple date: $12 / 19 / 81$

Depth to water: $127.89 \mathrm{ft}(38.98 \mathrm{~m})$ below TOC

Water elevation: $200.31 \mathrm{tt}(61.06 \mathrm{~m}) \mathrm{ms}$

WELL MSB 73B

MEASUREMENTS CONDUCTED IN THE FIELD

Somple date: $12 / 10 / 01$

Depth to water: 138.06 if $(42.39 \mathrm{~m})$ below TOC

Depth to water: $138.06 \mathrm{ft}(42.39 \mathrm{~m})$ below

WELL MSB 74B

MEASUREMENTS CONDUCTED IN THE FIELD

Sarmple date: $12 / 20 / 81$ ( $131.63 \mathrm{~m})$ below TOC

Water elevation: $210.72 \mathrm{tt} 164.23 \mathrm{ml} \mathrm{msl}$

WELL MSB 74C

MEASUREMENTS CONDUCTED IN THE FIELD

Somple date: $12 / 20 / 91$

Depth io water: $104.41 \mathrm{ft}(31.82 \mathrm{~m})$ beiow TOC Water elevation: $210.59 \mathrm{ft}(64.19 \mathrm{ml} \mathrm{ms}$

WELL MSB 74D

MEASUREMENTS CONDUCTED IN THE FIELL

Sample date: $12 / 20 / 81$

Depth to water: 80.99 f: $124.69 \mathrm{~m} /$ below TOC

Watet elevation: $234.11 \mathrm{ft} 171.36 \mathrm{ml} / \mathrm{msl}$
Time: 12:16

Time: 12:16

Time: 12:14

Time: 12:14

Time: $13: 41$

Time: 13:42

Time: $13: 50$

Time: 16:44

Time: $11: 65$

Time: 14:52

TIme: $14 \cdot 64$

Time: 14:52
WELL MSB 75B

MEASUREMENTS CONDUCTED IN THE FIELD

Sample date: $12 / 19 / 81$

Depth to water: $117.56 \mathrm{ft}(35.83 \mathrm{~m} /$ below TOC Water elevation: $209.16 \mathrm{ft}(63.75 \mathrm{~m}) \mathrm{ms} 1$

WELL MSB 75C

MEASUREMENTS CONDUCTED IN THE FIELD

Sample date: $12 / 19 / 81$
Depth to water: $118.76 \mathrm{ft}(36.20 \mathrm{~m} /$ below TOC Woter elevation: $208.74 \mathrm{ft}(63.62 \mathrm{~m}) \mathrm{mis}$

WELL MSB 76C

MEASUREMENTS CONDUCTED IN THE FIELD

Somple date: $12 / 19 / 91$

Depth to water: $132.66 \mathrm{ft}(40.43 \mathrm{~m})$ below rOC Water elevation: $220.16 \mathrm{ft}(67.10 \mathrm{~m}) \mathrm{msl}$

WELL MSB 77B

MEASUREMENTS CONDUCTED IN THE FIELD

Sample date: $12 / 21 / 91$

Depth 10 water: $135.96 \mathrm{ft}(41.44 \mathrm{~m})$ below $\mathrm{TOC}$ Water elevation: $221.74 \mathrm{ft}(67.69 \mathrm{~m}) \mathrm{msl}$

WELL MSB $77 C$

MEASUREMENTS CONDUCTED IN THE FIELD

Somple dete: $12 / 21 / 91$

Depth to water: $133.37 \mathrm{tt}(40.66 \mathrm{~m})$ below TOC Water elevation: $224.33 \mathrm{ft}(68.38 \mathrm{ml} \mathrm{msl}$

WELL MSB 77D

MEASUREMENTS CONDUCTED IN THE FIELD

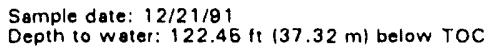
Water elevation: $236.36 \mathrm{ft}(71.74 \mathrm{~m} / \mathrm{msl}$

WELL MSB 77TA

MEASUREMENTS CONDUCTED IN THE FIELD

Sample date: $12 / 21 / 91$

Depth to water: 136.88 ft $(41.46 \mathrm{~m})$ below TOC Water elevation: $221.42 \mathrm{ft}(67.49 \mathrm{~m} / \mathrm{msi}$

WELL MSB 78D

MEASUREMENTS CONDUCTED IN THE FIELD

Sample date: $12119 / 91$

Depth 10 water: $139.63 \mathrm{ft}(42.66 \mathrm{~m})$ below TOC Water elevation: $223.97 \mathrm{ft}(68.27 \mathrm{~m}) \mathrm{ms}$

WELL MSB 79B

MEASUREMENTS CONOUCTED IN THE FIELD

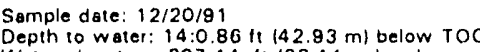
Water elevation: $207.14: \mathrm{ft}(63.14: \mathrm{m}) \mathrm{ms}$

WELL MSB 79C

MEASUREMENTS CONDUCTED IN THE FIELD

Sample date: $12 / 20 / 91$ Depth to water: $139.40 \mathrm{ft}(42.49 \mathrm{~m} /$ belo

\section{WELL MSB 81B}

MEASUREMENTS CONDUCTED IN THE FIELD

Sample date: $12121 / 81$

Depth 10 water: $47.78 \mathrm{ft}(14: 56 \mathrm{~m})$ below TOC Water elevation: $219.42 \mathrm{it} 166.88 \mathrm{ml} \mathrm{ins}$

WELL MSB 82A

MEASUREMENTS CONDUCTED IN THE FIELD

Sarriple date: 12120181

Devth to water: $14: 7.26 \mathrm{ft}(44.88 \mathrm{~m})$ below TOC

Time: $12: 66$ 


\section{WELL MSB $82 B$}

MEASUREMENTS CONDUCTED IN THE FIELD

Sor ple date: $12 / 20 / 81$

[. euch to water: $164.13 \mathrm{ft}(46.98 \mathrm{~m})$ below TOC

vis a eievation: $220.27 \mathrm{ft}(67.14: \mathrm{m}) \mathrm{msl}$

WELL MSB 82C

MEASUREMENTS CON'JUCTED IN THE FIELD

Sample date: $12 / 20 / 81$

Depth to water: $14: 6.60 \mathrm{ft} 144.36 \mathrm{~m}$ below TOC Water olevation: $228.50 \mathrm{th}(69.65 \mathrm{~m} / \mathrm{ms}$

WELL MSB 82D

MEASUREMENTS CONDUCTED IN THE FIELD

Somple date: 12/20/81

Depth io water: $14: 0.86 \mathrm{ft}(42.93 \mathrm{~m} /$ below TOC Wher elevalion: $232.84 \mathrm{ft}(70.97 \mathrm{~m} / \mathrm{ms}$

WELL MSB 82TA

MEASUREMENTS CONDUCTED IN THE FIELD

Sample date: $12 / 20 / 91$

(158.87 $(48.73 \mathrm{~m})$ below TOC Water elevation: $213.93 \mathrm{tt}(65.21 \mathrm{~m}) \mathrm{ms}$

WELL MSB 83B

MEASUREMENTS CONDUCTED IN THE FIELD

Sample date: $12 / 20 / 91$

Depth to water. $150.17 \mathrm{ft} 146.77 \mathrm{~m} /$ below TOC Water elevation: $221.83 \mathrm{ft}(67.61 \mathrm{n}) \mathrm{msl}$

WELL MSB 83C

MEASUREMENTS CONDUCTED IN THE FIELD

Somple date: $12 / 20 / 91$

14.3 .88 it $143.86 \mathrm{ml}$ below TOC Water elevation: $228.22 \mathrm{ft}(69.56 \mathrm{~m}) \mathrm{ms}$

WELL MSB 83D

MEASUREMENTS CONDUCTED IN THE FIELO

Sample date: $12 / 20 / 91$

Depth to water: $138.46 \mathrm{ft}(42.20 \mathrm{~m}$ ) below roc Water elevation: 233.24 t $(71.09 \mathrm{~m}) \mathrm{msl}$

WELL MSB 83TA

MEASUREMENTS CONDUCTED IN THE FIELD

Sample date: $12 / 20 / 91$

Depth to water: $166.30 \mathrm{H} 147.64 \mathrm{~m} /$ below TOC Water elevation: $216.60 \mathrm{H} 166.69 \mathrm{~m} / \mathrm{ms}$ |

WELL MSB 84C

MEASUREMENTS CONDUCTED IN THE FIELD

Sample date: $12 / 20 / 91$

Depth to water: $132.04 \mathrm{ft}(40.26 \mathrm{~m})$ below TOC Water elevation: $229.96 \%(70.09 \mathrm{~m} / \mathrm{ms}$

WELL MSB 85B

MEASUREMENTS CONDUCTED IN THE FIELD

Sample date: $12 / 20 / 91$

Depth to water: 169.02 it $148.47 \mathrm{~m} /$ below TOC Water elevation: $221.78 \mathrm{ft}(67.60 \mathrm{~m}) \mathrm{ms}$

WELL MSB 85C

MEASUREMENTS CONDUCTED IN THE TIELD

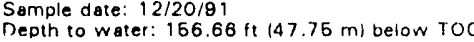
Watel elevation: $224.74 \mathrm{ft}(68.60 \mathrm{~m}) \mathrm{msl}$

WELL MSB 85D

MEASUREMENTS CONOUCTED IN THE FIELD

Sample date: $12 / 20 / 91$ Depith iu water: $14: 7.61 \mathrm{tt}(44.99 \mathrm{~m})$ velow TOC Water elevation: $233.79 \mathrm{ft}(71.26 \mathrm{~m}) \mathrm{ms}$ !
Time: $12: 64$

Time: 12:56

Time: $12: 64$

Time: $12: 58$

Time: $12: 22$

Time: 12:22

Time: $12: 24$

Time. 12:24

Time: $12: 48$

Time: 12:07

Time: 12:05

Time: 12:04
WELL MSB 85TA

MEASUREMENTS CONDUCTED IN THE FIELD

Sample date: $12 / 20 / 91$

Depth to water: 160.09 (1) $(48.80 \mathrm{~m})$ below TOC 作

WELL MSB 86C

MEASUREMENTS CONDUCTED IN THE FIELD

Sample date: $12 / 20 / 91$

Depth to water: $132.66 \mathrm{ft}(40.44 \mathrm{~m})$ below TOC Water elevation: $224.74 \mathrm{ft} 168.60 \mathrm{ml} \mathrm{ms}$

WELL SLW 1

MEASUREMENTS CONDUCTED IN THE FIELD

Depth to water: 128.77 tt $139.25 \mathrm{~m})$ below TOC Water elevation: $176.33 \mathrm{ft}(63.44 \mathrm{~m}) \mathrm{ms}$

WELL SLW 2

MEASUREMENTS CONDUCTED IN THE FIELD

Sample date: 12121191

Depth to water: $114: 63 \mathrm{ft}(34.94 \mathrm{~m})$ below TOC Water elevation: $189.97 \mathrm{ft}(57.90 \mathrm{ml} \mathrm{msl}$

WELL SLW 3

MEASUREMENTS CONOUCTED IN THE FIELD

Sample date: $12 / 21 / 91$

Wepth to water: $81.67 \mathrm{ft} 24.89 \mathrm{~m}$ ) below TOC Water elevation: $197.03 \mathrm{ft} 160.06 \mathrm{~m} / \mathrm{ms} /$

WELL SLW 4

MEASUREMENTS CONDUCTEO IN THE FIELD

Sample date: $12 / 21 / 91$ (1) $130.02 \mathrm{~m}$ ) below TOC Depth to water: $98.60 \mathrm{Ht}(30.02 \mathrm{~m})$ below TOC

WELL SLW 5

MEASUREMENTS CONDUCTED IN THE FIELD

Sample date: $12 / 21 / 91$ ( $13.28 \mathrm{~m})$ below TOC Depth to water: $43.68 \mathrm{ft}(13.28 \mathrm{~m})$ below

WELL SLW 6

MEASUREMENTS CONDUCTED IN THE FIELD

Sample date: $12 / 21 / 91$

Depth to water: $46.70 \mathrm{ft}(14.23 \mathrm{~m})$ below TOC Water elevation: $204.80 \mathrm{ft}(62.42 \mathrm{ml} \mathrm{msl}$

WELL SLW 7

MEASUREMENTS CONDUCTED IN THE FIELD

Sample date: $12 / 21 / 91$

Depth to water: $54.30 \mathrm{ft}(16.55 \mathrm{~m} /$ below TOC Wepth io water: $54.30 \mathrm{Ht}(16.65 \mathrm{~m} /$ below

WELL SI.W 8

MEASUREMENTS CONDUCTED IN THE FIELD

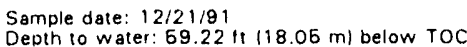
Depth to water: $69.22 \mathrm{ft}(18.05 \mathrm{~m} /$ below TOC
Water elevation: $199.28 \mathrm{ft}(60.44 \mathrm{~m}) \mathrm{ms}$

WELL SRW 1

MEASUREMENTS CONDUCTED IN THE FIELD

Semple date: $12 / 18 / 91$ Depth to water: $102.64 \mathrm{ft}(31.29 \mathrm{~m})$ below TOC Water elevation: $212.66 \mathrm{ft}(64.78 \mathrm{~m}) \mathrm{ms} 1$

WELL SRW 2

MEASUREMENTS CONDUCTED IN THE FIELD

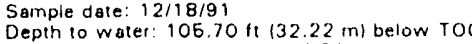
Water elevation: $214: .90 \mathrm{ft}(65.50 \mathrm{~m})$ insi
Time: $12: 07$

Time: $11: 58$

Time: $11: 24$

Time: $11: 56$

Tune: $11: 51$

TIrne: $11 \cdot 28$

Time: $11: 34$

Tıme: 11:36

Time: $11: 42$

Time: $11: 46$

Time: $12: 46$

Tine: $12: 38$ 
WELL SRW 2A

MEASUREMENTS CONDUCTED IN THE FIELD

Somple date: $12 / 18 / 91$

Depth to weter: $113.75 \mathrm{ft}(34.67 \mathrm{~m})$ below TOC

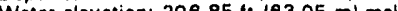

WELL SRW 2B

MEASUREMENTS CONDUCTED IN THE FIELD

Somplo dato: $12 / 18 / 91$

Depth to water: 113.02 ft $134.45 \mathrm{~m} /$ below TOC Deth o water: $207.58 \mathrm{ft}(183.27 \mathrm{~m} / \mathrm{ms}$

WELL SRW 3A

MEASUREMENTS CONDUCTED IN THE FIELO

Somple dets: $12 / 18 / 81$

24.14: ft $(37.84 \mathrm{~m})$ below TOC

Weth to wation: 24.14 ! f 137.84 ml below

WELL SRW 4

MEASUREMENTS CONDUCTED IN THE FIELD

Semple date: 12/18/91

Depth to weter: $107.39 \mathrm{ft}(32.73 \mathrm{~m})$ bolow TOC Water olevation: $212.71 \mathrm{ft}(64.83 \mathrm{~m} / \mathrm{msl}$

WELL SRW 5

MEASUREMENTS CONDUCTED IN THE FIELD

Semple dete: 12/18/91

Wepth to wator: 08.17 th $(28.92 \mathrm{~m})$ below TOC Weter olovation: $211.23 \mathrm{ft}(64.38 \mathrm{~m}) \mathrm{mel}$

WELL SRW 6

MEASUREMENTS CONDUCTED IN THE FIELL

Sample date: $12 / 18 / 81$

Wepth Water elevation: $211.86 \mathrm{ft}(64.61 \mathrm{~m}) \mathrm{msl}$

WELL SRW 7

MEASUREMENTS CONDUCTED IN THE FIELD

Sumplo date: $12 / 18 / 81$

Dopth to water: $88.28 \mathrm{ft}(28.80 \mathrm{~m})$ bolow TOC Weter alevation: $210.84 \mathrm{ft}(64.26 \mathrm{~m}) \mathrm{ms}$

WELL SRW 8

MEASUREMENTS CONDUCTED IN THE FIELD

Somple date: $12 / 18 / 81$

Depth to weter: $78.85 \mathrm{ft}(24.06 \mathrm{~m})$ below TOC Woter olevation: $209.16 \mathrm{ft} 163.76 \mathrm{ml} \mathrm{ms}$

WELL SRW 9

MEASUREMENTS CONDUCTED IN THE FIELD

Somple date: $12 / 18 / 91$

Depth to water: $52.82 \mathrm{ft}(16.04 \mathrm{~m} /$ below TOC Water elovetion: 200.78 $11.0120 \mathrm{~m} / \mathrm{msl}$

\section{WELL SRW 9A}

MEASUREMENTS CONDUCTED IN THE FIELD

Sample date: $12 / 18 / 91$

Depth to water: 54.32 th $\{16.56 \mathrm{~m})$ below rOC Woler elevation: $188.98 \mathrm{ft}(60.65 \mathrm{~m} / \mathrm{ms}$

WELL SRW 9B

MEASUREMENTS CONDUCTED IN THE FIELD

Sample dete: $12 / 18 / 81$

Depth to weter: $62.67 \mathrm{ft}(16.02 \mathrm{~m})$ below TOC Water elevation: $200.83 \mathrm{ft}(61.21 \mathrm{ml} \mathrm{ms}$

WELL SRW 10

MEASUREMENTS CONOUCTED IN THE FIELD

Somple date: $12 / 18 / 81$

There was no water in stand pipe.
Time: $12: 38$

Time: 12:41

Time: 12:36

Time: 13:06

Time: 13:02

Time: $12: 48$

Time: 12:54

Time: 12:15

Tine: $12: 26$

Time: $12: 26$

Time: $12: 27$

Time: 12:62
WELL SRW 11

MEASUREMENTS CONDUCTED IN THE FIELD

Sample date: $12 / 18 / 91$

Depth to water: 84.86 tt $125.90 \mathrm{ml}$ below TOC Weth to water: $84.86 \mathrm{ft} / 26.90 \mathrm{~m} / \mathrm{below}$

WELL SRW 12A

MEASUREMENTS CONDUCTEO IN THE FIELD

Semple date: $12 / 18 / 91$

Wopth 10 water: $41.77 \mathrm{ft} 112.73 \mathrm{ml}$ below TOC Water elevation: $184.63 \mathrm{ft}(69.29 \mathrm{ml} \mathrm{ms}$

WELL SRW 12B

MEASUREMENTS CONDUCTED IN THE FIELD

Semple date: $12 / 18 / 91$ it $(14: 15 \mathrm{~m})$ below TOC Wath to wator: 48.42 it $(14.57 \mathrm{~m}) \mathrm{ms}$

WELL SRW 12C

MEASUREMENTS CONDUCTED IN THE FIELO

Sample date: 12/18/91

Depth to water: 38.82 ft $(11.77 \mathrm{~m})$ below TOC Water alevation: $197.68 \mathrm{ft}(60.26 \mathrm{~m}) \mathrm{msl}$

WELL SRW 13A

MEASUREMENTS CONDUCTED IN THE FIELD

Sample date: $12 / 18 / 91$ Weter elevation: $201.78 \mathrm{ft}(61.50 \mathrm{~m}) \mathrm{ms}$

WELL SRW 13B

MEASUREMENTS CONDUCTED IN THE FIELD

Sample dote: $12 / 18 / 8$

Depth 10 water: 04.05 it $(28.67 \mathrm{~m})$ below TOC Water elevation: $203.66 \mathrm{ft}(62.07 \mathrm{~m} / \mathrm{ms}$ !

WELL SRW 13C

MEASUREMENTS CONOUCTED IN THE FIELD

Sample date: $12 / 18 / 91$

Depth to water: 88.34 th $226.93 \mathrm{ml}$ below $\mathrm{TOC}$ Water elevation: $209.36 \mathrm{ft}(63.81 \mathrm{~m} / \mathrm{ms} \mid$

WELL SRW 14:A

MEASUREMENTS CONDUCTED IN THE FIELO

Sample date: $12 / 18 / 91$. $137.70 \mathrm{ml}$ below TOC Water elevation: $203.30 \mathrm{ft}(61.97 \mathrm{~m}) \mathrm{msl}$

WELL SRW 14:B

MEASUREMENTS CONDUCTED IN THE FIELD

Sample date: $12 / 18 / 81$

Dopth 10 water: $121.50 \mathrm{ft} 137.03 \mathrm{ml}$ below TOC Depth to water: $121.60 \mathrm{ft}(37.03 \mathrm{~m})$ below

WELL SRW 14:C

MEASUREMENTS CONDUCTED IN THE FIELD

Somple dote: $12 / 18 / 91$

Semple dore: $12 / 18 / 91$ siand pipe.

Time: $11: 43$

\section{WELL SRW 15A}

MEASUREMENTS CONDUCTED IN THE FIELD

Sample date: $12 / 18 / 91$

Wepth ro walcr: $108.63 \mathrm{ht}(33.42 \mathrm{~m})$ below

WELL SRW 15B

MEASUREMENTS CONDUCTED IN THE FIELD

Sernple date: $12 / 18 / 91$

Depth to water: $109.68 \mathrm{tt}(33.40 \mathrm{~m})$ below TOC

Time: 13:08 
WELL SRW 15C

MEASUREMENTS CONDUCTED IN THE FIELD Somple date: $12 / 18 / 91$ Depth to water: $106.10 \mathrm{ft}(32.34 \mathrm{~m} /$ below TOC Water elevation: $213.00 \mathrm{ft} 164.92 \mathrm{~m} / \mathrm{msl}$

WELL SRW 16A

MEASUREMENTS CONDUCTED IN THE FIELD

Sample date: $12 / 18 / 91$

Time: $11: 26$

Depth to water: $13338 \mathrm{ft} 140.65 \mathrm{~m}$ ) below TOC Water elevation: $213.42 \mathrm{ft}(66.06 \mathrm{~m}) \mathrm{mgl}$

\section{WELL SRW 16B}

MEASUREMENTS CUNDUCTED IN THE FIELD

Sample date: $12 / 18 / 81$

Depth to water: 132.42 f: $(40.36 \mathrm{~m})$ below TOC Water elevation: $214: .38 \mathrm{ft}(66.34 \mathrm{~m}) \mathrm{ms}$ )

\section{WELL SRW 16C}

MEASUREMENTS CONDUCTED IN THE FIELD

Sample date: $12 / 18 / 91$

Dapth to vater: $131.81 \mathrm{ft}(40.21 \mathrm{~m})$ below TOC Water elevation: $214.69 \mathrm{ft}(65.44 \mathrm{~m}) \mathrm{msl}$

WELL YSC 1D

MEASUREMENTS CONDUCTED IN THE FIELD

Sample date: $11 / 21 / 91$

Depth to water: $50.27 \mathrm{ft}(16.32 \mathrm{~m})$ below TOC Water elevation: $224.13 \mathrm{tt}(68.32 \mathrm{~m} / \mathrm{msl}$

WELL YSC 4A

MEASUREMENTS CONDUCTED IN THE FIELD

Sample date: $11 / 21 / 81$

Depth to water: $104.46 \mathrm{ft}(31.84 \mathrm{~m})$ below TOC Water elevation: $186.74 \mathrm{ft} 166.61 \mathrm{~m} / \mathrm{ms}$

Time: 11:24

Time: 11:27

Time: 13:07

Time: 12:24 
NOTES 


\section{SITE INDEX BY WELL SERIES}

\section{Well Series}

ABP

ABW

$\mathrm{AC}$

ACB

AMB

AOB

ARP

ASB

BG

BGO

BGX

BRD

BRR

CBR

CCB

CDB

CMP

CRP

CSA

CSB

CSD

CSO

CSR

DBP

DCB

DOB

F

FAC

FAL

FBP

FCA

FCB

FET

FNB

FSB

FSB 1TA Well

FSS

FTF

GBW
Site Description

A-Area Metals Burning Pit

A Area near Firing Range: Background Well

A/M Area: Cluster Perimeter Wells and Plume Definition Wells

A-Area Coal Pile Runoff Containment Basin

Metallurgical Laboratory Seepage Basin

Motor Shop Oil Basin

A-Area Burning/Rubble Pits

Savannah River Laboratory (SRL) Seepage Basins

Burial Grounds

Burial Grounds Perimeter

E-Area Vaults Near the Burial Grounds

Road A Chemical Basin (Baxley Road)

Burma Road Rubble Pit

Central Shops Burning/Rubble Pit South of the Ford Building Seepage Basin

C-Area Coal Pile Runoff Containment Basin

C-Area Disassembly Basin

Chemicals, Metals, and Pesticides (CMP) Pits

C-Area Burning/Rubble Pit

Hydrofluoric Acid Spill Area

C-Area Reactor Seepage Basins

Central Shops Diesel Spill Site: Characterization and Remediation Wells

Fire Department Training Facility

Central Shops Burning/Rubble Pits

D-Area Burning/Rubble Pits

D-Area Coal Pile Runoff Containment Basin and Ash Basins

D-Area Oil Disposal Basin

F.Frea Seepage Basins

F-Area Acid/Caustic Basin

F-Area A Line

F-Area Burning/Rubble Pits

F-Area Canyon Building

F-Area Coal Pile Runoff Containment Basin

F-Area Effluent Treatment Cooling Water Basin

Old F-Area Seepage Basin

F-Area Seepage Basiris

F-Area Seepage Basins: Production Well

F-Area Sludge Land Application Site

F-Area Tank Farm

Near Hawthorne Fire 'Tower: Background Well 


\section{SITE INDEX}

Well Series

$2 \mathrm{H}$

HAC

HAP

HCA

HCB

HET

HMD

HR3

HR8

HSB

HSB 1TB Well

HSS

HTF

HWS

HXB

IDB

IDP

IDQ

K

$\mathrm{KAB}$

KAC

$\mathrm{KCB}$

$\mathrm{KDB}$

KDT

KRP

KSB

KSS

LAC

LAW

LCO

LDB

LFW

LRP

LSB

$\mathrm{MCB}$

MGA

MGC

MGE

MGG

MSB

MWD

NBG

NPM

$\mathrm{P}$

PAC

PCB

PDB

PRP
Site Description

H-Area Seepage Basins

H-Area Acid/Caustic Basin

H-Area Auxiliary Pump Pit

H-Area Canyon Building

H-Area Coal Pile Runoff Containment Basin

H-Area Effluent Treatment Cooling Water Basin

Hazardous Waste/Mixed Waste Disposal Facility

Old H-Area Relention Basin

H-Area Retention Basin

H-Area Seepage Basins

H-Area Seepage Basins: Production Well

H-Area Sludge Land Application Site

H-Area Tank Farm

Hazardous Waste Storage Facility

Ford Building Seepage Basin

Interim Waste Technology Site B: Characterization Wells

Interim Waste Technology Site P: Characterization Wells

Interim Waste Technology Site Q: Characterization Wells

K-Area Wind Tower at B Road: Piezometers

K-Area Ash Basin

K-Area Acid/Caustic Basin

K-Area Coal Pile Runoff Containment Basin

K-Area Disassembly Basin

K-Area Diesel Tank

K-Area Burning/Rubble Pit

K-Area Reactor Seepage Basin

K-Area Sludge Land Application Site

L-Area Acid/Caustic Basin

L-Area: Research Wells

L-Area Oil and Chemical Basin

L-Area Disassembly Basin

Sanitary Landfill

L-Area Burning/Rubble Pit

L-Area Reactor Seepage Basin

Miscellareous Chemical Basin

Series A, Burial Grounds Grid

Series C, Burial Grounds Grid

Series E, Burial Grounds Grid

Series G, Burial Grounds Grid

M-Area Hazardous Waste Management Facility (HWMF)

Potential Hazardous Waste/Mixed Waste Disposal Facility

Between the F-Area Canyon Building and the Naval Fuel Material Facility

Potential New Production Reactor Site (near Central Shops): Characterization Wells

B Area: Microbiology Wells [P 29 cluster]

F Area: Microbiology Wells (P 28 cluster)

I'NX Area: Background Wells [P 26 cluster)

P-Area Acid/Caustic Basin

P-Area Coal Pile Runoff Containment Basin

P-Area Disassembly Basin

P-Area Burning/Rubble Pit 


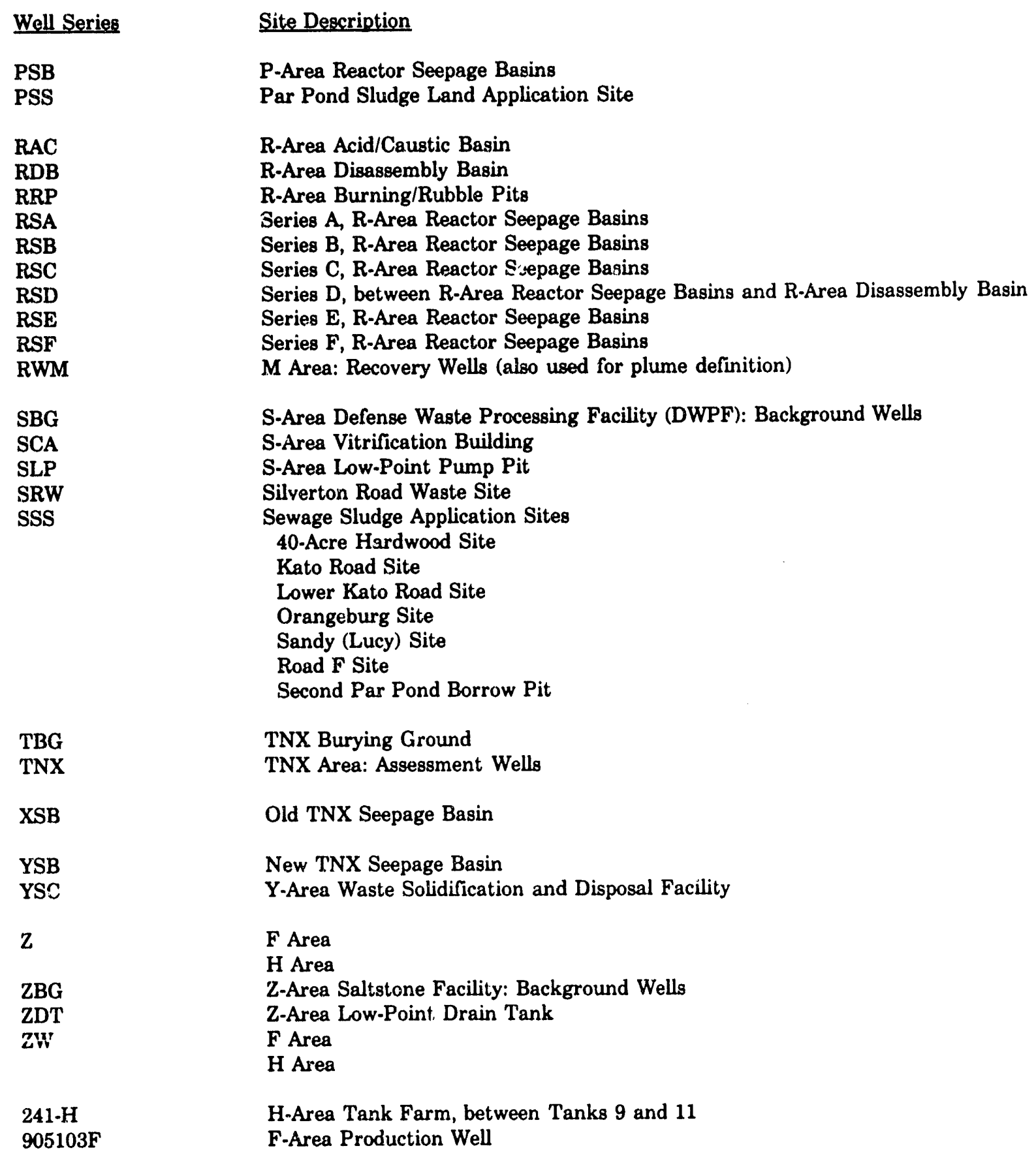


NOTES 


\section{GLOSSARY}

2,4-D. 2,4-Dichlorophenoxyacetic acid.

aerated sample. Groundwater sample supplied or charged with air. Aeration can occur naturally or during well pumping.

aliquot. A portion of a sample being used for analysis.

analyte. Analyzed constituent.

analytical detection limit. The lowest reasonably accurate concentration of an analyte that can be detected; this value varies depending on the method, instrument, and dilution used.

Appendix IX. List of constituents specified by Appendix IX in the Code of Federal Regulations, Title 40, Part 264. Analyses for Appendix IX constituents are required by the Resource Conservation and Recovery Act under specified conditions.

associated samples. Samples analyzed by a laboratory in the same batch with blind blanks or laboratory blanks.

bail. To remove water from a well by lowering a container into the water, allowing it to fill with water, and removing it from the well.

blank. Aliquot of deionized water generated by laboratory or sampling personnel and analyzed like a groundwater sample. See blind blank, internal blank, laboratory blank, and trip blank.

blind blank. A sample container of deionized water sent to a laboratory under an alias name as a quality control cherk.

blind replicate. A second sample taken from the same well at the same time as the primary sample, assigned an alias well name, and sent to a laboratory for analysis (as an unknown to the analyst).

BNA. Base/Neutral and Acid Extractables; groups of organic compounds analyzed as part of Appendix IX and Priority Pollutants.

cation. Positively charged ion.

CERCLA. Comprehensive Environmental Response, Compensation, and Liability Act.

CFR. Code of Federal Regulations; sections of this annual document contain EPA standards and regulations for environmental monitoring.

chain-of-custody record. A form that documents the collection, transport, analysis, and disposal of well samples.

comprehensive analyses. A group of analyses that forms the core of the EPD/EMS Groundwater Monitoring Program each quarter. See the Sample Scheduling section of this report for a complete list of constituents.

detection limit. See analytical detection limit.

dilution factor. The athematical factor by which a sample is diluted in order to bring the concentration of an analyte in the sample within the analytical range of a detector (e.g., $1 \mathrm{~mL}$ sample $+9 \mathrm{~mL}$ solvent $=1: 10$ dilution, or a dilution factor of 10 ).

\section{See analytical detection limit.}

DNAPL. Dense Non-Aqueous Phase Liquids; the liquid phase of chlorinated organic solvents. These liquids are denser than water and include commonly used industrial compounds such as tetrachloroethylene and trichloroethylene. 


\section{GLOSSARY}

DOE. United States Department of Energy.

duplicate result. A result derived by taking a portion of a primary sample and performing identical analyses on that portion and on the primary sample.

DWS. Drinking water standards (federal primary and secondary drinking water standards, as set forth by EPA).

E. A code letter used in the analytical data tables signifying an exponential (e.g., $3.4 \mathrm{E}+3=$ $\left.3.4 \times 10^{3}=3,400\right)$.

EM. EPD/EMS Laboratory at SRS.

EMS. The Environmental Monitoring Section of the Environmental Protection Department at. SRS.

EPA. United States Environmental Protection Agency.

EPD. Environmental Protection Department at SRS.

EPD/EMS. Environmental Protection Department's Environmental Monitoring Section.

ERA. Environmental Resource Associates of Arvada, CO.

flagging criteria. Criteria established to aid in determining the relative concentration and testing frequency for analytes. See the Flagging Criteria section of this report for further information.

gamma PHA. A group of analyses performed to determine activities of gamma-emitting radionuclides.

GC VOA. (Gas Chromatographic Volatile Organics Analyses). A group of volatile organic compounds that can be analyzed by gas chromatography.

GCMS VOA. (Gas Chromatograph/Mass Spectrometer Volatile Organics Analyses). A group of volatile organic compounds analyzed by gas chromatography and mass spectrometry methods.
GE. See General Engineering.

Ge-Hy. Ge-Hy Environmental Sampling of New Ellenton, SC.

General Engineering. General Engineering Laboratories of Charleston, SC.

halogenated compound. An organic compound bonded with one of the five halogen elements (astatine, bromine, chlorine, fluorine, and iodine).

herbicides/pesticides. A suite of analyses. See the Sample Scheduling section of this report for further information.

interlaboratory comparisons. Comparisons conducted between two or more laboratories.

internal blank. Deionized water sample generated by the laboratory; one is analyzed with each batch of samples as an in-house check of analytical procedures and equipment (same as a laboratory blank).

intralaboratory conuparisons. Comparisons conducted within a single laboratory.

J. A letter code used in the analytical data tables to indicate an estimated value.

laboratory blank. See internal blank.

LT. Less than.

MLA. M Area; used in the analytical data tables to refer to the M-Area Laboratory at SRS.

major ions. A group of analyses performed in the EPD/EMS Groundwater Monitoring Program to determine the concentrations of calcium, magnesium, potassium, and silica ions and the alkalinity of the sample.

mg. Milligrams.

$\mathbf{m g} / \mathbf{L}$. Milligrams per liter.

MRD. Mean relative difference. For further information, see the Quality Control Samples section of this report. 
msl. mean sea level.

MWMF. Mixed Waste Management Facility.

ng/L. Nanograms per liter.

NTU. Nephelometric turbidity units; the standard unit of turbidity measurement.

PCB. Polychlorinated biphenyl.

pCi. Picocurie; a unit of radiation equivalent to $3.7 \times 10^{-2}$ disintegrations per second.

piezometer. An instrument used to measure the potentiometric surface of the groundwater. Also, a well designed for this purpose. See potentiometric surface.

plume. A volume of contaminated air or water originating at a point-source emission (e.g., a smokestack) or a waste source (e.g., a hazardous-waste disposal site).

potentiometric surface. A surface to which water in an aquifer would rise by hydrostatic pressure if unconfined.

pump. To remove water from a well by using a stationary device to force water up a tube or pipe to the top of the well.

purge. To remove water from a well prior to sampling, generally by pumping or bailing. Under the EPD/EMS Groundwater Monitoring Program, four well volumes generally are purged before sampling.

QA. Quality assurance.

radioisotopes. Radioactive isotopes.

radionuclide. A nuclide at an unstable, highenergy level that seeks a more stable, lowerenergy level by emitting particles of energy. Through these emissions, the nuclear configuration decays to simpler nuclides.

RCRA. Resource Conservation and Recovery Act.

RCRA site. Solid-waste management unit under RCRA regulation.
RDL. See reference detection limit.

reference detection limit. The detection limit chosen to allow comparison of several analyses with different detection limits. For the purposes of this report, the individual detection limits of at least $90 \%$ of the analyses are less than the reference detection limit. See the Quality Control Samples section of this report for further information.

replicate result. The analytical result of a blind replicate sample. See blind replicate.

Resource Conservation and Recovery Act (RCRA). Federal legislation that regulates the transport, treatment, and disposal of solid and hazardous wastes.

RFI Program. RCRA Facility Investigation Program; EPA-regulated investigation of a solid-waste management unit with regard to its potential impact on the environment.

RFI/RI Program. RCRA Facility Investigation/Remedial Investigation Program; at SRS, an expansion of the RFI Program to include CERCLA and hazardous-substance regulations.

SCDHEC. South Carolina Department of Health and Environmental Control.

seepage basin. An excavation that receives wastewater. Insoluble materials settle out on the floor of the basin, and soluble materials seep with the water through the soil column, where they are removed partially by ion exchange with the soil. Designed to prevent overflow or surface runoff.

settling basin. A temporary holding basin (excavation) that receives wastewater, which is subsequently discharged.

site custodian. WSRC employee responsible for a site being monitored.

SRL. Savannah River Laboratory at SRS.

SRP. Savannah River Plant; now Savannah River Site.

SRS. Savannah River Site. 


\section{GLOSSARY}

tank farm. An installation of interconnected underground tanks used for storage of highlevel radioactive liquid wastes.

TOC. Top of casing. The elevation of the top of the well casing; used as a reference for water level measurements.

trip blank. A sample container of deionized water that is transported to the well sample location, treated as a well sample, and sent to the laboratory for analysis; trip blanks are used to check for contamination resulting from transport, shipping, and site conditions.

turbidity. A measure of the concentration of sediment or suspended particles in solution. See NTU.

(U). Unclassified.

$\boldsymbol{\mu g} / \mathbf{L}$. Micrograms per liter. $\boldsymbol{\mu} \mathbf{S} / \mathbf{c m}$. Microsiemens per centimeter, equivalent to micromhos per centimeter; the unit of conductance across two points, used as the measure of specific conductance in analytical data tables.

USDWS. United States Public Health Service drinking water standard.

volatile organic compounds. A broad range of organic compounds, commonly halogenated, that vaporize at ambient, or relatively low, temperatures (e.g., benzene, acetone, chloroform, and methyl alcohol).

well volume. The volume of water between the well water surface and the bottom of the screen; the volume of water standing inside the well casing.

WSRC. Westinghouse Savannah River Company. 


\section{REFERENCES}

American Public Health Association, American Water Works Association, and Water Pollution Control Federation. 1985. Standard Methods for the Examination of Water and Wastewater, 16 th edition. Washington, DC.

Christensen, E. J., and D. E. Gordon, eds. 1983. Technical Summary of Groundwater Quality Protection Program at Savannah River Plant, Volume I-Site Geohydrology and Solid and Hazardous Wastes, DPST-83-829. Aiken, SC: E. I. du Pont de Nemours \& Company, Savannah River Laboratory.

Environmental Monitoring (Environmental and Health Protection Department) and Exploration Resources. 1989. The Savannah River Site's Groundwater Monitoring Program Conducted by the Environmental and Health Protection Department for the First Quarter 1989, ESHEMS-890043. Aiken, SC: Westinghouse Savannah River Company, Savannah River Site.

Environmental Monitoring (Environmental and Health Protection Department) and Exploration Resources. 1989. The Savannah River Site's Groundwater Monitoring Program Conducted by the Environmental and Health Protection Department for the Second Quarter 1989, ESHEMS-890044. Aiken, SC: Westinghouse Savannah River Company, Savannah River Site.

Environmental Monitoring (Environmental and Health Protection Department) and Exploration Resources. 1989. The Savannah River Site's Groundwater Monitoring Program Conducted by the Environmental and Health Protection Department for the Third Quarter 1989, ESHEMS-890045. Aiken, SC: Westinghouse Savannah River Company, Savannah River Site.
Environmental Monitoring (Environmental and Health Protection Department) and Exploration Resources. 1989. The Savannah River Site's Groundwater Monitoring Program Conducted by the Environmental and Health Protection Department for the Fourth Quarter 1989, ESHEMS-890046. Aiken, SC: Westinghouse Savannah River Company, Savannah River Site.

Environmental Monitoring (Environmental Protection Department) and Exploration Resources. 1990. The Savannah River Site's Groundwater Monitoring Program, First Quarter 1990, ESHEMS-90-0131. Aiken, SC: Westinghouse Savannah River Company, Savannah River Site.

Environmental Monitoring (Environmental Protection Department) and Exploration Resources. 1991. The Savannah River Site's Groundwater Monitoring Program, Second Quarter 1990, ESH-EMS-900132. Aiken, SC: Westinghouse Savannah River Company, Savannah River Site.

Environmental Monitoring (Environmental Protection Department) and Exploration Resources. 1991. The Savannah River Site's Groundwater Monitoring Program, Third Quarter 1990, ESH-EMS-900133. Aiken, SC: Westinghouse Savannah River Company, Savannah River Site.

Environmental Monitoring (Environmental Protection Department) and Exploration Resources. 1991. The Savannah River Site's Groundwater Monitoring Program, Fourth Quarter 1990, ESH-EMS-900134. Aiken, SC: Westinghouse Savannah River Company, Savannah River Site.

Environmental Monitoring (Environmental Protection Department) and Exploration Resources. 1991. The Savannah River Site's Groundwater 


\section{REFERENCES}

Monitoring Program, First Quarter 1991, ESHEMS-910087. Aiken, SC: Westinghuuse Savannah River Company, Savannah River Site.

Environmental Monitoring (Environmental Protection Department) and Exploration Resources. 1992. The Savannah River Site's Groundwater Monitoring Program, Second Quarter 1991, ESH-EMS-910088. Aiken, SC: Westinghouse Savannah River Company, Savannah River Site.

Environmental Monitoring (Environmental Protection Lepartment) and Exploration Resources. 1992. The Savannah River Site's Groundwater Monitoring Program, Third Quarter 1991, ESH-EMS-910089. Aiken, SC: Westinghouse Savannah River Company, Savannah River Site.

Environmental Monitoring (Health Protection Department) and Exploration Software. 1987. The Savannah River Plant's Groundwater Monitoring Program Conducted by the Health Protection Department for the Second Quarter 1987, HPR-87-286. Aiken, SC: E. I. du Pont de Nemours \& Company, Savannak. River Plant.

Environmental Monitoring (Health Protection Department) and Exploration Software. 1.987. The Savannah River Plant's Groundwater Monitoring Program Conducted by the Health Protection Department for the Third Quarter 1987, HPR-87-339. Aiken, SC: E. I. du Pont de Nemours \& Company, Savannah River Plant.

Environmental Monitoring (Health Protection Department) and Exploration Software. 1988. The Savannah River Plant's Groundwater Monitoring Program Conducted by the Health Protection Department for the Fourth Quarter 1987, HPR-88-098. Aiken, SC: E. I. du Pont de Nemours \& Company, Savannah River Plant.

Environmental Monitoring (Health Protection Department) and Exploration Software. 1988. The Savannah River Plant's Groundwater Monitoring Program Conducted by the Health Protection Department for the First Quarter 1988, HPR-88-238. Aiken, SC: E. I. du Pont de Nemours \& Company, Savannah River Plant.

Environmental Monitoring (Health Protection Department) and Exploration Software. 1988. The Savannah River Plant's Groundwater Monitoring Program Conducted by the Health
Protection Department for the Second Quarter 1988, HPR-88-300. Aiken, SC: E. I. du Pont de Nemours \& Company, Savannah River Plant.

Environmental Monitoring (Health Protection Department) and Exploration Software. 1988. The Savannah River Plant's Groundwater Monitoring Program Conducted by the Health Protection Department for the Third Quarter 1988, HPR-88-489. Aiken, SC: E. I. du Pont de Nemours \& Company, Savannah River Plant.

Environmental Monitoring (Health Protection Department) and Exploration Software. 1989. The Savannah River Site's Groundweter Monitoring Program Conducted by the Health Protection Department for the Fourth Quarter 1988, HPR-89-193. Aiken, SC: Westinghouse Savannah River Company, Savannah River Site.

Environmental Protection Agency. 1977. Nation al Interim Primary Drinking Water Regulations, EPA-570/9-76-003. Washington, DC.

Environmental Protection Agency. 1980. Prescribed Procedures for Measurement of Radioactivity in Drinking Water. EPA-600/4-80032. Cincinnati, $\mathrm{OH}$.

Environmental Protection Agency. 1983. Methods for Chemical Analysis of Water and Wastes. PB84-128677. Cincinnati, OH.

Environmental Protection Agency. 1986a. Water Pollution Control; National Primary Drinking Water Regulations; Radionuclides; Proposed. Federal Register, pp. 34835-34862. September 30, 1986. Washington, DC.

Environmental Protection Agency, 1986b. RCRA Ground-Water Monitoring Technical Enforcement Guidance Document, OSWER-9950.1. Washington, DC: Office of Waste Programs Enforcement.

Environmental Protection Agency. 1986c. Test Methods for Evaluating Solid Waste, Volumes 1A, $1 \mathrm{~B}$, and 1C, Third edition. SW-846. Washington, DC.

Environmental Protection Agency. 1990. National Primary and Secondary Drinking Water Regulations; Synthetic Organic Chemicals and Inorganic Chemicals; Proposed Rule. Federal Register, July 25, 1990, pp. 30369-30448. Washington, DC. 
Environmental Protection Agency. 1991a. National Primary Drinking Water Regulations. Code of Federal Regulations, Title 40, Part 141, pp. 578-715. Washington, DC.

Environmental Protection Agency. 1991b. National Secondary Drinking Water Regulations. Code of Federal Regulations, Title 40, Part 143, pp. 758-762. Washington, DC.

Environmental Protection Agency. 1991c. National Primary Drinking Water Regulations; Radionuclides; Proposed Rule. Federal Register, July 18, 1991, pp. 33052-33127. Washington, DC.

Environmental Protection Department and Fxploration Resources. 1991. Environmental Protection Department's Well Inventory (Includes Current and Past Monitoring [through the fourth quarter of 1991]), ESH-EMS-910092. Aiken, SC: Westinghouse Savannah River Company, Savannah River Site.

Heath, E. M., L. B. Taus, C. M. Olson, and Exploration Software. 1986. The Savannah River Plant's Waste-Site Groundu'xter Monitoring Program Conducted by the Health Protection Department for the Third Quarter 1986, HPR-87-002. Aiken, SC: E. I. du Pont de Nemours \& Company, Savannah River Plant.

Heath, E. M., L. B. Taus, C. M. Olson, and Exploration Software. 1987. The Savannah River Plant's Groundwater Monitoring Program Conducted by the Health Protection Department for the Fourth Quarter 1986, HPR-87-072. Aiken, SC: E. I. du Pont de Nemours \& Company, Savannah River Plant.

Heath, E. M., L. B. Taus, C. M. Olson, and Exploration Software. 1987. The Savannah River Plant's Groundwater Monitoring Program Conducted by the Health Protection Department for the First Quarter 1987, HPR-87-158. Aiken, SC: E. I. du Pont de Nemours \& Company, Savannah River Plant.

Los Alamos National Laboratory. 1983. Manual of Methods for Radiobioassay, LA-9763-M. Los Alamos, NM.

Olson, C. M., and Exploration Software. 1986. The Savannah River Plant's Waste-Site Groundwater Monitoring Program Conducted by the Health Protection Department for the First Quarter 1986, HPR-86-158 (Revised). Aiken, SC: $\Gamma$ I. du Pont de Nemours \& Company, Savannah River Plant.

Olson, C. M., and Exploration Software. 1986. The Savannah River Flant's Waste-Site Groundwater Monitoring Program Conducted by the Health Protection Department for the Second Quarter 1986, HPR-86-226. Aiken, SC: E. I. du Pont de Nemours \& Company, Savannah River Plant.

Stone, J. A., and E. J. Christensen, eds. 1983. Technical Summary of Groundwater Quality Protection Program at Savannah River Plant, Volume II-Radioactive Waste, DPST-83-829. Aiken, SC: E. I. du Pont de Nemours \& Company, Savannah River Laboratory.

U.S. Department of Energy. 1988. Geohydrology Program Report. Aiken, SC: Environmental Division, U.S. Department of Energy, Savannah River Operations Office.

U.S. Department of Energy. 1989. Geoscience Implementation Plan. Aiken, SC: Environmental Division, U.S. Department of Energy, Savannah River Operations Office.

U.S. Department of Energy. 1986. Savannah River Plant Environmental Report for 1985, Volumes I and II, DPSPU-86-30-1. Aiken, SC.

U.S. Department of Energy. 1987. Savannah River Plant Environmental Report for 1986, Volumes I and II, DPSPU-87-30-1. Aiken, SC.

U.S. Department of Energy. 1988. Savannah River Plant Environmental Report for 1987, Volumes I and II, DPSPU-88-30-1. Aiken, SC.

U.S. Department of Energy. 1989. Savannah River Site Environmental Report for 1988, Volumes I and II, WSRC-RP-89-59-1. Aiken, SC.

U.S. Department of Energy. 1990. Savannah River Site Environmental Report for 1989, Volumes I and II, WSRC-IM-90-60. Aiken, SC.

U.S. Department of Energy. 1991. Savannah River Site Environinental Report for 1990, Volumes I and II, WSKL-IM-9i-28. Aiken, SC. 


\section{REFERENCES}

Westinghouse Savannah River Company. 1989.

Hydrogeologic Data Collection Procedures and

Specifications, DPSOP 254, Revision 1, October

1, 1989. Aiken, SC. 


\section{Appendix A. ANALYTICAL RESULTS}

This section presents the field and analytical results for samples collected during fourth quarter 1991. The tables are presented in alphabetical order by well series and in numerical order within each series. The Site Index by Well Series section contains the area name(s) for each series. The tabular data contain all the field and analytical results for well samples col- lected during this quarter. Results of laboratory analyses on blanks are in the Quality Control Samples section of this report. Further information on unusual conditions of sample collection, as well as samplers' observations on the samples, may be found in the Field Notes section of this report.

Key to the tables:

$\mathrm{E}=$ exponential notation (e.g., $1.1 \mathrm{E}-09=1.1 \times 10^{-9}=0.0000000011$ )

$\mathrm{EM}=\mathrm{EPD} / \mathrm{EMS}$ Laboratory

$\mathrm{F}=$ Flag

$\mathrm{GE}=$ General Engineering Laboratories

$1,2,3,4,6,7,8$-HPCDD $=1,2,3,4,6,7,8$-Heptachlorodibenzo-p-dioxin

$1,2,3,4,6,7,8$-HPCDF $=1,2,3,4,6,7,8$-Heptachlorodibenzo-p-furan

$1,2,3,4,7,8$-HXCDD $=1,2,3,4,7,8$-Hexachlorodibenzo-p-dioxin

$1,2,3,4,7,8$-HXCDF $=1,2,3,4,7,8$-Hexachlorodibenzo-p-furan

Lindane = gamma-Benzene hexachloride

$\mathrm{MA}=\mathrm{M}$-Area Laboratory

$\mathrm{mg} / \mathrm{L}=$ milligrams per liter

Mod = analytical modifier; see p. A-2 for explanation

$\mathrm{msl}=$ mean sea level

NTU $=$ nephelometric turbidity units

1,2,3,7,8-PCDD $=1,2,3,7,8$-Pentachlorodibenzo-p-dioxin

$1,2,3,7,8-\mathrm{PCDF}=1,2,3,7,8$-Pentachlorodibenzo-p-furan

$2,4,5-\mathrm{T}=2,4,5$-Trichlorophenoxyacetic acid

$2,3,7,8$-TCDD $=2,3,7,8$-Tetrachlorodibenzo-p-dioxin

2,3,7,8-TCDF $=2,3,7,8$-Tetrachlorodibenzo-p-furan

$\mathrm{TE}=$ Teledyne Isotopes

$\mathrm{TOC}=$ top of casing

$\mu \mathrm{Ci} / \mathrm{mL}=$ microcuries per milliliter

$\mu \mathrm{g} / \mathrm{L}=$ micrograms per liter

$\mu \mathrm{S} / \mathrm{cm}=$ microsiemens per centimeter 
Interpreting data with analytical modifiers (result qualifiers):

Result
(Blank)
$\mathrm{J}^{*}$
$\mathrm{~L}^{*}$
$\mathrm{M}^{*}$
$\mathrm{Q}^{*}$
$\mathrm{R}^{*}$
$\mathrm{~T}^{*}$
$\mathrm{~V}^{*}$
1
2

Definition

Data not qualified. Number should be interpreted exactly as reported.

Estimated because quantitation in the sample or in associated quality control samples did not meet specifications.

Off-scale high. The actual value is not known, but is known to be greater than the value shown.

Presence of material verified, but not quantified. Use of this code implies that the analytical-result field is blank.

Sample held beyond normal holding time. If the holding time is exceeded by less than 30 days, the sample is coded QJ; if the holding time is exceeded by 30 days or more, the sample is coded QR.

Rejected because performance requirements in the sample analysis or associated quality control analyses were not met.

Undetected; if present, below the criteria of detection. Use of this code implies that the analytical-result field is blank.

Indicates the analyte was detected in the associated method blank.

The associated result may be an underestimation of the true value die to analytical bias.

The associated result may be an overestimation of the true value due to analytical bias.

*TY: 288 codes are based on the STORET codes from the U.S. Environmental Protection Agency. 
ANALYTICAL RESULTS

WELL ABP TA

MEASUREMENTS CONDUCTED IN THE FIELD

Depth to water: $140.36 \mathrm{ft}(42.78 \mathrm{~m})$ below TOC

Water elevation: $219.54 \mathrm{ft}$ (

Water evacuated before sampling: $122 \mathrm{gal}$

LABORATORY ANALYSES

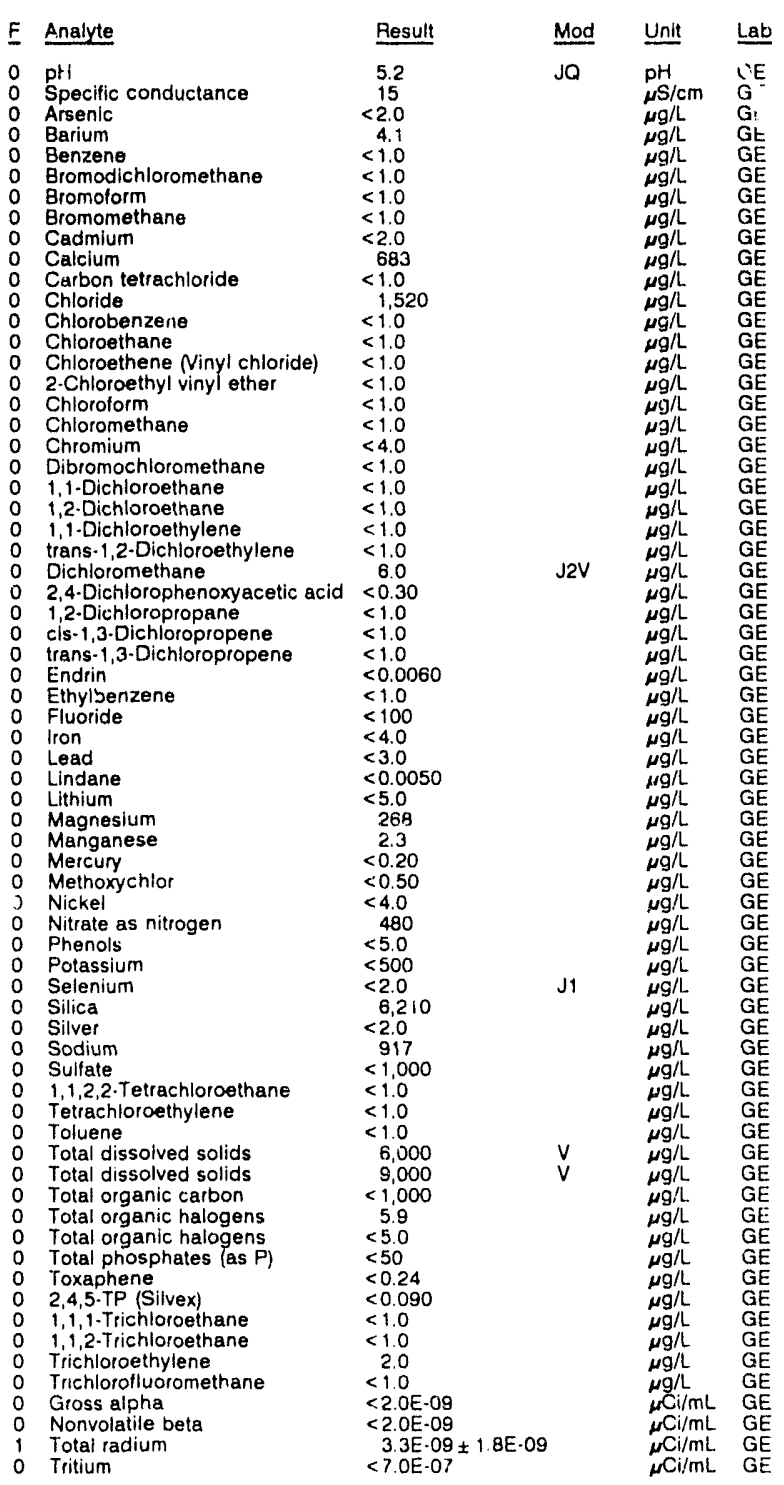

WELL ABP $2 A$

MEASUREMENTS CONDUCTED IN THE FIELD

Sample date: 11/01/91

Depth to water: $154.62 \mathrm{ft}(47.13 \mathrm{~m})$ below TOC Water elevation: $217.28 \mathrm{ft}(66.23 \mathrm{~m}) \mathrm{msl}$

Sp. conductance: $16 \mu \mathrm{\mu} / \mathrm{cm}$
Water evacuated before sampling: $95 \mathrm{gal}$

Tirne: $8: 35$

Alkalinity: $0 \mathrm{mg} / \mathrm{h}$

Water temperature: $179^{\circ} \mathrm{C}$

LABORATORY ANALYSES

\begin{tabular}{|c|c|c|c|}
\hline Analyte & Result & Mod & Unit \\
\hline $\begin{array}{ll}0 & \mathrm{pH} \\
0 & \text { Specific conductance } \\
0 & \text { Arsenic }\end{array}$ & $\begin{array}{r}5.3 \\
15 \\
<2.0\end{array}$ & JQ & $\begin{array}{l}\mathrm{pHi} \\
\mu \mathrm{S} / \mathrm{cm} \\
\mu \mathrm{g} / \mathrm{L}\end{array}$ \\
\hline
\end{tabular}

WELL ABP $2 A$ collected on $11 / 01 / 91$, laboratorv analyses (cont.)

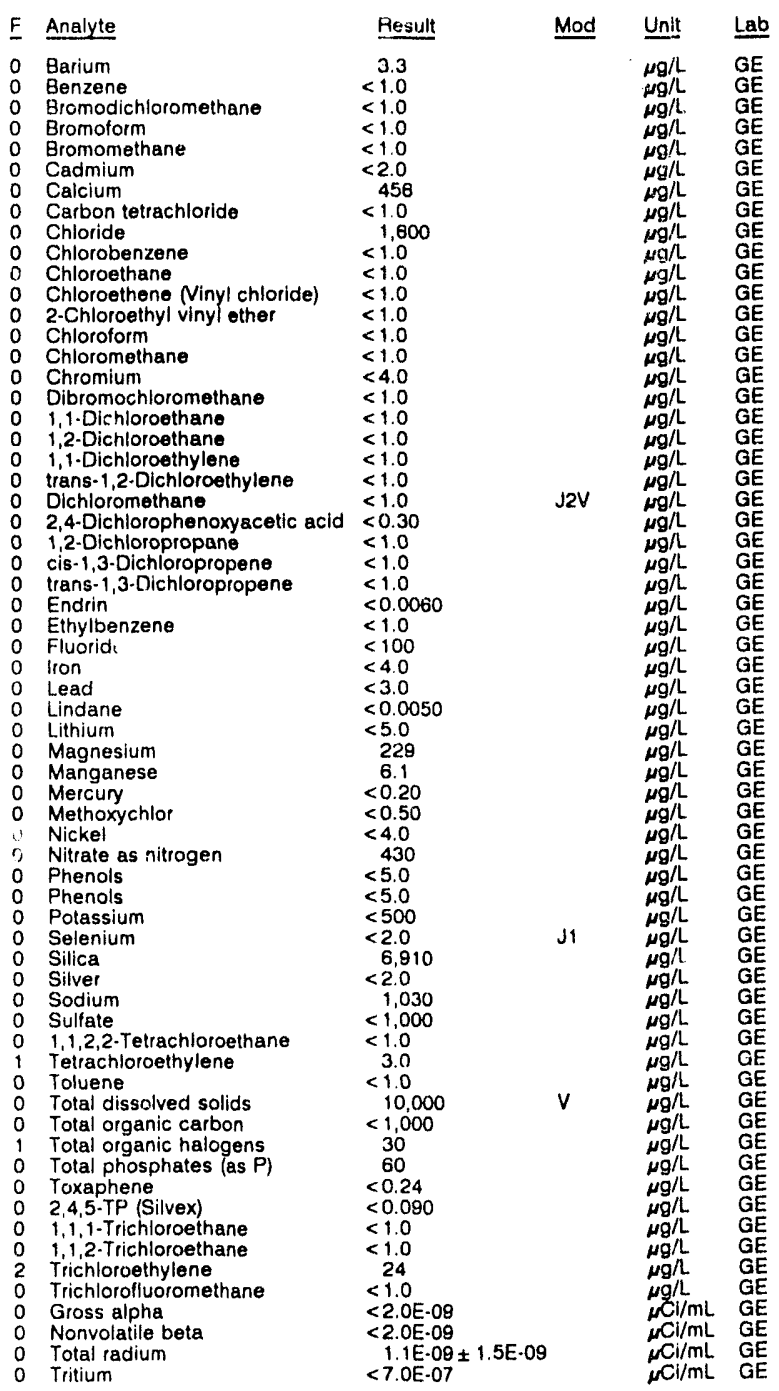

WELL ABP 3

MEASUREMENTS CONDUCTED IN THE FIELD

Sample date: 11/01/81

Depth to water: $134.18 \mathrm{ft}(40.90 \mathrm{~m})$ below TOC

Water elevation: $219.52 \mathrm{H}(66.91 \mathrm{~m}) \mathrm{msl}$

Sp. conductance: $18 \mu \mathrm{S} / \mathrm{cm}$

Water evacuated before sampling: $33 \mathrm{gal}$

LABORATORY ANALYSES

$\begin{array}{ll}\text { F } & \text { Analyte } \\ 0 & \text { pH } \\ 0 & \text { Specific conductance } \\ 0 & \text { Arsenic } \\ 0 & \text { Barium } \\ 0 & \text { Benzene } \\ 0 & \text { Bromodichloromethane } \\ 0 & \text { Bromoform } \\ 0 & \text { Bromomethane } \\ 0 & \text { Cadmium } \\ 0 & \text { Calcium } \\ 0 & \text { Carbon tetrachloride } \\ 0 & \text { Chloride } \\ 0 & \text { Chlorobenzene } \\ 0 & \text { Chloroethane } \\ 0 & \text { Chloroethene (Vinyl chlorlde) } \\ 0 & 2 \text {-Chloroethyl vinyl ether } \\ 0 & \text { Chloroform } \\ 0 & \text { Chloromethane } \\ 0 & \text { Chromium }\end{array}$

\begin{aligned} \multicolumn{1}{r}{ Result } \\ \hline 5.2 \\ 17 \\ $<2.0 \\ 4.9 \\ <1.0 \\ <1.0 \\ <1.0 \\ <1.0 \\ <2.0 \\ 475 \\ <10 \\ 1.490 \\ <1.0 \\ <1.0 \\ <1.0 \\ <1.0 \\ <1.0 \\ <1.0 \\ <4.0\end{aligned}$
Time: 10:15

Alkalinity: $3 \mathrm{mg}$

Water temperature: $18.0^{\circ} \mathrm{C}$

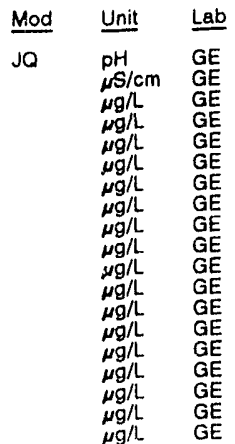

Time: 9:35

PH: 5.0

Alkalinity: $0 \mathrm{mg} / \mathrm{L}$

Chromium 
ANALYTICAL RESULTS

WELLABP 3 collectod on 11/01/91, laboratory analyses (cont.)

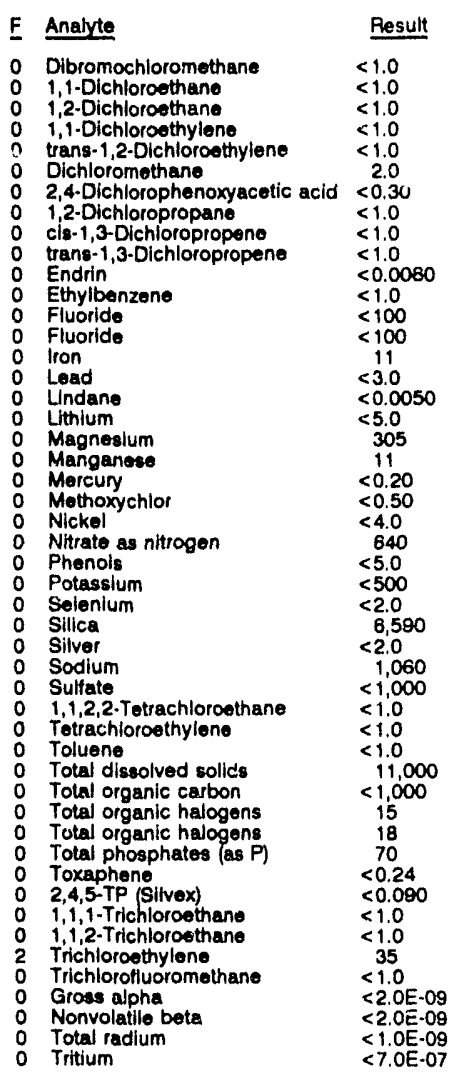

WELL ABP $3 C$

MEASUAEMENTS CONDUCTED IN THE FIEID

Sample date: $11 / 01 / 91$ Depth to water: $159.68 \mathrm{H}(48.68 \mathrm{~m})$ below TOC
Water olevation: $194.84 \mathrm{ft}(58.39 \mathrm{~m}) \mathrm{msl}$
Sp conductance: $73 \mu \mathrm{s} / \mathrm{cm}$

Sp. conductance: $73 \mu \mathrm{s} / \mathrm{cm}$
Water evacuated before sampling: $81 \mathrm{gal}$

LABORATORY ANALYSES

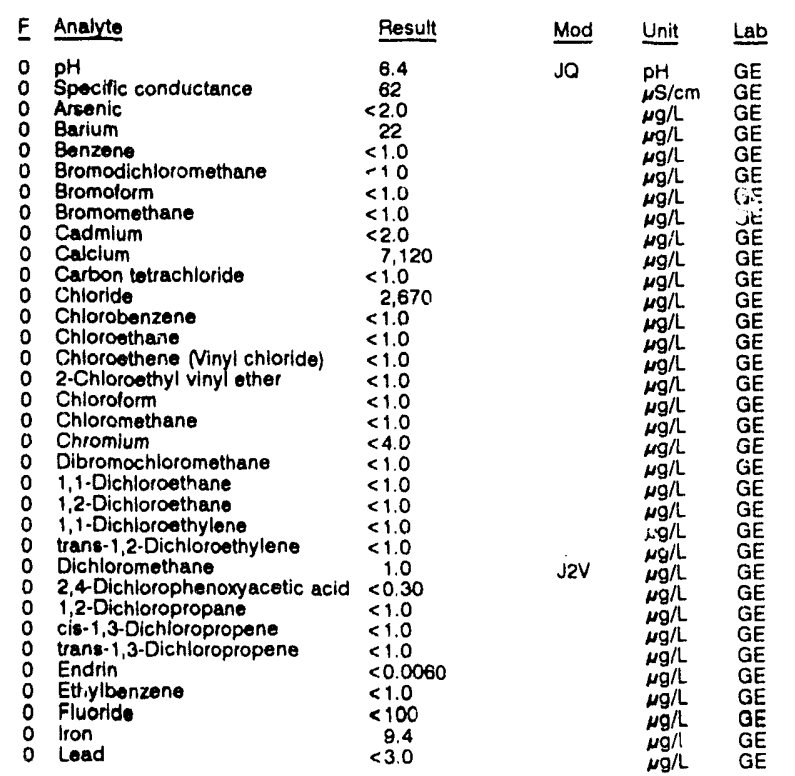

WELL ABP 3C collected on 11/01/91, laboratory analyses (cont.)
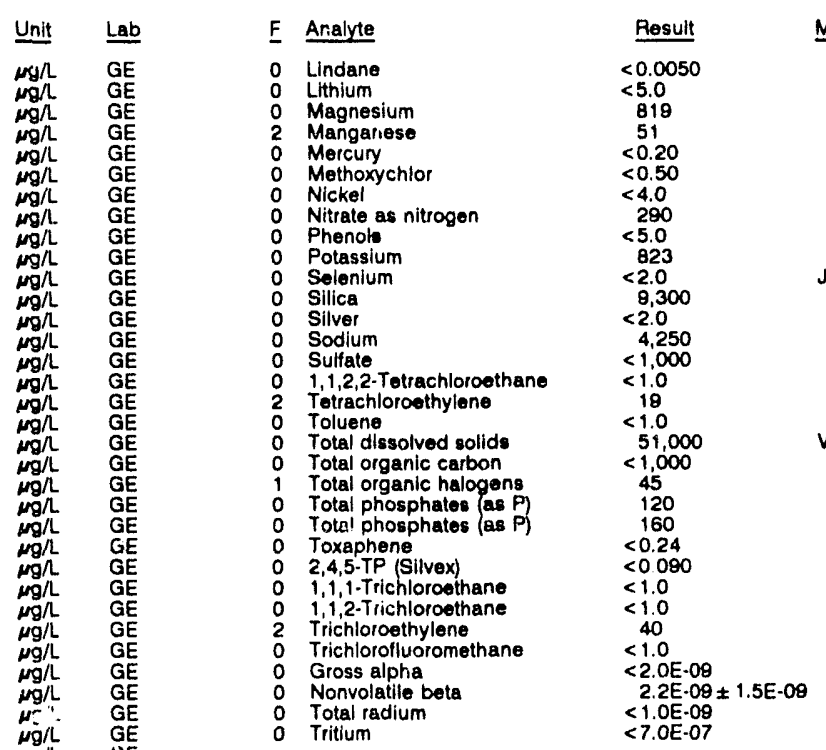

Mod Unit Lab

$<0.0050$

81

$<0.20$

$<4.0$

$<5.0$

$<2.0$
9,300
$<2.0$

4,250
$<1,000$

$<1.0$

$<1.0$

$<1,000$

120
160
1624

$<0.090$

$<1.0$

$<1.0$

2. $2 \mathrm{E} \cdot 09 \pm 1.5 \mathrm{E}-09$

$<7.0 \mathrm{E}-07$

\section{WELL ABP 4}

MEASUREMENTS CONDUCTED IN THE FIELD

Sample date: 11/01/91

Depth to water: $147.92 \mathrm{Ht}(45.09 \mathrm{~m})$ below TOC Water elevation: $216.38 \mathrm{ft}$ (

Water evacuated before sampling: $89 \mathrm{gal}$

pH: 5.0

LABORATORY ANALYSES

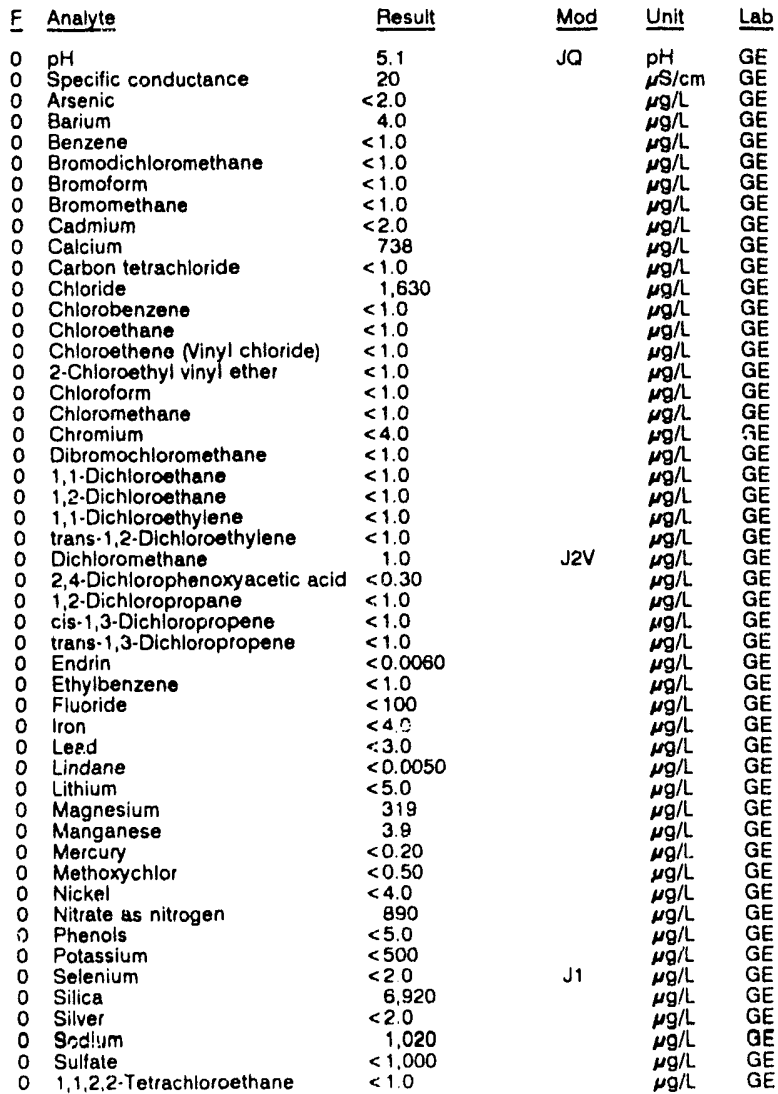


ANALYTICAL RESULTS

WELL ABP 4 collectod on $11 / 01 / 8$, laboratory analyses (cont.)

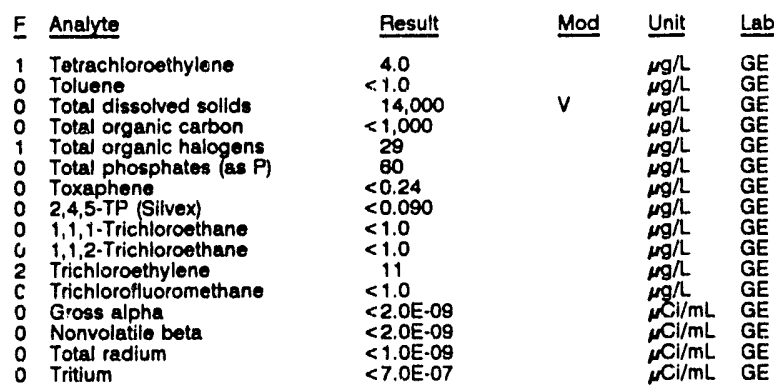

WELL ABP 8C

MEASUREMENTS CONDUCTED IN : E FIEL.O

Sample date: $11 / 15 / 91$

Depth to water: $177.38 \mathrm{H}(54.07 \mathrm{~m})$ below TOC

Water olevation: 194.7 ? $\mathrm{ft}(58.35 \mathrm{~m}) \mathrm{ms}$

Sp. conductance: $2374 \mu \mathrm{s} / \mathrm{cm}$

Water evacuated before sampling: 3 ga

LABORATORY ANALYSES

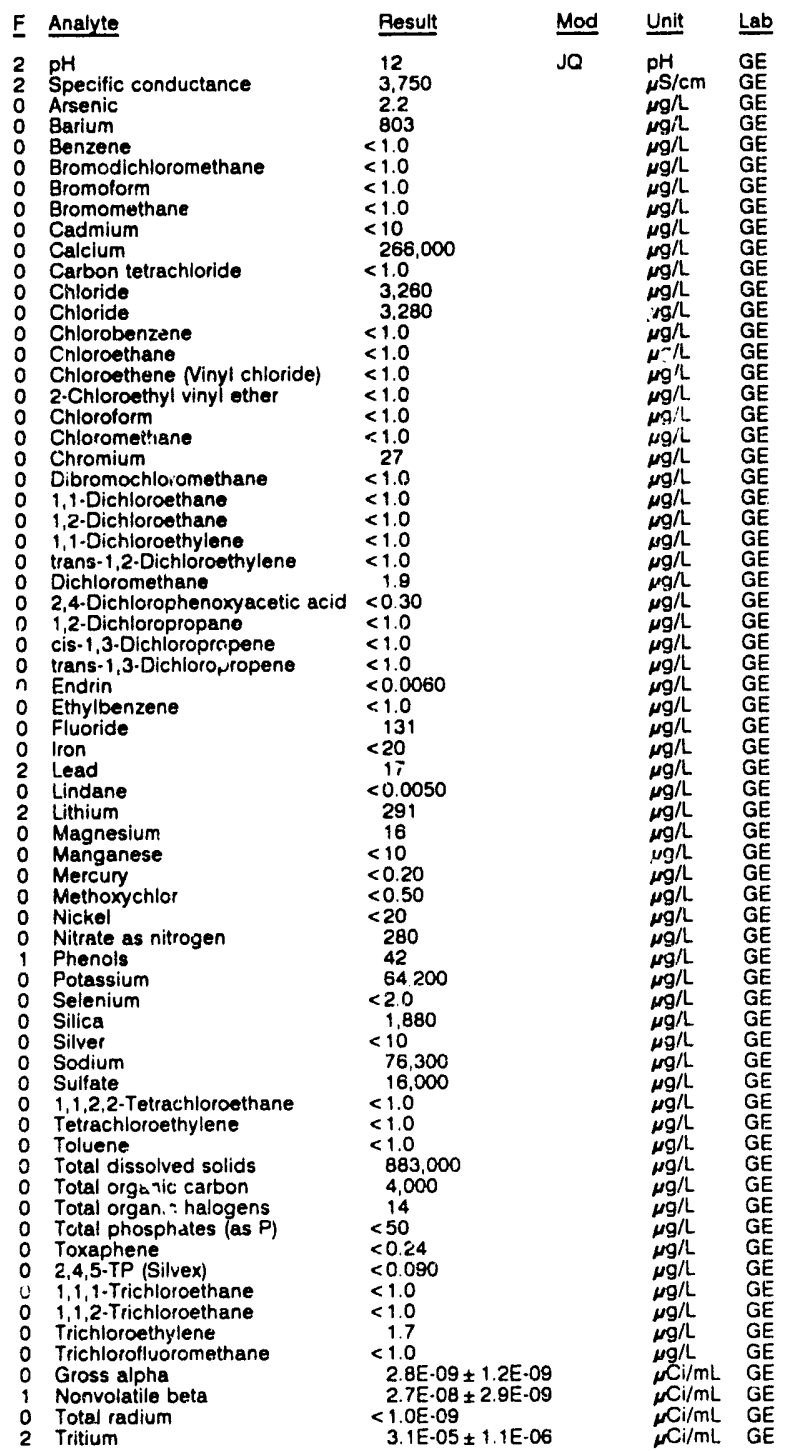

WELL ABP 8D

MEASUREMENTS CONDUCTED IN THE FIELD

Sample date: 11/15/91 4 Time: 7:10

Wath olevation: $217.54 \mathrm{ft}$

The well pumped dry before all field parameters were collected.

WELL ABW 1

MEASUREMENTS CONDUCTED IN THE FIELD

Sample date: 10/28/91

Depth to water: $10084 \mathrm{Ht}(30.74 \mathrm{~m})$ below TOC

Weter elevation: $223.96 \mathrm{f}(68.26 \mathrm{~m}) \mathrm{msl}$

Water evacuated before sampling: $102 \mathrm{gal}$

$\mathrm{pH}: 4.8$

Alkalinity: $0 \mathrm{mg} / \mathrm{L}$

LABORATORY ANALYSES

\begin{tabular}{|c|c|c|c|}
\hline Analyte & Result & Mod & Unit \\
\hline $\begin{array}{l}\text { Chloroform } \\
\text { 1,1-Dichloroethylene } \\
\text { trans-1,2-Oichloroethylene } \\
\text { Tetrachloroethylene } \\
\text { 1,1,1-Trichloroethane } \\
\text { Trichloroethylene }\end{array}$ & $\begin{aligned}<1.0 \\
<1.0 \\
<1.0 \\
1.4 \\
<1.0 \\
1.3\end{aligned}$ & & $\begin{array}{l}\mu g / L \\
\mu g / L \\
\mu g / L \\
\mu g / L \\
\mu g / L \\
\mu g / L\end{array}$ \\
\hline
\end{tabular}

WELL AC IA

MEASUREMENTS CONDUCTED IN THE FIELD

$\begin{array}{ll}\text { Sample date: } 11 / 11 / 91 & \text { Time: } 14: 35 \\ \text { Depth to water: } 48.34 \mathrm{H}(14.73 \mathrm{~m}) \text { below TOC } & \text { pH: } 5.5 \\ \text { Water elevation: } 213.76 \mathrm{H}(65.15 \mathrm{~m}) \mathrm{ms} & \text { Alkalinity: } 2 \mathrm{mg} / \mathrm{L} \\ \text { Sp. conductance: } 21 \mu \mathrm{cm} / \mathrm{cm} & \text { Water temperature: } 17.9^{\circ} \mathrm{C} \\ \text { Water evacuated betore sampling: } 192 \mathrm{gal} & \end{array}$

LABORATORY ANALYSES

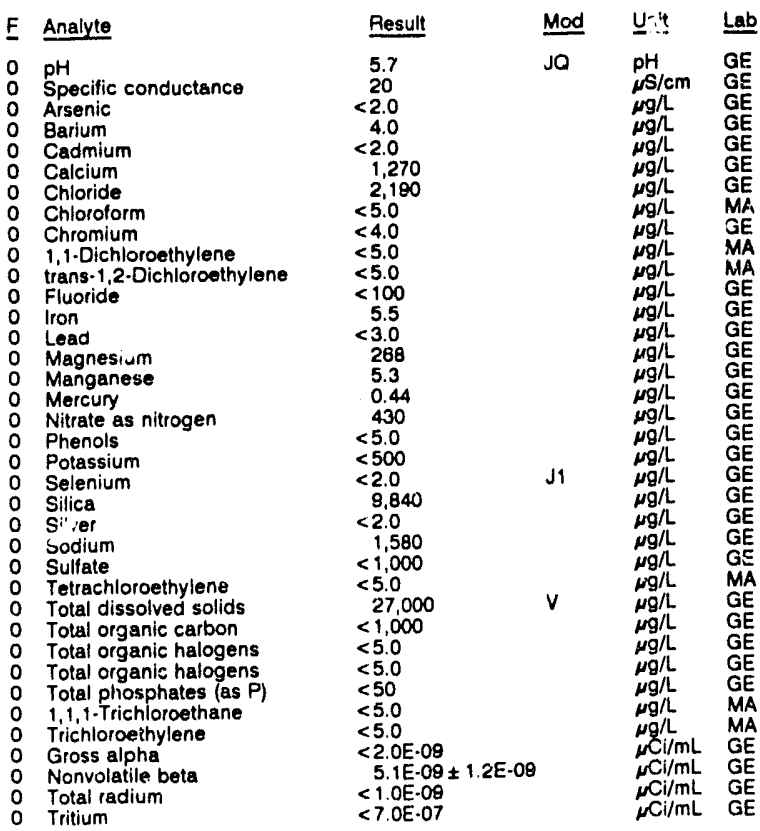




\section{ANALYTICAL RESULTS}

\section{WELL AC 1B}

MEASUREMENTS CONDUCTED IN THE FIELD

Sample date: $11 / 11 / 91$
Depth to water: $48.23 \mathrm{H}(14.70 \mathrm{~m})$ below TOC
Water elevation: $213.77 \mathrm{~h}((75.16 \mathrm{~m}) \mathrm{msl}$
Sp. conductance: $28 \mu \mathrm{sS} / \mathrm{cm}$
Water evacuated before sampling: $44 \mathrm{gal}$
LABORATORY ANALYSES

$\operatorname{Tim}_{p H: 5: 8}: 14: 15$

Alkalinity: $3 \mathrm{mg} / \mathrm{h}$

Water temiserature: $17.7^{\circ} \mathrm{C}$

LABORATORY ANALYSES

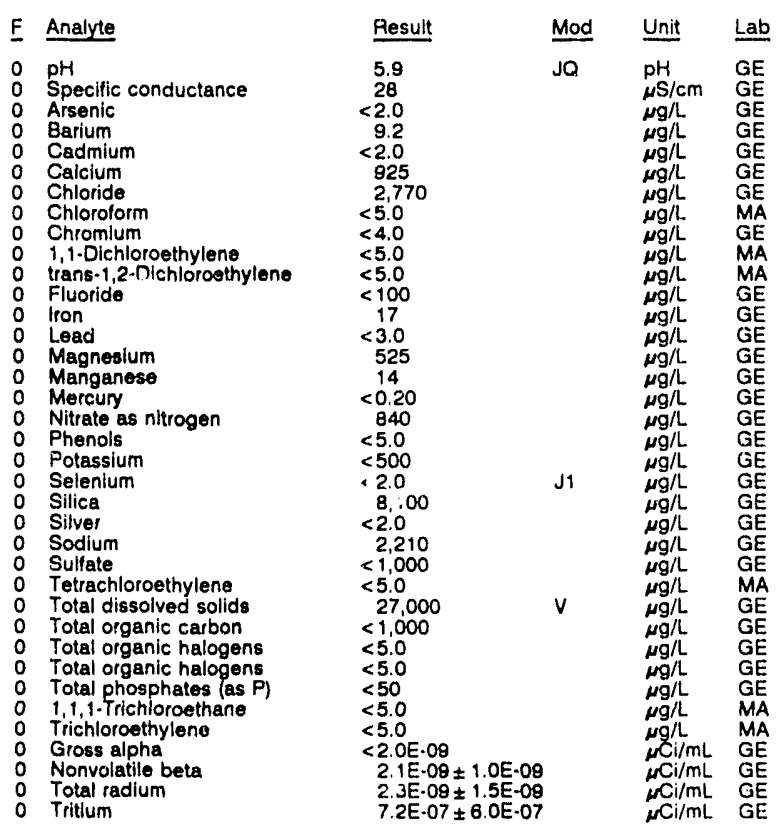

WELL AC $2 A$

MEASUREMENTS CONDUCTED IN THE FIELD

Sample date: $11 / 11 / 81$ f $(37.75 \mathrm{~m})$ below TOC Water elevation: $220.84 \mathrm{ft}(67.31 \mathrm{~m}) \mathrm{ms}$ !

Sp. conductance: $27 \mu \mathrm{s} / \mathrm{cm}$

Water evacuated belore sampling: $317 \mathrm{gal}$

LABORATORY ANALYSES

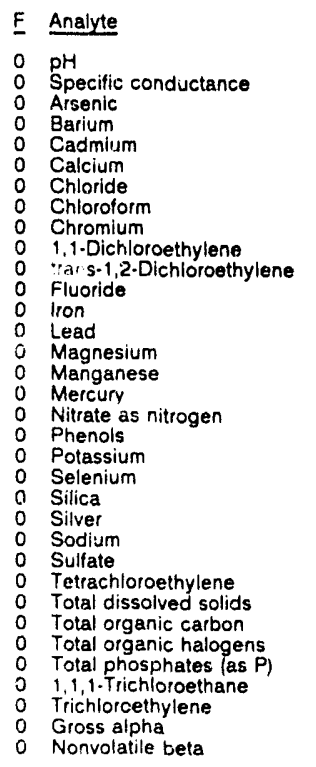

\begin{tabular}{l} 
Result \\
\hline 6.2 \\
29 \\
$<2.0$ \\
5.6 \\
$<2.0$ \\
3,090 \\
1.510 \\
$<5.0$ \\
$<4.0$ \\
$<5.0$ \\
$<5.0$ \\
$<100$ \\
$<4.0$ \\
$<3.0$ \\
335 \\
$<2.0$ \\
$<0.20$ \\
750 \\
$<5.0$ \\
$<500$ \\
$<2.0$ \\
7.640 \\
$<2.0$ \\
1.340 \\
$<1.000$ \\
$<550$ \\
21.000 \\
$<1.000$ \\
$<5.0$ \\
$<50$ \\
$<5.0$ \\
$<5.0$ \\
$<2.0 E .09$ \\
$<2.05 .09$
\end{tabular}

Time: $13: 40$

pH: 5.9

Alkalinity: $6 \mathrm{mg} / \mathrm{L}$

Water temperature: $18.1^{\circ} \mathrm{C}$

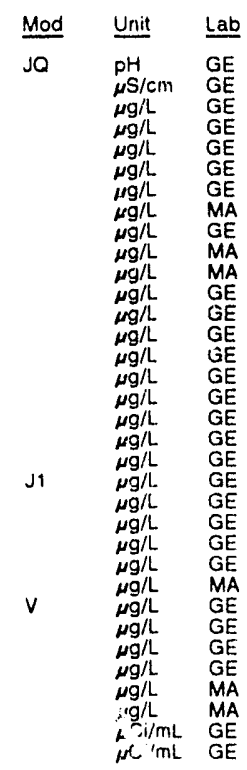

WELL AC $2 A$ collected on 11/11/91, laboratory analyses (cont.)

$\begin{array}{lllll}\text { Ennalyte } & \text { Result } & \text { Mad } & \text { Unit } & \text { Lab } \\ 0 & \text { Total radium } & <1.0 \mathrm{E} \cdot 09 & <\mathrm{Cl} / \mathrm{mL} & \mathrm{GE} \\ 0 & \text { Tritium } & & \mathrm{wC \textrm {Cl } / \mathrm { mL }} & \mathrm{GE}\end{array}$

WELL AC $2 B$

MEASUREMENTS CONDUCTED IN THE FIELD

Sample date: $11 / 11 / 91$

Depth to water: $117.23 \mathrm{ft}(35.73 \mathrm{~m})$ below TOC

Water elevation: $227.57 \mathrm{At}(68.36 \mathrm{~m}) \mathrm{msl}$

Water evacuated before sampling: $29 \mathrm{gal}$

Time: 13:25

pH: 5.4 . 20

Alkalinity: $2 \mathrm{mg} / \mathrm{L}$

LABORATORY ANALYSES

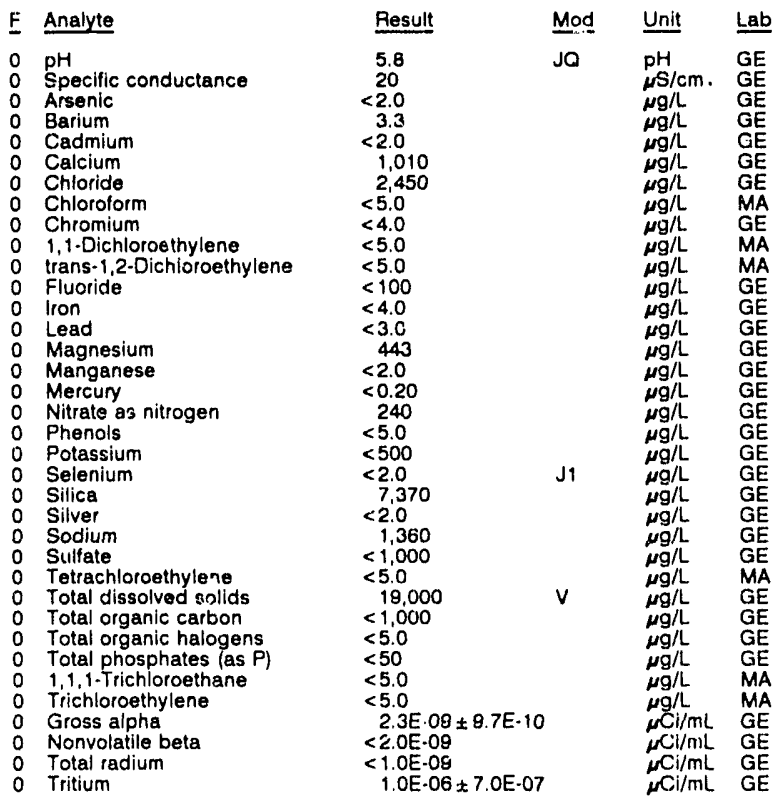

WELL AC $3 A$

MEASUREMENTS CONDUCTED IN THE FIELD

Sample date: $11 / 11 / 91$

Depth to water: $\theta 3.61 \mathrm{ft}(28.53 \mathrm{~m})$ below TOC

Water elevation: $208.69 \mathrm{ft}(63.81 \mathrm{~m}) \mathrm{msl}$

Water evacuated before sampling: $158 \mathrm{gal}$

PH: 6.

Alkalinity: $14 \mathrm{mg} / \mathrm{L}$

LABORATORY ANALYSES

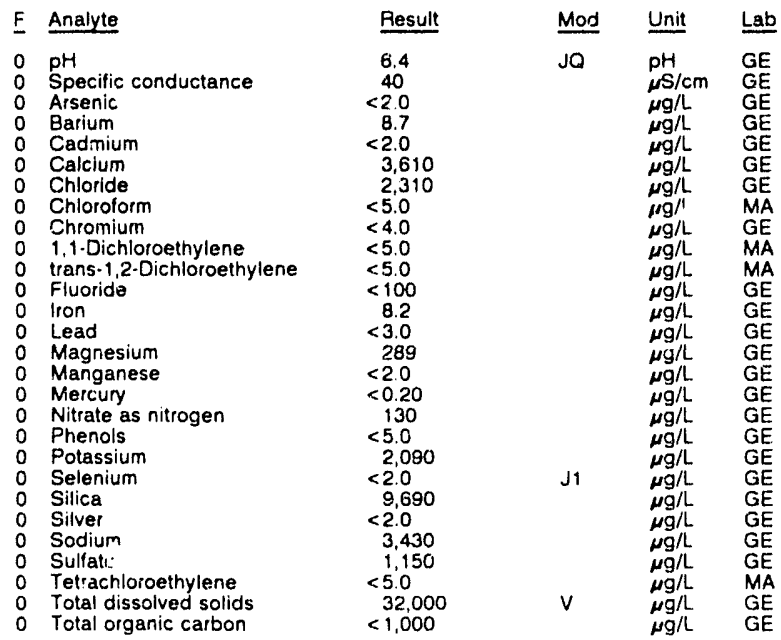


ANALYTICAL RESULTS

WELL AC $3 A$ collectod on 11/11/91, laboratory analyses (cont.)

\begin{tabular}{|c|c|c|c|}
\hline Analyte & Result & Mod & Unit \\
\hline $\begin{array}{ll}0 & \text { Total organic halogens } \\
0 & \text { Total phosphates (as P) } \\
0 & 1,1, \text { - Trichloroethane } \\
0 & \text { Trichlorothylene } \\
0 & \text { Gross alpha } \\
0 & \text { Nonvolatile beta } \\
0 & \text { Total radium } \\
0 & \text { Tritium }\end{array}$ & $\begin{aligned} & 9.1 \\
&< 50 \\
&<5.0 \\
&<5.0 \\
&<2.0 \mathrm{E}-09 \\
& 3.4 \mathrm{E}-09 \pm 1.1 \mathrm{E}-09 \\
&<1.0 \mathrm{E}-09<7.0 \mathrm{E}-r^{\prime}\end{aligned}$ & & 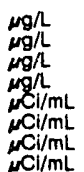 \\
\hline
\end{tabular}

WELL AC 3B

MEASUREMENTS CONDUCTED IN THE FIELD

Sample date: $11 / 11 / 91$
Depth to water: $92.10 \mathrm{Ht}(28.07 \mathrm{~m})$ below TOC
Water bievation: $210.40 \mathrm{ft}(64.13 \mathrm{~m}) \mathrm{ms}$ l
Sp conductance: 77

Sp. conductance: $77 \mu \mathrm{s} / \mathrm{cm}$
Water evacuated belore sampling: $353 \mathrm{gal}$

LABORATORY ANALYSTS

\section{E Analyte}

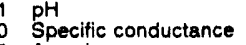

0 Arsenic

Barium

Calcium

Chloride

Chloroform

1,1-Dichloroethylene

trans-1,2-Dichloroethylene

Fluoride

0 iron

0 Magnesium

0 Manganese

0 Nitrate as nitrogen

0 Phenols

- Pocassium

Selenium

Silica

0 Sodium

Sulfate

Tetrachloroethylene

Total dissolved solids

Total organic halogens

Total phosphates (as P)

$1,1,1$.Trichioroethane

Trichloroethylen

Nonvolatile beta

Total radium

Tritium

\begin{tabular}{l} 
Result \\
\hline 9.3 \\
70 \\
2.6 \\
5.5 \\
$<2.0$ \\
12,500 \\
2,420 \\
$<5.0$ \\
$<4.0$ \\
$<5.0$ \\
$<5.0$ \\
$<100$ \\
$<4.0$ \\
$<3.0$ \\
320 \\
$<2.0$ \\
$<0.20$ \\
510 \\
$<5.0$ \\
$<500$ \\
$<2.0$ \\
11,800 \\
$<2.0$ \\
1,900 \\
$<1,000$ \\
$<5.0$ \\
50,000 \\
$<1,000$ \\
$<5.0$ \\
220 \\
$<5.0$ \\
$<5.0$ \\
$<2.0 \mathrm{E}-09$ \\
$<2.0 \mathrm{E}-09$ \\
$<1.0 \mathrm{E}-09$ \\
$<7.0 \mathrm{E}-07$ \\
\end{tabular}

Time: $15: 50$

Alkallnity: $26 \mathrm{mg} / \mathrm{h}$

Water temperature: $18.4^{\circ} \mathrm{C}$

\section{WELL ACB $1 \mathrm{~A}$}

MEASUREMENTS CONDUCTED IN THE FIELO

Sample date: 11/01/91

Depth to water: 121.54 it $(37.05 \mathrm{~m})$ below TOC

Water elevation: $238.06 \mathrm{tt}(72.56 \mathrm{~m}) \mathrm{ms}$

Sp. conductance: $71 \mu \mathrm{s} / \mathrm{cm}$

Water evacuated before sampling: $54 \mathrm{gal}$

LABORATORY ANALYSES

\begin{tabular}{|c|c|c|c|c|}
\hline F & Analyte & Result & Mod & Unit \\
\hline $\begin{array}{l}0 \\
0 \\
0 \\
0 \\
0 \\
0 \\
0 \\
0 \\
0 \\
0 \\
0\end{array}$ & $\begin{array}{l}\text { Chloroform } \\
\text { Chloroform } \\
1,1 \cdot \text { Dichloroethylene } \\
1,1 \cdot \text { Dichloroethylene } \\
\text { trans } 1,2 \cdot \text { Dichloroethylene } \\
\text { trans } 1,2 \text {. Dichloroethylene } \\
\text { Tetrachloroethylene } \\
\text { Tetrachloroethylene } \\
1,1,1-\text { Trichloroethane } \\
1,1,1-\text { Trichloroethane } \\
\text { Trichloroethylene } \\
\text { Trichloroethylene }\end{array}$ & $\begin{array}{l}<5.0 \\
<5.0 \\
<5.0 \\
<5.0 \\
<5.0 \\
<5.0 \\
<5.0 \\
<5.0 \\
<5.0 \\
<50 \\
<5.0 \\
<5.0\end{array}$ & & $\begin{array}{l}\mu g / L \\
\mu g / L \\
\mu g / L \\
\mu g / L \\
\mu g / L \\
\mu g / L \\
\mu g / L \\
\mu g / L \\
\mu g / L \\
\mu g / L \\
\mu g / L \\
\mu g / L\end{array}$ \\
\hline
\end{tabular}

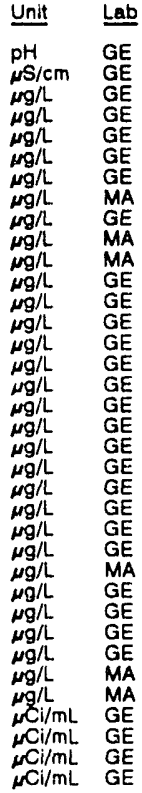

Tíme: $12: 00$

Alkalinity: $15 \mathrm{mg} / \mathrm{L}$

Water temperature. $18.6^{\circ} \mathrm{C}$
WELL ACB 2A

MEASUREMENTS CONDUCTED IN THE FIELD

Sample date: 11/01/81

Depth to water: 110.26 ft $(33.61 \mathrm{~m})$ below TOC

Water elevation: $238.54 \mathrm{ft}(73.01 \mathrm{~m}) \mathrm{ms}$ !

Water ovacuated before sampling: 83 gal

LABORATORY ANALYSES

\begin{tabular}{|c|c|c|c|c|}
\hline$\underline{F}$ & Analyte & Fiesult & Mod & Unit \\
\hline $\begin{array}{l}0 \\
0 \\
0 \\
0 \\
0 \\
0\end{array}$ & $\begin{array}{l}\text { Chloroform } \\
\text { 1,1-Dichloroethylens } \\
\text { truns-1,2-Dichloroethylene } \\
\text { Totrachloroothylene } \\
1,1,1-\text { Trichloroethane } \\
\text { Trichloroethylene }\end{array}$ & $\begin{array}{l}<1.0 \\
<1.0 \\
<1.0 \\
<1.0 \\
<1.0 \\
<1.0\end{array}$ & & $\begin{array}{c}\mu g / L \\
\mu g / L \\
\mu g / L \\
\mu g / L \\
\mu g / L \\
\mu g / L\end{array}$ \\
\hline
\end{tabular}

WELL ACB $3 A$

MEASUREMENTS CONDUCTED IN THE FIELD

Sample date: 11/01/91

Depth to water: $108.89 \mathrm{ft}(33.18 \mathrm{~m})$ below TOC

Water elevation: $238.41 \mathrm{ft}(72.87 \mathrm{~m}) \mathrm{msl}$

Water evacuated belore sampling: $87 \mathrm{gal}$

LABORATORY ANALYSES

\begin{tabular}{|c|c|c|c|c|}
\hline$E$ & Analyte & Result & Mod & Unit \\
\hline $\begin{array}{l}0 \\
0 \\
0\end{array}$ & $\begin{array}{l}\text { Chloroform } \\
1,1 \text {-Dichloroethylene } \\
\text { trans-1,2-Dichloroethylene } \\
\text { Tetrachloroethylene } \\
1,1,1 \text {-Trichloroethane } \\
\text { Trichloroethylene }\end{array}$ & $\begin{array}{l}<1.0 \\
<1.0 \\
<1.0 \\
<1.0 \\
<1.0 \\
<1.0\end{array}$ & & $\begin{array}{l}\mu g / L \\
\mu g / L \\
\mu g / L \\
\mu g / L \\
\mu g / L \\
\mu g / L\end{array}$ \\
\hline
\end{tabular}

WEL.L ACB 4A

MEASUREMENTS CONDUCTED IN THE FIELD

\begin{tabular}{|c|c|c|c|c|c|}
\hline \multicolumn{3}{|c|}{$\begin{array}{l}\text { Sample date: } 11 / 01 / 91 \\
\text { Depth to watar: } 119.21 \mathrm{ft}(36.34 \mathrm{~m}) \text { below TOC } \\
\text { Water elevation: } 239.69 \mathrm{Ht}(73.12 \mathrm{~m}) \mathrm{msl} \\
\text { Sp. curijuctance: } 123 \mu \mathrm{s} / \mathrm{cm} \\
\text { Water evacuated belore sampling: } 74 \mathrm{gal}\end{array}$} & \multicolumn{3}{|c|}{$\begin{array}{l}\text { Time: } 14: 55 \\
\text { pH: } 5.0 \\
\text { Alkalinity: } 1 \mathrm{mg} / \mathrm{h} \\
\text { Water temperature: } 18.7^{\circ} \mathrm{C}\end{array}$} \\
\hline \multicolumn{6}{|c|}{ IABOORATORY ANALYSES } \\
\hline$\underline{E}$ & Analyte & Result & Mod & Unit & Lab \\
\hline $\begin{array}{l}0 \\
0 \\
0 \\
0 \\
0 \\
0\end{array}$ & $\begin{array}{l}\text { Chloroform } \\
1,1 \text {-Dichloroethylene } \\
\text { trans } 1,2 \text {-Dichloroethylene } \\
\text { Tetrachloroethylene } \\
1,1,1 \cdot \text { Trichloroethane } \\
\text { Trichloroethylene }\end{array}$ & $\begin{array}{l}<5.0 \\
<5.0 \\
<5.0 \\
<5.0 \\
<5.0 \\
<5.0\end{array}$ & & 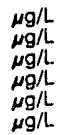 & $\begin{array}{l}M A \\
M A \\
M A \\
M A \\
M A \\
M A\end{array}$ \\
\hline
\end{tabular}

WELL AMB 4

MEASUREMENTS CONDUCTED IN THE FIELD

Sample date: 11/14/91 Time: 4:25

naccessibility or pump failure prevented sample collection.

\section{WELL AMB $4 A$}

MEASUREMENTS CONDUCTED IN THE FIELD

$\begin{array}{ll}\text { Sample date: } 11 / 14 / 81 & \text { Time: } 5: 50 \\ \text { Depth to water: } 161.4 \mathrm{H}(48.20 \mathrm{~m}) \text { below TOC } & \text { pH: } 9.0 \\ \text { Water elevation: } 219.10 \mathrm{Ht}(66.78 \mathrm{~m}) \mathrm{msl} & \text { Alkelinity: } 27 \mathrm{mg} / \mathrm{L} \\ \text { Sp. conductance: } 112 \mu \mathrm{cs} / \mathrm{cm} & \text { Water temperature: } 17.3 \circ \mathrm{C} \\ \text { Water evacuated before sampling: } 257 \mathrm{yal} & \end{array}$

Water evacuated before sampling: $257 \mathrm{yal}$

LABORATORY ANALYSES

\begin{tabular}{|c|c|c|c|c|}
\hline Analyte & Resuit & Mod & Unit & Lab \\
\hline $\begin{array}{l}\text { pH } \\
\text { pH } \\
\text { pH } \\
\text { pH } \\
\text { Specilic conductance } \\
\text { Specific conductance } \\
\text { Specific conductance } \\
\text { Specific conductance } \\
\text { Acenaphthene }\end{array}$ & $\begin{array}{r}8.7 \\
8.5 \\
8.6 \\
8.7 \\
90 \\
90 \\
95 \\
95 \\
<10\end{array}$ & $\begin{array}{l}\text { JQ } \\
\text { JO } \\
\text { JQ } \\
\text { JQ }\end{array}$ & $\begin{array}{l}\mathrm{pH} \\
\mathrm{pH} \\
\mathrm{pH} \\
\mathrm{pH} \\
\mu \mathrm{S} / \mathrm{cm} \\
\mu \mathrm{S} / \mathrm{cm} \\
\mu \mathrm{S} / \mathrm{cm} \\
\mu \mathrm{S} / \mathrm{cm} \\
\mu \mathrm{g} / \mathrm{L}\end{array}$ & $\begin{array}{l}\mathrm{GE} \\
\mathrm{GE} \\
\mathrm{GE} \\
\mathrm{GE} \\
\mathrm{GE} \\
\mathrm{GE} \\
\mathrm{GE} \\
\mathrm{GE} \\
\mathrm{GE}\end{array}$ \\
\hline
\end{tabular}


ANALYTICAL RESULTS

WELL AMB $4 A$ collected on 11/14/91, laboratory analyses (cont.)

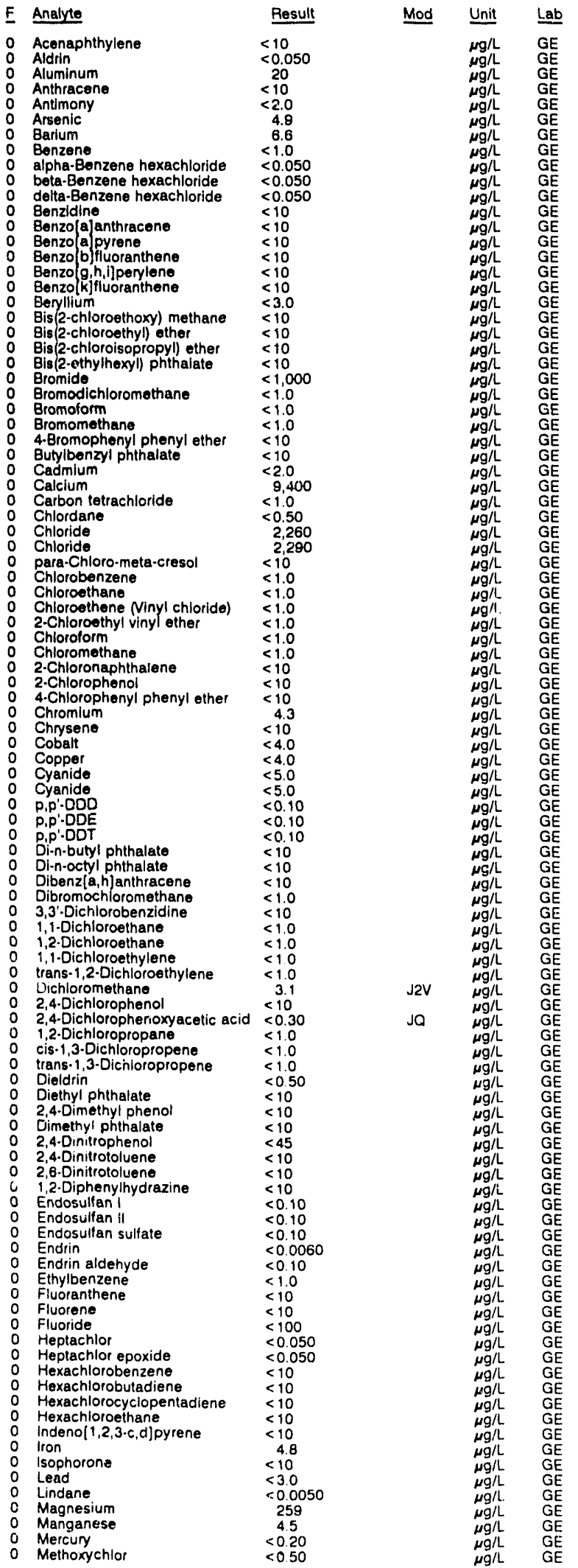

WELL AMB 4A collected on 11/14/91, laboratory analyses (cont.)

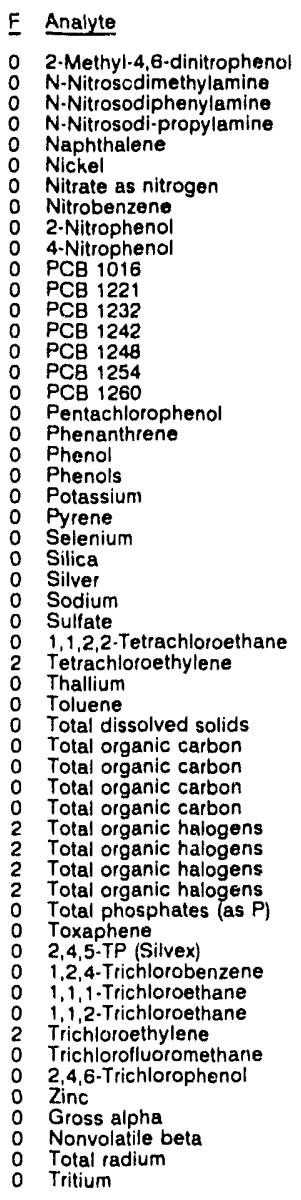

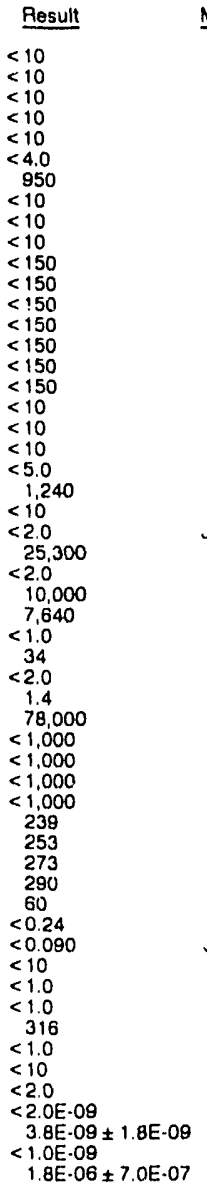

Mod Unit Lab

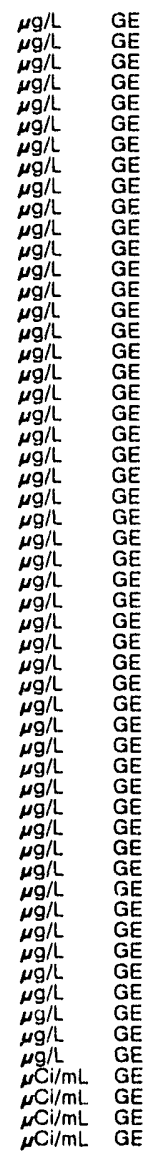

\section{WELL AMB 4B}

MEASUREMENTS CONDUCTED IN THE FIELD

Sample date: $11 / 14 / 91$ Depth to water: $155.27 \mathrm{H}(47.33 \mathrm{~m})$ below TOC Water elevation: $225.13 \mathrm{ft}(68.62 \mathrm{~m}) \mathrm{msl}$

Water evacuated before sampling: $192 \mathrm{gal}$

Time: $5: 1$

pH: 5.1

Alkalinity: $3 \mathrm{mg} / \mathrm{L}$

LABORATORY ANALYSES

\begin{tabular}{|c|c|c|}
\hline & Analyte & Result \\
\hline & $\mathrm{pH}$ & 5.4 \\
\hline & $\mathrm{pH}$ & 5.4 \\
\hline & $\mathrm{pH}$ & 5.5 \\
\hline & Specific conductance & 30 \\
\hline & Specific conductance & 30 \\
\hline & Specific conductance & 30 \\
\hline & Specific conductance & $\begin{array}{r}30 \\
<10\end{array}$ \\
\hline & $\begin{array}{l}\text { Acenaphthene } \\
\text { Acenaphthylene }\end{array}$ & $\begin{array}{l}<10 \\
<10\end{array}$ \\
\hline & Aldrin & $<0.050$ \\
\hline & Aluminum & $\begin{array}{l}<20 \\
<10\end{array}$ \\
\hline & $\begin{array}{l}\text { Anthracene } \\
\text { Antimony }\end{array}$ & $<2.0$ \\
\hline & Arsenic & $\begin{array}{r}<2.0 \\
7.2\end{array}$ \\
\hline & Benzene & $<1.0$ \\
\hline & alpha.Benzene hexachloride & $\begin{array}{l}<0.050 \\
<0.050\end{array}$ \\
\hline & $\begin{array}{l}\text { Deta.Benzene hexacnloride } \\
\text { delta-Benzene hexachloride }\end{array}$ & $<0.050$ \\
\hline & Benzidine & $<10$ \\
\hline & Benzo[a]anthracene & $\begin{array}{l}<10 \\
<10\end{array}$ \\
\hline & $\begin{array}{l}\text { Benzo|alpyrene } \\
\text { Benzo(b) fluoranthene }\end{array}$ & $<10$ \\
\hline & Benzolg,h,i]perylene & $<10$ \\
\hline & $\begin{array}{l}\text { Benzo[k]fluoranthene } \\
\text { Beryllium }\end{array}$ & $\begin{array}{l}<10 \\
<30\end{array}$ \\
\hline & Bis(2-chloroethoxy) methane & $<10$ \\
\hline
\end{tabular}

\begin{tabular}{|c|c|}
\hline Mod & Unit \\
\hline $\begin{array}{l}J Q \\
\mathrm{JQ} \\
\mathrm{JQ} \\
\mathrm{JQ}\end{array}$ & 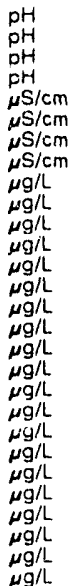 \\
\hline
\end{tabular}


ANALYTICAL RESULTS

WELL AMB $4 B$ collected on 11/14/91, laboratory analyses (cont.)

F Analyte

o Bis(2-chloroethyl) ether

0
0
0 Bis (2-ethylhexyl) phthalate

Bromide

Bromomethane

4. Bromophenyl phenyl ether

Butylbenzyl phthalate

Cadrium

Carbon tetrachloride

0 Chlordane

para-Chloro-meta-cresol

Chlorobenzene

Chloroethane

2-Chloroethyl vinyl ether

Chloroform

2-Chioronaphthalene

4-Chlorophenol

Chromium

Chrysene

Copper

0 Cyanide

$\begin{array}{ll}0 & 0 . p^{\prime}-D D E \\ 0 & p, p^{\prime}-D D D \\ 0\end{array}$

p.p'-DDT

o Di-n-butyl phthalate

Dibenz[a, h]anthracene

Dibromochloromethan

1,1-Dichloroethane

1,2-Oichlorsethane

trans-1,2-Dichloroethylene

0 Dichloromethane

2,4-Dichlorophenol

- 1,2-Dichloropropane

cis-1,3-Dichloropropene

trans-1,3-Dichloropropene

0 Diethyl phthalate

2,4-Dimethyl pheno

Dimethyl phthalate

2,4-Dinitrophenol

0 2,6-Dinitrotoluene

o 1,2-Diphenylhydrazine

0 Endosulfan 1

- Endosulfan sulfate

0 Endrin

0 Endrin aldehyde

E Ethylbenzene

o Fluorene

0 Fluoride

o Heptachlor

Hexachiorobenzene

Hexachlorobutadiene

Hexachlorcucyclope

Indeno $[1,2,3 \cdot c, d]$ pyrene

0 Iron

Isophorone

Lead

Magnesium

Manganes

Methoxychlo

2-Methyl-4,6-dinitrophenol

N-Nitrosodimethylamine

N-Nitrosodiphenylamine

N.Nitrosodi-p
Naphthalene

Nickel

Nitrate as nitrogen

2-Nitrophenol

4-Nitrophenol

PCB 1016

0 PCB 1221

- PCB 1232

PCG 1242

PCB 1254

Pentachlorophenol

Phenanthrene

Phenol
$<10$

$<10$
$<10$

$<1,000$

$<1.0$

$<1.0$

$<10$

2.0
1.190

$<1.0$
$<0.50$

3,840
$<10$

$<1.0$

$<1.0$

$<1.0$

$<1.0$

$<10$

$<10$

$<10$
$<10$

$<4.0$

$<40$
$<4.0$

$<4.0$
$<5.0$

$<0.10$

$<0.10$

$<0.10$

$<10$

$<10$

$<10$
$<1.0$

$<1.0$

$<1.0$

$<1.0$

$<1.0$

3.7
10

$<0.30$

$<1.0$

$<1.0$

$<<<0$

$<10$
$<10$

$<10$

$<45$
$<10$

$<10$
$<10$

$<10$

$<0.10$

$<0.10$

$<0.0060$

1.0

$<10$

$<10$
$<100$

$<0.050$

$<0.050$

$<10$

$<10$

$<10$

$<10$

16
$<10$

$<10$
$<3.0$
$<0.0050$

$<0.00$
435
20

20
$<020$

$<0.20$

$<10$
$<10$

$<10$
$<10$

$<10$
$<10$

$<10$

$<40$

$\begin{aligned} & 910 \\ < & 10 \\ < & 10\end{aligned}$

$<10$

10

$<150$

$<150$

$<150$
$<150$

$<150$
$<150$

$<150$

$<10$

$<10$
$<10$

$<10$
$<5.0$
Mod Uni

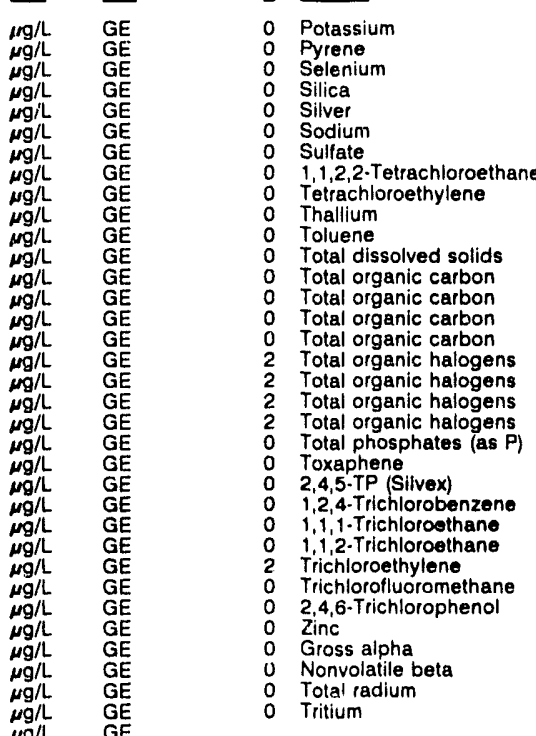

WELL AMB 4B collected on 11/14/91, laboratory analyses (cont.)

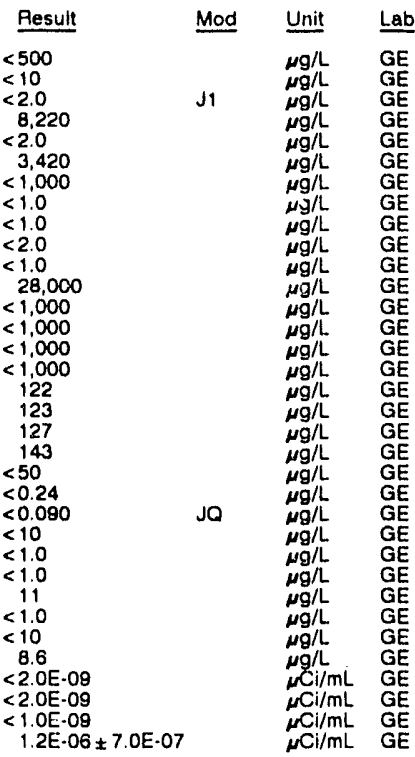

WELL AMB 4D

MEASUREMENTS CONDUCTED IN THE FIELD

Sample date: $12 / 11 / 91$

Depth to water: $144.65 \mathrm{H}(44.09 \mathrm{~m})$ below TOC

Water elevation: $235.65 \mathrm{Ht}(71.83 \mathrm{~m}) \mathrm{msl}$

Water evacuated before sampling: $60 \mathrm{gal}$

Time: 16

pH: 6.1

Waler temperature $18.6^{\circ} \mathrm{C}$

LABORATORY ANALYSES

F Analyte

$0 \mathrm{pH}$

$\mathrm{pH}$

$\mathrm{pH}$

Specific conductance

Specific conductance

Specific conductance

Specific conductance

Acenaphthylene

Aldrin

Aluminum

Anthracene

Arsenic

Barium

Benzen

alpha. Benzene hexachloride

beta-Benzene hexachloride

Benzidine

Benzola)anthracene

Benzola.pprene

Benzo(b)fluoranthene

Benzo $9, h, i]$ perylene

Benzo $k]$ flu

Bis(2-chloroethoxy) methane

Bis (2.chloroethyl) ether

Bis (2-chloroisopiopyl) ethe

Bromide

Bromodichloromethane

Bromolorm

Bromomethane

4-Bromophenyl phenyl

Butylbenzyl

Cadmium

Carbon tetrachloride

Chlordane

Chloride

para-Chloro-meta.cresol

Chlorobenzene

Chloroethene Ninyl chloride)

2.Chlorethyl vinyl chlor

o Chloroform

0 Chloromethane

\begin{tabular}{l} 
Result \\
\hline 6.5 \\
6.5 \\
6.6 \\
6.7 \\
90 \\
30 \\
95 \\
95 \\
$<10$ \\
$<10$ \\
$<0.050$ \\
106 \\
$<10$ \\
14 \\
$<2.0$ \\
13 \\
$<1.0$ \\
$<0.050$ \\
$<0.050$ \\
$<0.050$ \\
$<10$ \\
$<10$ \\
$<10$ \\
$<10$ \\
$<10$ \\
$<10$ \\
$<3.0$ \\
$<10$ \\
$<10$ \\
$<10$ \\
$<10$ \\
$<1.000$ \\
$<1.0$ \\
$<1.0$ \\
$<1.0$ \\
$<10$ \\
$<10$ \\
$<2.0$ \\
6.250 \\
1.3 \\
$<0.50$ \\
3,360 \\
$<10$ \\
$<1.0$ \\
$<1.0$ \\
$<1.0$ \\
$<1.0$ \\
$<1.0$ \\
$<1.0$ \\
\end{tabular}

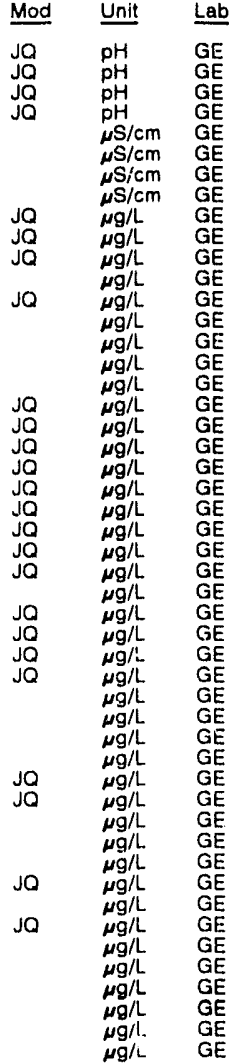


WELL AMB $4 D$ collected on 12/11/91, laboratory analyses (cont.)

E Analyte

$\begin{array}{ll}0 & 2-\text { Chloronaphthalene } \\ 0 & 2-\text { Chlorophenol } \\ 0 & 4 \cdot C h \text { lorophenyl phenyl ether } \\ 0 & \text { Chromium } \\ 0 & \text { Chrysene }\end{array}$

0 Cobalt

Cyanide

p,p'DDD

D p.p.DDE

Di-n-butyl phthalate

Dibenzla, hlanthreacen

Dibenzla, hlanthracene

3,3'-Dichlorobenzidine

1,1.Dichloroethane

1,1-Dichloroethylene

trans. 1,2 -Dichloroe
Dichloromethane

2,4-Dichlorophenol

2,4-Dichlorophenoxyacetic acid

1,2-Dichloropropane

trans-13-Dichlopene

Dieldrin

Diethyl phthalate

Dimethyl phthalate

2,4-Dinitrophenol

2,4-Dinitrotoluene

1,2 .Diphenylhydrazine

Endosulfan I

Endosulfan sulfate

Endrin

Endrin aldehyde

Ethylbenzen

Fluorene

Fluoride

Fluoride

Heptachlor epoxide

Hexachlorobenzene

Hexachlorobutadiene

Hexachlorocyclope

Indeno[ $1,2,3 \cdot c, d]$ pyrene

Iron

Isophorone

Lead

Magnesium

Manganese

Mercury

2-Methyl-4,6-dinitrophenol
N-Nitrosodimethylamine

N-Nitrosodiphenylamine

N.Nitrosodi-oropylamin

Naphthalene

Nickel

Nitrate as nitrogen

Nitrobenzene

2-Nitrophenol

4-Nitrophen

PCB 122

PCB 1232

PCB 1248

PCB 1254

Pentachlorophenol

Phenanthrene

Phenol

Phenols
Potassium

Pyrene

Selenium

Silica

0 Silver

Sulfate

Tetrachloroethylene

Thallium

- Tota! dissolved solids

Tola! dissolved solids

Total organic carbon

Total organic carbon

Total organic carbon

Total organic halogens

Total organic halogens

Total organic halogens
Tota: organic halogens

$<1.0$

$<1.0$

1.0

$<10$
$<0.30$

$<1.0$

$<0.50$

$<10$

$<10$

$<10$
$<45$

$<10$

$<10$
$<10$
$<0.10$
$<0.10$
$<0.10$

$<0.10$
$<0.10$

$<0.10$

$<0.0060$
$<0.10$
$<1.0$
$<10$

$<10$
$<100$
$<100$

$<100$

$<0.050$

$<10$
$<10$
$<10$

$<10$

$<10$
48

$<10$

$<3.0$
$<0.0050$

653

$<0.20$

$<0.50$

$<10$

$<10$

$<10$

$<4.0$
1.040

$<10$
$<10$

$<10$
$<10$
$<150$

$<150$

$<150$
$<150$
$<150$

$<150$

$<10$

$<10$

$<10$
$<50$
$<500$
$<10$

$<2.0$

$\begin{aligned} & 9,320 \\ &<2.0\end{aligned}$

9,100
1,880

1,880
$<1.0$

$<1.0$
5.3
$<2.0$

$<2.0$

88.000

$<1,000$

$<1,000$

$<1,000$

49
50
52

JQ

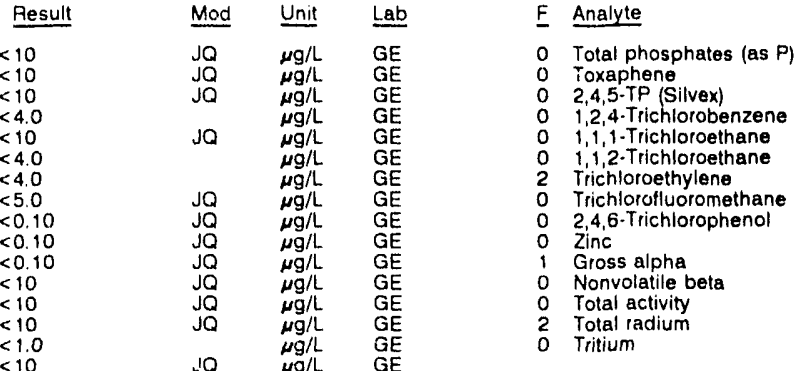

WELL AMB $4 D$ collected on 12/11/91, laboratory analyses (cont.)

\section{WELL AMB 5}

MEASUREMENTS CONDUCTED IN THE FIELD
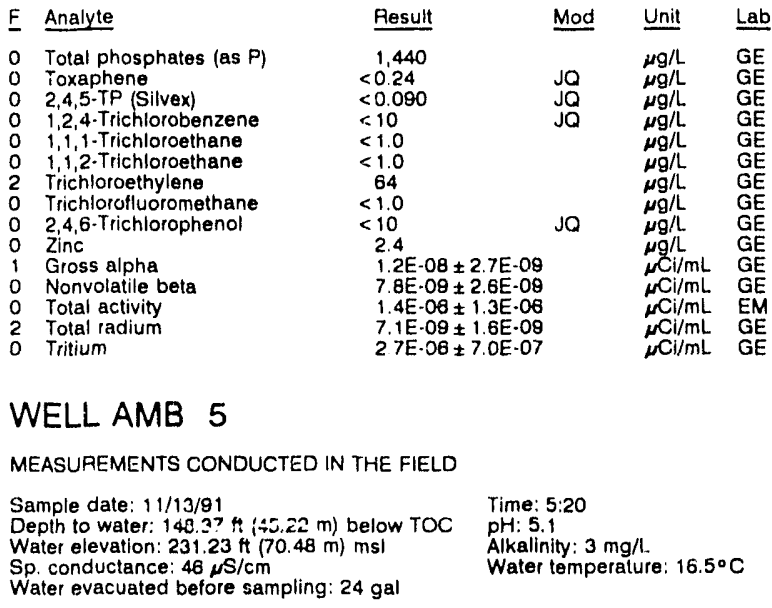

LABORATORY ANALYSES

$0 \mathrm{pH}$

$\begin{array}{ll}0 & \mathrm{pH} \\ 0 & \mathrm{pH} \\ 0 & \mathrm{pH}\end{array}$

O Specific conductance

O Specific conductance

Specific conductance

Arsenic

o Barium

- Cadmium

Carbon tetrachloride

0 Chloride

Chloroform

O Chromium

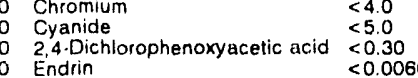

0 Fluoride

0 Iron

0 Lead

$\begin{array}{ll}0 & \text { Lindane } \\ 0 & \text { Magnesium } \\ 0 & \text { Manganese }\end{array}$

0 Mercury

Methuxychlor

- Nickel

Nitrate as nitrogen

Phenols

0 Potassium

o Silica

0 Silver

0 Sodium

Tetrachloroethylene

Total organic carbon

- Total organic, carbon

Total organic carbon

- Total organic carbon

2 Total organic halogens

Total organic halogens

Total organic halogens

Total organic halogens

Total phosphates (as P)

Toxaphene

1,1,1-Trichloroethane

2 Trichloroenylothane

Gross alpha

Nonvolatile beta

Total radium
Time: $5: 20$

Alkalinity: $3 \mathrm{mg} / \mathrm{l}$

Water temperature: $16.5^{\circ} \mathrm{C}$

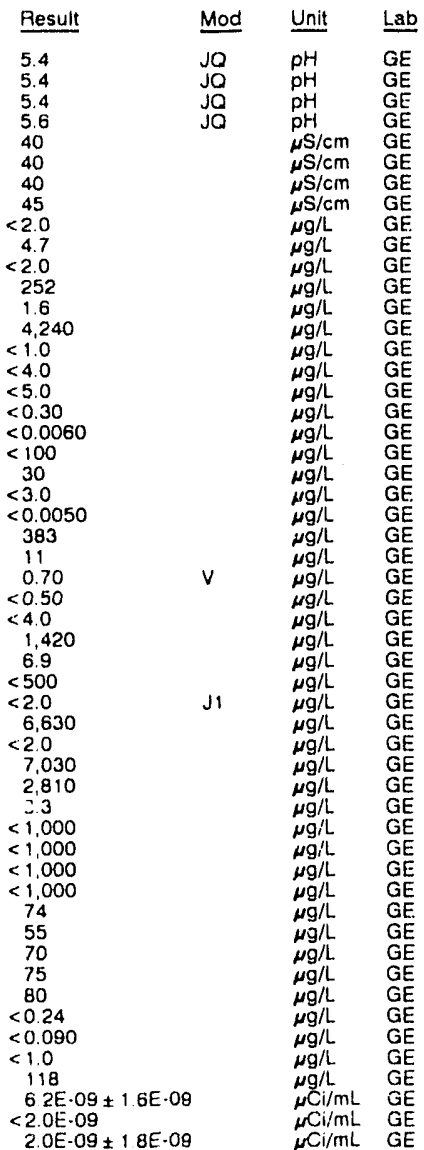


ANALYTICAL RESULTS

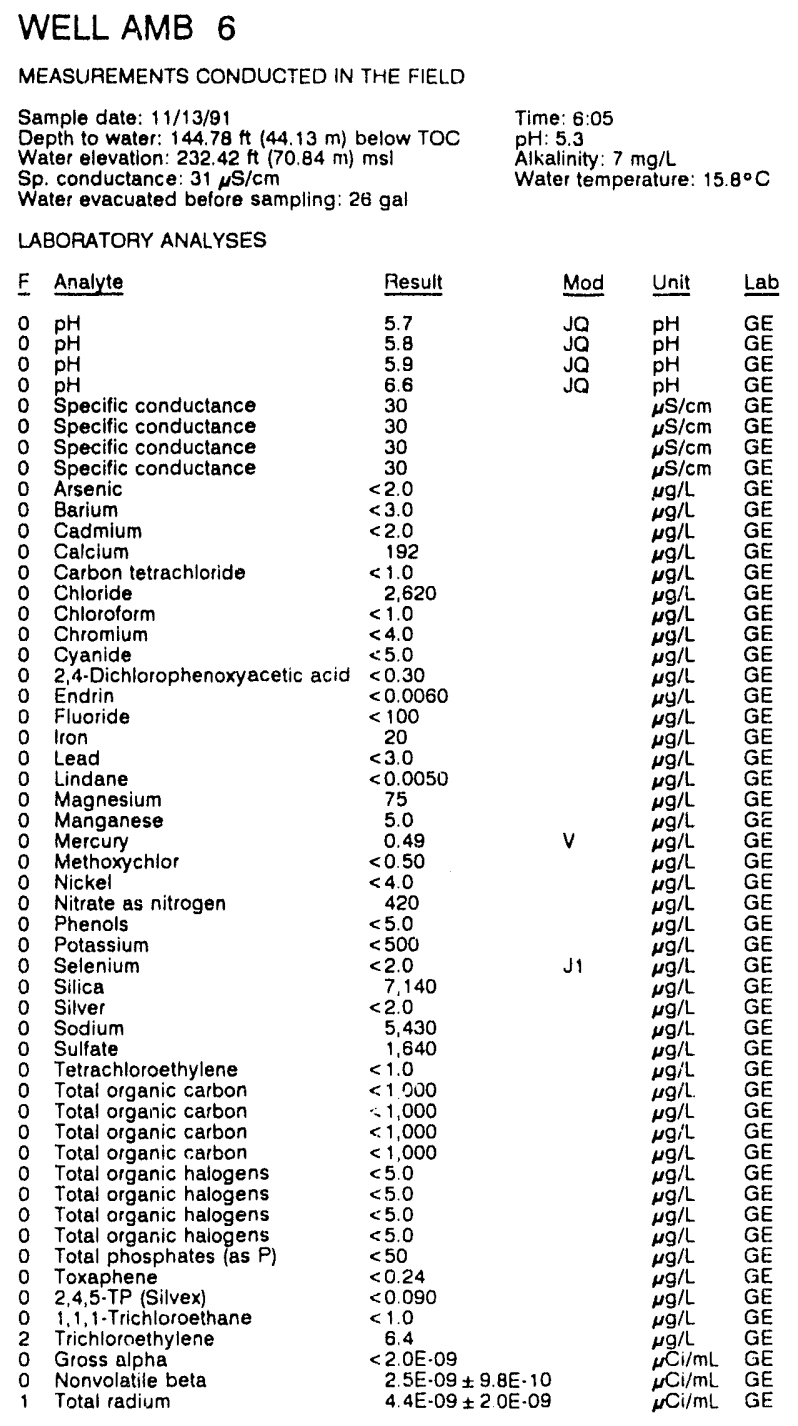

WELL AMB 7

MEASUREMENTS CONDUCTED IN THE FIELD

\begin{tabular}{|c|c|c|}
\hline \multicolumn{3}{|c|}{$\begin{array}{l}\text { Sample date: } 11 / 15 / 91 \\
\text { Depth to water: } 136.83 \mathrm{H}(41.71 \mathrm{~m}) \text { below TOC } \\
\text { Water elevation: } 233.07 \mathrm{ft}(71.04 \mathrm{~m}) \mathrm{msl} \\
\text { Sp. conductance: } 118 \mu \mathrm{s} / \mathrm{cm} \\
\text { Water evacuated before sampling: } 9 \mathrm{gal} \\
\text { The well went dy during purging. }\end{array}$} \\
\hline \multicolumn{3}{|c|}{ LABORATORY ANALYSES } \\
\hline & Analyte & Result \\
\hline & $\begin{array}{l}\text { pH } \\
\text { pH } \\
\text { pH } \\
\text { pH } \\
\text { Specific conductance } \\
\text { Specific conductance } \\
\text { Specific conductance } \\
\text { Specific conductance } \\
\text { Arsenic } \\
\text { Garium } \\
\text { Cadmium } \\
\text { Calcium } \\
\text { Carbon tetrachloride } \\
\text { Chloride } \\
\text { Chloroform } \\
\text { Chromium } \\
\text { Cyanide } \\
\text { 2,4-Dichiorophenoxyacetic ac }\end{array}$ & $\begin{array}{l}6.4 \\
6.4 \\
6.5 \\
6.5 \\
70 \\
70 \\
80 \\
85 \\
<2.0 \\
12 \\
<2.0 \\
4.670 \\
<1.0 \\
2.440 \\
<1.0 \\
<4.0 \\
<5.0 \\
<0.30\end{array}$ \\
\hline
\end{tabular}

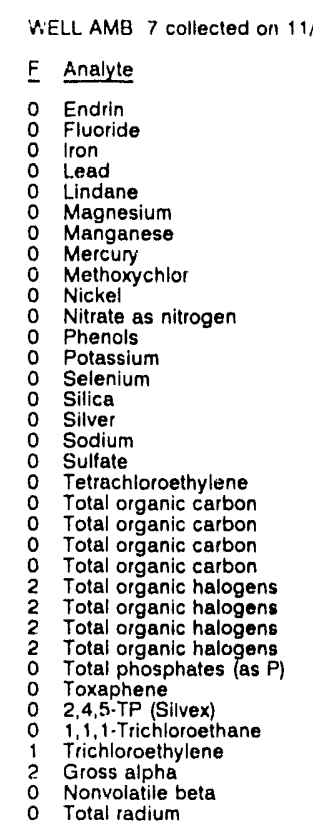

\section{WELL AMB 7A}

LABORATORY ANALYSES

MEASUREMENTS CONDUCTED IN THE FIELD

$\begin{array}{ll}\text { Sample date: } 11 / 14 / 91 & \text { Time: } 7: 30 \\ \text { Depth to water: } 155.27 \mathrm{Ht}(47.33 \mathrm{~m}) \text { below TOC } & \text { pH: } 6.7 \\ \text { Water elevation: } 218.33 \mathrm{ft}(66.55 \mathrm{~m}) \mathrm{msl} & \text { Alkalinity: } 20 \mathrm{mg} / \mathrm{L} \\ \text { Sp. conductance: } 67 \mu \mathrm{S} / \mathrm{cm} & \text { Water temperature: } 17.0^{\circ} \mathrm{C} \\ \text { Water evacuated belore sampling: } 271 \mathrm{gal} & \end{array}$

\begin{tabular}{|c|c|c|c|c|c|}
\hline$\underline{F}$ & Analyte & Pesult & Mod & Unit & Lab \\
\hline $\begin{array}{l}0 \\
0 \\
0 \\
0 \\
0 \\
0 \\
0 \\
0 \\
0 \\
0 \\
0 \\
0 \\
0 \\
0 \\
0 \\
0 \\
0 \\
0 \\
0 \\
0 \\
0 \\
0 \\
0 \\
0 \\
0 \\
0 \\
0 \\
0 \\
0 \\
0 \\
0 \\
0 \\
0 \\
0 \\
0 \\
0 \\
0 \\
0 \\
0 \\
0 \\
0 \\
0 \\
0 \\
0 \\
0 \\
0 \\
0 \\
0 \\
\\
\\
\\
\\
\end{array}$ & 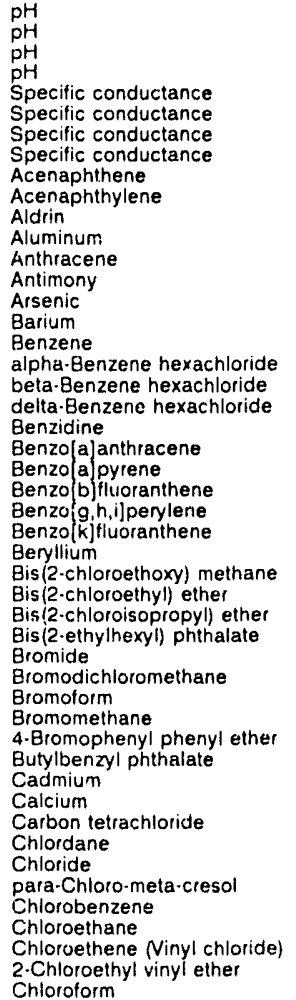 & $\begin{aligned} & 6.8 \\
& 6.9 \\
& 7.0 \\
& 7.0 \\
& 60 \\
& 60 \\
& 60 \\
& 60 \\
&<10 \\
&<10 \\
&<0.050 \\
& 25 \\
&<10 \\
&<2.0 \\
&<2.0 \\
& 7.4 \\
&<1.0 \\
&<0.050 \\
&<0.050 \\
&<0.050 \\
&<10 \\
&<10 \\
&<10 \\
&<10 \\
&<10 \\
&<10 \\
&<3.0 \\
&<10 \\
&<10 \\
&<10 \\
&<10 \\
&<1.000 \\
&<1.0 \\
&<1.0 \\
&<1.0 \\
&<10 \\
&<10 \\
&<2.0 \\
& 7.180 \\
& 1.2 \\
&<0.50 \\
& 1.970 \\
&<10 \\
&<1.0 \\
&<1.0 \\
&<1.0 \\
&<1.0 \\
&<1.0\end{aligned}$ & $\begin{array}{l}J Q \\
J Q \\
J Q \\
J Q\end{array}$ & 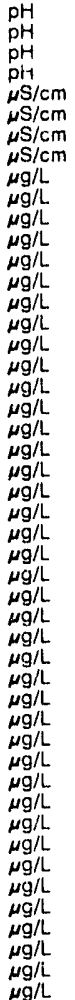 & $\begin{array}{l}\mathrm{GE} \\
\mathrm{GE} \\
\mathrm{GE} \\
\mathrm{GE} \\
\mathrm{GE} \\
\mathrm{GE} \\
\mathrm{GE} \\
\mathrm{GE} \\
\mathrm{GE} \\
\mathrm{GE} \\
\mathrm{GE} \\
\mathrm{GE} \\
\mathrm{GE} \\
\mathrm{GE} \\
\mathrm{GE} \\
\mathrm{GE} \\
\mathrm{GE} \\
\mathrm{GE} \\
\mathrm{GE} \\
\mathrm{GE} \\
\mathrm{GE} \\
\mathrm{GE} \\
\mathrm{GE} \\
\mathrm{GE} \\
\mathrm{GE} \\
\mathrm{GE} \\
\mathrm{GE} \\
\mathrm{GE} \\
\mathrm{GE} \\
\mathrm{GE} \\
\mathrm{GE} \\
\mathrm{GE} \\
\mathrm{GE} \\
\mathrm{GE} \\
\mathrm{GE} \\
\mathrm{GE} \\
\mathrm{GE} \\
\mathrm{GE} \\
\mathrm{GE} \\
\mathrm{GE} \\
\mathrm{GE} \\
\mathrm{GE} \\
\mathrm{GE} \\
\mathrm{GE} \\
\mathrm{GE} \\
\mathrm{GE} \\
\mathrm{GE} \\
\mathrm{GE}\end{array}$ \\
\hline
\end{tabular}




\section{ANALYTICAL RESULTS}

WELL AMB 7A collected on 11/14/91, laboratory analyses (cont.)

\begin{tabular}{|c|c|c|c|c|c|c|}
\hline Analyte & Result & Mod & Unit & Lab & $E$ & Analyte \\
\hline $\begin{array}{l}\text { Chloromethane } \\
\text { 2-Chloronaphthalene } \\
\text { 2-Chlorophenol } \\
\text { 4-Chlorophenyl phenyl ether } \\
\text { Chromium } \\
\text { Chrysene } \\
\text { Cobalt } \\
\text { Copper } \\
\text { Cyanide } \\
\text { p.p'-DDD } \\
\text { p,p'-DDE } \\
\text { p,p'-DDT } \\
\text { Di-n-butyl phthalate } \\
\text { Di-n-octyl phthalate } \\
\text { Dibenz[a, h]anthracene } \\
\text { Dibromochloromethane }\end{array}$ & $\begin{array}{l}<1.0 \\
<10 \\
<10 \\
<10 \\
<4.0 \\
<10 \\
<4.0 \\
<4.0 \\
<5.0 \\
<0.10 \\
<0.10 \\
<0.10 \\
<10 \\
<10 \\
<10 \\
<1.0\end{array}$ & & $\begin{array}{l}\mu g / L \\
\mu g / L \\
\mu g / L \\
\mu g / L \\
\mu g / L \\
\mu g / L \\
\mu g / L \\
\mu g / L \\
\mu g / L \\
\mu g / L \\
\mu g / L \\
\mu g / L \\
\mu g / L \\
\mu g / L \\
\mu g / L \\
\mu g / L\end{array}$ & $\begin{array}{l}\mathrm{GE} \\
\mathrm{GE} \\
\mathrm{GE} \\
\mathrm{GE} \\
\mathrm{GE} \\
\mathrm{GE} \\
\mathrm{GE} \\
\mathrm{GE} \\
\mathrm{GE} \\
\mathrm{GE} \\
\mathrm{GE} \\
\mathrm{GE} \\
\mathrm{GE} \\
\mathrm{GE} \\
\mathrm{GE} \\
\mathrm{GE}\end{array}$ & $\begin{array}{l}2 \\
0 \\
0 \\
0 \\
0 \\
0 \\
0 \\
2 \\
0 \\
0 \\
0 \\
0 \\
0 \\
1 \\
0\end{array}$ & $\begin{array}{l}\text { Total organic halogens } \\
\text { Total phosphates (as P) } \\
\text { Toxaphene } \\
2,4,5-\text { TP (Silvex) } \\
\text { 1,2,4-Trichlorobenzene } \\
1,1,1 \text {-Trichloroethane } \\
1,1,2 . \text { Trichloroethane } \\
\text { Trichloroethylene } \\
\text { Trichlorofluoromethane } \\
2,4,6 \cdot \text { Trichlorophenol } \\
\text { Zinc } \\
\text { Gross alpha } \\
\text { Nonvolatile beta } \\
\text { Total radium } \\
\text { Tritium }\end{array}$ \\
\hline
\end{tabular}

WELL AMB 7B

MEASUREMENTS CONDUCTED IN THE FIELD

Sample date: 11/14/91

Depth to water: $148.43 \mathrm{H}(45.24 \mathrm{~m})$ below TOC

Water elevation: $224.57 \mathrm{ft}(68.45 \mathrm{~m}) \mathrm{msl}$

$\mathrm{Sp}$. conductance: $32 \mathrm{\mu S} / \mathrm{cm}$

Water evacuated before sampling: $189 \mathrm{gal}$

LABORATORY ANALYSES

E Analyte

$0 \mathrm{pH}$

$\begin{array}{ll}0 & \mathrm{pH} \\ 0 & \mathrm{pH} \\ 0 & \mathrm{pH}\end{array}$

Specific conductance

O Specific conductance

Specific conductance

Specific conductance
Acenaphthene

- Acenaphthene

Aldrin

Aluininum

0 Antimony

Arsenic

Barium

Benzen

alpha-Benzene hexachioride

delta-Benzene hexachloride

Benzidine

Benzolalanthracene

Benzo a pyrene

Benzo b) Huoranthen

Benzo g,h,i)perylene

Beryllium

Bis(2-chloroethery) methane

Bis (2-chloroethyl) ether

Bis (2-chloroisopropyl) ether

Bis (2-ethylhexyl) phthalate

Bromide

Bromide

Bromodichloromethane

Bromoform

Bromomethane

4-Bromophenyl phenyl ethe

Butylbenzyl phthalat

Cadmium

Carbon tetrachloride

Chlordane

Chloride

para-Chloro-meta.cresol

Chlorobenzene

Chloroethane

Chloroethene Ninyl chlor

2-Chloroethy

Chloromethan

2.Chloronaphthalen

2.Chlorophenol

4.Chlorophenyl phenyl ethe

Chromium

Chrysene

Copper

Cyanide

p. $P \cdot D D D$

p.p'DDE

Di-n-butyl phthalate

Di-n-octyl phthalate

Dibenz (a,h)anthracene

Dibromochloromethane

3,3'-Dichlorobenzidine
1,1-Dichloroethane

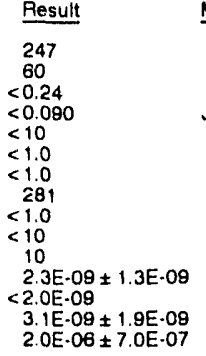

Mod Unit Lab

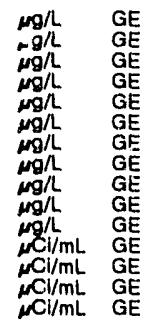

Time: $6: 50$

Alkalinity: $5 \mathrm{mg} / \mathrm{L}$

Water temperature: $17.1^{\circ} \mathrm{C}$

Pesult

5.5
5.5

5.5
5.7
30

30
30
30

30
30
$<10$

$<0.050$

$<20$

$<2.0$

$<2.0$

$<1.0$
$<0.050$

$<0.050$

$<10$

$<10$

$<10$

$<10$

$<3.0$

$<10$

$<10$

$<1,000$
$<1,000$

$<1.0$

$<10$

$<10$
$<2.0$

313
$<1.0$
$<0.50$

3,680

3,690

$<10$

$<1.0$

$<1.0$
$<1.0$
$<1.0$

$<1.0$

$<10$

$<10$
$<4.0$

$<10$

$<4.0$
$<4.0$

$<0$

$<0.10$

$<0.10$

$<10$

$<10$

$<10$
$<1.0$
$<10$

$<10$
$<1.0$

JO
JO
JO

Unit Lab

$\begin{array}{ll}\mathrm{pH} & \mathrm{GE} \\ \mathrm{pH} & \mathrm{GE} \\ \mathrm{pH} & \mathrm{GE} \\ \mathrm{pH} & \mathrm{GE}\end{array}$

$\mu \mathrm{S} / \mathrm{cm}$ GE

E


ANALYTICAL RESULTS

WELL AMB 78 collocted on 11/14/91, laboratory analyses (cont.)

F Analyte

: 1,2 - Dichloroethane

$1,1-D i c h l o r o e t h y l e n e$
0
trans-1, - - Dichloroothylene

Dichloromethane
0 2,4-Dichlorophenol

2,4-Dichlorophenol
0

2,4-Dichlorophenoxyacetic acid $<0.30$

0 cis-1,3-Dichloropropeno

o trans-1,3-Dichloropropene

Diethyl phthalate

2,4-Dimothyl phonol

2,4-Dinitrophenel

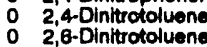

1,2-Diphenylhydrazine

o Endosulfan I

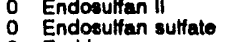

0 Endrin

Endrin aldehyde

o Eluoranthene

: Fluorene

O Fluoride

0 Heptachior

Heptachlor epoxido

O Hexachlorobonztadiene

- Hexachlorocyclopentadiene

o Hexachlorowthane

0 indeno $[1,2,3-c, d] p y r e n e$

$\begin{array}{ll}0 & \text { Iron } \\ 0 & \text { isophorone }\end{array}$

0 Lead

0 Lindane

Manganese

Mercury

2-Methyl-4,6-dinitrophenol

N-Nitrosodimethylamine

N-Nitrosodiphenylamine

Naphthalene

Nickel

Nitrate as nitrogen

2-Nitrophenol

4-Nitropheno

PCB 1221

PCB 1221

PCB 1242

PCE 1254

Pentachlorophenol

Phenanthrene

Phenol

Phenols

Pyrene

Selenium
Silica

Silica
Silver

Sodium

1,1,2,2-Totrachloroethane

Tetrachloroethylene

Thallium

Total dissolved solids

Total organic carbon

Total organic carbon

Total organic carbon

Total organic carbon

Total organic halogen

Total organic halogen

Total organic halogens
0 Total phosphates (as P)

Total phosphates as

2,4,5-TP (Silvex)

1,2,4-Trichlorobenzene

1, 1 Trichloroethan

Trichloroethylene

Trichlorofluoromethane

2,4,6-Trichlorophenol

$2,4,6-1$
Zinc

Gross alpha

Nonvolatile beta

Tritium

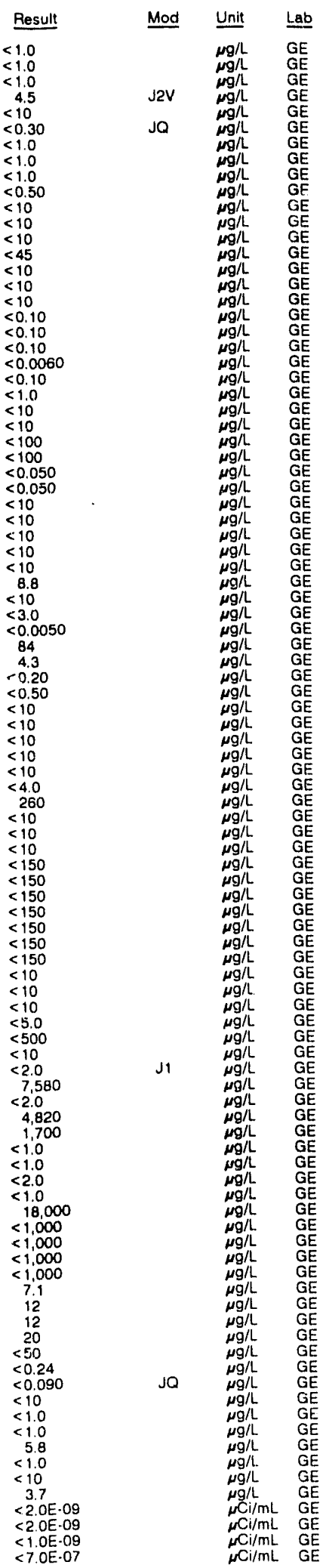

WELL AMB 8D

MEASUREMENTS CONDUCTED IN THE FIELD

Sample date: $11 / 13 / 91$

Depth to water: $137.45 \mathrm{tt}(41.90 \mathrm{~m})$ below TOO

Water elevation: $232.15 \mathrm{ft}(70.76 \mathrm{~m}) \mathrm{msl}$

Sp. Conductance: $63 \mu \mathrm{S} / \mathrm{cm}$
Water evacuated before sampling: $30 \mathrm{gal}$

LABORATORY ANALYSES

$0 \begin{gathered}\mathrm{pH} \\ 0\end{gathered}$

$00 \mathrm{pH}$

Specific conductance

Specific conductance

Specific conductance

Arsenic

Barium

Cadmium

Calcium

Carborn tetrachloride

Chloride

Chioroform

Chromium

$\begin{array}{ll}\text { Cyanide } & <4.0 \\ & <5.0\end{array}$

ophenoryacetic acid $<0.30$

Fluoride

lion

Lindane

Magnesium

Manganes

Mercury

Nethoxy

Nitrate as nitronen

Phenols

Selenium

Silica

Silver

Sodium

Sulfate

Total organic carbon

Total organic carbon

Total organic carbon

Total organic carbon

Total organic halogens

Total organic halogens
Total organic halogens

Total organic halogens

- Total phosphates (as P)

Toxaphene

0 2,4,5.TP (Silvex)

$1,1,1$.Trichioroethan

Gross alpha

Nonvolatile beta
0 Total radium

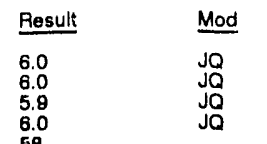

Unit Lab

Alkalinity: $17 \mathrm{mg} / \mathrm{L}$

Water temperature: $15.5^{\circ} \mathrm{C}$

WELL AMB 9D

MEASUREMENTS CONDUCTED IN THE FIELLD

Sample date: 11/13/91

Depth to water: 136.49 it $(41.60 \mathrm{~m})$ below TOC

Water elevation: $231.41 \mathrm{ft}(70.53 \mathrm{~m}) \mathrm{msl}$

Sp. conductance: $42 \mu \mathrm{S} / \mathrm{cm}$

Water evacuated before sampling: $31 \mathrm{gal}$

LABORATORY ANALYSES

\begin{tabular}{|c|c|c|c|}
\hline Analyte & Result & Mod & Unit \\
\hline $\mathrm{pH}$ & 5.8 & JQ & $\mathrm{pH}$ \\
\hline $\mathrm{pH}$ & 5.9 & JQ & $\mathrm{pH}$ \\
\hline $\mathrm{pH}$ & 6.1 & JQ & $\mathrm{pH}$ \\
\hline & 6.1 & $J Q$ & \\
\hline $\begin{array}{l}\text { Specific conductance } \\
\text { Specific conductance }\end{array}$ & $\begin{array}{l}39 \\
40\end{array}$ & & $\begin{array}{l}\mu \mathrm{S} / \mathrm{cm} \\
\mu \mathrm{S} / \mathrm{cm}\end{array}$ \\
\hline Specific conductance & 40 & & $\mu \mathrm{S} / \mathrm{cm}$ \\
\hline $\begin{array}{l}\text { Specific conductance } \\
\text { Arsenic }\end{array}$ & $\begin{array}{r}40 \\
20\end{array}$ & & $\mu \mathrm{S} / \mathrm{cm}$ \\
\hline $\begin{array}{l}\text { Arsenic } \\
\text { Barium }\end{array}$ & $\begin{array}{l}<2.0 \\
<3.0\end{array}$ & & $\mu g / L$ \\
\hline Cadmium & $<2.0$ & & $\mu \mathrm{g} / \mathrm{L}$ \\
\hline $\begin{array}{l}\text { Calcium } \\
\text { Carbon tetrachloride }\end{array}$ & $\begin{array}{r}382 \\
<10\end{array}$ & & $\mu g / L$ \\
\hline $\begin{array}{l}\text { Carbon fetrachlorlde } \\
\text { Chloride }\end{array}$ & $\begin{array}{r}<1.0 \\
2,900\end{array}$ & & $\mu \mathrm{g} / \mathrm{L}$ \\
\hline Chloroform & $<1.0$ & & $\mu g / L$ \\
\hline Chromium & $<4.0$ & & $\mu g / L$ \\
\hline $\begin{array}{l}\text { Cyanide } \\
24 \text {-Dichlorophenoxyac }\end{array}$ & $\begin{array}{l}<5.0 \\
<0.30\end{array}$ & & $\mu \mathrm{g} / \mathrm{L}$ \\
\hline 2,4-Dichlorophenoxyac & & & \\
\hline
\end{tabular}


ANALYTICAL RESULTS

WELL AMB $9 D$ collected on 11/13/91, laboratory analyses (cont.)

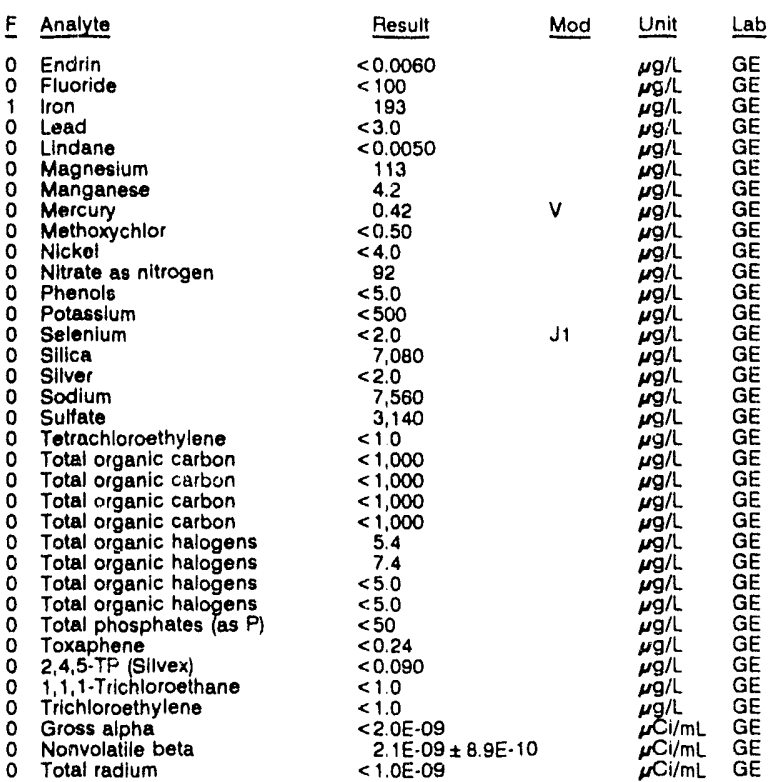

WELL AMB 10A

MEASUREMENTS CONDUCTED IN THE FIELD

Depth to water: $148.95 \mathrm{ft}(45.40 \mathrm{~m})$ below $T O C$

Water elevation: $217.55 \mathrm{Ht}(66.31 \mathrm{~m}) \mathrm{msl}$

The well went dry during purging: $100 \mathrm{gal}$

LABORATORY ANALYSES

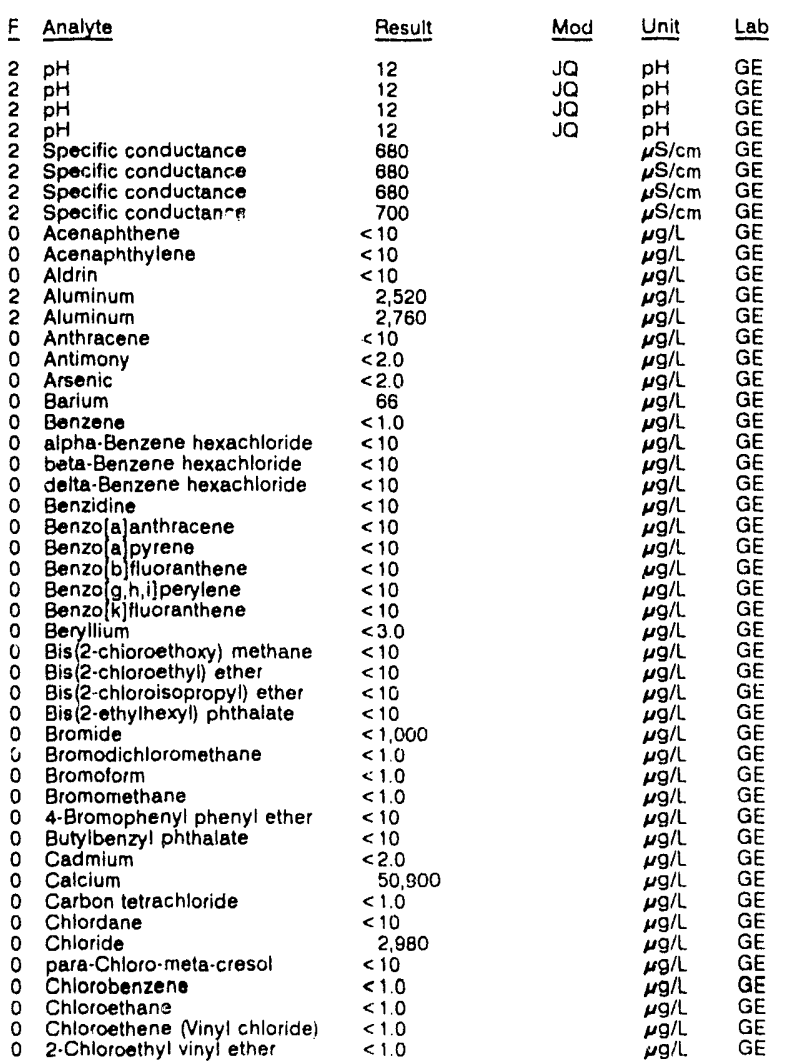

WELL AMB 10A collected on 12/03/91, laboratory analyses (cont.

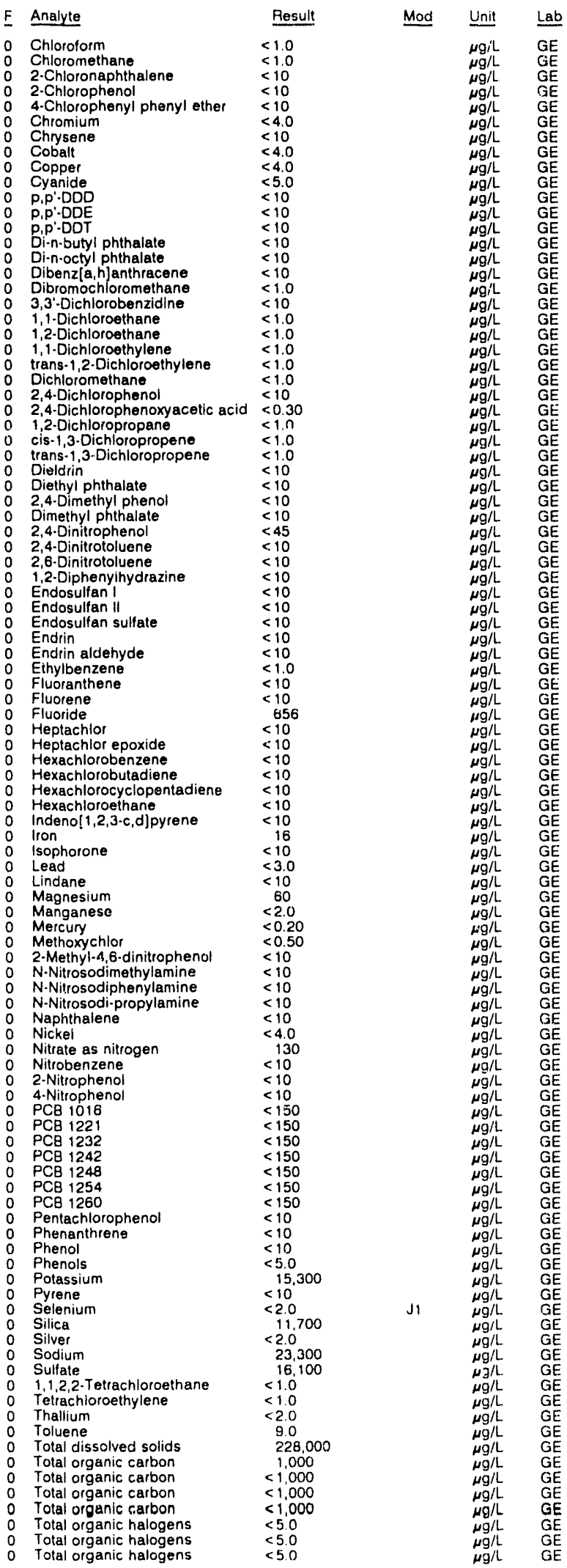


WELL AM8 10A collected on 12/03/81, laboratory analyses (cont.)

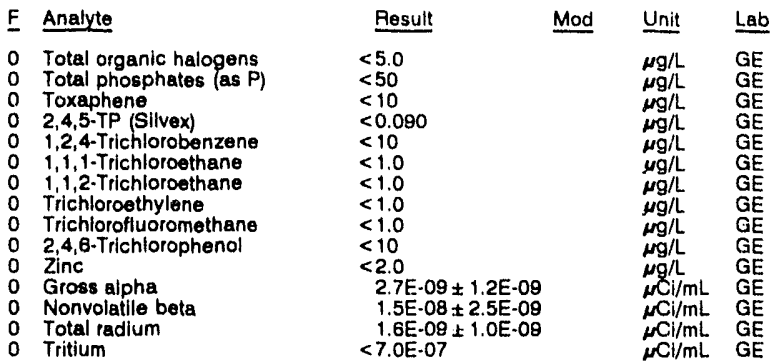

WELL AMB $10 B$

MEASUREMENTS CONDUCTED IN THE FIELD

Sample date: 12/02/91
Depth to water: $143.26 \mathrm{ft}(43.67 \mathrm{~m})$ below TOC
Water olevation: $223.14 \mathrm{ft}(88.01 \mathrm{~m}) \mathrm{msl}$
Sp. conductance: $124 \mu \mathrm{s} / \mathrm{cm}$
Water evacuated before sampling: $437 \mathrm{gal}$
LABORATORYY ANALYSES

$$
\begin{aligned}
& \text { Time: } 9: 15 \\
& \text { pH: } 6.6 \\
& \text { Alkalinity: } 50 \mathrm{mg} / \mathrm{L} \\
& \text { Water temperature: } 19.0^{\circ} \mathrm{C}
\end{aligned}
$$

F Analyte

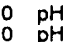

$\mathrm{p}_{0}^{\mathrm{pH}}$

Specific conductance

Specific conductance

Specific conductance

Acenaphthene

Acenaphthylene

Aluminum

Anthracene

Antimony

Arsenlc

Barlum

alpha-Benzene hexachloride

beta-Benzene hexachloride

delta-Banzene hexachloride

Benzidine

Benzolajanthracene

Benzola pyrene

Benzo b)fluoranthene

Benzo g, h, ilperylene

Beryllium

Beryllum

Bis 2-chloroethyl) ether

Bis 2-chloroethyl) ether

Bis (2-chloroisopropyl) ether

Bromide

Bromolorm

Bromomethane

Butylbenzyl phthalate

Cadmium

Calcium

Chlordane

para-Chloro-meta-cresol

Chlorobenzen

Chloroethene Minyl chloridel

Chlor

2-Chloroeth

Chloromethan

2-Chloronaphthalen

2-Chiorophenol

4-Chlorophenyl phenyl ethe

Chromium

Cobalt

Copper

P.P'-DDD

$p, p^{\prime} \cdot D D E$

Di-n-butyl phthalate

Dibenz $[a, h]$ anthracene

Dibromochloromethane

3,3'-Dichlorobenzidine

1,1-Dichloroethane

1,1-Dichtoroethylene

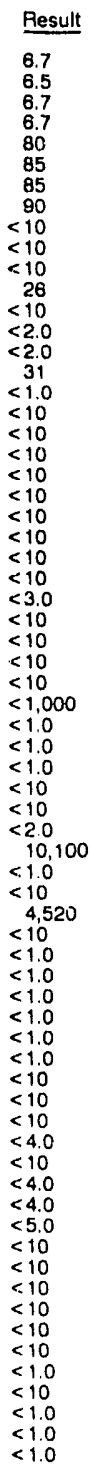

WELL AMB $10 \mathrm{~B}$ collected on 12/02/81, laboratory analyses (cont.)

F Analyte Result Mod

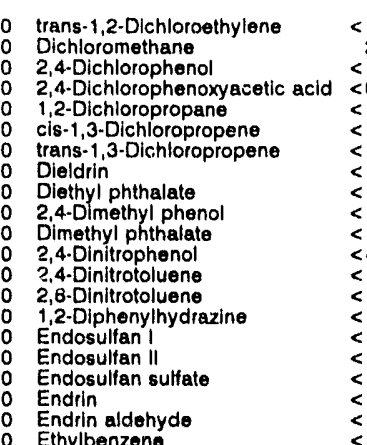

Ethylbenzeno $<1.0$

Fluoranthene

Fluoride $<100$

Heptachlor epoxide

Hexachlorobenzene $<10$

Hexachlorobutadiene

Hexachloroethane

0 Indeno[1,2,3-c,d]pyrene

Iron

Lead

Mindane

Magnesium

Mercury

2-Methyl-4,6-dinitrophenol

N-Nitrosodimethylamine

N-Nitrosodiphenylamine

N-Nitrosodi-propylamine

Naphthalen

Nitrate as nitrogen

Nitrobenzeno

2-Nitrophenol

4-Nitrophen
PCB 1016

O PCB 1221

0
0 PCB 1232

PCB 1248

PCB 1254

Pentachlorophenol

Phenanthrene

Phenol

P Potassium

Pyrene

0 Selenium

Silica
Silver

Sodium

Sodium

1,1,2,2-Tetrachloroethane

Tetrachloroethylene

Thallum

Total dissolved solids

Total organic carbon

Total organic carbon

Total organic carbon

Total organic halogens

Total organic halogens

Total organic halogens

Total organic halogens
Total phosphates las P

Total phosph

Toxaphene

$\begin{array}{lll}0 & 2,4,5-T P & \text { (Silvex) } \\ 0 & 1,2,4-T r i c h l o r o b e n z e n e\end{array}$

1,2,4-Trichlorobenzen

1,1,2-Trichloroethan

- Trichloroethylene

T Tichlorofluoromethane

$2,4,6-1$

Gross alpha

- Nonvolatile beta

- Total radium

Mesult Mod Unit Lat

2.9
$<10$

$<0.30$

$<1.0$

$<1.0$

$<10$

$<45$

$<10$

$<10$

(10

1.0

100
10
10
10

$<10$

$<10$
$<10$

$<10$

$<10$

$<3.0$
$<10$

634
19
6

$<0.20$
$<0.50$

$<10$

$<10$
$<10$

$<10$

$<10$
$<4.0$

160
$<10$

$<10$

$<10$

$<150$
$<150$

$<150$

$<150$

$<150$
$<150$

$<<150$

$<10$
$<10$

$<5.0$
1,830

$<10$
$<20$

$<2.0$
8,750

$<2.0$
5,770

5,770
1,420

$<1.0$
$<1.0$

$<2.0$

37,000

37,000
$<1,000$

$<1,000$
$<1,000$

$<1,000$

21
24

29
38

$<50$
$<10$

$<10$
$<0.090$

$<10$

$<1.0$

$<1.0$
$<1.0$

$<1.0$
$<10$

$<10$

2. 3 E- $00 \pm 1.0 \mathrm{E}-09$

$<2.0 \mathrm{E} .09$

$<1.0 \mathrm{E} \cdot 09$
$4.5 \mathrm{E}-06 \pm 7.0 \mathrm{E} \cdot 07$

Ja

$\begin{array}{ll}\mu \mathrm{g} / \mathrm{L} & \mathrm{GE} \\ \mu \mathrm{g} / \mathrm{L} & \mathrm{GE}\end{array}$

GE 
ANALYTICAL RESULTS

WELL AMB 1OD

MEASUREMENTS CONDUCTED IN THE FIELD

Sample date: 11/13/91

Depth to water: $131.36 \mathrm{ft}(40.04 \mathrm{~m})$ below TOC

Water elevation: $234.14 \mathrm{ft}$
$\mathrm{Sp}$. conductance: 52

Sp. conductance: $52 \mu \mathrm{s} / \mathrm{cm}$
Water evacuated before sampling: $39 \mathrm{gal}$

LABORATORY ANALYSES

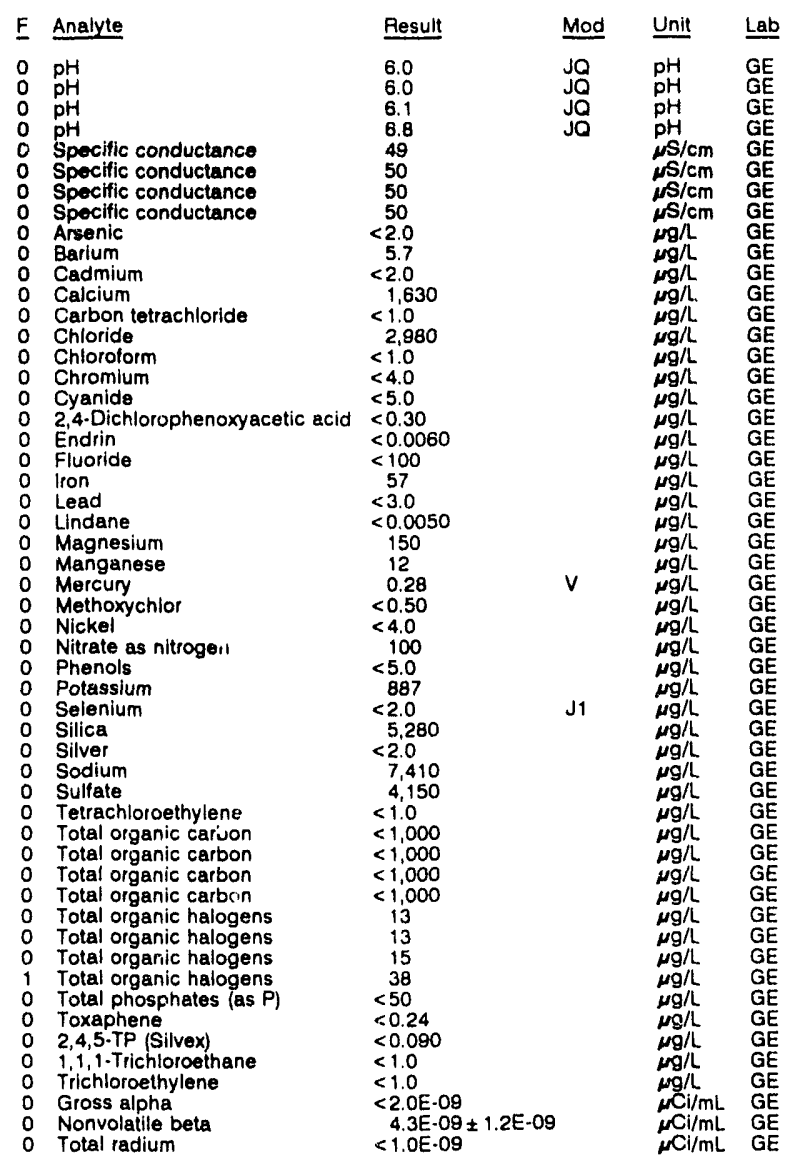

WELL AMB 10DD

MEASUREMENTS CONDUCTED IN THE FIELD

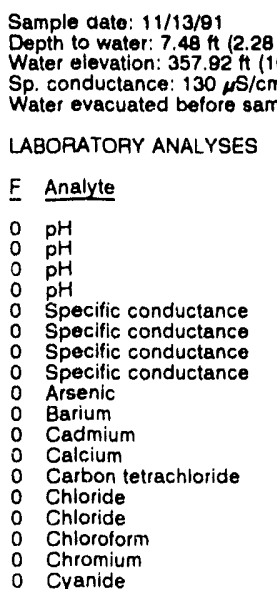

Time: 8:15

$\mathrm{pH}: 6.6$

Water temperature: $17.9^{\circ} \mathrm{C}$

Time: $7: 45$

Alk: 5.9 : $13 \mathrm{mg}$

Alkalinity: $13 \mathrm{mg} / \mathrm{L}$ : $14.8^{\circ} \mathrm{C}$ 
ANALYTICAL RESULTS

WELL AMB 118 collected on 12/02/91, laboratory analyses (cont.)

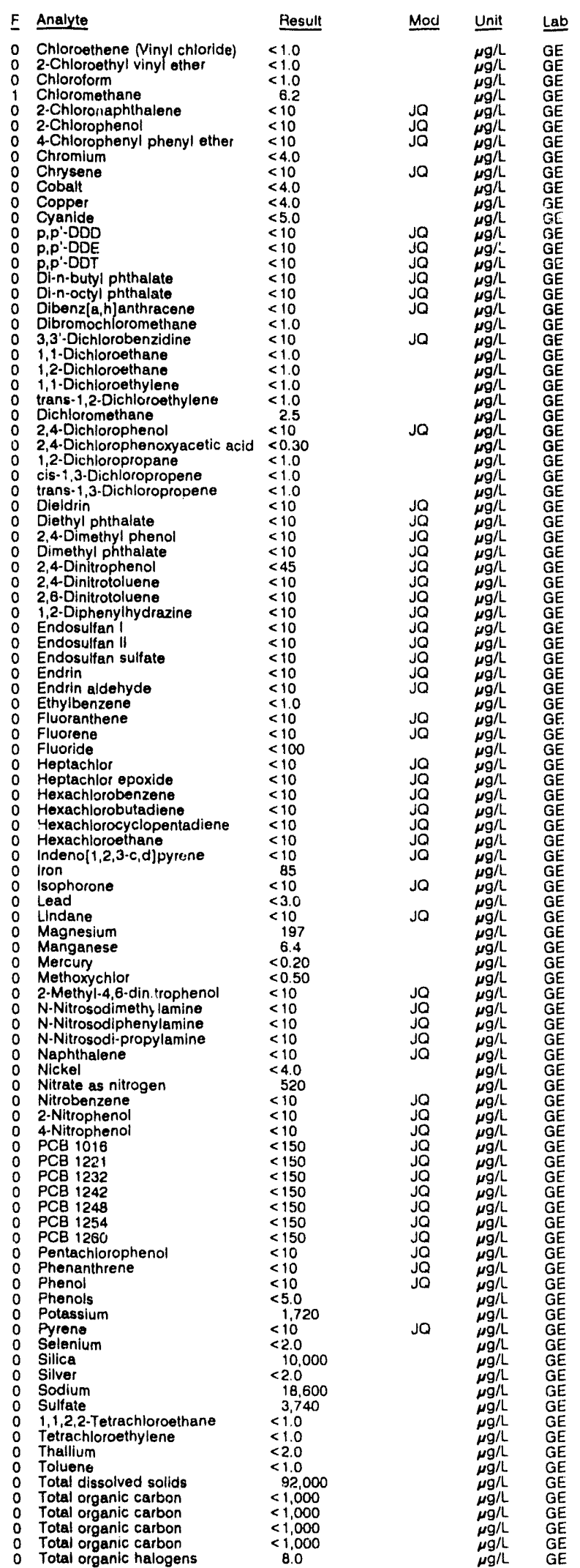

WELL AMB 118 collected on 12/02/91, laboratory analyses (cont)

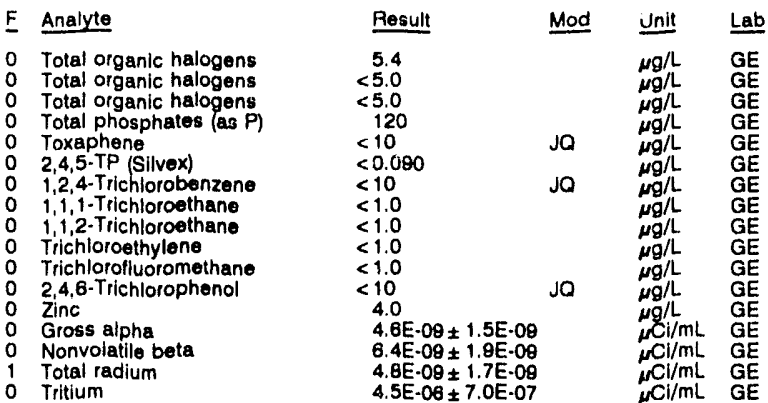

WELL AMB 11D

MEASUREMENTS CONDUCTED IN THE FIELD

$\begin{array}{ll}\text { Sample date: } 11 / 17 / 91 & \text { Time: } 13: 55 \\ \text { Depth to water: } 128.25 \mathrm{ft}(39.09 \mathrm{~m}) \text { below TOC } & \text { pH: } 8.4 \\ \text { Water elevation: } 235.75 \mathrm{ft}(71.86 \mathrm{~m}) \mathrm{msl} & \text { Alkalinity: } 21 \mathrm{mg} / \mathrm{h} \\ \text { Sp. conductance: } 64 \mu \mathrm{s} / \mathrm{cm} & \text { Water temperature: } 17.7^{\circ} \mathrm{C} \\ \text { Water evacuated before sampling: } 70 \mathrm{gal} & \end{array}$
LABORATORY ANALYSES

\begin{tabular}{|c|c|c|c|c|}
\hline Analyte & Result & Mod & Unit & Lab \\
\hline 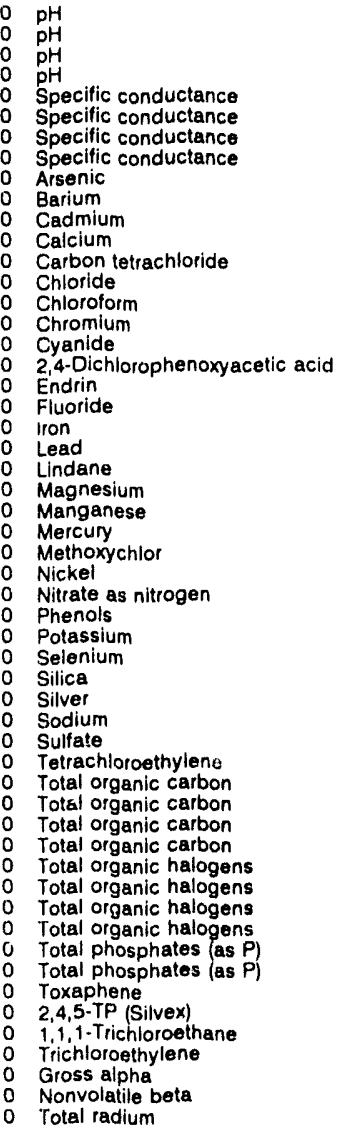 & $\begin{array}{l}6.4 \\
6.4 \\
6.6 \\
6.8 \\
50 \\
55 \\
70 \\
80 \\
<2.0 \\
13 \\
<2.0 \\
4.500 \\
<1.0 \\
2,700 \\
<1.0 \\
<4.0 \\
<5.0 \\
<0.30 \\
<0.0060 \\
<100 \\
11 \\
<3.0 \\
<0.0050 \\
68 \\
<2.0 \\
<0.20 \\
<0.50 \\
<4.0 \\
71 \\
<5.0 \\
<500 \\
<2.0 \\
7.080 \\
<2.0 \\
7.080 \\
4,230 \\
<1.0 \\
<1,000 \\
<1,000 \\
<1,000 \\
<1,000 \\
6.4 \\
6.6 \\
7.6 \\
17 \\
<50 \\
<50 \\
<0.24 \\
<0.090 \\
<1.0 \\
<1.0 \\
<2.0 \mathrm{E}-00 \\
<2.0 \mathrm{E}-08 \\
<1.0 \mathrm{E} \cdot 08\end{array}$ & $\begin{array}{l}\text { JQ } \\
\text { JQ } \\
\text { JQ } \\
\text { JQ }\end{array}$ & 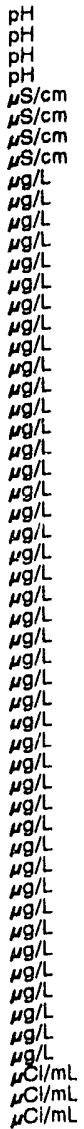 & $\begin{array}{l}G E \\
G E \\
G E \\
G E \\
G E \\
G E \\
G E \\
G E \\
G E \\
G E \\
G E \\
G E \\
G E \\
G E \\
G E \\
G E \\
G E \\
G E \\
G E \\
G E \\
G E \\
G E \\
G E \\
G E \\
G E \\
G E \\
G E \\
G E \\
G E \\
G E \\
G E \\
G E \\
G E \\
G E \\
G E \\
G E \\
G E \\
G E \\
G E \\
G E \\
G E \\
G E \\
G E \\
G E \\
G E \\
G E \\
G E \\
G E \\
G E \\
G E \\
G E \\
G E \\
G E \\
G E\end{array}$ \\
\hline
\end{tabular}




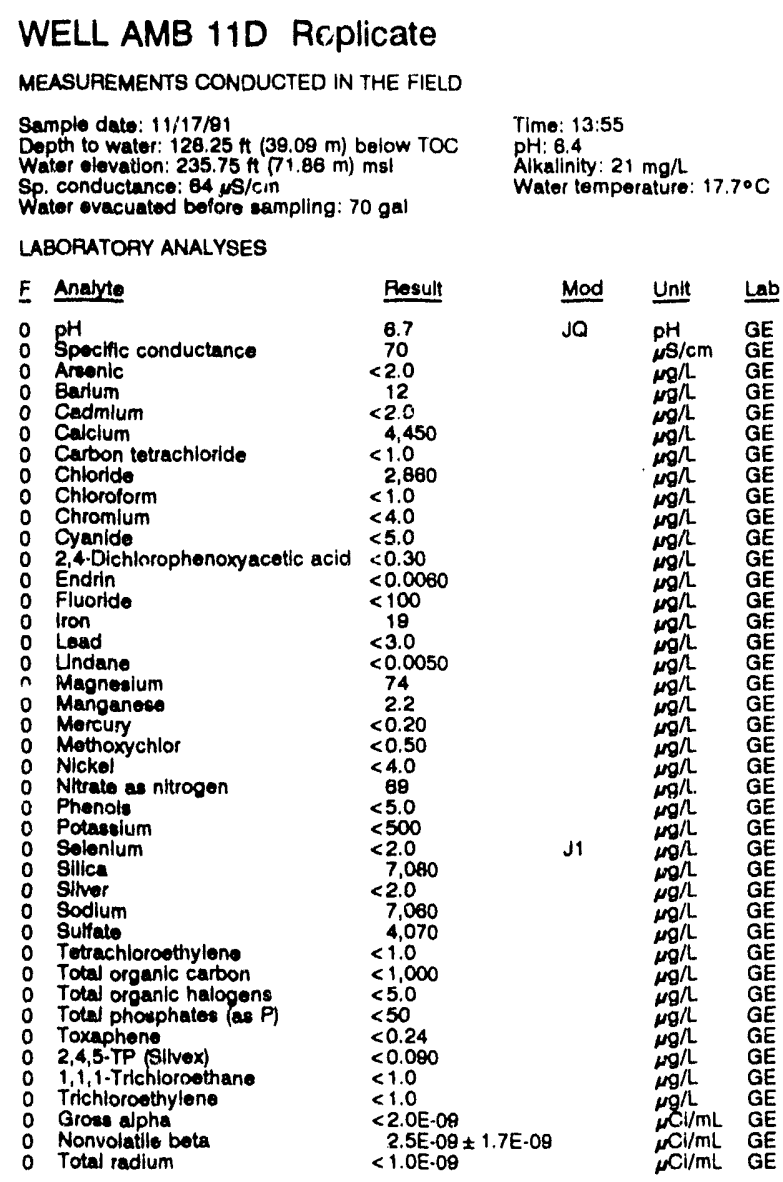

WELL AMB 12D

MEASUREMENTS CONDUCTED IN THE FIELD

Sample date: 11/14/91

Dopth to water: $137.50 \mathrm{Ht}(41.81 \mathrm{~m})$ below TOC Wator olevation: $232.30 \mathrm{ft} 170.81$
Sp. conductance: $80 \mu \mathrm{s} / \mathrm{cm}$

Sp. conductance: $80 \mu \mathrm{H} / \mathrm{cm}$
Water ovacuated before sampling: $34 \mathrm{gal}$

LABORATORY ANALYSES

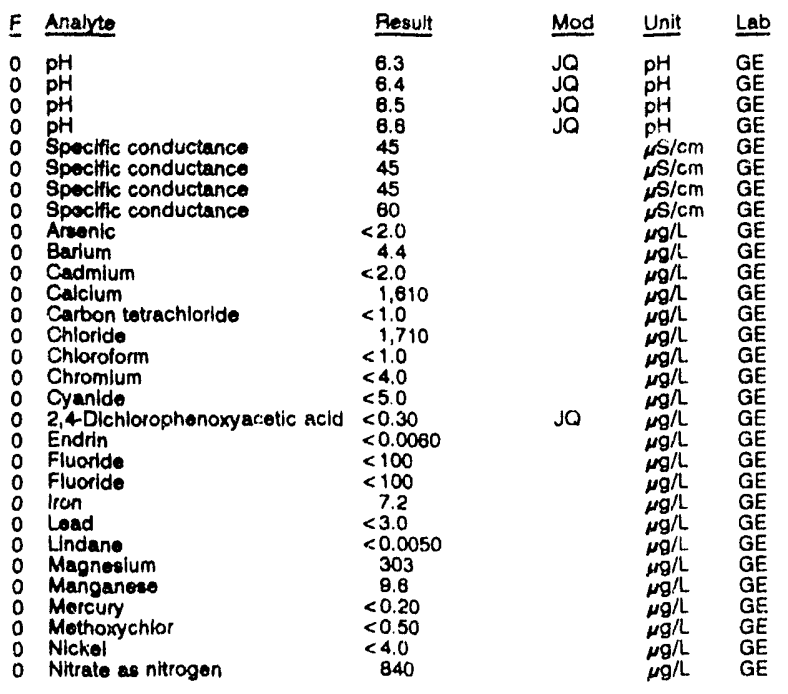

WELL AMB 120 collected on 11/14/91, laboratory analyses (cont.)
$E$ Analve.

o Phenols

0 Potassium

Silica

Silver

Sodium

Tulfate

Total organic carbon

Total organic carbon

Total organic carbon

Total organic carbon

Total organic halogens
Total organic halogens

Total organic halogens

Total organic halogens

Total phosphateo as P)

0 Total phosphates (as P)

Toxaphene

Trichloroethylene

2 Gross alpha

O Nonvolatile bote
1,4,5. -Trichloroet

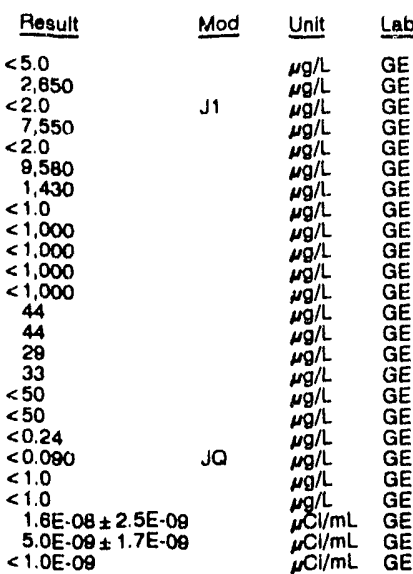

WELL AMB 13AR

MEASUREMENTS CONDUCTED IN THE FIELO

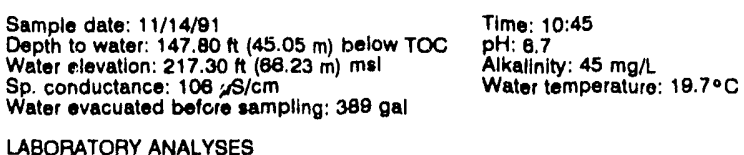

LABORATORY ANALYSES

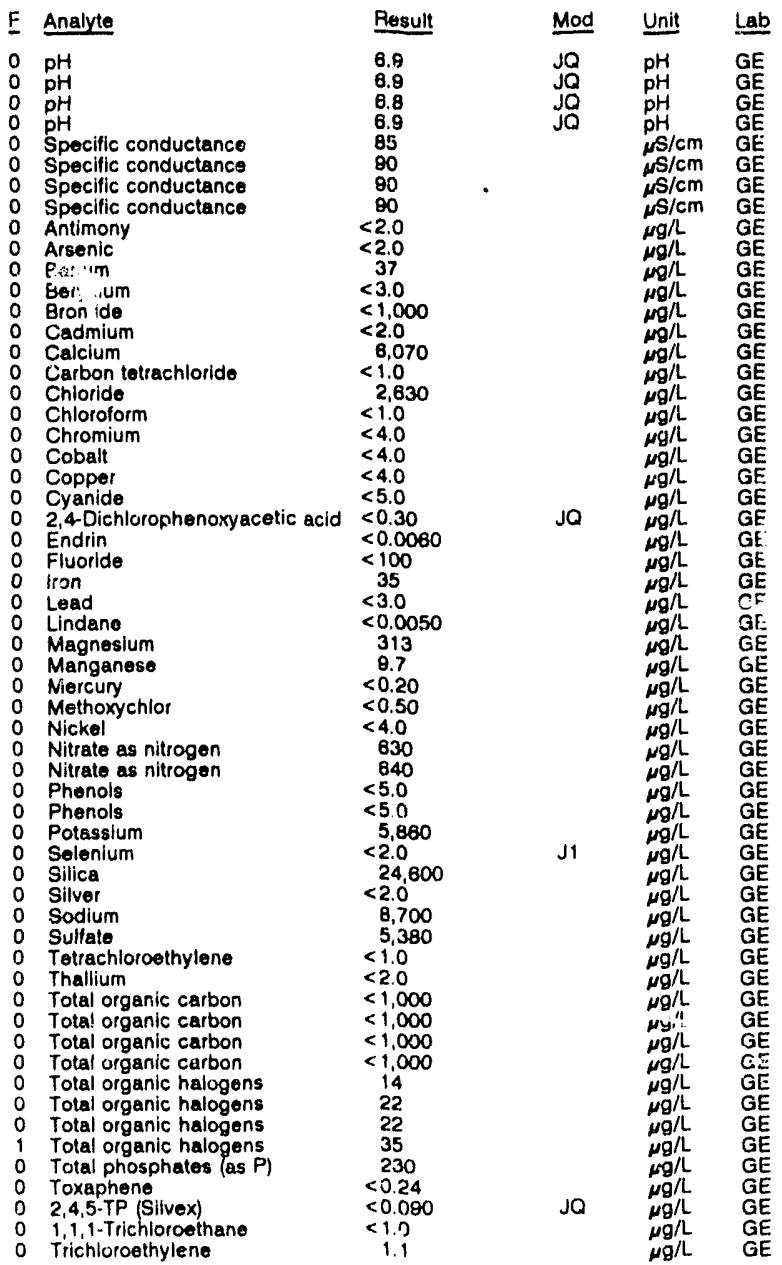


ANALYTICAL RESULTS

WELL AMB 13AR collected on 11/14/91, laboratory analyses (cont.)

\begin{tabular}{|c|c|c|c|c|}
\hline$F$ & Analyte & Result & Mod & Unit \\
\hline $\begin{array}{l}2 \\
0\end{array}$ & $\begin{array}{l}\text { Zinc } \\
\text { Zinc } \\
\text { Gross alpha } \\
\text { Nonvolatile beta } \\
\text { Total radium }\end{array}$ & $\begin{array}{l}2.3 \\
2.5 \\
3.7 E-08 \pm 3.9 \mathrm{E}-09 \\
1.1 \mathrm{E}-08 \pm 2.1 \mathrm{E}-09 \\
2.5 \mathrm{E} \cdot 09 \pm 1.7 \mathrm{E}-09\end{array}$ & & $\begin{array}{l}\mu g / \mathrm{L} \\
\mathrm{mg} / \mathrm{L} \\
\mathrm{N} \mathrm{L} / \mathrm{mL} \\
\mathrm{NCl} / \mathrm{mL} \\
\mathrm{NCi} / \mathrm{mL}\end{array}$ \\
\hline
\end{tabular}

NELL AOB 1

MEASUREMENTS CONDUCTED IN THE FIELD

Sample date: $11 / 13 / 81$
Depth to water: $104.76 \mathrm{H}(31.83 \mathrm{~m})$ below TOC
Water elevation: $236.34 \mathrm{ft}(72.04 \mathrm{~m}) \mathrm{msl}$
Sp. conductance: $41, \mathrm{~s} / \mathrm{cm}$
Water evacuated kefore sampling: $47 \mathrm{gal}$

Time: $9: 30$

pH: 5.0

Water temperature: $15.8^{\circ} \mathrm{C}$

LABORATORY ANALYSES

\section{F Analyte}

O Acenaphthene

Acenaphe

Acetonitrile (Methyl cyanide)

2-Acetylaminofluorene

Acrolein

Acrylonitile

Allyl chloride

Aniline

Anthracene

Aranite

Arsenic

Barium

aipha-Benzene hexachloride

beta-Benzene hexachloride

delta-Benzene hexachloride

Benzo[ajanthracen

Benzo a pyrene

Benzo [g, hilperylene

Benzyl alcohol

Beryllium

Bis (2-chloroethoxy) methane

Bis 2-chloroethyl) ether

Bis (2-ethylhexyl) phthalate
0 Bromodichloromethane

Bromoform

Bromomethane
4.Bromophenyl phenyl ether

2-soc-Butyl-4,6-dinitrophenol

Butylbenzyl phthaiate

Cadmium

Carbon disulfide

2,3,7,8-TCDF

$\begin{array}{ll}0 & \text { Chlordane } \\ 0 & \text { para-Chloro-meta-cresol }\end{array}$

Chlorobenzene

Chlorobenzilate

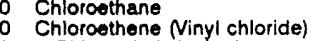

2.Chioroethyl viriyl ether

Chloroform

O Chloroform

$\begin{array}{ll}0 & \text { 2-Chloronaphth } \\ 0 & \text { 2-Chlorophenol }\end{array}$

$\begin{array}{ll}0 & \text { 2-Chlorophenol } \\ 0 & 4 \text {-Chlorophenyl phenyl ether } \\ 0 & \text { Chloroprene }\end{array}$

0 Chromiuin

o Ehrysene

0 Cobalt

$\begin{array}{ll}0 & \text { Copper } \\ 0 & \text { o-Cresol (2-Methylphenol) } \\ 0 & \text { m-Cresol (3-Methylphenol) }\end{array}$

p-Cresol (4-Methylphenol)

0 Cyanide

$\begin{array}{ll}0 & p, p^{\prime}-D D D \\ 0 & p, p^{\prime}-D D E\end{array}$

$<10$

Dirri-octyl phthalate $<10$

Didenzia,hjanthracene $<10$

0 Dibenzoturan < 10

1,2-Dibromo-3-chloropropane $<1,9$

Dibromochloromethane $<20$

Dibromomethane

trans-1,4-Dichloro-2-butene
Result Mod Unit Lab

$<10$

$<100$

$<10$

$<2 C$

50

$<10$

$<10$

2.0

$<1.0$

$<0.050$

$<10$

$<10$

$<10$
$<10$

$<3.0$

$<10$
$<10$

$<10$
$<10$

$<1.0$

$<10$

$<10$

$<2.0$
$<1.0$
$<1.0$

$<0.00040$

$<0.50$

$<10$

10

$<1.0$
$<1.0$

$<1.0$

$<1.0$

$<10$

$<10$
$<10$

$<200$

$<4.0$
$<4.0$

$<4.0$

$<10$

$<10$
$<5.0$

0
0
1.0
1.0
30

$\begin{array}{ll}\mu \mathrm{g} / \mathrm{L} & \mathrm{GE} \\ \mu \mathrm{g} / \mathrm{L} & \mathrm{GE} \\ \mu \mathrm{g} / \mathrm{L} & \mathrm{GE} \\ \mu \mathrm{g} / \mathrm{L} & \mathrm{GE} \\ \mu \mathrm{GE} / \mathrm{L} & \mathrm{GE}\end{array}$

WELL AOB 1 collected on 11/13/81, laboratory analyses (cont.)

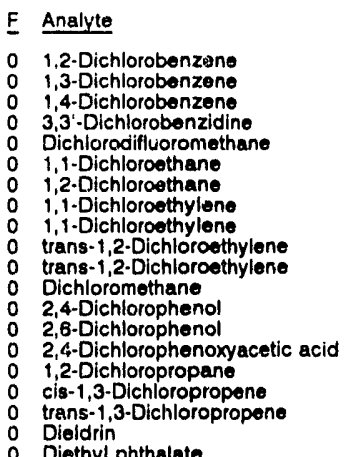

$\begin{array}{ll}\quad & <1.0 \\ & <0.50\end{array}$

$\begin{array}{ll}\text { Diethyl phthalate } & <10 \\ \text { Dimethoate } & <10\end{array}$

2,4-Dimethyl phenol $<10$

$\begin{array}{ll}\text { Dimethyl phthalate } & <10 \\ \text { p-Dimethylaminoezzobenzene } & <10\end{array}$

p-Dimethylaminoenzobenzene

3,3'-Dimothylbenzidine

a,a-Dimethylphenethylamine $<10$

1,3-Dinitrobenzene

2,4-Dinitrophenol

2,6-Dinitrotoluene

1,4-Dioxane

Diphenylamine

Endosulfan

Endosulfan II

Endozulfan sulfate

Endrin

Endrin aldehyde

Ethyl methanesulfonate

Ethylbenzene

Famphur

Fluoranthen

Heptachlor

Heptachlor

1,2,3,4,6,7,8-HPCDD

Heptachlorodibenzo-p-furans
0

O Hexachlorobenzene

- Hexachlorobutadiene

o Hexachlorocyclopen

Hexachlorodibenzo-p-dioxins

$1,2,3,4,7,8 \cdot \mathrm{HXCDF}$

Hexachlorodlbenzo-p-furans

Hexachlnroethane

Hexachlorophene

2-Hexanop

2-Hexanone
0 Indeno[1,2,3-c,d]pynt 1e

Iodomethane (Methyl ivdide)

Isobutyl alcohol

Isodrin

0 isophorone

0 isosafrole

0 Kepone

Lead

0 Lindane

M Mercury

Methapyrilene

Methoxychlor
Methyl ethyl ketone

Methyl ethyl ketone

Methyl isobutyl ketone

Methyl mothanesulfonate

2-Methyl-4,6-dinitrophenol

3-Methylcholarthrene

2-Methylnaphthalene

N-Nitrosodiethylamine

N-Nitrosodimethylamine

N-Nitrosodi-n-butylamine

- N-Nitrosodiphenylamine

o N-Nitrosodi-propylamine

N-Nitrosomethylethylamine

N-Nitrosomorpholine

N-Nitrosopiperidine

N-Nitrosopyrrolidine

Naphthalene

1,4-Naphthoquinone

1-Naphthylamine

2-Naph

Nickel

5-Nitro-0-toluidin

2-Nitroanliline

$\begin{array}{ll}0 & 3-N \text { Nitroaniline } \\ 0 & \text { 4-Nitroaniline }\end{array}$
Rosult $\quad$ Mod Unit

$<10$

$<10$

$<1.0$

$<1.0$

$<1.0$

$<1.0$

$<1.0$

$<1.0$

$<10$

$<10$
$<0.30$
$<1.0$

$<1.0$

GE

GE

GE

$M A$

GE

GE

GE

$\mu g /$ GE

$<10$
$<<10$
$<10$

$<10$
$<45$
$<45$

$<45$
$<10$
$<10$

$<10$
$<10$

$<10$
$<10$
$<10$

$<0.10$
$<0.10$

$<0.10$

$<0.0080$
$<0.10$

$<0.0060$
$<0.10$
$<10$

$<10$

$<1.0$

$<10$
$<10$

$<0.050$

$<0.00065$

$<0.00085$

$<0.00045$

$<10$
$<10$

$<10$
$<0.00045$

$<0.00045$

$<0.00040$

$<10$
$<10$

$<10$
$<10$
$<10$

$<1.0$

$<10$
$<15$
$<100$

$<100$

$<10$
$<10$

$<10$
$<10$
$<10$

$<3.00$

0.35

$<50$
$<10$

$<0.50$
$<1.0$
$<1.0$
$<10$

$<10$

$<10$
$<10$
$<10$

$<<10$

$<10$
$<10$

$<10$
$<10$
$<10$
$<10$

$<10$
$<10$
$<10$

$<10$

$<10$
$<10$

$<100$

$<10$

$<10$
$<10$
$<10$

$<10$

$<4.0$

$<10$
$<10$
$<10$
$<10$

$<10$
$<10$ 
WEL AOB 1 collocted on 11/13/91, laboratory analyses (cont.)

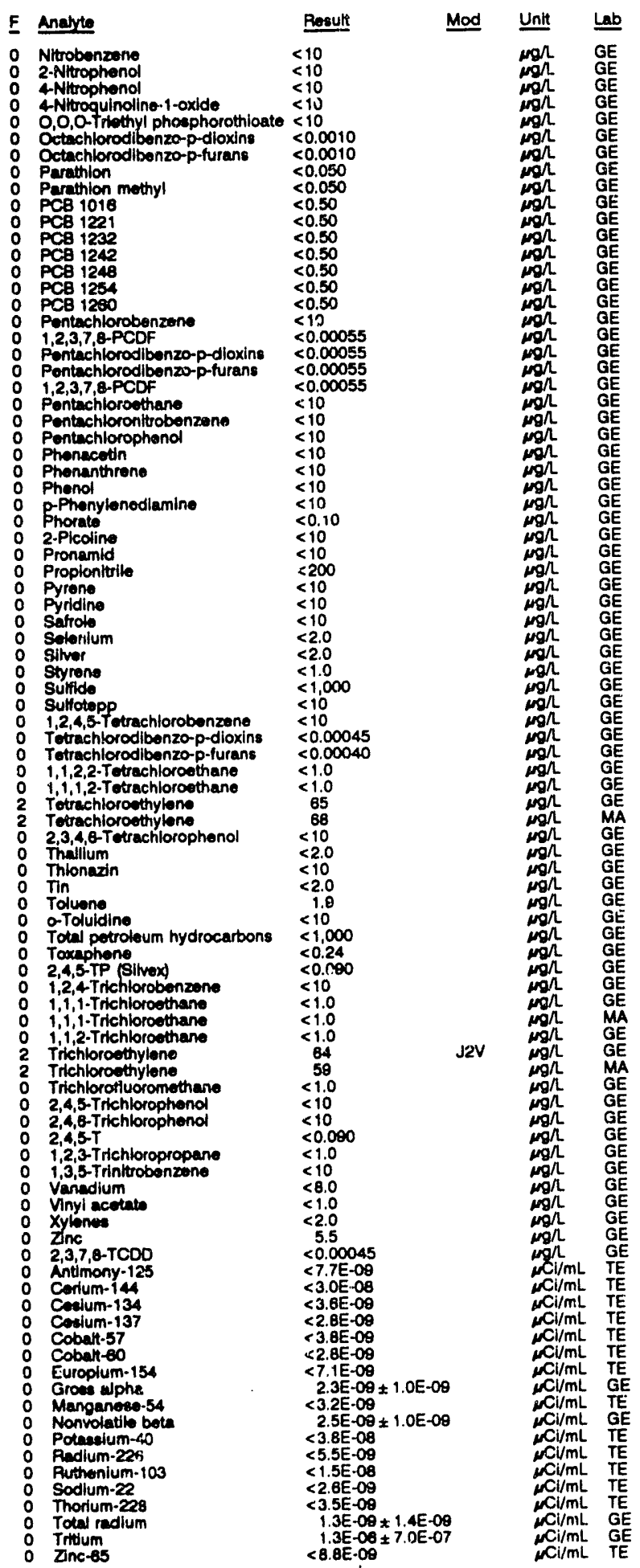

WELL AOB 1 Replicate

MEASUREMENTS CONOUCTED IN THE FIELD

Sample date: 11/13/91

Depth to water: $104.78 \mathrm{n}(31.83 \mathrm{~m})$ below TOC

Water olevation: $23.34 \mathrm{~h} n \mathrm{~T}$

Water evacualed before sampling: $47 \mathrm{gal}$

$\mathrm{pH}: 5.0$

ity: $2 \mathrm{mg} / \mathrm{L}$

ABOPATORY ANALYSES

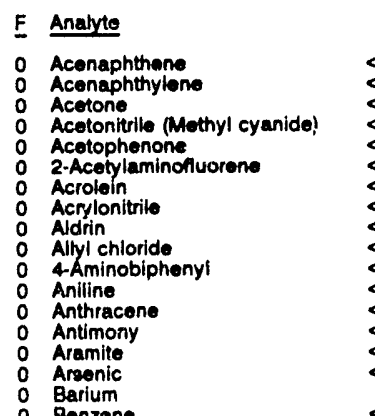

Pesult

$<10$
$<10$

$<10$
$<100$
$<1.0$

$<10$

$<10$

$<20$

$<0.050$
$<10$
$<10$

$<10$

$<2.0$

$<10$
$<2.0$
13

Barium

alpha.Benzene hexachloride

$\begin{array}{ll} & <.050 \\ \text { beta-Benzene hexachloride } & <0.050 \\ \text { defita-Benzene hexachloride } & <.050\end{array}$

Benzojajanthracene $\quad \leq 10$

$\begin{array}{ll}\text { Benzo ajpyrene } & <10 \\ \text { Benzo bj fluoranthene } & <10 \\ & <10\end{array}$

Benzolg, hiljperylene $<10$

$\begin{array}{ll}\text { Benzolkjfluoranthene } & <10 \\ \text { Benzyl alcohol } & <10\end{array}$

Beryllum $<3.0$

Bis (2-chlorisopropy) ether
Bis (2-chlorosthoxy) methane

Bis 2-chloroethyl) ether $<10$

Bis 2-othylhoxyl) phthalate $\quad<10$

Bromolorm

Bromomethane

4. Bromophenyl phenyl other <1

2-soc-8utyl-4, 8 -dinitrophenol $\leq 10$

Butylbenzyl phethalate $\quad<10$

Carbon disulfide $\quad<1.0$

$\begin{array}{ll}\text { Carbon totrachlorido } & <1.0 \\ 2,3,7,8-\text { TCDF } & <0.00040\end{array}$

2,3,7,8-TCDF

para-Chloro-meta-cresol $<10$

4-Chloroaniline $<10$

Chlorobenzene

Chlorobenzilato

Chloroethene Minyl chloride)

2-Chloroethyl vinyl other

Chloroform

Chlorolorm

Chloroform

Chloromethane

2-Chloronaphthe
2-Chlorophenol

4-Chlorophentyl phenyl ether

Chloroprene

Chromium

Cobatt

o-Cresol (2-Mathyiphenol)

m-Cresol (3-Methylphenol)

m-Cresol (3-Methylphenol)
p-Cresol (4-Methylphenol)

Cyanide

P.P.'DD

P,P.DDE

bi:-n-butyl phthaiate

Di-n-octyl phthalate

Dibenz[a,h]anthracene

Dibenzofuran

1,2-Dibromo-3-chloropropane

Dibromochloromethane

1,2-Dibromoethan

trens-1,4-Dichloro-2-butene

i. Dichlobonzente

1,4-Dichlorobenzene

3,3'-Dichlorobenzidine

Dichlorodifluoromethane

1,1-Dichloroethane

1,2-Dichlorosthane

o 1,1-Dichloroethylene

Mod

$\begin{array}{ll}\mu g h & G E \\ \mu g h & G E \\ \mu g h & G E \\ \mu g h & G E \\ \mu g h & G E \\ \mu g h & G E \\ \mu g h & G E \\ \mu g h & G E \\ \mu g h & G E \\ \mu g h & G E\end{array}$

GE

GE

GE 
ANALYTICAL RESULTS

WELL AOB 1 collectod on 11/13/91, laboratory analyses (cont.)

\section{F Analyto}

o 1,1-Dichloroethylene

0 trans-1,2-Dichloroethyiene

0
0
0

- Dichloromettiane

2,4-Dichlorophenol

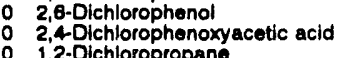

o cis-1,3-Dichloropropene

cls-1,3-Dichloropropene $<1,0$

D Diethyl phthalate

o Dimethoate

2 2,4-Dimethyl phenol

o p-Dimethylaminoazobenzene

o Dimethylbenz[a]anthracene

3,3-Dimethylbenzidine

o 1,3-Dinitrobenzene

2 2,4-Dinitrophonol

2,4-Dinitrotoluene

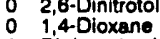

O Diphenylamine

o Disulfoton

- Endosulfan 1

- Endosulfan II

0 Endosultar

Endrin aldehyde

Ethyl mothacrylate

Ethy! methanesulfonate

Ethylbenzene

Fluoranthene

Fluorene

Heptachlor

Heptachlor epoxide

Heptachlorodibenzo-p-dioxins

$1,2,3,4,6,7,8-H P C D F$

Heptachlorodibenzo-p

Hexachlorobenzene

Hexachlorocyclopentadiene

$1,2,3,4,7,8 \cdot H \times C D D$

Hoxachlorodibonzo-p-dioxins

$1,2,3,4,7,8-H X C D$

Hexachlorodibenzo-p-furans

Hexachloroethane

Hexachloropropene

2-Hexanone

indeno $[1,2,3-c, d] p y r e n e$

indono[1,2,3-c,d]pyrene

isobutyl alcohol

isodrin

lsophorone

lsosafrole

Lead

Lindane

Mercury

Methacrylonitril

Methapyrilene

M-sul ethyl ketone

$\mathrm{M}, \cdots, 1$ isobutyl ketone

A. - id methacrylate

2-Methy|-4,6-dinitrophenol

3-Methylcholanthrene

2-Methylnaphthalene

N-Nitrosodimethylarnine

N-Nitrosodi-n-butylamine

N-Nitrosodiphenylamine

N-Nitrosod-propylamine

$\mathrm{N}$-Nitrosomorpholine

iv-Nitrosopiperidine

N-r litrosopyrtolid

1.4-Naphe

1-Naphthylamine

2-Naphthylamine

Nickel

5-Nitro-0-toluidine

2-Nitroaniline

3-Nitroaniline

Nitrobenzene

2-Nitropheno

4Nitrophenol

4-Nitroquinoline-1-oxide $<10$

0,0 . Triethyl phosphorothioate $<10$

$\begin{array}{ll}\text { Octachlorodibenzo-p-dioxins } & <0.0010 \\ \text { Octachlorodibenzo-p-furans } & <0.0010\end{array}$
$<1.0$

$<1.0$

$<1.0$

10

$<0.30$

$<1.0$
$<0.50$

10

$<10$

$<10$

$<10$

$<45$

10

$<10$

$<10$
$<10$

$<0.10$
$<0.10$

$<0.10$

$<0.0060$

$<10$

$<10$

$<1.0$
$<10$

$<10$
$<10$

$<0.050$
$<0.050$

$<0.00465$

$<0.00065$

$<0.00045$

$<10$

$<10$
$<0.00045$

$<0.00045$

$<0.00040$

$<10$

$<10$

$<1.0$

$<15$

$<100$

$<10$
$<10$

$<10$

$<3.0$
$<0.0050$

0.24

$<50$

$<0.50$

$<1.0$

$<10$

$<10$

$<10$

$<10$

$<10$
$<10$

$<10$

$<10$

$<10$
$<10$

$<10$
$<10$

$<10$
$<10$

$<10$
$<10$

$<10$
$<10$

$<40$

$<10$
$<10$

$<10$

$<10$

$<10$

$<10$

\section{Mod Unit Lab}

$\mu \mathrm{mg} / \mathrm{MA}$

GE

WELL AOB 1 collected on 11/13/91, laboratory analyses (cont)

$\begin{array}{ll}\text { F } & \text { Analyte } \\ 0 & \text { Parathion } \\ 0 & \text { Parathion methyl } \\ 0 & \text { PCB } 1018 \\ 0 & \text { PCB } 1221 \\ 0 & \text { PCB } 1232 \\ 0 & \text { PCB } 1242 \\ 0 & \text { PCB } 1248 \\ 0 & \text { PCB } 1254 \\ 0 & \text { PCB } 1260 \\ 0 & \text { Pentachlorobenzene } \\ 0 & 1,2,3,7,8-P C D F \\ 0 & \text { Pentachlorodibenzo-p-dioxins } \\ 0 & \text { Pentachlorodibenzo-p-furans }\end{array}$

Result Mod Unit Lab

$<0.050$

$<0.050$

$<0.50$

$<0.50$

$<<.50$

$<0.50$

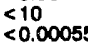

Pentachlorodibenzo-p-furans

1,2,3,7,8-PCDF

Pentachloronitrobenzene

Pentachlorophenol

Phenacetin

Phananthron
Phenol

p-Phenylenediamine <

2-Picoline

o Pronamid

Propionitite

0 Pyridine

Selenium

Silver

0 Styrene

0 Sulfide

1,2,4,5-Tetrachlorobenzene

Tetrachlorodibenzo-p-dioxins

1,1,2,2-Tetrachloroothane

o 1,1,1,2-Tetrachloroethane

2 Tetrachloroethylene

2 Tetrachloroothylene

2,3,4,6-Tetrachlorophenol

0 Thallium

0 Tin

o Toluene

$\begin{array}{ll}0 & \text { Toluene } \\ 0 & \text { o-Toluidine } \\ 0 & \text { Total petroleum hydrocarbons }\end{array}$

O Toxapherie

$\begin{array}{ll}0 & 2,4,5 . T P \\ 0 & 1,2,4 \text {-Trishlorex) } \\ 0 & 1,1 \text {. Trichloroenzene }\end{array}$

1,1,1-Trichloroethane

o $1,1,1$-Trichloroethane

1,1,2-Trichloroethane

2 Trichioroethylene

2 Trichloroethylone

2 Trichloroethylene

Trichlorofluoromethan

2,4,5-Trichlorophenol

2,4,6-Trichlo

$\begin{array}{ll}2,4,5-T \\ 0 & 1,4,3-T \text { Trichloropropane }\end{array}$

1,3,5-Trinitrobenzene

O Vanadium

0 Vinyl acetato

0 Xylenes

2,3,7,8-TCDD

0 Antimony-125

0 Cerium 144

O Cesium-134

0 Cobalt-57

0 Cobalt-60

- Europium-154

0 Gross alpha

- Manganese-54

- Nonvolatile beta

Potassium.40

0 Radium-226

O Ruthenium-

Thorium-228

1 Total radium

a Zinc-65

\section{$<0.00055$}

$<0.00055$

$<0.00055$
$<0.00055$
$<10$

$<10$

$<10$

$<10$
$<10$
$<10$

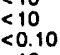

$<10$
$<10$

$<10$

$<200$
$<10$
$<10$

$<10$

$<10$
$<2.0$
$<2.0$

$<1.0$

$<1,000$

$<10$

$<0.00045$

$<0.000$
$<1.0$
$<1.0$

65
59
61
$<10$

$<10$
$<2.0$
$<10$

$<10$
$<2.0$
2.5

$<10$

$<1,000$
$<0.24$
$<0.080$

$<0.080$
$<10$
$<1.0$

$<1.0$

$<1.0$

$<1.0$
65
53

56
$<1.0$
$<10$

$<10$
$<10$ 
ANALYTICAL RESULTS

WELL AOB 2

MEASUREMENTS CONDUCTED IN THE FIELD

Sample date: 11/13/9

Dopth to water: $108.23 \mathrm{ft}(32.89 \mathrm{~m})$ below TOC

Sp. conductance: $237.17 \mathrm{tt}$ (72.

Water ovacuated before sampling: $45 \mathrm{gal}$

LABORATORY ANALYSES

F Analyte

- Acenaphthene

Acenaphthylene

Aldrin

Anthracene

Arrenic

Barlum

alpha-Benzene hexachloride

beta-Benzene hexachloride

delta-Benzane hexachlorido

Bonzo a pyrone

Benzolg, $h, 1]$ perylene

Benzo $k$, fiuoranthen

Borylium

Bis (2-chloroethoxy) methane

Bls (2-chloroethyl) other

Bis

Bromodichloromethane

Bromoform

列

Butylbenzyl phthalate

Carbon tetrachloride

Chlorlde

pera-Chloro-meta-cresol

Chlorobenzen

Chloroethene Ninyl chloride)

2.Chloroethyl vinyl other

Chlorm

Chloromen

2-Chloronaphthalene

2-Chlorophenol

4-Chlorophenyl phenyl ethe

Chrysene

0 Cobalt

Copper

$\begin{array}{ll}0 & p^{2}, p^{\prime} \cdot D O E \\ 0 & 0 D T\end{array}$

Di-n-butyl phthalate

Dibenz (a, h) anthracene

Dibromochloromethan

1,1-Dichloroethane

o 1,2-Dichloroethane

- 1,1-Dichloroethylene

1,1.Dichloroethylene

trans-1,2-Dichloroethylene

Dichloromethane

2,4-Dichlorophenol

1,2-Dicnloropropane
cis-1,3-Dichloropropene

trans-1,3-Dichioropropene

Diethyl phthalate

2,4-Dimethyl phenol

Dimethyl phthalate

2,4-Dinitrophenol

2,6-Dinitrotoluene

1,2-Diphenylhyc

Endosultan 11

Endosulfan sulfate

Endrin

Endrin aldehyde

Ethylbenzene

Fluoranthene

Fluorene

Fluoride

Fluorido

Heptachlor epoxide

Hexachiorobenzene

$i_{i 2}$ <achlorocyclopentadiene

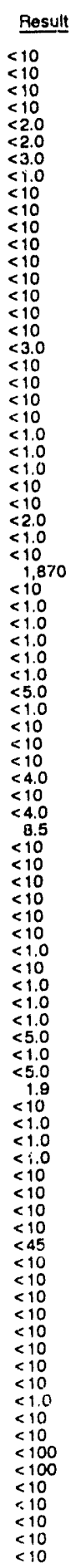

Time: 10: 5

pH: 5.3

Water temperature: $178^{\circ} \mathrm{C}$

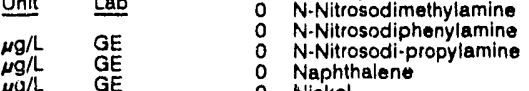

o Naphthalene

N Nitrate as nitrogen

- Nitrobenzens

2.Nitropheno

4-Nitrophen

D PCB 1018

O PCB 1232

- $P C B 1242$

PCB 1248

PCB 1250

Pentachlorophenol

Phenanthrene

Phenol

Selenium

Silver

Sodium

Sulfate

1,1,2,2-Tetrachloroethane

Tetrachlorvethylene

Thallium

Tin

Toluene
Total petroleum hydrocarbons

Toxaphene

1,1,1-Trichloroethane

1,1,1-Trichloroethane

1,1,2-Trichloroethan

Trichloroethylene

Trichlorofluoromethane

2,4,6-Trichlorophenol

Vanadicm

Xylenes

Antimony-125

Cerium-144

Cesium-134

Cobalt 57

Cobalt-60

Europium-154

Gross alpha

Mans dnese-54

Nonvo'atile beta

Potassium-40

Radium-226

Ruthenium-103

0 Sodium-22

Thorium-228

1 Tritium

J2V

WELLL AOB 3

MEASUREMENTS CONDUCTED IN THE FIELD

Depth to water: 114.28 H $(34.83 \mathrm{~m})$ below TOC

Water elevation: $238.32 \mathrm{ft}(72.64 \mathrm{~m}) \mathrm{msl}$

Sp. conductance: $33 \mu \mathrm{S} / \mathrm{cm}$

Tater evacuated before sampling: $13 \mathrm{gal}$

LABORATORY ANALYSES

\begin{tabular}{|c|c|c|c|}
\hline Analyte & Result & Mod & Unit \\
\hline $\begin{array}{l}\text { Acenaphthene } \\
\text { Acenaphthylene } \\
\text { Acetone } \\
\text { Acetonitrile (Methyl cyanide) } \\
\text { Acetophenone } \\
\text { 2.Acetylaminofluorene } \\
\text { Acrolein } \\
\text { Acrylonitrile } \\
\text { Aldrin } \\
\text { Allyl chloride } \\
\text { 4. Aminobiphenyl } \\
\text { Aniline } \\
\text { Anthracene }\end{array}$ & $\begin{array}{l}<10 \\
<10 \\
<100 \\
<10 \\
<10 \\
<10 \\
<20 \\
<20 \\
<0.050 \\
<50 \\
<10 \\
<10 \\
<10\end{array}$ & & $\begin{array}{l}\mu g / L \\
\mu g / L \\
\mu g / L \\
\mu g / L \\
\mu g / L \\
\mu g / L \\
\mu g / L \\
\mu g / L \\
\mu g / L \\
\mu g / L \\
\mu g / L \\
\mu g / L \\
\mu g / L\end{array}$ \\
\hline
\end{tabular}

Time: $6: 45$

pH: $5.3 .5 .5 \mathrm{mg}$

Water temperature: $16.7^{\circ} \mathrm{C}$

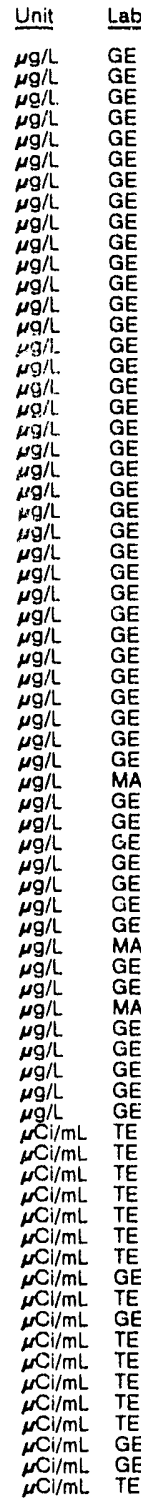

$\mathrm{GE}$ 
ANALYTICAL RESULTS

WELL. AOB 3 collected on 11/15/91, laboratory analyses (cont.)

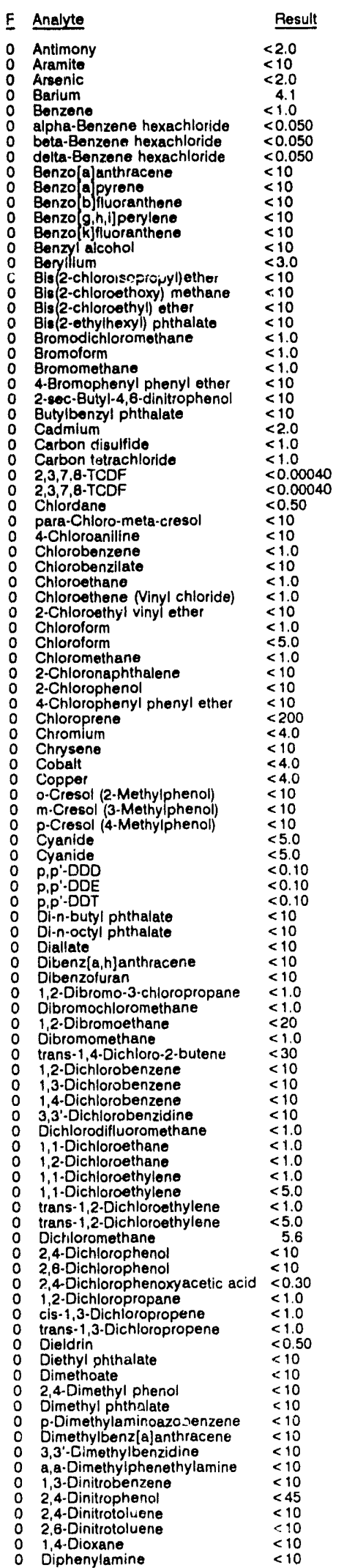

WELL AOB 3 collected on 11/15/91, laboratory analyses (cont.)

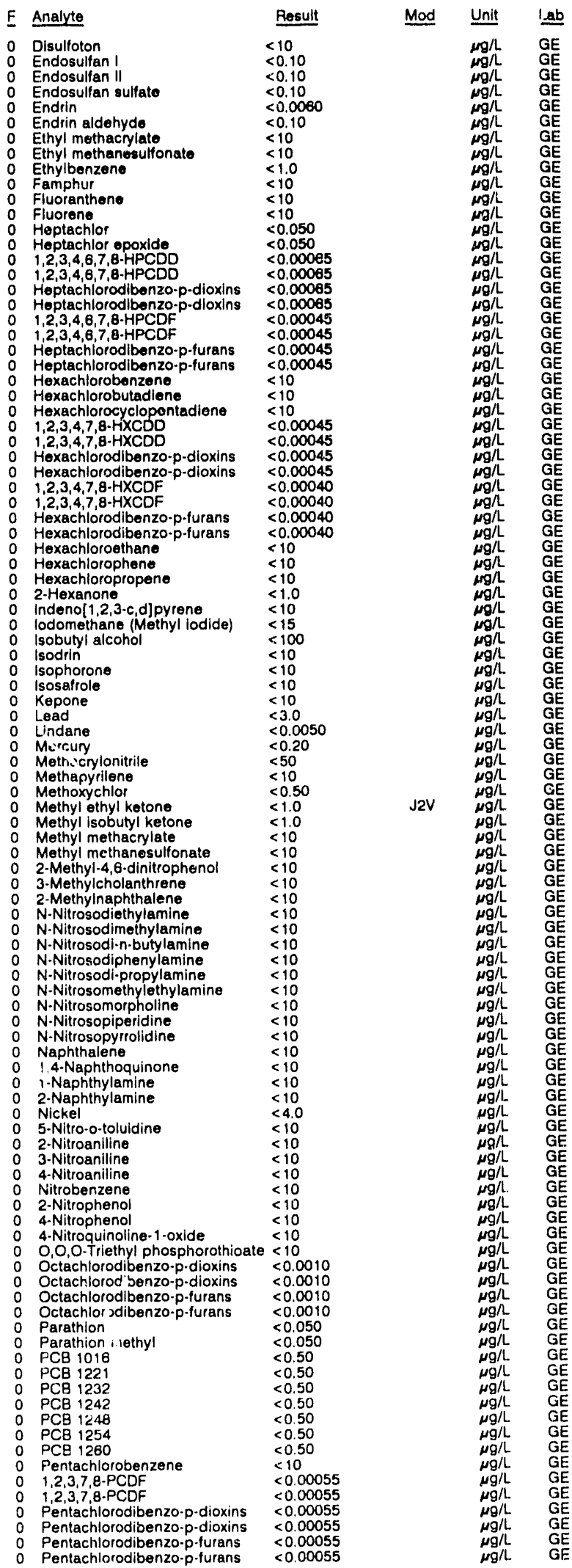




\section{ANALYTICAL RESULTS}

WELL AOB 3 collected on 11/15/91, laboratory analyses (cont.)

E Analyte

o 1,2,3,7,8-PCOF

Pentachloroethan

Pentachloronitrobenzen

Pentachlorophen

Phenarthren

Phenol

p.Phenylenediamine

Phorate

Pronamid

Proplonitrile

Pyrene

Pyridine

Selenium

Silver

Styrene

Sulfido

Sulfotepp

Totrachlorodibenzo-p-dioxins

Tetrachlorodibenzo-p-dloxins

Totrachlorodibenzo-p-furans

Tetrachlorodibenzo-p-furans

$1,1,2,2$-Totrachloroethane

$1,1,1,2$.Tetrachloroethane

Tetrachloroethylene

2,3,4,6-Tetrachlorophenol

Thallium

Tin

Toluene

Total petroleum hydrocarbons

Toxaphene

2,4,5-TP (Silvex)
1,2,4-Trichlorobenzene

1,1,1-Trichloroethane

1,1,1-Trichloroethane

1,1,2-Trichloricethan

Trichioroothylene

Trichlorofluoromethan

2,4,5-Trichlorophenol

2,4,6-Trichloropheno

$2,4,5-T$

1,2,3-Trichloropropane

Vanadium

Vinyl acetate

Xylenes

2,3,7,8.TCDO

2,3,7,8-TCDD

Antimony-125

Corlum-144

Cesium-134

Cobalt-57

Cobalt-60

Gross alphe

Manganese-54

Nonvolatile beta

Potassium 40

Radium-226

Ruthenium-10

Sodium.22

Total radium

Tritium

Zinc-65

\section{WELL ARP $1 \mathrm{~A}$}

MEASUREMENTS CONDUCTED Ii! THE FIELD

Sample citte: 11/11/91

Time: 16:40

0.24

$<10$

$<1.0$

$<5.0$
$<1.0$

$<1.0$

$<5.0$

$<10$

$<0.090$

$<10$

$<8.0$

$<1.0$

$<0.00045$

$<0.00045$

$<2.1 \mathrm{E} .08$

$<3$

$<2.7 E-09$

$<3.0 \mathrm{E} .09$

$4.5 \mathrm{E}-09 \pm 1.4 \mathrm{E}-09$

$<3.6 \mathrm{E}-09$

$<4.4 \mathrm{E} .08$

$<5.8 \mathrm{E} \cdot 09$

$<1.6 \mathrm{E}-08$

$<3.0 \mathrm{E}-09$

$2.1 \mathrm{E} \cdot 08 \pm 7.0 \mathrm{E}-07$

$<9.9 E-09$

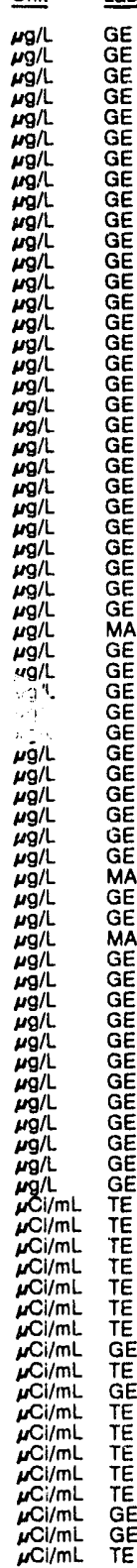

WELL ARP $1 A$

MEASUREMENTS CONDUCTED IN THE FIELD

Sample date: $11 / 13 / 91$

Depth to water: Not available

Water elevation. Not available

Water evacuated betore sampling: $45 \mathrm{gal}$

LABORATORY ANALYSES

F Analyte

- Chloroform

1,1-Dichloroethylene

0 trans-1,2-Dichloroethylene

o To achloroethylene

2 Trichloroethylene

$\begin{aligned} & \text { Result } \\ &<5.0 \\ &<5.0 \\ &<5.0 \\ &<5.0 \\ &<5.0 \\ & 62\end{aligned}$

WELL ARP 2

MEASUAEMENTS CONDUCTED IN THE FIELD

Sample date: 11/11/91

Depth to water: $118.89 \mathrm{Ht}(38.54 \mathrm{~m})$ below TOC

Waler elevalion: $217.41 \mathrm{ft}(86.27 \mathrm{~m}) \mathrm{msl}$

Water evacuated before sampling: $71 \mathrm{gal}$

LABORATORY ANALYSES

E Analyte

- Chloroform

Result

1,1-Dichloroethylene

o trans-1,2-Dichloroethylene

O Tetrachloroethylene

$\begin{array}{ll}0 & 1,1,1-T r i c h l o r o e t h a n \\ 0 & \text { Trichloroethylene }\end{array}$

$<5.0$
$<5.0$

$<5.0$

$<5.0$

WELL ARP 3

MEASUREMENTS CONDUCTED IN THE FIELD

Sample date: $12 / 08 / 91$

Depth to water: $119.39 \mathrm{ft}(36.39 \mathrm{~m})$ below TOC

Water elevation: $220.41 \mathrm{ft}(67.18 \mathrm{~m}) \mathrm{msl}$

Water evacuated before sampling: $85 \mathrm{gal}$

LABORATORY ANALYSES

F Analyte

- Chlorolorm

Result

1, -Dichloroethylene

Trans-1,2.Dichloroethylen

Tetrachloroethylene

Trichloroethylene

$<10$

$<10$

$<10$
$<10$

WELL ARP 4

MEASUREMENTS CONDUCTED IN THE FIELD

Sample date: 11/11/91

Depth to water: $132.14 \mathrm{At}(40.28 \mathrm{~m})$ below TOC

Water elevation: $216.26 \mathrm{ft}(65)$

Sp. conduci :nce: $19 \mu \mathrm{S} / \mathrm{cm}$
Water evacuated before sampling: $48 \mathrm{gal}$

LABORATORY ANALYSES

\begin{tabular}{|c|c|}
\hline Analyte & Result \\
\hline $\begin{array}{l}\text { Chlorolorm } \\
1,1-\text { Dichloroethylene } \\
\text { trans-1,2-Dichloroethylene } \\
\text { Tetrachloroethylene } \\
1,1,1-\text { Trichloroethane } \\
\text { Trichloroethylene }\end{array}$ & $\begin{array}{l}<5.0 \\
<5.0 \\
<5.0 \\
<5.0 \\
<5.0 \\
<5.0\end{array}$ \\
\hline
\end{tabular}

Time: 16:25

pH: 5.0

Alkalinity: $0 \mathrm{mg} / \mathrm{L}$

Water temperature: $17.8^{\circ} \mathrm{C}$

Time: 15:15

Alkalinity: i $\mathrm{mg} / \mathrm{L}$

Water temperature: $17.4^{\circ} \mathrm{C}$

\begin{tabular}{cc} 
Mod Unit & Lab \\
\hline$\mu g / L$ & $M A$ \\
$\mu g / L$ & $M A$ \\
$\mu g / L$ & $M A$ \\
$\mu g / L$ & $M A$ \\
$\mu g / L$ & $M A$ \\
$\mu g / L$ & $M A$
\end{tabular}

\begin{tabular}{ll} 
Mcy Unit & Lab \\
\hline$\mu g / L$ & $M A$ \\
$\mu g / L$ & $M A$ \\
$\mu g / L$ & $M A$ \\
$\mu g / L$ & $M A$ \\
$\mu g / L$ & $M A$ \\
$\mu g / L$ & $M A$
\end{tabular} 
ANALYTICAL RESULTS

WELL ASB $1 \mathrm{~A}$

MEASUREMENTS CONDUCTED IN THE FIELD

Sample date: 11/07/91

Depth to water: Not available

Sp. conductence: $77 \mathrm{\mu S} / \mathrm{cm}$

Water evacuated before sampling: $52 \mathrm{gal}$

LARORATORY ANALYSES

$\begin{array}{ll}\text { F } & \text { Analyte } \\ 0 & \mathrm{pH} \\ 0 & \text { Specific conductance }\end{array}$

0 Arsenic

0 Carium

0 Calcium

Chloride

Chloroform

o Chloroform

0 Copper

$1,1 \cdot$ Dichloroethylene
trans-1,2-Dichloroethylene

Fluoride

0 lion

- Magnesium

Manganese

o Nercur

Nitrate as nitrogen

$\begin{array}{ll}0 & \text { Phenols } \\ 0 & \text { Potassium }\end{array}$

Potassium

Silica

Silver

Sodium

Tetrachloroethylene

Tetrachloroethyleno

- Total organic halogens

Total organic halogens

Tolal phosphates (as P)

1.1,1-Tricnloroethane

0 Trichloroethylene

Zine

Americium-241

Antimony-125

Cerium-144

Cesium-134

Cobalt-57

Cobalt-60

Gross alpha

Manganese.54

Plutonium-238

Plutonium-239/240

P Plutonlum-242

- Potassium-40

Radium-228

Padium-228

R Ruthenium-103

Sodium-22

Strontium- $\varepsilon 9$
Strontium- 90

Strontium-90

- Total radium

Tritium

Uranium-233/234

0 Zinc-65
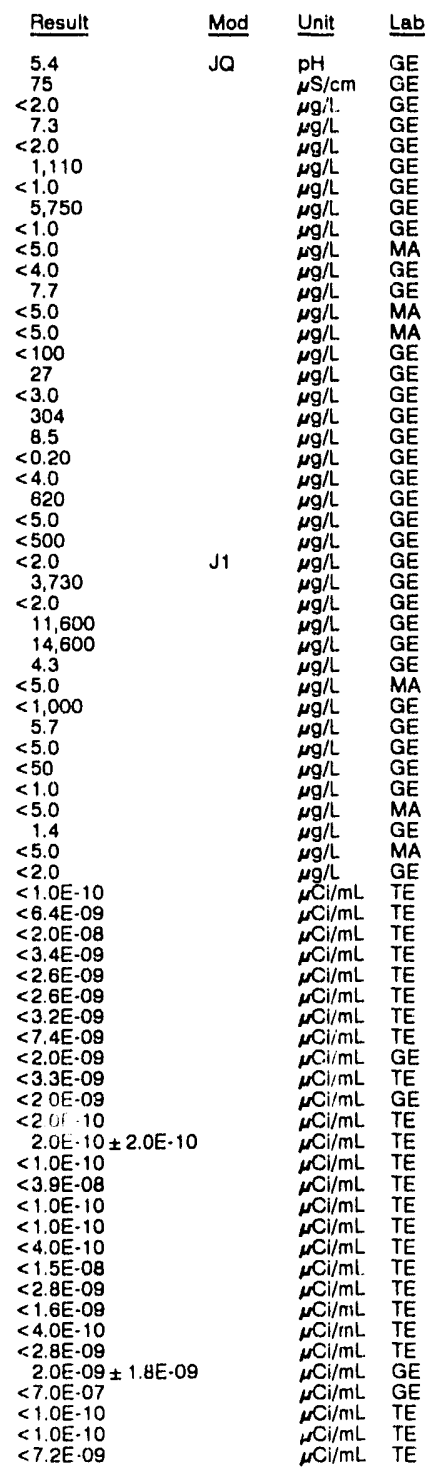

WELL ASB 2A

MEASUREMENTS CONDUCTED IN THE FIELD

Depth to water: $110.41 \mathrm{ft}(37.65 \mathrm{~m})$ below TOC

Wepth to waler. 1 . 41 in $(37.65 \mathrm{~m})$ below

Sp conductance: $74 \mu \mathrm{s} / \mathrm{cm}$

Water evacuated before sampling: $57 \mathrm{gal}$

LABORATORY ANALYSES

\begin{tabular}{|c|c|c|c|c|c|}
\hline E & Analyte & Result & Mod & Unit & Lab \\
\hline & $\begin{array}{l}\mathrm{pH} \\
\text { Specific conductance } \\
\text { Arsenic }\end{array}$ & $\begin{array}{r}6.1 \\
70 \\
<2.0\end{array}$ & JQ & $\begin{array}{l}\mathrm{pH} \\
\mu \mathrm{S} / \mathrm{cm} \\
\mu \mathrm{g} / \mathrm{L}\end{array}$ & $\begin{array}{l}\mathrm{GE} \\
\mathrm{GE} \\
\mathrm{GE}\end{array}$ \\
\hline
\end{tabular}

WELL ASB 2A collected on 11/07/91, laboratory analyses (cont.)

E Analyte

0 Barium

Cadmium

0 Carbon tetrachloride

Chloride

Chloroform

Chromium

O Copper

1,1-Dichloroethylene

trans-1,2-Dichloroethylene

$\begin{array}{ll}0 & \text { Fluoride } \\ 0 & \text { Iron }\end{array}$

0 Magnesium

Manganese

Mercury

Nickel

Nitrate as nitrogen

Phenols

Potassium

Selenium

$\begin{array}{ll}0 & \text { Silica } \\ 0 & \text { Silver }\end{array}$

Silver

Sodium

Tetrachloroethylene

Tetrachloroethylene

Total organic carbon

Total organic halogens

Total phosphates (as P)

o $1,1,1$. Trichloroethane

1,1,1-Trichloroethan

Trichloroethylene

- Zinc

Americium-241

Antimony-125

Cerium-144

Cesium-134
Cesium-137

Coball -57

Cobali-60

0 Gross alpha

Manganese-54

Plutonium-239/240

Plutonium-242

0 Potassium-40

- Radium-226

Radium-226

Radium-228

Ruthenium-103

Sodium-22

Strontium-89
Strontium-90

Strontium-90

Total radium

0 Tritium

Zinc-65
Nonvolatile bete

Uranium-233/234
9.5
$<2.0$
1.710

1.710
$<1.0$

4,500

$<1.0$
$<5.0$

4.2
$<4.0$

$<5.0$
$<5.0$

$<100$

37
$<3.0$
525

4.1
$<0.20$

$<4.0$

87
$<5.0$
$<5.0$

$<500$
$<2.0$

$<2.0$
4,540
$<2.0$

$<2.0$
12,200

6,710
1.8

$<5.0$
$<1,000$

$<5.0$

$<50$

$<1.0$

$<5.0$

$<5.0$

$<1.0 \mathrm{E}-10$
$<\mathrm{B} .1 \mathrm{E}-09$

$<8.1 E-09$
$<3.1 E .08$

$<3.7 \mathrm{E}-09$

$<2.4 \mathrm{E} .09$

$<3.9 E-09$

$<3.0 \mathrm{E}-09$
$<8.6 \mathrm{E}-09$

$<2.0 E-09$

$<3.0 E .09$

$<2.0 \mathrm{E} \cdot 09$

$<1.0 \mathrm{E}-10$
$<1.0 \mathrm{E}-10$

$<1.0 \mathrm{E}-10$

$8.0 \mathrm{E}-10 \pm 1.0 \mathrm{E} \cdot 10$
$8.0 \mathrm{E} \cdot 10 \pm 1.0 \mathrm{E} \cdot 10$

$<4.9 \mathrm{E}-08$

$<3.2 E \cdot 09$

$<1.5 \mathrm{E}-09$

$<4.0 E-10$

$<3.8 E-09$
$<1.0 E-09$

$<7.08-07$

$<1.0 E-10$
$<1.0 E-10$

$<1.0 E .10$
$<8.7 E \cdot 79$
Mod Unit Lab

$\stackrel{\mu g / L}{\mu g / L} \quad G E$

$G E$

WELL ASB $2 \mathrm{C}$

MEASUREMENTS CONDUCTED IN THE FIEL:

Depth to water: 126.07 it $(38.43 \mathrm{~m})$ below Tor

Water elevation: $223.33 \mathrm{Ht}(68.07 \mathrm{~m}) \mathrm{msl}$

conductance $49 \mu \mathrm{s} / \mathrm{cm}$

Water evacuated before sampling: $167 \mathrm{gal}$

LABORATOAY ANALYSES

\begin{tabular}{|c|c|c|c|}
\hline Analyte & Result & Mod & Unit \\
\hline $\begin{array}{ll}\text { pH } \\
\text { Specific con:4uctance } \\
\text { Arsenic } \\
\text { Barium } \\
\text { Cadmium } \\
\text { Calcium } \\
\text { Carbon tetrachicricio } \\
\text { Chloride } \\
\text { Chloroform } \\
\text { Chioroform } \\
\text { Chloroform } \\
\text { Chromium } \\
\text { Cipper } \\
\text { 1,1-Dichlorosthylene } \\
\text { 1.1-Dichloroethylene } \\
\text { trans-1,2.Dichloroethylene } \\
\text { trans-1,2-Dichloroethylene }\end{array}$ & 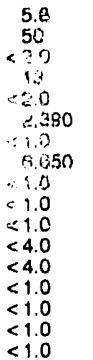 & JQ & $\begin{array}{l}p H \\
\mu \mathrm{S} / \mathrm{cm} \\
\mu g / L \\
\mu g / L \\
\mu g / L \\
\mu g / L \\
\mu g / L \\
\mu g / L \\
\mu g / L \\
\mu g / L \\
\mu g / L \\
\mu g / L \\
\mu g / L \\
\mu g / L \\
\mu g / L \\
\mu g / L \\
\mu g / L\end{array}$ \\
\hline
\end{tabular}


ANALYTICAL RESULTS

WELL ASB $2 C$ collected on 11/07/91, laboratory analyses (cont.)

E Analyte

Fluoride

Iron

Magnesium

Manganes

Mercury

Nitrate as nitrogen

Phenols

Potassium

Selenium

Silica

Sodium

Tetrachluroethylene

Tetrachloroethylene

Total dissolved solids

Total organic carbon

Total organic halogens

Total phosphates as P)

1.1.1. Irichloroethan

1,1,1-Trichloroethane

Trichloroethylene

Trichloroethylene

Zinc

Americium-241

Antimony $\cdot 125$
Cerium-144

Cesium-134

Cesium-137

Cobalt-57

Europium-154

Gross alpha

Nonvolatile beta

Plutonium-238

Plutonium-239/2

Potassium 40

Radium-226

Radium-226

Ruthenium-103

Sodium-22

Strontium-89

Strontium-90

Thorium-228

Total radiur

Uranium-233/234

Uianlum.238
$<100$

4.8
$<3.0$
532

24

$<0.20$

690
$<5.0$

924
$<2.0$

8.460
$<2.0$

5,010

$<1,000$

24

35,000
$<1,000$

85
$<50$

$<1.0$

$<1.0$
$<1.0$

58
46

47
19

$<1.0 \mathrm{E}-10$

$<3.5 \mathrm{E}-08$

$<4.3 E-09$

$<4.5 \mathrm{E} .09$

$<3.0 \mathrm{E} .09$

$<2.0 E-09$

$<3.9 E-09$

$<2.0 E \cdot 09$

$3.0 E \cdot 10 \pm 3.0 E \cdot 10$

$2.0 \mathrm{E} \cdot 10 \pm 2.0 \mathrm{E}-10$

3.0E-10 $\pm 2.0 \mathrm{E}-10$

$<7.7 E \cdot 08$
$<10 E \cdot 10$

< 1.0E-10 $1.8 \mathrm{E} \cdot 09 \pm 8.0 \mathrm{OE} \cdot 10$

$<1.08 .09$

$<1.9 \mathrm{E} \cdot 08$
$<3.8 \mathrm{E} \cdot 09$

$<1.6 \mathrm{E} \cdot 09$

$<4.0 E \cdot 10$

$<4.0 E-09$
$<1.0 E-09$

$1.5 \mathrm{E} .05 \pm 9.0 \mathrm{E}-07$

$<1.0 E \cdot 10$

$<1.0 E \cdot 10$
$<9.6 E \cdot 09$
Result Mod Unit

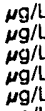

$\mu g / L \quad G E$

$\mu g / L \quad G E$

GE

E

E

GE

E

E

A

E

醇

$M A$

WELL ASB $3 A$

MEASUREMENTS CONDUCTED IN THE FIELD

Sample date: 11/07/91

Depth to water: $105.44 \mathrm{Ht}(32.14 \mathrm{~m})$ below TOC

Water elevation: $239.56 \mathrm{ft}(73.02 \mathrm{~m}) \mathrm{msl}$

Sp. conductance: $58 \mu \mathrm{s} / \mathrm{cm}$

Water evacuated before sampling: $57 \mathrm{gal}$

LABORATORY ANALYSES

$\begin{array}{ll}\text { F } & \text { Anulyte } \\ 0 & \text { pH } \\ 0 & \text { Specific conductance } \\ 0 & \text { Arsenic } \\ 0 & \text { Barium } \\ 0 & \text { Cadmium } \\ 0 & \text { Calcium } \\ 0 & \text { Carbon tetrachloride } \\ 0 & \text { Chloride } \\ 0 & \text { Chloroform } \\ 0 & \text { Chloroform } \\ 0 & \text { Chromium } \\ 0 & \text { Copper } \\ 0 & 1,1-\text { Dichloroethylene } \\ 0 & \text { trans-1,2-Dichloroethylene } \\ 0 & \text { Fluoride } \\ 0 & \text { lron } \\ 0 & \text { Lead } \\ 0 & \text { Magnesium } \\ 0 & \text { Manganese } \\ 0 & \text { Mercury } \\ 0 & \text { Nickel } \\ 0 & \text { Nitrate as nitrogen } \\ 0 & \text { Phenols } \\ 0 & \text { Potassium } \\ 0 & \text { Selenium } \\ 0 & \text { Silica }\end{array}$

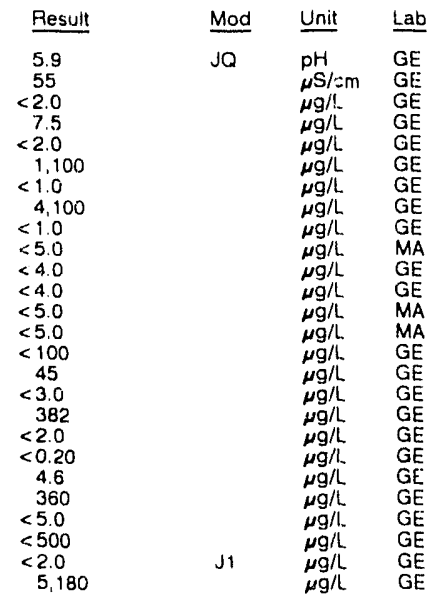

WELL ASB 3A collected on 11/07/91, laboratory analyses (cont.

$E$ Analyte

$\begin{array}{ll}0 & \text { Silver } \\ 0 & \text { Sodium }\end{array}$

0 Sodium

- Tetrachloroethylene

Tetrachloroethylene

Tolatic carbon

Total phosphates (as P)

1,1,1-Trichloroethane

Trichloroethylene

Trichloroethylene

Zinc

Americium-24

Antimony-125

Cesium-134

Cobalt-57

0 Cobalt-60

0 Europium-154

0 Gross alpha

0 Manganese-54

Nonvolatile beta

Plutonium-238

Plutonium-239/2

Potassium-40

0 Radium-226s

0 Redium-22

Ruthenium-103

Sodium.22

Strontium-89

Strontium 90

Thorium.228

1 Total radium

O Uritium $233 / 234$

0 Zinc-65

WELL ASB 3C

MEASUREMENTS CONDUCTED IN THE FIELD

Sample date: 12/06/91

Depth to water: $123.09 \mathrm{ft}(37.52 \mathrm{~m})$ below TOC

Water elevation: $222.91 \mathrm{ft} / 67$
Sp. conductance: $98 \mu \mathrm{s} / \mathrm{cm}$

Result Mod Unit Lab

$<.0$
8,980

4,710

$<5.00$

$<7,0$

$<50$
$<1.0$

$<5.0$

$<1.0$
$<5.0$

$\begin{aligned} & 3.5 \\ &<1.0 E-10\end{aligned}$

$<4.6 \mathrm{E}-08$

$<1.9 E-08$
$<1.8 E-09$

$<1.5 \mathrm{E} .09$

$<1.8 E-09$

$<5.3 E .09$
$<2.0 E-09$

$<2.3 \mathrm{E}-09$

$<4.0 \mathrm{E}-10$

$<1.0 E-10$

$<3.0 \mathrm{E}$

8. $0 \mathrm{E}-10 \pm 1.0 \mathrm{E}-10$

.

$<1.2 E-08$

$<2.0 \mathrm{E} \cdot 09$
$<1.7 \mathrm{E}-09$

$1.0 \mathrm{E}-09 \pm 8.0 \mathrm{E} \cdot 10$

$<2.5 \mathrm{E} \cdot 09$

.7E.09 $2.0 \mathrm{E} \cdot 09$

7.OE.07

$<1.0 \mathrm{E} \cdot 10$

$<4.8$ E-09

$\mu \mathrm{g} / \mathrm{L} \quad \mathrm{GE}$

$\mu{ }_{\mu g / L}^{\mu G / L}$

$\begin{array}{ll}\mu g / L & M A \\ \mu g / L & G E \\ \mu g / L & G E\end{array}$

$\begin{array}{ll}\mu \mathrm{g} / \mathrm{L} & \mathrm{GE} \\ \mu \mathrm{g} / \mathrm{L} & \mathrm{GE} \\ \mu \mathrm{g} / \mathrm{L} & \mathrm{GE}\end{array}$

Water evacuated before sampling: $214 \mathrm{gal}$

LABORATORY ANALYSES

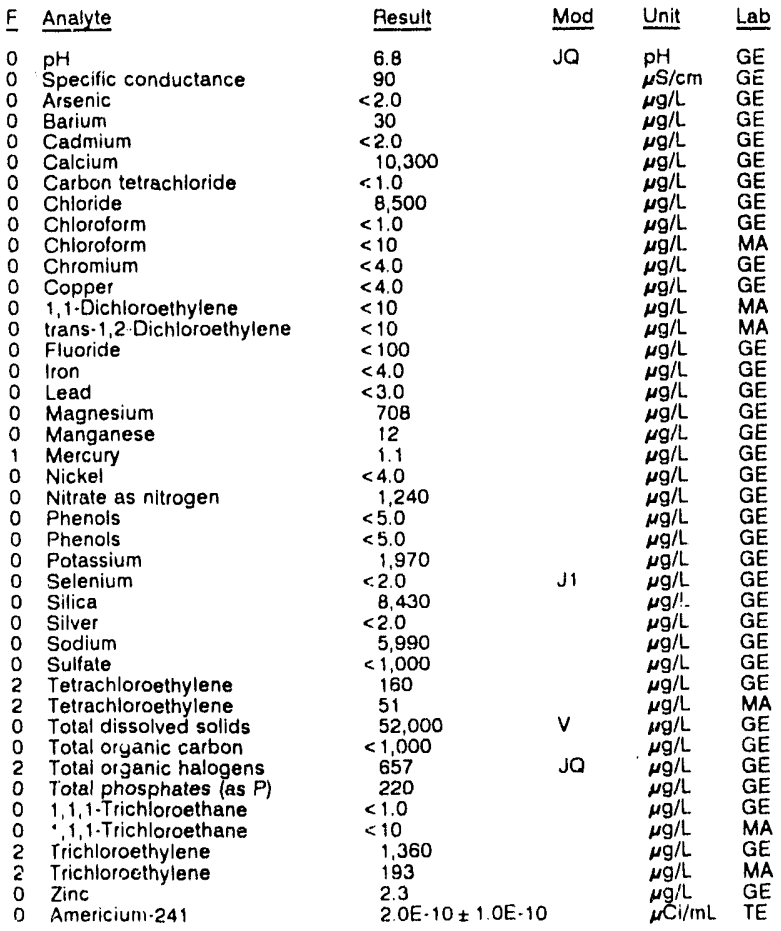


ANALYTICAL RESULTS

WELL ASB $3 C$ collected on 12/06/91, laboratory analyses (cont.)

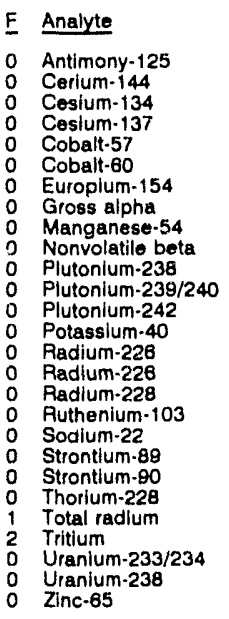

Pesult
$<7.5 \mathrm{E} \cdot 09$
$<2.2 \mathrm{M} \cdot 0 \mathrm{M}$
$<2.5 \mathrm{E} \cdot 09$
$<3.0 \mathrm{E} \cdot 09$
$<2.9 \mathrm{E} \cdot 09$
$<3.3 \mathrm{E} \cdot 09$
$<7.3 \mathrm{E} \cdot 09$
$2.3 \mathrm{E} \cdot 09 \pm 1.1 \mathrm{E} \cdot 09$
$<2.6 \mathrm{E} \cdot 09$
$5.1 \mathrm{E} \cdot 09 \pm 1.9 \mathrm{E} \cdot 09$
$2.0 \mathrm{E} \cdot 10 \pm 1.0 \mathrm{E} \cdot 10$
$2.0 \mathrm{E} \cdot 10 \pm 1.0 \mathrm{E} \cdot 10$
$<1.0 \mathrm{E} \cdot 10$
$<3.9 \mathrm{E} \cdot 08$
$4.0 \mathrm{E}-10 \pm 2.0 \mathrm{E} \cdot 10$
$<5.5 \mathrm{E}-09$
$1.9 \mathrm{E} \cdot 09 \pm 1.2 \mathrm{E} \cdot 09$
$<9.7 \mathrm{E} \cdot 09$
$<2.5 \mathrm{E} 08$
$<8.0 \mathrm{E} \cdot 10$
$<4.0 \mathrm{E} \cdot 10$
$<2.8 \mathrm{E} \cdot 09$
$4.1 \mathrm{E} \cdot 09 \pm 1.4 \mathrm{E}-09$
$2.5 \mathrm{E} \cdot 05 \pm 1.0 \mathrm{E}-08$
$<1.0 \mathrm{E} \cdot 10$
$<1.0 \mathrm{E} \cdot 10$
$<7.2 \mathrm{E} \cdot 09$

WELL ASB 4 collected on 11/11/91, laboratory analyses (cont.)

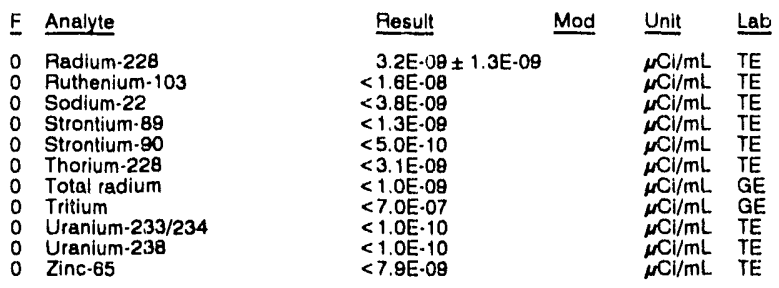

WELL ASB 5A

MEASUREMENTS CONDUCTED IN THE FIELD

Sample date: 11/07/91

Depth to water: $107.51 \mathrm{ft}(32.77 \mathrm{~m})$ below TOC

Water elevation: $237.49 \mathrm{Ht}(72.38 \mathrm{~m}) \mathrm{msl}$

Water evacuated before sampling: $51 \mathrm{gal}$

pH: 5.3

Water evacualod belore samr

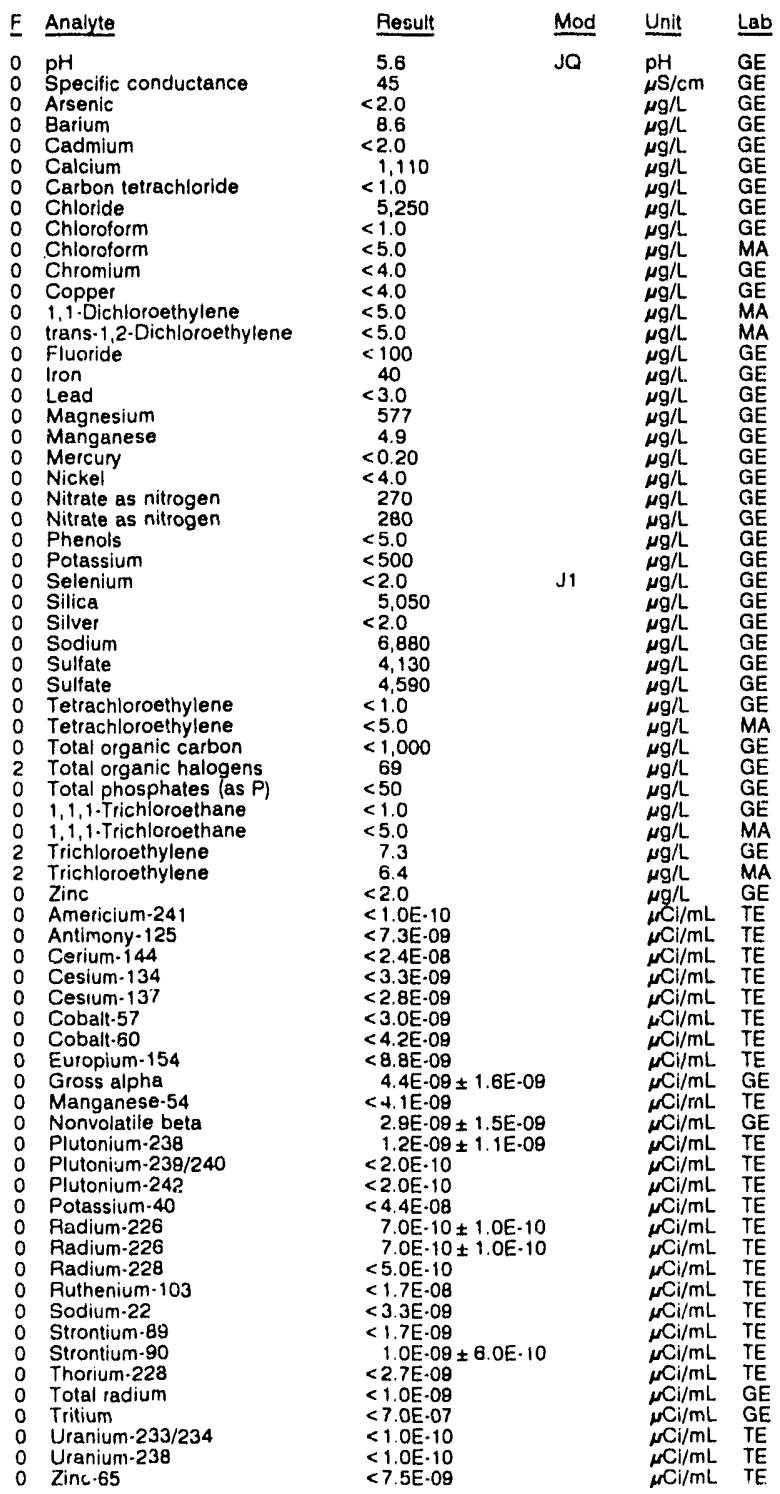

DORATORY ANALYSES
WELL ASB 4

MEASUREMENTS CONDUCTED IN THE FIELD

Sample date: $11 / 11 / 91$

Depth to water: $97.47 \mathrm{ft}(29.71 \mathrm{~m})$ below TOC

Water elevation: $238.13 \mathrm{tt}(72$

Sp. conductance: $44 \mu \mathrm{r} / \mathrm{cm}$
Water evacuated before sampling: $32 \mathrm{gal}$

LABORATORY ANALYSES

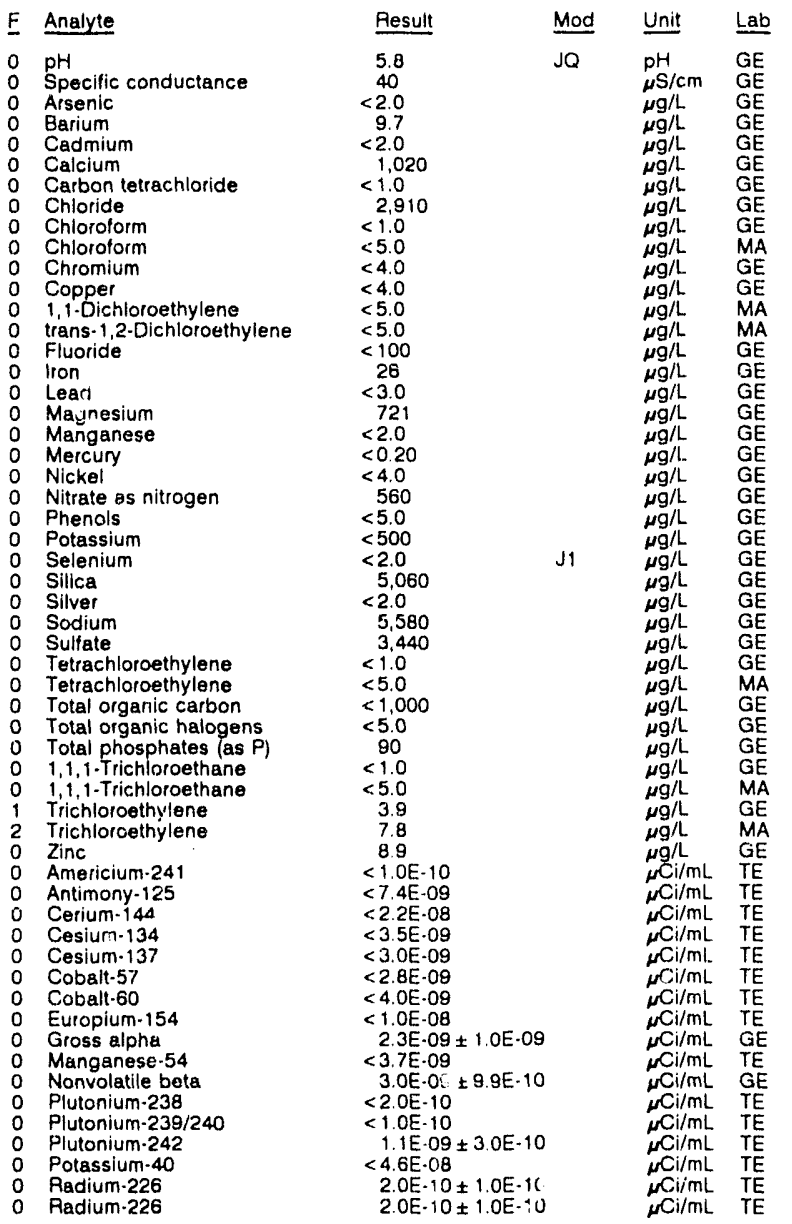

Time: $9: 50$

PH: 5.5

Alkalinity: $10 \mathrm{mg} / \mathrm{h}$ : $19.0^{\circ} \mathrm{C}$

E 
ANALYTICAL RESULTS

WELL ASB $6 A$

MEASUREMENTS CONDUCTED IN THE FIELD

Sample date: 11/07/91

Depth to water: 113.44 if $(34.58 \mathrm{~m})$ below TOC

Sp. conductance $108 \mathrm{tt}(72.17$

Water evacuated before sampling: $61 \mathrm{gal}$

LABORATORY ANALYSES

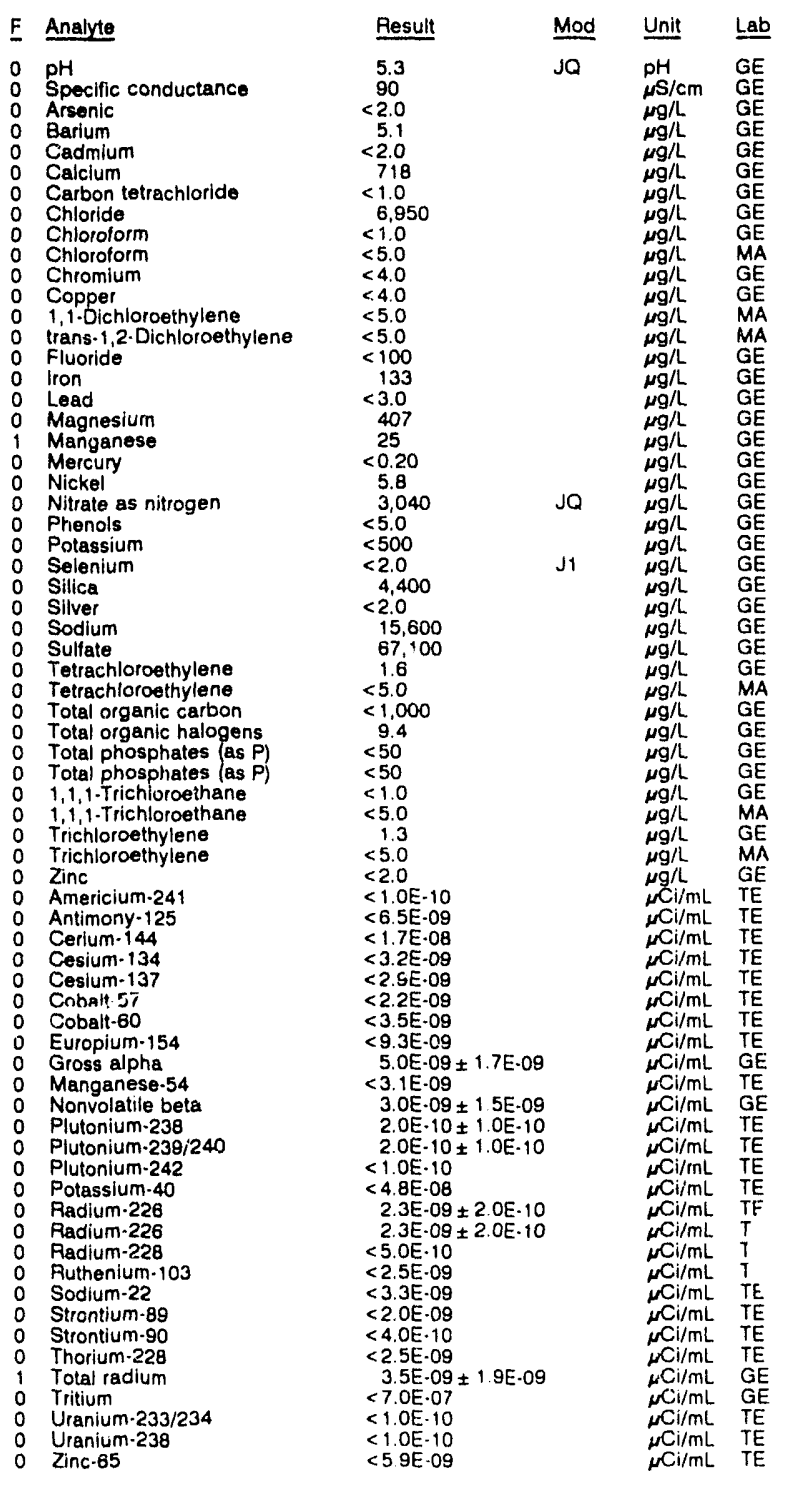

\section{WELL ASB 6AA}

MEASUAEMENTS CONDUCTED IN THE FIELD

Depth to water: $136.69 \mathrm{Ht}(41.68 \mathrm{~m})$ below TOC

Water elevation: 217.51 it $(66.30$ n

Waier evacuated before sampling: $366 \mathrm{gal}$

Time: $15: 25$

Al: 5.0

Water temperature: $18.4^{\circ} \mathrm{C}$

LABORATORY ANALYSES

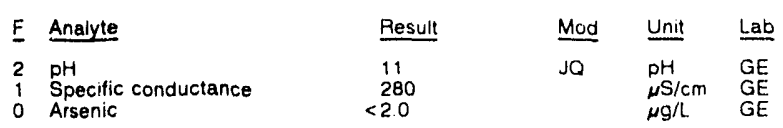

WELL ASB GAA collected on 12/05/91, laboratory analyses (cont.)

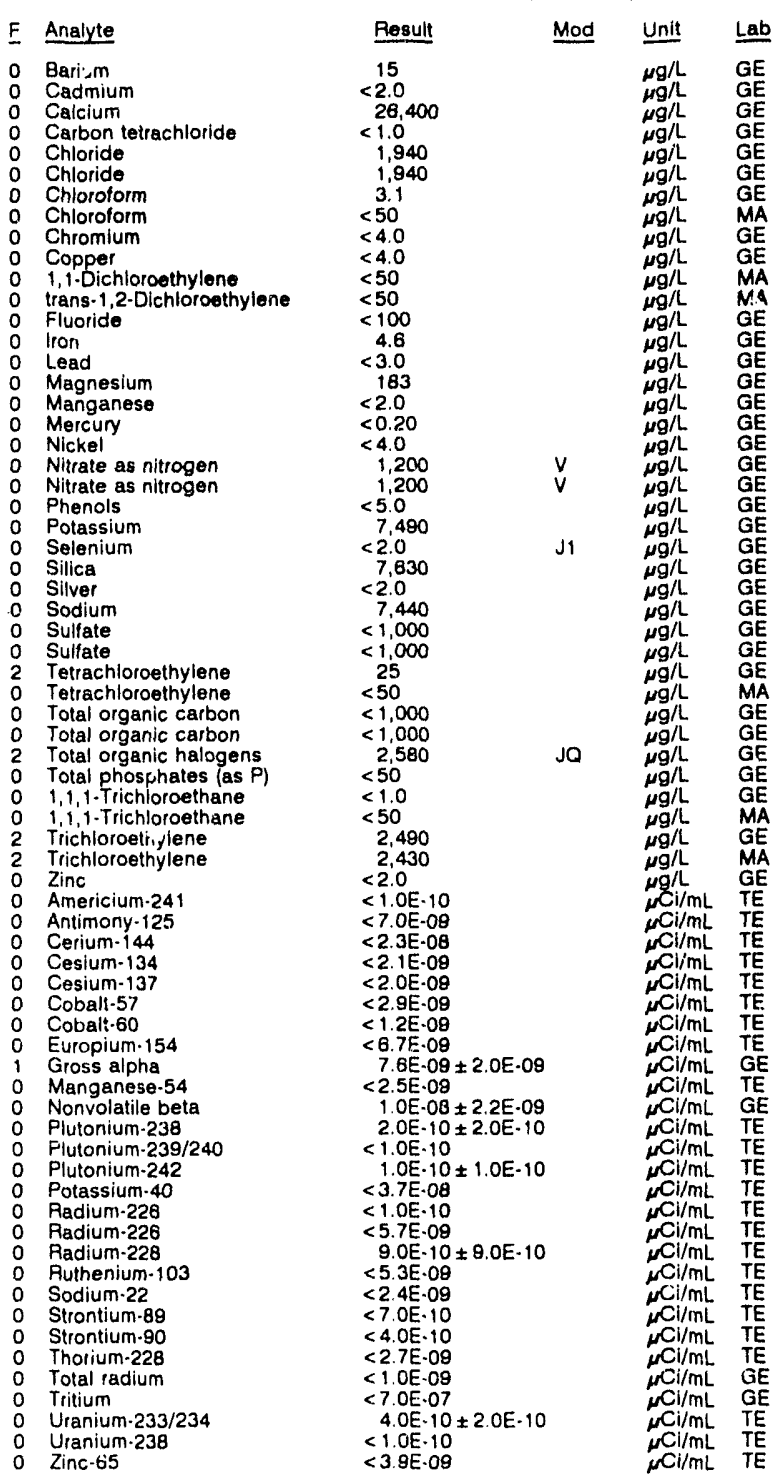

WELL ASB $6 \mathrm{C}$

MEASUREMENTS CONOUCTED IN THE FIELD

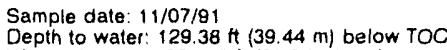

Depth to water: $129.38 \mathrm{H}(39.44 \mathrm{~m})$ below

Water evacuated belore sampling: $132 \mathrm{gal}$

pH. 5.5

pH: 5.5

Water temperature: $19.2^{\circ} \mathrm{C}$

LABOFATORY ANALYSES

$\begin{array}{ll}\text { F } & \text { Analyte } \\ 0 & \text { pH } \\ 0 & \text { Specific conductance } \\ 0 & \text { Arsenic } \\ 0 & \text { Barium } \\ 0 & \text { Cadmium } \\ 0 & \text { Calcium } \\ 0 & \text { Carbon letrachloride } \\ 0 & \text { Chloride } \\ 0 & \text { Chlorotorm } \\ 0 & \text { Chlorolorm } \\ 0 & \text { Chromium } \\ 0 & \text { Copper } \\ 0 & 1,1 \cdot \text { Dichloroethylene } \\ 0 & \text { trans } 1,2 \cdot \text { Dichloroethylene } \\ 0 & \text { Fluoride }\end{array}$

Pesult
5.7
40
$<2.0$
10
$<2.0$
2,230
$<1.0$
4.850
$<1.0$
$<10$
$<4.0$
$<4.0$
$<1.0$
$<10$
$<100$


ANALYTICAL RESULTS

WELL ASB 6C collected on 11/07/81, laboratory analyses (cont.)

\begin{tabular}{|c|c|c|c|}
\hline Analyte & Powult & Mod & Unit \\
\hline 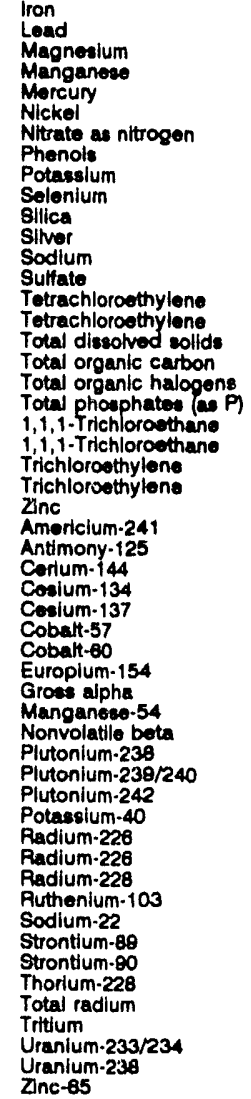 & 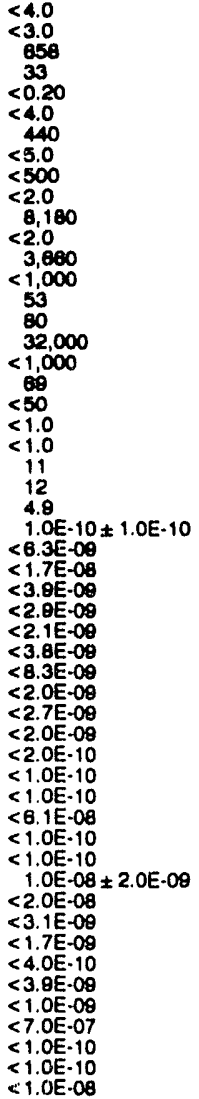 & נו & 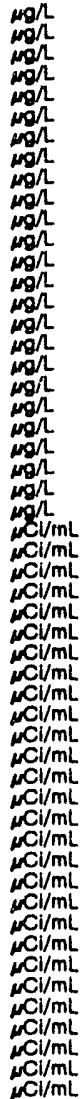 \\
\hline
\end{tabular}

WELL ASB 6TA

MEASUREMENTS CONDUCTED IN THE FIELD

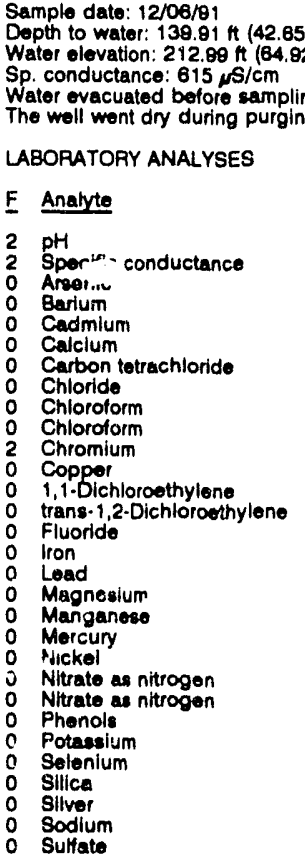

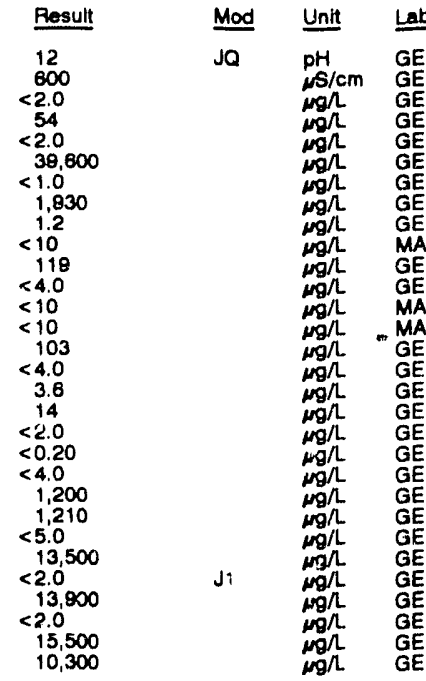

WELL ASB GTA colloctod on 12/08/81, laboratory analyees (cont.)

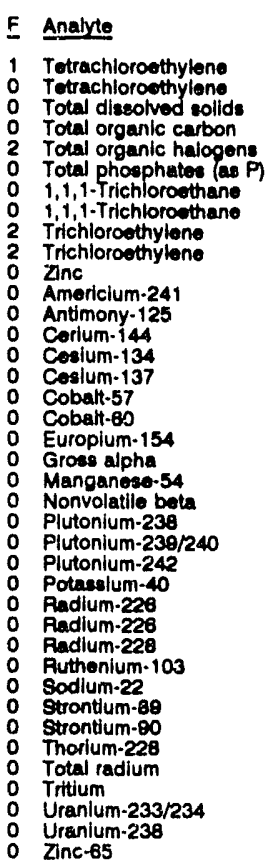

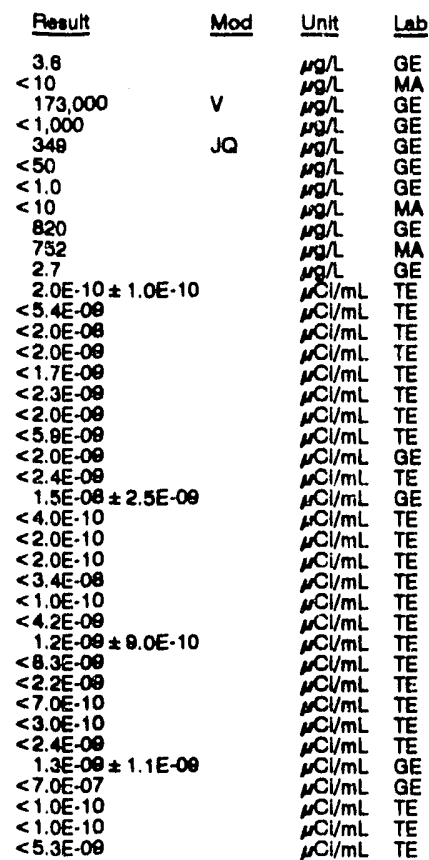

\section{WELL ASB 7}

MEASUREMENTS CONDUCTED IN THE FIELD

Sample date: 11/07/91

Depth to water: $118.07 \mathrm{At}(35.98 \mathrm{~m})$ bolow TOC Water olevation: $235.33 \mathrm{Ht}(71$.

Sp. conductance: $110, \mathrm{~s} / \mathrm{cm}$ Water ovacuated before sampling: $63 \mathrm{gal}$

pH: 5.0

Akalinity: $0 \mathrm{mg} \Omega$

Water tomperature: $18.9^{\circ} \mathrm{C}$

LABOPATORY ANALYSES

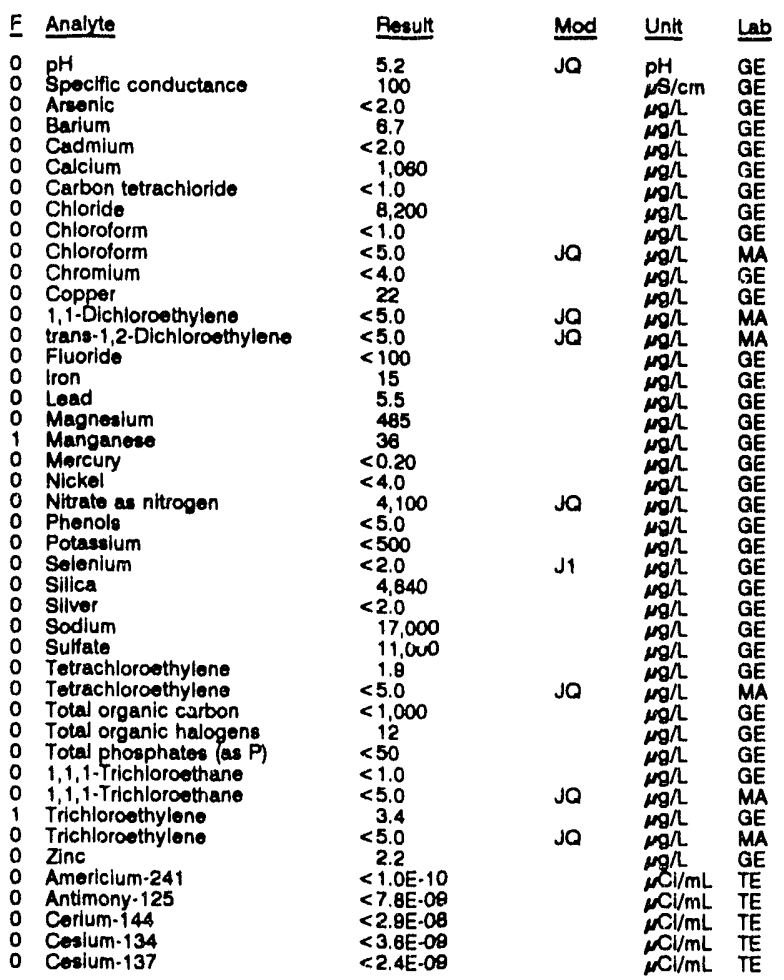




\section{ANALYTICAL RESULTS}

WELL ASB 7 collected on 11/07/91, laboratory analyses (cont.)

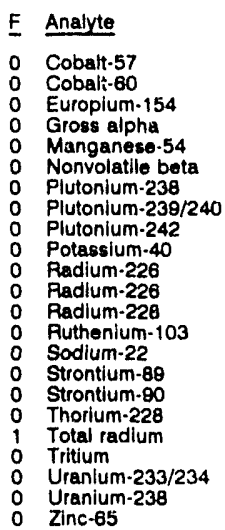

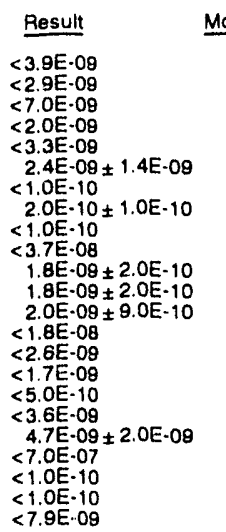

\begin{tabular}{|c|c|}
\hline Unit & Lab \\
\hline 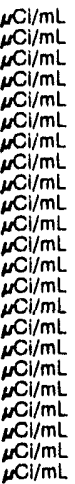 & $\begin{array}{l}T E \\
T E \\
T E \\
T E \\
G E \\
T E \\
G E \\
G E \\
T E \\
T E \\
T E \\
T E \\
T E \\
T E \\
T E \\
T E \\
T E \\
T E \\
T E \\
T E \\
T E \\
T E \\
G E \\
G E \\
T E \\
T E \\
T E\end{array}$ \\
\hline
\end{tabular}

WELL ASB 8

MEASUREMENTS CONDUCTED IN THE FIELD

\begin{tabular}{|c|c|}
\hline \multicolumn{2}{|r|}{$\begin{array}{l}\text { Sample date: } 11 / 07 / 91 \\
\text { Depth to water: } 114.08 \mathrm{ft}(34.77 \\
\text { Water elevation: } 234.92 \mathrm{f}(71.60 \\
\text { Sp. conductance: } 31 \mathrm{\mu S} / \mathrm{cm} \\
\text { Water evacuated before samplin }\end{array}$} \\
\hline \multicolumn{2}{|r|}{ LABORATORY ANALYSES } \\
\hline & \\
\hline & 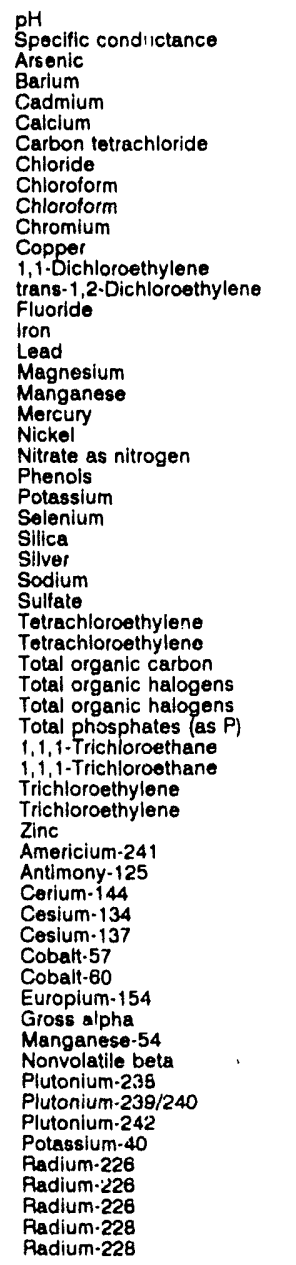 \\
\hline
\end{tabular}

Time: 11:45

pH: 4.7 Alkalinity: $0 \mathrm{mg} /$

Water temperature: $17.9^{\circ} \mathrm{O}$

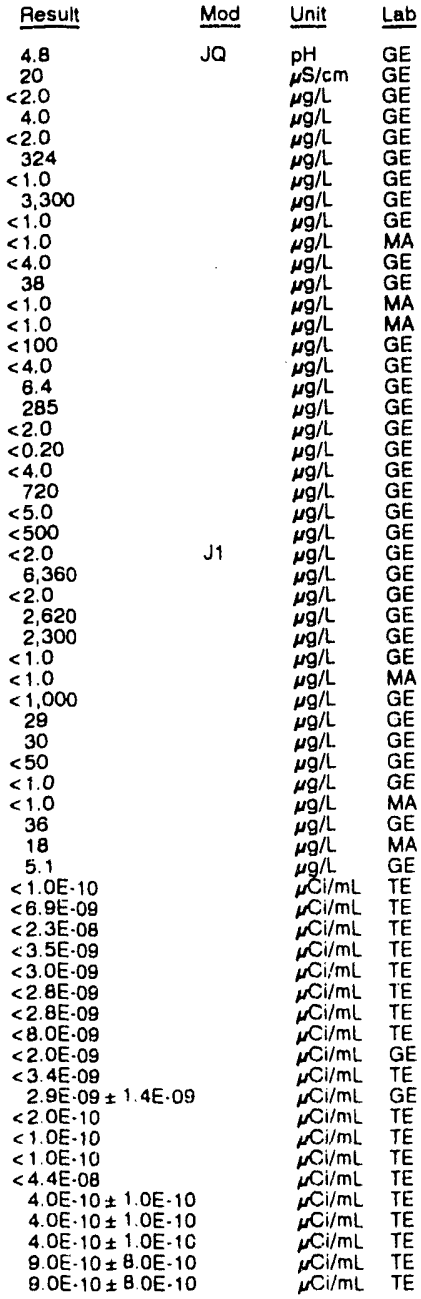

WELL ASB 8 collected on 11/07/91, laboratory analyses (cont.

\begin{tabular}{|c|c|c|c|c|}
\hline E & Analyte & Result & Mod & Unif \\
\hline $\begin{array}{l}0 \\
0 \\
0 \\
0 \\
0 \\
1 \\
0 \\
0 \\
0\end{array}$ & $\begin{array}{l}\text { Ruthenium-103 } \\
\text { Sodium-22 } \\
\text { Strontium-89 } \\
\text { Strontium-90 } \\
\text { Thorium-228 } \\
\text { Total radium } \\
\text { Tritium } \\
\text { Uranium-233/234 } \\
\text { Uranium-238 } \\
\text { Zinc-65 }\end{array}$ & 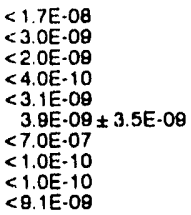 & & 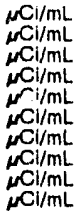 \\
\hline
\end{tabular}

WELL ASB $8 A$

MEASUREMENTS CONDUCTED IN THE FIELO

Sample date: 11/07/81

Depth to water: $130.46 \mathrm{~A}(38.76 \mathrm{~m})$ below TOC

Water elevation: $218.84 \mathrm{f}(66.70 \mathrm{~m}) \mathrm{msl}$

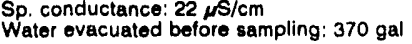

Time: $11: 05$

Alkalinity: $1 \mathrm{mg} / \mathrm{L}$

LABORATORY ANALYSES

F Analyte

o $\quad \mathrm{pH}$ Specific conductance

0 Arsenic

Barium

Calcium

Carbon tetrachloride

Chloride

Chloroform

Chloroform

Chromium

1,1-Dichloroethylene

trans.1,2-Dichloroothylen

Fluoride

lion

Magnesium

Manganese

Mercury

Nickel as nitrogen

gnols

seienium

Silica

Sodium

Tetrachloroethyiene

Tetrachloroethylene

Total organic carbon

Total organic carbon

Total organic halogens

Total phosphates (as P

$1,1,1$. Trichioroethane

Trichloroethylene

Trichloroethylene

Americium-24

Antimony-125

0 Cesium.134

Cesium.137

Cobalt. 57

Europium-154

Gross alpha

Mangane-e-54

Nonvolatile beta

Plutonium-238

Plutonium-239/240

Plutonium-242

Potassium-40

Radium-226

Radium-228

Ruthenium-103

Sodium-22

Strontium-89

Struntium-90

Thorium-228

Total radium

Tritium

Uranlum-233/234

Uranium.238
5.4

20
$<2.0$
5.9

$<2.0$

1,010
$<1.0$

2,130

$<5.0$

$<4.0$

$<4.0$
$<5.0$

$<5.0$

$<100$
$<100$

$<4.0$

$<3.0$
319
56

50.20
$<4.0$

840
8.0

$<5.0$

$<500$
$<2.0$

7.130
$<2.0$
1,730

1,730
$<1,000$

$<1,0$

$<5.0$

$<1,000$

22

$<1$.

$<5.0$

$<1.0$

9.5
$2.0 E-10 \pm 1.0 E-10$

$2.0 E-10 \pm$
$<7.1 \mathrm{E}-09$

$<1.8 E-08$

$<2.7 \mathrm{E}-09$

$<2.0 \mathrm{E}-09$

$<4.1 \mathrm{E}-09$

$<1.0 \mathrm{E} \cdot 08$

$<3.8 \mathrm{E}-09$

$<2.0 \mathrm{E}-09$

$3.0 \mathrm{E}-10 \pm 1.0 \mathrm{E}-10$

$<1.0 \mathrm{E}-10$

$<1.0 \mathrm{E} \cdot 10$

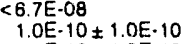

1. $0 E-10 \pm 1.0 E-10$
$1.0 E-10 \pm 1.0 E-10$

1.3E-09 $\pm 8, \cap E \cdot 10$

$<1.9 \mathrm{E} .08$
$<3.8 \mathrm{E} .09$

$<2.0 \mathrm{E} .09$

$<4.0 \mathrm{E}-10$

$<3.8 \mathrm{E}-09$
$<1.0 \mathrm{E}-09$

$<1.0 E-09$
$<7.0 E-07$

$<1.0 \mathrm{E}-10$

$<1.0 E-10$
$<1.0 E-08$

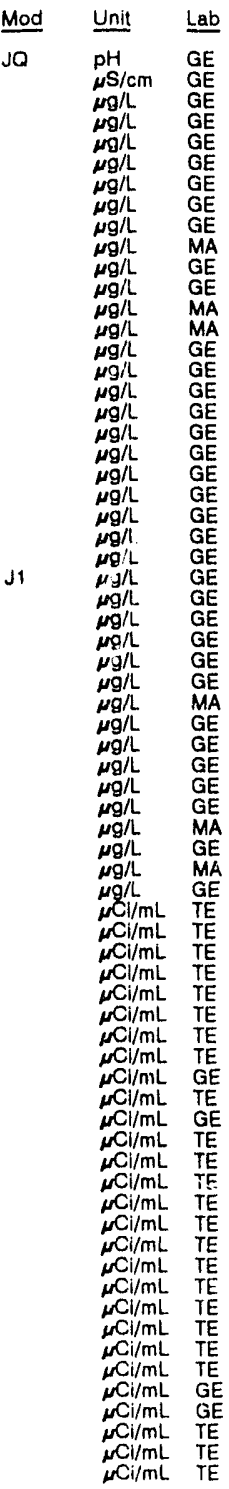


ANALYTICAL RESULTS

WELL ASB 8B

MEASUREMENTS CONDUCTED IN THE FIELD

Sample date: $12 / 05 / 91$
Depth to water: $130.25 \mathrm{H}(38.70 \mathrm{~m})$ below TOC
Water elovation: $219.55 \mathrm{ft}(66.92 \mathrm{~m}) \mathrm{msl}$
Sp. conductance: $27 \mathrm{NS} / \mathrm{cm}$
Water evacuated before sampling: $254 \mathrm{gal}$
LABORATORY ANALYSES

Time: 12:45

$\mathrm{pH}: 5.4$

Alkalinity: $1 \mathrm{mg} / \mathrm{L}$

Water temperalure: $17.2^{\circ} \mathrm{C}$

LABORATORY ANALYSES

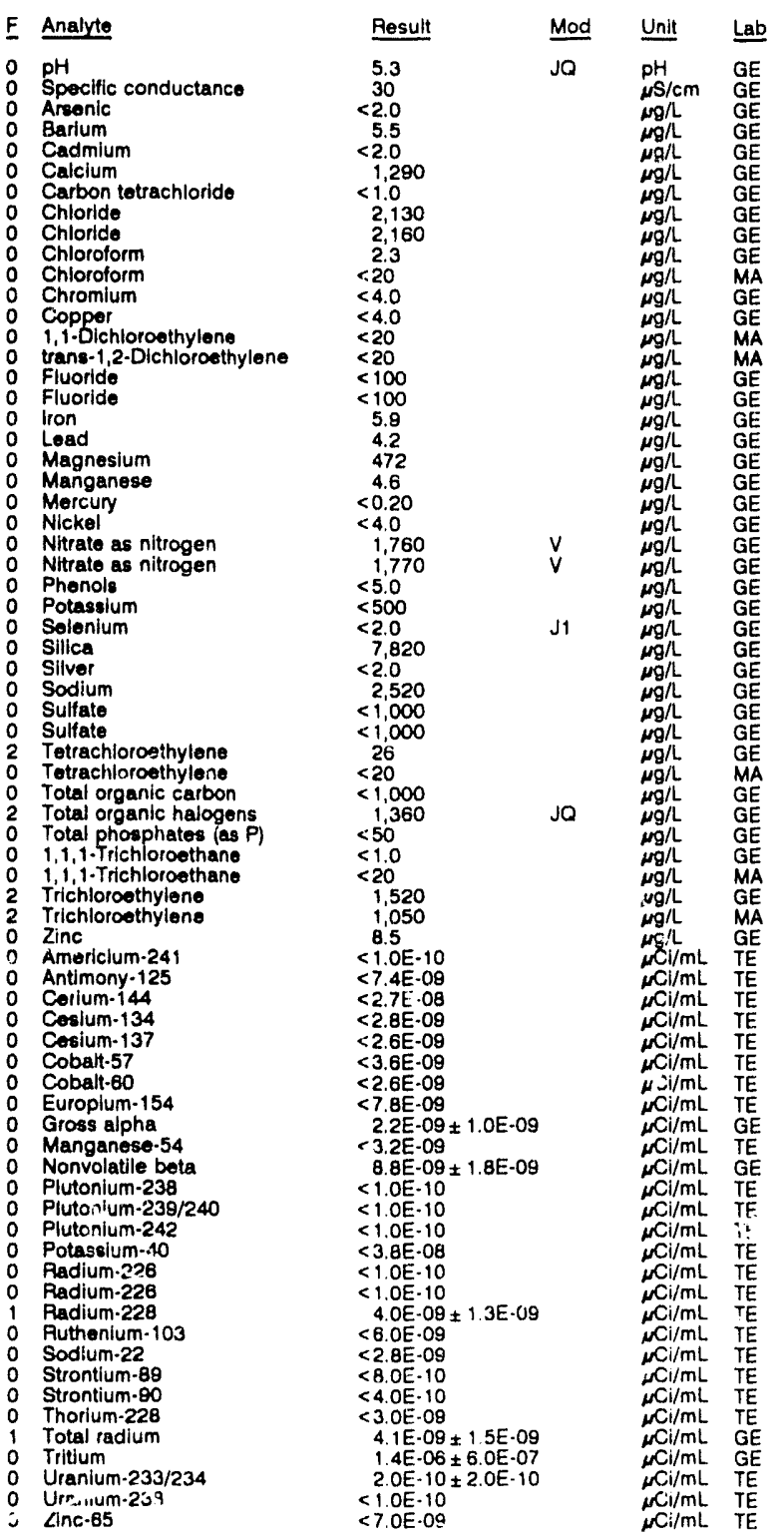

\section{WELL ASB $8 C$}

MEASUREMENTS CONDUCTED IN THE FIELD

$\begin{array}{ll}\text { Sample date: } 12 / 05 / 91 & \text { Time: } 12.25 \\ \text { Depth to water: } 126.87 \mathrm{ft}(38.87 \mathrm{~m}) \text { below TOC } & \text { pH: } 5.0 \\ \text { Water elevation: } 222.83 \mathrm{H}(67.92 \mathrm{~m}) \mathrm{ms} \text { i } & \text { Alkalinity: } 0 \mathrm{mg} / \mathrm{h} \\ \text { Sp. conductance: } 38 \mu \mathrm{s} / \mathrm{cm} & \text { Water temperature: } 17.3^{\circ} \mathrm{C} \\ \text { Water evacuated before sampling: } 105 \mathrm{gal} & \end{array}$

LABORATORY ANALYSES

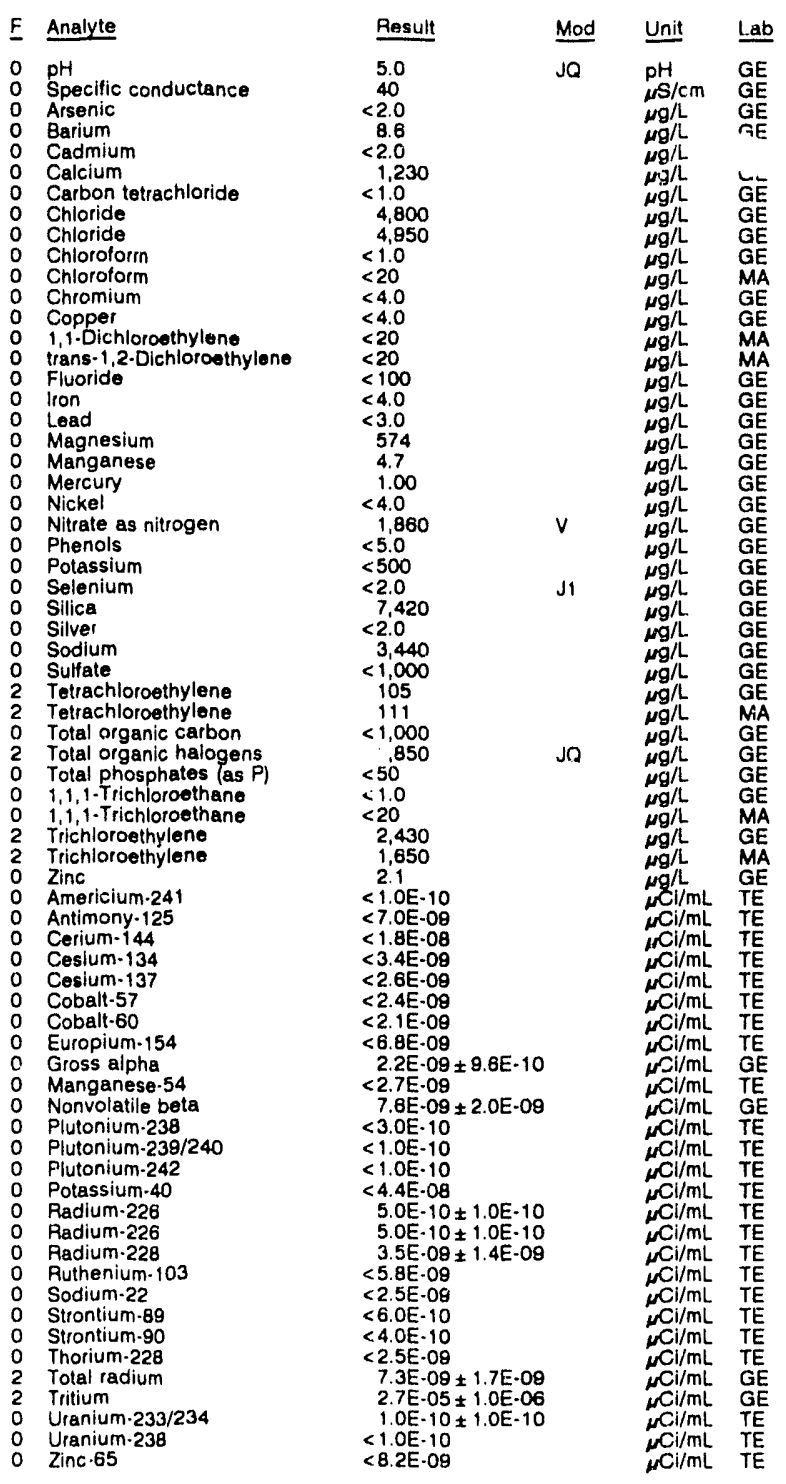

\section{WELL ASB 8TA}

MEASUIREMENTS SONDUCTED IN THE FIELD

Sample date: $11 / 07 / 81$

Depth to water: $134.69 \mathrm{ft}(41.05 \mathrm{~m})$ below TOC Water elevation: $214.81 \mathrm{ft}(65.51 \mathrm{~m}) \mathrm{ms}$

Sp conductunc. 22 .

pH: 5.1

inity: $1 \mathrm{mg} / \mathrm{L}$

Water evacuated before sampling: $487 \mathrm{gal}$

LABORATORY ANALYSES

\begin{tabular}{|c|c|c|c|}
\hline F Analyte & Result & Mod & Unit \\
\hline $\begin{array}{ll}0 & \mathrm{pH} \\
0 & \text { Specific conductance } \\
0 & \text { Arsenic }\end{array}$ & $\begin{array}{r}5.4 \\
20 \\
<2.0\end{array}$ & JO & $\begin{array}{l}\mathrm{pH} \\
\mu \mathrm{S} / \mathrm{cm} \\
\mu \mathrm{g} / \mathrm{L}\end{array}$ \\
\hline
\end{tabular}


ANALYTICAL RESULTS

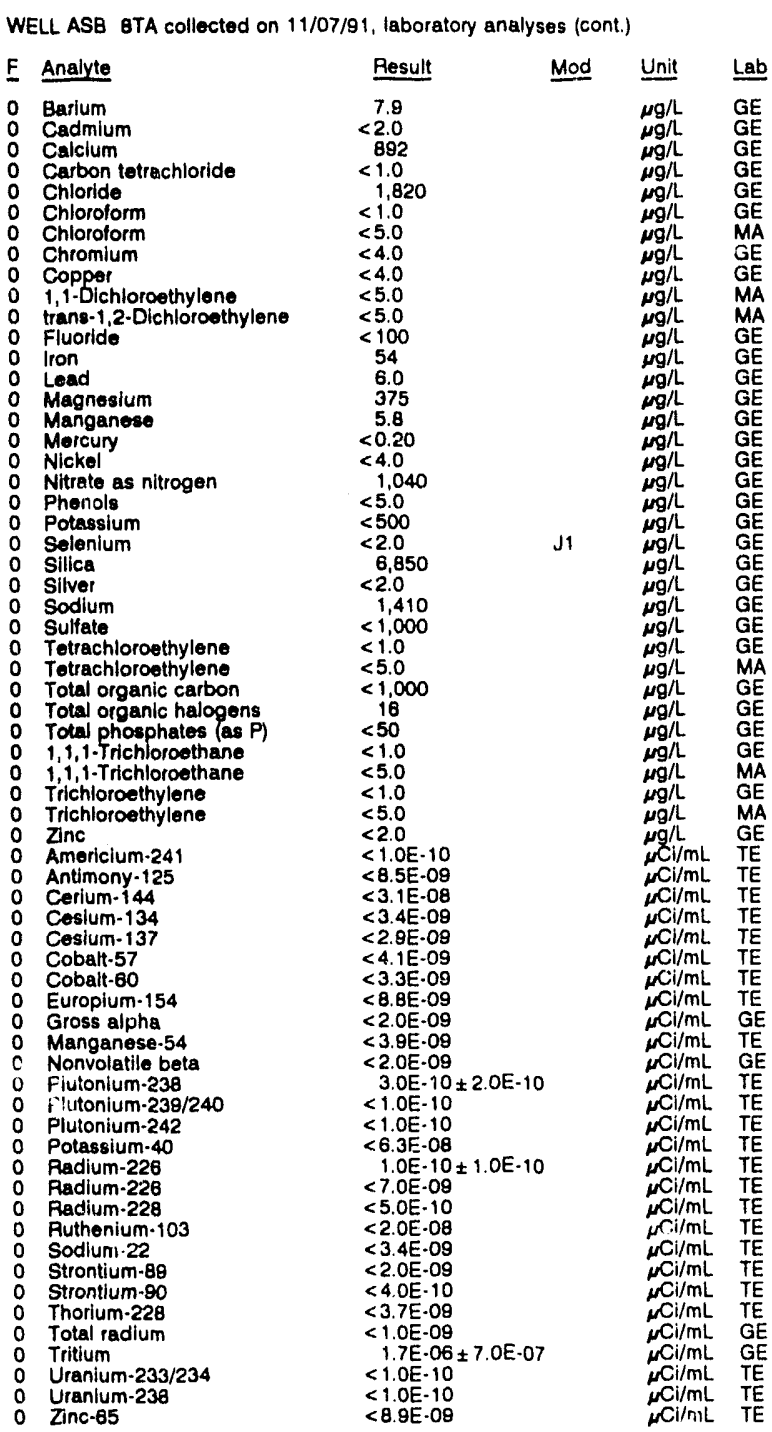

WELL ASB 9

MEASUREMENTS CONDUCTED IN THE FIELD

Sample date: $11 / 11 / 81$ (2) Depth to water: $66.76 \mathrm{ht}(20.35 \mathrm{~m})$ below TOC
Wate: olevation: $242.24 \mathrm{~h}(73.84 \mathrm{~m}) \mathrm{ms}$ । Sp. conductance: $48 \mu \mathrm{s} / \mathrm{cm}$.
Water evacuated before sampling: $76 \mathrm{gal}$ LABORATORY ANALYSES

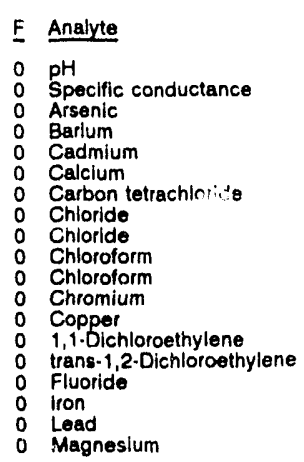

\begin{tabular}{c} 
Result \\
\hline 5.5 \\
45 \\
$<2.0$ \\
17 \\
$<2.0$ \\
876 \\
$<1.0$ \\
3.480 \\
3.480 \\
$<1.0$ \\
$<5.0$ \\
$<4.0$ \\
6.5 \\
$<5.0$ \\
$<5.0$ \\
$<100$ \\
6.2 \\
3.5 \\
521
\end{tabular}

Time: $11: 20$

Alkalinity: $1 \mathrm{mg} / \mathrm{L}$

Alkalinity: $1 \mathrm{mg} / \mathrm{L}$ : $17.4^{\circ} \mathrm{C}$
WELL ASB 9 collected on 11/11/91, laboratnry analyses (cont.)
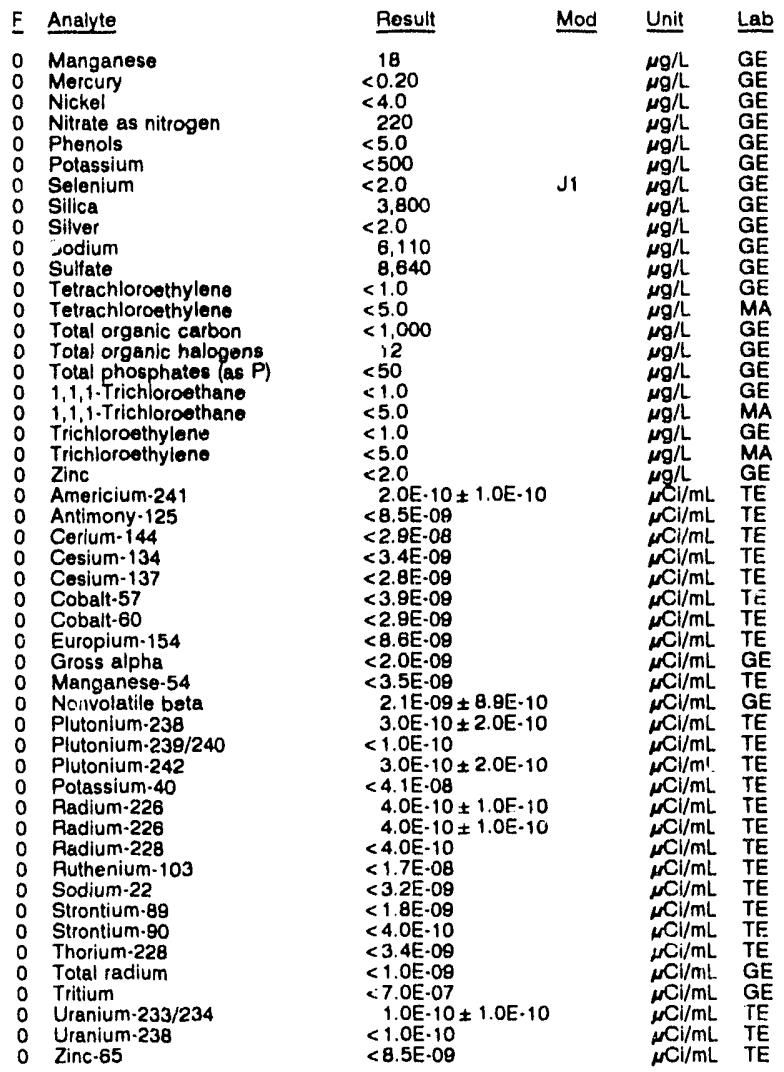

\section{WELL ASB 9B}

MEASUREMENTS CONDUCTED IN THE FIELD

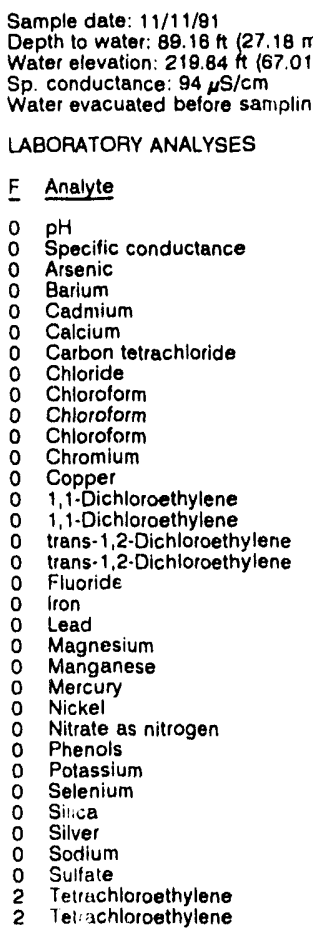

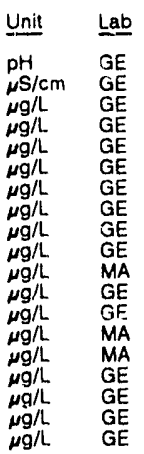

Time: $11: 45$

pH: 7.1 Alkalinity: $34 \mathrm{mg} / \mathrm{l}$ Alkalinity: $34 \mathrm{mg} / \mathrm{L}$ : $17.0^{\circ} \mathrm{C}$

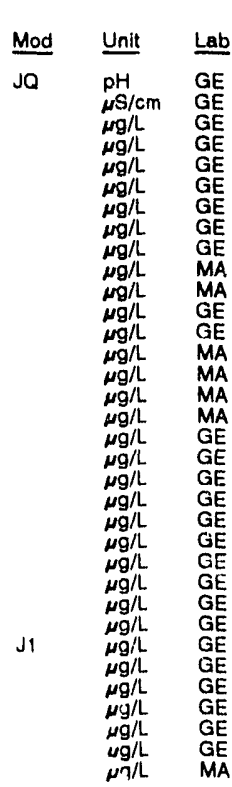


ANALYTICAL, RESULTS

WELL ASB 8B collocted on 11/11/81, laboratory analyses (cont.)

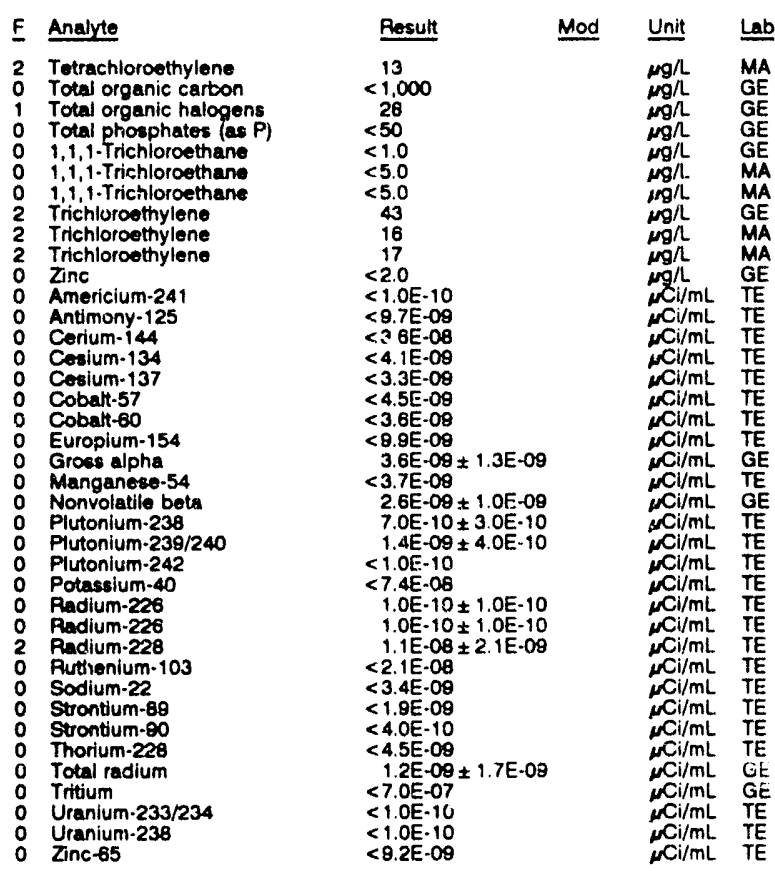

\section{WELL ASB 9B Replicate}

MEASUREMENTS CONDUCTED IN THE FIELD

Depth to water: $89.16 \mathrm{n}(27.18 \mathrm{~m})$ below TOC

Water elevation: 218.84 th $(87$.

Water ovacuated before sempling: $280 \mathrm{gal}$

LABORATORY ANALYSES

\begin{tabular}{|c|}
\hline A alyte \\
\hline 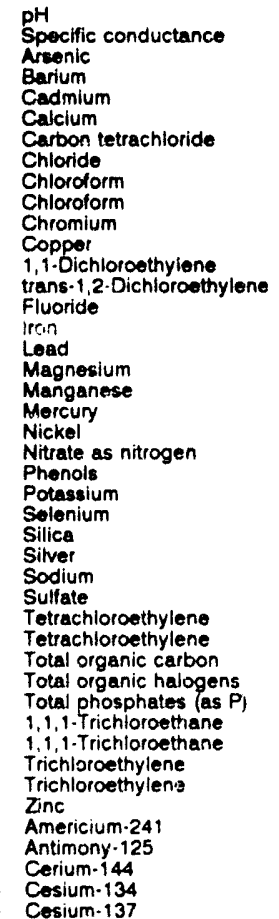 \\
\hline
\end{tabular}

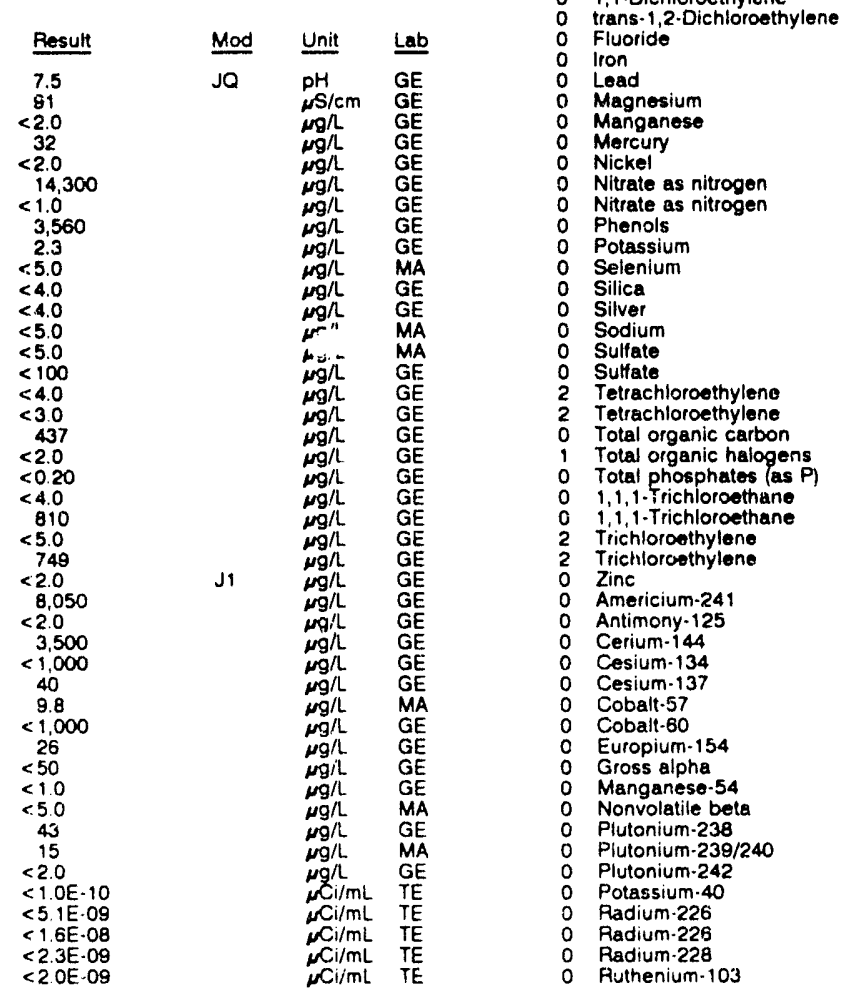

WELL. ASB $8 B$ collected on 11/11/91, laboratory analyses (cont.)

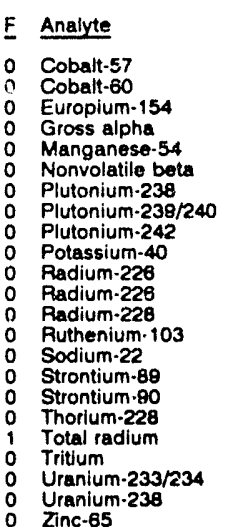

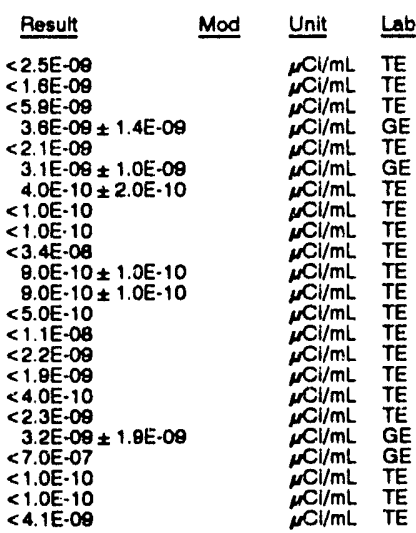

\section{WELL ASB $9 \mathrm{C}$}

MEASUREMENTS CONDUCTED IN THE FIELD

$\begin{array}{ll}\text { Sample date: } 11 / 11 / 81 & \text { Time: } 11: 00 \\ \text { Depth to wator: } 89.68 \mathrm{H}(27.33 \mathrm{~m}) \text { below TOC } & \text { pH: } 6.0 \\ \text { Water elevation: } 220.24 \mathrm{ft}(67.13 \mathrm{~m}) \mathrm{msl} & \text { Alkalinity: } 12 \mathrm{mg} / \mathrm{h} \\ \text { Sp conductance: } 50 \mu \mathrm{S} / \mathrm{cm} & \text { Water temperature: } 17.0^{\circ} \mathrm{C}\end{array}$
Water evacuated before sampling: $110 \mathrm{gal}$

LABOFATORY ANALYSES

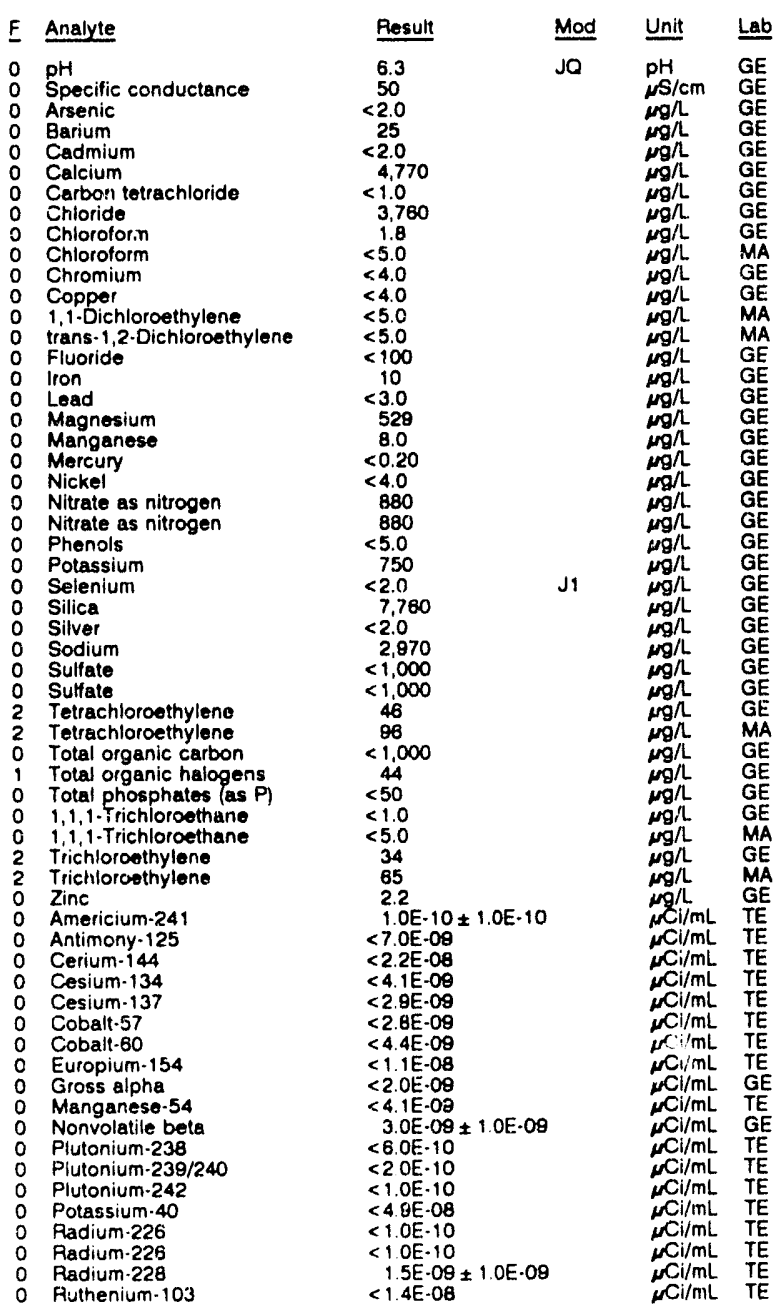


WELL ASB $8 C$ coilected on $11 / 11 / 81$, laboratory analyses (cont.)

\begin{tabular}{|c|c|c|c|c|}
\hline F Analyte & Besult & Mod & Unit & Lab \\
\hline $\begin{array}{l}\text { Sodiun1-22 } \\
\text { Strontium-89 } \\
\text { Strontium-80 } \\
\text { Thorlum-228 } \\
\text { Total radium } \\
\text { Tittum } \\
\text { Uranium-233/234 } \\
\text { Uranium-236 } \\
\text { Znc-65 }\end{array}$ & $\begin{array}{l}<4.2 E-09 \\
<1.2 E-09 \\
<4.0 E-10 \\
<2.8 E-09 \\
<1.0 E-09 \\
<7.0 E-07 \\
<1.0 E-10 \\
<1.0 E-10 \\
<1.0 E-08\end{array}$ & & 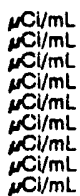 & $\begin{array}{l}\text { TE } \\
\text { TE } \\
\text { TE } \\
\text { TE } \\
G E \\
G E \\
\text { TE } \\
\text { TE } \\
\text { TE }\end{array}$ \\
\hline
\end{tabular}

\section{WELL ASB $10 \mathrm{C}$}

MEASUREMENTS CONDUCTED IN THE FIELD

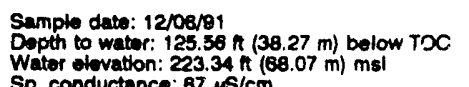
Sp. conductance: $87 \mathrm{~s} / \mathrm{cm}$

Time: $9: 50$

Alkalinity: $12 \mathrm{mgn}$ Water temperature: $18.1^{\circ} \mathrm{C}$
LABOPATOPY ANALYSES

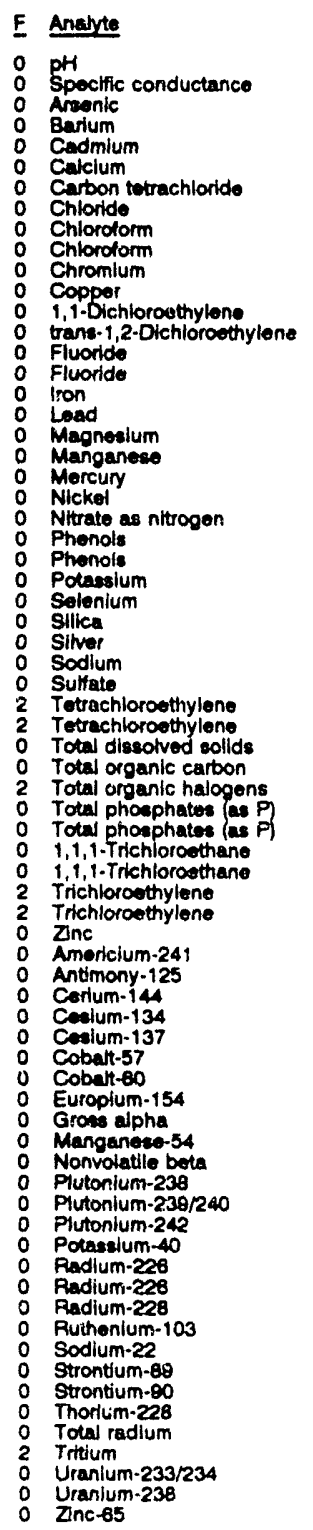

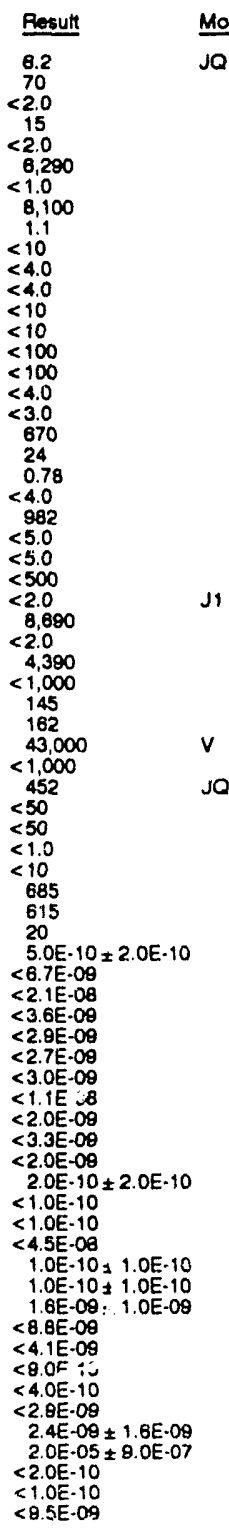

WELL BG 52

MEASUREMENTS CONDUCTED IN THE FIELD

$\begin{array}{ll}\text { Sample date: } 11 / 18 / 91 & \text { Time: } 10: 10 \\ \text { Dopth to water: } 58.70 \mathrm{ft}(17.89 \mathrm{~m}) \text { below TOC } & \mathrm{pH}: 6.8 \\ \text { Water olevation: } 231.10 \mathrm{~h}(70.44 \mathrm{~m}) \mathrm{msl} & \text { Water temperature: } 17.7^{\circ} \mathrm{C} \\ \text { Sp. conductance: } 45 \mu \mathrm{sm} & \end{array}$

No water was ovacuated before sampling.

LABORATOAY ANALYSES

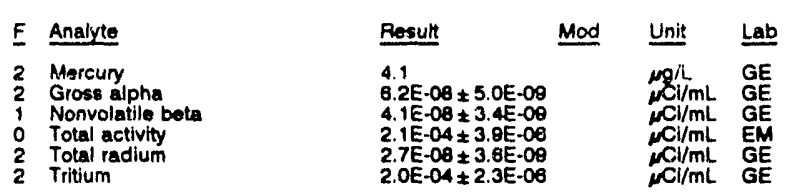

\section{WELL BG 54}

MEASUREMENTS CONDUCTED IN THE FIELD

$\begin{array}{ll}\text { Samplin date: } 10 / 15 / 91 & \text { Time: } 12: 30 \\ \text { Depth to water: } 48.20 \mathrm{nt}(14.06 \mathrm{~m}) \text { below TOC } & \mathrm{pH}: 6.3 \\ \text { Water elevation: } 231.00 \mathrm{~h}(70.41 \mathrm{~m}) \mathrm{msl} & \text { Water temperature: } 19.9^{\circ} \mathrm{C} \\ \text { Sp. conductance: } 62 \mu \mathrm{s} / \mathrm{cm} & \end{array}$

Sp. Conductance: $62 \mu \mathrm{S} / \mathrm{cm}$
No water was evacuated before sampling

Water temperature: $18.9^{\circ} \mathrm{C}$

LABORATORY ANALYSES

\begin{tabular}{|c|c|c|c|}
\hline Analyte & Result & Mod & Unit \\
\hline $\begin{array}{ll}0 & \text { Mercury } \\
0 & \text { Gross alpha } \\
0 & \text { Nonvolatile beta } \\
1 & \text { Total radium } \\
2 & \text { Tritium }\end{array}$ & $\begin{array}{l}0.46 \\
2.2 E-09 \pm 1.8 E-08 \\
7.5 E-09 \pm 2.5 E-09 \\
3.9 E-09 \pm 1.7 E-08 \\
2.2 E-05 \pm 8.0 E-07\end{array}$ & & 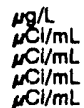 \\
\hline
\end{tabular}

WELL BG 55

MEASUREMENTS CONDUCTED IN THE FIELD

$\begin{array}{ll}\text { Sample date: } 10 / 15 / 91 & \text { Time: } 13: 10 \\ \text { Depth to water } 47.60 \mathrm{n}(14.51 \mathrm{~m}) \text { below TOC } & \mathrm{pH}: 6.2 \\ \text { Water elevation: } 229.30 \mathrm{Ht}(69.89 \mathrm{~m}) \mathrm{ms} & \text { Water temperature: } 20.0^{\circ} \mathrm{C} \\ \text { Sp. conductance: } 68 \mu \mathrm{s} / \mathrm{cm} & \\ \text { No water was ovacuated belore sampling } & \end{array}$

No water was ovacuated before sampling

Water temperature: $20.0^{\circ} \mathrm{C}$

LABORATORY ANALYSES

E Analyte

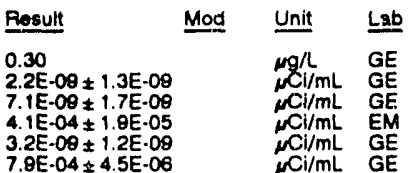

0 Mercury

0 Nonvolatile beto

- Total activity

Total radium

$7.8 \mathrm{E}-04 \pm 4.5 \mathrm{E}-0$

WELL BG 59

MEASUREMENTS CONOUCTED IN THE FIELD

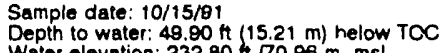

Water elevation: $232.80 \mathrm{~h} 70.06 \mathrm{~m}$, ms

Sp. conductance: $85 \mu \mathrm{S} / \mathrm{cm}$

No water was evacuated before sampling.

LABORATORY ANALYSES

F Analyte

- Mercury

Tonvolatile beta

2 Total radium

1 Tritium

\begin{tabular}{|c|c|c|}
\hline Result & Mod & Unit \\
\hline $\begin{array}{l}0.21 \\
7.1 \mathrm{E}-00 \pm 2.5 \mathrm{E}-09 \\
1.7 \mathrm{E}-08 \pm 3.0 \mathrm{E}-00 \\
\text { B. } 6 \mathrm{E}-00 \pm 1.9 \mathrm{E}-08 \\
1.7 \mathrm{E}-05 \pm 8.0 \mathrm{E}-07\end{array}$ & & $\begin{array}{l}\mu \mathrm{g} / \mathrm{L} \\
\mu \mathrm{Cl} / \mathrm{mL} \\
\mu \mathrm{Cl} / \mathrm{mL} \\
\mu \mathrm{Cl} / \mathrm{mL} \\
\mathrm{MCl} / \mathrm{mL}\end{array}$ \\
\hline
\end{tabular}


ANALYTICAL RESULTS

WELL BG 60

MEASUREMENTS CONDUCTED IN THE FIELD

Sample date: $10 / 15 / 91$

Depth to water: $41.00 \mathrm{ft}(12.50 \mathrm{~m})$ below TOC

Sp. conductance $43.50 \mathrm{~h}$ (71.4

No water was ovacuated before sampling.

Time: $13: 50$

Wafer temperature: $20.3^{\circ} \mathrm{C}$

LABORATORY ANALYSES

\begin{tabular}{|c|c|c|c|}
\hline Analyte & Posult & Mod & Unit \\
\hline $\begin{array}{ll}0 & \text { Mercury } \\
0 & \text { Grows alpha } \\
0 & \text { Nonvolatile beta } \\
2 & \text { Total radium } \\
1 & \text { Tritum }\end{array}$ & $\begin{array}{l}0.53 \\
5.1 \mathrm{E}-09 \pm 2.2 \mathrm{E}-09 \\
5.8 \mathrm{E}-09 \pm 2.4 \mathrm{E}-09 \\
5.7 \mathrm{E}-09 \pm 1.0 \mathrm{E}-09 \\
2.0 \mathrm{E}-05 \pm 9.0 \mathrm{E}-07\end{array}$ & & $\begin{array}{c}\mathrm{mg} / \mathrm{L} \\
\mathrm{N} \mathrm{L} / \mathrm{mL} \\
\mathrm{NCl} / \mathrm{mL} \\
\mu \mathrm{Cl} / \mathrm{mL} \\
\mathrm{NCl} / \mathrm{mL}\end{array}$ \\
\hline
\end{tabular}

\section{WELL BG 61}

MEASUREMENTS CONDUCTED IN THE FIELD

Sample date: 10/15/91

Depth to water: $38.40 \mathrm{ft}(12.01 \mathrm{~m})$ below TOC

Water olevation: $235.60 \mathrm{~h}(71.61 \mathrm{~m}) \mathrm{ms}$

No water was ovacuated before sampling.

Water temperature: $20.2^{\circ} \mathrm{C}$

LABORATORY ANALYSES

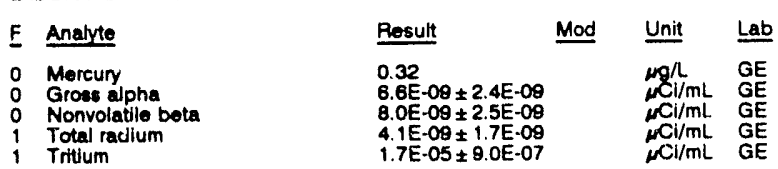

WELL BG 67

MEASUREMENTS CONDUCTED IN THE FIELD

Somple date: $11 / 18 / 91$

Depth to wator: $57.50 \mathrm{n}(17.53 \mathrm{~m})$ bolow TOC

Water olevation: $237.20 \mathrm{ft}(72$.

Sp. conductance. $38 \mathrm{\mu S} / \mathrm{cm}$

$\operatorname{Time:}_{\mathrm{pH}:} 11: 10$

Water temperature: $18.1^{\circ} \mathrm{C}$

LABORATORY ANALYSES

\begin{tabular}{|c|c|c|c|c|c|}
\hline$E$ & Analyte & Rosult & Mod & Unit & $\underline{\text { Lab }}$ \\
\hline $\begin{array}{l}1 \\
2 \\
0 \\
0 \\
2 \\
2\end{array}$ & $\begin{array}{l}\text { Mercury } \\
\text { Groas alpha } \\
\text { Nonvolatile beta } \\
\text { Total activity } \\
\text { Total radium } \\
\text { Tritum }\end{array}$ & $\begin{array}{r}1.1 \\
2.0 \mathrm{E}-08 \pm 2.8 \mathrm{E}-09 \\
<2.0 \mathrm{E}-09 \\
1.5 \mathrm{E}-03 \pm 8.8 \mathrm{E}-08 \\
8.1 \mathrm{E}-09 \pm 2.3 \mathrm{E}-09 \\
1.5 \mathrm{E}-03 \pm 6.0 \mathrm{E}-06\end{array}$ & & $\begin{array}{l}\mu \mathrm{g} / \mathrm{h} \\
\mu \mathrm{Ci} / \mathrm{mL} \\
\mathrm{NCi/mL} \\
\mu \mathrm{Cl} / \mathrm{mL} \\
\mu_{\mathrm{Cl}} / \mathrm{mL} \\
\mu \mathrm{Cl} / \mathrm{mL}\end{array}$ & $\begin{array}{l}\mathrm{GE} \\
\mathrm{GE} \\
\mathrm{GE} \\
\mathrm{EM} \\
\mathrm{GE} \\
\mathrm{GE}\end{array}$ \\
\hline
\end{tabular}

WELL BG 91

MEASUREMENTS CONDUCTED IN THE FIELD

Sample date: 10/22/91

Depth to water: $51.77 \mathrm{th}(15.78 \mathrm{~m})$ below TOC Water elevation: $221.63 \mathrm{ft} / 67.5 \%$

Water evacuated bolore sampling: $15 \mathrm{gal}$

The well went dry during purging

LABORATORY ANALYSES

\begin{tabular}{|c|c|c|c|c|}
\hline Analyte & Result & Mind & $\underline{\text { Unit }}$ & $\underline{\text { Lab }}$ \\
\hline $\begin{array}{l}\text { pH } \\
\text { Spocific conductance } \\
\text { Aluminum } \\
\text { Antimony } \\
\text { Barium } \\
\text { Boryllium } \\
\text { Cadmium } \\
\text { Calcium } \\
\text { Chloride } \\
\text { Chromium } \\
\text { Cobalt } \\
\text { Copper } \\
\text { Fluoride } \\
\text { Fluoride } \\
\text { lodine } \\
\text { lodine } \\
\text { lron } \\
\text { Lead } \\
\text { Magnesium } \\
\text { Manganese } \\
\text { Mercury }\end{array}$ & $\begin{aligned} 5.3 \\
45 \\
26 \\
<2.0 \\
12 \\
<3.0 \\
<2.0 \\
2,810 \\
3,280 \\
<4.0 \\
<4.0 \\
246 \\
<100 \\
<100 \\
362 \\
367 \\
91 \\
34 \\
969 \\
8.7 \\
-0.20\end{aligned}$ & JO & $\begin{array}{l}\mathrm{pH} \\
\mu S / \mathrm{cm} \\
\mu g / L \\
\mu g / L \\
\mu g / L \\
\mu g / L \\
\mu g / L \\
\mu g / L \\
\mu g / L \\
\mu g / L \\
\mu g / L \\
\mu g / L \\
\mu g / L \\
\mu g / L \\
\mu g / L \\
\mu g / L \\
\mu g / L \\
\mu g / L \\
\mu g / L \\
\mu g / L \\
\mu g / L\end{array}$ & $\begin{array}{l}\mathrm{GE} \\
\mathrm{GE} \\
\mathrm{GE} \\
\mathrm{GE} \\
\mathrm{GE} \\
\mathrm{GE} \\
\mathrm{GE} \\
\mathrm{GE} \\
\mathrm{GE} \\
\mathrm{GE} \\
\mathrm{GE} \\
\mathrm{GE} \\
\mathrm{GE} \\
\mathrm{GE} \\
\mathrm{GE} \\
\mathrm{GE} \\
\mathrm{GE} \\
\mathrm{GE} \\
\mathrm{GE} \\
\mathrm{GE} \\
\mathrm{GE}\end{array}$ \\
\hline
\end{tabular}

M

WELL BG 91 collected on 10/22/91, laboratory analyses (cont.)
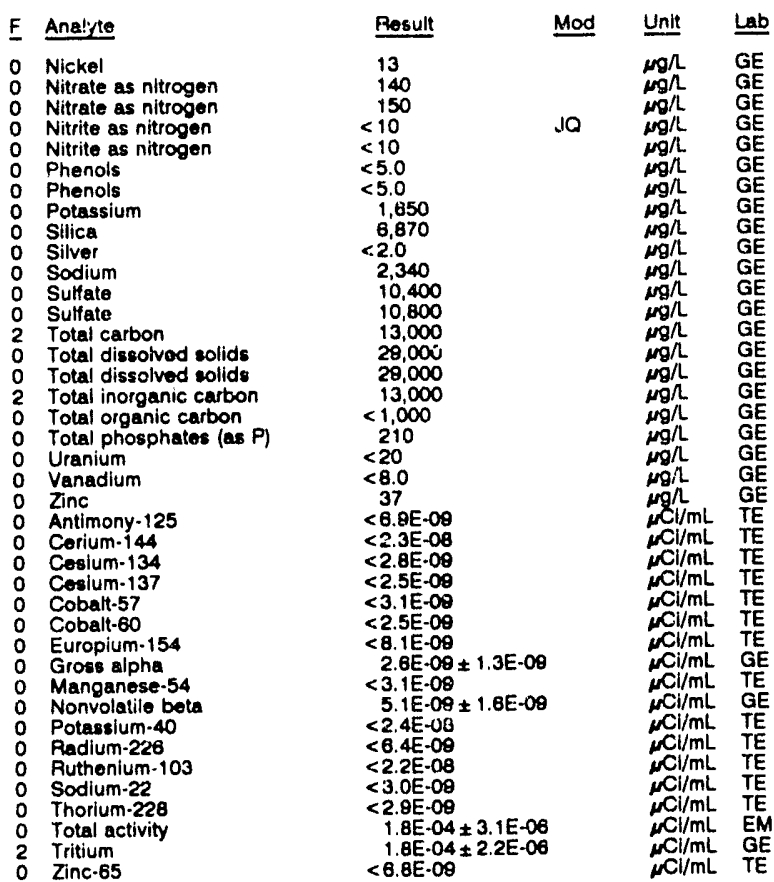

WELL BG 92

MEASUREMENTS CONDUCTED IN THE FIELD

\begin{tabular}{|c|c|}
\hline & $\begin{array}{l}\text { pH } \\
\text { Specific conductance } \\
\text { Aluminum } \\
\text { Antimony } \\
\text { Barium } \\
\text { Boryllium } \\
\text { Cadmium } \\
\text { Calcium } \\
\text { Chloride } \\
\text { Chromium } \\
\text { Cobait } \\
\text { Copper } \\
\text { Fluoride } \\
\text { lodine } \\
\text { lron } \\
\text { Lead } \\
\text { Magnesium } \\
\text { Manganese } \\
\text { Mercury } \\
\text { Nickel } \\
\text { Nitrate as nitrogen } \\
\text { Nitrite as nitrogen } \\
\text { Phenols } \\
\text { Potassium } \\
\text { Silica } \\
\text { Silver } \\
\text { Sodium } \\
\text { Sulfate } \\
\text { Total carbon } \\
\text { Total dissolved solids } \\
\text { Total inorganic carbon } \\
\text { Total organic carbon } \\
\text { Total phosphates (as P) } \\
\text { Uranium } \\
\text { Uranium } \\
\text { Vanadium } \\
\text { Zinc } \\
\text { Antimony -125 } \\
\text { Cerium-144 } \\
\text { Cesium- } 134 \\
\text { Cesium-137 } \\
\text { Cobalt-57 } \\
\text { Cobalt-60 }\end{array}$ \\
\hline
\end{tabular}

Time: $8: 25$
$\mathrm{pH}: 7.8$

Alkaltnity: $83 \mathrm{mg}$ Water tomperature: $17.8^{\circ} \mathrm{C}$

n: 211.77 th $(64.55)$

m) below TOC pling: $19 \mathrm{ga}$ 
ANAL: TICAL RESULTS

\begin{tabular}{|c|c|c|c|c|c|}
\hline$\underline{\mathbf{F}}$ & Analyte & Result & Mod & Unit & Lab \\
\hline $\begin{array}{l}0 \\
0 \\
0 \\
0 \\
0 \\
0 \\
0 \\
0 \\
0 \\
0 \\
0\end{array}$ & $\begin{array}{l}\text { Europlum-154 } \\
\text { Groes alpha } \\
\text { Manganose-54 } \\
\text { Nonvolatle beta } \\
\text { Potasalum-40 } \\
\text { Radlum-228 } \\
\text { Ruthenium-103 } \\
\text { Sodium-22 } \\
\text { Thorium-228 } \\
\text { Tritum } \\
\text { Znc- } 65\end{array}$ & $\begin{aligned}<8.4 E-09 \\
2.1 E-09 \pm 1.4 E-09 \\
<3.4 E-09 \\
8.3 E-09 \pm 1.8 E-09 \\
<3.6 E \cdot 08 \\
<6.0 E \cdot 09 \\
<2.8 E-08 \\
<3.2 E-09 \\
<3.8 E \cdot 09 \\
<7.0 E-07 \\
<0.1 E-09\end{aligned}$ & & 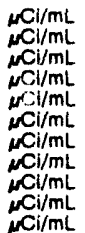 & $\begin{array}{l}T E \\
\mathrm{GE} \\
\mathrm{TE} \\
\mathrm{GE} \\
\mathrm{TE} \\
\mathrm{TE} \\
\mathrm{TE} \\
\mathrm{TE} \\
\mathrm{TE} \\
\mathrm{GE} \\
\mathrm{TE}\end{array}$ \\
\hline
\end{tabular}

WELL BG 93

MEASUREMENTS CONDUCTED IN THE FIELD

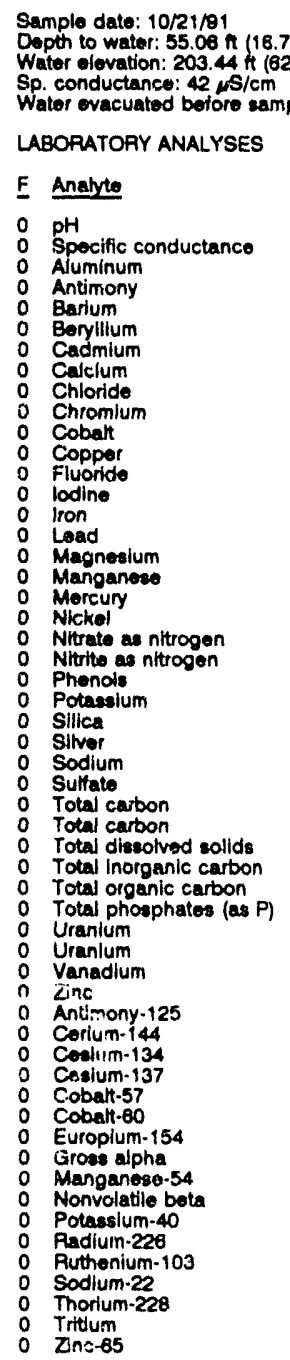

$<3.1 E-08$

$<1.6 \mathrm{E} .08$

$<2.0 E \cdot 09$

$<7.0 E \cdot 07$
WELL BG 94

MEASUREMENTS CONDUCTED IN THE FIELD

Sample date: 10/21/91

Depth to water: $57.88 \mathrm{ft}(17.64 \mathrm{~m})$ below TOC

Sp. conductance: 1002 Ht 158

Water evacuated bofore sampling: $105 \mathrm{gal}$

LABORATORY ANALYSES

E Analyte

O $\mathrm{pH}$ Specific conductance

A Aluminum

0 Barium

o Beryllium

0 Cadmium

0 Chloride

o Chromium

O Cobalt

o Copper

Fluoride
0 lodine

o Iron

o Lead

2 Manganese

0 Mercury

- Nitrate as nitrogen

- Nitrite as nitrogen

Phenols

- Silica

0 Silver

Sodium

Total carbon

Total dissolved solids

Total organic carbon

Total phosphates (as P)

Uranium

Uranlum

Vanadiun

- Antimony-125

Corium-144

Cesium-134

Cobalt-57

Europium-154

Gross alpha

Manganeso.54

Nonvolatile bela

Radium-226

Ruthenium-103

Sodium-22

0 Tritium

$\begin{array}{ll}0 & \text { Tritium } \\ 0 & \text { Zinc-65 }\end{array}$

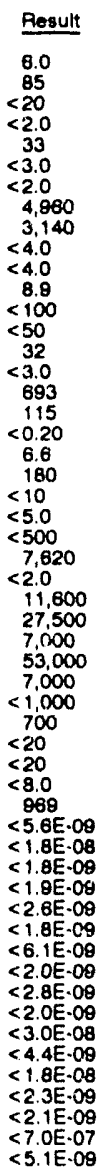

Time: $13: 40$

Alkalinity: $6 \mathrm{mg}$

Water temperature $18.6^{\circ} \mathrm{C}$

WELL BG 95

MEASUREMENTS CONDUCTED IN THE FIELD

Sample date: 10/21/81

Depth to water: $28.12 \mathrm{ft}(8.57 \mathrm{~m})$ below TOC

Water elevation: $184.38 \mathrm{th}(50.25 \mathrm{~m}) \mathrm{msl}$

Sp. (conduclance: $46 \mu \mathrm{s} / \mathrm{cm}$

sampling: $110 \mathrm{gal}$

LABORATORY ANALYSES

$\begin{array}{ll}\text { F } & \text { Analyte } \\ 0 & \text { pH } \\ 0 & \text { Specific conductance } \\ 0 & \text { Aluminum } \\ 0 & \text { Antimony } \\ 0 & \text { Barium } \\ 0 & \text { Beryllium } \\ 0 & \text { Cadmium } \\ 0 & \text { Calcium } \\ 0 & \text { Chloride } \\ 0 & \text { Chromium } \\ 0 & \text { Cobalt } \\ 0 & \text { Copper } \\ 0 & \text { Fluoride } \\ 0 & \text { lodine } \\ 0 & \text { lron } \\ 0 & \text { Lead } \\ 0 & \text { Magnesium }\end{array}$

\begin{tabular}{l} 
Result \\
\hline 5.6 \\
40 \\
$<20$ \\
$<2.0$ \\
8.4 \\
$<3.0$ \\
$<2.0$ \\
2.260 \\
3.160 \\
$<4.0$ \\
$<4.0$ \\
51 \\
$<100$ \\
$<50$ \\
25 \\
$<3.0$ \\
425
\end{tabular}

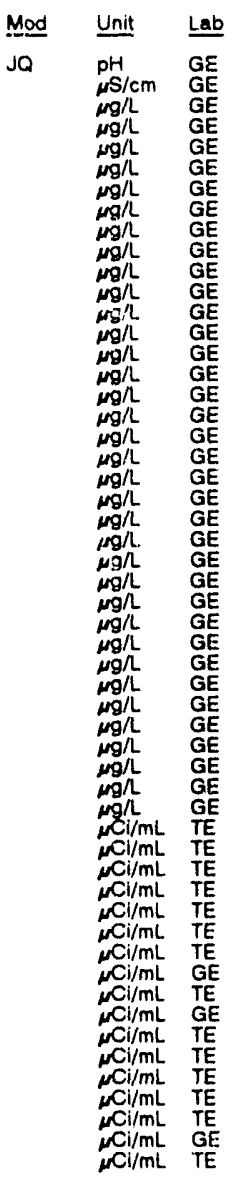

Time: $14: 10$

PH: 5.1 : Kalinity: $2 \mathrm{mg} / \mathrm{L}$

Water temperature: $18.3^{\circ} \mathrm{C}$

ence

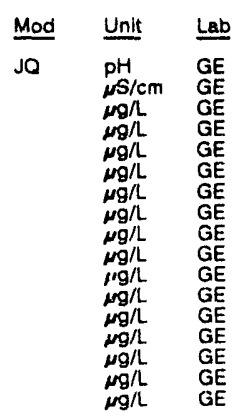

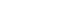


ANALYTICAL RESULTS

WELL BG 85 collectod on 10/21/91, laboratory analyses (cont.)

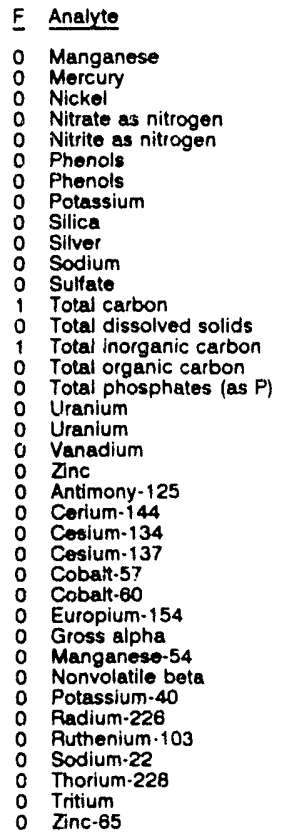

\begin{tabular}{c} 
Result \\
\hline 5.6 \\
$<0.20$ \\
$<4.0$ \\
610 \\
$<10$ \\
$<5.0$ \\
$<5.0$ \\
$<500$ \\
7,610 \\
$<2.0$ \\
4,420 \\
7.800 \\
7.000 \\
28,000 \\
7,000 \\
$<1,000$ \\
770 \\
$<20$ \\
$<20$ \\
$<8.0$ \\
872 \\
$<6.5 \mathrm{E} \cdot 09$ \\
$<2.3 \mathrm{E} \cdot 08$ \\
$<2.6 \mathrm{E}-09$ \\
$<2.5 \mathrm{E}-09$ \\
$<3.0 \mathrm{E} \cdot 09$ \\
$<3.1 \mathrm{E} \cdot 09$ \\
$<7.7 \mathrm{E} \cdot 09$ \\
$<2.0 \mathrm{E} \cdot 09$ \\
$<3.5 \mathrm{E}-09$ \\
$<2.0 \mathrm{E}-09$ \\
$<3.9 \mathrm{E}-08$ \\
$<5.1 \mathrm{E} \cdot 09$ \\
$<2.2 \mathrm{E} \cdot 08$ \\
$<2.7 \mathrm{E}-09$ \\
$<2.7 \mathrm{E} \cdot 09$ \\
$<7.0 \mathrm{E}-07$ \\
$<7.4 \mathrm{E} \cdot 09$ \\
\hline
\end{tabular}

\section{WELL BG 96}

MEASUREMENTS CONDUCTED IN THE FIELD

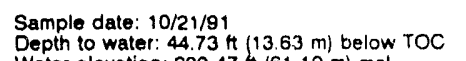
Depth to water: $44.73 \mathrm{Ht}(13.6 .3 \mathrm{~m})$ below $\mathrm{roc}$
Water elevation: $200.47 \mathrm{H}(61.10 \mathrm{~m}) \mathrm{msl}$

Sp. conductance: $26 \mu \mathrm{\mu S} / \mathrm{cm}$
Water evacuated before sampling $61 \mathrm{gal}$

LABORATOAY ANALYSES

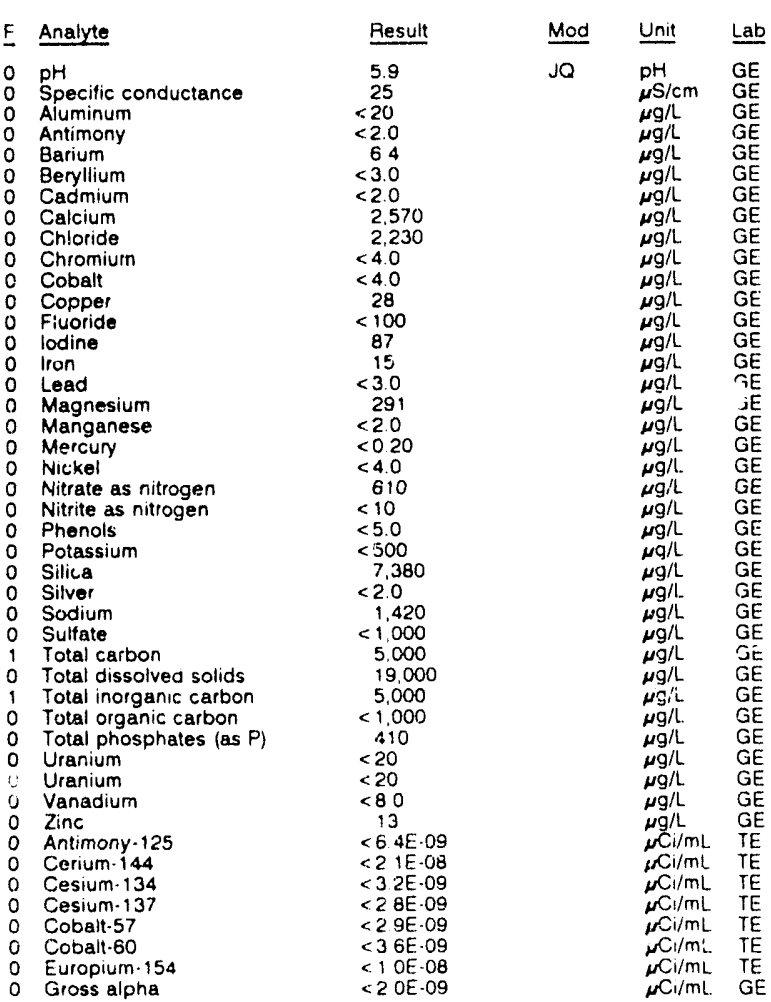

WELL BS 96 collected on 10/21/91, laboratory analyses icont.)

\begin{tabular}{|c|c|c|c|c|}
\hline$F$ & Analyte & - & Result & Unit \\
\hline & $\begin{array}{l}\text { Manganese-54 } \\
\text { Nonvolatile beta } \\
\text { Potassium-40 } \\
\text { Radium-226 } \\
\text { Ruthenium-103 } \\
\text { Sodium-22 } \\
\text { Thorium-228 } \\
\text { Tritium } \\
\text { Zinc-65 }\end{array}$ & & $\begin{array}{l}<3.0 \mathrm{E}-09 \\
2.2 \mathrm{E} \cdot 09 \pm 1.4 \mathrm{E} \cdot 09 \\
<4.5 \mathrm{E}-08 \\
<5.2 \mathrm{E} \cdot 09 \\
<2.2 \mathrm{E}-08 \\
<3.7 \mathrm{E} \cdot 09 \\
<3.0 \mathrm{E} \cdot 09 \\
1.5 \mathrm{E}-08 \pm 7.0 \mathrm{E}-07 \\
<7.9 \mathrm{E}-09\end{array}$ & 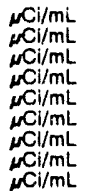 \\
\hline
\end{tabular}

\section{WELL BG 101}

MEASUREMENTS CONDUCTED IN THE FIELD

Depth to water: $34.30 \mathrm{n}(10.45 \mathrm{~m})$ below TOC

Water elevation: $197.10 \mathrm{H}(60.08 \mathrm{~m}) \mathrm{ms}$

Water evacuated before sampling: $94 \mathrm{gal}$

LABORATORY ANALYSES

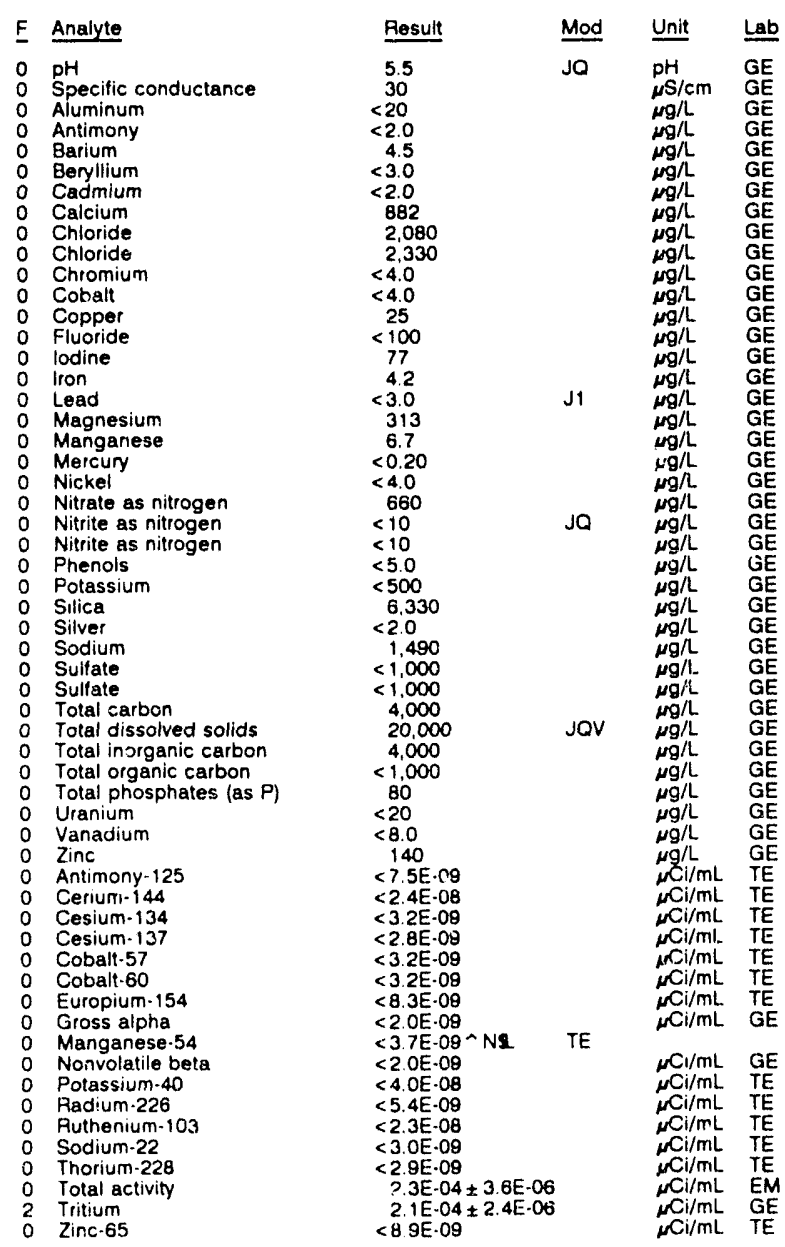


ANALYTICAL RESULTS

WELL BG 103

MEASUREMENTS CONDUCTEO IN THE FIELD

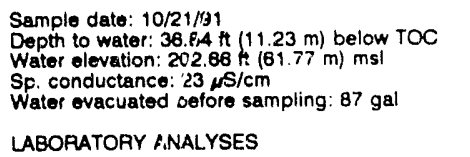

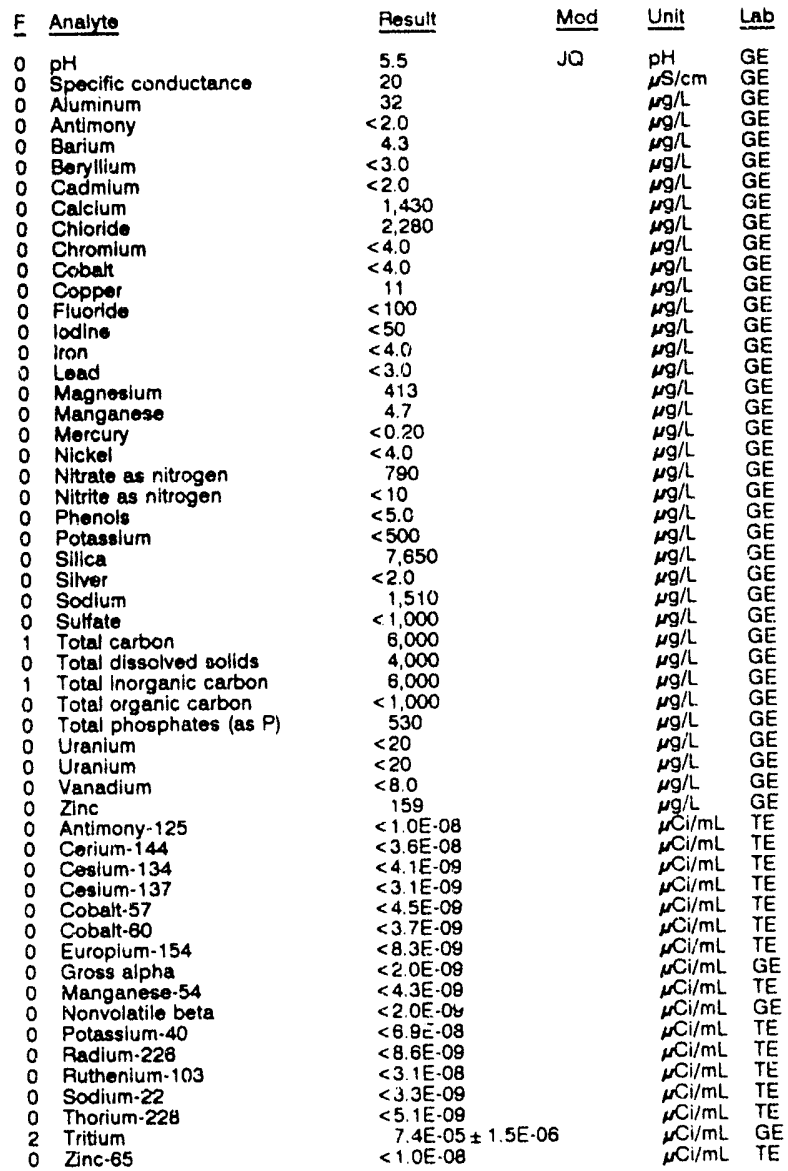

WELL BG 104

MEASUREMENTS CONDUCTED IN THE FIELD

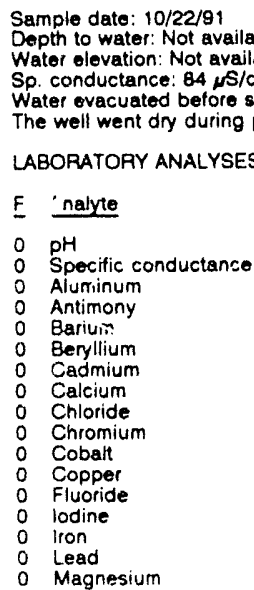

LABORATORY ANALYSES
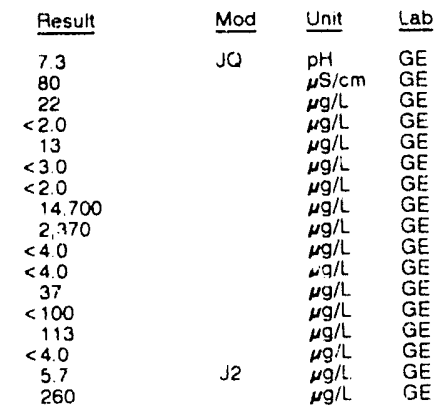

WEUL BG 104 collecteo on 10/22/91, laboratory analyses (cont)

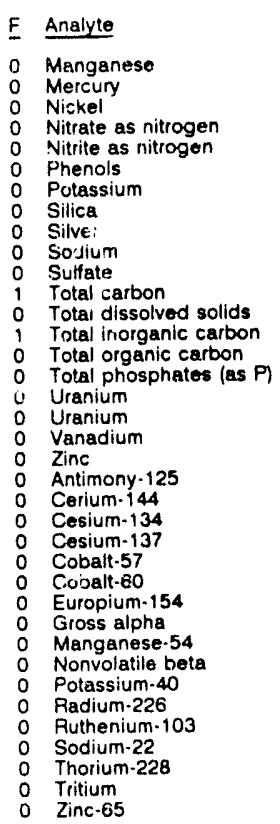

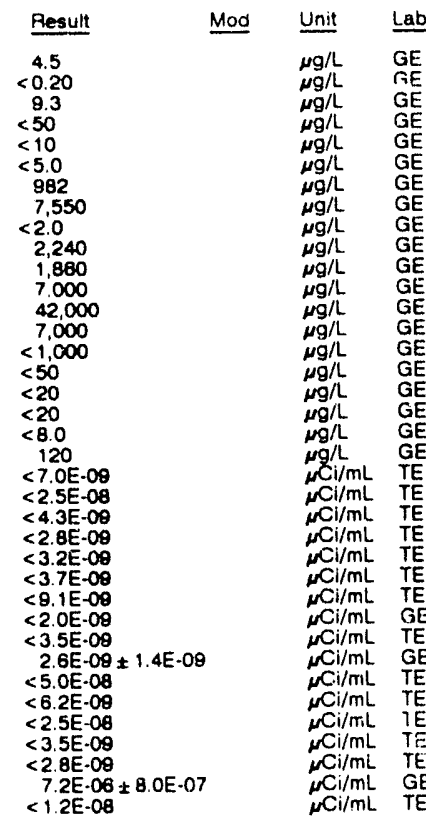

\section{WELL BG 107}

MEASUREMENTS CONDUCTED IN THE FIELD

$\begin{array}{ll}\text { Sample date: } 10 / 21 / 91 & \text { Time: } 17.05 \\ \text { Depth to water: } 12.23 \mathrm{ft}(3.73 \mathrm{~m}) \text { below TOC } & \text { pH: } 5.5 \\ \text { Water elevation: } 236.07 \mathrm{th}(71.96 \mathrm{~m}) \mathrm{mst} & \text { Alkalinity: } 8 \mathrm{mg} / \mathrm{L} \\ \text { Sp. conductance: } 38 \mu \mathrm{s} / \mathrm{cm} & \text { Water temperature: } 20.0^{\circ} \mathrm{C} \\ \text { Water evacuated betote sampling: } 73 \mathrm{gal} & \end{array}$

LABORATORY ANALYSES

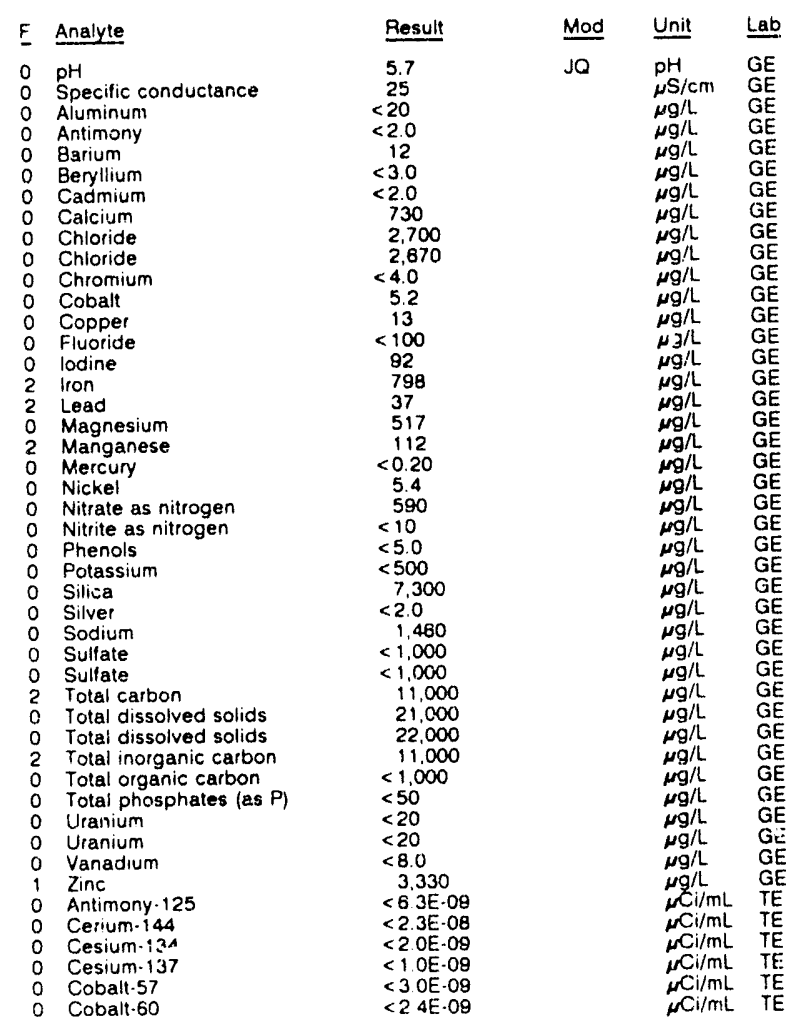


ANALYTICAL RESULTS

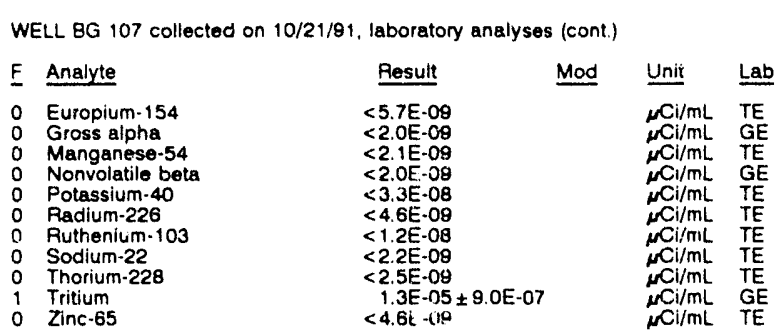

WELL BG 108

MEASUREMENTS CONDUCTED IN THE FIELD

Sample date: $10 / 21 / 81$
Depth to water: $28.76 \mathrm{ft}(8.16 \mathrm{~m})$ below TOC TIme: $16: 35$
Water elevation: 240.54 it $(73.32 \mathrm{~m}) \mathrm{ms}$ !
Inaccessibility or pump failure prevented sample collection.

WELL BG 108

MEASUREMENTS CONDUCTED IN THE FIELD

Sample date: $12 / 26 / 91$
Depth to water: $28.52 \mathrm{ft}(8.69 \mathrm{~m})$ below TOC Time: $10: 35$
Water elevation: $238.78 \mathrm{ft}(72.78 \mathrm{~m}) \mathrm{ms}$ (

inaccessibility or pump failure prevented sample collection.

WELL BG 109

MEASUREMENTS CONDUCTED IN THE FIELD

Sample date: 10/21/91

Depth to water: $43.89 \mathrm{ft}(13.38 \mathrm{~m})$ below TOC

Water elevation: $242.51 \mathrm{ft}(73.9$

Sp. conductance: $36 \mu \mathrm{s} / \mathrm{cm}$
Water evacuated before sampling: $37 \mathrm{gal}$

LABORATORY ANALYSES

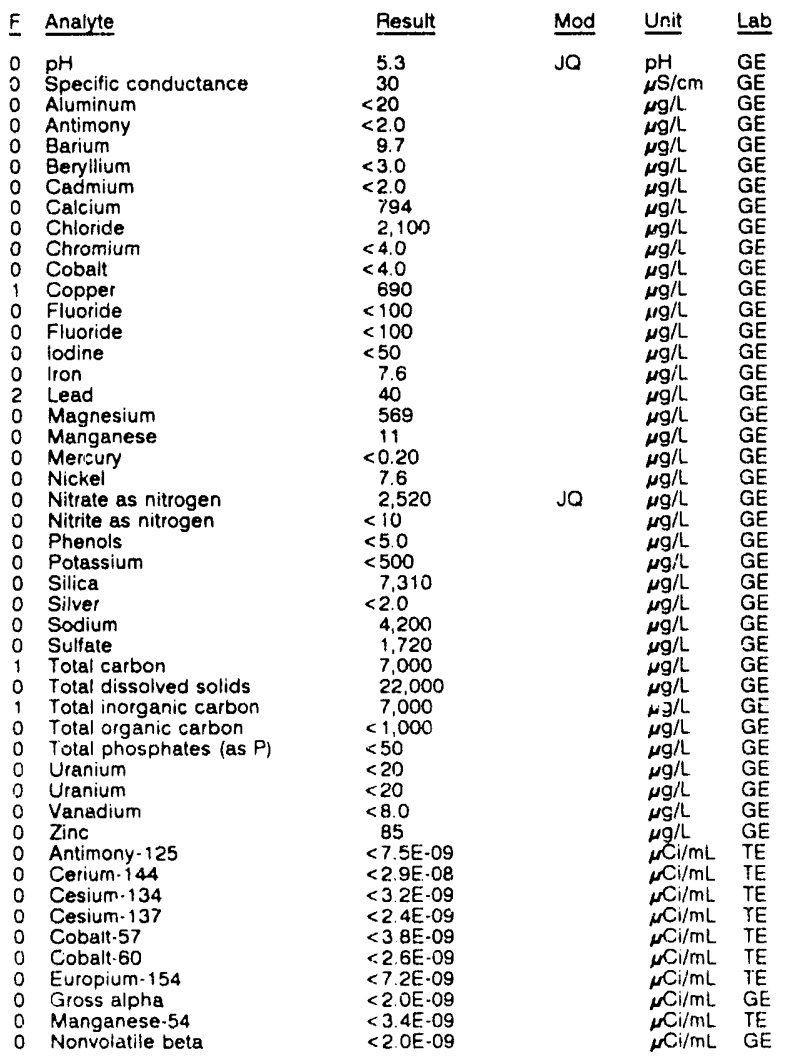

WELL BG 109 collected on 10/21/81, laboratory analyses (cont.)

\begin{tabular}{|c|c|c|c|}
\hline E Analyte & Result & Unit & Lah \\
\hline $\begin{array}{ll}0 & \text { Potassium-40 } \\
0 & \text { Radium-226 } \\
0 & \text { Ruthenlum-103 } \\
0 & \text { Sodium-22 } \\
0 & \text { Thorium-228 } \\
2 & \text { Tritium } \\
0 & \text { Zinc-65 }\end{array}$ & $\begin{array}{l}<3.4 E-08 \\
<5.5 E-09 \\
<2.5 E-08 \\
<2.7 E-09 \\
<3.1 E-09 \\
2.4 E-05 \pm 1.0 E-06 \\
<7.8 E-09\end{array}$ & $\begin{array}{l}\mu \mathrm{Cl} / \mathrm{mL} \\
\mu \mathrm{Cl} / \mathrm{mL} \\
\mu \mathrm{Cl} / \mathrm{mL} \\
\mu \mathrm{Cl} / \mathrm{mL} \\
\mu \mathrm{Cl} / \mathrm{mL} \\
\mu \mathrm{Cl} / \mathrm{mL} \\
\mu \mathrm{Cl} / \mathrm{mL}\end{array}$ & $\begin{array}{l}\text { TE } \\
\text { TE } \\
\text { TE } \\
\text { TE } \\
\text { TE } \\
\text { GE } \\
\text { TE }\end{array}$ \\
\hline
\end{tabular}

WELL BG 110

MEASUREMENTS CONDUCTED IN THE FIELO

$\begin{array}{ll}\text { Sample date: } 10 / 22 / 91 & \text { Time: } 12: 25 \\ \text { Depth to water: } 50.62 \mathrm{ft}(15.43 \mathrm{~m}) \text { below TOC } & \text { pH: } 4.6 \\ \text { Water elevation: } 243.68 \mathrm{ft}(74.27 \mathrm{~m}) \mathrm{msl} & \text { Alkalinity: } 0 \mathrm{mg} / \\ \text { Sp. conductance: } 68 \mu \mathrm{s} / \mathrm{cm} & \text { Water temperature: } 18.5^{\circ} \mathrm{C} \\ \text { Water evacuatod betore sampling: } 39 \mathrm{gal} & \\ \text { The well went dry during purging. } & \end{array}$

LABORATORY ANALYSES

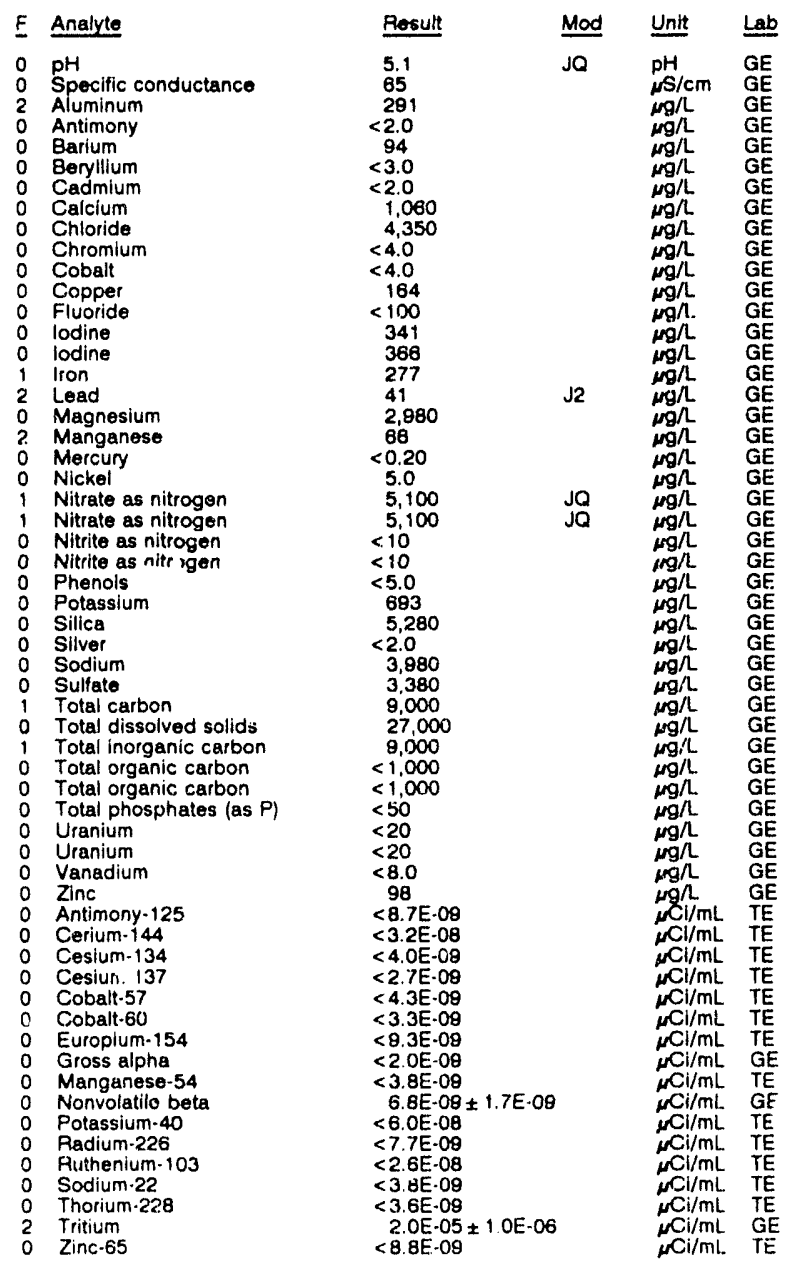


ANALYTICAL RESULTS

\section{WELL BG 121}

MEASUREMENTS CONDUCTEO IN THE FIELD

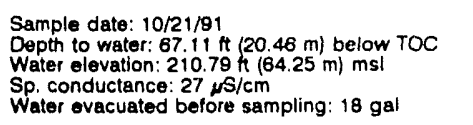

Time: $11: 20$

pH: 6.4 Alkalinity: $5 \mathrm{mg}$

Water temperature: $17.6^{\circ} \mathrm{C}$

LABORATORY ANALYSES

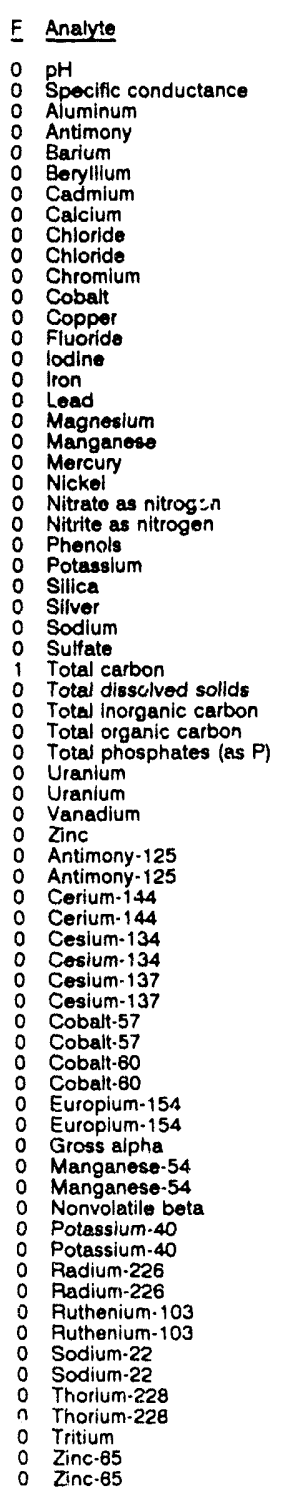

1.5E-06 $\pm 7.0 \mathrm{E}-07$

$<8.3 \mathrm{E}-09$
$<96 \mathrm{E}-09$

$\begin{array}{ll}\mu \mathrm{Ci} / \mathrm{mL} & \mathrm{TE} \\ \mu \mathrm{Ci} / \mathrm{mL} & T E \\ \mu \mathrm{Ci} / \mathrm{mL} & \mathrm{GE} \\ \mu \mathrm{Ci} / \mathrm{mL} & T E \\ \mu \mathrm{Ci} / \mathrm{mL} & T E\end{array}$
WELL BG 122

MEASUREMENTS CONDUCTED IN THE FIELD

Sample date: $10 / 21 / 91$ Depth fo water: $34.27 \mathrm{Ht}(10.45 \mathrm{~m})$ below TOC Water elevation: $213.63 \mathrm{ht}(65$. Sp. conductance: $66,45 / \mathrm{cm}$ Water evacuated betore sampling: $62 \mathrm{gal}$ LABORATORY ANALYSES

F Analyte

$\stackrel{\mathrm{pH}}{\mathrm{pH}} \mathrm{Specific}$ conductance

Aluminum

Antimony

Beryllium

Cadmium

Calcium

Chloride

Chromium

Cobalt

Fluoride

0 lodine

o lodine

Lead

- Magnesium

Manganese

Mercury

Nitrate as nitrogen

Nitrate as nitrogen

Nitrite as nitrogen

Nitrite as nitrogen

Potassium

Sotassium

Silve

0 Sodium

0 Sodium

Sulfate

Total carbon

Total carbon

Total dissoived solids

Total inorganic carbon

Total organic carbon

Total organic carbon

- Total phosph

0 Vanadium

0 Zinc

0 Antimony-125

Cerium-144

Cesium-137

Cobalt.57

Cobalt-60

Europium-154

Gross alpha

Manganese-54

Nonvolatile betassium.40

Padium-226

Ruthenium.103

Sodium-22

Tritium
Zinc-65

Time: $12: 00$

pH: 5.7 . $13 \mathrm{mg}$

Water temperature: $17.7^{\circ} \mathrm{C}$ lemperature: $17.7^{\circ} \mathrm{C}$

\section{WELL BG 125}

MEASUREMENTS CONDUCTED IN THE FIELD

Sample date: 10/16/91

Time: $9: 20$

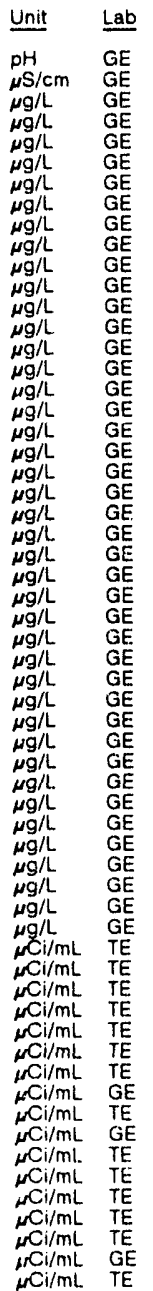

The well was dry.
Result

6.1
60
$<20$
$<2.0$
$<3.0$
$<3.0$
$<2.0$
385
2.780
2,810
$<4.0$
$<4.0$
14
$<100$
$<50$
$<50$
7.9
$<3.0$
133
3.0
$<0.20$
$<4.0$
280
280
$<10$
$<10$
$<5.0$
$<500$
5,670
$<2.0$
13,200
9.260
9.470
6.000
6,000
37.000
6.000
$<1.000$
$<1.000$
$<50$
$<20$
$<8.0$
123
$<7.9 \mathrm{E}-09$
$<2.6 \mathrm{E} .08$
$<3.6 \mathrm{E} \cdot 09$
$<2.9 \mathrm{E}-08$
$<3.4 \mathrm{E} \cdot 09$
$<3.7 \mathrm{E}-08$
$<9.5 \mathrm{E} \cdot 08$
$<2.0 \mathrm{E}-09$
$<3.4 \mathrm{E} \cdot 09$
$<2.0 \mathrm{E} \cdot 09$
$<44.4 \mathrm{E} \cdot 08$
$<5.7 \mathrm{E} \cdot 09$
$<2.3 \mathrm{E} \cdot 08$
$<3.5 \mathrm{E} \cdot 09$
$<3.0 \mathrm{E} \cdot 09$
$5.0 \mathrm{E}-05$
$<7.9 \mathrm{E} \cdot 09$

\begin{tabular}{|c|c|}
\hline Mod & Unit \\
\hline$J Q$ & 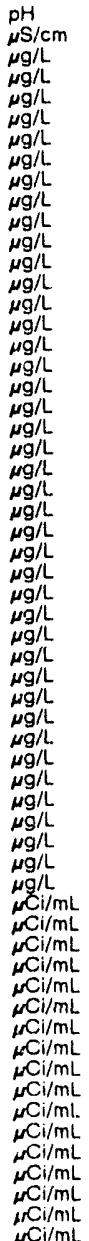 \\
\hline
\end{tabular}


WELL BGO 1D

MEASUREMENTS CONDUCTED IN THE FIELL

Sample date: 10/15/91

Depth to water: $54.58 \mathrm{~h}(16.64 \mathrm{~m})$ below TOC

Sp. conductance: $35 \mu \mathrm{s} / \mathrm{cm}$

Water evacuated before sampling: 8 gal

The well wen: dry during purging.

LABORATORY ANALYSES

$E$ Analyte

: $\mathrm{pH}$ Specific conductance

0 Aurtidity

Aluminum

Antimiony

Barlum

Barum

Bromodichloromethane

Bromolori:

Bromometriano

Calcium

Carbon tetrachloride

Chloride

Chlorobonzene

Chloroethane Ninyl chloride)

2.Chioroethyl vinyl ether

Chiorotorm

Chloromethan

Chromium

Cyanide

Dibromochloromethane

1,1. Dichioroethane

1.2-Dichloroethane

$1,1-$ Dichloroethylene
trans-1,2-Dichloroethylene

Dichloromethane

2.4-Dichlorophenoxy

cis-1,3-Dichloropropene

cis-1,3-Dichloropropene
trans-1,3-Oichloropropene

Endrin

Ethylbenzene

Fluoride

Iron

Lead

Magnesium

Manganese

Methoxychlor

Natuthalene

Nitrate as nitrogen

Phenols

Potassium

Selenium

Silica

Silver

Sodium

Sulfate Tet.ichioroethane

Tetrachloroethylene

Tin

Toluene

Total dissolved solids

Total organic carbon

Total organic halogens

Toxaphene

2,4,5.TP (Silvex)

1,1.1-Trichloroethane

1.1,2-Trichloroethan

Trichlorofluoromethane

Vanadium

Xylenes

Gross aipha

Total radium

Tritium

Uranium-233/234

Uranium-23i/234

Uranium-238
Result Mod Unit Lab

5.7
28
54
$<10$
33
-2.0
$<2.0$
17
$<1.0$
$<1.0$
$<1.0$
$<1.0$
$<2.0$
161
$<1.0$

<1.0

$<1.0$

161
$<1.0$
1.680

$<1,680$

$<1.0$

$<1.0$

$<1.0$

$<1.0$

$<4.0$

11
$<5.0$

$<1.0$

$<1.0$

$<1.0$

$<1.0$

$<0.30$

$<1.0$

$<1.0$

$<0.0060$

$<100$
$<100$

40

$<0.0050$

53

$\begin{aligned} & 53 \\ < & 0.20 \\ < & 0.50\end{aligned}$

$<0.50$
$<10$
$<4.0$
1.400

$<4.0$
$\quad .400$
$<.0$
$<500$

$<500$

$<2.0$

5,890
$<2.0$
5,400

5,460
$<1,000$

$<1.0$

$<100$

$<2.0$

26,000

$<1,000$

$<5.0$
$<50$

$<0.24$

$<0.090$

$<1.0$
$<1.0$

$<1.0$

$<8$

$<8.0$

$<2.0 E .09$

$<2.0 E-09$

5. 1 E- $06 \pm 7$ OE. 07

$2.0 E \cdot 10 \pm 2$ OE-10
2 OE $10 \pm 20 E \cdot 10$

$2 \mathrm{OE} \cdot 10 \pm 2.0 \mathrm{OE} \cdot 10$

$<1.0 E \cdot 10$
$<1$ OE. 10

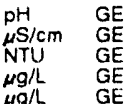

$\begin{array}{ll}\mu S / \mathrm{cm} & \mathrm{GE} \\ \mathrm{NTU} & \mathrm{GE} \\ \mu \mathrm{g} / \mathrm{GE} & \mathrm{GE} \\ \mu \mathrm{g} / \mathrm{GE} & \mathrm{GE}\end{array}$

$\begin{array}{ll}\mu g g / L & G E \\ \mu g g & G E \\ \mu g / L & G E \\ \mu g / L & G E\end{array}$

$\mu g / L \quad G E$

$\boldsymbol{\mu g} / \mathrm{h} \quad \mathrm{GE}$

Time: $8: 30$

Alkalinity: $1 \mathrm{mg} / \mathrm{L}$

Water temperature: $20.4^{\circ} \mathrm{C}$

$G E$
$G E$
$G E$
$G E$
$G E$
$G E$
$G E$
$G E$
$G E$
$G E$
$G E$
$G E$
$G E$
$G E$
$G E$
$G E$
$G E$
$G E$
$G E$
$G E$
$G E$
$G E$

WELLL BGO 2D

MEASUREMENTS CONDUCTEO IN THE FIELD

Sample date $10 / 14 / 91$

Depth to water: $57.81 \mathrm{tt}(17.62 \mathrm{~m})$ below TOC

Wp conductance: $239.09 \mathrm{Ht}(72.89$

Water evacuated before sampling: $53 \mathrm{gal}$

pH: 4.5

Alkalinity: $0 \mathrm{mg} / \mathrm{h}$

Water temperature: $198^{\circ} \mathrm{C}$

LABORATORY ANALYSES

Analyte Result Mod

: $\mathrm{pH}$ Specific conductance

Acetophenone

Aluminum

Antimony

Barium

Benzen

Bromodichloromethane

Bromolorm

Bromomethane

Cadmium

Carbon tetrachloride

Carbon

Chlorobenzene

Chloroethane

Chloroethenie Ninyl chloride

2.Chloroethyl vinyl ether

Chioroform

Chloromethane

Copper

Dibromochloromethan

1,1-Dichloroethane

1. . Dichor

trans-1,2-Dichloroethylene

Dichloromethane

2,4-Dichlorophenoxy

1,2.Dichloropropane
cis-1,3-Dichloropropen

trans-1,3-Dichloropropen

- Endrin

E Ethylbenzene

Fluoride
Iron

0 Lead

Lindane

Manganese

Mercury

Methoxychlor

Nickel

Nitrate as nitrogen

Phenols

0 Selenium

0 Silica

0 Silver

o Sulfate $1,1,2,2$-Tetrachloroethane

1,1,2,2-Tetrachloroetha

Tin

Total dissolved solids

- Total organic carbon

Total organic halogens

Toxaphene

2,4,5-TP (Silvex)

1,1.1. Trichloroethane

Trichlorothyoethane

- Trichlorofluoromethane

Vanadium

Xylenes

Gross alpha

Nonvolatile beia

Total radium

Uranium-233/234

vianium-238

$\begin{array}{llll}4.6 & \text { JO } & \mathrm{pH} & \mathrm{GE} \\ 4 \mathrm{~S} / \mathrm{cm} & \mathrm{GE} \\ 0.96 & & \mathrm{NTU} & \mathrm{GE} \\ & & \text { NT/L } & \mathrm{GE}\end{array}$

$<10$

$<2.0$

$<2.0$
20

$<\begin{array}{r}20 \\ <1.0\end{array}$

$<1.0$

$<1.0$
$<2.0$

$<1.120$

$<\begin{aligned} & 3.0 \\ & 3,360\end{aligned}$

$<1.0$

$<1.0$

$<1.0$

$<1.0$
$<1.0$

$<4.0$

$<4.0$

$<5.0$
$<1.0$

$<1.0$

$<1.0$

$<1.0$

$<0.30$

$<1.0$

$<1.0$
$<0.0080$

$<1.0$

$<100$

\begin{aligned} 7.8 \\ $<3.0 \\ < \\$\hline\end{aligned}

$<0.0050$

1.090
2.1
$<0.20$

$<0.20$

$<10$

$<4.00$

$<5.0$

$<500$
$<2.0$

$<2.0$

$<2.070$

2,470
3,130

3,130
$<1.0$

$<1.0$

$<2.0$

66,000
1,000

$<5.0$

50
$<0.24$

$<0.090$

$<1.0$

$<1.0$

$<1.0$

$<1.0$

$<2.0$

2.5E.09 $\pm 1.3 \mathrm{JE}-09$

$<1.0 \mathrm{E} \cdot 09$
$1.6 \mathrm{E}-05 \pm 1.1 \mathrm{E} \cdot 06$

$<1.0 \mathrm{E}-10$
$1.0 \mathrm{E}-10+1.0 \mathrm{E}: 0$ 


\section{ANALYTICAL RESULTS}

\section{WELL BGO 3D}

MEASUREMENTS CONDUCTED IN THE FIELD

Sample date: 10/15/91 Depth to water: $58.41 \mathrm{tt}(17.19 \mathrm{~m})$ below TOC Water elevation: $236.29 \mathrm{ft}$ (72

Sp. conductance: $47 \mu \mathrm{s} / \mathrm{cm}$

Water evacuated before sampling: 4 ga

The well went dry during purging.

LABORATORY ANALYSES

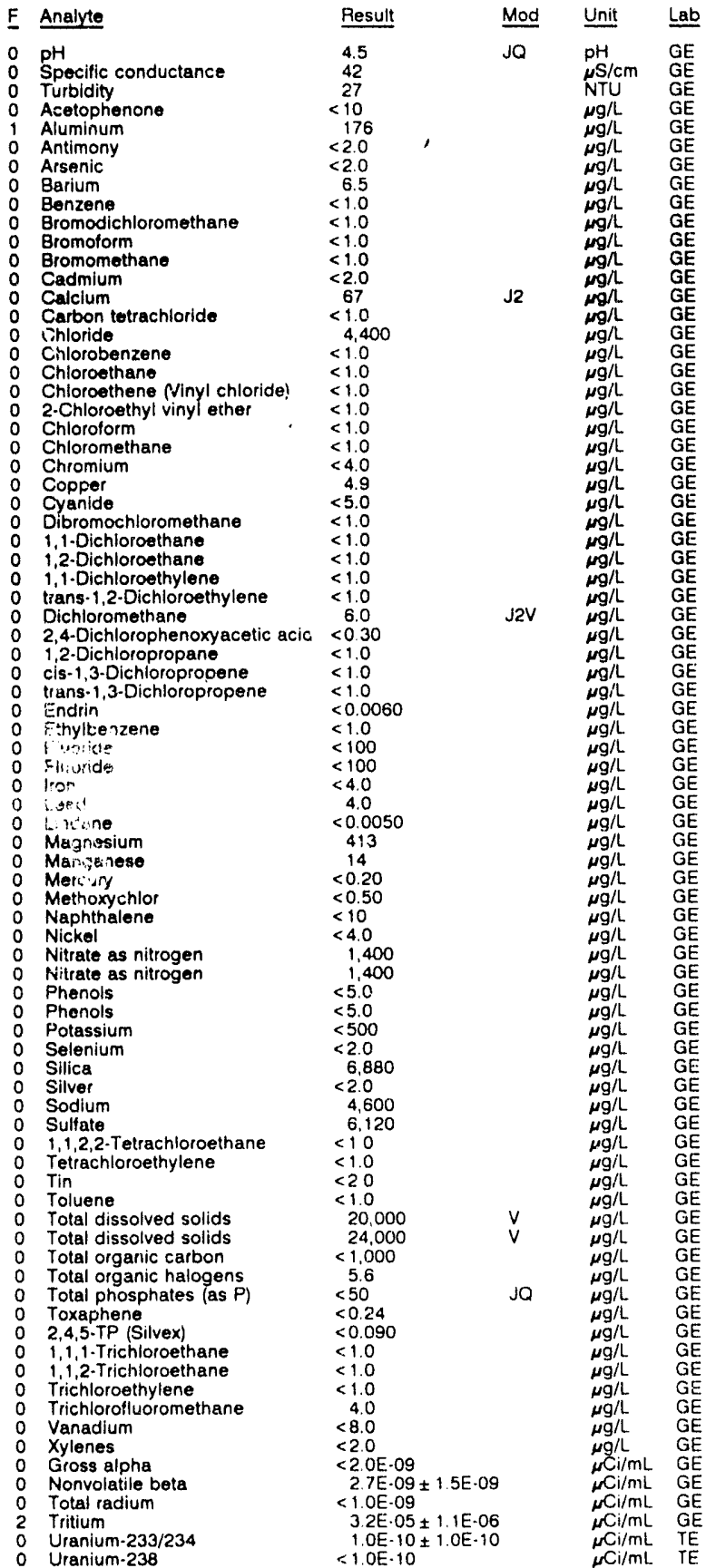

Time: $9: 00$

Alkalinity: $0 \mathrm{mg} / \mathrm{L}$

Water temperature $20.6^{\circ} \mathrm{C}$

WELL BGO 4D

MEASUREMENTS CONDUCTED IN THE FIELD

Sample date: 10/18/91

WELL BGO 5C

MEASUFEMENTS CONDUCTED IN THE FIELD

Sample date: 10/18/91 Inaccessibility or pump failure prevented sample collection.

\section{WELL BGO 50}

MEASUREMENTS CONDUCTED IN THE FIELD

Sample date: 10/18/91 Time: 14:05

WELL BGO 6A

MEASUREMENTS CONDUCTED IN THE FIELD Sample date: $10 / 14 / 91$ it $(38.22 \mathrm{~m})$ below TOC Water elevation: $160.22 \mathrm{At}(48.8$ Sp. conductance: $304 \mu \mathrm{S} / \mathrm{cm}$
Water evacuated before sampling: $138 \mathrm{gal}$ LABORATORY ANALYSES

$\mathrm{pH}$

Specific

Turbidity

Aluminum

Antimon'y

Arsenic

Benzene

Bromodichloromethane

Bromolorm

Bromomethane

Cadmium

Carbon tetrachloride

Carbon

Chloride

Chlorobenzene

Chloroeth.ane

Chloroethene Ninyl chloride)

2.Chloroethyl vinyl ether

Chlorotorm

Chloromethane

Chromiur?

Copper

Cyanide
Dibromochloromethane

1,1-Dichloroethane

1,2.Dichloroethane

1,1-Dichloroethylene
trans-1,2-Dichloroethylere

Dichloromethane

2.4-Dichlorophenoxyace

cis-1,3-Dichloropropene

trans-1 3-Dichloropropene

Endrit.

O Ethylbenzene

- Fluoride

$\begin{array}{ll}0 & \text { Iron } \\ 0 & \text { Lead } \\ 0 & \text { Lindane }\end{array}$

L Lindane

Manganese

0 Mercury

o Methoxychior

Naphthalen

Nickel

Nitrate as nitrogen

0 Phenols

Potassiurn

$\begin{array}{ll}0 & \text { Selenium } \\ 0 & \text { Silica } \\ & \text { Sivari }\end{array}$

0 Silver

0 Sodium

1,1,2,2-Tetrachloroethane

0 Tetiachloroethylerie
Time: $10: 55$

Alkalinity: $131 \mathrm{mg} / \mathrm{h}$ Water temperature: $18.5^{\circ} \mathrm{C}$

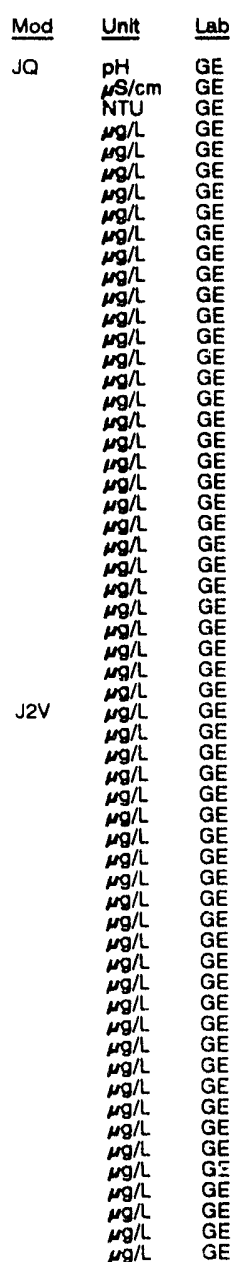


ANALYTICAL RESULTS

WELL QGO BA coilected on 10/14/91, laboratory analyses (cont.)

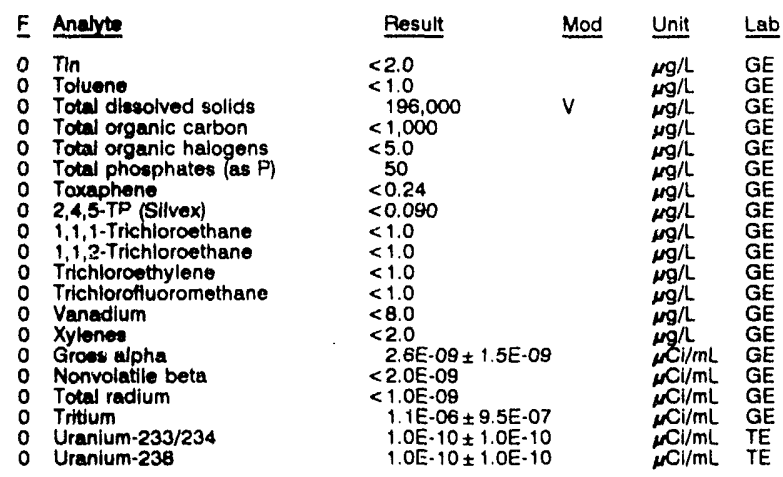

WELL BGO 6C

MEASUREMENTS CONDUCTED IN THE FIELO

Sample date: 10/14/91

Dopth to water: $63.77 \mathrm{~h}(18.44 \mathrm{~m})$ below TOC Water elovation: $221.83 \mathrm{tt} / 67$.

Water evacuated beforo sampling: $167 \mathrm{gal}$

LABORATORY ANALYSES

F Analyte

o $\mathrm{pH}$

Specific conductance

0 Acetophenone

Aluminum

Antimony

Arsenic

Benzene
0 Bromodichloromethane

Bromolorm

Cadmium:

Calcium

Carbon tetrachloride

Carbon

Chlorobenzene

Chloroethane

2-Chioroethyl vinyl ether

Chloroform

Chloromethane

Chromium

Cyanide

Oibromochloromethane

1,1-Dichloroethane

1,2-Dichloroethane

$1,1-D i c h l o r o e t h y l e n e$
0
0
trans-1,2-Dichloroethylene

2,4-Dichlorophenoxyacetic acid

1,2-Dichloropropane

o trans-1,3-Dichloropropene

Endrin

Ethylbenzen

O Fluorido

Iron

Lindane

Magnesium

Manganese

Methoxychlor

O Naphtha

Nitrate as nitrogen

Phenols

Potassium

Silica

Silver

Sodium
Sulfate

Sulfate

Totrachloroethylene

Tin

Toluene

Total dissolved solids

0 Total organic halogens

Result

7.3
124
0.50
$<10$
$<20$
$<2.0$
$<2.0$
12
$<1.0$
$<1.0$
$<1.0$
$<1.0$
$<2.0$

$<2.0$

$<1.0$

2,430

$<1.0$

$<1.0$

$<1.0$

$<1.0$
$<1.0$

$<4.0$

$<5.0$

$<1.0$

$<1.0$

$<1.0$

$<1.0$

$<1.0$
5.1
$<0.30$

$<1.0$
$<1.0$

$<1.0$
$<0.0060$

$<1.0$

$<100$

$<4.0$

$<0.0050$

554
$<2.0$

$<2.0$

$<0.20$

$<10$

$<4.0$

930
$<5.0$

$<500$

$<2.0$
12,500

12,500
$<2.0$

2,390

$<1,0$

$<1.0$
$<1.0$
$<2.0$
$<1.0$

$<1.0$

$<\begin{array}{r}77,000 \\ <1,000\end{array}$

$<1,000$
$<5.0$
110

Time: 11:10

Alkalinity: $40 \mathrm{mg} / \mathrm{L}$

Water temperature: $19.7 \circ \mathrm{C}$

\section{Mod Unit Lab}
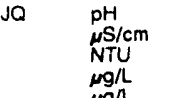

$\stackrel{\mathrm{PH}}{\mu \mathrm{S} / \mathrm{cm}} \mathrm{G}$

$\mathrm{GE}$
$\mathrm{GE}$
$\mathrm{GE}$
$\mathrm{GE}$
$\mathrm{GE}$

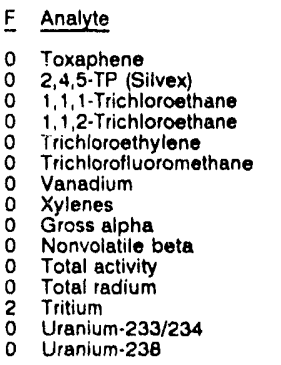

WELL BGO 6D

MEASUREMENTS CONDUCTED IN THE FIELD

$\begin{array}{ll}\text { Sample date: } 10 / 15 / 81 & \text { Time: } 9: 35 \\ \text { Depth to water: } 53.89 \mathrm{Ht}(16.43 \mathrm{~m}) \text { below TOC } & \text { pH: } 6.3 \\ \text { Water olevation: } 231.61 \mathrm{H}(70.60 \mathrm{~m}) \mathrm{msl} & \text { Alkalinity: } 46 \mathrm{mg} / \mathrm{L} \\ \text { Sp. conductance: } 113 \mu \mathrm{cm} / \mathrm{cm} & \text { Water temperature: } 18.5^{\circ} \mathrm{C} \\ \text { Water evacuated before sampling: } 6 \mathrm{gal} & \\ \text { The well went dry during purging. } & \end{array}$

LABORATORY ANALYSES

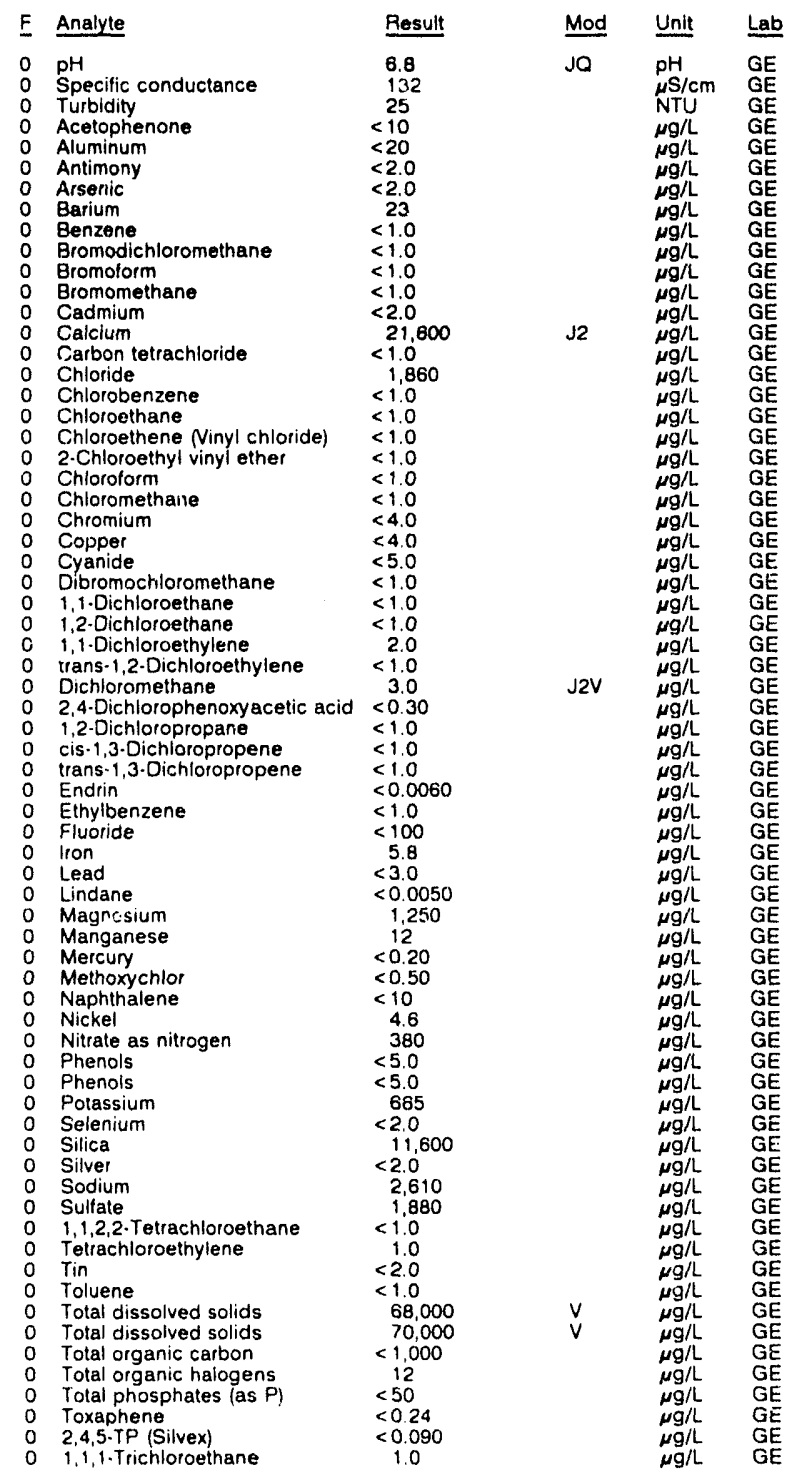

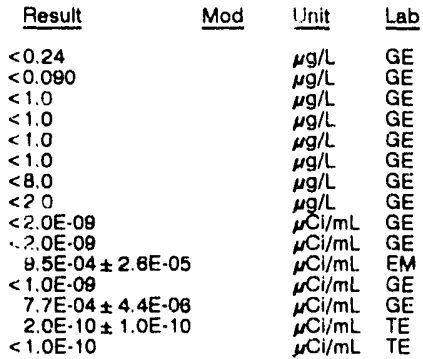

$a b$
$G E$
$G E$
$G E$
$G E$
$G E$
$G E$
$G E$
$G E$
$G E$
$G E$
$E M$
$G E$
$G E$
$T E$

E

.

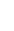

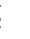


ANALYTICAL RESULTS

WELL BGO 6D collected on 10/15/91, laboratory analyses (cont.)

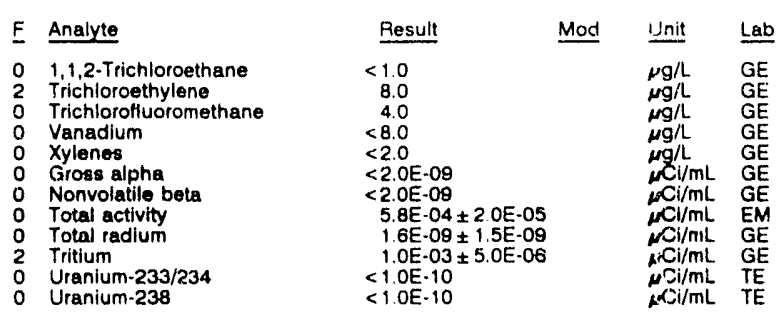

WELL BGO 7D

MEASUREMENTS CONDUCTED IN THE FIELD

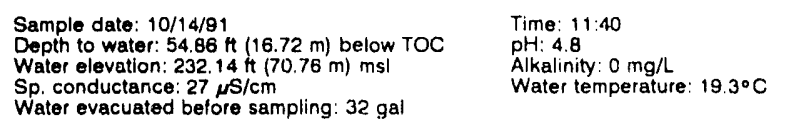

LABORATORY ANALYSES

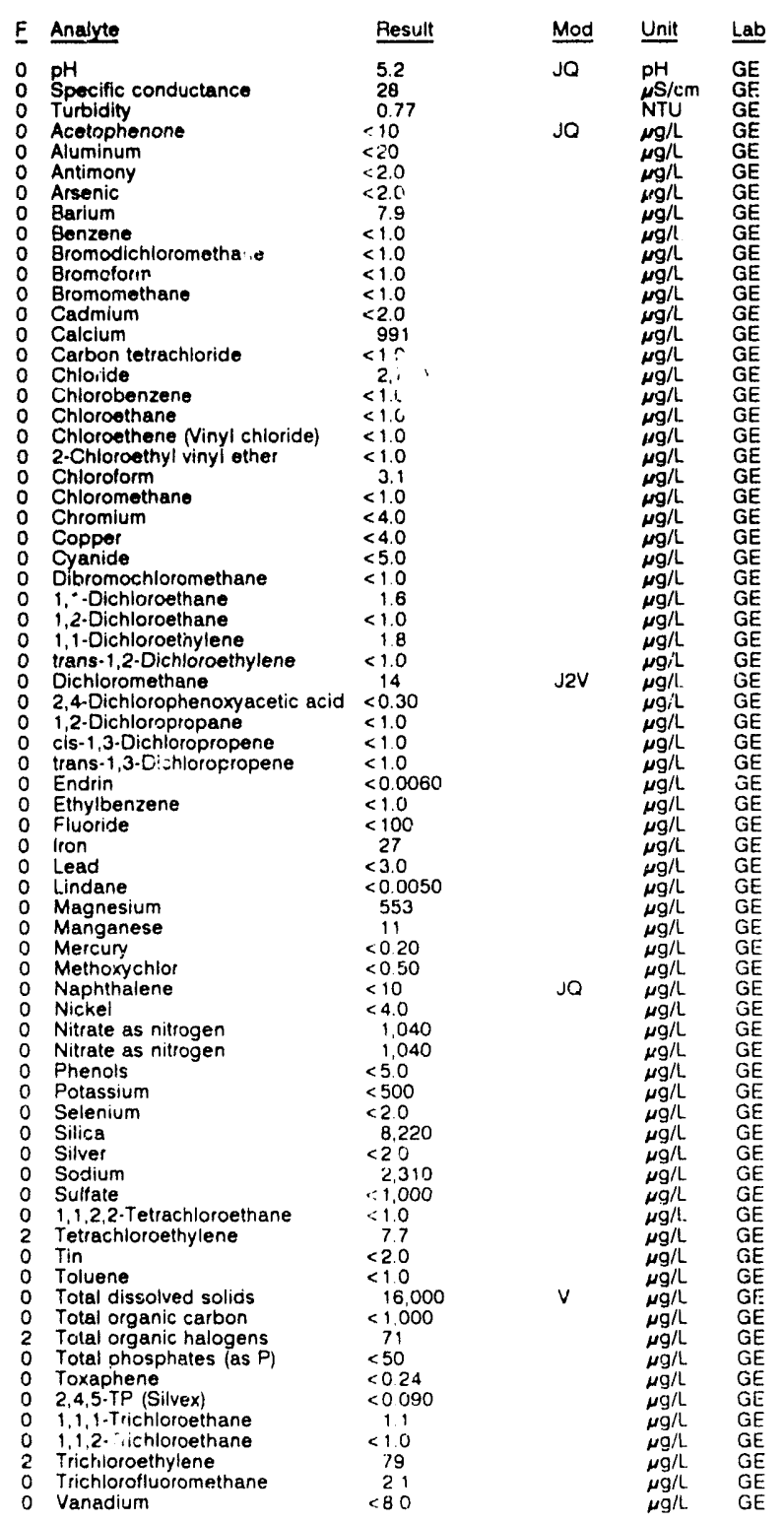

WELL BGO 70 collected on 10/14/91, laboratory analyses (cont.)

\begin{tabular}{|c|c|c|c|c|c|}
\hline E & Analyte & Result & Mod & Unit & Lab \\
\hline $\begin{array}{l}0 \\
0 \\
2 \\
0\end{array}$ & $\begin{array}{l}\text { Xylenes } \\
\text { Gross alpha } \\
\text { Nonvolatile beta } \\
\text { Total radium } \\
\text { Tritium } \\
\text { Uranium-233/234 } \\
\text { Uranium-236 }\end{array}$ & $\begin{aligned}<2.0 \\
2.1 E-09 \pm 1.2 E-09 \\
<2.0 \mathrm{E}-09 \\
1.5 \mathrm{E}-09 \pm 1.4 \mathrm{E}-09 \\
5.5 \mathrm{E} \cdot 04 \pm 3.8 \mathrm{E}-00 \\
<1.0 \mathrm{E}-10 \\
<1.0 \mathrm{E}-10\end{aligned}$ & & $\begin{array}{l}\mu \mathrm{g} / \mathrm{L} \\
\mu \mathrm{Ci} / \mathrm{mL} \\
\omega_{\mathrm{Ci} / \mathrm{mL}} \\
\omega \mathrm{Ci} / \mathrm{mL} \\
\mu \mathrm{Ci} / \mathrm{mL} \\
\mu \mathrm{Ci} / \mathrm{mL} \\
\mu \mathrm{Ci} / \mathrm{mL}\end{array}$ & $\begin{array}{l}\mathrm{GE} \\
\mathrm{GE} \\
\mathrm{GE} \\
\mathrm{GE} \\
\mathrm{GE} \\
\mathrm{TE} \\
\mathrm{TE}\end{array}$ \\
\hline
\end{tabular}

\section{WELL BGO $8 A R$}

MEASUREMENTS CONDUCTED IN THE FIELD

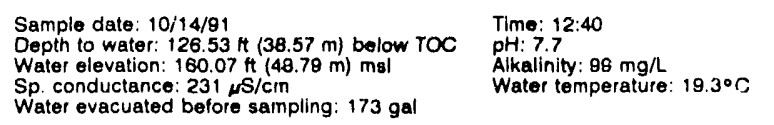

Water evacuated before sampling: $173 \mathrm{gal}$

LABORATORY ANALYSES

\begin{tabular}{|c|c|c|c|c|c|}
\hline E & Analyte & Result & Mod & Unit & Lab \\
\hline 1 & $\mathrm{pH}$ & 8.1 & Jo & $\mathrm{pH}$ & GE \\
\hline 0 & Specitic conductance & 222 & & $\mathrm{~S} / \mathrm{cm}$ & \\
\hline 0 & $\begin{array}{l}\text { Uurbidity } \\
\text { Acelophenono }\end{array}$ & $\begin{array}{l}4.2 \\
<10\end{array}$ & $\mathrm{JQ}$ & $\begin{array}{ll}\text { NTU } \\
\mu g / L\end{array}$ & \\
\hline & Aluminum & $<20$ & & $\mu g / L$ & SE \\
\hline 0 & Antimony & $<2.0$ & & $\mathrm{mg} / \mathrm{L}$ & $\mathrm{GE}$ \\
\hline $\begin{array}{l}0 \\
0\end{array}$ & $\begin{array}{l}\text { Arsenic } \\
\text { Batium }\end{array}$ & $\begin{array}{c}<2.0 \\
41\end{array}$ & & $\mu \mathrm{g} \cdot \mathrm{L}$ & $\mathrm{GE}$ \\
\hline & Benzene & $<1.0$ & & $\mu g / L$ & $\mathrm{GE}$ \\
\hline & Bromodichloromenane & $<1.0$ & & $\mu g / L$ & $\mathrm{GE}$ \\
\hline $0^{2}$ & $\begin{array}{l}\text { Bromoform } \\
\text { Bromomethane }\end{array}$ & $<1.0$ & & $\mu g / L$ & GE \\
\hline & Cadmium & $<2.0$ & & $\underset{\mu g / L}{\mu g / L}$ & $\mathrm{GE}$ \\
\hline g & Calcium & 43,900 & J2 & $\mu g / L$ & $\overrightarrow{G E}$ \\
\hline $\begin{array}{l}0 \\
0\end{array}$ & $\begin{array}{l}\text { Carbon tetrachloride } \\
\text { Chloride }\end{array}$ & $\begin{array}{l}<1.0 \\
2,880\end{array}$ & & $\underset{\mu g / L}{\mu g}$ & $\begin{array}{l}\mathrm{GE} \\
\mathrm{GE}\end{array}$ \\
\hline & Chlorobenzene & $<1.0$ & & $\mu g / L$ & \\
\hline c & Chloroethane & $<1.0$ & & $\mu g / L$ & GE \\
\hline d & $\begin{array}{l}\text { Chloroethene (Vinyl ch!oride) } \\
\text { 2.Chloroethyl vinyl ether }\end{array}$ & $\begin{array}{l}<1.0 \\
<10\end{array}$ & & $\mu \mathrm{g} / \mathrm{L}$ & $\begin{array}{l}\mathrm{GE} \\
\mathrm{GE}\end{array}$ \\
\hline 0 & Chlorolorm & $<1.0$ & & $\mu \mathrm{g} / \mathrm{L}$ & $G E$ \\
\hline c & Chloromethane & $<1.0$ & & $\mu g / h$ & $\overline{G E}$ \\
\hline 0 & Chromium & $<4.0$ & & $\mu g / L$ & $\mathrm{GE}$ \\
\hline $\begin{array}{l}0 \\
0\end{array}$ & $\begin{array}{l}\text { Copper } \\
\text { Cyanide }\end{array}$ & $\begin{array}{l}<4.0 \\
<50\end{array}$ & & $\mu g / L$ & $\mathrm{GE}$ \\
\hline c & Dibromochloromethane & $\begin{array}{l}<0.0 \\
<1.0\end{array}$ & & $\underset{\mu g / L}{\mu g / L}$ & $\mathrm{GE}$ \\
\hline 0 & 1,1-Dichloroethane & $<1.0$ & & $\mu g / L$ & $\overline{G E}$ \\
\hline 0 & 1,2-Dichloroethane & $<1.0$ & & $\mu g / h$ & $\mathrm{GE}$ \\
\hline $\begin{array}{l}0 \\
0\end{array}$ & $\begin{array}{l}\text { 1,1-Dichloroethylene } \\
\text { trans-1,2-Dichloroethylene }\end{array}$ & $\begin{array}{l}<1.0 \\
<1.0\end{array}$ & & $\mu \mathrm{g} / \mathrm{L}$ & $\mathrm{GE}$ \\
\hline 0 & Dichloromethane & 12 & $\mathrm{~J} 2 \mathrm{~V}$ & $\mu \mathrm{g} / \mathrm{L}$ & $\mathrm{GE}$ \\
\hline & 2,4-Dichlorophenoxyacetic acid & $<0.30$ & & $\mu \mathrm{g} / \mathrm{L}$ & \\
\hline $\begin{array}{l}0 \\
0\end{array}$ & 1,2-Dichloropropane & $\begin{array}{l}<1.0 \\
<10\end{array}$ & & $\mu g / L$ & GE \\
\hline & $\begin{array}{l}\text { is-1,3-Dichloropropene } \\
\text { trans-1,3-Dichloropropene }\end{array}$ & $\begin{array}{l}<1.0 \\
<1.0\end{array}$ & & $\begin{array}{l}\mu g / L \\
\mu g / L\end{array}$ & $\mathrm{GE}$ \\
\hline & Endrin & $<0.0060$ & & $\mu g / L$ & $\mathrm{GE}$ \\
\hline & Ethylbenzene & $<1.0$ & & $\mu g / L$ & GE \\
\hline & Fluoride & $<100$ & & $\mu g / L$ & \\
\hline & Iron & 11 & & $\mu \mathrm{g} / \mathrm{L}$ & GE \\
\hline & Lead & $<3.0$ & & $\mu g / L$ & GE \\
\hline & $\begin{array}{l}\text { Lindane } \\
\text { Magnesium }\end{array}$ & $<0.0050$ & & $\mu g / L$ & \\
\hline & $\begin{array}{l}\text { Magnesium } \\
\text { Minnganese }\end{array}$ & 1,360 & & $\mu g / L$ & \\
\hline & $\begin{array}{l}\text { Manganese } \\
\text { Mercury }\end{array}$ & $\begin{array}{l}37 \\
<0.20\end{array}$ & & $\mu g / h$ & $\mathrm{GE}$ \\
\hline 0 & Methoxychlor & $\begin{array}{l}<0.20 \\
<0.50\end{array}$ & & $\begin{array}{l}\mu g / L \\
\mu g / L\end{array}$ & $\mathrm{GE}$ \\
\hline 0 & Naphthaiene & $<10$ & & $\mu g / L$ & $\mathrm{GE}$ \\
\hline 0 & Nickel & $<4.0$ & & $\mu g / L$ & GE \\
\hline 0 & Nitrate as nitrogen & $<50$ & & $\mu \mathrm{g} / \mathrm{L}$ & \\
\hline 0 & $\begin{array}{l}\text { Phenols } \\
\text { Potassium }\end{array}$ & $<5.0$ & & $\mu g / L$ & \\
\hline c & $\begin{array}{l}\text { Potassium } \\
\text { Selenium }\end{array}$ & $\begin{array}{l}1.680 \\
<2.0\end{array}$ & & $\mu g / L$ & $\mathrm{GE}$ \\
\hline 0 & Silica & 36,600 & & $\mu g / \mathrm{L}$ & $\mathrm{GE}$ \\
\hline & Silver & $<2.0$ & & $\mu \mathrm{g} / \mathrm{L}$ & \\
\hline & $\begin{array}{l}\text { Sodium } \\
\text { Sultate }\end{array}$ & 2.590 & & $\mu g / L$ & \\
\hline & $\begin{array}{l}\text { Sulfate } \\
1,1,2,2 \cdot \text { Tetrachioroethane }\end{array}$ & 7,500 & & $\mu g / L$ & \\
\hline & $\begin{array}{l}\text { 1.1,2.2. Tetrachioloethane } \\
\text { Tetrac 'oroethylene }\end{array}$ & $<1.0$ & & $\mu g / L$ & \\
\hline & $\begin{array}{l}\text { Tetrach'oroethylene } \\
\text { Tin }\end{array}$ & $\begin{array}{l}<1.0 \\
<2.0\end{array}$ & & L & \\
\hline & $\begin{array}{l}\text { Tin } \\
\text { Toluene }\end{array}$ & $\begin{array}{l}<2.0 \\
<10\end{array}$ & & & \\
\hline & Total dissolved solids & 158,000 & $\mathrm{v}$ & $\mu \mathrm{g} / \mathrm{L}$ & \\
\hline & Total organic carbon & $<1,000$ & & $\mu g / L$ & \\
\hline 0 & Total organic halogens & $<5.0$ & & $\mu \mathrm{g} / \mathrm{L}$ & \\
\hline 0 & Total phosphates (as P) & $<50$ & & $\mu g / L$ & \\
\hline & Toxaphene & $<0.24$ & & $\mu g / L$ & \\
\hline & 2,4,5-TP (Silvex) & $<0.090$ & & $\mu \bar{g} / L$ & \\
\hline & 1.1.1.Trichloroethane & $<1.0$ & & $\mu \mathrm{g} / \mathrm{L}$ & \\
\hline & 1,1,2.Trichloroethane & $<1.0$ & & $\mu \mathrm{g} / \mathrm{L}$ & \\
\hline & Trichloroethylerie & $<1.0$ & & $\mu g / L$ & \\
\hline & Trichlorofluoromethane & $<10$ & & $\mu \mathrm{g} / \mathrm{h}$ & \\
\hline 0 & Vanadium & $<8.0$ & & $\mu g / h$ & \\
\hline & Xylenes & $<2.0$ & & $\mu g / L$ & \\
\hline & Gross alpha & $<2.0 E \cdot 09$ & & HČi $/ \mathrm{mL}$ & $\mathrm{GE}$ \\
\hline & Nonvolatile beta & $<2.0 E-09$ & & $\mu \mathrm{Ci} / \mathrm{mL}$ & \\
\hline & Total activity & $1.2 E-07 \pm 1.4 E \cdot 06$ & & $\mu \mathrm{Ci} / \mathrm{mL}$ & \\
\hline & Total radium & $<1.0 E .09$ & & & \\
\hline & Tritium & $<7.0 \mathrm{E} \cdot 07$ & & $\mu \mathrm{Cl} / \mathrm{m}$ & \\
\hline
\end{tabular}


ANALYTICAI, RESULTS

WELL BGO BAP colloctod on 10/14/9, laboratory analyses (cont.)

\begin{tabular}{|c|c|c|c|}
\hline Analyte & oult & Mod & Unit \\
\hline $\begin{array}{l}0 \\
0 \\
0\end{array}$ & $\begin{array}{l}<1.0 E-10 \\
2.0 E-10 \pm 2.0 E-10\end{array}$ & & ${ }_{\mu \mathrm{Ci} / \mathrm{mL}}$ \\
\hline
\end{tabular}

WELL BGO $8 \mathrm{C}$

MEASUREMENTS CONOUCTED IN THE FIELD

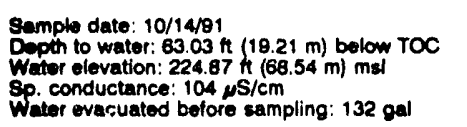

Time: $13: 00$

Alkalinity: $28 \mathrm{mg} /$

Aater temperature: $19.2^{\circ} \mathrm{C}$

LABOPUTORY ANALYSES

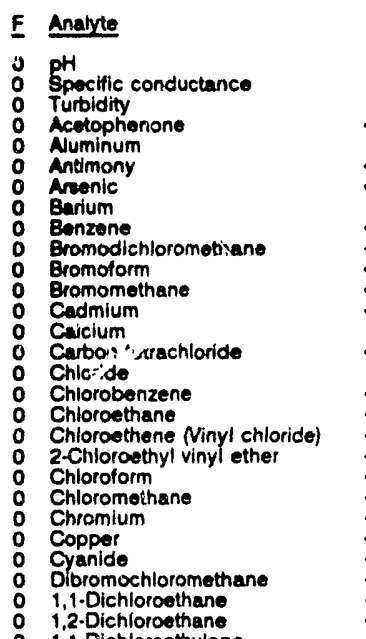

Besun

$1,1-$ Dichloroethylene
0 trans-1,2-Dichloroethylene

D Dichloromethano 14

2,4-Dichiorophenoxyacetic acid $<0.30$

0 cis-1,3-Dichloropropene $<1.0$

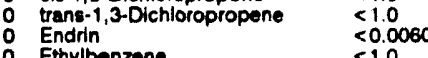

o Fluoride

Iron

o Lead

o Magnecilum

o Manganese

O Mothoxychior

0 Naphthaier

Nitrate as nitrogen

O Phenota

Potassium
Solenium

Silica

Silver

Sodium

Sulfate

Sulfate

Tetrachloroethylene

Tin

Tolvene

Total dissolved solid

Total organle carbon

Total organic halogens

Total phosph

2,4,5-TP (Silvox)

1,1,1-Trichloroethane

1,1,2. Trichloroetha

Trichlorofluoromethane

Vanadium

Xylenes

Nonvolatlie beta

Total radium

Tritium

Uranium-233/234
7.5
118
6.1

$<10$
37

37
$<2.0$
$<2.0$

$<2.0$

$<1.0$
$<1.0$
$<1.0$

$<2.0$

$<18,000$

2,460

$<1.0$

$<1.0$

$<1.0$

$<1.0$
$<1.0$
$<4.0$
$<4.0$

$<4.0$

$<1.0$

Mod Unit Lab

$<0.0060$
$<1.0$

$<100$
10
$<3.0$

$<3.0$
$<0.0050$

525

525
$<2.0$

$<2.0$
$<0.20$
$<0.50$

$<10$

$<4.0$

1,520
$<5.0$
3,000

3,000
$<2.0$

12,500
$<2.0$

4.0
4,710

4,710
1,020
1,030

$<1.0$

$<1.0$

$<1.0$
$<2.0$
$<1.0$

$<1.0$
50,000

55,000
$<1,000$

$<5.0$

180
$<0.24$

$<0.090$

$<1.0$

$<1.0$

$<1.0$

$<8.0$

$<2.0 \mathrm{E} \cdot 09$
$<2.0 \mathrm{E} \cdot 09$

$<2.0 \mathrm{E} \cdot 09 \times 1.3 \mathrm{E} \cdot 09$

2.8E-06

$<1$. OE. 10
$<1.0 \mathrm{O} \cdot 10$

WELL BGO $8 D$

MEASUREMENTS CONDUCTED IN THE FIELD

Sample date: 10/14/91 Depth to water: $55.37 \mathrm{ft}(16.88 \mathrm{~m})$ below TOC Water elevation: $232.43 \mathrm{H}(70$.

Sp. conductance: $24 \mathrm{ps} / \mathrm{cm}$.

Water evacuated before sampling: $31 \mathrm{gal}$

LABORATORY ANALYSES

: $\mathrm{pH}$ Specific conductance

Acetophenone

A Aluminum

- Antimony

Arsenic

B Barium

Bromodichloromethane

Bromolorm

Bromomethane

Cadmium

Carbon tetrachloride

Carbon to

Chloride

Chloroethane

Chloroethene Ninyl chloridel

2-Chloroethyl vinyl other

Chlorolorm

Chloromethane

Chromium

Copper

Dibromochloromethane

1,1-Dichloroothane

1,2-Dichloroethane

$1,1-D i c h$ oroethylene
trans-1,2-Dichloroethylene

trans-1,2-Dichlorooth

2.4-Dichlorophenoxyacetic acid

noxyacetic acid $<0.30$

1,2-Dichloropropane

trans-1,3-Dichlopene

Endrin

Ethylbenzene

Fluorida

Lead

Lindane

Magntsium

Manganese

Marcury

Naphthalene

Nickel

Nitrate as nitrogen

Phenols
Phenols

Potassium

Solenium

Silica

Silver

Sodium

Solfum

1,1,2,2-Tetrachloroethan

Tetrachloroethylene

Total dissolved solids

Total organic carbon

Total organic halogens

Total phosphates (as PI

Toxaphene

1,1,1-Trichloroethan

1,1,2-Trichloroethane

Trichloroethylene

Trichlorofiuoromethane

Vanadium

Xylenes

Gross alpha

Nonvolatile beta

Total radium

Ura $\lambda m-233 / 234$

Result

5.0

42
$<10$

$<20$

$<2.0$

$<1.0$

$<1.0$

$<1.0$

916
$<1.0$
$<1300$

2,300

$<1.0$

$<1.0$

$<1.0$

$<4.0$

$<5.0$

$<1.0$

$<1.0$

$<1.0$

$<1.0$

$<0.0060$

$<1.0$
$<100$

28

$<3.0000$

443

17
$<0.20$
$<0.50$

$<0.50$

$<4.0$

1.400

$<5.0$

$<500$

7,330

$<2.0$

$<1,000$

$<1.0$

$<2.0$

$<1.0$

$<1,000$

14

$<0.24$

$<0.090$

$<1.0$

3.7

$<8.0$

$<2.0$

$<2.0 E-09$

$<2.0 \mathrm{E}-09$

1.9E-09 $1.7 \mathrm{E} \cdot 09$

$1.4 \mathrm{E}-05 \pm 1.1$
$<1.0 \mathrm{E}-10$

$<1.0 \mathrm{E} \cdot 10$
$<1.0 \mathrm{E} \cdot 10$
Time: 12:15

Alkalinity: $0 \mathrm{mg} / \mathrm{L}$

Water temperature: $18.6^{\circ} \mathrm{C}$

Mod Unit

Jo

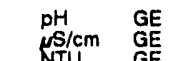

NTU GE

$\mu g / L$ GE

NE GE

$\mu g / L$
$g E$

$\operatorname{sg} h$ GE

$\mathrm{ggh}$

$\mu \mathrm{g} / \mathrm{G} \quad \mathrm{GE}$

$\omega g$ GE

woh GE

Mg GE

Mgh GE

$\operatorname{mon}_{\mathrm{g} h \mathrm{G}} \mathrm{GE}$

w $G E$

$\omega g$ G $G E$

J2V

$\mu g h$ GE



$\mu g$ 


\section{ANALYTICAL RESULTS}

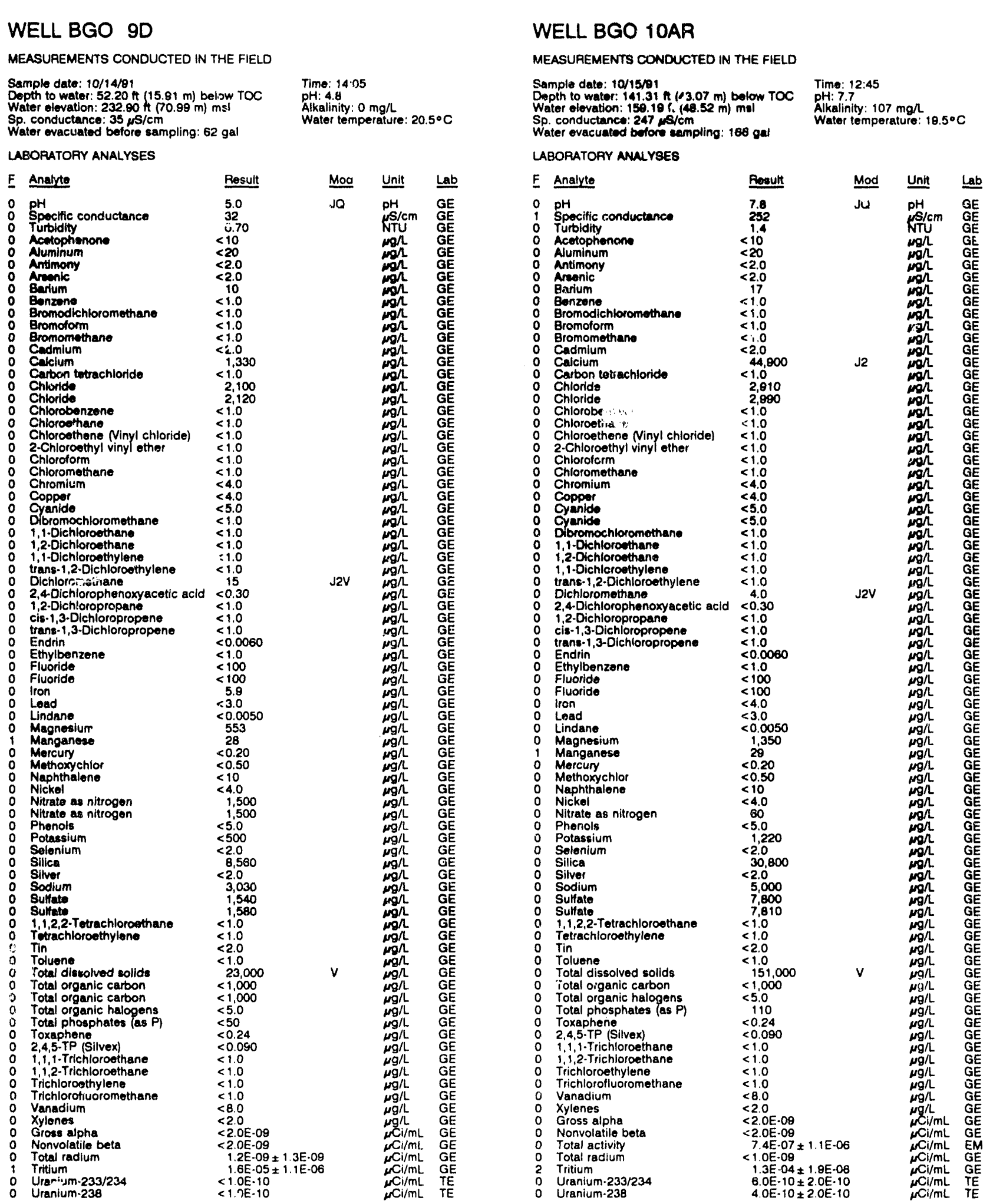


WELL BGO 10AR Replicate

MEASUREMENTS CONDUCTED IN THE FIELD

Sample dato: 10/15/31

Dopth to water: $141.31 \mathrm{n}(43.07 \mathrm{~m})$ below TOC
Weter etevation: $158.18 \mathrm{~h}(48.52 \mathrm{~m}) \mathrm{ms}$ ( Sp. conductenco: $247 \mu \mathrm{s} / \mathrm{cm}$

(2) 166 ga

LABOPATOFY ANULYSES

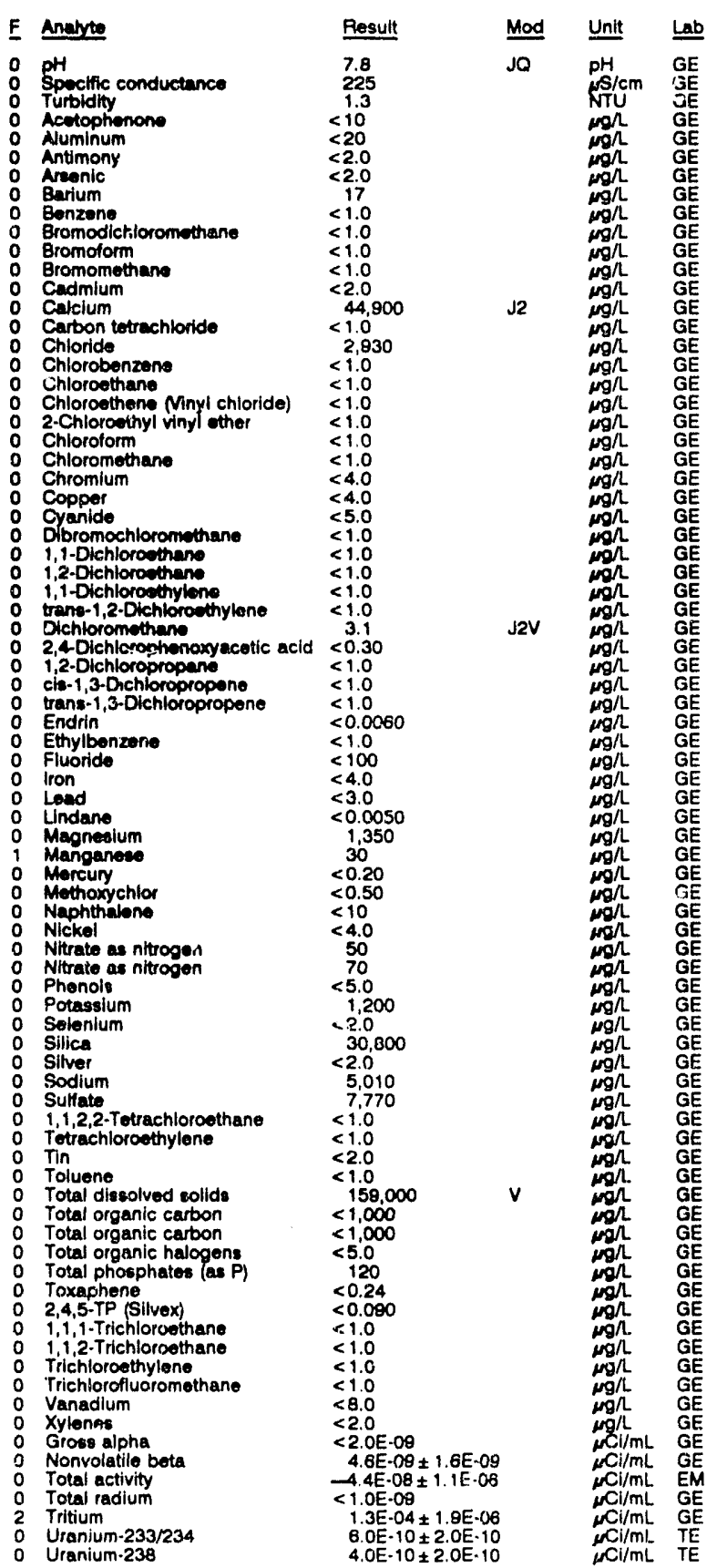

pH: 7.7

Alkainity: $107 \mathrm{mg}$

Wator temperature: $19.5^{\circ} \mathrm{C}$
WELL BGO 10C

MEASUREMENTS CONDUCTED IN THE FIELD

Sample date: 10/15/81

Depth to water: $78.04 \mathrm{ft}(24.09 \mathrm{~m})$ below TOC

Water elevation: $222.26(t)(67.75 \mathrm{~m}) \mathrm{msl}$

Water evacuated before sampling: 42 gal

The well went dry during purging.

LABORATORY ANALYSES

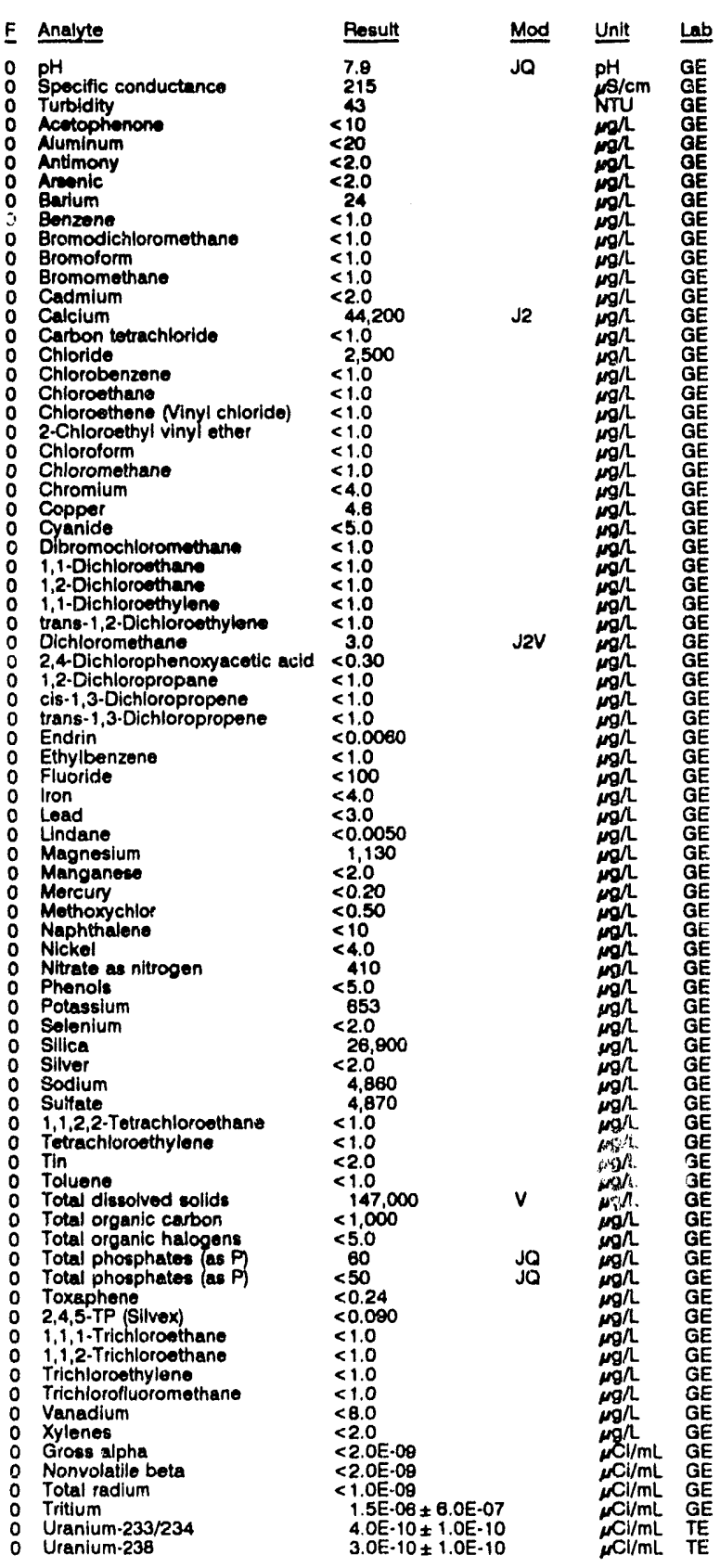

Time: 10:05

PH: 8.1 : $28 \mathrm{mg} / \mathrm{h}$

Water temperature: $18.3^{\circ} \mathrm{C}$ 


\section{ANALYTICAL RESULTS}

WELL BGO 10D

MEASUREMENTS CONDUCTED IN THE FIELD

Sample date: 10/16/81

Depth to water: $68.94 \mathrm{~h}(21.01 \mathrm{~m})$ below TOC

Water elovation: 232.56 tt (70.89

Water evacuated bofore sampling: $1 \mathrm{gs}$

There was insufficient water to fill all or some sample bottles
Ther

LABORATORY ANALYSES

E Analyte

1 Specific conductance

Turbidity

Acetophonon

Antimony

Arsenic

Barium

Benzene

Bromodichloromethane

Bromoform

Bromomethane

Cadmium

Carbon tetrachloride

Chlorobenzene

Chorothene Ninyl chloridel

2-Chioroethyl vinyl ether

Chloroform

Chloromethane

Chromium

Copper

Oibromochioromethane

1,1-Dichloroethane

1,2-Dichloroethane

trans-1,2-Dichloroethylene

Dichloromethane

cis-1,3-Dichioropropene

trans-1,3-Dichloropropen

Endrin

Ethylbenzene

Iron

Lead

Lindane

Magnosium

Mercury

Methoxychlor

Nickel

Nitrate as nitrogen

Phenois

Potassium

Silice

Siver

Sodium

Suliate

1,1,2,2-Tetrachloroethane

Totrachioroethylene

Tin

Total dissolved solids

Total organic carbon

Total organic halogens

rotal phosphates (as P)

Toxaphene

$1,1,1-$ Trichloroethane

$1,1,2$. Trichloroethan

Trichlorothyoromethane

Vanadium

Xylenes

Gross alpha

Nonvolatile beta

Total radiun

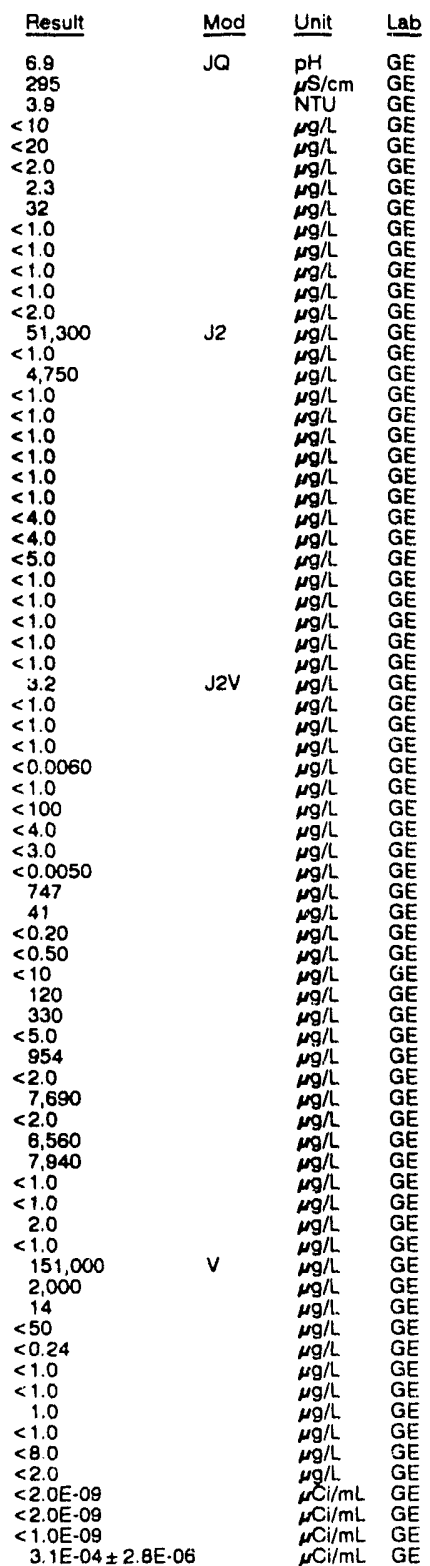

WELL BGO 11D

MEASUREMENTS CONDUCTED IN THE FIELD

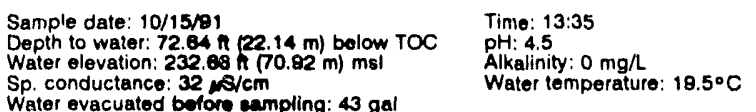

Water evacuated bofore campling: $43 \mathrm{gal}$

LABORATORY ANALYSES

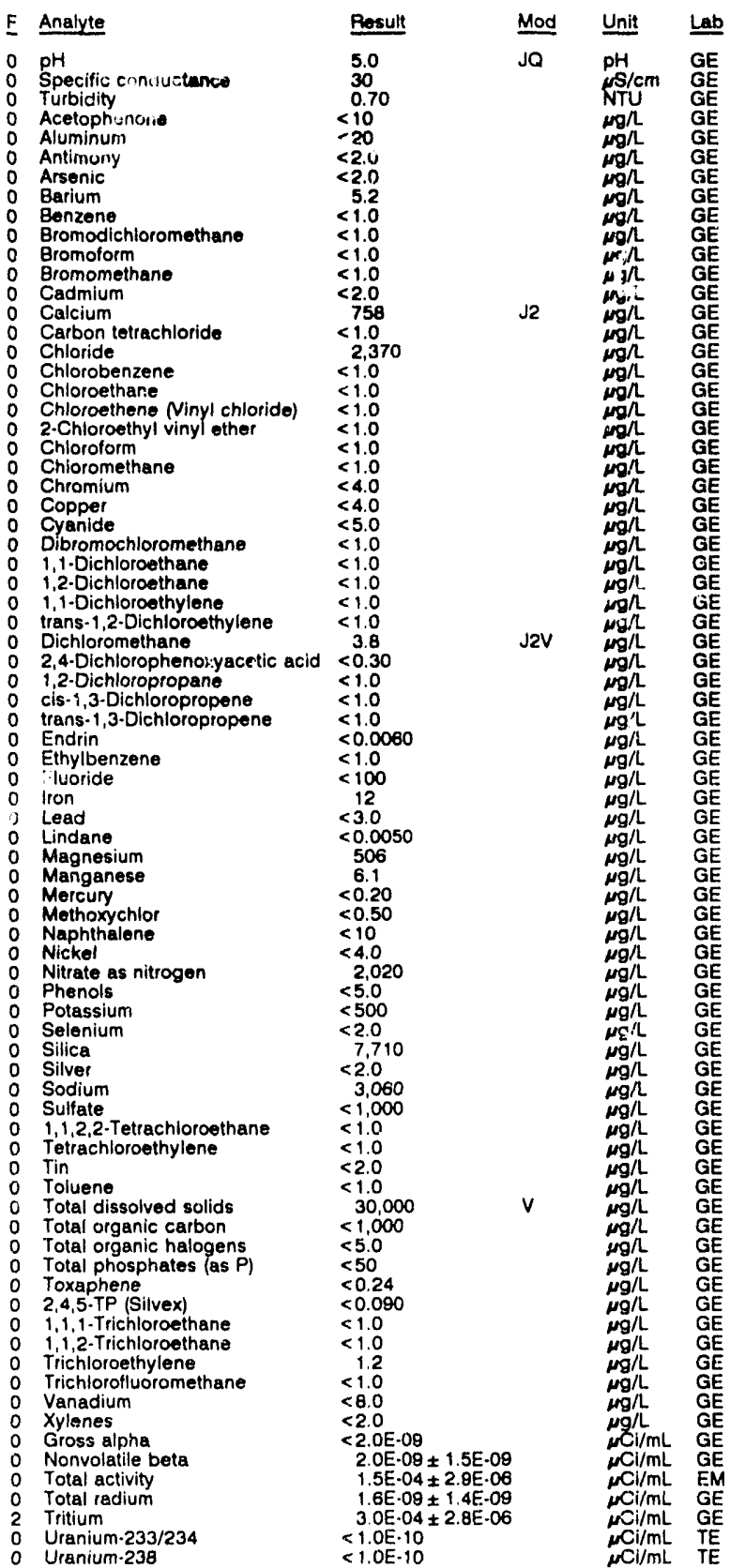


ANALYTICAL RESULTS

WELL BGO 12AR

MEASUREMENTS CONDUCTED IN THE FIELD Sample date: $10 / 16 / 91$
Depth to water: $154.73 \mathrm{ft}(47.16 \mathrm{~m})$ below TOC
Water olovation: $158.67 \mathrm{H}(48.36 \mathrm{~m}) \mathrm{msl}$
Sp. conductance: $257 \mathrm{~s} / \mathrm{cm}$ Time: 9:50 AH: 10.6 : $122 \mathrm{mg} / \mathrm{L}$ Water temperature: $18.2^{\circ} \mathrm{C}$ Sp. conouctance: $257 \mathrm{\mu S} / \mathrm{cm}$
Water evacuated before sampling: $196 \mathrm{gal}$ LABORATORY ANALYSES

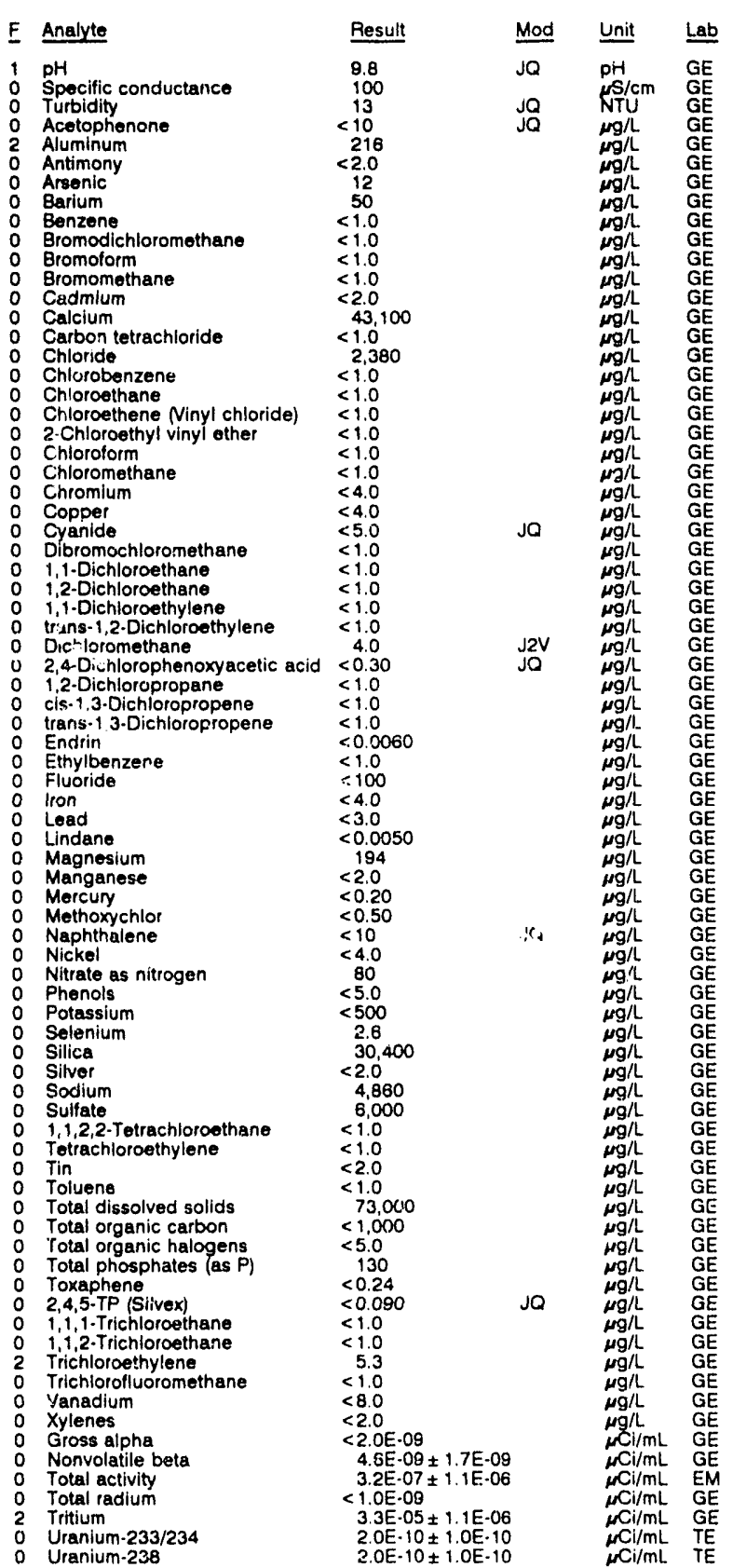

\section{WELL BGO 12AR Replicate}

MEASUREMENTS CONDUCTED IN THE FIELD

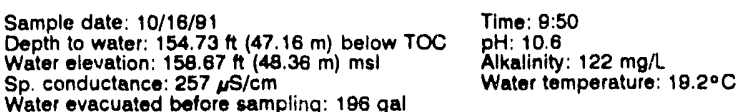
Water evacuated before sampling: $196 \mathrm{gal}$ LABORATORY ANALYSES

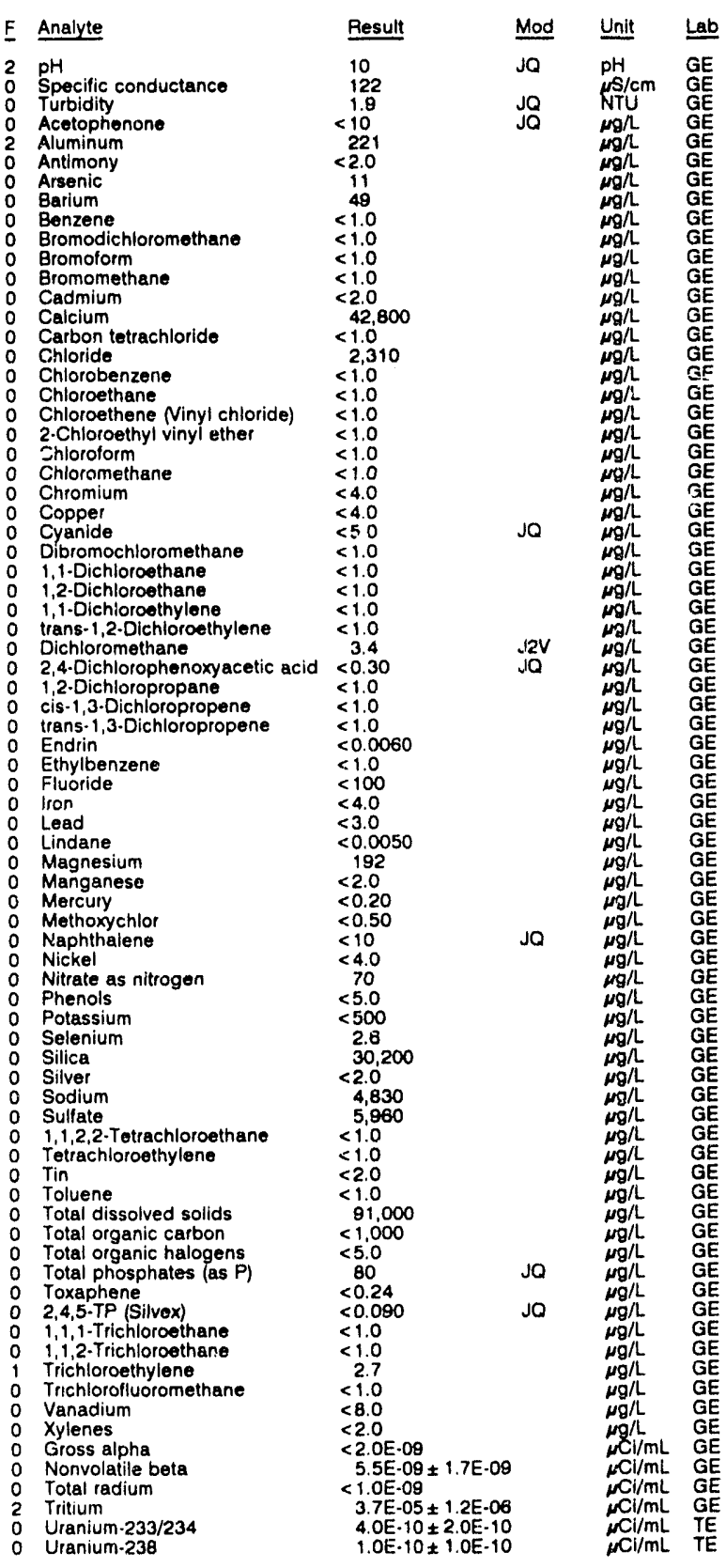


WELL BGO 12AR

MEASUREMENTS CONDUCTED IN THE FIELD

Sample dato: 10/18/91

Wopth to water: $154.73 \mathrm{n}(47.18 \mathrm{~m})$ bolow TOC Wator olovation: $158.67 \mathrm{~h}(48.38 \mathrm{~m}) \mathrm{msi}$ Wator evacuatod bofore sampling: 196 gal

LABOFATOAY ANALYSES

\begin{tabular}{|c|c|c|c|}
\hline E Analyte & Rogult & Mod & $\underline{\text { Unit }}$ \\
\hline Total activity & $5.3 E-07$ & & $\mu \mathrm{Cl} / \mathrm{mL}$ \\
\hline
\end{tabular}

WELL BGO 12CR

MEASUREMENTS CONDUCTED IN THE FIELD

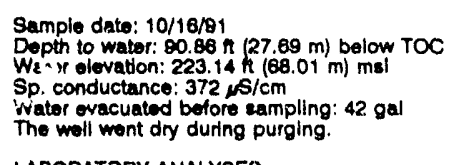

Time: $:: 50$

pH: 10.6

Alkalinity: $122 \mathrm{mg} / \mathrm{L}$

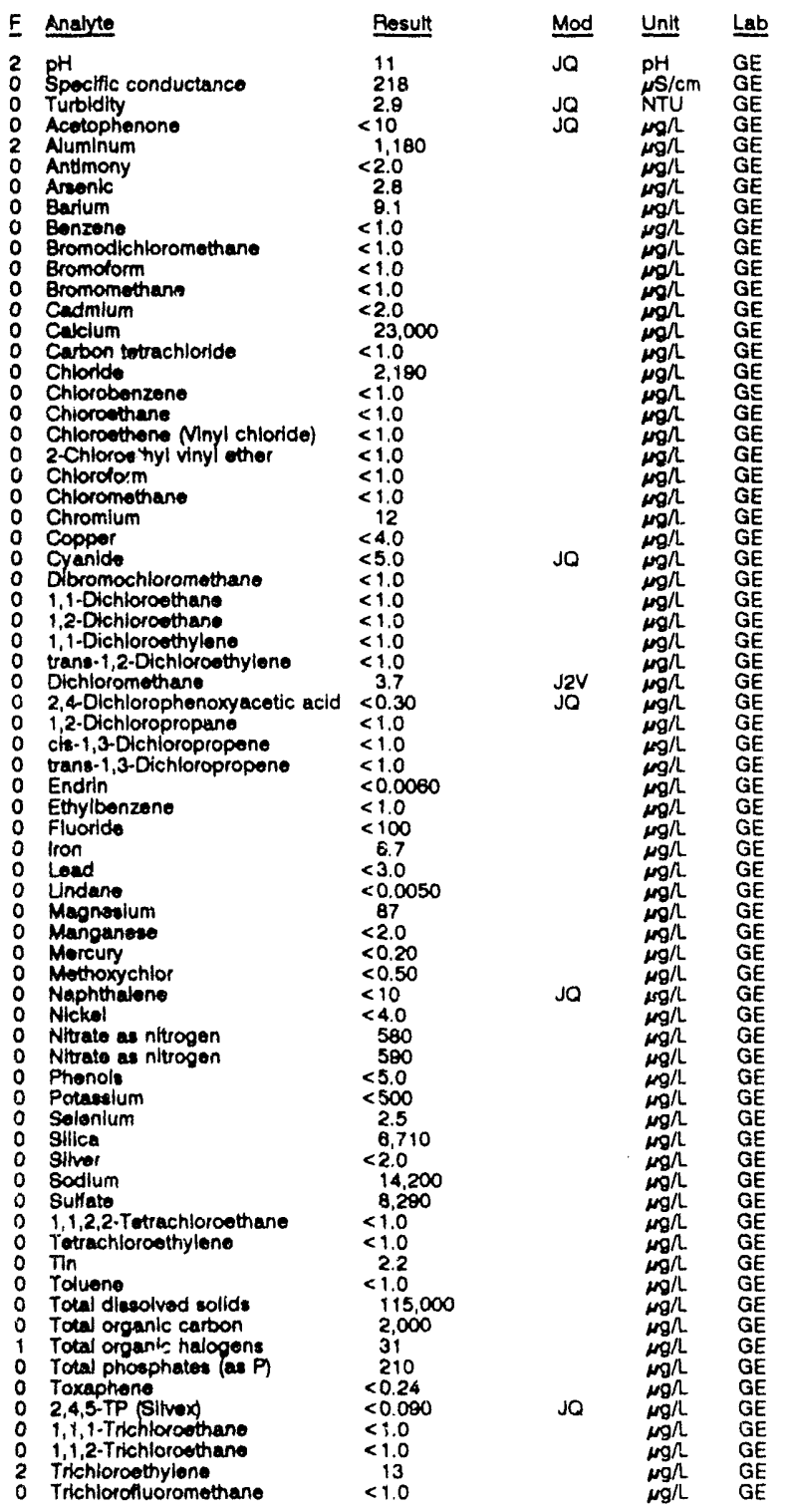

Time: 10:45 Water temperature: $18.1^{\circ} \mathrm{C}$
Alkalinity: $80 \mathrm{mg}$
WELL BGO 12CR collectod on 10/16/81, laboratory analyses (cont.)

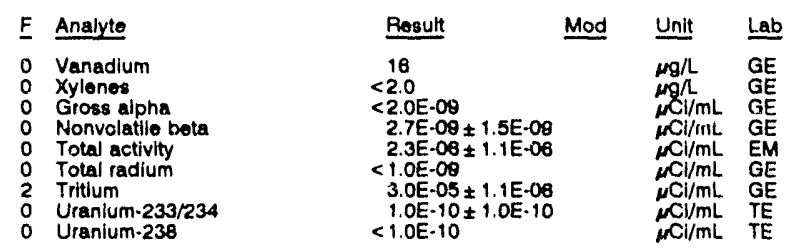

\section{WELL BGO 120}

MEASUREMENTS CONOUCTED IN THE FIELD

$\begin{array}{ll}\text { Sample date: } 10 / 18 / 91 & \text { Time: } 10: 30 \\ \text { Depth to water: } 81.04 \mathrm{H}(24.70 \mathrm{~m}) \text { below TOC } & \text { pH: } 7.0 \\ \text { Water olovation: } 232.68 \mathrm{H}(70.02 \mathrm{~m}) \mathrm{msl} & \text { Alkalinity: } 79 \mathrm{mg} / \mathrm{h} \\ \text { Sp. conductance: } 210 \mu \mathrm{cm} / \mathrm{cm} & \text { Water temperature: } 18.7 \circ \mathrm{C} \\ \text { Water evacuated bofore sampling: } 9 \mathrm{gal} & \end{array}$

Water ovacuated bofore sampling: 9 gal

LABORATORY ANALYSES

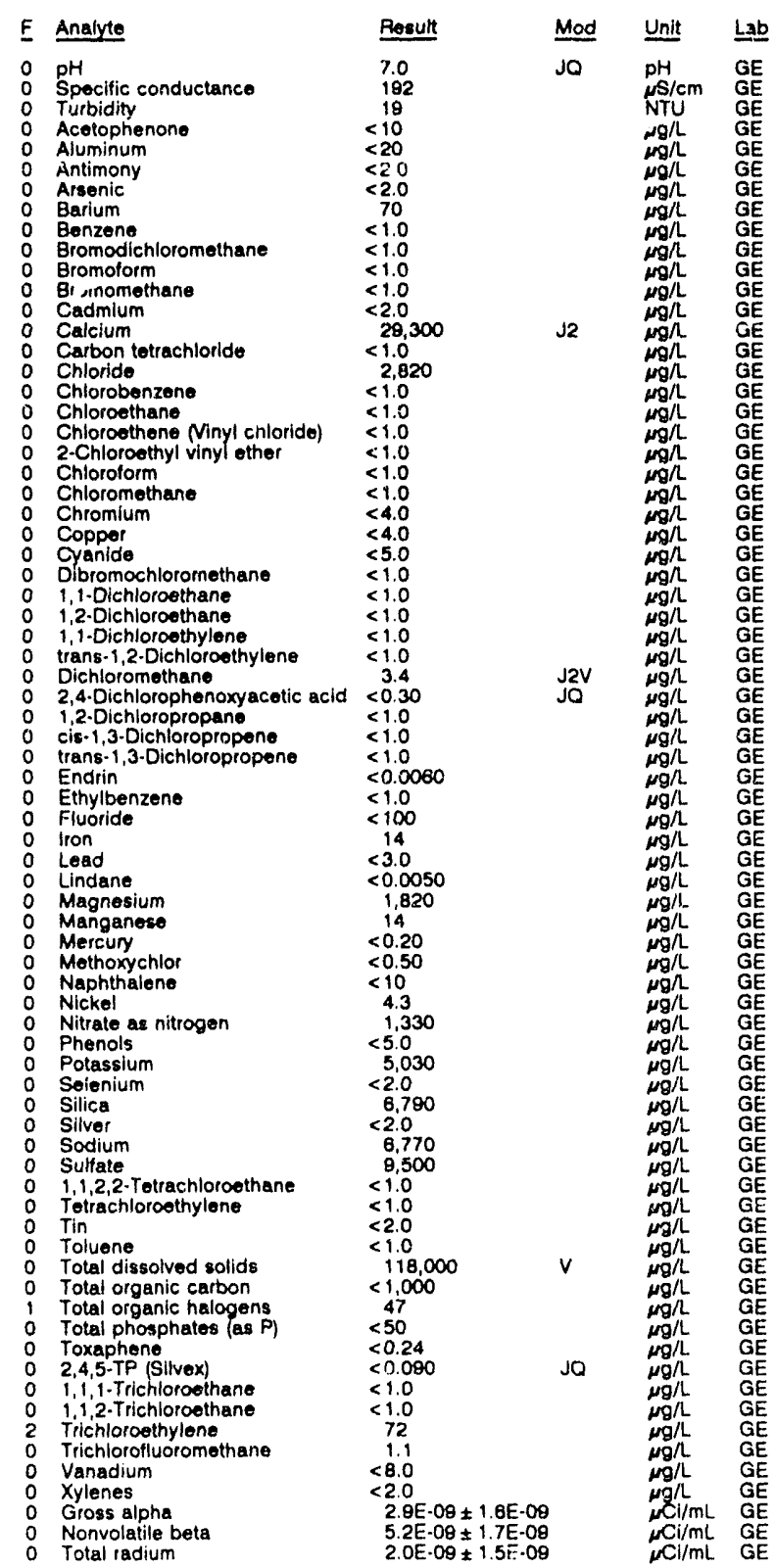


WELL BGO $12 D$ collected on 10/16/91, laboratory analyses (cont.)

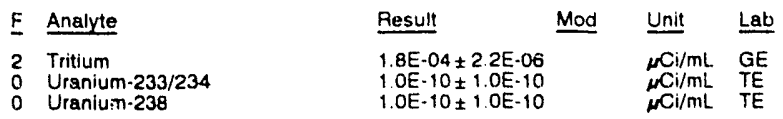

\section{WELL BGO 13DR}

MEASUREMENTS CONDUCTED IN THE FIELD
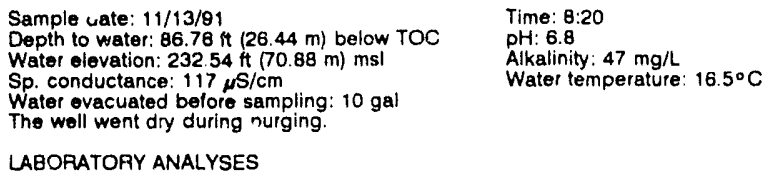

LABORATORY ANALYSES

\begin{tabular}{|c|c|c|c|c|c|}
\hline F & Analyte & Result & Mod & Unit & Lab \\
\hline 0 & $\mathrm{pH}$ & 7.6 & JQ & $\mathrm{pH}$ & GE \\
\hline & $\begin{array}{l}\text { Spocific conductance } \\
\text { Turbidity }\end{array}$ & $\begin{array}{l}110 \\
23\end{array}$ & JQ & ${ }_{\mathrm{NTU}}^{\mu \mathrm{S} / \mathrm{cm}}$ & $\begin{array}{l}\text { GE } \\
\text { GE }\end{array}$ \\
\hline & Turbidity & 23 & Jä & NTU & \\
\hline & Acetophenone & $\begin{array}{l}<10 \\
<20\end{array}$ & & $\mu g / \mathrm{L}$ & $\mathrm{GE}$ \\
\hline & $\begin{array}{l}\text { Aluminum } \\
\text { Antimony }\end{array}$ & $<20$ & & $\underset{\mu g / L}{\mu g / L}$ & $\begin{array}{l}\mathrm{GE} \\
\mathrm{GE}\end{array}$ \\
\hline & Arsenic & $<2.0$ & & $\mathrm{mg} / \mathrm{L}$ & GE \\
\hline & Barium & $\begin{array}{l}17 \\
<10\end{array}$ & & $\mu \mathrm{g} / \mathrm{L}$ & GE \\
\hline & $\begin{array}{l}\text { Benzene } \\
\text { Bromodichloromethane }\end{array}$ & $\begin{array}{l}<1.0 \\
<1.0\end{array}$ & & $\mu g / L$ & $\mathrm{GE}$ \\
\hline & $\begin{array}{l}\text { Bromoform } \\
\text { Britise }\end{array}$ & $<1.0$ & & $\mu g / L$ & $\mathrm{GE}$ \\
\hline & Bromomethane & $<1.0$ & & $\mu g / L$ & $\mathrm{GE}$ \\
\hline & $\begin{array}{l}\text { Cadmium } \\
\text { Calcium }\end{array}$ & $\begin{array}{l}<2.0 \\
6,680\end{array}$ & & $\begin{array}{l}\mu g / \mathrm{L} \\
\mu g / \mathrm{L}\end{array}$ & $\begin{array}{l}\mathrm{GE} \\
\mathrm{GE}\end{array}$ \\
\hline & Carbon tetrachloride & $<1.0$ & & $\mu \mathrm{g} / \mathrm{h}$ & $\mathrm{GE}$ \\
\hline & Chloride & $\begin{aligned} & 5,300 \\
&< 1,0\end{aligned}$ & & $\mu g / L$ & GE \\
\hline & $\begin{array}{l}\text { Chlooenzene } \\
\text { Chloroethane }\end{array}$ & $<1.0$ & & $\begin{array}{l}\mu g / L \\
\mu g / L\end{array}$ & $\mathrm{GE}$ \\
\hline & Chloroethene Ninyl chloride) & $<1.0$ & & $\mu g / L$ & $\mathrm{GE}$ \\
\hline & 2-Chloroethyl vinyl ether & $<1.0$ & & $\mu g / L$ & $\mathrm{GE}$ \\
\hline $\begin{array}{l}0 \\
0 \\
0\end{array}$ & $\begin{array}{l}\text { Chloroform } \\
\text { Chloromethane }\end{array}$ & $\begin{array}{r}4.0 \\
<1.0\end{array}$ & & $\mu$ & $\begin{array}{l}\mathrm{GE} \\
\mathrm{GE}\end{array}$ \\
\hline & Chromium & $<4.0$ & & $\mu g / L$ & $\mathrm{GE}$ \\
\hline & Copper & $<4.0$ & & $\mu g / L$ & \\
\hline 0 & $\begin{array}{l}\text { Cyanide } \\
\text { Dibromochloromethane }\end{array}$ & $\begin{array}{l}<5.0 \\
<1.0\end{array}$ & & $\mu g / L$ & GE \\
\hline 0 & 1, $t$-Dichloroethane & $<1.0$ & & $\begin{array}{l}\mu g / L \\
\mu g / L\end{array}$ & GE \\
\hline & 1,2-Dichloroethane & $<1.0$ & & $\mu g / L$ & $G E$ \\
\hline 0 & $\begin{array}{l}\text { 1,1-Dichloroethylene } \\
\text { trans-1,2-Dichloroethylene }\end{array}$ & $\begin{array}{l}<1.0 \\
<1.0\end{array}$ & & $\mu 9 / \mathrm{L}$ & $\begin{array}{l}\mathrm{GE} \\
\mathrm{GE}\end{array}$ \\
\hline & $\begin{array}{l}\text { trans-1,-2icniogernylene } \\
\text { Dichloromethane }\end{array}$ & $<1.0$ & & $\mu g / L$ & GE \\
\hline & 2,4-Dichlorophenoxyacetic acid & $<0.30$ & $\mathrm{JQ}$ & $\mu g / L$ & \\
\hline $\begin{array}{l}0 \\
0\end{array}$ & $\begin{array}{l}\text { 1,2-Dichtoropropane } \\
\text { cis-1,3-Dichloropropene }\end{array}$ & $\begin{array}{l}<1.0 \\
<1.0\end{array}$ & & $\mu g / L$ & $\begin{array}{l}\mathrm{GE} \\
\mathrm{GE}\end{array}$ \\
\hline 0 & trans-1,3-Dichloropropene & $<1.0$ & & $\mu g / L$ & $\mathrm{GE}$ \\
\hline 0 & $\begin{array}{l}\text { Enarin } \\
\text { Ethylbenzene }\end{array}$ & $<1.0$ & & $\mu$ & \\
\hline & Fluoride & $<100$ & & $\mathrm{mg} / \mathrm{L}$ & \\
\hline 0 & $\begin{array}{l}\text { Iron } \\
\text { Lead }\end{array}$ & $\begin{array}{r}43 \\
<3.0\end{array}$ & & $\mu g / L$ & \\
\hline o & Uindane & $<0.0050$ & & $\mu \mathrm{g} / \mathrm{L}$ & $\mathrm{GE}$ \\
\hline $\begin{array}{l}0 \\
2\end{array}$ & $\begin{array}{l}\text { Magnesium } \\
\text { Manganese }\end{array}$ & $\begin{array}{l}491 \\
182\end{array}$ & & $\operatorname{mg} / \mathrm{L}$ & $G E$ \\
\hline 0 & Mercury & $<0.20$ & & $\mu \mathrm{g} / \mathrm{h}$ & \\
\hline 0 & Methoxychlor & $<0.50$ & & $\mu g / L$ & \\
\hline $\begin{array}{l}0 \\
0\end{array}$ & $\begin{array}{l}\text { Naphthalene } \\
\text { Nickel }\end{array}$ & $<\begin{array}{l}10 \\
7.5\end{array}$ & & $\mathrm{mg} / \mathrm{L}$ & GE. \\
\hline 0 & Nitrate as nitrogen & 720 & & $\mu g / L$ & \\
\hline 0 & Phenois & $<5.0$ & & $\mu g / L$ & \\
\hline 0 & Potassium & 1,170 & & $\mu g /$ & $\mathrm{G}$ \\
\hline $\begin{array}{l}0 \\
0\end{array}$ & $\begin{array}{l}\text { Selenium } \\
\text { Silica }\end{array}$ & $\begin{array}{l}<2.0 \\
7,560\end{array}$ & J1 & $\mu g / L$ & $\begin{array}{l}\mathrm{GE} \\
\mathrm{GE}\end{array}$ \\
\hline 0 & Silver & $<2.0$ & & $\mu \mathrm{m} / \mathrm{L}$ & \\
\hline $\begin{array}{l}0 \\
0 \\
0\end{array}$ & $\begin{array}{l}\text { Sodium } \\
\text { Sulfate }\end{array}$ & $\begin{array}{l}13,800 \\
8,880\end{array}$ & & $\mu g / 1$ & $E$ \\
\hline $\begin{array}{l}0 \\
0\end{array}$ & $\begin{array}{l}\text { Sulfate } \\
1,1,2,2 \text {-Totrachloroethane }\end{array}$ & $\begin{array}{r}8,88 \\
<1.0\end{array}$ & & $\begin{array}{l}\mu g / L \\
\mu g / L\end{array}$ & \\
\hline 0 & Tetrachloroethylene & $<1.0$ & & $\mathrm{wg} / \mathrm{L}$ & $\mathrm{G}$ \\
\hline 0 & Tin & $<2.0$ & & $\mu \mathrm{g} / \mathrm{L}$ & \\
\hline 0 & $\begin{array}{l}\text { Toluene } \\
\text { Total dissolved solids }\end{array}$ & $<1.0$ & & $\mu g / L$ & \\
\hline $\begin{array}{l}0 \\
0\end{array}$ & $\begin{array}{l}\text { Total dissolved solids } \\
\text { Total organic carbon }\end{array}$ & $\begin{aligned} & 61,000 \\
< & 1,000\end{aligned}$ & & $\mu g / L$ & $\begin{array}{l}\mathrm{GE} \\
\mathrm{GE}\end{array}$ \\
\hline 0 & $\begin{array}{l}\text { Total organic carbon } \\
\text { Total organic halogens }\end{array}$ & $<1,000$ & & r $\mu$ & $\mathrm{GE}$ \\
\hline 0 & Total phosphates (as P) & $<50$ & & $\mu \mathrm{g} / \mathrm{L}$ & \\
\hline 0 & $\begin{array}{l}\text { Toxaphene } \\
24.5 . T P \text { (Silvex) }\end{array}$ & $<0.24$ & 10 & $\mu g / L$ & \\
\hline $\begin{array}{l}0 \\
0\end{array}$ & $\begin{array}{l}\text { 2,4,5-TP (Silvex) } \\
\text { 1,1,1-Trichloroethane }\end{array}$ & $\begin{array}{l}<0.090 \\
<1.0\end{array}$ & $\mathrm{JQ}$ & $\mu g / L$ & \\
\hline 0 & 1,1,2-Trichloroethane & $<10$ & & $\mu \mathrm{g} / \mathrm{L}$ & \\
\hline 2 & Trichloroethylene & 11 & & $\mu g / L$ & $G E$ \\
\hline 0 & Trichlorofluoromethane & $\begin{array}{l}<1.0 \\
<00\end{array}$ & & $\mu g / L$ & \\
\hline $\begin{array}{l}0 \\
0\end{array}$ & $\begin{array}{l}\text { Vanadium } \\
\text { Xyleries }\end{array}$ & $\begin{array}{l}<\theta 0 \\
<2.0\end{array}$ & & $\underset{\mu g / L}{\mu g / L}$ & $\mathrm{GE}$ \\
\hline $\begin{array}{l}0 \\
0\end{array}$ & $\begin{array}{l}\text { Xyleries } \\
\text { Gross alpha }\end{array}$ & $<2.0 E \cdot 09$ & & $\mathrm{r} C \mathrm{i} / \mathrm{mL}$ & $\mathrm{GE}$ \\
\hline 0 & Nonvoiatile beta & $25 \mathrm{E} \cdot 09 \pm 1.6 \mathrm{E} \cdot 09$ & & $\omega \mathrm{Ci} / \mathrm{mL}$ & \\
\hline 0 & Total activity & $1.1 \mathrm{E}-04 \pm 2.8 \mathrm{E} \cdot 06$ & & & \\
\hline 0 & Total radium & $<1.0 E-09$ & & $\sim \mathrm{Cl} / \mathrm{mL}$ & \\
\hline${ }_{0}^{2}$ & $\begin{array}{l}\text { Tritium } \\
\text { Utanium.233/234 }\end{array}$ & $\begin{array}{r}1.2 \mathrm{E}-04 \pm 1.8 \mathrm{E}-06 \\
1 \mathrm{CE}-10\end{array}$ & & $\mu \mathrm{Ci} / \mathrm{mL}$ & GE \\
\hline 0 & $\begin{array}{l}\text { Uranium-233/234 } \\
\text { Uranium-238 }\end{array}$ & $<10 E \cdot 10$ & & $\mathrm{Ci} / \mathrm{mL}$ & $E$ \\
\hline
\end{tabular}

WELL BGO 14AR

MEASUREMENTS CONDUCTED IN THE FIELD

Sample date: $10 / 15 / 91$

Depth to water: $140.98 \mathrm{ft}(42.87 \mathrm{~m})$ below roc Water elevation: $158.72 \mathrm{f}(48.68 \mathrm{~m}) \mathrm{msl}$ Water evacuated before sampling: $166 \mathrm{gal}$ LABORATORY ANALYSES

F Analyte

2 pH 2 Specific conductance

0 Turbidity

Acetophenone

2 Aluminum

Arsenic

Barium

Bromodichloromethane

Bromodichlor

Bromotorm

Cadmium

Cadmium

Carbon tetrachloride

Chloride

Chlorobenzene

Chlorthane Ninyl chloride

2. Chloroethyl vinyl ether

Chloroform

Chlornmethane

Chro.nium

Copper

Dibromochloromethane

1,1-Dichloroethane

1,2-Dichloroethane

1,1-Dichloroethylene

trans-1,2-Dichloroethylene

Dichloromethane

2,4-Dichlorophenoxyacetic acid $<0.30$

cis-1,3-Dichloropropene

Endrin

Ethylbenzene

Fluorid

lion

0 Lead

0 Magnesium

Manganese

Mercury

Methoxychlor

- Naphthalen

0 Nitrate as nitrogen

Phenols

Potassium

0 Selenium

Silica

Silver

Sulfate

Tetrachloroethylene

o Tin

- Total dissolved solids

Total organic carbon

Total organic halogens

Total phosphates (as P)

0 Toxaphene

o 2,4,5.TP (Silvex)

o 1,1,1-Trichloroethane

1,1,2-Trichloroethan

2 Trichloroethylene

Trichlorofluoromethane

Vanadium

Xylenes

Gross aipha

Notal activity

Total radium

2 Tritium

Uranium-233/234

ime: 14.50

Alkalinity: $343 \mathrm{mg} /$

Water temperature: $19.8^{\circ} \mathrm{C}$

\section{Result}

Mod Unit

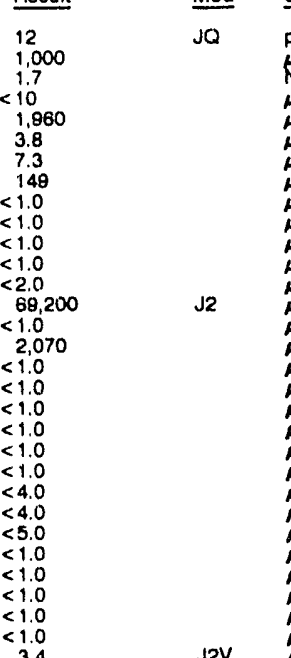

$\begin{array}{ll}\mathrm{pH} & \mathrm{G} \\ \boldsymbol{\mu} \mathrm{S} / \mathrm{cm} & \mathrm{G} \\ \mathrm{NTU} & \mathrm{G} \\ \boldsymbol{\mu g} / \mathrm{L} & \mathrm{G} \\ \mu \mathrm{g} / \mathrm{L} & \mathrm{G} \\ \boldsymbol{\mu g} / \mathrm{L} & \mathrm{G} \\ \mu \mathrm{g} / \mathrm{L} & \mathrm{G} \\ \mu \mathrm{g} / \mathrm{L} & \mathrm{G} \\ \mu \mathrm{g} / & \mathrm{G} \\ \mu \mathrm{g} / \mathrm{L} & \mathrm{G}\end{array}$

$\mathrm{GE}$
$\mathrm{GE}$
$\mathrm{GE}$
$\mathrm{GE}$
$\mathrm{GE}$
$\mathrm{GE}$
$\mathrm{GE}$
$\mathrm{GE}$
$\mathrm{GE}$
$\mathrm{GE}$
$\mathrm{GE}$ 
WELL BGO 14CR

MEASUREMENTS CONDUCTED IN THE FIELD

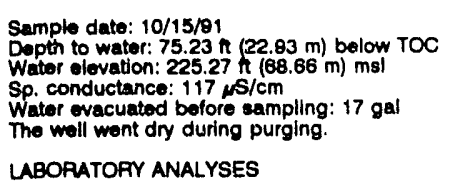

LABOFATOFY ANALYSES

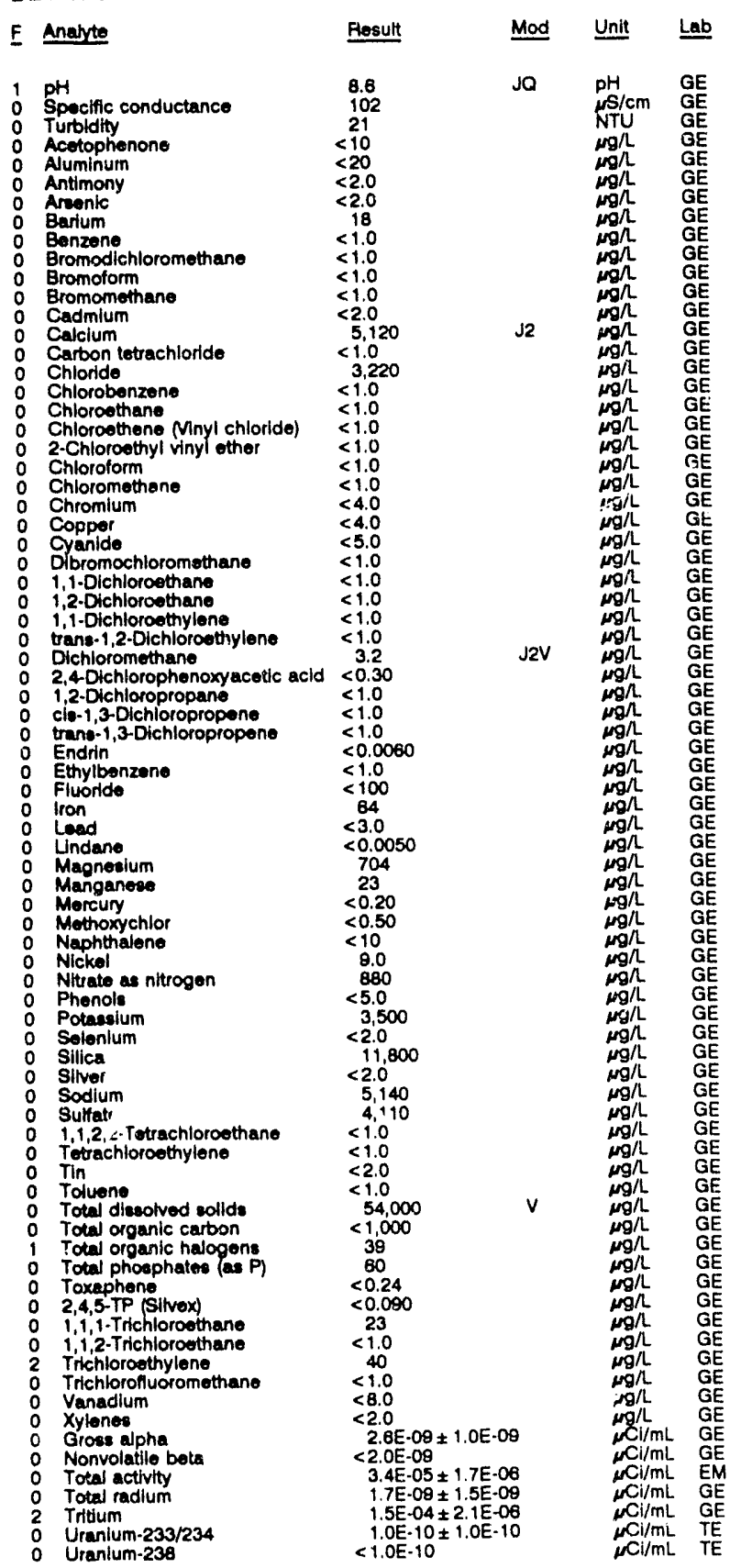

WELL BGO 14DR

MEASUREMENTS CONDUCTED IN THE FIELD

Sample date: 10/15/91

Depth to water: 88.07 \# $(20.75 \mathrm{~m})$ below TOC

Water olevalion: $232.23 \mathrm{ft}(70.78 \mathrm{~m}) \mathrm{ms}$ |

Water evacuated before sampling: $38 \mathrm{gal}$

LABORATORY ANALYSES

$E$ Analyte Result Mod Unit Lab

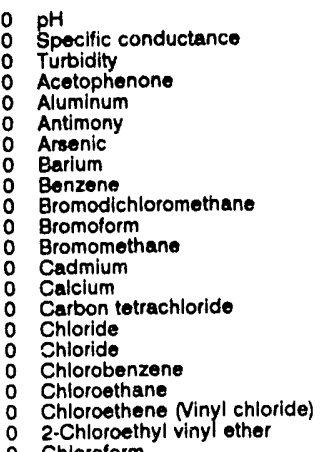

Chloroform

Chloromethane

Chromium

Copanide

Dibromochiorornethane

1,1-Dichloroethane

1,2-Dichloroethane

trans-1,2-Dichloroethylene

$6.4 \quad 5 a$

Time: 14:20

Ak: 5.5 : $8 \mathrm{mg}$

Water tomperature: $19.7^{\circ} \mathrm{C}$

Dichloromethane

1,2-Dichloropropane

cis-1,3-Dichloropropene

Endrin

Ethylbenzeno

Fluoride

lron

Lindane

Magnesium

Manganeso

Methoxychlor

Naphthalene

Nitrate as nitrogen

Phenols

Potassium

Selenium

Sillca

Silver

Sulfate

1, 1,2,2-Tetrachloroethane

Tetrachloroethylene

Iin

Total dissolved solids

Total organic carbon

Total organic halogens
Total phosphates (as P)

Toxaphene

2,4,5-TP (Silvex)

1,i,2-Trichloroethan

Trichloroethylene

Trichlorofluoromethane

Vanadium

Xylenes

Nonvolatile beta

Total activity

2 Tritium

Uranium-233/234

42
14
110
$<10$
$<20$
$<2.0$
$<2.0$
8.2
$<1.0$
$<1.0$
$<1.0$
$<1.0$
$<2.0$
$<2.140$
$<1.0$
$<1.0$
3,300
31.260
$<1.0$
$<1.0$
$<1.0$
$<1.0$
$<1.0$
$<1.0$
$<4.0$
$<4.0$
$<5.0$
$<1.0$
$<1.0$
$<1.0$
$<1.0$
$<1.0$
33.0
$<0.30$
$<1.0$
$<1.0$
$<1.0$
$<0.006$
$<10$

$<1.0$

$<1.00000$

$<1.0$
$<100$

$<100$
11

$<3.0$

433

34
$<0.20$
$<0.50$

$<0.50$

$<10$

880
$<5.0$

$<5.0$

$\begin{array}{r}873 \\ <2.0 \\ \hline\end{array}$

8.890
$<2.0$

$<.0$
5,010

2,440
$<1.0$

1.2
$<2.0$
$<1.0$

38,000

$<1,000$

$<5.0$
$>0$

$<0.24$
$<0.090$

$<1.0$

$<1.0$

$\begin{array}{r}10 \\ <1.0 \\ \hline\end{array}$

$<8.0$
$<2.0$

$<2.0 E-09$

$4.2 \mathrm{E}-04 \pm 4.7 \mathrm{E}-00$

$<1.0 \mathrm{E}-09$

5. $5 \mathrm{E}-04+3.8 \mathrm{E}-06$

$<1.0 E-10$
$<1.0 E-10$
JQ PH GE

$\begin{array}{ll}\mu \mathrm{S} / \mathrm{cm} & \mathrm{GE} \\ N \mathrm{G} & \mathrm{GE} \\ \mu \mathrm{G} / \mathrm{L} & \mathrm{GE}\end{array}$

$\mu \mathrm{g} / \mathrm{GE}$

.


ANALYTICAL RESULTS

WELL BGO 15D

MEASUREMENTS CONDUCTED IN THE FIELD

Sample date: $10 / 15 / 81$
Depth to wator: $66.88 \mathrm{H}(20.38 \mathrm{~m})$ below TOC
Water olevation: $231.84 \mathrm{ft}(70.87 \mathrm{~m}) \mathrm{ms} /$
Sp. conductance: $38 \mu \mathrm{S} / \mathrm{cm}$
Water ovacuated beforo sampling: $34 \mathrm{gal}$

Time: 11:45

PH: $5.2 .25 \mathrm{mg}$

Water temperature: $19.8^{\circ} \mathrm{C}$

LABORATORY ANALYSES

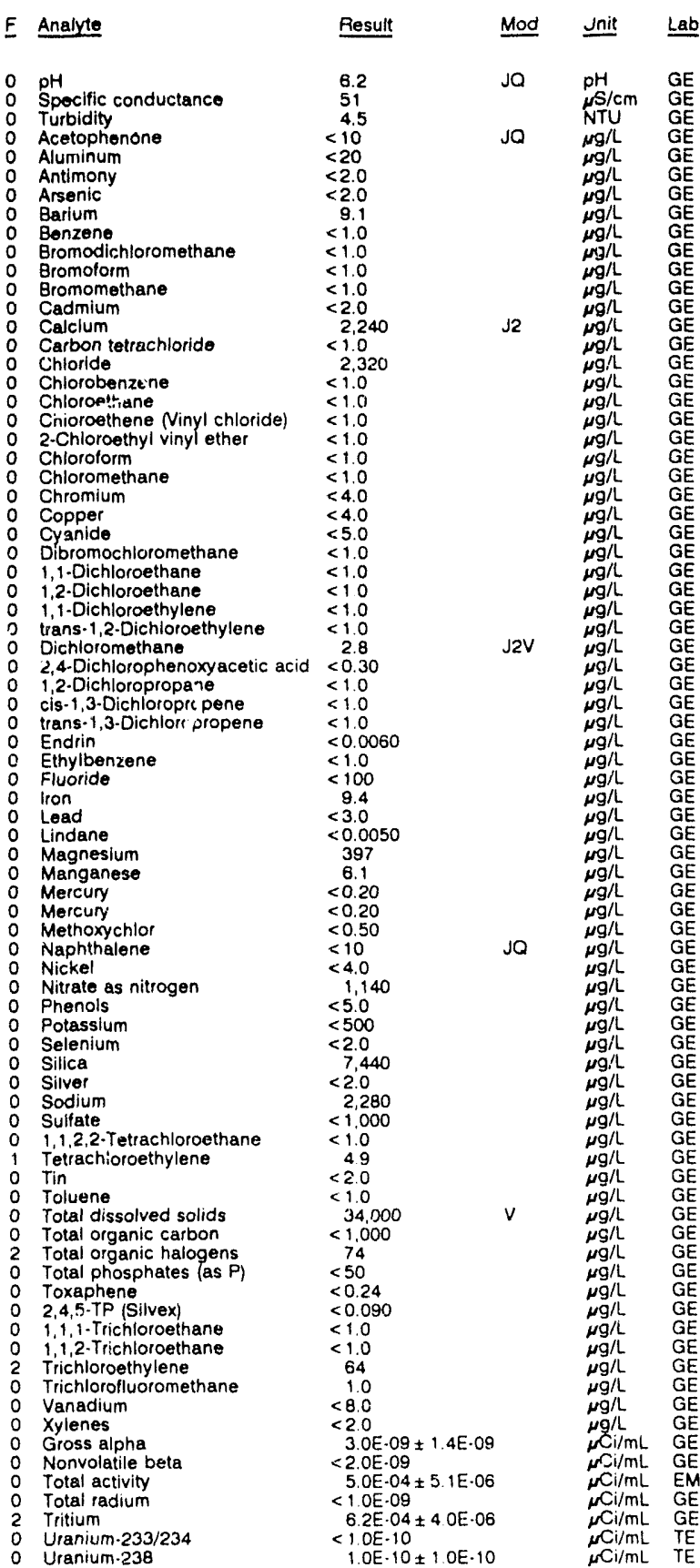

WELL BGO 16A

MEASUREMENTS CONDUCTED IN THE FIELD

Depth to water: $143.46 \mathrm{At}(43.73 \mathrm{~m})$ below TOC

Water elevation: $18.54 \mathrm{ht}(49.24 \mathrm{~m}) \mathrm{msl}$

Water evacuated bofore sampling: 22 gal

The well went dry during purging.

LABORATORY ANALYSES

E Analyte $\quad$ Rosult $\quad$ Mod Unit Lab

2 PH

Turbidity

Acetophenono

2 Aluminum

$\begin{array}{ll}0 & \text { Antimony } \\ 0 & \text { Arsenic } \\ 0 & \text { Benta }\end{array}$

: Arsenic

O Benzene

Bromodich

Bromoform

Bromomethane

Cadmium

Carbon tetrachloride

Chloride

Chlorobenzene

Chloroethene (Vinyl chloride)

2-Chloroethyl vinyl ether

Chloroform

Chloromethane

Chromium

Copper

Cyanide

Oibromochioromethan

1,1-Dichloroethane

1,2-Dichloroethane

trans-1,2-Dichloroethylene

Dichloromethane

2,4-Dichlorophenoxyacetic acid $<1.0$

1,2-Dichloropropane

cis-1,3-Dichioropropene
trans-1,3-Dichloropropene

Ethylbenzene

0 Fluoride

o lron

o Lindane

0 Magnesium

- Manganeso

Methoxychlor

0 Naphth

${ }_{0}$ Nittate as nitrogen

Phenols

Potassium

- Selenium

Silver

Sodium

Sulfate

1,1,2,2.Tetrachloroethane

Tetrachloroethylene

Tin

0 Toluene

Total dissolved solids

Total organic carbon

Total organic halogens
Total phosphates (as P)

0 Total phosp

2,4,5-TP (Silvex)

1,1,1-Trichloroethane

1,1,2-Trichloroethane

Trichloroethylene

Trichlorofluoromethane

o Vanadium

0 Xylenes

Gross al: "1a

Total radium

Tritium

Uranium.233/234

Uranium-238
Time: 13:00

Alkalinity: $338 \mathrm{mg} / \mathrm{h}$

Water temperatura: $17.8^{\circ} \mathrm{C}$

12

Q $\quad \mathrm{PH} \quad \mathrm{GE}$

$\begin{array}{ll}\mu \mathrm{S} / \mathrm{cm} & \mathrm{GE} \\ \mathrm{NTU} & \mathrm{GE} \\ \mu \mathrm{gE} & \mathrm{GE}\end{array}$

$<10$
697

2.2
$<2.0$
$<111$

$<1.0$

$<1.0$

$<2.0$

$<1.00$

$<1.0$
$<1.0$

$<1.0$

$<1.0$

$<1.0$
$<1.0$
$<1.0$
$<4.0$

$<4.0$
$<4.0$
7.2

$<1.0$

$<1.0$

$<1.0$

$<1.0$

$<1.30$
$<1.0$
$<1.0$

$<1.0$

$<0.0060$

$<1.0$

144
$<4.0$
$<3.0$

$<0.0050$

15
$<2.0$

$<2.0$
$<0.20$

$<0.50$

$<10$

$<4.0$
$<50$
$<5.0$

$<5.0$

11,600
$<2.0$
24,000

24,000
$<2.0$

14.100
9.180

$<1,0$

$<1.0$

$<2.0$

340,000
$<1,000$

11
$<50$
5

$<0.24$

<.

$<1.0$

$<10$

$<1.0$

$<8.0$

3. 4 E. $08+2.0 E-09$

3. $4 \mathrm{E}-08 \pm 3.4 \mathrm{E}-09$

$1.5 E .09 \pm 1.3 E-00$

$<7.0 E .07$

$3.0 E-10 \pm 2.0 E-10$
$<1.0 E \cdot 10$ 
ANALYTICAL RESULTS

WELL BGO 16D

MEASUREMENTS CONDUCTED IN THE FIELD

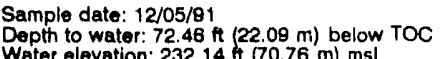

Water elevation: $232.14 \mathrm{ft}(70.76 \mathrm{~m}) \mathrm{ms}$

Inaccessibility or pump failure prevented sample collection.

WELL BGO 17D

MEASUREMENTS CONDUCTED IN THE FIELD

Sample date: $12 / 05 / 91$

inaccessibility of pump fallure prevented sample collection.

WELL BGO $18 \mathrm{~A}$

MEASUREMENTS CONDUCTED IN THE FIELD

Sample date: $12 / 05 / 9$

Depth to water: $133.38 \mathrm{ft}(40.85 \mathrm{~m})$ below TOC

Water olevation: $181.82 \mathrm{H} / 49.32$

Sp. conductance: $179 \mu \mathrm{\mu S} / \mathrm{cm}$. $164 \mathrm{gal}$

LABORATORY ANALYSES

E Analyte

pH

Turbidity

Acetophenone

Aluminum

Airsenic

Barlum

Bromodichloromethane

Bromodichlor

Eromomethane

Cadmium

Carbon tetrachioride

Chloride

Chlorobenzene

Chloroethene (Vinyl chloride)

2. Chloroethyi vinyl ether

Chloroform

Chloromethane

Chromium

Coper

Dibromochloromethane

1,1-Dichloroethane

o 1,2-Dichloroethane

o trans-1,2-Uichloroethylene

Dichloromethene

2,4-Dichlorophenoxyacetic acid

o 1,2-Dichluropropane

o cis-1,3-Dichloropropene

$\checkmark$ Endrin

Ethylbenzene

Fluoride
Iron

0 Lead

Lindane

Magnesium

Mercury

Methoxychlor

Naphthalene

Nickel

Nitrate as nitrogen

Phenols

Selenium

0 Silica

Silver

Sulfate

1, 1,2,2-Tetrachloroethane

Tetrachloroethylene

Tin

Toluene

Total organic carbon

Tolal organic carbonens

Total phosphates (as P)

Toxaphene
Time: $11: 35$

Alkalinity: $82 \mathrm{mg} / \mathrm{h}$

Water temperature: $17.1^{\circ} \mathrm{C}$

Result Mod Unit Lab

JQ $\quad \begin{array}{ll}\mathrm{PH} & \mathrm{GE} \\ \mathrm{NS} / \mathrm{cm} & \mathrm{GE}\end{array}$

$\begin{array}{ll}\mu H & G E \\ \mu S / c m & G E \\ N T U & G E \\ \mu g / L & G E\end{array}$

WELL BGO 18A collected on 12/05/91, laboratory analyses (cont.)

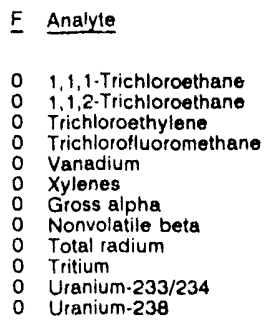

Result

$<1.0$

$<1.0$
$<1.0$

$<1.0$

$<8.0$

$<2.0 E-09$

$6.5 \mathrm{E}-09 \pm 2.1 \mathrm{E}-09$

$<1.0 \mathrm{E}-09$

$<7.0 E \cdot 07$

$<2.0 E-10$
$2.0 E-10 \pm 1.0 E-10$

WELL BGO 18D

MEASUREMENTS CONDUCTED IN THE FIELD

Sample date: $12 / 05 / 91$

Depth to water: $82.03 \mathrm{ft}(18.91 \mathrm{~m})$ below TOC

Water elevation: $232.87 \mathrm{Ht}(70.98 \mathrm{~m}) \mathrm{msl}$

Sater evacuated betore sampling: $58 \mathrm{gal}$

Time: $12: 10$

LABORATORY ANALYSES

E Analyte Result $\underline{\text { Mod Unit Lab }}$

${ }_{0}^{0} \mathrm{pH}$

0 Turbidity

Acetophenone

Aluminum

Arsenic

0 Barium

Bromodichloromethane

Bromotorm

Bromomethane

Cadmium

- Carbon tetrachloride

0 Chloride

Chlorobenzene

Chloroethane

Chloroethene Vinyl chloride)

2-Chloroethyl vinyl ether

Chloromethane

o Chromium

Copper

o Dibromochlorometharle

o 1,1-Dichloroethane

- 1,2-Dichloroethane

o 1,1-Dichloroethylene

o Dichloromethane

1,2-Dichloropropane

- cis-1,3-Oichloropropene

trans-1,3-Dichloropropene

E Endrin

0 Ethylbenzene

$\begin{array}{ll}0 & \text { Iron } \\ 0 & \text { Lead }\end{array}$

0 Lindane

Magnesium

Mercury

Methoxychlor

O Naphthalen

Nicke

Nitrate as nitrogen

Phenols

Potassium
Selenium

Silica

Silver

Sodium

$1,1,2,2$-Tetrachloroethane

Tetrachloroethylene

Tin

Tolvene

Total dissolved solids

Total organic carbon

Total organic halogens

Toxaphene

2.4,5-TP (Siivex)

1,1,1-Trichloroethane

1.1,2-Trichloroethan

Trichioroethylene

Trichlorofluoromethane

Vanadium

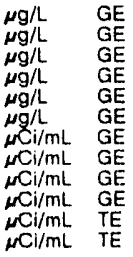

E

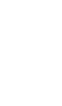




\section{ANALYTICAL RESULTS}

WELL BGO 180 collected on 12/05/91, laboratory analyses (cont.)

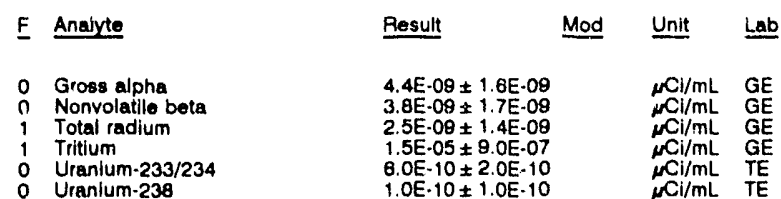

\section{WELL BGO 19D}

MEASUREMENTS CONDUCTED IN THE FIELD

Sample date: 12/05/91 Time: 11:15

inaccessibility or pump fallure prevented sample coilection.

\section{WELL BGO 20D}

MEASUREMENTS CONOUCTED IN THE FIELD

Sample date: 12/05/91 Depth to water: $48.85 \mathrm{ft}(14.89 \mathrm{~m})$ below TOC Sp. conductance: $62 \mu \mathrm{s} / \mathrm{cm}$

Water evacuated bofore sampling: $9 \mathrm{gal}$ The well went dry during purging. 9 ga

LABORATORY ANALYSES

E Analyte Result Mod Unit Lab

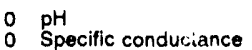

Acetophenone

Aluminum

Antimony

Arsenic

Barium

Bromodichloromethane

Bromotorm

Bromomethane

Cadmium

Carbon tetrachloride

Chloride

Chlorobenzene

Chloroethane

2-Chloroethyl vinyl ether

Chloromethane

Chromium

Copper

Cyanide

Dibromochioromethane

1,1-Dichloroethane

1,1-Dichloroethylene
trans-1,2-Dichloroethylene

Dichloromethane

2,4-Oichlorophenoxyacetic acid $<1.0$

1,2-Dichloropropane

cis-1,3-Dichloropropene
trans-1,3-Dichloropropene

Endrin

Fluorid

lion

Lindane

Magnesium

Manganese

Mercury

Naphthalene

Nickel

Nitrate as nitrogen

Phenols

Potassium

Selenium

Silica

Silver

Sulfate

1,1,2,2-Tetrachloroethane

Tetrachloroethylene

Tin

$<<$

Total dissolved solids

Total organic carbon

Total organic halogens

Total phosphates (as P)

Toxaphene

2,4,5-TP (Silvex)
Time: 12:25

pH. 5.6 . 22 mg/L

Alkalinity: $22 \mathrm{mg} / \mathrm{l}$. $192^{\circ} \mathrm{C}$
WELL BGO 200 rollected on 12/05/91, laboratory analyses (cont.

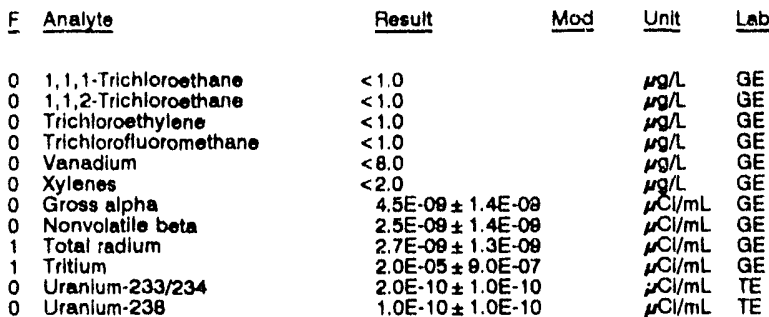

WELL BGO 21D

MEASUREMENTS CONDUCTED IN THE FIELD

Sample date: 12/05/81

Depth to water: $48.58 \mathrm{Ht}(15.11 \mathrm{~m})$ below TOC

Water ole'iation: $235.82 \mathrm{~h}(71.88 \mathrm{~m}) \mathrm{msl}$

Water evacuated bofore sampling: $12 \mathrm{gal}$

The well went dry during purging.

LABORATORY ANALYSES

E Analyte Result Mod Unit Lab

pH

0 Turbidity

Acetophenone

Aluminum

Antimony

Barium

Benz:-70

Bromodichloromethane

Bromoform

Bromometh

Cadmium

Carbon tetrachloride

Chloride

Chlorobenzene

Chloroethane

Chloroethene Ninyl chloride

2-Chloroethyi vinyl other

Chloroform

Chloromethane

Chromium

Copper

Cyanide

Dibromochloromethan

1,1-Dichloroethane

1,2-Dichloroethane

trans-1,2-Dichloroethylene

6.5

Time: $13: 30$

Halinity: $45 \mathrm{mg} / \mathrm{L}$

Water temperature: $18.0^{\circ} \mathrm{C}$

Dichloromethane $<1.0$

1,2-Dichloropropano

1,2-Dichloropropano

trans:1,3-Dichloropropene

Endrin

Ethylbenzene

Fluoride

Lead

0 Lindane

Magnesium

Manganeso

Mercury

Naphthalene

Nickel

Nitrate as nitrogen

Nitrate as nitrogen

Phenols

Potassium
Selenium

Silica

Silice

Sodium

Sultate

1,1,2,2-Tetrachloroethane

Tetrachloroethylene

Tin

Toluene

Total dissolved solids

Total organic carbon

Total organic halogens

Total phosphu

0
0

o $1,1,1$-Trichloroethane

1,1,2-Trichloroethan

0 Trich'oroethylene

- Trichlorofluoromethane

$<1.0$

$<1.0$
$<0.0060$

$<0.0000$
$<1.0$
$<100$

$<3.0$

$<0.0050$

264

$<0.20$

$<0.50$
$<10$

$<4.0$

4,000
3,950

$<5.0$

$<2.0$

6,390
$<2.0$
15,100

15,100
$<1,000$

$<1.0$

$<2.0$

$<8,000$

$<1.000$

5.8
$<50$
$<0.24$

$<0.090$

$<1.0$

$<1.0$
$<1.0$
$<1.0$

$<1.0$
$<8.0$
Jo $\quad p H \quad G E$

NTU GE 
WELL BGO 21D collected on 12/05/91, laboratory analyses (cont.)

\begin{tabular}{|c|c|c|c|}
\hline Analyte & Result & Mod & Unit \\
\hline $\begin{array}{l}\text { Xylones } \\
\text { Gross alpha } \\
\text { Nonvolatile beta } \\
\text { Total radium } \\
\text { Tritum } \\
\text { Uranium-233/234 } \\
\text { Uranium-238 }\end{array}$ & $\begin{array}{r}<2.0 \\
2.3 \mathrm{E}-09 \pm 1.2 \mathrm{E}-09 \\
6.4 \mathrm{E}-09 \pm 1.9 \mathrm{E}-09 \\
1.1 \mathrm{E}-09 \pm 1.3 \mathrm{E}-09 \\
4.2 \mathrm{E}-05 \pm 1.2 \mathrm{E}-00 \\
3.0 \mathrm{E}-10 \pm 2.0 \mathrm{E}-10 \\
<1.0 \mathrm{E}-10\end{array}$ & & $\begin{array}{l}\mu \mathrm{g} / \mathrm{L} \\
\mu \mathrm{Ci} / \mathrm{mL} \\
\mathrm{Ni} / \mathrm{mL} \\
\mu \mathrm{Ci} / \mathrm{mL} \\
\mu \mathrm{Ci} / \mathrm{mL} \\
\mu \mathrm{Ci} / \mathrm{mL} \\
\mu \mathrm{Ci} / \mathrm{mL}\end{array}$ \\
\hline
\end{tabular}

WELL BGO $\angle 2 D$

MEASUREMENTS CONDUCTED IN THE FIELD

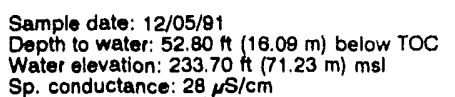
Water elevation: $233.70 \mathrm{ft}(71.23 \mathrm{~m}) \mathrm{ms}$
Sp. conductance: $28 \mu \mathrm{s} / \mathrm{cm}$ Water ovacuated before sampling: $104 \mathrm{gz}$

Alkalii.ty: $3 \mathrm{mg} / \mathrm{h}$ Water temperature: $17.9^{\circ} \mathrm{C}$ LABORATORY ANALYSES

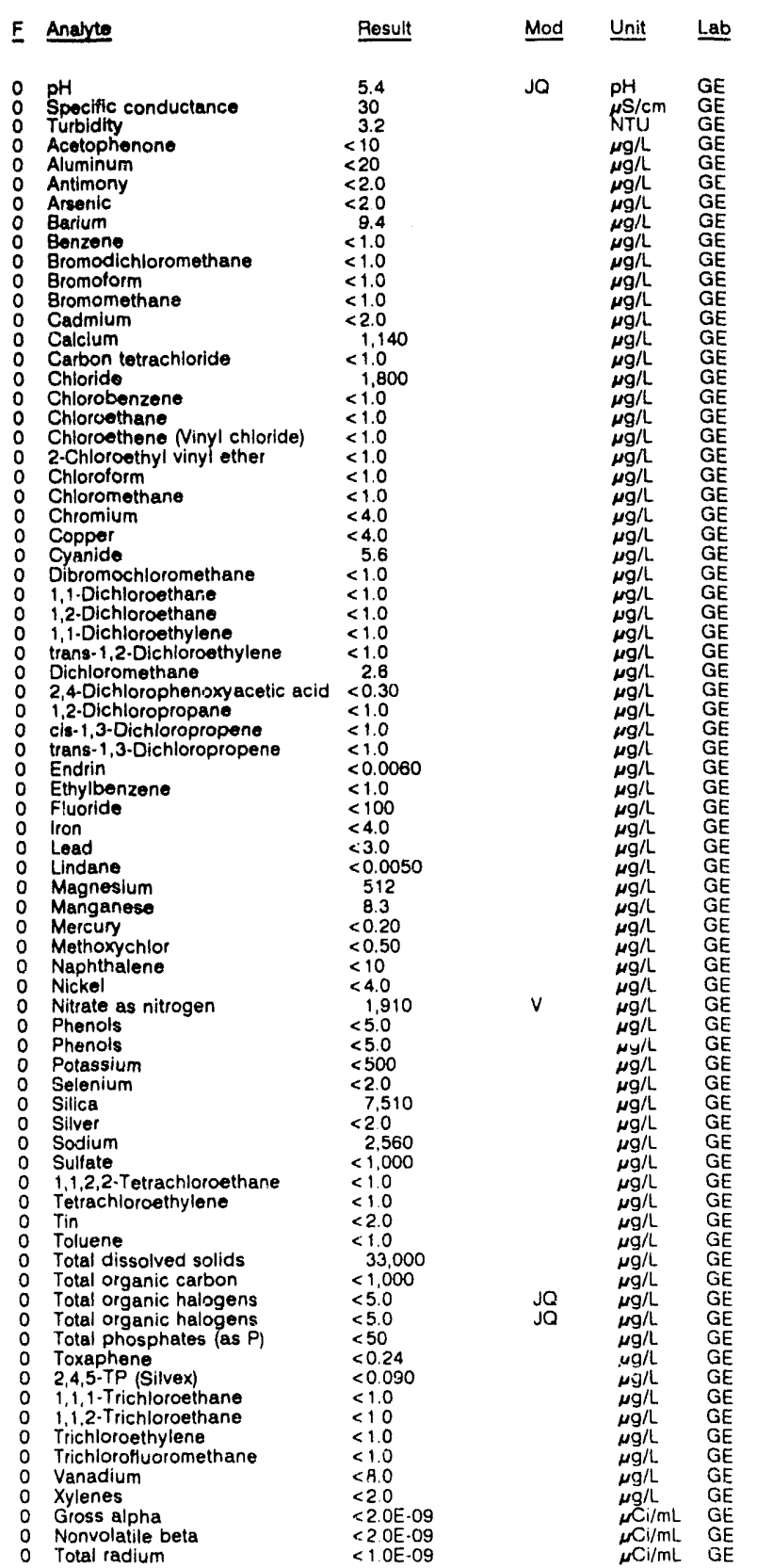

WELL BGU 220 collected on $12 / 05 / 91$, laboratory analyses (cont.)

$\begin{array}{lllll}\text { F Analyte } & \text { Result } & \text { Mod } & \text { Unit } & \text { Lab } \\ 1 \text { Tritium } & & & \\ 0 \text { Uranium-233/234 } & 1.8 \mathrm{EE} \cdot 05 \pm 8.0 \mathrm{E} \cdot 07 & \omega \mathrm{Cl} / \mathrm{mL} & \mathrm{GE} \\ 0 & \text { Uranium-238 } & <1.0 \mathrm{E} \cdot 10 & \omega \mathrm{Ci} / \mathrm{mL} & \mathrm{TE} \\ \mathrm{NCi} / \mathrm{mL} & \mathrm{TF}\end{array}$

WELL BGO 23D

MEASUREMENTS CONDUCTED IN THE FIELD

$\begin{array}{ll}\text { Sample date: } 12 / 05 / 91 & \text { Time: } 10: 00 \\ \text { Depth to water: } 52.30 \mathrm{Ht}(15.94 \mathrm{~m}) \text { below TOC } & \text { pH: } 6.1 \\ \text { Water elevation: } 236.90 \mathrm{ft}(72.21 \mathrm{~m}) \mathrm{msl} & \text { Alkalinity: } 9 \mathrm{mg} / \mathrm{h} \\ \text { Sp. conductance: } 37 \mu \mathrm{cm} & \text { Water temperature. } 18.9^{\circ} \mathrm{C} \\ \text { Water evacuated betore sampling: } 39 \mathrm{gal} & \end{array}$

LABORATORY ANALYSES

E Analyte Result Mod Unit Lab

$\begin{array}{ll}0 & \text { pH } \\ 0 & \text { Specific conductance } \\ 0 & \text { Turbidity }\end{array}$

- Acetophenone

- Aluminum

0 Arsenic

0 Barium

$\begin{array}{ll}0 & \text { Benzene } \\ 0 & \text { Bromodichloromethane }\end{array}$

Bromodichloro

Bromomethane

Bromometh
Cadmium

Calcium

- Carbon tetrachloride

Chloride

Chlorobenzene

Chloroethane

Chloroethene Ninyl chloride
2-Chloroethyl vinyl ether

Chioroform

Chloromethane

Chromium

Copper

Dibromochloromethane

1,1.Dichloroethane

1,2-Dichloroethane

1,1.Dichloroethylene

Dichloromethane

Result Mod Unit Lab

2,4-Dichlorophenoxyac

1,2-Dichloropropane

cis-1,3-Dichloropropene

Endrin

0 Ethylbenzene

0 Fluoride

Iron

0 Lindane

Magnesium

Mercury

Methoxychlor

Naphthalen

0 Nickel

N Nitrate as nitrogen

Phenols

0 Potassium

0 Silica

$\begin{array}{ll}0 & \text { Silver } \\ 0 & \text { Sodium }\end{array}$

Sodium

1,1,2,2-Tetrachloroethane

0 Tetrachloroethylene

0 Tin

Toluene

Total dissolved solids

Total organic carbon

Total organic halogens

Total organic halogens

Toxaphene

2,4,5.TP (Silvex)

1,1,1.Trichloroethane

1,1,2-Trichloroethan

Trichloroethylene

Vanadium

Xylenes

Nonvolatile bet

Total radium

2 Tritium

0 Uranium.233/234

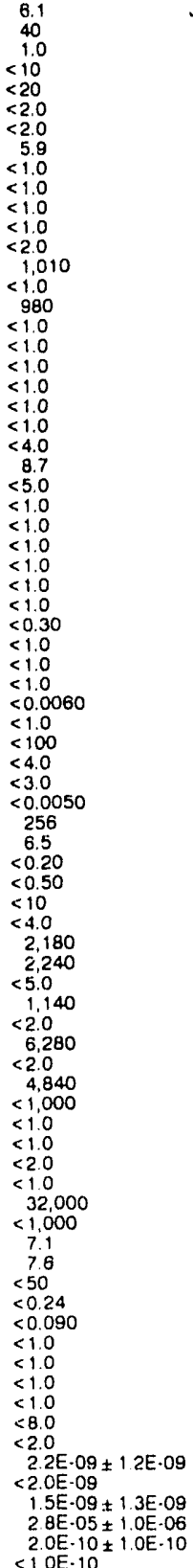

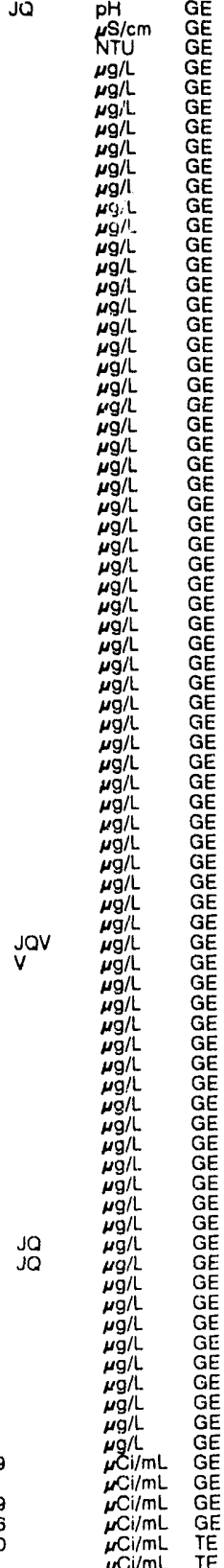


ANALYTICAL RESULTS

WELL BGO 24D

MEASUREMENTS CONDUCTED IN THE FIELD

Sample date: $12 / 05 / 91$

Depth to water: $55.13 \mathrm{An}(16.80 \mathrm{~m})$ below TOC

Water elevation. $238.07 \mathrm{Ht}(72.56 \mathrm{~m}) \mathrm{ms}$

prevented sample collection

WELL BGO 25A

MEASUREMENTS CONDUCTED IN THE FIELD

Sample date: 10/15/91

Depth to water: $134.19 \mathrm{ft}(40.90 \mathrm{~m})$ below TOC

Water elevation: $162.31 \mathrm{ft}(49.47$

Sp. conductance: $251 \mu \mathrm{S} / \mathrm{cm}$.

The well went dry during purging.

LABORATORY ANALYSES

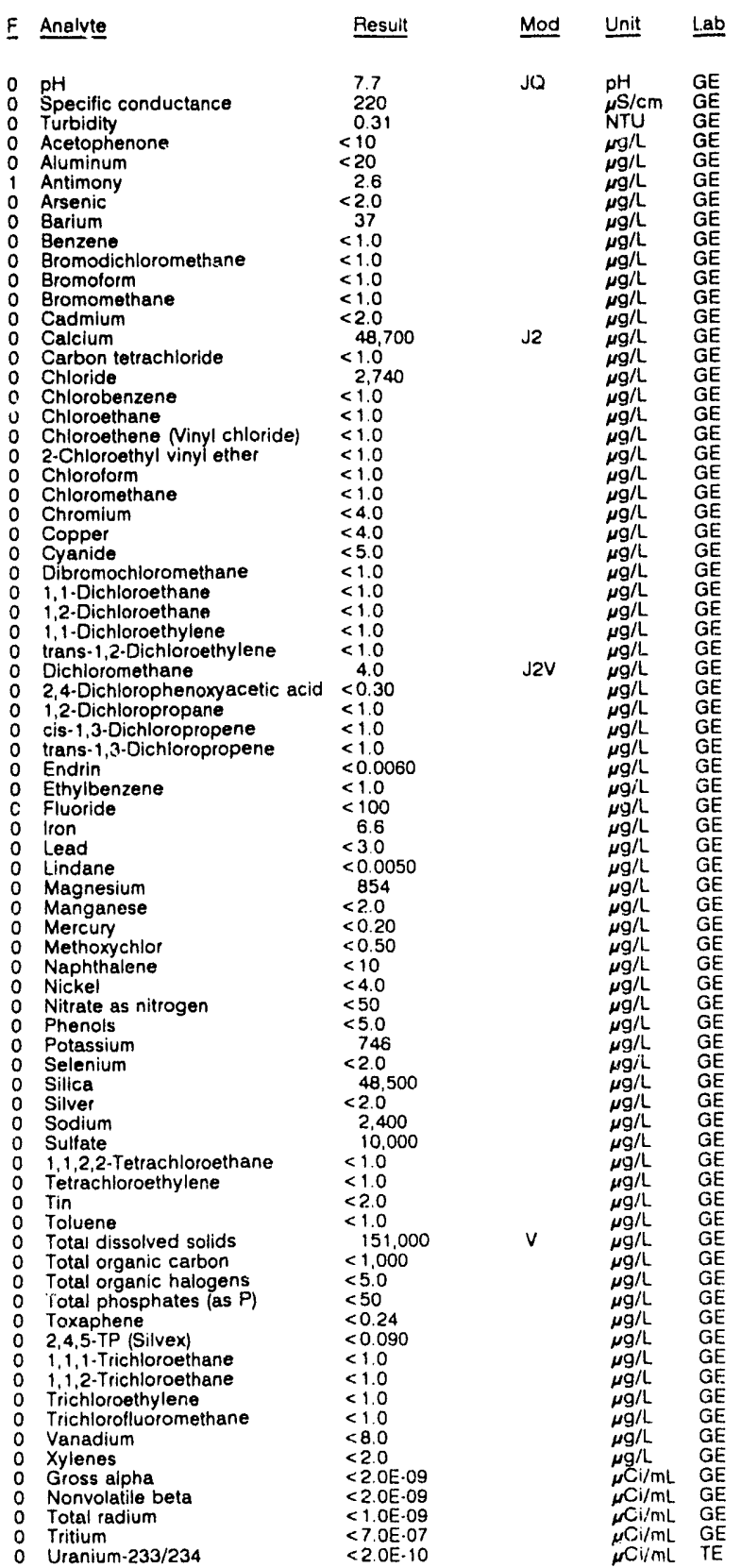

pH: 7.5

Alkalinity: $107 \mathrm{mg} / \mathrm{L}$

WELL FIGO 25 A collected on 10/15/91, laboratory analyses (cont)

$\begin{array}{lllll}- & \text { Result } & \text { Mod } & \text { Unit } & \text { Lab } \\ 0 \text { Uranium-238 } & <2.0 \mathrm{E} \cdot 10 & \mu \mathrm{Ci} / \mathrm{mL} & \mathrm{TE}\end{array}$

WELL BGO 26D

MEASUREMENTS CONDUCTED IN THE FIELD

Sample date: $10 / 16 / 91$

Depth to water: $55.29 \mathrm{ft}(16.85 \mathrm{~m})$ below TOC

Water eleyation: $230.21 \mathrm{t}(70.17 \mathrm{~m}) \mathrm{msl}$

Time: $13: 35$

Sp. conductance: $49 \mathrm{\mu s} / \mathrm{cm}$. $10 \mathrm{gal}$

LABORATORY ANALYSES

E Analyte Besult Mod Unit Lab

$\begin{array}{ll}0 & \mathrm{pH} \\ 0 & \text { Specific conductance }\end{array}$

0 Turbidity

Acetophenone

O Antimony

Antimonic

0 Barium

Benzene
0 Bromodichloromethane

0 Bromoform

0 Bromomethane

0 Cadmium

$\begin{array}{ll}0 & \text { Calcium } \\ 0 & \text { Carbon tetrachloride } \\ 0 & \text { Chloride }\end{array}$

0 Chlorobenzen

Chloroethene Ninyl chloride

2.Chloroethyl vinyl ether

Chloroform

Chloromethane

o Chromium

Copper

Cyanide
Dibromochloromethane

1,1-Dichloroethane

1,2-Dichloroethane

o trans-1,2-Dichloroethylene

Dichloromethane

2,4-Dichlorophenoryacetic acid

- 1,2-Dichloropropane

cis-1,3-Dichloropropene

Endrin

Ethylbenzene

0 Fluoride

0 Iron

0 Lead

0 Lindane

Manganese

Mercury

Methoxychior

Naphthat

Nitrate as nitrogen

Phenols

Polassium

Silica

Silver

Sodium

1,1,2,2-Tetrachloroethane

Tetrachloroethylene

0 Tin

- Toluene

Total dissolved solids

Total organic carbon

Total organic halogens
Total phosphates (as $P$ )

Toxaphene

2,4.5-TP (Silvex)

1,1,2-Trichloroethane

Trichloroethylene

Trichloroflucromethane

Vanadium

Antimony-125

Cerium $\cdot 144$

Cesium-134

Cesium-137

Cobalt -57

Eubalt-60

Gross alpha

Manganese-54

0 Nonvolatile be

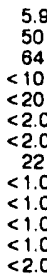

5.8
50
64
$<10$
$<20$
$<2.0$
$<2.0$
22
$<1.0$
$<1.0$
$<1.0$
$<1.0$

$<2.0$
4.010

$<.0$
2.720

$<1.0$

$<1.0$

$<1.0$
$<1.0$
$<1.0$
$<1.0$

$<4.0$
48
$<5.0$

$<1.0$

$<1.0$

$<1.0$

$<1.0$

$<0.30$

$<1.0$

$<1.0$

$<0.0060$

$<<1.0$

$<3$
93

4.5
$<0.0050$

668

14
$<0.20$

$<0.50$

$<10$
$<4.0$
1,330

1,330
$<5.0$
565

$\begin{array}{r}565 \\ <2.0 \\ \hline\end{array}$

$<.580$
4.0

$<2.0$

2,770
1,120

$<1.0$

$<2.0$

$<1.0$
38,000

$<1,000$

7.9
120

$<0.24$

$<0.090$

$<1.0$

$<1.0$

$<8.0$

$<7.0 \mathrm{E}-0$

$<2.4 \mathrm{E}-08$

$<3.0 E-09$

$<3.3 \mathrm{E} .09$

$<3.5 \mathrm{E} .09$

$<8 . \mathrm{BE}-09$

$<2.0 \mathrm{E}-09$

$<3.1$ E.09
$<2.0 \mathrm{E} .09$

$<4.0 \mathrm{E} .08$

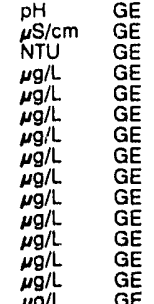

(


ANALYTICAL RESULTS

WELL BGO 26D collected on 10/16/91, laboratory analyses (cont.)

\begin{tabular}{|c|c|c|c|}
\hline Analyte & Result & Mod & Unit \\
\hline $\begin{array}{l}\text { Radium-228 } \\
\text { Ruthenium-103 } \\
\text { Sodium-22 } \\
\text { Thorium-228 } \\
\text { Total radium } \\
\text { Tritium } \\
\text { Uranium-233/234 } \\
\text { Uranium-238 } \\
\text { Zinc-65 }\end{array}$ & $\begin{array}{l}<5.3 E \cdot 09 \\
<2.2 E \cdot 08 \\
<3.0 E-09 \\
<2.9 E \cdot 09 \\
<1.0 \mathrm{E} \cdot 09 \\
1.1 \mathrm{E} \cdot 04 \pm 1.8 \mathrm{E}-06 \\
<1.0 \mathrm{H} \cdot 10 \\
<1.0 \mathrm{1} \cdot 10 \\
<7.9 \mathrm{~T} \cdot 09\end{array}$ & & $\begin{array}{l}\mu \mathrm{Ci} / \mathrm{mL} \\
\mu \mathrm{Ci} / \mathrm{mL} \\
\omega \mathrm{Ci} / \mathrm{mL} \\
\omega \mathrm{Ci} / \mathrm{mL} \\
\omega \mathrm{Ci} / \mathrm{mL} \\
\mu \mathrm{Ci} / \mathrm{mL} \\
\omega \mathrm{Ci} / \mathrm{mL} \\
\mu \mathrm{Ci} / \mathrm{mL} \\
\mu \mathrm{Ci} / \mathrm{mL}\end{array}$ \\
\hline
\end{tabular}

\section{WELL BGO 27C}

MEASUREMENTS CONDUCTED IN THE FIELL

Sample date: $10 / 16 / 91$

Wepth to water: 53.21 tt $(16.22 \mathrm{~m})$ below TOC

Water elevation: 222.78 Ht $(67.81$

Water evacuated before sampling: $154 \mathrm{gal}$

LABORATORY ANALYSES

E Analyte Result Mod Unit

$0 \mathrm{pH}$

Specific conductance

o Acetophenone

Acetophenone

Antimony

Arsenic

Barium

Bromodichloromethane

Bromoform

Bromomethane

Cadmium

Carbon tetrachloride

Chloride

Chloroethane

Ch-Chloroet

Chloromethan

0 Chromium

- Copper

Dibromochioromethane

1,1-Dichioroethane

$1,2 \cdot$ Dichloroethane

1,1-Dichloroelhylene
trans-1,2-Dichloroethylene

Dichloromethane

2,4-Dichlorophenoxyacetic acia

1,2-Dichloropropane

tis-1,3-0ichloropropene

0 Endrin

Endrin

Fluoride

0 Iron

Lindane

Magnesium

Manganes

Mercury

Naphthalene

Nicke

Nitrate as nitrogen

Phanols

Pelassium

Silica

Silica

Sodium

Sultate

1,1,2,2-Tetrachicroethane

0 Tetia

Toluene

Total dissolved solids

Total organic carbon

0 Total organic halogens
0 Total phosphates (as P)

Toxaphene

$0,4,5-T P$ (Silvex)
$0 \quad 1,1,1-$ Trichloroethane

$1,1,1$-Trichloroethane
$1,1,2$-Trichloroethane

2 Trichloroethylene

Trichlorofluoromethane

Xylenes

0 Antimony. 125

0 Cerium-144
Time: 12:05

Alkalinity: $41 \mathrm{mg} / \mathrm{h}$

Water temperature: $190^{\circ} \mathrm{C}$

Result Mod Unit Lab

$\begin{aligned} & 7.2 \\ & 115 \\ & 10 \\ &<10 \\ &<20 \\ &<2.0 \\ &<2.0 \\ & 5.0 \\ &<1.0 \\ &<1.0 \\ &<1.0 \\ &<1.0 \\ &<2.0 \\ & 25.5 \\ &<1.0 \\ & 2.05 \\ &<1.0 \\ &<1.0 \\ &<1.0 \\ &<1.0 \\ &<1.0 \\ &<1.0 \\ &<4.0 \\ &<4.0\end{aligned}$

$<5.0$
$<10$

$<10$

$<10$

$<1.0$
$<1.0$
3.1
$<0.30$
$<1.0$

$<1.0$
$<1.0$

$<1.0$

$<1.0$
$<0.0060$

$<1.0$

113
$<4.0$
$<3.0$

$<3.0$
$<0.0050$

312
$<2.0$

$<0.20$

$<0.50$

$<10$

$<.0$
1,230

$<5.0$
$<500$
$<2.0$
9.910

$<.0$
9,910

9,910
$<2.0$
1,690

1,690
$<1,000$

$<1,000$
$<1.0$

$<1.0$
$<2.0$

$<1.0$
62,000

$<1,000$
$<5.0$

$<5.0$
250

$<0.24$
$<0090$

$<1.0$

$<1.0$

13
$<1.0$

$<8.0$
$<2.0$

$<7.0 E \cdot 09$

$<2.4 E-08$
$<3.0 E-09$
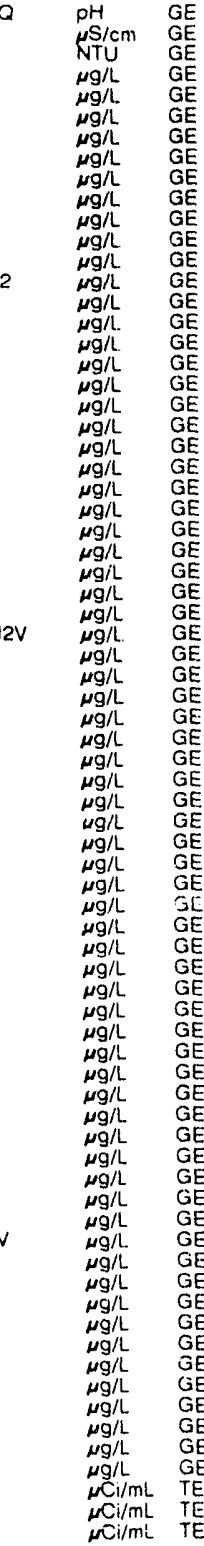

WELL BGO 27 C collected on 10/16/31, laboratory analyses (cont.)

\begin{tabular}{|c|c|c|}
\hline Analyte & Result & $\underline{\text { Un, it }}$ \\
\hline $\begin{array}{l}\text { Cesium-137 } \\
\text { Cobalt-57 } \\
\text { Ccbalt-60 } \\
\text { Europium-154 } \\
\text { Gross alpha } \\
\text { Manganese-54 } \\
\text { Nonvolatile beta } \\
\text { Potassium-40 } \\
\text { Radium-226 } \\
\text { Ruthenium-103 } \\
\text { Sodium-22 } \\
\text { Thorium-228 } \\
\text { Total radium } \\
\text { Tritium } \\
\text { Uranium-233/234 } \\
\text { Uranium-238 } \\
\text { Zinc-65 }\end{array}$ & 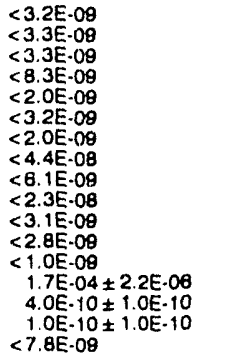 & $\begin{array}{l}\mu \mathrm{Cl} / \mathrm{mL} \\
\mu \mathrm{Cl} / \mathrm{mL} \\
\mu \mathrm{Cl} / \mathrm{mL} \\
\mu \mathrm{Cl} / \mathrm{mL} \\
\mu \mathrm{Cl} / \mathrm{mL} \\
\mu \mathrm{Cl} / \mathrm{mL} \\
\mu \mathrm{Cl} / \mathrm{mL} \\
\mu \mathrm{Cl} / / \mathrm{mL} \\
\mu \mathrm{Cl} / \mathrm{mL} \\
\mu \mathrm{Cl} / \mathrm{mL} \\
\mu \mathrm{Cl} / \mathrm{mL} \\
\mu \mathrm{Cl} / \mathrm{mL} \\
\mu \mathrm{Cl} / \mathrm{mL} \\
\mu \mathrm{Cl} / \mathrm{mL} \\
\mu \mathrm{Cl} / \mathrm{mL} \\
\mu \mathrm{Cl} / \mathrm{mL} \\
\mu \mathrm{Cl} / \mathrm{mL}\end{array}$ \\
\hline
\end{tabular}

WELL BGO 27D

MEASUREMENTS CONDUCTED IN THE FIELD

Sample date: 10/18/91

Depth to water: $46.31 \mathrm{ft}(14.12 \mathrm{~m})$ below TOC

Water elevation: $229.99 \pi(70.10 \mathrm{~m}) \mathrm{ms}$

Sp. conduclance. $35 \mu \mathrm{S} / \mathrm{cm}$

The well went dry during purging: $14 \mathrm{gal}$

LABORATORY ANALYSES

E Analyte Result Mod Unit Lab

$0 \begin{array}{ll}\mathrm{pH} \\ 0 & \text { Specific conductance }\end{array}$

Turbidity

Acetophenon

o Aluminum

0 Arsenic

0 Barium

B Bromodichloromethane

Bromoform

Bromomethane

0 Cadmium

0 Calcium

0 . Ca.bon tetrachloride

0 Chloride

Chlorobenzene

Chloroethane

Chloroethene Ninyl chloride)
2-Chloroethyl vinyl ether

0 Chloromethane

- Chromium

Copper

Dibromochloromethane

1,1-Dichioroethane

1,2-Dichloroethane

1,1-Dichloroethylene

Dichloromethane

2,4-Dichlorophenoxyacetic acid

1,2. Dichloropropane

cis-1,3. Dichloropropene

trans-1,3-Dichloropropen

Ethylbenzene

Fluoride

Iron

0 Lindane

Magnesium

Manganese

Mercury

Naphthalene

Nickel

Nitrate as nitrogen

Phenols

Potassium
Selenium

Silica

Silver

Sodium

Sulfate

1,1,2,2-Tetrachloroe

$\begin{array}{ll}0 & \text { Tetrachioro } \\ 0 & \text { Tin } \\ 0 & \text { Toluene }\end{array}$

Toluene
Tolal dissolved solids

Total organic carbon

- Total organic halogens

- Total organic halogens

0
0 Total phosphates (as P)
0 Total phosphates (as $P$ )

0 Total phosphaphe

$\begin{array}{cc}5.8 & \text { JQ } \\ 35 & \text { JQ } \\ 320 & \text { JO } \\ 10 & \end{array}$

$\begin{array}{ll}\mathrm{pH} & \mathrm{GE} \\ \mu \mathrm{S} / \mathrm{cm} & \mathrm{GE} \\ \text { NTU } & \mathrm{GE}\end{array}$

$\mu g / L \quad G E$

$<2.0$

$<1.0$

$<1.0$
$<1.0$

$<1.0$
$<2.0$

1,620

$<1.0$
2,140

$<1.0$

$<1.0$

$<1.0$

$<1.0$

$<1.0$

$<.0$
17

$<5.0$

$<1.0$

$<1.0$

$<1.0$

$<1.0$
3.3
$<0.30$

$<0.30$
$<1.0$
$<1.0$

$<1.0$

$<0.0060$

$<1.0$

$<100$
121

6.5
$<0.0050$

$<0.0050$

32
$<0.20$

$<0.20$
$<0.50$
$<10$

$\begin{array}{r}<.7 \\ \hline\end{array}$

1.950
$<5.0$

$<500$

2.4
6,710

$<2.0$
1,540

$<1,000$

$<1.0$

$<10$
$<2.0$

29.000

$<1,000$

$<5.0$
$<5.0$

60
$<50$

$<50$
$<0.24$

Time: 12:25

Alkalinity: $1 \mathrm{mg} / \mathrm{L}$

Alkalinity: $1 \mathrm{mg} / \mathrm{L}$ : $19.3^{\circ} \mathrm{C}$

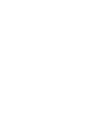

$\mu g / L$

E


ANALYTICAL RESULTS

WELL BGO 270 colloctord on 10/16/91, laboratory analyses (cont.)

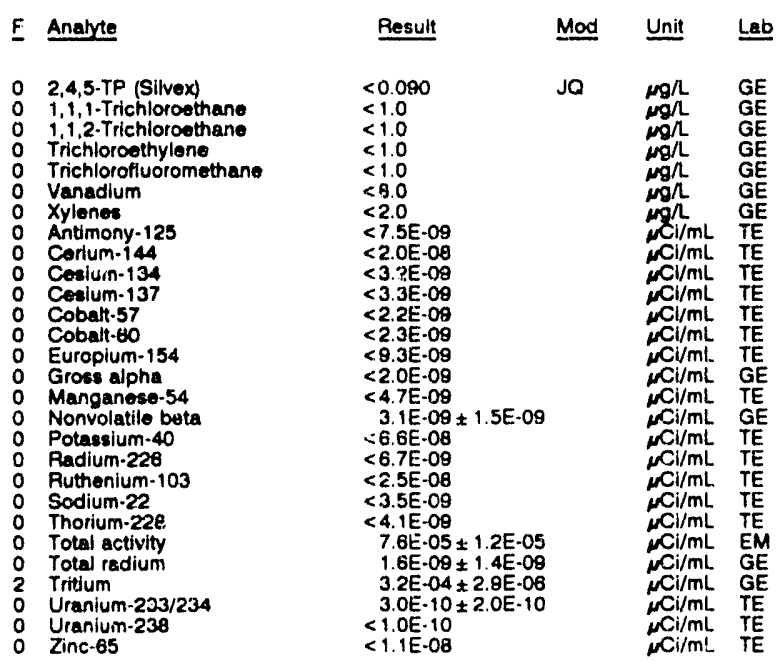

\section{WELL BGO 28D}

MEASUREMENTS CONDUCTED IN THE FIELD

Sample date: 10/18/91

Depth to water $18.65 \mathrm{H}(14.83 \mathrm{~m})$ below TOC Water elevation: $228.75 \mathrm{ft}(68.7$

Wate: evacuated before samplirg: $11 \mathrm{gal}$

The well went dry during purging

¿ABORATOAY ANALYSES

I Analyle Result Mod Unit Lab

SH

Turbidity

Acetophen

Antimony

Arsenic

Barium

Benzene

Bromodichloromethane

Bromoform

Bromumethane

Cadmium

Carbon tetrechloride

Carbon to

Chride

Chiorobenzene

Chloroethene Ninyl chloride)

2-Chloroethyl vinyl ether

Chloroform

Chloromethan

Chromiun

Copper

Dibromochloromethane

2 1,1-Dichlorosthane

1 1,2-Dichicroethane

o trans-1,2-Dichloroethylene

Dichloromethane

2,4-Dichlorophenoxyacetic acid $<0$

1,2-Dichloropropane

L $<1.0$

Endrin $<1.0$

0 Ethylbenzene $<1.0$

Fluoride

2 Lead

0 Lindane

Magnesium

Manganeso

Mercury

Naphthaiene

Nicke

Nitrate as nitrogen

Phonols

Selasium

Selenium

Sodium
Time: 14:05

Alkalinity: $13 \mathrm{mg} / \mathrm{h}$
Water temperature: $19.7^{\circ} \mathrm{C}$ 


\section{ANALYTICAL RESULTS}

WELL BGO 29A collected on 10/16/91, laboratory analyses (cont.)

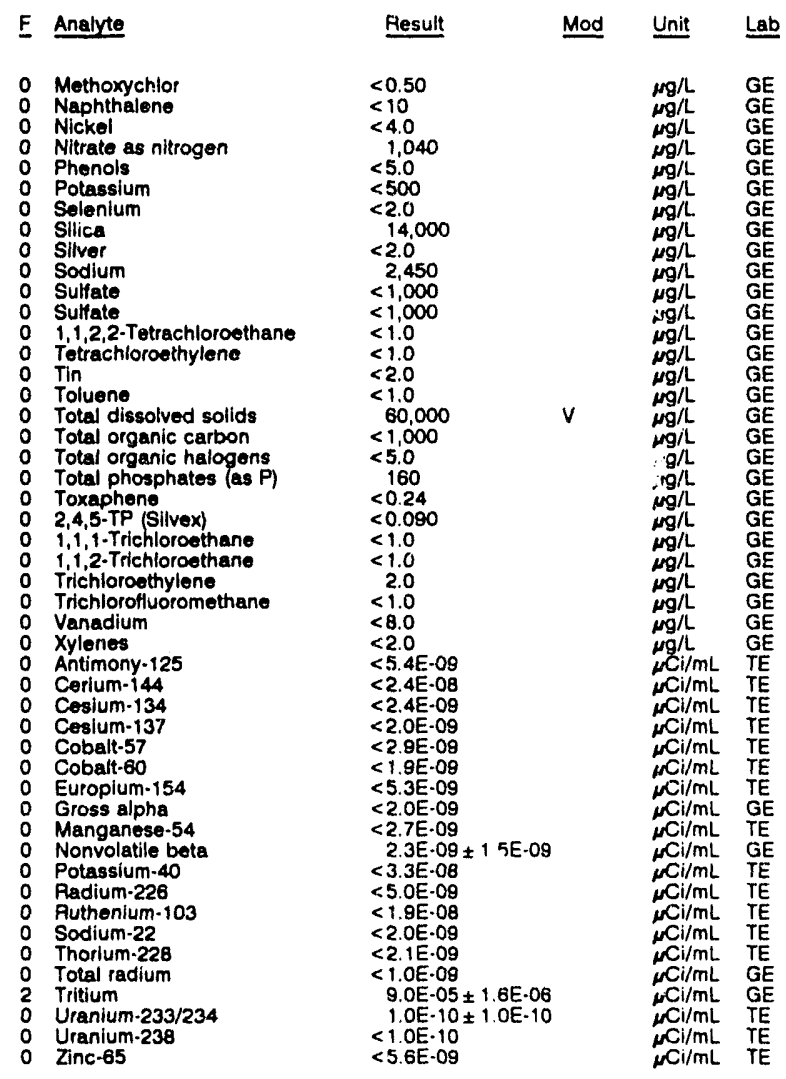

\section{WELL BGO 29C}

MEASUAEMENTS CONDUCTED IN THE FIELD

Sample date: 12/15/91 Depth to water: $41.31 \mathrm{ft}(12.59 \mathrm{~m})$ below TOC Water elevation: $223.49 \mathrm{~h}(68.12 \mathrm{~m}) \mathrm{msl}$ Water evacuated before sampling: $52 \mathrm{gal}$ The well went dry during purging.

LABORATORY ANALYSES

\begin{tabular}{|c|c|c|c|}
\hline Analyte & Result & Mod & Unit \\
\hline $\begin{array}{l}\text { pH } \\
\text { Specific conductance } \\
\text { Arsenic } \\
\text { Barium } \\
\text { Benzene } \\
\text { Eromodichloromethane } \\
\text { Bromoform } \\
\text { Bromomethane } \\
\text { Cadmium } \\
\text { Calcium } \\
\text { Carbon tetrachloride } \\
\text { Chloride } \\
\text { Chlorobenzene } \\
\text { Chloroethane } \\
\text { Chlorethene Ninyl chloride) } \\
\text { 2-Chloroethyl vinyl ether } \\
\text { Chloroform } \\
\text { Chloromethane } \\
\text { Chromium } \\
\text { Dibromochloromethane } \\
1,1-\text { Dichloroethane } \\
1,2 \cdot \text { Dichloroethane } \\
1,1-\text { Dichloroethylene } \\
\text { trans-1,2-Dichloroethylene } \\
\text { Dichoromethane } \\
2,4-\text { Dichlorophenoxyacetic acid } \\
1,2 \cdot \text { Dichloropropane } \\
\text { cis-1,3-Dichloropropene } \\
\text { trans-1,3-Dichloropropene } \\
\text { Endrin } \\
\text { Ethylbenzerle } \\
\text { Flyoride } \\
\text { lron } \\
\text { Lead } \\
\text { Lindane }\end{array}$ & $\begin{array}{l}6.1 \\
42 \\
<2.0 \\
12 \\
<1.0 \\
<1.0 \\
<1.0 \\
<1.0 \\
<2.0 \\
2.450 \\
<1.0 \\
2.150 \\
<1.0 \\
<1.0 \\
<1.0 \\
<1.0 \\
<1.0 \\
<1.0 \\
<4.0 \\
<1.0 \\
<1.0 \\
<1.0 \\
<1.0 \\
<1.0 \\
1.8 \\
<0.30 \\
<1.0 \\
<1.0 \\
<1.0 \\
<0.0060 \\
<1.0 \\
<100 \\
<5 \\
<3.0 \\
<0.0050\end{array}$ & $\begin{array}{l}\mathrm{J} 2 \mathrm{~V} \\
\mathrm{JQ}\end{array}$ & $\begin{array}{l}p H \\
\mu S / c m \\
\mu g / L \\
\mu g / L \\
\mu g / L \\
\mu g / L \\
\mu g / L \\
\mu g / L \\
\mu g / L \\
\mu g / L \\
\mu g / L \\
\mu g / L \\
\mu g / L \\
\mu g / L \\
\mu g / L \\
\mu g / L \\
\mu g / L \\
\mu g / L \\
\mu g / L \\
\mu g / L \\
\mu g / L \\
\mu g / L \\
\mu g / L \\
\mu g / L \\
\mu g / L \\
\mu g / L \\
\mu g / L \\
\mu g / L \\
\mu g / L \\
\mu g / L \\
\mu g / L \\
\mu g / L \\
\mu g / L \\
\mu g / L \\
\mu g / L\end{array}$ \\
\hline
\end{tabular}

WELL BGO 29C collected on 12/15/91, laboratory analyses (cont.)

\begin{tabular}{|c|c|c|c|c|c|}
\hline$\underline{F}$ & Analyte & Result & Mod & Unit & Lab \\
\hline $\begin{array}{l}0 \\
0 \\
0 \\
0 \\
0 \\
2 \\
0\end{array}$ & $\begin{array}{l}\text { Magneslum } \\
\text { Manganese } \\
\text { Mercury } \\
\text { Methoxychlor } \\
\text { Nickel } \\
\text { Nitrate as nitrogen } \\
\text { Phenols } \\
\text { Potassium } \\
\text { Solenium } \\
\text { Silica } \\
\text { Silver } \\
\text { Sodium } \\
\text { Sulfate } \\
1,1,2,2-\text { Tetrachloroethane } \\
\text { Tetrachloroethylene } \\
\text { Toluene } \\
\text { Total dissolved solids } \\
\text { Total organic carbon } \\
\text { Total organic halogens } \\
\text { Total organic halogens } \\
\text { Total phosphatos (as P) } \\
\text { Total phosphates (as P } \\
\text { Toxaphene } \\
2,4,5-\text { TP (Silvex) } \\
\text { 1,1, Trichloroothane } \\
\text { 1,1,2-Trichloroethane } \\
\text { Trichloroethylene } \\
\text { Trichlorofluoromethane } \\
\text { Gross alpha } \\
\text { Nonvolatile beta } \\
\text { Total activity } \\
\text { Total radium } \\
\text { Tritium } \\
\text { Uranium-233/234 } \\
\text { Uranium-238 }\end{array}$ & $\begin{array}{l}610 \\
19 \\
<0.20 \\
<0.50 \\
<4.0 \\
1,220 \\
9.6 \\
697 \\
<2.0 \\
8,7: 0 \\
<2.0 \\
3,330 \\
2,560 \\
<1.0 \\
<1.0 \\
<1.0 \\
26,000 \\
<2,000 \\
<5.0 \\
<5.0 \\
70 \\
<50 \\
<0.24 \\
<0.090 \\
<1.0 \\
<1.0 \\
1.3 \\
<1.0 \\
<2.0 \mathrm{E}-09 \\
<2.0 \mathrm{E}-09 \\
1.4 \mathrm{E}-04 \pm 1.4 \mathrm{E} \cdot 05 \\
1.4 \mathrm{E} \cdot 09 \pm 7.0 \mathrm{E}-10 \\
1.3 \mathrm{E} \cdot 04 \pm 1.6 \mathrm{E}-06 \\
1.0 \mathrm{E} \cdot 10 \pm 1.0 \mathrm{E} \cdot 10 \\
<1.0 \mathrm{E}-10\end{array}$ & 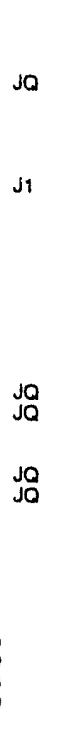 & $\begin{array}{l}\mu g / L \\
\mu g / L \\
\mu g / L \\
\mu g / L \\
\mu g / L \\
\mu g / L \\
\mu g / L \\
\mu g / L \\
\mu g / L \\
\mu g / L \\
\mu g / L \\
\mu g / L \\
\mu g / L \\
\mu g / L \\
\mu g / L \\
\mu g / L \\
\mu g / L \\
\mu g / L \\
\mu g / L \\
\mu g / L \\
\mu g / L \\
\mu g / L \\
\mu g / L \\
\mu g / L \\
\mu g / L \\
\mu g / L \\
\mu g / L \\
\mu g / L \\
\mu C i / m L \\
\mu C I / m L \\
\mu C l / m L \\
\mu C i / m L \\
\mu C i / m L \\
\mu C i / m L \\
\mu C I / m L\end{array}$ & $\begin{array}{l}G E \\
G E \\
G E \\
G E \\
G E \\
G E \\
G E \\
G E \\
G E \\
G E \\
G E \\
G E \\
G E \\
G E \\
G E \\
G E \\
G E \\
G E \\
G E \\
G E \\
G E \\
G E \\
G E \\
G E \\
G E \\
G E \\
G E \\
G E \\
G E \\
G E \\
E M \\
G E \\
G E \\
T E \\
T E\end{array}$ \\
\hline
\end{tabular}

WELL BGO 29D

MEASUREMENTS CONDUCTED IN THE FIELD

Sample date: $12 / 15 / 91$

Depth to water: $38.17 \mathrm{ft}(11.63 \mathrm{~m})$ below TOC

Water elevation: $227.33 \mathrm{ft}(69.29 \mathrm{~m}) \mathrm{ms}$ !

Water evacuated before sampling: $22 \mathrm{gal}$

Time: $9: 1$

$\mathrm{pH}: 5.6$

Alkalinity: $8 \mathrm{mg} / \mathrm{L}$

The well went dry during purging: $22 \mathrm{~g}$

LABORATORY ANALYSES

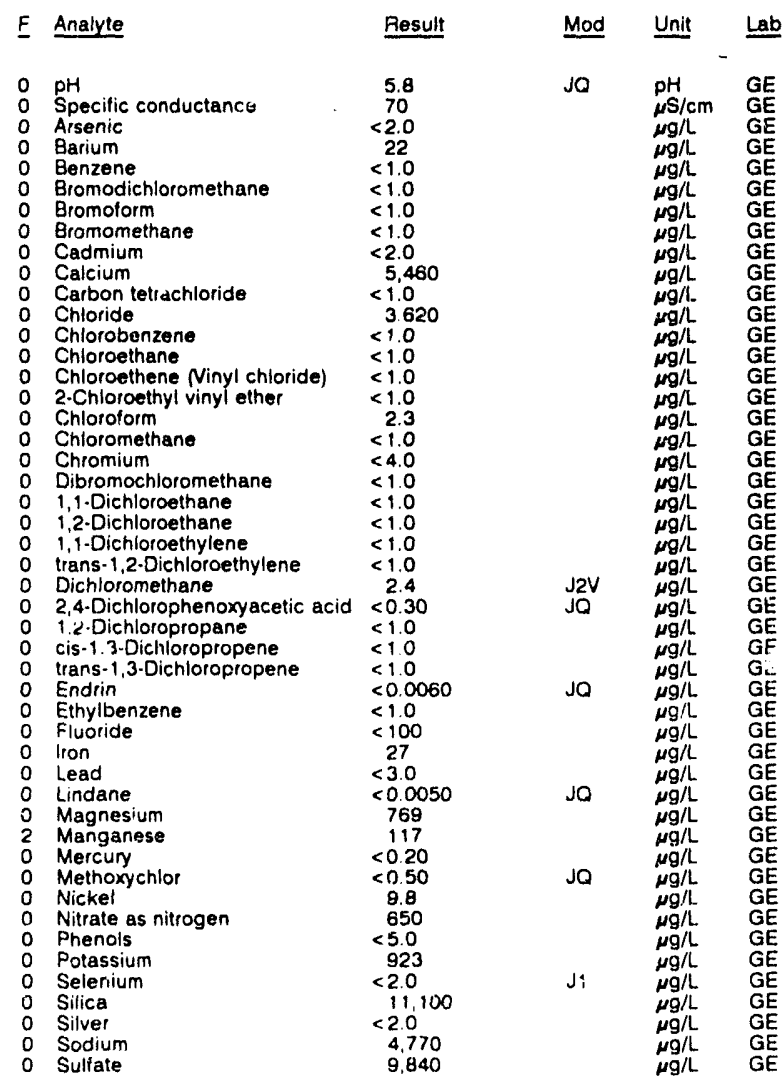


ANALYTICAL RESULTS

WELL BGO 290 collocted on 12/15/91, laboratory analyses (cont.)

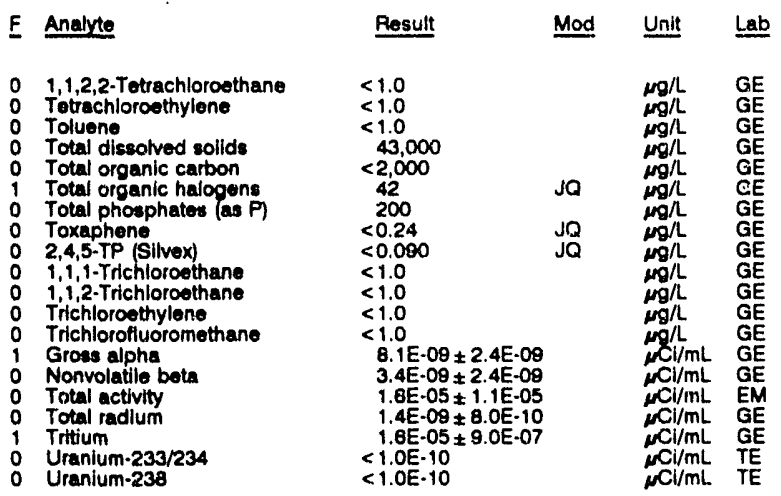

WELL BGO $30 \mathrm{C}$

MEASUREMENTS CONDUCTED IN THE FIELD

Sample date: 10/16/91

Depth to water: $53.11 \mathrm{th}(16.10 \mathrm{~m})$ below TOC Water olevation: $221.38 \mathrm{~h}(67.48 \mathrm{~m}) \mathrm{ms}$

. 73 s/cm

Water ovacuated before sampling: $25 \mathrm{gal}$

The well went dry during purging.

LABORATOAY ANALYSES

\begin{tabular}{|c|c|c|c|c|c|}
\hline & Analute & Result & Mod & Unit & Lab \\
\hline $\begin{array}{l}0 \\
0 \\
0 \\
0 \\
0 \\
0 \\
0 \\
0 \\
0 \\
0 \\
0 \\
0 \\
0 \\
0 \\
0 \\
0 \\
0 \\
0 \\
0 \\
0 \\
0 \\
0 \\
0 \\
0 \\
0 \\
0 \\
0 \\
0\end{array}$ & 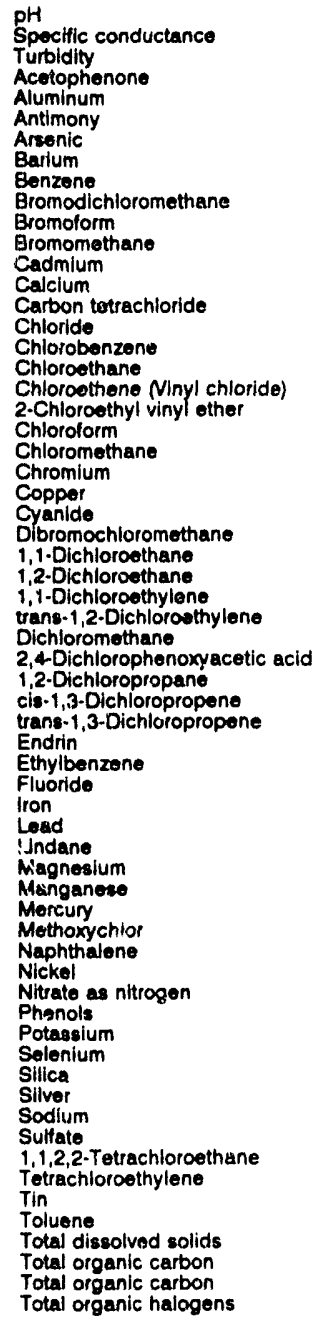 & $\begin{array}{l}6.9 \\
55 \\
320 \\
<10 \\
<20 \\
<2.0 \\
<2.0 \\
14 \\
<1.0 \\
<1.0 \\
<1.0 \\
<1.0 \\
<2.0 \\
3,610 \\
<1.0 \\
2,390 \\
<1.0 \\
<1.0 \\
<1.0 \\
<1.0 \\
<1.0 \\
<1.0 \\
<4.0 \\
<4.0 \\
<5.0 \\
<1.0 \\
<1.0 \\
<1.0 \\
<1.0 \\
<1.0 \\
4.7 \\
<0.30 \\
<1.0 \\
<1.0 \\
<1.0 \\
<0.0060 \\
<1.0 \\
<100 \\
10 \\
<3.0 \\
<0.0050 \\
2227 \\
113 \\
<0.20 \\
<0.50 \\
<10 \\
<4.0 \\
550 \\
<5.0 \\
<500 \\
2.4 \\
8,890 \\
<2.0 \\
5.140 \\
2.200 \\
<1.0 \\
11.1 \\
<2.0 \\
<1.0 \\
40,000 \\
<1.000 \\
<1.000 \\
7.7\end{array}$ & $\begin{array}{l}\mathrm{JQ} \\
\mathrm{JQ} \\
\mathrm{JQ}\end{array}$ & $\begin{array}{l}p H \\
\mu s / c m \\
\mu T u \\
\mu g / L \\
\mu g / L \\
\mu g / L \\
\mu g / L \\
\mu g / L \\
\mu g / L \\
\mu g / L \\
\mu g / L \\
\mu g / L \\
\mu g / L \\
\mu g / L \\
\mu g / L \\
\mu g / L \\
\mu g / L \\
\mu g / L \\
\mu g / L \\
\mu g / L \\
\mu g / L \\
\mu g / L \\
\mu g / L \\
\mu g / L \\
\mu g / L \\
\mu g / L \\
\mu g / L\end{array}$ & 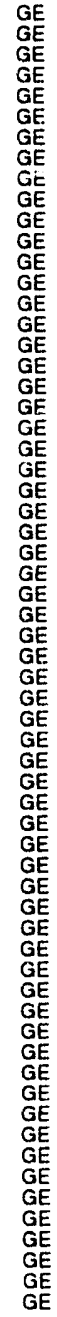 \\
\hline
\end{tabular}

WELL BGO 30 C coliectod on 10/16/91, laboratory analyses (cont.)

\begin{tabular}{|c|c|c|c|c|}
\hline Analyte & Result & Mod & Unit & Lab \\
\hline $\begin{array}{l}\text { Total phosphates (as P) } \\
\text { Toxaphene } \\
2,4,5-T P \text { (Silvox) } \\
1,1,1-\text { Trichloroethane } \\
1,1,2 \cdot \text { Trichloroethane } \\
\text { Trichloroethylene } \\
\text { Trichlorofluoromethane } \\
\text { Vanadium } \\
\text { Xylenes } \\
\text { Antimony-125 } \\
\text { Cerlum-144 } \\
\text { Cesium-134 } \\
\text { Cosium-137 } \\
\text { Cobalt-57 } \\
\text { Cobalt-60 } \\
\text { Europium-154 } \\
\text { Gross alpha } \\
\text { Manganese-54 } \\
\text { Nonvolatile bota } \\
\text { Potassium-40 } \\
\text { Radium-228 } \\
\text { Ruthenium-103 } \\
\text { Sodium-22 } \\
\text { Thorium-228 } \\
\text { Total activity } \\
\text { Total radium } \\
\text { Tritium } \\
\text { Uranium-233/234 } \\
\text { Uranlum-238 } \\
\text { Zinc-65 }\end{array}$ & $\begin{aligned} & 1.430 \\
&<0.24 \\
&<0.090 \\
&<1.0 \\
&<1.0 \\
& 7.8 \\
&<1.0 \\
&<8.0 \\
&<2.0 \\
&<7.6 \mathrm{E}-09 \\
&<2.4 \mathrm{E}-08 \\
&<4.2 \mathrm{E}-09 \\
&<3.1 \mathrm{E}-09 \\
&<3.1 \mathrm{E}-09 \\
&<3.3 \mathrm{E}-09 \\
&<1.1 \mathrm{E}-08 \\
&<2.0 \mathrm{E}-09 \\
&<4.3 \mathrm{E}-09 \\
&<2.0 \mathrm{E}-09 \\
&<4.3 \mathrm{E}-08 \\
&<5.2 \mathrm{E}-09 \\
&<2.6 \mathrm{E}-08 \\
&<4.2 \mathrm{E}-09 \\
&<3.4 \mathrm{E}-09 \\
& 7.1 \mathrm{E}-04 \pm 5.9 \mathrm{E}-08 \\
&<1.0 \mathrm{E}-09 \\
& 4.6 \mathrm{E}-04 \pm 3.4 \mathrm{E}-06 \\
& 2.0 \mathrm{E}-10 \pm 2.0 \mathrm{E}-10 \\
&<1.0 \mathrm{E}-10 \\
&<8.6 \mathrm{E}-09\end{aligned}$ & $\begin{array}{l}\text { JO } \\
\text { Ja }\end{array}$ & 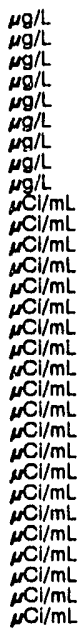 & $\begin{array}{l}\mathrm{GE} \\
\mathrm{GE} \\
\mathrm{GE} \\
\mathrm{GE} \\
\mathrm{GE} \\
\mathrm{GE} \\
\mathrm{GE} \\
\mathrm{GE} \\
\mathrm{GE} \\
\mathrm{TE} \\
\mathrm{TE} \\
\mathrm{TE} \\
\mathrm{TE} \\
\mathrm{TE} \\
\mathrm{TE} \\
\mathrm{TE} \\
\mathrm{GE} \\
\mathrm{TE} \\
\mathrm{GE} \\
\mathrm{TE} \\
\mathrm{TE} \\
\mathrm{TE} \\
\mathrm{TE} \\
\mathrm{TE} \\
\mathrm{EM} \\
\mathrm{GE} \\
\mathrm{GE} \\
\mathrm{TE} \\
\mathrm{TE} \\
\mathrm{TE}\end{array}$ \\
\hline
\end{tabular}

WELL BGO 30D

MEASUREMENTS CONDUCTED IN THE FIELD

Depth to water: $46.44 \mathrm{Ht}(14.16 \mathrm{~m})$ below TOC

Water elevation: $228.36 \mathrm{~h}(69.60 \mathrm{~m}) \mathrm{ms}$.

Sp. conductance: $108 \mu \mathrm{s} / \mathrm{cm}$

Wal

PH: 6.1 . $22 \mathrm{mg}$

The well went dry during purging

LABORATORY ANALYSES

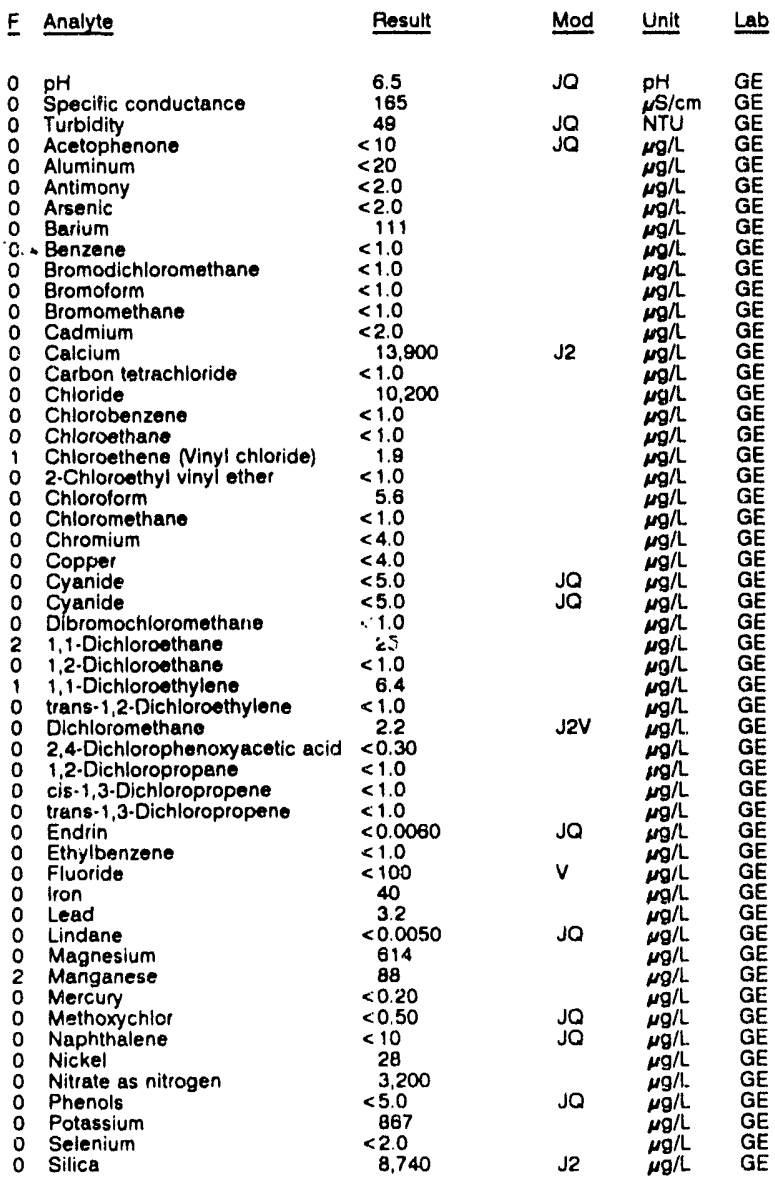




\section{ANALYTICAL RESULTS}

WELL BGO 300 collected on 10/16/91, laboratory analyses (cont.)

\begin{tabular}{|c|c|c|c|c|}
\hline Analyte & Result & Mod & Unit & Lab \\
\hline $\begin{array}{l}\text { Sllver } \\
\text { Sodium } \\
\text { Sulfate } \\
\text { Sulfate } \\
1,1,2,2 \text {-Tetrachloroethane } \\
\text { Totrachloroethylene } \\
\text { Tin } \\
\text { Toluene } \\
\text { Total diesolvec' solids } \\
\text { Total organic carbon } \\
\text { Total organic halogens } \\
\text { Total phosphates (as P) } \\
\text { Toxaphene } \\
2,4,5-T P \text { (Silvex) } \\
1,1,1-\text { Trichloroethane } \\
\text { 1,1,2-Trichloroethane } \\
\text { Trichloroothylene } \\
\text { Trichlorofluoromethane } \\
\text { Vanadium } \\
\text { Xylenes } \\
\text { Gross alpha } \\
\text { Nonvolatile beta } \\
\text { Total activity } \\
\text { Total radium } \\
\text { Tritium } \\
\text { Uranium-233/234 } \\
\text { Uranlum-238 }\end{array}$ & $\begin{array}{l}<2.0 \\
9,560 \\
1,800 \\
2,080 \\
<1.0 \\
1.0 \\
<2.0 \\
<1.0 \\
123,000 \\
<1,000 \\
82 \\
<50 \\
<0.24 \\
<0.090 \\
<1.0 \\
<1.0 \\
19 \\
<1.0 \\
<8.0 \\
<2.0 \\
7.2 E-09 \pm 1.9 E-09 \\
5.9 E \cdot 09 \pm 1.7 \mathrm{E} \cdot 09 \\
1.8 \mathrm{E} \cdot 02 \pm 2.1 \mathrm{E}-04 \\
1.5 \mathrm{E}-09 \pm 3.8 \mathrm{E}-09 \\
4.1 \mathrm{E} \cdot 02 \pm 3.2 \mathrm{E} \cdot 05 \\
<1.0 \mathrm{E} \cdot 10 \\
<1.0 \mathrm{E} \cdot 10\end{array}$ & JQV & $\begin{array}{l}\mu g / L \\
\mu g / L \\
\mu g / L \\
\mu g / L \\
\mu g / L \\
\mu g / L \\
\mu g / L \\
\mu g / L \\
\mu g / L \\
\mu g / L \\
\mu g / L \\
\mu g / L \\
\mu g / L \\
\mu g / L \\
\mu g / L \\
\mu g / L \\
\mu g / L \\
\mu g / L \\
\mu g / L \\
\mu g / L \\
\mu C i / m L \\
\mu C l / m L \\
\mu C i / m L \\
\mu C i / m L \\
\mu C i / m L \\
\mu C i / m L \\
\mu C i / m L\end{array}$ & $\begin{array}{l}\mathrm{GE} \\
\mathrm{GE} \\
\mathrm{GE} \\
\mathrm{GE} \\
\mathrm{GE} \\
\mathrm{GE} \\
\mathrm{GE} \\
\mathrm{GE} \\
\mathrm{GE} \\
\mathrm{GE} \\
\mathrm{GE} \\
\mathrm{GE} \\
\mathrm{GE} \\
\mathrm{GE} \\
\mathrm{GE} \\
\mathrm{GE} \\
\mathrm{GE} \\
\mathrm{GE} \\
\mathrm{GE} \\
\mathrm{GE} \\
\mathrm{GE} \\
\mathrm{GE} \\
\mathrm{EM} \\
\mathrm{GE} \\
\mathrm{GE} \\
\mathrm{TE} \\
\mathrm{TE}\end{array}$ \\
\hline
\end{tabular}

WELL BGO $31 \mathrm{C}$

MEASUREMENTS CONDUCTED IN THE FIELD

Sample date: 10/17/81

Depth to water: $44.99 \mathrm{ft}(13.71 \mathrm{~m})$ below TOC

Water elevation: $228.11 \mathrm{t}(69.5$

W. torductance: 30 s/cm

The well went dry during purging.

LABORATORY ANALYSES

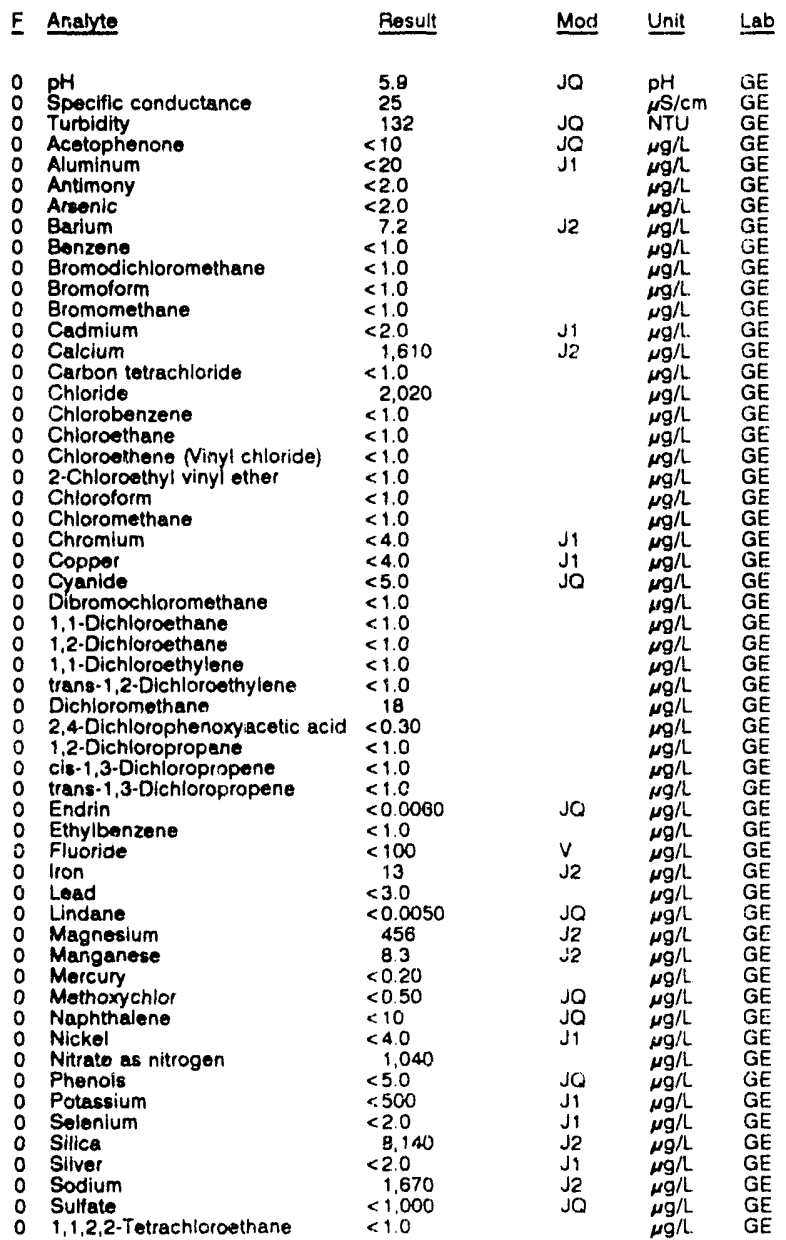

WELL $8 G O 31 \mathrm{C}$ collected on 10/17/91, laboratory analyses (cont.)

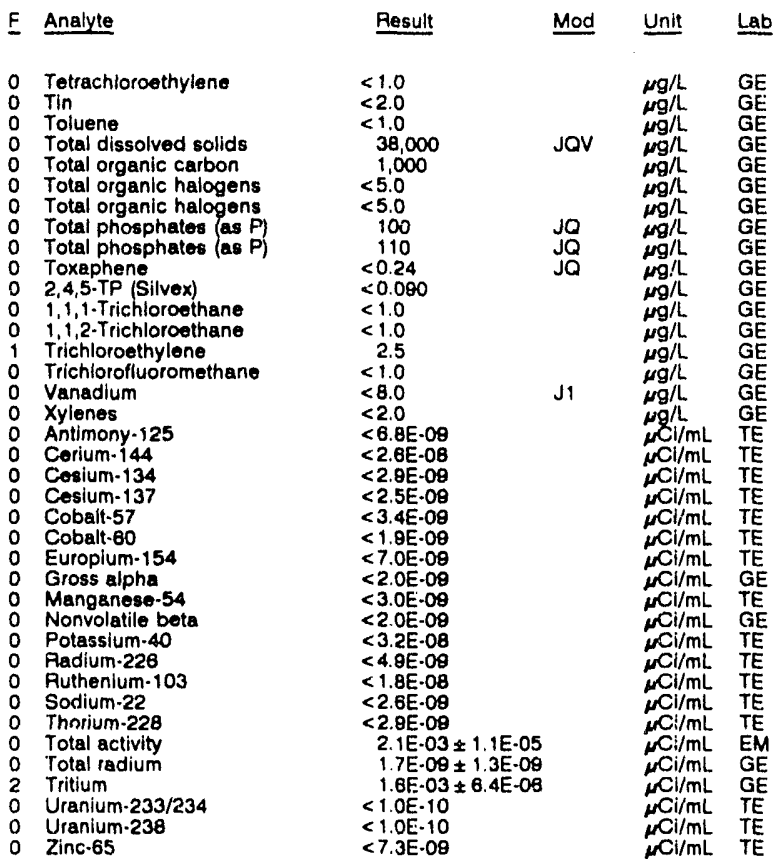

\section{WELL BGO 31D}

MEASUREMENTS CONDUCTED IN THE FIELD

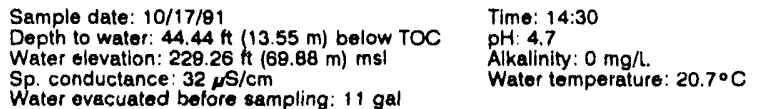

Water evecuated before sampling: $11 \mathrm{gal}$

The well went dry ci:rring purging.

LABORATORY ANALYSES

E Analyte Result $\underline{\text { Mod Unit Lab }}$

${ }_{0}^{0} \mathrm{pH}$ Specific conductance

Turhility

0 a ainum

0 Antimony

0 Arsenic

Barium

Benzene

Bromodichloromethane

Bromolorm

Cadmium

Cadmium

Carbon tetrachioride

Chloride

Chlorobenzene

Chloroethane

Chloroethene Ninyl chloride

2.Chloroethyl

Chloroform

Chromium

Copper

Dibromochloromethane

1 1.Dichlouthane

1,2-Dichloroethane

1,1. Dichloroethylene

trans-1,2-Dichloroethylene

2,4-Dichlorophenoxyacetic acid $<0.30$

1,2-Dichloropropane

cis-1,3-Dich oropropene

trans-1,

Ethylbenzene

a Fluoride

0 Iron

O Lead

Magnesium

Manganese

Methoxychior
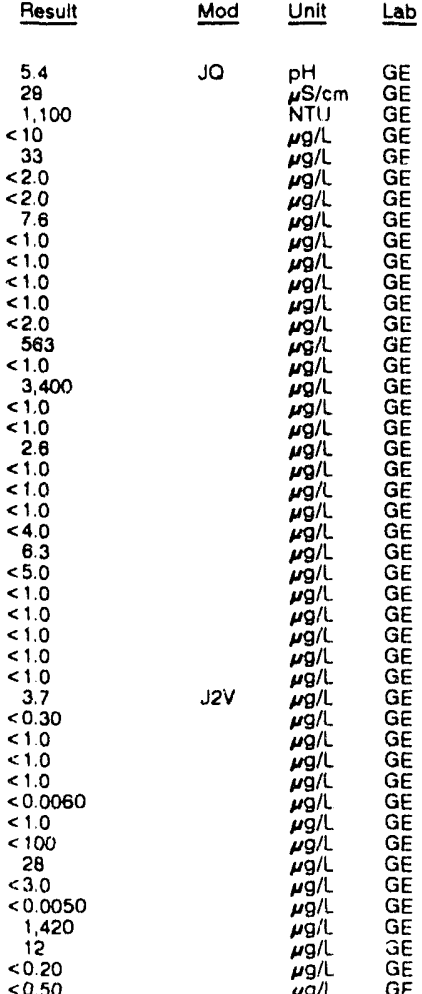
ANALYTICAL RESULTS

WELL BGO 31D coliected on 10/17/91, laboratory analyses (cont.)

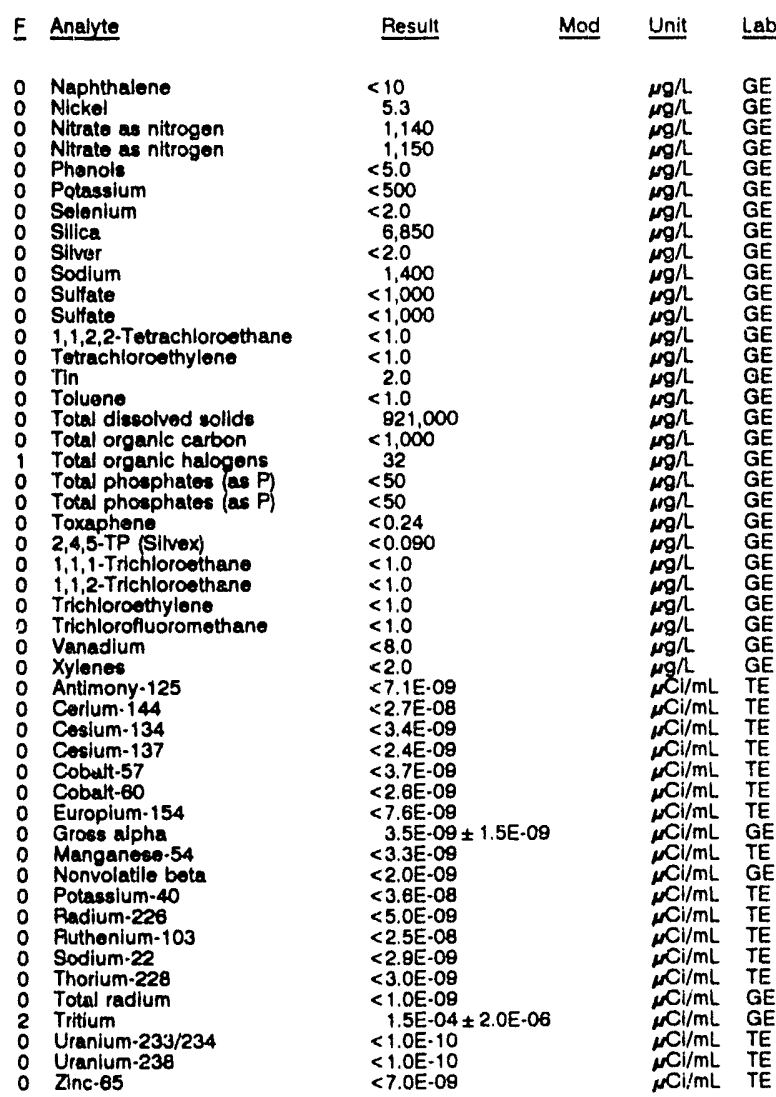

\section{WELL BGO 32D}

MEASUREMENTS CONOUCTED IN THE FIELD

Sampio date: 10/17/91 Depth to water: $51.45 \mathrm{ft}(15.68 \mathrm{~m})$ below TOC
Water olevation: $230.25 \mathrm{ht}(70.18 \mathrm{~m}) \mathrm{ms}$ l Sater olevation: $230.25 \mathrm{H} / 70.18$ Water ovaci-ated before sampling: $8 \mathrm{gal}$ The woll went dn durlng purging. 8

LABORATORY ANALYSES

\begin{tabular}{|c|c|c|c|c|c|}
\hline & Analyte & Result & Mod & Unit & Lab \\
\hline & 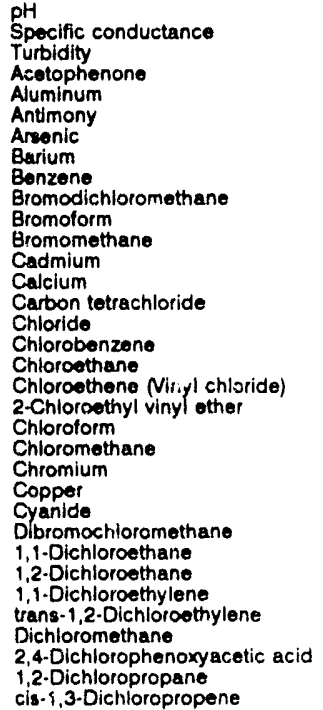 & $\begin{aligned} & 5.0 \\
& 60 \\
& 60 \\
&<10 \\
& 120 \\
&<2.0 \\
&<2.0 \\
& 16 \\
&<1.0 \\
&<1.0 \\
&<1.0 \\
&<1.0 \\
&<2.0 \\
& 860 \\
&<1.0 \\
& 3.840 \\
&<1.0 \\
&<1.0 \\
&<1.0 \\
&<1.0 \\
&<1.0 \\
&<1.0 \\
&<4.0 \\
& 114 \\
&<5.0 \\
&<1.0 \\
&<1.0 \\
&<1.0 \\
&<1.0 \\
&<1.0 \\
& 5.3 \\
&<0.30 \\
&<1.0 \\
&<1.0\end{aligned}$ & $\begin{array}{l}\text { JQ } \\
\text { JQ } \\
\text { JQ }\end{array}$ & 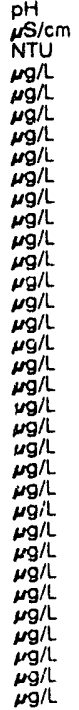 & $\begin{array}{l}G E \\
G E \\
G E \\
G E \\
G E \\
G E \\
G E \\
G E \\
G E \\
G E \\
G E \\
G E \\
G E \\
G E \\
G E \\
G E \\
G E \\
G E \\
G E \\
G E \\
G E \\
G E \\
G E \\
G E \\
G E \\
G E \\
G E \\
G E \\
G E \\
G E \\
G E \\
G E \\
G E \\
G E\end{array}$ \\
\hline
\end{tabular}

Time: $14: 00$

pH: 4.8 : 0

Water temperature: $20.1 \circ \mathrm{C}$
WELL BGO 32 D collected on 10/17/91, laboratory analyses (cont.)

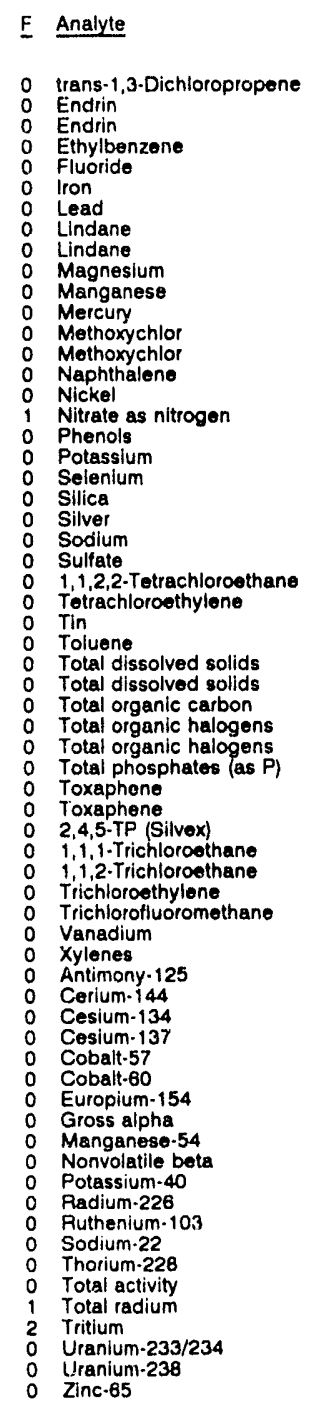

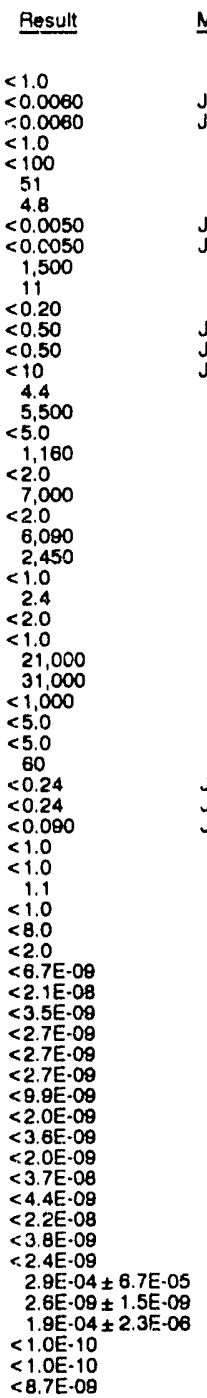

Mod Unit Lab

Jo $\quad \mu g / L \quad G E$

E 0 trans-1,3-Dichloropropene

0 Endin

Ethylbenzone

Iron

Lindane

Magnesium

Mercuny

Nicke

Phenols

Selenium

Silica

Sodium

1, 1,2,2-Tetrachloroethane

Totrachloroethylene

Total dissolved solids

Total dissolved solids

Total organic halogens

Total prganic halogens

Toxaphene

2,4,5-TP (Silvex)

1,1, -Trichloroothane

Trichloroethylene

Vanadium
Xylenes

Antimony-125

Cesium-137

Cobalt.57

Europium-154

Manganese-54

Nonvolatile beta

Radium-226

Sodium-22

Total radium

Uranlum-233/234

Zinc. 65

\section{WELL BGO 33C}

MEASUREMENTS CONDUCTEO IN THE FIELD

Sample date: 10/17/91

Depth to water: $52.32 \mathrm{ft}(15.95 \mathrm{~m})$ below TOC

Watar elevation: $227.08 \mathrm{ft}(8 \mathrm{~B}$

Water ovacuated betoro sampling: 120 gal

Alkalinity: $13 \mathrm{mg} / \mathrm{L}$

Water temperature: $18.4^{\circ} \mathrm{C}$

LABOPATORY ANALYSES

\begin{tabular}{|c|c|c|c|}
\hline Analyte & Result & Mod & Unit \\
\hline $\begin{array}{l}\text { pH } \\
\text { Specific conductance } \\
\text { Turbidity } \\
\text { Acetophenone } \\
\text { Aluminum } \\
\text { Antimony } \\
\text { Arsenic } \\
\text { Barium } \\
\text { Benzene } \\
\text { Bromodichloromethane } \\
\text { Bromoform } \\
\text { Bromomethane } \\
\text { Cadimium } \\
\text { Calcium } \\
\text { Carbon tetrachloride } \\
\text { Chloride } \\
\text { Chiorobenzene } \\
\text { Chloroethane } \\
\text { Chloroethene Ninyl chloride) }\end{array}$ & $\begin{aligned} & 6.2 \\
& 5.5 \\
& 3.2 \\
&<10 \\
&<20 \\
&<2.0 \\
&<2.0 \\
& 14 \\
&<1.0 \\
&<1.0 \\
&<1.0 \\
&<1.0 \\
&<2.0 \\
& 6.520 \\
& 1.0 \\
& 5.640 \\
&<1.0 \\
&<1.0 \\
&<1.0\end{aligned}$ & $\begin{array}{l}\mathrm{JQ} \\
\mathrm{J} Q \\
\mathrm{~J} Q \\
\mathrm{~J} 1 \\
\mathrm{~J} 2\end{array}$ & $\begin{array}{l}p H \\
\mu S / c m \\
N T U \\
\mu g / L \\
\mu g / L \\
\mu g / L \\
\mu g / L \\
\mu g / L \\
\mu g / L \\
\mu g / L \\
\mu g / L \\
\mu g / L \\
\mu g / L \\
\mu g / L \\
\mu g / L \\
\mu g / L \\
\mu g / L \\
\mu g / L \\
\mu g / L\end{array}$ \\
\hline
\end{tabular}


ANALYTICAL RESULTS

WELL BGO $33 \mathrm{C}$ collectod on 10/17/91, laboratory analyses (cont.)

\begin{tabular}{|c|c|c|c|c|}
\hline Analyte & Result & Mod & Unit & tab \\
\hline 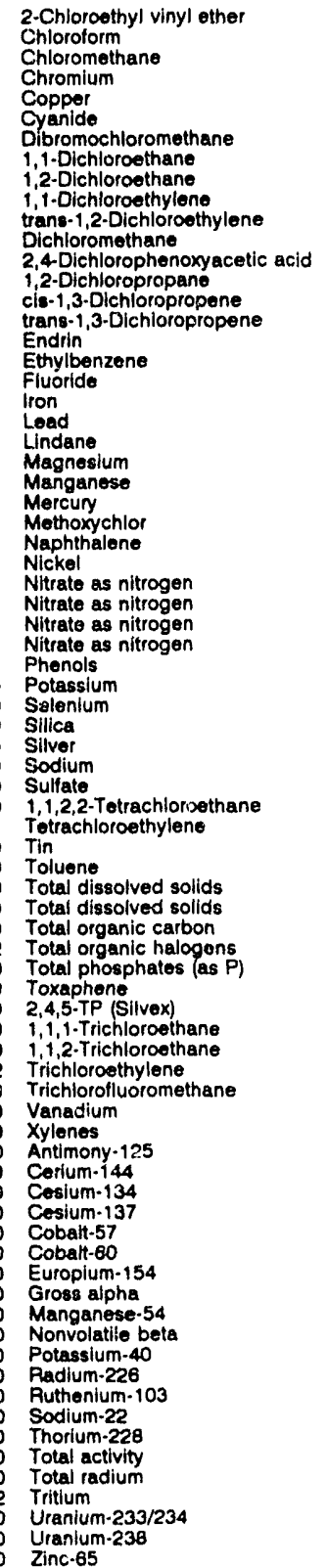 & $\begin{array}{l}<1.0 \\
<1.0 \\
<1.0 \\
<4.0 \\
<4.0 \\
<5.0 \\
<1.0 \\
<1.0 \\
<1.0 \\
<1.0 \\
<1.0 \\
11 \\
<0.30 \\
<1.0 \\
<1.0 \\
<1.0 \\
<0.0060 \\
<1.0 \\
<100 \\
<4.0 \\
<3.0 \\
<0.0050 \\
767 \\
32 \\
0.50 \\
<0.50 \\
<10 \\
<4.0 \\
950 \\
950 \\
950 \\
950 \\
<5.0 \\
<500 \\
<2.0 \\
10,300 \\
<2.0 \\
33.080 \\
<1.000 \\
<1.0 \\
4.1 \\
<2.0 \\
<1.0 \\
56.000 \\
69.000 \\
<1.000 \\
113 \\
230 \\
<0.24 \\
<0.080 \\
<1.0 \\
<1.0 \\
20 \\
<1.0 \\
<8.0 \\
<2.0 \\
<8.1 \mathrm{E}-09 \\
<3.1 \mathrm{E} \cdot 08 \\
<3.7 \mathrm{E}-09 \\
<2.7 \mathrm{E} \cdot 09 \\
<4.1 \mathrm{E}-09 \\
<2.9 \mathrm{E}-09 \\
<9.1 \mathrm{E}-09 \\
<2.0 \mathrm{E}-09 \\
<3.2 \mathrm{E}-09 \\
<2.0 \mathrm{E}-09 \\
<3.8 \mathrm{E}-08 \\
<5.9 \mathrm{E}-09 \\
<2.1 \mathrm{E} \cdot 08 \\
<3.4 \mathrm{E}-09 \\
<3.3 \mathrm{E}-09 \\
7.6 \mathrm{E}-03 \pm 6.3 \mathrm{E}-05 \\
<1.0 \mathrm{E} \cdot 09 \\
6.8 \mathrm{E}-03 \pm 1.3 \mathrm{E}-05 \\
<1.0 \mathrm{E} \cdot 10 \\
<1.0 \mathrm{E}-10 \\
<8.2 \mathrm{E}-09 \\
\end{array}$ & $\begin{array}{l}\text { JQ } \\
\mathrm{v} \\
\mathrm{J} 1 \\
\mathrm{~J} Q \\
\mathrm{~J} 2 \\
\mathrm{~J} 2 \\
\mathrm{~J} Q \\
\mathrm{~J} Q \\
\mathrm{~J} 1\end{array}$ & 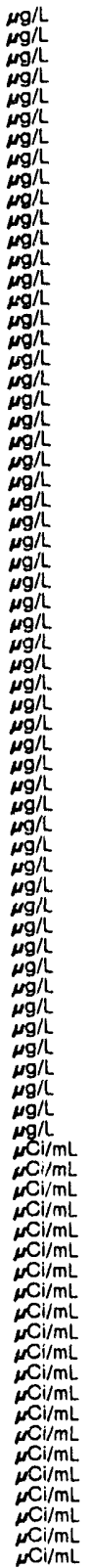 & $\begin{array}{l}\mathrm{GE} \\
\mathrm{GE} \\
\mathrm{GE} \\
\mathrm{GE} \\
\mathrm{GE} \\
\mathrm{GE} \\
\mathrm{GE} \\
\mathrm{GE} \\
\mathrm{GE} \\
\mathrm{GE} \\
\mathrm{GE} \\
\mathrm{GE} \\
\mathrm{GE} \\
\mathrm{GE} \\
\mathrm{GE} \\
\mathrm{GE} \\
\mathrm{GE} \\
\mathrm{GE} \\
\mathrm{GE} \\
\mathrm{GE} \\
\mathrm{GE} \\
\mathrm{GE} \\
\mathrm{GE} \\
\mathrm{GE} \\
\mathrm{GE} \\
\mathrm{GE} \\
\mathrm{GE} \\
\mathrm{GE} \\
\mathrm{GE} \\
\mathrm{GE} \\
\mathrm{GE} \\
\mathrm{GE} \\
\mathrm{GE} \\
\mathrm{GE} \\
\mathrm{GE} \\
\mathrm{GE} \\
\mathrm{GE} \\
\mathrm{GE} \\
\mathrm{GE} \\
\mathrm{TE} \\
\mathrm{TE} \\
\mathrm{TE} \\
\mathrm{GE} \\
\mathrm{GE} \\
\mathrm{GE} \\
\mathrm{GE} \\
\mathrm{GE} \\
\mathrm{GE} \\
\mathrm{GE} \\
\mathrm{GE} \\
\mathrm{GE} \\
\mathrm{GE} \\
\mathrm{GE} \\
\mathrm{GE} \\
\mathrm{GE} \\
\mathrm{GE} \\
\mathrm{GE} \\
\mathrm{GE} \\
\mathrm{GE} \\
\mathrm{GE} \\
\mathrm{TE} \\
\mathrm{TE} \\
\mathrm{TE} \\
\mathrm{TE} \\
\mathrm{TE} \\
\mathrm{TE} \\
\mathrm{TE} \\
\mathrm{GE} \\
\mathrm{TE} \\
\end{array}$ \\
\hline
\end{tabular}

WELL. BGO 33D

MEASUREMENTS CONDUCTED IN THE FIELD

Sample date: $10 / 17 / 81$

Depth to water: $47.17 \mathrm{ft}(14.38 \mathrm{~m})$ below TOC

Water elevation: $233.13 \mathrm{th}(71$

Sp. conductance: $65 \mu \mathrm{s} / \mathrm{cm}$.

The well went dry during purging.

LABORATORY ANALYSES

\begin{tabular}{|c|c|c|c|}
\hline Analyte & Result & Mod & Unit \\
\hline $\begin{array}{ll}0 & \text { pH } \\
0 & \text { Specific conductance } \\
0 & \text { Turbidity } \\
0 & \text { Acetophenone } \\
0 & \text { Aluminum } \\
0 & \text { Antimony }\end{array}$ & $\begin{aligned} & 5.5 \\
& 62 \\
& 180 \\
&< 10 \\
& 52 \\
&<2.0\end{aligned}$ & JO & $\begin{array}{l}\mathrm{pH} \\
\mu \mathrm{S} / \mathrm{cm} \\
\mathrm{NTU} \\
\mu \mathrm{g} / \mathrm{L} \\
\mu \mathrm{g} / \mathrm{L} \\
\mu \mathrm{g} / \mathrm{L}\end{array}$ \\
\hline
\end{tabular}

pH: 5.1 .

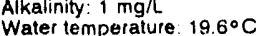

WELL. BGO 33D collected on 10/17/91, laboratory analyses (cont.)

F Analyte Result Mod Unit Lab

$\begin{array}{ll}0 & \text { Arsenic } \\ 0 & \text { Barium } \\ 0 & \text { Benzene } \\ 0 & \text { Bromodichloromethane } \\ 0 & \text { Bromoform } \\ 0 & \text { Bromomethane } \\ 0 & \text { Cadmium } \\ 0 & \text { Calcium } \\ 0 & \text { Carbon tetrachloride } \\ 0 & \text { Chloride } \\ 0 & \text { Chlorobenzene } \\ 0 & \text { Chloroethane } \\ 0 & \text { Chloroethene Ninyl chloride) } \\ 0 & \text { 2.Chlorethyl vinyl ether } \\ 0 & \text { Chloroform } \\ 0 & \text { Chloromethane } \\ 0 & \text { Chromium } \\ 0 & \text { Copper } \\ 0 & \text { Cyone }\end{array}$

Dibromochloromethane $<1.0$

0 1,1-Dichloroethane $<1.0$

1,2 . Dichloroethane $<1.0$

$<1.0$
0
0

0 2.4.Dichlorophenoxyucetic acid $<0.30$

1, 2-Dichloropropane

cis-1,3-Dichloropropene
0 trans-1,3-Dichloropropene

0 Endrin

0 Ethylbenzene

F Fluoride

1 Iron

0 Lead

O Magnesium

O Manganese

Methoxychlor

Naphthalen

0 Nickel

Nitrate as nitrogen
0 Nitrate as nitrogen

Phenols

O Potassium

$\begin{array}{ll}0 & \text { Selenium } \\ 0 & \text { Silica }\end{array}$

$\begin{array}{ll}0 & \text { Silica } \\ 0 & \text { Silver }\end{array}$

- Sodium

Sulfate

Tetrachloroethylene

0 Tin

Toluene

Total organic carbon

Total organic halogens

Total phosp

2,4,5-TP (Silvex)

i, 1 . Trichloroethane

1,1,2-Trichloroethane

Trichloroethylene

Trichlorofluoromethane

Vanadium

Xylenes

Cerium-144

Cesium-134

Cesium-137

Cobalt-57

Europium-154

Gross alpha

Manganese-54

Nonvolatile beta

Radium-226

Ruthenium-103

Sodium-22

Thorium-228

Tritium

Uranium-233/234

Uranium-238

$<2.0$
119
$<1.0$
$<1.0$
$<1.0$
$<1.0$
$<2.0$
1.680
$<1.0$
11,300
$<1.0$
$<1.0$
$<1.0$
$<1.0$
$<1.0$
$<1.0$
$<4.0$
6.2
$<5.0$
$<1.0$
$<1.0$
$<1.0$
$<1.0$
$<1.0$
4.5
$<0.30$
$<1.0$
$<1.0$
$<1.0$
$<0.0060$
$<1.0$
$<100$
$<100$
167
3.8
$<0.0050$
11.910
6.5
$<0.20$

$\begin{array}{ll}\mu g / L & G E \\ \mu g / L & G E \\ \mu g / L & G E \\ \mu g / L & G E\end{array}$

$<1.0$

$<1.0$
$<1.0$

1,680

11,300

$<1.0$

$<1.0$
6.2

GE

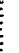

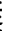

EE

GE

GE

J2V

$<4.0$

2,800
2,800

2,800
$<5.0$
1.860

1,860
$<2.0$
5,430

5.430
$<2.0$
5,030

5,030
$<1,000$

$<1.000$
$<1.0$
$<1.0$
$<2.0$

$<\begin{aligned} & <1.0 \\ & 35,000\end{aligned}$

$<1,000$

16
$<50$

$<0.24$
$<0.090$

$<0.090$
$<10$
$<1.0$
$<1.0$

$<1.0$

$<8.0$

$<2.0$

$<7.5 \mathrm{E}-09$
$<2.4 \mathrm{E}-0 \mathrm{0B}$

$<3.6 \mathrm{E} .09$

$<3.0 E-09$

$<3.0 E-09$

$<3.0 E .09$

$<1.0 \mathrm{E}-08$

$<2.0 E-09$

3. $4 \mathrm{E}-09 \pm 1.6 \mathrm{E}-09$

$<4.5 E .08$

$<5.25 .09$

$\angle 4.0 \mathrm{E} .09$

$<3.1 E .09$

$<1.0 \mathrm{E}-08$

1. $1 \mathrm{E}-04 \pm 1.8 \mathrm{E}-06$

$<1.0 E \cdot 10$

$<1.0 E-10$
$<1.0 \mathrm{E}-108$
$<1.08-08$ 
ANALYTICAL RESULTS

WELL BGO 34D

MEASUREMENTS CONOUCTED IN THE FIELLD

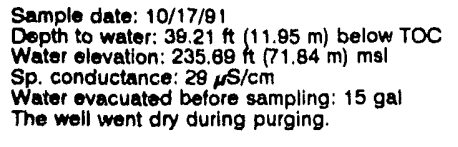

LABORATORY ANALYSES

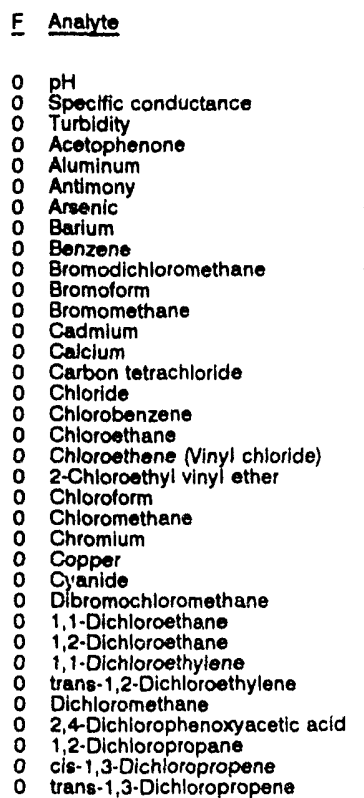

Result Mod Unit Lab

Time: $12: 00$

Aikalinity: $1 \mathrm{mg} / \mathrm{L}$

Water temperature: $19.1^{\circ} \mathrm{C}$

6.0

8.0
32
18
$<10$
24
22.0
$<2.0$
20
$<1.0$
$<1.0$
$<1.0$
$<1.0$
$<2.0$

1,810
$<1.0$
4,060

$<\begin{aligned} & 4,060 \\ & <1.0\end{aligned}$

$<1.0$

$<1.0$

$<1.0$

$<1.0$

$<4.0$
4.1

$<5.0$

$<1.0$

$<1.0$

$<1.0$

cis-1,3-Dichloropropen

trans-1,3-Dichloropropen

Ethylbenzene

Fluoride

Lead

Lindane

Magnesium

Mercury

Methoxychior

Naphth
Nickel

Nitrate as nitrogen

Phenols

Selenium

Selenivm

Silver

Sodium

$1,1,2$, Totiachloroethane

Tetrachloroethylene

Tin

Toluene

Total dissolyed solids

Total organic carbon

Total phosphates (as P)

Toxaphene

1,1,1-Trichloroethane

1,1,2-Trichloroethane

Trichlorofluoromethane

Vanadium

Antimony-125

Cerium-144

Cosium-137

Cobatt-57

Euraplum-154

Gross alpha

Manganese. 54

Nonvolatile bete

Potassium.40

Ruthenlum-103

Sodium-22

Thorium-228

Total radium

4.2
$<0.30$

$<1.0$

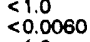

$<1.0060$
$<1.0$

$<100$

$<0.0050$

723
5.3
$<$

$<0.20$

$<10$

$<4.0$

$<500$

$<.0$
6,700

$<.0$
$<2.000$

1,800
$<1,000$

$<<1.0$

$<2.0$

$<1.0000$

$<1,000$

$<5.0$

$<0.24$

$<1.0$

$<1.0$

$<1.0$

$<1.0$

$<8.0$

$<7.6 \mathrm{E}-08$

$<3.1 E-08$

$<3.5 \mathrm{E}-09$

$<4.0 E-09$

$<2.8 E-09$

$<2.0 E .09$

$<3.7$ E.09

$<2.0 E-09$

$<3.7 \mathrm{E}-08$

$<5.2 E-09$

$<3.3 E-09$

$<3.5 E-09$

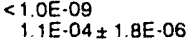

WELL BGO 34D collected on 10/17/91, laboratory analyses (cont.)

\begin{tabular}{|c|c|c|c|}
\hline Analyte & Result & Mod & Unit \\
\hline $\begin{array}{ll}0 & \text { Uranium-233/234 } \\
0 & \text { Uranium-238 } \\
0 & \text { Zinc-65 }\end{array}$ & $\begin{array}{l}<1.0 \mathrm{OE}-10 \\
<1.0 \mathrm{E}-10 \\
<8.2 \mathrm{E}-09\end{array}$ & & $\underset{\mu}{\mu \mathrm{Cl} / / m L}$ \\
\hline
\end{tabular}

\section{WELL BGO 35C}

MEASUREMENTS CONDUCTED IN THE FIELD

Sample date: 10/17/91

Depth to water: $43.25 \mathrm{Ht}(13.18 \mathrm{~m})$ below TOC

Wiater elevation: $230.15 \mathrm{~h}(70.15 \mathrm{~m}) \mathrm{msl}$

Water evacuated before sampling: $269 \mathrm{gal}$

LABORATORY ANALYSES

E Analyte Besuit Mod Unit

O $\mathrm{pH}$ Spectific conductance

Turbidity

Acetophenone

Aluminum

Arsenic

Barium

Benzene

Bromoform

Bromomethane

Cadmium

Carbon tetrachloride

Chloride

Chlorobenzene

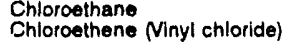

2-Chloroethyl vinyl ether

Chloroform

Chloromethane

Chromium

Copper

Cyanide

Dibromochloromethane

1,1-Dichloroethane

1,2-Dichloroethane

1,1-Dichloroethylene
trans-1,2-Dichloroethylene

Dichloromethane

2,4-Dichlorophenoxyacetic acid

1,2-Dichloropropane

cis-1,3-Dichloropropene

trans-1,3-Dichloropropene

Ethylbenzene

Fluoride

0 Iron

$\begin{array}{ll}0 & \text { Lead } \\ 0 & \text { Lindan }\end{array}$

0 Magnesium

Manganese

Methoxychlor

Naphthalene

Nickel

Nitrate as nitrogen

Phenols

Potassium

0 Selenium

Silver

Sodium

1,1,2, Tetrachloroethane

o Tetrachloroethylene

0 Tin

0 Toluene

Total dissolved solids

Total organic carbon

Total organic halogens
Total phosphates (as P)

Toxaphene

$2,4,5 \cdot$ TP (Silvex)

1,1,1-Trichloroethane

1,1,2-Trichloroethe

Trichlorofluoromethane

0 Vanadium

A Antimony- 125

Cerium-134

0 Cesium-137

Cobalt -57

Cobalt-60

Gross aipha
Tims: 11:15

Alkalinity: $28 \mathrm{mg} / \mathrm{h}$ Water tomperature: $18.0^{\circ} \mathrm{C}$

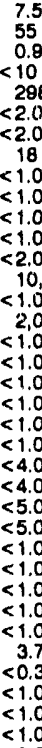

JQ $\quad \mathrm{pH} / \mathrm{GE}$

55

0.93
$<10$
298

2.0

18
$<1.0$

$<1.0$

$<1.0$
$<1.0$

10,200

$<1.0$

$<1.0$

$<1.0$

$<1.0$

$<1.0$

$<4.0$

$<5.0$

$<1.0$

$<1.0$

3.7
$<0.30$

$<1.0$
$<1.0$

$<1.0$
$<0.0060$

$<1.0$

$<4.0$

$<3.0$

248
5.3

$<0.20$
$<0.50$

$<10$

$<4.0$

$<5.0$

$<500$

$<2.0$

$<2.00$

$<1,000$

$<1.0$

$<<.0$
$<1.0$
$<<1.0$

20,000
$<1,000$
$<5.0$
$<50$

$<50$

$<0.24$

$<1.0$

$<1.0$
$<1.0$
$<1.0$

$<8.0$

$<8.5 \mathrm{E}-09$

$<4.3 \mathrm{E}-09$

$<3.2 \mathrm{E} .08$

$<4.1 E .09$

$<3.2 \mathrm{E}-08$

$<9.5 \mathrm{E} .09$
$<2.0 \mathrm{E} .09$ 
WELL BGO 35C colloctod on 10/17/81, laboratory analyses (cont.)

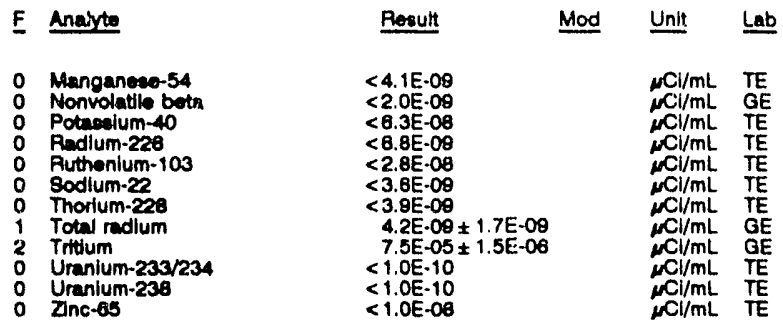

\section{WELL BGO 35D}

MEASUREMENTS CONDUCTED IN THE FIELD

\begin{tabular}{|c|c|}
\hline 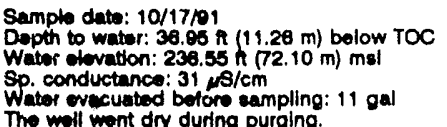 & $\begin{array}{l}\text { Timo: } 10: 50 \\
\text { pH: } 4.8 \\
\text { Alkalinity: } 0 \mathrm{mg} \Omega \\
\text { Water temperature: } 18.0^{\circ} \mathrm{C}\end{array}$ \\
\hline
\end{tabular}
Whe well went dry during purging: 11 ga

LABORMTORY ANALYSES

\begin{tabular}{|c|c|c|c|c|c|}
\hline$\underline{E}$ & Anayte & Result & Mod & Unit & Lab \\
\hline $\begin{array}{l}0 \\
0 \\
0 \\
0 \\
2 \\
0 \\
0 \\
0 \\
0 \\
0 \\
0 \\
0 \\
0 \\
0 \\
0 \\
0 \\
0 \\
0 \\
0 \\
0 \\
0 \\
0 \\
0 \\
0 \\
0 \\
0 \\
0 \\
0 \\
0 \\
0 \\
0 \\
0 \\
0 \\
0 \\
0 \\
0 \\
0 \\
0 \\
0 \\
0 \\
2 \\
0 \\
0 \\
0 \\
0 \\
0 \\
0 \\
0 \\
0 \\
0 \\
0 \\
0 \\
0 \\
0 \\
0 \\
0 \\
0 \\
0 \\
0 \\
0 \\
0 \\
0 \\
0 \\
0 \\
0 \\
0 \\
0 \\
0 \\
0 \\
0 \\
0\end{array}$ & 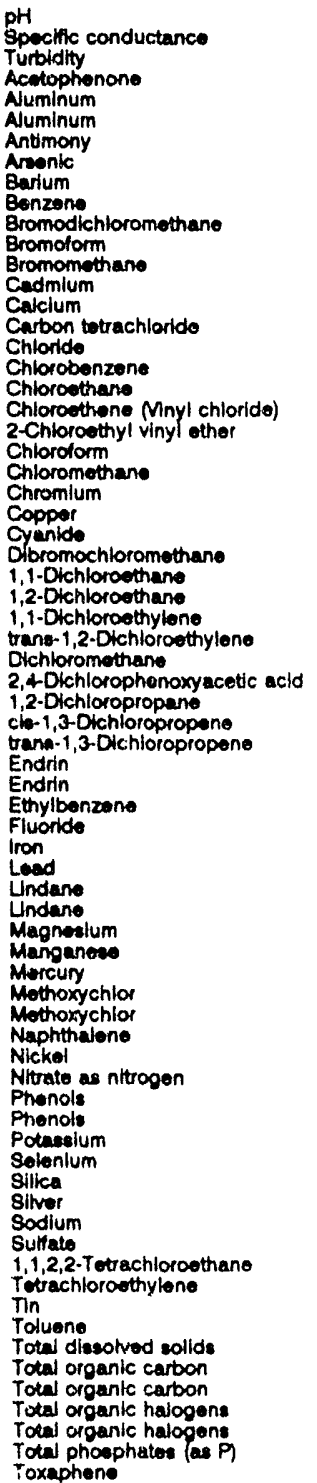 & 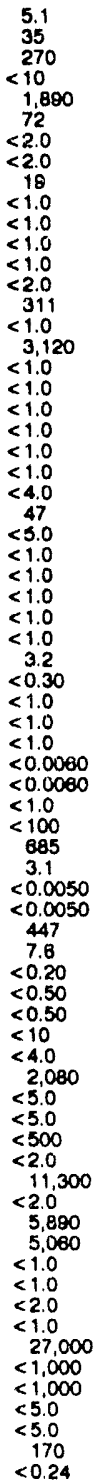 & $\begin{array}{l}\text { JQ } \\
\text { JQ } \\
\text { JO }\end{array}$ & 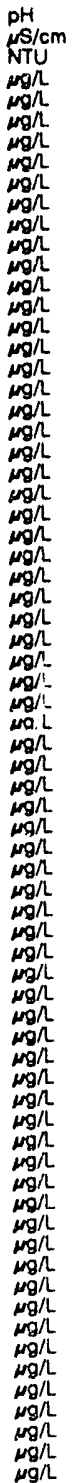 & $\begin{array}{l}G E \\
G E \\
G E \\
G E \\
G E \\
G E \\
G E \\
G E \\
G E \\
G E \\
G E \\
G E \\
G E \\
G E \\
G E \\
G E \\
G E \\
G E \\
G E \\
G E \\
G E \\
G E \\
G E \\
G E \\
G E \\
G E \\
G E \\
G E \\
G E \\
G E \\
G E \\
G E \\
G E \\
G E \\
G E \\
G E \\
G E \\
G E \\
G E \\
G E \\
G E \\
G E \\
G E \\
G E \\
G E \\
G E \\
G E \\
G E \\
G E \\
G E \\
G E \\
G E \\
G E \\
G E \\
G E \\
G E \\
G E \\
G E \\
G E \\
G E \\
G E \\
G E \\
G E \\
G E \\
G E \\
G E \\
G E \\
G E \\
G E \\
G E \\
G E\end{array}$ \\
\hline
\end{tabular}

WELL BGO 35D colloctod on 10/17/81, laboratory analyees (cont.)
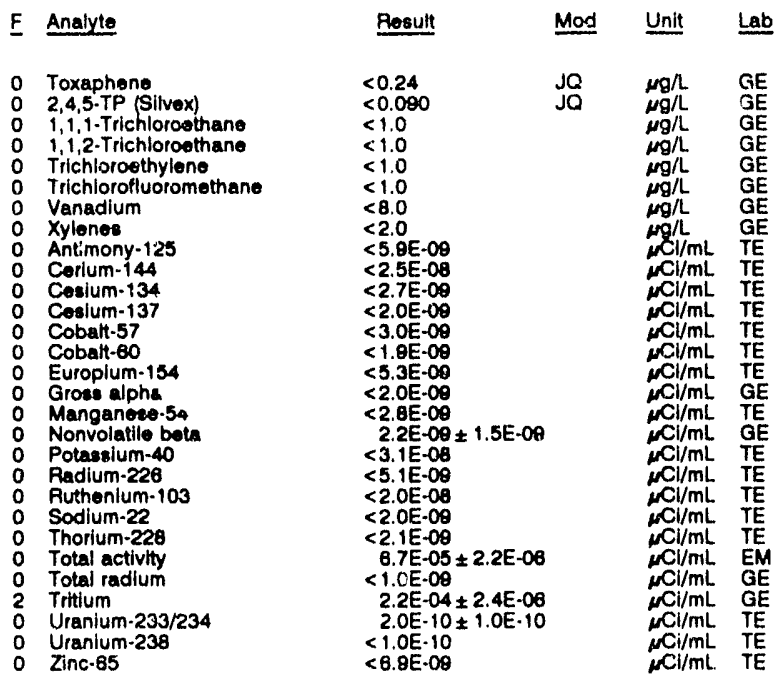

WELL BGO 36D

MEASUREMENTS CONDUCTED IN THE FIELD

\begin{tabular}{|c|c|}
\hline $\begin{array}{l}\text { Sample date: } 10 / 17 / 81 \\
\text { Depth to water: } 36.88 \mathrm{ft}(11.27 \mathrm{~m}) \text { below TOC } \\
\text { Water olovation: } 238.42 \mathrm{~h}(72.67 \mathrm{~m}) \mathrm{ms} \\
\text { Sp. conductance: } 27 \mathrm{NS} / \mathrm{cm} \\
\text { Water ovacuated bofore sampling: } 10 \mathrm{gal} \\
\text { The well went dry during purging. }\end{array}$ & $\begin{array}{l}\text { Time: } 10: 15 \\
\text { pH: } 5.0^{-15} \\
\text { Allatinity: } 1 \mathrm{mg} / \mathrm{L} \\
\text { Water temperature: } 19.2^{\circ} \mathrm{C}\end{array}$ \\
\hline
\end{tabular}

The well went dry during purging

LABORATORY ANALYSES

E Analyte Result Mod Unit Lab

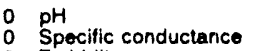

0 Turbidity

o Acetophenone

- Aluminum

Antimony

Arsenic

Benzene

Bromodichloromothane

Bromoform

Bromometh

Cadmium

Carbon tetrachloride

Chloride

Chlorobenzone

Chloroothano

Chloroethene Ninyl chloride

2-Chloroethyl

Chloroform

Chloromethane

Copper

Copper

Dibromochloromethane

Dibromochlorometh

1,1-Dichloroethane

1,2.Oichloroethane

$1,1 \cdot$ Dichloroethylene
trans-1,2-Dichloroethylene

Dichloromethane

Result Mod Unit Lab

2,4-Oichlor

0 1,2-Dichloropropane

0
0
0
trans-1,3-Dichloropropene

Endrin

Ethylbenzene

Fluoride

Iron

1 Lead

Magnesium

Mangnneso

Mercury

Naphthalene

Nickel

Nitrate as nitrogen

- Phenols

Phenols

Polassium

Selenium
0

5.7
29
180
$<10$
82
$<2.0$
$<2.0$
18
$<1.0$
$<1.0$
$<1.0$
$<1.0$
$<2.0$
149
$<1.0$
3.900
$<1.0$
$<1.0$
$<1.0$
$<1.0$
$<1.0$
$<1.0$
$<4.0$
23
$<5.0$
$<1.0$
$<1.0$
$<1.0$
$<1.0$
$<1.0$
5.1
$<0.30$
$<1.0$
$<1.0$
$<1.0$
$<0.0080$
$<1.0$
$<100$
133
8.2
$<0.0050$
458
118
$<0.20$
$<0.50$
$<10$
$<4.0$
1.080
$<5.0$
$<5.0$
$<500$
$<2.0$
6.400
$<2.0$

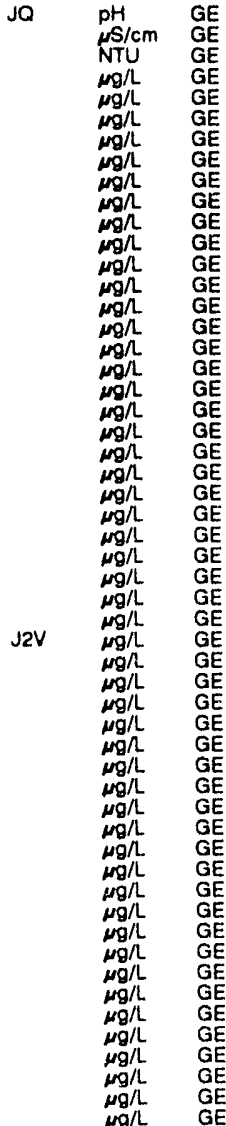


ANALYTICAL RESULTS

WELL BGO 36D collected on 10/17/81, laboratory analyses (cont.)

\begin{tabular}{|c|c|c|}
\hline Analyte & Result & Unit \\
\hline 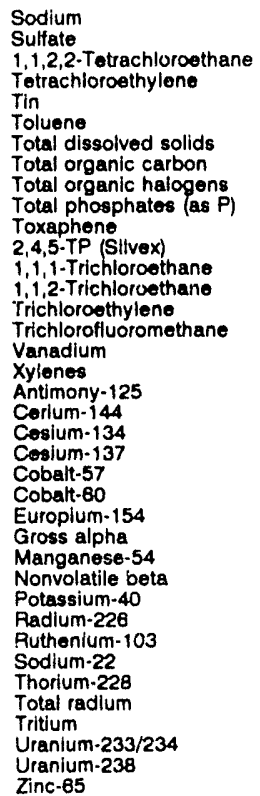 & $\begin{aligned} & 3,670 \\
&<1,000 \\
&<1.0 \\
&<1.0 \\
&<2.0 \\
&<1.0 \\
&<1,000 \\
&<1.000 \\
& 8.8 \\
& 110 \\
&<0.24 \\
&<0.090 \\
&<1.0 \\
&<1.0 \\
&<1.0 \\
&<1.0 \\
&<8.0 \\
&<2.0 \\
&<4.9 E-09 \\
&<2.1 \mathrm{E}-08 \\
&<1.6 \mathrm{E} \cdot 09 \\
&<1.7 \mathrm{E}-09 \\
&<2.8 \mathrm{E} \cdot 09 \\
&<1.5 \mathrm{E}-09 \\
&<5.0 \mathrm{E} \cdot 09 \\
& 3.1 \mathrm{E} \cdot 09 \pm 1.4 \mathrm{E}-09 \\
&<2.6 \mathrm{E}-09 \\
& 3.3 \mathrm{E}-09 \pm 1.6 \mathrm{E}-09 \\
&<3.1 \mathrm{E} \cdot 08 \\
&<4.7 \mathrm{E}-09 \\
&<1.6 \mathrm{E} \cdot 08 \\
&<1.9 \mathrm{E}-09 \\
&<2.3 \mathrm{E}-09 \\
&<1.0 \mathrm{E}-09 \\
& 9.7 \mathrm{E} \cdot 05 \pm 1.7 \mathrm{E} \cdot 06 \\
&<1.0 \mathrm{E}-10 \\
&<1.0 \mathrm{E} \cdot 10 \\
&<5.8 \mathrm{E}-09\end{aligned}$ & $\begin{array}{l}\mu g / L \\
\mu g / L \\
\mu g / L \\
\mu g / L \\
\mu g / L \\
\mu g / L \\
\mu g / L \\
\mu g / L \\
\mu g / L \\
\mu g / L \\
\mu g / L \\
\mu g / L \\
\mu g / L \\
\mu g / L \\
\mu g / L \\
\mu g / L \\
\mu g / L \\
\mu g / L \\
\mu C i / m L \\
\mu C i / m L \\
\mu C i / m L \\
\mu \mathrm{Ci} / \mathrm{mL} \\
\mu \mathrm{Ci} / \mathrm{mL} \\
\mu \mathrm{Ci} / \mathrm{mL} \\
\mu \mathrm{Cl} / \mathrm{mL} \\
\mu \mathrm{Ci} / \mathrm{mL} \\
\mu \mathrm{Ci} / \mathrm{mL} \\
\mu \mathrm{Cl} / \mathrm{mL} \\
\mu \mathrm{Ci} / \mathrm{mL} \\
\mu \mathrm{Ci} / \mathrm{mL} \\
\mu \mathrm{C} / \mathrm{mL} \\
\mu \mathrm{Ci} / \mathrm{mL} \\
\mu \mathrm{Ci} / \mathrm{mL} \\
\mu \mathrm{Cl} / \mathrm{mL} \\
\mu \mathrm{Ci} / \mathrm{mL} \\
\mu \mathrm{Ci} / \mathrm{mL} \\
\mu \mathrm{Ci} / \mathrm{mL} \\
\mu \mathrm{Ci} / \mathrm{mL}\end{array}$ \\
\hline
\end{tabular}

WELL BGO 37D

MEASUREMENTS CONDUCTED IN THE FIELD

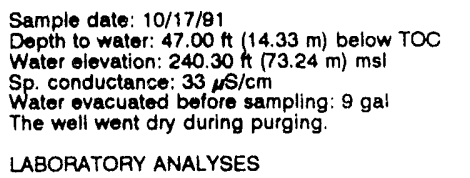

LABORATORY ANALYSES

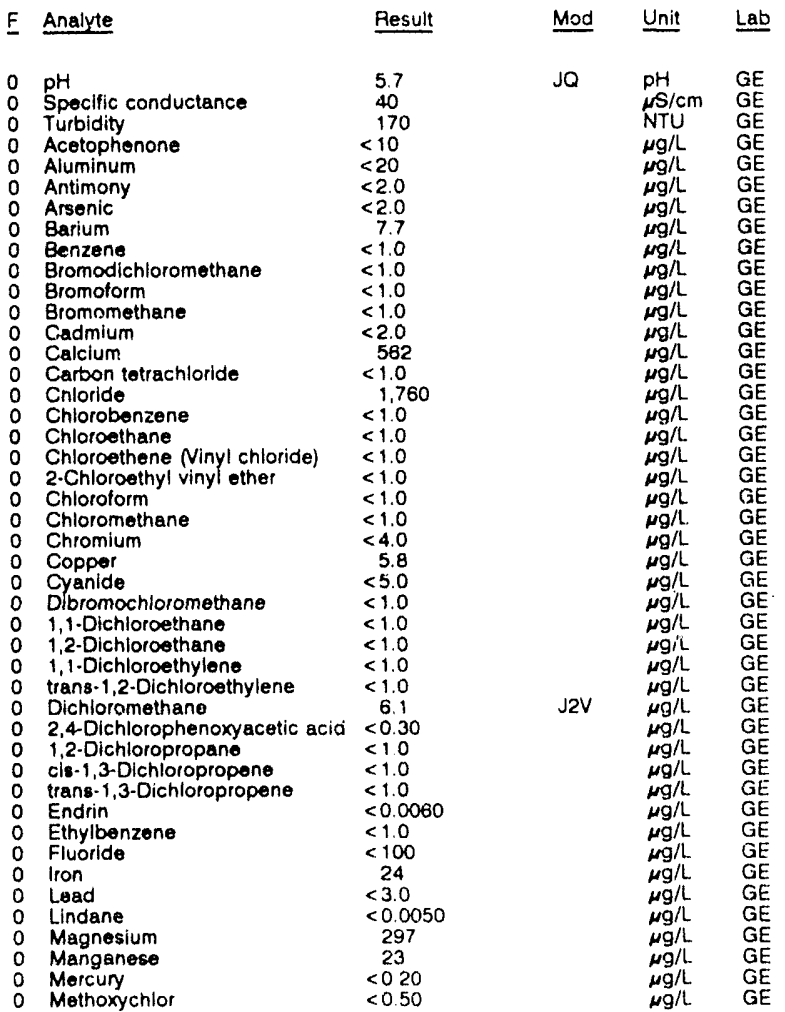

Time: $9: 50$

Alkalinity: $1 \mathrm{mg} / \mathrm{h}$

Water temperature: $19.5^{\circ} \mathrm{C}$
WELL. BGO 370 collected on 10/17/91, laboratory analyses (cont.)

\begin{tabular}{|c|c|c|c|}
\hline Analyte & Result & Mod & Unit \\
\hline $\begin{array}{l}\text { Naphthalene } \\
\text { Nickel } \\
\text { Nitrate as nitrogen } \\
\text { Phenols } \\
\text { Potassium } \\
\text { Selenium } \\
\text { Silica } \\
\text { Silver } \\
\text { Sodium } \\
\text { Sulfate } \\
1,1,2,2-\text { Tetrachloroethane } \\
\text { Tetrachloroethylene } \\
\text { Tin } \\
\text { Toluene } \\
\text { Total dissolved solids } \\
\text { Total organic carbon } \\
\text { Total organic carbon } \\
\text { Total organic halogens } \\
\text { Total phosphates (as P) } \\
\text { Toxaphente } \\
2,4,5-T P \text { (Silvox) } \\
1,1,1 . \text { Trichloroethane } \\
\text { 1,1,2-Trichloroethane } \\
\text { Trichioroethylene } \\
\text { Trichlorofluoromethane } \\
\text { Vanadium } \\
\text { Xylenes } \\
\text { Gross alpha } \\
\text { Nonvolatile beta } \\
\text { Total radium } \\
\text { Tritium } \\
\text { Uranium-233/234 } \\
\text { Uranium-238 }\end{array}$ & $\begin{array}{l}<10 \\
4.1 \\
2,620 \\
<5.0 \\
<500 \\
<2.0 \\
6,440 \\
<2.0 \\
5,590 \\
<1,000 \\
<1.0 \\
<1.0 \\
<2.0 \\
<1.0 \\
1.000 \\
<1,000 \\
<1.000 \\
<5.0 \\
100 \\
<0.24 \\
<0.090 \\
<1.0 \\
<1.0 \\
<1.0 \\
<1.0 \\
<8.0 \\
<2.0 \\
<2.0 \mathrm{E}-09 \\
<2.0 \mathrm{E}-09 \\
2.1 \mathrm{E}-09 \pm 1.6 \mathrm{E}-00 \\
8.0 \mathrm{E}-05 \pm 1.6 \mathrm{E}-06 \\
<1.0 \mathrm{E}-10 \\
<1.0 \mathrm{E}-10\end{array}$ & JO & $\begin{array}{l}\mu g / L \\
\mu g / L \\
\mu g / L \\
\mu g / L \\
\mu g / L \\
\mu g / L \\
\mu g / L \\
\mu g / L \\
\mu g / L \\
\mu g / L \\
\mu g / L \\
\mu g / L \\
\mu g / L \\
\mu g / L \\
\mu g / L \\
\mu g / L \\
\mu g / L \\
\mu g / L \\
\mu g / L \\
\mu g / L \\
\mu g / L \\
\mu g / L \\
\mu g / L \\
\mu g / L \\
\mu g / L \\
\mu g / L \\
\mu g / L \\
\mu C i / m L \\
\mu C l / m L \\
\mu C l / m L \\
\mu C l / m L \\
\mu C L / m L \\
\mu C l / m L\end{array}$ \\
\hline
\end{tabular}

\section{WELL BGO 38D}

MEASUREMENTS CONDUCTED IN THE FIELD

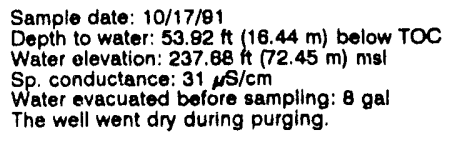

Time: $8: 15$

pH: 4.5 : $0 \mathrm{mgh}$

Water temperalure: $18.5^{\circ} \mathrm{C}$

LABOPATORY ANALYSES

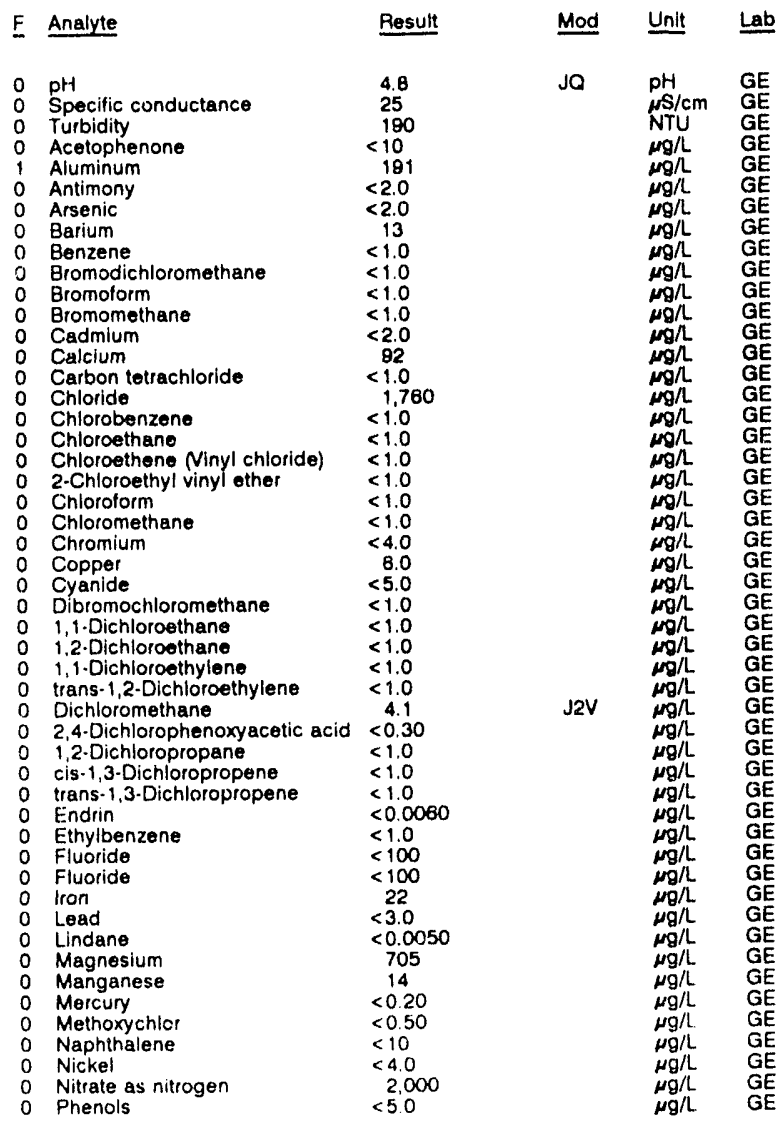


ANALYTICAL RESULTS

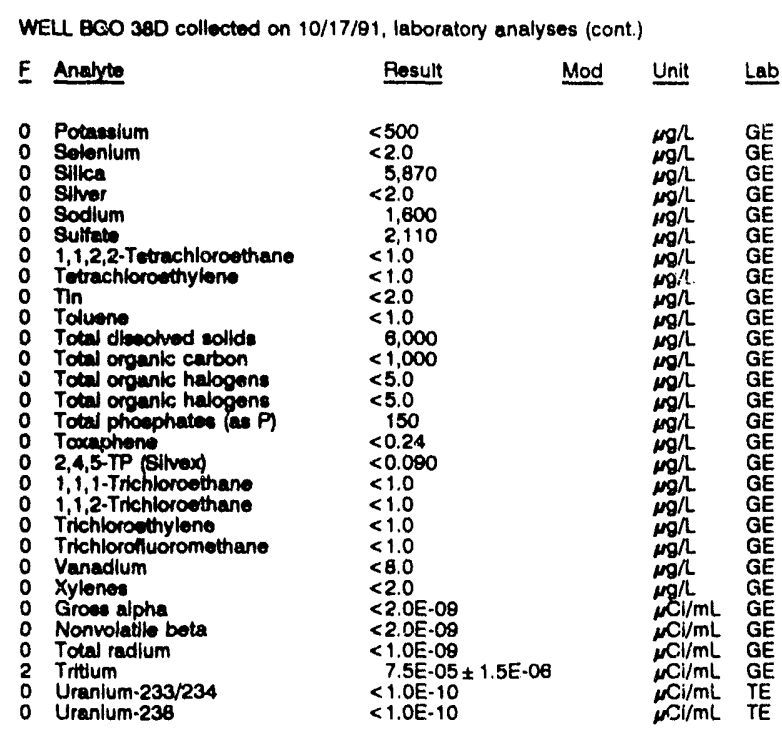

\section{WELL BGO 39D}

MEASUREMENTS CONDUCTED IN THE FIELD

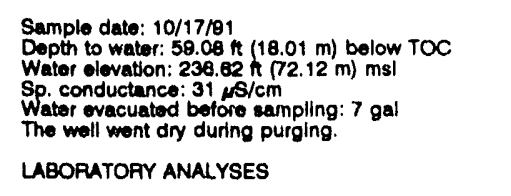

\section{E Analyte}

$\circ \mathrm{pH}$

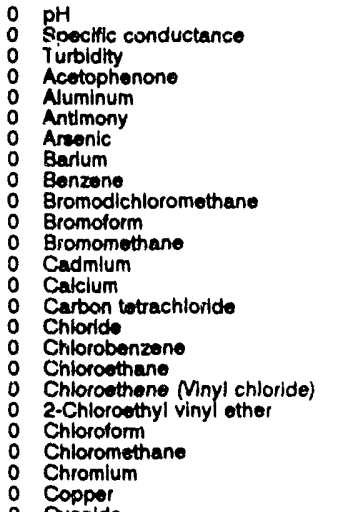

- Copper

Dioromochloromethane

1, -Dithloroothane

1,2-Dichloroethano

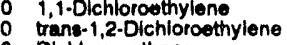

Dichloromothane

2,4-Dichlorophenoxyacetic acid

1,2-Dichloropropane

trans-1,3-Dichloropropene

Endrin

Ethylbenzene

Fluorido

0 Lead

0 Undane

Magneslum

Manganese

Mercury

Naphthalene

Nickel

Nitrato as nitrogen

Nitrate as nitrogen

Phenols

Solacienium

Sillica
Time: $8: 40$

Alkalinity: $0 \mathrm{mg} / \mathrm{L}$

Water temperature: $18.8^{\circ} \mathrm{C}$
WELL BGO 390 collected on 10/17/91, laboratory analyses (cont.)

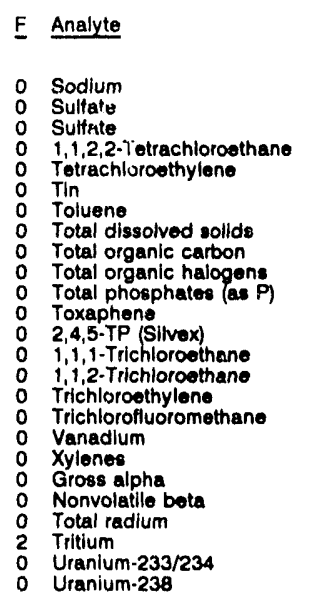

Result
3.550
5,920
8,430
$<1.0$
1.1
$<2.0$
$<1.0$
4,000
$<1,000$
12
90
$<0.24$
$<0.090$
$<1.0$
$<1.0$
$<1.0$
$<1.0$
$<8.0$
$<2.0$
$3.7 E-09 \pm 1.5 E-09$
$2.2 E-09 \pm 1.5 E-09$
$1.6 E-09 \pm 1.4 E-09$
$7.4 E-05 \pm 1.5 E-00$
$2.0 E-10 \pm 1.0 E-10$
$1.0 E-10 \pm 1.0 \mathrm{E}-10$

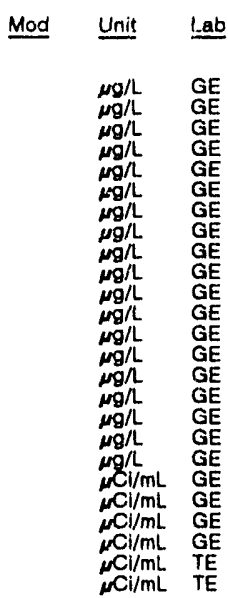

WELL BGO 40D

MEASUREMENTS CONDUCTED IN THE FIELD

Sampie date: 10/22/81

Depth to water: $84.48 \mathrm{ft}(19.85 \mathrm{~m})$ below TOC

Water elevation: $223.94 \mathrm{~h}(68.26 \mathrm{~m}) \mathrm{ms}$

Sp. conductance: $551 \mu \mathrm{s} / \mathrm{cm}$

There was insufficient water to fill a or some sample bottles.

LABORATORY ANALYSES

E Analyte Result Mod Unit Lab

O ph

$\begin{array}{rr}7.2 & J Q \\ 460 & \\ 100 & J 0 \\ <10 & J Q\end{array}$

Acetophenono

Aluminum

Antimony

Arsenic

Barium

Bromodichloromethane

Bromoform

Bromomethane

Cadmium

Carbon tetrachlorido

Chloride

Chlorobenzene

Chloroothane

Chloroethene Ninyl chloride

2-Chloroethyl vinyl other

Chloroform

Chloromethane

Chromium

Copper

Dibromochloromethane

1.1.Dichloroethane

1,2-Dichloroethane

1,1-Dichloroethylene

Dichloromethane

2,4-Dichlorophenoxyacetic acid

1,2-Dichloropropane

cis-1,3-Dichloropropene

trans-1,3-Dichloropropene

Endrin

0 Ethylbenzene

Ethylbenzen

0 Iron

Lead

0 Lindane

2 Magnesium

Mercun

Mothoxychlor

Methoxychlor

Naphthalon

Nitrate as nitrogen

Phenols

Potassium

Silica

Silver

Sodium
0 Sulfate

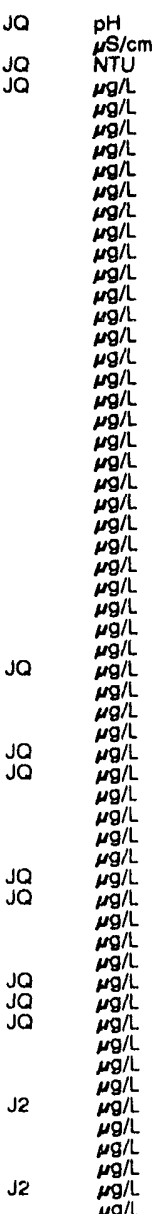

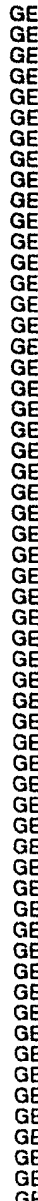


ANALYTICAL RESULTS

WELL BGO 400 collected on 10/22/91, laboratory analyses (cont.)

\begin{tabular}{|c|c|c|c|}
\hline Analyte & Result & Mod & Unit \\
\hline $\begin{array}{l}\text { 1,1,2,2-Totrachloroethane } \\
\text { Totrachloroethylene } \\
\text { TIn } \\
\text { Toluene } \\
\text { Total dissolved sollds } \\
\text { Total organic carton } \\
\text { Total organic halogens } \\
\text { Total phosphates (as P) } \\
\text { Toxaphene } \\
\text { Toxaphene } \\
2,4,5 \text {-To (Silvex) } \\
1,1,1 \text {-Trichloroethane } \\
1,1,2 \text {-Trichloroethane } \\
\text { Trichloroethylene } \\
\text { Trichlorofluoromethane } \\
\text { Vanadlum } \\
\text { Xylenee } \\
\text { Groses alpha } \\
\text { Nonvolatile beta } \\
\text { Total activity } \\
\text { Total radium } \\
\text { Trittum } \\
\text { Uranium-233/234 } \\
\text { Uranium-238 }\end{array}$ & $\begin{array}{l}<1.0 \\
12 \\
<2.0 \\
<1.0 \\
1.000 \\
2,000 \\
56 \\
230 \\
<0.24 \\
<0.24 \\
<0.90 \\
<1.0 \\
<1.0 \\
2.7 \\
<1.0 \\
<8.0 \\
<2.0 \\
5.3 E-08 \pm 2.5 E-09 \\
5.4 E-08 \pm 3.6 E \cdot 09 \\
4.3 E-08 \pm 1.1 E \cdot 06 \\
<1.0 E-09 \\
<7.0 E-07 \\
<1.0 E-10 \\
2.0 E-10 \pm 1.0 E-10\end{array}$ & $\begin{array}{l}\mathrm{J} Q \\
\mathrm{~J} Q \\
\mathrm{~J}\end{array}$ & $\begin{array}{l}\mu g / L \\
\mu g / L \\
\mu g / L \\
\mu g / L \\
m g / L \\
\mu g / L \\
\mu g / L \\
\mu g / L \\
\mu g / L \\
\mu g / L \\
\mu g / L \\
\mu g / L \\
\mu g / L \\
\mu g / L \\
\mu g / L \\
\mu g / L \\
\mu g / L \\
\mu C L / m L \\
\mu C l / m L \\
\mu C l / m L \\
\mu C l / m L \\
\mu C l / m L \\
\mu C l / m L \\
\mu C l / m L\end{array}$ \\
\hline
\end{tabular}

\section{WE'LL BGO 41A}

MEASUREMENTS CONDUCTED IN THE FIELD

Sample date: 11/07/91

Depth to water: $141.26 \mathrm{Ht}(43.08 \mathrm{~m})$ below TOC

Water elevation: $158.04 \mathrm{ft}(48.48 \mathrm{~m}) \mathrm{msl}$

Water evacuated beto

The well went dry during purging: $21 \mathrm{gal}$

LABORATORY ANALYSES

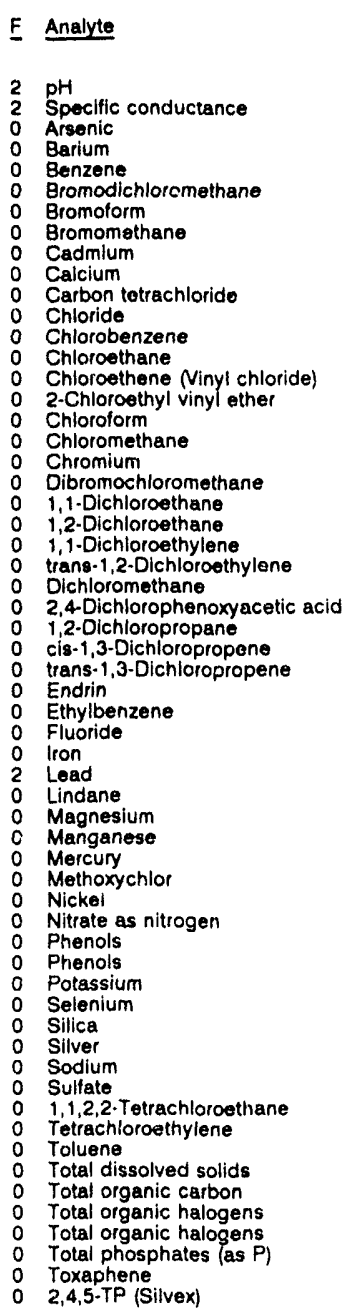

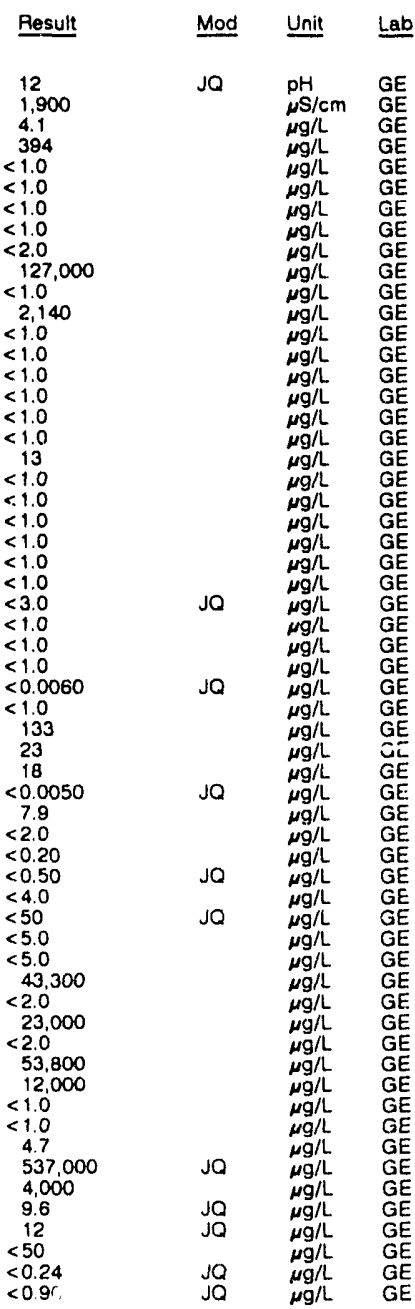

WELL. BGO $41 \mathrm{~A}$ collected on 11/07/91, laboratory analyees (cont)

\begin{tabular}{|c|c|c|c|c|}
\hline Analyte & Result & Mod & Unit & Lab \\
\hline $\begin{array}{l}\text { 1,1,1-Trichloroethane } \\
1,1,2 \cdot \text { Trichloroothane } \\
\text { Trichloroethylone } \\
\text { Trichlorofluoromethane } \\
\text { Gross alpha } \\
\text { Nonvolatile bota } \\
\text { Total actlvity } \\
\text { Total radium } \\
\text { Tritium } \\
\text { Uranium-233/234 } \\
\text { Uranlum-238 }\end{array}$ & $\begin{aligned} 2.4 \\
<1.0 \\
<1.0 \\
<1.0 \\
7.7 \mathrm{E}-09 \pm 2.6 \mathrm{E}-09 \\
5.5 \mathrm{E}-08 \pm 3.0 \mathrm{E}-09 \\
3.1 \mathrm{E}-08 \pm 1.6 \mathrm{E}-00 \\
<1.0 \mathrm{E}-09 \\
<7.0 \mathrm{E}-07 \\
<1.0 \mathrm{E}-10 \\
<1.0 \mathrm{E}-10\end{aligned}$ & & 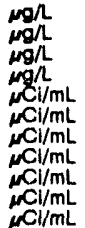 & $\begin{array}{l}\mathrm{GE} \\
\mathrm{GE} \\
\mathrm{GE} \\
\mathrm{GE} \\
\mathrm{GE} \\
\mathrm{GE} \\
\mathrm{EM} \\
\mathrm{GE} \\
\mathrm{GE} \\
\mathrm{TE} \\
\mathrm{TE}\end{array}$ \\
\hline
\end{tabular}

WELL BGO 42C

MEASUREMENTS CONDUCTED IN THE FIELO

$\begin{array}{ll}\text { Sample date: } 11 / 07 / 91 & \text { Time: } 8: 10 \\ \text { Dopth to water: } 72.97 \mathrm{ft}(22.24 \mathrm{~m}) \text { below TOC } & \text { pH: } 8.2 \\ \text { Water elevation: } 224.93 \mathrm{ft}(68.58 \mathrm{~m}) \mathrm{msl} & \text { Alkalinity: } 15 \mathrm{mg} / \mathrm{h} \\ \text { Sp. conductance: } 63 \mu \mathrm{s} / \mathrm{cm} & \text { Water temperature: } 16.4^{\circ} \mathrm{C} \\ \text { Water evacuated before sampling: } 18 \mathrm{gal} & \end{array}$

Water ovacuated before sampling: $18 \mathrm{gal}$

The well went dry during purging.

LABORATORY ANALYSES

E Analyte Result Mod Unit Lab

O $\mathrm{pH}$

Arsenic

Barium

Bromodichloromethane

Bromolorm

Bromomethane

Cadmium

Carcium

Chloride

Chlorobenzene

Chloroethene Ninyl chloride

2.Chloroethyl vinyl ether

2-Chloroethy

Chloroform

Chromium

o Dibromochloromethane

1,1-Dichloroethane

1,2-Dichloroethane

1,1-Dichloroethylene

trans $1,2 \cdot$ Dichloroethy

Dichioromethane

1,2-Dichloropropane

cis-1,3-Dichloropropene

0 trans-1,

E Endrin

Fluorid

0 Lead

0 Lindane

O Magnesium

O Manganose

Mercury

Nickel

Nitrate as nitrogen

Phenols

Potasslum

$\begin{array}{ll}0 & \text { Selenium } \\ 0 & \text { Silica }\end{array}$

Silica

Sodium

Sulfate

Ti,2,2-Tetrachloroethat

0 Toluene

Total dissolved solids

Total organic carbon

Total organic halogens

Toxaphene

2,4,5.TP (Silvex)

1,1,1-Trichloroethane

1,1,2-Trichloroethane

2 Trichloroethylene

o Trichloroffuoromethane

- Gross alpha

Nonvolatile beta

Total activity

- Tritium

O Uranium-233/234

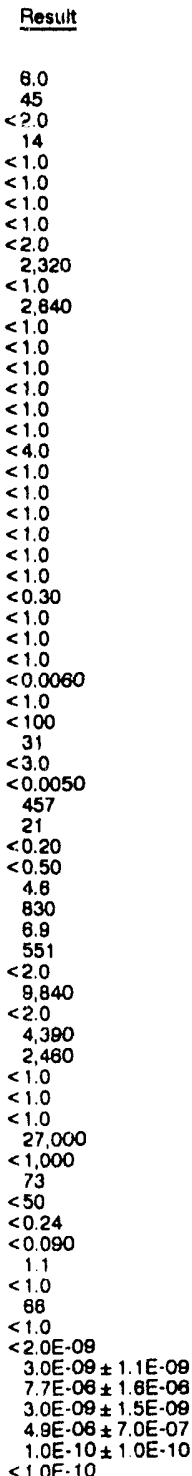

JQ

$\begin{array}{ll}\mathrm{pH} & \mathrm{GE} \\ \mu \mathrm{S} / \mathrm{cm} & \mathrm{GE} \\ \mathrm{mg} / \mathrm{L} & \mathrm{GE} \\ \mathrm{mg} / \mathrm{L} & \mathrm{GE} \\ \mathrm{m} / \mathrm{L} & \mathrm{GE} \\ \mathrm{m} / \mathrm{L} & \mathrm{GE} \\ \mathrm{m} / \mathrm{L} & \mathrm{GE} \\ \mathrm{mg} / \mathrm{L} & \mathrm{GE}\end{array}$

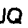

$\mathrm{JO}$

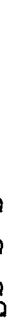

Jo

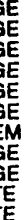


WELL BGO 43A

MEASUREMENTS CONDUCTED IN THE FIELD

Sample date: 11/05/91

Wepto

Sp. conductance: $4380 \mathrm{ps} / \mathrm{cm}$

Water evacuated before sampling: $21 \mathrm{gal}$

The woll want dry during purging.

LABORATORY ANALYSES

\begin{tabular}{|c|c|c|c|}
\hline Analyte & Result & Mod & Unit \\
\hline 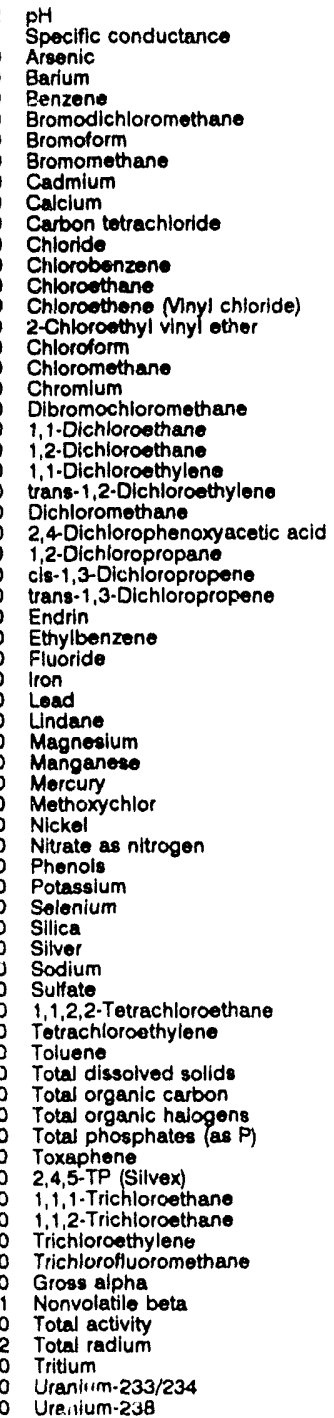 & 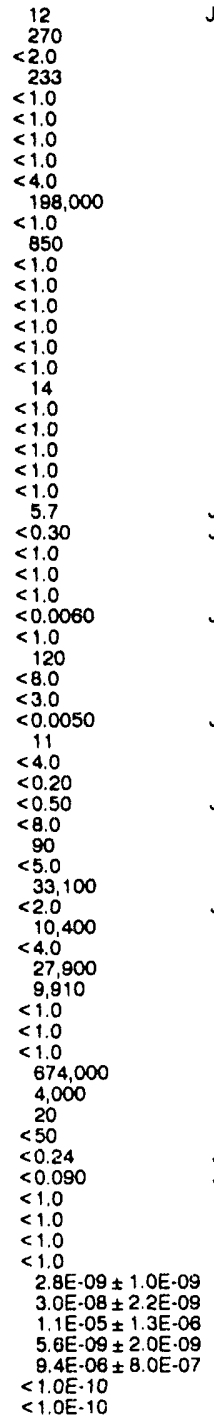 & $\begin{array}{l}\mathrm{J} \mathrm{JQ} \\
\mathrm{JQ}\end{array}$ & 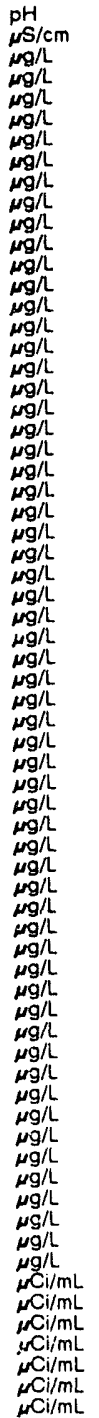 \\
\hline
\end{tabular}

\section{WELL BGO 43AA}

MEASUREMENTS CONDUCTED IN THE FIELD

Sample date: 11/04/81

Depth to water: $157.00 \mathrm{Ht}(47.85 \mathrm{~m})$ below TOC

Water olevation: $157.30 \mathrm{ft}(47.95 \mathrm{~m}) \mathrm{ms}$

Sp conductance: 227 $5 / \mathrm{cm}$

Water evacuated betore sampling: $564 \mathrm{gal}$

Time: 8:10

pH: 12.8 Alkalinity: $1114 \mathrm{mg} / \mathrm{h}$

Water temperature: $16.6^{\circ} \mathrm{C}$

LABORATORY ANALYSES

\begin{tabular}{llllll} 
E Analyte & Result & Mod & Unit & Lab \\
\cline { 2 - 5 } & & & & \\
2 & pH & 10 & JO & $\mathrm{pH}$ & $\mathrm{GE}$ \\
0 & Specific conductance & 170 & & $\mu \mathrm{Sicm}$ & $\mathrm{GE}$ \\
0 & Arsenic & 4.3 & &
\end{tabular}

WELL BGO 43AA collected on 11/04/91, laboratory analyses (cont.)

E Analyte Besult Mod Unit Lab

Barium

Benzene
0 Bromodichloromethane

Bromolorm

Bromomethane $<1.0$

Cadmium $<2.0$

0 Carbon tetrachioride $\quad<1.0$

$\begin{array}{lr}0 \text { Chloride } & 2,490 \\ 0 & 2,540\end{array}$

Choride

Chloroethane $<1.0$

Chloroethene Minyl chloride) $<1.0$

2.Chloroethyl vinyl other $<1.0$

0 Chloromethane $\quad<1.0$

0 Chromium

0 Dibromochloromethan

$\begin{array}{ll}0 & 1,1 \cdot \text { Dichloroethane } \\ 0 & 1,2 \cdot \text { Dichloroethane }\end{array}$

$\begin{array}{ll}0 & 1,2 \cdot \text { Dichloroethane } \\ 0 & 1,1 \cdot \text { Dichloroethylene }\end{array}$

o trans-1,2-Dichloroothylene

0 Dichloromethane

1,2-Dichloropropane

o cis-1,3-Dichloropropene

0 tyans-1,

Endrin
0 Ethylbenzeno

0 Fluoride

0 Iron

0 Lead

o Lindane

0 Magnesium

Mercury

Mrthoxychlor

0 Nitrate as nitrogen

0 Phenols

- Potassium

Selenium

$\begin{array}{ll}0 & \text { Silica } \\ 0 & \text { Silver }\end{array}$

Silver

Sodium

0 Sulfate

Sulfate

1,1,2,2-Tetrachloroe

Tetrachlorod

Toluene

Total dissolved solids

Total organic halogens

Total phosphates las ?

Toxaphene
2,4,5-TP (Silvex)

$1,1,1$-Trichloroethan

$1,1,2$-Trichloroethan

Trichloroethylene
Trichlorofluoromethane

Trichlorofluoro
Gross alpha

Nonvolatile beta

Total activity

Total radiu

Uranium-233/234

\section{Hg/L GE}

1.0
1.0
1.0
28
2.0
2.540
1.0
1.0
1.0
4.0
1.0

$<1.0$
$<1.0$

$<1.0$

$<1.0$

11
$<0.30$

$<1.0$

$<1.0$
$<1.0$

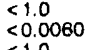

$<1.0$

165
173
$<4.0$

$<4.0$
$<3.0$

$<0.0050$

463
$<2.0$

$<2.0$
$<0.20$

$<0.50$
$<4.0$
$<50$

$<50$
$<5.0$

$<5.0$
9,060
$<2.0$

$<2.0$
20,200
$<2.0$

$<2.0$

11,100

11,200

$<1.0$
$<1.0$

$<1.0$

95,000
$<1,000$

$<1,000$

12
50
$<024$

$<0.24$

$<1.0$

$<1.0$

$<1$

$<1.0$
$<2.0 E-09$

$<2.0 E-09$
$8.8 \mathrm{E}-09 \pm 1.9 \mathrm{E}-09$

$8.8 \mathrm{E} \cdot 09 \pm 1.9 \mathrm{E}-09$
$-1.9 \mathrm{E} \cdot 07 \pm 1.4 \mathrm{E} \cdot 06$

2.3E- $09 \pm 1.8 \mathrm{E}-09$

$<7.0 \mathrm{E}-07$

$5.0 \mathrm{E} \cdot 10 \pm 2.0 \mathrm{E} \cdot 10$
$3.0 \mathrm{E} \cdot 10 \pm 1.0 \mathrm{E} \cdot 10$

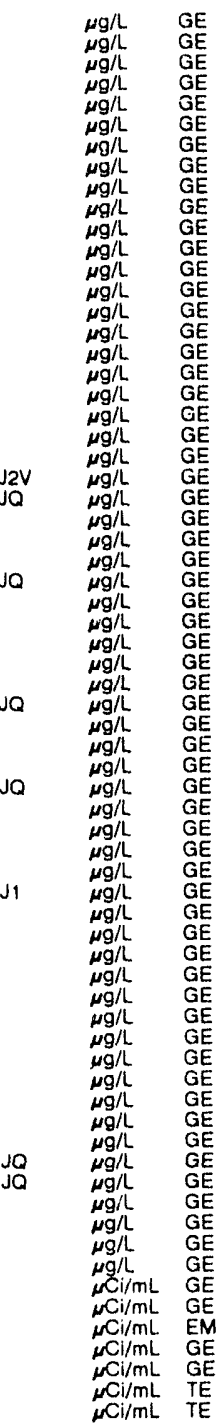

\section{WELL BGO 43D}

MEASUREMENTS CONDUCTED IN THE FIELD

Sample date: $11 / 04 / 91$

epth to water: $82.51 \mathrm{H}(25.15 \mathrm{~m})$ below TOC

Sp conductance $232.79 \mathrm{tt}(70$.

Water evacuated before sampling: 92 ge

PH: 62

Alkalinity. $8 \mathrm{mg} / \mathrm{h}$

Water temperature: $13.3^{\circ} \mathrm{C}$

LABORATORY ANALYSES

\begin{tabular}{|c|c|c|c|c|}
\hline$F$ & Analyte & Result & Mod & Unit \\
\hline 0 & $\begin{array}{l}\text { pH } \\
\text { Specific conductance } \\
\text { Arsenic } \\
\text { Barium } \\
\text { Benzene } \\
\text { Bromodichloromethane } \\
\text { Bromoform } \\
\text { Bromomethane } \\
\text { Cadmium } \\
\text { Calcium } \\
\text { Carbon tetrachloride } \\
\text { Chloride } \\
\text { Chlorobenzene } \\
\text { Chloroethane } \\
\text { Chloroethene Vinyl chloride) }\end{array}$ & $\begin{aligned} & 6.1 \\
& 80 \\
&<2.0 \\
& 23 \\
&<1.0 \\
&<1.0 \\
&<1.0 \\
&<1.0 \\
&<2.0 \\
& 7.590 \\
&<1.0 \\
& 2.870 \\
&<1.0 \\
&<1.0 \\
&<1.0\end{aligned}$ & $J u$ & $\begin{array}{l}\mathrm{pH} \\
\mu \mathrm{S} / \mathrm{cm} \\
\mu \mathrm{g} / \mathrm{h} \\
\mu \mathrm{g} / \mathrm{L} \\
\mu \mathrm{g} / \mathrm{L} \\
\mu \mathrm{g} / \mathrm{L} \\
\mu g^{\prime \prime h} \\
\mu \mathrm{g} / \mathrm{L} \\
\mu \mathrm{g} / \mathrm{i} \\
\mu \mathrm{g} / \mathrm{L} \\
\mu \mathrm{g} / \mathrm{L} \\
\mu \mathrm{g} / \mathrm{L} \\
\mu \mathrm{g} / \mathrm{L} \\
\mu \mathrm{g} / \mathrm{L} \\
\mu \mathrm{g} / \mathrm{L}\end{array}$ \\
\hline
\end{tabular}


ANALYTICAL RESULTS

WELL BGO 430 collected on 1!/04/91, laboratory analyses (cont.)

\begin{tabular}{|c|c|c|c|c|c|}
\hline & Analyte & Result & Mod & Unit & $\underline{L a b}$ \\
\hline & 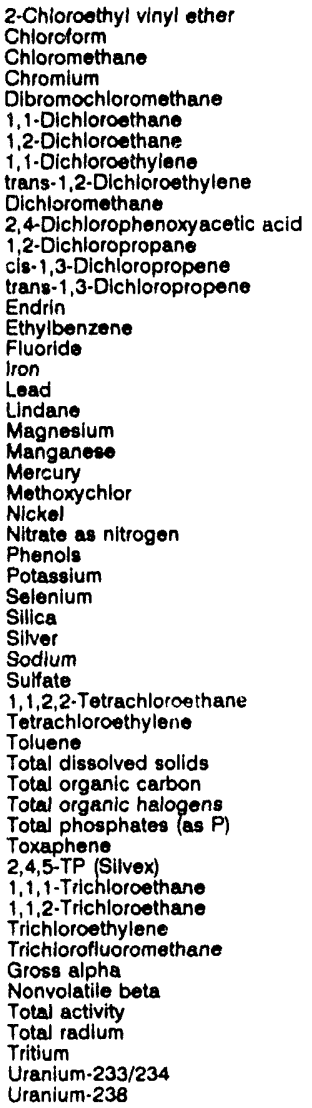 & 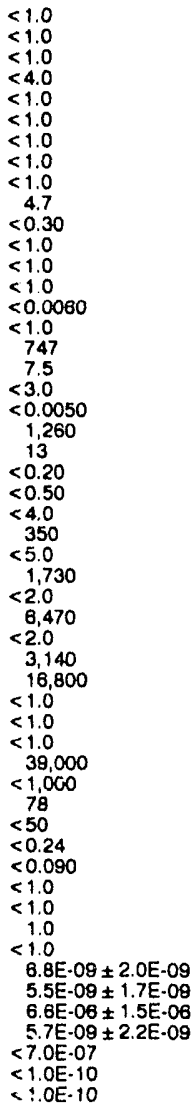 & $\begin{array}{l}\mathrm{J} 2 \mathrm{~V} \\
\mathrm{JQ}\end{array}$ & 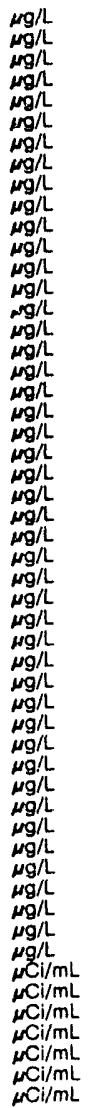 & $\begin{array}{l}G E \\
G E \\
G E \\
G E \\
G E \\
G E \\
G E \\
G E \\
G E \\
G E \\
G E \\
G E \\
G E \\
G E \\
G E \\
G E \\
G E \\
G E \\
G E \\
G E \\
G E \\
G E \\
G E \\
G E \\
G E \\
G E \\
G E \\
G E \\
G E \\
G E \\
G E \\
G E \\
G E \\
G E \\
G E \\
G E \\
G E \\
G E \\
G E \\
G E \\
G E \\
G E \\
G E \\
G E \\
G E \\
G E \\
G E \\
G E \\
E M \\
G E \\
G E \\
T E \\
T E\end{array}$ \\
\hline
\end{tabular}

\section{WELL BGO 45A}

MEASUREMENTS CONDUCTED IN THE FIELD

Sample date: 10/22/91

Depth to water: $117.56 \mathrm{ft}(35.83 \mathrm{~m})$ below TOC

Water elevation: $161.34 \mathrm{ft}(49.18 \mathrm{~m}) \mathrm{ms}$

Water evacuatod before sampling: $118 \mathrm{gal}$

LABORATORY ANALYSES

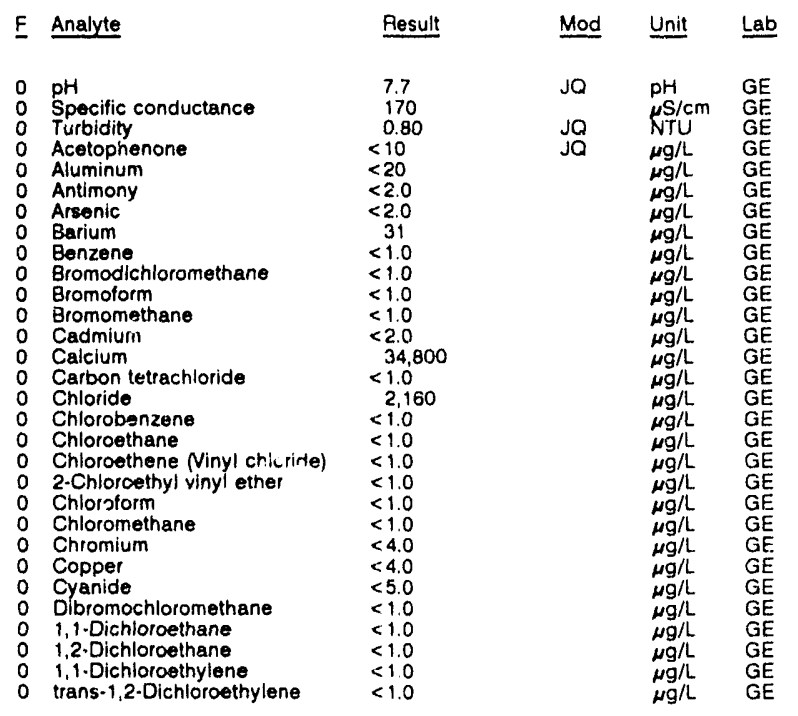

WELL BGO 45A collected on 10/22/91, laboratory analysos (cont.)

\begin{tabular}{|c|c|c|c|c|c|}
\hline & Analyte & Rosuit & Mod & Unit & Lab \\
\hline & 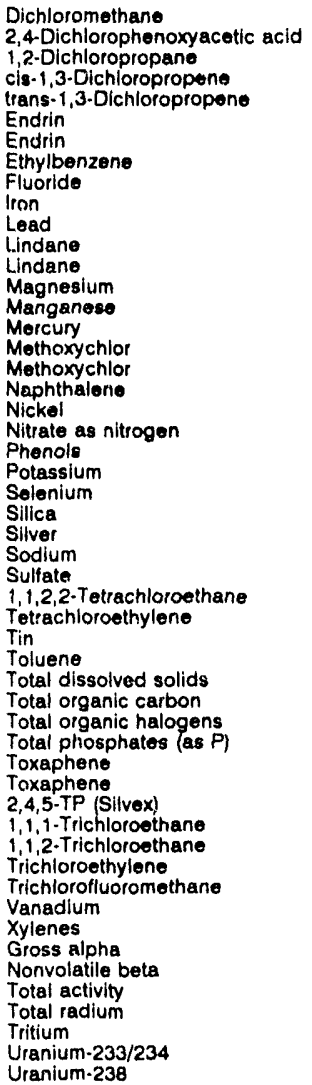 & 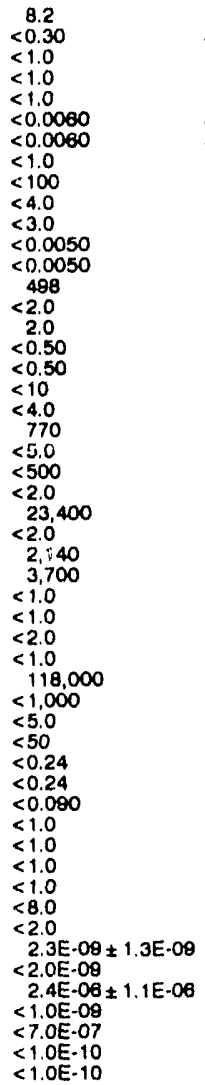 & $\begin{array}{l}\mathrm{JQ} \\
\mathrm{JQ} \\
\mathrm{JQ}\end{array}$ & 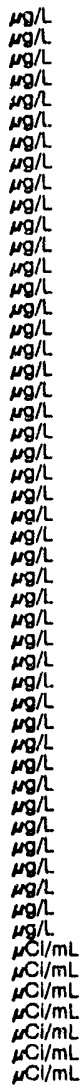 & $\begin{array}{l}G E \\
G E \\
G E \\
G E \\
G E \\
G E \\
G E \\
G E \\
G E \\
G E \\
G E \\
G E \\
G E \\
G E \\
G E \\
G E \\
G E \\
3 \\
G E \\
G E \\
G E \\
G E \\
G E \\
G E \\
G E \\
G E \\
G E \\
G E \\
G E \\
G E \\
G E \\
G E \\
G E \\
G E \\
G E \\
G E \\
G E \\
G E \\
G E \\
G E \\
G E \\
G E \\
G E \\
G E \\
G E \\
G E \\
G E \\
G E \\
E M \\
G E \\
G E \\
T E \\
T E\end{array}$ \\
\hline
\end{tabular}

\section{WELL BGO 45B}

MEASUREMENTS CONDUCTED IN THE FIELD

F Analyte Result Ul Unit Lab

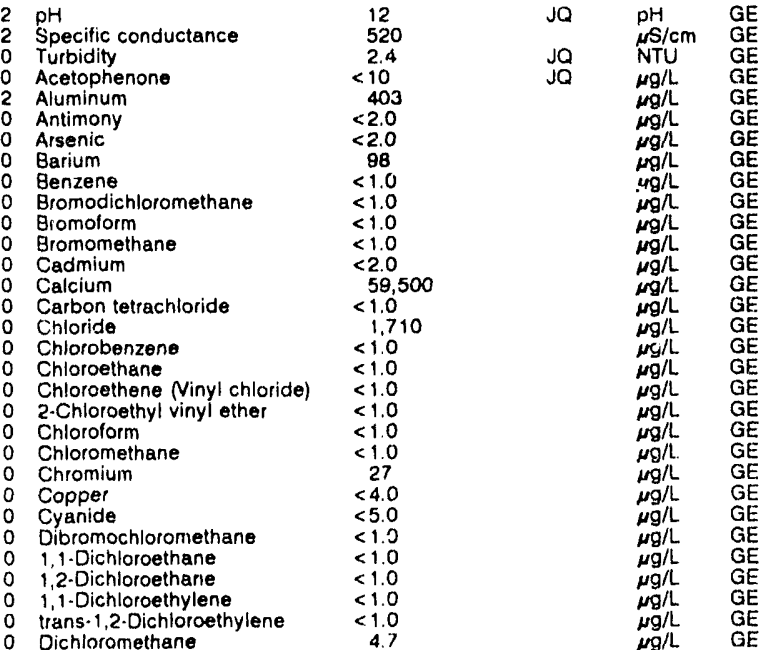

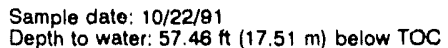

Water elevation: $221.14 \mathrm{ft}(67.40 \mathrm{~m}) \mathrm{msl}$

Sp. conductance: $1632 \mu \mathrm{S} / \mathrm{cm}$

Sp. conductance: $1632 \mu \mathrm{s} / \mathrm{cm}$
Water evacuated belore sampling: $43 \mathrm{gal}$
The well went dry during purging.

LABORATOAY ANALYSES

Time: $15: 30$

Alkalinity: $538 \mathrm{mg} / \mathrm{L}$

Water temperature: $18.4^{\circ} \mathrm{C}$

pH: 9.9

Alkalinity: $82 \mathrm{mg} / \mathrm{L}$
Water temperature: $19.5^{\circ} \mathrm{C}$ 
WELL BGO $45 B$ collected on 10/22/91, laboratory analyses (cont.)

\begin{tabular}{|c|c|c|c|c|c|}
\hline$E$ & Analyte & Result & Mod & Unit & \\
\hline $\begin{array}{l}0 \\
0 \\
0 \\
0 \\
0 \\
0 \\
0 \\
0 \\
0 \\
0 \\
0 \\
0 \\
0\end{array}$ & 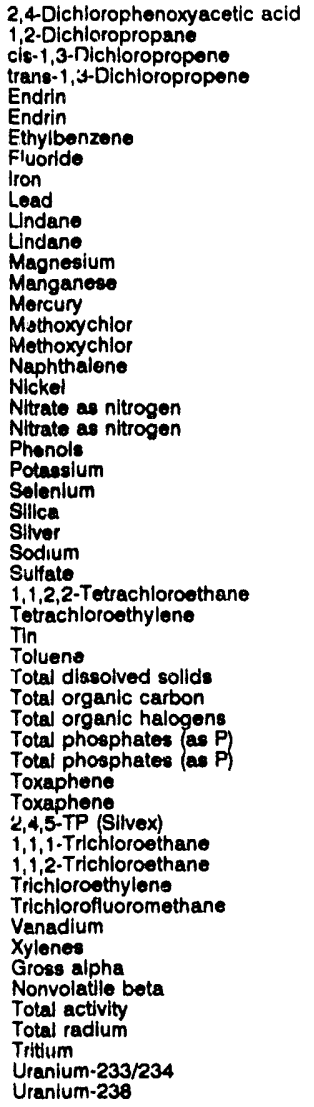 & 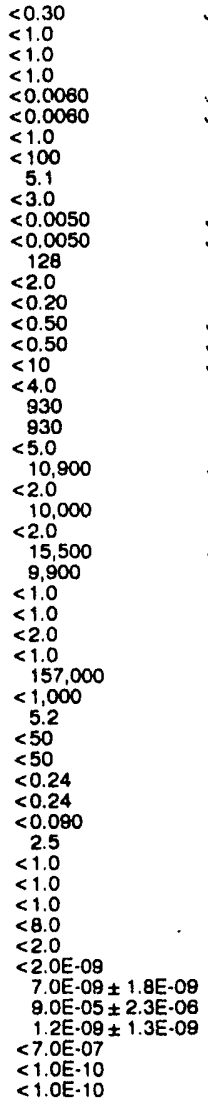 & $\begin{array}{l}\mathrm{JQ} \\
\mathrm{JQ} \\
\mathrm{JQ}\end{array}$ & $\begin{array}{l}\mu g / L \\
\mu g / L \\
\mu g / L \\
\mu g / L \\
\mu g / L \\
\mu g / L \\
\mu g / L \\
\mu g / L \\
\mu g / L \\
\mu g / L \\
\mu g / L \\
\mu g / L \\
\mu g / L \\
\mu g / L \\
\mu g / L \\
\mu g / L \\
\mu g / L \\
\mu g / L \\
\mu g / L \\
\mu g / L \\
\mu g / L \\
\mu g / L \\
\mu g / L \\
\mu g / L \\
\mu g / L \\
\mu g / L \\
\mu g / L \\
\mu g / L \\
\mu g / L \\
\mu g / L \\
\mu g / L \\
\mu g / L \\
\mu g / L \\
\mu g / L \\
\mu g / L \\
\mu g / L \\
\mu g / L \\
\mu g / L \\
\mu g / L \\
\mu g / L\end{array}$ & 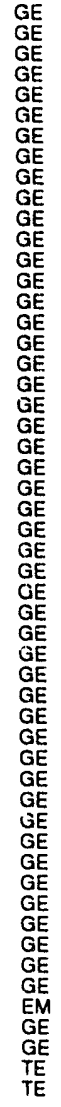 \\
\hline
\end{tabular}

WELL BGO 45C

MEASUREMENTS CONOUCTED IN THE FIELD

Depth to water: $53.94 \mathrm{th}(18.44 \mathrm{~m})$ below TOC

Water elevation: $224.66 \mathrm{ht}(68.48 \mathrm{~m}) \mathrm{msl}$

Sp. conductance: $102 \mu \mathrm{S} / \mathrm{cm}$

Water evacuated belore sampling: $2 n$ gal

The well went dry during purging.

LABORATORY ANALYSES

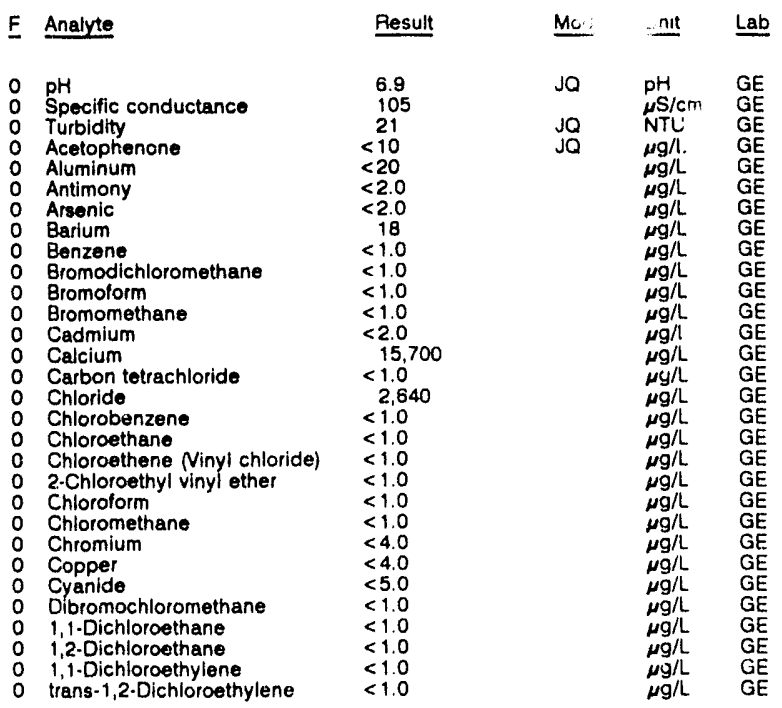

pH: 6.5

Alkalinity: $38 \mathrm{mg} / \mathrm{h}$
WELL BGO $45 \mathrm{C}$ collectod on 10/22/91, laboratory analyses (cont.)

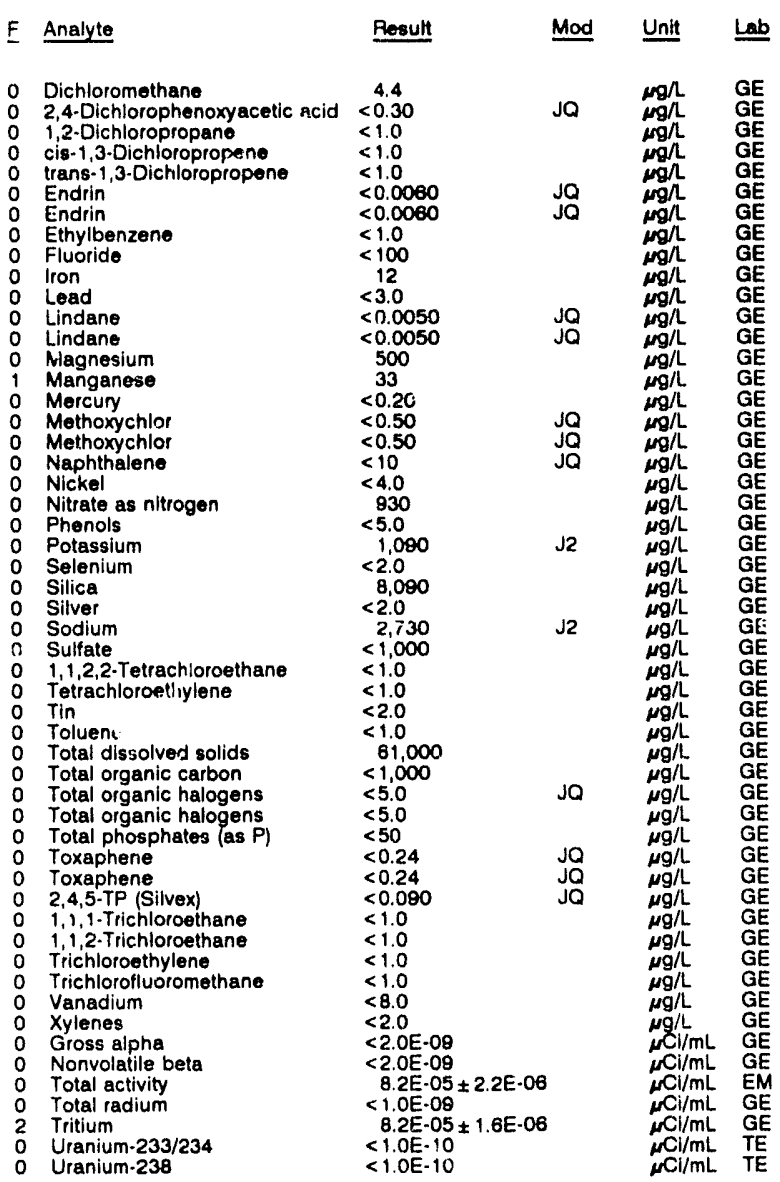

\section{WELL BGO 45D}

MEASUREMENTS CONDUCTED IN THE FIELD

Sample date: $10 / 22 / 91$

Depth to water: $48.81 \mathrm{ft}(14.88 \mathrm{~m})$ below TOC

Water elevation: $229.79 \mathrm{ft}(70.04 \mathrm{~m}) \mathrm{ms}$.

Sp. conductance: $28 \mu \mathrm{S} / \mathrm{cm}$
Water evacuated betore sampling: $54 \mathrm{gal}$

Water evacuated before sam

E Analyte Result Mod Unit Lab

${ }_{0}^{0} \quad \mathrm{pH}$ Specific conductance

Turbidity

Aluminum

Antimony

Arsenic

0 Barium

Bromodichloromethane

Bromoform

Bromomethane

Cadmium

Carbon tetrachloride

Chloride

Chloride

Chlorobenzene

Chloroethene Ninyl chloride)

2-Cnloroethyl vinyl ether

0 Chloroform

o Chloromethane

Chromiun

Copper

0 Dil:-.ncchloromethane

2. Oichlorethane

1, 1. Oichloroethylene 
ANALYTICAL RESULTS

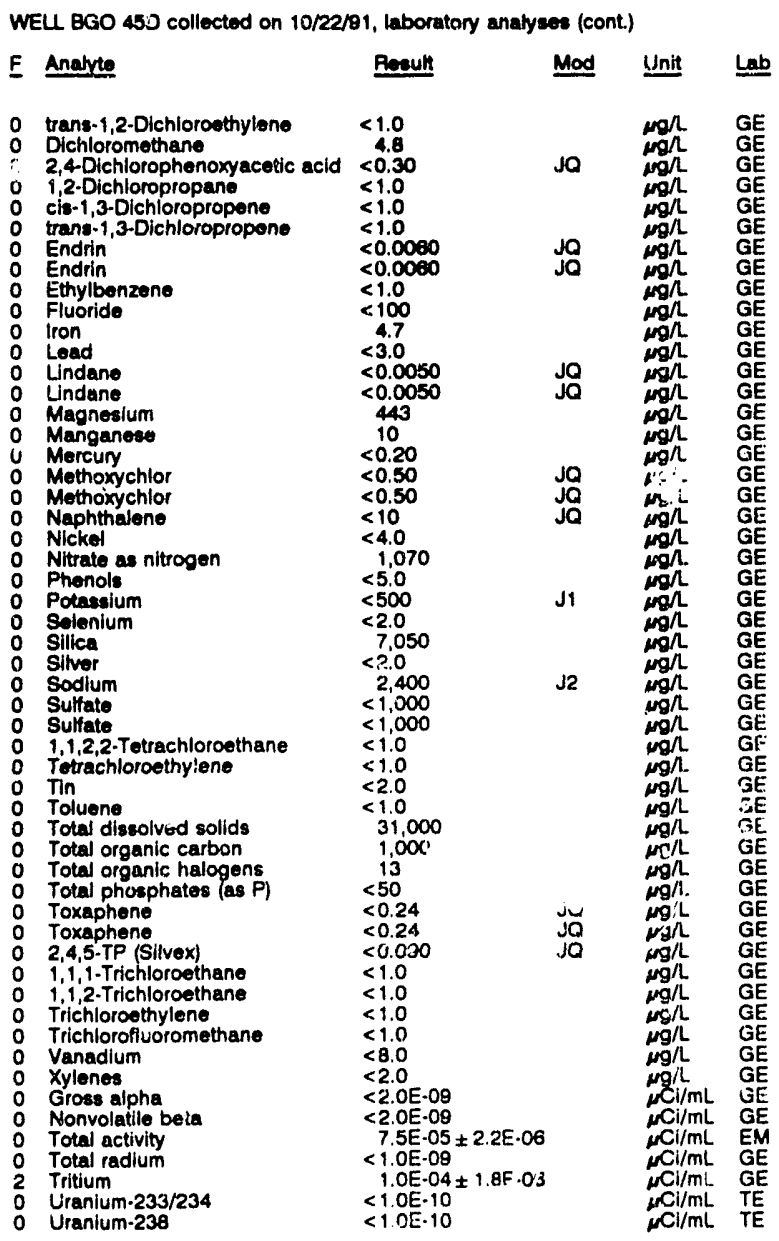

WELL BGO 46B

MEASUREMENTS CONDUCTED IN THE FIELD

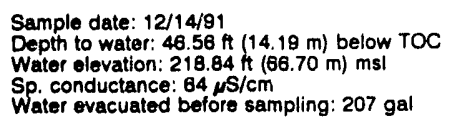

Time: $14: 10$

$\mathrm{pH}: 6.3$

Alkalinity: $20 \mathrm{mg} / \mathrm{L}$

Water temperature: $19.7^{\circ} \mathrm{C}$

LABORATORY ANALYSES

\begin{tabular}{|c|c|c|c|c|c|}
\hline$F$ & Analyte & Result & Mod & Unit & Lab \\
\hline $\begin{array}{l}0 \\
0 \\
0 \\
0 \\
0 \\
0 \\
0 \\
0 \\
0 \\
0 \\
0 \\
0 \\
0 \\
0 \\
0 \\
0 \\
0 \\
0 \\
0 \\
0 \\
0 \\
0 \\
0 \\
0 \\
0 \\
0 \\
0 \\
0 \\
0 \\
0 \\
0 \\
0 \\
0\end{array}$ & $\begin{array}{l}\text { pH } \\
\text { Specific conductance } \\
\text { Arsenic } \\
\text { Barium } \\
\text { Benzene } \\
\text { Bromodichloromethane } \\
\text { Bromoform } \\
\text { Bromomethane } \\
\text { Cadmium } \\
\text { Calcium } \\
\text { Carbon tetrachloride } \\
\text { Chloride } \\
\text { Chlorobenzene } \\
\text { Chloroethane } \\
\text { Chloroethene Ninyl chloride) } \\
\text { 2-Chloroethyl vinyl ether } \\
\text { Chloroform } \\
\text { Chlorometl ne } \\
\text { Chromlum } \\
\text { Dibromochloromethane } \\
1,1-\text { Dichloroethane } \\
1,2-\text { Dichloroethane } \\
1,1-\text { Dichloroethyler.e } \\
\text { trans-1,2-Dichloroethylene } \\
\text { Dichloromethane } \\
2,4-\text { Dichlorophenoxyacetic acid } \\
\text { 1,2-Dichloropropans } \\
\text { cis-1,3-Dichloropropene } \\
\text { trans-1,3-Dichioropropene }\end{array}$ & $\begin{aligned} & 6.7 \\
& 65 \\
&<2.0 \\
& 3.2 \\
&<1.0 \\
&<1.0 \\
&<1.0 \\
&<1.0 \\
&<2.0 \\
& 9.030 \\
&<1.0 \\
& 2,340 \\
&<1.0 \\
&<1.0 \\
&<1.0 \\
&<1.0 \\
&<1.0 \\
&<1.0 \\
&<4.0 \\
&<1.0 \\
&<1.0 \\
&<1.0 \\
&<1.0 \\
&<1.0 \\
&<1.0 \\
&<0.30 \\
&<1.0 \\
&<1.0 \\
&<1.0\end{aligned}$ & JO & 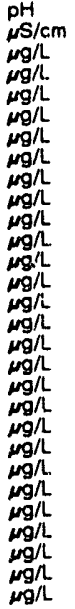 & $\begin{array}{l}\mathrm{GE} \\
\mathrm{GE} \\
\mathrm{GE} \\
\mathrm{GE} \\
\mathrm{GE} \\
\mathrm{GE} \\
\mathrm{GE} \\
\mathrm{GE} \\
\mathrm{GE} \\
\mathrm{GE} \\
\mathrm{GE} \\
\mathrm{GE} \\
\mathrm{GE} \\
\mathrm{GE} \\
\mathrm{GE} \\
\mathrm{GE} \\
\mathrm{GE} \\
\mathrm{GE} \\
\mathrm{GE} \\
\mathrm{GE} \\
\mathrm{GE} \\
\mathrm{GE} \\
\mathrm{GE} \\
\mathrm{GE} \\
\mathrm{GE} \\
\mathrm{GE} \\
\mathrm{GE} \\
\mathrm{GE} \\
\mathrm{GE}\end{array}$ \\
\hline
\end{tabular}

WELL BGO 468 colloctod on 12/14/91, laboratory analyses (cont.)

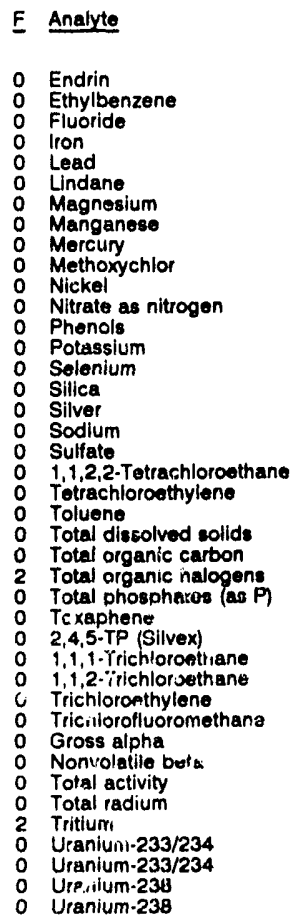

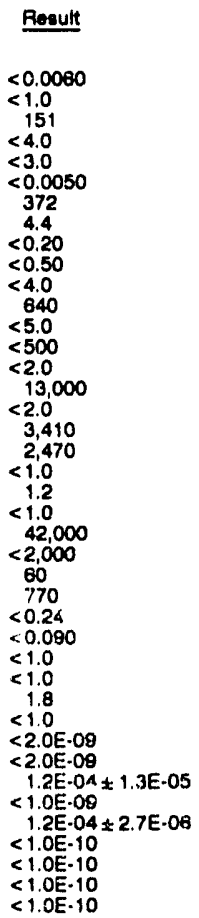

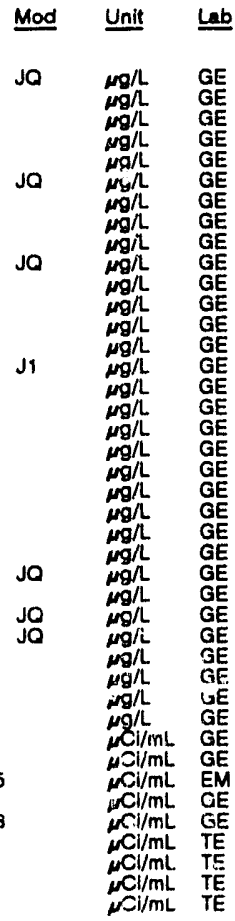

\section{WELL BGO $46 C$}

MEASUREMENTS CONDUCTED IN THE FIELD

Sample dete: 12/15/81

Depth to water: $44.64 \mathrm{ft}(13.81 \mathrm{~m})$ below TOC

Nater elevation: $220.46 \mathrm{ht}(67.20 \mathrm{~m}) \mathrm{ms}$.

Wh. co.iductarice: $74 \mu \mathrm{H} / \mathrm{cm}$.

pH: 6.6 . $20 \mathrm{mg}$

Water temperature: $17.2^{\circ} \mathrm{C}$ The we!l went dry during purging.

LABOFALIORY ANALYSES

E Analyte Result Mod Unit Lab

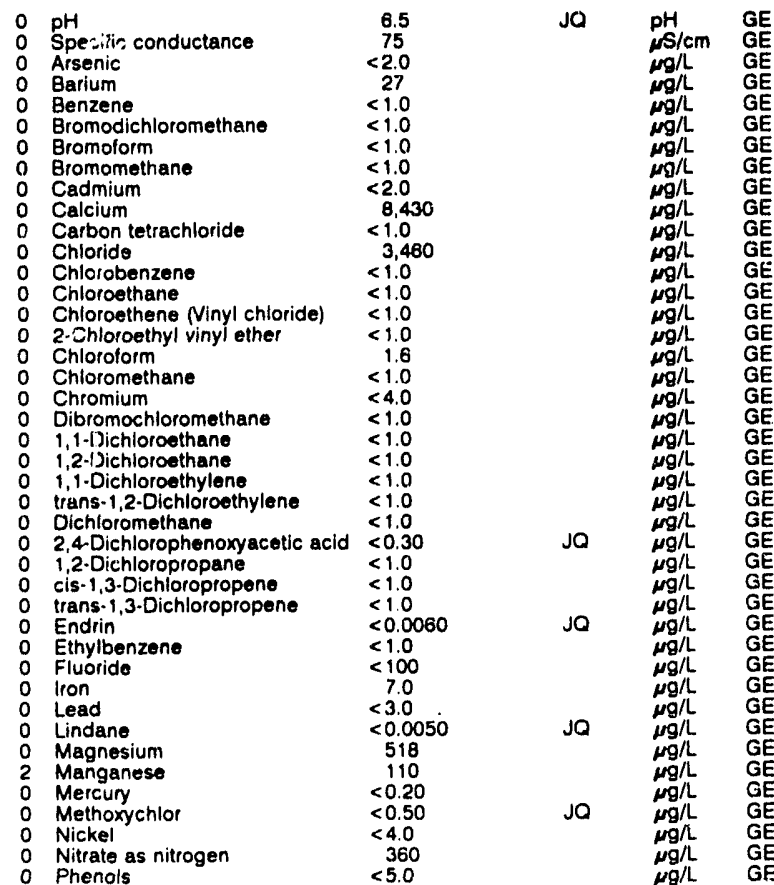


ANALYTICAL RESULTS

WELL. BGO 47C

MEASUREMENTS CONDUCTED IN THE FIELD

Sample dato: 11/04/81

Dopth to water: $43.91 \mathrm{ft}(13.16 \mathrm{~m})$ below TOC
Water elovation: $224.41 \mathrm{ft}\left(68.4 \mathrm{~S}^{\mathrm{in}}\right) \mathrm{ms}$ (

Sp. conductance: $34 \mu \mathrm{s} / \mathrm{cm}$

Water evacuated before sampling: $122 \mathrm{gal}$

LABORATORY ANALYSES

E Anabyte Bosult Mod Unit Lab

Specific conductance

: Arsenic

Benzeno

Bromodichloromethane

Bromoform

Bromomethan

Cadmium

Carbon tetrachloride

Chioride

Chiorobenzene

Chloroethene Ninyl chloride

2.Chloroethyl vinyl ether

Chlorotorm

Chloromethane

Chromium

Dibromochloromethane

1,1-Dichioroethane

1 i. Dichloroethylene

trans-1,2-Dichloroethylene

Dichloromethane

2,4-Dichlorophenoxyacetic acid

1,2-Dichloropropane

cis-1,3-Dichloropropene
trans-1,3-Dichloropropene

Endrin

Ethylbenzene

Fluoride

Iron

0 Lead

Magnesium

Manganese

Mercury

Mickel

Nitrate as nitrogen

Phenols

Potasgium

Selenium

Silica

Sodium

Sulfate

Totrachloroethylene

Toluene

Total dissolved solids

Total organic carbon

Total organic halogens

Total phosphates (as P)

Toxaphene

2,4,5-TP (Silvox)

1, 1,1-Trichloroethane

$1,1,2-$ Trichloroethane
Trichloroethylene

Trichiorofluoromethane

Cross alpha

Nonvolatile beta

Total activity

Tritium

Uranium-233/234

Uranium.238
Time: 16:25

pH: 5.9

Alkalinity: $5 \mathrm{mg} /$

Water temperature: $19.5^{\circ} \mathrm{C}$

Mod Unit Lab

6.0
35
$<2.0$
8.0
$<1.0$
$<1.0$
$<1.0$
$<1.0$

$<1.0$

2,350
$<1.0$

$\begin{aligned} 1,980 & <.0\end{aligned}$

$<1.0$

$<1.0$

$<1.0$

$<1.0$

$<4.0$

$<1.0$

$<1.0$

$<1.0$

$<1.0$

$<1.0$

$<1.0$

$<<<0.0060$

$<1.0$

$<100$
$<100$

$<4.0$

$<0.0050$

575
11

$<0.20$

$<0.50$

1,510
$<50$

786
$<2.0$

8.860
$<2.0$

$<2.0$

$<1,000$

$<1.0$

$<1.0$

$<16,000$

$<1,000$
32

50
$<0.2$
$<0.0$, ।
$<1$.

$<1.0$

2.7
$<1.0$

$<<<2.00-09$

$<2.0 \mathrm{OE} .09$

3. KE-04 $\pm 4.5 E-06$

$3.6 E-09 \pm 1.8 E-09$

$<1.0 \mathrm{E}-10$
$J Q \quad P H / G E$

$\begin{array}{ll}\mu g h & \mathrm{GE} \\ \mu \mathrm{g} / & \mathrm{GE} \\ \mu \mathrm{g} / \mathrm{GE} & \mathrm{GE}\end{array}$

GE

EE

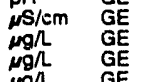

WELL BGO 47D

MEASUREMENTS CONDUCTED IN THE FIELD

Sample date: 11/04/01

Depth to water: $39.16 \mathrm{ft}(11.94 \mathrm{~m})$ below TOC

Water olevation: $228.24 \mathrm{~h}(88.5$

Sp. conductance: $41 \mu \mathrm{s} / \mathrm{cm}$

Wher evacualod betore sampling: 0 gal

LABORATORY ANALYSES

E Analyte Result Mod Unit Lab

$\begin{array}{ll}0 & \mathrm{pH} \\ 0 & \text { Specific conductance }\end{array}$

0 Arsenic

Bromodichloromethane

Bromolorm

Bromomethan

Cadmium

Carbon tetrachloride

Carbon toride

Chlorobenzene

Chlorcethane

Chloroethene Ninyl chloride)

.Chloroethyl vinyl ether

Chloroform

Chloromethane

Cibromochloromethane

1.1-Dichloroethane

1, -Dichloroethylene

trans-1,2-Dichloroethylene

trans-1,2-Dichloroe

2,4-Dichlorophenoxyacetic acid

1,2-Dichloropropane

cis-1,3-Dichloropropene

Endrin

Ethylbenzene

Fluoride
Iron

Lead

Lindane

Magnesium

Mercuny

Methoxychlor

Nickel

Nitrate as nitrogen

Phenols

Selenium

Silica

Silver

Sodium

Sulfate . Tetrachioroethane

Tettachloroethylene

Tetrachior

- Total dissolved solids

Total organic carbon

Total organic carbon

Total organic halogens

0 Toxaphene

2,4,5-TP (Silvex)

1,1,1-Trichloroethune

2. Trichloroethylene

Trichlorofluoromethane

Gross alpha

Nonvolatile beta

Total activity

2 Tritium

Uranium-233/234

Uranium-238
Time: 16:00

Alkalinity: $3 \mathrm{mg}$

Water temperature: $18.0^{\circ} \mathrm{C}$

5.7

so $\quad \stackrel{p H}{\mu S / c m} \quad \mathrm{GE}$

$<2.0$

$<1.0$

$<1.0$

$<1.0$

2,270
$<10$

1.0
2,820

$<1.0$

$<1.0$

$<1.0$

$<1.0$

$<4.0$

$<1.0$

$<1.0$

$<1.0$

$<0.30$

$<1.0$

$<1.0$
$<1.0$
$<0.0060$

$<0.0060$

$<100$
5.7

$<3.0$

$<0.0050$
800

800
22

$<0.20$
$<0.50$

$<0.50$
$<4.0$

2,300
$<5.0$

$<500$

$<2.0$

$<2.0$
3,480

$<1,000$

$<1.0$
$\quad 1.6$

1.6
$<1.0$
$<.000$

18,000

$<1,000$

23
$<50$

$<0.24$
$<0.090$

$<1.0$

$<1.0$
8.8

9.8
$<1.0$

$<2.0 E .09$

1. $3 \mathrm{E}-03 \pm 8.2 \mathrm{E}-06$

4.2E-09 $1.8 E-09$

$<1.0 \mathrm{E} \cdot 10$
$2.0 \mathrm{E} \cdot 09+1.3 \mathrm{E} \cdot 09$ 
WELL BGO $48 C$

MEASUREMENTS CONDUCTED IN THE FIELD

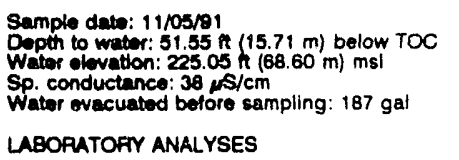

Time: $14: 15$

PH: 5.6 : 5 mall

Water temperature: $19.1^{\circ} \mathrm{C}$

LABOPATOFIY ANALYSES

F Anabyte Result Mod Unit Lab

O pH

Arrenic

O Benzene

Bromodichloromethane

o Bromotorm 01

O Cadmium

O Cartum

o Chloride

- Chlorobenzene

Chiorothane

2-Chloroethyl vinyl other

Chlorolorm

Chloromethane

Chromium

o 1,2-Dichloroethane

1,1-Oichloroethylene

o trans-1,2-Dichlorce

2,4-Dichlorophenoxyacetic acid

1,2-Dichloropropane

o cis-1,3-Dichloropropene

0 Endrin

O Ethylbenzene

o Fluoride

o Iron

Lindane

Magnesium

Manganese

Methoxychior

Nickel

Nitrate as nitrogen

Nitrate as nitrogon

Phonols

Potassium
Selenium

Selenium

Silva

Sodium

1,1,2,2-Tetrachloroethane

Tetrachloroethylene

Tolvene

Total dissolved solids

Total organic carbon

Total phosphates (as P)

Toxaphene

2,4,5-Tr (Silvex)

1,1,2-Trichloroethane

Trichloroethylene

Trichlorofivoromethane

Gross alpha

Total activity

Totel radium

Tritium

Uranium-233/234

Uranium-238
5.9
50
$<2.0$
12
$<1.0$
$<1.0$
$<1.0$
$<1.0$
$<2.0$
2.3
$<1.0$
$<1.7$
$<1.0$
$<1.0$
$<1.0$
$<1.0$
1.2
$<1.0$
$<4.0$
$<1.0$
$<1.0$
$<1.0$
$<1.0$
$<1.0$
118
$<0.30$
$<1.0$
$<1.0$

$<1.0$
$<1.0$

$<1.0$
$<0.0060$
$<1.0$
$<100$

$<100$

$<4.0$

$<0.0050$
573

$\begin{aligned} & 16 \\ < & 0.20 \\ < & 0.50 \\ < & 4.0\end{aligned}$

1,900
1,900

$\begin{aligned} & 1,900 \\ < & 5.0\end{aligned}$

707
$<2.0$
7,650

7,650
$<2.0$
2.370

2,370
$<1,000$

$\begin{array}{r}<1.5 \\ 1.0 \\ \hline\end{array}$

$<1.0$

31,000
$<1,000$

$<1.000$
$<50$
$<50$

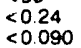

$<0.090$
$<1.0$

$<1.0$

2.3
$<1.0$

$<2.0 \mathrm{E}-09$

$2.5 \mathrm{E} \cdot 09 \pm 8.9 \mathrm{E} \cdot 10$

1.5E-03 $\pm 8.6 \mathrm{E}-06$

$<1.0 \mathrm{E}-09$

$1.4 \mathrm{E}-03 \pm 5.9 \mathrm{E} \cdot 06$

$<1.0 \mathrm{OE} \cdot 10$
$<1.0 \mathrm{E} \cdot 10$
WELL BGO 48D

MEASUREMENTS CONDUCTED IN THE FIELD

Sample date: 11/05/81

Depth to water: $48.35 \mathrm{ft}(14.74 \mathrm{~m})$ below TOC

Water elevation: $228.55 \mathrm{~h}$ (68.

W. conduclance. $58 \mathrm{ps} / \mathrm{cm}$.

pH: 4.7 : 7 : 0 malinity: 0 mo:

Water temparature: $18.5 \circ \mathrm{C}$

LABORATOAY ANALYSES

F Analyte Result Mod Unit Lab

$\begin{array}{ll}0 & \mathrm{pH} \\ 0 & \text { Specific conductance }\end{array}$

0 Arsenic

0 Barium

Bromodichloromethane

Bromoform

Bromomethan

Cadcium

Carbon tetrachloride

Chloride

Chlorobenzene

Chioroethene Ninyl chloride)

2.Chloroethyl vinyl ether

Chloroform

Chloromethan

Dibromochloromethane

1,1-Dichloroethane

o 1,2-Dichioroethane

1,1-Dichloroethylen

trans-1,2-Dichloroet!iylene

Dichloromethane
2.4-Dichlorophenoxyacetic acid

1,2-Dichloropropane

0 cis-1,3-Dichloropropene

Endrin

Ethylbenzene

(inoride

lion

Lindane

Magnesium

Mangan

Methoxychlo

Nicke

Nitrate as nitrogen
Nitrate as nitrogen

Phenols

Potassium

Selassium

Silica

Sodium

Sodium

1,1,2,2-Tetrachloroethan

Tetrachloroethylene

Tolvene

Total dissolved solids

Total dissolved solids

Total organic carbon

Total organic carbon

Total organic halogens
Total phosphates (as P)

Toxaphene

2,4,5-TP (Silvex)

1,1,1. Trichloroethane

Trichloroethylene

Trichlorofluoromethane

Gross alpha

- Nonvolatile beta

Total activity

Total radium

2 Tritium

U Uranium-233/234

Result Mod Unit Lab

JO $\quad \mathrm{PH}$ GE

$<5$.

2.22
$<1.0$

$<1.0$

$<1.0$

$<2.170$

$<1.0$

$<8.0$

$<\begin{aligned}<1.0 \\ <1.0\end{aligned}$

$<1.0$

2.0
$<1.0$

$<\begin{array}{r}<1.0 \\ <4.0\end{array}$

$<1.0$

$<10$

$<1.0$

$<1.0$
$<0.30$

$<1.0$

$<1.0$

$<0.006$ n

$<1.0$

4.6
3.2

$<0.0050$

1,020

$\begin{aligned} & 12 \\ & 0.36 \\ &<0.50 \\ &<4.0\end{aligned}$

$<4.0$

2,500
$<5.0$

$<5.0$

$\begin{array}{r}638 \\ <2.0 \\ \hline\end{array}$

$<2.0$

$<2.0$

5,000

$<1.0$

38.000

38,000
38,000

$<1,000$

1,000

153
50

50
$<0.24$
$<0.000$

$<0.090$

$<1.0$
$<1.0$

71
$<10$

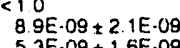

5. $3 \mathrm{E} .09+1.6 \mathrm{E} .09$

3. $4 \mathrm{E}-02 \pm 4.1 \mathrm{E} \cdot 05$

$6.5 \mathrm{E}-09$ \$4.9E-09

3. $1 E \cdot 02 \pm 2.7 E-05$

$1.0 \mathrm{E}-10 \pm$
$<10 \mathrm{E} \cdot 10$ 
WELL BGO 49A

MEASUREMENTS CONDUCTED IN THE FIELD

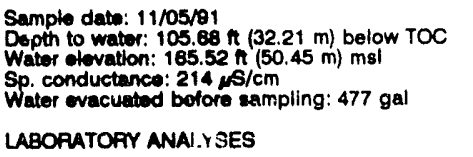

Time: $11: 10$

PHikallinity: $89 \mathrm{mg} / \mathrm{h}$

Water temperature: $18.6^{\circ} \mathrm{C}$

LABOPATOFY ANAI.YSES

\begin{tabular}{|c|c|c|c|}
\hline Analyte & Result & Mod & $\underline{\text { Unit }}$ \\
\hline 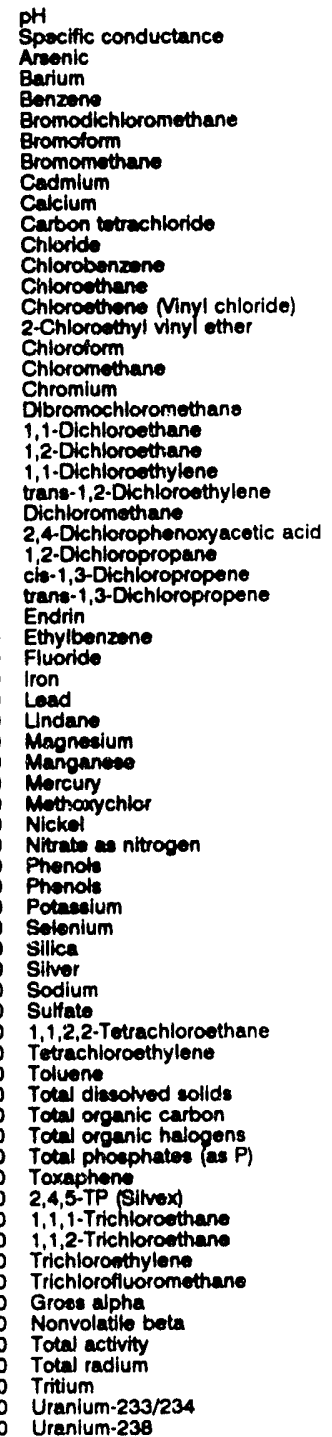 & 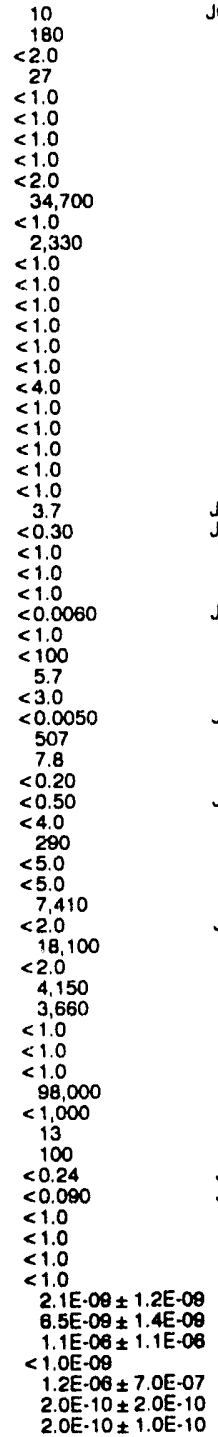 & JaV & 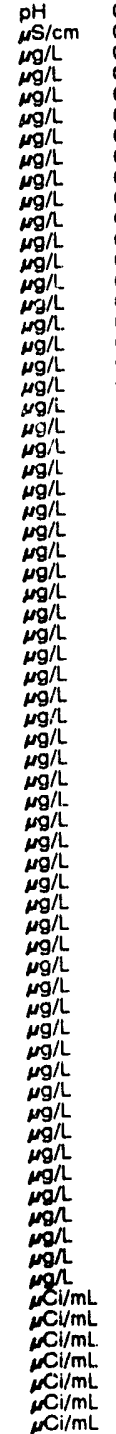 \\
\hline
\end{tabular}

WELL BGO 49C

MEASUREMENTS CONDUCTED IN THE FIELD

Sample date: 11/05/91

Depth to water: $41.70 \mathrm{Ht}(12.71 \mathrm{~m})$ below TOr

Water elevation: $228.40 \mathrm{~h}(\mathrm{t}) \mathrm{P}$

Sp. conduclance.

Time: 12:40

Alkalinity: $35 \mathrm{mg} / \mathrm{L}$

Water temperature: $18.1^{\circ} \mathrm{C}$

LABORATORY ANALYSES

E Analyte Besult Mod Unit Lab

$\therefore$ PH

Arsenic

Barium

Benzene

Eromolorm

Bromometh

Cadmium

Calcium
Carbon totrachloride
Chloride

Chlorobenzene

Chloroethene (Ninyl chloride)

2-Chloroethyl vinyl other

Chloroform

Chloromethane

Dibromochloromethane

1,1-Dichloroethane

1, - Dichloroothane

trans-1,2-Dichloroethylere

8.5
0

1,2-Dichloropropane

cis-1,3-Dichloropropene

: trans-1 1 -

- Ethylbenzene

0 Fluoride

0
0 Lead

0 Lead

- Magnesium

Manganese

Mercury

Nickel

Nitrate as nitrogen

Nitrate as nitrogen

Phenols

Potassium

Selenium

Silica

Silver

Sodium

Sulfate

Tetrachloroethylene

Toluene

Total dissolved solids

Total organic carbon

Total phosphates (as P)

Toxaphene

2,4,5-TP (Silvex)

1,1, rrichioroethane

Trichlorcethylene

Trichlisfofluoromethane

o Gross alpha

Nonvolatile beta

Total activity

1 Tritium

Uranium.233/2.34

Uranium.238
7.3
80
$<2.0$
38
$<1.0$
$<1.0$
$<1.0$
$<1.0$
$<2.0$

6,810
$<1.0$

2,530

$<1.0$

$<1.0$

$<1.0$

$<1.0$

$<4.0$

$<1.0$

$<1.0$

i.

$<1.0$
6.5
$<0.30$

$<1.0$

$<1.0$

$<0.0060$

$<1.0$
102

102
30

$<3.0$

261
$<2.0050$
$<20$

$<2.0$

$<0.20$
$<0.50$

$<4.0$

550
610

$<\begin{aligned} & 8.0 \\ & 2.810\end{aligned}$

2,810
$<2.0$
11.100

$<2.0$

6,630
8

$<1.0$

$<1.0$

$<1.0$

$<1,000$

420

$<0.24$

(<10

$<1.0$

$<1.0$
$<1.0$

$<2.0 \mathrm{E}-09$

$5.6 E \cdot 09 * 1.3 E-00$

$2.1 \mathrm{E}-05 \pm 1.5 \mathrm{E}-00$

$<1.0 E-09$

$1.9 E-05 \pm 9.0 E-07$

$2.0 \mathrm{E} \cdot 10 \pm 2.0 \mathrm{E} \cdot 10$
$<1.0 \mathrm{E}-10$ $\underset{\mu \mathrm{S} / \mathrm{cm}}{\mathrm{pH}} \quad \mathrm{GE}$

$\mu g /$

$\mu g / L \quad G E$

$\mu_{\mu g / h} \mathrm{GE}$

$\mu g$

$\mu g$

$\mu g / 2$

GE 
WELL BGO 49D

MEASUREMENTS CONDUCTED IN THE FIELD

Sample date: 11/08/01 Depth to water: $35.21 \mathrm{At}(10.73 \mathrm{~m})$ below TOC Water olevation: $238.29 \mathrm{ft}(72.0$ Sp. conductance: $28 \mathrm{\mu S} / \mathrm{cm}$ Water ovacualod boloro sampling: $18 \mathrm{ga}$ The well went dy during purging.

LABORATORY ANALYSES

\begin{tabular}{|c|c|c|c|}
\hline Anaiyte & Result & Mod & Unit \\
\hline 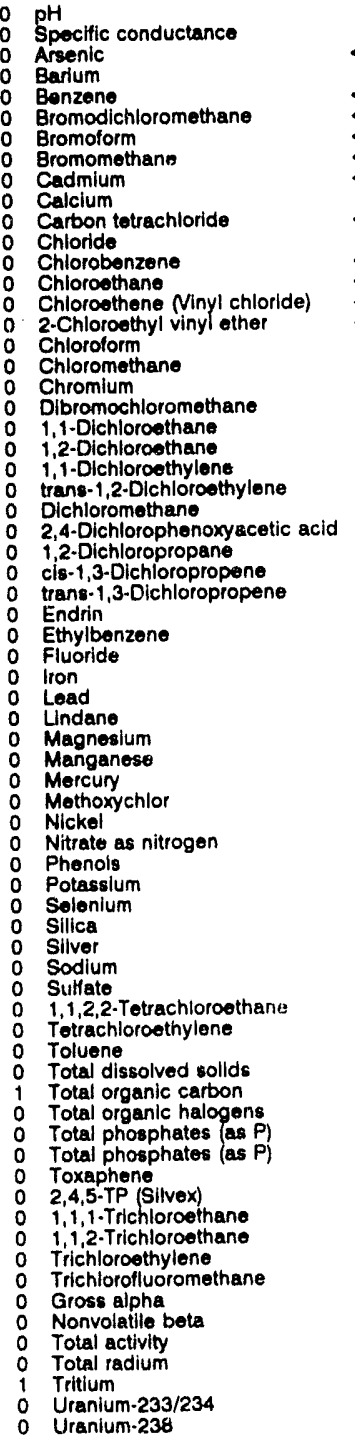 & $\begin{array}{l}5.6 \\
30 \\
<2.0 \\
9.8 \\
<1.0 \\
<1.0 \\
<1.0 \\
<1.0 \\
<2.0 \\
588 \\
<1.0 \\
1,560 \\
<1.0 \\
<1.0 \\
<1.0 \\
<1.0 \\
<1.0 \\
<1.0 \\
<4.0 \\
<1.0 \\
<1.0 \\
<1.0 \\
<1.0 \\
<1.0 \\
<1.0 \\
<0.30 \\
<1.0 \\
<1.0 \\
<1.0 \\
<0.0060 \\
<1.0 \\
<100 \\
4.6 \\
<1.0 \\
<0.0050 \\
297 \\
4.6 \\
<0.20 \\
<0.50 \\
<4.0 \\
1.050 \\
<50 \\
<500 \\
<2.0 \\
5.880 \\
<2.0 \\
3.440 \\
<1.000 \\
<1.0 \\
<1.0 \\
<1.0 \\
42.000 \\
5.000 \\
12 \\
<50 \\
<50 \\
<0.24 \\
<0.090 \\
<1.0 \\
<1.0 \\
<1.0 \\
<1.0 \\
<2.0 \mathrm{E}-09 \\
<2.0 \mathrm{E} \cdot 09 \\
2.3 \mathrm{E} \cdot 05 \pm 1.5 \mathrm{E} \cdot 06 \\
<1.0 \mathrm{E}-09 \\
2.0 \mathrm{E} \cdot 05 \pm 9.0 \mathrm{E}-07 \\
1.0 \mathrm{E}-10 \pm 1.0 \mathrm{E}-10 \\
<1.0 \mathrm{E} \cdot 10\end{array}$ & ${ }_{\mathrm{j} Q}^{\mathrm{J} V}$ & 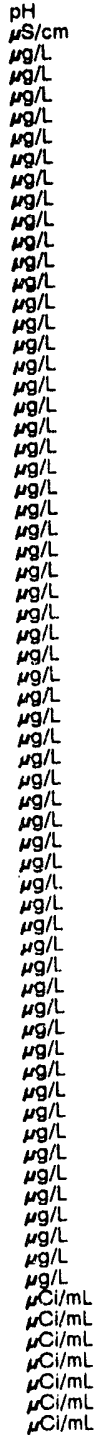 \\
\hline
\end{tabular}

WELL BGO 50A

MEASUREMENTS CONDUCTED IN THIE FIELD

Sample date: $12 / 15 / 91$

Depth to water: $85.26 \mathrm{ft}(29.04 \mathrm{~m})$ below TOC

Water evacuated belore sampling: $78 \mathrm{gal}$
Water olevation: $160.14 \mathrm{ft}(48.81 \mathrm{~m}) \mathrm{ms}$.

Sp. conductance: 349 , $1 / \mathrm{cm}$

PH: 5.4 .4 $1 \mathrm{mgl}$

Water temperatuin: $16.4^{\circ} \mathrm{C}$

The well wont dry during purging

LABORATORY ANALYSES

E Analyte Result Mod Unit Leb

ater temperature: $17.0^{\circ} \mathrm{C}$

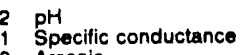

Arsenic

Barium

Bromodichloromethane

Bromodichlor
Bromoform

Bromomethane

Cadmium

Carbon totrachioride

Chloride

Chlorobenzene

Chloroethene Ninyl chloride)

2-Chloroothyl vinyl ether

Chioroform

Chromium

Dibromochloromethane

1,1-Dichloroethane

1.1.Dichloroethylen

trans-1,2-Dichloroethylene

- Dichloromothane

2,4-Dichlorophenoxyacetic acid $<1,5$

1,2-Dichloropropane

0
0 cis-1,3-Dichloropropene
0

0 Endrin

0 Ethylbenzen

- Fluoride

Iron

Lead

0 Magnosium

Manganese

Mercury

0 Methoxych

0 Nickel

Nitrate as nitrogen

Phenols

Potassium

Selenium

Silica

Silver

Sodium

$1,1,2,2$-Tetrachloroethane

Tetrachloroethylene

Toluene

Total dissolved solids

Total organic carbon

Total organic halogens
Total phosphates (as P)

Toxaphene

2,4,5.TP (Silve:

1,1,1-Trichloroethane

1,1,2-Irichloroethan

Trichloroethylene

Trichlorofluoromethane

Gross alpha

- Nonvolatile beta

Total actlvity

0 Total radium

O Uritium

- Uranium-233/234

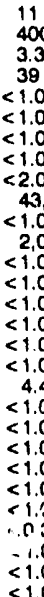

$<1.0$

$<0.0060 \quad J Q$

JQ $\quad \mathrm{pH} \quad \mathrm{GE}$

11
400
3.3
39
1.0
1.0
1.0
1.0
2.0
49.7
1.0
2.080
1.0
1.0
1.0
1.0
1.0
1.0
4.4
1.0
1.0
1.0
1.0
1.0
1.0
030
1.0
1.0
1.0
0.008
1.0
148

148
$<4.0$

$<3.0$

256
$<2.0$
$<0.20$

$<0.50$

$<4.0$
370
$<5.0$

3,110
$<2,0$
17,800

$<2.0$
21,400

21,400
7,600

$<1.0$
1.6

$<1.0$

161,000

$<2,000$
12
400
$<0.24$

$<0.24$

$<1.0$
$<1.0$
1.2

$<1.2$

$<.0$
$8.2 \mathrm{E}-09$

8.2E- $09 \pm 2.5 \mathrm{E}-09$

$<2.0 \mathrm{E}-09$

$2.5 \mathrm{E}-08 \pm 1.1 \mathrm{E}-05$

$<7.0 E-07$

$4.0 \mathrm{E} \cdot 10 \pm 2.0 \mathrm{E} \cdot 10$

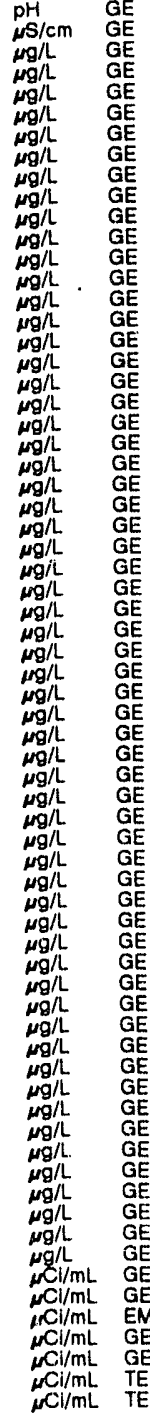

WELL BGO 50C

MEASUREMENTS CONDUCTED IN THE FIELD

Sample date: $12 / 15 / 91$ ( $10.96 \mathrm{~m})$ below TOC Depth to water: $35.97 \mathrm{ft}(10.96 \mathrm{~m})$ below

Water elevation: 218.53 h

:kalinity: $157 \mathrm{mg} / \mathrm{L}$

Water evacuated before sampling: $57 \mathrm{gal}$

The well went dry during purging

LABORATORY ANALYSES

\begin{tabular}{|c|c|c|c|c|c|}
\hline & Analyte & Result & Mod & Unit & Lab \\
\hline & $\begin{array}{l}\text { pH } \\
\text { Specific conductance } \\
\text { Arsenic }\end{array}$ & $\begin{array}{r}6.1 \\
45 \\
<2.0\end{array}$ & JO & $\begin{array}{l}\mathrm{pH} \\
\mu \mathrm{S} / \mathrm{cm} \\
\mu \mathrm{g} / \mathrm{h}\end{array}$ & $\begin{array}{l}\mathrm{GE} \\
\mathrm{GE} \\
\mathrm{GE}\end{array}$ \\
\hline
\end{tabular}


ANALYTICAL RESULTS

WELL BGO $50 \mathrm{C}$ collectod on 12/15/91, laboratory analyses (cont.)

\begin{tabular}{|c|c|c|c|}
\hline Analyte & Result & Mod & $\underline{\text { Unit }}$ \\
\hline 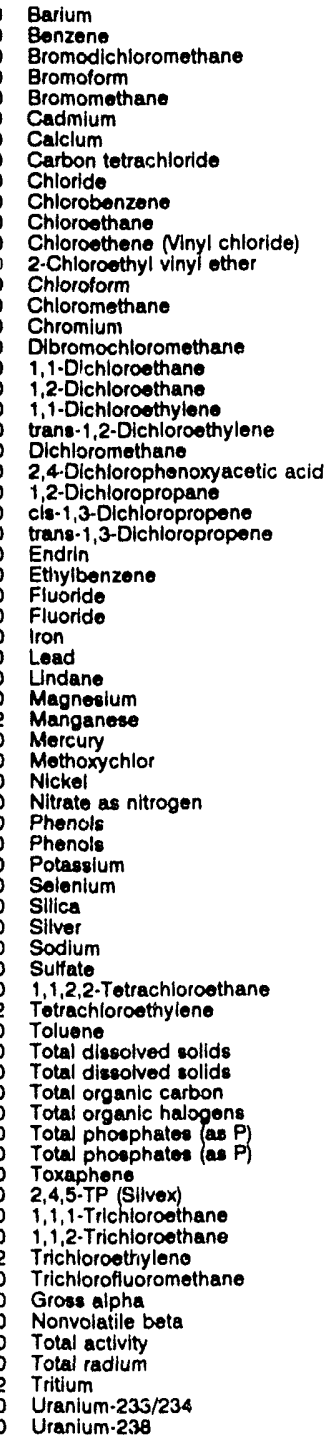 & $\begin{array}{l}\quad 9.5 \\
<1.0 \\
<1.0 \\
<1.0 \\
<1.0 \\
<2.0 \\
3.350 \\
<1.0 \\
2.660 \\
<1.0 \\
<1.0 \\
<1.0 \\
<1.0 \\
<1.0 \\
<1.0 \\
<4.0 \\
<1.0 \\
<1.0 \\
<1.0 \\
<1.0 \\
<1.0 \\
<1.0 \\
<0.30 \\
<1.0 \\
<1.0 \\
<1.0 \\
<0.0060 \\
<1.0 \\
<100 \\
<100 \\
8.8 \\
<3.0 \\
<0.0050 \\
455 \\
59 \\
<0.20 \\
<0.50 \\
<4.0 \\
760 \\
<5.0 \\
<5.0 \\
814 \\
<2.0 \\
11.100 \\
<2.0 \\
3.080 \\
2,610 \\
<1.0 \\
30 \\
<1.0 \\
24,000 \\
26,000 \\
<2.000 \\
<5.0 \\
150 \\
180 \\
<0.24 \\
<0.090 \\
<1.0 \\
<1.0 \\
20 \\
<1.0 \\
<2.0 \mathrm{E}-09 \\
<2.0 \mathrm{E}-09 \\
4.8 \mathrm{E} \cdot 05 \pm 1.2 \mathrm{E} \cdot 05 \\
<1.0 \mathrm{E}-09 \\
4.9 \mathrm{E}-05 \pm 1.8 \mathrm{E} \cdot 06 \\
<1.0 \mathrm{E}-10 \\
<1.0 \mathrm{E}-10 \\
\end{array}$ & $\begin{array}{l}\text { JO } \\
\text { JO }\end{array}$ & 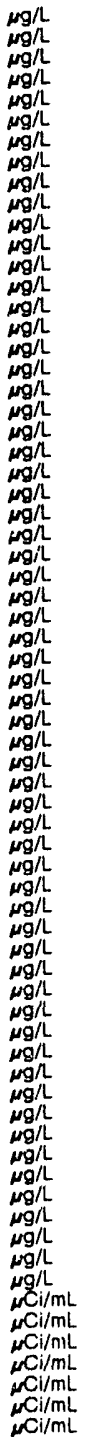 \\
\hline
\end{tabular}

\section{WELL BGO 50D}

MEASUREMENTS CONDUCTED IN THE FIELD

Sample date: $12 / 14 / 81$

Depth to water: $29.98 \mathrm{~h}(8.14 \mathrm{~m})$ below TOC

Water olevation: $226.01 \mathrm{~h}$ (68)

Water conductance: $95 \mathrm{\mu S} / \mathrm{cm}$.

LABORATORY ANALYSES

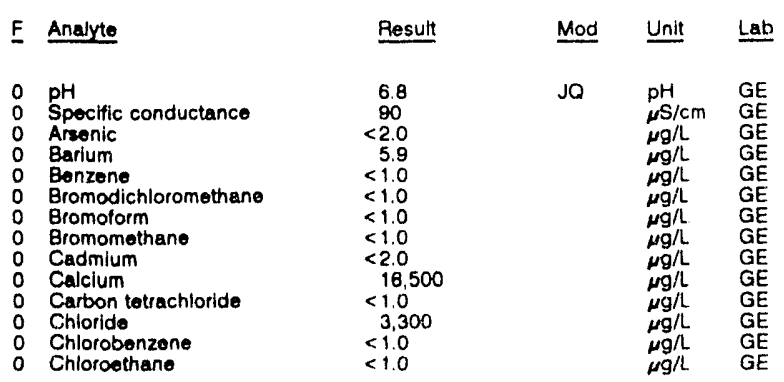

WELL BGO $50 D$ collected on 12/14/91, laboratory analyses (cont)

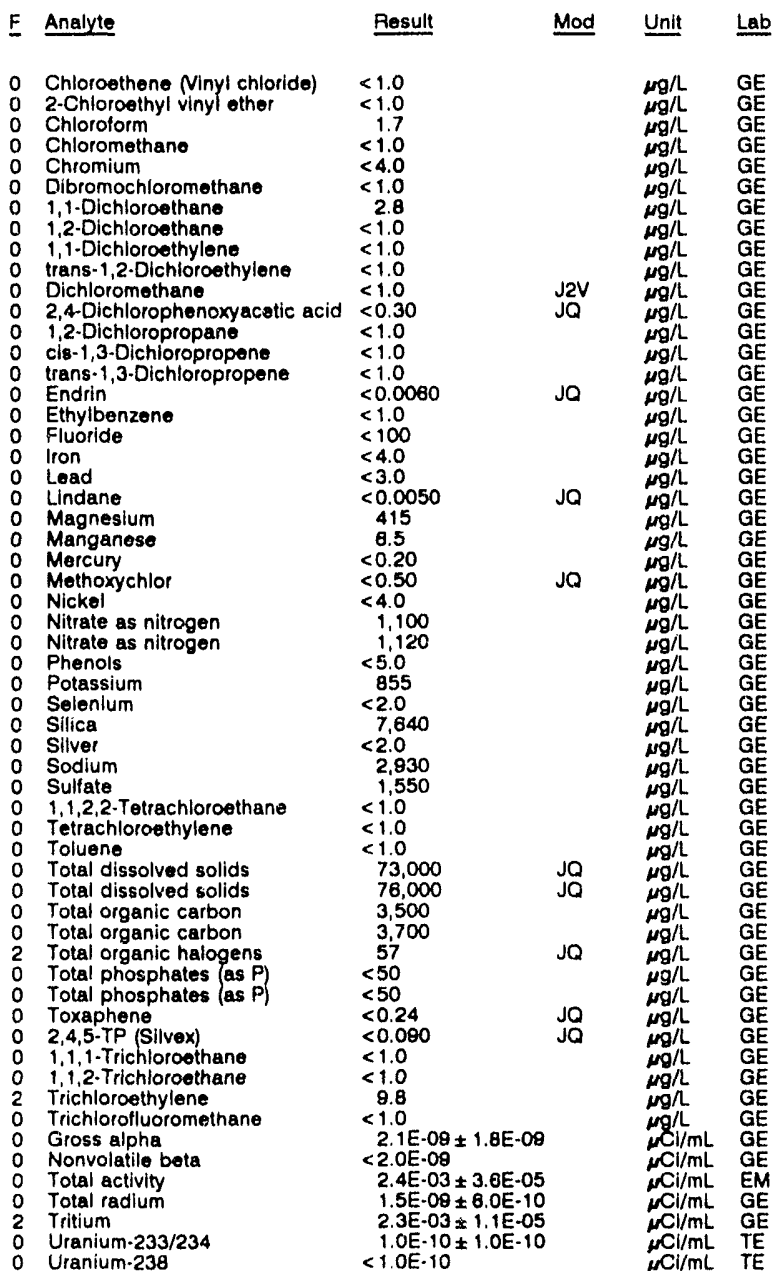

WELL BGX $1 A$

MEASUREMENTS CONDUCTED IN THE FIELD

Sample date: $10 / 22 / 91$

Depth to water: $132.26 \mathrm{ft}(40.31 \mathrm{~m})$ below TOC

Water elevation: $158.94 \mathrm{Ht}(48.45 \mathrm{~m}) \mathrm{msl}$

Sp. conductance: $4670 \mu \mathrm{s} / \mathrm{cm}$ Water temperature: $18.8^{\circ} \mathrm{C}$

The well went dry during purging.

LABORATORY ANALYSES

\begin{tabular}{|c|c|c|c|}
\hline Analyte & Result & Mod & Unit \\
\hline $\begin{array}{l}\text { pH } \\
\text { pH } \\
\text { pH } \\
\text { pH } \\
\text { Specific conductance } \\
\text { Specific conductance } \\
\text { Specific conductance } \\
\text { Specific conductance } \\
\text { Arsenic } \\
\text { Barium } \\
\text { Benzene } \\
\text { Bromodichloromethane } \\
\text { Bromotorm } \\
\text { Bromomethane } \\
\text { Cadmium } \\
\text { Calcium } \\
\text { Carbon tetrachloride } \\
\text { Chlorlde } \\
\text { Chlorobenzene } \\
\text { Chloroethane } \\
\text { Chloroethene Vinyl chloride) } \\
\text { 2.Chloroethyl vinyl ether } \\
\text { Chlorolorm } \\
\text { Chloromethane } \\
\text { Chronium }\end{array}$ & $\begin{array}{l}12 \\
12 \\
13 \\
13 \\
3,800 \\
3,800 \\
4,000 \\
4,010 \\
<2.0 \\
332 \\
<1.0 \\
<1.0 \\
<1.0 \\
<1.0 \\
<2.0 \\
118,000 \\
<1.0 \\
2,480 \\
<1.0 \\
<1.0 \\
<1.0 \\
<1.0 \\
<1.0 \\
<1.0 \\
22\end{array}$ & $\begin{array}{l}\mathrm{JO} \\
\mathrm{JO} \\
\mathrm{JO} \\
\mathrm{JO}\end{array}$ & $\begin{array}{l}\mathrm{pH} \\
\mathrm{pH} \\
\mathrm{pH} \\
\mathrm{pH} \\
\mu \mathrm{S} / \mathrm{cm} \\
\mu \mathrm{S} / \mathrm{cm} \\
\mu \mathrm{S} / \mathrm{cm} \\
\mu \mathrm{S} / \mathrm{cm} \\
\mu \mathrm{g} / \mathrm{L} \\
\mu \mathrm{g} / \mathrm{L} \\
\mu g / \mathrm{L} \\
\mu \mathrm{g} / \mathrm{L} \\
\mu \mathrm{g} / \mathrm{L} \\
\mu g / \mathrm{L} \\
\mu g / \mathrm{L} \\
\mu g / \mathrm{L} \\
\mu g / \mathrm{L} \\
\mu g / \mathrm{L} \\
\mu g / \mathrm{L} \\
\mu g / \mathrm{L} \\
\mu g / \mathrm{L} \\
\mu \mathrm{g} / \mathrm{L} \\
\mu \mathrm{g} / \mathrm{L} \\
\mu g / \mathrm{L} \\
\mu \mathrm{g} / \mathrm{L}\end{array}$ \\
\hline
\end{tabular}




\section{ANALYTICAL RESULTS}

WELL BGX 1A collected on 10/22/91, laboratory analyses (cont.)

\begin{tabular}{|c|c|c|c|}
\hline Analyte & Result & Mod & $\underline{\text { Unit }}$ \\
\hline 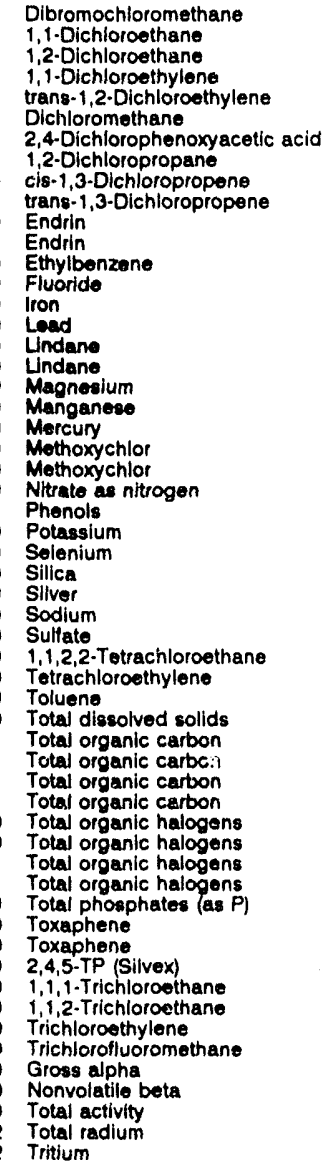 & 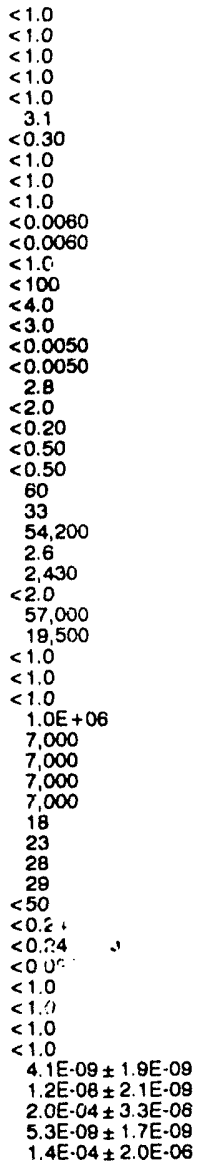 & $\begin{array}{l}\text { JO } \\
\text { JO } \\
\text { J }\end{array}$ & $\begin{array}{l}\mu g / L \\
\mu g / L \\
\mu g / L \\
\mu g / L \\
\mu g / L \\
\mu g / L \\
\mu g / L \\
\mu g / L \\
\mu g / L \\
\mu g / L \\
\mu g / L \\
\mu g / L \\
\mu g / L \\
\mu g / L \\
\mu g / L \\
\mu g / L \\
\mu g / L \\
\mu g / L \\
\mu g / L \\
\mu g / L \\
\mu g / L \\
\mu g / L \\
\mu g / L \\
\mu g / L \\
\mu g / L \\
\mu g / L \\
\mu g / L \\
\mu g / L \\
\mu g / L \\
\mu g / L \\
\mu g / L \\
\mu g / L \\
\mu g / L \\
\mu g / L \\
\mu g / L \\
\mu g / L \\
\mu g / L \\
\mu g / L \\
\mu g / L \\
\mu g / L\end{array}$ \\
\hline
\end{tabular}

\section{WELL BGX $1 \mathrm{C}$}

MEASUREMENTS CONDUCTED IN THE FIL D D

Sample date: 10/22/81

Dopth to water: $73.48 \mathrm{~h}(22.39 \mathrm{~m})$ below TOC

Water olovation: $217: 4 \mathrm{~h} 168.4$

$\mathrm{msl}$

PH: $\$ 1.4,09 \mathrm{mg}$

Water temperature: $19.0^{\circ} \mathrm{C}$

The woll wacuated belore campling: $16 \mathrm{ge}$

LABORATORY ANALYSES

\begin{tabular}{|c|c|c|c|c|}
\hline Anadyte & Result & Mod & Unit & Lab \\
\hline $\begin{array}{l}\text { pH } \\
\text { pH } \\
\text { pHt } \\
\text { pH } \\
\text { Specilic conductance } \\
\text { Specific conductance } \\
\text { Specific conductance } \\
\text { Specific conductance } \\
\text { Areenic } \\
\text { Barlum } \\
\text { Benzene } \\
\text { Bromodichloromethane } \\
\text { Bromoform } \\
\text { Bromomethane } \\
\text { Cadmium } \\
\text { Calcium } \\
\text { Carbon totrachloride } \\
\text { Chloride } \\
\text { Chlorobenzene } \\
\text { Chloroethane } \\
\text { Chloroethene Ninyl chloride) } \\
\text { 2-Chloroothyl vinyl other } \\
\text { Chloroform } \\
\text { Chloromethane } \\
\text { Chromium } \\
\text { Dibromochloromethane } \\
\text { 1,1-Dichloroethane }\end{array}$ & $\begin{array}{l}11 \\
11 \\
11 \\
11 \\
250 \\
255 \\
265 \\
285 \\
<20 \\
74 \\
>1.0 \\
<1.0 \\
<1.0 \\
<1.0 \\
<2.0 \\
29,000 \\
<1.0 \\
1.270 \\
<10 \\
<1.0 \\
<1.0 \\
<1.0 \\
<1.0 \\
<1.0 \\
<4.0 \\
<1.0 \\
<1.0\end{array}$ & $\begin{array}{l}\text { JQ } \\
\text { JO } \\
\text { Jo } \\
\text { JO }\end{array}$ & $\begin{array}{l}\mathrm{pH} \\
\mathrm{pH} \\
\mathrm{pH} \\
\mathrm{pH} \\
\mu \mathrm{S} / \mathrm{cm} \\
\mu \mathrm{s} / \mathrm{cm} \\
\mu S / \mathrm{cm} \\
\mu \mathrm{S} / \mathrm{cm} \\
\mu g / L \\
\mu g / L \\
\mu g / L \\
\mu g / L \\
\mu g / L \\
\mu g / L \\
\mu g / L \\
\mu g / L \\
\mu g / L \\
\mu g / L \\
\mu g / L \\
\mu g / L \\
\mu g / L \\
\mu g / L \\
\mu g / L \\
\mu g / L \\
\mu g / L \\
\mu g / L \\
\mu g / L\end{array}$ & $\begin{array}{l}G E \\
G E \\
G E \\
G E \\
G E \\
G E \\
G E \\
G E \\
G E \\
G E \\
G E \\
G E \\
G E \\
G E \\
G E \\
G E \\
G E \\
G E \\
G E \\
G E \\
G E \\
G E \\
G E \\
G E \\
G E \\
G E \\
G E\end{array}$ \\
\hline
\end{tabular}

WELL BGX 1C collocted on 10/22/91, laboratory analyses (cont.)

\begin{tabular}{|c|c|c|c|}
\hline Analyte & Posult & Mod & Unit \\
\hline 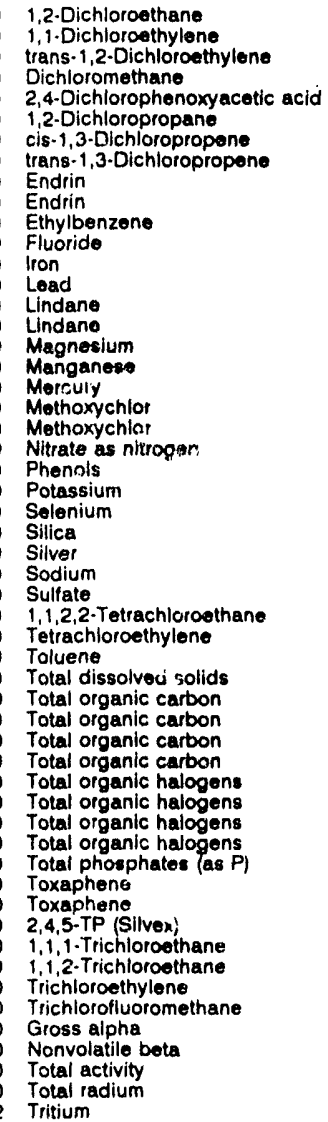 & 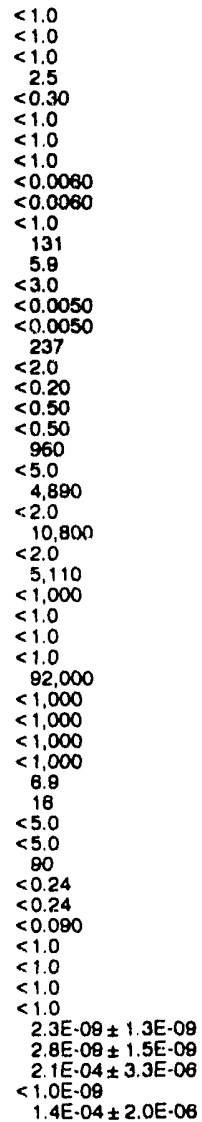 & $\begin{array}{l}\mathrm{JO} \\
\mathrm{JQ} \\
\mathrm{JQ}\end{array}$ & 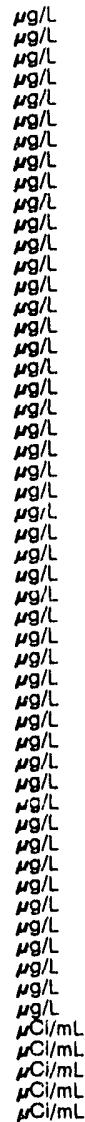 \\
\hline
\end{tabular}

WELL BGX 1D

MEASUREMENTS CONDUCTED IN THE FIELD

Sample date: 10/22/91

Depth to water: $61.04 \mathrm{th}(18.61 \mathrm{~m})$ below TOC

Water olevation: $230.26 \mathrm{ft}(70$.

Sp. conductance: $71 \mathrm{\mu S} / \mathrm{cm}$

The rell went dy during purging. 7 gal

LABORATOAY ANALYSES

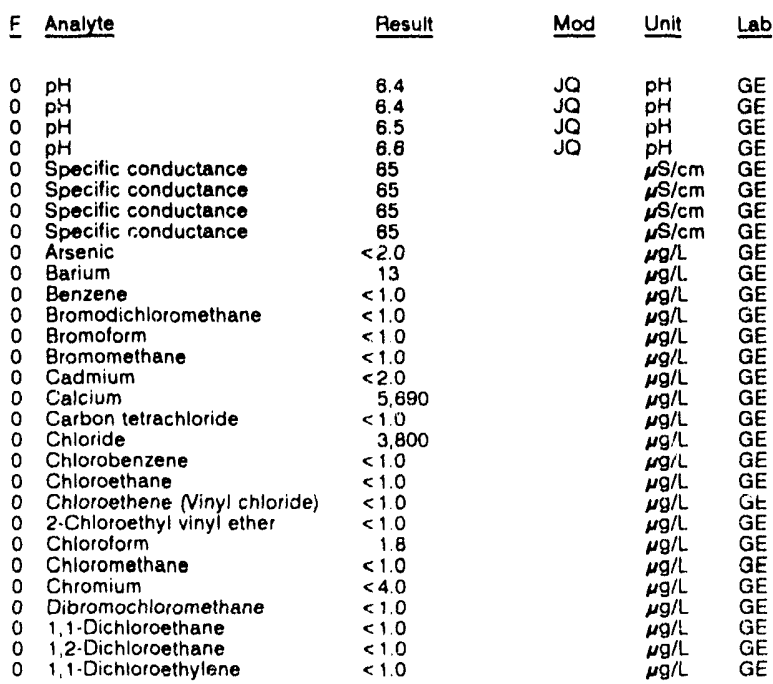


ANALYTICAL RESULTS

WELL BGX 1D collected on 10/22/91, laboratory analyses (cont)

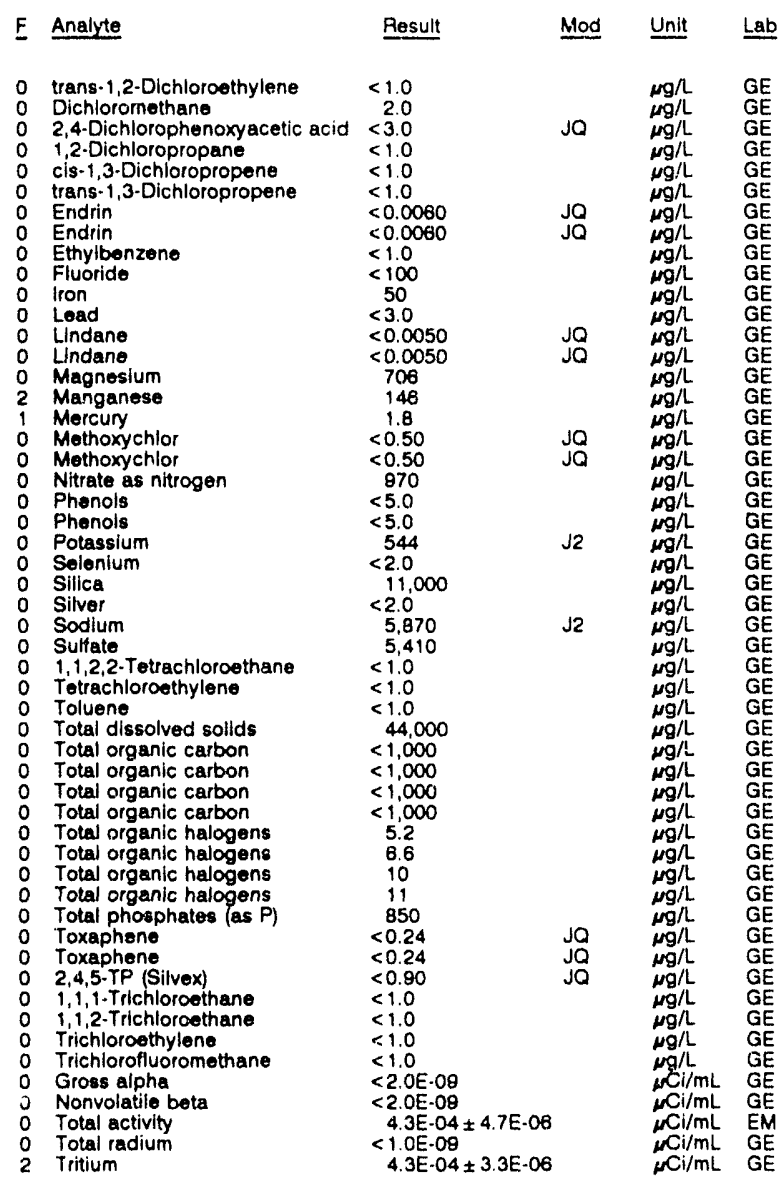

\section{WELL BGX 2B}

MEASUREMENTS CONDUCTED IN THE FIELD

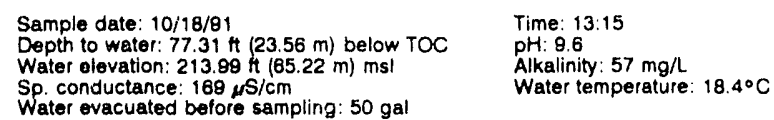

Sp. conductance: $168 \mu \mathrm{S} / \mathrm{cm} \quad$ Water temperature: $18.4^{\circ} \mathrm{C}$

The well went dry during purging

LABOPATORY ANALYSES

\begin{tabular}{|c|c|c|c|}
\hline Analyte & Result & Mod & Unit \\
\hline $\begin{array}{l}\mathrm{pH} \\
\text { pH } \\
\text { pH } \\
\text { pH } \\
\text { Specific conductance } \\
\text { Specific conductance } \\
\text { Speclfic conductance } \\
\text { Specific conductance } \\
\text { Arsenic } \\
\text { Barium } \\
\text { Benzenc } \\
\text { Gromodichioromethane } \\
\text { Bror Jform } \\
\text { Bromomethane } \\
\text { Cadmium } \\
\text { Calcium } \\
\text { Carbon totrachloride } \\
\text { Chlonde } \\
\text { Chlorobenzene } \\
\text { Chloroethane } \\
\text { Chloroethene Ninyl chloride) } \\
\text { 2-Chloroethyl vinyl ether } \\
\text { Chloroform } \\
\text { Chloromethane } \\
\text { Chromium } \\
\text { Dibromoshloromethane } \\
1,1 \text {-Dichloroethane } \\
1,2-\text { Dichloroethane } \\
\text { 1,1-Dichloroethylene } \\
\text { trans-1,2-Dichloroethylerie }\end{array}$ & $\begin{array}{l}7.9 \\
8.0 \\
8.0 \\
8.0 \\
202 \\
204 \\
205 \\
210 \\
<2.0 \\
78 \\
<1.0 \\
<1.0 \\
<1.0 \\
<1.0 \\
<2.0 \\
41.200 \\
<1.0 \\
2.730 \\
<1.0 \\
<1.0 \\
<1.0 \\
<1.0 \\
<1.0 \\
<1.0 \\
<4.0 \\
<1.0 \\
<1.0 \\
<1.0 \\
<1.0 \\
<1.0\end{array}$ & $\begin{array}{l}\mathrm{JQ} \\
\mathrm{JQ} \\
\mathrm{JQ} \\
\end{array}$ & 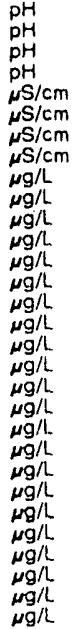 \\
\hline
\end{tabular}

WELL BGX 28 collected on 10/18/91, laboratory analyses (cont.)

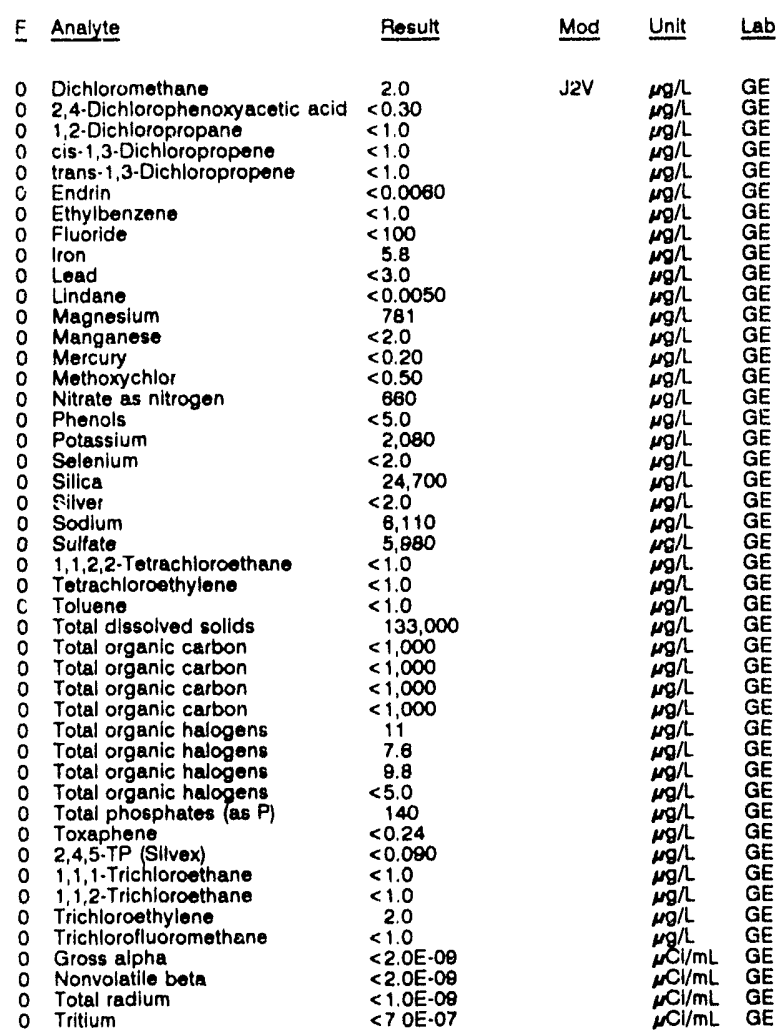

WELL BGX 2D

MEASUREMENTS CONDUCTED IN THE FIELD

Sample date: 10/18/91

Depth to water: $73.78 \mathrm{Ht}(22.48 \mathrm{~m})$ below TOC

Water elevation: $217.31 \mathrm{tt}(68.24 \mathrm{~m}) \mathrm{msl}$

Wp. conductance: $35 \mu \mathrm{s} / \mathrm{cm}$

Time: $13: 35$
pH: 5.5

Alkalinity: $4 \mathrm{mg} / \mathrm{L}$

Water tomperatu: $18.5^{\circ} \mathrm{C}$

LABORATORY ANALYSES

\begin{tabular}{|c|c|c|c|}
\hline Analyte & Result & Mod & Unit \\
\hline $\begin{array}{l}\text { pH } \\
\text { pH } \\
\text { pH } \\
\text { pH } \\
\text { Specific conductance } \\
\text { Specific conductance } \\
\text { Specific conductance } \\
\text { Specific conductance } \\
\text { Arsenic } \\
\text { Barium } \\
\text { Benzene } \\
\text { Bromodichloromethane } \\
\text { Bromolorm } \\
\text { Bromomethane } \\
\text { Cadmium } \\
\text { Calcium } \\
\text { Carbon tetrachloride } \\
\text { Chloride } \\
\text { Chloride } \\
\text { Chlorobenzene } \\
\text { Chloroethane } \\
\text { Chlorothene Ninyl chloride) } \\
\text { 2-Chloroethyl vinyl ether } \\
\text { Chloroform } \\
\text { Chloromethane } \\
\text { Chromium } \\
\text { Dibromochloromethane } \\
1,1 \text {-Dichloroethane } \\
1,2 \cdot \text { Dichloroethane } \\
1,1 \text {-Dichloroethylene } \\
\text { trans-1,2-Dichloroethylene } \\
\text { Dichloromethane } \\
2,4 \text {-Dichlorophenoxyacetic acld } \\
1,2 \text {-Dichloropropane } \\
\text { cis-1,3-Dichloropropene } \\
\text { trans-1,3-Dichloroplopene } \\
\text { Endrin }\end{array}$ & $\begin{array}{l}5.7 \\
5.8 \\
5.8 \\
5.8 \\
30 \\
30 \\
30 \\
32 \\
<2.0 \\
5.6 \\
<1.0 \\
<1.0 \\
<1.0 \\
<1.0 \\
<2.0 \\
2.760 \\
<1.0 \\
2.140 \\
2.190 \\
<1.0 \\
<1.0 \\
<1.0 \\
<1.0 \\
<1.0 \\
<1.0 \\
<4.0 \\
<1.0 \\
<1.0 \\
<1.0 \\
<1.0 \\
<1.0 \\
1.0 \\
<0.30 \\
<1.0 \\
<1.0 \\
<1.0 \\
<0.0060\end{array}$ & $\begin{array}{l}\mathrm{JO} \\
\mathrm{JO} \\
\mathrm{JO} \\
\mathrm{JO}\end{array}$ & 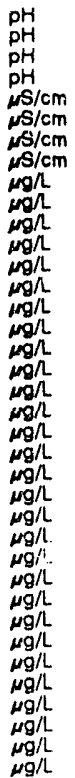 \\
\hline
\end{tabular}


WEI $\perp$ BQX $2 D$ collected on 10/18/81, laboratory analyses (cont.)

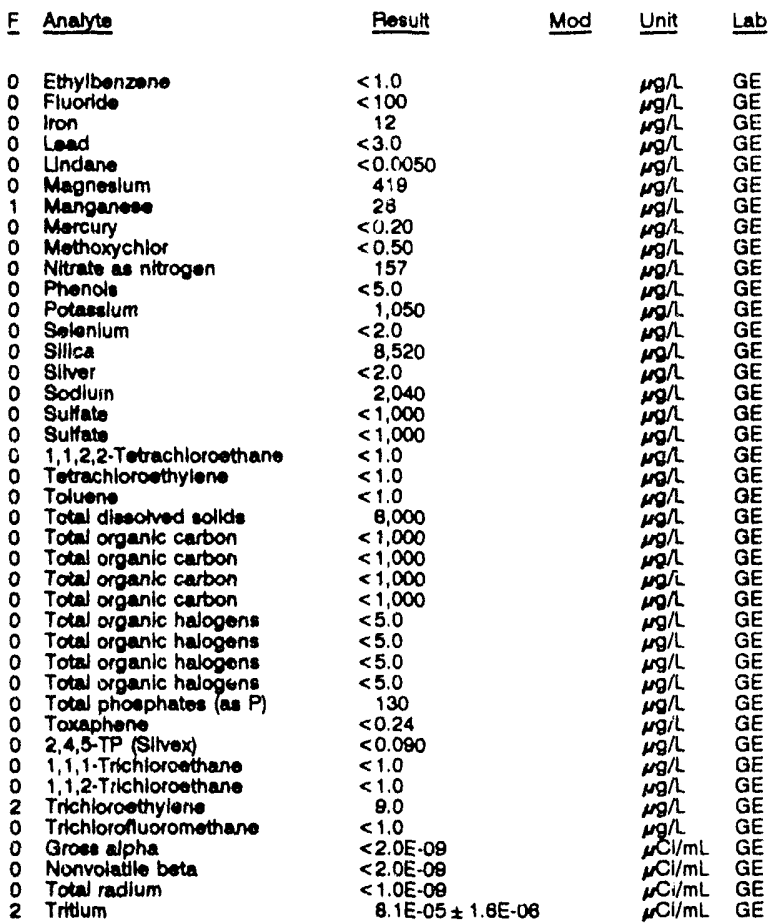

WELL BGX 3D

MEASUREMENTS CONDUCTED IN THE FIELD

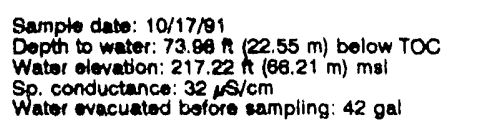

Time: 15:30

pH: 5.4

Water temperature: $18.4^{\circ} \mathrm{C}$

LABORATORYY ANALYSES

\begin{tabular}{|c|c|c|}
\hline & Anelyte & Result \\
\hline & 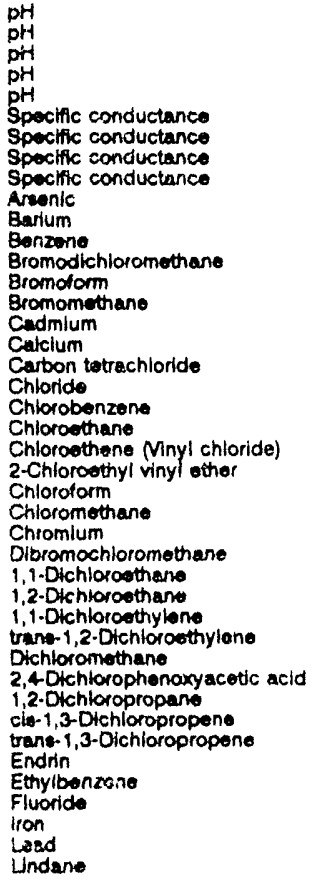 & $\begin{array}{l}5.8 \\
5.8 \\
5.8 \\
5.8 \\
5.8 \\
30 \\
30 \\
30 \\
30 \\
<2.0 \\
8.1 \\
<1.0 \\
<1.0 \\
<1.0 \\
<1.0 \\
<2.0 \\
1.400 \\
<1.0 \\
2,360 \\
<1.0 \\
<1.0 \\
<1.0 \\
<1.0 \\
2.0 \\
<1.0 \\
<4.0 \\
<1.0 \\
<1.0 \\
<1.0 \\
<1.0 \\
<1.0 \\
2.5 \\
<0.30 \\
<1.0 \\
<1.0 \\
<1.0 \\
<0.0060 \\
<1.0 \\
<100 \\
15 \\
<3.0 \\
<0.0050\end{array}$ \\
\hline
\end{tabular}

WELL BGX 3D colloctod on 10/17/01, laboratory analyses (cont.)

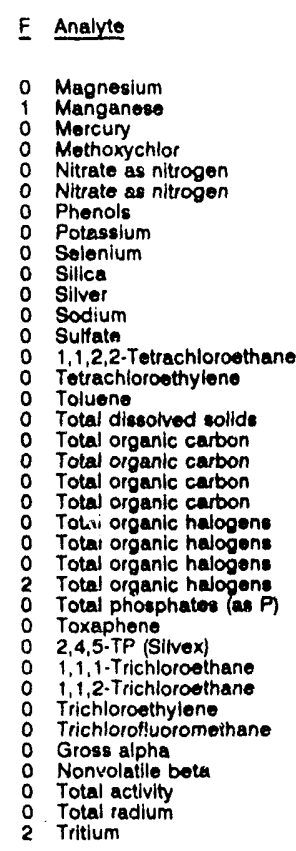

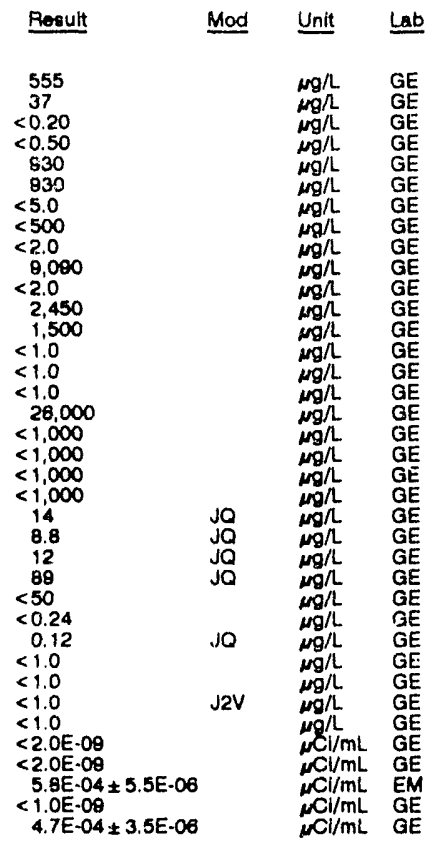

\section{WELL BGX 4A}

MEASUREMENTS CONDUCTED IN THE FIELD

Sample date: 10/18/81

(15) Water olevation: 155.87 \& 147.51

Wator evacuated before sampling: $130 \mathrm{gal}$

LABORATORY ANALYSES

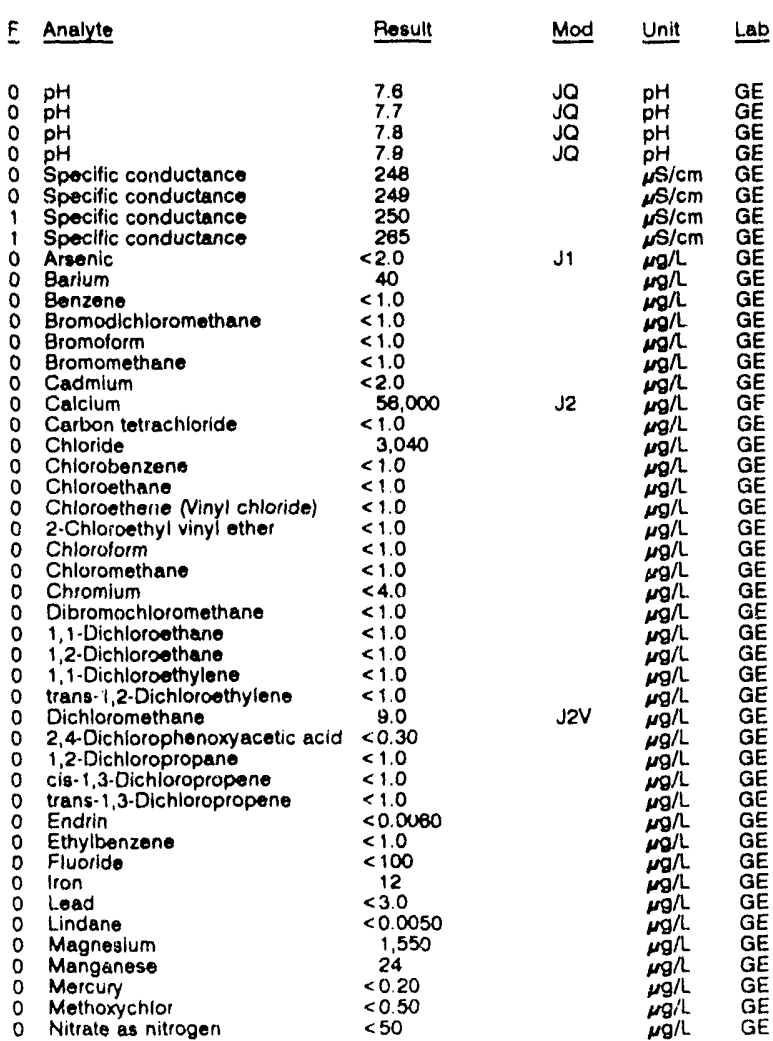


ANALYTICAL RESULTS

WELL BGX 4A collected on 10/18/91, laboratory analyses (cont.)

\begin{tabular}{|c|c|c|}
\hline Analyte & Result & Unit \\
\hline 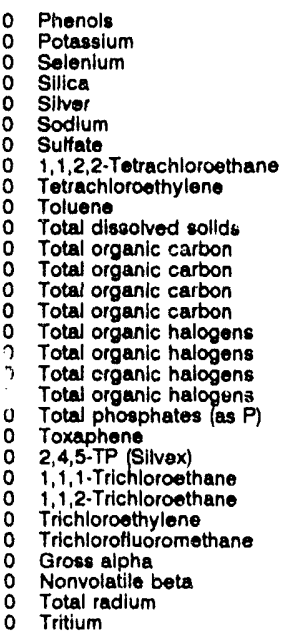 & $\begin{array}{l}<5.0 \\
2,030 \\
<2.0 \\
33.800 \\
<2.0 \\
3,000 \\
8,880 \\
<1.0 \\
<1.0 \\
<1.0 \\
152,000 \\
<1,000 \\
<1,000 \\
<1,000 \\
<1,000 \\
<5.0 \\
<5.0 \\
<5.0 \\
<5.0 \\
70 \\
<0.24 \\
<0.000 \\
<1.0 \\
<1.0 \\
<1.0 \\
<1.0 \\
2.76-09 \pm 1.5 E-08 \\
<2.0 E-08 \\
1.03-09 \pm 1.4 E-09 \\
<7.0 E-07\end{array}$ & 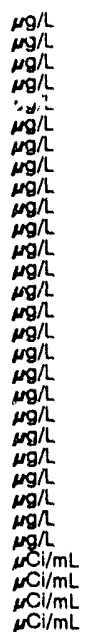 \\
\hline
\end{tabular}

\section{WELL BGX 4C}

MEASUREMENTS CONDUCTED IN THE FIELD

$\begin{array}{ll}\text { Sample date: } 10 / 18 / 91 & \text { Time: } 12: 05 \\ \text { Depth to water: } 73.83 \mathrm{Ht}(22.50 \mathrm{~m}) \text { below TOC } & \text { pH: } 6.7 \\ \text { Water elevation: } 216.97 \mathrm{H}(68.13 \mathrm{~m}) \mathrm{msl} & \text { Alkalinity: } 39 \mathrm{mg} / \mathrm{L} \\ \text { Sp. conductance: } 113 \mu \mathrm{cm} / \mathrm{cm} & \text { Water temperature: } 18.8^{\circ} \mathrm{C} \\ \text { Water evacuated before sampling: } 122 \mathrm{gal} & \end{array}$

LABORATORY ANALYSES

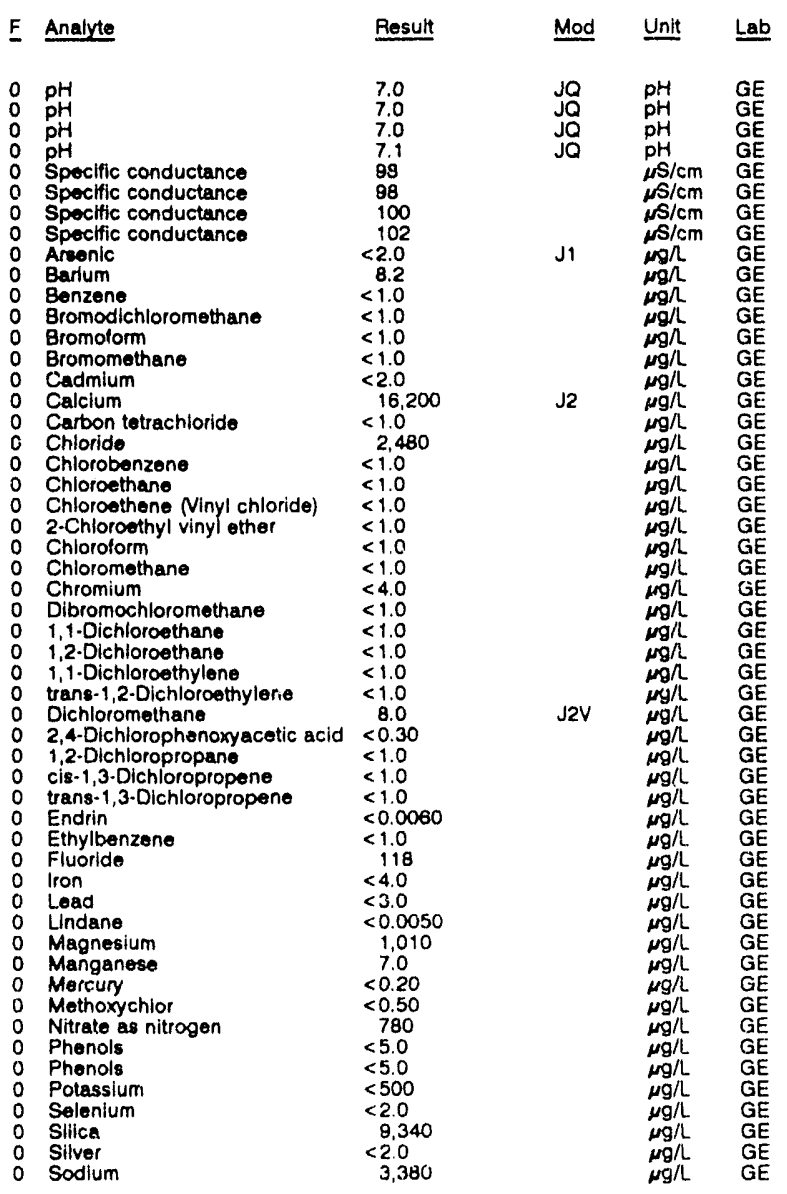

WELL BGX $4 C$ colloctod on 10/18/91, laboratory analyses (cont.)

\begin{tabular}{|c|c|c|c|}
\hline Analyte & Result & Mod & Unit \\
\hline 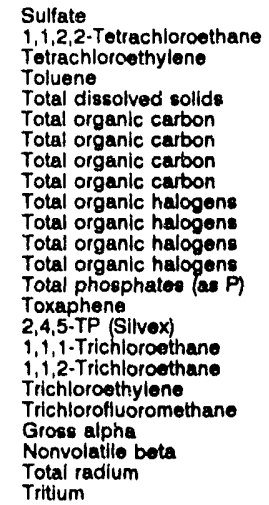 & $\begin{array}{l}1,450 \\
<1.0 \\
<1.0 \\
<1.0 \\
52,000 \\
<1,000 \\
<1,000 \\
<1,000 \\
<1.000 \\
7.2 \\
<5.0 \\
<5.0 \\
<5.0 \\
120 \\
<0.24 \\
<0.090 \\
<1.0 \\
<1.0 \\
2.0 \\
<1.0 \\
<2.0 \mathrm{E}-09 \\
<2.0 \mathrm{E}-09 \\
<1.0 \mathrm{E}-09 \\
<7.0 \mathrm{E}-07\end{array}$ & & 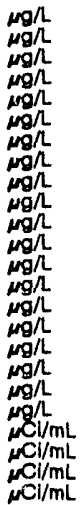 \\
\hline
\end{tabular}

\section{WELL BGX 4D}

MEASUREMENTS CONDUCTED IN THE FIELD Sample date: 10/18/81 Depth to water: $72.95 \mathrm{~A}(22.24 \mathrm{~m})$ below TOC Water olevation: $217.85 \mathrm{t}(68.43 \mathrm{~m}) \mathrm{msl}$ Water ovacuated bolore sampling: $38 \mathrm{gal}$

PH: 5.8 . 0 m

Whtor tomperature: $18.8^{\circ} \mathrm{C}$

LABORATORY ANALYSES

\begin{tabular}{|c|c|c|c|}
\hline Analyte & Result & Mod & Unit \\
\hline 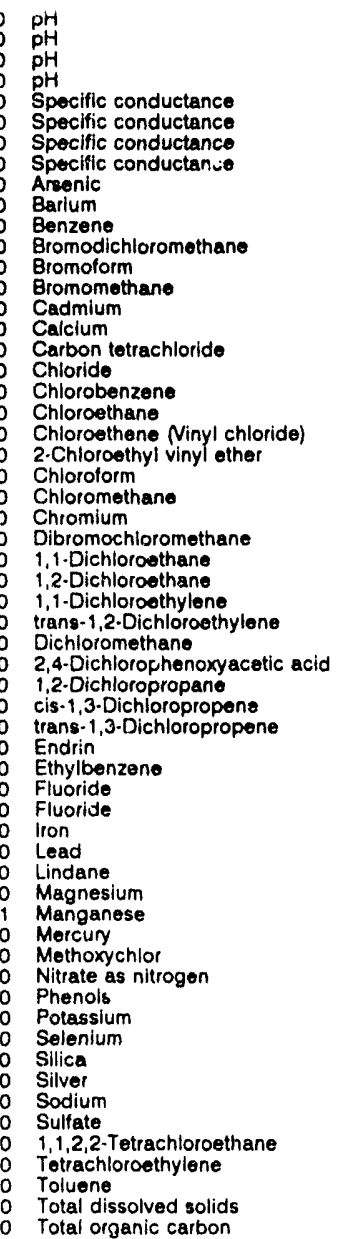 & $\begin{aligned} & 5.8 \\
& 5.8 \\
& 6.0 \\
& 6.0 \\
& 38 \\
& 40 \\
& 40 \\
& 40 \\
&<2.0 \\
& 8.5 \\
&<1.0 \\
&<1.0 \\
&<1.0 \\
&<1.0 \\
&<2.0 \\
& 1,850 \\
&<1.0 \\
& 2.740 \\
&<1.0 \\
&<1.0 \\
&<1.0 \\
&<1.0 \\
&<1.0 \\
&<1.0 \\
&<4.0 \\
&<1.0 \\
&<1.0 \\
&<1.0 \\
&<1.0 \\
&<1.0 \\
& 1.5 \\
&<0.30 \\
&<1.0 \\
&<1.0 \\
&<1.0 \\
&<0.0060 \\
&<1.0 \\
&<100 \\
&<100 \\
& 4.8 \\
&<3.0 \\
&<0.0050 \\
& 520 \\
& 30 \\
&<0.20 \\
&<0.50 \\
&<1.780 \\
&<5.0 \\
&<500 \\
&<2.0 \\
& 8.040 \\
&<2.0 \\
& 4.270 \\
& 1.080 \\
&<1.0 \\
&<1.0 \\
&<1.0 \\
& 7.000 \\
&<1.000\end{aligned}$ & $\begin{array}{l}\text { JQ } \\
\text { JO } \\
\text { JO } \\
\text { JO }\end{array}$ & 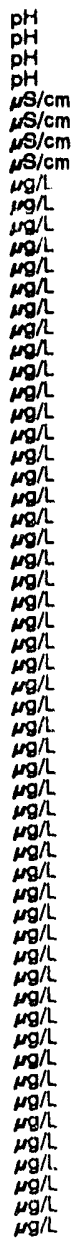 \\
\hline
\end{tabular}


ANALYTICAL RESULTS

WELL BGX 40 collocted on 10/18/91, laboratory analyses (cont.)

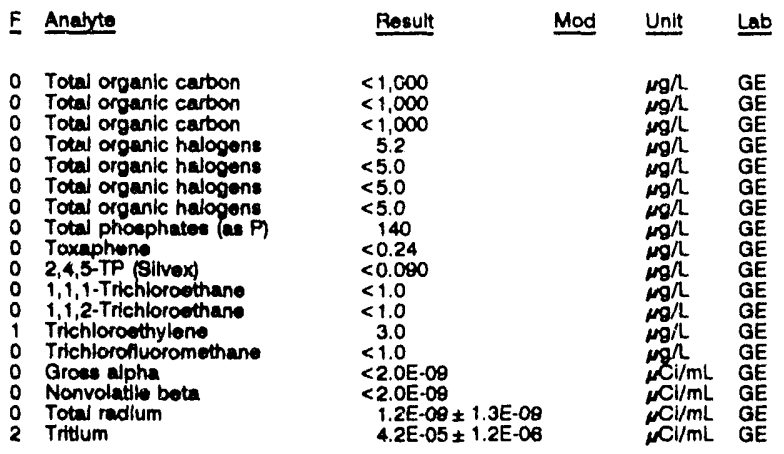

\section{WELL BGX 5D}

MEASUREMENTS CONDUCTED IN THE FIELD

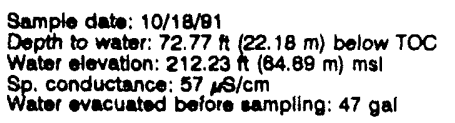

Timo: 11:20

Alkalinity: $4 \mathrm{mg} / \mathrm{h}$

Alkalinity: $4 \mathrm{mg} / \mathrm{L}$ : $18.70 \mathrm{C}$

\section{LABORATORY ANALYSES}

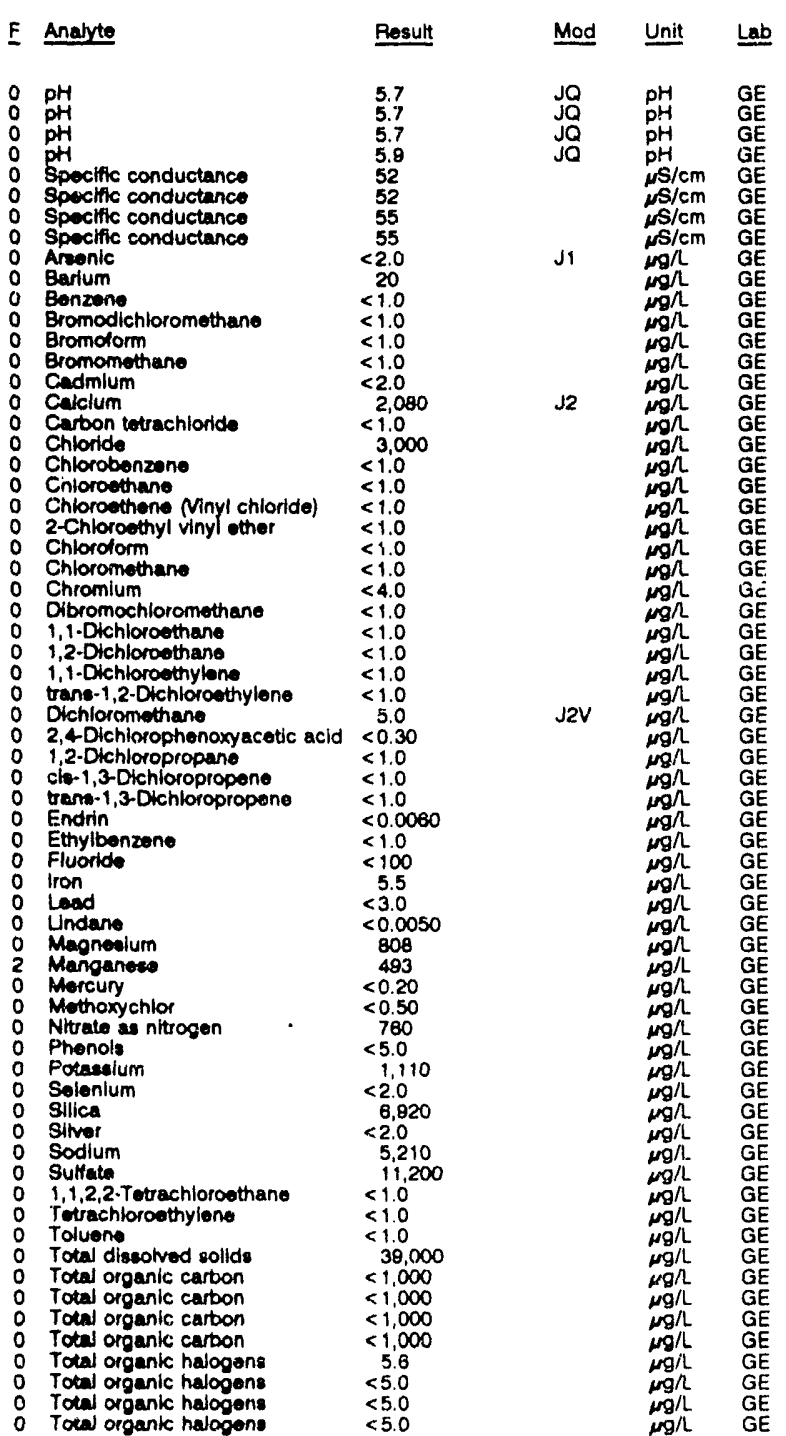

WELL BGX 5D colloctod on 10/18/81, laboratory analyses (cont.)

\begin{tabular}{|c|c|c|c|}
\hline Anaiyte & Rosult & Mod & Unit \\
\hline $\begin{array}{l}\text { Total phosphates (as P) } \\
\text { Toxaphene } \\
2,4,5-\text { TP (Silvex) } \\
1,1,1 \text {-Trichloroothane } \\
1,1,2 \text {-Trichloroethane } \\
\text { Trichloroethylene } \\
\text { Trichlorofluoromethane } \\
\text { Gross alpha } \\
\text { Nonvolatile beta } \\
\text { Total radium } \\
\text { Trttium }\end{array}$ & $\begin{aligned} & 110 \\
&< 0.24 \\
&< 0.090 \\
&<1.0 \\
&<1.0 \\
&<1.0 \\
& 19 \\
&<2.0 E-09 \\
& 2.0 E-09 \pm 1.5 E-09 \\
& 2.4 E-09 \pm 1.5 \mathrm{E}-09 \\
& 1.1 \mathrm{E}-00 \pm 7.0 \mathrm{E}-07\end{aligned}$ & & $\begin{array}{l}\mu g / \mathrm{L} \\
\mu \mathrm{g} / \mathrm{L} \\
\mu \mathrm{g} / \mathrm{L} \\
\mu \mathrm{g} / \mathrm{L} \\
\mu \mathrm{g} / \mathrm{L} \\
\mu \mathrm{g} / \mathrm{L} \\
\mu \mathrm{g} / \mathrm{L} \\
\mu \mathrm{LI/mL} \\
\mu \mathrm{Cl} / \mathrm{mL} \\
\mu \mathrm{Cl} / \mathrm{mL} \\
\mu \mathrm{Cl} / \mathrm{mL}\end{array}$ \\
\hline
\end{tabular}

WELL BGX 6D

MEASUREMENTS CONDUCTED IN THE FIELD

$\begin{array}{ll}\text { Sample dato: } 10 / 17 / 91 & \text { Time: } 18: 20 \\ \text { Dopth to water: } 87.30 \mathrm{~h}(20.51 \mathrm{~m}) \text { bolow TOC } & \text { pH: } 8.2 \\ \text { Wator olovation: } 209.70 \mathrm{ft}(83.82 \mathrm{~m}) \mathrm{msl} & \text { Alkalinity: } 24 \mathrm{mg} / \mathrm{h} \\ \text { Sp. conductanco: } 79 \mu \mathrm{s} / \mathrm{cm} & \text { Water temperature: } 18.8^{\circ} \mathrm{C} \\ \text { Wator ovacuatod bofore eampling: } 50 \mathrm{gal} & \end{array}$

LABORATORY ANALYSES

E Analyte Besult Mod Unit Lab

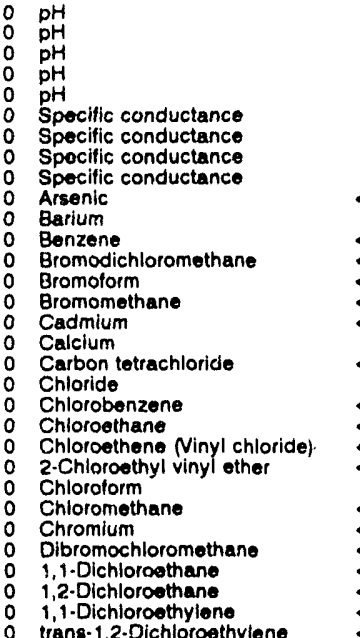

$\begin{array}{lll}0 & 1,1-D i c h l o r o e t h y l o n e & <1.0 \\ 0 & \text { trans-1,2-Dichloroethyiene } & <1.0\end{array}$

$\begin{array}{ll}0 & \text { Dichioromethane } \\ 0 & 2.8 \\ 0 & 2.4 \text {-Dichlorophenoxyacetic acid }<0.30\end{array}$

0 1,2-D: thloropropane $<1.0$

0 cis-1,3-Dichloropropene
0 trans-1,3-Dichloropropene

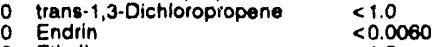

0 Ethylbenzene $<1.0$

$\begin{array}{lll}0 & \text { Fluoride } & <100 \\ 0 & \text { Fluoride } & <100\end{array}$

0 lron

0 Lindane

0 Lindane

2 Magnesium

Mercuny

Methoxychlor

Nitrate as nitrogen

Phenols

Potassium

Selenium

O Silica

o $\begin{array}{ll}0 & \text { Silver } \\ 0 & \text { Sodium }\end{array}$

- Sodium

Sulfate

T,1,2,2-Tetrachloroet

Tetrachloro

- Tolvene dissolved solids

Total dissolved solids

Total organic carbon

- Total organic carbon

Total organic carbon

Total organic + . Jogens

Total organic halogens

2 Total organic halogens

2 Total organic halogens

0 Toxaphene

$\begin{array}{ll}0 & 2,4,5 \cdot T P \text { (Silvex) } \\ 0 & 1,1,1-T \text { Trichloroethane }\end{array}$

0
0
0

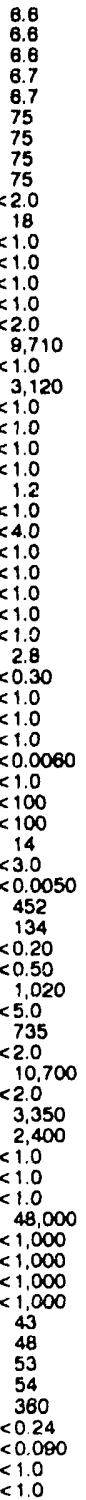

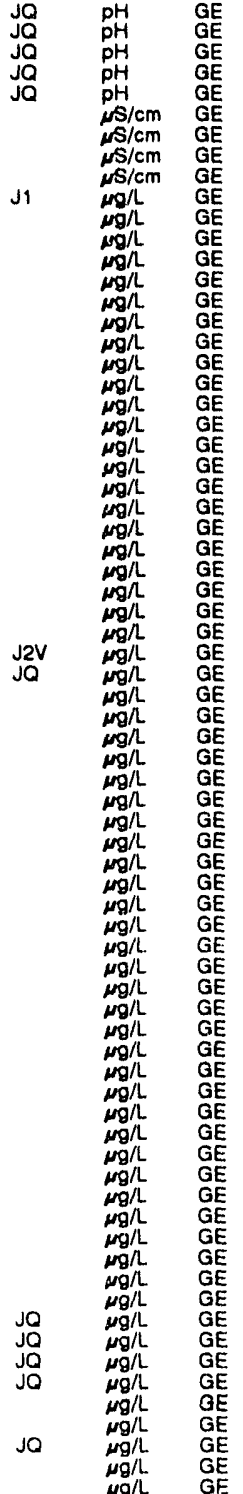


ANALYTICAL RESULTS

WELL BGX 6D collected on 10/17/91, laboratory analyses (cont.)

\begin{tabular}{|c|c|c|c|}
\hline Analyte & Result & Mod & Unit \\
\hline $\begin{array}{l}\text { Trichloroethylene } \\
\text { Trichlorofluoromethane } \\
\text { Gross alpha } \\
\text { Nonvolatlie beta } \\
\text { Total activity } \\
\text { Total radlum } \\
\text { Tritium }\end{array}$ & $\begin{array}{l}<1.0 \\
2.3 \\
<2.0 \mathrm{E}-09 \\
<2.0 \mathrm{E}-09 \\
5.3 \mathrm{E}-06 \pm 1.3 \mathrm{E}-06 \\
<1.0 \mathrm{E}-09 \\
<7.0 \mathrm{E}-07\end{array}$ & $\mathrm{~J} 2 \mathrm{~V}$ & 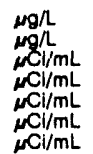 \\
\hline
\end{tabular}

\section{WELL BGX 7D}

MEASUREMENTS CONDUCTED IN THE FIELD

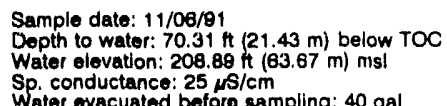

Time: 10:50

PH: 5.3 Alkalinity: $2 \mathrm{mg} / \mathrm{h}$

Water temperature: $18.4^{\circ} \mathrm{C}$
WELL BGX 70 collocted on 11/06/91, laboratory analyses (cont.)

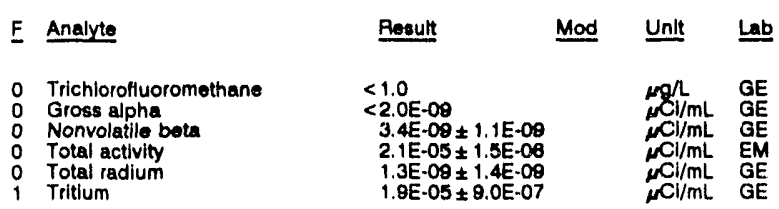

WELL BGX 8D

MEASUREMENTS CONDUCTED IN THE FIELD

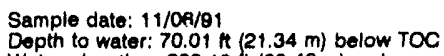

Water elovation: $208.19 \mathrm{Ht}(63.46 \mathrm{~m}) \mathrm{msl}$

Sp. conductance: $40 \mu \mathrm{N} / \mathrm{cm}$.

Timo: $12: 0$

Alkalinity: $6 \mathrm{mg} / \mathrm{L}$

LABORATORY ANALYSES

LABORATORY ANALYSES

E Analyte Result

$0 \begin{array}{cr}\mathrm{pH} \\ 0 & \mathrm{pH}\end{array}$

$\begin{array}{ll}0 & \mathrm{pH} \\ 0 & \mathrm{pH} \\ 0 & \mathrm{pH} \\ 0 & \mathrm{pH} \\ 0 & \mathrm{Spectic}\end{array}$

Specific conductance

Specific conductance

Speciffc conductance

Specific conductance

Arsenic

Barium

Bromodichloromethane

Bromoform

Cadmium

Carbon tetrachloride

Chloride

Chlorobenzene

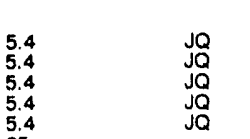

E Analyte

Mod Unit Lab

$\begin{array}{ll}0 & \mathrm{pH} \\ 0 & \mathrm{pH} \\ 0 & \mathrm{pH} \\ 0 & \mathrm{pH}\end{array}$

0
0
0

- Specific conductance

Specific conductance

Speciflc conductance

Specific conductance

Arsenic

0 Barium

Bromodichloromethane

Bromoform

- Cadmium

Cadmium

Carbon totrachioride

Chioride

Chlorobenzene

Chloroethene Ninyl chloride)

2-Chlorosthyl vinyl ether

Chloroform

Chloromethane

Chromlum

Dibromochloromethane

1,1-Dichloroethane

1,2-Dichloroethane

trans-1,2-Dichloroethylene

trans-1,2-Dichloroth

2,4-Dichlorophenoxyacetic acid

1,2-Dichloropropane

o trans-1,3-Dichloropropene

0 Endrin

0 Ethylbenzene

0 Fluoride

$\begin{array}{ll}0 & \text { Iron } \\ 0 & \text { Lead }\end{array}$

0 Lindane

Magnesium

Manganes

Mercury

Nitrate as nitrogen

Phenols

Potassium

Selenium

Silver

Sodium

1,1,2,2-Tetrachloroethane

Totrachlor

Total dissolved solids

Total organic carbon

Total organic carbon

Total organic carbon

- Total organic carbon

Total organic halogens

Total organic halogens

Total organic halogens

Total organic halogens

Total organic halogens

Total phosphates (as P)

Toxaphene

2,4,5. IP (Silvex)

1,1.1richloroethan

Trichloricethylens

o Trichlorofluoromethane

Gross alpha
6.1
6.1
6.1
6.1
6.2
50
50
50
50
50
$<2.0$
23
$<1.0$
$<1.0$
$<1.0$
$<1.0$
$<2.0$
3.99
$<1.0$
2.450
$<1.0$
$<1.0$
$<1.0$
$<1.0$
$<1.0$
$<1.0$
$<4.0$
$<1.0$
$<1.0$
$<1.0$
$<1.0$
$<1.0$
$<1.0$
$<0.30$
$<1.0$
$<1.0$
$<1.0$

$\begin{array}{ll}8.1 & J 0 \\ 6.1 & J Q \\ 8.1 & J 0 \\ 8.1 & J Q \\ 8.2 & J 0\end{array}$

$\begin{array}{lll}\mathrm{pH} & \mathrm{GE} \\ \mathrm{pH} & \mathrm{GE} \\ & \mu \mathrm{S} / \mathrm{cm} & \mathrm{GE}\end{array}$

3,990

2,450

$<0.006$

$<100$

47
$<3.0$

$<0.0050$

560

38
$<0.20$

$<0.50$

$\begin{aligned} & 1,460 \\ < & 5.0\end{aligned}$

1.020
1.020

$<2.0$

8,220
$<2.0$
$<$

2,790
$<1,000$

$<1.0$

$<1.0$

35,000

$<1,000$

$<1,000$

$<1,000$
$<1,000$

$<1,000$

$<5.0$

$<5.0$

$<5.0$

$<5.0$

$<5.0$
$<50$
$<0.24$
$<0.090$

$<1.0$

$<1.0$
1.1

$<1.0$
$<2$ OE -09
$\begin{array}{cc}\mathrm{pH} & \mathrm{gE} \\ \mathrm{pH} & \mathrm{GE} \\ \mathrm{pH} & \mathrm{GE}\end{array}$

\section{ME}


WELL BGX 80 collected on 11/06/91, laboratory analyses (cont.)

\begin{tabular}{|c|c|c|c|c|c|}
\hline F & Analyte & Result & Mod & Unit & Lab \\
\hline $\begin{array}{l}0 \\
0 \\
1 \\
2\end{array}$ & $\begin{array}{l}\text { Nonvolatile bota } \\
\text { Total activity } \\
\text { Total radlum } \\
\text { Totium }\end{array}$ & $\begin{array}{r}<2.0 \mathrm{E} \cdot 09 \\
8.6 \mathrm{E} \cdot 04 \pm 6.9 \mathrm{E} \cdot 06 \\
2.6 \mathrm{E} \cdot 09 \pm 1.6 \mathrm{E}-09 \\
8.8 \mathrm{E} \cdot 04 \pm 4.8 \mathrm{E}-06\end{array}$ & & $\begin{array}{l}\mu \mathrm{Cl} / \mathrm{mL} \\
\mu \mathrm{Cl} / \mathrm{mL} \\
\mu \mathrm{Cl} / \mathrm{mL} \\
\mu \mathrm{Cl} / \mathrm{mL} .\end{array}$ & $\begin{array}{l}\mathrm{GE} \\
\mathrm{EM} \\
\mathrm{GE} \\
\mathrm{GE}\end{array}$ \\
\hline
\end{tabular}

WELL BGX 9D

MEASUREMENTS CONDUCTED IN THE FIELD

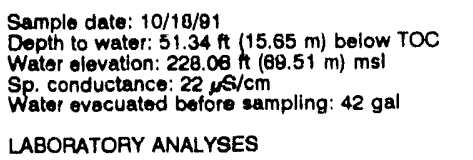

F Analyte Result Mod Unit Lab

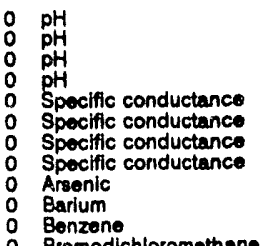

Bonzeno

Bromoform

- Carbon tetrachloride

- Chlorlde

Chlorobenzen

O Chloroethane

2-Chioroothyl vinyl other

Chloroform

Chromium

Dibromochloromethane

1,1-Dichloroothane

1,2 -Dichloroethane

trans-1,2-Dichloroethyiene

Dichloromothane

2,4-Dichlorophenoxy

1,2-Dichloropropane

cls-1,3-Dichloropropene

Endrin

Ethylbenzene $\quad<0.0080$

Fluoride

Iron

Lead

Magno vium

Manganese

Nitrate as nitrogen

Phenols

Selenium

silica

Silver

Sodium

$1,1,2,2$-Tetrachloroethane

Tetrachloroethylene

Toluene

Total dissolved solids

Total organic carbon

Total organic carboll

Total organic carbon

Total organic halogons

Total organic halogens

Total organlc halogen

Total organic halogens

Total phospt atos las P

Toxaphene

2,4,5-TP (Silvex)

1,1,1-Trichloroethane

Trichloroethylene

Trichlorofluoromethane

Gross alpha

Nonvolatile beta

Total radium
Tritium

160

$<0.24$

$<1.0$

$<1.0$

$<2.0 E-09$

$<2.0 E-09$

$<1.0 E-09$
$5.7 E \cdot 06 \pm 7.0 E-07$

WELL BGX 10D

MEASUREMENTS CONDUCTED IN THE FIELD

Sample date: $10 / 18 / 81$

Depth to watur: $49.32 \mathrm{ft}(15.03 \mathrm{~m})$ below TOC

Water elevation: $227.58 \mathrm{ft} / 68$

Water evacuated before sampling: $5 \mathrm{gal}$

The well went diy during purging.

LABORATORY ANALYSES

E Analyte Result Mod Unit Lab
Time: $10: 50$

PH: 5.0 : $0 \mathrm{mgh}$

Water temperature: $18.2^{\circ} \mathrm{C}$

$0 \mathrm{pH}$

$00 \mathrm{pH}$

${ }_{0}^{0} \mathrm{pH}$

Specific conductance

Specific conductance

Specific conductance

Arsenic

B Barium

Bromodichloromethane

Bromoform

Bromomethane

Cadmium

Carbon tetrachloride

Carbon tert

Chlorobenzene

Chlobenzeno

Chloroethene (Vinyl chloride)

2-Chloroethyt vinyl ether

Chlorotorm

Chloromethane

Chromium

Dibromochloromethane

1,1-Dichloroethane

1,2-Dichloroethane

tians-1,2-Dichloroethylene

Dichloromethane

2,4-Dichlorophenoxyacetic acid

1,2.0 hlopropane

is-1,3-Dichioprope

Endrin

Ethylbenzene

o Irori

o Lead

0 Lindane

- Magnesium

Manganes

Methoxychlor

Nitrate as nitrogen

Phenols

Selenium

Silica

Silver

Sodium

Sultate

Tetrachlorothyleno

Toluene

Total dissolved solids

Total dissolved solids

Total organic carbon

Total organic carbon

Total organic carbon

Total organic carbon

Total organic halogen

Total organic halogens

Total organic halogens

Total organic halogens

Total phosp h

1,1,1-Trichloroethane

1,1,2-Trichloroethane

Trichloroethylene

Gross alpha

- Nonvolatile beta

2 Total radium

Tritium

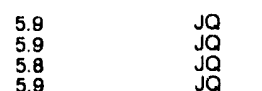

$\begin{array}{ll}\mathrm{FH} & \mathrm{GE} \\ \mathrm{pH} & \mathrm{GE} \\ \mathrm{pH} & \mathrm{GE}\end{array}$

5.9
25

28

28
$<2.0$

8.9
$<1.0$

$<1.0$

$<1.0$

$<2.0$

1,030
$<1.0$

$<1.0$

$<1.0$

$<1.0$

$<1.0$

$<4.0$

$<1.0$

$<1.0$

$<1.0$

$<1.0$

$<0.30$

$<1.0$

$<1.0$

$<0.0060$

$<1.0$

$<100$
73
$<3.0$

$<0.0050$

462
81

$<0.20$

$<0.50$
1.360

1,360
$<5.0$

$<500$

$<2.0$
7,230

$<2.0$

2,720
$<1,000$

$<1.0$

$<1.0$

18,000
24,000

$<1,000$

$<1,000$

$<1,000$

12
$<5.0$

$<5.0$
$<5.0$
100
$<0.24$

$<0.24$

1.0

$<1.0$

$<1.0$

$<2.0 E \cdot 09$

$<2.0 \mathrm{E} \cdot 09$

$1.7 \mathrm{E} \cdot 08 \pm 2.6 \mathrm{E}-09$
$2.7 \mathrm{E}-06 \pm 7.0 \mathrm{E} \cdot 07$

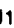
$\begin{array}{ll}\mathrm{PH} / \mathrm{cm} & \mathrm{GE} \\ \mu \mathrm{GE}\end{array}$

$\mu \underset{\mu g / L}{G} \mathrm{GE}$

$\begin{array}{ll}\mu g / L & G E \\ \mu g / L & G E\end{array}$

$\underset{\mu g / L}{\mu g / L}$

$\mu g / L \quad G E$

$\mu g / L$ GE
Time: 10:15

Alkalinity: $6 \mathrm{mg} / \mathrm{h}$ Water temperaturo: $17.6^{\circ} \mathrm{C}$ $\mu \mathrm{S} / \mathrm{cm}$ GE 
ANALYTICAL RESULTS

\section{WELL BGX 12C}

MEASUIREMENTS CONDUCTED IN THE FIELD

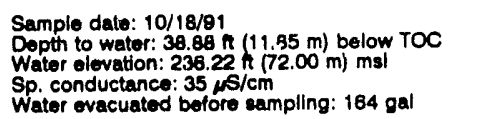

Time: 8:40

PH: 5.7 Alkalinity: $7 \mathrm{mg} / \mathrm{L}$

Water temperature: $18.5^{\circ} \mathrm{C}$

LABOPATORY ANALYSES

F Analyce

$\begin{array}{ll}0 & \mathrm{pH} \\ 0 & \mathrm{pH} \\ 0 & \mathrm{pH} \\ 0 & \mathrm{pH} \\ 0 & \mathrm{ppoch}\end{array}$

Spectic conductance

Specific conductance

Specific conductance

Arsenic

Barium

Bromodichloromethane

Bromoform

Bromomethane

Cadmium

Calcium

Carbon

Chloride
Chlorobenzene
Chloroethane

Chlorcethene Ninyl chloride

2-Chloroethyl vinyl ether

Chloroform

Chloromethan

Chromium

Dibromochloromethane

1,1-Dichloroethane

1,1-Dichloroethylene
o trans-1,2-Dichlorothylene

Dichloromethane

2,4-Dichlorophenoxyacetic acio

1,2-Dichloropropane

o cls-1,3-Dichloropropene

Enans-1,

Endrin
Ethylbenzene
Fluoride

o Fluoride

0 Leed

0 Lindane

M Magnesium

Morcury

Methoxychlor

Nitrate as nitrogen

Phenols

Potassium

0 Silica

$\begin{array}{ll}0 & \text { Silver } \\ 0 & \text { Sodium }\end{array}$

Sodium

Sulfate

$1,1,2,2$-Tetrachlorceth
Tetrachloroethyiene

0 Toluene

Toluene
Total dissolvec solids

Total organic carbon

Total orgaric cribon

- Total organic carbon

Total organic carbon

Total organic carbon

Total organic halogens

Total organic halogens

Total organic halogens

Total phosphates (as P)

Toxapheno

2,4,5-TP (Silvex)

$1,1,1 \cdot$ Trichloroetharie

Trichioroethyleno

Trichlorofiuoromethane

Gross alpha

Nonvolatiie beta

Total radiun
Tritium $\begin{array}{ll}5.9 & \text { JQ } \\ 5.8 & \text { JO } \\ 5.8 & \text { JO } \\ 6.0 & \text { JO }\end{array}$

6.0
30
30

31
32
32

$<2.0$
3.7
$<1.0$

$<1.0$

$<1.0$

$<1.0$

$<1450$

$<1.0$

$<1.0$

$<1.0$

$<1.0$

$<4.0$

$<1.0$

$<1.0$
$<1.0$

$<1.0$

$<1.0$
$<1.0$
$<0.30$

$<1.0$

$<0.0060$

$<1.0$
$<100$

31
$<3.0$

$<3.0$
$<0.0050$

271

$<0.20$
$<0.50$

230

$<5.0$
$<500$

$<2.0$
12,000

\begin{tabular}{l}
12,000 \\
$<2.0$ \\
\hline
\end{tabular}

4,500

4.300
$<1.0$

$<1.0$

$<10$
32,000

32,000
$<1,000$
$<1,000$

$<1,000$

$<1,000$

$<1,000$

7.3
10

$<5.0$
$<5.0$

$<5.0$
140

150
$<0.24$
$<0.090$

$<1.0$

$<1.0$

$<2.0 \mathrm{E}-09$

$<2.0 E .09$

$<1.0 E-09$
$<7.0 E-07$
WELL BGX 12C Replicate

MEASUREMENTS CONDUCTED IN THE FIELD

Sample date: 10/18/91

Depth to water: 38.88 it $(11.85 \mathrm{~m})$ below TOC

Water elevation: $238.22 \mathrm{Ht}(72$.

Sp. Conductance: $35 \mathrm{ps} / \mathrm{cm}$. $184 \mathrm{gal}$

Alkalinity: $7 \mathrm{mg} / \mathrm{L}$

Water tomperature: $18.5^{\circ} \mathrm{C}$

LABORATORY ANALYSES

E Analyte Result Mod Unit Lab

$\begin{array}{ll}0 & \mathrm{pH} \\ 0 & \mathrm{pH} \\ 0 & \mathrm{pH} \\ 0 & \mathrm{pH} \\ 0 & \text { Specific conductance } \\ 0 & \text { Specific conductance } \\ 0 & \text { Specific conductance } \\ 0 & \text { Specific conductance } \\ 0 & \text { Arsenic } \\ 0 & \text { Earium } \\ 0 & \text { Benzene } \\ 0 & \text { Bromodichloromethane } \\ 0 & \text { Bromoform }\end{array}$

Bromomethane

0 Cadmium

Calcium

Carbon tetrachloride

o Chloride

Chlorobenzene

Chloroethane

Chloroethene Ninyl chloride
2-Chloroethyl vinyl other

Chloromethan

Chromium

Dibromochloromethane

1,1-Dichloroetinant

1,2-Dichloroethane

1,1-Dichloroethylene
trans-1,2-Dichloroethylene

trans-1,2-Dichlore

2,4-Dichlorophenoxyacetic acld $<0.30$

1,2-Dichloropropane

cis-1,3-Dichloropropene

trans-1,3-Dichloropropen

Endrin

Ethylbenzene

Fluoride

Lead

Magnesium

Manganeso

Manganese

Mercury

Nitrate as nitrogen

Phenols

Potassium
Selenium

Sitica

Silver

Sodium

Sodum

1,1,2,2-Tetrachloroethane

Tetrachloroethylene

Toluene

Total dissolved solids

Total organic carbon

Total organic carbon

Total organic carbon

Total organic halogens

Total organic halogens

Total organic halogens

Total organic halogens

Toxaphen

2,4,5-TP (Silvex)

1,1,1-Trichloroethane

1,1,2-Trichloroethane

Trichloroethylene

Gross alpha

Nonvolatile beta

Nonvolatile beta

Tritium
6.0
6.2
8.2
6.2
30
30
30
32
$<2.0$
3.6
$<1.0$
$<1.0$
$<1.0$
$<1.0$
$<2.0$
700
683
$<1.0$
2,5
$<1.0$
$<1.0$
$<1.0$
$<1.0$
$<1.0$
$<1.0$
$<4.0$
$<1.0$
$<1.0$
$<1.0$
$<1.0$
$<1.0$
5.0
$<0.30$
$<1.0$
$<1.0$
$<11.0$

$\because 1.0$

$<1.0$

$<100$

$<3.0$

258
23
23

$<0.20$

$<0.50$

340
$<5.0$

$<500$

11,600

4,480

4,850

3,060

$<1.0$
$<1.0$

$<1.0$

16,000
$<1,000$

$<1,000$

$<1,000$

$<1,000$

5.0
8.8

$\mathbf{9 . 8}$
$<5.0$
$<5.0$

160
$<0.24$

$<0.090$

$<1.0$

$<1.0$
$<1.0$

4.0

2. $6 \mathrm{E}-09 \pm 1.3 \mathrm{E}-09$

$<2.0 E-00$

$1.5 \mathrm{E}-09 \div 1.4 \mathrm{E}-09$

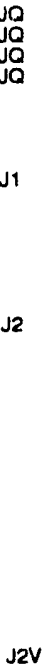

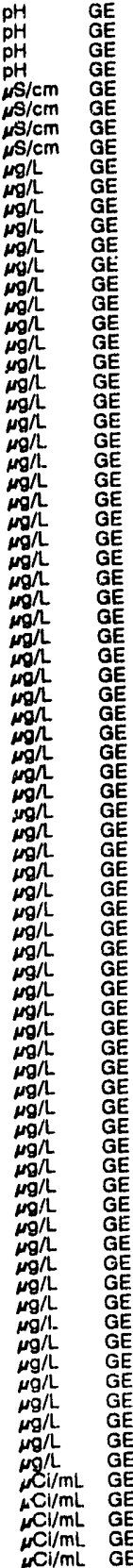


WELL BGX 12D

MEASUREMENTS CONDUCTED IN THE FIELD

Sample dato: 10/18/91

Dopth to wator: $34.55 \mathrm{n}(10.53 \mathrm{~m})$ below TOC

Sp. conductance: $20 \mathrm{~s} / \mathrm{cm}$

Witer evacuatod botore sampling: 10 gal

The woll went dry during purging.

LABOFATORY ANALYSES

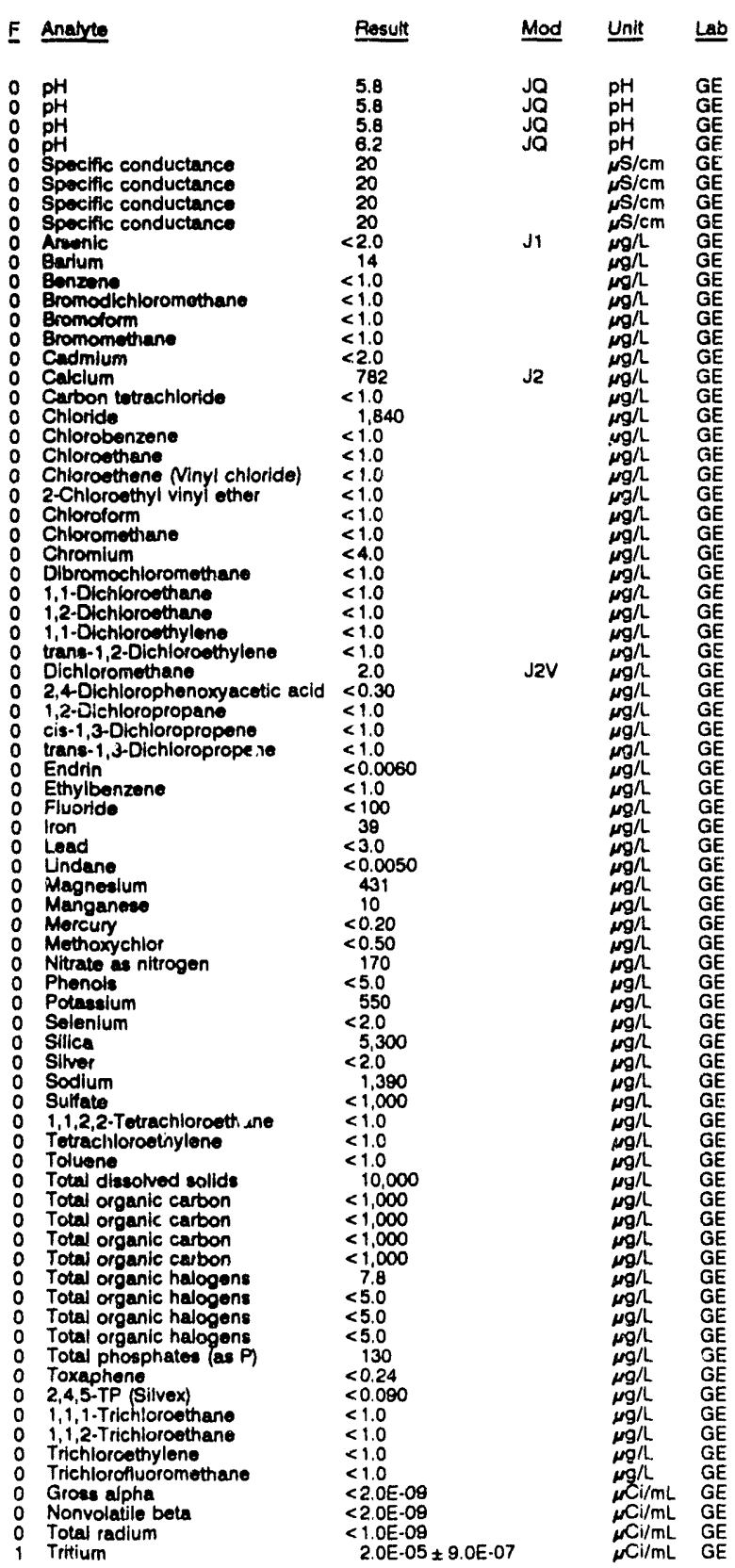

WELL BRD 1

MEASUREMENTS CONDUCTED IN THE FIELD

Sample date: $11 / 12 / 91$

Depth to water: $38.23 \mathrm{ft}(11.26 \mathrm{~m})$ below TOC

Wo

Water ovacuated before sampling: $46 \mathrm{gal}$

Time: $8: 10$

Alkalinity: $4 \mathrm{mg} / \mathrm{L}$

Water temperature: $16.9^{\circ} \mathrm{C}$

LABORATORY ANALYSES

E Analyte Result Mod Unit Lab

pH

Arsenic

Barium

Bromodichloromethane

Bromoform

Bromomethane

Cadmium

C Carbon tetrachlorido

0 Chloride

Chlorobenzene

Chlorosthane

o Chloroethene Ninyl chlorid

O Chloromethane

O Chromium

o 1,1-Cichloroethane

1,2-Dichloroethane

trans-1,2-Dlchloroethylene

- Dichloromethane

Mod Unit Lab

2,4-Dichlorophenoxy

1,2-Dichloropropane

o cis-1,3-Dichloropropene

0 Enans-1,

Ethylbonzene

F Fluoride

0 lion

L Lead

0 Lindane

: Lithium

- Marnesium

- Mercury

Methoxychlor

N Nickel

- Nitrate as nitrogen

0 Phenols

Potassium

Silica

: ${ }_{0}$ Silver

Sodium

Sulfate

1,1,2,2. Tetrachloroe

Toluene

- Total dissolved solids

- Total organic carbon

- Total organic halogens

0 Total phosphates (as P)

- Toxaphene

2 2,4,5-TP (Silvex)

o 1,1,1-Trchioroethane

1,1,2.Trichloroethan

- Trichloroethylene

o Gross alpha

Nonvolatile beta

Total radium

5.3
25
$<2.0$
10.0
$<1.0$
$<10$
$<1.0$
$<1.0$
$<2.0$
$<77$
$<1.0$
$<1.380$
$<1.0$
$<1.0$
$<1.0$
$<1.0$
$<1.0$
$<1.0$
$<4.0$
$<1.0$
$<1.0$
$<1.0$
$<1.0$
$<1.0$
$<10$

$<1.0$

$<0.30$

$<1.0$

$<1.0$
$<0.0060$

$<0.0060$

$<100$

$<58$

$<0.0050$

$<5.0$

373
17

0.42
$<0.50$

7.6
1,390

$<5.0$
507

$<20$
11.100

$<\begin{aligned} & 11,100 \\ & <2.0\end{aligned}$

1,970
$<1,000$

$<1.0$

$<1.0$

$<1.0$

$<1,000$

$<1,000$
$<5.0$
$<50$

$<50$
$<50$

$<0.24$
$<0.090$

$<1.0$

$<1.0$

2.3E-09 $0.5 \mathrm{E}-10$

3. $0 E-09 \pm 9.7 E-10$

2.3E-09 $1.8 \mathrm{EE}-09$

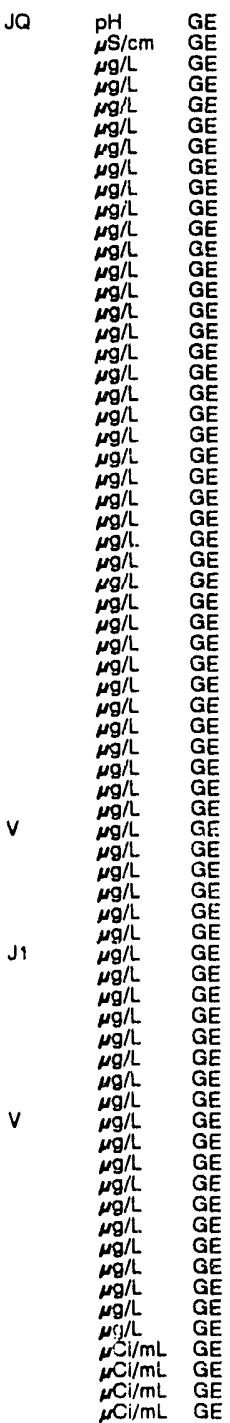

WELL BRD 2

MEASUREMENTS CONDUCTED IN THE FIELD

Sample date: $11 / 12 / 91$

Depth to water: $38.63 \mathrm{H}(11.77 \mathrm{~m})$ below TOC

.

Wer evacuated betore sampling: 53 a

Time: $9: 15$

: $5 \mathrm{mg} / \mathrm{L}$

ABORATORY ANALYSES

\begin{tabular}{|c|c|c|c|c|}
\hline Analyte & Resuit & Mod & Unit & Lab \\
\hline $\begin{array}{l}\text { pH } \\
\text { Specific conductance } \\
\text { Arsenic }\end{array}$ & $\begin{array}{r}5.8 \\
30 \\
<20\end{array}$ & JO & $\begin{array}{l}\mathrm{pH} \\
\mu \mathrm{S} / \mathrm{cm} \\
\mu \mathrm{g} / \mathrm{L}\end{array}$ & $\begin{array}{l}\mathrm{GE} \\
\mathrm{GE} \\
\mathrm{GE}\end{array}$ \\
\hline
\end{tabular}


ANALYTICAL RESULTS

WELL BRD 2 collectod on 11/12/91, laboratory analyses (cont.)

\begin{tabular}{|c|c|c|c|}
\hline Analyte & Result & Mod & Unit \\
\hline 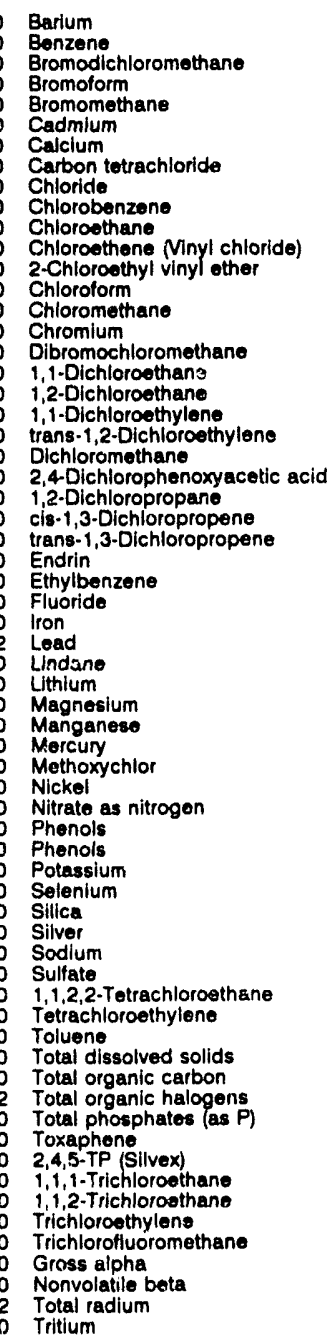 & 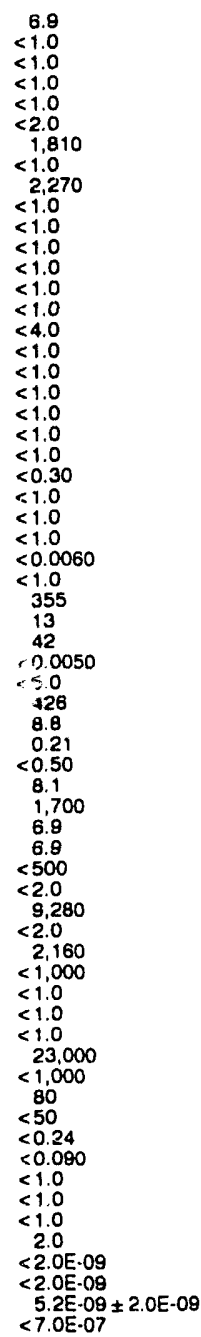 & J1 & 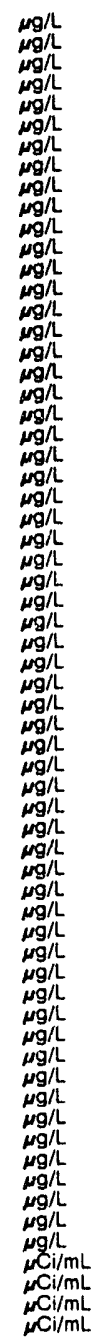 \\
\hline
\end{tabular}

WELL ER.D 3

MEASUREMENTS CONDUCTED IN THE FIELD

Sample date: $11 / 12 / 81$

Time: $8: 20$

The well was $d r y$.

Time: $8: 50$
PH. 500 Alkalinity: $0 \mathrm{ing} / \mathrm{h}$
Water temperature: $17.0^{\circ} \mathrm{C}$

WELL BRD 4

MEASUREMENTS CONDUCTED IN THE FIELD

Sample date: 11/12/91

Depth to water: $31.98 \mathrm{Ht}(9.74 \mathrm{~m})$ below TOC

Water oievation: $165.84 \mathrm{Ht}(50.54$

Water evacuated before sampling: $97 \mathrm{gal}$

LABORATORY ANALYSES

\begin{tabular}{|c|c|c|c|}
\hline E Analyte & Result & Mod & Unit \\
\hline $\begin{array}{l}\text { pH } \\
\text { Specific conductance } \\
\text { Arsenic } \\
\text { Barium } \\
\text { Benzene } \\
\text { Bromodichloromethane } \\
\text { Bromoform } \\
\text { Bromomethane } \\
\text { Cadmium }\end{array}$ & $\begin{aligned} & 5.2 \\
& 3.2 \\
&<2.0 \\
& 5.6 \\
&<1.0 \\
&<1.0 \\
&<1.0 \\
&<1.0 \\
&<2.0\end{aligned}$ & JO & $\begin{array}{l}\mathrm{pH} \\
\mu \mathrm{S} / \mathrm{cm} \\
\mu \mathrm{g} / \mathrm{h} \\
\mu \mathrm{g} / \mathrm{h} \\
\mu \mathrm{g} / \mathrm{L} \\
\mu \mathrm{g} / \mathrm{h} \\
\mu \mathrm{g} / \mathrm{L} \\
\mu \mathrm{g} / \mathrm{h} \\
\mu \mathrm{g} / \mathrm{L}\end{array}$ \\
\hline
\end{tabular}

WELL ERD 4 collected on 11/12/91, laboratory aralyses (cont.)

E Analyte Besult Mod Unit Lab

$\begin{array}{ll}0 & \text { Calclum } \\ 0 & \text { Carbon tetrachloride } \\ 0 & \text { Chloride } \\ 0 & \text { Chlorobenzens } \\ 0 & \text { Chloroethane } \\ 0 & \text { Chloroethene Ninyl chloride) } \\ 0 & 2 \text {-Chioroethyl vinyl other } \\ 0 & \text { Chloroform } \\ 0 & \text { Chloromethane } \\ 0 & \text { Chromium } \\ 0 & \text { Dibromochloromethane } \\ 0 & 1,1 \text {-Dichloroethane } \\ 0 & 1,2 \text {-Dichloroethane } \\ 0 & 1,1-\text { Dichloroethylene } \\ 0 & \text { trans-1,2-Dichloroethylene } \\ 0 & \text { Dichloromethane }\end{array}$

$<\begin{gathered}995 \\ <1.0 \\ <.400\end{gathered}$

2,490
$<1.0$

$<1.0$

$<1.0$

$<1.0$

$<4.0$

$<1.0$

$<1.0$

$<1.0$
1.1
$<0.30$

2,4-Dichlorophenoxyacotic acid $<0.30$

1,2-Dichloropropane

cis-1,3-Dichloropropene $<1.0$

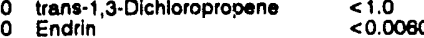

$\begin{array}{ll}0 & \text { Ethylbenzene } \\ 0 & <1.0 \\ 0 & <100\end{array}$

Iron

0 Lindane

o Linnium

- Magnesium

: Mangan

Methoxychior

O Nickel

N Nitrale as nittrogen

O Phenols

$\begin{array}{ll}0 & \text { Potassium } \\ 0 & \text { Selenium }\end{array}$

o Selenium

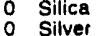

o sodium

Sulfate Tetrachloroethane

T, $1,2,2$. Totrachloroeth

o Tluentoroethylo

- Total dissolved solids

- Total organic carbon

- Total organic halogens

Total organic halogons
0 Total phosphates (as P)

- Toxaphene

o 2,4,5. TP (Silvex)

$\begin{array}{ll}0 & 1,1,1 . \text { Trichloroethane } \\ 0 & 1,1,2 . \text { Trichloroethane }\end{array}$

0 1,1,2-Trichloroethan

${ }_{0}$ Trichloroethylene

0 Teirhlorofluorom

o Nonvolatile beta

Total radium

$<100$
5.1

5.1
$<3.0$
$<0.0050$

$<0.00$
$<5.0$
466

5.8
$<0.20$
$<0.50$

$<0.50$

$<4.0$

$<5.0$

$<500$

$<2.0$

$<2.000$

$<1,000$

$<1.0$

$<1.0$

28,000

$<1,000$

$<5.0$

$<50$

$<0.24$

$<0.090$

$<1.0$

$<1.0$

$<1.0$

$<2.00-00$

$<1.0 E-09$

$2.3 \mathrm{E}-06+7.0 \mathrm{E}-07$

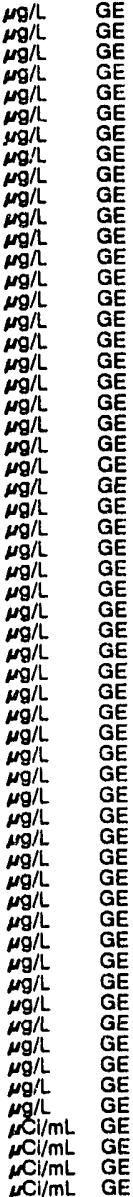

WELL BRD 5D

MEASUREMENTS CONDUCTED IN THE FIELD

Sample date: 11/12/91

Depth to water: 38.93 it $(11.87 \mathrm{~m})$ below TOC

Water elevation: $186.07 \mathrm{ft}(50.62 \mathrm{~m}) \mathrm{msl}$

Sp. conductance: $43 \mu \mathrm{s} / \mathrm{cm}$.

Alkalinity: $14 \mathrm{mg} / \mathrm{L}$

Water temperature: $17.3^{\circ} \mathrm{C}$

LABORATORY ANALYSES

\begin{tabular}{|c|c|c|c|}
\hline Analyte & Result & Mod & Unit \\
\hline $\begin{array}{l}\text { pH } \\
\text { Specific conductance } \\
\text { Arsenic } \\
\text { Barium } \\
\text { Benzene } \\
\text { Bromodichloromethane } \\
\text { Bromoform } \\
\text { Bromomethane } \\
\text { Cadmium } \\
\text { Calcium } \\
\text { Carbon tetrachloride } \\
\text { Chloride } \\
\text { Chlorobenzene } \\
\text { Chloroethane } \\
\text { Chloroethene Ninyl chloride) } \\
\text { 2-Chloroethyl vinyl ether } \\
\text { Chloroform } \\
\text { Chloromethane } \\
\text { Chromium } \\
\text { Dibromochloromethane } \\
\text { 1,1.Dichloroothane } \\
\text { 1,2.Dichloroethane } \\
1,1 . \text { Dichloroethylene } \\
\text { trans-1,2-Dichloroethylene } \\
\text { Dichloromethane }\end{array}$ & $\begin{aligned} & 6.2 \\
& 40 \\
&<2.0 \\
& 8.2 \\
&<1.0 \\
&<1.0 \\
&<1.0 \\
&<1.0 \\
&<2.0 \\
& 2.150 \\
&<1.0 \\
& 2,100 \\
&<1.0 \\
&<1.0 \\
&<1.0 \\
&<1.0 \\
&<1.0 \\
&<1.0 \\
&<4.0 \\
&<1.0 \\
&<1.0 \\
&<1.0 \\
&<1.0 \\
&<1.0 \\
& 2.0\end{aligned}$ & JO & $\begin{array}{l}p H \\
\mu S / c m \\
\mu g / L \\
\mu g / L \\
\mu g / L \\
\mu g / L \\
\mu g / L \\
\mu g / L \\
\mu g / L \\
\mu g / L \\
\mu g / L \\
\mu g / L \\
\mu g / L \\
\mu g / L \\
\mu g / L \\
\mu g / L \\
\mu g / L \\
\mu g / L \\
\mu g / L \\
\mu g / L \\
\mu g / L \\
\mu g / L \\
\mu g / L \\
\mu g / L \\
g g / L\end{array}$ \\
\hline
\end{tabular}


ANALYTICAL RESULTS

WELL BRO 5D collected on 11/12/91, laboratory analyses (cont.)

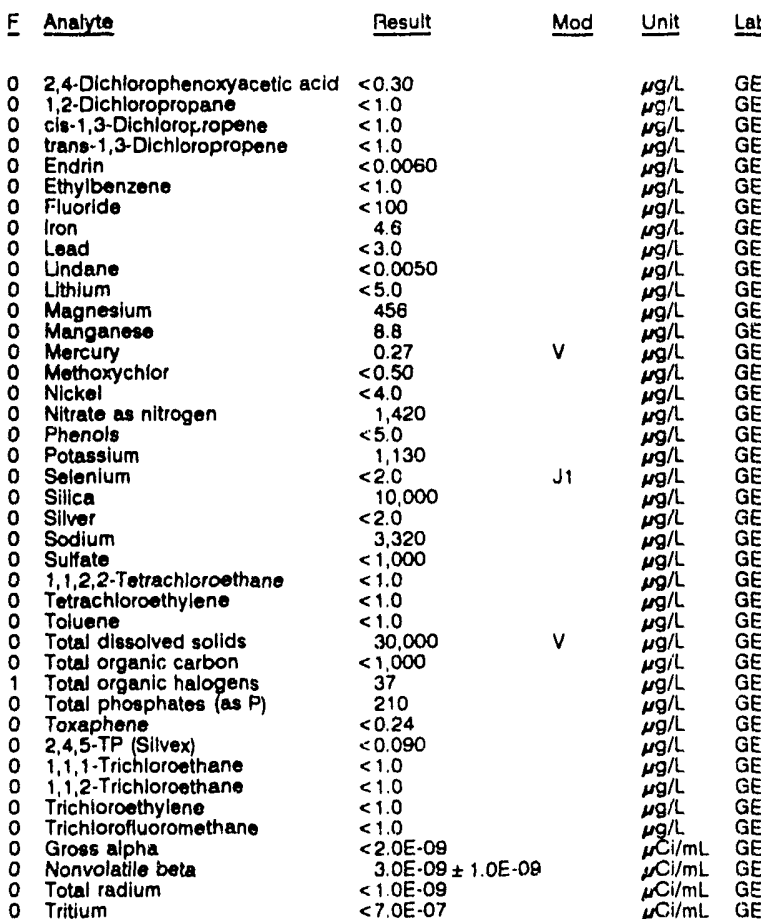

WELL BRA 1D

MEASUREMENTS CONDUCTED IN THE FIELD
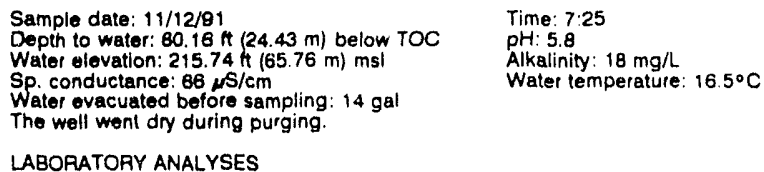

LABORATORY ANALYSES

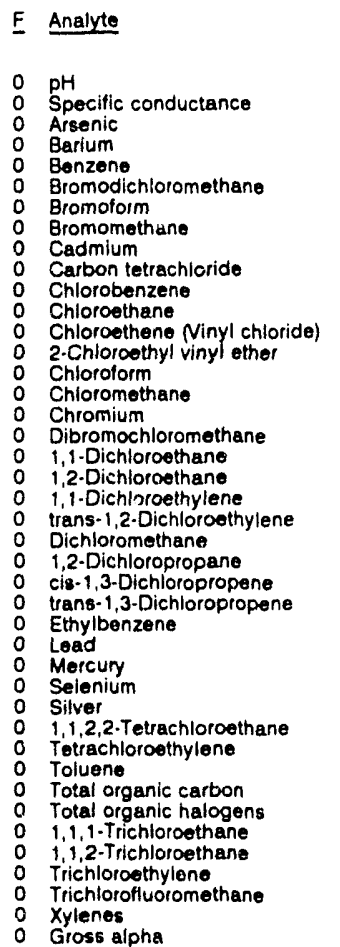

\begin{tabular}{l} 
Result \\
\multicolumn{1}{l}{} \\
6.0 \\
55 \\
$<2.0$ \\
13 \\
$<1.0$ \\
$<1.0$ \\
$<1.0$ \\
$<1.0$ \\
$<2.0$ \\
$<1.0$ \\
$<1.0$ \\
$<1.0$ \\
$<1.0$ \\
$<1.0$ \\
$<1.0$ \\
$<1.0$ \\
$<4.0$ \\
$<1.0$ \\
$<1.0$ \\
$<1.0$ \\
$<1.0$ \\
$<1.0$ \\
$<1.0$ \\
$<1.0$ \\
$<1.0$ \\
$<1.0$ \\
$<1.0$ \\
3.5 \\
0.28 \\
$<2.0$ \\
$<2.0$ \\
$<1.0$ \\
$<1.0$ \\
$<1.0$ \\
$<1.000$ \\
$<5.0$ \\
$<1.0$ \\
$<1.0$ \\
$<1.0$ \\
$<1.0$ \\
$<2.0$ \\
$<2.0 E-09$ \\
\end{tabular}

WELL BRA 1D collected on 11/12/91, laboratory analyses (cont.)

\begin{tabular}{|c|c|c|c|}
\hline Analyte & Result & Mod & Unit \\
\hline $\begin{array}{ll}0 & \text { Nonvolatile beta } \\
0 & \text { Total radium } \\
0 & \text { Tritium }\end{array}$ & $\begin{array}{r}3.8 \mathrm{E}-0 \\
<1.0 \mathrm{0} \cdot 0 \\
\quad 6.8 \mathrm{E}-0\end{array}$ & & $\underset{\substack{\mu \mathrm{Cl} / / \mathrm{mL} \\
\mu \mathrm{Cl} / \mathrm{mL}}}{\mu}$ \\
\hline
\end{tabular}

WELL BRR 2D

MEASUREMENTS CONDUCTED IN THE FIELD

$\begin{array}{ll}\text { Sample date: } 11 / 12 / 81 & \text { Time: } 5: 50 \\ \text { Depth to water: } 77.26 \mathrm{~h}(23.55 \mathrm{~m}) \text { below TOC } & \text { pH: } 5.7 \\ \text { Water levation: } 214.64 \mathrm{ft}(65.42 \mathrm{~m}) \mathrm{msl} & \text { Alkalinity: } 22 \mathrm{mg} / \mathrm{L} \\ \text { Sp. Conductance: } 73 \mu \mathrm{s} / \mathrm{cm} & \text { Water temperature: } 17.1^{\circ} \mathrm{C} \\ \text { Water evacuated bolore sampling: } 16 \mathrm{gal} & \end{array}$

Water evacuated bolore sampling: $16 \mathrm{gal}$

The well went dry during purging.

LABORATORY ANALYSES

E Analyte Result Mod Unit Lab

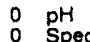

0 Arsenic

Barium

Bromodichloromethane

Bromomethane

Cadmium

Chlorobenzene

Chloroethane

Chloroethene Ninyl chloride)

2.Chloroethyl vinyl ether

Chloroform

Chloromethane

Chromium

1.1-Dichloroethane

1,2-Dichloroethane

$1,1 \cdot$ Dichloroethylene
trans-1,2-Dichloroethylene

trans-1,2-Dichloro

1,2-Dichloropropane

cis-1,3-Dichloropropene

Ethylbenzene

1 Lead

o Mercury

Seleniu

Silver

1,1,2,2-Tetrachloroethane

Tetrachloroethylene

Total organic carbon

Total organic halogens

o Total organic halogens

0 1,1.1. Trichloroethane

Tri,2-Trichloroethane

Trichiorofluoromethane

Xylenes

Gross alpha

Nonvolatile beta

Total radium

\begin{tabular}{|c|c|c|c|}
\hline 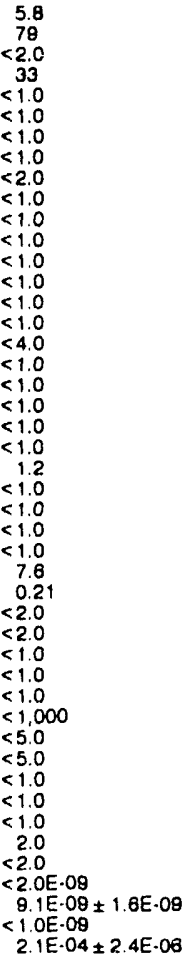 & $\begin{array}{l}V_{1} \\
J_{1}\end{array}$ & $\begin{array}{l}p H \\
\mu S / c m \\
\mu g / L \\
\mu g / L \\
\mu g / \\
\mu g / L \\
\mu g / L \\
\mu g / L \\
\mu g / L \\
\mu g / L \\
\mu g / L \\
\mu g / L \\
\mu g / L \\
\mu g / L \\
\mu g / L \\
\mu g / L \\
\mu g / L \\
\mu g / \\
\mu g / L \\
\mu g / L \\
\mu g / L \\
\mu g / L \\
\mu g / L \\
\mu g / L \\
\mu g / L \\
\mu g / L \\
\mu g / L \\
\mu g / L \\
\mu g / L \\
\mu g / L \\
\mu g / L \\
\mu g / L \\
\mu g / L \\
\mu g / L \\
\mu g / L \\
\mu g / L \\
\mu g / L \\
\mu g / L \\
\mu g / L \\
\mu g / L \\
\mu g / L \\
\mu g / L \\
\mu C / / m L \\
\mu C i / m L \\
\mu C i / m L \\
\mu C i / m L\end{array}$ & $\begin{array}{l}\mathrm{GE} \\
\mathrm{GE} \\
\mathrm{GE} \\
\mathrm{GE} \\
\mathrm{GE} \\
\mathrm{GE} \\
\mathrm{GE} \\
\mathrm{GE} \\
\mathrm{GE} \\
\mathrm{GE} \\
\mathrm{GE} \\
\mathrm{GE} \\
\mathrm{GE} \\
\mathrm{GE} \\
\mathrm{GE} \\
\mathrm{GE} \\
\mathrm{GE} \\
\mathrm{GE} \\
\mathrm{GE} \\
\mathrm{GE} \\
\mathrm{GE} \\
\mathrm{GE} \\
\mathrm{GE} \\
\mathrm{GE} \\
\mathrm{GE} \\
\mathrm{GE} \\
\mathrm{GE} \\
\mathrm{GE} \\
\mathrm{GE} \\
\mathrm{GE} \\
\mathrm{GE} \\
\mathrm{GE} \\
\mathrm{GE} \\
\mathrm{GE} \\
\mathrm{GE} \\
\mathrm{GE} \\
\mathrm{GE} \\
\mathrm{GE} \\
\mathrm{GE} \\
\mathrm{GE} \\
\mathrm{GE} \\
\mathrm{GE} \\
\mathrm{GE} \\
\mathrm{GE} \\
\mathrm{GE} \\
\mathrm{GE}\end{array}$ \\
\hline
\end{tabular}

WELL BRR 3D

MEASUREMENTS CONDUCTED IN THE FIELD

Sample date: $11 / 12181$

Wamplo

Water elevation: $214.03(23.87 \mathrm{~m})$ below

p. conductance: $75 \mu \mathrm{S} / \mathrm{cm}$

$\mathrm{pH}: 5.4$
Alkalinity $7 \mathrm{mg}$

Alkalinity: $7 \mathrm{mg} / \mathrm{L}$ : $16.9^{\circ} \mathrm{C}$

Water evacuated before sampling: $17 \mathrm{gal}$

LABORATORY ANALYSES

\begin{tabular}{|c|c|c|c|}
\hline Anaiyte & Result & Mod & Unit \\
\hline $\begin{array}{l}\text { pH } \\
\text { Specific conductance } \\
\text { Arsenic } \\
\text { Barium } \\
\text { Benzene } \\
\text { Bromodichloromethane } \\
\text { Bromoform } \\
\text { Bromomethane } \\
\text { Cadmium } \\
\text { Carbon tetrachloride } \\
\text { Chlorobenzene } \\
\text { Chloroethane } \\
\text { Chloroethene Ninyl chioride) } \\
\text { 2.Chloroethyl vinyl ether } \\
\text { Chloroform } \\
\text { Chloromethane } \\
\text { Chromium }\end{array}$ & $\begin{aligned} & 5.6 \\
& 65 \\
&<2.0 \\
& 18 \\
&<1.0 \\
&<1.0 \\
&<1.0 \\
&<1.0 \\
&<2.0 \\
&<1.0 \\
&<10 \\
&<1.0 \\
&<1.0 \\
&<1.0 \\
&<1.0 \\
&<1.0 \\
&<40\end{aligned}$ & מנ & $\begin{array}{l}\mathrm{pH} \\
\mu \mathrm{S} / \mathrm{cm} \\
\mu g / L \\
\mu g / L \\
\mu g / L \\
\mu g / L \\
\mu g / L \\
\mu g / L \\
\mu g / L \\
\mu g / L \\
\mu g / L \\
\mu g / L \\
\mu g / L \\
\mu g / L \\
\mu g / L \\
\mu g / L \\
\mu g / L\end{array}$ \\
\hline
\end{tabular}


ANALYTICAL RESULTS

WELL BRR 3D collected on 11/12/91, laboratory analyses (cont.)

\begin{tabular}{|c|c|c|c|}
\hline Analyte & Result & Mod & Unit \\
\hline $\begin{array}{l}\text { Dibromochloromethane } \\
1,1 \text {-Dichloroethane } \\
1,2 \text {-Dichlorcethane } \\
1,1-\text { Dichloroethylene } \\
\text { trans-1,2-Dichloroethylene } \\
\text { Dichloromethane } \\
1,2 \text {-Dichloropropane } \\
\text { cis-1,3-Dichloropropene } \\
\text { trans-1,3-Dichloropropene } \\
\text { Ethylbenzene } \\
\text { Lead } \\
\text { Mercury } \\
\text { Selenium } \\
\text { Silver } \\
1,1,2,2 \text {-Tetrachloroethane } \\
\text { Totrachloroethyiene } \\
\text { Toluene } \\
\text { Total organic carbon } \\
\text { Total organic halogens } \\
1,1,1 \text {-Trichloroethane } \\
\text { 1,1,2-Trichlorcethane } \\
\text { Trichloroethylene } \\
\text { Trichlorofluoromethene } \\
\text { Xylenes } \\
\text { Gross alpha } \\
\text { Nonvolatile beta } \\
\text { Total radium } \\
\text { Tritium }\end{array}$ & $\begin{aligned}<1.0 \\
<1.0 \\
<1.0 \\
<1.0 \\
<1.0 \\
<1.0 \\
<1.0 \\
<1.0 \\
<1.0 \\
<1.0 \\
12 \\
0.28 \\
<2.0 \\
<2.0 \\
<1.0 \\
<1.0 \\
<1.0 \\
<1.000 \\
11 \\
<1.0 \\
<1.0 \\
1.3 \\
3.5 \\
<2.0 \\
4.0 \mathrm{E} \cdot 09 \pm 1.3 \mathrm{E}-09 \\
1.2 \mathrm{E}-08 \pm 1.7 \mathrm{E} \cdot 09 \\
<1.0 \mathrm{E}-09 \\
8.9 \mathrm{E} \cdot 05 \pm 1.6 \mathrm{E} \cdot 06\end{aligned}$ & $\begin{array}{l}V \\
J_{1}\end{array}$ & $\begin{array}{l}\mu g / L \\
\mu g / L \\
\mu g / L \\
\mu g / L \\
\mu g / L \\
\mu g / L \\
\mu g / L \\
\mu g / L \\
\mu g / L \\
\mu g / L \\
\mu g / L \\
\mu g / L \\
\mu g / L \\
\mu g / L \\
\mu g / L \\
\mu g / L \\
\mu g / L \\
\mu g / L \\
\mu g / L \\
\mu g / L \\
\mu g / L \\
\mu g / L \\
\mu g / L \\
\mu g / L \\
\mu C i / m L \\
\mu C i / m L \\
\mu C i / m L \\
\mu C i / m L\end{array}$ \\
\hline
\end{tabular}

WELL BRR 4D

MEASUREMENTS CONDUCTED IN THE FIELD

$\begin{array}{ll}\text { Sample date: } 11 / 12 / 91 & \text { Time: } 6: 30 \\ \text { Depth to water: } 78.10 \mathrm{ft}(23.81 \mathrm{~m}) \text { below TOC } & \text { pH: } 6.3 \\ \text { Water olevation: } 214.10 \mathrm{ft}(65.26 \mathrm{~m}) \mathrm{msl} & \text { Alkalinity: } 57 \mathrm{mg} / \mathrm{L} \\ \text { Sp. conductance: } 152 \mu \mathrm{s} / \mathrm{cm} & \text { Water temperature: } 16.1{ }^{\circ} \mathrm{C} \\ \text { Water evacuated before sampling: } 16 \mathrm{gal} & \\ \text { The well went dry during purging. } & \end{array}$

LABORATORY ANALYSES

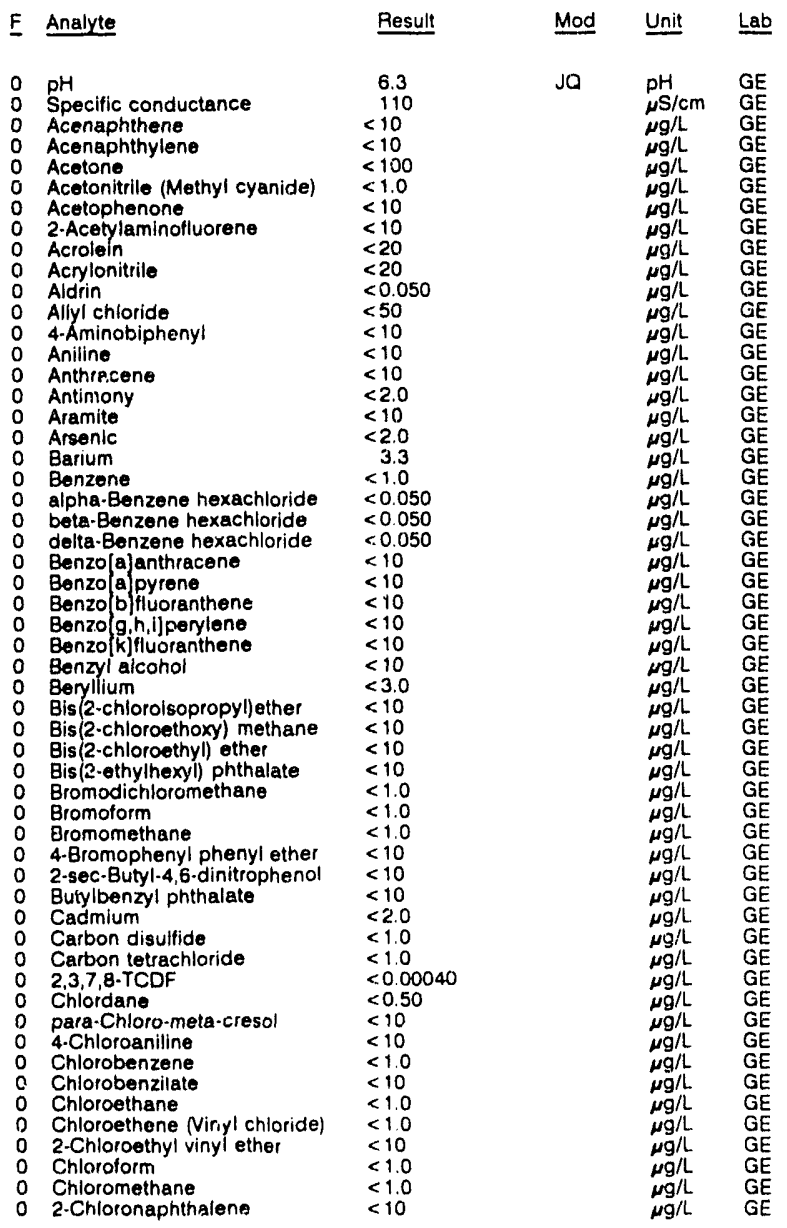

WELL BRR $4 D$ collected on $11 / 12 / 91$, laboratory analyses (cont.)

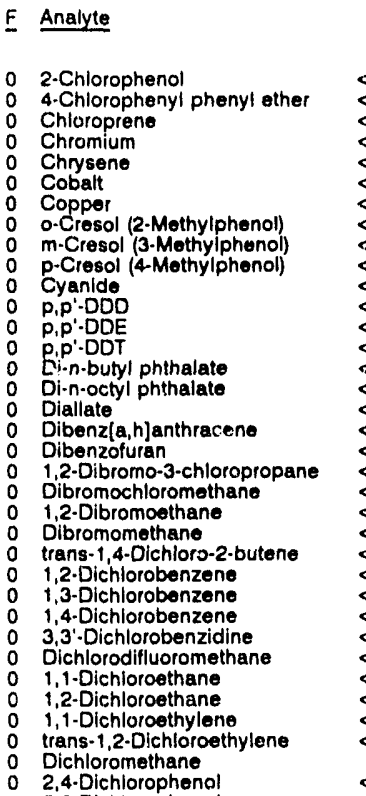

Resull Mod Unit Lab

$<10$
$<10$

$<200$

$<4.0$

$<4.0$

$<4.0$

$<10$

$<5.10$

$<0.10$

$<10$

10

$<10$

$<1.0$

$<20$

$<30$

$<10$

$<10$

$<1.0$

1.0

$<1.0$

$<10$

$\begin{array}{ll}2,8-\text { Dichlorophenol } & <10 \\ 2,4 \text {-Dichlorophenoxyacetic acid } & <0.30\end{array}$

1,2-Dichloropropane $<1.0$

cis-1,3-Dichloropropene

trans-13-Dichloropropene

Dieldrin

$<1.0$

$<1.0$

Diethyl phthalate

2,4-Dimethyl pheno

Dimethyl phthalate

p.Dimethylaminoazobenzene

3.3'-Dimethylbenzidine

a.a.Dimethylphenethylamine

1,3-Dinitrobenzene

2,4-Dinitrophenol

2,4-Dinitrotoluene

2,6-Dinitrotolvene

1,4-Dioxane

Diphenylanin

Disulfoton

Endosulfan I

Endosulfan suifate

Endrin

Endrin aldehyde

Ethyl methacrylate

Ethyl methanesu

0 Famphur

Fluoranthene

Fluorene

Heptachior

Heptachlor epoxide

1,2,3,4,6,7,8.HPCDD

Heptachlorodibenzo-p-dioxins

$1,2,3,4,6,7,8$-HPCDF
Heptachlorodibenzo-p-furans

Hexachlorobenzene

Hexachlorobutadiene

Hexachlorocyclopen

0
0 Hexachlorodibenzo-p-dioxins

$1,2,3,4,7,8 \cdot H X C D F$
Hexachlorodibenzo-p-furans

Hexachloroethane

Hexachlorophene

Hexachloropropene

2-Hexanone

Indeno $\{1,2,3-c, d] p y r e n e$

0 lodomethane (Methyl iodide)

|sobutyl alcohol

0 Isodrin

0 Isophorone

$\begin{array}{ll}0 & \text { Isosalrole } \\ 0 & \text { Kepone }\end{array}$

0 Lead

0 Lindane

Mercury

Methacrylot :rilo

Methapyrilene

Methoxychlor
Methyl ethyl ketone

Methyl isobutyl ketone
0 Methyl methacrylate

0 Methyl methacrylate 
ANALYTICAL RESULTS

WELL BRR 40 collected on $11 / 12 / 91$, laboratory analyses (cont.)

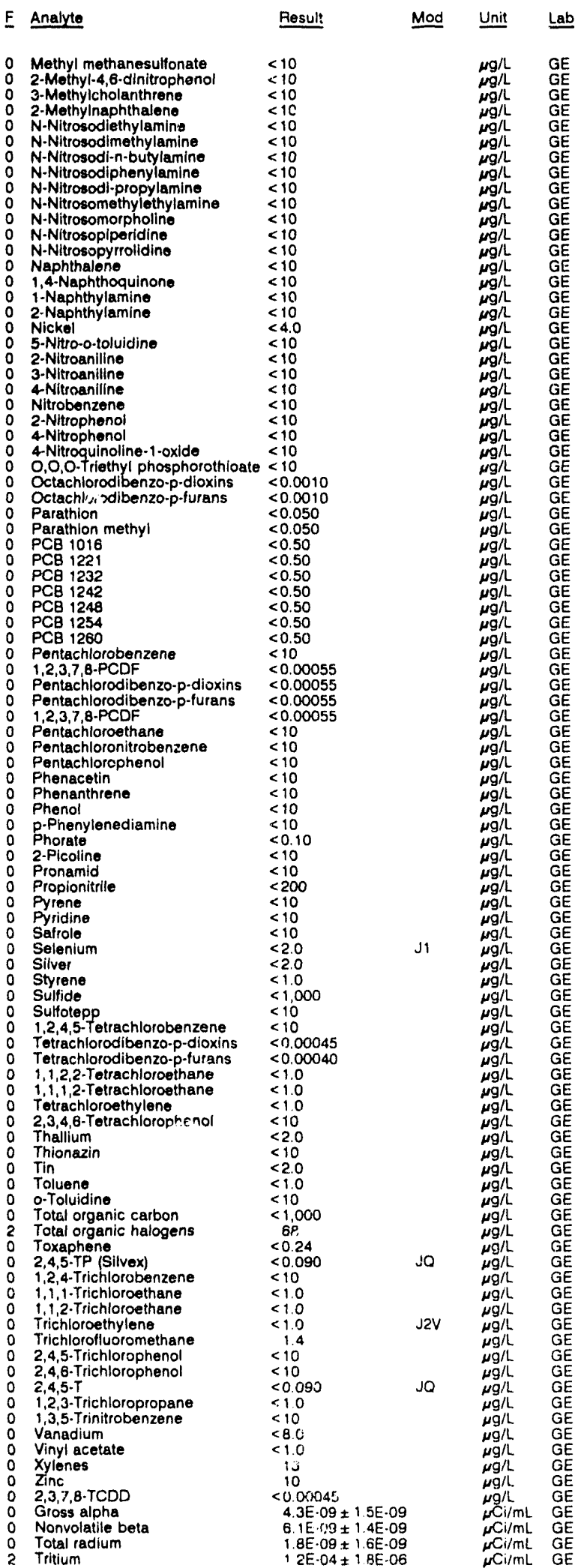

WELL BRR 5D

MEASUREMENTS CONDUCTED IN THE FIELD

$\begin{array}{ll}\text { Sample date: } 11 / 12 / 91 & \text { Time: } 7: 00 \\ \text { Depth to water: } 80.83 \mathrm{ht}(24.64 \mathrm{~m}) \text { below TOC } & \text { pH: } 5.6 \\ \text { Water olevation: } 213.77 \mathrm{~h}(65.16 \mathrm{~m}) \mathrm{msl} & \text { Alkalinity: } 15 \mathrm{mg} / \mathrm{h} \\ \text { Sp. conductance: } 85 \text { ys/.cm } & \text { Water temperature: } 16.8^{\circ} \mathrm{C} \\ \text { Water evacuated betore sampling: } 12 \mathrm{gal} & \end{array}$

Water evacuated betore sampling: $12 \mathrm{gal}$

The well went dry during purging.

LABORATORY ANALYSES

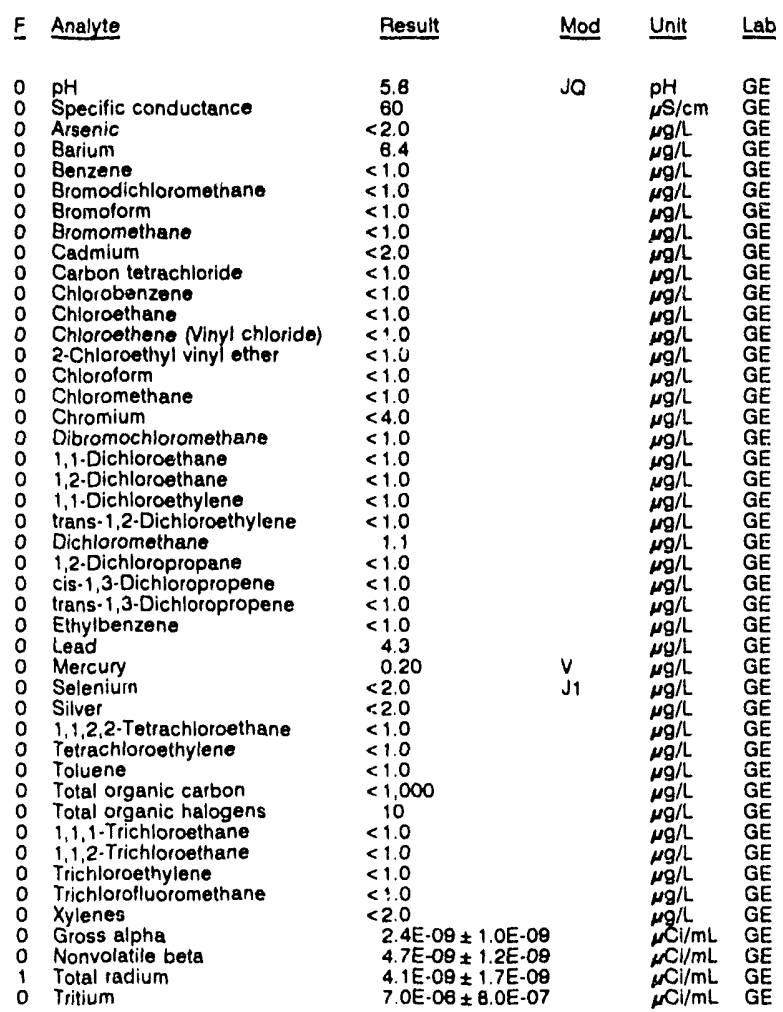

\section{WELL CBR 1D}

MEASUREMENTS CONDUCTED IN THE FIELD

\begin{tabular}{|c|c|c|c|c|c|}
\hline & $\begin{array}{l}\text { mple date: } 11 / 11 / 91 \\
\text { pth to water: } 48.02 \mathrm{ft}(14.64 \mathrm{~m}) \mathrm{b} \\
\text { ter elevation: } 252.58 \mathrm{H}(78.99 \mathrm{~m}) \\
\text { conductance: } 31, \mu \mathrm{s} / \mathrm{cm} \\
\text { ter evacuated betore sampling: } 5\end{array}$ & $\begin{array}{l}\text { low TOC } \\
\text { msi } \\
7 \mathrm{gal}\end{array}$ & $\begin{array}{l}\text { Time: } 7: 40 \\
\text { pH: } 5.4 \\
\text { Alkalinity: } 6 \\
\text { Water tempe }\end{array}$ & ure: 16.8 & \\
\hline & BORATORY ANALYSES & & & & \\
\hline$\underline{E}$ & Analyte & Result & Mod & Unit & Lab \\
\hline $\begin{array}{l}0 \\
0 \\
0 \\
0 \\
0 \\
0 \\
0 \\
0 \\
0 \\
0 \\
0 \\
0 \\
0 \\
0 \\
0 \\
0 \\
0 \\
0 \\
0 \\
0 \\
0 \\
0 \\
0 \\
0 \\
0 \\
0\end{array}$ & $\begin{array}{l}\text { pH } \\
\text { Specific conductance } \\
\text { Arsenic } \\
\text { Barium } \\
\text { Benzene } \\
\text { Bromodichloromethane } \\
\text { Bromoform } \\
\text { Bromomethane } \\
\text { Cadmium } \\
\text { Calcium } \\
\text { Carbon tetrachloride } \\
\text { Chloride } \\
\text { Chlorobenzene } \\
\text { Chloroethane } \\
\text { Chloroethene Ninyl chloride) } \\
\text { 2.Chloroethyl vinyl ether } \\
\text { Chlorolorm } \\
\text { Chloromethane } \\
\text { Chromiurn } \\
\text { Dibromochloromethane } \\
\text { 1,1-Dichloroethane } \\
\text { 1,2.Dichloroethane } \\
1,1-\text { Dichloroethylene } \\
\text { trans-1,2-Dichloroethylene } \\
\text { Dichloromethane } \\
\text { 2,4-Dichiorophenoxyacetic acid }\end{array}$ & $\begin{aligned} & 5.8 \\
& 30 \\
&<2.0 \\
& 11 \\
&<1.0 \\
&<1.0 \\
&<1.0 \\
&<1.0 \\
&<2.0 \\
& 350 \\
&<1.0 \\
& 2,240 \\
&<1.0 \\
&<1.0 \\
&<1.0 \\
&<1.0 \\
&<1.0 \\
&<1.0 \\
&<4.0 \\
&<1.0 \\
&<1.0 \\
&<1.0 \\
&<1.0 \\
&<1.0 \\
& 1.1 \\
&<0.30\end{aligned}$ & jo & $\begin{array}{l}\mathrm{pH} \\
\mu \mathrm{S} / \mathrm{cm} \\
\mu g / L \\
\mu g / L \\
\mu g / L \\
\mu g / L \\
\mu g / L \\
\mu g / L \\
\mu g / L \\
\mu g / L \\
\mu g / L \\
\mu g / L \\
\mu g / L \\
\mu g / L \\
\mu g / L \\
\mu g / L \\
\mu g / L \\
\mu g / L \\
\mu g / L \\
\mu g / L \\
\mu g / L \\
\mu g / L \\
\mu g / L \\
\mu g / L \\
\mu g / L \\
\mu g / L\end{array}$ & $\begin{array}{l}\mathrm{GE} \\
\mathrm{GE} \\
\mathrm{GE} \\
\mathrm{GE} \\
\mathrm{GE} \\
\mathrm{GE} \\
\mathrm{GE} \\
\mathrm{GE} \\
\mathrm{GE} \\
\mathrm{GE} \\
\mathrm{GE} \\
\mathrm{GE} \\
\mathrm{GE} \\
\mathrm{GE} \\
\mathrm{GE} \\
\mathrm{GE} \\
\mathrm{GE} \\
\mathrm{GE} \\
\mathrm{GE} \\
\mathrm{GE} \\
\mathrm{GE} \\
\mathrm{GE} \\
\mathrm{GE} \\
\mathrm{GE} \\
\mathrm{GE} \\
\mathrm{GE}\end{array}$ \\
\hline
\end{tabular}


ANALYTICAL RESULTS

WELL CBR 10 collocted on 11/11/91, laboratory analyses (cont.)

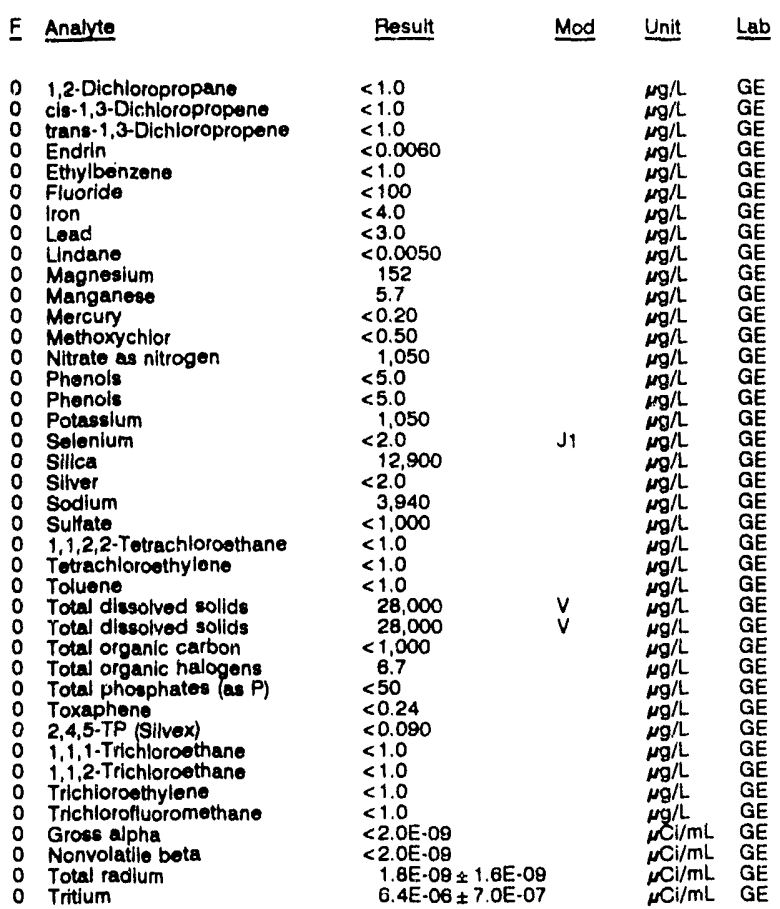

WELL CBR 2D

MEASUREMENTS CONDUCTED IN THE FIELD

Sample date: $11 / 11 / 91$ Water olovation: $252.18 \mathrm{H}(76.87 \mathrm{~m}) \mathrm{msl}$

conductance: 37 sicm

Water ovacuated before sampling: $48 \mathrm{gal}$

LABORATOAY ANALYSES

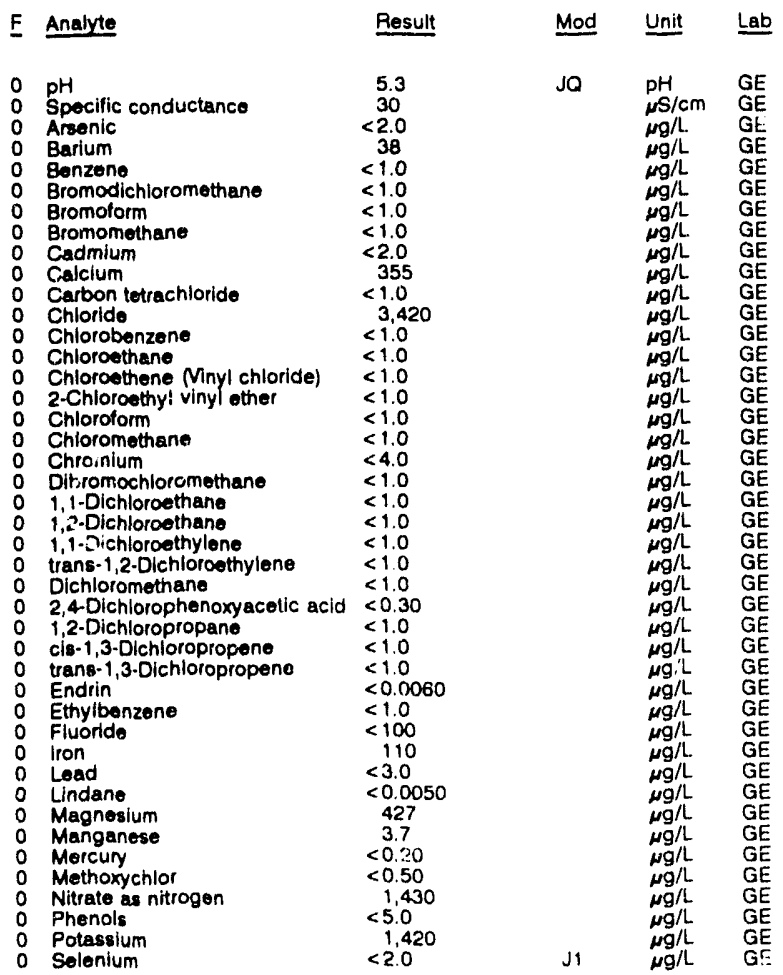

WELL CBR 2D collected on 11/11/91, laboratory analyses (cont.)

\begin{tabular}{|c|c|c|c|}
\hline Analyte & Result & Mod & Unit \\
\hline $\begin{array}{l}\text { Silica } \\
\text { Silver } \\
\text { Sodium } \\
\text { Sulfate } \\
1,1,2,2 \text {-Tetrachloroethane } \\
\text { Totrachloroethylene } \\
\text { Toluene } \\
\text { Total dissolved solids } \\
\text { Total organic carbon } \\
\text { Total organic halogens } \\
\text { Total phosphates (as P) } \\
\text { Toxaphene } \\
\text { 2,4,5-TP (Silvex) } \\
\text { 1,1,1-Trichloroothane } \\
\text { 1,1,2-Trichloroethane } \\
\text { Trichloroethylene } \\
\text { Trichlorofluoromethane } \\
\text { Gross alpha } \\
\text { Nonvolatile bote } \\
\text { Total radlum } \\
\text { Tritium }\end{array}$ & $\begin{aligned} & 16,000 \\
&<2.0 \\
& 3,170 \\
&<1,000 \\
&<1.0 \\
&<1.0 \\
&<1.0 \\
& 31,000 \\
&<1,000 \\
&<5.0 \\
&<50 \\
&<0.24 \\
&<0.000 \\
&<1.0 \\
&<1.0 \\
&<1.0 \\
&<1.0 \\
&<2.0 E-09 \\
& 4.2 E \cdot 09 \pm 1.1 E-09 \\
&<1.0 E \cdot 09 \\
& 1.0 E \cdot 05 \pm 8.0 E-07\end{aligned}$ & $v$ & $\begin{array}{l}\mu g / L \\
\mu g / L \\
\mu g / L \\
\mu g / L \\
\mu g / L \\
\mu g / L \\
\mu g / L \\
\mu g / L \\
\mu g / L \\
\mu g / L \\
\mu g / L \\
\mu g / L \\
\mu g / L \\
\mu g / L \\
\mu g / L \\
\mu g / L \\
\mu g / L \\
\mu C i / m L \\
\mu C i / m L \\
\mu C l / m L \\
\mu C i / m L\end{array}$ \\
\hline
\end{tabular}

WELL CBR 2D Replicate

MEASUREMENTS CONDUCTED IN THE FIELD

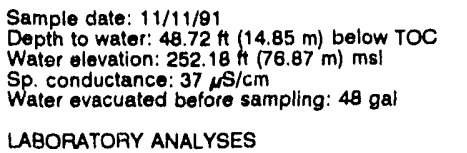

Time: 6:50

PH: 4.8 : $1 \mathrm{mal}$

Water temperature: $16.0^{\circ} \mathrm{C}$

LABORATORY ANALYSES

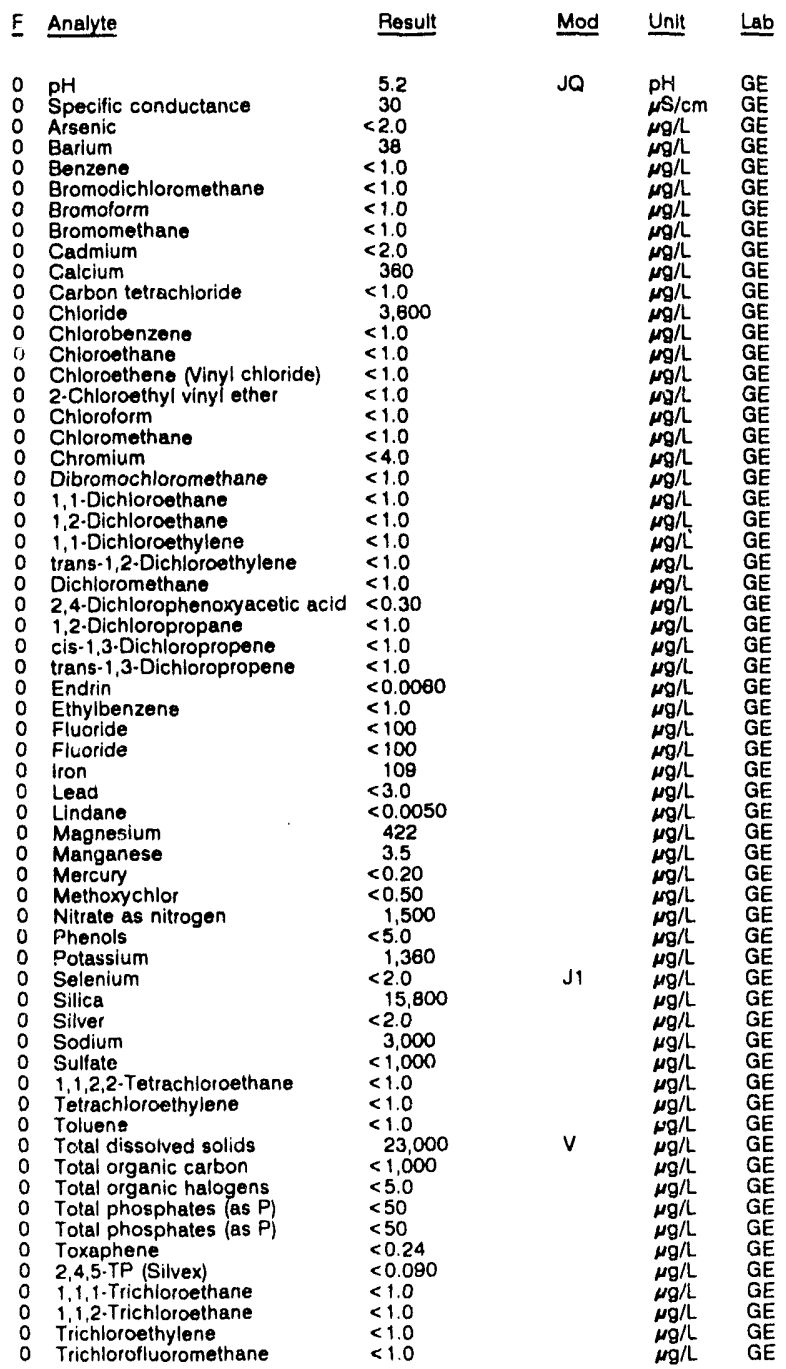


WELL CBR 2D collocted on 11/11/91, laboratory analyses (cont)

\begin{tabular}{|c|c|c|c|}
\hline E Analyte & Result & Mod & Unit \\
\hline $\begin{array}{ll}\text { O Grose alpha } \\
0 & \text { Nonvolatile beta } \\
2 & \text { Total radium } \\
1 & \text { Tritlum }\end{array}$ & $\begin{array}{l}<2.0 \mathrm{E}-09 \\
4.2 \mathrm{E}-09 \pm 1.1 \mathrm{E}-09 \\
2.9 \mathrm{E}-08 \pm 3.9 \mathrm{E}-09 \\
1.2 \mathrm{E}-05 \pm 8.0 \mathrm{E}-07\end{array}$ & & $\begin{array}{c}\mu \mathrm{Cl} / \mathrm{mL} \\
\mu \mathrm{Ci} / \mathrm{mL} \\
{ }_{\mu} \mathrm{Ci} / \mathrm{mL} \\
\mu \mathrm{Cl} / \mathrm{mL}\end{array}$ \\
\hline
\end{tabular}

\section{WELL CBR 3D}

MEASUREMENTS CONDUCTED IN THE FIELD

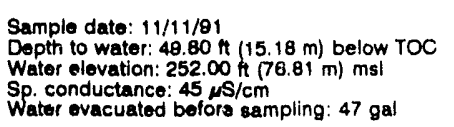

Time: $7: 15$

pH: 4.9

Sp. conductance: $45 \mu \mathrm{rs} / \mathrm{cm}$
Water ovacuated befors sampling: $47 \mathrm{gal}$

Water temperature: $16.9^{\circ} \mathrm{C}$

LABORATORY ANALYSES

\begin{tabular}{|c|c|c|c|}
\hline Analyte & Result & Mod & Unit \\
\hline 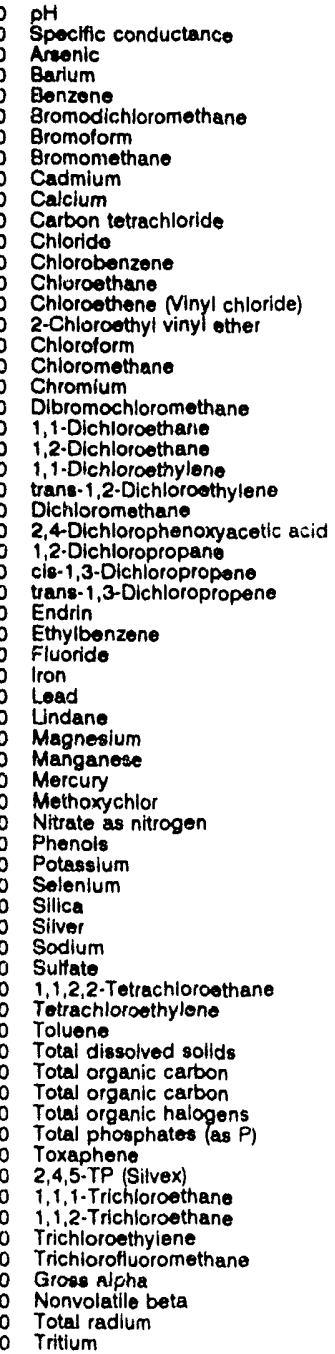 & $\begin{array}{l}5.4 \\
40 \\
<2.0 \\
40 \\
<1.0 \\
<1.0 \\
<1.0 \\
<1.0 \\
<2.0 \\
406 \\
<1.0 \\
2,380 \\
<1.0 \\
<1.0 \\
<1.0 \\
<1.0 \\
<1.0 \\
<1.0 \\
<4.0 \\
<1.0 \\
<1.0 \\
<1.0 \\
<1.0 \\
<1.0 \\
<1.0 \\
<0.30 \\
<1.0 \\
<1.0 \\
<1.0 \\
<0.0060 \\
<1.0 \\
<100 \\
51 \\
<3.0 \\
<0.0050 \\
965 \\
4.1 \\
<0.20 \\
<0.50 \\
2,990 \\
<5.0 \\
1.850 \\
<2.0 \\
13.100 \\
<2.0 \\
3.180 \\
<1.000 \\
<1.0 \\
<1.0 \\
<1.0 \\
38.000 \\
<1.000 \\
<1.000 \\
7.5 \\
<50 \\
<0.24 \\
<0.090 \\
<1.0 \\
<1.0 \\
<1.0 \\
<1.0 \\
<2.0 E-09 \\
3.0 E-09 \pm 1.1 E \cdot 08 \\
<1.0 E \cdot 09 \\
3.8 E-06 \pm 7.0 E-07\end{array}$ & Jo & 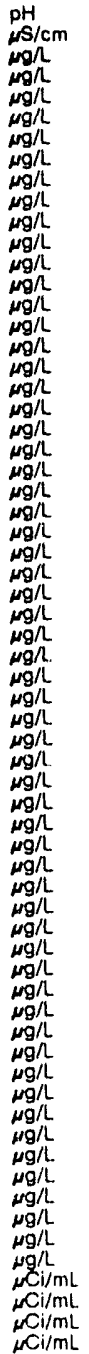 \\
\hline
\end{tabular}

WELL CCB 1

MEASUREMENTS CONDUCTED IN THE FIELO

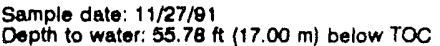

Sp. conductence: 22 ps/cm

TH: 4.8

Alkalinity: $2 \mathrm{mg} / \mathrm{L}$

Water temperature: $18.3^{\circ} \mathrm{C}$

\section{WELL CCB 2}

MEASUREMENTS CONDUCTED IN THE FIELD

Sample date: 11/27/91

Depth to wator: $51.82 \mathrm{ft}(15.79 \mathrm{~m})$ below TOC

Wator olevation: $218.58 \mathrm{ht}(68$.

Alkalinity: $0 \mathrm{mg} / \mathrm{h}$

Water ovacuated botore sampling: $52 \mathrm{gal}$

Water temperature: $18.8^{\circ} \mathrm{C}$

WELL CCB 3

MEASUREMENTS CONDUCTED IN THE FIELD

\section{Sample date: 11/27/81 \\ Depth to water: $4.12 \mathrm{ft}(13.45 \mathrm{~m})$ below TOC \\ Water olevation: $223.28 \mathrm{ht}(88.08 \mathrm{~m}) \mathrm{msl}$}

Water evacuated belore sampling: $46 \mathrm{gal}$

Time: 7:00

Alkalinity: $2 \mathrm{mg} / \mathrm{l}$

Water temperature: $18.1^{\circ} \mathrm{C}$

WELL CCB 4

MEASUREMENTS CONDUCTED IN THE FIELD

Sample date: $11 / 27 / 91$

Dopth to water: $58.83 \mathrm{ft}(17.80 \mathrm{~m})$ below TOC

Water elevation: 224.07 it

(14 $\mathrm{s} / \mathrm{cm}$

pH: 5.0

Alkalinity: $3 \mathrm{mg} / \mathrm{L}$

Water temperature: $18.7^{\circ} \mathrm{C}$

\section{WELL CDB 1}

MEASUREMENTS CONDUCTED IN THE FIELD

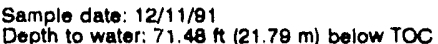

Depth to water: $71.48 \mathrm{At}(21.78 \mathrm{~m})$ below
Water elovithin: $217.42 \mathrm{~h}(86.27 \mathrm{~m}) \mathrm{msl}$
Sp. conductance: $64 \mathrm{~s} / \mathrm{cm}$

Water ovacuated bofore sampling: $17 \mathrm{gal}$

The well went dry during purging.

LABORATORY ANALYSES

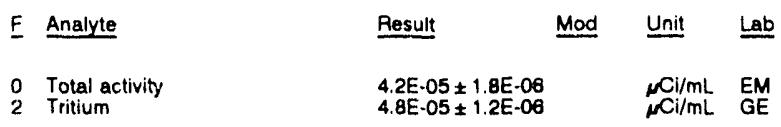

WELL CDB 2

MEASUREMENTS CONOUCTED IN THE FIELD

Sample dale: 12/11/91

Depth to water: $70.87 \mathrm{~h}(21.83 \mathrm{~m})$ below TOC

Water elevation: $217.63 \mathrm{ft}(66.33 \mathrm{~m}) \mathrm{mst}$

Sp. conduclance. $80 \mu \mathrm{s} / \mathrm{cm}$

PH: $5.5: 10$

PHkalinity: $10 \mathrm{mg} /$

Water temporature: $19.2^{\circ} \mathrm{C}$

Whe well went dited bofore sampling: $13 \mathrm{ga}$

LABORATORY ANALYSES

\begin{tabular}{|c|c|c|c|}
\hline Analyte & Result & Mod & Unit \\
\hline $\begin{array}{l}\text { Total activity } \\
\text { Tritium }\end{array}$ & $\begin{array}{l}5.9 \mathrm{E}-04 \pm 5.5 \mathrm{E}-06 \\
5.4 \mathrm{E}-04 \pm 3.6 \mathrm{E}-06\end{array}$ & & $\underset{\mu \mathrm{Ci} / \mathrm{mL}}{\mu \mathrm{Ci} / \mathrm{mL}}$ \\
\hline
\end{tabular}


ANALYTICAL RESULTS

WELL CMP 8

MEASUREMENTS CONDUCTED IN THE FIELD

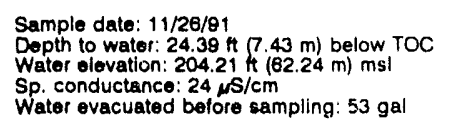

Time: $9: 20$

Alikalinity: $3 \mathrm{mg} / \mathrm{L}$

Water :emperature: $16.9^{\circ} \mathrm{C}$

LABORATORY ANALYSES

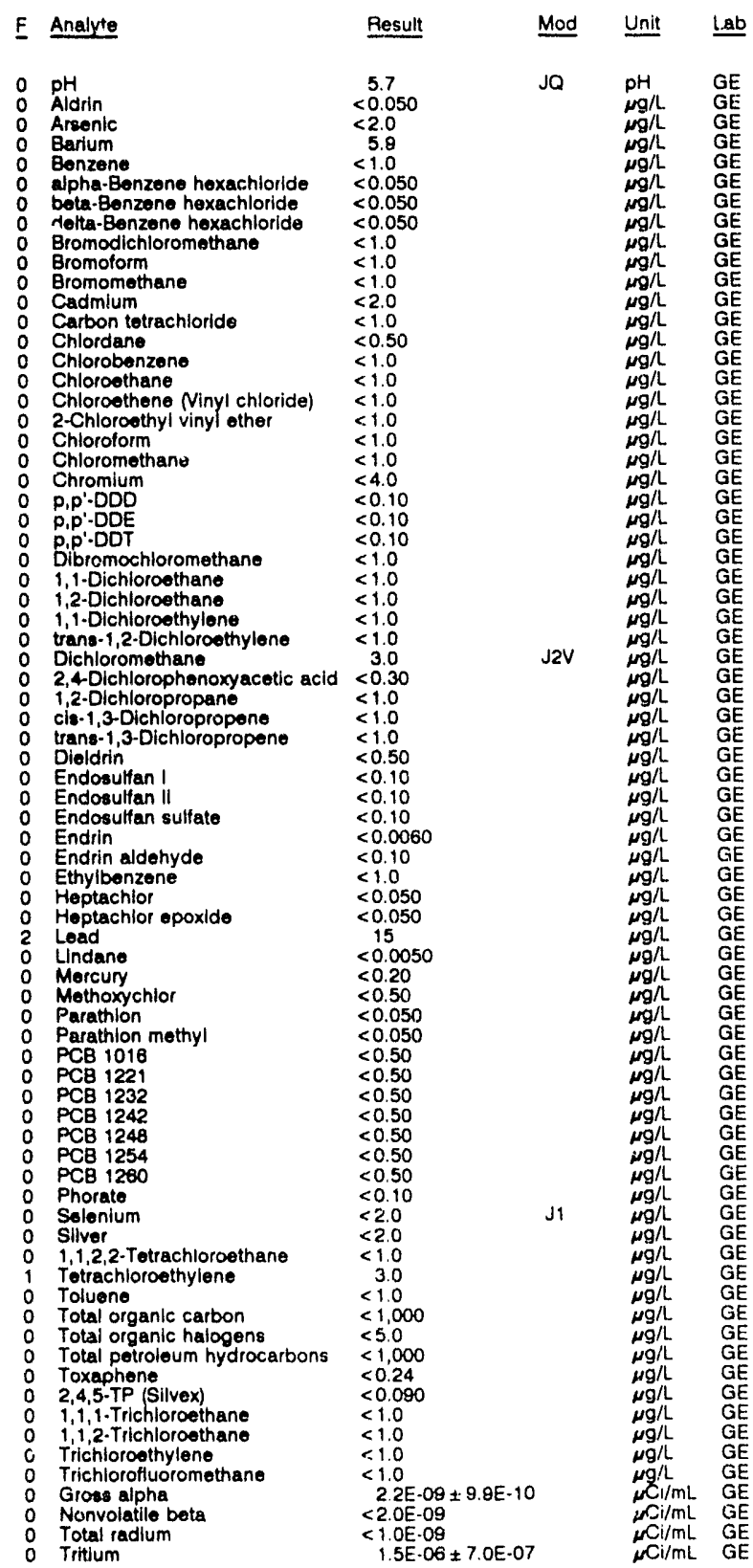

WELL CMP 8A

MEASUREMENTS CONDUCTED IN THE FIELD

Sample date: 11/28/91

Depth to water: $45.93 \mathrm{H}(14.00 \mathrm{~m})$ below TOC

Watel elevation: $183.77 \mathrm{ft}(56.01$

Sp. conductance: $123 \mu \mathrm{s} / \mathrm{cm}$
Water evacuated before sampling: $446 \mathrm{gal}$

LABORATORY ANALYSES

E Analyte Result Mod Unit Lab

$\begin{array}{ll}0 & \mathrm{pH} \\ 0 & \text { Aldrin } \\ 0 & \text { Arsenic }\end{array}$

$\begin{array}{ll}0 & \text { Arsenic } \\ 0 & \text { Barium }\end{array}$

Benzene

alpha-Benzene hexachloride

$<0.050$

Bromotorm

Cadmium

Carbon tetrachloride

Chlordane

Chlorobenzene

Chloroethane

Chloroethene Ninyl chloride

2-Chloroethyl vinyl ether

Chloroform

Chloromethane

Chromium

P,P'-DDE

P,

Dibromochloromethane

1,1-Dichloroethane

1,2-Dichloroethane

trans-1,2-Dichloroethylene

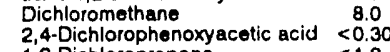

1,2-Dichloropropane

cis-1,3-Dichloropropene

0 Dieldrin

0 Endosulfan I

Endosulfan II

Endosulfan sulfate

Endrin aldehyde

Ethylbenzene

Heptachlor
Heptachlor opoxide

Lead

0 Lindane

Methoxychior

Parathion

0 PCB 1016

PCB 1221

o PCB 1232

0 PCB 1242

O PCB 1248

O
0 PCB 1254

o Phorate

Silver

1,1,2,2-Tetrachloroethane

Totrachlo

Toluene

Tola organic carbon

Total petroleum hydrocarbons

Toxaphene

2,4,5.TP (Silvex)

1,1,1-Trichloroethane

1,1,2-Trichloroetha

O Trichloroethylene

0 Trichlorofluor

- Nonvolatile beta

Total radium

Tritium
Time: $9: 40$

PH: 6.6 Alkalinity: $37 \mathrm{mg} / \mathrm{L}$

Alkalinity: $37 \mathrm{mg} / \mathrm{h}$
Water temperature: $15.8^{\circ} \mathrm{C}$

Jo

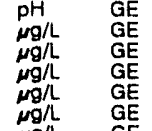

$<1.0$

$\leq 1.0$

$<2.0$

$<0.50$

$<1.0$

$<1.0$

$<1.0$
$<1.0$
$<1.0$
$<40$

$<4.0$

$<0.10$

$<1,0$

$<10$

$<1.0$

8.0
$<0.30$

$<1.0$
$<1.0$

$<1.0$

$<0.50$

$<0.10$

$<0.10$

$<0.0060$

$<0.10$

$<0.050$

$<0.050$

$<3.0$
$<0.0050$

$<0.0050$
$<0.20$

$<0.20$
$<0.50$

$<0.050$

$<0.050$

$<0.50$

$<0.50$

$<0.50$

$<0.50$

$<0.50$

$<0.10$

$<2.0$

$<2.0$

$<1.0$
1.0

$<1.0$
$<1,000$

15

$<1,000$

$<0.24$
$<0.090$

$<1.0$

$<1.0$

1.0

$2.3 \mathrm{EE} \cdot 09 \pm 1.2 \mathrm{E}-09$
$2.5 \mathrm{E}-00 \pm 1.7 \mathrm{E} \cdot 00$

$2.5 \mathrm{E}-08$
$<1.0 \mathrm{E}-09$

$<1.0 E .09$
$<7.05 .07$ 
WELL CMP 8B

MEASUREMENTS CONDUCTED IN THE FIELD

Sample date: 11/28/91 Depth to water: $30.92 \mathrm{H}(9.42 \mathrm{~m})$ below rOC $\mathrm{Sp}$. conductance: $131 \mathrm{\mu s} / \mathrm{cm}$

Water ovacuated before sampling: 1 to gal

LABORATORY ANALYSES

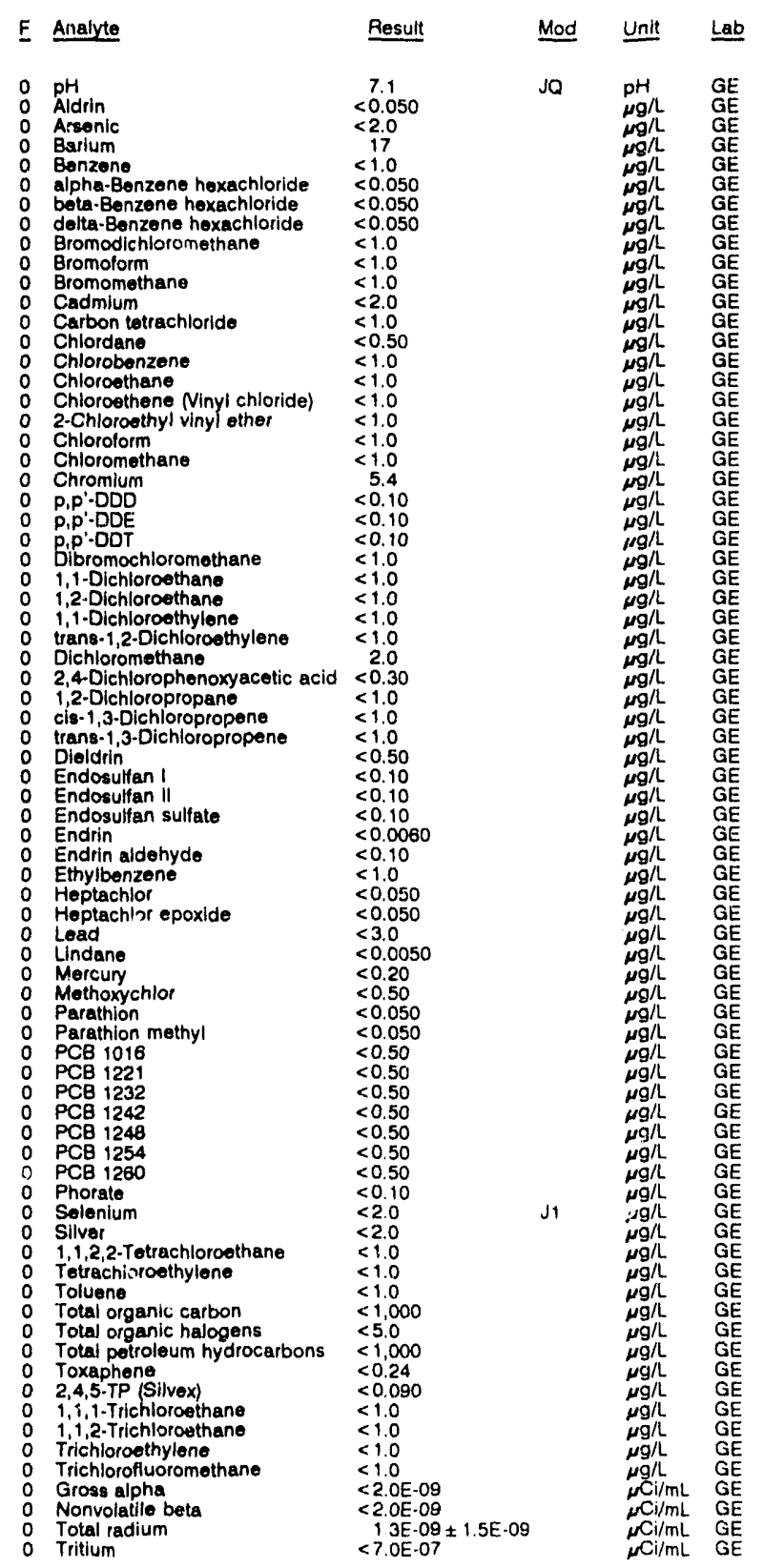

WELL CMP 9B

MEASUREMENTS CONDUCTED IN THE FIELD

Sample date: $11 / 26 / 91$

Depth to water: $120.87 \mathrm{Ht}(36.84 \mathrm{~m})$ below TOC

Wate elevation: $184.23 \mathrm{ft}(59.20 \mathrm{~m}) \mathrm{msl}$

Water evacuated before sampling: $119 \mathrm{gal}$

LABORATORY ANALYSES

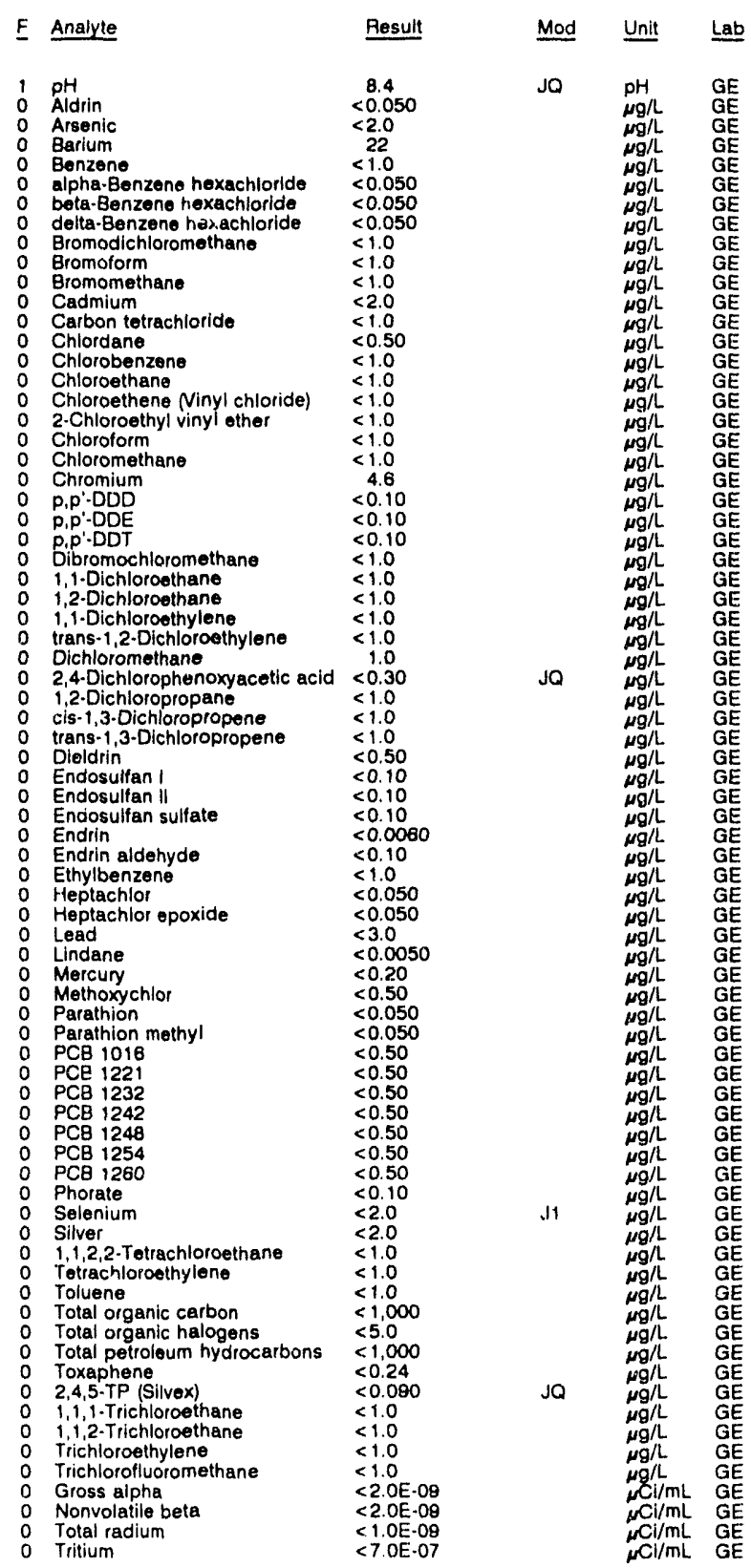

Time: 10:55

Alk. 8.7 : 73

Water temperate. $18.2^{\circ} \mathrm{C}$

$G E$

政

GE


ANALYTICAL RESULTS

WELL CMP 10

MEASUREMENTS CONDUCTED IN THE FIELD

Sample date: $11 / 28 / 81$
Depth to water: $119.69 \mathrm{Ht}(38.48 \mathrm{~m})$ below TOC
Water olevation: $191.21 \mathrm{H}(58.28 \mathrm{~m}) \mathrm{ms}$ ?

$\mathrm{Sp}$. conductance: $21 \mathrm{~s} \mathrm{~S} / \mathrm{cm}$

Water evacuated betore sampling: $40 \mathrm{gal}$

LABORATORY ANALYSES

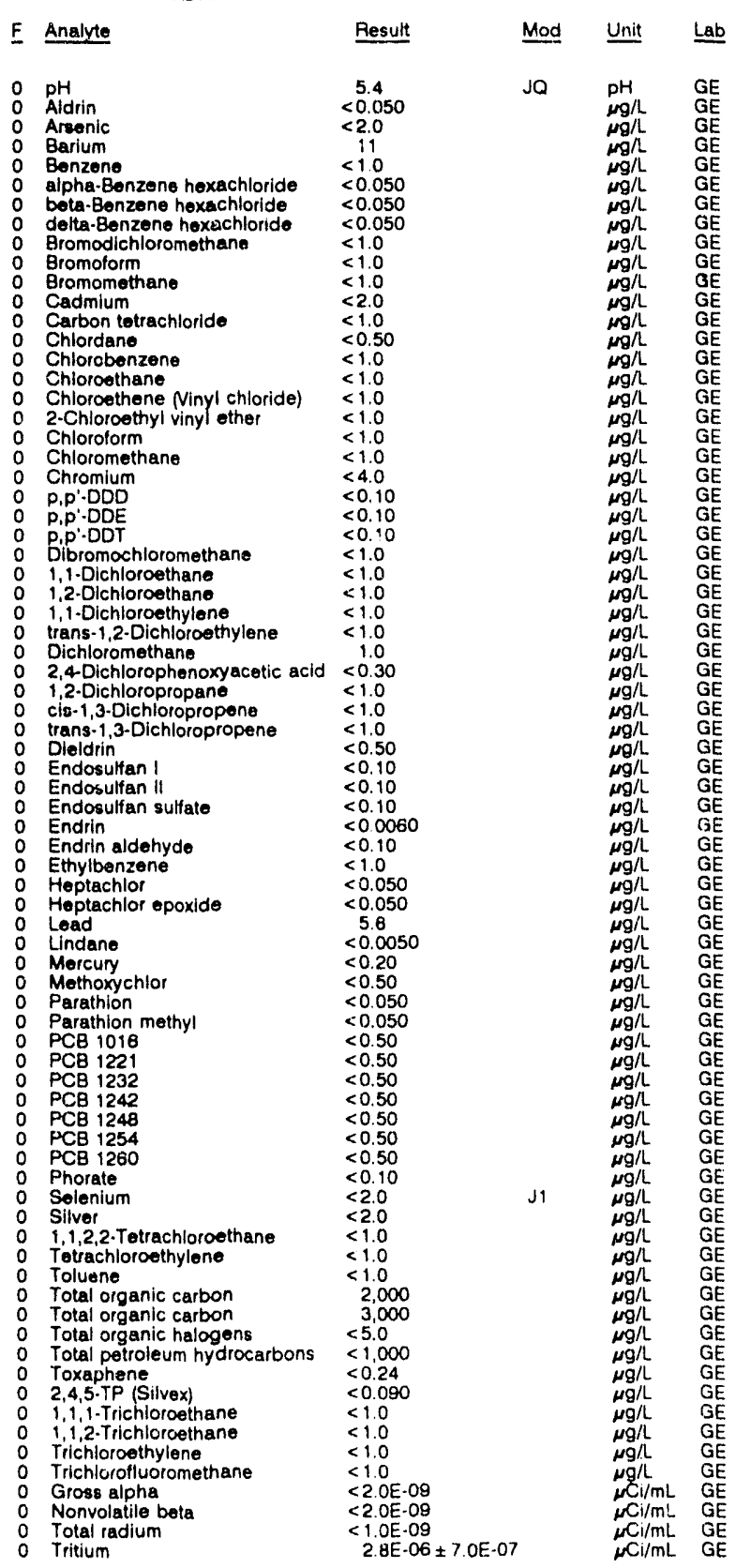

WELL CMP 10B

MEASUREMENTS CONDUCTED IN THE FIELD

Sample dato: 11/28/91

Depth to water: $114.87 \mathrm{At}(35.01 \mathrm{~m})$ below TOC

Water colovation: $185.93 \mathrm{Ht}(5 \mathrm{~B} .7$

Water ovacuated bofore sampling: $154 \mathrm{gal}$

LABORATORY ANALYSES

E Analyte Result Mod Unit

0 pH

0 Arsenic

Barium

alpha-Benzene hexachloride

beta-Benzene hoxachioride

delta-Benzene hexachloride

Bromodichloromethane

Bromoform

Bromomethan

Cadmium

Chlordane

Chlorobenzene

Chloroethene (Vinyl chloride)

2-Chloroethyl vinyl ether

Chloroform

0 Chloromethane

Chromium

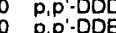

$\begin{array}{lll}0 & p, p^{\prime}-\text { DOD } & <0.10 \\ 0 & p, p^{\prime}-\text {-DDE } & <0.10 \\ 0 & p^{\prime} \cdot p^{\prime}-\text { DDT } & <0.10\end{array}$

0 Dibromochloromethane $<0.10$

o 1,1-Dichloroothane

1,2-Dichloroothane

trans-1,2-Dichloroethylene $\quad<1.0$

0 Dichloromethane

2,4.Dichlorophenoxyacetic acid

1,2-Dichloropropane

cis-1,3-Dichloropropene

propene

0 Dieldrin

Endosulfan I

Endosultan sulfate

Endrin

Endrin aldehyde

Ethylbenzene

o Heptachlor epoxide

Load

Lindane

Mercury

Methoxychlor

Parathion

Parathion methyl

$\begin{array}{lll}0 & \text { PCB } 1016 \\ 0 & \text { PCB } 1221\end{array}$

PCB 1232

PCB 1242

PCB 1240

PCB 1254

Phorate

Silver

1,1,2,2-Totrachloroethane

Tetrachloroethylens

Toluene

Total organic cation

Total organic halogen

Total organic halo

Total petroleum hydrocarbons

Toxaphene

$2,4,5-T P$ (Silvex)
$1,1,1$. Trichloroethane

$1,1,1$ - Trichloroethane

Trichloroethylene

Trichlorofluoromethane

Gross alpha

Nonvolatile beta

Tritium
Time: 12:35

Alkalinity: $92 \mathrm{mg} / \mathrm{h}$

Water temperature: $18.4^{\circ} \mathrm{C}$
8.0
$<0.050$
$<2.0$
31

$<1.0$

$<0.050$

$<0.050$

$<1.0$

$<1.0$

$<1.0$

$<1.0$

$<1.0$

$<1.0$

$<1.0$
$<1.0$

$<1.0$

$<0.10$

$<1.0$

0.1
9.1

$<0.30$
$<1.0$

$<1.0$
$<1.0$

$<1.0$

$<0.50$

$<0.10$

$<0.10$

$<0.0060$

$<0.10$

$<0.050$

$<0.050$

$<3.0$

$<0.0050$

$<0.20$
$<0.50$

$<0.050$

$<0.050$

$<0.50$

$<0.50$
$<0.50$
$<0.50$

$<0.50$
$<0.50$

$<0.50$

$<0.10$
$<2.0$
$<2.0$

$<2.0$
$<1.0$
$<1.0$

$<1.000$

$<5.0$
$<5.0$

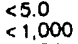

$<1.000$
$<0.24$

0.080

$<1.0$

$<1.0$

$<2.0 \mathrm{E}-\mathrm{OO}$

$<2.0 E-C 9$

$<1.0 E-08$

$<1.0 E-09$
$<7.0 E .07$
JO $\mathrm{PH} \quad \mathrm{GE}$

$\begin{array}{ll}\mathrm{pH} & \mathrm{GE} \\ \mu \mathrm{g} / \mathrm{G} & \mathrm{GE}\end{array}$

$\begin{array}{ll}\mu g / L & G E \\ \mu G / L & G E \\ \mu g / \Lambda & G E\end{array}$

$\mu g, \quad G E$

$\begin{array}{ll}\mu g / & G E \\ \mu g / & G E\end{array}$

$\mu g / \mathrm{GE}$

$\underset{\mu g h}{\mathrm{mg} / \mathrm{GE}}$

$\mu g /$ GE

$\mu g / h$ GE

$\mu g / \mathrm{GE}$

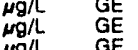

$\begin{array}{ll}\mu g / L & G E \\ \mu g h & G E\end{array}$

$\begin{array}{ll}\mu g / & \mathrm{GE} \\ \mu \mathrm{g} / \mathrm{L} & \mathrm{GE}\end{array}$

$\mu g / \mathrm{GE}$

in GE

$\mu g / \mathrm{GE}$ 
WELL CMP 11

MEASUREMENTS CONDUCTED IN THE FIELD

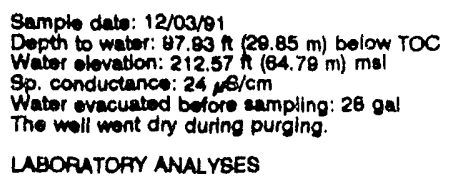

Timo: $11: 00$

AH: 4.8 .

Wator tomporature: $20.0^{\circ} \mathrm{C}$

LABOFATORY ANALYSES

E Alagyte Mosult Mod Unit

: PHorin

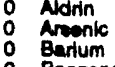

Banzon:

alpha-Bonzene hexachloride

beta-Benzene hoxachiorido

detiv-Benzane hexachlorido

Bromotorm

Bromomethane

Cadmium

Carbon trachlorido

Chlordane

Chiorobenzano

Chlorpetten Minyl chloride)

2-Chioroothyl vinyl ether

2.Chloroothy

Chioromethane

Chromium

P.P'-DOD

P,p'DDDT

Bibromochlorometivane

1,2-Dichloroethane

1,1-Dchloroethyleno

Dichliomethane

(1)

1,2-Dichloropropane

che-1,3-Dichloropropene

trann-1,3-0

Endoculfan

Endoaulfan II

Endooulfan sulfato

Endrin

Endinn aldehydo

Ethylbenzene

Heptechlor epoxide

Load

Mercury

Mothaxychior

Perattion methy

PCB 1016

PCE 1221

PCB 1242

$P C B$
$P C B$
1254

PC8 1280

Phorate

Solonium

1,1,2,2-Tutrachloroethane

Tetrachloroethylene

Toluene

Total organie carbon

rotal organic halogens

Toxaption

2,4,5-TP (Silvax)

$1,1,1$-Thechloroothane

Tinchiorosthylene

Trichiorofluoromethane

Grows wph

Total radlum

Tritum

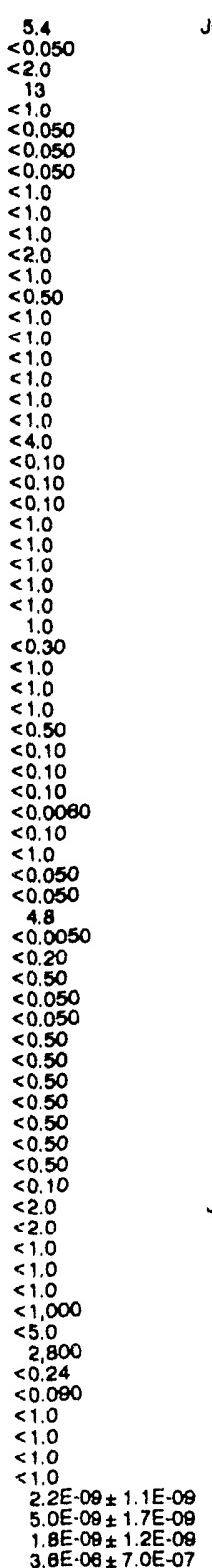

Ja

$\begin{array}{ll}P H & G E \\ \operatorname{mon} & G E \\ \operatorname{mon} & G E \\ \operatorname{mon} & G E \\ \operatorname{mon} & G E \\ \operatorname{mon} & G E\end{array}$

WELL CMP 11B

MEASUREMENTS CONDUCTED IN THE FIELD

Sample date: 11/26/91

Depth to water: $114.16 \mathrm{Ht}(34.80 \mathrm{~m})$ bolow TOC Sp. conductinc: 188.04 it (58.75

Water ovacualed before sampling: 148 gal

PH: 7.8 Akn: $89 \mathrm{mg}$

LABORATORY ANALYSES

F Analyte $\underline{\text { Rosult }}$ Mod Unit Lab

00

Bartum

Denzane

delta-Benzene hexachior

Bromodichloromethane

Bromoform

Bromomothane

Cadmilum

Carbon tetrachloride

Chlordane

Chlorobenzene

Chloroethene Ninyl chloride)

2-Chloroethyl vinyl ether

Chioroform

Chloromethane

Chromium

0 P, $\mathrm{P}^{\prime} \cdot \mathrm{DOD}$

P.P.DDE

O Gibromochloromethane

i,1-Dichloroethane

1,2.Dichlorosthane

1,1.Dichloroethylene
0 trans-1,2-Dichloroethylene

trans-1,2-Dichloroath

Dichloromethane

1,2-Dichloropropane

1,2-Dichloiropropane

trans-1,3-Dichloropropene

Dieidrin

o Endosulian I

O Endosulfan II

0 Endrin

- Endrin aldehyde

o Ethylbenzen

o Heptachlor epoxivio

0 Lead

L Lndane

o Methoxychlor

0 Parathion

o Parathion methyl

- PCB 1016

- PCE 1232

O $P C B 1242$

O $P C B 1248$

O
0

o Phorate

o Solonium

0 Silver

o 1,1,2,2-Tetrachloroethane

- Totrachloroethylene

0 Toluene

Total organic carbon

Total crganic halogens

o Toxaphene

o 2,4,5-TP (Silvex)

1,1,2-Trichloroethan

Trichloroethylen

- Trichlorofluoromethane

- Gross alpha

$\begin{array}{ll}0 & \text { Nonvolatlle bota } \\ 0 & \text { Total radium } \\ 0 & \text { Tritium }\end{array}$

$\begin{aligned} & 8.0 \\ &< 0.050 \\ &<2.0\end{aligned}$

$<2.0$
31
$<1.0$

$<1.0$

$<0.050$

$<0.050$
$<1.0$

$<1.0$

$<2.0$
$<1.0$

$<0.50$

$<1.0$
$<1.0$

$<1.0$

$<10$

$<1.0$

$<1.0$

4.1
$<0.10$

$<0.10$

$<1.0$

$<1.0$

$<1.0$

$<1.0$

$<10$
$<0.30$
$<1.0$
$<1.0$

$<1.0$
$<1.0$
$<1.0$
$<0.50$

$<0.50$
$<0.10$

$<0.10$

$<0.10$
$<0.0060$

$<0.0080$
$<0.10$
$<1.0$
$<0.050$

$<0.050$

$<3.050$

$<0.0050$

$<0.20$

$<0.050$

$<0.050$

$<0.50$

$<0.50$

$<0.50$

$<0.50$

$<0.50$

$<0.50$
$<0.10$

$<2.0$

$<2.0$
$<1.0$
$<1.0$

$<1.0$

$<5,0$

$<1,000$
$<0,24$

$<0.080$

$<1.0$

$<1.0$

$<1.0$

$<1.0$
$<2.0 E-08$

$<2.0 E .09$

$<1.0 E-09$
$<7.0 E .07$

JQ $\mathrm{pH} \quad \mathrm{GE}$

$\mu g h$ GE

mon GE

gn $G E$

$g / \quad G E$
beta-Benzene hexachloride

Endosulfan sulfaio

- 1,1,1-Trichloroethane 
ANALYTICAL RESULTS

\section{WELL CMP 12}

MEASUREMENTS CONDUCTED IN THE FIELD

Sample date: 12/03/91

Depth to water: $72.25 \mathrm{~h}(22.02 \mathrm{~m})$ below TOC

Sp. conductance: $16 \mu \mathrm{S} / \mathrm{cm}$

Water evacuatod before sampling: $25 \mathrm{gal}$

LABORATORY ANALYSES

$E$ Analyte $\quad$ Result

$\therefore$ Aldrin

Aldrin

0 Barium

alpha-Benzene hexachloride

beta-Benzene hexachloride

detta-Benzene hoxachlorlde

Bromodichloromethane

Bromoform

Bromomethane

Cadmium

Carbon totrachloride

Chlordano

Chlorobonzene

Chlorosthane

2.Chloroethyl vinyl ether

2.Chloroorm

Chloromethane

Chromium

P.P.ODD

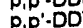

Bibromochloromethane

1, 1. Dichloroothane

1,1-Dichloroethylene

trans-1,2-Dichloroethylene

Dichloromethane

2,4-Dichiorophenoxyacetic acld

1,2-Dichloropropano

cis.1,3-Dichoropropent.

trans-1,3

Endosulfan I

Endosulfan II

Endosulfan sulfate

Endrin

Endrin aldehyde

Ethylbenzene

Heptachlor
Heptachlor epoxide

Load

Lindane

Mercury

Methoxychior
Parathion

Parathion methyl

PCB 1018

PCB 1221

PCB 1232

O $\mathrm{PCB} 1242$

PCB 1254

Phorate

Solonium

Silver

1,1,2,2-Totrachloroethane

Totrachloroethylene

Toluene

Total organic carbon

Total organic halogens

Toxaphene

2,4,5-TP (Silvex)

$2,4,5-T p$ (Silvex)
$1,1,1$-Trichloroethane

Trichloroethyleno

Trichlorofluoromethane

Groes alpha

o Nonvolatile beta

O Total radium
Time: 13:00

Alkalinity: $0 \mathrm{mg} / \mathrm{h}$

Water temperature: $20.00 \mathrm{C}$

$\begin{array}{cccc}5.5 & \mathrm{JQ} & \mathrm{pH} & \mathrm{GE} \\ <0.050 & \mathrm{gQ} & \mathrm{\mu g} / \mathrm{G} & \mathrm{GE}\end{array}$

$<2.0$
3.8

3.8
$<1.0$

$<0.050$

$<0.050$

$<1.0$

$<1.0$

$<2.0$

$<1.0$

$<0.50$
$<1.0$

$<1.0$

$<1.0$

$<1.0$

$<1.0$
$<1.0$
$<4.0$

$<4.0$
$<0.10$
$<0.10$
$<0.10$

$<0.10$
$<0.10$
$<1.0$

$<1.0$

$<1.0$

$<1.0$
$<1.0$
1.0

$\begin{aligned} & 1.0 \\ < & 0.30 \\ < & 1.0 \\ < & 1.0 \\ < & 1.0\end{aligned}$

$<1.0$

$<0.50$

$<0.10$

$<0.10$

$<0.0060$

$<0.10$

$<0.050$

$<0.050$

8.2
$<0.0050$

$<0.20$

$<0.50$

$<0.050$

$<0.50$

$<0.50$
$<0.50$
$<0.50$
$<0.50$

$<0.50$

$<0.50$

$<0.10$

$<0.10$
$<2.0$
$<2.0$
$<1.0$

4.0
$<1.0$

$<1.00$

20
$<1,000$

$<1,000$
$<0.24$

$<0.090$

$<1.0$

$<1.0$
1.0

1.0
$2.2 E-09 \pm 9.8 E-10$
$5.0 E-09 \pm 1.7 E-08$

$<1.0 E-09$
$3.1 E-08 \pm 7.0 E-07$
WELL CMP 12A

MEAGUREMENTS CONDUG:TED IN THE FIELD

Sample date: 12/03/91

Dopth to water: $101.68 \mathrm{H}(30.09 \mathrm{~m})$ bolow TOC

Sp. conductance: $173 \mathrm{~ms} / \mathrm{cm}$

Water ovacuatod before sampling: $421 \mathrm{gal}$

LABORATORY ANALYSES

E Analyte Result Mod Unit Lab

o pld $_{0}^{\text {Aldin }}$

0 Arreonic

Barium

alpha-Benzene hexachloride

beta-Benzene hoxachloride

Bromodichloromethane

Bromotorm

Bromomoth

Cadmium

Carbon tetrachloride

Chlordane

Chlorobenzane

Chlorothane

2-Chloroethyl vinyl other

2-Chloroethy

Chloromethane

Chromium

P,P':DDD

P.P':DDE

B.P'-DDT

1,1-Dichloroethane

1,2-Dichloroethane

1,1 -Dichloroethylene
trans 1,2 -Dichloroethylene

Dichioromethane

2,4-Dichlorophenoxyacetic acid

1,2-Dichloropropane

cis-1,3-Dichloropropeno
trans-1,3-Dichloropropene

Dieldrin

Endosulfan

Endosultan is

Endosulfan sulfato

Endrin

Endrin aldehyde

Ethylbenzen

Heptachlor
Heptachlor epoxide

Load

0 Lindane

O Morcury

Parathion mothyl

PCB 1016

PCB 1232

PCB 1248

PCB 1254

Phorate

Selenium

Silver

o 1,1,2,2-Tetrachloroethane

Totrachloroethylene

0 Toluene

Total organic carbon

Total organic halogons

Total organic helogens

Toxaphene

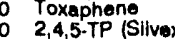

$\begin{array}{ll}0 & 2,4,5-T P \\ 0 & 1,1,1 \text {-Trichloroethan }\end{array}$

o 1,1,1-Trichloroethane

O Irichloroethylene

Trichloroethylono

- Nonvolatile beta

O Total radium

Tritium

7.4
$<0.050$

Ja $\quad \mathrm{pH} \quad \mathrm{GE}$

2.2

$<1.0$

$<0.050$

$<1.0$

$<1.0$

$<2.0$

$<0.50$

$<1.0$

$<1.0$

$<1.0$

$<1.0$

$<0.10$

$<0.10$

$<1.0$

$<1.0$

$<1.0$

$<1.0$
$<1.0$
$<0.30$
$<1.0$

$<1.0$

$<1.0$
$<0.50$
$<0.10$
$<0.10$

$<0.10$

$<0.0000$

$<0.10$

$<1.0$

$<0.050$

$<3.0$
$<0.0050$

$<0.20$

$<0.50$

$<0.050$

$<0.50$

$<0.50$

$<0.50$

$<0.50$

$<0.50$

$<0.50$

$<0.50$

$<0.10$
$<2.0$
$<2.0$
$<1.0$

$<1.0$

$<1.0$

$<5.0$

$<5.000$

$<1,000$
$<0.24$

$<0.090$

$<1.0$

$<1.0$

$<2.0 \mathrm{E}-00$

$<2.0 E-08$
$<1,0 \mathrm{E}-09$

$<1.0 E-09$
$<7.0 \mathrm{E}-07$

Time: 13:55

Alkalinity: $63 \mathrm{mg} /$

Water tomperaturo: $18.3^{\circ} \mathrm{C}$

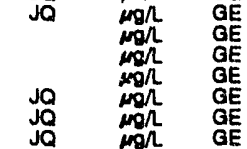

Ja

Jo

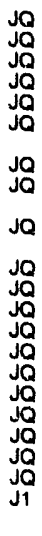

jo

10
10
10
10
10
10
70

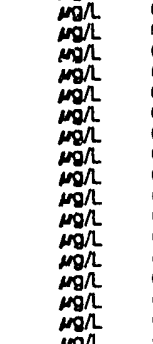

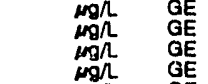

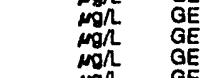

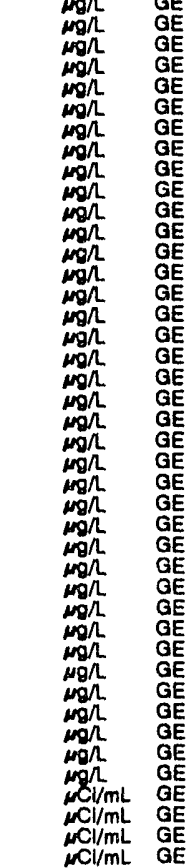




\section{WELL CMP 128}

MEASUREMENTS CONOUCTED IN THE FIELD

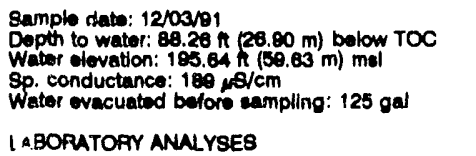

I A.BORATORY ANALYSES

\begin{tabular}{|c|c|c|c|c|}
\hline Analyte & Result & Mod & Unit & Lab \\
\hline 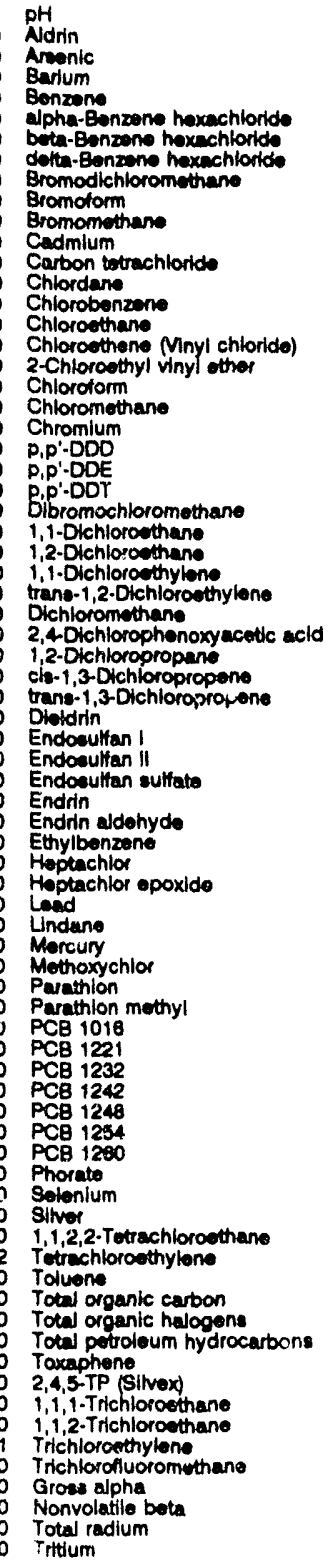 & $\begin{array}{l}8.0 \\
<0.050 \\
<2.0 \\
27 \\
<1.0 \\
<0.050 \\
<0.050 \\
<0.050 \\
<1.0 \\
<1.0 \\
<1.0 \\
<2.0 \\
<1.0 \\
<0.50 \\
<1.0 \\
<1.0 \\
<1.0 \\
<1.0 \\
<1.0 \\
<1.0 \\
<4.0 \\
<0.10 \\
<0.10 \\
<0.10 \\
<1.0 \\
<1.0 \\
<1.0 \\
<1.0 \\
<1.0 \\
<1.0 \\
<0.30 \\
<1.0 \\
<1.0 \\
<1.0 \\
<0.50 \\
<0.10 \\
<0.10 \\
<0.10 \\
<0.0060 \\
<0.10 \\
<1.0 \\
<0.050 \\
<0.050 \\
<3.0 \\
<0.0050 \\
<0.20 \\
<0.50 \\
<0.050 \\
<0.050 \\
<0.50 \\
<0.50 \\
<0.50 \\
<0.50 \\
<0.50 \\
<0.50 \\
<0.50 \\
<0.10 \\
<2.0 \\
<2.0 \\
<1.0 \\
8.2 \\
<1.0 \\
<1.000 \\
<5.0 \\
<1.000 \\
<0.24 \\
<0.090 \\
<1.0 \\
<1.0 \\
4.8 \\
1.0 \\
2.3 E-09 \pm 1.1 E-08 \\
3.88-08 \pm 1.8 E-09 \\
<1.0 E-09 \\
8.4 E-07 \pm 7.0 E-07\end{array}$ & 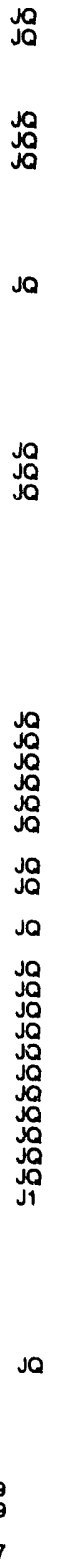 & 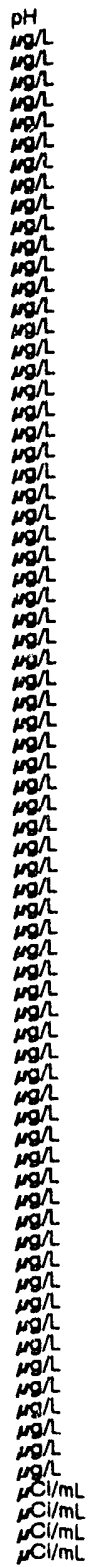 & $\begin{array}{l}G E \\
G E \\
G E \\
G E \\
G E \\
G E \\
G E \\
G E \\
G E \\
G E \\
G E \\
G E \\
G E \\
G E \\
G E \\
G E \\
G E \\
G E \\
G E \\
G E \\
G E \\
G E \\
G E \\
G E \\
G E \\
G E \\
G E \\
G E \\
G E \\
G E \\
G E \\
G E \\
G E \\
G E \\
G E \\
G E \\
G E \\
G E \\
G E \\
G E \\
G E \\
G E \\
G E \\
G E \\
G E \\
G E \\
G E \\
G E \\
G E \\
G E \\
G E \\
G E \\
G E \\
G E \\
G E \\
G E \\
G E \\
G E \\
G E \\
G E \\
G E \\
G E \\
G E \\
G E \\
G E \\
G E \\
G E \\
G E \\
G E \\
G E \\
G E \\
G E \\
G E \\
G E \\
G E\end{array}$ \\
\hline
\end{tabular}

Tme: $13: 20$
pH: 7.7
Alkalinity: $84 \mathrm{mghl}$

Water tomperature: $18.5^{\circ} \mathrm{C}$

WELL CMP 13

MEASUREMENTS CONDUCTED IN THE FIELD

Sample date: 12/03/91

Depth to water: 81.28 it $(24.77 \mathrm{~m})$ bolow TOC

Water olevation: $207.02 \mathrm{~h}(63.3$

Wator tomporature: $18.6^{\circ} \mathrm{C}$

try during puigh: $12 \mathrm{gal}$

LABORATOAY ANALYSES

E Analyte Rooult Mod Unit Lab

o ${ }_{0}^{\mathrm{pH}}$

0 Areenic

Barlum

alpha-Benzone hexachlorlde

beta-Benzens haxachlorlde

Bromodichloromethane

Bromolorm

Bromomethane

Cadmlum

- Carbon tetrachlonde

Chlordane

Chlorobenzene

Chloroothane

Chloroethene Minyl chloride)
2-Chloroethyl vinyl other

Chlorolorm

Chromium

p, $p^{\prime}=D D D$

P,P'-ODE

O Bibromochloromethane

1,1-Dichlorowthane

o 1,2-Oichlorowthane

o 1,1 -Dichloroethylene

Dichioromethane

2,4-Dichlorophenoxyacetic acld

1,2-Dichloropropano

trans-1,3-Dichloropropene

Dioldrín

Endosulfan

Endosulfan sulfate

Endrin

Endrin aldehyde

Heptachlor

Heptachior opoxide

Lead

0 Undane

Methoxychlor

Parathion

Parathion methyl

0
0 PCB 1016

PCB 1232

PCB 1242

o PCB 1254

0 PCE 1260

0 Phorate

o sitver

1,1,2,2-Tetrachloroethane

2 Tetiachloroethyleno

0 Tolueno

Total organic carbon

- Total organic halogens

- Total potroleum hydrociartions

O Toxaphene

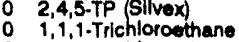

1,1,1.Trichloroethane

2 Trichloroethylene

o Trichlorcilluoromethane

- Gross alpha

- Nonvolatile beta

- Total radium

Tritium

$\quad 6.6$
$<0.050$
$<2.0$
1.0
$<1.0$
$<0.050$
$<0.050$
$<0.050$
$<1.0$
$<1.0$
$<1.0$
$<2.0$
$<1.0$
$<0.50$
$<1.0$
$<1.0$

$\begin{array}{lll}\text { JO } & \mathrm{pH} & \mathrm{GE} \\ \mathrm{MO} & \mathrm{GE}\end{array}$

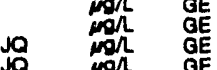

Jo $\operatorname{sen}$ aE

$<1.0$

$<1.0$

$<1.0$

$<4.0$
$<0.10$
$<0.10$
$<0.10$

$<1.0$

$<1.0$

$<1.0$

$<0.30$

$<1.0$

$<1.0$

$<0.50$
$<0.10$
$<0.10$

$<0.10$
$<0.10$

$<0.0080$

$<0.10$

$<0.050$
$<0.050$

$<0.0050$

$<0.20$

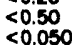

$<0.050$
$<0.050$

$<0.50$

$<0.50$
$<0.50$

$<0.50$

$<0.50$

$<0.50$

$<2.0$

$<2.0$
$<1.0$
$<1.0$

$<1.0$
1.8
$<1.0$

$<i, 000$

7.3
$<1,000$

$<0.24$

$<0.080$
$<1.0$
$<1.0$

$<1.0$
17

4.5
$2.3 \mathrm{E}-08 \div 8.6 \mathrm{E}-10$
$2.5 \mathrm{E}-00 \pm 1.5 \mathrm{E}-08$

$<1.0 \mathrm{E}-08$

$2.0 \mathrm{E}-00 \pm 7.0 \mathrm{E}-07$

Jo
Time: 14:20 


\section{WELL CMP 13B}

MEASUREMENTS CONDUCTED IN THE FIELD

Sample dato: 11/2e/81

Depth to water: $93.52 \mathrm{ft}(28.51 \mathrm{~m})$ below TOC

Wator olovation: 195.58 is 158

Water ovacuated bofore sampling: $181 \mathrm{gal}$

LABORATOPY ANALYSES

E Analyte Mesult Mod Unit Lab

1 pH

Areonic

Barium

alpha-Benzene hexachloride

beta-Bonzeno hoxachiorido

Bromodichtoromethan

Bromoform

Bromomethane

Cadmium

Carbon tetrachionde

Chiordano

Chlorobenzene

Chloroethane

Chloroothene Ninyl chlorid
2-Chloroethyl vinyl ether

2-Chloroethy

Chloromethane

Chromium

P,P'.DDD

P.P'-DDE

Bibromochloromethane

1,1.Dichloroethane

1,2.Dichloroethane

1,1-Dichloroethylene

Dichloromethane

2,4-Oichiorophenaxyacedic acld

1,2-Dichloropropane

cis-1,3-Dichioropropeno

trans-1,3-Dichlormpropene

Endosultan 1

Endooulfan II

Endrin

o Endrin aldehyde

O Ethylbonzone

Heptachlor epoxide

Load

Lindane

Mercury

Parathion

Parathion methy

PCB 1016

PCB 1221

PCB 1242

PCB 1246

PCB 1254

() PCB 1280

o Solenium

o silver

1,1,2,2-Tetrachloroethane

Tetrachloroethylone

Toluene

Total organic carton

Total organic halogens

Total petroleum hydrocarbons

Toxaphene

2,4,5-TP (Silvex)

1,1,1-Trichloroethane

1,1,2.Trichloroethe

Trichlorofluoromethane

Gross alpha

Nonvolatilo beta

Total raclum
Tritium
Tima: 14:15

Alkalinity: $82 \mathrm{mg} /$

Water tomperature: $18.8^{\circ} \mathrm{C}$

Jo

$\begin{array}{cccc}8.6 & J Q & \mathrm{pH} & \mathrm{GE} \\ <0.050 & \mathrm{JO} & \operatorname{mon} & \mathrm{GE} \\ <2.0 & & \mathrm{men} & \mathrm{GE} \\ 36 & & \operatorname{mon} & \mathrm{GE} \\ <1.0 & & \operatorname{mon} & \mathrm{GE}\end{array}$

1.00

$<0.050$

$<0.050$

$<1.0$

$<1.0$

$<1.0$
$<2.0$
$<1.0$

$<0.50$

$<1.0$

$<1.0$

$<1.0$

$<1.0$
$<1.0$

$<1.0$

$<0.10$
$<0.10$
$<0.10$
$<1.0$

$<1.0$

$<1.0$

0.1

$<<<.30$

$<1.0$
$<1.0$
$<0.50$

$<0.50$

$<0.10$

$<0.0060$

$<0.0060$
$<0.10$
$<1.0$

$<0.050$

$<0.050$

$<3.0$
$<0.0050$

$<0.0050$

$<0.50$

$<0.050$

$<0.50$

$<0.50$

$<0.50$

$<0.50$

$<0.50$

$<0.50$

$<0.10$

$<2.0$

$<2.0$
$<1.0$
$<1.0$

$<1.0$

$<1,000$

$<5.00$

1,200
$<0.24$
$<0.000$

$<1.0$
$<1.0$
$<1.0$

$<1.0$

$<2.0 E-09$

$<2.0 E-00$

$<1.0 \mathrm{E}-0$

$<1.0 E-00$
$<7.0 E-07$

\section{WELL CMP 14B}

MEASUREMENTS CONDUCTED IN THE FIELD

Sample date: 11/28/9

Depth to wator: $69.68 \mathrm{~h}(21.24 \mathrm{~m})$ bolow TOC

Water olevation: 104.82 h $(50.38$

Sp. conductance: $178 \mu \mathrm{S} / \mathrm{cm}$. $170 \mathrm{gal}$

LABORATORY ANALYSES

E Analyte Beoult Mod Unit Leb

1 ply

O Areenic

Barium

alpha-Benzene hoxachloride

beta-Benzene hexachloride

delta-Benzene hoxachlorid

Bromodichior

Bromoform

Broniometh

Cadmon totrachlorido

Carbon to

Chiordane

Chiorobenzen

Chlorothene Minyl chlorlde)

2-Chloroethyl vinyl ether

Chloroform

Chloromethane

Chromium

P.P.-DDD

P,P'-DDE

bibromochloromethane

1,1.Dichloroethane

1,2-Dichloroethane

o 1,1-Dichloroethylone

trane-1,2-Dicingroet

(1)

onoxyacetic acid $<0.30$

1,2-Dichloropropane

cla-1,3-Dichloropropeno

Dieldrin

Endosulfan

Endosulian II

Endrin

- Endrin aldehydo

O Ethylbanzen

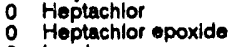

Load

Undant

Methoxychior

Parathlon

Parathion meth

PCB 1221

PCB 1232

PCB 1246

PCB 1254

Phorate

Solenium

Sitvor

1,1,2,2-Tetrachloroethane

Totrachioroethylene

Tolvene

Total organic carbon

Total petroleum hydrocarbone

Toxaphene

2,4,5-TP (Silvex)

1,1,1-Trichloroethane

1,1,2-Trichlorothano

Trichloroethylene

- Trichlorofluoromethane

- Gross alpha

Nonvolatile bete

o Tritulum

Time: 15:06

PH: 8.1.08: 84 ma/

Wattor tomperature: $17.7 \cdot 0$

$<2.0$

$<<.050$

$<0.050$

$<1.0$

$<1.0$

$<2.0$

$<0.50$

$<1.0$

$<1.0$

$<1.0$
$<1.0$
$<1.0$

$<4.0$

$<0.10$

$<0.10$

$<1.0$

$<1.0$

$<1.0$

$<1.0$

$<<.50$

$<0.10$

$<0.10$

$<0.0060$

$<0.10$

$<1.0$

$<0.050$

$<0.050$

$<0.0050$

$<0.50$

$<0.050$

$<0.050$

$<0.50$

$<0.50$

$<0.50$

$<0.50$

$<0.50$

$<0.10$

$<2.0$

$<1.0$

$<1,000$

$<1,000$

$<1,000$

$<0.24$

$<1.0$

$<1.0$

$<1.0$

$2.4 E-09 \pm 1.2 E-00$

$<2.0 E-08$

$<1.0 E-\infty \theta$

8. $4 E-07 \pm 7.0 E-07$
No pH GE

Ro $\operatorname{con}$ den

RO

PO

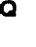

PO

Ja

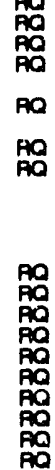


WELL CMP 14C

MEASUREMENTS CONDUCTED IN THE FIELD

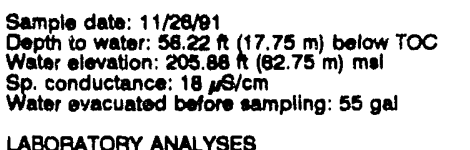

Time: 14:50

Alkalinity: $0 \mathrm{mgh}$ Water temperature: $15.8^{\circ} \mathrm{C}$

LABOPATORY ANALYSES

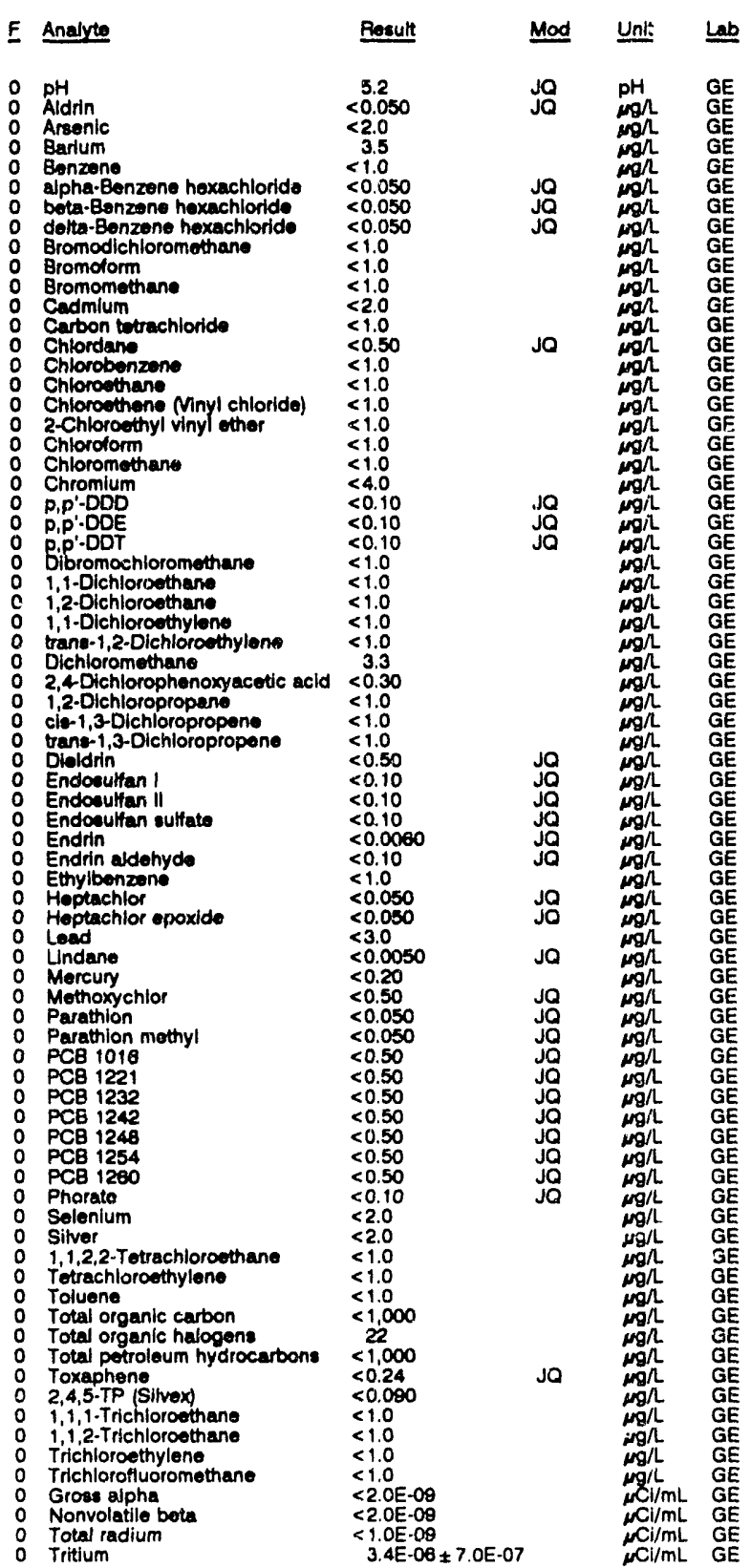

WELL CMP 15A

MEASUREMENTS CONOUCTED IN THE FIELD

Dopth to water: 84.89 n $(28.84 \mathrm{~m})$ bolow TOC Wator olovation: $181.54 \mathrm{~h}(55.33 \mathrm{~m}) \mathrm{ma}$

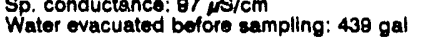
Time: 12:30

Alkalinity: $25 \mathrm{mg} / \mathrm{h}$ Water tomperature: $20.5^{\circ} \mathrm{C}$ LABORATORY ANALYSES

$\therefore$ pH

A Aldrin

: Zarlum

o alpha-Benzeno hexachloride

beta-Benzeno hexachloride

delta-Benzene hexachlorido

Bromodichloromethane

Bromomethano

Cadmium

Chlordane

Chlobenzene

Chloroethene Minyl chloride)

Choolhene Minyl chlordol

2-Chloroethy

- Chloromethane

Chromium

:

:

- Bibromochloromethane

1,1-Dichloroethane

0 1,2-Dichloroothane

$\begin{array}{ll}1,1-D i c h l o r o e t h y l e n e \\ 0 & \text { trans-1,2-Dichloroethylene }\end{array}$

o Dichloromethane

2,4-Dichlorophenoxyacetic acid

1,2-Dichloropropano

- cla-1,3-Dichloropropene

0 Dieldrin

- Endosulfan

o Endosutfan 1

- Endosulfan sulfato

O Endrin

- Endrin aldohyde

0 Ethylbonzono

: Heptachlor

Laed

o Lindane

O Methoxychlor

Parathion methyl

PCB 1018

PCB 1221

FCE 1232

- PCB 1248

- PCB 1254

0 PCB 1260

o Phorate

O Selenium

: Silver

1,1,2,2-Tetrachloroothano

Tetrachlordeethylene

Tuluene

Total organic carbon

Total ofganic halogens

Toxapheno

2,4,3-TP (Silvex)

1.12.Trichloroethane

Trichloroethylene

Trichlorofluoromethane

Gross alpha

Total radium

Tritium

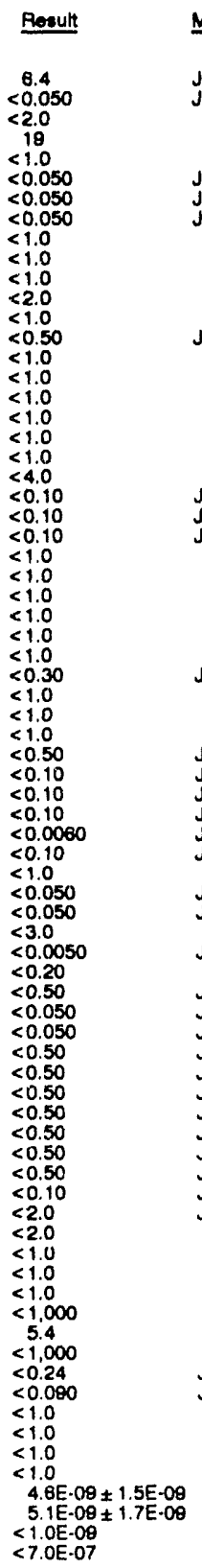

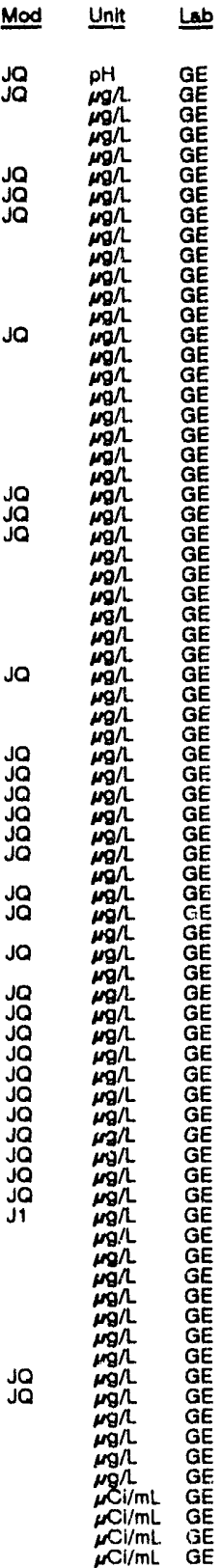


ANALYTICAL RESULTS

WELL CMP 15B

MEASUREMENTS CONDUCTED IN THE FIELD

Sample date: 12/03/91

Dopth to water: $71.86 \mathrm{nt}(21.83 \mathrm{~m})$ below TOC

Water olevation: $204,44 \mathrm{H}(62.3$

Sp. conductance: $85 \mu \mathrm{s} / \mathrm{cm}$.

Water ovacuated before campling:

LABORATOFY ANALYSES

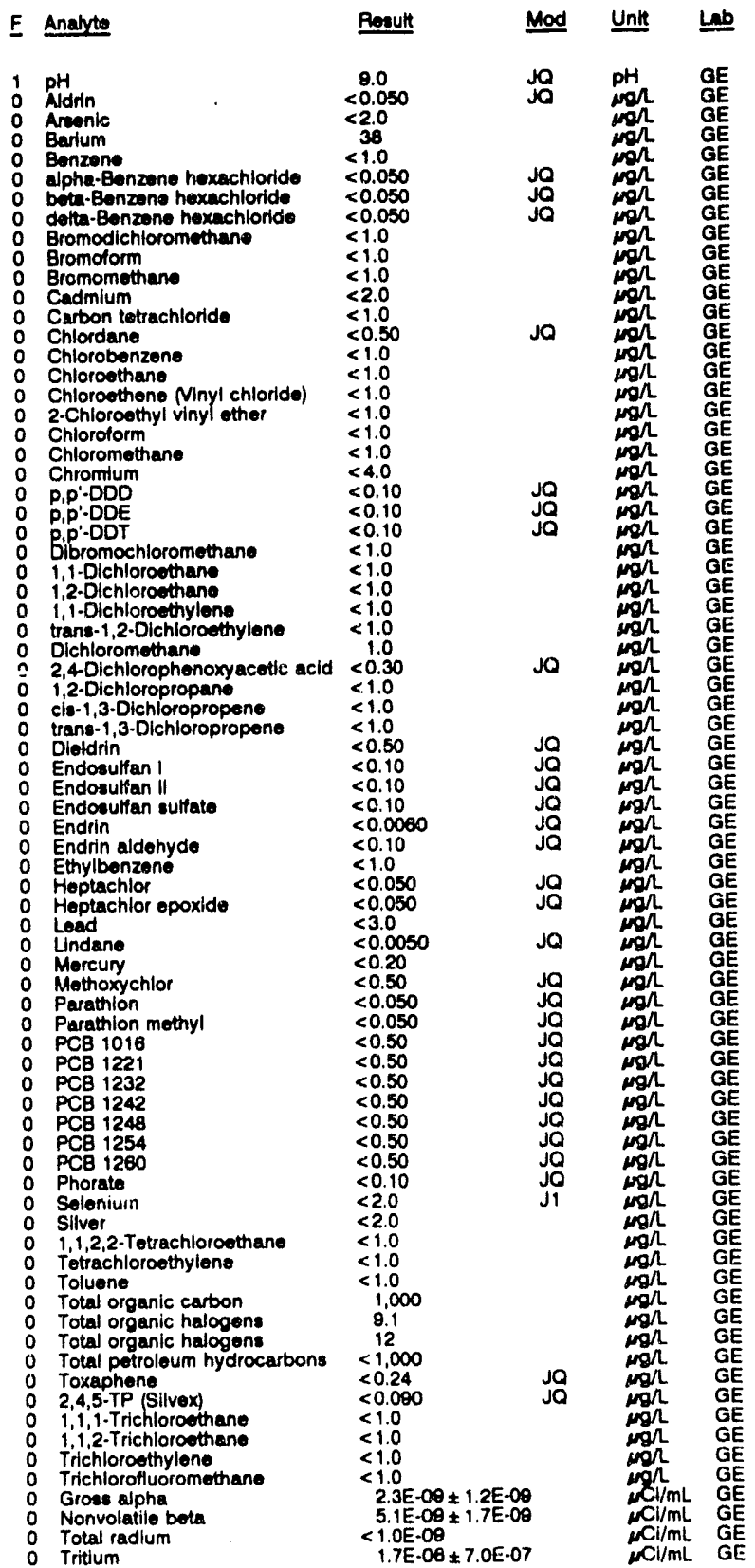

WELL CMP 15C

MEASUREMENTS CONOUCTED IN THE FIELD

Sample date: 12/23/81

Dopth to water: $37.10 \mathrm{ft}(11.31 \mathrm{~m})$ below TOC

ator elevation: $230.90 \mathrm{~h}(73.12 \mathrm{~m}) \mathrm{mal}$

Weter evacuated beforo eampling: 29 gal

The woll went dry during purging.

LABOPATOFY ANALYSES

F Analyte Preult Mod Unit Lab

0 pH

: Ardrin

Barium

Bonzeno herachloride

beta-Benzens hexachloride

delta-Benzene hoxachloride

Bromodichloromethane

Bromoform

Bromometh

Carbon tetrachloride

Chlordane

Chlorobenzene

Chloroethane Minyl chloride)

2-Chloroothyl vinyl other

Chloroform

Chloromettiene

Chromlum

p., p'-DODE

B.P.CIDT
Bibromochloromethane

1,1-Dichloroethans

1,2-Cjichloroethane

1,1-Dlchloroethylone

Dichloromethane

2,4-Dichlorophenoxyacetic acid

1,2-Dichloropropane

o cie-1,3-Dlchloropropene

trans-1,3-0

Dieldrín

Endosultan 1

Endosulfan sulfato

Endrin

Endrin aldehyde

Ethylbenzen

o Heptachlor epoxide

0 Lead

0 Undane

0 Mercury

Parathion

O Parathion methyl

O PCB 1016

0 PCB 1221

O PCB 1232

O PCB 1248

P PCB 125

PCB 1260

Phorato

0 Selen

$1, i, 2,2$-Tetrachloroethane

Tetrachloroethylen

0 Toluene

Total organic carbon

Total organic halogens

Toxaphene

2,4,5-TP (Sitvox)

1,1.1.Trichloroethane

1,1,2-Trichlorosthen

Trichiorofivoromethane

Groses siphe

Nonvolatile beta

Total radlum
5.4
$<0.050$
$<2.0$
$<1.0$

$<3.0$

$<0.050$

$<0.050$

$<1.0$

$<1.0$

$<1.0$

$<2.0$
$<1.0$
$<0.50$

$<1.0$

$<1.0$

$<1.0$

$<1.0$

$<0.10$

$<0.10$

$<0.10$

$<1.0$
$<1.0$
$<1.0$

$<1.0$

$<1.00$

$<1.0$
$<1.0$
$<1.0$
$<0.50$

$<1.0$

$<0.10$

$<0.10$

$<0.10$

$<0.10$

$<0.050$

$<0.050$

$<3.0$
$<0.0050$

$<0.20$

$<0.50$

$<0.050$

$<0.50$

$<0.50$

$<0.50$

$<0.50$

$<0.50$

$<0.50$
$<0.10$

$<0.10$

$<2.0$

$<1.0$
$<1.0$

$<1.0$

2,000
7.1
$<1,000$

$<<0.24$

$<0.080$

$<1.0$

$<1.0$

$<1.0$

$<2.0 E-\infty 9$

$<2.0 E-00$

$<$ 3. $6 \mathrm{E}-00 \pm 7.0 \mathrm{E}-07$

Ja

Timo: 11:50

PH: 4.8 : $1 \mathrm{mal}$

Water tomperature: $20.8 \circ \mathrm{C}$
Jo PH GE

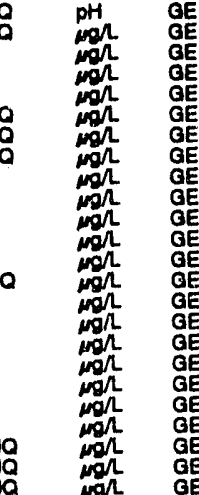

Jo

No

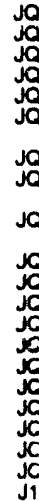




\section{WELL CMP 16B}

MEASUREMENTS CONDUCTED IN THE FIELD

Sample dato: 11/28/91 Depth to water: $121.78 \mathrm{At}(37.12 \mathrm{~m})$ below TOC Wator olovalon. 185.82 (3.12 m) ms

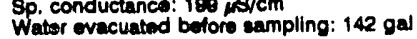

LABOPATORY ANALYSES

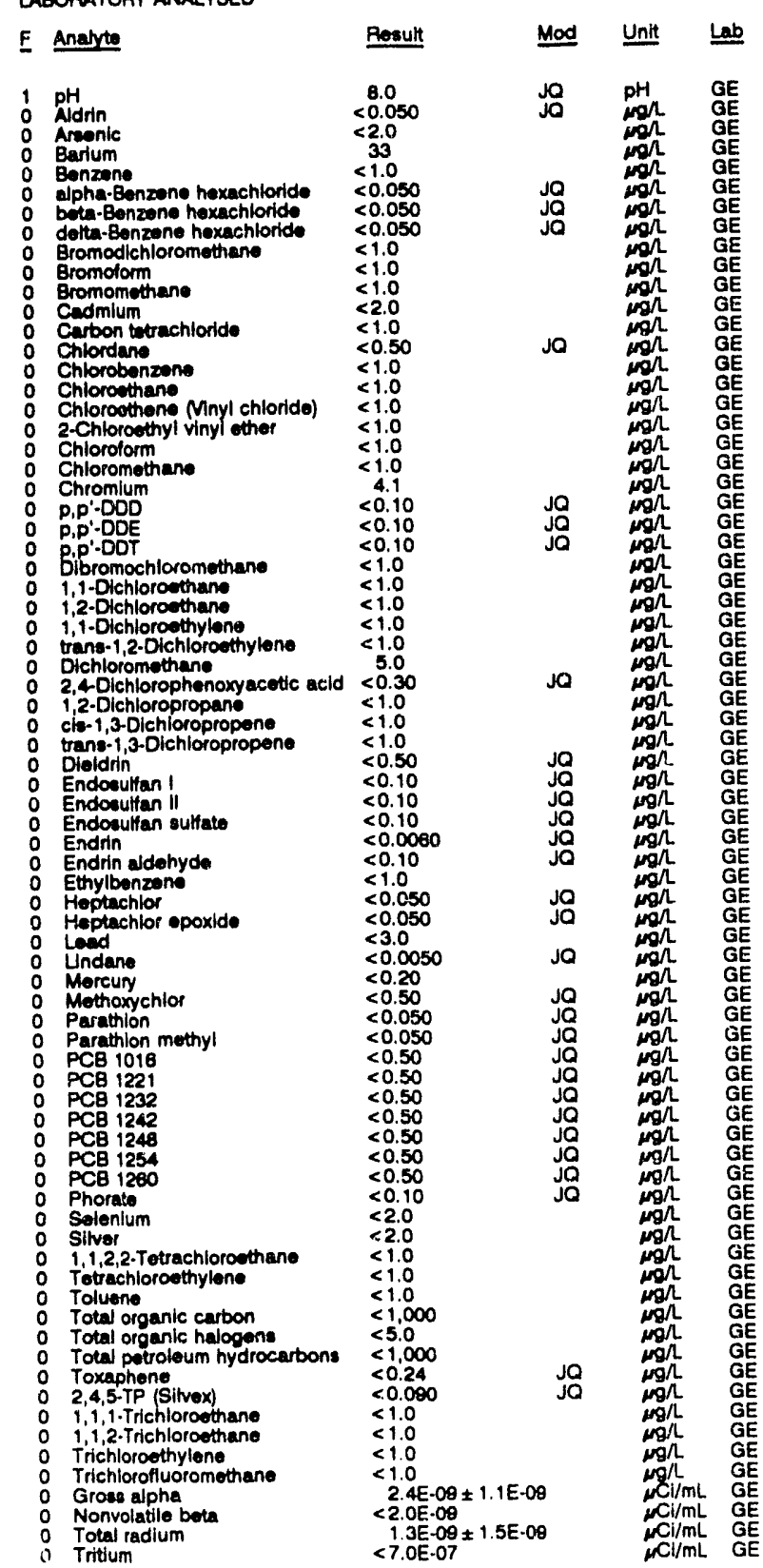

\section{WELL CRP 2}

MEASUREMENTS CONDUCTED IN THE FIELD

Sample date: $11 / 27 / 91$
Depth to water: $72.37 \mathrm{~h}(22.08 \mathrm{~m})$ bolow TOC
Water olevation: $208.33 \mathrm{~h}(62.89 \mathrm{~m}) \mathrm{msl}$
Sp. conductance: $14 \mathrm{~s} / \mathrm{cm}$
Water evacuated before sampling: $114 \mathrm{gal}$

Time: 8:25

PH: 5.1

Alkalinity: $3 \mathrm{mg} /$

Water temperature: $18.4^{\circ} \mathrm{C}$

\section{WELL CRP 4}

MEASUREMENTS CONDUCTED IN THE FIELD

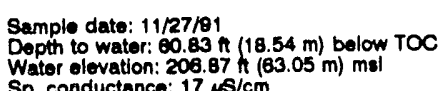

Water olevation: 206.87 h $(83.05 \mathrm{~m}) \mathrm{msl}$

Sp. conductance: $17 \mathrm{\mu S} / \mathrm{cm}$
Water ovacuated botore eampling: $68 \mathrm{gal}$

PH: 5.2

Alkalinity: $3 \mathrm{mg} /$

Water tomporature: $16.5^{\circ} \mathrm{C}$

WELL CSA 1

MEASUREMENTS CONOUCTED IN THE FIELL

Sample dato: 11/23/91

Dopth to water: 30.78 ft $(15.47 \mathrm{~m})$ below TOC

Water olovation: $240.04 \mathrm{~h}$.

pH: 5.0

Alkalinity: $0 \mathrm{mg}$

Water ovacuated before sampling: $21 \mathrm{gal}$

WELL CSA 2

MEASUREMENTS CONDUCTED IN THE FIELD

Sample date: 11/28/91 2 (15.02 m) bolow TOC

Depth to water: $40.28 \mathrm{At}(15.02 \mathrm{~m})$ below

Water olovation: $240.82 \mathrm{~h}$ (13.4

Water evacuatod bofore sampling: $59 \mathrm{gol}$

Time: 16:00

PH: 4.8 : $2 \mathrm{mgl}$

Water temperature: $18.5^{\circ} \mathrm{C}$

WELL CSA 3

MEASUREMENTS CONDUCTED IN THE FIELD

Sample date: 11/28/81

Depth to water: $48.22 \mathrm{H}(14.70 \mathrm{~m})$ below TOC

Wath ole

Water ovacuated before sampling: $58 \mathrm{gal}$

Timo: 16:15

Alkalinity: $0 \mathrm{mgh}$

Water tomperature: $18.1^{\circ} \mathrm{C}$

\section{WELL CSA 4}

MEASUREMENTS CONOUCTED IN THE FIELD

Sample data: 11/28/91

Water olevation: $239.68 \mathrm{t}(73.05 \mathrm{~m}) \mathrm{msl}$

Water evacuatod bofore sampling: $56 \mathrm{gal}$
Time: $16: 3$

PH: 3.1 : $1 \mathrm{mal}$

Water temperature: $18.1^{\circ} \mathrm{C}$

\section{WELL CSB $1 \mathrm{~A}$}

MEASUREMENTS CONDUCTED IN THE FIELD

Sample date: 12/11/91

Depth to water: 77.10 th $(23.50 \mathrm{~m})$ below TOC

Water olovation: $214.70 \mathrm{ht}(85.44 \mathrm{~m}) \mathrm{ms}$

Sp. conduclance: $192 \mu \mathrm{s} / \mathrm{cm}$

Weter evacuated belore sampling: 12 gal

The well went dry during purging.

LABORATORY ANALYSES

\begin{tabular}{|c|c|c|c|}
\hline E Analyte & Result & Mod & Unit \\
\hline $\begin{array}{ll}0 & \text { Carbon tetrachloride } \\
0 & \text { Chloroform } \\
0 & \text { Tetrachioroothylone } \\
0 & 1,1,1-\text { Trichloroethane }\end{array}$ & $\begin{array}{l}<1.0 \\
<1.0 \\
<1.0 \\
<1.0\end{array}$ & & $\begin{array}{l}\mu g / L \\
\mu g / L \\
\mu g / L \\
\mu g h\end{array}$ \\
\hline
\end{tabular}

\section{WELL CMP 16C}

MEASUREMENTS CONDUCTED IN THE FIELD

Sample date: $11 / 28 / 01$

Time: 11:00

The well was dry.
Time: 11:10

Alkalinity: $78 \mathrm{mg}$

Water temperature: $20.5^{\circ} \mathrm{C}$ 
WELL CSB $1 A$ colloctod on 12/11/91, laboratory analysee (cont.)

$\begin{array}{lllll}\text { F Analyte } & \text { Result } & \text { Mod } & \text { Unit } & \text { Lab } \\ 0 & \text { Trichloroothylone } & <1.0 & & \\ 0 & \text { Total activity } & 3.0 E-04 \pm 4.5 E-00 & M L^{\prime} & \text { GE }\end{array}$

WELL CSB 3A

MEASUREMENTS CONOUCTED IN THE FIELD

\begin{tabular}{|c|c|c|c|c|c|}
\hline \multicolumn{3}{|c|}{$\begin{array}{l}\text { Sample dato: } 12 / 11 / 91 \\
\text { Depth to water: } 71.47 \mathrm{ft}(21.78 \mathrm{~m}) \text { below TOC } \\
\text { Water elevation: } 213.43 \mathrm{ft}(65.05 \mathrm{~m}) \mathrm{ms} \\
\text { Sp. conductance: } 34 \text { fs/cm } \\
\text { Water evacuated before sampling: } 20 \mathrm{gal} \\
\text { The woll went dy during purging. }\end{array}$} & \multicolumn{3}{|c|}{$\begin{array}{l}\text { Time: } 11: 00 \\
\text { pH: } 8.0 \\
\text { Alkealinity: } 10 \mathrm{mgh} \\
\text { Weter tomporature: } 18.8 \cdot \mathrm{C}\end{array}$} \\
\hline \multicolumn{6}{|c|}{ LABORATORY AIJALYSES } \\
\hline & Analyte & Result & Mod & Unit & 느 \\
\hline & $\begin{array}{l}\text { Carbon totrachioride } \\
\text { Chioroform } \\
\text { Tetrachloroethylene } \\
\text { 1,1,1-Trichloroethane } \\
\text { Trichlorothylene } \\
\text { Total activity }\end{array}$ & $\begin{array}{l}<1.0 \\
<1.0 \\
<1.0 \\
<1.0 \\
1.1 \\
3.9 \mathrm{E}-02\end{array}$ & E.04 & 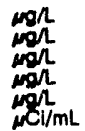 & $\begin{array}{l}\mathrm{GE} \\
\mathrm{GE} \\
\mathrm{GE} \\
\mathrm{GE} \\
\mathrm{GE} \\
\mathrm{EM}\end{array}$ \\
\hline
\end{tabular}

WELL CSB 4A

MEASUREMENTS CONDUCTED IN THE FIELD

\begin{tabular}{|c|c|c|c|c|c|}
\hline \multicolumn{3}{|c|}{$\begin{array}{l}\text { Sample date: } 12 / 11 / 91 \\
\text { Dopth to water: } 71.91 \mathrm{ft}(21.82 \mathrm{~m}) \text { below TOC } \\
\text { Water olovation: } 213.19 \mathrm{ht}(64.98 \mathrm{~m}) \mathrm{ms} \\
\text { Sp. conductance: } 21 \mathrm{fS} / \mathrm{cm} \\
\text { Water ovacuatod betore sampling: } 66 \mathrm{gal}\end{array}$} & \multicolumn{3}{|c|}{$\begin{array}{l}\text { Time: } 10: 50 \\
\text { pH: } 5.3 \\
\text { Alkalinity: } 1 \mathrm{mg} / \\
\text { Water temperalure: } 20.3^{\circ} \mathrm{C}\end{array}$} \\
\hline \multicolumn{6}{|c|}{ LABORATORY ANALYSES } \\
\hline$\underline{F}$ & Analyte & Result & Mod & Unit & Lab \\
\hline $\begin{array}{l}0 \\
0 \\
0 \\
0 \\
0 \\
0\end{array}$ & $\begin{array}{l}\text { Carbon totrachloride } \\
\text { Chloroform } \\
\text { Tetrachloroethylene } \\
1,1,1-\text { Trichloroethane } \\
\text { Trichloroethylene } \\
\text { Total activity }\end{array}$ & $\begin{array}{l}<1.0 \\
<1.0 \\
<1.0 \\
<1.0 \\
<1.0 \\
4.9 \mathrm{E}-02\end{array}$ & E-04 & 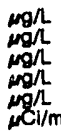 & $\begin{array}{l}\mathrm{GE} \\
\mathrm{GE} \\
\mathrm{GE} \\
\mathrm{GE} \\
\mathrm{GE} \\
\mathrm{EM}\end{array}$ \\
\hline
\end{tabular}

\section{WELL CSB 5A}

MEASUREMENTS CONOUCTED IN THE FIELD

\begin{tabular}{|c|c|c|c|c|c|}
\hline \multicolumn{3}{|c|}{$\begin{array}{l}\text { Sample date: } 12 / 11 / 91 \\
\text { Dopth to water: } 69.43 \mathrm{Ht}(21.16 \mathrm{~m}) \text { below TOC } \\
\text { Water olevation: } 213.37 \mathrm{~h}(65.04 \mathrm{~m}) \mathrm{msl} \\
\text { Sp. conductance: } 93 \mu \mathrm{s} / \mathrm{cm} \\
\text { Water ovacuated bolore sampling: } 11 \mathrm{gal} \\
\text { The well went dry during purging. }\end{array}$} & \multicolumn{3}{|c|}{$\begin{array}{l}\text { Time: } 10: 25 \\
\text { pH: } 8.0 \\
\text { Alkalinity: } 33 \mathrm{mg} / \mathrm{h} \\
\text { Water temperature: } 18.7^{\circ} \mathrm{C}\end{array}$} \\
\hline \multicolumn{6}{|c|}{ LABOPATORY ANALYSES } \\
\hline$\underline{F}$ & Analyte & Result & Mod & Unit & Lab \\
\hline $\begin{array}{l}0 \\
0 \\
0 \\
0 \\
0 \\
0 \\
0\end{array}$ & $\begin{array}{l}\text { Carbon tetrachloride } \\
\text { Chlorofortit } \\
\text { Tetrachloroethylene } \\
1,1,1 \text {-Trichloroethane } \\
\text { Trichloroethylene }\end{array}$ & $\begin{array}{l}<1.0 \\
<1.0 \\
<1.0 \\
<1.0 \\
<1.0 \\
1.0 \mathrm{E}-03\end{array}$ & E-05 & 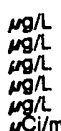 & $\begin{array}{l}\mathrm{GE} \\
\mathrm{GE} \\
\mathrm{GE} \\
\mathrm{GE} \\
\mathrm{GE} \\
\mathrm{EM}\end{array}$ \\
\hline
\end{tabular}

\section{WELL CSD $1 D$}

MEASUREMENTS CONOUCTED IN THE FIELD

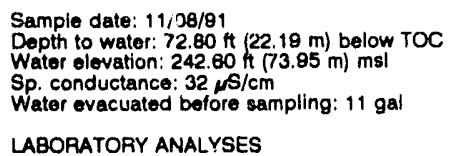

$$
\begin{aligned}
& \text { Time: } 7: 00 \\
& \text { pH: } 5.5 \\
& \text { Alkalinity: } 0 \mathrm{mg} / \mathrm{L} \\
& \text { Water temperature: } 15.5^{\circ} \mathrm{C}
\end{aligned}
$$

\begin{tabular}{|c|c|c|c|}
\hline E Analyte & Result & Mod & Unit \\
\hline $\begin{array}{ll}0 & \text { Calclum } \\
0 & \text { Dissolved organic carbon } \\
0 & \text { Magnesium } \\
0 & \text { Nitrite as nitrogen } \\
0 & \text { Potassium } \\
0 & \text { Silica } \\
0 & \text { Sulfide } \\
0 & \text { Total petroleum hydrocarbons } \\
0 & \text { Total phosphates (as } \mathrm{P} \text { ) }\end{array}$ & $\begin{array}{l}813 \\
1,000 \\
305 \\
<10 \\
1,390 \\
47,300 \\
<5,000 \\
<1,000 \\
220\end{array}$ & & $\begin{array}{l}\mathrm{mg} / \mathrm{L} \\
\mathrm{mg} / \mathrm{h} \\
\mathrm{mg} / \mathrm{h} \\
\mathrm{mg} / \mathrm{L} \\
\mathrm{mg} / \mathrm{L} \\
\mathrm{mg} / \mathrm{h} \\
\mathrm{mg} / \mathrm{L} \\
\mathrm{mg} / \mathrm{L} \\
\mathrm{mg} / \mathrm{L}\end{array}$ \\
\hline
\end{tabular}

LABORATORY ANALYSES

\begin{tabular}{|c|c|c|c|c|c|}
\hline \multicolumn{3}{|c|}{$\begin{array}{l}\text { Sample date: 11/09/91 } \\
\text { Depth to wator: Not avallable } \\
\text { Wator olevation: Not avallable } \\
\text { Sp. conductance: } 29 \text { ps/cm } \\
\text { Water ovacuated bofore sampling: } 2 \text { gal } \\
\text { The well went dry durling purging. }\end{array}$} & \multicolumn{3}{|c|}{$\begin{array}{l}\text { Tlmo: } 4: 35 \\
\text { PH: } 5.8 \\
\text { Alkallinity: } 6 \mathrm{mg} / \mathrm{L} \\
\text { Water tomperature: } 15.3^{\circ} \mathrm{C}\end{array}$} \\
\hline \multicolumn{6}{|c|}{ LABORATORY ANALYSES } \\
\hline$\underline{\mathbf{F}}$ & Analyte & Result & Mod & Unit & $\underline{\text { Lab }}$ \\
\hline $\begin{array}{l}0 \\
0 \\
0 \\
0 \\
0 \\
0 \\
0 \\
0 \\
0 \\
0\end{array}$ & $\begin{array}{l}\text { Calcium } \\
\text { Dlssolved organic carbon } \\
\text { Dlsolved organic carbon } \\
\text { Magneslum } \\
\text { Nitrte as nitrogen } \\
\text { Potasslum } \\
\text { Sllica } \\
\text { Sulfide } \\
\text { Total potroleum hydrocarbons } \\
\text { Total phosphates (as P) }\end{array}$ & $\begin{aligned} & 571 \\
&< 1,000 \\
&<1,000 \\
& 339 \\
&<10 \\
& 1,500 \\
& 34,300 \\
&<1,00 \\
&<1,000 \\
& 140\end{aligned}$ & J2 & 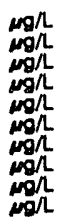 & $\begin{array}{l}\mathrm{GE} \\
\mathrm{GE} \\
\mathrm{GE} \\
\mathrm{GE} \\
\mathrm{GE} \\
\mathrm{GE} \\
\mathrm{GE} \\
\mathrm{GE} \\
\mathrm{GE} \\
\mathrm{GE}\end{array}$ \\
\hline
\end{tabular}

WELL CSD 2D

MEASUREMENTS CONDUCTED IN THE FIELD

Time: 4:35

PH: 5.8 ikallinity: $6 \mathrm{mg} / \mathrm{h}$

Water temporature: $15.3^{\circ} \mathrm{C}$

Wer

LABORATORY ANALYSES

\section{WELL CSD 4D}

MEASUREMENTS CONDUCTED IN THE FIELD

Samplo date: 11/00/91

Depth to water: $67.18 \mathrm{ht}(20.48 \mathrm{~m})$ bolow TOC

Water elevation: $241.32 \mathrm{~h}(73.58 \mathrm{~m}) \mathrm{msl}$

Sp. conductance: $400 \mu \mathrm{s} / \mathrm{cm}$

Water evacuated before sampling: $21 \mathrm{gal}$

Tho well went dry during purging.

LABORATORY ANALYSES

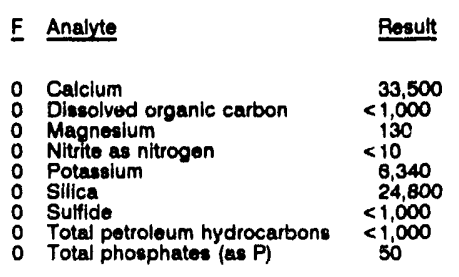

Time: $4: 45$

PH: 11.4 Water temperature: $18.0^{\circ} \mathrm{C}$

WELL CSD 8D

MEASUREMENTS CONDUCTED IN THE FIELD

Sample date: 11/08/91

Dopth to water: $62.88 \mathrm{ft}(18.17 \mathrm{~m})$ below TOC

Water elevation: $241.02 \mathrm{At}$ (73.4

Water evacuated bofore sampling: 37 gal

LABORATORY ANALYSES

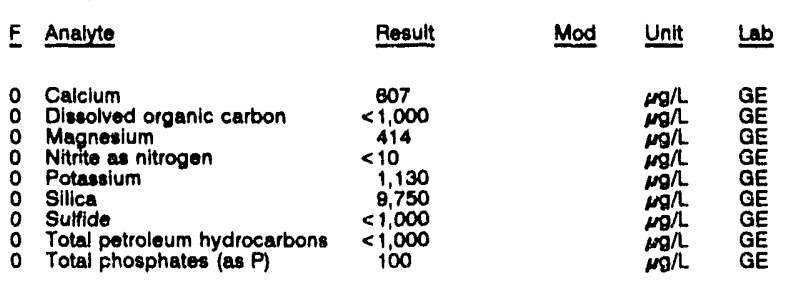

\section{WELL CSD 9D}

MEASUREMENTS CONDUCTED IN

LD

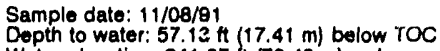

Water elevation: $241.07 \mathrm{ft}(73.48 \mathrm{~m}) \mathrm{m}$

\begin{tabular}{|c|c|c|c|c|}
\hline & Analyte & Pesult & Mad & Unit \\
\hline & $\begin{array}{l}\text { Calclum } \\
\text { Dissoived organic carbon } \\
\text { Magnesium } \\
\text { Nitrite as nitrogen } \\
\text { Potasslum } \\
\text { Silica } \\
\text { Sulfide } \\
\text { Total petroleum hydrocarbons } \\
\text { Total phosphates (as P) }\end{array}$ & $\begin{aligned} & 279 \\
&< 1,000 \\
& 3,92 \\
&< 10 \\
& 1,460 \\
& 17,300 \\
&<1,000 \\
&<1,000 \\
& 690\end{aligned}$ & & 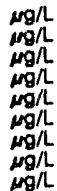 \\
\hline
\end{tabular}

Sp. conductance: $38, \mathrm{~S} / \mathrm{cm}$

Water evacuated bofore sampling: $39 \mathrm{gal}$

LABOPATOFY ANALYSES
Time: $5: 00$

Water temperature: $17.0^{\circ} \mathrm{C}$

Time: $5: 15$

Alkalinity: $6 \mathrm{mg} / \mathrm{h}$

Water temperature, $18.3^{\circ} \mathrm{C}$

EE 
ANALYTICAL RESULTS

\section{WELL CSD 10D}

MEASUAEMENTS CONDUCTED IN THE FIELD

Sample date: 11/08/91

Depth to water: $55.83 \mathrm{ft}(17.02 \mathrm{~m})$ below TOC

Water elevation: $240.77 \mathrm{~h}(73.39 \mathrm{~m}) \mathrm{ms}$

Water evacuated before sampling: $43 \mathrm{gal}$

LABORATORY ANALYSES

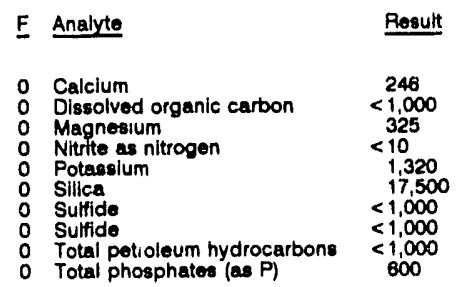

\section{WELL CSD 11D}

MEASUREMENTS CONDUCTED IN THE FIELD

Sample date: 11/09/91

Depth to water: $52.76 \mathrm{ft}(16.08 \mathrm{~m})$ below TOC

Wator olevation: $240.24 \mathrm{ft}(73.23 \mathrm{~m}) \mathrm{ms}$

Water evacuatod bofore sampling: $20 \mathrm{gal}$

The well went dry during purging.

LABORATORY ANALYSES

\begin{tabular}{|c|c|}
\hline Analyte & Result \\
\hline $\begin{array}{l}\text { Calcium } \\
\text { Dissolved organic carbon } \\
\text { Magnesium } \\
\text { Nitritte as nitrogen } \\
\text { Nitrite as nitrogen } \\
\text { Potassium } \\
\text { Silica } \\
\text { Sulfide } \\
\text { Sulfide } \\
\text { Total petroleum hydrocarbons } \\
\text { Total phosphates (as P) }\end{array}$ & $\begin{array}{l}43,400 \\
<1,000 \\
1,680 \\
<10 \\
<10 \\
1,780 \\
28,700 \\
<1,000 \\
<1,000 \\
1,000 \\
1,100\end{array}$ \\
\hline
\end{tabular}

\section{WELL CSD 12D}

MEASUREMENTS CONDUCTED IN THE FIELD

Sample date: $11 / 11 / 91$
Depth to water: $60.38 \mathrm{ft}(18.40 \mathrm{~m})$ below TOC
Water olevation: $241.22 \mathrm{tt}(73.52 \mathrm{~m}) \mathrm{ms}$ (

Sp conductance $31.22 \mathrm{~cm}$

Water evacuated before sampling: $44 \mathrm{gal}$

LABORATORY ANALYSES

\begin{tabular}{|c|c|}
\hline Analyte & Result \\
\hline $\begin{array}{l}\text { Calcium } \\
\text { Dissolvod organic carbon } \\
\text { Magneslum } \\
\text { Nitrite as nitrogen } \\
\text { Nitrite as nitrogen } \\
\text { Potassium } \\
\text { Sillica } \\
\text { Sulfide } \\
\text { Total potroleum hydrocarbons } \\
\text { Total phosphates (as P) }\end{array}$ & $\begin{aligned} & 964 \\
&< 1,000 \\
& 634 \\
&<10 \\
&<10 \\
& 676 \\
& 8,220 \\
&<1,000 \\
&<1,000 \\
& 220\end{aligned}$ \\
\hline
\end{tabular}

\section{WELL CSD 13D}

MEASUREMENTS CONDUCTED IN THE FIELD

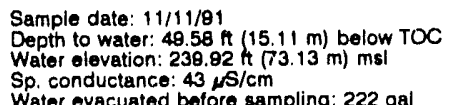

Water evacuated before sampling: $222 \mathrm{gal}$

LABOFATORY ANALYSES

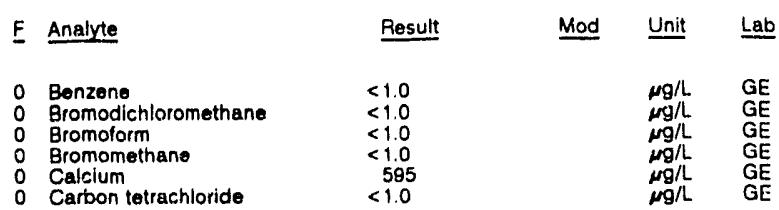

Time: $5: 35$

pH: 5.2 . $3 \mathrm{mgh}$

Water remperature: $18.4^{\circ} \mathrm{C}$

Mod Unit Lab

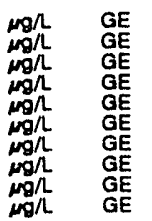

Time: $5: 10$

Alkalinity: $146 \mathrm{mg} / \mathrm{h}$

Alkalinity: $146 \mathrm{mg} / \mathrm{h}$. $17.6^{\circ} \mathrm{C}$

Mod Unit Lab

J2

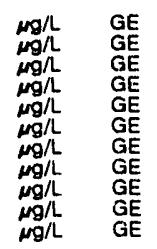

Time: 5:05

$\mathrm{pH}: 4.8$

Alkalinity: $4 \mathrm{mg} / \mathrm{m}$

Water temperature: $18.2^{\circ} \mathrm{C}$

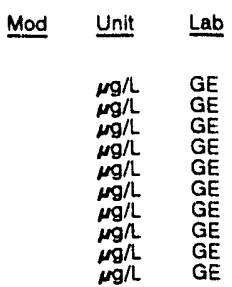

\section{Time: $5: 30$}

PH: 5.2

Water temperature: $17.0^{\circ} \mathrm{C}$

$\mu g / \mathrm{L} \quad \mathrm{GE}$

WELL CSD 13D collected on 11/11/91, laboratory annlyees (cont)

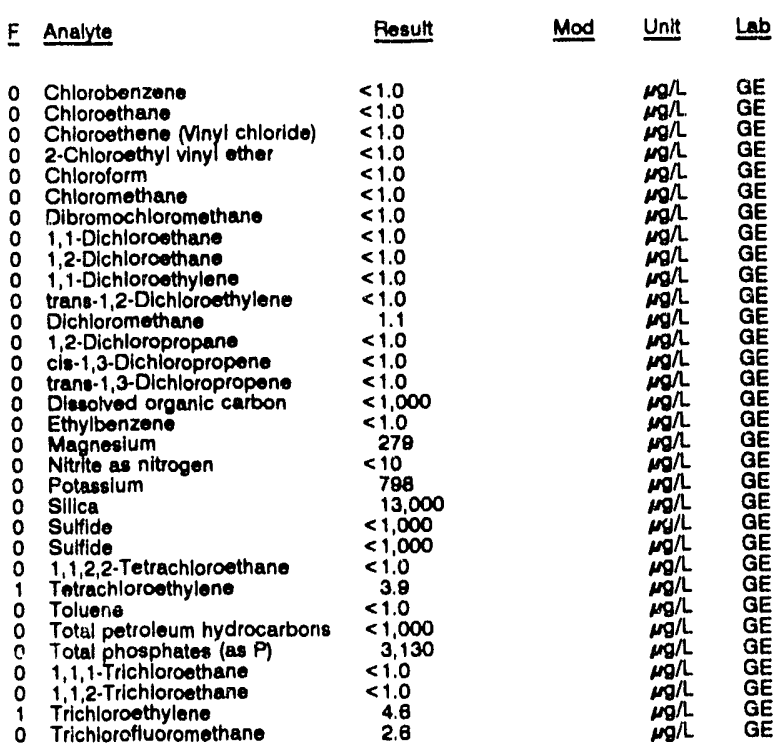

WELL CSD 13D Replicate

MEASUREMENTS CONDUCTED IN THE FIELD

Sample date: 11/11/91

Depth to water: $49.58 \mathrm{~A}(15.11 \mathrm{~m})$ below TOC

Water olevation: $238.92 \mathrm{tt}(73.13 \mathrm{~m}) \mathrm{msl}$

Water ovacuated betore sampling: $222 \mathrm{gal}$

LABORATORY ANALYSES

F Analyte

Result

Time: $5: 30$

pH: 5.2

Water temperature: $17.0^{\circ} \mathrm{C}$

Benzene

Bromodichlo

Bromomethano

Calclum

Carbon tetrachioride

Chlorobenzeno

Chloroothene Ninyl chloride)

2-Chloroethyl vinyl ether

Chloroform

Chloromethane

Dibromochloromethane

1,1-Dichloroothane

1,2-Dichloroothane

trans-1,2-Dichloroethylene

Dichloromethane

o 1,2-Dichloropropane

cis-1,3-Dichloropropene

trans-1,3-Dichloropropene

Dissolved organic carbon

Ethylbenzene

Magnesium

Nitnie as nito

Silica

Sultide

1,1,2,2-Totrachloroethane

Tetrachloroethylene

Total petroloum hydrocarbons

Total phosphates (as P)

1,1,1-Trichloroethane

T,1,2-Trichloroethan

Trichlorofluoromethane
$<1.0$

$<1.0$

$<1.0$

582

$<1.0$

$<1.0$

$<1.0$

$<1.0$

$<1.0$

$<1.0$

$<1.0$

$<1.0$

$<1.0$

$<1.00$

$<1,0$

250
$<10$

733

11,500
$<1,000$

$<1.0$

4.6
$<1.0$

$<1.000$

2,830

$<1.0$
$<1.0$

4.7
4.1
Mod Unit Lab

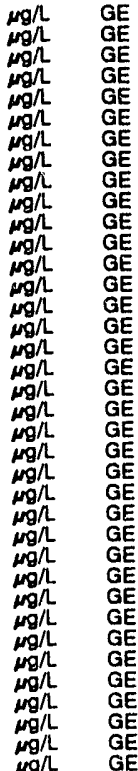


ANALYTICAL RESULTS

WELL CSO 1

MEASUREMENTS CONDUCTED IN THE FIELD

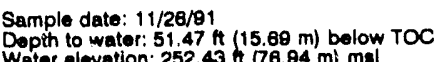

Wator olovaton: 252.43 h

Water evacuated bofore sampling: $54 \mathrm{gal}$

\section{WELL CSO 2}

MEASUREMENTS CONDUCTED IN THE FIELD

Sample date: $11 / 26 / 91$.

Water elevation: 250.43 it $(78.33 \mathrm{~m}) \mathrm{ms}$

Sp. conductance: $30 \mathrm{\mu S} / \mathrm{cm}$.

WELL CSR 1

MEASUREMENTS CONDUCTED IN THE FIELD

Sample date: 11/27/91

Depth to water: $16.18 \mathrm{Ht}(4.93 \mathrm{~m})$ below TOC

Sp. conductan

Water ovacuated before sampling: $54 \mathrm{gal}$

WELL CSR 2

MEASUREMENTS CONDUCTED IN THE FIELD

Sample date: $12 / 26 / 91$
Depth to water: $36.83 \mathrm{n}(11.23 \mathrm{~m})$ below TOC

Water olevation: $280.87 \mathrm{~h}(79.51 \mathrm{~m}) \mathrm{ms}$

Sp. conductance: $48 \mu \mathrm{s} / \mathrm{cm}$

Water ovacuated before sampling: $10 \mathrm{gal}$

The weil went dry during purging.

\section{WELL CSR 3}

MEASUREMENTS CONDUCTED IN THE FIELD

Sample date: $12 / 26 / 81$

Depth to water: $27.46 \mathrm{ft}(8.37 \mathrm{~m})$ below TOC

Water olevation: $257.74 \mathrm{tt}(78$

sampling: $32 \mathrm{ge}$

The well went dry during purging.

\section{WELL CSR 4}

MEASUREMENTS CONDUCTED IN THE FIELD

Sample date: 11/27/81

Depth to water: $25.98 \mathrm{ft}(7.92 \mathrm{~m})$ below TOC

Water elevation: 258.72 \& $(78$

Water

WELL DBP 1

MEASUREMENTS CONDUCTED IN THE FIELD

Sample date: 11/27/81

Depth to water: $16.78 \mathrm{ft}(5.12 \mathrm{~m})$ below TOC

Wp conductanco: $8.41 \mathrm{tt}(38 \mathrm{~m}$

Water ovacuated before sampling: $68 \mathrm{ga}$
Timo: $17: 00$

PH: 4.8 : $1 \mathrm{mglt}$

Water temperature: $17.8^{\circ} \mathrm{C}$

Time: 18:50

$\mathrm{pH}: 4.8$

Alkalinity: $0 \mathrm{mg} / \mathrm{h}$

Water temporature: $17.3^{\circ} \mathrm{C}$

\section{Time: $9: 15$}

Alkalinity: $1 \mathrm{mo} / \mathrm{L}$

Water temperature: $16.7^{\circ} \mathrm{C}$

Time: 10:50

$\mathrm{H}: 5.7$

Water temperature: $17.0^{\circ} \mathrm{C}$

Alkalinity: $1 \mathrm{mg}$

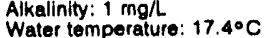

Time: $9: 35$

Alkalinity: $0 \mathrm{mg}$

Water temperature: $18.8^{\circ} \mathrm{C}$

Time: $9: 55$

PH: 4.8 : $0 \mathrm{mg}$

Water temperature: $18.8^{\circ} \mathrm{C}$
WELL DBP 2

MEASUREMENTS CONDUCTED IN THE FIELD

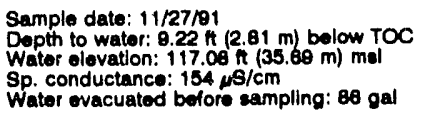

Timo: 9:00

$\mathrm{pH}: 4.3$

Alkalinity: $0 \mathrm{mg} /$

Water tomporalure: $18.0^{\circ} \mathrm{C}$

\section{WELL DBP 3}

MEASUREMENTS CONDUCTED IN THE FIELD

Sample date: $11 / 27 / 91$
Dopth to water: $6.88 \mathrm{n}(2.12 \mathrm{~m})$ below TOC
Water elevation: $121.34 \mathrm{f}(36.88 \mathrm{~m}) \mathrm{msl}$
Sp. conductanco: $61 \mu \mathrm{cm} / \mathrm{cm}$
Water evacuated before sampling: $82 \mathrm{gal}$

Time: $\theta: 35$

$\mathrm{pH}: 5.5$

Alkalinity: $1 \mathrm{mg}$

Water tomperature: $15.1^{\circ} \mathrm{C}$

WELL DBP 4

MEASUREMENTS CONDUCTED IN THE FIELD

Sample date: 11/27/91

Depth to water: $7.18 \mathrm{n}(2.18 \mathrm{~m})$ bolow TOC

Water olevation: $118.02 \mathrm{f}(38.28 \mathrm{~m}) \mathrm{msl}$

Sp. conductance: $116 \mu \mathrm{S} / \mathrm{cm}$.

Time: $9: 20$

PH: 4.4

Alkalinity: $0 \mathrm{mgh}$

Water tompergture: $17.7^{\circ} \mathrm{C}$

\section{WELI DCB 2A}

MEASUREMENTS CONDUCTED IN THE FIELD

Sample date: 11/27/91

Depth to water: $8.79 \mathrm{ft}(2.98 \mathrm{~m})$ below TOC

Water elovation: $124.51 \mathrm{it}(37.85 \mathrm{~m}) \mathrm{mal}$

co: $43 \mu \mathrm{s} / \mathrm{cm}$

Water evacuated before sampling: $71 \mathrm{gel}$

Timo: 10:15

Alkalinity: $0 \mathrm{mg} / \mathrm{l}$

Water temperature: $21.4^{\circ} \mathrm{C}$

\section{WELL DCB 3A}

MEASUREMENTS CONDUCTED IN THE FIELD

Sample date: $11 / 27 / 91$

Depth to water: $12,48 \mathrm{ft}(3.80 \mathrm{~m})$ bolow TOC

$120.52 \mathrm{t}(38.73 \mathrm{~m}) \mathrm{mgl}$

Water evacuated bofore sampling: 64 ga

Time: 10:45

PH: 5.2

Water temperature: $18.7^{\circ} \mathrm{C}$

\section{WELL DCB 4A}

MEASUREMENTS CONDUCTED IN THE FIELD

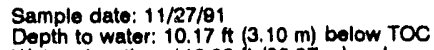

Water elevation: $118.33 \mathrm{ht}(36.37 \mathrm{~m}) \mathrm{msl}$

Sp. conductance: $814 \mu / \mathrm{sm}$
Water ovacuated before sampling: $70 \mathrm{gal}$

Time: 11:00

pH: 4 .

: $0 \mathrm{mg} /$ Water temperature: $21.1^{\circ} \mathrm{C}$

\section{WELL DCB 5A}

MEASUREMENTS CONDUCTED IN THE FIELD

Sample date: 11/27/81

Depth to water: $4.15 \mathrm{tt}(1.26 \mathrm{~m})$ below TOC

Water elevation: $118.75 \mathrm{tt}(38.20 \mathrm{~m}) \mathrm{ms}$ |

Sp. conductance: $862 \mu \mathrm{s} / \mathrm{cm}$

Water ovacuatod betore sampling: $86 \mathrm{gal}$

Timo: 11:15

AH: 4.8 inity: $0 \mathrm{mgl}$

Water tomperature: $20.9^{\circ} \mathrm{C}$ 
ANALYTICAL RESULTS

\section{WELL DCB 6}

MEASUREMENTS CONDUCTED IN THE FIELD

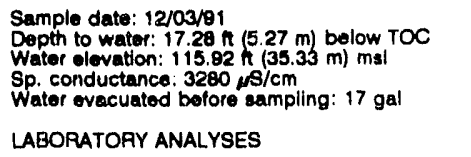

\begin{tabular}{|c|c|}
\hline Analyie & Result \\
\hline 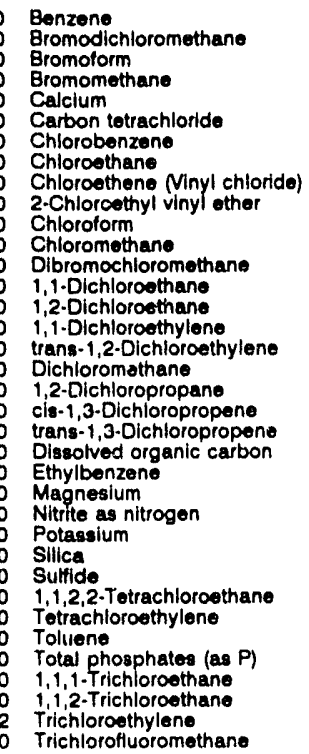 & $\begin{array}{l}<1.0 \\
<1.0 \\
<1.0 \\
<1.0 \\
260,000 \\
<1.0 \\
<1.0 \\
<1.0 \\
<1.0 \\
<1.0 \\
<1.0 \\
<1.0 \\
<1.0 \\
<1.0 \\
<1.0 \\
<1.0 \\
<1.0 \\
<1.0 \\
<1.0 \\
<1.0 \\
<1.0 \\
3,000 \\
<1.0 \\
1197,000 \\
<10 \\
4,430 \\
26,700 \\
<1.000 \\
<1.0 \\
1.3 \\
<1.0 \\
51.0 \\
<1.0 \\
<1.0 \\
<1.0\end{array}$ \\
\hline
\end{tabular}

\section{WELL DCB 7}

MEASUREMENTS CONDUCTED IN THE FIELD

Sample date: $12 / 03 / 91$

.57 $475 \mathrm{~m})$ below TOC Sp. conductance: $2180 \mathrm{tt}(35.73$ Water ovacuated before samping: $22 \mathrm{gal}$

LABORATORY ANALYSES

\begin{tabular}{|c|c|c|c|}
\hline Analyte & Result & Mod & Unit \\
\hline $\begin{array}{l}\text { Benzene } \\
\text { Bromodichloromethane } \\
\text { Bromoform } \\
\text { Bromomethane } \\
\text { Calcium } \\
\text { Carbon tetrachloride } \\
\text { Chlorobenzene } \\
\text { Chloroethane } \\
\text { Chloroethene Ninyl chloride) } \\
\text { 2-Chloroethyl vinyl ether } \\
\text { Chloroform } \\
\text { Chloromethane } \\
\text { Dibromochloromethane } \\
1,1-\text {-ichloroethane } \\
\text { 1,2-Dichloroethane } \\
1,1 \text {-Dichloroothylene } \\
\text { trans-1,2-Dichloroethylene } \\
\text { Dichloromethane } \\
1,2 \text {-Dichloropropane } \\
\text { cis-1,3-Dichloropropene } \\
\text { trans-1,3-Dichloropropene } \\
\text { Dissolved organic carbon } \\
\text { Ethylbenzene } \\
\text { Magnesium } \\
\text { Nitrite as nitrogen } \\
\text { Potassium } \\
\text { Silica } \\
\text { Sulfide } \\
1,1,2,2-\text { Tetrachloroethane } \\
\text { Totrachloroethylene } \\
\text { Toluene } \\
\text { Tital phosphates (as P) } \\
1,1 \text { - Trichloroethane } \\
1,1,2-\text { Trichloroethane } \\
\text { Trichloroethylene }\end{array}$ & $\begin{array}{l}<1.0 \\
<1.0 \\
<1.0 \\
<1.0 \\
38,900 \\
<1.0 \\
<1.0 \\
<1.0 \\
<1.0 \\
<1.0 \\
<1.0 \\
<1.0 \\
<1.0 \\
<1.0 \\
<1.0 \\
<1.0 \\
<1.0 \\
<1.0 \\
<1.0 \\
<1.0 \\
<1.0 \\
2,000 \\
<1.0 \\
33,900 \\
<10 \\
610 \\
17.000 \\
<1.000 \\
<1.0 \\
<1.0 \\
<1.0 \\
<50 \\
<1.0 \\
<1.0 \\
42\end{array}$ & & $\begin{array}{l}\mu g / L \\
\mu g / L \\
\mu g / L \\
\mu g / L \\
\mu g / L \\
\mu g / L \\
\mu g / L \\
\mu g / L \\
\mu g / L \\
\mu g / L \\
\mu g / L \\
\mu g / L \\
\mu g / L \\
\mu g / L \\
\mu g / L \\
\mu g / L \\
\mu g / L \\
\mu g / L \\
\mu g / L \\
\mu g / L \\
\mu g / L \\
\mu g / L \\
\mu g / L \\
\mu g / L \\
\mu g / L \\
\mu g / L \\
\mu g / L \\
\mu g / L \\
\mu g / L \\
\mu g / L \\
\mu g / L \\
\mu g / L \\
\mu g / L \\
\mu g / L \\
\mu g / L\end{array}$ \\
\hline
\end{tabular}

WELL DCB 7 collected on 12/03/81, laboratory enalyser (cont)

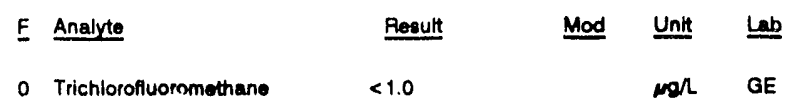

WELL DCB 7 Replicate

MEASUREMENTS CONDUCTED IN THE FIELD

$\begin{array}{ll}\text { Sample date: } 12 / 03 / 91 & \text { Time: } 13: 40 \\ \text { Depth to water: } 15.57 \mathrm{n}(4.75 \mathrm{~m}) \text { below TOC } & \text { pH: } 2.8 \\ \text { Water olevation: } 117.23 \mathrm{~h}(35.73 \mathrm{~m}) \mathrm{mel} & \text { Alkalinity: } 0 \mathrm{mgh} \\ \text { Sp. conductance: } 2180 \mu \mathrm{s} / \mathrm{cm} & \text { Water tomperature: } 23.8^{\circ} \mathrm{C}\end{array}$

Water evacuated before sampling: $22 \mathrm{gal}$

LABORATORY ANALYSES

\begin{tabular}{|c|c|c|c|}
\hline Analyte & Regult & Mod & Unt \\
\hline 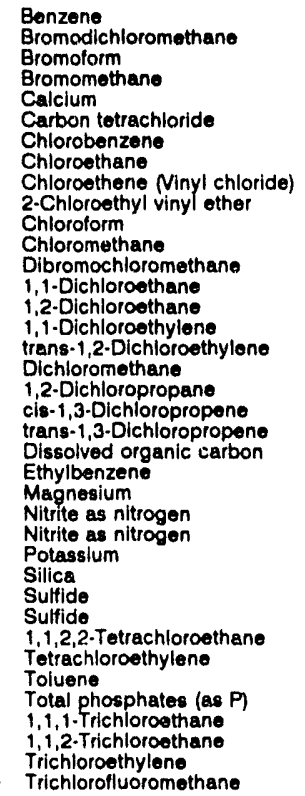 & $\begin{array}{l}<1.0 \\
<1.0 \\
<1.0 \\
<1.0 \\
39,100 \\
<1.0 \\
<1.0 \\
<1.0 \\
<1.0 \\
<1.0 \\
<1.0 \\
<1.0 \\
<1.0 \\
<1.0 \\
<1.0 \\
<1.0 \\
<1.0 \\
<1.1 \\
<1.0 \\
<1.0 \\
<1.0 \\
1.000 \\
<1.0 \\
33,700 \\
<10 \\
<10 \\
5998 \\
16,000 \\
<1,000 \\
<1,000 \\
<1.0 \\
<1.0 \\
<1.0 \\
<50 \\
<1.0 \\
<1.0 \\
42 \\
<1.0\end{array}$ & & 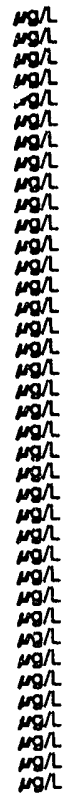 \\
\hline
\end{tabular}

\section{WELL DCB 8}

MEASUAEMENTS CONDUCTED IN THE FIELD

Sample date: $11 / 27 / 91$
Depth to water: $10.88 \mathrm{Ht}(3.35 \mathrm{~m})$ bolow TOC

Water olevation: $125.82 \mathrm{ft}(38.35 \mathrm{~m}) \mathrm{ms}$ )

Sp conductance: 39 ricm

Alkalinity: $0 \mathrm{mar}$

Water temperature: $20.2^{\circ} \mathrm{C}$

WELL DCB 9

MEASUREMENTS CONOUCTED IN THE FIELD

Sample date: $11 / 27 / 91$

Depth to water: $8.32 \mathrm{tt}(2.54 \mathrm{~m})$ below TOC

Water elevation: $113.88 \mathrm{tt}(34.74 \mathrm{~m}) \mathrm{msl}$

Sp conductance: $1887 \mathrm{ps} / \mathrm{cm}$

ling: $50 \mathrm{gal}$

Time: 11:55

PH: 3.5

Water temperalure: $18.5^{\circ} \mathrm{C}$

WELL DCB 10

MEASUREMENTS CONDUCTED IN THE FIELD

Sample date: 11/27/91

Depth to water: $7.27 \mathrm{ft}(2.22 \mathrm{~m})$ below TOC

$116.63 \mathrm{ft}(35.55 \mathrm{~m}) \mathrm{msl}$

wance $3350 \mathrm{~s} / \mathrm{cm}$

Water evacuated befcre sampling: $\mathbf{4 4} \mathrm{gal}$
Time: $11: 40$

PH: 2.6

Water temperature: $19.0^{\circ} \mathrm{C}$ 
ANALYTICAL RESULTS

WELL DCB 11

MEASUREMENTS CONDUCTED IN THE FIELD

Sample dato: 11/27/81

Dopth to water: $9.40 \mathrm{~h}(2.89 \mathrm{~m})$ bolow TOC

Water elovation: $121.11 \mathrm{nt}(38.81 \mathrm{~m}) \mathrm{msl}$

Sp. conductance: $2700 \mathrm{~ms} / \mathrm{cm}$

Whe wacuated bofore eampling: $12 \mathrm{ga}$

The well wont dy during purging.

WELL DCB 12

MEASUREMENTS CONDUCTED IN THE FIELD

Sample dato: 11/27/9

Dopth to water: 7.69 f $(2.34 \mathrm{~m})$ bolow TOC

Water olovation: $100.21 \mathrm{ht}$ (33)

Water evecuated betors sampling: $55 \mathrm{gal}$

WELLL DCB 13

MEASUREMENTS CONDUCTED IN THE FIELD

Semple date: 11/27/1

Welow TOC

Water elevetion: $117.05 \mathrm{~h}(35.68 \mathrm{~m}) \mathrm{msl}$

Sp. conduetance: $342 \omega \mathrm{S} / \mathrm{cm}$

campling: 6 gal

during purging.

\section{WELL DCB 15}

MEASUREMENTS CONDUCTED IN THE FIELD

Sample dute: 11/27/91

Depth to water: $18.31 \mathrm{f}(4.97 \mathrm{~m})$ bolow TOC

Water elevation: 111.20 h $(33.82 \mathrm{~m}) \mathrm{ms}$ |

Water ovacuated befors eampling: $30 \mathrm{gal}$

\section{WELLL DCB 16}

MEASUREMENTS CONDUCTED IN THE FIELD

Sample date: 11/27/91

Water olevation: 111.27 (33.

Weter evactanted before sampling: $29 \mathrm{gal}$

WELL DOB 1

MEASUREMENTS CONDUCTED IN THE FIELD

Sample date: 12/03/91

Dopth to water: $7.67 \mathrm{ft}(2.34 \mathrm{~m})$ below TOC

Water elevation: $144.03 \mathrm{Ht}(43.00 \mathrm{~m}) \mathrm{msl}$

We.

Water ovecuated before sampling: 77 gal

IABORATOFY ANALYSES

\begin{tabular}{|c|c|c|c|c|c|}
\hline & Analyte & Result & Mod & Unit & Lab \\
\hline $\begin{array}{l}0 \\
0 \\
0 \\
0 \\
0 \\
0 \\
0 \\
0 \\
0 \\
0 \\
0 \\
0 \\
0 \\
0 \\
0 \\
0 \\
0\end{array}$ & 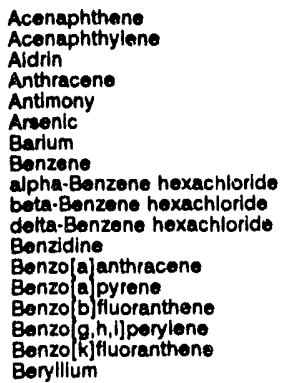 & $\begin{array}{l}<10 \\
<10 \\
<10 \\
<10 \\
<2.0 \\
<2.0 \\
40 \\
<1.0 \\
<10 \\
<10 \\
<10 \\
<10 \\
<10 \\
<10 \\
<10 \\
<10 \\
<10 \\
<3.0\end{array}$ & & 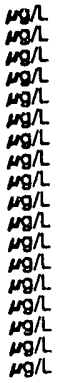 & $\begin{array}{l}\mathrm{GE} \\
\mathrm{GE} \\
\mathrm{GE} \\
\mathrm{GE} \\
\mathrm{GE} \\
\mathrm{GE} \\
\mathrm{GE} \\
\mathrm{GE} \\
\mathrm{GE} \\
\mathrm{GE} \\
\mathrm{GE} \\
\mathrm{GE} \\
\mathrm{GE} \\
\mathrm{GE} \\
\mathrm{GE} \\
\mathrm{GE} \\
\mathrm{GE} \\
\mathrm{GE}\end{array}$ \\
\hline
\end{tabular}

Time: 13:10

Alkalinity: $33 \mathrm{mon}$

Water temperature: $20.6^{\circ} \mathrm{C}$

pH: 3.6

Water temperature: $18.0^{\circ} \mathrm{C}$

Time: 13:20

PH: 6.0 . $75 \mathrm{mgn}$

Water temperature: $20.8^{\circ} \mathrm{C}$

Time: 13:00

Alkalinity: $147 \mathrm{mgh}$

Water ten perature: $22.1^{\circ} \mathrm{C}$

Time: $12: 40$

$\mathrm{pH}: 8$.

Alkalinity: $245 \mathrm{mg} / \mathrm{L}$

Timo: $11: 40$

Aikelinity: $85 \mathrm{mg}$

Water ty: $25 \mathrm{mg} / \mathrm{L}$

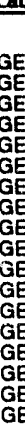

WELL DOB 1 collocted on 12/03/91, laboratory analyese (cont.)

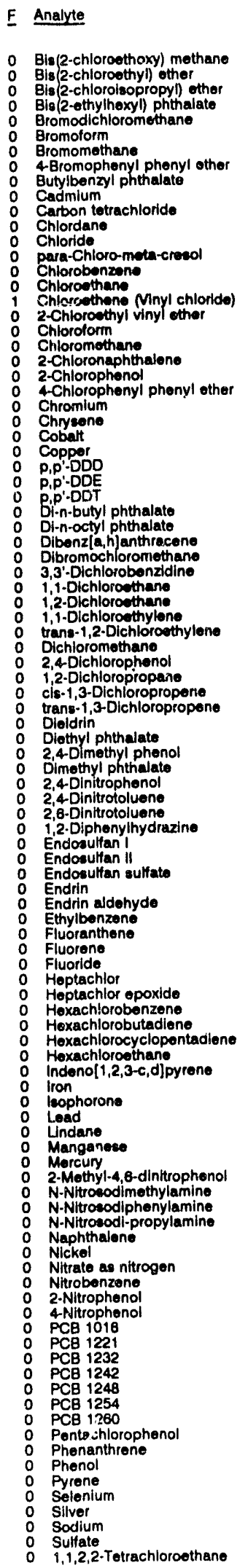

Result

Mod Unit Le

$<10$
$<10$

$<10$
$<10$

$<1.0$

$<1.0$

$<10$
$<10$

$<2.0$

$<10$
$<10$

$<10$

$<1.0$

$<1.0$

$<1.0$
$<1.0$

$<10$

$<10$
$<10$

$<4.0$

$<4.0$

18
$<10$
$<10$

$<10$
$<10$

10

$<10$
$<1.0$

$<10$
$<1.0$

$<1.0$

$<1.0$

1.1
$<10$

$<1.0$

$<10$

$<10$

$<45$ 
ANALYTICAL RESULTS

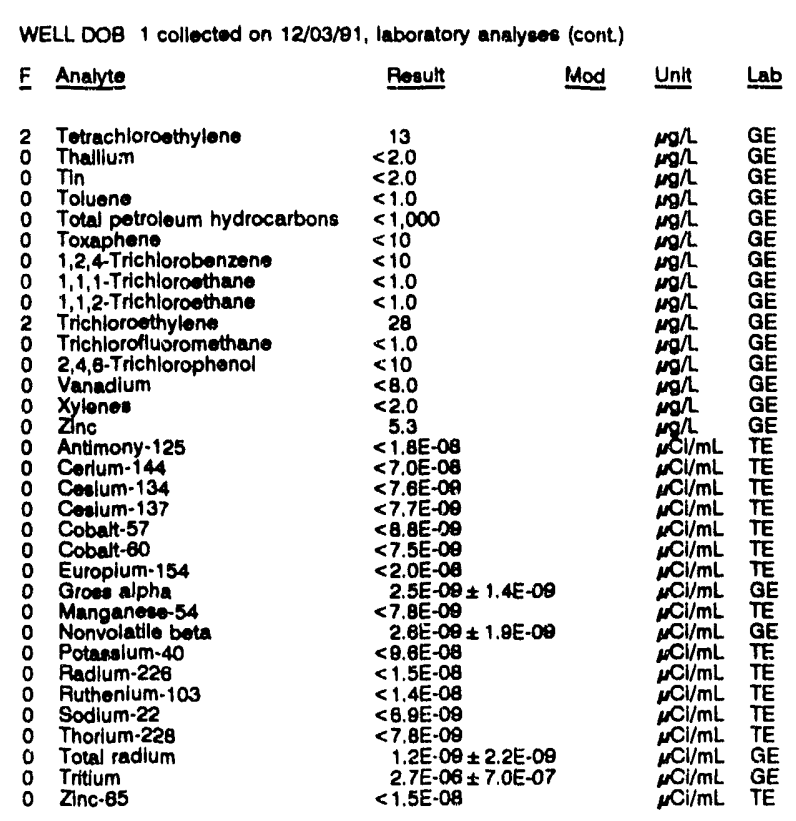

WELL DOB 2

MEASUREMENTS CONDUCTED IN THE FIELD

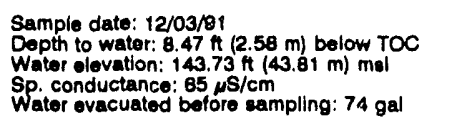

Sp. conductance: $65 \mu \mathrm{s} / \mathrm{cm}$
Wator ovacuated botore sampling: $74 \mathrm{gal}$

LABORATORY ANALYSES

\begin{tabular}{|c|c|c|c|}
\hline Analyte & Roeutt & Mod & Unit \\
\hline 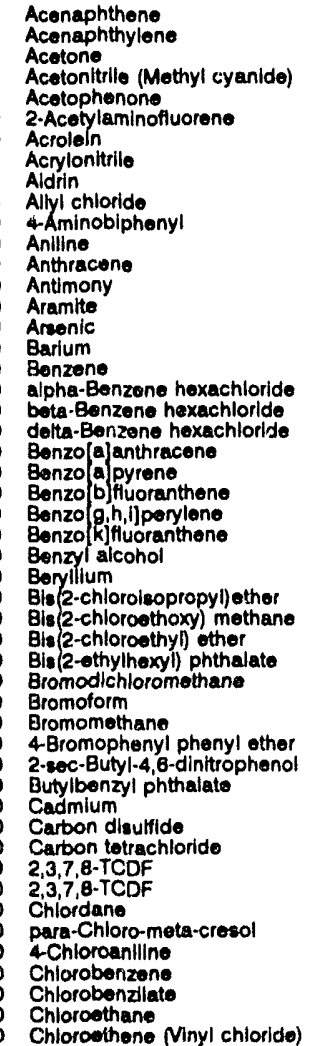 & 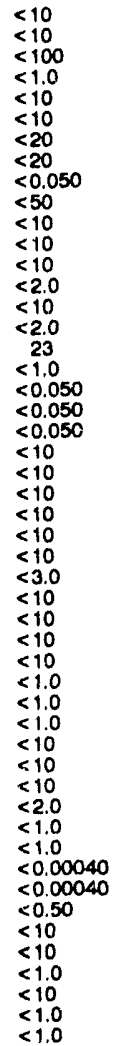 & & 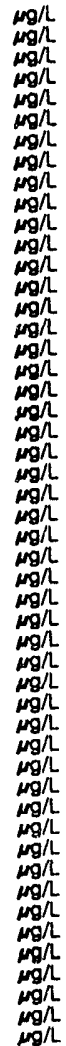 \\
\hline
\end{tabular}

Time: 11:05

Alkallinity: $1 \mathrm{mg} / \mathrm{h}$

Alkalinity: $1 \mathrm{mg} / \mathrm{L}$ : $10.8^{\circ} \mathrm{C}$
WELL DOB 2 collected on 12/03/91, laboratory analyses (cont.)

E Analyte Rosult Mod Unit Lab

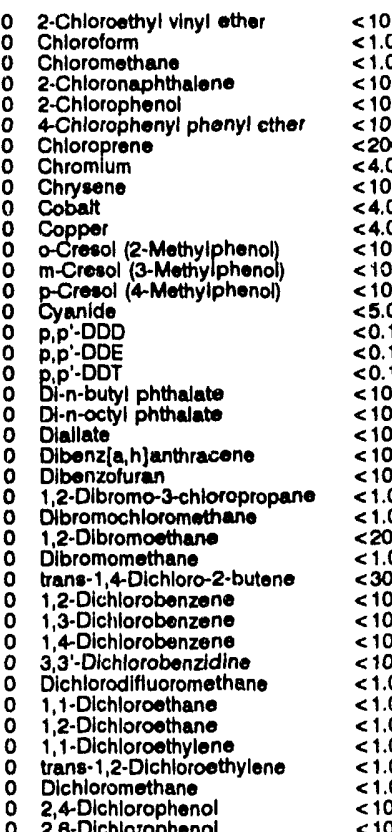

2,4 -Dichlorophenol
1,2 -Dichorophonoxyacetic acid $<0.30$
$<1.0$

o cis:1,3-Dichloropropene

$\begin{array}{lll} & <1.0 \\ 0 & \text { trans-1,3-Dichloropropene } & <0.50\end{array}$

Dieldrin Dhthalate $\quad<0.50$

Dimethoate

2,4-Dimethyl phenol

p-Dimethylaminoazobonzene $<10$

Dimethylbenz[a]anthracene $<10$

3,3'-Dimethylbenzidine $<10$

a, a-Oimethylphenethylamine

1,3-Dinitrobenzene

2,4-Dinitrophenol

2,4-Dinitrotoluene

1,4-Dloxane

Diphenylam

Disulfoton

Endosulfan I

Endosulfan sulfate

Endosultan

Endrin aldehyde

Endrin aldohyde

Ethyl mothacrylate

Ethylbenzene

Famphur

Fluoranthen
Fluoreno

Heptachior

Heptachlor epoxide

$1,2,3,4,6,7,8-H P C D D$

Hoptachlorodbenzo-p.dioxins $<0.00065$

Heptachlorodibenzo-p-dioxins $<0.00065$

, 2,3,4,6,7,6-HPCDF

$1,2,3,4,6,7,8-H P C D F$

Heptachlorodibenzo-p-furans

Hoptachiorodibenzo-p

Hexachlorobenzeno

Hexachlorocyclopentadiene

$1,2,3,4,7,8 \cdot H \times C D D$

$1,2,3,4,7,8$-HXCDD

Hexachlorodibenzo-p-dioxins

$0 \quad 1,2,3,4,7,8-H X C D F$

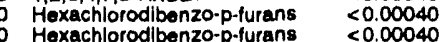

Hexachloroothane < 10

Hexachlorophene

Hexachloropropene

2-Hoxanone

indeno $(1,2,3-c, d]$ pyrene

lodomothane (Methyl iodide)

leobutyl alcoho

$<10$

$<10$

$<10$

$<<150$ $\mathrm{mg} / \mathrm{h} \quad \mathrm{GE}$

$\begin{array}{ll}\mu g / L & G E \\ \mu g / L & G E \\ \mu g / L & G E\end{array}$

GE

GE

$G E$

GE

E

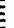

(1)

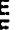

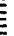

45

0 
ANALYTICAL RESULTS

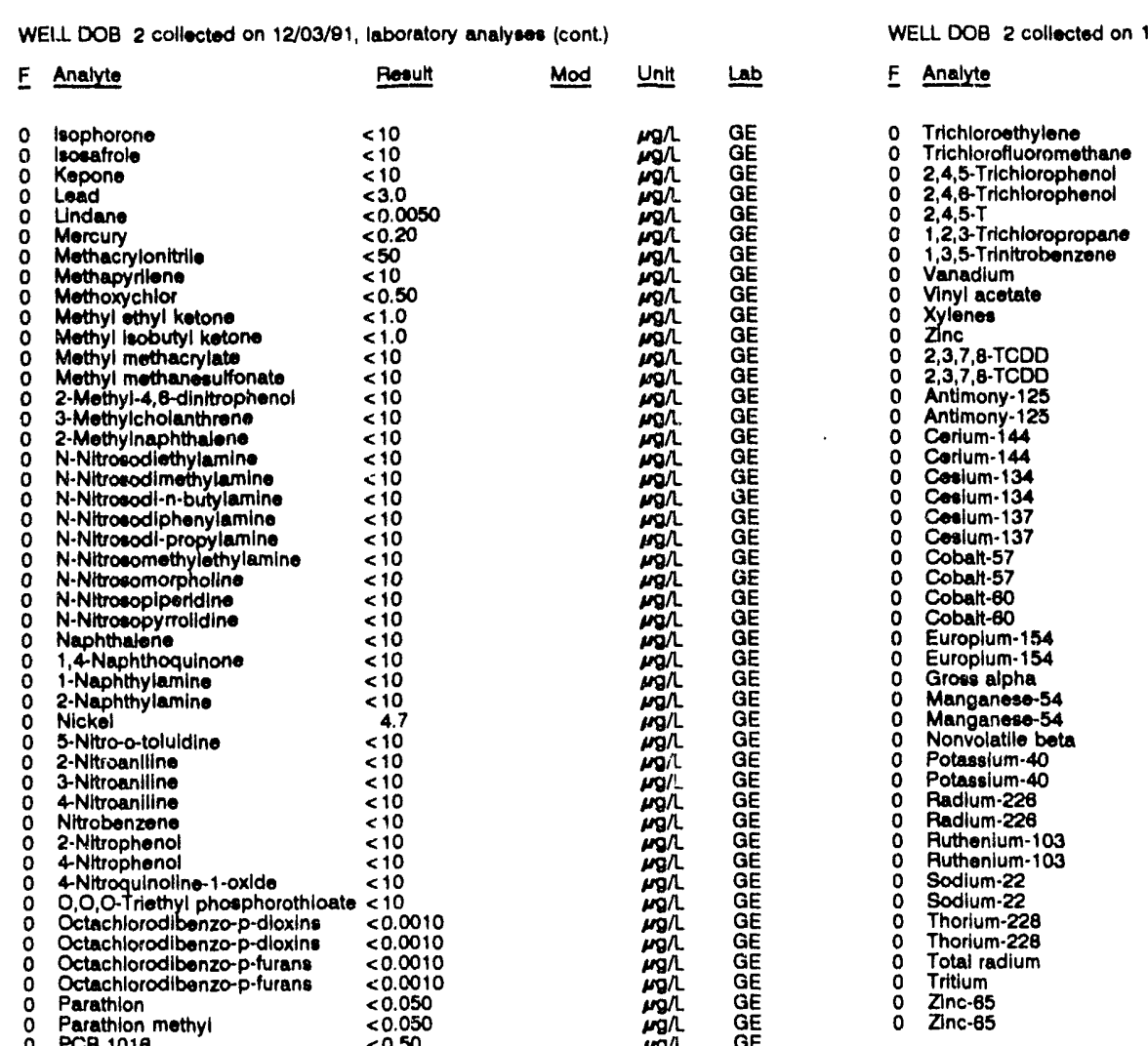

WEIL. DOB 2 collectod on 12/03/81, laboratory analyees (cont.)

WELL DOB 3

MEASUREMENTS CONDUCTED IN THE FIELD

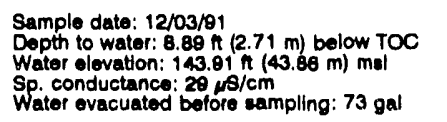

Wator ovacuatod bofore sampling: $73 \mathrm{gal}$

LABORATOAY ANALYSES

\begin{tabular}{|c|c|c|c|}
\hline Analyte & Rosult & Mod & Unit \\
\hline 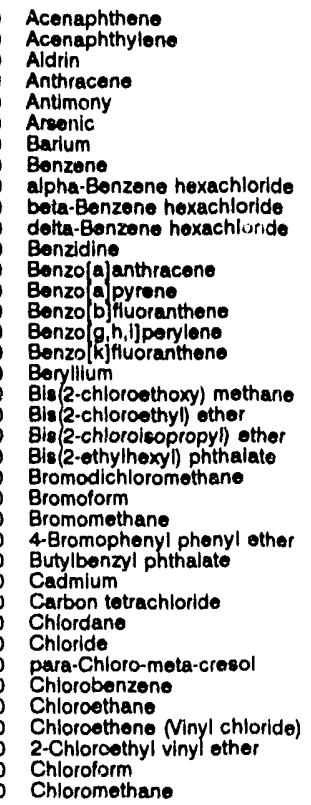 & $\begin{array}{l}<10 \\
<10 \\
<10 \\
<10 \\
<2.0 \\
<2.0 \\
17 \\
11.0 \\
<10 \\
<10 \\
<10 \\
<10 \\
<10 \\
<10 \\
<10 \\
<10 \\
<10 \\
<3.0 \\
<10 \\
<10 \\
<10 \\
<10 \\
<1.0 \\
<1.0 \\
<1.0 \\
<10 \\
<10 \\
<2.0 \\
<1.0 \\
<10 \\
1,140 \\
<10 \\
<1.0 \\
<1.0 \\
<1.0 \\
<1.0 \\
<1.0 \\
<1.0\end{array}$ & & 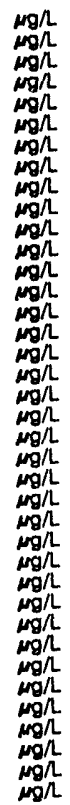 \\
\hline
\end{tabular}

Rosult Mod Unit Lab

\begin{tabular}{|c|c|c|}
\hline 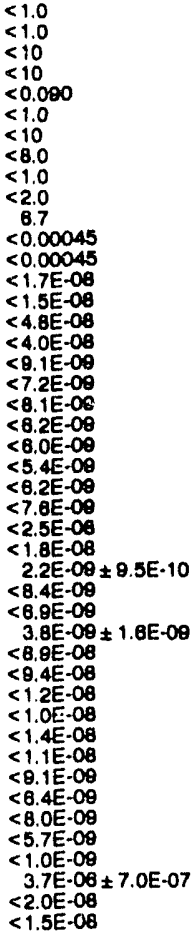 & 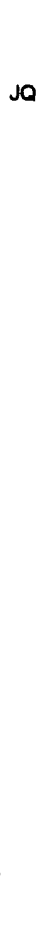 & 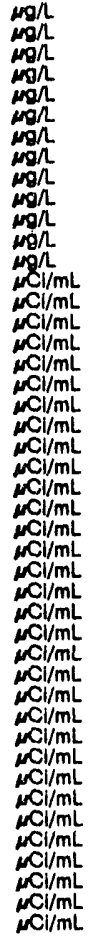 \\
\hline
\end{tabular}

Time: 10:30

PH: 5.7 . $3 \mathrm{mal}$

Nkalinity: $3 \mathrm{mg} /$
Wator tomporature: $21.4^{\circ} \mathrm{C}$

$<0.00055$

$<0.00055$

$<0.00055$

$<0.00055$

$<10$

$<10$

$<10$

$<10$

$<10$

$<0.10$

$<10$

$<100$

$<10$

$<10$
$<10$

$<2.0$

$<1.000$

$<10$

$<0.00045$

$<0.00045$

$<0.00040$

$<1.0$

$<1.0$

$<1.0$
$<10$

$<2.0$

$<10$
$<2.0$

$<2.0$
$<1.0$

$<10$

o Toluene

o-Toluidine

Toxaphene

2,4,5-TP (Silvex) $<0.000$

$1,2,4$ Trichlorobenzene $<10$

$\begin{array}{ll}0 & 1,1,1 \cdot \text { Trichloroethane } \\ 0 & 1,1,2 \cdot \text { Trichloroothane }\end{array}$

$<10$
$<1.0$

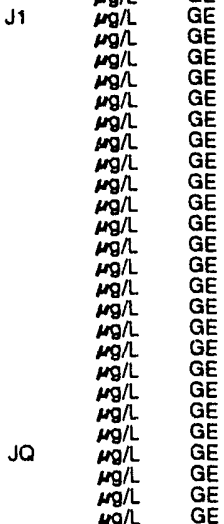

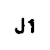


ANALYTICAL RESULTS

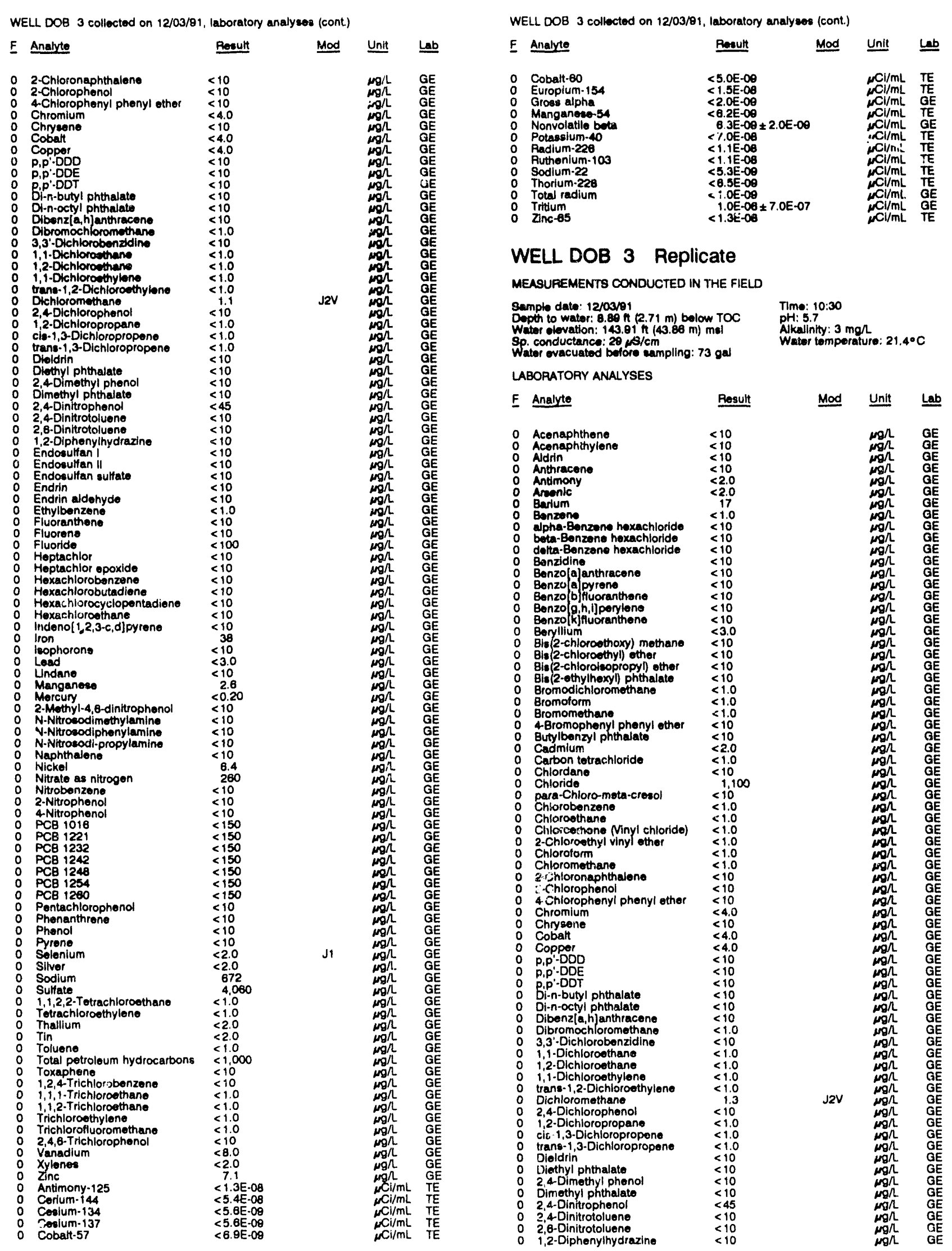


ANALYTICAL RESULTS

WEL DOB 4 collected on 12/03/91, laboratory analyees (cont)

E Anempre

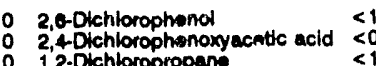

1,2-Ochloropropano $<1.0$

$\begin{array}{lll} & <1.0 \\ 0 & \text { trand-1,3-Dichloropropene } & <1.0 \\ & <0.50\end{array}$

Diethyl phthalate $<10$

Dimethoatio $<10$

Dimethyl phthalato $<10$

0 p-Oimethylaminoazobenzene $<10$

0 bimethyibenzla]anthracene $<10$

$\begin{array}{lll}0 & 3,3 \text {-Dimethylbonzddine } & <10 \\ 0 & \text { a.a.-Oimethylphenethylamine } & <10\end{array}$

0 1,3-Oinitrobenzene <10

2,4Dinitrophenol $<10$

0 2,8-Oinitrotoluane

o Diphenyiamin

O Diphenyiam

o Endosulfan I

O Endocultan II

Endin

o Endrin aldohydo

Ethyl methesiylate $<10$

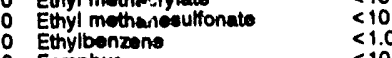

0 Fluorene

Heptachior

Hoptachior epoxide

Heptachiorodibenzo-p-dloxins

1,2,3,4,6,7,6-HPCDF

Haxuchiorobenzene

Haxachlorobutadiene

Haxechlorocycloos

Hexachiorodibenzo-p-dioxins

$1,2,3,4,7,6-H \times C D F$
Hoxachlorodibenzo-p-furan

Hexachioroethane

Hoxachloropropen

2. Hexanone

indeno $(1,2,3-c, d]$ pyrene

ladomethane (Mathy! lodide)

teobutyl alcohol

roodin

leophorone

Kopon

Lead

Lindane

Mothacrylonitril

Methepyrilene

Methaxychlor

Methyl ethyl ketone

Mothyl methacryiato

Mothyl methancaulionato

3-Methylcholanthren

2-M-Mhylnuphthalone

N-Nlrosodiethylamine

$N$-Nitroeod-n-butylamine

N-Nitrocodiphenylamine

N-Nireost-propylamine

N-Nitrosomorpholine

N-Nitroeopiperidine

Nephtinalone

1,4 Naphthoquinone

1.Naphthylamine

2.Naphtrylamine

5-Nitro-a-toluldine

2-Nitroanlline

3-Nitroaniline

4Nitroanilina

2-Nitroptienol

4Nitrophenal

ANitroguinaline-1-axide

$0,0,0$ - triethyl phosphorothioato

octarchloradibenzo-p-dioxins

cetarhlorodibenzo-p-dioxins

Petachior

Parathion methy

PCB 1018

P PCB 1221

\begin{tabular}{l} 
O \\
PCB 1232 \\
\hline
\end{tabular}
Mod Unit Lab

Ja

man

GE
GE
GE

$\operatorname{mon}_{\mu \mathrm{g}} \mathrm{GE}$

GE

$<10$

$<0.10$

0.10

.0060

$<10$

$<1.0$

$<10$

$<0.050$

$<0.00085$

$<0.00065$

$<0.00045$

$<10$

$<10$

$<0.00045$

$<0.00045$

$<0.00040$

$<10$

$\leq<0$

$<1.0$

$<1.0$

$<15$

$<10$

$<10$
$<10$
$<10$

$<10$

$<3.0$

$<0.0050$

$<50$

$<10$
$<0.50$

$<1.0$

$<1.0$

$<10$

$<10$

$<10$

$<10$

$<10$

$<10$

$<10$
$<10$

$<10$

$<10$

$<10$

$<10$

$<10$

$<10$
$<10$

10

$<4.0$

$<10$

$<10$

$<10$

$<10$
$<10$

$<10$
$<10$

$<10$

$<0.0010$

$<0.050$

$<0.050$

coso

$<0.50$
WEL DOB 4 collectod on 12/03/81, laboratory analyees (cont.)

E Analyte Recult Mod Unit Lab

$\begin{array}{ll}0 & \text { PCB } 1240 \\ 0 & \text { PCB } 1254 \\ 0 & \text { PCB } 1260 \\ 0 & \text { Pentachlorobenzene } \\ 0 & 1,2,3,7,8-P C D F \\ 0 & \text { Pentachlorodibenzo-p-dioxins } \\ 0 & \text { Pentachlorodibenzo-p-furans } \\ 0 & 1,2,3,7,8-P C D F\end{array}$

$<0.50$

$<0.50$

$<10$
$<0.00055$

$<0.00055$

$<0.00055$

Pontachlorodthane $<10$

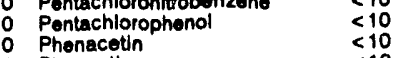

Phonanthrene

p-Phenylenediamine

2.Plcolin

Pronamid

Pyrene

Pyridine

Safrolo

Sitver

Styrene

1,2,4,5-Totrachlorobenzene

Totrachiorodibenzo-p-dioxins

Tetrachlorodibenzo-p-furans

1,1,2,2-Tetrachloroothane

o 1,1,1,2-Tetrachloroeth

o 2,3,4,6-Tetrachlorophenol

o Thallium

0 Tin

Tolvene

o-Toluldirio

um hydrocarbons

2,4,5-TP (Silvex)

1,2,4-Trichlorobenzen

1,1,2-Trichloroothane

Trichloroethylene

Trichlorofluoromethane

2,4,5-Trichlorophenol

$2,4,6-T$ richlorophenol
$2,4,5-T$
0

1,3,5-Trintitrobenzene

Vanadium

Vinyl acetate

Xylenes

2,3,7,6-TCDO

Antimony-125

Corlum-14

Cosium-137

Cobalt-57

Cobat-60

Groes alpha

Manganese-54

Nonvolatile beta

Potassium-40

Padium-228

- Sodium-22

- Thorium-228

- Total radium

$\begin{array}{ll}0 & \text { Tritium } \\ 0 & \text { Zinc-65 }\end{array}$

$<10$

$<10$
$<0.10$

$<0.10$

$<10$

$<200$

$<10$

$<10$

$<2.0$
$<2.0$
$<1.0$

$<1,000$

$<10$

$<0.00045$

$<1.0$

5.1
$<10$

$<10$

$<10$

$<2.0$

$<1,000$

$<1,000$
$<0.24$

$<0.000$

$<10$
$<1.0$

$<1.0$

$<1.0$

$<10$

$<0.090$

$<1.0$

$<100$

$<1.0$

$<2.0$

$<0.7 \mathrm{TE}-06$

$<6.7 E-08$

$<7.2 E-09$

$<6.8 \mathrm{E}-09$

$<8.8 \mathrm{E}-\mathrm{Cr}$

$<1.8 E-08$

$<2.05 .00$

$<1.4 E-00$

$5.0 E-09 \pm 1.7 E-00$

$<8.3 E-98$

$<1.4 E-06$

$<1.5 E-08$

$<6.2 \mathrm{E}-00$

$<7.8 \mathrm{E}-09$

$<1.0 E-09$

$<1.3 \mathrm{E}-08$.08

WELL F 14

MEASUREMENTS CONDUCTED IN THE FIELD

Sample date: 12/22/91 $2.15 \mathrm{~m})$ below TOC

Water olevation: $209.59 \mathrm{Ht}(63.88 \mathrm{~m}) \mathrm{ms}$

Sp. conductance: $468 \mu \mathrm{S} / \mathrm{cm}$

PH: 4.0 : $0 \mathrm{mgn}$

Water tomperature: $18.1^{\circ} \mathrm{C}$

WELL F 15

MEASUREMENTS CONDUCTED IN THE FIELD

Sample date: $12 / 22 / 81$

Depth to water: $43.26 \mathrm{ft}(13.18 \mathrm{~m})$ below TOC

Water elevation: $210.24 \mathrm{ht}(04$.

Alkalinity: $0 \mathrm{mg}$

Water temperalure: $17.8^{\circ} \mathrm{C}$ 
ANALYTICAL RESULTS

WELL F 16

MEASUREMENTS CONOUCTED IN THE FIELD

Sample date: 12/22/91

Wopth to water: $47.74 \mathrm{~A}(14.50 \mathrm{~m})$ bolow TOC

Sp. conductance: $26 \mathrm{ss} / \mathrm{cm}$

p. conductance: 26 $\mu s / \mathrm{cm}$.

WELL $F \quad 17$

MEASUREMENTS CONDUCTED IN THE FIELD

Sample date: 12/201

Dopth to wator: $33.83 \mathrm{ft}(10.31 \mathrm{~m})$ below TOC

Water olevation: $205.97 \mathrm{~h}(62.78 \mathrm{~m}) \mathrm{ms}$

Sp. conductance: $58 \mu \mathrm{s} / \mathrm{cm}$

Water evacuated bofore eampling: 2 gal

The well went dry during purging.

WELL F 25

MEASUREMENTS CONDUCTED IN THE FIELD

Sample date: 12/22/81

Depth to water: 48.52 it $(14.18 \mathrm{~m})$ below TOC

Water olevation: $214.38 \mathrm{ht}(85.34 \mathrm{~m}) \mathrm{ms}$

Sp conductance 31 is/cm

Water ovacuated bofore sampling: $5 \mathrm{ga}$

WELLL FAC 3

MEASUREMENTS CONDIKTED IN THE FIELD

Sample date: 11/07/91

Depth to water: 88.76 A $(28.44 \mathrm{~m})$ below TOC

Water elevation: $225.04 \mathrm{ht}(68.59 \mathrm{~m}) \mathrm{msl}$

Sp. conductance: $288 \mu \mathrm{s} / \mathrm{cm}$

Wator evacuatod bofore eampling: 5 gal

The well went dry during purging.

LABORATORY ANALYSES

\begin{tabular}{|c|c|c|c|}
\hline Analyte & Result & Mod & Unit \\
\hline 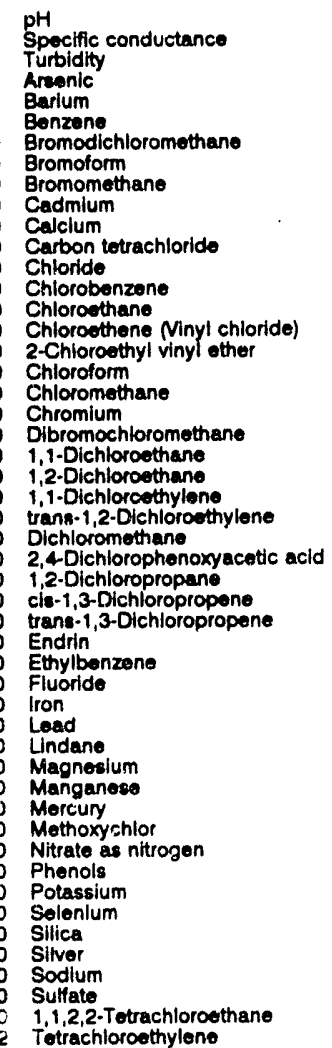 & $\begin{array}{l}7.8 \\
280 \\
1,360 \\
<2.0 \\
11 . \\
<1.0 \\
<1.0 \\
<1.0 \\
<1.0 \\
<2.0 \\
33,600 \\
<1.0 \\
6,150 \\
<1.0 \\
<1.0 \\
<1.0 \\
<1.0 \\
<1.0 \\
<1.0 \\
<4.0 \\
<1.0 \\
<1.0 \\
<1.0 \\
<1.0 \\
<1.0 \\
1.1 \\
<0.30 \\
<1.0 \\
<1.0 \\
<1.0 \\
<0.0060 \\
<1.0 \\
<100 \\
<4.0 \\
<3.0 \\
<0.0050 \\
2,720 \\
<2.0 \\
<0.20 \\
<0.50 \\
360 \\
<5.0 \\
4,000 \\
2.1 \\
14,700 \\
<2.0 \\
19,000 \\
58,000 \\
<1.0 \\
26\end{array}$ & $\begin{array}{l}\text { J2V } \\
\text { JO }\end{array}$ & 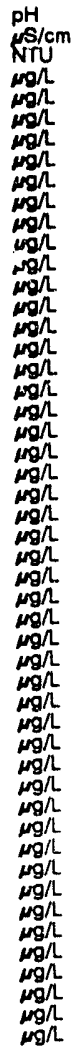 \\
\hline
\end{tabular}

Time: 10:40

PHikalinity: $2 \mathrm{mg} / \mathrm{h}$

Water temperature: $17.8^{\circ} \mathrm{C}$

Time: 8:15

Alkalinity: $80 \mathrm{mg}$

Water tomperature: $15.8^{\circ} \mathrm{C}$

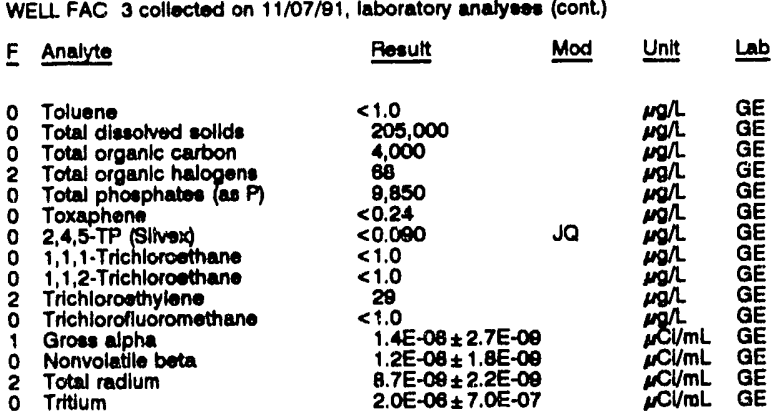

WELL FAC 4

MEASUREMER TS CONDUCTED IN THE FIELLD

Sample date: $11 / 07 / 91$ ( $24.4 \mathrm{~m})$ bolow TOC

Wator olovation: $229.73 \mathrm{ft}(70.02 \mathrm{~m}) \mathrm{msl}$

Sp. conductance. $144, \mathrm{~s} / \mathrm{cm}$

Time: $5: 1$

LABORATORY ANALYSES

F Analyte Rosult Mod Unit Lat

Specific conductance

Turbldity

Arsonic

Barium

Bromodichloromethans

Bromoform

Bromomethan

Cadmium

Carbon totrachioride

Chlorobenzene

Chloroethane

2-Chloroethyl vinyl other

Chloroform

Chioromethane

Dlbromochloromethane

1,1-Dichloroethan

1,2-Dichlorothane

1,1-Dichlorosthylene
trans-1,2-Dichioroethylene

Dichloromethan

(phoxyacetic acld

1,2-Dichloropropane

1,

trans-1,

Ethyibenzene

Fluoride

Iron

Lead

Lindane

Magneslum

2 Manganeso

Morcury

Methoxychlor

Nhenole

Potassium

Selenlum

0 Silver

0 Sodium

Sulfate

$1,2,2$-Totrachloroethane

Totrachloroethylene

Toluene

Total dissolyed soliess

Total organic carbon

Total organic halegens

Toxaphene

2,4,5-TP (Silvox)

1,1,1-Trichloroothane

1,1,2-Trichloroethan

Trichloroethylene

Trich!orofluoromethan

Gross alpha

Nonvolatile beta

Total rad

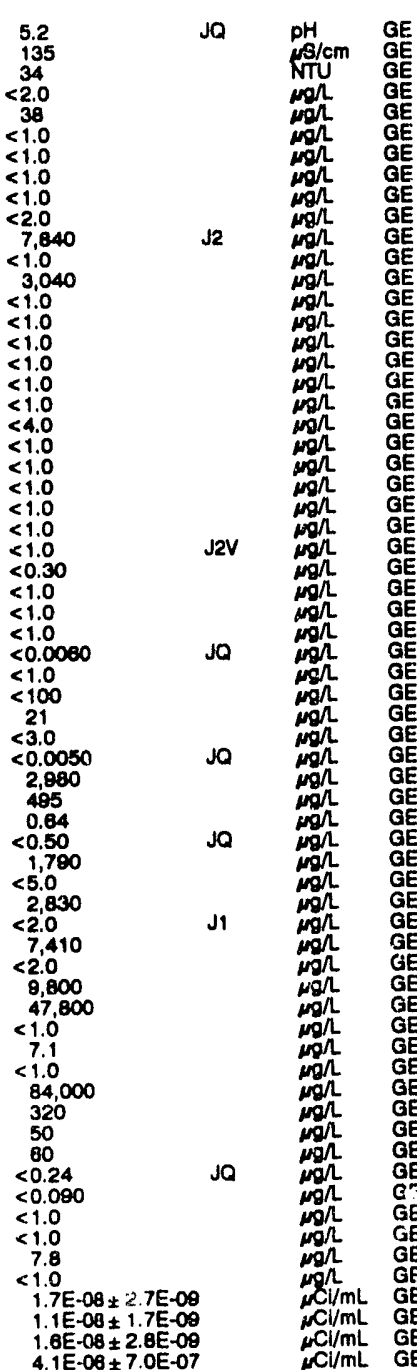




\section{WELL FAC 5}

MEASUREMENTS CONOUCTED IN THE FIELD

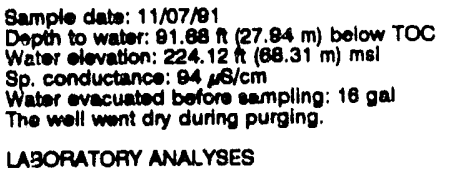

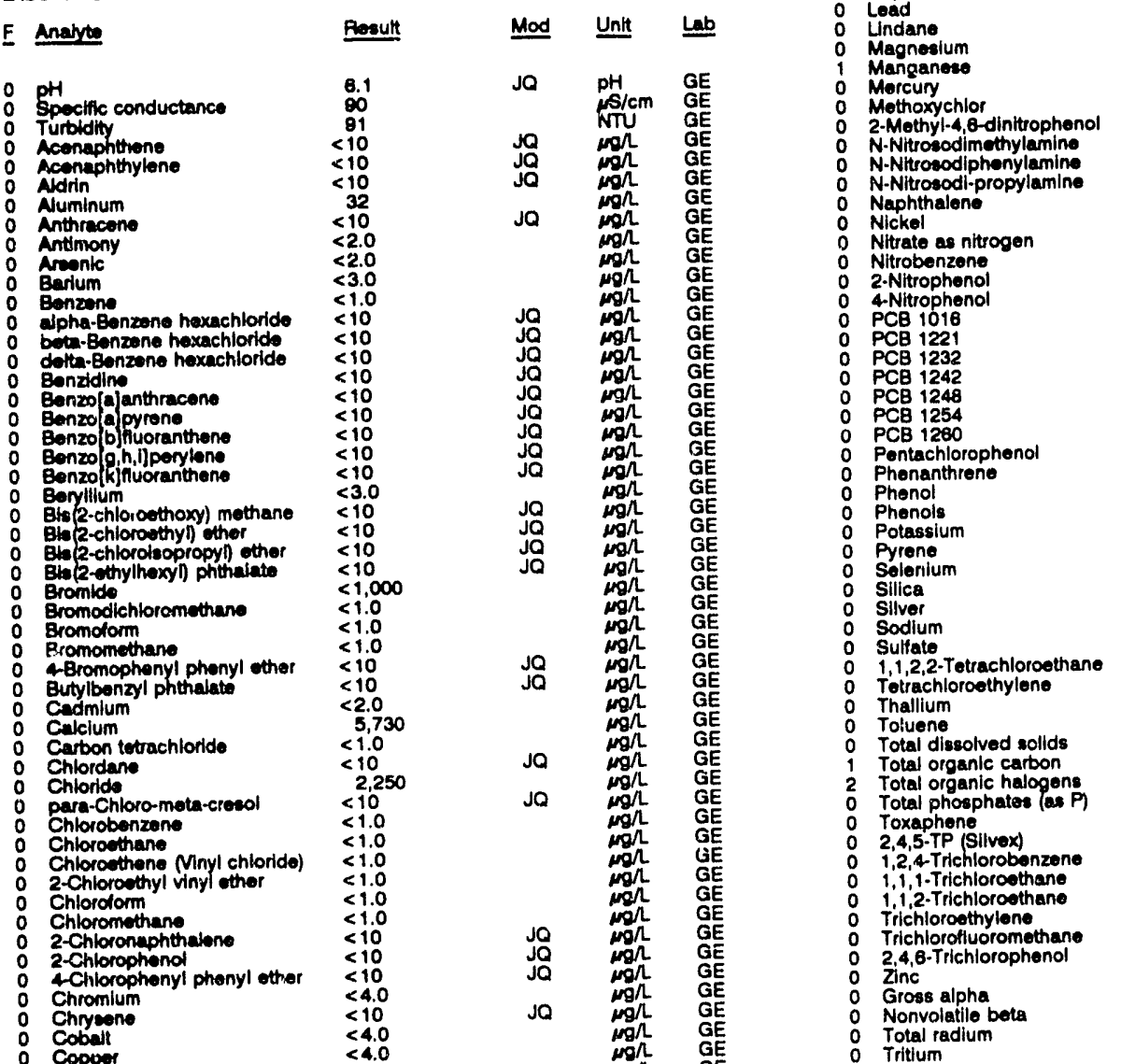

Coppor

P.p.-Dod

p.p, Dof

R.p-DoT phenalate

Di-n-octyl phthalato

Dibonz[a,h]anthracene

Dibromochloromethane

3,3-Dichlorobenzldine

1,2-Dichloroethane

1,1-Dichloroethylons

trana-1,2-Dichlorodich

2,4-Dichiorophenol

1,2-Dtchloropropane

cis-1,3-Dichloropropene

trans-1,3-0

Diethyl phthaiate

2,4Dimothyl phono

Dimethyl phthalato

2,4-Dintrophenol

2,4-Dintrotoluen

1,2-Diphenylhydrazine

o Endosultan I

O Endoeulfian sulfate

O Endrin

O Endrin aldehyde

O Ethylbenzone

0 Fluorene

Heptachlor
Time: 7:05 Water tomporature: $16.0^{\circ} \mathrm{C}$
Alkalinity: $7 \mathrm{mg} / \mathrm{s}$

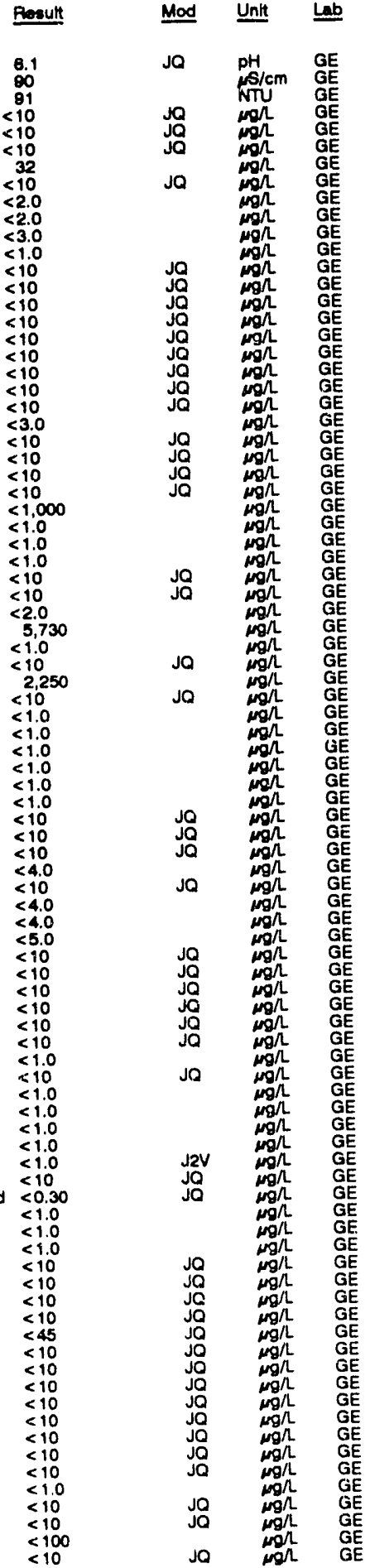

\section{WELL FAC 6}

\section{MEASUREMENTS CONDUCTED IN THE FIELD}

Sanple date: 11/07/81

(2) Water olovation: 222.88 tt $(87.83 \mathrm{~m}) \mathrm{ms}$ )

Sp conductance: $78 \mathrm{\mu S} / \mathrm{cm}$

Water ovacuated bofore sampling: $7 \mathrm{gal}$

F Analyte Result Mod Unit Lab

$\begin{array}{ll}0 & \text { Heptachlor epoxide } \\ 0 & \text { Hexachlorobonzzene } \\ n & \text { Hoxachlorobutadiene } \\ 0 & \text { Hexachlorocyclopentadione } \\ 0 & \text { Hexuchloroethene } \\ \text { o } & \text { indeno[1,2,3-c,d]pyrene }\end{array}$

$<10$

$<10$
$<10$
$<10$

$<3.0 \quad$ jo

2,180

$<0.20$

$<10$

$<10$
$<10$

$<10$

$<4.0$
$<10$

$<10$
$<10$
$<150$

$<150$
$<150$
$<150$

$<150$
$<150$
$<150$

$<150$
$<150$
$<150$

$<10$
$<10$

$<10$

2,810
$<10$

$<2.0$
6.710
$<2.0$
3.800

3,800
25,000

$<1.0$
$<1.0$
$<2.0$
$<1.0$

61,000

8,000

240
$<10$
$<0.080$

$<10$
$<1.0$
$<1.0$

$<1.0$
2.3

$<10$

9.6 $09+13 E-00$

$3.8 E-09 \pm 1.3 E-09$
$5.1 E-08 \pm 1.2 E-00$

$<1.0 E-09$

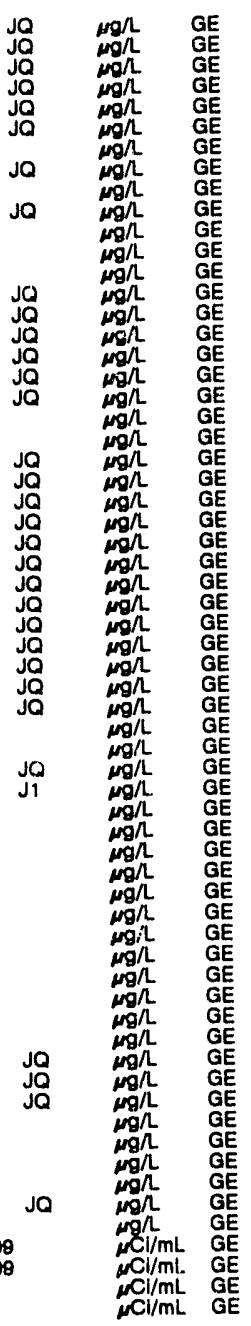

LABORATOFY ANALYSES

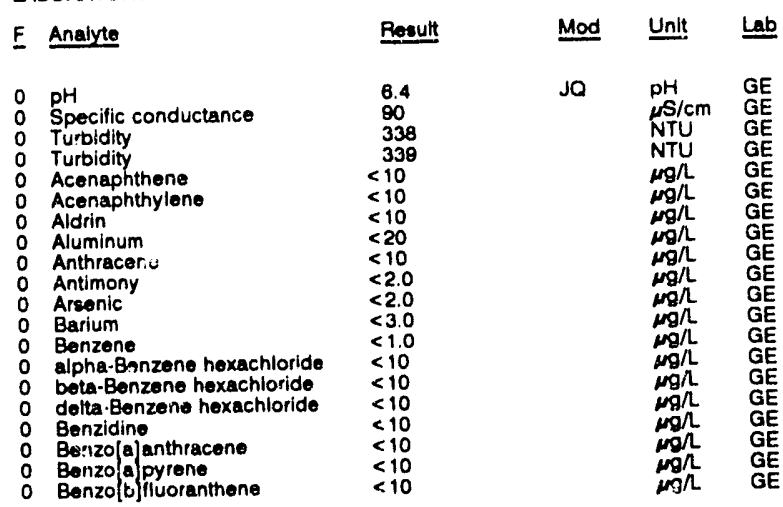


ANALYTICAL RESULTS

WELL FAC 6 collected on 11/07/81, laboratory analyses (cont.)

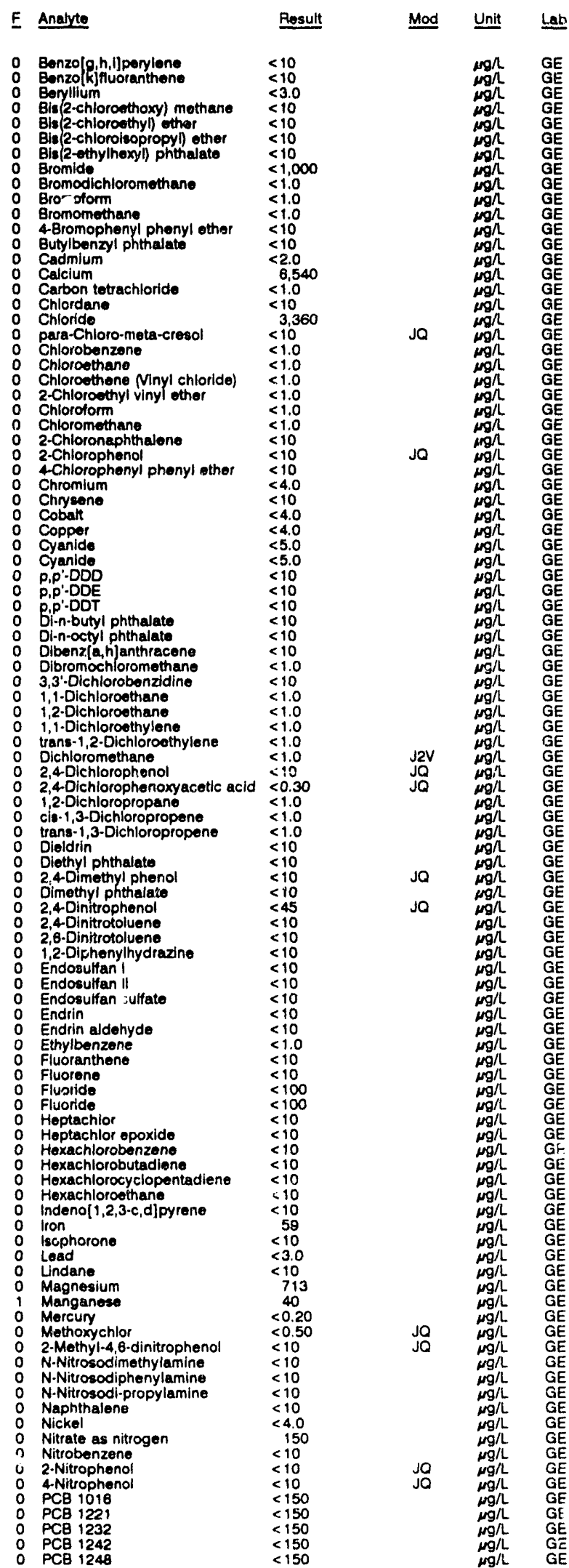

WELL FAC 6 colloctod on 11/07/91, laboratory analyees (cont.)

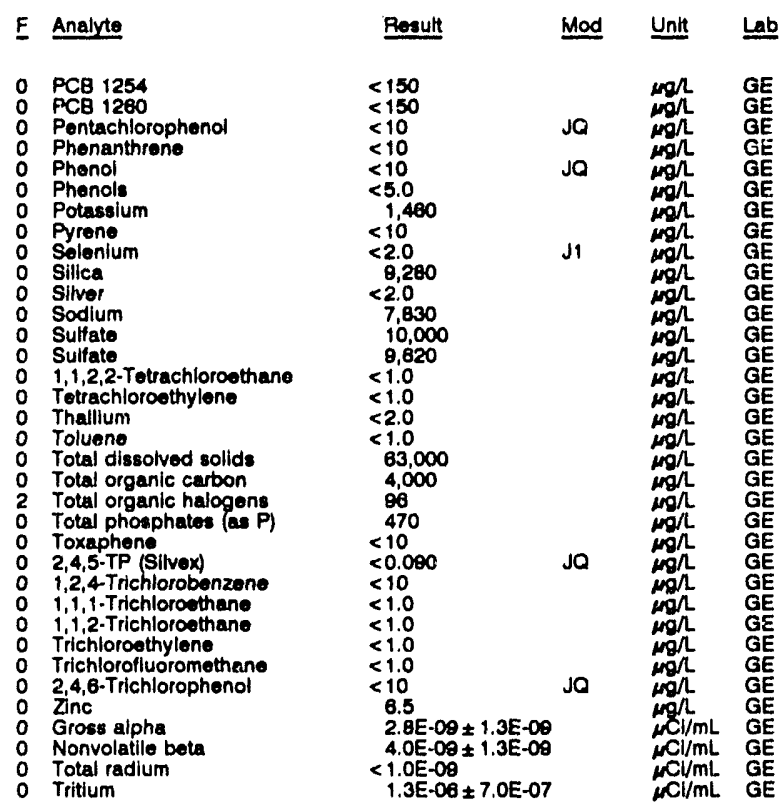

\section{WELL FAC 7}

MEASUREMENTS CONDUCTED IN THE FIELD

Sample date: 11/07/91

(2079 $2706 \mathrm{ml}$ below TOC

Water elevation: $223.21 \mathrm{ft}(68.04 \mathrm{~m}) \mathrm{msl}$

Sp. conductance: 53 S $/ \mathrm{cm}$

Alkalinity: $8 \mathrm{mg} / \mathrm{L}$

Water tomperature: $13.8^{\circ} \mathrm{C}$

The well went dry during purging.

LABOPATOAY ANALYSES

E Analyte Result Mod Unit Lab

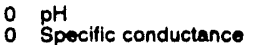

0 Specitic

Arsenic

Barium

Bromodichloromethane

Bromodich

Bromomethane

Cadmium

Calcium

Carbon tetrachloride

Chloride

Chiorobenzene

Chloroethane

2.Chloroothyl vinyl ether

Chloroform

Chloromethane

Chromium

Dibromochloromethane

1,1-Dichloroethane

1,2-Dichloroethane

1,1-Dichlorosthylene
0 trans-1,2-Dichloroethylene

2,4Dichlorophenoxyacetic acid

1,2-Dichloropropane

cis-1,3-Dichloropropene

trandi, J-Ochloroproper

Ethylbenzene

Fluoride

Fluoride

Iron

Lead

Magnesium

Manganese

Mercury

Methoxychlor

Phenols

Phenols

Potassium

Selenium

$\begin{array}{ll}0 & \text { Silica } \\ 0 & \text { Silver }\end{array}$

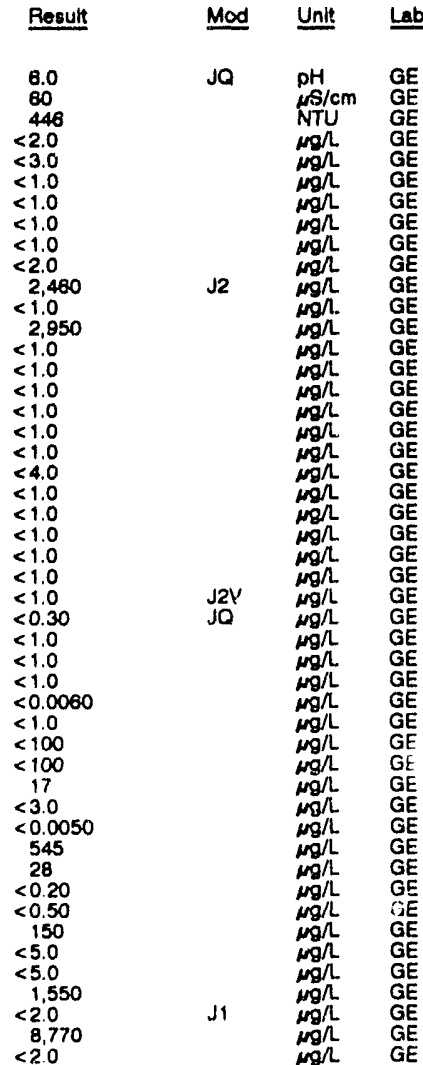


WELL FAC 7 collected on 11/07/91, laboratory analyses (cont.)

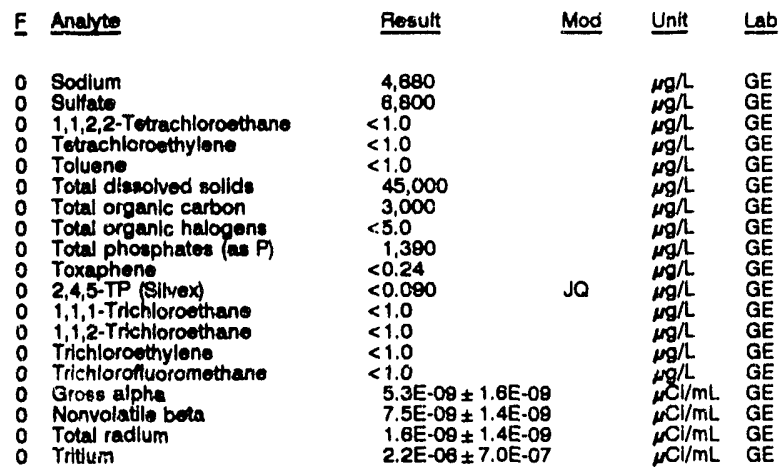

WELL FAC 8

MEASUREMENTS CONDUCTED IN THE FIELD

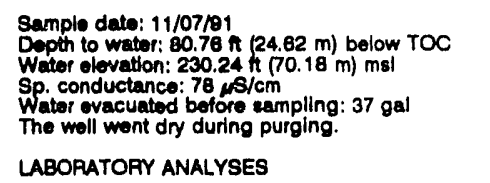

$$
\begin{aligned}
& \text { Time: } 10: 00 \\
& \text { pH: }: 0 \\
& \text { Alkalinity: } 17 \mathrm{mg} / \mathrm{L} \\
& \text { Water temperature: } 16.2^{\circ} \mathrm{C}
\end{aligned}
$$

LABORATORY ANALYSES

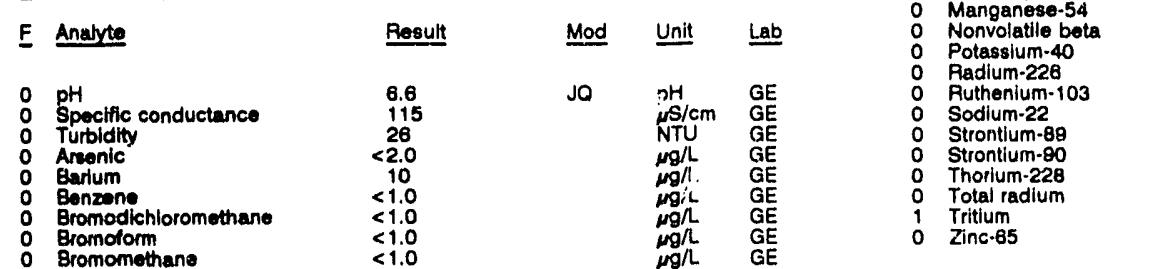

F Analyte

- Tritium

$\begin{array}{llll}\text { Result } & \text { Mod Unit } & \text { Lat } \\ 1.5 E-06 \pm 7.0 E-07 & \mu \mathrm{Cl} / \mathrm{mL} & \mathrm{GE}\end{array}$

WELL FAL 1

MEASUREMENTS CONDUCTED IN THE FIELD

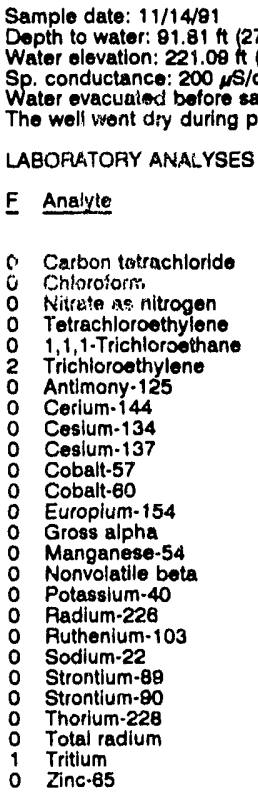

WELL FAL 2

MEASUREMENTS CONDUCTED IN THE FIELD

Sample date: $11 / 14 / 81$ (t) $28.28 \mathrm{~m})$ below TOC Depth to water: $92.77 \mathrm{ft}(28.28 \mathrm{~m}$ ) below TOC

\begin{tabular}{|c|c|c|}
\hline Result & Mod & Unit \\
\hline 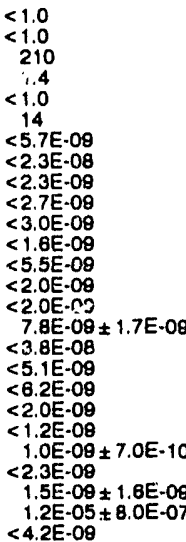 & & 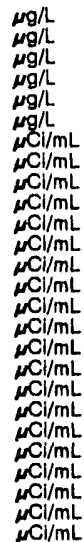 \\
\hline
\end{tabular}
Water elevation: $219.33 \mathrm{Ht}(68.8$

Water evacuated before sampling: $4 \mathrm{gal}$

Cadmium

Carbon tetrachloride

Chloride

Chlorobenzen

Chloroethene (Ninyl chloride)

2-Chloroothy

Chloromethane

Dibromochioromethane

1,1-Dichloroethane

1,2-Dichloroethane

0 trans-1,2-Dichloroethylene

Dichloromethane

3,4-Dichlorophenaxyace

1,2-Dichloropropane

Cis-1,3-Dichiorcpropene
trans-1,3-Dichloropropene

Endrin

Ethylbenzene

$\begin{array}{ll}0 & \text { Fluoride } \\ 0 & \text { Iron } \\ & \end{array}$

0 Load

0 Undane

Manganate

Mercury

Methoxychlor

Nitrate as nitrogen

Phonoly

Potassium

Solonium

Sillic

Silver

Sodlum

1,1,2,2-Tetrachloroethane

Tetrachloroethylene

Toluene

Total dissolved solids

Total organic carbon

Total organic halogens

Toxaphene

0 2,4,5-TP (Silvex)

1,1,1-Trichloroethane

1,1,2-Trichloroothen

- Trichlorofluoromethane

- Groes alpha

Totai radium

8,330
$<1.0$

$<1.0$

$<1.0$

$<1.0$
$<1.0$
$<1.0$

$<1.0$

$<1.0$
$<4.0$
$<1.0$
$<1.0$

$<1.0$

$<1.0$
$<1.0$
$<1.0$

$<1.0$
$<0.30$
$<1.0$
$<1.0$
$<1.0$

$<1.0$

$<0.0060$

$<0.00$
$<1.0$
$<100$

$<100$

$<3.0$

297
7.4

0.38
$<0.50$

$\begin{aligned} & 140 \\ &<5.0\end{aligned}$

1,020
$<2.0$
8,070

8.070
$<2.0$
7.080

7,080
5,640

5,640
$<1.0$
$<1.0$

$<1.0$

75,000

3,000
6.7
70

70
$<0.24$
$<0.090$

$<0.24$
$<0.090$
$<1.0$

$<1.0$

$<1.0$

3. $3 \mathrm{E}-09 \pm 1.5 \mathrm{E} \cdot 09$

$3.3 \mathrm{E} \cdot 09 \pm 1.2 \mathrm{E}-09$

$<1.0 \mathrm{E} .09$

\begin{tabular}{|c|c|c|}
\hline Analyte & Result & $\underline{\text { Unit }}$ \\
\hline 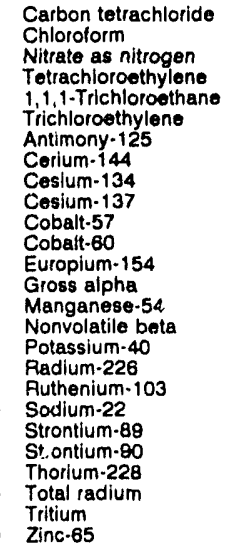 & $\begin{array}{l}<1.0 \\
1.0 \\
180 \\
1.4 \\
<1.0 \\
25 \\
<1.6 \mathrm{E} \cdot 08 \\
<4.2 \mathrm{E}-08 \\
<6.4 \mathrm{E}-09 \\
<8.0 \mathrm{E} \cdot 09 \\
<5.5 \mathrm{E}-09 \\
<6.8 \mathrm{E}-09 \\
<2.1 \mathrm{E} \cdot 08 \\
<2.0 \mathrm{E}-09 \\
<6.4 \mathrm{E}-09 \\
8.8 \mathrm{E} \cdot 09 \pm 1.7 \mathrm{E}-09 \\
<9.1 \mathrm{E} \cdot 08 \\
<1.0 \mathrm{E}-08 \\
<1.9 \mathrm{E}-08 \\
<7.6 \mathrm{E} \cdot 09 \\
<2.0 \mathrm{E}-09 \\
<8.0 \mathrm{E} \cdot 10 \\
<8.2 \mathrm{E}-09 \\
<1.0 \mathrm{E}-09 \\
1.0 \mathrm{E}-05 \pm 8.0 \mathrm{E} \cdot 07 \\
<1.4 \mathrm{E} \cdot 08\end{array}$ & 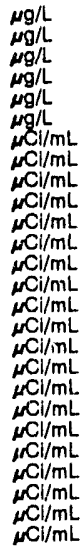 \\
\hline
\end{tabular}

The well went dry during purging.

LABORATORY ANALYSES

\section{WELL FBP $1 A$}

MEASUREMENTS CONDUCTED IN THE FIELD

Depth to water: $77.85 \mathrm{ft}(23.73 \mathrm{~m})$ below TOC

Water elevation: $210.05 \mathrm{Ht}(64.02 \mathrm{~m}) \mathrm{msl}$

Tinie: 12:05

PH: 7.0

Water temperature: $23.2^{\circ} \mathrm{C}$

Time: $12: 20$

Alkalinity: $12 \mathrm{mg} / \mathrm{L}$

Water temperature: $21.7^{\circ} \mathrm{O}$

Water evacuated before sampling: $127 \mathrm{gat}$
Time: $15: 30$

Alkalinity: $0 \mathrm{mg} / \mathrm{l}$

Water temperature: $18.5^{\circ} \mathrm{C}$ 
ANALYTICAL RESULTS

\section{WELL FBP $2 A$}

MEASUREMENTS CONDUCTED IN THE FIELD

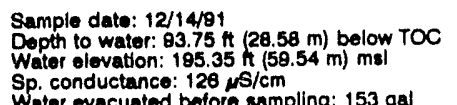

\section{Time: 16:05}

pH: 4.6 : 0 mal

Water temperature: $18.6^{\circ} \mathrm{C}$

Witer evacuated before sampling: $153 \mathrm{gal}$

\section{WELL FBP $3 A$}

MEASUREMENTS CONDUCTED IN THE FIELD

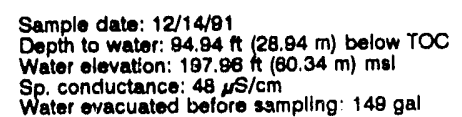

\section{Time: 18:45}

pH: 4.8 Alkalinity: $1 \mathrm{mg} /$

Water temperature: $18.5^{\circ} \mathrm{C}$

\section{WELLL FBP 4}

MEASUAEMENTS CONDUCTED IN THE FIELD

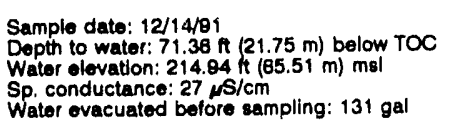

Time: $17: 15$

PH: 4.5

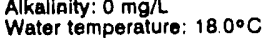

Water ovacuated betore sampling: $131 \mathrm{gal}$

WELL FCA $1 \mathrm{~N}$

MEASUREMENTS CONDUCTED IN THE FIELD

Sample date: $11 / 14 / 81$

Time: $14: 40$

The well was dry.

WELL FCA $2 \mathrm{C}$

MEASUREMENTS CONDUCTED IN THE FIELD

\begin{tabular}{|c|c|c|c|c|c|}
\hline \multicolumn{3}{|c|}{$\begin{array}{l}\text { Sample date: } 11 / 14 / 91 \\
\text { Depth to water: } 14.91 \mathrm{tt}(4.54 \mathrm{~m}) \text { below TOC. } \\
\text { Water elovation: } 297.29 \mathrm{Ht}(90.62 \mathrm{~m}) \mathrm{msl} \\
\text { Sp. conductance: } 292 \mu \mathrm{sm} \\
\text { Water ovacuated before sampling: } 1 \mathrm{gal} \\
\text { There was insufficient water to fill all or some }\end{array}$} & \multicolumn{3}{|c|}{$\begin{array}{l}\text { Time: } 11: 00 \\
\text { pH: } 7.7 \\
\text { Alkalinity: } 125 \mathrm{mg} / \mathrm{h} \\
\text { Water temperature: } 20.2^{\circ} \mathrm{C}\end{array}$} \\
\hline \multicolumn{6}{|c|}{ LABORATORY ANALYSES } \\
\hline & Analyte & Result & Mod & Unit & $\underline{\text { Lab }}$ \\
\hline & $\begin{array}{l}\text { Gross alpha } \\
\text { Nonvolatile beta } \\
\text { Total radium }\end{array}$ & \multicolumn{2}{|c|}{$\begin{array}{l}1.5 E-08 \pm 2.7 E-08 \\
3.9 E-08 \pm 3.3 E-09 \\
3.6 E-08 \pm 1.4 E-08\end{array}$} & 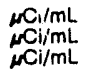 & $\begin{array}{l}\mathrm{GE} \\
\mathrm{GE} \\
\mathrm{GE}\end{array}$ \\
\hline
\end{tabular}

WELL FCA 2D

MEASUREMENTS CONDUCTED IN I HE FIELD

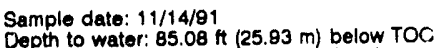

Water olovation: $227.12 \mathrm{ft}(69.23 \mathrm{~m}) \mathrm{ms}$ !

Sp. conductance: $124 \mathrm{pS} / \mathrm{cm}$

Water ovacuated bolore eampling: $5 \mathrm{gal}$

Wator tempere

The well went dry during purging.

LABORATORY ANALYSES

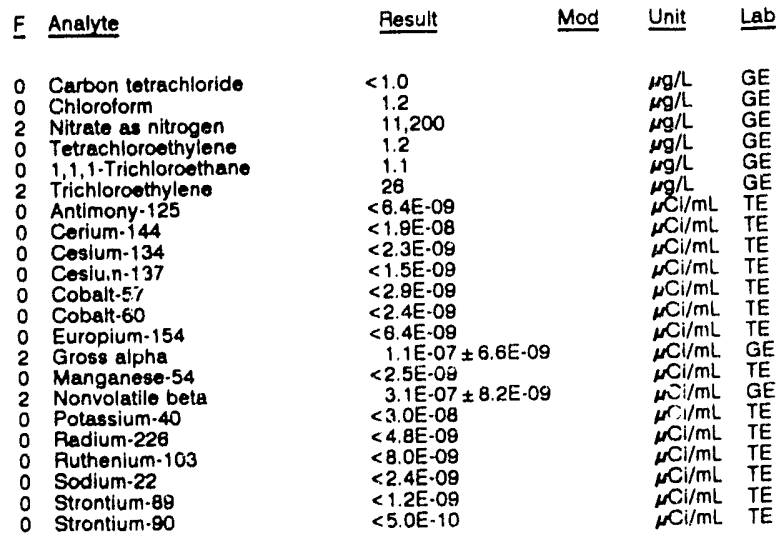

WELL FCA 2D collected on 11/14/81, laboratory analyees (cont)

\begin{tabular}{|c|c|c|c|}
\hline Analyte & Hosult & $\underline{M \infty d}$ & $\underline{\text { Unit }}$ \\
\hline $\begin{array}{l}\text { Thorlum-228 } \\
\text { Total radium } \\
\text { Tritium } \\
\text { Zinc-65 }\end{array}$ & $\begin{aligned}<2.2 E-09 \\
1.1 \mathrm{E}-09 \pm 1.6 \mathrm{E}-09 \\
1.7 \mathrm{E}-05 \pm 8.0 \mathrm{E}-07 \\
<4.6 \mathrm{E}-09\end{aligned}$ & & 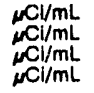 \\
\hline
\end{tabular}

WELL FCA 98

MEASUREMENTS CONDUCTED IN THE. FIELD

Sample date: $11 / 13 / 91$
The woll was dry.

WELL FCA 9C

MEASUREMENTS CONDUCTED IN THE FIELD

Time: $13: 40$
Inaccessibility of pump fallure prevented sample colloction.

\section{WELL FCA 9D}

MEASUREMENTS CONDUCTED IN THE FIELD

$\begin{array}{ll}\text { Sample date: } 11 / 14 / 81 & \text { Time: } 13: 50 \\ \text { Dopth to wator: } 84.98 \mathrm{Ht}(25.90 \mathrm{~m}) \text { below TOC } & \text { pH: } 4.2 \\ \text { Water elevation: } 228.94 \mathrm{ft}(69.17 \mathrm{~m}) \mathrm{msl} & \text { Alkalinity: } 0 \mathrm{mg} / \mathrm{h} \\ \text { Sp. conductance: } 82 \mu \mathrm{s} / \mathrm{cm} & \text { Water tomperature: } 21.4 \circ \mathrm{C} \\ \text { Water evacuated bofore sampling: } 13 \mathrm{gal} & \end{array}$

LABOPATORY ANALYSES

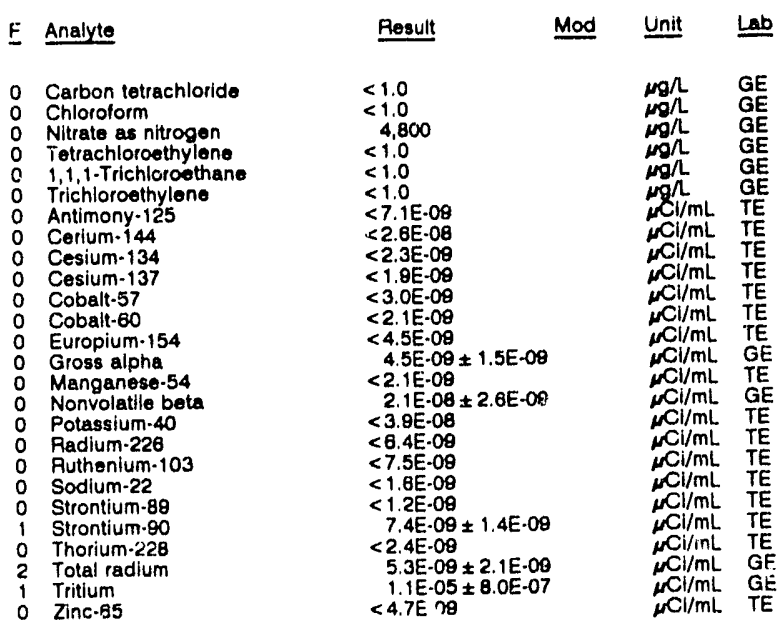

\section{WELL FCA $10 A$}

MEASUREMENTS CONDUCTED IN THE FIELD

Sample date: 11/14/81 Depth to water: $85.05 \mathrm{ft}(25.92 \mathrm{~m})$ below TOC Water elevation: $226.75 \mathrm{it}(68.11 \mathrm{~m}) \mathrm{msl}$ Sp. conductance: $158 \mu \mathrm{s} / \mathrm{cm}$ Water evacuated before sampling: $15 \mathrm{gal}$ LABORATORY ANALYSES

\begin{tabular}{|c|c|c|}
\hline Anaiyte & Result & Unit \\
\hline $\begin{array}{l}\text { Carbon tetrachloride } \\
\text { Chloroform } \\
\text { Nitrate as nitrogen } \\
\text { Tetrachloroethylene } \\
1,1,1-\text { Trichloroethane } \\
\text { rrichioroethylene } \\
\text { Antimony-125 } \\
\text { Cerium-144 } \\
\text { Cesium- } 134 \\
\text { Cesium-137 } \\
\text { Cobatt-57 } \\
\text { Cobalt-60 } \\
\text { Europium-154 } \\
\text { Gross alpha } \\
\text { Mariganese-54 } \\
\text { Nonvolatile beta }\end{array}$ & $\begin{array}{l}<1.0 \\
<1.0 \\
11.000 \\
<1.0 \\
<1.0 \\
<1.0 \\
<7.4 E \cdot 08 \\
<2.3 E \cdot 08 \\
<3.1 E-09 \\
<3.2 E-09 \\
<3.1 E \cdot 09 \\
<3.3 E-09 \\
<9.4 E \cdot 09 \\
1.2 E-08 \pm 2.3 E-09 \\
<3.2 E-09 \\
1.9 E-08 \pm 2.5 E \cdot 09\end{array}$ & 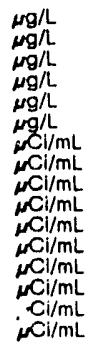 \\
\hline
\end{tabular}


ANALYTICAL RESULTS

\begin{tabular}{|c|c|c|c|}
\hline E Analyte & Rosult & Mod & Unit \\
\hline $\begin{array}{ll}0 & \text { Potassium-40 } \\
0 & \text { Radium-226 } \\
0 & \text { Ruthenium-103 } \\
0 & \text { Sodium-22 } \\
0 & \text { Strontium-68 } \\
0 & \text { Strontium-80 } \\
0 & \text { Thorlum-228 } \\
2 & \text { Total radium } \\
1 & \text { Tritium } \\
0 & \text { Zinc- } 65\end{array}$ & $\begin{array}{r}<4.1 \mathrm{E} \cdot 08 \\
<5.7 \mathrm{E} \cdot 09 \\
<1.4 \mathrm{E} \cdot 08 \\
<3.3 \mathrm{E}-09 \\
<1.5 \mathrm{E} \cdot 09 \\
<8.0 \mathrm{E}-10 \\
<2.8 \mathrm{E} \cdot 09 \\
8.0 \mathrm{E} \cdot 09 \pm 2.4 \mathrm{E} \cdot 09 \\
1.3 \mathrm{E} \cdot 05 \pm 9.0 \mathrm{E} \cdot 07 \\
<6.1 \mathrm{E} \cdot 09\end{array}$ & & $\begin{array}{l}\mu \mathrm{Ci} / \mathrm{mL} \\
\mu \mathrm{Ci} / \mathrm{mL} \\
\mu \mathrm{Cl} / \mathrm{mL} \\
\mu \mathrm{Ci} / \mathrm{mL} \\
\mu \mathrm{Ci} / \mathrm{mL} \\
\mu \mathrm{Cl} / \mathrm{mL} \\
\mu \mathrm{Cl} / \mathrm{mL} \\
\mu \mathrm{Cl} / \mathrm{mL} \\
\mu \mathrm{Cl} / \mathrm{mL} \\
\mu \mathrm{Cl} / \mathrm{mL}\end{array}$ \\
\hline
\end{tabular}

WELL FCA 10B

MEASUREMENTS CONDUCTED IN THE FIELO

\begin{tabular}{|c|c|c|c|c|c|}
\hline \multicolumn{2}{|c|}{$\begin{array}{l}\text { Sample date: } 11 / 13 / 81 \\
\text { The well was dry. }\end{array}$} & & \multicolumn{3}{|c|}{ Time: $14: 20$} \\
\hline \multicolumn{6}{|c|}{ WELL FCA 10C } \\
\hline \multicolumn{6}{|c|}{ MEASUREMENTS CONDUCTED IN THE FIELD } \\
\hline \multicolumn{2}{|c|}{$\begin{array}{l}\text { Sample date: } 11 / 14 / 91 \\
\text { The well was dry. }\end{array}$} & \multicolumn{4}{|c|}{ Time: $14: 20$} \\
\hline \multicolumn{6}{|c|}{ WELL FCA 10D } \\
\hline \multicolumn{6}{|c|}{ MEASURE TS CONDUCTED IN THE FIELD } \\
\hline \multicolumn{4}{|c|}{ 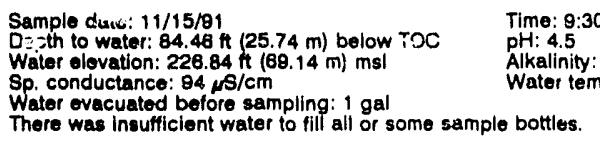 } & giture: 20 & \\
\hline \multicolumn{6}{|c|}{ LABORATORY ANALYSES } \\
\hline & Analyte & Result & Mod & Unit & $\underline{\text { Lab }}$ \\
\hline & $\begin{array}{l}\text { Gross alpha } \\
\text { Nonvolatlle beta } \\
\text { Strontium-88 } \\
\text { Strontium.80 } \\
\text { Total radium }\end{array}$ & $\begin{aligned} & 6.8 \mathrm{E}-08 \\
& 2.8 \mathrm{E}-08 \\
&< 1.4 \mathrm{E}-08 \\
&< 4.0 \mathrm{E}-10 \\
& 1.0 \mathrm{E}-08\end{aligned}$ & $\begin{array}{l}8 \mathrm{E}-09 \\
8 \mathrm{E}-09 \\
8 \mathrm{E}-09\end{array}$ & 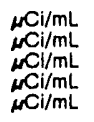 & $\begin{array}{l}\mathrm{GE} \\
\mathrm{GE} \\
\mathrm{TE} \\
\mathrm{TE} \\
\mathrm{GE}\end{array}$ \\
\hline
\end{tabular}

WELL FCA 16A

MEASUREMENTS CONDUCTED IN THE FIELD

Sample date: 11/15/91

Depth to water: $85.58 \mathrm{ft}(28.09 \mathrm{~m})$ below TOC

Water elevation: $226.61 \mathrm{ft}(68.0$

Sp. conductance: $62 \mu \mathrm{s} / \mathrm{cm}$

Water evacuated belore sampling:
The well went dry during purging.

LABORATORY ANALYYSES

\begin{tabular}{|c|c|c|c|}
\hline Analyte & Result & Mod & Unit \\
\hline $\begin{array}{l}\text { Carton tetrachloride } \\
\text { Chloroform } \\
\text { Nitrate as nitrogen } \\
\text { Nitrate as nitrogen } \\
\text { Tetrachloroethylene } \\
\text { 1.1, 1-Trichloroethane } \\
\text { Trichloroethylene } \\
\text { Antimony-125 } \\
\text { Cerium-144 } \\
\text { Cesium-134 } \\
\text { Cesium-137 } \\
\text { Cobaft-57 } \\
\text { Cobalt-60 } \\
\text { Europlum-154 } \\
\text { Gross alpha } \\
\text { Manganese-54 } \\
\text { Nonvolatile bi-ta } \\
\text { Potassium-40 } \\
\text { Radium-228 } \\
\text { Ruthenium-103 } \\
\text { Sodium-22 } \\
\text { Strontium-89 } \\
\text { Strontium- } 90 \\
\text { Thorium-228 } \\
\text { Total radium } \\
\text { Tritlum } \\
\text { Zinc-85 }\end{array}$ & 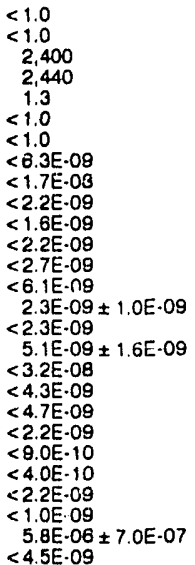 & $\begin{array}{l}\text { JO } \\
\text { JO }\end{array}$ & 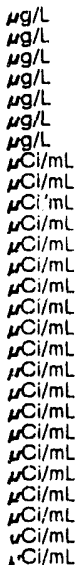 \\
\hline
\end{tabular}

WELL FCA 16B

MEASUREMENTS CONDUCTED IN THE FIELD

Sample date: $11 / 14 / 81$

Time: $18: 40$

The weil was dry.

WELL FCA $16 D$

MEASUAEMENTS CONDUCTED IN THE FIELD

Sample date: $11 / 13 / 91$
Inaccessibility of pump failure prevented sample collection.

Tample date: $11 / 13 / 91$
Inaccessibility or pump failure prevented sample collection.

\section{WELL FCA $16 T$}

MEASUREMENTS CONDUCTED IN THE FIELD

Sample date: $11 / 14 / 91$

The well was dry.

Time: 16:30

WELL FCA 19D

MEASUREMENTS CONDUCTED IN THE FIELD

Sample date: $11 / 14 / 91$

Depth to water: $92.30 \mathrm{ft}(28.13 \mathrm{~m})$ below TOC

Water elevation: $219.30 \mathrm{tt}(68.84 \mathrm{~m}) \mathrm{ms}$

Sp. conductance: $289 \mu \mathrm{S} / \mathrm{cm}$

Water evacuated before sampling: 6 gal

The well went dry during purging.

LAEORATOAY ANALYSES

\begin{tabular}{|c|c|c|}
\hline F Analyte & Result & Unit \\
\hline 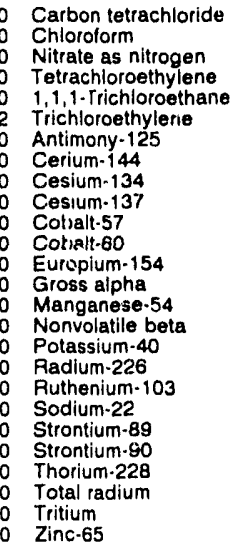 & $\begin{array}{l}1.8 \\
1.3 \\
610 \\
<1.0 \\
2.7 \\
13 \\
<6.9 \mathrm{E} \cdot 09 \\
<2.1 \mathrm{E} \cdot 08 \\
<3.1 \mathrm{E} \cdot 09 \\
<2.9 \mathrm{E} \cdot 09 \\
<2.8 \mathrm{E} \cdot 09 \\
<3.6 \mathrm{E} \cdot 09 \\
<9.4 \mathrm{E} \cdot 09 \\
<2.0 \mathrm{E} \cdot 09 \\
<3.3 \mathrm{E} \cdot 09 \\
1.3 \mathrm{E} \cdot 09 \pm 2.6 \mathrm{E} \cdot 09 \\
<4.3 \mathrm{E} \cdot 08 \\
<5.2 \mathrm{E} \cdot 09 \\
<8.7 \mathrm{E}-09 \\
<3.5 \mathrm{E} \cdot 09 \\
<1.0 \mathrm{E} \cdot 09 \\
9.0 \mathrm{E} \cdot 10 \pm 8.0 \mathrm{E} \cdot 10 \\
<3.1 \mathrm{E} \cdot 09 \\
<1.0 \mathrm{E} \cdot 09 \\
9.0 \mathrm{E} \cdot 06 \pm 8.0 \mathrm{E} \cdot 07 \\
<7.0 \mathrm{E} \cdot 09\end{array}$ & 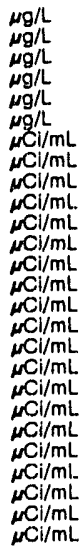 \\
\hline
\end{tabular}

WELL FCB 2

MEASUREMENTS CONDUCTED IN THE FIELD

Sample date: 11/07/91

Depth to water: $77.86 \mathrm{ft}(23.73 \mathrm{~m})$ below TOC

Water elevation: $229.44 \mathrm{ft}(69.93 \mathrm{~m}) \mathrm{ms}$ !

Water evacuated before sampling: $84 \mathrm{gal}$

Time: 11:45

pH: 6.9

Water temperature: $23.8^{\circ} \mathrm{C}$

LABORATORY ANALYSES

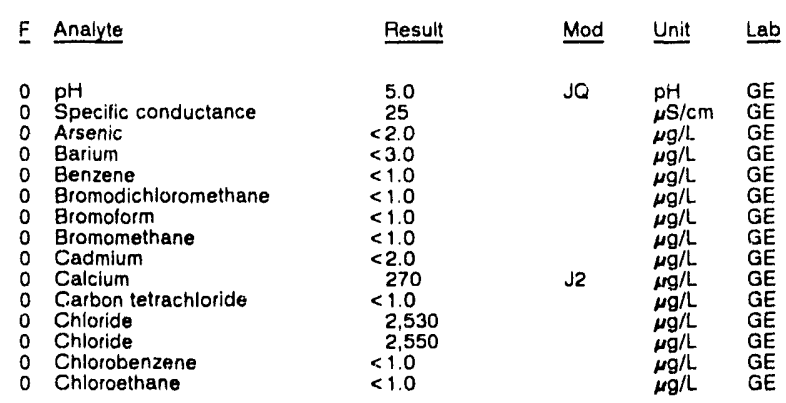


ANALYTICAL RESULTS

WELL FCB 2 collected on 11/07/91, laboratory analyses (cont.)

\begin{tabular}{|c|c|c|c|}
\hline Analyte & Result & Mod & Unit \\
\hline 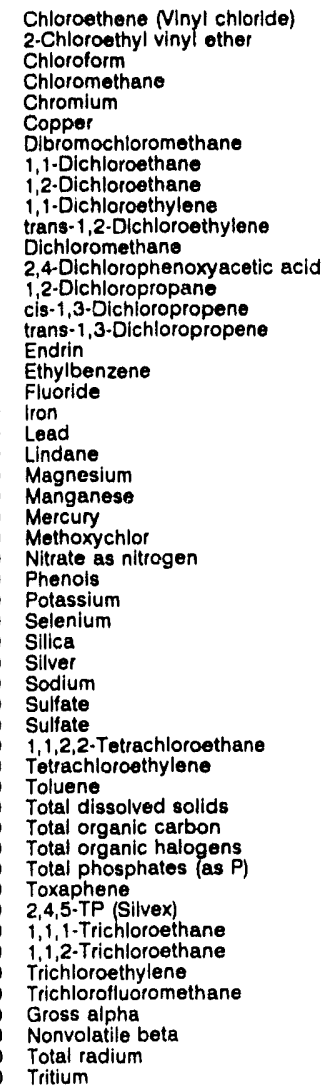 & $\begin{array}{l}<1.0 \\
<1.0 \\
<1.0 \\
<1.0 \\
<4.0 \\
8.8 \\
<1.0 \\
<1.0 \\
<1.0 \\
<1.0 \\
<1.0 \\
<1.0 \\
<0.30 \\
<1.0 \\
<1.0 \\
<1.0 \\
<0.0060 \\
<1.0 \\
<100 \\
62 \\
6.9 \\
<0.0050 \\
201 \\
2.5 \\
<0.20 \\
<0.50 \\
870 \\
<5.0 \\
<500 \\
<2.0 \\
6.970 \\
<2.0 \\
2.730 \\
1.430 \\
1.470 \\
<1.0 \\
1.2 \\
<1.0 \\
29.000 \\
<1.000 \\
9.2 \\
<50 \\
<0.24 \\
<0.090 \\
<1.0 \\
<1.0 \\
2.3 \\
<1.0 \\
2.2 \mathrm{E}-09 \pm 9.9 \mathrm{E}-10 \\
2.9 \mathrm{E}-09 \pm 1.0 \mathrm{E}-09 \\
<1.0 \mathrm{E} 00 \\
9.5 \mathrm{E}-06 \pm 8.0 \mathrm{E} \cdot 07 \\
\\
\\
\end{array}$ & $\mathrm{~J}_{2} \mathrm{~V}$ & $\begin{array}{l}\mu g / L \\
\mu g / L \\
\mu g / L \\
\mu g / L \\
\mu g / L \\
\mu g / L \\
\mu g / L \\
\mu g / L \\
\mu g / L \\
\mu g / L \\
\mu g / L \\
\mu g / L \\
\mu g / L \\
\mu g / L \\
\mu g / L \\
\mu g / L \\
\mu g / L \\
\mu g / L \\
\mu g / L \\
\mu g / L \\
\mu g / L \\
\mu g / L \\
\mu g / L \\
\mu g / L \\
\mu g / L \\
\mu g / L \\
\mu g / L \\
\mu g / L \\
\mu g / L \\
\mu g / L \\
\mu g / L \\
\mu g / L \\
\mu g / L \\
\mu g / L \\
\mu g / L \\
\mu g / L \\
\mu g / L \\
\mu g / L \\
\mu g / L \\
\mu g / L \\
\mu g / L \\
\mu g / L \\
\mu g / L \\
\mu g / L \\
\mu g / L \\
\mu g / L \\
\mu g / L \\
\mu g / L \\
\mu C \mathrm{i} / \mathrm{mL} \\
\mu C \mathrm{i} / \mathrm{mL} \\
\mu C \mathrm{i} / \mathrm{mL} \\
\mu C \mathrm{i} / \mathrm{mL}\end{array}$ \\
\hline
\end{tabular}

WELL FCB 2 Replicate

MEASUREMENTS CONDUCTED IN THE FIELD

Sample date: 11/07/91

Depth to water: $7786 \mathrm{ft}(23.73 \mathrm{~m})$ below TOC

Water elevation: $229.44 \mathrm{ft}(69.93 \mathrm{~m}) \mathrm{ms}$ !

mpling: $64 \mathrm{gal}$

LABORATORY ANALYSES

\begin{tabular}{|c|c|c|}
\hline & Analyte & Result \\
\hline $\begin{array}{l}0 \\
0\end{array}$ & $\begin{array}{l}\text { pH } \\
\text { Specific conductance } \\
\text { Assenic } \\
\text { Barium } \\
\text { Benzene } \\
\text { Bromodichloromethane } \\
\text { Bromoform } \\
\text { Bromomethane } \\
\text { Cadmium } \\
\text { Calcium } \\
\text { Carbon tetrachloride } \\
\text { Chloride } \\
\text { Chlorobenzene } \\
\text { Chloroethane } \\
\text { Chloroethene Ninyl chloride) } \\
\text { 2.Chloroethyl vinyl ether } \\
\text { Chloroform } \\
\text { Chloromethane } \\
\text { Chromium } \\
\text { Copper } \\
\text { Dibromochloromethane } \\
1,1 \cdot \text { Dichloroethane } \\
\text { 1,2-Dichloroethane } \\
\text { 1,1-Lichloroethylene } \\
\text { trans-1,2-Dichloroethylene } \\
\text { Dichloromethane } \\
2,4-\text { Dichlorophenoxyacetic acid } \\
1,2-\text { Dichloropropane } \\
\text { cis-1,3-Dichloropropene } \\
\text { trans-1,3-Dichloropropene } \\
\text { Endrin }\end{array}$ & $\begin{aligned} & 5.1 \\
& 25 \\
&<2.0 \\
&<3.0 \\
&<1.0 \\
&<1.0 \\
&<1.0 \\
&<1.0 \\
&<2.0 \\
& 267 \\
&<1.0 \\
& 2,250 \\
&<1.0 \\
&<1.0 \\
&<1.0 \\
&<1.0 \\
&<1.0 \\
&<1.0 \\
&<4.0 \\
& 9.8 \\
&<1.0 \\
&<1.0 \\
&<1.0 \\
&<1.0 \\
&<1.0 \\
&<1.0 \\
&<0.30 \\
&<1.0 \\
&<1.0 \\
&<1.0 \\
&<0.0060\end{aligned}$ \\
\hline
\end{tabular}

Time: $10: 20$

pH: 4.8

Water temperature: $17.9^{\circ} \mathrm{C}$
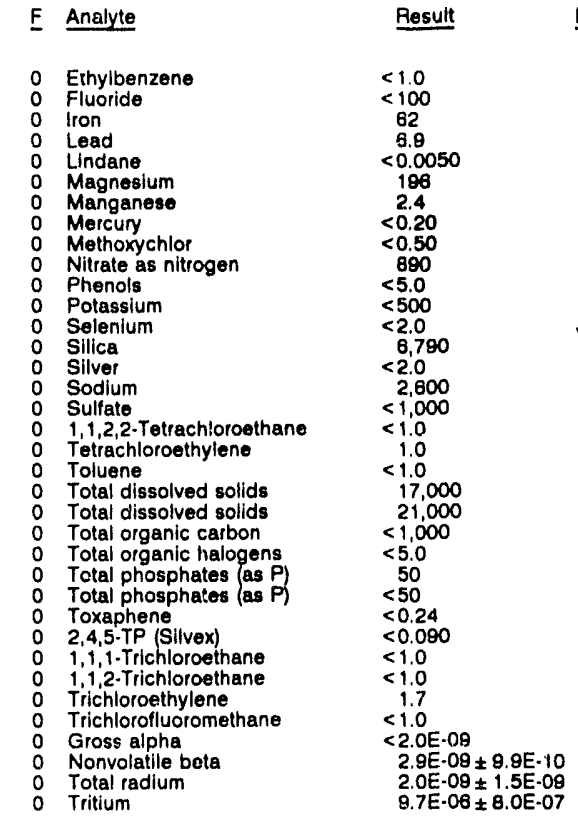

WELL FCB 2 collected on 11/07/91, laboratory analyses (cont.)

\begin{tabular}{|c|c|c|c|}
\hline Analyte & Result & Mod & Unit \\
\hline $\begin{array}{l}\text { Ethylbenzene } \\
\text { Fluoride } \\
\text { lron } \\
\text { Lead } \\
\text { Lindane } \\
\text { Magneslum } \\
\text { Manganese } \\
\text { Mercury } \\
\text { Methoxychlor } \\
\text { Nitrate as nitrogen } \\
\text { Phenols } \\
\text { Potassium } \\
\text { Selenium } \\
\text { Silica } \\
\text { Silver } \\
\text { Sodium } \\
\text { Sulfate } \\
1,1,2,2-\text { Tetrachloroethane } \\
\text { Tetrachloroethylene } \\
\text { Toluene } \\
\text { Total dissolved solids } \\
\text { Total dissolved solids } \\
\text { Total organic carbon } \\
\text { Total organic halogens } \\
\text { Tctal phosphates as P) } \\
\text { Total phosphates (as P) } \\
\text { Toxaphene } \\
2,4,5 \cdot \text { TP (Silvex) } \\
1,1,1 \text {-Trichloroethane } \\
\text { 1,1,2-Trichloroethane } \\
\text { Trichloroethylene } \\
\text { Trichlorofluoromethane } \\
\text { Gross alpha } \\
\text { Nonvolatile bota } \\
\text { Total radium } \\
\text { Tritium }\end{array}$ & $\begin{array}{l}<1.0 \\
<100 \\
62 \\
6.9 \\
<0.0050 \\
196 \\
2.4 \\
<0.20 \\
<0.50 \\
890 \\
<5.0 \\
<500 \\
<2.0 \\
6,790 \\
<2.0 \\
2,000 \\
<1.000 \\
<1.0 \\
1.0 \\
<1.0 \\
17.000 \\
21.000 \\
<1.000 \\
<5.0 \\
50 \\
<50 \\
<0.24 \\
<0.090 \\
<1.0 \\
<1.0 \\
1.7 \\
<1.0 \\
<2.0 \mathrm{E}-0 \mathrm{O} \\
2.9 \mathrm{E}-09 \pm 9.9 \mathrm{E}-10 \\
2.0 \mathrm{E}-09 \pm 1.5 \mathrm{E}-09 \\
9.7 \mathrm{E}-08 \pm 8.0 \mathrm{E}-07\end{array}$ & J1 & $\begin{array}{l}\mu g / L \\
\mu g / L \\
\mu g / L \\
\mu g / L \\
\mu g / L \\
\mu g / L \\
\mu g / L \\
\mu g / L \\
\mu g / L \\
\mu g / L \\
\mu g / L \\
\mu g / L \\
\mu g / L \\
\mu g / L \\
\mu g / L \\
\mu g / L \\
\mu g / L \\
\mu g / L \\
\mu g / L \\
\mu g / L \\
\mu g / L \\
\mu g / L \\
\mu g / L \\
\mu g / L \\
\mu g / L \\
\mu g / L \\
\mu g / L \\
\mu g / L \\
\mu g / L \\
\mu g / L \\
\mu g / L \\
\mu g / L \\
\mu C / / m L \\
\mu C I / m L \\
\mu C / / m L \\
\mu C l / m L\end{array}$ \\
\hline
\end{tabular}

WELL FCB 3

MEASUREMENTS CONDUCTED IN THE FIELD

Sample date: 11/07/91

Depth to water: $79.87 \mathrm{ft}(24.34 \mathrm{~m})$ below TOO

Water elevation: $222.43 \mathrm{ft}(67.80 \mathrm{~m}) \mathrm{msi}$

Sp. conductance: $79 \mu \mathrm{s} / \mathrm{cm}$
Water evacuated betore sampling: $124 \mathrm{gal}$

LABORATORY ANALYSES

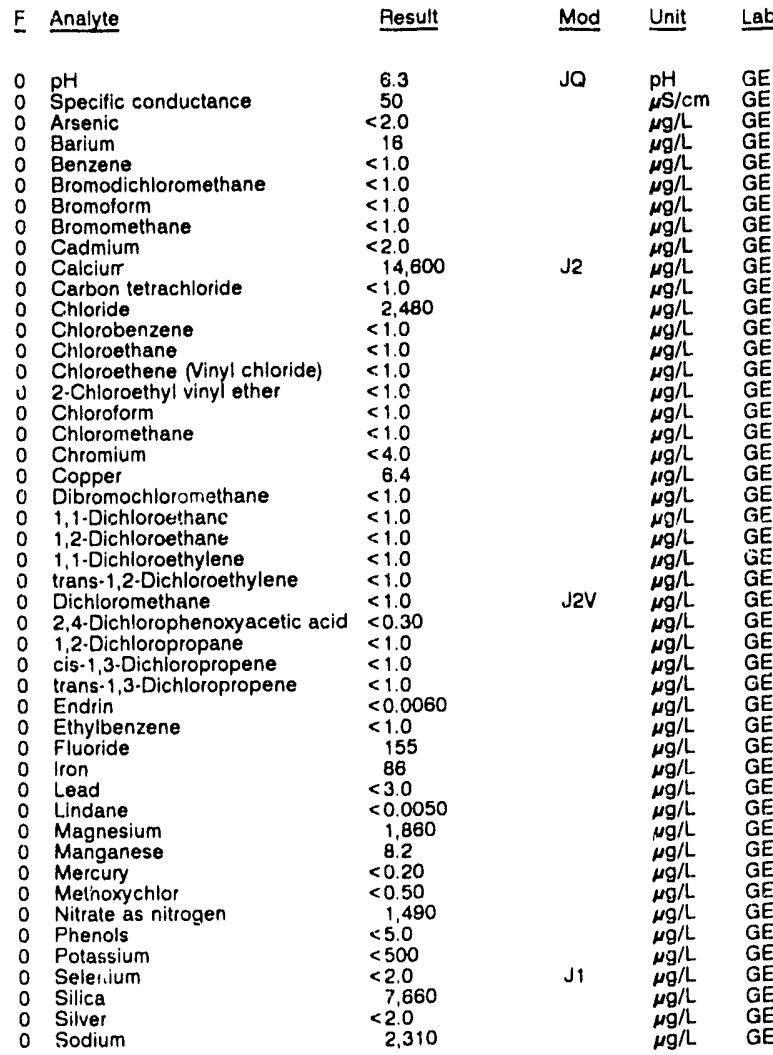


ANALYTICAL RESULTS

WELL FCB 3 collocted on 11/07/91, laboratory analyses (cont.)

\begin{tabular}{|c|c|c|c|c|c|}
\hline E & Analyte & Result & Mod & Unit & Lab \\
\hline & 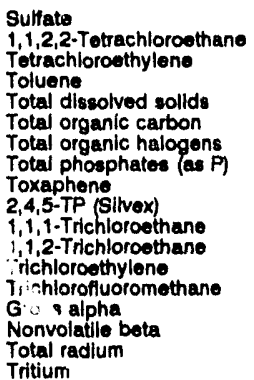 & $\begin{array}{l}<1.000 \\
<1.0 \\
<1.0 \\
<1.0 \\
62,000 \\
<1.000 \\
<5.0 \\
320 \\
<0.24 \\
<0.090 \\
<1.0 \\
<1.0 \\
<1.0 \\
<1.0 \\
7.1509 \pm 1.8 E-09 \\
5.7 E-05 \pm 1.3 \mathrm{E}-00 \\
2.2 \mathrm{E}-09 \pm 3.2 \mathrm{E}-09 \\
1.1 \mathrm{E}-05 \pm 8.0 \mathrm{E}-07\end{array}$ & & 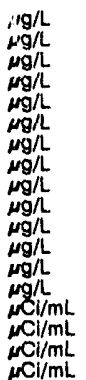 & $\begin{array}{l}G E \\
G E \\
G E \\
G E \\
G E \\
G E \\
G E \\
G E \\
G E \\
G E \\
G E \\
G E \\
G E \\
G E \\
G E \\
G E \\
G E \\
G E\end{array}$ \\
\hline
\end{tabular}

\section{WELL FCB 4}

MEASUREMENTS CONDUCTED IN THE FIELD

$\begin{array}{ll}\text { Sample date: } 11 / 14 / 91 & \text { Time: } 8: 05 \\ \text { Depth to water: } 76.43 \mathrm{ft}(23.30 \mathrm{~m}) \text { below TOC } & \text { pH: } 5.3 \\ \text { Water elevation: } 230.17 \mathrm{ft}(70.16 \mathrm{~m}) \mathrm{ms} & \text { Alkalinity: } 1 \mathrm{mg} / \mathrm{h} \\ \text { Sp. conductance: } 32 \mathrm{\mu s} / \mathrm{cm} & \text { Water temperature: } 18.5^{\circ} \mathrm{C} \\ \text { Water ovacuated before sampling: } 16 \mathrm{ggl} & \end{array}$
The well went dry during purging:
The $\mathrm{g} 9 \mathrm{l}$

LABORATORY ANALYSES

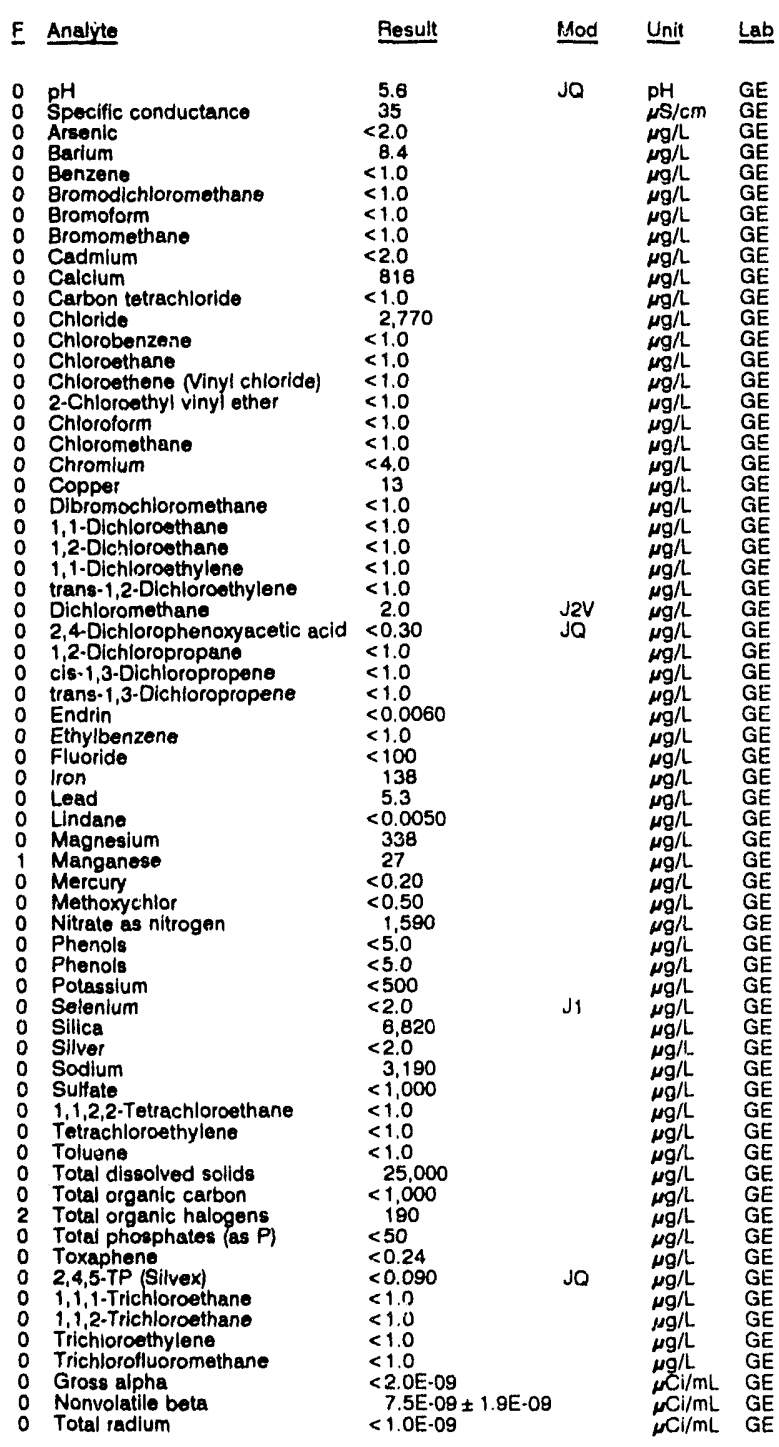

WELL FCB 4 collected on 11/14/81, laboratory analyses (cont.)
F Analyte
Result
Mod Unit Lab
0 Tritium
$9.5 E-08 \pm 8.0 E-07$
$\mu \mathrm{CI} / \mathrm{mL}$ GE

WELL FCB 5

MEASUREMENTS CONDUCTEO IN THE FIELO

Sample dato: 11/08/91

Depth to water: $75.18 \mathrm{ft}(22.82 \mathrm{~m})$ below TOC

Water elevation: $228.72 \mathrm{H}(69.71 \mathrm{~m}) \mathrm{ms}$ )

Water ovacuated bofore sampling: $5 \mathrm{gal}$

The woll went dry during purging.

LABORATORY ANALYSES

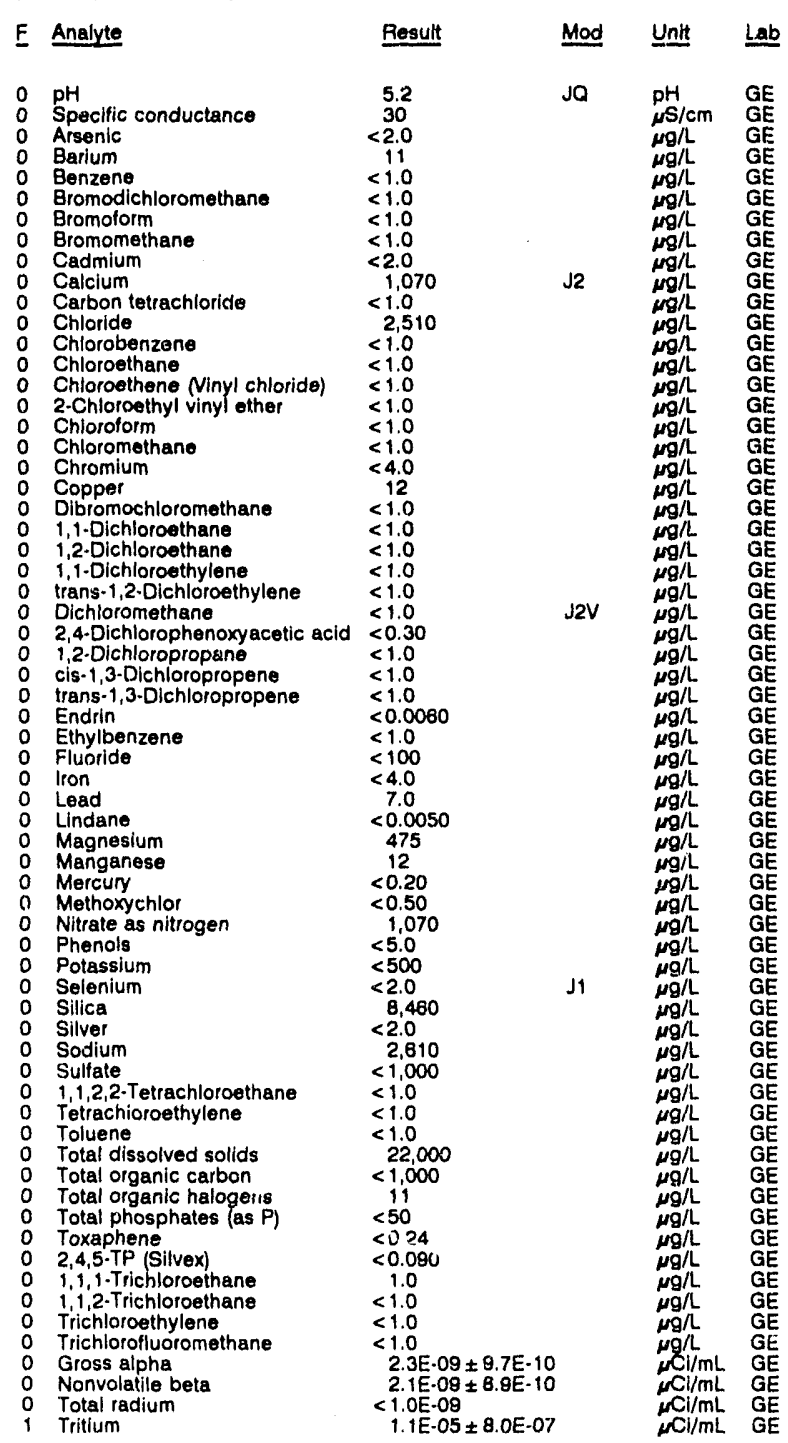

Timo: 8:00

pH: 5.1 . 1 malinity: $3 \mathrm{mg}$

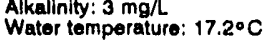


WELL FCB 6

MEASUREMENTS CONDUCTED IN THE FIELD

Sample date: 11/08/91

Depth to water: $82.27 \mathrm{~h}(25.08 \mathrm{~m})$ below TOC

Water olevation: $228.23 \mathrm{~h}(69.5$

Sp. conductanco: $140 \mathrm{\mu s} / \mathrm{cm}$

Water ovacuated before sampling: 2 ga

LABOFATORY ANALYSES

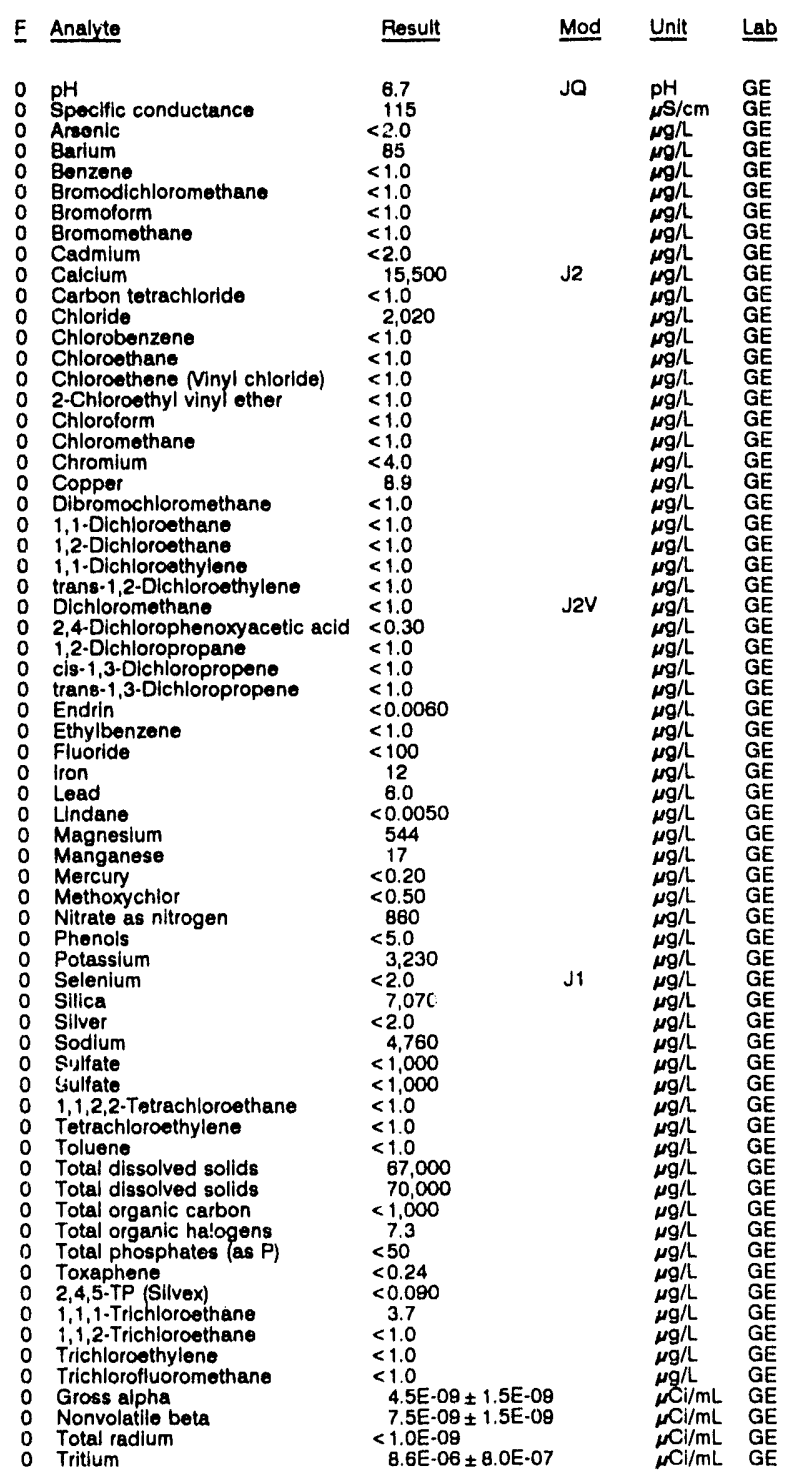

WELL FCB 7

MEASUREMENTS CONDUCTED IN THE FIELD

Sample date: 11/07/81

Time: $11: 15$

Time: $7: 45$

pH: 6.7 Alkalinity: $78 \mathrm{mg}$

Water temperature: $16.8^{\circ} \mathrm{C}$

政

E

GE

Sa

WELL FET 1D

ME/SUREMENTS CONOUCTED IN THE FIELD

Sample date: 12/03/91

Depth to water: $44.48 \mathrm{ft}(13.56 \mathrm{~m})$ below TOC

Water olevation: $225.51 \mathrm{tt}(88.74 \mathrm{~m}) \mathrm{msl}$

Sp. conductance: $62 \mu \mathrm{s} / \mathrm{cm}$

Water evacuated bofore sampling: $8 \mathrm{gal}$

Time: $8: 55$

$2 \mathrm{mgl}$

WELL FET 2D

MEASUREMENTS CONDUCTED IN THE FIELD

Sample date: 11/22/81

Depth to water: $45.58 \mathrm{~A}(13.80 \mathrm{~m})$ below TOC

Water elevation: $224.41 \mathrm{~h}(88.40 \mathrm{~m}) \mathrm{ms}$

We conductance: $42 \mathrm{~s} / \mathrm{cm}$

Time: 14:05

PH: 4.8 : $0 \mathrm{mg}$

Water temperature: $20.1^{\circ} \mathrm{C}$

\section{WELL FET 3D}

MEASUAEMENTS CONDUCTED IN THE FIELD

Sample date: 11/22/81

Depth to water: $60.78 \mathrm{ft}(18.52 \mathrm{~m})$ below TOC

Water elevation: $224.44 \mathrm{ft}(68.41 \mathrm{~m}) \mathrm{ms}$

Sp. conductance: $64 \mu \mathrm{\mu S} / \mathrm{cm}$.

Time: 14:20

Alkalinity: $1 \mathrm{mg}$

Water temperature: $19.0^{\circ} \mathrm{C}$

WELL FET 4D

MEASUREMENTS CONDUCTED IN THE FIELD

Sample date: 11/22/91

Depth to water: $61.93 \mathrm{ft}(18.88 \mathrm{~m})$ below TOC

Water elevation: $224.87 \mathrm{ft}(68.57 \mathrm{~m}) \mathrm{ms}$ |

Sp. conductance: $47 \mu \mathrm{s} / \mathrm{cm}$
Water evacuated before sampling: $52 \mathrm{gal}$

Time: 14:50

pH: 4.6

Water temperature: $20.1^{\circ} \mathrm{C}$

WELL FNB 1

MEASUREMENTS CONDUCTED IN THE FIELD

Sample date: 10/31/91

Depth to water: $68.95 \mathrm{Ht}(21.32 \mathrm{~m})$ below TOC

Water elevation: $214.35 \mathrm{ft}(65.33 \mathrm{~m}) \mathrm{msl}$

Sp. conductance: $73 \mu \mathrm{S} / \mathrm{cm}$
Water evacuated before sampling: $97 \mathrm{gal}$

LABORATORY ANALYSES

E Analyte Result Mod Unit Lab

pH

0 Arsenic

o Barlum

0 Benzene

Beryllium

Bromodich

Bromoform

0 Bromomethan

留:mium

Carbon tetrachloride

Carbon te

Chloride

Chloride

Chlorobenzene

Chloroethane

Chloroethene Ninyl chloride)

2.Chloroethyl vinyl ether

Chloroform

Chloromethane

Chromium

Coppe

Dibromochloromethane

1,1-Dichloroethane

1,2 -Dichloroethane

$1,1-D i c h l o r o e t h y l e n e$
trans-1,2-Dichloroethylene

o Dichloromethane

1,2-Dichloropropane

cis-1,3-Dichloropropene

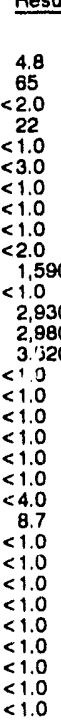

Time: $8: 00$

pH: 4.6

Alkalinity: $0 \mathrm{mg} / \mathrm{L}$

trans-1,3-Dichloropropene 
WELL FNB 1 collected on 10/31/91, laboratory analyses (cont.)

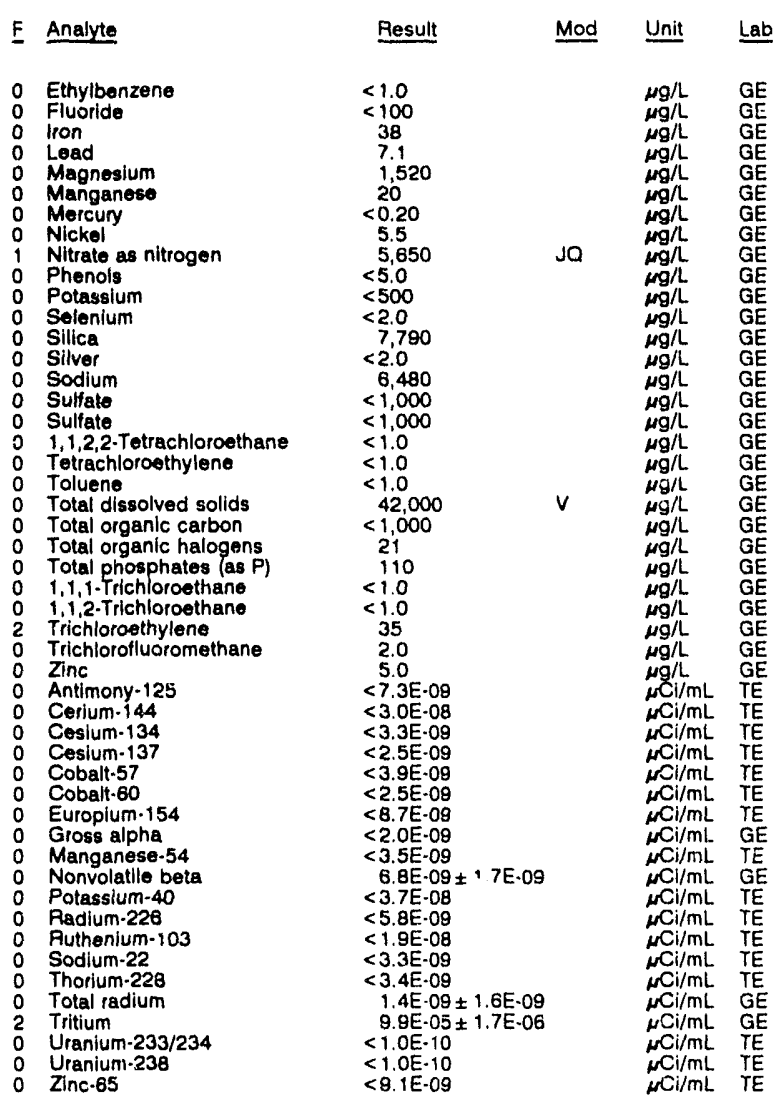

WELL FNB 2

MEASUREMENTS CONDUCTED IN THE FIELD

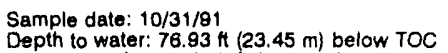

Depth to water: $76.93 \mathrm{ft}(23.45 \mathrm{~m})$ below TOC
Water elevation: $210.87 \mathrm{ft}(64.27 \mathrm{~m}) \mathrm{msl}$
Sp. conductance: $152 \mu \mathrm{sm} / \mathrm{cm}$

Water evacuated before sampling: $79 \mathrm{gal}$

LABORATORY ANALYSES

\begin{tabular}{|c|c|c|c|c|c|}
\hline$F$ & Analyte & Result & Mod & Unit & $\underline{L a b}$ \\
\hline 0 & 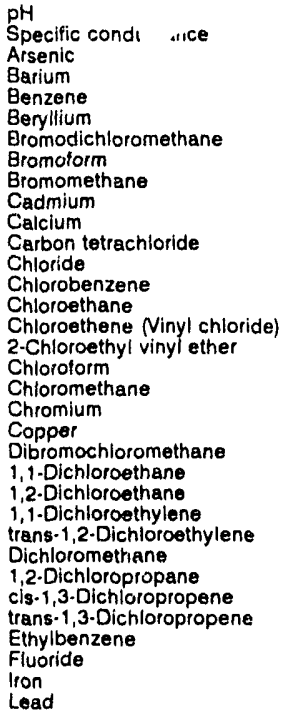 & $\begin{aligned} & 41 \\
& 120 \\
&<2.0 \\
& 45 \\
&<1.0 \\
&<3.0 \\
&<1.0 \\
&<1.0 \\
&<1.0 \\
&<2.0 \\
& 1.300 \\
&<1.0 \\
& 4.050 \\
&<1.0 \\
&<1.0 \\
&<1.0 \\
&<1.0 \\
&<1.0 \\
&<1.0 \\
&<4.0 \\
& 12 \\
&<1.0 \\
&<1.0 \\
&<1.0 \\
&<1.0 \\
&<1.0 \\
&<1.0 \\
&<1.0 \\
&<1.0 \\
&<1.0 \\
&<1.0 \\
& 120 \\
& 85 \\
&<3.0\end{aligned}$ & J2V & $\begin{array}{l}p H \\
\mu S / c m \\
\mu g / L \\
\mu g / L \\
\mu g / L \\
\mu g / L \\
\mu g / L \\
\mu g / L \\
\mu g / L \\
\mu g / L \\
\mu g / L \\
\mu g / L \\
\mu g / L \\
\mu g / L \\
\mu g / L \\
\mu g / L \\
\mu g / L \\
\mu g / L \\
\mu g / L \\
\mu g / L \\
\mu g / L \\
\mu g / L \\
\mu g / L \\
\mu g / L \\
\mu g / L \\
\mu g / L \\
\mu g / L \\
\mu g / L \\
\mu g / L \\
\mu g / L \\
\mu g / L \\
\mu g / L \\
\mu g / L \\
\mu g / L\end{array}$ & $\begin{array}{l}\mathrm{GE} \\
\mathrm{GE} \\
\mathrm{GE} \\
\mathrm{GE} \\
\mathrm{GE} \\
\mathrm{GE} \\
\mathrm{GE} \\
\mathrm{GE} \\
\mathrm{GE} \\
\mathrm{GE} \\
\mathrm{GE} \\
\mathrm{GE} \\
\mathrm{GE} \\
\mathrm{GE} \\
\mathrm{GE} \\
\mathrm{GE} \\
\mathrm{GE} \\
\mathrm{GE} \\
\mathrm{GE} \\
\mathrm{GE} \\
\mathrm{GE} \\
\mathrm{GE} \\
\mathrm{GE} \\
\mathrm{GE} \\
\mathrm{GE} \\
\mathrm{GE} \\
\mathrm{GE} \\
\mathrm{GE} \\
\mathrm{GE}\end{array}$ \\
\hline
\end{tabular}

Time: $9: 30$

Alkalinity: $0 \mathrm{mg} / \mathrm{L}$

Water temperature: $18.8^{\circ} \mathrm{C}$

ab

GE

WELL FNB 2 collected on 10,31/91, laboratory analyses (cont.)

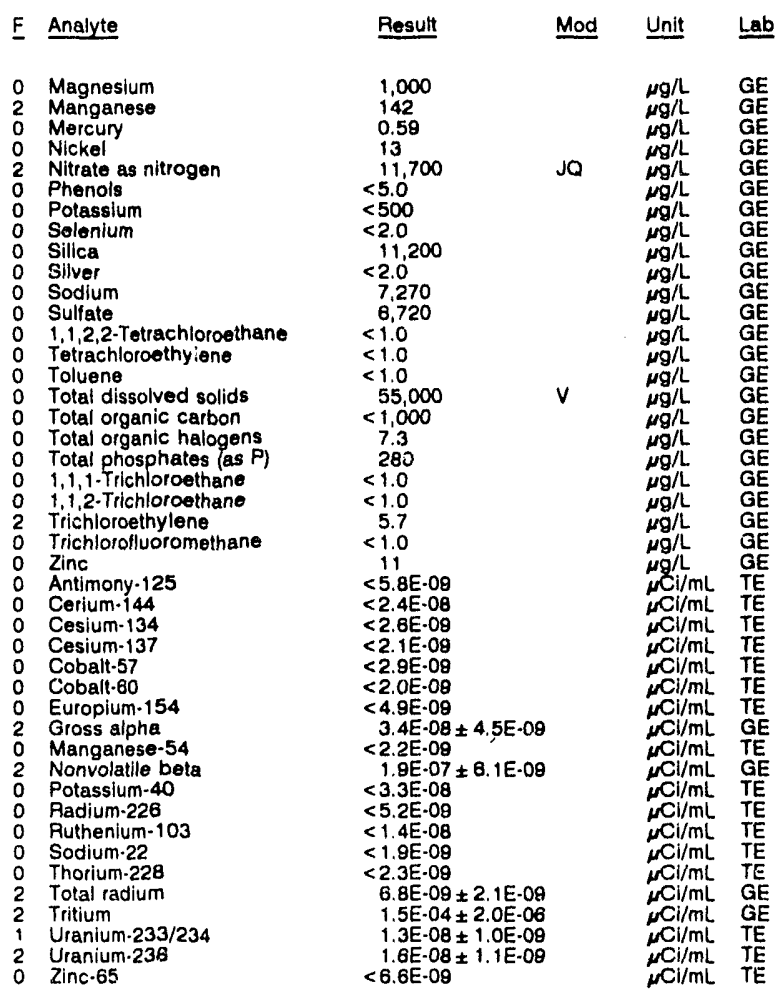

WELL FNB 3

MEASUREMENTS CONDUCTEO IN THE FIELO

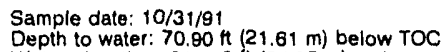

Whater elevation: $213.10 \mathrm{Ht}$ (64.

Sp. conductance: $112 \mu \mathrm{s} / \mathrm{cm}$
Water evacuated before samping: $81 \mathrm{gal}$

LABORATORY ANALYSES

$\begin{array}{ll}\text { F } & \text { Analyte } \\ & \\ 0 & \text { pH } \\ 0 & \text { Specific conductance } \\ 0 & \text { Arsenic } \\ 0 & \text { Barium } \\ 0 & \text { Benzene } \\ 0 & \text { Beryllium } \\ 0 & \text { Bromodichloromethane } \\ 0 & \text { Bromolorm } \\ 0 & \text { Bromomethane } \\ 0 & \text { Cadmium } \\ 0 & \text { Calcium } \\ 0 & \text { Carbon tetrachloride } \\ 0 & \text { Chloride } \\ 0 & \text { Chlorobenzene } \\ 0 & \text { Chloroethane } \\ 0 & \text { Chloroethene Ninyl chloride) } \\ 0 & 2 \text {-Chloroethyl vinyl ether } \\ 0 & \text { Chlorolorm } \\ 0 & \text { Chloromethane } \\ 0 & \text { Chromium } \\ 0 & \text { Copper } \\ 0 & \text { Dibromochloromethane } \\ 0 & 1,1 \cdot \text { Dichloroethane } \\ 0 & 1,2 \cdot \text { Dichloroethane } \\ 0 & \text { i,i-Dichloroethylene } \\ 0 & \text { trans-1,2.Dichloroethylene } \\ 0 & \text { Dichloromethane } \\ 0 & 1,2-\text {-Dichloropropane } \\ 0 & \text { cis-1,3-0ichloropropene } \\ 0 & \text { trans-1,3.Dichloropropene } \\ 0 & \text { Ethylbenzene } \\ 0 & \text { Fluoride } \\ 0 & \text { Fluoride } \\ 0 & \text { Iron } \\ 0 & \text { Lead } \\ 0 & \text { Magnesium } \\ 2 & \text { Manganese } \\ 0 & \text { Mercury } \\ 0 & \text { Nickel } \\ & \end{array}$

\begin{tabular}{l} 
Result \\
\multicolumn{1}{l}{} \\
4.6 \\
90 \\
$<2.0$ \\
33 \\
$<1.0$ \\
$<3.0$ \\
$<1.0$ \\
$<1.0$ \\
$<1.0$ \\
$<2.0$ \\
2.210 \\
$<1.0$ \\
3.440 \\
$<1.0$ \\
$<1.0$ \\
$<1.0$ \\
$<1.0$ \\
$<1.0$ \\
$<1.0$ \\
$<4.0$ \\
5.4 \\
$<1.0$ \\
$<1.0$ \\
$<1.0$ \\
$<1.0$ \\
$<1.0$ \\
$<1.0$ \\
$<1.0$ \\
$<1.0$ \\
$<1.0$ \\
$<1.0$ \\
$<100$ \\
$<100$ \\
18 \\
$<3.0$ \\
2.170 \\
105 \\
$<020$ \\
7.1
\end{tabular}

Time: 10:05

Alkalinity: $0 \mathrm{mg} / \mathrm{L}$

Water temperature: $18.3^{\circ} \mathrm{C}$

Mod Unit Lab

E


ANALYTICAL RESULTS

WELL FNB 3 collectod on 10/31/91, laboratory analyses (cont.)

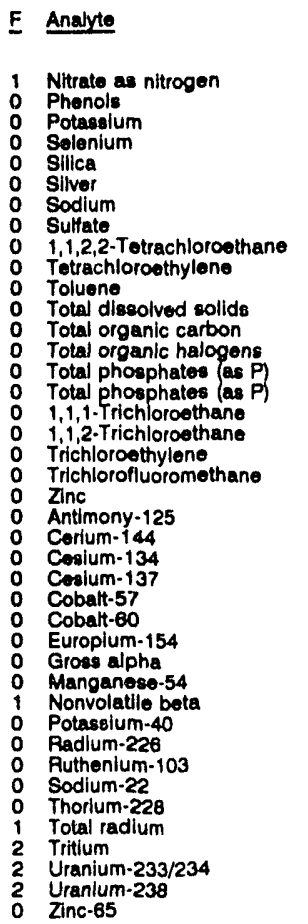

\begin{tabular}{l} 
Plosult \\
\hline \\
8,100 \\
$<5.0$ \\
$<500$ \\
$<2.0$ \\
7.710 \\
$<2.0$ \\
8,490 \\
13,800 \\
$<1.0$ \\
$<1.0$ \\
$<1.0$ \\
53,000 \\
$<1.000$ \\
6.3 \\
770 \\
840 \\
$<1.0$ \\
$<1.0$ \\
$<1.0$ \\
$<1.0$ \\
40 \\
$<7.3 E-09$ \\
$<2.3 E-08$ \\
$<3.2 E-09$ \\
$<3.4 E-09$ \\
$<3.2 E-09$ \\
$<3.3 E-09$ \\
$<8.4 E-09$ \\
$<2.0 E-09$ \\
$<3.7 E-09$ \\
$4.9 E-08 \pm 6.5 E-09$ \\
$<4.3 E-08$ \\
$<5.8 E-09$ \\
$<1.8 E-08$ \\
$<3.2 E-09$ \\
$<3.0 E-09$ \\
$4.1 E-09 \pm 1.9 E-09$ \\
$6.2 E-05 \pm 1.4 E-06$ \\
$1.5 E-08 \pm 3.0 E-10$ \\
$2.7 E-08 \pm 4.0 E-10$ \\
$<9.0 E-09$ \\
\end{tabular}

Mod

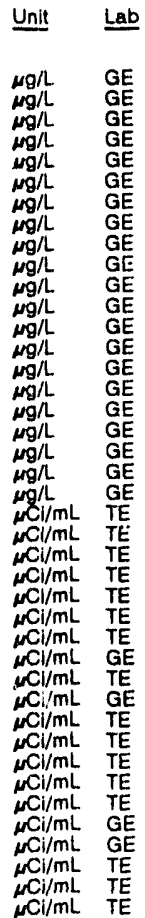

\section{WELL FNB 3 Replicate}

MEASUREMENTS CONDUCTED IN THE FIELD

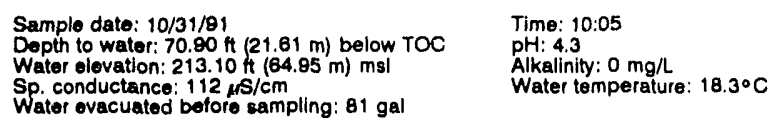

LABORATORY ANALYSES

\begin{tabular}{|c|}
\hline Analyze \\
\hline $\begin{array}{l}\text { pH } \\
\text { Specific conductance } \\
\text { Arsenic } \\
\text { Barium } \\
\text { Benzene } \\
\text { Beryllium } \\
\text { Bromodichloromethane } \\
\text { Bromoform } \\
\text { Bromomethane } \\
\text { Cadmium } \\
\text { Calclum } \\
\text { Carbon totrachloride } \\
\text { Chloride } \\
\text { Chlorobenzene } \\
\text { Chloroethane } \\
\text { Chloroethene Ninyl chloride) } \\
\text { 2-Chloroethyl vinyl ether } \\
\text { Chloroform } \\
\text { Chloromethane } \\
\text { Chromium } \\
\text { Copper } \\
\text { Dibromochloromethane } \\
\text { 1,1-Dichloroethane } \\
\text { 1,2-Dichloroethane } \\
\text { 1,1-Dichloroethylene } \\
\text { trans-1,2-Dichloroethylene } \\
\text { Dichloromethane } \\
\text { 1,2-Dichloropropane } \\
\text { cls-1,3-Dichloropropene } \\
\text { trans-1,3-Dichloropropene } \\
\text { Ethylberizene } \\
\text { Fluoride } \\
\text { lron } \\
\text { Lad } \\
\text { Magneslum } \\
\text { Manganese } \\
\text { Mercury } \\
\text { Nickel } \\
\text { Nitrate as nitrogen } \\
\text { Phenols } \\
\text { Potassium } \\
\text { Selenium }\end{array}$ \\
\hline
\end{tabular}

\begin{tabular}{l} 
Pesult \\
\hline \\
4.6 \\
85 \\
$<2.0$ \\
33 \\
$<1.0$ \\
$<3.0$ \\
$<1.0$ \\
$<1.0$ \\
$<1.0$ \\
$<2.0$ \\
2.200 \\
$<1.0$ \\
3,620 \\
$<1.0$ \\
$<1.0$ \\
$<1.0$ \\
$<1.0$ \\
$<1.0$ \\
$<1.0$ \\
$<4.0$ \\
5.0 \\
$<1.0$ \\
$<1.0$ \\
$<1.0$ \\
$<1.0$ \\
$<1.0$ \\
$<1.0$ \\
$<1.0$ \\
$<1.0$ \\
$<1.0$ \\
$<1.0$ \\
$<100$ \\
18 \\
$<3.0$ \\
2.150 \\
104 \\
0.23 \\
7.9 \\
8.550 \\
$<5.0$ \\
$<500$ \\
$<2.0$ \\
\end{tabular}

WELL FNB 3 collected on 10/31/91, laboratory analyses (cont.)

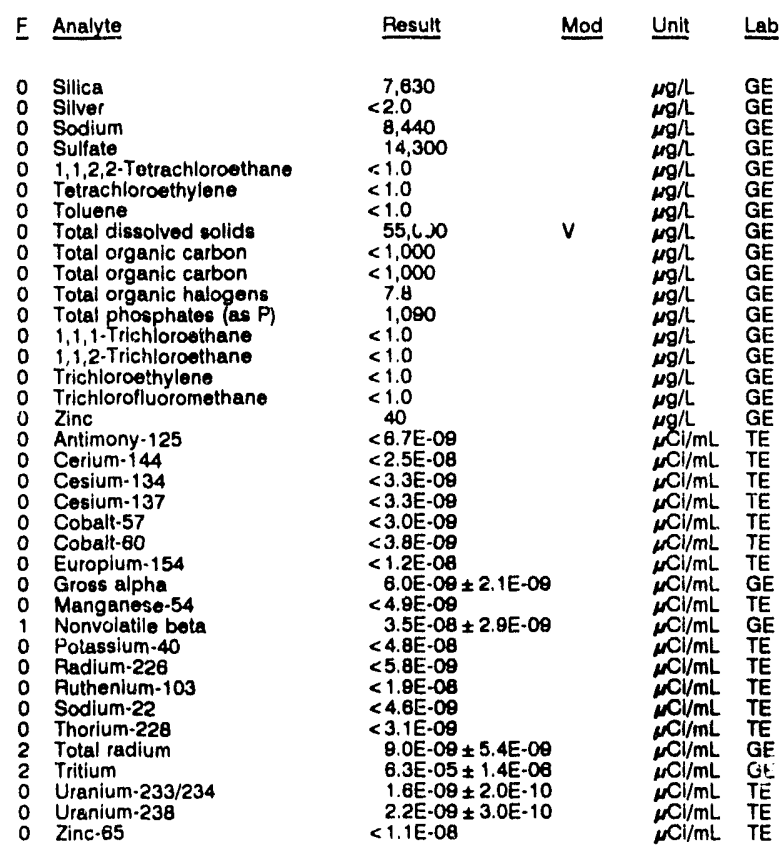

\section{WELL FNB 4}

I. IEASUREMENTS CONDUCTED IN THE FIELD

$\begin{array}{ll}\text { Sample date: } 10 / 31 / 91 & \text { Time: } 10: 50 \\ \text { Depth to water: } 73.88 \mathrm{H}(22.55 \mathrm{~m}) \text { below TOC } & \text { pH: } 4.3 \\ \text { Water elevation: } 217.52 \mathrm{H}(66.30 \mathrm{~m}) \mathrm{ms} & \text { Alkalinity: } 0 \mathrm{mg} / \mathrm{L} \\ \text { Sp. conductance: } 29 \mu \mathrm{s} / \mathrm{cm} & \text { Water temperature: } 18.4^{\circ} \mathrm{C} \\ \text { Water evacuated belore sampling: } 100 \mathrm{gal} & \end{array}$

Water evacuated betore sampling: $100 \mathrm{gal}$

LABORATCRY ANALYSES

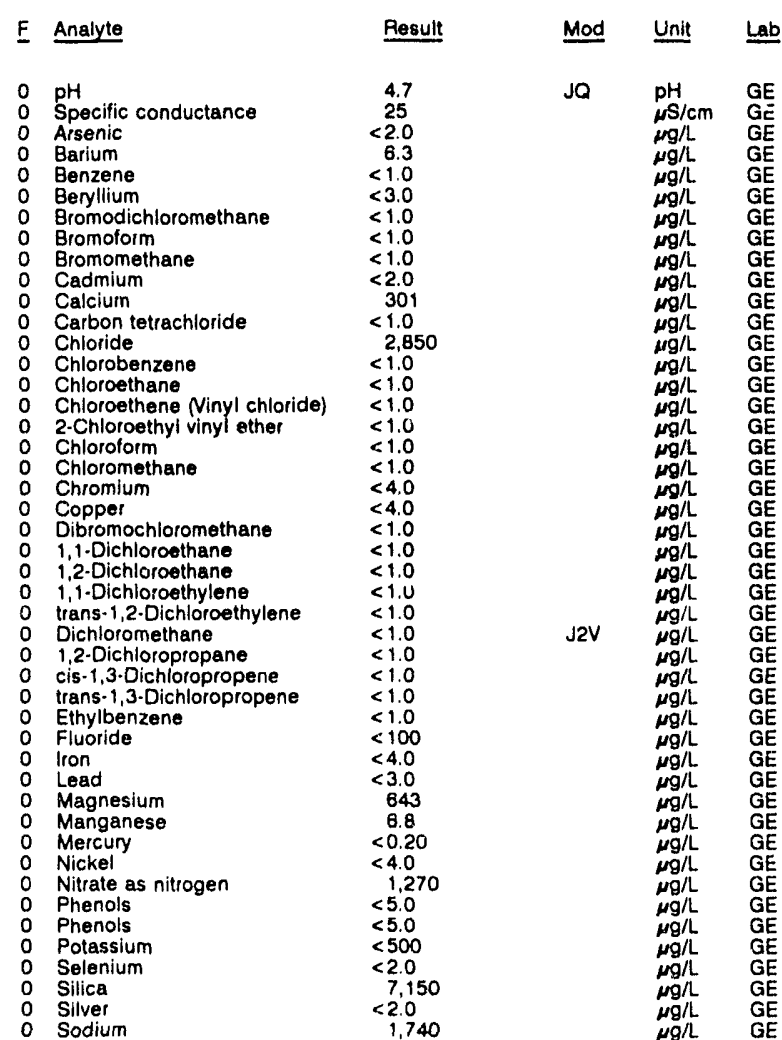


ANALYTICAL RESULTS

WELL FNB 4 collected on 10/31/91, laboratory analyses (cont.)

\begin{tabular}{|c|c|c|c|}
\hline Analyte & Result & Mod & Unit \\
\hline 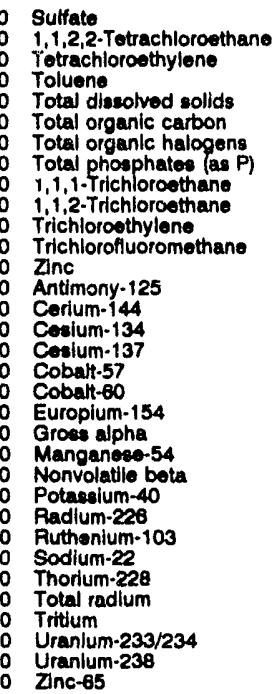 & $\begin{array}{l}1,550 \\
<1.0 \\
<1.0 \\
<1.0 \\
15,000 \\
<1,000 \\
12 \\
60 \\
<1.0 \\
<1.0 \\
<1.0 \\
<1.0 \\
<2.0 \\
<8.0 E-09 \\
<3.1 E-08 \\
<3.8 E-09 \\
<2.8 E-09 \\
<4.2 E-09 \\
<2.9 E-09 \\
<9.5 E-09 \\
22.1 E-09 \pm 1.2 E-09 \\
<3.8 E-09 \\
<2.0 E-09 \\
<3.6 E-08 \\
<6.0 E-09 \\
<2.3 E-08 \\
<3.6 E-09 \\
<3.8 E-09 \\
27.2 E-09 \pm 1.7 E-09 \\
<7.0 E-07 \\
2.0 E-10 \pm 1.0 E-10 \\
<1.0 E-10 \\
<8.3 E-09\end{array}$ & $v$ & 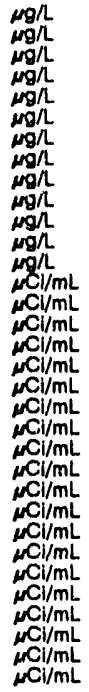 \\
\hline
\end{tabular}

\section{WELL FSB 1TA}

MEASUREMENTS CONDUCTED IN THE FIELD

Sample date: $10 / 14 / \theta 1$

Wapth to water: Not avallable

Wator olevalon. Not avallable

Water evacuated before sampling: $900 \mathrm{gal}$

LABORATORY ANALYSES

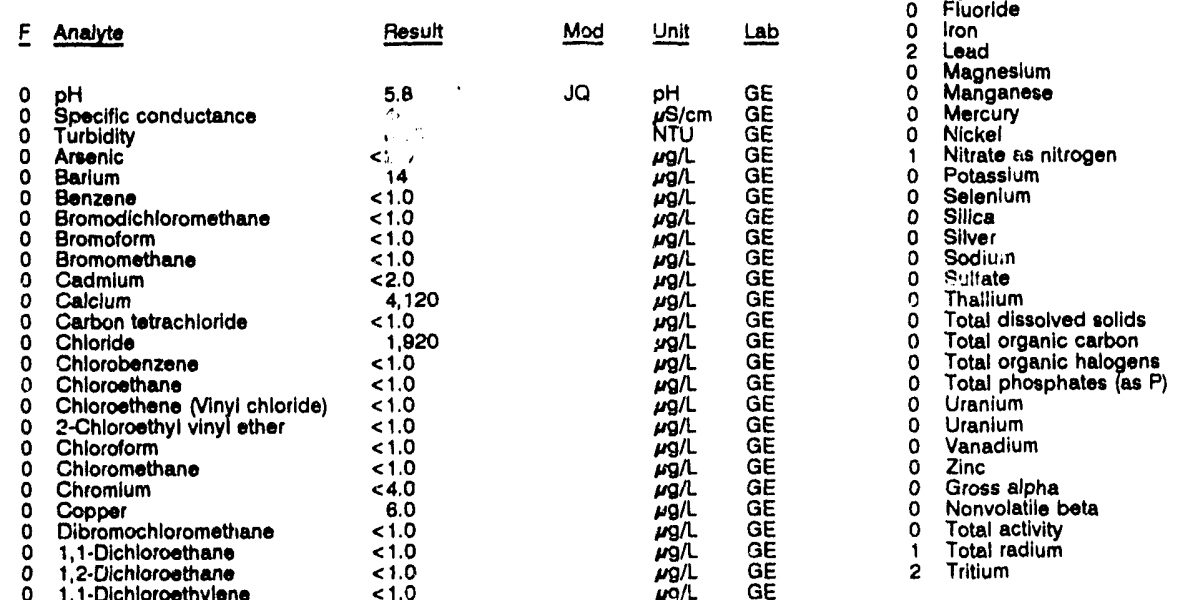

Time: $6: 25$

Alkalinity: $7 \mathrm{mg} / \mathrm{L}$

Water temperature: $184^{\circ} \mathrm{C}$

J2V

$<1.0$

1,1-Dichloroethylene
trans-1,2-Dichloroethylene

Dichloromethane

2,4-Dichlorophenoxyacetic acid $<0.30$

1,2-Dichloropropano

trans.1,3-Dlchlopropono.

Endrin

Ethylbenzene

Flucride

lion

Linuane

Magneslum

Manganose

Mercury

Mothoxychior

Nitrate as nitrogen

Phenois

Selenium

Silica

Silver

Sodium

1,1,2,2.Tetrachloroethane

$<1.0$
$<1.0$

$<1.0$

$<0.0060$

$<1.0$

$<100$

1,730
$<3.0$

$<3.0$
$<0.0050$
390

398

$<0.20$
$<0.50$
70
$<5.0$

$<5.0$

$<2.0$

$<2.0$

99.300

$<\begin{aligned} & 10,900 \\ & <1.0\end{aligned}$
WELL FSB ITA colloctod on 10/14/91, lab sratory aralyses (cont.)

\begin{tabular}{|c|c|c|c|}
\hline Analyte & Resuls & Mod & Unit \\
\hline $\begin{array}{l}\text { Totrachloroethylene } \\
\text { Toluene } \\
\text { Total dissolved solids } \\
\text { Total organic carbon } \\
\text { Total organic halogens } \\
\text { Total phosphates (as P) } \\
\text { Toxaphene } \\
2,4,5-\text { TF (Silvex) } \\
1,1,4-\text { Trichloroethane } \\
1,1,2-\text { Trichloroothane } \\
\text { Trichloroothylene } \\
\text { Trichlorofluoromethane } \\
\text { Gross alpha } \\
\text { Nonvolatile beta } \\
\text { Total radlum } \\
\text { Tritlum }\end{array}$ & $\begin{array}{l}<1.0 \\
<1.0 \\
46,000 \\
<1,000 \\
<5.0 \\
70 \\
<0.24 \\
<0.090 \\
<1.0 \\
<1.0 \\
<1.0 \\
<1.0 \\
3.0 \mathrm{E} \cdot 09 \pm 1.4 \mathrm{E}-09 \\
2.4 \mathrm{E} \cdot 09 \pm 1.5 \mathrm{E}-09 \\
1.2 \mathrm{E}-09 \pm 1.4 \mathrm{E}-09 \\
<7.0 \mathrm{E}-07\end{array}$ & v & 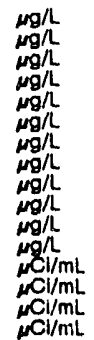 \\
\hline
\end{tabular}

\section{WELL FSB 76}

MEASUREMENTS CONDUCTED IN THE FIELD

$\begin{array}{ll}\text { Sample date: } 10 / 14 / 91 & \text { Time: } 7: 10 \\ \text { Depth to water: } 77.23 \mathrm{~h}(23.54 \mathrm{~m}) \text { below TOC } & \text { pH: } 4.7 \\ \text { Water olevation: } 216.97 \mathrm{H}(88.13 \mathrm{~m}) \mathrm{msl} & \text { Alkalinity: } 0 \mathrm{mg} / \mathrm{h} \\ \text { Sp. conductance: } 52 \mu 5 / \mathrm{cm} & \text { Water temperature: } 17.6^{\circ} \mathrm{C} \\ \text { Water ovacuated bolore sampling: } 52 \mathrm{gal} & \end{array}$

LABORATORY ANALYSES

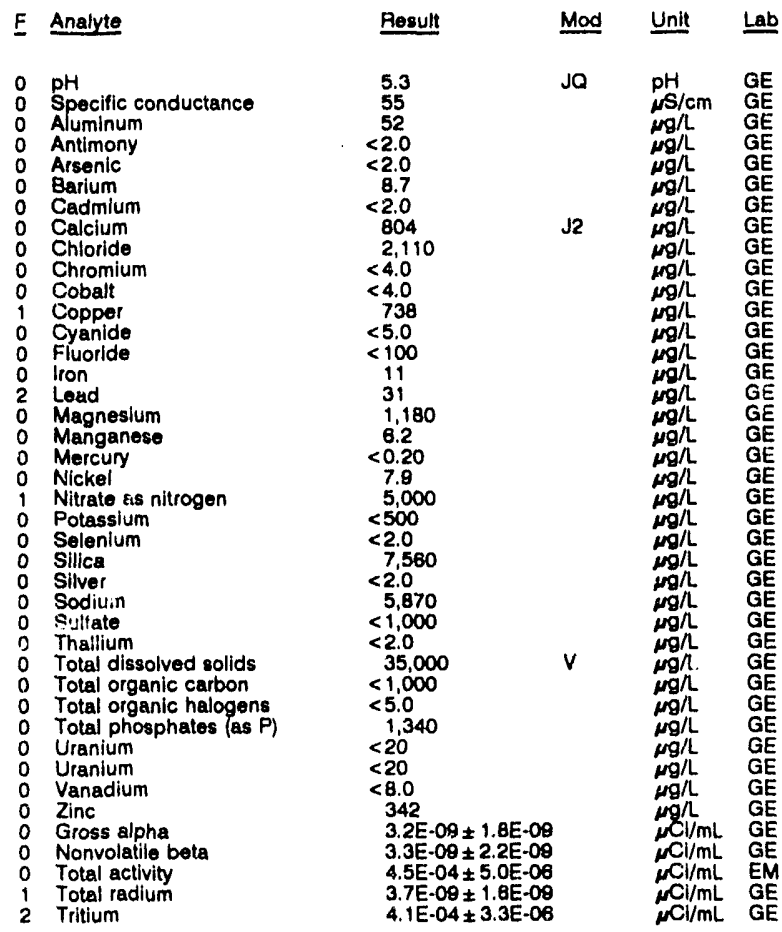

WELL FSB 76A

MEASUREMENTS CONDUCTED IN THE FIELD

Sample date: 10/14/91

Depth to water: $139.88 \mathrm{ft}(42.64 \mathrm{~m})$ below TOC

Time: $8: 30$
pH: 6.6

Water evacuated before sampling: $307 \mathrm{gal}$

Alkalinity: $56 \mathrm{mg} / \mathrm{L}$

LABORATORY ANALYSES

\begin{tabular}{|c|c|c|c|c|}
\hline Analyte & Pesult & Mod & Unit & Lab \\
\hline $\begin{array}{l}\text { pH } \\
\text { Specific conductance } \\
\text { Aluminum } \\
\text { Antimony } \\
\text { Arsenic } \\
\text { Barium } \\
\text { Cadmium } \\
\text { Calcium } \\
\text { Chloride }\end{array}$ & $\begin{array}{c}7.0 \\
142 \\
<20 \\
<2.0 \\
<2.0 \\
25 \\
<2.0 \\
19,200 \\
2520\end{array}$ & JQ & $\begin{array}{l}\mathrm{pH} \\
\mu S / \mathrm{cm} \\
\mu g / L \\
\mu g / L \\
\mu g / L \\
\mu g / L \\
\mu g / L \\
\mu g / L\end{array}$ & $\begin{array}{l}\mathrm{GE} \\
\mathrm{GE} \\
\mathrm{GE} \\
\mathrm{GE} \\
\mathrm{GE} \\
\mathrm{GE} \\
\mathrm{GE} \\
\mathrm{GE} \\
\mathrm{GE}\end{array}$ \\
\hline
\end{tabular}


ANALYTICAL RESULTS

WELL FSB 7EA colloctod on 10/14/81, laboratory analyses (cont.)

\begin{tabular}{|c|c|c|c|}
\hline Analyte & Pesult & Mod & $\underline{\text { Unit }}$ \\
\hline 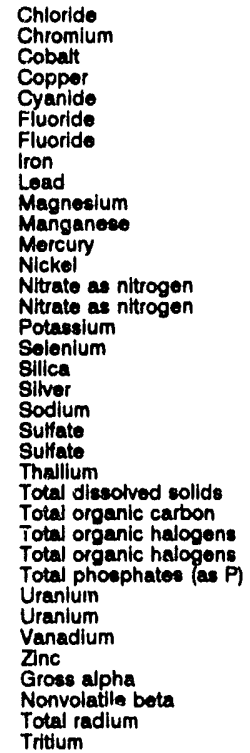 & $\begin{array}{l}2,560 \\
<4.0 \\
<4.0 \\
<4.0 \\
<5.0 \\
148 \\
152 \\
<4.0 \\
<3.0 \\
649 \\
<2.0 \\
<0.20 \\
<4.0 \\
110 \\
110 \\
1,510 \\
<2.0 \\
26,800 \\
<2.0 \\
1,870 \\
8,590 \\
8,630 \\
<2.0 \\
82,000 \\
<1,000 \\
<5.0 \\
<5.0 \\
260 \\
<20 \\
<20 \\
<8.0 \\
<2.0 \\
<2.0 \mathrm{E} \cdot 09 \\
3.4 \mathrm{E}-09 \pm 1.6 \mathrm{E}-09 \\
<1.0 \mathrm{E}-09 \\
4.9 \mathrm{E}-06 \pm 1.0 \mathrm{E}-00\end{array}$ & $v$ & 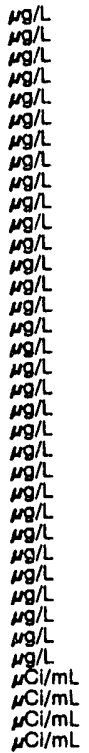 \\
\hline
\end{tabular}

\section{WELL FSB 76B}

MEASUAEMENTS CONDUCTED IN THE FIELD

Sample date: 10/14/91

$32 \mathrm{ft}(43.86 \mathrm{~m})$ below TOC

Water olevation: $150.48 \mathrm{ft}(45.87 \mathrm{~m}) \mathrm{ms}$

Water evacuated betore sampling: $135 \mathrm{gal}$

LABORATORY ANALYSES

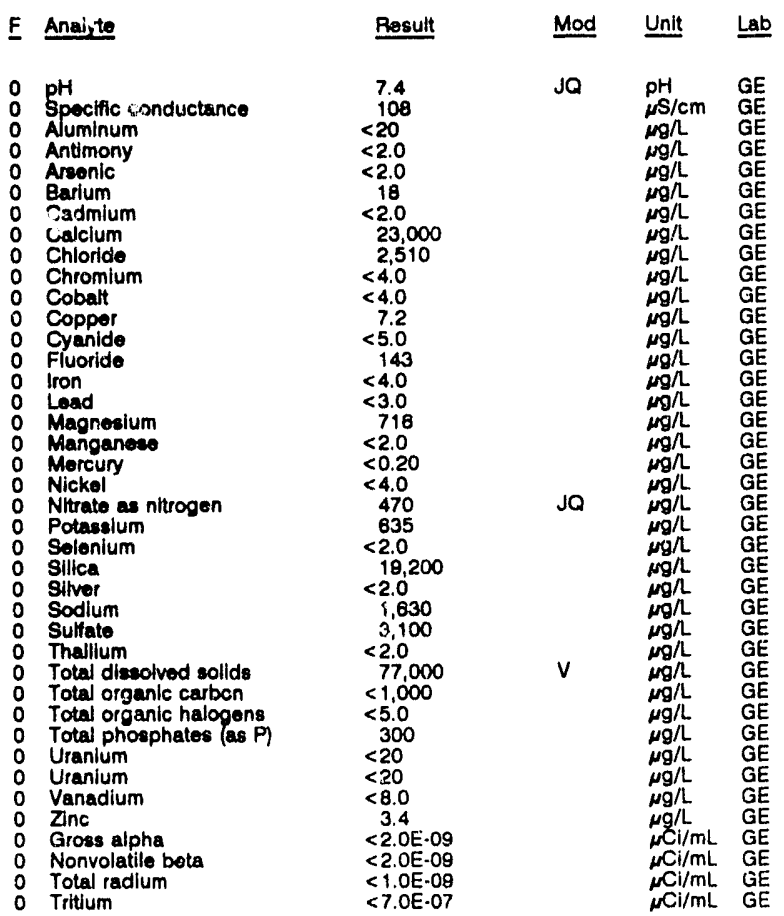

WELL FSB 76C

MEASUREMENTS CONDUCTED IN THE FIELD

Samplo date: 10/14/81

Depth to water: $81.02 \mathrm{ft}(24.70 \mathrm{~m})$ below TOC

Water elevation: $212.58 \mathrm{ht}(64.80 \mathrm{~m}) \mathrm{ms}$

Water evacuated before sampling: $152 \mathrm{gat}$

LABORATORY ANALYSES

F Analyte

Result Mod Unit Lab

${ }_{0}^{0} \quad \mathrm{pH}$ Specific conductance

- Aluminum

Arsenlc

Barium

Cadmium

Chloride

Chloride

Cobalt

O Copper

o Cyanide

$\begin{array}{ll}0 & \text { Fluoride } \\ 0 & \text { Iron } \\ 0 & \text { Lead }\end{array}$

Magnesium

Manganese

Mercury

Nickel

Nitrate as nitrogen

Potassium

Selenium

Silica

Sodium

Sulfate

Sulfate

Thallium

Total dissolved sollds

Total organic carbon

Total organic halogens

O Uranium

Uranium

Vinc

Zinc

Gross alpha

Nonvolatile bola
Total radium

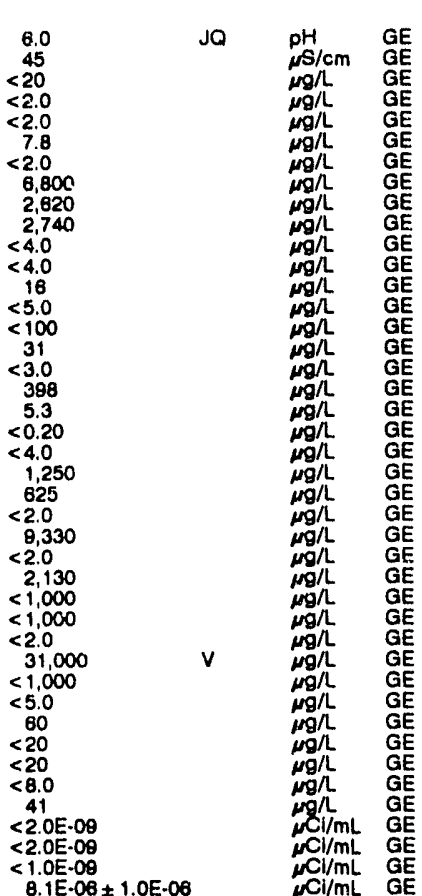

\section{WELL FSB 77}

:MEASUREMENTS CONDUCTEO IN THE FIELO

Semple date: 10/14/91

Depth to water: $61.38 \mathrm{ft}(18.70 \mathrm{mi})$ below TOC

Water elovion: $211.94 \mathrm{ht}(64.60 \mathrm{~m}) \mathrm{ms}$ )

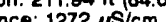

Timo: $7: 40$

Wallnity: $13 \mathrm{mg} / \mathrm{L}$

Water temperature: $18.0^{\circ} \mathrm{C}$

Water evacuated before sampling: $67 \mathrm{gal}$

LABORATORY ANALYSES

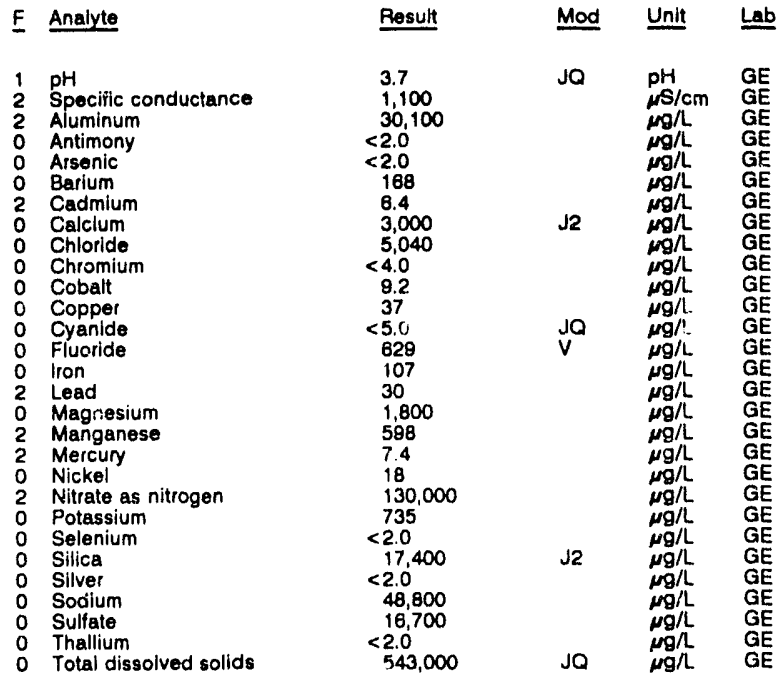




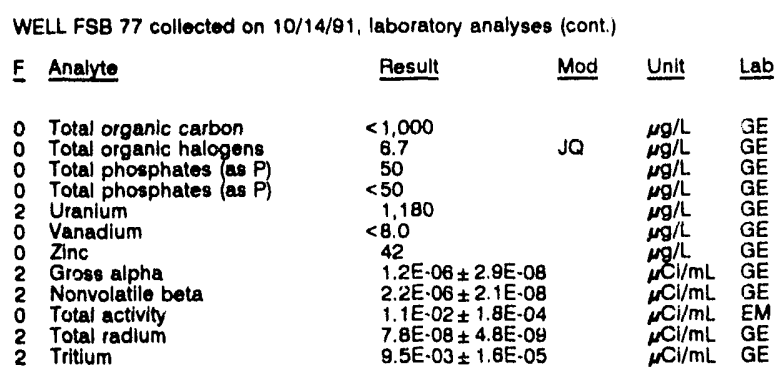

WELL FSB 78

MEASUREMENTS CONDUCTED IN THE FIELD

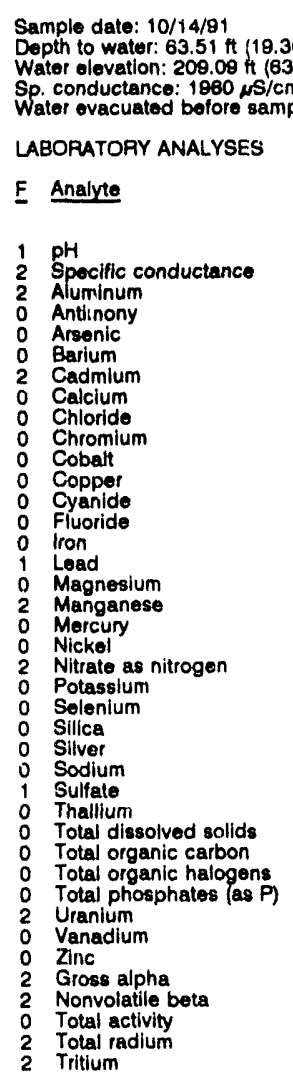

Time: 10:15

Alkalinity: $0 \mathrm{mg} / \mathrm{l}$

Water temperature: $20.1^{\circ} \mathrm{C}$

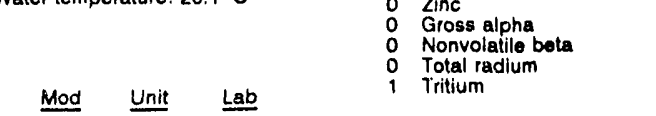

\begin{tabular}{|c|c|c|}
\hline Result & Mod & Unit \\
\hline $\begin{array}{l}3.5 \\
1,650 \\
27,500 \\
<2.0 \\
<2.0 \\
212 \\
16 \\
2,260 \\
2,580 \\
4.8 \\
20 \\
35 \\
5.0 \\
137 \\
137 \\
12 \\
1,200 \\
491 \\
0.21 \\
24 \\
184,000 \\
5,500 \\
<2.0 \\
105,000 \\
2.3 \\
197,000 \\
399,000 \\
<2.0 \\
1.2 \mathrm{E} \cdot+06 \\
2,000 \\
13 \\
<50 \\
1,540 \\
<8.0 \\
87 \\
6.1 \mathrm{E}-07 \pm 4.3 \mathrm{E}-08 \\
1.6 \mathrm{E}-06 \pm 4.4 \mathrm{E}-08 \\
1.5 \mathrm{E}-02 \pm 2.0 \mathrm{E}-04 \\
8.3 \mathrm{E}-08 \pm 5.0 \mathrm{E}-09 \\
1.4 \mathrm{E}-02 \pm 1.9 \mathrm{E}-05\end{array}$ & $\begin{array}{l}\mathrm{J} 2 \\
\mathrm{Ja} \\
\mathrm{Ja} \\
\mathrm{JQ}\end{array}$ & $\begin{array}{l}\mathrm{pH} \\
\mu \mathrm{S} / \mathrm{cm} \\
\mu g / L \\
\mu g / L \\
\mu g / L \\
\mu g / L \\
\mu g / L \\
\mu g / L \\
\mu g / L \\
\mu g / L \\
\mu g / L \\
\mu g / L \\
\mu g / L \\
\mu g / L \\
\mu g / L \\
\mu g / L \\
\mu g / L \\
\mu g / L \\
\mu g / L \\
\mu g / L \\
\mu g / L \\
\mu g / L \\
\mu g / L \\
\mu g / L \\
\mu g / L \\
\mu g / L \\
\mu g / L \\
\mu g / L \\
\mu g / L \\
\mu g / L \\
\mu g / L \\
\mu g / L \\
\mu g / L \\
\mu g / L \\
\mu g / L \\
\mu \mathrm{C} / / \mathrm{mL} \\
\mu \mathrm{Ci} / \mathrm{mL} \\
\mu \mathrm{Ci} / \mathrm{mL} \\
\mu \mathrm{Ci} / \mathrm{mL} \\
\mu \mathrm{Ci} / \mathrm{mL}\end{array}$ \\
\hline
\end{tabular}

WELL FSB 78A

MEASUREMENTS CONOUCTED IN THE FIELD

Sample date: $10 / 14 / 91$ H $(35.78 \mathrm{~m})$ below TOC Water olevation: $155.22 \mathrm{ft}(47.31$

Sp. conductance: $98 \mathrm{\mu S} / \mathrm{cm}$
Wathr evacuated before sampling $336 \mathrm{gal}$

Wainf evacuatod bolore samp

$\begin{array}{ll}\text { E Analyte } \\ 0 & \text { pH } \\ 0 & \text { Specific conductance } \\ 0 & \text { Aluminum } \\ 0 & \text { Antimony } \\ 0 & \text { Arsenic } \\ 0 & \text { Barium } \\ 0 & \text { Cadmium } \\ 0 & \text { Calcium } \\ 0 & \text { Chloride } \\ 0 & \text { Chromlum } \\ 0 & \text { Cobalt } \\ 0 & \text { Copper } \\ 0 & \text { Cyanide } \\ 0 & \text { Fluoride }\end{array}$

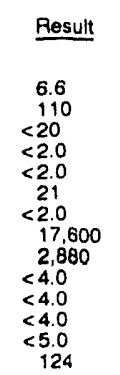

Time: $11: 00$

pH: 6.5

Alkalinity: $46 \mathrm{mg} / \mathrm{L}$ : $20.2^{\circ} \mathrm{C}$

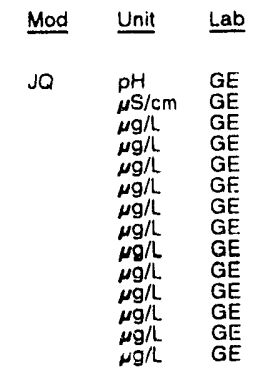

WELL FSB 78A collected on 10/14/91, laboratory analyses (cont.)

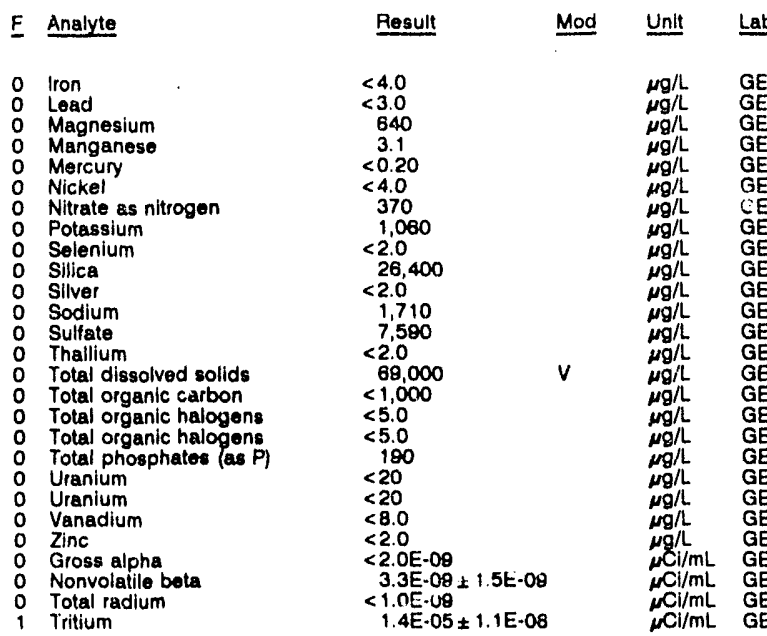

\section{WELL FSB 78B}

MEASUREMENTS CONDUCTED IN THE FIELD

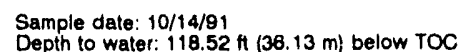
Depth to water: $118.52 \mathrm{Ht}(36.13 \mathrm{~m})$ below TOC PH: 7.2 Water elevation: $154.28 \mathrm{th}(47.03 \mathrm{~m}) \mathrm{ms}$ Alkalinity: $77 \mathrm{mg} / \mathrm{h}$ Sp. conductance: $226 \mu \mathrm{s} / \mathrm{cm}$. LABDRATORY ANALYSES

\begin{tabular}{|c|c|c|c|c|c|}
\hline & Analyte & Result & Mod & Unit & Lab \\
\hline & $\begin{array}{l}\text { pH } \\
\text { S,jecific conductance } \\
\text { Aluminum } \\
\text { Antimony } \\
\text { Arsenic } \\
\text { Barium } \\
\text { Cadmium } \\
\text { Calcium } \\
\text { Chloride } \\
\text { Chromium } \\
\text { Cobalt } \\
\text { Copper } \\
\text { Cyanide } \\
\text { Fluoride } \\
\text { lon } \\
\text { Lead } \\
\text { Magnesium } \\
\text { Manganese } \\
\text { Mercury } \\
\text { Nickel } \\
\text { Nitrate as nitrogen } \\
\text { Potassium } \\
\text { Selenium } \\
\text { Silica } \\
\text { Sityel } \\
\text { Sodium: } \\
\text { Sulfate } \\
\text { Thallium } \\
\text { Total dissolved solids } \\
\text { Total organic carbon } \\
\text { Total organic halogens } \\
\text { Total organic halogens } \\
\text { Total phosphatos (as P) } \\
\text { Total phosphates (as P) } \\
\text { Uranium } \\
\text { Uranium } \\
\text { Vanadium } \\
\text { Zinc } \\
\text { Gross alpha } \\
\text { Nonvolatile beta } \\
\text { rotal activity } \\
\text { Total radium } \\
\text { Tritium }\end{array}$ & $\begin{array}{l}7.4 \\
230 \\
23.3 \\
<2.0 \\
<2.0 \\
41 \\
<2.0 \\
38,200 \\
2,360 \\
<4.0 \\
<4.0 \\
<4.0 \\
<5.0 \\
<100 \\
<4.0 \\
<3.0 \\
833 \\
<2.0 \\
<0.20 \\
<4.0 \\
8.500 \\
707 \\
<2.0 \\
18.700 \\
<2.0 \\
5,690 \\
1.020 \\
<2.0 \\
142,000 \\
<1.000 \\
<5.0 \\
<5.0 \\
90 \\
120 \\
<20 \\
<20 \\
<8.0 \\
2.6 \\
<2.0 \mathrm{E} \cdot 09 \\
1.1 \mathrm{E} \cdot 08 \pm 2.1 \mathrm{E} \cdot 09 \\
21.8 \mathrm{E} \cdot 04 \pm 4.0 \mathrm{E} \cdot 08 \\
<1.0 \mathrm{E} \cdot 09 \\
2.5 \mathrm{E} \cdot 04 \pm 2.6 \mathrm{E}-06\end{array}$ & JQ & $\begin{array}{l}p H \\
\mu \mathrm{S} / \mathrm{cm} \\
\mu g / L \\
\mu g / L \\
\mu g / L \\
\mu g / L \\
\mu g / L \\
\mu g / L \\
\mu g / L \\
\mu g / L \\
\mu g / L \\
\mu g / L \\
\mu g / L \\
\mu g / L \\
\mu g / L \\
\mu g / L \\
\mu g / L \\
\mu g / L \\
\mu g / L \\
\mu g / L \\
\mu g / L \\
\mu g / L \\
\mu g / L \\
\mu g / L \\
\mu g / L \\
\mu g / L \\
\mu g / L \\
\mu g / L \\
\mu g / L \\
\mu g / L \\
\mu g / L \\
\mu g / L \\
\mu g / L \\
\mu g / L \\
\mu g / L \\
\mu g / L \\
\mu g / L \\
\mu g / L \\
\mu C L / m L \\
\mu C i / m L \\
\mu C l / m L \\
\mu C i / m L \\
\mu C i / m L\end{array}$ & $\begin{array}{l}\mathrm{GE} \\
\mathrm{GE} \\
\mathrm{GE} \\
\mathrm{GE} \\
\mathrm{GE} \\
\mathrm{GE} \\
\mathrm{GE} \\
\mathrm{GE} \\
\mathrm{GE} \\
\mathrm{GE} \\
\mathrm{GE} \\
\mathrm{GE} \\
\mathrm{GE} \\
\mathrm{GE} \\
\mathrm{GE} \\
\mathrm{GE} \\
\mathrm{GE} \\
\mathrm{GE} \\
\mathrm{GE} \\
\mathrm{GE} \\
\mathrm{GE} \\
\mathrm{GE} \\
\mathrm{GE} \\
\mathrm{GE} \\
\mathrm{GE} \\
\mathrm{GE} \\
\mathrm{GE} \\
\mathrm{GE} \\
\mathrm{GE} \\
\mathrm{GE} \\
\mathrm{GE} \\
\mathrm{EM} \\
\mathrm{GE}\end{array}$ \\
\hline
\end{tabular}


ANALYTICAL RESULTS

\section{WELL FSB 78C}

MEASUREMENTS CONDUCTED IN THE FIELD

Sample date: 10/15/91

Depth to water: $65.43 \mathrm{At}(19.94 \mathrm{~m})$ below TOC

Water elevation: $208.07 \mathrm{kt}(63.42 \mathrm{~m}$

Water e' belore sampling: 36 gal

The well - y during purging

LABORATORY ANALYSES

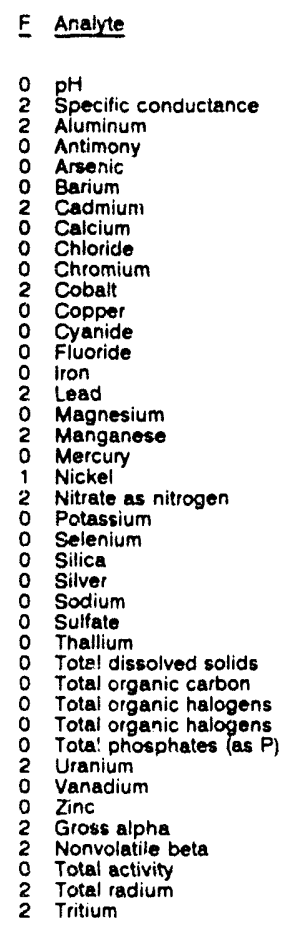

\begin{tabular}{|c|c|c|c|c|}
\hline Result & Mod & Unit & Lab & $\begin{array}{ll}0 & \text { Zinc } \\
2 & \text { Gross alpha }\end{array}$ \\
\hline $\begin{array}{l}4.5 \\
1,750 \\
10,700\end{array}$ & JO & $\mathrm{pH}$ & $\begin{array}{l}G E \\
G E \\
G E\end{array}$ & $\begin{array}{ll}2 & \text { Nonvolatile beta } \\
0 & \text { Total activity } \\
2 & \text { Total radium } \\
2 & \text { Tritium }\end{array}$ \\
\hline
\end{tabular}

Time: $8: 35$

Alkalinity: $0 \mathrm{mg} / \mathrm{h}$

Weter temperature: $19.2^{\circ} \mathrm{C}$

\section{WELL FSB 79}

MEASUREMENTS CONDUCTED IN THE FIELO

Sample date: 10/24/91

Depth to water: $15.05 \mathrm{ft}(4.59 \mathrm{~m})$ below TOC

Watel elevation: $202.75 \mathrm{tt}(61.80 \mathrm{~m}) \mathrm{ms}$

Sp. conductance: $1446 \mu \mathrm{\mu s} / \mathrm{cm}$
Water evacuated before sampling: $75 \mathrm{gal}$

LABOFATORY ANALYSES
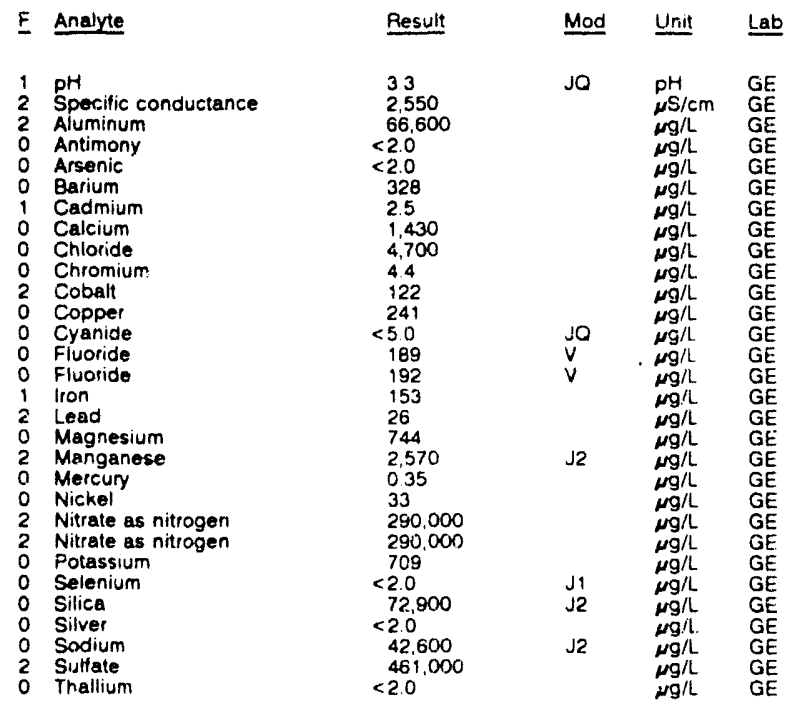

WELL FSB 79A

$<5.0 \quad \mathrm{JO}$

LABORATORY ANALYSES

F Analyte

$\begin{array}{ll}0 & \mathrm{pH} \\ 0 & \text { Specific conductance }\end{array}$

- Aluminum

O Antimony

$\begin{array}{lll}0 & \text { Arsenic } \\ 0 & \text { Barium } \\ 0 & \text { Cadmium } & \\ 0 & \end{array}$

0 Cadriun

Calciun

o Chloride

o Cobalt

O Copper

O Cyanide

Iron

o Lead

- Magnesium

o Mercury

0 Nickel

0 Nitrate as nitrogen

- Potassium

0 Selenium

$\begin{array}{ll}0 & \text { Silica } \\ 0 & \text { Silver }\end{array}$

$\begin{array}{ll}0 & \text { Silver } \\ 0 & \text { Sodium }\end{array}$

0 Sulfate

Thallium

Total dissolved solids

- Total organic halogens

Total phosphutes (as P)

Uranium

- Uranium

0 Zanadiu

o Gross alpha

0 Nonvolatile beta

T Total radium

WELL FSB 79B

Sp. conductance $166 \mathrm{\mu S} / \mathrm{cm}$

LABORATORY ANALYSES

$\begin{array}{ll}\text { F } & \text { Analyte } \\ 0 & \text { pH } \\ 0 & \text { Specific conductance } \\ 0 & \text { Aluminum } \\ 0 & \text { Antimony } \\ 0 & \text { Arsenic } \\ 0 & \text { Barium } \\ 0 & \text { Cadmium } \\ 0 & \text { Calcium } \\ 0 & \text { Chloride } \\ 0 & \text { Chromium } \\ 0 & \text { Cobalt }\end{array}$

\begin{tabular}{|c|c|c|c|c|}
\hline Analyte & Pesult & Mod & Unit & $\underline{\text { Lab }}$ \\
\hline $\begin{array}{l}\text { Total dissolved solids } \\
\text { Total organic carbon } \\
\text { Total organic carbon } \\
\text { Total organic halogens } \\
\text { Total phosphates (as P) } \\
\text { Total phosphates (as P) } \\
\text { Uranium } \\
\text { Vanadium } \\
\text { Zinc } \\
\text { Gross alpha } \\
\text { Nonvolalle beta } \\
\text { Total activity } \\
\text { Total radium } \\
\text { Tritium }\end{array}$ & $\begin{array}{l}998,000 \\
3,000 \\
3,000 \\
<5.0 \\
<50 \\
<50 \\
1,390 \\
<8.0 \\
188 \\
7.9 \mathrm{E}-07 \pm 4.0 \mathrm{E}-00 \\
1.5 \mathrm{E}-06 \pm 4.2 \mathrm{E}-08 \\
1.9 \mathrm{E}-02 \pm 1.0 \mathrm{E}-04 \\
9.7 \mathrm{E}-06 \pm 5.0 \mathrm{E}-00 \\
2.6 \mathrm{E}-02 \pm 2.5 \mathrm{E}-05\end{array}$ & JaV & $\begin{array}{l}\mu g / \mathrm{L} \\
\mu g / \mathrm{L} \\
\mu g / \mathrm{L} \\
\mu g / \mathrm{L} \\
\mu g / \mathrm{L} \\
\mu g / \mathrm{L} \\
\mu g / \mathrm{L} \\
\mu g / \mathrm{L} \\
\mu g / \mathrm{L} \\
\mu \mathrm{Li} / \mathrm{mL} \\
\mu \mathrm{CL} / \mathrm{mL} \\
\mu \mathrm{Cl} / \mathrm{mL} \\
\mu \mathrm{Cl} / \mathrm{mL} \\
\mu \mathrm{Cl} / \mathrm{mL}\end{array}$ & $\begin{array}{l}\mathrm{GE} \\
\mathrm{GE} \\
\mathrm{GE} \\
\mathrm{GE} \\
\mathrm{GE} \\
\mathrm{GE} \\
\mathrm{GE} \\
\mathrm{GE} \\
\mathrm{GE} \\
\mathrm{GE} \\
\mathrm{GE} \\
\mathrm{EM} \\
\mathrm{GE} \\
\mathrm{GE}\end{array}$ \\
\hline
\end{tabular}

MEASUREMENTS CONDUCTED IN THE FIELD

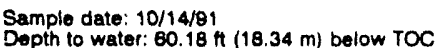

Water elevation: $157.92 \mathrm{ft}(48.13 \mathrm{~m}) \mathrm{msl}$

Water evacuated betore sampling: $351 \mathrm{ggl}$

Time: $9: 30$

pH: 6.2

Whalinity: $24 \mathrm{mg} / \mathrm{L}$

Pesult Mod Unit Lab

Total organic carbon

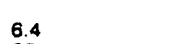

6.4
82
$<20$
$<2.0$
$<2.0$
18
$<2.0$

$<2.0$
12,800
2,360

$\begin{aligned} & 2,360 \\ <4.0 & \end{aligned}$

$<4.0$

$<4.0$

$<100$

$<3.0$

$<2.0$
$<0.20$

$<0.20$

$<4.0$
290
754

754
$<2.0$
18,100
$<2.0$

1,680
3.790

$<2.0$

54,000
$<1,000$

$<1,000$

$<5.0$

150
$<20$
$<20$

$<20$
$<20$
$<8.0$
$<2.0$

2. $3 \mathrm{E}-09 \pm 1.3 \mathrm{E}-08$

2. $2 \mathrm{E}-09 \pm 1.5 \mathrm{E}-09$

$<1.0 E \cdot 09$

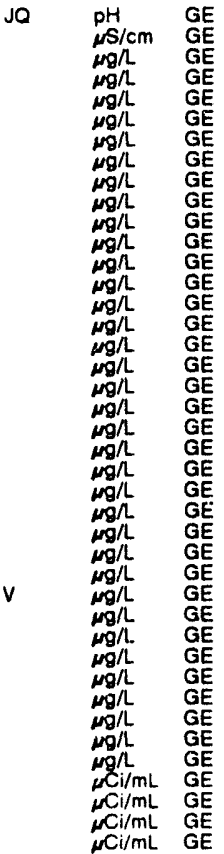

MEASUREMENTS CONDUCTED IN THE FIELD

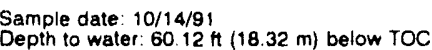

Water elevation: $158.08 \mathrm{ft}(48.18 \mathrm{~m}) \mathrm{msl}$

pH: 6.8

Alkalinity: $81 \mathrm{mg} / \mathrm{L}$

列 $203 \mathrm{gal}$
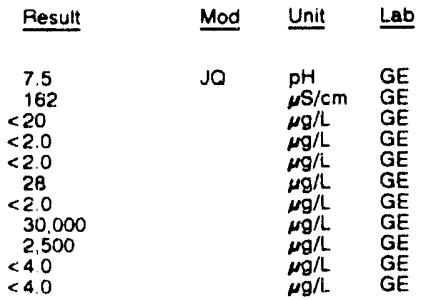
ANALYTICAL RESULTS

\begin{tabular}{|c|c|c|c|}
\hline Analyte & Result & Mod & Unit \\
\hline $\begin{array}{l}\text { Copper } \\
\text { Cyanide } \\
\text { Cyanide } \\
\text { Fluoride } \\
\text { lron } \\
\text { Lead } \\
\text { Magnesium } \\
\text { Manganese } \\
\text { Mercury } \\
\text { Nickel } \\
\text { Nitrate as nitrogen } \\
\text { Potassium } \\
\text { Selenium } \\
\text { Silica } \\
\text { Silver } \\
\text { Sodiurr } \\
\text { Sulfate } \\
\text { Thallium } \\
\text { Total diaeolved solids } \\
\text { Total organic carbon } \\
\text { Total organic halogens } \\
\text { Total phosphates (as P) } \\
\text { Total phosphates (as P) } \\
\text { Uraniurn } \\
\text { Uranium } \\
\text { Vanadium } \\
\text { Zinc } \\
\text { Gross alpha } \\
\text { Nonvolatile beta } \\
\text { Total radium } \\
\text { Tritium }\end{array}$ & $\begin{array}{l}<4.0 \\
<50 \\
<5.0 \\
133 \\
<4.0 \\
<3.0 \\
642 \\
<2.0 \\
<0.20 \\
<4.0 \\
1.180 \\
568 \\
<2.0 \\
25.800 \\
<2.0 \\
1.780 \\
2,520 \\
<2.0 \\
86,000 \\
<1,000 \\
10 \\
330 \\
350 \\
<20 \\
<20 \\
<8.0 \\
<2.0 \\
<2.0 E-09 \\
<2.0 E \cdot 09 \\
1.2 E \cdot 09 \pm 1.3 E \cdot 09 \\
2.3 E \cdot 05 \pm 1.2 E \cdot 06\end{array}$ & $v$ & $\begin{array}{l}\mu g / L \\
\mu g / L \\
\mu g / L \\
\mu g / L \\
\mu g / L \\
\mu g / L \\
\mu g / L \\
\mu g / L \\
\mu g / L \\
\mu g / L \\
\mu g / L \\
\mu g / h \\
\mu g / L \\
\mu g / L \\
\mu g / L \\
\mu g / L \\
\mu g / L \\
\mu g / L \\
\mu g / L \\
\mu g / L \\
\mu g / L \\
\mu g / L \\
\mu g / L \\
\mu g / L \\
\mu g / L \\
\mu g / L \\
\mu g / L \\
\mu C i / m L \\
\mu C i / m L \\
\mu C \mathrm{C} / \mathrm{mL} \\
\mu \mathrm{Ci} / \mathrm{mL}\end{array}$ \\
\hline
\end{tabular}

\section{WELL. FSB 79C}

MEASUREMENTS CONDUCTED IN THE FIELD

$\begin{array}{ll}\text { Sample date: } 10 / 15 / 91 & \text { Time } 7.05 \\ \text { Depth to water: } 21.43 \mathrm{H}(6.53 \mathrm{~m}) \text { below TOC } & \text { pH: } 3.3 \\ \text { Water elevation: } 106.97 \mathrm{H}(60.04 \mathrm{~m}) \mathrm{ms} & \text { Alkalinity: O mg/h } \\ \text { Sp. conductance: } 1370 \mu \mathrm{s} / \mathrm{cm} & \text { Water temperature. } 18.8^{\circ} \mathrm{C} \\ \text { Water evacuated before sampling: } 124 \mathrm{gal} & \end{array}$

LABORATORY ANALYSES

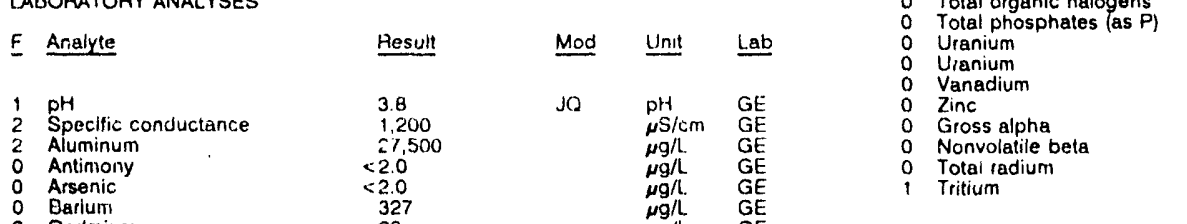

WELL FSB $87 \mathrm{~A}$

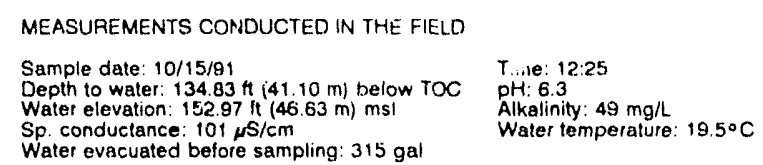

LABORATORY ANALYSES

\begin{tabular}{|c|c|c|c|c|c|}
\hline F & Analyie & Result & Mod & Unit & Lab \\
\hline $\begin{array}{l}0 \\
0 \\
0 \\
0 \\
0 \\
0 \\
0 \\
0 \\
0 \\
0 \\
0 \\
0 \\
0 \\
0 \\
0 \\
0 \\
0 \\
0 \\
0 \\
0 \\
0 \\
0 \\
0 \\
0 \\
0 \\
0 \\
0 \\
0\end{array}$ & 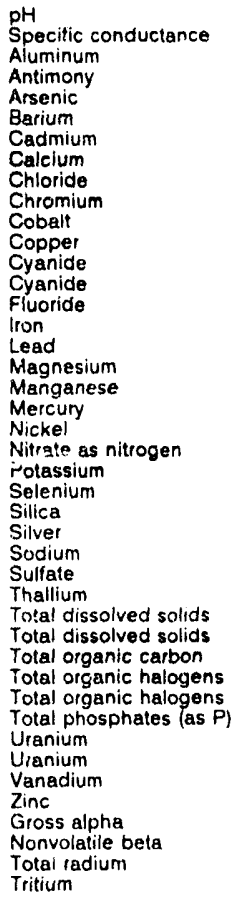 & $\begin{array}{l}6.8 \\
102 \\
<20 \\
<2.0 \\
<2.0 \\
19 \\
<2.0 \\
18,800 \\
2.540 \\
<4.0 \\
<4.0 \\
<4.0 \\
<5.0 \\
<5.0 \\
124 \\
<4.0 \\
<3.0 \\
631 \\
<2.0 \\
<0.20 \\
<4.0 \\
380 \\
900 \\
<2.0 \\
26.300 \\
<2.0 \\
1.600 \\
5.550 \\
<2.0 \\
64.000 \\
69.000 \\
<1.000 \\
<5.0 \\
<5.0 \\
220 \\
<20 \\
<20 \\
<8.0 \\
<2.0 \\
<2.0 \mathrm{E} \cdot 09 \\
<2.0 E \cdot 09 \\
1.2 \mathrm{E} \cdot 09 \pm 1.3 \mathrm{E} \cdot 09 \\
11.2 \mathrm{E} \cdot 05 \pm 8.0 \mathrm{E} \cdot 07\end{array}$ & $\underset{v}{v}$ & $\begin{array}{l}p H \\
\mu S / c m \\
\mu g / L \\
\mu g / L \\
\mu g / L \\
\mu g / L \\
\mu g / L \\
\mu g / L \\
\mu g / L \\
\mu g / L \\
\mu g / L \\
\mu g / L \\
\mu g / L \\
\mu g / L \\
\mu g / L \\
\mu g / L \\
\mu g / L \\
\mu g / L \\
\mu g / L \\
\mu g / L \\
\mu g / L \\
\mu g / L \\
\mu g / L \\
\mu g / L \\
\mu g / L \\
\mu g / L \\
\mu g / L \\
\mu g / L \\
\mu g / L \\
\mu g / L \\
\mu g / L \\
\mu g / L \\
\mu g / L \\
\mu g / L \\
\mu g / L \\
\mu g / L \\
\mu g / L \\
\mu g / L \\
\mu g / L \\
\mu C i / m L \\
\mu C i / m L \\
\mu C \mathrm{i} / \mathrm{mL} \\
\mu C i / m L\end{array}$ & $\begin{array}{l}G E \\
G E \\
G E \\
G E \\
G E \\
G E \\
G E \\
G E \\
G E \\
G E \\
G E \\
G E \\
G E \\
G E \\
G E \\
G E \\
G E \\
G E \\
G E \\
G E \\
G E \\
G E \\
G E \\
G E \\
G E \\
G E \\
G E \\
G E \\
G E \\
G E \\
G E \\
G E \\
G E \\
G E \\
G E \\
G E \\
G E \\
G E \\
G E \\
G E \\
G E \\
G E \\
G E\end{array}$ \\
\hline
\end{tabular}

\section{WELL FSB 87B}

MEASUREMENTS CONDUCTED IN THE FIELD

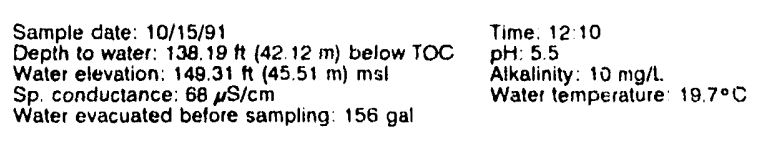

Water evacuated before sampling: $156 \mathrm{gal}$

LABORATORY ANALYSES

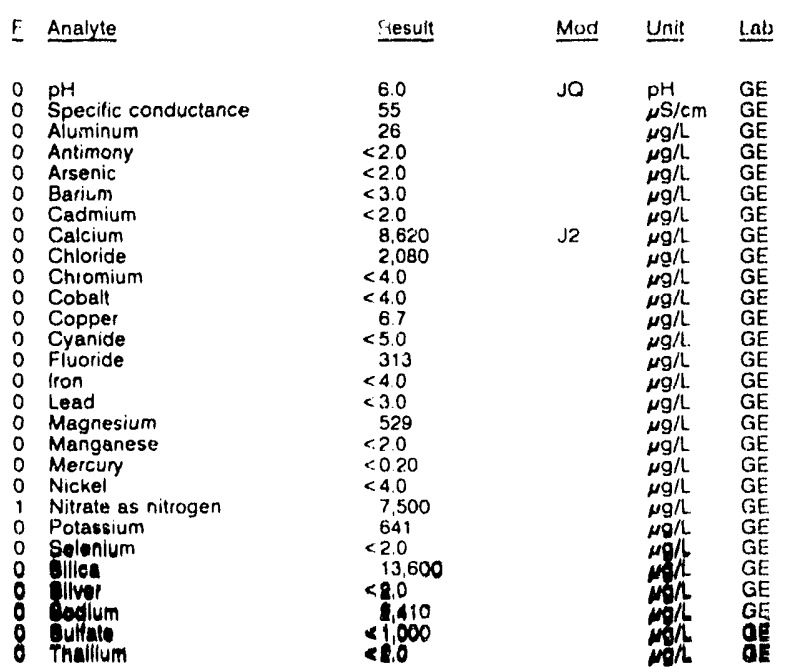


ANALYTICAL RESULTS

WELL FSB 878 collected on 10/15/91, laboratory analyses (cont.)

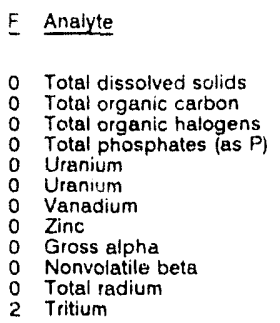

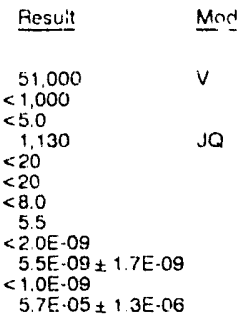

Mod Unit Lab

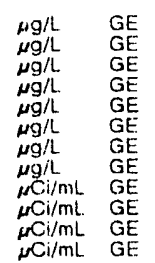

WELL FSB $87 \mathrm{C}$

MEASUREMENTS CONDUCTED IN THE HELO

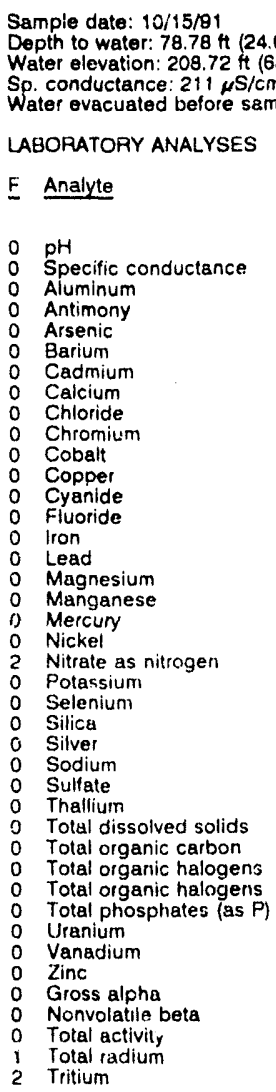

Time: $11: 40$

PH: 5.6

Water temperature: $20.1^{\circ} \mathrm{C}$

Sp. conduclance: $211 \mu \mathrm{S} / \mathrm{cm}$

LABORATORY ANALYSES

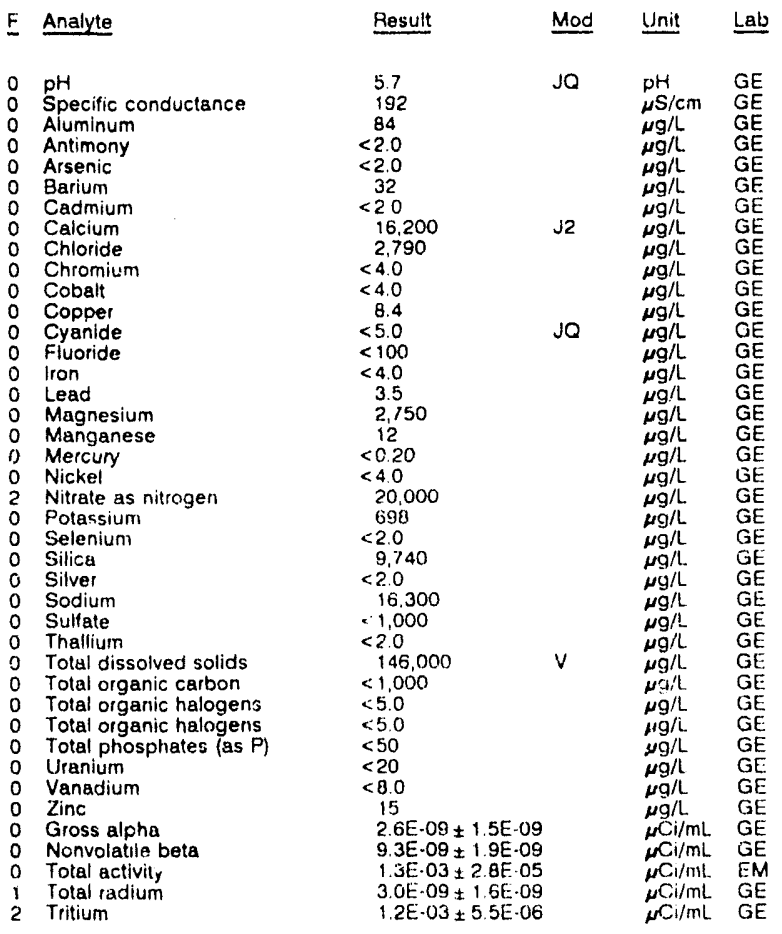

\section{WELL FSB 87D}

MEASUREMENTS CONOUCTED IN THE FIELD

Sample date: $10 / 15 / 91$

Time: 12:45

\section{WELL FSB 88C}

MEASUREMENTS CONDUCTED IN THE FIELD

Sample date: $10 / 15 / 91$

Depth to water: $70.56 \mathrm{ft}(21.51 \mathrm{~m})$ below TOC

Water elevation: $21244 \mathrm{Ht}(64.7$

Sp conductance: $45 \mathrm{\mu s} / \mathrm{cm}$

Alkalinity $12 \mathrm{mg} / \mathrm{l}$

Water temperinture: $19.5 \circ \mathrm{C}$

LABOPATORY ANALYSES

\begin{tabular}{|c|c|c|c|}
\hline F Analyte & Result & Mod & Unit \\
\hline $\begin{array}{ll}0 & \text { pH } \\
0 & \text { Speolfic conductance } \\
\text { Aluminum }\end{array}$ & $\begin{array}{r}5.9 \\
40 \\
<20\end{array}$ & JO & $\begin{array}{l}\mathrm{pH} \\
\mu \mathrm{S} / \mathrm{cm} \\
\mu \mathrm{g} / \mathrm{l}\end{array}$ \\
\hline
\end{tabular}

WELL FSB 88 C collected on 10/15/91, laboratory analyses (cont)

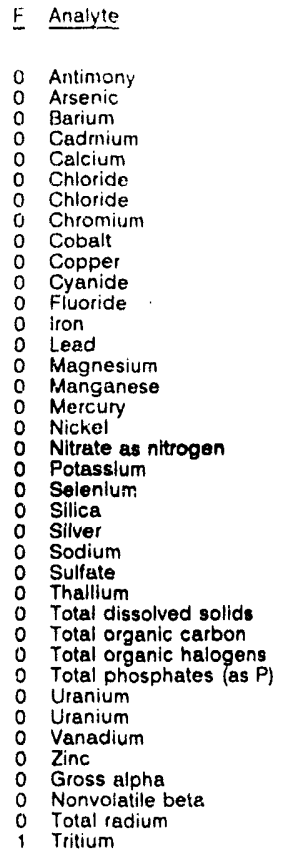

WELL FSB 88D

MEASUREMENTS CONDUCTED IN THE FIELD

Sample date: $10 / 15 / 91$

Depth to water: $66.46 \mathrm{Ht}(20.26 \mathrm{~m}$ ) below roc

Water elevation: $215.94 \mathrm{ft}(65.82 \mathrm{~m}) \mathrm{ms}$ !

Sp. conductance: $247 \mu \mathrm{S} / \mathrm{cm}$
Water evacuated before sampling: $15 \mathrm{gal}$

Result Mod Unit Lab

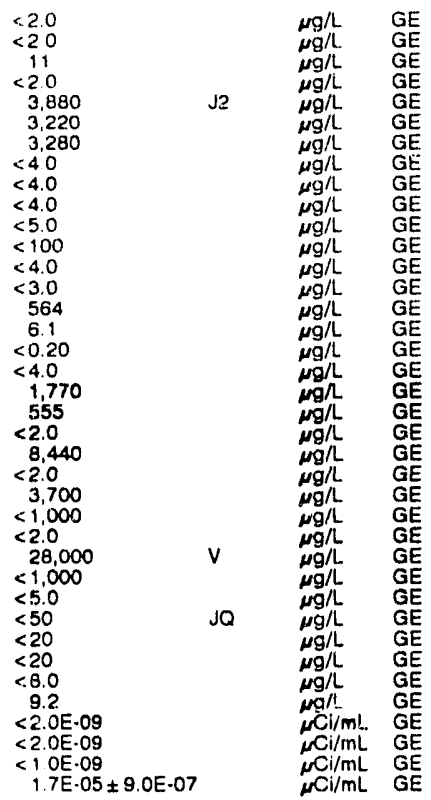

The well went dry during purging.

LABORATORY ANALYSES

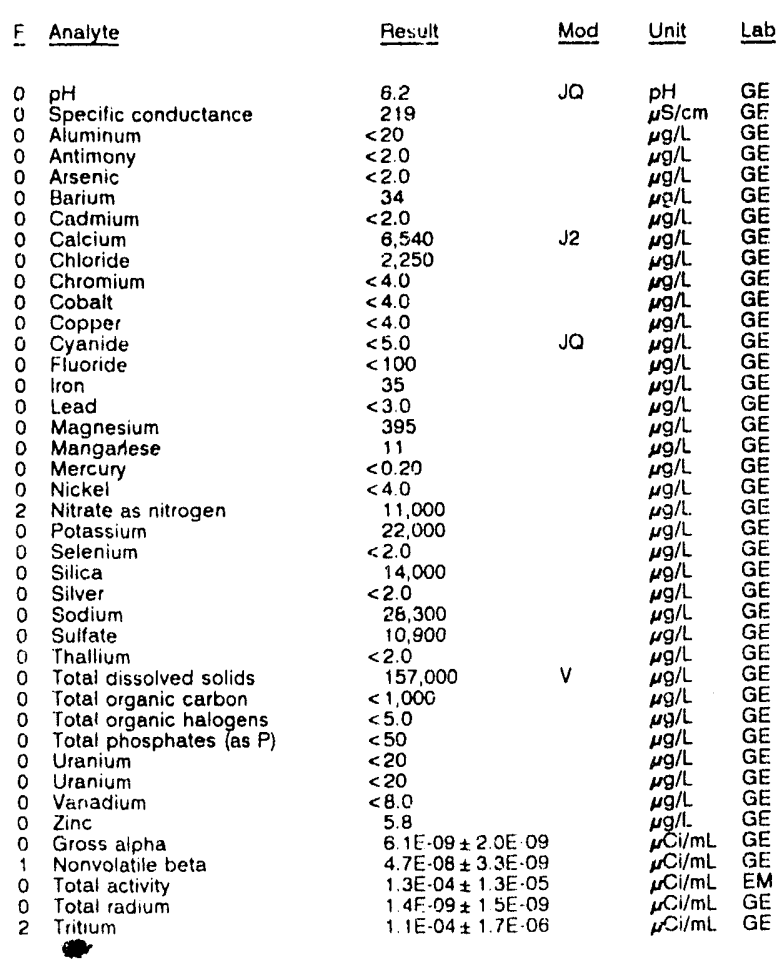

\section{Time: $9: 50$}

PH: 8.0 . $70 \mathrm{mgn}$ Alkalinity: $70 \mathrm{mg} \Omega$
Water temperature: $19.4^{\circ} \mathrm{C}$ 
ANALYTICAL RESULT:

\section{WELL FSB 89C}

MEASUREMENTS CONDUCTED IN THE FIELD

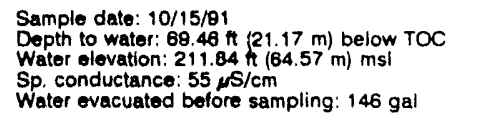

LABORATORY ANALYSES

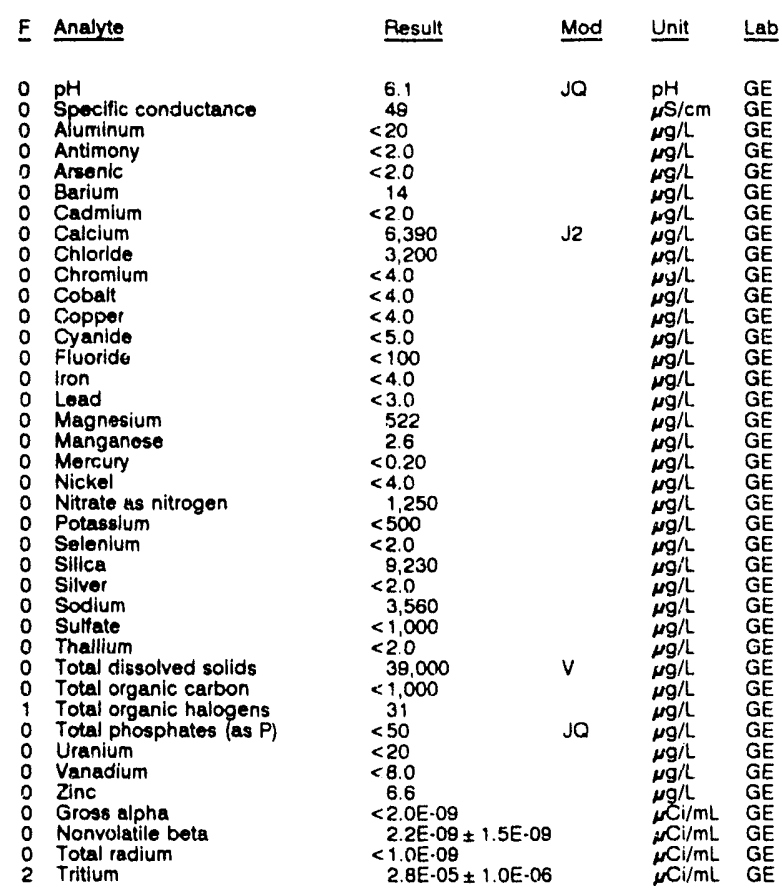

\section{WELL FSB 89D}

MEASUREMENTS CONDUCTED IN THE FIELD

Sample date: 10/15/91 Dopth to water: $65.84 \mathrm{ht}(20.07 \mathrm{~m})$ below TOC Water elevation: $215.36 \mathrm{H}(65.64 \mathrm{~m}) \mathrm{ms}$ ) Water ovacuated before sampling: $35 \mathrm{gal}$ LABORATORY ANALYSES

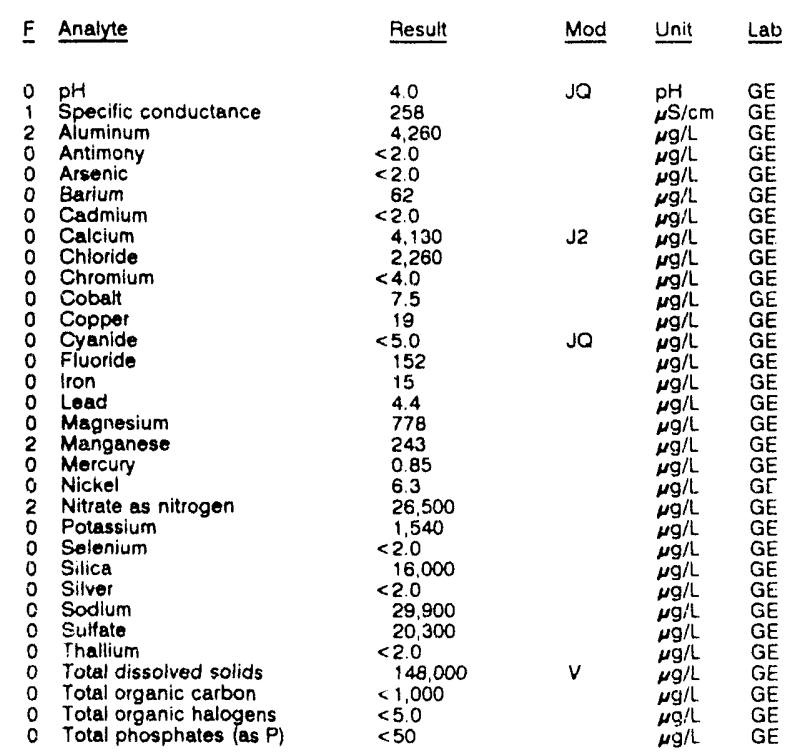

WELL FSE 890 collected on 10/15/91, laboratory analyses (cont.)

\begin{tabular}{|c|c|c|c|}
\hline E Analyte & Result & Mod & Unit \\
\hline $\begin{array}{ll}0 & \text { Uranium } \\
0 & \text { Vanadium } \\
0 & \text { Zinc } \\
2 & \text { Gross alpha } \\
2 & \text { Nonvolatile beta } \\
0 & \text { Total activity } \\
0 & \text { Total activity } \\
2 & \text { Total radium } \\
2 & \text { Tritium }\end{array}$ & $\begin{array}{l}<20 \\
<8.0 \\
31 \\
1.4 \mathrm{E}-07 \pm 8.1 \mathrm{E}-09 \\
4.8 \mathrm{E} \cdot 07 \pm 9.6 \mathrm{E}-08 \\
9.8 \mathrm{E}-04 \pm 2.4 \mathrm{E}-05 \\
9.8 \mathrm{E}-04 \pm 2.4 \mathrm{E}-05 \\
2.2 \mathrm{E}-08 \pm 3.0 \mathrm{E}-09 \\
9.2 \mathrm{E}-04 \pm 4.8 \mathrm{E}-06\end{array}$ & & $\begin{array}{l}\mu \mathrm{g} / \mathrm{L} \\
\mu \mathrm{g} / \mathrm{L} \\
\mu \mathrm{g} / \mathrm{L} \\
\mu \mathrm{Ci} / \mathrm{mL} \\
\mu \mathrm{Ci} / \mathrm{mL} \\
\mu \mathrm{Ci} / \mathrm{mL} \\
\mu \mathrm{Ci} / \mathrm{mL} \\
\mu \mathrm{Cl} / \mathrm{mL} \\
\mu \mathrm{Ci} / \mathrm{mL}\end{array}$ \\
\hline
\end{tabular}

WELL. FSB 90C

MEASUREMENTS CONDUCTED IN THE FIELD

Sample date: 10/15/91

Depth to water: $67.67 \mathrm{ft}(20.63 \mathrm{~m})$ below TOC

Water elevation: $210.73 \mathrm{H}(64.23 \mathrm{~m}) \mathrm{ms}$ !

Sp. conductance: $181 \mu \mathrm{s} / \mathrm{cm}$

Time: $9: 30$

Alkalinity: $29 \mathrm{mg} / \mathrm{L}$

Water temperature: $19.5^{\circ} \mathrm{C}$

LABORATORY ANALYSES

E Analyte Result Mod Unit Lab

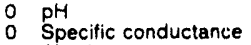

o Aluminum

Arsenic

0 Barium

Cadmium

Calcium

O Chromium

0 Cobalt

O Copper

O Cyanide

0 lion

0 Lead

Magnesium

1 Manganese

Nickel

Nitrate as nitrogen

Potassium

Selenium

Silver

Sodium

Sulfate

Total dissolved solids

Total organic carbon

Total organic carbon

Total organic halogens

Total phosph

Uranium

Uranium

Zine

o Gross alpha

Nonvolatile beta

Total activity

2 Tritium

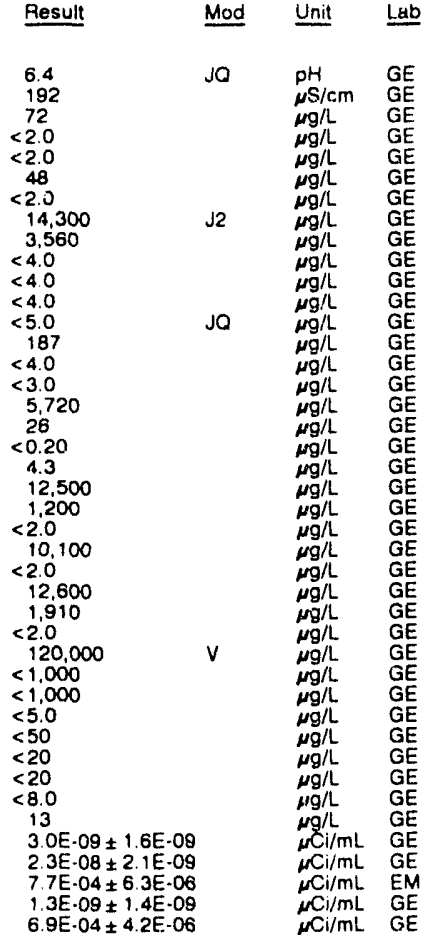

WELL FSB 90D

MEASUREMENTS CONDUCTED IN THE FIELD

$\begin{array}{ll}\text { Sample date: } 10 / 15 / 91 & \text { Time: } 9.00 \\ \text { Depth to water: } 64.36 \mathrm{H}(19.62 \mathrm{~m}) \text { below TOC } & \text { pH: } 4.1 \\ \text { Water elevation: } 214.24 \mathrm{H}(65.30 \mathrm{~m}) \mathrm{msl} & \text { Alkalinity: } 0 \mathrm{mg} / \mathrm{h} \\ \text { Sp. conductance: } 411 \mu \mathrm{cm} / \mathrm{cm} & \text { Water temperature: } 19.2^{\circ} \mathrm{C} \\ \text { Water evacuated before sampling: } 12 \mathrm{gal} & \end{array}$

The well went dry during purgirit

LABORATORY ANALYSES

\begin{tabular}{|c|c|c|c|}
\hline Analyte & Result & Mod & Unit \\
\hline $\begin{array}{l}\text { pH } \\
\text { Specific conductance } \\
\text { Aluminum } \\
\text { Antimony } \\
\text { Arsenic } \\
\text { Barium } \\
\text { Cadmium } \\
\text { Calcium } \\
\text { Chloride } \\
\text { Chromium } \\
\text { Cobalt } \\
\text { Coppet } \\
\text { Cyanide } \\
\text { Fluoride } \\
\text { iron }\end{array}$ & $\begin{array}{l}4.4 \\
350 \\
8.510 \\
<2.0 \\
<2.0 \\
108 \\
2.8 \\
2.700 \\
2.580 \\
<4.0 \\
8.1 \\
57 \\
<5.0 \\
504 \\
39\end{array}$ & JO & $\begin{array}{l}\mathrm{pH} \\
\mu \mathrm{S} / \mathrm{cm} \\
\mu g / L \\
\mu g / L \\
\mu g / L \\
\mu g / L \\
\mu g / L \\
\mu g / L \\
\mu g / L \\
\mu g / L \\
\mu g / L \\
\mu g / L \\
\mu g / L \\
\mu g / L \\
\mu g / L\end{array}$ \\
\hline
\end{tabular}


ANALYTICAL RESULTS

\begin{tabular}{|c|c|c|c|}
\hline Analyte & Result & Mod & Unit \\
\hline $\begin{array}{l}\text { Lead } \\
\text { Magneslum } \\
\text { Manganese } \\
\text { Mercury } \\
\text { Nickel } \\
\text { Nitrate as nitrogen } \\
\text { Nitrate as nitrogen } \\
\text { Potassium } \\
\text { Selenium } \\
\text { Silica } \\
\text { Silver } \\
\text { Sodium } \\
\text { Sulfate } \\
\text { Thallium } \\
\text { Toltul dissolved solids } \\
\text { Total organic carbon } \\
\text { Total organic halogens } \\
\text { Total phosphates (as P) } \\
\text { Uranium } \\
\text { Uranium } \\
\text { Vanidium } \\
\text { Zinc } \\
\text { Gross alpha } \\
\text { Nonvolatile beta } \\
\text { Total activity } \\
\text { Total radium } \\
\text { Tritium }\end{array}$ & $\begin{array}{l}40 \\
908 \\
413 \\
0.32 \\
8.8 \\
40,500 \\
40.500 \\
823 \\
<2.0 \\
14.300 \\
<2.0 \\
37,600 \\
2,310 \\
<2.0 \\
205.000 \\
<1.000 \\
550 \\
<50 \\
412 \\
412 \\
<8.0 \\
66 \\
1.4 \mathrm{E} \cdot 07 \pm 8.4 \mathrm{E} \cdot 09 \\
6.2 \mathrm{E} .07 \pm 1.1 \mathrm{E} \cdot 08 \\
1.2 \mathrm{E}-03 \pm 2.7 \mathrm{E}-05 \\
2.1 \mathrm{E} \cdot 08 \pm 2.7 \mathrm{E}-09 \\
1.0 \mathrm{E}-03 \pm 5.0 \mathrm{E}-06\end{array}$ & $\begin{array}{l}v \\
\\
\\
\end{array}$ & 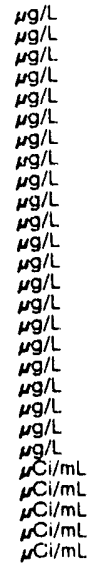 \\
\hline
\end{tabular}

\section{WELL FSB $91 \mathrm{C}$}

MEASUREMENTS CONDUCTED IN THE FIELD

$\begin{array}{ll}\text { Sample date: } 10 / 17 / 91 & \text { Time: } 7: 05 \\ \text { Depth to water: } 68.46 \mathrm{H}(20.87 \mathrm{~m}) \text { below TOC } & \text { pH: } 5.7 \\ \text { Water elevation: } 210.84 \mathrm{Ht}(64.26 \mathrm{~m}) \mathrm{msl} & \text { Alkalinity: } 19 \mathrm{mg} / \mathrm{L} \\ \text { Sp. conductance: } 473 \mu \mathrm{s} / \mathrm{cm} & \text { Water temperature: } 17.5^{\circ} \mathrm{C} \\ \text { Water evacuated before sampling: } 30 \mathrm{gal} & \end{array}$

Water evacuated before samp

The well went dry during purging: $30 \mathrm{gal}$

LABORATORY ANALYSES

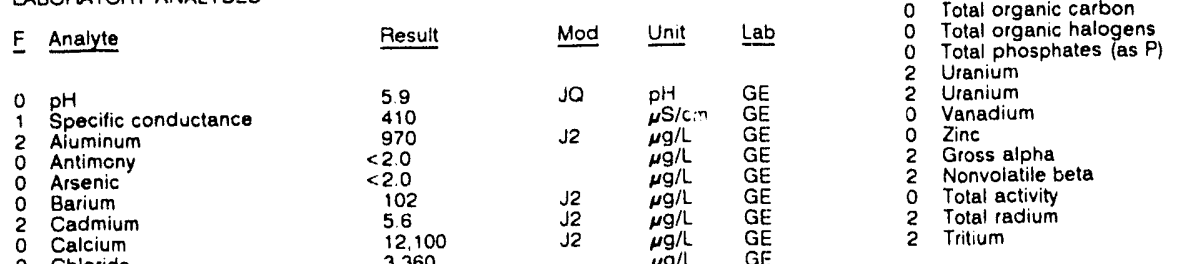

WELL FSB 910

MEASUREMENTS CONDUCTED IN THE FIELD

Sample date: $10 / 16 / 91$

Time: $7: 10$

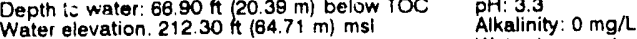

Sp. conductance: $840 \mu \mathrm{s} / \mathrm{cm}$. $30 \mathrm{get}$

Water temperature: $19.5^{\circ} \mathrm{C}$

LABORATORY ANALYSES

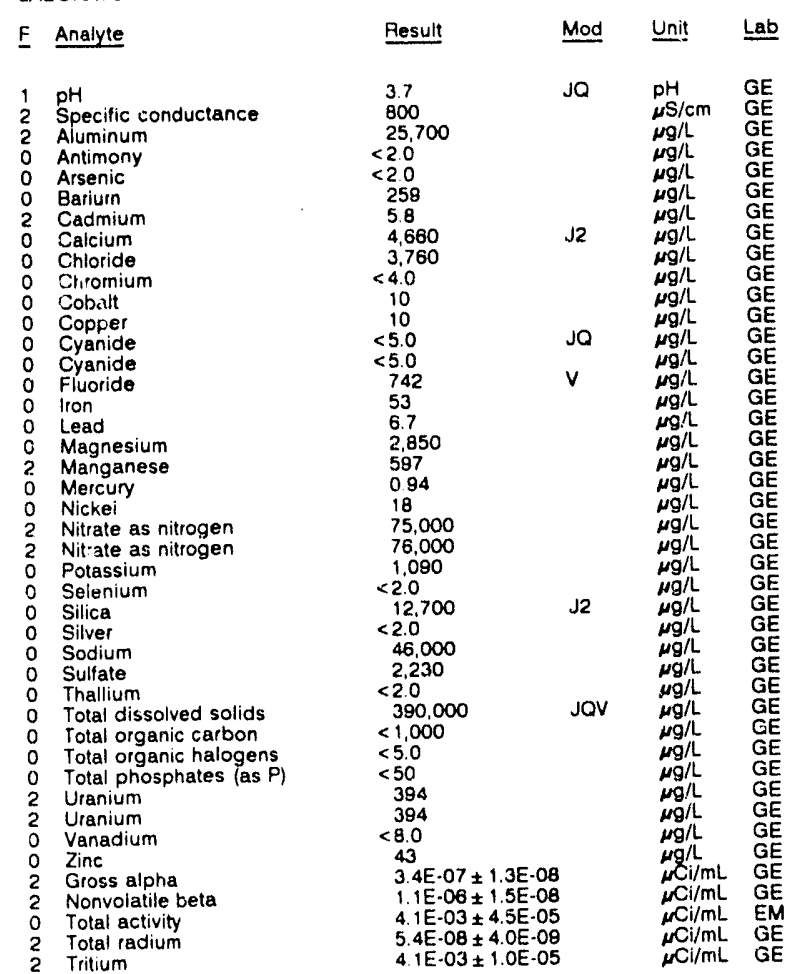

\section{WELL. FSB 92D}

MEASUREMENTS CONOUCTED IN THE FIELD

Depth to water: $64.15 \mathrm{ft}(19.55 \mathrm{~m})$ below TOC

Water elevation: $211.75 \mathrm{Ht} i 64.54 \mathrm{ml} \mathrm{ms}$

Water elevation: $211.75 \mathrm{t}$ i64.54

Water evacuated before sampling: $26 \mathrm{gal}$

pH: 33

Iron

Magnesium

Manganese

Nickel

Nitrate as nitrogen

Potassium

Silica

Silver

Sod:um

Sulfate

Total dissolved solids

Total organic carbon

Total organic halogens

Uranium

Vanadium

Zinc

Gross alpha

Nonvolatile beta

Total activity

Tritium

$1,570 \quad \mathrm{~J} 2$

320
$<0.20$
5.5

5.5
43,500

$<500$

$<2.0$

3.470
$<2.0$
12.500

12,500
1,170

$\begin{aligned} & 1,170 \\ &<20\end{aligned}$

$\begin{aligned} & 413,000 \\ < & 1,000\end{aligned}$

$<1,000$
13
70

$<20$
$<80$

$31_{33 E \cdot 08 \pm 91 E \cdot 09}{ }^{J 2}$

$13 \mathrm{E} \cdot 06 \pm 1.6 \mathrm{E} \cdot 08$

$2.4 E .03 \pm 3.7 E .05$

9. $5 \mathrm{E} \cdot 0 \mathrm{0B} \pm 5 \cdot 4 \mathrm{E} \cdot 09$
$2.2 \mathrm{E} \cdot 03 \pm 75 \mathrm{E} \cdot 06$

LABORATOAY ANALYSES

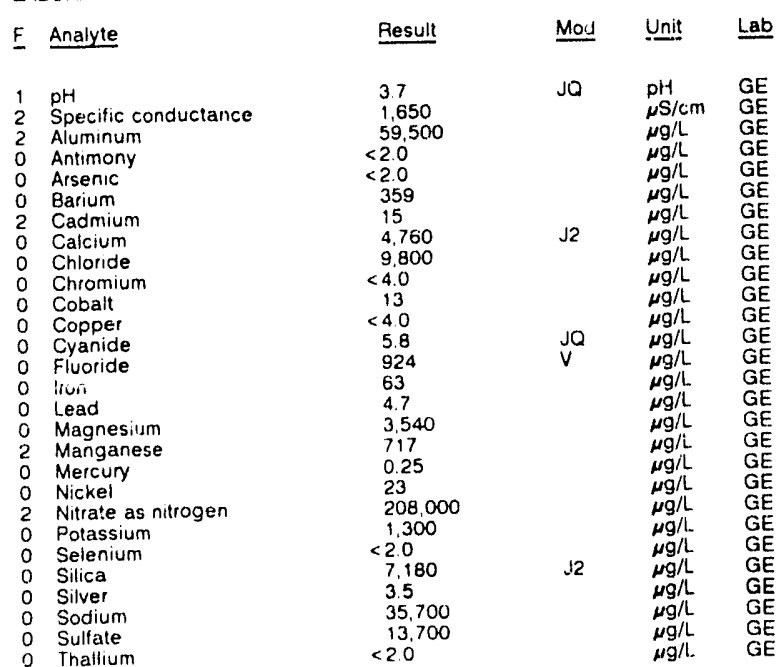


ANALYTICAL RESULTS

WELL FSB 920 collected on 10/15/91, laboratory analyses (cont)

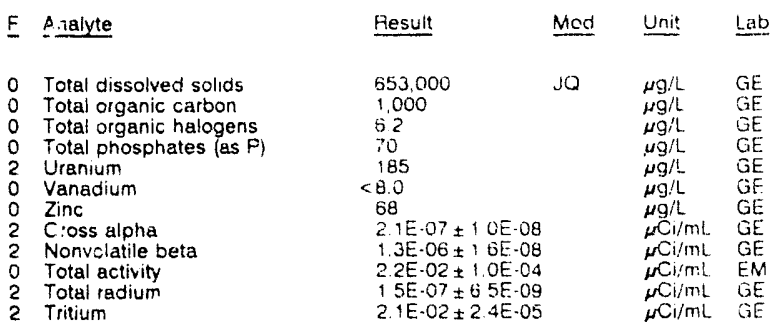

WE!L FSB 93C

MEASUREMENTS CONDUCTED IN THE FIELD

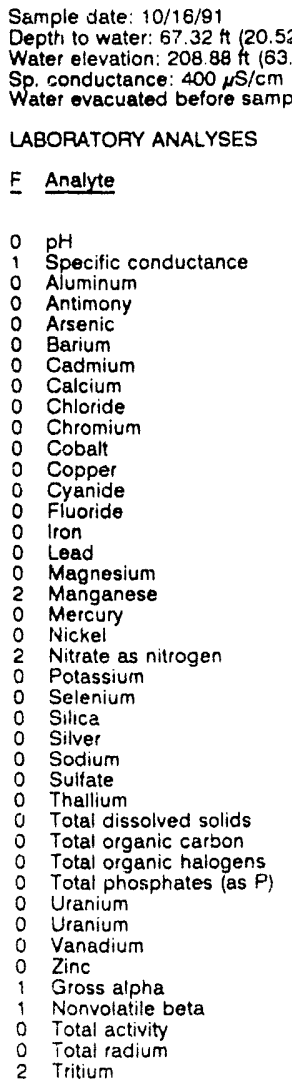

\section{Time 7.40}

Alkalinity: $0 \mathrm{mg} /$

Water temperature: $180^{\circ} \mathrm{C}$

LABORATORY ANALYSES

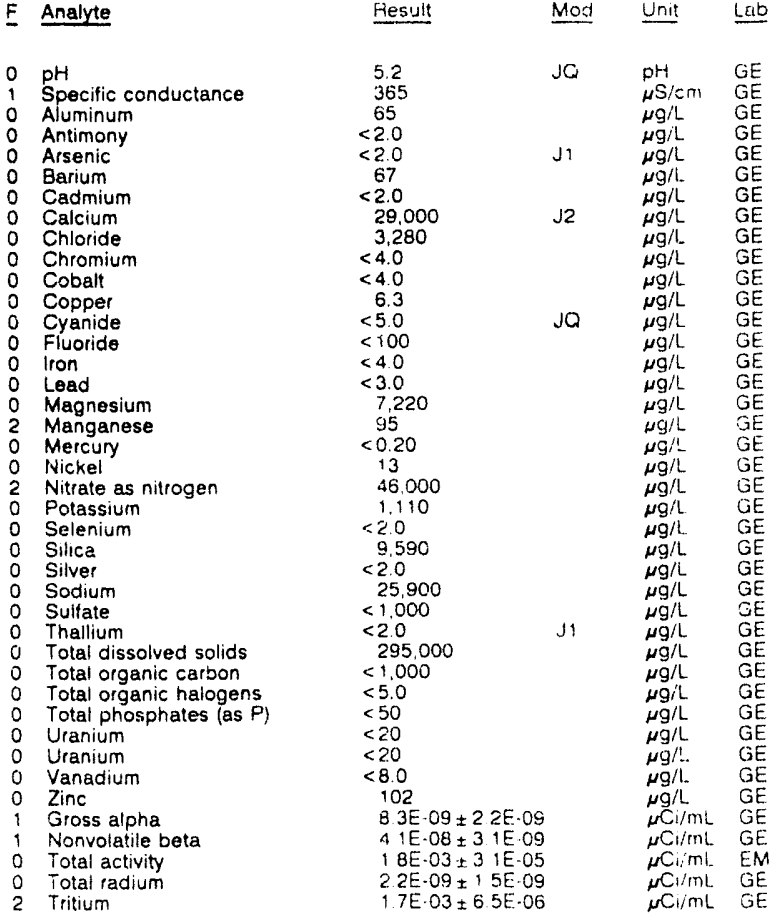

WELL FSB 93D

MEASUREMENTS CONDUCTED IN THE FIELO

Sample date: $10 / 17 / 91$ Depth to water: $65.46 \mathrm{ft}(19.95 \mathrm{~m})$ below TOC Water elevation: $210.64 \mathrm{ft}(64.20 \mathrm{~m}) \mathrm{ms}$ l

Sp. conductance: $1056 \mu \mathrm{S} / \mathrm{cm}$

Water evacuated before sampling: $10 \mathrm{ga}$

The well went dry during purging

LABORATORY ANALYSES

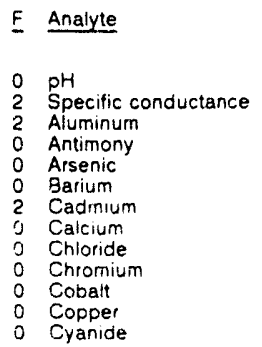

\begin{tabular}{|c|c|c|}
\hline Result & Mod & Unit \\
\hline 4.5 & JO & $\mathrm{PH}$ \\
\hline 14,300 & $\mathrm{~J} 2$ & $\begin{array}{l}\mu \mathrm{s} / \mathrm{cm} \\
\mu \mathrm{g} / \mathrm{L}\end{array}$ \\
\hline $\begin{array}{l}<2.0 \\
<20\end{array}$ & & \\
\hline $\begin{array}{r}<2.0 \\
305\end{array}$ & $\mathrm{~J} 2$ & $\mu g / L$ \\
\hline 24 & $\mathrm{~J} 2$ & $\mu g: L$ \\
\hline 36.800 & Jü & $\mu g / L$ \\
\hline 4.040 & 11 & $\mu$ \\
\hline $\begin{array}{r}<40 \\
76\end{array}$ & 13 & $\mu g / h$ \\
\hline 28 & $\sqrt{2}$ & $\mu \mathrm{giL}$ \\
\hline$<50$ & 10 & $\mu \mathrm{g} / \mathrm{L}$ \\
\hline
\end{tabular}

WELL FSA 930 collected on 10/17/91, haboratory analyses cont:

$\begin{array}{ll}\text { F } & \text { Analyte } \\ & \\ 0 & \text { Fluorite } \\ 0 & \text { lron } \\ 2 & \text { Lead } \\ 0 & \text { Mannesiurn } \\ 2 & \text { Mainganese } \\ 0 & \text { Mercury } \\ 0 & \text { Nickel } \\ 2 & \text { Nitrate as nitrogen } \\ 2 & \text { Nitrate as nitrogen } \\ 0 & \text { Potassium } \\ 0 & \text { Selenium } \\ 0 & \text { Silica } \\ 0 & \text { Silver } \\ 0 & \text { Sodium } \\ 0 & \text { Sulfate } \\ 0 & \text { Thallium } \\ 0 & \text { Total dissolved solids } \\ 0 & \text { Total organic carbon } \\ 0 & \text { Total organc halogens } \\ 0 & \text { Total phosphates (as } \\ 2 & \text { Uranium } \\ 2 & \text { Uranium } \\ 0 & \text { Vanadium } \\ 0 & \text { Zinc } \\ 2 & \text { Gross alpha } \\ 2 & \text { Nonvolatile beta } \\ 0 & \text { Total activity } \\ 2 & \text { Total radium } \\ 2 & \text { Tritium }\end{array}$

\begin{tabular}{|c|c|c|c|}
\hline Sesult & Mod & Unit & Lit \\
\hline 705 & $\mathrm{v}$ & $\mu g / \mathrm{L}$ & aE \\
\hline 14? & $\sqrt{2}$ & $\mu \mathrm{g} / \mathrm{L}$ & \\
\hline 16 & & $\mu \mathrm{g} / \mathrm{L}$ & \\
\hline 9,390 & $\mathrm{~J} 2$ & $\mu \mathrm{g} \cdot \mathrm{L}$ & \\
\hline 606 & J? & $\mu g, t$ & \\
\hline$<020$ & & $\mu \mathrm{g} / \mathrm{L}$ & \\
\hline 13 & $\sqrt{2}$ & $\mu \mathrm{g} / 1$ & \\
\hline 105,005 & & $i \mathrm{~g} / \mathrm{L}$ & \\
\hline 108,000 & & $19 / \mathrm{L}$ & \\
\hline 3,160 & $\sqrt{2}$ & 背 & \\
\hline$<20$ & $\mathrm{J1}$ & $\mathrm{dg} / \mathrm{L}$ & \\
\hline 11.200 & $\sqrt{2}$ & $: \Delta \mathrm{g} / \mathrm{L}$ & \\
\hline$<2.0$ & J1 & . & \\
\hline $5: 300$ & $\sqrt{ } \hat{z}$ & $\mu \mathrm{T} / \mathrm{L}$ & \\
\hline $\begin{array}{l}i 03,000 \\
<20\end{array}$ & & $\mu g / L$ & \\
\hline 595,000 & JQV & $\begin{array}{l}\mu \mathrm{G} / \mathrm{h} \\
\mu \mathrm{g} / \mathrm{L}\end{array}$ & \\
\hline $\begin{array}{l}2000 \\
50\end{array}$ & & $\mu \mathrm{g} / \mathrm{L}$ & \\
\hline $\begin{array}{l}50 \\
\times 50\end{array}$ & & $\mu \mathrm{g} / \mathrm{L}$ & \\
\hline$<50$ & & $\mu \mathrm{g} / \mathrm{L}$ & \\
\hline 226 & & $\mu g / L$ & \\
\hline 226 & & & \\
\hline$<80$ & $\sqrt{11}$ & $\mu \mathrm{g} / \mathrm{L}$ & \\
\hline 54 & $\sqrt{2}$ & $\mu \mathrm{g} / \mathrm{L}$ & \\
\hline $\begin{array}{l}\text { 4. } 6 E \cdot 08 \pm 1.9 E .08 \\
3.7 E .06 \pm 3.3 E \cdot 06\end{array}$ & & $\begin{array}{l}\mu \mathrm{Cl} / \mathrm{mL} \\
\mu \mathrm{Ci} / \mathrm{mL}\end{array}$ & \\
\hline $96 E-03 \pm 1.7 \mathrm{E} \cdot 04$ & & $\mu \mathrm{Ci} / \mathrm{mL}$ & \\
\hline $94 \mathrm{E} \cdot 08 \pm 5.8 \mathrm{E} \cdot 09$ & & MCi/mL. & \\
\hline $87 E-03 \pm 1.5 E-05$ & & $\mu \mathrm{Cl}, \mathrm{mL}$ & \\
\hline
\end{tabular}

WELL FSB $94 \mathrm{C}$

MEASUREMENTS CONOUCTED IN THE FIELO

Sample date: $10 / 17 / 91$

Depth to water $73.16 \mathrm{H}(22.30 \mathrm{~m})$ below TOC

Water elevation $20794 \mathrm{ft}(63.38 \mathrm{~m}) \mathrm{ms}$

Sp. conductance: $2197 \mu \mathrm{s} / \mathrm{cm}$

Water evacuated before sampling $54 \mathrm{gal}$
The well went dry during purging

Time: $7: 35$

pH: 42

Water temperature 18500

ABORATORY ANALYSES

\begin{tabular}{|c|c|c|c|c|c|}
\hline $\mathrm{F}$ & Analyte & Result & Mod & Unit & Lab \\
\hline 0 & $\mathrm{pH}$ & 47 & 10 & $\mathrm{pH}$ & GE \\
\hline & Specific conductarice & 1.700 & & $\mu \mathrm{S} / \mathrm{cm}$ & $\mathrm{GE}$ \\
\hline & Aluminum & 13,400 & $\sqrt{2}$ & $\mu \mathrm{g} / \mathrm{L}$ & $\mathrm{GE}$ \\
\hline & Antimony & $<20$ & & $\mu \mathrm{g} / \mathrm{L}$ & $\mathrm{GE}$ \\
\hline & Arsenic & $<20$ & & $\mu \mathrm{g} / \mathrm{L}$ & GE \\
\hline 0 & Burium & 253 & $\mathrm{j} 2$ & $\mu \mathrm{g} / \mathrm{L}$ & $\mathrm{GE}$ \\
\hline 2 & Cadmium & 96 & $\mathrm{~J} 2$ & $\mu \mathrm{g} / \mathrm{h}$ & $G E$ \\
\hline 0 & Calcium & 49.200 & $\sqrt{2}$ & $\mu g / h$ & $G E$ \\
\hline 0 & Chloride & 9.700 & & $\mu \mathrm{g} / \mathrm{L}$ & GE \\
\hline 0 & Chromium & $<40$ & $J_{1}$ & $\mu \mathrm{g} / \mathrm{L}$ & $G E$ \\
\hline 2 & Cobalt & 200 & J? & $\mu \mathrm{g} / \mathrm{L}$ & $G E$ \\
\hline 0 & Copper & 93 & J2 & $\mu g / \mathrm{h}$ & $\mathrm{GE}$ \\
\hline 0 & Cyanide & $<50$ & JO & $\mu \mathrm{g} / \mathrm{h}$ & $\mathrm{GE}$ \\
\hline 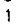 & Fluoride & 2,980 & $v$ & $\mu \mathrm{g} / \mathrm{L}$ & $\mathrm{GE}$ \\
\hline 0 & Iron & 148 & $\sqrt{2}$ & $\mu \mathrm{g} / \mathrm{h}$ & GE \\
\hline 1 & Lead & 12 & & $\mu \mathrm{g} / \mathrm{t}$ & GE \\
\hline 0 & Magnesium & 7.580 & Ja & $\mu \mathrm{g} / \mathrm{L}$ & $G E$ \\
\hline 2 & Manganese & 5.780 & $5 ?$ & $\mu \mathrm{g} / \mathrm{L}$ & $\mathrm{GE}$ \\
\hline 0 & Mercury & 0020 & & $\mu g: \mathrm{L}$ & $\mathrm{GE}$ \\
\hline 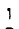 & Nickel & 53 & $\mathrm{~J} 2$ & $\mu g / L$ & GE \\
\hline 2 & Nituale as nitrogen & 250,000 & & $\mu g / \mathrm{L}$ & $\mathrm{GE}$ \\
\hline 0 & Potassium & 4.700 & $5 ?$ & $\mu \mathrm{g} / \mathrm{L}$ & $G E:$ \\
\hline 0 & Selenium & $<20$ & Ji & $\mu \mathrm{g} / \mathrm{L}$ & $G E$ \\
\hline 0 & Silica & 3.060 & $\mathrm{~J} 2$ & $\mu \mathrm{g} / \mathrm{h}$ & $G E$ \\
\hline 0 & Silver & $<20$ & Ji & $\mu \mathrm{g} / \mathrm{L}$ & $\mathrm{GE}$ \\
\hline 0 & Sodium & 54,400 & $\mathrm{~J} 2$ & $\mu \mathrm{g} . \mathrm{L}$ & $\mathrm{GE}$ \\
\hline 0 & Sulfate & 54,000 & & $\mu g / L$ & $\mathrm{GE}$ \\
\hline 0 & Thallium & $<20$ & & $\mu g / L$ & $\mathrm{GE}$ \\
\hline 0 & Total dissolved solids & $15 E+06$ & $J O V$ & $\mu \mathrm{g} / \mathrm{L}$ & $G E$ \\
\hline 0 & Total organic carbon & $<1000$ & & $\mu \mathrm{g} / \mathrm{L}$ & GE \\
\hline 0 & Total organic halogens & 1.7 & & $\mu \mathrm{g} / \mathrm{h}$ & $G E$ \\
\hline 0 & Total phosphates (as $F$ ) & 210 & & $\mu g / L$ & $\mathrm{GE}$ \\
\hline 0 & Uranium & $<20$ & J1 & $\mu \mathrm{g} / \mathrm{h}$ & $\mathrm{GE}$ \\
\hline 0 & Vanadium & $<80$ & Ji & $\mu g / L$ & $\overline{\mathrm{GE}}$ \\
\hline 0 & Zine & 91 & $\sqrt{2} 2$ & $\mu \mathrm{g} / \mathrm{L}$ & $\mathrm{GE}$ \\
\hline 0 & Gross alpha & $<2.0 E-09$ & & $\mu \mathrm{Ci} / \mathrm{mL}$ & $\mathrm{GE}$ \\
\hline 2 & Nonvolatile beta & 2. $6 \mathrm{E} \cdot 06 \pm 5.6 \mathrm{E} \cdot 08$ & & $\mathrm{mCi} / \mathrm{mL}$ & $\mathrm{GE}$ \\
\hline 0 & Total activity & $1.2 \mathrm{E} \cdot 02 \pm 1.8 \mathrm{E} \cdot 04$ & & $\mu \mathrm{C}_{1} / \mathrm{mL}$ & $E M$ \\
\hline 2 & Total radium & $9.4 \mathrm{E}-08 \pm 6.0 \mathrm{E}-09$ & & $\mu \mathrm{Cl}_{1} / \mathrm{mL}$ & $\mathrm{AE}$ \\
\hline 2 & Tritium & $1.1 \mathrm{E} \cdot 02 \pm 1.7 \mathrm{E} .05$ & & $\mu \mathrm{Cl} / \mathrm{mL}$ & $\mathrm{E}$ \\
\hline
\end{tabular}


ANALYTICAL RESULTS

\section{WELI_ FSB 94DR}

MEASUREMENTS CONDUUTED IN THE FIELD

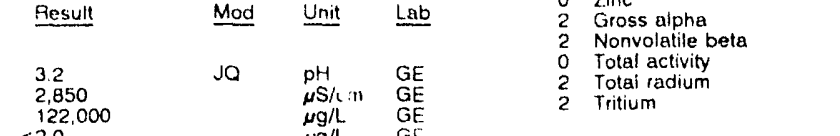

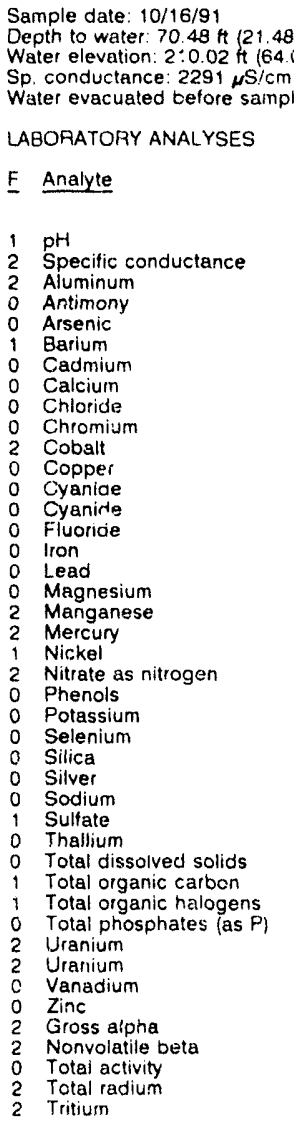

Time: $\theta: 10$

Alkalinity $0 \mathrm{mg} / \mathrm{h}$

Water temperature: $13.5^{\circ} \mathrm{C}$

Water evacuated before sampling: $70 \mathrm{gal}$

LABORATORY ANALYSES

\section{WELL FSB 95CR}

MEASUREMENTS CONDUCTED IN THE FIELD

Sample date: 10/16/91

Depth to water 76.54 it $(23.33 \mathrm{~m})$ below TOC

Water elevation: $207.46 \mathrm{ft}\{63.23 \mathrm{~m}$

Water evacuated before sampling: $146 \mathrm{gat}$

LABORATOAY ANALYSES
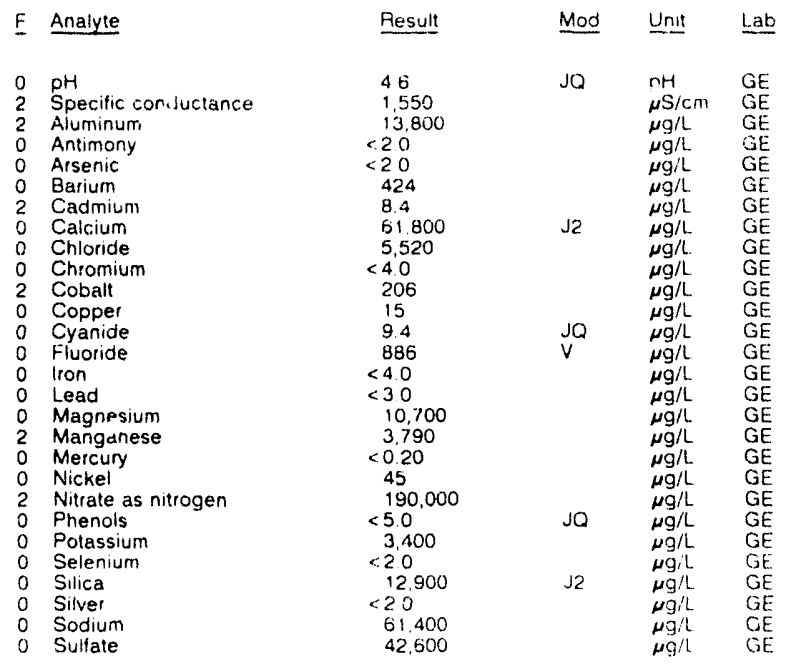

WELL FSB 95CA collected on 10/16/91, laboratory analyses (cont)

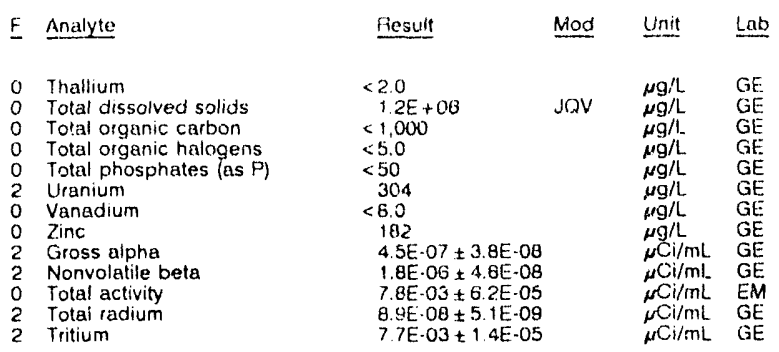

WELL FSB 95DR

MEASUREMENTS CONDUCTED IN THE FIELD

Sample date: 10/18/91 Depth to water: 74.26 ft $(22.63 \mathrm{~m})$ below TOC Water elevation: $209.84 \mathrm{ft}(63.96 \mathrm{~m}) \mathrm{msl}$ Sp conductance: $2295 \mathrm{\mu S} / \mathrm{cm}$
Water evacuated before sampling: $60 \mathrm{gal}$

Time: $8: 20$

pH: 2.9 . 0

Aikalinity: $0 \mathrm{mg} / \mathrm{h}$ : $180^{\circ} \mathrm{O}$

LABOHATISAY ANALYSES

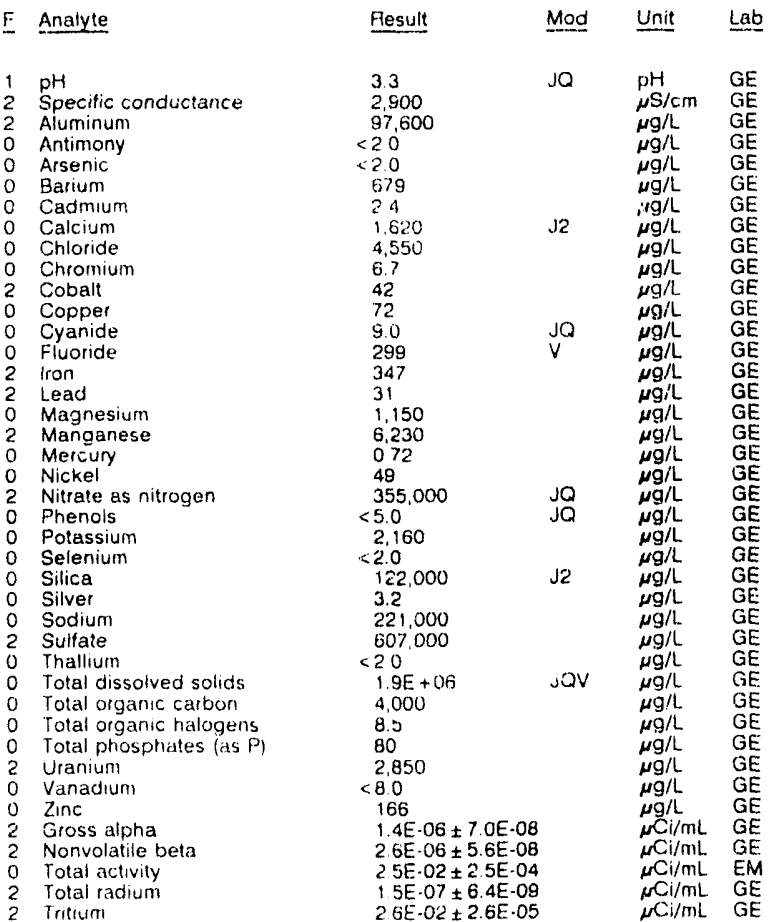

\section{WELL FSB 96AR}

MEASUREMENTS CONDUCTED IN THE FIELD

Sample date. 10/16/91

Eepth to water: $129.24 \mathrm{~h}(39.39 \mathrm{~m})$ below TOC

Water elevation: $151.96 \mathrm{ft}(46.32 \mathrm{nl}) \mathrm{ms}$ ?

Water evacuated before sampling $191 \mathrm{gal}$

Alkalinity $90 \mathrm{mg} / \mathrm{L}$

Water temperature $19.3^{\circ} \mathrm{C}$

LABORATOFY ANALYSES
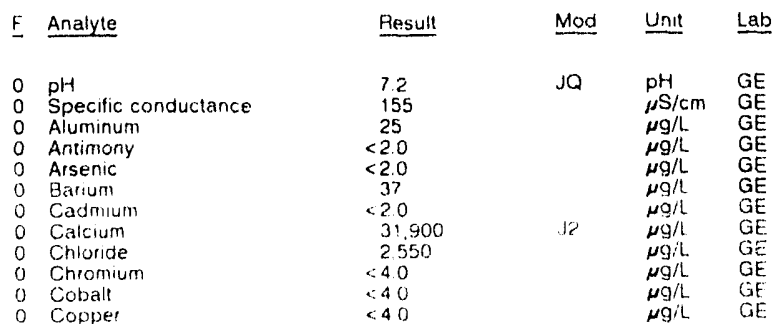
WELL FSB 96AR collected on 10/16/91, laboratory analyses (cont.)

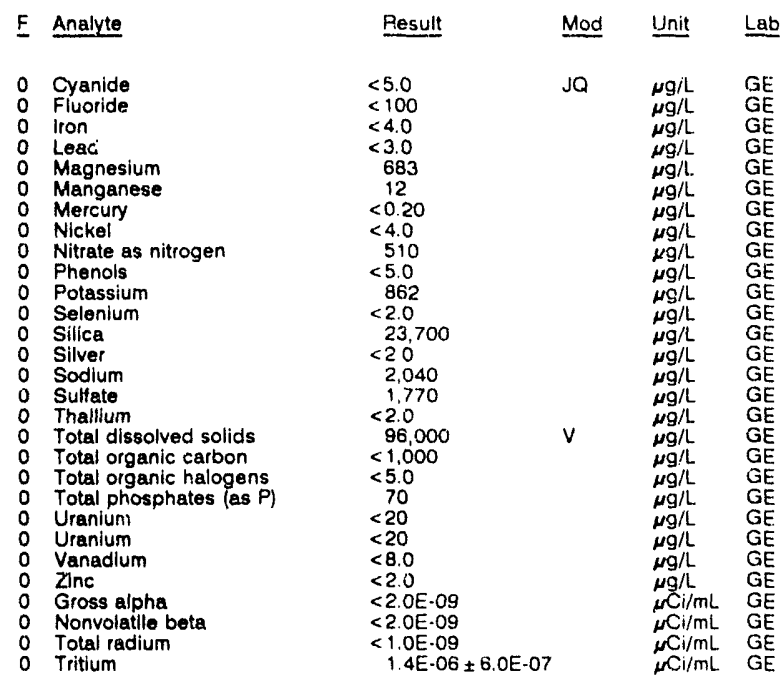

\section{WELL FSB 97A}

MEASUREMENTS CONDUCTEO IN THE FIELO

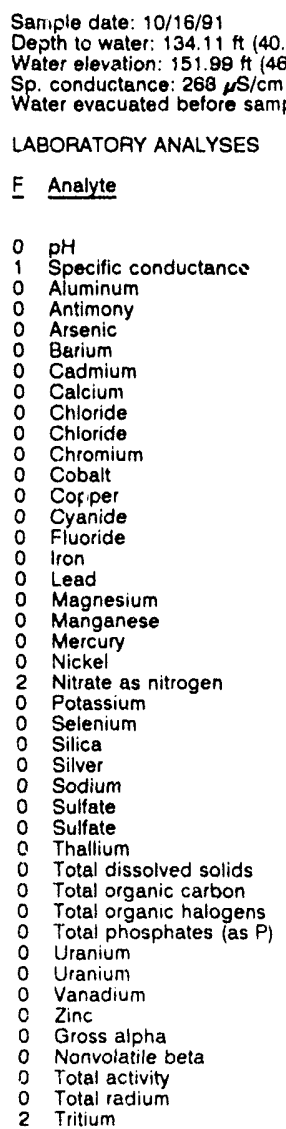

Time: $9: 55$

PH: 6.8 . $76 \mathrm{mg}$ Wuter temperature $19.4^{\circ} \mathrm{C}$

sampling: $174 \mathrm{ga}$

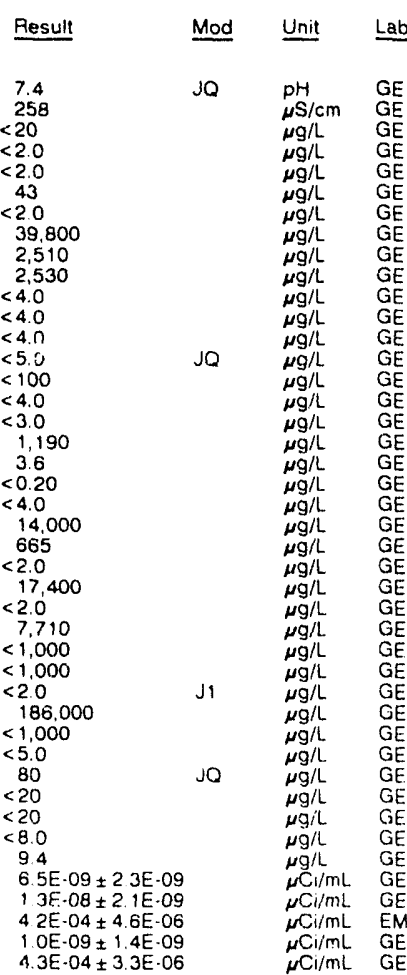

WELL FSB 97C

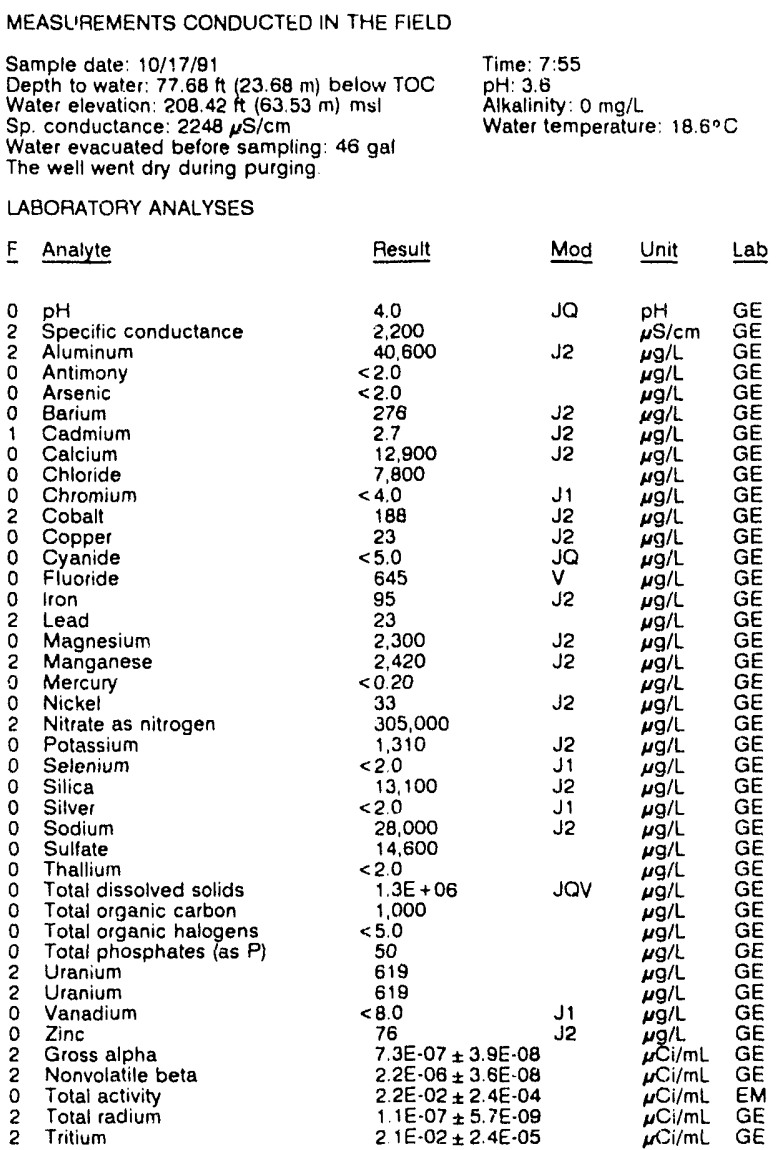

\section{WELL FSB 97D}

MEASUREMENTS CONDUCTED IN THE FIELD

Sample date $10 / 17 / 91$

Depth to water: $75.26 \mathrm{ft}(22.94 \mathrm{~m})$ below TOC Water elevation: $210.74 \mathrm{ft}(64.23 \mathrm{~m}) \mathrm{msl}$

Sp. conductance $2254 \mathrm{~s} / \mathrm{cm}$

Water evacuated befcre sampling: $5 \mathrm{gal}$

The well went dry during purging

LABORATORY ANALYSES

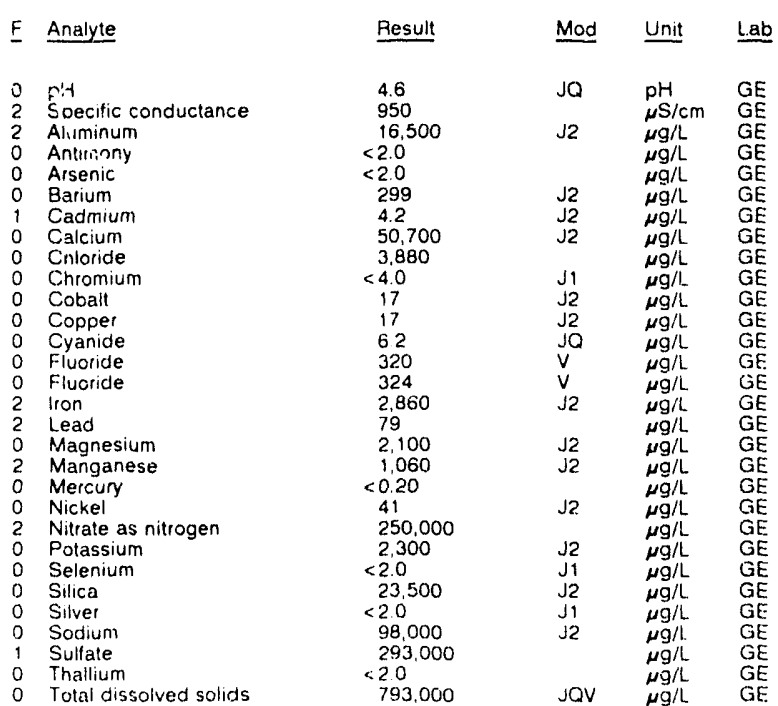

Time: $8: 10$

Alkalinity: $0 \mathrm{mg} / \mathrm{L}$

Water temperature: $18.7^{\circ} \mathrm{C}$ 
ANALYTICAL RESULTS

WELL FSB 970 collected on 10/17/91, laboratory analyses (cont.)

\begin{tabular}{|c|c|c|c|c|}
\hline Analyte & Result & Mod & Unit & Lab \\
\hline $\begin{array}{l}\text { Total organic carbon } \\
\text { Total organic carbon } \\
\text { Total organic halogens } \\
\text { Total phosphates (as P) } \\
\text { Uranium } \\
\text { Uranium } \\
\text { Vanadium } \\
\text { Zinc } \\
\text { Gross alpha } \\
\text { Nonvolatile beta } \\
\text { Total activity } \\
\text { Total radium } \\
\text { Tritium }\end{array}$ & $\begin{array}{l}1.000 \\
1,000 \\
<5.0 \\
70 \\
1,080 \\
1,080 \\
<8.0 \\
83 \\
3.7 \mathrm{E}-07 \pm 2.5 \mathrm{E}-08 \\
8.9 \mathrm{E}-07 \pm 2.3 \mathrm{E}-08 \\
2.5 \mathrm{E}-02 \pm 1.1 \mathrm{E}-04 \\
3.7 \mathrm{E}-08 \pm 3.7 \mathrm{E}-09 \\
8.6 \mathrm{E}-03 \pm 1.5 \mathrm{E}-05\end{array}$ & $\begin{array}{l}\mathrm{J} 1 \\
\mathrm{~J} 2\end{array}$ & $\begin{array}{l}\mu \mathrm{g} / \mathrm{L} \\
\mu \mathrm{g} / \mathrm{L} \\
\mu \mathrm{g} / \mathrm{L} \\
\mu \mathrm{g} / \mathrm{L} \\
\mu \mathrm{g} / \mathrm{L} \\
\mu \mathrm{g} / \mathrm{L} \\
\mu \mathrm{g} / \mathrm{L} \\
\mu \mathrm{g} / \mathrm{L} \\
\mu \mathrm{Ci} / \mathrm{mL} \\
\mu \mathrm{Ci} / \mathrm{mL} \\
\mu \mathrm{Ci} / \mathrm{mL} \\
\mu \mathrm{Ci} / \mathrm{mL} \\
\mu \mathrm{Ci} / \mathrm{mL}\end{array}$ & $\begin{array}{l}\mathrm{GE} \\
\mathrm{GE} \\
\mathrm{GE} \\
\mathrm{GE} \\
\mathrm{GE} \\
\mathrm{GE} \\
\mathrm{GE} \\
\mathrm{GE} \\
\mathrm{GE} \\
\mathrm{GE} \\
\mathrm{EM} \\
\mathrm{GE} \\
\mathrm{GE}\end{array}$ \\
\hline
\end{tabular}

WELL FSB $98 C$

MEASUREMENTS CONDUCTED IN THE FIELD

Sample date $10 / 23 / 91$

Depth to water: $74.08 \mathrm{ft}(22.58 \mathrm{~m})$ below TOC

Water elevation: $209.02 \mathrm{ft}(63.71 \mathrm{~m}) \mathrm{ms}$

Sp. conductance: $1746 \mu \mathrm{S} / \mathrm{cm}$
Water evacuated betore sampling: $163 \mathrm{gal}$

LABORATOAY ANALYSES

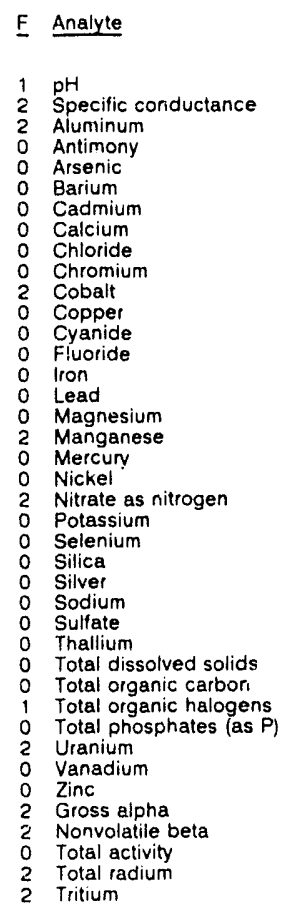

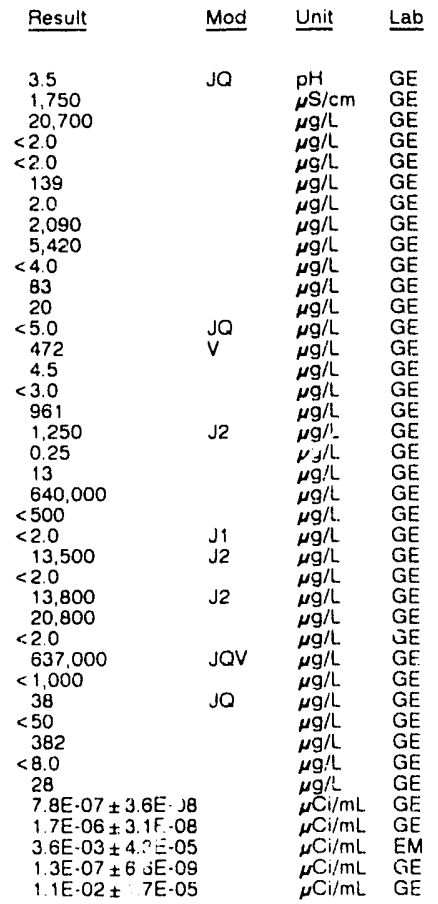

\section{WELL FSB 980}

MEASUREMENTS CONDUCTED IN THE FIELD

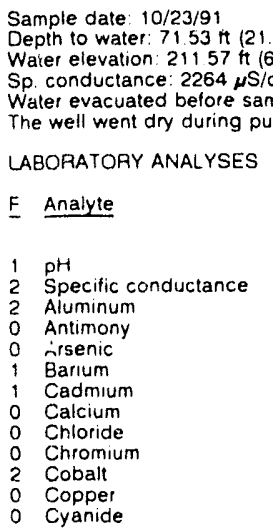

Time: 6:45

$\mathrm{pH}: 3$.

Alkaliniîy: $0 \mathrm{mg} / \mathrm{L}$

Water temperature: $18.6^{\circ} \mathrm{C}$

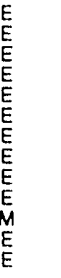

PH: 3.8 . $\mathrm{mg}$

Alkalinity: $0 \mathrm{mg} / \mathrm{L}$ : $19.3^{\circ} \mathrm{C}$

y $14 \mathrm{gal}$

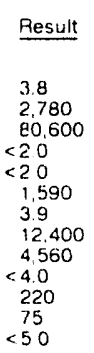

Jo $\quad \underset{\mu g / L}{\mu g / L} \quad G$
Mod 'Jnit Lab

JO $\mathrm{pH} \quad \mathrm{GE}$

$\begin{array}{ll}\mu \mathrm{S} / \mathrm{cm} & \mathrm{GE} \\ \mu \mathrm{g} / \mathrm{L} & \mathrm{GE}\end{array}$

$\mu \underset{\mu g / L}{\mu}$

$\mu g /$

w9

$\mu \nu / \mathrm{GE}$

$\mu g / L \quad G E$
WELL FSB $98 D$ collected on 10/23/91, laboratory analyses (cont.)

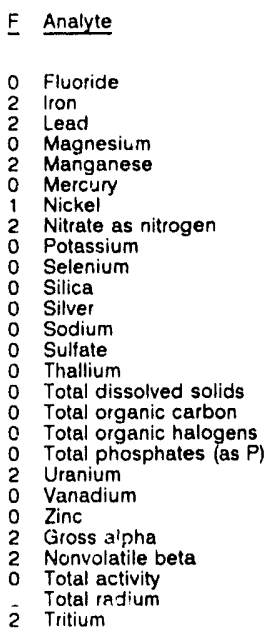

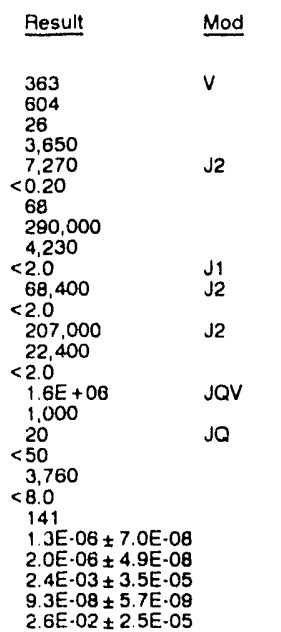

$\underline{\text { Unit }} \underline{\text { Lab }}$

\section{WELL FSB 99A}

MEASUREMENTS CONDUCTED IN THE FIELD

Sample date: 10/16/91

Depth to water: $138.06 \mathrm{ft}(42.08 \mathrm{~m})$ below TOC

Water elevation: $149.54 \mathrm{ft}(45.58 \mathrm{~m}) \mathrm{misl}$

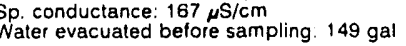

LABORATORY ANALYSES

E Analyte Result Mod Unit Lab

${ }_{0}^{0} \mathrm{pH}$ Specific conductance

0 Aluminum

0 Antimony

o Arsenic

o Barium

o Cadmium

o Chloride

o Chromium

0 Cobalt

O Copper

Fluoride

Iron

O Magnesium

Manganese

0 Mercury

Nickel

Potassium

Selenium

$\begin{array}{ll}0 & \text { Sitica } \\ 0 & \text { Silver }\end{array}$

$\begin{array}{ll}0 & \text { Silver } \\ 0 & \text { Sodium }\end{array}$

Sodium

Sulfate

Thattium

Total dissolved solids

Total cissolved solids

- Total organic halogens

Total organic halogens

0 Total phosphates (as P)

- Uranium

- Vanadium

Gross alpha

o Nonvolatile beta

Total radium

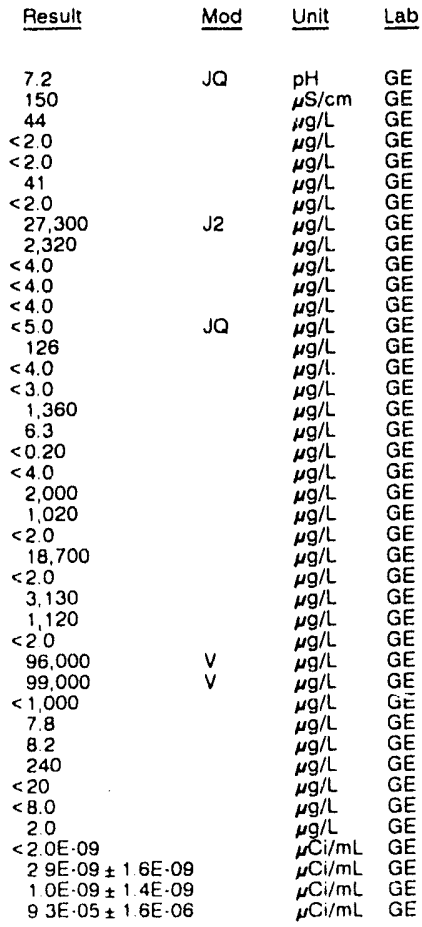

Time: 10:35

pH: 7.1

Alkalinity: $65 \mathrm{mg} / \mathrm{h}$
Water temperature: $18.3^{\circ} \mathrm{C}$ 


\section{ANALYTICAL RESULTS}

WELL FSB 99C

MEASUREMENTS CONOUCTED IN THE FIELD

Sample date: 10/16/91 Depth to water: 77.99 it $(23.77 \mathrm{~m})$ below TOC Water elevation: $209.71 \mathrm{H} / 63.92 \mathrm{~m}$
Sp. conductance: $384 \mu \mathrm{S} / \mathrm{cm}$

Water evacuated before sampling: $138 \mathrm{gal}$

LABORATORY ANALYSES

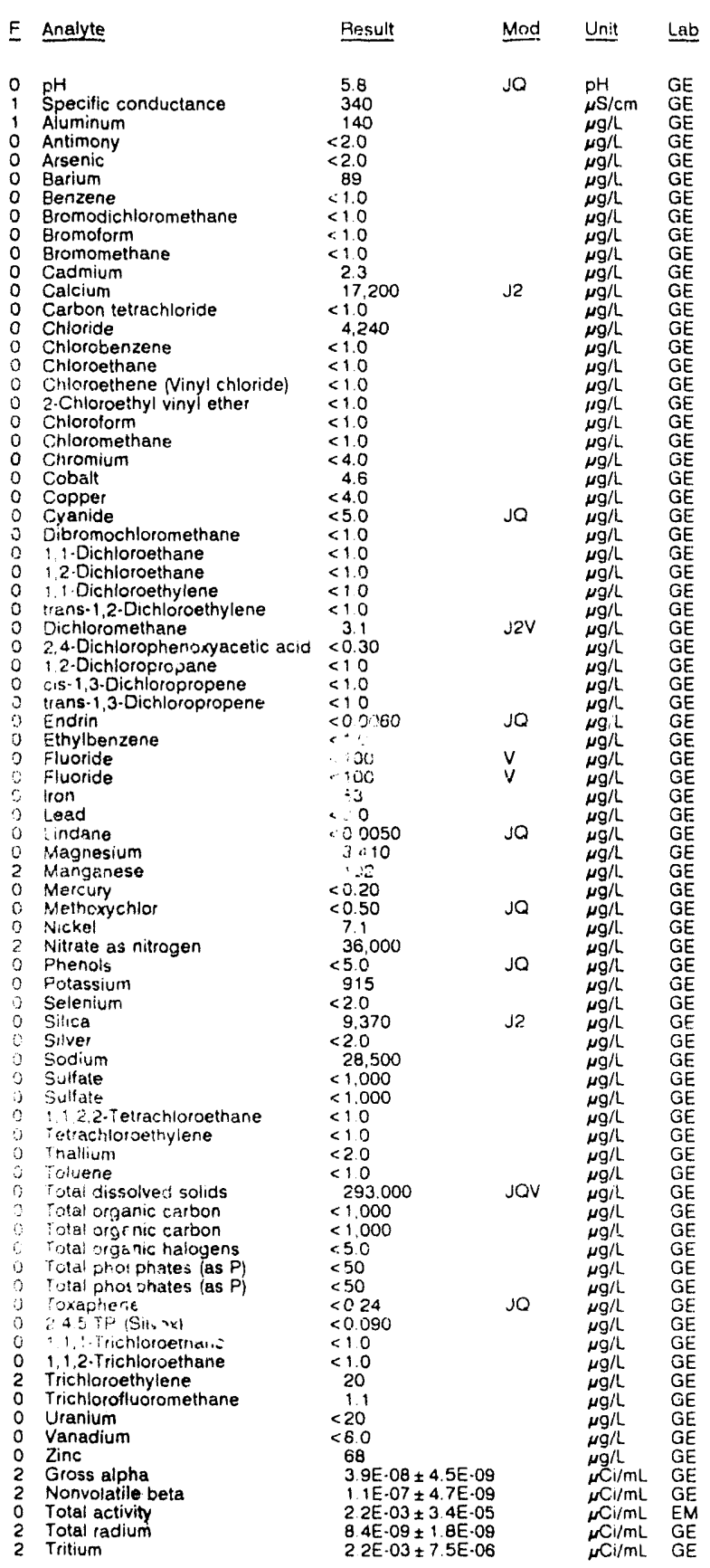

WELL. FSB 99D

MEASUREMENTS CONDUCTED IN THE FIELD

Sample date: 10/18/81

Depth to water: $74.79 \mathrm{Ht}(22.80 \mathrm{~m})$ below TOC

Water elevation: 212.81 th

Water evacuated before sampling $39 \mathrm{gl}$

Time: 10:20

Alkalinity $3 \mathrm{mgll}$

Water temperature $18.8^{\circ} \mathrm{C}$

LABORATORY ANALYSES
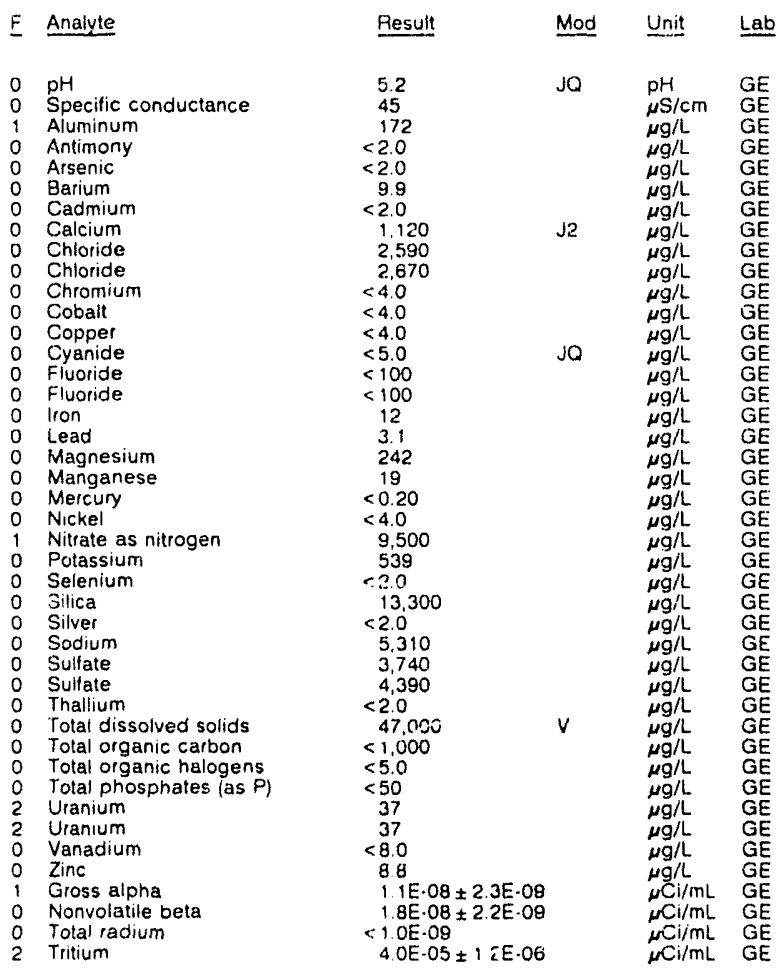

WELL FSB100A

MEASUREMENTS CONOUCTED IN THE FIELD

Sample date: $10 / 16 / 9$ /

Depth to water: $135.89 \mathrm{Ht}(41.42 \mathrm{~m})$ below roc

Water elevation $15011 \mathrm{H}(45.75 \mathrm{~m}) \mathrm{msl}$

Water evacuated before sampling: $143 \mathrm{gal}$

LABORATORY ANALYSES

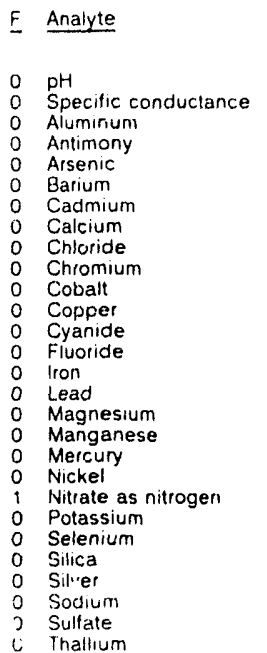

\begin{tabular}{|c|c|c|}
\hline Pesulf & Mod & Unit \\
\hline 71 & 10 & \\
\hline $\begin{array}{l}182 \\
<20\end{array}$ & & $\mu \mathrm{S} / \mathrm{cm}$ \\
\hline $\begin{array}{l}<20 \\
<2.0\end{array}$ & & $\mu g / L$ \\
\hline $\begin{array}{r}20 \\
<20 \\
40\end{array}$ & & $\mu g / L$ \\
\hline $\begin{array}{r}40 \\
<20\end{array}$ & & $\mu g g / L$ \\
\hline $\begin{array}{l}28,000 \\
2540\end{array}$ & 12 & $\mu \mathrm{g} / \mathrm{h}$ \\
\hline $\begin{aligned} 2,540 \\
<40 \\
<\end{aligned}$ & & $\mu g / L / L$ \\
\hline $\begin{array}{r}<4.0 \\
<4.0\end{array}$ & & $\begin{array}{r}\mu g / / \\
\mu g / L\end{array}$ \\
\hline $\begin{array}{r}<50 \\
<100\end{array}$ & so & $\mu g / /$ \\
\hline $\begin{array}{l}<40 \\
<30\end{array}$ & & $\mu \mathrm{g} / \mathrm{L}$ \\
\hline $\begin{array}{l}<3.0 \\
1.450\end{array}$ & & $\begin{aligned} \mu g / L \\
\mu / L\end{aligned}$ \\
\hline 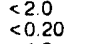 & & $\mu g / L$ \\
\hline $\begin{array}{r}<4.0 \\
7,000\end{array}$ & & $\mu g / L$ \\
\hline 1.610 & & $\mu g / L$ \\
\hline $\begin{array}{r}<20 \\
15,500\end{array}$ & & ${ }_{\mu g / L}^{\mu g / L}$ \\
\hline$<20$ & & $\mu \mathrm{g} / \mathrm{L}$ \\
\hline $\begin{array}{l}6.930 \\
1.440\end{array}$ & & $\begin{array}{ll}N 9 / 4 \\
y g / 4\end{array}$ \\
\hline < 20 & $\pi$ & ,il \\
\hline
\end{tabular}

Time 11:30

Alkalinity $64 \mathrm{mg} / \mathrm{L}$ Water temperature: $19.6^{\circ} \mathrm{C}$ 
ANALYTICAL RESULTS

WELL FSB100A collected on 10/16/91, laboratory analyses (cont)

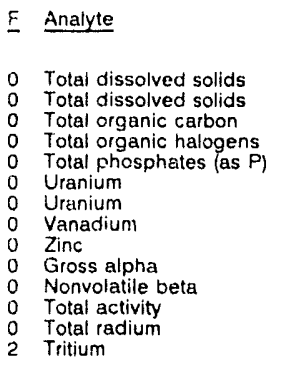

$\begin{aligned} & \text { Pesult } \\ & 102,000 \\ & 113,000 \\ &<1.000 \\ & 1.4 \\ & 290 \\ &<20 \\ &<20 \\ &<8.0 \\ & 4.2 \\ &<2.0 \mathrm{E} \cdot 09 \\ & 5.6 \mathrm{E} \cdot 09 \pm 1.7 \mathrm{E}-09 \\ & 1 \mathrm{BE} \cdot 04 \pm 3.1 \mathrm{E} \cdot 06 \\ &<1.0 \mathrm{E} \cdot 09 \\ & 1.6 \mathrm{E}-04 \pm 2.1 \mathrm{E} \cdot 06\end{aligned}$

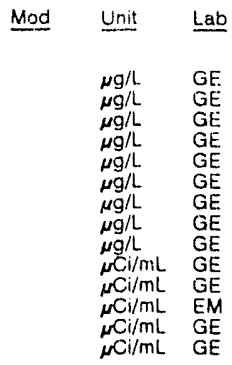

\section{WELL FSB101A}

MEASUREMENTS CONDUCTED IN THE FIELD

Sample date: $10 / 17 / 91$

Depth to water: $134.26 \mathrm{ft}(40.92 \mathrm{~m})$ below TOC

Water elevation: $150.94 \mathrm{ft}(46.01 \mathrm{~m}) \mathrm{ms}$

Water evacuated before sampling: $152 \mathrm{gal}$

LABORATORY ANALYSES

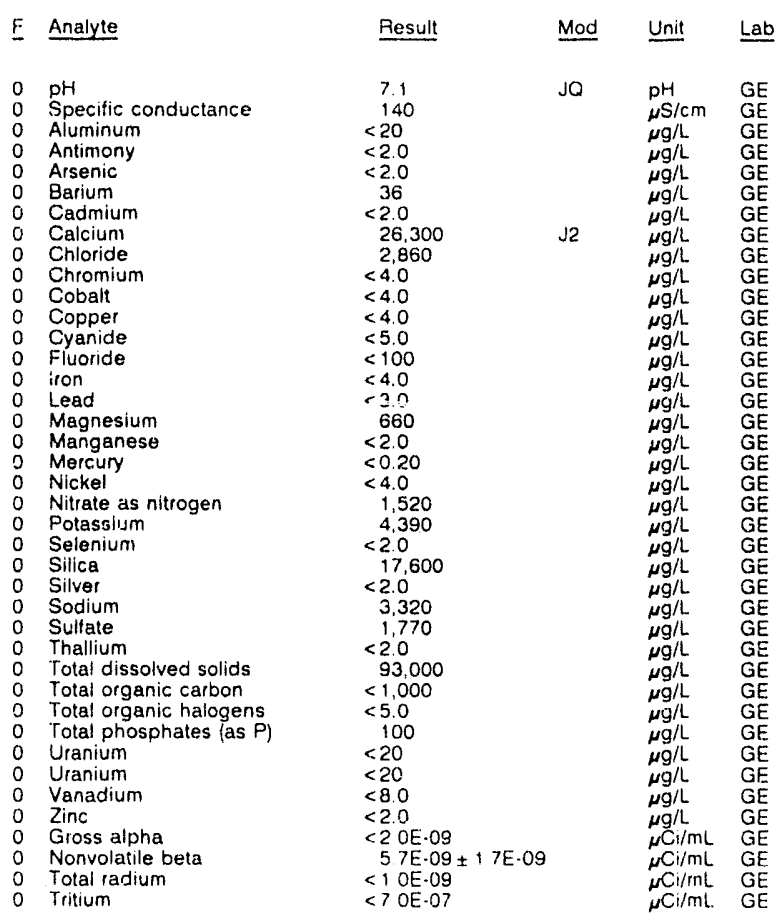

\section{WELL FSB101A Replicate}

MEASUREMENTS CONDUCTED IN THE FIELD

Depth to water: $134.26 \mathrm{ft}(40.92 \mathrm{~m})$ below TrC

Water elevation: $150.94 \mathrm{ft}(46.01 \mathrm{~m}) \mathrm{ms}$

Water evacuated before sampling: $152 \mathrm{gal}$

LABORATORY ANALYSES

\begin{tabular}{|c|c|c|c|}
\hline Analyte & Result & Mod & Unit \\
\hline $\begin{array}{ll}0 & \text { pH } \\
0 & \text { Specific conductance } \\
0 & \text { Aluminum } \\
0 & \text { Antımony } \\
0 & \text { Arsenic } \\
0 & \text { Barium } \\
0 & \text { Cadmium } \\
0 & \text { Calcium } \\
0 & \text { Chloride } \\
0 & \text { Chromium } \\
0 & \text { Cobalt } \\
0 & \text { Copper }\end{array}$ & $\begin{array}{l}7.1 \\
150 \\
20 \\
<2.1 \\
<2.0 \\
35 \\
<2.0 \\
25,600 \\
2.620 \\
<40 \\
<40 \\
<40\end{array}$ & JO & $\begin{array}{l}\mathrm{pH} \\
\mu \mathrm{S} / \mathrm{cm} \\
\mu g / L \\
\mu g / L \\
\mu g / L \\
\mu g / L \\
\mu g / L \\
\mu g / L \\
\mu g / L \\
\mu g / L \\
\mu g / L\end{array}$ \\
\hline
\end{tabular}

WELL FS8101A collected on 10/17/91, laboratory analyses (cont)

\begin{tabular}{|c|c|c|c|c|c|}
\hline F & Analyte & Result & Mod & Unit & Lab \\
\hline 0 & Cyanide & $<j .0$ & & $\mu g / L$ & GE \\
\hline 0 & Fluoride & $<100$ & & $\mu \mathrm{g} / \mathrm{L}$ & $\mathrm{GE}$ \\
\hline 0 & Iron & $<4.0$ & & $\mu \mathrm{g} / \mathrm{L}$ & $\mathrm{GE}$ \\
\hline 0 & $\begin{array}{l}\text { Lead } \\
\text { Magnesium }\end{array}$ & $\begin{array}{r}<3.0 \\
661\end{array}$ & & $\mu g / L$ & GF \\
\hline 0 & Manganese & 3.6 & & $\mu \mathrm{g} / \mathrm{L}$ & \\
\hline 0 & Mercury & $<0.20$ & & $\mu \mathrm{g} / \mathrm{h}$ & \\
\hline 0 & Nickei & $<4.0$ & & $\mu g / L$ & \\
\hline 0 & Nitrate as nitrogen & 900 & & $\mu g / L$ & \\
\hline 0 & Potassium & 4,380 & & $\mu \mathrm{G} / \mathrm{L}$ & \\
\hline 0 & Selenium & $<2.0$ & & $\mu g / L$ & \\
\hline 0 & $\begin{array}{l}\text { Silica } \\
\text { Silver }\end{array}$ & $\begin{array}{l}17,400 \\
<2,0\end{array}$ & & $\mu g / h$ & \\
\hline 0 & Sodium & 3,390 & & $\mu g / L$ & E \\
\hline 0 & Sulfate & 1,890 & & $\mu \mathrm{g} / \mathrm{L}$ & \\
\hline 0 & Thallium & $<20$ & & $\mu g / \mathrm{h}$ & \\
\hline 0 & Total dissolved solids & 88,000 & v & $\mu g / L$ & \\
\hline 0 & Total organic carbon & $<1,000$ & & $\mu g / \mathrm{L}$ & \\
\hline 0 & Total organic halogens & $<5.0$ & & $\mu g / L$ & \\
\hline 0 & Total phosphates (as P) & 90 & & & \\
\hline 0 & Uranium & $<20$ & & $\mu \mathrm{g} / \mathrm{L}$ & \\
\hline 0 & Uranium & $<20$ & & $\mu g / L$ & \\
\hline 0 & Vanadium & $<8.0$ & & & \\
\hline 0 & & 26 & & $\mu \mathrm{g} / \mathrm{L}$ & \\
\hline 0 & Gross alpha & $<20 \mathrm{OE} .09$ & & $\mathrm{~m} \mathrm{C} i / \mathrm{mL}$ & \\
\hline 0 & Nonvolatile beta & 2.3E-09 $\neq 1.5 \mathrm{E}-08$ & & $m C i / m L$ & \\
\hline 0 & $\begin{array}{l}\text { Total radium } \\
\text { Tritium }\end{array}$ & $\begin{array}{l}<1.0 E \cdot 09 \\
<7.0 E \cdot 07\end{array}$ & & $\mu \mathrm{Ci}$ & $\mathrm{GE}$ \\
\hline
\end{tabular}

\section{WELL FSB10?C}

MEASUREMENTS CONDUCIEO IN THE FIELD

Sample date: $10 / 17 / 91$

Depth to water: $5.76 \mathrm{ft}(1.76 \mathrm{~m})$ belcw TOC

Waler elevation. $195.34 \mathrm{Ht}(59.54 \mathrm{~m}) \mathrm{misl}$

Water evacuated before sampling. $130 \mathrm{gal}$

Time 920

Art 43 alinity 0 orgit

Water lumperature $170^{\circ}$

LABORATORY ANALYSES

\begin{tabular}{|c|c|c|c|c|c|}
\hline E & Analyte & Resuit & Mod & Um: & $\operatorname{tab}$ \\
\hline 0 & $\mathrm{pH}$ & $4 i$ & 10 & filt & fit \\
\hline & Specific conductance & 200 & & $\mu \mathrm{S}<\mathrm{m}$ & oi \\
\hline & Aluminum & 945 & & wat & at \\
\hline U & Antimony & $<20$ & & Wil. & $G E$ \\
\hline 0 & Arsenic & $<20$ & & Hgil & at \\
\hline & Barium & 95 & & wght & Gt \\
\hline & Cadmium & 5.4 & & $\mu 9 !$ & $G E$ \\
\hline 0 & Calcium & 15,900 & & $\mu \div$ & G \\
\hline 0 & Chloride & 2,580 & & $\mu:$ & GE: \\
\hline & Chromium & $<4.0$ & & $\mu \mathrm{g}$ & (at) \\
\hline 1 & Cobait & 38 & & $\mu \mathrm{LL}$ & SE \\
\hline 0 & Copper & $<40$ & & $\mu \mathrm{G}$ & of \\
\hline 0 & Cyanide & $<50$ & & $\mu \mathrm{giL}$ & tit \\
\hline U & Cyanide & $<5.0$ & & $\mu \mathrm{g} / \mathrm{t}$ & $\sigma E$ \\
\hline 0 & Fluoride & 291 & & $\mu g / L$ & Git \\
\hline 0 & Iron & $<40$ & & $\mu g / L$ & GE \\
\hline n & Lead & $\therefore 3 u$ & & $\mu \mathrm{g} \mathrm{L}$ & $\mathrm{OE}$ \\
\hline 0 & Magnesium & 5.250 & & $\mu g / \mathrm{L}$ & GE \\
\hline 2 & Manganese & 860 & & $\mu \mathrm{g} / \mathrm{L}$ & $\mathrm{GE}$ \\
\hline 0 & Mercury & 0.56 & & $\mu g: \mathrm{t}$ & GE \\
\hline 0 & Nickel & 16 & & $\mu \vec{g} / \mathrm{t}$ & GE \\
\hline 2 & Nitrate as nitrogen & 45,000 & & $\mu g^{\prime \prime}$. & GE \\
\hline 0 & Potassium & 780 & & $10 \mathrm{~L}$ & GE \\
\hline 0 & Selenium & $<2.0$ & & $\mu g i l$ & $\mathrm{G}[\mathrm{C}$ \\
\hline 0 & Silica & 11,000 & & $\mu \mathrm{g} / \mathrm{L}$ & $\mathrm{GE}$ \\
\hline 0 & Silver & $<2.0$ & & $\mu \mathrm{g} t$ & $\sigma t$ \\
\hline 0 & Sodium & 34,600 & & $\mu q i t$ & Gt \\
\hline 0 & Sulfate & 3,600 & & $\mu$ & 5 \\
\hline 0 & Thallium & .20 & $J$ & $\mu \mathrm{g} / 1$ & ot: \\
\hline 0 & Total dissolved solicis & 229,000 & & $\mathrm{pan}$ & if. \\
\hline 0 & Tolal organic carbon & $=1.000$ & & $\mu a t$ & of \\
\hline 0 & Total organic halogens & $<50$ & & $\mu \mathrm{gih}$ & tik. \\
\hline 0 & Total organic halogens & .50 & & $\mu \mathrm{g} / \mathrm{L}$ & of \\
\hline 0 & Total phosphates (as P) & $<50$ & & $\mu \mathrm{g} / \mathrm{L}$ & $\mathrm{GE}$ \\
\hline D & Uranium & $<20$ & & $\mu g / L$ & $G E$ \\
\hline 0 & Uranium & $<20$ & & $\mu g / L$ & GE \\
\hline & Vanadium & $<8.0$ & & $\mu g / L$ & $\mathrm{GE}$ \\
\hline $\begin{array}{l}0 \\
2\end{array}$ & $\begin{array}{l}\text { Zinc } \\
\text { Gross alpha }\end{array}$ & 40 & & $\mu g / L$ & $\begin{array}{l}\mathrm{GE} \\
\mathrm{GE}\end{array}$ \\
\hline 2 & Nonvolatile beta & 4.8E-07 $\pm 9.8 \mathrm{E}-09$ & & $\mu \mathrm{Ci} / \mathrm{mL}$ & $\mathrm{GE}$ \\
\hline 0 & Total ectivity & $1.4 \mathrm{E}-03+2.9 \mathrm{E}-05$ & & $\mu \mathrm{Ci} / \mathrm{mL}$ & $E M$ \\
\hline 2 & Total radium & $9.9 \mathrm{E} \cdot 09 \pm 2.1 \mathrm{E}-09$ & & $\mu \mathrm{Ci} / \mathrm{mL}$ & $\mathrm{GE}$ \\
\hline & Tritium & $1.2 E \cdot 03 \pm 5.5 E \cdot 06$ & & $\mu \mathrm{Ci} / \mathrm{mL}$ & IE \\
\hline
\end{tabular}




\section{WELL FSB103C}

MEASURENIENTS CONOUCTED IN THE FIELD

Sample date: 12/10/91 Depth to water: $38.14 \mathrm{ft}(11.63 \mathrm{~m})$ below TOC Water elevation: $204.26 \mathrm{ft}(62.26 \mathrm{~m}) \mathrm{ms}$

Alkalinity: $8 \mathrm{mg} / \mathrm{l}$

Water temperature: $20.7^{\circ} \mathrm{C}$

Water evacuated before sampling: $150 \mathrm{gal}$

LABORATORY ANALYSES

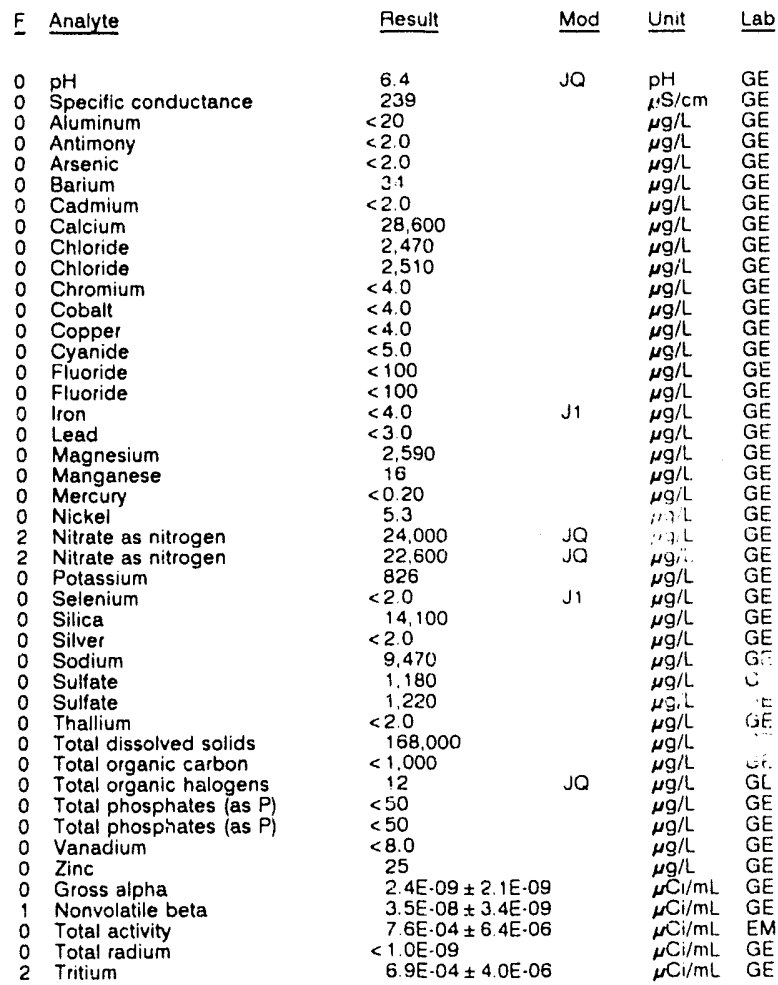

\section{WELL FSB104C}

MEASUREMENTS CONDUCTED IN THE FIELD

Sample date $12 / 09 / 91$

Depth to water: $16.68 \mathrm{ft}(5.08 \mathrm{~m})$ below TOC

Water elevation: $202.42 \mathrm{ft} / 61$

LABORATORY ANALYSES

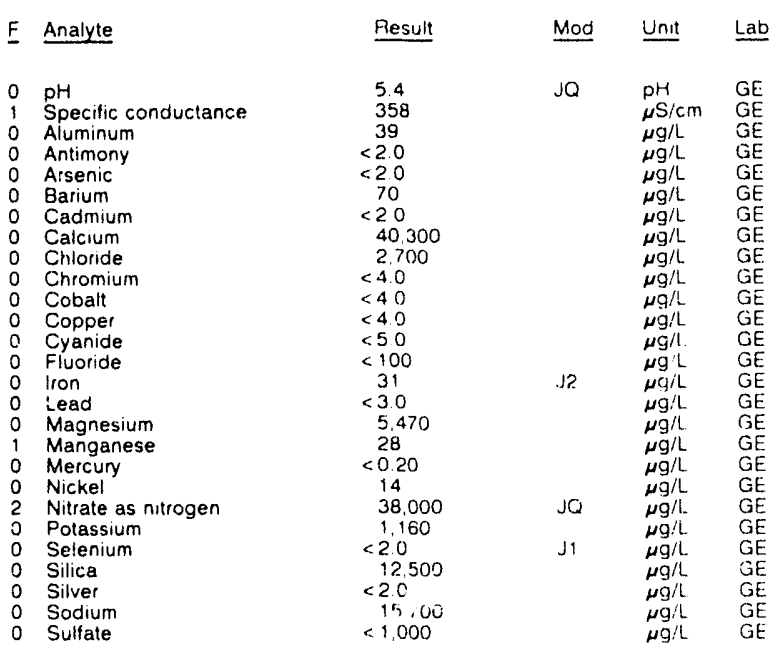

WELL FSB 104C collected on 12/09/91, laboratory analyses (cont.)
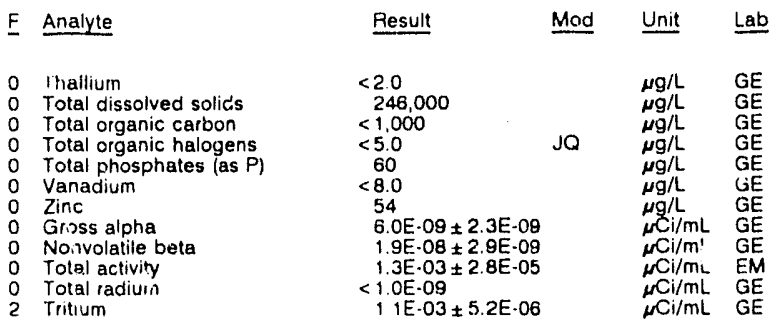

\section{WELL FSB104D}

MEASUREMENTS CONDUCTED IN THE FIFLD

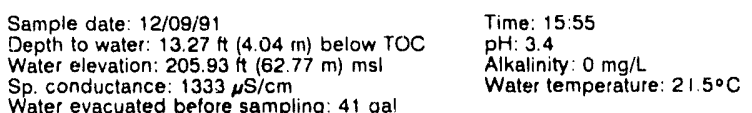

Sp. conductance: $1333 \mu \mathrm{S} / \mathrm{cm}$
Water evacuated before sampling: 41 gal

LABORATORY ANAL:SES

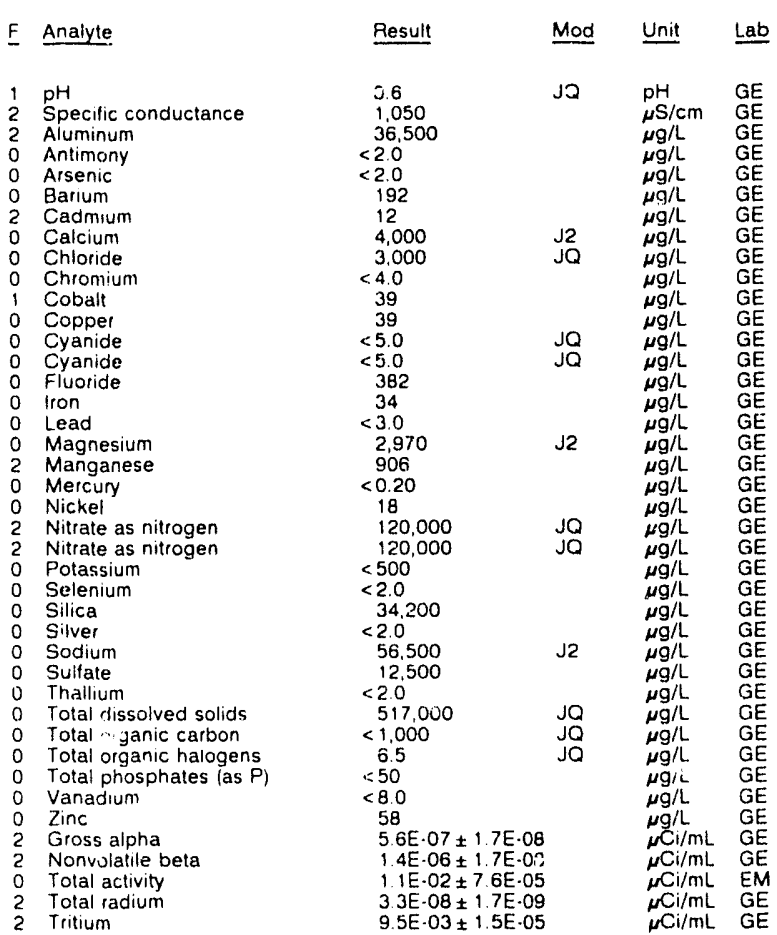

\section{WELL FSB105C}

MEASUREMENTS CONDUCTEO IN THE FIELD

Sample date $10 / 17 / 91$

Depth to water $72.06 \mathrm{H}(21.96 \mathrm{~m})$ below TC: Water elevation: $213.74 \mathrm{Ht}(65.15 \mathrm{~m}) \mathrm{msl}$

Sp conductance $1750 \mu \mathrm{S} / \mathrm{cm}$

Time: 9.00

Alkalinity $0 \mathrm{mg}$

Water temperature: $190^{\circ} \mathrm{C}$

Water evacuated before sampling: $174 \mathrm{gal}$

LABORATORY ANALYSES

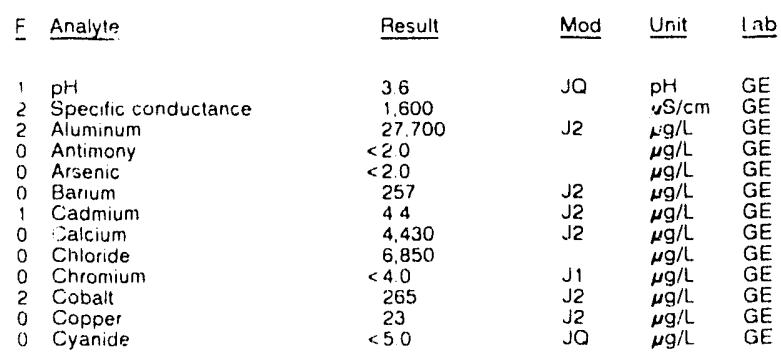


WELL FSB105C collected on 10/17/91, laboratory analyses (cont.)

\begin{tabular}{|c|c|c|c|}
\hline Analyte & Result & Mod & Unit \\
\hline $\begin{array}{l}\text { Fluoride } \\
\text { lion } \\
\text { Lead } \\
\text { Magnesium } \\
\text { Manganese } \\
\text { Mercury } \\
\text { Nicket } \\
\text { Nitrate as nitrogen } \\
\text { Potassium } \\
\text { Selenium } \\
\text { Silica } \\
\text { Silver } \\
\text { Sodlium } \\
\text { Sulfate } \\
\text { Thallium } \\
\text { Total dissolved solids } \\
\text { Total organic carbon } \\
\text { Total organic halogens } \\
\text { Total phosphates (as P) } \\
\text { Total phosphates (as P) } \\
\text { Uranium } \\
\text { Uranium } \\
\text { Vanadium } \\
\text { Zinc } \\
\text { Grrs3 alpha } \\
\text { Nonvolatile Jeta } \\
\text { Tetol activity } \\
\text { Total radium } \\
\text { Tritium }\end{array}$ & $\begin{array}{l}667 \\
13 \\
<3.0 \\
1,920 \\
2,440 \\
<0.20 \\
32 \\
230,000 \\
<500 \\
<2.0 \\
9,420 \\
<2.0 \\
2 ., 000 \\
4,990 \\
<2.0 \\
948,000 \\
<1,000 \\
5.5 \\
100 \\
<50 \\
124 \\
124 \\
<8.0 \\
61 \\
3.6 E-07 \pm 2.9 E-08 \\
1.7 \mathrm{E} \cdot 06 \pm 3.1 \mathrm{E}-08 \\
1.4 \mathrm{E}-02 \pm 8.7 \mathrm{E}-05 \\
4.5 \mathrm{E} \cdot 08 \pm 3.6 \mathrm{E}-09 \\
1.4 \mathrm{E}-02 \pm 1.9 \mathrm{E}-05\end{array}$ & $\begin{array}{l}V \\
\mathrm{~J} 2 \\
\mathrm{~J} 2 \\
\mathrm{~J} 2 \\
\mathrm{~J} 1 \\
\mathrm{~J} 1 \\
\mathrm{~J} 2 \\
\mathrm{~J} 1 \\
\mathrm{~J} 2 \\
\mathrm{~J} Q \\
\mathrm{~J} Q \mathrm{~V}\end{array}$ & 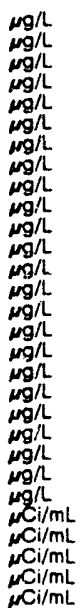 \\
\hline
\end{tabular}

\section{WELL FSB105DR}

MEASUREMENTS CONDUCTED IN THE FIELD

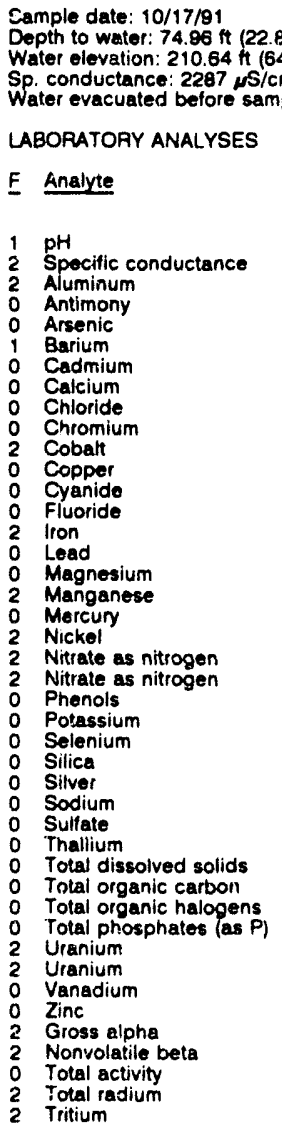

Time: $8: 40$

$\mathrm{pH}: 3.0$

Water temperafure: $18.6^{\circ} \mathrm{C}$

Water evacuated before sampling: $58 \mathrm{gat}$

ABORATORY ANALYSES

\begin{tabular}{|c|c|c|c|}
\hline Analyte & Result & Mod & Unit \\
\hline $\begin{array}{l}\text { pH } \\
\text { Spocific conductance } \\
\text { Aluminum } \\
\text { Antimony } \\
\text { Arsenic } \\
\text { Barium } \\
\text { Cadmium } \\
\text { Calcium } \\
\text { Chloride } \\
\text { Chromium } \\
\text { Cobalt } \\
\text { Copper } \\
\text { Cyanide } \\
\text { Fluoride } \\
\text { lron } \\
\text { Lead } \\
\text { Magnesium } \\
\text { Manganese } \\
\text { Mercury } \\
\text { Nickel } \\
\text { Nitrate as nitrogen } \\
\text { Nitrate as nitrogen } \\
\text { Phenols } \\
\text { Potassium } \\
\text { Selenium } \\
\text { Silica } \\
\text { Silver } \\
\text { Sodium } \\
\text { Sulfate } \\
\text { Thallium } \\
\text { Total dissolved solids } \\
\text { Total organic carbon } \\
\text { Total organic halopens } \\
\text { Total phosphates as P) } \\
\text { Uranium } \\
\text { Uranium } \\
\text { Vanadium } \\
\text { Zinc } \\
\text { Gross alpha } \\
\text { Nonvolatile beta } \\
\text { Total activity } \\
\text { Total radium } \\
\text { Tritium }\end{array}$ & $\begin{array}{l}3.4 \\
2,550 \\
157.000 \\
<2.0 \\
<2.0 \\
1,360 \\
<4.0 \\
11,300 \\
8,800 \\
4.4 \\
416 \\
157 \\
<5.0 \\
516 \\
844 \\
4.3 \\
2,690 \\
14.300 \\
0.53 \\
124 \\
300,000 \\
300.000 \\
<5.0 \\
3,060 \\
<2.0 \\
50,200 \\
<4.0 \\
91,800 \\
25,800 \\
<2.0 \\
1.2 E+06 \\
2,000 \\
15 \\
<50 \\
3,160 \\
3,160 \\
<16 \\
207 \\
1.2 E \cdot 06 \pm 6.5 E-08 \\
2.4 E \cdot 06 \pm 5.3 E \cdot 08 \\
3.4 E \cdot 02 \pm 3.0 E \cdot 04 \\
4.4 E-08 \pm 3.6 E \cdot 09 \\
3.4 E \cdot 02 \pm 3.0 E-05\end{array}$ & $\begin{array}{l}\mathrm{J2} \\
\mathrm{J} 1 \\
\mathrm{~J} 2 \\
\mathrm{~J} 2 \\
\mathrm{~J} 2 \\
\mathrm{~J} 2 \\
\mathrm{~J} 0 \\
\mathrm{~V} \\
\mathrm{~J} 2 \\
\mathrm{~J} 2 \\
\mathrm{~J} 2 \\
\mathrm{~J} 2 \\
\\
\mathrm{~J} 2 \\
\mathrm{~J} 2 \\
\mathrm{~J} 1 \\
\mathrm{~J} 2 \\
\mathrm{~J} 1 \\
\mathrm{~J} 2\end{array}$ & $\begin{array}{l}p \mu \\
\mu L \\
\mu g / L \\
\mu g / L \\
\mu g / L \\
\mu g / L \\
\mu g / L \\
\mu g / L \\
\mu g / L \\
\mu g / L \\
\mu g / L \\
\mu g / L \\
\mu g / L \\
\mu g / L \\
\mu g / L \\
\mu g / L \\
\mu g / L \\
\mu g / L \\
\mu g / L \\
\mu g / L \\
\mu g / L \\
\mu g / L \\
\mu g / L \\
\mu g / L \\
\mu g / L \\
\mu g / L \\
\mu g / L \\
\mu g / L \\
\mu g / L \\
\mu g / L \\
\mu g / L \\
\mu g / L \\
\mu g / L \\
\mu g / L \\
\mu g / L \\
\mu g / L \\
\mu g / L \\
\mu g / L \\
\mu C i / m L \\
\mu C i / m L \\
\mu C i / m L \\
\mu C i / m L \\
\mu C i / m L\end{array}$ \\
\hline
\end{tabular}

WELL FSB106C

MEASUREMENTS CONDUCTED IN THE FIELD

Sample date: 10/22/91 Depth to water: $33.00 \mathrm{ft}(10.06 \mathrm{~m})$ below TOC Wp. cond 1 tance: 609 . 161.60

pH: 5.1

Water temperature: $18.7^{\circ} \mathrm{C}$

Water evacuated before sampling: $121 \mathrm{gal}$

LABORATORY ANALYSES

\begin{tabular}{|c|c|c|c|}
\hline Analyte & Result & Mod & Unit \\
\hline $\begin{array}{l}\text { pH } \\
\text { Specific conductance } \\
\text { Aluminum } \\
\text { Antimony } \\
\text { Arsenic } \\
\text { Barium } \\
\text { Cadmium } \\
\text { Calcium } \\
\text { Chloride } \\
\text { Chromium } \\
\text { Cobalt } \\
\text { Coppe: } \\
\text { Cyanide } \\
\text { Cyanide } \\
\text { Fluoride } \\
\text { Iron } \\
\text { Lead } \\
\text { Magnesium } \\
\text { Manganese } \\
\text { Mercury } \\
\text { Nickel } \\
\text { Nitrate as nitrogen } \\
\text { Potassium } \\
\text { Selenium } \\
\text { Silica } \\
\text { Silver } \\
\text { Sodium } \\
\text { Sulfate } \\
\text { Thallium } \\
\text { Total dissolved solids } \\
\text { Total organic carbon } \\
\text { Total organic halogens } \\
\text { Total phosphales (as P) } \\
\text { Uranium } \\
\text { Vanadium } \\
\text { Zinc } \\
\text { Gross alpha } \\
\text { Nonvolatile beta } \\
\text { Total activity } \\
\text { Total radium } \\
\text { Tritiurn }\end{array}$ & $\begin{array}{l}5.3 \\
650 \\
1,380 \\
<2.0 \\
<2.0 \\
95 \\
5.5 \\
18,800 \\
4,020 \\
<4.0 \\
30 \\
<4.0 \\
<5.0 \\
<5.0 \\
542 \\
<4.0 \\
<3.0 \\
3,870 \\
649 \\
<0.20 \\
8.3 \\
76,500 \\
656 \\
<2.0 \\
3,890 \\
<2.0 \\
26,100 \\
3,200 \\
<2.0 \\
475,000 \\
<1,000 \\
36 \\
<50 \\
<20 \\
<8.0 \\
21 \\
<2.0 \mathrm{E}-09 \\
1.2 \mathrm{E}-06 \pm 1.6 \mathrm{E}-08 \\
2.5 \mathrm{E}-03 \pm 3.6 \mathrm{E}-05 \\
4.6 \mathrm{E}-08 \pm 4.05 \mathrm{E}-09 \\
2.3 \mathrm{E}-03 \pm 7.5 \mathrm{E}-06\end{array}$ & $\begin{array}{l}\mathrm{J} 1 \\
\mathrm{~J} 2 \\
\mathrm{~J} 2 \\
\mathrm{JQV} \\
\mathrm{J} O\end{array}$ & $\begin{array}{l}p H \\
\mu S / c m \\
\mu g / L \\
\mu g / L \\
\mu g / L \\
\mu g / L \\
\mu g / L \\
\mu g / L \\
\mu g / L \\
\mu g / L \\
\mu g / L \\
\mu g / L \\
\mu g / L \\
\mu g / L \\
\mu g / L \\
\mu g / L \\
\mu g / L \\
\mu g / L \\
\mu g / L \\
\mu g / L \\
\mu g / L \\
\mu g / L \\
\mu g / L \\
\mu g / L \\
\mu g / L \\
\mu g / L \\
\mu g / L \\
\mu g / L \\
\mu g / L \\
\mu g / L \\
\mu g / L \\
\mu g / L \\
\mu g / L \\
\mu g / L \\
\mu g / L \\
\mu g / L \\
\mu C I / m L \\
\mu C l / m L \\
\mu C i / m L \\
\mu C l / m L \\
\mu C i / m L\end{array}$ \\
\hline
\end{tabular}

WELL FSB106D

MEASUREMENTS CONDUCTED IN THE FIELD

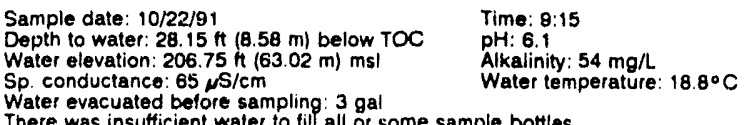

Wp. conductance: 65 s $/ \mathrm{cm}$

There was insufficient water to fill all or some sample bottles.

LABORATORY ANALYSES

\begin{tabular}{|c|c|c|c|}
\hline Analyte & Result & Mod & Unit \\
\hline $\begin{array}{l}\text { pH } \\
\text { Specific conductance } \\
\text { Aluminum } \\
\text { Antimony } \\
\text { Arsenic } \\
\text { Barium } \\
\text { Benzene } \\
\text { Bromodichloromethane } \\
\text { Bromoform } \\
\text { Bromomethane } \\
\text { Cadmium } \\
\text { Calcium } \\
\text { Carbon tetrachloride } \\
\text { Chloride } \\
\text { Chloride } \\
\text { Chloroberizene } \\
\text { Chloroethane } \\
\text { Chloroethene Ninyl chloride) } \\
\text { 2-Choroethyl vinyl ether } \\
\text { Chloroform } \\
\text { Chloromethane } \\
\text { Chromium } \\
\text { Cobalt } \\
\text { Copper } \\
\text { Cyanide } \\
\text { Dibromochloromethane } \\
1,1-\text { Dichloroethane } \\
1,2 \text {.Dichloroethane } \\
\text { 1,1-Dichloroethylene } \\
\text { trans. } 1.2 \text {-Dichloroethylene }\end{array}$ & $\begin{array}{l}6.5 \\
100 \\
75 \\
3.2 \\
<2.0 \\
16 \\
<1.0 \\
<1.0 \\
<1.0 \\
<1.0 \\
<2.0 \\
14,300 \\
<1.0 \\
3,380 \\
3,580 \\
<1.0 \\
<1.0 \\
<1.0 \\
<1.0 \\
<1.0 \\
<1.0 \\
<4.0 \\
<4.0 \\
30 \\
<5.0 \\
<10 \\
<1.0 \\
<10 \\
<1.0 \\
<10\end{array}$ & JO & $\begin{array}{l}p H \\
\mu S / c m \\
\mu g / L \\
\mu g / L \\
\mu g / L \\
\mu g / L \\
\mu g / L \\
\mu g / L \\
\mu g / L \\
\mu g / L \\
\mu g / L \\
\mu g / L \\
\mu g / L \\
\mu g / L \\
\mu g / L \\
\mu g / L \\
\mu g / L \\
\mu g / L \\
\mu g / L \\
\mu g / L \\
\mu g / L \\
\mu g / L \\
\mu g / L \\
\mu g / L \\
\mu g / L \\
\mu g / L \\
\mu g / L \\
\mu g / L \\
\mu g / L \\
\mu g / L\end{array}$ \\
\hline
\end{tabular}


WELL FSB108D colloctod on 10/22/91, laboratory analyses (cont.)

\begin{tabular}{|c|c|c|c|}
\hline Analyte & Result & Mod & Unit \\
\hline 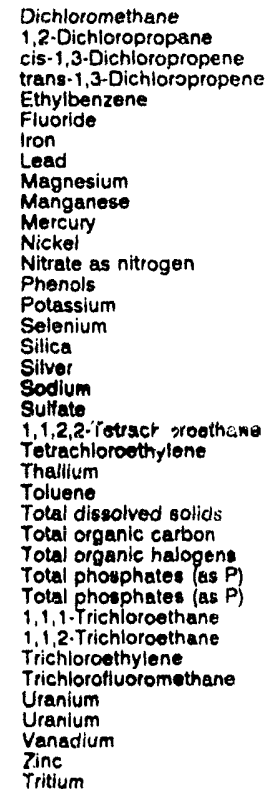 & $\begin{array}{l}1.6 \\
<1.0 \\
<1.0 \\
<1.0 \\
<1.0 \\
<100 \\
187 \\
6.5 \\
904 \\
19 \\
<0.20 \\
22 \\
1,220 \\
<50 \\
501 \\
<2.0 \\
7,850 \\
<2.0 \\
5,210 \\
2,380 \\
<1.0 \\
<1.0 \\
<2.0 \\
<1.0 \\
50.000 \\
<1,000 \\
41 \\
<50 \\
<50 \\
<1.0 \\
<1.0 \\
<1.0 \\
<1.0 \\
<20 \\
<20 \\
<8.0 \\
409 \\
6.6 \mathrm{E}-05\end{array}$ & & 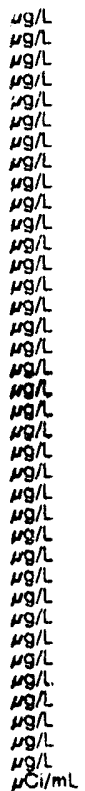 \\
\hline
\end{tabular}

\section{WELL FSB107C}

MEASUREMENTS CONOUCTED IN THE FIELD

Sample dete: 10/22/91 Dopth to waler: $60.18 \mathrm{n}$ (18.34 m) below TOC Sp conductance: 175 \% 164. Water evacuated belore sampling: $157 \mathrm{gal}$

LABORATORY ANALYSES

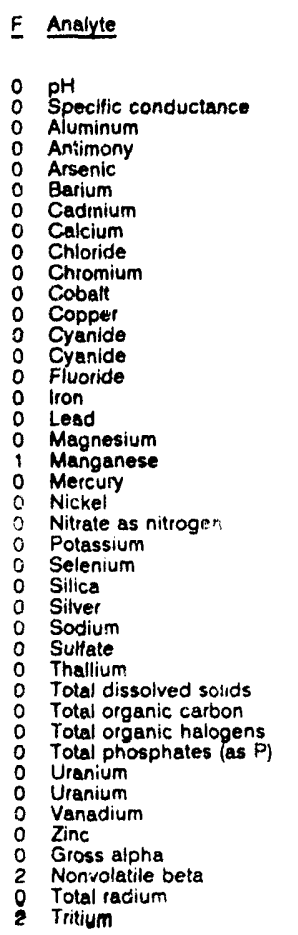

\begin{tabular}{|c|c|c|}
\hline Result & Mod & Unit \\
\hline $\begin{aligned} & 6.8 \\
& 160 \\
&<20 \\
&<2.0 \\
&<2.0 \\
& 26 \\
&<2.0 \\
& 26,400 \\
& 3,480 \\
&<4.0 \\
&<4.0 \\
&<4.0 \\
&<5.0 \\
&<5.0 \\
&<100 \\
&<4.0 \\
&<3.0 \\
& 1,910 \\
& 35 \\
&<0.20 \\
&<4.0 \\
& 4,250 \\
&<500 \\
&<2.0 \\
& 8,190 \\
&<2.0 \\
& 5,420 \\
&<1.000 \\
&<2.0 \\
& 107,000 \\
&<1,000 \\
& 18 \\
& 130 \\
&<20 \\
&<20 \\
&<8.0 \\
& 63 \\
& 41 \mathrm{E} \cdot 09 \pm 1.8 \mathrm{E} \cdot 09 \\
& 5.1 \mathrm{E} \cdot 0 \mathrm{~B} \pm 3.4 \mathrm{E} \cdot 09 \\
& 1.6 \mathrm{E} \cdot 09 \pm 1.0 \mathrm{E} \cdot 09 \\
& 1.4 \mathrm{E} \cdot 04 \pm 2.1 \mathrm{E} \cdot 06\end{aligned}$ & Jo & 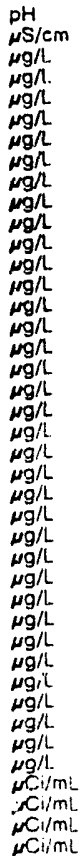 \\
\hline
\end{tabular}

WELL FSB107D

MEASUREMENTS CONDUCTED IN THE FIELD

Sample date: 10/22/91 Depth to water: $57.16 \mathrm{H}(17.42 \mathrm{~m})$ below roc Water elevation: 213.84 ft 165.18 Water evacuated before sampling: $34 \mathrm{gal}$ Time: 10:30 $\mathrm{pH}: 3.6$ $0 \mathrm{mg}$ LABORATORY ANALYSES

\begin{tabular}{|c|c|c|c|}
\hline Analyte & Result & Mod & Unit \\
\hline $\begin{array}{l}\text { pH } \\
\text { Specific conductance } \\
\text { Aluminum } \\
\text { Antimony } \\
\text { Arsenic } \\
\text { Barium } \\
\text { Cadmium } \\
\text { Calcium } \\
\text { Chloride } \\
\text { Chromium } \\
\text { Cobalt } \\
\text { Copper } \\
\text { Cyanide } \\
\text { Fluoride } \\
\text { lron } \\
\text { Lead } \\
\text { Magnesium } \\
\text { Manganese } \\
\text { Mercury } \\
\text { Nickel } \\
\text { Nitrate as nitrogen } \\
\text { Potassium } \\
\text { Selenium } \\
\text { Sil.. } \\
\text { Silver } \\
\text { Sodium } \\
\text { Sulfate } \\
\text { Thallium } \\
\text { Total dissolved solids } \\
\text { Total organic carbon } \\
\text { Total organic halogens } \\
\text { Total phosphates (as P) } \\
\text { Uranium } \\
\text { Vanadium } \\
\text { Zinc } \\
\text { Gross alpha } \\
\text { Nonvolatile beta } \\
\text { Total activity } \\
\text { Total radium } \\
\text { Tritium }\end{array}$ & 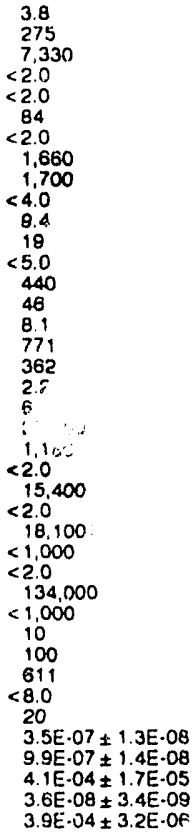 & Jo & $\begin{array}{l}p H \\
\mu \mathrm{S} / \mathrm{cm} \\
\mu g / L \\
\mu g / L \\
\mu g / L \\
\mu g / L \\
\mu g / L \\
\mu g / L \\
\mu g / L \\
\mu g / L \\
\mu g / L \\
\mu g / L \\
\mu g / L \\
\mu g / L \\
\mu g / L \\
\mu g / L \\
\mu g / L \\
\mu g / L \\
\mu g / L \\
\mu g / L \\
\mu g / L \\
\mu g / L \\
\mu g / L \\
\mu g / L \\
\mu g / L \\
\mu g / L \\
\mu g / L \\
\mu g / L \\
\mu g / L \\
\mu g / L \\
\mu g / L \\
\mu g / L \\
\mu g / L \\
\mu g / L \\
\mu g / L \\
\mu L L / / m L \\
\mu C i / m L \\
\mu C i / m L \\
\mu C i / m L \\
\mu C i / m L\end{array}$ \\
\hline
\end{tabular}

WELL FSB108D

MEASUREMENTS CONDUCTED IN THE FIELD

Sample date: $10 / 21 / 91$ Depth to water: $82.36 \mathrm{~A}(25.10 \mathrm{~m})$ below TOC Water elevation: $215.64 \mathrm{~h}(65.73 \mathrm{~m}) \mathrm{msl}$ Sp. conductance: $81 \mu \mathrm{S} / \mathrm{cm}$ The well went dry during purging.

LABORATOAY ANALYSES

\begin{tabular}{|c|c|c|c|}
\hline Analyte & Result & Mod & Unit \\
\hline $\begin{array}{l}\text { pH } \\
\text { Specific conductance } \\
\text { Aluminum } \\
\text { Antimony } \\
\text { Arsenic } \\
\text { Barium } \\
\text { Cadmium } \\
\text { Calcium } \\
\text { Choride } \\
\text { Chromium } \\
\text { Cobalt } \\
\text { Copper } \\
\text { Cyanide } \\
\text { Fluoride } \\
\text { lron } \\
\text { Lead } \\
\text { Magnesium } \\
\text { Manganese } \\
\text { Mercury } \\
\text { Nickel } \\
\text { Nitrate as nitrogen } \\
\text { Nitrate as nitrogen } \\
\text { Potassium } \\
\text { Selenium } \\
\text { Silica } \\
\text { Silver } \\
\text { Sodium } \\
\text { Sulfate } \\
\text { Sulfals } \\
\text { Thallium } \\
\text { Total disuolved solld: }\end{array}$ & 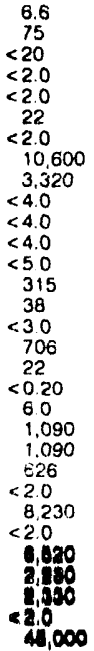 & JO & 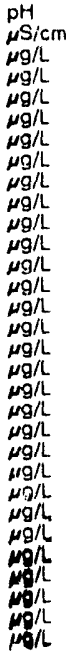 \\
\hline
\end{tabular}


ANALYTICAL RESULTS

WE'L FSB108D collected on 10/21/91, laboratory analyses (cont.)

\begin{tabular}{|c|c|c|c|}
\hline F Analyte & Result & Mod & Unit \\
\hline $\begin{array}{l}\text { Total organic carbon } \\
\text { Total organic halogens } \\
\text { Total organic halogens } \\
\text { Total phosphates (as P) } \\
\text { Uranium } \\
\text { Vunadium } \\
\text { Zinc } \\
\text { Gross alpha } \\
\text { Nonvolatile beta } \\
\text { Total radium } \\
\text { Tritium }\end{array}$ & $\begin{array}{l}<1.000 \\
8.9 \\
11 \\
<50 \\
<20 \\
<8.0 \\
22 \\
<2.0 E-09 \\
<2.0 \mathrm{E}-09 \\
<1.0 \mathrm{E}-09 \\
1.0 \mathrm{E}-05 \pm 8.0 \mathrm{E}-07\end{array}$ & & $\begin{array}{l}\mu g / \mathrm{L} \\
\mu g / \mathrm{L} \\
\mu g / \mathrm{L} \\
\mu g / \mathrm{L} \\
\mu g / \mathrm{L} \\
\mu g / \mathrm{L} \\
\mu g / \mathrm{L} \\
\mu \mathrm{i} / \mathrm{mL} \\
\mu \mathrm{Ci} / \mathrm{mL} \\
\mu \mathrm{Ci} / \mathrm{mL} \\
\mu \mathrm{Ci} / \mathrm{mL}\end{array}$ \\
\hline
\end{tabular}

WELL FSB109D

MEASUREMENTS CONDUCTED IN THE FIELD

Sample date: 10/21/81

Depth to water: $81.43 \mathrm{n}(24.82 \mathrm{~m})$ below TOC

Water elevation: $211.67 \mathrm{tt}(84.52 \mathrm{~m}) \mathrm{ms}$ )

Water evacuated before sampling: $14 \mathrm{gal}$

The well went dry during purging.

LABORATORY ANALYSES

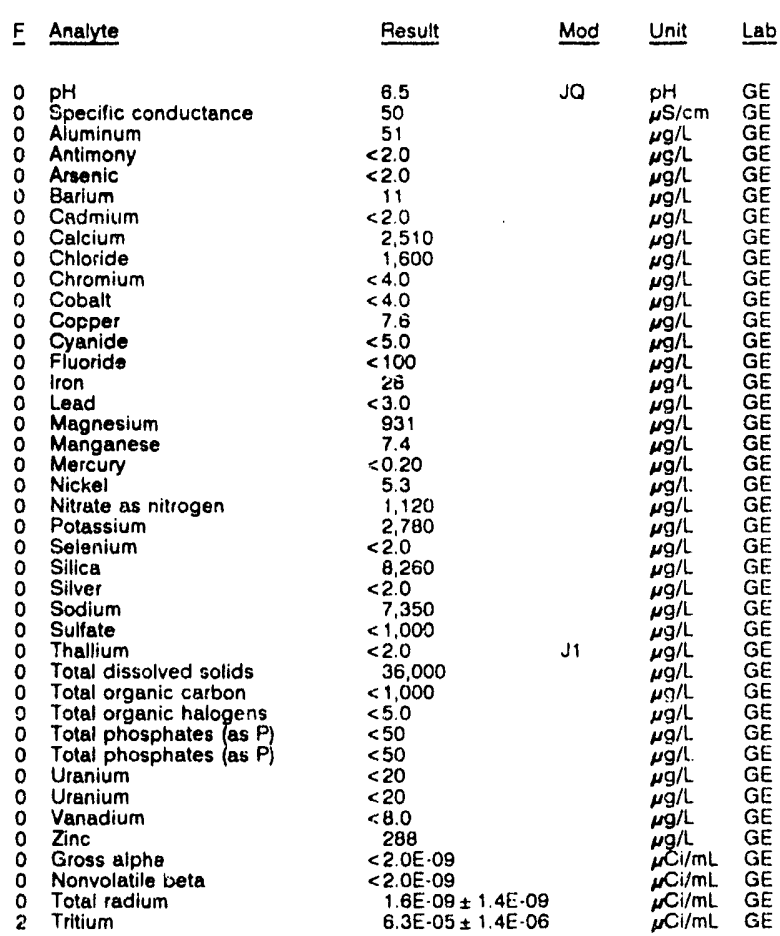

\section{WELL FSB110C}

MEASUREMENTS CONDUCTED IN THE FIELD

Sample date: $10 / 15 / 9$,

Depth to water: $31.93 \mathrm{ft}(9.73 \mathrm{~m})$ below TOC Water elevation: $20257 \mathrm{ft}(61.74 \mathrm{~m}) \mathrm{msl}$

Sp conductance: $341 \mathrm{HS} / \mathrm{cm}$

Water evacuated before sampling: $170 \mathrm{gal}$

LABORATORY ANALYSES

\begin{tabular}{|c|c|c|c|}
\hline Analyte & Result & Mod & Unit \\
\hline 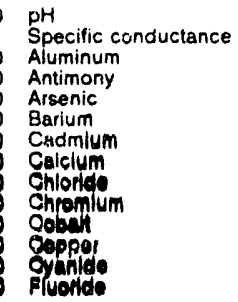 & $\begin{array}{l}6.5 \\
340 \\
57 \\
<2.0 \\
<2.0 \\
75 \\
<2.0 \\
37.500 \\
2.920 \\
<4.0 \\
<4.0 \\
<4.0 \\
850 \\
<100\end{array}$ & JO & 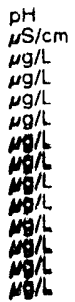 \\
\hline
\end{tabular}

Time: $8: 20$

Alkalinity: $17 \mathrm{mg} / \mathrm{L}$

Water temperature: $19.3{ }^{\circ} \mathrm{C}$

w

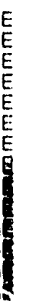

WELL FSB1 10C collected on 10/15/91, laboratory analyses (cont.)

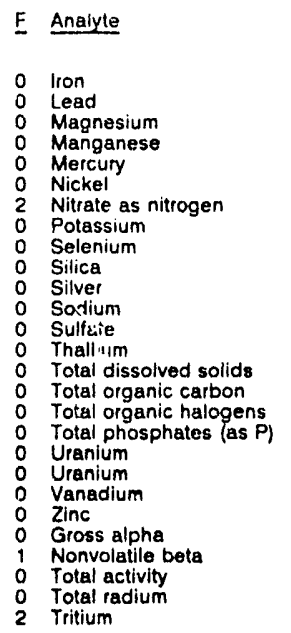

Result

Mod Unit Lab

\section{Time: 10:50}

Al: 8.1 . $31 \mathrm{mg}$

Alkalinity: $31 \mathrm{mg} / \mathrm{h}$

Tritium

\section{WELL FSB110D}

MEASUREMENTS CONOUCTED IN THE FIELD

Sample date: 10/15/91

Cepth to water: $28.16 \mathrm{ft}(8.58 \mathrm{~m})$ below TOC

Waler elevalion: $206.34 \mathrm{Ht}(62.89 \mathrm{~m}) \mathrm{msl}$

Water evacuated before sampling: $40 \mathrm{gal}$

The. 7.35

Alkalinity: $0 \mathrm{mg} / \mathrm{L}$

Water temperature: $18.8^{\circ} \mathrm{C}$

LABORATORY ANALYSES

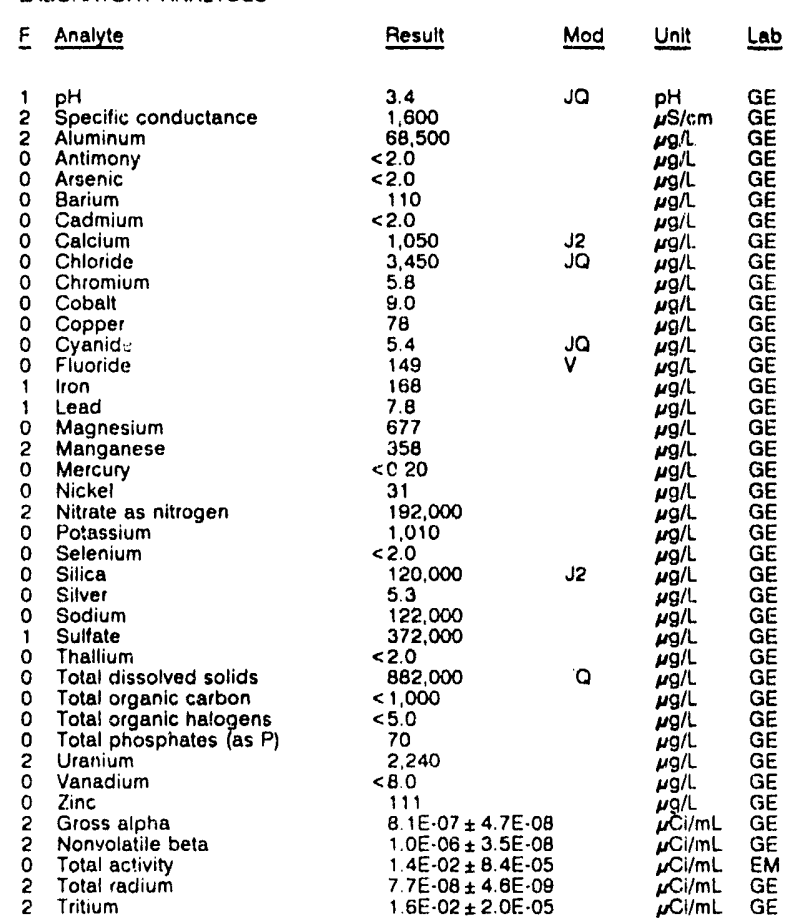




\section{WELL FSB111C}

MEASUREMENTS CONDUCTED IN THE FIELD

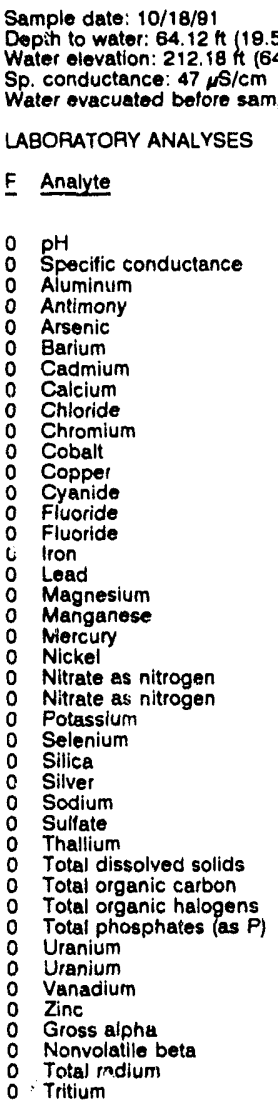

msi
$140 \mathrm{gal}$

Time: : $: 50$

Alkalinity: $8 \mathrm{mg} / \mathrm{h}$

Water temperature: $17.8^{\circ} \mathrm{C}$

\begin{tabular}{|c|c|c|}
\hline Result & Mod & Unit \\
\hline $\begin{array}{l}6.0 \\
52 \\
<20 \\
<2.0 \\
<2.0 \\
7.0 \\
<2.0 \\
5,360 \\
0.540 \\
<4.1 \\
<4.0 \\
<4 . C \\
<5 . C \\
<100 \\
<100 \\
<4.0 \\
<3.0 \\
386 \\
4.4 \\
<0.20 \\
<4.0 \\
1,760 \\
1,780 \\
<500 \\
<2.0 \\
9.500 \\
<2.0 \\
3,280 \\
<1,000 \\
<2.0 \\
34,000 \\
<1.000 \\
<5.0 \\
250 \\
<20 \\
<20 \\
<8.0 \\
5.0 \\
<2.0 E \cdot .09 \\
<2.0 E \cdot 09 \\
1.0 E \cdot 09 \pm 1.4 E \cdot C 9 \\
<7.0 E-07\end{array}$ & $\mathrm{~J} 2$ & $\begin{array}{l}p H \\
\mu \mathrm{S} / \mathrm{cm} \\
\mu g / \mathrm{L} \\
\mu g / \mathrm{L} \\
\mu g / \mathrm{L} \\
\mu g / L \\
\mu g / L \\
\mu g / L \\
\mu g / L \\
\mu g / L \\
\mu g / L \\
\mu g / L \\
\mu g / L \\
\mu g / L \\
\mu g / L \\
\mu g / L \\
\mu g / L \\
\mu g / L \\
\mu g / L \\
\mu g / L \\
\mu g / L \\
\mu g / L \\
\mu g / L \\
\mu g / L \\
\mu g / L \\
\mu g / L \\
\mu g / L \\
\mu g / L \\
\mu g / L \\
\mu g / L \\
\mu g / L \\
\mu g / L \\
\mu g / L \\
\mu g / L \\
\mu g / L \\
\mu g / L \\
\mu g / L \\
\mu g / L \\
\mu C i / m L \\
\mu C i / m L \\
\mu C i / m L \\
\mu C i / m L\end{array}$ \\
\hline
\end{tabular}

\section{WELL FSB111D}

MEASUREMENTS CONDUCTED IN THE FIELD

Sample date: $10 / 18 / 91$

Depth to water: $61.15 \mathrm{ft}(18.64 \mathrm{~m})$ below TOC

Sp conductanc: $215.45 \mathrm{ft}(65.67$

Water evacuated belore sampling: $36 \mathrm{gal}$

LABORATORY ANALYSES
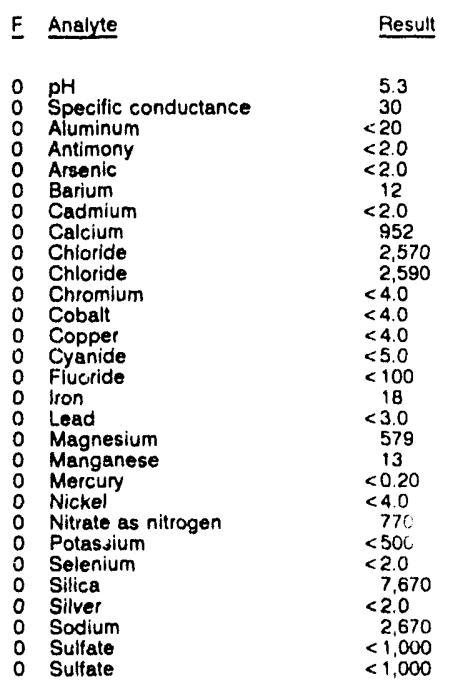

WELL FSB 1110 collected on 10/18/91, laboratory analyses (cont.)

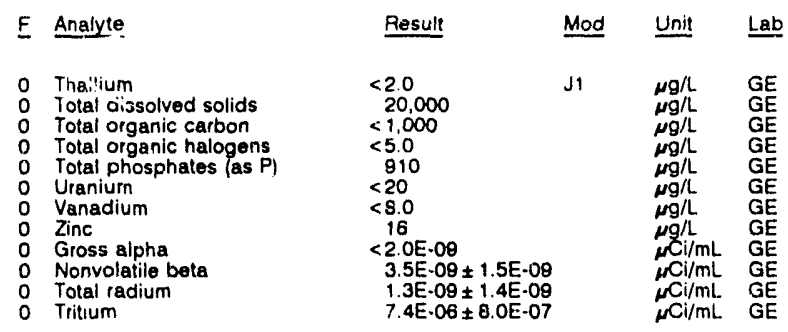

WELL FSB112A

MEASUREMENIS CONDUCTED IN THE FIELD

Sample date: 10/21/91

Depth to water: $75.73 \mathrm{Ht}(23.08 \mathrm{~m})$ below TOC

Water elevation: $153.37 \mathrm{H}(46.75 \mathrm{~m}) \mathrm{ms}$ l

Sp. conductance: $162 \mu \mathrm{S} / \mathrm{cm}$
Water evacuated before sampling: $190 \mathrm{gal}$

Time. 9.30

Alkalinity: $92 \mathrm{mg} / \mathrm{L}$

Water temperature: $17.7^{\circ} \mathrm{C}$

LABOFATORY ANALYSES

E Analyte Result Mod Unit Lab

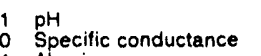

Aluminum

Antimony

Arsenic

Barium

Bromodichloromethane

Bromororm

Bromomethan

Calcium

Carbon tetrachioride

Chloride

Chlorobenzene

Chloroethane

Chloroethene Ninyl chloride) $<1$ - Chloroethyl vinyl ether

$\begin{array}{ll}\text { Chloroform } & <1.0 \\ \text { Chloromethane } & <1.0\end{array}$

Cobalt

Copper

Cyanid

Dibromochloromethane

1,1-Dichloroethane

1,2-Dichloroethane

1,1-Dichloroethylene
0 trans-1,2-Dichloroethylene

Dichloromethane

2,4.Dichlorophenoxyacetic acid

1,2-Dichloropropane

cis-1,3-Dichloropropene
ttans-1,3-Dichloropropene

0 Endrin

0 Endrin

- Ethylbenzene

0 Fluoride

0 Iron

0 Lead

O Lindane

- Lindane

- Manganese

Mercury

Methoxychlor

Nickel

Nitrate as nitrogen

Nitrate as nitrogen

Potassium

Selenium

o Silica

Silver

Sodium

Sulfate

Tetrachloroethylene

Thallium

Toluene

Total dissulved solids

Total organic carbon

Total organic halogens

Total phosphates (as P)

- Toxaphene

2,4,5.TP (Silvex)

$0 \quad 1,1,1$. Trichloroethane

9.1
160
152
$<2.0$
$<2.0$
43
$<1.0$
$<1.0$
$<1.0$
$<1.0$
$<2.0$
27.90
$<1.0$
2.490
$<1.0$
$<1.0$
$<1.0$
$<1.0$
$<1.0$
$<1.0$
$<4.0$
$<4.0$
$<4.0$
$<5.0$
$<1.0$
$<1.0$
$<1.0$
$<1.0$
$<1.0$
51.1
$<0.30$
$<1.0$
$<1.0$
$<1.0$
$<0.006$
$<0.0060$
$<110$

27,900
$<1.0$

$<1.0$
2,490

$<0.0060$

$<0.0060$
$<0.0060$

$<0.0060$
$<1.0$

167
$<4.0$

$<0.0050$

$<0.0050$

608

$<0.20$

$<0.50$
$<0.50$

$<0.50$
$<4.0$

1,960
2,020

2,020
$<5.0$
2,710

$\begin{array}{r}2,710 \\ <2.0 \\ \hline\end{array}$

38,500

$<2.0$
3.690
9.980
$<1.0$

$<1.0$
$<2.0$

$<2.0$
1.1

138,000
$<1,000$

$<1,000$
15

330

330
$<0.24$
$<0.24$

$<0.24$
$<0.24$
$<0.090$

$<0.090$
$<1.0$

$<1.0$
$<1.0$ 
ANALYTICAL RESULTS

WELL FSB112A collected on 1C/21/91, laboratory analyses (cont.)

\begin{tabular}{|c|c|c|}
\hline Analyte & Result & Unit \\
\hline $\begin{array}{l}\text { Trichloroethylene } \\
\text { Trichlorofluoromethane } \\
\text { Uranium } \\
\text { Uranium } \\
\text { Vanadium } \\
\text { Zinc } \\
\text { Gross alpha } \\
\text { Nonvolatile beta } \\
\text { Total radium } \\
\text { Tritium }\end{array}$ & $\begin{array}{l}<1.0 \\
<1.0 \\
<20 \\
<20 \\
<8.0 \\
<2.0 \\
<2.0 \mathrm{E}-09 \\
2.7 \mathrm{E}-08 \pm 2.7 \mathrm{E} \cdot 09 \\
<1.0 \mathrm{E}-09 \\
1.1 \mathrm{E} \cdot 04 \pm 1.8 \mathrm{E}-06\end{array}$ & $\begin{array}{l}\mu \mathrm{g} / \mathrm{L} \\
\mu \mathrm{g} / \mathrm{L} \\
\mu \mathrm{g} / \mathrm{L} \\
\mu \mathrm{g} / \mathrm{L} \\
\mu \mathrm{g} / \mathrm{L} \\
\mu \mathrm{g} / \mathrm{L} \\
\mu \mathrm{C} \mathrm{i} / \mathrm{mL} \\
\mu \mathrm{Ci} / \mathrm{mL} \\
\mu \mathrm{Ci} / \mathrm{mL} \\
\mu \mathrm{Ci} / \mathrm{mL}\end{array}$ \\
\hline
\end{tabular}

\section{WELL FSB112C}

MEASUREMENTS CONDUCTED IN THE FIELD

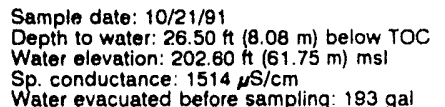

Time: $10: 20$

Alk: 47 inity: $0 \mathrm{mg} / \mathrm{L}$

Water temperature: $18.2^{\circ} \mathrm{C}$

LABORATORY ANALYSTS

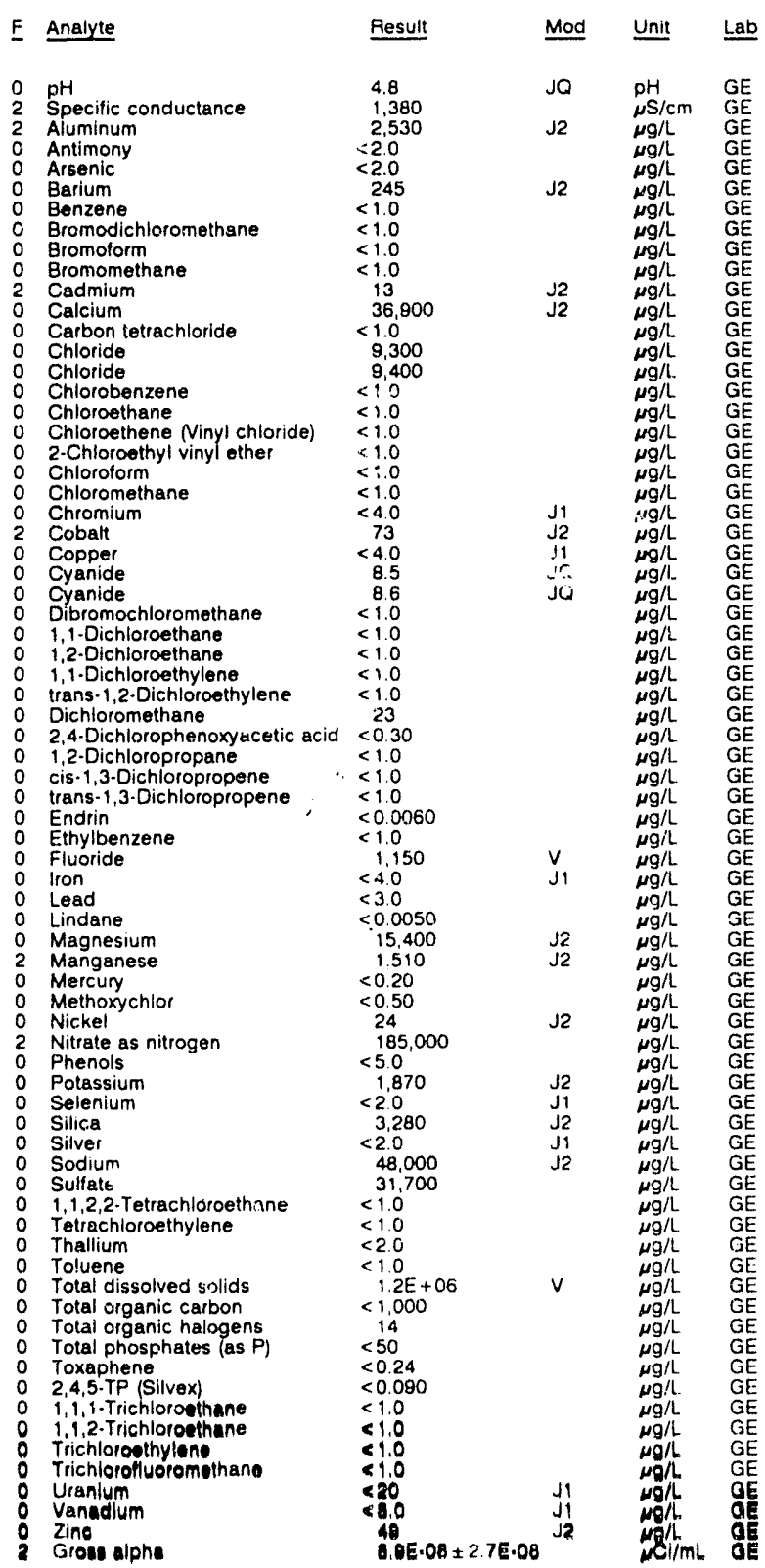

WELL FSB1 12C collected on 10/21/91, laboratory analyses (cont.)

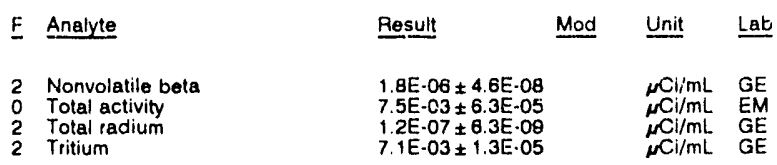

WELL FSB112D

MEASUREMENTS CONDUCTED IN THE FIELD

Sample date: $10 / 21 / 91$
Depth to water: $22.93 \mathrm{ft}(6.89 \mathrm{~m})$ below TOC

Water elevation: $208.67 \mathrm{Ht}(62.99 \mathrm{~m}) \mathrm{msl}$

Sp conductance: $1788, \mathrm{~s} / \mathrm{cm}$

Time: $9: 15$

Alkalinity: $0 \mathrm{mg} / \mathrm{L}$

Water evacuated before sampling: $47 \mathrm{gal}$

LABORATORY ANALYSES

E Analyte Result Mod Unit Lab

1 PH 2 Specific conductance

2 Aluminum

Antimony

Arsenic
0 Barium

Bromodichloromethane

Bromodich

Eromomethan

Cadmium

Carbon tetrachloride

Chloride

Chlorobenzene

Chloroethane

Criloroethene Ninyl chloride
$2 \cdot$ Chloroethyl vinyl ether

Chloromethane

Chromium

2 Cobalt

Copper

o Dibromochloromethane

1.1.Dichioroethane

1.2-Dichloroethane

o trans-1,2-Dichloroethylene

0 Dichloromethane

$\begin{array}{lll}0 & \text { Dichloromethane } & 1.2 \\ 0 & 2,4 \text {-Dichlorophenoxyacetic acid }<0.30 \\ 0 & 1,2 \text {-Dichloropropane } & <1.0\end{array}$

cis-i,3-Dichloropropene

0 trans-1,

0 Endrin

0 Fluoride

0 Iron

O Lead

0 Magnesium

Mangane

Mercury

Nickel

2 Nitrate as nitrogen

Phenols

0 Potassium

0 Selenium

$\begin{array}{ll}0 & \text { Silica } \\ 0 & \text { Silver }\end{array}$

$0 \begin{array}{ll}0 & \text { Silver } \\ 0 & \text { Sodium } \\ 0 & \text { Sullate }\end{array}$

Sodium

1,1,2,2-Tetrachloroethane

Tetrachloroethylene

Thallium

Toluene
Total dissolved solids

Total organic carbon

Total organic halogens

Total phosphates (as P)

Toxaphene

2,4,5.TP (Gilvex)

1,1,1-Trichloroethane

1,1,2. Trichloroethan

o Trichlorofluoromethane

Uranium

Vanadium

Gross alpha

2 Nonvolatile bela

Total radium

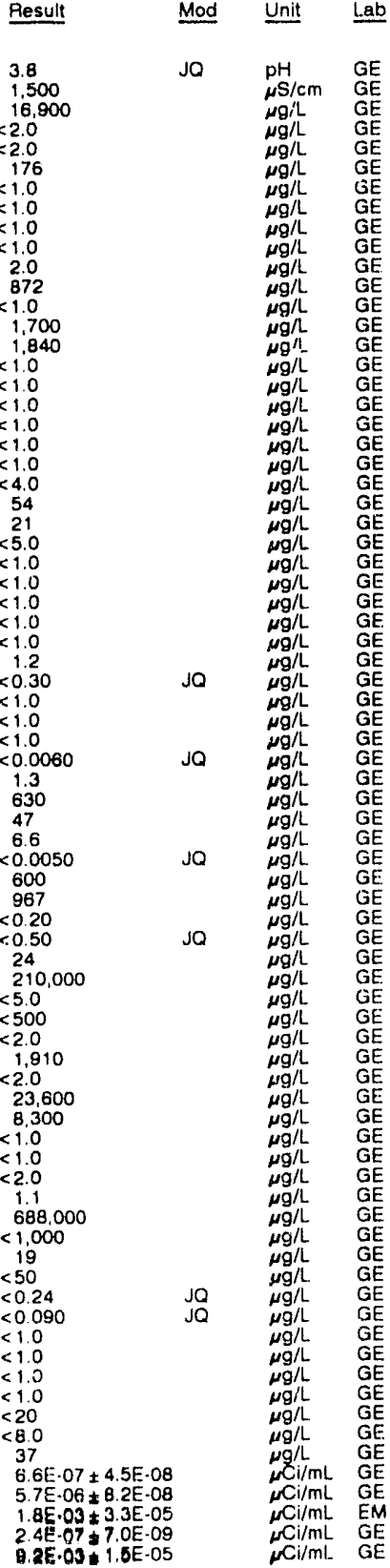


WELL FSB113A

MEASUREMENTS CONDUCTED IN THE FIELD

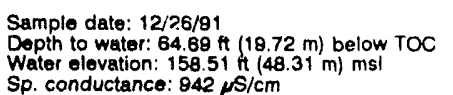

Sp. conductance: $942 \mu \mathrm{sS} / \mathrm{cm}$.

Water evacuated belore samp

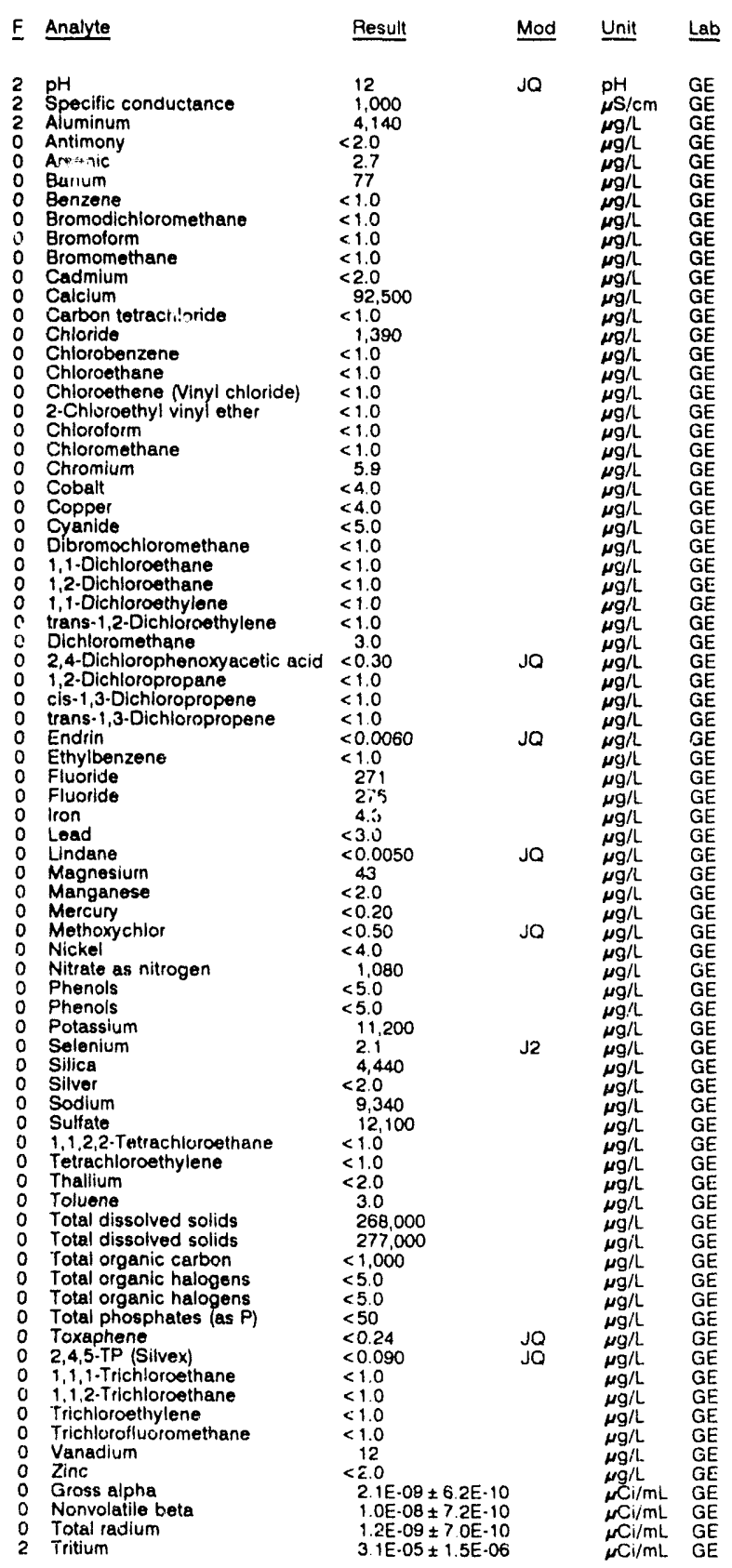

WELL FSB113C

MEASUREMENTS CONDUCTED IN THE FIELD

Sampie date: 10/23/91

Depth to water: $20.59 \mathrm{Ht}(6.28 \mathrm{~m})$ below TOC

Water elevation: $202.31 \mathrm{t}(61.66 \mathrm{~m}) \mathrm{ms}$ l

Water evacuated before sampling: $32 \mathrm{gal}$

The well went dry during purging.

\section{LABORATORY ANALYSES}

$\begin{array}{ll}2 & \text { pH } \\ 2 & \text { Specific conductance } \\ 2 & \text { Aluminum } \\ 0 & \text { Antimony } \\ 0 & \text { Arsenic } \\ 0 & \text { Barium } \\ 0 & \text { Benzene } \\ 0 & \text { Bromodichloromethane } \\ 0 & \text { Bromoform } \\ 0 & \text { Gromomethane } \\ 0 & \text { Cadmium } \\ 0 & \text { Calcium } \\ 0 & \text { Carbon tetrachloride } \\ 0 & \text { Chloride } \\ 0 & \text { Chlorobenzene } \\ 0 & \text { Chloroethane } \\ 0 & \text { Chloroethene Ninyl chloride) } \\ 0 & 2 \cdot \text { Chloroethyl vinyl ether } \\ 0 & \text { Chloroform } \\ 0 & \text { Chloromethane } \\ 0 & \text { Chromiln }\end{array}$

Cobromium

0 Cobalt

O Cyanide

Dibroniochloromethane

1.1-Dichloroethane

o 1,2-Dichloroethane

1,1-Dichloroethylene
0 trans-1,2-Dichloroethylene

0
0
0

2,4-Dichlorophenoxyacetic acio

1,2-Dichloropropane

0
0
0

0 trans-1,

0 Ethylbenzene

0 Fluoride

0 lron

0 Lindane

o Magnesium

Manganese

Mercury
0 Methoxychior

Methox

Nitrate as nitrogen

Phenols

Potassium

Selenium

Silica

Silver

Sodium

Sulfate

Tetrachloroethylene

Thallium

Total dissolved solids

Total organic carbon

Total organic halogens

Toxaphene
2,4,5.TP (Silvex)

1,1,1. Trichloroethane

i,1,2-Trichloroethane

Trichloroethylene

Trichlorofluoromethane

0 Uianium

O Vanadiur

o Gross alpha

- Nonvolatile beta

Total radium
Time: $7: 45$

PH: 11.4 : $213 \mathrm{mg} / \mathrm{h}$

Water temperature: $17.0^{\circ} \mathrm{C}$ 
ANALYTICAL RESULTS

WELL FSB113D

MEASUREMENTS CONDUCTED IN THE FIELD
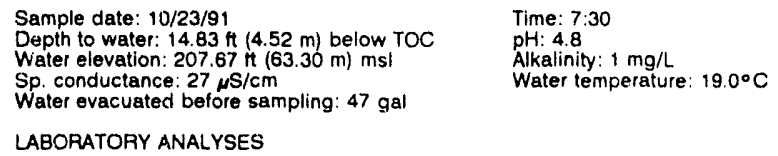

LABORATORY ANALYSES

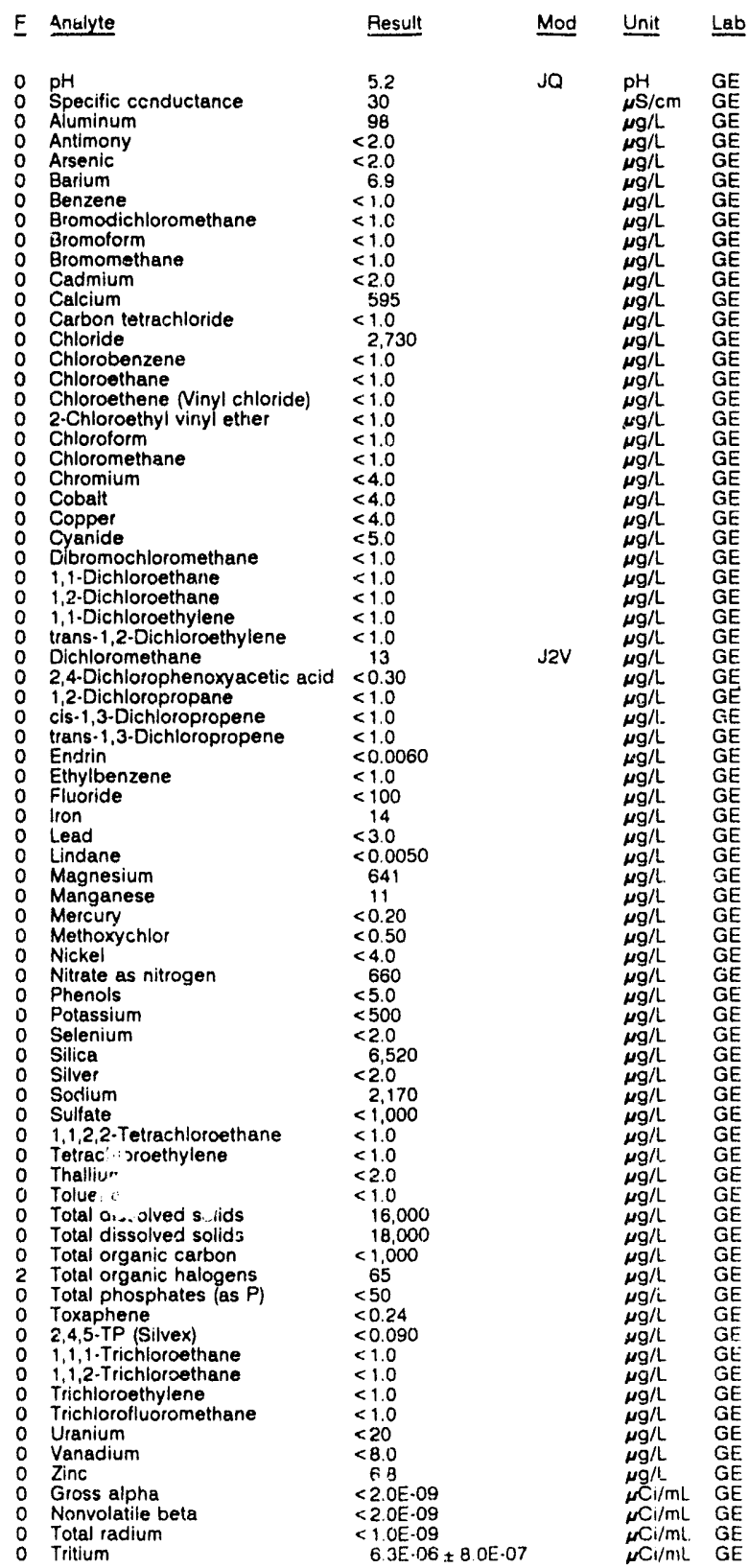

\section{WELL FSB114A}

MEASUREMENTS CONOUCTED IN THE FIELD

Sample date: 10/18/91

Depth to water: 97.08 it $(29.59 \mathrm{~m})$ below TOC

Water elevation $154.92 \mathrm{Ht}(47.22 \mathrm{~m}) \mathrm{ms}$ ! $\mathrm{pH}: 8.8$

Alkalinity: $93 \mathrm{mg} / \mathrm{h}$

Water evacuated before sampling: $157 \mathrm{gal}$

LABORATORY ANA.LYSES

$E$ Analyte $\quad$ Result Mod Unit Lab

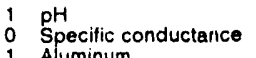

0 Auminum

$\begin{array}{lll}0 & \text { Antimony } \\ 0 & \text { Arsenic } \\ 0 & \text { Bansen }\end{array}$

O Arsium

0 Benzene

Bromodichloromethane

Bromoform

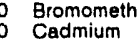

0 Calcium

- Carbon tetrachloride

0 Chloride

Chlorobenzene

Chloroethane

Chloroethene Ninyl chloride

0 Chloroform

o Chloromethane

0 Chromium

0 Cobalt

o Copper

0 Cyanide

- Dibromochloromethane

1,1-Dichloroethan

1,2-Dichloroethane

0 trans-1,2-Dichloroethylene

0 Dichloromethane

0 2,4-Dichlorophenoxyacetic acid

o 1,2-Dichloropropane

cis-1,3-Dichloropropene
0
0

0 Endrin

0 Ethylbenzene

0 Fluoride

0 Iron

0 Lead

Lindane

Magnesium

Mangan

Methoxychlor

Nickel

Nitrate as nitrogen

Phenols

0 Potassium

0 Selenium

0 silica

0 Silver

Sodium

1,1,2,2-Tetrachloroethane

Tetrachloroethylene

Thallium

Total dissolved solids

Total organic carbon

Total organic halogens

Total organic halogens

Total phosphates (as P)

Toxaphene

2.4.5-TP (Silvex)

1,1,1.Trichloroethane

1,1,2-Trichloroethan

Trichloroethylene

Trichlorofluoromethane

Uranium

0 Zinc

Zinc

Gross alpha

2 Total radium

b

\begin{tabular}{|c|}
\hline $\begin{array}{l}9.1 \\
146 \\
165\end{array}$ \\
\hline
\end{tabular}

$\begin{array}{lll}165 & \mu \mathrm{g} / \mathrm{h} & \mathrm{GE} \\ <2.0 & \mu \mathrm{GE} / \mathrm{GE} \\ <2.0 & \mu \mathrm{GE} & \mathrm{GE}\end{array}$

$<2.0$
$<5$

$<1.0$

$<1.0$

$<1.0$

25,600

$<., 0$
2.910

$<1.0$

$<1.0$

$<1.0$

$<1.0$

$<1.0$
$<40$

$<4.0$

$<4.0$

$<5.0$

$<1.0$

$<1.0$

$<1.0$

$<1.0$
2.2

$<\begin{array}{r}2.2 \\ <0.30\end{array}$

$<1.0$

$<1.0$

$<0.0060$

$<1.0$
$<100$

$<3.0$

$<0.005$

602
$<2.0$

$<<<0$

$<0.50$

$<4.0$

1,900
$<50$

$<5.0$

8,850

15,200
$<2.0$

4,470

1,880

$<1.0$

$<1.0$
$<2.0$

$<2.0$
$<1.0$
$<1.000$

80,000

$<1,000$

$<5.0$

170
$<0.24$

$<0.090$

$<1.0$

$<1.0$

$<1.0$
$<1.0$

$<1.0$
$<20$

$<20$
$<8.0$
$<2.0$

$\begin{array}{ll}2 & \text { Total radium } \\ 2 & \text { Tritium }\end{array}$

$2.4 \mathrm{E}-09 \pm 1.6 \mathrm{E}-09$

9.5E-09 $\pm 1.9 \mathrm{E} \cdot 09$

$2.8 \mathrm{E} \cdot 05 \pm 1.1 \mathrm{E}-06$ 


\section{WELL FSB114C}

MEASUREMENTS CONDUCTED IN THE FIELD

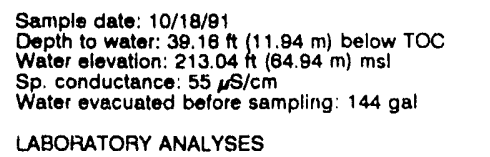

E Analyto Besult Mod Unit

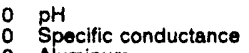

0 Aluminum

o Antimony

0 Arsenic

0 Benzene

Bromodichloromethane

0 Bromotorm

Bromoriethane

0 Cadmium

$\begin{array}{ll}0 & \text { Cajcium } \\ 0 & \text { Carbon tetrachloride } \\ 0 & \text { Chloride }\end{array}$

Chlorobenzene

Chloroethane

2-Chlorosthyl vinyl ether

0 Chloroform

o Chloromethane

Chromlum

Cobalt

o Cyanide

Dibromochloromethane

1,1.Dichloroethane

1,2-Dichloroethane

tians-1,2-Dichloroethylene

Dichloromethane

2,4-Dichlorophenoxyacetic acid

1,2-Dichloropropane

cis-1,3-Dichloropropene

trans-1,

Ethylbenzene

Fivorida

Leas

Lead

Magnesium

Manganes

Methoxychlo

Nickel

Nitrate as nitrogen

Phenols

Potassium

Selenium

Silica

Silver

Sodium

1,1,2,2-Tetrachloroethane

Tetrachloroethylene

Thallium

Total dissolved solids

Total organic carbon

Total organic halogens
Total phosphates (as P)

Toxaphene

2,4,5-TP (Silvax)

1,1,1-Trichloroethane

$1,1,2$-Trichloroethan
Trichloroethylene

Trichlorofluoromethane

Uranium

Zinc

Gross alpha

Nonvolatile beta

Total radium
Tritium

Result Mod Unit Lab

$6.1 \quad J Q$

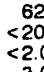

3.0
16
$<1.0$

$<1.0$

$<1.0$

$<2.0$

5,100
$<1.0$
3,760

3,760
$<10$

$<1.0$

$<1.0$

$<1.0$

$<1.0$

$<4.0$

$<4.0$

$<5.0$

$<1.0$

$<1.0$

$<1.0$
$<1.0$

3.8
$<0.30$

$<0.30$
$<1.0$
$<1.0$

$<1.0$

$<0.0060$

$<1.0$
$<100$

24
$<100$

$<0.0050$

520
12

12
$<0.20$
$<0.50$

$<0.50$
$<4.0$

2,000

$<5.0$

$<5.0$
624

$<2.0$
9,710

$<.0$
$<2.70$

3.780
1,000

$<1,000$

$<1.0$

$<2.0$

28,000

$<1,000$

$<5.0$

$<50$
$<0.24$

$<0.090$

$<1.0$

$<1.0$
1.2

1.2
$<1.0$

$<20$

$<8.0$

$12.0 E .09$
$<2.0 E-09$

$<1.0 \mathrm{E}-09$

2. $3 \mathrm{E}-05 \neq 1,0 \mathrm{E}=08$

$\begin{array}{ll}\mathrm{PH} & \mathrm{GE} \\ \mathrm{HS} / \mathrm{cm} & \mathrm{GE}\end{array}$

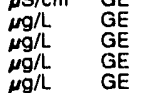

$\mu g / L$ GE
Time: $7: 40$

Alkalinity: $15 \mathrm{mg} / \mathrm{h}$

Water temperature: $17.9^{\circ} \mathrm{C}$

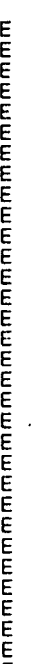

\section{WELL FSB114D}

MEASUREMENTS CONDUCTED IN THE FIELD

Sample date: $10 / 18 / 91$
Depth to water: $35.36 \mathrm{Ht}(10.78 \mathrm{~m})$ below TOC
Water elevation: $216.84 \mathrm{H}(66.09 \mathrm{~m}) \mathrm{msl}$
Sp. conductance: $48 \mu \mathrm{s} / \mathrm{cm}$
Water evacuated betore sampling: $50 \mathrm{gal}$

Time: : 8:00

Alkalinity: $5 \mathrm{mg} / \mathrm{h}$

Water lemperature: $17.3^{\circ} \mathrm{C}$

LABORATORY ANALYSES

E Analyle Result Mod Unit Lab

$\begin{array}{ll}0 & \mathrm{pH} \\ 0 & \text { Specific conductance }\end{array}$

Aluminum

Arsenic

Berium

Bromodichloromethane

Bromoform

Bromome

Cadmium

Carbon tetrachloride

Chloride

Chloroethene Ninyl chloride

Chorethyl vinyl ether

Chloroform

Chloromethane

Chromiur

Cobalt

Copper

Dibromencinloromethane

1,1. Eichloroelhane

1,2-Dichloroethane

trans-1,2-Dichloroethylene
o

$\begin{array}{ll}\text { trans-1,2-Dichloroethylene } & <1.0 \\ \text { Dichloromethane } & 3.2 \\ \text { 2,4-Dichiorophenoxyacetic acid }<0.30\end{array}$

cis-1.3.Dichloropropen

trans-1,3-Dichloropropene

Endrin

Ethylbenzent

0 Fluoride

0 Iron

0 Lead

O Magnesium

1 Manganese

Mercury

Nickel

Nitrate as nitrogen

Phenols

Selassium

0 Silica

0 Silver

Sodium

1,1,2,2-Tetrachloroethane

Tetrachloroethylene

Thallium

C Tatal dissolved solids

Total organic carbon

Total organic halogens

0 Toxaphene

o 2,4,5-TP (Silvex)

1,1,1-Trichloroethane

Trichloroethylene

Trichlorofluoromethane

Uranium

inc

o Gross alpha

Nonvolatile bete

Total radium

JQ

$\begin{array}{ll}\mathrm{pH} & \mathrm{GE} \\ \mu \mathrm{S} / \mathrm{cm} & \mathrm{GE}\end{array}$

$\begin{aligned} & \\ & 5.4 \\ & 50 \\ & 29 \\ &<2.0 \\ &<2.0 \\ & 12 \\ & 11.0 \\ &<1.0 \\ &<1.0 \\ &<1.0 \\ &<1.0 \\ &<2.0 \\ & 1.0 \\ &<1.0 \\ & 3.7 \\ &<1.0 \\ &<1.0 \\ &<1.0 \\ &<1.0 \\ &<1.0 \\ &<1.0 \\ & 54.0 \\ &<4.0 \\ &<4.0 \\ &<5.0 \\ &<1.0 \\ &<1.0 \\ &<1.0 \\ &<1.0 \\ &<1.0 \\ & 3.2 \\ &<0.30 \\ &<1.0 \\ &<1.0 \\ &<1.0 \\ &<10.060\end{aligned}$

$<1.0$
$<0.0060$

$<0.0060$
$<1.0$

$<100$

$<100$

4.4
$<0.0050$

615

35

$<0.20$

6.6
2.100

2.100
$<5.0$

$<5.0$
$<500$

$<2.0$

$<2.0$

6.310
1.660

1,660
$<1.0$

$<1.0$

$<2.0$
$<1.0$

33,000

$<1,000$

$<5.0$
$<50$

$<0.24$

$<0.090$

$<1.0$

$<1.0$
$<1.0$

$<1.0$

$<1.0$
$<20$
$<8.0$

$<8.0$

$<2.0 E \cdot 09$
$<2.0 \mathrm{E} \cdot 09$

$<2.0 E \cdot 09$
$1.2 \mathrm{E}-09 \pm 1.3 \mathrm{EE} \cdot 09$
2. $1 \mathrm{E}-06 \pm 7.0 \mathrm{E} \cdot 07$

$\mu g / L$
$\mu g / \Lambda$
$\mu g / \Lambda$

$\mu \mathrm{g}$

rrivm 
ANALYTICAL RESULTS

WELL FSB114D Replicate

MEASURIMANTS CONDUCTED IN THE FIELD

Sample date: 10/18/91 Depth to water: $35.36 \mathrm{ft}(10.78 \mathrm{~m})$ below TOC Sp. conductance: $48.84 \mathrm{st}$ Water evacuated befor. sampling: $50 \mathrm{gal}$

Time: $8: 00$

Alkalinity: $5 \mathrm{mg} / \mathrm{L}$

Water temperature: $173^{\circ} \mathrm{C}$

LABORATORY ANALYSES

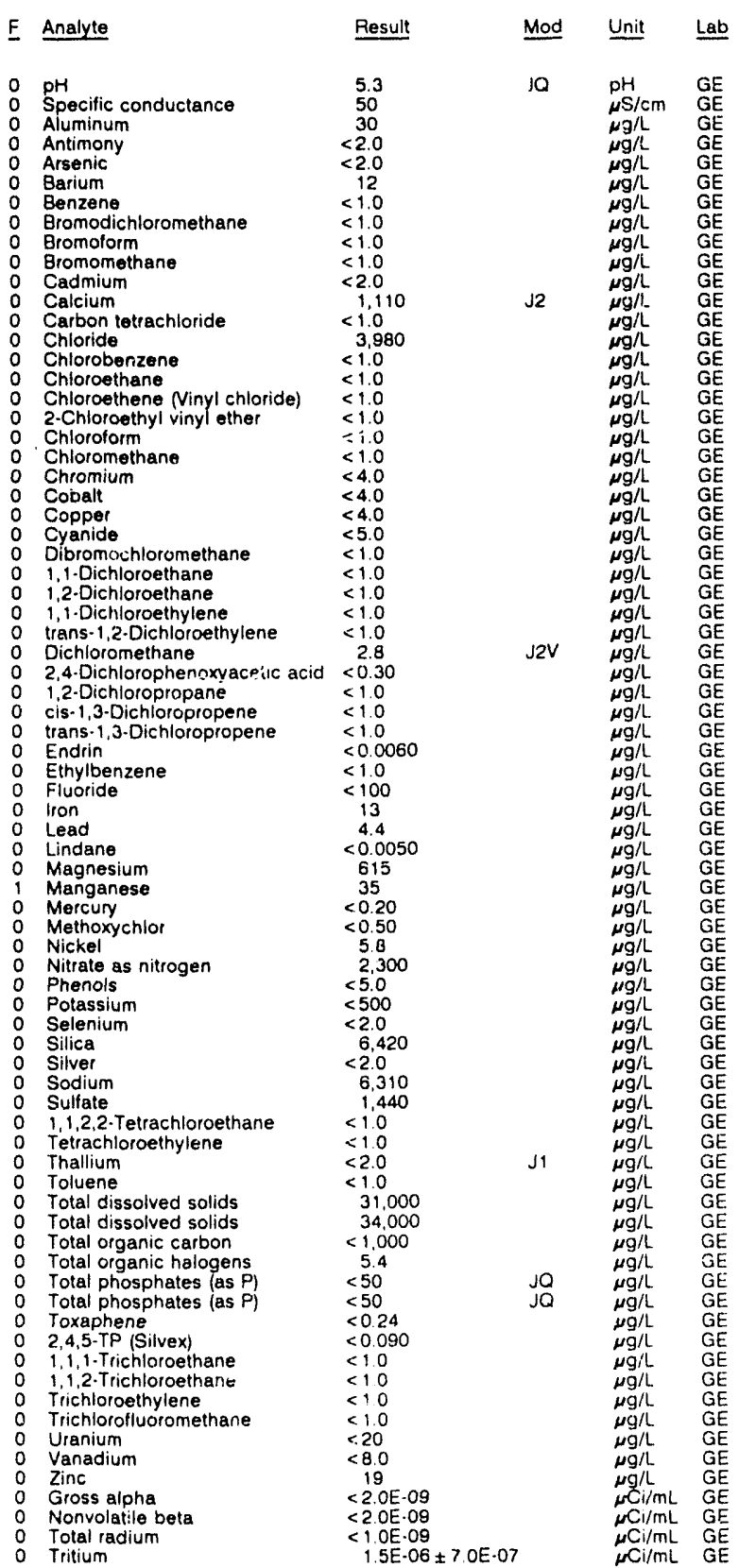

WELL FSB115C

MEASUREMENTS CONDUCTED IN THE FIELD

Sample date: $10 / 22 / 91$

Depth to water: $25.68 \mathrm{tt}(7.83 \mathrm{~m})$ below TOC

Sp. conductence: $25.11 \mathrm{~h}(55.5$

Water evacuated before sampling: $18 \mathrm{gal}$

The well went dry duting purging.

LABORATORY ANALYSES

E Analyte Result Mod Unit Lab

$\stackrel{\mathrm{pH}}{0}$ Specific conductance

Aluminum

Antimony

Arsenic
Barium

0 Benzene

Bromodichloromethane

Bromolorm

Bromomethan

Calcium

0 Calcium

Chloride

Chloride

Chorobenzene

Chloroethene (Vinyl chloride)

2-Cholhethe Ninyl chlorid

2-Chloroethy

Chloromethane

Chromium

0 Cobalt

O Cyanide

o Dibromochloromethane

1.1-Dichloroethan:

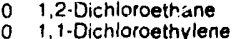

0
0
0
trans-1,2-Dichloroethylene

Dichloromethane $<1.0$

0 2,4-Dichlorophenoxyacetic acid $<0.30$

0 1,2. Dichloropropane

o cis-1,3.Dichloropropene

0 Endrin

E Ethylbenzene

0 Fluoride

0 Iron

0 Lead

L Lindane

Manganese

Mercury

Methoxychlor

Nickel

Nitrate as nitrogen

0 Phenols

0 Potassium

- Selenium

0 Silica

0 Silver

0 Sodium

0 Sullate

0 Sulfate

1,1,2,2-Tetrachloroethane

- Tetrachioroethylene

Thallium

Toluene
0 Total dissolved solids

Total organic carbon

Total organic halogens
Total phosphates (as P

Toxaphene

2,4,5.TP (Silvex)

$1,1,1 \cdot$ Trichloroethane

1.1.2.Trichloroethan

Trichlorofluosomethane

Uranium

Vanadium

Zinc

Nonvolatile bote

Total radium

Tritium
Time: $7: 15$

Alkalinity: $7 \mathrm{mg} / \mathrm{l}$

Water temperature: $17.4^{\circ} \mathrm{C}$

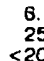

$<2.0$
$<2.0$
$<20$

$<.0$
$<1.8$
$<<1.0$

$<1.0$
$<1.0$
$<1.0$
$<1.0$

$<1.0$
$<2.0$

1,450
$<10$

1,630
1,630

$<1.0$

$<1.0$
$<1.0$
$<1.0$

$<1.0$

$<1.0$

$<4.0$

$4<.0$
$<50$
$<5$

$<1.0$

$<1.0$

$<1.0$

$<.0$
1.0

$<0.30$
$<1.0$
$<1.0$
$<1.0$

$<1.0$

$<1.0$
$<100$

72
$<3.0$

$<0.0050$

259
8.0

$<0.20$

$<0.50$

520
520

520
$<5.0$
585

585
$<2.0$

<.220

$<.0$
2.120

2.010

2,060

$<1.0$
$<10$

$<1.0$
$<2.0$

$<1.0$

20,000
$<1,000$

110

$<50$

$<0.24$
$<0.090$

$<10$

$<10$

$<1.0$

$<20$
$<8.0$

$<8$.

$<2.0 \% 108$
$<2.0 \mathrm{E} .09$

<. 1 E. $09 \pm 8.0 \mathrm{E}-10$ $1.1 \mathrm{E} \cdot 09 \pm 8.0 \mathrm{E} \cdot 10$
$2.6 \mathrm{E} \cdot 06 \pm 7.0 \mathrm{E} \cdot 07$

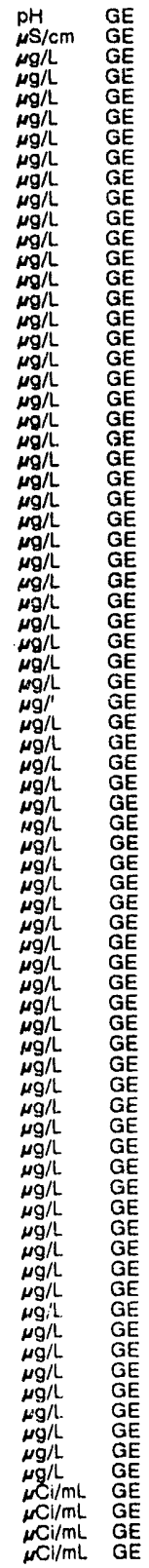


WELL. FSB115D

MEASUREMENTS CONDUCTED IN THE FIELD

Sample date: 10/22/91

Depth to water: $18.78 \mathrm{ft}(5.11 \mathrm{~m})$ below TOC
Water elevation: $191.74 \mathrm{ft}(58.44 \mathrm{~m}) \mathrm{msl}$

Sp. conductance: $12 \mu \mathrm{S} / \mathrm{cm}$

Water evacuated before sampling: $24 \mathrm{gal}$

LABORATORY ANALYSES

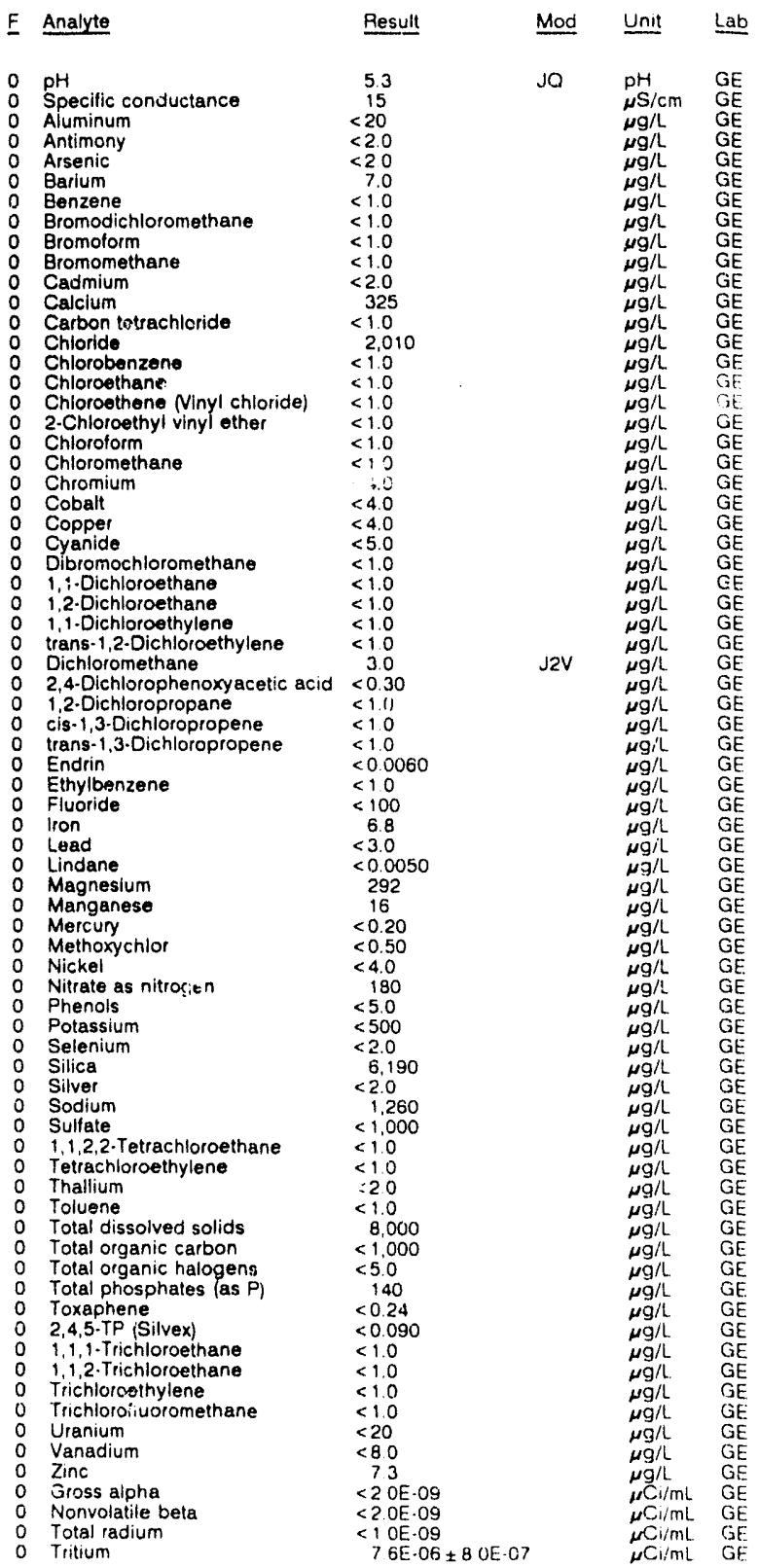

PH: 4.6 Alkalinity. $2 \mathrm{mg} / \mathrm{h}$

Aater temperature: $18.4^{\circ} \mathrm{C}$
WELL FSB116C

MEASUREMENTS CONDUCTED IN THE FIELD

Sample date: 10/22/9!

Depth to water: 13.06 \#t $(3.98 \mathrm{~m})$ below TOC

Water elevation: $189.44 \mathrm{ft}$ (57

Sp conductance : $21 \mu \mathrm{S} / \mathrm{cm}$
Water evacuated betore sampling: $76 \mathrm{gal}$

LABORATORY ANALYSES

E Analyte Besult Mod Unit Lab

$\begin{array}{lll}0 & \mathrm{pH} \\ 0 & \text { Specific conductance } & 0 \\ 0 & \text { Antinony } & 0\end{array}$

Aluminum

Arsenic

Barium

Benzene
Bromodichloromethane

Bromoformethane

Cadmium

Calcium

Carbon tetrachioride

Chloride

Chloroethane

Chlorcethene Ninyl chloride

2.Chloroethyl vinyl ether

Chloroform

Chloromethane

Chromium

Cobalt

Copper

Cyanide
Dibroinochloromethane

1.1.Dichloroethane

1,2-Dichloroethane

11.01chloroethylene
trans $-1,2 \cdot$ Dichloroethylene

Dichloromethane

$\begin{array}{ll}\text { trans. 1.2. Dichloroethylene } & <1.0 \\ \text { Dichloromethane } & 4.3 \\ 2,4 \text { - Dichlorophenoxyacetic acid } & <0.30 \\ 1,2 \cdot \text { Dichloropropane } & <1.0\end{array}$

cis-1.3.Dichloropropene

tans.13.Dichloroprope

Endrin

Ethyltenzene

Fluoride

iron

Lead

Magnesium

Magnesium

Manganese

Methoxychlor

Nickel

Nitrate as nitrogen

Pnenols

Selenium

Silica

Silver

Sodium

Sullate

Tetrachloroethylene

Thallium

Toluent
Tolal dissoived solids

Total organic carbon

Total organic halogens

Total phosphates (as P)

Toxaphene

2.4,5.TP (Silvex)

1.12. Trichloroethan

Trichloroethylene

Trichlorofluoromethane

Uranium

Vanadiu

Zinc

Gross alpria

Tonvolatile bet

Total radium
Tritium
Time 8:20

Alkalinity: $1 \mathrm{mg}$

Water temperature $17.7^{\circ} \mathrm{C}$ 
ANALYTICAL RESULTS

WELL FSB116D

MEASUREMENTS CONDUCTED IN THE FIELD

Sample date: 10/22/91

Depth to water: $11.21 \mathrm{ft}(3.42 \mathrm{~m})$ below TOC

Water elevation: $191.88 \mathrm{ft}(58 \mathrm{~m}$

Sp. conductance: $28 \mathrm{\mu s} / \mathrm{cm}$ ming $3 \mathrm{~ms}$

The well went dry during purging.

LABORATOFY ANALYSES

E Analyte Result $\underline{\text { Mnd Unit Lab }}$

$\begin{array}{ll}\mathrm{pH} \\ 0 & \text { Specific conductance }\end{array}$

Aluminum

Arsenic

Barium

Barium

Bromodichloromethane

Bromoform

Bromomethane

Cadmium

Calcium

Carbon tetrachloride

Chloride

Chlorobenzene

Chlorethane

Chloraform

Chloromethane

Chromium

Cobalt

Copper

Dibromochloromethane

1,1-Dichloroethane

1,1-Dichlorcethylen

trans-1,2-Dichloroethylene

Dichloromethane

2.4-Dichlorophenoxyacetic acid

1,2-Dichloropropane

cis.1.3.Dichloropropene

Endrin

Ethylbenzene

0 Fluoride

0 Iron

Lindane

Magnesium

Mercury

Nitrate as ritrogen

Phenols

Selenium

Silica

Sodium

Sodium

1,1,2,2-Tetrachloroethane

Tetrachloroethylene

Thallium

Total dissolved solids

Total organic carbon

Total organic carbon

Total organic halogens
Total phosphates (as P)

Total phosp

2.4,5-TP (Silvex)

1,1,1-Trichloroethane

1,1,2-Trichloroethan

Trichlorofluoromethane

Uranium

Vanadium

Zinc

Gross aipha

Nonvolatile beta

Total radium
Time: 800

Alkalinity: $14 \mathrm{mg} / \mathrm{L}$

Water temperature: $17.70 \mathrm{C}$

JO

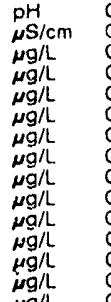

$<1.0$

$<1.0$

$<1.0$

$<1.0$

$<4.0$

$<4.0$
8.0
8.2

$<5.0$
$<1.0$

$<1.0$

$<1.0$

$<1.0$

$<1.0$
6.2

6.2
$<0.30$

$<1.0$
$<1.0$

$<1.0$

$<1.0$
$<0.0060$

$<10$
$<100$

104
$<30$

$<0.0050$

491
21

$\begin{aligned} & 21 \\ &< 0.20 \\ &< 0.50 \\ &< 4.0 \\ & 95\end{aligned}$

$<4.0$
95

$<5.0$
$<500$

$<500$
$<20$

6.810
$<2.0$
3.330

3,330

$<10$

$<1.0$
$<2.0$

$<2.0$

17,000

1,000
2,000

2,000
$<5.0$
60

60

$<0.24$
$<0.090$

4.5
$<10$

$<1.0$
$<10$
$<10$

$<10$
$<1.0$
$<20$
$<8.0$

$<20$
$<8.0$
19

$2.1 E \cdot 09 \pm 12 E \cdot 09$

$<2$ OE. 09

$62 E \cdot 06 \pm 8.0 E \cdot 07$
62.09
WELL FSB117D

MEASUREMENTS CONOUCTED IN THE FIELD

Sample date: $10 / 22 / 91$

Water elevation: $2059 \mathrm{ft}(7.80 \mathrm{~m})$ below TOC

Sp. conductance: $882 \mu \mathrm{S} / \mathrm{cm}$

Alkalinity: $0 \mathrm{mg} / \mathrm{h}$

Water temperature: $18.2^{\circ} \mathrm{C}$

(a) sampling: $40 \mathrm{ga}$

LABORATORY ANALYSES

E Analyte Besult Mod Unit Lab

2 ppecific conductance

Aluminum

Antimony

0 Barium

Barium

Bromodichloromethane

Gromoform

Bromomethan

Cadmium

Carbon tetrachloride

Chloride

Chlorobenzene

Chloroethene Ninyl chloride)

Chloroethene Ninyl chloric

2-Chloroethy

Chloromethane

Chiomium

Cobalt

Cyanide

Dibromochloromethane

o 1.1.Dichloroethane

1,2-Dichloroethane

1,1-Dichloroethylene
0 trans-1,2-Dichloroethylene

trans-1,2-Dichloroethylene
Dichioromethane
2,4.Dichlorophenoxyacetic acid

1.2-Dichloropropane

Cis-1,3-Oichloropropene

0 Endrin

0 Ethylbenzene

o Fluoride

o Iron

0 Lead

Magnesium

Mercury
Methoxychlor

Nickel

Nitrate as nitrogen

Phenols

Selenium

$\begin{array}{ll}0 & \text { Selenium } \\ 0 & \text { Silica } \\ 0 & \text { Silver }\end{array}$

0 Sodium

Sulfate

1,1,2,2-Tetrachloroethane

Tetrachloroethylene

Thallium

Toluene

Total organic carbon

Total organic halogens

Total organic halogens

Tulal phosphates (as P)

Toxaphene

2,4.5.TP (Silvex)

$1,1,1$. Trichloroethane

Trich Trichloroethane

o Trichlorofluoromethane

2 Uianium

0 Vanadium

0 Ziric

2 Gross alpha

2 Nonvolatile beta

o Total activity

2 Total radiu

J

3.7
750
33.700
$<2.0$
$<2.0$

Jo

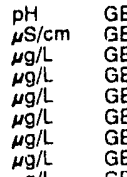

$<1.0$

$<1.0$

$<1.0$
2.8

1.840
$<1.0$
3.840

3,840
$<1.0$

$<1.0$
$<1.0$
$<1.0$

$<1.0$
$<1.0$
$<1.0$

$<1.0$
$<4.0$

14
29
$<50$

29
$<5.0$
$<1.0$

$<1.0$

$<1.0$
$<1.0$
$<1.0$

$<1.0$
33
$<0.30$
$<1.0$

$<1.0$

$<1.0$
$<1.0$

$<0.0060$

$<1.0$

380
118

6.2
$<0.0050$

1,490
728

$<0.20$
$<0.50$

$<0.50$

13
82.000

$<5.0$
629

\begin{tabular}{l}
629 \\
$<2.0$ \\
\hline
\end{tabular}

16.800
$<2.0$

14.600

2.980
$<1.0$

$<10$

$<1.0$

217,000

$<1,000$

$\begin{array}{r}5.3 \\ 5.5 \\ \hline\end{array}$

$<50$
$<0.24$
$<0.09$

$<0.090$

$<10$

$<10$

$<1.0$

1.770
$<80$

44

9. $1 \mathrm{E} \cdot 07 \pm 3.8 \mathrm{E} \cdot 0$

4. $0 E \cdot 03 \pm 1.1 \mathrm{E} \cdot 04$

5. $.0 E \cdot 08+03+1.0 \mathrm{EE} \cdot 05$
0.05 
ANALYTICAL RESULTS

\section{WELL FSB118D}

MEASUREMENTS CONOUCTED IN THE FIELD

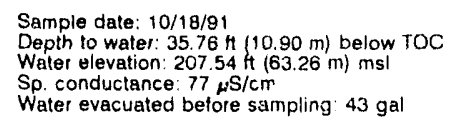

LABORATORY ANALYSES

F Analyte

0 Apecific

o Antimony

Arsenic

0 Barium

Bromodichloromethane

Bromoform

Bromometh

Cadmium

Carbon tetrachloride

Chloride
Chlorobenzene

Chlorobenzene

Chloroethene Ninyl chloride)

2-Chloroethyl vinyl ether

Chlorotorm

Chloremethane

Chromiurn

0 Cobalt

Copper

Cyanide
Dibromochloromethane

1,1 .Dichloroethane

1,2-Dichloroethane

trans-1,2-Dichloroethylene

Dichiorichenthe

2,4-Oichlorophenoxyacetic acid

1,2.Dichloropropane

cis-1,3-Dichlore, "ropene

0 Endrin

0 Ethylbenzene

Fluoride

tron

Lead

Magnesium

Manganese

Mercury

Methoxych

Nitrate as nittogen

Phenols

Polassium

Silice

Silver

Sodium

Sulfate

Tetrachloroethylene

Tetrachlo

Thallium

Toluene
Total dissolved solids

Tolal dissolved solids
Total organic carbon

Total organic halogens

Total phosphates (as P)

Toxaphene
2.4.5.TP (Silvex)

1, 1, - Trichloroethane

1,1,2. Trichloroethan

Trichlorofluoromethane

Uranium

Uranium

Vanadium

Gisss alpha

Nonvolatile be
Total radium

$0 \begin{aligned} & \text { Total radium } \\ & 0 \\ & \text { Tritium }\end{aligned}$

$\begin{aligned} & 6.6 \\ & 12<2 \\ &<20 \\ &<2.0 \\ &<2.0 \\ & 88 \\ &<1.0 \\ &<1.0 \\ &<1.0 \\ &<1.0 \\ &<2\end{aligned}$

result Mod Unit Lab

$<1.0$
$<2.0$

14,000
$<10$

$<1.0$

$<1.0$

$<1.0$

3.5
$<1.0$

$<4.0$

$<4.0$

$<4.0$

$<1.0$

$<1.0$

$<1.0$

$<1.0$

$<1.0$

$<1.0$
$<10$

$<1.0$

$<0.0060$

$<1.0$
$<100$

$<100$
42

$<3.0$
$<0.0050$

$<0.0050$
631

19
$<0.20$

$<0.20$
$<0.50$

$<4.0$
$<1.070$

$<5,0$

$<5.0$
$<500$

$<2.0$
7.470

$<2.0$

2,880
$<1,000$

$<1,0$

1.1
$<2.0$
$<1.0$

$<.0$
50,000

50,000
$<1,000$

$<5.0$
$<50$

$<0.24$

0.09

$<1.0$

$<1.0$

5.3
$<20$

$<20$
$<8.0$

$\begin{aligned} & 13 \\ &<2.0 E \cdot 09\end{aligned}$

$<2.0 \mathrm{E}-09$

C $7.1 \mathrm{E} \cdot 06 \pm 8.0 \mathrm{E} \cdot 07$

Mod Unit Lab

JQ $\mathrm{pH}$ GE

$\begin{array}{ll}p H & G E \\ \mu S / \mathrm{cm} & \mathrm{GE} \\ \mu \mathrm{L} / \mathrm{L} & \mathrm{GE}\end{array}$

$\begin{array}{ll}\mu g / \mathrm{L} & \mathrm{GE} \\ \mu \mathrm{g} / \mathrm{L} & \mathrm{GE} \\ \mu \mathrm{g} / \mathrm{L} & \mathrm{GE}\end{array}$

$\begin{array}{ll}\mu g / L & \mathrm{GE} \\ \mu \mathrm{g} / \mathrm{L} & \mathrm{GE} \\ \mu g / \lambda & \mathrm{GE}\end{array}$

$\mu g / L \quad G E$

$\mu \mathrm{g} / \mathrm{G} \quad \mathrm{GE}$

$\mathrm{J} 2$

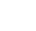

\section{(a)}

$\mu g / L \quad G E$

$g / L \quad G E$

Time: $10: \cdot 3$

$\mathrm{pH}: 6.1$

Alkalinity $43 \mathrm{mg} / \mathrm{L}$

Water ter iperature: $17.3^{\circ} \mathrm{C}$

$G E$

\section{WELL FSB119D}

MEASUREMENTS CONDUCTED IN THE FILLD

Sample date: 10/22/91

Depth to water $46.17 \mathrm{H}(14.07 \mathrm{~m})$ below TOC

Water elevation: $207.93 \mathrm{ft}(63.38 \mathrm{~m}) \mathrm{ms}$.

Sp. conductance: $1445 \mu \mathrm{S} / \mathrm{cm}$

Water evacuated before sampling: $39 \mathrm{gal}$

LABORATORY ANALYSES

E Analyte Result Mod Unit Lab

$1 \quad \stackrel{\mathrm{pH}}{2} \mathrm{Specific} \mathrm{conductance}$

2 Aluminum

0 Antimony

0 Arsenic

Barium

0 Bromodichloromethane

- Bromoform

Bromomethan

2 Cadmium

- Carbon tetrachloride

Carbon

o Chlorobenzene

Chlorobenzene

Chloroethene (Vinyl chloride)

2.Chloroethyl vinyl ether

o Chloromethane

I Cobalt

Copper

Cyanide

Dibromochlorornethane

1,1-Dichloroethane

1,2-Dichloroethane

o trans-1,2-Dichloroethylene

o Dichioromethane

0 2.4-Dichlorophenoxyacetic acid

o 1,2-Dichloropropane

O cis-1,3-Dichloropropene

0 Endrin

Ethylberizene

$\begin{array}{ll}0 & \text { Fluoride } \\ 2 & \text { Iron }\end{array}$

2 Lead

L Lindane

Magnesium

2 Manganes

Mercury

Nickel

Nitrate as nitrogen

Phenols

Potassium

0 Selenium

$\begin{array}{ll}0 & \text { Silica } \\ 0 & \text { Silver }\end{array}$

Sodium

Suliate

$1,1,2,2 \cdot$ Tetrachloroethane

Tetrachloroethylene

Thailium

Total dissolved solids

Total organic carbon

Total organic halogens

Total phosphates (as P)

Toxaphene

2,4,5-TP (Silvex)

1,1,1-Trichloroethane

Triutloroethylene

o Trichlorolluoromethan

2 Uranium

Vanadium

Zinc

Gross alpha

2 Nonvolatile be

Total activity

Total radiur
Tritium
Time 10.00
pH: 3.5
Alkalinity: $0 \mathrm{mg} / \mathrm{L}$
Water temperature: $19.5^{\circ} \mathrm{C}$

$3.7 \quad$ Ja

DH $\quad \mathrm{GE}$

$\begin{array}{ll}\mu \mathrm{S} / \mathrm{cm} & \mathrm{GE} \\ \mu \mathrm{g} / \mathrm{L} & \mathrm{GE}\end{array}$

$\begin{array}{lll}58,100 & \mu \mathrm{g} / \mathrm{L} & \mathrm{GE} \\ -2.0 & \mu \mathrm{g} / \mathrm{L} & \mathrm{GE}\end{array}$

52.0
$<2.0$

262
$<1.0$

$<1.0$
$<1.0$

$<1.0$
$<1.0$

$<1.0$
9.9

6.050
+1.0

6,300

$<1.0$

$<1.0$

$<1.0$
$<1.0$

$<1.0$
$<10$

$<4.0$
38

34
$<5.0$

$<1.0$

$<1.0$

$<1.0$
$<1.0$

31.0
$<0$

$<1.0$

$<1.0$
$<1.0$

$<0.0060$

$<1.0$
552

552
763
16
$<0.0050$

$<0.0050$

3,950
1,250

0.90

$<0.50$

31
170,000

$<5.0$
1.340

$<2.0$

18,600
$<2.0$

53,100
9,860

9,860
$<10$

$<10$

$<2.0$

593,000

1,000
39

50
$<0.24$

$<0.090$

$<1.0$
$<10$

$<10$

$<10$

$\begin{aligned} & 1,250 \\ < & 8.0\end{aligned}$

$<8.0$

$7.4 \mathrm{E} \cdot 07 \pm 4.1 \mathrm{E} \cdot 08$

2. $2 \mathrm{E} \cdot 08 \pm 3.6 \mathrm{E} \cdot 08$

8. $9 \mathrm{E} \cdot 08 \pm 5.4 \mathrm{E} \cdot 09$

8. $9 E \cdot 08 \pm 5.4 E \cdot 09$
$14 E \cdot 02 \pm 1.9 E \cdot 05$

\author{
(1)
}

$\mathrm{GE}$
$\mathrm{EE}$
$\mathrm{GE}$
$\mathrm{GE}$
$\mathrm{GE}$
$\mathrm{GE}$

GE


WELL FSB120A

MEASUREMENTS CONDUCTED IN THE FIELD

Sample date: $10 / 21 / 91$

Depth to water: $132.73 \mathrm{Ht}(40.46 \mathrm{~m})$ below TOC

Sp. conductance $643 \mu \mathrm{s} / \mathrm{cm}$

Water evacuated before sampling: $127 \mathrm{gat}$

LABORATORY ANALYSES

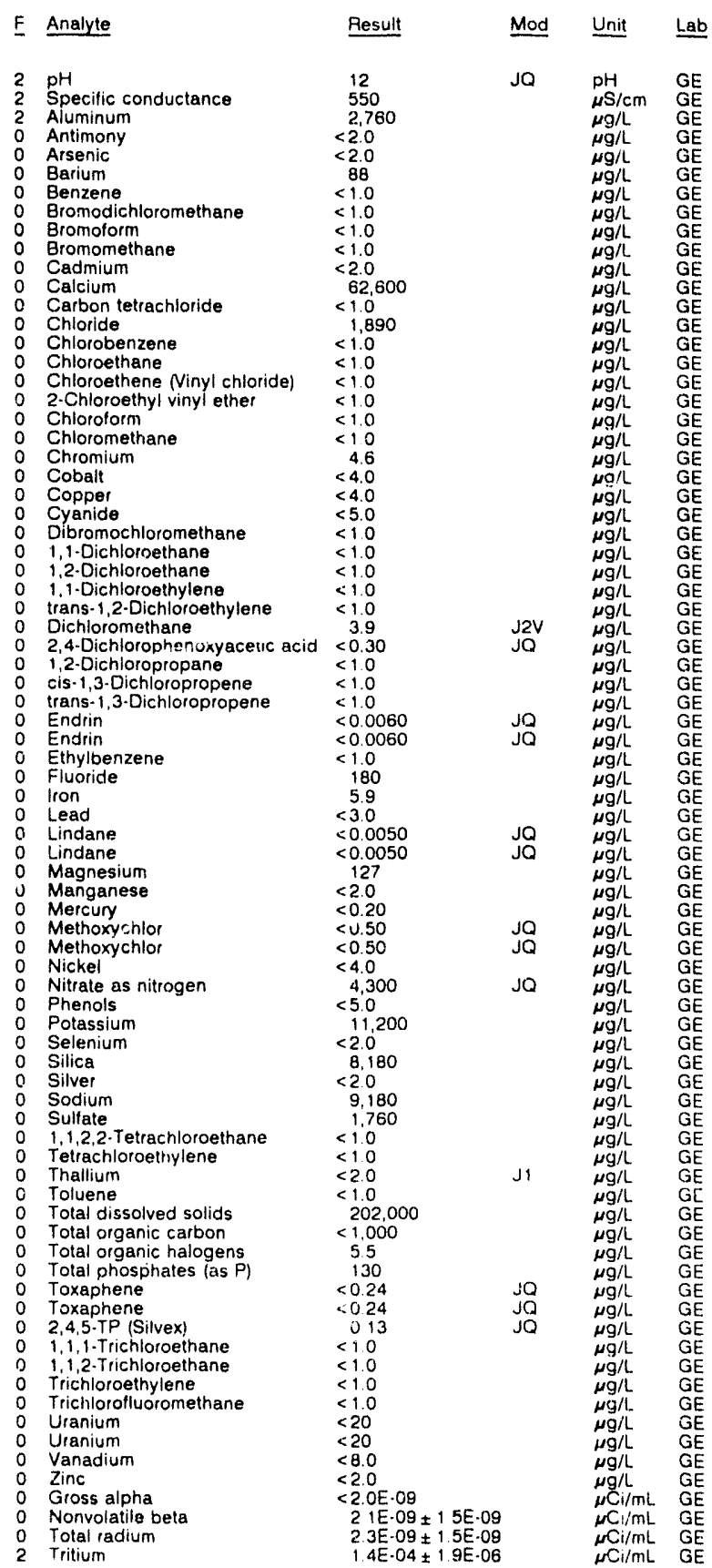

WELL FSB120A Replicate

MEASUFEMENTS CONOUCTED IN THE FIELD

Sample date: 10/21/91

Depth to water: $132.73 \mathrm{ft}(40.46 \mathrm{~m})$ below TOC

Water elevation: $147.37 \mathrm{ft}$ (44.96

Water evacuated before samipling: $127 \mathrm{gal}$

LABORATORY ANALYSES

$\begin{array}{ll}2 & \mathrm{pH} \\ 2 & \text { Specific conductance } \\ 2 & \text { Aluminum }\end{array}$

Aluminum

Antimony

Arsertic
Barium

$\begin{array}{ll} & \text { Benzene } \\ 0 & \text { Bromodichloromethane }\end{array}$

Bromodich

Gromomethane

Cadmium

Calcium

Chloride

Chlorobenzene

Chloroethane

Chloroethene Ninyl chloride

2.Chloroethy

Chloromethan

Chromium

Cobalt

Copper

Dibromochloromethane

1,1-Dichloroethane

1,2.Dichloroethane

1,1-Dichloroethylene
trans-1,2-Dichloroethylene

Dichloromethane

$<1.0$

2.2-Dichlorophopane

cis-1,3-Dichloropropene
trans-1,3-Dichloropropene

Endrin

0 Ethylbenzene

Fluoride

Iron

0 Lead

O Magnesium

Manganese

Methoxychior

Nickel

Nitrate as nitrogen

Phenols

0 Potassium

Selenium
Silica

Silica

$\begin{array}{ll}0 & \text { Silver } \\ 0 & \text { Sodium }\end{array}$

0 Sodium

Sulfate

Tetrachloroethylene

Thallium

Toluene

- Total dissolved solicts

- Total organic carbon

o Total organic halogens

0 Total phosp

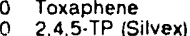

i 1.1.Trichloroethane

1.1,2-Trichloroethan

Trichloroethylene

Trichlorofluoromethane

Uranium

O Uranium

- Vanadiun

0 Zinc

Gross alpha

$\begin{array}{ll}0 & \text { Nonvolatile be } \\ 0 & \text { Total radium } \\ 2 & \text { Tritium }\end{array}$
Time: $7: 30$

Alkalinity: $179 \mathrm{mg} / \mathrm{L}$

Water temperature $190^{\circ} \mathrm{C}$

Pesult Mod Unit Lab

12

Q $\mathrm{pH} \quad \mathrm{GE}$

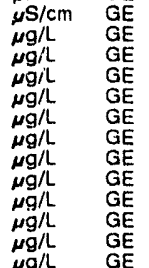

1,910

$<<1.0$

$<1.0$

$<1.0$

$<1.0$
$<1.0$

4.8
$<4.0$

$<4.0$

$<1.0$

$<1.0$
$<1.0$
$<1.0$

$<1.0$
$<1.0$
$<0.30$

$<0.30$
$<1.0$
$<1.0$

$<1.0$
$<0.0060$

$<1.0$
$<0.0060$
$<10$
173

$<3.0$
$<0.0050$

162

$\begin{aligned} & 162 \\ &<2.0\end{aligned}$

$<0.20$

$\begin{array}{rl}< & 0.50 \\ <4.0 & 4.200\end{array}$

4.200
$<5.0$
10.900

10,900
$<2.0$

$\quad .370$
$<2.0$

$<2.0$
9,200
1,640

9,200
1,640
$<1.0$
$<10$

$<1.0$
$<2.0$

$<2.0$
$<1.0$

204,000
$<1,000$

$<1,000$
$<50$
110

$<0.24$

$<0.090$
$<10$
$<10$

$<10$
$<1.0$

$<1.0$

$<20$

$<20$

2.7

2. 6 E- $09 \pm 1.5 E-09$

$1.7 \mathrm{E} \cdot 08 \pm 2.3 \mathrm{E} \cdot 09$
$1.6 \mathrm{E} \cdot 09 \pm 1.4 \mathrm{E} \cdot 09$

$1.6 \mathrm{E}-09 \pm 1.4 \mathrm{E}-09$
$1.5 \mathrm{E} \cdot 04 \pm 2.0 \mathrm{E} \cdot 08$ 


\section{ANALYTICAL RESULTS}

WELL FSB120C

MEASUREMENTS CONDUCTED IN THE FIELD

Sample date: $10 / 21 / 91$

Depth to water: $73.29 \mathrm{ft} 22.34 \mathrm{~m})$ below TOC

Water elevation: 206.41 it $(62$

Water evacuated before sampling: i $46 \mathrm{gal}$

LABORATOHY ANALYSES

\begin{tabular}{|c|c|c|c|c|c|}
\hline E & Anaiyte & Pesult & Mod & Unit & Lab \\
\hline 0 & pH & 6.4 & JQ & $\mathrm{pH}$ & GE \\
\hline & Specific conductance & $\begin{array}{l}1,500 \\
56\end{array}$ & & $\mu \mathrm{S} / \mathrm{cm}$ & \\
\hline & $\begin{array}{l}\text { Aluminum } \\
\text { Antimony }\end{array}$ & $\begin{aligned} & 56 \\
&<2.0\end{aligned}$ & $\sqrt{2}$ & $\underset{\mu g / L}{\mu g / L}$ & $\begin{array}{l}\mathrm{GE} \\
\mathrm{GE}\end{array}$ \\
\hline & Arsenic & $<2.0$ & & $\mu \mathrm{g} / \mathrm{L}$ & GE \\
\hline & Barium & 139 & $\mathrm{~J} 2$ & $\mu \mathrm{g} / \mathrm{L}$ & $\mathrm{GE}$ \\
\hline & Benzene & $<1.0$ & & $\mu g / L$ & $\mathrm{GE}$ \\
\hline 0 & $\begin{array}{l}\text { Bromodichloromethane } \\
\text { Bromoform }\end{array}$ & $\begin{array}{l}<1.0 \\
<1.0\end{array}$ & & $\begin{array}{l}\mu \mathrm{g} / \mathrm{L} \\
\mu \mathrm{g} / \mathrm{L}\end{array}$ & $\begin{array}{l}\text { GE } \\
\text { GE }\end{array}$ \\
\hline & Bromomethane & $<1.0$ & & $\mu \mathrm{g} / \mathrm{L}$ & $\mathrm{GE}$ \\
\hline & $\begin{array}{l}\text { Cadmium } \\
\text { Calcium }\end{array}$ & $\begin{array}{l}<2.0 \\
30.300\end{array}$ & $\begin{array}{l}\mathrm{J} 1 \\
\mathrm{~J} 2\end{array}$ & $\mu \mathrm{g} / \mathrm{L}$ & $\mathrm{GE}$ \\
\hline & Carbon tetrachloride & $<1.0$ & & $\mu g / L$ & GE \\
\hline & Chloride & 3.180 & & 棌 & $\mathrm{GE}$ \\
\hline & Chlorobenzene & $<1.0$ & & $\mu g / L$ & E \\
\hline & $\begin{array}{l}\text { Chloroethane } \\
\text { Chloroethene (Vinyl chloride) }\end{array}$ & $<1.0$ & & $\begin{array}{l}\mu \mathrm{g} / \mathrm{L} \\
\mu \mathrm{g} / \mathrm{L}\end{array}$ & GE \\
\hline & 2-Chloroethyl vinyl ether & $<1.0$ & & $\mu \mathrm{g} / \mathrm{L}$ & $\mathrm{GE}$ \\
\hline & Chlorotorm & $<1.0$ & & $\mu g / L$ & \\
\hline & Chloromethane & $<1.0$ & & $\mu g / L$ & \\
\hline & Chromium & $<4.0$ & $J 1$ & $\mu g / L$ & \\
\hline & $\begin{array}{l}\text { Cobalt } \\
\text { Copper }\end{array}$ & $\begin{array}{r}8.5 \\
<4.0\end{array}$ & $\sqrt{2}$ & $\mu g / L$ & GE \\
\hline & $\begin{array}{l}\text { Copper } \\
\text { Cyanide }\end{array}$ & $\begin{array}{l}<4.0 \\
<5.0\end{array}$ & ja & $\mu g / L$ & $\mathrm{GE}$ \\
\hline & Dibromochloromethane & $<1.0$ & & $\mu \mathrm{g} / \mathrm{L}$ & \\
\hline & 1.1-Dichloroethane & $<1.0$ & & $\mu \mathrm{g} / \mathrm{L}$ & \\
\hline & 1,2-Dichloroethane & $\begin{array}{l}<1.0 \\
<1.0\end{array}$ & & $\mu g / L$ & GE \\
\hline & $\begin{array}{l}\text { 1,1-Dichloroethylene } \\
\text { trans-1,2-Dichloroethylene }\end{array}$ & $<1.0$ & & $\begin{array}{l}\mu g / \mathrm{L} \\
\mu \mathrm{g} / \mathrm{h}\end{array}$ & GE \\
\hline & Dichloromethane & 29 & & $\mu \mathrm{g} / \mathrm{L}$ & \\
\hline & 2,4-Dichlorophenoxyacetic acid & $<0.30$ & & $\mu g / 2$ & \\
\hline & 1,2-Dichloropropane & $<1.0$ & & $\mu g / L$ & \\
\hline & & $\begin{array}{l}<1.0 \\
<10\end{array}$ & & $\mu g / \mathrm{L}$ & $\begin{array}{ll}G E \\
G E\end{array}$ \\
\hline & $\begin{array}{l}\text { trans-1,3-Dichloropropene } \\
\text { Endrin }\end{array}$ & $\begin{array}{l}<1.0 \\
<0.0060\end{array}$ & & $\begin{array}{l}\mu g / \mathrm{L} \\
\mu \mathrm{g} / \mathrm{L}\end{array}$ & \\
\hline & Ethylbenzene & $<1,0$ & & $\mu g / L$ & \\
\hline & Fluoride & 139 & $v$ & $\mu g / L$ & E \\
\hline & Iron & $<40$ & J1 & $\mu \mathrm{g} / \mathrm{L}$ & \\
\hline & $\begin{array}{l}\text { Lead } \\
\text { Lindane }\end{array}$ & $\begin{array}{l}<3.0 \\
<0.0050\end{array}$ & & $\mu \mathrm{g} / \mathrm{L}$ & GE \\
\hline & $\begin{array}{l}\text { Lindane } \\
\text { Magnesium }\end{array}$ & $\begin{array}{r}<0.0050 \\
10.800\end{array}$ & $\sqrt{2}$ & $\begin{array}{l}\mu g / L \\
\mu g / L\end{array}$ & GE \\
\hline & Manganese & 202 & $\sqrt{2}$ & $\mu g / L$ & $\mathrm{GE}$ \\
\hline & $\begin{array}{l}\text { Mercury } \\
\text { Methoxychlor }\end{array}$ & $\begin{array}{l}<0.20 \\
<0.50\end{array}$ & & $\mu g / 2$ & GE \\
\hline & $\begin{array}{l}\text { Methoxychlor } \\
\text { Nickel }\end{array}$ & $\begin{array}{l}<0.50 \\
9.1\end{array}$ & $\sqrt{2}$ & $\mu$ & $\mathrm{GE}$ \\
\hline & Nitrate as nitrogen & 54.000 & & $\mu \mathrm{g} / \mathrm{L}$ & \\
\hline & $\begin{array}{l}\text { Phenols } \\
\text { Potassium }\end{array}$ & $\begin{aligned}<5.0 \\
2.650\end{aligned}$ & $\sqrt{2}$ & $\underset{\mu g / L}{\mu g / L}$ & GE \\
\hline & Selenium & $<2.0$ & $\sqrt{1}$ & $\mu g / L$ & E \\
\hline & Silica & 9,150 & J2 & $\mu \mathrm{g} / \mathrm{L}$ & $E$ \\
\hline & $\begin{array}{l}\text { Silver } \\
\text { Sodium }\end{array}$ & $\begin{array}{l}<2.0 \\
35,800\end{array}$ & $\begin{array}{ll}\mathrm{j} 1 \\
\mathrm{j} 2\end{array}$ & $\mu \mathrm{g} / \mathrm{L}$ & GE \\
\hline & Sulfate & 3,720 & & $\mu \mathrm{g} / \mathrm{L}$ & $\mathrm{GE}$ \\
\hline & $1,1,2,2 \cdot$ Tetrachloroethane & $<10$ & & $\mu \mathrm{g} / \mathrm{L}$ & \\
\hline & Tetrachloroethylene & $<10$ & & $\mu g / L$ & \\
\hline & Thallium & $<2.0$ & & $\mu g / L$ & \\
\hline & $\begin{array}{l}\text { Toluene } \\
\text { Total dissolved solids }\end{array}$ & $<10$ & & $\mu \mathrm{g} / \mathrm{L}$ & \\
\hline & $\begin{array}{l}\text { Total dissolved solids } \\
\text { Total dissolved solids }\end{array}$ & 395,000 & $\mathrm{v}$ & $\mu \mathrm{g} / \mathrm{L}$ & \\
\hline & $\begin{array}{l}\text { Total dissolved solids } \\
\text { Total organic carbon }\end{array}$ & $\begin{aligned} & 431,000 \\
< & 1,000\end{aligned}$ & $\mathrm{v}$ & $\mu g / L$ & \\
\hline & $\begin{array}{l}\text { Total organic carbon } \\
\text { Total organic halogens }\end{array}$ & $\begin{array}{l}<1,000 \\
28\end{array}$ & & $\mu 9 / \mathrm{L}$ & \\
\hline & $\begin{array}{l}\text { Total organic halogens } \\
\text { Tolal organic halogens }\end{array}$ & $\begin{array}{l}28 \\
3:\end{array}$ & & $\mu g / L$ & GE \\
\hline 0 & Total phosphates (as P) & $<50$ & & $\mu g / L$ & \\
\hline & $\begin{array}{l}\text { Toxaphene } \\
245 \text {-TP (Silvex) }\end{array}$ & $<0.24$ & & $\mu g / 2$ & \\
\hline & $\begin{array}{l}2,4,5-\mathrm{TP} \text { (Silvex) } \\
1,1,1-\text { Trichloroethane }\end{array}$ & $<0.090$ & & $\mu g / L$ & \\
\hline 0 & $\begin{array}{l}\text { 1,1,1-Trichloroethane } \\
1,1,2 \text {-Trichloroethane }\end{array}$ & $\begin{array}{l}<1.0 \\
<1.0\end{array}$ & & $\mu \mathrm{g} / \mathrm{L}$ & \\
\hline & $\begin{array}{l}\text { l,1,2-Trichloroethane } \\
\text { Trichloroethylene }\end{array}$ & $\begin{array}{l}<1.0 \\
<1.0\end{array}$ & & $\mu g / L$ & \\
\hline & $\begin{array}{l}\text { Irichloroethylene } \\
\text { Trichlorofluoromethane }\end{array}$ & $<1.0$ & & $\mu \mathrm{q} / \mathrm{h}$ & \\
\hline 0 & Uranium & $<20$ & J1 & $\mu \mathrm{g} / \mathrm{t}$ & \\
\hline 0 & Vanadium & $<8.0$ & J1 & $\mu g / L$ & \\
\hline 0 & Zinc & 19 & $\sqrt{2}$ & $\mu g / L$ & \\
\hline 2 & $\begin{array}{l}\text { Gross alpha } \\
\text { Nonvolatile beta }\end{array}$ & $\begin{array}{l}1.6 \mathrm{E} \cdot 08 \pm 3.5 \mathrm{E} \cdot 09 \\
5.0 \mathrm{E} \cdot 08 \pm 3.4 \mathrm{E} \cdot 09\end{array}$ & & 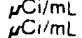 & $\begin{array}{l}G E \\
G E\end{array}$ \\
\hline 0 & Total activity & $22 \mathrm{E} \cdot 03 \pm 36 \mathrm{E} \cdot 05$ & & $\mathrm{~N}_{\mathrm{C}} / \mathrm{mL}$ & \\
\hline 2 & Total radium & $.08 \pm 26 \mathrm{E}-09$ & & $\mathrm{wC}_{\mathrm{C}} / \mathrm{mL}$ & GE \\
\hline 2 & Tritium & 2. $1 \mathrm{E} \cdot 03 \pm 7.0 \mathrm{E}-06$ & & $\mathrm{mCl} / \mathrm{mL}$ & $\mathrm{GE}$ \\
\hline
\end{tabular}

WELL FSB120D

MEASUREMENTS CONDUCTED IN THE FIELLO

Sample date: $10 / 21 / 91$

epth to water: $70.84 \mathrm{H}(21.59 \mathrm{~m})$ below TOC

Sp. conductance: 150 H 163 (6m

LABORATORY ANALYSES

F Analyte Plesult Mod Unit Lab

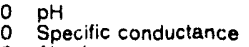

- Aluminum

Antimony

Arsenic

Benzene

Bromodichloromethane

0 Bromoform

o Bromome!hane

Cadnium

Calcium

Carbon te

Chlorobenzene

Chloroethene Vinyl chloride)

o 2.Chloroethyl vinyl ether

0 Chloroform

o Chloromethane

Chromium

Copper

O Copper

Dibromochloromethane

1.1.Dichloroethane

1,2-Dichloroethane

o trans-1,2-Dichloroethyle

- Dichloromethane

2,4-Dichlorophenoxyacetic acid

1,2.Dichloropropane

inans 1 . Dichloprope

0 Endrin

Ethylbenzene

Fluoride

Iron

0 Lindane

Magnesium

Manganes

Metcury

Nitrate as nitrogen

Potassium

Sitica

Silver

Sodium

Sulfate

1.1,2,2-Tetrachloroethane

Tetrachloroethylene

Thallium

Tolal dissolved solids

Total organic carbon

Tolal organic halogens

Total phosphato

2.4.5-TP (Silvex)

1.1,1-Trichloroethan

1.1,2-Trichloroethan

Trichloroethylene

Trichlorofluoromethane

Uranium

- Zine

Zine

Nonvolatile beta

Total radium
Trtium
7.8
135
$<20$
$<2.0$
$<2.0$
24
$<1.0$
$<1.0$
$<1.0$
$<1.0$
$<2.0$
6.43
$<1.0$

$<.0$
2.940

$<1.0$

$<1.0$

$<1.0$

$<1.0$

$<1.0$

$<4.0$

$<4.0$

$<5.0$

$<1.0$

$<1.0$

$<1.0$

$<1.0$

$<0.30$
$<10$

$<10$

$<0.0060$

$<1.0$
$<100$

$<100$

5.3
$<3.0$
$<0.050$

$<0$ (.). 50

546
5.0

5.0
$<0.20$
$<0.50$
7.8

7.8
540

540
$10.0 \mathrm{~m} n$

10.040
$<2.0$

$<.030$
$<3.0$

23,200

9,620
$<10$

$<1.0$
$<1.0$

$<20$

85.000

$<1.000$

$<1.000$
$<50$
$<50$
$<0.24$

$<0.090$

$<10$

$<10$

$\begin{array}{rl}<1 & 0 \\ <10 & 0\end{array}$

$<20$

$<0$
37

<. 2 OE.O9

1 OE. $08+19 E-09$

4 . $2 E .06 \pm 7$ OE. 07

Jo

Time: $8: 00$

Alkalinity: $76 \mathrm{mg}$

Water temperature: $18.7^{\circ} \mathrm{C}$

$\begin{array}{ll}\mathrm{pH} & \mathrm{GE} \\ \mu \mathrm{S} / \mathrm{cm} & \mathrm{GE}\end{array}$

$\begin{array}{ll}\mu \mathrm{S} / \mathrm{cm} & \mathrm{GE} \\ \mu \mathrm{g} / \mathrm{L} & \mathrm{GE}\end{array}$ 
WELL FSB121C

MEASUAEMENTS CONOUCTEO IN THE FIELO

Sample date: 10/21/91 Depth to water: $51.96 \mathrm{ft}(15.84 \mathrm{~m})$ below TOC Water elevation: $204.54 \mathrm{H}(62.34 \mathrm{~m}) \mathrm{msl}$ Water evacuated before sampling: $147 \mathrm{gal}$ LABORATORY ANALYSES

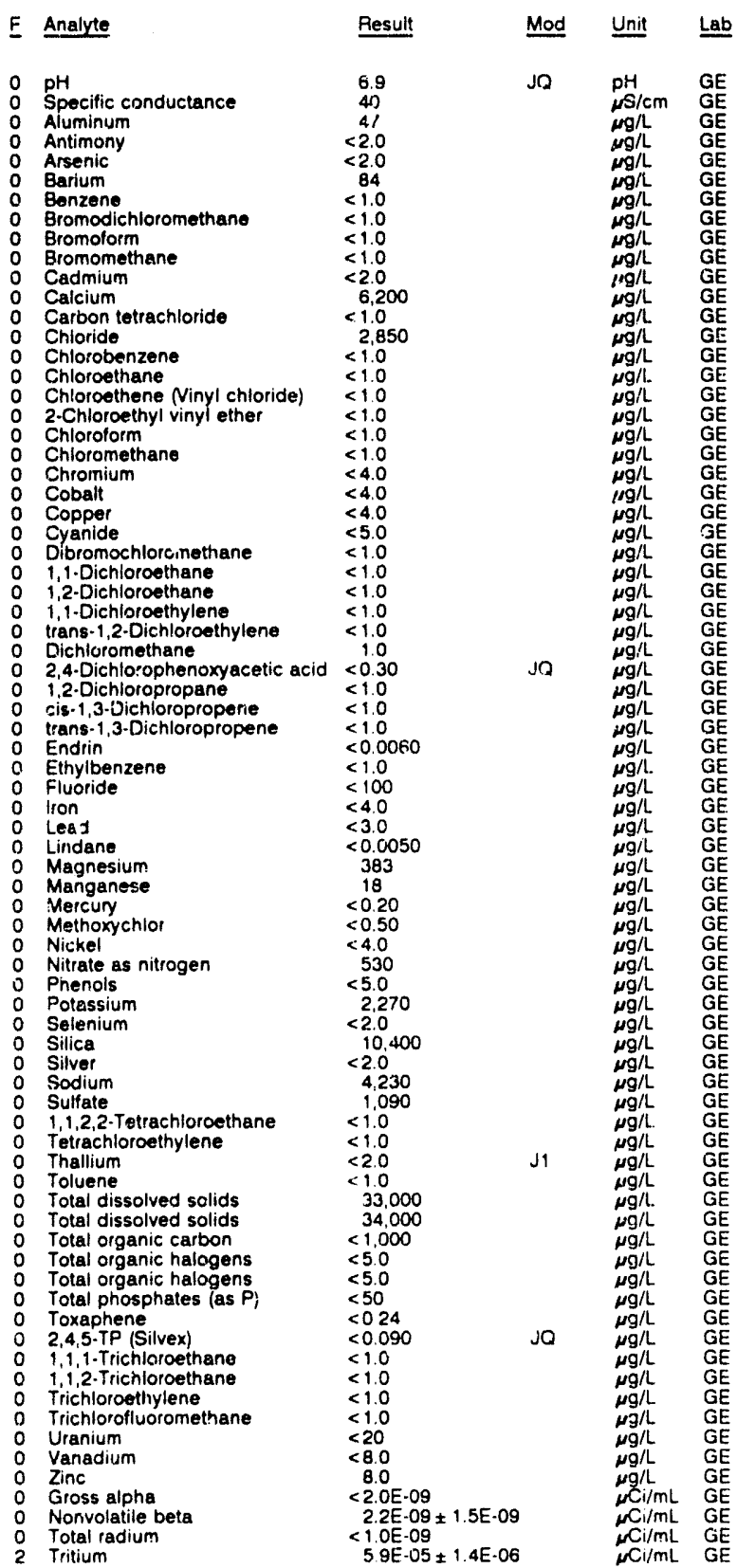

WELL. FSB122C

MEASUREMENTS CONDUCTED IN THE FIELD

Sample date: 12/09/91

Depth to water: $16.68 \mathrm{At}(5.15 \mathrm{~m})$ below TOC

Viater elevation: $201.12 \mathrm{ft}(61.30 \mathrm{~m}) \mathrm{msl}$

Water evacuated before sampling: $108 \mathrm{gal}$

LABORATORY ANALYSES

F Analyte Result Mod Unit Lab

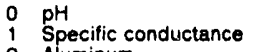

2 Aluminum

Antimony

Arsenic
0 Barium

Benzene

Bromodich

Bromoform

Cadmium

Calcium

Carbon tetrachioride

Chloride

Chlorobenzene

Chloroethane

Chloroethene Ninyl chloride)

2-Chloroethyl

Chlorolorm

Chromium

Cobalt

Copper

o Cyanide

o Dibromochloromethane

o 1,1-Dichioroethane

1,2-Dichloroethane

o 1,1 -Dichloroethylene

trans-1,2-Dichloroet

Dichloromethane

1,2-Dichloropropane

o cis-1,3-Dichloropropene
0
trans-1,3-Dichloropropene

Endrin

Ethylbenzene

Fluoride

lion

Lead

Magnesium

Manganese

Mercury

xychlor

Nitrate as nitrogen

Nitrate as ni
Phenols

Potassium

Selenium

0 Silica

0 Solver

Sodium

Sulfate

Tetrachlotoethylene

Thallium

Total dissolved solids

Total organic carbon

Total organic halogens

Total organic halogens

Total phosphates (as P)

0 Toxaphene

2,4,5.TP (Silvex)

i, 1 2-Trichloroethan

Trichloroethylene

Trichlorofluoromethane

Vanadium

Zinc

Gross alpha

2 Nonvolatile be

Total activity

2 Total radium
Time: 14:55

pH: 4.4 : $0 \mathrm{mg}$

Water temperature: $20.1^{\circ} \mathrm{C}$

4.7
430
539
$<2.0$
$<2.0$
131
$<1.0$
$<1.0$
$<1.0$
$<1.0$
$<2.0$

23,700

4.120

$<1.0$

$<1.0$

$<1.0$

$<1.0$

$<1.0$

11
$<4.0$

$<5.0$

$<1.0$

$<1.0$

$<1.0$

$<0.30$

$<1.0$

$<10$

$<0.0060$

$<1.0$
245

245
$<4.0$

$<0.0050$

$<0.0050$
12,300

12,300
182
$<0.20$
$<0.50$

15
61,000

15,000
$<5.0$
1,390

1.390
$<2.0$

10,400

$<2.0$
42,700

3,680

$<1.0$

$<1.0$

362,000

3,000

3.000
$<5.0$
$<5.0$

$<5.0$

$<0.24$
$<0.090$

1.0

$<1.0$

$<1.0$

$<1.0$
$<8.0$
84

$1.0 E-08 \pm 3.3 E-09$

$8.0 \mathrm{E}-09 \pm 1.0 \mathrm{E}-09$

$2.0 \mathrm{E}-03 \pm 6.9 \mathrm{E}-06$
9.5E-08 $\pm 4.8 E-09$
JO $\mathrm{pH} \quad \mathrm{GE}$

$\begin{array}{ll}\mu \mathrm{S} / \mathrm{cm} & \mathrm{GE} \\ \mu \mathrm{g} / \mathrm{L} & \mathrm{GE}\end{array}$

$\underset{\mu g / L}{\mu g} \quad \mathrm{GE}$

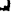

r

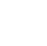

(n)

Jo

a

Jo

Jo

J2

J2

JQ

JQ

Jo

JO
Jo
JO

Jo 
ANALYTICAL RESULTS

WELL FSB122D

MEASUREMENTS CONDUCTED IN THE FIELD

Sample date: 1209 1

Depth to water: 12.78 ft $(3.90 \mathrm{~m})$ below TOC

Sp. conductanc: $204.82 \mathrm{Ht}(62.44$

Water evacuated before sampling $48 \mathrm{gal}$

LABORATORY ANALYSES

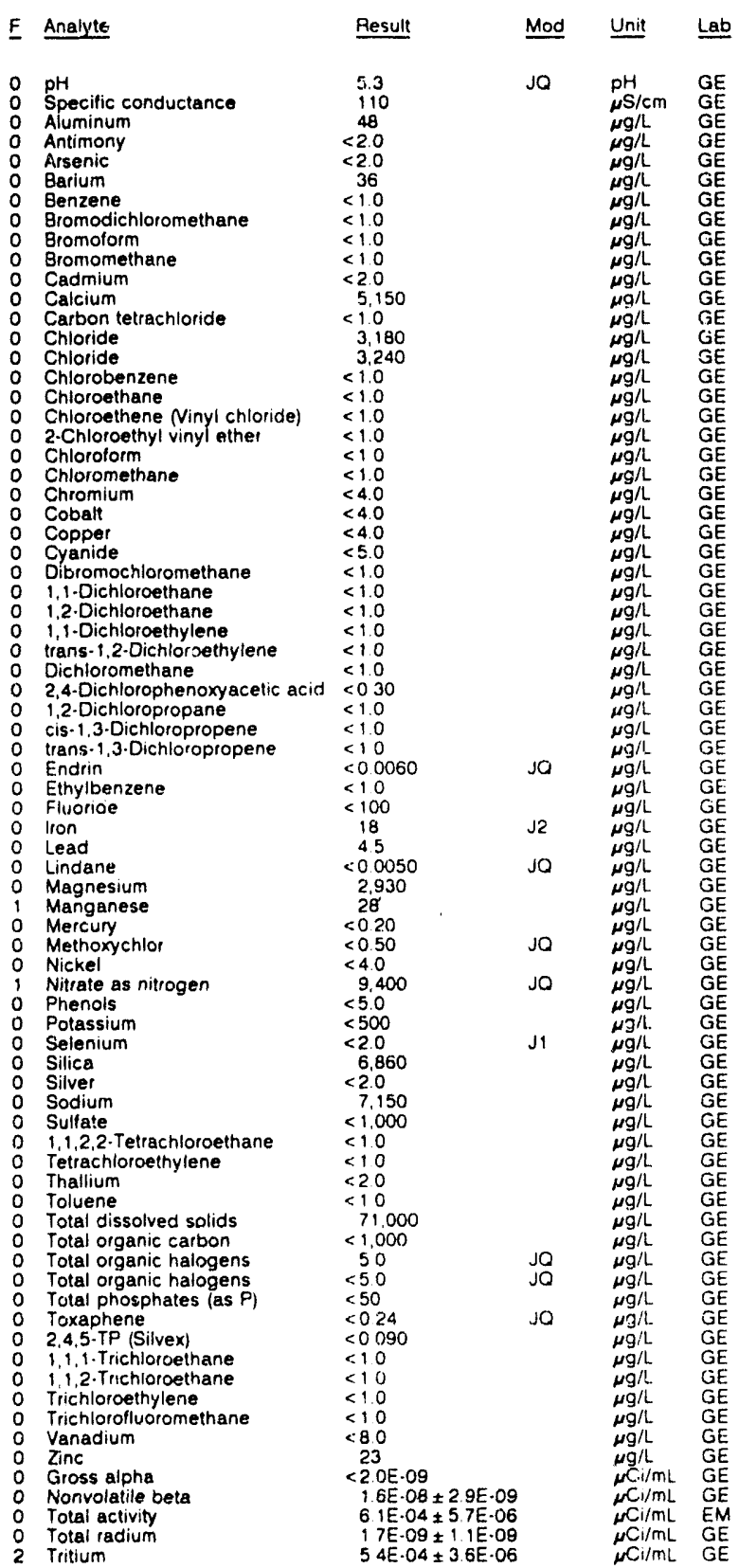

WELL FSB123C

MEASUREMENTS CONDUCTED IN THE FIELD

Sample date: $10 / 18 / 91$

Depth to water: $28.13 \mathrm{H}(8.57 \mathrm{~m})$ below TOC

Sp conductanc $209.97 \mathrm{ht}$ (64.

Water evacuated before sampling. $143 \mathrm{gal}$

LABORATOAY ANALYSES

F Analyte Result Mod Unit Lab

: $\mathrm{pH}_{0} \mathrm{H}$ ecific conductance

Aluminum

... Asenic

Barium

Benzene

Bromodich

Bromomethane

C idmium

Carbon tetrachioride

Carbon te

Chlorobenzene

Chloroethane

2.Chloroethyl vinyl ether

Chlorolorm

Chloromethane

Chromium

Cobalt

Copper

Dyanide

1,1.Dichloroethane

1,2-Dichloroethane
$0 \quad 1,1$. Dichloroethylen

trans-1,2-Dichloroethylene

2.4.Dichlorophenoxyacetic acid

cis.

I Ians.13. Dichloropropen

Endrin

Ethylbenzene

0 Fluoride

0 Iron

0 Lindane

o Magnesium

Manganes

Methorychior

Nicke

Nitrate as nitrogen

Potassium

0 Selenium

o Silica

- Silver

0 Sodium

0 Sulfate

Tetrachloroethylene

0 Thallium

0 Tolvene

- Total dissolved solids

Total organic carbon

Total urganic halogens
Total phosphates (as $P$ )

Total phosphates
Toxaphene

2.4.5.TP (Silvex)

1.1.2. Trichloroethane

Trichloroethylene

Trichiorofluoromethane

Uranium

Zinc

Ginc

- Nonvolatile beta

Total radium

\author{
Time: $9: 45$ \\ Alkalinity. $20 \mathrm{mg}$ \\ Water temperature $173^{\circ} \mathrm{C}$
}

63

Jo $\quad{ }_{\mu \mathrm{S} / \mathrm{cm}}^{\mathrm{pH}} \quad \mathrm{GE}$

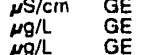

$<20$
$<2.0$
$<2.0$

$<2.0$

$<1.0$

$<10$
$<10$

$<2.0$

9,230
$<10$

4,140

$<10$

$<10$

$<10$
$<10$

$<1.0$
$<40$

$<4.0$

$<4.0$
$<50$

$<10$

$<10$

$<10$

$<1.0$

4.4
$<0.30$

$<10$

$<10$

$<00060$

$<10$
$<100$

$<40$
$<30$

$<30$
$<00050$

$\begin{aligned} & 680 \\ 14 & <20 \\ < & 020\end{aligned}$

$<020$
$<050$

$<4.0$

4.000
$<5.0$

$<5.0$
529

$<2.0400$

11.400
$<2.0$

$\begin{array}{r}3.760 \\ \hline\end{array}$

$<1.000$

$<10$

$<10$
$<20$
$<10$

$<10$
67000

67,000
$<1,000$

$<50$

210
$<024$

$<0.090$

$<10$

1.0
12

$<10$

$<20$

80

18
$<2.0 E .09$
$<2.0 E .09$

$<1.0 E .09$
$<7.0 E .07$ 
ANALYTICAL RESULTS

WELL FSB123D

MEASUREMENTS CONDUCTED IN THE FIELD

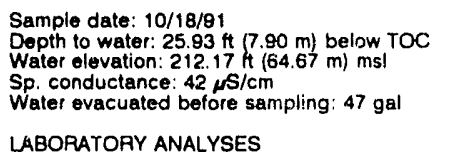

Time: $9: 20$

ph: 4.8 : 0 mg/L

Alkalinity: $0 \mathrm{mg} / \mathrm{L}$ : $17.0 \circ \mathrm{C}$

LABORATORY ANALYSES

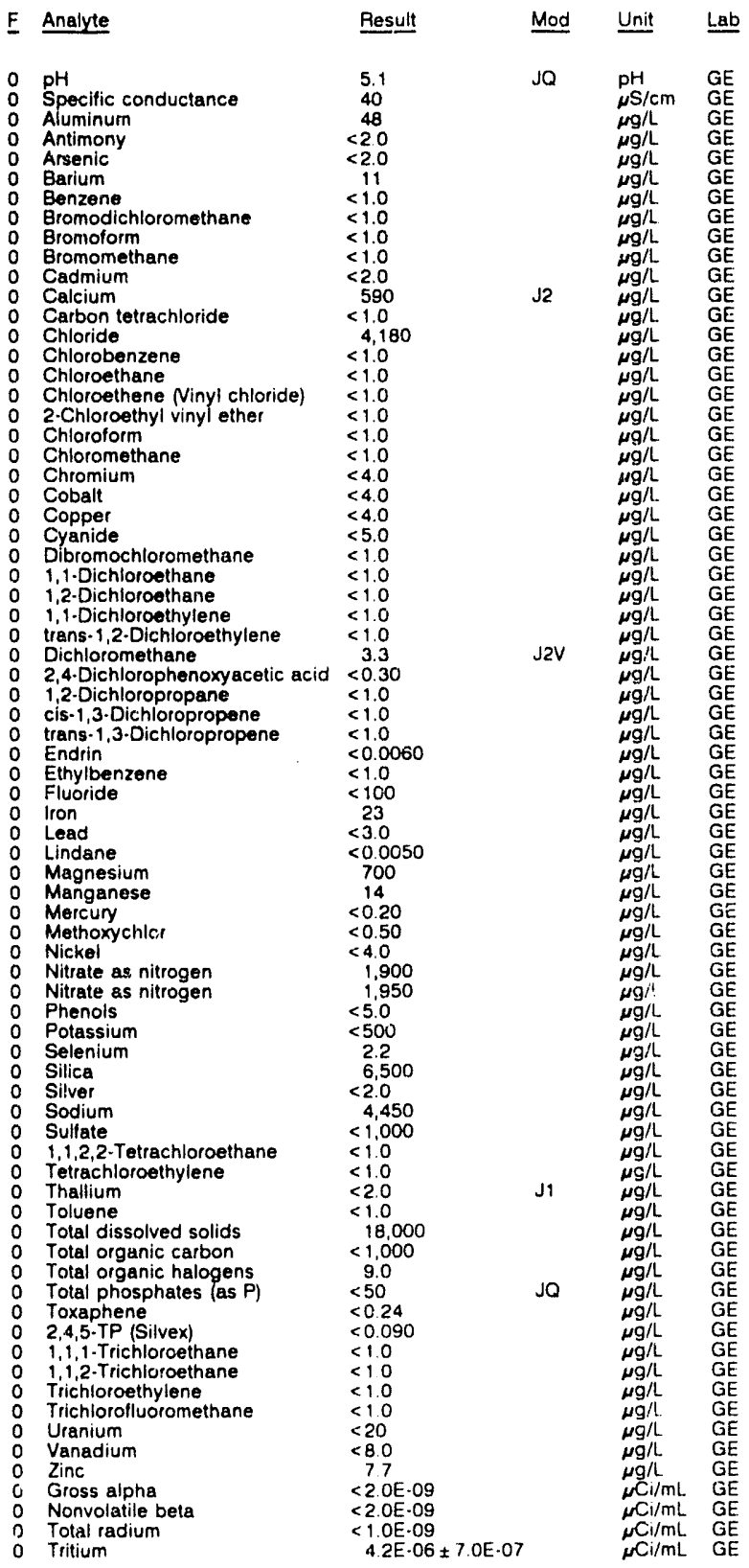

WELL FSS 1D

MEASUREMENTS CONOUCTED IN THE FIELD

Sample date. 11/13/91

Depth to water: $40.33 \mathrm{H}(12.29 \mathrm{~m})$ below TOC

Water elevation: $225.67 \mathrm{ft} / \mathrm{k}$

Alkalinity: $32 \mathrm{mg} / \mathrm{h}$

The wevacuated bolure sampling: 9 gal

LABORATORY ANALYSES

E Analyte Result Mod Unit Lab

${ }_{0}^{0} \quad \mathrm{pH}$

0 Arsenic

0 Benzene

- Bromodichloromethane

Bromomethane

o Cadmium

Calcium

Carbon tetrachloride

Chloride

Chlorobenzene

Chloreethene Ninyl chloride)

2.Chloroethyl vinyl ether

Chloroform

Chromium

Copper

Dibromochloromethane

1.1.-Dichloroethane

1, Dichloroethane

trans-1,2-Dichloroethylene

24.0ichmernane

phenoxyacetic acid

cis. Dichloropropane

Irans-1.3-Dichloropropene

0 Endrin

- Ethylbenzerie

- Fluoride

0 Lead

0 Lindane

Magnesium

Manganes

0 Methoxychlor

0 Nickel

Nitrate as nitrogen

Nitrite as nitrogen

Phenols

0 Selenium

S Silica

0 Silver

o Sodium

1. $1,2,2$-Tetrachloroethane

Tetrachloroethylene

0 Toluene

Total dissolved solids

Total organic carbon

2 Total organic halogens

0 Toxaphene

2.4.5.TP (Silvex)

1.1.1.Trichloroethane

0 Trichloroethylene

- Trichlorofluoromethane

- Gross alpha

- Nonvolatile beta

1 Total radium

67

$\begin{array}{ll}p H & G E \\ \mu \mathrm{S} / \mathrm{cm} & \mathrm{GE} \\ \mu \mathrm{g} / \mathrm{h} & \mathrm{GE}\end{array}$

$<2.0$
11
$<1.0$

$<1.0$

$<1.0$
$<1.0$

28,300

$<1.050$

$<1.0$

$<1.0$
$<1.0$

$<1.0$

$<1.0$
$<1.0$

$<1.0$
$<4.0$

$<4.0$

$<1.0$

$<1.0$

$<1.0$
$<1.0$

1.8

$<3.0$

$\leq 1.0$

$<1.0$

$<0.0060$

$<1.0$

128
$<3.0$

$<0.0050$

509
19

$<0.20$
$<0.50$
8.0
180

8.0
180
$<10$

$<5.0$

560

$<2.0$
7,590

$<2.00$

4,460
1,780

4,0
$<1.0$

$<1.0$
$<1.0$

$<1.0000$

$<1,000$

461
420
$<0.24$
$<0.90$

$<0.90$

$<1.0$

$<1.0$

$<1.0$

3. $2 \mathrm{E}-09+1.5 \mathrm{E}-09$

$4.2 E \cdot 09 \pm 1.2 E .09$

3. $2 \mathrm{E} \cdot 00 \pm 1.6 \mathrm{E} \cdot 09$
$8.06 .06 \pm 8.0 \mathrm{E} .07$

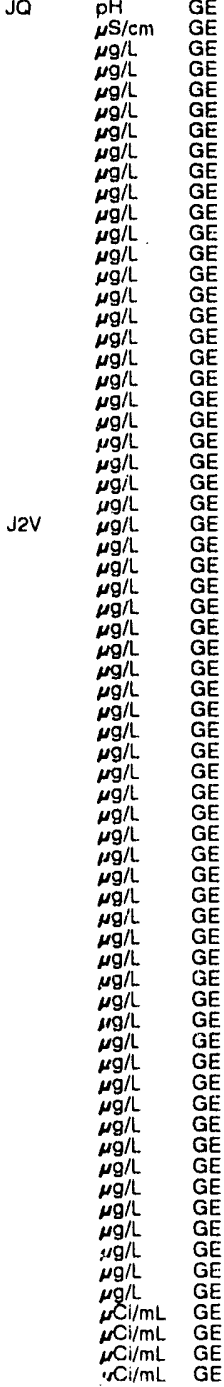

WELL FSS $2 D$

MEASUREMENTS CONDUCTED IN THE FIELD

$12 \mathrm{~m})$ below TOC

Water elevation: $225.12 \mathrm{Ht}$

. conductance $71 \mu \mathrm{S} / \mathrm{cm} .62 \mathrm{~m}) \mathrm{ms}$

Water evacuated before sampling: $13 \mathrm{gal}$

The well went dry during purging.

LABORATORY ANALYGES

\begin{tabular}{|c|c|c|c|}
\hline E Analyte & Result & Mod & Unalt \\
\hline $\begin{array}{ll}0 & \text { PH } \\
0 & \text { Specifie conduclance } \\
0 & \text { Almenic } \\
\text { Oarium } & \end{array}$ & $\begin{array}{r}5.6 \\
70 \\
\times 2.0 \\
20\end{array}$ & NO & $\begin{array}{l}\mathrm{pH} \\
\mu \mathrm{g} / \mathrm{cm} \\
\mu \mathrm{g} / \mathrm{h} \\
\mu \mathrm{g} / \mathrm{h}\end{array}$ \\
\hline
\end{tabular}


ANALYTICAL RESULTS

WELL FSS $2 D$ collected on $11 / 13 / 91$, laboratory analyses (cont)

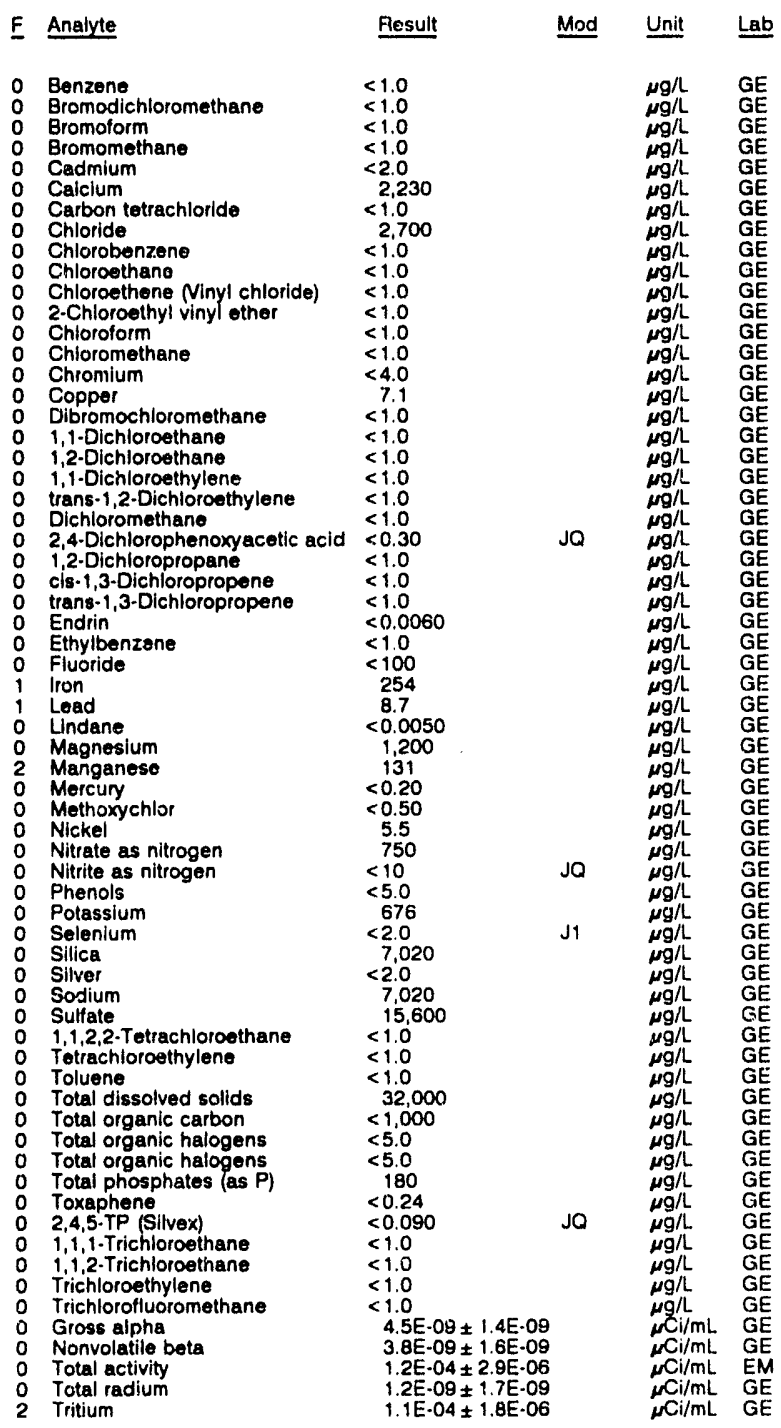

WELL FSS 3D

MEASUREMENTS CONDUCTED IN THE FIELD

Sample date: 11/13/91

Depth to water: $35.21 \mathrm{~A}(10.73 \mathrm{~m})$ below TOC

Water olevation: $222.99 \mathrm{ft}(67.97$

Sp. conductance: $52 \mu \mathrm{s} / \mathrm{cm}$

Water evacuated before sampling
The well went dry during purging.

LABORATORY ANALYSES

\begin{tabular}{|c|c|c|c|c|c|}
\hline$\underline{F}$ & Analyte & Result & Mod & Unit & $\underline{\text { Lab }}$ \\
\hline $\begin{array}{l}0 \\
0 \\
0 \\
0 \\
0 \\
0 \\
0 \\
0 \\
0 \\
0 \\
0 \\
0 \\
0 \\
0 \\
0 \\
0 \\
0 \\
0\end{array}$ & $\begin{array}{l}\text { pH } \\
\text { Specific conductance } \\
\text { Arsenic } \\
\text { Barium } \\
\text { Benzene } \\
\text { Bromodichloromethane } \\
\text { Bromoform } \\
\text { Bromomethane } \\
\text { Cadmium } \\
\text { Calcium } \\
\text { Carbon tetrachloride } \\
\text { Chloride } \\
\text { Chlorobenzene } \\
\text { Chloroethane } \\
\text { Chloroethene Ninyl chloride) } \\
\text { 2-Chloroethyl vinyl ether } \\
\text { Chloroform } \\
\text { Chloromethane }\end{array}$ & $\begin{aligned} & 5.8 \\
& 55 \\
&<2.0 \\
&<19 \\
&<1.0 \\
&<1.0 \\
&<1.0 \\
&<1.0 \\
&<2.0 \\
&<1.410 \\
&<1.0 \\
& 3.500 \\
&<1.0 \\
&<1.0 \\
&<1.0 \\
&<1.0 \\
&<1.0 \\
&<1.0\end{aligned}$ & JO & $\begin{array}{l}p H \\
\mu S / c m \\
\mu g / L \\
\mu g / L \\
\mu g / L \\
\mu g / L \\
\mu g / L \\
\mu g / L \\
\mu g / L \\
\mu g / L \\
\mu g / L \\
\mu g / L \\
\mu g / L \\
\mu g / L \\
\mu g / L \\
\mu g / L \\
\mu g / L \\
\mu g / L\end{array}$ & $\begin{array}{l}G E \\
G E \\
G E \\
G E \\
G E \\
G E \\
G E \\
G E \\
G E \\
G E \\
G E \\
G E \\
G E \\
G E \\
G E \\
G E \\
G E \\
G E\end{array}$ \\
\hline
\end{tabular}

WELL FSS 3D collected on 11/13/91, laboratory analyses (cont.)

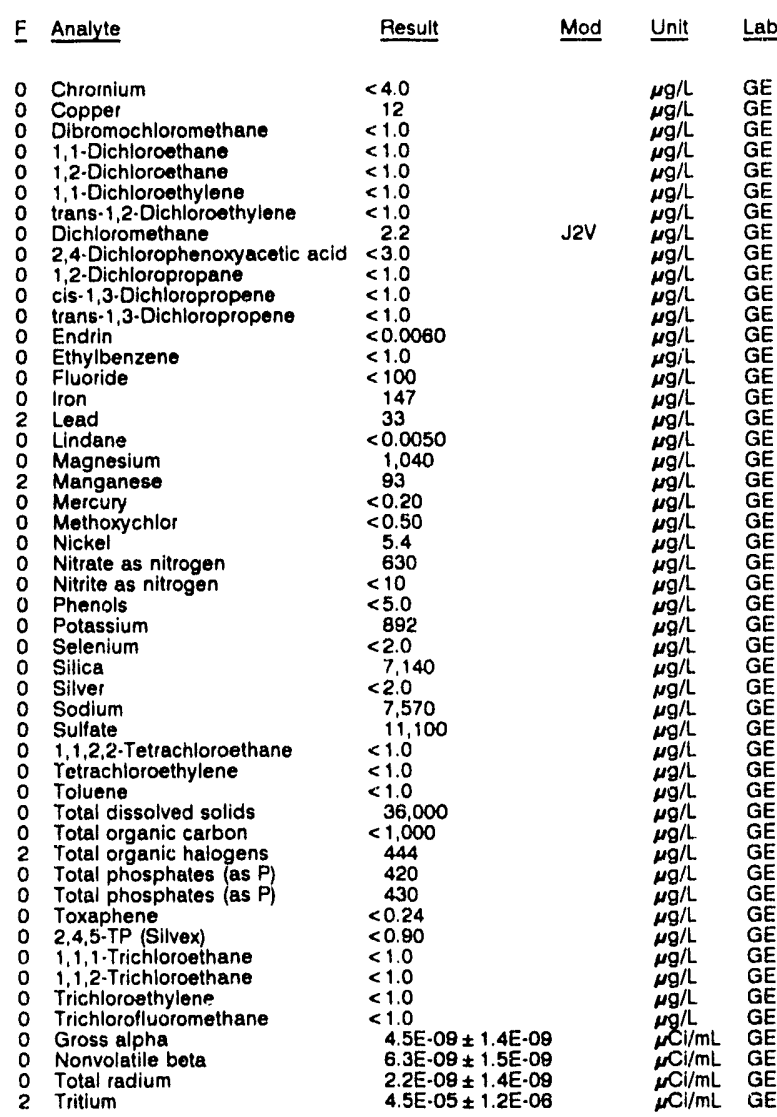

\section{WELL FSS 4D}

MEASUREMENTS CONDUCTED IN THE FIELD

\begin{tabular}{|c|c|c|c|c|c|}
\hline E & Analyte & Result & Mod & Unit & Lab \\
\hline & $\begin{array}{l}\text { pH } \\
\text { Specific conductance } \\
\text { Arsenic } \\
\text { Barium } \\
\text { Benzene } \\
\text { Bromodichloromethane } \\
\text { Bromoform } \\
\text { Bromomethane } \\
\text { Cadmium } \\
\text { Calcium } \\
\text { Carbon tetrachloride } \\
\text { Chloride } \\
\text { Chlorobenzene } \\
\text { Chloroethane } \\
\text { Chloroethene Ninyl chloride) } \\
\text { 2-Chloroethyl vinyl ether } \\
\text { Chloroform } \\
\text { Chloromethane } \\
\text { Chromium } \\
\text { Coppet } \\
\text { Dibromochloromethane } \\
1,1 \cdot \text { Dichloroethane } \\
1.2 \cdot \text { Dichloroethane } \\
1,1-\text { Dichloroethylene } \\
\text { trans-1,2-Dichloroethylene } \\
\text { Dichloromethane } \\
2.4 \text {-Dichlorophenoxyacetic acid } \\
1,2 \cdot \text { Dichloropropane } \\
\text { cis-1,3-Dichloropropene } \\
\text { trans-1,3-Dichloropropene } \\
\text { Endrin } \\
\text { Ethylbenzene } \\
\text { Fluoride }\end{array}$ & $\begin{aligned} & 5.1 \\
& 40 \\
&<2.0 \\
& 7.4 \\
&<1.0 \\
&<1.0 \\
&<1.0 \\
&<1.0 \\
&<2.0 \\
& 1.230 \\
&<1.0 \\
& 4.060 \\
&<1.0 \\
&<1.0 \\
&<1.0 \\
&<1.0 \\
&<1.0 \\
&<1.0 \\
&<4.0 \\
& 81.1 \\
&<1.0 \\
&<1.0 \\
&<1.0 \\
&<1.0 \\
&<1.0 \\
& 2.0 \\
&<0.30 \\
&<1.0 \\
&<1.0 \\
&<1.0 \\
&<0.0060 \\
&<1.0 \\
&<100\end{aligned}$ & $\begin{array}{l}\text { JaV } \\
\text { RQ }\end{array}$ & $\begin{array}{l}p H \\
\mu S / c m \\
\mu g / L \\
\mu g / L \\
\mu g / L \\
\mu g / L \\
\mu g / L \\
\mu g / L \\
\mu g / L \\
\mu g / L \\
\mu g / L \\
\mu g / L \\
\mu g / L \\
\mu g / L \\
\mu g / L \\
\mu g / L \\
\mu g / L \\
\mu g / L \\
\mu g / L \\
\mu g / L \\
\mu g / L \\
\mu g / L \\
\mu g / L \\
\mu g / L \\
\mu g / L \\
\mu g / L \\
\mu g / L \\
\mu g / L \\
\mu g / L \\
\mu g / L \\
\mu g / L \\
\mu g / L \\
\mu g / L\end{array}$ & $\begin{array}{l}\mathrm{GE} \\
\mathrm{GE} \\
\mathrm{GE} \\
\mathrm{GE} \\
\mathrm{GE} \\
\mathrm{GE} \\
\mathrm{GE} \\
\mathrm{GE} \\
\mathrm{GE} \\
\mathrm{GE} \\
\mathrm{GE} \\
\mathrm{GE} \\
\mathrm{GE} \\
\mathrm{GE} \\
\mathrm{GE} \\
\mathrm{GE} \\
\mathrm{GE} \\
\mathrm{GE} \\
\mathrm{GE} \\
\mathrm{GE} \\
\mathrm{GE} \\
\mathrm{GE} \\
\mathrm{GE} \\
\mathrm{GE} \\
\mathrm{GE} \\
\mathrm{GE} \\
\mathrm{GE} \\
\mathrm{GE} \\
\mathrm{GE} \\
\mathrm{GE} \\
\mathrm{GE} \\
\mathrm{GE} \\
\mathrm{GE}\end{array}$ \\
\hline
\end{tabular}

Depth to water: $70.57 \mathrm{ft}(21.51 \mathrm{~m})$ below TOC

Water elevation: $221.23 \mathrm{ft}(67.43 \mathrm{~m}) \mathrm{msl}$

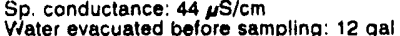

The well went dry during purging.

LABORATORY ANALYSES

Time: 11:15

PH: 4.8 . $0 \mathrm{mg} / \mathrm{L}$

Water temperature: $18.8^{\circ} \mathrm{C}$

Alkalinity: $4 \mathrm{mg} / \mathrm{h}$

Alkalinity: $4 \mathrm{mg} / \mathrm{L}$
Water temperature: $18.66^{\circ} \mathrm{C}$

ab 


\section{ANALYTICAL RESULTS}

WELL FSS $4 D$ collected on $11 / 13 / 91$, laboratory analyses (cont.)

$\begin{array}{ll}\text { F } & \text { Analyte } \\ & \\ 0 & \text { Iron } \\ 0 & \text { Lead } \\ 0 & \text { Lindane } \\ 0 & \text { Magnesium } \\ 0 & \text { Manganese } \\ 0 & \text { Mercury } \\ 0 & \text { Methoxychlor } \\ 0 & \text { Nickel } \\ 0 & \text { Nittrate as nitrogen } \\ 0 & \text { Nitrite as nitrogen } \\ 0 & \text { Phenols } \\ 0 & \text { Phenols } \\ 0 & \text { Potassium } \\ 0 & \text { Selenium } \\ 0 & \text { Silica } \\ 0 & \text { Silver } \\ 0 & \text { Sodium } \\ 0 & \text { Sulfate } \\ 0 & 1,1,2,2-\text { Totrachloroethane } \\ 0 & \text { Totrachloroethylene } \\ 0 & \text { Toluene } \\ 0 & \text { Total dissolved solids } \\ 0 & \text { Total organlc carbon } \\ 0 & \text { Total organic carbon } \\ 1 & \text { Total organic halogens } \\ 0 & \text { Total phosphates (as } \mathrm{P} \text { ) } \\ 0 & \text { Toxaphene } \\ 0 & 2,4,5-T P \text { (Silvex) } \\ 0 & 1,1,1-\text { Trichloroethane } \\ 0 & 1,1,2-\text { Trichloroethane } \\ 0 & \text { Trichloroethylene } \\ 0 & \text { Trichlorofluoromethane } \\ 0 & \text { Gross alpha } \\ 0 & \text { Nonvolatile beta } \\ 0 & \text { Total radium } \\ 2 & \text { Tritium } \\ & \end{array}$

$\quad$ Result

41
$<3.0$
$<0.0050$
710
13
$<0.20$
$<0.50$
$<4.0$
1,960
$<10$
$<5.0$
$<5.0$
$<500$
$<2.0$
8,730
$<2.0$
4,200
$<1,000$
$<1.0$
$<1.0$
$<1.0$
27.000
$<1,000$
$<1,000$
34
$<50$
$<0.24$
$<0.090$
$<1.0$
$<1.0$
$<1.0$
$<1.0$
$4.5 \mathrm{E} \cdot 09 \pm 1.4 \mathrm{E} \cdot 09$
$31.0 \mathrm{E} \cdot 09 \pm 1.5 \mathrm{E} \cdot 09$
$<1.0 \mathrm{E} \cdot 09$
$2.4 \mathrm{E} \cdot 05 \pm 1.0 \mathrm{E} \cdot 06$

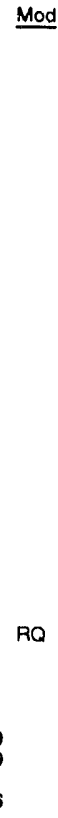

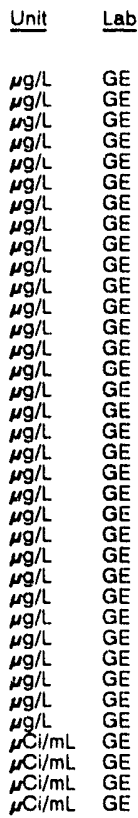

\section{WELLL FTF 1}

MEASURENENTS CONDUCTED IN THE FIELD

Sample date: $11 / 11 / 9$

The well was dry.

Time: 10:00

WELL FTF 2

MEASUREMENTS CONDUCTED IN THE FIELD

Sample date: $11 / 11 / 91$

Depth to water: $54.20 \mathrm{ft}(16.52 \mathrm{~m})$ below TOC

Water elevation: $227.10 \mathrm{ft}(69.22 \mathrm{~m}) \mathrm{ms}$

$\mathrm{Sp}$. conductance: $152 \mu \mathrm{s} / \mathrm{cm}$
No water was evacuated before sampling

Time: 10:05

pH: 6.4

Water temperature: $21.4^{\circ} \mathrm{C}$

WELL FTF 3

MEASUREMENTS CONDUCTED IN THE FIELD

Sample date: $11 / 11 / 9$

Depth to water: $5300 \mathrm{tt}(16.15 \mathrm{~m})$ below $\mathrm{rOC}$

Water elevation: $227.00 \mathrm{~h}(69.19 \mathrm{~m}) \mathrm{ms}$

No water was evacuated before sampling

$\mathrm{pH}: 7.0$

Water temperature: $31.3^{\circ} \mathrm{C}$

WELL FTF 4

MEASUREMENTS CONDUCTED IN THE FIELD

Sample date: $11 / 19 / 81$

Depth to water: $52.00 \mathrm{ft}(15.85 \mathrm{~m})$ below TOC

Water elevation: $226.50 \mathrm{H}(68.04 \mathrm{~m}) \mathrm{ms}$

No water was evacuated before sampling.
Time: $10: 25$
$\mathrm{pH}: 7.1$

Water temperature: $22.0^{\circ} \mathrm{C}$
WELL FTF 5

MEASUREMENTS CONDUCTED IN THE FIELD

Sample date: $11 / 11 / 91$

Depth to water: $51.20 \mathrm{H}(15.61 \mathrm{~m})$ below TOC

Water elevation. $226.10 \mathrm{ht}(68.82 \mathrm{~m}) \mathrm{ms}$

No water was evacuated belore sampling.

Time: $10: 30$
$\mathrm{pH}: 7.1$

Water temperature: $24.8^{\circ} \mathrm{C}$

WELL FTF 6

MEASUREMENTS CONDUCTED IN THE FIELD

Sample date: $11 / 11 / 91$

Depth to water: $51.50 \mathrm{ft}(15.70 \mathrm{~m})$ below TOC

Water elevation: $226.50 \mathrm{ft}(69.04 \mathrm{~m}) \mathrm{msl}$

Sp. conductance: $333 \mathrm{\mu S} / \mathrm{cm}$

sampling

Time: $10: 40$
pH: 6.8

Water temperature: $31.4^{\circ} \mathrm{C}$

\section{WELL FTF 7}

MEASUREMENTS CONDUCTED IN THE FIELD

Sample date: 11/11/91

Depth to water: $53.50 \mathrm{ft}(18.31 \mathrm{~m})$ below TOC

$226.50 \mathrm{ft}(68.04 \mathrm{~m}) \mathrm{ms}$

Sp. conductance: $61 \mu \mathrm{S} / \mathrm{cm}$

No water was evacuated before sampling

Water temperature: $39.5^{\circ} \mathrm{C}$

\section{WELL FTF 8}

MEASUREMENTS CONDUCTED IN THE FIELD

Sample date: $11 / 11 / 91$
The well was $d r y$.

Time: 10:55$$
\text { Time. } 10.55
$$

\section{WELL FTF 9}

MEASUREMENTS CONDUCTED IN THE FIELD

Sample date: $11 / 11 / 91$

Depth to water: $46.00 \mathrm{ft}(14.02 \mathrm{~m})$ below TOC

(ap.

No water was ovacuat

Water temperature: $22.6^{\circ} \mathrm{C}$

\section{WELL FTF 10}

MEASUREMENTS CONDUCTED IN THE FIELD

Sample date: 11/11/91

$46.00 \mathrm{~A}(14.02 \mathrm{~m})$ below TOC

Water elevation: $225.10 \mathrm{ft}(68.61 \mathrm{~m}) \mathrm{ms}$

No water was evacuated before sampling

Time: $13: 25$

Water temperature: $25.3^{\circ} \mathrm{C}$

\section{WELL FTF 11}

MEASUREMENTS CONDUCTED IN THE FIELD

Sample date: $11 / 11 / 91$

Depth to water: $42.20 \mathrm{ft}(12.86 \mathrm{~m})$ below TOC

Water elevation: $229.00 \mathrm{ft}(69.80 \mathrm{~m}) \mathrm{ms}$

Sp. conductance: $60 \mu \mathrm{S} / \mathrm{cm}$

No water was evacuated before sampling.

Time: $12: 55$

Time: 12.8

Water temperature: $25.0^{\circ} \mathrm{C}$ 
WELL FTF 12

MEASUREMENTS CONDUCTED IN THE FIELD

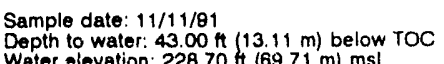

So conductance: $1380 \mathrm{~s} / \mathrm{cm}$

No water was evacuated before sampling

\section{WELL FTF 13}

MEASUREMENTS CONDUCTED IN THE FIELO

Sample date: $11 / 11 / 91$

Water elevation: $225.30 \mathrm{tt}(68.67 \mathrm{~m}) \mathrm{msl}$

Sp. conductance: $146 \mathrm{HS} / \mathrm{cm}$

No water was evacuated before sampling

WELL FTF 14

MEASUREMENTS CONDUCTED IN THE FIELD

Sample date: $11 / 11 / 81$

The well was dry.

Time: $12: 50$

Water temperature: $20.6^{\circ} \mathrm{C}$

Time: $13: 50$

pH: 7.0

Water temperature: $20.6^{\circ} \mathrm{C}$

\section{WELL FTF 15}

MEASUREMENTS CONDUCTED IN THE FIELD

Sample date: $11 / 11 / 91$
Depth to water $60.50 \mathrm{ft}(18.44 \mathrm{~m})$ below TOC
Water elevation: $226.00 \mathrm{ft}(68.89 \mathrm{~m}) \mathrm{ms}$
Sp. conductance: $41 \mu \mathrm{s} / \mathrm{cm}$

No water was evacuated before sampling.

\section{WELL FTF 16}

MEASUREMENTS CONDUCTED IN THE FIELD

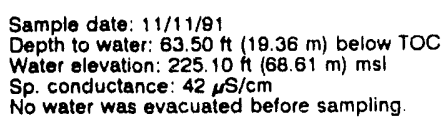

No water was evacuated before sampling

\section{WELL FTF 17}

MEASUAEMENTS CONDUCTED IN THE FIELD

Sample date: $11 / 11 / 91$ (19." 3 m) below TOC

Depth to water: $64.40 \mathrm{H}(19 ., 3 \mathrm{~m})$ below

Water elevation: $225.20 \mathrm{ft}\left(\mathrm{e}_{\text {. }}\right.$.

$\mathrm{Sp}$. conductance: $54 \mu \mathrm{S} / \mathrm{cm}$
No water was evacuated before sampling

\section{WELL FTF 18}

MEASUREMENTS CONDUCTED IN THE FIELD

Sample date: $11 / 11 / 91$

Depth to water: $63.00 \mathrm{ft}(18.20 \mathrm{~m})$ below $10 \mathrm{C}$

Water elevation: $225.00 \mathrm{ft}(68.58 \mathrm{~m}) \mathrm{msl}$

$\mathrm{Sp}$. conductance: $61 \mu \mathrm{s} / \mathrm{cm}$

No water was evacuated before sampling

Time: $13: 35$
$\mathrm{pH}: 7.6$

Water temperature. $20.3^{\circ} \mathrm{C}$

\section{Time: $13: 40$
pH: 7.6}

\section{Time: $13: 55$
pH: 7.7}

Time: $14: 00$
pH: 7.6

\section{WELL FTF 19}

MEASUREMENTS CONDUCTED IN THE FIELD

$\begin{array}{ll}\text { Sample date: } 11 / 11 / 91 & \text { Time: } 14: 05 \\ \text { Depth to water: } 63.50 \mathrm{Ht}(19.36 \mathrm{~m}) \text { below TOC } & \mathrm{pH}: 7.3 \\ \text { Water elevation: } 223.70 \mathrm{Ht}(68.18 \mathrm{~m}) \mathrm{msl} & \text { Water temperature: } 25.8^{\circ} \mathrm{C} \\ \text { Sp. conductance: } 59 \mu \mathrm{s} / \mathrm{cm} & \\ \text { No water was evacuated before sampling. } & \end{array}$

\section{WELL FTF 20}

MEASUREMENTS CONDUCTED IN THE FIELD

Sample date: $11 / 11 / 91$
Depth to water: $62.50 \mathrm{Ht}(18.05 \mathrm{~m})$ below TOC
Water elevation: $224.60 \mathrm{ft}(68.46 \mathrm{~m}) \mathrm{ms}$
Sp. conductance: $44 \mu \mathrm{S} / \mathrm{cm}$
No water was evacuated before sampling.

Time: $14: 10$

Water temperature: $26.2^{\circ} \mathrm{C}$

\section{WELL FTF 21}

MEASUREMENTS CONDUCTED IN THE FIELD

Sample date: $11 / 11 / 81$
Depth to water: $82.50 \mathrm{Ht}(19.05 \mathrm{~m})$ below TOC
Water elevation: $225.00 \mathrm{Ht}(68.58 \mathrm{~m}) \mathrm{ms}$.
Sp. conductance: $4490 \mu \mathrm{s} / \mathrm{cm}$

No water was evacuated before sampling

$\operatorname{Time:}_{\mathrm{pH}: 7.3}$

Water temperature: $24.5^{\circ} \mathrm{C}$

\section{WELL FTF 22}

MEASUREMENTS CONDUCTEO IN THE FIELD

Sample date: $11 / 11 / 91$

Depth to water: $62.50 \mathrm{H}(19.05 \mathrm{~m})$ below TOC

Water elevation: $224.30 \mathrm{H}(68.37 \mathrm{~m}) \mathrm{ms}$

Sp. conductance: $81 \mu \mathrm{S} / \mathrm{cm}$

No water was evacuated before sampling.

Time: 14:25

pH. 7.2

Water temperature: $25.2^{\circ} \mathrm{C}$

\section{WELL FTF 23}

Water temperature: $23.0^{\circ} \mathrm{C}$

MEASUREMENTS CONDUCTED IN THE FIELD

Sample date: $11 / 11 / 91$

Depth to water $62.00 \mathrm{ft}(18.90 \mathrm{~m})$ below TOC

$24.00 \mathrm{ft}(68.28 \mathrm{~m}) \mathrm{ms}$

$54 \mu \mathrm{S} / \mathrm{cm}$

\section{WELL FTF 24A}

Water temperature: $20.6^{\circ} \mathrm{C}$

MEASUREMENTS CONDUCTED IN THE FIELD

Sample date. 11/11/91

Depth to water $44.50 \mathrm{n}(13.56 \mathrm{~m})$ below TOC

Water elevation: $225.80 \mathrm{ft}(68.82 \mathrm{~m}) \mathrm{msl}$

Sp conductance: $117 \mu \mathrm{S} / \mathrm{cm}$
No water wis evacuated before sampling.

Time: 13:05

Time: $14 \cdot 30$

$\mathrm{pH}: 7.2$

Water temperature: $22.8^{\circ} \mathrm{C}$

\section{WELL FTF 25A}

Water temperafure: $20.9^{\circ} \mathrm{C}$
MEASUAEMENTS CONDUCTED IN THE FIELD

Sample date: $11 / 11 / 91$

Depth to water: $45.00 \mathrm{Ht}(13.72 \mathrm{~m})$ below TOC

Water elevation: $226.20 \mathrm{ft}(68.85 \mathrm{~m}) \mathrm{msl}$

Sp. conductance : $161 \mu \mathrm{S} / \mathrm{cm}$

No water was evacuated before sampling.
Time: $13: 20$

$\mathrm{pH}: 7.0$

Water temperature: $24.6^{\circ} \mathrm{C}$ 
WELL FTF 26

MEASUREMENTS CONDUCTED IN THE FIELD

Sample date: $11 / 11 / 91$

Depth to water: $45.00 \mathrm{ft}(13.72 \mathrm{~m})$ below TOC

Sp.

WELL FTF 27

MEASUAEMENTS CONDUCTED IN THE FIELD

Sample date: $11 / 11 / 91$

Depth to water: $45.00 \mathrm{ft}(13.72 \mathrm{~m}$ ) below TOC

elevation: $225.50 \mathrm{~h}(68.73 \mathrm{~m}) \mathrm{ms}$

No water was evacuated before sampling

WELL GBW 1

MEASUREMENTS CONDUCTED IN THE FIELD

Sample date: $12 / 08 / 91$

Depth to water: $67.33 \mathrm{ft}(20.52 \mathrm{~m})$ below TOC

Water elevation: $266.27 \mathrm{ft}(81.16 \mathrm{~m}) \mathrm{msl}$

Sp. conducterice: $10 \mu \mathrm{S} / \mathrm{cm}$

Water evacuated before sampling: $19 \mathrm{ga}$

The well went dry during purging

WELL H 14

MEASUREMENTS CONDUCTED IN THE FIELD

Sample date: 12/22/91

Depth to water: 19.98 it $(6.09 \mathrm{~m})$ below TOC

Sp. conductance: $321 \mu \mathrm{S} / \mathrm{cm}$

Water evacuated before sampling: $18 \mathrm{gal}$

WELL H 15

MEASUREMENTS CONDUCTED IN THE FIELD

Sample date: $12 / 22 / 81$
The well was dry.

WELL H 16

MEASUREMENTS CONDUCTED IN THE FIELD

Sample date: $12 / 22 / 91$

Depth to water: 16.89 (t $5.15 \mathrm{~m}$ ) below TOC

Water elevation: $224.61 \mathrm{tt}(68.46 \mathrm{~m}) \mathrm{msl}$

$\mathrm{Sp}$. conductance: $34 \mu \mathrm{S} / \mathrm{cm}$

Water evacuated before sampling: 2 gal

\section{WELL H 17}

MEASUREMENTS CONDUCTED IN THE FIELD

Sample date: $12 / 22 / 91$

Depth to water: $1951 \mathrm{tt}(5.95 \mathrm{~m})$ below TOC

Water elevation: $223.78 \mathrm{ht}(68$

Water evacuated before sampling: $1 \mathrm{gal}$

Time: $13: 15$

Water temperature: $24.8^{\circ} \mathrm{C}$

Time: $13: 10$

Water temperature: $25.5^{\circ} \mathrm{C}$

Time: $8: 50$

Alkalinity: $1 \mathrm{mg} / \mathrm{L}$

Water temperature: $16.6^{\circ} \mathrm{C}$

Time: 12:05

$\mathrm{pH}: 4.6$

Alkalinity: $0 \mathrm{mg} / \mathrm{h}$

Water temperature: $19.3^{\circ} \mathrm{C}$

Time: 13.05

Alkalinity: $4 \mathrm{mg} / \mathrm{h}$

Water temperature: $20.3^{\circ} \mathrm{C}$

Time: $13: 20$

PH: 5.4 : $11 \mathrm{mg}$

Water temperature: $20.6^{\circ} \mathrm{C}$
WELL H 18,4

MEASUREMENTS CONOUCTED IN THE FIELD

Sample date: $12 / 22 / 91$

Depth to water: $17.02 \mathrm{ft}(5.19 \mathrm{~m})$ below TOC

Depth to water: $17.02 \mathrm{ft}(5.19 \mathrm{~m})$ below
Water elevation: $222.48 \mathrm{ft}(67.81 \mathrm{~m}) \mathrm{msl}$

Sp conductance: $55 \mathrm{HS} / \mathrm{cm}$.

Water evacuated before sampling: 5 gal

The well went dry during purging.

WELL H 19

MEASURFMENTS CONDUCTED IN THE FIELD

Samp date: $12 / 22 / 81$

Time: 11:25

The ,oll was dry.

Time: 12:45

Alkalinity: $8 \mathrm{mg} / \mathrm{L}$

Water temperature: $20.4^{\circ} \mathrm{C}$

WELL HAC 1

MEASUREMENTS CONDUCTED IN THE FIELD

Sample date: $12 / 02 / 81$

Depth to water: $27.95 \mathrm{H}(8.52 \mathrm{~m})$ below TOC

Water elevation: $270.45 \mathrm{ft}(82.43 \mathrm{~m}) \mathrm{ms}$ !

Sp conductance: $177 \mu \mathrm{S} / \mathrm{cm}$

Water evacuated before sampling: $39 \mathrm{gal}$

LABORATORY ANALYSES

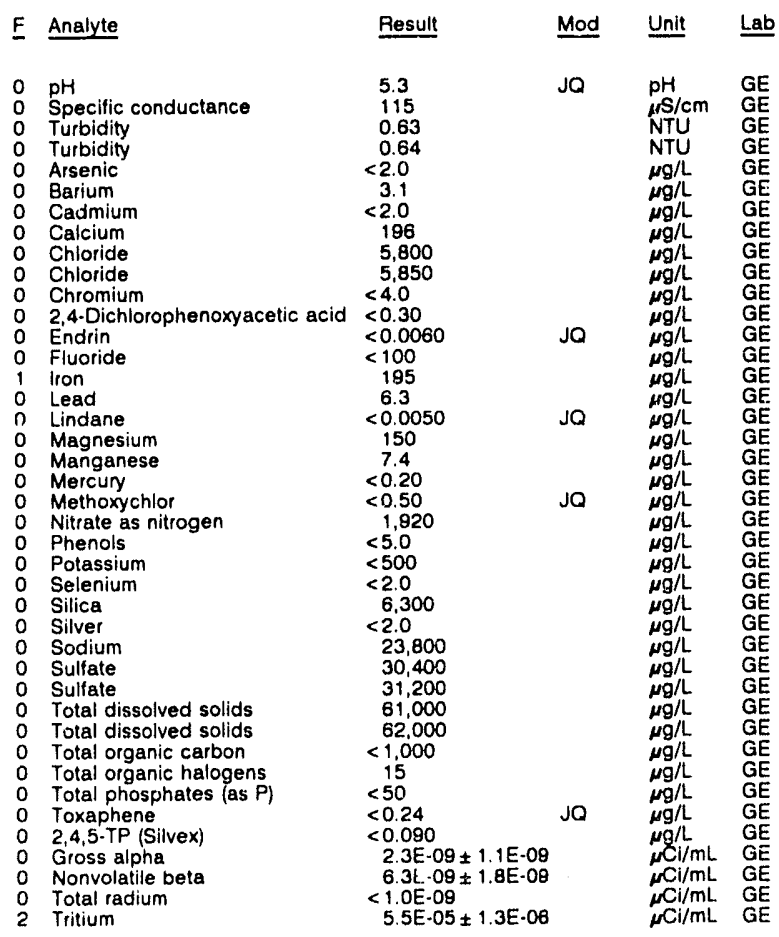

WELL HAC 2

MEASUREMENTS CONDUCTED IN THE FIELD

Sample date: $12 / 02 / 91$

Depth to water: $28.26 \mathrm{ft}(8.61 \mathrm{~m})$ below TOC

Water elevation: $269.84 \mathrm{ft}(82.25 \mathrm{~m}) \mathrm{ms}$

p. conductance: $537 \mu \mathrm{S} / \mathrm{cm}$

Water evacuated before sampling: $6 \mathrm{gal}$

The well went dry during purging.

LABORATORY ANALYSES

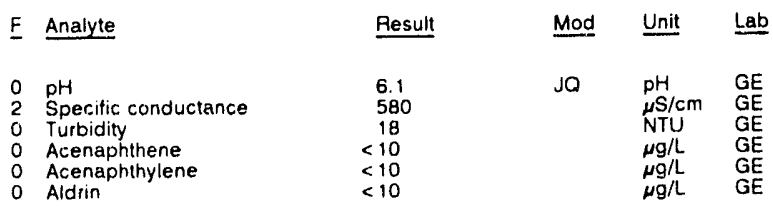

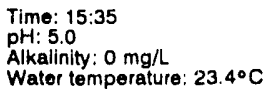

pH: 5.0

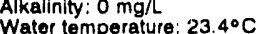


ANALYTICAL RESULTS

WELL HAC 2 collected on 12/02/91, laboratory analyses (cont.)

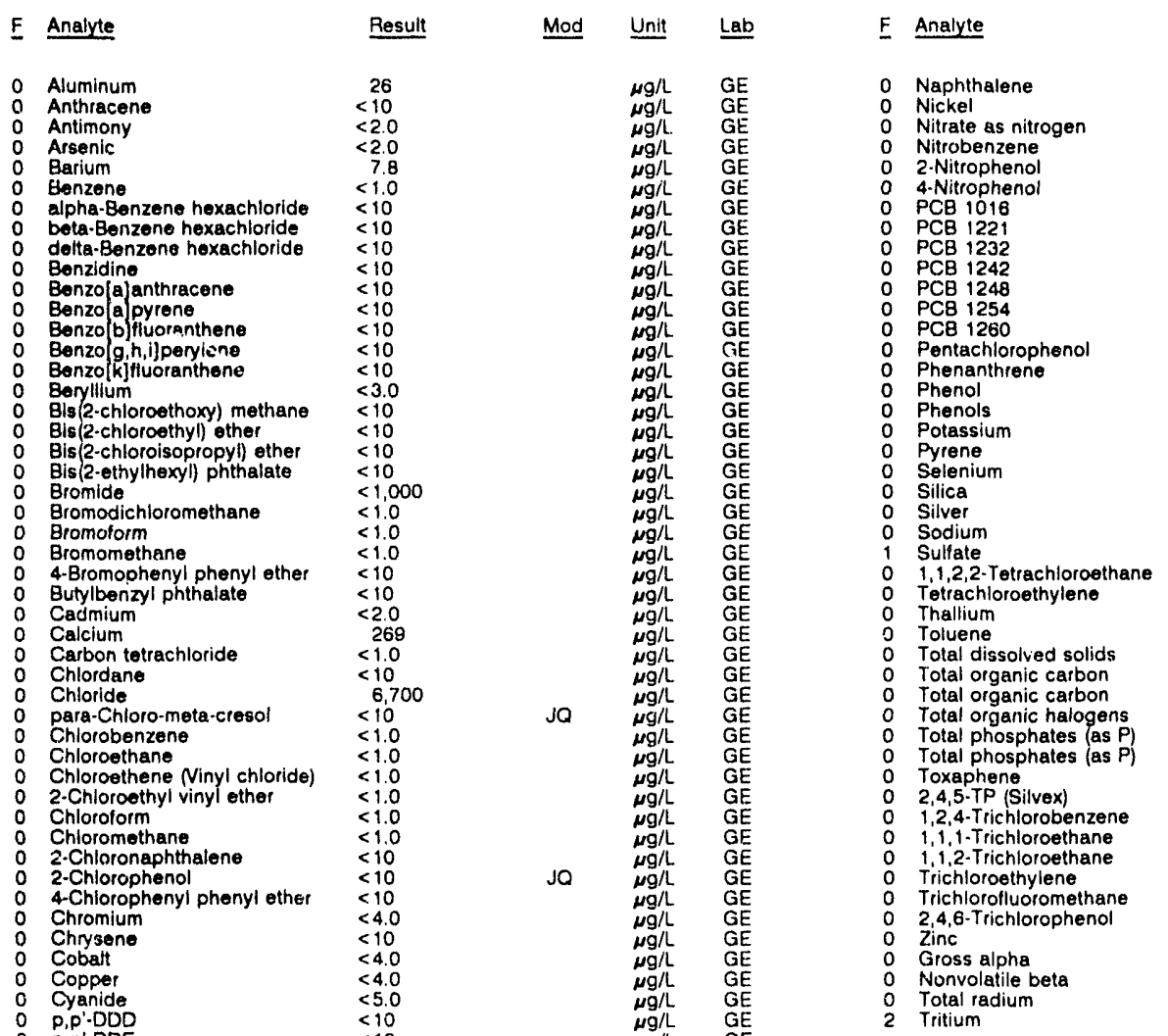

WELL HAC 2 collected on 12/02/91, laboratory analyses (cont.)

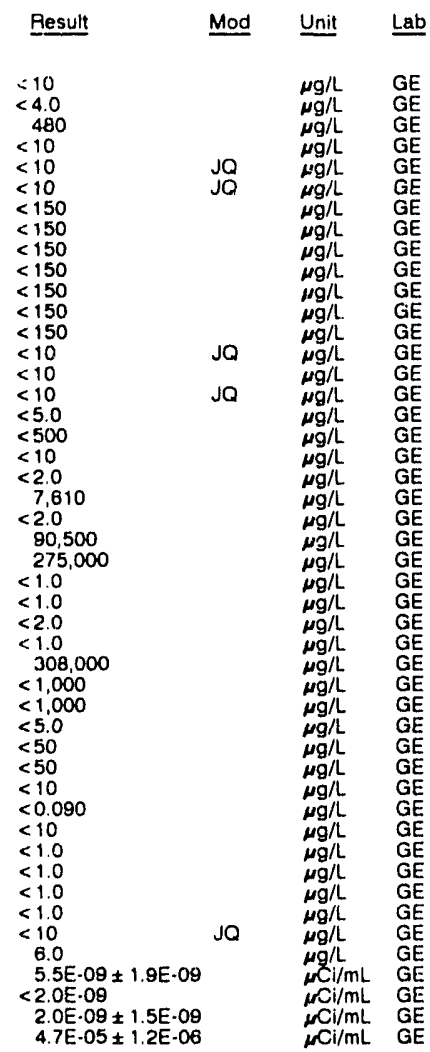

WELL HAC 3

MEASUREMENTS CONDUCTED IN THE FIELD

Sample date: $12 / 02 / 91$

Depth to water: $27.92 \mathrm{H}(8.51 \mathrm{~m})$ below TOC

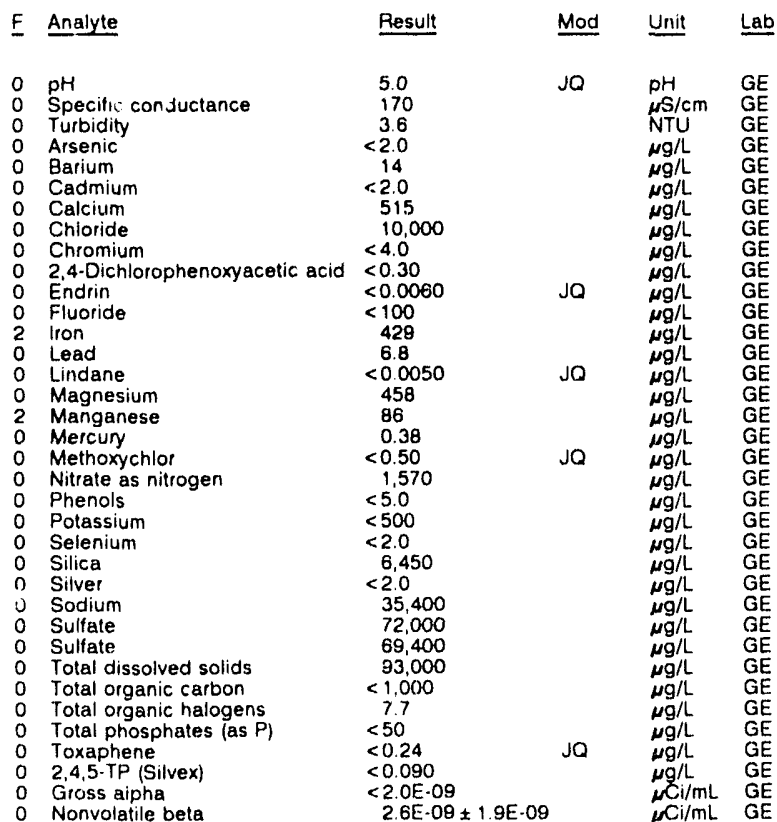

Water elevation: $270.08 \mathrm{ft}(82.32 \mathrm{~m}) \mathrm{msl}$

Sp. conductance: $181 \mu \mathrm{S} / \mathrm{cm}$

Water evacuated before sampling: 9 ga

LABORATORY ANALYSES

Time: 12:35

$\mathrm{pH}: 4.9$

Alkalinity: $0 \mathrm{mg} / \mathrm{L}$ : $23.3^{\circ} \mathrm{C}$
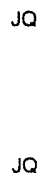

Jo

2,4-Dinitrotoluene

1,2.Diphenylhydrazine

Endosulfan 1

Endosulfan II

Endrin aldehyde

Ethylbenzen

Fluorene

Fluoride

Heptachlor

Hexachlorobenzene

Hexachlorobutadiene

Hexachloroethan

indeno[ $1,2,3-c, d] p y r e n e$

Iron

Lead

Lindane

Magnesium

Mercury

Methoxychlor

N-Nitrosodimethylamine

N.-Nitrosodiphenylamine
3.5
$<10$
$<0.30$

$<1.0$

$<10$

$<10$

$<45$

$<10$

$<10$

$<10$

$<10$

$<10$

$<100$

$<10$

$<10$

$<10$

$<10$

$<10$
350

15
0.58
$<0.50$

$<10$
$<10$

$<10$
$<10$
$<10$ 
ANALYTICAL RESULTS

WELL HAC 3 coilected on 12/02/91, laboratory analyses (cont.)

\begin{tabular}{|c|c|c|c|}
\hline$E$ Analyte & Result & Mod & $\underline{\text { Unit }}$ \\
\hline $\begin{array}{ll}0 & \text { Total radium } \\
2 & \text { Tritium }\end{array}$ & $\begin{array}{l}1.3 \mathrm{E}-09 \pm 1.1 \mathrm{E}-09 \\
3.3 \mathrm{E}-05 \pm 1.1 \mathrm{E}-06\end{array}$ & & $\underset{\mu \mathrm{C} i / m \mathrm{~mL}}{\mu \mathrm{Ci} / \mathrm{L}}$ \\
\hline
\end{tabular}

WELL HAC 4

MEASUREMENTS CONDUCTED IN THE FIELD

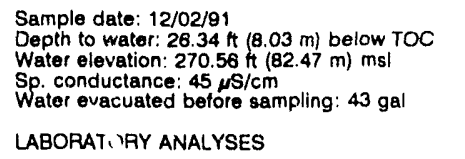

$$
\begin{aligned}
& \text { Time: } 12: 10 \\
& \text { pH: } 4.6 \\
& \text { Alkalinity: } 0 \mathrm{mg} / \mathrm{h} \\
& \text { Water temperalure: } 22.8^{\circ} \mathrm{C}
\end{aligned}
$$

LABORAT, IRY ANALYSES

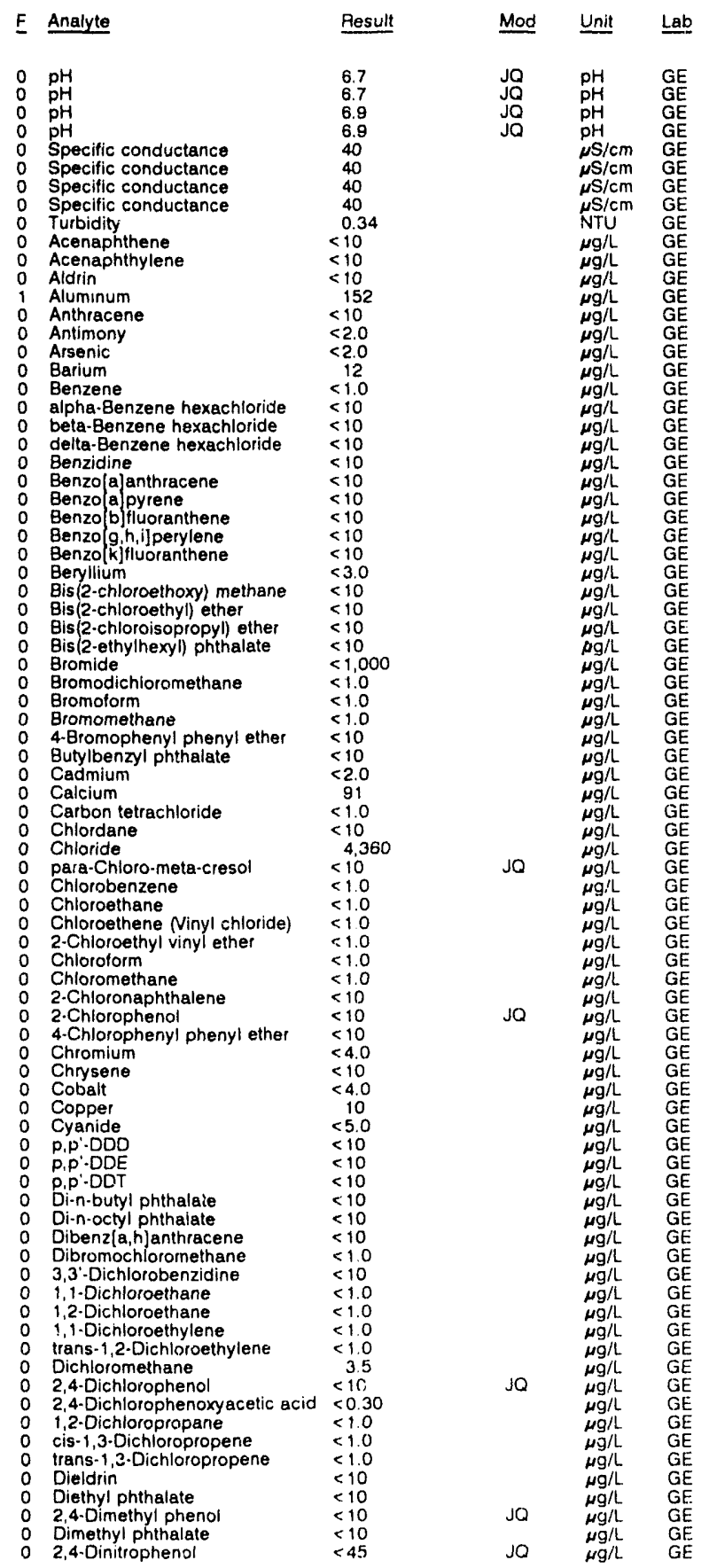

WELL HAC 4 collected on 12/02/91, laboratory analyses (cont.)

E Analyte Result Mod Unit Lab

$\begin{array}{ll}0 & 2,4-D i n i t r o t o l u e n e \\ 0 & 2,6-D i n i t r o t o l u e n e \\ 0 & 1,2 \text {-Diphenyihydrazine } \\ 0 & \text { Endosulfan I } \\ 0 & \text { Endosulfan II } \\ 0 & \text { Endosulfan sulfate } \\ 0 & \text { Endrin } \\ 0 & \text { Endrin aldehyde } \\ 0 & \text { Ethylbenzene } \\ 0 & \text { Fluoranthene } \\ 0 & \text { Fiuorene } \\ 0 & \text { Fluoride } \\ 0 & \text { Heptachlor } \\ 0 & \text { Heptachlor epoxide } \\ 0 & \text { Hexachlorobenzene } \\ 0 & \text { Hexachlorobutadiene }\end{array}$

Hexachlorobutadiene

o Hexachloroethane

Indeno[1,2,3-c,d]pyrene

0 Iron

o Isophorone

1 Lead

o Magnesium

1 Mangan

O Metcury

2-Methyl.4.6-dinitropheno

- N-Nitrosodimethylamine

o N-Nitrosodiphenylamine

o N-Nitrosodi-propylamin

0 Naphthalen

Nickel
0 Nitrate as nitrogen

0 Nitrobenzene

2-Nittopheno

$\begin{array}{ll}\text { 4.Nitrophen } \\ 0 & \text { PCB } 1016\end{array}$

PCB 1221
0

O
PCB 1232

0
0

P PCB 1254

O Pentachlorophenol

Phenanthrene

Phenol

Phenols

Potassium
Pyrene

Syrene

Silica

o $\begin{array}{ll}\text { Silica } \\ 0\end{array}$

O Sodium

Sulfate

Tetrachloroethylene

o Thallium

Toluene

- Total dissolved solids

Total organic carbor

Total organic carbon

Total organic carbur.

Total organic carbon

Total organic halogens

Total organic halogens

Tolal organic halogens

Total organic halogens
Total phosphates (as P)

0 Toxaphene

2,4,5.TP (Silvex)

1,2,4-Trichlorobenzene

o 1,1,3-Trichloroethane

o 1,1,2-Trichloroethan

o Trichlorofluoromethane

2,4,6-Trichlorophenol

inc

Gross alpha

Nonvolatile bela

0 Total radium

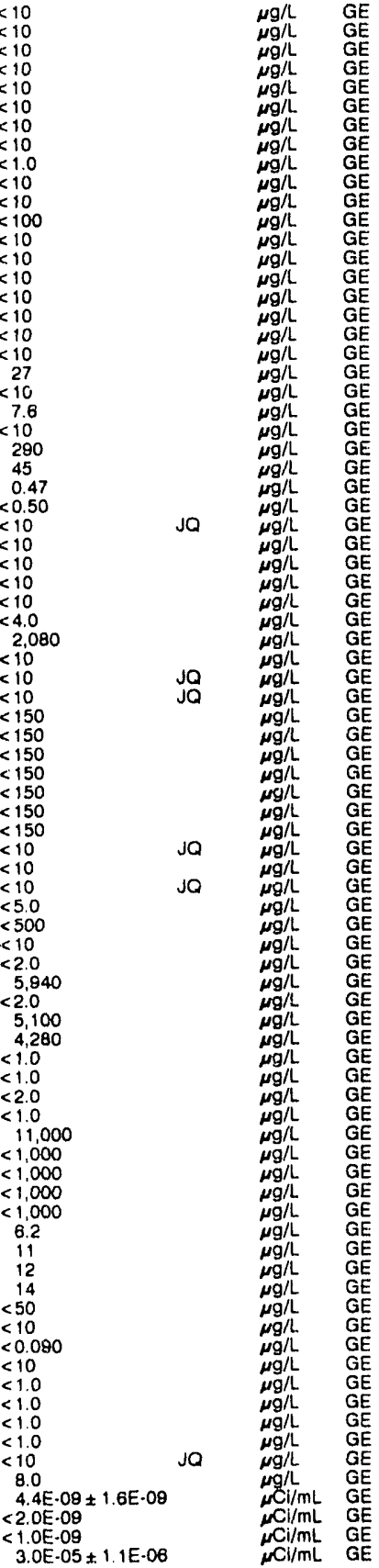

WELL HAP 1

MEASUREMENTS CONDUCTED IN THE FIELD

Sample date: 11/12/91

Depth to water: $17.49 \mathrm{Ht}(5.33 \mathrm{~m})$ below TOC

Water elevation: $271.61 \mathrm{H} / 82.7$

water evacuated before sampling: $40 \mathrm{gal}$
Alkalinity: $65 \mathrm{mg} / \mathrm{L}$

Water temperature: $22.1^{\circ} \mathrm{C}$
Time: $11: 40$ 


\section{ANALYTICAL RESULTS}

\section{WELL HAP 2}

MEASUREMENTS CONDUCTED IN THE FIELD

Sample date: 11/12/91 Sample date: $11 / 12 / 91$
Depth to water: $18.99 \mathrm{ft}(5.79 \mathrm{~m})$ below TOC
Water elevation: $270.81 \mathrm{ft}(82.57 \mathrm{~m}) \mathrm{ms}$ l Sp.

Water evacuated before sampling: $71 \mathrm{gal}$

WELL HCA 1

MEASUREMENTS CONOUCTEO IN THE FIELO

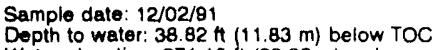

Water olevation: $271.18 \mathrm{~h}(82.66 \mathrm{~m}) \mathrm{ms}$

Sp. conductance: $47 \mu \mathrm{S} / \mathrm{cm}$

Water evacuated betore sampling: $17 \mathrm{gal}$

The wull went dry during purging.

LABORATORY ANALYSES

\begin{tabular}{|c|c|c|}
\hline Analyte & Result & Unit \\
\hline $\begin{array}{l}\text { Nitrate as nitrogen } \\
\text { Antimony-125 } \\
\text { Corium-144 } \\
\text { Cesium-134 } \\
\text { Cesium-137 } \\
\text { Cobalt-57 } \\
\text { Cobalt-60 } \\
\text { Europium-154 } \\
\text { Gross alpha } \\
\text { Manganese-54 } \\
\text { Nonvolatile beta } \\
\text { Potassium-40 } \\
\text { Radium-226 } \\
\text { Ruthenium-103 } \\
\text { Sodium-22 } \\
\text { Thorium-228 } \\
\text { Total tadium } \\
\text { Tritium }\end{array}$ & $\begin{aligned} & 1.930 \\
&<1.9 E \cdot 08 \\
&<4.5 \mathrm{E}-09 \\
&<6.9 \mathrm{E} \cdot 09 \\
&<7.1 \mathrm{E}-09 \\
&<6.2 \mathrm{E} \cdot 09 \\
&<8.7 \mathrm{E}-09 \\
&<2.2 \mathrm{E}-08 \\
& 2.2 \mathrm{E} \cdot 09 \pm 1.2 \mathrm{E} \cdot 09 \\
&<7.7 \mathrm{E} \cdot 09 \\
& 5.0 \mathrm{E}-09 \pm 1.7 \mathrm{E} \cdot 09 \\
&<1.0 \mathrm{E} \cdot 07 \\
&<1.2 \mathrm{E} \cdot 08 \\
&<1.5 \mathrm{E} \cdot 08 \\
&<7.9 \mathrm{E}-09 \\
&<7.5 \mathrm{E} \cdot 09 \\
& 1.6 \mathrm{E} \cdot 09 \pm 1.2 \mathrm{E} \cdot 09 \\
& 5.5 \mathrm{E} \cdot 05 \pm 1.3 \mathrm{E} \cdot 06\end{aligned}$ & $\begin{array}{l}\mu \mathrm{g} / \mathrm{L} \\
\mu \mathrm{Ci} / \mathrm{mL} \\
\mu \mathrm{Ci} / \mathrm{mL} \\
\mu \mathrm{Ci} / \mathrm{mL} \\
\mu \mathrm{Ci} / \mathrm{mL} \\
\mu \mathrm{Ci} / \mathrm{mL} \\
\mu \mathrm{Ci} / \mathrm{mL} \\
\mu \mathrm{Ci} / \mathrm{mL} \\
\mu \mathrm{Ci} / \mathrm{mL} \\
\mu \mathrm{Ci} / \mathrm{mL} \\
\mu \mathrm{Ci} / \mathrm{mL} \\
\mu \mathrm{Ci} / \mathrm{mL} \\
\mu \mathrm{Ci} / \mathrm{mL} \\
\mu \mathrm{Ci} / \mathrm{mL} \\
\mu \mathrm{Ci} / \mathrm{mL} \\
\mu \mathrm{Ci} / \mathrm{mL} \\
\mu \mathrm{Ci} / \mathrm{mL} \\
\mu \mathrm{Ci} / \mathrm{mL} \\
\mu \mathrm{Ci} / \mathrm{mL}\end{array}$ \\
\hline
\end{tabular}

WELL HCA 2

MEASUREMENTS CONDUCTED IN THE FIELD

Sample date: 12/02/81

Depth to water: $38.47 \mathrm{Ht}(11.73 \mathrm{~m})$ below TOC

Water elevation: $272.33 \mathrm{ft}(83.01 \mathrm{~m}) \mathrm{ms}$

Sp. conductance: $183 \mu \mathrm{s} / \mathrm{cm}$

Water evacuated before sampling: $80 \mathrm{gal}$

Time: $11: 25$

phl: 5.0 Alkalinity: $1 \mathrm{mg} / \mathrm{L}$

Water temperature $195^{\circ} \mathrm{C}$

Alkalinity: $1 \mathrm{mg} / \mathrm{l}$

Water temperature: $23.8^{\circ} \mathrm{C}$

LABORATOAY ANALYSES

\begin{tabular}{|c|c|c|}
\hline Analyte & Result & Unit \\
\hline $\begin{array}{l}\text { Nitrate as nitrogen } \\
\text { Nitrate as nitrogen } \\
\text { Antimony-125 } \\
\text { Cerium-1 } 44 \\
\text { Cesium-134 } \\
\text { Cesium-137 } \\
\text { Cobalt-57 } \\
\text { Cobait-60 } \\
\text { Europium-154 } \\
\text { Gross alpha } \\
\text { Manganese-54 } \\
\text { Nonvolatile beta } \\
\text { Potassium-40 } \\
\text { Padium-228 } \\
\text { Ruthenium-103 } \\
\text { Sodium-22 } \\
\text { Thorium-228 } \\
\text { Total radium } \\
\text { Tritium } \\
\text { Zinc-65 }\end{array}$ & 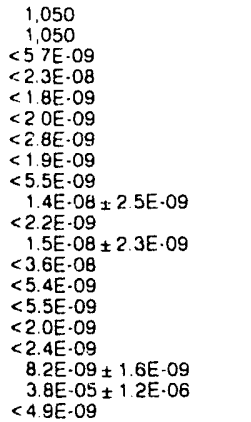 & $\begin{array}{l}\mu \mathrm{g} / \mathrm{L} \\
\mu \mathrm{g} / \mathrm{L} \\
\mu \mathrm{Ci} / \mathrm{mL} \\
\mu \mathrm{Cl} / \mathrm{mL} \\
\mu \mathrm{Ni} / \mathrm{mL} \\
\mu \mathrm{Cl} / \mathrm{mL} \\
\mu \mathrm{Ci} / \mathrm{mL} \\
\mu \mathrm{Ci} / \mathrm{mL} \\
\mu \mathrm{Ci} / \mathrm{mL} \\
\mu \mathrm{Ci} / \mathrm{mL} \\
\mu \mathrm{Ci} / \mathrm{mL} \\
\mu \mathrm{Ci} / \mathrm{mL} \\
\mu \mathrm{Cl} / \mathrm{mL} \\
\mu \mathrm{Ci} / \mathrm{mL} \\
\mu \mathrm{Ci} / \mathrm{mL} \\
\mu \mathrm{Ci} / \mathrm{mL} \\
\mu \mathrm{Ci} / \mathrm{mL} \\
\mu \mathrm{Ci} / \mathrm{mL} \\
\mu \mathrm{C} / / \mathrm{mL} \\
\mu \mathrm{Cl} / \mathrm{mL}\end{array}$ \\
\hline
\end{tabular}

WELL HCA 3

MEASUREMENTS CONDUCTED IN THE FIELD

Sample date: $12 / 02 / 81$

Depth to water: $39.32 \mathrm{~A}(11.98 \mathrm{~m})$ below TOC

Water elevation: $270.88 \mathrm{~h}(82.60 \mathrm{~m}) \mathrm{ms}$

Sp. conductance: $97 \mu \mathrm{S} / \mathrm{cm}$

Water evacuated betore sampling: $14 \mathrm{ga}$

LABORATORY ANALYSES

\begin{tabular}{|c|c|c|}
\hline Analyte & Result & Unit \\
\hline $\begin{array}{l}\text { Nitrate as nitrogen } \\
\text { Antimony-125 } \\
\text { Cerium-144 } \\
\text { Cesium-134 } \\
\text { Cesium-137 } \\
\text { Cobalt-57 } \\
\text { Cobalt-60 } \\
\text { Europium.154 } \\
\text { Gross alpha } \\
\text { Manganese-54 } \\
\text { Nonvolatile beta } \\
\text { Potassium-40 } \\
\text { Radium-226 } \\
\text { Puthenium-103 } \\
\text { Sodium-22 } \\
\text { Thorium-228 } \\
\text { Total radium } \\
\text { Tritium } \\
\text { Zinc-65 }\end{array}$ & $\begin{aligned} & 94 \\
&<5.7 E-08 \\
&<2.3 \mathrm{E} \cdot 08 \\
&<1.8 \mathrm{E} \cdot 08 \\
&<2.0 \mathrm{E} \cdot 09 \\
&<2.0 \mathrm{E} \cdot 09 \\
&<1.9 \mathrm{E} \cdot 09 \\
&<5.5 \mathrm{E} \cdot 09 \\
& 2.3 \mathrm{E} \cdot 09 \pm 1.3 \mathrm{E} \cdot 09 \\
&<2.2 \mathrm{E} \cdot 09 \\
& 3.8 \mathrm{E} \cdot 09 \pm 1.8 \mathrm{E} \cdot 09 \\
&<3.6 \mathrm{E} \cdot 08 \\
&<5.4 \mathrm{E} \cdot 09 \\
&<5.6 \mathrm{E} \cdot 09 \\
&<2.0 \mathrm{E} \cdot 09 \\
&<2.4 \mathrm{E} \cdot 09 \\
& 2.7 \mathrm{E} \cdot 09 \pm 1.2 \mathrm{E} \cdot 09 \\
& 7.1 \mathrm{E} \cdot 05 \pm 1.5 \mathrm{E} \cdot 06 \\
&<4.9 \mathrm{E}-09\end{aligned}$ & $\begin{array}{l}\mu \mathrm{g} / \mathrm{L} \\
\mu \mathrm{Ci} / \mathrm{mL} \\
\mu \mathrm{Cl} / \mathrm{mL} \\
\mu \mathrm{Ci} / \mathrm{mL} \\
\mu \mathrm{Ci} / \mathrm{mL} \\
\mu \mathrm{Ci} / \mathrm{mL} \\
\mu \mathrm{CC} / \mathrm{mL} \\
\mu \mathrm{Ci} / \mathrm{mL} \\
\mu \mathrm{Ci} / \mathrm{mL} \\
\mu \mathrm{Ci} / \mathrm{mL} \\
\mu \mathrm{Ci} / \mathrm{mL} \\
\mu \mathrm{Ci} / \mathrm{mL} \\
\mu \mathrm{Ci} / \mathrm{mL} \\
\mu \mathrm{Ci} / \mathrm{mL} \\
\mathrm{NCC} / \mathrm{mL} \\
\mu \mathrm{Ci} / \mathrm{mL} \\
\mu \mathrm{Ci} / \mathrm{mL} \\
\mu \mathrm{Ci} / \mathrm{mL} \\
\mu \mathrm{Ci} / \mathrm{mL}\end{array}$ \\
\hline
\end{tabular}

WELL HCA 4

MEASUREMENTS CONDUCTED IN THE FIELD

Depth to water: $39.41 \mathrm{tt}(12.01 \mathrm{~m})$ below TOC

Water elevation: $271.29 \mathrm{H}(82.69 \mathrm{~m}) \mathrm{ms}$

Sp. conductance $101 \mu \mathrm{S} / \mathrm{cm}$

Water evacuated before sampling: $22 \mathrm{gal}$

Alkalinity: $38 \mathrm{mg} / \mathrm{L}$

Water temperature: $2311^{\circ} \mathrm{C}$

The well went dry during purging

LABORATORY ANALYSES

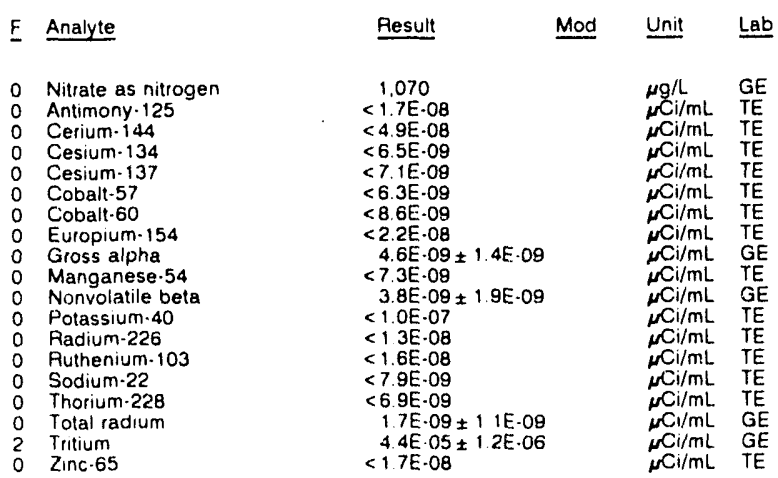

\section{WELLL HCB 1}

MEASUREMENTS CONDUCTED IN THE FIELD

Depth 10 Time $12: 30$

Water elevation. $263.96 \mathrm{ft}(80.46 \mathrm{~m}) \mathrm{ms}$ Alkalinity. $\mathrm{mg}$

. $243 \mathrm{HS} / \mathrm{cm}$

Wate temperature $200^{\circ} \mathrm{C}$

WELL HCB 2

MEASUREMENTS CONDUCTED IN THE FIELD

Sample date. 11/12/9

Depth 10 water: $14.34 \mathrm{Ht}(4.37 \mathrm{~m})$ below TOC

Wiater elevation $267.36 \mathrm{H}(\mathrm{B} 1.49 \mathrm{~m}) \mathrm{ms}$ )

Sp. conductance $946 \mu \mathrm{S} / \mathrm{cm}$
Water evacuated betore sampling $72 \mathrm{gal}$
Time: $14: 25$

Alkalinity: $34 \mathrm{mg} / \mathrm{L}$ Water temperature: $24.2^{\circ} \mathrm{C}$ 
ANALYTICAL RESULTS

WELL HCB 3

MEASUREMENTS CONDUCTED IN THE FIELD

Sample date: 11/12/81

Depth to water: $8.54 \mathrm{H}(2.60 \mathrm{~m})$ below TOC

$266.86 \mathrm{ft}(81.34 \mathrm{~m}) \mathrm{ms}$

P. conductance: $44 \mu \mathrm{S} / \mathrm{cm}$

Water evacuated before sampling: $87 \mathrm{gal}$

\section{WELL HCB 4}

MEASUREMENTS CONDUCTED IN THE FIELD

Sample date: $11 / 12 / 91$

epth to water: 12.88 it $(3.93 \mathrm{~m})$ below TOC

Wa. conducten: $264.92 \mathrm{tt}$ (80.7

Water evacuated $148 \mu \mathrm{S} / \mathrm{cm}$.

\section{WELL HET 10}

MEASUREMENTS CONDUCTED IN THE FIELD

Sample date: 12/03/91

Depth to water: $14.57 \mathrm{ft}(4.44 \mathrm{~m})$ below TOC

Water elevation: $267.63 \mathrm{tt}(81.57 \mathrm{~m}) \mathrm{ms}$

Sp. conductance: $55 \mu \mathrm{S} / \mathrm{cm}$

Water evacuated belore sampling: $16 \mathrm{gal}$

The well went dry during purging

\section{WELL HET $2 D$}

MEASUREMENTS CONDUCTED IN THE FIELD

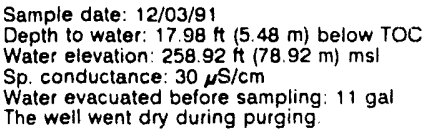

WELL HET 3D

MEASUREMENTS CONDUCTED IN THE FIELD

Sample date: $12 / 03 / 91$

Depth to water: $16.88 \mathrm{H}(5.15 \mathrm{~m})$ below TOC

Water elevation: $259.82 \mathrm{ft}(79.19 \mathrm{~m}) \mathrm{ms}$

Sp. conductance. $28 \mu \mathrm{S} / \mathrm{cm}$

Water evacuated before sampling: $12 \mathrm{gal}$

The well went dry during purging.

\section{WELL HET 4D}

MEASUREMENTS CONDUCTED IN THE FIELD

Sample date: $12 / 03 / 91$

Depth to water: $17.26 \mathrm{ft}$ (5.26 m) below TOC Water elevation $259.44 \mathrm{H}(79$
Sp. conductance: $46 \mu \mathrm{S} / \mathrm{cm}$

Water evacualed before sampling: 16 gat

\section{WELL HMD 10}

MEASUREMENTS CONDUCTED IN THE FIELD

Sample date: $10 / 22 / 91$

Depth to water: $51.92 \mathrm{ft}(15.83 \mathrm{~m})$ below TOC

Sp. conductance. $33 \mu \mathrm{S} / \mathrm{cm}$

Water evacuated before sampling: 7 ga

LABORATORY ANALYSES

\begin{tabular}{|c|c|c|c|}
\hline E Analyte & Result & Mod & Unit \\
\hline $\begin{array}{ll}0 & \mathrm{pH} \\
0 & \mathrm{pH} \\
0 & \mathrm{pH} \\
0 & \mathrm{pH}\end{array}$ & $\begin{array}{l}6.4 \\
6.4 \\
6.4 \\
6.4\end{array}$ & $\begin{array}{l}\text { JO } \\
\text { JO } \\
\text { JO } \\
\text { JO }\end{array}$ & $\begin{array}{l}\mathrm{pH} \\
\mathrm{pH} \\
\mathrm{pH} \\
\mathrm{pH}\end{array}$ \\
\hline
\end{tabular}

Time: 900

Alkatinity: $11 \mathrm{mg} / \mathrm{h}$
Water temperature $18.6^{\circ} \mathrm{C}$
Alkalinity: $0 \mathrm{mg} / \mathrm{L}$

Water temperature $20.7^{\circ} \mathrm{C}$

Time: 9.15

Alkalinity: $0 \mathrm{mg} / \mathrm{h} \cdot 20.1^{\circ} \mathrm{C}$
Time: $11: 5$

Alk 3.9 inity: $0 \mathrm{mg} / \mathrm{L}$

Water temperature: $20.4^{\circ} \mathrm{C}$

pH: 4.7

Alkalinity: $0 \mathrm{mg} / \mathrm{h}$

$\mathrm{pH}: 4.4$
Alkalinity: $0 \mathrm{mg} / \mathrm{L}$
Water temperature $19.7^{\circ} \mathrm{C}$

Water temperature: $20.3^{\circ} \mathrm{C}$
WELL HMD 10 collected on 10/22/91, laboratory analyses (cont.)

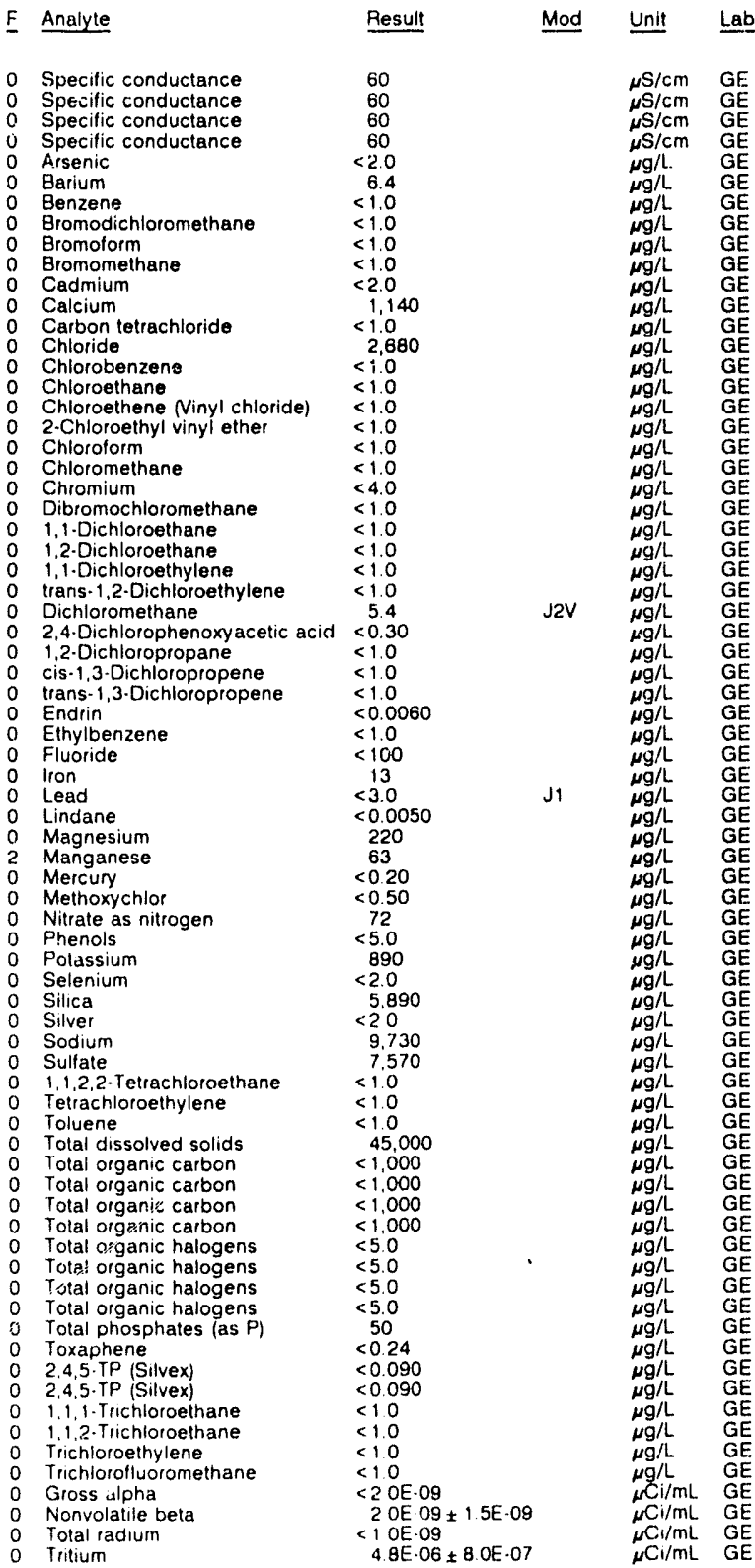

WELL HMD 2D

MEASUREMENTS CONDUCTED IN THE FIELD

Sample date: $10 / 22 / 91$
Depth to water: $56.89 \mathrm{ft}(17.34 \mathrm{~m})$ below TOC

Sp. conductance $66 \mu \mathrm{S} / \mathrm{cm}$

Water evacuated before sampling: $37 \mathrm{gal}$

LABORATORY ANALYSES

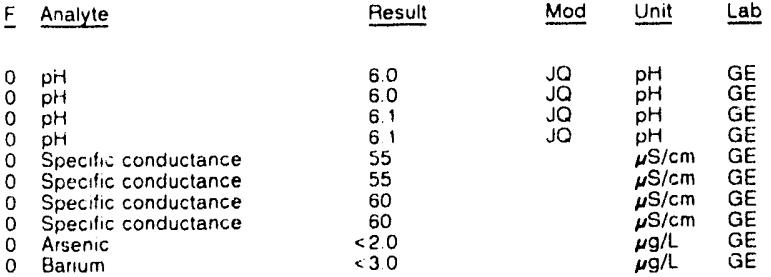

Time: $9: 55$

Alkalinity: $10 \mathrm{mg} / \mathrm{L}$

Alkalinity: $10 \mathrm{mg} / \mathrm{L}$ : $19.0^{\circ} \mathrm{O}$ ab 


\section{ANALYTICAL RESULTS}

WELL HMD 2D collected on 10/22/91, laboratory analyses (cont.)

\begin{tabular}{|c|c|}
\hline Analyte & Result \\
\hline $\begin{array}{l}\text { Benzene } \\
\text { Bromodichloromethane } \\
\text { Bromoform } \\
\text { Bromomethane } \\
\text { Cadmium } \\
\text { Calcium } \\
\text { Carbon tetrachloride } \\
\text { Chloride } \\
\text { Chloride } \\
\text { Chlorobenzene } \\
\text { Chloroethane } \\
\text { Chloroethene Ninyl chloride) } \\
\text { 2-Chloroethyl vinyl ether } \\
\text { Chloroform } \\
\text { Chloromethane } \\
\text { Chromium } \\
\text { Dibromochloromethane } \\
\text { 1,1-Dichloroethane } \\
\text { 1,2-Dichloroethane } \\
\text { 1,1-Dichloroethylene } \\
\text { trans-1,2-Dichloroethylene } \\
\text { Dichloromethane } \\
\text { 1,2.Dlchloropropane } \\
\text { cis-1,3-Dichloropropene } \\
\text { trans-1,3-Dichloropropene } \\
\text { Endrin } \\
\text { Ethybenzene } \\
\text { Fluoride } \\
\text { Fluoride } \\
\text { Iron } \\
\text { Lead } \\
\text { Lindane } \\
\text { Magnesium } \\
\text { Manganese } \\
\text { Mercury } \\
\text { Methoxychlor } \\
\text { Nitrate as nitrogen } \\
\text { Nitrate as nitrogen } \\
\text { Phenols } \\
\text { Potassium } \\
\text { Selenium } \\
\text { Silica } \\
\text { Sitver } \\
\text { Sodium } \\
\text { Sulfate } \\
\text { Sulfate } \\
\text { 1,1,2,2-Tetrachloroethane } \\
\text { Tetrachloroethylene } \\
\text { Toluene } \\
\text { Total dissolved solids } \\
\text { Total organic carbon } \\
\text { Total organic carbon } \\
\text { Total organic carbon } \\
\text { Total organic carbon } \\
\text { Total organic halogens } \\
\text { Total organic halogens } \\
\text { Total organic halogens } \\
\text { Total organic halogens } \\
\text { Total phosphates (as P) } \\
\text { Toxaphene } \\
\text { 1,1,1-Trichloroethane } \\
\text { 1,1,2-Trichloroethane } \\
\text { Trichloroethylene } \\
\text { Trichlorofluoromethane } \\
\text { Gross alpha } \\
\text { Nonvolatile beta } \\
\text { Total radium } \\
\text { Tritium }\end{array}$ & 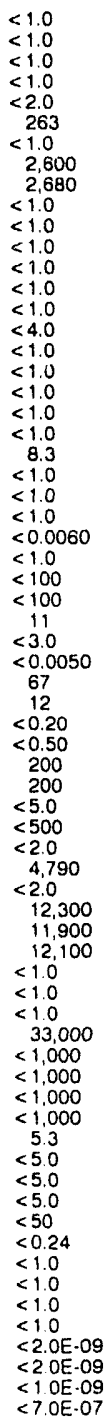 \\
\hline
\end{tabular}

\section{WELL HMD 3D}

MEASUREMENTS CONDUCTED IN THE FIELD

Sample date: 10/22/91

Depth to water. $55.62 \mathrm{ft}(16.95 \mathrm{~m})$ below TOC

Sp. conductance: $47 \mu \mathrm{S} / \mathrm{cm}$

Water evacuated before sampling: $44 \mathrm{ga}$

LABORATORY ANALYSES

\begin{tabular}{|c|c|c|c|}
\hline Analyte & Result & Mod & Unit \\
\hline $\begin{array}{l}\mathrm{pH} \\
\text { pH } \\
\text { pH } \\
\text { pH } \\
\text { Specific conductance } \\
\text { Specific conductance } \\
\text { Specific conductance } \\
\text { Specific conductance } \\
\text { Arsenic } \\
\text { Barlum } \\
\text { Benzene } \\
\text { Bromodichioromethane } \\
\text { Bromoform } \\
\text { Bromomethane } \\
\text { Cadmium }\end{array}$ & $\begin{array}{r}5.5 \\
5.5 \\
5.5 \\
5.6 \\
45 \\
45 \\
45 \\
45 \\
<20 \\
12 \\
<1.0 \\
<1.0 \\
<10 \\
<10 \\
<20\end{array}$ & $\begin{array}{l}\mathrm{JO} \\
\mathrm{JQ} \\
\mathrm{JQ} \\
\mathrm{JQ}\end{array}$ & $\begin{array}{l}\mathrm{pH} \\
\mathrm{pH} \\
\mathrm{pH} \\
\mathrm{pH} \\
\mu \mathrm{S} / \mathrm{cm} \\
\mu \mathrm{S} / \mathrm{cm} \\
\mu \mathrm{S} / \mathrm{cm} \\
\mu \mathrm{S} / \mathrm{cm} \\
\mu \mathrm{g} / \mathrm{L} \\
\mu \mathrm{g} / \mathrm{L} \\
\mu \mathrm{g} / \mathrm{L} \\
\mu \mathrm{g} / \mathrm{L} \\
\mu \mathrm{g} / \mathrm{L} \\
\mu \mathrm{g} / \mathrm{L}\end{array}$ \\
\hline
\end{tabular}

Time: 10:30

$\mathrm{pH}: 5.1$

Alkalinity: $1 \mathrm{mg} / \mathrm{L}$
Water temperature $184^{\circ} \mathrm{C}$
WELL HMD 3D collected on 10/22/91, laboratory analyses (cont)

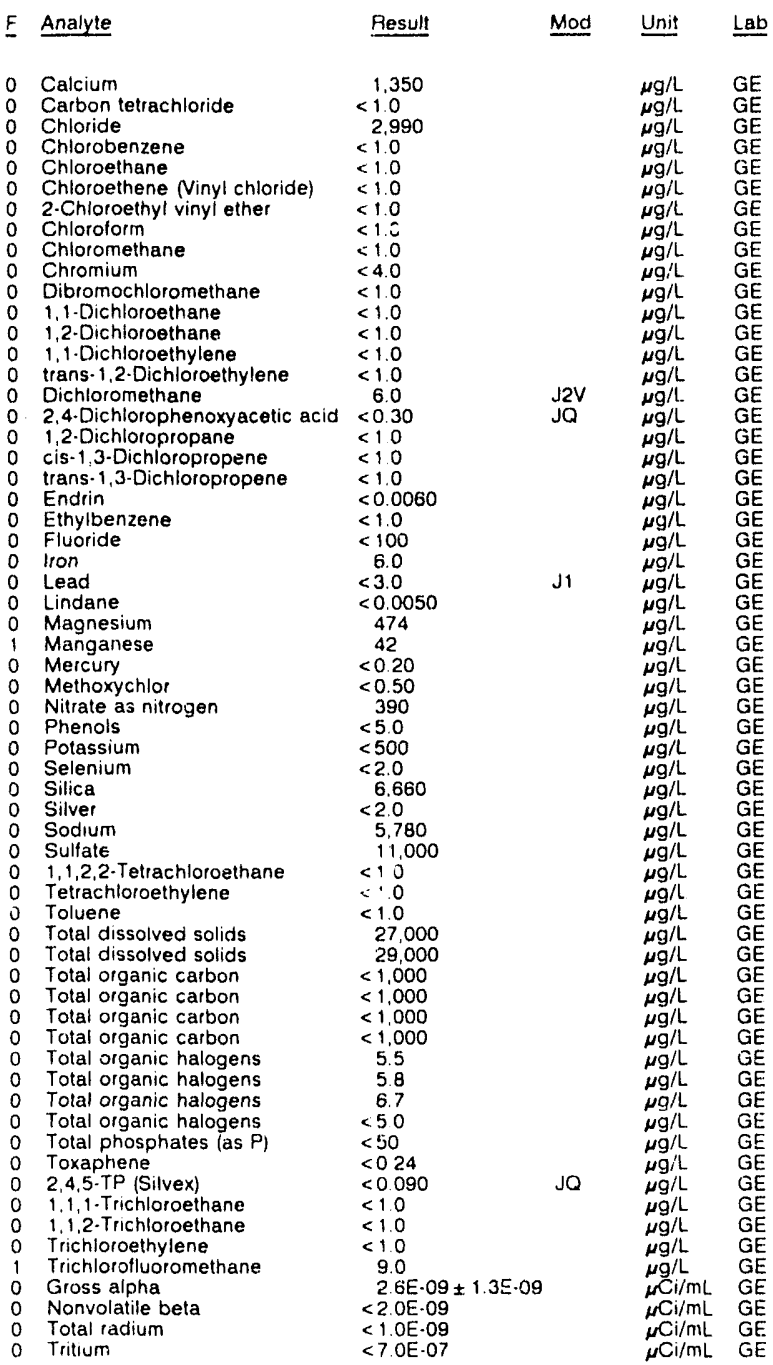

WELL HMD 3D Replicate

MEASUREMENTS CONDUCTEO IN THE FIELO

Sample date: $10 / 22 / \mathrm{S} 1$
Depth to water: $55.62 \mathrm{Ht}(16.95 \mathrm{~m})$ below TOC

Sp. conductance $47 \mu \mathrm{S} / \mathrm{cm}$
Watel evacuated before sampling: $44 \mathrm{gal}$

$\mathrm{pH}: 5$.

Alkalinity: $1 \mathrm{mg} / \mathrm{L}$

Water temperature: $18.4^{\circ} \mathrm{C}$

LABORATORY ANALYYSES

\begin{tabular}{|c|c|c|c|c|c|}
\hline$\underline{F}$ & Analyte & Besult & Mod & Unit & $\underline{\text { Lab }}$ \\
\hline & $\mathrm{pH}$ & 56 & Jo & $\mathrm{pH}$ & $\mathrm{GE}$ \\
\hline 0 & Specific conductance & 45 & & $\mu \mathrm{S} / \mathrm{cm}$ & GE \\
\hline 0 & Arsenic & $<2.0$ & & $\mu \mathrm{g} / \mathrm{L}$ & \\
\hline 0 & Barium & 12 & & $\mu \mathrm{g} / \mathrm{L}$ & $\bar{E}$ \\
\hline 0 & Benzene & $<1.0$ & & $\mu \mathrm{g} / \mathrm{L}$ & $\mathrm{G} \varepsilon$ \\
\hline 0 & Bromodichloromethane & $<1.0$ & & $\mu \mathrm{g} / \mathrm{L}$ & \\
\hline 0 & Bromolorm & $<10$ & & $\mu g / \mathrm{L}$ & $\bar{E}$ \\
\hline 0 & Bromomethane & $<1.0$ & & $\mu \mathrm{g} / \mathrm{L}$ & $\mathrm{E}$ \\
\hline 0 & Cadmium & $<2.0$ & & $\mu \mathrm{g} / \mathrm{L}$ & \\
\hline 0 & Calcium & 1.340 & & $\mu \mathrm{g} / \mathrm{L}$ & \\
\hline 0 & Carbon tetrachloride & $<10$ & & $\mu \mathrm{g} / \mathrm{L}$ & \\
\hline 0 & Chloride & 2,970 & & $\mu g / \mathrm{h}$ & \\
\hline 0 & Chlorobenzene & $<10$ & & $\mu \mathrm{g} / \mathrm{h}$ & \\
\hline 0 & Chloroethane & $<10$ & & $\mu \mathrm{g} / \mathrm{L}$ & \\
\hline 0 & Chloroethere (Vinyl chloride) & $<1.0$ & & $\mu g / L$ & \\
\hline 0 & 2. Chloroethyl vinyl ether & $<1.0$ & & $\mu \mathrm{g} / \mathrm{L}$ & \\
\hline 0 & Chloroform & $<10$ & & $\mu g / \mathrm{h}$ & GE \\
\hline 0 & Chloromethane & $<1.0$ & & $\mu \mathrm{g} / \mathrm{L}$ & \\
\hline 0 & Chromiurn & $<40$ & & $\mu \mathrm{g} / \mathrm{h}$ & \\
\hline 0 & Dibromochloromethane & $<1.0$ & & $\mu \mathrm{g} / \mathrm{L}$ & \\
\hline 0 & 1.1.Dichloroethane & $<10$ & & $\mu \mathrm{g} / \mathrm{L}$ & \\
\hline
\end{tabular}


ANALYTICAL RESULTS

WELL HMD 3D collected on 10/22/91, laboratory analyses (cont.)

\begin{tabular}{|c|c|}
\hline Analyte & Result \\
\hline $\begin{array}{l}\text { 1,2-Dichloroethane } \\
1,1 \cdot \text { Dichloroethylene } \\
\text { trans-1,2-Dichloroethylene } \\
\text { Dichloromethane } \\
2,4-\text { Dichlorophenoxyacetic acid } \\
1,2 \cdot \text { Dichloropropane } \\
\text { cis-1,3-Dichloropropene } \\
\text { trans-1,3-Dichloropropene } \\
\text { Endrin } \\
\text { Ethylbenzene } \\
\text { Fluoride } \\
\text { Iron } \\
\text { Lead } \\
\text { Lindane } \\
\text { Magnesium } \\
\text { Manganese } \\
\text { Mercury } \\
\text { Methoxychlor } \\
\text { Nitrate as nitrogen } \\
\text { Phenols } \\
\text { Phenols } \\
\text { Potassium } \\
\text { Selenium } \\
\text { Silica } \\
\text { Silver } \\
\text { Sodium } \\
\text { Sulfate } \\
\text { 1,1,2,2-Tetrachloroethane } \\
\text { Tetrachloroethylene } \\
\text { Toluene } \\
\text { Total dissolved solids } \\
\text { Total organic carbon } \\
\text { Total organic halogens } \\
\text { Total phosphates (as P) } \\
\text { Toxaphene } \\
2,4,5-\text { TP (Silvex) } \\
1,1,1-\text { Trichloroethane } \\
1,1,2-\text { Trichloroethane } \\
\text { Trichloroethylene } \\
\text { Trichlorofluoromethane } \\
\text { Gross alpha } \\
\text { Nonvolatile beta } \\
\text { Total radium } \\
\text { Tritium }\end{array}$ & $\begin{array}{l}<1.0 \\
<1.0 \\
<1.0 \\
4.5 \\
<0.30 \\
<1.0 \\
<1.0 \\
<1.0 \\
<0.0060 \\
<1.0 \\
<100 \\
6.0 \\
<3.0 \\
<0.0050 \\
474 \\
42 \\
<0.20 \\
<0.50 \\
400 \\
<5.0 \\
<5.0 \\
<500 \\
<2.0 \\
6,690 \\
<2.0 \\
5,760 \\
10,700 \\
<1.0 \\
<1.0 \\
<1.0 \\
30,000 \\
<1.000 \\
<5.0 \\
<50 \\
<0.24 \\
0.113 \\
<1.0 \\
<1.0 \\
<1.0 \\
12 \\
<2.0 E-09 \\
<2.0 E-09 \\
<1.0 E-09 \\
<7.0 E-07\end{array}$ \\
\hline
\end{tabular}

\section{WELL HMD 4D}

MEASUREMENTS CONDUCTED IN THE FIELL

Sample date: $10 / 22 / 91$
Denth to water: $47.11 \mathrm{~h}(14.36 \mathrm{~m})$ below TOC

Sp conductance: $31 \mu \mathrm{S} / \mathrm{cm}$

The well went $d r$ duing

purging

LABORATORY ANALYSES

\begin{tabular}{|c|c|c|c|c|c|}
\hline $\mathrm{F}$ & Arialyte & Result & Mod & Unit & $\underline{\text { Lab }}$ \\
\hline 0 & $\mathrm{pH}$ & 6.1 & $\mathrm{JQ}$ & $\mathrm{pH}$ & $\mathrm{GE}$ \\
\hline 0 & $\mathrm{pH}$ & 6.1 & JQ & $\mathrm{pH}$ & $\mathrm{GE}$ \\
\hline 0 & $\mathrm{pH}$ & 6.1 & $J Q$ & $\mathrm{pH}$ & $\mathrm{GE}$ \\
\hline 0 & $\mathrm{pH}$ & 6.2 & JO & $\mathrm{pH}$ & GE \\
\hline 0 & Specific conductance & 30 & & $\mu \mathrm{S} / \mathrm{cm}$ & $\mathrm{GE}$ \\
\hline 0 & Specific conductance & 30 & & $\mu \mathrm{S} / \mathrm{cm}$ & GE \\
\hline 0 & Specific conductance & 30 & & $\mu \mathrm{S} / \mathrm{cm}$ & GE \\
\hline $\begin{array}{l}0 \\
0\end{array}$ & $\begin{array}{l}\text { Specific conductance } \\
\text { Arsenic }\end{array}$ & $\begin{aligned} 30 \\
<20\end{aligned}$ & & $\mu \mathrm{S} / \mathrm{cm}$ & $G E$ \\
\hline $\begin{array}{l}0 \\
0\end{array}$ & $\begin{array}{l}\text { Arsenic } \\
\text { Barium }\end{array}$ & $\begin{aligned} 20 \\
77\end{aligned}$ & & $\underset{\mu g / L}{\mu g / L}$ & $\begin{array}{l}\mathrm{GE} \\
\mathrm{GE}\end{array}$ \\
\hline 0 & Benzene & $<10$ & & $\mu g / \mathrm{L}$ & $\mathrm{GE}$ \\
\hline 0 & Bromodichloromethane & $<10$ & & $\mu \mathrm{g} / \mathrm{L}$ & $\mathrm{GE}$ \\
\hline 0 & Bromotorm & $<1.0$ & & $\mu \mathrm{g} / \mathrm{L}$ & $G E$ \\
\hline 0 & Bromomethane & $<1.0$ & & $\mu \mathrm{g} / \mathrm{L}$ & GE \\
\hline $\begin{array}{l}0 \\
0\end{array}$ & $\begin{array}{l}\text { Cadmium } \\
\text { Calcium }\end{array}$ & $<2.0$ & & $\mu \mathrm{g} / \mathrm{L}$ & GE \\
\hline 0 & Calcium & 1,340 & & $\mu \mathrm{g} / \mathrm{L}$ & $\mathrm{GE}$ \\
\hline 0 & Carbon tetrachioride & $<10$ & & $\mu g / L$ & $G E$ \\
\hline 0 & Chloride & 2,080 & & $\mu g / L$ & GE \\
\hline $\begin{array}{l}0 \\
0\end{array}$ & $\begin{array}{l}\text { Chlorobenzene } \\
\text { Chloroethane }\end{array}$ & $\begin{array}{l}<10 \\
<10\end{array}$ & & $\mu \mu_{\mu} / \mathrm{h}$ & $\mathrm{GE}$ \\
\hline 0 & Chloroethene (Vinyl chloride) & $<10$ & & $\mu g / L$ & $G E$ \\
\hline 0 & 2.-Chloroethyl vinyl ether & $<10$ & & $\mu g / L$ & \\
\hline & Chloroform & $<1.0$ & & $\mu \mathrm{g} / \mathrm{L}$ & \\
\hline 0 & Chloromethane & $<1.0$ & & $\mu \mathrm{g} / \mathrm{h}$ & \\
\hline 0 & Chromium & $<4.0$ & & $\mu \mathrm{g} / \mathrm{L}$ & \\
\hline 0 & Dibromochloromethane & $<10$ & & $\mu g / L$ & \\
\hline 0 & 1,1-Dichloroethane & $<10$ & & $\mu \mathrm{g} / \mathrm{L}$ & \\
\hline 0 & 1,2-Dichloroethane & $<1.0$ & & $\mu \mathrm{g} / \mathrm{L}$ & \\
\hline 0 & 1,1.Dichloroethylene & $<1.0$ & & $\mu \mathrm{g} / \mathrm{L}$ & \\
\hline 0 & Irans-1,2-Dichloroethylene & $<10$ & & $\mu \mathrm{g} / \mathrm{L}$ & \\
\hline 0 & Dichloromethane & 5.4 & $\mathrm{~J} 2 \mathrm{~V}$ & $\mu \mathrm{g} / \mathrm{L}$ & \\
\hline & 2,4-Dichlorophenoxyacetic acid & $\div 0.30$ & Jo & $\mu \mathrm{g} / \mathrm{L}$ & \\
\hline & 1,2-Dichloropropane & $<1.0$ & & $\mu \mathrm{g} / \mathrm{L}$ & GE \\
\hline & cis-1,3-Dichioropropene & $<1.0$ & & $\mu \mathrm{g} / \mathrm{L}$ & \\
\hline 0 & trans-1,3-Dichloropropene & $\begin{array}{l}<10 \\
<00060\end{array}$ & & $\mu \mathrm{g} / \mathrm{L}$ & AE \\
\hline$\stackrel{0}{0}$ & $\begin{array}{l}\text { Endrin } \\
\text { Ethylbenzene }\end{array}$ & $\begin{array}{l}<0.0060 \\
<1.0\end{array}$ & & $\begin{array}{l}\mu g / \mathrm{h} \\
\mu \mathrm{g} / \mathrm{L}\end{array}$ & \\
\hline a & Fluoride & $<100$ & & $\mu \mathrm{g} / \mathrm{L}$ & \\
\hline 0 & Iron & 77 & & $\mu \mathrm{g} / \mathrm{L}$ & $\mathrm{E}$ \\
\hline
\end{tabular}

Time: 11

Alkalinity $10 \mathrm{mg} / \mathrm{L}$

Water temperature $2020^{\circ} \mathrm{C}$
WELLL HMD 4D collected on 10/22/91, laboratory analyses (cont.)

\begin{tabular}{|c|}
\hline Analyte \\
\hline $\begin{array}{l}\text { Lead } \\
\text { Lindane } \\
\text { Magnesium } \\
\text { Manganese } \\
\text { Mercury } \\
\text { Methoxychlor } \\
\text { Nitrate as nittogen } \\
\text { Phenols } \\
\text { Potassium } \\
\text { Selenium } \\
\text { Silica } \\
\text { Silver } \\
\text { Sodium } \\
\text { Sulfate } \\
1,1,2,2 \cdot \text { Tetrachioroethane } \\
\text { Tetrachloroethylene } \\
\text { Toluene } \\
\text { Total dissolved solids } \\
\text { Total organic carbon } \\
\text { Total organic carbon } \\
\text { Total organic carbon } \\
\text { Total organic carbon } \\
\text { Total organic halogens } \\
\text { Total organic halogens } \\
\text { Total organic halogens } \\
\text { Total organic halogens } \\
\text { Total phosphates (as P) } \\
\text { Toxaphene } \\
2,4,5-\text { TP (Silvey) } \\
1,1,1 \text { Trichloroethane } \\
\text { 1,1,2-Trichloroethane } \\
\text { Trichloroethylene } \\
\text { Trichlorofluoromethane } \\
\text { Gross alpha } \\
\text { Nonvolatile beta } \\
\text { Total radium } \\
\text { Tritium }\end{array}$ \\
\hline
\end{tabular}

Result

Mod Unit Lab

$<3.0$

$<0.0050$
262
39

262
$<9$
$<0.20$

$<0.50$

430
$<5.0$

878
$<2.0$

$<2.0$
$<2.450$
$<2.0$

$<2.0$

1,430
+1.0

$<1.0$

$<1.0$

$<1,000$

$<1,000$

$<1,000$

$<1,3$

$<5.0$
$<5.0$

$<5.0$
$<5.0$

$<50$

$<0.24$
$<0.090$

$<1.0$

$<1.0$

$<1.0$

2. $2 \mathrm{E} \cdot 0 \theta \pm 1.3 \mathrm{E}-0 \theta$

$<2.0 \mathrm{E}-09$

1. $2 \mathrm{E}-09 \pm 9.0 \mathrm{E}-10$
2. $1 \mathrm{E} \cdot 06 \pm 7.0 \mathrm{E}-07$

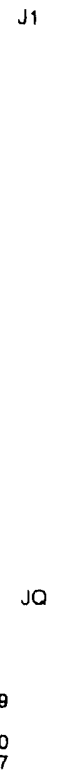

$\begin{array}{ll}\mu \mathrm{g} / \mathrm{L} & \mathrm{GE} \\ \mu \mathrm{g} / \mathrm{L} & \mathrm{GE} \\ \mu \mathrm{g} / \mathrm{L} & \mathrm{GE} \\ \mu \mathrm{g} / \mathrm{L} & \mathrm{GE} \\ \mu \mathrm{g} / \mathrm{L} & \mathrm{GE} \\ \mu \mathrm{g} / \mathrm{L} & \mathrm{GE} \\ \mu \mathrm{g} / \mathrm{L} & \mathrm{GE} \\ \mu \mathrm{g} / \mathrm{L} & \mathrm{GE} \\ \mu \mathrm{g} / \mathrm{L} & \mathrm{GE} \\ \mu \mathrm{g} / \mathrm{L} & \mathrm{GE} \\ \mu \mathrm{g} / \mathrm{L} & \mathrm{GE} \\ \mu \mathrm{g} / \mathrm{L} & \mathrm{GE} \\ \mu \mathrm{g} / \mathrm{L} & \mathrm{GE} \\ \mu \mathrm{g} / \mathrm{L} & \mathrm{GE} \\ \mu \mathrm{g} / \mathrm{GE} & \mathrm{GE} \\ \mu \mathrm{g} / \mathrm{L} & \mathrm{GE} \\ \mu \mathrm{g} / \mathrm{L} & \mathrm{GE} \\ \mu \mathrm{g} / \mathrm{L} & \mathrm{GE} \\ \mu \mathrm{g} / \mathrm{L} & \mathrm{GE} \\ \mu \mathrm{g} / \mathrm{L} & \mathrm{GE} \\ \mu \mathrm{g} / \mathrm{L} & \mathrm{GE} \\ \mu \mathrm{g} / / & \mathrm{GE} \\ \mu \mathrm{g} / \mathrm{L} & \mathrm{GE} \\ \mu \mathrm{g} / \mathrm{L} & \mathrm{GE} \\ \mu \mathrm{g} / \mathrm{L} & \mathrm{GE} \\ \mu \mathrm{g} / \mathrm{L} & \mathrm{GE} \\ \mu \mathrm{g} / \mathrm{L} & \mathrm{GE} \\ \mu \mathrm{g} / \mathrm{L} & \mathrm{GE} \\ \mu \mathrm{g} / \mathrm{L} & \mathrm{GE} \\ \mu \mathrm{g} / \mathrm{L} & \mathrm{GE} \\ \mu \mathrm{g} / \mathrm{L} & \mathrm{GE} \\ \mu \mathrm{g} / \mathrm{L} & \mathrm{GE} \\ \mu \mathrm{g} / \mathrm{L} & \mathrm{GE} \\ \mu \mathrm{CL} / \mathrm{mL} & \mathrm{GE} \\ \mu \mathrm{Ci} / \mathrm{mL} & \mathrm{GE} \\ \mu \mathrm{CL} / \mathrm{mL} & \mathrm{GE} \\ \mu \mathrm{Cl} / \mathrm{mL} & \mathrm{GE}\end{array}$

WELL HR3 11

MEASUREMENTS CONDUCTED IN THE FIELD

Sample date: $11 / 22 / 91$
Depth to water: $13.15 \mathrm{Ht}(4.01 \mathrm{~m})$ below TOC
Water elevation: $258.25 \mathrm{Ht}(78.72 \mathrm{~m}) \mathrm{ms} /$
Sp. conductance: $39 \mu \mathrm{cs} / \mathrm{cm}$
Water evacuated before sampling. $152 \mathrm{gal}$

Time: 13:50

$\mathrm{pH}: 4.5$

Water temperature: $19.0^{\circ} \mathrm{C}$

WELL HR3 13

MEASUREMENTS CONOUCTED IN THE FIELD

Sample date 11/22/91

Depth to water: $18.66 \mathrm{H}(5.69 \mathrm{~m})$ below TOC

Water elevation: $257.54 \mathrm{Ht}$

Sp. conductance: $75 \mu \mathrm{S} / \mathrm{cm}$
Water evacuated before sampling: $138 \mathrm{gal}$

pH: 5.9

Alkalinity: $13 \mathrm{mg} / \mathrm{L}$

Water temperature: $20.8^{\circ} \mathrm{C}$

WELL HR8 11

MEASUAEMENTS CONDUCTED IN THE FIELD

Sample date: $11 / 22 / 91$

Depth to water: $12.78 \mathrm{~h}(3.90 \mathrm{~m})$ below TOC

Water elevation: 246.42 it $(75$.

Water evacuated betore sampling: $101 \mathrm{gal}$

Alkalinity: $0 \mathrm{mg} / \mathrm{L}$
Water temperature $20.4^{\circ} \mathrm{C}$

WELL HR8 12

MEASUREMENTS CONDUCTED IN THE FIELD

Sample date: $11 / 22 / 91$

Depth to water: 19.05 A $(5.50 \mathrm{~m})$ below TOC

Water elevation 233.45 it 172

Sp. conductance $34 \mu \mathrm{S} / \mathrm{cm}$
Water evacuated before sampling: $87 \mathrm{gal}$
Time $11: 45$

PH: 42 : $0 \mathrm{mgl}$

Water temperature: $20.5^{\circ} \mathrm{C}$ 
WELL HR8 13

MEASUREMENTS CONDUCTED IN THE FIELD

Sample date: $11 / 22 / 91$
Dopth to water: $16.29 \mathrm{H}(4.97 \mathrm{~m})$ below TCS
Water elevation: $236.81 \mathrm{Ht}(72.18 \mathrm{~m}) \mathrm{ms}$
Sp. conductance: $48 \mu \mathrm{s} / \mathrm{cm}$

Time: $11: 25$

PH: 4.2 . $0 \mathrm{mglt}$ Water temperature: $19.7^{\circ} \mathrm{C}$

Water evacuated before sampling: $92 \mathrm{gat}$

\section{WELL HR8 14}

MEASUREMENTS CONDUCTED IN THE FIELD

Sample date: $11 / 22 / 91$
inaccessibility or pump failure prevented sample collection

Time: $12: 30$

\section{WELL HSB 1TB}

MEASUREMENTS CONDUCTED IN THE FIELD

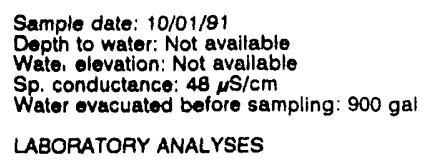

LABOPATORY ANALYSES

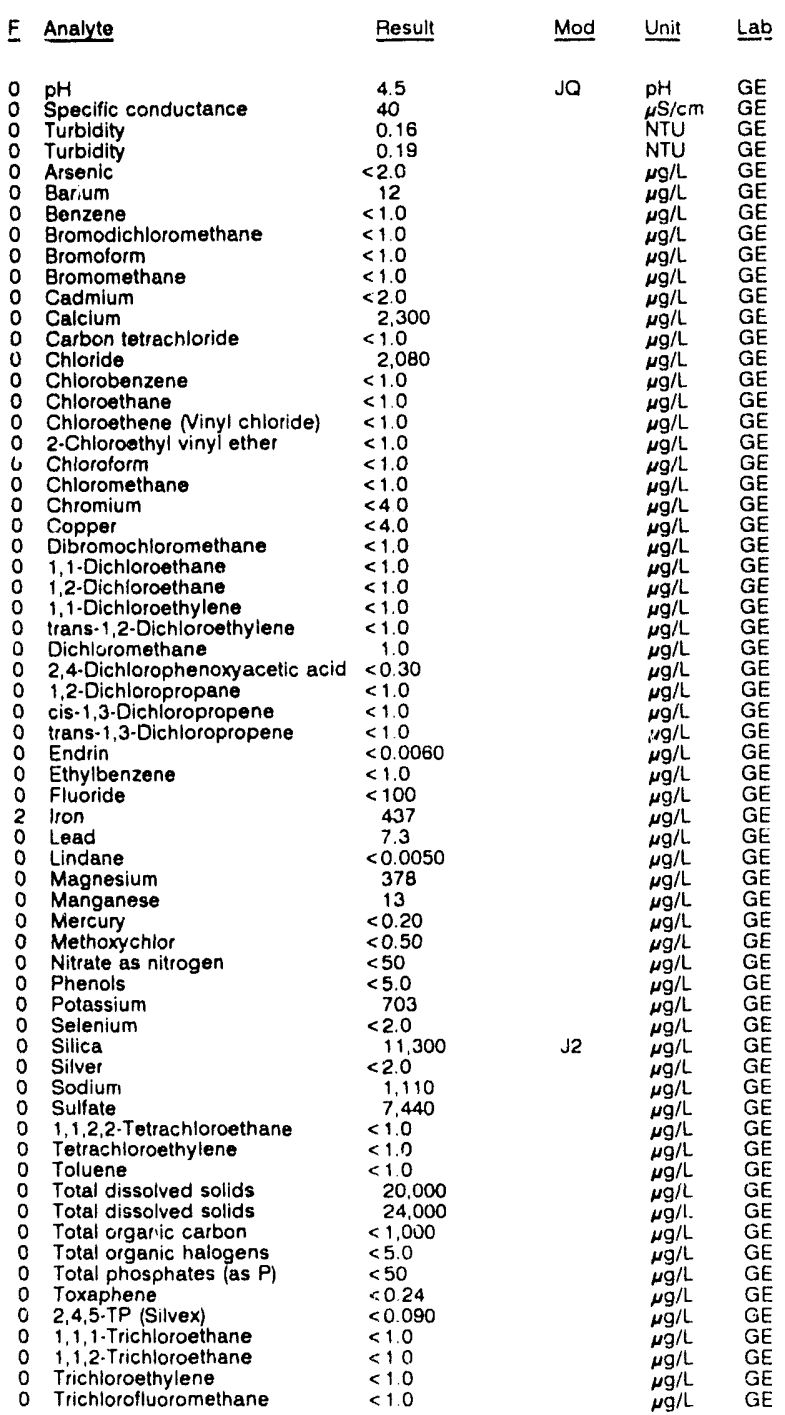

WELL HSB 1 TH collected on 10/01/91, laboratory analyses (cont.)

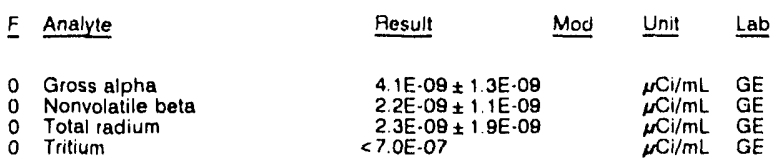

\section{WELL HSB 65}

MEASUIREMENTS CONDUCTED IN THE FIELD

Sample date: $10 / 01 / 91$
Depth to water: $37.71 \mathrm{ft}(11.49 \mathrm{~m})$ below TOC
Water elevation: $234.29 \mathrm{f}(71.41 \mathrm{~m}) \mathrm{ms}$
Sp. conductance: $40 \mu \mathrm{s} / \mathrm{cm}$
Water evacuated before sampling: $57 \mathrm{gal}$

Time: $11: 25$

pH: 4.5

Water temperature: $19.2^{\circ} \mathrm{C}$

LABORATOHY ANALYSES

E Analyte Result $\underline{\text { Mod Unit Lab }}$

$\begin{array}{ll}0 & \mathrm{pH} \\ 0 & \text { Specific conductance } \\ 0 & \text { Turbidity } \\ 0 & \text { Acetophenone }\end{array}$

Aluminum

Arsenic

0 Barium

Benzene

Bromoform

Bromomethane

Cadmium

Calcium

Chloride

Chloride

Chlorobenzene

Chlorotihane

2.Chloroethyl vinyl ether

Chloromethane

Chromium

Cobalt

Copper

Cyanide

Dibromochloromethane

1,1-Lichloroethane

1,2-Dichloroethane

1,1-Dichlotoethylene
tran: $: 2$-Dichloroethylene

Dichloromethane

2.4-Dichlorophenoxyacetic acid 1.7

1,2-Dichioropropane

cis-1,3-Dichloropropene

trans: 1,3

Ethylbenzene

Fluoride

iron

Lead

Lindane

Maynesium

sercury

Methoxychlor

Naphthaler
Nickel

Nitrate as nitrogen

Phenols

Selenium

0 Silica

Silver

Sodium

1,1,2,2. Tetrachioroethane

Tetrachloroethylene

Tin

Tolvene

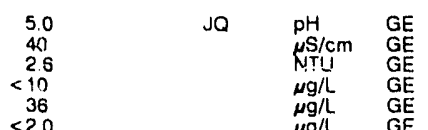

Total dissolved solids

onan carbon

Total phosphates (as $P$ )

Toxaphene

2.4.5-TP (Silvex)

1,1,2-Trichloroethane

Trichloroethylene

Trichlorofluoromethane

Vanadium

Xylene

Gross alpha

Nonvolatile beta

Tolal radium

$<10$

$<.320$
2,320

$<5.0$
533

$<.0$
6.240

6.240
$<2.0$

3,730
$<1,000$

$<1.0$

$<1.0$

$<2.0$

18,000

2,010
$<5$

$<50$

$<0.24$
$<0.090$

$<0.090$
$<1.0$

$<10$

$<10$

$<8.0$

$<20$
$\times 20$

JE.09

$\therefore$ OE.09

$52 \mathrm{E} \cdot 05 \pm 10 \mathrm{OE} \cdot 06$

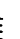 .}


WELL HSB 65A

MEASUREMENTS CONDUCTED IN THE FIELD

Sample date: $10 / 01 / 91$
Depth to water: $101.45 \mathrm{H}(30.92 \mathrm{~m})$ below TOC
Water olevation: $172.15 \mathrm{H}(52.47 \mathrm{~m}) \mathrm{ms}$ ! Water olevation: $172.15 \mathrm{Ht}(52.47 \mathrm{~m}$

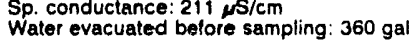

LABORATORY ANALYSES

E Analyte Result Mod Unit Lab

$\begin{array}{ll}0 & \mathrm{pH} \\ 0 & \text { Specific conductance } \\ 0 & \text { Turbidity }\end{array}$

Acetophienone

Aluminum

Arsenic

? Barium

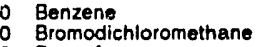

Bromoform

0 Bromometha

Cadmium

- Calcium

o Chloride

o Chlorobenzene

Chloroethene Ninyl chloride

2.Chloroethyl vinyl other

Chlorotorm

o Cobalt

0 Copper

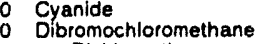

0 1,1-Oichloroethane

1.2-Dichloroethane

0 trans-1,2-Dichloroethylene

Mod Unit Lab

Time: 10:30

pH: 7.5

Alkalinity: $90 \mathrm{mg} / \mathrm{h}$
Water temperature: $19.8^{\circ} \mathrm{C}$

Dichlorometnane

2,4-Dichlorophenoxyacetic acid

$\begin{array}{ll}1,2-D i c h l o r o p r o p a n e \\ 0 & \text { cis-1,3-Dichloropropene }\end{array}$

trans-1,3.Dichloropropene

0 Endrin

E Ethylbenzene

$\begin{array}{ll}0 & \text { Fluoride } \\ 0 & \text { Iron }\end{array}$

0 Lead

0 Lindane

O Magnitsium

Methoxychlor

Naphthalene

Nickel

Nitrate as nitrogen

\% Phenols

O Potassium

$\begin{array}{ll}0 & \text { Silica } \\ 0 & \text { Silver }\end{array}$

o Sodium

Sulfate

1 Tin

- Total dissolved solids

Total organic carbon

: Total organic halogens

Total phosph

2,4,5.TP (Silvex)

i, 1, 1-Trichloroethane

o richloroethylene

Trichloofluoromethane

0 Vanadium

0 Xylenes

0 Zinc

Gross alpha

Nonvolatile beta

Total radium

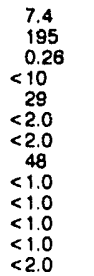

$<2.0$

$<\begin{gathered}37,300 \\ <1.0\end{gathered}$

$<1,0$

$<1.0$

$<1.0$

$<1.0$

$<4.0$

$<4.0$

$<5.0$

$<1.0$

$<1.0$

$<1.0$

$<1.0$

$<1.0$
$<1.0$

$<1.0$

$<1.0$

$<100$

$<40$
$<3.0$

$<0.0050$

855
$<2.0$

$<0.20$

$<0.50$

$<10$

$<30$
$<50$

$<5.0$

$<2,0$

$<<2.000$

2,030
5,720

$<1.0$
$<1.0$

11
$<10$

$<1.07,000$

$<1,000$

$<5.0$

$<0.24$

$<0.24$
$<0.090$

$<1.0$

$<1.0$

$<1.0$

$<8.0$

$<8.0$

$<2.0$
$<2.0 \mathrm{E}-09$

$<2.0 \mathrm{E} .09$

$<1.0 \mathrm{E} \cdot 09$
$3.4 \mathrm{E} \cdot 05 \pm 8.0 \mathrm{E}-07$
WELL HSB 65B

MEASUREMENTS CONDUCTED IN THE FIELD

Sample date: 10/01/91

Depth to water: $47.99 \pi(14.63 \mathrm{~m})$ below TOC

Water elevation: $22571 \mathrm{ht}$ (68.

Sp. conductance: $202 \mu \mathrm{S} / \mathrm{cm}$

Water evacuated before sampling: 269 gal

LABORATORY ANALYSES

E Analyte Result Mod Unit Lab

0 pH

Specific conductance

- Acetophenone

Aluminum

Arsenic

Barium

Bromudichloromethane

Bromoform

Cadmium

Cadmium

Carbon tetrachloride

Chloride

Chlorobenzene

Chlorothene (Viriyl chloride

2.Chloroethyl vinyl ether

Chloroform

Chloromethane

Chromium

Cobalt

- Cyar je

- Dibroin'schloromethane

1, -Drehl rocthane

0 i. Dinthe

0 tans-1,2-Dichloroethylene

- Dichloromethave

70

Time: 10:05

Alkalinity: $94 \mathrm{mg} / \mathrm{L}$

Water temperatuie: $19.4^{\circ} \mathrm{C}$

2,4-Dichlorophenoxyac

1,2-Dichloropropane

D trans-1.3-Dichloropropene

O Endin

0 Ethylben: 18

0 Fivistide

0 Lead

0 Lindane

Magnesium

Manganes

Methoxychlor

- Naphthalene

Nicke

Nitrate as nitrogen

Phenols

Selenium

Silica

0 Silver

Sodiurn

0 Sulfate

o Tetrachloroethylene

0 Tin

Total dissolved solids

Total organic carbon

Total phosphates (as P)

Toxaphene

0 2,4,5.TP (Silvex)

1,1,1-Trichloroethane

Trichloroethylene

Trichlorofluoromethane

Vanadium

Xylenes

Gross alpha

Nonvolatile tet

Total rádium

7.8
185
2.4
$<10$
$<$

$<10$
$<20$

$<2.0$

$<2.0$

$<1.0$
$<1.0$

$<1.0$
$<1.0$

$<1.0$

38,400

$<1.0$

$<1.0$

<1.0

$<1.0$
$<1.0$
$<10$

$<1.0$

4.8
$<4.0$

$<4.0$

$<5.0$
$<1.0$

$<1.0$
$<10$

$<1.0$

$-1.0$

$<030$

$<1.0$

$<10$

$<0.0060$

$<10$
$<100$

$<100$

$<4.0$
$<3.0$

$-0.0050$

914
$<2.0$

$<<2.0$

$<10$
$<4.0$

$<50$

$<5.0$

$<2.0$

17,000

$<2.0$

$<1,000$

1.00
$<1.0$

$<1.0$

6.4
$<1.0$

107.000

$<1,000$

$<5.0$
$<50$

$<0.24$

$<0.090$

$<<<0$

$<1.0$
$<1.0$

$<1.0$

$<1.0$

$<8.0$
$<2.0$

$<2.0$

$<2 \mathrm{OE}-09$
$<20 \mathrm{E}-09$

$<1$ OE-O9

$<10 E-09$
$<7.0 E-07$

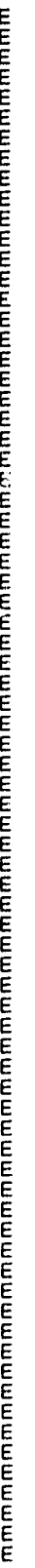


ANALYTICAL RESULTS

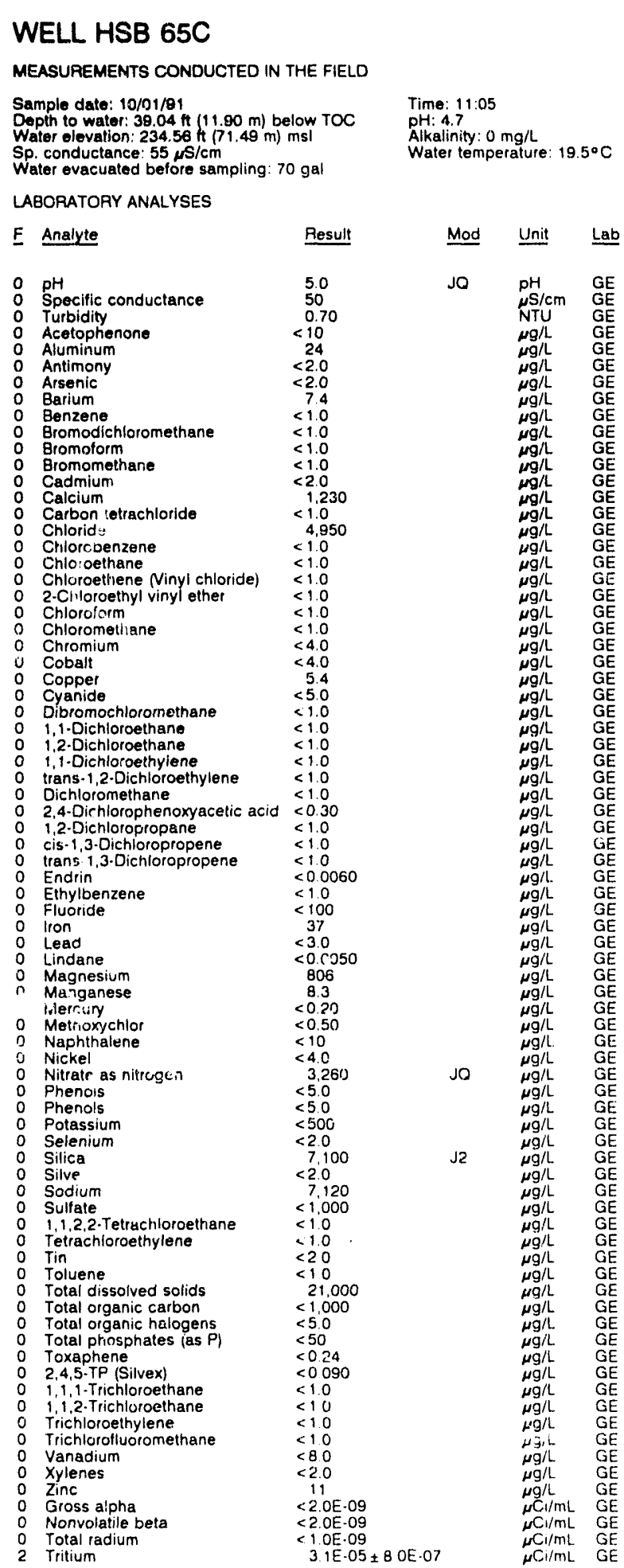

WELL HSB 66

MEASUREMENTS CONDUCTED IN THE FIELLD

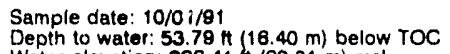

Water elevation: $226.41 \mathrm{ht}(69.01 \mathrm{~m}) \mathrm{ms}$

Sp. conductance: $27 \mu \mathrm{S} / \mathrm{cm}$

Water evacuated betore sampling: $74 \mathrm{gal}$

LABORATORY ANALYYSES
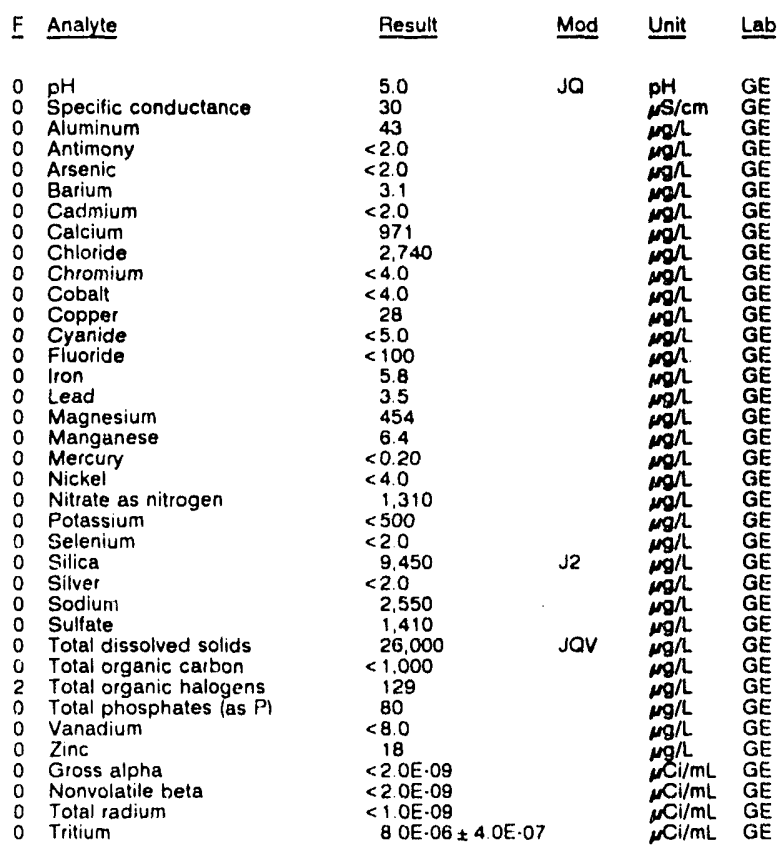

WELL HSB 67

MEASUREMENTS CONDUCTED IN THE FIELD

Sample date: 10/01/91

Depth to water: $13.23 \mathrm{Ht}(4.03 \mathrm{~m})$ below TOC

Water elevation: $224.57 \mathrm{ft} 6 \mathrm{Bg}^{\mathrm{m}}$

Sp. conductance: $139 \mu \mathrm{S} / \mathrm{cm}$
Water evacuated before sampling $62 \mathrm{gal}$

Time: 12:05

Alkalinity: $1 \mathrm{mgh}$

Water temperature: $18.5^{\circ} \mathrm{C}$

LABORATORY ANALYSES

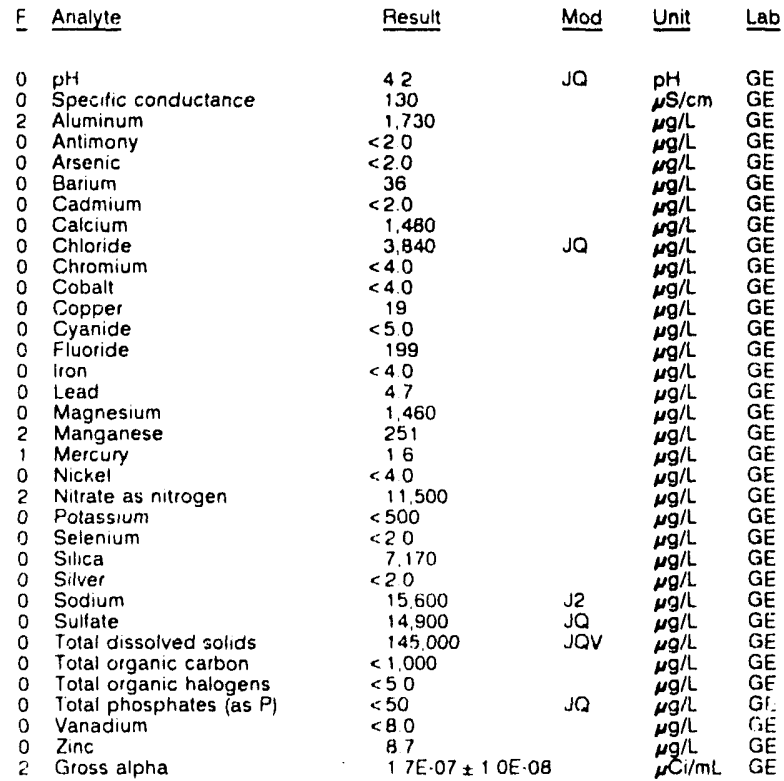


ANALYTICAL RESULTS

WELL HSB 67 collected on 10/01/91, laboratory analyses (cont.)

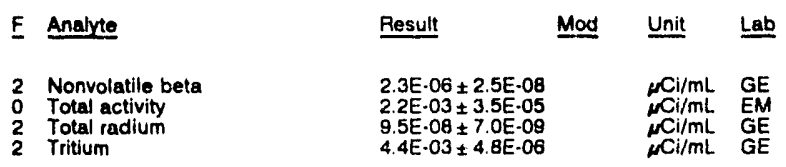

\section{WELL HSB 68}

MEASUREMENTS CONDUCTED IN THE FIELD

Sample date: $10 / 01 / 91$
Depth to water: $27.60 \mathrm{ht}(8.41 \mathrm{~m})$ below TOC
Water elevation: $222.50 \mathrm{ft}(67.82 \mathrm{~m}) \mathrm{ms}$ l
Sp. conductance: $357 \mu$ S/cm
Water evacuated before sampling: $28 \mathrm{gal}$
LABORATORY ANALYSES

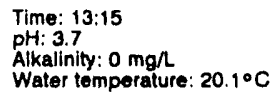

LABORATORY ANALYSES

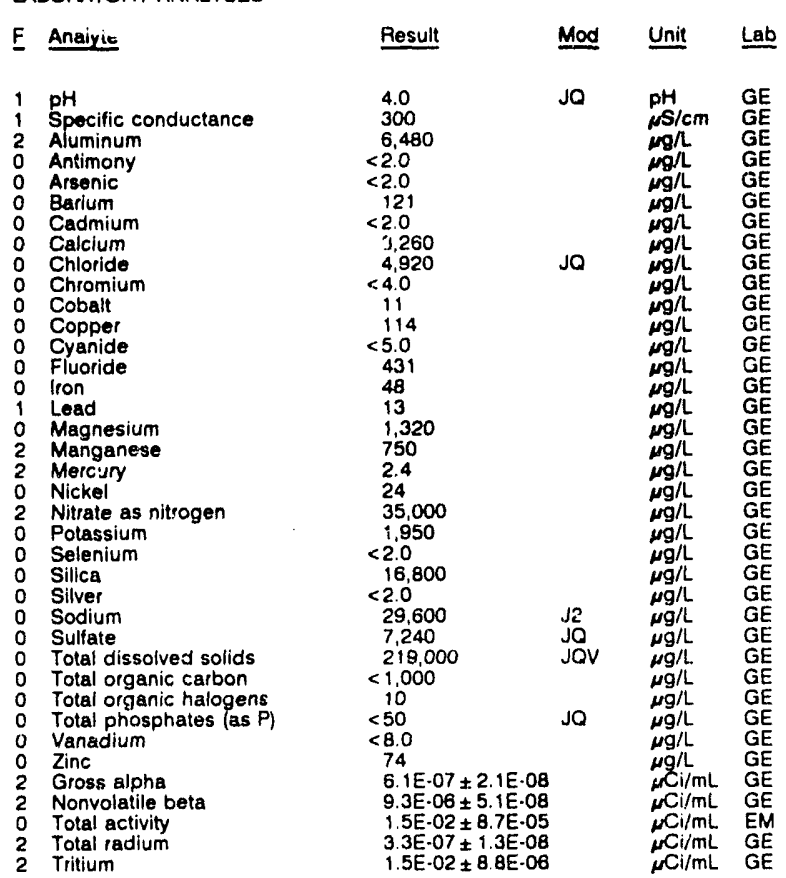

WELL HSB 68A

MEASUREMENTS CONDUCTED IN THE FIELD Sample date: $10 / 01 / 91$
Depth to water: $76.71 \mathrm{Ht}(23.38 \mathrm{~m})$ below TOC
Water elevation: $172.69 \mathrm{ft}(52.64 \mathrm{~m})$ insl Sp. conductance $139 \mathrm{~s} / \mathrm{cm}$ Water evacuated before sampling: $328 \mathrm{gal}$ LABORATORY ANALYSES
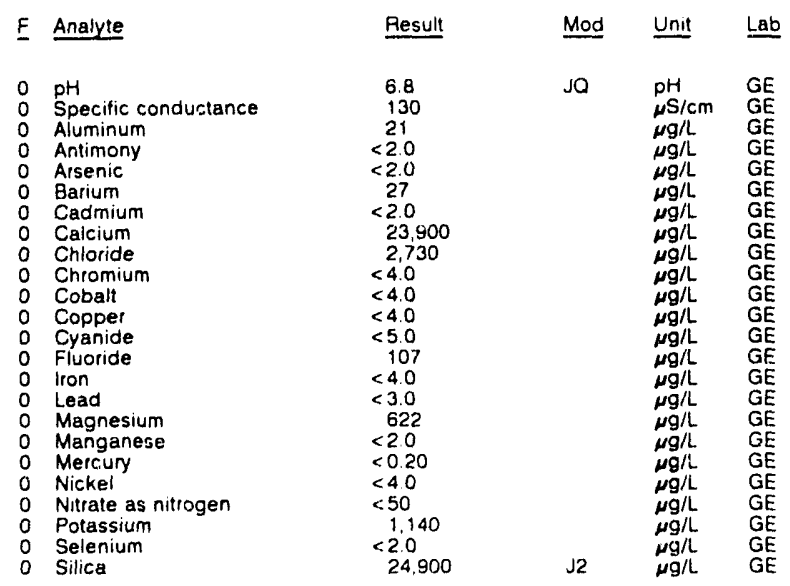

WELL. HSB 68A collected on 10/01/91, laboratory analyses (cont.)

\begin{tabular}{|c|c|c|c|c|}
\hline Anafyte & Resulit & Mod & Unit & Lab \\
\hline $\begin{array}{l}\text { Silver } \\
\text { Sodium } \\
\text { Sulfate } \\
\text { Total dissolved solids } \\
\text { Total organic charbon } \\
\text { Total organic halogens } \\
\text { Total phosphates (as P) } \\
\text { Vanadium } \\
\text { Zinc } \\
\text { Gross alpha } \\
\text { Nonvolatile beta } \\
\text { Total radium } \\
\text { Tritium }\end{array}$ & $\begin{array}{l}<2.0 \\
1,880 \\
6,260 \\
97,000 \\
<1,000 \\
53 \\
190 \\
<8.0 \\
<2.0 \\
<2.0 \mathrm{E}-09 \\
6.1 \mathrm{E} \cdot 09 \pm 1.4 \mathrm{E}-09 \\
<1.0 \mathrm{E} \cdot 09 \\
9.5 \mathrm{E} \cdot 07 \pm 2.0 \mathrm{E} \cdot 07\end{array}$ & JOV & $\begin{array}{l}\mu g / L \\
\mu g / L \\
\mu g / L \\
\mu g / L \\
\mu g / L \\
\mu g / L \\
\mu g / L \\
\mu g / L \\
\mu g / L \\
\mu C i / m L \\
\mu C l / m L \\
\mu C l / m L \\
\mu C \mathrm{~L} / \mathrm{mL}\end{array}$ & $\begin{array}{l}\mathrm{GE} \\
\mathrm{GE} \\
\mathrm{GE} \\
\mathrm{GE} \\
\mathrm{GE} \\
\mathrm{GE} \\
\mathrm{GE} \\
\mathrm{GE} \\
\mathrm{GE} \\
\mathrm{GE} \\
\mathrm{GE} \\
\mathrm{GE} \\
\mathrm{GE}\end{array}$ \\
\hline
\end{tabular}

WELL HSB 68B

MEASUREMENTS CONDUCTED IN THE FIELD

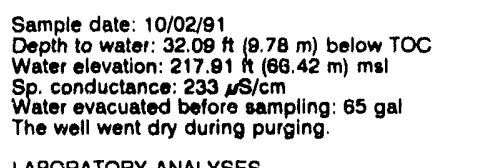

Time: 8:05

pH: 7.8 . $112 \mathrm{mgl}$

Water temperature: $18.6^{\circ} \mathrm{C}$

LABORATORY ANALYSES

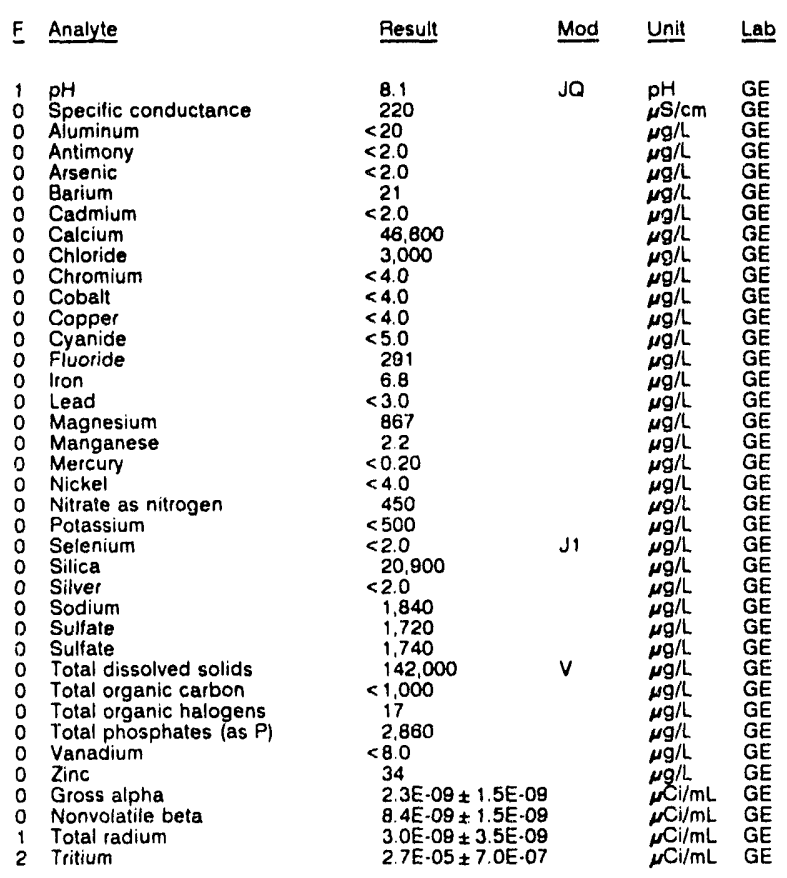

\section{WELL HSB 68C}

MEASUREMENTS CONDUCTEO IN THE FIEL.D

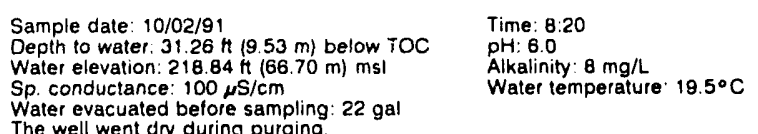

Water evacuated before sampling

LABORATORY ANALYSES

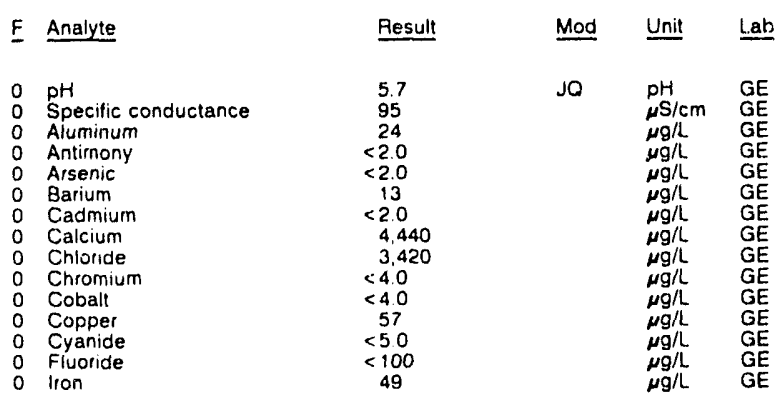


ANALYTICAL RESULTS

WELL HSB 68C collected on 10/02/91, laboratory analyses (cont.)

\begin{tabular}{|c|c|c|c|}
\hline Analyte & Pesult & Mod & Unit \\
\hline $\begin{array}{l}\text { Lead } \\
\text { Magnesium } \\
\text { Manganese } \\
\text { Mercury } \\
\text { Nickel } \\
\text { Nitrate as nitrogen } \\
\text { Potassium } \\
\text { Selenium } \\
\text { Silica } \\
\text { Silver } \\
\text { Sodium } \\
\text { Sulfate } \\
\text { Total dissolved solids } \\
\text { Total organic carbon } \\
\text { Total organic halogens } \\
\text { Total phosphates (as P) } \\
\text { Vanadium } \\
\text { Zinc } \\
\text { Gross alpha } \\
\text { Nonvolatile beta } \\
\text { Total activity } \\
\text { Total radium } \\
\text { Tritium }\end{array}$ & $\begin{array}{l}6.7 \\
926 \\
36 \\
<0.20 \\
<4.0 \\
8,900 \\
584 \\
<2.0 \\
8.910 \\
<20 \\
11,000 \\
<1,000 \\
43,000 \\
<1,000 \\
87 \\
<50 \\
<8.0 \\
130 \\
2.9 \mathrm{E} \cdot 09 \pm 1.0 \mathrm{E} \cdot 09 \\
9.5 \mathrm{E} \cdot 09 \pm 1.6 \mathrm{E} \cdot 09 \\
1.2 \mathrm{E} \cdot 03 \pm 2.6 \mathrm{0} \cdot 05 \\
1.3 \mathrm{E} \cdot 09 \pm 1.0 \mathrm{E} \cdot 09 \\
1.4 \mathrm{E} \cdot 03 \pm 5.2 \mathrm{E} \cdot 06\end{array}$ & $\begin{array}{l}\mathrm{V} \\
\text { jo } \\
\text { jo }\end{array}$ & $\begin{array}{l}\mu g / \mathrm{L} \\
\mu \mathrm{g} / \mathrm{L} \\
\mu g / \mathrm{L} \\
\mu g / \mathrm{L} \\
\mu g / \mathrm{L} \\
\mu g / \mathrm{L} \\
\mu \mathrm{g} / \mathrm{L} \\
\mu \mathrm{g} / \mathrm{L} \\
\mu \mathrm{g} / \mathrm{L} \\
\mu \mathrm{g} / \mathrm{L} \\
\mu \mathrm{g} / \mathrm{L} \\
\mu \mathrm{g} / \mathrm{L} \\
\mu \mathrm{g} / \mathrm{L} \\
\mu \mathrm{g} / \mathrm{L} \\
\mu \mathrm{g} / \mathrm{L} \\
\mu \mathrm{g} / \mathrm{L} \\
\mu \mathrm{g} / \mathrm{L} \\
\mu \mathrm{g} / \mathrm{L} \\
\mu \mathrm{Ci} / \mathrm{mL} \\
\mu \mathrm{Ci} / \mathrm{mL} \\
\mu \mathrm{Ci} / \mathrm{mL} \\
\mu \mathrm{Ci} / \mathrm{mL} \\
\mu \mathrm{Ci} / \mathrm{mL}\end{array}$ \\
\hline
\end{tabular}

WELL HSB 69

MEASUREMENTS CONDUCTED IN THE FIELD Sample date: $10 / 01 / 91$
Depth to water: $15.66 \mathrm{Ht}(4.83 \mathrm{~m})$ below TOC
Water elevation: $220.14 \mathrm{H}(67.10 \mathrm{~m}) \mathrm{ms}$
Sp. conductance: $266 \mu \mathrm{sm} / \mathrm{m}$
Water evacuated before sampling: $55 \mathrm{gal}$ Time $14 \cdot 15$ $\mathrm{pH}: 3.7$ Alkalinity: $0 \mathrm{mg} / \mathrm{h}$
Water temperature $209^{\circ} \mathrm{C}$ LABORATORY ANALYSES

$\begin{array}{ll}\text { F } & \text { Analyte } \\ & \\ 1 & \text { pH } \\ 0 & \text { Specific conductance } \\ 2 & \text { Aluminum } \\ 0 & \text { Antimony } \\ 0 & \text { Arsenic } \\ 0 & \text { Barium } \\ 0 & \text { Cadmium } \\ 0 & \text { Calcium } \\ 0 & \text { Chioride } \\ 0 & \text { Chromium } \\ 0 & \text { Cobalt } \\ 0 & \text { Copper } \\ 0 & \text { Cyanide } \\ 0 & \text { Fluoride } \\ 0 & \text { Iron } \\ 0 & \text { Lead } \\ 0 & \text { Magnesium } \\ 2 & \text { Manganese } \\ 0 & \text { Mercury } \\ 0 & \text { Nickel } \\ 2 & \text { Nitrate as nitrogen } \\ 0 & \text { Potassium } \\ 0 & \text { Selenium } \\ 0 & \text { Silica } \\ 0 & \text { Silver } \\ 0 & \text { Sodium } \\ 0 & \text { Sulfate } \\ 0 & \text { lotal dissolved solids } \\ 0 & \text { Total organic carbon } \\ 0 & \text { Total orgaric halogens } \\ 0 & \text { Total phosphates (as } P \text { ) } \\ 0 & \text { Vanadium } \\ 0 & \text { Zinc } \\ 2 & \text { Gross alpha } \\ 2 & \text { Nonvolatile beta } \\ 0 & \text { Total activity } \\ 2 & \text { Total radium } \\ 2 & \text { Tritium } \\ & \end{array}$

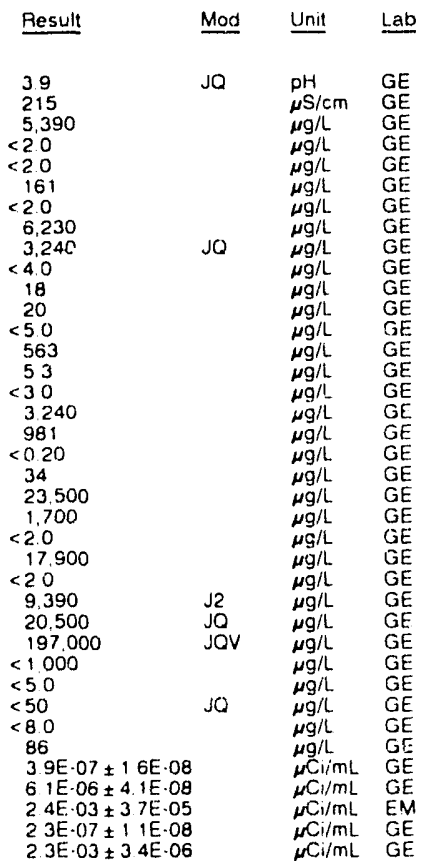

\section{WELL HSB 69A}

MEASUREMENTS CONDUCTED IN THE FIELD Sample date. $10 / 01 / 91$
Depth to water $63.71 \mathrm{H}(19.42 \mathrm{~m})$ below TOC
Water elevation: $172.89 \mathrm{ht}(52.70 \mathrm{~m})$ msl
Sp conductance. $167 \mu \mathrm{S} / \mathrm{cm}$

Water evacuated before sampling $236 \mathrm{gal}$

LABORATORY ANALYSES

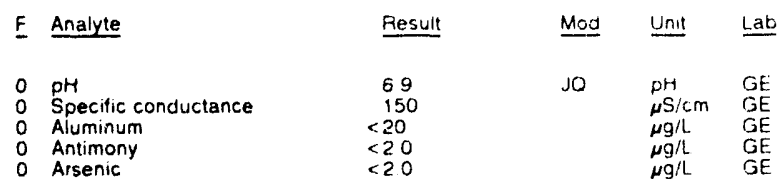

WELL HSB 69A collected on 10/01/91, laboratory analyses (cont.)

$\begin{array}{ll}\text { F } & \text { Analyte } \\ & \\ 0 & \text { Barium } \\ 0 & \text { Cadmium } \\ 0 & \text { Calcium } \\ 0 & \text { Chloride } \\ 0 & \text { Chromium } \\ 0 & \text { Cobalt } \\ 0 & \text { Copper } \\ 0 & \text { Cyanide } \\ 0 & \text { Fluoride } \\ 0 & \text { Iron } \\ 0 & \text { Lead } \\ 0 & \text { Magnesium } \\ 0 & \text { Manganese } \\ 0 & \text { Mercury } \\ 0 & \text { Nickel } \\ 0 & \text { Nitrate as nitrogen } \\ 0 & \text { Potassium } \\ 0 & \text { Selenium } \\ 0 & \text { Silica } \\ 0 & \text { Silver } \\ 0 & \text { Sodium } \\ 0 & \text { Sulfate } \\ 0 & \text { Total dissolved solids } \\ 0 & \text { Total dissolved solids } \\ 0 & \text { Total organic carbon } \\ 1 & \text { Total organic halogens } \\ 0 & \text { Total phosphates (as } P \text { ) } \\ 0 & \text { Vanadium } \\ 0 & \text { Zinc } \\ 0 & \text { Gross alpha } \\ 0 & \text { Nonvolatile beta } \\ 0 & \text { Tolal radium } \\ 0 & \text { Tritium } \\ & \text { Wium }\end{array}$

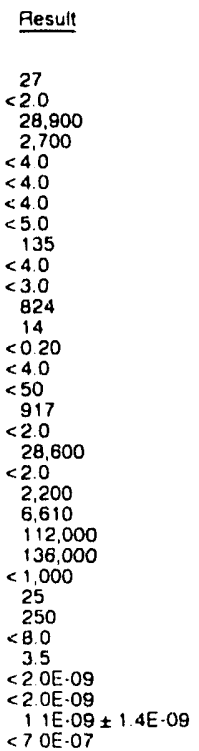

Mod Unit Lab

\section{WELL HSB 70}

MEASUAEMENTS CONOUCTED IN THE FIELD

$\begin{array}{ll}\text { Sample date: } 10 / 02 / 91 & \text { Time: } 13.00 \\ \text { Depth to water: } 16.34 \mathrm{ft}(4.98 \mathrm{~m}) \text { below TOC } & \text { pH: } 4.8 \\ \text { Water elevation } 22646 \mathrm{H}(69.03 \mathrm{~m}) \mathrm{msl} & \text { Alkalinity: } 0 \mathrm{mg} / \mathrm{L} \\ \text { Sp conductance } 69 \mu \mathrm{S} / \mathrm{cm} & \text { Water temperature } 20.6^{\circ} \mathrm{C} \\ \text { Water evacuated belore sampling } 54 \mathrm{gal} & \end{array}$

LABOFATORY ANALYSES

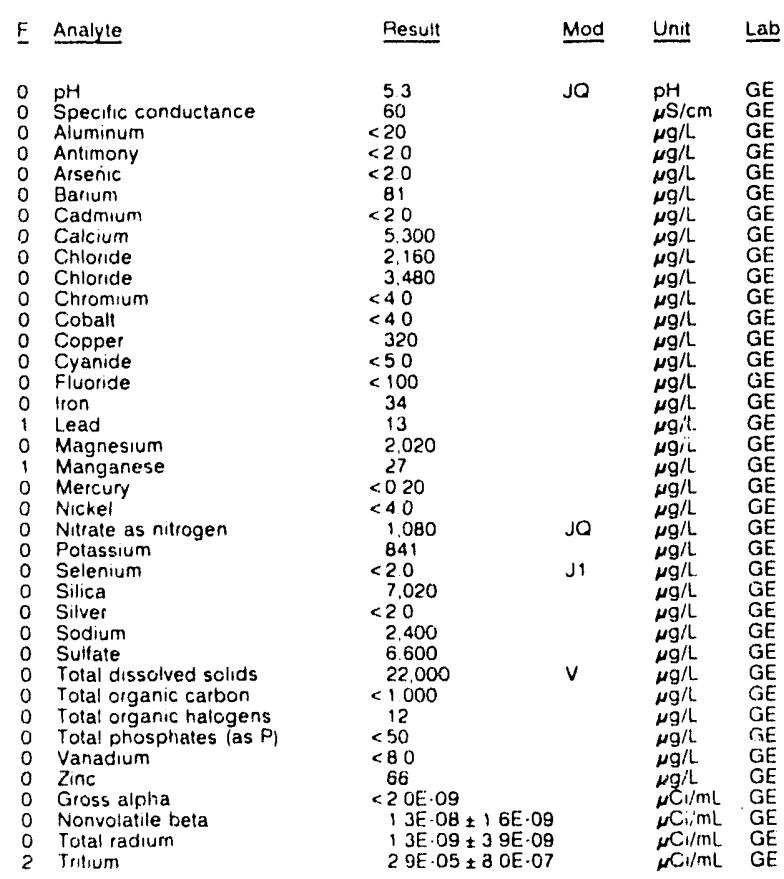


ANALYTICAL RESULTS

WELL HSB $70 \mathrm{C}$

MEASUREMENTS CONDUCTED IN THE FIELD

Sample date: 10/02/9:

Depth to water: 17.65 th (5.38 m) below TOC

Water elevation: $225.45 \mathrm{ft}(68.7$

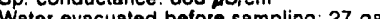

Wa

LABORATORY ANALYSES

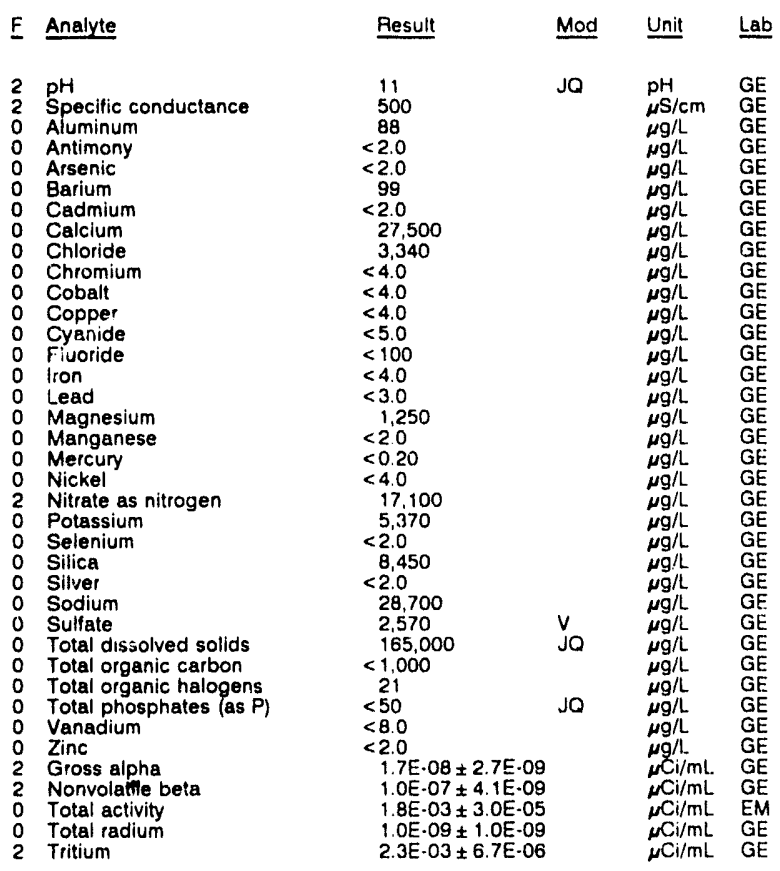

WELLL HSB 71

MEASUREMENTS CONDUCTED IN THE FIELD

Sample date: $10 / 08 / 91$

Depth to water: $15.11 \mathrm{Ht}(4.6 \mathrm{r} \mathrm{m})$ below TOC

Water elevation: 226.29 it

sampling $61 \mathrm{ga}$

LABORATORY ANALYSES

$\begin{array}{ll}\text { F } & \text { Analyte } \\ & \\ 0 & \text { pH } \\ 0 & \text { Specific conductance } \\ 0 & \text { Aluminum } \\ 0 & \text { Antimony } \\ 0 & \text { Arsenic } \\ 0 & \text { Garium } \\ 0 & \text { Cadmium } \\ 0 & \text { Calcium } \\ 0 & \text { Chloride } \\ 0 & \text { Chromium } \\ 0 & \text { Cobalt } \\ 0 & \text { Copper } \\ 0 & \text { Cyanide } \\ 0 & \text { Fluoride } \\ 0 & \text { lron } \\ 1 & \text { Lead } \\ 0 & \text { Magnesium } \\ 0 & \text { Manganese } \\ 0 & \text { Mercury } \\ 0 & \text { Nickel } \\ 0 & \text { Nitrate as nitrogen } \\ 0 & \text { Potassium } \\ 0 & \text { Selenium } \\ 0 & \text { Silica } \\ 0 & \text { Silver } \\ 0 & \text { Sodium } \\ 0 & \text { Sulfate } \\ 0 & \text { Total dissolved solids } \\ 0 & \text { Total organic carbon } \\ 0 & \text { Total organic halogens } \\ 0 & \text { Total phosphates (as P) } \\ 0 & \text { Vanadium } \\ 0 & \text { Zinc } \\ & \end{array}$

Result

5.3
20
47
$<2.0$
$<2.0$
$<3.0$
$<2.0$
369
2.960
$<4.0$
$<4.0$
149
$<5.0$
$<100$
30
11
417
$<2.0$
$<0.20$
$<4.0$
$<50$
$<500$
$<2.0$
6.350
$<2.0$
2.390
$<1.000$
19.000
$<1.000$
$<5.0$
940
$<8.0$
21

Time: 12:40

pH: 11.3 .30 .90

Water temperature: $20.10 \mathrm{C}$
WELL HSB 71 collected on 10/08/91, laboralory analyses (cont.)

\begin{tabular}{|c|c|c|c|c|c|}
\hline$F$ & Analyte & Result & Mod & Unit & Lab \\
\hline $\begin{array}{l}0 \\
1 \\
2\end{array}$ & $\begin{array}{l}\text { Gross alpha } \\
\text { Nonvolatile beta } \\
\text { Total activity } \\
\text { Total radium } \\
\text { Tritium }\end{array}$ & $\begin{array}{l}<2.0 E-09 \\
<2.0 E-09 \\
2.0 E-04 \pm 3.2 E-06 \\
2.5 E-09 \pm 1.3 E-09 \\
2.2 E-04 \pm 1.1 E-06\end{array}$ & & $\begin{array}{l}\mu \mathrm{Ci} / \mathrm{mL} \\
\mu \mathrm{Ci} / \mathrm{mL} \\
\mu \mathrm{Ci} / \mathrm{mL} \\
\mu \mathrm{Ci} / \mathrm{mL} \\
\mu \mathrm{Cl} / \mathrm{mL}\end{array}$ & $\begin{array}{l}\mathrm{GE} \\
\mathrm{GE} \\
\mathrm{EM} \\
\mathrm{GE} \\
\mathrm{GE}\end{array}$ \\
\hline
\end{tabular}

WELL HSB 71C

MEASUREMENTS CONDUCTEO IN THE FIELD

Sample date: 10/08/81

Depth to water: 16.83 it $(5.13 \mathrm{~m})$ below TOC

Water elevation: $224.77 \mathrm{ft}(68.51 \mathrm{~m}) \mathrm{msl}$

Sp. conductance: $581 \mu \mathrm{S} / \mathrm{cm}$

The well went dry during pupling: $22 \mathrm{gal}$

wry during purging

LABORATORY ANALYYSES

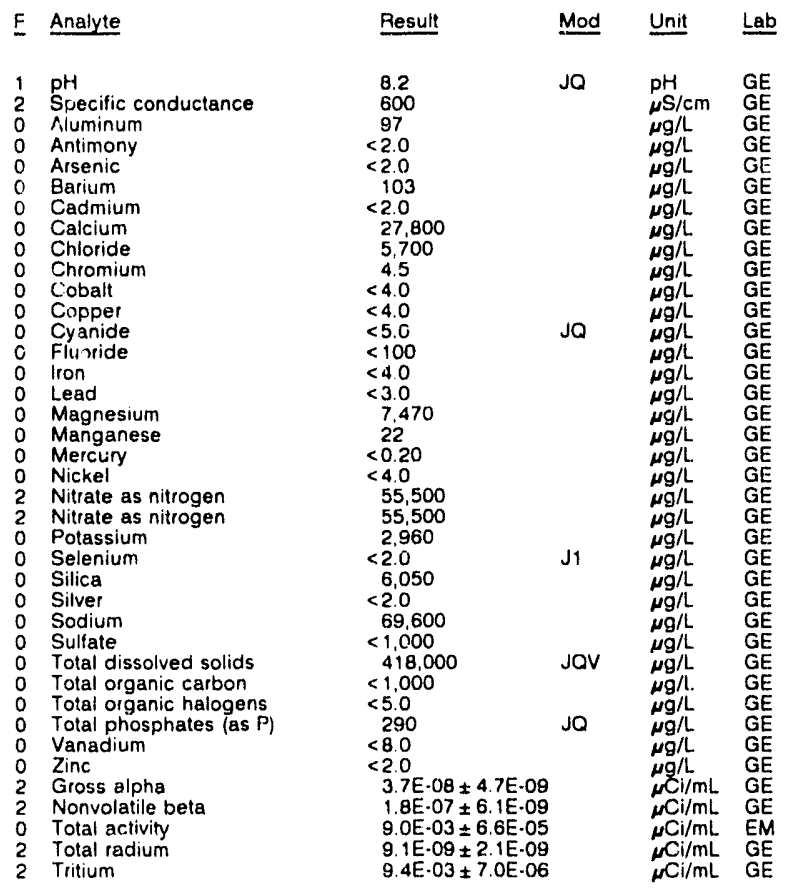

WELL HSB 83A

MEASUREMENTS CONDUCTED IN THE FIELD

Sample date $10 / 03 / 91$

Depth to water: $63.17 \mathrm{H}(19.25 \mathrm{~m})$ below TOC

Water elevation: $174.13 \mathrm{tt}(53.08 \mathrm{~m}) \mathrm{ms}$

p conductance: $188 \mu \mathrm{S} / \mathrm{cm}$

Water evacuated before sampling. $2.86 \mathrm{gal}$

LABORATOAY ANALYSES

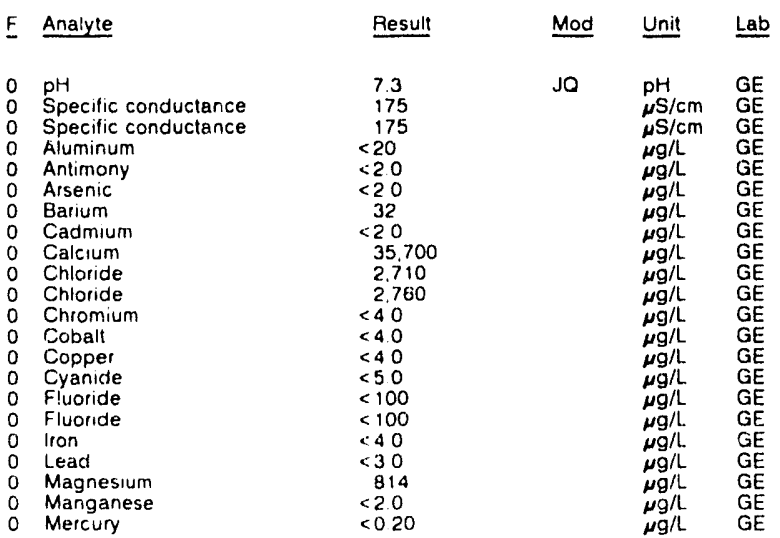

Time: $10: 40$
pH: 10.3
Alkalinity: $32 \mathrm{mg} / \mathrm{L}$
Water temperature: $18.0^{\circ} \mathrm{C}$

M

.




\section{ANALYTICAL RESULTS}

WELL HSB 83A collected on 10/03/91, laboratory analyses (cont.)

\begin{tabular}{|c|c|c|c|}
\hline Analyte & Result & Mod & Unit \\
\hline $\begin{array}{l}\text { Nickel } \\
\text { Nitrate as nitrogen } \\
\text { Potassium } \\
\text { Selenium } \\
\text { Silica } \\
\text { Silver } \\
\text { Sodium } \\
\text { Sultate } \\
\text { Sultate } \\
\text { Total dissolved solids } \\
\text { Total organic carbon } \\
\text { Total organic halogens } \\
\text { Total phosphates (as P) } \\
\text { Venadium } \\
\text { Zinc } \\
\text { Groes alpha } \\
\text { Nonvolatife beta } \\
\text { Total radium } \\
\text { Tritium }\end{array}$ & $\begin{array}{l}<4.0 \\
<50 \\
836 \\
<2.0 \\
28,100 \\
<2.0 \\
1,810 \\
5,990 \\
6,030 \\
130,000 \\
<1,000 \\
14 \\
50 \\
<8.0 \\
<2.0 \\
<2.0 E-09 \\
2.3 E-09 \pm 1.1 E-09 \\
<1.0 E \cdot 09 \\
3.2 E-06+3.0 E \cdot 07\end{array}$ & $\begin{array}{l}\mathrm{J} 1 \\
\mathrm{~J} 2\end{array}$ & 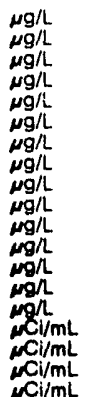 \\
\hline
\end{tabular}

\section{WELL HSB 83B}

MEASUREMENTS CONDUCTED IN THE FIELO

Sample date: $10103 / 8$

Depth to water: $12.77 \mathrm{n}(3.89 \mathrm{~m})$ below TOC Water elevation: $224.23 \mathrm{tt}(68.35 \mathrm{~m}) \mathrm{msl}$

PH: 6.7 Alkalinity: $49 \mathrm{mg} / \mathrm{l}$

Water temperature: $19.3^{\circ} \mathrm{C}$

LABORATORY ANALYSES

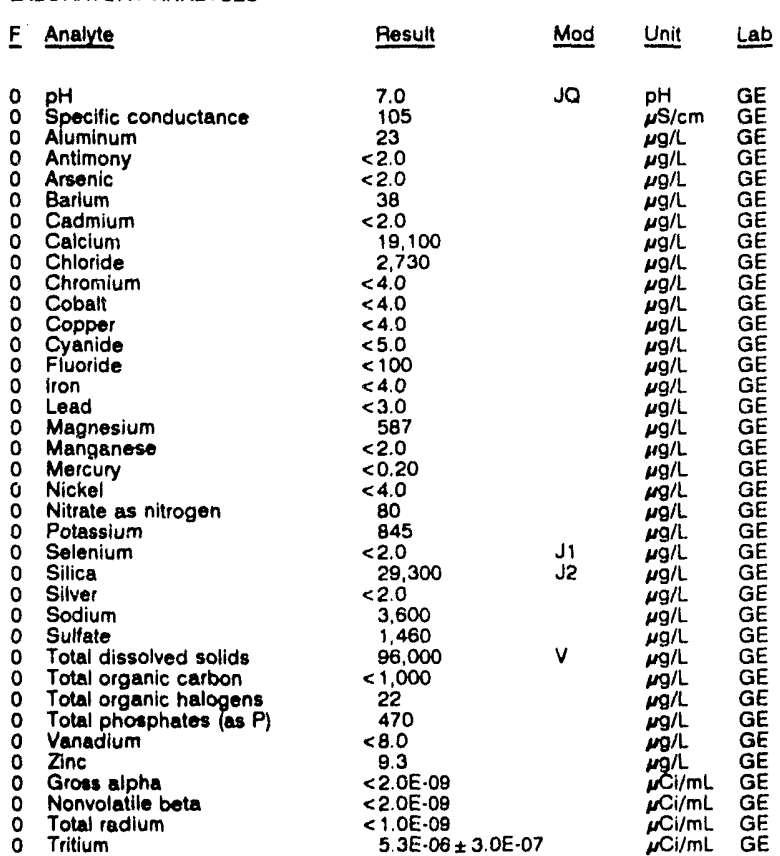

WELL HSB 83C

MEASUREMENTS CONDUCTED IN THE FIELD

Sample date: 10/03/91

Depth to water: $11.18 \mathrm{H}(3.41 \mathrm{~m})$ below TOC Water elevation: $225.81 \mathrm{ft}(68.88 \mathrm{~m}) \mathrm{ms}$

Water evacuated before sampling: $172 \mathrm{gal}$

LABOPATORY ANALYSES

$\begin{array}{ll}\text { E } & \text { Analyte } \\ 0 & \text { pH } \\ 0 & \text { Specific conductance } \\ 0 & \text { Aluminum } \\ 0 & \text { Antimony } \\ 0 & \text { Arsenic } \\ 0 & \text { Barium } \\ 0 & \text { Cadmium } \\ 0 & \text { Calcium } \\ 0 & \text { Chloride } \\ 0 & \text { Chromium }\end{array}$

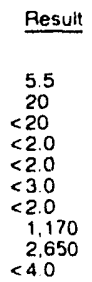

Time: $13: 50$

Alkalinity: $1 \mathrm{mg}$

Water temperature: $19.2^{\circ} \mathrm{C}$

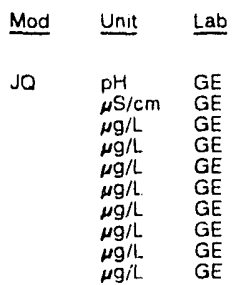

WELL HSB B3C collected on 10/03/91, laboratory analyses (cont.)

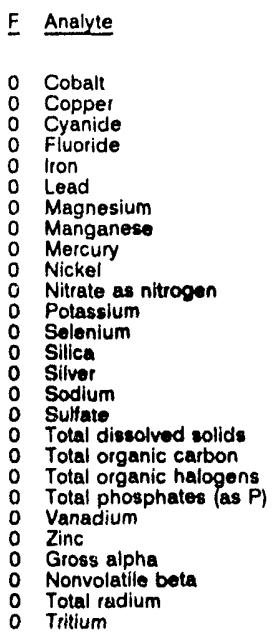

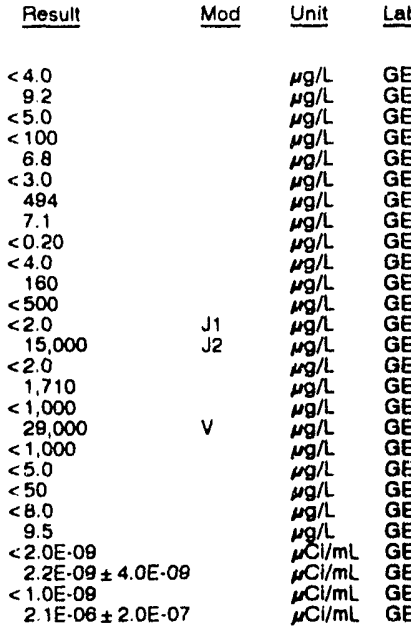

WELL HSB 83D

MEASUREMENTS CONDUCTED IN THE FIELD
Sample date: 10/03/91

Depth to water: $11.87 \mathrm{~h}(3.62 \mathrm{~m})$ below TOC

Water olevation: 225.13 it $(68$

Sp. conductance: $119 \mu \mathrm{s} / \mathrm{cm} / \mathrm{m}$ ) $\mathrm{ms}$

vacuated before sampling: $69 \mathrm{gal}$

LABORATORY ANALYSES

F Analyte

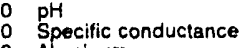

Aluminum

Antimony

Arsenic
0 Barium

Cadmium

Calcium

Chloride

Cobait

Copper

0 Cyanide

Iron

Lead

2 Magnesium

Mercun

Nickel

Potassium

Selenium

Silica

$\begin{array}{ll}0 & \text { Silver } \\ 0 & \text { Sodium } \\ 0 & \text { Sulfate }\end{array}$

Total dissolved solids

Total organic carbon

Total organic halogens

Vanadiu

Zinc

Gross alpha

Nonvolatile bet

Total activity

Tritium
Nitrate as nitrogen

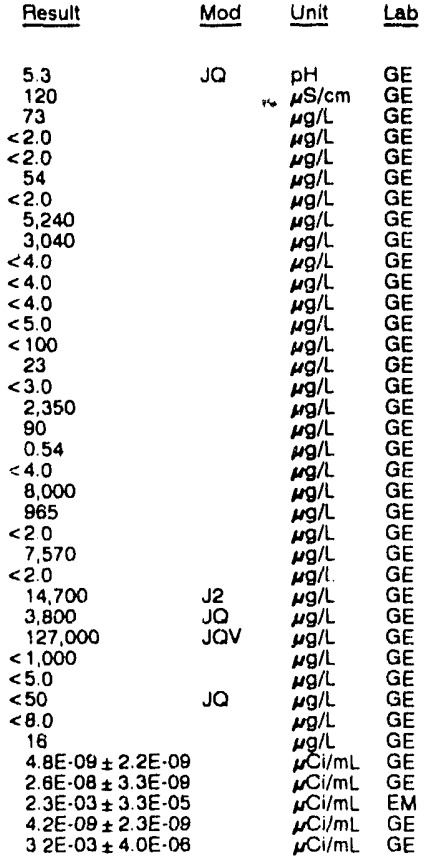

Time: 12:50

PH: 5.1

Alkalinity: $1 \mathrm{mg} / \mathrm{h}$ : $18 . F^{\circ} \mathrm{C}$ 
ANALYTICAL RESULTS

WELL HSB 84A

MEASUREMENTS CONDUCTED IN THE FIELD

Sample date: 10/02/81

Depth to water: $56.03 \mathrm{H}(17.08 \mathrm{~m})$ below TOC

Sp. conductance: $1107 \mathrm{ft}(52.68$

Water evecumed before sampling: $305 \mathrm{gal}$

LABORATOFY ANAL YSES
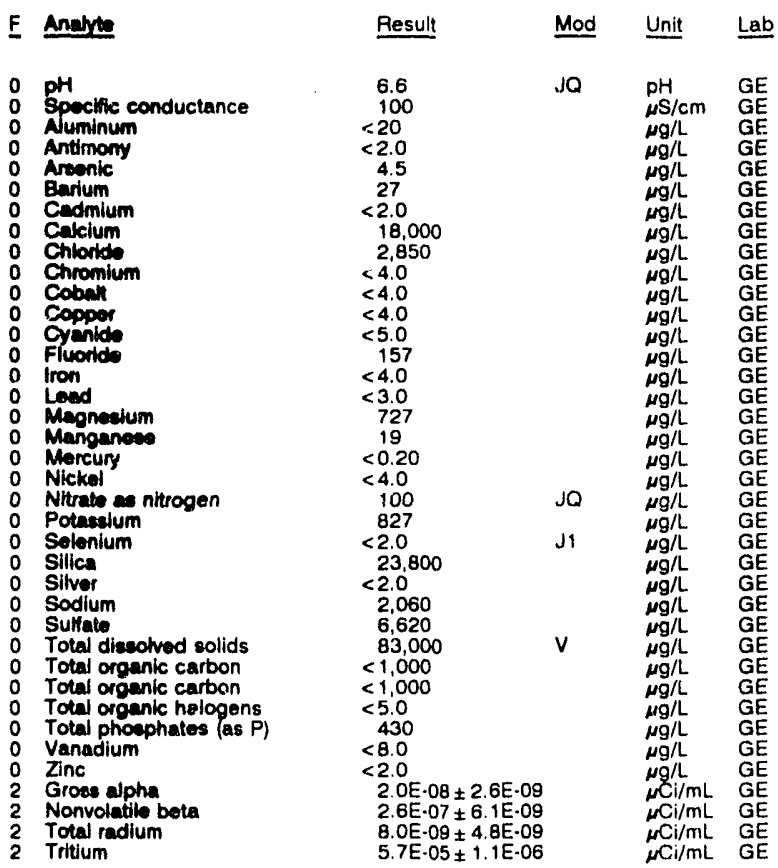

WELL HSB 84B

MEASUREMENTS CONDUCTED IN THE FIELD

Sample date: 10/02/81

Depth to water: $17.20 \mathrm{ft}(5.24 \mathrm{~m})$ below TOC Water elevation: $211.70 \mathrm{ft}(64.5$

Sp. conductance: $202 \mu \mathrm{S} / \mathrm{cm}$

Water evacuated before sampling: $259 \mathrm{gal}$

LABORATORY ANALYSES

$\begin{array}{ll}\text { F } & \text { Analyte } \\ & \\ 0 & \text { pH } \\ 0 & \text { Specific conductance } \\ 0 & \text { Aluminum } \\ 0 & \text { Antimony } \\ 0 & \text { Arsenic } \\ 0 & \text { Barium } \\ 0 & \text { Cadmium } \\ 0 & \text { Calcium } \\ 0 & \text { Chloride } \\ 0 & \text { Chromium } \\ 0 & \text { Cobalt } \\ 0 & \text { Copper } \\ 0 & \text { Cyanlde } \\ 0 & \text { Fluoride } \\ 0 & \text { Fluoride } \\ 0 & \text { Iron } \\ 0 & \text { Lead } \\ 0 & \text { Magnesium } \\ 0 & \text { Manganese } \\ 0 & \text { Mercury } \\ 0 & \text { Nickel } \\ 0 & \text { Nitrate as nitrogen } \\ 0 & \text { Potassium } \\ 0 & \text { Selenium } \\ 0 & \text { Silica } \\ 0 & \text { Silver } \\ 0 & \text { Sodium } \\ 0 & \text { Sulfate } \\ 0 & \text { Total dissolved solids } \\ 0 & \text { Total organic carbon } \\ 0 & \text { Total organic halogens } \\ 0 & \text { Total phosphates (as P) } \\ 0 & \text { Vanadium } \\ & \end{array}$

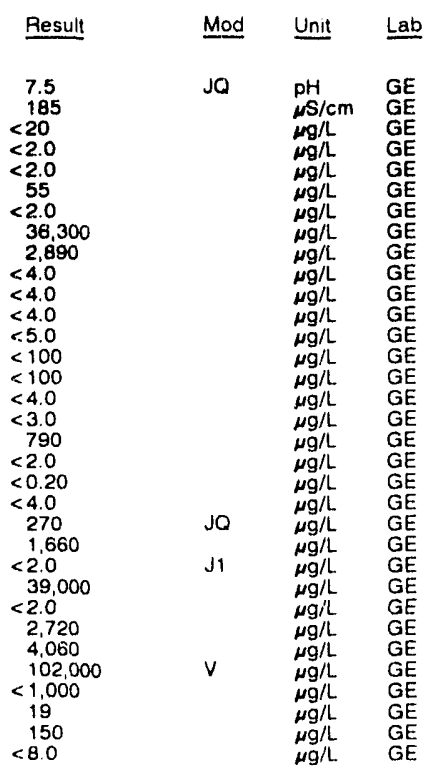

WELL HoH 848 collected on 10/02/91, laboratory analyses (cont.)

\begin{tabular}{|c|c|c|c|}
\hline F Analyte & Pesult & Mod & Unit \\
\hline $\begin{array}{ll}0 & \text { Zinc } \\
0 & \text { Gross alpha } \\
0 & \text { Nonvolatile beta } \\
0 & \text { Total radium } \\
2 & \text { Tritium }\end{array}$ & $\begin{array}{l}<2.0 \\
<2.0 \mathrm{E} \cdot 09 \\
4.6 \mathrm{E} \cdot 09 \pm 1.3 \mathrm{E} \cdot 09 \\
<1.0 \mathrm{E}-09 \\
2.6 \mathrm{E}-05 \pm 7.0 \mathrm{E} \cdot 07\end{array}$ & & $\begin{array}{l}\mu \mathrm{g} / \mathrm{L} \\
\mu \mathrm{Cl} / \mathrm{mL} \\
\mu \mathrm{Cl} / \mathrm{mL} \\
\mu \mathrm{Ci} / \mathrm{mL} \\
\mu \mathrm{Ci} / \mathrm{mL}\end{array}$ \\
\hline
\end{tabular}

WELL HSB 84C

MEASUREMENTS CONDUCTED IN THE FIELD

Sample date: 10/02/91

Depth to water: $14.52 \mathrm{ft}(4.43 \mathrm{~m})$ below TOC

Water elevation: $214.58 \mathrm{~h}(65.40 \mathrm{~m}) \mathrm{ms}$

mpling: $17 \mathrm{gal}$

Time: $10: 00$

Alkalinity: $29 \mathrm{mg} / \mathrm{L}$

Wator temperature: $19.8^{\circ} \mathrm{C}$

LABORATORY ANALYSES

O $\mathrm{pH}$

Aluminum

O Antimony

0 Barium

- Cadmium

o Calcium

o Chloride

o Chromium

Coppe

0 Cyanide

0 Iron

Magnesium

Mangesium

0 Mercury

2 Nitrate as nitrogen

Potassium

$\begin{array}{ll}0 & \text { Selenium } \\ 0 & \text { Silica }\end{array}$

Silver

Sodium

Sulfate

Total dissolved solids

Total dissolved solid

Total organic carbon

Total phosphates (as P)

Vanadium

Zinc

Gross alpha

Nonvolatile beta

Total activity

2 Tritium
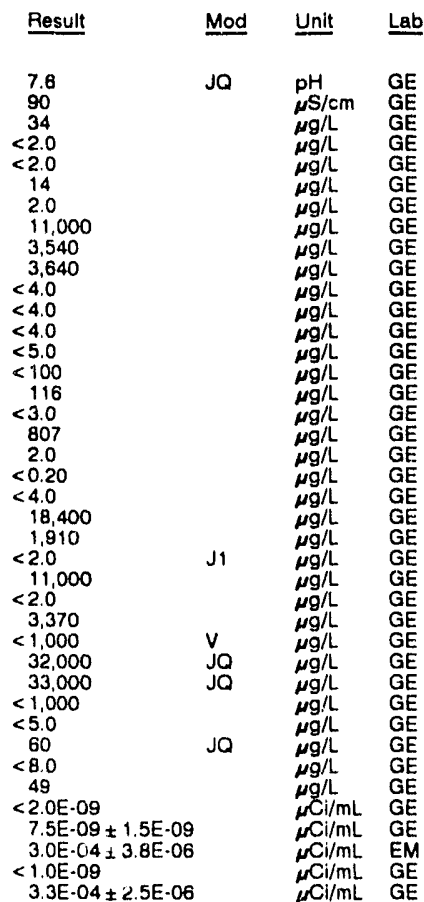

WELL HSB 84D

MEASUREMENTS CONDUCTED IN THE FIELD

Sample date: 10/02/91

Depth to water: $8.21 \mathrm{ft}(2.81 \mathrm{~m})$ below TOC

Water elevation: $218.59 \mathrm{ft}(66.93 \mathrm{~m}) \mathrm{ms}$

Sp. conductance: $141, \mathrm{~S} / \mathrm{cm}$

Water evacuated before sampling: $53 \mathrm{gal}$

Time: $8: 45$

pH: 3.9

Alkalinity: $0 \mathrm{mg} / \mathrm{l}$

Water temperature: $20.1^{\circ} \mathrm{C}$

LABORATORY ANALYSES

$\begin{array}{ll}\text { F } & \text { Analyte } \\ 0 & \text { pH } \\ 0 & \text { Specific conductance } \\ 2 & \text { Aluminum } \\ 0 & \text { Antimony } \\ 0 & \text { Arsenic } \\ 0 & \text { Garium } \\ 0 & \text { Cadmium } \\ 0 & \text { Calcium } \\ 0 & \text { Chloride } \\ 0 & \text { Chromium } \\ 0 & \text { Cobalt } \\ 0 & \text { Copper } \\ 0 & \text { Cyanide } \\ 0 & \text { Fluoride } \\ 0 & \text { lron } \\ 0 & \text { Lead } \\ 0 & \text { Magnesium } \\ 2 & \text { Manganese } \\ 0 & \text { Mercury } \\ 0 & \text { Nickel } \\ 2 & \text { Nitrate as nitrogen }\end{array}$
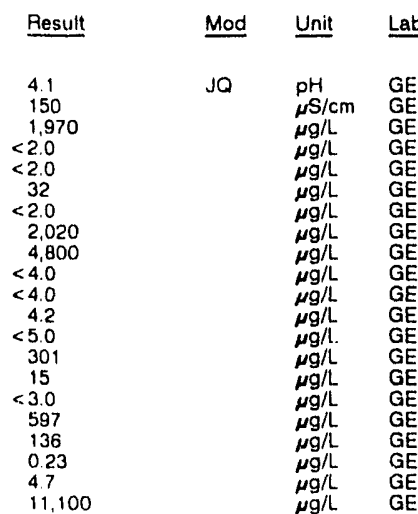
ANALYTICAL RESULTS

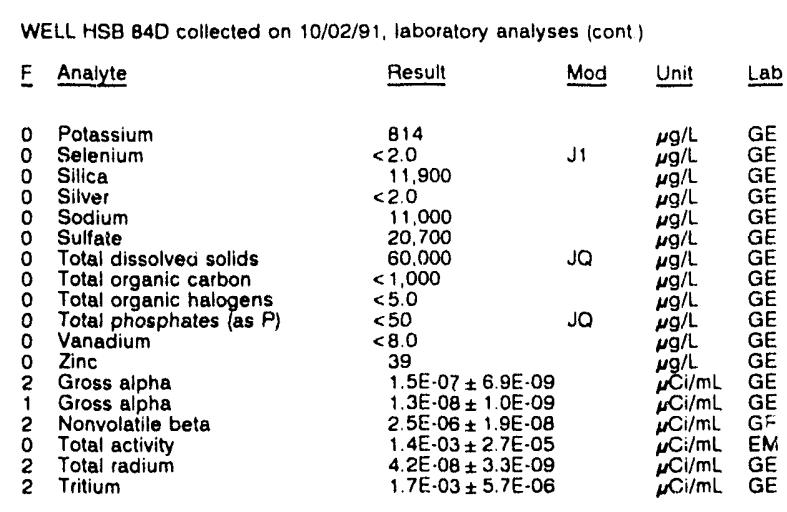

\section{WELL HSB 85A}

MEASUREMENTS CONDUCTED IN THE FIELD

Sample date: $10 / 02 / 91$
Depth to water: $124.62 \mathrm{H}(37.98 \mathrm{~m})$ below TOC
Water elevation: $169.78 \mathrm{Ht}(51.75 \mathrm{~m}) \mathrm{mst}$
Sp. conductance: $185 \mu \mathrm{s} / \mathrm{cm}$
Water evacuated belore sampling: $285 \mathrm{gal}$
LABORATORY ANALYSES

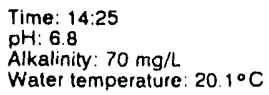

LABORATORY ANALYSES

E Analyte Result Mod Unit

\begin{tabular}{|c|c|c|c|}
\hline Analyte & Result & Mod & Unit \\
\hline 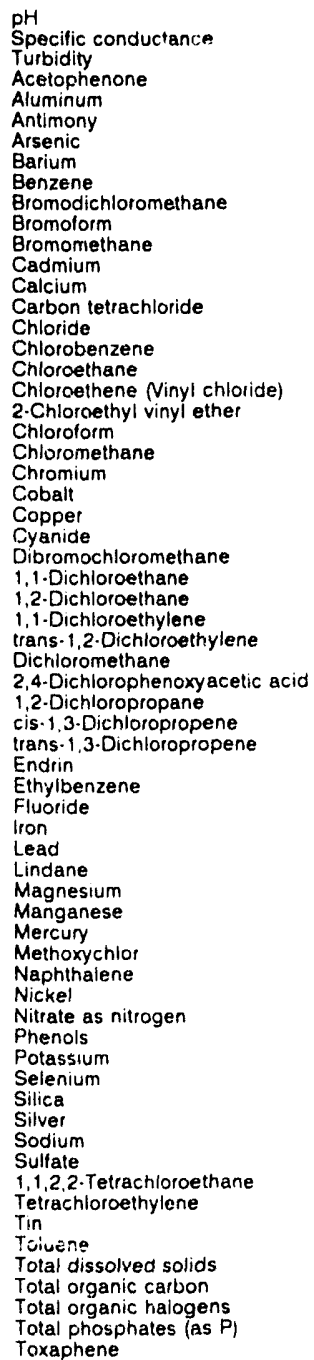 & $\begin{aligned} & 7.0 \\
& 165 \\
& 1.1 \\
&<10 \\
&<20 \\
&<2.0 \\
&<2.0 \\
& 31 \\
&<1.0 \\
&<1.0 \\
&<1.0 \\
&<1.0 \\
&<2.0 \\
& 33.900 \\
&<1.0 \\
& 2,890 \\
&<1.0 \\
&<1.0 \\
&<1.0 \\
&<1.0 \\
&<1.0 \\
&<1.0 \\
&<4.0 \\
&<4.0 \\
&<4.0 \\
&<5.0 \\
&<1.0 \\
&<1.0 \\
&<1.0 \\
&<1.0 \\
&<1.0 \\
&<1.0 \\
&<0.30 \\
&<1.0 \\
&<1.0 \\
&<1.0 \\
&<0.0060 \\
&<1.0 \\
& 103 \\
&<40 \\
&<30 \\
&<0.0050 \\
& 867 \\
&<2.0 \\
&<020 \\
&<0.50 \\
&<10 \\
&<4.0 \\
&<50 \\
&<5.0 \\
& 1.140 \\
&<2.0 \\
& 28.100 \\
&<2.0 \\
& 1.760 \\
& 6.660 \\
&<10 \\
&<1.0 \\
& 516 \\
&<1.0 \\
& 1121.000 \\
&<1.000 \\
&<50 \\
& 1120 \\
&<024\end{aligned}$ & JQ & 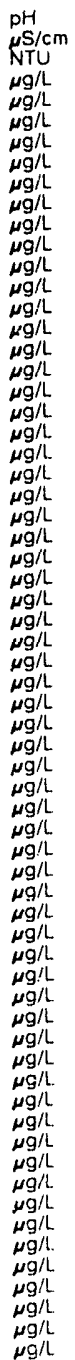 \\
\hline
\end{tabular}

WE!L HSB 85A collected on 10/02/91, laboratory analyses (cont.)

\begin{tabular}{|c|c|c|c|}
\hline Analyle & Result & Mod & Unit \\
\hline $\begin{array}{l}\text { 2,4.5-TP (Silvex) } \\
1,1,1 \cdot \text { Tricnloroethane } \\
1,1,2-\text { Trichloroethane } \\
\text { Trichloroethylene } \\
\text { Trichlorofluoromethane } \\
\text { Vanadium } \\
\text { Xylenes } \\
\text { Zinc } \\
\text { Gross alpha } \\
\text { Nonvolatile beta } \\
\text { Total radium } \\
\text { Tritium }\end{array}$ & $\begin{array}{l}<0.090 \\
<1.0 \\
<1.0 \\
<1.0 \\
<1.0 \\
<8.0 \\
<2.0 \\
<2.0 \\
<2.0 E-09 \\
<2.05 \cdot 09 \\
<1.0 \mathrm{E} \cdot 09 \\
<7.0 \mathrm{E} \cdot 07\end{array}$ & & $\begin{array}{l}\mu g / L \\
\mu g / L \\
\mu g / L \\
\mu g / L \\
\mu g / L \\
\mu g / L \\
\mu g / L \\
\mu g / L \\
\mu \mathrm{L} / \mathrm{mL} \\
\mu \mathrm{CC} / \mathrm{mL} \\
\mu \mathrm{Ci} / \mathrm{mL} \\
\mu \mathrm{Ci} / \mathrm{mL}\end{array}$ \\
\hline
\end{tabular}

WELL HSB 85B

MEASUREMENTS CONDUCTED IN THE FIELO

Sample date: $10 / 02 / 91$

Depth to water: $59.37 \mathrm{ft}(18.10 \mathrm{~m})$ below TOC Water elevation: $235.13 \mathrm{H}(71.67 \mathrm{~m}) \mathrm{msl}$

Water evacuated before sampling: $48 \mathrm{gal}$

The well went dry duting purging.

LABORATORY ANALYSES

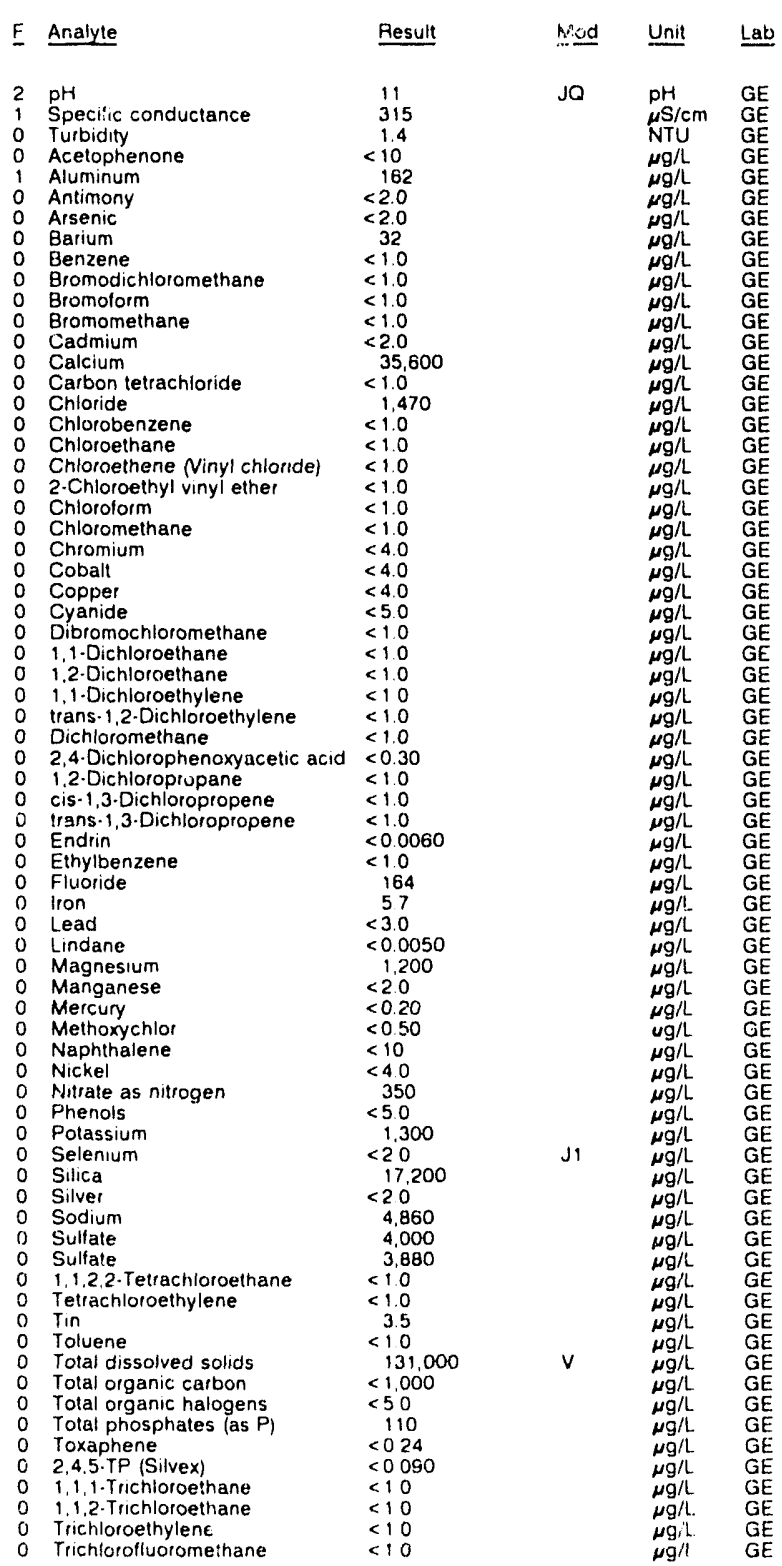

iime. 13:35

pH: 10.3 .

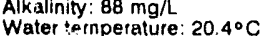


ANALYTICAL RESULTS

WELL HSB 858 collected on 10/02/9i, laboratory analyses (cont.)

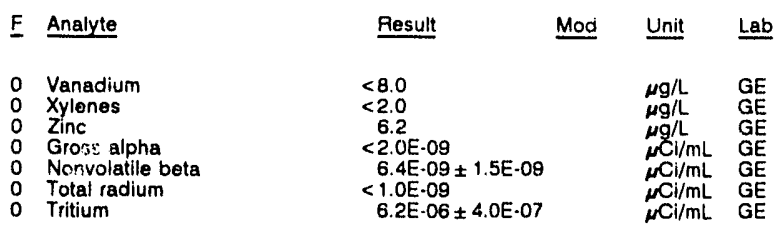

WELL HSB 85C

MEASUAEMENTS CONDUCTED IN THE FIELD

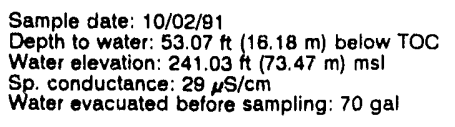

Time: 14:00

pH: 4.6 Alkalinity: $0 \mathrm{mg} / \mathrm{L}$

Water temperature: $20.1^{\circ} \mathrm{C}$

LABORATORY ANALYSES

\section{E Analyte \\ Specific conductance}

0 Suibidity

Acetophenone

Aluminum

Antimony

Arsenic

Benzene

Bromodichloromethane

Bromomethane

Cadmium

Calcium
Carbon tetrachloride
Chloride

Chlorobenzene

Chloroethane

2-Chloroethyl vinyl ether

Chlorolorm

Chloromethan

Chromium

Copper

Cyanide

0 1,1-Dichloroethane

1,2-Dichloroethane

1,1-Dichloroethylene
trans-1,2-Dichloroethylene
Dichloromethane

2,4.Dichlorophenoxyacetic acid $<1.0$

1,2.Dichloropropane

cis-1,3-Dichloropropene

trans-1,3-Dichloropropene

O Endrin

Ethylbenzene

Fluoride

0 Iron

Lead

Lindane

Magnesium

Manganese

Methoxychlor

Naphthalene

Nickel

Nitrate as nitrogen

Phenols

Selassium

Silica

Silver

0 Sodium

Sulfate

1,1,2,2-Tetrachloroetha
Tetrachloroethylene

Tin

Toluene

Total dissolved solids

Total organic carbon

Total organic carbon

Total phosphates las P

Toxaphene

1,1,1-Trichloroethane

1,1,2-Trichloroethane

Trichloroethylene

Trichlorofluoromethane

Vanadium

0 Xylenes

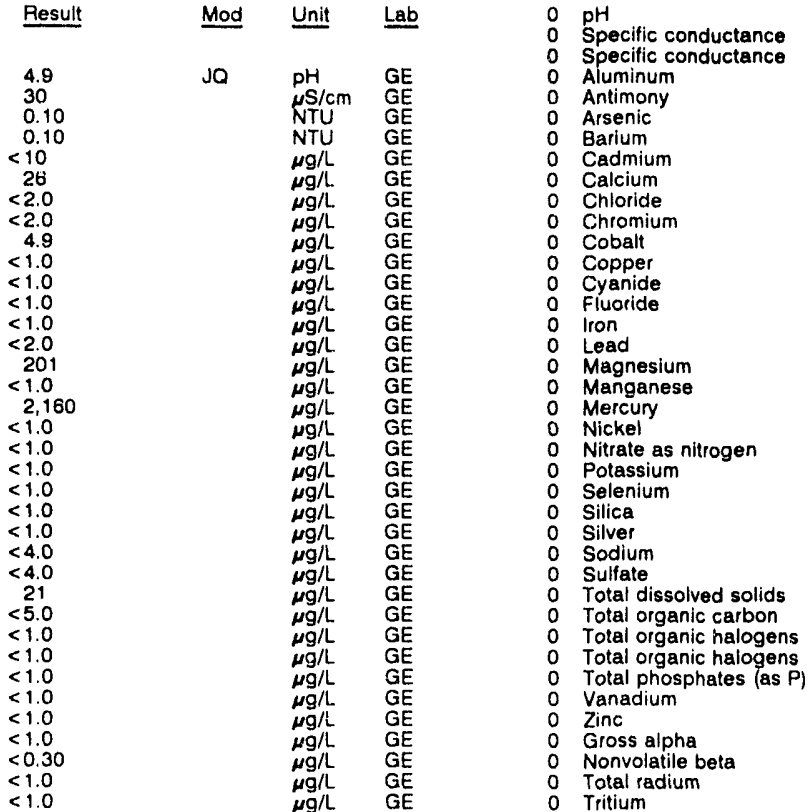

$<1.0$

$<0.0060$

$<1.0$

$<100$

$<100$

$<4.0$
$<3.0$

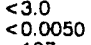

107
2.4

2.4
$<0.20$
$<0.50$

$<0.50$

$<<4.0$

$<4.0$

$<5.0$
$<500$

$<2.0$
6,320

$<2.0$
3.610

3,610
$<1,000$

$<1.0$

$<1.0$

$<10$
$<1.0$

30,000
$<1,000$
$<1,000$

9.6

$<50$
$<0.24$

$<0.24$

$<1.0$

$<1.0$
$<1.0$
$<1.0$

$<1.0$
$<8.0$

$<2.0$
2.9
WELL HSB BSC collected on 10/02/91, laboratory analyses (cont.)

\begin{tabular}{|c|c|c|c|}
\hline E Analyte & Result & Mod & Unit \\
\hline $\begin{array}{ll}0 & \text { Gross alpha } \\
0 & \text { Nonvolatile beta } \\
0 & \text { Total radium } \\
0 & \text { Tritium }\end{array}$ & $\begin{array}{l}<2.0 E-09 \\
<2.0 \mathrm{E}-09 \\
<1.0 \mathrm{E}-09 \\
3.8 \mathrm{~B}-06 \pm 3.0 \mathrm{E}-07\end{array}$ & & $\begin{array}{l}\mu \mathrm{Cl} / \mathrm{mL} \\
\mu \mathrm{Cl} / \mathrm{mL} \\
\mu \mathrm{Cl} / \mathrm{mL} \\
\mu \mathrm{Cl} / \mathrm{mL}\end{array}$ \\
\hline
\end{tabular}

WELL HSB 86A

MEASUREMENTS CONDUCTEO IN THE FIELD

Sample date: 10/02/91

Depth to water: $82.83 \mathrm{ft}(28.28 \mathrm{~m})$ below TOC

Water elevation: $169.57 \mathrm{~h}(51.69 \mathrm{~m}) \mathrm{ms}$

Sp. conductance: $131 \mu \mathrm{s} / \mathrm{cm}$
Water evacuated before sampling: $279 \mathrm{gal}$

pH: 8.4

Alkalinity: $37 \mathrm{mg} / \mathrm{L}$

Water temperature: $20.0^{\circ} \mathrm{C}$

LABOPATORY ANALYSES

\begin{tabular}{|c|c|c|c|}
\hline Analyte & Result & Mod & Unit \\
\hline $\begin{array}{l}\text { pH } \\
\text { Specific conductance } \\
\text { Specific conductance } \\
\text { Aluminum } \\
\text { Antimony } \\
\text { Arsenic } \\
\text { Barium } \\
\text { Cadmium } \\
\text { Calcium } \\
\text { Chloride } \\
\text { Chromium } \\
\text { Cobalt } \\
\text { Copper } \\
\text { Cyanide } \\
\text { Fluoride } \\
\text { ron } \\
\text { Lead } \\
\text { Magnesium } \\
\text { Manganese } \\
\text { Mercury } \\
\text { Nickel } \\
\text { Nitrate as nitrogen } \\
\text { Potassium } \\
\text { Selenium } \\
\text { Silica } \\
\text { Silver } \\
\text { Sodium } \\
\text { Sulfate } \\
\text { Total dissolved solids } \\
\text { Total organic carbon } \\
\text { Total organic halogens } \\
\text { Total organic halogens } \\
\text { Total phosphates (as P) } \\
\text { Vanadium } \\
\text { Zinc } \\
\text { Gross alpha } \\
\text { Nonvolatile beta } \\
\text { Total radium } \\
\text { Tritium }\end{array}$ & $\begin{array}{l}8.8 \\
120 \\
120 \\
<20 \\
<<.0 \\
<2.0 \\
22 \\
<2.0 \\
22,300 \\
2,650 \\
<4.0 \\
<4.0 \\
<4.0 \\
<5.0 \\
128 \\
<4.0 \\
<3.0 \\
743 \\
<2.0 \\
<0.20 \\
<4.0 \\
<50 \\
887 \\
<2.0 \\
27,500 \\
<2.0 \\
1,600 \\
10,800 \\
89,000 \\
<1,000 \\
21 \\
22 \\
210 \\
<8.0 \\
3.1 \\
<2.0 \mathrm{E} \cdot 09 \\
<2.0 \mathrm{E}-09 \\
<1.0 \mathrm{E}-09 \\
<7.0 \mathrm{E}-07\end{array}$ & $\begin{array}{l}\mathrm{JQ} \\
\mathrm{J} 1\end{array}$ & $\begin{array}{l}p H \\
\mu S / \mathrm{cm} \\
\mu \mathrm{S} / \mathrm{cm} \\
\mu g / L \\
\mu g / L \\
\mu g / L \\
\mu g / L \\
\mu g / L \\
\mu g / L \\
\mu g / L \\
\mu g / L \\
\mu g / L \\
\mu g / L \\
\mu g / L \\
\mu g / L \\
\mu g / L \\
\mu g / L \\
\mu g / L \\
\mu g / L \\
\mu g / L \\
\mu g / L \\
\mu g / L \\
\mu g / L \\
\mu g / L \\
\mu g / L \\
\mu g / L \\
\mu g / L \\
\mu g / L \\
\mu g / L \\
\mu g / L \\
\mu g / L \\
\mu g / L \\
\mu g / L \\
\mu g / L \\
\mu g / L \\
\mu C i / m L \\
\mu C i / m L \\
\mu C l / m L \\
\mu C l / m L\end{array}$ \\
\hline
\end{tabular}

WELL HSB 86B

MEASUREMENTS CONDUCTED IN THE FIELD

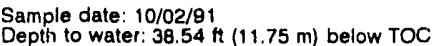
Water elevation: $223.36 \mathrm{ft}(68.08 \mathrm{~m}) \mathrm{ms}$

Sp. conductance: $215 \mu \mathrm{S} / \mathrm{cm}$

Water evacuated before sampling: $287 \mathrm{gal}$

Time: 7.1

Alkalinity: $80 \mathrm{mg} / \mathrm{L}$.

Water temperature: $20.3^{\circ} \mathrm{C}$

LABORATORY ANALYSES

$\begin{array}{ll}\text { F } & \text { Analyte } \\ 0 & \text { pH } \\ 0 & \text { Specific conductance } \\ 0 & \text { Specific conductance } \\ 0 & \text { Aluminum } \\ 0 & \text { Antimony } \\ 0 & \text { Arsenic } \\ 0 & \text { Barium } \\ 0 & \text { Cadmium } \\ 0 & \text { Calcium } \\ 0 & \text { Chloride } \\ 0 & \text { Chromlum } \\ 0 & \text { Cobalt } \\ 0 & \text { Copper } \\ 0 & \text { Cyanide } \\ 0 & \text { Fluoride } \\ 0 & \text { lron } \\ 0 & \text { Lead } \\ 0 & \text { Magnesium } \\ 0 & \text { Manganese } \\ 0 & \text { Mercury } \\ 0 & \text { Nickel } \\ 0 & \text { Nitrate as nitrogen } \\ 0 & \text { Potassium }\end{array}$

\begin{tabular}{l} 
Result \\
\hline \\
7.4 \\
190 \\
200 \\
$<20$ \\
$<2.0$ \\
$<2.0$ \\
38 \\
$<2.0$ \\
41,800 \\
2,880 \\
$<4.0$ \\
$<4.0$ \\
$<4.0$ \\
$<5.0$ \\
$<100$ \\
$<4.0$ \\
$<3.0$ \\
866 \\
$<2.0$ \\
$<0.20$ \\
$<4.0$ \\
$<50$ \\
$<500$
\end{tabular}

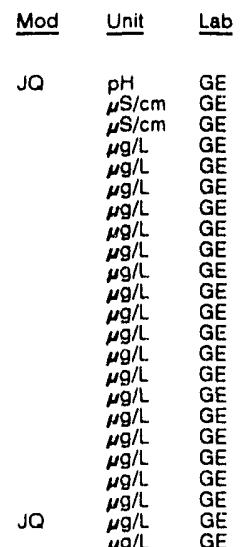


ANALYTICAL RESULTS

WELL. HSB $88 B$ collectod on 10/02/91, la joratory analyses (cont)

\begin{tabular}{|c|c|c|c|c|c|}
\hline$E$ & Analyte & Result & Mod & Unit & Lab \\
\hline $\begin{array}{l}0 \\
0 \\
0 \\
0 \\
0 \\
0 \\
0 \\
0 \\
0 \\
0 \\
0 \\
0 \\
0 \\
0 \\
0\end{array}$ & $\begin{array}{l}\text { Selenium } \\
\text { Sillica } \\
\text { Silver } \\
\text { Sodlum } \\
\text { Sulfate } \\
\text { Total dissolved solids } \\
\text { Total organic carbon } \\
\text { Total organic halogens } \\
\text { Total phosphates (as P) } \\
\text { Vanadium } \\
\text { Zinc } \\
\text { Gross alpha } \\
\text { Nonvolatile beta } \\
\text { Total radium } \\
\text { Tritium }\end{array}$ & $\begin{array}{l}<2.0 \\
36,400 \\
<2.0 \\
2.070 \\
2,980 \\
121.000 \\
<1.000 \\
<5.0 \\
50 \\
<8.0 \\
<2.0 \\
<2.0 E-09 \\
<2.0 E \cdot 09 \\
<1.0 \mathrm{E} \cdot 09 \\
<7.0 \mathrm{E} \cdot 07\end{array}$ & J1 & $\begin{array}{l}\mu g / L \\
\mu g / L \\
\mu g / L \\
\mu g / L \\
\mu g / L \\
\mu g / L \\
\mu g / L \\
\mu g / L \\
\mu g / L \\
\mu g / L \\
\mu g / L \\
\mu C i / m L \\
\mu C i / m L \\
\mu C i / m L \\
\mu C i / m L\end{array}$ & $\begin{array}{l}\mathrm{GE} \\
\mathrm{GE} \\
\mathrm{GE} \\
\mathrm{GE} \\
\mathrm{GE} \\
\mathrm{GE} \\
\mathrm{GE} \\
\mathrm{GE} \\
\mathrm{GE} \\
\mathrm{GE} \\
\mathrm{GE} \\
\mathrm{GE} \\
\mathrm{GE} \\
\mathrm{GE} \\
\mathrm{GE}\end{array}$ \\
\hline
\end{tabular}

\section{WELL HSB 86C}

MEASUREMENTS CONDUCTED IN THE FIELD

Sample date: 10/02/91

Dopth to water: $37.51 \mathrm{n}(11.43 \mathrm{~m})$ below TOC Water elevation: $225.39 \mathrm{ft}(88.70 \mathrm{~m}) \mathrm{ms}$ |

Water evacuated before sampling: $94 \mathrm{gal}$

LABORATORY ANALYSES

\begin{tabular}{|c|c|c|c|c|}
\hline Analyte & Result & Mod & Unit & Lab \\
\hline $\begin{array}{l}\text { pH } \\
\text { Specific conductence } \\
\text { Aluminum } \\
\text { Antimony } \\
\text { Arsenic } \\
\text { Barium } \\
\text { Cadmium } \\
\text { Caicium } \\
\text { Chloride } \\
\text { Chromium } \\
\text { Cobalt } \\
\text { Copper } \\
\text { Cyanide } \\
\text { Fluoride } \\
\text { lron } \\
\text { Lead } \\
\text { Magnesium } \\
\text { Manganese } \\
\text { Mercury } \\
\text { Nickel } \\
\text { Nitrate as nitrogen } \\
\text { Potassium } \\
\text { Selenium } \\
\text { Silica } \\
\text { Silver } \\
\text { Sodium } \\
\text { Sulfate } \\
\text { Total dissolved solids } \\
\text { Total organic carbon } \\
\text { Total organic halogens } \\
\text { Total phosphates (as P) } \\
\text { Vanadium } \\
\text { Zinc } \\
\text { Gross alpha } \\
\text { Nonvolatile beta } \\
\text { Total activity } \\
\text { Total radium } \\
\text { Tritium }\end{array}$ & $\begin{array}{l}4.3 \\
335 \\
786 \\
<2.0 \\
<2.0 \\
93 \\
15 \\
10,400 \\
3,160 \\
<4.0 \\
79 \\
6.2 \\
<5.0 \\
246 \\
14 \\
<3.0 \\
3,540 \\
3,720 \\
<0.20 \\
123 \\
39,000 \\
1,980 \\
<2.0 \\
21,100 \\
<2.0 \\
35,900 \\
33,500 \\
258,000 \\
<1,000 \\
<5.0 \\
<50 \\
<8.0 \\
107 \\
55 \mathrm{E} \cdot 08 \pm 6.7 \mathrm{E} \cdot 09 \\
3.8 \mathrm{E}-07 \pm 1.1 \mathrm{E} \cdot 08 \\
12 \mathrm{E} \cdot 02 \pm 1.7 \mathrm{E}-04 \\
2.0 \mathrm{E} \cdot 08 \pm 3.6 \mathrm{E} \cdot 09 \\
1.5 \mathrm{E} \cdot 02 \pm 8.6 \mathrm{E} \cdot 06\end{array}$ & $\begin{array}{l}\mathrm{J} 2 \\
\mathrm{JQ} \\
\mathrm{JQV}\end{array}$ & $\begin{array}{l}\mathrm{pH} \\
\mu \mathrm{S} / \mathrm{cm} \\
\mu g / L \\
\mu g / L \\
\mu g / L \\
\mu g / L \\
\mu g / L \\
\mu g / L \\
\mu g / L \\
\mu g / L \\
\mu g / L \\
\mu g / L \\
\mu g / L \\
\mu g / L \\
\mu g / L \\
\mu g / L \\
\mu g / L \\
\mu g / L \\
\mu g / L \\
\mu g / L \\
\mu g / L \\
\mu g / L \\
\mu g / L \\
\mu g / L \\
\mu g / L \\
\mu g / L \\
\mu g / L \\
\mu g / L \\
\mu g / L \\
\mu g / L \\
\mu g / L \\
\mu g / L \\
\mu g / L \\
\mu C i / m L \\
\mu C \mathrm{i} / \mathrm{mL} \\
\mu K \mathrm{i} / \mathrm{mL} \\
\mu C \mathrm{~L} / \mathrm{mL} \\
\mu \mathrm{Ci} / \mathrm{mL}\end{array}$ & $\begin{array}{l}\mathrm{GE} \\
\mathrm{GE} \\
\mathrm{GE} \\
\mathrm{GE} \\
\mathrm{GE} \\
\mathrm{GE} \\
\mathrm{GE} \\
\mathrm{GE} \\
\mathrm{GE} \\
\mathrm{GE} \\
\mathrm{GE} \\
\mathrm{GE} \\
\mathrm{GE} \\
\mathrm{GE} \\
\mathrm{GE} \\
\mathrm{GE} \\
\mathrm{GE} \\
\mathrm{GE} \\
\mathrm{GE} \\
\mathrm{GE} \\
\mathrm{GE} \\
\mathrm{GE} \\
\mathrm{GE} \\
\mathrm{GE} \\
\mathrm{GE} \\
\mathrm{GE} \\
\mathrm{GE} \\
\mathrm{GE} \\
\mathrm{GE} \\
\mathrm{GE} \\
\mathrm{EM} \\
\mathrm{GE}\end{array}$ \\
\hline
\end{tabular}

\section{WELL HSB 860}

MEASUREMENTS CONDUCTED IN THE FIELD

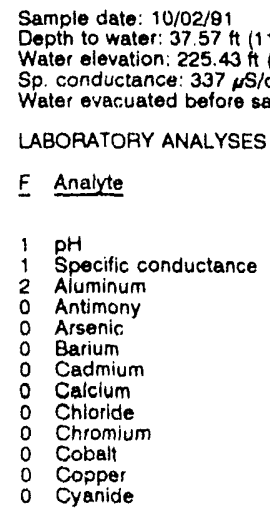

Time: $16: 20$

PH: 3.7

Water temperature: $20.3^{\circ} \mathrm{C}$

Time: $16: 05$

PH: 4.2 Alkalinity: $0 \mathrm{mg} / \mathrm{L}$

Water temperature: $20.4^{\circ} \mathrm{C}$

$\underline{\text { Lab }}$
WELL HSB 86D collected on 10/02/91, laboratory analyses (cont.)

\begin{tabular}{|c|c|c|c|c|c|}
\hline$F$ & Analyte & Result & Mod & Unit & Lab \\
\hline $\begin{array}{l}0 \\
0\end{array}$ & $\begin{array}{l}\text { Fluoride } \\
\text { lron } \\
\text { Lead } \\
\text { Magnesium } \\
\text { Manganese } \\
\text { Mercury } \\
\text { Nickel } \\
\text { Nitrate as nitrogen } \\
\text { Potassium } \\
\text { Selenium } \\
\text { Silica } \\
\text { Silver } \\
\text { Sodium } \\
\text { Sulfate } \\
\text { Total dissolved sollds } \\
\text { Total organic carbon } \\
\text { Total organic halogens } \\
\text { Total phosphates (as P) } \\
\text { Vanadium } \\
\text { Zinc } \\
\text { Gross alpha } \\
\text { Nonvolatile beta } \\
\text { Total activity } \\
\text { Total radium } \\
\text { Tritium }\end{array}$ & 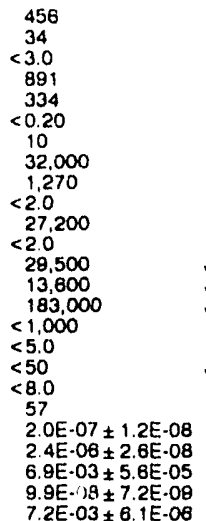 & $\begin{array}{l}\mathrm{J} 2 \\
\mathrm{JO} \\
\mathrm{JOV} \\
\mathrm{J}\end{array}$ & $\begin{array}{l}\mu g / L \\
\mu g / L \\
\mu g / L \\
\mu g / L \\
\mu g / L \\
\mu g / L \\
\mu g / L \\
\mu g / L \\
\mu g / L \\
\mu g / L \\
\mu g / L \\
\mu g / L \\
\mu g / L \\
\mu g / L \\
\mu g / L \\
\mu g / L \\
\mu g / L \\
\mu g / L \\
\mu g / L \\
\mu g / L \\
\mu C i / m L \\
\mu C i / m L \\
\mu C i / m L \\
\mu C i / m L \\
\mu C i / m L\end{array}$ & $\begin{array}{l}\mathrm{GE} \\
\mathrm{GE} \\
\mathrm{GE} \\
\mathrm{GE} \\
\mathrm{GE} \\
\mathrm{GE} \\
\mathrm{GE} \\
\mathrm{GE} \\
\mathrm{GE} \\
\mathrm{GE} \\
\mathrm{GE} \\
\mathrm{GE} \\
\mathrm{GE} \\
\mathrm{GE} \\
\mathrm{GE} \\
\mathrm{GE} \\
\mathrm{GE} \\
\mathrm{GE} \\
\mathrm{GE} \\
\mathrm{GE} \\
\mathrm{GE} \\
\mathrm{GE} \\
\mathrm{EM} \\
\mathrm{GE} \\
\mathrm{GE}\end{array}$ \\
\hline
\end{tabular}

\section{WELL HSB $100 \mathrm{C}$}

MEASUREMENTS CONDUCTED IN THE FIELD

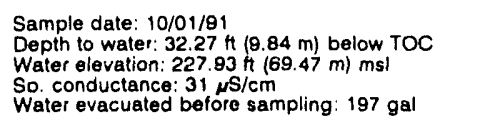

Time: $16 \cdot 10$

PH: 5.5

Water temperature: $20.2^{\circ} \mathrm{C}$

LABORATORY ANALYSES

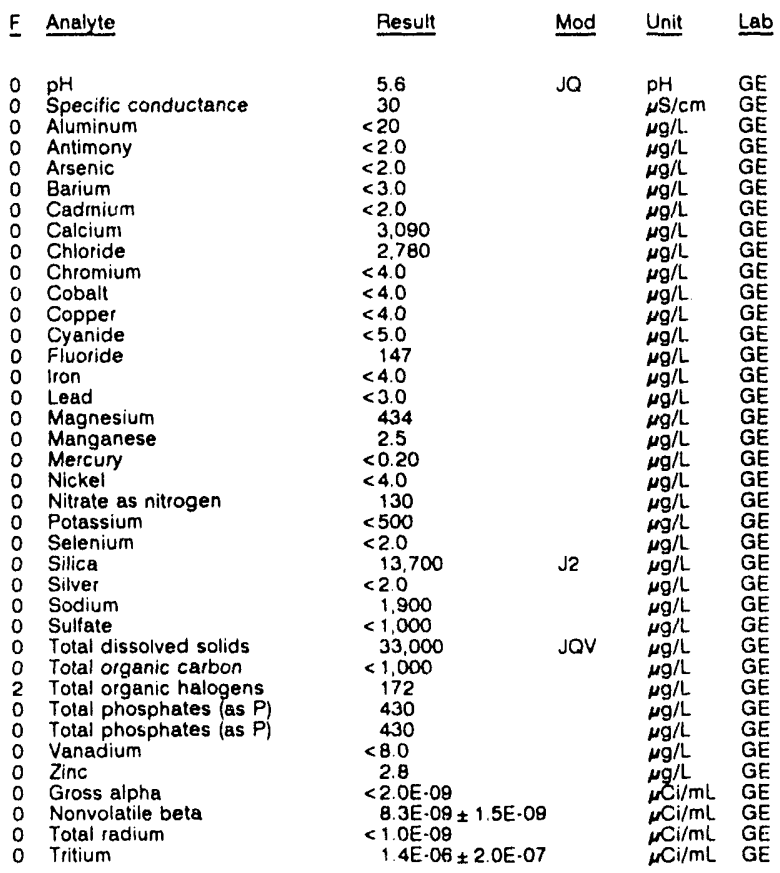

\section{WELL HSB100D}

MEASUREMENTS CONDUCTED IN THE FIELD

\begin{tabular}{|c|c|c|c|c|}
\hline Analyte & Result & Mod & Unit & Lab \\
\hline $\begin{array}{ll}0 & \text { pH } \\
0 & \text { Specific conductance } \\
0 & \text { Aluminum }\end{array}$ & $\begin{array}{r}5.5 \\
70^{\circ} \\
<20\end{array}$ & JO & $\begin{array}{l}\mathrm{pH} \\
\mu \mathrm{S} / \mathrm{cm} \\
\mu \mathrm{g} / \mathrm{L}\end{array}$ & $\begin{array}{l}\mathrm{GE} \\
\mathrm{GE} \\
\mathrm{GE}\end{array}$ \\
\hline
\end{tabular}

Sample date: 10/01/81

Depth to water: $24.81 \mathrm{H}(7.56 \mathrm{~m})$ below TOC

Water elevation: $235.29 \mathrm{ft}(71.72 \mathrm{~m}) \mathrm{msl}$

$\mathrm{Sp}$ conductance $76 \mu \mathrm{S} / \mathrm{cm}$

Water evacuated belore sampling $48 \mathrm{gal}$

LABORATORY ANALYSES

Time: $15: 55$

pH: 5.1 . $1 \mathrm{mg}$

Alkalinity: $1 \mathrm{mg} / \mathrm{L}, 1.10 \mathrm{C}$

4,570
$<2.0$

73
$<2.0$

$<.340$
3,220

$<4.0$
9.7

9.7
5.5
$<5.0$ jo

$\begin{array}{ll}\mu g / L & \mathrm{GE} \\ \mu \mathrm{g} / \mathrm{L} & \mathrm{GE} \\ \mu g / \mathrm{L} & \mathrm{GE}\end{array}$
Aluminum 
ANALYTICAL RESULTS

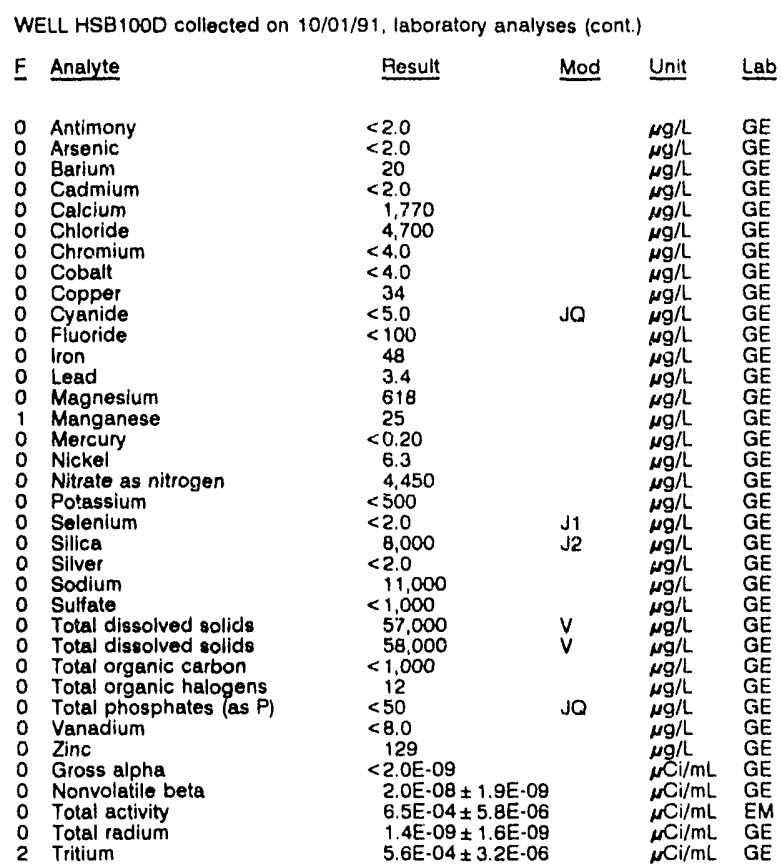

WELL HSB101C

MEASUREMENTS CONDUCTED IN THE FIELD

Sample date: 10/03/91

Depth to water: $31.47 \mathrm{ft}(9.59 \mathrm{~m})$ below TOC

Water elevation: $227.03 \mathrm{Ht}(69 \mathrm{~m}$

Water evacuated before sampling: $159 \mathrm{gal}$

LABORATORY ANALYSES

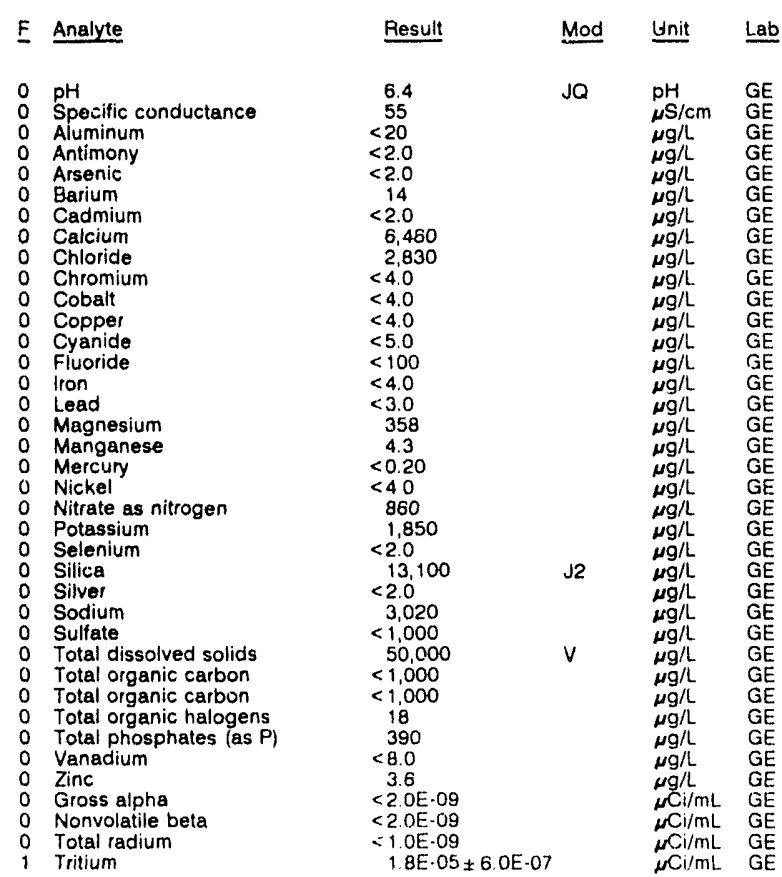

WELL HSB101D

MEASUREMENTS CONDUCTED IN THE FIELD

Sample date: 10/03/81

$\begin{array}{ll}\text { Sample date: } 10 / 03 / 81 & \text { Time: } 8: 05 \\ \text { Depth to water: } 28.87 \mathrm{ht}(8.19 \mathrm{~m}) \text { below TOC } & \text { pH: } 8.5 \\ \text { Water elevation: } 231.83 \mathrm{H}(70.66 \mathrm{~m}) \mathrm{msl} & \text { Alkalinity: } 154\end{array}$

Sp. conductance: $707 \mu \mathrm{s} / \mathrm{cm}$

Alkalinity: $154 \mathrm{mg} / \mathrm{L}$

Water temperature: $20.6^{\circ} \mathrm{C}$

LAPRIRATORY ANALYYSES

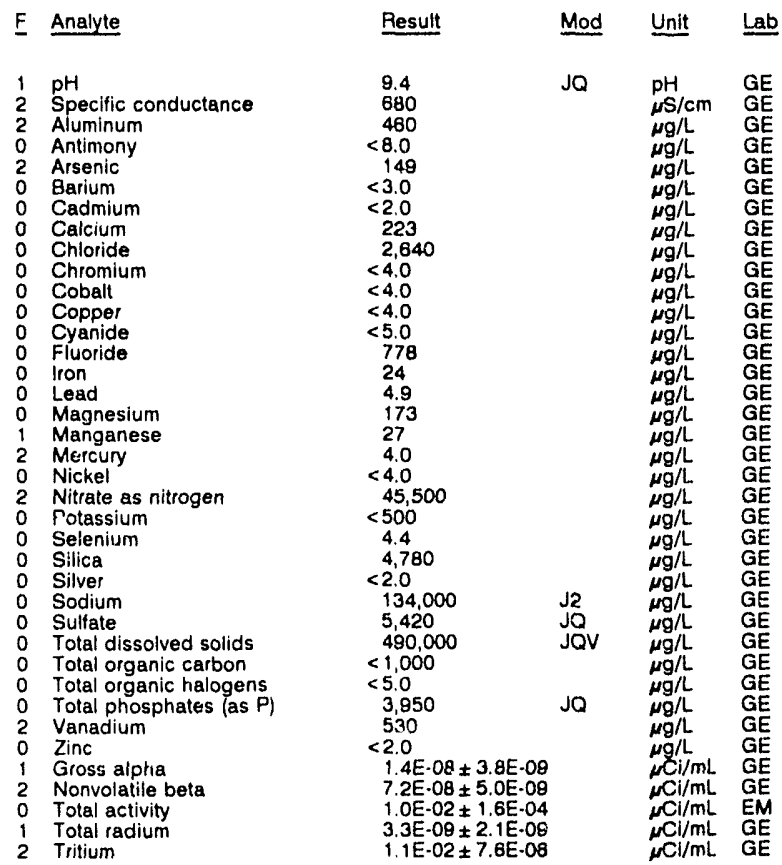

\section{WELL HSB102C}

MEASUREMENTS CONDUCTED IN THE FIELO

Sample date: 10/03/81

Depth to water: $33.15 \mathrm{ft}(10.10 \mathrm{~m})$ below TOC

Water elevation: $225.85 \mathrm{ft}(68.84 \mathrm{~m}) \mathrm{ms}$

Water evacuated before sampling: $155 \mathrm{gal}$

LABORATORY ANALYSES

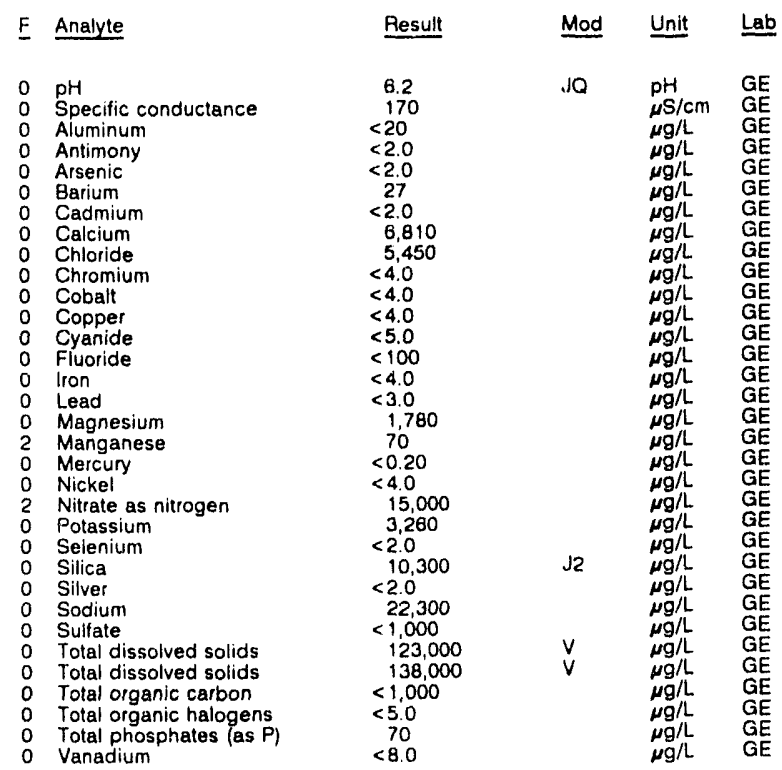


ANALYTICAL RESULTS

WELL HSB102C collected on 10/03/91, laboratory analyses (cont.)

\begin{tabular}{|c|c|c|c|}
\hline F Analyte & Result & Mod & Unit \\
\hline $\begin{array}{l}\text { Zinc } \\
\text { Gross alpha } \\
\text { Nonvolatile beta } \\
\text { Total radium } \\
\text { Tritium }\end{array}$ & $\begin{array}{r}12 \\
2.4 \mathrm{E} \cdot 09 \pm 1.4 \mathrm{E}-09 \\
8.6 \mathrm{E}-09 \pm 1.5 \mathrm{E}-09 \\
<1.0 \mathrm{E}-09 \\
1.9 \mathrm{E}-04 \pm 1.9 \mathrm{E}-06\end{array}$ & & $\begin{array}{l}\mu \mathrm{g} / \mathrm{L} \\
\mu_{\mathrm{Ci} / \mathrm{mL}} \\
\mu \mathrm{Ci} / \mathrm{mL} \\
\mu \mathrm{Ci} / \mathrm{mL} \\
\mu \mathrm{Ci} / \mathrm{mL}\end{array}$ \\
\hline
\end{tabular}

\section{WELL HSB102D}

MEASUREMENTS CONDUCTED IN THE FIELD

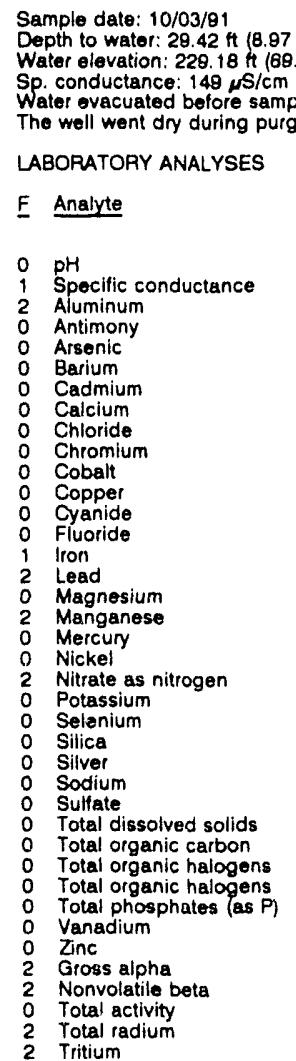

Time: $9: 20$

PH: 3.9 Alkalinity: 0 mglt

Water temperature $20.2^{\circ} \mathrm{C}$

$229.18 \mathrm{H}(68.8$

The well went dy during purging.

LABORATORY ANALYSES

\begin{tabular}{|c|c|c|c|}
\hline Analyte & Result & Mod & Unit \\
\hline $\begin{array}{l}\text { pH } \\
\text { Specific conductance } \\
\text { Aluminum } \\
\text { Antimony } \\
\text { Arsenic } \\
\text { Barium } \\
\text { Cadmium } \\
\text { Calcium } \\
\text { Chloride } \\
\text { Chromium } \\
\text { Cobalt } \\
\text { Copper } \\
\text { Cyanide } \\
\text { Fluoride } \\
\text { Iron } \\
\text { Lead } \\
\text { Magnesium } \\
\text { Manganese } \\
\text { Mercury } \\
\text { Nickel } \\
\text { Nitrate as nitrogen } \\
\text { Potassium } \\
\text { Selanium } \\
\text { Silica } \\
\text { Silver } \\
\text { Sodium } \\
\text { Sulfate } \\
\text { Total dissolved solids } \\
\text { Total organic carbon } \\
\text { Total organic halogens } \\
\text { Total organic halogens } \\
\text { Total phosphates (as P } \\
\text { Vanadium } \\
\text { Zinc } \\
\text { Gross alpha } \\
\text { Nonvolatile beta } \\
\text { Total activity } \\
\text { Total radium } \\
\text { Tritium }\end{array}$ & $\begin{array}{l}4.0 \\
285 \\
9,600 \\
<2.0 \\
<2.0 \\
44 \\
<2.0 \\
3,860 \\
3,620 \\
<4.0 \\
<4.0 \\
12 \\
<5.0 \\
208 \\
281 \\
50 \\
1,070 \\
572 \\
0.59 \\
18 \\
30,500 \\
2,330 \\
<2.0 \\
12,100 \\
<2.0 \\
9,480 \\
5,860 \\
92,500 \\
<1,000 \\
11 \\
15 \\
80 \\
<8 . C \\
68 \\
4.7 \mathrm{E} \cdot 07 \pm 1.7 \mathrm{E} \cdot 08 \\
4.3 \mathrm{E} \cdot 06 \pm 3.5 \mathrm{E} \cdot 08 \\
2.2 \mathrm{E} \cdot 03 \pm 8.5 \mathrm{E} \cdot 05 \\
1.6 \mathrm{E} \cdot 07 \pm 9.2 \mathrm{E} \cdot 09 \\
5.3 \mathrm{E} \cdot 03 \pm 5.4 \mathrm{E} \cdot 06\end{array}$ & $\begin{array}{l}\mathrm{j} 2 \\
\text { Jo } \\
\text { JOV }\end{array}$ & $\begin{array}{l}p H \\
\mu \mathrm{S} / \mathrm{cm} \\
\mu g / L \\
\mu g / L \\
\mu g / L \\
\mu g / L \\
\mu g / L \\
\mu g / L \\
\mu g / L \\
\mu g / L \\
\mu g / L \\
\mu g / L \\
\mu g / L \\
\mu g / L \\
\mu g / L \\
\mu g / L \\
\mu g / L \\
\mu g i L \\
\mu g / L \\
\mu g / L \\
\mu g / L \\
\mu g / L \\
\mu g / L \\
\mu g / L \\
\mu g / L \\
\mu g / L \\
\mu g / L \\
\mu g / L \\
\mu g / L \\
\mu g / L \\
\mu g / L \\
\mu g / L \\
\mu g / L \\
\mu g / L \\
\mu C i / m L \\
\mu C i / m L \\
\mu C i / m L \\
\mu C \mathrm{C} / \mathrm{mL} \\
\mu C \mathrm{Ci} / \mathrm{mL}\end{array}$ \\
\hline
\end{tabular}

\section{WELL HSB103C}

MEASUREMENTS CONOUCTED IN THE FIELD

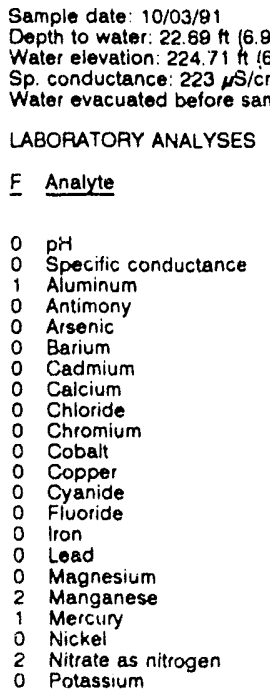

$$
\begin{aligned}
& \text { Time: } 11.55 \\
& \text { pH: } 5.0 \\
& \text { Alkalinity } 1 \mathrm{mg} / \mathrm{L} \\
& \text { Water temperature } 19.6^{\circ} \mathrm{C}
\end{aligned}
$$

\begin{tabular}{|c|c|c|c|c|c|}
\hline F & Analyte & Result & Mod & Unit & Lab \\
\hline $\begin{array}{l}0 \\
0 \\
1 \\
0 \\
0\end{array}$ & $\begin{array}{l}\text { py } \\
\text { Specific conductance } \\
\text { Aluminum } \\
\text { Antimony } \\
\text { Arsenic } \\
\text { Barium } \\
\text { Cadmium } \\
\text { Calcium } \\
\text { Chloride } \\
\text { Chromium } \\
\text { Cobalt } \\
\text { Copper } \\
\text { Cyanide } \\
\text { Fluoride } \\
\text { Iron } \\
\text { Load } \\
\text { Magnesium } \\
\text { Manganese } \\
\text { Mercury } \\
\text { Nickel } \\
\text { Nitrate as nitrogen } \\
\text { Potassium }\end{array}$ & $\begin{array}{l}5.2 \\
200 \\
156 \\
<2.0 \\
<2.0 \\
62 \\
<2.0 \\
8.930 \\
5.250 \\
<4.0 \\
10 \\
<4.0 \\
<5.0 \\
138 \\
<4.0 \\
<3.0 \\
5.150 \\
419 \\
1.2 \\
5.0 \\
22.500 \\
1.630\end{array}$ & $\mathrm{JQ}$ & 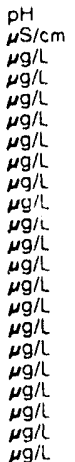 & $\begin{array}{l}\mathrm{GE} \\
\mathrm{GE} \\
\mathrm{GE} \\
\mathrm{GE} \\
\mathrm{GE} \\
\mathrm{GE} \\
\mathrm{GE} \\
\mathrm{GE} \\
\mathrm{GE} \\
\mathrm{GE} \\
\mathrm{GE} \\
\mathrm{GE} \\
\mathrm{GE} \\
\mathrm{GE} \\
\mathrm{GE} \\
\mathrm{GE} \\
\mathrm{GE} \\
\mathrm{GE} \\
\mathrm{GE} \\
\mathrm{GE} \\
\mathrm{GE} \\
\mathrm{GE}\end{array}$ \\
\hline
\end{tabular}

LABORATORY ANALYSES

\begin{tabular}{|c|c|c|c|c|c|}
\hline$\underline{E}$ & Analyte & Result & Mod & Unit & Lab \\
\hline 0 & $\begin{array}{l}\text { Selenium } \\
\text { Silica } \\
\text { Silver } \\
\text { Sodium } \\
\text { Sulfate } \\
\text { Total dissolved solids } \\
\text { Total organic carbon } \\
\text { Total organic halogens } \\
\text { Total phosphates (as P) } \\
\text { Vanadium } \\
\text { Zinc } \\
\text { Gross alpha } \\
\text { Nonvolatile beta } \\
\text { Total activity } \\
\text { Total radium } \\
\text { Tritium }\end{array}$ & $\begin{array}{l}<2.0 \\
9,860 \\
<2.0 \\
20.500 \\
1.020 \\
557,000 \\
<1.000 \\
59 \\
<50 \\
<8.0 \\
20 \\
4.3 \mathrm{E} \cdot 09 \pm 1.2 \mathrm{E} \cdot 09 \\
1.6 \mathrm{E}-08 \pm 1.9 \mathrm{E} \cdot 09 \\
6.5 \mathrm{E}-04 \pm 5.4 \mathrm{E}-06 \\
3.3 \mathrm{E} \cdot 09 \pm 1.5 \mathrm{E} \cdot 00 \\
7.5 \mathrm{E}-04 \pm 3.8 \mathrm{E} \cdot 06\end{array}$ & J1 & $\begin{array}{l}\mu g / \mathrm{L} \\
\mu \mathrm{g} / \mathrm{L} \\
\mu \mathrm{g} / \mathrm{L} \\
\mu \mathrm{g} / \mathrm{L} \\
\mu \mathrm{g} / \mathrm{L} \\
\mu \mathrm{g} / \mathrm{L} \\
\mu \mathrm{g} / \mathrm{L} \\
\mu \mathrm{g} / \mathrm{L} \\
\mu \mathrm{g} / \mathrm{L} \\
\mu \mathrm{g} / \mathrm{L} \\
\mu \mathrm{g} / \mathrm{L} \\
\mu \mathrm{Ci} / \mathrm{mL} \\
\mu \mathrm{Ci} / \mathrm{mL} \\
\mu \mathrm{Ci} / \mathrm{mL} \\
\mu \mathrm{Ci} / \mathrm{mL} \\
\mu \mathrm{Ci} / \mathrm{mL}\end{array}$ & $\begin{array}{l}\mathrm{GE} \\
\mathrm{GE} \\
\mathrm{GE} \\
\mathrm{GE} \\
\mathrm{GE} \\
\mathrm{GE} \\
\mathrm{GE} \\
\mathrm{GE} \\
\mathrm{GE} \\
\mathrm{GE} \\
\mathrm{GE} \\
\mathrm{GE} \\
\mathrm{GE} \\
\mathrm{EM} \\
\mathrm{GE} \\
\mathrm{GE}\end{array}$ \\
\hline
\end{tabular}

WELL HSB103C collected on 10/03/91, laboratory analyses (cont)

\section{WELL HSB103D}

MEASUREMENTS CONDUCTED IN THE FIELD

$\begin{array}{ll}\text { Sample date: } 10 / 03 / 81 & \text { Time: } 12: 05 \\ \text { Depth to water: } 21.45 \mathrm{H}(8.54 \mathrm{~m}) \text { below TOC } & \text { pH: } 4.2 \\ \text { Water elevation: } 226.15 \mathrm{H}(88.93 \mathrm{~m}) \mathrm{msl} & \text { Alkalinity: } 0 \mathrm{mg} / \mathrm{L} \\ \text { Sp conductance: } 207 \mu \mathrm{S} / \mathrm{cm} & \text { Water temperature } 210^{\circ} \mathrm{C}\end{array}$

Sp conductance $207 \mu \mathrm{S} / \mathrm{cm}$
Water evacuated before sampling 33 gal

LABORATORY ANALYSES

$\begin{array}{ll}0 & \mathrm{pH} \\ 0 & \text { Specific conductance }\end{array}$

2 Aluminum

Antimony

$\begin{array}{ll}0 & \text { Arsenic } \\ 0 & \text { Barium } \\ 0 & \text { Cadmium }\end{array}$

O Barium

0 Calcium

Chloride

0 Cobalt

0 Copper

O Cyanide

o Fluoride

$\begin{array}{ll}0 & \text { Iron } \\ 0 & \text { Lead }\end{array}$

0 Magnesium

Manganese

Mercury

Nickel

Potassium

Selenium

0 Silica

0 Sitver

0 Sultate

Total dissolved solids

- Total crganic carbon

0 Total organic halogens
0 Total phosphates (as P)

o Vanadium

D Zinc

2 Gross alpha

2 Nonvolatile beta

- Total activity

2 Total radium

\begin{tabular}{l} 
Result \\
\hline \\
4.4 \\
195 \\
875 \\
$<2.0$ \\
$<2.0$ \\
34 \\
$<2.0$ \\
1.180 \\
5,680 \\
$<4.0$ \\
$<4.0$ \\
$<4.0$ \\
$<5.0$ \\
$<100$ \\
11 \\
$<3.0$ \\
1.760 \\
219 \\
1.6 \\
$<4.0$ \\
20.500 \\
1.070 \\
$<2.0$ \\
7.850 \\
$<2.0$ \\
28,700 \\
6.260 \\
170,00 \\
$<1.000$ \\
7.4 \\
$<50$ \\
$<8.0$ \\
5.1 \\
$5.9 \mathrm{E}-08 \pm 6.3 \mathrm{E} \cdot 09$ \\
$8.6 \mathrm{E}-07 \pm 1.6 \mathrm{E} \cdot 08$ \\
$3.2 \mathrm{E} \cdot 03 \pm 3.9 \mathrm{E} \cdot 05$ \\
$4.3 \mathrm{E} \cdot 08 \pm 4.8 \mathrm{E} \cdot 09$ \\
$3.5 \mathrm{E} \cdot 03 \pm 4.2 \mathrm{E} \cdot 06$ \\
\end{tabular}

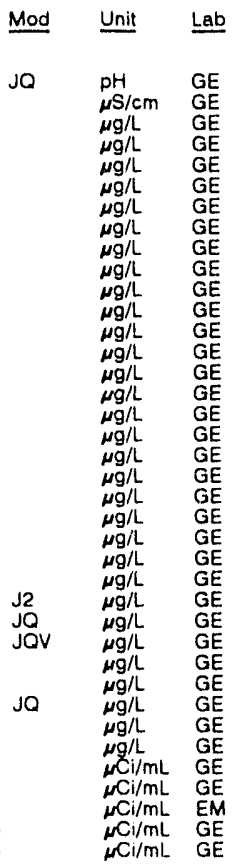

\section{WELL HSB104C}

MEASUAEMENTS CONDUCTED IN THE FIELD

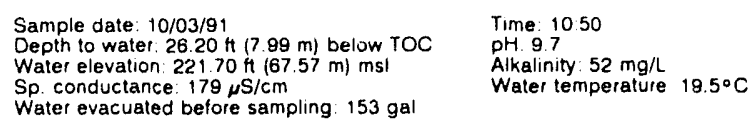

\begin{tabular}{|c|c|c|c|}
\hline Analyte & Result & Mod & Unit \\
\hline $\begin{array}{ll}\text { pH } \\
\text { Specific conductance } \\
2 \text { Aluminum } \\
\text { Antimony } \\
\text { A Asenic } \\
\text { Barium } \\
\text { Badmium } \\
\text { Calcium } \\
\text { Calion } \\
\text { Chioride } \\
0 \text { Chromium } \\
0 \text { Cobalt } \\
\text { D Copper }\end{array}$ & $\begin{aligned} 98 \\
170 \\
512 \\
<20 \\
<20 \\
56 \\
<20 \\
17,000 \\
3,640 \\
<40 \\
<40 \\
<40\end{aligned}$ & JO & $\begin{array}{l}\mathrm{pH} \\
\mu \mathrm{S} / \mathrm{cm} \\
\mu \mathrm{g} / \mathrm{L} \\
\mu \mathrm{g} / \mathrm{L} \\
\mu \mathrm{g} / \mathrm{L} \\
\mu \mathrm{g} / \mathrm{L} \\
\mu g / L \\
\mu \mathrm{g} / \mathrm{L} \\
\mu \mathrm{g} / \mathrm{L} \\
\mu \mathrm{g} / \mathrm{L} \\
\mu \mathrm{g} / \mathrm{L} \\
\mu \mathrm{g} / \mathrm{L}\end{array}$ \\
\hline
\end{tabular}

Water evacuated before sampling: $153 \mathrm{gal}$

LABORATORY ANALYSES 
WELL HSB104C collected on 10/03/91, laboralory analyses (cont)
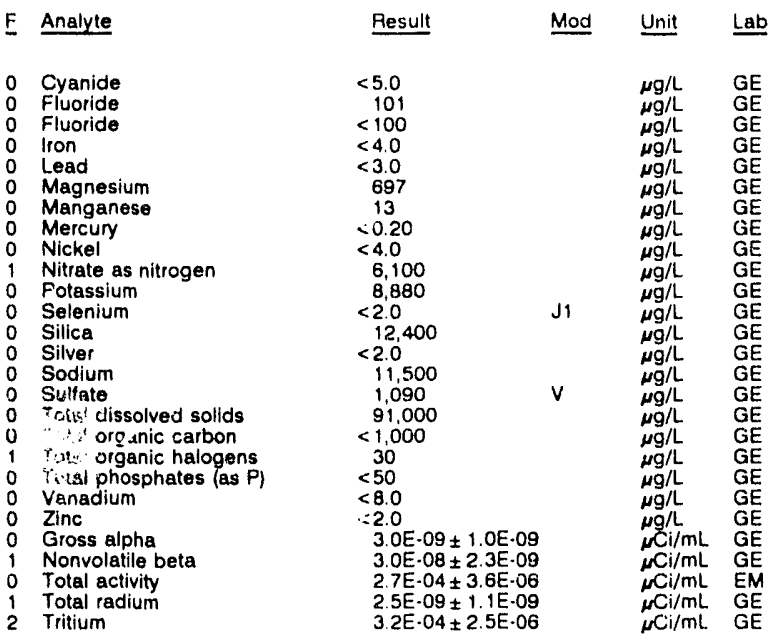

\section{WELL HSB104D}

MEASUREMENTS CONOUCTED IN THE FIELD

Sample date: 10/03/91

Depth to water: $22.03 \mathrm{ft}(6.71 \mathrm{~m})$ below TOC

Water elevation: 225.77 it 168

Water evacuated 230 rere

Time: $9: 55$

Alkalinity: $0 \mathrm{mg} / \mathrm{L}$

Alkalinity: $0 \mathrm{mg} / \mathrm{h}$. $2000^{\circ} \mathrm{C}$

LABORATORY ANALYSES

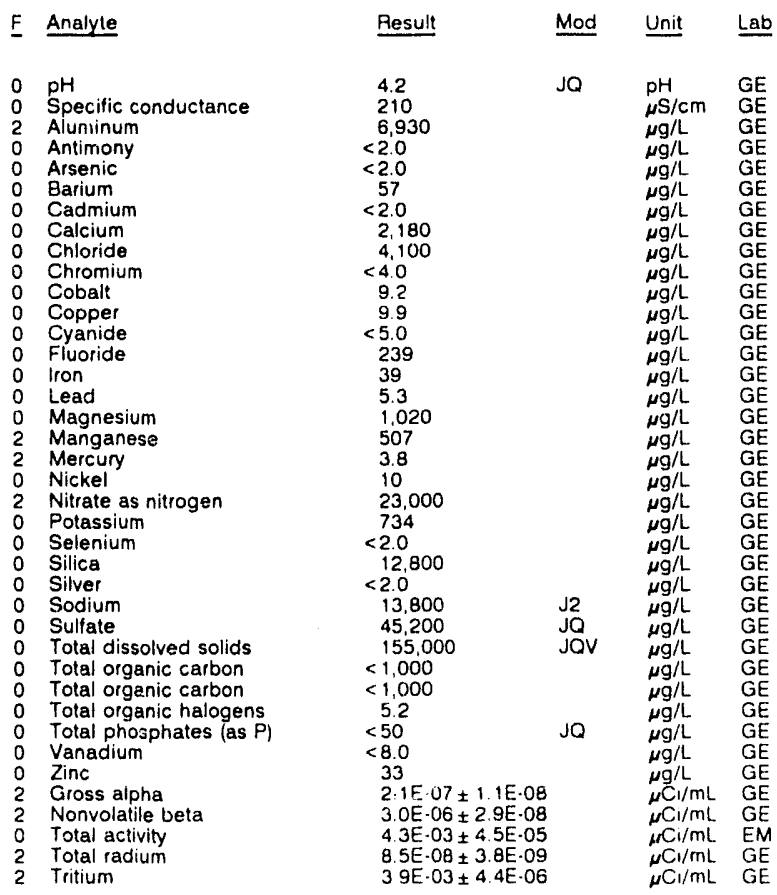

WELL HSB105C

MEASUREMENTS CONDUCTEO IN THE FIELLD

Sample date: $10 / 03 / 91$

Depth to water: $28.86 \mathrm{tt}(8.80 \mathrm{~m})$ below TOC

Water elevation: $220.64 \mathrm{ft}(87.2$

Water evacuated bef ire sampling: $180 \mathrm{gal}$

LABORATORY ANALYSES

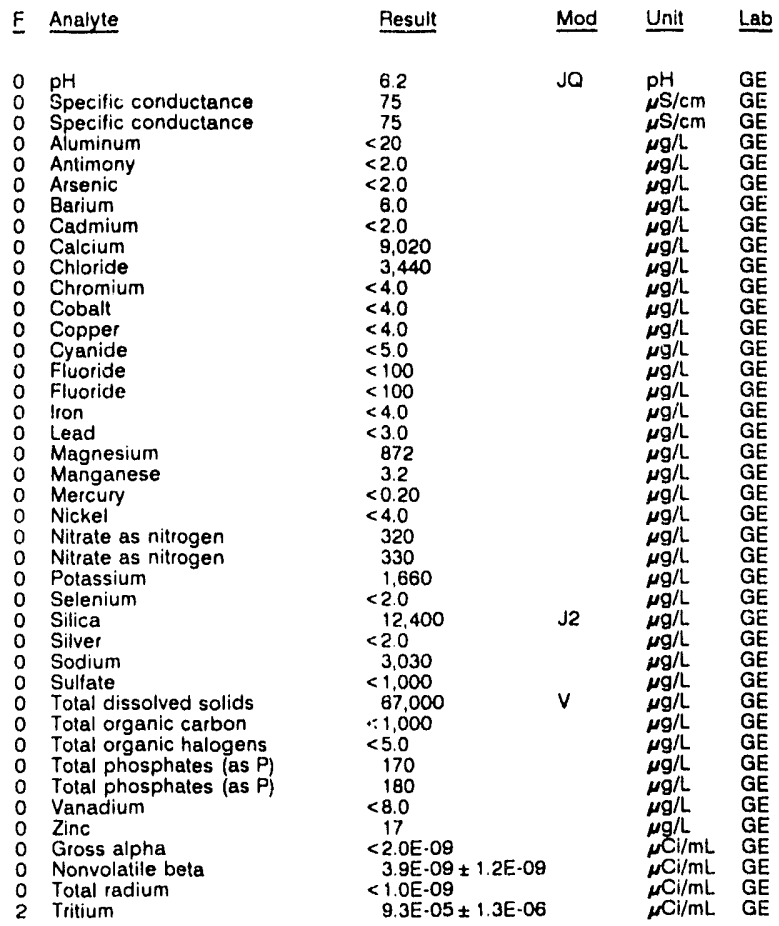

\section{WELL HSB105D}

MEASUREMENTS CONOUCTED IN THE FIELD

Sample date: $10 / 03 / 91$
Depth to water: $23.34 \mathrm{Ht}(7.11 \mathrm{~m})$ below TOC Water elevation: $226.16 \mathrm{Ht}(68.93 \mathrm{~m}) \mathrm{msl}$

Sp conductance: 435 S $/ \mathrm{cm}$

Time: $11: 10$

PH: 3.7 : $0 \mathrm{mg}$ Water temperature: $19.6^{\circ} \mathrm{C}$

Water evacuated before sampling: $40 \mathrm{gal}$

LABORATORY ANALYSES

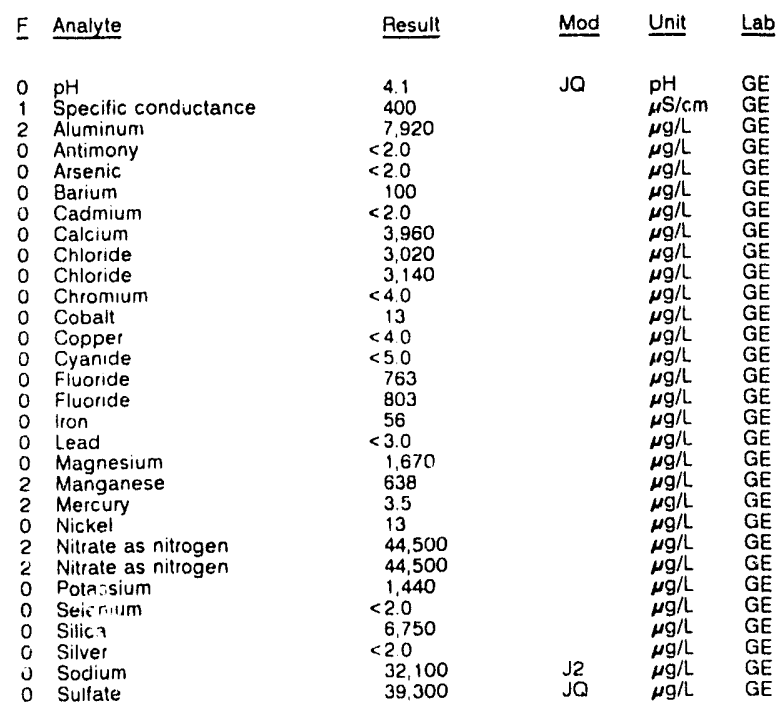




\section{ANALYTICAL RESULTS}

WELL HSB 1050 collacted on 10/03/91, laboratory analyses (cont.)
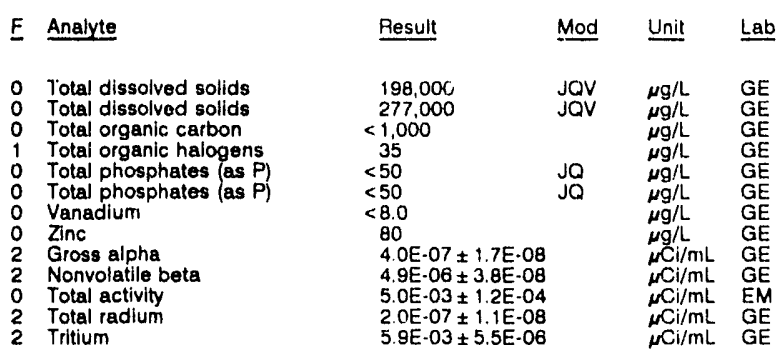

WELL HSB106C

MEASUREMENTS CONDUCTED IN THE FIELD

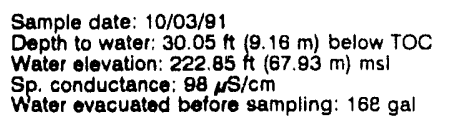

\section{Time: $14: 45$}

Alkalinity: $6 \mathrm{mg} / \mathrm{L}$

Water temperature: $19.5^{\circ} \mathrm{C}$

LABORATORY ANALYSES

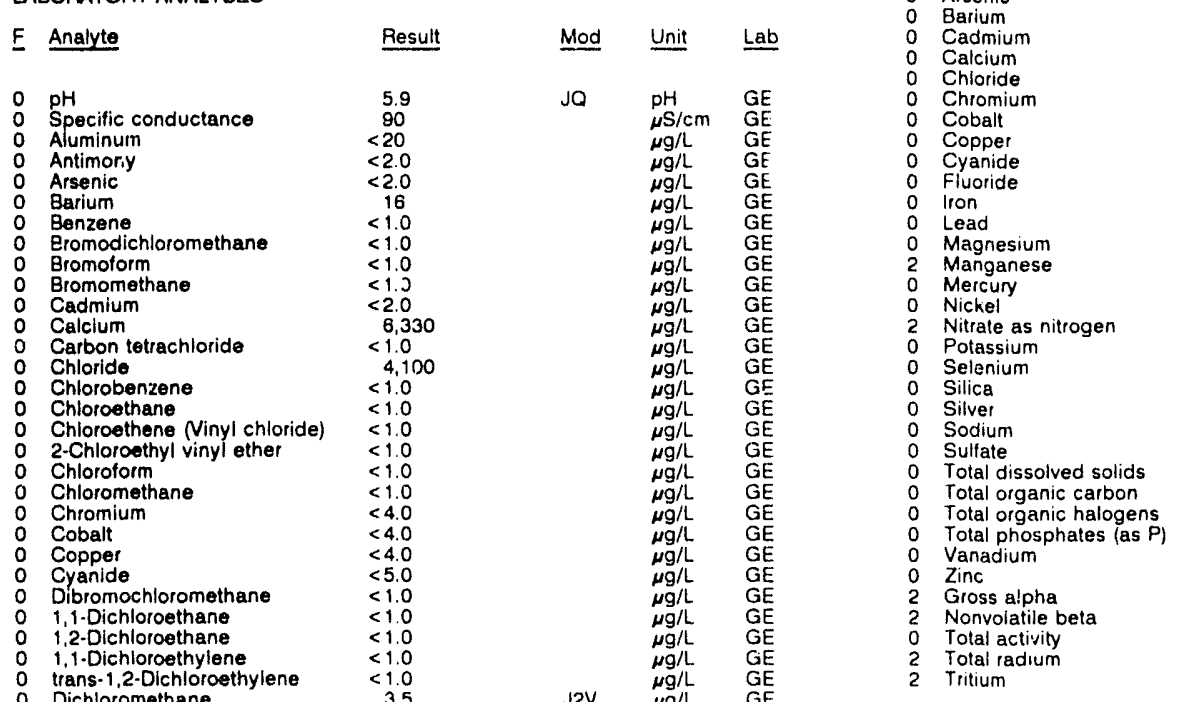

WELLL HSB107C

MEASUREMENTS CONDUCTED IN THE FIELD

Sample date: 10/03/91

Depth to water: 41.24 H $(12.57 \mathrm{~m})$ below TOC

Water elevation: $220.36 \mathrm{ft}(67.17 \mathrm{~m}) \mathrm{msl}$

Water evacuated before sampling. $160 \mathrm{ga}$

LABORATORY ANALYSES

$\begin{array}{ll}\text { E } & \text { Analyte } \\ 0 & \text { pH } \\ 0 & \text { Specific conductance } \\ 0 & \text { Aluminum } \\ 0 & \text { Antimony } \\ 0 & \text { Arsenic } \\ 0 & \text { Barium } \\ 0 & \text { Cadmium } \\ 0 & \text { Calcium } \\ 0 & \text { Chloride } \\ 0 & \text { Chromium } \\ 0 & \text { Cobalt } \\ 0 & \text { Copper } \\ 0 & \text { Cyanide } \\ 0 & \text { Fluoride } \\ 1 & \text { lron } \\ 0 & \text { Lead } \\ 0 & \text { Magriesium } \\ \text { Tanganese } & \text { Manganes } \\ 0 & \text { Mercury } \\ 0 & \text { Nickel } \\ 0 & \text { Nitrale as nitrogen } \\ 0 & \text { Potassium } \\ 0 & \text { Selenium } \\ 0 & \text { Silica }\end{array}$

\begin{tabular}{l} 
Pesult \\
\hline \\
7.0 \\
145 \\
$<20$ \\
$<2.0$ \\
$<2.0$ \\
47 \\
$<2.0$ \\
15.200 \\
3.460 \\
$<4.0$ \\
$<4.0$ \\
$<4.0$ \\
$<5.0$ \\
167 \\
268 \\
$<3.0$ \\
902 \\
476 \\
$<0.20$ \\
$<40$ \\
4.400 \\
3.040 \\
$<2.0$ \\
10.400
\end{tabular}

LABORATORY ANALYSES

\section{WELL HSB106D}

(7)

$(69.10 \mathrm{~m}) \mathrm{ms}$
Time: $: 4: 25$

PH: 4.1

Water temperature: $20.00 \mathrm{C}$

\begin{tabular}{|c|c|c|}
\hline Result & Mod & Unit \\
\hline $\begin{array}{l}4.3 \\
200 \\
917 \\
<2.0 \\
<2.0 \\
41 \\
<2.0 \\
1.980 \\
2,650 \\
<4.0 \\
8.5 \\
5.1 \\
<5.0 \\
155 \\
54 \\
<3.0 \\
1.540 \\
230 \\
0.87 \\
7.6 \\
34,600 \\
516 \\
<2.0 \\
9.130 \\
<2.0 \\
25,200 \\
24,500 \\
104,000 \\
<1.000 \\
<5.0 \\
<50 \\
<8.0 \\
23 \\
4.9 E \cdot 08 \pm 4.0 E \cdot 09 \\
7.6 E-07 \pm 1.0 E \cdot 08 \\
1.8 E \cdot 03 \pm 3.0 E \cdot 05 \\
2.1 E \cdot 08 \pm 2.4 E \cdot 09 \\
1.9 E \cdot 03 \pm 3.2 E \cdot 06\end{array}$ & JQ & $\begin{array}{l}p H \\
\mu S / c m \\
\mu g / L \\
\mu g / L \\
\mu g / L \\
\mu g / L \\
\mu g / L \\
\mu g / L \\
\mu g / L \\
\mu g / L \\
\mu g / L \\
\mu g / L \\
\mu g / L \\
\mu g / L \\
\mu g / L \\
\mu g / L \\
\mu g / L \\
\mu g / L \\
\mu g / L \\
\mu g / L \\
\mu g / L \\
\mu g / L \\
\mu g / L \\
\mu g / L \\
\mu g / L \\
\mu g i L \\
\mu g / L \\
\mu g / L \\
\mu g / L \\
\mu g / L \\
\mu g / L \\
\mu g / L \\
\mu g / L \\
\mu C i / m L \\
\mu C i / m L \\
\mu C i / m L \\
\mu C i / m L \\
\mu C i / m L\end{array}$ \\
\hline
\end{tabular}

$\mu \mathrm{Cl} / \mathrm{mL}$ GE $\begin{array}{ll}9 \mathrm{E}-09 \pm 1.1 \mathrm{E}-09 & \mu \mathrm{Ci} / \mathrm{mL} \\ 8 \mathrm{GE}-04 \pm 2.8 \mathrm{E}-06 & \mu \mathrm{Ci} / \mathrm{mL}\end{array}$

क्

\begin{tabular}{|c|c|c|c|}
\hline Analyte & Result & Unit & $\underline{\text { Lab }}$ \\
\hline $\begin{array}{ll}\int_{0} & \text { Nonvolatile beta } \\
0 & \text { Total activity } \\
0 & \text { Total radium } \\
2 & \text { Tritium }\end{array}$ & $\begin{array}{l}4.9 \mathrm{E}-08 \pm 1.3 \mathrm{E} \cdot 08 \\
3.2 \mathrm{E} \cdot 04 \pm 3.9 \mathrm{E} \cdot 06 \\
1.9 \mathrm{E} \cdot 08 \pm 1.1 \mathrm{E} \cdot 00 \\
3.8 \mathrm{E} \cdot 04 \pm 2.8 \mathrm{E} \cdot 06\end{array}$ & $\begin{array}{l}\mu \mathrm{Cl} / \mathrm{mL} \\
\mu \mathrm{Cl} / \mathrm{mL} \\
\mu \mathrm{Ci} / \mathrm{mL} \\
\mu \mathrm{Ci} / \mathrm{mL}\end{array}$ & $\begin{array}{l}\mathrm{GE} \\
\mathrm{EM} \\
\mathrm{GE} \\
\mathrm{GE}\end{array}$ \\
\hline
\end{tabular}


ANALYTICAL RESULTS

\begin{tabular}{|c|c|c|c|c|}
\hline Analyte & Result & Mod & $\underline{\text { Unit }}$ & Lab \\
\hline $\begin{array}{l}\text { Silver } \\
\text { Sodium } \\
\text { Sulfate } \\
\text { Total dissolved solids } \\
\text { Total organic carbon } \\
\text { Total organic halogens } \\
\text { Toial phosphates (as P) } \\
\text { Vanadium } \\
\text { Zinc } \\
\text { Gross alpra } \\
\text { Nonvolatile beta } \\
\text { Total activity } \\
\text { Total radium } \\
\text { Tritium }\end{array}$ & $\begin{array}{l}<2.0 \\
11,800 \\
<1,000 \\
80,000 \\
<1.000 \\
<5.0 \\
220 \\
<8.0 \\
4.3 \\
<2.0 \mathrm{E} \cdot 09 \\
1.3 \mathrm{E}-08 \pm 1.7 \mathrm{E} \cdot 09 \\
3.6 \mathrm{E} \cdot 04 \pm 4.2 \mathrm{E} \cdot 06 \\
2.3 \mathrm{E} \cdot 09 \pm 1.1 \mathrm{E} \cdot 09 \\
4.3 \mathrm{E} \cdot 04 \pm 1.5 \mathrm{E} \cdot 06\end{array}$ & v & $\begin{array}{l}\mu \mathrm{g} / \mathrm{L} \\
\mu g / \mathrm{L} \\
\mu \mathrm{g} / \mathrm{L} \\
\mu \mathrm{g} / \mathrm{L} \\
\mu \mathrm{g} / \mathrm{L} \\
\mu \mathrm{g} / \mathrm{L} \\
\mu \mathrm{g} / \mathrm{L} \\
\mu \mathrm{g} / \mathrm{L} \\
\mu \mathrm{g} / \mathrm{L} \\
\mu \mathrm{Li} / \mathrm{mL} \\
\mu \mathrm{Ci} / \mathrm{mL} \\
\mu \mathrm{Ci} / \mathrm{mL} \\
\mu \mathrm{Ci} / \mathrm{mL} \\
\mu \mathrm{Ci} / \mathrm{mL}\end{array}$ & $\begin{array}{l}G E \\
G E \\
G E \\
G E \\
G E \\
G E \\
G E \\
G E \\
G E \\
G E \\
G E \\
G M \\
G E \\
G E\end{array}$ \\
\hline
\end{tabular}

\section{WELL HSB107D}

MEASUREMENTS CONOUCTEO IN THE FIELD

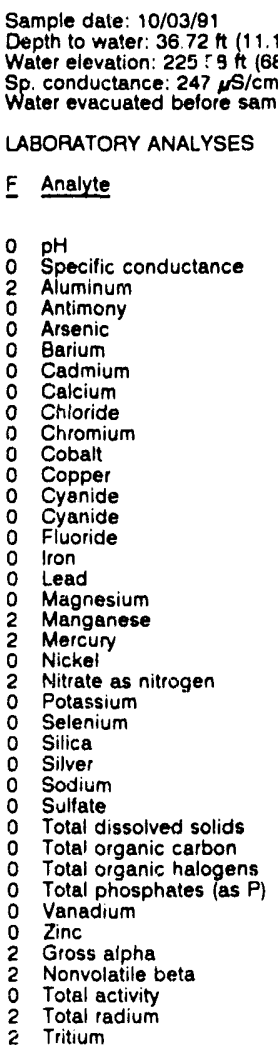

\section{Time: $15: 10$}

Alkalinity: $0 \mathrm{mg} / \mathrm{l}$ Water temperature: $20.2^{\circ} \mathrm{C}$ Water evacuated before sampling: $27 \mathrm{gal}$ LABORATORY ANALYSES

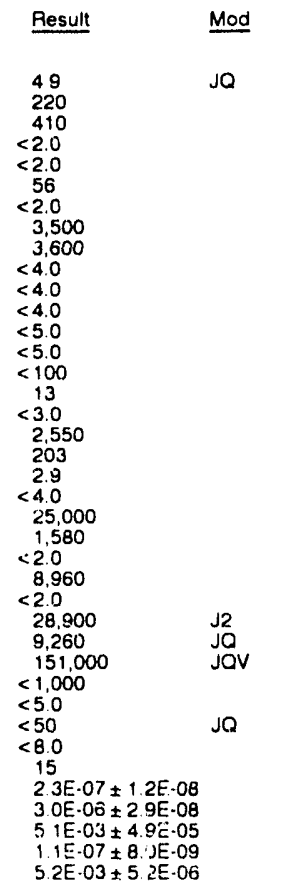

Unit Lab

WE!LL HSB108C

MEASUREMENTS CONDUCTED IN THE FIELD

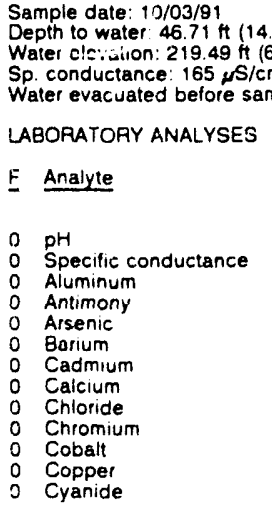

Time: 16.50

Alkalinity. $59 \mathrm{mg} / \mathrm{L}$

Water temperature. $202^{\circ} \mathrm{C}$

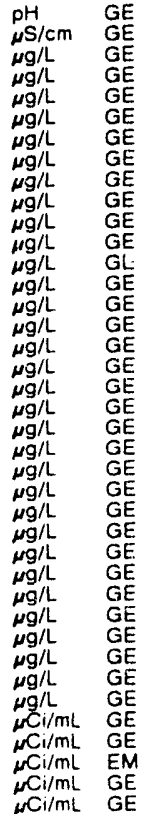

WELL HSB108C collected on 10/03/91, laboratory analyses (cont.)
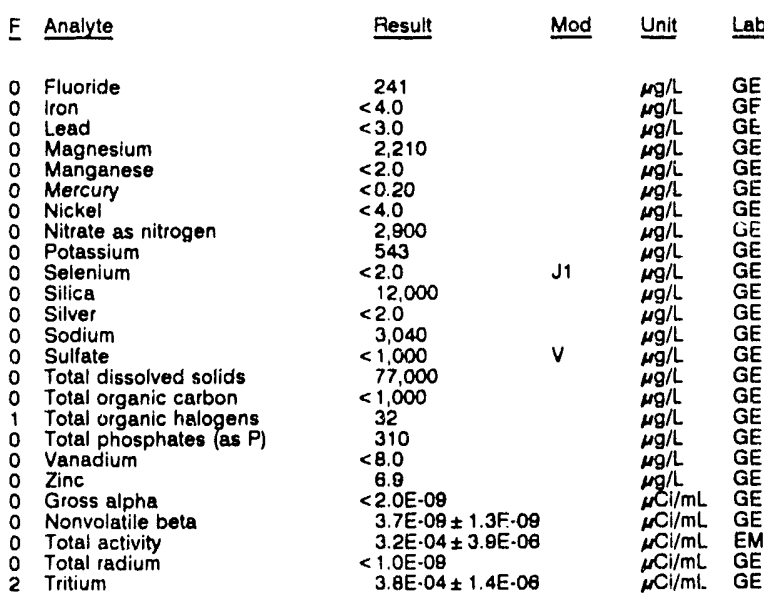

WELL HSB108D

MEASUREMENTS CONDUCTED IN THE FIELD

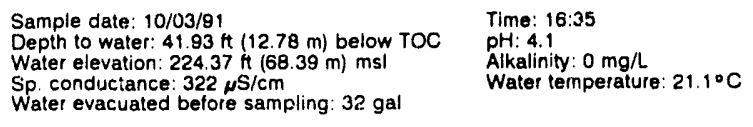

LABORATORY ANALYSES

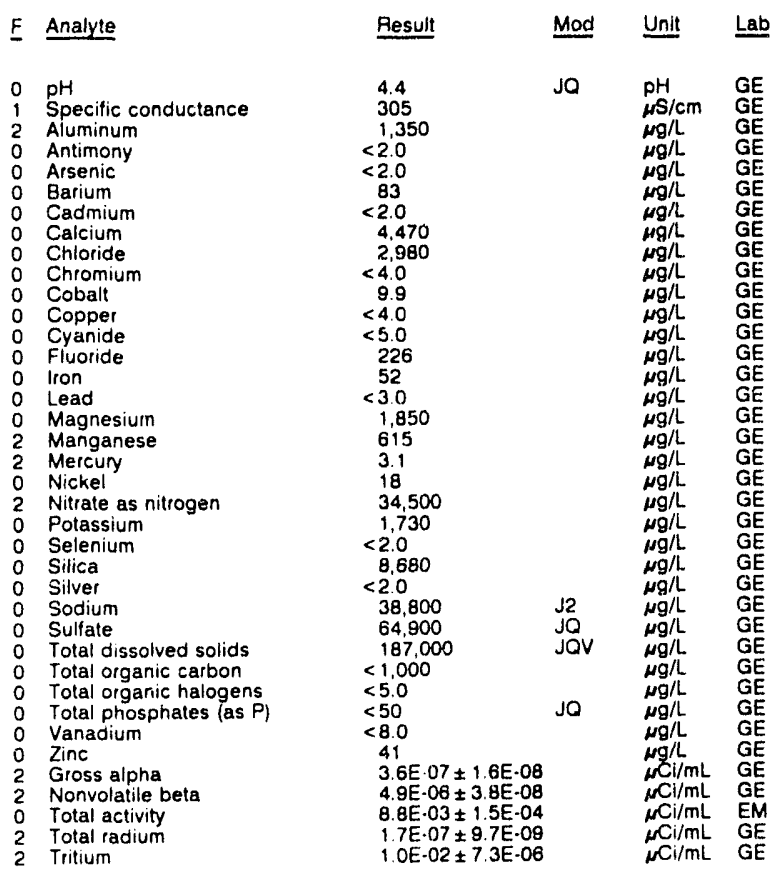

\section{WELL HSB109C}

MEASUREMENTS CONDUCTED IN THE FIELD

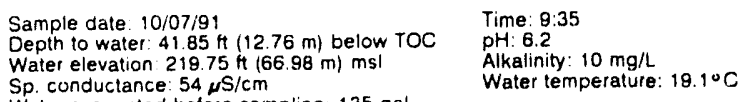

Water elevation $2.8 .75 \mathrm{~s}(66.88 \mathrm{~m}) \mathrm{msl}$ Alkalinity. $10 \mathrm{mgh}$

Water evacuated before sainzling $135 \mathrm{gal}$

LABOFATORY ANALYSES

\begin{tabular}{|c|c|c|c|}
\hline E Analyte & Result & Mot & Unit \\
\hline $\begin{array}{l}\text { pH } \\
\text { Specific conductance } \\
\text { Aluminum }\end{array}$ & $\begin{array}{r}6.4 \\
55 \\
<20\end{array}$ & JO & $\begin{array}{l}\mathrm{pH} \\
\mu \mathrm{S} / \mathrm{cm} \\
\mu \mathrm{g} / \mathrm{L}\end{array}$ \\
\hline
\end{tabular}


ANALYTICAL RESULTS

WELL HSB109C collectod on 10/07/91, laboratory analyses (cont.)

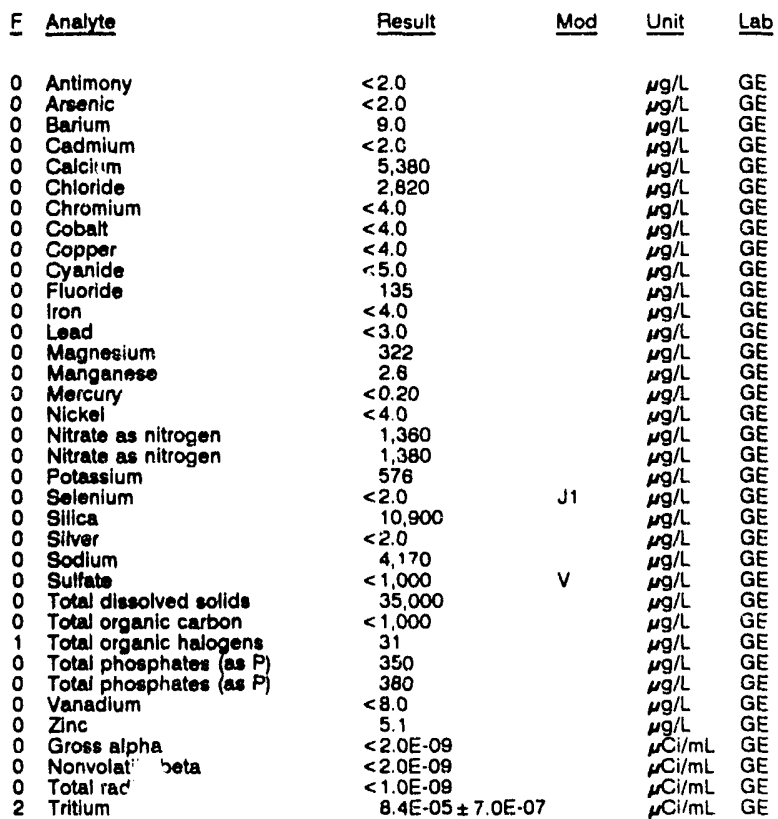

WELL HSE 109D

MEASUREMENTS TMINUCTED IN THE FIELD

Sample date: 10/07/81 Depth to water: $37.81 \mathrm{ft}(11.52 \mathrm{~m})$ below TOC Water olovation: 223.39 \&t 68 Sp. conductance: 74 $\mu \mathrm{s} / \mathrm{cm}$. ater evacuated before sampling: $27 \mathrm{ga}$ LABORATOAY ANALYSES

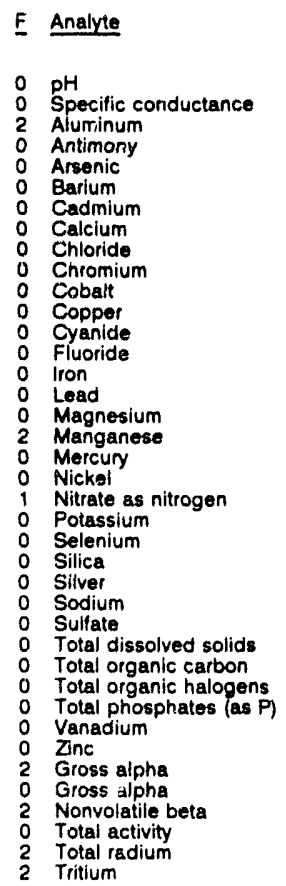

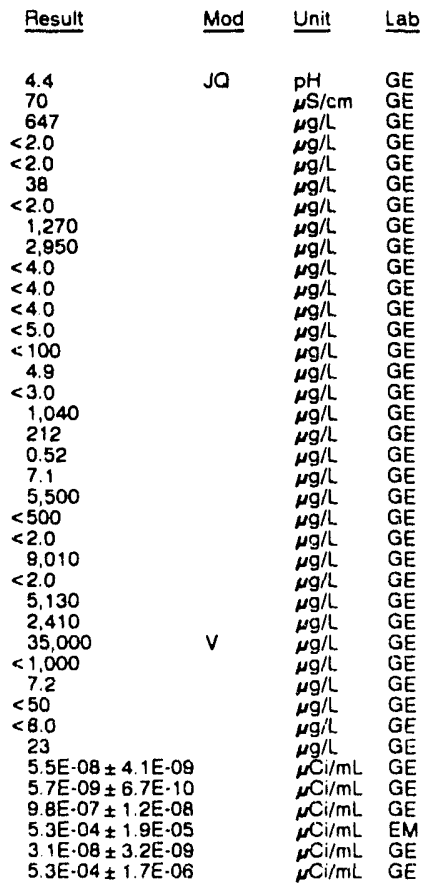

WELL HSB110C

MEASUREMENTS CONDUCTED IN THE FIELD

Semple date: 10/07/91

Depth to water: $35.55 \mathrm{~h}(10.84 \mathrm{~m})$ below TOC

Water elevation: $220.15 \mathrm{ft}$

Water evacuated before sampling: $128 \mathrm{gal}$

LABORATORY ANALYSES

E Analyte Result Mod Unit Lab

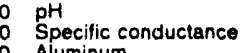

0 Aluminum

0 Arsenic

Barium

Cadmium

o Chloride

Chromium

o Cobalt

o Cyanide

Iron

0 Lead

- Magnesium

Manganese

O Nickel

Nitrate as nitrogen

Potassium

Silica

Silver

Sodium

Sulfate

Total dissolved solids

Total organic carbon

Tolal organic carbon

Total organic halogens

Vansdium

Zinc

Gross alpha

Nonvolatile bet

Tritium

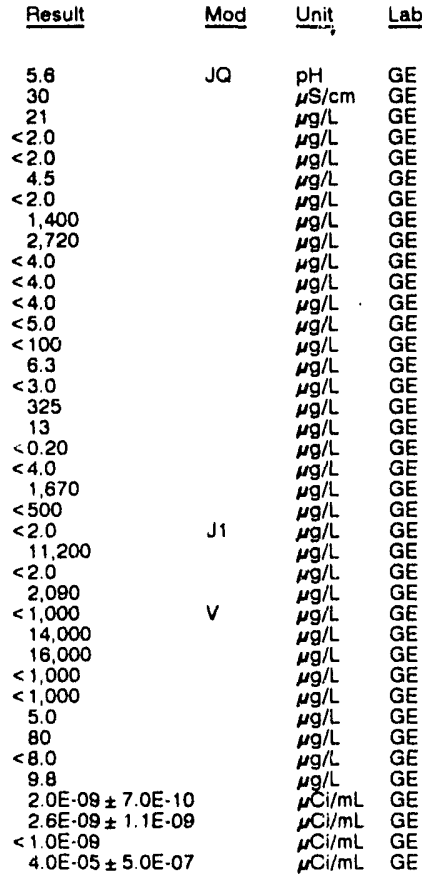

\section{WELL HSB110D}

MEASUREMENTS CONDUCTED IN THE FIELD

Sample date: 10/07/91

Depth to water: $33.11 \mathrm{ft}(10.09 \mathrm{~m})$ below rOC

Water elevation: $222.49 \mathrm{ft}(67.82 \mathrm{~m}) \mathrm{ms}$ !

Water evacuated before sampling: $29 \mathrm{gal}$

Time: 10:45

$\mathrm{pH}: 5.4$

Alkalinity: $1 \mathrm{mg} / \mathrm{L}$

Water temperature: $18.6^{\circ} \mathrm{C}$

LABORATORY ANALYSES

\begin{tabular}{|c|c|c|c|}
\hline Analyte & Result & Mod & Unit \\
\hline $\begin{array}{l}\text { pH } \\
\text { Specific conductance } \\
\text { Aluminum } \\
\text { Antimony } \\
\text { Arsenic } \\
\text { Barium } \\
\text { Cadmium } \\
\text { Calcium } \\
\text { Chloride } \\
\text { Chromium } \\
\text { Cobalt } \\
\text { Copper } \\
\text { Cyanide } \\
\text { Fluoride } \\
\text { tron } \\
\text { Lead } \\
\text { Magnesium } \\
\text { Manganese } \\
\text { Mercury } \\
\text { Nickel } \\
\text { Nitrate as nitrogen } \\
\text { Potassium } \\
\text { Selenium } \\
\text { Silica } \\
\text { Silvel } \\
\text { Sodium } \\
\text { Sulfate } \\
\text { Total dissolved solids } \\
\text { Total organic carbon } \\
\text { Total organic halogens } \\
\text { Total phosphates (as P) } \\
\text { Vanadium }\end{array}$ & $\begin{array}{l}4.5 \\
80 \\
924 \\
<2.0 \\
<2.0 \\
9.6 \\
<2.0 \\
698 \\
3.360 \\
<4.0 \\
<4.0 \\
<4.0 \\
<50 \\
120 \\
12 \\
<3.0 \\
145 \\
81 \\
<020 \\
<4.0 \\
365,000 \\
1.940 \\
<2.0 \\
13.000 \\
<2.0 \\
6,660 \\
136,000 \\
47,000 \\
2.000 \\
7.0 \\
<50 \\
<8.0\end{array}$ & JQ & $\begin{array}{l}\mathrm{pH} \\
\mu S / \mathrm{cm} \\
\mu g / L \\
\mu g / L \\
\mu g / L \\
\mu g / L \\
\mu g / L \\
\mu g / L \\
\mu g / L \\
\mu g / L \\
\mu g / L \\
\mu g / L \\
\mu g / L \\
\mu g / L \\
\mu g / L \\
\mu g / L \\
\mu g / L \\
\mu g / L \\
\mu g / L \\
\mu g / L \\
\mu g / L \\
\mu g / L \\
\mu g / L \\
\mu g / L \\
\mu g / L \\
\mu g / L \\
\mu g / L \\
\mu g / L \\
\mu g / L \\
\mu g / L \\
\mu g / L \\
\mu g / L\end{array}$ \\
\hline
\end{tabular}


ANALYTICAL RESULTS

WELL HSB1 10D collected on 10/07/91, laboratory analyses (cont.)

\begin{tabular}{|c|c|c|c|}
\hline E Analyte & Pesult & Mod & Unif \\
\hline $\begin{array}{ll}0 & \text { Zinc } \\
1 & \text { Gross alpha } \\
2 & \text { Nonvolatile beta } \\
0 & \text { Total activity } \\
2 & \text { Total radium } \\
2 & \text { Tritium }\end{array}$ & $\begin{array}{l}15 \\
1.2 E-08 \pm 2.0 E \cdot 09 \\
2.0 E-07 \pm 5.3 E \cdot 09 \\
2.1 E-04 \pm 3.3 E \cdot 06 \\
1.0 E-00 \pm 1.9 E \cdot 09 \\
1.7 E \cdot 04 \pm 1.0 E \cdot 08\end{array}$ & & $\begin{array}{l}\mu \mathrm{g} / \mathrm{L} \\
\mu \mathrm{Ci} / \mathrm{mL} \\
\mu \mathrm{Ci} / \mathrm{mL} \\
\mu^{2} \mathrm{Ci} / \mathrm{mL} \\
\mu_{\mathrm{Ci}} / \mathrm{mL} \\
\mu \mathrm{Ci} / \mathrm{mL}\end{array}$ \\
\hline
\end{tabular}

WELLL HSB111C

MEASUAEMENTS CONDUCTED IN THE FIELD

Sample date: 10/07/91

Depth to wator: $34.83 \mathrm{H}(10.62 \mathrm{~m})$ below TOC

Water elevation: $221.17 \mathrm{Ht} 167.41$

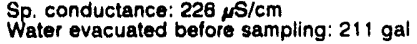

LABORATORY ANALYSES

\begin{tabular}{|c|c|c|c|}
\hline Analyte & Result & Mod & Unit \\
\hline $\begin{array}{l}\text { pH } \\
\text { Specific conductance } \\
\text { Aluminum } \\
\text { Antimony } \\
\text { Arsenic } \\
\text { Barium } \\
\text { Cadmium } \\
\text { Calcium } \\
\text { Chloride } \\
\text { Chromium } \\
\text { Cobalt } \\
\text { Copper } \\
\text { Cyanide } \\
\text { Fluoride } \\
\text { lron } \\
\text { Lead } \\
\text { Magnesium } \\
\text { Manganese } \\
\text { Mercury } \\
\text { Nickel } \\
\text { Nitrate as nitrogen } \\
\text { Nitrate as nitrogen } \\
\text { Potassium } \\
\text { Selenium } \\
\text { Silica } \\
\text { Silver } \\
\text { Sodium } \\
\text { Sulfate } \\
\text { Total dissolved solids } \\
\text { Total organic carbon } \\
\text { Total organic halogens } \\
\text { Total organic halogens } \\
\text { Total phosphates as P) } \\
\text { Vanadium } \\
\text { Zinc } \\
\text { Gross alpha } \\
\text { Nonvolatile beta } \\
\text { Total activity } \\
\text { Total radium } \\
\text { Tritium }\end{array}$ & $\begin{array}{l}5.0 \\
225 \\
200 \\
<2.0 \\
<2.0 \\
23 \\
<2.0 \\
15,800 \\
3,960 \\
<4.0 \\
<4.0 \\
<4.0 \\
<5.0 \\
137 \\
<4.0 \\
<3.0 \\
3,420 \\
38 \\
<0.20 \\
8.1 \\
24,500 \\
24,500 \\
589 \\
<2.0 \\
10,700 \\
<2.0 \\
16,800 \\
1,180 \\
192,000 \\
<1,000 \\
<5.0 \\
<5.0 \\
130 \\
<8.0 \\
33 \\
9.0 E-09 \pm 2.2 E-09 \\
6.5 E-08 \pm 3.7 E-09 \\
3.2 E-03 \pm 4.1 E-05 \\
2.1 E-09 \pm 1.4 \mathrm{E}-09 \\
3.5 E-03 \pm 4.2 \mathrm{E}-06\end{array}$ & JOV & 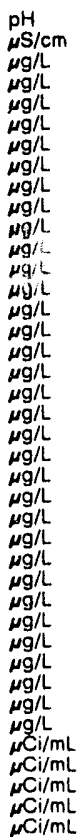 \\
\hline
\end{tabular}

\section{WELL HSB111D}

MEASUREMENTS CONDUCTED IN THE FIELD

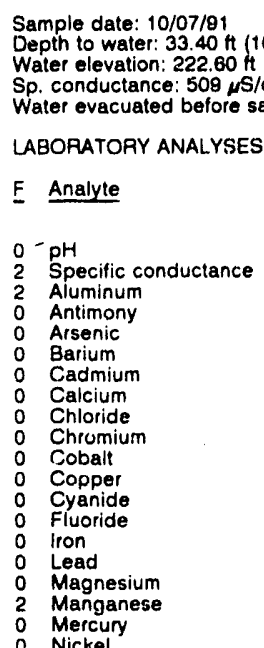

Time: 12.05

Alkalinity: $0 \mathrm{mgll}$

Water temperature: $19.5^{\circ} \mathrm{C}$

Alkalinity: $0 \mathrm{mg} / \mathrm{h}$

Water temperature: $18.9^{\circ} \mathrm{C}$

ab

WELL HSB1110 collected on 10/07/91, laboratory analyses (cont.)
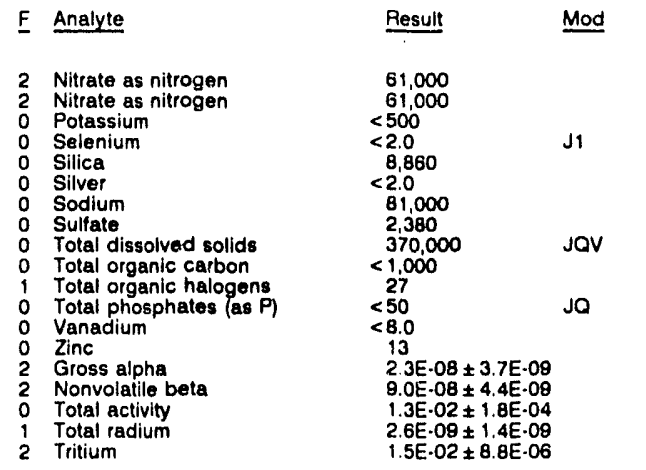

\begin{tabular}{ll} 
Unit & Lab \\
\cline { 1 - 2 } & \\
$\mu g / L$ & $G E$ \\
$\mu g / L$ & $G E$ \\
$\mu g / L$ & $G E$ \\
$\mu g / L$ & $G E$ \\
$\mu g / L$ & $G E$ \\
$\mu g / L$ & $G E$ \\
$\mu g / L$ & $G E$ \\
$\mu g / L$ & $G E$ \\
$\mu g / L$ & $G E$ \\
$\mu g / L$ & $G E$ \\
$\mu g / L$ & $G E$ \\
$\mu g / L$ & $G E$ \\
$\mu g / L$ & $G E$ \\
$\mu g / L$ & $G E$ \\
$\mu C i / m L$ & $G E$ \\
$\mu C i / m L$ & $G E$ \\
$\mu C L / m L$ & $E M$ \\
$\mu C L / m L$ & $G E$ \\
$\mu C i / m L$ & $G E$
\end{tabular}

WELL HSB111E

MEASUREMENTS CONDUCTED IN THE FIELD

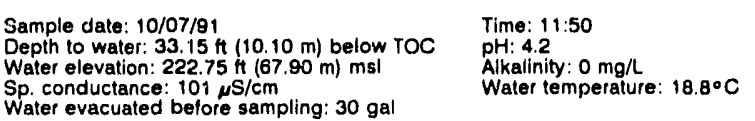

Water elevalion. $222.75 \mathrm{ft}(07.00$

Alkalinity: $0 \mathrm{mg} / \mathrm{L}$ : $18.8^{\circ} \mathrm{C}$

Water evacuated before sampling: $30 \mathrm{gal}$

LABORATORY ANALYSES

E Analyte $\underline{\text { Result }} \underline{\text { Mod Unit Lab }}$

${ }_{0}^{0} \mathrm{pH}$ Specific conductance

2 Aluminum

A Antimony

Arsenic

0 Barium

Calcium

Chloride

Chromium

Cobalt

o Copper

Fyanide

Iron

Lead

Manganese

Mercury

Nickel

Nitrate as nitrogen

Potassium

Selenium

Silica

Sodium

Sulfate

Total dissolved solids

Total organic carbon

Total organic halogens
Total phosphates (as P)

Vanadium

Zine

2 Gross alpha

Nonvolatile beta

Total activity

Total radium

Tritium
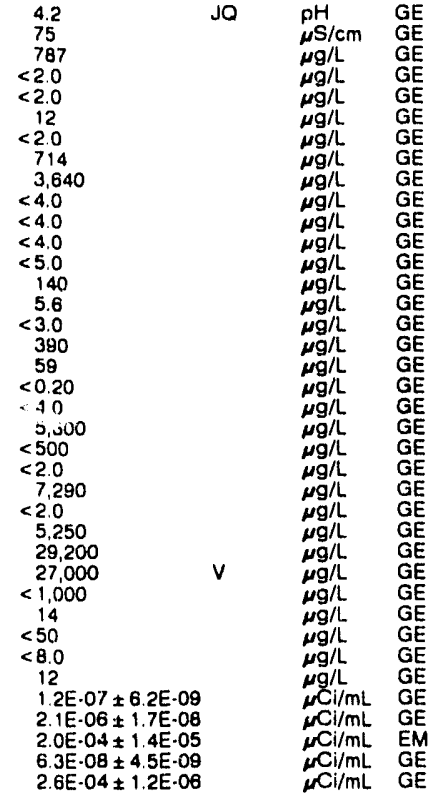

WELL HSB112C

MEASUREMENTS CONDUCTED IN THE FIELD

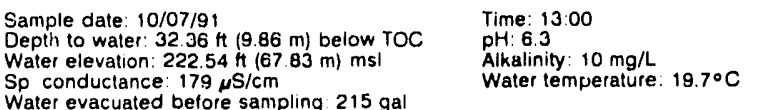

Water evacuated before sampling $215 \mathrm{gal}$

LABORATORY ANALYSES

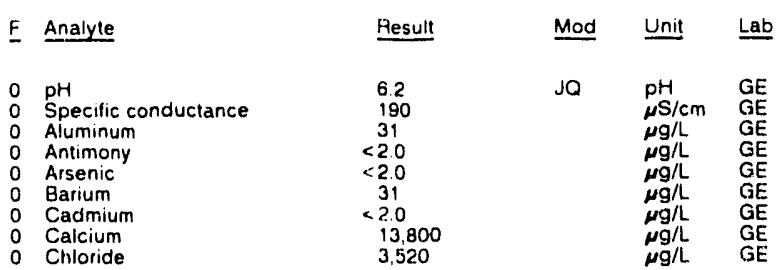


ANALYTICAL RESULTS

WELL HSB1 12C collected on 10/07/91, laboratory analyses (cont.)

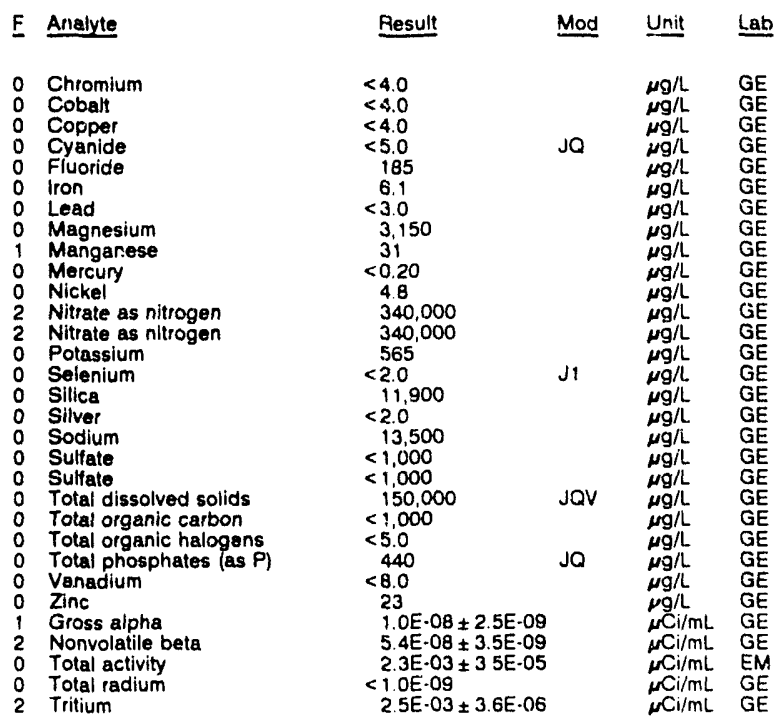

\section{WELL HSB112D}

MEASUREMENTS CONDUCTED IN THE FIELD

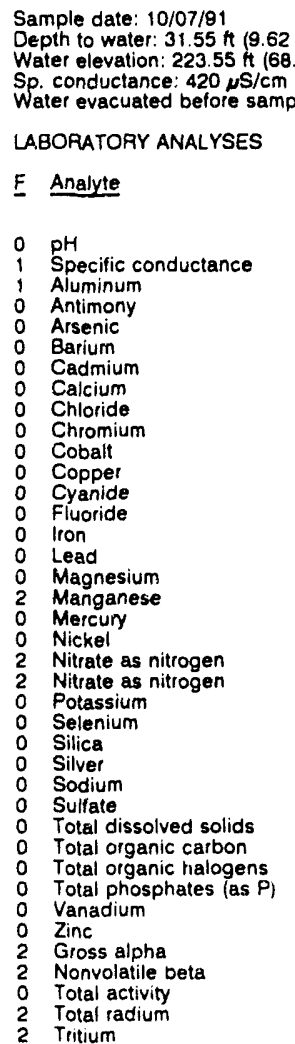

Time: 12:45

Aikalinity: $0 \mathrm{mg} / \mathrm{L}$

Water temperature: $19.7^{\circ} \mathrm{C}$

Water evacuated before sampling: 92 gal

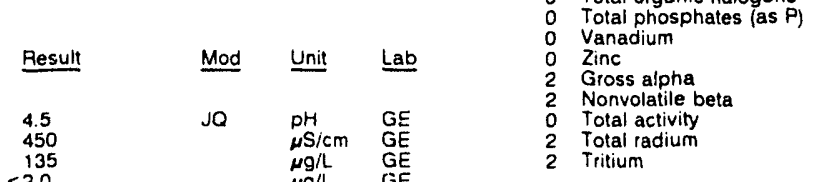

\section{WELL HSB113C}

MEASUREMENTS CONDUCTED IN THE FIELD

Sample date: $10 / 07 / 91$

epth lo water: $37.74 \mathrm{ft}(11.50 \mathrm{~m})$ below TOC

: $223.26 \mathrm{ft}(68.05 \mathrm{~m}) \mathrm{msl}$

(a) $128 \mathrm{sm}$

Water evacuated before sampling: $188 \mathrm{gal}$

LABORATORY ANALYSES

\begin{tabular}{|c|c|c|c|}
\hline Analyte & Result & Mod & Unit \\
\hline $\begin{array}{l}\text { pH } \\
\text { Specific conductance } \\
\text { Aluminum } \\
\text { Antimony } \\
\text { Alsenic } \\
\text { Barium } \\
\text { Cadmium } \\
\text { Calcium } \\
\text { Chloride } \\
\text { Chloride } \\
\text { Chromium } \\
\text { Cobalt } \\
\text { Copper } \\
\text { Cyanide } \\
\text { Cyanide } \\
\text { Fluoride } \\
\text { lron } \\
\text { Lead } \\
\text { Magnesium } \\
\text { Manganese } \\
\text { Mercury } \\
\text { Nickel } \\
\text { Nitrate as nitrogen } \\
\text { Potassium } \\
\text { Selenium } \\
\text { Silica } \\
\text { Silver } \\
\text { Sodium } \\
\text { Suifale } \\
\text { Total dissolved solids } \\
\text { Total organic carbon }\end{array}$ & $\begin{aligned} 5.4 \\
120 \\
132 \\
<2.0 \\
<2.0 \\
33 \\
<2.0 \\
8.010 \\
3,360 \\
4,480 \\
<40 \\
<4.0 \\
<40 \\
<50 \\
<5.0 \\
109 \\
<4.0 \\
<30 \\
2.590 \\
52 \\
<0.20 \\
<4.0 \\
12.500 \\
789 \\
<2.0 \\
10.300 \\
<2.0 \\
9.520 \\
<1.000 \\
73,000 \\
<1.000\end{aligned}$ & JQ & $\begin{array}{l}p H \\
\mu \mathrm{H} / \mathrm{cm} \\
\mu g / L \\
\mu g / L \\
\mu g / L \\
\mu g / L \\
\mu g / L \\
\mu g / L \\
\mu g / L \\
\mu g / L \\
\mu g / L \\
\mu g / L \\
\mu g / L \\
\mu g / L \\
\mu g / L \\
\mu g / L \\
\mu g / L \\
\mu g / L \\
\mu g / L \\
\mu g / L \\
\mu g / L \\
\mu g / L \\
\mu g / L \\
\mu g / L \\
\mu g / L \\
\mu g / L \\
\mu g / L \\
\mu g / L \\
\mu g / L \\
\mu g / L \\
\mu g / L\end{array}$ \\
\hline
\end{tabular}


ANALYTICAL RESULTS

WELL HSB113C collected on 10/07/91, laboratory analyses (cont.)

\begin{tabular}{|c|c|c|c|}
\hline Analyte & Result & Mod & Unit \\
\hline $\begin{array}{l}\text { Total organic carbon } \\
\text { Total organic halogens } \\
\text { Total phosphates (as P) } \\
\text { Variadium } \\
\text { Zinc } \\
\text { Gross alpha } \\
\text { Nonvolatile beta } \\
\text { Total activity } \\
\text { Total radium } \\
\text { Tritium }\end{array}$ & $\begin{array}{l}<1,000 \\
31 \\
<50 \\
<8.0 \\
37 \\
5.2 \mathrm{E} \cdot 09 \pm 1.6 \mathrm{E} \cdot 09 \\
4.3 \mathrm{E}-08 \pm 2.6 \mathrm{E} \cdot 09 \\
1.4 \mathrm{E} \cdot 03 \pm 2.8 \mathrm{E} \cdot 05 \\
2.6 \mathrm{E} \cdot 00 \pm 1.0 \mathrm{E} \cdot 00 \\
1.5 \mathrm{E} \cdot 03 \pm 2.8 \mathrm{E} \cdot 06\end{array}$ & & $\begin{array}{l}\mu g / \mathrm{L} \\
\mu g / \mathrm{L} \\
\mu \mathrm{g} / \mathrm{L} \\
\mu \mathrm{g} / \mathrm{L} \\
\mu \mathrm{g} / \mathrm{L} \\
\mu \mathrm{Ci} / \mathrm{mL} \\
\mu C \mathrm{C} / \mathrm{mL} \\
\mu \mathrm{CL} / \mathrm{mL} \\
\mu \mathrm{Ci} / \mathrm{mL} \\
\mu \mathrm{Ci} / \mathrm{mL}\end{array}$ \\
\hline
\end{tabular}

\section{WELL HSB113D}

MEASUREMENTS CONDUCTED IN THE FIELD

$\begin{array}{ll}\text { Sample date: } 10 / 07 / 91 & \text { Time: } 13: 30 \\ \text { Depth to water: } 37.06 \mathrm{Ht}(11.30 \mathrm{~m}) \text { below TOC } & \text { pH: } 3.6 \\ \text { Water elevation: } 223.84 \mathrm{ft}(68.23 \mathrm{~m}) \mathrm{ms} & \text { Alkalinity: } 0 \mathrm{mg} / \mathrm{L} \\ \text { Sp. conductance: } 381 \mu \mathrm{cm} / \mathrm{cm} & \text { Water temperature: } 19.8^{\circ} \mathrm{C} \\ \text { Water evacuated before sampling: } 20 \mathrm{gal} & \end{array}$
LABORATORY ANALYSES

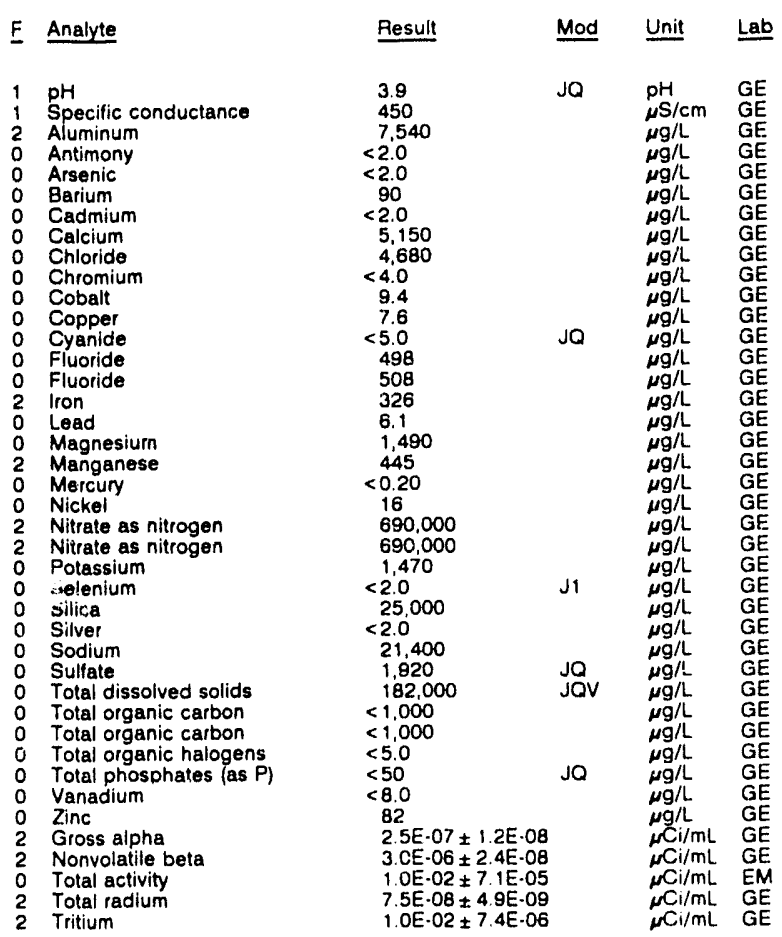

\section{WELL HSB114C}

MEASUREMENTS CONDUCTED IN THE FIELD

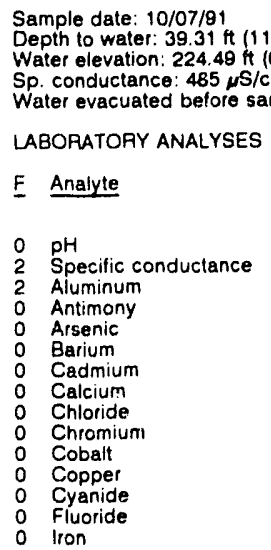

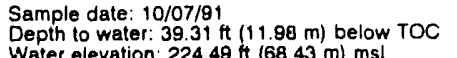

Water elevalion. $224.49 \mathrm{H} / 68.48$

Water evacuated belore sampling: $102 \mathrm{gal}$

LABORATORY ANALYSES

Time: $15: 00$

PH: 4.5

Water temperature: $20.8^{\circ} \mathrm{C}$

Mod Unit Lab

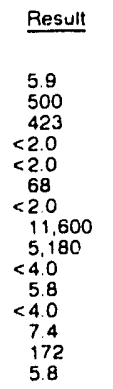

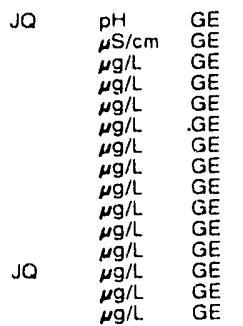

WELL HSB 114 C collected on 10/07/91, laboratory analyses (cont.)

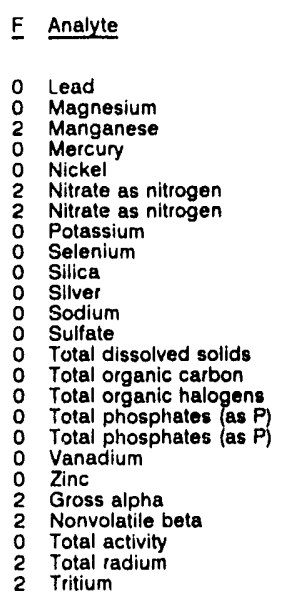

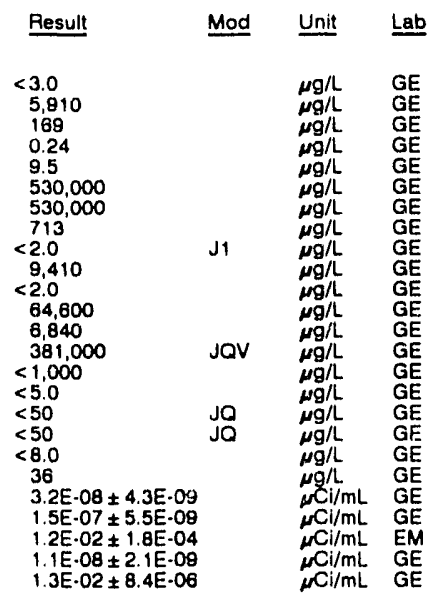

\section{WELL HSB114D}

MEASUREMENTS CONDUCTED IN THE FIELO

$\begin{array}{ll}\text { Sample date: } 10 / 07 / 91 & \text { Time: } 14: 50 \\ \text { Depth to water: } 39.37 \mathrm{H}(12.00 \mathrm{~m}) \text { below TOC } & \text { pH: } 3.7 \\ \text { Water elevation: } 224.63 \mathrm{Ht}(68.47 \mathrm{~m}) \mathrm{msl} & \text { Alkalinity: } 0 \mathrm{mg} / \mathrm{L} \\ \text { Sp. conductance: } 284 \mu \mathrm{s} / \mathrm{cm} & \text { Water temperature: } 21.5^{\circ} \mathrm{C} \\ \text { Water evacuated before sampling: } 26 \mathrm{gal} & \end{array}$

LABORATORY ANALYSES

\begin{tabular}{|c|c|c|c|c|c|}
\hline$F$ & Analyte & Result & Mod & Unit & Lab \\
\hline $\begin{array}{l}0 \\
0 \\
0 \\
0 \\
0 \\
0 \\
0 \\
2 \\
0\end{array}$ & $\begin{array}{l}\text { pH } \\
\text { Specific conductance } \\
\text { Aluminum } \\
\text { Antimony } \\
\text { Arsenic } \\
\text { Barium } \\
\text { Cadmium } \\
\text { Calcium } \\
\text { Chloride } \\
\text { Chromium } \\
\text { Cobalt } \\
\text { Copper } \\
\text { Cyanide } \\
\text { Fluoride } \\
\text { lron } \\
\text { Lead } \\
\text { Magnesium } \\
\text { Manganese } \\
\text { Mercury } \\
\text { Nickel } \\
\text { Nitrate as nitrogen } \\
\text { Nitrate as nitrogen } \\
\text { Fotassium } \\
\text { Selenium } \\
\text { Silica } \\
\text { Silver } \\
\text { Sodium } \\
\text { Sulfate } \\
\text { Total dissolved solids } \\
\text { Total organic carbon } \\
\text { Total organic halogens } \\
\text { Total phosphates (as P) } \\
\text { Vanadium } \\
\text { Zinc } \\
\text { Gross alpha } \\
\text { Nonvolatile beta } \\
\text { Total activity } \\
\text { Total radium } \\
\text { Tritium }\end{array}$ & $\begin{array}{l}4.0 \\
280 \\
6.070 \\
<2.0 \\
<2.0 \\
49 \\
<2.0 \\
4,140 \\
3,100 \\
<4.0 \\
8.5 \\
8.1 \\
<5.0 \\
707 \\
44 \\
7.5 \\
1.010 \\
389 \\
<0.20 \\
15 \\
26,500 \\
26,500 \\
2.520 \\
<2.0 \\
23.500 \\
<2.0 \\
12,200 \\
37,800 \\
139,000 \\
<1.000 \\
<5.0 \\
<50 \\
<8.0 \\
91 \\
2.1 \mathrm{E} \cdot 07 \pm 9.8 \mathrm{E} \cdot 00 \\
3.3 \mathrm{E} \cdot 06 \pm 2.5 \mathrm{E} \cdot 08 \\
3.4 \mathrm{E} \cdot 03 \pm 4.2 \mathrm{E}-05 \\
7.2 \mathrm{E} \cdot 08 \pm 4.6 \mathrm{E} \cdot 09 \\
3.1 \mathrm{E} \cdot 03 \pm 3.9 \mathrm{E} \cdot 06\end{array}$ & Jo & $\begin{array}{l}p H \\
\mu \mathrm{S} / \mathrm{cm} \\
\mu g / L \\
\mu g / L \\
\mu g / L \\
\mu g / L \\
\mu g / L \\
\mu g / L \\
\mu g / L \\
\mu g / L \\
\mu g / L \\
\mu g / L \\
\mu g / L \\
\mu g / L \\
\mu g / L \\
\mu g / L \\
\mu g / L \\
\mu g / L \\
\mu g / L \\
\mu g / L \\
\mu g / L \\
\mu g / L \\
\mu g / L \\
\mu g / L \\
\mu g / L \\
\mu g / L \\
\mu g / L \\
\mu g / L \\
\mu g / L \\
\mu g / L \\
\mu g / L \\
\mu g / L \\
\mu g / L \\
\mu g / L \\
\mu C i / m L \\
\mu C i / m L \\
\mu C i / m L \\
\mu C i / m L \\
\mu C i / m L\end{array}$ & $\begin{array}{l}G E \\
G E \\
G E \\
G E \\
G E \\
G E \\
G E \\
G E \\
G E \\
G E \\
G E \\
G E \\
G E \\
G E \\
G E \\
G E \\
G E \\
G E \\
G E \\
G E \\
G E \\
G E \\
G E \\
G E \\
G E \\
G E \\
G E \\
G E \\
G E \\
G E \\
G E \\
G E \\
G E \\
G E \\
G E \\
G E \\
E M \\
G E \\
G E\end{array}$ \\
\hline
\end{tabular}


ANALYTICAL RESULTS

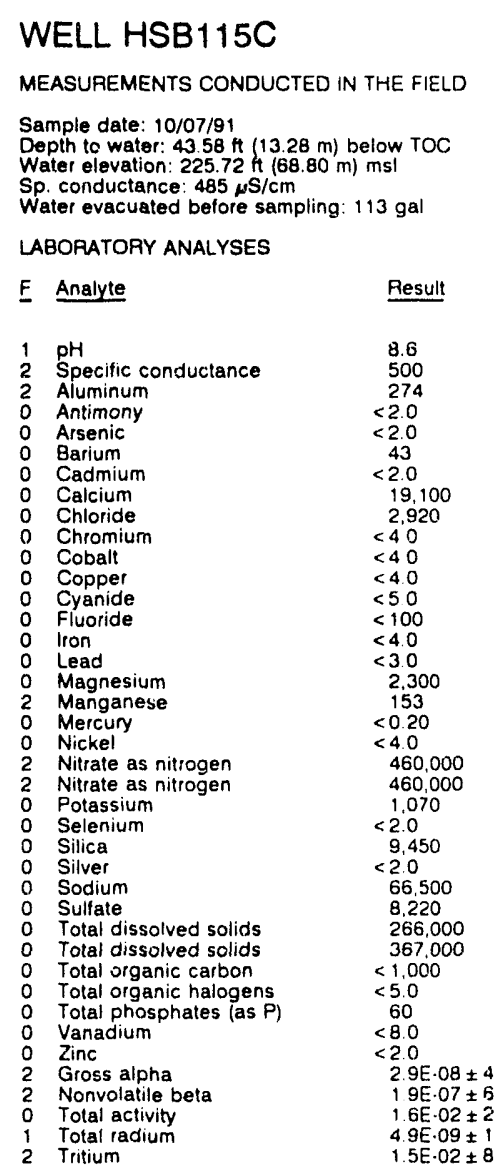

MEASUREMENTS CONDUCTED IN THE FIELD

Time: $15: 30$

$\mathrm{pH}: 8.8$

Alkalinity: $23 \mathrm{mg} / \mathrm{L}$

Water temperature: $20.3^{\circ} \mathrm{C}$

LABORATORY ANALYSES

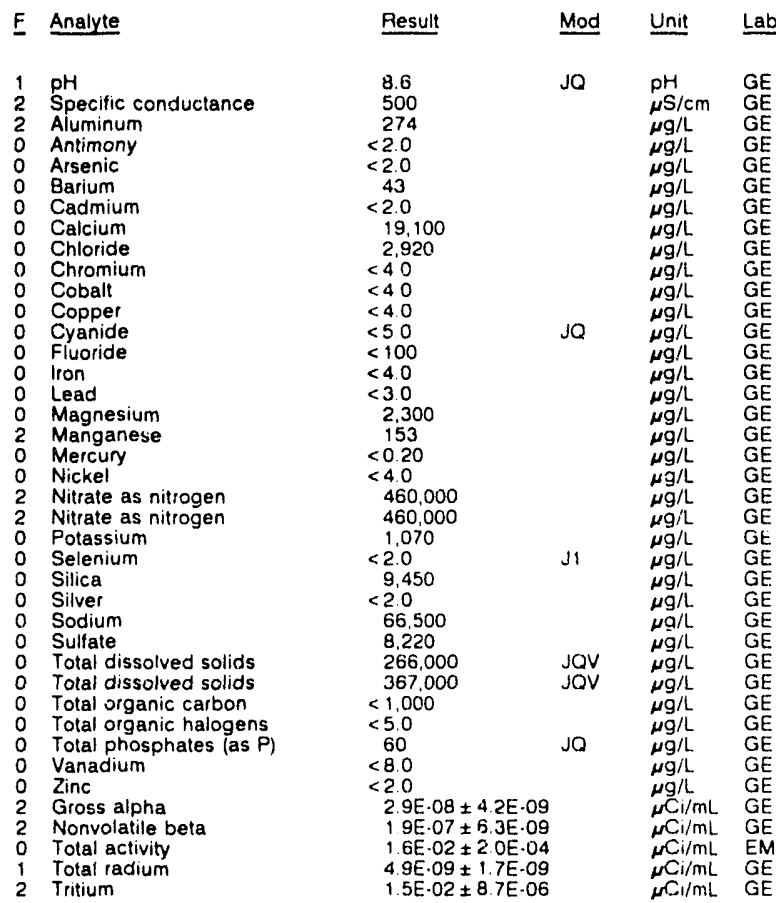

\section{WELL HSB115D}

\section{MEASUREMENTS CONDUCTED IN THE FIELD}

Sample date: $10 / 08 / 91$

Depth to water: $43.39 \mathrm{ft}(13.23 \mathrm{~m})$ below TOC

Water elevation: $225.71 \mathrm{Ht} / 68$
Sp conductance $303 \mu \mathrm{s} / \mathrm{cm}$

Water evacuated before sampling 5 gal

The well went dry during purging

LARORATORY ANALYSES
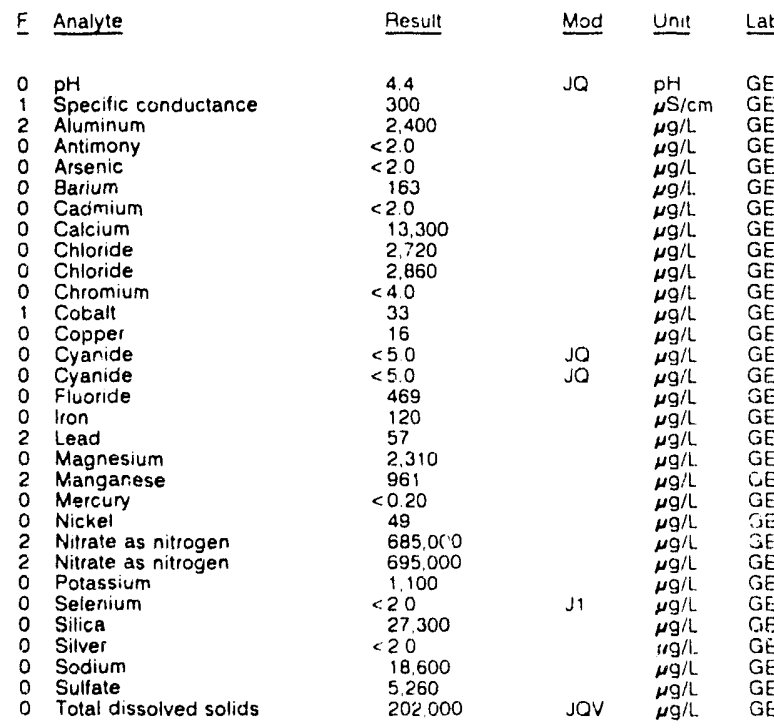

\section{Time: 8.45}

pH: 42 alkalinity $0 \mathrm{mg} / \mathrm{l}$

Water tempetature $190^{\circ} \mathrm{C}$

Lab
$G E$
$G E$
$G E$
$G E$
$G E$
$G E$
$G E$
$G E$
$G E$
$G E$
$G E$
$G E$
$G E$
$G E$
$G E$
$G E$
$G E$
$G E$
$G E$
$G E$
$G E$
$G E$
$G E$
$G E$
$G E$
$G E$
$G E$
$G E$
$G E$
$G E$
$G E$
$G E$
$G E$
$G E$
$G E$
$G E$
$G E$
$E M$
$G E$
$G E$

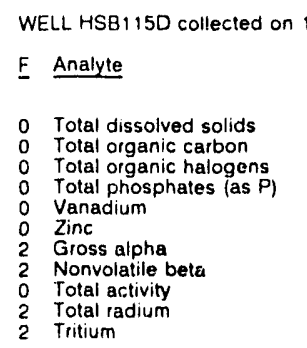

WELL HSB116C

MEASUREMENTS CONDUCTED IN THE FIELD

$\underline{\text { Unit }} \underline{\text { Lab }}$

Result Mod Unit Lab

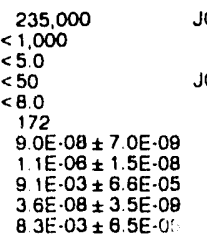

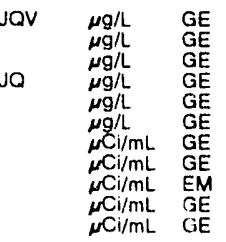

\begin{tabular}{|c|c|c|c|}
\hline Analyte & Result & Mod & $\underline{\text { Unit }}$ \\
\hline $\begin{array}{l}\text { Total dissolved solids } \\
\text { Total organic carbon } \\
\text { Total organic halogens } \\
\text { Total phosphates (as P) } \\
\text { Vanadium } \\
\text { Zine } \\
\text { Gross alpha } \\
\text { Nonvolatile beta } \\
\text { Total activity } \\
\text { Total radium } \\
\text { Tritium }\end{array}$ & $\begin{array}{l}235,000 \\
<1.000 \\
<5.0 \\
<50 \\
<8.0 \\
172 \\
9.0 \mathrm{E} \cdot 08 \pm 7.0 \mathrm{E} \cdot 00 \\
1.1 \mathrm{E} \cdot 08 \pm 1.5 \mathrm{E} \cdot 08 \\
91 \mathrm{E} \cdot 03 \pm 6.6 \mathrm{E} \cdot 05 \\
3.6 \mathrm{E} \cdot 08 \pm 3.5 \mathrm{E} \cdot 00 \\
8.3 \mathrm{E} \cdot 03 \pm 6.5 \mathrm{E} \cdot 0\end{array}$ & JoV & $\begin{array}{l}\mu g / \mathrm{L} \\
\mu \mathrm{g} / \mathrm{L} \\
\mu g / \mathrm{L} \\
\mu g / \mathrm{L} \\
\mu g / \mathrm{L} \\
\mu g / \mathrm{L} \\
\mu \mathrm{Ci} / \mathrm{mL} \\
\mu \mathrm{Ci} / \mathrm{mL} \\
\mu \mathrm{Ci} / \mathrm{mL} \\
\mu \mathrm{Ci} / \mathrm{mL} \\
\mu \mathrm{Ci} / \mathrm{mL}\end{array}$ \\
\hline
\end{tabular}

Time: 1620

Alkalinity $0 \mathrm{mg} / \mathrm{L}$

Vhater temperature $209^{\circ} \mathrm{C}$

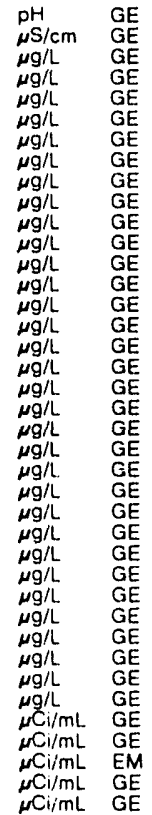

$\mathrm{GE}$
$\mathrm{GE}$
$\mathrm{GE}$
$\mathrm{GE}$
$\mathrm{GE}$
$\mathrm{GE}$
$\mathrm{GE}$
$\mathrm{GE}$
$\mathrm{GE}$
$\mathrm{GE}$
$\mathrm{GE}$
$\mathrm{GE}$
$\mathrm{GE}$
$\mathrm{GE}$
$\mathrm{GE}$
$\mathrm{GE}$
$\mathrm{GE}$
$\mathrm{GE}$
$\mathrm{GE}$
$\mathrm{GE}$
$\mathrm{GE}$
$\mathrm{GE}$
$\mathrm{GE}$
$\mathrm{GE}$
$\mathrm{GE}$
$\mathrm{GE}$
$\mathrm{GE}$
$\mathrm{GE}$
$\mathrm{GE}$
$\mathrm{GE}$
$\mathrm{GE}$
$\mathrm{GE}$
$\mathrm{GE}$
$\mathrm{GE}$
$\mathrm{GE}$
$\mathrm{GE}$
$\mathrm{EM}$
$\mathrm{GE}$
$\mathrm{GE}$
Sarnple date $10 / 07 / 91$

Depth to water: $30.67 \mathrm{Ht}(9.35 \mathrm{~m})$ below TOC

Water elevation: $226.83 \mathrm{ft}(69.14 \mathrm{~m}) \mathrm{msl}$

Sp conductance: $554 \mu \mathrm{S} / \mathrm{cm}$

Water evacuated before sampling. $122 \mathrm{gal}$

LABORATORY ANALYSES

$\begin{array}{ll}\text { F } & \text { Analyte } \\ & \\ 0 & \text { pH } \\ 2 & \text { Specific conductance } \\ 1 & \text { Aluminum } \\ 0 & \text { Antimony } \\ 0 & \text { Arsenic } \\ 0 & \text { Barium } \\ 0 & \text { Cadmium } \\ 0 & \text { Calcium } \\ 0 & \text { Chloride } \\ 0 & \text { Chromium } \\ 2 & \text { Cobalt } \\ 0 & \text { Copper } \\ 0 & \text { Cyanide } \\ 0 & \text { Fluoride } \\ 0 & \text { Iron } \\ 0 & \text { Lead } \\ 0 & \text { Magnesium } \\ 2 & \text { Manganese } \\ 0 & \text { Mercury } \\ 0 & \text { Nickel } \\ 2 & \text { Nitrate as nitrogen } \\ 2 & \text { Nitrate as nitrogen } \\ 0 & \text { Potassium } \\ 0 & \text { Selenium } \\ 0 & \text { Silica } \\ 0 & \text { Silvet } \\ 0 & \text { Sodium } \\ 0 & \text { Sulfate } \\ 0 & \text { Total dissolved solids } \\ 0 & \text { Total organic carbon } \\ 0 & \text { Total organic halogens } \\ 0 & \text { Total phosphates (as P) } \\ 0 & \text { Vanadium } \\ 0 & \text { Znc } \\ 2 & \text { Gross alpha } \\ 2 & \text { Nonvolatile beta } \\ 0 & \text { Total activity } \\ 2 & \text { Total radium } \\ 2 & \text { Tritium } \\ & \end{array}$

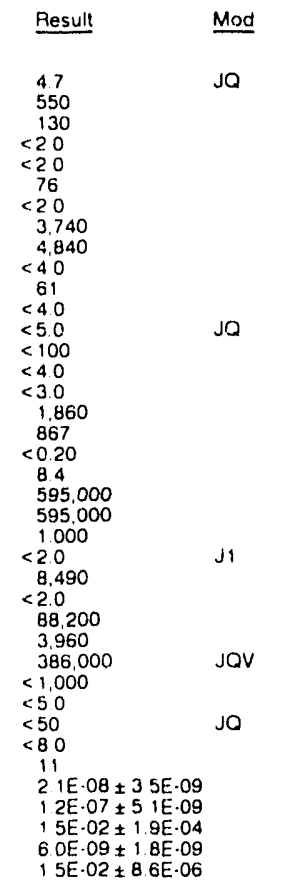

WELL HSB116D

MEASUREMENTS CONDUCTED IN THE FIELD

Sample date $10 / 07 / 91$

Depth to water: $29.41 \mathrm{H}(8.96 \mathrm{~m})$ below TOC.

Watef elevation $227.39 \mathrm{Ht}(6931 \mathrm{~m}) \mathrm{msl}$

Sp conductance $379 \mu \mathrm{S} / \mathrm{cm}$

Time: 16:00

Alkalinity: $0 \mathrm{mg} / \mathrm{L}$

Water temperature: $200^{\circ} \mathrm{C}$

Water evacuated betore sampling $34 \mathrm{gal}$

LABORATORY ANALYSES
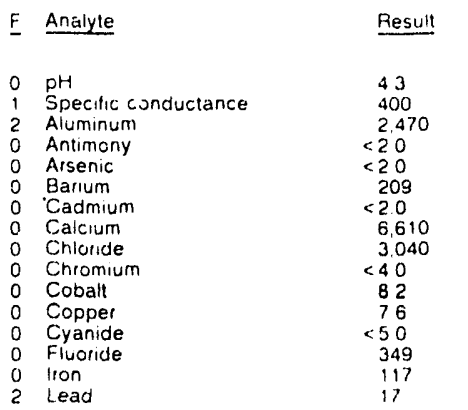
ANALYTICAL RESULTS

WELL HS\$1 16D collected on 10/07/91, laboratory analyses (cont.)

\begin{tabular}{|c|c|c|c|}
\hline Analyte & Result & Mod & Unit \\
\hline $\begin{array}{l}\text { Magnesium } \\
\text { Mariganese } \\
\text { Mercury } \\
\text { Nickel } \\
\text { Nitrate as nitrogen } \\
\text { Nitrate as nitrogen } \\
\text { Potassium } \\
\text { Selenium } \\
\text { Silica } \\
\text { Silver } \\
\text { Sodium } \\
\text { Sulfate } \\
\text { Total dissolved solids } \\
\text { Total organic carbon } \\
\text { Total organic halogens } \\
\text { Total phosphates (as P) } \\
\text { Vanadium } \\
\text { Zinc } \\
\text { Gross alpha } \\
\text { Nonvolatile beta } \\
\text { Total activity } \\
\text { Total radium } \\
\text { Tritium }\end{array}$ & $\begin{array}{l}2,560 \\
642 \\
<0.20 \\
16 \\
455,000 \\
455,000 \\
2,210 \\
<2.0 \\
11,800 \\
<2.0 \\
36,700 \\
23,800 \\
206,000 \\
<1,000 \\
<5.0 \\
<50 \\
<8.0 \\
92 \\
6.0 \mathrm{E} \cdot 07 \pm 1.8 \mathrm{E} \cdot 08 \\
7.8 \mathrm{E} \cdot 06 \pm 3.9 \mathrm{E} \cdot 08 \\
1.1 \mathrm{E} \cdot 02 \pm 1.7 \mathrm{E} \cdot 04 \\
2.0 \mathrm{E} \cdot 07 \pm 9.5 \mathrm{E} \cdot 09 \\
1.2 \mathrm{E} \cdot 02 \pm 7.6 \mathrm{E} \cdot 06\end{array}$ & $\begin{array}{l}\text { Jov } \\
\text { Jo }\end{array}$ & $\begin{array}{l}\mu g / L \\
\mu g / L \\
\mu g / L \\
\mu g / L \\
\mu g / L \\
\mu g / L \\
\mu g / L \\
\mu g / L \\
\mu g / L \\
\mu g / L \\
\mu g / L \\
\mu g / L \\
\mu g / L \\
\mu g / L \\
\mu g / L \\
\mu g / L \\
\mu g / L \\
\mu g / L \\
\mu C i / m L \\
\mu C i / m L \\
\mu C i / m L \\
\mu C \mathrm{i} / \mathrm{mL} \\
\mu C \mathrm{i} / \mathrm{mL}\end{array}$ \\
\hline
\end{tabular}

\section{WELL HSB117A}

MEASUREMENTS CONDUCTED IN THE FIELD

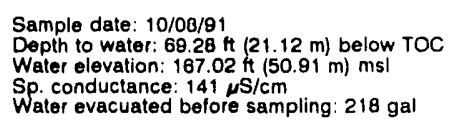

Time: $11: 25$

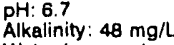

Water temperature: $18.2^{\circ} \mathrm{C}$

LABORATORY ANALYSES

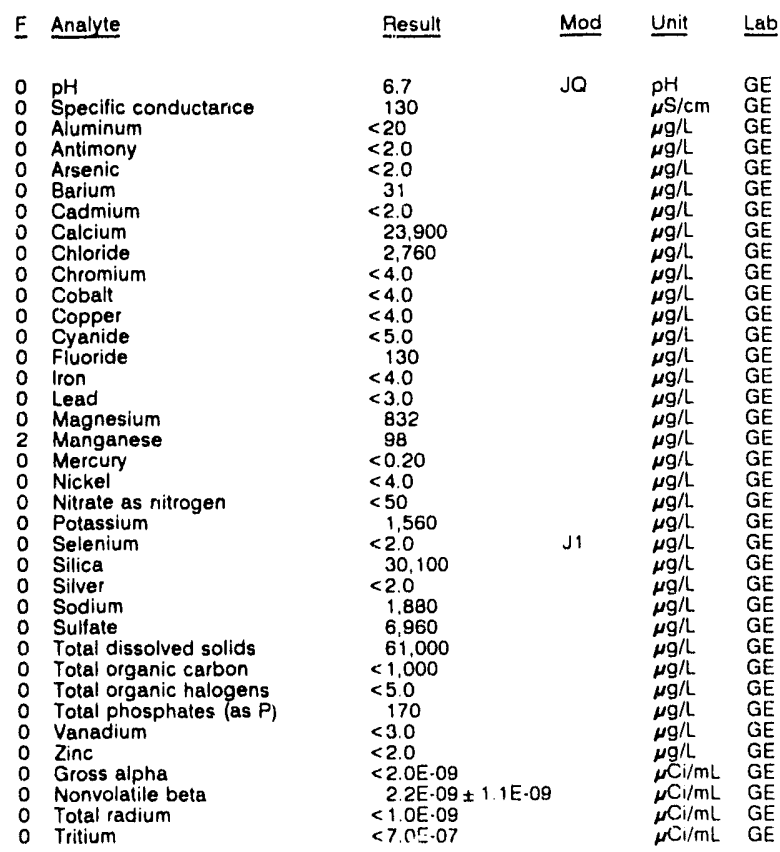

\section{WELL HSB117C}

MEASUREMENTS CONDUCTED IN THE FIELD

Sample date: $10 / 08 / 91$

Depth to water: $13.25 \mathrm{ft}(4.04 \mathrm{~m})$ below TOC

Water elevation: $223.05 \mathrm{ft}(67.9$

Water evacuated before sampling: $155 \mathrm{gal}$

LABORATORY ANALYSES

\begin{tabular}{|c|c|c|c|c|c|}
\hline & Analyte & Result & Mod & Unit & Lab \\
\hline & $\begin{array}{l}\text { pH } \\
\text { Specific conductance } \\
\text { Aluminum } \\
\text { Antimony } \\
\text { Arsenic } \\
\text { Barium }\end{array}$ & $\begin{array}{r}5.1 \\
400 \\
384 \\
<2.0 \\
<2.0 \\
6.5\end{array}$ & JO & $\begin{array}{l}\mathrm{pH} \\
\mu \mathrm{S} / \mathrm{cm} \\
\mu \mathrm{g} / \mathrm{L} \\
\mu \mathrm{g} / \mathrm{L} \\
\mu \mathrm{g} / \mathrm{L} \\
\mu \mathrm{g} / \mathrm{L}\end{array}$ & $\begin{array}{l}\mathrm{GE} \\
\mathrm{GE} \\
\mathrm{GE} \\
\mathrm{GE} \\
\mathrm{GE} \\
\mathrm{GE}\end{array}$ \\
\hline
\end{tabular}

Time: $11: 10$

Alkalinity: $0 \mathrm{mg} / \mathrm{L}$

Water temperarure $18.1^{\circ} \mathrm{C}$
WELL HSB $117 \mathrm{C}$ collected on 10/08/91, laboratory analyses (cont.)

\begin{tabular}{|c|c|c|c|c|}
\hline$\underline{F}$ & Analyte & Result & Mod & Unit \\
\hline $\begin{array}{l}0 \\
0\end{array}$ & $\begin{array}{l}\text { Cadmium } \\
\text { Calciurn } \\
\text { Chloride } \\
\text { Chromium } \\
\text { Cobalt } \\
\text { Copper } \\
\text { Cyanide } \\
\text { Fluoride } \\
\text { lron } \\
\text { Lead } \\
\text { Magnesium } \\
\text { Manganese } \\
\text { Mercury } \\
\text { Nickel } \\
\text { Nitrate as nitrogen } \\
\text { Nitrate as nitrogen } \\
\text { Potassium } \\
\text { Selenium } \\
\text { Silica } \\
\text { Silver } \\
\text { Sodium } \\
\text { Sulfate } \\
\text { Total dissolved solids } \\
\text { Total dissolved solids } \\
\text { Total organic carbon } \\
\text { Total organic halogens } \\
\text { Total phosphates (as P) } \\
\text { Vanadium } \\
\text { Zinc } \\
\text { Gross alpha } \\
\text { Nonvolatile beta } \\
\text { Total activity } \\
\text { Tolar radium } \\
\text { Tritium }\end{array}$ & $\begin{array}{l}<2.0 \\
8,240 \\
5,200 \\
<4.0 \\
5.0 \\
<4.0 \\
<5.0 \\
115 \\
<4.0 \\
<3.0 \\
4,950 \\
113 \\
0.24 \\
4.5 \\
51,500 \\
51,500 \\
670 \\
<2.0 \\
8,240 \\
<2.0 \\
62,500 \\
1,090 \\
274,000 \\
301,000 \\
<1,000 \\
<5.0 \\
<50 \\
<8.0 \\
11 \\
2.2 E-08 \pm 3.3 E \cdot 09 \\
1.3 \mathrm{E} \cdot 07 \pm 4.4 \mathrm{E} \cdot 09 \\
1.9 \mathrm{E} \cdot 03 \pm 3.2 \mathrm{E} \cdot 05 \\
8.0 \mathrm{E} \cdot 09 \pm 1.7 \mathrm{E} \cdot 09 \\
1.0 \mathrm{E} \cdot 02 \pm 7.3 \mathrm{E} \cdot 06\end{array}$ & $\begin{array}{l}v \\
v\end{array}$ & $\begin{array}{l}\mu g / L \\
\mu g / L \\
\mu g / L \\
\mu g / L \\
\mu g / L \\
\mu g / L \\
\mu g / L \\
\mu g / L \\
\mu g / L \\
\mu g / L \\
\mu g / L \\
\mu g / L \\
\mu g / L \\
\mu g / L \\
\mu g / L \\
\mu g / L \\
\mu g / L \\
\mu g / L \\
\mu g / L \\
\mu g / L \\
\mu g / L \\
\mu g / L \\
\mu g / L \\
\mu g / L \\
\mu g / L \\
\mu g / L \\
\mu g / L \\
\mu g / L \\
\mu g / L \\
\mu C \mathrm{i} / \mathrm{mL} \\
\mu C \mathrm{i} / \mathrm{mL} \\
\mu C \mathrm{i} / \mathrm{mL} \\
\mu C \mathrm{i} / \mathrm{mL} \\
\mu C \mathrm{i} / \mathrm{mL}\end{array}$ \\
\hline
\end{tabular}

\section{WELL HSB117D}

MEASUREMENTS CONDUCTED IN THE FIELD

$\begin{array}{ll}\text { Sample date: } 10 / 08 / 91 & \text { Time: } 11: 35 \\ \text { Depth to water: } 10.84 \mathrm{H}(3.30 \mathrm{~m}) \text { below TOC } & \text { pH: } 5.0 \\ \text { Water elevation: } 225.46 \mathrm{Ht}(68.72 \mathrm{~m}) \mathrm{ms} & \text { Alkalinity: } 0 \mathrm{mg} / \mathrm{L} \\ \text { Sp conductance: } 24 \mathrm{\mu S} / \mathrm{cm} & \text { Water temperature: } 18.5^{\circ} \mathrm{C} \\ \text { Water evacuated before sampling: } 69 \mathrm{gal} & \end{array}$
Water evacuated before sampling: $69 \mathrm{gal}$

LABORATORY ANALYSES

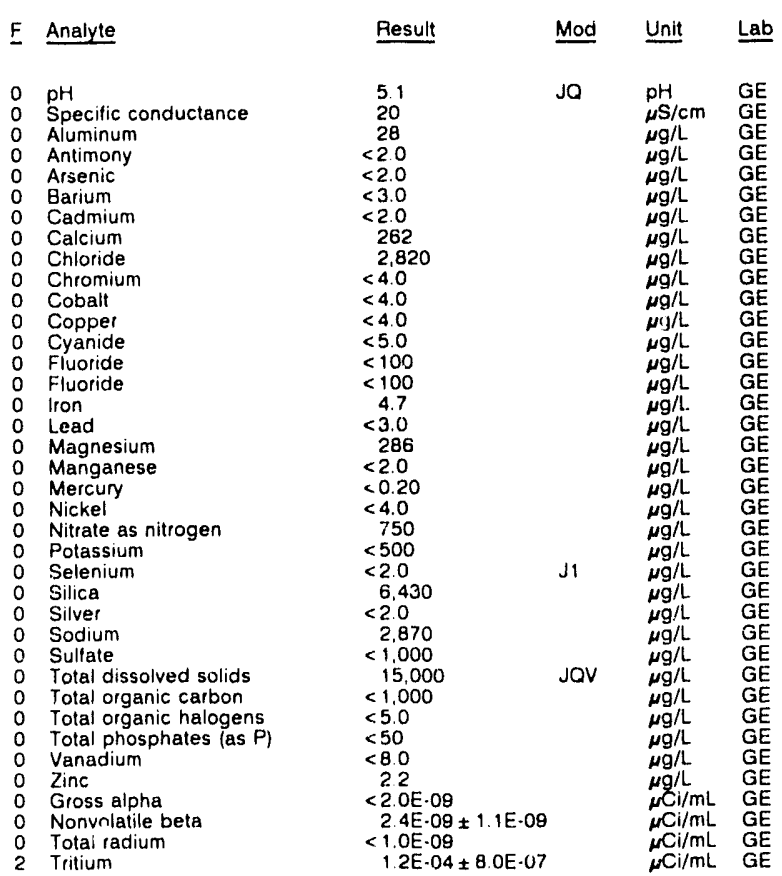


WELL HSB118A

MEASUREMENTS CONDUCTED IN THE FIELD

Sample date: 10/04/91

Depth to water: $79.00 \mathrm{ft}(24.08 \mathrm{~m})$ below TOC

Water elevation: $168.30 \mathrm{ft}(5$

Water evacuated before sampling: 203 gat

LABORATORY ANALYSES

$\begin{array}{ll}\text { F } & \text { Analyte } \\ 0 & \text { pH } \\ 0 & \text { Specific conductance } \\ 0 & \text { Aluminum } \\ 0 & \text { Antimony } \\ 0 & \text { Arsenic } \\ 0 & \text { Barium } \\ 0 & \text { Cadmium } \\ 0 & \text { Calcium } \\ 0 & \text { Chloride } \\ 0 & \text { Chromium } \\ 0 & \text { Cobalt } \\ 0 & \text { Coppel } \\ 0 & \text { Cyanide } \\ 0 & \text { Fluoride } \\ 0 & \text { Iron } \\ 0 & \text { Lead } \\ 0 & \text { Magnesium } \\ 1 & \text { Manganese } \\ 0 & \text { Mercury } \\ 0 & \text { Nickel } \\ 0 & \text { Nitrate as nitrogen } \\ 0 & \text { Potassium } \\ 0 & \text { Selenium } \\ 0 & \text { Silica } \\ 0 & \text { Silver } \\ 0 & \text { Sodium } \\ 0 & \text { Sulfate } \\ 0 & \text { Total dissolved solids } \\ 0 & \text { Total organic carbon } \\ 0 & \text { Total organic halogens } \\ 0 & \text { Total phosphates (as } P \text { ) } \\ 0 & \text { Vanadium } \\ 0 & \text { Zinc } \\ 0 & \text { Gross alpha } \\ 0 & \text { Nonvolatile beta } \\ 0 & \text { Total radium } \\ 2 & \text { Tritium } \\ & \end{array}$

\begin{tabular}{|c|c|c|}
\hline Result & Mod & Unit \\
\hline 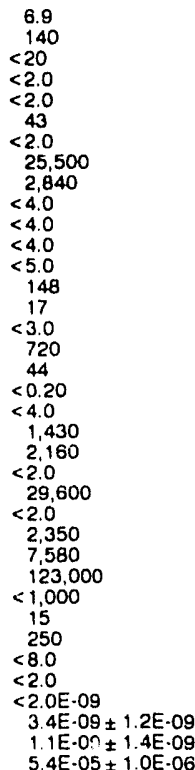 & JO & $\begin{array}{l}\rho H \\
\mu \mathrm{S} / \mathrm{cm} \\
\mu g / L \\
\mu g / L \\
\mu g / L \\
\mu g / L \\
\mu g / L \\
\mu g / L \\
\mu g / L \\
\mu g / L \\
\mu g / L \\
\mu g / L \\
\mu g / L \\
\mu g / L \\
\mu g / L \\
\mu g / L \\
\mu g / L \\
\mu g / L \\
\mu g / L \\
\mu g / L \\
\mu g / L \\
\mu g / L \\
\mu g / L \\
\mu g / L \\
\mu g / L \\
\mu g / L \\
\mu g / L \\
\mu g / L \\
\mu g / L \\
\mu g / L \\
\mu g / L \\
\mu g / L \\
\mu g / L \\
\mu C \mathrm{i} / \mathrm{mL} \\
\mu C \mathrm{i} / \mathrm{mL} \\
\mu C \mathrm{C} / \mathrm{mL} \\
\mu C i / m L\end{array}$ \\
\hline
\end{tabular}

\section{WELL HSB118A Replicate}

MEASUREMENTS CONOUCTED IN THE FIELD

Sample date: $10 / 04 / 91$

Water elevation: $16830 \mathrm{th}(51,30 \mathrm{~m}) \mathrm{ms}$

Sp conductance: 157 $4 \mathrm{~S} / \mathrm{cm}$

Water evacuated before sampling. $203 \mathrm{gal}$

LABORATORY ANALYSES

\begin{tabular}{|c|c|c|c|c|}
\hline Analyte & Result & Mod & Unit & Lab \\
\hline $\begin{array}{l}\text { pH } \\
\text { Specific conductance } \\
\text { Aluminum } \\
\text { Antimony } \\
\text { Arsenic } \\
\text { Barium } \\
\text { Cadmium } \\
\text { Calcium } \\
\text { Chloride } \\
\text { Chromium } \\
\text { Cobalt } \\
\text { Copper } \\
\text { Cyanide } \\
\text { Fluoride } \\
\text { lron } \\
\text { Lead } \\
\text { Magnesium } \\
\text { Manganese } \\
\text { Mercury } \\
\text { Nickel } \\
\text { Nitrate as nitrogen } \\
\text { Potassium } \\
\text { Selenium } \\
\text { Silica } \\
\text { Silver } \\
\text { Sodium } \\
\text { Sulfate } \\
\text { Total dissolved solids } \\
\text { Total organic carbon } \\
\text { Total organic halogens } \\
\text { Total phosphates (as P) } \\
\text { Vanadium } \\
\text { Zinc } \\
\text { Gross alpha }\end{array}$ & $\begin{array}{c}6.9 \\
150 \\
<20 \\
<2.0 \\
<2.0 \\
42 \\
<2.0 \\
26,000 \\
2,810 \\
<4.0 \\
<4.0 \\
<4.0 \\
<5.0 \\
128 \\
17 \\
<3.0 \\
716 \\
45 \\
<0.20 \\
<4.0 \\
1,280 \\
2,180 \\
<2.0 \\
29,700 \\
<2.0 \\
2,290 \\
7,440 \\
87.000 \\
<1.000 \\
5.6 \\
210 \\
<80 \\
<2.0 \\
<2.0 E \cdot 09\end{array}$ & JQ & $\begin{array}{l}p H \\
\mu \mathrm{S} / \mathrm{cm} \\
\mu g / L \\
\mu g / L \\
\mu g / L \\
\mu g / L \\
\mu g / L \\
\mu g / L \\
\mu g / L \\
\mu g / L \\
\mu g / L \\
\mu g / L \\
\mu g / L \\
\mu g / L \\
\mu g / L \\
\mu g / L \\
\mu g / L \\
\mu g / L \\
\mu g / L \\
\mu g / L \\
\mu g / L \\
\mu g / L \\
\mu g / L \\
\mu g / L \\
\mu g / L \\
\mu g / L \\
\mu g / L \\
\mu g / L \\
\mu g / L \\
\mu g / L \\
\mu g / L \\
\mu g / L \\
\mu g / L \\
\mu C i / m L\end{array}$ & $\begin{array}{l}\mathrm{GE} \\
\mathrm{GE} \\
\mathrm{GE} \\
\mathrm{GE} \\
\mathrm{GE} \\
\mathrm{GE} \\
\mathrm{GE} \\
\mathrm{GE} \\
\mathrm{GE} \\
\mathrm{GE} \\
\mathrm{GE} \\
\mathrm{GE} \\
\mathrm{GE} \\
\mathrm{GE} \\
\mathrm{GE} \\
\mathrm{GE} \\
\mathrm{GE} \\
\mathrm{GE} \\
\mathrm{GE} \\
\mathrm{GE} \\
\mathrm{GE} \\
\mathrm{GE} \\
\mathrm{GE} \\
\mathrm{GE} \\
\mathrm{GE} \\
\mathrm{GE} \\
\mathrm{GE} \\
\mathrm{GE} \\
\mathrm{GE} \\
\mathrm{GE} \\
\mathrm{GE} \\
\mathrm{GE} \\
\mathrm{GE} \\
\mathrm{GE}\end{array}$ \\
\hline
\end{tabular}

WELL HSB118A collected on 10/04/91, laboratory analyses (cont.)

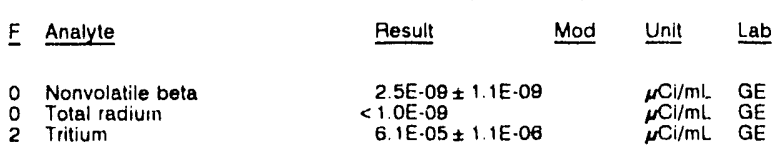

WELL HSB119A

MEASUREMENTS CONDUCTEO IN THE FIELD

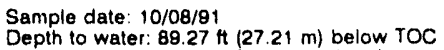

Water elevation: $167.83 \mathrm{ft}(51.16 \mathrm{~m}) \mathrm{ms}$ )

Sp conductance $182 \mu \mathrm{s} / \mathrm{cm}$

7 ine: 78.10

pH. 7.2 20 moll

Water temperature: $20.0^{\circ} \mathrm{C}$

Water evacuated before sampling: $196 \mathrm{gal}$

LABORATORY ANALYSES

pH

A Aluminum

C Antimony

0 Arsenic

0 Cadmium

Calcium

Chloride

Cobalt

Cyanide

0 Fluoride

Iron

Magnesium

Manganese

Mercury

Nitrate as nitrogen

Potassium

Selenium

Silica

Silver

Sulfate

Total dissolved solids

Total organic carbon

Total organic halogens

Total phosphates (as P)

0 Zanadium

G Gins alpha

Gross alpha
Nonvolatile beta

Nonvolatile bela

Total activity

2 Tritium!

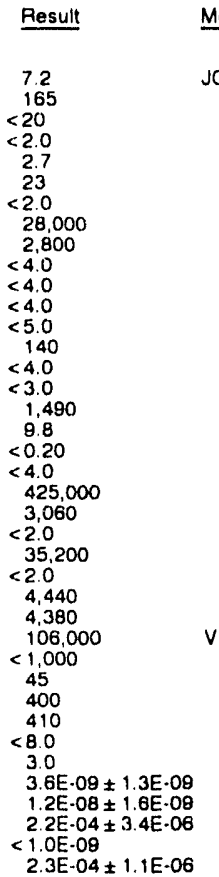

$\underline{\text { Unit }} \quad \underline{\text { Lab }}$

WELL HSB120A

MEASUREMENTS CONOUCTED IN THE FIELD

Sample date: 10/04/91

$10103 \mathrm{ft}(30,79 \mathrm{~m})$ below TOC Water elevation: $167.17 \mathrm{ft}(50.95 \mathrm{~m}) \mathrm{ms}$

Sp. conductance: $210 \mu \mathrm{S} / \mathrm{cm}$

Water evacuated before sampling: '200 gal

LABORATOAY ANALYSES

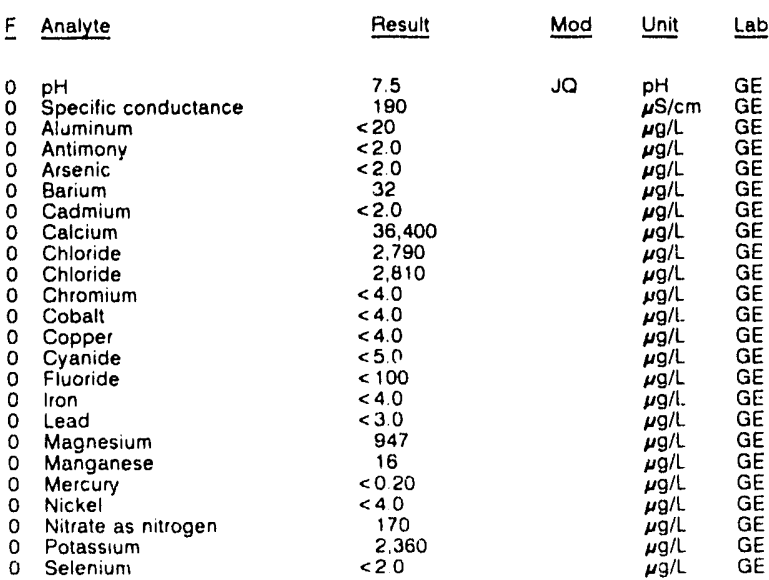


ANALYTICAL RESULTS

WELL HSB120A collected on 10/04/91, laboratory ailalyses (cont.)

\begin{tabular}{|c|c|c|c|}
\hline Analyte & Result & Mod & Unit \\
\hline $\begin{array}{l}\text { Silica } \\
\text { Silver } \\
\text { Sodium } \\
\text { Sulfale } \\
\text { Sulfate } \\
\text { Total dissolved solids } \\
\text { Total organic carbon } \\
\text { Total organic halogens } \\
\text { Total phosphates (as P) } \\
\text { Vanadium } \\
\text { Zinc } \\
\text { Gross alpha } \\
\text { Nonvolatile beta } \\
\text { Total radium } \\
\text { Tritium }\end{array}$ & $\begin{array}{l}30,800 \\
<2.0 \\
3,090 \\
6,930 \\
6,950 \\
151,000 \\
<1,000 \\
7.6 \\
70 \\
<8.0 \\
<2.0 \\
<2.0 \mathrm{E}-09 \\
<2.0 \mathrm{E}-09 \\
<1.0 \mathrm{E}-09 \\
<7.0 \mathrm{E}-07\end{array}$ & $v$ & $\begin{array}{l}\mu \mathrm{g} / \mathrm{L} \\
\mu \mathrm{g} / \mathrm{L} \\
\mu \mathrm{g} / \mathrm{L} \\
\mu \mathrm{g} / \mathrm{L} \\
\mu \mathrm{g} / \mathrm{L} \\
\mu \mathrm{g} / \mathrm{L} \\
\mu \mathrm{g} / \mathrm{L} \\
\mu \mathrm{g} / \mathrm{L} \\
\mu \mathrm{g} / \mathrm{L} \\
\mu \mathrm{g} / \mathrm{L} \\
\mu \mathrm{g} / \mathrm{L} \\
\mu \mathrm{Cl} / \mathrm{mL} \\
\mu \mathrm{Ci} / \mathrm{mL} \\
\mu \mathrm{Ci} / \mathrm{mL} \\
\mu \mathrm{Ci} / \mathrm{mL}\end{array}$ \\
\hline
\end{tabular}

\section{WELL HSB121A}

MEASUREMENTS CONOUCTED IN THE FIELD

\begin{tabular}{|c|c|c|c|c|c|}
\hline \multicolumn{3}{|c|}{$\begin{array}{l}\text { Sample date: } 10.04 / 81 \\
\text { Depth to water: } 102.04 \mathrm{ft}(31.10 \mathrm{~m}) \text { below TOC } \\
\text { Water olevation: } 172.58 \mathrm{ft}(52.60 \mathrm{~m}) \mathrm{msl} \\
\text { Sp. conductance: } 324 \mu \mathrm{cm} / \mathrm{cm} \\
\text { Water evacuated before sampling: } 221 \mathrm{gal}\end{array}$} & \multicolumn{3}{|c|}{$\begin{array}{l}\text { Time: } 14: 35 \\
\text { pH: } 7.5 \\
\text { Alkalinity: } 81 \mathrm{mg} / \mathrm{h} \\
\text { Water temperature: } 18.8^{\circ} \mathrm{C}\end{array}$} \\
\hline \multicolumn{6}{|c|}{ LABORATORY ANALYSES } \\
\hline & Analyte & Result & Mod & Unit & Lat \\
\hline & $\begin{array}{l}\text { pH } \\
\text { Specific conductance } \\
\text { Aluminum } \\
\text { Antimony } \\
\text { Arsenic } \\
\text { Barium } \\
\text { Cadmium } \\
\text { Calcium } \\
\text { Chloride } \\
\text { Chromium } \\
\text { Cobs!t } \\
\text { Coppor } \\
\text { Cyanide } \\
\text { Fluoride } \\
\text { Iron } \\
\text { Lead } \\
\text { Magnesium } \\
\text { Manganese } \\
\text { Mercury } \\
\text { Nickel } \\
\text { Nitrate as nitrogen } \\
\text { Potassium } \\
\text { Selenium } \\
\text { Silica } \\
\text { Silver } \\
\text { Sodium } \\
\text { Sulfate } \\
\text { Total dissolved solids } \\
\text { Total organic carbon } \\
\text { Total organic halogens } \\
\text { Total phosphates (as P) } \\
\text { Vanadium } \\
\text { Zinc } \\
\text { Gross alpha } \\
\text { Nonvolatile beta } \\
\text { rotal radium } \\
\text { Tritium }\end{array}$ & $\begin{array}{l}7.6 \\
200 \\
<20 \\
<2.0 \\
<2.0 \\
54 \\
<2.0 \\
39,300 \\
2,880 \\
<4.0 \\
<4.0 \\
<4.0 \\
<5.0 \\
<100 \\
21 \\
<3.0 \\
803 \\
7.8 \\
<0.20 \\
<4.0 \\
110 \\
3,100 \\
<2.0 \\
41,400 \\
<2.0 \\
3,170 \\
10,400 \\
167,000 \\
<1,000 \\
14 \\
<50 \\
<8.0 \\
<2.0 \\
<2.0 \mathrm{E}-09 \\
2.2 \mathrm{E} \cdot 09.09 \\
<1.0 \mathrm{E} \cdot 09 \\
<7.0 \mathrm{E}-07\end{array}$ & $=-09$ & $\begin{array}{l}\mathrm{pH} \\
\mu \mathrm{S} / \mathrm{cm} \\
\mu \mathrm{g} / \mathrm{L} \\
\mu \mathrm{g} / \mathrm{L} \\
\mu \mathrm{g} / \mathrm{L} \\
\mu \mathrm{g} / \mathrm{L} \\
\mu \mathrm{g} / \mathrm{L} \\
\mu g / \mathrm{L} \\
\mu g / \mathrm{L} \\
\mu g / \mathrm{L} \\
\mu \mathrm{g} / \mathrm{L} \\
\mu \mathrm{g} / \mathrm{L} \\
\mu \mathrm{g} / \mathrm{L} \\
\mu \mathrm{g} / \mathrm{L} \\
\mu \mathrm{g} / \mathrm{L} \\
\mu \mathrm{g} / \mathrm{L} \\
\mu \mathrm{g} / \mathrm{L} \\
\mu \mathrm{g} / \mathrm{L} \\
\mu \mathrm{g} / \mathrm{L} \\
\mu \mathrm{g} / \mathrm{L} \\
\mu \mathrm{g} / \mathrm{L} \\
\mu \mathrm{g} / \mathrm{L} \\
\mu \mathrm{g} / \mathrm{L} \\
\mu \mathrm{g} / \mathrm{L} \\
\mu \mathrm{g} / \mathrm{L} \\
\mu \mathrm{g} / \mathrm{L} \\
\mu \mathrm{g} / \mathrm{L} \\
\mu \mathrm{g} / \mathrm{L} \\
\mu \mathrm{g} / \mathrm{L} \\
\mu \mathrm{g} / \mathrm{L} \\
\mu \mathrm{g} / \mathrm{L} \\
\mu \mathrm{g} / \mathrm{L} \\
\mu \mathrm{g} / \mathrm{L} \\
\mu \mathrm{C} \mathrm{i} / \mathrm{mL} \\
\mu \mathrm{Ci} / \mathrm{mL} \\
\mu C \mathrm{i} / \mathrm{mL} \\
\mu C \mathrm{i} / \mathrm{mL}\end{array}$ & $\begin{array}{l}G E \\
G E \\
G E \\
G E \\
G E \\
G E \\
G E \\
G E \\
G E \\
G E \\
G E \\
G E \\
G E \\
G E \\
G E \\
G E \\
G E \\
G E \\
G E \\
G E \\
G E \\
G E \\
G E \\
G E \\
G E \\
G E \\
G E \\
G E \\
G E \\
G E \\
G E \\
G E \\
G E \\
G E \\
G E\end{array}$ \\
\hline
\end{tabular}

WELL. HSB122A

MEASUREMENTS CONDUCTEO IN THE FIELD

Sample date: 10/04/91

Depth 10 water: $99.30 \mathrm{ft}(30.27 \mathrm{~m})$ below TOC

Water elevation: $172.30 \mathrm{ft}(52.5$

Sp. conductance: $225 \mu \mathrm{S} / \mathrm{cm}$

LABORATORY ANALYSES

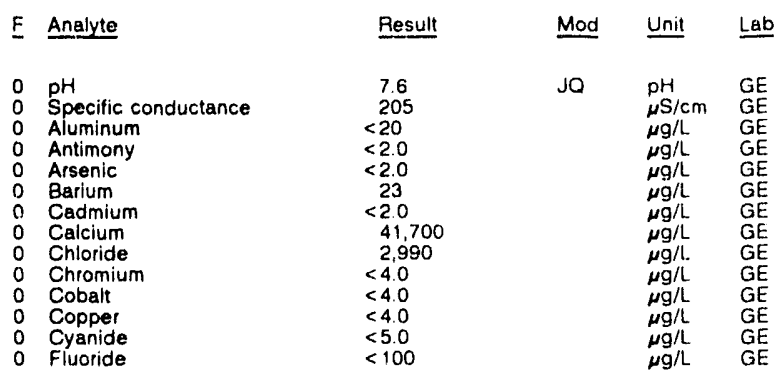

WELL HSB122A collected on 10/04/91, laboratory analyses (cont.)

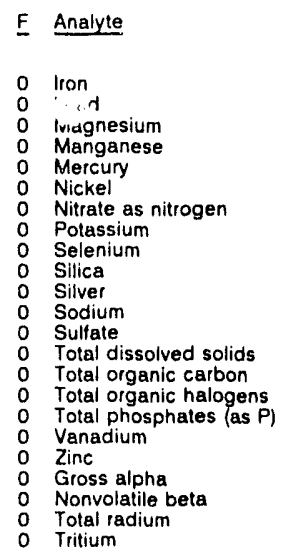

\begin{tabular}{|c|c|c|}
\hline Result & Mod & Unit \\
\hline $\begin{aligned} & 17 \\
&<3.0 \\
& 807 \\
& 5.0 \\
&<0.20 \\
&<4.0 \\
& 110 \\
& 921 \\
&<2.0 \\
& 37,800 \\
&<2.0 \\
& 1.850 \\
& 11.300 \\
& 160,000 \\
&<1,000 \\
& 12 \\
& 60 \\
&<8.0 \\
&<2.0 \\
&<2.0 E \cdot 09 \\
&<2.0 E \cdot 09 \\
& 1.1 \mathrm{E} \cdot 08 \pm 1.4 \mathrm{E} \cdot 08 \\
&<7.0 \mathrm{E} \cdot 07\end{aligned}$ & v & $\begin{array}{l}\mu \mathrm{g} / \mathrm{L} \\
\mu \mathrm{g} / \mathrm{L} \\
\mu \mathrm{g} / \mathrm{L} \\
\mu g / \mathrm{L} \\
\mu \mathrm{g} / \mathrm{L} \\
\mu \mathrm{g} / \mathrm{L} \\
\mu \mathrm{g} / \mathrm{L} \\
\mu \mathrm{g} / \mathrm{L} \\
\mu \mathrm{g} / \mathrm{L} \\
\mu \mathrm{g} / \mathrm{L} \\
\mu \mathrm{g} / \mathrm{L} \\
\mu \mathrm{g} / \mathrm{L} \\
\mu \mathrm{g} / \mathrm{L} \\
\mu \mathrm{g} / \mathrm{L} \\
\mu \mathrm{g} / \mathrm{L} \\
\mu \mathrm{g} / \mathrm{L} \\
\mu \mathrm{g} / \mathrm{L} \\
\mu g / \mathrm{L} \\
\mu \mathrm{g} / \mathrm{L} \\
\mu \mathrm{C} / \mathrm{mL} \\
\mu \mathrm{Cl} / \mathrm{mL} \\
\mu \mathrm{Ci} / \mathrm{mL} \\
\mu \mathrm{Ci} / \mathrm{mL}\end{array}$ \\
\hline
\end{tabular}

WELL HSB123A

MEASUREMENTS CONDUCTED IN THE FIELD

Depth to water: $91.91 \mathrm{ft}(28.01 \mathrm{~m})$ below TOC

Water elevation: $172.59 \mathrm{ft}(52.61 \mathrm{~m}) \mathrm{ms}$ )

Sp. conductance $217 \mu$ stcm

Time: 16:15

Alkalinity: $85 \mathrm{mg} / \mathrm{L}$

Water teniperature: $18.9^{\circ} \mathrm{C}$

Water evacuated before sampling: $211 \mathrm{ga}$

LABORATORY ANALYSES

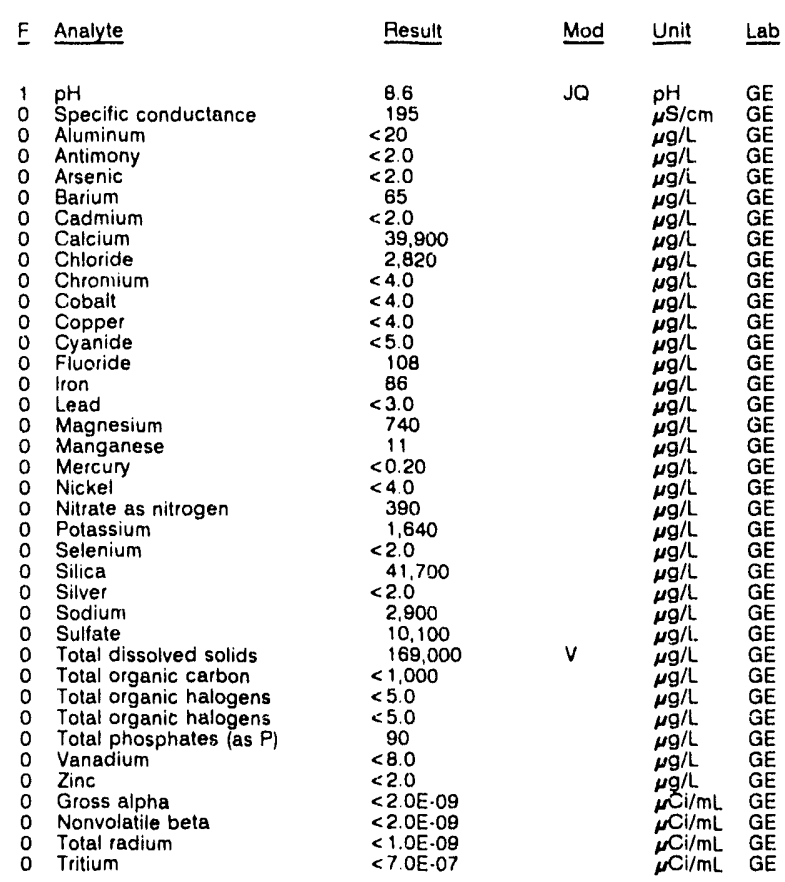

\section{WELL HSB124A}

MEASUREMENTS CONDUCTED IN THE FIELD

Sample date: 10/04/91

Depth to water: 76.07 it $(23.19 \mathrm{~m})$ below TOC

Water elevation: $190.13 \mathrm{H}(57.95 \mathrm{~m}) \mathrm{ms}$

Sp conductance: $605 \mu \mathrm{S} / \mathrm{cm}$

Water evacuated before sampling: $44 \mathrm{gal}$

The well went dry during purging

LABORATORY ANALYSES

\begin{tabular}{llllll} 
E Analyte & Result & Mod & Unit & Lab \\
\cline { 2 - 5 } & & & & \\
2 & $\mathrm{pH}$ & 11 & $\mathrm{JO}$ & $\mathrm{pH}$ & $\mathrm{GE}$ \\
2 & Specific conductance & 510 & & $\mu \mathrm{S} / \mathrm{cm}$ & $\mathrm{GE}$ \\
0 & Aluminum & 70 & & $\mu \mathrm{g} / \mathrm{L}$ & $\mathrm{GE}$ \\
0 & Antimony & $<2.0$ & & $\mu \mathrm{g} / \mathrm{L}$ & $\mathrm{GE}$ \\
0 & Arsenic & $<2.0$ & & $\mu \mathrm{g} / \mathrm{L}$ & $\mathrm{GE}$
\end{tabular}




\section{ANALYTICAL RESULTS}

WELL HSB124A collected on 10/04/91, laboratory analyses (cont.)

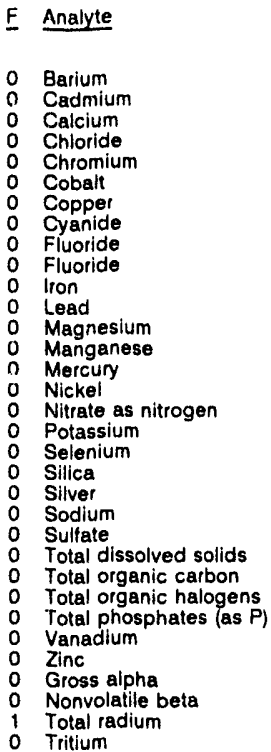

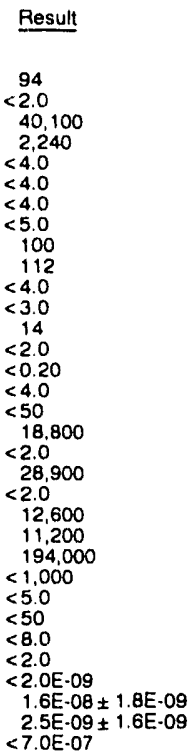
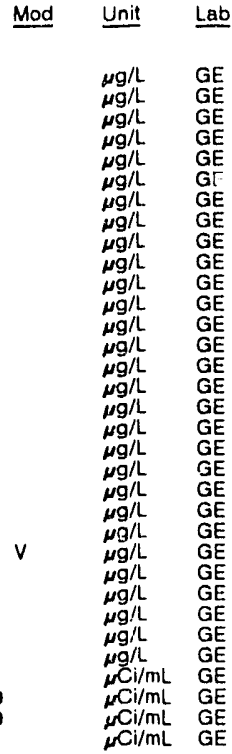

WELL HSB125C

MEASUREMENTS CONDUCTED IN THE FIELD

Sample date: 10/10/91

Depth to water: $7.38 \mathrm{Ht}(2.25 \mathrm{~m})$ below YOC Water elevation: $224.52 \mathrm{ft}(68.4$

Water evacuated before sampling: $207 \mathrm{gal}$

LABORATORY ANALYSES

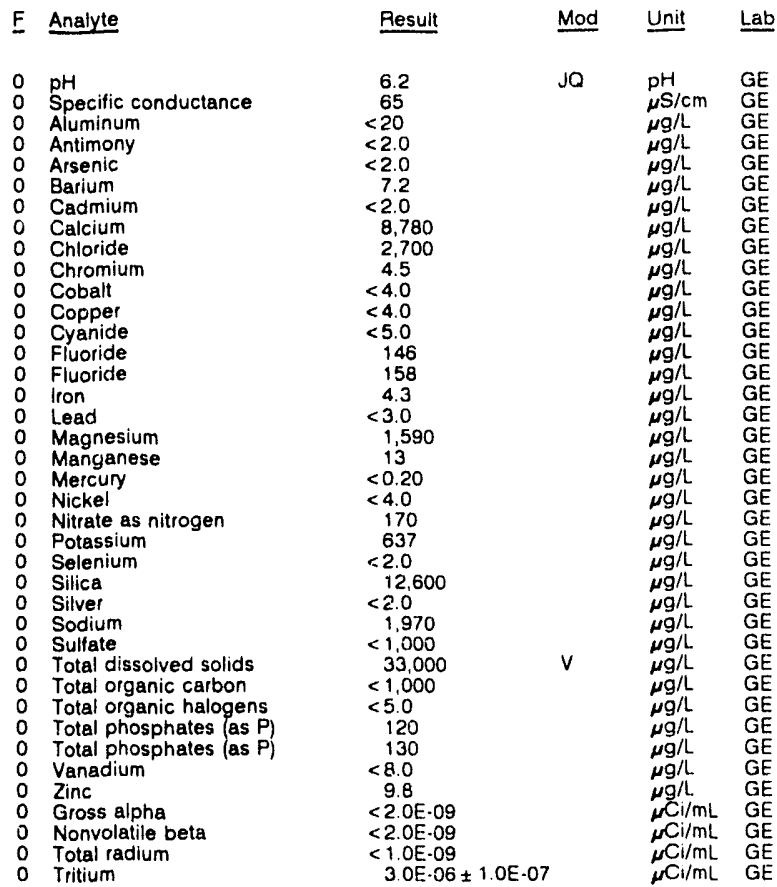

WELL HSB125D

MEASUREMENTS CONDUCTED IN THE FIELO

Sample date: 10/10/91

Depth to water: $10.55 \mathrm{tt}(3.22 \mathrm{~m})$ below TOC

Water elevation: $221.15 \mathrm{ft} / 67.4$

Water evacuated before sampling: 57 gal

Time: $11: 40$

: 4.7 . 0 :

Water temperature: $19.1 \% \mathrm{C}$

LABORATORY ANALYSES

\begin{tabular}{|c|c|c|c|}
\hline Analyte & Result & Mod & Unit \\
\hline $\begin{array}{ll}0 & \text { pH } \\
1 & \text { Specific conductance } \\
0 & \text { Aluminum } \\
0 & \text { Antimony } \\
0 & \text { Arsenic } \\
0 & \text { Barium } \\
0 & \text { Cadmium } \\
0 & \text { Caicium } \\
0 & \text { Chloride } \\
0 & \text { Chromium } \\
0 & \text { Cobalt } \\
0 & \text { Copper } \\
0 & \text { Cyanide } \\
0 & \text { Fluoride } \\
2 & \text { lon } \\
0 & \text { Lead } \\
0 & \text { Magnesium } \\
2 & \text { Manganese } \\
1 & \text { Mercury } \\
0 & \text { Nickel } \\
2 & \text { Nitrate as nitrogen } \\
2 & \text { Nitrate as nitrogen } \\
0 & \text { Potassium } \\
0 & \text { Selenium } \\
0 & \text { Silica } \\
0 & \text { Silver } \\
0 & \text { Sodium } \\
0 & \text { Sulfate } \\
0 & \text { Total dissolved solids } \\
0 & \text { Total organic carbon } \\
0 & \text { Total organic halogens } \\
0 & \text { Total phosphates (as P) } \\
0 & \text { Vanadium } \\
0 & \text { Zinc } \\
0 & \text { Gross alpha } \\
1 & \text { Nonvolatile beta } \\
0 & \text { Total activity } \\
0 & \text { Total radium } \\
2 & \text { Tritium }\end{array}$ & $\begin{array}{l}4.9 \\
325 \\
75 \\
<2.0 \\
<2.0 \\
12 \\
<2.0 \\
272 \\
3,320 \\
<4.0 \\
<4.0 \\
<4.0 \\
<5.0 \\
<100 \\
405 \\
<3.0 \\
474 \\
196 \\
1.3 \\
<4.0 \\
35,000 \\
35,000 \\
<500 \\
<2.0 \\
7,050 \\
<2.0 \\
46,500 \\
8,180 \\
246,000 \\
<1.000 \\
5.6 \\
<50 \\
<8.0 \\
2.7 \\
4.4 \mathrm{E}-09 \pm 1.0 \mathrm{E} \cdot 00 \\
4.4 \mathrm{E} \cdot 08 \pm 3.2 \mathrm{E} \cdot 09 \\
4.8 \mathrm{E} \cdot 03 \pm 5.1 \mathrm{E} \cdot 05 \\
1.7 \mathrm{E}-09 \pm 1.3 \mathrm{E} \cdot 09 \\
5.0 \mathrm{E} \cdot 03 \pm 5.0 \mathrm{E} \cdot 06\end{array}$ & $\begin{array}{l}\text { J2 } \\
\text { JO }\end{array}$ & $\begin{array}{l}p H \\
\mu \mathrm{S} / \mathrm{cm} \\
\mu g / L \\
\mu g / L \\
\mu g / L \\
\mu g / L \\
\mu g / L \\
\mu g / L \\
\mu g / L \\
\mu g / L \\
\mu g / L \\
\mu g / L \\
\mu g / L \\
\mu g / L \\
\mu g / L \\
\mu g / L \\
\mu g / L \\
\mu g / L \\
\mu g / L \\
\mu g / L \\
\mu g / L \\
\mu g / L \\
\mu g / L \\
\mu g / L \\
\mu g / L \\
\mu g / L \\
\mu g / L \\
\mu g / L \\
\mu g / L \\
\mu g / L \\
\mu g / L \\
\mu g / L \\
\mu g / L \\
\mu g / L \\
\mu C I / m L \\
\mu C i / m L \\
\mu C / / m L \\
\mu C l / m L \\
\mu C i / m L\end{array}$ \\
\hline
\end{tabular}

\section{WELL HSB126C}

MEASUREMENTS CONDUCTED IN THE FIELO

Sample date: 10/10/91

Depth to water: 34 it (2.54 m) below TOC Water elevation: $204.26 \mathrm{ft}(62.26 \mathrm{~m}) \mathrm{msl}$

Wale elevalion. $204.26 \mathrm{H}(62$.

Water evacuated before sampling: $73 \mathrm{gal}$

Time: $9: 20$

Alkalinity: $73 \mathrm{mg} / \mathrm{L}$

Water temperature: $17.6^{\circ} \mathrm{C}$

LABORATORY ANALYSES

\begin{tabular}{|c|c|c|c|}
\hline Analyte & Resull & Mod & Unit \\
\hline $\begin{array}{l}\text { pH } \\
\text { Specitic conductance } \\
\text { Aluminum } \\
\text { Antimony } \\
\text { Arsenic } \\
\text { Barium } \\
\text { Cadmium } \\
\text { Calcium } \\
\text { Chloride } \\
\text { Chloride } \\
\text { Chromium } \\
\text { Cobalt } \\
\text { Copper } \\
\text { Cyanide } \\
\text { Fluoride } \\
\text { lron } \\
\text { Lead } \\
\text { Magnesium } \\
\text { Manganese } \\
\text { Mercury } \\
\text { Nickel } \\
\text { Nitrate as nitrogen } \\
\text { Potassium } \\
\text { Selenium } \\
\text { Silica } \\
\text { Silvel } \\
\text { Sodium } \\
\text { Sulfate } \\
\text { Total dissolved solids } \\
\text { Total organic carbon } \\
\text { Total organic halogens } \\
\text { Total phosphates (as P) }\end{array}$ & $\begin{array}{l}7.9 \\
210 \\
<20 \\
<2.0 \\
<2.0 \\
10 \\
<2.0 \\
34,800 \\
3,000 \\
2,970 \\
4.2 \\
<4.0 \\
<4.0 \\
<5.0 \\
<100 \\
<4.0 \\
<3.0 \\
1,330 \\
<2.0 \\
<0.20 \\
<4.0 \\
110 \\
649 \\
<2.0 \\
27.100 \\
<2.0 \\
5,710 \\
1,730 \\
108,000 \\
<1,000 \\
<5.0 \\
50\end{array}$ & JQ & $\begin{array}{l}p H \\
\mu \mathrm{S} / \mathrm{cm} \\
\mu g / L \\
\mu g / L \\
\mu g / L \\
\mu g / L \\
\mu g / L \\
\mu g / L \\
\mu g / L \\
\mu g / L \\
\mu g / L \\
\mu g / L \\
\mu g / L \\
\mu g / L \\
\mu g / L \\
\mu g / L \\
\mu g / L \\
\mu g / L \\
\mu g / L \\
\mu g / L \\
\mu g / L \\
\mu g / L \\
\mu g / L \\
\mu g / L \\
\mu g / L \\
\mu g / L \\
\mu g / L \\
\mu g / L \\
\mu g / L \\
\mu g / L \\
\mu g / L \\
\mu g / L\end{array}$ \\
\hline
\end{tabular}


ANALYTICAL RESULTS

WELL HSB126C collected on 10/10/91, laboratory analyses (cont.)
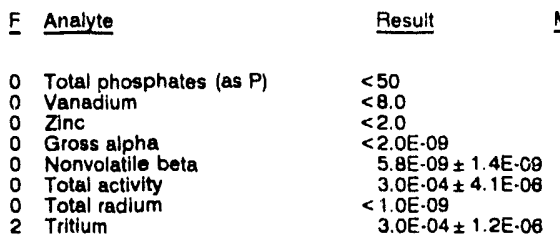

Mod Unit Lab

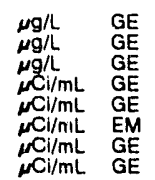

WELL HSB126D

MEASUREMENTS CONDUCTED IN THE FIELD

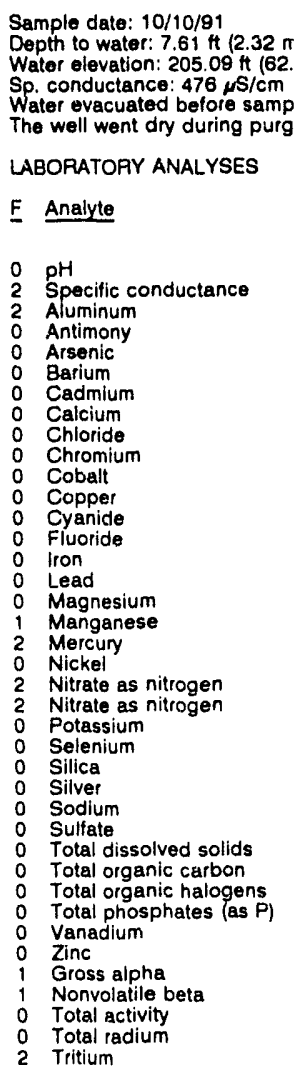

Time: 9:35

Alkalinity: $0 \mathrm{mg} / \mathrm{h}$

Water temperature: $19.1^{\circ} \mathrm{C}$

ling: $\theta$ al

LABORATORY ANALYSES

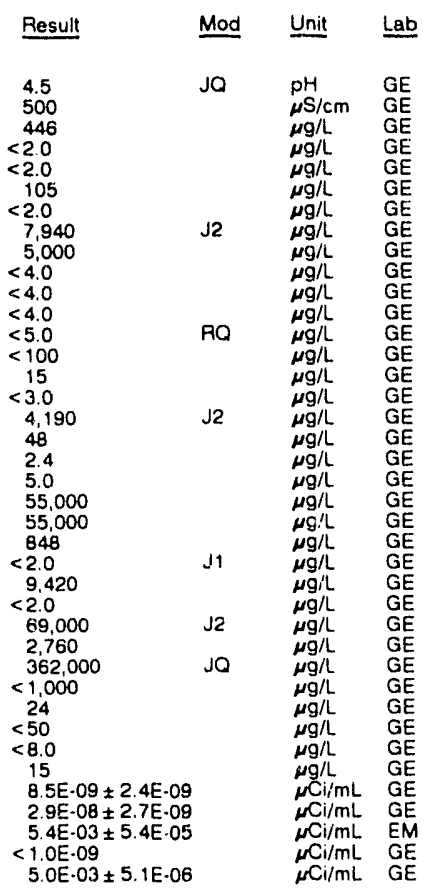

WELL HSB127C

MEASUREMENTS CONDUCTED IN THE FIELD

Sample date: $10 / 09 / 81$

Depth to water: $15.05 \mathrm{Ht}(4.59 \mathrm{~m})$ below TOC

Water elevation: $210.85 \mathrm{Ht} / 64$.

Water evacuated before sampling: $163 \mathrm{gal}$

LABOPATORY ANALYSES

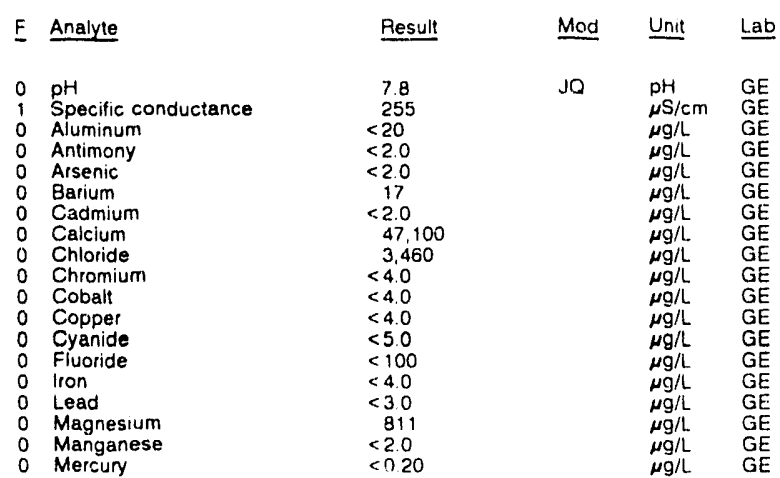

WELL. HSB127C collected on 10/09/91, laboratory analyses (cont.)

\begin{tabular}{|c|c|c|c|}
\hline Analyte & Result & Mod & Unit \\
\hline $\begin{array}{l}\text { Nickel } \\
\text { Nitrate as nitrogen } \\
\text { Potassium } \\
\text { Selenium } \\
\text { Silica } \\
\text { Silver } \\
\text { Sodium } \\
\text { Sulfate } \\
\text { Total dissolved solids } \\
\text { Total organic carbon } \\
\text { Total organic halogens } \\
\text { Total phosphates (as P) } \\
\text { Vanadium } \\
\text { Zinc } \\
\text { Gross alpha } \\
\text { Nonvolatile beta } \\
\text { Total activity } \\
\text { Total radium } \\
\text { Tritium }\end{array}$ & $\begin{array}{l}<4.0 \\
510,000 \\
<500 \\
<2.0 \\
14,400 \\
<2.0 \\
4,070 \\
<1,000 \\
130,000 \\
<1,000 \\
<5.0 \\
<50 \\
<8.0 \\
3.5 \\
1.4 E \cdot 08 \pm 4.3 E \cdot 00 \\
7.0 E \cdot 08 \pm 7.9 E \cdot 09 \\
1.1 \mathrm{E} \cdot 03 \pm 2.6 \mathrm{E} \cdot 05 \\
2.1 \mathrm{E} \cdot 09 \pm 1.2 \mathrm{E} \cdot 09 \\
1.0 \mathrm{E} \cdot 03 \pm 2.3 \mathrm{E} \cdot 00\end{array}$ & JQ & $\begin{array}{l}\mu g / L \\
\mu g / L \\
\mu g / L \\
\mu g / L \\
\mu g / L \\
\mu g / L \\
\mu g / L \\
\mu g / L \\
\mu g / L \\
\mu g / L \\
\mu g / L \\
\mu g / L \\
\mu g / L \\
\mu g / L \\
\mu C L / / m L \\
\mu C i / m L \\
\mu C i / m L \\
\mu C i / m L \\
\mu C i / m L\end{array}$ \\
\hline
\end{tabular}

\section{WELL HSB127D}

MEASUREMENTS CONDUCTED IN THE FIELD

Sample date: 10/09/91

Depth to water: $7.72 \mathrm{ft}(2.35 \mathrm{~m})$ below TOC

Water elevation: $218.38 \mathrm{Ht}(66.56 \mathrm{~m}) \mathrm{msl}$

Sp. conductance: $255 \mu \mathrm{S} / \mathrm{cm}$
Water evacuated before sampling: $54 \mathrm{gal}$

Alkalinity: $0 \mathrm{mg} / \mathrm{L}$

Water temperature: $20.5^{\circ} \mathrm{C}$

LABORATORY ANALYSES

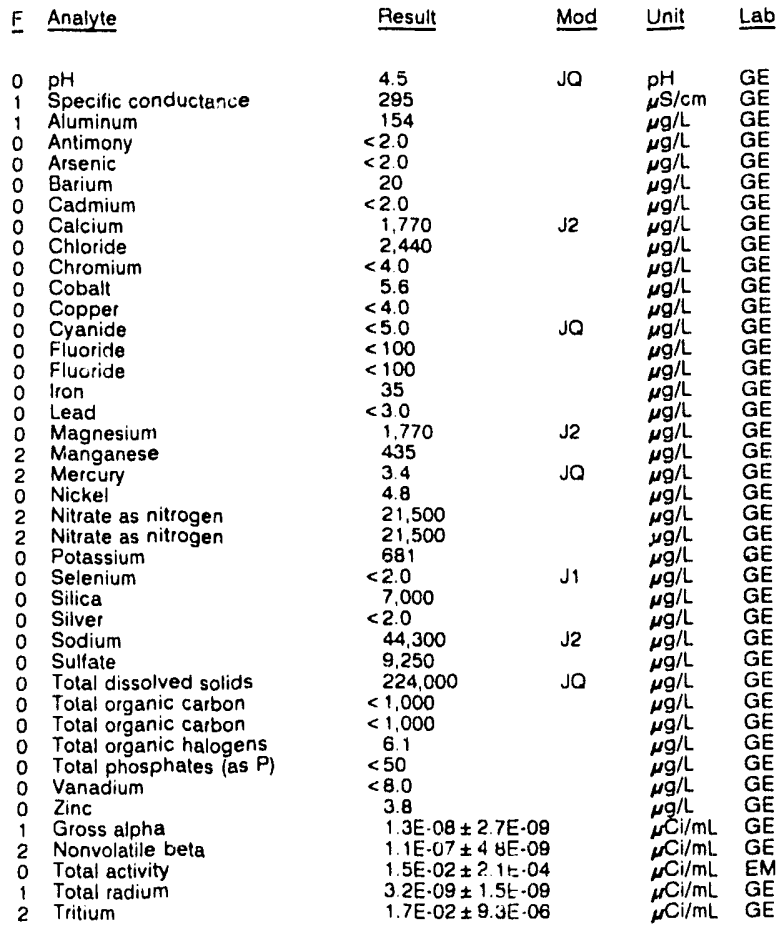

WELL HSB129C

MEASUREMENTS CONDUCTED IN THE FIELD

Sample date: 10/09/91

Depth to water: $8.76 \mathrm{ft}(2.67 \mathrm{~m})$ below TOC

Water elevation: $206.34 \mathrm{ft}(62.89 \mathrm{~m}) \mathrm{nis}$.

Water evacuated before sampling: $154 \mathrm{gal}$

LABORATORY ANALYSES

\begin{tabular}{|c|c|c|c|}
\hline Analyte & Result & Mod & Unit \\
\hline $\begin{array}{ll}0 & \mathrm{pH} \\
0 & \text { Specific conductance } \\
0 & \text { Aluminum } \\
0 & \text { Antimony } \\
0 & \text { Arsenic } \\
0 & \text { Barium }\end{array}$ & $\begin{aligned} & 5.4 \\
& 200 \\
& 92 \\
&<2.0 \\
&<2.0 \\
& 57\end{aligned}$ & JO & $\begin{array}{l}p H \\
\mu \mathrm{S} / \mathrm{cm} \\
\mu \mathrm{g} / \mathrm{L} \\
\mu g / L \\
\mu g / L \\
\mu g / L\end{array}$ \\
\hline
\end{tabular}


ANALYTICAL RESULTS

WELL HSB129C collectod on 10/09/91, laboratory analyses (cont.)

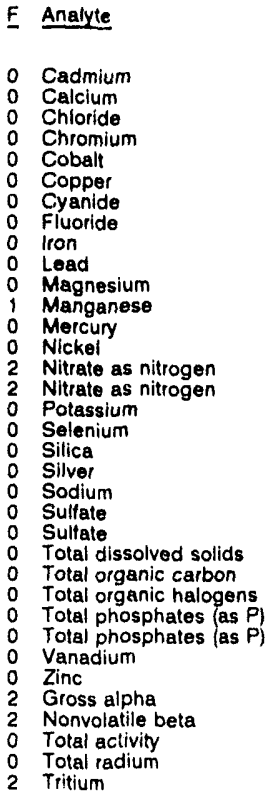

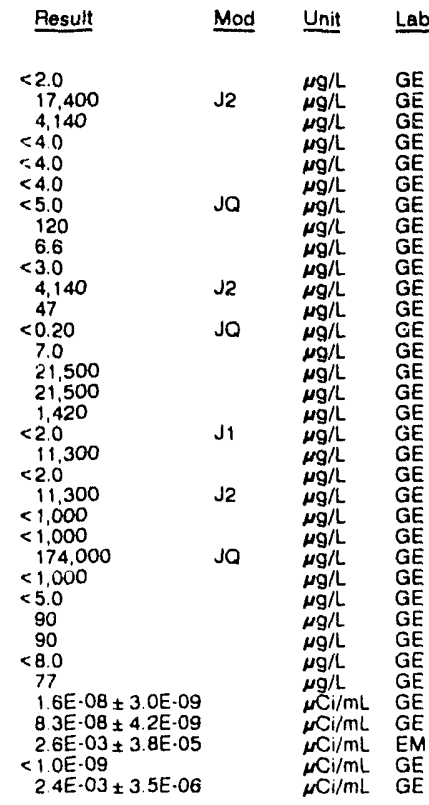

\section{WELL HSB129D}

MEASUREMENTS CONDUCTED IN THE FIELO

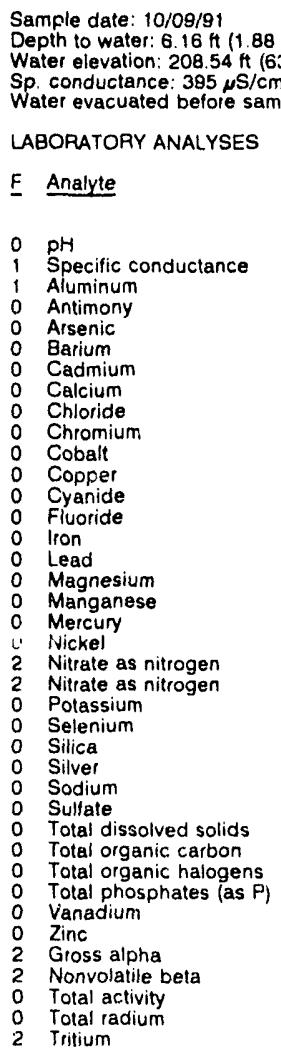

Time: $13: 15$

$\mathrm{PH}: 4.4$ Alkalinity: $0 \mathrm{mg} / \mathrm{L}$

Alkalinity: $0 \mathrm{mg} / \mathrm{L}$ : $19.0 \mathrm{C}$

sampling: $61 \mathrm{gat}$

Result Mod Unit Lab

$4.6 \quad J O \quad \mathrm{pH} \quad \mathrm{GE}$

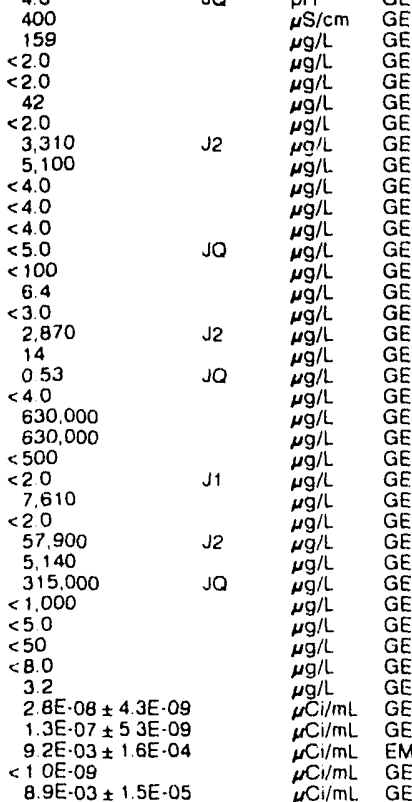

WELL HSB130C

MEASUREMENTS CONDUCTED IN THE FIELD

Sample date: $10 / 11 / 91$

Dopth to water: $17.94 \mathrm{ft}(5.47 \mathrm{~m})$ below TOC

Water elevution: $200.38 \mathrm{ft} / 8$

Water evacuated before sampling: $106 \mathrm{gal}$

LABORATORY ANALYSES

$\begin{array}{ll}\text { F } & \text { Analyte } \\ & \\ 1 & \text { pH } \\ 0 & \text { Specific conductance } \\ 0 & \text { Aluminum } \\ 0 & \text { Antimony } \\ 0 & \text { Arsenic } \\ 0 & \text { Barium } \\ 0 & \text { Cadmium } \\ 0 & \text { Calcium } \\ 0 & \text { Chloride } \\ 0 & \text { Chromium } \\ 0 & \text { Cobalt } \\ 0 & \text { Copper } \\ 0 & \text { Cyanide } \\ 0 & \text { Fluoride } \\ 0 & \text { lron } \\ 0 & \text { Lead } \\ 0 & \text { Magnesium } \\ 0 & \text { Manganese } \\ 0 & \text { Mercury } \\ 0 & \text { Nickel } \\ 0 & \text { Nitrate as nitrogen } \\ 0 & \text { Potassium } \\ 0 & \text { Selenium } \\ 0 & \text { Silica } \\ 0 & \text { Silver } \\ 0 & \text { Sodium } \\ 0 & \text { Sulfate } \\ 0 & \text { Total dissolved solids } \\ 0 & \text { Total organic carbon } \\ 0 & \text { Total organic halogens } \\ 0 & \text { Total organic halogens } \\ 0 & \text { Total phosphates (as P) } \\ 0 & \text { Vanadium } \\ 0 & \text { Zinc } \\ 0 & \text { Gross alpha } \\ 0 & \text { Norvolatile beta } \\ 0 & \text { Total radium } \\ 0 & \text { Tritium } \\ & \end{array}$

Result

8.0
180
$<20$
$<2.0$
$<2.0$
23
$<2.0$
30,800
2,240
$<4.0$
$<4.0$
$<4.0$
$<5.0$
$<100$
$<4.0$
$<3.0$
701
$<2.0$
$<0.20$
$<4.0$
240
538
$<2.0$
14,700
$<2.0$
2,200
$<1,000$
77,000
$<1.000$
$<5.0$
$<5.0$
$<50$
$<8.0$
$<2.0$
$<2.0 E-09$
$<2.0 \mathrm{E}-09$
$2.4 \mathrm{E}-09 \pm 1.3 \mathrm{E}-09$
$<7.0 \mathrm{E} \cdot 07$

Mod Unit Lab

WELL HSB130C Replicate

MEASUREMENTS CONDUCTED IN THE FIELD

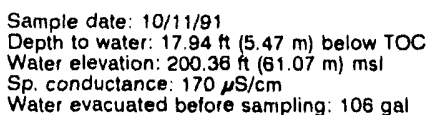

Time: $13: 40$

PH: 8.0 .0. $71 \mathrm{mg}$ Water temperature: $17.8^{\circ} \mathrm{C}$

JO $\mathrm{PH}$ GE

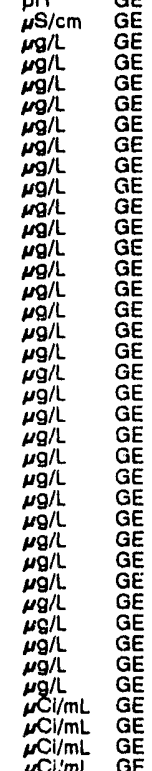

LABORATORY ANALYSES

\begin{tabular}{|c|c|c|c|}
\hline Analyce & Result & Mod & Unit \\
\hline $\begin{array}{l}\text { pH } \\
\text { Specitic conductance } \\
\text { Aluminum } \\
\text { Antimony } \\
\text { Arsenic } \\
\text { Barium } \\
\text { Cadmium } \\
\text { Calcium } \\
\text { Chloride } \\
\text { Chromium } \\
\text { Cobalt } \\
\text { Copper } \\
\text { Cyanide } \\
\text { Fluoride } \\
\text { lron } \\
\text { Lead } \\
\text { Magnesium } \\
\text { Manganese } \\
\text { Mercury } \\
\text { Nickel } \\
\text { Nitrate as nitrogen } \\
\text { Potassium } \\
\text { Selenium } \\
\text { Silica } \\
\text { Silver } \\
\text { Sodium } \\
\text { Sulfate } \\
\text { Total dissolved solids } \\
\text { Total organic carbon } \\
\text { Total organic halogens } \\
\text { Total phosphates (as P) } \\
\text { Vanadium } \\
\text { Zinc }\end{array}$ & $\begin{array}{l}8.0 \\
160 \\
<20 \\
<2.0 \\
<2.0 \\
23 \\
<2.0 \\
30,600 \\
2.300 \\
<4.0 \\
<4.0 \\
<4.0 \\
<5.0 \\
<100 \\
<4.0 \\
<3.0 \\
689 \\
<2.0 \\
<0.20 \\
<4.0 \\
280 \\
507 \\
<2.0 \\
14.500 \\
<2.0 \\
2.180 \\
<1.000 \\
3,000 \\
<1.000 \\
<5.0 \\
<50 \\
<8.0 \\
<2.0\end{array}$ & Jo & $\begin{array}{l}p H \\
\mu S / c m \\
\mu g / L \\
\mu g / L \\
\mu g / L \\
\mu g / L \\
\mu g / L \\
\mu g / L \\
\mu g / L \\
\mu g / L \\
\mu g / L \\
\mu g / L \\
\mu g / L \\
\mu g / L \\
\mu g / L \\
\mu g / L \\
\mu g / L \\
\mu g / L \\
\mu g / L \\
\mu g / L \\
\mu g / L \\
\mu g / L \\
\mu g / L \\
\mu g / L \\
\mu g / L \\
\mu g / L \\
\mu g / L \\
\mu g / L \\
\mu g / L \\
\mu g / L \\
\mu g / L \\
\mu g / L \\
\mu g / L\end{array}$ \\
\hline
\end{tabular}


ANALYTICAL RESULTS

WELL HSB130C collected on 10/11/91, laboratory analyses (cont.)

\begin{tabular}{|c|c|c|}
\hline E Analyte & Result & Unit \\
\hline $\begin{array}{ll}0 & \text { Gross alpha } \\
0 & \text { Nonvolatile beta } \\
0 & \text { Total radium } \\
0 & \text { Tritium }\end{array}$ & $\begin{array}{l}<2.0 E \cdot 09 \\
<2.0 E \cdot 09 \\
2.0 E \cdot 09 \pm 9.0 E \cdot 10 \\
<7.0 E \cdot 07\end{array}$ & $\begin{array}{l}\mu \mathrm{Ci} / \mathrm{mL} \\
\mu \mathrm{Ci} / \mathrm{mL} \\
\mu \mathrm{Ci} / \mathrm{mL} \\
\mu \mathrm{Ci} / \mathrm{mL}\end{array}$ \\
\hline
\end{tabular}

\section{WELL HSB130D}

MEASUREMENTS CONDUCTED IN THE FIELD

Sample date: 10/11/91

Depth to water: $17.56 \mathrm{H}(5.35 \mathrm{~m})$ below TOC

Water elevation: $201.04 \mathrm{Ht}$

Sp. conductance: $78 \mu \mathrm{s} / \mathrm{cm}$
Water evacuated betore sampling: $50 \mathrm{gal}$

PH. J.3. 3 . $36 \mathrm{mg} / \mathrm{l}$

Waier temperature: $19.70^{\circ} \mathrm{C}$

LABORATORY AIVALYSES

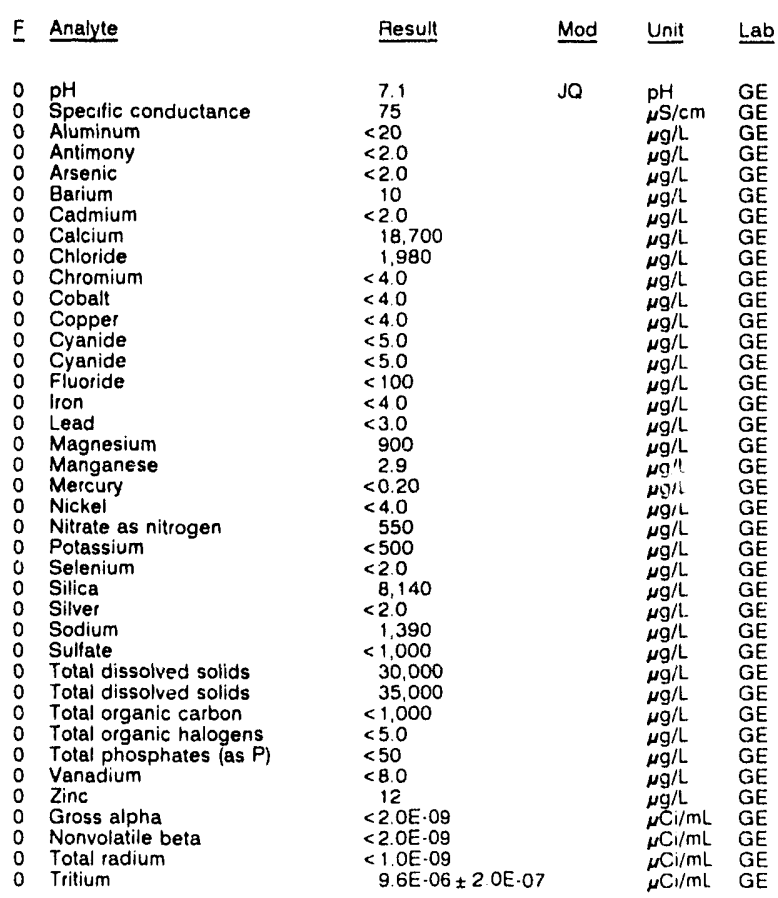

\section{WELL HSB131C}

MEASUREMENTS CONDUCTED IN THE FIELD

Sample date: $10 / 10 / 91$

Depth to water: $7.88 \mathrm{tt}(2.40 \mathrm{~m})$ below TOC

Water elevation: $203.82 \mathrm{ft}(62$.

Water evacuated before sampling: $145 \mathrm{gal}$

LABORATORY ANALYSES
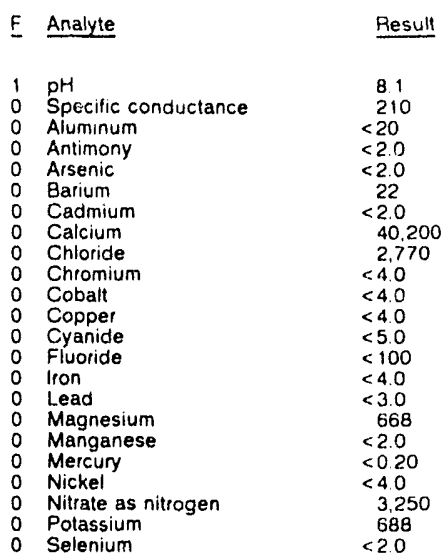

Time: 14.55

pH: 7.6

Alkalinity: $94 \mathrm{mg} / \mathrm{L}$
Water temperature $18.2^{\circ} \mathrm{C}$

EE

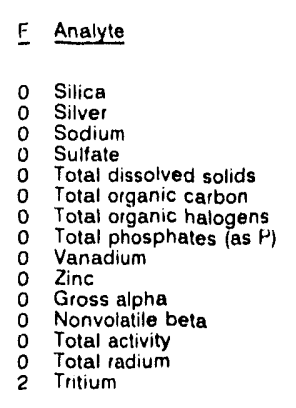

Result $\quad$ Mod

16.300
$<2.0$
3.350
$<1,000$
102,000
$<1.000$
$<5.0$
$<50$
$<8.0$
$<2.0$
$<2.0 \mathrm{CE} \cdot 09$
$<2.0 \mathrm{E} \cdot 08$
$1.8 \mathrm{BE} \cdot 04 \pm 3.2 \mathrm{E}-06$
$<1.0 \mathrm{CE} \cdot 09$
$1.6 \mathrm{E} \cdot 04 \pm 9.0 \mathrm{E} \cdot 07$

\begin{tabular}{ll} 
Unit & Lab \\
\hline & \\
$\mu g / L$ & $G E$ \\
$\mu \mathrm{g} / L$ & $\mathrm{GE}$ \\
$\mu g / L$ & $\mathrm{GE}$ \\
$\mu \mathrm{g} / \mathrm{L}$ & $\mathrm{GE}$ \\
$\mu \mathrm{g} / \mathrm{L}$ & $\mathrm{GE}$ \\
$\mu \mathrm{g} / \mathrm{L}$ & $\mathrm{GE}$ \\
$\mu \mathrm{g} / \mathrm{L}$ & $\mathrm{GE}$ \\
$\mu \mathrm{g} / \mathrm{L}$ & $\mathrm{GE}$ \\
$\mu \mathrm{g} / \mathrm{L}$ & $\mathrm{GE}$ \\
$\mu \mathrm{g} / \mathrm{GE}$ & $\mathrm{GE}$ \\
$\mu \mathrm{Ci} / \mathrm{mL}$ & $\mathrm{GE}$ \\
$\mu \mathrm{Ci} / \mathrm{mL}$ & $\mathrm{GE}$ \\
$\mu \mathrm{Cl} / \mathrm{mL}$ & $\mathrm{EM}$ \\
$\mu \mathrm{Ci} / \mathrm{mL}$ & $\mathrm{GE}$ \\
$\mu \mathrm{Ci} / \mathrm{mL}$ & $\mathrm{GE}$
\end{tabular}

\section{WELL HSB131D}

MEASUREMENTS CONDUCTED IN THE FIELD

Sample date: $10 / 10 / 91$

Depth to water: $6.78 \mathrm{ft}(2.07 \mathrm{~m})$ below TOC

Water elevation: $205.32 \mathrm{H}(62.58 \mathrm{~m}) \mathrm{ms}$ )

Sp. conductance: $27 \mathrm{\mu S} / \mathrm{cm}$

Time: $15: 10$
pH: 5.1

PH: 5.1 . $1 \mathrm{mg}$

Water temperature $21.8^{\circ} \mathrm{C}$

LABORATORY ANALYSES

$\begin{array}{ll}\text { E } & \text { Analyte } \\ & \\ 0 & \text { pH } \\ 0 & \text { Specific conductance } \\ 0 & \text { Aluminum } \\ 0 & \text { Antimony } \\ 0 & \text { Arsenic } \\ 0 & \text { Barium } \\ 0 & \text { Cadmium } \\ 0 & \text { Calcium } \\ 0 & \text { Chloride } \\ 0 & \text { Chromium } \\ 0 & \text { Cobalt } \\ 0 & \text { Copper } \\ 0 & \text { Cyanide } \\ 0 & \text { Fluoride } \\ 2 & \text { iron } \\ 2 & \text { lron } \\ 0 & \text { Lead } \\ 0 & \text { Magnesium } \\ 0 & \text { Manganese } \\ 0 & \text { Mercury } \\ 0 & \text { Nickel } \\ 0 & \text { Nitrate as nitrogen } \\ 0 & \text { Potassium } \\ 0 & \text { Selenium } \\ 0 & \text { Silica } \\ 0 & \text { Silver } \\ 0 & \text { Sodium } \\ 0 & \text { Sulfate } \\ 0 & \text { Total dissolved solids } \\ 0 & \text { Total dissolved solids } \\ 0 & \text { Total organic carbon } \\ 0 & \text { Total organic halogens } \\ 0 & \text { Total phosphates (as } P \text { ) } \\ 0 & \text { Vanadium } \\ 0 & \text { Zinc } \\ 0 & \text { Gross alpha } \\ 0 & \text { Nonvolatile beta } \\ 0 & \text { Total radium } \\ 0 & \text { Tritium } \\ & \end{array}$

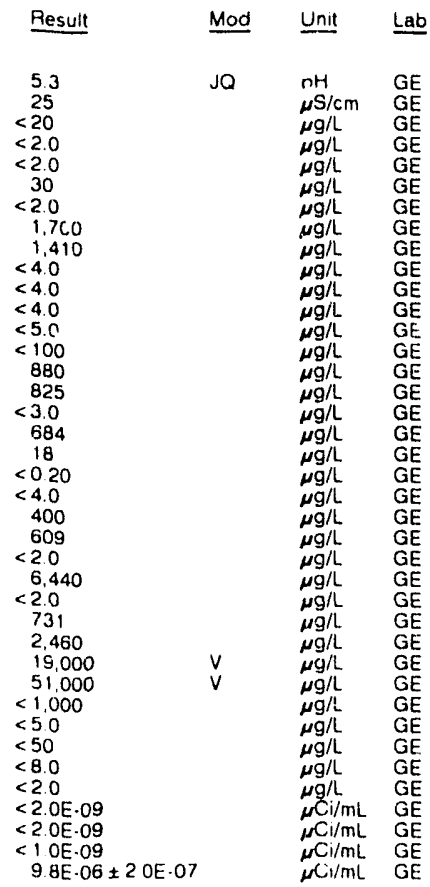

\section{WELL HSB132C}

MEASUREMENTS CONDUCTED IN THE FIELD

Sample date: $10 / 04 / 91$

Depth to water $18.78 \mathrm{Ht}(5 / 2 \mathrm{~m})$ below TOC

Water elevation. $22.172 \mathrm{t} / 67$

Sp. conduclance. $29 \mu \mathrm{S} / \mathrm{cm}$

Water evacuated before sampling: $139 \mathrm{gal}$

LABORATORY ANALYSES

$\begin{array}{ll}\text { F } & \text { Analyte } \\ 0 & \text { pH } \\ 0 & \text { Specilic conductance } \\ 0 & \text { Aluminum } \\ 0 & \text { Antimony } \\ 0 & \text { Arsenic } \\ 0 & \text { Garium } \\ 0 & \text { Cadmium } \\ 0 & \text { Caicium } \\ 0 & \text { Chloride } \\ 0 & \text { Chromium } \\ 0 & \text { Cobalt } \\ 0 & \text { Copper }\end{array}$

\begin{tabular}{l} 
Result \\
\multicolumn{1}{l}{} \\
56 \\
30 \\
53 \\
$<20$ \\
$<20$ \\
42 \\
$<20$ \\
756 \\
2.550 \\
$<40$ \\
$<40$ \\
$<40$
\end{tabular}

Time 1315

pH 51 i

Alkalinity i mg/
Water temperature $196^{\circ} \mathrm{C}$

EE

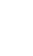


ANALYTICAL RESULTS

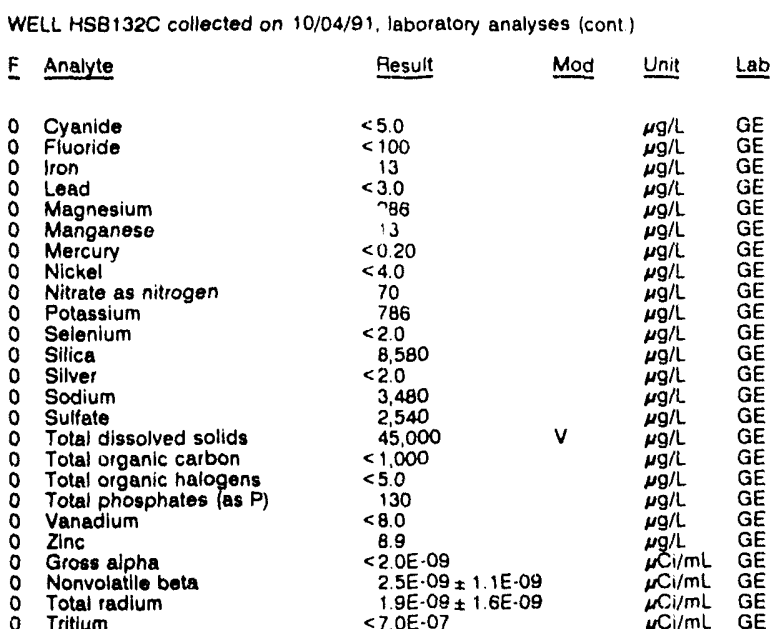

WELL HSB132D

MEASUREMENTS CONDUCTED IN THE FIELD

\begin{tabular}{|c|c|c|c|c|c|}
\hline \multicolumn{3}{|c|}{$\begin{array}{l}\text { Sample date: } 10 / 04 / 91 \\
\text { Depth to water: } 19.51 \mathrm{H}(5.95 \mathrm{~m}) \text { below TOC } \\
\text { Water elevation: } 221.19 \mathrm{ft}(67.42 \mathrm{~m}) \mathrm{msl} \\
\text { Sp. conductance: } 24 \mathrm{\mu S} / \mathrm{cm} \\
\text { Water evacuated betore sampling: } 39 \mathrm{gal}\end{array}$} & \multicolumn{3}{|c|}{$\begin{array}{l}\text { Time: } 12.25 \\
\text { pH: } 5.1 \\
\text { Alkalinity: } 1 \mathrm{mg} / \mathrm{L} \\
\text { Water ten.,perature: } 20.00 \mathrm{C}\end{array}$} \\
\hline \multicolumn{6}{|c|}{ LABORATORY ANALYSES } \\
\hline E & Analyte & Result & Mod & Unit & Lab \\
\hline $\begin{array}{l}0 \\
0 \\
0 \\
0 \\
0 \\
0 \\
0 \\
0 \\
0 \\
0 \\
0 \\
0 \\
0 \\
0 \\
0 \\
0 \\
0 \\
0\end{array}$ & $\begin{array}{l}\text { pH } \\
\text { Specific conductance } \\
\text { Aluminum } \\
\text { Antimony } \\
\text { Arsenic } \\
\text { Barium } \\
\text { Cadmium } \\
\text { Calcium } \\
\text { Chloride } \\
\text { Chromium } \\
\text { Cobalt } \\
\text { Copper } \\
\text { Cyanide } \\
\text { Fluoride } \\
\text { lron } \\
\text { Lead } \\
\text { Magnesium } \\
\text { Manganese } \\
\text { Mercury } \\
\text { Nickel } \\
\text { Nitrate as nitrogen } \\
\text { Potassium } \\
\text { Selenium } \\
\text { Silica } \\
\text { Silver } \\
\text { Sodium } \\
\text { Sulfate } \\
\text { Total dissolved solids } \\
\text { rutal organic carbon } \\
\text { Total organic carbon } \\
\text { Total organic halogens } \\
\text { Total organic halogens } \\
\text { Total phosphates (as P) } \\
\text { Vanadium } \\
\text { Zinc } \\
\text { Gross aipha } \\
\text { Nonvolatile beta } \\
\text { Total radium } \\
\text { Tritium }\end{array}$ & $\begin{array}{l}5.5 \\
25 \\
<20 \\
<2.0 \\
<2.0 \\
5.9 \\
<2.0 \\
555 \\
2.360 \\
<4.0 \\
<4.0 \\
6.0 \\
<5.0 \\
<100 \\
<4.0 \\
<3.0 \\
329 \\
8.2 \\
<0.20 \\
<4.0 \\
1.010 \\
<500 \\
<2.0 \\
5.790 \\
<2.0 \\
2.760 \\
<1.000 \\
33.000 \\
<1.000 \\
<1000 \\
<5.0 \\
<5.0 \\
<50 \\
<8.0 \\
18 \\
<2.0 E-09 \\
<20 E-09 \\
<1.0 E-09 \\
17 E-05\end{array}$ & Ja & 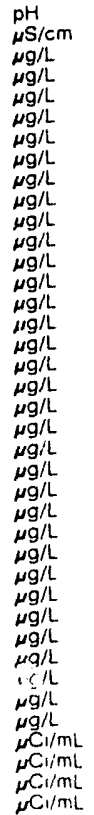 & $\begin{array}{l}\mathrm{GE} \\
\mathrm{GE} \\
\mathrm{GE} \\
\mathrm{GE} \\
\mathrm{GE} \\
\mathrm{GE} \\
\mathrm{GE} \\
\mathrm{GE} \\
\mathrm{GE} \\
\mathrm{GE} \\
\mathrm{GE} \\
\mathrm{GE} \\
\mathrm{GE} \\
\mathrm{GE} \\
\mathrm{GE} \\
\mathrm{GE} \\
\mathrm{GE} \\
\mathrm{GE} \\
\mathrm{GE} \\
\mathrm{GE} \\
\mathrm{GE} \\
\mathrm{GE} \\
\mathrm{GE} \\
\mathrm{GE} \\
\mathrm{GE} \\
\mathrm{GE} \\
\mathrm{GE} \\
\mathrm{GE} \\
\mathrm{GE} \\
\mathrm{GE} \\
\mathrm{GE} \\
\mathrm{GE} \\
\mathrm{GE} \\
\mathrm{GE} \\
\mathrm{GE} \\
\mathrm{GE} \\
\mathrm{GE}\end{array}$ \\
\hline
\end{tabular}

WELL HSB133C

MEASUREMENTS CONOUCTEO IN THE FIELO

Sample date: 10/04/81

Depth to water: $23.70 \mathrm{H}(7.22 \mathrm{~m})$ below TOC

Water elevation: $231.90 \mathrm{~h} / 7$
Sp. conductance: $43 \mu \mathrm{s} / \mathrm{cm}$

Sp. conductance: $43 \mu \mathrm{s} / \mathrm{cm}$
Water evacuated before sampling: $154 \mathrm{gal}$

LABORATORY ANALYSES

\begin{tabular}{|c|c|c|c|}
\hline Analyte & Result & Mod & Unit \\
\hline 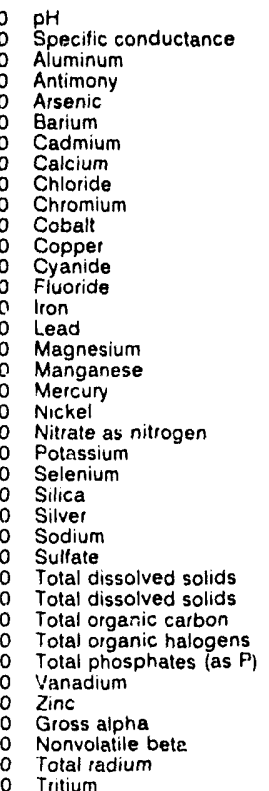 & 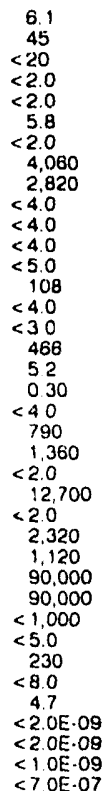 & $v$ & 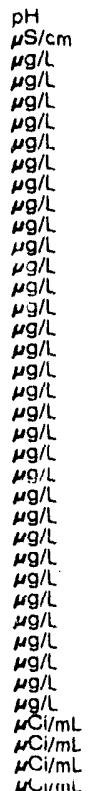 \\
\hline
\end{tabular}

WELL HSB133D

MEASUREMENTS CONDUCTED IN THL 'IELD

Sample date: 10/04/91

Depth to water: 18.91 th $(5.76 \mathrm{~m})$ below TOC

Water elevation. $236.39 \mathrm{H}(72.05 \mathrm{~m}) \mathrm{msl}$

Sp. conductance: $64 \mu \mathrm{S} / \mathrm{sm}$
Water evacuated before sampling: $73 \mathrm{gal}$

LABORATORY ANALYSES

\begin{tabular}{|c|c|c|c|}
\hline Analyte & Result & Mod & Unit \\
\hline 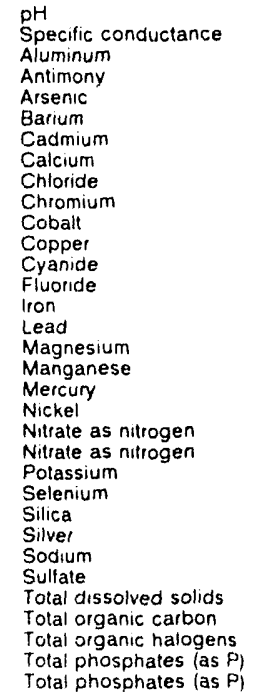 & $\begin{array}{l}5.6 \\
60 \\
620 \\
<2.0 \\
<2.0 \\
<3.0 \\
<20 \\
2.500 \\
5.950 \\
<40 \\
<40 \\
<4.0 \\
<50 \\
235 \\
73 \\
<30 \\
142 \\
40 \\
<0.20 \\
-4.0 \\
410 \\
490 \\
<500 \\
<2.0 \\
6.540 \\
<2.0 \\
8.400 \\
5530 \\
32.000 \\
<1.000 \\
<50 \\
<50 \\
<50\end{array}$ & JO & 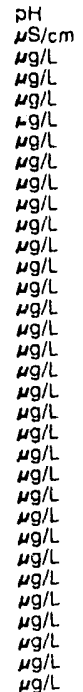 \\
\hline
\end{tabular}

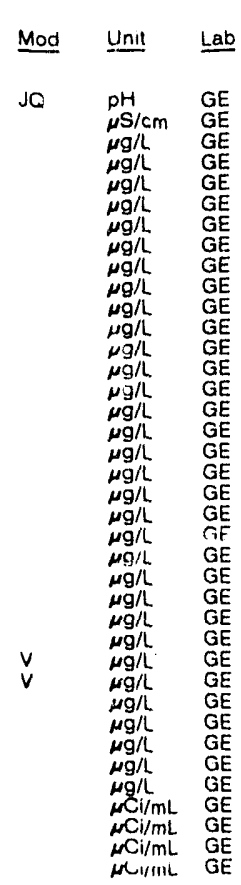

\author{
Time: 11.05 \\ Alkalinity: $10 \mathrm{mg} / \mathrm{L}$ \\ Water temperature. $19.0 \circ \mathrm{C}$
}

Time: 1020

Alkalinity: $6 \mathrm{mg} / \mathrm{L}$

Water temperature: $18.2^{\circ} \mathrm{C}$ 
ANALYTICAL RESULTS

WELL HSB1330 collected on 10/04/91, laboratory analyses (cont)

\begin{tabular}{|c|c|c|c|c|c|}
\hline$E$ & Analyie & Result & Mod & Unit & Lab \\
\hline $\begin{array}{l}0 \\
0 \\
0 \\
0 \\
0\end{array}$ & $\begin{array}{l}\text { Vanadium } \\
\text { Znce } \\
\text { Gross alpha } \\
\text { Nonvolatile bets } \\
\text { Total radium } \\
\text { Tritium }\end{array}$ & $\begin{array}{l}<8.0 \\
<2.0 \\
<2.0 E-09 \\
<2.0 E-09 \\
<1.0 E-09 \\
\quad 41 E-05 \pm 9.0 E-07\end{array}$ & & 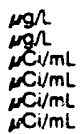 & $\begin{array}{l}\mathrm{GE} \\
\mathrm{GE} \\
\mathrm{GE} \\
\mathrm{GE} \\
\mathrm{GE} \\
\mathrm{GE}\end{array}$ \\
\hline
\end{tabular}

\section{WELL HSB 134C}

MEASUREMENTS CONDUCTLD IN THE FIELD

\begin{tabular}{|c|c|}
\hline $\begin{array}{l}\text { Sample date: } 10 / 10 / 91 \\
\text { Depth to water: } 16.55 \mathrm{~h}(5.04 \mathrm{~m}) \text { below } 70 \mathrm{C} \\
\text { Water elevertion: } 221.85 \mathrm{~h}(67.62 \mathrm{~m}) \mathrm{msl} \\
\text { Sp. conductance: } 48 \mathrm{~s} / \mathrm{cm}\end{array}$ & $\begin{array}{l}\text { Time: } 13: 10 \\
\text { pH: } 5.5 \\
\text { Alkalinity: } 5 \mathrm{mgh} \\
\text { Water temperature } 18.80^{\circ} \mathrm{C}\end{array}$ \\
\hline
\end{tabular}

Water evacuated before sampling: $191 \mathrm{gal}$

LABORATORY ANALYSES
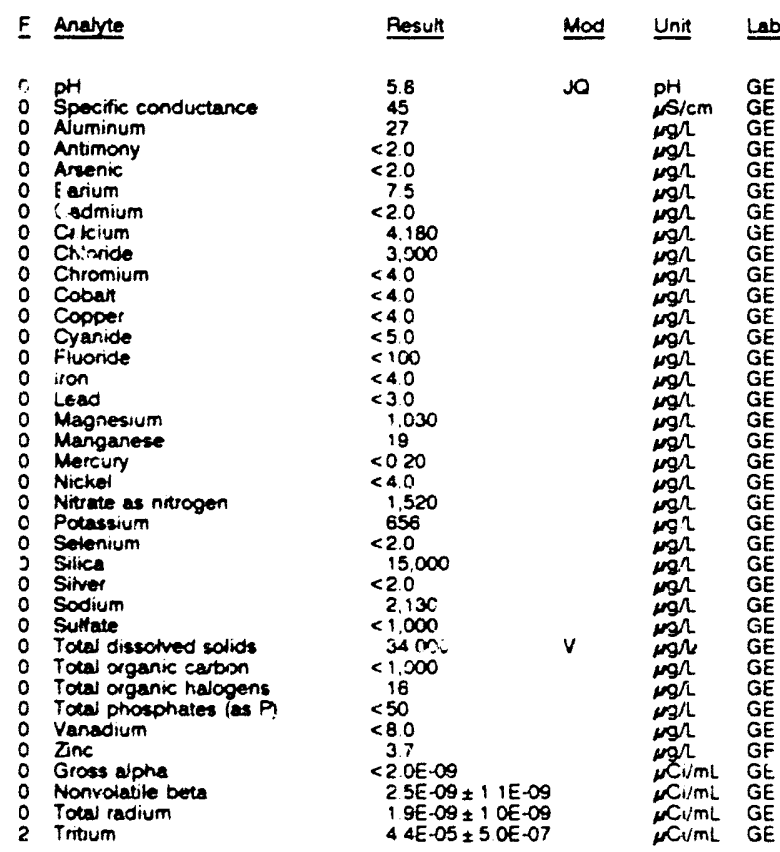

WELL HSB134D

MEASUREMENTS CONOUCTED IN THE FIELD

Sample date 1G'10\%1

Depth to water 1585 ft $(4.83$ m) beiow TOC Noler elevation: $222.25 \%$ it

Water evactuated 87 psicmi

LABORATOPY ANALYSES

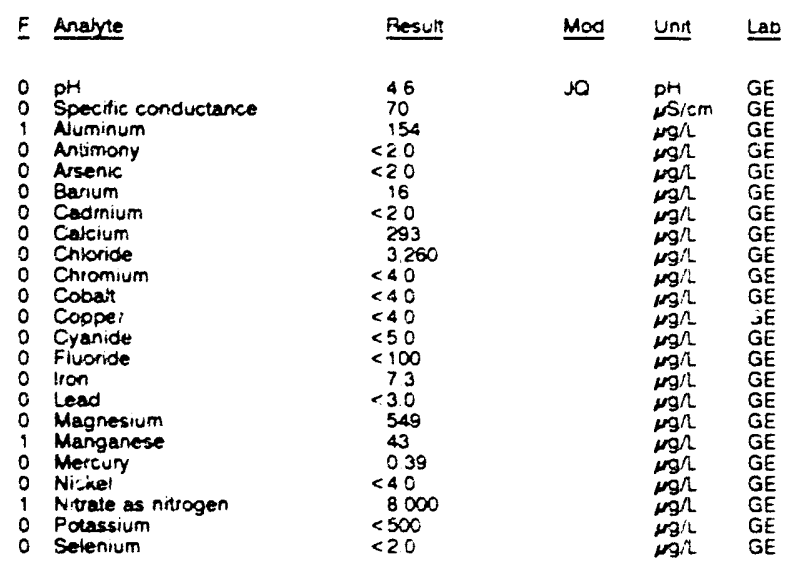

WELL HSE 1340 collected on 10/10/91, laboratory analyses (cont.)

\begin{tabular}{|c|c|c|c|c|}
\hline Analyte & Result & Mod & Unit & Lab \\
\hline $\begin{array}{l}\text { Silica } \\
\text { Silver } \\
\text { Sodium } \\
\text { Sulfate } \\
\text { Total dissolved solids } \\
\text { Tctal organic carbon } \\
\text { Total organic carton } \\
\text { Total organic halogens } \\
\text { Total phosphates (as P) } \\
\text { Vanadium } \\
\text { Zinc } \\
\text { Gross alpha } \\
\text { Nonvolatile beta } \\
\text { Total activity } \\
\text { Total radium } \\
\text { Tritium }\end{array}$ & $\begin{array}{l}6,210 \\
<2.0 \\
8,870 \\
5,260 \\
22.000 \\
<1,000 \\
<1,000 \\
<5.0 \\
<50 \\
<8.0 \\
7.6 \\
1.2 E-08 \pm 1.0 E-09 \\
1.4 E-07 \pm 4.6 E-09 \\
4.4 E-04 \pm 1.0 E-05 \\
9.4 E-09 \pm 1.0 E-00 \\
2.6 E-04 \pm 1.1 E-00\end{array}$ & Jo & 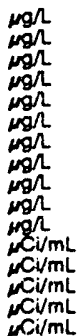 & $\begin{array}{l}G E \\
G E \\
G E \\
G E \\
G E \\
G E \\
G E \\
G E \\
G E \\
G E \\
G E \\
G E \\
G E \\
E M \\
G E \\
G E\end{array}$ \\
\hline
\end{tabular}

WELL HSB135C

MEASUREMENTS CONDUCTED IN THE FIELD

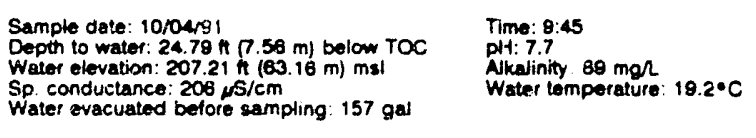

Watel evacuated before sampling: $157 \mathrm{gal}$

LABORATOAY ANALYSES

\begin{tabular}{|c|c|c|c|c|}
\hline Analyte & Resuh & Mod & Unit & Lo \\
\hline 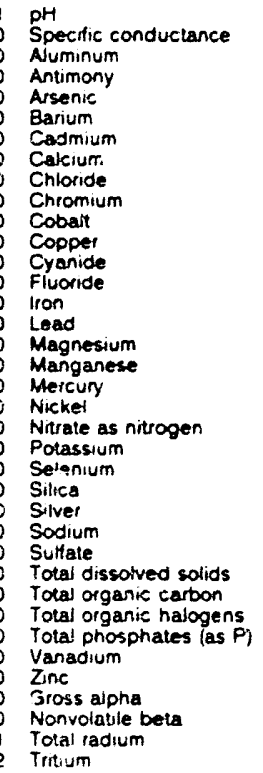 & $\begin{array}{l}81 \\
200 \\
<20 \\
<2.0 \\
<20 \\
<17 \\
<2.0 \\
38,800 \\
2,940 \\
<4.0 \\
<4.0 \\
<4.0 \\
<5.0 \\
141 \\
<4.0 \\
<3.0 \\
518 \\
<2.0 \\
<020 \\
<4.0 \\
650 \\
<500 \\
<2.0 \\
27.800 \\
<2.0 \\
1.660 \\
<1.000 \\
81.000 \\
<1.000 \\
<50 \\
2.540 \\
<80 \\
<2.0 \\
<2.0 E-09 \\
3.1 E .09 \pm 1.2 E-09 \\
27 E-09 \pm 1.8 E-09 \\
41 E-05 \pm 9.0 E-07\end{array}$ & Jo & 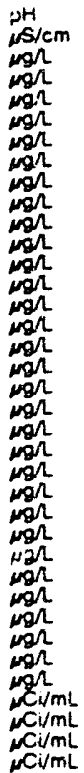 & $\begin{array}{l}G E \\
G E \\
G E \\
G E \\
G E \\
G E \\
G E \\
G E \\
G E \\
G E \\
G E \\
G E \\
G E \\
G E \\
G E \\
G E \\
G E \\
G E \\
G E \\
G E \\
G E \\
G E \\
G E \\
G E \\
G E \\
G E \\
G E \\
G E \\
G E \\
G E \\
G E \\
G E \\
G E \\
G E \\
G E \\
G E \\
G E\end{array}$ \\
\hline
\end{tabular}

WELL HSB135D

MEASUREMENTS CONDUCTED IN THE FIELD

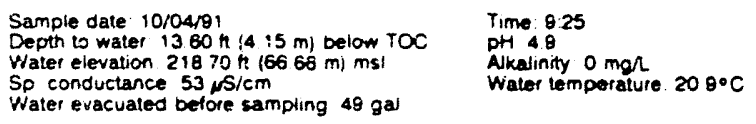

Water evacuated betore sampling $49 \mathrm{gal}$

LABORATORY ANALYSES

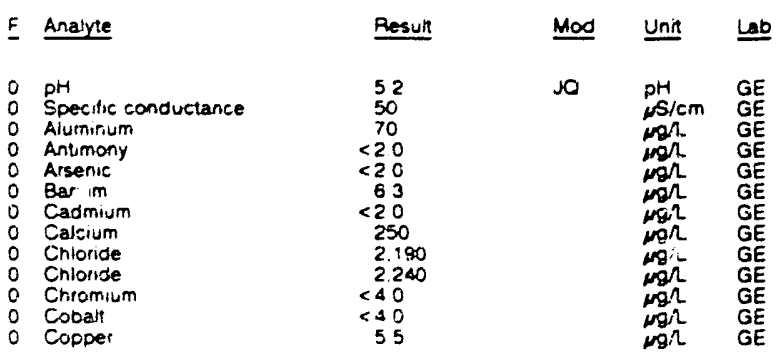


ANALYTICAL RESULTS

WELL HSB135D collected on 10/04/91, laboratory analyses (cont.)

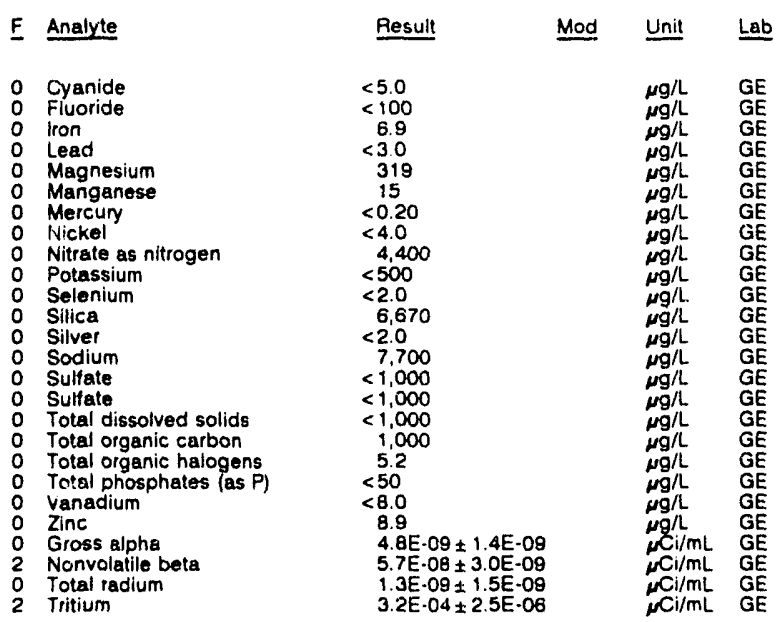

\section{WELL HSB136C}

MEASUREMENTS CONDUCTEO IN THE FIELD

Sample date: 10/09/91

Depth to water: $9.67 \mathrm{ft}(2.95 \mathrm{~m})$ below TOC

Water elevation: 218.23 it $(68.52 \mathrm{~m}) \mathrm{ms}$

Water evacuated before sampling: $151 \mathrm{gat}$

LABORATORY ANALYSES

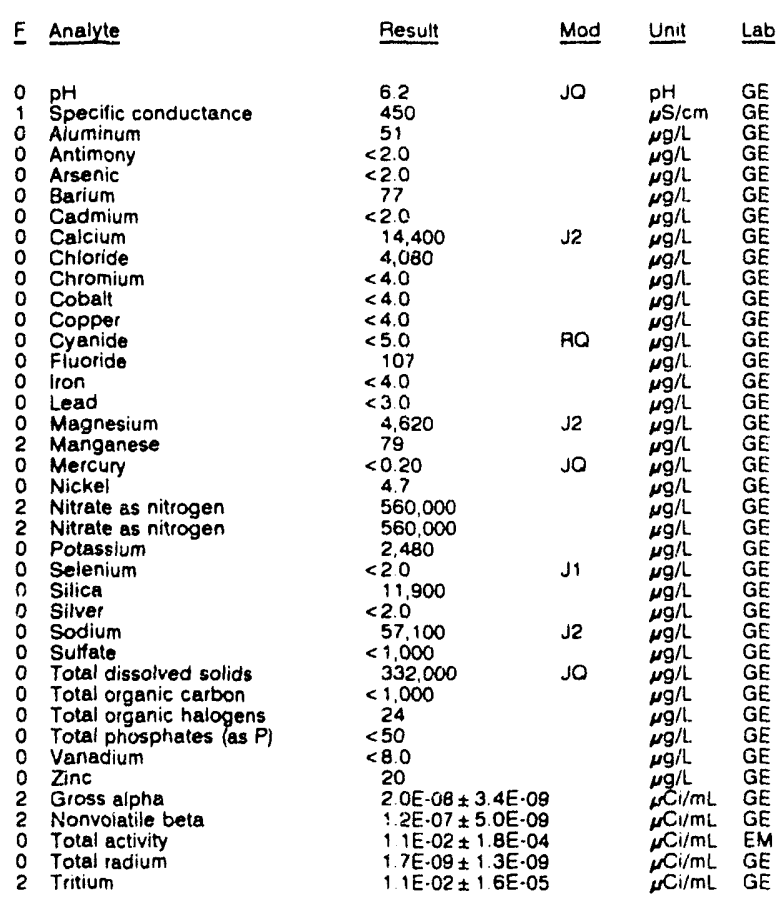

\section{WELL HSB136D}

MEASUREMENTS CONDUCTED IN THE FIELD

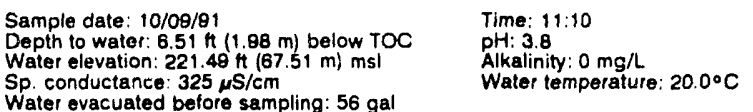

Water evacuated before sampling: $56 \mathrm{ga}$

LABORATORY ANALYSES

\begin{tabular}{|c|c|c|c|}
\hline Analyte & Result & Mod & Unit \\
\hline 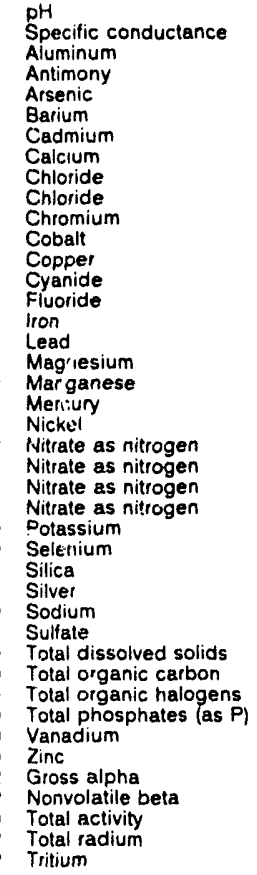 & $\begin{array}{l}4.1 \\
250 \\
4,650 \\
<2.0 \\
<2.0 \\
95 \\
<2.0 \\
3,050 \\
3,400 \\
3,480 \\
<4.0 \\
9.3 \\
<4.0 \\
<5.0 \\
403 \\
9.4 \\
<3.0 \\
947 \\
371 \\
<0.20 \\
15 \\
34,000 \\
34,000 \\
33.500 \\
33,500 \\
1,350 \\
<2.0 \\
13,700 \\
<2.0 \\
27,700 \\
21.900 \\
238,000 \\
<1.000 \\
<5.0 \\
<50 \\
<8.0 \\
49 \\
2.0 \mathrm{E}-07 \pm 9.7 \mathrm{E} \cdot 09 \\
2.2 \mathrm{E} \cdot 00 \pm 2.0 \mathrm{E}-00 \\
1.2 \mathrm{E} \cdot 02 \pm 1.8 \mathrm{E} \cdot 04 \\
9.1 \mathrm{E} \cdot 00 \pm 1.1 \mathrm{E}-00 \\
9.3 \mathrm{E} \cdot 03 \pm 1.5 \mathrm{E}-05\end{array}$ & $\begin{array}{l}\mathrm{J} 1 \\
\mathrm{~J} 2 \\
\mathrm{~J} Q\end{array}$ & $\begin{array}{l}p H \\
\mu S / c m \\
\mu g / L \\
\mu g / L \\
\mu g / L \\
\mu g / L \\
\mu g / L \\
\mu g / L \\
\mu g / L \\
\mu g / L \\
\mu g / L \\
\mu g / L \\
\mu g / L \\
\mu g / L \\
\mu g / L \\
\mu g / L \\
\mu g / L \\
\mu g / L \\
\mu g / L \\
\mu g / L \\
\mu g / L \\
\mu g / L \\
\mu g / L \\
\mu g / L \\
\mu g / L \\
\mu g / L \\
\mu g / L \\
\mu g / L \\
\mu g / L \\
\mu g / L \\
\mu g / L \\
\mu g / L \\
\mu g / L \\
\mu g / L \\
\mu g / L \\
\mu g / L \\
\mu g / L \\
\mu L i / m L \\
\mu C i / m L \\
\mu C i / m L \\
\mu C i / m L \\
\mu C i / m L\end{array}$ \\
\hline
\end{tabular}

\section{WELL HSB137C}

MEASUREMENTS CONDUCTED IN THE FIELD

Sample date: $10 / 09 / 91$ Water elevation: $221.50 \mathrm{ft}(67.51 \mathrm{~m}) \mathrm{ms}$

Sp conductance $508 \mathrm{~s} / \mathrm{cm}$ Water evacuated before sampling: $151 \mathrm{gal}$

Alkalinity: $0 \mathrm{mg} /$ ater temperature: $20.0^{\circ} \mathrm{C}$

LABORATORY ANALYSES

\begin{tabular}{|c|c|c|c|}
\hline Aroyte & Result & Mod & Unit \\
\hline $\begin{array}{l}\text { pH } \\
\text { Specific conductance } \\
\text { Aluminum } \\
\text { Antimony } \\
\text { Arsenic } \\
\text { Barium } \\
\text { Cadmium } \\
\text { Calcium } \\
\text { Chloride } \\
\text { Chromium } \\
\text { Cobalt } \\
\text { Copper } \\
\text { Cyanide } \\
\text { Fluoride } \\
\text { lion } \\
\text { Lead } \\
\text { Magnesium } \\
\text { Manganese } \\
\text { Mercury } \\
\text { Nickel } \\
\text { Nitrate as nitrogen } \\
\text { Nitrate as nitrogen } \\
\text { Potassium } \\
\text { Selenium } \\
\text { Silica } \\
\text { Silver } \\
\text { Sodium } \\
\text { Suifate } \\
\text { Total dissolved solids }\end{array}$ & $\begin{array}{c}5.7 \\
500 \\
82 \\
<2.0 \\
<2.0 \\
62 \\
<2.0 \\
27,400 \\
3,880 \\
<4.0 \\
<4.0 \\
<4.0 \\
<5.0 \\
108 \\
<4.0 \\
<3.0 \\
4,920 \\
74 \\
<0.20 \\
88 \\
59,500 \\
59,500 \\
1,230 \\
<2.0 \\
11,900 \\
<2.0 \\
60,000 \\
5,700 \\
323,000\end{array}$ & $\begin{array}{l}\mathrm{J1} \\
\mathrm{J} 2\end{array}$ & $\begin{array}{l}p H \\
\mu S / c m \\
\mu g / L \\
\mu g / L \\
\mu g / L \\
\mu g / L \\
\mu g / L \\
\mu g / L \\
\mu g / L \\
\mu g / L \\
\mu g / L \\
\mu g / L \\
\mu g / L \\
\mu g / L \\
\mu g / L \\
\mu g / L \\
\mu g / L \\
\mu g / L \\
\mu g / L \\
\mu g / L \\
\mu g / L \\
\mu g / L \\
\mu g / L \\
\mu g / L \\
\mu g / L \\
\mu g / L \\
\mu g / L \\
\mu g / L \\
\mu g / L\end{array}$ \\
\hline
\end{tabular}


ANALYTICAL RESULTS

WELL HSB137C collected on 10/09/91, laboratory analyses (cont.)

\begin{tabular}{|c|c|c|c|}
\hline Analyie & Result & Mod & Unit \\
\hline $\begin{array}{l}\text { Total organic carbon } \\
\text { Total organic halogens } \\
\text { Total phosphates (as P) } \\
\text { Vanadium } \\
\text { Zinc } \\
\text { Gross alph.- } \\
\text { Nonvolatile beta } \\
\text { Total activity } \\
\text { Total radium } \\
\text { Tritium }\end{array}$ & $\begin{array}{l}<1.000 \\
<5.0 \\
70 \\
<8.0 \\
45 \\
2.5 E \cdot 08 \pm 3.8 \mathrm{E} \cdot 09 \\
1.3 \mathrm{E}-07 \pm 5.2 \mathrm{E}-09 \\
1.2 \mathrm{E} \cdot 02 \pm 1.8 \mathrm{E} \cdot 04 \\
<1.0 \mathrm{E} \cdot 09 \pm 1.7 \mathrm{C} \cdot 05 \\
1.1 \mathrm{E} \cdot 02 \pm 1.7 \mathrm{E} \cdot 05\end{array}$ & & $\begin{array}{l}\mu g / L \\
\mu g / L \\
\mu g / L \\
\mu g / L \\
\mu g / L \\
\mu C i / m L \\
\mu C i / m L \\
\mu C i / m L \\
\mu C i / m L \\
\mu C i / m L \\
\mu C i / m L\end{array}$ \\
\hline
\end{tabular}

\section{WELL HSB137D}

MEASUREMENTS CONDUCTED IN THE FIELD

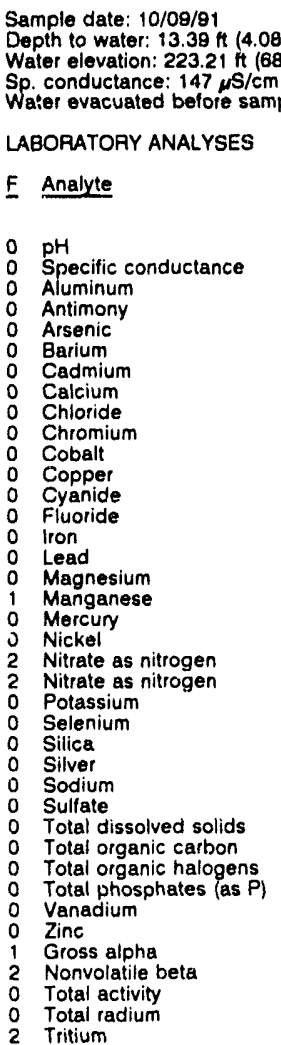

Time: $8: 15$

pH: 4.8 : $0 \mathrm{~mol}$

Water temperature: $18.3^{\circ} \mathrm{C}$$$
\text { ce: } 147 \mu \mathrm{S} / \mathrm{cm}
$$

\section{LABORATORY ANALYSES}

\begin{tabular}{|c|c|c|c|}
\hline Analyte & Result & Mod & Unit \\
\hline $\begin{array}{l}\text { pH } \\
\text { Specific conductance } \\
\text { Aluminum } \\
\text { Antimony } \\
\text { Arsenic } \\
\text { Barium } \\
\text { Cadmium } \\
\text { Calcium } \\
\text { Chloride } \\
\text { Chromium } \\
\text { Cobalt } \\
\text { Copper } \\
\text { Cyanide } \\
\text { Fluoride } \\
\text { lron } \\
\text { Lead } \\
\text { Magnesium } \\
\text { Manganese } \\
\text { Mercury } \\
\text { Nickel } \\
\text { Nitrate as nitrogen } \\
\text { Nitrate as nitrogen } \\
\text { Potassium } \\
\text { Selenium } \\
\text { Silica } \\
\text { Silver } \\
\text { Sodium } \\
\text { Sulfate } \\
\text { Total dissolved solids } \\
\text { Total organic carbon } \\
\text { Total organic halogens } \\
\text { Total phosphates (as P) } \\
\text { Vanadium } \\
\text { Zinc } \\
\text { Gross alpha } \\
\text { Nonvolatile beta } \\
\text { Total activity } \\
\text { Total radium } \\
\text { Tritium }\end{array}$ & $\begin{array}{l}5.1 \\
140 \\
100 \\
<2.0 \\
<2.0 \\
15 \\
<2.0 \\
1.620 \\
2,260 \\
<4.0 \\
<4.0 \\
45 \\
<5.0 \\
<100 \\
53 \\
5.5 \\
1,670 \\
48 \\
<0.20 \\
4.8 \\
17,000 \\
17,000 \\
658 \\
<2.0 \\
8,680 \\
<2.0 \\
20.000 \\
2,800 \\
120,000 \\
<1,000 \\
<5.0 \\
<50 \\
<8.0 \\
97 \\
111 \mathrm{E} \cdot 08 \pm 2.4 \mathrm{E} \cdot 09 \\
9.5 \mathrm{E} .08 \pm 4.4 \mathrm{E} \cdot 09 \\
4.8 \mathrm{E} \cdot 03 \pm 5 \cdot 1 \mathrm{E} \cdot 05 \\
1.9 \mathrm{E} \cdot 09 \pm 1.3 \mathrm{E} \cdot 09 \\
5.6 \mathrm{E} \cdot 03 \pm 1.2 \mathrm{E} \cdot 05\end{array}$ & $\begin{array}{l}\mathrm{J}_{1} \\
\mathrm{~J} 2\end{array}$ & $\begin{array}{l}p H \\
\mu \mathrm{S} / \mathrm{cm} \\
\mu g / L \\
\mu g / L \\
\mu g / L \\
\mu g / L \\
\mu g / L \\
\mu g / L \\
\mu g / L \\
\mu g / L \\
\mu g / L \\
\mu g / L \\
\mu g / L \\
\mu g / L \\
\mu g / L \\
\mu g / L \\
\mu g / L \\
\mu g / L \\
\mu g / L \\
\mu g / L \\
\mu g / L \\
\mu g / L \\
\mu g / L \\
\mu g / L \\
\mu g / L \\
\mu g / L \\
\mu g / L \\
\mu g / L \\
\mu g / L \\
\mu g / L \\
\mu g / L \\
\mu g / L \\
\mu g / L \\
\mu g / L \\
\mu C i / m L \\
\mu C i / m L \\
\mu C i / m L \\
\mu C i / m L \\
\mu C i / m L\end{array}$ \\
\hline
\end{tabular}

\section{WELL HSB138D}

\section{MEASUREMENTS CONDUCTED IN THE FIELD}

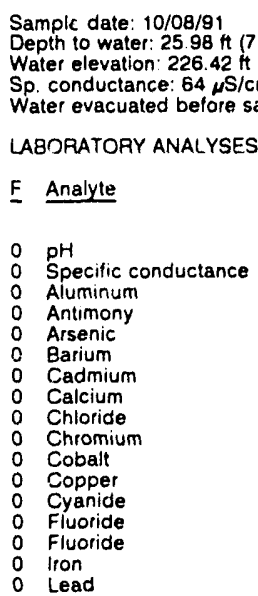

$$
\begin{aligned}
& \text { Time: } 10: 05 \\
& \text { pH: } 5.7 \\
& \text { Alkalinity: } 1 \mathrm{mg} / \mathrm{L} \\
& \text { Water temperature } 18.4^{\circ} \mathrm{C}
\end{aligned}
$$

\section{LABDRATORY ANALYSES}
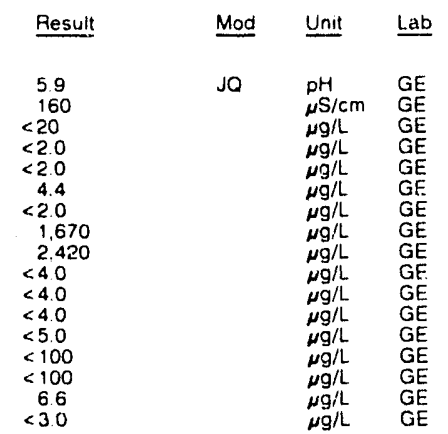

\begin{tabular}{|c|c|c|}
\hline Result & Mod & Unit \\
\hline $\begin{aligned} & 174 \\
&<20 \\
&<0.20 \\
&<4.0 \\
& 5,000 \\
&<500 \\
&<2.0 \\
& 5,810 \\
&<2.0 \\
& 8,670 \\
& 1,920 \\
& 43,000 \\
&<1,000 \\
&<5.0 \\
&<50 \\
&<50 \\
&<3.0 \\
& 12 \\
&<2.0 \mathrm{E} \cdot 00 \\
& 1.4 \mathrm{E} \cdot 08 \pm 1.6 \mathrm{E} \cdot 09 \\
& 6.9 \mathrm{E} \cdot 04 \pm 2.1 \mathrm{E} \cdot 05 \\
& 1.6 \mathrm{E} \cdot 09 \pm 1.1 \mathrm{E} \cdot 09 \\
& 7.8 \mathrm{E} \cdot 04 \pm 2.0 \mathrm{E} \cdot 06\end{aligned}$ & v & $\begin{array}{l}\mu g / L \\
\mu g / L \\
\mu g / L \\
\mu g / L \\
\mu g / L \\
\mu g / L \\
\mu g / L \\
\mu g / L \\
\mu g / L \\
\mu g / L \\
\mu g / L \\
\mu g / L \\
\mu g / L \\
\mu g / L \\
\mu g / L \\
\mu g / L \\
\mu g / L \\
\mu g / L \\
\mu C i / m L \\
\mu C i / m L \\
\mu C i / m L \\
\mu C i / m L \\
\mu C i / m L\end{array}$ \\
\hline
\end{tabular}

WELL HSB 138D collected on 10/08/91, laboratory analyses (cont.)

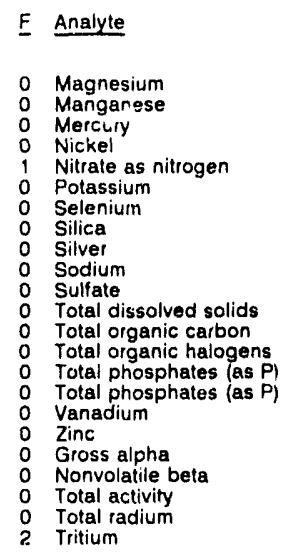

\section{WELL HSB139A}

MEASUREMENTS CONDUCTED IN THE FIELD

Sample date: 10/10/91

59.19 ft $(18.04$ m) below TOC Water elevation: $174.51 \mathrm{Ht}(53.19 \mathrm{~m}) \mathrm{msl}$ Water evacuated before sampling: $228 \mathrm{gal}$

LABORATORY ANALYSES

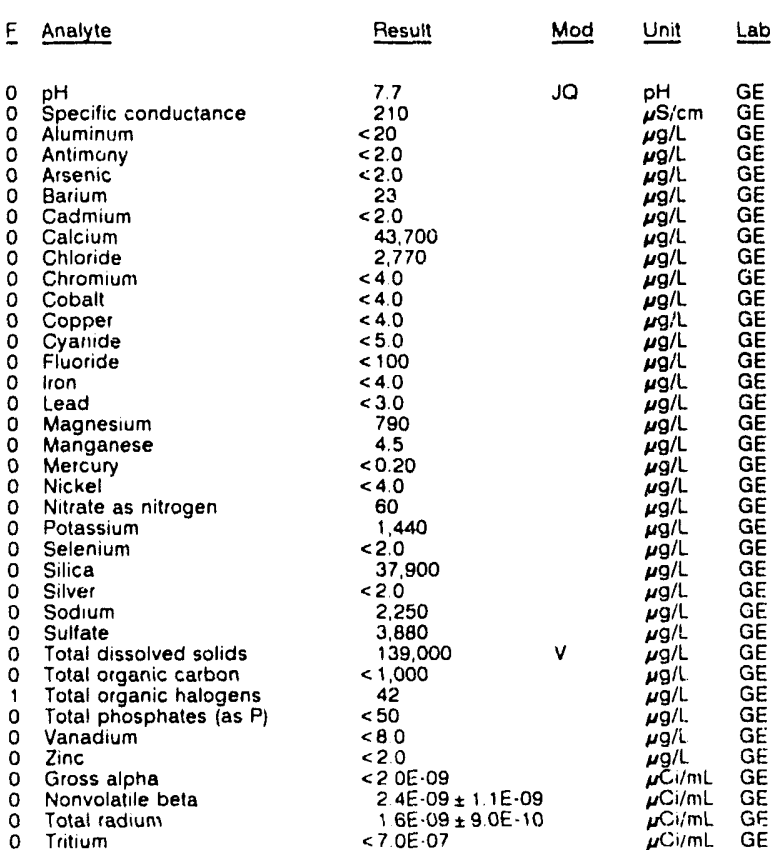

\begin{tabular}{|c|c|c|c|c|c|}
\hline \multicolumn{3}{|c|}{$\begin{array}{l}\text { Sample date: } 10 / 10 / 91 \\
\text { Depth to water: } 18.98 \mathrm{H}(5.79 \mathrm{~m}) \text { below TOC } \\
\text { Water elevation: } 214.82 \mathrm{H}(65.48 \mathrm{~m}) \mathrm{ms} \\
\text { Sp. conductance: } 411 \mu \mathrm{S} / \mathrm{cm} \\
\text { Water evacuated before sampling } 28 \mathrm{gai} \\
\text { The well went dry during purging }\end{array}$} & \multirow{2}{*}{\multicolumn{2}{|c|}{$\begin{array}{l}\text { Time: } 8.25 \\
\text { pit: } 5.6 \\
\text { Alkalinity: } 9 \mathrm{mg} / \mathrm{h} \\
\text { Water tempergture } 18.3^{\circ}\end{array}$}} & \\
\hline \multicolumn{4}{|c|}{ LABORATORY ANALYSES } & & \\
\hline$\underline{F}$ & Analyte & Resuit & Mod & $\underline{\text { Unit }}$ & Lab \\
\hline $\begin{array}{l}0 \\
1 \\
1 \\
0 \\
0 \\
0\end{array}$ & $\begin{array}{l}\text { pH } \\
\text { Specific conductance } \\
\text { Aluminum } \\
\text { Antimony } \\
\text { Arsenic } \\
\text { Barium }\end{array}$ & $\begin{aligned} & 57 \\
& 355 \\
& 131 \\
&<20 \\
&<20 \\
& 72\end{aligned}$ & jo & $\begin{array}{l}\mathrm{pH} \\
\mu \mathrm{S} / \mathrm{cm} \\
\mu \mathrm{g} / \mathrm{L} \\
\mu \mathrm{g} / \mathrm{L} \\
\mu \mathrm{g} / \mathrm{L} \\
\mu \mathrm{g} / \mathrm{L}\end{array}$ & $\begin{array}{l}\mathrm{GE} \\
\mathrm{GE} \\
\mathrm{GE} \\
\mathrm{GE} \\
\mathrm{GE} \\
\mathrm{GE}\end{array}$ \\
\hline
\end{tabular}

\section{WELLL HSB139C}

MEASUREMENTS CONDUCTED IN THE FIELD 
ANALYTICAL RESULTS

\begin{tabular}{|c|c|c|c|c|}
\hline E Analyte & Result & Mod & Unit & Lab \\
\hline 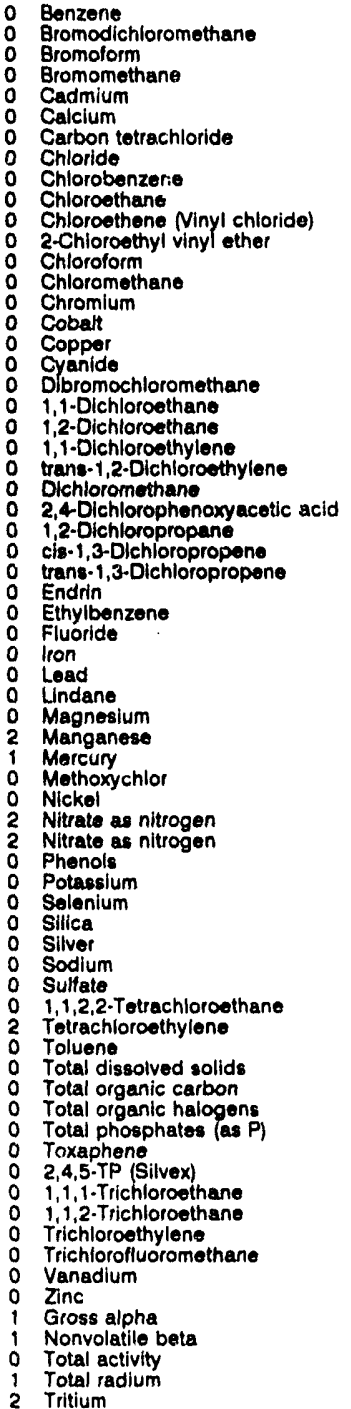 & 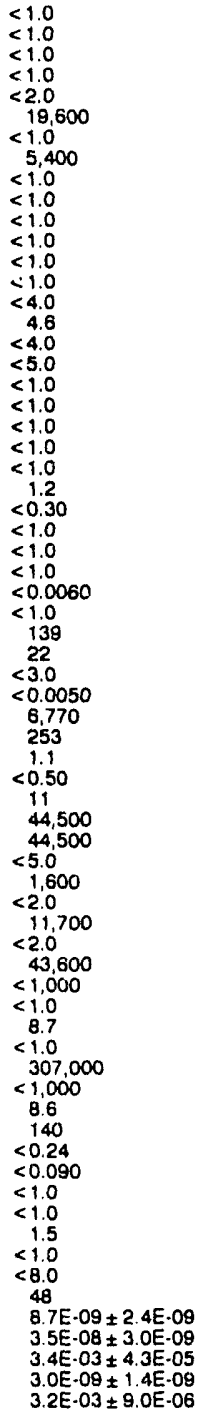 & $\begin{array}{l}\text { JQ } \\
\text { J1 }\end{array}$ & 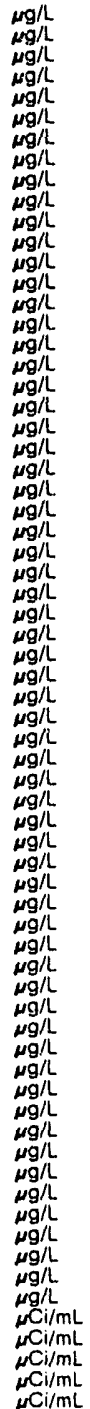 & $\begin{array}{l}G E \\
G E \\
G E \\
G E \\
G E \\
G E \\
G E \\
G E \\
G E \\
G E \\
G E \\
G E \\
G E \\
G E \\
G E \\
G E \\
G E \\
G E \\
G E \\
G E \\
G E \\
G E \\
G E \\
G E \\
G E \\
G E \\
G E \\
G E \\
G E \\
G E \\
G E \\
G E \\
G E \\
G E \\
G E \\
G E \\
G E \\
G E \\
G E \\
G E \\
G E \\
G E \\
G E \\
G E \\
G E \\
G E \\
G E \\
G E \\
G E \\
G E \\
G E \\
G E \\
G E \\
G E \\
G E \\
G E \\
G E \\
G E \\
G E \\
G E \\
G E \\
G E \\
G E \\
G E \\
G E \\
G E \\
G E\end{array}$ \\
\hline
\end{tabular}

WELL HSB 139D collected on 10/10/91, laboratory analyses (cont.)

\begin{tabular}{|c|c|c|c|c|}
\hline$F$ & Analyte & Result & Mod & Unit \\
\hline $\begin{array}{l}0 \\
0 \\
0 \\
0\end{array}$ & $\begin{array}{l}\text { Lead } \\
\text { Magnesium } \\
\text { Manganese } \\
\text { Mercury } \\
\text { Nickel } \\
\text { Nitrate as nitrogen } \\
\text { Potassium } \\
\text { Selenium } \\
\text { Silica } \\
\text { Silver } \\
\text { Sodium } \\
\text { Sulfate } \\
\text { Total dissolved solids } \\
\text { Total organic carbon } \\
\text { Total organic halogens } \\
\text { Total phosphates (as P) } \\
\text { Vanadium } \\
\text { Zinc } \\
\text { Gross alpha } \\
\text { Nonvolatile beta } \\
\text { Total radium } \\
\text { Tritium }\end{array}$ & $\begin{array}{l}<3.0 \\
668 \\
65 \\
<0.20 \\
<4.0 \\
640 \\
559 \\
<2.0 \\
6,250 \\
<2.0 \\
1,880 \\
1,680 \\
15,000 \\
<1,000 \\
<5.0 \\
<50 \\
<8.0 \\
27 \\
4.7 E-09 \pm 3.7 E \cdot 00 \\
8.2 E \cdot 00 \pm 4.0 E \cdot 09 \\
1.9 E-09 \pm 1.0 E \cdot 09 \\
1.1 E-04 \pm 8.0 E \cdot 07\end{array}$ & v & $\begin{array}{l}\mu g / L \\
\mu g / L \\
\mu g / L \\
\mu g / L \\
\mu g / L \\
\mu g / L \\
\mu g / L \\
\mu g / L \\
\mu g / L \\
\mu g / L \\
\mu g / L \\
\mu g / L \\
\mu g / L \\
\mu g / L \\
\mu g / L \\
\mu g / L \\
\mu g / L \\
\mu g / L \\
\mu C \mathrm{C} / \mathrm{mL} \\
\mu \mathrm{C} / / \mathrm{mL} \\
\mu \mathrm{Cl} / \mathrm{mL} \\
\mu \mathrm{Ci} / \mathrm{mL}\end{array}$ \\
\hline
\end{tabular}

WELL HSB140A

MEASUREMENTS CONDUCTED IN THE FIELD

Sample date: $10 / 11 / 91$

Depth to water: $59.55 \mathrm{ft}(18.15 \mathrm{~m})$ below TOC

Water elevation: 176.35 th $/ 53.75$

o. conductance. $169 \mu \mathrm{S} / \mathrm{cm}$ m) msl

Water evacuated before sampling: $250 \mathrm{gal}$

LABORATORY ANALYSES

F Analyte

$\begin{array}{ll}0 & \mathrm{pH} \\ 0 & \text { Specific conductance } \\ 0 & \text { Aluminum }\end{array}$

0 Antimony

Arsenic

Barium

Benzene
0 Bromodichloromethane

0 Bromomethane

Cadmium

0 Carbon tetrachloride

Chloride

- Chlorobenzene

Chloroethane

Chloroethene Ninyl chloride

2.Chloroethyl vinyl ether

Chloroform

Chloromethane

Chromium

0 Copper

Cyanide

Dibromochloromethane

1.1.Dichloroethane

1,2-Oichloroethane

trans-1,2-Dichloroethylene

Dichloromethane

2.4-Dichlorophenoxyacetic acid <0.30

1,2-Dichloropropane

cis-1,3-Dichloropropene

0 trans-1,

o Ethylbenzene

Fluorid

lion

Lead

Magnesium

Manganese

0 Mercury

- Methoxych

Nickel
Nitrate as nitrogen

Phenols

Potassium
Selenium

Silica

Silver

Sodium

Sodium

Sulfate

$1,1,2,2 \cdot$ Tetrachloroe

Tetrachlor

Total dissolved solids

Total organic carbon

Total organic halogen

Toxaphene

$\begin{aligned} & 7.6 \\ & 160 \\ & 49 \\ &<2.0 \\ & 4.9 \\ & 42 \\ &<1.0 \\ &<1.0 \\ &<1.0 \\ &<1.0 \\ &<2.0 \\ & 26.20 \\ &<1.0 \\ & 2.550 \\ &<1.0 \\ &<1.0 \\ &<1.0 \\ &<1.0 \\ &<1.0 \\ &<1.0 \\ &<4.0 \\ &<4.0 \\ &<4.0 \\ &<5.0 \\ &<1.0 \\ &<1.0 \\ &<1.0 \\ &<1.0 \\ &<1.0 \\ & 11.2 \\ &<0.30 \\ &<1.0 \\ &<1.0 \\ &<1.0\end{aligned}$

$<0.0060$
$<1.0$

122

$<3.0$

$<0.0050$

607

$<0.20$

$<0.50$

$<4.0$

$<50$

$<.0$
4.470

$<2.0$
28,400

28,400
$<2.0$

$<.0$
4.440

9,260

$<10$

$<1.0$

90,000
$<1,000$

6.8

6.8
250
$<0.24$
Time: 12:35

Alkalinity: $61 \mathrm{mg} / \mathrm{s}$

Water temperature: $19.4^{\circ} \mathrm{C}$

Mod Unit

Mod Unit Lab

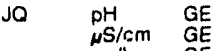

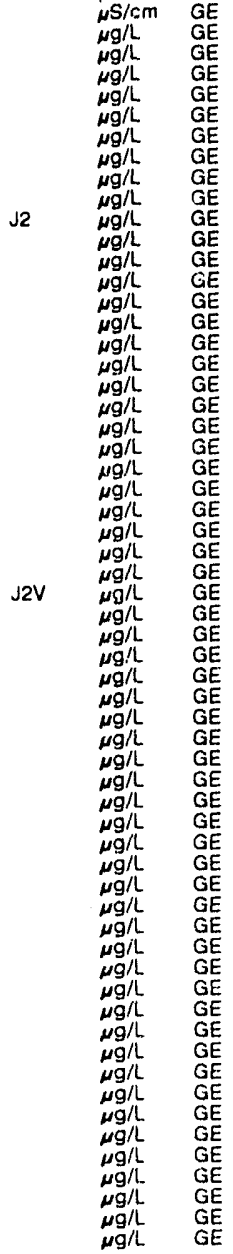


ANALYTICAL RESULTS

WELL HSB140A collected on 10/11/91, laboratory analyses (cont.)

\begin{tabular}{|c|c|c|}
\hline Analyte & Pesult & Unit \\
\hline $\begin{array}{l}2,4,5-T P \text { (Silvex) } \\
1,1,1-\text { Trichloroethane } \\
1,1,2-\text { Trlchloroethane } \\
\text { Trichloroethylene } \\
\text { Trichlorofluoromethane } \\
\text { Uranium } \\
\text { Uranium } \\
\text { Vanadium } \\
\text { Zinc } \\
\text { Gross alpha } \\
\text { Nonvolatile beta } \\
\text { Total radium } \\
\text { Tritium }\end{array}$ & $\begin{array}{l}<0.090 \\
<1.0 \\
<1.0 \\
<1.0 \\
<1.0 \\
<20 \\
<20 \\
<8.0 \\
<2.0 \\
<2.0 \mathrm{E} \cdot 09 \\
7.4 \mathrm{E} \cdot 09 \pm 1.4 \mathrm{E} \cdot 09 \\
<1.0 \mathrm{E} \cdot 09 \\
1.4 \mathrm{E} \cdot 05 \pm 1.1 \mathrm{E} \cdot 06\end{array}$ & $\begin{array}{l}\mu \mathrm{g} / \mathrm{L} \\
\mu \mathrm{g} / \mathrm{L} \\
\mu \mathrm{g} / \mathrm{L} \\
\mu \mathrm{g} / \mathrm{L} \\
\mu \mathrm{g} / \mathrm{L} \\
\mu \mathrm{g} / \mathrm{L} \\
\mu \mathrm{g} / \mathrm{L} \\
\mu \mathrm{g} / \mathrm{L} \\
\mu \mathrm{g} / \mathrm{L} \\
\mu \mathrm{Ci} / \mathrm{mL} \\
\mu \mathrm{Cl} / \mathrm{mL} \\
\mu \mathrm{Li} / \mathrm{mL} \\
\mu \mathrm{Ci} / \mathrm{mL}\end{array}$ \\
\hline
\end{tabular}

\section{WELL HSB140C}

MEASUREMENTS CONDUCTED IN THE FIELD

Depth to water: $28.91 \mathrm{tt}(8.81 \mathrm{~m})$ below TOC Water elevation: $206.69 \mathrm{th}(63.00 \mathrm{~m}) \mathrm{msl}$

Water evacuated before sampling: $118 \mathrm{gal}$

LABORATORY ANALYSES

\begin{tabular}{|c|c|c|c|}
\hline Analyte & Result & Mod & Unit \\
\hline 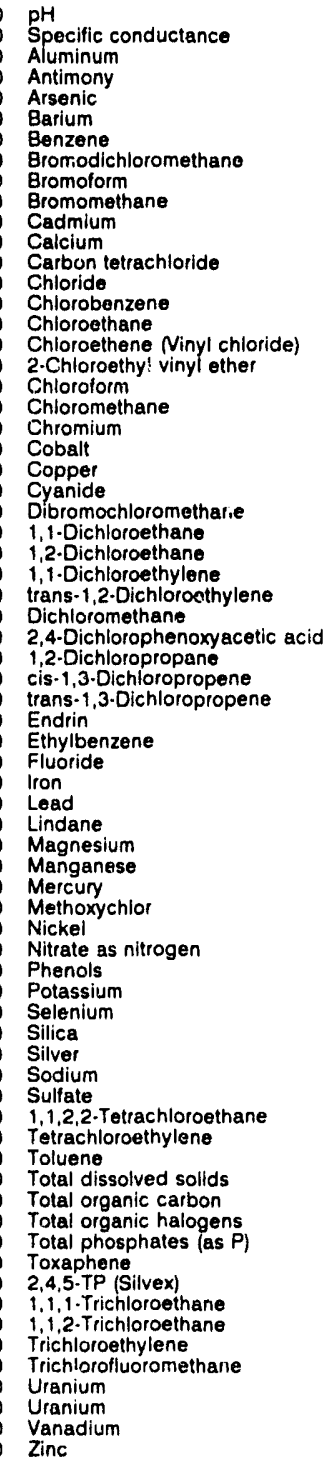 & 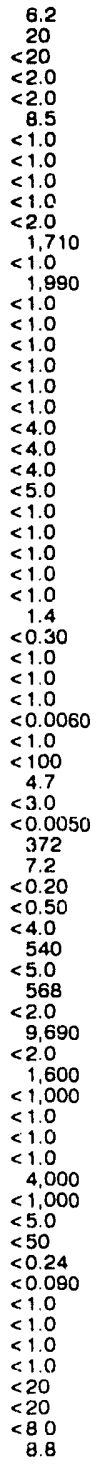 & $\mathrm{J} 2 \mathrm{~V}$ & 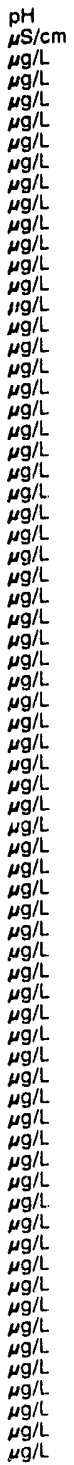 \\
\hline
\end{tabular}

Time: 11:55

Alkalinity: $1 \mathrm{mg} /$

Wates temperature: $19.0^{\circ} \mathrm{C}$
WELL HSB 140C collected on 10/11/91, laboratory analyses (cont.)

\begin{tabular}{|c|c|c|c|}
\hline F Analyte & Result & Mod & Unit \\
\hline $\begin{array}{ll}0 & \text { Gross alpha } \\
0 & \text { Nonvolatile beta } \\
0 & \text { Total radium } \\
0 & \text { Tritium }\end{array}$ & $\begin{array}{l}<2.0 \mathrm{E}-09 \\
4.8 \mathrm{E}-09 \pm 1.2 \mathrm{E}-09 \\
<1.0 \mathrm{E}-09 \\
8.5 \mathrm{E}-06 \pm 1.0 \mathrm{E}-06\end{array}$ & & 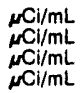 \\
\hline
\end{tabular}

WELL HSB140D

MEASUREMENTS CONDUCTED IN THE FIELD

$\begin{array}{ll}\text { Sample date: } 10 / 11 / 91 & \text { Time: } 12: 15 \\ \text { Depth to water: } 19.47 \mathrm{ft}(5.93 \mathrm{~m}) \text { below TOC } & \text { pH: } 4.6 \\ \text { Water elevation: } 216.73 \mathrm{~h}(68.06 \mathrm{~m}) \mathrm{msl} & \text { Alkalinity: } 0 \mathrm{mg} / \mathrm{h} \\ \text { Sp. conductance: } 18 \mathrm{\mu S} / \mathrm{cm} & \text { Water temperature: } 18.8^{\circ} \mathrm{C} \\ \text { Water evacuated before sampling: } 59 \mathrm{gal} & \end{array}$

Water evacuated before sampling: $59 \mathrm{gal}$

LABORATORY ANAL.YSES

F Analyte Besult Mod Unit Lab

$0 \mathrm{pH}$

Specific conductance

Aluminum

Arsenic

Barium

Benzene

Bromodichloromethane

Bromolorm

Gromomethane

Cadmium

Calcium

Carbon tetrachloride

Chlorobenzene

Chloroethene Ninyl chloride)

-Chloroethyl vinyl ether

Chloroform

Chloromethane

Chromium

Copper

Copper

Dibromochloromethane

1,1-Dichloroethane

1,2.-Dichloroethane

trans-1,2-Dichloroethylene

Dichloromethane

24 -Dichlorophenoryacetic acid 1.4

1,2-Dichloropropane

cis-1 3-Dichloropropene

trans-1,3-Dichloropropene

Endrin

Ethylbenzene

Fluoride

Lead

Lindane

Magnesium

Manganese

Mercury

Methoxych
Nickel

Nitrate as nitrogen

Phenols

Petassium

Silica

Silica

Sodium

Sodium

1,1,2,2-Tetrachloroethane

Tetrachloroethylene

Toluen

Total dissolved solids

Total organic carbon

Total organic halogens

Total organic halogens

Total phosphat

2.4.5.TP (Silvex)

1,1,1-Trichloroethane

1,1,2-Trichloroeth

Trichlorofluoromethane

IJanium

Van

Zinc

Nonvolatile bet

Total radium

Tritium
5.2

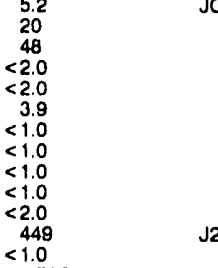

PH $\mathrm{GE}$

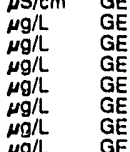

$<1.0$

$<1.0$

$<1.0$

$<1.0$

$<4.0$

$<4.0$

$<5.0$

$<1.0$

$<1.0$

$<1.0$

$<0.30$

$<0.30$
$<1.0$
$<1.0$
$<1.0$

$<1.0$

$<1.0$

$<100$

18
$<3.0$
$<0.0050$

478
2.7

$<0.20$

$<0.50$

$<4.0$

$\begin{array}{r}590 \\ <5.0 \\ \hline\end{array}$

$<500$
$<2.0$

$<2.0$
5,720

$<2.0$

$<1,000$

$<1.0$

$<1.0$

$<1,000$

$<50$

$<5$.

$<50$

$<0.24$

$<0.09$

$<1.0$

$<1.0$

$<20$

$<20$
$<8.0$

$2.9 \mathrm{E} \cdot 09 \pm 9.0 \mathrm{E} \cdot 10$

$7.9 \mathrm{E} \cdot 09 \pm 1.4 \mathrm{E}-09$

$<1.0 \mathrm{E}-09$
$2.2 \mathrm{E}-05 \pm 1.2 \mathrm{E}-06$

\section{ab \\ E}

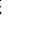


WELL HSB141A

MEASUREMENTS CONDUCTED IN THE FIELL

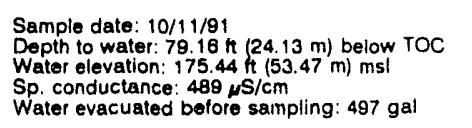

Water eyacuated betore sampling: $497 \mathrm{gal}$

LABORATOAY ANALYSES

\begin{tabular}{|c|c|c|c|c|c|}
\hline & Analyte & Result & Mod & Unit & Lab \\
\hline & 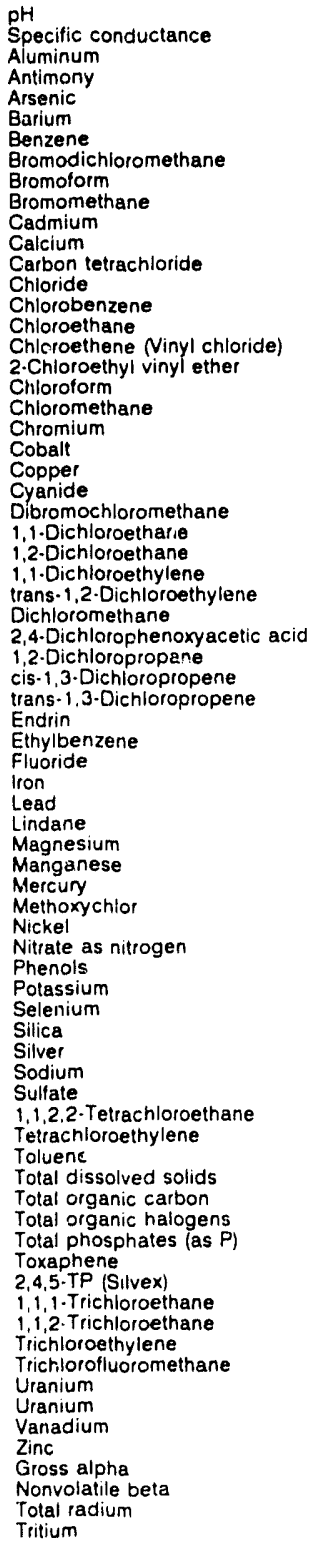 & $\begin{array}{l}11 \\
400 \\
2,260 \\
<2.0 \\
<2.0 \\
34 \\
<1.0 \\
<1.0 \\
<1.0 \\
<1.0 \\
<2.0 \\
42.800 \\
<1.0 \\
2.250 \\
<1.0 \\
<1.0 \\
<1.0 \\
<1.0 \\
<1.0 \\
<1.0 \\
<4.0 \\
<4.0 \\
<4.0 \\
<5.0 \\
<1.0 \\
<1.0 \\
<1.0 \\
<1.0 \\
<1.0 \\
1.7 \\
<0.30 \\
<1.0 \\
<1.0 \\
<1.0 \\
<0.0060 \\
<1.0 \\
122 \\
7.1 \\
<3.0 \\
<0.0050 \\
39 \\
<2.0 \\
<0.20 \\
<0.50 \\
<4.0 \\
70 \\
<5.0 \\
7.970 \\
<2.0 \\
8.310 \\
<2.0 \\
2.690 \\
5.580 \\
<1.0 \\
<1.0 \\
<1.0 \\
102.000 \\
<1.00 \\
6.0 \\
<50 \\
<0.24 \\
<0.090 \\
<1.0 \\
<1.0 \\
<1.0 \\
<10 \\
<20 \\
<20 \\
991 \\
2.5 \\
<20 \mathrm{E} \cdot 09 \\
52 \mathrm{E} \cdot 09 \pm 1.3 \mathrm{E} \cdot 09 \\
<1.0 \mathrm{E} \cdot 09 \\
11.1 \mathrm{E} \cdot 05 \pm 11 \mathrm{E} \cdot 06\end{array}$ & J2V & 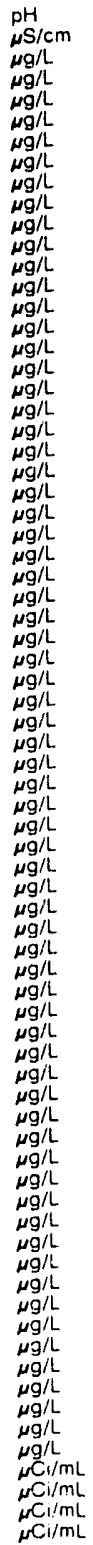 & 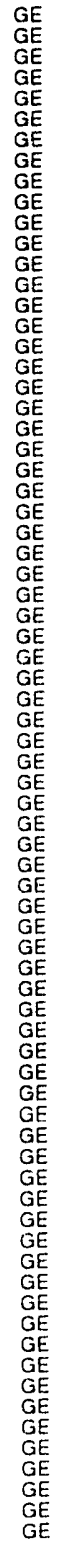 \\
\hline
\end{tabular}

WELL HSB141C

MEASUREMENTS CONDUCTED IN THE FIELD

$\begin{array}{ll}\text { Sample date: } 10 / 11 / 81 & \text { Time: } 15: 45 \\ \text { Depth to water: } 24.87 \mathrm{H}(7.58 \mathrm{~m}) \text { below TOC } & \text { pH: } 12.0 \\ \text { Water elevation: } 229.83 \mathrm{ft}(70.05 \mathrm{~m}) \mathrm{msl} & \text { Alkalinity: } 0 \mathrm{mg} / \mathrm{L} \\ \text { Sp. conductance: } 1867 \mu \mathrm{s} / \mathrm{cm} & \text { Water temperature: } 18.0^{\circ} \mathrm{C} \\ \text { Water evacuated before sampling: } 43 \mathrm{gal} & \end{array}$

Water evacuated before sampling: $\mathbf{4 3} \mathrm{gal}$
The well went dry during purging.

LABOPATORY ANALYSES

$E$ Analyte Result Mod Unit L Lak

2 pH 2 Specific conductance

$\begin{array}{ll}2 & \text { Specific conductance } \\ 2 & \text { Aluminum } \\ 0 & \text { Antimony } \\ 0 & \text { Arsenic } \\ 0 & \text { Benium }\end{array}$

Barium

Bromodichloromethane

Bromoform

Bromomethane

Cadmium

O Calcium

Chloride

Chlorabenzene

Chloroethane

2-Chloroethyl vinyl ether

2-Chloroethy

Chloromethane

Chromium

Cobalt

Copper

Dibromochloromethane

1,1. Dichloroethane

1,2. Dichloroethane

trans-1,2-Dichloroethylene
trach

Dichloromethane

2,4-Dichlorophenoxyace

1.2-Dichloropropane
cis-1,3-Dichloropropene

trans: 1,3 -Dichloropropene

Endrin

Ethylbenzene

0 lron

Lead

- Lead

Magnesium

Mercury

Methoxychlor

Nicke

Nickel as nitrogen
Nitrate ate as nitrogen

Phenols
Phenols

Phenols

Potassium
Selenium

Selenium

Silica

$\begin{array}{ll}0 & \text { Silver } \\ 0 & \text { Sodium }\end{array}$

: Sodium

Sulfate $1,2,2$-Tetrachloroethane

1,1,2,2-Tetrachloroe

Tetrachlo
0 Toluene

Toluene

Total organic carbon

Total organic halogens

Total phosphates (as P)

0 Toxaphene

2.4.5.TP (Silvex)

1,1,1. Trichloroethane

Trichloroethylene
Trichlorofluoromethane

Trichlorofluy
0 Uranium
0

Uranium

Vanadium

Zinc

Gross alpha

Nonvolatile beta

Total radiun
Tritium

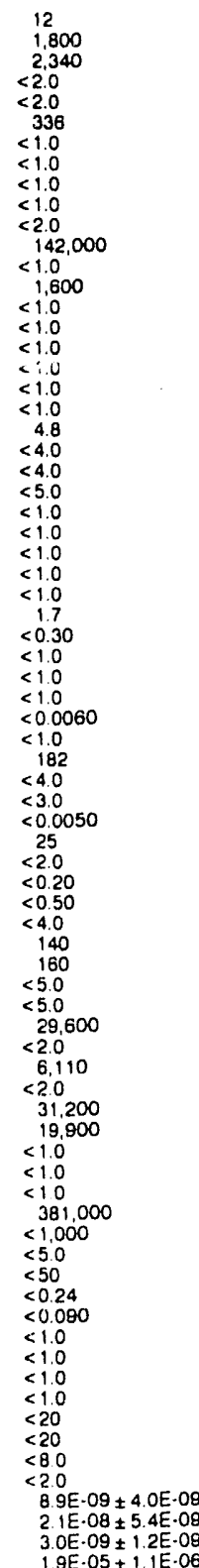

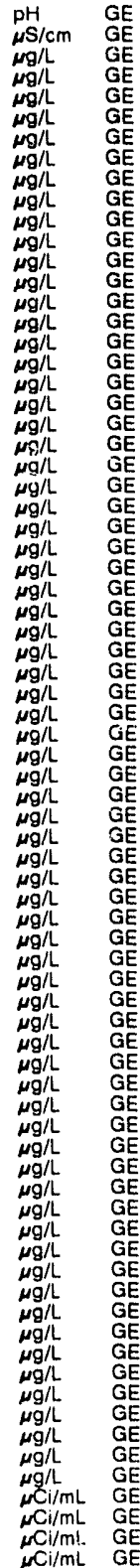


WELL HSB141D

MEASUREMENTS CONDUCTED IN THE FIELD

Sample date: 10/11/81

Depth to water: 15.30 h $(4.68 \mathrm{~m})$ below TOC

Water olevation: $238.50 \mathrm{tt} 73.00$

Sp. conductance: $24 \mu \mathrm{s} / \mathrm{cm}$

Wator evacuated before sampling:
The well went dy during purging.

LABORATORY ANALYSES

E Analyte Besult Mod Unit Lab

2 Spocific conductance

Alumin:

Areonic

Barium

Bromodichloromethane

Bromotorm

Cadmlum

Cadcium

Carbon tetrachloride

Chlorobenzene

Chloroethene Ninyl chloride)

2-Chloroethyl vinyl other

Chloroform

Chloromothan

Cobalt

Cobatt

Cyanido

Dibromochlorometha

o 1,2-Dichloroethane

$1,1-$ Dichloroethylene
o trans-1,2-Dichloroethylene

o Dichloromethano

$\begin{array}{ll}\text { D } & \text { Dichloromethane } \\ 0 & 2,4 \text {-Dichlorophenoxyacetic acid } \\ 0 & 1,2 \text {-Dichloropropane }\end{array}$

c cis-1,3-Dichloropropene

Endrin

O Ethylbenzene

Fluoride

0
0
0

L Load

Lindane

Magnesium

Manganese

Mercury
Methoxychlor

: Mickel

Nitrate as nitrogen

Phonols

Potassium

Solenlum

O Sillca

o Sodium

o Sulfate

- Totrachloroethylene

: Toluene

Total dissolved solids

- Total organic halogens

- Total phosphates (as P)

2,4,5.TP (Silvex)

$1,1,1-$ Trichloroethane

Trichloroethylene

Trichlorofluoromethane

0 Uranium

o Uranium

Vanadium

- Zinc

Gross alpha

Nonvolatile beta

Total radium

$\begin{array}{ll}5.7 & \text { JO } \\ 1,750 & \\ 45 & \\ <2.0 & \\ <2.0 & \\ <3.0 & \\ <1.0 & \\ <1.0 & \\ <1.0 & \\ <1.0 & \\ <2.0 & \\ 323 & \\ <1.0 & \end{array}$

323
$<1.0$
1.730

$<1.0$

$<1.0$

$<1.0$
$<1.0$
$<1.0$

$<1.0$

$<4.0$

$<4.0$

$<5.0$

$<1.0$

$<1.0$

$<1.0$

3.0
$<0.30$

$<1.0$
$<1.0$
$<1.0$

$<1.0$

$<1.0$
$<100$
$<100$
35

35
$<3.0$

$<0.0050$

240
6.5

$<0.20$

$<0.50$

$<4.0$
310
$<5.0$

$<5.0$
$<500$
$<20$

$<2.0$
6.130
$<2.0$

$<2.0$

1,390
$<1.0$

$<1.0$
$<1.0$

$<1.0$

8,000
$<1,000$

$<5.0$

$<0.24$

$<0.090$

$<1.0$

$<1.0$

$<1.0$

$<20$

$<8.0$

2.9

$3.9 E-09 \pm 1.2 \mathrm{E}-09$

$1.3 \mathrm{E}-09 \pm 1.2 \mathrm{E}-09$
$3.7 \mathrm{E}-05 \pm 1.3 \mathrm{E}-06$
WELL HSB142C

MEASUREMENTS CONDUCTED IN THE FIELD

Sample date: 10/08/91

Depth to water: $5.41 \mathrm{tt}(1.65 \mathrm{~m})$ below TOC

Water elevation: 198.58 if

Sp. conductance: $24 \mu \mathrm{S} / \mathrm{cm}$.

LABORATORY ANALYSES

E Analyte Result Mod Unit Lab

O $\mathrm{pH}^{\mathrm{pH}}$ Specific conductance

0 Aluminum

Antimony

Arsenic

0 Barium

o Benzene

Bromodichlorom

- Bromomethane

0 Cadmium

C Carbon tetrachloride

0 Chloride

Chiorobenzene

Chloroethane

Chloroethene Ninyl chloride

2-Chloroethyl vinyl ether

Chloroform

Chloromethan

Cobalt

Copper

Cyanide

Dibromochiorometh

1.1-Dichloroethane

1,1-Dichloroethylene

$1,1 \cdot D$ ichloroethylene
trans-1,2-Dichloroethylene

Dichloromethane

2,4-Dichlorophenoxyacetic acid

1,2-Dichloropropane

0
0
trans-1,3-Dichloropropene

Endrin

Ethylbenzene

Fluoride

0 Lead

Lindane

Magnesium

Manganese

Methoxychlor

Nickel

Nitrate as nitrogen

Phenois

Potassium

Selenium

Silver

Sodium

$1,1,2,2$-Tetrachloroethane

Tetrachloroethylene

Toluene

Total dissolved solids

Total organic carbon

Total organic halogens
Total phosphates (as P)

Toxaphene

2,4,5-TP (Silvex)

1,1,1-Trichloroethane

$1,1,2$-Trichloroetha
Trichloroethylene

Trichlorofluoromethane

Uranium

- Uranium

Vanadil

Zinc

Nonvolatile beta

Total radium

Time: $14: 00$

Alkalinity: $1 \mathrm{mg} / \mathrm{L}$

Water temperature: $17.6^{\circ} \mathrm{C}$

Mod Unit Lab

$\begin{aligned} & 5.5 \\ & 20 \\ &<20 \\ &<2.0 \\ &<2.0 \\ &<3.0 \\ &<1.0 \\ &<1.0 \\ &<1.0 \\ &<1.0 \\ &<2.0\end{aligned}$

$<1.0$

$<1,630$

$<\begin{aligned} & 1.0 \\ & 2,750\end{aligned}$

$<1.0$

$<1.0$

$<1.0$

$<1.0$

$<4.0$

$<4.0$

$<5.0$
$<1.0$

$<1.0$

$<1.0$

$<1.0$
4.9

$<30$
$<1.0$

$<1.0$

$<1.00060$

$<.0060$
$<1.0$

$<100$

$<4.0$
$<3.0$

$<0.005$

381
4.8

4.8
$<0.20$
$<0.50$

$<<4.50$

$<4.0$
300

$<5.0$
$<500$
$<2.0$

$<2.0$

$<2.0$
1,870

$<1,000$

$<1.0$

$<1.0$

23,000
$<1,000$

$<5.0$

$<0.24$

$<0.0$

$<1.0$
$<1.0$

$<1.0$
$<10$

$<20$

$<20$

$<8.0$

3. $5 E \cdot 00+3.1 \mathrm{E} \cdot 09$

8.2E- $09 \pm 4.3 \mathrm{E} \cdot 08$

$<1.0 E-00$

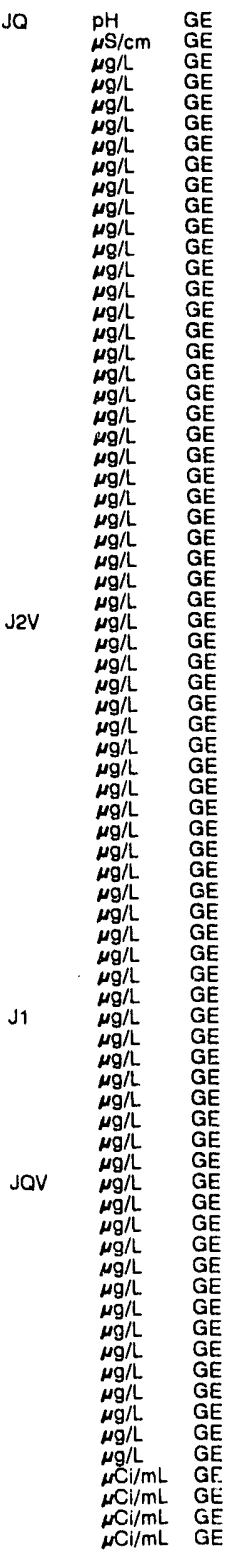




\section{WELL HSB142D}

MEASUREMENTS CONDUCTED IN THE FIELD

Sample date: 10/08/81 Depth to water: $6.79 \mathrm{Ht}(2.07 \mathrm{~m})$ below TOC

Water elevation: $197.41 \mathrm{H} / \mathrm{cm}$

Sp. conductance. 36 s/cm

The well went dry during purging.

LABORATORY ANALYSES

E Analyte Result Mod Unit Lab

Ppecilic conductance

Aluminum

Antimony

Arsenic
Barium

Benzene

chloromethane

Bromotorm

Bromo

Cadmium

Carbon tetrachloride

Chloride

Chlorobenzene

Chloroethane

2-Chloroethyl vinyl ether

Chloroform

Chloromethane

Chromium

Cobalt

Copper

Cyanide

$<1.0$

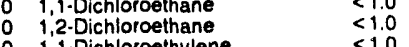

$1,1-$ Dichloroethylene
0

O trans.1,2.Dichioroethylene $\quad 3.6$

2.4-Dichlorophenoxyacetic acid $<0.30$

$\begin{array}{lll}0 & 1,2 \cdot \text { Dichloropropane } & <1.0 \\ 0 & \text { cis-1,3-Dichloropropene } & <1.0 \\ 0 & \text { trans-1,3-Dichloropropene } & <1.0\end{array}$

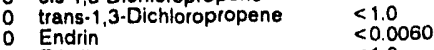

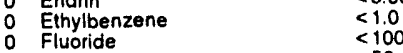

$\begin{array}{lll}0 & \text { Fluoride } & <100 \\ 0 & \text { lron } & 56 \\ 0 & \text { Lead } & <3.0\end{array}$

L Lindane

Magnesium

Mercury

Methoxychlor

Nickel

Nitrate as nitrogen

Phenois

Potassium

Silica

Silver

Sulfate

Tetrachloroethylene

Toluene

Tolal dissolved solids

Total organic carbon

Total ohosphates (as P)

2,4,5-TP (Silvex)

1,1,1-Trichloroethane

1,1,2-Trichloroethan

Trichloroethylene

Utanium

Uranium

O Vanadiun

Zinc

Gross alpha

Nonvolatile b

Total activity

2 Tritium
Time: $14: 25$

Alkalinity: $0 \mathrm{mg} / \mathrm{h}$

Water temperalure: $20.5^{\circ} \mathrm{C}$

5.1

57
$<2.0$
$<2.0$
17
$<1.0$
$<1.0$
$<1.0$
$<1.0$
$<2.0$

$<1.0$
4,000

$<1.0$

$<1.0$

$<1.0$
$<1.0$

4.0

(1)

30
.0
.0
.0
.00
.00
56
3.0
0.00

$<0.0050$
513
21

21
$<0.20$
$<0.50$

4.2

540
$<5.0$

$<500$

$<2.0$

9,780
$<2.0$

3,780
3,770

$<1.0$

$<1.2$
$<1.0$
30,000

$<1,000$

$<0.24$

$<0.0$

$<1.0$

$<1.0$

$<1.0$

$<20$

$<20$
$<8.0$

9.6
$<2.0 \mathrm{E} \cdot 09$

4.0E-09 $\pm 1.2 \mathrm{E}-09$

$4.2 \mathrm{E} \cdot 04 \pm 4.6 \mathrm{E}-06$

$4.5 \mathrm{E}-04 \pm 1.5 \mathrm{E}-06$
WELL HSB143C

MEASUREMENTS CONDUCTED IN THE FIELD

Sample date: $10 / 11 / 91$ 1 $3.60 \mathrm{~m})$ below TOC

Water elevation: $210.39 \mathrm{ft}$

Sp. conductance: $31 \mu \mathrm{S} / \mathrm{cm}$.

Water evacuated belore sampling: $108 \mathrm{gal}$

LABORATORY ANALYSES

E Analyte Result Mod Unit Lab

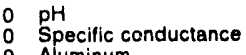

Aluminum

0 Antimony

0 Arsenic

0 Benzene

Bromodichloromethane

Bromoform

Cadmium

Calcium

- Carbon tetrachloride

Chloride

Chlorobenzene

Chloroethene Ninyl chloride)

2-Chloroethyl vinyl ether

2.Chloroethy

Chloroform

Chromium

Cobalt

Copper

Cyanide

1,1-Dichloroethane

1,2-Dichloroethane

1,1-Dichloroethylene
trans-1,2-Dichloroethylen

Dichloromethane

2,4-Dichlotophenoxyacetic acid

1,2-Dichloropropane

cis-1,3-Dichloropropene

Endrin

Ethylbenzene

Fluoride

Iron

Lindane

Magnesium

Manganese

Mercury

Nickel

Nitrate as nitrogen

Phenols

Potassium
Selenium

o Silica

o Silica

Sodium

Sulfate

Tetrachloroethylene

Toluene

Total dissolved solids

Total dissolved solids

Total organic carbon

Total organic halogens

Toxaphene

2,4,5-TP (Silvex)

1,1,1-Trichloroethane

1,1,2-Trichloroethane

Trichlorofluoromethane

Uranium

Uranium

Vanadiu

Gross alpha

2 Nonvolatile beta

Total radium

Time: $15: 05$

Alkalinity: $1 \mathrm{mg} /$

Water temperature: $18.6^{\circ} \mathrm{C}$

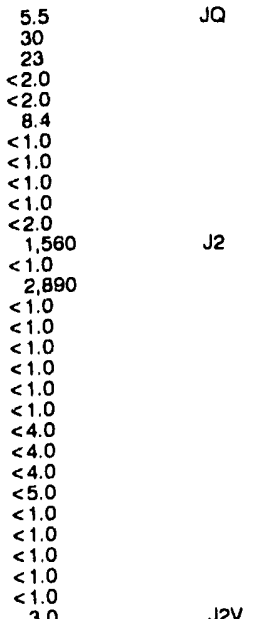

$\begin{array}{ll}\mathrm{pH} & \mathrm{GE} \\ \mu \mathrm{S} / \mathrm{cm} & \mathrm{GE} \\ \mu \mathrm{g} / \mathrm{L} & \mathrm{GE} \\ \mu \mathrm{g} / \mathrm{L} & \mathrm{GE} \\ \mu \mathrm{g} / \mathrm{L} & \mathrm{GE} \\ \mu \mathrm{g} / \mathrm{L} & \mathrm{GE} \\ \mu \mathrm{g} / \mathrm{L} & \mathrm{GE} \\ \mu \mathrm{g} / \mathrm{L} & \mathrm{GE} \\ \mu \mathrm{g} / \mathrm{L} & \mathrm{GE} \\ \mu \mathrm{g} / \mathrm{L} & \mathrm{GE} \\ \mu \mathrm{g} / \mathrm{L} & \mathrm{GE}\end{array}$

$<1.0$

$<1.0$

$<10$

$<100$

$<4.0$

$<0.0050$

247
13

$<0.20$

$<4.0$

420
$<5.0$

$<500$

6,500

$<2.0$

$<1,000$

$<1.0$

$<1.0$

6,000
10,000

$<1,000$

$<5.0$

$<0.24$

$<1.0$

$<1.0$

$<1.0$

$<20$

$<20$

$<20$
$<8.0$
2.8

4. $2 \mathrm{E} \cdot 09 \pm 1.1 \mathrm{E}-09$

5. $3 \mathrm{E}-08 \pm 2.0 \mathrm{E}-09$

$<1.0 \mathrm{E} \cdot 09$
$2.5 \mathrm{E} \cdot 05 \pm 1.2 \mathrm{E} \cdot 06$

$\mu \mathrm{g} \Omega \quad \mathrm{GE}$

$\mu g / L \quad G E$

$\mu g / L \quad G E$ 
WELL HSB143D

MEASUREMENTS CONDUCTED IN THE FIELO

Sample date: $10 / 11 / 81$
Depth to water: $8.33 \mathrm{ft}(2.54 \mathrm{~m})$ below TOC
Water elevation: $214.57 \mathrm{H}(65.40 \mathrm{~m}) \mathrm{ms}$ l

Water elevation: $214.57 \mathrm{H}(65.40 \mathrm{~m}) \mathrm{ms}$

Sp. conductance: $18 \mu \mathrm{S} / \mathrm{cm}$
Water evacuated belore sampling: $46 \mathrm{gal}$

LABORATORY ANALYSES

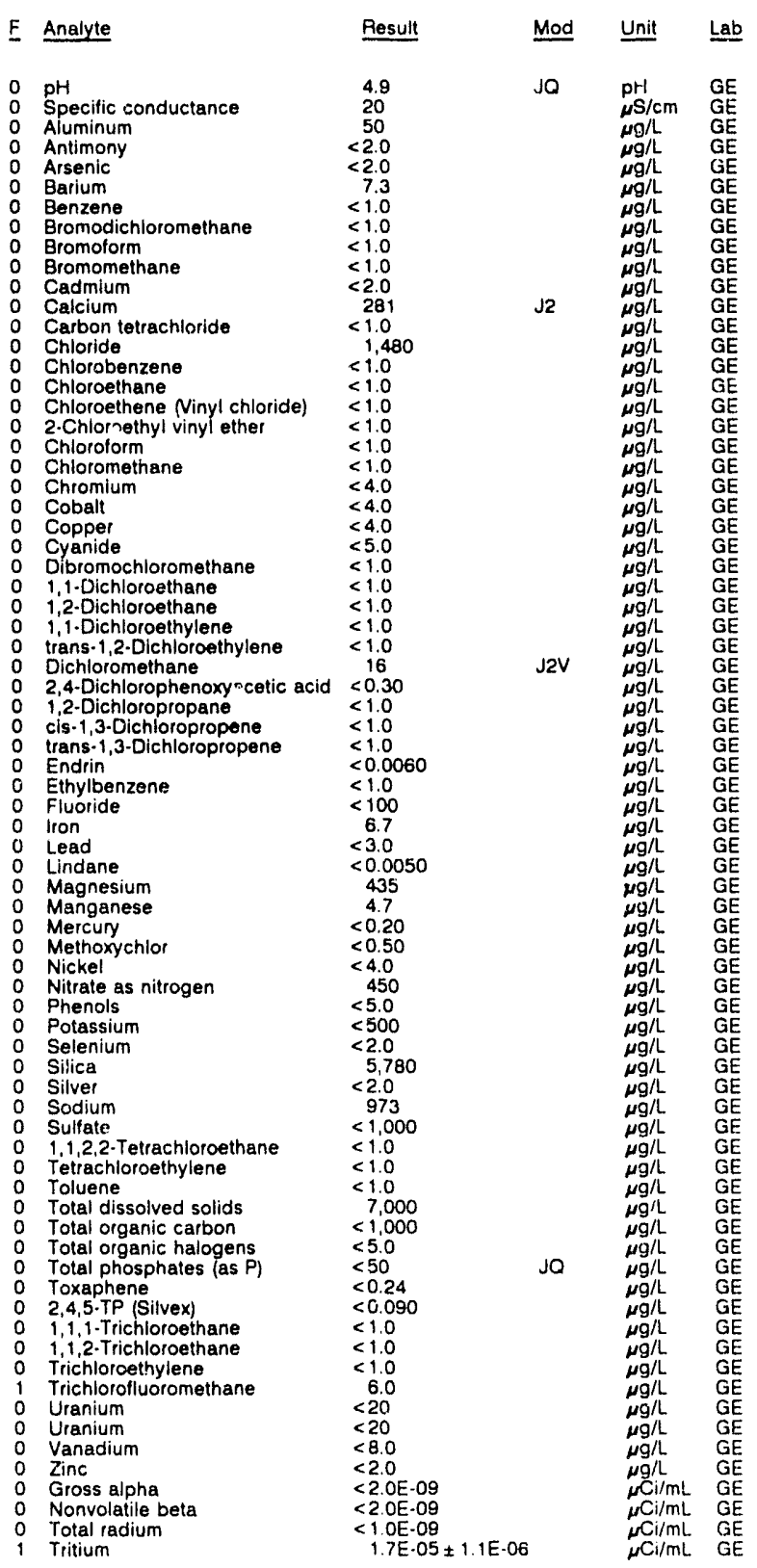

Time: $15: 20$

PH: 4.6 Alkalinity: $0 \mathrm{mg} / \mathrm{L}$

Water temperature: $19.1^{\circ} \mathrm{C}$
WELL HSB144A

MEASUREMENTS CONDUCTED IN THE FIELD

Sample date: $10 / 09 / 81$.

Water elevation: $171.19 \mathrm{H} / 52$.

Th: 15.00

Water evacuated before sampling: $243 \mathrm{gal}$

LABORATORY ANAL.YSES

E Analyte Result Mod Unit Lab

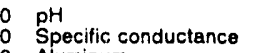

Aluminum

Antimony

Arsenic

Barium

Bromodichloromethane

Bromoform

Bromomethane

Cadmium

Calcium

Chloride

Chlorobenzen

Chloroethene (Vinyl chloride)

Chloroethene Ninyl chloride)
2-Chloroethyl vinyl ether

Chloromethane

Chromium

Cobalt

Copper

0 Cyanido

0 Dibromochloromethane

1,1-Dichloroethane

1,2-Dichloroethane

1,1-Dichloroethylene
trans-1,2-Dichloroethylene

Dichloromethane

2,r-Dichlorophenoxyacetic acid

1,2-Dichloropropane

0
0 tis-1,-Dichloropropene
trans-1, . nirhloropropene

0 Endrin

E Ethylbeanzene

0 Fluoricie

0 Iron

0 Lead

o Lindane

2 Manganese

Mercury

Methoxychlor

Nickel

Nitrate as nitrogen

Nitrate as nitrogen

Phenols
0 Potassium

Potassium

Silica

Silica

Sodium

0 Sodium

1,1,2,2. Tetrachloroethane

Tetrachloroethylene

Toluene

- Total dissolved solids

Total organic carbon

Total organic halogens
0 Yotal phosphates (as P)

Toxaphene

2,4,5-TP (Silvex)

1,1,1-Trichloroethane

1,1,2-Trichloroethan

Trichloroethylene

Uranium

Vanadium

0 Zinc

Gross alpha

Total activity

Total radium

Result

Jo

$\mathrm{pH} \quad \mathrm{GE}$

7.2
160
$<20$

$<20$
$<2.0$
2.6
39

39
$<1.0$

$<1.0$

$<1.0$

$<2.0$
26,500

$<.0$
2,540

2,540
$<1.0$

$<1.0$
$<1.0$
$<1.0$

$<1.0$

$<1.0$

$<4.0$
$<4.0$
$<4.0$

$<4.0$
$<5.0$
$<1.0$
$<1.0$

$<1.0$
$<1.0$

$<1.0$

$<1.0$
$<1.0$
3.5
$<0.30$

$<1.0$

$<0.0060$

$<1.0$
128
$<4.0$

$<4.0$

$<0.0050$
$>777$

777
59

$<0.20$
$<0.50$

$<0.50$
$<4.0$

4,000
4,000

4,000
$<5.0$
4,360

4,360
$<2.0$

28,900

$<2.0$
8,820

$\begin{aligned} & 3,420 \\ < & 1.0 \\ < & 1.0\end{aligned}$

$<1.0$

149,000

$<1,000$

$<5.0$

$\begin{array}{r}300 \\ <0.24 \\ \hline\end{array}$

$<0.090$

$<1.0$

$<1.0$
$<1.0$
$<1.0$
$<20$

$<20$
$<8.0$
$<2.0$

$<2.0 \mathrm{E} .08$

$1.0 \mathrm{E} \cdot 08 \pm 1.9 \mathrm{E}-08$

$2.6 \mathrm{E} \cdot 03 \pm 3.8 \mathrm{E} \cdot 05$

$<1.0 \mathrm{E} .09$

2. $4 \mathrm{E}-03 \pm 7.8 \mathrm{E}-06$ b 


\section{ANALYTICAL RESULTS}

\section{WELL HSB145C}

MEASUREMENTS CONDUCTED IN THE FIELD

Sample date: $10 / 10 / 9$

Wepth to water: $21.68 \mathrm{ft}(6.60 \mathrm{~m})$ below TOC

Sp. conductance: 355 H $(65.24$

Water evacuated before sampling: $129 \mathrm{gal}$

LABORATORY ANALYSES

E Analyte Result Mod Unit Lab

1 Specific conductance

Aluminum

Antimony

Arsenic

Barlum

Benzene
Bromodichloromethan

Bromoform

Bromomethan

Cadmium

Carbon tetrachloride

Chlorobenzene

Chlorothane Ninyl chloridel

Chloroethene Ninyl chloride

Chloroform

Chloromethane

Chromium

Cobalt

Cyanide

Oibromochioromethane

1,1-Dichloroethane

1,1.Dichlorethane

trans-1,2-Dichloroethylene

2,4-Dichlorophenoxyacetic acid

1,2-Dichloropropane

trans-1,3-Dichloropropen

Ethylbenzene

Fluoride

Iron

Lead

Magnesium

Manganes

Methoxychlo

Nicke

Nitrate as nitrogen

Phenols

Potassium
Selenium

Silice

Solver

Sodin

1,1,2,2 - Buthorothane

Tetrachloriceshiviene

Toluene

Total dissolved is

Total organic carcisn

Total phosphates (as P)

Toxaphene

2,4,5-TP (Silvex)

1,1,1.Trichloroethane

1,1,2-Trichloroethan

Trichlorofluoromethane

Uranium

V Uanium

Zine

1 Gross alpha

Nonvolatile be

Total activity

2 Tritium

Time: $14: 15$

Alkalinity: $19 \mathrm{mg} / \mathrm{L}$

Water temperature: $19.5^{\circ} \mathrm{C}$
WELL HSB145D

MEASUREMENTS CONDUCTED IN THE FIELD

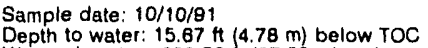

Water elevation: $220.53 \mathrm{ft}(67.22 \mathrm{~m}) \mathrm{ms}$

Sp. conductance: $352 \mu \mathrm{S} / \mathrm{cm}$

Water evacuated before sampling: $95 \mathrm{gal}$

Time: $13: 55$

LABORATORY ANALYSES

F Analyte $\underline{\text { Result }}$ Mod Unit Lab

1 Specific conductance

Antimony

Arsenic

Barium

Benzen

Bromodichloromethane

Bromoform

Bromomethane

Cadmium

Carbon tetrachloride

Carbon tetride

Chloride

Chlorobenzene

Chloroethane

Chloroethene Ninyl chloride)

2.Chloroethyl

Chloromethane

Chromiurn

Cobalt

O Copper

Cyanide
0

1,1-Dichloroethane

1,2-Dichloroethane

1,1-Dichloroethylene

trans-1,2-Dichloroethylene

$\begin{array}{ll}\text { trans-1,2-Dichloroethylene } & <1.0 \\ \text { Dichloromethane } & 1.1 \\ \text { 2,4-Dichlorophenoxyacetic acid }<0.30\end{array}$

1,2-Dichloropropane

cis-1,3-Dichloropropene

trans-1,3-Dichloropropene

Ethylbenzene

Fluoride

Iron

Lindane

Magnesium

Manganese

Methoxychior

Nicke

Nitrate as nitrogen

Nitrate as nitrogen

Nitrate as nitrogen

Phenols

Potassium

Selenium

Silica

Silver

Sulfate

Sullate

1,1,2,2-Tetrachloroethane

Tetrach

Total dissolved solids

Tolal

Toxaphene

2,4,5.TP (Silvex)

$1,1,1$. Trichloroethane

1,1,2-Trichloroethan

Trichlorofluoromethane

Uranium

Vanadium

Gross alpha

Nonvolatile beta
Total activity

Total activity

Tritium

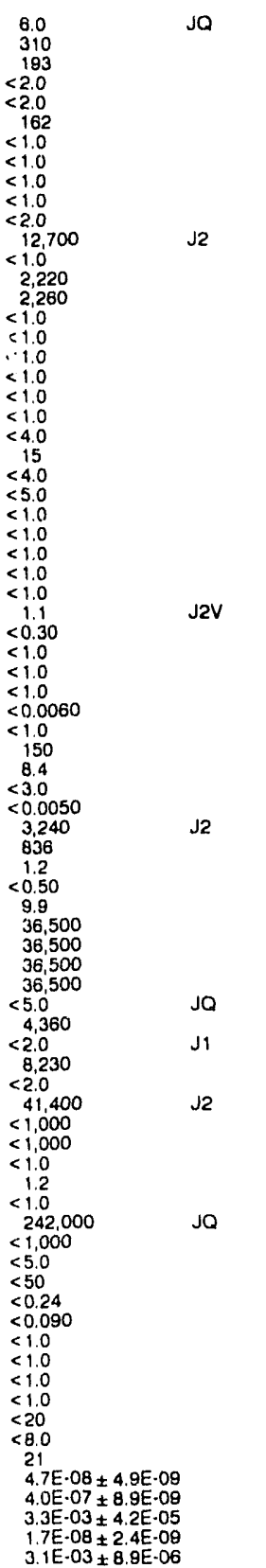

$\mathrm{pH} \quad \mathrm{GE}$

$\mu \mathrm{g} / \mathrm{L} \quad \mathrm{GE}$

$\mu \mathrm{g} / \mathrm{L} \quad \mathrm{GE}$

$\mu \mathrm{g} / \mathrm{L} \quad \mathrm{GE}$

$\mu g, \quad G / L$

$\mu \mathrm{\mu g/L} \quad \mathrm{GE}$

$\underset{\mu g / L}{\mu g} \quad \mathrm{GE}$

$\mu \mathrm{g} / \mathrm{GE}$

$\mu \mathrm{g} \Lambda \quad \mathrm{GE}$

${ }_{\mu \mathrm{g} /}^{\mu} \quad \mathrm{GE}$

$\mu \mathrm{g} / \mathrm{L} \quad \mathrm{GE}$

$\mu \mathrm{g} / \mathrm{L} \quad \mathrm{GE}$

$\mu g, h \quad G E$

$\mu g / 2$

$\mu g / L \quad G E$

$\mu g / \lambda$

$\mu \mathrm{g} / \mathrm{G} \quad \mathrm{GE}$

$\mu \quad{ }_{\mu g / L} \quad \mathrm{GE}$

$\begin{array}{ll}\mu g / L & G E \\ \mu g / L & G E\end{array}$

$\mu \quad \mu g / L \quad G E$

$\mu g / L \quad G E$

$\mu g / L \quad G E$

$\underset{\mu g / L}{\mu g} \quad G$

$\underset{\mu g / L}{\mu} \quad G E$

$\underset{\mu g / L}{\mu g}, G$

$\mu g / L \quad G E$

$\mu g / L \quad G E$

$\mu \mathrm{g} / \mathrm{L}$ GE

$\mu \mathrm{g} / \mathrm{L} \quad \mathrm{GE}$

$\boldsymbol{\mu g} / \mathrm{L} \quad \mathrm{GE}$

$\mu \mathrm{gg/L} \quad \mathrm{GE}$

$\mu g / L \quad G E$

$\mu g / L \quad G E$

$\mu \mathrm{g} / \mathrm{L} \quad \mathrm{GE}$

$\mu \mathrm{ClimL} G \mathrm{GE}$

$\omega \mathrm{C} i / \mathrm{mL}$ G $\mu g h$ GE

$\underset{\mu g / L}{\mu g}, \quad G E$ 
ANALYTICAL RESULTS

WELL HSB146A

MEASUREMENTS CONDUCTED IN THE FIELD

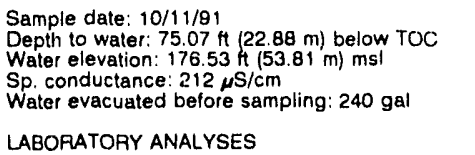

LABOFATORY ANALYSES

F Analyte Besult Mod Unit Lab

0 Specific conductance

Aluminum

Arsenic

Arsenic

Barium

Bromodichioromethane

Bromoform

Bromomethane

Cadmium

Calcium

Chlorid

Chlorobenzene

Chloroethane

Chloroethene Ninyl chloride
2-Chloroethyl vinyl ether

2.-Chloroethy

Chloromethane

Chromium

Cobalt

Cyanide

Cyanide

Dibromochloromethane

1,1-Dichloroethane

o 1,2-Dichloroethane

o trans-1,2-Dichloroethylene

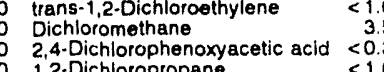

1,2-Dichloropropane

cis-1,3-Dichloropropene

0 trans-

o Ethylbenzene

0 Fluoride

0 lion

o Lindane

- Magnesium

Mercury

Methoxychlor

Nickel

Nitrate as nitrogen

Phenols

Selenium

Selenium

Silica

$\begin{array}{ll}0 & \text { Silver } \\ 0 & \text { Sodium } \\ 0 & \text { Sulfate }\end{array}$

1,1,2,2-Tetrachloroethane

Tetrachioroethylene

Toluene

Total dissolved solids

Total organic carbon

Total organic halogens

Toxaphen

2,4,5-TP (Silvex)

1,1,1-Trichloroethane

1,1,2-Trichlorsethane

Trichlorofluoromethane

Uranium

Uranium

O Vanadil

Gross alpha

Nonvolatile beta

Total radium

Time: $9: 15$

Alkalinity: $81 \mathrm{mg} /$

Water temperature $19.0^{\circ} \mathrm{C}$

7.7

\section{WELL HSB146C}

MEASUREMENTS CONDUCTED IN THE FIELD

$\begin{array}{llll}\mathrm{pH} & \mathrm{GE} & 0 & \mathrm{pH} \\ \mu \mathrm{S} / \mathrm{cm} & \mathrm{GE} & 0 & \text { Specific conductance } \\ \mu \mathrm{g} / \mathrm{L} & \mathrm{GE} & 1 & \text { Aluminum }\end{array}$

Antimony

Arsenic

Arsenic

Benzen

Bromodichloromethane

Bromoform

Bromomethane

Cadmium

Carbon tetrachloride

Chlorobenzene

Chloroethene Ninyl chloride

2.Chloroethyl vinyl ether

Chloroform

Chloromethane

Chromium

Copper

Cyanide

Dibromochloromethane

1,1-Dichloroethane

1,2-Dichloroethane

trans 1,2 -Dichloroethylene

Dichloromethane

noxyacetic acid

cis-1,3-Dichloropropene

trans-1.3-Dichloropene

Endrin

Ethylbenzene

Fluo

Lead

Lindane

Magnesium

Mercury

Methoxychlor

Nitrate as nitrogen

Phenols

Selenium

Silica

Silver

Sodium

1,1,2,2-Tetrachlofuethane

Tetrachloroethylene

Toluene

Total dissolved solids

Tolal organic carbon

Total organic halogens
Total phosphates (as P)

Toxaphene

2,4,5-TP (Sivex)

1,1, Trichloroethane

$1,1,2$ - Trichioroethan

Trichlorofluoromethane

Uranium

Uranium

Vanad

Gross alpha

Nonvolatile beta

Total radium

Tritium
Time: $\mathbf{9 : 0 0}$

Alkalinity: $26 \mathrm{mg} / \mathrm{h}$ Water temperature: $18.4^{\circ} \mathrm{C}$ 
WELL HSB146D

MEASUREMENTS CONDUCTED IN THE FIELO

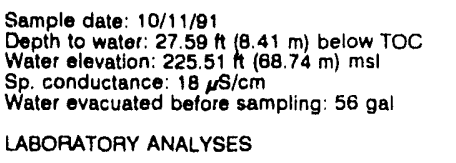

Time: $9: 35$

Alkalinity: $1 \mathrm{mg} / \mathrm{L}$

Water temperature $18.7^{\circ} \mathrm{C}$

LABOPATORY ANALYSES

E Analyte $\quad$ Result $\quad \underline{\text { Mod Unit Lab }}$

$\begin{array}{ll}\mathrm{pH} \\ 0 & \text { Specific conductance }\end{array}$

Aluminum

Arsenic

Barium

Benzene

Bromodichloromethane

Bromotorm

Bromometh

Cadmium

Carbon tetrachloride

Carbon

Chloride

Chloroethane
Chloroethene Ninyl chloride)

2-Chloroethyl vinyl ether

Chlorotorm

Chloromethane
Chromium
Cobalt

Coper $\quad<5$.

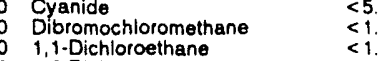

$\begin{array}{lll}0 & 1,1-\text { Dichloroethane } & <1.0 \\ 0 & 1,2 \text { Dichloroethane } & <1.0 \\ 0 & 1,1-\text { Dichloroethylene } & <1.0\end{array}$

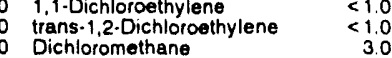

$\begin{array}{ll}2,4-D i c h l o r o p h e n & \\ 0 & 3.0 \\ 0 & <y a c e t i c\end{array}$

o 1,2-Dichloropropane $<1.0$

0 cis-1,3-Dichloropropene

0 E trans-1,

Endrin $<0.0060$

0 Fluoride

0 lion

Lead

0 Lindane

Manganese

Methoxychlor

Nitrale as nitrogen

Nitrate as nit
Phenols

Potassium

Selenium

Silica

Sitver

Sodium

Sulfate

$\begin{array}{ll}0 & 1,1,2,2 \cdot \text { Tetrachloroethane } \\ 0 & \text { Tetrachloroethylene }\end{array}$

0 Toluene

0 Total dissolved solids

0 Total organic carbon

0 Total organic halogens
0 Total phosphates (as P)

- Total phosphates

0
0
0

$\begin{array}{ll}0 & 1,1,1-\text { Trichloroethane } \\ 0 & 1,1,2-T r i c h l o r o e t h a n e\end{array}$

o Trichloroethylene

2 Trichlorofluoromethane

- Uranium

O Vranium

0 Zine

o Gross alpha

- Nonvolatile beta

2 Tritium

$\begin{array}{ll} & 5.6 \\ 20 & \text { JO } \\ <20 & \\ <2.0 & \\ <2.0 & \\ 15 & \\ <1.0 & \\ <1.0 & \\ <1.0 & \\ <1.0 & \\ <2.0 & \\ 1.460 & \text { J2 }\end{array}$

1,390

$<1.0$

$<1.0$

1.0

.

(n)

-10
0

0

$<0.30$

$<1.0$
$<0.0060$

$<1.0$

11
$<30$

$<0.0050$
227

227
11

$<0.20$
$<0.50$

$<0.50$
$<4.0$
540

540
$<5.0$

$<500$
$<2.0$
5.710

$<2.0$

$<1,000$
$<1.0$
$<10$

$<1.0$

3,000
$<1,000$

$<1,000$
$<50$

$<50$
60
$<0.24$
$<0.090$

$<1.0$

$<1.0$

10
$<20$

$<20$
$<20$
$<8.0$
11

$<2.0 E \cdot 09$

$<2.0 \mathrm{E} \cdot 09$

$1.0 \mathrm{E} \cdot 09 \pm 1.4 \mathrm{E} \cdot 09$
$2.1 \mathrm{E} \cdot 05 \pm 1.2 \mathrm{E} \cdot 06$
WELL HSB147D

MEASUREMENTS CONDUCTED IN THE FIELD

Sample date: $10 / 08 / 91$

Depth to water: $32.24 \mathrm{H}(9.83 \mathrm{~m})$ below TOC
Water elevation: $235.06 \mathrm{~h}(71.65 \mathrm{~m}) \mathrm{ms}$ l

$\mathrm{Si}$. coriuuctance $26 \mu \mathrm{S} / \mathrm{cm}$

Water evacuated before sampling: $10 \mathrm{gal}$
The well went dry during purging

LABORATORY ANALYSES

E Analyte Result Mod Unit Lab

$\begin{array}{ll}0 \mathrm{pH} \\ 0 & \text { Specific conductance }\end{array}$

0 Aluininum

0 Antimony

0 Arsenic

0 Benzene

Bromodichloromethane

O Bromolorm

0 Bromometh

Cadmium

${ }_{0}$ Carbon tetrachloride

0 Chioride

0 Chlorobenzene

Chlorobenzen

Chloroethene Ninyl chloride

2.Chloroethyl vinyl ethe

o Chloroform

Chromium

O Copper

Cyanide

Oibromochloromethane

1,1-Dichloroethane

1,2-Dichloroethane

trans-1,2-Dichloroethylene

0 Dichloromethane

2,4-Dichiorophenoxyacetic acid

1,2-Dichloropropane

cis-1,3-Dichloropropene

$\begin{array}{ll}0 & \text { Endrin } \\ 0 & \text { Ethylbenzene }\end{array}$

o Fluoride

o Iron

o Lead

- Magnesium

- Manganes

Mercury

Methoxychlor

O Nickel

Nitrate as nitrogen

Phenols

o Selenium

O Silica

0 Silver

Sodium

Sulfate

1,1,2,2.Tetrachioroetha

- Tetrachloroethylene

Toluene

Total dissolved solids

Total organic carbon

Total organic halogens

Total phosphates (as P)

Toxaphene

2,4,5.TP (Silvex)

1.1.2-Trichloroethane

Trichloroethylene

Trichlorofluoromethane

Uranium

Uranium

Zine

Gross alpha

Nonvolatile beta

Total radium
Tritium
Time: 9.05

Alkalinity: $1 \mathrm{mg} /$

Water temperalure: $16.6^{\circ} \mathrm{C}$

5
25
$<20$
$<2$

$<2.0$
$<2.0$
$<2.0$

9.6
$<1.0$

$<1.0$

$<1.0$

$<1.0$
$<2.0$
770

778
$<1.0$

$<10$
4,200

$<1.0$

$<10$

$<1.0$

$<1.0$

$<4.0$

$<4.0$

$<4.0$

$<5.0$
$<1.0$

$<1.0$

$<1.0$

$<1.0$

$<.0$
3.9

$<30$

$<1.0$
$<1.0$

$<1.0$

$<10$
$<100$

$<100$

$<3.0$

$<0.0050$

661
3.1

$<0.20$

$<4.0$

$<4.0$

$<5.0$
$<500$

$<2.0$

7.150
$<2.0$

2,200
$<1,000$

$<10$

$<10$

$<1.0$

$<1.000$

5.1
$<5.0$

$<50$
$<0.24$

$<0.24$
$<90$

$<1.0$

$<10$

$<1.0$
$<1.0$

$<20$

$<20$
$<20$
$<8.0$

< 8.0

8.9
$<2.06 .09$

$<2.0 E .09$

$<1$ OE.09

2. $2 \mathrm{E} \cdot 05 \pm 3.0 \mathrm{E} \cdot 07$

Jo

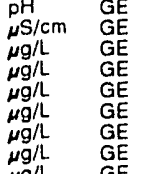

$\begin{array}{ll}p H & G E \\ \mu \mathrm{S} / \mathrm{cm} & \mathrm{GE} \\ \mu \mathrm{g} / & \mathrm{GE} \\ \mu \mathrm{g} / \mathrm{L} & \mathrm{GE} \\ \mu \mathrm{g} / \mathrm{L} & \mathrm{GE} \\ \mu \mathrm{g} / \mathrm{L} & \mathrm{GE} \\ \mu \mathrm{g} / \mathrm{L} & \mathrm{GE} \\ \mu \mathrm{g} / & \mathrm{GE} \\ \mu \mathrm{g} / \mathrm{L} & \mathrm{GE}\end{array}$ 
ANALYTICAL RESULTS

WELL HSB148C

MEASUREMENTS CONDUCTED IN THE FIELD

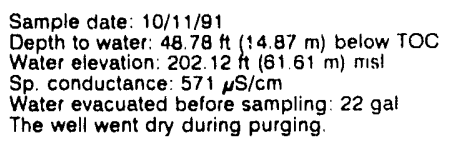

Time: $12: 55$

Alkalinity: $127 \mathrm{mg} / \mathrm{L}$

Water temperature: $18.0^{\circ} \mathrm{C}$

The well went dry during purging.

LABORATORY ANALYSES

E Analyte Result Mod Unit

2 pH 1 Specific conductance

Antimony

Antimony

Aarium

Benzene

Bromodichloromethane

Bromoform

Bromomethane

Cadmium

Carbon tetrachloride

Chlorobenzen

Chloroethane

2.Chloroethyl vinyl ether

Chloroform

Chloromethane

Chromium

Cobalt

Cyanide

Dibromochloromethane

i,1-Dichloroethane

1.2-Dichloroethane

1,1-Dichloroethylene
trans-1,2-Dichloroethylene

Dichloromethane
2,4-Dichlorophenoxyacetic acid $<0$

1,2-Dichloropropane
cis-1,3-Dichloropropene

cis-1,3.Dichloropropene

0 trans 1

0 Fluoride

Lead

Lindane

Magnesium

Manganes

Mercury

Nicket

Pitrate as nitrogen

Phenols

Potassium
Selenium

Selenium

Silver

Sodium

$1,1,2.2 \cdot$-Tetrachloroethane

Tetrachloroethylene

Tolvene

Totai dissolved solids

Total organic carbon

Total organic carbon

Total phosphates (as P)

Toxaphene

1,1.1. Trichloroethane

1, 2. Trichloroethane

Trichloroethylene

Trichlorofluoromethane

Uranium

Vanadinc

Gross alpha

Nonvolatile be

Total radium

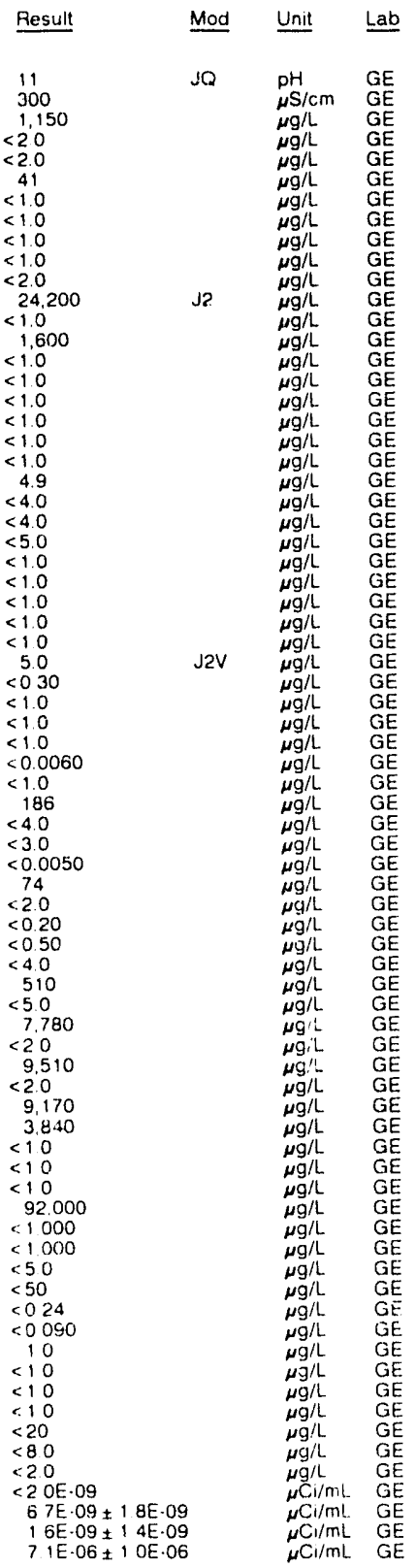

WELL HSB148D

MEASUREMFNTS CONDUCTED IN THE FIELD

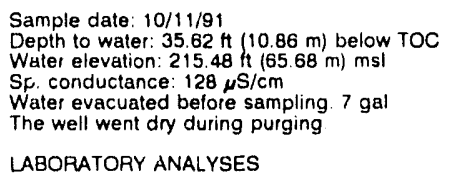

Time: $13: 10$

Alkalinity: $35 \mathrm{mg} / \mathrm{h}$

Water temperature: $17.9^{\circ} \mathrm{C}$

The well went dry during purging.

LABORATORY ANALYSES

E Analyte Besult Mod Unit Lab

$\begin{array}{ll}2 & \mathrm{pH} \\ 0 & \text { Specific conductance }\end{array}$

2 Aluminum

Arsenic

Barium

Benzene

Bromodichloromethane

Bromoform

Bromomethane

Cadmium

Carbon tetrachloride

Chloride

Chloroethane

Chloroethene Ninyl chloride

2.Chloroethyl vinyl ether

Chloroform

Chloromethane

Chromium

Cobalt

Copper
Cyanide

Cyanide
Dibromochloromethane

1.1.Dichloroethane

1,2-Dichloroethane

vans-1,2-Dichloroethylene

Dichloromethane

11

Jo

pH GE

2,4-Dichlorophenoxyacetic acid 3.0

1,2-Dichloropropane

cis-1,3-Dichloropropene

trans-1.3.

Ethylbenzene

Fluoride

Iron

Lindane

Magnesium

Manganes

Mercury

Nickel

Nitrate as nitrogen

Phenols

Selassium

Silica

Silver

Sodium

Sulfate

Tetrachloroethylene

Toluene

Total dissolved solids

Total dissolved solids

Total organic carbon

rotal phosphates (as P)

Toxaphene

2,4,5.TP (Silvex)

1.1.1.Trichloroethane

1.2. Trichloroethan

Trichloroethylene
Trichlorofluoromethane

Uranium

Vanadium

Zinc

- Gross aipha

- Nonvolatite beta

$\begin{array}{ll}0 & \text { Total radium } \\ 2 & \text { Tritium }\end{array}$

11

1,070
$<2.0$

$<2.0$

$<1.0$

$<1.0$

$<1.0$

$<2.0$

$<1.0$

2,470
$<10$

$<10$
$<10$

$<1.0$

$<1.0$

$<100$

4.4
$<4.0$

$<4.0$

$<5.0$

$<1.0$

$<1.0$

$<1.0$

$<1.0$
3.0

$<1.0$

$<1.0$

$<0.0060$

$<1.0$
$<100$

$<100$

$<3.0$

$<0.0050$

109

$<2.0$
$<0.20$

$<0.20$
$<0.50$

$<40$
100

$<5.0$

$<2.250$
$<20$

10,500

$<.0$
3.050

3,190

$<1.0$

$<1.0$
$<1.0$

27,000

28,000

$<5 . \bar{U}$

$<50$

$<0.24$

$<10$

$<10$

$<1.0$
$<1.0$

$<1.0$

$<20$

$<20$
9.8
$<20$

$<20$
$<2.0 \mathrm{E} \cdot 09$

$3.0 \mathrm{E}-09$
$01.6 \mathrm{E}-09$

$<1.0 E \cdot 09$
$2.1 E \cdot 05 \pm 1.2 E \cdot 06$ 
WELL HSB149D

MEASUREMENTS CONDUCTED IN THE FIELD

Sample date: $10 / 09 / 91$ Depth to water: $16.29 \mathrm{Ht}(4.97 \mathrm{~m})$ below TOC
Water elevation: $223.71 \mathrm{Ht}(68.19 \mathrm{~m}) \mathrm{ms}$ I
Sp. conductance: $23 \mu \mathrm{s} / \mathrm{cm}$
Water evacuated before samplirig: $44 \mathrm{gal}$

LABORATOHY ANALYSES

E Analyte Result Mod Mnit

Time: $16: 20$

Alkalinity: $0 \mathrm{mg} / \mathrm{L}$ $\begin{array}{ll}0 & \mathrm{pH} \\ 0 & \text { Specific conductance }\end{array}$ Antimony

Arsenic

Barlum

Benzene

Cadmium

Carbon tetrachloride

Chloride

Chloroethane

Chloroethene Ninyl chitoride
2.Chloroethyl vinyl other

Chromlum

Cobalt

Copper

Dibromochloromethane

1,1.Dichloroethane

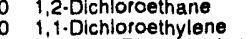

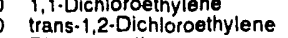

Dichloromethane

2,4-Dichlorophenoxyacetic acid $<1.0$

1,2-Dichloropropane

0
0
0
trans-1,3-Dichloropropene

0 Ethylbenzene

Fluoride

Iron

Lindane

Magnesium

Manganese

Methoxychlor

Nickel

Nitrate as nitrogen

Phenols

Potassium

Selenium

Silica

Sodium

Sulfate

Tetrachloroethylene

Toluene

Total dissolved solids

Total organic carbon

Total organic carbon

Total organic halogens

Total organic halogens

Toxaphene

2,4,5-TP (Silvex)

1.1,2-Trichloroethan

Trichloroethylene

Trichlorofluoromethane

Uranium

Uranium

Zana

Gross alphe

Nonvolatile beta

Total radium

Tritium

4.9
30
65
$<2.0$
$<2.0$
4.6
$<1.0$
$<1.0$
$<1.0$
$<1.0$
$<2.0$
$<261$
$<1.0$
2.35
$<1.0$
$<1.0$
$<1.0$
$<1.0$
$<1.0$
$<1.0$
$<4.0$

$<1.0$
$<1.0$
$<4.0$

$<4.0$

$<4.0$

$<1.0$

$<1.0$

$<1.0$

$<1.0$

$<100$
37

$<5.0$

$<20$
Water temperalure: $20.0^{\circ} \mathrm{C}$

Mod Unit Lab

2,350

$<0.30$
$<1.0$

$<1.0$
$<0.0060$

$<1.0$

$<3.0$
$<0.0050$

333

$<0.20$
$<0.50$

7.3
920
$<5.0$

$<500$

$<2.0$

$<2.0$

2,660
1,400

1,400
$<1.0$
$<1.0$

$<1.0$

68,000
$<2000$

$<2,000$

$<5.0$

$<0.24$

$<0.090$

$<1.0$

$<1.0$

$<1.0$

$<20$

$<2.0 E-09$

$2.3 \mathrm{E} \cdot 09 \pm 11 \mathrm{E}-09$

< $.0 E-09$
$4.7 \mathrm{E} .05+5.0 \mathrm{E} .07$

JQ

$\begin{array}{ll}\mathrm{pH} & \mathrm{GE} \\ \mu \mathrm{S} / \mathrm{cm} & \mathrm{GE} \\ \mu \mathrm{g} / \mathrm{L} & \mathrm{GE} \\ \mu \mathrm{g} / \mathrm{L} & \mathrm{GE} \\ \mu \mathrm{g} / \mathrm{L} & \mathrm{GE}\end{array}$

$\mu g / L \quad G E$

$\mu g / \mathrm{L} \quad \mathrm{GE}$

$\mu g / L \quad G \quad G$

$\begin{array}{ll}\mu \mathrm{g} / \mathrm{L} & \mathrm{GE} \\ \mu \mathrm{g} / \mathrm{L} & \mathrm{GE} \\ \mu \mathrm{g} / \mathrm{GE} & \mathrm{G}\end{array}$

$\mu \mathrm{g} / \mathrm{L} \quad \mathrm{GE}$

$\mu g / \mathrm{L} \quad \mathrm{GE}$

$\begin{array}{ll}\mu \mathrm{g} / \mathrm{L} & \mathrm{GE} \\ \mu \mathrm{g} / \mathrm{L} & \mathrm{GE}\end{array}$

$\mu \mathrm{g} / \mathrm{L} \quad \mathrm{GE}$

$\mu g / L \quad G E$

$\begin{array}{ll}\mu g / h & G E \\ \mu g / h & G E\end{array}$

$\mu \mathrm{gg/L} \quad \mathrm{GE}$

$\begin{array}{ll}\mu \mathrm{g} M & \mathrm{GE} \\ \mu \mathrm{g} & \mathrm{GE} \\ \mu \mathrm{g} & \mathrm{GE}\end{array}$

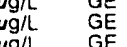

$\underset{\mu g / \Lambda}{\mu g} \quad \mathrm{GE}$

${ }_{\mu g / L}^{\mu g / L} \quad \mathrm{GE}$

\section{WELL HSB150D}

MEASUREMENTS CONDUCTED IN THE FIELD

Sample date: 10/10/91

$13.05 \mathrm{Ht}(3.98 \mathrm{~m})$ below TOC

Water elevation: $225.95 \mathrm{ht}(68 \mathrm{~g}$

Water evacuated belore sampling: $50 \mathrm{gal}$

LABORATOAY A: :ULYYSES

E Analyte Resull Mod Unit Lab

$0 \mathrm{pH}$

Specific conductance

Aluminum

Antimony

Arsenic

Barium

Bromodichloromethane

Bromoform

Bromomethane

Cadmium

Caibon tetrachloride

Chloride

Chlorobenzene

Chloroethane

2.Chloroethyl vinyl ether

2.Chloroethy

Chioroform

Chiorometh

Cobalt

Cobalt

Copper

Dibromochloromethane

1,1.Dichloroethane

1,2. Dichloroethane

1,1 -Dichloroethylene
trans-1,2-Dichloroethylene

Dichloromethane

2,4-Dichlorophenoxyacetic acid

1,2-Dichloropropane

un 1,3 ichlopropene

Endrin

Ethylbenzerie

Fluoride

Lead

Lindane

Magnesium

Mercury

Methoxychior

Nickel

Nitrate as nitrogen

Phenols

Potassium
Selenium:

Silica

Silver

0 Sodium

Sulfate

1,1,2,2-Tetrachloroethane

Tetrachlor

Total dissolved solids

Total organic carbon

Total organic halogens

Total phosp

2,4,5-TP(Silvex)

1,1,1-Trichloroethan

1,1,2-Trichloroethane

irichloroethylene

Trichlorofluoromethane

Uranium

Vranium

Zinc

Zinc alpha

Nonvolatile beta

Total radium

2 Tritium
Result

$\begin{aligned} & 5.1 \\ & 40 \\ & 22 \\ &<2.0 \\ &<2.0 \\ & 5.5 \\ &<1.0 \\ &<1.0 \\ &<1.0 \\ &<1.0 \\ &<2.0 \\ & 800 \\ &<1.0 \\ & 41.120 \\ &<1.0 \\ &<1.0 \\ &<1.0 \\ &<1.0 \\ &<1.0 \\ &<1.0 \\ &<4.0 \\ &<4.0 \\ &<4.0 \\ &<5.0 \\ &<1.0 \\ &<1.0 \\ &<1.0 \\ &<1.0 \\ &<1.0 \\ & 9.0 \\ &<0.30 \\ &<1.0 \\ &<1.0 \\ &<1.0 \\ &<1.0\end{aligned}$

9.0
$<0.30$

$<0.0060$

$<1.0$

$<100$

$<3.0$

$<0.0050$

14

$<0.20$
$<0.50$

$<4.0$

$\begin{aligned} & 1.150 \\ <5.0 & \end{aligned}$

$<500$

$<2.0$
7.030

$<2.0$

1,380

$<10$

$<1.0$

31,000

$<5.000$

$<50$

$<0.24$
$<0090$

$<10$

$<10$

$<10$

$<1.0$

$<<<20$

$<80$

$<2.0 \mathrm{E} .09$

$2.0 E \cdot 09$
$2.5 \mathrm{E}-09 \pm 1.1 \mathrm{E}-09$

$<1.0 E .09$.
Ime: 10:50

Alkalinity: $1 \mathrm{mg} / \mathrm{L}$ ater temperature : $20.3^{\circ} \mathrm{C}$

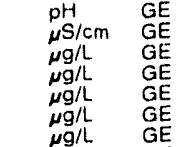

JaV

$\mu \mathrm{Ci} / \mathrm{mL}$
$\mu \mathrm{Ci} / \mathrm{mL}$
$\mu \mathrm{C} i / \mathrm{mL}$


ANALYTICAL RESULTS

WELL HSB150D Replicate

MEASUREMENTS CONDUCTED IN THE FIELD

Sample date: 10/10/91

Depth to water: $13.05 \mathrm{tt}(3.98 \mathrm{~m})$ below TOC

Water elevation: $225.95 \mathrm{ft}$ (68.

Water evacuated before sampling: $50 \mathrm{ga}$

LABORATORY ANALYSES

E Analyte Result Mod Unit Lab

${ }_{0}^{0} \mathrm{pH}$ Specific conductence

Aluminum

Antimony

Barium

Bromodichloromethane

Bromolorm

Bromomethari:

Cadmium

Calcium

Carbon te

Chloride

Chlorobenzene

Chloroethene Ninyl chloride

2-Chloroethyl vinyl ether

Chioromethane

Chromium

Eopper

Cyanide

Dibromochloromethane

1, Dichloroethana

1,1 -Dichtoroethylene

trans-1,2-Dichloioethylene

24-Dichlorophenoxyacetic acid

i, 2-Dichloropropano

cis-1,3-Dichloropropene

trans-1,3-Dichloropropene

Endrin

Ethylbenzen

Iron

Lead

Magnesium

Manganese

Mercury

Nickel

Nitrate as nitrogen

Nitrate as nitrogen

Potassium

Sulenium

Silica

Sodium

Sulfate

1,1,2,2-Tetrachloroethane

Tetrachioroethylene

Toluene

Total dissolved solids

Tola organic carbon

Total phosphates (as P)

Toxaphene

$2,4,5-$ TP (Silvex)
$1,1,1$-Trichloroethane

i, 1,2 -Trichloroethan

Trichloroethylene

Trichlorofluoromethane

Uranium

Vanadium

Zine

Gross alpha

Nonvolatile beta

Total radium
Time: $10: 50$

Alkalinity: $1 \mathrm{mg} / \mathrm{L}$

Water temperature: $20.3^{\circ} \mathrm{C}$

Jo

$\begin{array}{ll}\mathrm{pH} & \mathrm{GE} \\ \mu \mathrm{S} / \mathrm{cm} & \mathrm{GE}\end{array}$

5.2
40
$<20$

$<20$
$<2.0$
$<2.0$

5.5
$<1.0$

$<1.0$

$<1.0$

811
$<1.0$

4,060
4,140

$<1.0$

$<1.0$

$<10$

$<1.0$

$<4.0$

$<4.0$

$<4.0$
$<5.0$

$<1.0$

$<1.0$

$<1.0$
$<1.0$

$<1.0$
6.0

$<0.30$
$<1.0$

$<1.0$

$<0.0060$

$<1.0$

$<100$
117

$<3.0$
$<0.005$

$<0.0050$
567

$\begin{aligned} & 567 \\ & 14 \\ &< 0.20\end{aligned}$

$<0.50$

$<4.0$

1,060

$<5.0$

$<500$

$<2.0$
7.010

$<2.0$

1,070

$<1.0$

$<1.0$

$<1,000$

$<5.0$

50
$<0.24$

$<0.090$

$<1.0$

$<1.0$

$<10$

$<20$

$<20$

$<8.0$

$<2.0 E \cdot 09$
$3.0 E \cdot 09 \pm 1.1 E \cdot 09$

$<1.0 E-09$

$1.6 \mathrm{E} \cdot 04 \pm 9.0 \mathrm{E} \cdot 07$

$\begin{array}{ll}\mu \mathrm{Ci} / \mathrm{mL} & \mathrm{GE} \\ \mu \mathrm{Ci} / \mathrm{mL} & \mathrm{GE}\end{array}$
WELL HSB151C

MEASUREMENTS CONDUCTED IN THE FIELD

Sample date: 10/08/91

Depth to water: $5.59 \mathrm{ft}(1.70 \mathrm{~m})$ below TOC

Water elevation: $208.01 \mathrm{ft}$

Sp. conductance: $86 \mu \mathrm{S} / \mathrm{cm}$
Watet evacuated before sampling: $98 \mathrm{gal}$

LABORATORY ANALYSES

$E$ Analyte

Time: 13:30

PH: 4.8 : 0 malinity: $0 \mathrm{mg}$

Water temperature: $16.2^{\circ} \mathrm{C}$

$\mathrm{pH}$

Specific conductance

Antimony

0 Arsenic

0 Barium

Bromodichloromethane

0 Bromoform

Bromomethane

Cadmium

Carbon tetrachioride

Chloride

Chlobenzen

Chloroethene (Vinyl chloride)

2-Chloroethyl vinyl ether

Chlorolorm

o Chloromethane

$0_{0}$ Cobromium

Copper

O Cyanide

Cyanide

Dibromochloromethane

1,1-Dichloroethane

1,2-Dichloroethane

1,1-Dichloroethylene
trans-1,2-Dichioroethylene

Dichlor

2,4-Dichlothane

1. Dichloropropane

1,2.Dichloropropane

trans.1,3-Dichloropropen

Endrin

$\begin{array}{ll}0 & \text { Fluoride } \\ 0 & \text { Iron }\end{array}$

0 lean

0 Lindane

Magnesium

Mercury

Nickel

Nickel

Nitrate as nit

Potassium

Selenium

Silica

Silver

Sodium

1,1,2,2-Tetrachloroethane

Tetrachloroethylene

Toluene

Total dissolved solids

Total organic carbon

Total organic carbor

Total organic halogens

Total phosphates (as P)

Total phosphat

2,4,5.TP (Silvex)

1,1,1-Trichloroethane

Ti, 1, Trichloroeth

Trichlorofluoromethan

0 Uranium

Uranium

Z Zine

Zinc

Nonvolatile bet

Total activity

2 Total radium
Result Mod Unit Lab

$<1.0$

$<1.0$
$<100$

$<100$

6.2
$<3.0$

$<0.0050$

1,370

$<0.20$

$<0.50$
$<4.0$
7.500

$<.0$
578

$<2.0$

$<.0$
9.520

1,480

$<1.0$
$<1.0$

$<1.0$

52,000
$<1,000$

$<1,000$
$<1,000$

$<5.0$

$<5.0$

$<0.24$

$<1.0$

$<1.0$

20

$<20$

$<.0$
2.9

3. $6 \mathrm{E}-09 \pm 1.2 \mathrm{E} \cdot 09$

2. $3 \mathrm{E}-08 \pm 2.0 \mathrm{E}-09$

$2.0 E-03 \pm 3.3 E-05$

$1.4 E \cdot 09 \pm 1.2 E-129$
$2.2 E-03 \pm 3.4 E \cdot 6 G$

JO $\quad \mathrm{PH} \quad \mathrm{GE}$

$\mu \mathrm{g} / \mathrm{L}$ GE

$\begin{array}{ll}\mu g / L & G E \\ \mu g / L & G E \\ \mu g / L & G E\end{array}$

$\mu g / L \quad G E$

$\mu / L \quad G E$

$g / L \quad G E$

g/L

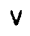

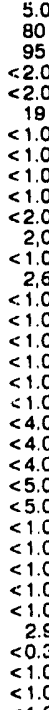


WELL HSB151D

MEASUREMENTS CONDUCTED IN THE FIELLD

Sample date: 10/08/91

Depth to water: $6.39 \mathrm{Ht}(1.85 \mathrm{~m})$ below TOC
Water elevation: $207.21 \mathrm{th}(83.16 \mathrm{~m}) \mathrm{ms}$

Sp. conductance: $25 \mu \mathrm{s} / \mathrm{cm}$

Water evacuated before sampling: $31 \mathrm{gal}$

LABORATORY ANALYSES

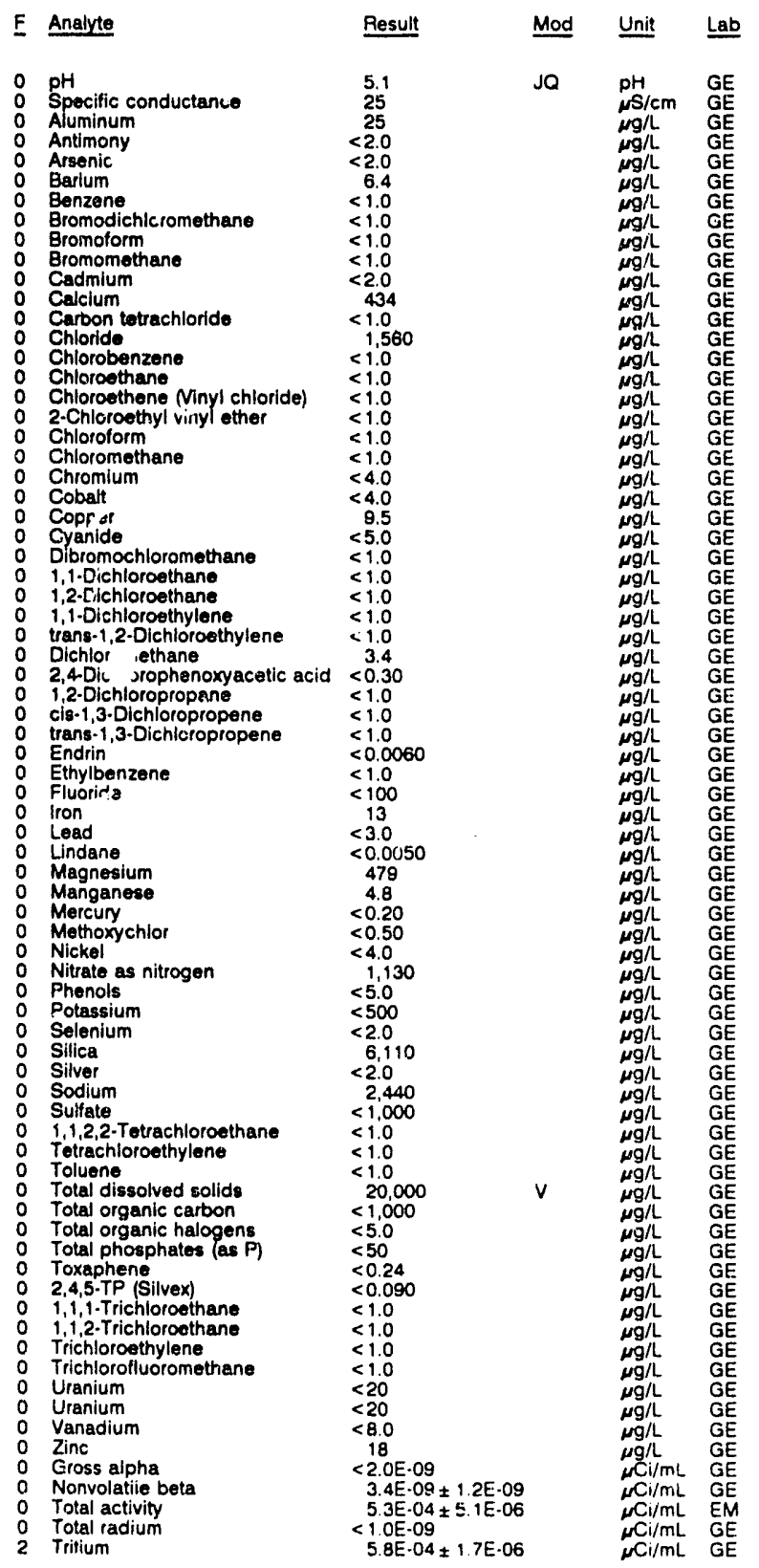

WELL HSB152C

MEASUREMENTS CONDUCTED IN THE FIELD

\begin{tabular}{|c|c|}
\hline $\begin{array}{l}\text { Sample date: } 10 / 08 / 81 \\
\text { Depth to water: } 15.06 \mathrm{th}(4.59 \mathrm{~m}) \text { below TOC } \\
\text { Water elevation: } 199.04 \mathrm{ft}(60.67 \mathrm{~m}) \mathrm{msl} \\
\text { Sp. conductance: } 85, \mu \mathrm{ss} / \mathrm{cm}\end{array}$ & $\begin{array}{l}\text { Time: } 12: 30 \\
\text { pH: } 5.1 \text { A } \\
\text { Akatinity: } 0 \mathrm{mg} / \mathrm{L} \\
\text { Water temperature: } 16.7^{\circ} \mathrm{C}\end{array}$ \\
\hline
\end{tabular}

LABORATORY ANALYSES

E Analyte Result Mod Unit Lab

Specific conductance

o Antimony

Arsenic

0 Barium

Benzene
Bromodichloromethane

0 Bromolorm

Bromomethane

Cadmium

o Carbon tetrachloride

Chloride

Chlorobenzene

Chloroethene (Vinyl chloride)

2.Chloroethyl vinyl ether

Chloroform

o Chloromethane

C Chromium

0 Cobalt

Copper

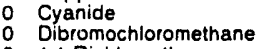

1,1-Dichloroethane

$\begin{array}{ll}0 & 1,2 \cdot \text { Dichloroethane } \\ 0 & 1,1 \cdot D i c h l o r o e t h y l e n e\end{array}$

1, Dichloroethylene
trans-1,2-Dichloroethylene

Dichloromethane

2,4-Dichlorophenoxyacetic acid

1,2-Dichlorop' spane

cis-1,3.Dichlornpropene

Endrin

0 Ethylbenzene

0 Fluoride

o lion

L Lead

Magnesium

Manganeso

Mercury

Methoxychlor

Nicke

Nitrate as nitrogen

Nitrate as
Phenols

Phenols

Potassium

Silivar

Sodium

Sulfate

$1,1,2,2$-Tetrachloroethane

Tetrachlorcethylene

Toluene

Total dissolved solids

Total organic carbon

Total organic halogens
Total phosphates (as P)

Toxaphene

2.4,5.TP (Silvex)

1.1,1-Trichloroethane

Trichloroethylene

Trichloroft'uoromethane

O Uranium

- Uranium

O Vanadium

0 Zinc

0
1 Gross alpha
1 Nonvolatile beta

O Total activity

$\begin{array}{ll}0 & \text { Total radium } \\ 2 & \text { Tritium }\end{array}$

Jo

5.4
80
$6 \%$
$<2.0$
$<2.0$

$<2.0$

28
$<1.0$
$<1.0$

$<1.0$

$<1.0$
$<2.0$

$<, 060$
4,060

$<1.000$

$<1.0$

$<1.0$

$<1.0$

$<1.0$

$<1.0$
$<4.0$

$<4.0$

$<4.0$
$<5.0$

$<1.0$

$<1.0$

$<1.0$
$<1.0$

$<1.0$
$<1.0$

$<0.30$

$<1.0$
$<1.0$

$<1.0$

$<<<0.0060$

$<1.0$

8.8
$<3.0$

$<3.0$
$<0.0050$

2,260
40

40
$<0.20$

$<0.50$
$<4.0$
6.000
6.500

6.500

$<<5$

721
$<20$

$<2.0$

$<2.0$
$<570$

6.570

$<1,000$

$<1.0$
$<1.0$
$<1.0$

$<1.0$

$<1,000$

$<5.0$

$<50$

$<<<24$

$<1.0$

$<10$

$<100$

$<1.0$

$<20$

$<80$

4.9E-09 $41.4 \mathrm{E}-09$

$4.9 E \cdot 09 \pm 1.4 E-09$
$4.1 \mathrm{E} .08 \pm 2.6 \mathrm{E}-09$
$11 \mathrm{E} .03 \pm 25 \mathrm{E} \cdot 05$

1 1 $1 \mathrm{E} \cdot 03$
$<1 \mathrm{OE}-09$

$<\begin{aligned} & <\mathrm{E} \cdot 09 \\ & 1 \mathrm{E} .03 \pm 24 \mathrm{E} \cdot 06\end{aligned}$ 
ANALYTICAL RESULTS

WELL HSB152D

MEASUREMENTS CONDUCTED IN THE FIELD

Sample date: 10/08/91

Depth to water: Not available

Sp conductance: $45 \mathrm{~s} / \mathrm{cm}$

Water evacuated before sampling: 3 gal

The well went dry during purging.

LABORATORY ANALYSES

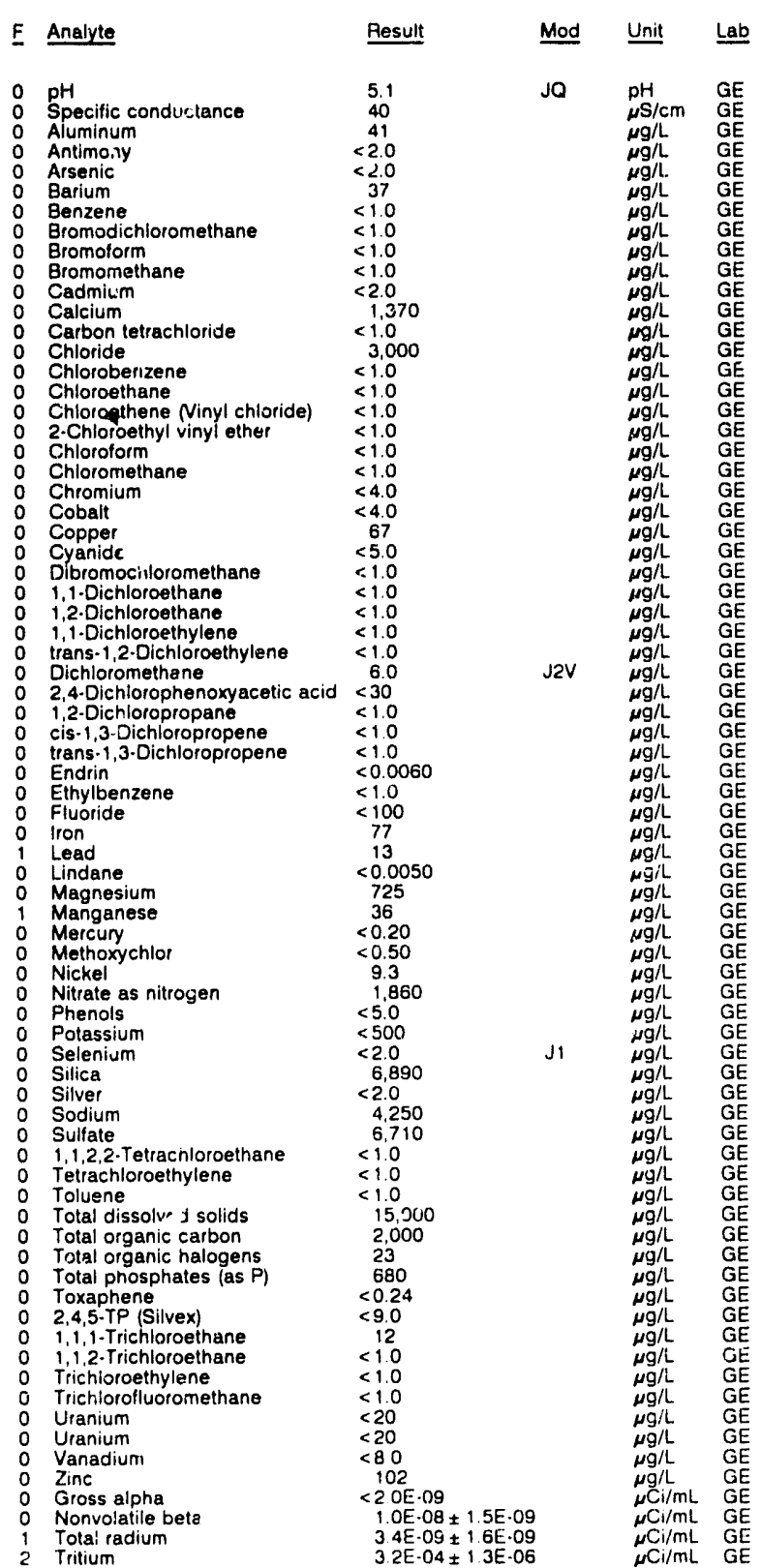

WELL HSS 1D

MEASUREMENTS CONDUCTED IN THE FIELD

Depth to water: $38.98 \mathrm{Ht}(11.88 \mathrm{~m})$ below TOC

Water elevation: $271.12 \mathrm{H}(82.64 \mathrm{~m}) \mathrm{ms}$

Water evacuated before sampling: $27 \mathrm{gal}$

The well went dry during purging.

LABORATORY ANALYSES

\begin{tabular}{|c|c|c|c|}
\hline Analyte & Result & Mod & Unit \\
\hline $\begin{array}{l}\text { pH } \\
\text { Specific conductance } \\
\text { Chloride } \\
\text { Chloride } \\
\text { Nittrate as nitrogen } \\
\text { Nitrate as nitrogen } \\
\text { Nitrite as nitrogen } \\
\text { Nitrite as nitrogen } \\
\text { Sodium } \\
\text { Total dissolved solids } \\
\text { Total dissolved solids }\end{array}$ & $\begin{array}{l}5.7 \\
25 \\
1.810 \\
1,820 \\
960 \\
980 \\
<10 \\
<10 \\
1,660 \\
21,000 \\
22,000\end{array}$ & JQ & $\begin{array}{l}\mathrm{pH} \\
\mu \mathrm{S} / \mathrm{cm} \\
\mu g / L \\
\mu g / L \\
\mu g / L \\
\mu g / L \\
\mu g / L \\
\mu g / L \\
\mu g / L \\
\mu g / L \\
\mu g / L\end{array}$ \\
\hline
\end{tabular}

WELL HSS 2D

MEASUREMENTS CONDUCTED IN THE FIELO

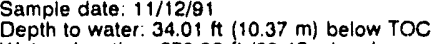

Water elevation: $270.39 \mathrm{H}(82.42 \mathrm{~m}) \mathrm{ms}$

mpling: $94 \mathrm{gal}$

LABORATORY ANALYSES

F Analyte

Result
5.6
30
2,300
1,070
$<10$
1,780
34,000

Time: $10: 55$

Alkalinity: $1 \mathrm{mg} / \mathrm{L}$

Water temperature: $17.5^{\circ} \mathrm{C}$

Mod Unit Lab

$\begin{array}{ll}0 & \mathrm{pH} \\ 0 & \text { Specific conductance }\end{array}$

0 Chloride

Nitrate as nitrogen

0 Sodium

(this

34,000

WELL HSS 2D Replicate

MEASUREMENTS CONDUCTED IN THE FIEID

Sample date: $11 / 12 / 91$ (

Water elevation: $270.39 \mathrm{H}(82.42 \mathrm{~m}) \mathrm{ms}$ )

mpling: $94 \mathrm{gal}$

LABORATORY ANALYSES
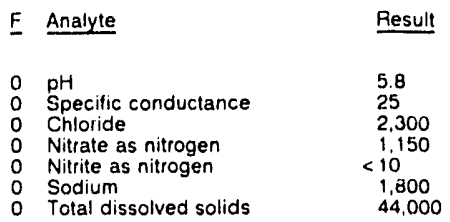

Time: $10: 55$

Alkalinity: $1 \mathrm{mg} / \mathrm{L}$

Water temperature: $17.5^{\circ} \mathrm{C}$

WELL HSS 3D

MEASUREME:: TS CONDUCTED IN THE FIELO

Depth to water: $25.74 \mathrm{ft}(7.85 \mathrm{~m})$ below TOC

Water elevation $28406 \mathrm{~h}(8658 \mathrm{~m}) \mathrm{ms}$

Sp. conductance: $25 \mu \mathrm{S} / \mathrm{cm}$
Water evacuated before sampling. $56 \mathrm{ga}$

LABORATORY ANALYSES

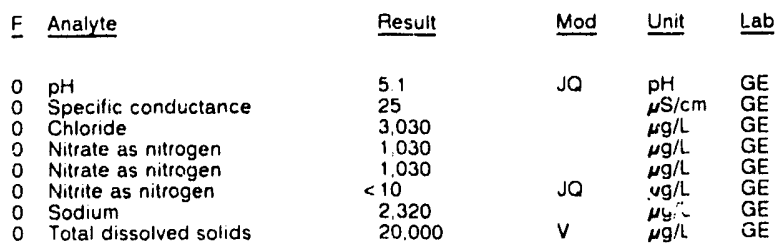

\begin{tabular}{|c|c|c|}
\hline $\begin{array}{l}\text { Time: } 14: 50 \\
\text { pH: } 4.8 \\
\text { Alkalinity: } 0 \\
\text { Water tempe }\end{array}$ & UL 20 & \\
\hline Mod & Unit & Lab \\
\hline JQ & $\begin{array}{l}\mathrm{pH} \\
\mu \mathrm{S} / \mathrm{cm} \\
\mu \mathrm{g} / \mathrm{L} \\
\mu \mathrm{g} / \mathrm{L} \\
\mu \mathrm{g} / \mathrm{L}\end{array}$ & $\begin{array}{l}\mathrm{GE} \\
\mathrm{GE} \\
\mathrm{GE} \\
\mathrm{GE} \\
\mathrm{GE}\end{array}$ \\
\hline & $\begin{array}{l}v g / L \\
\mu g:\end{array}$ & $\begin{array}{l}\mathrm{GE} \\
\mathrm{GE} \\
\mathrm{GE}\end{array}$ \\
\hline
\end{tabular}




\section{ANALYTICAL RESULTS}

\section{WELL HTF 1}

MEASUREMENTS CONOUSTED IN THE FIELD

Sample date: $10 / 11 / 01$

Depth to water: $6.00 \mathrm{ft}(1.83 \mathrm{~m})$ below TOC

Water elevation: $276.00 \mathrm{Ht}(84.13 \mathrm{~m}) \mathrm{ms}$

No water was ovacuated before sampling

\section{WELL HTF 2}

MEASUREMENTS CONDUCTED IN THE FIELD

Sample date: 10/14/81

Depth to water: $5.00 \mathrm{H}(1.52 \mathrm{~m})$ below TOC

Water elevation: $276.80 \mathrm{ft}(84.37 \mathrm{~m}) \mathrm{mst}$

Sp. conductance: $134 \mu \mathrm{s} / \mathrm{cm}$
No water was ovacuated before sampling.

\section{WELL HTF 3}

MEASUREMENTS CONDUCTED IN THE FIELD

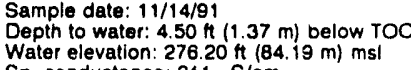

Sp. conductance : $211 \mu \mathrm{S} / \mathrm{cm}$

No water was evacuated before sampling.

\section{WELL HTF 4}

MEASUREMENTS CONDUCTED IN THE FIELD

Sample date: $11 / 14 / 91$

Depth to water: $6.20 \mathrm{ft}(1.89 \mathrm{~m})$ below TOC

Water eievation: $276.70 \mathrm{H}(84.34 \mathrm{~m}) \mathrm{msl}$

Sp. conductance: $135 \mu \mathrm{S} / \mathrm{cm}$

No water was evacuated before sampling

\section{Time: $9: 40$}

$\mathrm{pH}: 6.5$

Water temperature: $23.3^{\circ} \mathrm{C}$

WELL. HTF 5

MEASUREMENTS CONDUCTED IN THE FIELD

Sample date: $11 / 14 / 91$

Inaccessibility or pump failure prevented sample collection

WELLL HTF 6

MEASUREMENTS CONOUCTED IN THE FIELD

Sample date: $10 / 14 / 9$

Inaccessibility or pump failure prevented sample collection

\section{Time: $14: 10$}

Water temperature: $29.1^{\circ} \mathrm{C}$

Water temperature. $30.4^{\circ} \mathrm{C}$

WELL HTF 7

MEASUREMENTS CONDUCTED IN THE FIELO

Sample date: $10 / 14 / 9$

Depth to water: $27.50 \mathrm{ft}(8.38 \mathrm{~m})$ below TOC

Water elevation: $277.80 \mathrm{ft}(84.67 \mathrm{~m}) \mathrm{msl}$

Sp. conductance: $1036 \mu \mathrm{S} / \mathrm{cm}$

Time: $14: 30$

Water temperature: $31.8^{\circ} \mathrm{C}$

LABORATORY ANALYSES

F Analyte

$0 \mathrm{pH}$

Barium

2 Lead

Mercury

Nitrate as nitrogen

Silver

Sodium

Antimony-125

Cerium-144

Cesium 134

Cesium.137
Time: $10: 50$
$\mathrm{pH}: 6.4$

Water temperature $: 24.7^{\circ} \mathrm{C}$

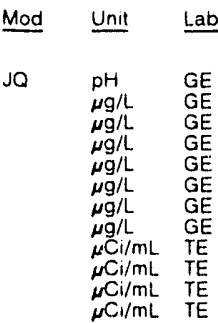

WELL HTF 7 collected on 10/14/91, laboratory analyses (cont.)

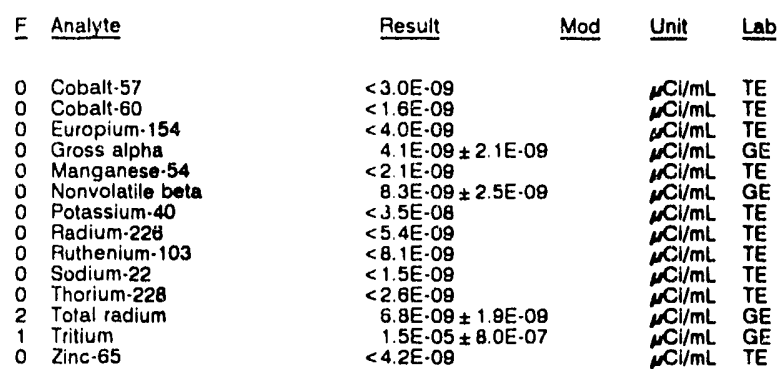

\section{WELL HTF 8}

MEASUREMENTS CONDUCTED IN THE FIELD

Sample date: 10/14/91 Time: Not available

Inaccessibility or pump failure preventeo sample collection.

\section{WELL HTF 9}

MEASUREMENTS CONDUCTED IN THE FIELD

\begin{tabular}{|c|c|}
\hline $\begin{array}{l}\text { Sample date: } 10 / 11 / 91 \\
\text { Depth to water: } 47.50 \mathrm{Ht}(14.48 \mathrm{~m}) \text { below TOC } \\
\text { Water elevation: } 276.50 \mathrm{f}(84.29 \mathrm{~m}) \mathrm{ms} \text { l }\end{array}$ & $\begin{array}{l}\text { Time: } 10: 20 \\
\mathrm{pH}: 7.1 \\
\text { Water temperature } 25.40 \mathrm{C}\end{array}$ \\
\hline
\end{tabular}

No water was evacuated before sampling. Water temperature: $25.4^{\circ} \mathrm{C}$

\section{WELL HTF 10}

MEASUREMENTS CONDUCTED IN THE FIELD

Sample date: 10/11/91

Depth to water: $47.20 \mathrm{Ht}(14.39 \mathrm{~m})$ below TOC Time: $10: 10$

Water elevation: $275.50 \mathrm{ft}(83.97 \mathrm{~m}) \mathrm{ms}$

p. conductance: $167 \mu \mathrm{S} / \mathrm{cm}$

Water temperature: $23.5^{\circ} \mathrm{C}$

\section{WELL HTF 11}

MEASUREMENTS CONDUCTED IN THE FIELD

Sample date: 10/11/91

Time: 10:00

Water e waler. $46.80 \mathrm{H}(14.26 \mathrm{~m})$ below TOC

Sp. conductance: $98 \mathrm{\mu S} / \mathrm{cm}$

pH: 7.0

Water temperature: $23.7^{\circ} \mathrm{C}$

\section{WELL HTF 12}

MEASUREMENTS CONDUCTED IN THE FIELD

Sample date: $10 / 11 / 91$

Depth to water: $47.40 \mathrm{ft}(14.45 \mathrm{~m})$ below TOC

Water elevation: $275.50 \mathrm{H}(83.97 \mathrm{~m}) \mathrm{ms}$

Sp. conductance: $35 \mu \mathrm{S} / \mathrm{cm}$

Time: $11: 30$
$\mathrm{pH}: 7.8$

No waler was evacuated before sampling

Water temperature: $30.6^{\circ} \mathrm{C}$

\section{WELL HTF 13}

MEASUREMENTS CONDUCTEO IN THE FIELO

Sample date: 10/11/91

Depth to water: $47.50 \mathrm{ft}(14.48 \mathrm{~m})$ below TOC

Water elevation: $276.90 \mathrm{ft}(84.40 \mathrm{~m}) \mathrm{ms}$

Sp. conduclance. $228 \mu \mathrm{S} / \mathrm{cm}$

Water temperature: $26.8^{\circ} \mathrm{C}$ 


\section{ANALYTICAL RESULTS}

WELL HTF 15

MEASUREMENTS CONDUCTED IN THE FIELD

Sample date: $10 / 11 / 91$

Depth to water: $46.80 \mathrm{H}(14.26 \mathrm{~m})$ below TOC

源

$\mu \mathrm{S} / \mathrm{cm}$

WELL HTF 16

MEASUREMENTS CONOUCTED IN THE FIELD

Sample date: 10/15/81

Depth to water: $27.80 \mathrm{ft}(8.47 \mathrm{~m})$ below TOC

Water elevation: $27.2 .50 \mathrm{ft}(83.06 \mathrm{~m}) \mathrm{ms}$

Sp. conductance: $52 \mu \mathrm{S} / \mathrm{cm}$
No water was evacuated before sampling.

P.: 7.1

Time: $10: 40$

$\mathrm{pH}: 6$.

Water temperature: $28.4^{\circ} \mathrm{C}$

\section{WELL HTF 17}

MEASUREMENTS CONDUCTED IN THE FIELD

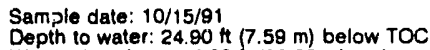

Water elevation: $265.30 \mathrm{~h}(80.86 \mathrm{~m}) \mathrm{ms}$

Sp. conductance: $44 \mu \mathrm{S} / \mathrm{cm}$

No water was evacuated before sampling.

\section{V:ELL HTF 18}

MEASUREMENTS CONDUCTED IN THE FIELD

Sample date: 10/11/91

Depth to water: $49.20 \mathrm{ft}(15.00 \mathrm{~m})$ below TOC

Wator elevation: $274.50 \mathrm{ft}(83.67 \mathrm{~m}) \mathrm{ms}$.

Sp. conductance: $59 \mu \mathrm{s} / \mathrm{cm}$

No water was evacuated before sampling.

\section{WELL HTF 19}

MEASUREMENTS CONDUCTED IN THE FIELO

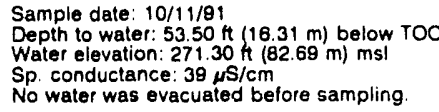

WELL HTF 20

MEASUREMENTS CONDUCTED IN THE FIELD

Sample date: $10 / 11 / 91$

Depth to water: $55.00 \mathrm{Ht}(16.76 \mathrm{~m})$ below TOC

Water elevation: $268.90 \mathrm{Ht}(82.27 \mathrm{~m}) \mathrm{msl}$

No water was evacuated before sampling.

\section{WELL HTF 21}

MEASUREMENTS CONDUCTED IN THE FIELD

Sample date: $10 / 11 / 91$

Depth to water: $53.20 \mathrm{H}(16.22 \mathrm{~m})$ below TOC

Water elevation: $271.50 \mathrm{Ht}(82.75 \mathrm{~m}) \mathrm{ms}$

Sp. conductance: $48 \mu \mathrm{S} / \mathrm{cm}$

No water was evacuated before sampling

Time: $9: 55$
pH: 6.5
Water temperature: $22.5^{\circ} \mathrm{C}$

\section{Time: $10: 50$ \\ Water temperature: $23.5^{\circ} \mathrm{C}$}

pH: 7.2

Water temperature: $23.0^{\circ} \mathrm{C}$

Time: $11: 10$
pH: 6.5

Water temperature: $27.5^{\circ} \mathrm{C}$

Time: 1120
pH: 6.5

Water temperature: $25.5^{\circ} \mathrm{C}$

WELL HTF 22

MEASUREMENTS CONDUCTED IN THE FIELD

Sample date: 10/11/91

Depth to water: $54.80 \mathrm{H}(16.70 \mathrm{~m})$ below TOC

Sp. conductance: 145 S $/ \mathrm{cm}$

Wo water was evacuated before sampling.

Time: 13:05

Water temperature: $25.8^{\circ} \mathrm{C}$

\section{WELL HTF 23}

MEASUREMENTS CONDUCTED IN THE FIELD

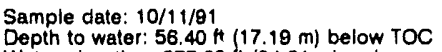

Water elevation: $277.60 \mathrm{ft}(84.61 \mathrm{~m}) \mathrm{ms}$ l

Sp. conductance: $136 \mu \mathrm{S} / \mathrm{cm}$

No water was evacuated before sampling.

Time: 13:00

Water temperature: $25.8^{\circ} \mathrm{C}$

\section{WELL HTF 24}

MEASUREMENTS CONDUCTED IN THE FIELD

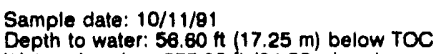

Water elevation: $277.30 \mathrm{~h}(84.52 \mathrm{~m}) \mathrm{ms}$

Sp. conductance: $47 \mu \mathrm{S} / \mathrm{cm}$
No water was evacuated before sampling.

Time: $12: 50$

Water temperature: $25.3^{\circ} \mathrm{C}$

\section{WELL HTF 25}

MEASUREMENTS CONDUCTED IN THE FIELD

Sample date: 10/11/91

Depth to water: $57.50 \mathrm{Ht}(17.53 \mathrm{~m})$ below TOC

Water elevation: $276.80 \mathrm{ft}(84.37 \mathrm{~m}) \mathrm{ms}$

Sp. conductance: $40 \mu \mathrm{S} / \mathrm{cm}$

No water was evacuated before sampling

Time: $12: 45$

Water temperature: $27.6^{\circ} \mathrm{C}$

\section{WELL HTF 26}

MEASUREMENTS CONOUCTED IN THE FIELD

Sample date: $10 / 14 / 91$
Depth to water: $59.60 \mathrm{ft}(18.17 \mathrm{~m})$ below TOC
Water elevation: $275.90 \mathrm{t}(84.10 \mathrm{~m}) \mathrm{msl}$
Sp. conductance: $53 \mathrm{sS} / \mathrm{cm}$

No water was evacuated before sampling

Time: $15: 10$

Water temperature: $26.2^{\circ} \mathrm{C}$

WELL HTF 27

MEASUREMENTS CONDUCTED IN THE FIELD

Sample date $10 / 11 / 91$

Depth to water: $54.80 \mathrm{Ht}(16.70 \mathrm{~m})$ below TOC

Water elevation: $278.30 \mathrm{ft}(84.83 \mathrm{~m}) \mathrm{ms}$

Sp. conductance: $111 \mu \mathrm{S} / \mathrm{cm}$

No water was evacuated before sampling.

$\mathrm{pH}: 5.7$

Water temperature: $26.2^{\circ} \mathrm{C}$

WELL HTF 28

MEASUREMENTS CONDUCTED IN THE FIELD

Sample date: 10/11/91

Depth to water: $55.60 \mathrm{H}(16.95 \mathrm{~m})$ below TOC

Water elevation: $278.10 \mathrm{ft}(84.77 \mathrm{~m}) \mathrm{ms}$

Sp. conductance: $33 \mu \mathrm{S} / \mathrm{cm}$

No water was evacuated before sampling
Time: $13: 20$

$\mathrm{pH}: 7.2$

Water temperature $24.0^{\circ} \mathrm{C}$ 


\section{ANALYTICAL RESULTS}

WELL HTF 29

MEASUREMENTS CONDUCTED IN THE FIELD

Sample date: $10 / 11 / 81$

Depth to water: $54.30 \mathrm{n}$ (16.55 m) below TOC

Water elevation: $279.20 \mathrm{ht}(85.10 \mathrm{~m}) \mathrm{msl}$

pH: 7.1

Water temperature: $24.6^{\circ} \mathrm{C}$

WㄷLL HTF 31

MEASUREMENTS CONDUCTED IN THE FIELD

Sample date: $10 / 11 / 91$

Depth to water: $54.80 \mathrm{H}(16.70 \mathrm{~m})$ below $10 \mathrm{C}$

Water elevation: $272.90 \mathrm{H}(83.18 \mathrm{~m}) \mathrm{ms}$

$\mathrm{Sp}$. conductance: $50 \mu \mathrm{S} / \mathrm{cm}$

No water was evacuated before sampling.

Time: $13: 30$

$\mathrm{pH}: 7.5$

Water temperature: $25.5^{\circ} \mathrm{C}$

WELL HTF 32

MEASUREMENTS CONDUCTED IN THE FIELD

Sample date: 10/11/91

Depth to water: $52.00 \mathrm{ft}(15.85 \mathrm{~m})$ below TOC

Water elevation: $277.10 \mathrm{ft}(84.46 \mathrm{~m}) \mathrm{ms}$

No water was evacuated before sampling

\section{Time: $12: 30$}

Water temperature: $26.0^{\circ} \mathrm{C}$

\section{WELL HTF 34}

MEASUREMENTS CONDUCTED IN THE FIELD

Sample date: 10/14/91

Inaccessibility or pump failure prevented cample collection

\section{WELL HWS $1 \mathrm{~A}$}

MEASUREMENTS CONDUCTED IN THE FIELD

Sample date: $11 / 27 / 91$

Depth to water: $79.96 \mathrm{ft}(24.37 \mathrm{~m})$ below TOC

Water elevation: $244.64 \mathrm{ft}(74.57 \mathrm{~m}) \mathrm{msl}$

Sp. conductance: $17 \mu \mathrm{S} / \mathrm{cm}$

Water evacuated before sampling: 22 ga

The well went dry during purging

ViVELL. HWS 2

MEASUREMENTS CONDUCTED IN THE FIELD

Sample date: $11 / 26 / 91$

Depth to water: $7899 \mathrm{H}(24.08 \mathrm{~m})$ below TCO

Water elevation: $244.21 \mathrm{ft}$

Water evacuated before sampling: $76 \mathrm{gal}$

\section{WELL HXB 1}

MEASUREMENTS CONDUCTED IN THE FIELO

Sample date $11 / 11 / 91$

Wepth to water: 5426 it $(16.54 \mathrm{~m})$ below TOC

Water elevation: $251.94 \mathrm{ft}$

Water evacuated before sampling: $99 \mathrm{gal}$

\section{Time: 6:05}

Alkalinity $0 \mathrm{mg} / \mathrm{L}$

Water temperature: $157^{\circ} \mathrm{C}$

$\mathrm{pH}: 4.8$

Alkalinity: $0 \mathrm{mg} / \mathrm{L}$
WELL HXB 2

MEASUREMENTS CONDUCTED IN THE FIELD

Sample date: $11 / 11 / 81$

Depth to water: $52.00 \mathrm{Ht}(15.85 \mathrm{~m})$ below TOC

$252.40 \mathrm{H}(76.93 \mathrm{~m}) \mathrm{msl}$

$\mathrm{pH}: 4.9$

Water temperature: $17.3^{\circ} \mathrm{C}$

\section{WELL HXB 3}

MEASUAEMENTS CONDUCTED IN THE FIELD

Sample date: $11 / 11 / 91$

water: $5206 \mathrm{tt}(15.87 \mathrm{~m})$ below TOC

Water elevation: $252.14 \mathrm{ft}(76.85 \mathrm{~m}) \mathrm{ms}$

Sp. conductance: 28 s $/ \mathrm{cm}$

sampling: $105 \mathrm{gal}$

Time: $6: 25$

Alkalinity: $3 \mathrm{mg} / \mathrm{L}$

Water temperature: $16.1{ }^{\circ} \mathrm{C}$

\section{WELL HXB 4D}

MEASUREMENTS CONDUCTED IN THE FIELD

Water evacuated before sampling:
The well went dry during purging

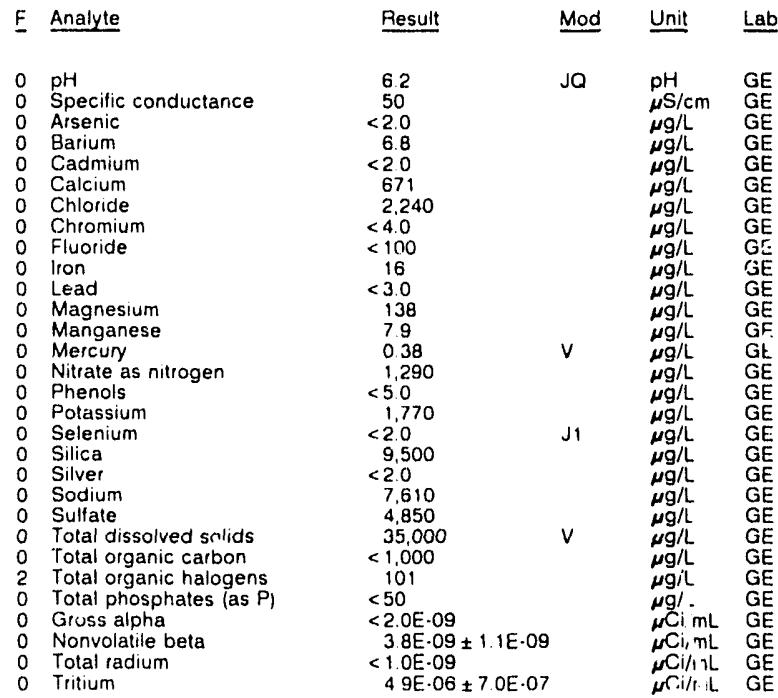

Sample date: 11/12/91

Depth to water: $54.46 \mathrm{Ht}(16.60 \mathrm{~m})$ below TOC

Water elevation: $252.54 \mathrm{ht} .76 .98 \mathrm{~m}) \mathrm{msl}$

Sp. conductance: $57 \mu \mathrm{S} / \mathrm{cm}$

mpling: $15 \mathrm{gal}$

LABORATORY ANALYSES

\section{WELL HXB 5D}

MEASUREMENTS CONDUCTED IN THE FIELD

Sample date: $11 / 12 / 91$

Depth to water: 56.27 it $(17.15 \mathrm{~m})$ below TOC

Water elevation: $25253 \mathrm{ft}(76.97 \mathrm{~m}) \mathrm{msl}$

Sp. conduclance. $46 \mu \mathrm{S} / \mathrm{cm}$

Water evacuated before sampling: $18 \mathrm{gal}$

The well went dry during purging

LABORATORY ANALYSES

$\begin{array}{ll}\text { F } & \text { Analyte } \\ & \\ 0 & \text { pH } \\ 0 & \text { Specific conductance } \\ 0 & \text { Arsenic } \\ 0 & \text { Barium } \\ 0 & \text { Cadmium } \\ 0 & \text { Calcium } \\ 0 & \text { Chloride } \\ 0 & \text { Chromium } \\ 0 & \text { Fluoricle } \\ 0 & \text { Fluoride } \\ 0 & \text { iron } \\ 0 & \text { Lead } \\ 0 & \text { Magnesium }\end{array}$

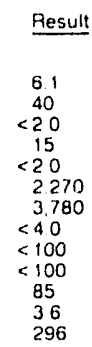

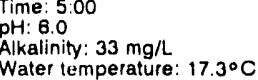

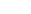


ANALYTICAL RESULTS

WELL HXB 5D collected on 11/12/91, laboratory analyses (cont.)

\begin{tabular}{|c|c|c|c|c|c|}
\hline$F$ & Analyte & Pesult & Mod & Unit & Lab \\
\hline $\begin{array}{l}1 \\
0 \\
0 \\
0 \\
0 \\
0\end{array}$ & $\begin{array}{l}\text { Manganese } \\
\text { Mercury } \\
\text { Nitrate as nitrogen } \\
\text { Phenols } \\
\text { Potassium } \\
\text { Selenium } \\
\text { Sillica } \\
\text { Silver } \\
\text { Sodlum } \\
\text { Sulfate } \\
\text { Sulfate } \\
\text { Total dissolved solids } \\
\text { Total organic carbon } \\
\text { Total organic carbon } \\
\text { Total organic halogens } \\
\text { Total phosphates (as P) } \\
\text { Gross alpha } \\
\text { Nonvolatile beta } \\
\text { Total radium } \\
\text { Tritium }\end{array}$ & $\begin{aligned} & 48 \\
& 0.35 \\
& 1,160 \\
&<5.0 \\
& 655 \\
&<2.0 \\
& 14,600 \\
&<2.0 \\
& 4,750 \\
& 1,600 \\
& 1,610 \\
& 32,000 \\
&<1.000 \\
&<1,000 \\
& 48 \\
&<50 \\
&<2.0 E \cdot 09 \\
&<2.0 E \cdot 09 \\
&<1.0 E \cdot 09 \\
& 1.8 E \cdot 04 \pm 2.2 E \cdot 06\end{aligned}$ & J1 & $\begin{array}{l}\mu g / L \\
\mu g / L \\
\mu g / L \\
\mu g / L \\
\mu g / L \\
\mu g / L \\
\mu g / L \\
\mu g / L \\
\mu g / L \\
\mu g / L \\
\mu g / L \\
\mu g / L \\
\mu g / L \\
\mu g / L \\
\mu g / L \\
\mu g / L \\
\mu C L / m L \\
\mu C i / m L \\
\omega C i / m L \\
\mu C i / m L\end{array}$ & $\begin{array}{l}\mathrm{GE} \\
\mathrm{GE} \\
\mathrm{GE} \\
\mathrm{GE} \\
\mathrm{GE} \\
\mathrm{GE} \\
\mathrm{GE} \\
\mathrm{GE} \\
\mathrm{GE} \\
\mathrm{GE} \\
\mathrm{GE} \\
\mathrm{GE} \\
\mathrm{GE} \\
\mathrm{GE} \\
\mathrm{GE} \\
\mathrm{GE} \\
\mathrm{GE} \\
\mathrm{GE} \\
\mathrm{GE} \\
\mathrm{GE}\end{array}$ \\
\hline
\end{tabular}

WELL IDB $1 A$

MEASUREMENTS CONDUCTED IN THE FIELD

Sample date: $12 / 04 / 91$

Depth to water: $106.63 \mathrm{ft}(32.50 \mathrm{~m})$ below TOC

Water elevation: $190.17 \mathrm{ft}(57.96 \mathrm{~m}) \mathrm{msl}$

Water evacuated before sampling: $21 \mathrm{gal}$

The well went dry during purging

LABORATORY ANALYSES

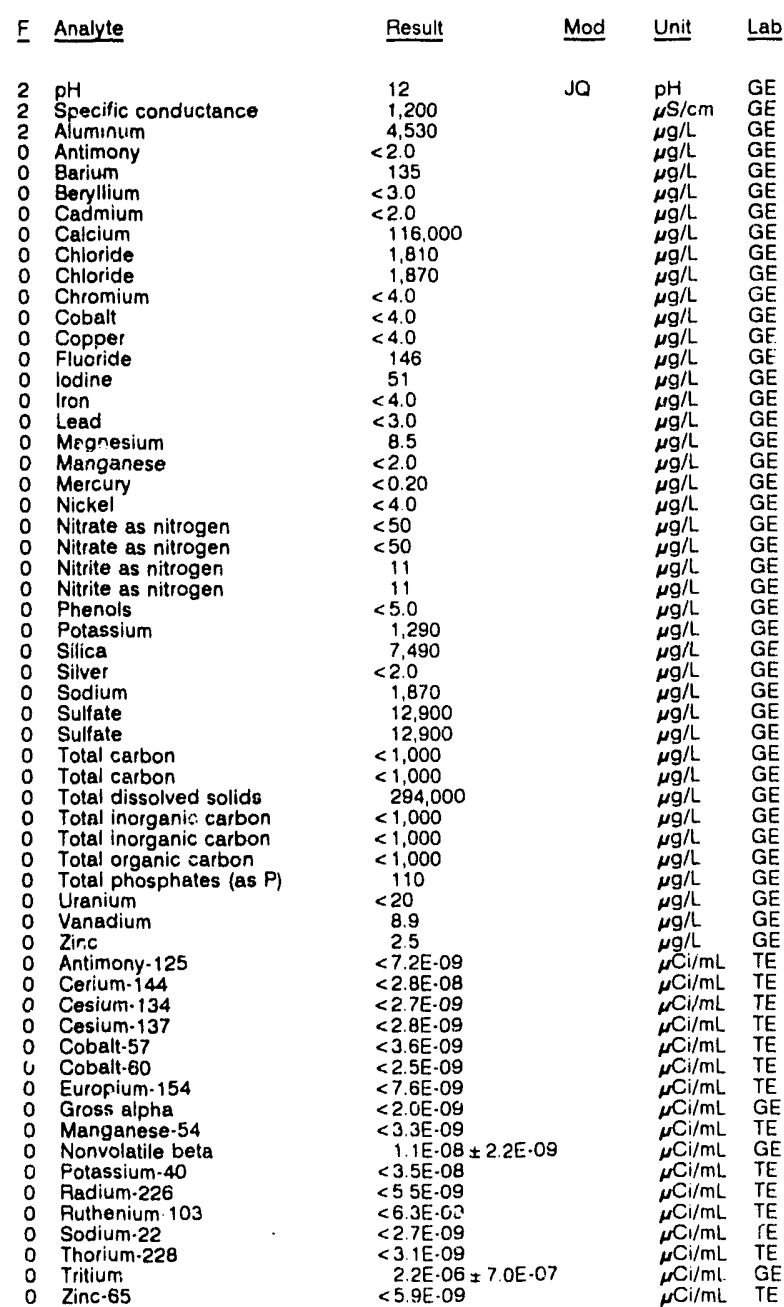

WELL IDB 1B

MEASUREMENTS CONDUCTED IN THE FIELD

$\begin{array}{ll}\text { Sample date: } 12 / 04 / 91 & \text { Time: } 15: 45 \\ \text { Depth to water: } 111.38 \mathrm{ft}(33.95 \mathrm{~m}) \text { below TOC } & \text { pH: } 9.8 \\ \text { Water elevation: } 185.92 \mathrm{ft}(56.67 \mathrm{~m}) \mathrm{ms} & \text { Alkalinity: } 42 \mathrm{mg} / \mathrm{h} \\ \text { Sp conductance: } 96 \mu \mathrm{cm} / \mathrm{cm} & \text { Water temperature: } 17.2^{\circ} \mathrm{C} \\ \text { Water evacuated before sampling: } 24 \mathrm{gal} & \\ \text { The well went dry during purging. } & \end{array}$

LABORATORY ANALYSES

\begin{tabular}{|c|c|c|c|}
\hline Analyte & Result & Mod & Unit \\
\hline 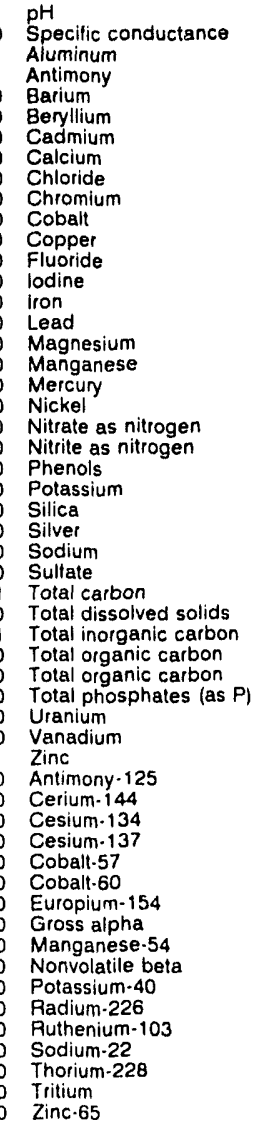 & $\begin{array}{l}9.7 \\
100 \\
110 \\
4.2 \\
41 . \\
<3.0 \\
<2.0 \\
10,500 \\
2,140 \\
<4.0 \\
<4.0 \\
<4.0 \\
<100 \\
57 \\
15 \\
<3.0 \\
201 \\
<2.0 \\
<0.20 \\
<4.0 \\
<50 \\
<10 \\
<5.0 \\
5,360 \\
31.000 \\
<2.0 \\
3.190 \\
7,290 \\
7.000 \\
66,000 \\
6.000 \\
<1.000 \\
<1,000 \\
320 \\
<20 \\
<8.0 \\
<2.0 \\
<5.3 \mathrm{E} \cdot 09 \\
<2.0 \mathrm{E} \cdot 08 \\
<2.2 \mathrm{E} \cdot 09 \\
<1.6 \mathrm{E} \cdot 09 \\
<2.6 \mathrm{E} \cdot 09 \\
<2.1 \mathrm{E} \cdot 09 \\
<5.4 \mathrm{E} \cdot 09 \\
2.5 \mathrm{E} \cdot 09 \pm 1.2 \mathrm{E} \cdot 09 \\
<2.3 \mathrm{E} \cdot 09 \\
1.3 \mathrm{E} \cdot 08 \pm 2.2 \mathrm{E} \cdot 09 \\
<3.4 \mathrm{E} \cdot 08 \\
<5.1 \mathrm{E} \cdot 09 \\
<4.8 \mathrm{E} \cdot 09 \\
<2.1 \mathrm{E} \cdot 09 \\
<1.9 \mathrm{E} \cdot 09 \\
1.1 \mathrm{E} \cdot 06 \pm 7.0 \mathrm{E} \cdot 07 \\
<5.4 \mathrm{E} \cdot 09 \\
\end{array}$ & 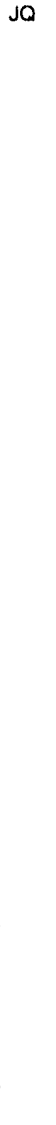 & 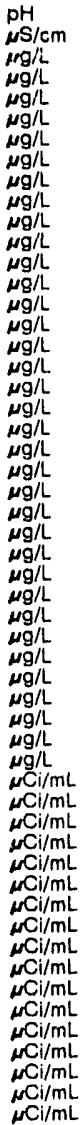 \\
\hline
\end{tabular}

WELL IDB $1 C$

MEASUREMENTS CONDU: $6 ?$ iN THE FIELD

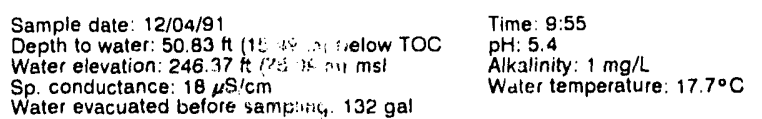

Water evacuated before sampitic, $132 \mathrm{gal}$

LABORATOAY ANALYSES

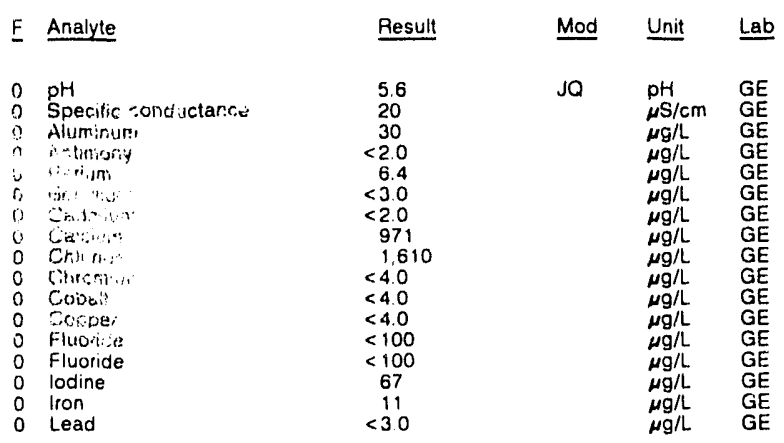


ANALYTICAL RESULTS

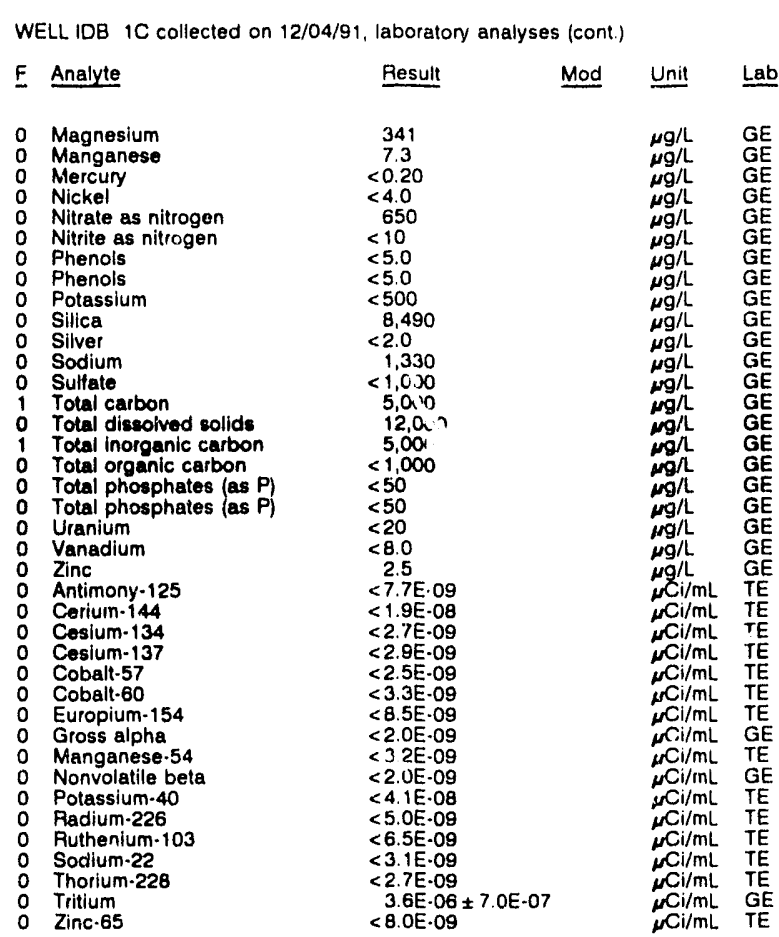

WELL IDB 2A

MEASUREMENTS CONDUCTED IN THE FIELD

Sample date: $12 / 04 / 91$

(14.04 ft $(34.76 \mathrm{~m})$ below TOC

Water elevation: $190.26 \mathrm{H}$ (57.

Water evacuated beforo sampling: $572 \mathrm{gal}$

LABORATORY ANALYSES
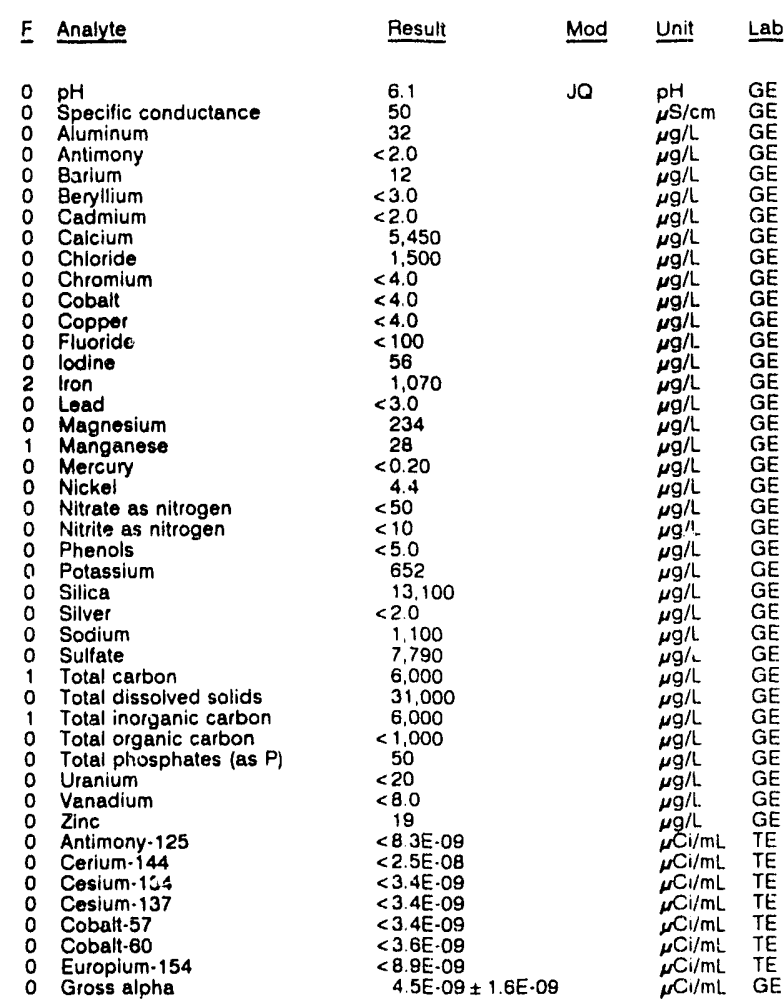

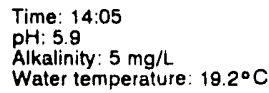

\section{Mod Unit Lab}

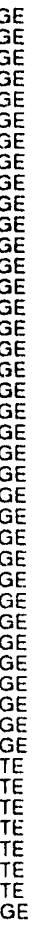

WELLL IDB $2 A$ collected on 12/04/91, laboratory analyses (cont.)

\begin{tabular}{|c|c|c|c|}
\hline Analyte & Result & Mod & Unit \\
\hline $\begin{array}{l}\text { Manganese-54 } \\
\text { Nonvolatile bota } \\
\text { Potassium-40 } \\
\text { Padium-226 } \\
\text { Pauthen-22-103 } \\
\text { Rathenium-103 } \\
\text { Sodium-22 } \\
\text { Thorium-228 } \\
\text { Tritium } \\
\text { Tinc-65 }\end{array}$ & $\begin{array}{l}<3.4 \mathrm{E}-09 \\
8.8 \mathrm{E}-09 \pm 2.0 \mathrm{E} \cdot 00 \\
<6.6 \mathrm{E} \cdot 08 \\
<7.5 \mathrm{E} \cdot 09 \\
<6.8 \mathrm{E} \cdot 09 \\
<3.2 \mathrm{E} \cdot 09 \\
<3.1 \mathrm{E} \cdot 09 \\
1.0 \mathrm{E} \cdot 00 \pm 6.0 \mathrm{E} \cdot 07 \\
<8.1 \mathrm{E} \cdot 09\end{array}$ & & 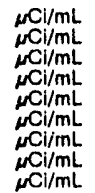 \\
\hline
\end{tabular}

WELL IDB 2B

MEASUREMENTS CONDUCTED IN THE FIELD

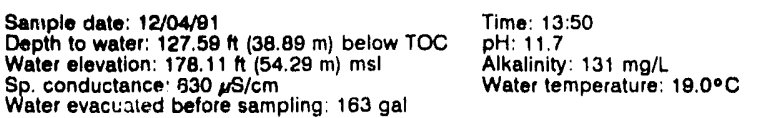

Water evacuated before sampling: $163 \mathrm{gal}$

LABORATORY ANALYSES

\begin{tabular}{|c|c|c|c|}
\hline Analyte & Result & Mod & Unit \\
\hline 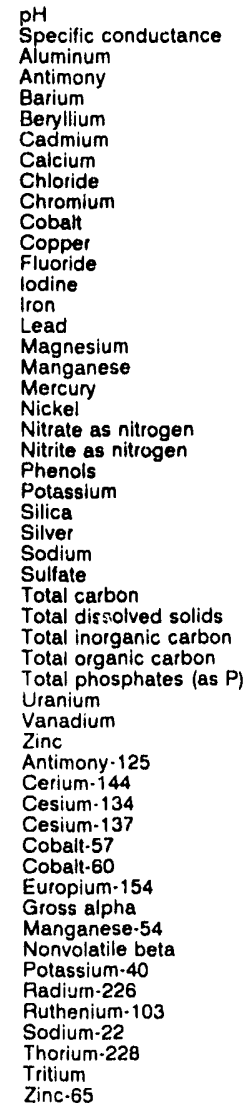 & 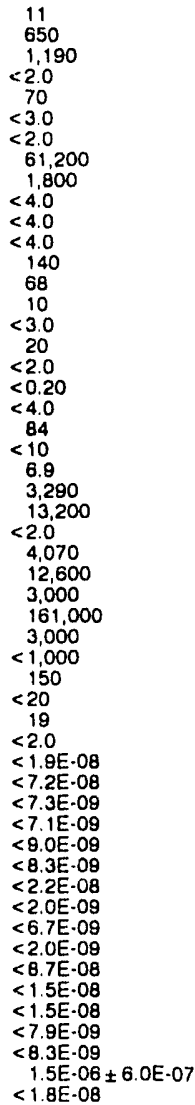 & JQ & 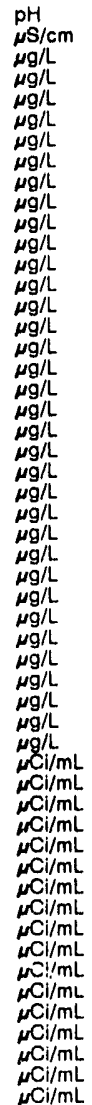 \\
\hline
\end{tabular}

WELL IDB 2C

MEASUREMENTS CONDUCTED IN THE FIEL.D

Sample date: 12/04/91

Depth to water: $63.68 \mathrm{H}(19.41 \mathrm{~m})$ below TOC

Water elevation: $242.72 \mathrm{Ht}(73.88 \mathrm{~m}$

Water evacuated before sampling: $126 \mathrm{gal}$

Alkalinity: $65 \mathrm{mg} / \mathrm{t}$

Water temperature: $18.1^{\circ} \mathrm{C}$

LABORATORY ANALYSES

\begin{tabular}{|c|c|c|c|}
\hline Analyte & Result & Mod & Unit \\
\hline $\begin{array}{ll}1 & \mathrm{pH} \\
0 & \text { Specific conductance } \\
2 & \text { Aluminum } \\
0 & \text { Antimony }\end{array}$ & $\begin{array}{c}9.7 \\
80 \\
483 \\
<20\end{array}$ & JO & 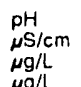 \\
\hline
\end{tabular}


ANALYTICAL RESULTS

WELL IDB 2C coliected on 12/04/91, laboratory analyses (cont.)

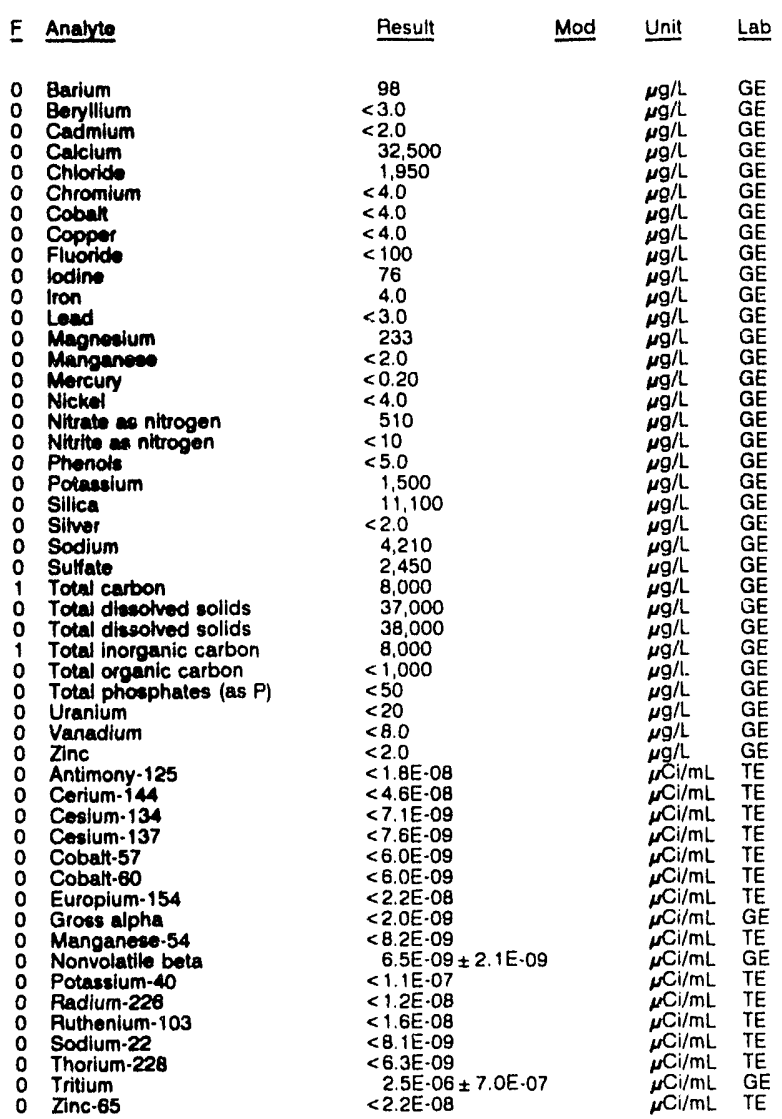

WELL IDB 3

MEASUREMENTS CONDUCTED IN THE FIELD

Sample date: 12/10/91 Depth to water: $81.18 \mathrm{ft}(24.74 \mathrm{~m})$ below TOC Water elevation: $243.72 \mathrm{Ht}(74.29 \mathrm{7}) \mathrm{msl}$

Sp, conductance: $516 \mu \mathrm{s} / \mathrm{cm}$

Water evacuated betore sampling: $6 \mathrm{gal}$

The well went dry during purging

LABORATORY ANALYSES

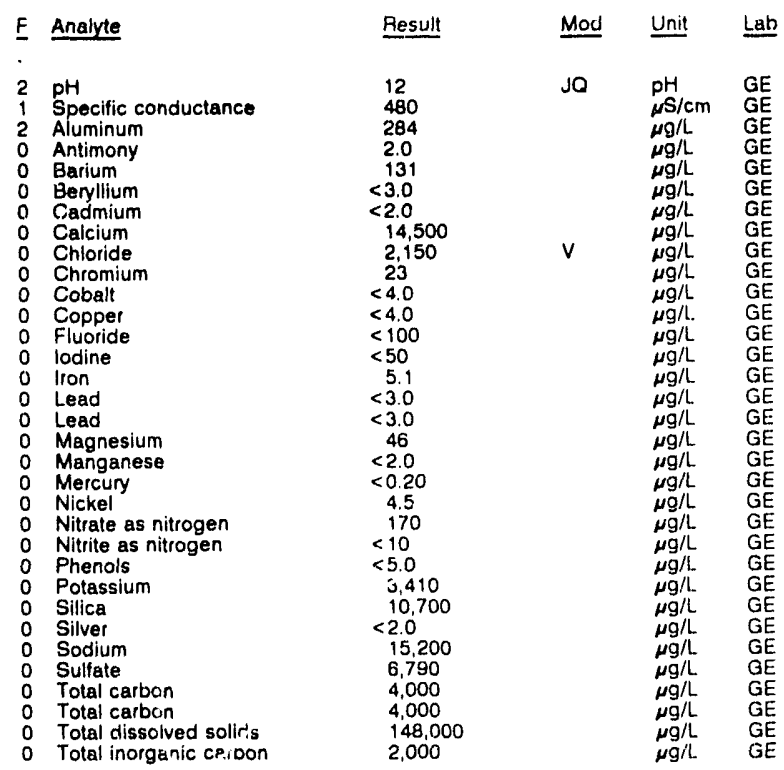

WELL IDB 3 collected on 12/10/91, laboratory arialyses (cont.)
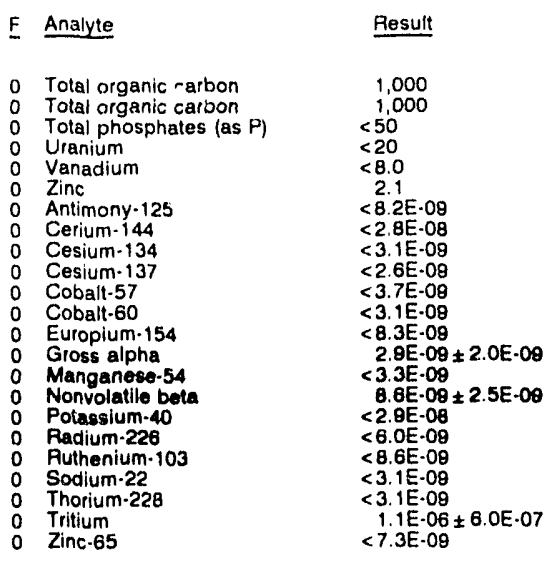

Mod

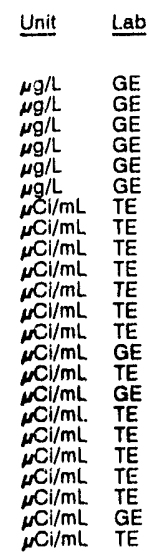

WELL IDB 4

MEASUREMENTS CONDUCTED IN THE FIEL.D

Sample date: $12 / 09 / 91$

Depth to water: $58.84 \mathrm{Ht}(17.93 \mathrm{~m})$ below TOC

Water elevation: $257.76 \mathrm{H}(78.57 \mathrm{~m}) \mathrm{msl}$

Sp. conductance: $25 \mu \mathrm{s} / \mathrm{cm}$
Water evacuated betore sampling: $48 \mathrm{gal}$

Alkalinity: $4 \mathrm{mg} / \mathrm{h}$

Aater temperature: $18.8^{\circ} \mathrm{C}$

LABORATORY ANALYSES

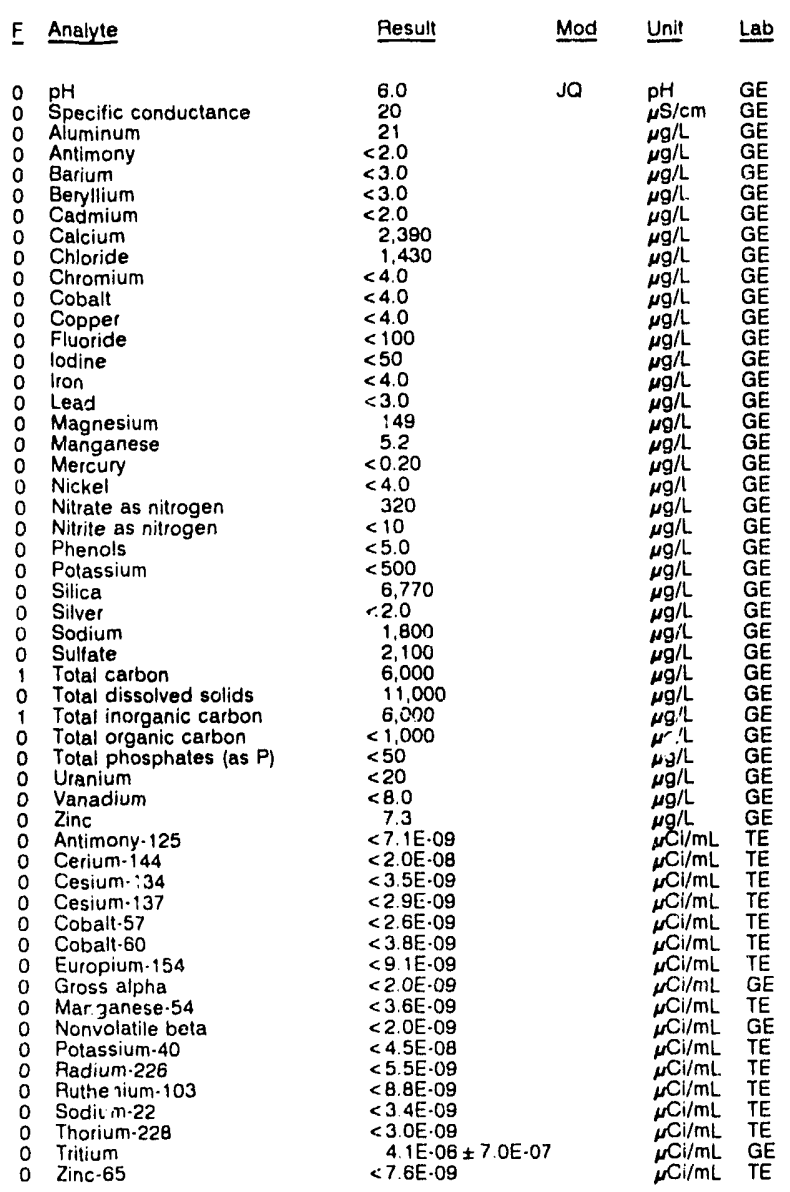


WELL IDB 5

MEASUREMENTS CONDUCTED IN THE FIELD

Sample date: $12 / 10 / 91$

Depth to water: $67.10 \mathrm{H}(20.45 \mathrm{~m})$ below TOC
Water elevation: $254.80 \mathrm{ft}(77.66 \mathrm{~m}) \mathrm{ms}$ l

Sp. conductance: $18 \mu \mathrm{S} / \mathrm{cm}$

Water evacuated before sampling: $11 \mathrm{gal}$

LABORATORY ANALYSES

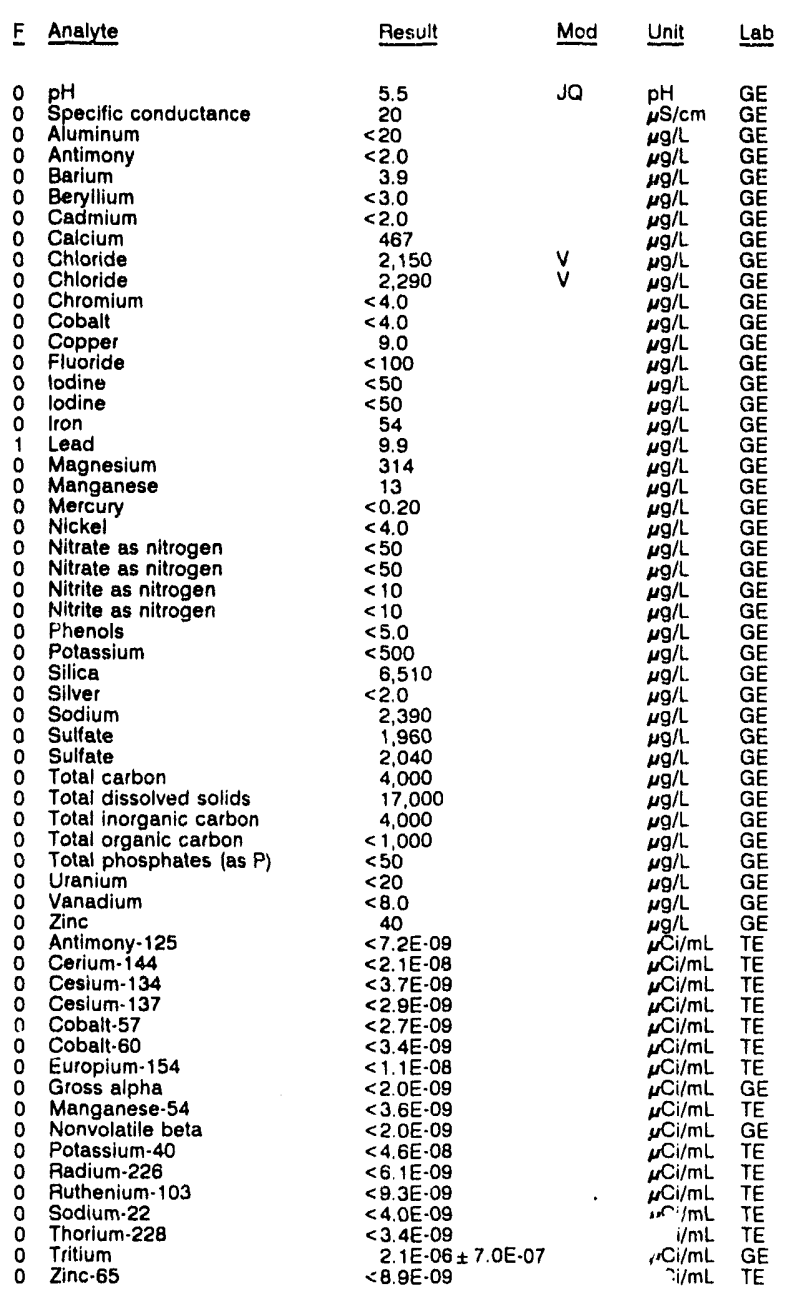

\section{WELL IDB 6}

MEASUREMENTS CONDUCTED IN THE FIELO

Sample date: 12104 1

Depth to water: $55.53 \mathrm{H}(16.93 \mathrm{~m})$ below TOC

Water elevation: $263.47 \mathrm{ft}(80.31 \mathrm{~m}) \mathrm{msl}$

Water evacuated before sampling: $60 \mathrm{gal}$

LABORATORY ANALYSES
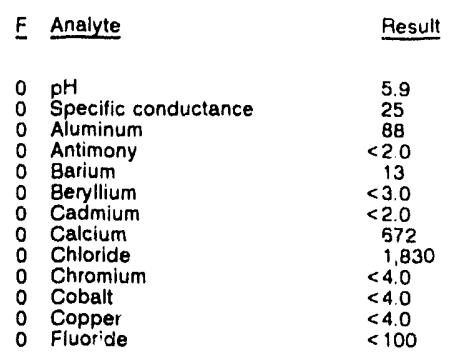

Time: 15:10

Alkalinity: $3 \mathrm{mg} / \mathrm{L}$

Water temperature: $18.0^{\circ} \mathrm{C}$

Time: 9:30

Alkalinity: $1 \mathrm{mg} / \mathrm{L}$

Water temperature: $18.6^{\circ} \mathrm{C}$

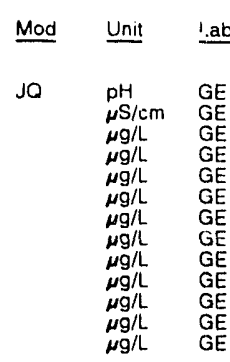

WELL IDB 6 collected on 12/04/91, laboratory analyses (cont.)

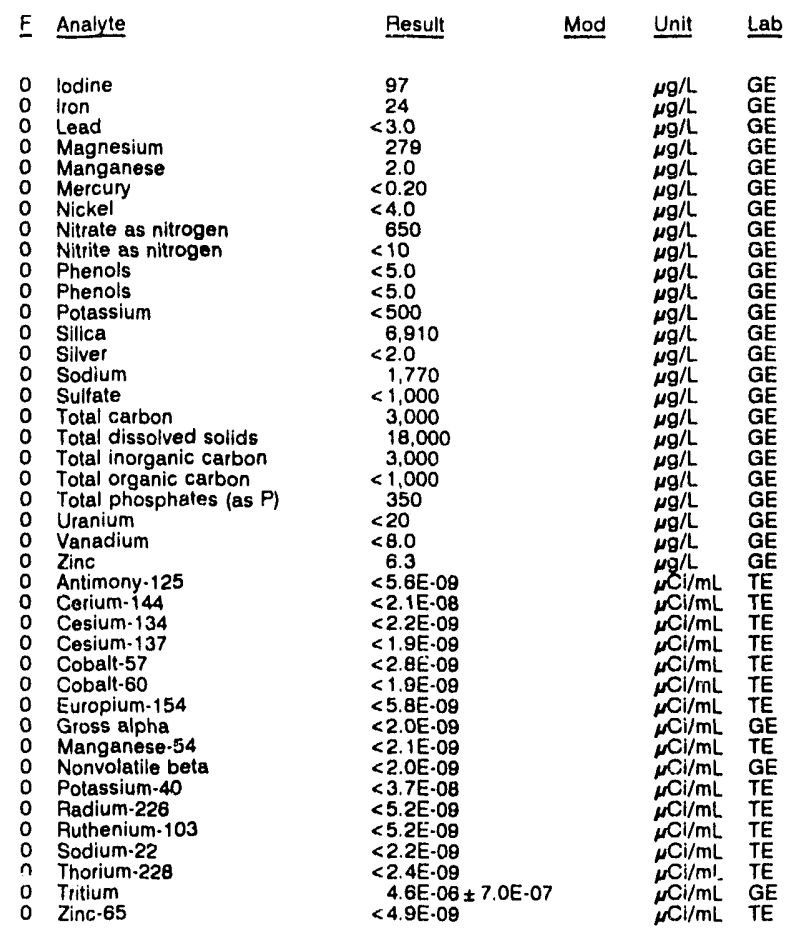

\section{WELL IDB 7}

MEASUREMENTS CONDUCTED IN THE FIELO

Sample date: $12 / 09 / 91$ ( $14.94 \mathrm{~m}$ ) below TOC

Water elevation: $264.38 \mathrm{ft}(80.58 \mathrm{~m}) \mathrm{msl}$

Sp. conductance: $32 \mu \mathrm{s} / \mathrm{cm}$
Water evacuated before sampling: $60 \mathrm{gal}$

LABORATORY ANALYSES

\begin{tabular}{|c|c|c|c|c|c|}
\hline $\mathbf{F}$ & Analyte & Result & Mod & Unit & Lab \\
\hline 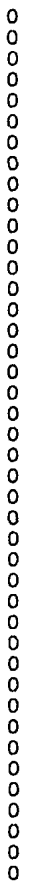 & $\begin{array}{l}\text { pH } \\
\text { Specific conductance } \\
\text { Aluminum } \\
\text { Antimony } \\
\text { Barium } \\
\text { Geryllium } \\
\text { Cadmium } \\
\text { Caicium } \\
\text { Chloride } \\
\text { Chromium } \\
\text { Cobalt } \\
\text { Copper } \\
\text { Fluoride } \\
\text { lodine } \\
\text { lron } \\
\text { Lead } \\
\text { Magnesium } \\
\text { Manganitse } \\
\text { Mercury } \\
\text { Nickel } \\
\text { Nitrate as nitrogen } \\
\text { Nitrite as nitrogen } \\
\text { Phenols } \\
\text { Potassium } \\
\text { Silica } \\
\text { Silver } \\
\text { Sodium } \\
\text { Sulate } \\
\text { Total carbon } \\
\text { Total dissolved solids } \\
\text { Total inorganic carbon } \\
\text { Total organic carbon } \\
\text { Total organic carbon } \\
\text { Total phosphates (as P) } \\
\text { Uranium } \\
\text { Vanadium } \\
\text { Zinc } \\
\text { Antimony-125 } \\
\text { Cerium-144 } \\
\text { Cesium-134 } \\
\text { Cesium-137 } \\
\text { Cobalt-57 }\end{array}$ & $\begin{array}{l}4.5 \\
30 \\
89 \\
<2.0 \\
11 \\
<3.0 \\
<2.0 \\
100 \\
4,200 \\
<4.0 \\
<4.0 \\
<4.0 \\
<100 \\
<50 \\
6.3 \\
<3.0 \\
469 \\
<2.0 \\
<0.20 \\
<4.0 \\
1,150 \\
<10 \\
<5.0 \\
<500 \\
6,110 \\
<2.0 \\
2,450 \\
18,900 \\
4,000 \\
15,000 \\
4,000 \\
<1,000 \\
<1,000 \\
<50 \\
<20 \\
<8.0 \\
2.4 \\
<6.9 E-09 \\
<2.2 E-08 \\
<3.0 \mathrm{E} \cdot 09 \\
<3.1 \mathrm{E}-09 \\
<2.8 \mathrm{E}-09\end{array}$ & JO & $\begin{array}{l}p H \\
\mu \mathrm{S} / \mathrm{cm} \\
\mu g / L \\
\mu g / L \\
\mu g / L \\
\mu g / L \\
\mu g / L \\
\mu g / L \\
\mu g / L \\
\mu g / L \\
\mu g / L \\
\mu g / L \\
\mu g / L \\
\mu g / L \\
\mu g / L \\
\mu g / L \\
\mu g / L \\
\mu g / L \\
\mu g / L \\
\mu g / L \\
\mu g / L \\
\mu g / L \\
\mu g / L \\
\mu g / L \\
\mu g / L \\
\mu g / L \\
\mu g / L \\
\mu g / L \\
\mu g / L \\
\mu g / L \\
\mu g / L \\
\mu g / L \\
\mu g / L \\
\mu g / L \\
\mu g / L \\
\mu g / L \\
\mu g / L \\
\mu C I / m L \\
\mu C i / m L \\
\mu C i / m L \\
\mu C i / m L \\
\mu C i / m L\end{array}$ & $\begin{array}{l}\mathrm{GE} \\
\mathrm{GE} \\
\mathrm{GE} \\
\mathrm{GE} \\
\mathrm{GE} \\
\mathrm{GE} \\
\mathrm{GE} \\
\mathrm{GE} \\
\mathrm{GE} \\
\mathrm{GE} \\
\mathrm{GE} \\
\mathrm{GE} \\
\mathrm{GE} \\
\mathrm{GE} \\
\mathrm{GE} \\
\mathrm{GE} \\
\mathrm{GE} \\
\mathrm{GE} \\
\mathrm{GE} \\
\mathrm{GE} \\
\mathrm{GE} \\
\mathrm{GE} \\
\mathrm{GE} \\
\mathrm{GE} \\
\mathrm{GE} \\
\mathrm{GE} \\
\mathrm{GE} \\
\mathrm{GE} \\
\mathrm{GE} \\
\mathrm{GE} \\
\mathrm{GE} \\
\mathrm{GE} \\
\mathrm{GE} \\
\mathrm{GE} \\
\mathrm{GE} \\
\mathrm{GE} \\
\mathrm{GE} \\
\mathrm{TE} \\
\mathrm{TE} \\
\mathrm{TE} \\
\mathrm{TE} \\
\mathrm{TE}\end{array}$ \\
\hline
\end{tabular}

Time: 13:20

Alkalinity: $0 \mathrm{mg}$

Water temperature: $19.0^{\circ} \mathrm{C}$

.


WELL IDB 7 collected on 12/09/91, laboratory analyses (cont.)

\begin{tabular}{|c|c|c|}
\hline Analyte & Result & Unit \\
\hline $\begin{array}{l}\text { Cobalt-60 } \\
\text { Europium-154 } \\
\text { Gross alpha } \\
\text { Manganese-54 } \\
\text { Nonvolatile beta } \\
\text { Potasslum-40 } \\
\text { Radium-226 } \\
\text { Authenium-103 } \\
\text { Sodium-22 } \\
\text { Thorium-228 } \\
\text { Tritium } \\
\text { Zinc-65 }\end{array}$ & $\begin{aligned}<3.4 \mathrm{E}-09 \\
<7.7 \mathrm{E}-09 \\
<2.0 \mathrm{E}-09 \\
<2.9 \mathrm{E}-09 \\
<2.0 \mathrm{E}-09 \\
<4.0 \mathrm{E} \cdot 08 \\
<5.6 \mathrm{E}-09 \\
<7.8 \mathrm{E}-09 \\
<2.7 \mathrm{E}-09 \\
<2.6 \mathrm{E}-09 \\
4.0 \mathrm{E}-06 \pm 7.0 \mathrm{E} \cdot 07 \\
<8.2 \mathrm{E}-09\end{aligned}$ & $\begin{array}{l}\mu \mathrm{Ci} / \mathrm{mL} \\
\mu \mathrm{Ci} / \mathrm{mL} \\
\mu \mathrm{Ci} / \mathrm{mL} \\
\mu \mathrm{Ci} / \mathrm{mL} \\
\mu \mathrm{Ci} / \mathrm{mL} \\
\mu \mathrm{Ci} / \mathrm{mL} \\
\mu \mathrm{Ci} / \mathrm{mL} \\
\mu \mathrm{Cl} / \mathrm{mL} \\
\mu \mathrm{Ci} / \mathrm{mL} \\
\mu \mathrm{Ci} / \mathrm{mL} \\
\mu \mathrm{Ci} / \mathrm{mL} \\
\mu \mathrm{Ci} / \mathrm{mL}\end{array}$ \\
\hline
\end{tabular}

WELL IDB 8

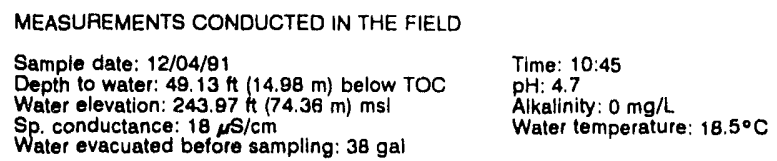

LABORATORY ANALYSES

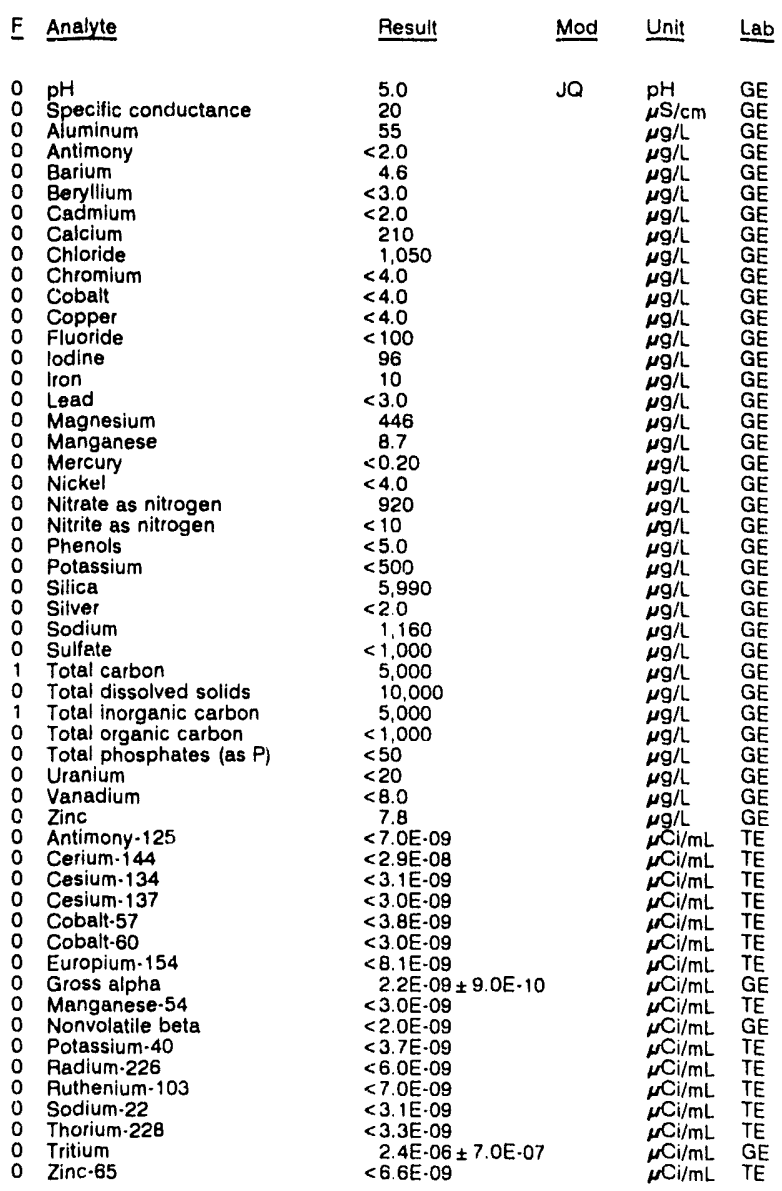

WELL IDB 9

MEASUREMENTS CONDUCTED IN THE FIELD

Sample date: $12 / 04 / 91$

Depth to water: $43.02 \mathrm{Ht}(13.11 \mathrm{~m})$ below TOC

Water elevation: $245.28 \mathrm{~h}(74.76 \mathrm{~m}) \mathrm{ms}$

Water evacuated before sampling: $115 \mathrm{gal}$

LABORATOAY ANALYSES

E Analyte Result Mod Unit Lab

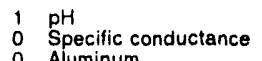

o Aluminum

0 Antimony

0 Barium

$\begin{array}{ll}0 & \text { Beryllium } \\ 0 & \text { Cadmium }\end{array}$

- Calclum

o Chromium

O Cobalt

- Copper

O Fluoride

0 lodine

- lodine

o lron

$\begin{array}{ll}\text { o } & \text { Lead } \\ \text { o } & \text { Magnesium }\end{array}$

Manganese

Mercury

Nitrate as nitrogen

o Nitrite as nitrogen

0 Phenols

$\begin{array}{ll}0 & \text { Potas } \\ 0 & \text { Silica }\end{array}$

0 Silver

0 Sodium

2 Total carbon

- Total dissolved solids

2 Total inorganic carbon

Total organic carbon

O Vanadium

0 Zine

O Antimony. 125

Cerium-144

Cesium-134

0 Cobalt -57

Cobalt-60

Europium 154

Gross alpha

Manganese-54

Potassium.40

O Radium-226

0 Ruthenium-103

${ }_{0}$ Sodium-22

Tritium

\begin{tabular}{|c|c|c|}
\hline 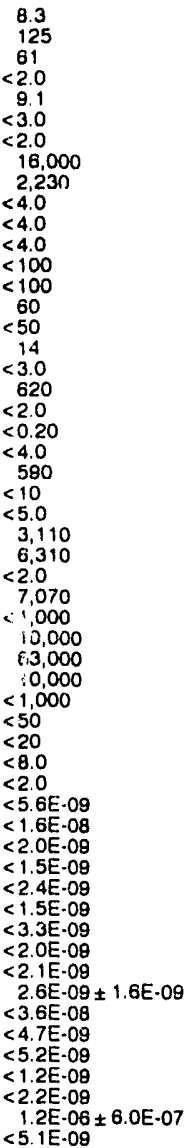 & JO & 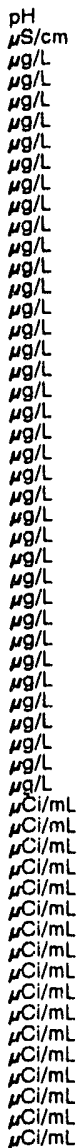 \\
\hline
\end{tabular}

WELL IDB 10

MEASUREMENTS CONDUCTED IN THE FIELD

Sample date: 12/09/91

Depth to water: $34.46 \mathrm{H}(10.50 \mathrm{~m})$ below TOC

Water elevation: $261.34 \mathrm{ft}(79.66 \mathrm{~m}) \mathrm{ms}$

Sp. conductance: $28 \mu \mathrm{S} / \mathrm{cm}$

Alka 0.7 : $50 \mathrm{mg}$

Alkalinity: $58 \mathrm{mg} / \mathrm{L}$

Water evacuated before sampling: $119 \mathrm{gal}$

LABORATORY ANALYSES

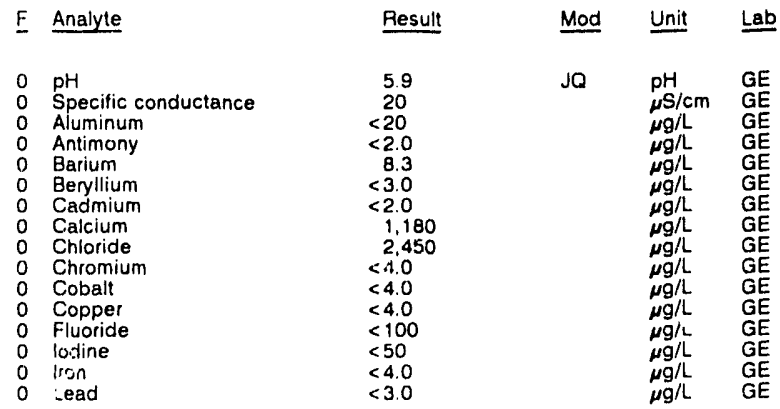


ANALYTICAL RESULTS

\begin{tabular}{|c|c|c|c|}
\hline E Anulyte & Result & Unit & $\underline{L a b}$ \\
\hline $\begin{array}{ll}0 & \text { Magnesium } \\
0 & \text { Manganose } \\
0 & \text { Mercury } \\
0 & \text { Nickel } \\
0 & \text { Nitrate as nitrogen } \\
0 & \text { Nitrate as nitrogen } \\
0 & \text { Nitrite as nitrogen } \\
0 & \text { Nitrite as nitrogen } \\
0 & \text { Phenols } \\
0 & \text { Potasslum } \\
0 & \text { Silica } \\
0 & \text { Silver } \\
0 & \text { Sodiunt } \\
0 & \text { Sulfate } \\
1 & \text { Total carbon } \\
1 & \text { Total carbon } \\
0 & \text { Total dissolved solids } \\
1 & \text { Total inorganic carbon } \\
1 & \text { Total inorganic carbon } \\
0 & \text { Total organic carbon } \\
0 & \text { Total phosphates (as } P \text { ) } \\
0 & \text { Uranium } \\
0 & \text { Vanadium } \\
0 & \text { Zinc } \\
0 & \text { Artinony-125 } \\
0 & \text { Ce um-144 } \\
0 & \text { Cesium-134 } \\
0 & \text { Cesium-137 } \\
0 & \text { Cobalt-57 } \\
0 & \text { Cobalt-60 } \\
0 & \text { Europium-154 } \\
0 & \text { Gross alpha } \\
0 & \text { Manganese-54 } \\
0 & \text { Nonvolatile beta } \\
0 & \text { Potassium-40 } \\
0 & \text { Radium-226 } \\
0 & \text { Ruthenium-103 } \\
0 & \text { Sodium-22 } \\
0 & \text { Thorium-228 } \\
0 & \text { Tritium } \\
0 & \text { Zinc-65 } \\
0 & \end{array}$ & $\begin{array}{l}442 \\
2.2 \\
<0.20 \\
<4.0 \\
530 \\
530 \\
<10 \\
<10 \\
<5.0 \\
2,280 \\
6,580 \\
<2.0 \\
2,020 \\
<1,000 \\
5,000 \\
5,000 \\
14,000 \\
5,000 \\
5,000 \\
<1,000 \\
<50 \\
<20 \\
<8.0 \\
3.7 \\
<7.0 \mathrm{E}-09 \\
<2.2 \mathrm{E}-00 \\
<3.2 \mathrm{E}-09 \\
<3.0 \mathrm{E}-09 \\
<2.9 \mathrm{E}-09 \\
<3.6 \mathrm{E}-09 \\
<9.9 \mathrm{E}-09 \\
2.0 \mathrm{E}-09 \pm 1.8 \mathrm{E}-09 \\
<3.1 \mathrm{E}-09 \\
<2.0 \mathrm{E}-09 \\
<4.1 \mathrm{E}-08 \\
<5.5 \mathrm{E}-09 \\
<8.9 \mathrm{E}-09 \\
<3.4 \mathrm{E}-09 \\
<3.2 \mathrm{E}-09 \\
5.8 \mathrm{E}-06 \pm 7.0 \mathrm{E}-07 \\
<7.2 \mathrm{E}-09\end{array}$ & 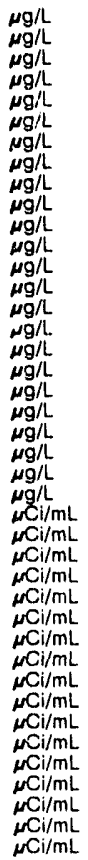 & $\begin{array}{l}G E \\
G E \\
G E \\
G E \\
G E \\
G E \\
G E \\
G E \\
G E \\
G E \\
G E \\
G E \\
G E \\
G E \\
G E \\
G E \\
G E \\
G E \\
G E \\
G E \\
G E \\
G E \\
G E \\
G E \\
T E \\
T E \\
T E \\
T E \\
T E \\
T E \\
G E \\
T E \\
G E \\
T E \\
T E \\
T E \\
T E \\
G E \\
T E\end{array}$ \\
\hline
\end{tabular}

INELL IDP 1

MEASUREMENTS CONDUCTED IN THE FIELD

Sample date: $12 / 12 / 91$

Depth to water: $74.85 \mathrm{ft}(22.81 \mathrm{~m})$ below TOC

Water elevation: $206.15 \mathrm{Ht} / 62$

Water ovacuated before sampling: $71 \mathrm{gal}$

LABORATORY ANALYSES

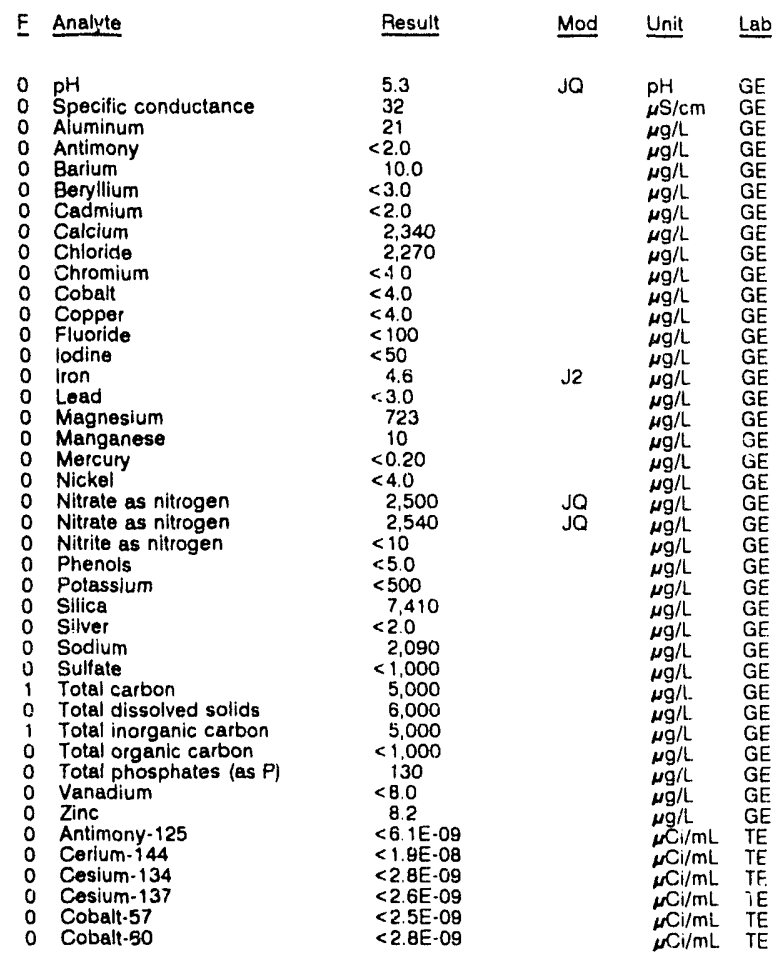

Time: 11:30

$\mathrm{pH}: 5.3$

Alkalinity: $1 \mathrm{mg} /$

Water temperature: $18.2 \circ \mathrm{r}$

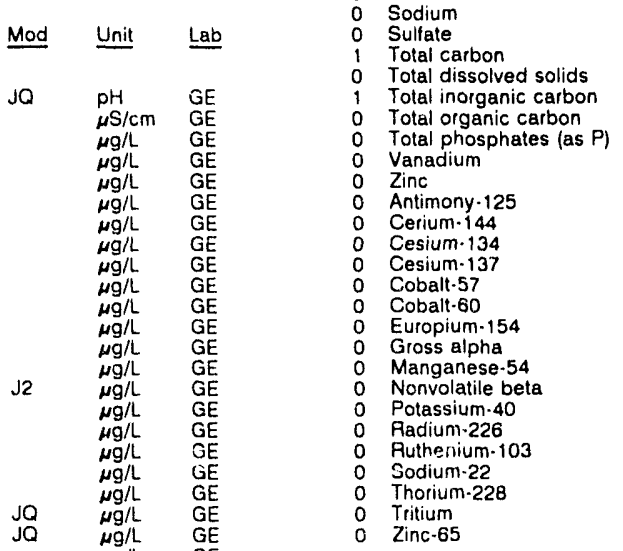

WELL IDP $3 A$

MEASUREMENTS CONDUCTED IN THE FIELD

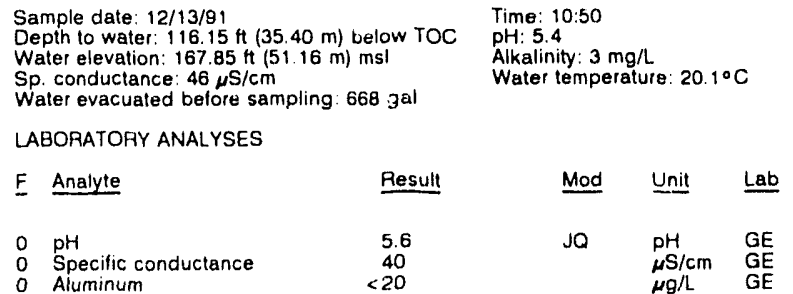

Aluminum
WELL IDP 1 collected on 12/12/91, laboratory analyses (cont.)

\begin{tabular}{|c|c|c|}
\hline Analyte & Result & Unii \\
\hline $\begin{array}{l}\text { Europium } \cdot 154 \\
\text { Gross alpha } \\
\text { Manganese-54 } \\
\text { Nonvolatile beta } \\
\text { Potassium } 40 \\
\text { Radium-226 } \\
\text { Ruthenium } \cdot 103 \\
\text { Sodium-22 } \\
\text { Thorium-228 } \\
\text { Tritium } \\
\text { Zinc-65 }\end{array}$ & $\begin{aligned}<6.5 E-09 \\
<2.0 \mathrm{E}-09 \\
<2.5 \mathrm{E}-09 \\
<2.0 \mathrm{E}-09 \\
<3.7 \mathrm{E}-08 \\
<5.0 \mathrm{E}-09 \\
<6.5 \mathrm{E}-09 \\
<2.2 \mathrm{E}-09 \\
<2.6 \mathrm{E}-09 \\
3.8 \mathrm{E}-06 \pm 7.0 \mathrm{E}-07 \\
<6.6 \mathrm{E}-09\end{aligned}$ & $\begin{array}{l}\mu \mathrm{Ci} / \mathrm{mL} \\
\mu \mathrm{Ci} / \mathrm{mL} \\
\mu \mathrm{Ci} / \mathrm{mL} \\
\mu \mathrm{Ci} / \mathrm{mL} \\
\mu \mathrm{Ci} / \mathrm{mL} \\
\mu \mathrm{Ci} / \mathrm{mL} \\
\mu \mathrm{Ci} / \mathrm{mL} \\
\mu \mathrm{Ci} / \mathrm{mL} \\
\mu \mathrm{Ci} / \mathrm{mL} \\
\mu \mathrm{CL} / \mathrm{mL} \\
\mu \mathrm{Ci} / \mathrm{mL}\end{array}$ \\
\hline
\end{tabular}

WELL IDP 2

MEASUREMENTS CONDUCTED IN THE FIELD

Sample date: $12 / 12 / 91$ ( $17.58 \mathrm{~m})$ below TOC

Depth to water: $57.68 \mathrm{Ht}(17.58 \mathrm{~m})$ below

Water evacuated before sampling: $65 \mathrm{gal}$

pH: 5.1 Alkalinity: $0 \mathrm{mg}$

Water temperature: $18.0^{\circ} \mathrm{C}$

LABORATORY ANALYSES

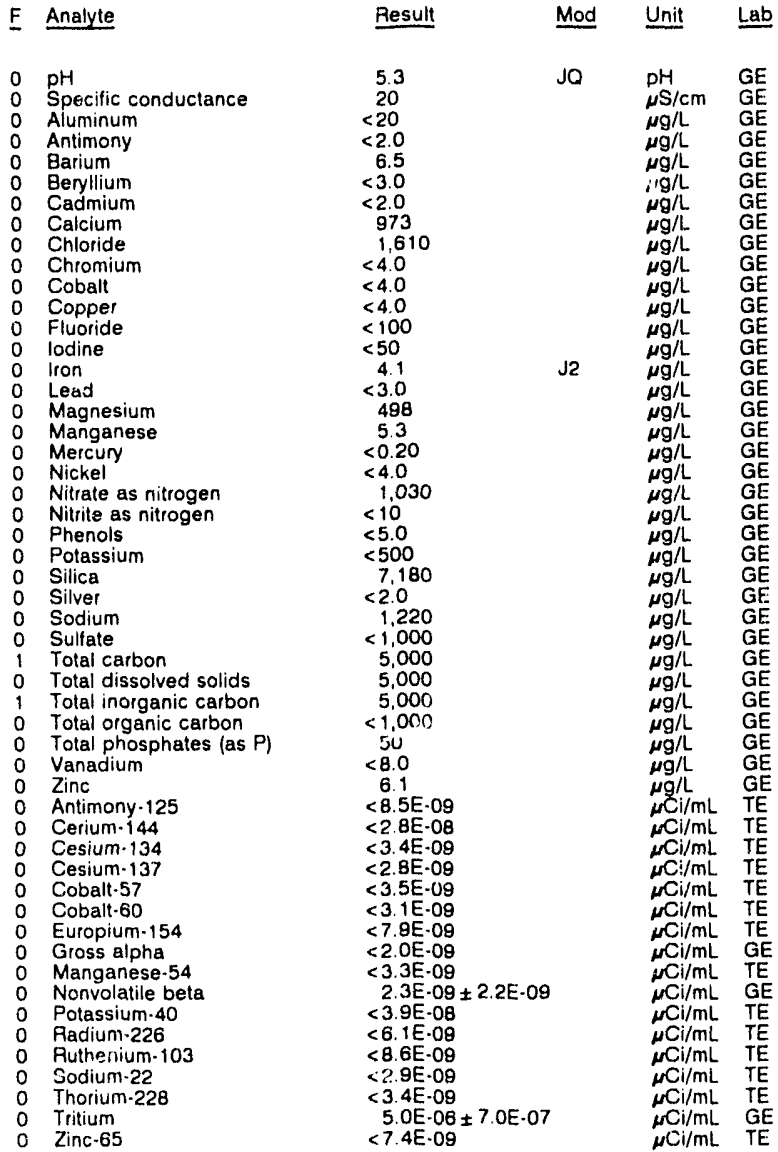


ANALYTICAL RESULTS

WELL IDP 3A collected on 12/13/91, laboratory analyses (cont.)

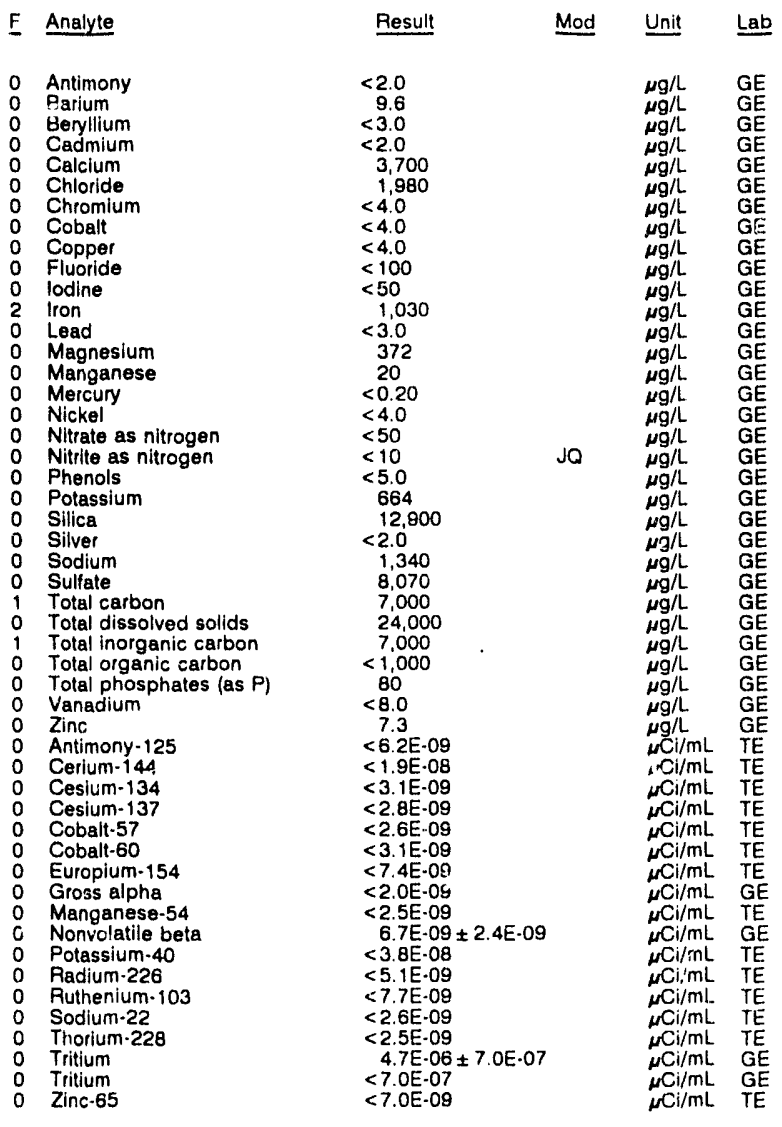

WELL IDP 3A Replicate

MEASUREMENTS CONDUCTED IN THE FIELD

Sample date: $12 / 13 / 91$

Depth to water: $116.15 \mathrm{ft}(35.40 \mathrm{~m})$ below TOC Water elevation: $167.85 \mathrm{ft}$ (51.1

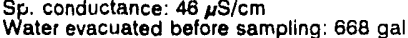

LABORATORY ANALYSES
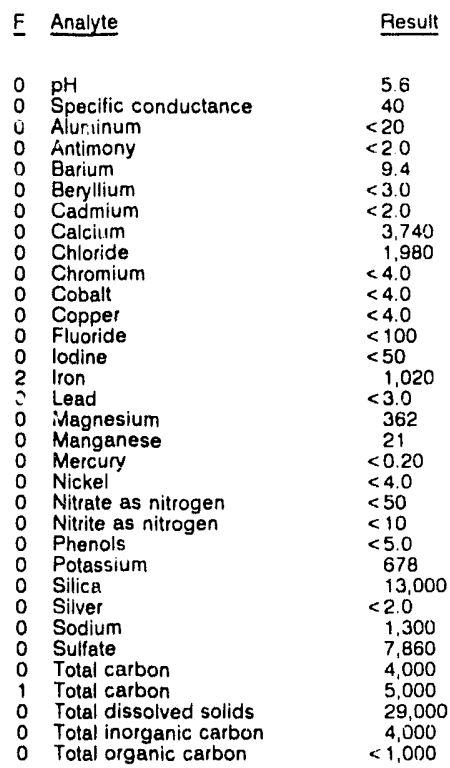

Time: 10:50

$\mathrm{pH}: 5.4$

Alkalinity: $3 \mathrm{mg} / \mathrm{L}$

Water temperature: $20.1^{\circ} \mathrm{C}$

\section{Mod Unit Lab}

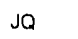

$\begin{array}{ll}\rho H & \mathrm{gE} \\ \mu \mathrm{S} / \mathrm{cm} & \mathrm{GE} \\ \mu \mathrm{g} / \mathrm{L} & \mathrm{GE} \\ \mu \mathrm{g} / \mathrm{L} & \mathrm{GE} \\ \mu \mathrm{g} / \mathrm{L} & \mathrm{GE} \\ \mu \mathrm{g} / \mathrm{L} & \mathrm{GE} \\ \mu \mathrm{g} / \mathrm{L} & \mathrm{GE} \\ \mu \mathrm{g} / \mathrm{L} & \mathrm{GE} \\ \mu \mathrm{g} / \mathrm{L} & \mathrm{GE} \\ \mu \mathrm{g} / \mathrm{L} & \mathrm{GE} \\ \mu \mathrm{g} / \mathrm{L} & \mathrm{GE} \\ \mu \mathrm{g} / \mathrm{L} & \mathrm{GE} \\ \mu \mathrm{g} / & \mathrm{GE} \\ \mu \mathrm{g} / \mathrm{L} & \mathrm{GE} \\ \mu \mathrm{g} / \mathrm{L} & \mathrm{GE} \\ \mu \mathrm{g} / \mathrm{L} & \mathrm{GE} \\ \mu \mathrm{g} / \mathrm{L} & \mathrm{GE} \\ \mu \mathrm{g} / \mathrm{L} & \mathrm{GE} \\ \mu \mathrm{g} / \mathrm{L} & \mathrm{GE} \\ \mu \mathrm{g} / \mathrm{L} & \mathrm{GE} \\ \mu \mathrm{g} / \mathrm{L} & \mathrm{GE} \\ \mu \mathrm{g} / \mathrm{L} & \mathrm{GE} \\ \mu \mathrm{g} / \mathrm{L} & \mathrm{GE} \\ \mu \mathrm{g} / \mathrm{L} & \mathrm{GE} \\ \mu \mathrm{g} / \mathrm{L} & \mathrm{GE} \\ \mu g / \mathrm{L} & \mathrm{GE} \\ \mu \mathrm{g} / \mathrm{L} & \mathrm{GE} \\ \mu \mathrm{g} / \mathrm{L} & \mathrm{GE} \\ \mu \mathrm{g} / \mathrm{L} & \mathrm{GE} \\ \mu \mathrm{g} / \mathrm{L} & \mathrm{GE} \\ \mu \mathrm{g} / \mathrm{L} & \mathrm{GE} \\ \mu \mathrm{g} / \mathrm{L} & \mathrm{GE} \\ \mu \mathrm{g} / \mathrm{L} & \mathrm{GE} \\ & \end{array}$
WELL IDP $3 A$ collected on 12/13/91, laboratory analyses (cont)

$\begin{array}{ll}\text { E } & \text { Analyte } \\ & \\ 0 & \text { Total phosphates (as P) } \\ 0 & \text { Vanadium } \\ 0 & \text { Zinc } \\ 0 & \text { Antimony-125 } \\ 0 & \text { Cerium-144 } \\ 0 & \text { Cesium-134 } \\ 0 & \text { Cesium-137 } \\ 0 & \text { Cobalt-57 } \\ 0 & \text { Cobalt-60 } \\ 0 & \text { Europium-154 } \\ 0 & \text { Gross alpha } \\ 0 & \text { Manganese-54 } \\ 0 & \text { Nonvolatile beta } \\ 0 & \text { Potassium-40 } \\ 0 & \text { Radium-226 } \\ 0 & \text { Ruthenium-103 } \\ 0 & \text { Sodium-22 } \\ 0 & \text { Thorium-228 } \\ 0 & \text { Tritium } \\ 0 & \text { Zinc- } 65\end{array}$

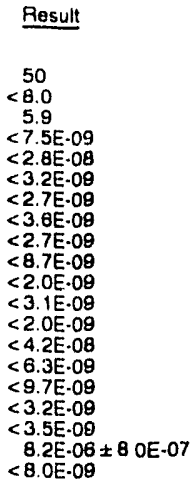

Mod Unit Lab

WELL IDP $3 B$

MEASUREMENTS CONDUCTED IN THE FIELD

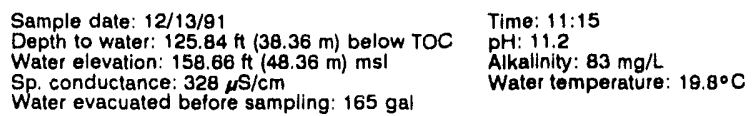

Water evacuated before sampling: $165 \mathrm{gal}$

LABORATORY ANALYSES

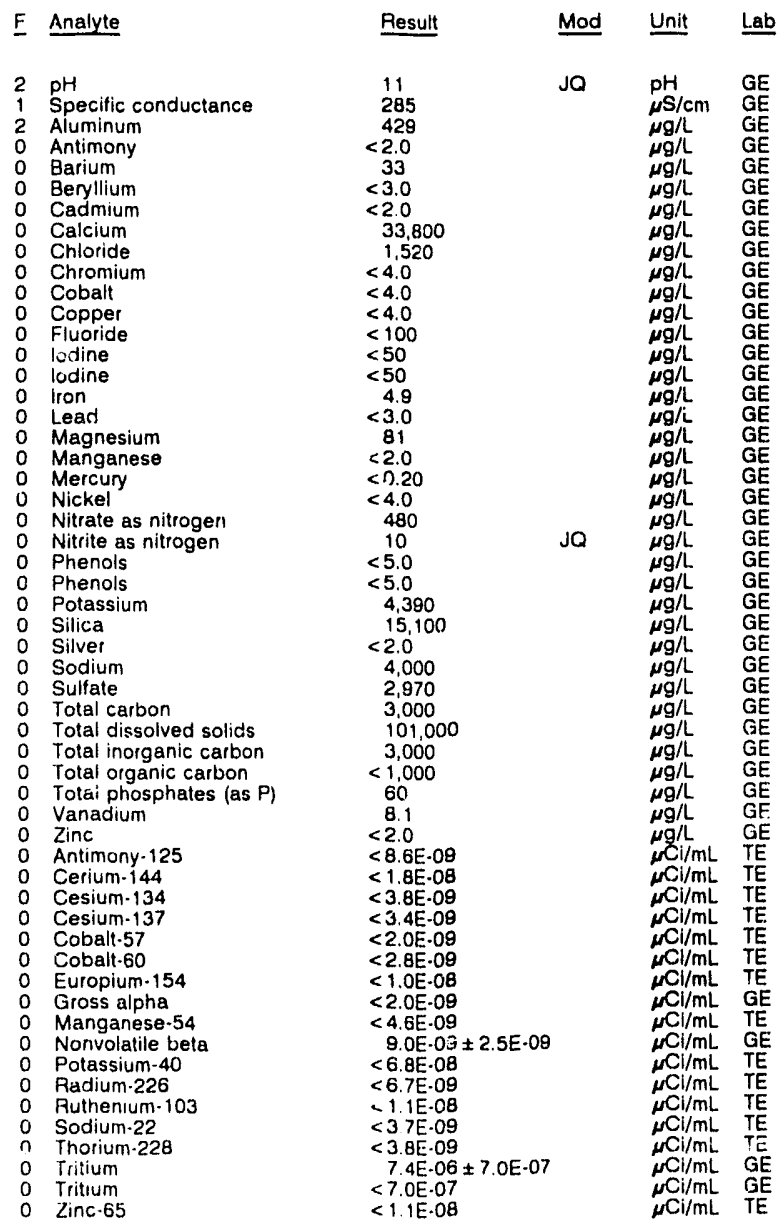


ANALYTICAL RESULTS

WELL IDP $3 C$

MEASUREMENTS CONDUCTED IN THE FIELD

Sainple date: $12 / 13 / 81$

Depth to water: $80.12 \mathrm{~A}(24.42 \mathrm{~m})$ below TOC

Water olevation: $204.88 \mathrm{H}(62.48$

Sp. conductance: $174 \mu \mathrm{s} / \mathrm{cm}$

Water evacuatod before sampling: $17 \mathrm{ga}$

LABORATORY ANALYSES

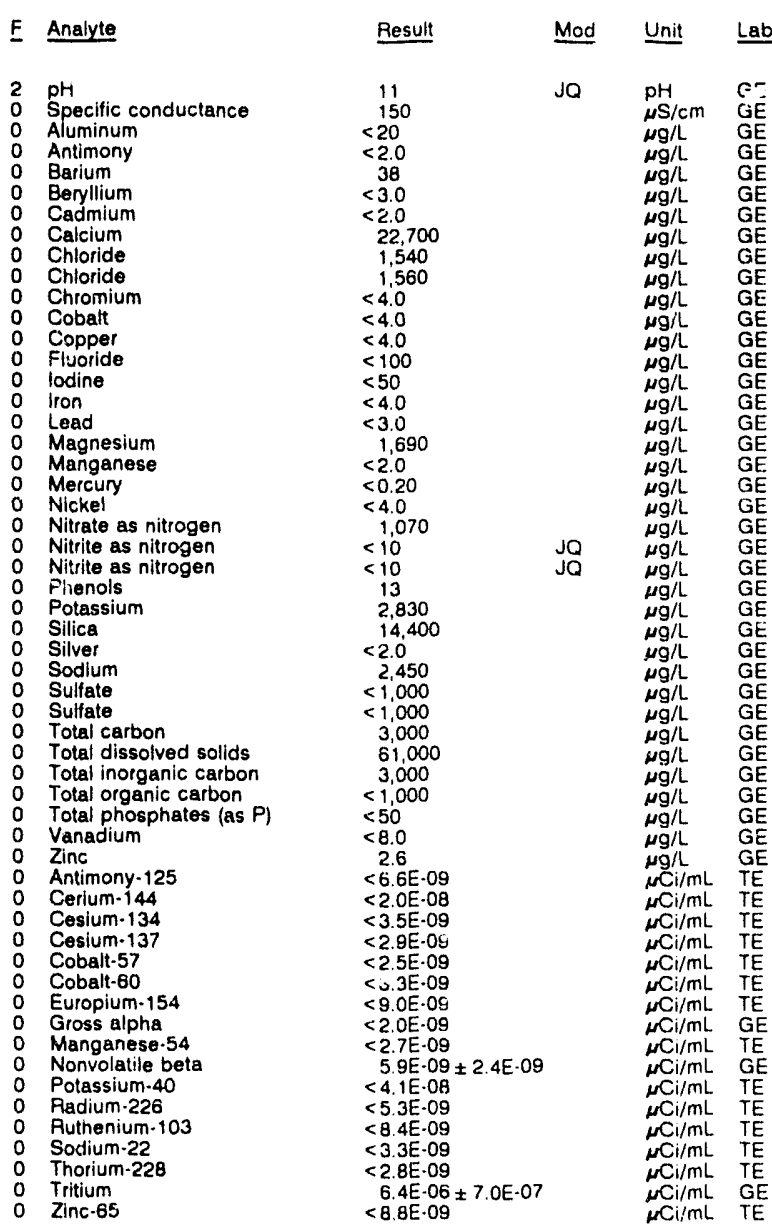

WELL IDP 3D

MEASUREMENTS CONDUCTED IN THE FIELD

Sample date: $12 / 12 / 81$

Time: $9: 25$

pH: 10.8.

Water temperature: $19.0^{\circ} \mathrm{C}$

The well was dry.

Time: $14: 35$

WELL IDP 4

MEASUREMENTS CONDUCTED IN THE FIELD

Sample date: 12/13/91

Depth to water: $46.17 \mathrm{~h}(14.07 \mathrm{~m}$ ) below TOC

Sp. conductance: $31 \mathrm{Hs} \mathrm{cm}$

Water evacuated before sampling $3 \mathrm{gal}$

The well went dry during purging: 3 ga

LABORATORY ANALYSES

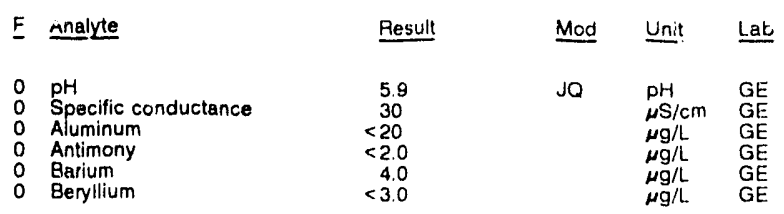

WELL IDP 4 collected on 12/13/91, laboratory analyses (cont.)

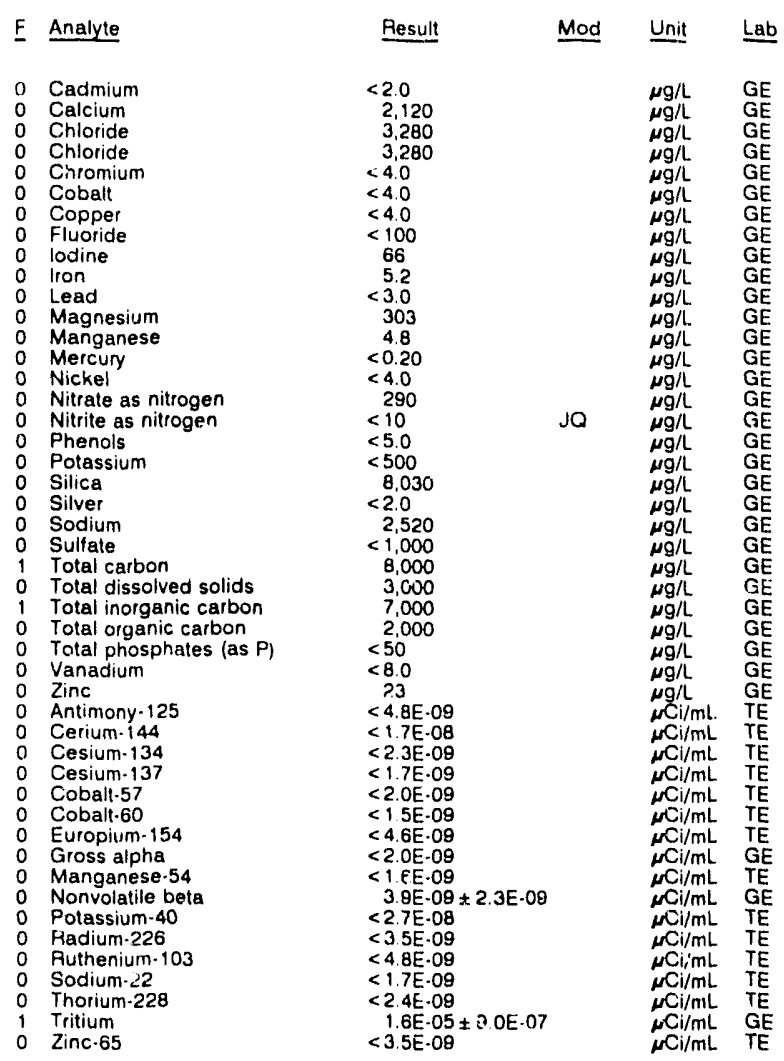

\section{WELL IDP 5}

MEASUREMENTS CONDUCTED IN THE FIELD

Depth to water: $5282 \mathrm{ft}(16.10 \mathrm{~m})$ below TOC

Water elevation: $200.98 \mathrm{tt}(6123 \mathrm{~m}) \mathrm{ms}$ !

Sp conductance. $55 \mu \mathrm{S} / \mathrm{cm}$.

Water evacuated before sampling: $46 \mathrm{gal}$

LABORATORY ANALYSES

$\begin{array}{ll}\text { F } & \text { Analyte } \\ & \\ 0 & \text { pH } \\ 0 & \text { Specific conductance } \\ 0 & \text { Aluminum } \\ 0 & \text { Antimony } \\ 0 & \text { Barium } \\ 0 & \text { Beryllium } \\ 0 & \text { Cadmium } \\ 0 & \text { Calcium } \\ 0 & \text { Chloride } \\ 0 & \text { Chrornium } \\ 0 & \text { Cobalt } \\ 0 & \text { Coppet } \\ 0 & \text { Fluoride } \\ 0 & \text { lodine } \\ 0 & \text { lron } \\ 1 & \text { Lead } \\ 0 & \text { Magnesium } \\ 0 & \text { Manganese } \\ 0 & \text { Mercury } \\ 0 & \text { Nickel } \\ 0 & \text { Nitrate as nitrogen } \\ 0 & \text { Nitrite as nitrogen } \\ 0 & \text { Phenols } \\ 0 & \text { Potassium } \\ 0 & \text { Silica } \\ 0 & \text { Silvel } \\ 0 & \text { Sodium } \\ 0 & \text { Sulfate } \\ 1 & \text { Total carbon } \\ 0 & \text { Total dissolved solids } \\ 1 & \text { Total inorganic carbon } \\ 0 & \text { Total organic carbon } \\ 0 & \text { Total phosphates (as } P \text { ) } \\ 0 & \text { Vanadium } \\ 0 & \text { Zinc } \\ 0 & \text { Antimony-125 } \\ & \end{array}$

\begin{tabular}{|c|c|c|}
\hline Result & Mod & Unit \\
\hline $\begin{array}{c}5.9 \\
37 \\
<20 \\
2.3 \\
11 \\
<30 \\
<2.0 \\
2,830 \\
3,520 \\
<4.0 \\
<4.0 \\
<4.0 \\
<100 \\
<50 \\
19 \\
11 \\
743 \\
7.0 \\
<0.20 \\
<4.0 \\
1,530 \\
<10 \\
<5.0 \\
<500 \\
8,150 \\
<2.0 \\
3,010 \\
<1,000 \\
9,000 \\
22,000 \\
8,000 \\
<1,000 \\
<50 \\
<8.0 \\
15 \\
<65 E .09\end{array}$ & Jo & $\begin{array}{l}\mathrm{pH} \\
\mu \mathrm{S} / \mathrm{cm} \\
\mu g / L \\
\mu g / L \\
\mu g / L \\
\mu g / L \\
\mu g / L \\
\mu g / L \\
\mu g / L \\
\mu g / L \\
\mu g / L \\
\mu g / L \\
\mu g / L \\
\mu g / L \\
\mu g / L \\
\mu g / L \\
\mu g / L \\
\mu g / L \\
\mu g / L \\
\mu g / L \\
\mu g / L \\
\mu g / L \\
\mu g / L \\
\mu g / L \\
\mu g / L \\
\mu g / L \\
\mu g / L \\
\mu g / L \\
\mu g / L \\
\mu g / L \\
\mu g / L \\
\mu g / L \\
\mu g / L \\
\mu g / L \\
\mu g / L \\
\mu C \mathrm{i} / \mathrm{mL}\end{array}$ \\
\hline
\end{tabular}

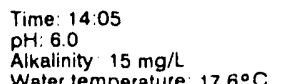

Alkalinity $15 \mathrm{mg} / \mathrm{L}$ Water temperature: $17.6^{\circ} \mathrm{C}$ 
ANALYTICAL RESULTS

WELL IDP 5 collecied on 12/12/91, laboratory analyses (cont.)

\begin{tabular}{|c|c|c|c|}
\hline F Analyte & Result & Unit & $\underline{\text { Lab }}$ \\
\hline $\begin{array}{ll}0 & \text { Cerium-144 } \\
0 & \text { Cesium-134 } \\
0 & \text { Cesiur } 177 \\
0 & \text { Cobs } \\
0 & \text { Coba. } \\
0 & \text { Europiun. 154 } \\
0 & \text { Gross alpha } \\
0 & \text { Manganese-54 } \\
0 & \text { Nonvolatile beta } \\
0 & \text { Potassium-40 } \\
0 & \text { Padium-226 } \\
0 & \text { Puthenium-103 } \\
0 & \text { Sodium-22 } \\
0 & \text { Thorium-228 } \\
0 & \text { Tritium } \\
0 & \text { Zinc-65 }\end{array}$ & $\begin{array}{l}<1.3 \mathrm{BE} \cdot 08 \\
<3.3 \mathrm{~B} \cdot 09 \\
<2.5 \mathrm{E} \cdot 09 \\
<2.0 \mathrm{E} \cdot 09 \\
<2.6 \mathrm{E}-09 \\
<7.7 \mathrm{E}-09 \\
<2.0 \mathrm{E} \cdot 09 \\
<4.0 \mathrm{E} \cdot 09 \\
<2.0 \mathrm{E}-09 \\
<6.1 \mathrm{E} \cdot 08 \\
<5.8 \mathrm{E}-09 \\
<7.6 \mathrm{E}-09 \\
<2.8 \mathrm{E} \cdot 09 \\
<3.1 \mathrm{E} \cdot 09 \\
4.9 \mathrm{E}-06 \pm 7.0 \mathrm{0E} \cdot 07 \\
<7.8 \mathrm{E}-09\end{array}$ & $\begin{array}{l}\omega \mathrm{Ci} / \mathrm{mL} \\
\omega \mathrm{Ci} / \mathrm{mL} \\
\omega \mathrm{Ci} / \mathrm{mL} \\
\omega \mathrm{Ci} / \mathrm{mL} \\
\omega \mathrm{Ci} / \mathrm{mL} \\
\omega \mathrm{Ci} / \mathrm{mL} \\
\omega \mathrm{Ci} / \mathrm{mL} \\
\omega \mathrm{Ci} / \mathrm{mL} \\
\omega \mathrm{Ci} / \mathrm{mL} \\
\omega \mathrm{Ci} / \mathrm{mL} \\
\omega \mathrm{Ci} / \mathrm{mL} \\
\omega \mathrm{Ci} / \mathrm{mL} \\
\omega \mathrm{Ci} / \mathrm{mL} \\
\omega \mathrm{Ci} / \mathrm{mL} \\
\omega \mathrm{Ci} / \mathrm{mL} \\
\omega \mathrm{Ci} / \mathrm{mL}\end{array}$ & $\begin{array}{l}\text { TE } \\
\text { TE } \\
\text { TE } \\
\text { TE } \\
\text { JE } \\
\text { IE } \\
\text { GE } \\
\text { TE } \\
\text { GE } \\
\text { TE } \\
\text { TE } \\
\text { TE } \\
\text { TE } \\
\text { TE } \\
G E \\
\text { TE }\end{array}$ \\
\hline
\end{tabular}

\section{WELL. IDP 6}

MEASUREMENTS CONDUCTED IN THE FIELD

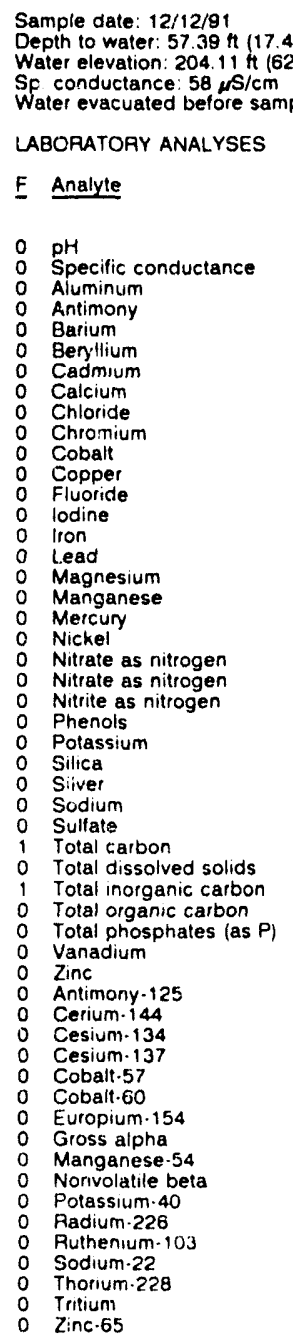

Time: 12.00

PH: 5.8 : $3 \mathrm{mg} / \mathrm{L}$

Water temperature $182^{\circ} \mathrm{C}$

Water evacuated before sampling: $51 \mathrm{gal}$

LABORATORY ANALYSES

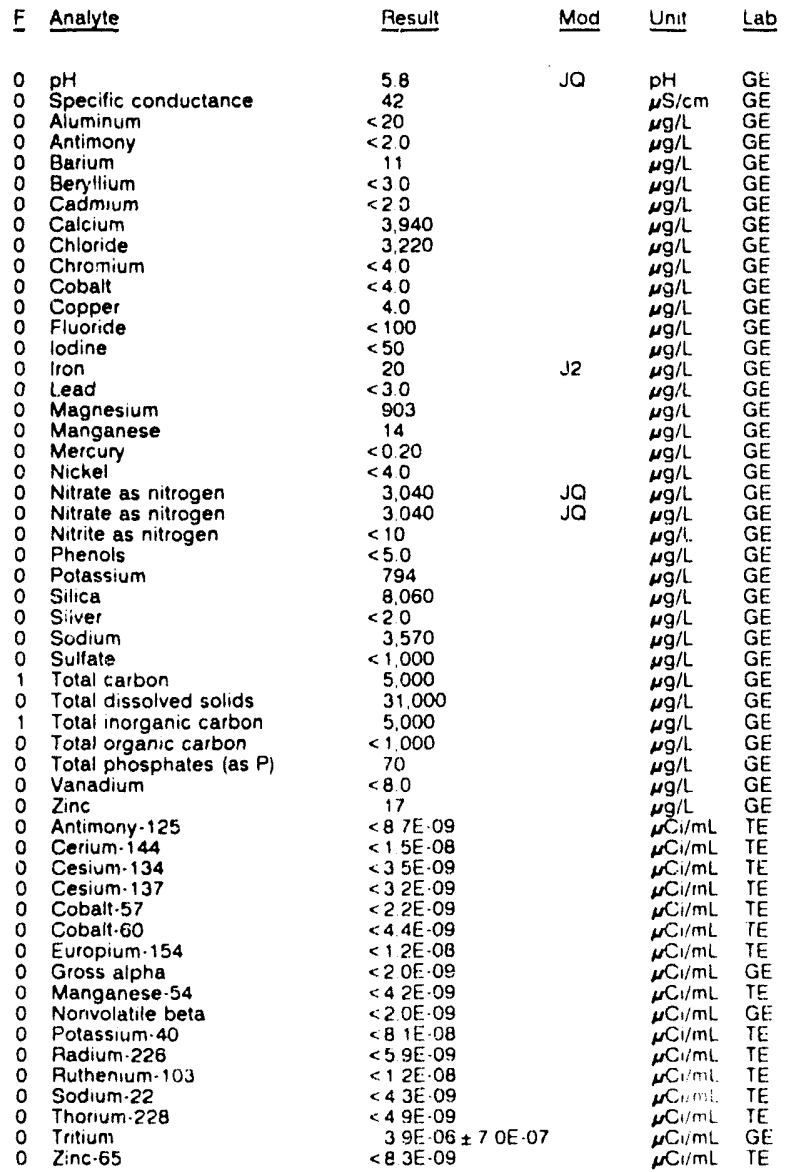

WELL IDP 7

MEASUREMENTS CONDUCTED IN THE FIELD

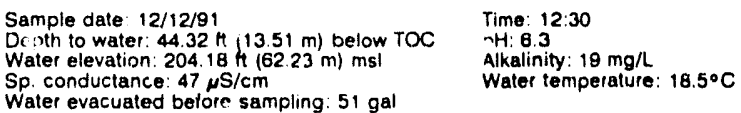

Water evacuated betore sampling: $51 \mathrm{gal}$

LABORATORY ANALYSES

\begin{tabular}{|c|c|c|c|c|}
\hline Analyte & Result & Mod & Unit & Lab \\
\hline 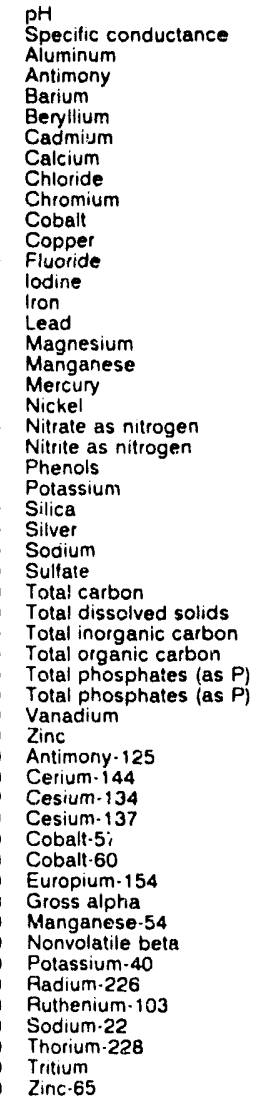 & 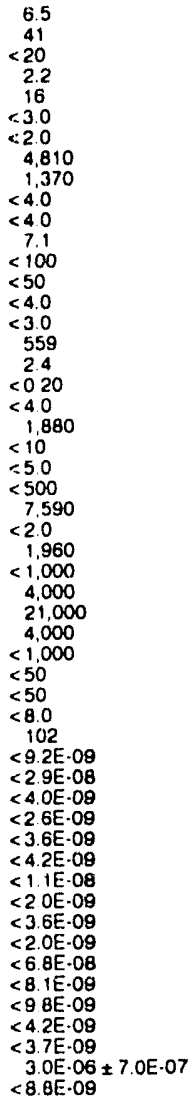 & JO & 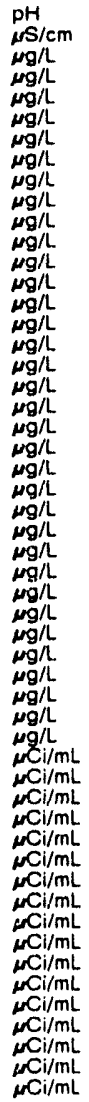 & $\begin{array}{l}\mathrm{GE} \\
\mathrm{GE} \\
\mathrm{GE} \\
\mathrm{GE} \\
\mathrm{GE} \\
\mathrm{GE} \\
\mathrm{GE} \\
\mathrm{GE} \\
\mathrm{GE} \\
\mathrm{GE} \\
\mathrm{GE} \\
\mathrm{GE} \\
\mathrm{GE} \\
\mathrm{GE} \\
\mathrm{GE} \\
\mathrm{GE} \\
\mathrm{GE} \\
\mathrm{GE} \\
\mathrm{GE} \\
\mathrm{GE} \\
\mathrm{GE} \\
\mathrm{GE} \\
\mathrm{GE} \\
\mathrm{GE} \\
\mathrm{GE} \\
\mathrm{GE} \\
\mathrm{GE} \\
\mathrm{GE} \\
\mathrm{GE} \\
\mathrm{GE} \\
\mathrm{GE} \\
\mathrm{GE} \\
\mathrm{GE} \\
\mathrm{GE} \\
\mathrm{GE} \\
\mathrm{GE} \\
\mathrm{TE} \\
\mathrm{TE} \\
\mathrm{TE} \\
\mathrm{TE} \\
\mathrm{TE} \\
\mathrm{TE} \\
\mathrm{TE} \\
\mathrm{GE} \\
\mathrm{TE} \\
\mathrm{GE} \\
\mathrm{TE} \\
\mathrm{TE} \\
\mathrm{TE} \\
\mathrm{TE} \\
\mathrm{TE} \\
\mathrm{GE} \\
\mathrm{TE}\end{array}$ \\
\hline
\end{tabular}

WELL IDP 8

MEASUREMENTS CONDUCTED IN THE FIELD

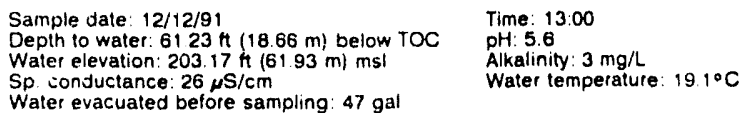

$\mathrm{Sp}$. conductance: $26 \mu \mathrm{s} / \mathrm{cm}$
Water evacuated before sampling: $47 \mathrm{gal}$

LABORATORY ANALYSES

\begin{tabular}{|c|c|c|c|}
\hline Analyte & Result & Mod & Unit \\
\hline $\begin{array}{l}\text { pH } \\
\text { Specific conductance } \\
\text { Aluminum } \\
\text { Antimony } \\
\text { Barium } \\
\text { Beryllium } \\
\text { Cadmium } \\
\text { Calcium } \\
\text { Chloride } \\
\text { Chromium } \\
\text { Cobalt } \\
\text { Copper } \\
\text { Fluoride } \\
\text { lodine } \\
\text { lodine } \\
\text { lron } \\
\text { Lead } \\
\text { Magnesium }\end{array}$ & $\begin{aligned} & 5.8 \\
& 22 \\
&<20 \\
&<2.0 \\
& 11 \\
&<3.0 \\
&<2.0 \\
& 1.660 \\
& 2.080 \\
&<40 \\
&<40 \\
& 7.1 \\
&<100 \\
&<50 \\
&<50 \\
& 18 \\
&<3.0 \\
& 409\end{aligned}$ & Jo & $\begin{array}{l}\rho H \\
\mu \mathrm{H} / \mathrm{cm} \\
\mu g / \mathrm{L} \\
\mu g / \mathrm{L} \\
\mu g / \mathrm{L} \\
\mu g / \mathrm{L} \\
\mu g / \mathrm{L} \\
\mu g / \mathrm{L} \\
\mu g / \mathrm{L} \\
\mu g / \mathrm{L} \\
\mu g / \mathrm{L} \\
\mu g / \mathrm{L} \\
\mu g / \mathrm{L} \\
\mu g / \mathrm{L} \\
\mu g / L \\
\mu g / L \\
\mu g / L \\
\mu g / L\end{array}$ \\
\hline
\end{tabular}


ANALYTICAL RESULTS

WELL IDP 8 collected on 12/12/91, laboratory analyses (cont.)

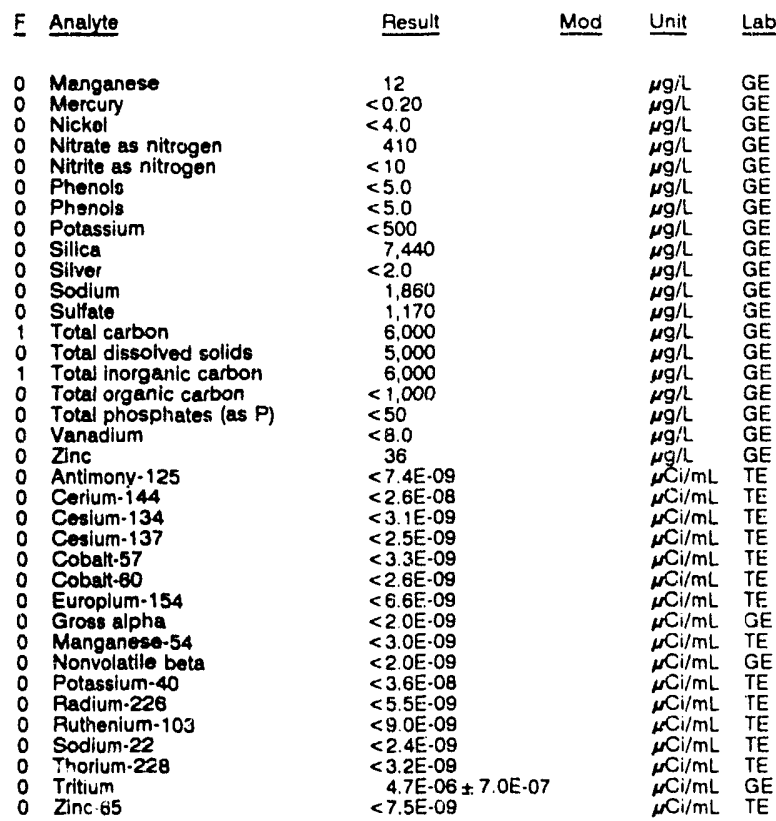

WELL IDP 9

MEASUREMENTS CONDUCTED IN THE FIELD

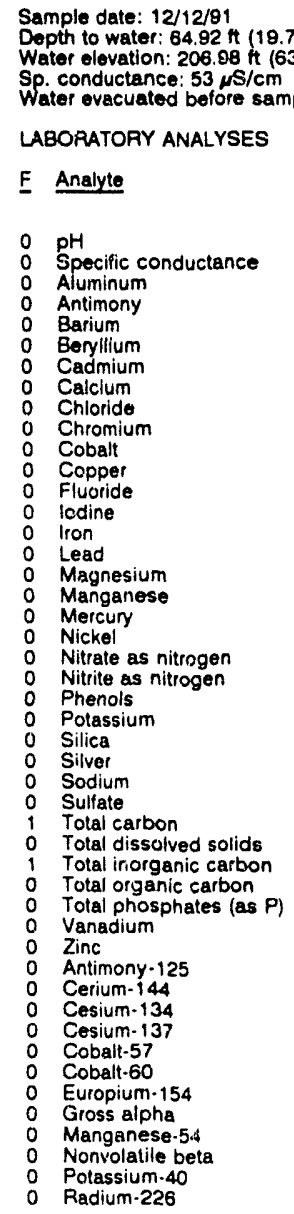

Time: $11: 00$

PH: 6.2

Water temperature $20.1 \circ \mathrm{C}$

Water evacuated before sampling: 62 gal

LABORATORY ANALYSES

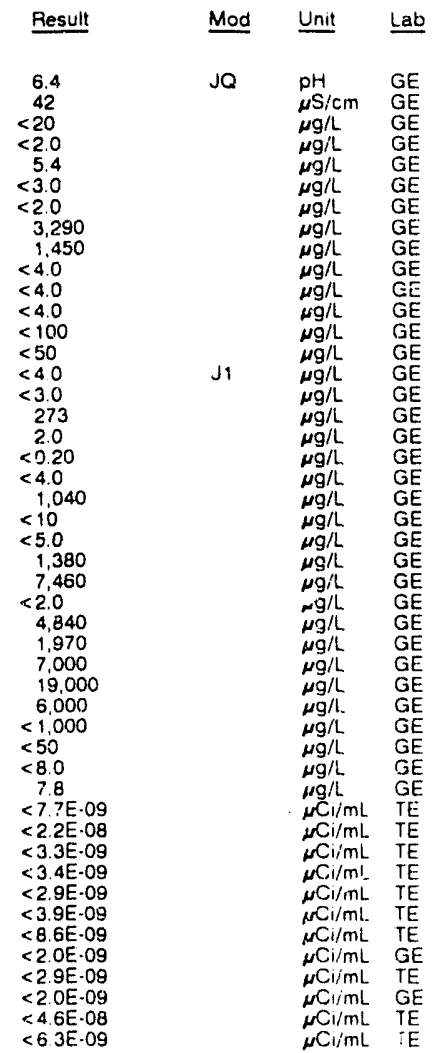

WELL IDP 9 collected on 12/12/91, laboratory analyses (cont.)

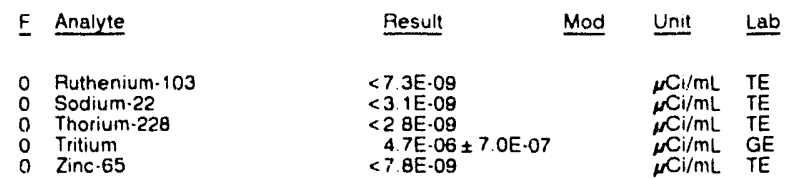

WELL IDP 10

MEASUREMENTS CONOUCTED IN THE FIELD

Sample date: $12 / 12 / 91 \quad$ Time: $17: 30$

WELL IDQ 1

MEASUREMENTS CONOUCTED IN THE FIELD

Sample date: $12 / 12 / 91 \quad$ Time: $14: 50$

WELL IDQ 2

MEASUREMENTS CONDUCTEO THE FIELO

$\begin{array}{ll}\text { Sample tate: } 12 / 13 / 91 & \text { Time: } 13: 15 \\ \text { Depth to water: } 89.44 \mathrm{Ht}(27.26 \mathrm{~m}) \text { below TOC } & \text { pH: } 4.9 \\ \text { Water elevation: } 173.76 \mathrm{ft}(52.96 \mathrm{~m}) \mathrm{msl} & \text { Alkalinity: } 0 \mathrm{mg} / \mathrm{L} \\ \text { Sp. conductance: } 18 \mu \mathrm{c} / \mathrm{cm} & \text { Water temperature: } 18.4^{\circ} \mathrm{C} \\ \text { Water evacuated before sampling: } 36 \mathrm{gal} & \end{array}$

Water evacuated before sampling: $36 \mathrm{gal}$

The woll went dry during purging.

LABORATORY ANALYSES

F. Analyte Result Mod Unit

: $\mathrm{pH}$ Specific conductance

0 Aluminum

Antimony

Barium

Beryllium

Calcium

Cliloride

Chromium

Cobalt

Copper

0 Fluoride

0 lodine

0 Iron

o Magnesium

o Manganese

0 Mercury

0 Nickel

- Nitrate as nitrogen

N Nitrite as nitrogen

o Phenols

0 Potassium

0 Silica

$\begin{array}{ll}0 & \text { Silver } \\ 0 & \text { Sodium }\end{array}$

0 Sulfate

Total carbon

Total dissolved solids

Tolal inorganic carbon

- Total organic carbon

- Total phosphates (as P

0 Vanadium

0 Zinc

O Antimony 125

Cesium-144

Cesium-137

Cobalt 57

Cobalt-60

Europium-154
Gross alpha

Gross alpha

Nonvolatile beta

Potassium 40

Padium.226

Ruthenium-

Sodium-22

0 Tritium

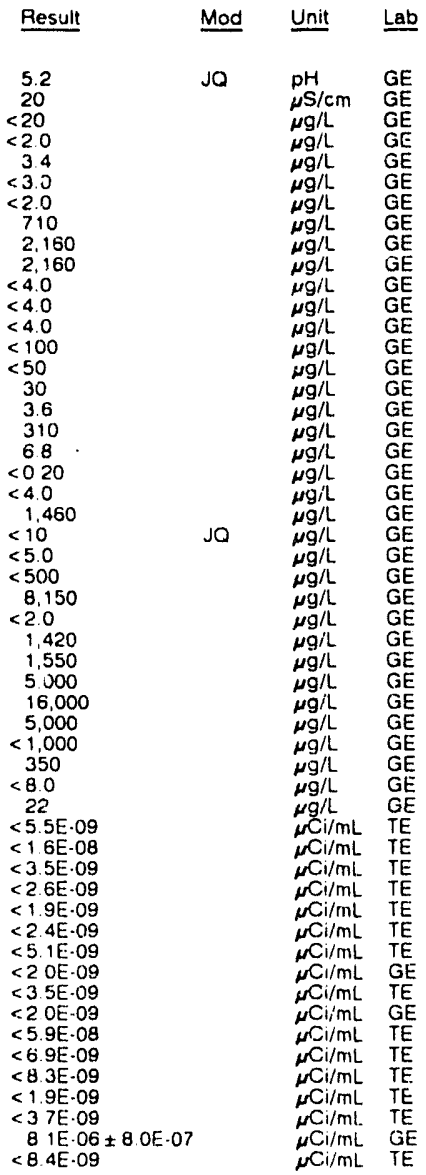


ANALYTICAL RESULTS

WELL IDQ 3A

MEASUREMENTS CONDUCTED IN THE FIELD

Sample date: 12/13/91

Depth to water: $38.85 \mathrm{At}(11.84 \mathrm{~m})$ below TOC

Water elevation: $166.45 \mathrm{ft}(50,73$

Sp. conductance: $46 \mu \mathrm{s} / \mathrm{cm}$
Water evacuated hefore sampling. $935 \mathrm{gal}$

LABORATORY ANALYSES

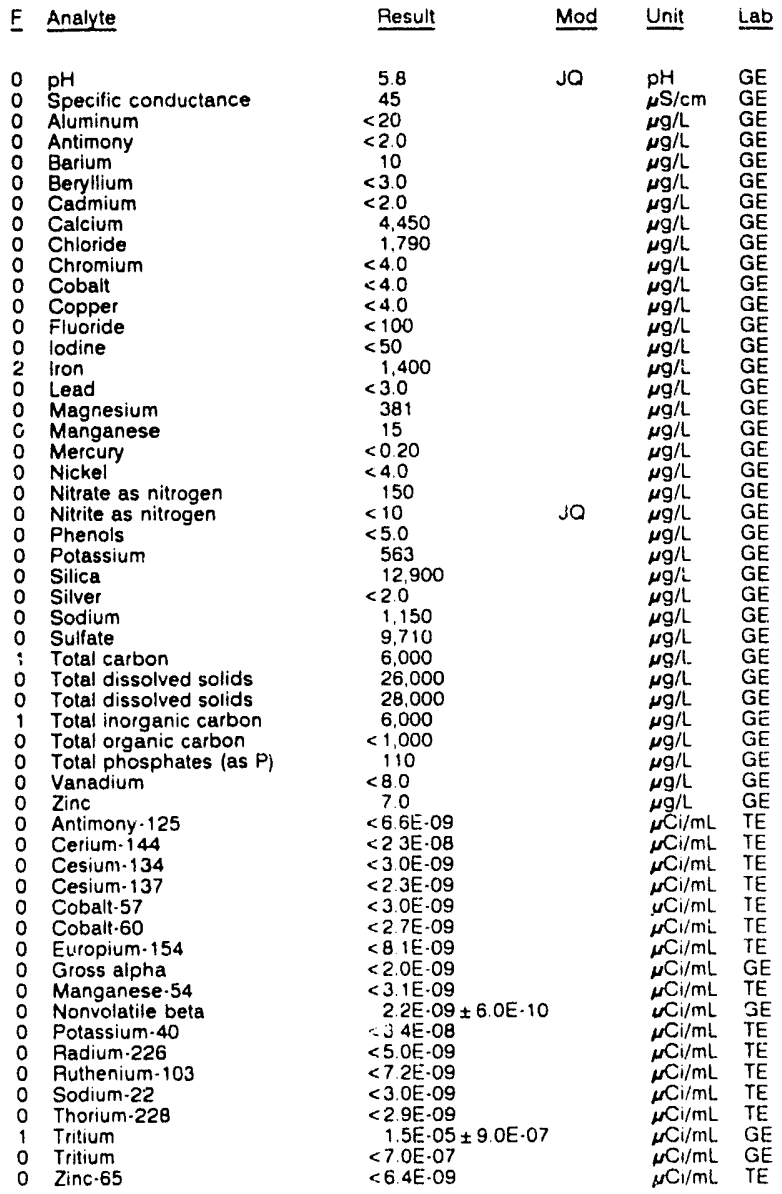

WELL IDQ 3B

MEASUREMENTS CONDUCTED IN THE FIELLO

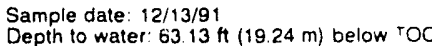

Water elevation 142.47 it $(4.43$

Sp. conduclance $112 \mu \mathrm{S} / \mathrm{cm}$.

Water evacuated before sampling $89 \mathrm{ga}$

LABORATORY ANALYSES

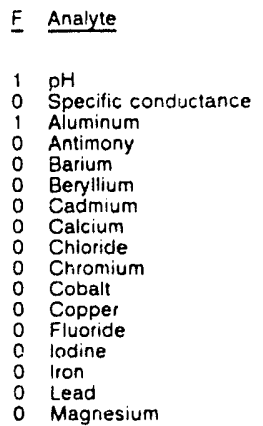

\begin{tabular}{l} 
Result \\
\hline \\
91 \\
100 \\
115 \\
$<2.0$ \\
37 \\
$<3.0$ \\
$<2.0$ \\
14.000 \\
1.990 \\
$<4.0$ \\
$<40$ \\
$<40$ \\
102 \\
$<50$ \\
31 \\
$<30$ \\
406
\end{tabular}

Time: 14:35

$\mathrm{pH}: 5.6$

$4 \mathrm{mg} / \mathrm{L}$

Aler $204^{\circ} \mathrm{C}$

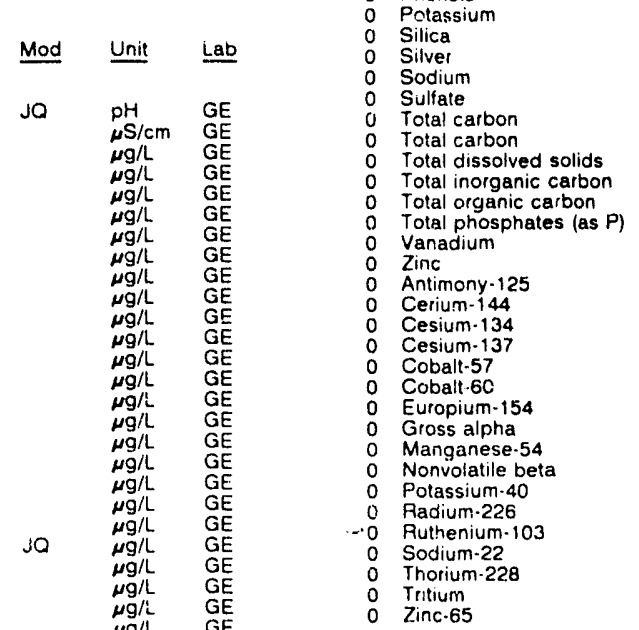

WELL IDQ 3C

MEASUREMENTS CONOUCTED IN THE FIELD

Sample date: 12/13/91

Depth to watet: $39.10 \mathrm{H}(11.92 \mathrm{~m})$ below TOC

Water elevation: $167.40 \mathrm{Ht}(51.02 \mathrm{~m})$ msl

Sp. conduclance: $25 \mu \mathrm{S} / \mathrm{cm}$

The well went do during sampling 13 gal

uring purging

LABORATORY ANALYSES

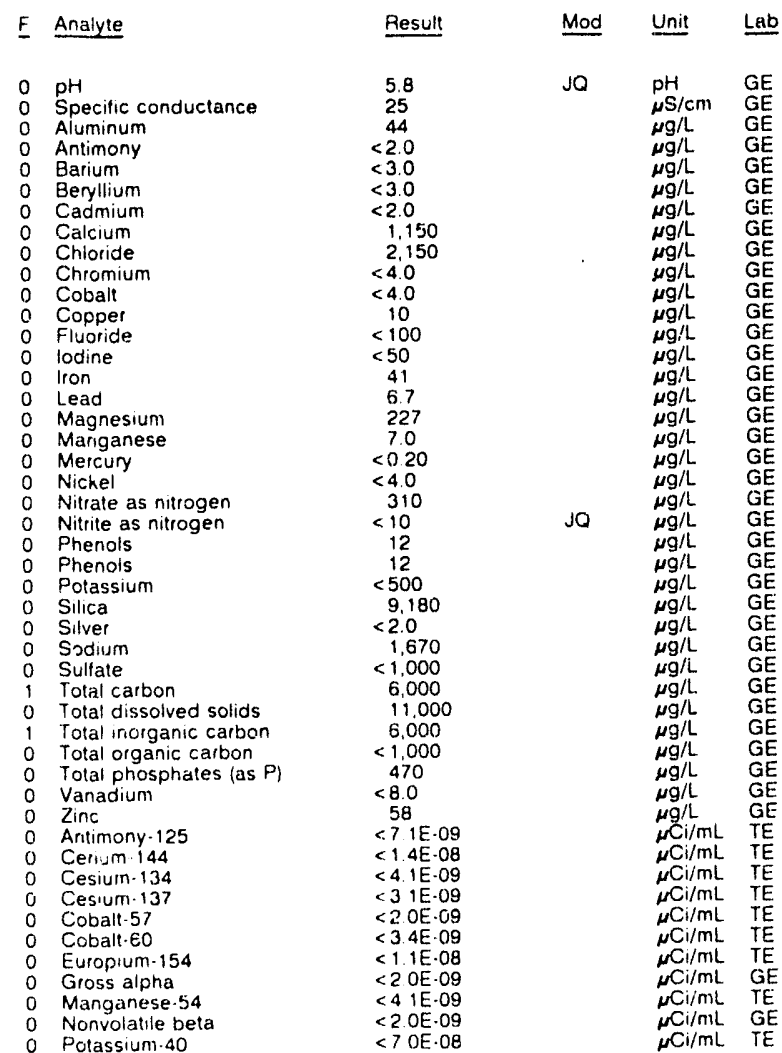

Time: $14: 45$

$\mathrm{pH}: 5.6$

Alkalinily: $4 \mathrm{mg} / \mathrm{L}$

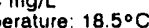

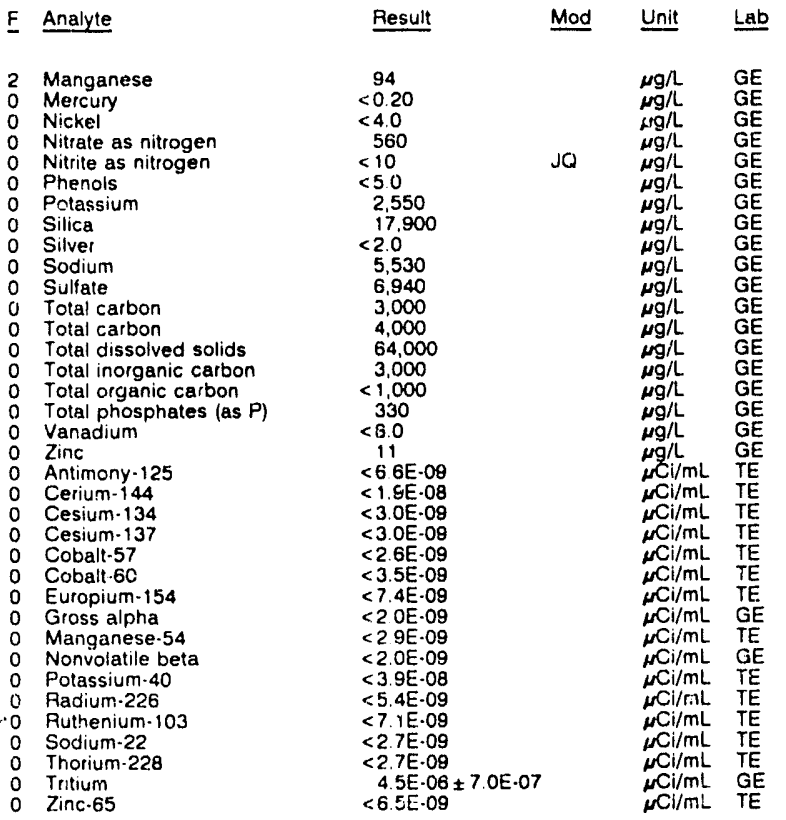

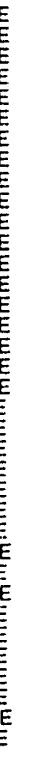


WELL IDQ 3C collected on 12/13/91, labo, ' ' analyses (cont)

\begin{tabular}{|c|c|c|c|}
\hline Analyte & Result & Mod & Unit \\
\hline $\begin{array}{l}\text { Radium-228 } \\
\text { Ruthenium-103 } \\
\text { Sodium-22 } \\
\text { Thorium-228 } \\
\text { Tritium } \\
\text { Zinc-65 }\end{array}$ & $\begin{aligned} &< 5.6 \mathrm{E}-09 \\
&<9.6 \mathrm{E}-09 \\
&<4.0 \mathrm{E}-09 \\
&<3.5 \mathrm{E}-09 \\
& 7.0 \mathrm{E}-06 \pm 8.0 \mathrm{E}-07 \\
&<7.0 \mathrm{E}-09\end{aligned}$ & & 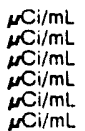 \\
\hline
\end{tabular}

WELL IDQ 4

MEASUREMENTS CONDUCTED IN THE FIELD

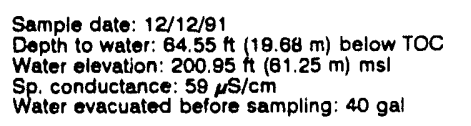

Time: $15: 10$

Alkalinity: $24 \mathrm{mg} / \mathrm{L}$

Water temperature: $18.9^{\circ} \mathrm{C}$

Water evacuated before sampling: $40 \mathrm{gal}$

LABORATORY ANALYSES

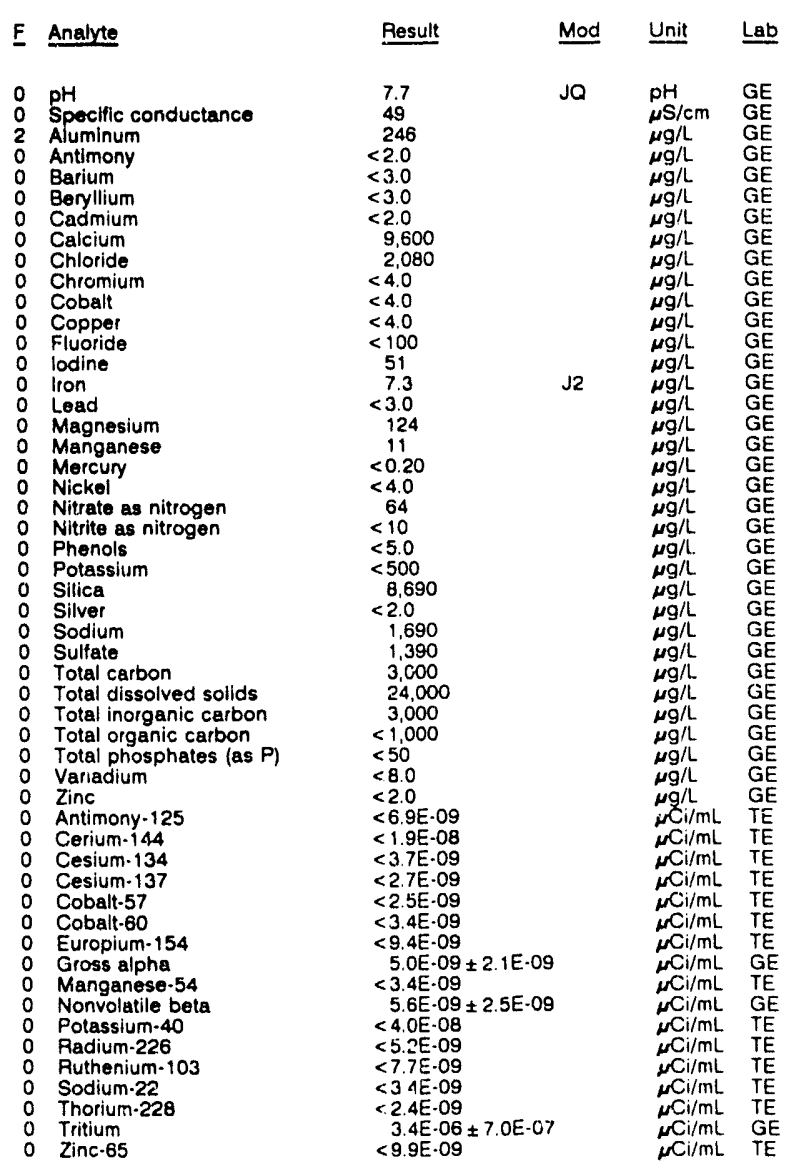

\section{WELL IDQ 4 Replicate}

MEASUREMENTS CONDUCTED IN THE FIELD

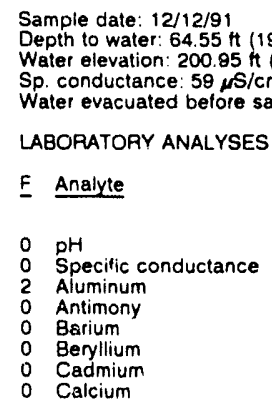

Time, $15: 10$

Alkalinity: $24 \mathrm{mg}$

Water temperature $18.9^{\circ} \mathrm{C}$

Water evacuated before sampling $40 \mathrm{gal}$

LABORATORY ANALYSES

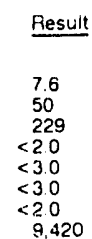

WELL IDO 4 collected on 12/12/91, laboratory analyses (cont.)

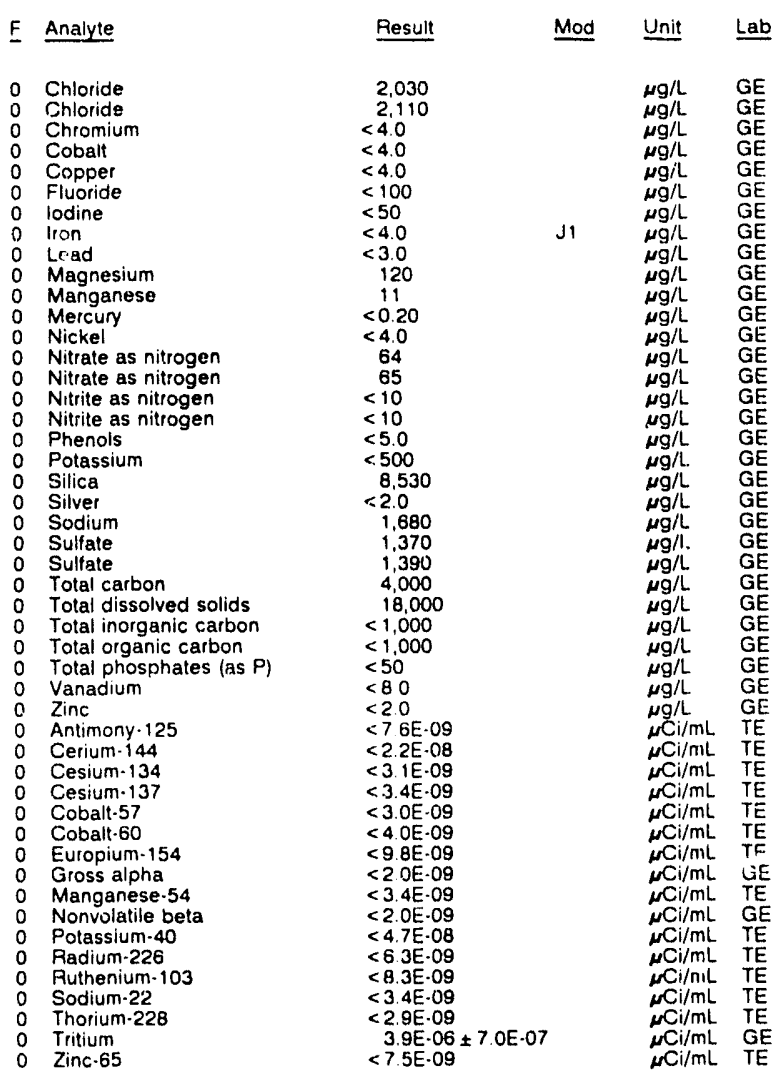

\section{WELL IDQ 5}

MEASUREMENTS CONDUCTED IN THE FIELD

Sample date: $12 / 13 / 91$

Depth to water: $69.57 \mathrm{ft}(21.21 \mathrm{~m})$ below TOC

Water elevation: $197.63 \mathrm{ft}(60.24 \mathrm{~m}) \mathrm{ms}$ :

Sp. conductance: $33 \mu \mathrm{s} / \mathrm{cm}$

Water evacuated before sampling: $5 \mathrm{gal}$

The well went dry during purging

LABORATORY ANALYSES

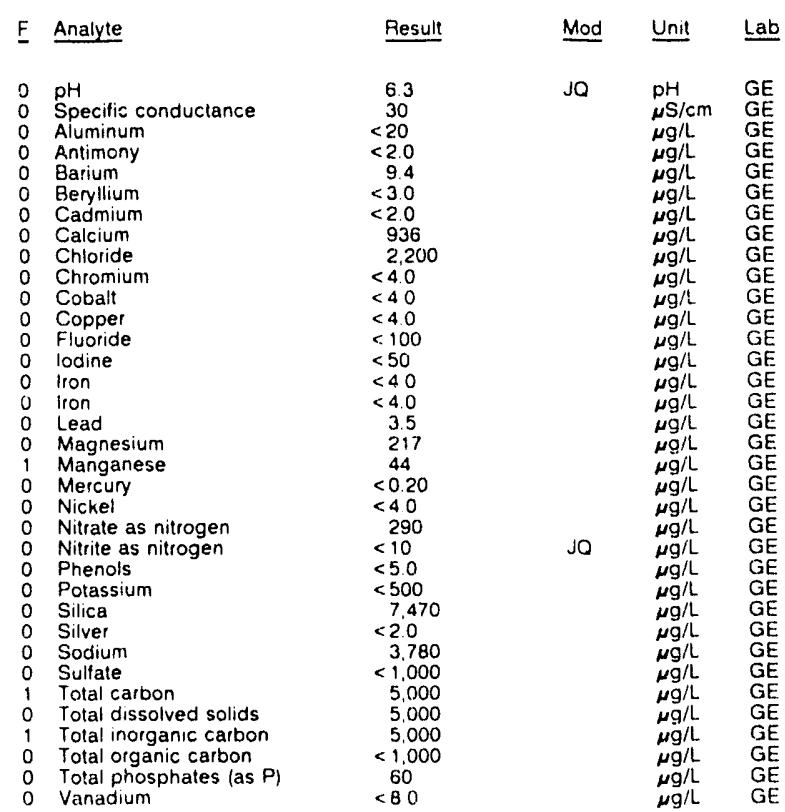


ANALYTICAL RESULTS

WELL IDO 5 collected on 12/13/91, laboratory analyses (cont)

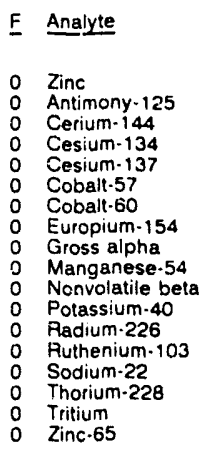

Result

Mod

$\begin{aligned} & 317 \\ &<7.6 E \cdot 09 \\ &<2.7 E \cdot 08 \\ &<3.2 E \cdot 09 \\ &<2.7 E \cdot 09 \\ &<3.5 E \cdot 09 \\ &<3.0 E \cdot 09 \\ &<8.5 E \cdot 09 \\ &<2.0 E \cdot 09 \\ &<3.3 E \cdot 09 \\ &<2.0 E-09 \\ &<37 \mathrm{E} \cdot 08 \\ &<5.9 \mathrm{E} \cdot 09 \\ &<9.0 \mathrm{E}-09 \\ &<3.1 \mathrm{E} \cdot 09 \\ &<3.2 \mathrm{E} \cdot 09 \\ & 8.6 \mathrm{E} \cdot 06 \pm 8.0 \mathrm{C} \cdot 07 \\ &<7.0 \mathrm{E} \cdot 09\end{aligned}$

Unit $\underline{\text { Lab }}$

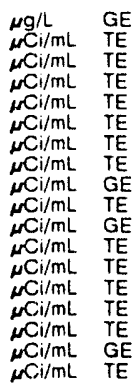

WELL IDQ 6

MEASUREMENTS CONDUCTED IN THE FIELD

Sampie date: $12 / 13 / 91$

Depth to water: $61.92 \mathrm{ft}(18.87 \mathrm{~m})$ below TOC

Water elevation: $196.18 \mathrm{ht}(59.80 \mathrm{~m}) \mathrm{ms}$

Sp. conductance: $490 \mu \mathrm{S} / \mathrm{cm}$

The well went dn during pumpling: $8 \mathrm{gal}$

LABORATORY ANALYSES

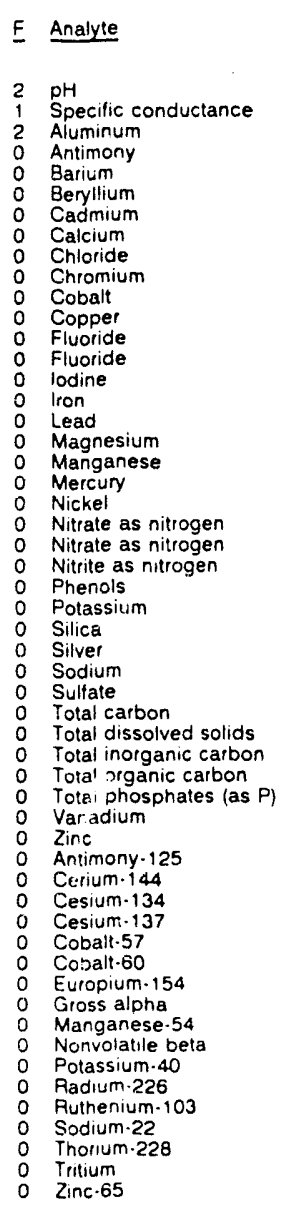

Time: $12: 40$
pH: 11.5
Alkalinity: $128 \mathrm{mg} / \mathrm{h}$
Water temperature $182^{\circ} \mathrm{C}$

6.960
3.920

124,000

1,000
1,000

$<0$
27

27
20
$<71 E .09$

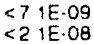

$<3$ OE. 09

$<2.9 E \cdot 09$

$<2.7 \mathrm{E} .09$

$<$ GE.09
$<.09$

$<7$ GE.09

$<29 \mathrm{E} .09$

$<2.0 E .09$

$<57 \mathrm{C} .09$

$<8.2 \mathrm{E} .09$

$<2$ BE. 09

$<2$ BE. 09
6 OE. $06 \pm 7$ OE. 07

6 OE. O6
$<7$ OE. 09
WELL IDQ 7

MEASUREMENTS CONDUCTED IN THE FIELD

$\begin{array}{ll}\text { Sample date. } 12 / 13 / 91 & \text { Time: } 12.20 \\ \text { Depth n water } 51.89 \mathrm{ft}(15.82 \mathrm{~m}) \text { below TOC } & \text { pH: } 7.3 \\ \text { Water elevation. } 188.71 \mathrm{H}(57.52 \mathrm{~m}) \mathrm{msl} & \text { Alkalinity. } 83 \mathrm{mg} / \mathrm{L} \\ \text { Sp. conductance: } 193 \mu \mathrm{S} / \mathrm{cm} & \text { Water temperature } 18.4^{\circ} \mathrm{C} \\ \text { Water evacuated before sampling } 7 \mathrm{gal} & \\ \text { The well went dry during purging } & \end{array}$

LABORATORY ANALYSES

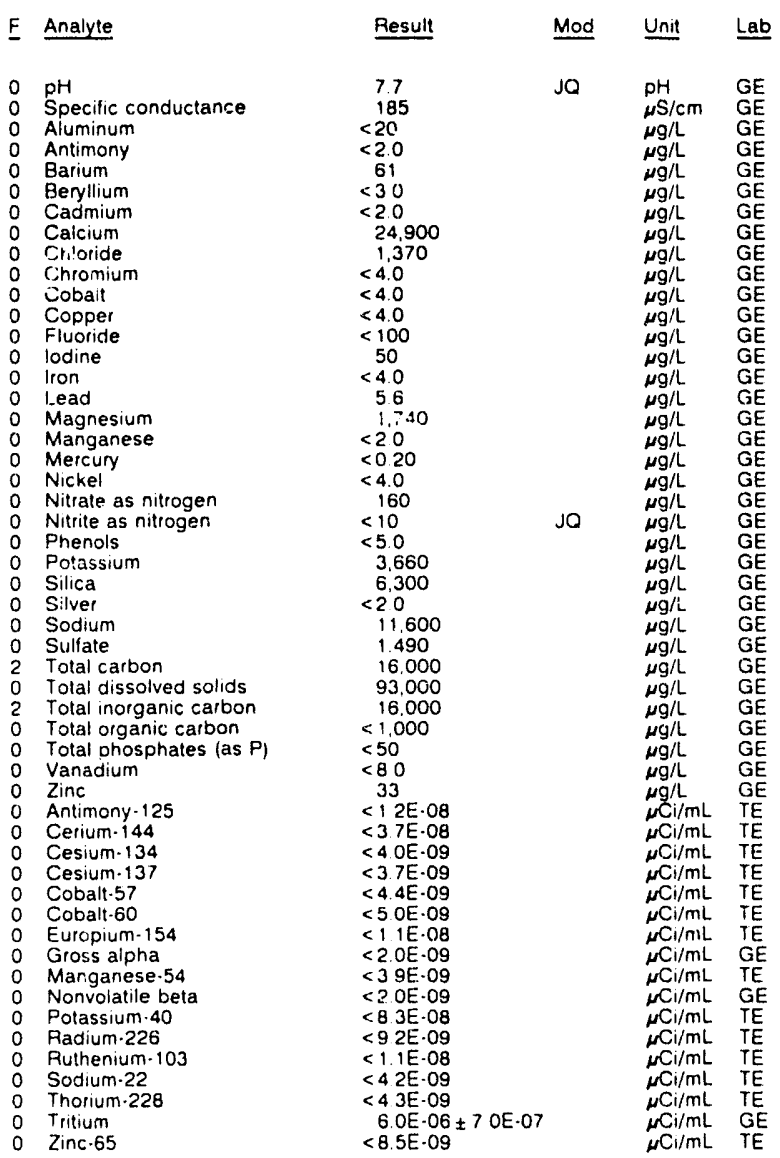

\section{WELL IDQ 8}

MEASUREMENTS CONDUCTED IN THE FIELD
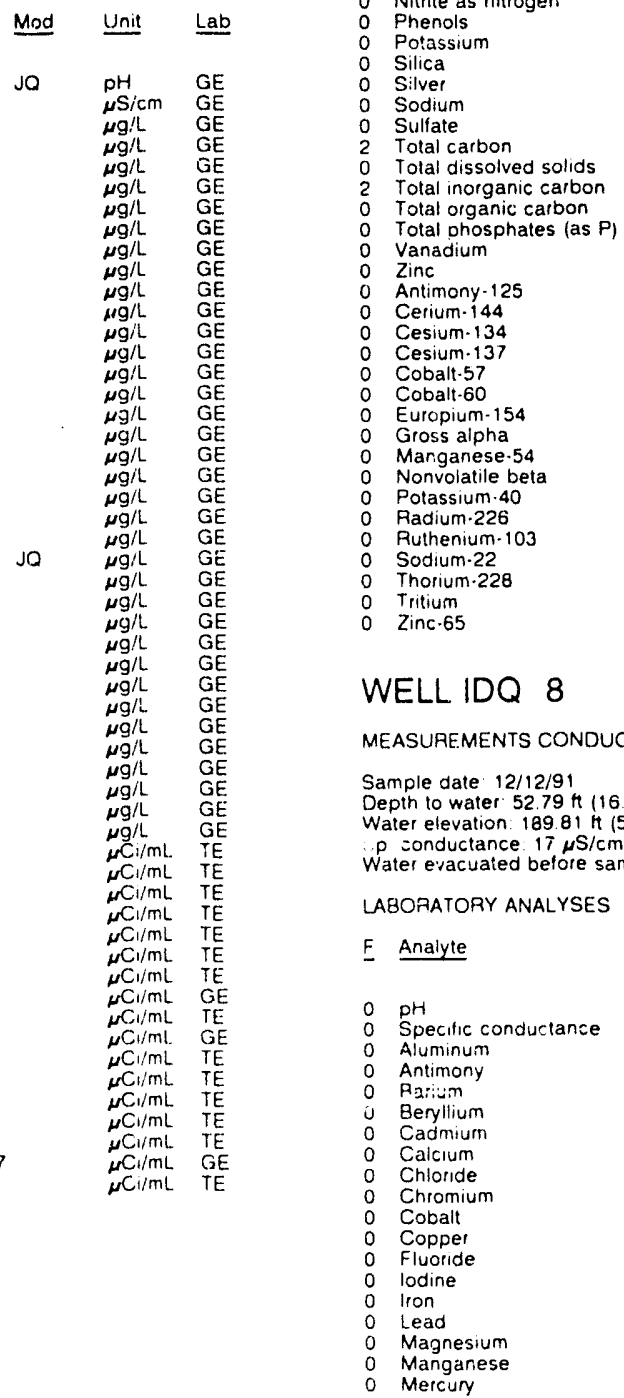

$6.0 E .06$
$<8.5 E .09$

ab
GE
$G E$
$G E$
$G E$
$G E$
$G E$
$G E$
$G E$
$G E$
$G E$
$G E$
$G E$
$G E$
$G E$
$G E$
$G E$
$G E$
$G E$
$G E$
$G E$
$G E$
$G E$
$G E$
$G E$
$G E$
$G E$
$G E$
$G E$
$G E$
$G E$
$G E$
$G E$
$G E$
$G E$
$G E$
$T E$
$E$
$E E$
$G E$
$G E$
$G E$
$G E$
$G E$
$E E$
$G E$
$G E$
$T E$
$G E$
$G E$

Alkalinity. $83 \mathrm{mg} / \mathrm{L}$

(1)

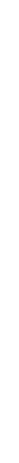


ANALYTICAL RESULTS

WELL IDO 8 collected on 12/12/91, laboratory analyses (cont)

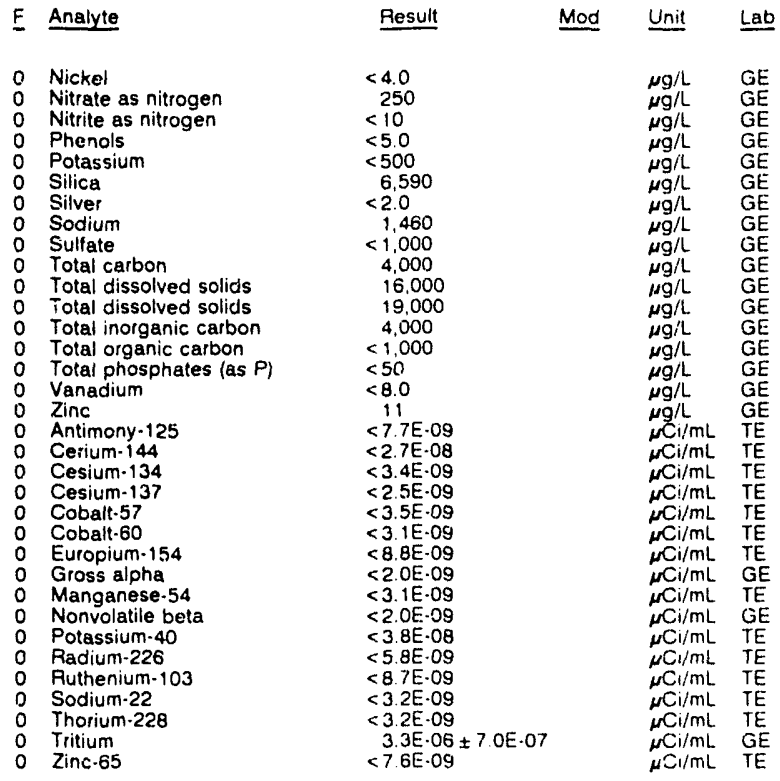

WELL IDQ 9

MEASUREMENTS CONOUCTED IN THE FIELD

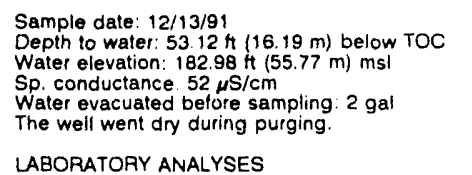

LABORATORY ANALYSES

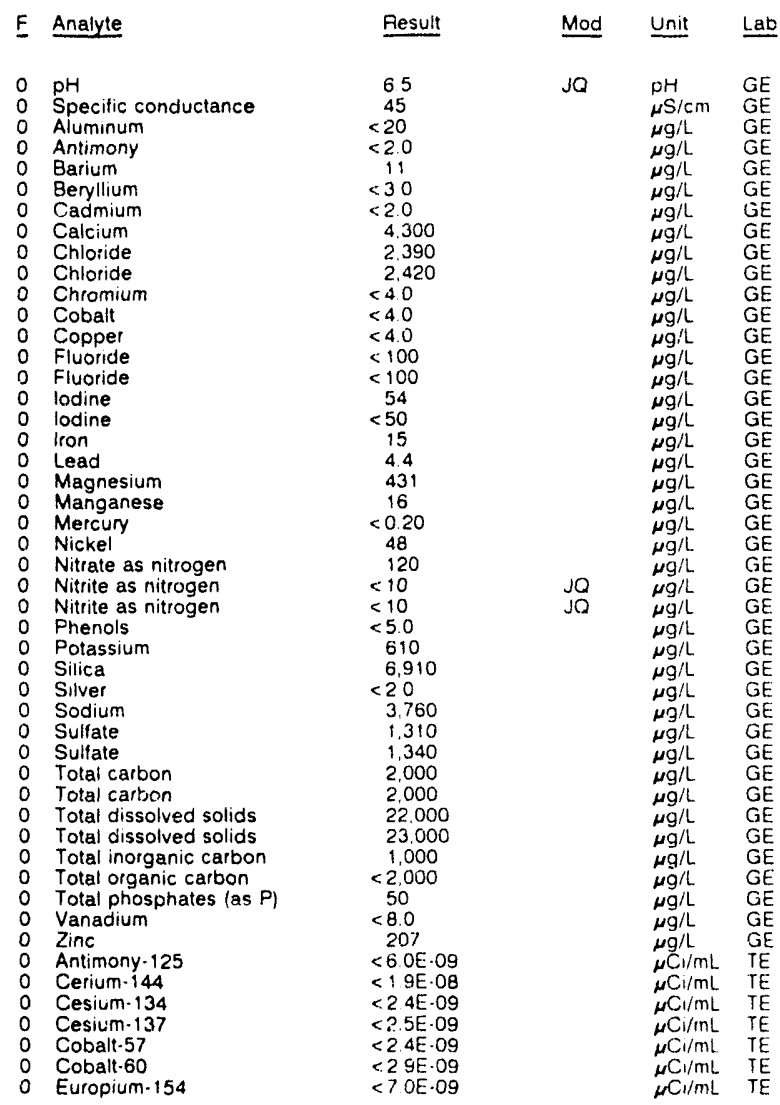

WELL IDQ 9 collected on 12/13/91, laboratory analyses (cont.)

\begin{tabular}{|c|c|c|}
\hline Analyte & Result & Unit \\
\hline $\begin{array}{ll}0 & \text { Gross alpha } \\
0 & \text { Manganese-54 } \\
0 & \text { Nonvolatile beta } \\
0 & \text { Potassium-40 } \\
0 & \text { Radium-226 } \\
0 & \text { Ruthenium-103 } \\
0 & \text { Sodium-22 } \\
0 & \text { Thorium }-228 \\
0 & \text { Total activity } \\
0 & \text { Tritium } \\
0 & \text { Zinc-65 }\end{array}$ & $\begin{aligned} & 2.7 \mathrm{E} \cdot 09 \pm 1.8 \mathrm{E} \cdot 09 \\
&<23 \mathrm{E} \cdot 09 \\
&<23 \mathrm{OE} \cdot 09 \\
&<3.7 \mathrm{E} \cdot 08 \\
&<5.1 \mathrm{E} \cdot 09 \\
&<7.2 \mathrm{E} \cdot 09 \\
&<2.5 \mathrm{E} \cdot 09 \\
&<2.5 \mathrm{E} \cdot 09 \\
& 4.1 \mathrm{E} \cdot 06 \pm 1.4 \mathrm{E} \cdot 06 \\
& 5.8 \mathrm{E} \cdot 06 \pm 7.0 \mathrm{E} \cdot 07 \\
& \therefore 63 \mathrm{E} \cdot 09\end{aligned}$ & 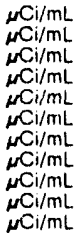 \\
\hline
\end{tabular}

WELL IDQ 10

MEASUREMENTS CONDUCTED IN THE FIELD

Sample dale: $12 / 13191$

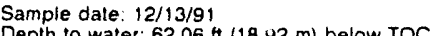

Water elevation: $17.06 \mathrm{H}(18.92 \mathrm{~m}) \mathrm{be}$ (O) $\mathrm{TOC}$

Water temperature $Q \because<\mathrm{C}$

The weil went dry during purging: 5 gat

LABORATORY ANALYSES

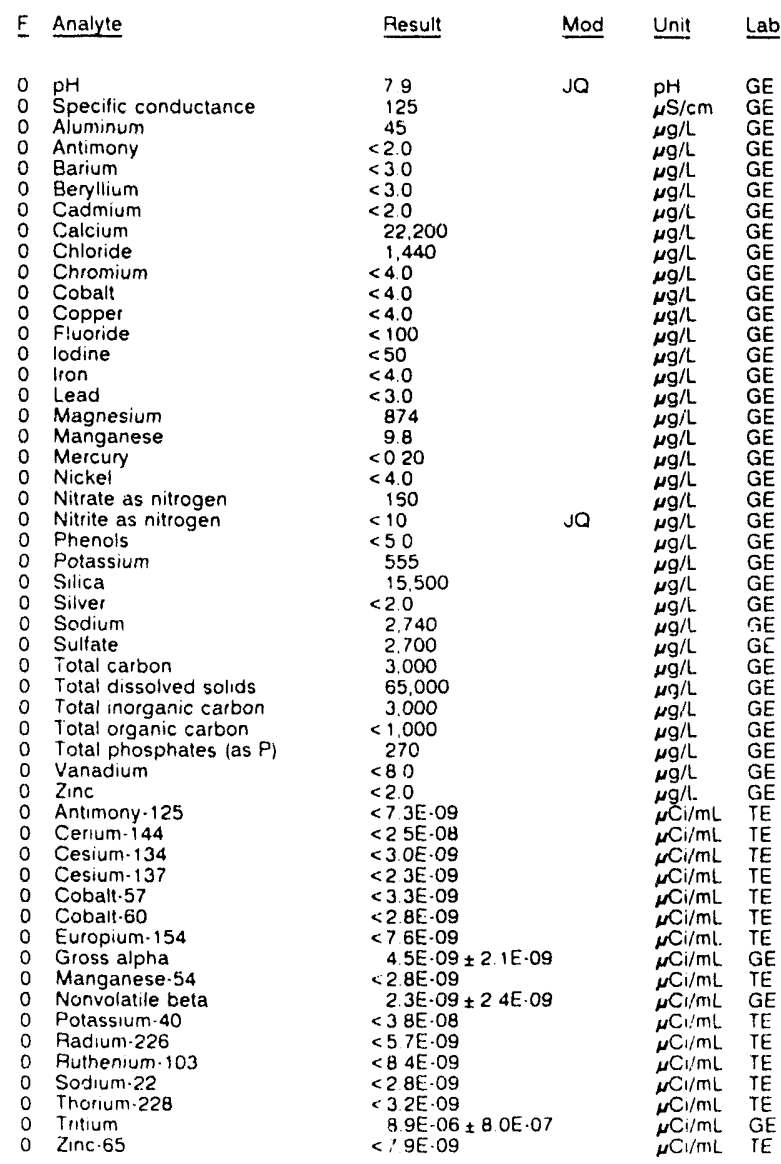

WELL IDQ 11

MEASUREMENTS CONDUCTEO IN THE FIELD

Sampis date $12 / 12 / 91$ Time 1645

Depth to wa

Inaccessibility or pump lailure prevented santple collection 
ANALYTICAL RESULTS

WELLL IDQ 12

MEASUREMENTS CONOUCTED IN THE FIELO Sample date: $12 / 12 / 91$
Depth to water: $53.45 \mathrm{H}(16.29 \mathrm{~m})$ below TOC
Water glevation: $188.75 \mathrm{ft}(57.53 \mathrm{~m})$ misl

Sp. conductance: $17 \mu \mathrm{S} / \mathrm{cm}$
Water evacuated before sampling: $63 \mathrm{gal}$

LABORATORY ANALYSES

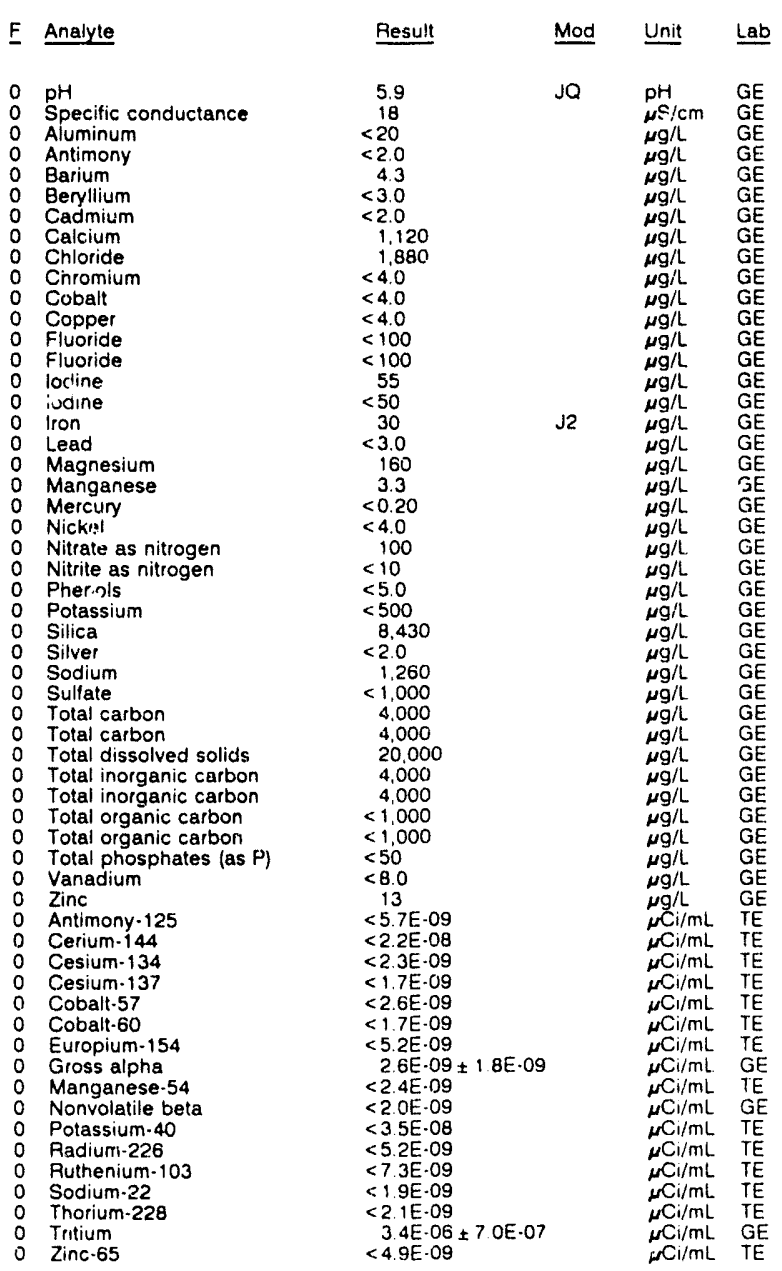

\section{WELL K 301P}

MEASUREMENTS CONDUCTED IN THE FIELD

Sample date: 10/24/91

(10. $55.26 \mathrm{ft}(16.84 \mathrm{~m})$ below TOC

Water elevation: $208.04 \mathrm{H}(63.41 \mathrm{~m}) \mathrm{ms}$

Sp conductance $80 \mu \mathrm{S} / \mathrm{cm}$

Water evacuated before samplirig: $8 \mathrm{gal}$

LARORATORY ANALYSES

\begin{tabular}{|c|c|c|}
\hline Analute & Result & Unit \\
\hline $\begin{array}{l}\text { Antimony-125 } \\
\text { Cerium-144 } \\
\text { Cesium-134 } \\
\text { Cesium-137 } \\
\text { C-romium-51 } \\
\text { Cobait-60 } \\
\text { lodine-13! } \\
\text { Niobium-95 } \\
\text { Ruthenium-103 } \\
\text { Ruthenium-106 } \\
\text { Strontium-89/90 } \\
\text { Tritium } \\
\text { Tritium } \\
\text { Zirconium-95 }\end{array}$ & $\begin{array}{l}<4.1 \mathrm{E} \cdot 08 \\
<1.1 \mathrm{E} \cdot 07 \\
<1.7 \mathrm{E} \cdot 08 \\
<2.4 \mathrm{E} \cdot 08 \\
<1.4 \mathrm{E} \cdot 06 \\
<2.2 \mathrm{E} \cdot 08 \\
<6.1 \mathrm{E} \cdot 05 \\
<1.0 \mathrm{OE} \cdot 07 \\
<7.9 \mathrm{E} \cdot 08 \\
<2.1 \mathrm{E} \cdot 07 \\
1.2 \mathrm{E} \cdot 10 \pm 14 \mathrm{AE} \cdot 09 \\
2.4 \mathrm{E} \cdot 05 \pm 1.0 \mathrm{E} \cdot 06 \\
3.0 \mathrm{E} \cdot 05 \pm 1.6 \mathrm{E} \cdot 06 \\
<78 \mathrm{E} \cdot 08\end{array}$ & 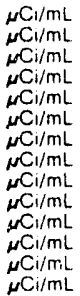 \\
\hline
\end{tabular}

Time: 15.50

Alkalinity: $3 \mathrm{mg} / \mathrm{L}$

Water temperature: $18.6^{\circ} \mathrm{O}$
WELL K 301P

MEASUREMENTS CONDUCTED IN THE FIELD

Sampie date: $11 / 20 / 91$

Depth to water: $55.39 \mathrm{ft}(16.88 \mathrm{~m})$ below TOC

Water elevation: $207.91 \mathrm{ft}(63.37 \mathrm{~m}) \mathrm{msl}$

Sp. conductance: $51 \mu \mathrm{S} / \mathrm{cm}$

Time: $5: 20$

Water evacuated before sampling: $8 \mathrm{gal}$

LABORATORY ANALYSES

\begin{tabular}{|c|c|c|}
\hline Analyte & Result & Unit \\
\hline $\begin{array}{l}\text { Aluminum } \\
\text { Antimony-125 } \\
\text { Cerium-144 } \\
\text { Cesium-134 } \\
\text { Cesium-137 } \\
\text { Chromium-51 } \\
\text { Cobalt-60 } \\
\text { lodine-131 } \\
\text { Niobium-95 } \\
\text { Ruthenium-103 } \\
\text { Ruthenium-106 } \\
\text { Tritium } \\
\text { Tritium } \\
\text { Zirconium-95 }\end{array}$ & $\begin{array}{l}<20 \\
<4.0 \mathrm{E} \cdot 08 \\
<1.1 \mathrm{E} \cdot 07 \\
<1.3 \mathrm{E} \cdot 08 \\
<1.3 \mathrm{E} \cdot 08 \\
<6.3 \mathrm{E} \cdot 07 \\
<1.6 \mathrm{E} \cdot 08 \\
<5.8 \mathrm{E} \cdot 08 \\
<4.8 \mathrm{E} \cdot 08 \\
<4.4 \mathrm{E} \cdot 08 \\
<1.3 \mathrm{E} \cdot 07 \\
3.2 \mathrm{E} \cdot 05 \pm 1.1 \mathrm{E} \cdot 06 \\
3.5 \mathrm{E} \cdot 05 \pm 1.5 \mathrm{E} \cdot 06 \\
<4.4 \mathrm{E} \cdot 08\end{array}$ & $\begin{array}{l}\mu g / \mathrm{L} \\
\mu \mathrm{i} / \mathrm{mL} \\
\mu \mathrm{Ci} / \mathrm{mL} \\
\mu \mathrm{C} / \mathrm{mL} \\
\mu \mathrm{Ci} / \mathrm{mL} \\
\mu \mathrm{Ci} / \mathrm{mL} \\
\mu \mathrm{Ci} / \mathrm{mL} \\
\mu \mathrm{Ci} / \mathrm{mL} \\
\mu \mathrm{Ci} / \mathrm{mL} \\
\mu \mathrm{Ci} / \mathrm{mL} \\
\mu \mathrm{Ci} / \mathrm{mL} \\
\mu \mathrm{Ci} / \mathrm{mL} \\
\mu \mathrm{Ci} / \mathrm{mL} \\
\mu \mathrm{Ci} / \mathrm{mL}\end{array}$ \\
\hline
\end{tabular}

WELL. K 301P

MEASUREMENTS CONDUCTED IN THE FIELD

Sample date: $12 / 13 / 91$

Depth to water: 54 \& i f $(16.58 \mathrm{~m})$ below TOC

Water elevation: $208.89 \mathrm{H}(63.67 \mathrm{~m}) \mathrm{msl}$

Water evacuated before sampling: 9 gat

LABORATORY ANALYSES

F Analyte

Result Mod Unit Lab

Antimony -125

0 Cesium-134

o Cesium-137

o Chromium.51

0 Cobalt-60

o lodine-131

Niobium 95

$\begin{array}{ll}0 & \text { Ruthenium-103 } \\ 0 & \text { Ruthenium-106 }\end{array}$

0 Ruthen

2 Tritium

0 Zirconium.95

Time: $18: 00$

Alkalinity: $14 \mathrm{mg} / \mathrm{L}$

Water temperature: $21.0^{\circ} \mathrm{C}$

WELL KAB 1

MEASUREMENTS CONDUCTED IN THE FIELD

Sample date 11/21/91

Depth to water: $57.50 \mathrm{ft}(17.53 \mathrm{~m})$ below TOC Water elevation: $208.50 \mathrm{ft}(63.55 \mathrm{~m}) \mathrm{ms}$ |

Sp conductance. $294 \mu \mathrm{S} / \mathrm{cm}$

$400 \mathrm{mg} / \mathrm{L} \quad \mathrm{GE}$

$<5.0 E \cdot 08$
$<1.0 E \cdot 07$

$<1,9 \mathrm{E} \cdot 08$

$<2.1 \mathrm{E} .08$
$<4.3 \mathrm{E} .07$

$<2.2 \mathrm{E} \cdot 08$
$<9.8 \mathrm{E}-07$

$<12 \mathrm{E} \cdot 08$

$<3.9 \mathrm{E} \cdot 08$

$4.0 E-05 \pm 1.2 E \cdot 06$

$4.0 E-05 \pm 1.2 E \cdot 06$
$3.4 E-05 \pm 1.5 E \cdot 06$

${ }_{\mu \mathrm{C} i / m L} \mathrm{EM}$

$M \mathrm{Ci} / \mathrm{mL}$ EM

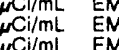

$\underset{\mu C \mathrm{C} i / \mathrm{mL}}{\mathrm{N}} \mathrm{EM}$

$\mathrm{NCi} / \mathrm{mL}$ EM

$\mu \mathrm{Ci} / \mathrm{mL}$ EM

$\mathrm{NCi/mL}$ GE

$\mu \mathrm{Ci} / \mathrm{mL} \quad \mathrm{EM}$

ater evacuated before sampling: $22 \mathrm{gal}$

PH. 5.7 : $16 \mathrm{mg}$

Water temperature: $21.8^{\circ} \mathrm{C}$

\section{WELL KAB 2}

MEASUREMENTS CONDUCTED IN THE FIELD

Sample date $11 / 21 / 91$

Depth 10 water: 41

Water elevation: $219.51 \mathrm{ft}(66.91 \mathrm{~m}) \mathrm{ms}$

Water evacuated belore sampling $39 \mathrm{gal}$
Wature

pti: 5.3

Water temperature: $21.5^{\circ} \mathrm{C}$

WELL KAB 3

MEASUREMENTS CONDUCTED IN THE FIELD

Depth to water $42.85 \mathrm{ft}(13.06 \mathrm{~m})$ below TOC

Water elevation: $207.25 \mathrm{ft}(63.17 \mathrm{~m}) \mathrm{msl}$

ductance $119 \mu \mathrm{S} / \mathrm{cm}$

PH. 5.2

Water temperature: $19.5^{\circ} \mathrm{C}$ 
WELL KAB 4

MEASUREMENTS CONDUCTED IN THE FIELD

Sample date: $11 / 21 / 91$
Depth to water: $48.87 \mathrm{Ht}(14.90 \mathrm{~m})$ below TOC
Water elevation: $205.53 \mathrm{ft}(62.65 \mathrm{~m}) \mathrm{ms}$
Sp. conductance: $615 \mu \mathrm{S} / \mathrm{cm}$

Water evacuated before sampling: $49 \mathrm{gal}$

WELL KAC 1

MEASUREMENTS CONDUCTED IN THE FIELO

Sample date: $11 / 18 / 91$

Depth to water: $44.17 \mathrm{H}(13.46 \mathrm{~m})$ below TOC

Water elevation: $22183 \mathrm{ft} / 67.6$
Sp. conductance: $313 \mu \mathrm{S} / \mathrm{cm}$

Sp. conductance: $313 \mu \mathrm{S} / \mathrm{cm}$
Water evacuated before sampling $60 \mathrm{gal}$

LABORATORY ANALYSES

\begin{tabular}{|c|c|c|}
\hline$\underline{F}$ & Analyte & Result \\
\hline & $\mathrm{pH}$ & 60 \\
\hline & Specific conductance & 310 \\
\hline & Turbidity & 2.8 \\
\hline & $\begin{array}{l}\text { Acenaphthene } \\
\text { Acenaphthylene }\end{array}$ & $\begin{array}{l}<10 \\
<10\end{array}$ \\
\hline & $\begin{array}{l}\text { Aldrin } \\
\text { Alde }\end{array}$ & $\begin{array}{l}<10 \\
<i 0\end{array}$ \\
\hline & Aluminum & $<20$ \\
\hline & Anthracene & $<10$ \\
\hline & Antimony & $<2.0$ \\
\hline & Arsenic & $<2.0$ \\
\hline & Barium & $<3.0$ \\
\hline & Benzene & $<1.0$ \\
\hline & alpha-Benzene hexachloride & $<10$ \\
\hline & beta-Benzene hexachloride & $<10$ \\
\hline & $\begin{array}{l}\text { aera-benzene nexacniomate } \\
\text { Benzidine }\end{array}$ & $\begin{array}{l}<10 \\
<10\end{array}$ \\
\hline & Benzola\}anthracene & $<10$ \\
\hline & Benzola pyrene & $<10$ \\
\hline & Berizo(b) fluoranthene & $<10$ \\
\hline & 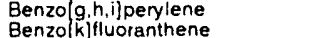 & $\begin{array}{l}<10 \\
<10\end{array}$ \\
\hline & Beryllium & $<30$ \\
\hline & Bis (2-chloroethoxy) methane & $<10$ \\
\hline & Bis (2-chloroethyl) e ier & $<10$ \\
\hline $\begin{array}{l}0 \\
0\end{array}$ & Bis (2-chloroisof:upyl) ether & $<10$ \\
\hline $\begin{array}{l}0 \\
0\end{array}$ & $\begin{array}{l}\text { Bis (2-ethylhexyl) phthalate } \\
\text { Bromide }\end{array}$ & $\begin{array}{l}<10 \\
<1000\end{array}$ \\
\hline & Bromide & $<1,000$ \\
\hline 0 & Bromodichloromiethane & $<10$ \\
\hline & Bromotorm & $\therefore 1.0$ \\
\hline $\begin{array}{l}0 \\
0\end{array}$ & Bromomethane & $<1.0$ \\
\hline 0 & 4.8romophenyl phenyl ether & $<10$ \\
\hline 0 & $\begin{array}{l}\text { Butylbenzyl phthalate } \\
\text { Cadmium }\end{array}$ & $\begin{array}{l}<10 \\
<20\end{array}$ \\
\hline 0 & Calcium & 165 \\
\hline 0 & Carbon tetrachioride & $<10$ \\
\hline 0 & Chlordane & $<10$ \\
\hline & Chloride & 13100 \\
\hline 0 & para-Chloro-meta-cresol & $<10$ \\
\hline 0 & Chlorobenzene & $<10$ \\
\hline 0 & Chloroethane & $<10$ \\
\hline 0 & Chloroethene (Vinyl chloride) & $<1.0$ \\
\hline 0 & 2. Chloroethyi vinyl ether & $<10$ \\
\hline 0 & Chlorotorm & $<1.0$ \\
\hline 0 & Chloromethane & $<1.0$ \\
\hline 0 & 2.Chtoronaphthalene & $<10$ \\
\hline 0 & 2-Chiorophenal & $<10$ \\
\hline & 4. Chlorophenyl phenyl ethe: & $<10$ \\
\hline & Chromium & $<4.0$ \\
\hline 0 & Chrysene & $<10$ \\
\hline 0 & Cobalt & $<40$ \\
\hline 0 & Coppe: & 14 \\
\hline 0 & Cyanide & $<5.0$ \\
\hline 0 & $p, p^{\prime} \cdot D D D$ & $<10$ \\
\hline 0 & p.p.ODE & $<10$ \\
\hline 0 & p.p'-DOT & $<10$ \\
\hline 0 & Di-n-butyl phthalate & $<10$ \\
\hline 0 & Di.n-octyl phthalate & $<10$ \\
\hline 0 & Dibenz $[a, h]$ anthracene & $<10$ \\
\hline 0 & Dibromochloromethane & $<10$ \\
\hline 0 & 3,3-Dichiorobenzidine & $<10$ \\
\hline 0 & 1.1-Dichioroethane & $<10$ \\
\hline 0 & 1.2-Dichloroethane & $<10$ \\
\hline 0 & 1.1.Dichloroethylene & $<10$ \\
\hline 0 & t:ans-1,2-Dichloroethylene & $<1.0$ \\
\hline 0 & Dichloromethane & 1.0 \\
\hline 0 & 2,4. Dichlorophenol & $<10$ \\
\hline 0 & 2,4. Dichlorophenoxyacetic acid & $<0.30$ \\
\hline 0 & 1,2-Dichloropropane & $<10$ \\
\hline 0 & cis-1.3-Dichloropropene & $<10$ \\
\hline 0 & trans-1,3-Dichloropropene & $<10$ \\
\hline 0 & Dieldrin & $<10^{\circ}$ \\
\hline 0 & Dietryl phthaia & $<10$ \\
\hline 0 & 2,4. Dimethyl phenol & $<10$ \\
\hline
\end{tabular}

Time: 1050

PH: 6.8

Water temperature: $21.1^{\circ} \mathrm{C}$

Time: $12: 40$
pH: 5.7

Alkalinity: $13 \mathrm{mg} / \mathrm{h}$

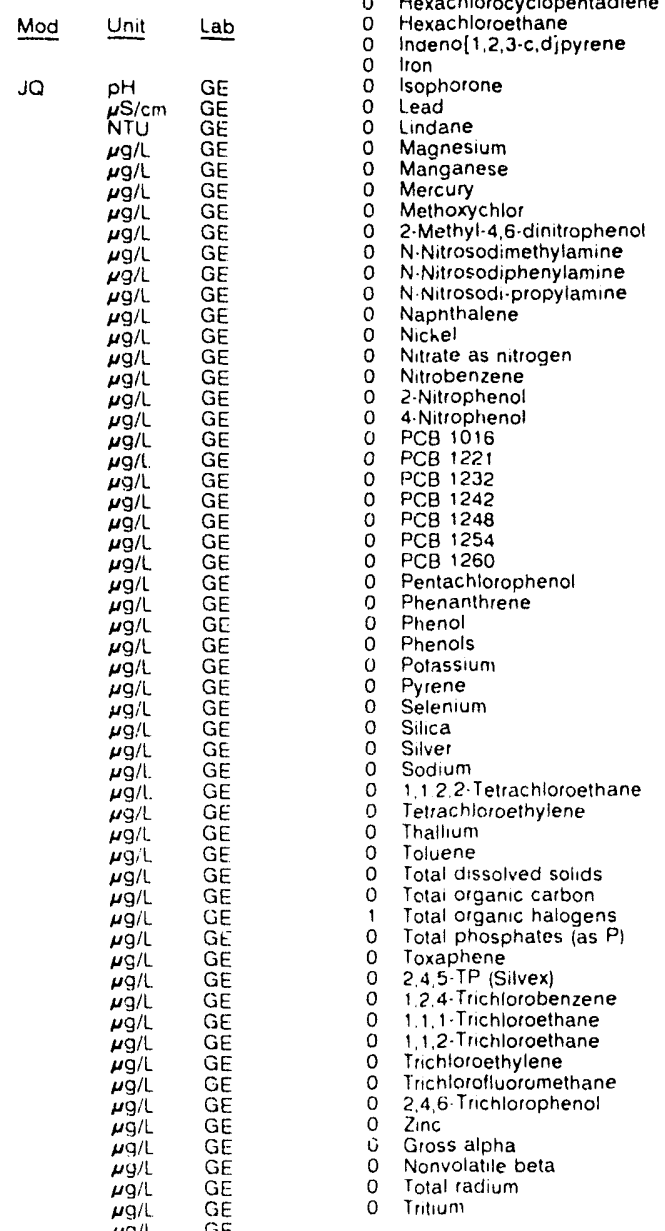

0 Dimethyl phthalate

2,4.Dinitrophenol

$\begin{array}{ll}0 & 2,6 \cdot \text { - Dnitrotoluene } \\ 0 & 1,2 \cdot \text { Diphenylhydrazine }\end{array}$

0 Endosulfan

O Endosulfan "I

O Endrin

0 Endrin aldehyde

$\begin{array}{ll}0 & \text { Ethylbenzene } \\ 0 & \text { Fluoranthene }\end{array}$

F Fluorene

0 Fluoride

Hexachlorocyclopentadiene

Hexachloroethane

0 Lead

Lindane

2.Methyl-46-dinitropheno

N.Nitrosodimethylamine

sodiphenylamin
WELL KAC I collected on 11/18/91, laboratory analyses (cont.)

E Analyte Result Mod Unit Lab

$\begin{aligned}< & <100\end{aligned}$

0 Heptachlor epoxide $\quad<10$

O Hexachlorobenzene $<10$

$<10$
$<45$

$<45$
$<10$
$<10$

$<10$
$<10$

$<10$
$<10$
$<10$

$<10$

$<10$
$<10$

$<10$
$<10$

$<10$
$<10$

$<10$
22

$<10$
32

30
24

2.1
$<0.20$

$<10$

$<10$

$<10$

$<10$
$<10$

$<4.0$

$<10$
$<10$

$<10$

$<150$

$<150$
$<150$

$<150$

$<150$

$<150$
$<10$

$<10$
$<10$

$<10$
$<50$
$<500$

$<500$
$<20$

$<2.0$
5.940
$<20$

$<2.0$
57,200

$<10$

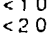

$<20$
$<10$
1186

186,000
$<1.000$

35
35

$<50$

$<0090$

$<10$

$<10$

$<10$
$<10$

$<10$

89
$25 \mathrm{E} \cdot 09+13 \mathrm{E} \cdot 09$

उE.0B 22 2E.09

$<1$ OE. 09

3 JE. $06 \pm 7$ OE -07

WELL KAC 1 Replicate

MEASUAEMENTS CONDUCTED IN THE FIELD

Sample date 11/18/91

Depth to water $44.17 \mathrm{Ht}(1346 \mathrm{~m})$ below IOS

Water elevation $22183 \mathrm{H}(67.61 \mathrm{~m}) \mathrm{msl}$

Sp conductance $313 \mu \mathrm{s} / \mathrm{cm}$

Alalinity $13 \mathrm{mg} / \mathrm{L}$

Water evacuated before sampling 60 gat

LABORATORY ANALYSES

\begin{tabular}{|c|c|c|c|}
\hline Analyte & Result & Mod & Unit \\
\hline $\begin{array}{l}\text { pH } \\
\text { Specific conductance } \\
\text { Turbidity } \\
\text { Acenaphthene } \\
\text { Acenaphthylene } \\
\text { Aldrun }\end{array}$ & $\begin{aligned} & 60 \\
& 295 \\
& 33 \\
&<10 \\
&<10 \\
&< 10\end{aligned}$ & JQ & $\begin{array}{l}\mathrm{pH} \\
\mu S / \mathrm{cm} \\
\text { NTU } \\
\mu g / \mathrm{l} \\
\mu \mathrm{g} / \mathrm{L}\end{array}$ \\
\hline
\end{tabular}


WELL KAC I collected on 11/18/91, laboratory analyses (cont.)

\begin{tabular}{|c|c|c|c|c|c|c|}
\hline Analyte & Result & Mod & Unit & $\underline{\text { Lab }}$ & $\underline{F}$ & Analyte \\
\hline 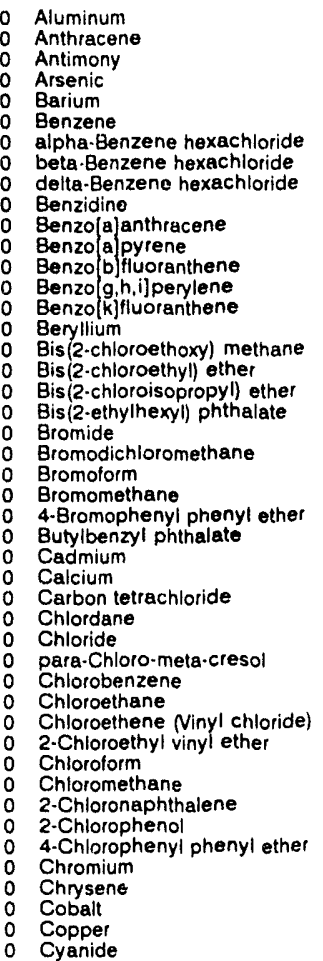 & $\begin{array}{l}<20 \\
<10 \\
2.4 \\
<2.0 \\
<3.0 \\
<1.0 \\
<10 \\
<10 \\
<10 \\
<10 \\
<10 \\
<10 \\
<10 \\
<10 \\
<10 \\
<3.0 \\
<10 \\
<10 \\
<10 \\
<10 \\
<1.000 \\
<1.0 \\
<1.0 \\
<1.0 \\
<10 \\
<10 \\
<2.0 \\
162 \\
<1.0 \\
<10 \\
12,600 \\
<10 \\
<1.0 \\
<1.0 \\
<1.0 \\
<1.0 \\
<1.0 \\
<1.0 \\
<10 \\
<10 \\
<10 \\
<4.0 \\
<10 \\
<4.0 \\
15 \\
<5.0\end{array}$ & & $\begin{array}{l}\mu g, L \\
\mu g / L \\
\mu g / L \\
\mu g / L \\
\mu g / L \\
\mu g / L \\
\mu g / L \\
\mu g / L \\
\mu g / L \\
\mu g / L \\
\mu g / L \\
\mu g / L \\
\mu g / L \\
\mu g / L \\
\mu g / L \\
\mu g / L \\
\mu g / L \\
\mu g / L \\
\mu g / L \\
\mu g / L \\
\mu g / L \\
\mu g / L \\
\mu g / L \\
\mu g / L \\
\mu g / L \\
\mu g / L \\
\mu g / L \\
\mu g / L \\
\mu g / L \\
\mu g / L \\
\mu g / L \\
\mu g / L \\
\mu g / L \\
\mu g / L \\
\mu g / L \\
\mu g / L \\
\mu g / L \\
\mu g / L \\
\mu g / L \\
\mu g \\
\mu g / L \\
\mu g / L \\
\mu g / L \\
\mu g / L\end{array}$ & $\begin{array}{l}\mathrm{GE} \\
\mathrm{GE} \\
\mathrm{GE} \\
\mathrm{GE} \\
\mathrm{GE} \\
\mathrm{GE} \\
\mathrm{GE} \\
\mathrm{GE} \\
\mathrm{GE} \\
\mathrm{GE} \\
\mathrm{GE} \\
\mathrm{GE} \\
\mathrm{GE} \\
\mathrm{GE} \\
\mathrm{GE} \\
\mathrm{GE} \\
\mathrm{GE} \\
\mathrm{GE} \\
\mathrm{GE} \\
\mathrm{GE} \\
\mathrm{GE} \\
\mathrm{GE} \\
\mathrm{GE} \\
\mathrm{GE} \\
\mathrm{GE} \\
\mathrm{GE} \\
\mathrm{GE} \\
\mathrm{GE} \\
\mathrm{GE} \\
\mathrm{GE} \\
\mathrm{GE} \\
\mathrm{GE} \\
\mathrm{GE} \\
\mathrm{GE} \\
\mathrm{GE} \\
\mathrm{GE} \\
\mathrm{GE} \\
\mathrm{GE} \\
\mathrm{GE}\end{array}$ & $\begin{array}{l}0 \\
0 \\
0 \\
0 \\
0 \\
0 \\
0 \\
0 \\
0 \\
0 \\
0 \\
0 \\
0 \\
0 \\
0 \\
0 \\
0 \\
0 \\
0 \\
0 \\
0 \\
0 \\
0 \\
0 \\
0 \\
0 \\
0 \\
0 \\
0 \\
0 \\
0 \\
0 \\
0 \\
0 \\
0 \\
0 \\
0 \\
0 \\
0 \\
0 \\
0 \\
0 \\
0 \\
0 \\
0 \\
0\end{array}$ & $\begin{array}{l}\text { N-Nitrosodi-propylamine } \\
\text { Naphthalene } \\
\text { Nickel } \\
\text { Nitrate as nitrogen } \\
\text { Nitrobenzene } \\
\text { 2-Nitrophenol } \\
\text { 4-Nitrophenol } \\
\text { PCB } 1016 \\
\text { PCB } 1221 \\
\text { PCB } 1232 \\
\text { PCB } 1242 \\
\text { PCB } 1248 \\
\text { PCB } 1254 \\
\text { PCB 1260 } \\
\text { Pentachlorophenol } \\
\text { Phenanthrene } \\
\text { Phenol } \\
\text { Phenols } \\
\text { Potassium } \\
\text { Pyrene } \\
\text { Selenium } \\
\text { Silica } \\
\text { Sllver } \\
\text { Sodium } \\
1,1,2,2-\text { Tetrachloroethane } \\
\text { Tetrachloroethylene } \\
\text { Thallium } \\
\text { Toluene } \\
\text { Total dissolved solids } \\
\text { Total organic caibon } \\
\text { Total organic halogens } \\
\text { Total organic halogens } \\
\text { Total phosphates (as P) } \\
\text { Toxaphene } \\
2,4,5 \cdot \text { TP (Silvex) } \\
1,2,4-\text { Trichlorobenzene } \\
1,1,1-\text { richloroethane } \\
1,1,2-\text { Trichloroethane } \\
\text { Trichloroethylene } \\
\text { Trichlorofluoromethane } \\
2,4,6-\text { Trichlorophenol } \\
\text { Zinc } \\
\text { Gross alpha } \\
\text { Nonvolatile beta } \\
\text { Total radium } \\
\text { Tritium }\end{array}$ \\
\hline
\end{tabular}

- Cyanide

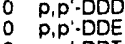

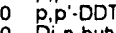

Di-n-butyl phthalate

Dibenz[a,h]anthracen

Dibromochloromethane

3,3'-Dichlorobenzidine

1,2-Dichloroethane

1,1-Dichloroethylene

o trans-1,2-Dichloroethylene

Dichloromethane

2,4.Dichlorophenoxyacetic acid

0 1

0 cis-1,3-Dichloropropene $<1.0$

trans-1,3-Dichloropropene $<1.0$

Dieidrin $<10$

24-Dimethyl phenol

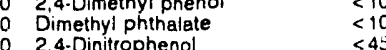

2,4-Dinitrotoluene

2.6-Dinitrotoluene

1,2-Diphenylhy

Endosulfan

Endosulfan sulfate

Endrin

Endrin aldehyde

Ethylbenzene

Fluorene

Fluoride

Fluoride

Heptachlor

Heplachlor epoxide

Hexachlorobutadiene

Hexachlorocyclopentadiene

Hexachloroethane

Indeno[1,2,3-c,d]pyrene

Iron

isophorone

Lead

Magnesium

Magnesium

Manganese

Methorychlor

2-Methyl-4,6-dinitropheno

N-Nitrosodimethylamine

N.Nitrosodimethylam: ne

0 Tritium

\section{WELL KAC 2}

Sp conduclance $368 \mu \mathrm{S} / \mathrm{cm}$

LABORATORY ANALYSES

Result Mod Unit Lab

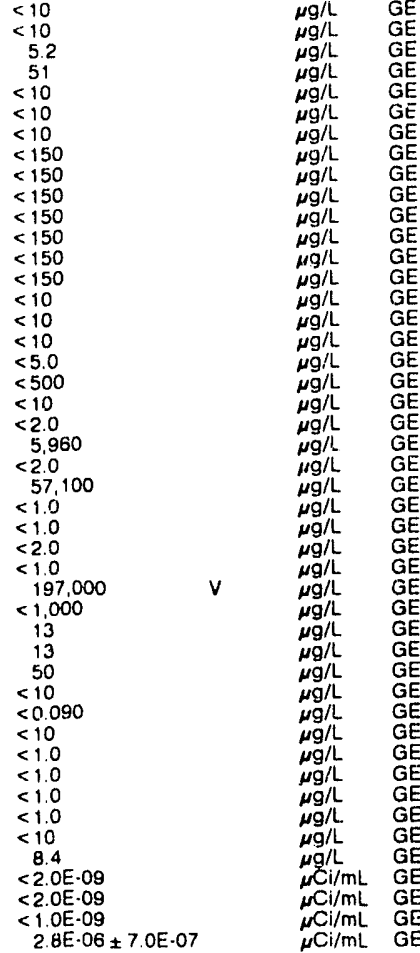

MEASUREMENTS CONDUCTED IN THE FIELD

Deptin to waler: $34.58 \mathrm{Ht}(10.54 \mathrm{~m})$ below TOC

Water elevation: $22292 \mathrm{Ht}(6795 \mathrm{~m}) \mathrm{ms}$

mpling: 72 gal

H: 5.9

Alkalinity: $23 \mathrm{mg} / \mathrm{L}$

Water temperaluse: $18.1^{\circ} \mathrm{C}$

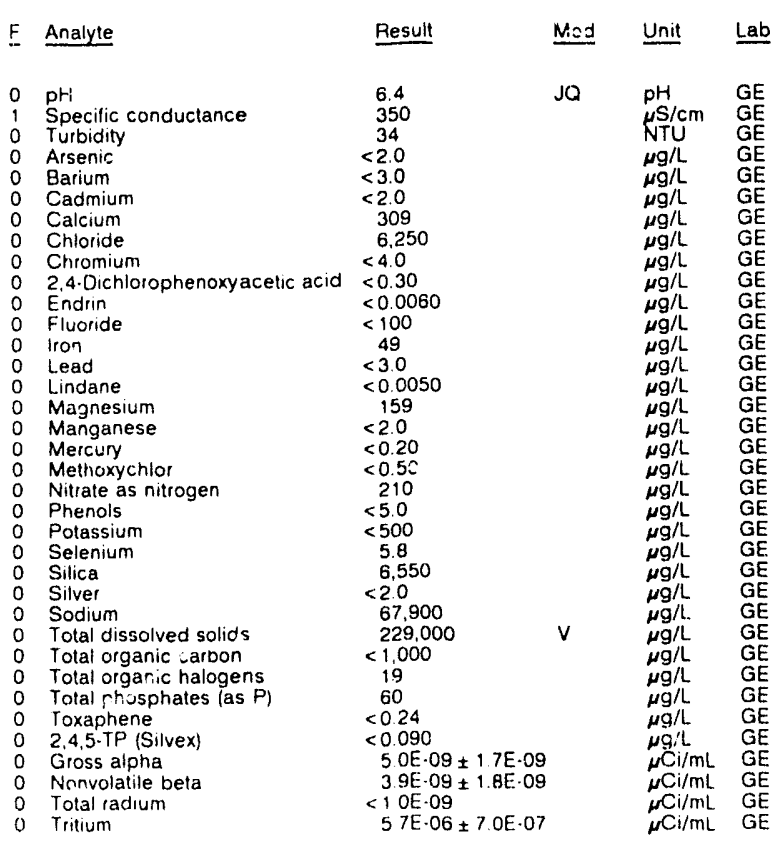


ANALYTICAL RESULTS

\section{WELL KAC 3}

MEASUREMENTS CONDUCTED IN THE FIELD

Sample date: $11 / 18 / 91$

Depth to water: $34.60 \mathrm{ft}(10.55 \mathrm{~m})$ below TOC

Water elevation: $223.20 \mathrm{Ht}(68.0$

Water evacuated before sampling: 72 gal

LABORATORY ANALYSES

E Analyte Result $\underline{\text { Mod Unit Lab }}$

$\begin{array}{ll}0 & \mathrm{pH} \\ 0 & \mathrm{pH} \\ 0 & \mathrm{pH} \\ 0 & \mathrm{pH} \\ 0 & \text { Specific conductance }\end{array}$

Specific conductance

Specific conductance

Acenaphthene

Acenaphthylene

Aldrin

Anthracene

Antimony

Arsenic

Barium

alpha.Benzene hexachloride

alpha-Benzene hexachloride

beta-Benzene hexachloride

delta-Benzen

- Benzidine

- Benzolajpyrene

Benzo a pyrene

Benzo g,hilperyiene

Benzo [k]fluoranthene

Bis(2-chloroethoxy) methane

Bis (2-chloroethyl) ether

Bis (2-chloroisopropyl) ether

Bis(2-ethylhexyl) phthalate

Bromodichloromethane

Bromomethane

Butylbenzyl phthalate

Cadmium

Calcium

Chlordane

Chloride

para-Chloro-meta-cresol

Chlorobenzene

Chloroethene (Vinyl chloride)

2-Chloroethyl vinyl ether

Chloroform

2-Chioronaphthalen

2-Chioronaphtha

4-Chlorophenyl phenyl ethe

Chromium

Cobrysene

Copper

p.p'ODO

$p, p \cdot$.DDE

Di-n-butyl phthalate

Di-r-octyl phthalate

Dibetane

3, r richlorobenzidine

1. 1. D chloroethane

1.2-Dic loroethane

trans-1,2-Dichloroeinylene

Dichlorometr...-

2,4.Dichlorophenol

1,2-Dichloropropane

cis-1,3-Dichloropropene

trans $1,3-\square$

Diethyl phthalate

2,4-Dimethyl phenol

Dimethyl phthalate

2.4-Dinitrotoluene

2,6-Dinitrotoluene

1,2-Diphenylhydrazine

Endosulfan II

Endosulfan sulfate

Endrín

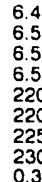

$<10$

$<20$

$<10$

$<2.0$

$<1.0$

$<10$

$<10$

-10
-10

$<10$

$<10$

$<10$
$<10$
$<10$

$<1,000$

$<1.0$

$<1.0$
$<1.0$
$<10$

$<10$
-10

$<2.0$
1.020

$<1.0$

8.500

$<1.0$

$<1.0$

$<1.0$

$<1.0$

$<10$

$<10$

$<10$

$<4.0$

$<10$

9.5
$<5.0$

10

$<10$

$<10$

$<10$

$<10$

$<10$

$<1.0$

10

$<1.0$

$<10$
$<1.0$

$<10$

$<10$

$<10$
$<10$

45

$<10$
$<10$

$<10$

$<10$

$<10$
$<10$
$<10$
Time: 11:25

Alkalinity: $27 \mathrm{mg} / \mathrm{L}$

Water temperature: $18.7^{\circ} \mathrm{C}$

JO JO JO
JO

$\mathrm{pH} \quad \mathrm{GE}$

$\begin{array}{ll}\mathrm{pH} & \mathrm{GE} \\ \mu \mathrm{S} / \mathrm{cm} & \mathrm{GE}\end{array}$

$\mu \mathrm{S} / \mathrm{cm}$ GE

NTU

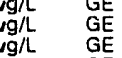

$\mu g / \lambda$ GE

WELL KAC 3 collected on 11/18/91, laboratory analyses (cont.)

$E$ Analyte

- Endrin aldehyde

Ethylbenzene

Fluorene

Fluoride

Heptachlor epoxide

Hexachlorobenzene

Hexachlorobutadiene

Hexachlorocyclope

0 indeno[1,2,3-c,d]pyrene

0 lion

0 Isophororie

Lead

Lindane

Magnesium

Mercury

Methoxychlor

N-Nitrosodimethylamine

N-Nitrosodiphenylamine

N-Nitrosodi-propylamine

Naphthalene

Nitrate as nitrogen

Nitrobenzene

2. Nitrophenol

4.Nitropheno

$P C B$
$P C B$
1221

PCB 1232

PCB 1242

PCB 1254

PCB 1260

Phenanthrene

Phenol

Phenois

Pyrene

Selenium

Silica

Sodium

1,1,2,2-Tetrachloroethan

Tetrachloroethylene

Thallium

Total dissolved solids

Total crganic carbon

Total organic carbon

Total organic carbon

Total organic halogens

Total organic halogens

Total organic halogens

Total organic halogens

0 Total phosphates (as P

0 Toxaphene

0 2,4,5-TP (Silvex)

$1,2,4$-Trichlorobenzen

i, 1,1 -Trichloroethane

- Trichlorofluoromethane

2 4.6-Trichlorophenol

0 Zinc

Gross alpha

Total radium

Tritium

WELL KAC 4

MEASUREMENTS CONDUCTEE IN THE FIELLD

Sample date: $11 / 18 / 91$

Depth to water $38.94 \mathrm{ft}(11.87 \mathrm{~m})$ below TOC

Water elevation. $221.06 \mathrm{th}(67.38 \mathrm{~m}) \mathrm{ms}$

Sp. conductance $74 \mu \mathrm{S} / \mathrm{cm}$

Water evacualed before sampling: $113 \mathrm{ga}$

LABORATORY ANALYSES

\begin{tabular}{|c|c|c|c|}
\hline Analyte & Resuit & Mod & Unit \\
\hline $\begin{array}{l}\text { pHy } \\
\text { Specific conductance } \\
\text { Turbidity } \\
\text { Arsenic } \\
\text { Barium } \\
\text { Cadmium } \\
\text { Calcium } \\
\text { Chloride } \\
\text { Chromium }\end{array}$ & $\begin{array}{r}54 \\
70 \\
2.8 \\
<2.0 \\
4.2 \\
<2.0 \\
347 \\
8.600 \\
<40\end{array}$ & JO & $\begin{array}{l}\mathrm{pH} \\
\mu \mathrm{S} / \mathrm{cm} \\
\mathrm{NTU} \\
\mu g / \mathrm{L} \\
\mu g / \mathrm{L} \\
\mu g / \mathrm{L} \\
\mu g / \mathrm{L} \\
\mu g / \mathrm{L} \\
\mu g / \mathrm{L}\end{array}$ \\
\hline
\end{tabular}

Time $13: 40$

Alkalinity, $1 \mathrm{mg} / \mathrm{L}$

Water temperature $18.3^{\circ} \mathrm{C}$ $\mu \mathrm{g} / \mathrm{L} \quad \mathrm{GE}$

$\begin{array}{ll}\mu \mathrm{g} / \mathrm{L} & \mathrm{GE} \\ \mu \mathrm{g} / \mathrm{LE} & \mathrm{GE}\end{array}$

$\mu g / L \quad G E$

$\begin{array}{ll}\mu \mathrm{g} / \mathrm{L} & \mathrm{GE} \\ \mu \mathrm{g} / \mathrm{L} & \mathrm{GE} \\ \mathrm{GE} & \end{array}$

$\mu g / h$ GE

$\mu g / \lambda$ GE

$\begin{array}{ll}\mu g / L & G E \\ \mu g / L & G E\end{array}$

$\mu g / L \quad G E$

$\mu g / 2 \quad G E$

$\begin{array}{ll}\mu \mathrm{g} / \mathrm{L} & \mathrm{GE} \\ \boldsymbol{\mu} \mathrm{g} / \mathrm{L} & \mathrm{GE} \\ \boldsymbol{\mu} \mathrm{GE} & \mathrm{GE}\end{array}$

$\mu g, \quad G E$

$\mu g / \Lambda \quad G E$

$\mu g / L \quad G E$

$\mu g / L \quad G E$

$\mu g / \mathrm{GE}$

$\mu g / L \quad G E$

$\mu g / L \quad G E$

$\mu \mathrm{g} / \mathrm{L} \quad \mathrm{GE}$

$\mu g / L \quad G E$

$\mu g / L \quad G E$

$g / \mathrm{GE}$

$\begin{array}{ll}\mathrm{g} / \mathrm{L} & \mathrm{GE} \\ \mathrm{g} / \mathrm{L} & \mathrm{GE} \\ \mathrm{g} / \mathrm{L} & \mathrm{GE}\end{array}$

$\begin{array}{ll}g / L & G E \\ g / L & G E \\ g / L & G E\end{array}$

$g / L \quad G E$

$\begin{array}{ll}\mathrm{g} / \mathrm{L} & \mathrm{GE} \\ \mathrm{g} / \mathrm{L} & \mathrm{GE} \\ \mathrm{g} / \mathrm{L} & \mathrm{GE}\end{array}$

g/h $\quad G E$

\begin{tabular}{ll}
$g / L$ & $G E$ \\
$g / L$ & $G E$ \\
\hline$C i / m L$ & $G E$
\end{tabular}

$\mathrm{Ci} / \mathrm{mL}$ GE
g/L GE

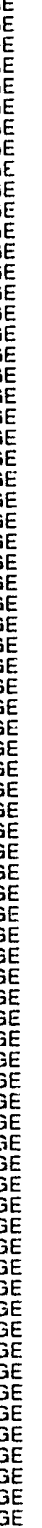


ANALYTICAL RESULTS

WELL KAC 4 collected on 11/18/91, laboratory analyses (cont)

\begin{tabular}{|c|c|c|c|}
\hline Analyte & Result & Mod & Unit \\
\hline $\begin{array}{l}\text { 2,4-Dichlorophenoxyacetic acid } \\
\text { Endrin } \\
\text { Fluoride } \\
\text { fron } \\
\text { Lead } \\
\text { Lindane } \\
\text { Magnesium } \\
\text { Manganese } \\
\text { Mercury } \\
\text { Methoxychlor } \\
\text { Nitrate as nitrogen } \\
\text { Nitrate as nitrogen } \\
\text { Phenols } \\
\text { Phenols } \\
\text { Potassium } \\
\text { Selenium } \\
\text { Silica } \\
\text { Silver } \\
\text { Sodium } \\
\text { Total dissolved solids } \\
\text { Total organic carbon } \\
\text { Total organic halogens } \\
\text { Total phosphates (as P) } \\
\text { Toxaphene } \\
\text { 2,4,5-TP (Silvex) } \\
\text { Gross alpha } \\
\text { Nonvolatile beta } \\
\text { Total radium } \\
\text { Tritium }\end{array}$ & $\begin{array}{l}<0.30 \\
<0.0060 \\
<100 \\
5.0 \\
<3.0 \\
<0.0050 \\
393 \\
2.5 \\
<0.20 \\
<0.50 \\
160 \\
160 \\
<5.0 \\
<5.0 \\
<500 \\
2.0 \\
6,390 \\
<2.0 \\
11.600 \\
54,000 \\
<1.000 \\
15 \\
160 \\
<0.24 \\
<0.090 \\
2.2 \mathrm{E}-09 \pm 1.0 \mathrm{E} \cdot 09 \\
<2.0 \mathrm{E}-09 \\
<1.0 \mathrm{E}-09 \\
2.1 \mathrm{E} \cdot 06 \pm 7.0 \mathrm{E} \cdot 07\end{array}$ & v & $\begin{array}{l}\mu g / L \\
\mu g / L \\
\mu g / L \\
\mu g / L \\
\mu g / L \\
\mu g / L \\
\mu g / L \\
\mu g / L \\
\mu g / L \\
\mu g / L \\
\mu g / L \\
\mu g / L \\
\mu g / L \\
\mu g / L \\
\mu g / L \\
\mu g / L \\
\mu g / L \\
\mu g / L \\
\mu g / L \\
\mu g / L \\
\mu g / L \\
\mu g / L \\
\mu g / L \\
\mu g / L \\
\mu g / L \\
\mu C i / m L \\
\mu C i / m L \\
\mu C i / m L \\
\mu C i / m L\end{array}$ \\
\hline
\end{tabular}

WELL KAC 5

MEASUREMENTS CONDUCTED IN THE FIELD

Sample date: $11 / 18 / 91$

Depth to water: $35.94 \mathrm{ft}(10.95 \mathrm{~m})$ below TOC Waler elevation: $223.06 \mathrm{Ht}(67.9$

Water evacuated before sampling: $49 \mathrm{gal}$

LABORATORY ANALYSES

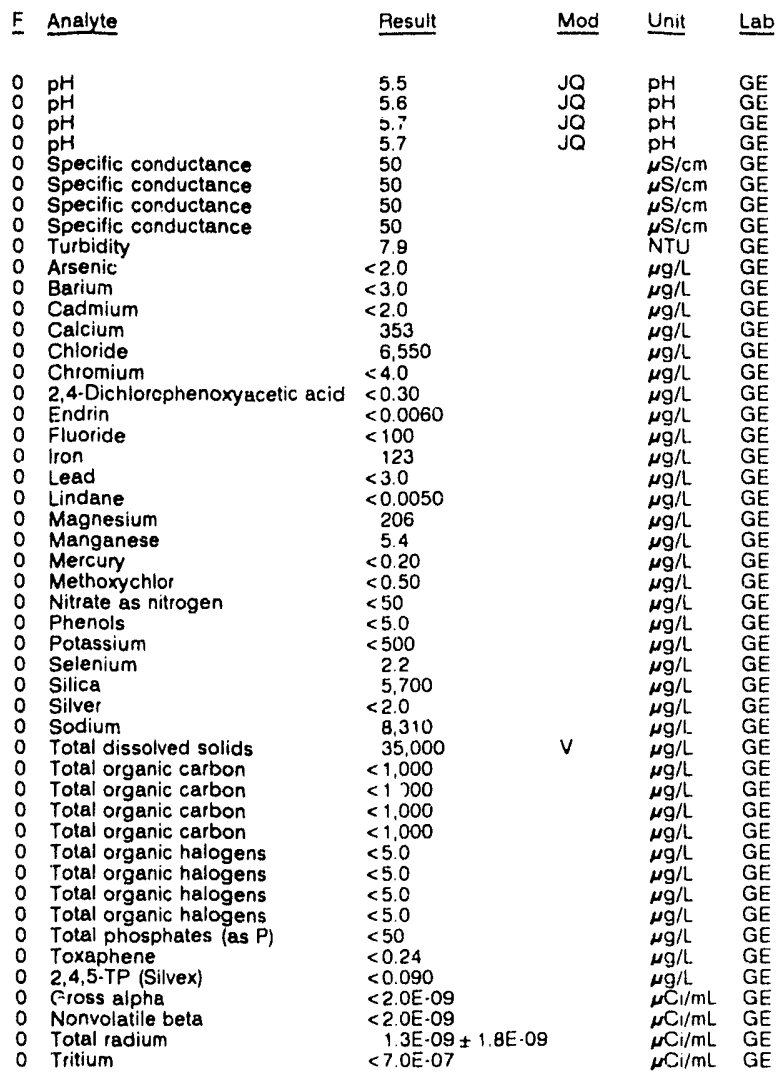

WELL KAC 6

MEASUREMENTS CONDUCTED IN THE FIELD

$\begin{array}{ll}\text { Sample date: } 11 / 18 / 91 & \text { Time: } 9: 10 \\ \text { Depth to water: } 35.88 \mathrm{~h}(10.93 \mathrm{~m}) \text { below TOC } & \text { pH: } 5.3 \\ \text { Water elevation: } 223.14 \mathrm{ft}(68.01 \mathrm{~m}) \mathrm{ms} & \text { Alkalinity: } 1 \mathrm{mg} / \mathrm{h} \\ \text { Sp. conductance: } 90 \mu \mathrm{s} / \mathrm{cm} & \text { Water temperature: } 18.2^{\circ} \mathrm{C} \\ \text { Water evacuated before sampling: } 9 \mathrm{gal} & \\ \text { The well went dry during puiging. } & \end{array}$

LABORATORY ANALYSES

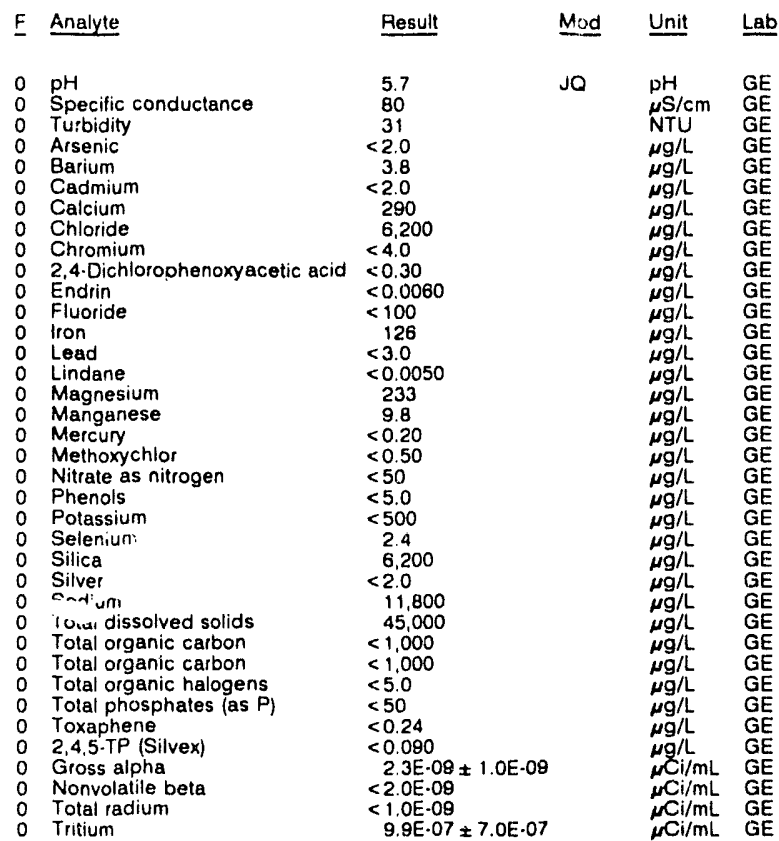

WELL KAC 7

MEASUREMENTS CONOUCTED IN THE FIELD

\begin{tabular}{|c|c|c|c|c|c|}
\hline & $\begin{array}{l}\text { ple date: } 11 / 19 / 91 \\
\text { th to water: } 43.23 \mathrm{Ht}(13.18 \mathrm{~m}) \text { be } \\
\text { ler elevation. } 221.87 \mathrm{ft}(67.63 \mathrm{~m}) \\
\text { conductance: } 136 \mu \mathrm{S} / \mathrm{cm} \\
\text { er evacuated before sampling: } 9 \\
\text { well went dry during purging. }\end{array}$ & $\begin{array}{l}\text { elow TOC } \\
\mathrm{msl} \\
\text { gal }\end{array}$ & $\begin{array}{l}\text { Time: } 8: 55 \\
\text { pH: } 6.0 \\
\text { Alkalinity: } 35 \\
\text { Water tempe }\end{array}$ & ure: $18.5^{\circ}$ & \\
\hline & BORATOAY ANALYSES & & & & \\
\hline$E$ & Analyte & Result & Mod & Unit & $\underline{\text { Lab }}$ \\
\hline $\begin{array}{l}0 \\
0 \\
0 \\
0 \\
0 \\
0\end{array}$ & $\begin{array}{l}\text { pH } \\
\text { Specific conductance } \\
\text { Turbidity } \\
\text { Turbidity } \\
\text { Arsenic } \\
\text { Barium } \\
\text { Cadmium } \\
\text { Calcium } \\
\text { Chloride } \\
\text { Chromium } \\
\text { 2,4.Dichlorophenoxyacetic actd } \\
\text { Endrin } \\
\text { Fluoride } \\
\text { Fluoride } \\
\text { Iron } \\
\text { Lead } \\
\text { Lindane } \\
\text { Magnesium } \\
\text { Manganese } \\
\text { Mercury } \\
\text { Methoxychlor } \\
\text { Nittate as nitrogen } \\
\text { Phenols } \\
\text { Potassium } \\
\text { Selenium } \\
\text { Silica } \\
\text { Silvel } \\
\text { Sodium } \\
\text { Total dissolved solids } \\
\text { Total organic carbon } \\
\text { Total organic halogens } \\
\text { Total phosphates (as P) } \\
\text { Toxaphene } \\
\text { 245.TP (Silvex) }\end{array}$ & $\begin{array}{l}6.4 \\
125 \\
38 \\
39 \\
<2.0 \\
5.2 \\
<2.0 \\
4.140 \\
8,400 \\
<4.0 \\
<0.30 \\
<0.0060 \\
<100 \\
<100 \\
1,390 \\
3.5 \\
<0.0050 \\
110 \\
12 \\
<0.20 \\
<0.50 \\
1.820 \\
<5.0 \\
<500 \\
<2.0 \\
4,800 \\
<2.0 \\
23,700 \\
72,000 \\
5,000 \\
55 \\
150 \\
<0.24 \\
<0.090\end{array}$ & $\mathrm{JQ}$ & $\begin{array}{l}\mathrm{pH} \\
\mu \mathrm{S} / \mathrm{cm} \\
\mathrm{NTU} \\
\mathrm{NTU} \\
\mu \mathrm{g} / \mathrm{L} \\
\mu \mathrm{g} / \mathrm{L} \\
\mu \mathrm{g} / \mathrm{L} \\
\mu g / L \\
\mu g / L \\
\mu g / L \\
\mu g / L \\
\mu g / L \\
\mu g / L \\
\mu g / L \\
\mu g / L \\
\mu g / L \\
\mu g / L \\
\mu g / L \\
\mu g / L \\
\mu g / L \\
\mu g / L \\
\mu g / L \\
\mu g / L \\
\mu g / L \\
\mu g / L \\
\mu g / L \\
\mu g / L \\
\mu g / L \\
\mu g / L \\
\mu g / L \\
\mu g / L \\
\mu g / L \\
\mu g / L \\
\mu g / L\end{array}$ & $\begin{array}{l}\mathrm{GE} \\
\mathrm{GE} \\
\mathrm{GE} \\
\mathrm{GE} \\
\mathrm{GE} \\
\mathrm{GE} \\
\mathrm{GE} \\
\mathrm{GE} \\
\mathrm{GE} \\
\mathrm{GE} \\
\mathrm{GE} \\
\mathrm{GE} \\
\mathrm{GE} \\
\mathrm{GE} \\
\mathrm{GE} \\
\mathrm{GE} \\
\mathrm{GE} \\
\mathrm{GE} \\
\mathrm{GE} \\
\mathrm{GE} \\
\mathrm{GE} \\
\mathrm{GE} \\
\mathrm{GE} \\
\mathrm{GE} \\
\mathrm{GE} \\
\mathrm{GE} \\
\mathrm{GE} \\
\mathrm{GE} \\
\mathrm{GE} \\
\mathrm{GE} \\
\mathrm{GE} \\
\mathrm{GE} \\
\mathrm{GE} \\
\mathrm{GE}\end{array}$ \\
\hline
\end{tabular}




\section{ANALYTICAL RESULTS}

WELL KAC 7 collected on 11/19/91 laboratory analyses (cont.)

\begin{tabular}{|c|c|c|c|}
\hline Analyte & Result & Mod & Unit \\
\hline $\begin{array}{ll}0 & \text { Gross alpha } \\
0 & \text { Nonvolatile beta } \\
0 & \text { Total radium } \\
0 & \text { Tritium }\end{array}$ & $\begin{array}{l}<2.0 E \cdot 09 \\
<2.0 \mathrm{OE} \cdot 09 \\
<1.0 \mathrm{E} \cdot 09 \\
7.5 \mathrm{E} \cdot 06 \pm 8.0 \mathrm{E} \cdot 07\end{array}$ & & 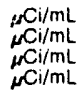 \\
\hline
\end{tabular}

\section{WELL KCB 1}

MEASUREMENTS CONDUCTED IN THE FIELD

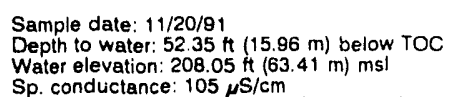

Water elevation: $208.05 \mathrm{tt}(63.41 \mathrm{~m}) \mathrm{msl}$

Sp. condlictance: $105 \mu \mathrm{S} / \mathrm{cm}$
Water evacuated before sampling: $64 \mathrm{gal}$

\section{Time: $17: 00$}

$\mathrm{pH}: 5.1$

Alkalinity: $1 \mathrm{mg} / \mathrm{h}$

Water temperature: $20.3^{\circ} \mathrm{C}$

\section{WELL KCB 2}

MEASUREMENTS CONDUCTED IN THE FIELD

Sample date: 11/20/91

Depth to water: $47.02 \mathrm{ft}(14.33 \mathrm{ml})$ below TOC

Water elevation: $207.38 \mathrm{Ht}(63.21 \mathrm{~m}) \mathrm{msl}$

$49 \mathrm{\mu s} / \mathrm{cm}$

PH: 4.5

Alkalinity. $0 \mathrm{mg} / \mathrm{h}$. $200^{\circ} \mathrm{C}$

WELL KCB 3

MEASUREMENTS CONDUCTED IN THE FIELD

Sample date: $11 / 20191$

Depth to water: $42.27 \mathrm{ft}(12.88 \mathrm{~m})$ below TOC

Water elevation: $205.63 \mathrm{ft}(62.68 \mathrm{~m}) \mathrm{msl}$

conductance: $459 \mu \mathrm{s} / \mathrm{cm}$

Water evacuated before sampling: $56 \mathrm{gal}$

Time: 10.35

Alkalinity: $0 \mathrm{mg} / \mathrm{L}$

Water temperature $21.0^{\circ} \mathrm{C}$

\section{WELL KCB 4}

MEASUREMENTS CONDUCTED IN THE FIELD

Sample date: $11 / 20 / 9$

Time: 16:25

\section{WELL KDB 1}

MEASUREMENTS CONDUCTED IN THE FIELD

Sample date: 10/22/91

Depth to water. $61.79 \mathrm{~h}(18.83 \mathrm{~m})$ below TOC

Water elevation: $211.31 \mathrm{tt}(64.41 \mathrm{~m}) \mathrm{ms}$

Water evacuated before samplin

The well went dry during purging: $18 \mathrm{gal}$

collection.

LABORATORY ANALYSES

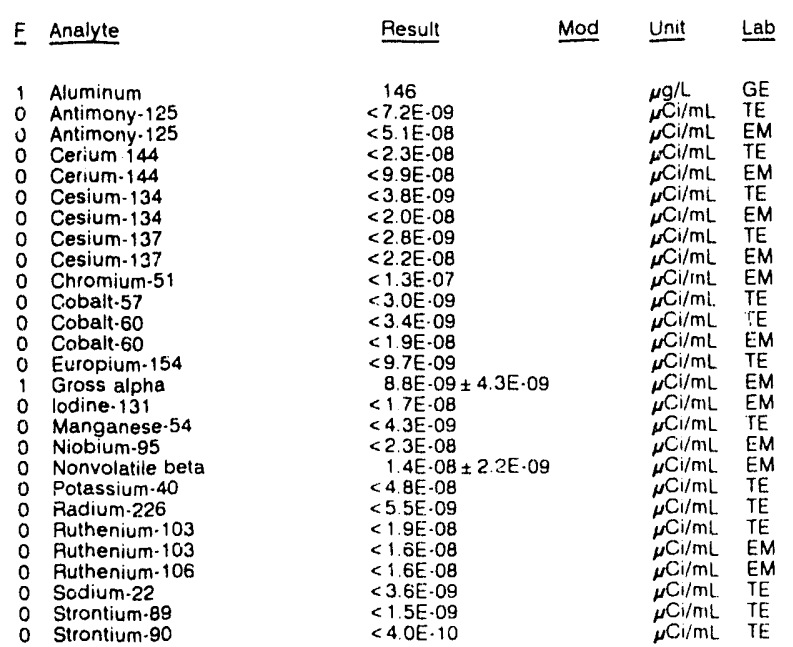

WELL KDB 1 collected on 10/22/91, laboratory analyses (cont.)

\begin{tabular}{|c|c|c|c|c|}
\hline$F$ & Analyte & Result & Mod & Unit \\
\hline${ }_{0}^{2}$ & $\begin{array}{l}\text { Thorium-228 } \\
\text { Total activity } \\
\text { Tritium } \\
\text { Tritium } \\
\text { Zinc-65 } \\
\text { Zirconium-95 }\end{array}$ & $\begin{array}{l}<3.1 \mathrm{E} \cdot 09 \\
3.1 \mathrm{E} \cdot 03 \pm 4.0 \mathrm{O} \cdot 05 \\
9.0 \mathrm{E} \cdot 04 \pm 4.7 \mathrm{E} \cdot 06 \\
3.2 \mathrm{E} \cdot 03 \pm 4.2 \mathrm{E} \cdot 05 \\
<8.6 \mathrm{E} \cdot 09 \\
<3.5 \mathrm{E} \cdot 08\end{array}$ & & $\begin{array}{l}\mu \mathrm{Ci} / \mathrm{mL} \\
\mu \mathrm{Ci} / \mathrm{mL} \\
\mu \mathrm{Ci} / \mathrm{mL} \\
\mu \mathrm{Ci} / \mathrm{mL} \\
\underset{1}{ } \mathrm{Ci} / \mathrm{mL} \\
\mu \mathrm{Ci} / \mathrm{mL}\end{array}$ \\
\hline
\end{tabular}

WELL KDB 1

MEASUREMENTS CONDUCTED IN THE FIELD

Sample date: 11/22/91

Time: 11:15

Water elevation: $211.47 \mathrm{ft}(64.46 \mathrm{~m}) \mathrm{msl} \quad$ Alkalinity: $0 \mathrm{mg} / \mathrm{h}$

Waterenation: $100 \mu \mathrm{S} / \mathrm{cm} \quad$ Water temperature: $21.4^{\circ} \mathrm{C}$

Water evacuated befnre sampling: 21 gal

The well went dry during purging.

LABORATORY ANALYSES

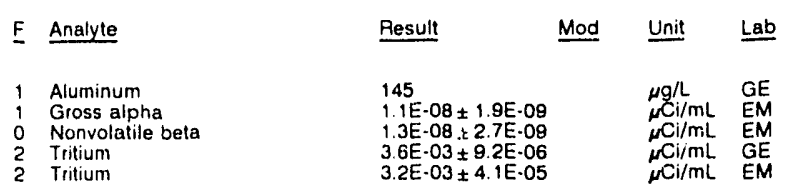

WELL KDB 1

MEASUREMENTS CONDUCTED IN THE FIELO

Time: $11: 15$

Water elevation: $211.30 \mathrm{ft}(64.41 \mathrm{~m}) \mathrm{msl} \quad$ Alkalinity: $7 \mathrm{mg} / \mathrm{h}$

$84 \mathrm{~s} / \mathrm{cmi}$

Water evacuated before sampling: $20 \mathrm{gal}$

The well went dry during purging
The

LABORATORY ANALYSES

\begin{tabular}{|c|c|c|c|c|}
\hline Analyte & Pesult & Mod & Unit & Lab \\
\hline $\begin{array}{ll}1 & \text { Aluminum } \\
0 & \text { Gross alpha } \\
0 & \text { Nonvolatile beta } \\
2 & \text { Tritium } \\
2 & \text { Tritium }\end{array}$ & $\begin{array}{l}163 \\
1.2 \mathrm{E} \cdot 10 \pm 3.2 \mathrm{E} \cdot 09 \\
2.1 \mathrm{E} \cdot 08 \pm 3.3 \mathrm{E}-09 \\
2.2 \mathrm{E} \cdot 03 \pm 7.2 \mathrm{E} \cdot 06 \\
2.2 \mathrm{E} \cdot 03 \pm 3.4 \mathrm{E} \cdot 05\end{array}$ & & $\begin{array}{l}\mu \mathrm{g} / \mathrm{L} \\
\mu \mathrm{Ci} / \mathrm{mL} \\
\mu \mathrm{Ci} / \mathrm{mL} \\
\mu \mathrm{Ci} / \mathrm{mL} \\
\mu \mathrm{Cl} / \mathrm{mL}\end{array}$ & $\begin{array}{l}G E \\
E M \\
E M \\
G E \\
E M\end{array}$ \\
\hline
\end{tabular}

\section{WELL KDB 2}

MEASUREMENTS CONDUCTED IN THE FIELD

sample date 10/22/91

Uepth to water: $63.05 \mathrm{ft}(19.2 \mathrm{~m})$ below TOC

Water elevation: $210.45 \mathrm{ft}(64.15 \mathrm{~m}) \mathrm{msl}$

Water evacuated betore sampling: $73 \mathrm{gal}$

Time: 12:55

Alkalinity: $0 \mathrm{mg} / \mathrm{L}$

Water tempurature: $25.1^{\circ} \mathrm{C}$

LABORATORY ANALYSES

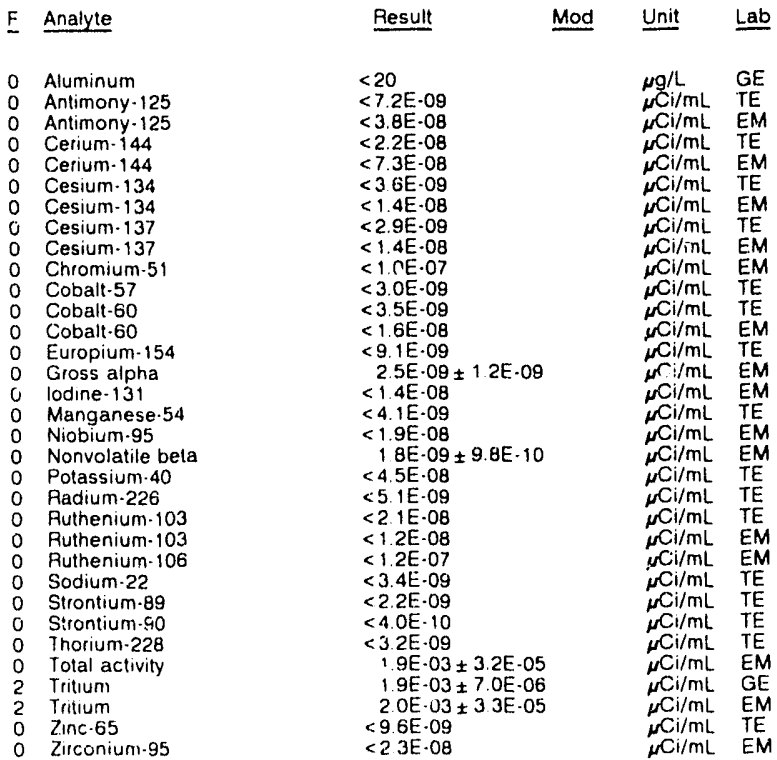


ANALYTICAL RESULTS

WELL KDB 2

MEASUREMENTS LONDUCTED IN THE FIELD

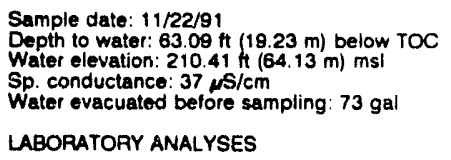

Time: $10: 5 \mathrm{C}$

PH: 4.9

Alkalinity: $0 \mathrm{mig} L$

Water temperature: $22.4^{\circ} \mathrm{C}$ LABORATORY ANALYSES

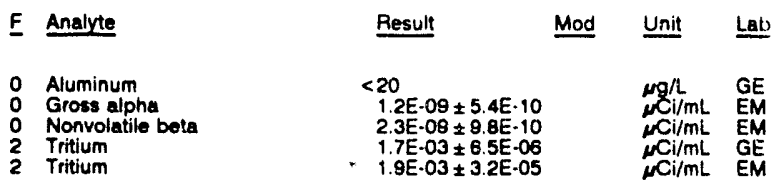

WELL KDB 2

MEASUREMENTS CONOUCTED IN THE FIELD

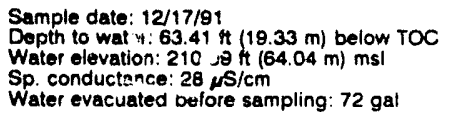

Time: $10: 45$

pH: 5.0

Alkalinity: $0 \mathrm{mg} / \mathrm{L}$.

Water temperature: $21.0^{\circ} \mathrm{C}$

LABORATORY ANALYSES

\begin{tabular}{|c|c|c|c|}
\hline Analyte & Result & Mod & Unit \\
\hline $\begin{array}{ll}0 & \text { Aluminum } \\
0 & \text { Gross alpha } \\
0 & \text { Nonvolatile beta } \\
2 & \text { Tritium } \\
2 & \text { Tritium }\end{array}$ & $\begin{array}{l}29 \\
2.0 E \cdot r \pm 1.2 E-09 \\
3=-09 \pm 1.2 E-09 \\
1.3 E-03 \pm 5.5 E-05 \\
1.4 E-03 \pm 2.8 E \cdot 05\end{array}$ & & 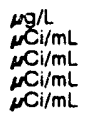 \\
\hline
\end{tabular}

WELL KDB 3

MEASUREMENTS CONDUCTED IN THE FIELD

$\begin{array}{ll}\text { Sample date: } 10 / 22 / 91 & \text { Time: } 13: 30 \\ \text { Depth to water: } 62.25 \mathrm{ft}(18.97 \mathrm{~m}) \text { below TOC } & \text { pH: } 6.6 \\ \text { Water elevation: } 211.15 \mathrm{ft}(64.36 \mathrm{~m}) \mathrm{ms} & \text { Alkalinity: } 148 \mathrm{mg} / \mathrm{L} \\ \text { Sp. conductance: } 287 \text { NS/cm } & \text { Water temperature: } 247^{\circ} \mathrm{C} \\ \text { Water evacuated before sampling: } 22 \mathrm{gal} & \\ \text { The well went dry during purging. } & \end{array}$

dry during purging.

LABORATORY ANALYSES

\begin{tabular}{|c|c|c|}
\hline Analyte & Pesult & Unit \\
\hline $\begin{array}{l}\text { Aluminum } \\
\text { Antimony-125 } \\
\text { Antimony-125 } \\
\text { Corium-144 } \\
\text { Cerium-144 } \\
\text { Cesium-134 } \\
\text { Cesium-134 } \\
\text { Cesium-137 } \\
\text { Cesium-137 } \\
\text { Chromium-51 } \\
\text { Cobalt-57 } \\
\text { Cobalt-60 } \\
\text { Cobait } 60 \\
\text { Europium-154 } \\
\text { Gross alpha } \\
\text { lodine-13i } \\
\text { Manganese-54 } \\
\text { Niobium-95 } \\
\text { Nonvolatile beta } \\
\text { Potassium-40 } \\
\text { Radium-226 } \\
\text { Ruthenium-103 } \\
\text { Ruthenium-103 } \\
\text { Ruthenium-106 } \\
\text { Sodium-22 } \\
\text { Strontium-89 } \\
\text { Strontium- } 80 \\
\text { Thorium-228 } \\
\text { Tritium } \\
\text { Tritium } \\
\text { Zinc-65 } \\
\text { Zirconium-95 }\end{array}$ & 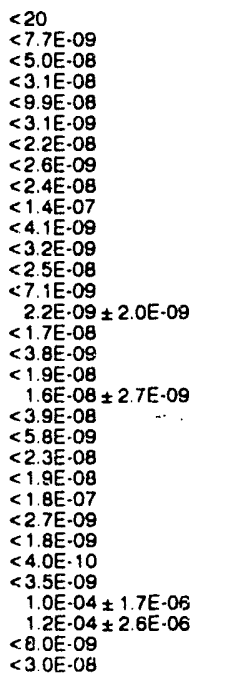 & 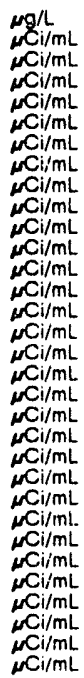 \\
\hline
\end{tabular}

WELL KDB 3

MEASUREMENTS CONDUCTED IN THE FIELD

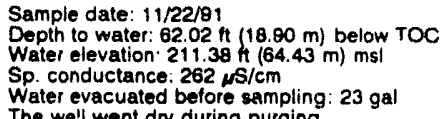

Sample date: $11 / 22 / 91$

Depth to water: $62.02 \mathrm{~h}(18.00 \mathrm{~m})$ below TOC

Water elevation. $211.38 \mathrm{~A}(64.43 \mathrm{~m}) \mathrm{ms}$ !

Sp. conductance: $262 \mu \mathrm{S} / \mathrm{cm}$

Water evacuated before sampling: $23 \mathrm{gal}$

Time: $11: 30$

Alkalinity: $114 \mathrm{mg} / \mathrm{L}$

Water temperature: $21.7^{\circ} \mathrm{C}$

LABORATORY ANALYSES
$E$ Analyte
Mod Unit Lab
0 Aluminum
2 Tritium
$1.0 E-04 \pm 1.7 E-06$
$\begin{array}{ll}M g / L & G E \\ \mu N i / m L & G E \\ M C i / m L & E M\end{array}$

WELL KDB 3

MEASUREMENTS CONDUCTED IN THE FIELD

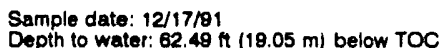

Water elevation: $210.81 \mathrm{ft}(84.29 \mathrm{~m}) \mathrm{msl}$

Sp. conductance: $214 \mu \mathrm{s} / \mathrm{cm}$

pH: 6.5

Alkalinity: $89 \mathrm{mg} / \mathrm{h}$

Water evacuated bofore sampling: $23 \mathrm{gal}$

Water temperature: $18.6^{\circ} \mathrm{J}$

LABORATORY ANALYSES

\begin{tabular}{|c|c|c|c|}
\hline Analyte & Result & Mod & Unit \\
\hline $\begin{array}{ll}0 & \text { Aluminum } \\
2 & \text { Tritium } \\
2 & \text { Tritium }\end{array}$ & $\begin{array}{l}<20 \\
1.0 \mathrm{E}-04 \\
1.1 \mathrm{E}-04\end{array}$ & & 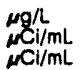 \\
\hline
\end{tabular}

\section{WELL KDT 10}

MEASUREMENTS CONDUCTED IN THE FIELD

Semple date: 12/17/81

Depth to water: $62.18 \mathrm{ft}(18.95 \mathrm{~m})$ below TOC

Water elevation: $210.82 \mathrm{H}(64.26 \mathrm{~m}) \mathrm{msl}$

Sp. conductance: 55 s/cm

Water evacuated before sampling: $15 \mathrm{gal}$

pH: 4.8 .

Water temperature: $18.0^{\circ} \mathrm{C}$

The well went dry during purging.

LABORATORY ANÁ: YSES

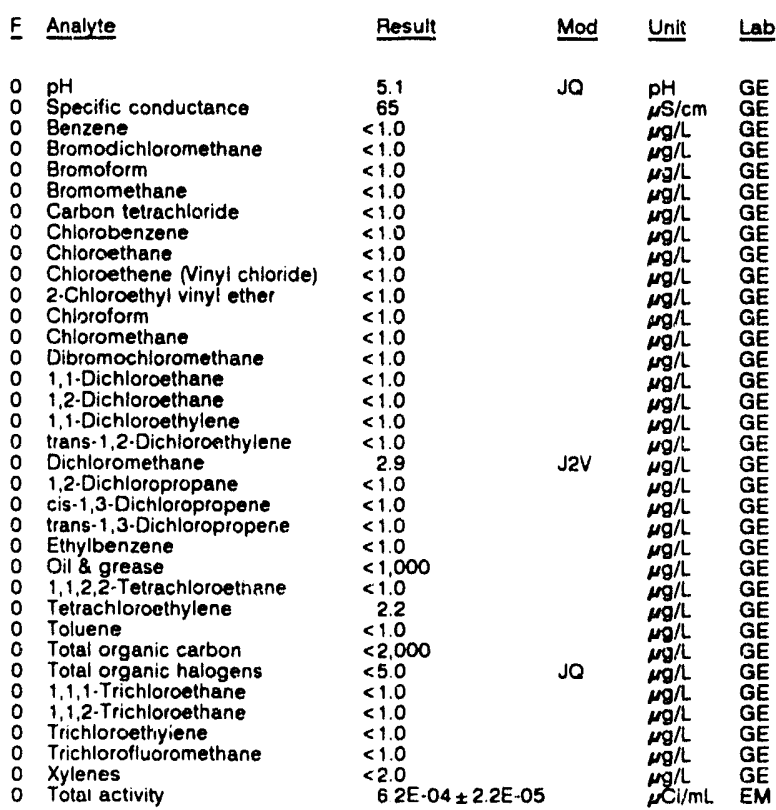


ANALYTICAL RESULTS

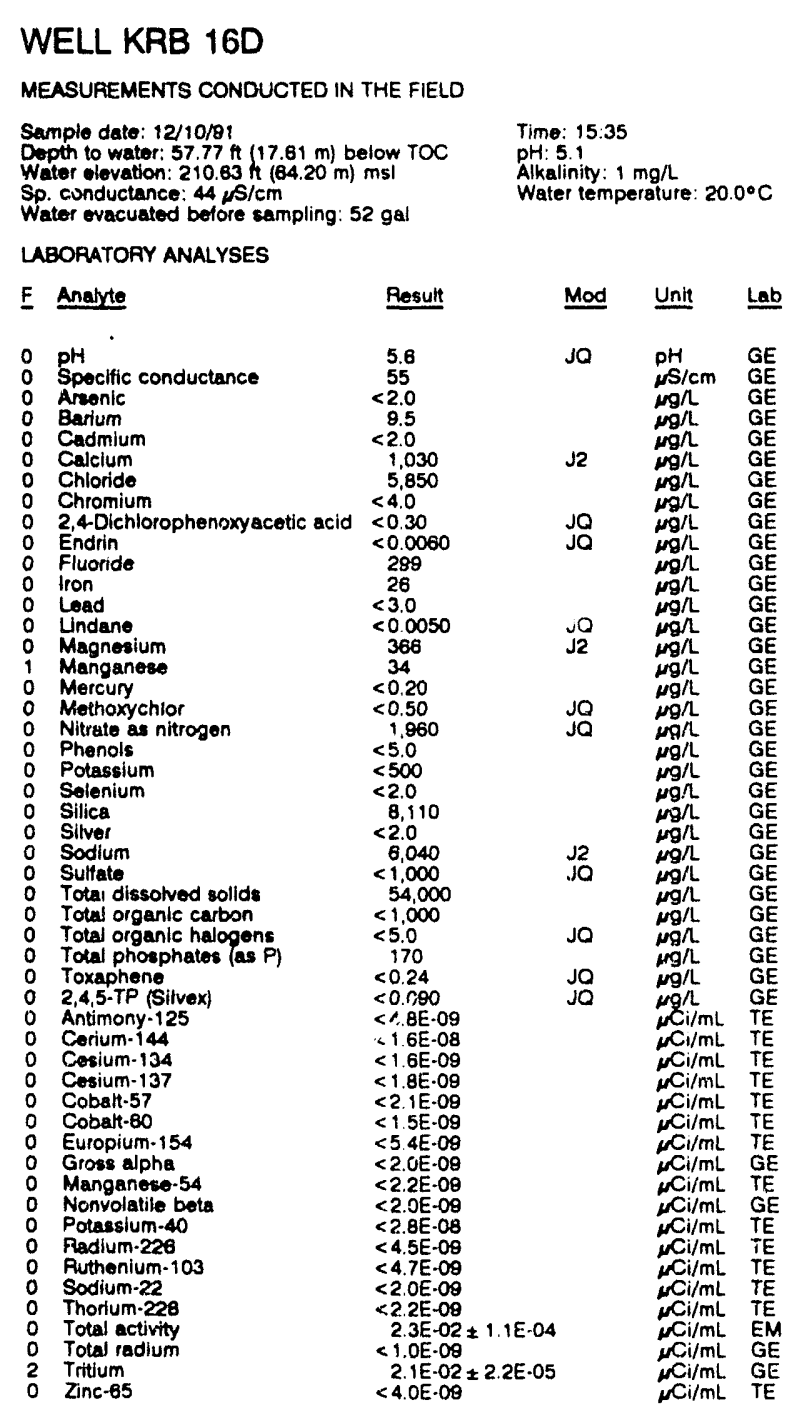

\section{WELL KRB 17D}

MEASUREMENTS CONDUCTED IN THE FIELD

Sample dace: $12 / 10 / 91$

Depth to water: 78.23 th $(23.24 \mathrm{~m})$ below TOC

Water elevation: $207.97 \mathrm{ft}(63.39 \mathrm{~m}) \mathrm{ms}$ )

Sp. conductance: $81 \mu \mathrm{s} / \mathrm{cm}$
Water evacuated before sampling: $57 \mathrm{gal}$

LABORATORY ANALYSES

\begin{tabular}{|c|c|c|c|c|c|}
\hline \multicolumn{3}{|c|}{$\begin{array}{l}\text { Sample daie: } 12 / 10 / 91 \\
\text { Depth to water: } 76.23 \mathrm{H}(23.24 \mathrm{~m}) \text { below TOC } \\
\text { Water elevation: } 207.97 \mathrm{Ht}(63.38 \mathrm{~m}) \mathrm{ms} \\
\text { Sp. conductance: } 81 \mu \mathrm{s} / \mathrm{cm} \\
\text { Water evacuated belore sampling: } 57 \mathrm{gal}\end{array}$} & \multicolumn{3}{|c|}{$\begin{array}{l}\text { Time: } 16: 10 \\
\text { pH: } 6.3 \\
\text { Alkalinity: } 27 \mathrm{mg} / \mathrm{h} \\
\text { Water temperature: } 19.6^{\circ} \mathrm{C}\end{array}$} \\
\hline \multicolumn{6}{|c|}{ LABORATORY ANALYSES } \\
\hline$\underline{\boldsymbol{F}}$ & Anafyte & Result & Mod & $\underline{U} n_{i}$ & $\underline{L a b}$ \\
\hline $\begin{array}{l}0 \\
0 \\
0 \\
0 \\
0 \\
0 \\
0 \\
0 \\
0 \\
0 \\
0 \\
0 \\
0 \\
0 \\
0 \\
0 \\
0 \\
0 \\
0 \\
0\end{array}$ & $\begin{array}{l}\text { pH } \\
\text { Specific conductarlice } \\
\text { Arsenic } \\
\text { Barium } \\
\text { Cadmium } \\
\text { Calcium } \\
\text { Chloride } \\
\text { Chromium } \\
\text { 2,4Dichlorophenoxyacetic acid } \\
\text { Endrin } \\
\text { Fiuoride } \\
\text { iron } \\
\text { Lead } \\
\text { Lindane } \\
\text { Magnesium } \\
\text { Manganese } \\
\text { Mercury } \\
\text { Methoxychlor } \\
\text { Nitrate as nitrogen } \\
\text { Phenols }\end{array}$ & $\begin{array}{l}6.6 \\
100 \\
<2.0 \\
6.7 \\
<2.0 \\
11.000 \\
7.300 \\
<4.0 \\
<0.30 \\
<0.0060 \\
350 \\
<4.0 \\
<30 \\
<0.0050 \\
560 \\
9.8 \\
<0.20 \\
<0.50 \\
1.130 \\
<5.0\end{array}$ & $\begin{array}{l}\mathrm{JO} \\
\mathrm{JO}\end{array}$ & $\begin{array}{l}\mathrm{pH} \\
\mu \mathrm{s} / \mathrm{cm} \\
\mu g / L \\
\mu g / L \\
\mu g / L \\
\mu g / L \\
\mu g / L \\
\mu g / L \\
\mu g / L \\
\mu g / L \\
\mu g / L \\
\mu g / L \\
\mu g / L \\
\mu g / L \\
\mu g / L \\
\mu g / L \\
\mu g / L \\
\mu g / L \\
\mu g / h \\
\mu g / L\end{array}$ & $\begin{array}{l}\mathrm{GE} \\
\mathrm{GE} \\
\mathrm{GE} \\
\mathrm{GE} \\
\mathrm{GE} \\
\mathrm{GE} \\
\mathrm{GE} \\
\mathrm{GE} \\
\mathrm{GE} \\
\mathrm{GE} \\
\mathrm{GE} \\
\mathrm{GE} \\
\mathrm{GE} \\
\mathrm{GE} \\
\mathrm{GE} \\
\mathrm{GE} \\
\mathrm{GE} \\
\mathrm{GE} \\
\mathrm{GE} \\
\mathrm{GE}\end{array}$ \\
\hline
\end{tabular}

WELL KRB 170 collected on 12/10/91, laboratory analyses (cont.)

\begin{tabular}{|c|c|c|c|c|c|}
\hline$\underline{F}$ & Analyte & Resulf & Mod & Unit & Lab \\
\hline & $\begin{array}{l}\text { Potassium } \\
\text { Selenium } \\
\text { Silica } \\
\text { Silver } \\
\text { Sodium } \\
\text { Sulfate } \\
\text { Total dissolved solids } \\
\text { Total dissolvod solids } \\
\text { Total organic carbon } \\
\text { Total organic halogens } \\
\text { Total phosphates (as P) } \\
\text { Toxaphene } \\
\text { 2,45-TP (\$ilvex) } \\
\text { Antimony-125 } \\
\text { Cerium-144 } \\
\text { Cesium-134 } \\
\text { Cesium-137 } \\
\text { Cobalt-57 } \\
\text { Cobalf-60 } \\
\text { Europium-154 } \\
\text { Gross alpha } \\
\text { Manganese-54 } \\
\text { Nonvolatile bota } \\
\text { Potassium-40 } \\
\text { Radium-226 } \\
\text { Ruthenium-103 } \\
\text { Sodium-22 } \\
\text { Thorium-228 } \\
\text { Total activity } \\
\text { Total radium } \\
\text { Tritium } \\
\text { Zinc-65 }\end{array}$ & 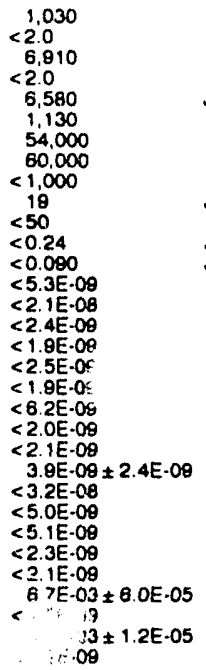 & $\begin{array}{l}\text { JQ } \\
\text { JQ } \\
\text { JO }\end{array}$ & 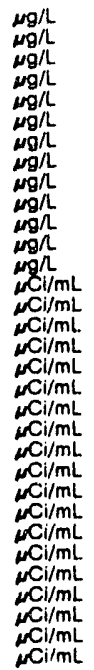 & $\begin{array}{l}G E \\
G E \\
G E \\
G E \\
G E \\
G E \\
G E \\
G E \\
G E \\
G E \\
G E \\
G E \\
G E \\
T E \\
T E \\
T E \\
T E \\
T E \\
T E \\
T E \\
G E \\
T E \\
G E \\
T E \\
T E \\
T E \\
T E \\
T E \\
E M \\
G E \\
G E \\
T E\end{array}$ \\
\hline
\end{tabular}

WLLL KRB $18 D$

MEASUREMENTS CONDUCTED IN THE FIELD

$\begin{array}{ll}\text { Sample date: } 12 / 11 / 81 & \text { Time: } 11: 30 \\ \text { Depth to water: } 76.86 \mathrm{ht}(23.43 \mathrm{~m}) \text { below TOC } & \text { pH: } 6.0 \\ \text { Water elevation: } 205.74 \mathrm{ft}(62.71 \mathrm{~m}) \mathrm{msl} & \text { Alkalinity: } 15 \mathrm{mg} / \mathrm{L} \\ \text { Sp. conductance: B3 } \mathrm{SS} / \mathrm{cm} & \text { Water temperature: } 18.8 \circ \mathrm{C} \\ \text { Water evacuated belore sampling: } 16 \mathrm{gal} & \\ \text { The well went dry duting purging. } & \end{array}$

LABORATORY ANALYSES

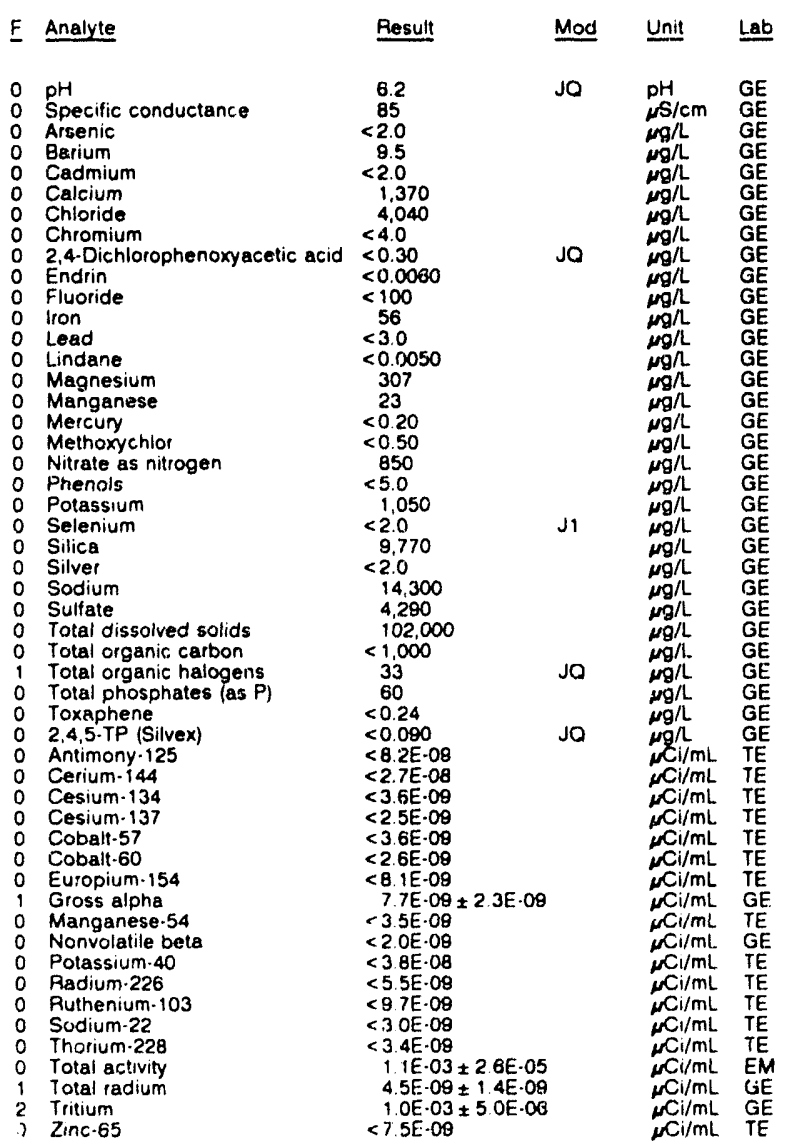


ANALYTICAL RESULTS

WFLL KRB 19D

MEASUREMENTS CONDUCTED IN THE FIELD

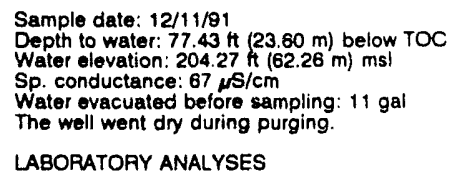

$$
\begin{aligned}
& \text { Time: } 11.50 \\
& \text { pH: } 5.8 \\
& \text { Alkalinity: } 11 \mathrm{mg} / \mathrm{L} \\
& \text { Water temperature: } 18.8^{\circ} \mathrm{C}
\end{aligned}
$$

\begin{tabular}{|c|c|c|c|c|c|}
\hline$F$ & Analyte & Result & Mod & Unit & Lab \\
\hline & 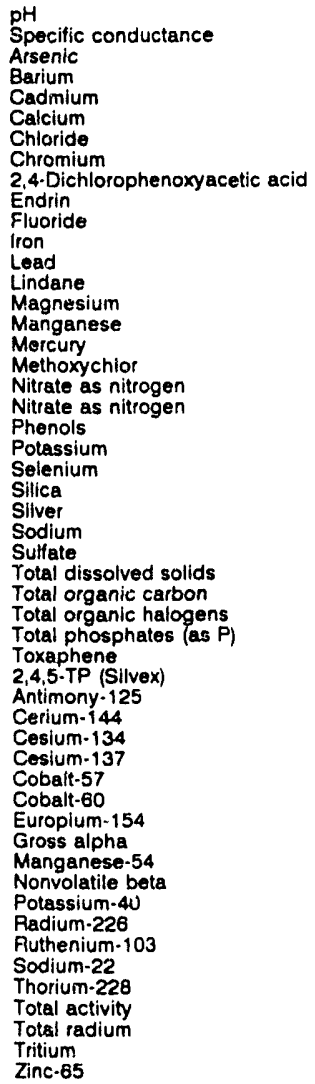 & $\begin{array}{l}6.2 \\
70 \\
<2.0 \\
11 \\
<2.0 \\
2,550 \\
7,850 \\
<4.0 \\
<0.30 \\
<0.0060 \\
<100 \\
127 \\
4.5 \\
<0.0050 \\
184 \\
39 \\
0.20 \\
<0.50 \\
510 \\
510 \\
<5.0 \\
<500 \\
<2.0 \\
9,380 \\
<2.0 \\
10,300 \\
5,400 \\
68,000 \\
<1.000 \\
5.0 \\
<50 \\
<0.24 \\
<0.090 \\
<6.7 \mathrm{E}-09 \\
<2.1 \mathrm{E}-09 \\
<3.2 \mathrm{E}-09 \\
<3.1 \mathrm{E}-09 \\
<2.7 \mathrm{E}-09 \\
<3.5 \mathrm{E}-09 \\
<6.5 \mathrm{E}-09 \\
<2.0 \mathrm{E}-09 \\
<2.6 \mathrm{E}-09 \\
2.3 \mathrm{E}-09 \pm 2.4 \mathrm{E}-09 \\
<3.9 \mathrm{E}-0 \mathrm{~B} \\
<5.6 \mathrm{E}-09 \\
<7.3 \mathrm{E}-09 \\
<2.4 \mathrm{E}-09 \\
<2.8 \mathrm{E}-09 \\
8.8 \mathrm{E}-02 \pm 2.1 \mathrm{E}-04 \\
<1.0 \mathrm{E}-09 \\
7.9 \mathrm{E}-02 \pm 4.3 \mathrm{E}-05 \\
<6.8 \mathrm{E}-09 \\
\end{array}$ & $\begin{array}{l}\mathrm{JQ} \\
\mathrm{JQ}\end{array}$ & 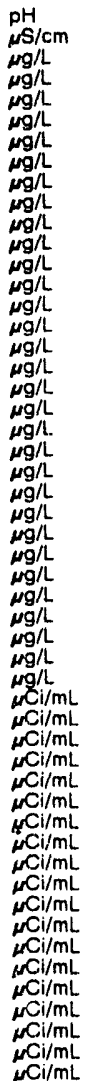 & $\begin{array}{l}G E \\
G E \\
G E \\
G E \\
G E \\
G E \\
G E \\
G E \\
G E \\
G E \\
G E \\
G E \\
G E \\
G E \\
G E \\
G E \\
G E \\
G E \\
G E \\
G E \\
G E \\
G E \\
G E \\
G E \\
G E \\
G E \\
G E \\
G E \\
G E \\
G E \\
G E \\
G E \\
G E \\
G E \\
G E \\
G E \\
T E \\
T E \\
T E \\
T E \\
T E \\
T E \\
T E \\
G E \\
T E \\
G E \\
T E \\
T E \\
T E \\
T E \\
T E \\
E M \\
G E \\
G E \\
T E\end{array}$ \\
\hline
\end{tabular}

LABORATORY ANALYSES

\section{WELL KRP 1}

MEASUREMENTS CONDUCTED IN THE FIELD

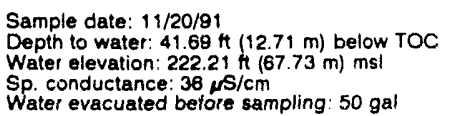

Time: 15:15

Alkalinity: $0 \mathrm{mg} / \mathrm{L}$

Water temperature: $19.3^{\circ} \mathrm{C}$

WELL KRP 2

MEASUREMENTS CONDUCTED IN THE FIELD

Sample date: 11/20/81

Depth to water: $3368 \mathrm{At}(10.27 \mathrm{~m})$ below TOC

Water elevation: 222.42 it $(67$

Sp. conductance: $29 \mathrm{\mu S} / \mathrm{cm}$
Water evacuated before sampling: $61 \mathrm{gal}$
WELL KRP 3

MEASUREMENTS CONDUCTED IN THE FIELD

Sample date: $11 / 20 / 91$
Depth to water: $31.03 \mathrm{ft}(9.46 \mathrm{~m})$ below TOC
Water elevation: $223.47 \mathrm{ft}(68.11 \mathrm{~m}) \mathrm{msl}$
Sp. conductance: $20 \mu \mathrm{cm} / \mathrm{cm}$
Water evacuated before sampling: $52 \mathrm{gal}$

Time: $15: 50$

Alkalinity: $0 \mathrm{mg} / \mathrm{L}$ Water temperature: $18.4^{\circ} \mathrm{C}$

WELL KRP 4

MEASUREMENTS CONDUCTED IN THE FIEL.D

Sampla date: 11/20/91

Depth to water: $33.94 \mathrm{tt}(10.35 \mathrm{~m})$ below TOC

Water elevation: 221.66 t $(87.56 \mathrm{~m}) \mathrm{msl}$

Sp. conductance: $63 \mu \mathrm{sS} / \mathrm{cm}$

Time: $16: 10$

pH: 4.7

Water temperature: $18.9^{\circ} \mathrm{C}$

WELL KSB 1

MEASUREMENTS CONDUCTED IN THE FIELD

Sample date: 10/24/91

Depth to water: $58.93 \mathrm{ft}(18.27 \mathrm{~m})$ below TOC

Water elevation: $207.47 \mathrm{~h}(63.24 \mathrm{~m}) \mathrm{ms}$

Water evacuated before sampling: $84 \mathrm{gal}$

Alkalinity: $1 \mathrm{mg} / \mathrm{L}$

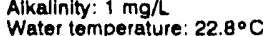

LABORATORY ANALYSES

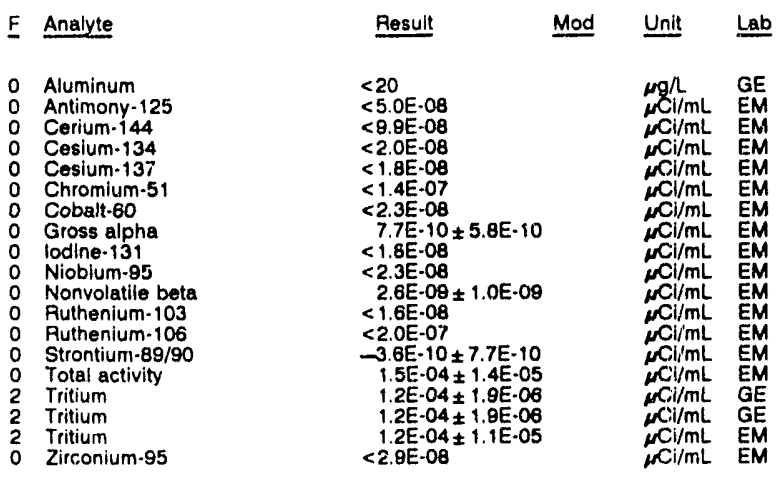

WELL KSB 1

MEASUREMENTS CONDUCTED IN THE FIELO

Sample date: $11 / 19 / 91$

Depth to water: $59.86 \mathrm{ft}(18.25 \mathrm{~m})$ below TOC

Water elevation: $207.54 \mathrm{tt}(63.26 \mathrm{~m}) \mathrm{ms}$ !

Sp. conductance: $24 \mu \mathrm{S} / \mathrm{cm}$

Time: $6: 10$

$\mathrm{pH}: 4.8$

Alkalinity: $0 \mathrm{mg} / \mathrm{L}$

\begin{tabular}{|c|c|c|c|c|}
\hline$F$ & Analyte & Result & Mod & Unit \\
\hline $\begin{array}{l}0 \\
0 \\
?\end{array}$ & $\begin{array}{l}\text { Aluminum } \\
\text { Gross alpha } \\
\text { Nonvolatile beta } \\
\text { Tritium } \\
\text { Tritium }\end{array}$ & $\begin{array}{l}77 \\
4.3 \mathrm{E}-10+3.4 \mathrm{E}-10 \\
9.6 \mathrm{E}-10 \pm 7.4 \mathrm{E}-1 \mathrm{C} \\
1.2 \mathrm{E}-04 \pm 1.6 \mathrm{E}-06 \\
1.5 \mathrm{E}-04 \pm 1.1 \mathrm{E}-0 .\end{array}$ & & $\begin{array}{c}\mu \mathrm{g} / \mathrm{L} \\
\mu \mathrm{Cl} / \mathrm{mL} \\
\mu \mathrm{Cl} / \mathrm{mL} \\
\mu \mathrm{Ci} / \mathrm{mL} \\
\mu \mathrm{Ci} / \mathrm{mL}\end{array}$ \\
\hline
\end{tabular}

Water evacuated before sampling: $84 \mathrm{gal}$

LABORATORY ANALYSES 
WELL KSB 1

MEASUREMENTS CONDUCTED IN THE FIELD

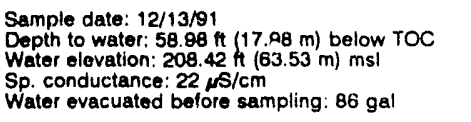

Time: $16: 20$

pH: 48

Alkalinity: $0 \mathrm{mg} / \mathrm{L}$

Water temperature: $22.1^{\circ} \mathrm{C}$

LABORATORY ANALYSES

\begin{tabular}{|c|c|c|c|}
\hline Analyte & Result & Mod & Unit \\
\hline $\begin{array}{l}\text { Aluminum } \\
\text { Gross alpha } \\
\text { Nonvolatile beta } \\
\text { Tritium } \\
\text { Tritium } \\
\text { Tritium }\end{array}$ & $\begin{array}{l}<20 \\
1.1 \mathrm{E}-09 \pm 7.5 \mathrm{E}-10 \\
9.9 \mathrm{E}-10 \pm 8.6 \mathrm{E}-10 \\
1.3 \mathrm{E}-04 \pm 1.8 \mathrm{E}-00 \\
1.5 \mathrm{E} \cdot 04 \pm 1.1 \mathrm{E}-05 \\
1.4 \mathrm{E}-04 \pm 9.0 \mathrm{E}-07\end{array}$ & & $\begin{array}{l}\mu g / \mathrm{L} \\
\mu \mathrm{Ci} / \mathrm{mL} \\
\mathrm{NCi} / \mathrm{mL} \\
\mu \mathrm{Ci} / \mathrm{mL} \\
\mu \mathrm{Ci} / \mathrm{mL} \\
\mu \mathrm{Ci} / \mathrm{mL}\end{array}$ \\
\hline
\end{tabular}

WELL KSB 2

MEASUREMENTS CONDUR:TED IN THE FIELO

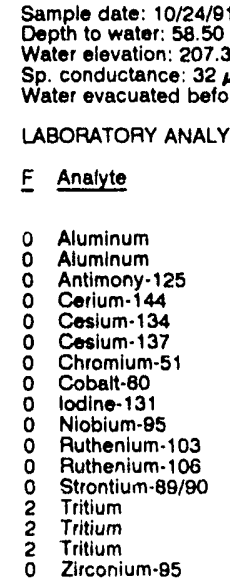

Water temperature: $21.5^{\circ} \mathrm{C}$

$88 \mathrm{gal}$
LABORATORY ANALYSES

\begin{tabular}{|c|c|c|}
\hline Result & Mod & Unit \\
\hline $\begin{aligned} & 21 \\
& 20 \\
&<4.8 \mathrm{E}-08 \\
&<1.2 \mathrm{E}-07 \\
&<2.0 \mathrm{E} \cdot 08 \\
&<2.0 \mathrm{E} \cdot 08 \\
&<1.3 \mathrm{E}-06 \\
&<2.1 \mathrm{E}-08 \\
&<6.1 \mathrm{E}-05 \\
&<1.5 \mathrm{E}-07 \\
&<8.2 \mathrm{E}-08 \\
&<1.6 \mathrm{E} \cdot 07 \\
&-4.9 \mathrm{E}-10 \pm 1.4 \mathrm{E} \cdot 09 \\
& 4.2 \mathrm{E}-05 \pm 1.2 \mathrm{E} \cdot 06 \\
& 4.8 \mathrm{E} \cdot 05 \pm 1.2 \mathrm{E}-06 \\
& 5.0 \mathrm{E}-05 \pm 1.8 \mathrm{E} \cdot 06 \\
&<98 \mathrm{E} \cdot 08\end{aligned}$ & & $\begin{array}{l}\mu \mathrm{g} / \mathrm{L} \\
\mu \mathrm{g} / \mathrm{L} \\
\mu \mathrm{Ci} / \mathrm{mL} \\
\mu \mathrm{Ci} / \mathrm{mL} \\
\mu \mathrm{Ci} / \mathrm{mL} \\
\mu \mathrm{Ci} / \mathrm{mL} \\
\mu \mathrm{Ci} / \mathrm{mL} \\
\mu \mathrm{Ci} / \mathrm{mL} \\
\mu \mathrm{Ci} / \mathrm{mL} \\
\mathrm{Ci} / \mathrm{mL} \\
\mu \mathrm{Ci} / \mathrm{mL} \\
\mu \mathrm{Ci} / \mathrm{mL} \\
\mu \mathrm{Ci} / \mathrm{mL} \\
\mu \mathrm{Ci} / \mathrm{mL} \\
\mu \mathrm{Ci} / \mathrm{mL} \\
\mu \mathrm{Ci} / \mathrm{mL} \\
\mu \mathrm{Ci} / \mathrm{mL}\end{array}$ \\
\hline
\end{tabular}

\section{WELL KSB 2}

MEASUREMENTS CONDUCTED IN THE FIELD

\begin{tabular}{|c|c|c|c|c|c|}
\hline \multicolumn{3}{|c|}{$\begin{array}{l}\text { Sample date: } 11 / 18 / 91 \\
\text { Depth to water: } 58.48 \mathrm{ft}(17.82 \mathrm{~m}) \text { below TOC } \\
\text { Water elevation: } 207.32 \mathrm{ft}(63.18 \mathrm{~m}) \mathrm{ms} ! \\
\text { Sp. conductance: } 30 \mathrm{~s} / \mathrm{cm} \\
\text { Water evacuated before sampling: } 88 \mathrm{gal}\end{array}$} & \multicolumn{3}{|c|}{$\begin{array}{l}\text { Time: } 5: 45 \\
\text { pH: } 4.4 \\
\text { Alkalinity: } 0 \mathrm{mg} / \mathrm{L} \\
\text { Water temperature: } 19.2^{\circ} \mathrm{C}\end{array}$} \\
\hline \multicolumn{6}{|c|}{ LABORATORY ANALYSES } \\
\hline$\underline{F}$ & Anaiyte & Result & Mod & Unit & $\underline{L a b}$ \\
\hline $\begin{array}{l}0 \\
0 \\
0 \\
0 \\
0 \\
0 \\
0 \\
0 \\
0 \\
0 \\
0 \\
0 \\
0 \\
2 \\
0\end{array}$ & $\begin{array}{l}\text { Antimony-125 } \\
\text { Cerium-144 } \\
\text { Cesium-134 } \\
\text { Cosium-137 } \\
\text { Chromium-51 } \\
\text { Cobalt-60 } \\
\text { Gross alpha } \\
\text { lodine-131 } \\
\text { Niobium-95 } \\
\text { Nonvolatile beta } \\
\text { Ruthenium-103 } \\
\text { Ruthenium-106 } \\
\text { Strontium-89/90 } \\
\text { Tritium } \\
\text { Zirconium-95 }\end{array}$ & $\begin{array}{l}<4.5 \mathrm{E} \cdot 08 \\
<1.0 \mathrm{E} \cdot 07 \\
<1.8 \mathrm{E} \cdot 08 \\
<1.8 \mathrm{E} \cdot 08 \\
<8.3 \mathrm{E} \cdot 07 \\
<2.5 \mathrm{E} \cdot 08 \\
3.6 \mathrm{E} \cdot 10 \pm \\
<8.1 \mathrm{E} \cdot 06 \\
<7.6 \mathrm{E}-08 \\
9.6 \mathrm{E} \cdot 10 \pm \\
<5.9 \mathrm{E} \cdot 08 \\
<2.0 \mathrm{E} \cdot 07 \\
-7.2 \mathrm{E} \cdot 10 \pm \\
5.1 \mathrm{E} \cdot 05 \pm \\
<7.7 \mathrm{E} \cdot 08\end{array}$ & E. & 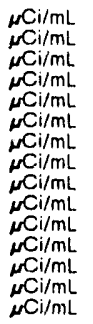 & $\begin{array}{l}E M \\
E M \\
E M \\
E M \\
E M \\
E M \\
E M \\
E M \\
E M \\
E M \\
E M \\
E M \\
E M \\
E M \\
E M\end{array}$ \\
\hline
\end{tabular}

WELL KSB 2

MEASUREMENTS CONGUCTED IN THE FIELO

Sample date: $12 / 13 / 91$
Depth to water: $5763 \mathrm{Ht}(17.57 \mathrm{~m})$ below TOC
Water elevation: $20817 \mathrm{th}(63.45 \mathrm{~m}) \mathrm{msl}$
Sp. conductance: $30 \mu \mathrm{S} / \mathrm{cm}$
Water evacuated before sampling: $90 \mathrm{gal}$

Time: $17: 30$

$\mathrm{pH}: 4.5$

Alkalinity: $0 \mathrm{mg} / \mathrm{L}$ ater temperature $21.0^{\circ} \mathrm{C}$

LABOIZATORY ANALYSES

\begin{tabular}{|c|c|c|}
\hline Analyte & Result & $\underline{\text { Unit }}$ \\
\hline $\begin{array}{l}\text { Aluminum } \\
\text { Antimony-125 } \\
\text { Crrium-144 } \\
\text { C: sium-134 } \\
\text { Cesium-137 } \\
\text { Chromium-51 } \\
\text { Cobalt-60 } \\
\text { lodine-131 } \\
\text { Niobium-95 } \\
\text { Ruthenium-103 } \\
\text { Ruthenium-106 } \\
\text { Strontium-89/90 } \\
\text { Tritium } \\
\text { Tritium } \\
\text { Zirconium-95 }\end{array}$ & 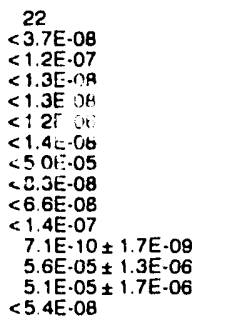 & $\begin{array}{l}\mu g / \mathrm{L} \\
\mu \mathrm{Ci} / \mathrm{mL} \\
\mu \mathrm{Ci} / \mathrm{mL} \\
\mu \mathrm{Cl} / \mathrm{mL} \\
\mu \mathrm{Ci} / \mathrm{mL} \\
\mu \mathrm{Ci} / \mathrm{mL} \\
\mu \mathrm{Ci} / \mathrm{mL} \\
\mu \mathrm{Ci} / \mathrm{mL} \\
\mu \mathrm{Cli} / \mathrm{mL} \\
\mu \mathrm{Ci} / \mathrm{mL} \\
\mu \mathrm{Ci} / \mathrm{mL} \\
\mu \mathrm{Ci} / \mathrm{mL} \\
\mu \mathrm{Ci} / \mathrm{mL} \\
\mu \mathrm{Ci} / \mathrm{mL} \\
\mu \mathrm{Cl} / \mathrm{mL}\end{array}$ \\
\hline
\end{tabular}

\section{WELL KSB 3}

MEASUREMENTS CONDUCTED IN THE FIELD

$\begin{array}{ll}\text { Sample date: } 10 / 24 / 91 & \text { Time: } 10: 40 \\ \text { Depth to water: } 54.60 \mathrm{H}(16.64 \mathrm{~m}) \text { below TOC } & \text { pH: } 4.6 \\ \text { Water elevation: } 206.90 \mathrm{Ht}(63.06 \mathrm{~m}) \mathrm{ms} & \text { Alkalinity: } 0 \mathrm{mg} / \mathrm{h} \\ \text { Sp. conductance: } 38 \mu \mathrm{cm} / \mathrm{cm} & \text { Water temperature: } 21.3^{\circ} \mathrm{C} \\ \text { Water evacuated before sampling: } 98 \mathrm{gal} & \end{array}$
Water evacuated before sampling: $98 \mathrm{gal}$ LABORATORY ANALYSES

\begin{tabular}{|c|c|c|}
\hline Analyte & Result & Unit \\
\hline $\begin{array}{l}\text { Aluminum } \\
\text { Antimony-125 } \\
\text { Cerium-144 } \\
\text { Cesium-134 } \\
\text { Cesium-137 } \\
\text { Chromium-51 } \\
\text { Cobalt-60 } \\
\text { lodir:3-131 } \\
\text { Niobium-95 } \\
\text { Ruthenium-103 } \\
\text { Ruthenium-106 } \\
\text { Strontium.89/90 } \\
\text { rritium } \\
\text { Tritium } \\
\text { Zirconium-95 }\end{array}$ & $\begin{aligned}<20 \\
<4.8 \mathrm{E}-08 \\
<1.2 \mathrm{E}-07 \\
<1.8 \mathrm{E}-08 \\
<2.1 \mathrm{E}-08 \\
<1.4 \mathrm{E}-06 \\
<2.6 \mathrm{E}-08 \\
<5.9 \mathrm{E} \cdot 05 \\
<1.3 \mathrm{E}-07 \\
<9.3 \mathrm{E} \cdot 08 \\
<1.8 \mathrm{E}-07 \\
5.3 \mathrm{E} \cdot 10 \pm 1.6 \mathrm{E} \cdot 09 \\
4.6 \mathrm{E} \cdot 05 \pm 1.3 \mathrm{E} \cdot 06 \\
5.6 \mathrm{E} \cdot 05 \pm 1.8 \mathrm{E}-06 \\
<8.1 \mathrm{E}-08\end{aligned}$ & $\begin{array}{l}\mu g / \mathrm{L} \\
\mu \mathrm{C} i / \mathrm{mL} \\
\mu \mathrm{Ci} / \mathrm{mL} \\
\mu \mathrm{Ci} / \mathrm{mL} \\
\mu \mathrm{Ci} / \mathrm{mL} \\
\mu \mathrm{Ci} / \mathrm{mL} \\
\mu \mathrm{Ci} / \mathrm{mL} \\
\mu \mathrm{Ci} / \mathrm{mL} \\
\mu \mathrm{Ci} / \mathrm{mL} \\
\mu \mathrm{Ci} / \mathrm{mL} \\
\mu \mathrm{Ci} / \mathrm{mL} \\
\mu \mathrm{Ci} / \mathrm{mL} \\
\mu \mathrm{Ci} / \mathrm{mL} \\
\mu \mathrm{Ci} / \mathrm{mL} \\
\mu \mathrm{Ci} / \mathrm{mL}\end{array}$ \\
\hline
\end{tabular}

WELL KSB 3

MEASUAEMENTS CONDUCTED IN THE FIELD

\begin{tabular}{|c|c|c|c|c|c|c|}
\hline \multicolumn{3}{|c|}{$\begin{array}{l}\text { Sample date: } 11 / 19 / 91 \\
\text { Depth to water: } 54.51 \mathrm{Ht}(16.61 \mathrm{~m}) \text { below TOC } \\
\text { Water elevation: } 206.99 \mathrm{Ht}(63.09 \mathrm{~m}) \mathrm{ms} \\
\text { Sp conductance: } 36 \mu \mathrm{s} / \mathrm{cm} \\
\text { Water evacuated before sampling: } 99 \mathrm{gal}\end{array}$} & \multicolumn{4}{|c|}{$\begin{array}{l}\text { Time: } 5: 20 \\
\text { pH: } 4.5 \\
\text { Alkalinity: } 0 \mathrm{mg} / \mathrm{h} \\
\text { Water temperature: } 19.7^{\circ} \mathrm{C}\end{array}$} \\
\hline \multicolumn{7}{|c|}{ LABORATORY ANAL.YSES } \\
\hline$\underline{F}$ & Analyte & Pesult & & Mod & $\underline{\text { Unit }}$ & Lab \\
\hline $\begin{array}{l}0 \\
0 \\
0 \\
0 \\
0 \\
0 \\
0 \\
0 \\
0 \\
0 \\
0 \\
0 \\
0 \\
2 \\
2 \\
0\end{array}$ & $\begin{array}{l}\text { Aluminum } \\
\text { Antimony-125 } \\
\text { Cerium-144 } \\
\text { Cesium-134 } \\
\text { Cesium-137 } \\
\text { Chromium-51 } \\
\text { Cobalt-60 } \\
\text { Gross alpha } \\
\text { lodine-131 } \\
\text { Niobium-95 } \\
\text { Nonvolatile beta } \\
\text { Ruthenium-103 } \\
\text { Ruthenium-106 } \\
\text { Tritium } \\
\text { Tritium } \\
\text { Zirconium-95 }\end{array}$ & $\begin{aligned}<20 \\
<4.0 \mathrm{E} \cdot 08 \\
<1.2 \mathrm{E} \cdot 07 \\
<2.3 \mathrm{E} \cdot 08 \\
<2.3 \mathrm{E} \cdot 08 \\
<7.3 \mathrm{E} \cdot 07 \\
<2.6 \mathrm{E} \cdot 08 \\
5.7 \mathrm{E} \cdot 10 \\
<7.5 \mathrm{E} \cdot 06 \\
<6.4 \mathrm{E} \cdot 08 \\
1.7 \mathrm{E} \cdot 09 \\
<5.7 \mathrm{E} \cdot 08 \\
<2.2 \mathrm{E} \cdot 07 \\
5.8 \mathrm{E} \cdot 05 \\
6.2 \mathrm{E} \cdot 05 \\
<7.2 \mathrm{E} \cdot 08\end{aligned}$ & $\begin{array}{l}3.9 \mathrm{E} \cdot 10 \\
8.8 \mathrm{E} \cdot 10\end{array}$ & & 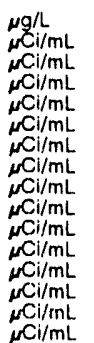 & $\begin{array}{l}G E \\
E M \\
E M \\
E M \\
E M \\
E M \\
E M \\
E M \\
E M \\
E M \\
E M \\
E M \\
E M \\
G E \\
E M \\
E M\end{array}$ \\
\hline
\end{tabular}


ANALYTICAL RESULTS

\section{WELL KSB 3}

MEASUREMENTS CONDUCTED IN THE FIELO

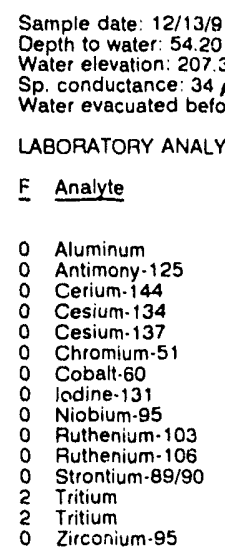

Time: $17: 05$

pH: 4.6 Alkalinity: $0 \mathrm{mg} / \mathrm{L}$

Water temperature: $20.9^{\circ} \mathrm{C}$

Water evacuated before sampling: $99 \mathrm{gal}$

LABORATORY ANALYSES

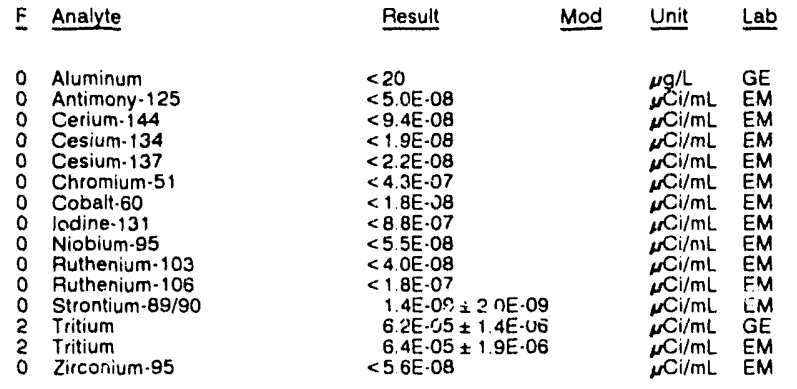

WELL KSB 4A

MEASUREMENTS CONDUCTED IN THE FIELD

Sample date: $10 / 24191$

Depth to water: $56.55 \mathrm{tt}(17.24 \mathrm{~m})$ helow TOC Water elevation: $207.55 \mathrm{ft}(53.26 \mathrm{~m}) \mathrm{ms} 1$ Sp. conductance: $35 \mu \mathrm{S} / \mathrm{cm}$
Water evacuated before sampling: $100 \mathrm{gal}$

LABORATOAY ANALYSES

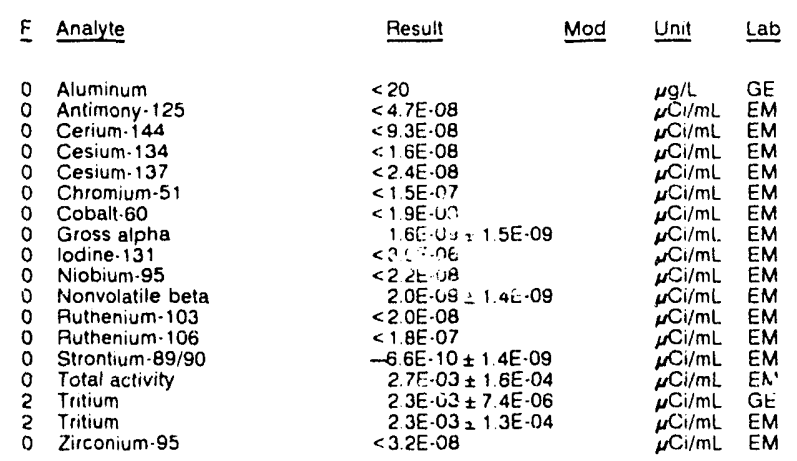

WELL KSB 4A

MEASUREMEN $\sim$ CONDUCTED IN THE FIELD

Sample date: 11/19/91

Depth to water $56.46 \mathrm{Ht}(17.21 \mathrm{~m})$ below TOC Water elevation. $207.64 \mathrm{ft}(63.29 \mathrm{~m}) \mathrm{ms}$

Sp. conductance $31 \mu \mathrm{S} / \mathrm{cm}$
Water evacuated before sampling $100 \mathrm{gal}$

Time: 10:15

PH: 5.0 Alkalinity: $2 \mathrm{mg} / \mathrm{L}$

Water temperature: $22.3^{\circ} \mathrm{C}$

LABORATORY ANALYSES

\begin{tabular}{|c|c|c|c|}
\hline Analyte & Result & Mod & Unit \\
\hline $\begin{array}{l}\text { Aluminum } \\
\text { Gross alpha } \\
\text { Nonvolatile beta } \\
\text { Tritium } \\
\text { Tritium }\end{array}$ & $\begin{array}{l}<20 \\
1.5 E \cdot 10 \pm 4.7 E \cdot 10 \\
99 E \cdot 10 \pm 1.4 E \cdot 09 \\
18 E \cdot 03 \pm 6.7 E \cdot 06 \\
20 E \cdot 03 \pm 1.2 E \cdot 04\end{array}$ & & $\begin{array}{l}\mu \mathrm{g} / \mathrm{L} \\
\mu \mathrm{Cl}_{1 / \mathrm{mL}} \\
\mu \mathrm{Cl}^{\prime} / \mathrm{mL} \\
\mu \mathrm{Cl}_{1 / \mathrm{mL}} \\
\mu \mathrm{Cl}_{1} / \mathrm{mL}\end{array}$ \\
\hline
\end{tabular}

pH: 4.6

Alkalinity: $0 \mathrm{mg} / \mathrm{L}$

Water temperature $21.0^{\circ} \mathrm{C}$

\section{WELL KSB 4A}

MEASUREMENTS CONOUCTED IN THE FIELD

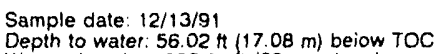

Water elevation: $208.08 \mathrm{ft}(63.42 \mathrm{~m}) \mathrm{ms}$

Sp. conductance: $30 \mu \mathrm{S} / \mathrm{cm}$

Water evacuated before sampling: $101 \mathrm{gal}$

LABORATORY ANALYSES

\begin{tabular}{|c|c|c|c|c|c|}
\hline $\mathrm{E}$ & Analyte & Result & Mod & $\underline{\text { Unit }}$ & Lab \\
\hline 0 & $\begin{array}{l}\text { Aluminum } \\
\text { Gross alpha } \\
\text { Nonvolatile beta } \\
\text { Tritium } \\
\text { Tritium }\end{array}$ & $\begin{array}{l}<20 \\
9.0 \mathrm{E} \cdot 12 \pm 6.0 \mathrm{E} \cdot 10 \\
1.3 \mathrm{E}-09 \pm 1.3 \mathrm{E}-09 \\
1.7 \mathrm{E} \cdot 03 \pm 6.2 \mathrm{E} \cdot 06 \\
1.1 \mathrm{E} \cdot 03 \pm 1.2 \mathrm{E}-04\end{array}$ & & $\begin{array}{l}\mu \mathrm{g} / \mathrm{L} \\
\mu \mathrm{C} / / \mathrm{mL} \\
\mu \mathrm{Cl} / \mathrm{mL} \\
\mu \mathrm{Ci} / \mathrm{mL} \\
\mu \mathrm{Cl} / \mathrm{mL}\end{array}$ & $\begin{array}{l}G E \\
E M \\
\vdots M \\
\text { GE } \\
E M\end{array}$ \\
\hline
\end{tabular}

WELL KSS 1D

MEASUF.EMENTS CONDUCTED IN THE FIELD

Sample date: $11 / 18 / 91$

Depth to water: $51.84 \mathrm{ft}(15.80 \mathrm{~m})$ below TOC

Water elevation: $177.96 \mathrm{ft}(54.24 \mathrm{~m}) \mathrm{ms}$ |

Sp. conductance: $55 \mu \mathrm{s} / \mathrm{cm}$

Water evacuated before sampling. $54 \mathrm{gal}$

LABORATORY ANALYSES

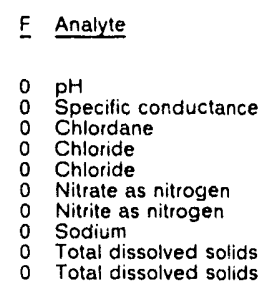

\begin{tabular}{l} 
Result \\
\hline \\
6.1 \\
50 \\
$<0.50$ \\
3,120 \\
3,160 \\
440 \\
$<10$ \\
2,010 \\
40,000 \\
40,000
\end{tabular}

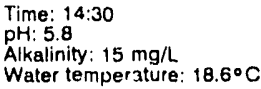

Time: 16:40

Alkalinity: $0 \mathrm{mg} / \mathrm{l}$

Water temperature: $22.1^{\circ} \mathrm{C}$

\section{WELL KSS 10 Replicate}

MEASUREMENTS CONDUCTEO IN THE FIELD

Sample date: $11 / 18 / 91$

Depth to water: $51.84 \mathrm{Ht}(15.80 \mathrm{~m})$ below TOC

Water elevation: $177.96 \mathrm{ft}(54.24 \mathrm{~m}) \mathrm{msl}$

So. conductance: $55 \mu \mathrm{S} / \mathrm{cm}$

Water evacuated belore sampling: $54 \mathrm{gal}$

LABORATORY ANALYSES

E Analyte

Result
6.2
45
$<0.50$
3,240
500
$<10$
2,000
44,000

Time: $14: 30$
pH: 5.8

Alkalinity: $15 \mathrm{mg} / \mathrm{L}$

Water temperature: $18.6^{\circ} \mathrm{C}$

Mod Unit Lab

${ }_{0}^{0} \mathrm{pH}$

O Chiordane

0 Chloride

0 Nitrate as nitrogen

0 Nitrite as

Total dissolved solids

WELL KSS 20

MEASUREMENTS CONDUCTED IN THE FIELD

Sample date: 11/18/91

Depth to water: $25.69 \mathrm{ft}(7.83 \mathrm{~m})$ below TOC

Water elevation: $166.61 \mathrm{ft}(50.78 \mathrm{~m}) \mathrm{msl}$

Sp. conductance: $25 \mu \mathrm{s} / \mathrm{cm}$
Water evacuated before sampling: $58 \mathrm{gal}$

LABORATORY ANALYSES

\begin{tabular}{|c|c|c|c|}
\hline Analyte & Result & Mod & Unit \\
\hline $\begin{array}{l}\mathrm{pH} \\
\text { Specific conductance } \\
\text { Chlordane } \\
\text { Chloride } \\
\text { Nitrate as nitrogen } \\
\text { Nitrite as nitrogen } \\
\text { Sodium } \\
\text { Total dissclved solids }\end{array}$ & $\begin{array}{l}5.7 \\
2.5 \\
<0.50 \\
2.100 \\
560 \\
<10 \\
1,680 \\
33,000\end{array}$ & $\mathrm{JQ}$ & $\begin{array}{l}\mathrm{pH} \\
\mu \mathrm{S} / \mathrm{cm} \\
\mu g / L \\
\mu \mathrm{g} / \mathrm{L} \\
\mu g / L \\
\mu g / / \\
\mu g / L \\
\mu g / L\end{array}$ \\
\hline
\end{tabular}


WELL KSS 3D

MEASUREMENTS CONDUCTED IN THE FIELD Sample date: $11 / 18 / 91$
Depth to water: 19.37 it $(5.90 \mathrm{~m})$ below TOC
Water elevation: $185.83 \mathrm{Ht}(50.55 \mathrm{~m}) \mathrm{msl}$
Sp. conductance: 37 .SS/cm
Water evacuated before sampling: $70 \mathrm{gal}$ LABORATORY ANALYSES

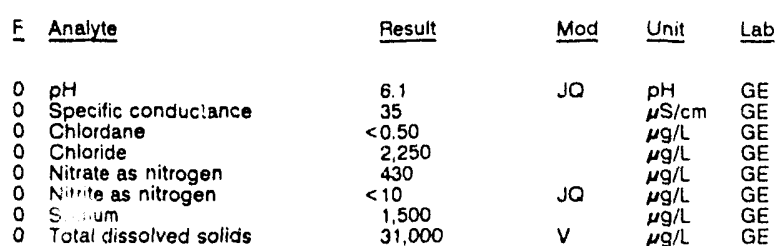

\section{WELL LAC 1}

MEASUREMENTS CONDUCTED IN THE FIELD

Sample date: 10/24/91 Depth to water $20.13 \mathrm{Ht}(6.14 \mathrm{~m})$ below TOC Wo conductance $28.07 \mathrm{~h}(66.4$

Water evacuated before sampling: 71 gal

LABORATORY ANALYSES

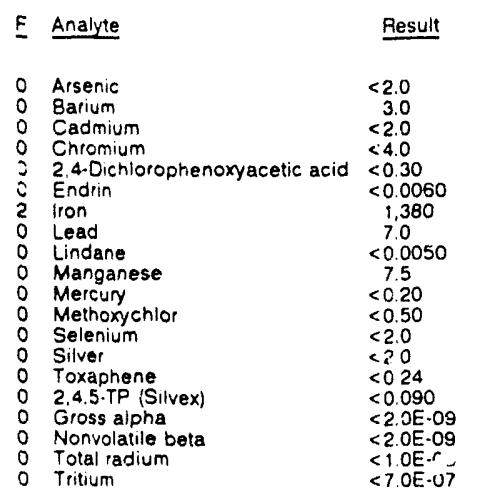

Time: 15:30

PH: 5.6

Water tempetature: $18.3 \circ \mathrm{C}$

\section{Time: $7: 40$ \\ Alkalinity: $4 \mathrm{mgl}$ \\ Water temperature: $20.8^{\circ} \mathrm{C}$}

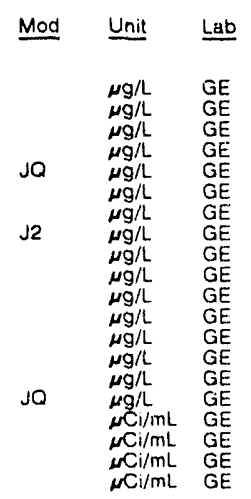

WELL LAC 2

MEASUREMENTS CONDUCTED IN THE FIELD

Sample date: 10/24/81

Depth to water: $21.92 \mathrm{ft}(6.68 \mathrm{~m})$ below TOC Wates elevation: 218.28 it (68.5

Sp. conductance $31 \mu \mathrm{rS} / \mathrm{cm}$
Water evacuated before sampling: $65 \mathrm{gal}$

LABORATORY ANALYSES

\begin{tabular}{|c|c|c|c|}
\hline Analyte & Result & Mod & Unit \\
\hline $\begin{array}{l}\text { Arsenic } \\
\text { Barium } \\
\text { Cadmium } \\
\text { Chromium } \\
2,4 \text {-Dichlorophenoxyacetic acid } \\
\text { Endrin } \\
\text { lron } \\
\text { Lead } \\
\text { Lindane } \\
\text { Manganese } \\
\text { Mercury } \\
\text { Methoxychlor } \\
\text { Selenium } \\
\text { Silver } \\
\text { Toxaphene } \\
2,4,5 \text {-TP (Silvex) } \\
\text { Gross aipha } \\
\text { Nonvolatile beta } \\
\text { Total radium } \\
\text { Tritium }\end{array}$ & $\begin{array}{l}<2.0 \\
7.8 \\
<2.0 \\
<4.0 \\
<0.30 \\
<0.0060 \\
25 \\
45 \\
<0.0050 \\
2.2 \\
<020 \\
<0.50 \\
<2.0 \\
<2.0 \\
<0.24 \\
<0.090 \\
<2.0 E \cdot 09 \\
<2.0 E \cdot 09 \\
<1.0 E \cdot 09 \\
6.0 E \cdot 06 \pm 80 E \cdot 07\end{array}$ & $\sqrt{ } 2$ & $\begin{array}{l}\mu g / L \\
\mu g / L \\
\mu g / L \\
\mu g / L \\
\mu g / L \\
\mu g / L \\
\mu g / L \\
\mu g / L \\
\mu g / L \\
\mu g / L \\
\mu g / L \\
\mu g / L \\
\mu g / L \\
\mu g / L \\
\mu g / L \\
\mu g / L \\
\mu C i / m L \\
\mu C I / m L \\
\mu C l / m L \\
\mu C i / m L\end{array}$ \\
\hline
\end{tabular}

WELL LAC 3

MEASUREMENTS CONDUCTED IN THE FIELD

Sample date: $10 / 24 / 91$

Depth to water: $19.45 \mathrm{Ht}(5.93 \mathrm{~m})$ below TOC

Water elevation: $218.35 \mathrm{ft}(66.55 \mathrm{~m}) \mathrm{msl}$

Water evacuated before sampling: $73 \mathrm{gal}$

LABORATORY ANALYSES

\begin{tabular}{|c|c|c|c|}
\hline Analyte & Result & Mod & Unit \\
\hline $\begin{array}{l}\text { Arsenic } \\
\text { Barium } \\
\text { Cadmium } \\
\text { Chrornium } \\
\text { 2,4-Dichlorophenoxyacetic acid } \\
\text { Endrin } \\
\text { lron } \\
\text { Lead } \\
\text { Lindane } \\
\text { Manganese } \\
\text { Mercury } \\
\text { Methoxychlor } \\
\text { Selenium } \\
\text { Silver } \\
\text { Toxaphene } \\
\text { 2.4,5.TP (Silvex) } \\
\text { Gross alpha } \\
\text { Nonvolatile beta } \\
\text { Total radium } \\
\text { Tritium }\end{array}$ & $\begin{array}{l}<2.0 \\
<3.0 \\
<2.0 \\
<4.0 \\
<0.30 \\
<0.0060 \\
40 \\
<3.0 \\
<0.0050 \\
2.8 \\
<0.20 \\
<0.50 \\
<2.0 \\
<2.0 \\
<0.24 \\
<0.090 \\
<20 E \cdot 09 \\
<2.0 E \cdot 09 \\
3.1 E \cdot 09 \pm 14 E-09 \\
<7.0 E \cdot 07\end{array}$ & $\mathrm{J1}$ & $\begin{array}{l}\mu g / \mathrm{L} \\
\mu \mathrm{g} / \mathrm{L} \\
\mu \mathrm{g} / \mathrm{L} \\
\mu \mathrm{g} / \mathrm{L} \\
\mu \mathrm{g} / \mathrm{L} \\
\mu \mathrm{g} / \mathrm{L} \\
\mu \mathrm{g} / \mathrm{L} \\
\mu \mathrm{g} / \mathrm{L} \\
\mu \mathrm{g} / \mathrm{L} \\
\mu \mathrm{g} / \mathrm{L} \\
\mu \mathrm{g} / \mathrm{L} \\
\mu \mathrm{g} / \mathrm{L} \\
\mu \mathrm{g} / \mathrm{L} \\
\mu \mathrm{g} / \mathrm{L} \\
\mu \mathrm{g} / \mathrm{L} \\
\mu \mathrm{g} / \mathrm{L} \\
\mu \mathrm{Ci} / \mathrm{mL} \\
\mu \mathrm{Ci} / \mathrm{mL} \\
\mu \mathrm{Ci} / \mathrm{mL} \\
\mu \mathrm{Ci} / \mathrm{mL}\end{array}$ \\
\hline
\end{tabular}

WELL LAC 4

MEASUREMENTS CONDUCTED IN THE FIELD

Sample date: $10 / 24 / 91$

Depth to water: $18.73 \mathrm{H}(5.71 \mathrm{~m})$ :elow TOC

Water elevation: $218.37 \mathrm{Ht}(66.50 \mathrm{~m}) \mathrm{msl}$

Water evacuated before sampling: $87 \mathrm{gal}$

LABORATORY ANALYSES

\begin{tabular}{|c|c|c|c|c|}
\hline Analyte & Result & Mod & Unit & Lab \\
\hline $\begin{array}{l}\text { Arsenic } \\
\text { Barium } \\
\text { Cadmium } \\
\text { Chromium } \\
\text { 2,4-Dichlorophenoxyacetic acid } \\
\text { Endrin } \\
\text { Iton } \\
\text { Lead } \\
\text { Lindane } \\
\text { Manganese } \\
\text { Mercury } \\
\text { Methoxychior } \\
\text { Selenium } \\
\text { Silver } \\
\text { Toxaphene } \\
\text { 2.4,5.TP (Silvex) } \\
\text { Gross alpha } \\
\text { Nonvolatile beta } \\
\text { Total radium } \\
\text { Tritium }\end{array}$ & $\begin{array}{l}<2.0 \\
<30 \\
<20 \\
<4.0 \\
<0.30 \\
<0.0060 \\
16 \\
<3.0 \\
<0.0050 \\
<2.0 \\
<0.20 \\
<0.50 \\
<20 \\
<20 \\
<0.24 \\
<0.090 \\
<2.0 E \cdot 09 \\
<2.0 E .09 \\
<1.0 E \cdot 09 \\
<70 E \cdot 07\end{array}$ & JO & $\begin{array}{l}\mu g / L \\
\mu g / L \\
\mu g / L \\
\mu g / L \\
\mu g / L \\
\mu g / L \\
\mu g / L \\
\mu g / L \\
\mu g / L \\
\mu g / L \\
\mu g / L \\
\mu g / L \\
\mu g / L \\
\mu g / L \\
\mu g / L \\
\mu g / L \\
\mu C i / m L \\
\mu C i / m L \\
\mu C i / m L \\
\mu C i / m L\end{array}$ & $\begin{array}{l}G E \\
G E \\
G E \\
G E \\
G E \\
G E \\
G E \\
G E \\
G E \\
G E \\
G E \\
G E \\
G E \\
G E \\
G E \\
G E \\
G E \\
G E \\
G E\end{array}$ \\
\hline
\end{tabular}

\section{WELL LAW 1D}

MEASUREMENTS CONDUCTED IN THE FIELD

Sample date 12/14/91

Depth to water: $41.35 \mathrm{th}(12.60 \mathrm{~m})$ below TOC

Water elevation. $176.75 \mathrm{ft}(53.87 \mathrm{~m}) \mathrm{msl}$

Water evacuated belore sampling: $446 \mathrm{gal}$

LABORATORY ANALYSES

\begin{tabular}{|c|c|c|c|c|}
\hline Analyce & Pesult & Mod & Unit & Lab \\
\hline $\begin{array}{l}\text { pH } \\
\text { Specitic conductance } \\
\text { Acenaphthene } \\
\text { Acenaphthylene } \\
\text { Aldrin } \\
\text { Anthracene } \\
\text { Arsenic } \\
\text { Barlum } \\
\text { Benzene } \\
\text { alpha-Benzene hexachloride } \\
\text { beta. Benzene hexachloride } \\
\text { delta.Benzene hexachloride } \\
\text { Benzdine } \\
\text { Benzo[a]anthracene }\end{array}$ & $\begin{aligned} & 6.4 \\
& 80 \\
&< 10 \\
&< 10 \\
&< 10 \\
&< 10 \\
&<20 \\
& 21 \\
&<10 \\
&<10 \\
&<10 \\
&<10 \\
&<10 \\
&<10\end{aligned}$ & $\begin{array}{l}J Q \\
J Q \\
J Q \\
J Q \\
J Q\end{array}$ & $\begin{array}{l}\rho H \\
\mu S / c m \\
\mu g / L \\
\mu g / L \\
\mu g / L \\
\mu g / L \\
\mu G / L \\
\mu g / L \\
\mu g / L \\
\mu g / L \\
\mu g / L \\
\mu g / L \\
\mu g / L \\
\mu g / L\end{array}$ & $\begin{array}{l}G E \\
G E \\
G E \\
G E \\
G E \\
G E \\
G E \\
G E \\
G E \\
G E \\
G E \\
G E \\
G E \\
G E\end{array}$ \\
\hline
\end{tabular}

Time: 7:05

pH: 6.3

Alkalinity. $57 \mathrm{mg} / \mathrm{h}$

Time: 8.00

Alkalinity: $37 \mathrm{mg} / \mathrm{L}$

Water temperature $21.5^{\circ} \mathrm{C}$

PH. 5.7 . $16 \mathrm{mg}$

Water temperature $195^{\circ} \mathrm{C}$ $\mu g / L \quad G$ 
ANALYTICAL RESULTS

WELL LAW 10 collected on 12/14/91, laboratory analyses (cont.)

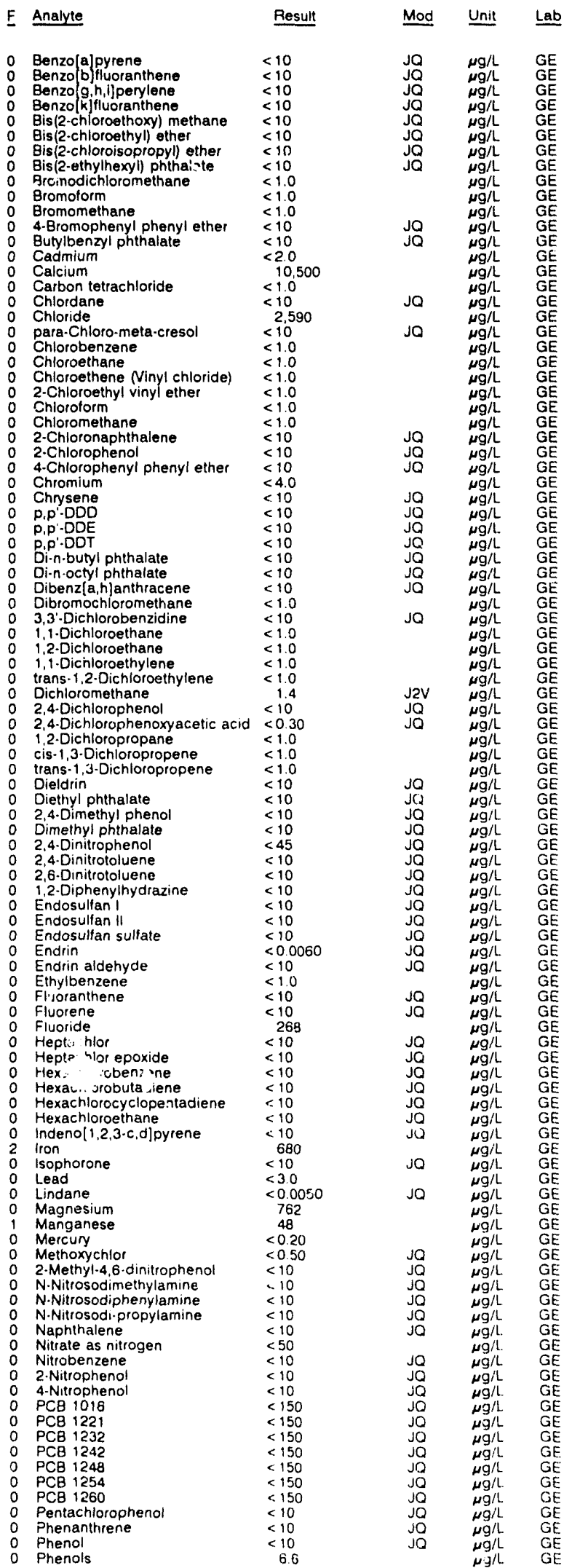

WELL LAW 1D collected on 12/14/91, laboratory analyses (cont.)

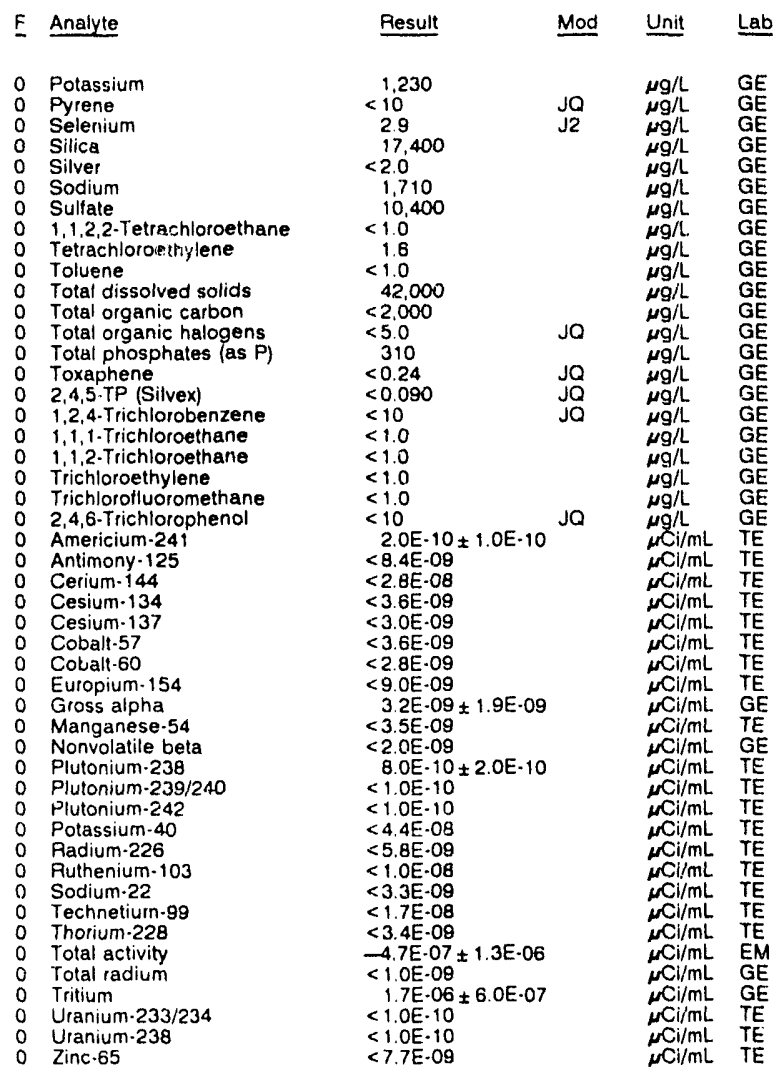

\section{WELLL LAW 2B}

MEASUAEMENTS CONDUCTED IN THE FIELD

Sample date: $12 / 11 / 91$

Depth to water: $48.99 \mathrm{ft}(14.93 \mathrm{~m})$ below TOC

Water elevation: 176.31 it 153.74

Sp. conductance $376 \mu \mathrm{S} / \mathrm{cm}$
Water evacuated before sampling: $610 \mathrm{gal}$

LASORATORY ANALYSES

\begin{tabular}{|c|c|c|c|c|c|}
\hline E & Analyte & Result & Mod & Unit & Lab \\
\hline 2 & $\mathrm{pH}$ & 11 & Jo & $\mathrm{pH}$ & \\
\hline 1 & Specific conductance & 310 & & $\mu \mathrm{S} / \mathrm{cm}$ & \\
\hline 0 & Acenaphthene & $<10$ & JO & $\mu g / L$ & \\
\hline 0 & Acenaphthylene & $<10$ & JQ & $\mu \mathrm{g} / \mathrm{L}$ & \\
\hline 0 & Aldrin & $<10$ & $\mathrm{JQ}$ & $\mu \mathrm{g} / \mathrm{L}$ & \\
\hline 0 & Anthracene & $<10$ & Jo & $\mu g / L$ & $\mathrm{GE}$ \\
\hline 0 & Arsenic & $<20$ & & $\mu \mathrm{g} / \mathrm{L}$ & \\
\hline 0 & Barium & 71 & & $\mu \mathrm{g} / \mathrm{L}$ & \\
\hline 0 & Benzene & $<10$ & & $\mu g / L$ & \\
\hline 0 & alpha-Eenzene hexachioride & $<10$ & JQ & $\mu \mathrm{g} / \mathrm{L}$ & $G E$ \\
\hline 0 & beta-Benzene hexachloride & $<10$ & Jo & $\mu \mathrm{g} / \mathrm{L}$ & \\
\hline & delta.Benzene hexachloride & $<10$ & JQ & $\mu g / L$ & \\
\hline 0 & Benzıdine & $<10$ & Jo & $\mu \mathrm{g} / \mathrm{L}$ & \\
\hline 0 & Benzola)anthracene & $<10$ & JQ & $\mu \mathrm{g} / \mathrm{L}$ & \\
\hline 0 & Benzolalpyrene & $<10$ & Jo & $\mu \mathrm{g} / \mathrm{L}$ & \\
\hline 0 & Benzo b] fluoranthene & $<10$ & $J Q$ & $\mu \mathrm{g} / \mathrm{L}$ & \\
\hline 0 & Benzo[g, $h, i]$ perylene & $<10$ & ق & $\mu g / L$ & \\
\hline 0 & Benzo[k]fiuoranthene & $<10$ & $\mathrm{JO}$ & $\mu g / L$ & \\
\hline 0 & Bis (2-chloroethexy) methane & $<10$ & Jo & $\mu g / L$ & \\
\hline 0 & Bis (2-chloroethyl) ether & $<10$ & Jo & $\mu \mathrm{g} / \mathrm{L}$ & \\
\hline 0 & Bis (2-chloroisopropyl) ether & $<10$ & JQ & $\mu g / L$ & \\
\hline 0 & $\begin{array}{l}\text { Bis (2-ethylhexyl) phthalate } \\
\text { Bromodichloromethane }\end{array}$ & $\begin{array}{l}<10 \\
<10\end{array}$ & JQ & $\underset{\mu \mathrm{g} / \mathrm{L}}{\mu}$ & \\
\hline 0 & Bromoform & $<1.0$ & & $\mu \mathrm{g} / \mathrm{L}$ & \\
\hline 0 & Eromomethane & $<1.0$ & & $\mu \mathrm{g} / \mathrm{L}$ & \\
\hline 0 & $\therefore$ Bromophenyl phenyl ether & $<10$ & jo & $\mu g / L$ & \\
\hline 0 & $\begin{array}{l}\text { Butylbenzy! phthalate } \\
\text {. }\end{array}$ & $<10$ & Jo & $\mu \mathrm{g} / \mathrm{l}$ & \\
\hline 0 & Cadmium & $<2.0$ & & $\mu \mathrm{g} / \mathrm{L}$ & \\
\hline 0 & Calcium & 56,600 & & $\mu g / L$ & \\
\hline 0 & Carbon tetrachloride & $<1.0$ & & $\mu \mathrm{g} / \mathrm{L}$ & \\
\hline 0 & Chlordane & $<10$ & Jo & $\mu \mathrm{g} / \mathrm{L}$ & \\
\hline 0 & Chloride & 1,950 & & $\mu \mathrm{g} / \mathrm{L}$ & \\
\hline 0 & $\begin{array}{l}\text { para-Chioro-meta-cresol } \\
\text { Chlorobenzene }\end{array}$ & $\begin{array}{l}<10 \\
<10\end{array}$ & Jo & $\begin{array}{l}\mu \mathrm{g} / \mathrm{L} \\
\mu \mathrm{g} / \mathrm{L}\end{array}$ & \\
\hline 0 & Chloroethane & $<10$ & & $\mu \mathrm{g} / \mathrm{h}$ & \\
\hline
\end{tabular}

Time: 13:10

Alkatinity: $141 \mathrm{mg} / \mathrm{l}$

Alkatinity: $141 \mathrm{mg} / \mathrm{L}$ 
ANALYTICAL RESULTS

WELL LAW $2 B$ collected on 12/11/91, laboratory analyses (cont.)

\begin{tabular}{|c|c|c|c|c|c|c|}
\hline Analyte & Result & Mod & Unit & Lab & $E$ & Analyte \\
\hline $\begin{array}{l}\text { Chloroethene Ninyt chloride) } \\
\text { 2-Chloroethyl vinyl ether } \\
\text { Chloroform } \\
\text { Chloromethane } \\
\text { 2-Chloronaphthalene } \\
\text { 2-Chlorophenol } \\
\text { 4-Chlorophenyl phenyl ether } \\
\text { Chromium } \\
\text { Chrysene } \\
\text { p,p'-DDD } \\
\text { p,p'-DDE } \\
\text { p,p'-DDT } \\
\text { Di-n-butyl phthalate } \\
\text { Dl-n-octyl phthalate } \\
\text { Dibenzla,h]anthracene } \\
\text { Dibromochloromethane } \\
\text { 3,3'-Dichlorobenzidine } \\
\text { 1,-Dichlooethane } \\
\text { 1,2-Dichloroethane } \\
\text { 1,1-Dichloroethylene } \\
\text { trans-1,2-Dichloroethylene } \\
\text { Dichlorornethane } \\
\text { 2,4-Dichlorophenol } \\
\text { 2,4-Dichlorophenoxyacetic acid } \\
\text { 1,2-Dichloropropane } \\
\text { cis-1,3-Dichloropropene } \\
\text { trans-1,3-Dichloropropene }\end{array}$ & $\begin{array}{l}<1.0 \\
<1.0 \\
<1.0 \\
<1.0 \\
<10 \\
<10 \\
<10 \\
<4.0 \\
<10 \\
<10 \\
<10 \\
<10 \\
<10 \\
<10 \\
<10 \\
<1.0 \\
<10 \\
<1.0 \\
<1.0 \\
<1.0 \\
<1.0 \\
<1.0 \\
<10 \\
<0.30 \\
<1.0 \\
<1.0 \\
<1.0\end{array}$ & $\begin{array}{l}\mathrm{JO} \\
\mathrm{J} Q \\
\mathrm{JO} \\
\mathrm{JQ} \\
\mathrm{JQ} \\
\mathrm{JQ} \\
\mathrm{J} Q \\
\mathrm{~J} Q \\
\mathrm{~J} Q \\
\mathrm{JO} \\
\mathrm{J}\end{array}$ & $\begin{array}{l}\mu g / L \\
\mu g / L \\
\mu g / L \\
\mu g / L \\
\mu g / L \\
\mu g / L \\
\mu g / L \\
\mu g / L \\
\mu g / L \\
\mu g / L \\
\mu g / L \\
\mu g / L \\
\mu g / L \\
\mu g / L \\
\mu g / L \\
\mu g / L \\
\mu g / L \\
\mu g / L \\
\mu g / L \\
\mu g / L \\
\mu g / L \\
\mu g / L \\
\mu g / L \\
\mu g / L \\
\mu g / L \\
\mu g / L \\
\mu g / L\end{array}$ & $\begin{array}{l}\mathrm{GE} \\
\mathrm{GE} \\
\mathrm{GE} \\
\mathrm{GE} \\
\mathrm{GE} \\
\mathrm{GE} \\
\mathrm{GE} \\
\mathrm{GE} \\
\mathrm{GE} \\
\mathrm{GE} \\
\mathrm{GE} \\
\mathrm{GE} \\
\mathrm{GE} \\
\mathrm{GE} \\
\mathrm{GE} \\
\mathrm{GE} \\
\mathrm{GE} \\
\mathrm{GE} \\
\mathrm{GE} \\
\mathrm{GE} \\
\mathrm{GE} \\
\mathrm{GE} \\
\mathrm{GE} \\
\mathrm{GE} \\
\mathrm{GE} \\
\mathrm{GE}\end{array}$ & $\begin{array}{l}0 \\
0 \\
0 \\
0 \\
0 \\
0 \\
0 \\
0 \\
0 \\
0 \\
0 \\
0 \\
0 \\
0 \\
0 \\
0 \\
0 \\
0 \\
0 \\
0 \\
0 \\
0 \\
0 \\
0 \\
0 \\
0 \\
0\end{array}$ & $\begin{array}{l}2,4,6-\text { Trichlorophenol } \\
\text { Americium-241 } \\
\text { Antimony-125 } \\
\text { Cerium-144 } \\
\text { Cesium-134 } \\
\text { Cesium-137 } \\
\text { Cobalt-57 } \\
\text { Cobalt-60 } \\
\text { Europium-154 } \\
\text { Gross alpha } \\
\text { Manganese-54 } \\
\text { Nonvolatile beta } \\
\text { Plutonium-238 } \\
\text { Plutonium-239/240 } \\
\text { Plutonium-242 } \\
\text { Potassium-40 } \\
\text { Radium-226 } \\
\text { Ruthenium-103 } \\
\text { Sodium-22 } \\
\text { Technetium-99 } \\
\text { Thorium-228 } \\
\text { Total activity } \\
\text { Total radium } \\
\text { Tritium } \\
\text { Uranium-233/234 } \\
\text { Uranium-238 } \\
\text { Zinc-65 }\end{array}$ \\
\hline
\end{tabular}

WELL LAW 28 collected on 12/11/91, laboratory analyses (cont.)

\begin{tabular}{|c|c|c|}
\hline Result & Mod & Unit \\
\hline $\begin{array}{l}<10 \\
2.0 E-10 \pm 2.0 E \cdot 10 \\
<6.8 E-09 \\
<2.0 E-08 \\
<2.8 E-09 \\
<2.6 E \cdot 09 \\
<2.6 E-09 \\
<2.5 E-09 \\
<1.2 E-08 \\
<2.0 E-09 \\
<3.3 E-09 \\
<2.0 E-09 \\
<1.0 E-10 \\
<1.0 E-10 \\
<1.0 E-10 \\
<4.0 E-08 \\
<4.7 E-09 \\
<1.1 E-08 \\
<4.5 E-09 \\
<1.9 E-08 \\
<2.9 E-09 \\
9.6 E-06 \pm 1.3 E-06 \\
1.7 E \cdot 09 \pm 1.1 E \cdot 09 \\
1.0 E-05 \pm 8.0 E-07 \\
<1.0 E-10 \\
<1.0 E \cdot 10 \\
<7.8 E \cdot 09\end{array}$ & JQ & $\begin{array}{l}\mu g / \mathrm{L} \\
\mu \mathrm{Ci} / \mathrm{mL} \\
\mu \mathrm{Ci} / \mathrm{mL} \\
\mu \mathrm{Ci} / \mathrm{mL} \\
\mu \mathrm{Ci} / \mathrm{mL} \\
\mu \mathrm{Ci} / \mathrm{mL} \\
\mu \mathrm{Ci} / \mathrm{mL} \\
\mu \mathrm{Ci} / \mathrm{mL} \\
\mu \mathrm{Ci} / \mathrm{mL} \\
\mu \mathrm{Ci} / \mathrm{mL} \\
\mu \mathrm{Ci} / / \mathrm{mL} \\
\mu \mathrm{Ci} / \mathrm{mL} \\
\mu \mathrm{Ci} / \mathrm{mL} \\
\mu \mathrm{Ci} / \mathrm{mL} \\
\mu \mathrm{Ci} / \mathrm{mL} \\
\mu \mathrm{Ci} / \mathrm{mL} \\
\mu \mathrm{Ci} / \mathrm{mL} \\
\mu \mathrm{Ci} / \mathrm{mL} \\
\mu \mathrm{Ci} / \mathrm{mL} \\
\mu \mathrm{Ci} / \mathrm{mL} \\
\mu \mathrm{Ci} / \mathrm{mL} \\
\mu \mathrm{Ci} / \mathrm{mL} \\
\mu \mathrm{Ci} / \mathrm{mL} \\
\mu \mathrm{Ci} / \mathrm{mL} \\
\mu \mathrm{Ci} / \mathrm{mL} \\
\mu \mathrm{Ci} / \mathrm{mL} \\
\mu \mathrm{Ci} / \mathrm{mL}\end{array}$ \\
\hline
\end{tabular}

WELL LAW 3B

MEASUREMENTS CONDUCTED IN THE FIELD

Sample date: $12 / 14 / 91$
Depth to water: $69.88 \mathrm{Ht}(21.30 \mathrm{~m})$ below TOC

Time: $10: 40$

Water elevation:

Inaccessibility or pump failure prevented sample collection.

WELL LAW 3B

MEASUREMENTS CONDUCTED IN THE FIELD

Sample date: $12 / 30 / 91$

Depth to water: $69.80 \mathrm{ft}(21.28 \mathrm{~m})$ below TOC

Water elevation: $178.60 \mathrm{th}(54.44 \mathrm{~m}) \mathrm{ms}$ l

Water evacuated before sampling. $589 \mathrm{\Omega al}$

pH: 11.5

Alkalinity: $112 \mathrm{mg} / \mathrm{L}$

LABORATORY ANALYSES

\begin{tabular}{|c|c|c|c|c|c|}
\hline $\mathrm{F}$ & Analyte & Resul: & Mod & Unit & Lab \\
\hline 2 & Specific conduclance & 620 & & $\mu \mathrm{S} / \mathrm{cm}$ & GE \\
\hline $\begin{array}{l}0 \\
0\end{array}$ & Acenaphthene & $<10$ & & $\mu \mathrm{g} / \mathrm{L}$ & GE \\
\hline 0 & $\begin{array}{l}\text { Acenaphthylene } \\
\text { Aldrin }\end{array}$ & $\begin{array}{l}<10 \\
<10\end{array}$ & & $\mu g / L$ & $\begin{array}{ll}\mathrm{GE} \\
\mathrm{GE}\end{array}$ \\
\hline 0 & Anthracene & $<10$ & & $\mu \mathrm{g} / \mathrm{L}$ & $G E$ \\
\hline 0 & Arsenic & 5.4 & & $\mu g / L$ & $G E$ \\
\hline $\begin{array}{l}0 \\
0\end{array}$ & $\begin{array}{l}\text { Barium } \\
\text { Benzene }\end{array}$ & $\begin{array}{r}122 \\
<1.0\end{array}$ & & $\begin{array}{l}\mu g / L \\
\mu g / L\end{array}$ & $\begin{array}{l}\mathrm{GE} \\
\mathrm{GE}\end{array}$ \\
\hline 0 & alpha-Benzene hexachloride & $<10$ & & $\mu \mathrm{g} / \mathrm{L}$ & $\mathrm{GE}$ \\
\hline 0 & beta-Benzene hexachloride & $<10$ & & $\mu g / L$ & GE \\
\hline $\begin{array}{l}0 \\
0\end{array}$ & $\begin{array}{l}\text { delta-Benzene hexachloride } \\
\text { Benzidine }\end{array}$ & $\begin{array}{l}<10 \\
<10\end{array}$ & & $\mu g / L$ & $\begin{array}{l}\mathrm{GE} \\
\mathrm{GE}\end{array}$ \\
\hline 0 & Benzo[a]anthracene & $<10$ & & $\mu g / L$ & $\mathrm{GE}$ \\
\hline 0 & Benzola pyrene & $<10$ & & $\mu \mathrm{g} / \mathrm{L}$ & $\mathrm{GE}$ \\
\hline 0 & Benzo(b) fluoranthene & $<10$ & & $\mu g / \mathrm{L}$ & $\begin{array}{l}G E \\
G E\end{array}$ \\
\hline 0 & 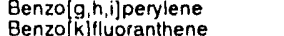 & $\begin{array}{l}<10 \\
<10\end{array}$ & & $\mu g / L$ & $\begin{array}{l}\mathrm{GE} \\
\mathrm{GE}\end{array}$ \\
\hline 0 & Bis (2-chloroethoxy) methane & $<10$ & & $\mu \mathrm{g} / \mathrm{h}$ & $\mathrm{GE}$ \\
\hline 0 & Bis (2.chloroethyl) ether & $<10$ & & $\mu \mathrm{g} / \mathrm{L}$ & $\mathrm{GE}$ \\
\hline 0 & Bis $(2 \cdot$ chloroisopropyl) ether & $<10$ & & $\mu \mathrm{g} / \mathrm{L}$ & $G \bar{G}$ \\
\hline 0 & Bis (2 ethylhexyl) phthalate & $<10$ & & $\mu g / L$ & $\mathrm{GE}$ \\
\hline 0 & Bromodichloromethane & $<10$ & & $\mu g / \mathrm{L}$ & E \\
\hline 0 & Bromoform & $<1.0$ & & $\mu \mathrm{g} / \mathrm{L}$ & GE \\
\hline 0 & Bromomethane & $<1.0$ & & $\mu \mathrm{g} / \mathrm{L}$ & \\
\hline 0 & 4. Bromophenyl phenyl ether & $<10$ & & $\mu \mathrm{g} / \mathrm{L}$ & $\mathrm{GE}$ \\
\hline 0 & Butylbenzyl phthalate & $<10$ & & $\mu \mathrm{g} / \mathrm{L}$ & GE \\
\hline 0 & Cadmium & $<2.0$ & & $\mu g / L$ & GE \\
\hline J & $\begin{array}{l}\text { Calcium } \\
\text { Carbon tetrachioride }\end{array}$ & $\begin{array}{l}78,600 \\
<10\end{array}$ & & $\mu \mathrm{g} / \mathrm{L}$ & $\begin{array}{l}\mathrm{GE} \\
\mathrm{GE}\end{array}$ \\
\hline 0 & Chlordane & $<10$ & & $\mu g / \mathrm{L}$ & $\mathrm{GE}$ \\
\hline 0 & Chloride & 1,630 & & $\mu g / L$ & \\
\hline 0 & para-Chloro-meta-cresol & $<10$ & & $\mu g / L$ & \\
\hline 0 & Chlorobenzene & $<1.0$ & & & \\
\hline 0 & Chloroethane & $<1.0$ & & $\mu g / \mathrm{L}$ & \\
\hline 0 & Chloroethene (Vinyl chloride) & $<1.0$ & & $\mu g / L$ & \\
\hline 0 & 2.Chloroethyl vinyl ether & $<1.0$ & & $\mu g / h$ & \\
\hline 0 & Chloroform & $<1.0$ & & $\mu \mathrm{g} / \mathrm{L}$ & $\mathrm{GE}$ \\
\hline 0 & Chloromethane & $<1.0$ & & $\mu \mathrm{g} / \mathrm{L}$ & E \\
\hline 0 & 2.Chloronaphthalene & $<10$ & & $\mu \mathrm{g} / \mathrm{L}$ & \\
\hline 0 & 2. Chlorophenol & $<10$ & & $\mu \mathrm{g} / \mathrm{L}$ & \\
\hline 0 & 4.Chlo:ophenyl phenyl ether & $<10$ & & $\mu g / L$ & \\
\hline 0 & Chromium & $<40$ & & $\mu \mathrm{g} / \mathrm{L}$ & \\
\hline 0 & Chrysene & $<10$ & & $\mu \mathrm{g} / \mathrm{L}$ & \\
\hline 0 & p.p'.0DO & $<10$ & & $\mu g / L$ & $G E$ \\
\hline
\end{tabular}


ANALYTICAL RESULTS

WELL LAW 3B collected on 12/30/91, laboratory analyses (cont.)

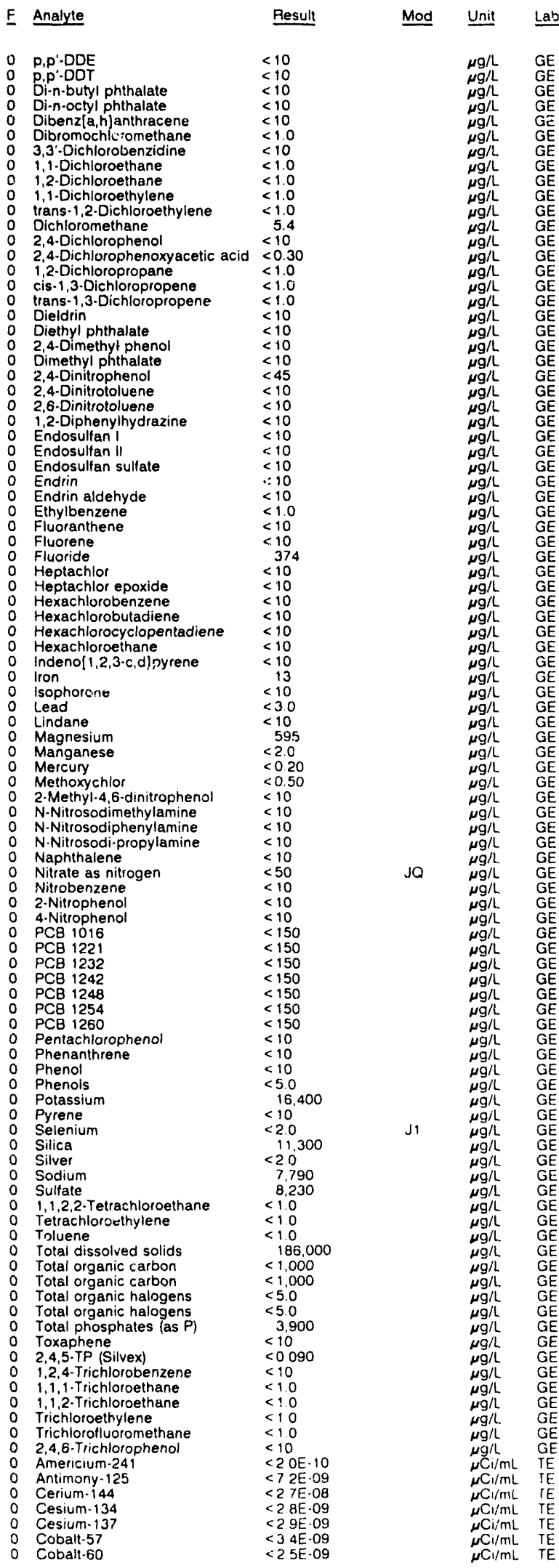

WELL LAW 38 collected on 12/30/91, laboratory analyses (cont)

\begin{tabular}{|c|c|c|}
\hline Analyte & Result & Unit \\
\hline $\begin{array}{l}\text { Europium-154 } \\
\text { Gross alpha } \\
\text { Manganese-54 } \\
\text { Nonvolatile beta } \\
\text { Plutonium-238 } \\
\text { Plutonium-239/240 } \\
\text { Plutonium-242 } \\
\text { Potassium-40 } \\
\text { Radium-226 } \\
\text { Ruthenium-103 } \\
\text { Sodium-22 } \\
\text { Technetium-99 } \\
\text { Thorium-228 } \\
\text { Total activity } \\
\text { Total radium } \\
\text { Tritium } \\
\text { Uranium-233/234 } \\
\text { Uranium-238 } \\
\text { Zinc-65 }\end{array}$ & 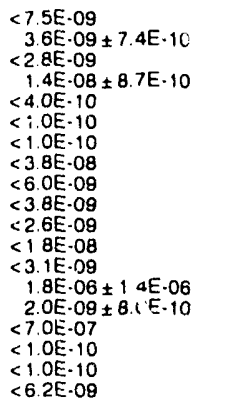 & $\begin{array}{l}\mu \mathrm{Ci} / \mathrm{mL} \\
\mu \mathrm{Ci} / \mathrm{mL} \\
\mu \mathrm{Ci} / \mathrm{mL} \\
\mu \mathrm{Ci} / \mathrm{mL} \\
\mu \mathrm{Ci} / \mathrm{mL} \\
\mu \mathrm{Ci} / \mathrm{mL} \\
\mu \mathrm{Ci} / \mathrm{mL} \\
\mu \mathrm{Ci} / \mathrm{mL} \\
\mu \mathrm{Ci} / \mathrm{mL} \\
\mu \mathrm{Ci} / \mathrm{mL} \\
\mu \mathrm{Ci} / \mathrm{mL} \\
\mu \mathrm{Ci} / \mathrm{mL} \\
\mu \mathrm{Ci} / \mathrm{mL} \\
\mu \mathrm{Ci} / \mathrm{mL} \\
\mu \mathrm{Ci} / \mathrm{mL} \\
\mu \mathrm{Ci} / \mathrm{mL} \\
\mu \mathrm{Ci} / \mathrm{mL} \\
\mu \mathrm{Ci} / \mathrm{mL} \\
\mu \mathrm{Ci} / \mathrm{mL}\end{array}$ \\
\hline
\end{tabular}

\section{WELL LCO 1}

MEASUREMENTS CONOUCTED IN THE FIELO

Sample date: $11 / 19 / 91$
Depth to water: 23.42 tt $(7.14 \mathrm{~m})$ below TOC

Depth to water: $23.42 \mathrm{H}(7.14 \mathrm{~m})$ below $\mathrm{TOC}$

Water evacuated belore sampling: $56 \mathrm{gal}$

Time: $8: 15$

PH: 5.4 alkainity $10 \mathrm{mg} / \mathrm{L}$

Water temperature: $20.2^{\circ} \mathrm{C}$

LABORATORY ANALYSES

$0 \mathrm{pH}$

Specific corduciance

Acenapht! ene

Acenaph
Acetone

Acetonitrile (Methyl cyanide)

Acetophenone

2.Acetylaminofluorene

Acrolein

Acrylonitrile

Aldrin

Allyl chloride

Aniline

Anthracer.e

Antimony

Aramite

Arsenic

0 Benzene

alpha. Benzene hexachloride

beta-Benzene hexachloride

delta-Benzene hexachloride

Benzolalanthracene

Benzola pyrene

Benzo b] fluoranthene

Benzolg, h, ilperylene

Benzo kffiuoranthen
Benzyl alcohol

Benzyl alcoho

Bis (2.chloroisopropyl)ethe

Bis (2.chloroisopropylyether

Bis(2-chlorcethoxy) methane
Bis (2-chloroethyl) ether

Bis (2.ethylhexyl) ether

Bromodichloromethane

Bromoform

Bromomethane

4. Bromophenyl phenyl ether

2.5ec.Butyl.4,6-dinitrophenol

Butylbenzyl phthalate

Carbon disulfide

Carbon tetrachloride

2.3,7.8.TCDF

Chlordan

para.Chloro-meta.cresol

4.Chioroaniline

Chlorobenzilate

Chloroethane

Chloroethene Ninyl chloride)

Chloroform

Chloromethane
2.Chloronaphthalene

2.Chlorophenol
4.Chlorophenyl phenyl ether

Chloroprene

Chronium

Chrysen

Cobalt

O.Cresol [2.Methylphenol)

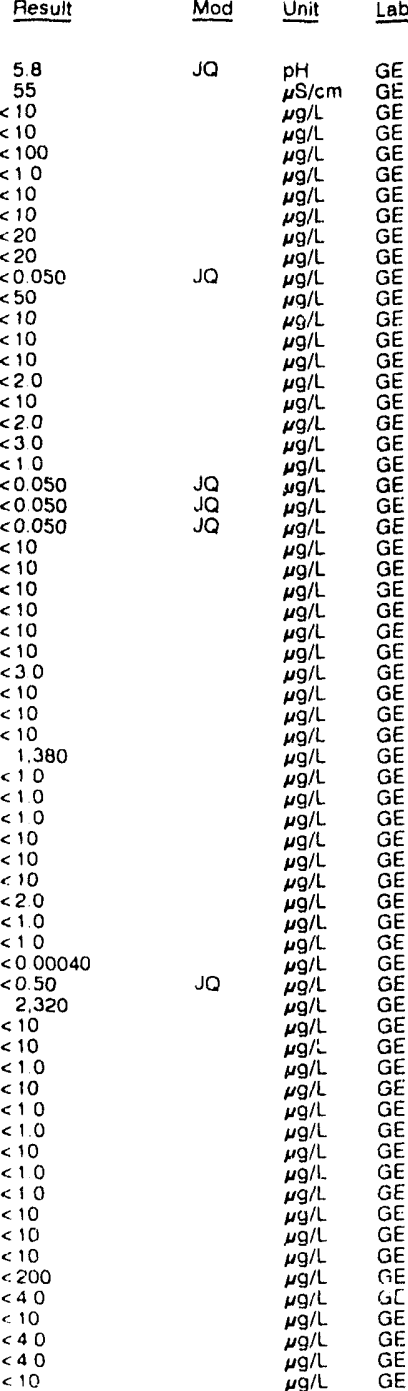


ANALYTICAL RESULTS

WELL LCO 1 collected on 11/19/91, laboratory analyses (cont.)

\begin{tabular}{|c|}
\hline Analyie \\
\hline 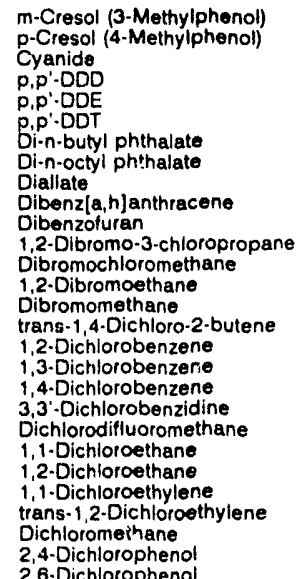 \\
\hline
\end{tabular}

2.4.Dichlorophenoxyacetic acid $<0.30$

cis-1ichloropropane $<1.0$

trans-1,3-Dichloropropene $\quad<1.0$

Dieldrin ichalate $<0.50$

Dimethe

2,4-Dimethyl pheno

p-Dimethylaminoazobenzene

Dimethylbenz(a)anthracene

3.3. Dimethylbenzidine

a,a.Dimethylphenethylamine

3. Dinitrobenzene

2,4-Dinitrophenol

2,6-Dinitrotoluen

1,4-Dioxane

Dissolved organic carbon

Disulfoton

Endosulfan I

Endosulfan sulfate

Endin

Endrin aldehyde

Ethyl methane sulfonate

Ethylbenzene

Famphur

Fluoranthene

Heptachlor

Heptachlor epoxide

Heptachlorodibenzo-p-dioxins

$1,2,3,4,6,7,8 \cdot H P C D F$
Heptachlorodibenzo-p.furans

Hexachlorobenzene

Hexachlorocyclopentadiene

Hexachlorocyclopent

Hexachlorodibenzo-p-dioxins

Mexachiorodibenzo-p.turans

Hexachloroethane

Hexachlorophene

2. Hexariune

Indeno $1,2,3 \cdot c, d$ lpyrene

lodom

Isobutyl alcoho

Isodrin

Isophorone

Isosafrole
0

Lead

Manganese

Manganese

Methacrylonitile

Methapysilen

Methoxychior

Methyl ethyl ketone

Methyl methacrylate

Methyi methanesulfonate

2-Methyl-4,6-dinitropheno

3-Methylchnlanthrene

2-Methyln' whthalene
N-Nitroso jiethylamine
$<10$

$<10$
$<5.0$

$<0.10$
$<0.10$

$<10$

$<10$

$<1.0$

$<20$

$<1.0$
$<30$

10

$<10$
$<10$

$<1.0$

10

1.0

-1
2

$<1.0$
$<10$

$<10$

10

$<10$

$<10$
$<15$
$<45$

$<45$
$<10$

$<10$
$<10$

$<1,000$

$<10$

$<0.10$
$<0.10$

$<0.10$
$<0.0060$

$<0.10$

$<10$

$<1.0$

$<10$

$<10$
$<10$

$<0.050$
$<0.050$

$<0.00065$

$<0.00065$

$<0.00045$

$<10$

$<10$

$<10$
$<0.00045$

$<0.00045$

$<0.00040$

$<10$

$<10$
$<10$

$<10$

$<10$

$<15$

64
$<100$

$<10$

$<10$

$<10$

$<10$
3.2

$<0.0050$

$<<0.20$

$<50$

$<0.50$
$<1.0$
$<10$

$<1.0$

$<10$

$<10$
$<10$

$<10$

$<10$
$<10$ $\mu g / L \quad G E$
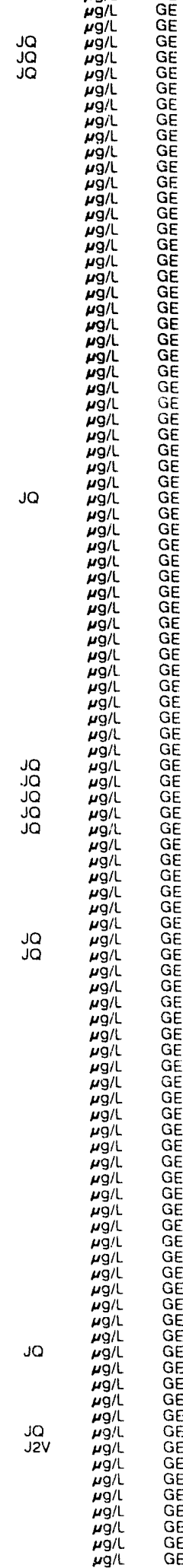

WELL LCO 1 collected on 11/19/91, laboratory analyses (cont.)

E Analyte Besilt Mod Unit Lab

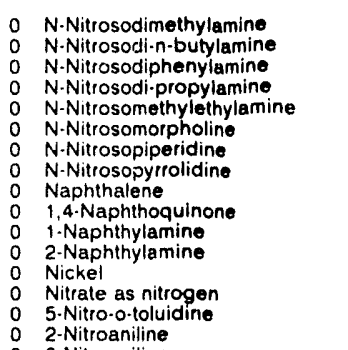

3.Nitroariline

4.Nitroaniline

- Nitrobenzene

2.Nitrophenol

$<10$

$<10$
$<10$

$<10$

10

$<10$
$<10$
$<10$

$<10$

$<10$
$<10$

$<10$

7.7
2,200
$<10$

$<10$

$<10$

$<10$

$<10$

4-Nitroquinoline-1-oxif $<<10$

0 Octachlorodibenzo.p.dioxins <0.0010

0 Octachlorodibenzo-p.furans $\quad<0.0010$

o Parathion

- Parathion methyl

PCB 1016

O $\mathrm{PCB} 1232$

P PCB 1242

PCB 1248

PCB 1254

Pentachlorobenzene

P.2.3.7.8.PCDF

Pentachlorodibenzo-p.dioxins

Pentachlorodibenzo-p-turans

Pentachloroethen

Pentachloronitrobenzene

Pentachlorophenol

Phenacetin

0 Phenanth

p.Phenylenediamine

Phorate

2.PIcoline

Pronamid
Propionitrile

Pyrene

Pyridine
Safrole

Selenium

Silver

Styrene

Sulfate

Sulfide

1.2.4.5.Tetrachlorobenzene

Tetrachlorodibenzo-p-dioxins

Tetrachiorodibenzo-p-turans

1,1,1,2-Tetrachloroethane

Tetrachioroethylene

2,3,4,6-Tetrachlorophenol

Thallium

Thionazin

Toluene

O-Toluidine
Total dissolved sotids

Tolal organic calbon

Toxaphene

1,2,4-Trichlorobenzene

1,2,1.Trichloroethane

1,1,2-Trichloroethane

Trichloroethylene

Trichlorofluoromethane

2.4,5-Trichlorophenal

2.4,6.Trichloropheno

$\begin{array}{ll}0 & 2,4,5 \cdot 1 \\ 0 & 1,2,3\end{array}$

1,2.3.Trichloropropane

1.3,5. Trinitrobenzene

Vinyl acetate

Xylenes

X Xylenes

2,3,7,8-TCDO

Americium-241

Antimony 125

Cerium.144

Cesium.137

Cobalt.57

Cobalt.60

Gross aipha

0 Manganese.54

$<0.050$

$<0.50$

$<0.50$
$<0.50$

$<0.50$

$<0.50$

$<0.50$

$<0.50$

$<0.00055$

$<0.00055$

$<0.00055$

$<10$

$<10$

$<10$
$<10$
$<10$

$<10$
$<10$
$<0.10$

$<10$
$<0.10$
$<10$

$<10$

$<200$

$<10$
$<10$

$<2.0$

$<2.0$
$<1.0$

$<.0$
2,230

$<1,000$

$<10$
$<10$

$<0.00045$

$<10$

$<1.0$
$<1.0$

$<1.0$
$<10$

$<2.0$

$<10$
$<20$

20
25

$<10$
85,000

85,000
$<1,000$

$<0.24$
$<0.090$

$<10$

$<10$

$<10$
$<10$

12
$<10$

$<10$

$<0090$

$<10$

$<10$

$<8.0$
$<10$

$<1.0$
$<2.0$

$\begin{aligned} & 3.8 \\ < & 0.00045\end{aligned}$

$<0.00045$
$<1.0 \mathrm{E} \cdot 10$

$<1.0 \mathrm{E} \cdot 10$
$<7 \mathrm{BE} .09$

$<3.2 \mathrm{E} \cdot 08$

$<3$ OE.09

$<4$ OE.09

< $3.0 E .09$

$<81 E .09$

$2.2 E \cdot 09$
$<33 \mathrm{E} .09$

$a b$

$\mu g / \mathrm{L} \quad \mathrm{GE}$

gh GE

$g / 2 \quad G E$

G $\quad G E$

$G E$
$G / L$

$\begin{array}{ll}G E \\ M & G E \\ M & G E\end{array}$

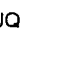

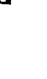


ANALYTICAL RESULTS

WELL LCO 1 collected on 11/19/91, laboratory analyses (cont)

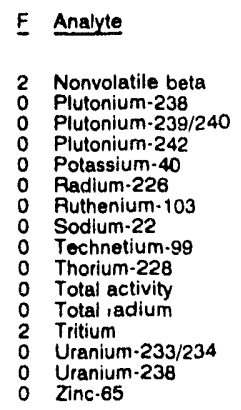

Mod Unit Lab

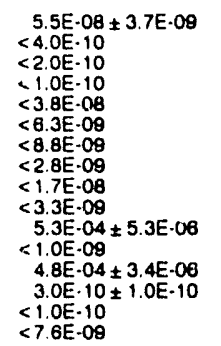

WELL LCO 2 coirected on 11/19/91, laboratory analyses (cont)

$\begin{array}{ll}\text { F } & \text { Analyte } \\ 0 & 1,2 \text {-Diphenylhydrazine } \\ 0 & \text { Dissolved organic carbon } \\ 0 & \text { Endosulfan I } \\ 0 & \text { Endosulfan II } \\ 0 & \text { Endosulfan sulfate } \\ 0 & \text { Endrin } \\ 0 & \text { Endrin alaehyde } \\ 0 & \text { Ethylbenzene } \\ 0 & \text { Fluoranthene } \\ 0 & \text { Fluorene } \\ 0 & \text { Heptachlor } \\ 0 & \text { Heptachl } \text { epoxide } \\ 0 & \text { Hexachlorobenzene } \\ 0 & \text { Hexachlorobutadiene }\end{array}$

Hexachlorocyclopentadiene

Hexachloroethane

Indeno $[1,2,3-c, d] p y r e n e$

Iron

0 Isophorone

1 Lead

0 Lindane

C Mercury
0 2-Methyl-4,6-dinitrophenol

N.Nitrosodimethylamine

N-Nitrosodiphenylamine

N.Nitrosodiphenylamine

Naphthalene

Nitrate as nitrogen

Nitrobenzene

2.Nitrophenol

0 PCB 1016

0 PCB 1221

0
0 PCB 1232

0 PCB 1248

- PCB 1254

0 Pentachlorophenol

0 Phenanthrene

Phenol

Pyrene

Selenium

0 Silver

Sul1,2.Tetrachloroethane

Tetrachloroethylene

Toluene

Total dissolved solids

Total organic

o Toxaphene

1,2,4-Trichlorobenzen

1,1.2. Trichloroethane

Trichloroethylene

2,4,6-Trichlorophenol

Americium-241

Antimony-125

Cerium-144

Cesium-134

Cesium-137

Cobalt. 57

Europium-154

Gross alpha

Manganese- 54
Nonvolatiie beta

Nonvolatile beta

Plutonium-238

Pitonium.n.242

Potassium-40

Radium.226

Ruthenium-103

Sodiun 22

Technetium.99

Thorium-228

Total radium

Uranium-233/234

Uranium.23
Result

Mod

$<10$
$<1.000$
$<10$

$<10$
$<10$

$<10$

$<10$
$<10$

1.0
$<10$

$<10$
$<10$

$<10$
$<10$

$<10$
$<10$

$<10$
$<10$
$<10$

$<10$
49

410
13

$<10$
3.0

$<0.20$
$<10$

$<10$
$<10$

$<10$
$<10$

1,530

$<10$
$<10$
$<10$

$<150$

$<150$
$<150$

$<150$

$<150$
$<150$

$<10$

$<10$
$<10$
$<10$

$<10$
$<10$
$<2.0$

$<2.0$

$<1.000$

$<1.0$
2.0
$<1.0$

$<1.0$

$<1,000$

$<10$
$<10$

$<1.0$
$<1.0$
$<1.0$
$<1.0$

$<1.0$

$<1.0 E-10$

$<1.7 E .09$

$<3.2 \mathrm{E} .09$

$<3.6 E .09$

$<3.2 \mathrm{E} .09$

$<11 \mathrm{E} .08$

$<2.0 E .09$
$<4.3 E .09$

$<4.3 E .09$
$<2.0 \mathrm{E} .09$

$<1.0 E \cdot 10$

$2.0 E \cdot 10 \pm 1.0 E-10$

$1.0 E-10+10$

$<6.8 \mathrm{E}-08$

$<1.1 \mathrm{E} .00$

$<4.2 \mathrm{E} .09$

$<\begin{aligned} & <.6 \mathrm{E} .09 \\ & <<.009\end{aligned}$

$<3.4 \mathrm{E} .09$

1.7E.09 $1.9 E-09$

5. $2 E .06 \pm 7.0 E \cdot 07$

$<1.0 E-10$

\begin{tabular}{l}
$<9.0 \mathrm{E} \cdot 09$ \\
\hline
\end{tabular}
Unit Lab

$\begin{array}{ll}\boldsymbol{\mu} \mu / L & G E \\ \mu g / \Lambda & G E \\ \mu g g & G E\end{array}$

$\mu \mathrm{g} / \mathrm{L} \quad \mathrm{GE}$

$\mu g / L$ GE

$\mu \mathrm{g} / \mathrm{L} \quad \mathrm{GE}$

$\mu \quad \mu \mathrm{g} / \mathrm{GE}$

$\mu \mathrm{g} / \mathrm{GE}$

$\begin{array}{ll}\mu g / & \mathrm{GE} \\ \mu g / \mathrm{GE} & \mathrm{G}\end{array}$

$\mu g / L$ GE

$\mu g / L \quad G E$

$\mu g$ GE

$\mu \mathrm{g} / \mathrm{GE}$

$\mu g / h \quad G E$

$\boldsymbol{\mu g} / \mathrm{L} \quad \mathrm{GE}$

$\mu \mathrm{g} / \mathrm{h}$

$\mu \mathrm{g} / \mathrm{h}$

$\underset{\mu g h /}{\mu g h}$

$\underset{\mu g / h}{\mu g / h}$

wgh

$\stackrel{9 g h}{2}$

wg/

$\mu g$ GE

$\mu \mathrm{g} / \mathrm{GE}$

$\begin{array}{ll}\mu \mathrm{g} / \mathrm{L} & \mathrm{GE} \\ \mu \mathrm{GE} & \mathrm{G} / \mathrm{GE}\end{array}$

$\mu \mathrm{g} / \mathrm{L} \quad \mathrm{GE}$

$\mu g / L \quad G E$



$g \mathrm{gh}$



$\mu \mathrm{ci} / \mathrm{mL}$

${ }_{\mu \mathrm{Ci} / \mathrm{mL}}$

$\mu \mathrm{C} / \mathrm{mL}$

$\mu \mathrm{Ci} / \mathrm{mL}$

$\mu \mathrm{C} \mathrm{C} / \mathrm{mL}$

$\mu \mathrm{Ci} / \mathrm{mL}$ GE

$\mu \mathrm{Ci} / \mathrm{ml}$ TE

wCir.iL GE

$\mu \mathrm{Ci} / \mathrm{mL}$ TE

$\mu \mathrm{Cl} / \mathrm{mL}$

$\mu \mathrm{Ci} / \mathrm{mL}$

$\mu \mathrm{Ci} / \mathrm{mL}$ TE

$\mu \mathrm{CI} / \mathrm{mL}$ TE

$\mu C i / m L$ GE

$\mu \mathrm{C} i / \mathrm{mL}$ TE

$\mu \mathrm{Ci} / \mathrm{mL}$ T

Diethyl phthalate

2.4-Dimethyl phenol

Dimethyl phthalate

2,4-Dinitrophenol

2,5.Dinitrotoluene

$<10$

$<10$

$<10$
$<10$
$<10$

$<10$

$<10$
$<10$
$<45$

$<10$
$<10$

$\mu g$
$\mu g$
$\mu g$
$\mu g$
$\mu g$
$\mu g$
$\mu g$
$\mu g /$
$\mu g$
$\mu g /$
$\mu g$
$\mu g$
$\mu g$
$\mu g$
$\mu g$
$\mu g$
$\mu g$
$\mu g$ 
ANALYTICAL RESULTS

WELL LCO 3

MEASUREMENTS CONDUCTED IN THE FIELD

Sample date: $11 / 19 / 91$
Depth to water: $23.17 \mathrm{ft}(7.06 \mathrm{~m})$ below TOC
Water elevation: $28.23 \mathrm{tg}(66.52 \mathrm{~m}) \mathrm{msl}$
S. conductance: $272 \mu \mathrm{SS} / \mathrm{cm}$
Water evacuated betor' sampling: $58 \mathrm{gal}$
LABORATORY ANALYSES

\begin{tabular}{|c|}
\hline Analyte \\
\hline 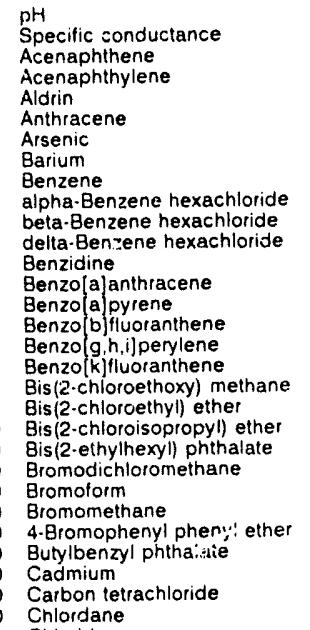 \\
\hline
\end{tabular}

Result Mod Unit Lab

Time: 7.05

$\mathrm{pH}: \mathrm{B} 5$

Wate temperature $192^{\circ} \mathrm{C}$

8.9

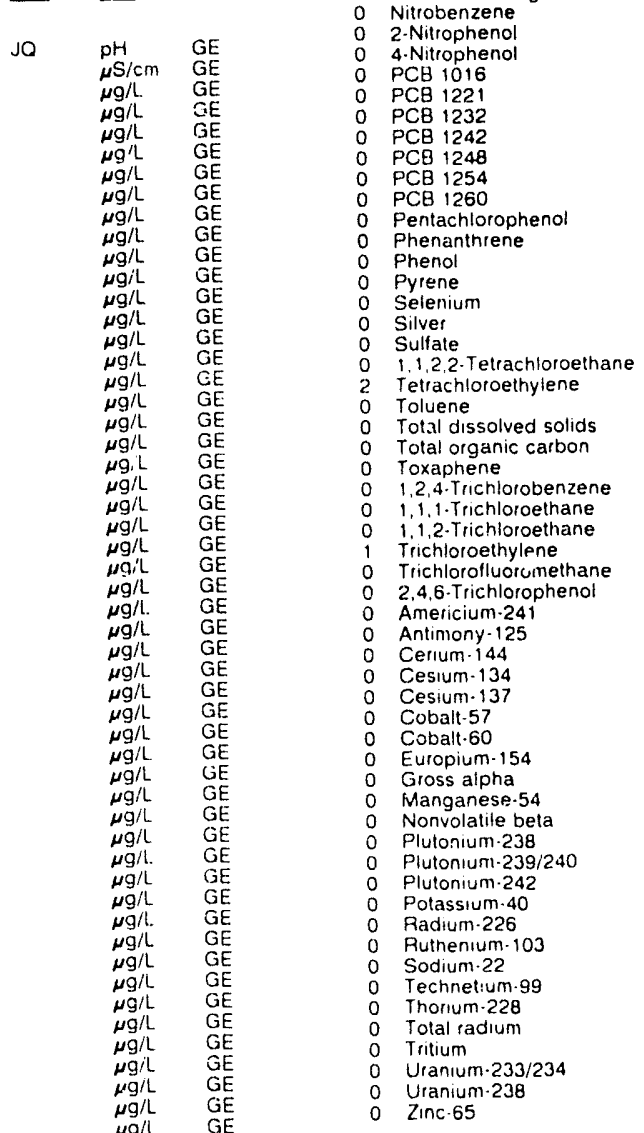

WELL LCO 3 collected on 11/19/91, laboratory analyses (cont.)

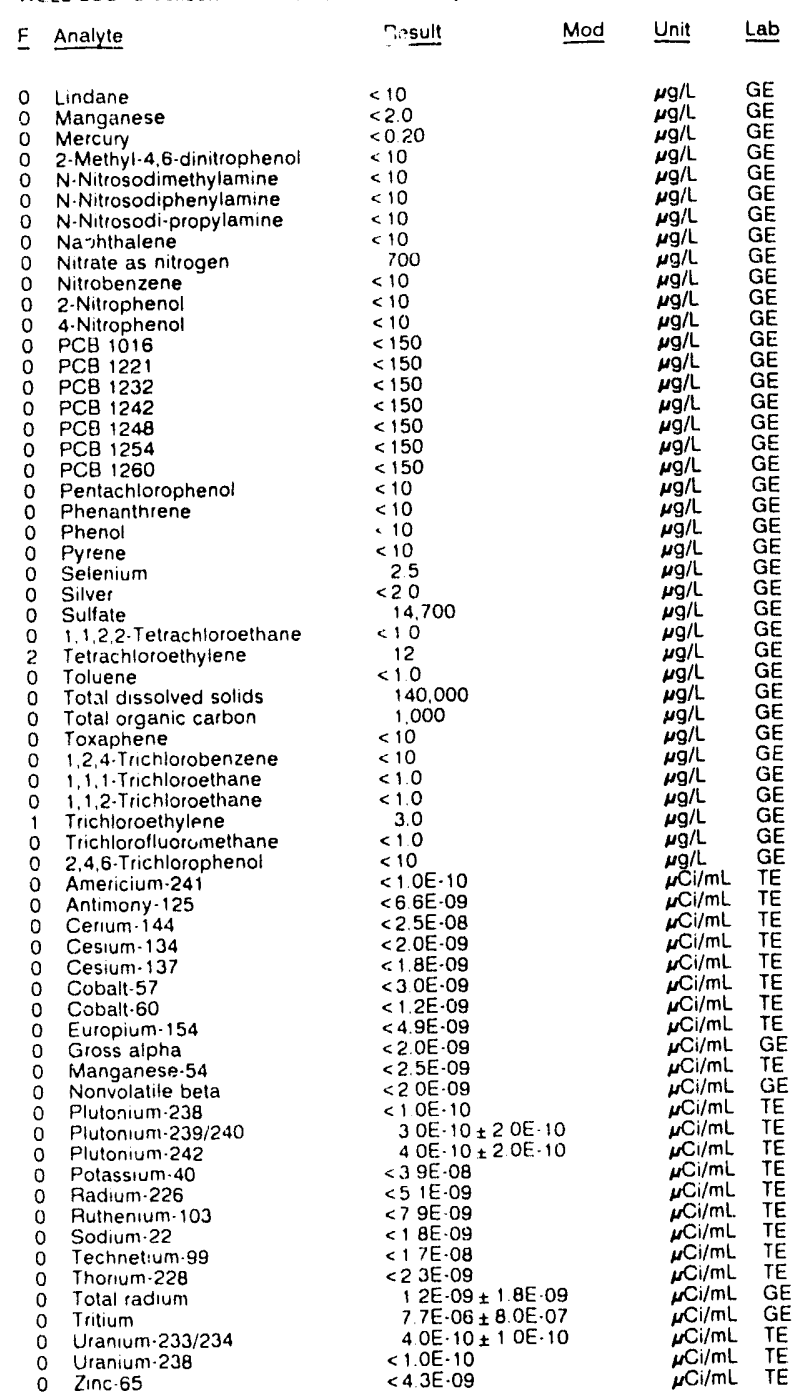

\section{WELL LCO 4}

MEASUREMENTS CONDUCTED IN THE FIELO

\begin{tabular}{|c|c|}
\hline $\begin{array}{l}\text { Sample date. } 11 / 19 / 91 \\
\text { Depth to water. } 21.33 \mathrm{H}(650 \mathrm{~m}) \text { below tOC } \\
\text { Water elevation } 21587 \mathrm{ft}(65.80 \mathrm{~m}) \mathrm{ms} \\
\text { Sp conductance } 696 \mu \mathrm{S} / \mathrm{cm}\end{array}$ & $\begin{array}{l}\text { Time. } 740 \\
\text { pH } 48 \\
\text { Alkalinity } 1 \mathrm{mg} / \mathrm{h} \\
\text { Water temperature } 185^{\circ} \mathrm{C}\end{array}$ \\
\hline
\end{tabular}

LABORATORY ANALYSES

\begin{tabular}{|c|c|c|c|c|c|}
\hline$\underline{F}$ & Analyte & Result & Mod & Unit & Lab \\
\hline & $\begin{array}{l}\mathrm{pH} \\
\text { Specific conductance }\end{array}$ & $\begin{array}{l}53 \\
800\end{array}$ & $J Q$ & $\mathrm{pH}$ & $\mathrm{GE}$ \\
\hline & $\begin{array}{l}\text { Specinic conductance } \\
\text { Acenaphthene }\end{array}$ & $\begin{array}{l}800 \\
<10\end{array}$ & & $\begin{array}{l}\mu \mathrm{S} / \mathrm{cm} \\
\mu \mathrm{g} / \mathrm{L}\end{array}$ & $\mathrm{GE}$ \\
\hline & Acenaphthylene & $<10$ & & $\mu \mathrm{g} / \mathrm{L}$ & GE \\
\hline & Aldrin & $<10$ & & $\mu \mathrm{g} / \mathrm{L}$ & GE \\
\hline & Anthracene & $<10$ & & $\mu \mathrm{g} / \mathrm{L}$ & $\mathrm{GE}$ \\
\hline & Arsenic & $<20$ & & $\mu \mathrm{git}$ & $G E$ \\
\hline 0 & Barium & 10 & & $\mu \mathrm{g} / \mathrm{L}$ & $\mathrm{GE}$ \\
\hline & Benzene & $<10$ & & $\mu g / L$ & $\mathrm{GE}$ \\
\hline & alpha. Benzene hexachloride & $<10$ & & $\mu \mathrm{g} / \mathrm{L}$ & $G E$ \\
\hline & beta. Benzene hexachloride & $<10$ & & $\mu \mathrm{g} / \mathrm{L}$ & $\mathrm{GE}$ \\
\hline & delta.Benzene hexachionide & $<10$ & & $\mu \mathrm{g} / \mathrm{L}$ & $\mathrm{GE}$ \\
\hline & Benzidine & $<10$ & & $\mu \mathrm{g} / \mathrm{h}$ & GE \\
\hline & Benzo[a]anthracerie & $=10$ & & $\mu \mathrm{g} / \mathrm{L}$ & GE \\
\hline & Benzolalpyrene & $<10$ & & $\mu \mathrm{g} / \mathrm{L}$ & $\mathrm{GE}$ \\
\hline & Benzolb] fluoranthene & $<10$ & & $\mu g$ il & $\mathrm{GE}$ \\
\hline & Benzo[g hijperylene & $<10$ & & $\mu \mathrm{g} / \mathrm{h}$ & $\mathrm{GE}$ \\
\hline & Benzo[k]lluoranthene & $<10$ & & $\mu \mathrm{g} / \mathrm{L}$ & $\mathrm{GE}$ \\
\hline & Bis (2-chioroethoxy) methane & $\cdot 10$ & & $\mu \mathrm{g} / \mathrm{L}$ & $\mathrm{GE}$ \\
\hline 0 & Bis (2-chloroethyil) ether & $<10$ & & $\mu \mathrm{g} / \mathrm{L}$ & $\mathrm{GE}$ \\
\hline
\end{tabular}


ANALYTICAL RESULTS

WELL LCO 4 collected on 11/19/91, laboratory analyses (cont.)

\begin{tabular}{|c|c|c|c|c|c|}
\hline Analyte & Result & Unit & Lab & E & Analyte \\
\hline 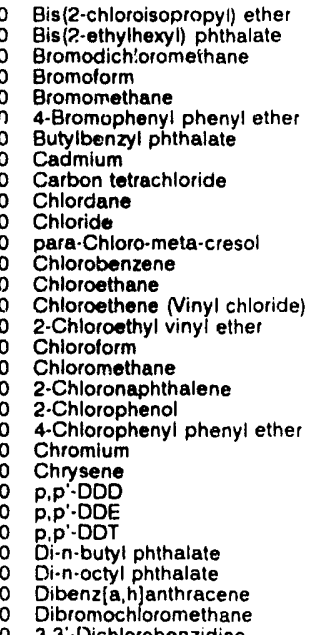 & $\begin{array}{l}<10 \\
114 \\
<1.0 \\
<1.0 \\
<1.0 \\
<10 \\
<10 \\
<2.0 \\
<1.0 \\
<10 \\
15,100 \\
<10 \\
<1.0 \\
<1.0 \\
<1.0 \\
<1.0 \\
<1.0 \\
<1.0 \\
<10 \\
<10 \\
<10 \\
<4.0 \\
<10 \\
<10 \\
<10 \\
<10 \\
<10 \\
<10 \\
<10 \\
<10\end{array}$ & $\begin{array}{l}\mu \mathrm{g} / \mathrm{L} \\
\mu \mathrm{g} / \mathrm{L} \\
\mu \mathrm{g} / \mathrm{L} \\
\mu \mathrm{g} / \mathrm{L} \\
\mu \mathrm{g} / \mathrm{L} \\
\mu \mathrm{g} / \mathrm{L} \\
\mu \mathrm{g} / \mathrm{L} \\
\mu \mathrm{g} / \mathrm{L} \\
\mu \mathrm{g} / \mathrm{L} \\
\mu \mathrm{g} / \mathrm{L} \\
\mu \mathrm{g} / \mathrm{L} \\
\mu \mathrm{g} / \mathrm{L} \\
\mu \mathrm{g} / \mathrm{L} \\
\mu \mathrm{g} / \mathrm{L} \\
\mu \mathrm{g} / \mathrm{L} \\
\mu \mathrm{g} / \mathrm{L} \\
\mu \mathrm{g} / \mathrm{L} \\
\mu \mathrm{g} / \mathrm{L} \\
\mu \mathrm{g} / \mathrm{L} \\
\mu \mathrm{g} / \mathrm{L} \\
\mu \mathrm{g} / \mathrm{L} \\
\mu \mathrm{g} / \mathrm{L} \\
\mu \mathrm{g} / \mathrm{L} \\
\mu \mathrm{g} / \mathrm{L} \\
\mu \mathrm{g} / \mathrm{L} \\
\mu \mathrm{g} / \mathrm{L} \\
\mu \mathrm{g} / \mathrm{L} \\
\mu \mathrm{g} / \mathrm{L} \\
\mu \mathrm{g} / \mathrm{L} \\
\mu \mathrm{g} / \mathrm{L}\end{array}$ & $\begin{array}{l}\mathrm{GE} \\
\mathrm{GE} \\
\mathrm{GE} \\
\mathrm{GE} \\
\mathrm{GE} \\
\mathrm{GE} \\
\mathrm{GE} \\
\mathrm{GE} \\
\mathrm{GE} \\
\mathrm{GE} \\
\mathrm{GE} \\
\mathrm{GE} \\
\mathrm{GE} \\
\mathrm{GE} \\
\mathrm{GE} \\
\mathrm{GE} \\
\mathrm{GE} \\
\mathrm{GE} \\
\mathrm{GE} \\
\mathrm{GE} \\
\mathrm{GE} \\
\mathrm{GE} \\
\mathrm{GE} \\
\mathrm{GE} \\
\mathrm{GE} \\
\mathrm{GE} \\
\mathrm{GE} \\
\mathrm{GE} \\
\mathrm{GE} \\
\mathrm{GE}\end{array}$ & $\begin{array}{l}0 \\
0 \\
2 \\
0 \\
0 \\
0 \\
0 \\
0 \\
0 \\
0 \\
0 \\
0 \\
0 \\
0 \\
0 \\
0 \\
0 \\
0 \\
0 \\
0 \\
0 \\
0 \\
0 \\
0 \\
0 \\
2 \\
2 \\
0 \\
0 \\
0\end{array}$ & 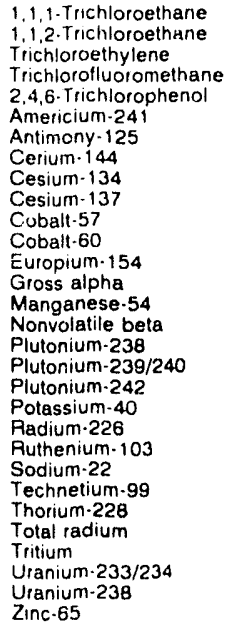 \\
\hline
\end{tabular}

3,3'.Dichlorobenzidine

1.1.Dichloroethane

1,2-Dichloroethane

1,1-Dichloroethylene
trans-1,2-Dichloroethylen

0 Dichloromethane

2,4-Dichlorophenol

1,2-Dichloropropane

cis-1,3-Dichloropropene
0 trans-1,3-Dichloropropene

Dieldrin

Diethyl phthalate

2,4-Dimethyl phenol

Dimethyl phthalate

2,4-Dinitrotoluene

2,6.Dinitrotoluene

1,2-Diphenylhydrazine

Dissolved organic carbon

Endosulfan I

Endosulfan sulfate

Endrin

Endrin aldehyde

Ethylbenzene

Fivorene

Heptachlor

Heptachlor epoxide

Rexachlorobenzene

Hexachlorobutadiene

Hexachlorocyclope

Hexachloroethane
indeno $[1,2,3-c, d]$ pyrene

isophorone

Lead

Lindane

Manganese

2-Methyl-4,6-dinitropheno

N-Nitrosodimethylamine

$\mathrm{N}$-Nitrosodiphenylamine

$N$-Nitrosodi-propylamin

Naphthalene

Nitrate as nitrogen

Nitrobenzene

2-Nitrophenol

4-Nitrophenol
$\mathrm{PCB} 1016$

PCB 1016

PCB 1232

P PCB 1242

PCB 1248

PCB 1254

PCB 1260

Phenanthrene

Phenol

Pyrene

Selenium

Silver

Sulfate

1,1,2,2-Tetrachloroethane

Tetrachloroethylene

Toluene

Total dissolved solids

Total organic
Toxaphene

1,2,4.Trichlorobenzene

Sample date: 10/21/91

LABORATORY ANALYSES

WELL LDB 1

Sample date 11/19/91

LABORATORY ANALYSES
WELL LDB 1

MEASUREMENTS CONDUCTED IN THE FIELD

Depth to water: Not available

Water elevation: Not available

Water evacuated before sampling: $23 \mathrm{gal}$

The well went dry during purging.

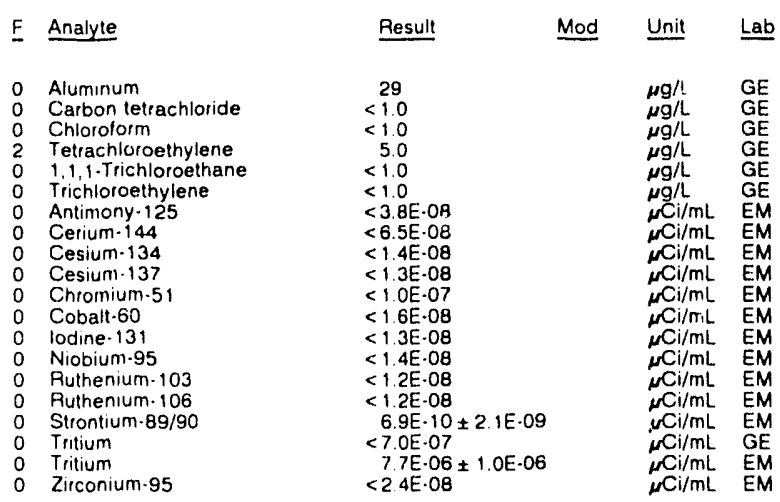

MEASUREMENTS CONOUCTED IN THE FIELD

Depth to water. Not available

Water elevation: Not available

Sp. conductance. $72 \mu \mathrm{S} / \mathrm{cm}$

The well went dry during purging

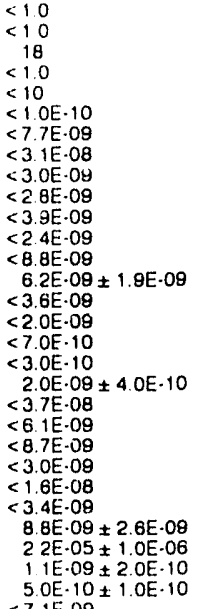

Mod Unit Lab

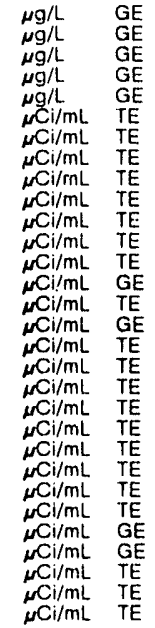

\begin{tabular}{|c|c|c|c|}
\hline F Analyte & Result & Mod & Unit \\
\hline $\begin{array}{ll}0 & \text { Aluminum } \\
0 & \text { Gross alpha } \\
0 & \text { Nonvolatile beta } \\
0 & \text { Tritum } \\
0 & \text { Tritium }\end{array}$ & $\begin{array}{l}36 \\
8.3 \mathrm{E} \cdot 10 \pm 4.6 \mathrm{E} \cdot 10 \\
2.8 \mathrm{E} \cdot 09 \pm 1.1 \mathrm{E} \cdot 09 \\
6.6 \mathrm{E} \cdot 06 \pm 8.0 \mathrm{E} \cdot 07 \\
8.0 \mathrm{E} \cdot 06 \pm 9.1 \mathrm{E} \cdot 07\end{array}$ & & $\begin{array}{l}\mu \mathrm{g} / \mathrm{L} \\
\mu \mathrm{Ci} / \mathrm{mL} \\
\mu \mathrm{Cl} / \mathrm{mL} \\
\mu \mathrm{Ci} / \mathrm{mL} \\
\mu \mathrm{Ci} / \mathrm{mL}\end{array}$ \\
\hline
\end{tabular}




\section{ANALYTICAL RESULTS}

WELL LDB 1

MEASUREMENTS CONDUCTED IN THE FIELD

Sample date: $12 / 16 / 9$

Depth to water: Not available

Water elevation: Not available

Water evacuated belore sampling: $21 \mathrm{ga}$

The well went dry during purging.

LABORATORY ANALYSES

E Analyte

- Aluminum

$\begin{array}{ll}0 & \text { Aluminum } \\ 0 & \text { Antimony-125 } \\ 0 & \text { Corlum-144 } \\ 0 & \text { Cecium-134 } \\ 0 & \text { Cosium-137 } \\ 0 & \text { Chromium-51 } \\ 0 & \text { Cobalt-60 } \\ 0 & \text { lodine-131 } \\ 0 & \text { Niobium-95 } \\ 0 & \text { Ruthenium-103 } \\ 0 & \text { Ruthenium-106 } \\ 0 & \text { Strontium-89/90 } \\ 1 & \text { Tritium } \\ 0 & \text { Tritium } \\ 0 & \text { Zirconium-95 }\end{array}$

\section{WELL LDB 2}

MEASUREMENTS CONDUCTED IN THE FIELD

Sample date: 10/21/81

Depth to water: Not available

Water elevation: Not available

Water evacuated before sampling: 24 gal

The well went dry during purging
The

LABORATOAY ANALYSES

\begin{tabular}{|c|c|c|c|c|}
\hline Analyte & Result & Mod & Unit & $\underline{\text { Lab }}$ \\
\hline $\begin{array}{l}\text { Aluminum } \\
\text { Carbon tetrachloride } \\
\text { Chloroform } \\
\text { Tetrachloroethylene } \\
1,1,1-\text { Trichloroethane } \\
\text { Trichloroethyiene } \\
\text { Antimony-125 } \\
\text { Cerium-144 } \\
\text { Cesium-134 } \\
\text { Cesium-137 } \\
\text { Chromium-51 } \\
\text { Cobalt-60 } \\
\text { lodine-131 } \\
\text { Niobium-95 } \\
\text { Ruthenium-103 } \\
\text { Ruthenium-106 } \\
\text { Strontium-89/90 } \\
\text { Tritium } \\
\text { Tritium } \\
\text { Zirconium- } 85\end{array}$ & $\begin{aligned} & 28 \\
&<1.0 \\
&<1.0 \\
&<1.0 \\
&<1.0 \\
&<1.0 \\
&<3.5 \mathrm{E} \cdot 08 \\
&<7.4 \mathrm{E} \cdot 08 \\
&<1.2 \mathrm{E} \cdot 08 \\
&<1.3 \mathrm{E}-08 \\
&<1.1 \mathrm{E} \cdot 07 \\
&<1.7 \mathrm{E} \cdot 08 \\
&<1.4 \mathrm{E} \cdot 08 \\
&<1.7 \mathrm{E} \cdot 08 \\
&<1.2 \mathrm{E} \cdot 08 \\
&<1.4 \mathrm{E} \cdot 08 \\
& 1.3 \mathrm{E} \cdot 10 \leq 1.5 \mathrm{E} \cdot 09 \\
&<7.0 \mathrm{E} \cdot 07 \\
& 5.6 \mathrm{E} \cdot 06 \pm 9.7 \mathrm{E} \cdot 07 \\
&<2.6 \mathrm{E} \cdot 08\end{aligned}$ & & $\begin{array}{l}\mu \mathrm{g} / \mathrm{L} \\
\mu \mathrm{g} / \mathrm{L} \\
\mu \mathrm{g} / \mathrm{L} \\
\mu \mathrm{g} / \mathrm{L} \\
\mu \mathrm{g} / \mathrm{L} \\
\mu \mathrm{g} / \mathrm{L} \\
\mu \mathrm{Ci} / \mathrm{mL} \\
\mu \mathrm{Ci} / \mathrm{mL} \\
\mu=\mathrm{i} / \mathrm{mL} \\
\mu \mathrm{Ci} / \mathrm{mL} \\
\mu \mathrm{Ci} / \mathrm{mL} \\
\mu \mathrm{Ci} / \mathrm{mL} \\
\mu \mathrm{Ci} / \mathrm{mL} \\
\mu \mathrm{Ci} / \mathrm{mL} \\
\mu \mathrm{Ci} / \mathrm{mL} \\
\mu \mathrm{Ci} / \mathrm{mL} \\
\mu \mathrm{Ci} / \mathrm{mL} \\
\mu \mathrm{Ci} / \mathrm{mL} \\
\mu \mathrm{CC} / \mathrm{mL} \\
\mu \mathrm{Ci} / \mathrm{mL}\end{array}$ & $\begin{array}{l}G E \\
G E \\
G E \\
G E \\
G E \\
G E \\
E M \\
E M \\
E M \\
E M \\
E M \\
E M \\
E M \\
E M \\
E M \\
E M \\
E M \\
G E \\
E M \\
E M\end{array}$ \\
\hline
\end{tabular}

WELL LDB 2

MEASUREMENTS CONDUCTED IN THE FIELD

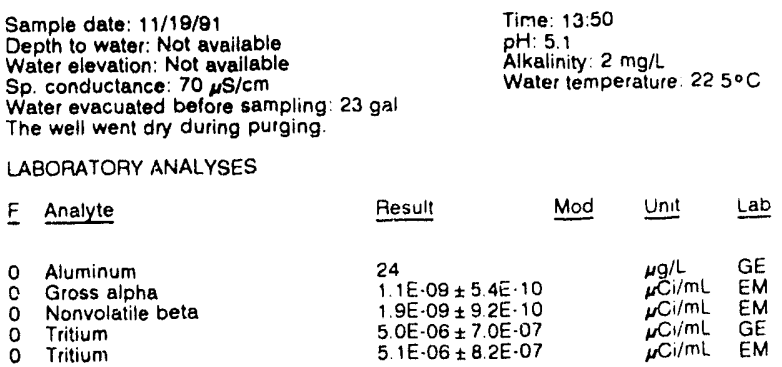

Water temperature: $18.9^{\circ} \mathrm{C}$

Time: $13: 30$

Alkalinity: $0 \mathrm{mg}$

Wates temperature: $21.5^{\circ} \mathrm{C}$

WELL LDB 2

MEASUREMENTS CONDUCTED IN THE FIELD

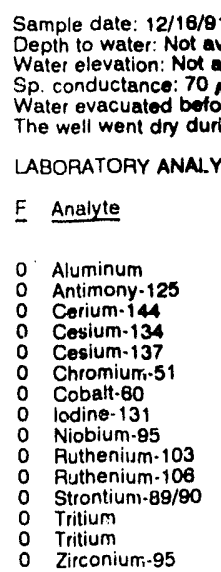

$$
\begin{aligned}
& \text { Time: } 14: 25 \\
& \text { pH: } 5.0 \\
& \text { Alkalinity: } 0 \text { mg/L } \\
& \text { Water temperature: } 18.9^{\circ} \mathrm{C}
\end{aligned}
$$

PH: 5.1 . $1 \mathrm{malinity:} 1 \mathrm{mg} / \mathrm{L}$

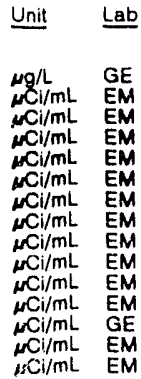

$1.2 \mathrm{E}-05 \pm 2.0 \mathrm{E}-09$
$1.0 \mathrm{E}-\mathrm{O} 7$

7.7E-06
$<8.8 \mathrm{E}-0 \%$

Zirconium.95

\section{WELL LFW 6}

MEASUREMENTS CONDUCTED IN THE FIELD

Sample date: 10/24/81

water: $16.29 \mathrm{H}(4.97 \mathrm{~m})$ below iOC

. $155.41 \mathrm{H}(47.37 \mathrm{~m}) \mathrm{ms}$

(ance: $420 \mathrm{~s} / \mathrm{cm}$

Water evacuated before sempling: $50 \mathrm{gal}$

LABORATORY ANALYSES

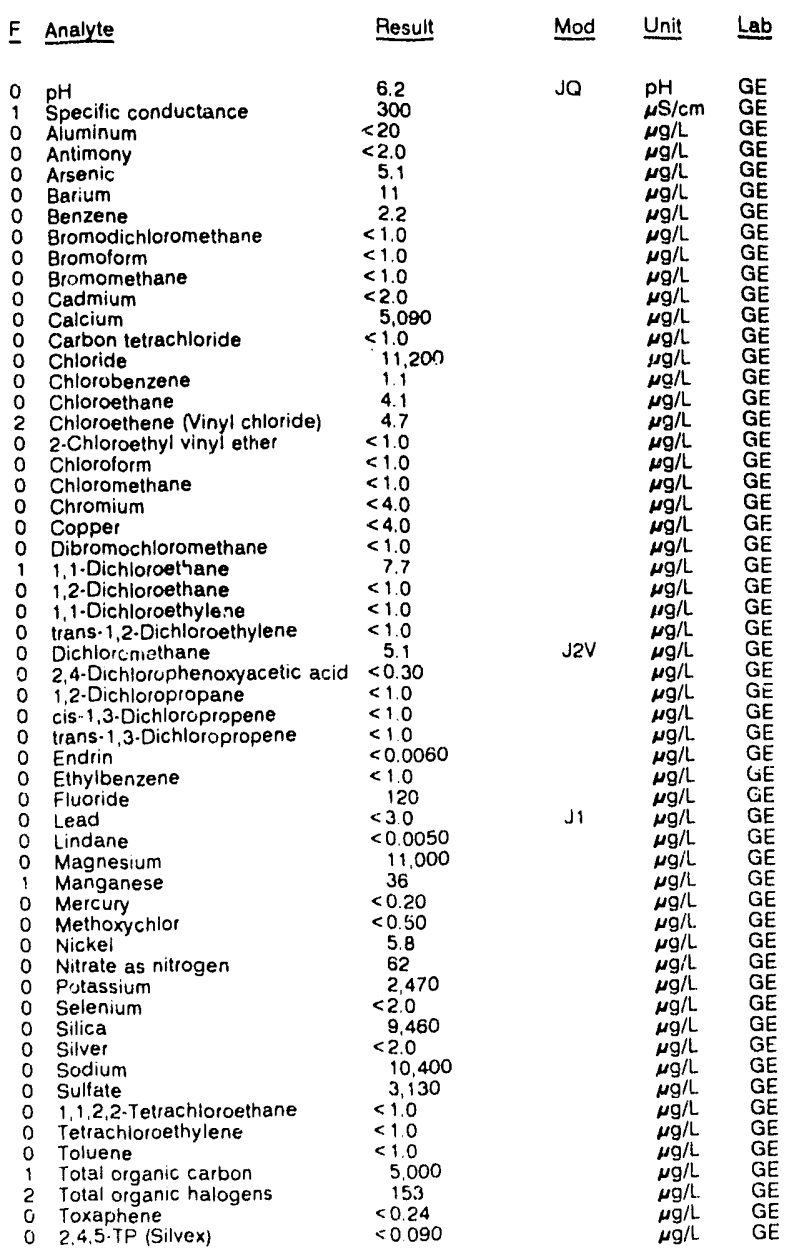

Time: $15: 05$

Alkalinity: $96 \mathrm{mg} /$

Water temperature: $20.5^{\circ} \mathrm{C}$

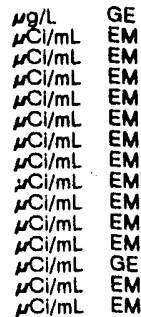

Result Mod Unit Lab

$<5.0 E-08$
$<1.2 E .07$

2.0E.08

2.3E.0B

$1.2 \mathrm{E} \cdot 07$

$5.6 \mathrm{E} \cdot 10 \pm 1.8 \mathrm{E} \cdot 0 \mathrm{0}$

. $\mathrm{EE} \cdot 06 \pm 8.0 \mathrm{E} \cdot 07$

. $2 \mathrm{E}$

.


ANALYTICAL RESULTS

WELL LFW 6 collected on 10/24/91, laboratory analyses (cont.)

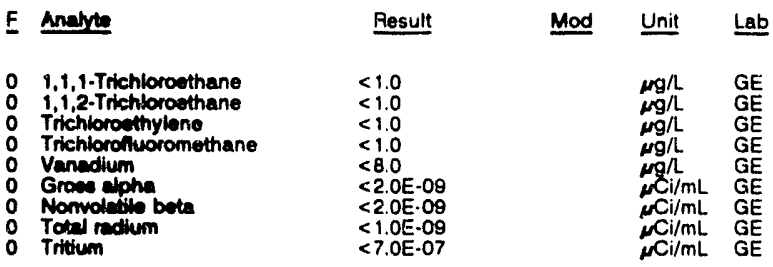

WELL LFW 8

MEASUREMENTS CONDUCTED IN THE FIELD

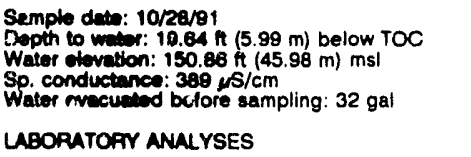

$$
\begin{aligned}
& \text { Time: } 12: 30 \\
& \text { pH: } 6.6 \\
& \text { Alkalinity: } 173 \mathrm{mg} / \mathrm{h} \\
& \text { Water temperature: } 21.0^{\circ} \mathrm{C}
\end{aligned}
$$

\begin{tabular}{|c|c|c|c|}
\hline Anatrie & Result & Mod & Unit \\
\hline 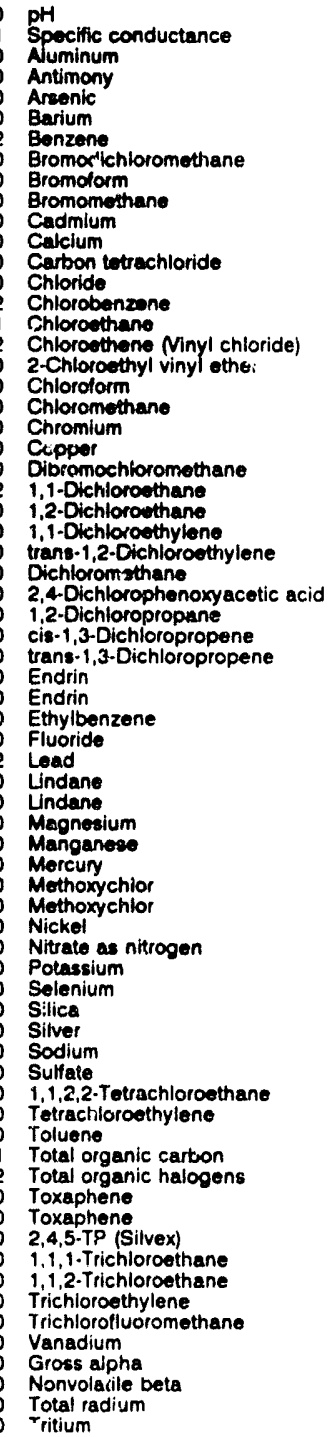 & $\begin{array}{l}6.4 \\
270 \\
<20 \\
<2.0 \\
8.4 \\
6.5 \\
5.1 \\
<1.0 \\
<1.0 \\
<1.0 \\
<2.0 \\
6.960 \\
<1.0 \\
25.400 \\
13 \\
8.6 \\
167 \\
<1.0 \\
<1.0 \\
<1.0 \\
<4.0 \\
<4.0 \\
<1.0 \\
53 \\
2.3 \\
<1.0 \\
<1.0 \\
5.4 \\
<0.30 \\
<1.0 \\
<1.0 \\
<1.0 \\
<0.0060 \\
<0.0060 \\
22 \\
216 \\
16 \\
<0.0050 \\
<0.0050 \\
14.100 \\
22 \\
<0.20 \\
<0.50 \\
<0.50 \\
<4.0 \\
<50 \\
1.700 \\
<2.0 \\
6.060 \\
<2.0 \\
21.300 \\
<1.000 \\
<1.0 \\
<1.0 \\
8.0 \\
8.000 \\
210 \\
<0.24 \\
<0.24 \\
<0.090 \\
<1.0 \\
<1.0 \\
<1.0 \\
<1.0 \\
<8.0 \\
4.5 \mathrm{E}-09 \pm 1.8 \mathrm{E} \cdot 09 \\
9.5 \mathrm{E} \cdot 09 \pm 1.8 \mathrm{E} \cdot 09 \\
1.6 \mathrm{E} \cdot 09 \pm 1.5 \mathrm{E} \cdot 09 \\
1.9 \mathrm{E}-06 \pm 7.0 \mathrm{E} \cdot 07\end{array}$ & JQ & $\begin{array}{l}\mathrm{pH} \\
\mu \mathrm{S} / \mathrm{cm} \\
\mu g / L \\
\mu g / L \\
\mu g / L \\
\mu g / L \\
\mu g / L \\
\mu g / L \\
\mu g / L \\
\mu g / L \\
\mu g / L \\
\mu g / L \\
\mu g / L \\
\mu g / L \\
\mu g / L \\
\mu g / L \\
\mu g / L \\
\mu g / L \\
\mu g / L \\
\mu g / L \\
\mu g / L \\
\mu g / L \\
\mu g / L \\
\mu g / L \\
\mu g / L \\
\mu g / L \\
\mu g / L \\
\mu g / L \\
\mu g / L \\
\mu g / L \\
\mu g / L \\
\mu g / L \\
\mu g / L \\
\mu g / L \\
\mu g / L \\
\mu g / L \\
\mu g / L \\
\mu g / L \\
\mu g / L \\
\mu g / L \\
\mu g / L \\
\mu g / L \\
\mu g / L \\
\mu g / L \\
\mu g / L \\
\mu g / L \\
\mu g / L \\
\mu g / L \\
\mu g / L \\
\mu g / L \\
\mu g / L \\
\mu g / L \\
\mu g / L \\
\mu g / L \\
\mu g / L \\
\mu g / L \\
\mu g / L \\
\mu g / L \\
\mu g / L \\
\mu g / L \\
\mu g / L \\
\mu g / L \\
\mu g / L \\
\mu g / L \\
\mu g / L \\
\mu c i / m L \\
\mu C i / m L \\
\mu N / / m L \\
\mu C i / m L\end{array}$ \\
\hline
\end{tabular}

LABORATOFY ANALYSES
WELL LFW 10A

MEASUREMENTS CONDUCTED IN THE FIELD

$\begin{array}{ll}\text { Sample date: } 10 / 24 / 81 & \text { Time: } 9: 15 \\ \text { Depth to water: } 21.61 \mathrm{ft}(6.59 \mathrm{~m}) \text { below TOC } & \text { pH: } 6.4 \\ \text { Water elevation: } 153.89 \mathrm{Ht}(46.91 \mathrm{~m}) \mathrm{msl} & \text { Alkalinity: } 131 \mathrm{mg} / \mathrm{h} \\ \text { Sp. conductance: } 668 \mu \mathrm{cm} & \text { Water temperature: } 20.5^{\circ} \mathrm{C} \\ \text { Water evacuated before sampling: } 67 \mathrm{gal} & \end{array}$

LABORATORY ANALYSES

E Analyte Result Mod Unit

$2_{2}^{\circ} \stackrel{\mathrm{pH}}{\text { Specitic conductance }}$

Aluminum

Antimony

Barium

Bonzene

Bromotorm

Bromomethane

Cadmium

Calcium

Chloride

Chlorosthane

Chloroethene Ninyl chioride)

2-Chloroethyl vinyl ethe

2.Chloroethy

Chloromethane

Chromium

Dibromochloromethane

1,1-Dichloroethane

1,2. Dichloroethane

1,1-Dichloroethylene

Dichloromethane

2,4-Dichlorophenoxyacetic acid $\quad 757$

1,2-Dichloropropane

trans

Endrin

Ethylbenzene

Fluoride

Lead

Magnesium

Manganese

Mercury

Methoxychlor

Niekel

Nitrate as nitrogen

Potassium

Selenium

Silica

Sodium

Sulfate

Sulfate

1,1,2,2-Tetrachloroethane

Tetrachloroethylene

Toluene

Total organic carbon

Total organic halogens

Toxaphene

2,4,5-TP (Silvex)

1,1,2-Trichloroethane

Trichloroethylene

Trichloroflue

Vanadium

Gross alpha

Nonvolatie beta
Total radium

2 Tritium

Result Mod Unit Lab

WELL LFW 16

MEASUREMENTS CONOUCTED IN THE FIELD

Simple date: $10 / 24 / 91$

Depth to water: $21.46 \mathrm{ft}(6.54 \mathrm{~m})$ below TOC

Water elevation: $157.34 \mathrm{Ht}$

6.1
500
$<20$
$<2.0$
5.5
12
9.9
$<1.0$
$<1.0$
$<1.0$
$<2.0$
25.800
$<1.0$

$<1.0$

$<1.0$

$<1.0$

$<1.0$

$<4.0$

$<4.0$

6.6

$<20$
7.6
$<1.0$

757
$<0.30$

$<1.0$
$<1.0$

$<1.00000$

36

$<<<.00050$

19,7

$<0.20$

6.5

$<500$

$<2.0$
10,300

10,300
$<2.0$

45,300
3,100

3,100
3,080

$<1.0$
23
87

47,000

982
$<0.24$

0.11
21
$<1.0$

$<1.0$

$<1.0$

$<2.0 \mathrm{E}-09$

4. $6 \mathrm{E}-09 \pm 8.4 \mathrm{E}-09$

$1.0 \mathrm{E}-09 \pm 8.0 \mathrm{E}-10$

JO $\mathrm{PH} \quad \mathrm{GE}$

$\underset{\mu S / c m}{\mathrm{pH}} \mathrm{GE}$

Noh GE

Mgn GE

S. conductance: $79 \mu \mathrm{S} / \mathrm{cm}$

Alkali:ity: $8 \mathrm{mg} / \mathrm{h}$

\begin{tabular}{|c|c|c|c|}
\hline E Analyte & Result & Mod & Unit \\
\hline $\begin{array}{ll}0 & \text { pH } \\
0 & \text { Specific conductance } \\
0 & \text { Aluminum } \\
0 & \text { Antimony } \\
0 & \text { Arsenic }\end{array}$ & $\begin{aligned} & 5.5 \\
& 75 \\
< & 20 \\
< & 2.0 \\
< & 2.0\end{aligned}$ & Ja & $\begin{array}{l}\mathrm{pH} \\
\mu \mathrm{S} / \mathrm{cm} \\
\mu g / L \\
\mu g / L \\
\mu g / L\end{array}$ \\
\hline
\end{tabular}

Water evacuated belore sampling: $69 \mathrm{ga}$

LABORATORY ANALYSES 
ANALYTICAL RESULTS

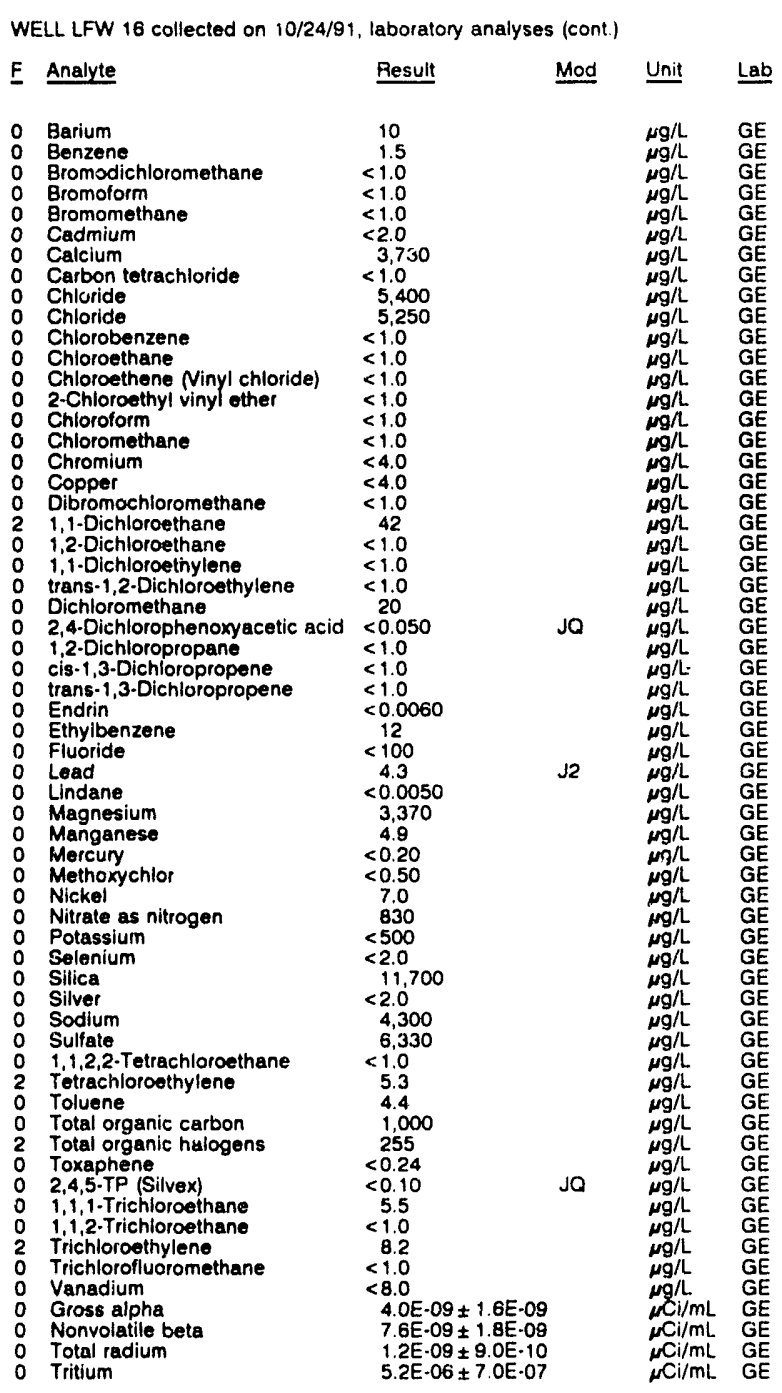

\section{WELL LFW 17}

MEASUREMENTS CONDUCTED IN THE FIELD

Sample date: 10/24/91

Depth to water: $21.38 \mathrm{H}(6.52 \mathrm{~m})$ below TOC

Water olevation: $156.42 \mathrm{H}(47.68$

Wp. conductance. 301 rS/cm

LABORATORY ANALYSES

\begin{tabular}{|c|c|c|c|}
\hline Analyte & Result & Mod & Unit \\
\hline $\begin{array}{l}\text { pH } \\
\text { Specific conductance } \\
\text { Aluminum } \\
\text { Antimony } \\
\text { Arsenic } \\
\text { Barium } \\
\text { Benzene } \\
\text { Bromodichloromethane } \\
\text { Bromoform } \\
\text { Bromomethane } \\
\text { Cadmium } \\
\text { Calcium } \\
\text { Carbon tetrachloride } \\
\text { Chloride } \\
\text { Chlorobenzene } \\
\text { Chloroethane } \\
\text { Chloroethene Ninyl chloride) } \\
\text { 2-Chlorvethyl vinyl ether } \\
\text { Chloroform } \\
\text { Chloromethane } \\
\text { Chromium } \\
\text { Copper }\end{array}$ & $\begin{array}{l}6.4 \\
160 \\
<20 \\
<2.0 \\
18 \\
4.1 \\
3.9 \\
<1.0 \\
<1.0 \\
<1.0 \\
<2.0 \\
4.740 \\
<1.0 \\
14.700 \\
79 \\
3.9 \\
<1.0 \\
<1.0 \\
<1.0 \\
<1.0 \\
<4.0 \\
<4.0\end{array}$ & JQ & $\begin{array}{l}p H \\
\mu \mathrm{S} / \mathrm{cm} \\
\mu g / L \\
\mu g / L \\
\mu g / L \\
\mu g / L \\
\mu g / h \\
\mu g / L \\
\mu g / L \\
\mu g / L \\
\mu g / h \\
\mu g / L \\
\mu g / L \\
\mu g / L \\
\mu g / L \\
\mu g / L \\
\mu g / L \\
\mu g / L \\
\mu g / L \\
\mu g / L \\
\mu g / L \\
\mu g / L\end{array}$ \\
\hline
\end{tabular}

WELL. LFW 17 collected on 10/24/91, laboratory analyses (cont.)

\begin{tabular}{|c|c|c|c|}
\hline Analyte & Result & Mod & Unit \\
\hline $\begin{array}{l}\text { Dibromochloromethane } \\
1,1 \cdot \text { Dichloroethane } \\
1,2 \cdot \text { Dichloroethane } \\
1,1 \cdot \text { Dichloroethylene } \\
\text { trans-1,2-Dichloroethylene } \\
\text { Dichloromethane } \\
2,4-\text { Dichlorophenoxyacetic acid } \\
1,2 \cdot \text { Dichioropropane } \\
\text { cis-1,3-Dichloropropene } \\
\text { trans-1,3-Dichloropropene } \\
\text { Endrin } \\
\text { Ethylbenzene } \\
\text { Fluoride } \\
\text { Lead } \\
\text { Lindane } \\
\text { Magnesium } \\
\text { Manganese } \\
\text { Mercury } \\
\text { Methoxychlor } \\
\text { ilickel } \\
\text { Nitrate as nitrogen } \\
\text { Potassium } \\
\text { Selenium } \\
\text { Silica } \\
\text { Silver } \\
\text { Sodium } \\
\text { Sulfate } \\
\text { 1,1,2,2-Tetrachloroethane } \\
\text { Tetrachloroethylene } \\
\text { Toluene } \\
\text { Total organic carbon } \\
\text { Total organic halogens } \\
\text { Toxaphene } \\
2,4,5 \cdot \text { TP (Silvex) } \\
1,1 \text { - Trichloroethane } \\
\text { 1,1,2-Trichloroethane } \\
\text { Trichloroethylene } \\
\text { Trichlorofluoromethane } \\
\text { Vanadium } \\
\text { Gross alpha } \\
\text { Nonvolatile beta } \\
\text { Total radium } \\
\text { Tritium }\end{array}$ & $\begin{array}{l}<1.0 \\
28 \\
4.4 \\
<1.0 \\
<1.0 \\
3.0 \\
<0.050 \\
<1.0 \\
<1.0 \\
<1.0 \\
<0.0060 \\
25 \\
<100 \\
<3.0 \\
<0.0050 \\
8,240 \\
32 \\
<0.20 \\
<0.50 \\
8.7 \\
110 \\
515 \\
<2.0 \\
6.470 \\
<2.0 \\
15,700 \\
1.160 \\
<1.0 \\
<1.0 \\
6.0 \\
5,000 \\
1 B 4 \\
<0.24 \\
<0.10 \\
<1.0 \\
<1.0 \\
<1.0 \\
<1.0 \\
<8.0 \\
2.5 E-09 \pm 1.4 E \cdot 09 \\
<2.0 E \cdot 09 \\
<1.0 E \cdot 09 \\
2.3 E \cdot C 3 \pm 7.0 E \cdot 07\end{array}$ & JQ & $\begin{array}{l}\mu g / L \\
\mu g / L \\
\mu g / L \\
\mu g / L \\
\mu g / L \\
\mu g / L \\
\mu g / L \\
\mu g / L \\
\mu g / L \\
\mu g / L \\
\mu g / L \\
\mu g / L \\
\mu g / L \\
\mu g / L \\
\mu g / L \\
\mu g / L \\
\mu g / L \\
\mu g / L \\
\mu g / L \\
\mu g / L \\
\mu g / L \\
\mu g / L \\
\mu g / L \\
\mu g / L \\
\mu g / L \\
\mu g / L \\
\mu g / L \\
\mu g / L \\
\mu g / L \\
\mu g / L \\
\mu g / L \\
\mu g / L \\
\mu g / L \\
\mu g / L \\
\mu g / L \\
\mu g / L \\
\mu g / L \\
\mu g / L \\
\mu g / L \\
\mu C i / m L \\
\mu C i / m L \\
\mu C I / m L \\
\mu C i / m L\end{array}$ \\
\hline
\end{tabular}

\section{WELL LFW 18}

MEASUREMENTS CONDUCTED IN THE FIELD

Sample date: 10/24/81

Depth to water: $18.98 \mathrm{H}(5.79 \mathrm{~m})$ below TOC

Water elevation: $156.02 \mathrm{H}(47.56 \mathrm{~m}) \mathrm{ms}$ !

Water evacuated before sampling: $70 \mathrm{gal}$

Alkalinity: $117 \mathrm{mg} / \mathrm{L}$

Alkalinity: $117 \mathrm{mg} / \mathrm{h}$

LABORATORY ANALYSES

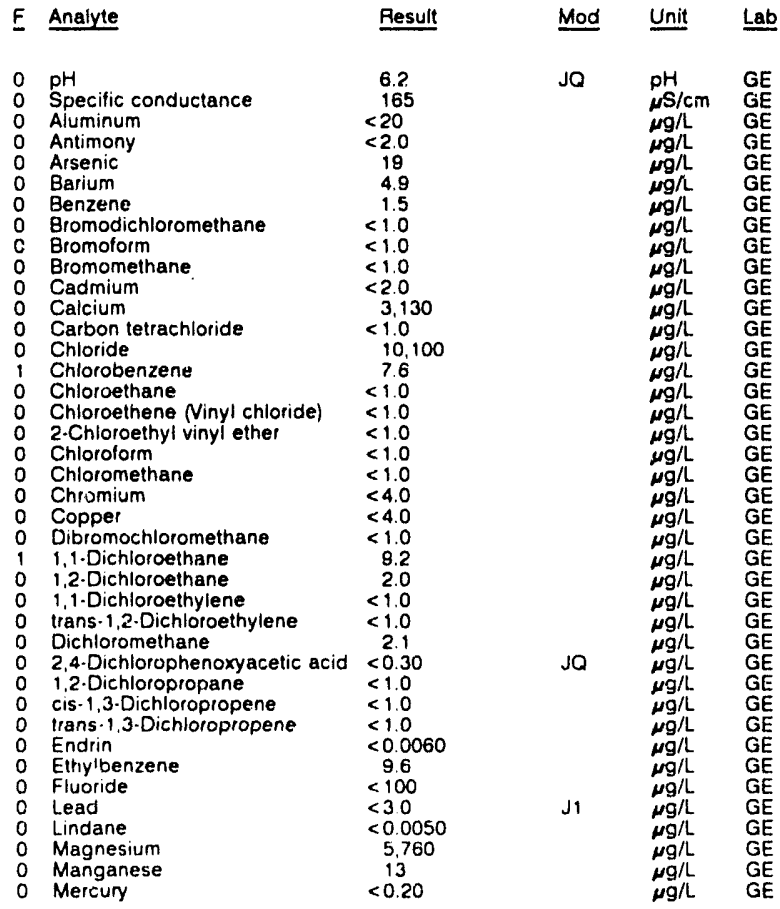


ANALYTICAL RESULTS

WELL LFW 18 collected on 10/24/91, laboratory analyses (cont)

\begin{tabular}{|c|c|c|c|}
\hline Analyte & Result & Mod & Unit \\
\hline $\begin{array}{l}\text { Methoxychlor } \\
\text { Nickel } \\
\text { Nitrate as nitrogen } \\
\text { Potassium } \\
\text { Selenium } \\
\text { Sillca } \\
\text { Silver } \\
\text { Sodium } \\
\text { Sulfate } \\
1,1,2,2 \text {-Tetrachloroethane } \\
\text { Totrachloroethylene } \\
\text { Toluene } \\
\text { Total organic carbon } \\
\text { Total organic halogens } \\
\text { Toxaphene } \\
2,4,5-\text { TP (Silvex) } \\
1,1,1-\text { Trichloroethane } \\
1,1,2-\text { Trichloroethane } \\
\text { Trichloroethylene } \\
\text { Trichlorofluoromethane } \\
\text { Vanadium } \\
\text { Gross alpha } \\
\text { Nonvolatile beta } \\
\text { Tota. radium } \\
\text { Tritium }\end{array}$ & $\begin{array}{l}<0.50 \\
<4.0 \\
<50 \\
1.100 \\
<2.0 \\
7,680 \\
<2.0 \\
8,010 \\
<1.000 \\
<1.0 \\
<1.0 \\
1.9 \\
2,000 \\
155 \\
<0.24 \\
<0.090 \\
<1.0 \\
<1.0 \\
<1.0 \\
<1.0 \\
<8.0 \\
<2.0 \mathrm{E} \cdot 09 \\
4.6 \mathrm{E}-09 \pm 1.6 \mathrm{E} \cdot 09 \\
1.9 \mathrm{E}-09 \pm 1.0 \mathrm{E} \cdot 09 \\
<7.0 \mathrm{E} \cdot 07\end{array}$ & JQ & $\begin{array}{l}\mu g / L \\
\mu g / L \\
\mu g / L \\
\mu g / L \\
\mu g / L \\
\mu g / L \\
\mu g / L \\
\mu g / L \\
\mu g / L \\
\mu g / L \\
\mu g / L \\
\mu g / L \\
\mu g / L \\
\mu g / L \\
\mu g / L \\
\mu g / L \\
\mu g / L \\
\mu g / L \\
\mu g / L \\
\mu g / L \\
\mu g / L \\
\mu C i / m L \\
\mu C i / m L \\
\mu C i / m L \\
\mu C i / m L\end{array}$ \\
\hline
\end{tabular}

\section{WELL LFW 19}

MEASUREMENTS CONDUCTED IN THE FIELD

Sample date: 10/24/91 Time: 13:50

\section{WELL LFW 19}

MEASUREMENTS CONDUCTED IN THE FIELD

Sample date: $12 / 16 / 91$

below TOC

Water elevation: $156.56 \mathrm{ft}(47.7$

Water evacuated 18 efor sampling: $70 \mathrm{gal}$

LABORATORY ANALYSES

\begin{tabular}{|c|c|c|c|}
\hline Analyte & Result & Mod & Unit \\
\hline 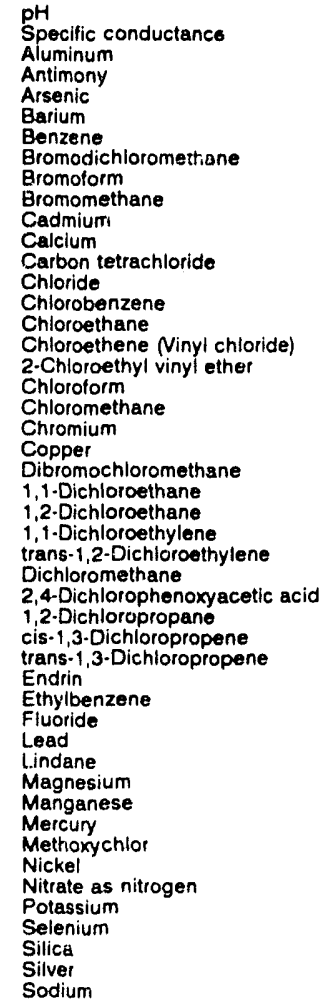 & $\begin{aligned} & 5.2 \\
& 20 \\
&<20 \\
&<2.0 \\
&<2.0 \\
&<3.0 \\
&<1.0 \\
&<1.0 \\
&<1.0 \\
&<1.0 \\
&<2.0 \\
& 374 \\
&<1.0 \\
& 2,230 \\
&<1.0 \\
&<1.0 \\
&<1.0 \\
&<1.0 \\
&<1.0 \\
&<1.0 \\
&<4.0 \\
& 4.6 \\
&<1.0 \\
&<1.0 \\
&<1.0 \\
&<1.0 \\
&<1.0 \\
& 1.6 \\
&<0.30 \\
&<1.0 \\
&<1.0 \\
&<1.0 \\
&<0.0060 \\
&<1.0 \\
&<100 \\
& 7.4 \\
&<0.0050 \\
& 441 \\
& 3.6 \\
&<0.20 \\
&<0.50 \\
& 4.0 \\
& 380 \\
&<500 \\
&<2.0 \\
& 6.910 \\
&<2.0 \\
& 11.150\end{aligned}$ & $\begin{array}{l}\mathrm{J} 2 \mathrm{~V} \\
\mathrm{JQ}\end{array}$ & $\begin{array}{l}p H \\
\mu S / c m \\
\mu g / L \\
\mu g / L \\
\mu g / L \\
\mu g / L \\
\mu g / L \\
\mu g / L \\
\mu g / L \\
\mu g / L \\
\mu g / L \\
\mu g / L \\
\mu g / L \\
\mu g / L \\
\mu g / L \\
\mu g / L \\
\mu g / L \\
\mu g / L \\
\mu g / L \\
\mu g / L \\
\mu g / L \\
\mu g / L \\
\mu g / L \\
\mu g / L \\
\mu g / L \\
\mu g / L \\
\mu g / L \\
\mu g / L \\
\mu g / L \\
\mu g / L \\
\mu g / L \\
\mu g / L \\
\mu g / L \\
\mu g / L \\
\mu g / L \\
\mu g / L \\
\mu g / L \\
\mu g / L \\
\mu g / L \\
\mu g / L \\
\mu g / L \\
\mu g / L \\
\mu g / L \\
\mu g / L \\
\mu g / L \\
\mu g / L \\
\mu g / L\end{array}$ \\
\hline
\end{tabular}

Time: $15: 40$

PH: 5.1 : 1 : 0

Water temperature: $17.4^{\circ} \mathrm{C}$

GE
$G E$
$G E$
$G E$
$G E$
$G E$
$G E$
$G E$
$G E$
$G E$
$G E$
$G E$
$G E$
$G E$
$G E$
$G E$
$G E$
$G E$
$G E$
$G E$
$G E$
$G E$
$G E$
$G E$
$G E$
$G E$
$G E$
$G E$
$G E$
$G E$
$G E$
$G E$
$G E$
$G E$
$G E$
$G E$
$G E$
$G E$
$G E$
$G E$
$G E$
$G E$
$G E$
$G E$
$G E$
$G E$
$G E$
$G E$
WELL LFW 19 collected on 12/16/91, laboratory analyses (cont.)

\begin{tabular}{|c|c|c|c|}
\hline Analyte & Result & Mod & Unit \\
\hline $\begin{array}{l}\text { Sulfate } \\
1,1,2,2 \cdot \text { Tetrachloroethane } \\
\text { Tetrachloroethylene } \\
\text { Toluene } \\
\text { Total organic carbon } \\
\text { Total organic halogens } \\
\text { Toxaphene } \\
2,4,5-T P \text { (Silvex) } \\
1,1,1-\text { Trichloroettiane } \\
1,1,2 \text {-Trichloroethane } \\
\text { Trichloroethylene } \\
\text { Trichlorofluoromethane } \\
\text { Vanadium } \\
\text { Gross alpha } \\
\text { Nonvolatile beta } \\
\text { Total radium } \\
\text { Tritium }\end{array}$ & $\begin{array}{l}<1.000 \\
<1.0 \\
<1.0 \\
<1.0 \\
2.000 \\
<5.0 \\
<0.24 \\
<0.000 \\
<1.0 \\
<1.0 \\
<1.0 \\
<1.0 \\
<8.0 \\
1.0 \mathrm{E}-08 \pm 2.5 \mathrm{E}-09 \\
4.7 \mathrm{E} \cdot 09 \pm 2.5 \mathrm{E}-09 \\
8.4 \mathrm{E} \cdot 09 \pm 1.6 \mathrm{E} \cdot 09 \\
6.8 \mathrm{E} \cdot 06 \pm 7.0 \mathrm{E}-07\end{array}$ & $\begin{array}{l}\text { JQ } \\
\text { JQ }\end{array}$ & $\begin{array}{l}\mu g / L \\
\mu g / L \\
\mu g / h \\
\mu g / h \\
\mu g / L \\
\mu g / L \\
\mu g / L \\
\mu g / L \\
\mu g / h \\
\mu g / L \\
\mu g / L \\
\mu g / L \\
\mu g / L \\
\mu C / / m L \\
\mu C l / m L \\
\mu C l / m L \\
\mu C i / m L\end{array}$ \\
\hline
\end{tabular}

WELL LFW 20

MEASUREMENTS CONDUCTED IN THE FIELD
Sample date: 10/24/81

(

ater evacuated before sampling: $70 \mathrm{gal}$

LABORATORY ANALYSES

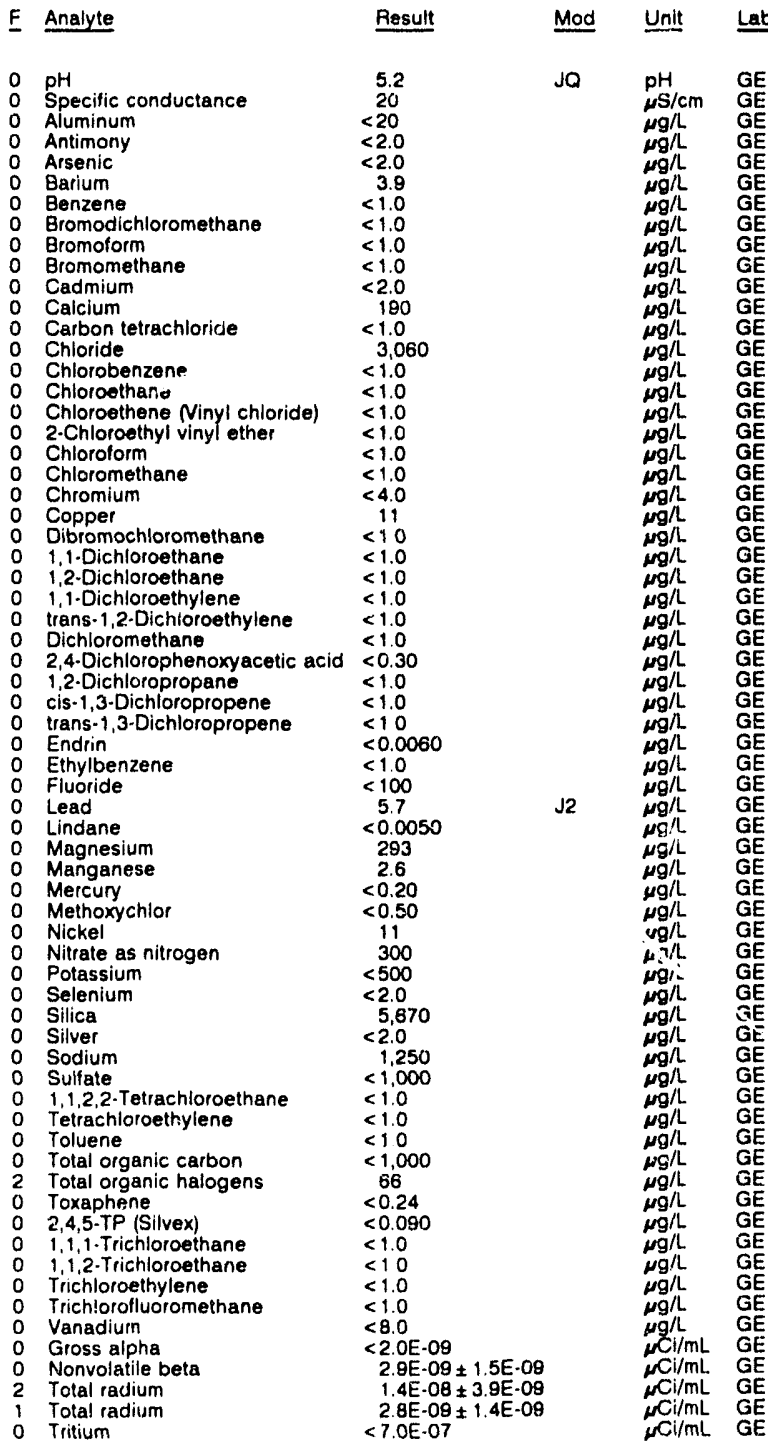

\section{Time: 13:30}

$\mathrm{pH}: 4.8$

Alkalinity: $0 \mathrm{mg} / \mathrm{h}$

ater temperature: $21.1^{\circ} \mathrm{C}$
Depth to water: $19.70 \mathrm{H}(6.00 \mathrm{~m})$ below TOC

Water elevation: $160.80 \mathrm{tt}$ 
WELL LFW 21

MEASUREMENTS CONDUCTED IN THE FIELD

$\begin{array}{ll}\text { Sample date: } 10 / 25 / 91 & \text { Time: } 12: 30 \\ \text { Depth to water: } 23.78 \mathrm{n}(7.25 \mathrm{~m}) \text { below TOC } & \text { pH: } 6.3 \\ \text { Water elovation: } 151.82 \mathrm{ft}(46.28 \mathrm{~m}) \mathrm{msl} & \text { Alkalinity: } 216 \mathrm{mg} / \mathrm{h} \\ \text { Sp. conductance: } 522 \mu 5 / \mathrm{cm} & \text { Water temperature: } 21.3^{\circ} \mathrm{C} \\ \text { Water ovacuated before sampling: } 74 \mathrm{gal} & \end{array}$

LABORATORY ANALYSES

E Analyte Result Mod Unit Lab

O pH prific conductance

1 Specific conc

Antimony

Arsenic

Barium

Bromodichloromethane

Bromolorm

Bromomethane

Cudmium

Carcium

Chloride

Chiorobenzene

Chloroethene Ninyl chloride)

2-Chioroethyl vinyl other

2.Chioroothy

Chloromethan

Chromium

Chromium

Dibromochloromethane

1.1-Dichloroethane

1 i,-Dichloroethylene

o trans-1,2-Dichloroethylene

o Dichioromethane

2,4-Dichlorophenoxyacetic acid

1,2-Dichloropropane

o cis-1,3-Dichloropropene

trans-1,3-Dichloropropene

Endrin

O Ethylbenzene

0 Lead

Lindane

Magnesium

Manganese

Mercury

Methoxychior

Methoxychlor

Nitrate as nitrogen

Potassium

Selica

Silluer

Sodium

Sulfate

1,1,2,2-Tetrachloroethane

Totrachloroethylene

Toluene

Total organic carbon

Total organic halogens

Toxaphene

2,4,5-TP (Silvex)

1,1,1-Trichioroethane

1,1,2.Trichloroethe

Trichlorofiuoromethane

Vanadium

Gross alpha

Total radium

Tritium
$<2.0$

10,100
$<1.0$

15,400

1.2.
$<1.0$

$<1.0$

$<1.0$

$<1.0$
$<4.0$

$<4.0$
$<4.0$
$<1.0$
82

82
$<1.0$
3.9
$<1.0$

$<1.0$

633
$<0.30$

$<1.0$
$<1.0$

$<1.0$

$<0.0060$
$<0.0060$

23
230

$<<<0.0050$

$<0.0050$

10,500

142
$<0.20$
$<0.50$

$<0.50$
$<0.50$
4.6
$<50$

$<50$
$<500$

$<2.0$
10,800

10,800
$<2.0$

30,700
3,010

3,8
$<1.0$
6.4

6.4
30

38,000

468

$<0.24$
$<0.24$

$<0.090$

8.3
$<1.0$
5.6
$<1.0$

5.6
$<1.0$

$<2.0 E-09$

$<\begin{aligned} & <2.0 E-09 \\ & 4.2 E-08 \pm 1.6 E-09\end{aligned}$

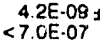

61
360
$<20$
$<2.0$
3.4
8.6
5.6
$<1.0$
$<1.0$
$<1.0$

\section{WELL LFW 22}

MEASUREMENTS CONDUCTED IN THE FIELD

Sample date: 10/25/91

Depth to water: $21.80 \mathrm{At}(6.64 \mathrm{~m}$; below TOC

Sp. conductance $434 \mathrm{HS} / \mathrm{cm}$

Water evacuated before sempling: 80 gal

Alkalinity: $153 \mathrm{mg} / \mathrm{L}$

Water temperature: $20.9^{\circ} \mathrm{C}$

LABORATORY ANALYSES

E Analyte Plesult Mod Unit Lab

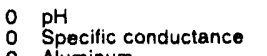

Aluminum

Antimony

Arsenic

Barium

Bromodichloromethane

Bromolorm

Bromomethane

Cadmium

Calcium

Chloride

Chlorobenzene

Chloroethene Ninyl chloride)

2.Chloroethyl vinyl ether

2.Chloroethy

Chloromethane

Chromium

Copper

Dibromochloromethane

1,1.Dichloroethane

1,2-Dichloroethane

1
0
trans-1,2-Dichloroethylene

0 Dichloromethane

2,4-Dichlorophenoxyacetic acid

$\begin{array}{lll}2,2-D i c h l o r o p r o p a n e & <1.0 \\ 0 & \text { cis-1,3-Dichloropropene } & <1.0\end{array}$

trans-1,3-Dichloropropene $<1.0$

0 Endrin

0 Ethylbenzene

O Fluoride

0 Fluoride

0 Lead

0 Lindane

o Magnesium

Manganese

Mercury

Methoxychlor

Methoxych

Nitrate as nitrogen

Potassium

0 Selenium

- Silica

$\begin{array}{ll}0 & \text { Sitver } \\ 0 & \text { Sodium }\end{array}$

Sodfum

1,1,2,2-Tetrachloroetha

Telrachioroethylene

0 Toluene

2 Total nrganic carbon

2 Total organic halogens

0 Toxaphene

Toxaphene

1,1,1.Trichloroethane

i, 2-Trichloroethane

Trichloroethylene

2 Trichlorofluoromethane

Gross alpha

Nonvolatile be
Total radium

0 Tritium
5.7

5.7
220
$<2.0$
4.3
5.5
2.3
$<1.0$
$<1.0$
$<1.0$
$<2.0$
3.0
$<1.0$
17.70
41.0

$<1.0$

3.040
$<1.0$

$<1.0$

$<1.0$

$<1.0$

$<1.0$

$<1.0$
$<4.0$
$<4.0$

$<4.0$

64

$<1.0$

4.6
$<1.0$

$<1.0$

$<0.006$

39
148
149

149
3.0

$<0.0050$
$<0.0050$

5,780

31
$0.2 ?$

$<0.50$
$<0.50$
$<4.0$
100

100
$<500$

$<500$
$<2.0$
7530

7.530
$<2.0$
9.950

3,260
$<1.0$

$<1.0$
2.1
74

74
50,000
461

461
$<0.24$

$<0.24$
$<0.24$

$<0.090$

11
$<1.0$

12
102
$<8.0$

$<8.0$

4. $4 \mathrm{E}-09 \pm 1.9 \mathrm{E}-09$

$<1.0 E \cdot 09$
$<7.0 \mathrm{E} \cdot 07$
Jo $\quad \mathrm{pH} / \mathrm{GE}$

$\begin{array}{ll}\mu S / \mathrm{cm} & \mathrm{GE} \\ \mu \mathrm{g} / \mathrm{L} & \mathrm{GE} \\ \mu \mathrm{g} / \mathrm{L} & \mathrm{GE}\end{array}$

$\mu g, \quad G / L$

$\mu g / L \quad G E$

G

$g / \mathrm{L} \quad \mathrm{GE}$

$g / L \quad G E$

$g / 2 \quad G E$

$G E$
$G / L$

g/h $\quad \mathrm{GE}$

$g / L \quad G E$

GE

g $\quad G E$

$\begin{array}{ll}\mu g / L & G E \\ \mu g / L & G E\end{array}$

$\mu g / L \quad G E$

$g / \mathrm{GE}$

$\begin{array}{ll}\mu g / h & G E \\ \mu g / L & G E\end{array}$

J2

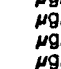

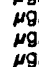

$g / L \quad G E$

$\mu g / L$

$\mu g / \mathrm{GE}$

$\mu \mathrm{g} / \mathrm{G} \quad \mathrm{GE}$

$\underset{\mu \mathrm{g} / L}{\mu} \quad \mathrm{GE}$

$\mu \quad G / L \quad G E$

$\mu g / L \quad G E$ $\mu g$ GE 
ANALYTICAL RESULTS

WELL LFW 23

MEASUREMFNTS CONDUCTED IN THE FIELD

Sample date: $10 / 25 / 91$
Depth to water: $19.16 \mathrm{H}(5.84 \mathrm{~m})$ below TOC
Water elevation: $152.64 \mathrm{H}(46.53 \mathrm{~m}) \mathrm{msl}$
Sp. conductance: $21 \mu \mathrm{S} / \mathrm{cm}$
Water evacuated before sampling: $73 \mathrm{gal}$

LABORATORY ANALYSES

F Analyte Result Mod Unit Lab

$\begin{array}{ll}0 & \mathrm{pH} \\ 0 & \text { Specific conductance }\end{array}$

Aluminum

Antimony

Arsenic

Barium

Bromodichloromethane

Bromoform

Bromomethane

Cadmium

Carbon tetrachloride

Carbon tetre

Chlorobenzene

Chloroethane

Chloroethene Ninyl chloride)

2.-Chloroethyl vinyl ether

Chloroform

Chloromethane

Chromium

Copper

Dibromochloromethane

1,2.Dichloroethane

1,2-Dichloroethane

o trans-1,2-Dichloroethylene

2,4-Dichlorophenoxyacetic acid $<0.30$

cis.1, D. Dichiorane

trans-1,3-Dichoroprene

Endrin

Endrin

0 Fluoride

Lead

Lindane

Magnesium

Manganese

Mercury

Methoxychlor

Nickel

Nitrate as nitrogen

Potassium

O Silica

0 Silver

Sodium

Sulfate

Tetrachloroethylene

Tolvene

Total organic carbon

Total organic carbon

o Toxaphene

o Toxaphene

1,1,1-Trichloroethane

$1,1,2$-Trichloroethan

Trichlorofluoromethane

Vanadium

Gross alpha

Nonvolatile bet

Total radium
Time: $11: 30$

Alkalinity: $0 \mathrm{mg} / \mathrm{L}$

Water temperature: $20.8^{\circ} \mathrm{C}$

5.0

20
$<20$
$<2.0$

$<2.0$
$<2.0$
4.1

$<1.0$
$<1.0$

$<1.0$

$<1.0$

317

$<1.0$
2,100

$<1.0$

$<1.0$

$<1.0$

$<1.0$

$<4.0$

$<1.0$

$<1.0$

$<1.0$

$<1.0$
$<1.0$

$<1.0$

$<1.0$

$<0.0060$

$<0.0060$

2.9
$<100$

5.6
$<0.0050$

$<0.0050$

485

$<2.0$

$<0.20$

$<0.50$

9.6
660
$<500$

$<500$

$<2.0$

$<2.0$
1,680

$<1,000$

$<1.0$

$<1.0$

$<1,000$

$<1,000$

8.8

$<0.24$
$<0.24$

$<0.090$

$<1.0$

$<1.0$

1.5
$<8.0$

$<2.0 E .09$

2. $4 \mathrm{E} \cdot 09 \pm 1.4 \mathrm{E}-09$

$2.9 \mathrm{E} \cdot 09 \pm 1.4 \mathrm{E} \cdot 09$
$<7.0 \mathrm{E}-07$
WELL LFW 24

MEASUREMENTS CONDUCTED IN THE FIELD

Sample date: 10/25/91

Depth to water: $15.88 \mathrm{Ht}(4.87 \mathrm{~m})$ below TOC

Water elevation: $155.31 \mathrm{ft}(47.3$

Sp. conductance: $17 \mu \mathrm{sS} / \mathrm{cm}$

Water evacuated before sampling: $82 \mathrm{gal}$

LABORATORY ANALYSES

0 pH

Specific conductance

Aluminum

Antimony

Barium

Benzene

Bromodichloromethane

Bromoform

Bromomethan

Cadmium

Carbon tetrachloride

Carbon

Chlorobenzene

Chloroethene Ninyl chioride)

2.Chloroethyl vinyl ether

Chloroform

- Chloromethane

o Chromium

o Copper

Dibromochloromethane

1,1-Dichloroethane

1,2-Dichloroethane

$1,1 \cdot$ Dichloroethylene
o trans-1,2-Dichloroethylene

2,4-Dichlorophenoxyacetic acid

1.

cis $1,3-D i c h l o p a p$

trans-1,3-Dichloropropen

0 Endrin

O Endrin

0 Ethylbenzene

0 Fluoride

0 Lead

${ }_{0}$ Lindane

0 Magnesium

Manganes

Mercury

Methoxychlor

Nickel

Nitrate as nitrogen

Potassium

Selenium

Silica

O Silver

- Sodium

0 1,1,2,2-Tetrachloroethane

Teliachloroethylene

Toluene

Total organic carbon

Total organic halogens

Toxaphene

Toxaphen

2,45-TP (Silvex

1,1,1-Trichloroethane

i. 1. 2. Trichlorothan

Trichloroethylene

Trichlorofluoromethan

- Vanadium

Gross alpha

Nonvolatile beta

Total radium
Tritium
Time: 11:00

Alkalinity: $0 \mathrm{mg} / \mathrm{L}$

Water temperature: $19.7^{\circ} \mathrm{C}$

Result Mod Unit Lab

4.9

J $\quad \mathrm{pH} \quad \mathrm{GE}$

$\mu \mathrm{S} / \mathrm{cm}$ GE

$\mu \mathrm{g} / \mathrm{L} \quad \mathrm{GE}$

$\mu \mathrm{g} / \mathrm{GE}$

$\mu g / L \quad G E$

g/L GE

$\mu g / L \quad G E$

$\mu g / L \quad G E$

$\mu g / h \quad G E$

$\mu g / \mathrm{G} \quad \mathrm{GE}$

$\mu g / L \quad G E$

g/L GE

$\mu \mathrm{g} / \mathrm{L} \quad \mathrm{GE}$

$\mu g / L \quad G E$

790
-500
5

$<<500$

6,500
$<2,0$

$<2.0$
1,080
4,660

$<1,0$

$<1.0$

$<1,000$

$<5.0$

$<0.24$

$<0.24$

$<0.090$

$<1.0$

$<1.0$

$<1.0$

3. $3 \mathrm{E}-09 \pm 1.4 \mathrm{E}-09$

6.7E.09 $\pm 1.7 \mathrm{E}-08$

$1.8 \mathrm{E}-09 \pm 1.1 \mathrm{E}-09$
$<7.0 \mathrm{E}-07$
11

$\mu g /$
$\mu g$
$\mu g /$
$\mu g / L$

$\mu g / L \quad G E$

$\begin{array}{ll}\mu g / L & G E \\ \mu g / L & G E\end{array}$

$\underset{\mu g / L}{\mu g / L} \mathrm{GE}$

$\mu g / L$ GE

$\mu g / \lambda$
$\mu g / \lambda$
$\mu g / L$

$\begin{array}{ll}\mu g / L & G E \\ \mu g / L & G E\end{array}$

${ }_{\mu g / L} \quad G E$

$\mu g / L \quad G E$

$\begin{array}{ll}\mu g / L & \mathrm{GE} \\ \mu \mathrm{g} / L & \mathrm{GE}\end{array}$

$\mu g / L$ GE

$\mu \mathrm{g} / \mathrm{LL} \quad \mathrm{GE}$

$\mu \mathrm{C} / \mathrm{mL}$ Ge

$\mu \mathrm{cCl} / \mathrm{mL}$ GE 
WELL LFW 25

MEASUREMENTS CONDUCTED IN THE FIELL

Sampie date: 10/25/91

Dopth to water: 16.41 th $(5.00 \mathrm{~m})$ below TOC

Water elevation: $158.29 \mathrm{ft}(48.25 \mathrm{~m}) \mathrm{msl}$
Sp. conductance: $16, \mathrm{Ss} / \mathrm{cm}$
Water evacuated beiore sampling: $93 \mathrm{gal}$

LABORATORY ANALYSES

E Analyte Result Mod Unit Lab

: $\mathrm{pH}$

Antimony

Arsenic

Barium

Bromodichloromethane

Bromoform

Cadmium

Carbon tetrachloride

Chloride

Chlorobenzene

Chloroethane

Chloroethene Ninyl chloride

2.Chloroethyl vinyl ether

Chioroform

Chloromethane

Chromiur

Copper

1,1-Dichloroethane

1,1-Dichloroethylene

o trans-1,2-Dichloroothyiene

o Dichioromethane

1,2-Dichloropropane

cis-1,3-Dichloropropene

o trans-1,3-Dichloropropene

0 Endrin

0 Endrin

0 Eltuoride

0 Lead

L Lindane

Lindane

Magnesium

Mercury

Methoxychlor

Methoxychlor

Nickel

Nitrate as nitrogen

Potassium

Selenium

Silica

Silver

Sodium

$1,1,2,2$-Tetrachloroethane

Tetrachloroethylene

Toluache
Total organic carbon

tolal organic carbon

Toxaphene

2,4,5.TP (Silvex)

1,1,1-Trichloroethan

1,1,2-Trichloroethan

Trichloroethylene

Trichlorofluoromethane

Vanadium

Gross alpha

Nonvolatile beta

Tritium
Time: $9: 10$

PH: 4.7 Alkalinity: $0 \mathrm{mg} / \mathrm{L}$

Water temperature: $193^{\circ} \mathrm{C}$

$<20$

$<2.0$
$<2.0$
$<2$

4.6
$<1.0$
$<$

$<1.0$

$<1.0$
$<1.0$
$<2.0$
212

212
$<1.0$
1.720

$<1.0$

$<1.0$
$<1.0$

$<1.0$

$<1.0$

$<4.0$

$<1.0$

$<1.0$

$<1.0$
$<1.0$

5.4
$<0.30$

$<0.30$
$<1.0$
$<1.0$

$<1.0$

$<0.0060$

$<0.0060$
$<1.0$
$<100$
$<30$

$<100$
$<3.0$

$<0.0050$

464

464
$<2.0$
$<0.20$

$<0.20$
$<0.50$

$<0.50$

5.7

650
650
$<500$

$<2.0$

6,320
$<2.0$

967
2,090

$\begin{aligned} & 2,090 \\ &< 1.0\end{aligned}$

$<1.0$
$<1.0$

$<1,000$

$<1,000$

$<0.24$

$<0.090$

$<10$

$<1.0$

$<1.0$

$<8.0$

5. $8 \mathrm{E}-09 \pm 1.7 \mathrm{E} \cdot 09$

1. $1 \mathrm{E} \cdot 08 \pm 1.9 \mathrm{E} \cdot 09$

$2.7 \mathrm{E} .09 \pm 1.4 \mathrm{E} .09$
$<70 \mathrm{E} .07$
5.0
$\begin{array}{llll}\mathrm{pH} & \mathrm{GE} & 0 & \mathrm{pH} \\ \mu \mathrm{S} / \mathrm{cm} & \mathrm{GE} & 0 & \text { Specitic conductance }\end{array}$

Aluminum

Antimony

Arsenic
Barium

Benzene
Bromodichloromethane

Bromotorm

Bromomethan

Cadmium

Calcium

Carbon tetrachloride

Chloride

Chlorobenzene

Chloroethane

2.Chloroethyl vinyl ether

Chloroform

Chloromethane

Chromiun

Dibromochloromethane

1.1.Dichloroethane

1.2-Dichioroethane

1.1-Dichloroethylene

trans-1,2-Dichloroethylene

$\begin{array}{ll}\text { Dichloromethane } & 8.5 \\ 2,4-D \text { ichlorophenoxyacetic acid } & <0.30\end{array}$

cis-1,3-Dichloropropene
trans-1,3-Dichloropropene

Endrin

Ethylbenzene

Lindane

Lindane

Magnesium

Magnesium

Manganese

Methoxychlor
Methoxychlor

Nitrate as nitrogen

Potassium

Selenium

Silica

Silver

Sodium

Silfate

Tetrachloroethylene

Toluerie

Total organic carbon

Total organic halogens

Toxaphene

Toxaphene

1,1,1-Trichloroethane

1,1.2. Trichloroethan

Trichloroethyiene

Virchlorolluoro

Gross alpha

Nonvolatile beta

Total radium
1,2-Dichloropropane
Time: $10: 30$

Alkalinity: $0 \mathrm{mg} / \mathrm{L}$

Water temperature: $18.8^{\circ} \mathrm{C}$

Result Mod Unit Lab

5.2

15
$<20$
$<20$

$<20$
$<2.0$
$<2.0$
3.4

3.4
$<1.0$

$<1.0$

$<1.0$

$<2.0$

$<1.0$
$<320$

$<1.0$

$<1.0$
$<1.0$

$<1.0$
$<1.0$

$<1.0$
$<1.0$
$<4.0$
$<4.0$

$<4.0$
$<4.0$

$<1.0$

c10

$<1.0$

8.5
$<0.30$

$<1.0$

$<10$

$<0.0060$

$<0.006$

$<1.0$
$<100$

$<3.0$

$<0.0050$

$<0.0050$

247
$<2.0$

$<0.20$

$<0.50$

$<0.50$

$<4.0$
120
$<500$

$<500$
$<2.0$

$<2.0$

$<.0$
1,060

$<1,000$

$<1.0$

$<1.0$

$<1,000$

$\begin{aligned} & 9.6 \\ < & 0.24\end{aligned}$

$<0.24$

$<0.090$

$<1.0$

$<1.0$

$<1.0$
$<8.0$

$<8.0$

$2.6 \mathrm{E} \cdot 09 \pm 1.4 \mathrm{E}-09$

$<1.0 \mathrm{E} .08$

JQ $\mathrm{pH} \quad \mathrm{GE}$

$\begin{array}{ll}\mu \mathrm{S} / \mathrm{cm} & \mathrm{GE} \\ \mu \mathrm{g} / \mathrm{LE} & \mathrm{GE}\end{array}$

$\begin{array}{ll}\mu g / L & G E \\ \mu g / L & G E\end{array}$

$\mu g / L \quad G E$

$g / L \quad G E$

$\mu g / L \quad G E$

g $\quad \mathrm{GE}$

$\mu g / L \quad G E$

$\begin{array}{ll}\mu g / L & G E \\ \mu g / L & G E\end{array}$ 
ANALYTICAL RESULTS

WELL LFW 27

MEASUREMENTS CONDUCTED IN THE FIELD

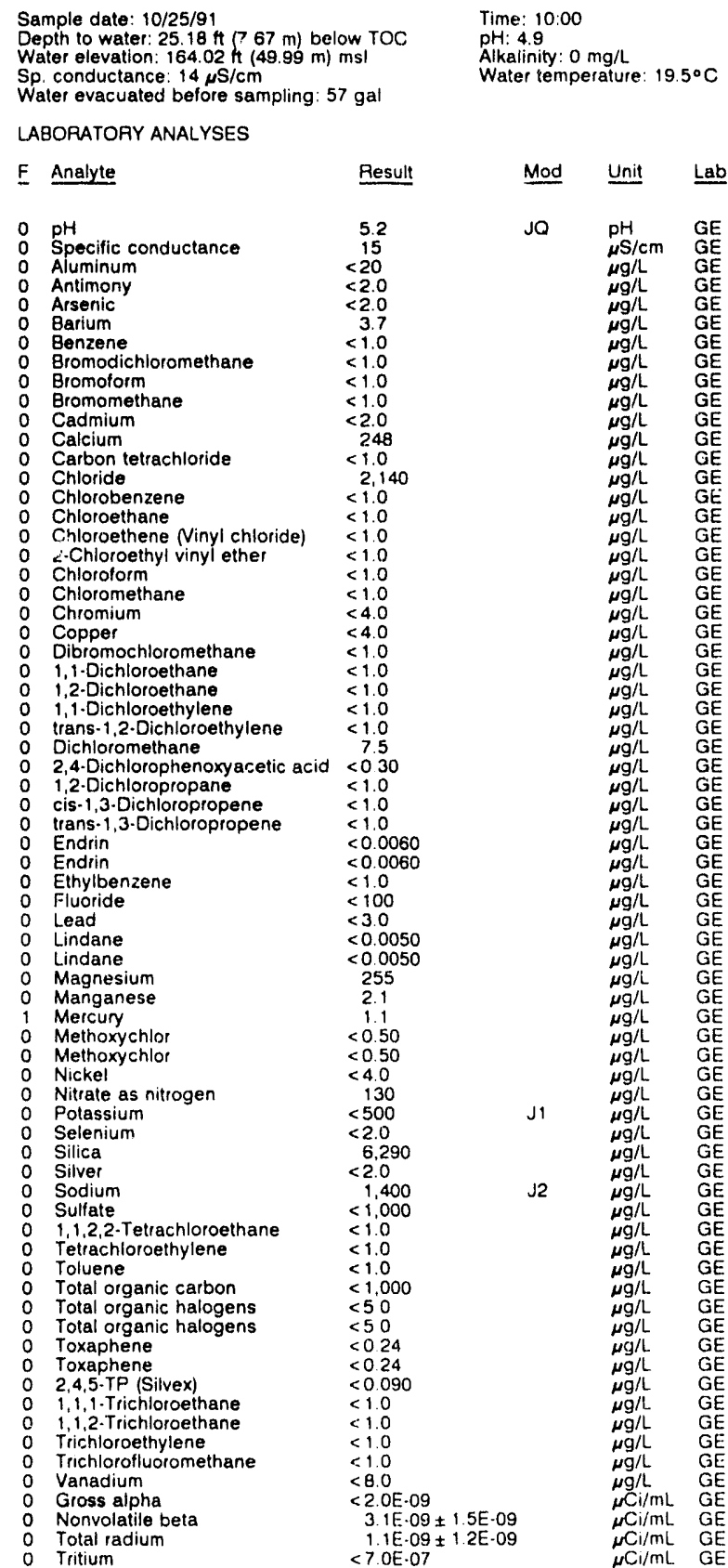

WELL LFW 27 Replicate

MEASUREMENTS CONDUCTED IN THE FIELD

Sample date: $10 / 25 / 91$
Depth to water: $25.18 \mathrm{k}$
Water elevation: $164.02 \mathrm{ft}(49.99 \mathrm{~m})$ below $\mathrm{ms}$ TOC
Sp. conductance: $14 \mu \mathrm{s} / \mathrm{cm}$
Water evacuated before sampling: $57 \mathrm{gal}$
LABORATORY ANALYSES

Time: 10:00

PH: 4.9

Water temperature: $19.5^{\circ} \mathrm{C}$

LABORATORY ANALYSES

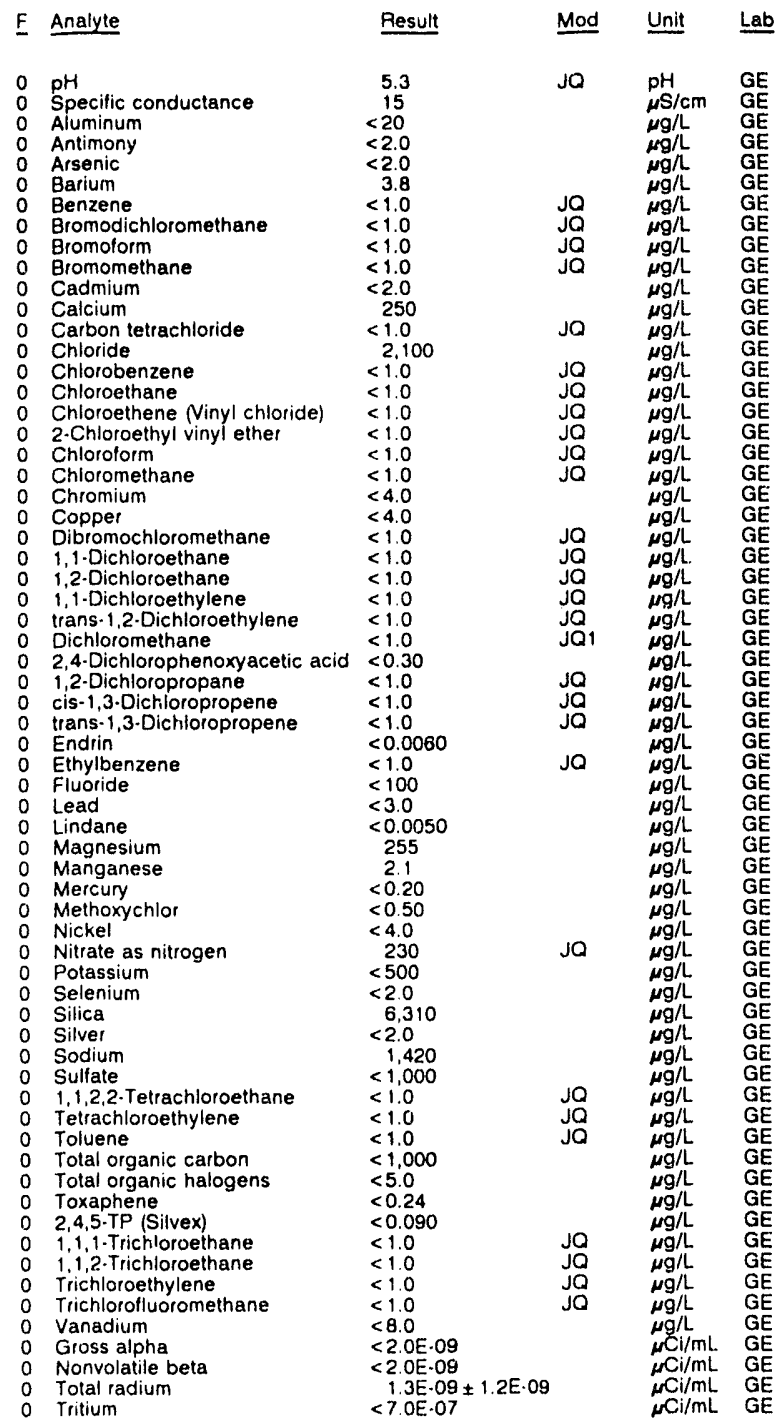

\section{WELL LFW 28}

MEASUREMENTS CONDUCTEO IN THE FIELO

Sample date: $10 / 29 / 91$ Depth to water: $27.00 \mathrm{H}(8.25 \mathrm{~m})$ below TOC

Water elevalion. $165.34 \mathrm{~h} / 50$.

Sp. Conductance: $31 \mu \mathrm{S} / \mathrm{cm}$.

The well went dry during purging.

LABORATORY ANALYSES

\begin{tabular}{|c|c|c|c|}
\hline Analyte & Result: & Mod & Unit \\
\hline $\begin{array}{l}\text { pH } \\
\text { Specific conductance } \\
\text { Aluminum } \\
\text { Antimuny } \\
\text { Antimony } \\
\text { Arsenic }\end{array}$ & $\begin{aligned} & 5.7 \\
& 30 \\
&< 20 \\
&<2.0 \\
&<2.0 \\
&<2.0\end{aligned}$ & $J Q$ & $\begin{array}{l}\mathrm{pH} \\
\mu \mathrm{S} / \mathrm{cm} \\
\mu \mathrm{g} / \mathrm{h} \\
\mu \mathrm{g} / \mathrm{h} \\
\mu \mathrm{g} / \mathrm{L} \\
\mu \mathrm{g} / \mathrm{L}\end{array}$ \\
\hline
\end{tabular}


ANALYTICAL RESULTS

WELL LFW 28 collecied on 10/29/91, laboratory analyses (cont)

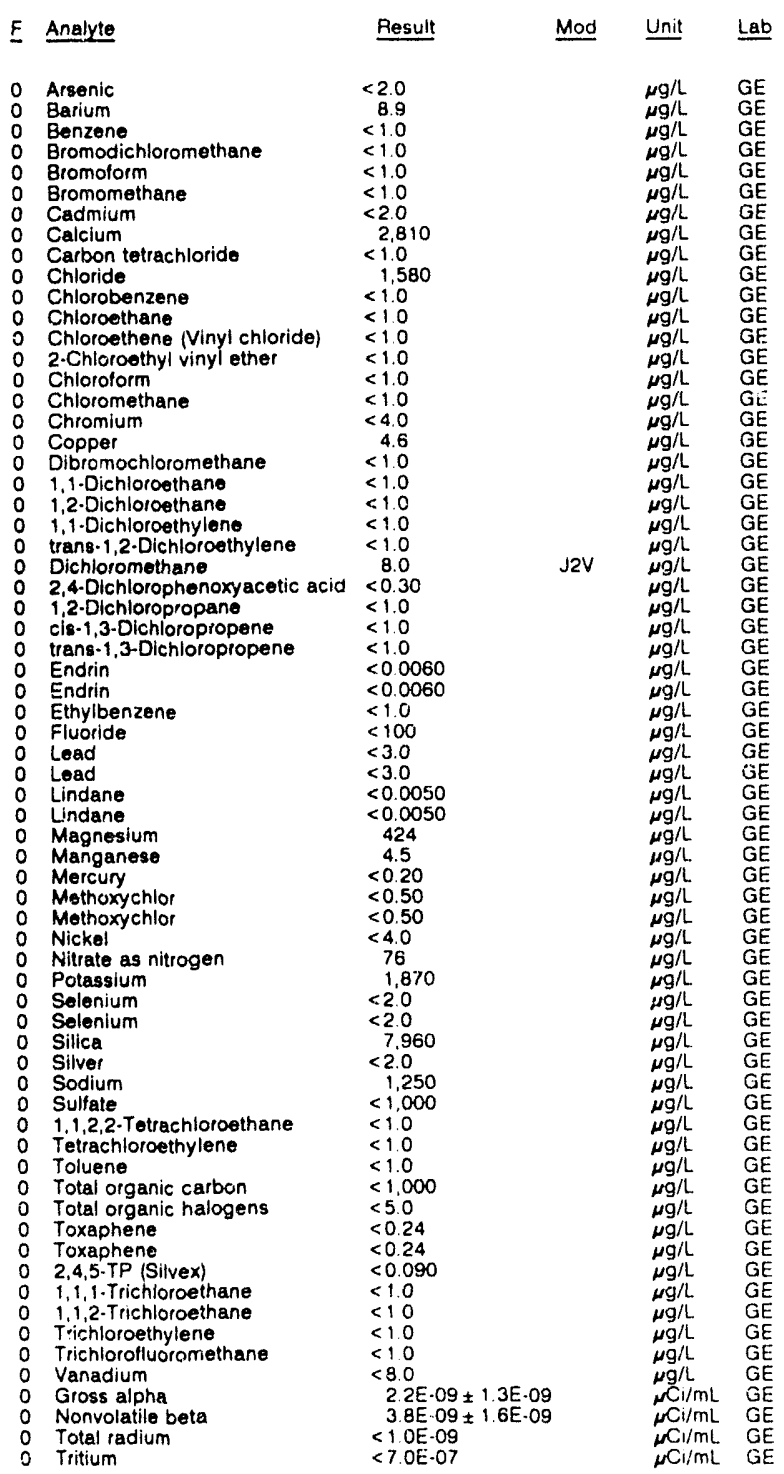

\section{WELL LFW 29}

MEASUREMENTS CONDUCTED IN THE FIELD

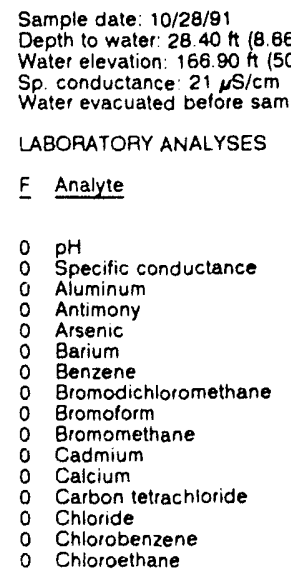

Time 9.45

pHi: 45
Alkalinity $0 \mathrm{mg} / \mathrm{L}$

Water temperature $183^{\circ} \mathrm{C}$

WELL LFW 29 collected on 10/28/91, laboratory analyses (cont)

F Analyte Presult Mod Unit Lab

Chloroethene Ninyl chloride) $<1$

2.Chloroethyl vinyl ether $<10$

$\begin{array}{ll}\text { Chloroform } & <1.0 \\ \text { Chloromethane } & <1.0 \\ \text { Chromium } & <4.0\end{array}$

Copper

Dibromochloromethane $\quad<4.0$

1.1.Dichloroethane

1,2-Dichloroethane $<1.0$

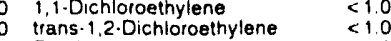

Dichloromethane $<1.0$

2,4-Dichlorophenoxyacetic acid $<0.30$
1 -Dichioroproparie

0 is-1.3.Dichloropropene $<1.0$

trans-1,3-Dichloropropene $<1.0$

E Endrin $\quad<1.0$

0 Fluoride $<100$

0 Lead $<3.0$

Magnesium 587

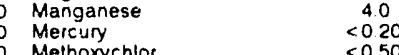

0 Methoxychlor $\quad<0.50$

$\begin{array}{ll}\text { Nickel Nitrate as nitrogen } & <4.0 \\ & 860\end{array}$

Potassium

Selenium

Silica

Siver

Sultate

Sulfate $\quad<1.000$

Tetrachloroethylene

Toluene

- Total organic carbon $\quad<1,000$

Total organic carbon

- Total organic halogens

0 Toxaphene

o 1,1,1-Trichloroethane

1.1.2. Trichloroethane

Trichlorolhylene

$<1.0$

O Gross alph

- Nonvolatile bet

1 Tonal radium

0 Tritium

\section{WELL LFW 30}

MEASUREMENTS CONDUCTED IN THE FIELD

$\begin{array}{ll}\text { Sample date } 10 / 28 / 91 & \text { Time } 9.15 \\ \text { Depth to water: } 42.76 \mathrm{ft}(13.03 \mathrm{~m}) \text { below TOC } & \mathrm{pH} .5 .1 \\ \text { Water elevation: } 167.24 \mathrm{th}(50.98 \mathrm{~m}) \mathrm{msl} & \text { Alkalinity } 0 \mathrm{mg} / \mathrm{L} \\ \text { Sp conductance } 22 \mu \mathrm{S} / \mathrm{cm} & \text { Water temperature: } 18.1^{\circ} \mathrm{C} \\ \text { Water evacuated before sampling } 45 \mathrm{gal} & \end{array}$

LABORATORY ANALYSES

\begin{tabular}{|c|c|c|c|}
\hline Analyte & Result & Mod & Unit \\
\hline $\mathrm{pH}$ & 54 & JQ & $\mathrm{pH}$ \\
\hline Spectific conductance & 20 & & $\mathrm{MS} / \mathrm{cm}$ \\
\hline & & & $\mu g / \mathrm{L}$ \\
\hline Antimony & $<2.0$ & & $\mu \mathrm{g} / \mathrm{L}$ \\
\hline Arsenic & $<2.0$ & & $\mu \mathrm{g} / \mathrm{L}$ \\
\hline Barrum & 53 & & $\mu \mathrm{g} / \mathrm{L}$ \\
\hline Benzene & $<10$ & & $\mu \mathrm{g} / \mathrm{h}$ \\
\hline Bromodichloromethane & $<10$ & & $\mu \mathrm{g} / \mathrm{L}$ \\
\hline Bromotorm & $<1.0$ & & $\mu \mathrm{g} / \mathrm{L}$ \\
\hline Bromomethane & $<10$ & & $\mu \mathrm{g} / \mathrm{L}$ \\
\hline Cadmium & $<20$ & & $\mu \mathrm{g} / \mathrm{L}$ \\
\hline Calcium & 927 & & $\mu \mathrm{g} / \mathrm{h}$ \\
\hline Cartion tetrachtoride & $<10$ & & $\mu \mathrm{g} / \mathrm{L}$ \\
\hline Chloride & 1.580 & & $\mu \mathrm{g} / \mathrm{L}$ \\
\hline Chlorobenzene & $<10$ & & $\mu \bar{g} / \mathrm{h}$ \\
\hline Chioroethane & $<10$ & & $\mu \mathrm{g} / \mathrm{h}$ \\
\hline Chlorvethene (Vinyl chlon:de) & $<10$ & & $\mu \mathrm{g} / \mathrm{L}$ \\
\hline 2. Cnloroethyl vinyl ether & $<10$ & & $\mu \mathrm{g} / \mathrm{L}$ \\
\hline Chioroform & $<10$ & & $\mu \mathrm{g} / \mathrm{L}$ \\
\hline Chloromethane & $<1.0$ & & $\mu \mathrm{g} / \mathrm{L}$ \\
\hline Chromium & $<40$ & & $\mu \mathrm{g} / \mathrm{h}$ \\
\hline Copper & $<40$ & & $\mu \mathrm{g} / \mathrm{L}$ \\
\hline Dibromochloromethane & $<10$ & & $\mu \mathrm{g} / \mathrm{L}$ \\
\hline 1.1-Dichloroethane & $<10$ & & $\mu \mathrm{g} / \mathrm{L}$ \\
\hline 1.2. Dichloroethane & $<10$ & & $\mu \mathrm{gil}$ \\
\hline 1,1. Dichloroethylene & $<10$ & & $\mu g / \mathrm{L}$ \\
\hline trans-1,2-Dichloroethylene & $<10$ & & $\mu \mathrm{g} / \mathrm{h}$ \\
\hline Dichloriomethane & $<10$ & & $\mu \mathrm{g} / \mathrm{L}$ \\
\hline 2,4. Dichlorophenoxyacetic acid & $<0.30$ & & $\mu \mathrm{g} / \mathrm{L}$ \\
\hline 1.2. Dichiorcpropane & $<10$ & & $\mu g / \mathrm{h}$ \\
\hline cis-13-Dichiorupropene & $<10$ & & $\mu g / L$ \\
\hline trans. 1.3. Dichloropropene & $<1.0$ & & $\mu \mathrm{g} / \mathrm{L}$ \\
\hline Endrin & $<00060$ & & $\mu \mathrm{g} / \mathrm{L}$ \\
\hline
\end{tabular}


ANALYTICAL RESULTS

WELL LFW 30 collected on 10/28/91. laboratory analyses (cont.)

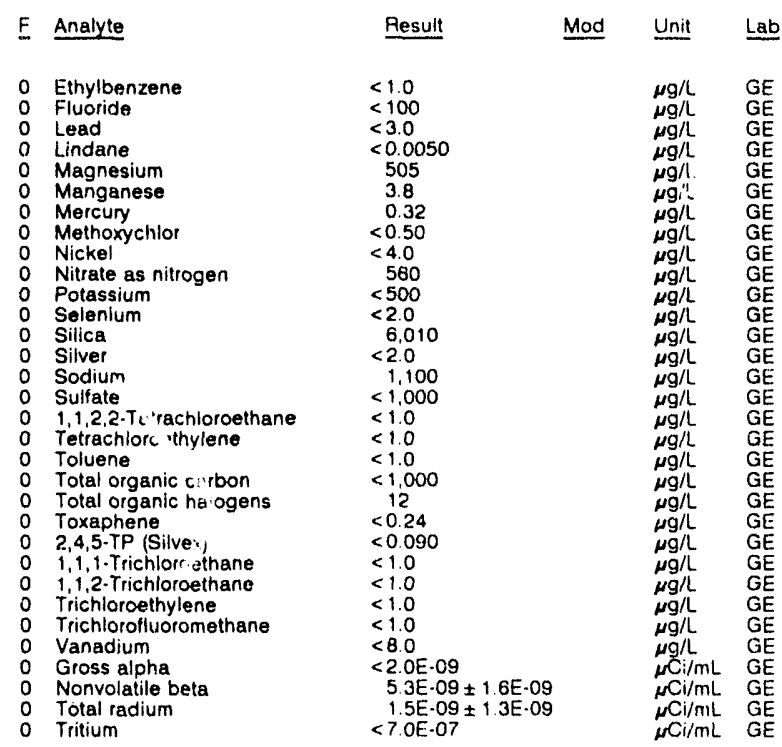

\section{WELL LFW 31}

MEASUREMENTS CONDUCTED IN THE FIELD

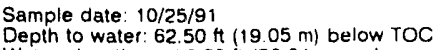
Depth to water: $62.50 \mathrm{H}(19.05 \mathrm{~m})$ below TOC
Water elevation: $66.80 \mathrm{Ht}(50.84 \mathrm{~m}) \mathrm{msl}$

Sp. conductance: $24 \mu \mathrm{S} / \mathrm{cm}$
Water evacuated before sampling: 59 gal

LABORATORY ANALYSES

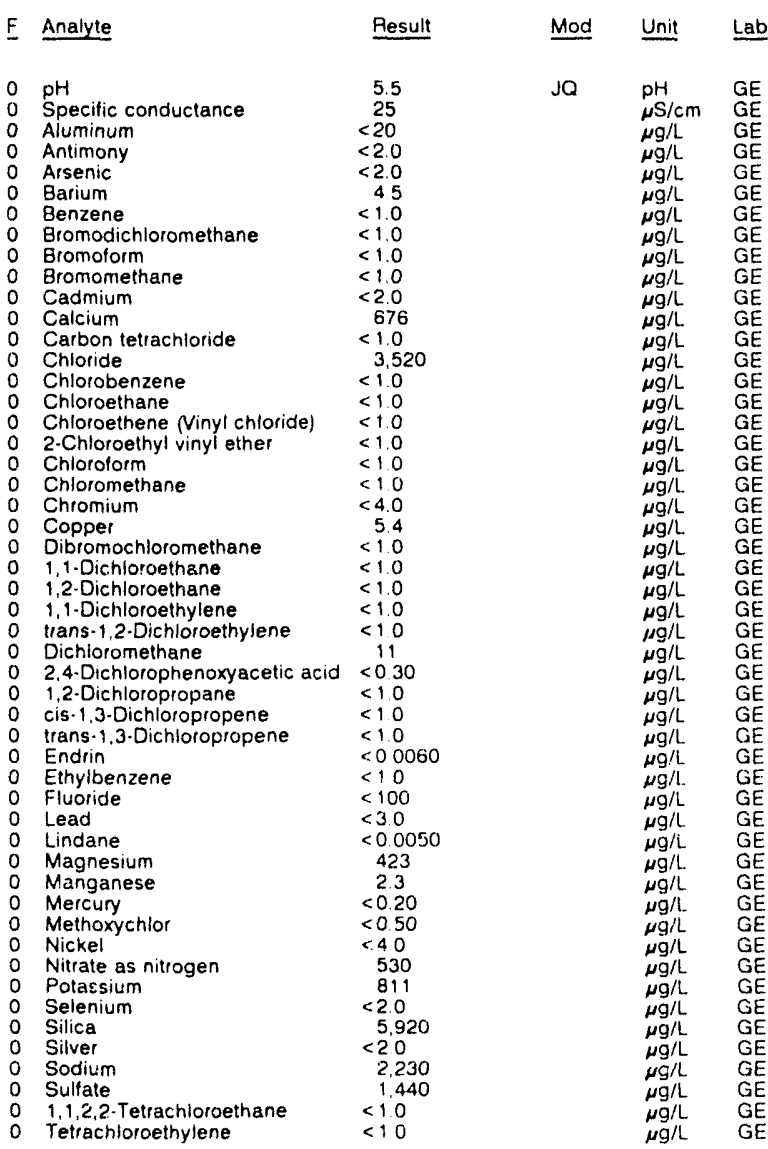

WELL LFW 31 collected on 10/25/91, laboratory analyses (cont.)

\begin{tabular}{|c|c|c|c|c|c|}
\hline $\mathrm{F}$ & Analyte & Result & Mod & Unit & Lab \\
\hline 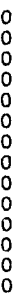 & $\begin{array}{l}\text { Toluene } \\
\text { Total organic carbon } \\
\text { Total organic halogens } \\
\text { Toxaphene } \\
2,4,5-\text { TP (Silvex) } \\
1,1,1 \text {. Trichloroethane } \\
1,1,2 \text {-Trichloroethane } \\
\text { Trichloroethylene } \\
\text { Trichlorofluoromethane } \\
\text { Vanadium } \\
\text { Gross alpha } \\
\text { Nonvolatile bota } \\
\text { Total radium } \\
\text { Tritium }\end{array}$ & $\begin{array}{l}<1.0 \\
<1.000 \\
10 \\
<0.24 \\
<0.090 \\
<1.0 \\
<1.0 \\
<1.0 \\
<1.0 \\
<8.0 \\
<2.0 E \cdot 09 \\
<2.0 E-09 \\
<1.0 E-09 \\
<7.0 E \cdot 07\end{array}$ & & $\begin{array}{l}\mu g / L \\
\mu g / L \\
\mu g / L \\
\mu g / L \\
\mu g / L \\
\mu g / L \\
\mu g / L \\
\mu g / L \\
\mu g / L \\
\mu g / L \\
\mu C i / m L \\
\mu C i / m L \\
\mu C l / m L \\
\mu C i / m L\end{array}$ & $\begin{array}{l}\mathrm{GE} \\
\mathrm{GE} \\
\mathrm{GE} \\
\mathrm{GE} \\
\mathrm{GE} \\
\mathrm{GE} \\
\mathrm{GE} \\
\mathrm{GE} \\
\mathrm{GE} \\
\mathrm{GE} \\
\mathrm{GE} \\
\mathrm{GE} \\
\mathrm{GE} \\
\mathrm{GE}\end{array}$ \\
\hline
\end{tabular}

WELLL LFW 32

MEASUREMENTS CONDUCTED IN THE FIELD

Sample date: $10 / 25 / 91$

Depth to water: $59.14 \mathrm{Ht}(18.03 \mathrm{~m})$ below TOC

Water elevation: $164.56 \mathrm{ft}(50.16 \mathrm{~m}) \mathrm{msl}$

Water evacuated before sampling: $55 \mathrm{gal}$

LABORATORY ANALYSES

E Analyte Result Mod Unit Lab

0 pH

$0 \quad$ Specific conductance

A Aluminum

Arsenic

Barium

Bromodichloromethane

Bromomethan

Cadmium

Calcium

Carbon tetrachloride

Chloride

Chlorobenzene

Chloroethane

Chloroethene Ninyl chloride)

2. Chloroethyl vinyl ether

Chloroform

Chromium $<4.0$

Copper $<4.0$

$\begin{array}{lll}0 & \text { Dibromochloromethane } & <1.0 \\ 0 & 1,1 . \text { Dichloroethane } & <1.0 \\ 0 & 12 \text {. Dichloroethane } & <10\end{array}$

1,1-Dichloroethylen

1,1.Dichloroethylene

Dichloromethane

$<1.0$
$<1.0$

2.4-Dichlorophenoxyacetic acid <0.30

1,2-Dichloropropane

cis-1,3-Dichloremeroene

Endrin

Ethylbenzene

Fluoride

0 Lead

Magnesium

Manganese

Mercury

Methoxychlor

0 Nickel

Nitrate as nitrogen

Potassium

Selenium

Silica

- Silver

0 Sodium

Sulfate

Tetrachloroethylene

Toluene

Total organic carbon

Total organic halogen

2,4.5.TP (Silvex)

1.1.1-Trichloroethane

1,1,2. Trichloroethane

Trichlorofluoromethan

Vanadium

Gross alpha

0 Nonvolatife beta

$\begin{array}{ll}0 & \text { Total radium } \\ 0 & \text { Tritium }\end{array}$

5.2
20
20
2.0
2.0
3.3
1.0
1.0
1.0
1.0
2.0
292
1.0
2.700
1.0
1.0
1.0
1.0
10
10
40
40
10
1.0
1.0
110
1.0
7.3
0.30
1.0
110

$<1.0$

$<1.0$
$<0.0060$

$<1.0$

$<100$
$<3.0$

$<3.0$
$<0.0050$

$\begin{aligned} & 436 \\ &<2.0 \\ &< 0.20 \\ &< 0.50\end{aligned}$

$<0.20$
$<0.50$

$<4.0$

450
563

563
$<2.0$
6.100

6.100
$<2.0$

1,730
$<1000$

$<1,000$

$<10$
$<10$

$<1.0$
$<1.000$
8.1
$<0.24$

$<0.24$

10

$<1.0$

$<1.0$

$<1.0$
$<80$

$2.5 \mathrm{E} \cdot 09 \pm 1.3 \mathrm{E}-09$
$3.5 \mathrm{E} \cdot 09 \pm 1.5 \mathrm{E}-09$

$<1.0 E \cdot 09$
$<7.0 E \cdot 07$
Time: 13:55

PH: 4.9 . 0 mg

Water temperature: $18.8^{\circ} \mathrm{C}$ 
WELL LFW 33

MEASUREMENTS CONDUCTED IN THE FIELD

Sample date: 10/25/91

Depth to water: $50.52 \mathrm{H}(15.40 \mathrm{~m})$ below TOC Water elevation: $163.18 \mathrm{~h}(49.74 \mathrm{~m}) \mathrm{msl}$

Water evacuated before sampling: 51 gal

LABORATORY ANALYSES

\begin{tabular}{|c|c|c|c|}
\hline Analyte & Result & Mod & Unit \\
\hline 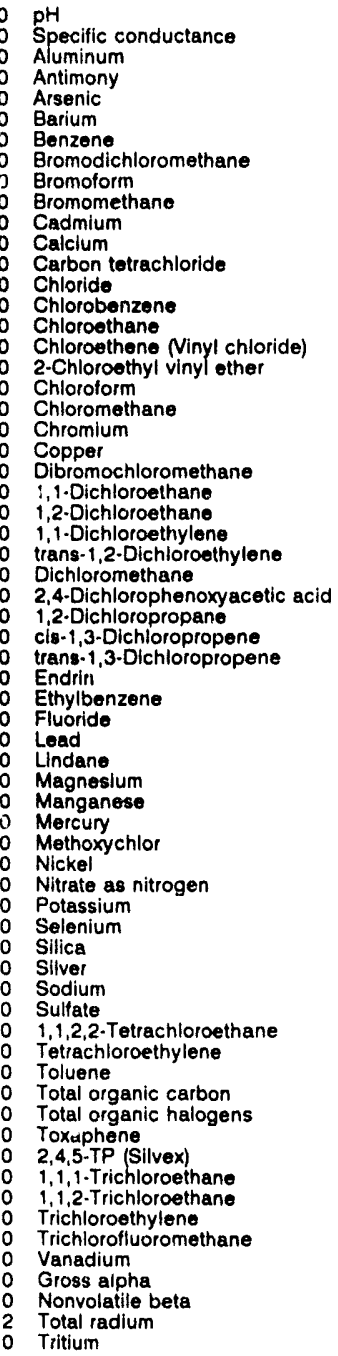 & 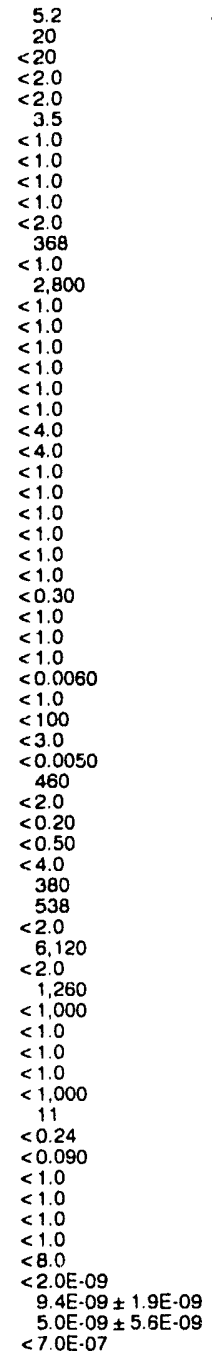 & $\mathrm{J} 2 \mathrm{~V}$ & 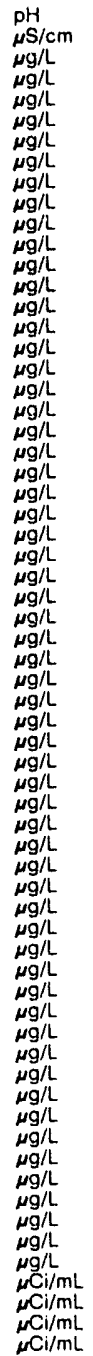 \\
\hline
\end{tabular}

Time: $13: 30$

PH: 4.9

Akalinity: O mg/l 18.00

ab
WELL LFW 34 collected on 10/25/91, laboratory analyses (cont.)

E Analyte Result Mod Unit Lab

O Benzene

$<1.0$
$<1.0$

Bromoform

Bromomethan

Cadmium

Carbon tetrachloride

Chloride

Chlorobenzen

Ciloroethene Ninyl chloride)

2.Ciloroethyl vinyl ether

2-Chloroethy

Chloromethane

Chromium

Copper

Dibromochloromethane

1,1-Dichloroethane

1,2-Dichloroethane

1,1-Dichloroethylene

trans-1,2-Dichloroe

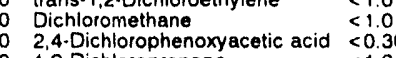

1,2-Dichloropropane

cis-1,3-Dichloropropene

trans-1,3-Dichloro

o Ethylbenzene

0 Fluoride

0 Lindane

Magnesium

Manganese

Mercury

Nicke

Nitrate as nittogen

$\begin{array}{ll}0 & \text { Potassium } \\ 0 & \text { Selenium }\end{array}$

0 Silica

o Silve:

0 Sulfate

0 Sulfate $1,1,2,2 \cdot$ Tetrachloroethane

Tetrachloroethylene

0 Toluene

- Total organic carbon

0 Total organic halogens

o Total organic halogens

0 Toxaphene

2,4,5-TP (Silvex)

1,1,2-Trichloroethane

Trichloroethylene

Trichlorofluoromethane

O Vanadium

Gross alpha

1 Total radium

0 Tritium

$<1.0$

$<1.0$
$<2.0$

746
$<1.0$

2,650

$<1.0$
$<1.0$

$<1.0$
$<1.0$

$<1.0$

$<1.0$
$<1.0$
$<4.0$
$<4.0$

$<4.0$
$<4.0$
$<1.0$
$<1.0$

$<1.0$
$<1.0$
$<1.0$

$<1.0$

$<1.0$
$<1.0$

$<0.30$
$<1.0$
$<1.0$

$<1.0$

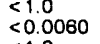

$<0.0060$
$<1.0$
$<100$
$<3.0$

$<3.0$
$<0.0050$

460

460
2.3
$<0.20$

$<0.20$

$<0.50$
$<4.0$
450
$<500$

$<2.0$
6,260

$\begin{aligned} & 6,260 \\ &<2.0\end{aligned}$

1,320
$<1,000$

$<1,000$
$<1.0$
$<1.0$

$<1.0$

$<1,000$

$<1,000$
$<5.0$
$<5.0$

$<0.24$

$<1.0$
$<1.0$
$<1.0$

$<1.0$

$<8.0$

$<2.0 \mathrm{OE} \cdot 09$

$4.0 \mathrm{E}-09 \pm 1.6 \mathrm{E}-09$

$<7.0 \mathrm{E} \cdot 07$

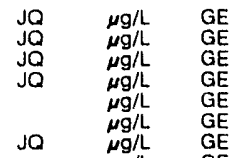

WELL LFW 35

MEASUREMENTS CONDUCTED IN THE FIELD

Sample date: $10 / 24 / 91$
Depth to water: $23.18 \mathrm{tt}(7.07 \mathrm{~m})$ below TOC

Depth to water: $23.18 \mathrm{H}(7.07 \mathrm{~m})$ below TO
Water elevation: $160.52 \mathrm{tt}(48.93 \mathrm{~m}) \mathrm{ms}$.

Water elevation: $160.52 \mathrm{tt}(48.93$

Sp. conductance: $23 \mu \mathrm{\mu} / \mathrm{cm}$
Water evacuated before sanipling: $47 \mathrm{gal}$

PH: 4.8 .

LABORATORY ANALYSES

\section{WELL LFW 34}

MEASUREMENTS CONDUCTED IN THE FIELD

Sample date: $10 / 25 / 91$
Depth to water: $39.23 \mathrm{Ht}(11.96 \mathrm{~m})$ below TOC
Water elevation: $161.77 \mathrm{tt}(49.31 \mathrm{~m}) \mathrm{msl}$
Sp. conductance: $19 \mu \mathrm{s} / \mathrm{cm}$
Water evacuated before sampling: $49 \mathrm{gal}$

\begin{tabular}{|c|c|c|c|c|}
\hline Analyte & Result & Mod & Unit & Lab \\
\hline $\begin{array}{ll}0 & \mathrm{pH} \\
0 & \text { Specific conductance } \\
0 & \text { Aluminum } \\
0 & \text { Antimony } \\
0 & \text { Arsenic } \\
0 & \text { Barium } \\
0 & \text { Benzene } \\
0 & \text { Bromodichloromethane } \\
0 & \text { Bromoform } \\
0 & \text { Bromomethane } \\
0 & \text { Cadmium } \\
0 & \text { Calcium } \\
0 & \text { Carbon tetrachloride } \\
0 & \text { Chloride } \\
0 & \text { Chlorobenzene } \\
0 & \text { Chloroethane } \\
0 & \text { Chloroethene (Ninyl chloride) } \\
0 & 2 \cdot \text { Chloroethyl vinyl ether } \\
0 & \text { Chloroform } \\
0 & \text { Chloromethane } \\
0 & \text { Chromium } \\
0 & \text { Coppet } \\
0 & \text { Dibromochloromethane }\end{array}$ & $\begin{aligned} & 5.1 \\
& 25 \\
&<20 \\
&<2.0 \\
&<2.0 \\
& 4.9 \\
&<1.0 \\
&<1.0 \\
&<1.0 \\
&<1.0 \\
&<2.0 \\
& 365 \\
&<1.0 \\
& 2.580 \\
&<1.0 \\
&<1.0 \\
&<1.0 \\
&<1.0 \\
&<1.0 \\
&<1.0 \\
&<4.0 \\
&<4.0 \\
&<1.0\end{aligned}$ & JQ & $\begin{array}{l}\mathrm{pH} \\
\mu \mathrm{S} / \mathrm{cm} \\
\mu \mathrm{g} / \mathrm{L} \\
\mu g / L \\
\mu g / L \\
\mu g / L \\
\mu g / L \\
\mu g / L \\
\mu g / L \\
\mu g / L \\
\mu g / L \\
\mu g / L \\
\mu g / L \\
\mu g / L \\
\mu g / L \\
\mu g / L \\
\mu g / L \\
\mu g / L \\
\mu g / L \\
\mu g / L \\
\mu g / L \\
\mu g / L \\
\mu g / L\end{array}$ & $\begin{array}{l}\mathrm{GE} \\
\mathrm{GE} \\
\mathrm{GE} \\
\mathrm{GE} \\
\mathrm{GE} \\
\mathrm{GE} \\
\mathrm{GE} \\
\mathrm{GE} \\
\mathrm{GE} \\
\mathrm{GE} \\
\mathrm{GE} \\
\mathrm{GE} \\
\mathrm{GE} \\
\mathrm{GE} \\
\mathrm{GE} \\
\mathrm{GE} \\
\mathrm{GE} \\
\mathrm{GE} \\
\mathrm{GE} \\
\mathrm{GE} \\
\mathrm{GE} \\
\mathrm{GE} \\
\mathrm{GE}\end{array}$ \\
\hline
\end{tabular}

\begin{tabular}{|c|c|c|}
\hline \multicolumn{2}{|c|}{$\begin{array}{l}\text { Time: } 13: 05 \\
\text { pH: } 5.1 \\
\text { Alkalinity: } 0 \mathrm{mg} / \mathrm{L} \\
\text { Water temperalure }\end{array}$} & \\
\hline Mod & Unit & Lab \\
\hline $\mathrm{JQ}$ & $\begin{array}{l}\mathrm{pH} \\
\mu \mathrm{S} / \mathrm{cm} \\
\mu \mathrm{g} / \mathrm{L} \\
\mu \mathrm{g} / \mathrm{L} \\
\mu \mathrm{g} / \mathrm{L} \\
\mu \mathrm{g} / \mathrm{L}\end{array}$ & $\begin{array}{l}\mathrm{GE} \\
\mathrm{GE} \\
\mathrm{GE} \\
\mathrm{GE} \\
\mathrm{GE} \\
\mathrm{GE}\end{array}$ \\
\hline
\end{tabular}
LABORATORY ANALYSES

\begin{tabular}{|c|c|c|c|c|c|}
\hline$E$ & Analyte & Result & Mod & Unit & $\underline{L a b}$ \\
\hline $\begin{array}{l}0 \\
0 \\
0 \\
0 \\
0 \\
0\end{array}$ & $\begin{array}{l}\text { pH } \\
\text { Specific conductance } \\
\text { Aluminum } \\
\text { Antimony } \\
\text { Arsenic } \\
\text { Barium }\end{array}$ & $\begin{aligned} & 5.3 \\
& 20 \\
&<20 \\
&<2.0 \\
&<2.0 \\
& 6.8\end{aligned}$ & $J Q$ & $\begin{array}{l}\mathrm{pH} \\
\mu \mathrm{S} / \mathrm{cm} \\
\mu \mathrm{g} / \mathrm{L} \\
\mu \mathrm{g} / \mathrm{L} \\
\mu \mathrm{g} / \mathrm{h} \\
\mu \mathrm{g} / \mathrm{L}\end{array}$ & $\begin{array}{l}\mathrm{GE} \\
\mathrm{GE} \\
\mathrm{GE} \\
\mathrm{GE} \\
\mathrm{GE} \\
\mathrm{GE}\end{array}$ \\
\hline
\end{tabular}

Lab

Alkalinity: $0 \mathrm{mg} / \mathrm{L}$
Water temperature: $20.7^{\circ} \mathrm{C}$ 
ANALYTICAL RESULTS

WELL LFW 35 collected on 10/24/91, laboratory analyses (cont.)

\begin{tabular}{|c|c|c|c|c|}
\hline Analyte & Result & Mod & Unit & $\underline{L a b}$ \\
\hline $\begin{array}{l}\text { 1,1-Dichloroethane } \\
1,2 \cdot \text {-Dichloroethane } \\
1,1-\text { Dichloroethylene } \\
\text { trans-1,2-Dichloroethylene } \\
\text { Dichloromethane } \\
\text { 2,4-Dichlorophenoxyacetic acid } \\
1,2 \text {-Dichloropropane } \\
\text { cis-1,3-Dichloropropene } \\
\text { trans-1,3-Dichloropropene } \\
\text { Endrin } \\
\text { Ethylbenzene } \\
\text { Fluoride } \\
\text { Fluoride } \\
\text { Lead } \\
\text { Lindane } \\
\text { Magnesium } \\
\text { Manganese } \\
\text { Mercury } \\
\text { Methorychlor } \\
\text { Nickel } \\
\text { Nitrate as nitrogen } \\
\text { Potassium } \\
\text { Selenium } \\
\text { Silica } \\
\text { Silver } \\
\text { Sodium } \\
\text { Sulfate } \\
1,1,2,2 \text {-Tetrachloroethane } \\
\text { Tetrachloroethylene } \\
\text { Toluene } \\
\text { Total organic carbon } \\
\text { Total organic halogens } \\
\text { Total organic halogens } \\
\text { Toxaphene } \\
\text { 2,4,5-TP (Silvex) } \\
\text { 1,1,1-Trichloroethane } \\
\text { 1,1,2-Trichloroethane } \\
\text { Trichloroethylene } \\
\text { Trichlorofluoromethane } \\
\text { Vanadium } \\
\text { Gross alpha } \\
\text { Nonvolatile beta } \\
\text { Total radium } \\
\text { Tritium }\end{array}$ & $\begin{array}{l}<1.0 \\
<1.0 \\
<1.0 \\
<1.0 \\
11.1 \\
<0.30 \\
<1.0 \\
<1.0 \\
<1.0 \\
<0.0060 \\
<1.0 \\
<100 \\
<100 \\
<3.0 \\
<0.0050 \\
618 \\
3.2 \\
<0.20 \\
<0.50 \\
<4.0 \\
1.240 \\
<500 \\
<2.0 \\
6.420 \\
<2.0 \\
21.710 \\
<1.000 \\
<1.0 \\
<1.0 \\
<1.0 \\
<1.000 \\
44 \\
45 \\
<0.24 \\
<0.090 \\
<1.0 \\
<1.0 \\
<1.0 \\
<1.0 \\
<8.0 \\
<2.0 E \cdot 09 \\
2.9 E \cdot 09 \pm 1.5 E \cdot 09 \\
<1.0 E \cdot 09 \\
<7.0 E \cdot 07\end{array}$ & J1 & $\begin{array}{l}\mu g / L \\
\mu g / L \\
\mu g / L \\
\mu g / L \\
\mu g / L \\
\mu g / L \\
\mu g / L \\
\mu g / L \\
\mu g / L \\
\mu g / L \\
\mu g / L \\
\mu g / L \\
\mu g / L \\
\mu g / L \\
\mu g / L \\
\mu g / L \\
\mu g / L \\
\mu g / L \\
\mu g / L \\
\mu g / L \\
\mu g / L \\
\mu g / L \\
\mu g / L \\
\mu g / L \\
\mu g / L \\
\mu g / L \\
\mu g / L \\
\mu g / L \\
\mu g / L \\
\mu g / L \\
\mu g / L \\
\mu g / L \\
\mu g / L \\
\mu g / L \\
\mu g / L \\
\mu g / L \\
\mu g / L \\
\mu g / L \\
\mu g / L \\
\mu g / L \\
\mu C i / m L \\
\mu C i / m L \\
\mu C i / m L \\
\mu C i / m L\end{array}$ & $\begin{array}{l}\mathrm{GE} \\
\mathrm{GE} \\
\mathrm{GE} \\
\mathrm{GE} \\
\mathrm{GE} \\
\mathrm{GE} \\
\mathrm{GE} \\
\mathrm{GE} \\
\mathrm{GE} \\
\mathrm{GE} \\
\mathrm{GE} \\
\mathrm{GE} \\
\mathrm{GE} \\
\mathrm{GE} \\
\mathrm{GE} \\
\mathrm{GE} \\
\mathrm{GE} \\
\mathrm{GE} \\
\mathrm{GE} \\
\mathrm{GE} \\
\mathrm{GE} \\
\mathrm{GE} \\
\mathrm{GE} \\
\mathrm{GE} \\
\mathrm{GE} \\
\mathrm{GE} \\
\mathrm{GE} \\
\mathrm{GE} \\
\mathrm{GE} \\
\mathrm{GE} \\
\mathrm{GE} \\
\mathrm{GE} \\
\mathrm{GE} \\
\mathrm{GE} \\
\mathrm{GE} \\
\mathrm{GE} \\
\mathrm{GE} \\
\mathrm{GE} \\
\mathrm{GE} \\
\mathrm{GE} \\
\mathrm{GE} \\
\mathrm{GE} \\
\mathrm{GE} \\
\mathrm{GE}\end{array}$ \\
\hline
\end{tabular}

\section{WELL LFW 36}

MEASUREMENTS CONDUCTED IN THE FIELD

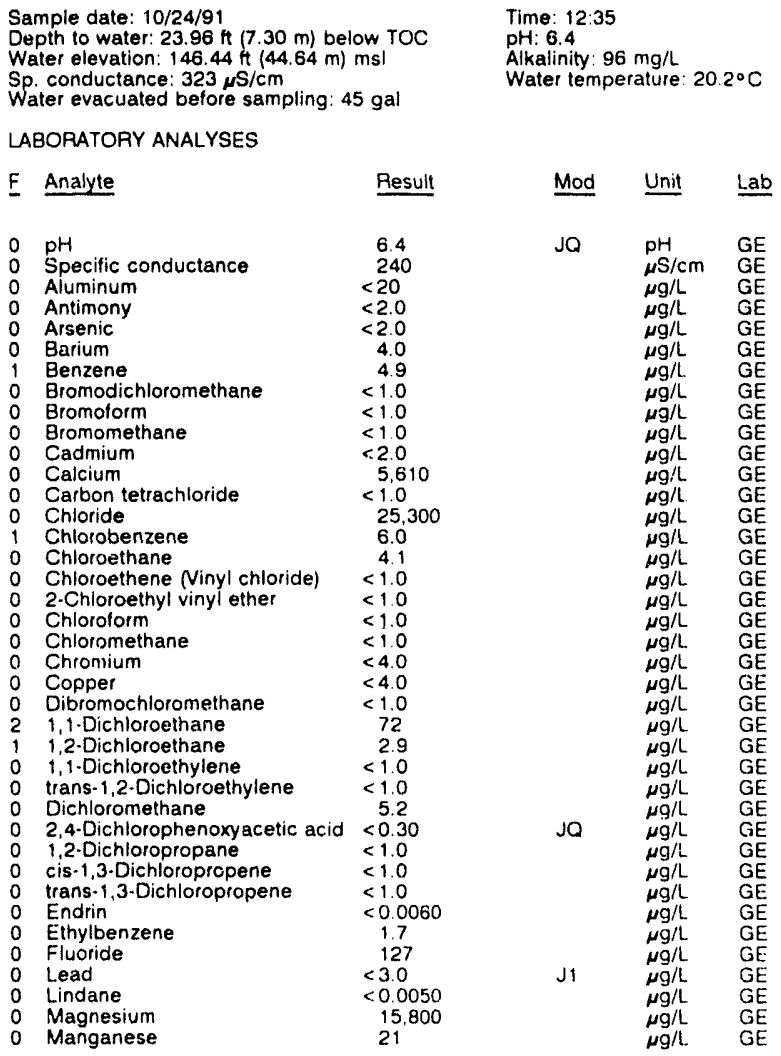

WELL LFW 36 collected on 10/24/91, laboratory analyses (cont.)
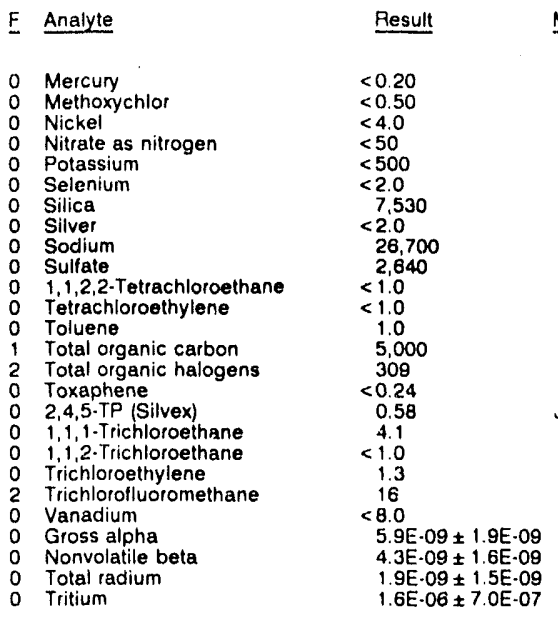

$\underline{\text { Lab }}$

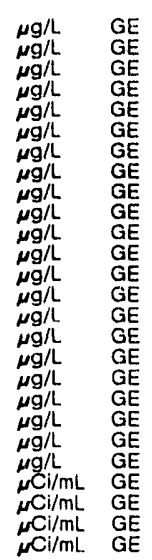

\section{WELL LFW 37}

MEASUREMENTS CONDUCTED IN THE FIELD

Sample date: 10/24/81

Depth to water: $26.84 \mathrm{Ht}(8.18 \mathrm{~m})$ below TOC Water elevation: $143.06 \mathrm{Ht}(43.61 \mathrm{~m}) \mathrm{msl}$

Sp. conductance: $115 \mu \mathrm{S} / \mathrm{cm}$
Water evacuated before sampling: $37 \mathrm{gal}$

Time: 12:05

PH: 5.1

Water temperature: $19.7{ }^{\circ} \mathrm{C}$

LABORATOAY ANALYSES

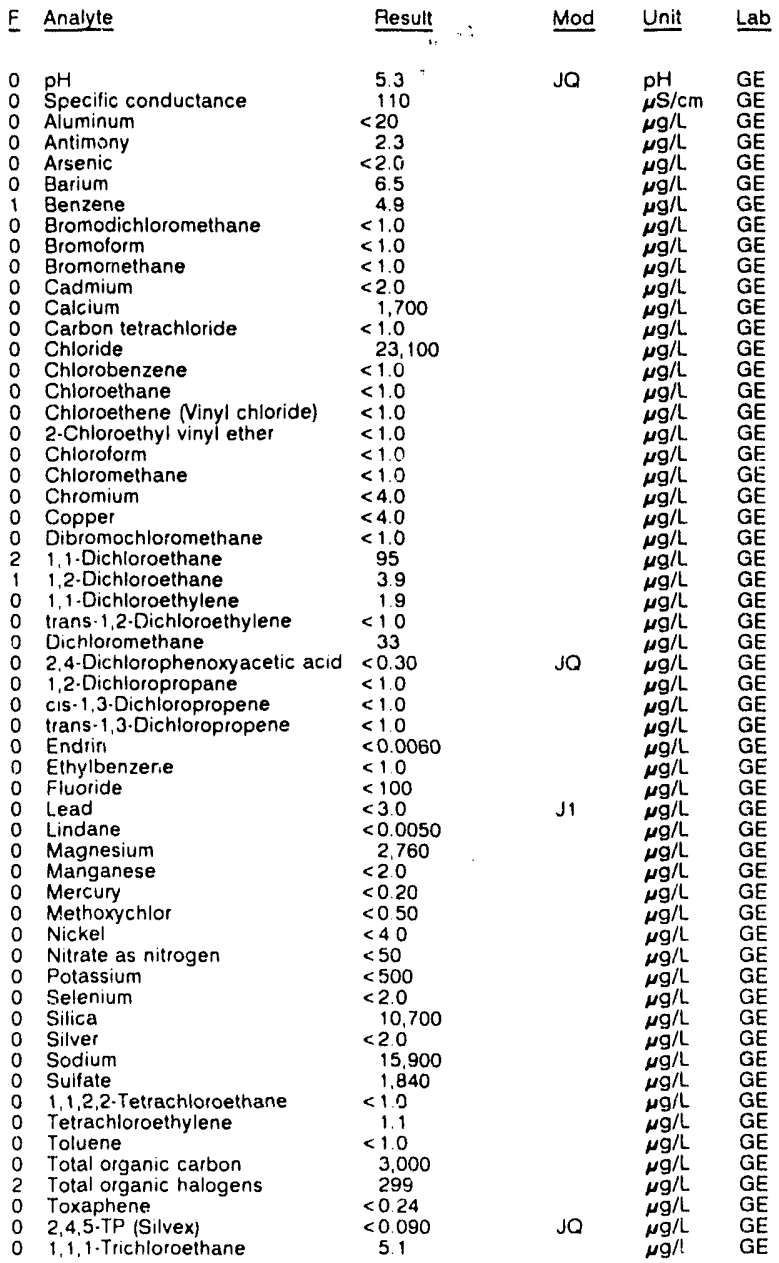


WELL LFW 37 collected on 10/24/91, laboratory analyses (cont)

\begin{tabular}{|c|c|c|c|c|c|}
\hline & Analyte & Result & Mod & Unit & L.ab \\
\hline $\begin{array}{l}0 \\
2 \\
2\end{array}$ & $\begin{array}{l}\text { 1,1.2-Trichloroethane } \\
\text { Trichloroethylene } \\
\text { Trichlorofluoromethane } \\
\text { Vanadium } \\
\text { Gross alpha } \\
\text { Nonvolatile beta } \\
\text { Total radium } \\
\text { Tritium }\end{array}$ & $\begin{array}{r}<1.0 \\
7.4 \\
20 \\
<8.0 \\
2.5 \mathrm{E} \cdot 09 \pm 1.7 \mathrm{E}-09 \\
7.0 \mathrm{E} \cdot 09 \pm 1.8 \mathrm{E} \cdot 09 \\
<1.0 \mathrm{E} \cdot 09 \\
6.3 \mathrm{E} \cdot 06 \pm 8.0 \mathrm{E}-07\end{array}$ & & $\begin{array}{l}\mu \mathrm{g} / \mathrm{L} \\
\mu \mathrm{g} / \mathrm{L} \\
\mu \mathrm{g} / \mathrm{L} \\
\mu \mathrm{g} / \mathrm{L} \\
\mu \mathrm{Cl} / \mathrm{mL} \\
\mu \mathrm{Ci} / \mathrm{mL} \\
\mu \mathrm{CC} / \mathrm{mL} \\
\mu \mathrm{Cl} / \mathrm{mL}\end{array}$ & $\begin{array}{l}\mathrm{GE} \\
\mathrm{GE} \\
\mathrm{GE} \\
\mathrm{GE} \\
\mathrm{GE} \\
\mathrm{GE} \\
\mathrm{GE} \\
\mathrm{GE}\end{array}$ \\
\hline
\end{tabular}

\section{WELL LFW 38}

MEASUREMENTS CONDUCTED IN THE FIELD

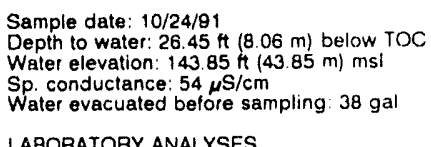

Time: $11: 40$

Alkalinity. $0 \mathrm{mg} / \mathrm{h}$

Water temperature $20.10 \mathrm{C}$

LABORATORY ANALYSES

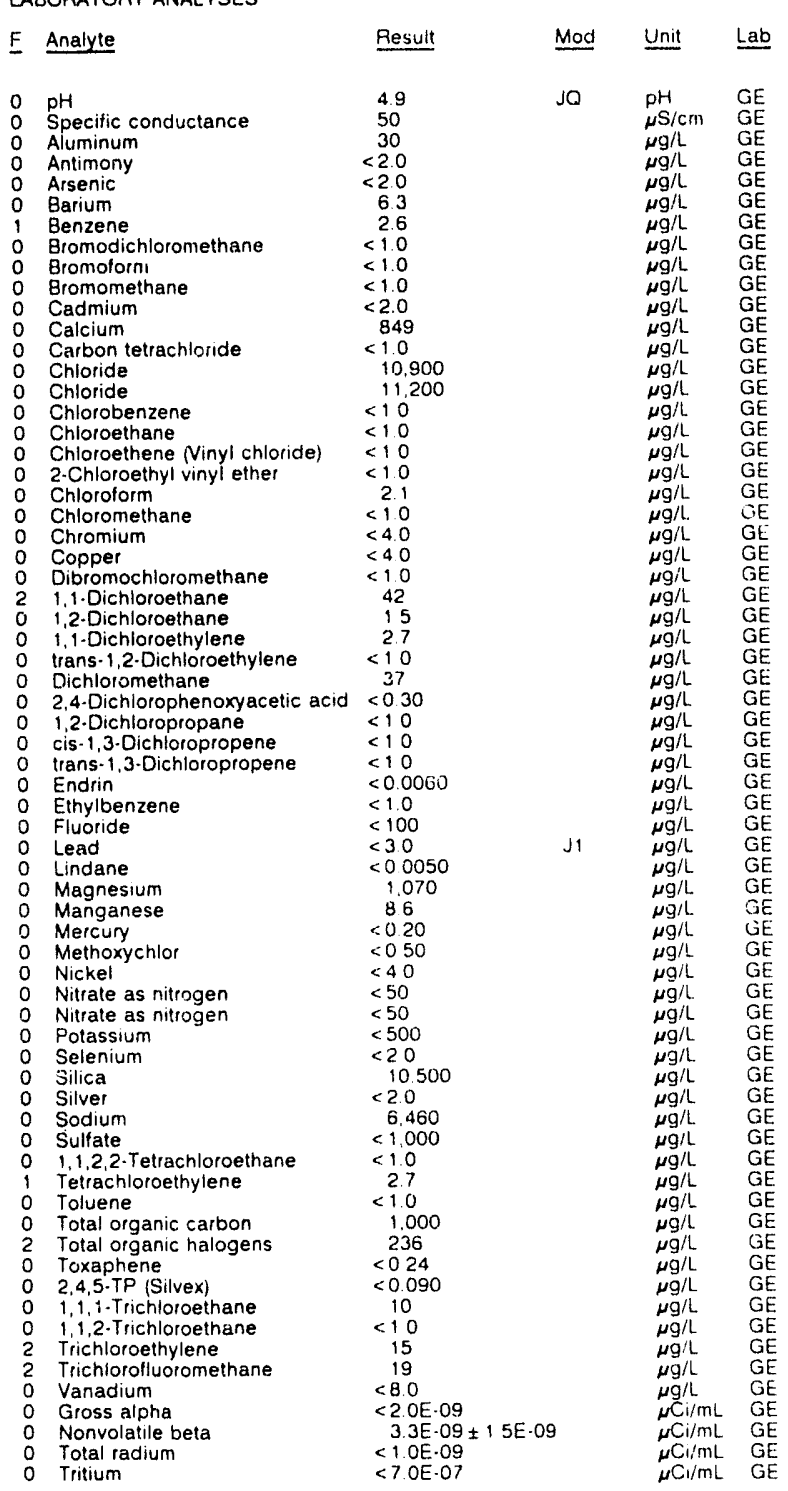

\section{WELL LFW 39}

MEASUREMENTS CONDUCTED IN THE FIELD

$\begin{array}{ll}\text { Sample date } 10 / 24 / 91 & \text { Time: } 11.15 \\ \text { Oepth to water } 2731 \mathrm{Ht}(8.32 \mathrm{~m}) \text { below roC } & \text { pH: } 4.5 \\ \text { Water elevation. } 144.09 \mathrm{H}(43.92 \mathrm{~m}) \mathrm{msl} & \text { Alkalinity. } 0 \mathrm{mg} / \mathrm{L} \\ \text { Sp conductance. } 34 \mathrm{\mu S} / \mathrm{cm} & \text { Water temperalure: } 20.0^{\circ} \mathrm{C} \\ \text { Water evacuated betore sampling } 36 \mathrm{gal} & \end{array}$

LABORATORY ANALYSES

E Analyte Result $\underline{\text { Mod Unit Lab }}$

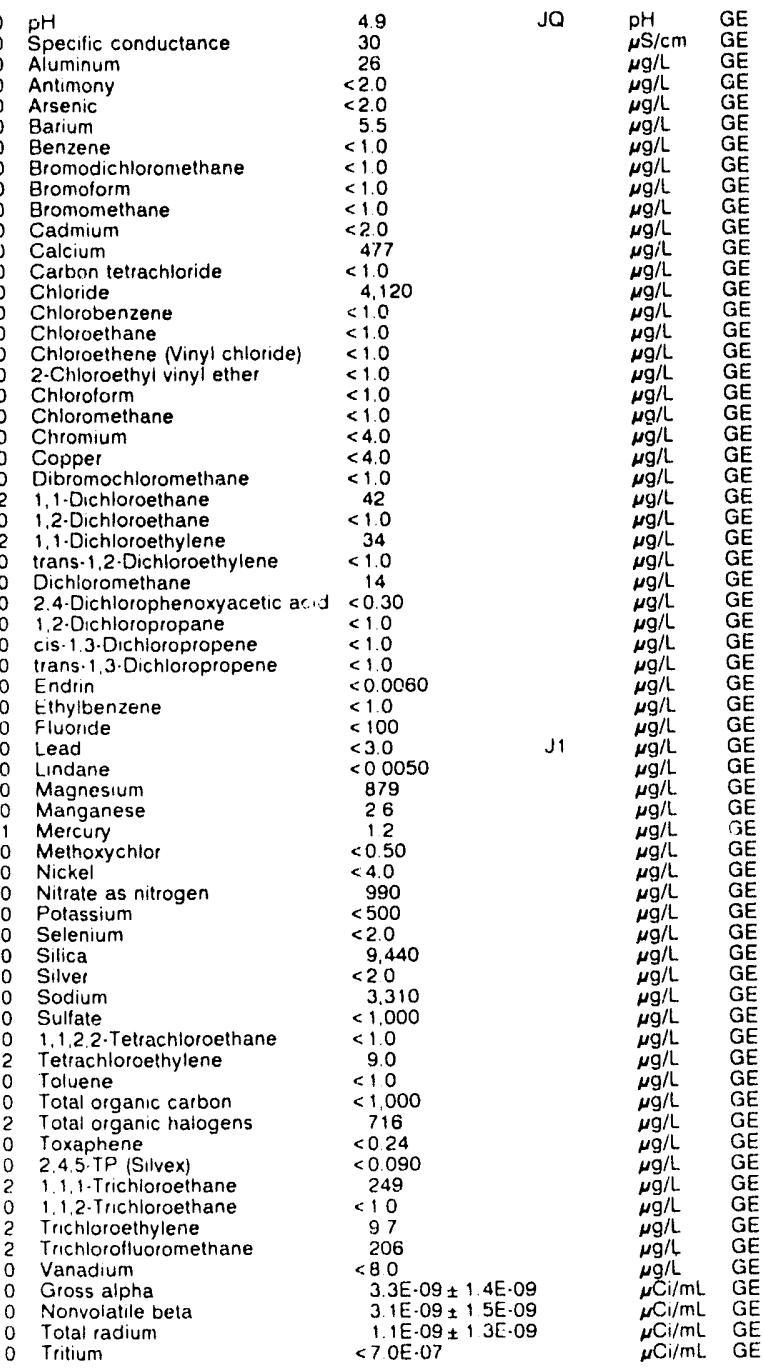

WELL LFW 40

MEASUREMENTS CONDUCTED IN THE FIELD

$34 \mathrm{~m})$ below TOC

. $143.64 \mathrm{ft}(43.78 \mathrm{~m}) \mathrm{ms}$ !

$\mathrm{Sp}$ conductance $14 \mathrm{\mu S} / \mathrm{cm}$
Water evacuated before sampling: 36 gal

LABORATORY ANALYSES

\begin{tabular}{|c|c|c|c|}
\hline Analyte & Result & Mod & Unit \\
\hline $\mathrm{pH}$ & 5.2 & JO & \\
\hline Specis ic conductance & 15 & & $\mu \mathrm{S} / \mathrm{cm}$ \\
\hline Aluminum & $<20$ & & $\mu g / L$ \\
\hline Antimony & $<20$ & & $\mu g / L$ \\
\hline Atsenic & $<20$ & & $\mu \mathrm{g} / \mathrm{L}$ \\
\hline Barlum & $<30$ & & $\mu \mathrm{g} / \mathrm{L}$ \\
\hline
\end{tabular}


ANALYTICAL RESULTS

WELL LFW 40 collected on 10/24/91, laboratory anaiyses (cont.)

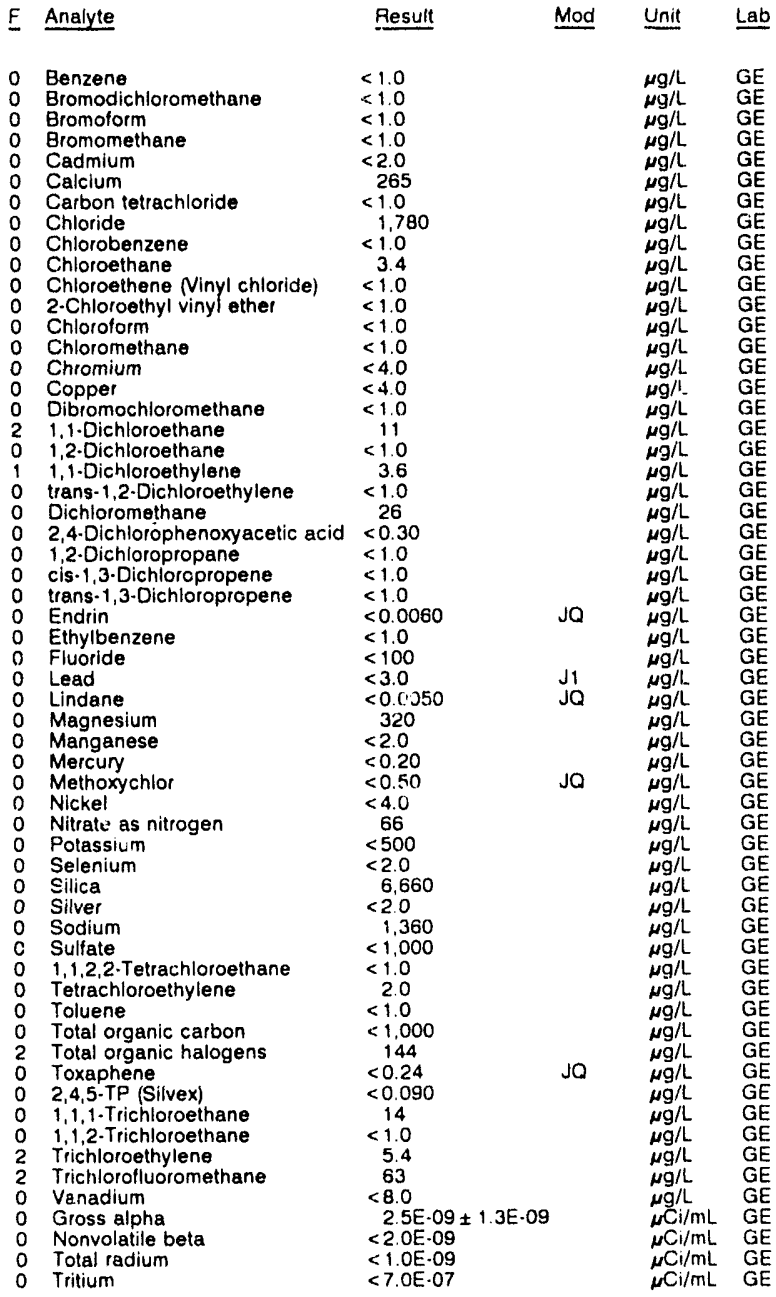

\section{WELL LFW 41}

MEASUREMENTS CONDUCTED IN THE FIELO

\begin{tabular}{|c|c|c|c|c|c|}
\hline \multicolumn{3}{|c|}{$\begin{array}{l}\text { Sample date: } 10 / 24 / 91 \\
\text { Depth to water: } 24.95 \mathrm{Ht}(7.60 \mathrm{~m}) \text { below TOC } \\
\text { Water elevation: } 145.55 \mathrm{Ht}(44.36 \mathrm{~m}) \mathrm{msl} \\
\text { Sp. conductance } 14 \mu \mathrm{s} / \mathrm{cm} \\
\text { Water evacuated before sampling: } 42 \mathrm{gal}\end{array}$} & \multicolumn{3}{|c|}{$\begin{array}{l}\text { Time: } 10: 15 \\
\text { pH: } 4.8 \\
\text { Alkalinity: } 0 \mathrm{mg} / \mathrm{L} \\
\text { Water temperature: } 19.3^{\circ} \mathrm{C}\end{array}$} \\
\hline \multicolumn{6}{|c|}{ LABORATORY ANALYSES } \\
\hline E & Analyte & Result & Mod & $\underline{\text { Unit }}$ & $\underline{L a b}$ \\
\hline $\begin{array}{l}0 \\
0 \\
0 \\
0 \\
0 \\
0 \\
0 \\
0 \\
0 \\
0 \\
0 \\
0 \\
0 \\
0 \\
0 \\
0 \\
0 \\
0 \\
0 \\
0 \\
0 \\
0 \\
0 \\
0\end{array}$ & $\begin{array}{l}\text { pH } \\
\text { Specific conductance } \\
\text { Aluminum } \\
\text { Antimony } \\
\text { Arsenic } \\
\text { Barium } \\
\text { Benzene } \\
\text { Bromodichloromethane } \\
\text { Bromolorm } \\
\text { Bromomethane } \\
\text { Cadmium } \\
\text { Calcium } \\
\text { Carbon tetrachloride } \\
\text { Chloride } \\
\text { Chlorobenzene } \\
\text { Chloroethane } \\
\text { Chloroethene (Vinyl chloride) } \\
\text { 2-Chloroethyl viriyl ether } \\
\text { Chloroform } \\
\text { Chloromethane } \\
\text { Chromium } \\
\text { Copper } \\
\text { Dibromochloromethane } \\
\text { 1.1. Dichloroethane }\end{array}$ & $\begin{aligned} & 5.3 \\
& 10 \\
&<20 \\
&<2.0 \\
&<2.0 \\
&<3.0 \\
&<1.0 \\
&<1.0 \\
&<1.0 \\
&<1.0 \\
&<2.0 \\
& 1.96 \\
&<1.0 \\
& 1.900 \\
&<1.0 \\
&<1.0 \\
&<1.0 \\
&<1.0 \\
&<1.0 \\
&<1.0 \\
&<4.0 \\
&<4.0 \\
&<1.0 \\
&<1.0\end{aligned}$ & JO & $\begin{array}{l}p H \\
\mu S / c m \\
\mu g / L \\
\mu g / L \\
\mu g / L \\
\mu g / L \\
\mu g / L \\
\mu g / L \\
\mu g / L \\
\mu g / L \\
\mu g / L \\
\mu g / L \\
\mu g / L \\
\mu g / L \\
\mu g / L \\
\mu g / L \\
\mu g / L \\
\mu g / L \\
\mu g / L \\
\mu g / L \\
\mu g / L \\
\mu g / L \\
\mu g / L \\
\mu g / L\end{array}$ & $\begin{array}{l}\mathrm{GE} \\
\mathrm{GE} \\
\mathrm{GE} \\
\mathrm{GE} \\
\mathrm{GE} \\
\mathrm{GE} \\
\mathrm{GE} \\
\mathrm{GE} \\
\mathrm{GE} \\
\mathrm{GE} \\
\mathrm{GE} \\
\mathrm{GE} \\
\mathrm{GE} \\
\mathrm{GE} \\
\mathrm{GE} \\
\mathrm{GE} \\
\mathrm{GE} \\
\mathrm{GE} \\
\mathrm{GE} \\
\mathrm{GE} \\
\mathrm{GE} \\
\mathrm{GE} \\
\mathrm{GE} \\
\mathrm{GE}\end{array}$ \\
\hline
\end{tabular}

Time: 10:15

pH: 4.8

Water temperalure: $193^{\circ} \mathrm{C}$

Water evacuated before sampling: $42 \mathrm{gal}$

LABORATORY ANALYSES
WELL LFW 41 collected on 10/24/91, laboratory analyses (cont.)

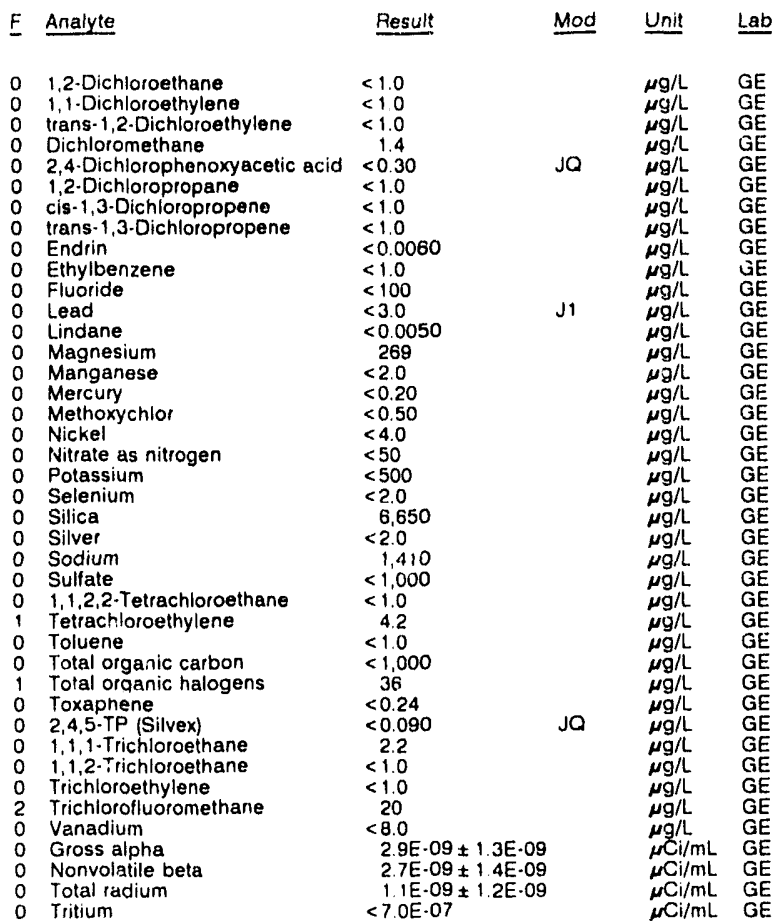

\section{WELL LFW 42}

MEASUREMENTS CONDUCTED IN THE FIELO

Sample date: 10/24/91

Depth to water: $22.37 \mathrm{Ht}(6.82 \mathrm{~m})$ below TOC

Water elevation: $147.73 \mathrm{ft}(45.03 \mathrm{~m}) \mathrm{msl}$

$\begin{array}{ll}\mathrm{pH}: \mathrm{:} & 4.8 \\ \mathrm{msl} & \text { Alkalinity: } 0 \mathrm{mg} / \mathrm{L}\end{array}$

Water temperature: $20.0^{\circ} \mathrm{C}$

LABORATORY ANALYSES

$0 \mathrm{pH}$

Specific conductance

Aluminum

Arsenic

Arsenic

Benzene
Bromodichloromethane

Bromoform

Bromomethane

Cadmium

Carbon tetrachloride

Chloride

Chioride

Chlorobenzene

Chloroethane

2.Chloroethyl vinyi ether

Chloroform

Chloromethan

Chromium

Copper
Dibromochloromethane

1,1. Dichloroethane

1.2.Dichloroethane

1.1.Dichloroethylen

tians-1,2-Dichloroethylene

Resulf

Mod Unit Lab

2.4.Dichlorophenoxyacetıc acid

1.2-Dichloropropane

cis-1,3-Dichloropropene

trans-1,3-Dichloropropene

Endrin

Ethylbenzene

0 Fluoride

Fluoride

Lead

- Magnesium

Manganese
0 Mercury

5.4
15
$<20$
3.0
$<2.0$
$<3.0$
$<1.0$
$<1.0$
$<1.0$
$<1.0$
$<2.0$
217
$<10$
11890
11.930
$<1.0$
$<1.0$
$<1.0$
$<1.0$
$<1.0$
$<1.0$
$<4.0$
$<4$.
$<1.0$
$<1.0$
$<1.0$
$<1.0$
$<1.0$
$<1.0$
$<0.30$
$<1.0$
$<1.0$
$<1.0$
$<0.0060$
$<1.0$
$<100$
$<100$
$<3.0$
$<0.0050$
281
$<2.0$
$<020$

JQ

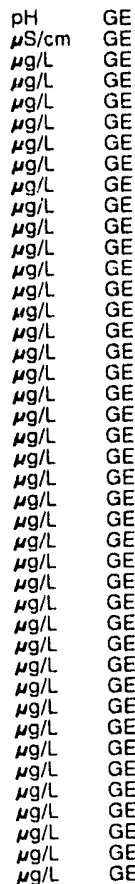


ANALYTICAL RESULTS

WELL LFW 42 collected on 10/24/91, laboratory analyses (cont)

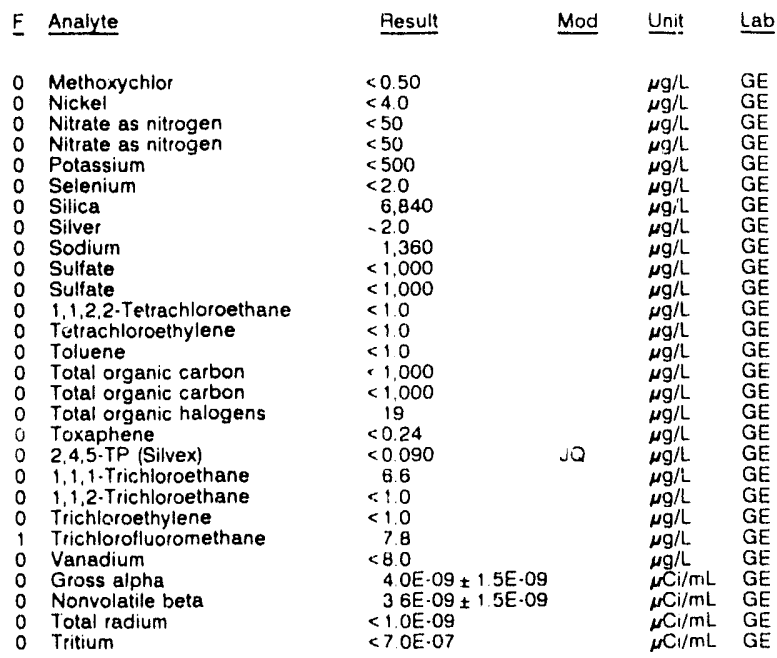

\section{WELL LFW 43B}

MEASUREMENTS CONOUCTED IN THE FIELD

Depth to water, $36.08 \mathrm{ft}(11.00 \mathrm{~m})$ below TOC Water elevation: $166.92 \mathrm{ft}(50.88 \mathrm{~m}) \mathrm{msl}$

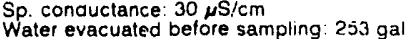

LABORATORY ANALYSES

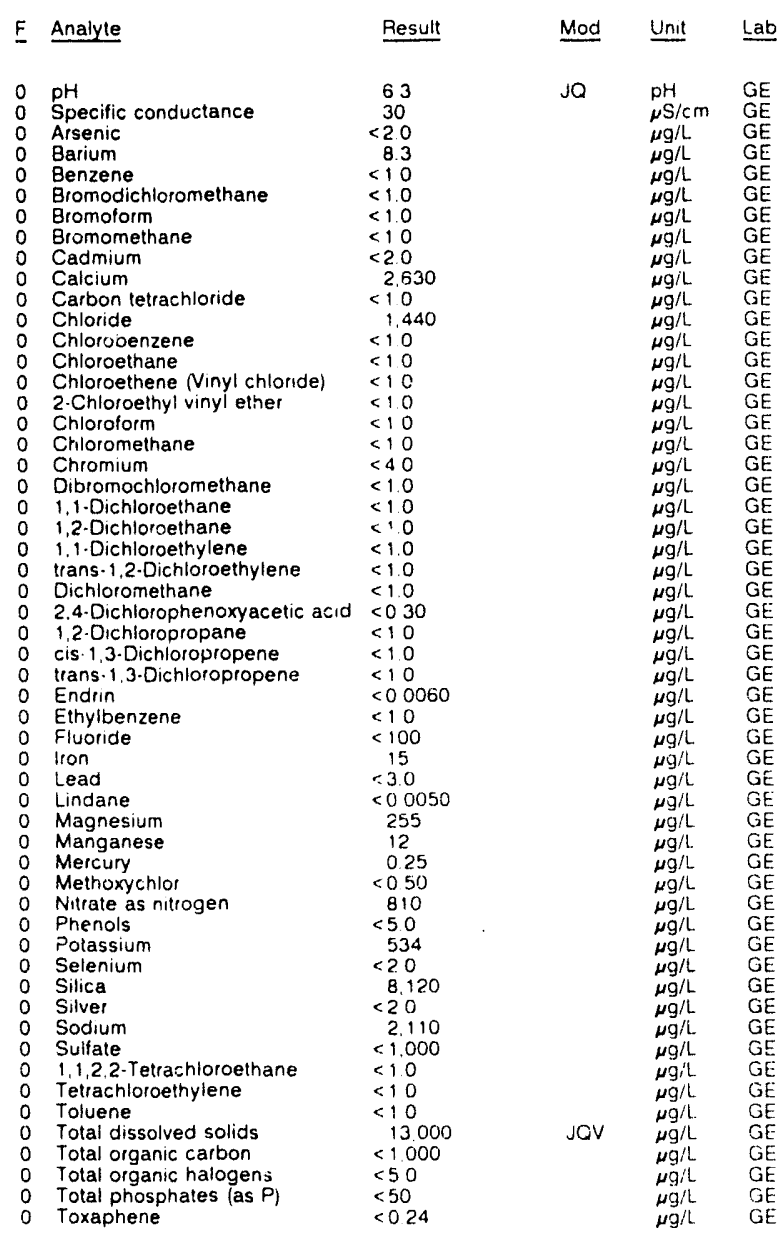

WELL LFW 438 collected on 10/28/91, laboratory analyses (cont.)

\begin{tabular}{|c|c|c|c|c|}
\hline$F$ & Analyte & Result & Mod & Unit \\
\hline 0 & $\begin{array}{l}2,4,5 \cdot \text { TP (Silvex) } \\
1,1,1 \cdot \text { Trichloroethane } \\
1.1,2 \cdot \text { Trichloroethane } \\
\text { Trichloroethylene } \\
\text { Trichlorofluoromethane } \\
\text { Gross alpha } \\
\text { Nonvolatile beta } \\
\text { Total radium } \\
\text { Tritium }\end{array}$ & $\begin{array}{l}<0.090 \\
<1.0 \\
<1.0 \\
<10 \\
<10 \\
<2.0 E \cdot 09 \\
<2.0 E \cdot 09 \\
10 E-09 \pm 1.4 E \cdot 09 \\
<7.0 E \cdot 07\end{array}$ & & $\begin{array}{l}\mu \mathrm{g} / \mathrm{L} \\
\mu \mathrm{g} / \mathrm{L} \\
\mu \mathrm{g} / \mathrm{L} \\
\mu \mathrm{g} / \mathrm{L} \\
\mu \mathrm{g} / \mathrm{L} \\
\mu \mathrm{Cl} / \mathrm{mL} \\
\mu \mathrm{Cl} / \mathrm{mL} \\
\mu \mathrm{Ci} / \mathrm{mL} \\
\mu \mathrm{Cl} / \mathrm{mL}\end{array}$ \\
\hline
\end{tabular}

WELL LFW 43B Replicate

MEASUREMENTS CONDUCTED IN THE FIEL.D

Sample date. 10/28/91

Depth to water: $36.08 \mathrm{ft}(11.00 \mathrm{~m})$ below TOC

Wate elevation: $166.92 \mathrm{Ht}(50$

Time: 1105

Water evacuated before sampling $253 \mathrm{gal}$

LABORATORY ANALYSES

E Analyte Result Mud Unit Lab

$\begin{array}{ll}0 & \text { pH } \\ 0 & \text { Specific conductance }\end{array}$

Arsenic

Barium

Benzene

Bromodichloromethane

Bromoform

Bromometh

Cadmium

Carbon tetrachloride

Chloride

Chlorobenzene

Chloroethane

Chioroethane Ninyl chloride)

2.Chloroethyl viny' ether

Chlorotorm

Chloromethane

6.3

Dibromochloromethane $\quad<1.0$

1.1.Dichloroethane

1.2.Dichloroethane

1.1-Dichioroethylene <10

$\begin{array}{ll}\text { trans.1.2. Dichloroethylene } & <10 \\ \text { Dichlo. Jmethane } & 90\end{array}$

2,4.Dichlorophenoxyacetic acid $<0.30$

1.2-Dichloropropane $<10$

cis. 1.2 7ichloropropene

Irans. 1 3.Dichloropropene

0 Endrin

E Ethylbenzen

C Fluoride

0 lion

0 Lead

L Lindane

- Manganese

Mercury

Metioxychlor

iftrate as nitrogen

tnols

tassium

Selenium

Silica

Silver

Sodiun

Sultate

Tetrachloroethylene

Toluene

Total dissolved solids

Total organic carbon

Total organic halogeris

Total phusphates (as P)
Total phosphates (as P)

Total phosphate

Toxaphene
24.5.ip (Silvex)

2.4.5.P (Silvex)
1.1. Trichloroethane

richloroethylene

Trichloroethylene

Gross alpha

Nonvolatile beta

Total tadium

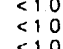

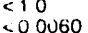

$<00060$
$<100$
$<100$

$\begin{aligned} & 24 \\ &<30 \\ &< \\ &< 00050\end{aligned}$

$<00050$

258
12

$<020$

$<0.50$
810

810
$<5.0$

$<5.0$
518

$<2.0$
8.290

$\begin{array}{r}8,290 \\ <2.0 \\ \hline\end{array}$

2,100

$\begin{aligned} & 2,100 \\ &< 1,000 \\ &< 10 \\ &< 10\end{aligned}$

$<10$
$<10$

17,000
$<1000$

$<50$

$<50$
$<50$
$<50$

$<50$

$<0090$

$<10$
$<110$
$<10$
$<10$

$<10$

$<2$ OE.09

$<2$ OE.09
$<1$ OE.09

$<1$ OE.09
$<7$ OE.07

$\begin{array}{lll}\rho \mathrm{H} & \mathrm{GE} \\ \mu \mathrm{S} / \mathrm{cm} & \mathrm{GE} \\ & \mu \mathrm{G} / \mathrm{GE} & \mathrm{GE}\end{array}$

$\mu \mathrm{g} / \mathrm{L} \quad \mathrm{GE}$

$\mu \mathrm{g} / \mathrm{G} \quad \mathrm{GE}$

$\mu \mathrm{\mu g} / \mathrm{GE} \quad \mathrm{GE}$

$\mu g / L \quad G E$

$\mu \mathrm{g} / \mathrm{h} \quad \mathrm{GE}$

$\mu g / \mathrm{L} \quad \mathrm{GE}$
$\mu g / \mathrm{L}$ $\begin{array}{ll}\boldsymbol{\mu} g / L & G E \\ \mu g / L & G E \\ \mu g / L & G E \\ \mu g / L & G E\end{array}$

$\mu g g / 2 \quad G E$

$\mu g / L \quad G E$

$\mu g / L$ GE

$\underset{\mu g / L}{\mu g} \quad \mathrm{GE}$

$\mu g / L \quad G E$

$\begin{array}{ll}\mu g / L & G E \\ \mu g / L & G E\end{array}$

$\mu g, \quad G E$

$\mu g, \quad G E$

$\mu g / L \quad G E$

Jov

$\mu$

$\mu \mathrm{g} / \mathrm{L} \quad \mathrm{GE}$

$\mu \mathrm{g} / \mathrm{L} \quad \mathrm{GE}$

$\mu g, \quad G E$

$\mu \mathrm{g} / \mathrm{L} \quad \mathrm{GE}$

$\mu \mathrm{g} / \mathrm{GE}$

$\begin{array}{ll}\mu g / L & G E \\ \mu g / L & G E\end{array}$

$\mu \mathrm{cil} / \mathrm{mL}$ GE

$\mu \mathrm{Cli} / \mathrm{mL}$ GE $\mu \mathrm{g} / \mathrm{L} \quad \mathrm{GE}$ 
ANALYTICAL RESULTS

WELL LFW 43C

MEASUREMENTS CONOUCTED IN THE FIELD

Sample date: 10/28/91

Depth to water: $35.38 \mathrm{n}(10.78 \mathrm{~m})$ below TOC

Sp. conductance. $167.24 \pi$ t

Water evacuated before sampling: $103 \mathrm{gal}$

LABORATORY ANALYSES

\begin{tabular}{|c|c|c|c|}
\hline Analyte & Result & Mod & Unit \\
\hline 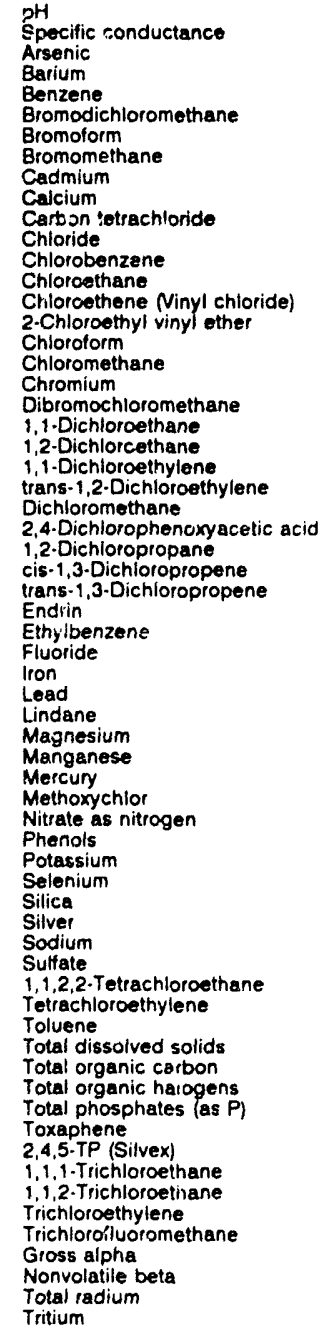 & $\begin{aligned} & 5.8 \\
& 20 \\
&<2.0 \\
& 7.6 \\
&<1.0 \\
&<1.0 \\
&<1.0 \\
&<1.0 \\
&<2.0 \\
& 1.850 \\
&<1.0 \\
& 1.610 \\
&<1.0 \\
&<1.0 \\
&<1.0 \\
&<1.0 \\
&<1.0 \\
&<1.0 \\
&<4.0 \\
&<1.0 \\
&<1.0 \\
&<1.0 \\
&<1.0 \\
&<1.0 \\
& 8.0 \\
&<0.30 \\
&<1.0 \\
&<1.0 \\
&<1.0 \\
&<0.0060 \\
&<1.0 \\
&<100 \\
& 5.7 \\
&<3.0 \\
&<0.0050 \\
& 361 \\
& 113 \\
&<0.20 \\
&<0.50 \\
& 420 \\
&<5.0 \\
&<500 \\
&<2.0 \\
& 7.050 \\
&<2.0 \\
& 11.140 \\
&<1.000 \\
&<1.0 \\
&<1.0 \\
&<1.0 \\
& 8.000 \\
&<1.000 \\
&<5.0 \\
&<50 \\
&<0.24 \\
&<0.090 \\
&<1.0 \\
&<1.0 \\
&<1.0 \\
&<1.0 \\
&<2.0 \mathrm{E}-09 \\
& 2.6 \mathrm{E} \cdot 09 \\
&<1.0 \mathrm{E}-09 \\
&<7.0 \mathrm{E} \cdot 07 \\
& 1.5 \mathrm{E} \cdot 09 \\
&\end{aligned}$ & JOV & $\begin{array}{l}p H \\
\mu S / c m \\
\mu g / L \\
\mu g / L \\
\mu g / L \\
\mu g / L \\
\mu g / L \\
\mu g / L \\
\mu g / L \\
\mu g / L \\
\mu g / L \\
\mu g / L \\
\mu g / L \\
\mu g / L \\
\mu g / L \\
\mu g / L \\
\mu g / L \\
\mu g / L \\
\mu g / L \\
\mu g / L \\
\mu g / L \\
\mu g / L \\
\mu g / L \\
\mu g / L \\
\mu g / L \\
\mu g / L \\
\mu g / L \\
\mu g / L \\
\mu g / L \\
\mu g / L \\
\mu g / L \\
\mu g / L \\
\mu g / L \\
\mu g / L \\
\mu g / L \\
\mu g / L \\
\mu g / L \\
\mu g / L \\
\mu g, L \\
\mu g / L \\
\mu g / L \\
\mu g / L \\
\mu g / L \\
\mu g / L \\
\mu g / L \\
\mu g / L \\
\mu g / L \\
\mu g / L \\
\mu g / L \\
\mu g / L \\
\mu g / L \\
\mu g / L \\
\mu g / L \\
\mu g / L \\
\mu g / L \\
\mu g / L \\
\mu g / L \\
\mu g / L \\
\mu g / L \\
\mu g / L \\
\mu c i / m L \\
\mu C i / m L \\
\mu C i / m L \\
\mu C l / m L\end{array}$ \\
\hline
\end{tabular}

WELL LFW 43D

MEASIIAEMENTS CONDUCTED IN THE FIELD

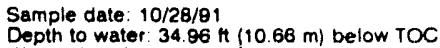
Water elevation: $167.94 \mathrm{H}(51.19 \mathrm{~m}) \mathrm{ms}$ ।

Sp. conductance: $24 \mathrm{~s} / \mathrm{cm}$

sampling $46 \mathrm{gat}$

Time: 10:30

pH: 5.3

Water temperalure: $18.3^{\circ} \mathrm{C}$

LABORATORY ANALYSES

\begin{tabular}{|c|c|c|c|}
\hline Analyte & Result & Mod & Unit \\
\hline $\begin{array}{ll}0 & \text { pH } \\
0 & \text { Specific conductance } \\
0 & \text { Arsenic } \\
0 & \text { Barium } \\
0 & \text { Benzene } \\
\text { Bromodichloromethane } \\
0 \text { Bromolorm }\end{array}$ & $\begin{aligned} & 5 A \\
& 25 \\
< & 20 \\
& 11 \\
< & 10 \\
< & 10 \\
< & 10\end{aligned}$ & JO & $\begin{array}{l}\mathrm{pH} \\
\mu \mathrm{S} / \mathrm{cm} \\
\mu g / \mathrm{L} \\
\mu g / L \\
\mu g / L \\
\mu g / L \\
\mu g / L\end{array}$ \\
\hline
\end{tabular}

WELL LFW 430 collected on 10/28/91, laboratory analyses (cont.)

\begin{tabular}{|c|c|c|c|c|}
\hline Analyte & Resuit & Mod & Unit & Lab \\
\hline 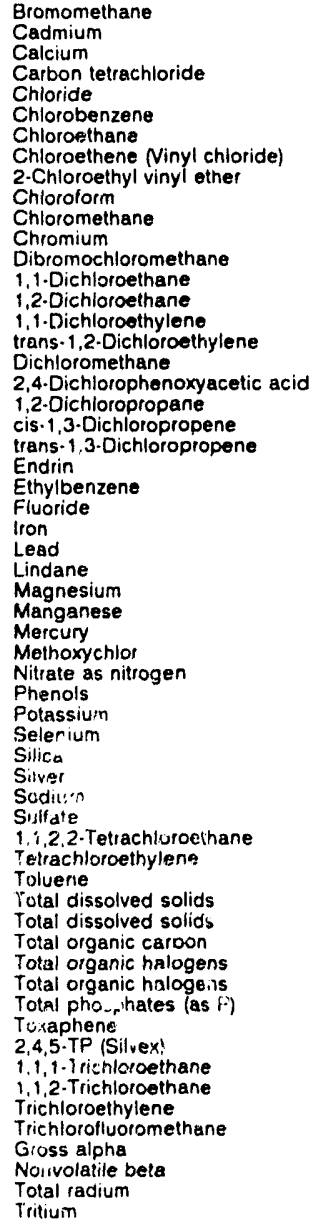 & $\begin{array}{l}<1.0 \\
<2.0 \\
11.030 \\
<1.0 \\
2.150 \\
<1.0 \\
<1.0 \\
<1.0 \\
<1.0 \\
<1.0 \\
<1.0 \\
<4.0 \\
<1.0 \\
<1.0 \\
<1.0 \\
<1.0 \\
<1.0 \\
30 \\
<0.30 \\
<1.0 \\
<1.0 \\
<1.0 \\
<0.0060 \\
<1.0 \\
<100 \\
6.6 \\
<3.0 \\
<0.0050 \\
697 \\
22 \\
<0.24 \\
<0.50 \\
840 \\
<5.0 \\
<500 \\
<2.0 \\
5500 \\
<2.00 \\
1.440 \\
<1.000 \\
<1.0 \\
<1.0 \\
<1.0 \\
8.000 \\
8.00 \% \\
<1.00 \\
<5.0 \\
<5.0 \\
<50 \\
<0.24 \\
<0.090 \\
<1.0 \\
<1.0 \\
<1.0 \\
<1.0 \\
<2.0 E-09 \\
<2.0 E \cdot 09 \\
<1.0 E \cdot 09 \\
<7.0 E .07\end{array}$ & $\begin{array}{l}\text { JOV } \\
\text { JOV }\end{array}$ & 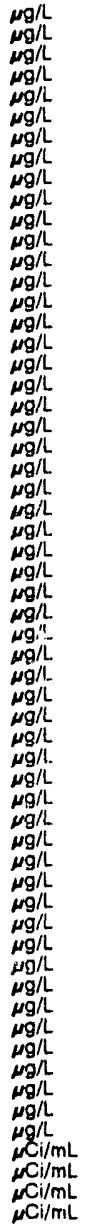 & $\begin{array}{l}\mathrm{GE} \\
\mathrm{GE} \\
\mathrm{GE} \\
\mathrm{GE} \\
\mathrm{GE} \\
\mathrm{GE} \\
\mathrm{GE} \\
\mathrm{GE} \\
\mathrm{GE} \\
\mathrm{GE} \\
\mathrm{GE} \\
\mathrm{GE} \\
\mathrm{GE} \\
\mathrm{GE} \\
\mathrm{GE} \\
\mathrm{GE} \\
\mathrm{GE} \\
\mathrm{GE} \\
\mathrm{GE} \\
\mathrm{GE} \\
\mathrm{GE} \\
\mathrm{GE} \\
\mathrm{GE} \\
\mathrm{GE} \\
\mathrm{GE} \\
\mathrm{GE} \\
\mathrm{GE} \\
\mathrm{GE} \\
\mathrm{GE} \\
\mathrm{GE} \\
\mathrm{GE} \\
\mathrm{GE} \\
\mathrm{GE} \\
\mathrm{GE} \\
\mathrm{GE} \\
\mathrm{GE} \\
\mathrm{GE} \\
\mathrm{GE} \\
\mathrm{GE} \\
\mathrm{GE} \\
\mathrm{GE} \\
\mathrm{GE} \\
\mathrm{GE} \\
\mathrm{GE} \\
\mathrm{GE} \\
\mathrm{GE} \\
\mathrm{GE} \\
\mathrm{GE} \\
\mathrm{GE} \\
\mathrm{GE} \\
\mathrm{GE} \\
\mathrm{GE} \\
\mathrm{GE} \\
\end{array}$ \\
\hline
\end{tabular}

\section{WELL LFW 44D}

MEASUREMENTS CONDUCTEO IN THE FIELD

Sample date: $10 / 28 / 91$

Depth to water: $14.81 \mathrm{~h}(4.51 \mathrm{~m})$ below TOC

Water elevation. $155.48 \mathrm{~h}$ ( 47

Water evacuated before sampling: $43 \mathrm{gal}$

LABORATORY ANALYSES

\begin{tabular}{|c|c|c|c|}
\hline Anaiyte & Result & Mod & Unit \\
\hline $\begin{array}{l}\text { pH } \\
\text { Specific conductance } \\
\text { Arsenic } \\
\text { Barium } \\
\text { 8enzene } \\
\text { Bromodichloromethane } \\
\text { Bromoform } \\
\text { Bromomethane } \\
\text { Cadmium } \\
\text { Calcium } \\
\text { Carbon tetrachloride } \\
\text { Chloride } \\
\text { Chlorobenzene } \\
\text { Chloroethane } \\
\text { Chloroethene Ninyl chloride) } \\
\text { 2.Chloroethyl vinyl ether } \\
\text { Chlorolorm } \\
\text { Chiloromethane } \\
\text { Chromium } \\
\text { Dibromochloromethane } \\
1,1 . \text { Dichloroethane } \\
1.2 \cdot \text { Dichioroethane } \\
\text { 1.1.Dichloroethylere } \\
\text { trans-1,2.Dichloroethylene }\end{array}$ & $\begin{aligned} & 5.2 \\
& 20 \\
&<2.0 \\
& 3.2 \\
&<1.0 \\
&<10 \\
&<1.0 \\
&<10 \\
&<20 \\
& 432 \\
& 41.0 \\
& 3.180 \\
&<10 \\
&<1.0 \\
&<10 \\
&<10 \\
&<10 \\
&<10 \\
&<40 \\
&<10 \\
&<10 \\
&<10 \\
&<1.0 \\
&<10\end{aligned}$ & JO & $\begin{array}{l}p H \\
\mu S / c m \\
\mu g / L \\
\mu g / L \\
\mu g / L \\
\mu g / L \\
\mu g / L \\
\mu g / L \\
\mu g / L \\
\mu g / L \\
\mu g / L \\
\mu g / L \\
\mu g / L \\
\mu g / L \\
\mu g / L \\
\mu g / L \\
\mu g / L \\
\mu g / L \\
\mu g / L \\
\mu g / L \\
\mu g / L \\
\mu g / L \\
\mu g / L \\
\mu g / L\end{array}$ \\
\hline
\end{tabular}

Time: $12: 05$

pH: 4.8 . 0 mall

Alkalinity: $0 \mathrm{mg} / \mathrm{h}$

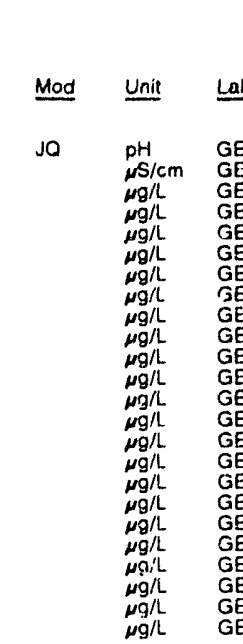


ANALYTICAL RESULTS

WELL LFW 440 collected on 10/28/91, laboratory analyses (cont.)

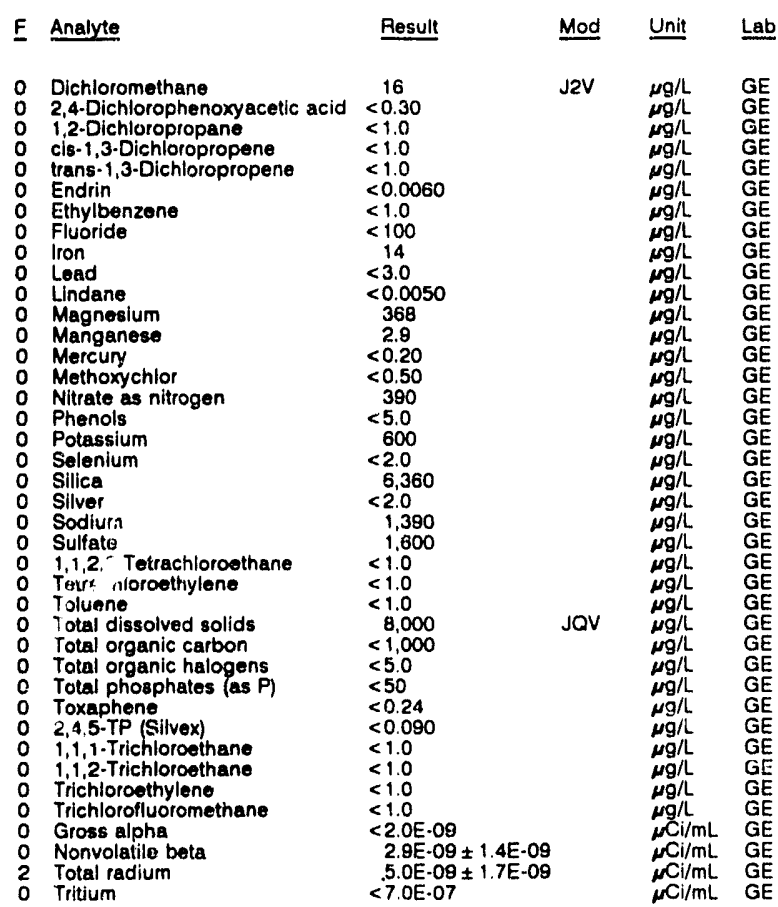

\section{WELL LFW 45D}

MEASUREMENTS CONDUCTED IN THE FIELD

Sample date: $10 / 28 / 91$

(4.13 m) below TOC

Water elevation: $152.75 \mathrm{Ht}(46.5$

Water conductance: 15 $\mathrm{NS} / \mathrm{cm}$.

LABOPAIORY ANALYSES

E Analyte Result Mod Unit

0 Ppecific ..nductance

Specific

irstnic

Arsanic
Barium

Barium

Ben?:gne

Bromodichloromethane

Bromoform

Bromoform

Bromomethane

Bromomethane

Cadmium

Calcium

Carbon tetrachloride

Chloride

Chlorobenzene

Chlorobenzen

Chloroethane

Chloroethene Ninyl chloride)

Chloroethene (Vinyl chioride)

2.Chloroethyl vinyl ether

2.Chloroethyl vinyl ether

Chioroform

Chloroform

Chloromethane

Chromium

Dibromochloromethane

Dibromochloremethane

1,1-Dichloroethane

1,1-Dichloroethane

1,2-Dichloroethane

1,1-Dichloroethylene

1,1-Dichloroethylene

trans-1,2-Dichloroethylene

trans-1,2-Dichloroet

D Dichlotomethane
Time: 14:45

PH: 4.9 : 0 alinity: $0 \mathrm{mg} / \mathrm{l}$

Water temperature: $20.0^{\circ} \mathrm{C}$

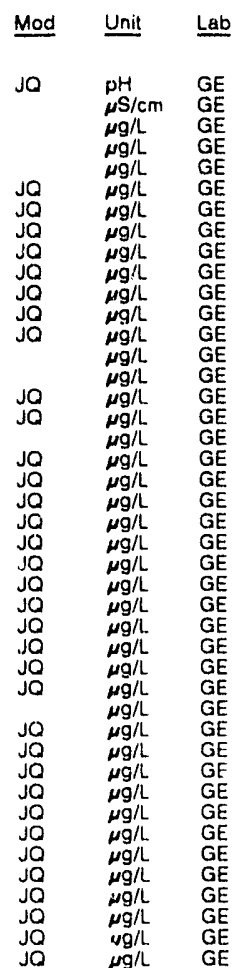

WELL LFW 45D collected on 10/28/91, laboratory analyses (cont.)

E Analyte Result Mod Unit Lab

0 2,4-Dichlorophenoxyacetic acid $<0.30$

0 1,2-Dichloropropane

$<0.30$
$<1.0$
$<1.0$

cis-1,3-Dichloropropene $<1.0$

cis-1,3-Dichloropropene

trans-1,3-Dichloropropene

Endrin

Endrin

0 Etriylbenzene

0 Ethylbenzen

Iron

0 Lead

0 Lindane

Lindane

Magnesium

o Mercury

Methoxychlor

Nitrate as nitrogen

Phenols

Phenols

Selenium

Silice

Silver

Sodium

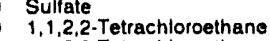

1,1,2,2-Tetrachloroethane

Tetrachloroethylene

0 Toluene

0 Toluene

- Total dissolved solids

Total organic carbon

Total organic halogens

Total organic halogens

Total phosph

Toxaphene

$0 \quad 2,4,5 \cdot$ TP (Silvex)

o $1,1,1$-Trichloroethane

o 1,1.1-Trichloroethane

0 i,1,2-Trichloroethane

0 Trichloroethyiene

o Trichloroethylene

Trichlorofluoremeth

- Gross alpha

- Nonvolatile beta

0 Total radium

$<1.0$
$<1.0$
$<1.0$
$<1.0$

$<1.0$

$<0.0060$

$<1.0$

$<100$
8.2

8.2
$<3.0$

$<3.00050$

$<0.0050$

286.
3.9

3.20
$<0.50$

$<0.50$

$<0.50$
170
$<5.0$
$<5.0$

890
$<2.0$

$<2.0$

6,580
$<2.0$

934
$<1,000$

$<1.0$
$<1.0$

$<1.0$

$<1.0$

$<1.0$

7,000
$<1,000$

$<5.0$
$<5.0$

$<50$

$<0.24$
$<0.24$

$<0.24$
$<0.090$

$<1.0$
$<1.0$

$<1.0$
$<1.0$

$<1.0$

$<1.0$

$<1.0$

$<1.0$
$<1.0$

$<2.0 \mathrm{E}-09$

$<2.0 \mathrm{E}-09$

WELL LFW 46D

MEASUREMENTS CONDUCTED IN THE FIELD

Sample date: $10 / 28 / 91$

Depth to water: $13.75 \mathrm{Ht}(4.19 \mathrm{~m})$ below TOC

Water elevation: $151.35 \mathrm{ft}(46.13 \mathrm{~m}) \mathrm{ms}$

$\mathrm{Sp}$. conductance: $97 \mu \mathrm{s} / \mathrm{cm}$

sampling: $38 \mathrm{gal}$

$\mathrm{pH}: 5.5$

Alkalinity: $64 \mathrm{mg} / \mathrm{h}$

Water temperature: $20.6^{\circ} \mathrm{C}$

LABORATORY ANALYSES

Result

5.7
90
$<2.0$
13
$<1.0$
$<1.0$
$<1.0$
$<1.0$
$<2.0$
8.150
$<1.0$
2.730
$<1.0$
$<1.0$
$<1.0$
$<1.0$
$<1.0$
$<1.0$
$<4.0$
$<1.0$
$<1.0$
$<1.0$
$<1.0$
$<1.0$
1.0

\begin{tabular}{|c|c|}
\hline Mod & Unit \\
\hline JQ & $\begin{array}{l}\mathrm{pH} \\
\mu \mathrm{S} / \mathrm{cm} \\
\mu \mathrm{g} / \mathrm{L} \\
\mu \mathrm{g} / \mathrm{L} \\
\mu \mathrm{g} / \mathrm{L} \\
\mu \mathrm{g} / \mathrm{L} \\
\mu g / L \\
\mu g / / \\
\mu g / L \\
\mu g / L \\
\mu / L \\
\mu g / L \\
\mu g / L \\
\mu g / L \\
\mu g / L \\
\mu g / L \\
\mu g / L \\
\mu g / L \\
\mu g / L \\
\mu g / L \\
\mu g / L \\
\mu g / L \\
\mu g / L \\
\mu g / L\end{array}$ \\
\hline
\end{tabular}

Specific conductance

0 Arsenic

Barium

Bromodichloromethane

Bromomethane

O Cadmium

Carbon tetrachloride

Chioride

Chlorobenzene

Chloroethene Ninyl chloride

D Chlorene Ninyl chlorid

Chloromethane

Dibromochloromethane

1,1-Dichloroethane

1,1-Dichloroethylene

trans-1,2-Dichloroethylene

- Dichloromethane

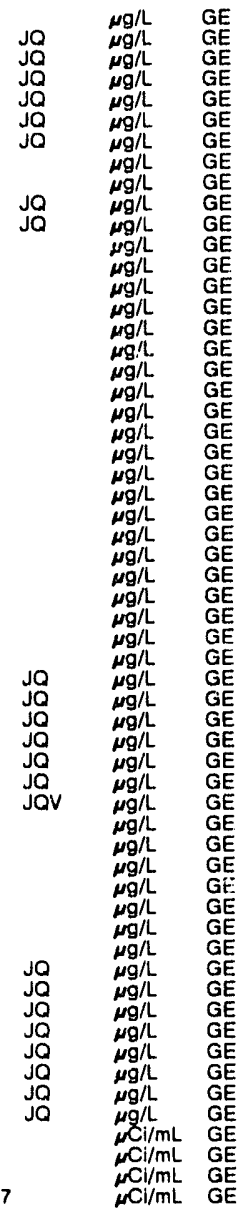


ANALYTICAL RESULTS

WELL LFW 48D collocted on 10/28/91, laboratory analyses (cont.)

\begin{tabular}{|c|c|c|c|}
\hline Analyte & Rosult & Mod & Unit \\
\hline 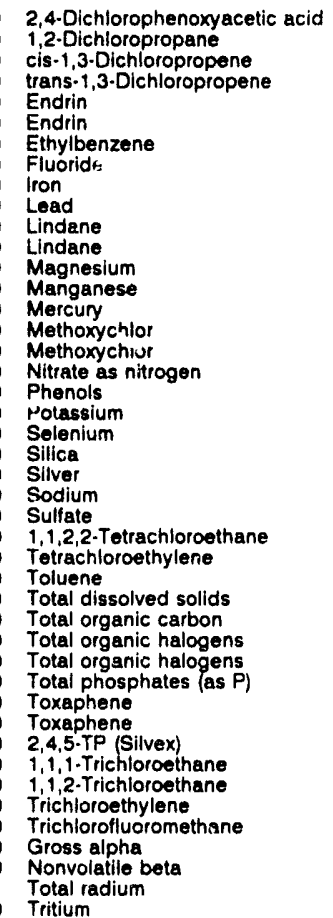 & $\begin{array}{l}<0.30 \\
<1.0 \\
<1.0 \\
<1.0 \\
<0.0060 \\
<0.0060 \\
<1.0 \\
<100 \\
12 \\
<3.0 \\
<0.0050 \\
<0.0050 \\
3.970 \\
7.0 \\
<0.20 \\
<0.50 \\
<0.50 \\
87 \\
<5.0 \\
867 \\
<2.0 \\
6.180 \\
<2.0 \\
1,220 \\
26.400 \\
<1.0 \\
<1.0 \\
<1.0 \\
46,000 \\
<1,000 \\
5.8 \\
<5.0 \\
410 \\
<0.24 \\
<0.24 \\
<0.090 \\
<1.0 \\
<1.0 \\
<1.0 \\
<1.0 \\
3.6 \mathrm{E}-09 \pm 1.5 \mathrm{E} \cdot 09 \\
5.2 \mathrm{E} \cdot 09 \pm 1.7 \mathrm{E} \cdot 09 \\
3.1 \mathrm{E} \cdot 09 \pm 1.7 \mathrm{E} \cdot 09 \\
<7.0 \mathrm{E}-07\end{array}$ & JQV & $\begin{array}{l}\mu g / L \\
\mu g / L \\
\mu g / L \\
\mu g / L \\
\mu g / L \\
\mu g / L \\
\mu g / L \\
\mu g / L \\
\mu g / L \\
\mu g / L \\
\mu g / L \\
\mu g / L \\
\mu g / L \\
\mu g / L \\
\mu g / L \\
\mu g / L \\
\mu g / L \\
\mu g / L \\
\mu g / L \\
\mu g / L \\
\mu g / L \\
\mu g / L \\
\mu g / L \\
\mu g / L \\
\mu g / L \\
\mu g / L \\
\mu g / L \\
\mu g / L \\
\mu g / L \\
\mu g / L \\
\mu g / L \\
\mu g / L \\
\mu g / L \\
\mu g / L \\
\mu g / L \\
\mu g / L \\
\mu g / L \\
\mu g / L \\
\mu g / L \\
\mu g / L \\
\mu C i / m L \\
\mu C i / m L \\
\mu C i / m L \\
\mu C i / m L\end{array}$ \\
\hline
\end{tabular}

WELL LFW 47C

MEASUREMENTS CONDUCTED IN THE FIELD

Sample date: $10 / 28 / 91$

Depth to water: $12.46 \mathrm{th}(3.80 \mathrm{~m})$ below TOC

Water elevation: $148.94 \mathrm{Ht}(45.46$

Water evacuated before sampling: $114 \mathrm{gal}$

LABORATORY ANALYSES

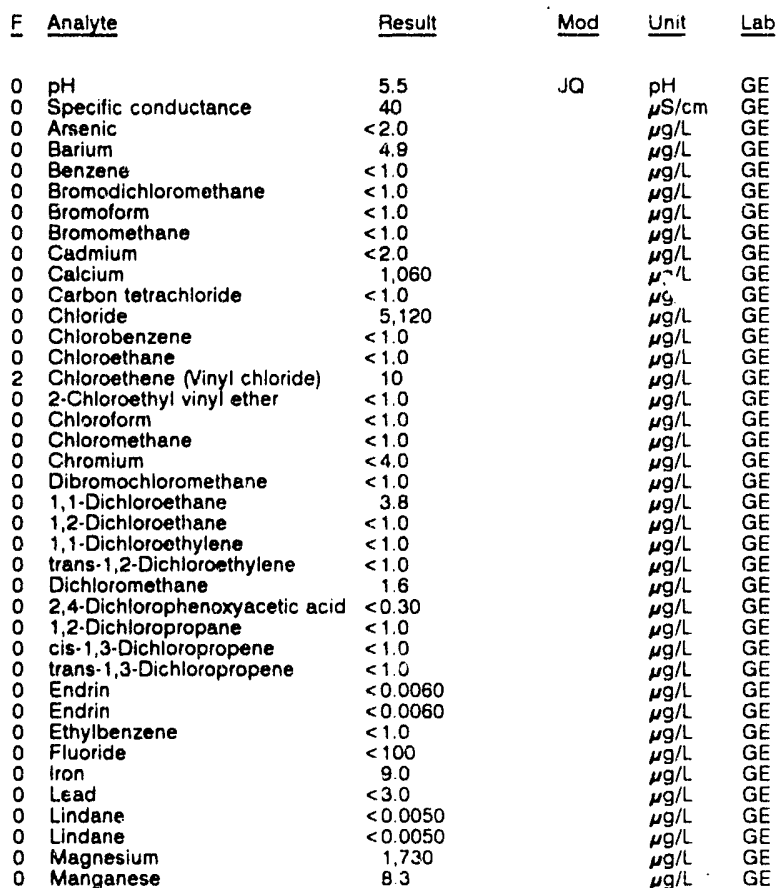

WELL LFW 47C collected on 10/28/91, laboratory analyses (cont.)

F Analyte

Result

Mod Unit Lat

- Mercury

o Methoxychlor

o Nitrate as nitrogen

0 Phenols

Phenols

0 Selenium

0 Silica

S Silver

Sodium

Sulfate

Tetrachloroethylens

Total dissolved solids

Total organic carbon

Total phosphates (as P)

Toxaphene

Toxaphene

2,4,5-TP (Silvex)

1,1,1-Trichloroethane

1,1,2-Trichloroethan

Trichlorofluoromethane

Gross alpha

Nonvolatile beta
Total radium

Tritium

$<0.20$

$<0.50$
$<0.50$

330

$<5.0$
$<5.0$

513
$<2.0$
7.860

$<2.0$

$<2.0$
3.020

3,020
$<1,000$

$<1.0$

$<1.0$
$<1.0$

19,000

$<1,000$

45
$<50$

$<0.24$

$<0.24$
$<0.090$

$<1.0$

$<1.0$

$<1.0$

$<2.0 \mathrm{E} \cdot 09$

$2.0 \mathrm{E}-09 \pm 1.5 \mathrm{E}-09$

$<1.0 E-09$
$<7.0 E-07$

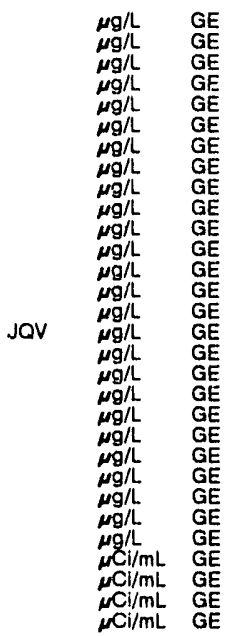

WELL LFW 47D

MEASUREMENTS CONDUCTED IN THE FIELD

Sample date: 10/28/94

Depth to water: $12.22 \mathrm{Ht}(3.72 \mathrm{~m})$ below TOC

Water elevation: $149.48 \mathrm{Ht}$ (45.

Sp. conductance: $24 \mu \mathrm{s} / \mathrm{cm}$.

Time: 13:10

Alkalinity: $1 \mathrm{mg} / \mathrm{L}$

ater evacuated before sampling: $\mathbf{4 0} \mathrm{gal}$

LABORATORY ANALYSES

E Analyte

Result

Mod Unit Lab

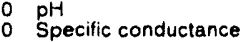

- Arsenic

Barium

Benzene

Bromodichloromethane

Bromoform

Bromomethan

Cadmium

Carbon tetrachloride

Chloride

Chlorobenzene

Chloroethene Ninyl chloride

2.Chloroethyl vinyl ether

Chloroform

o Chloromethane

Dibromochloromethane

1,1-Dichloroethan

1,2-Dichlorcethane

1,1-Dichloroethylerie

trans $\cdot 1,2 \cdot$ Dichloro

Dichloromethane

2,4-Dichioropherioxy

cis.1,3.Dichloropropene

o trans-1,3-Dichloropropene

0 Endrin

- Ethylbenzene

0 Fluoride

0 Fluoride

0 Iron

0 Lead

0 Lindane

Magnesium

Manganes

Mercury

Methoxychlor

Nitrate as nitrogen

Nitrate as nitrogen

Phenols

0 Potassium

Silica

Silver

Sodium

1,1,2,2-Tetrachloroethane

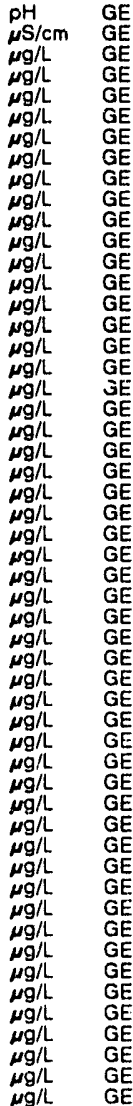


ANALYTICAL RESULTS

\begin{tabular}{|c|c|c|c|c|}
\hline $\mathbf{F}$ & Analyte & Result & Mod & Unit \\
\hline $\begin{array}{l}0 \\
0 \\
0 \\
0 \\
0 \\
0 \\
0 \\
0 \\
0 \\
0 \\
0 \\
0 \\
0 \\
0 \\
0 \\
0\end{array}$ & $\begin{array}{l}\text { Tetrachloroethylene } \\
\text { Toluene } \\
\text { Total dissolved solids } \\
\text { Total organic carbon } \\
\text { Total organic halogens } \\
\text { Total phoephates (as P) } \\
\text { Toxaphene } \\
\text { Toxaphene } \\
2,4,5-T P \text { (Silvex) } \\
1,1,1 \text {-Trichloroethane } \\
1,1,2 \cdot \text { Trichloroethane } \\
\text { Trichioroethylene } \\
\text { Trichlorofluoromethane } \\
\text { Gross alpha } \\
\text { Nonvolatile beta } \\
\text { Total radium } \\
\text { Tritium }\end{array}$ & $\begin{array}{l}<1.0 \\
<1.0 \\
18,000 \\
<1,000 \\
12 . \\
<50 \\
<0.24 \\
<0.24 \\
<0.090 \\
<1.0 \\
<1.0 \\
<1.0 \\
<1.0 \\
<2.0 E \cdot 09 \\
<2.0 \mathrm{CE} \cdot 09 \\
1.0 \mathrm{C} \cdot 09 \pm 1.4 \mathrm{E} \cdot 09 \\
<7.0 \mathrm{E} \cdot 07\end{array}$ & JOV & $\begin{array}{l}\mu g / L \\
\mu g / L \\
\mu g / h \\
\mu g / h \\
\mu g / L \\
\mu g / L \\
\mu g / L \\
\mu g / L \\
\mu g / L \\
\mu g / L \\
\mu g / L \\
\mu g / L \\
\mu g / L \\
\mu C i / m L \\
\mu C i / m L \\
\mu C i / m L \\
\mu C i / m L\end{array}$ \\
\hline
\end{tabular}

\section{WELL LFW 48C}

MEASUREMENTS CONDUCTED IN THE FIELD

Sample date: 10/28/91 Depth to water: $20.29 \mathrm{~h}(6.18 \mathrm{~m})$ below TOC Water elevation: $149.01 \mathrm{~h}(45.42$ Sp. conductance: $25 \mu \mathrm{S} / \mathrm{cm}$
Water evacuated before sampling: $135 \mathrm{gal}$ LABORATORY ANALYSES

\begin{tabular}{|c|c|c|c|c|c|}
\hline E & Analyte & Result & Mod & Unit & Lab \\
\hline & 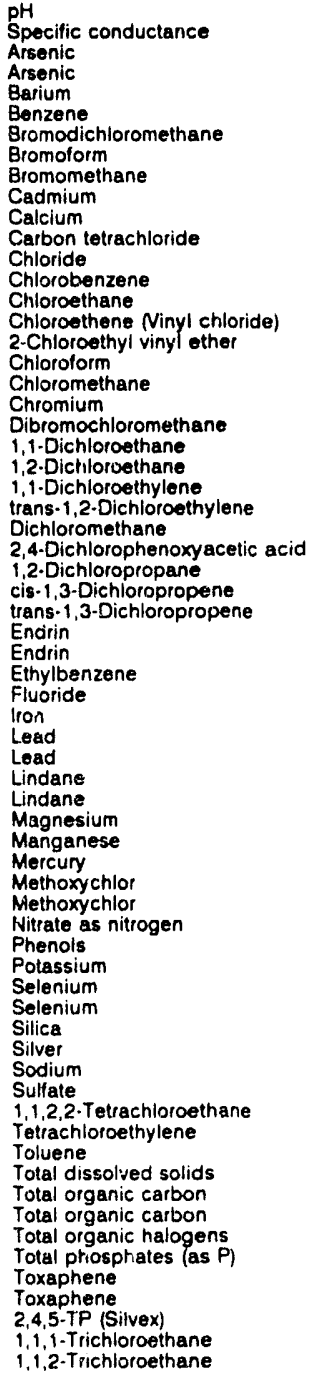 & $\begin{array}{l}5.5 \\
20 \\
<2.0 \\
<2.0 \\
6.3 \\
<1.0 \\
<1.0 \\
<1.0 \\
<1.0 \\
<2.0 \\
898 \\
<1.0 \\
1.780 \\
<1.0 \\
<1.0 \\
<1.0 \\
<1.0 \\
<1.0 \\
<1.0 \\
<4.0 \\
<1.0 \\
<1.0 \\
<1.0 \\
<1.0 \\
<1.0 \\
4.1 \\
<0.30 \\
<1.0 \\
<1.0 \\
<1.0 \\
<0.0060 \\
<0.0060 \\
<1.0 \\
<100 \\
28 \\
<3.0 \\
<3.0 \\
<0.0050 \\
<0.0050 \\
363 \\
18 \\
<0.20 \\
<0.50 \\
<0.50 \\
430 \\
<5.0 \\
508 \\
<2.0 \\
<2.0 \\
7.050 \\
<2.0 \\
11.440 \\
<1.000 \\
<1.0 \\
<1.0 \\
<1.0 \\
14.000 \\
<1.000 \\
<1.000 \\
7.7 \\
<50 \\
<0.24 \\
<0.24 \\
<0.090 \\
<1.0 \\
<10 \\
<10\end{array}$ & JOV & $\begin{array}{l}\mathrm{pH} \\
\mu \mathrm{S} / \mathrm{cm} \\
\mu g / \\
\mu g / L \\
\mu g / L \\
\mu g / L \\
\mu g / L \\
\mu g / L \\
\mu g / L \\
\mu g / L \\
\mu g / L \\
\mu g / L \\
\mu g / L \\
\mu g / L \\
\mu g / L \\
\mu g / L \\
\mu g / L \\
\mu g / L \\
\mu g / L \\
\mu g / L \\
\mu g / L \\
\mu g / L \\
\mu g / L \\
\mu g / L \\
\mu g / L \\
\mu g / L \\
\mu g / L \\
\mu g / L \\
\mu g / L \\
\mu g / L \\
\mu g / L \\
\mu g / L \\
\mu g / L \\
\mu g / L \\
\mu g / L \\
\mu g / L \\
\mu g / L \\
\mu g / L \\
\mu g / L \\
\mu g / L\end{array}$ & 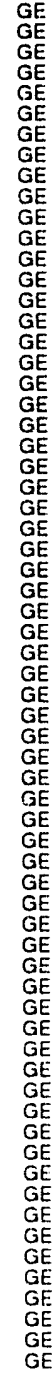 \\
\hline
\end{tabular}

Time: 9:50

Alkalinity: $3 \mathrm{mg} / \mathrm{h}$ Water temperature: $18.1^{\circ} \mathrm{C}$
WELL LFW $48 C$ collected on 10/29/91, laboratory analyses (cont.)

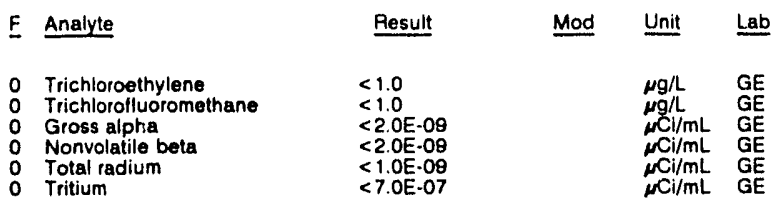

WELL LFW 48D

MEASUREMENTS CONDUCTED IN THE FIELD

Sample dete: 10/29/81

Depth to water: $20.16 \mathrm{Ht}(6.14 \mathrm{~m})$ below roC

Water elevation: $149.34 \mathrm{ht}(45.52 \mathrm{~m}) \mathrm{msl}$

Water evacuated before sampling: $39 \mathrm{gal}$

LABORATORY ANALYSES

F Analyte Result Mod Unit Lab

$0 \mathrm{pH}$

Specific conductance

0 Arsenic

\begin{tabular}{ll}
0 & Arsenic \\
0 & Barium \\
\hline
\end{tabular}

Barium

Bromodichloromethane

Bromoform

Bromomethane

Cadmium

o Calcium

0 Chloride

2 Chlorobenzene

Chloroethane

2-Chloroethyl vinyl ether

Chloromethan

Chromium

Dibromochloromethane

1,1-Dichloroethare

1,2-Dichloroethane

1,1 -Dichlorsethylene
0 trans-1,2-Dichloroethylene

0 Dichloromethane $\quad<1.0$

2,4-Dichlorophenoxyacetic acid $<0.30$

1,2-Dichloropropane

o cis-1,3-Dichloropropene

0 trans: 1,3-Dichloropropene

0 Endrin

E Ethylbenzene

0 Fluoride

2 Fluorice

2 Iron

0 Lead

0 Lindane

L Lindane

Magnesium

Manganese

Methoxychlor

Methoxychlor

Nitrate as nitrogen

Nitrate as nitrogen

Phenols

Selenium

Selenium

Silica

Silver

Sodium

1,1,2,2-Tetrachloroethane

Tetrachloroethylene

Toluene

Total dissolved solids

Total organic carbon

Total phosphates (as P)

Toxaphene

Toxaphene

1.1. Trichloroethan

1. 1, T. Trichloroethan

Trichloroethylene

Time: $9: 30$

Alkalinity: $168 \mathrm{mg} /$ Water temperature: $18.9^{\circ} \mathrm{C}$

Trichlorofluoromethane

Gross alpha

Nonvolatile beta

Tritium
6.5
275
9.8
8.8
8.2
$<1.0$
$<1.0$
$<1.0$
$<1.0$

$<1.0$

8,480
-1.0

27,600

13
12

108
$<1.0$

$<1.0$

$<1.0$

$<4.0$

88

$<1.0$
$<1.0$
6.7
$<0.30$

$<1.0$

$<1.0$

$<0.0060$

21

323

41,600
$<3.0$

$<3.0$
$<3.0$

$<0.0050$
$<0.0050$

16,400

27

$<0.20$

$<0.50$

$<50$

$<5.0$

1,670

$<2.0$

5,800

$<2.0$

25,500

$<1,0$

$<1.0$

$143,000 \mathrm{JQV}$

7,000
449

$<50$

$<0.24$

$<0.24$
$<0.090$

$<1.0$

$<1.0$

$<10$

2.1E-09 $\pm 1.4 \mathrm{E}-09$

4.2E.09 $\pm 1.6 \mathrm{E} \cdot 09$

< 1. 0 . 09 . 09.06 .07 
ANALYTICAL RESULTS

WELL LFW 55C

MEASUREMENTS CONDUCTED IN THE FIELL

Sample date: 10/29/91

Wepth to water: $9.38 \mathrm{H}(2.86 \mathrm{~m})$ below TOC

nce: $40 \mathrm{~s} / \mathrm{cm}$

Water evacuated before sampling: $139 \mathrm{gal}$

LABORATORY ANALYSES

\begin{tabular}{|c|c|c|c|c|}
\hline F & Analyte & Result & Mod & Unit \\
\hline $\begin{array}{l}0 \\
0 \\
0 \\
0 \\
0 \\
0 \\
0 \\
0 \\
0 \\
0 \\
0 \\
0 \\
0 \\
0 \\
0 \\
2 \\
0 \\
0 \\
0 \\
0 \\
0 \\
0 \\
0 \\
0 \\
0 \\
0 \\
0 \\
0 \\
0 \\
0 \\
0 \\
0 \\
0 \\
0 \\
0 \\
0 \\
0 \\
0 \\
0 \\
0 \\
0 \\
0 \\
0 \\
0 \\
0 \\
0 \\
0 \\
0 \\
0 \\
0 \\
0 \\
0 \\
0 \\
0 \\
0 \\
0 \\
0 \\
0 \\
0 \\
0 \\
0 \\
0 \\
0 \\
0 \\
0 \\
0 \\
0 \\
0 \\
0 \\
0 \\
0\end{array}$ & 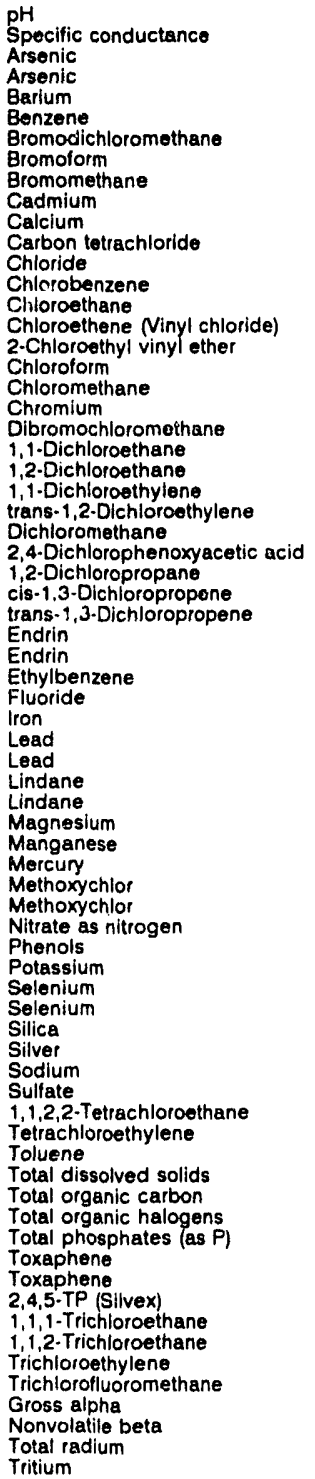 & $\begin{aligned} & 5.5 \\
& 35 \\
&<2.0 \\
&<2.0 \\
& 3.4 \\
&<1.0 \\
&<1.0 \\
&<1.0 \\
&<1.0 \\
&<2.0 \\
& 1.060 \\
&<1.0 \\
& 4,540 \\
&<1.0 \\
&<1.0 \\
& 5.6 \\
&<1.0 \\
&<1.0 \\
&<1.0 \\
&<4.0 \\
&<1.0 \\
&<1.0 \\
&<1.0 \\
&<1.0 \\
&<1.0 \\
& 7.5 \\
&<0.30 \\
&<1.0 \\
&<1.0 \\
&<1.0 \\
&<0.0060 \\
&<0.0060 \\
&<1.0 \\
&<100 \\
& 24 \\
&<3.0 \\
&<3.0 \\
&<0.0050 \\
&<0.0050 \\
& 1.410 \\
& 10 \\
&<0.20 \\
&<0.50 \\
&<0.50 \\
& 840 \\
&<5.0 \\
&<500 \\
&<2.0 \\
&<2.0 \\
& 88.050 \\
&<2.0 \\
& 3.160 \\
& 1.010 \\
&<1.0 \\
&<1.0 \\
&<1.0 \\
& 23.000 \\
&<1.000 \\
& 1.9 \\
&<50 \\
&<0.24 \\
&<0.24 \\
&<0.090 \\
&<1.0 \\
&<1.0 \\
&<1.0 \\
&<1.0 \\
& 2.2 \mathrm{E} \cdot 09 \pm 1.3 \mathrm{E}-09 \\
&<2.0 \mathrm{E} \cdot 09 \\
&<1.0 \mathrm{E}-09 \\
&<7.0 \mathrm{E} \cdot 07 \\
&\end{aligned}$ & JOV & $\begin{array}{l}p H \\
\mu S / c m \\
\mu g / L \\
\mu g / L \\
\mu g / L \\
\mu g / L \\
\mu g / L \\
\mu g / L \\
\mu g / L \\
\mu g / L \\
\mu g / L \\
\mu g / L \\
\mu g / L \\
\mu g / L \\
\mu g / L \\
\mu g / L \\
\mu g / L \\
\mu g / L \\
\mu g / L \\
\mu g / L \\
\mu g / L \\
\mu g / L \\
\mu g / L \\
\mu g / L \\
\mu g / L \\
\mu g / L \\
\mu g / L \\
\mu g / L \\
\mu g / L \\
\mu g / L \\
\mu g / L \\
\mu g / L \\
\mu g / L \\
\mu g / L \\
\mu g / L \\
\mu g / L \\
\mu g / L \\
\mu g / L \\
\mu g / L \\
\mu g / L \\
\mu g / L \\
\mu g / L \\
\mu g / L \\
\mu g / L \\
\mu g / L \\
\mu g / L \\
\mu g / L \\
\mu g / L \\
\mu g / L \\
\mu g / L \\
\mu g / L \\
\mu g / L \\
\mu g / L \\
\mu g / L \\
\mu g / L \\
\mu g / L \\
\mu g / L \\
\mu g / L \\
\mu g / L \\
\mu g / L \\
\mu g / L \\
\mu g / L \\
\mu g / L \\
\mu g / L \\
\mu g / L \\
\mu g / L \\
\mu g / L \\
\mu C i / m L \\
\mu C i / m L \\
\mu C i / m L \\
\mu c i / m L\end{array}$ \\
\hline
\end{tabular}

\section{WELL LFW 55D}

MEASUREMENTS CONDUCTED IN THE FIELD

Sample date: 10/28/91

Sample date: $10 / 29 / 91$
Depth to water: $8.42 \mathrm{ft}(2.57 \mathrm{~m})$ below TOC
Wate? elevation: $148.98 \mathrm{ft}(44.80 \mathrm{~m}) \mathrm{ms}$

Sp. conductance: $24 \mu \mathrm{s} / \mathrm{cm}$
Water evacuated before sampling: $53 \mathrm{gal}$

LABORATOAY ANALYSES

F Analyte Result Mod Unit Lab

O $\mathrm{pH}$ Specific conductance

Arsenic

Arsenic

Barium

Bromodichloromethane

Bromoform

Bromomethane

Cadmium

Carbon tetrachloride

Chloride

Chloride
Chlorobenzene
Chloroethane

Chloroethene Ninyl chloride)

2.Chloroethyl vinyl ether

Chloroform

Chloromethane

Chromium

Dibromochloromethane

1,1-Dichloroethane
1,2-Dichloroethane

1,1-Dichloroethylene

trans-1,2-Dichloroethylene

2,4-Dichlorophenoxyacetic acid

i, 2-Dichloropropane

cis 1,3.Dichloropropen

trans-1,3-Dichloropropene

Endrin

Ethylbenzene

Fluoride

0 Iron

0 Lead

Lindane

Lindane

Magnesium

Manganes

Methoxychlor

Methoxychlor

Phenols

Potassium

Selenium

Selenium

Silica

Silver

Sodium

Sulfate

Tetrachloroethylene

0 Toluene

Total dissolved solids

Total organic carbon

Total phosphates (as P)

Total phosphates (as P)

Total phosphates (as P)

Toxapherie

o Toxaphene

1,1,1-Trichloroethane

1,1,2-Trichloroethane

Trichloroethylene

Trichlorofluoromethane

- Gross alpha

Nonvolatile beta

Total radium
Time: 10:30

Alkalinity: $1 \mathrm{mg} / \mathrm{L}$

Water temperature: $18.7 \circ \mathrm{C}$

5.4
25
$<2.0$
$<2.0$
8.3
$<1.0$
$<1.0$
$<1.0$
$<1.0$
$<2.0$
1.06
$<1.0$
2.45
$<1.0$
$<1.0$
$<1.0$
$<1.0$
$<1.0$
$<1.0$
$<4.0$
$<1.0$
$<1.0$
$<1.0$
$<1.0$
$<1.0$
7.0
$<0.30$
$<1.0$
$<1.0$
$<1.0$
$<0.00$
$<0.0060$

$<1.0$
$<0.0060$

$<0.0060$

$<1.0$

13
$<3.0$

$<3.0$

$<0.0050$

643

19
$<0.20$
$<0.50$

$<0.50$

$<20$
$<5.0$
$<527$
82.0

$<2.0$

6.570
$<2.0$

1,150
2,350

$<1.0$
$<1.0$

$<1.0$
10,000

10,000
$<1,000$

19
$<50$

$<50$

$<50$

$<0.24$

$<0.090$

$<1.0$

$<1.0$

$<2.0 \mathrm{E}-08$

$<2.0 E-09$

$<1.0 E-09$
$<7.0 E-07$

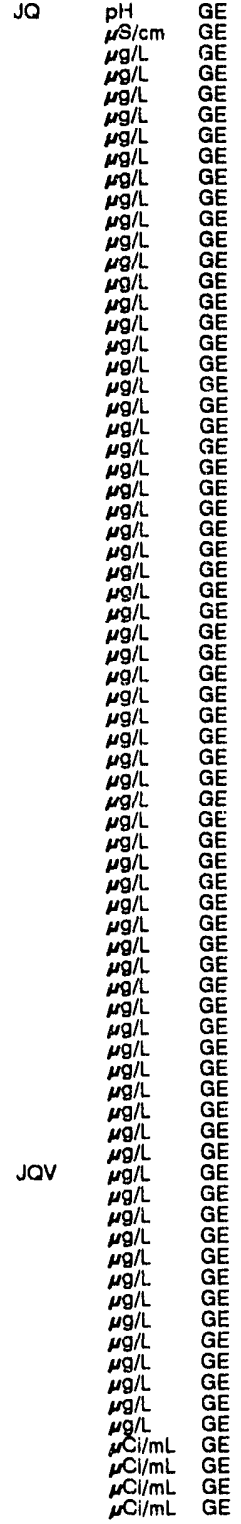


WELL LFW 56D

MEASUREMENTS CONDUCTED IN THE FIELD

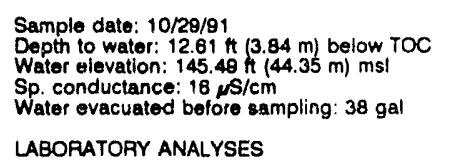

\section{F Analyte

Result Mod Unit Lab \\ Mod Unit Lab}

$\therefore$ Specific conductance

Arsenic

Barium

Benzene

Bromodichloromethane

Bromoform

Bromomethane

Cadmium

Carbon tetrachloride

Chloride

Chlorobenzene

Chloroethene Ninyl chloride)

2-Chloroethyl vinyl ether

Chlorotorm

Chloromethane

Chromium

Dibromochloromethane

1,2.Dichlorothothane

$1,1-$ Dichloroethylene
0
trans-1,2-Dichloroethyien

trans-1,2-Dichloroethylene
Dichlornmethane

2,4-Dichlorophenoxyacetic acid

1,2.Dichloropropane

cis-1,3-Dichloropropene

Endrin

Ethylbenzene

Fluoride

Iron

Lead

Lindane

Magnesium

Manganeso

Methoxychio

Nitrate as nitrogen

Phenols

Potassium
Selenium

Selenium

Silica

Silver

Sodium

Sulfate

Tetrachloroethylene

Toluene

Total dissolved solids

Total dissolved solids

Total organic halogens

Total organic halogens

Tolal phosphates

Toxaphene

2,4,5-TP (Silvex)

1,1,1-Trichloroethane

1,1,2-Trichloroethan

o Trichlorofluoromethane

- Gross alpha

- Nonvolatile beta

0 Total radium
5.3

$<2.0$

$<3.0$

$<1.0$

$<1.0$
$<1.0$

$<1.0$

$<2.08$

$<1.0$

2,220

$<1.0$

$<1.0$

$<1.0$

$<1.0$

$<4.0$

$<1.8$

$<1.0$

$<1.0$

$<0.30$

$<1.0$

$<1.0$

$<0.0060$

$<0.0060$

$<1.0$

19

$<3.0$

$<0.0050$
$<0.0050$

$30 y$

3.3
$<0.20$

$<0.20$
$<0.50$

$<0.50$

$<5.0$
$<500$

$<500$
$<2.0$

$<2.0$

6,320
$<2.0$

1,220
$<1,000$

$<1,000$

$<1.0$

$<1,000$

7,000
$<1,000$

$<1,000$

$<5.0$

$<50$

$<0.24$

$<0.24$

$<1.0$

$<1.0$

$<1.0$

$<2.0 \mathrm{E}-09$

$<2.0 E \cdot 09$

$<1.0 E-09$
$3.4 E-06 \pm 7.0 E-07$

JO $\quad \mathrm{pH}$ GE
Time: 11:30

Alkalinity: $0 \mathrm{mg} / \mathrm{h}$

Water temperature: $19.5^{\circ} \mathrm{C}$

$\begin{array}{ll}\mu \mathrm{S} / \mathrm{cm} & \mathrm{GE} \\ \mu \mathrm{g} / \mathrm{L} & \mathrm{GE} \\ \mu \mathrm{g} / \mathrm{L} & \mathrm{GE}\end{array}$

$\mu_{\mu g / L} \mathrm{GE}$

$\begin{array}{ll}\mu g / \mu & G E \\ \mu g / h & G E\end{array}$

$\mu \mathrm{g} / \mathrm{GE}$

$\mu g / \mathrm{GE}$

$\mu \mathrm{gg} / \mathrm{L} \quad \mathrm{GE}$

$\begin{array}{ll}\mu g / h & G E \\ \mu g / h & G E\end{array}$

$\begin{array}{ll}\mu g / L & \mathrm{GE} \\ \mu g / \Lambda & \mathrm{GE} \\ \mu g / h & \mathrm{GE}\end{array}$

$\mu g h \quad G E$

$\mu g / L$

J2V

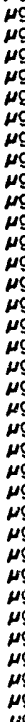

WELL LFW 57B

MEASUREMENTS CONDUCTED IN THE FIELO

Sample date: $10 / 29 / 91$

Depth to water: $21.60 \mathrm{Ht}(6.58 \mathrm{~m})$ below TOC

Water elevation: $143.80 \mathrm{~h}$ (43.8

Sp. conduclance. $55 \mathrm{ss} / \mathrm{cm}$.

Walor ovacualed bolore sam

E Analyte Result Mod Unit Lai

Ppecific conductance

Arsenic

0 Arsenic

Barium

Bromodichloromethan

Bromolorm

Bromomethan

Cadmium

Carbon totrachloride

Chloride

Chlorobenzene

Chloroethene Ninyl chloride)

o 2-Chloroethyl vinyl ether

o Chlorotorm

o Chloromethane

- Chromium

D Dibromochloromethane

1,1-Dichloroethane

1,2-Dichloroethane

o trans-1,2-Dichloroethylene

(n)

o 2,4-Dichlorophenuxyacetic acid

1,2. Dichloropropane

cis-1,3-Dichloropropene

Endrin

0 Ethylbenzene

0 Fluoride

0 Iron

0 Lead

Lindane

Lindane

Magnesium

Mangane

Methoxychior

Methoxychlor

Phenols

Polassium

Selenium

Selenium

Silica

S Silver

Sodium

1,1,2,2-Tetrachloroethane

Tetrach

Toluene

Total dissolved solids

Total organic carbon

Total phosphates (as P)

Toxaphene

2,4,5-TP (Silvex)
Toxphene

1,1,1.Trichloroethane

1.12.Trichloroethane

Trichlorofluorom

Nonvolatile beta

Total radium
Tritium
Time: $12: 40$

Alkalinity: $0 \mathrm{mg}$

Waler temperature: $18.5^{\circ} \mathrm{C}$

4.4
50
$<2.0$
$<2.0$
8.1
$<1.0$
$<1.0$
$<1.0$
$<1.0$
$<20$

1,480

$<2,550$

$<1.0$

$<1.0$

$<1.0$

$<1.0$

$<4.0$

$<1.0$

$<1.0$

$<1.0$

$<1.0$

$<0.30$

$<1.0$
$<1.0$
$<1.0$

$<0.0060$

$<0.0080$

$<1.0$

71

$<3.0$

$<0.0050$

$<0.0050$

554
35

$<0.20$

$<0.50$

$<0.50$
980
$<5.0$
$<500$

$<500$
$<2.0$

$<2.0$
10.400

$<2.0$

2,050
44,200

$<1.0$

$<1.0$
$<1.0$

$<1.0$

$<1,000$

10

$\begin{aligned} & 60 \\ &<0.24 \\ &<0.24\end{aligned}$

$<0.24$

$<1.0$

$<1.0$
$<1.0$

$<1.0$
$<1.0$

$6.5 \mathrm{E}-09 \pm 1.8 \mathrm{E}-09$

2. $8 \mathrm{E} \cdot 09 \pm 1.0 \mathrm{EE} \cdot 09$

$2.9 \mathrm{E} \cdot 09 \pm$
$<7.0 \mathrm{E} \cdot 07$

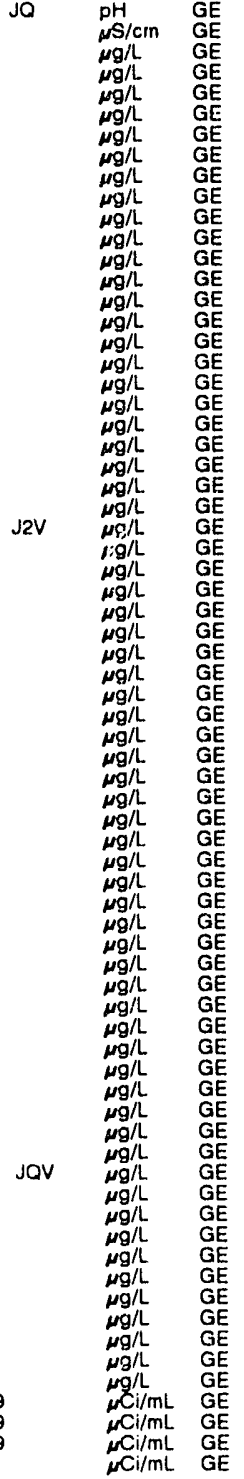


ANALYTICAL RESULTS

WELL LFW 57C

MEASUREMENTS CONOUCTED IN THE FIELO

Sample date: $10 / 29 / 91$
Depth to water: $21.08 \mathrm{ft}(6.43 \mathrm{~m})$ below TOC
Water elevation: $143.82 \mathrm{ft}(43.87 \mathrm{~m}) \mathrm{msl}$
Sp. conductance: $31 \mu 5 / \mathrm{cm}$
Water evacuated before sampling: $96 \mathrm{gal}$
LABORATORY ANA! YSES

E Analyte

0 Specific conductance

0 Arsenic

Barium

Benzene
Bromodichloromethane

Bromotorm

Bromomethane

Cadmium

Carbon tetrachloride
Chloride

Chlorobenzene

Chore

2-Chloroethyl vinyl ether

Chloroform

Chloromethane

Dibromochloromethane

1,1-Dichloroethane

1,2-Dichloroethane

1,1-Dichloroethylene
0 trans-1,2-Dichloroethylene

trans-1,2-Dichloroethylene
Dichloromethane

2,4-Dichlorophenoxyacetic acid <0

1,2-Dichloropropane

cis-1,3-Dichloropropene

Endrin

Ethylbenzene

Fluoride

Iron

Lead

Lindane

Magnesium

Manganese

Methoxychlor

Nitrate as nitrogen

Potassium

Selenium

Selenium

Silica

Silver

Sodium

Sulfate

Tetrachloroethylene

Total organic carbon

Total organic carbon

Total organic halogens

Toxaphene

2,4,5-TP (Silvex)

$1,1,1$-Trichloroethane

$1,1,2$-Trichloroethan

Trichlorofluoromethane

Gross alpha

Nonvolatile beta

Total radium

\section{Result}

5.6
30
$<2.0$
$<2.0$

$<2.0$
5.2

$<1.0$

$<1.0$

$<1.0$

$<2.0$

$<1.0$

$<1.0$

$<1.0$

$<1.0$
$<1.0$
$<1.0$

$<4.0$

$<1.0$

3.0

$<1.0$

$<1.0$

$<0.30$

$<1.0$

$<1.0$

$<1.0$

$<0.000$
$<1.0$
$<100$

14

$<3.0$
$<3.0$

$<0.0050$

832
13

13
$<0.20$

$<0.50$

790
$<500$

$<500$
$<2.0$
$<2.0$

$<, 090$

8,090
$<2.0$
2,160

2,160
$<1,000$

$<1.0$

$<1.0$

$<1.0$

$<1,000$

12
13

$<0.24$

$<1.0$

$<1.0$
$<1.0$
$<1.0$

$<2.0 \mathrm{E}-09$

$<2.0$ E-09

$<1.0 E-09$
$<7.0 E-07$
Time: 12:15

pH: 5.3

Water temperature: $18.1^{\circ} \mathrm{C}$

Mod Unit

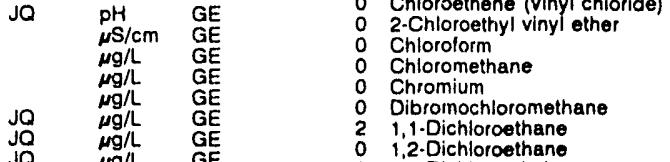

o 1,1-Dichloroethane

trans-1,2-Dichloroethylene

o Dichloromethane

2,4-Dichlorophenoxyacetic acid

1,2-Dichloropropane

cis-1,3-Dichloropropene
trans-1,3-Dichloropropene

Endrin

O Endrin

0 Ethylbenzen

o Iron

Lead

0 Lindane

0 Lindane

0 Magnesium

Manganese

Mercury

Methoxychlor

Nitrate as nitrogen

Phenols

Potassium

Selenium

0 Silica

O $\begin{array}{ll}\text { Silica } \\ 0\end{array}$

0 Sodium

0 Sulfate

1,1,2,2-Tetrachloroethane

Tetrachloroethylene

Toluene

Total dissolved solids

Total organic carbon

Total organic halogens
Total phosphates (as P)

Toxaphene

Toxaphene

1,1,1-Trichloroethane

Trichloroethylene

Trichlorofluoromethane

- Gross alpha

0 Nonvolatile beta

Total radium
1, 1, Trichorothane
Mod Unit Lab

$<1$

$<1.0$

$<1.0$
$<1.0$

$<2.0$

1.0
3,280

$<1,280$

$<1.0$

$<1.0$

$<1.0$

$<1.0$

$<4.0$

$<1.0$

$<1.0$

$<1.0$

4.4
$<0.30$

$<1.0$

$<1.0$

$<0.0060$

$<0.0060$

$<100$

$<4.0$

$<3.0$

$<0.0050$

1,370
20
$<0.20$

$<0.50$

$<0.50$

$<50$

$<5.0$
$<500$
$<2.0$
$<2.0$

$<.0$
5.890

$<2.0$

2,850
1,220

$<1.0$

$<1.0$
$<1.0$

14,000
$<1,000$

19
$<50$

$<50$
$<0.24$

$<0.24$
$<0.24$

$<1.0$

$<1.0$

$<1.0$

$<2.0 E \cdot 0 \theta$

$1.2 E-09 \pm 1.3 E-09$
$<7.0 E \cdot 07$

$\mu g / L \quad G$
$\mathrm{GE}$
$\mathrm{GE}$
$\mathrm{GE}$
$\mathrm{GE}$

WELL LFW 58D

MEASUREMENTS CONDUCTED IN THE FIELO

Sample date: 10/29/91

Depth to water: $25.67 \mathrm{ft}(7.82 \mathrm{~m})$ below TOC

Water elevation: $141.93 \mathrm{~h}(43.26 \mathrm{~m}) \mathrm{ms}$

Water evacuated before sampling: $49 \mathrm{gal}$

LABORATORY ANALYSES

WELL LFW 57D

MEASUREMENTS CONDUCTED IN THE FIELD

Sample date: 10/29/91

Depth to water: $20.81 \mathrm{ft}(6.37 \mathrm{~m})$ below TOC

Water elevation: $143.89 \mathrm{ft}(43 \mathrm{n}$

S. conductance: $19 \mu \mathrm{s} / \mathrm{cm}$

Waler evacuated before sam

ABORATORY ANALYSES

\begin{tabular}{|c|c|c|c|}
\hline F Analyte & Result & Mod & Unit \\
\hline $\begin{array}{ll}0 & \mathrm{pH} \\
0 & \text { Specific conductance } \\
0 & \text { Atsenic } \\
0 & \text { Arsenic } \\
0 & \text { Barium }\end{array}$ & $\begin{array}{r}5.9 \\
30 \\
<2.0 \\
<2.0 \\
5.0\end{array}$ & JQ & $\begin{array}{l}\mathrm{pH} \\
\mu \mathrm{S} / \mathrm{cm} \\
\mu g / \mathrm{h} \\
\mu g / L \\
\mu g / L\end{array}$ \\
\hline
\end{tabular}

Time: 12:00

pH: 5.4

$7 \mathrm{mg} / \mathrm{L}$

Water temperature: $19.3^{\circ} \mathrm{C}$

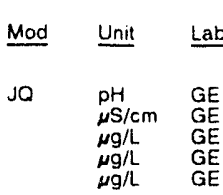

\begin{tabular}{|c|c|c|c|c|}
\hline$\underline{F}$ & Analyte & Result & Mod & Unit \\
\hline $\begin{array}{l}0 \\
0 \\
0 \\
0 \\
0 \\
0 \\
0 \\
0 \\
0 \\
0 \\
0 \\
0 \\
0 \\
0 \\
0 \\
0 \\
0\end{array}$ & $\begin{array}{l}\text { pH } \\
\text { Specific conductance } \\
\text { Arsenic } \\
\text { Arsenic } \\
\text { Barium } \\
\text { Benzene } \\
\text { Bromodichloromethane } \\
\text { Bromolorm } \\
\text { Bromomethane } \\
\text { Cadmium } \\
\text { Calcium } \\
\text { Carbon tetrachloride } \\
\text { Chloride } \\
\text { Chlorobenzene } \\
\text { Chloroethane } \\
\text { Chloroethene Ninyl chloride) } \\
\text { 2-Chloroethyl vinyl ether }\end{array}$ & $\begin{array}{r}5.3 \\
30 \\
<2.0 \\
<2.0 \\
6.5 \\
<1.0 \\
<1.0 \\
<1.0 \\
<1.0 \\
<2.0 \\
1.1 .30 \\
<1.0 \\
4,360 \\
<1.0 \\
<1.0 \\
<1.0 \\
<1.0\end{array}$ & JO & $\begin{array}{l}p H \\
\mu S / c m \\
\mu g / L \\
\mu g / L \\
\mu g / L \\
\mu g / L \\
\mu g / L \\
\mu g / L \\
\mu g / L \\
\mu g / L \\
\mu g / L \\
\mu g / L \\
\mu g / L \\
\mu g / L \\
\mu g / L \\
\mu g / L \\
\mu g / L\end{array}$ \\
\hline
\end{tabular}


WELL LFW 58D collected on 10/29/91, laboratory analyses (cont.)

\begin{tabular}{|c|c|c|c|c|c|}
\hline & Analyte & Result & Mod & Unit & Lab \\
\hline $\begin{array}{l}0 \\
0 \\
0 \\
0 \\
2 \\
0 \\
0 \\
0 \\
0 \\
0 \\
0 \\
0 \\
0 \\
0 \\
0 \\
0 \\
0 \\
0 \\
0 \\
0 \\
0 \\
0 \\
0 \\
1 \\
1 \\
0 \\
0 \\
0 \\
0 \\
0 \\
0 \\
0 \\
0 \\
0 \\
0 \\
0 \\
0 \\
0 \\
0 \\
0 \\
0 \\
2 \\
0 \\
0 \\
0 \\
0 \\
0 \\
0 \\
2 \\
2 \\
0 \\
0 \\
0\end{array}$ & 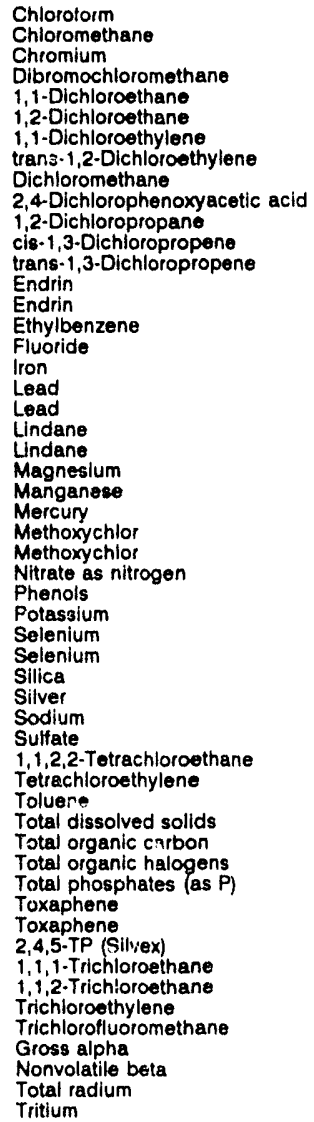 & $\begin{array}{l}<1.0 \\
<1.0 \\
<4.0 \\
<1.0 \\
244 \\
<1.0 \\
<1.0 \\
<1.0 \\
8.0 \\
<0.60 \\
<1.0 \\
<1.0 \\
<1.0 \\
<0.0060 \\
<0.0060 \\
<1.0 \\
<100 \\
<4.0 \\
<3.0 \\
<3.0 \\
<0.0050 \\
<0.0050 \\
595 \\
30 \\
1.6 \\
<0.50 \\
<0.50 \\
170 \\
<5.0 \\
<500 \\
<2.0 \\
<2.0 \\
10.600 \\
<2.0 \\
2.990 \\
<1.000 \\
<1.0 \\
210 \\
<1.0 \\
19.000 \\
<1.000 \\
129 \\
<50 \\
<0.24 \\
<0.24 \\
<0.10 \\
19 \\
<1.0 \\
8.3 \\
123 \\
<2.0 E-09 \\
<2.0 E-09 \\
<1.0 E \cdot 09 \\
<7.0 E-07\end{array}$ & JOV & $\begin{array}{l}\mu g / L \\
\mu g / L \\
\mu g / L \\
\mu g / L \\
\mu g / L \\
\mu g / L \\
\mu g / L \\
\mu g / L \\
\mu g / L \\
\mu g / L \\
\mu g / L \\
\mu g / L \\
\mu g / L \\
\mu g / L \\
\mu g / L \\
\mu g / L \\
\mu g / L \\
\mu g / L \\
\mu g / L \\
\mu g / L \\
\mu g / L \\
\mu g / L \\
\mu g / L \\
\mu g / L \\
\mu g / L \\
\mu g / L \\
\mu g / L \\
\mu g / L \\
\mu g / L \\
\mu g / L \\
\mu g / L \\
\mu g / L \\
\mu g / L \\
\mu g / L \\
\mu g / L \\
\mu g / L \\
\mu g / L \\
\mu g / L \\
\mu g / L \\
\mu g / L \\
\mu g / L \\
\mu g / L \\
\mu g / L \\
\mu g / L \\
\mu g / L \\
\mu g / L \\
\mu g / L \\
\mu g / L \\
\mu g / L \\
\mu g / L \\
\mu c i / m L \\
\mu C \mathrm{C} / \mathrm{mL} \\
\mu \mathrm{C} / / \mathrm{mL} \\
\mu C \mathrm{Cl} / \mathrm{mL}\end{array}$ & $\begin{array}{l}\mathrm{GE} \\
\mathrm{GE} \\
\mathrm{GE} \\
\mathrm{GE} \\
\mathrm{GE} \\
\mathrm{GE} \\
\mathrm{GE} \\
\mathrm{CE} \\
\mathrm{GE} \\
\mathrm{GE} \\
\mathrm{GE} \\
\mathrm{GE} \\
\mathrm{GE} \\
\mathrm{GE} \\
\mathrm{GE} \\
\mathrm{GE} \\
\mathrm{GE} \\
\mathrm{GE} \\
\mathrm{GE} \\
\mathrm{GE} \\
\mathrm{GE} \\
\mathrm{GE} \\
\mathrm{GE} \\
\mathrm{GE} \\
\mathrm{GE} \\
\mathrm{GE} \\
\mathrm{GE} \\
\mathrm{GE} \\
\mathrm{GE} \\
\mathrm{GE} \\
\mathrm{GE} \\
\mathrm{GE} \\
\mathrm{GE} \\
\mathrm{GE} \\
\mathrm{GE} \\
\mathrm{GE} \\
\mathrm{GE} \\
\mathrm{GE} \\
\mathrm{GE} \\
\mathrm{GE} \\
\mathrm{GE} \\
\mathrm{GE} \\
\mathrm{GE} \\
\mathrm{GE} \\
\mathrm{GE} \\
\mathrm{GE} \\
\mathrm{GE} \\
\mathrm{GE} \\
\mathrm{GE} \\
\mathrm{GE} \\
\mathrm{GE} \\
\mathrm{GE} \\
\mathrm{GE} \\
\mathrm{GE}\end{array}$ \\
\hline
\end{tabular}

WELL LFW 58D Replicate

MEASUREMENTS CONDUCTED IN THE FIELD

Sample date: 10/28/91

Depth to water: $25.67 \mathrm{ft}(7.82 \mathrm{~m})$ below TOC

Water elevation: $141.93 \mathrm{th}$

Water evacuated before sampling: 49 gal
Watuct $32 \mu \mathrm{sm}$

LABOPATORY ANALYSES

\begin{tabular}{|c|c|c|c|c|c|}
\hline$\underline{F}$ & Analyte & Result & Mod & Unit & Lab \\
\hline $\begin{array}{l}0 \\
0 \\
0 \\
0 \\
0 \\
0 \\
0 \\
0 \\
0 \\
0 \\
0 \\
0 \\
0 \\
0 \\
0 \\
0 \\
0 \\
0 \\
0 \\
0 \\
0 \\
0 \\
0 \\
0 \\
0 \\
0 \\
0 \\
0 \\
0\end{array}$ & $\begin{array}{l}\text { pH } \\
\text { Specific condustance } \\
\text { Arsenic } \\
\text { Arsenic } \\
\text { Barium } \\
\text { Benzene } \\
\text { Bromodichioromethane } \\
\text { Bromoform } \\
\text { Bromomethane } \\
\text { Cadmium } \\
\text { Calcium } \\
\text { Carbon tetrachioride } \\
\text { Chloride } \\
\text { Chlorobenzene } \\
\text { Chloroethane } \\
\text { Chloroethene Ninyl chloride) } \\
\text { 2-Chloroethyl vinyl ether } \\
\text { Chloroform } \\
\text { Chloromethane } \\
\text { Chromium } \\
\text { Dibromochloromethane } \\
1,1-\text { Dichlorothane } \\
1,2-\text { Dichloroethane } \\
\text { 1,1-Dichloroethylene } \\
\text { trans-1,2-Dichloroethylene } \\
\text { Dictiviomethane } \\
2,4-\text { Dichlorophenoxyacetic acid } \\
1,2-\text { Dichloropropane } \\
\text { cis-1,3-Dichloropropene }\end{array}$ & $\begin{aligned} & 5.3 \\
& 30 \\
&<2.0 \\
&<2.0 \\
& 6.7 \\
&<1.0 \\
&<1.0 \\
&<1.0 \\
&<1.0 \\
&<2.0 \\
& 1.140 \\
&<1.0 \\
& 4,620 \\
&<1.0 \\
&<1.0 \\
&<1.0 \\
&<1.0 \\
&<1.0 \\
&<1.0 \\
&<4.0 \\
&<1.0 \\
&<1.0 \\
&<1.0 \\
&<1.0 \\
&<1.0 \\
& 17 \\
&<0.30 \\
&<1.0 \\
&<1.0\end{aligned}$ & $\mathrm{~J} 2 \mathrm{~V}$ & $\begin{array}{l}p H \\
\mu \mathrm{S} / \mathrm{cm} \\
\mu g / L \\
\mu g / L \\
\mu g / L \\
\mu g / L \\
\mu g / L \\
\mu g / L \\
\mu g / L \\
\mu g / L \\
\mu g / L \\
\mu g / L \\
\mu g / L \\
\mu g / L \\
\mu g / L \\
\mu g / L \\
\mu g / L \\
\mu g / L \\
\mu g / L \\
\mu g / L \\
\mu g / L \\
\mu g / L \\
\mu g / L \\
\mu g / L \\
\mu g / L \\
\mu g / L \\
\mu g / L \\
\mu g / L \\
\mu g / L\end{array}$ & $\begin{array}{l}G E \\
G E \\
G E \\
G E \\
G E \\
G E \\
G E \\
G E \\
G E \\
G E \\
G E \\
G E \\
G E \\
G E \\
G E \\
G E \\
G E \\
G E \\
G E \\
G E \\
G E \\
G E \\
G E \\
G E \\
G E \\
G E \\
G E \\
G E \\
G E\end{array}$ \\
\hline
\end{tabular}

WELL LFW 58D collected on 10/29/91, laboratory analyses (cont)

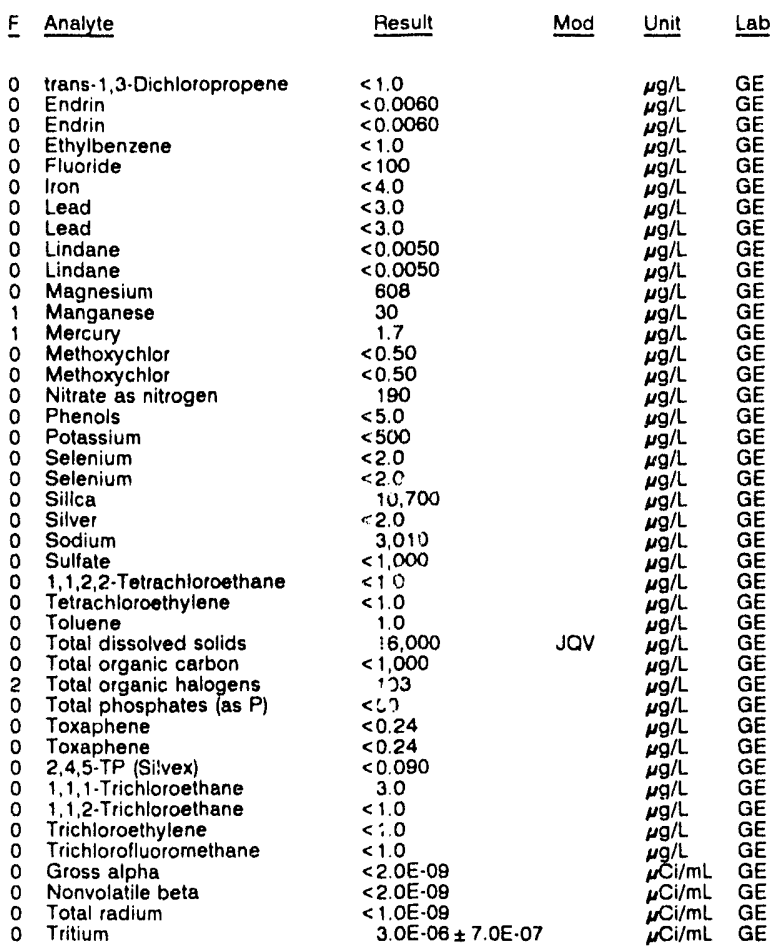

WELL LFW 59B

MEASUREMENTS CONDUCTED IN THE FIELD

Sample date: $10 / 31 / 91$

Depth to water: $25.07 \mathrm{Ht}(7.64 \mathrm{~m})$ below TOC

Water elevation: $143.03 \mathrm{Ht}(43.60 \mathrm{~m}) \mathrm{ms}$

Water evacuated before sampling: $203 \mathrm{gal}$

pH: 3.9

Alkalinity: $0 \mathrm{mgl}$

Water temperature: $19.0^{\circ} \mathrm{C}$

LABORATORY ANALYSES

\begin{tabular}{|c|c|c|c|}
\hline Analyte & Result & Mod & Unit \\
\hline $\begin{array}{l}\text { pH } \\
\text { Specific conductance } \\
\text { Arsenic } \\
\text { Barium } \\
\text { Benzene } \\
\text { Bromodichloromethane } \\
\text { Bromoform } \\
\text { Bromomethane } \\
\text { Cadmium } \\
\text { Calcium } \\
\text { Carbon tetrachloride } \\
\text { Chloride } \\
\text { Chlorobenzene } \\
\text { Chloroethane } \\
\text { Chloroethene Ninyl chloride) } \\
\text { 2-Chloroethyl vinyl ether } \\
\text { Chloroform } \\
\text { Chloromethane } \\
\text { Chromium } \\
\text { Dibromochloromethane } \\
\text { 1,1-Dichloroethane } \\
\text { 1,2-Dichloroethane } \\
\text { 1,1-Dichloroethylene } \\
\text { trans-1,2-Dichloroethylene } \\
\text { Dichloromethane } \\
\text { 2,4-Dichlorophenoxyacetic acid } \\
\text { 1,2-Dichloropropane } \\
\text { cis-1,3-Dichloropropene } \\
\text { t(ans-1,3-Dichloropropene } \\
\text { Endrin } \\
\text { Ethylbenzent } \\
\text { Fluoride } \\
\text { lron } \\
\text { Lead } \\
\text { Lindane } \\
\text { Magnesium } \\
\text { Manganese } \\
\text { Mercury } \\
\text { Methoxychlor } \\
\text { Nitrate as nitrogen } \\
\text { Phenols }\end{array}$ & $\begin{array}{l}4.4 \\
40 \\
<2.0 \\
63 \\
<1.0 \\
<1.0 \\
<1.0 \\
<1.0 \\
<2.0 \\
1.110 \\
<1.0 \\
2.430 \\
<1.0 \\
<1.0 \\
<1.0 \\
<1.0 \\
<1.0 \\
<1.0 \\
<4.0 \\
<1.0 \\
<1.0 \\
<1.0 \\
<1.0 \\
<1.0 \\
<1.0 \\
<0.30 \\
<1.0 \\
<1.0 \\
<1.0 \\
<0.0060 \\
<1.0 \\
<100 \\
19 \\
<3.0 \\
<0.9050 \\
449 \\
31 \\
<0.20 \\
<0.50 \\
480 \\
<5.0\end{array}$ & $\mathrm{~J} 2 \mathrm{~V}$ & $\begin{array}{l}p H \\
\mu \mathrm{S} / \mathrm{cm} \\
\mu g / L \\
\mu g / L \\
\mu g / L \\
\mu g / L \\
\mu g / L \\
\mu g / L \\
\mu g / L \\
\mu g / L \\
\mu g / L \\
\mu g / L \\
\mu g / L \\
\mu g / L \\
\mu g / L \\
\mu g / L \\
\mu g / L \\
\mu g / L \\
\mu g / L \\
\mu g / L \\
\mu g / L \\
\mu g / L \\
\mu g / L \\
\mu g / L \\
\mu g / L \\
\mu g / L \\
\mu g / L \\
\mu g / L \\
\mu g / L \\
\mu g / L \\
\mu g / L \\
\mu g / L \\
\mu g / L \\
\mu g / L \\
\mu g / L \\
\mu g / L \\
\mu g / L \\
\mu g / L \\
\mu g / L \\
\mu g / L \\
\mu g / L\end{array}$ \\
\hline
\end{tabular}


ANALYTICAL RESULTS

WELL LFW 598 collected on 10/31/91, laboratory analyses (cont.)

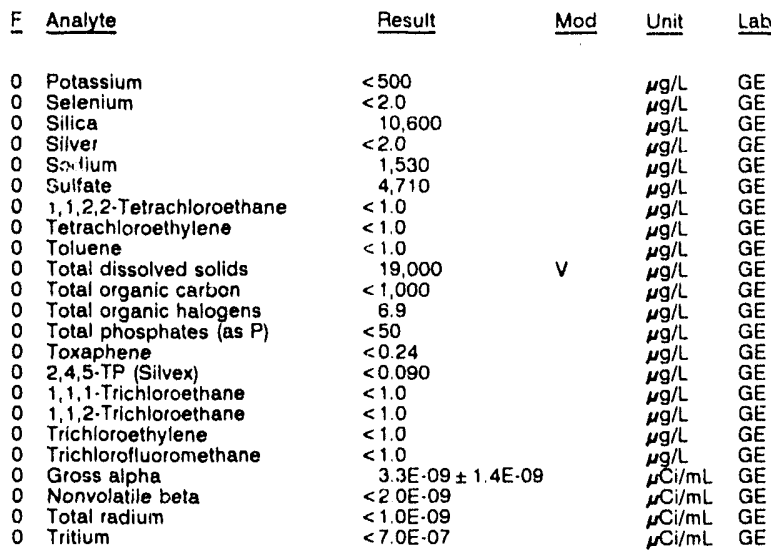

\section{WELL LFW 59C}

MEASUREMENTS CONDUCTED IN THE FIELD

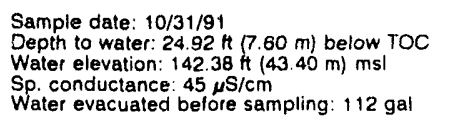

LABORATORY ANALYSES

E Analyte Besult Mod Unit Lab

${ }_{0}^{0} \mathrm{pH}_{0} \mathrm{Specific} \mathrm{conductance}$

0 Arsenic

0 Barium

B Bromodichloromethane

Bromotorm

Bromomethane

0 Cadmium

o Calcium

- Carbon tetrachloride

Chloride

Chlorobenzene

Chloroethane

Chloroethene Ninyl chloride
2-Chloroethyl vinyl ether

Chloroform

Chloromethan

Chromium

1.1-Dichloroethane

1,2. Oichloroethane

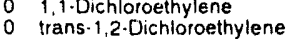

Dichloromethane

$\begin{array}{ll}\text { Dichloromethane } & <10 \\ \text { 2.4.Dichlorophenoxyacetic acid } & <0.30 \\ \text { 1.2. Dichloropropane } & <1.0\end{array}$

cis-1,3-Dichloropropene
0
trans-1,3-Dichloropropene

Ethylbenzene

Fluoride

Iron

Lead

Magnesium

Manganes

Methoxychio

Nitrate as nitrogen

Phenols

Potassium

Selenium

Silica

Sodium

1,1,2,2-Tetrachloroethane

0 Tetrachioroethylene

Total dissolved solids

Total organic halogens

Toxaphene

2.4.5.TP (Silvex)

1,1,1. Trichloroethane

- 1,1.2-Trichloroethane

2 Trichloroethylene
Time: $12: 25$

PH: 4.5 Alkalinity: $0 \mathrm{mg} / \mathrm{h}$

Water temperature: $190^{\circ} \mathrm{C}$

5.0
40
$<2.0$
9.5
$<1.0$
$<1.0$
$<1.0$
$<1.0$
$<2.0$
1.150
$<1.0$
5.950
5.950

$<10$

$<1.0$
$<1.0$
$<1.0$

1.0
$<10$

$<1.0$
$<4.0$

$<4.0$
$<1.0$
17

1.0

$<.0$
$<1.0$
10

$<0.30$
$<1.0$
$<1.0$

$<1.0$
$<1.0$

$<1.00060$

$<10$
$<100$

44
$<30$

$<0$ ก050

1.150

12
0.31
$<0.50$

$<0.50$
1,030
$<50$

578
-20

-20
9.400

$<2.0$
3.880

3.880
1.830
$<1.0$
1.0

$<10$

22,000

266

$<50$
$<024$

$<0240$

10
$<10$

$<10$
80

Jo

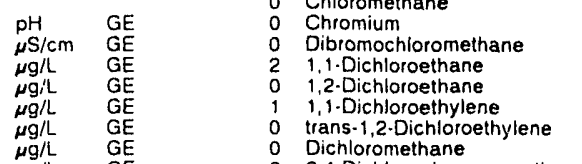

trans-1,2-Dichloro
0 Dichloromethane

2,4.Dichlorophenoxyacetic acid

1,2-Dichloropropane

cis-1,3-Dichloropropene

trans-1,

Endrin

Fluoride

Iron

Lead

O Magnesium

Manganese

Mercury

Methoxychlor

Nitrate as nitrogen
0 Nitrate as nitrogen

Phenois

- Potassium

0 Selenium

$\begin{array}{ll}0 & \text { Silica } \\ 0 & \text { Silvei }\end{array}$

$\begin{array}{ll}0 & \text { Silver } \\ 0 & \text { Sodium }\end{array}$

o Sulfate

o 1,1,2,2-Tetrachloroethane

Tetrachioroethylene

Toluene

- Total dissolved solids

Total organic carbon

Total organic halogens

Toxaphene

2,4.5.TP (Silvex)

1,1,1.Trichloroethane

1,1,2-Trichloroethane

2 Trichloroethylene

2 Trichlorofluoromethane

Gross alipha

Nonvolatile beta

2 Total radium

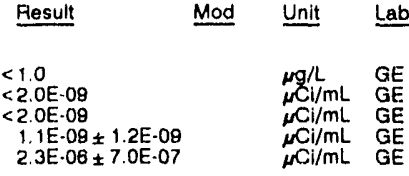

me: $13: 05$

pH: 4.8 . 0.

Water temperature: $19.7^{\circ} \mathrm{C}$

Result Mod Unit Lab

$\begin{aligned} & 5.3 \\ & 25 \text { JQ } \\ &<2.0 \\ & 7.1 \\ &<1.0 \\ &<1.0 \\ &<1.0 \\ &<1.0 \\ &<2.0 \\ & 835 \\ &<1.0 \\ & 3.880 \\ &<1.0 \\ &<1.0 \\ &<1.0 \\ &<1.0 \\ &<1.0 \\ &<1.0 \\ &<4.0 \\ &<1.0 \\ & 119 \\ &<1.0 \\ & 3.8 \\ &<1.0 \\ & 3.8\end{aligned}$

$\stackrel{\mathrm{pH}}{\mathrm{HS} / \mathrm{cm}} \quad \mathrm{GE}$

$\begin{array}{ll}\mu g / L & G E \\ \mu g / L & G E\end{array}$

$\mu g / L \quad G E$

$\mu g / L \quad G E$

$\mu g / L \quad G E$

$\mu g / L \quad G E$

$\mu g / L \quad G E$

$g / L \quad G E$

$3.8 \quad$ J2V

$<0.30$

$<1.0$

$<0.0060$

$<1.0$

$<100$
6.6

$<3.0$

738

$<0.20$

$<50$

$<50$
$<5.0$
$<500$

$<2.0$

$<2.0$
2.140

2.140
$<1.000$

$<1.0$
2.5

2.5
$<1.0$
15000

$\begin{aligned} & 15,000 \\ < & 1,000\end{aligned}$

$<1,000$
$<50$

$<0.24$

$<0.090$

40
$<1.0$
27

27
109

$<2.0 \mathrm{E}-09$

$<2.0 E-09$

$9.3 \mathrm{E} \cdot 09 \pm 2.2 \mathrm{E} \cdot 09$
$<70 \mathrm{E} \cdot 07$

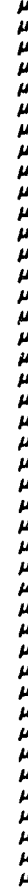

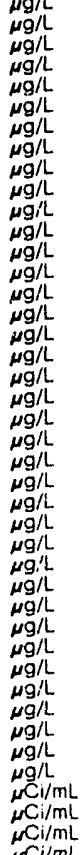


ANALYTICAL RESULTS

\section{WELL LFW 60D}

MEASUREMENTS CONDUCTED IN THE FIELD

Sample date: 10/29/9

Sp. conductance: $40 \mu \mathrm{S} / \mathrm{cm}$

Water evacuated before sampling: $10 \mathrm{gal}$

LABORATORY ANALYSES

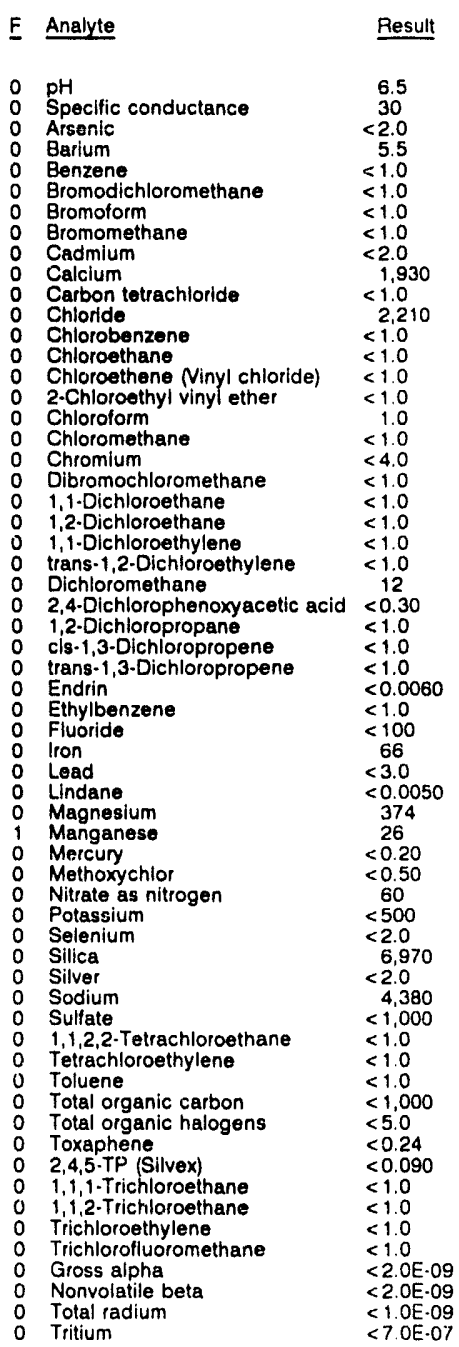

WELL LFW 61C

MEASUREMENTS CONOUCTED IN THE FIELD

\section{Sample date: $10 / 31 / 91$}

Depth to water: $26.60 \mathrm{H}(8.11 \mathrm{~m})$ below TOC

Water elevation: $141.70 \mathrm{ft}(43.1$

Sp. conductance: $25 \mu \mathrm{s} / \mathrm{cm}$
Water evacuated before sampling: $81 \mathrm{gal}$

LABORATORY ANALYYSES

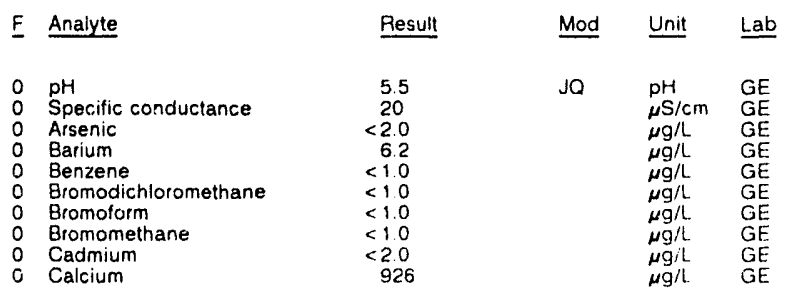

WELL LFW 61C collected on 10/31/91, laboratory analyses (cont.)

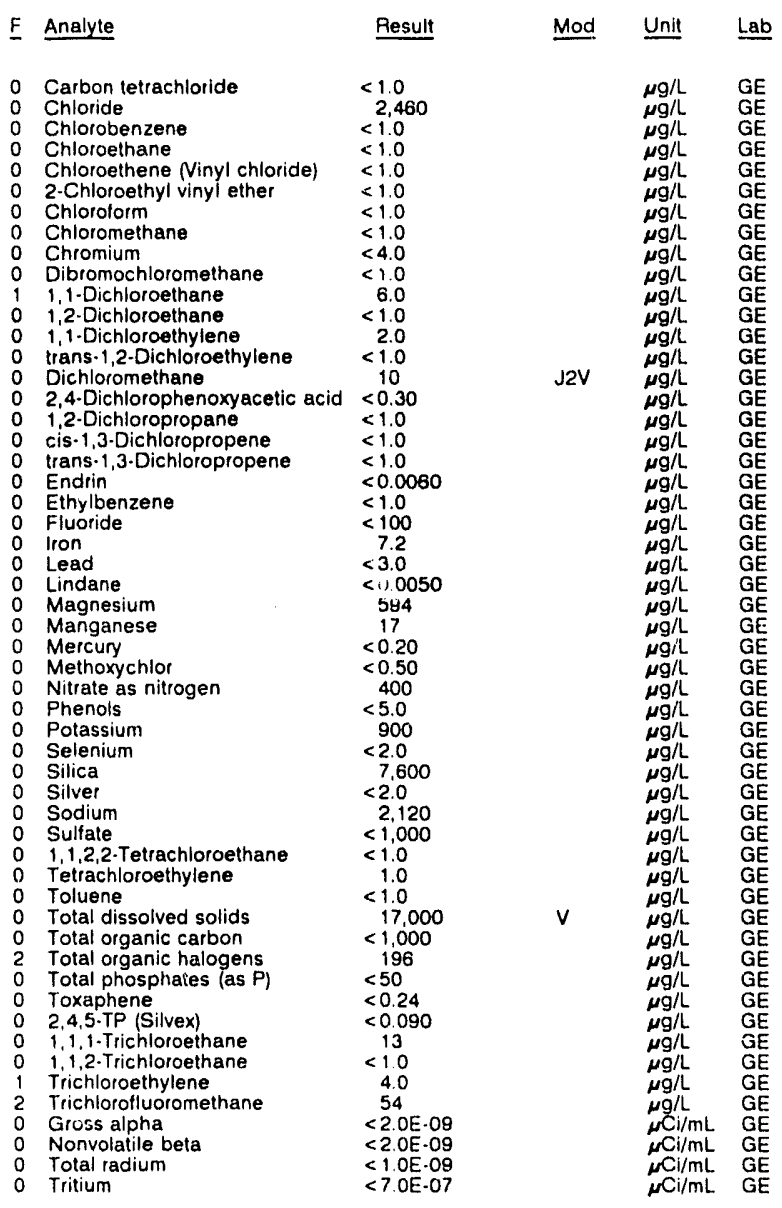

\section{WELL LFW 61D}

MEASUREMENTS CONDUCTED IN THE FIELD

Sample date: 10/31/91

Depth to water: $24.88 \mathrm{ft}(7.58 \mathrm{~m})$ below TOC

Water elevation: $143.42 \mathrm{ht}(43.7$

. conductance: $25 \mu \mathrm{S} / \mathrm{cm}$

Time: 13:35

Alkalinity: $0 \mathrm{mg} / \mathrm{L}$

Water temperature: $19.0^{\circ} \mathrm{C}$

\section{LABORATORY ANALYSES}

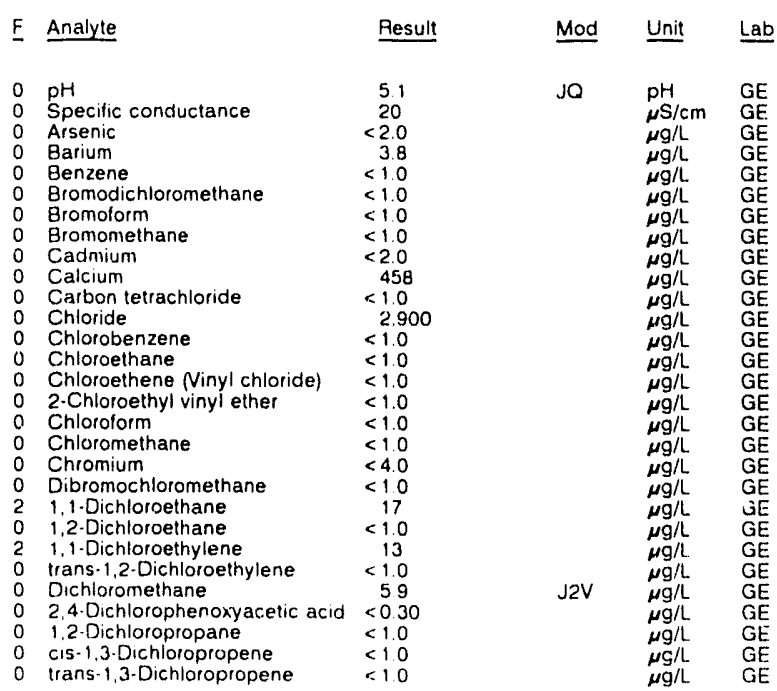


ANALYTICAL RESULTS

\begin{tabular}{|c|c|c|c|c|c|}
\hline$E$ & Analyte & Result & Mod & Unit & Lab \\
\hline & $\begin{array}{l}\text { Endrin } \\
\text { Ethylbenzene } \\
\text { Fluoride } \\
\text { ron } \\
\text { Lead } \\
\text { Lindane } \\
\text { Magnesium } \\
\text { Manganese } \\
\text { Mercury } \\
\text { Methoxychior } \\
\text { Nitrate as nitrogen } \\
\text { Phenols } \\
\text { Potassium } \\
\text { Selenium } \\
\text { Silica } \\
\text { Silver } \\
\text { Sodium } \\
\text { Sulfate } \\
\text { 1,1,2,2-Tetrachlorr: } 1 \text { rane } \\
\text { Tetrachloroethylen } \\
\text { Toluene } \\
\text { Total dissolved solids } \\
\text { Total organic carbon } \\
\text { Total organic halogens } \\
\text { Total phosphates (as P) } \\
\text { Toxaphene } \\
2,4,5 \cdot \text { TP (Silvex) } \\
1,1,1 \cdot \text { Trichloroethane } \\
\text { 1,1,2-Trichloroethane } \\
\text { Trichloroethylene } \\
\text { Trichlorofluoromethane } \\
\text { Gross alpha } \\
\text { Nonvolatile beta } \\
\text { Total radium } \\
\text { Tritium }\end{array}$ & $\begin{array}{l}<0.0060 \\
<1.0 \\
<100 \\
4.1 \\
6.3 \\
<0.0050 \\
715 \\
<2.0 \\
<0.20 \\
<0.50 \\
150 \\
<5.0 \\
<500 \\
<2.0 \\
8,710 \\
<2.0 \\
1,830 \\
1,160 \\
<1.0 \\
30 \\
<1.0 \\
17.000 \\
<1,000 \\
231 \\
90 \\
<0.24 \\
<0.090 \\
70 \\
<1.0 \\
8.6 \\
116 \\
4.5 \mathrm{E} \cdot 09 \pm 1.6 \mathrm{E} \cdot 09 \\
<2.0 \mathrm{E} \cdot 09 \\
3.2 \mathrm{E} \cdot 09 \pm 1.5 \mathrm{E} \cdot 09 \\
<7.0 \mathrm{E} \cdot 07\end{array}$ & $v$ & $\begin{array}{l}\mu g / L \\
\mu g / L \\
\mu g / L \\
\mu g / L \\
\mu g / L \\
\mu g / L \\
\mu g / L \\
\mu g / L \\
\mu g / L \\
\mu g / L \\
\mu g / L \\
\mu g / L \\
\mu g / L \\
\mu g / L \\
\mu g / L \\
\mu g / L \\
\mu g / L \\
\mu g / L \\
\mu g / L \\
\mu g / L \\
\mu g / L \\
\mu g / L \\
\mu g / L \\
\mu g / L \\
\mu g / L \\
\mu g / L \\
\mu g / L \\
\mu g / L \\
\mu g / L \\
\mu g / L \\
\mu g / L \\
\mu C i / m L \\
\mu C i / m L \\
\mu C i / m L \\
\mu C i / m L\end{array}$ & $\begin{array}{l}G E \\
G E \\
G E \\
G E \\
G E \\
G E \\
G E \\
G E \\
G E \\
G E \\
G E \\
G E \\
G E \\
G E \\
G E \\
G E \\
G E \\
G E \\
G E \\
G E \\
G E \\
G E \\
G E \\
G E \\
G E \\
G E \\
G E \\
G E \\
G E \\
G E \\
G E \\
G E \\
G E \\
G E \\
G E\end{array}$ \\
\hline
\end{tabular}

\section{WELL LFW 62B}

MEASUREMENTS CONDUCTED IN THE FIELD

Sample date: $10 / 31 / 91$
Depth to water: $22.59 \mathrm{ft}(6.89 \mathrm{~m})$ below TOC
Water elevation: $142.31 \mathrm{Ht}(43.38 \mathrm{~m}) \mathrm{msl}$
Sp. conductance: $32 \mu \mathrm{S} / \mathrm{cm}$
Water evacuated belore sampling: $210 \mathrm{gal}$
LABORATORY ANALYSES

E Analyte Result Mod Unit

$\begin{array}{lll}0 & \mathrm{pH} \\ 0 & \text { Specific conductance }\end{array}$

Arsenic

Barium

Benzene
Bromodichloromethane
Bromolorm

Bromomethane

Bromometh

Calcium

Carbon tetrachloride

Chloride

Chlorobenzene

Chloroethane

Chloroethene Ninyl chloridd
2-Chloroethyl vinyl ether

Chloromethan

Dibromochloromethane

1.1.Dichloroethane

1,2.Dichloroethane

1.1.Dichloroethylene

Dichloromethane

1,2-Dichloropropane

cis-1,3-Dichloropropene

trans-1,3-Dichloropropene

Endrin

Ethylbenzene

Fluoride

Iron

1 Lead

Lindane

Manganese

Mercury

Methoxychior

0 Nitrate as

Potassium

Selenium

0 Silica

0 Silver

Sodium

1,1,2,2.Tetrachloroethane

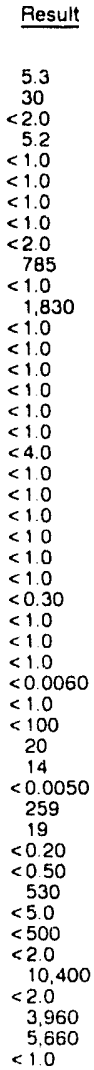

Time: $11: 40$

$\mathrm{pH}: 5.0$

Alkalinity: $0 \mathrm{mg} / \mathrm{L}$

Water temperature: $19.1^{\circ} \mathrm{C}$

Jo

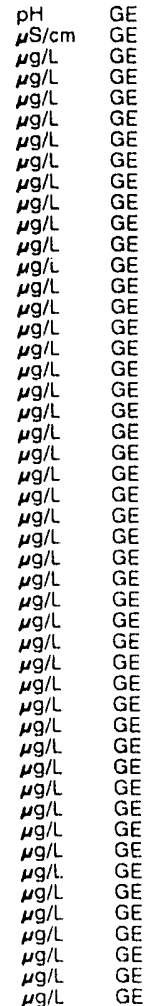

WELL. LFW 62B collected on 10/31/91, laboratory analyses (cont.)

\begin{tabular}{|c|c|c|c|}
\hline Analyte & Result & Mod & Unit \\
\hline $\begin{array}{l}\text { Tetrachloroethylene } \\
\text { Toluene } \\
\text { Total dissolved sollds } \\
\text { Total dissolved solids } \\
\text { Total organic carbon } \\
\text { Total organic halogens } \\
\text { Total phosphates (as P) } \\
\text { Toxaphene } \\
2,4,5-T P \text { (Silvex) } \\
1,1,1 \text {-Trichloroethane } \\
1,1,2 \text {-Trichloroethane } \\
\text { Trichloroethylene } \\
\text { Trichlorofluoromethane } \\
\text { Gross alpha } \\
\text { Nonvolatile beta } \\
\text { Total radium } \\
\text { Tritium }\end{array}$ & $\begin{array}{l}<1.0 \\
<1.0 \\
45,000 \\
47,000 \\
<1,000 \\
10 \\
200 \\
<0.24 \\
<0.090 \\
<1.0 \\
<1.0 \\
<1.0 \\
<1.0 \\
1.4 E \cdot 08 \pm 4.8 E-09 \\
7.7 E-09 \pm 4.3 \mathrm{E} \cdot 09 \\
2.2 \mathrm{E} \cdot 09 \pm 1.7 \mathrm{E} \cdot 09 \\
<7.0 \mathrm{E}-07\end{array}$ & $\begin{array}{l}v \\
v\end{array}$ & $\begin{array}{l}\mu g / L \\
\mu g / L \\
\mu g / L \\
\mu g / L \\
\mu g / L \\
\mu g / L \\
\mu g / L \\
\mu g / L \\
\mu g / L \\
\mu g / L \\
\mu g / L \\
\mu g / L \\
\mu g / L \\
\mu C / / m L \\
\mu C / / m L \\
\mu C l / m L \\
\mu C / / m L\end{array}$ \\
\hline
\end{tabular}

WELL LFW 62C

MEASUREMENTS CONDUCTED IN THE FIELD

Sample date: 10/29/91

below TOC

Water elevation: $142.63 \mathrm{ft}(43.4$

Sp. conductance: $26 \mu \mathrm{S} / \mathrm{cm}$

LABORATORY ANALYSES

F Analyte Pesult Mod Unit Lab

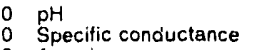

Arsenic

Arsenic

Barium

$\begin{array}{ll}\text { Benzene } \\ 0 & \text { Bromodichloromethane }\end{array}$

Bromoform

Bromomethane

Carbon tetrachloride

Chloride

Chlorobenzene

Chioroethane

2.Chloroethyl vinyl ether

2.Chloroethy

Chloroform

Chlorometh

Dibromochloromethane

1,1-Dichloroethane

1,2-Dichloroethane

1.1. Dichloroethylene

trans-1,2-Dichloroethylene

$\begin{array}{ll}\text { Dichloromethane } & 5.0 \\ \text { 2,4-Dichlorophenoxyacetic acid }<0.30\end{array}$

1,2-Dichloropropane

cis-1,3-Dichloropropene

Endrin

Endrin

Ethylbenzene

Iron

0 Lead

0 Lindane

Lindane

Magnesium

Manganese

Mercury

Methoxychior

Nituate as nitrogen

Phenols

Phenols

Potassium

Selenium

Selenium
Silica

Silica

Sodium

Sulfate

$1,1,2,2 \cdot$ Tetrachloroethar
Tetrachloroethylene

Toluene

Total dissolved solids

Total organic carbon

Total organic halogens

Total phos

Toxaphene

Toxapnene

1,1,1-Trichloroethane

1,1,2-Trichloroethane

ime: $14:$

Alkalinity: $1 \mathrm{mg} / \mathrm{L}$

Water temperature: $19.1^{\circ} \mathrm{C}$

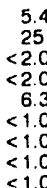

25
$<2.0$
$<2.0$
6.3
$<1.0$
$<1.0$
$<1.0$
$<1.0$

$<2.0$

$<, 1$
2,100

$<1.0$
$<1.0$

$<1.0$

$<1.0$

$<1.0$

$\therefore 4.0$

$<1.0$

$<10$

$<1.0$

$<1.0$

$<1.0$

$<0.0060$
$<0.0060$

$<1.0$

$<100$

$<4.0$

$<3.0$

$<0.0050$

812

18

0.34
$<0.50$
$<0.50$

$<0.50$

1.470

$<5.0$

540
$<20$

$<2.0$

7.940
$<2.0$

$<2.0$

$<1,000$

$<1.0$
2.0

$\begin{array}{r}2.0 \\ <1.0 \\ \hline 17.000\end{array}$

17,000

$<1,000$

22
$<50$
$<024$

$<0.24$
$<0.24$

$<0.090$

$<1.0$
$<1.0$

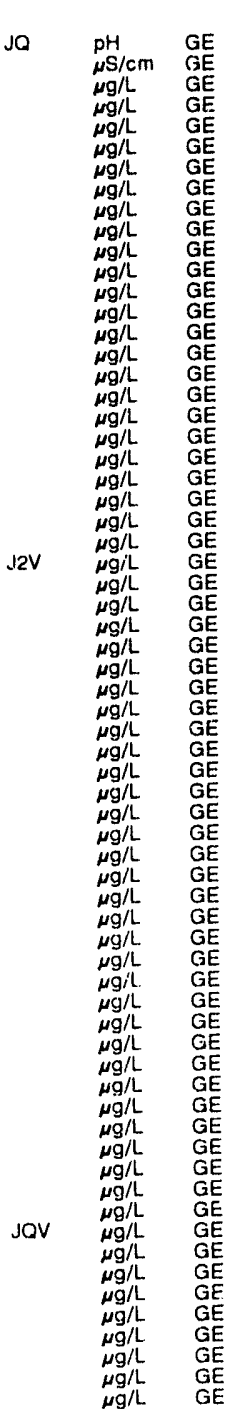




\section{ANALYTICAL RESULTS}

WELL LFW 62C collected on 10/29/91, laboratory analyses (cont.)

\begin{tabular}{|c|c|c|c|}
\hline Analyte & Result & Mod & Unit \\
\hline $\begin{array}{l}\text { Trichloroethylene } \\
\text { Trichlorofluoromethane } \\
\text { Gross alpha } \\
\text { Nonvolatile beta } \\
\text { Total radium } \\
\text { Tritium }\end{array}$ & $\begin{aligned} & 6.0 \\
& 1.0 \\
&<2.0 \mathrm{E} \cdot 09 \\
&<2.0 \mathrm{E} \cdot 09 \\
&<1.0 \mathrm{E} \cdot 09 \\
&<7.0 \mathrm{E} \cdot 07\end{aligned}$ & & 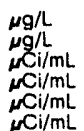 \\
\hline
\end{tabular}

\section{WELL LFW 62D}

MEASUREMENTS CONDUCTED IN THE FIELD Depth to water: $21.69 \mathrm{Ht}(8.61 \mathrm{~m})$ below TOC Water elevation. $143.11 \mathrm{ft}(43.62 \mathrm{~m}) \mathrm{msl}$ We conductance: 34 s/cm Water evacuated before sampling: $10 \mathrm{gal}$ The well went dry during purging.

LABORATORY ANALYSES

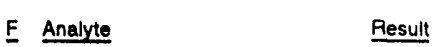

Time: $14: 25$

Alkalinity: $5 \mathrm{mg} / \mathrm{h}$

Water temperature: $19.1^{\circ} \mathrm{C}$

F Analyte

0 pH

Arsenic

Arsenic

Barium

Bromodichloromethane

Bromoform

Bromomethane

Cadmium

Carbon tetrachloride

Chloride

Chlorobenzene

Chloroethane

2-Chloroethyl vinyl ether

Chloroform

Chloromethar

Dibromochloromethane

1,1-Dichloroethane

1,1-Dichloroethylene

trans-1,2-Dichioroeth

1,2-Dichloropropan

cis-1,3-Dichloropropene

trans-1,3-Dichloropropene

Endrin

Ethylbenzene

Ethylbenzen

Iron

Lead

Lindan

Lindane

Magnesium

Manganes

Mercury

Methoxychlor

Nitrate as nitrogen

Phenols

Selenium

Silica

Silica

Sodium

Sulfate

$1,1,2,2 \cdot$ Tetrachioroethane

Tetrachloroethylene

Toluen

Total dissolved solids

Total organic carbon

Total organic halogens
Total phosphates las P)

Toxaphene

Toxaphen

2,4,5.TP (Silvex)

1,1,1-Trichloroethane

1,1,2-Trichloroethane

Trichloroethylene

Trichlorofluoromethane

Gross alpha

Nonvolatile beta

Total ra
Resuit Mod Unit Lab

JO

5.4
30
$<2.0$
$<2.0$
9.4
$<1.0$
$<1.0$
$<1.0$
$<1.0$

$<2.0$

$<1.0$

$<1.0$

$<1.0$
$<1.0$
$<1.0$
$<1.0$

$<1.0$

$<1.0$
$<1.0$
$<1.0$
27

$<1.0$

4.0
$<1.0$

$<1.0$
$<0.30$

$<1.0$

$<1.0$

$<0.0060$

$<0.0060$
$<1.0$
$<100$

$<100$

29
$<3.0$

$<3.0$

$<0.0050$

729
46

$<0.20$

$<0.50$

$<0.50$

$<5.0$

$<500$
$<2.0$

$<2.0$

$<2.0$

3,020

$<1.000$
$<1.0$

4.0
$<1.0$

26,000
$<1,000$

247

$<50$
$<0.24$

$<0.24$

36
$<1.0$

$<1.0$
8.0

26

$<2.0 E .09$
$<2.0 E .09$

$<1.0 E .09$
$<7.0 E .07$

J2V

WELLL LRP 1

MEASUREMENTS CONDUCTEO IN THE FIELO

Sample date: 11/25/91

Depth to water: $43.55 \mathrm{Ht}(13.27 \mathrm{~m})$ below TOC

Sp. conductance $19.35 \mathrm{~h}(63$.

Water evacuated before sampling: $62 \mathrm{gal}$

Time: 9:20

pH: 4.8 Alkalinity: $1 \mathrm{mgl}$

Water temperature: $15.9^{\circ} \mathrm{C}$

WELL LRP 2

MEASUREMENTS CONDUCTED IN THE FIELD

Sample date: $11 / 25 / 91$

Depth to water: $45.83 \mathrm{ft}(13.97 \mathrm{~m})$ below TOC

Water elevation: $210.87 \mathrm{ht}(64.27 \mathrm{~m}) \mathrm{ms}$ |

Sp. conductance: $29 \mu \mathrm{s} / \mathrm{cm}$
Water evacuated before sampling: $69 \mathrm{gal}$

Time: 9:35

pH: 5.1

Water temperature: $16.0^{\circ} \mathrm{C}$

WELL LRP 3

MEASUREMENTS CONDUCTED IN THE FIELD

Sample date: 11/25/91

Depth to water: $48.17 \mathrm{ft}(14.68 \mathrm{~m})$ below TOC

Water elevation: $210.03 \mathrm{ft}(64.02 \mathrm{~m}) \mathrm{ms}$

Water evacuated before sampling: $49 \mathrm{gal}$

Time: $9: 50$

pH: 4.9

Alkalinity: $1 \mathrm{mg} / \mathrm{L}$

Water temperature: $16.4^{\circ} \mathrm{C}$

WELL LRP 4

MEASUREMENTS CONOUCTED IN THE FIELO

Sample date: $11 / 25 / 91$

Depth to water: $46.48 \mathrm{Ht}(14.17 \mathrm{~m})$ below TOC

Water elevation: $209.12 \mathrm{Ht}$ (63.

Sp. conduclance: $25 \mu \mathrm{s} / \mathrm{cm}$.

Time: $8: 45$

oH: 4.9

Alkalinity: $0 \mathrm{mg} / \mathrm{L}$

Water evacuated before sampling: $94 \mathrm{gal}$

WELL LSB 1

MEASUREMENTS CONDUCTED IN THE FIELD

Sample date: 10/24/91

Depth to water: $17.79 \mathrm{ft}(5.42 \mathrm{~m})$ below TOC

Sp conductance: $20.91 \mathrm{th}$

Time: 8.30

H: 4.3

$0 \mathrm{mg}$

Water evacuated before sampling: $58 \mathrm{gal}$

LABORATORY ANALYSES

\begin{tabular}{|c|c|c|c|}
\hline Analyte & Result & Unit & $\underline{L a b}$ \\
\hline $\begin{array}{l}\text { Aluminum } \\
\text { Lead } \\
\text { Antimony-125 } \\
\text { Cerium-144 } \\
\text { Cesium-1144 } \\
\text { Cesium-137 } \\
\text { Chromium.51 } \\
\text { Cobalt-60 } \\
\text { Gross alpha } \\
\text { lodine-131 } \\
\text { Niobium-95 } \\
\text { Nonvolatile beta } \\
\text { Ruthenium-103 } \\
\text { Ruthenium-106 } \\
\text { Strontium-89/90 } \\
\text { Total activity } \\
\text { Tritium } \\
\text { Zirconium-95 }\end{array}$ & $\begin{aligned} & 49 \\
& 14 \\
&<4.3 \mathrm{E} \cdot 08 \\
&<8.3 \mathrm{E}-08 \\
&<1.4 \mathrm{E}-08 \\
&<1.4 \mathrm{E} \cdot 08 \\
&<1.1 \mathrm{E}-07 \\
&<1.8 \mathrm{E} \cdot 08 \\
&<2.0 \mathrm{E} \cdot 09 \\
&<1.5 \mathrm{E}-08 \\
&<2.2 \mathrm{E} \cdot 08 \\
&<2.0 \mathrm{E} \cdot 09 \\
&<1.4 \mathrm{E}-08 \\
&<1.3 \mathrm{E}-07 \\
&-7.1 \mathrm{E}-10 \pm 1.5 \mathrm{E} \cdot 09 \\
& 4.1 \mathrm{E}-03 \pm 4.7 \mathrm{E} \cdot 05 \\
& 3.7 \mathrm{E} \cdot 03 \pm 9.4 \mathrm{E} \cdot 06 \\
&<2.7 \mathrm{E} \cdot 08\end{aligned}$ & $\begin{array}{l}\mu \mathrm{g} / \mathrm{L} \\
\mu \mathrm{g} / \mathrm{L} \\
\mu \mathrm{Ci} / \mathrm{mL} \\
\mu \mathrm{Ci} / \mathrm{mL} \\
\mu \mathrm{Ci} / \mathrm{mL} \\
\mu \mathrm{Ci} / \mathrm{mL} \\
\mu \mathrm{Ci} / \mathrm{mL} \\
\mu \mathrm{Ci} / \mathrm{mL} \\
\mu \mathrm{Ci} / \mathrm{mL} \\
\mu \mathrm{Ci} / \mathrm{mL} \\
\mu \mathrm{Ci} / \mathrm{mL} \\
\mu \mathrm{Ci} / \mathrm{mL} \\
\mu \mathrm{Ci} / \mathrm{mL} \\
\mu \mathrm{Ci} / \mathrm{mL} \\
\mu \mathrm{Ci} / \mathrm{mL} \\
\mu \mathrm{Ci} / \mathrm{mL} \\
\mu \mathrm{Ci} / \mathrm{mL} \\
\mu \mathrm{Ci} / \mathrm{mL}\end{array}$ & $\begin{array}{l}G E \\
G E \\
E M \\
E M \\
E M \\
E M \\
E M \\
E M \\
G E \\
E M \\
E M \\
G E \\
E M \\
E M \\
E M \\
E M \\
G E \\
E M\end{array}$ \\
\hline
\end{tabular}


WELL LSB 1

MEASUREMENTS CONDUCTED IN THE FIELD

Sample date: 11/19/91

Depth to water: $17.73 \mathrm{Ht}(5.40 \mathrm{~m})$ below TOC

Water elevation: $214.97 \mathrm{ft}(65.52 \mathrm{~m}) \mathrm{msl}$

Sp. conductance: $25 \mu \mathrm{S} / \mathrm{cm}$

Water evacuated before sampling: $58 \mathrm{gal}$

LABORATORY ANALYSES

\begin{tabular}{|c|c|c|c|}
\hline E Analyte & Result & Mod & Unit \\
\hline $\begin{array}{ll}0 & \text { Aluminum } \\
0 & \text { Gross alpha } \\
0 & \text { Nonvolatile beta } \\
2 & \text { Tritium } \\
2 & \text { Tritium }\end{array}$ & $\begin{array}{l}36 \\
3.5 E-10 \pm 3.1 E-10 \\
6.7 E-10 \pm 8.6 E-10 \\
3.7 E-03 \pm 9.5 E-06 \\
4.3 E-03 \pm 4.8 E-05\end{array}$ & & $\begin{array}{l}\mu g / L \\
\mu \mathrm{mL} \\
\mu \mathrm{L} / / \mathrm{mL} \\
\mu \mathrm{Ci} / \mathrm{mL} \\
\mu \mathrm{CL} / \mathrm{mL} \\
\mu \mathrm{Ci} / \mathrm{mL}\end{array}$ \\
\hline
\end{tabular}

WELLL LSB 1

MIESUUREMENTS CONDUCTED IN THE FIELD

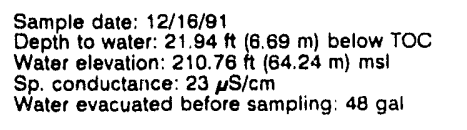

Time: $9: 30$

$\mathrm{pH}: 4.5$

Alkalinity: $0 \mathrm{mg} / \mathrm{L}$

Water temperature: $19.9^{\circ} \mathrm{C}$

$\mathrm{MCl} / \mathrm{mL} \quad \mathrm{EM}$

LABORATORY ANALYSES

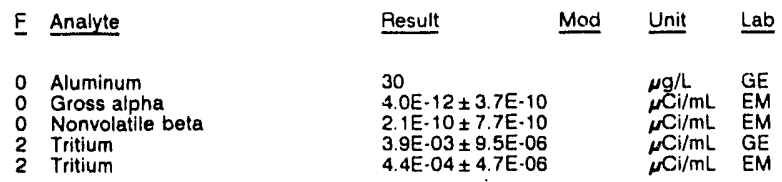

WELL LSB 2

MEASUREMENTS CONDUCTED IN THE FIELD

Sample date: $10 / 24 / 91$
Depth to water: $19.91 \mathrm{Ht}(6.07 \mathrm{~m})$ below TOC
Water elevation: $215.28 \mathrm{Ht}(65.62 \mathrm{~m}) \mathrm{msl}$
Sp. conductance: $31 \mu \mathrm{s} / \mathrm{cm}$

Water evacuated before sampling: $53 \mathrm{gal}$

\section{Time: $13: 40$}

$\mathrm{pH}: 4.9$

Water temperature: $19.4^{\circ} \mathrm{C}$

LABORATORY ANALYSES

\begin{tabular}{|c|c|c|c|}
\hline Analyte & Result & Mod & Unit \\
\hline $\begin{array}{l}\text { Aluminum } \\
\text { Lead } \\
\text { Antimony-125 } \\
\text { Cerium-144 } \\
\text { Cesium- } 134 \\
\text { Cesium-137 } \\
\text { Chromium-51 } \\
\text { Cobalt-60 } \\
\text { Gross alpha } \\
\text { lodine-131 } \\
\text { Nioblum-95 } \\
\text { Nonvolatile beta } \\
\text { Ruthenium-103 } \\
\text { Ruthenium-106 } \\
\text { Strontium } 89 / 90 \\
\text { Tritium } \\
\text { Zirconium-95 }\end{array}$ & $\begin{aligned} & 204 \\
& 7.8 \\
&<3.5 \mathrm{E} \cdot 08 \\
&<7.3 \mathrm{E} \cdot 08 \\
&<1.2 \mathrm{E} \cdot 08 \\
&<1.4 \mathrm{E} \cdot 08 \\
&<9.9 \mathrm{E} \cdot 08 \\
&<1.5 \mathrm{E} \cdot 08 \\
&<2.0 \mathrm{E} \cdot 09 \\
&<1.3 \mathrm{E} \cdot 08 \\
&<1.8 \mathrm{E} \cdot 08 \\
&<2.0 \mathrm{E} \cdot 09 \\
&<1.2 \mathrm{E} \cdot 08 \\
&<1.3 \mathrm{E} \cdot 07 \\
& 2.0 \mathrm{E} \cdot 09 \pm 1.9 \mathrm{E} \cdot 09 \\
&<7.0 \mathrm{E} \cdot 07 \\
&<2.6 \mathrm{E} \cdot 08\end{aligned}$ & $\mathrm{~J} 2$ & $\begin{array}{l}\mu \mathrm{g} / \mathrm{L} \\
\mu \mathrm{g} / \mathrm{L} \\
\mu \mathrm{Ci} / \mathrm{mL} \\
\mu \mathrm{Ci} / \mathrm{mL} \\
\mu \mathrm{Ci} / \mathrm{mL} \\
\mu \mathrm{Ci} / \mathrm{mL} \\
\mu \mathrm{Ci} / \mathrm{mL} \\
\mu \mathrm{Ci} / \mathrm{mL} \\
\mu \mathrm{Ci} / \mathrm{mL} \\
\mu \mathrm{Ci} / \mathrm{mL} \\
\mu \mathrm{Ci} / \mathrm{mL} \\
\mu \mathrm{Ci} / \mathrm{mL} \\
\mu \mathrm{Ci} / \mathrm{mL} \\
\mu \mathrm{Ci} / \mathrm{mL} \\
\mu \mathrm{Ci} / \mathrm{mL} \\
\mu \mathrm{Ci} / \mathrm{mL} \\
\mu \mathrm{Ci} / \mathrm{mL}\end{array}$ \\
\hline
\end{tabular}

WELL LSB 2

MEASUREMENTS CONIUUCTED IN THE FIELD

Sample date: $11 / 19 / 91$

Depth to water: $19.85 \mathrm{ft}(6.05 \mathrm{~m})$ below TOC

Water elevation: $215.35 \mathrm{ft}$

Time: $8: 45$

$\mathrm{pH}: 4.4$

Alkalinity: $0 \mathrm{mg} / \mathrm{L}$

Water temperature: $21.0^{\circ} \mathrm{C}$

Water evacuated before sampling: $54 \mathrm{gal}$

LABORATORY ANALYSES

\begin{tabular}{|c|c|c|c|c|}
\hline$\underline{F}$ & Analyte & Result & Mod & Unit \\
\hline & $\begin{array}{l}\text { Aluminum } \\
\text { Gross alpha } \\
\text { Nonvolatile beta } \\
\text { Tritium } \\
\text { Tritium }\end{array}$ & $\begin{array}{l}184 \\
77 \mathrm{E} \cdot 10 \pm 4.3 \mathrm{E} \cdot 10 \\
1.2 \mathrm{E} \cdot 09 \pm 7.8 \mathrm{BE} \cdot 10 \\
48 \mathrm{BE} \cdot 06 \pm 7.0 \mathrm{DE} \cdot 07 \\
5.1 \mathrm{E} \cdot 06 \pm 8.2 \mathrm{E} \cdot 07\end{array}$ & & $\begin{array}{l}\mu \mathrm{g} / \mathrm{L} \\
\mu \mathrm{C} / / \mathrm{mL} \\
\mu \mathrm{Ci} / \mathrm{mL} \\
\mu \mathrm{Ci} / \mathrm{mL} \\
\mu \mathrm{Cl} / \mathrm{mL}\end{array}$ \\
\hline
\end{tabular}

Time: 9.15

PH: 4.1 : $0 \mathrm{mg} / \mathrm{h}$

Alkalinity: $0 \mathrm{mg} / \mathrm{h}$
Alkalinity: $0 \mathrm{mg} / \mathrm{L}$

WELL LSB 2

MEASUREMENTS CONDUCTED IN THE FIELD

Sample date: 12/16/91

Depth to water: $23.55 \mathrm{ft}(7.18 \mathrm{~m})$ below TOC

Water elevation. $211.65 \mathrm{ft}(64.51 \mathrm{~m}) \mathrm{ms}$ |

Sp. conductance: $32 \mu \mathrm{S} / \mathrm{cm}$

pH: 4.5

$0 \mathrm{mg}$

Water evacuated before sampling: $44 \mathrm{gal}$

LABORATORY ANALYSES

\begin{tabular}{|c|c|c|c|}
\hline F Analyte & Result & Mod & Unit \\
\hline 1 Aluminum & 190 & & $\mu \mathrm{g} / \mathrm{L}$ \\
\hline Tritium & 5.3E-06 $+8.1 \mathrm{E} \cdot 07$ & & $\mathrm{NCi/mL}$ \\
\hline
\end{tabular}

\section{WELL LSB 3}

MEASUREMENTS CONDUCTED IN THE FIELO

\section{Sample date: 10/24/91}

Depth to water: $16.10 \mathrm{th}(4.91 \mathrm{~m})$ below rOC

Water elevation: $220.30 \mathrm{ft}(67.15 \mathrm{~m}) \mathrm{msl}$

Sp. conductance. $21 \mu \mathrm{s} / \mathrm{cm}$

Water evacuated before sampling: $62 \mathrm{ga}$

LABORATORY ANALYSES

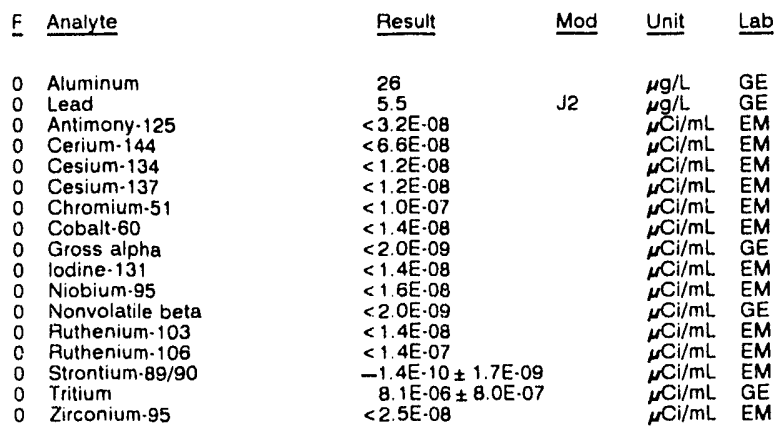

\section{WELL LSB 3}

MEASUREMENTS CONOUCTED IN THE FIELD

Sample date: $11 / 19 / 91$

Depth to water: $16.07 \mathrm{ft}(4.90 \mathrm{~m})$ below TOC

Water elevation: $220.33 \mathrm{ft}(67.16 \mathrm{~m}) \mathrm{ms}$

Sp conductance: $20 \mu \mathrm{S} / \mathrm{cm}$

Water evacuated before sampling: $62 \mathrm{gal}$

Time: $9: 15$

$\mathrm{pH}: 4.8$

Alkalinity: $0 \mathrm{mg} / \mathrm{L}$

Water temperature: $21.2^{\circ} \mathrm{C}$

LABORATORY ANALYSES

$\begin{array}{lllll}\text { F Analyte } & \text { Result } & \text { Mod } & \text { Unit } & \text { Lab } \\ 0 & \text { Aluminum } & & \\ 0 & \text { Gross alpha } & 26 & \mu \mathrm{g} / \mathrm{L} & \mathrm{GE} \\ 0 & \text { Nonvolatile beta } & 2.1 \mathrm{E} \cdot 10 \pm 2.6 \mathrm{E} \cdot 10 & \mu \mathrm{Ci} / \mathrm{mL} & \mathrm{EM} \\ 2 & \text { Tritum } & 5.5 \mathrm{E} \cdot 10 \pm 6.6 \mathrm{E} \cdot 10 & \mu \mathrm{Ci} / \mathrm{mL} & \mathrm{EM} \\ 2 & \text { Tritium } & 2.1 \mathrm{E} \cdot 05 \pm 1.0 \mathrm{E} \cdot 06 & \mu \mathrm{Ci} / \mathrm{mL} & \mathrm{GE} \\ & 2.5 \mathrm{E} \cdot 05 \pm 1.3 \mathrm{E} \cdot 06 & \mu \mathrm{Ci} / \mathrm{mL} & \mathrm{EM}\end{array}$

\section{WELL LSB 3}

MEASUREMENTS CONOUCTED IN THE FIELD

Sample date 12/16/91

Time: 14:50

$\begin{array}{ll}\text { Depth to water. } 20.09 \mathrm{ft}(6.12 \mathrm{~m}) \text { below TOC } & \mathrm{PH} \text {. } 4.8 \\ \text { Water elevation: } 216.31 \mathrm{tt}(65.93 \mathrm{~m}) \mathrm{ms} \text { l } & \text { Alkalinity: } 0 \mathrm{mg} / \mathrm{h}\end{array}$

Sp conductance 20 S/cm

Water evacuated before sampling: $52 \mathrm{gal}$

LABORATORY ANALYSES

\begin{tabular}{|c|c|c|c|c|c|}
\hline$E$ & Analyte & Result & Mod & Unit & $\underline{L a b}$ \\
\hline & $\begin{array}{l}\text { Aluminum } \\
\text { Tritium } \\
\text { Tritium }\end{array}$ & $\begin{array}{l}39 \\
39 \mathrm{gE} \cdot 05 \pm 1 \cdot 1 \mathrm{E} \cdot 06 \\
3 \cdot 5 \mathrm{E} \cdot 05 \pm 1.5 \mathrm{E} \cdot 06\end{array}$ & & $\begin{array}{l}\mu \mathrm{g} / \mathrm{L} \\
\mu \mathrm{CL} / \mathrm{mL} \\
\mu \mathrm{Ci} / \mathrm{mL}\end{array}$ & $\begin{array}{l}\mathrm{GE} \\
\mathrm{GE} \\
\mathrm{EM}\end{array}$ \\
\hline
\end{tabular}


WELL LSB 4

MEASUREMENTS CONDUCTED IN THE FIELO

Sample date: 10/24/91 Copth to water: $10.58 \mathrm{~h}(3.22 \mathrm{~m})$ below TOC
Water elevation: $220.92 \mathrm{ht}(67.34 \mathrm{~m}) \mathrm{ms}$ l

Water evacuated before sampling: $77 \mathrm{ga}$

LABORATORY ANALYSES

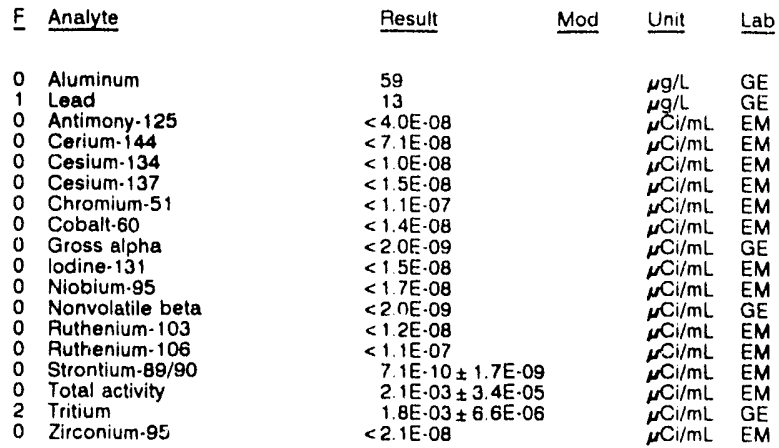

WELL LSB 4

MEASUREMENTS CONDUCTED IN THE FIELD

Sample date: 11/19/91

Depth to water: 10.55 it (3.22 m) beiow TOC

Water elevation: $220.95 \mathrm{th}(67.35 \mathrm{~m}) \mathrm{msl}$

p. conductance: $32 \mu \mathrm{S} / \mathrm{cm}$

Water evacuated before sampling: $77 \mathrm{gal}$

LABORATORY ANALYSES

\begin{tabular}{llllll} 
E Analyte & Result & Mod & & Unit & Lab \\
\cline { 3 - 5 } & & & \\
0 & Aluminum & 67 & & \\
0 & Gross alpha & $1.4 \mathrm{E} \cdot 10 \pm 2.4 \mathrm{E} \cdot 10$ & & $\mu \mathrm{G} / \mathrm{L} / \mathrm{mL}$ & $\mathrm{EE}$ \\
0 & Nonvolatile beta & $8.0 \mathrm{E} \cdot 10 \pm 7.1 \mathrm{E} \cdot 10$ & & $\mu \mathrm{Ci} / \mathrm{mL}$ & $\mathrm{EM}$ \\
2 & Tritium & $2.0 \mathrm{E} \cdot 03 \pm 7.1 \mathrm{E} \cdot 06$ & & $\mu \mathrm{Ci} / \mathrm{mL}$ & $\mathrm{GE}$ \\
2 & Tritium & $2.2 \mathrm{E} \cdot 03 \pm 1 \mathrm{E} \cdot 05$ & & $\mu \mathrm{Ci} / \mathrm{mL}$ & $\mathrm{EM}$
\end{tabular}

WELL LSB 4

MEASUREMENTS CONDUCTED IN THE FIELD

Sample date: 12/16/91

Depth to water: $1558 \mathrm{ft}(4.75 \mathrm{~m})$ below TOC

Water elevation: $215.91 \mathrm{ft}$

Sp. conductance $32 \mu \mathrm{S} / \mathrm{cm}$

Water evacuated beiore sampling: $64 \mathrm{gal}$

Time: $9: 30$

PH: 4.7

Alkalinity: $2 \mathrm{mg} / \mathrm{L}$

Water temperature: $21.8^{\circ} \mathrm{C}$

$\mu \mathrm{Ci} / \mathrm{mL}$ EM

LABORATORY ANALYSES

\begin{tabular}{|c|c|c|c|c|}
\hline$E$ & Analyte & Result & Mod & Unit \\
\hline $\begin{array}{l}0 \\
0\end{array}$ & $\begin{array}{l}\text { Aluminum } \\
\text { Gross alpha } \\
\text { Nonvolatile beta } \\
\text { Tritium } \\
\text { Tritium }\end{array}$ & $\begin{array}{l}74 \\
12 \mathrm{E} \cdot 09 \pm 9.2 \mathrm{E} \cdot 10 \\
1.6 \mathrm{E} \cdot 09 \pm 1.0 \mathrm{E} \cdot 09 \\
2.1 \mathrm{E} \cdot 03 \pm 7 \cdot 1 \mathrm{E} \cdot 06 \\
25 \mathrm{E} \cdot 03 \pm 36 \mathrm{E} \cdot 05\end{array}$ & & $\begin{array}{l}\mu g / \mathrm{L} \\
\mu \mathrm{Cl} / \mathrm{mL} \\
\mu \mathrm{Ci} / \mathrm{mL} \\
\mu \mathrm{Ci} / \mathrm{mL} \\
\mu \mathrm{Ci} / \mathrm{mL}\end{array}$ \\
\hline
\end{tabular}

\section{WELL MCB 2}

MEASUREMENTS CONDUCTED IN THE FIELD

Sample date: $11 / 15 / 91$

Welow TOC

Sp conductance $221.19 \mathrm{ft}$ (67.

Time: $10: 20$

Alkalinity $0 \mathrm{mg}$

Water temperature $21.0^{\circ} \mathrm{C}$

Water evacuated before sampling. 13 gal

The well went dry during purging

LABORATORY ANALYSES

\begin{tabular}{|c|c|c|c|}
\hline F Analyte & Result & Mod & Unit \\
\hline $\begin{array}{ll}0 & \mathrm{pH} \\
0 & \text { Specific conductance } \\
0 & \text { Arsenic } \\
0 & \text { Barium } \\
0 & \text { Benzene } \\
0 & \text { Bromodichioromethane } \\
0 & \text { Bromolorm } \\
0 & \text { Bromomethane } \\
0 & \text { Cadmium }\end{array}$ & $\begin{array}{rl} & 59 \\
& 20 \\
< & 2.0 \\
3.7 \\
1 & 0 \\
< & 10 \\
<10 \\
<10 \\
<20\end{array}$ & $\mathrm{JO}$ & $\begin{array}{l}\mathrm{pH} \\
\mu \mathrm{H} / \mathrm{cm} \\
\mu g / L \\
\mu g / L \\
\mu g / L \\
\mu g / L \\
\mu g / L \\
\mu g / L\end{array}$ \\
\hline
\end{tabular}

WELL MCB 2 collected on 11/15/91, laboratory analyses (cont.)

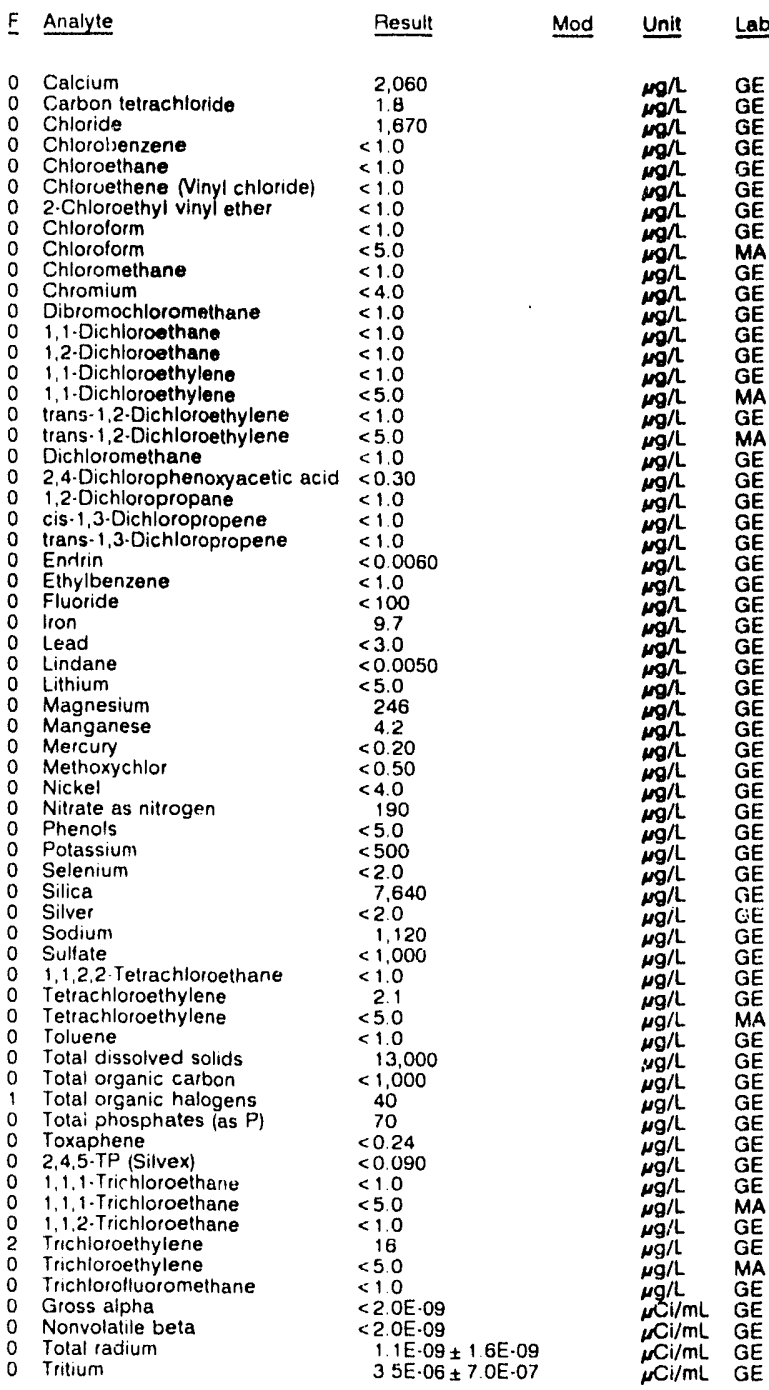

WELL MCB 4

MEASUAEMENTS CONDUCTED IN THE FIELD

Sample date. $11 / 15 / 91$

Depth to water: $128.76 \mathrm{ft}(39.25 \mathrm{~m})$ below TOC Water elevation: $221.64 \mathrm{ft}(67.56 \mathrm{~m}) \mathrm{msl}$ Sp conductance $18 \mu \mathrm{S} / \mathrm{cm}$

The well wert dry during purging: $10 \mathrm{gal}$

pH: 51

Aater temperature: $16.2^{\circ} \mathrm{C}$

LABORATOHY ANALYSES

\begin{tabular}{|c|c|c|c|}
\hline Analyte & Result & Mod & Unit \\
\hline $\begin{array}{l}\text { pH } \\
\text { Specific conductance } \\
\text { Alsenic } \\
\text { Barium } \\
\text { Benzene } \\
\text { Bromodichloromethane } \\
\text { Bromolorm } \\
\text { Gromomethane } \\
\text { Cadmium } \\
\text { Calcium } \\
\text { Carbon tetrachloride } \\
\text { Chloride } \\
\text { Chlorobenzene } \\
\text { Chloroethane } \\
\text { Chloroethene (Vinyl chloride) } \\
2 \text { Chloroethyl viril ether } \\
\text { Chloroform } \\
\text { Chloroform } \\
\text { Criloromethare } \\
\text { Chromium }\end{array}$ & $\begin{array}{rl}53 \\
15 \\
<20 \\
6.7 \\
<110 \\
<110 \\
<110 \\
<10 \\
<20 \\
768 \\
700 \\
11710 \\
<110 \\
<110 \\
<10 \\
<10 \\
<10 \\
<10 \\
<110 \\
<4 & 0\end{array}$ & JQ & $\begin{array}{l}p H \\
\mu \mathrm{S} / \mathrm{cm} \\
\mu \mathrm{g} / \mathrm{L} \\
\mu \mathrm{g} / \mathrm{L} \\
\mu \mathrm{g} / \mathrm{L} \\
\mu \mathrm{g} / \mathrm{L} \\
\mu \mathrm{g} / \mathrm{L} \\
\mu \mathrm{g} / \mathrm{L} \\
\mu \mathrm{g} / \mathrm{L} \\
\mu \mathrm{g} / \mathrm{L} \\
\mu \mathrm{g} / \mathrm{L} \\
\mu \mathrm{g} / \mathrm{L} \\
\mu \mathrm{g} / \mathrm{L} \\
\mu \mathrm{g} / \mathrm{L} \\
\mu \mathrm{g} / \mathrm{L} \\
\mu \mathrm{g} / \mathrm{L} \\
\mu \mathrm{g} / \mathrm{L} \\
\mu \mathrm{g} / \mathrm{L} \\
\mu \mathrm{g} / \mathrm{L} \\
\mu \mathrm{g} / \mathrm{L}\end{array}$ \\
\hline
\end{tabular}


ANALYTICAL RESULTS

WELL MCB 4 collected on 11/15/91, laboratory analyses (cont.)

\begin{tabular}{|c|c|c|}
\hline Analyte & Result & Unit \\
\hline 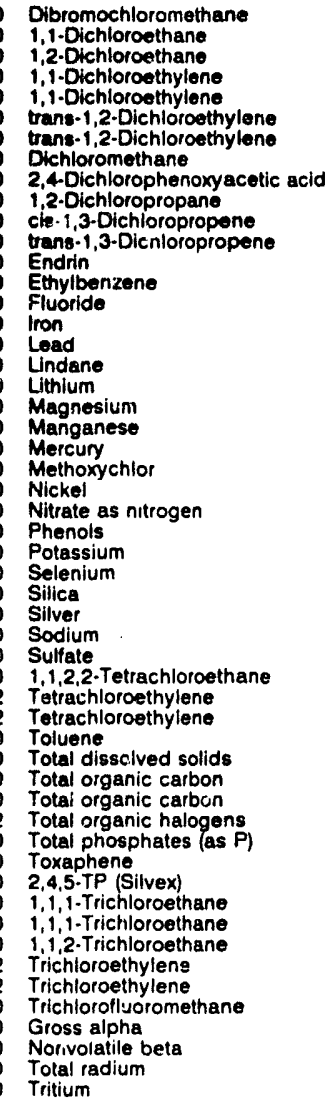 & $\begin{array}{l}<1.0 \\
<1.0 \\
<1.0 \\
<1.0 \\
<10 \\
<1.0 \\
<10 \\
1.6 \\
<0.30 \\
<1.0 \\
<1.0 \\
<1.0 \\
<0.0060 \\
<1.0 \\
<100 \\
8.7 \\
<3.0 \\
<0.0050 \\
<5.0 \\
125 \\
5.4 \\
<0.20 \\
<0.50 \\
<4.0 \\
150 \\
<5.0 \\
<500 \\
<2.0 \\
6.700 \\
<2.0 \\
1.300 \\
<1.000 \\
<1.0 \\
36 \\
16 \\
<1.0 \\
8,000 \\
<1.000 \\
<1.000 \\
114 \\
<50 \\
<0.24 \\
<0.090 \\
<1.0 \\
<10 \\
<1.0 \\
93 \\
84 \\
<1.0 \\
<2.0 \mathrm{E} \cdot 09 \\
<2.0 \mathrm{E} \cdot 09 \\
1.5 \mathrm{E} \cdot 09 \pm 1.6 \mathrm{E} \cdot 09 \\
3.3 \mathrm{E} \cdot 06 \pm 7.0 \mathrm{E} \cdot 07\end{array}$ & 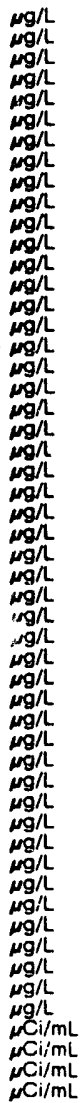 \\
\hline
\end{tabular}

WELL MCB 5

MEASUREMENTS CONDUCTED IN THE FIELD

Sample date: $12 / 06 / 91$
Depth to water: $116.18 \mathrm{ft}(35.41 \mathrm{~m})$ below TOC
Water elevation: $223.42 \mathrm{ft}(68.10 \mathrm{~m}) \mathrm{ms}$ !
Sp. conductance: $47 \mu \mathrm{cm} / \mathrm{cm}$
Water evacuated before sampling: $11 \mathrm{gal}$
The well went dry during purging.
LABORATORY ANALYSES

Time: $14: 35$

$\mathrm{pH}: 7.6$

Alkalinity: $12 \mathrm{mg} / \mathrm{L}$

Water temperature $18.0^{\circ} \mathrm{C}$

LABORATORY ANALYSES

\begin{tabular}{|c|c|c|c|}
\hline Analyte & Resul: & Mod & Unit \\
\hline 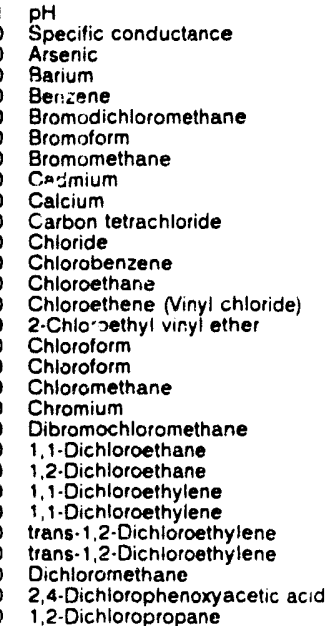 & $\begin{aligned} 81 \\
50 \\
<2.0 \\
7.3 \\
<1.0 \\
<1.0 \\
<1.0 \\
<1.0 \\
<2.0 \\
6,090 \\
<1.0 \\
11.540 \\
<1.0 \\
<1.0 \\
<1.0 \\
<1.0 \\
110 \\
<50 \\
<1.0 \\
<4.0 \\
<1.0 \\
<1.0 \\
<1.0 \\
<1.0 \\
<5.0 \\
<1.0 \\
<5.0 \\
2.4 \\
<0.30 \\
<10\end{aligned}$ & J2V & $\begin{array}{l}p H \\
\mu S / c m \\
\mu g / L \\
\mu g / L \\
\mu g / L \\
\mu g / L \\
\mu g / L \\
\mu g / L \\
\mu g / L \\
\mu g / L \\
\mu g / L \\
\mu g / L \\
\mu g / L \\
\mu g / L \\
\mu g / L \\
\mu g / L \\
\mu g / L \\
\mu g / L \\
\mu g / L \\
\mu g / L \\
\mu g / L \\
\mu g / L \\
\mu g / L \\
\mu g / L \\
\mu g / L \\
\mu g / L \\
\mu g / L \\
\mu g / L \\
\mu g / L \\
\mu g / L\end{array}$ \\
\hline
\end{tabular}

WELL MCB 5 collected on 12/06/91, laboratory analyses (cont.)

\begin{tabular}{|c|c|c|c|}
\hline I Analyte & Result & Mod & Unit \\
\hline 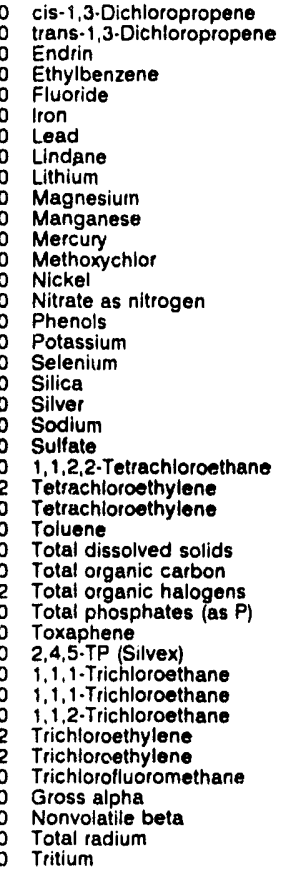 & $\begin{array}{l}<1.0 \\
<1.0 \\
<0.0060 \\
<1.0 \\
<100 \\
<4.0 \\
<3.0 \\
<0.0050 \\
<5.0 \\
147 \\
8.1 \\
<0.20 \\
<0.50 \\
<4.0 \\
145 \\
<5.0 \\
<500 \\
<2.0 \\
9,160 \\
<2.0 \\
1.110 \\
1.080 \\
<1.0 \\
22 \\
<5.0 \\
<1.0 \\
32,000 \\
<1.000 \\
103 \\
<50 \\
<0.24 \\
<0.090 \\
<1.0 \\
<5.0 \\
<1.0 \\
114 \\
108 \\
1.4 \\
<2.0 E-09 \\
<2.0 E \cdot 09 \\
<1.0 E-09 \\
<7.0 E \cdot 07\end{array}$ & $\begin{array}{l}v \\
\text { Ja } \\
\text { Ja }\end{array}$ & $\begin{array}{l}\mu g / L \\
\mu g / L \\
\mu g / L \\
\mu g / L \\
\mu g / L \\
\mu g / L \\
\mu g / L \\
\mu g / L \\
\mu g / L \\
\mu g / L \\
\mu g / L \\
\mu g / L \\
\mu g / L \\
\mu g / L \\
\mu g / L \\
\mu g / L \\
\mu g / L \\
\mu g / L \\
\mu g / L \\
\mu g / L \\
\mu g / L \\
\mu g / L \\
\mu g / L \\
\mu g / L \\
\mu g / L \\
\mu g / L \\
\mu g / L \\
\mu g / L \\
\mu g / L \\
\mu g / L \\
\mu g / L \\
\mu g / L \\
\mu g / L \\
\mu g / L \\
\mu g / L \\
\mu g / L \\
\mu g / L \\
\mu g / L \\
\mu C i / m L \\
\mu C / / m L \\
\mu C i / m L \\
\mu C i / m L\end{array}$ \\
\hline
\end{tabular}

WELL MCB 5C

MEASUREMENTS CONDUCTED IN THE FIELD

Sample date: $12 / 06 / 9$

Depth to water: $144.49 \mathrm{te}(44.04 \mathrm{~m})$ below TOC Water elevation: $194.61 \mathrm{Ht}(59.32 \mathrm{~m}) \mathrm{ms}$ i

Sp. conductance: $4330 \mu \mathrm{S} / \mathrm{cm}$

Water temperature: $17.5^{\circ} \mathrm{C}$

purging.

LABORATORY ANALYSES

E Analyte $\quad$ Result Mod Unit Lab

\begin{tabular}{|c|c|c|c|}
\hline 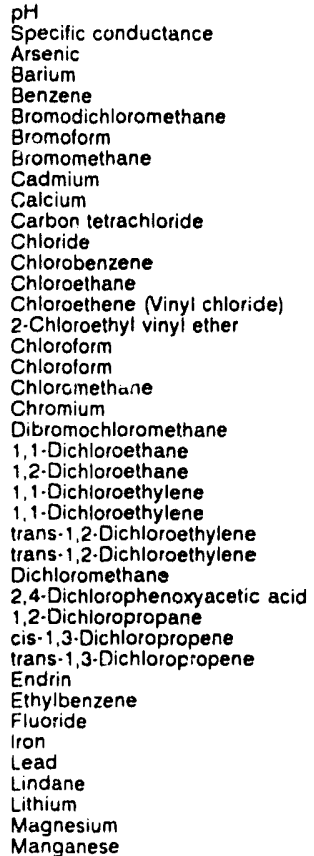 & $\begin{aligned} & 13 \\
& 4.900 \\
&<2.0 \\
& 968 \\
&<1.0 \\
&<1.0 \\
&<1.0 \\
&<1.0 \\
&<2.0 \\
& 233,000 \\
&<1.0 \\
& 580 \\
&<1.0 \\
&<1.0 \\
&<1.0 \\
&<1.0 \\
&<1.0 \\
&<5.0 \\
&<1.0 \\
& 20 \\
&<1.0 \\
&<1.0 \\
&<1.0 \\
&<1.0 \\
&<5.0 \\
&<1.0 \\
&<5.0 \\
& 1.8 \\
&<0.30 \\
&<1.0 \\
&<1.0 \\
&<10 \\
&<0.0060 \\
&<1.0 \\
&<100 \\
&<4.0 \\
& 7.7 \\
&<0.0050 \\
& 1.760 \\
& 6.1 \\
&<2.0\end{aligned}$ & $\mathrm{~J}_{2} \mathrm{~V}$ & $\begin{array}{l}p H \\
\mu S / c m \\
\mu g / L \\
\mu g / L \\
\mu g / L \\
\mu g / L \\
\mu g / L \\
\mu g / L \\
\mu g / L \\
\mu g / L \\
\mu g / L \\
\mu g / L \\
\mu g / L \\
\mu g / L \\
\mu g / L \\
\mu g / L \\
\mu g / L \\
\mu g / L \\
\mu g / L \\
\mu g / L \\
\mu g / L \\
\mu g / L \\
\mu g / L \\
\mu g / L \\
\mu g / L \\
\mu g / L \\
\mu g / L \\
\mu g / L \\
\mu g / L \\
\mu g / L \\
\mu g / L \\
\mu g / L \\
\mu g / L \\
\mu g / L \\
\mu g / L \\
\mu g / L \\
\mu g / L \\
\mu g / L \\
\mu g / L \\
\mu g / L \\
\mu g / L\end{array}$ \\
\hline
\end{tabular}




\section{ANALYTICAL RESULTS}

WELL MCB 5C collected on 12/06/91, laboratory enalyses (cont.)

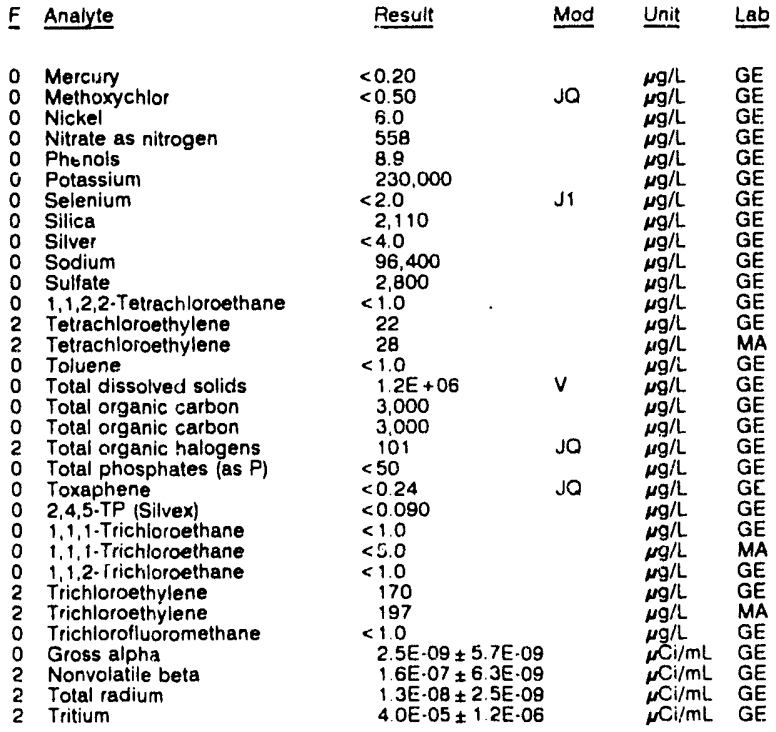

WELL ...'DB 6

MEASUREMEN S CONDUCTED IN THE FIELD

Sample date: $11 \cdot 7 / 91$
Depth to water:

Water elevation: it $(66$

Sp. conductance: $-\mu \mathrm{S} / \mathrm{cm}$.

Water evacualed betore sampling: $5 \mathrm{gal}$

LABORATORY ANALYSES

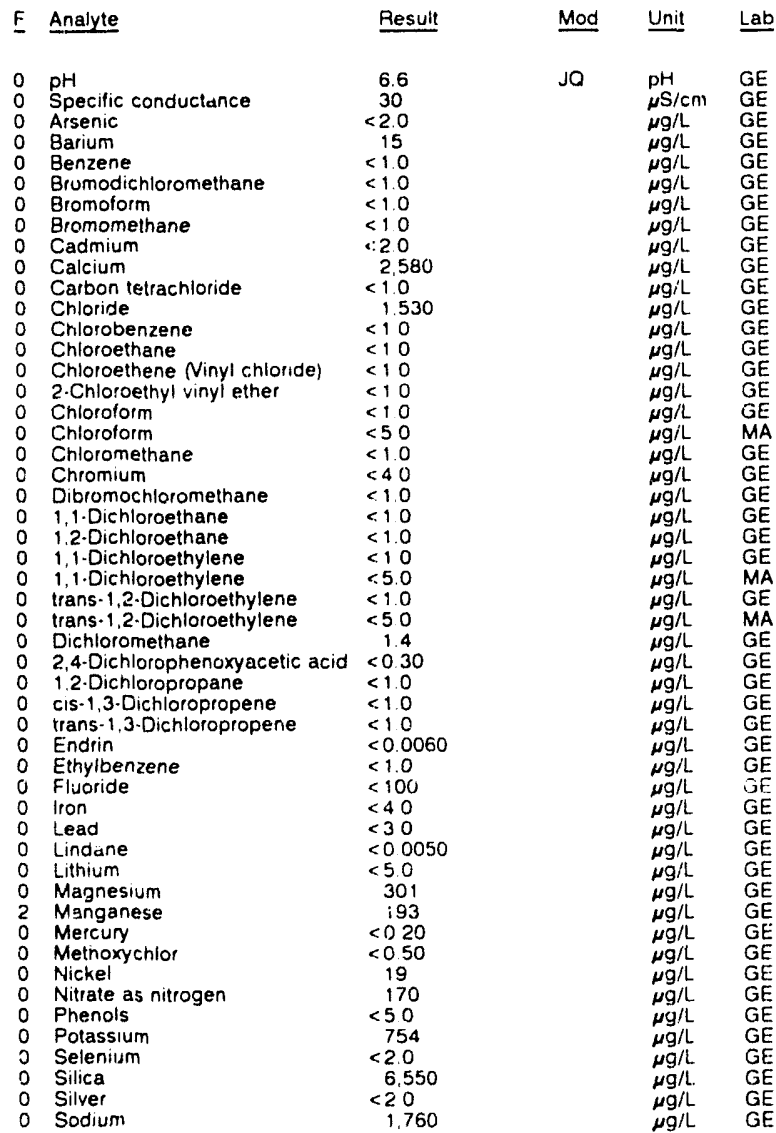

WELL MCB 6 collected on 11/15/91, laboratory analyses (cont.)

\begin{tabular}{|c|c|c|}
\hline Analyze & Result & $\underline{\text { Unit }}$ \\
\hline $\begin{array}{l}\text { Sulfate } \\
1,1,2,2 \text {-Tetrachloroethane } \\
\text { Telrachlorothylene } \\
\text { Tetrachloroethylene } \\
\text { Toluene } \\
\text { Total dissolved solids } \\
\text { Total organic carbon } \\
\text { Total organic halogens } \\
\text { Total organic halogens } \\
\text { Total phosphates (as P) } \\
\text { Toxaphene } \\
2,4,5-\text { TP (Silvex) } \\
1,1,1 \text { - Trichloroethane } \\
1,1,1 \text { Trichloroethane } \\
1,1,2 \text {. Trichloroethane } \\
\text { Trichloroethylene } \\
\text { Trichloroethylene } \\
\text { Trichlorofluooromethane } \\
\text { Gross alpha } \\
\text { Nonvolatile beta } \\
\text { Total radium } \\
\text { Tritium }\end{array}$ & $\begin{array}{l}<1.000 \\
<1.0 \\
1.5 \\
<5.0 \\
<1.0 \\
18.000 \\
<1.000 \\
<5.0 \\
<5.0 \\
120 \\
<0.24 \\
<0.090 \\
<1.0 \\
<5.0 \\
<1.0 \\
4.7 \\
<5.0 \\
<1.0 \\
8.9 E-09 \pm 2.0 E-09 \\
3.8 E \cdot 09 \pm 1.7 E \cdot 09 \\
<1.0 \mathrm{C} \cdot 09 \\
3.7 \mathrm{E} \cdot 06 \pm 7.0 \mathrm{E} \cdot 07\end{array}$ & $\begin{array}{l}\mu g / L \\
\mu g / L \\
\mu g / L \\
\mu g / L \\
\mu g / L \\
\mu g / L \\
\mu g / L \\
\mu g / L \\
\mu g / L \\
\mu g / L \\
\mu g / L \\
\mu g / L \\
\mu g / L \\
\mu g / L \\
\mu g / L \\
\mu g / L \\
\mu g / L \\
\mu g / L \\
\mu C i / m L \\
\mu C i / m L \\
\mu C i / m L \\
\mu C i / m L\end{array}$ \\
\hline
\end{tabular}

\section{WELL MCB 6C}

MEASUREMENTS CONDI ICTED IN THE FIELD

Depth to water: $139.25 \mathrm{ft}(42.44 \mathrm{~m})$ below TOC

Water elevation: $192.85 \mathrm{t}(58.78 \mathrm{~m}) \mathrm{ms}$

PH: 6.5

Water temperature: $18.2^{\circ} \mathrm{C}$

LABORATORY ANALYSES

E Analyte Result Mod Unit Lab

Time: $8: 15$

Alk 6.0 . 13 inity $13 \mathrm{mg}$

Alkalinity: $13 \mathrm{mg} / \mathrm{h}$. $15.4^{\circ} \mathrm{C}$

$0 \mathrm{pH}$

Specific conductance

0 Arsenic

Barium

$\begin{array}{ll}0 & \text { Banzene } \\ 0 & \text { Gromodichloromethane }\end{array}$

Bromomethane

Cadmium

Carbon tetrachloride

Chloride

Chlorobenzene

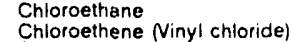

2.Chloroethyl vinyl ether

Chloroform

Chloroform

Chlorometh

Dibromochloromethane

1,1-Dichloroethane

1.1-Dichloroethane
1.2.-Dichloroethane

1.2.Dichloroethane

trans. 12.Dichloroethylene

trans-1,2.Dichloroethylene

Dichloromethane
2,4-Dichlorophenoxyacetic acid

1,2-Dichloropropane

cis-1,3-Dichloropropene

Irans-1,3-Dichloropropene

Endrin

Ethylbenzen

0 Iron

0 Lead

Lindane

Magnesium

Manganese

Nickel

Nickel as nitrogen

Phenols

Potásium

Selenium
Silica

Silica

Silver

Sodium

Sulfate $1,2,2$-Tetrachloroethane

$1,1,2,2 \cdot$ Tetrachloroe
Tetrachloroethyiene

Tetrachloroethyiene

- Toluene

Total dissolved solids

Total organic carbon

Total organic halogens

Toxaphene

6.7

$\begin{array}{cccc}6.7 & \text { JO } & \mathrm{pH} & \mathrm{GE} \\ 60 & & \mu \mathrm{S} / \mathrm{cm} & \mathrm{GE} \\ <2.0 & & \mu \mathrm{g} / \mathrm{L} & \mathrm{GE} \\ 22 & & \mu \mathrm{g} / \mathrm{L} & \mathrm{GE} \\ <1.0 & & \mu \mathrm{G} / \mathrm{L} & \mathrm{GE}\end{array}$

$<1.0$

$<1.0$

$<1.0$

$<2.0$

$<\begin{aligned} & 6.520 \\ & <1.0\end{aligned}$

$<1.0$

$<1.0$
$<1.0$

$<1.0$

$<5.0$
$<1.0$
$<4.0$

$<4.0$

$<1.0$

$<1.0$

$<10$

$<5.0$

$<1.0$

$<5.0$
4.0
$<3.0$

$<10$
$<10$
$<1.0$

$<1.0$
$<0.0060$

$<1.0$
$<0.0060$
$<1.0$

$<100$
9.9

9.9
$<3.0$
$<0.005$

$<0.0050$
7.8
264
29

29
$<0.20$

$<0.50$
$<40$

$<40$
640
$<50$
3200

$<50$
3,200
$<20$

$<2.0$
30.400

$<2.0$
3.190

3.190
3.210

$<1.0$

$<10$
$<50$

$<5.0$
2.4
61,000

61,000
$<1,000$

35
50 
ANALYTICAL RESULTS

WELL MCB $6 C$ collected on 11/13/91, laboratory analyses (cont.)

\begin{tabular}{|c|c|c|c|}
\hline Analyte & Result & Mod & Unit \\
\hline $\begin{array}{l}\text { 2,4,5-TP (Silvex) } \\
\text { 1,1,1-Trichloroethane } \\
\text { 1,1,1-Trichloroethane } \\
\text { 1,1,2-Trichloroethane } \\
\text { Trichloroethylene } \\
\text { Trichloroethylene } \\
\text { Trichlorofluoromethane } \\
\text { Gross alpha } \\
\text { Nonvolatile beta } \\
\text { Total radium } \\
\text { Tritium }\end{array}$ & $\begin{array}{l}<0.90 \\
<1.0 \\
<5.0 \\
<1.0 \\
<1.0 \\
<5.0 \\
<1.0 \\
<2.0 \mathrm{E} \cdot 09 \\
6.3 \mathrm{E}-09 \pm 1.6 \mathrm{E}-09 \\
<1.0 \mathrm{E} \cdot 09 \\
1.6 \mathrm{E}-05 \pm 9.0 \mathrm{E}-07\end{array}$ & JQ & $\begin{array}{l}\mu g / L \\
\mu g / L \\
\mu g / L \\
\mu g / L \\
\mu g / L \\
\mu g / L \\
\mu g / L \\
\mu C i / m L \\
\mu C i / m L \\
\mu C i / m L \\
\mu C i / m L\end{array}$ \\
\hline
\end{tabular}

WELL MCB 7C

MEASUREMENTS CONDUCTED IN THE FIELD

Sample date: $12 / 06 / 9$ Depth to water: $143.73 \mathrm{ft}(43.81 \mathrm{~m})$ below TOC Water elevation: $183.97 \mathrm{ft}(59.12 \mathrm{~m}) \mathrm{ms}$ | Sp. conductance: $3840 \mu \mathrm{s} / \mathrm{cm}$ The evacualed before sampling: 12 ga

LABORATORY ANALYSES

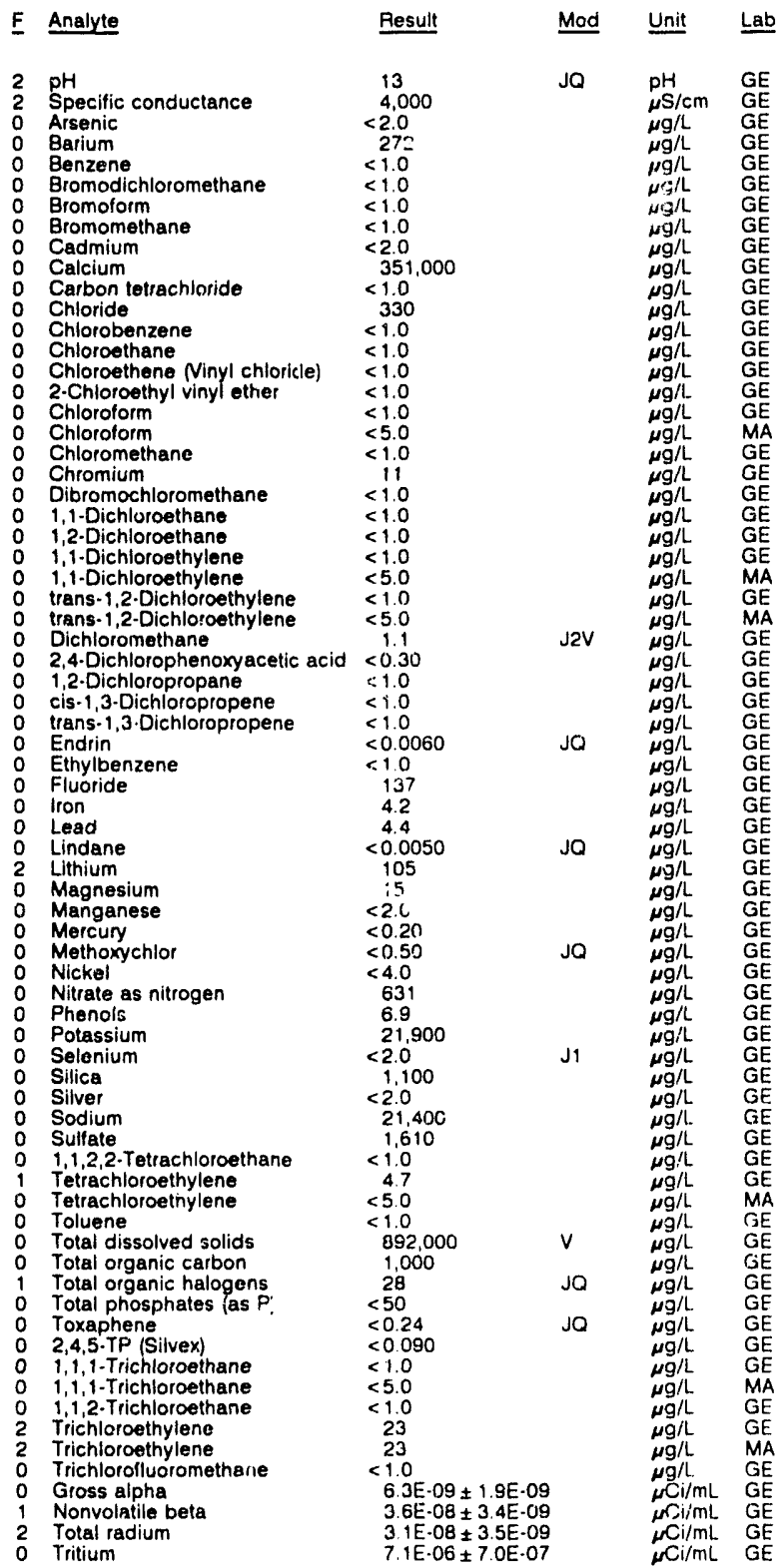

WELL MGA 36

MEASUREMENTS CONDUCTED IN THE FIELD

Sample date: $11 / 18 / 91$ Depth to water: $61.00 \mathrm{ft}(18.59 \mathrm{~m})$ below TOC

Water elevation: $237.30 \mathrm{ft}(72.33 \mathrm{~m}) \mathrm{ms}$

No water was evacuated before sampling.

Time: $11: 20$

Water temperature: $18.0^{\circ} \mathrm{C}$

WELL MGC 9

MEASUREMENTS CONDUCTED IN THE FIELD

Sample date: $11 / 18 / 91$

Depth to water: $51.50 \mathrm{ft}(15.70 \mathrm{~m})$ below TOC

Water elevation: $232.60 \mathrm{ft}(70.90 \mathrm{~m}) \mathrm{ms}$

Sp. conductance: $271 \mu \mathrm{s} / \mathrm{cm}$

\section{Time: $9: 50$
pH: 6.6}

Water temperature: $17.4^{\circ} \mathrm{C}$

\section{WELL MGC 11}

MEASUREMENTS CONDUCTED IN THE FIELD

Sample date: $11 / 18 / 91$

Time: 10:30

pH: 12.5

Alkalinity: $974 \mathrm{mg} / \mathrm{L}, 17.4^{\circ} \mathrm{C}$

The well was $d n$.

WELL MGC 19

MEASUREMENTS CONDUCTED IN THE FIELD

Sample date: $11 / 18 / 91$

Depth to water: $53.00 \mathrm{ft}(16.15 \mathrm{~m})$ below TOC

$233.60 \mathrm{ft}(71.20 \mathrm{~m}) \mathrm{ms}$

p. conductance: $26 \mu \mathrm{S} / \mathrm{cm}$

$\mathrm{pH}: 5.7$

No water was evacuated before sampling.

Water temperature: $18.1^{\circ} \mathrm{C}$

\section{WELL MGC 23}

MEASUREMENTS CONDUCTED IN THE FIELD

Sample date: $11 / 18 / 91$

Time: 10:50

The well was $d \gamma$.

\section{WELL MGC 32}

MEASUREMENTS CONDUCTED IN THE FIELD

Depth to water: $51.00 \mathrm{ft}(15.54 \mathrm{~m})$ below TOC

Water elevation: $247.00 \mathrm{ft}(75.29 \mathrm{~m}) \mathrm{ms}$

Sp conductance $54 \mu \mathrm{S} / \mathrm{cm}$

No water was evacuated betore sampling.

Time: 11:00

Water temperature: $17.8^{\circ} \mathrm{C}$

\section{WELL MGC 36}

MEASUREMENTS CONDUCTED IN THE FIELD

Sample date: $11 / 18 / 91$

Depth to water: $59.00 \mathrm{ft}(17.98 \mathrm{~m})$ below TOC

Water elevation: 237.60 it $(72.42 \mathrm{~m}) \mathrm{ms}$ I

Sp. conductance $29 \mu \mathrm{S} / \mathrm{cm}$

No water was evacuated before sampling.
Time: $11: 30$

$\mathrm{pH}: 7.1$

Water temperature: $18.0^{\circ} \mathrm{C}$

\section{WELL MGE 9}

MEASUREMENTS CONDUCTED IN THE FIELD

Sample date: $11 / 18 / 5$

Depth to water: 53.50 .. $6.31 \mathrm{~m})$ below TOC

Water elevation: $230.10 \mathrm{ft}(70.14 \mathrm{~m}) \mathrm{ms}$

Sp. conductance: $93 \mu \mathrm{s} / \mathrm{cm}$

$(70.14 \mathrm{~m}) \mathrm{ms}$

Time: $10: 00$

No water was evacuated before sampling.
Water temperature: $17.4^{\circ} \mathrm{C}$ 


\section{WELL MGE 21}

MEASUREMENTS CONDUCTED IN THE FIELD

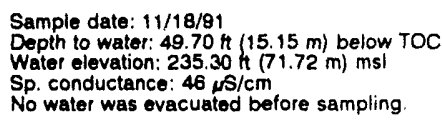

No water was evacuated before sampling

\section{WELL MGE 30}

MEASUREMENTS CONDUCTED IN THE FIELD

Sample date: 11/18/91

Depth to wator: 44.00 t (13.41 m) below TOC

Water elevation: $238.20 \mathrm{ht}$ (72.

Sp. conductance: $57, \mathrm{~s} / \mathrm{cm}$

\section{WELL MGE 34}

MEASUAEMENTS CONDUCTED IN THE FIELD

Sample date: 11/18191

Depth to water: $55.50 \mathrm{in}(16.92 \mathrm{~m})$ below TOC

Water olevation: 238.80 t $(72.82 \mathrm{~m}) \mathrm{ms}$ |

Sp. conductance. 55 s $1 \mathrm{~cm}$

No water was evacuated before sampling.

\section{WELL MGG 15}

MEASUREMENTS CONDUCTED IN THE FIELD

Sample date: $11 / 18 / 91$ Water tevation: 232.70 (15.64 m) below rod

Sp. conductance $59 \mathrm{~s} / \mathrm{cm}$

No water was evacuated bofore sampling.

\section{WELL MGG 19}

MEASUREMENTS CONDUCTED IN THE FIELD

Sample date: $11 / 18 / 91$

Depth to water: $49.70 \mathrm{ft}(15.15 \mathrm{~m})$ below TOC

Water elevation: $230.30 \mathrm{~h}(70.20 \mathrm{~m}) \mathrm{ms}$.

Sp. conductance: $82 \mu \mathrm{s} / \mathrm{cm}$

No water was evacuated before sampling.

\section{WELL MGG 23}

MEASUAEMENTS CONDUCTED IN THE FIELO

Sample date: $11 / 18 / 81$

Depth to water: $42.00 \mathrm{n}$ (12.80 m) below TOC

Water elevation: $235.80 \mathrm{~h}(71.87 \mathrm{~m}) \mathrm{ms}$

No water was ovacuated before sampling.

\section{WELL MGG 28}

MEASUREMENTS CONDUCTED IN THE FIELD

Sample data: 11/18/91

Depth to water: $30.60 \mathrm{n}(12.07 \mathrm{~m})$ below TOC

Water elovation: 238.90 h (72.

No water was evecuated before sampling
Time: $12: 20$

Water temperature: $18.5^{\circ} \mathrm{C}$

Time: $12: 10$

Water temperature: $18.0^{\circ} \mathrm{C}$

Water temperalure: $17.8^{\circ} \mathrm{C}$

Time: $12: 40$

Water lemperature: $18.1^{\circ} \mathrm{C}$

Time: $12: 30$

Water temperature: $18.0^{\circ} \mathrm{C}$

Time: $12: 15$
$\mathrm{pH}: 6.1$

Water temperature: $18.2^{\circ} \mathrm{C}$

Time: $12: 00$

Water temperature: $18.2^{\circ} \mathrm{C}$
WELL MGG 36

MEASUREMENTS CONDUCTED IN THE FIELD

Sample date: $11 / 18 / 91$

Depth to water: $51.50 \mathrm{n}(15.70 \mathrm{~m})$ below TOC

Water elevation: $239.70 \mathrm{~h}(73.06 \mathrm{~m}) \mathrm{ms}$ I

No water was evacuated betore sampling.

Time: $11: 50$

Water temperature: $17.7^{\circ} \mathrm{C}$

WELL MSB 1B

MEASUREMENTS CONDUCTED IN THE FIELD

Sample date: 10/02/91

Depth to water: $144.38 \mathrm{in}(44.00 \mathrm{~m})$ below TOC

Water elevation: $210.44 \mathrm{f}(64.14 \mathrm{~m}) \mathrm{ms}$

Water evacuated betore sampling: $186 \mathrm{gal}$

LABORATORY ANALYSES

F Analyte Result Mod Unit

$\begin{array}{ll}\text { pH } \\ 0 & \text { Specific conductance } \\ 0 & \text { Aluminum }\end{array}$

Arsenic

Barium

Bromodichloromethane

Bromodich

Bromolorm

Cadmium

Caicium

Carbon tetrachloride

Chloride

Chlorobenzene

Chloroethane

Chloroethene Ninyl chloride)

2.Chloroethyl vinyl ether

Chloroform

Chloromethane

Chromium

Copper

Dibromochloromethane

1,1-Dichloroethane

i, 2 - Dichloroethane

1.2. Dichloroethane

trans-1,2-Dichloroethylene

Dichloromethane

1,2-Dichloropropane

cis-1,3-Dichloropropene
trans-1,3-Dichloropropene

Ethylbenzene

Fluoride

Iron

Magnesium

Manganese

Mercury
Nickel

Nitrate as nitrogen

Phenols

Potassium

Selenium

Silica

Silver

Sodium

Sultate

$1,1,2,2-$ Tetrachloroethane

Tetrachloroethylene

Tolvene

Total dissolved solids

Total organic carbon

Total organic halogens

1.1,1. Trichloroethane

i. Trichlorothan

Trichloreathylene

Trichlorofluoromethane

Uranium

Zine

Gross alpha

Nonvolatile beta

Total radium
Tritım
Timo: 12:10

pH: 5.5

Alkalinity: $6 \mathrm{mg} / \mathrm{h}$. $18.8^{\circ} \mathrm{C}$
5.7
25
$<20$
$<2.0$
6.3
$<1.0$
$<1.0$
$<1.0$
$<1.0$
$<2.0$

$<\begin{aligned} & 1.440 \\ & <1.0\end{aligned}$

2,150
$<1.0$

$<1.0$

$<1.0$

$<1.0$

$<1.0$
$<1.0$

$<4.0$

$<4.0$

$<1.0$

$<1.0$

$<1.0$

2.0

$<1.0$

$<1.0$

$<1.0$
$<100$

$<100$
$<4.0$

$<3.0$

407
14
$<0.20$

1,040

$<5.0$

734
$<2.0$

$<2.040$

$<2.0$

$<1,000$

$<1.0$

1.0
$<1.0$

$<1.0$
49,000

$<1,000$

225
$<50$

$<1.0$

370
$<1.0$

$<20$

8.1
$<2.0 E-08$

$<2.0 E-09$

1.0E-09

Jo $\underset{\mu \mathrm{SH} / \mathrm{cm}}{\mathrm{pH}} \mathrm{G}$

$\mu \mathrm{g} / \mathrm{GE}$ 
ANALYTICAL RESULTS

WELL MSB $1 \mathrm{C}$

MEASUREIMENTS CONDUCTED IN THE FIELD

Sample date: 10/03/91 Depth to water: $138.13 \mathrm{tt}(42.10 \mathrm{~m})$ below TOC Wator olovation: $216.97 \mathrm{ft}(66$. Whiter evecumed bofore sampling: 29 al The woll went dry during purging: $29 \mathrm{ga}$

LABORATOPY ANALYSES

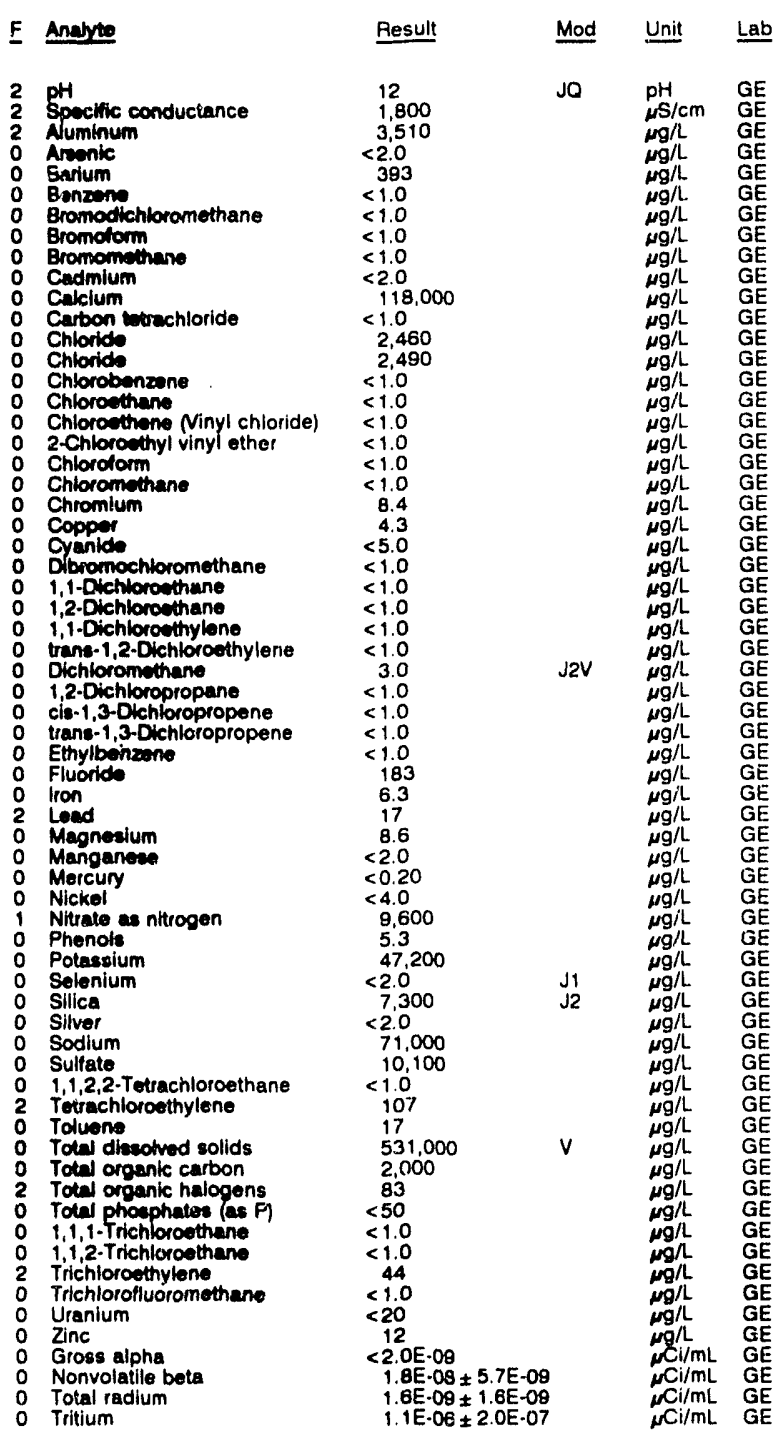

\section{WELL MSB 1CC}

MEASUREMENTS CONDUCTED IN THE FIELD

Depth to wator: $136.78 \mathrm{ft}(41.68 \mathrm{~m})$ below TOC Water elevation: $218.11 \mathrm{ft}(66.48 \mathrm{~m})$ melow

Sp. conductance: $192 \mathrm{\mu s} / \mathrm{cm}$

evacuated before sampling: $13 \mathrm{ga}$

The well went dry during purging.

LABORATORY ANALYSES

\begin{tabular}{|c|c|c|c|}
\hline Analyte & Result & Mod & Unif \\
\hline $\begin{array}{l}\text { pH } \\
\text { Specific conductance } \\
\text { Aluminum } \\
\text { Arsenic } \\
\text { Barium } \\
\text { Benzene }\end{array}$ & $\begin{aligned} & 6.9 \\
& 170 \\
&<20 \\
&<2.0 \\
& 27 \\
&<1.0\end{aligned}$ & JQ & $\begin{array}{l}\mathrm{pH} \\
\mu \mathrm{S} / \mathrm{cm} \\
\mu \mathrm{g} / \mathrm{L} \\
\mu g / \mathrm{L} \\
\mu g / \mathrm{L} \\
\mu \mathrm{g} / \mathrm{L}\end{array}$ \\
\hline
\end{tabular}

WELL MSB 1CC collected on 10/03/91, laboratory analyses (cont.)

\begin{tabular}{|c|c|c|c|}
\hline Analyte & Result & Mod & Unit \\
\hline 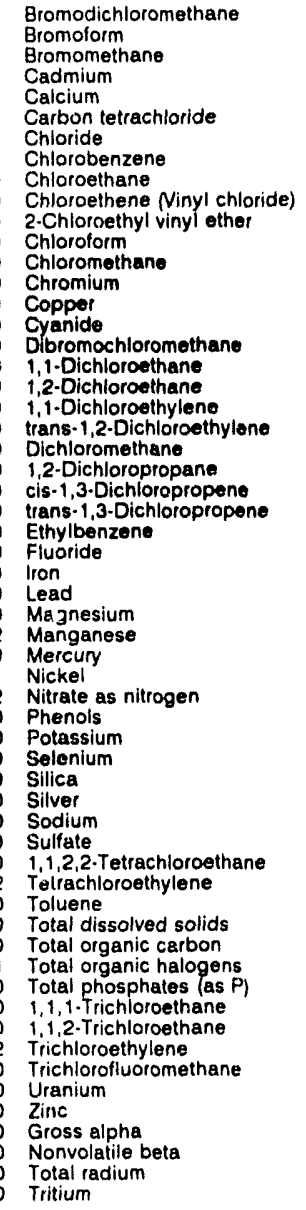 & 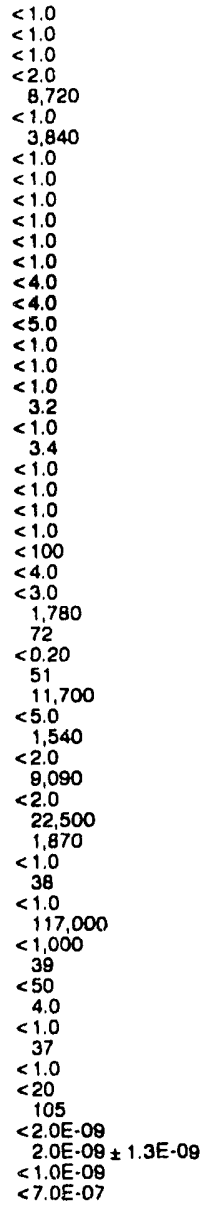 & $\begin{array}{l}\mathrm{J} 1 \\
\mathrm{~J} 2\end{array}$ & 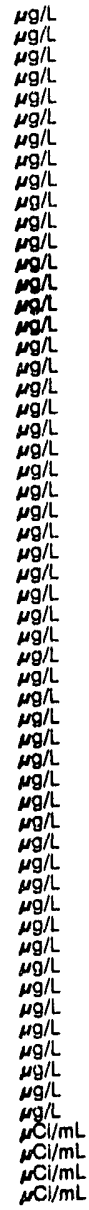 \\
\hline
\end{tabular}

WELL MSB 1D

MEASUREMENTS CONDUCTED IN THE FIELD

Sample date: $10 / 02 / 91$

Depth to water: $125.81 \mathrm{H}(38.35 \mathrm{~m})$ below TOC

Water elevation: $229.09 \mathrm{H}(69.83 \mathrm{~m}) \mathrm{msl}$

sampling: $48 \mathrm{gal}$

Time: $11: 30$

$\mathrm{pH}: \mathbf{5 . 8}$

Alkalinity: $12 \mathrm{mg} / \mathrm{h}$

LABORATORY ANALYSES

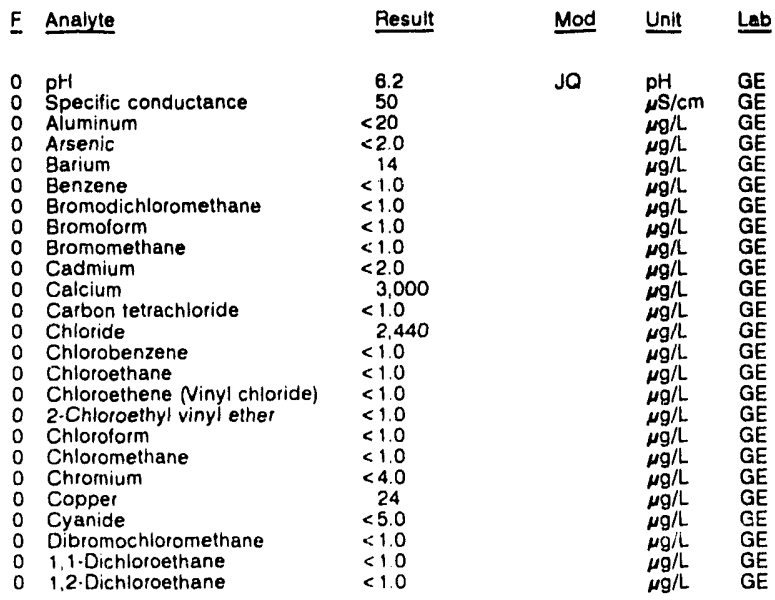


ANALYTICAL RESULTS

WELL MSB 1D collected on 10/02/91, laboratory analyses (cont.)

\begin{tabular}{|c|c|c|c|c|c|}
\hline & Analyte & Result & Mod & Unit & $\underline{L a b}$ \\
\hline $\begin{array}{l}0 \\
0 \\
0 \\
0 \\
0 \\
0 \\
0 \\
0 \\
0 \\
0 \\
0 \\
2 \\
0 \\
0 \\
0 \\
0 \\
0 \\
0 \\
0 \\
0 \\
0 \\
0 \\
0 \\
2 \\
0 \\
0 \\
0 \\
0 \\
0 \\
0 \\
0 \\
2 \\
0 \\
0 \\
0 \\
0 \\
0 \\
0 \\
1 \\
0\end{array}$ & $\begin{array}{l}\text { 1,1-Dichloroethylene } \\
\text { trans-1,2-Dichloroethylene } \\
\text { Dichloromethane } \\
1,2-\text { Dichloroplopane } \\
\text { cis-1,3-Dichloropropene } \\
\text { trans-1,3-Dichloropropene } \\
\text { Ethylbenzene } \\
\text { Fluoride } \\
\text { fron } \\
\text { Lead } \\
\text { Magnesium } \\
\text { Manganese } \\
\text { Mercury } \\
\text { Nickel } \\
\text { Nitrate as nitrogen } \\
\text { Phenols } \\
\text { Potassium } \\
\text { Selenium } \\
\text { Silica } \\
\text { Silver } \\
\text { Sodium } \\
\text { Sulfate } \\
\text { 1,1,2.2-Tetrachloroethane } \\
\text { Totrachloroethylene } \\
\text { roluene } \\
\text { Total dissolved solids } \\
\text { Total organic carbon } \\
\text { Total organic halogens } \\
\text { Total phosphates (as P) } \\
\text { 1,1,1-Trichloroethane } \\
\text { 1,1,2.Trichloroethane } \\
\text { Trichloroethylene } \\
\text { Trichlorofluoromethane } \\
\text { Uranium } \\
\text { Uranium } \\
\text { Zinc } \\
\text { Gross alpha } \\
\text { Nonvolatile beta } \\
\text { Total radium } \\
\text { Tritium }\end{array}$ & $\begin{array}{l}<1.0 \\
<1.0 \\
1.0 \\
<1.0 \\
<1.0 \\
<1.0 \\
<1.0 \\
<100 \\
25 \\
<3.0 \\
656 \\
61 \\
<0.20 \\
<4.0 \\
2,640 \\
<5.0 \\
760 \\
<2.0 \\
8,520 \\
<2.0 \\
6,450 \\
2,160 \\
<1.0 \\
10 \\
<1.0 \\
66,000 \\
2,000 \\
15 \\
<50 \\
<1.0 \\
<1.0 \\
12 \\
<1.0 \\
<20 \\
<20 \\
108 \\
2.8 E \cdot 09 \pm 1.2 E \cdot 09 \\
2.1 E \cdot 09 \pm 1.1 E \cdot 09 \\
2.5 E \cdot 09 \pm 3.4 E \cdot 09 \\
2.0 E \cdot 06 \pm 2.0 E \cdot 07\end{array}$ & J1 & $\begin{array}{l}\mu g / L \\
\mu g / L \\
\mu g / L \\
\mu g / L \\
\mu g / L \\
\mu g / L \\
\mu g / L \\
\mu g / L \\
\mu g / L \\
\mu g / L \\
\mu g / L \\
\mu g / L \\
\mu g / L \\
\mu g / L \\
\mu g / L \\
\mu g / L \\
\mu g / L \\
\mu g / L \\
\mu g / L \\
\mu g / L \\
\mu g / L \\
\mu g / L \\
\mu g / L \\
\mu g / L \\
\mu g / L \\
\mu g / L \\
\mu g / L \\
\mu g / L \\
\mu g / L \\
\mu g / L \\
\mu g / L \\
\mu g / L \\
\mu g / L \\
\mu g / L \\
\mu g / L \\
\mu g / L \\
\mu C i / m L \\
\mu C i / m L \\
\mu C \mathrm{C} / m L \\
\mu C \mathrm{i} / \mathrm{mL}\end{array}$ & $\begin{array}{l}\mathrm{GE} \\
\mathrm{GE} \\
\mathrm{GE} \\
\mathrm{GE} \\
\mathrm{GE} \\
\mathrm{GE} \\
\mathrm{GE} \\
\mathrm{GE} \\
\mathrm{GE} \\
\mathrm{GE} \\
\mathrm{GE} \\
\mathrm{GE} \\
\mathrm{GE} \\
\mathrm{GE} \\
\mathrm{GE} \\
\mathrm{GE} \\
\mathrm{GE} \\
\mathrm{GE} \\
\mathrm{GE} \\
\mathrm{GE} \\
\mathrm{GE} \\
\mathrm{GE} \\
\mathrm{GE} \\
\mathrm{GE} \\
\mathrm{GE} \\
\mathrm{GE} \\
\mathrm{GE} \\
\mathrm{GE} \\
\mathrm{GE} \\
\mathrm{GE} \\
\mathrm{GE} \\
\mathrm{GE} \\
\mathrm{GE} \\
\mathrm{GE} \\
\mathrm{GE} \\
\mathrm{GE} \\
\mathrm{GE} \\
\mathrm{GE} \\
\mathrm{GE} \\
\mathrm{GE}\end{array}$ \\
\hline
\end{tabular}

WELL MSB 2B

MEASUREMENTS CONDUCTED IN THE FIELD

Sample date: $11 / 22 / 91$

Depth to water: $142.41 \mathrm{ft}(43.41 \mathrm{~m})$ below TOC

Water elevation: $212.19 \mathrm{Ht}(64.6 \mathrm{~m}$

Sp. conductance. $2269 \mu \mathrm{s} / \mathrm{cm}$. 36 ater evacuated before sampling: 36 gal

Water evacuated before sampling
The well went dry during purging.

LABOHATORY ANALYSES

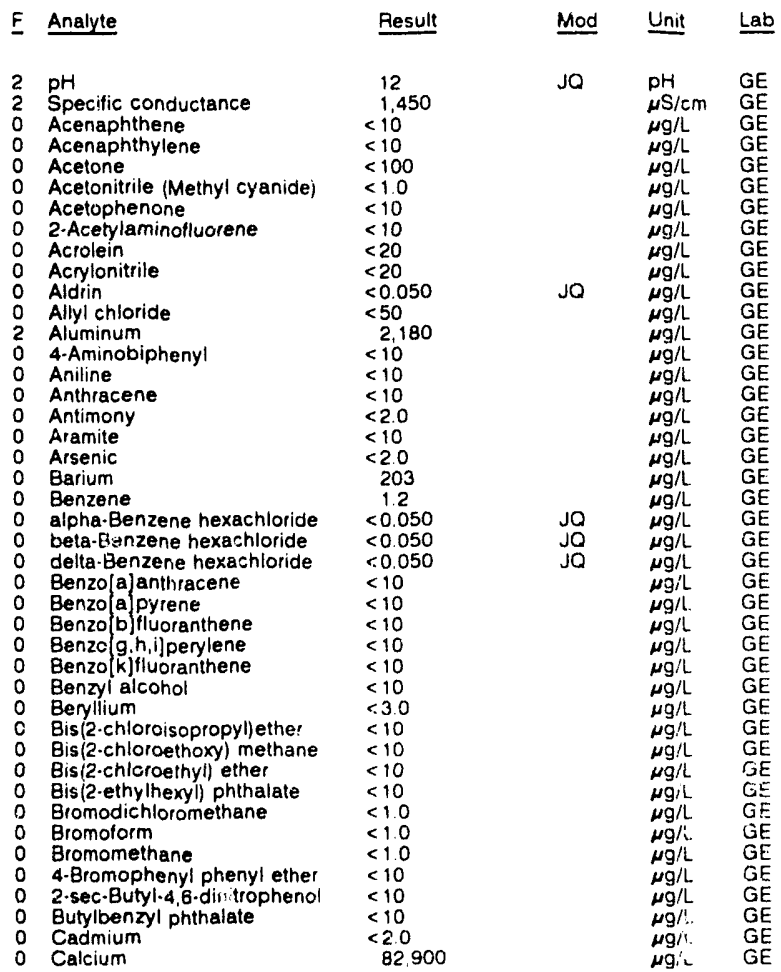

WELL MSB 28 collected on 11/22/91, laboratory analyses (cont.)

E Analyte Result Mod Unit Lab

$\begin{array}{ll}0 & \text { Carbon disulfide } \\ 0 & \text { Carbon letrachloride } \\ 0 & 2,3,7,8-T C D F \\ 0 & \text { Chlordane } \\ 0 & \text { Chloride } \\ 0 & \text { para-Chloro-meta-cresol } \\ 0 & 4 \text {-Chloroaniline } \\ 0 & \text { Chlorobenzene } \\ 0 & \text { Chlorobenzilate } \\ 0 & \text { Chloroethane } \\ 0 & \text { Chloroethene Ninyl chloride) } \\ 0 & 2 \text {-Chloroethyl vinyl ether } \\ 0 & \text { Chlorolorm } \\ 0 & \text { Chloromethane }\end{array}$

$<10$

$<0.00040 \quad \mu g / L \quad G \quad G E$

$\begin{array}{lll}1,250 & \mu g / L & G E \\ & \mu g / L & G E\end{array}$

$<10$
$<10$
3.5

$<10$

$<1.0$

$<1.0$
$<10$

1.5
$<1.0$

2.Chloronaphthalene $\quad<10$

2.Chlorophenol

$\begin{array}{ll}\text { Chloroprene } & <10 \\ & <200\end{array}$

Chromium 10.0

Cobalt

Coppet
o-Cresol (2-Methylphenol)

m-Cresol (3-Methylphenol)

p-Cresol (4-Methylphenol)

Cyanide

$P, P^{\prime} \cdot D D D$

P.P.DDE

Di-n.butyl phthalate

Diallate

Dibenz $[a, h]$ anthracene

Dibenzofuran

1,2-Dibromo-3-chloropropane

Dibromochloromethane

1,2.Dibromoethane

trans-1,4-Dichloro-2-butene

1,2.Dichlorobenzene

1.4.Dichlorobenzene

3,3'-Dichlorobenzidine

Dichlorodifluoromethan

1.2.Dichloroethane

1,1-Dichloroethylene

trans-1,2-Dichloroethylene

2.4-Dichlorophenol

2,4-Dichlorophenoxyacetic acid $<0.30$

1,2-Dichloropropane

cis-1,3-Dichloropropene
trans-1,3-Dichloropropene

Dieldrin

Diethyl phthalate

2,4-Dimethyl phenol

p.Dimethylaminoazobenzene

Dimethylbenz(a)anthracene

3,3'-Dimethylbenzidine

a,a-Dimethylphenethylamine

1,3.Dinitrobenzene

2.4.Dinitrophenol

2,6-Dinitrotoluene

o 1,4-Dioxane

0 Diphenylamin

- Disulfoton

O Endosulfan I

Endosulfan sulfate

Endrin

Endrin aldehyde

Ethyl methanesulfonate

o Ethylbenzene

o Famphur

Fluoranthene

Fiuorene

O Fluoride

Heptachlor epoxide

o Heptachlorodibenzo-p.dioxins

Heplachlorodibenzo-p.furans

Hexachlorobenzene

Hexachlorocyclopentadiene

Hexachlorocyclope

0 Hexachlorodibenzo-p-dioxins

- $1,2,3,4,7,8 \cdot H \times C D$

- Hexachlorodibenzo-p-furans

Hexachloroethan

Hexachloropropene

2.Hexanone

$<10$

$<10$

$<10$

$<10$

$<10$

160
$<0.050$

$<0.050$

$<0.00065$

$<0.00045$

$<0.00045$

$<10$

$<0.00045$

$<0.00045$

$<0.00040$

$<10$

$<10$

$<10$
$<1.0$

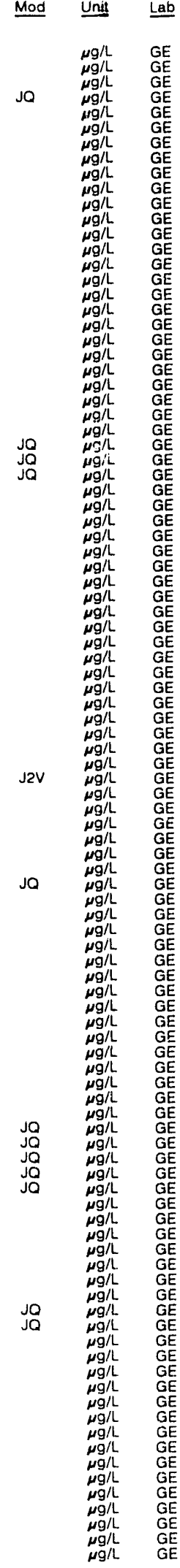


ANALYTICAL RESULTS

WELL. MSB 28 collected on 11/22/91, laboratory analyses (cont.)

\begin{tabular}{|c|c|c|c|c|c|c|}
\hline Analyte & Result & Mod & Unit & $\underline{\text { Lab }}$ & $\underline{F}$ & Analyte \\
\hline $\begin{array}{l}\text { Indeno[1,2,3-c,d]pyrene } \\
\text { lodomethane (Methyl iodide) } \\
\text { lron } \\
\text { Isobutyl alcohol } \\
\text { Isodrin } \\
\text { lsophorone } \\
\text { lsosafrole } \\
\text { Kepone } \\
\text { lead } \\
\text { Lindane } \\
\text { Magnesium } \\
\text { Manganese } \\
\text { Mercury } \\
\text { Methacrylonitrile } \\
\text { Methapyrilene } \\
\text { Methoxychlol } \\
\text { Methyl ethyl ketone } \\
\text { Methyl isobutyl ketone } \\
\text { Methyl mothacrylate } \\
\text { Methyl methanesultonate } \\
\text { 2-Methyl-4,6-dinitrophenol } \\
\text { 3-Methylcholanthrene } \\
\text { 2-Methylnaphthalene } \\
\text { N-Nitrosodiethylamine } \\
\text { N-Nitrosodimethylamine } \\
\text { N-Nitrosod|-n-butylamine }\end{array}$ & $\begin{array}{l}<10 \\
<15 \\
12 \\
<100 \\
<10 \\
<10 \\
<10 \\
<10 \\
14 \\
10.0050 \\
6.7 \\
<2.0 \\
<0.20 \\
<50 \\
<10 \\
<0.50 \\
<1.0 \\
<1.0 \\
<10 \\
<10 \\
<10 \\
<10 \\
<10 \\
<10 \\
<10 \\
<10\end{array}$ & Ja & $\begin{array}{l}\mu g / L \\
\mu g / L \\
\mu g / L \\
\mu g / L \\
\mu g / L \\
\mu g / L \\
\mu g / L \\
\mu g / L \\
\mu g / L \\
\mu g / L \\
\mu g / L \\
\mu g / L \\
\mu g / L \\
\mu g / L \\
\mu g / L \\
\mu g / L \\
\mu g / L \\
\mu g / L \\
\mu g / L \\
\mu g / L \\
\mu g / L \\
\mu g / L \\
\mu g / L \\
\mu g / L \\
\mu g / L \\
\mu g / L\end{array}$ & $\begin{array}{l}G E \\
G E \\
G E \\
G E \\
G E \\
G E \\
G E \\
G E \\
G E \\
G E \\
G E \\
G E \\
G E \\
G E \\
G E \\
G E \\
G E \\
G E \\
G E \\
G E \\
G E \\
G E \\
G E \\
G E \\
G E\end{array}$ & $\begin{array}{l}2 \\
2 \\
0 \\
0 \\
0 \\
0 \\
0 \\
0 \\
2 \\
0 \\
0 \\
0 \\
0 \\
0 \\
0 \\
0 \\
0 \\
0 \\
0 \\
0 \\
0 \\
0 \\
1 \\
0 \\
0\end{array}$ & $\begin{array}{l}\text { Total organic carbon } \\
\text { Total ogganic halogens } \\
\text { Total phosphates (as P) } \\
\text { Toxaphene } \\
2,4,5-T F \text { (Silvex) } \\
1,2,4-\text { Trichlorobenzene } \\
1,1,1-\text { Trichloroethane } \\
1,1,2-\text { Trichloroethane } \\
\text { Trichloroethylene } \\
\text { Trichlorofluoromethane } \\
2,4,5-\text { Trichlorophenol } \\
2,4,6-\text { Trichlorophenol } \\
2,4,5-T \\
1,2,3-T r i c h l o r o p r o p a n e \\
1,3,5-T \text { Trinitrobenzene } \\
\text { Uranium } \\
\text { Vanadium } \\
\text { Vinyl acetate } \\
\text { Xylenes } \\
\text { Zinc } \\
2,3,7,8-\text { TCDD } \\
\text { Gross alphe } \\
\text { Nonvolatile beta } \\
\text { Total radium } \\
\text { Tritium }\end{array}$ \\
\hline
\end{tabular}

WELL MSB 2C

MEASUREMENTS CONDUCTED IN THE FIELD

Sample date: $11 / 22 / 91$

Depth to water: 139.88 H $(42.64 \mathrm{~m})$ below TOC Water elevation: $214.82 \mathrm{tt}(65.48 \mathrm{~m}) \mathrm{msl}$ Water evacuated belore sampling: $11 \mathrm{gal}$ The well went dry during purging.

LABORATORY ANALYSES

F Analyte $\quad$ Result Mod Unit Lab

$2 \quad{ }^{2 H}$

Acenaphthene

Acenaph

Acetonitrile (Methyl cyanide)

Acetophenono

Acrolein

Acrylonitrile

Aldrin

Allyl chlorido

4-Aminobiphenyl

0 Aniline

0 Anthracene

1 Antimoriy

- Aramite

0 Arsenic

0 Barium

Benzene

alpha-Benzene hexachloride

delta-Benzene hexachlorid

Benzojajanthracene

Benzo a pyrene

Benzo b] fluoranthene

Benzo $g, h$, i)perylene

Benzo kjfluoran

Beryllium

Bis(2-cl.toroisopropyl)ether

Bis (2.chloroethoxy) methane

Bis (2-chloroethyl) ether

Bis(2-ethylhexyl) phthalate

Bromodichlorone phthata

Bromoform

4-Bromophenyl phenyl ether

4-Bromophenyl phenyl ether

Butylbenzyl phithalate

Cadmium

Calcium

Carbon tetrachloride

2,3,7,8.TCD

Chiordane

Chlordane

para-Chloro-meta-cresol

4-Chloroaniline

Chlorobenzene

Chlorobenzilat

Chloroethane

Chloroethene Ninyl chloride)

2-Chloroethyl vinyl ether

Chloroform

Chlorometharis

Result
13,000
1,130
260
$<0.24$
$<0.090$
$<10$
$<1.0$
$<1.0$
62,000
$<1.0$
$<10$
$<10$
$<0.090$
$<1.0$
$<10$
$<20$
12
$<1.0$
$<2.0$
16
$<0.00045$
$3.2 \mathrm{E} \cdot 09 \pm 1.4 \mathrm{E} \cdot 09$
$2.0 \mathrm{E}-08 \pm 3.2 \mathrm{E} \cdot 09$
$1.1 \mathrm{E} \cdot 09 \pm 1.6 \mathrm{E}-09$
$2.2 \mathrm{E}-06 \pm 7.0 \mathrm{E} \cdot 07$

Mod Unit Lab

$\begin{array}{ll}\mu \mathrm{g} / \mathrm{L} & \mathrm{GE} \\ \mu \mathrm{g} / \mathrm{L} & \mathrm{GE} \\ \mu \mathrm{g} / \mathrm{L} & \mathrm{GE} \\ \mu \mathrm{g} / \mathrm{L} & \mathrm{GE} \\ \mu \mathrm{g} / \mathrm{L} & \mathrm{GE} \\ \mu \mathrm{g} / \mathrm{L} & \mathrm{GE} \\ \mu \mathrm{g} / \mathrm{L} & \mathrm{GE} \\ \mu \mathrm{g} / \mathrm{L} & \mathrm{GE} \\ \mu \mathrm{g} / \mathrm{L} & \mathrm{GE} \\ \mu \mathrm{g} / \mathrm{L} & \mathrm{GE} \\ \mu \mathrm{g} / \mathrm{L} & \mathrm{GE} \\ \mu \mathrm{g} / L & \mathrm{GE} \\ \mu \mathrm{g} / \mathrm{L} & \mathrm{GE} \\ \mu \mathrm{g} / \mathrm{L} & \mathrm{GE} \\ \mu \mathrm{g} / \mathrm{L} & \mathrm{GE} \\ \mu \mathrm{g} / \mathrm{L} & \mathrm{GE} \\ \mu \mathrm{g} / \mathrm{L} & \mathrm{GE} \\ \mu \mathrm{g} / \mathrm{L} & \mathrm{GE} \\ \mu \mathrm{g} / \mathrm{L} & \mathrm{GE} \\ \mu \mathrm{g} / \mathrm{L} & \mathrm{GE} \\ \mu \mathrm{g} / \mathrm{L} & \mathrm{GE} \\ \mu \mathrm{Cl} / \mathrm{mL} & \mathrm{GE} \\ \mu \mathrm{Ci} / \mathrm{mL} & \mathrm{GE} \\ \mu \mathrm{CI} / \mathrm{mL} & \mathrm{GE} \\ \mu \mathrm{Cl} / \mathrm{mL} & \mathrm{GE}\end{array}$

$\mathrm{pH}: 11.1$

Alkalinity: $119 \mathrm{mg} / \mathrm{L}$

11

JQ $\mathrm{pH}$ GE

650
$<10$

$<10$
$<10$
$<100$

$<100$

$<1.0$
$<10$
$<10$

$<20$

$<20$
$<0.050$

$<50$
42

42
$<10$

$<10$
$<10$

$<10$
3.6
$<10$

$<10$
$<2.0$

7.0
1.3

$<0.050$

$<0.050$

$<10$
$<10$

$<10$

$<10$
$<10$

$<10$

$<10$
$<3.0$

$<3.0$
$<10$

$<10$

$<10$

$<10$

$<1.0$

$<1.0$

$<10$
$<10$

$<10$
$<2.0$

11,000
$<1.0$
$<1.0$

$<1.0$
$<0.00040$

$<0.00040$
$<0.00040$

$<.50$
3.080

30
$<10$

$<10$

$<1.0$

$<1.0$
$<1.0$

$<10$
$<1.0$
$<1.0$
$\begin{array}{ll}\mathrm{pH} & \mathrm{G} \\ \mu \mathrm{S} / \mathrm{cm} & \mathrm{G} \\ \mu \mathrm{g} / \mathrm{L} & \mathrm{G} \\ \mu \mathrm{g} / \mathrm{L} & \mathrm{G} \\ \mu \mathrm{g} / \mathrm{L} & \mathrm{G}\end{array}$

Jo

$\mu g / L$
$\mu g / L$
$\mu g / L$

$\begin{array}{ll}\mu g / L & G E \\ \mu g / L & G E\end{array}$

$\begin{array}{cc}g / \mathrm{L} & \mathrm{GE} \\ \mathrm{g} / \mathrm{L} & \mathrm{GE} \\ \mathrm{g} / \mathrm{L} & \mathrm{GE}\end{array}$

$\mu g / L$

$\mu g / L \quad G E$

$\mu g / L \quad G$

\begin{tabular}{l} 
Ja \\
ja \\
\hline 0
\end{tabular}

$\begin{array}{ll}\mu g / L & G E \\ \mu g / L & G E \\ \mu g / L & G E\end{array}$

$\mu g / L \quad G$

$\underset{\mu g / L}{\mu g} \quad \mathrm{GE}$

$\underset{\mu \mathrm{g} / \mathrm{L}}{\mu \mathrm{GE}}$

$\mu g / h \quad G E$

$\mu g / L \quad G E$

$\mu g / L \quad G E$

$\mu g / \mathrm{GE}$

$\mu g / L$

$\mu g / \mathrm{G} \quad \mathrm{GE}$

$\begin{array}{cc}\mu / L & G E \\ g / L & G E \\ G / L & G E\end{array}$ $\mu g / L \quad G E$

(1) 
ANALYTICAL RESULTS

WELL. MSB $2 C$ collected on 11/22/91, laboratory analyses (cont)

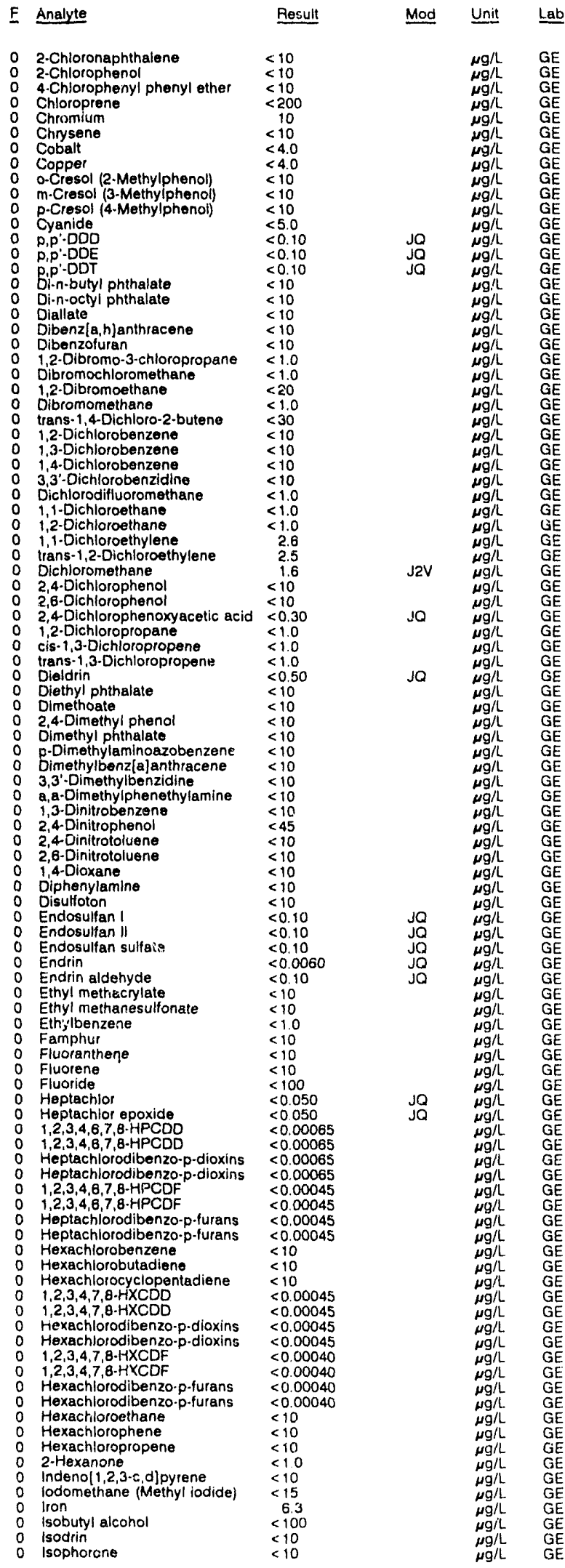

WELL MSB 2C collected on 11/22/91, laboratory analyses (cont)

F Analyte Besuit Mod Unit Lab

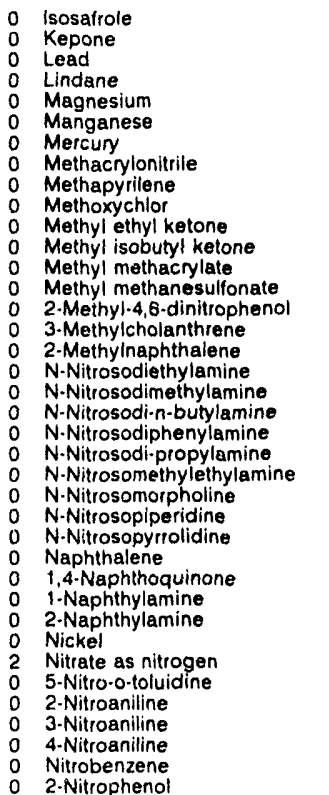

$<10$
$<10$
$<30$
$<30$

$<3.0$
$<0.0050$

90
$<2.0$

$<0.20$

$<50$

$<0.50$

$<1.0$

$<10$

$<10$

$<10$

$<10$

$<10$

$<10$

$<10$

$<10$

$<<10$

$<10$
$\leq 10$
$\leq 10$

$<10$
$<10$

$<10$

18,000

$<10$

$<10$

$<10$

Nitrobenzene

a-Nitopheno

4-Nitroquinaline-1-oxide

O.O-Triethyl phosphorothioate $<$

Octachlorodibenzo-p-dioxins

Octachlorodibenzo-p.dioxins

Octachlorodibenzo-p.furans

Octachlorodibenzo-p.furans

Parathion

Parathion methyl

PCB 1016

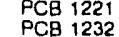

PCB 1242

PCB 1248

PCB 1254

- Pentachlorobenzene

$1,2,3,7,8 \cdot P C D F$

Pentachlorodibenzo-p.dioxin

Pentachlorodibenzo-p-dioxins

Pentachlorodibenzo-p-furans

Pentachlorodibenz
$1,2,3,7,8$-PCDF

$1,2,3,7,8-P C D F$

Pentachloronitrobenzene

Pentachlorophenol

Phenacetin

Phenol

Phenols

p.Phenylenediamine

Phorate

Pronamid

Pronamionitrile

Pyrene

Pyridine
Safrole

Selenium

Sitica

Silver

Styrene

Sulfate

Sulfide

1,2,4,5. Tetrachlorobenzene

$1,2,4,5 \cdot$ - Tetrachlorobenzene
Tetrachlorodibenzo-p-dioxins

Tetrachlorodibenzo-p-dioxins

Tetrachlorodibenzo-p-furans

Tetrachlorodibenzo-p.firans

$1,1,2,2$-Tetrachloroethane

$1,1,1,2$-Tetrachloroeth

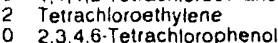

0 Thallium

O Thionazin

o Toluene

$<<0.0010$

$<0.0010$

$<0.0010$
$<0.050$

$<0.050$

$<0.50$

$<0.50$
$<0.50$

$<0.50$

$<0.50$

$<0.0005$

$<0.00055$

$<0.00055$

$<0.00055$

$<0.00055$
$<0.00055$

$<0.00055$

10

$<10$

$<10$

$<10$

$<10$
$<10$
$<5.0$

$<5.0$
$<10$

$<0.10$
$<10$

$<10$
47,700

$<10$

$<200$
$<10$
$<10$

$<10$
$<10$
$<10$

$<10$
$<2.0$

6.430
$<2.0$

43,600
$<1.0$

$<1.0$
13,400

$<1,000$

$<10$

$<<0.00045$

$<0.00045$

$<0.00040$

$<1.0$
$<1.0$

2,800

$<10$
$<2.0$

$<10$
$<2.0$

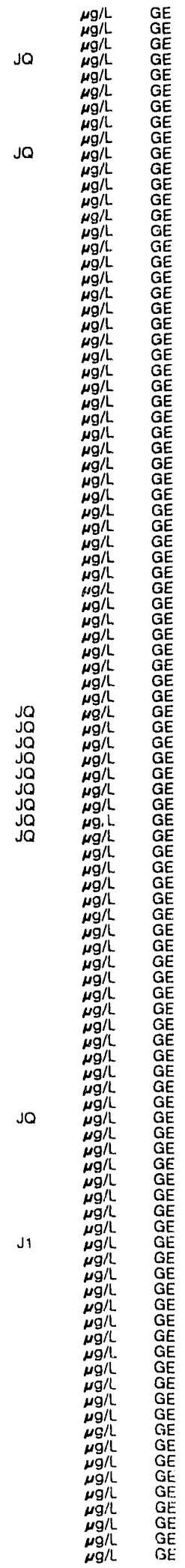


ANALYTICAL RESULTS

WELL MSB $2 C$ collected on 11/22/91, laboratory analyses (cont.)

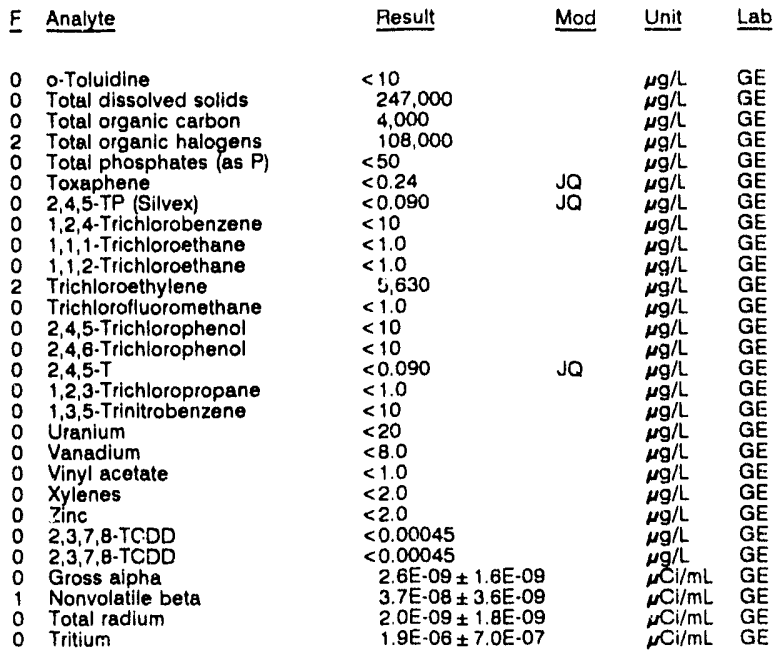

\section{WELL MSB 2D}

MEASUREMENTS CONDUCTED IN THE FIELD

Sample date: $10 / 03 / 91$

Depth to water: $123.50 \mathrm{ft}(37.64 \mathrm{~m})$ below TOC Water elevation: $230.30 \mathrm{ft}(70.20 \mathrm{~m}) \mathrm{ms}$

Sp. conductance: $74 \mu \mathrm{s} / \mathrm{cm}$

Water evacuated before sampling: $46 \mathrm{gal}$

LABORATORY ANALYSES

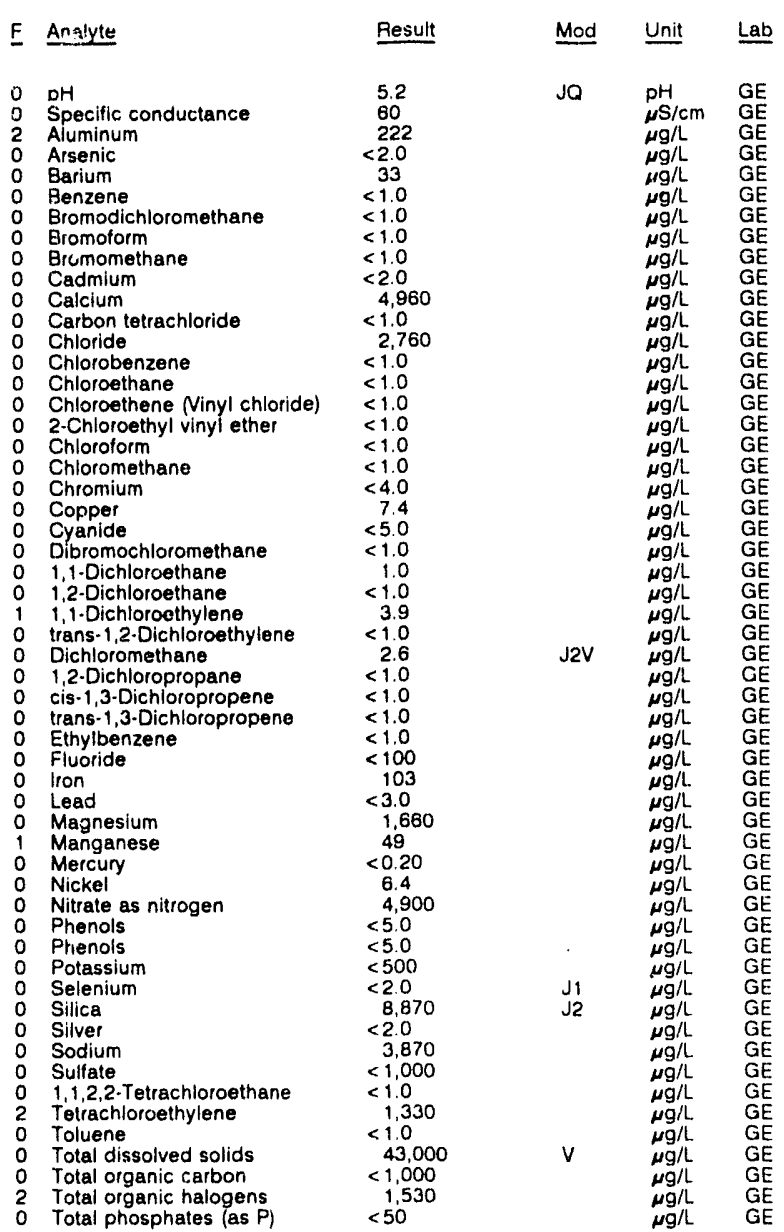

WELL MSB 20 collected on 10/03/91, laboratory analyses (cont)

\begin{tabular}{|c|c|c|}
\hline Analyte & Result & Unit \\
\hline $\begin{array}{l}\text { 1,1,1-Trichloroethane } \\
\text { 1,2-Trichloroethane } \\
\text { irichloroethylene } \\
\text { Trichlorofluoromethane } \\
\text { Uranium } \\
\text { Zinc } \\
\text { Gross alpha } \\
\text { Nonvolatile beta } \\
\text { Total radium } \\
\text { Tritium }\end{array}$ & $\begin{aligned} 6.0 \\
<1.0 \\
548 \\
1.3 \\
<20 \\
18 \\
5.6 \mathrm{E} \cdot 09 \pm 1.6 \mathrm{E} \cdot 00 \\
2.9 \mathrm{E} \cdot 00 \pm 1.3 \mathrm{E} \cdot 09 \\
8.0 \mathrm{E} \cdot 00 \pm 2.3 \mathrm{E}-00 \\
8.2 \mathrm{E} \cdot 07 \pm 2.0 \mathrm{E} \cdot 07\end{aligned}$ & $\begin{array}{l}\mu g / L \\
\mu g / L \\
\mu g / L \\
\mu g / L \\
\mu g / L \\
\mu g / L \\
\mu C l / m L \\
\mu C l / m L \\
\mu C l / m L \\
\mu C l / m L\end{array}$ \\
\hline
\end{tabular}

WELL MSB 3B

MEASUREMENTS CONDUCTED IN THE FIELD

Sample date: 12/13/81

Depth to water: $152.58 \mathrm{ht}(46.50 \mathrm{~m})$ below TOC

Water elevation: $208.44 \mathrm{ft}(63.53 \mathrm{~m}) \mathrm{ms}$

Alkalinity: $38 \mathrm{mg} / \mathrm{L}$

Water temperature: $17.8^{\circ} \mathrm{C}$

LABORATORY ANALYSES

$2 \mathrm{pH}$

Specific conductance

Acenaphthene

Acenaph

Acetonitrile (Methyl cyanide)

Acetophenone

2-Acetylaminofluorene

Acrolein

Acrylonitrile

Aldrin

Aluminum

4-Aminobiphenyl

Aniline

Anthracene

Aramite

Arsenic

Arsenic
Barium

Benzene

bela-Benzene hexachloride

delta-Benzene hexachloride

Benzo ajanthracene

Benzolalpyrene

Benzo b] fluoranthene

Benzo g, h,ilperylene

Benzo [j] fluoranth

Benzyl alco

Bis(2-chloroisopropyl)ether

Bis (2-chloroisopropyl)ether
Bis (2-chloroethoxy) methane

Bis (2-chloroethyl) ether

Bis (2.ethylhexyl) phthala

Bromodich

- Bromomethane

4-Bromophenyl phenyl ether

2-sec-Butyl-4,6-dinitrophenol

Butylbenzyl phthalate

Cadmium

Carbon disulfide

- Carbon tetrachloride

0 2,3,7,8-TCDF

O Chlordane

Chloride
0 para-Chloro-meta-creso

4-Chloroaniline

Chlorobenzene

Chlorobenzilate

Chloroethene Ninyl chloride)

2-Chloroethyl vinyl ether

Chloroform

o Chloromethane

2-Chloronaphthalen

2.Chlorophenol

4 4-Chlorophenyl phenyl ether

o Chloroprene

0 Chromium

0
0
0

o Copper

o-Cresol (2-Methylphenol)

m-Cresol (3-Methylph

p-Cresol (4-Methylphenol)

0 Cyanide

0
0

0 P.p.:DDE

Di-n-butyl phthalate 
ANALYTICAL RESULTS

WELL MSB 38 collected on 12/13/91, laboratory analyses (cont)

E Analyte $\quad$ Result Mod Unit Lab

- Di-n-octyl phthalate

$\begin{array}{ll}0 & \text { Diallate } \\ 0 & \text { Dibenz[a,h]anthracene } \\ 0 & \text { Dibenzofuran }\end{array}$

$\begin{array}{ll}0 & \text { Dibenzofuran } \\ 0 & 1,2 \text {-Dibromo-3-chloropropane }\end{array}$

0 Dibromochloromethane

1,2-Dibromoethane

0 Dibromomethane

o 1,2-Dichlorobenzene

1,3-Dichlorobenzene

3,3'-Dichlorobenzidine

1,1-Dichloroethane

1,2-Dichloroethane

trans-1,2-Dichloroethylene

Dichloromethane

2,4-Dichlorophenol

2,6-Dichlorophenol
2,4-Dichlo:ophenoxyacetic acid

1,2-Dichloropropane

cis-1,3-Dichloropropene

Dieldrin

Diethyl phthalate

2,4-Dimethyl phenol

Dimethyl phthalate

p-Dimethylaminoazobenzene

3,3'-Dimethyibenzidine

a,a-Dimethylphenethylamine

1.3.Dinitrobenzene

2,4-Dinitrotoluene

2,8-Dinitrotoluane

1,4-Dioxane

Diphenylam

Endosulfan

Endosulfan sulfate

Endrin

Endrin aldehyde

Ethyl methanesulfonate

Ethylbenzene

Fluoranthen

Fluorene

Heptachlor

Heptachlor epoxide

Heptachlorodibenzo-p-dioxins

$1,2,3,4,6,7,8-H P C D$

Heptachlorodibenzo-p-furans

Hexachlorobenzene

Hexachlorocyclopentadiene

Hexachlorodibenzo-p-dioxins

$1,2,3,4,7,8 \cdot H X C D F$
Hexachlorodibenzo-p-furans

Hexachlorodibenzo

Hexachlorophene

Hexachlorop

indeno[ $[1,2,3-c, d] p y r e n e$

lodomethane (Methyl iodide)

iron

isobutyl alcoho

Isodrin

isophorone

Kepone

Lead

Magnesium

Manganese

Mercury

Methacrylonitrile

Methapyrilene

Methoxychlor

Methyl isobutyl keton

Methyl methacrylate

Methyl methanesulfonate

2-Methyl-4,6-dinitrophen

3-Methylcholanthren

N-Nitrosodiethylamine

N-Nitrosodimethylamine

N-Nitrosodi-n-butylamine

$N$-Nitrosodiphenylamine

$N$-Nitrosodi-propylamine

N-Nitrosomethylethy
$<10$
$<10$
$<10$
$<10$
$<25$
$<25$
$<500$
$<25$
$<750$

$<10$

$<10$
$<10$
$<25$

$<25$

$<25$

$<5$
54

$<10$

\begin{tabular}{l}
10 \\
10 \\
10 \\
10 \\
25 \\
5 \\
00 \\
25 \\
50 \\
10 \\
10 \\
10 \\
25 \\
55 \\
25 \\
25 \\
25 \\
54 \\
10 \\
10 \\
\hline 0
\end{tabular}

$<25$
$<25$
$<25$

$<0.50$

$<10$

$<10$

$<10$

$<10$

$<10$

$<10$

$<45$

$<10$
$<10$

$<10$

$<10$

$<0.10$

$<0.10$

$<0.0060$

$<0.10$
$<10$

$<10$

$<25$

$<10$

$<10$

$<<0.050$

$<0.00065$

$<0.00065$

$<0.00045$

$<10$

$<10$

$<10$
$<0.00045$

$<0.00045$

$<0.00040$

$<10$

$<10$

$<10$
$<25$
$<10$

$<10$
$<375$

4.2
$<2500$

$<10$

$<10$

$<10$

$<3.0$

$<4.005$
$<2.0$

$<<0.20$

$<1,250$

$<10$

$<25$

$<25$

$<10$

$<10$

$<10$

$<10$

$<10$

$<10$
$<10$

$<10$
$<10$

$<10$
$<10$

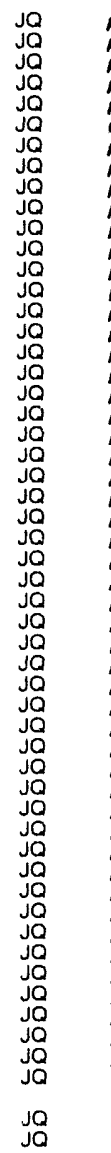

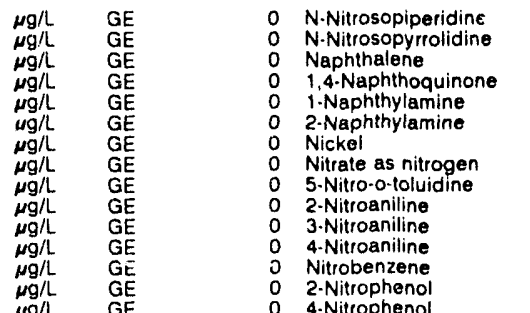

E Analyte Result

Mod Unit Lab

4-Nitrophenol $<<$ -

O,

$\begin{array}{ll}\text { Octachlorodibenzo-p.dioxins } & <0.0010 \\ \text { Octachlorodibenzo-p-furans } & <0.0010\end{array}$

Parathion

Parathion methyl $<0.050$

O PCB $1016<0.50$

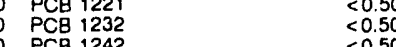

$\begin{array}{ll}\text { PCB } 1242 & <0.50 \\ \text { PCB } 1248 & <0.50\end{array}$

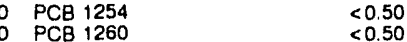

Pentachlorobenzene $<10$

$<0.00055$
$<0005$

$\begin{array}{ll} & \\ 0 & \end{array}$

$1,2,3,7.8 . P C D F \quad<0.0005$

Pentachlocothane

Pentachioronitrobenzene $<10$

Pentachlorophenol

Phenacetin

Phenol

Phenols

p.Phenylenediamine

0 Phorate

2-Picoline

Pronamid

Propionitrile

Pyrene

Safrole

0 Selenium

0 Silica

$\begin{array}{lll}0 & \text { Silver } \\ 0 & \text { Sodium } & \\ 0 & & \end{array}$

Sodium

0 Sulfate

0 Sulfide

Sulfotepp

1,2,4.5. Tetrachlorobenzene

Tetrachlorodibenzo-p-p.dioxins

o etrach-Tetrachloroethane

- i. 1,2 Tetrachloroethane

2 Tetrachloroethylene

o 2,3,4.6-Tetrachlorophenol

Thallium

Tin

o Toluen

o O-Toluidine

- Total dissolved solids

Total organic carbon

T Total phosphates (as P)

0 Toxaphene

$0 \quad 2,4,5 \cdot$ TP (Silvex)

1,2.4-Trichlorobenzene

1.1.1. Trichloroethane

Thich - Trichloroth

o Trichlorofluoromethane

Trentorichome

$2,4,5$.Trchlorophenol

$02,4,5$.

o 1,2.3. Trichloropropane

o 13,5.Trinitrobenzene

- Vanadium

0 Xylenes

0 Zinc

o 2,3,7,8-TCDD

Gross alpha

Nonvolatile beta

0 Tritium

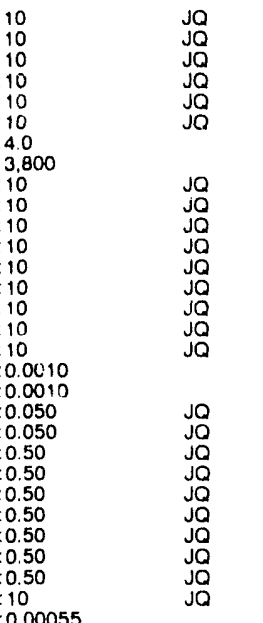

10

$<10$

$<10$

$<10$

$<5.0$
$<5.0$

$<0.10$
$<10$

$<0.10$
$<10$

7,920
$<10$

$<5,000$

$<10$

$<10$

$<2.0$

$<2.00$

5,890

$<25$

$<1,000$

$<10$

$<10$
$<0.00045$

$<0.00040$

$<25$

$>110$

110
$<20$

$<2.0$
$<10$

$<2.0$
15
$<10$

$<10$

$<1,000$
1,010

50
$<024$

$<0.24$
$<0.090$

$<10$

$<25$

1,180

$<25$

$<10$

$<0.090$

$<500$

$<10$

$<8.0$

$<50$

$<0.00045$

$<2.0 \mathrm{E} \cdot 0 \mathrm{0}$

8. $8 E \cdot 09 \pm 2.6 \mathrm{E} \cdot 09$

$<1.0 E-09$
$1.6 E \cdot 06 \pm 6.0 E-07$ $\mu g / \mathrm{GE}$

$\begin{array}{ll}\mu g / \Lambda & \mathrm{GE} \\ \mu g / h & \mathrm{GE}\end{array}$

$\mu g$ GE

$\begin{array}{ll}\mu g / L & G E \\ \mu g / L & G E \\ \mu g / L & G E\end{array}$

$\begin{array}{ll}\mu g / \mu & G E \\ \mu \mathrm{g} / \mathrm{h} & \mathrm{GE} \\ \mu \mathrm{GE} & \end{array}$

$\mu \mathrm{g} / \mathrm{GE}$

$\mu \mathrm{g} / \mathrm{L} \quad \mathrm{GE}$

$\begin{array}{ll}\mu g / L & G E \\ \mu g / L & G E \\ \mu g / L & G E\end{array}$

$\mathrm{g} / \mathrm{GE}$
$\mathrm{gE}$

$\mathrm{GE}$
$g / \mathrm{GE}$

G

$\begin{array}{ll}\mu g / L & G E \\ \mu g / L & G E\end{array}$

$\mu g / L$

/ $G E$ 
ANALYTICAL RESULTS

WELL MSB 3C

MEASUREMENTS CONDUCTED IN THE FIELD

Sample date: $11 / 22 / 91$
Depth to water: $142.18 \mathrm{ft}(43.33 \mathrm{~m})$ below TOC
Water elevation: $218.64 \mathrm{ft}(66.64 \mathrm{~m}) \mathrm{ms}$

Water elevation: $218.64 \mathrm{Ht} / 66.64$
Sp. conductance: $1455 \mu \mathrm{S} / \mathrm{cm}$

Water evacuated before sampling. $17 \mathrm{gal}$

The well went dry during purging.

LABORATOAY ANALYSES

E Analyte Besult Mod Unit Lab

$\begin{array}{ll}2 & \mathrm{pH} \\ 1 & \text { Specific conductance } \\ 0 & \text { Acenaphthene } \\ 0 & \text { Acenaphthylene } \\ 0 & \text { Acetone }\end{array}$

Acetonitrile (Methyl cyanide)

Acetophenone

Acrolein

Acrylonitile

Aldrin chloride

Aluminum

4-Aminobiphenyl

Anthracene

Antimony

Aramite

Arsenic
Barium

Benzen

alpha.Benzene hexachloride

beta-Benzene hexachloride

delta-Benzene hexachloride

Benzo(a) anthracen

Benzolb fluoranthene

Benzolg, h,ilperylene

Benzyl alcohol

Benzyl alcoh

Bis (2-chloroisopropyl)ether

Bis (z-chloroethoxy) methane

Bis (2-chloroethyl) ethe

Bis (2-ethylhexyl) phthalate

Bromodichlon

Bromomethane

4. Biomophenyl phenyl ether

2-sec-Butyl.4.6.dinitropheno

Butyibenzyl phthalate

Cadmium

Carbon disulfide

Carbon tetrachloride

2,3,7,8-TCDF

Chlordane

para-Chloro-meta-cresol

4-Chloroaniline

Chlorobenzene

Chlorobenzilate

Chloroethane

2-Chloroethyl vinyl ether

Chloroform

2-Chloronaphthalene

2-Chlorophenol

4.Chlorophenyl phenyl ether

Chlaroprene

Chromium

Chrysen
Cobalt

Coppe

o.Cresol (2-Methylphenol)

m.Cresol (3-Methylphenol)

Cyanide
p.p'-DDD

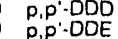

p.P.DDE

Di-n-butyl phthalate

Di.n.octyl phithalate

Dibenzla,h]anthracene

Dibenzoturan

1,2-Dibromo-3-chloropropane

Dibromochloromethane

1,2.Dibromoethane

trans-1.4-Dichloro-2-butene

1,2-Dichlorobenzene

1,3-Dichlorobenzene

1,4-Dichlorobenzene

3,3'-Dichlorobenzidine

1,1-Dichlorcethane
Time: 10:15

Alkalinity: $340 \mathrm{mg} / \mathrm{L}$

Water temperature: $18.1^{\circ} \mathrm{C}$

11

$<10$
$<10$

$<100$

$<1.0$
$<10$
$<10$

$<10$
$<20$
$<20$

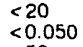

$<50$
165

$<10$

$<<10$

$<2.0$
$<10$

$<2.0$

66
$<1.0$

$<0.050$
$<0.050$

$<0.050$

$<10$

$<10$

$<10$

$<10$

$<3.0$

$<10$

$<10$

$<10$
$<10$

$<1.0$
$<1.0$
$<1.0$

$<1.0$

$<10$

$<10$
$<10$

$<2.0$
21,000

$<1.0$

$<0.00040$

$<0.50$

$<10$
$<10$

$<10$
1.3

$<10$

$<1.0$

$<1.0$

$<10$
$<1.0$
$<1.0$
$<10$

$<10$

$<10$

$<200$

$<4.0$
$<10$

$<4.0$

$<4.0$

$<10$

$<10$
$<10$

$<5.0$
$<0.10$
$<0.10$
$<0.10$

$<0.10$
$<0.10$
$<0.10$
$<10$

$<10$

$<10$
$<10$

$<10$

$<1.0$

$<20$

$<30$

$<10$

$<10$

$<10$

$<10$

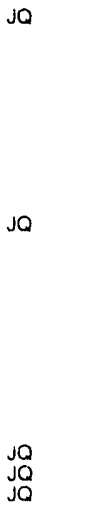

\begin{tabular}{|c|c|c|c|}
\hline $\begin{array}{l}\mathrm{pH} \\
\mu \mathrm{S} / \mathrm{cm} \\
\mu \mathrm{g} / \mathrm{L} \\
\mu \mathrm{g} / \mathrm{L} \\
\mu \mathrm{g} / \mathrm{L} \\
\mu \mathrm{g} / \mathrm{L} \\
\mu \mathrm{g} / \mathrm{L} \\
\mu \mathrm{g} / \mathrm{L} \\
\mu \mathrm{g} / \mathrm{L} \\
\mu \mathrm{g} / \mathrm{L} \\
\mu \mathrm{g} / \mathrm{L} \\
\mu \mathrm{g} / \mathrm{L} \\
\mu \mathrm{g} / \mathrm{L} \\
\mu \mathrm{g} / \mathrm{L}\end{array}$ & $\begin{array}{l}\mathrm{GE} \\
\mathrm{GE} \\
\mathrm{GE} \\
\mathrm{GE} \\
\mathrm{GE} \\
\mathrm{GE} \\
\mathrm{GE} \\
\mathrm{GE} \\
\mathrm{GE} \\
\mathrm{GE} \\
\mathrm{GE} \\
\mathrm{GE} \\
\mathrm{GE} \\
\mathrm{GE}\end{array}$ & $\begin{array}{l}0 \\
0 \\
0 \\
0 \\
0 \\
0 \\
0 \\
0 \\
0 \\
0 \\
0 \\
0 \\
0 \\
0\end{array}$ & $\begin{array}{l}\text { Diethyl phthalate } \\
\text { Dimethoate } \\
\text { 2.4-Dimethyl phenol } \\
\text { Dimethyl phthalate } \\
\text { p-Dimethylaminoazobenzene } \\
\text { Dimethylbenz[a]anthracene } \\
\text { 3,3'-Dimethylbenzidine } \\
\text { a,a-Dimethylphenethylarnine } \\
\text { 1,3.Dinitrobenzene } \\
\text { 2,4-Dinitrophenol } \\
\text { 2,4-Dinitrotoluene } \\
\text { 2,6-Dinitrotoluene } \\
\text { 1,4-Dioxane } \\
\text { Diphenylamine } \\
\text { Disulfoton }\end{array}$ \\
\hline
\end{tabular}

O Endosulfan II

0 Endosulfan sulfate

0 Endrin

0 Endrin aldehyde

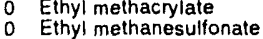

0 Ethylbenzene

o Famphur

Fluoranthene

0 Fluoride

0 Heptachlor

Heptachlor epoxide
0
0

- Heptachlolodibenzo-p.dioxins

$1,2,3,4,6,7,8 \cdot \mathrm{HPCDF}$

Heptachlorodibenzo-p.furans

Hexachlorobenzene

Hexachlorocyclopentadiene

1,2,3,4,7,8-HXCDO

Hexachlorodibenzo-p-dioxins

Hexachlorodibenzo

Hexachlorodibenzo-p.furans

Hexachloroethane

o Hexachloropropene

o 2-Hexanone

0 Indeno $[1,2,3 \cdot c, d] p y r e n e$

o lodomethane (Methyl iodide)

o Isobutyl alcohol

$\begin{array}{ll}0 & \text { Isodrin } \\ 0 & \text { Isophorone }\end{array}$

0 Isosafrole

o Kepone

0 Lead

0 Lindane

Magnesium

Mercury

Methacrylonitrile

Methapyrilen

Methoxychlor

Methyl ethyl ketone

Methyl isobutyl ketone

Methyl methacrylate

2-Methyl-4,6-dinitrophenol

3.Methylcholanthiene

2.Methylnaphthalene

2.Methylnaphthalene

N.Nitrosodimethylamine

N.Nitrosodi-n-butylamine

N.Nitrosodiphenylamine

N-Nitrosodi-propylamine

N.Nitrosomethylethylamin

$N \cdot N i t r o s o m o r p h o l i n e$

$N$-Nitrosopiperidine
N-Nitrosopyrrolidine

N-Nitrosopyrrolid

1.4-Naphthoquinone

1.Naphthylamine

Nickel

Nickel as nitrogen

Nitrate as nitroge

2.Nitroaniline

3. Nitroaniline

4-Nitroaniline

Nitrobenzene

2. Nitrophenol
4.Nitrophenal
Result

$<1.0 \quad \mu \mathrm{g} / \mathrm{L} \quad \mathrm{GE}$

5.8
3.4
2.

$<10$

$<3.0$

$<3.0$

$<1.0$
$<1.0$

$<0.50$

$<<$

$<10$
$<10$

$<10$

$<10$
$<10$

$<10$

$<45$

$<10$

$<10$

$<10$
$<10$

$<0.10$
$<0.10$

$<0.10$
$<0.0060$
$<0.10$

$<10$

$<10$

$<10$

$<<10$

111
$<0.050$

$<0.00065$

$<0.00065$

$<0.00045$

$<10$

$<10$

$<0.00045$

$<0.00045$
$<0.00040$

$<0.00040$

$<10$

$<10$

$<1.0$
$<10$

$<15$

$<4.0$
$<100$

$<10$

$<10$

$<10$

$<10$
$<3.0$

$<0.0050$

409
$<2.0$

$<0.20$

$<50$
$<10$

$<0.50$

$<1.0$

$<10$

$<10$

$<<10$

$<10$

$<<0$

$<10$
$<10$

$<10$

$<10$
$<10$

$<10$
$<10$

$<10$

$<10$
$<10$

$<10$

$<4.0$
188,000

$<10$
$<10$

$<10$
$<10$

$<10$

$<10$
$<10$
$<10$

Mod Unit Lab

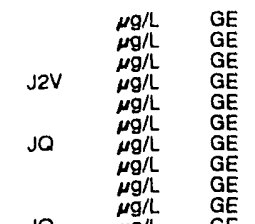

Jo

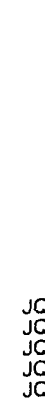

$\mathrm{JO}$
$\mathrm{JO}$
$\mathrm{JO}$

jo

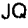

$J Q$

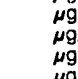

p

\section{$\mu$}

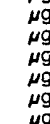


WELL MSB 3C collected on 11/22/91, labnratory analyses (cont)

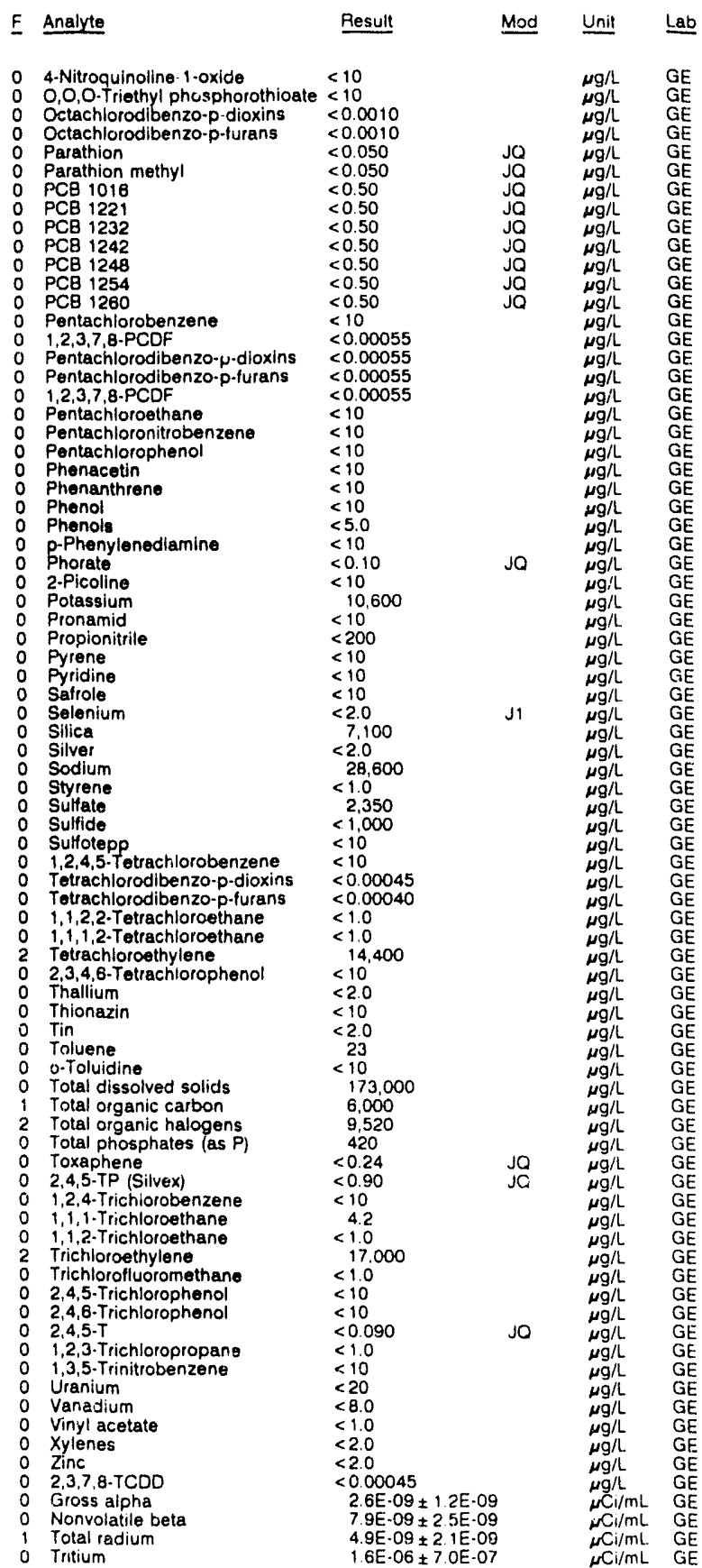

\section{WELL MSB 3D}

MEASUREMENTS CONDUCTED IN THE FIELD

Depth to water: $130.41 \mathrm{Ht}(39.75 \mathrm{~m})$ below $T O C$

Water elevation: $230.09 \mathrm{ft}(70.13 \mathrm{~m}) \mathrm{ms}$ i

No water was evacuated belore sampling

LABORATORY ANALYSES

\begin{tabular}{|c|c|c|c|}
\hline Analyte & Result & Mod & Unit \\
\hline $\begin{array}{ll}0 & \mathrm{pH} \\
0 & \text { Specific conductance } \\
0 & \text { Acenaphthene }\end{array}$ & $\begin{array}{r}6.3 \\
95 \\
<10\end{array}$ & $\begin{array}{l}\text { JO } \\
\text { JO }\end{array}$ & $\begin{array}{l}\mathrm{pH} \\
\mu \mathrm{S} / \mathrm{cm} \\
\mu \mathrm{g} / \mathrm{h}\end{array}$ \\
\hline
\end{tabular}

WFLL MSB 3D collected on 12/13/91, laboratory analyses (cont.)

E Analyte Hesult Mod Unit Lab

$\begin{array}{ll}0 & \text { Acenaphthylene } \\ 0 & \text { Acetone } \\ 0 & \text { Acetonitrile (Methyl cyanide) } \\ 0 & \text { Acetophenone } \\ 0 & 2 \cdot \text { Acetylaminofluorene } \\ 0 & \text { Acrolein } \\ 0 & \text { Acrylonitrile } \\ 0 & \text { Aldrin } \\ 0 & \text { Allyl chloride } \\ 0 & \text { Aluminum } \\ 0 & 4 \text {-Aminobiphenyl } \\ 0 & \text { Aniline } \\ 0 & \text { Anthracene } \\ 0 & \text { Antimony } \\ 0 & \text { Aramite } \\ 0 & \text { Arsenic } \\ 0 & \text { Earium } \\ 0 & \text { genzene }\end{array}$

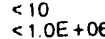

$<10,000$

$<10$

$<1000000$

$<200,000$

$<500,000$

$<500,000$
$<10$

$<10$

$<10$
$<20$
$<10$
$<20$

$<3.0$

Garium

alpha. Benzene hexachloride

beta.Benzene hexachloride

delta-Benzene hexachlorida

Benzolajanthracen

Benzo a pyrene

Benzo b fluoranthene
Benzolg.h,i]perylene

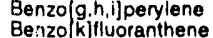

Benzyl alcohol

Beryllium

Bis(2.chloroisopropyl)ether

Bis (2-chloroethoxy) methane

Bis (2-chloroethyl) ether
Bis(2-ethylhexyl) phthalate

Bromodichloromethane

Bromotorm

4.Bromophenyl phenyl ether

2.sec. Butyl-4,0-dinitropheno

Butylbenzyl phthalate

Cadmium

Carbon disulfide

Carbon tetrachloride

2,3,7,8-TCDF

Chlordane

0 Chloride

Chloride

para-Chloro-meta-creso

4-Chloroaniline

Chlorobenzene

Chlorobenzilate

Chloroethane

Chloroethene (Vinyl chloride)

2.Chloroethyl vinyl ether

Chloroform

Chloromethane

2.Chloronaphthal
2-Chlorophenol

4-Chlorophenyl phenyl ether

Chloroprene

Chrysene

0 Chrysen

Cobalt

O-Cresol (2-Methylphenol)

m.Cresol (3.Methylphenol)

p.Cresol (4-Methylphenol)

Cyanide

P.P.DDD

$\begin{array}{ll}0 & p, p^{\prime} \cdot D D E \\ 0 & 0 . p^{\prime} \cdot D D T\end{array}$

Di.n.butyl phthalate

Di.n-octyl phthalate

Diallate

Dibenz[a,h]anthracene

Dibenzofuran
1,2.Dibromo-3.chloropropane

Dibromochloromethane

1,2.Dibromoethane

Dibromomethane

-butene

1.2.Dichlorobenzene

1.3. Dichlorobenzene

3.3. Dichlorobenzidine

2 Oichlorodifluoromethan

1.1.Dichloroethane

1,1-Dichloroethylene

trans-1,2.Dichloroethylene $\quad<10,000$

Dichloromethane

$<10$

2,4.Dichlorophenoxyacetic acid $<030$

1.2-Dichloropropane

$\begin{array}{ll}\text { cis-1,3.Dichloropropene } & <10,000\end{array}$

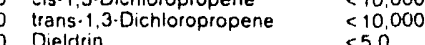

O Oiethyl phthalate

$<5.0$

$<10$
$<10$

JO $\mu g / \mathrm{L} \quad \mathrm{GE}$

GE

0.50

$<0.50$

10

$<10$

$<10$

100,000

10
10

$<10,000$

10,000

$<10$
$<10$
$<10$

$<2.0$
2.300

$<10,000$
$<10,000$

$<0.00040$

3.480

$\begin{array}{r}3,5 \\ <10 \\ \hline\end{array}$

$<10$
$<10,000$

10.000

$<10,000$
$<10$

7.050
$<10.000$

$<10$

$<2.0 E+06$

$<40$

$<40$

$<10$
$<10$
$<10$

$<50$

$<1.0$
$<1.0$

$<10$
$<10$

$<10$

$<1$ < 10,000

$<10,000$

10,000

$<10$

$<10$

$<10$

11,000

0,000

10,000
19300

\begin{abstract}
o Dimethoale
\end{abstract}

$$
\text { < }
$$

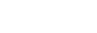


ANALYTICAL RESULTS

WELL MSB 3D collected on 12/13/91, laboratory analyses (cont)

\begin{tabular}{|c|c|c|}
\hline F & Analyte & Result \\
\hline & 2.4-Dimethyl phenol & $<10$ \\
\hline & Dimethyl phthalate & $<10$ \\
\hline & p-Dimethylamifioazobenzene & $<10$ \\
\hline & $\begin{array}{l}\text { Dimethylbenz[a]anthracene } \\
3,3^{\prime} \text {-Dimethylbenzidine }\end{array}$ & $\begin{array}{l}<10 \\
<10\end{array}$ \\
\hline & a,a-Dimethylphenethylamine & $<10$ \\
\hline & 1,3-Dinitrobenzene & $<10$ \\
\hline & 2,4-Dinitrophenol & $<45$ \\
\hline & 2,4-Dinitrololuene & $<10$ \\
\hline & $\begin{array}{l}\text { 2,6-Dinitrotoluene } \\
\text { 1, 4-Dioxane }\end{array}$ & $<10$ \\
\hline & $\begin{array}{l}\text { 1,4-Oioxane } \\
\text { Diphenylamine }\end{array}$ & $\begin{array}{l}<10 \\
<10\end{array}$ \\
\hline & Disulfoton & $<10$ \\
\hline & Endosulfan I & $<1.0$ \\
\hline & $\begin{array}{l}\text { Endosulfan II } \\
\text { Endosultan sulfate }\end{array}$ & $\begin{array}{l}<10 \\
<10\end{array}$ \\
\hline & Endrin & $\begin{array}{l}<1.0 \\
<0.060\end{array}$ \\
\hline & Endrin aldehyde & $<1.0$ \\
\hline & $\begin{array}{l}\text { Ethyl methacrylate } \\
\text { Ethyl methanesulfonate }\end{array}$ & $<10$ \\
\hline & $\begin{array}{l}\text { Ethyl methanesulfonate } \\
\text { Ethylbenzene }\end{array}$ & $\begin{array}{l}<10 \\
<10,000\end{array}$ \\
\hline & Famphur & $<10$ \\
\hline & Fluorant'ene & $<10$ \\
\hline & $\begin{array}{l}\text { Fluorene } \\
\text { Fluoride }\end{array}$ & $<10$ \\
\hline & $\begin{array}{l}\text { Fluoride } \\
\text { Heptachlor }\end{array}$ & $\begin{array}{l}<100 \\
<0.50\end{array}$ \\
\hline & Heptachlor epoxide & $<0.50$ \\
\hline & $1,2,3,4,6,7,8 \cdot \mathrm{HPCDD}$ & $<0.00065$ \\
\hline & $\begin{array}{l}1,2,3,4,6,7,8-H P C D D \\
\text { Heptachlorodibenzo.p.dioxins }\end{array}$ & $\begin{array}{l}<0.00065 \\
<0.00065\end{array}$ \\
\hline & Heptachlorodibenzo-p.dioxins & $<0.00065$ \\
\hline & $1,2,3,4,6,7,8 \cdot \mathrm{HPCDF}$ & $<0.00045$ \\
\hline & $1,2,3,4,6,7,6-\mathrm{HPCDF}$ & $<0.00045$ \\
\hline & Heptachlorodibenzo-p-furans & $<0.00045$ \\
\hline & Heptachlorodibenzo-p.furans & $<0.00045$ \\
\hline & $\begin{array}{l}\text { Hexachlorobenzene } \\
\text { Hexachlorobutadiene }\end{array}$ & $\begin{array}{l}<10 \\
<10\end{array}$ \\
\hline & Hexachlorocyclopentadiene & $\begin{array}{l}<10 \\
<10\end{array}$ \\
\hline & $1,2,3,4,7,8$-HXCDO & $<0.00045$ \\
\hline & $1,2,3,4,7,8-H \times C O D$ & $<0.00045$ \\
\hline & Hexachlorodibenzo-p-dioxins & $<0.00045$ \\
\hline & Hexachlorodibenzo-p-dioxins & $<0.00045$ \\
\hline & $\begin{array}{l}1,2,3,4,7,8 \cdot H X C D F \\
, 2,3,8-H X C D F\end{array}$ & $<0.00040$ \\
\hline & $\begin{array}{l}1,2,3,4,7,8-\mathrm{HXCDF} \\
\text { Hexachlorodibenzo.p.furans }\end{array}$ & $\begin{array}{l}<0.00040 \\
<0.00040\end{array}$ \\
\hline & $\begin{array}{l}\text { Hexachlorodibenzo-p.turans } \\
\text { Hexachlorodibenzo-p.furans }\end{array}$ & $\begin{array}{l}<0.00040 \\
<0.00040\end{array}$ \\
\hline & Hexachloroethane & $<10$ \\
\hline & Hexachlorophene & $<10$ \\
\hline & Hexachloropropene & $<10$ \\
\hline & 2-Hexanone & $<10,000$ \\
\hline & $\begin{array}{l}\text { Indenol } 1,2,3-c, d] p y r e n e \\
\text { lodomethane (Methyl iodide) }\end{array}$ & $\begin{array}{l}<10 \\
<150000\end{array}$ \\
\hline & $\begin{array}{l}\text { lodomethane (Methyl iodide) } \\
\text { Iron }\end{array}$ & $\begin{array}{l}<150,000 \\
5.1\end{array}$ \\
\hline & isobutyl alcohol & $<10 E+06$ \\
\hline & Isodrin & $<10$ \\
\hline & Isophorone & $<10$ \\
\hline & Isosafrole & $<10$ \\
\hline & Kepone & $<10$ \\
\hline & Lead & $<3.0$ \\
\hline & Lindane & $<0.050$ \\
\hline & $\begin{array}{l}\text { Magnesium } \\
\text { Manganese }\end{array}$ & 545 \\
\hline & $\begin{array}{l}\text { Manganese } \\
\text { Mercury }\end{array}$ & $\begin{aligned} & 51 \\
&<0.20\end{aligned}$ \\
\hline & Methacrylonitrile & $\begin{array}{l}<0.20 \\
<500,000\end{array}$ \\
\hline & Methapyrilene & $<10$ \\
\hline & Methoxychlor & $<5.0$ \\
\hline & Methyl ethyl ketone & $<10,000$ \\
\hline & Methyl isobutyl ketone & $<10,000$ \\
\hline & Nethyl methacrylate & $<10$ \\
\hline & Methyl methanesulfonate & $\cdot 10$ \\
\hline & 2. Methyl.4.6 & $<10$ \\
\hline & 3-Methyleholanthrene & $<10$ \\
\hline & 2-Methylnaphthalene & $<10$ \\
\hline & N.Nitrosodie & $<10$ \\
\hline & N-Nitro & $<10$ \\
\hline & $N \cdot$ Nitrosodi-n-butylamine & $<10$ \\
\hline & N.Nitrosodiphenylamine & $<10$ \\
\hline & N-Nitrosodi-propylamine & $<10$ \\
\hline & N.Nitrosomet & $<10$ \\
\hline & N. Nitrosomorpholine & $<10$ \\
\hline & N-Nitrosopipefidine & $<10$ \\
\hline & N-Nitroso & $<10$ \\
\hline & Naphtha & $<10$ \\
\hline & 1.4-Naphthoquinone & $<10$ \\
\hline & i-Naphthyiamine & $<10$ \\
\hline & 2. Naphthylamine & $<10$ \\
\hline & Nickel & $<40$ \\
\hline & Nitrate as nitrogen & 2.280 \\
\hline & $5 \cdot$ Nitro-0.toluidine & $<10$ \\
\hline & 2. Nitroaniline & $<10$ \\
\hline & 3. Nitroanilir & $<10$ \\
\hline & 4. Nitroaniline & $<10$ \\
\hline & Nitrobenzene & $<10$ \\
\hline & 2. Nitrophenol & $<10$ \\
\hline & 4. Nitrophenol & $<10$ \\
\hline & 4-Nitroquinoline 1 & $<10$ \\
\hline & 00,0 -Triethyl phosphorothioate & $<10$ \\
\hline & Octachlorodibenzo-p-dioxins & $<00010$ \\
\hline & Octachlorodibenzo-p-dioxins & $\begin{array}{r}<0.0010 \\
<00010\end{array}$ \\
\hline
\end{tabular}

WELL MSB 3D collected on 12/13/91, laboratory analyses (cont.)

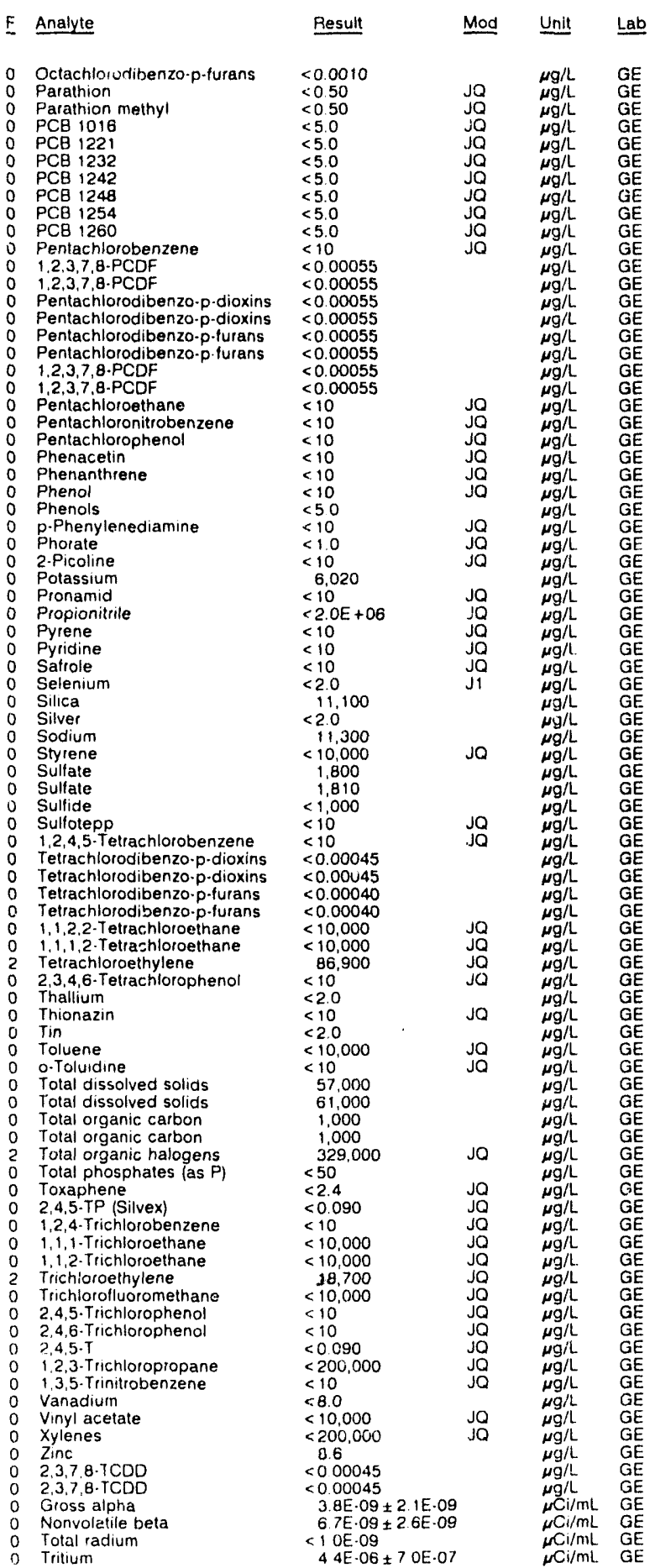


WELL MSB 4B

MEASUREMENTS CONDUCTED IN THE FIELD

Sample date: $10 / 02 / 91$
Depth to water: $146.16 \mathrm{ft}(44.55 \mathrm{~m})$ below TOC
Water elevation: $209.14 \mathrm{ft}(63.75 \mathrm{~m}) \mathrm{msl}$
Sp. conductance: $26 \mu \mathrm{cm} / \mathrm{cm}$
Water evacuated before sampling: $180 \mathrm{gal}$
LABORATORY ANALYSES

Time: $12: 50$

Alkalinity: $2 \mathrm{mg} / \mathrm{L}$

Water temperature: $20.0^{\circ} \mathrm{C}$

LABORATORY ANALYSES

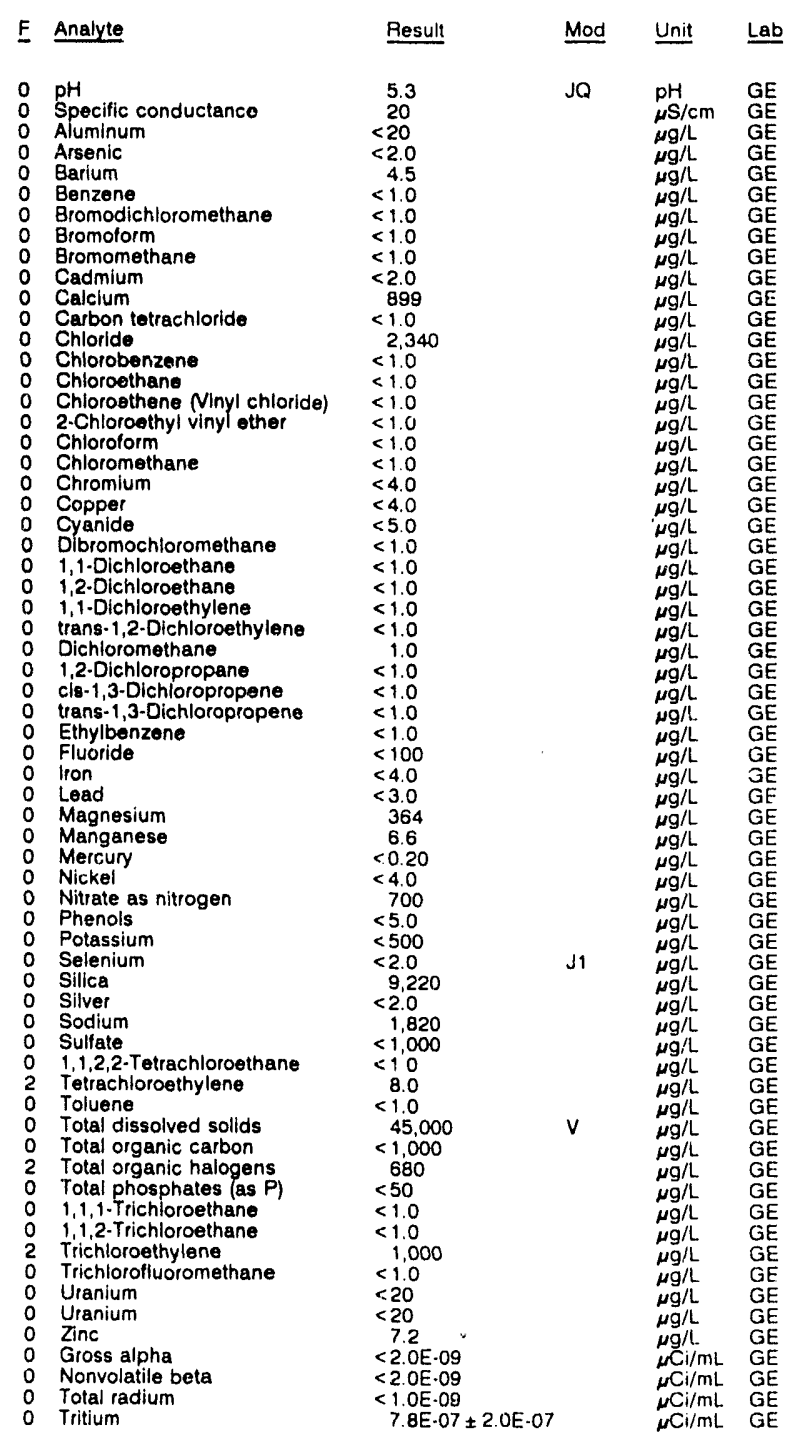

\section{WELL MSB 4C}

MEASUREMENTS CONDUCTED IN THE FIELO

Sample date: $11 / 22 / 91$

140.14 ft $(42.72 \mathrm{~m})$ below TOC

Water elevation: 215.06 \& 165 .

Water evacuated before sampling: $31 \mathrm{gal}$

The well went dry during purging.

LABORATORY ANALYSES

\begin{tabular}{|c|c|c|c|}
\hline Analyte & Result & Mod & Unit \\
\hline $\begin{array}{l}\text { pH } \\
\text { Specific conductance } \\
\text { Acenaphthene } \\
\text { Acenaphthylene } \\
\text { Acetone } \\
\text { Acetonitrile (Methyl cyanide) }\end{array}$ & $\begin{array}{l}7.9 \\
200 \\
<10 \\
<10 \\
<100 \\
<1.0\end{array}$ & JO & $\begin{array}{l}\mathrm{pH} \\
\mu \mathrm{S} / \mathrm{cm} \\
\mu \mathrm{g} / \mathrm{L} \\
\mu \mathrm{g} / \mathrm{L} \\
\mu g / \mathrm{L} \\
\mu \mathrm{g} / \mathrm{L}\end{array}$ \\
\hline
\end{tabular}

WELL. MSB 4C collected on 11/22/91, laboratory analyses (cont.)

E Analyte Result Mod Unit Lab

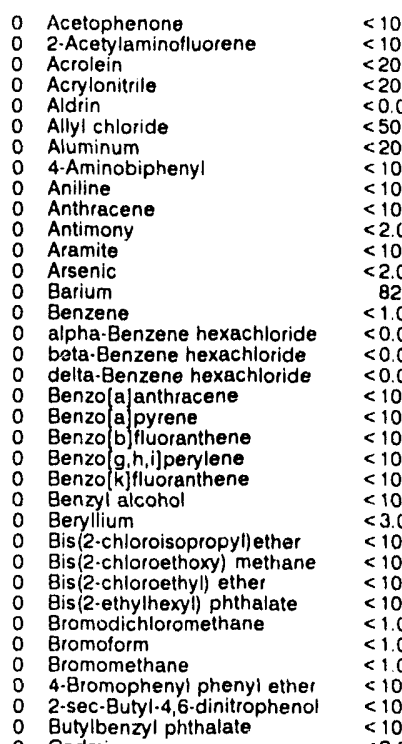

$\begin{array}{ll} & <10 \\ 0 \text { Cadmium } & <2.0\end{array}$

Carbon disulfide $\quad 17,800$

0 Carbon tetrachloride $\quad<1.0$

$\begin{array}{ll}2,3,7,8-T C D F & <0.00040 \\ \text { Chlordane } & <0.50\end{array}$

0 Chloride

para-Chloro-meta-cresol

4-Chloroaniline

Chlorobenzene

Chlorobenzilate

Chloroethene (Vinyl chloride)

Chloroethene (Vinyl chloride)
2.Chloroethyl vinyl ether

2.Chloroethyl

Chlorolorm $<1.0$

2.Chioronaphthalene $\quad<10$

2.Chlorophenol $<10$

Chloroprene $\quad<200$

Chromium $\quad<10$

$\begin{array}{ll}\text { Chromium } & 4.0 \\ \text { Chrysene } & <10 \\ \text { Cobalt } & <4.0 \\ \text { Copper } & <4.0\end{array}$

$\begin{array}{ll}0 & \text { Copper } \\ 0 & 0 . C r e s o l \\ \text { (2.Methylphenol) }\end{array}$

o m.Cresol (3-Methylphenol)

p.Cresol (4-Methylphenol)

0 Cyanide

$\begin{array}{lll}0 & 0 . p^{\prime} \cdot \mathrm{DDO} \\ 0 & \mathrm{p}, \mathrm{p}^{\prime} \cdot \mathrm{DODE}\end{array}$

P.P.
p.DDT

Di-n-butyl phthalate

Di-n-octyl phthalate

O Diallate

O Dibenzofuran

1,2-Dibromo-3-chloropropane

- Dibromochloromethane $<1$.

1,2-Dibromoethane $<20$

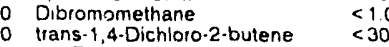

o 1,2-Dichlorobenzene $<10$

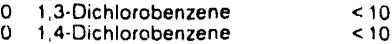

0 3., Dichlorobenzidine $\quad<10$

0 Dichlorodifluoromethane $<1.0$

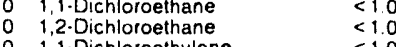

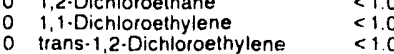

0 Dichloromethane

o 2,4.Dichlurophenol

2,6.Dichlorophenoi

$<10$

2,4-Dichloropher jxyacetic acid <3.

1,2-Dichloropropane

$\begin{array}{lll}0 & \text { cis-1,3-Dichloropropene } & <1.0 \\ 0 & \text { trans-1.3-Dichloropropene } & <10\end{array}$

$<0.50$

0 Diethyl phthalate

0 Dimethoate

2,4-Dimethyl pheno

Dimethyl phthalate
0
p-Dimethylaminoazobenzene

o Dimethylbenz[a]anthracene

0
0
$0,3^{\prime} \cdot$ Dimethylbenzidine

10

1.0

$<10$
$<10$

$<0.10$

$<0.10$

$<10$

$<10$

$\mu \underset{\mu g / L}{G} \quad G E$

$\underset{\mu g / L}{\mu g E}, \quad G$

$\begin{array}{ll}\mu g / L & G E \\ \mu g / L & G E\end{array}$

GE


ANALYTICAL RESULTS

WELL MSB $4 \mathrm{C}$ collected on 11/22/91, laboratory analyses (cont.)

\begin{tabular}{|c|c|c|c|c|c|c|c|}
\hline$E$ & Analyte & Result & Mod & $\underline{\text { Unit }}$ & $\underline{\text { Lab }}$ & $\underline{F}$ & Analyte \\
\hline $\begin{array}{l}0 \\
0 \\
0 \\
0 \\
0 \\
0 \\
0 \\
0 \\
0 \\
0 \\
0 \\
0 \\
0 \\
0 \\
0 \\
0 \\
0 \\
0 \\
0 \\
0 \\
0 \\
0 \\
0 \\
0 \\
0 \\
0\end{array}$ & 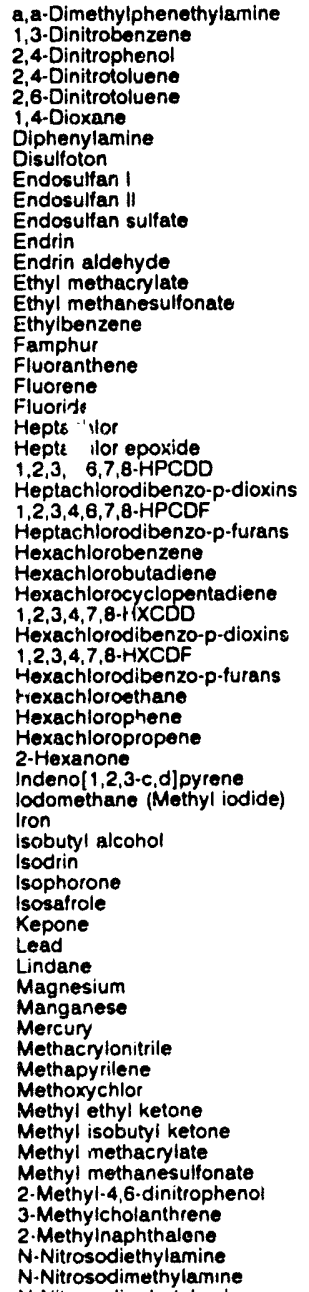 & 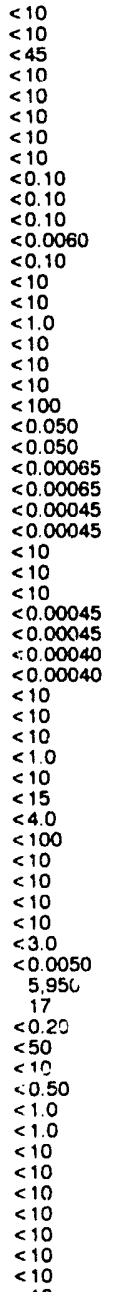 & & 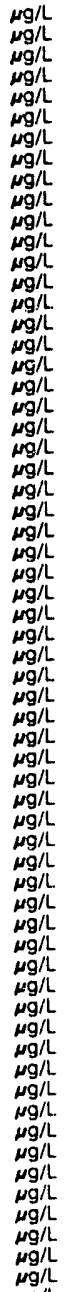 & 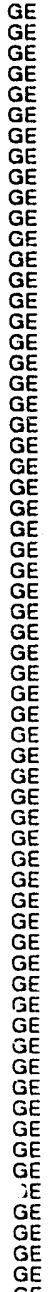 & $\begin{array}{l}0 \\
0 \\
0 \\
0 \\
0 \\
0 \\
0 \\
0 \\
0 \\
0 \\
0 \\
0 \\
0 \\
0 \\
0 \\
0 \\
0 \\
0 \\
0 \\
0 \\
0 \\
0 \\
0 \\
0 \\
0 \\
0 \\
0 \\
0 \\
0 \\
0 \\
2 \\
0 \\
0 \\
0 \\
0 \\
0 \\
0 \\
0 \\
0 \\
2 \\
0 \\
0 \\
0 \\
0 \\
0 \\
0 \\
0 \\
2 \\
0 \\
0 \\
0 \\
0 \\
0 \\
0 \\
0 \\
0 \\
0 \\
0 \\
0 \\
0 \\
0 \\
0 \\
0 \\
1 \\
1\end{array}$ & 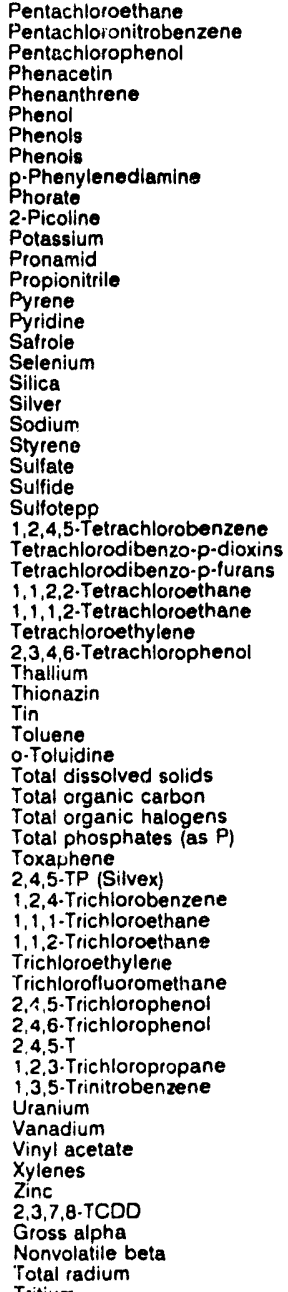 \\
\hline
\end{tabular}

WELL MSB $4 C$ collected on 11/22/91, laboratory analyses (cont.)

Result Mod Unit Lab

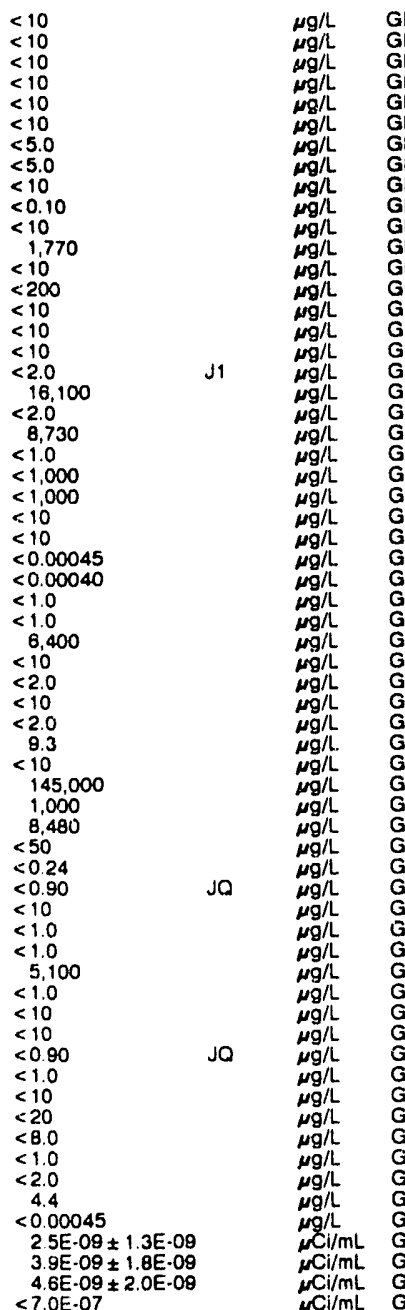

\section{WELL MSB 4D}

MEASUREMENTS CONDUCTED IN THE FIELD

$\begin{array}{ll}\text { Sample date: } 10 / 02 / 91 & \text { Time: } 12: 30 \\ \text { De th to water: } 127.38 \mathrm{H}(38.83 \mathrm{~m}) \text { below TOC } & \text { pH: } 4.5 \\ \text { Watcr elevation: } 228.22 \mathrm{H}(68.56 \mathrm{~m}) \mathrm{ms} & \text { Alkalinity: } 0 \mathrm{mg} / \mathrm{h} \\ \text { Sp. conductance: } 102 \mu \mathrm{cs} / \mathrm{cm} & \text { Water temperature: } 20.5^{\circ} \mathrm{C} \\ \text { Water evacuated before sarnpling: } 50 \mathrm{gal} & \end{array}$
Watet evacuated before sampling: $50 \mathrm{gal}$

LABORATORY ANALYSES

\begin{tabular}{|c|c|c|c|}
\hline Analyte & Result & Mod & $\underline{\text { Unit }}$ \\
\hline $\begin{array}{l}\text { pH } \\
\text { Specific conductance } \\
\text { Aluminum } \\
\text { Arsenic } \\
\text { Barium } \\
\text { Benzene } \\
\text { Bromodichloromethane } \\
\text { Bromoform } \\
\text { Bromomethane } \\
\text { Cadmium } \\
\text { Calcium } \\
\text { Carbon tetrachloride } \\
\text { Chloride } \\
\text { Chloride } \\
\text { Chlorobenzene } \\
\text { Chloroethane } \\
\text { Chloroethene Ninyl chloride) } \\
\text { 2.Chloroethyl vinyl ether } \\
\text { Chlorolorm } \\
\text { Chloromethane }\end{array}$ & $\begin{array}{l}4.7 \\
90 \\
188 \\
<2.0 \\
24 \\
<5.0 \\
<5.0 \\
<5.0 \\
<5.0 \\
<2.0 \\
3.480 \\
<50 \\
2.920 \\
2,940 \\
<50 \\
<50 \\
<50 \\
<50 \\
<50 \\
<50\end{array}$ & Jo & $\begin{array}{l}\mathrm{pH} \\
\mu \mathrm{H} / \mathrm{cm} \\
\mu g / L \\
\mu g / L \\
\mu g / L \\
\mu g / L \\
\mu g / L \\
\mu g / L \\
\mu g / L \\
\mu g / L \\
\mu g / L \\
\mu g / L \\
\mu g / L \\
\mu g / L \\
\mu g / L \\
\mu g / L \\
\mu g / L \\
\mu g / L \\
\mu g / L \\
\mu g / L\end{array}$ \\
\hline
\end{tabular}




\section{ANALYTICAL RESULTS}

WELL MSB 4D collected on 10/02/91, laboratory analyses (cont)

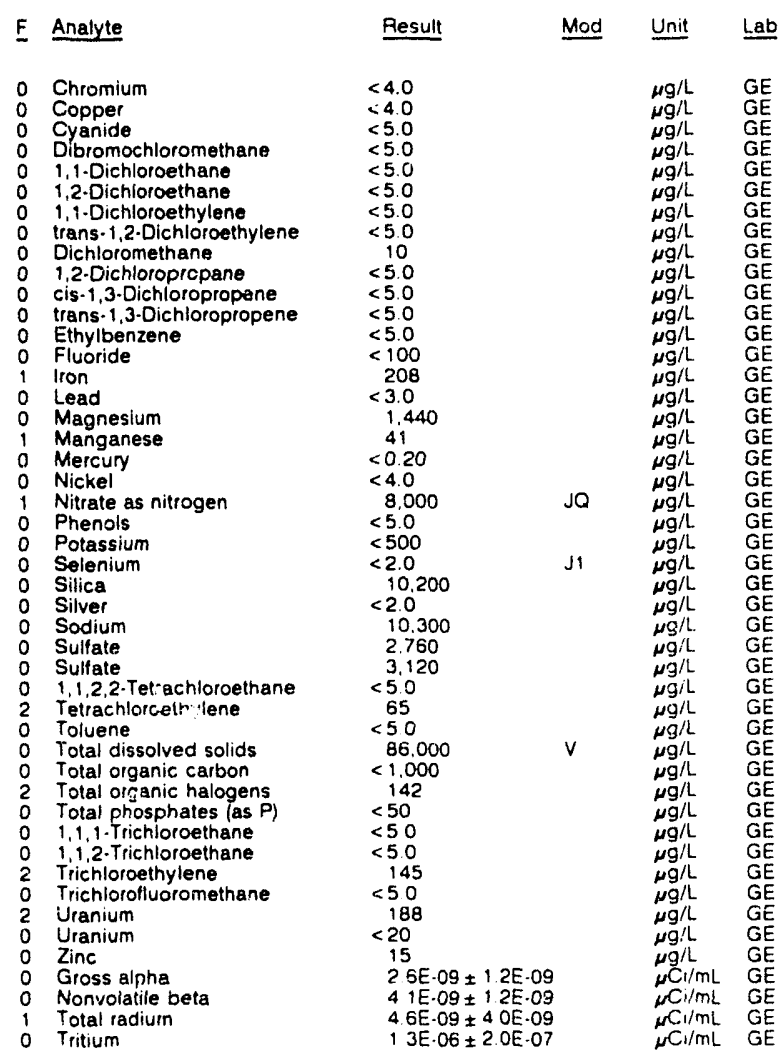

WELL MSB 5A

MEASUREMENTS CONOUCTED IN THE FIELD

Sample date: $10 / 02 / 91$ H $136.22 \mathrm{~m}\}$ below TOC Water elevation: 225.76 it 68.81

conductance $68 \mu \mathrm{S} / \mathrm{cm}$

Water evacuated betore sampling $21 \mathrm{gat}$

LABORATORY ANALYSES

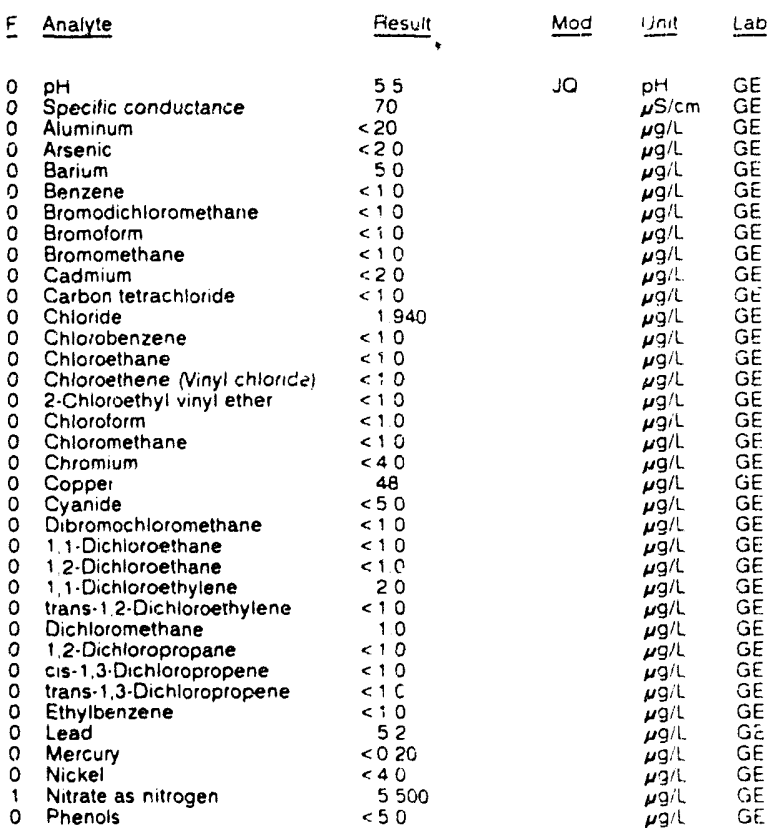

WELL MSB SA collected on 10/02/91, laboratory analyses (cont.)

\begin{tabular}{|c|c|c|c|c|c|}
\hline & Analyte & Result & Mod & Unit & Laㅡ \\
\hline 0 & $\begin{array}{l}\text { Selenium } \\
\text { Silver } \\
\text { Sodium } \\
\text { Sulfate } \\
\text { Sulfate } \\
1,1,2,2 \cdot \text { Tetrachloroethane } \\
\text { Tetrachloroethylene } \\
\text { Toluene } \\
\text { Total phosphates (as P) } \\
1,1,1 . \text { Trichloroethane } \\
1,1,2 \cdot \text { Trichloroethane } \\
\text { Trichloroethylene } \\
\text { Trichlorofluoromethane } \\
\text { Zinc } \\
\text { Uranium aloha activity }\end{array}$ & $\begin{array}{l}<2.0 \\
<2.0 \\
10,600 \\
<1.000 \\
<1.000 \\
<1.0 \\
9.0 \\
<1.0 \\
<50 \\
1.0 \\
<10 \\
5.0 \\
<1.0 \\
40 \\
<1.0 E-09\end{array}$ & J1 & $\begin{array}{l}\mu g / L \\
\mu g / L \\
\mu g / L \\
\mu g / L \\
\mu g / L \\
\mu g / L \\
\mu g / L \\
\mu g / L \\
\mu g / L \\
\mu g / L \\
\mu g / L \\
\mu g / L \\
\mu g / L \\
\mu g / L \\
\mu \mathrm{Li} / \mathrm{mL}\end{array}$ & $\begin{array}{l}\mathrm{GE} \\
\mathrm{GE} \\
\mathrm{GE} \\
\mathrm{GE} \\
\mathrm{GE} \\
\mathrm{GE} \\
\mathrm{GE} \\
\mathrm{GE} \\
\mathrm{GE} \\
\mathrm{GE} \\
\mathrm{GE} \\
\mathrm{GE} \\
\mathrm{GE} \\
\mathrm{GE} \\
\mathrm{GE}\end{array}$ \\
\hline
\end{tabular}

WELL MSB 5B

MEASUREMENTS CONDUCTED IN THE FIELD

Sample date $10 / 03 / 91$

Depth to water: $137.02 \mathrm{H}(41.76 \mathrm{~m})$ below TOC

Water elevation: $208.48 \mathrm{H}(63.55 \mathrm{~m}) \mathrm{msl}$

Water evacuated before sampling. $200 \mathrm{gal}$

pH: 5.2

Waler $185^{\circ} \mathrm{C}$

LABORATORY ANAL.YSES

E Analyte Besult Mod Unit Lab

$\begin{array}{ll}0 & \text { phi } \\ 0 & \text { Specific conductance } \\ 0 & \text { Aluminum } \\ 0 & \text { Arsenic } \\ 0 & \text { Garium } \\ 0 & \text { Benzene } \\ 0 & \text { Bromodichlorcmethane } \\ 0 & \text { Gromolorm } \\ 0 & \text { Eromomethane } \\ 0 & \text { Cadmium } \\ 0 & \text { Calcium } \\ 0 & \text { Carbon tetrachloride } \\ 0 & \text { Chloride } \\ 0 & \text { Chloropenzene }\end{array}$

Chiorobenzene

Chloroethene Ninyl chloride

2. Chloroethyl vinyl ethe

Chlorotorm

Chloromethane

Chromium

Cyanide

Dibromochlorometnane

1, 1. Dichioroethane

1,2.Dichloroethane

trans-1,2.Dichioroethyiene

Dichioromethane

1.2-Dichioropropane

cis-1.3-Dichloropropene
trans-1.3-Dichloropropene

Ethylbenzene

Fluoride

lion

O Magnesium

Manganese

Nercury

Nitrale as nitrogen

Phenols

Selensium

Silica

Silve

Sodium

Sulfale

1.1,2,2-Tetrachioroethane

Tetrachloroethylene

Tolvene

Total dissolved solids

Total organic carbon

Total organic halogens
Total phosphates (as $P$ )

1 1.1.Trichloroethane

1.1.2. Trichloroethane

Trichloroethylene

Trichiorofluoromethane

$\begin{array}{ll}0 & \text { Uranium } \\ 0 & \text { Zinc } \\ 0 & \text { Giss aph } \\ & \end{array}$

o Gross aipha

Nonvolatile beta

Totat radium
Tritium

5.7
20

JQ $\mathrm{pH} \quad \mathrm{GE}$

$<2$.

73
$<10$
410

$<1.0$

$<1.0$

$<2.0$
888

$<10$

$<10$
$<10$

$<10$

$<10$
$<10$

$<10$
$<10$

$<40$

$<5.0$

(1)

-10
-10

$<10$

$<10$

24
$<10$

$<10$

$<10$
$<10$
144
$<40$

$<4.0$
$<3.0$

$<3.0$
259
90

$<020$

$<4.0$
540
$<50$
5.30

$<20$

12.700

$<20$
2.190
$<1.000$
$<10$
$>15$

$<10$
75
$<10$

27,000
$\times 1,000$

$<1.000$
97

$<50$
$<10$

$<10$
$<10$

11
$<10$
$<20$
72

$<2$ OE. 09

$<2$ OE. 09

$<1$ OE.09
$<7$ OE.07

$\mathrm{Gb}$
$\mathrm{GE}$
$\mathrm{GE}$
$\mathrm{GE}$
$\mathrm{GE}$
$\mathrm{GE}$
$\mathrm{GE}$
$\mathrm{GE}$
$\mathrm{GE}$
$\mathrm{GE}$
$\mathrm{GE}$
$\mathrm{GE}$
$\mathrm{GE}$
$\mathrm{GE}$ 
ANALYTICAL RESULTS

WELL MSB 5C

MEASUAEMENTS CONOUCTED IN THE FIELD

Sample date: 10/03/91 Depth to water: $123.54 \mathrm{ft}(37.66 \mathrm{~m})$ below TOC Water elevation: $222.16 \mathrm{ft}(67.72 \mathrm{~m}) \mathrm{ms}$ l

Sp. conductance: $774 \mu \mathrm{S} / \mathrm{cm}$

Water evacuated b fore sampling: $17 \mathrm{gal}$

The well went diry $c$.ng purging.

LABORATORY ANALYSES

F Analyte

$2 \begin{array}{ll}2 & \mathrm{pH} \\ 2 & \mathrm{Spe}\end{array}$

Spe ific conductance

Aluminum

0 Barium

Benzene

Bromodichloromethane

Bromoform

Bromomethane

Cadmium

Calcium

Chlorobenzene

Chloroethene Ninyl chloride)

2-Chloroethyl vinyl other

Chloroform

Chloromethane

o Chromium

Copper

O Obromochloromethane

1,1-Dichloroethane

1,2-Dichloroethane

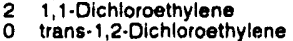

Dichloromethane

1,2-Dichloropropane

cis-1,3. Dichloropropene

o Ethylbenzene

0 Fluoride

0 Iron

- Magnesium

Mercury

0 Nickel

2 Nitrate as nit?ogen

Phenois

Potassium
Selenium

Silica

Sodium

Sulfate

Tetrachloroethylene

Toluene

0 Total dissolved solids

Total organic carbon

Total organic halogens

0 1,1.1-Trichloroethane

1,1,2-Trichloroethan

${ }_{0}^{2}$ Trichlorosthylene

0 Uranium

Zinc

Gross alpha

Nonvolatile be

Tritium

Result

11 JQ

Jo

24
$<2.0$

$<1.0$

$<1.0$

$<1.0$

$<2.0$

5,950
$<1.0$
41.040

$<1.0$

$<1.0$

$<1.0$

$<1.0$

$<4.0$

$<4.0$

$<1.0$

$<1.0$

11

$<1.0$
2.5
$<1.0$

$<1.0$

$<10$

$<1.0$

111
$<4.0$

$<3.0$

643
$<2.0$

$<0.20$

$<4.0$

$<5.0$

46,900

$<2.0$

$<.550$
$<0.700$

60,700
18,600

$<1,0$

868

8.4
289,000

2,000

96
$<50$

7.8
$<10$

$<.0$
5.7

$<<0$

$<2.0 \mathrm{E} .09$

2. $2 \mathrm{E}-00 \pm 2.1 \mathrm{E}-09$

$<\begin{gathered}2.3 \mathrm{JE} \cdot 09 \pm 1.8 \mathrm{E} \cdot 09 \\ <7.0 \mathrm{E} \cdot 07\end{gathered}$

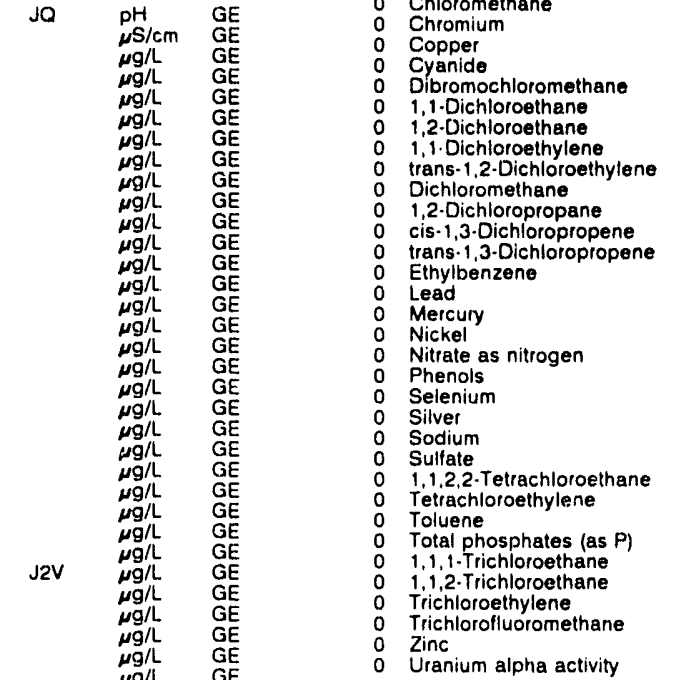

Time: $7: 30$

Alkalinity: $139 \mathrm{mg} / \mathrm{L}$

Water temperature: $18.4^{\circ} \mathrm{C}$

WELL MSB 6B

MEASUREMENTS CONDUCTED IN THE FIELD

Sample date: 11/22/91

Depth to water: $138.20 \mathrm{ft}(42.12 \mathrm{~m})$ below TOC

Water elevation: $207.10 \mathrm{f}(63.12 \mathrm{~m}) \mathrm{msl}$

conduclance. $80 \mu \mathrm{S} / \mathrm{cm}$

Water evacuated before sampling. $214 \mathrm{gal}$

LABORATORY ANALYSES

E Analyte

$\mathrm{pH}$

Speci

0 Acenaphthene

Acenaphthylen

Aceton

Acetonitrile (Methyl cyanide)

Acetophenone

2.Acetylaminofluorene

Acrolein

Acrylonitril

Allyl chloride

4.Aminobiphenyl

Aniline

Antimony

Aramite

Arsenic

Barium

Benzente

alpha.Benzene hexachloride

toride

delta-Benzene hexachloride

Benzo[a]anthracene

Benzo a pyrene

Benzo(b)fluoranthene

Benzolg,h,i]perylene

Benzo(k)lluoranthe

Benzyl alcon

Bis(2.chloroisopropyl)ether

Bis (2-chloroethoxy) methane

Bis(2-chloroethyl) ether
Bistis

Bis (2.ethylhexyl) phthalate

Bromodichloromethane

Bromoform

Bromomethane

4.Bromophenyl phenyl ether

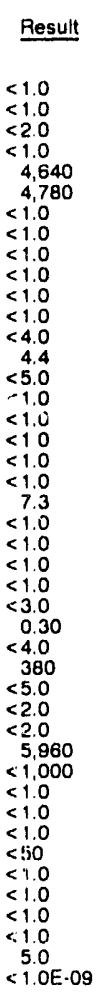

J2V

Mod Unit Lab

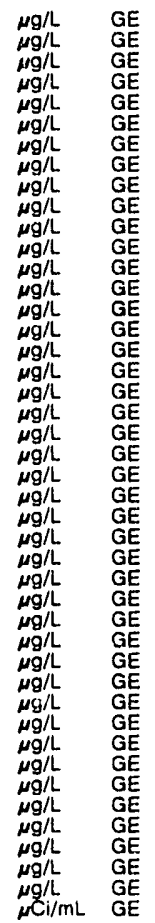

Time: 11:45

pH: 6.0

Alkalinity: $21 \mathrm{mg} / \mathrm{L}$

Water temperature: $19.0^{\circ} \mathrm{C}$

\section{Result}

Mod Unit Lab

6.8
55

$<10$
$<10$

$<10$
$<100$
$<1.0$
$<10$

$<10$

$<20$

$<0.050$

$<50$
64

64
$<10$

$<10$

$<2.0$

$<10$

$<2$
$<1.0$

$<0.050$

$<0.050$

$<10$

$<10$

$<10$

$<10$

$<10$
$<10$

$<3.0$

$<10$

$<10$
$<10$
$<10$

$<0$
$<10$

$<10$
$<10$
JO

$\begin{array}{ll}\mu H & G E \\ \mu \mathrm{S} / \mathrm{cm} & \mathrm{GE} \\ \mu \mathrm{g} / \mathrm{L} & \mathrm{GE} \\ \mu \mathrm{g} / \mathrm{L} & \mathrm{GE} \\ \mu \mathrm{g} / \mathrm{L} & \mathrm{GE} \\ \mu \mathrm{g} / \mathrm{L} & \mathrm{GE} \\ \mu \mathrm{g} / \mathrm{L} & \mathrm{GE} \\ \mu \mathrm{g} / \mathrm{L} & \mathrm{GE} \\ \mu \mathrm{g} / \mathrm{L} & \mathrm{GE} \\ \mu \mathrm{g} / \mathrm{L} & \mathrm{GE} \\ \mu \mathrm{g} / \mathrm{L} & \mathrm{GE} \\ \mu \mathrm{g} / \mathrm{L} & \mathrm{GE} \\ \mu \mathrm{g} / \mathrm{L} & \mathrm{GE} \\ \mu \mathrm{g} / \mathrm{L} & \mathrm{GE} \\ \mu \mathrm{g} / \mathrm{L} & \mathrm{GE} \\ \mu \mathrm{g} / \mathrm{L} & \mathrm{GE} \\ \mu \mathrm{g} / \mathrm{L} & \mathrm{GE} \\ \mu \mathrm{g} / \mathrm{L} & \mathrm{GE} \\ \mu \mathrm{g} / \mathrm{L} & \mathrm{GE} \\ \mu \mathrm{g} / \mathrm{L} & \mathrm{GE} \\ \mu \mathrm{g} / \mathrm{L} & \mathrm{GE} \\ \mu \mathrm{g} / \mathrm{L} & \mathrm{GE} \\ \mu \mathrm{g} / \mathrm{L} & \mathrm{GE} \\ \mu \mathrm{g} / \mathrm{L} & \mathrm{GE} \\ \mu \mathrm{g} / \mathrm{L} & \mathrm{GE} \\ \mu \mathrm{g} / \mathrm{L} & \mathrm{GE} \\ \mu \mathrm{g} / \mathrm{L} & \mathrm{GE} \\ \mu \mathrm{g} / \mathrm{L} & \mathrm{GE} \\ \mu \mathrm{g} / \mathrm{L} & \mathrm{GE} \\ \mu \mathrm{g} / \mathrm{L} & \mathrm{GE} \\ \mu \mathrm{g} / \mathrm{L} & \mathrm{GE} \\ \mu \mathrm{g} / \mathrm{L} & \mathrm{GE} \\ \mu \mathrm{g} / \mathrm{L} & \mathrm{GE} \\ \mu \mathrm{g} / \mathrm{L} & \mathrm{GE} \\ \mu \mathrm{g} / \mathrm{L} & \mathrm{GE} \\ \mu \mathrm{g} / \mathrm{L} & \mathrm{GE} \\ \mu \mathrm{g} / \mathrm{L} & \mathrm{GE} \\ \mu \mathrm{g} / \mathrm{L} & \mathrm{GE} \\ \mu \mathrm{g} / \mathrm{L} & \mathrm{GE} \\ & \end{array}$ 
ANALYTICAL RESULTS

WELL. MSB 68 collected on 11/22/91, laboratory analyses (cont.)

F Analyte

0 2-sec-Butyl-4,6-dinitrophenol

0 Cadmium

Calcium

Carbon tetrachloride $\quad<1$

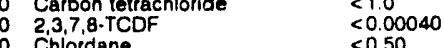

0 Chloride

para-Chioro-meta-cresol

4-Chloroaniline

Chlorobenzilate

Chloroethane

2.Chloroethyl vinyl ether

Chioroform

Chloromethane

$\begin{array}{ll}0 & \text { 2-Chloronaphthat } \\ 0 & \text {-Chlorophenol }\end{array}$

4-Chlorophenyl phenyl ether

o Chloroprene

0 Chromium

0 Cobalt

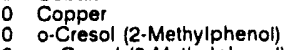

$\begin{array}{lll}0 & \text { m-Cresol (3.Methylphenol) } & <1 \\ 0 & \text { p.Cresol (4-Methylphenol) } & <10 \\ 0 & \text { Cyanide } & <5\end{array}$

0 P., DDD $<0.10$

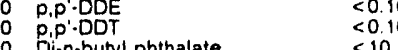

Di-n-butyl phthalate $<10$

Diallate

O Dibenzía,h]anthracene $\quad<10$

1,2-Dibromo-3-chloropropane $<1$

- Dibromochloromethane $<1$

1,2.Dibromoethane $<20$

0 trans-1,4-Dichloro-2-butene $<30$

1,2.Dichlorobenzene $\quad<10$

$0 \quad 1,4$-Dichlorobenzene $<10$

3,3'-Dichlorobenzidine $<10$

o Dichlorodifluoromethane $\quad<1.0$

1,2. Dichloroethane $<1.0$

trans-1,2.Dichloroethylene $\quad<1.0$

Dichloromethane
2,4-Dichtorophenol

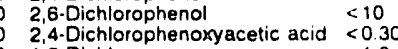

1,2-Dichloropropane

cis-1,3-Dichloropropene

trans-1,3-Dichloropropen

Diethyl phthalate

2,4-Dimethyl phenol

p.Dimethylaminoazobenzene

Dimethylbenz[a]anthracene

3,3. Dimethylbenzidine

1,3.Dinitrobenzene

2,4.Dinitrophenol

2,4-Dinitrotoluene

1,4.Dioxane

Disulfoton

Endosulfan I

Endosulfan sulfate

Endrin

Endrin aldehyde

Ethyl methacrylate

Ethylbenzene

Famphur

Fluoranthene

Fluorene

Fluoride

Heptachlor epoxide

Heptachlorodibenzo-p-dioxins

0
0 Heptachlorodibenzo-p-furans

Hexachlorobenzene

Hexachlorobutadiene

Hexachlorodibenzo-p-dioxins

$1,2,3,4,7,8 \cdot H X C D F$
0 Hexachlorodibenzo-p.furans
10
$<10$

.0

1,910

$<10$

$<10$

$<1.0$
$<10$

$<1.0$

10
$<10$

$<200$
$<4.0$

$<10$
$<4.0$

4.0

10
10

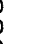

10

促

.0
10
0
30
0
0

$<1.0$
$<1.0$

$<0.50$

$<10$
$<10$

$<10$

$<10$

$<10$

$<10$
$<10$

$<10$
$<10$
$<45$

$<10$

$<10$

$<10$
$<10$

$<10$

$<0.10$
$<0.10$

$<0.0060$

$<0.10$

$<10$

$<1.0$

$<10$

$<10$

$<100$
$<0.0=0$

$<0.050$

$<0.00065$

$<0.00065$

$<0.00045$

$<10$
$<10$

$<10$

$<0.00045$

$<0.00045$
$<0.00040$

$<0.00040$
Mod

$\mu g / L \quad G E$

$\begin{array}{ll}\mu g / L & G E \\ \mu g / L & G E \\ \mu g / L & G E \\ \mu g / L & G E\end{array}$

$\mathrm{GE}$

GE

$E$ Analyte Besult Mod Unit Lab

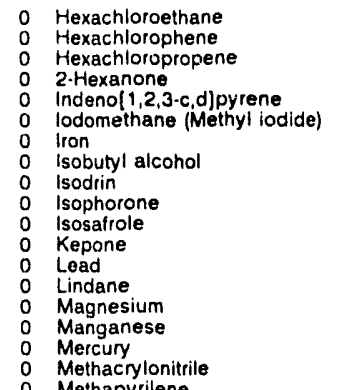

$<10$
$<10$

$<10$
$<10$
$<10$

$<10$

$<15$

$<100$

$<10$
$<10$
$<10$

$<10$

$<0.0050$

410
7.6

Methacrylonitrile

Methapyrilene

Methyl ethyl ketone

Methyl isobutyl ketone

Methyl methacrylate
Methyl methanesulfonate

2-Methyl.4,6-dinitrophenol

3.Methylcholanthrene

2. Methylnaphthalene

N.Nitrosodiethylamine $\quad<10$

N.Nitrosodimethylamine $\quad<10$

N.Nitrosodiphenylamine $<10$

N-Nitrosodi-propylamine $\quad<10$

N.Nitrosomethylethylamine $\quad<10$

$\begin{array}{ll}N \text {-Nitrosomorpholine } & <10 \\ N \text {-Nitrosopiperidine } & <10\end{array}$

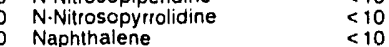

$\begin{array}{ll}\text { 1.4. Naphthoquinone } & <10 \\ \text { 1. Naphthylamine } & <10\end{array}$

$\begin{array}{lll}\text { 1.Naphthylamine } & <10 \\ 0 & 2 \text {-Naphthylamine } & <10\end{array}$

$\begin{array}{lll}0 & \text { Nickel } & <4.0 \\ 2 & \text { Nitrate as nitrogen } & 20,000 \\ 0 . \text { Nitro-0-toluidine } & <10\end{array}$

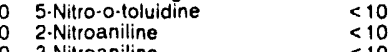

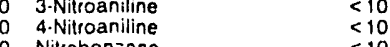

$\begin{array}{ll}< & <10 \\ 0 & <10\end{array}$

$\begin{array}{ll}\text { 4.Nitrophenol } & <10 \\ 0 & <10\end{array}$

0 0,0,0-Triethyl phosphorothioate $<10$

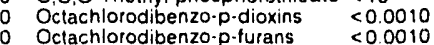

- Parathion

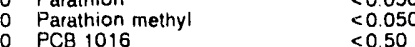

$\begin{array}{lll}0 & \text { PCB } 1016 & <0.50 \\ 0 & \text { PCB } 1221 & <0.50\end{array}$

$\begin{array}{lll}0 & \text { PCB } 1232 & <0.50 \\ 0 & \text { PCB } 1242 & <0.50\end{array}$

0 PCB $1248 \quad<0.50$

0 PCB $1254 \quad<0.50$

0 Pentachlorobenzene $\quad<10$

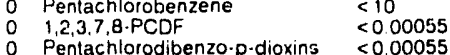

0 Pentachlorodibenzo-p.furans $<0.0005$

0 Pentach 8.PCDF

0 Pentuchloroethane

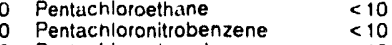

0 Pentachlorophenol $\quad<10$

$\begin{array}{ll}0 & <10 \\ 0 \text { Phenacetin } & <10\end{array}$

0 p.Phenylenediamine

$\begin{array}{ll}0 & \text { Phorate } \\ 0 & \text { 2.Picoline }\end{array}$

0 2.Picoline

Potassium

Pronamid

o Propione

0 Pyridine

- Selenium

- Silica

$\begin{array}{ll}0 & \text { Silver } \\ 0 & \text { Sodium }\end{array}$

0 Styrene

o Sulfate

Sulfide

1,2,4,5-Tetrachlorobenzene

- Tetrachlorodibenzo-p-dioxins

- Telrachlorabenzo-p.turans

1,1,2,2. Tetrachloroethane

2 $1,1,2$-elrachloroethane

$\begin{array}{ll}2 & \text { Tetrachloroethylene } \\ 0 & 2,3,4,6 \text {-Teirachlorophenol }\end{array}$

0 Thionazin

$<10$
$<10$
$<5.0$

$<5.0$
$<10$

$\begin{aligned} &< 0.10 \\ &<10 \\ & 2,190\end{aligned}$

2,190
$<10$

$<200$

$<10$

$<10$
$<10$

14,600

$<2.0$
3.600

$<1.0$

$<1,000$

$<1,000$

$<10$

$<0.00045$
$<0.00040$

$<1.0$

$<1.0$

53
$<10$
$<$

$<2.0$
$<10$

Mod Unit Lab

$\begin{array}{ll}\mu \mathrm{g} / \mathrm{L} & \mathrm{GE} \\ \mu \mathrm{g} / \mathrm{L} & \mathrm{GE}\end{array}$ 
ANALYTICAL RESULTS

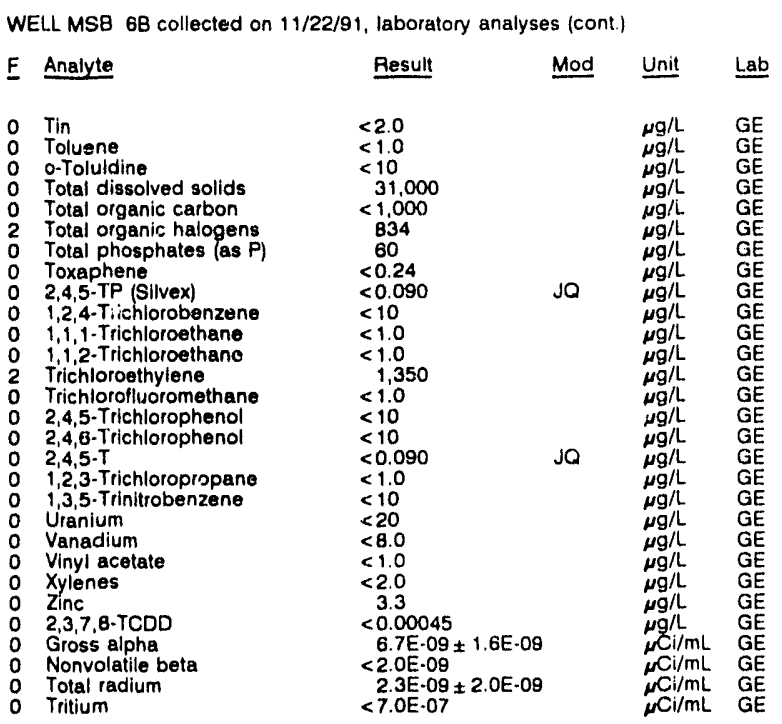

WELL MSB 6C

MEASUREMENTS CONOUCTED IN THE FIELD

Sample date: $10 / 03 / 91$

Depth to water: $122.20 \mathrm{ft}(37.25 \mathrm{~m})$ below TOC

Water elevation: 222.00 it 167.67

Sp. conductance: $940 \mu \mathrm{S} / \mathrm{cm}$

Water evacuated belore sampling: 16 ga

LABORATORY ANALYSES

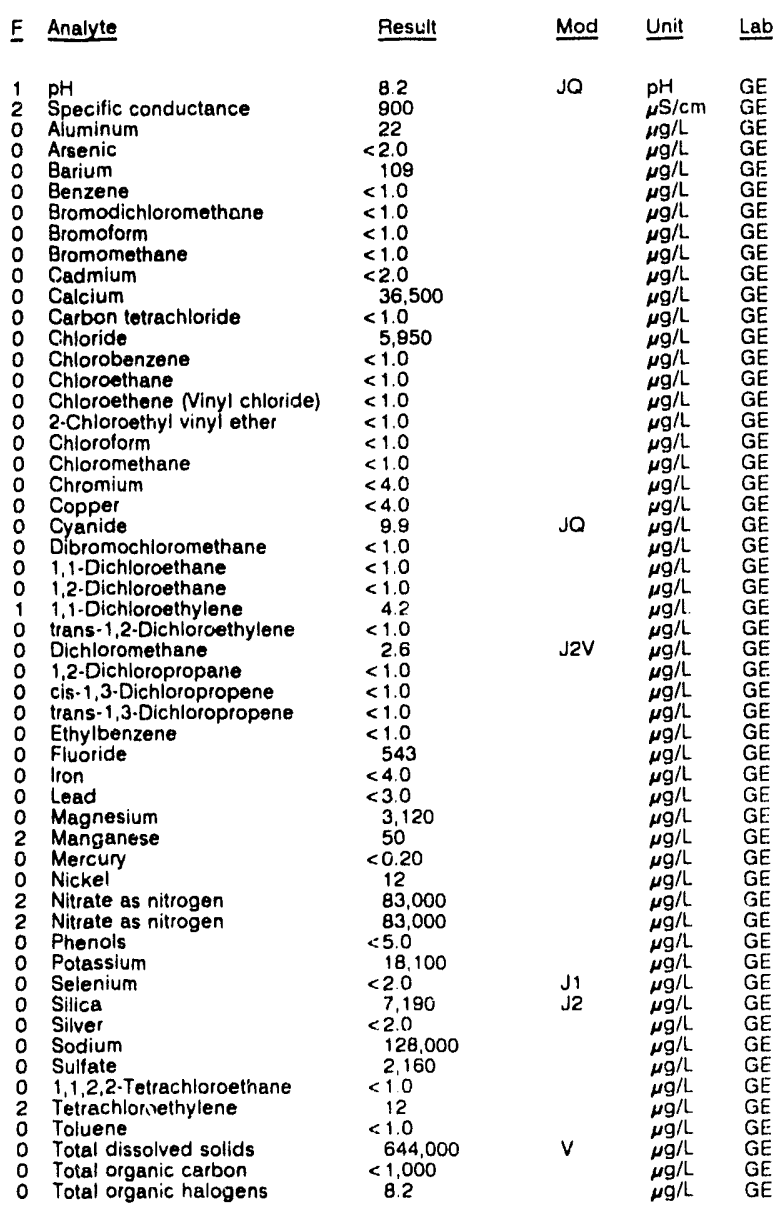

WELL MSB 6C collected on 10/03/91, laboratory analyses (cont.)

\begin{tabular}{|c|c|c|c|}
\hline Analyte & Result & Mod & Unit \\
\hline $\begin{array}{l}\text { Total phosphates (as P) } \\
\text { Total phosphates (as P) } \\
1,1,1 \text {. Trichloroethane } \\
1,1,2 \cdot \text { Trichloroethane } \\
\text { Trichloroethylene } \\
\text { Trichlorofluoromethane } \\
\text { Uranium } \\
\text { Zinc } \\
\text { Gross alpha } \\
\text { Nonvolatile teta } \\
\text { Total radium } \\
\text { Tritium }\end{array}$ & $\begin{array}{r}<50 \\
<50 \\
5.4 \\
<1.0 \\
4.0 \\
<1.0 \\
<20 \\
6.6 \\
1.3 \mathrm{E}-08 \pm 6.1 \mathrm{E} \cdot 09 \\
7.3 \mathrm{E}-08 \pm 7.6 \mathrm{E}-00 \\
3.5 \mathrm{E}-09 \pm 1.8 \mathrm{E}-00 \\
<7.0 \mathrm{E}-07\end{array}$ & & $\begin{array}{l}\mu g / L \\
\mu g / L \\
\mu g / L \\
\mu g / L \\
\mu g / L \\
\mu g / L \\
\mu g / L \\
\mu g / L \\
\mu C l / m L \\
\mu C l / m L \\
\mu C l / m L \\
\mu C l / m L\end{array}$ \\
\hline
\end{tabular}

WELL MSB 7A

MEASUREMENTS CONDUCTEO IN THE FIELD

Sample date: $10 / 03 / 91$

Depth to water: $119.08 \mathrm{ft}(36.30 \mathrm{~m})$ below TOC

Water elevation: $225.42 \mathrm{H}(68.71 \mathrm{~m}) \mathrm{ms}$ l

Water evacuated before sampling: $36 \mathrm{gal}$

PH: 5.0 : $4 \mathrm{mg}$

LABORATORY ANALYSES

E Analyte Result Mod Unit Lab

O

Specific conductance

o Aluminum

0 Arsenic

0 Barium

Benzene

Bromodichloromethane

o Bromomethane

- Bromomethan

0 Carbon tetrachloride

Chloride

Chlorobenzene

Chloroethene Ninyl chloride)

2.Chloroethyl vinyl ether

o Chloroiorin

o Chloromethane

O Chromium

O Copper

Cyanide

1,1.Dichloroethane

1,2.Dichloroethane

1,1.Dichloroethylene

trans-1,2-Dichloroethylene

- Dichloromethane

- 1,2-Dichloropropane

cis-1,3-Dichlopene

0 Ethylbenzene

0 Lead

o Mercury

0 Nickel

2 Nitrate as nitrogen

Phenols

Selenium

Silver

Sodium

Sulfate

1.12.2.Tetrachloroethane

Tetrachloroethylene

Tolvene

1,1,1. Trichloroethane

1,1,2-Trichloroethan

Trichloroethylene

Trich

Uranium alpha activity

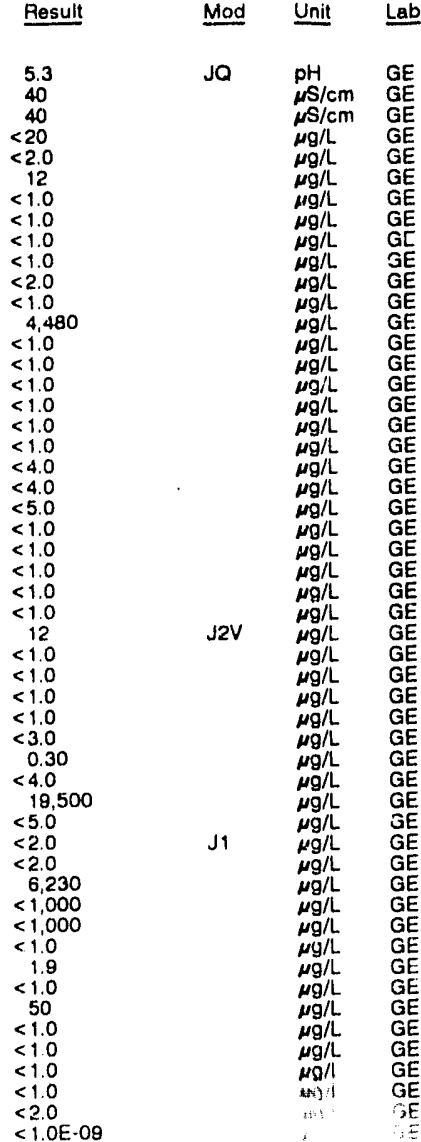


WELL MSB 7B

MEASUREMENTS CONDUCTED IN THE FIELD

Sample date: 10/03/91 Depth to water: $137.35 \mathrm{t}(41.86 \mathrm{~m})$ below TOC Sp. conductance: $918 \mu \mathrm{S} / \mathrm{cm}$

Water evacuated before sampling: 44 gal

LABORATORY ANALYSES

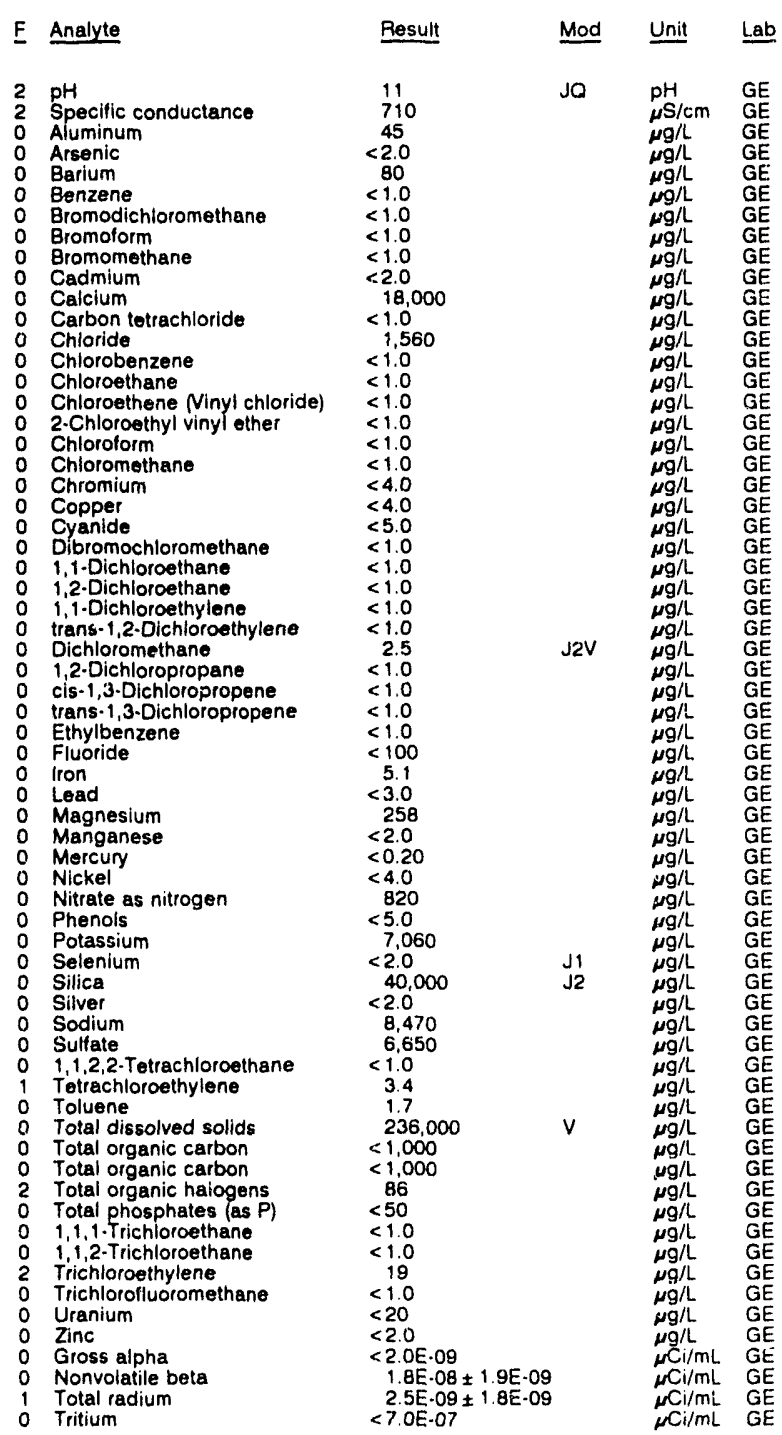

\section{WELL MSB 7C}

MEASUREMENTS CONDUCTED IN THE FIELLO

\begin{tabular}{|c|c|c|c|c|c|}
\hline & $\begin{array}{l}\text { mple date: } 10 / 03 / 91 \\
\text { pth to water: } 123.38 \mathrm{ft} \\
\text { ter elevation: } 221.21 \mathrm{ft} \\
\text { conductance: } 558 \mathrm{rs} / \\
\text { ter evacuated before se } \\
\text { well went dry during }\end{array}$ & $\begin{array}{l}\text { melow TOC } \\
\text { msl } \\
1 \mathrm{gal}\end{array}$ & $\begin{array}{l}\text { Time: } 9: 50 \\
\text { pH: } 6.3 \\
\text { Alkalinity: } \\
\text { Water temp }\end{array}$ & $\begin{array}{l}\mathrm{mg/h} \\
\text { ature: } 19\end{array}$ & \\
\hline & BORATORY ANALYSES & & & & \\
\hline $\mathbf{F}$ & Analyte & Resuit & Mod & $\underline{\text { Unit }}$ & Lab \\
\hline $\begin{array}{l}0 \\
2 \\
0 \\
0 \\
0\end{array}$ & $\begin{array}{l}\text { pH } \\
\text { Specific conductance } \\
\text { Aluminum } \\
\text { Arsenic } \\
\text { Barium } \\
\text { Benzene }\end{array}$ & $\begin{aligned} & 6.7 \\
& 520 \\
&<20 \\
&<2.0 \\
& 57 \\
&<10\end{aligned}$ & Jo & $\begin{array}{l}\mathrm{pH} \\
\mu \mathrm{S} / \mathrm{cm} \\
\mu \mathrm{g} / \mathrm{L} \\
\mu \mathrm{g} / \mathrm{L} \\
\mu \mathrm{g} / \mathrm{L} \\
\mu g / \mathrm{h}\end{array}$ & $\begin{array}{l}\mathrm{GE} \\
\mathrm{GE} \\
\mathrm{GE} \\
\mathrm{GE} \\
\mathrm{GE} \\
\mathrm{GE}\end{array}$ \\
\hline
\end{tabular}

WELL MSB 7C collected on 10/03/91, laboratory analyses (cont.)

\begin{tabular}{|c|c|c|c|c|c|}
\hline & Analyte & Result & Mod & Unit & Lab \\
\hline & 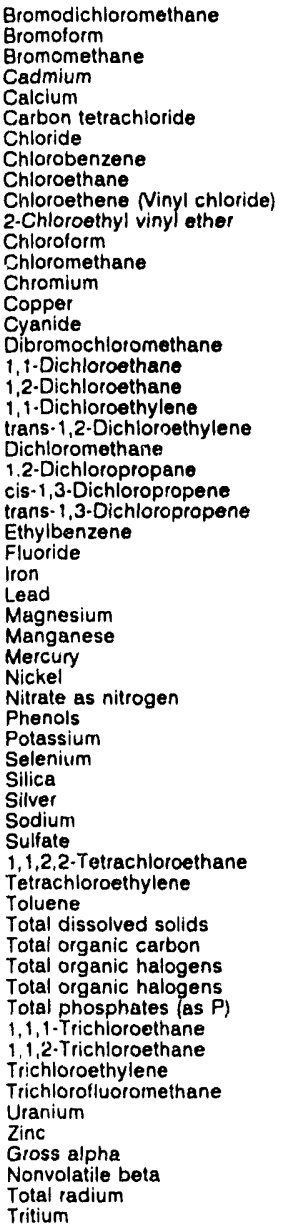 & $\begin{array}{l}<1.0 \\
<1.0 \\
<1.0 \\
<2.0 \\
12.700 \\
<1.0 \\
55,350 \\
<1.0 \\
<1.0 \\
<1.0 \\
<1.0 \\
<1.0 \\
<1.0 \\
<4.0 \\
<4.0 \\
<5.0 \\
<1.0 \\
<1.0 \\
<1.0 \\
4.5 \\
<1.0 \\
2.5 \\
<1.0 \\
<1.0 \\
<1.0 \\
<1.0 \\
<100 \\
298 \\
<3.0 \\
3.580 \\
59 \\
<0.20 \\
4.3 \\
59,500 \\
<5.0 \\
11.300 \\
<2.0 \\
8.300 \\
<2.0 \\
79,200 \\
<1.000 \\
<1.0 \\
35 \\
<1.0 \\
395,000 \\
<1.000 \\
34 \\
33 \\
50 \\
5.3 \\
<1.0 \\
1.8 \\
<1.0 \\
<20 \\
113 \\
1.5 \mathrm{E} \cdot 08 \pm 2.7 \mathrm{E} \cdot 09 \\
6.0 \mathrm{E}-08 \pm 3.1 \mathrm{E} \cdot 09 \\
4.7 \mathrm{E} \cdot 09 \pm 2.0 \mathrm{E} \cdot 08 \\
<7.0 \mathrm{E} \cdot 07 \\
\end{array}$ & $\begin{array}{l}\mathrm{J} 1 \\
\mathrm{~J} 2\end{array}$ & $\begin{array}{l}\mu g / L \\
\mu g / L \\
\mu g / L \\
\mu g / L \\
\mu g / L \\
\mu g / L \\
\mu g / L \\
\mu g / L \\
\mu g / L \\
\mu g / L \\
\mu g / L \\
\mu g / L \\
\mu g / L \\
\mu g / L \\
\mu g / L \\
\mu g / L \\
\mu g / L \\
\mu g / L \\
\mu g / L \\
\mu g / L \\
\mu g / L \\
\mu g / L \\
\mu g / L \\
\mu g / L \\
\mu g / L \\
\mu g / L \\
\mu g / L \\
\mu g / L \\
\mu g / L \\
\mu g / L \\
\mu g / L \\
\mu g / L \\
\mu g / L \\
\mu g / L \\
\mu g / L \\
\mu g / L \\
\mu g / L \\
\mu g / L \\
\mu g / L \\
\mu g / L \\
\mu g / L \\
\mu g / L \\
\mu g / L \\
\mu g / L \\
\mu g / L \\
\mu g / L \\
\mu g / L \\
\mu g / L \\
\mu g / L \\
\mu g / L \\
\mu g / L \\
\mu g / L \\
\mu g / L \\
\mu g / L \\
\mu g / L \\
\mu C i / m L \\
\mu c i / m L \\
\mu C l / m L \\
\mu C i / m L\end{array}$ & $\begin{array}{l}G E \\
G E \\
G E \\
G E \\
G E \\
G E \\
G E \\
G E \\
G E \\
G E \\
G E \\
G E \\
G E \\
G E \\
G E \\
G E \\
G E \\
G E \\
G E \\
G E \\
G E \\
G E \\
G E \\
G E \\
G E \\
G E \\
G E \\
G E \\
G E \\
G E \\
G E \\
G E \\
G E \\
G E \\
G E \\
G E \\
G E \\
G E \\
G E \\
G E \\
G E \\
G E \\
G E \\
G E \\
G E \\
G E \\
G E \\
G E \\
G E \\
G E \\
G E \\
G E \\
G E \\
G E \\
G E \\
G E \\
G E \\
G E \\
G E\end{array}$ \\
\hline
\end{tabular}

WELL MSB BA

MEASUREMENTS CONDUCTED IN THE FIELD

Sample date: $10 / 02 / 91$
The well was dry. Time: 10:25

WELL MSB 8B

MEASUREMENTS CONDUCTED IN THE FIELD

Sample date $10 / 02 / 91$ Depth to water: $135.45 \mathrm{Ht}(41.29 \mathrm{~m})$ below TOC Water elevation: $208.45 \mathrm{tt}(63.54 \mathrm{~m}) \mathrm{msl}$

Sp. conductance: $29 \mathrm{\mu S} / \mathrm{cm}$
Water evacuated before sampling: $164 \mathrm{gal}$

LABORATORY ANALYSES

\begin{tabular}{|c|c|c|c|c|}
\hline Analyte & Result & Mod & Unit & $\underline{L a b}$ \\
\hline $\begin{array}{l}\text { pH- } \\
\text { Specitic conductance } \\
\text { Aluminum } \\
\text { Arsenic } \\
\text { Barium } \\
\text { Benzene } \\
\text { Bromodichloromethane } \\
\text { Bromoform } \\
\text { Bromomethane } \\
\text { Cadmium } \\
\text { Calcium } \\
\text { Carbon tetrachloride } \\
\text { Chloride } \\
\text { Chlorobenzene }\end{array}$ & $\begin{aligned} & 5.3 \\
& 20 \\
& 29 \\
&<2.0 \\
& 9.2 \\
&<1.0 \\
&<1.0 \\
&<1.0 \\
&<1.0 \\
&<2.0 \\
& 1.220 \\
&<1.0 \\
& 2.630 \\
&<1.0\end{aligned}$ & JO & $\begin{array}{l}p H \\
\mu S / c m \\
\mu g / L \\
\mu g / L \\
\mu g / L \\
\mu g / L \\
\mu g / L \\
\mu g / L \\
\mu g / L \\
\mu g / L \\
\mu g / L \\
\mu g / L \\
\mu g / L \\
\mu g / L\end{array}$ & $\begin{array}{l}\mathrm{GE} \\
\mathrm{GE} \\
\mathrm{GE} \\
\mathrm{GE} \\
\mathrm{GE} \\
\mathrm{GE} \\
\mathrm{GE} \\
\mathrm{GE} \\
\mathrm{GE} \\
\mathrm{GE} \\
\mathrm{GE} \\
\mathrm{GE} \\
\mathrm{GE} \\
\mathrm{GE}\end{array}$ \\
\hline
\end{tabular}


ANALYTICAL RESULTS

WELL MSB BB collected on 10/02/91, laboratory analyses (cont.)

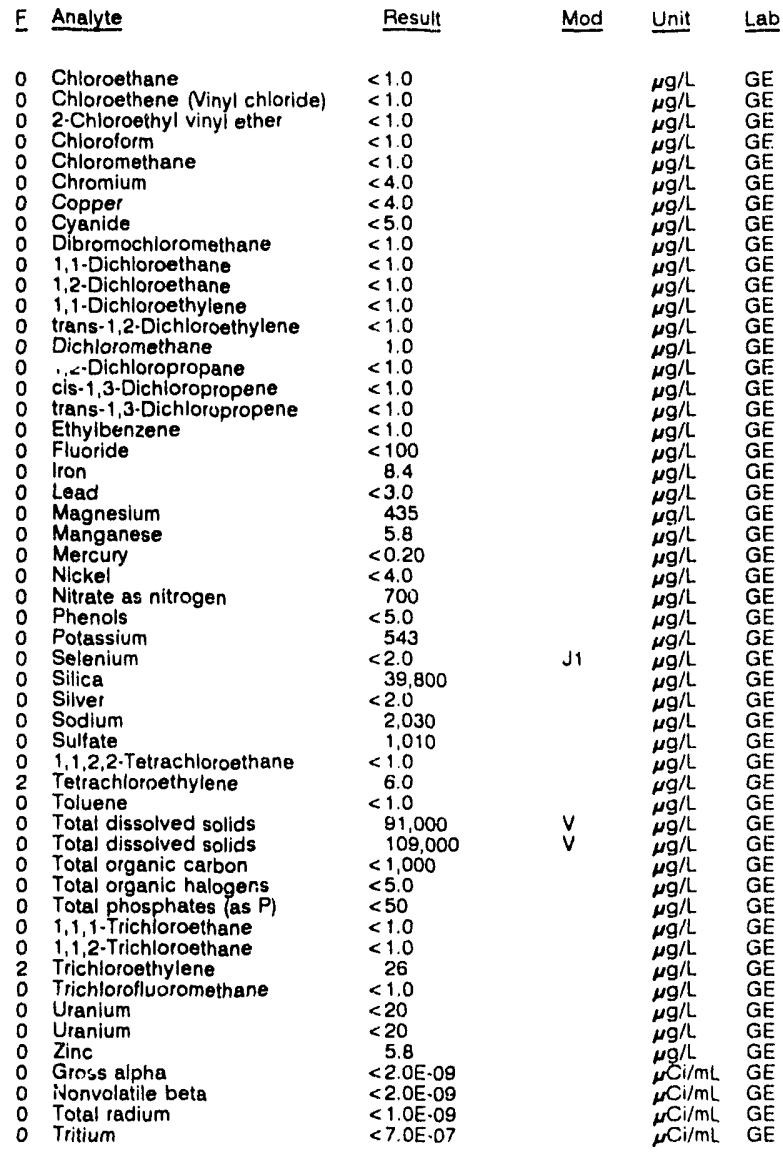

\section{WELL MSB $8 C$}

MEASUREMENTS CONDUCTED IN THE FIELD

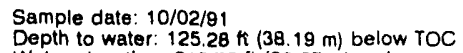
Depth to water: $125.28 \mathrm{f}(38.19 \mathrm{~m})$ below $\mathrm{T}$
Water elevation: $218.72 \mathrm{ft}(66.67 \mathrm{~m}) \mathrm{ms}$

Water evacuated before sampling: $72 \mathrm{gal}$

LABORATORY ANALYSES

\begin{tabular}{|c|c|c|c|c|}
\hline & Analyte & Result & Mod & Unit \\
\hline & 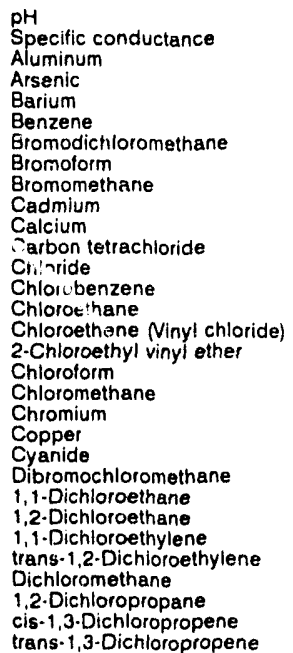 & $\begin{aligned} & 5.5 \\
& 170 \\
& 48 \\
&<2.0 \\
& 36 \\
&<1.0 \\
&<1.0 \\
&<1.0 \\
&<1.0 \\
&<2.0 \\
& 7.970 \\
&<1.0 \\
& 4.750 \\
&<1.0 \\
&<1.0 \\
&<1.0 \\
&<1.0 \\
&<1.0 \\
&<1.0 \\
&<4.0 \\
&<4.0 \\
&<5.0 \\
&<1.0 \\
&<1.0 \\
&<1.0 \\
& 14 \\
&<1.0 \\
& 1.0 \\
&<1.0 \\
&<1.0 \\
&<1.0\end{aligned}$ & JO & 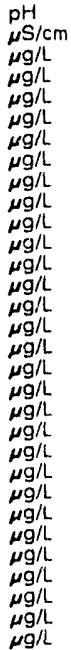 \\
\hline
\end{tabular}

WELL. MSB 8C collected on 10/02/91, laboratory analyses (cont.)

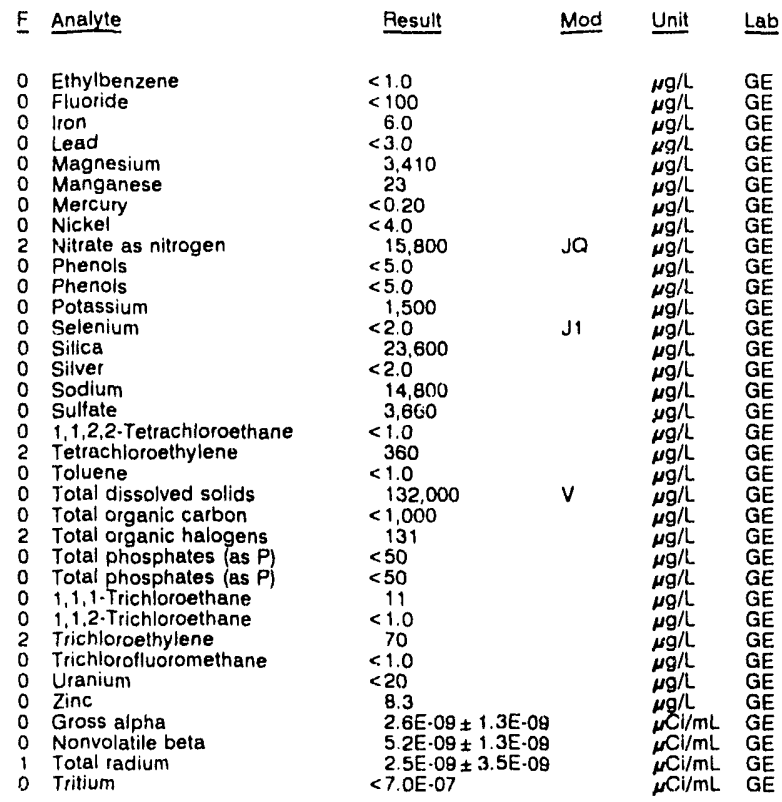

WELL MSB 9A

MEASUREMENTS CONDUCTED IN THE FIELD

Sample date: $12 / 10 / 91$

Depth to water: $150.24 \mathrm{Ht}(45.79 \mathrm{~m})$ below TOC Water elevation: $209.16 \mathrm{ft}(63.75 \mathrm{~m}) \mathrm{ms}$ No water was evacuated before sampling.

PH: 10.4 Alkalinity: $38 \mathrm{mg}$

Water te $38 \mathrm{mg} / \mathrm{L} .18 .0 \mathrm{C}$

WORATORY ANALYSES

\begin{tabular}{|c|c|c|c|}
\hline Analyte & Result & Mod & Unit \\
\hline 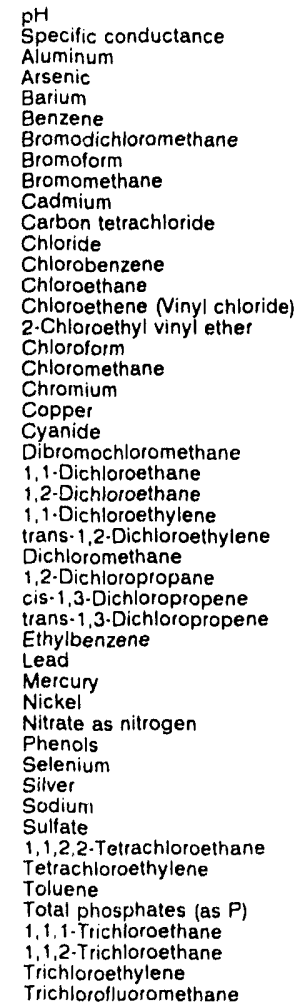 & $\begin{array}{l}10 \\
140 \\
<20 \\
<2.0 \\
13 \\
<5,000 \\
<5,000 \\
<5,000 \\
<5,000 \\
<2.0 \\
<5,000 \\
3,960 \\
<5,000 \\
<5,000 \\
<5,000 \\
<5,000 \\
<5,000 \\
<5,000 \\
<4.0 \\
<4.0 \\
<5.0 \\
<5,000 \\
<5,000 \\
<5,000 \\
<5,000 \\
<5,000 \\
16,000 \\
<5,000 \\
<5,000 \\
<5,000 \\
<5,000 \\
<30 \\
<0.20 \\
<4.0 \\
3,240 \\
19 \\
<2.0 \\
<2.0 \\
8,930 \\
1,270 \\
<5,000 \\
229,000 \\
<5,000 \\
<50 \\
<5,000 \\
<5,000 \\
230,000 \\
<5,000\end{array}$ & $\mathrm{~J} 2 \mathrm{~V}$ & $\begin{array}{l}p H \\
\mu \mathrm{s} / \mathrm{cm} \\
\mu g / L \\
\mu g / L \\
\mu g / L \\
\mu g / L \\
\mu g / L \\
\mu g / L \\
\mu g / L \\
\mu g / L \\
\mu g / L \\
\mu g / L \\
\mu g / L \\
\mu g / L \\
\mu g / L \\
\mu g / L \\
\mu g / L \\
\mu g / L \\
\mu g / L \\
\mu g / L \\
\mu g / L \\
\mu g / L \\
\mu g / L \\
\mu g / L \\
\mu g / L \\
\mu g / L \\
\mu g / L \\
\mu g / L \\
\mu g / L \\
\mu g / L \\
\mu g / L \\
\mu g / L \\
\mu g / L \\
\mu g / L \\
\mu g / L \\
\mu g / L \\
\mu g / L \\
\mu g / L \\
\mu g / L \\
\mu g / L \\
\mu g / L \\
\mu g / L \\
\mu g / L \\
\mu g / L \\
\mu g / L \\
\mu g / L \\
\mu g / L \\
\mu g / L\end{array}$ \\
\hline
\end{tabular}


ANALYTICAL RESULTS

WELL MSB 9A collected on 12/10/91, laboratory analyses (cont.)

\begin{tabular}{|c|c|c|c|}
\hline F Analyte & Result & Mod & Unit \\
\hline $\begin{array}{ll}0 & \text { Uranlum } \\
0 & \text { Zinc } \\
0 & \text { Zinc }\end{array}$ & $\begin{array}{c}<20 \\
139 \\
139\end{array}$ & & $\begin{array}{l}\mu g / l \\
\mu g / h \\
\mu g / h\end{array}$ \\
\hline
\end{tabular}

WELL MSB 9B

MEASUREMENTS CONDUCTED IN THE FIELD

Sample date: $12 / 10 / 91$
Depth to water: $129.72 \mathrm{H}(39.54 \mathrm{~m})$ below TOC Water elevation: $229.88 \mathrm{ft}(70.07 \mathrm{~m}) \mathrm{msl}$

No water was evacuated before sampling.

LABORATORY ANALYSES

E Analyte

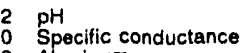

- Aluminum

- Arsenic

O Barium

0 Bromodichloromethane

Bromotorm

Bromomethane

Carbon tetrachloride

O Chlorido

o Chloride

2 Chloroethane

2.Chloroethyl vinyl other

o Chloroform

o Chloromethane

o Chromium

O Copper

o Dibromochloromethane

1,1-Dichloroethan

1,2.Dichloroethane

trans-1,2-Dichloroethylene

Dichloromethane

1,2-Dichloropropane

trans-1, 3-Dichloropropene

Ethylbenzene

Lead

Mercury

Nitrate as nitrogen

Phenols

Selenium

0 Sodium

0 Sulfate

1,1,2,2-Tetrachloroethane

2 Tetrachlorbethylene

0 Total phosphates (as P)

o 1,1,1-Trichloroethane

1,1,2-Trichloroethe

2 Trichloroethylene

Uranium

Zinc

\begin{tabular}{l} 
Piesult \\
\hline \\
10 \\
180 \\
22 \\
$<2.0$ \\
20 \\
4.2 \\
$<1.0$ \\
$<1.0$ \\
$<1.0$ \\
$<2.0$ \\
$<1.0$ \\
10,300 \\
10,300 \\
4.7 \\
$<1.0$ \\
140 \\
$<1.0$ \\
1.1 \\
$<1.0$ \\
$<4.0$ \\
$<4.0$ \\
8.8 \\
$<1.0$ \\
1.2 \\
$<1.0$ \\
17 \\
942 \\
4.4 \\
$<1.0$ \\
$<1.0$ \\
$<1.0$ \\
2.8 \\
$<3.0$ \\
$<0.20$ \\
$<4.0$ \\
320 \\
17 \\
$<2.0$ \\
$<2.0$ \\
13,000 \\
2.520 \\
$<1.0$ \\
102,000 \\
2.9 \\
$<50$ \\
$<1.0$ \\
$<1.0$ \\
61,700 \\
$<1.0$ \\
$<20$ \\
73 \\
\end{tabular}

WELL MSB 9C

MEASUREMENTS CONDUCTED IN THE FIELD

Sample date: $12 / 10 / 91$

Depth to water: $129.83 \mathrm{H}(39.60 \mathrm{~m})$ below TOC Water elevation: $229.17 \mathrm{At}(68.85 \mathrm{~m}) \mathrm{ms}$ |

Sp. conduclance: $236 \mu \mathrm{s} / \mathrm{cm}$

sampling.

LABORATORY ANALYSES

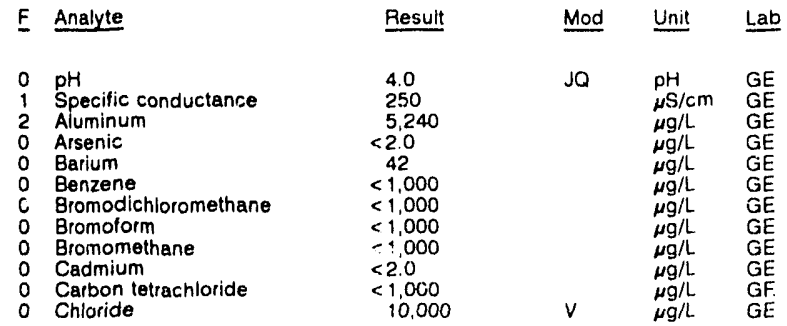

WELL MSB 9C collected on 12/10/91, laboratory analyses (cont.

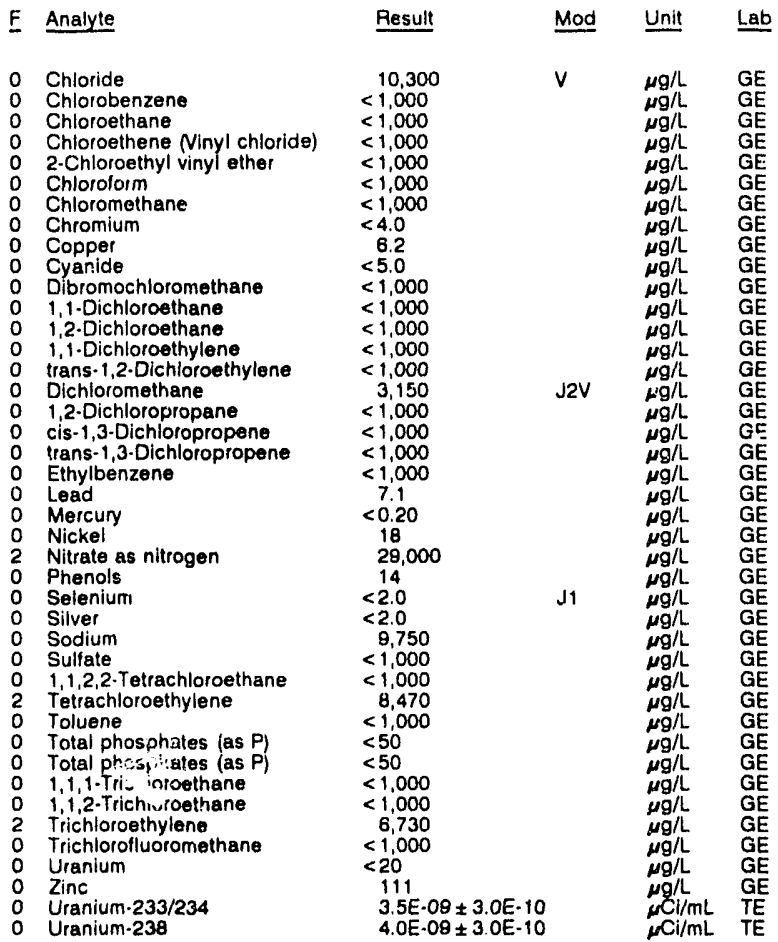

\section{WELL MSB 10A}

MEASUREMENTS CONDUCTED IN THE FIELD

Sample date: 10/08/81

Depth to water: $145.46 \mathrm{tt}(44.34 \mathrm{~m})$ below TOC

Water elevation: $209.54 \mathrm{t}(63.87 \mathrm{~m}) \mathrm{msl}$

Sp. conductance: $22 \mu \mathrm{s} / \mathrm{cm}$
Water evacuated before sampling: $240 \mathrm{gal}$

LABORATORY ANALYSES

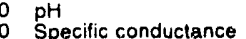

0 Aluminum

0 Arsenic

Benzene

Bromodichloromethane

Bromoform

o Bromomethane

Cadmium

Chloride

Chlorobenzene

Chloroethane

2.Chioroethyl vinyl ether

2-Chloroethyl

o Chloromethane

o Chromium

- Copper

o Cyanide

- Dibromochloromethane

1,1-Dichloroethane

1,2-Dichloroethane

$1,1-$ Dichloroethylene
0 trans-1,2-Dichloroethylene

Dichloromethane

1,2-Dichloropropane

cis-1,3-Dichloropropene

Ethylbenzene

Lead

Mercury

Nitrate as nitrogen

Phenols

Selenium

Silver

Sodium

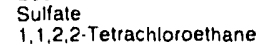

\begin{tabular}{l}
$\quad$ Result \\
\hline \\
5.7 \\
20 \\
$<20$ \\
$<2.0$ \\
4.7 \\
$<1.0$ \\
$<1.0$ \\
$<1.0$ \\
$<1.0$ \\
$<2.0$ \\
$<1.0$ \\
2.220 \\
$<1.0$ \\
$<1.0$ \\
$<1.0$ \\
$<1.0$ \\
$<1.0$ \\
$<1.0$ \\
$<4.0$ \\
$<4.0$ \\
$<5.0$ \\
$<1.0$ \\
$<1.0$ \\
$<1.0$ \\
$<1.0$ \\
$<1.0$ \\
4.9 \\
$<1.0$ \\
$<1.0$ \\
$<1.0$ \\
$<1.0$ \\
$<3.0$ \\
$<0.20$ \\
$<4.0$ \\
250 \\
$<5.0$ \\
$<2.0$ \\
$<2.0$ \\
1.480 \\
$<1.000$ \\
$<1.0$
\end{tabular}

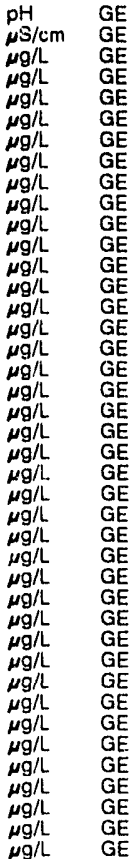


ANALYTICAL RESULTS

WELL MSB 10A collected on 10/08/91, laboratory analyses (cont)

\begin{tabular}{|c|c|c|c|}
\hline Analyte & Result & Mod & Unit \\
\hline $\begin{array}{l}\text { Tetrachloroethylene } \\
\text { Toivene } \\
\text { Total phosphates (as P) } \\
1,1,1 \text {-Trichloroethane } \\
1,1,2 \cdot \text { Trichloroethane } \\
\text { Trichloroethylene } \\
\text { Trichlorofluoromethane } \\
\text { Uranium } \\
\text { Uranium } \\
\text { Zinc }\end{array}$ & $\begin{aligned} & 4.4 \\
&< 1.0 \\
&<50 \\
&<1.0 \\
&<1.0 \\
& 14 \\
&<1.0 \\
&<20 \\
&<20 \\
& 21\end{aligned}$ & & $\begin{array}{l}\mu \mathrm{g} / \mathrm{L} \\
\mu \mathrm{g} / \mathrm{L} \\
\mu \mathrm{g} / \mathrm{L} \\
\mu \mathrm{g} / \mathrm{L} \\
\mu \mathrm{g} / \mathrm{L} \\
\mu \mathrm{g} / \mathrm{L} \\
\mu \mathrm{g} / \mathrm{L} \\
\mu \mathrm{g} / \mathrm{L} \\
\mu \mathrm{g} / \mathrm{L} \\
\mu \mathrm{g} / \mathrm{L}\end{array}$ \\
\hline
\end{tabular}

WELL MSB 1OB

MEASUREMENTS CONDUCTED IN THE FIELD

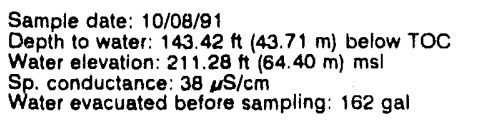

Time: 10:30

$\mathrm{pH}: 5.1$

Alkalinity: $2 \mathrm{mg} / \mathrm{L}$ Water temperature: $17.2^{\circ} \mathrm{C}$ LABORATORY ANALYSES

\begin{tabular}{|c|c|}
\hline Analyte & Result \\
\hline 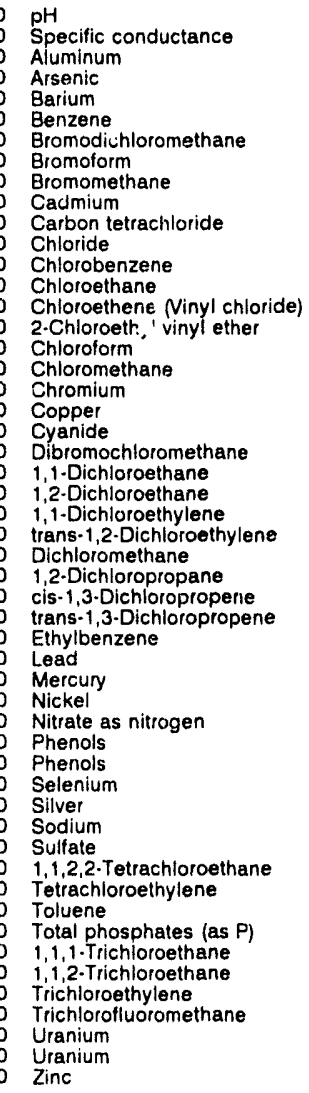 & $\begin{aligned} & 5.3 \\
& 35 \\
&<20 \\
&<2.0 \\
& 11 \\
&<1.0 \\
&<1.0 \\
&<1.0 \\
&<1.0 \\
&<2.0 \\
&<1.0 \\
& 2.330 \\
&<1.0 \\
&<1.0 \\
&<1.0 \\
&<1.0 \\
&<1.0 \\
&<1.0 \\
&<4.0 \\
&<4.0 \\
&<5.0 \\
&<1.0 \\
&<1.0 \\
&<1.0 \\
&<1.0 \\
&<1.0 \\
& 7.4 \\
&<1.0 \\
&<1.0 \\
&<1.0 \\
&<1.0 \\
&<3.0 \\
&<0.20 \\
&<4.0 \\
&<50 \\
&<5.0 \\
&<5.0 \\
&<2.0 \\
&<2.0 \\
& 2.500 \\
& 9.070 \\
&<1.0 \\
&<1.0 \\
&<1.0 \\
&<50 \\
&<1.0 \\
&<1.0 \\
& 2.3 \\
&<1.0 \\
&<20 \\
&<20 \\
& 25\end{aligned}$ \\
\hline
\end{tabular}

\section{WELL MSB 10C}

MEASUREMENTS CONDUCTED IN THE FIELD

Sample date: $12 / 10 / 91$ Water elevation: $228.82 \mathrm{tt}(69.75 \mathrm{~m}) \mathrm{msl}$

Sp conductance: $6650 \mu \mathrm{S} / \mathrm{cm}$

No water was evacuated before sampling.

LABORATORY ANALYSES

$\begin{array}{llllll}\text { F Analyte } & \text { Result } & \text { Mod } & \text { Unit } & \text { Lab } \\ 2 & & & & \\ 2 & \text { pH } & 13 & \mathrm{JO} & \mathrm{pH} & \mathrm{GE} \\ 2 & \text { Specific conductance } & 8,000 & & \mu \mathrm{S} / \mathrm{cm} & \mathrm{GE} \\ 2 & \text { Aluminum } & 230 & & \mu \mathrm{g} / \mathrm{L} & \mathrm{GE} \\ 0 & \text { Arsenic } & <2.0 & & \mu \mathrm{g} / \mathrm{L} & \mathrm{GE}\end{array}$

WELL. MSB 10C collected on 12/10/91, laboratory analyses (cont.)

\begin{tabular}{|c|c|c|c|}
\hline Analyte & Result & Mod & Unit \\
\hline $\begin{array}{l}\text { Barium } \\
\text { Barium } \\
\text { Benzene } \\
\text { Bromodichloromethane } \\
\text { Bromoform } \\
\text { Bromomethane } \\
\text { Cadmium } \\
\text { Carbon tetrachloride } \\
\text { Chloride } \\
\text { Chlorobenzene } \\
\text { Chloroethane } \\
\text { Chloroethene Ninyl chloride) } \\
\text { 2-Chloroethyl vinyl ether } \\
\text { Chloroorm } \\
\text { Chloromethane } \\
\text { Chromium } \\
\text { Copper } \\
\text { Cyanide } \\
\text { Dibromochloromethane } \\
1,1 \cdot \text { Dichloroethane } \\
1,2 \text {-Dichloroethane } \\
1,1-\text { Dichloroethylene } \\
\text { trans-1,2-Dichloroethylene } \\
\text { Dichloromethane } \\
1,2 \cdot \text { Dichloropropane } \\
\text { cis-1,3-Dichloropropene } \\
\text { trans-1,3-Dichloropropene } \\
\text { Ethylbenzene } \\
\text { Lead } \\
\text { Mercury } \\
\text { Nickel } \\
\text { Nitrate as nitrogen } \\
\text { Phenols } \\
\text { Selenium } \\
\text { Silver } \\
\text { Sodium } \\
\text { Sulfate } \\
1,1,2,2 \cdot \text {-Tetrachloroethane } \\
\text { Tetrachloroethylene } \\
\text { Toluene } \\
\text { Total phosphates (as P) } \\
1,1,1-\text { Trichloroethane } \\
1,1,2-\text { Trichloroethane } \\
\text { Trichloroethylene } \\
\text { Trichlorofluoromethane } \\
\text { Ularium } \\
\text { Zinc }\end{array}$ & $\begin{aligned} & 2,250 \\
& 2,660 \\
&<1.0 \\
&<1.0 \\
&<1.0 \\
&<1.0 \\
&<2.0 \\
&<1.0 \\
&<250 \\
&<1.0 \\
&<1.0 \\
&<1.0 \\
&<1.0 \\
&<1.0 \\
&<1.0 \\
& 17 \\
& 13 \\
&<5.0 \\
&<1.0 \\
&<1.0 \\
&<1.0 \\
&<1.0 \\
&<1.0 \\
& 2.4 \\
&<1.0 \\
&<1.0 \\
&<1.0 \\
&<1.0 \\
& 5.9 \\
&<0.20 \\
&<4.0 \\
& 210 \\
&<5.0 \\
&<2.0 \\
&<20 \\
& 5,580 \\
&<1.000 \\
&<1.0 \\
& 180 \\
&<1.0 \\
&<50 \\
&<1.0 \\
&<1.0 \\
& 152 \\
&<1.0 \\
&<200 \\
& 99\end{aligned}$ & $\mathrm{~J} 2 \mathrm{~V}$ & $\begin{array}{l}\mu g / L \\
\mu g / L \\
\mu g / L \\
\mu g / L \\
\mu g / L \\
\mu g / L \\
\mu g / L \\
\mu g / L \\
\mu g / L \\
\mu g / L \\
\mu g / L \\
\mu g / L \\
\mu g / L \\
\mu g / L \\
\mu g / L \\
\mu g / L \\
\mu g / L \\
\mu g / L \\
\mu g / L \\
\mu g / L \\
\mu g / L \\
\mu g / L \\
\mu g / L \\
\mu g / L \\
\mu g / L \\
\mu g / L \\
\mu g / L \\
\mu g / L \\
\mu g / L \\
\mu g / L \\
\mu g / L \\
\mu g / L \\
\mu g / L \\
\mu g / L \\
\mu g / L \\
\mu g / L \\
\mu g / L \\
\mu g / L \\
\mu g / L \\
\mu g / L \\
\mu g / L \\
\mu g / L \\
\mu g / L \\
\mu g / L \\
\mu g / L \\
\mu g / L \\
\mu g / L\end{array}$ \\
\hline
\end{tabular}

WELL MSB 11A

MEASUREMENTS CONDUCTED IN THE FIELD

Sample date: 10/08/91

Depth to water: $151.76 \mathrm{ft}(46.26 \mathrm{~m})$ below TOC Water elevation: $213.14 \mathrm{ft}(64.97 \mathrm{~m}) \mathrm{msl}$ Sp. conductance: $28 \mu \mathrm{S} / \mathrm{cm}$

gal

PH: 5.8

Water temperalure: $17.7^{\circ} \mathrm{C}$

LABORATORY ANALYSES

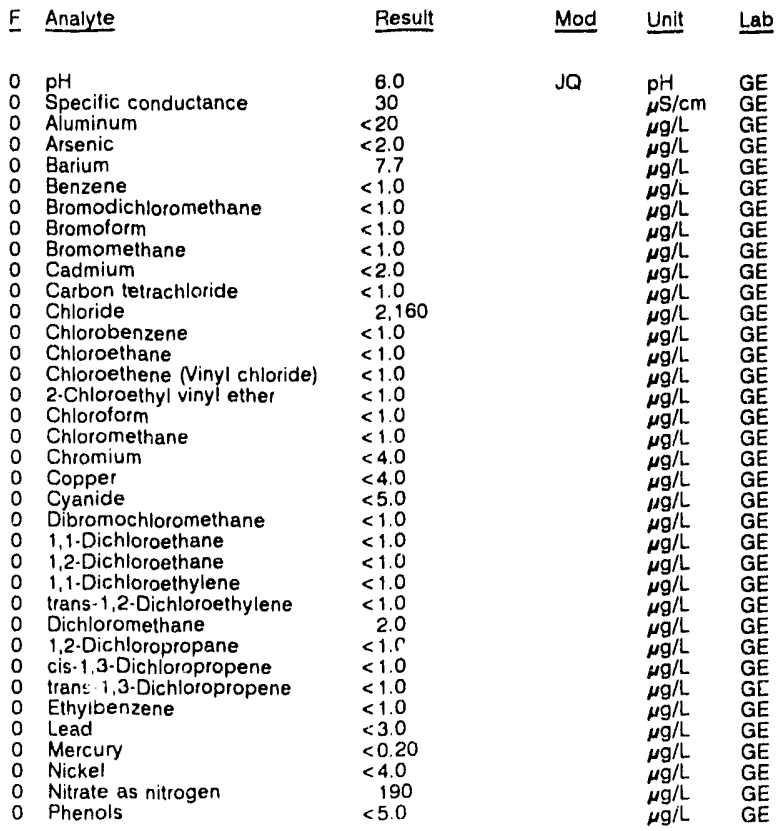


WELL MSB 11A coliected on 10/08/91, laboratory analyses (cont)

\begin{tabular}{|c|c|c|c|}
\hline Analyte & Result & Mod & Unit \\
\hline $\begin{array}{ll}0 & \text { Selenium } \\
0 & \text { Silver } \\
0 & \text { Sodium } \\
0 & \text { Sulfate } \\
0 & 1,1,2,2 \cdot \text { Tetrachloroethane } \\
0 & \text { Tetrachloroethylene } \\
0 & \text { Toluene } \\
0 & \text { Total phosphates (as P) } \\
0 & 1,1,1-\text { Trichloroethane } \\
0 & 1,1,2 \cdot \text { Trichloroethane } \\
2 & \text { Trichlooethylene } \\
0 & \text { Trichlorofluoromethane } \\
0 & \text { Uranium } \\
0 & \text { Uranium } \\
0 & \text { Zinc }\end{array}$ & $\begin{array}{l}<2.0 \\
<2.0 \\
1.500 \\
<1,000 \\
<1.0 \\
<1.0 \\
<1.0 \\
<50 \\
<1.0 \\
<1.0 \\
8.0 \\
<1.0 \\
<20 \\
<20 \\
104\end{array}$ & & $\begin{array}{l}\mu g / L \\
\mu g / L \\
\mu g / L \\
\mu g / L \\
\mu g / L \\
\mu g / L \\
\mu g / L \\
\mu g / L \\
\mu g / L \\
\mu g / L \\
\mu g / L \\
\mu g / L \\
\mu g / L \\
\mu g / L \\
\mu g / L\end{array}$ \\
\hline
\end{tabular}

WELL MSB 11B

MEASUREMENTS CONDUCTED IN THE FIELD Sample date: $10 / 09 / 91$
Depth to water: $148.27 \mathrm{Ht}(45.19 \mathrm{~m})$ below TOC
Water elevation: $216.53 \mathrm{Ht}(66.00 \mathrm{~m}) \mathrm{ms}$
Sp. conductance: $26 \mu \mathrm{s} / \mathrm{cm}$
Water evacuated before sampling: $148 \mathrm{gal}$ Time: $8: 35$

$\mathrm{pH}: 5.5$

Alkalinity: $8 \mathrm{mg} / \mathrm{L}$ Water temperature: $15.6^{\circ} \mathrm{C}$ LABORATORY ANALYSES

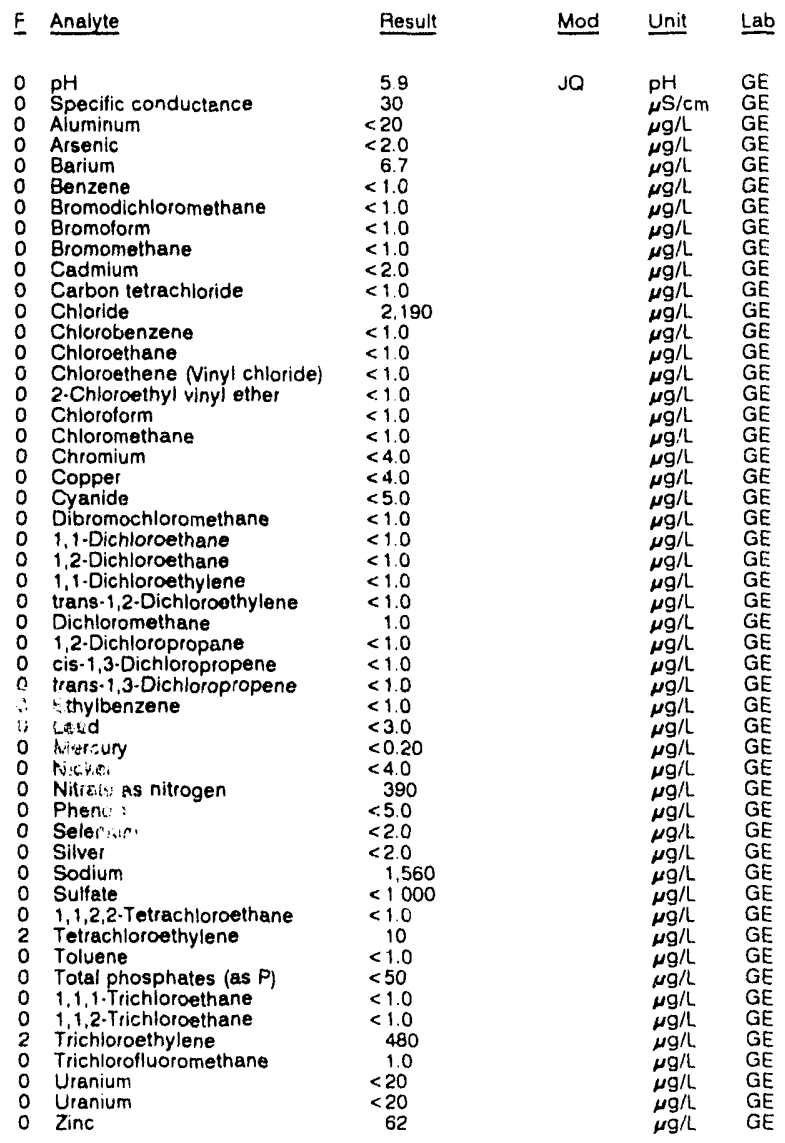

WELL MSB 11B Replicate

MEASUREMENTS CONDUCTED IN THE FIELD

Sample date: 10/09/91

Depth to water: $148.27 \mathrm{ft}_{\mathrm{i}}(45.19 \mathrm{~m})$ below TOC Water elevation: $216.53 \mathrm{ft}$ (66.0 Water evacuated before sampling: $148 \mathrm{gal}$

LABORATORY ANALYSES

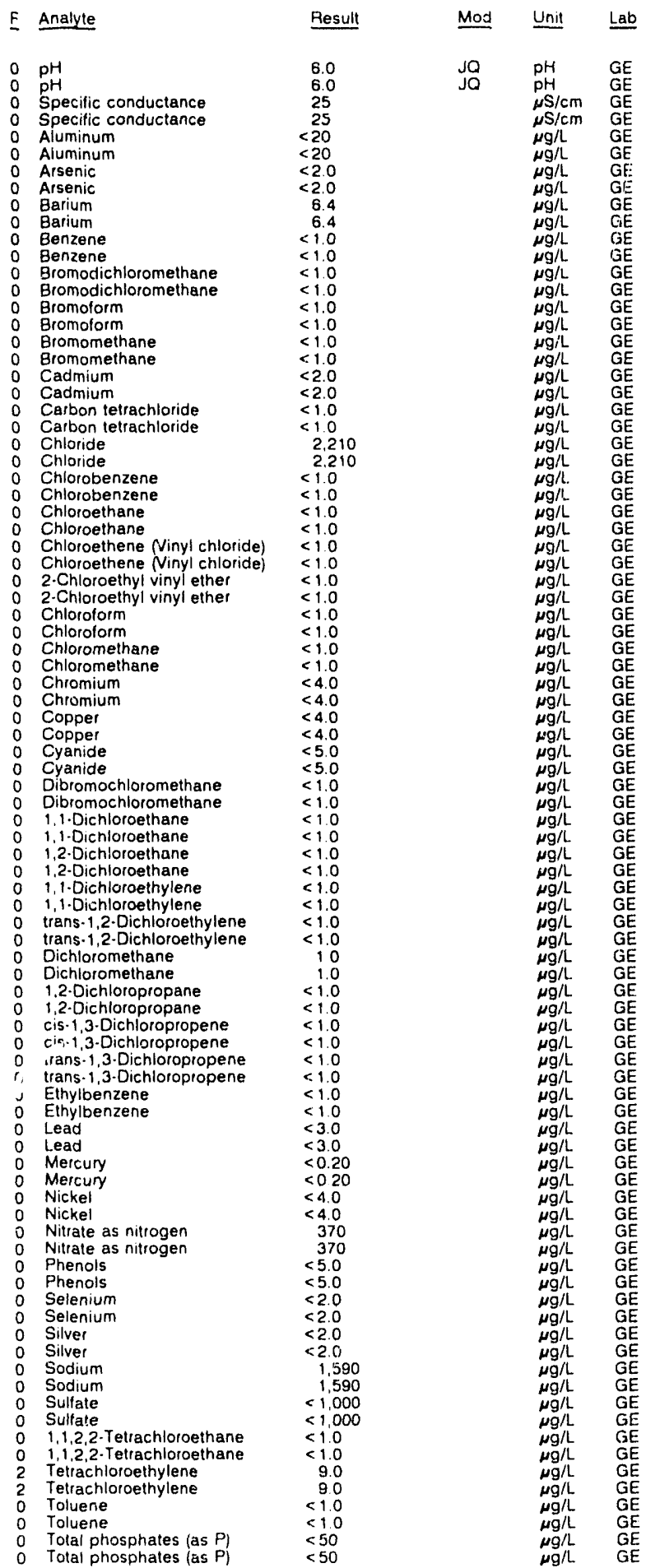

Time: : $: 35$

pH: 5.5

Water temperature: $15.6^{\circ} \mathrm{C}$

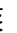
E (1) 
ANALYTICAL RESULTS

WELL MSB 11 B collected on 10/09/91, laboratory analyses (cont.)

\begin{tabular}{|c|c|c|c|c|}
\hline F & Analyte & Pesult & Mod & Unit \\
\hline $\begin{array}{l}0 \\
0 \\
0 \\
0 \\
2 \\
2 \\
0 \\
0 \\
0 \\
0 \\
0 \\
0\end{array}$ & $\begin{array}{l}\text { 1,1,1-Trichloroethane } \\
1,1,1 \cdot \text { Trichloroethane } \\
1,1,2-\text { Trichloroethane } \\
1,1,2 \cdot \text { Trichloroethane } \\
\text { Trichloroethylene } \\
\text { Trichloroethylene } \\
\text { Trichlorcfluoromethane } \\
\text { Trichlorofluoromethane } \\
\text { Uranium } \\
\text { Uranium } \\
\text { Zinc } \\
\text { Zinc }\end{array}$ & $\begin{aligned}<1.0 \\
<1.0 \\
<1.0 \\
<1.0 \\
250 \\
250 \\
<1.0 \\
<1.0 \\
<20 \\
<20 \\
63 \\
63\end{aligned}$ & & $\begin{array}{l}\mu g / L \\
\mu g / L \\
\mu g / L \\
\mu g / L \\
\mu g / L \\
\mu g / L \\
\mu g / L \\
\mu g / L \\
\mu g / L \\
\mu g / L \\
\mu g / L \\
\mu g / L\end{array}$ \\
\hline
\end{tabular}

\section{WELL MSB 11C}

MEASUAEMENTS CONDUCTED IN THE FIELD

Depth to water: $146.78 \mathrm{H}(44.74 \mathrm{~m})$ below TOC

Water elevation: $218.12 \mathrm{ft}(66.48 \mathrm{~m}) \mathrm{msl}$

No water was evacuated before sampling.

LABORATORY ANALYSES

\begin{tabular}{|c|c|c|c|}
\hline Analyte & Result & Mod & Unit \\
\hline 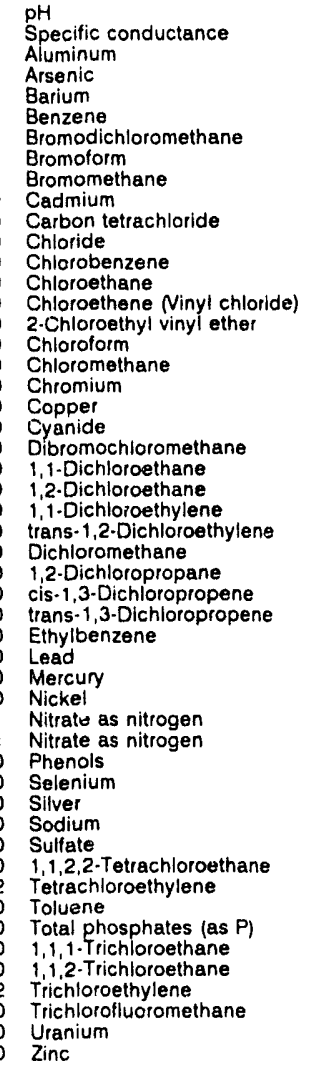 & 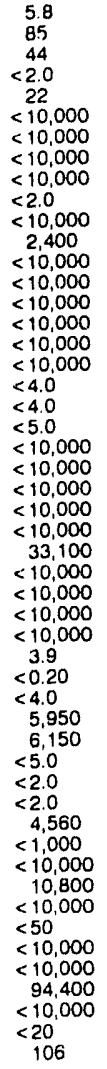 & $\begin{array}{l}\mathrm{JQ} \\
\mathrm{Jl}\end{array}$ & $\begin{array}{l}\mathrm{pH} \\
\mu \mathrm{S} / \mathrm{cm} \\
\mu \mathrm{g} / \mathrm{L} \\
\mu \mathrm{g} / \mathrm{L} \\
\mu \mathrm{g} / \mathrm{L} \\
\mu \mathrm{g} / \mathrm{L} \\
\mu \mathrm{g} / \mathrm{L} \\
\mu \mathrm{g} / \mathrm{L} \\
\mu \mathrm{g} / \mathrm{L} \\
\mu \mathrm{g} / \mathrm{L} \\
\mu \mathrm{g} / \mathrm{L} \\
\mu \mathrm{g} / \mathrm{L} \\
\mu \mathrm{g} / \mathrm{L} \\
\mu \mathrm{g} / \mathrm{L} \\
\mu \mathrm{g} / \mathrm{L} \\
\mu \mathrm{g} / \mathrm{L} \\
\mu \mathrm{g} / \mathrm{L} \\
\mu \mathrm{g} / \mathrm{L} \\
\mu \mathrm{g} / \mathrm{L} \\
\mu \mathrm{g} / \mathrm{L} \\
\mu \mathrm{g} / \mathrm{L} \\
\mu \mathrm{g} / \mathrm{L} \\
\mu \mathrm{g} / \mathrm{L} \\
\mu \mathrm{g} / \mathrm{L} \\
\mu \mathrm{g} / \mathrm{L} \\
\mu \mathrm{g} / \mathrm{L} \\
\mu \mathrm{g} / \mathrm{L} \\
\mu \mathrm{g} / \mathrm{L} \\
\mu \mathrm{g} / \mathrm{L} \\
\mu \mathrm{g} / \mathrm{L} \\
\mu \mathrm{g} / \mathrm{L} \\
\mu \mathrm{g} / \mathrm{L} \\
\mu \mathrm{g} / \mathrm{L} \\
\mu \mathrm{g} / \mathrm{L} \\
\mu \mathrm{g} / \mathrm{L} \\
\mu \mathrm{g} / \mathrm{L} \\
\mu g / \mathrm{L} \\
\mu \mathrm{g} / \mathrm{L} \\
\mu \mathrm{g} / \mathrm{L} \\
\mu \mathrm{g} / \mathrm{L} \\
\mu \mathrm{g} / \mathrm{L} \\
\mu \mathrm{g} / \mathrm{L} \\
\mu \mathrm{g} / \mathrm{L} \\
\mu \mathrm{g} / \mathrm{L} \\
\mu \mathrm{g} / \mathrm{L} \\
\mu g / \mathrm{L} \\
\mu \mathrm{g} / \mathrm{L} \\
\mu \mathrm{g} / \mathrm{L} \\
\mu \mathrm{g} / \mathrm{L} \\
\mu \mathrm{g} / \mathrm{L} \\
\mu \mathrm{g} / \mathrm{L}\end{array}$ \\
\hline
\end{tabular}

WELL MSB 11D

MEASUREMENTS CONCUCTED IN THE FIELD

Sample date: $11 / 18 / 91$ $\mathrm{ft}(41.69 \mathrm{~m})$ below TOC

Water elevation: $228.42 \mathrm{ft}(69.62 \mathrm{~m}) \mathrm{msl}$

Water evacuated before sampling: $66 \mathrm{gal}$

LABORATORY ANALYSES

\begin{tabular}{|c|c|c|c|}
\hline Analyte & Result & Mod & Unit \\
\hline $\begin{array}{ll}0 & \mathrm{pH} \\
0 & \text { Specific conductance } \\
0 & \text { Aluminum }\end{array}$ & $\begin{array}{l}5.1 \\
25 \\
21\end{array}$ & JO & $\begin{array}{l}\mathrm{pH} \\
\mu \mathrm{S} / \mathrm{cm} \\
\mu \mathrm{g} / \mathrm{L}\end{array}$ \\
\hline
\end{tabular}

$$
\begin{aligned}
& \text { pH: } 4.8 \\
& \text { Alkalinity } 1 \mathrm{mg} / \mathrm{L} \\
& \text { Water temperature: } 16.6^{\circ} \mathrm{C}
\end{aligned}
$$

\begin{tabular}{|c|c|c|c|}
\hline Analyte & Result & Mod & Unit \\
\hline $\begin{array}{l}\text { Arsenic } \\
\text { Barium } \\
\text { Benzene } \\
\text { Bromodichloromethane } \\
\text { Bromoform } \\
\text { Bromomethane } \\
\text { Cadmium } \\
\text { Carbon tetrachloride } \\
\text { Chloride } \\
\text { Chlorobenzene } \\
\text { Chloroethane } \\
\text { Chloroethene Ninyl chloride) } \\
\text { 2-Chloroethyl vinyl ether } \\
\text { Chloroform } \\
\text { Chloromethane } \\
\text { Chromium } \\
\text { Copper } \\
\text { Cyanide } \\
\text { Dibromochloromethane } \\
1,1-\text { Dichloroethane } \\
1,2-\text { Dichloroethane } \\
1,1 \cdot \text { Dichloroethylene } \\
\text { trans-1,2-Dichloroethylene } \\
\text { Dichloromethane } \\
1,2 \cdot \text { Dichloropropane } \\
\text { cis-1,3-Dichloropropene } \\
\text { trans-1,3-Dichloropropene } \\
\text { Ethylbenzene } \\
\text { Lead } \\
\text { Mercury } \\
\text { Nickel } \\
\text { Nittate as nitrogen } \\
\text { Phenols } \\
\text { Selenium } \\
\text { Silver } \\
\text { Sodium } \\
\text { Sulfate } \\
1,1,2,2-\text {-Tetrachloroethane } \\
\text { Tetrachloroethylene } \\
\text { Toluene } \\
\text { Total phosphates (as P) } \\
1,1,1-\text { Trichloroethane } \\
\text { 1,1,2-Trichloroethane } \\
\text { Trichloroethylene } \\
\text { Trichlorofluoromethane } \\
0 \text { Uranium } \\
\text { Zinc }\end{array}$ & $\begin{array}{l}<2.0 \\
5.4 \\
<1.0 \\
<1.0 \\
<1.0 \\
<1.0 \\
<2.0 \\
<1.0 \\
2.810 \\
<1.0 \\
<1.0 \\
<1.0 \\
<1.0 \\
<1.0 \\
<1.0 \\
<4.0 \\
<4.0 \\
<5.0 \\
<1.0 \\
<1.0 \\
<1.0 \\
<1.0 \\
<1.0 \\
<1.0 \\
<1.0 \\
<1.0 \\
<1.0 \\
<1.0 \\
<3.0 \\
<0.20 \\
<4.0 \\
1.200 \\
<5.0 \\
<2.0 \\
<2.0 \\
2.820 \\
1.930 \\
<1.0 \\
64 \\
<1.0 \\
<50 \\
<1.0 \\
<1.0 \\
330 \\
<1.0 \\
<20 \\
1.2 \\
\end{array}$ & & $\begin{array}{l}\mu g / L \\
\mu g / L \\
\mu g / L \\
\mu g / L \\
\mu g / L \\
\mu g / L \\
\mu g / L \\
\mu g / L \\
\mu g / L \\
\mu g / L \\
\mu g / L \\
\mu g / L \\
\mu g / L \\
\mu g / L \\
\mu g / L \\
\mu g / L \\
\mu g / L \\
\mu g / L \\
\mu g / L \\
\mu g / L \\
\mu g / L \\
\mu g / L \\
\mu g / L \\
\mu g / L \\
\mu g / L \\
\mu g / L \\
\mu g / L \\
\mu g / L \\
\mu g / L \\
\mu g / L \\
\mu g / L \\
\mu g / L \\
\mu g g \\
\mu g / L \\
\mu g / L \\
\mu g / L \\
\mu g / L \\
\mu g / L \\
\mu g / L \\
\mu g / L \\
\mu g / L \\
\mu g / L \\
\mu g / L \\
\mu g / L \\
\mu g / L \\
\mu g / L\end{array}$ \\
\hline
\end{tabular}

WELL MSB 110 collected on 11/18/91, laboratory analyses (cont.)

WELL MSB 11E

MEASUREMENTS CONDUCTED IN THE FIELD

Sample date: $10 / 08 / 91$

Time: 11:35

The well was dry.

WELL MSB 11F

MEASUREMENTS CONDUCTED IN THE FIELD

Sample date: $12 / 10 / 91$

Water elevation: $229.71 \mathrm{H}(70.02 \mathrm{~m}) \mathrm{ms}$

Sp. conductance: $23 \mu \mathrm{S} / \mathrm{cm}$

No water was evacuated before sampling.

LABORATORY ANALYSES

${ }_{0}^{0} \quad$ Specific conductance

Alumin

0 Arsenic

O Barium

O Bromodichloromethane

Bromotorm

Cadmium

Carbon tetrachloride

Chloride

Chlorobenzene

Chloroethane

Chloroethene (vinyl chloride)

2-Chloroethyl vinyl ether

Chloroform

Chloromethane

Chromium

Copper

Dibromochloromethane

1,1-Dichloroethane

1,2.Dichloroethane

0 trans-1,2-Dichloroethylene

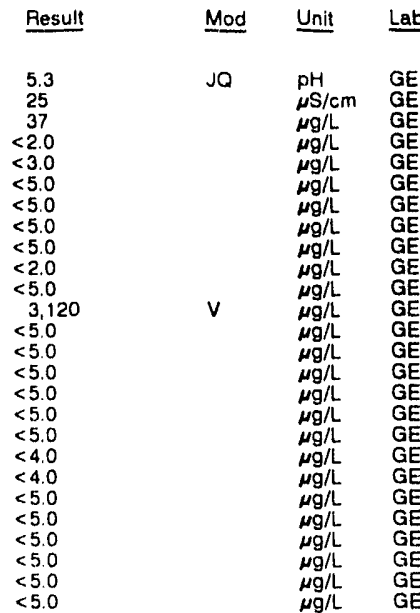

Time: 15:05

Alkalinity: $0 \mathrm{mg} / \mathrm{L}$ Water temperature: $18.0^{\circ} \mathrm{C}$ 
ANALYTICAL RESULTS

WELL MSB $11 \mathrm{~F}$ collected on 12/10/91, laboratory analyses (cont)

\begin{tabular}{|c|c|}
\hline Analyte & Result \\
\hline $\begin{array}{l}\text { Dichloromethane } \\
1,2-\text { Dichoropropane } \\
\text { cis-1,3-Dichloropropene } \\
\text { trans-1,3-Dichloropropene } \\
\text { Ethylbenzene } \\
\text { Lead } \\
\text { Mercury } \\
\text { Nickel } \\
\text { Nitrate as nitrogen } \\
\text { Phenols } \\
\text { Selenium } \\
\text { Silver } \\
\text { Sodium } \\
\text { Sulfate } \\
\text { 1,1,2,2-Tetrachloroethane } \\
\text { Tetrachloroethylene } \\
\text { Toluene } \\
\text { Total phosphates (as P) } \\
1,1,1 \text { - Yrichloroethane } \\
\text { 1,1,2-Trichloroethane } \\
\text { Trichloroethylene } \\
\text { Trichlorofluoromethane } \\
\text { Uranium }\end{array}$ & $\begin{array}{l}16 \\
<5.0 \\
<5.0 \\
<5.0 \\
<5.0 \\
<3.0 \\
<0.20 \\
<4.0 \\
410 \\
<5.0 \\
<2.0 \\
<2.0 \\
2.360 \\
<1.000 \\
<5.0 \\
251 \\
<5.0 \\
<50 \\
2.9 \\
<5.0 \\
789 \\
<5.0 \\
<20 \\
44\end{array}$ \\
\hline
\end{tabular}

WELL MSB 12A

MEASUREMENTS CONDUCTFD IN THE FIELD Sample date: $11 / 18 / 91$
Depth to water: $141.40 \mathrm{ht}(43.10 \mathrm{~m})$ below TOC
Water elevation: $206.40 \mathrm{ft}(62.81 \mathrm{~m}) \mathrm{msl}$ Sp. conductance: $19 \mathrm{ss} / \mathrm{cm}$ Water evacuated belore sampling: $296 \mathrm{gal}$ LABOPATORY ANALYSES

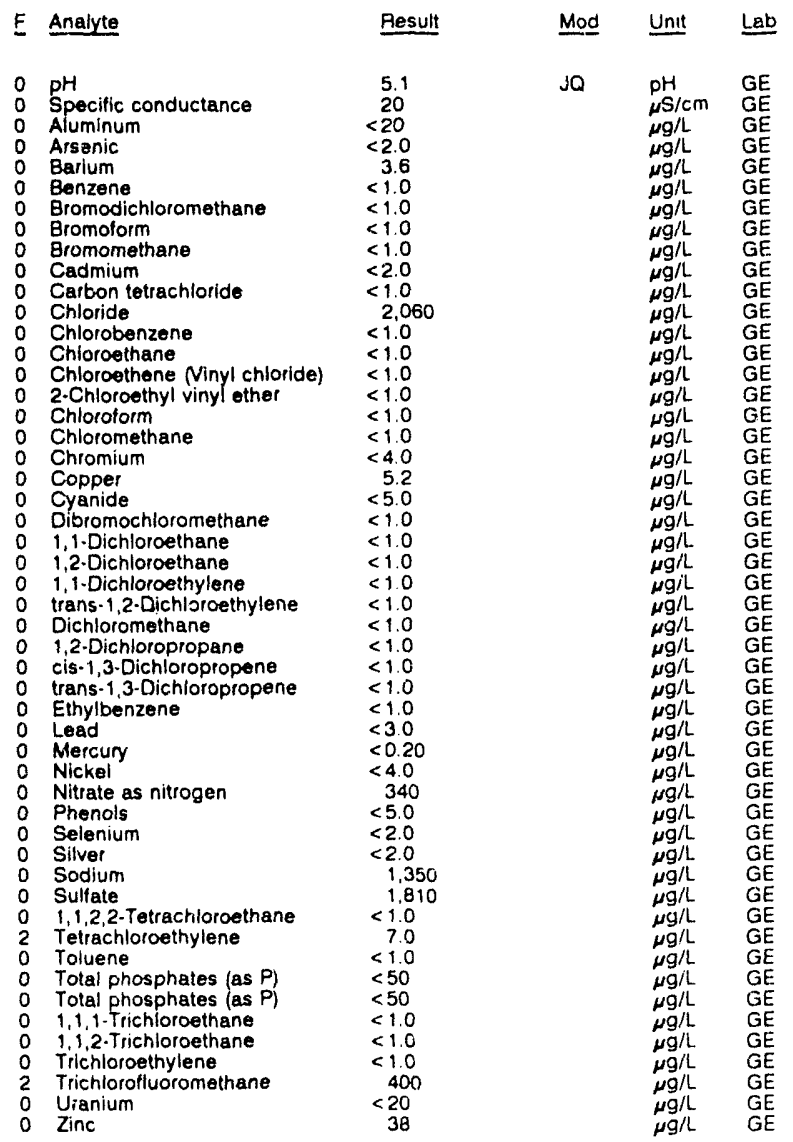

WELL MSB $12 B$

MEASUREMENTS CONDUCTED IN THE FIELD $\begin{array}{ll}\text { Sample date: } 11 / 18 / 91 & \text { Time: } 10.05 \\ \text { Depth to water: } 132.64 \mathrm{Ht}(40.43 \mathrm{~m}) \text { below TOC } & \text { pH: } 4.6 \\ \text { Water elevation: } 215.76 \mathrm{ft}(65.76 \mathrm{~m}) \mathrm{msl} & \text { Alkalinity: } 0 \mathrm{mg} / \mathrm{h} \\ \text { Sp. conductance: } 128 \mu \mathrm{s} / \mathrm{cm} & \text { Water temperature: } 18.0 \circ \mathrm{C} \\ \text { Water evacuated belore sampling } 156 \mathrm{gal} & \end{array}$ LABORATORY ANALYSES

\begin{tabular}{|c|c|c|c|}
\hline Analyte & Result & Mod & Unit \\
\hline 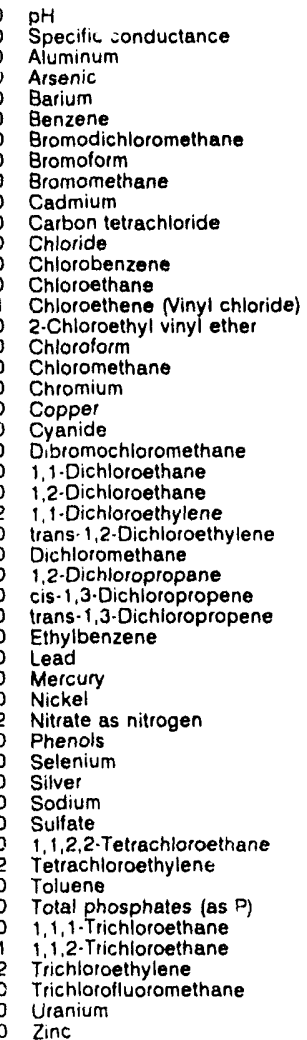 & $\begin{aligned} & 4.8 \\
& 120 \\
& 51 \\
&<2.0 \\
& 1.0 \\
& 1.0 \\
&<10 \\
&<1.0 \\
&<1.0 \\
&<2.0 \\
&<1.0 \\
& 3.980 \\
& 1.0 \\
&<1.0 \\
& 1.0 \\
&<1.0 \\
&<1.0 \\
&<1.0 \\
&<4.0 \\
& 7.2 \\
&<5.0 \\
&<1.0 \\
&<1.0 \\
&<1.0 \\
& 1.9 \\
&<1.0 \\
& 1.0 \\
&<1.0 \\
&<1.0 \\
&<1.0 \\
&<1.0 \\
&<3.0 \\
&<0.20 \\
&<4.0 \\
& 11.500 \\
&<5.0 \\
&<2.0 \\
&<2.0 \\
& 12.800 \\
& 1.400 \\
& 3.0 \\
& 4.700 \\
&<1.0 \\
&<50 \\
& 7.0 \\
& 4.0 \\
& 10.900 \\
&<1.0 \\
&<20 \\
& 15\end{aligned}$ & JO & $\begin{array}{l}p H \\
\mu S / c m \\
\mu g / h \\
\mu g / L \\
\mu g / h \\
\mu g / h \\
\mu g / h \\
\mu g / L \\
\mu g / L \\
\mu g / h \\
\mu g / L \\
\mu g / L \\
\mu g / L \\
\mu g / L \\
\mu g / L \\
\mu g / L \\
\mu g / L \\
\mu g / L \\
\mu g / L \\
\mu g / L \\
\mu g / L \\
\mu g / L \\
\mu g / L \\
\mu g / L \\
\mu g / L \\
\mu g / L \\
\mu g / L \\
\mu g / L \\
\mu g / L \\
\mu g / L \\
\mu g / L \\
\mu g / L \\
\mu g / L \\
\mu g / L \\
\mu g / L \\
\mu g / L \\
\mu g / L \\
\mu g / L \\
\mu g / L \\
\mu g / L \\
\mu g / L \\
\mu g / L \\
\mu g / L \\
\mu g / L \\
\mu g / L \\
\mu g / L \\
\mu g / L \\
\mu g / L \\
\mu g / L \\
\mu g / L\end{array}$ \\
\hline
\end{tabular}

WELL MSB $12 C$

MEASUREMENTS CONOUCTED IN THE FIELD

Sample date: $11 / 18 / 91$

Depth to water: $127.18 \mathrm{ft}(38.77 \mathrm{~m})$ below TOC Water elevation: 220.71 it (67.27 nis ins) Water evacuated before sampling $1: 2 \mathrm{gal}$

pH: 5.0 . $1 \mathrm{mg}$

Alkalinity: $1 \mathrm{mg} / \mathrm{h}: 16.7^{\circ} \mathrm{C}$

WBORATORY ANALYSES

\begin{tabular}{|c|c|c|c|}
\hline Analyte & Result & Mod & Unit \\
\hline $\begin{array}{l}\text { pH } \\
\text { Specific conductance } \\
\text { Aluminum } \\
\text { Arsenic } \\
\text { Barium } \\
\text { Berizene } \\
\text { Brornodichloromethane } \\
\text { Bromoform } \\
\text { Bromomethane } \\
\text { Cadmium } \\
\text { Carbon tetrachloride } \\
\text { Chloride } \\
\text { Chlorobenzene } \\
\text { Chloroethane } \\
\text { Chloroethene Ninyl chlor de) } \\
\text { 2.Chloroethyl vinyl ether } \\
\text { Chlorolorm } \\
\text { Chloromethane } \\
\text { Chromium } \\
\text { Copper } \\
\text { Cyanide }\end{array}$ & $\begin{aligned} & 5.3 \\
& 145 \\
& 53 \\
&<2.0 \\
& 39 \\
&<10 \\
&<1.0 \\
&<1.0 \\
&<1.0 \\
&<2.0 \\
&<1.0 \\
& 4.400 \\
&<1.0 \\
&<1.0 \\
&<1.0 \\
&<1.0 \\
&<1.0 \\
&<1.0 \\
&<40 \\
&<4.0 \\
&<50\end{aligned}$ & Oג & $\begin{array}{l}p H \\
\mu S / c m \\
\mu g / L \\
\mu g / L \\
\mu g / L \\
\mu g / L \\
\mu g / L \\
\mu g / L \\
\mu g / L \\
\mu g / L \\
\mu g / L \\
\mu g / L \\
\mu g / L \\
\mu g / L \\
\mu g / L \\
\mu g / L \\
\mu g / L \\
\mu g / L \\
\mu g / L \\
\mu g / L \\
\mu g / L\end{array}$ \\
\hline
\end{tabular}


ANALYTICAL RESULTS

WELL MSB 12 C collected on 11/18/91, laboratory analyses (cont.)

\begin{tabular}{|c|c|c|c|}
\hline Analyte & Result & Mod & Unit \\
\hline $\begin{array}{l}\text { Dibromochloromethane } \\
1,1-\text { Dichloroethane } \\
1,2 \cdot \text { Dichloroethane } \\
1,1 \cdot \text { Dichloroethylene } \\
\text { trans-1,2-Dichloroethylene } \\
\text { Dichloromethane } \\
1,2 \cdot \text { Dichloropropane } \\
\text { cis-1,3-Dichloropropene } \\
\text { trans-1,3-Dichloropropene } \\
\text { Ethylbenzene } \\
\text { Lead } \\
\text { Mercury } \\
\text { Nickel } \\
\text { Nitrate as nitrogen } \\
\text { Phenols } \\
\text { Selenium } \\
\text { Silver } \\
\text { Sodium } \\
\text { Sulfate } \\
1,1,2,2-\text { Tetrachloroethane } \\
\text { Tetrachloroethylene } \\
\text { Toluene } \\
\text { Total phosphates (as P) } \\
1,1,1-\text { Trichloroethane } \\
1,1,2 \cdot \text { Trichloroethane } \\
\text { Trichlooethylene } \\
\text { Trichlorofluoromethane } \\
\text { Uranium } \\
\text { Zinc }\end{array}$ & $\begin{array}{l}<1.0 \\
1.0 \\
<1.0 \\
66 \\
<1.0 \\
<1.0 \\
<1.0 \\
<1.0 \\
<1.0 \\
<1.0 \\
<3.0 \\
0.65 \\
<4.0 \\
14,700 \\
<5.0 \\
<2.0 \\
<2.0 \\
15,800 \\
<1,000 \\
<1.0 \\
1.300 \\
<1.0 \\
<50 \\
25 \\
2.0 \\
3,800 \\
<1.0 \\
<20 \\
2.05\end{array}$ & $J Q$ & $\begin{array}{l}\mu g / L \\
\mu g / L \\
\mu g / L \\
\mu g / L \\
\mu g / L \\
\mu g / L \\
\mu g / L \\
\mu g / L \\
\mu g / L \\
\mu g / L \\
\mu g / L \\
\mu g / L \\
\mu g / L \\
\mu g / L \\
\mu g / L \\
\mu g / L \\
\mu g / L \\
\mu g / L \\
\mu g / L \\
\mu g / L \\
\mu g / L \\
\mu g / L \\
\mu g / L \\
\mu g / L \\
\mu g / L \\
\mu g / L \\
\mu g / L \\
\mu g / L \\
\mu g / L\end{array}$ \\
\hline
\end{tabular}

WELL MSB 12D

MEASUREMENTS CONDUCTED IN THE FIELD

Sample date: $10 / 08 / 91$

ine well was $d r y$.

\section{WELL MSB 12TA}

MEASUREMENTS CONDUCTED IN THE FIELD

Sample date: $10 / 09 / 91$

Depth to water: $156.21 \mathrm{ft}(47.61 \mathrm{~m})$ below TOC

Water elevation: $192.29 \mathrm{At}(58 \mathrm{G}$

Water evacuated betore sampling: $803 \mathrm{gal}$

LABCRATORY ANALYSES

\begin{tabular}{|c|c|c|c|c|c|}
\hline Analyte & Result & Mod & Unit & $\underline{\text { Lab }}$ & $\begin{array}{l}1,1,1 . \text { Trichloroethane } \\
1,1,2-\text { Trichloroethane } \\
1,1,2 \text {-Trichloroethane }\end{array}$ \\
\hline $\begin{array}{l}\mathrm{pH} \\
\mathrm{pH} \\
\text { Specific conductance } \\
\text { Specific conductance } \\
\text { Aluminum } \\
\text { Aluminum } \\
\text { Arsenic } \\
\text { Arsenic }\end{array}$ & $\begin{array}{r}6.2 \\
6.2 \\
30 \\
30 \\
21 \\
21 \\
<2.0 \\
<20\end{array}$ & JO & $\begin{array}{l}\mathrm{pH} \\
\mathrm{pH} \\
\mu \mathrm{S} / \mathrm{cm} \\
\mu \mathrm{S} / \mathrm{cm} \\
\mu \mathrm{g} / \mathrm{L} \\
\mu \mathrm{g} / \mathrm{L} \\
\mu \mathrm{c} / \mathrm{l}\end{array}$ & $\begin{array}{l}\mathrm{GE} \\
\mathrm{GE} \\
\mathrm{GE} \\
\mathrm{GE} \\
\mathrm{GE} \\
\mathrm{GE} \\
\mathrm{GE}\end{array}$ & $\begin{array}{ll}0 & \text { Trichloroethylene } \\
0 & \text { Trichlorofluoromethane } \\
0 & \text { Trichlorofluoromethane } \\
0 & \text { Uranium } \\
0 & \text { Uranium } \\
0 & \text { Zinc } \\
0 & \text { Zinc }\end{array}$ \\
\hline
\end{tabular}

Arsenic

Barium

Barium

Benzene

Bromodichloromethane

Bromodichloromethane

Bromoform

Bromoform

Bromomethane

Bromomethane

Cadmium

Cadmium

Carbon tetrachloride

Chloride

Chloride

Chloride

Chlorobenzene

Chloroethane

Chloroethane

Chloroethene Ninyl chloride

Chloroethene Ninyl chloride

2.Chloroethyl vinyl ether

2.Chloroethy

Chloroform

Chloromethane

Chloromethane

Chromium

Copper

Coppe

Cyanide
Cyanide
Time: 8:05

Alkalinity $12 \mathrm{mgl}$

Water temperatue $170^{\circ} \mathrm{C}$

Time: 12:00

\section{WELL MSB 12TB}

MEASUREMENTS CONDUCTED !N THE FIELD

Sample date: 10/09/91

Depth to water: $156.64 \mathrm{ft}(47.74 \mathrm{~m})$ below TOC Water elevation: $192.26 \mathrm{H}(58.60 \mathrm{~m}) \mathrm{msi}$ Water evacuated before sampling: $521 \mathrm{gal}$

Pesult Mod Unit Lab

$<1.0$
$<1.0$

$<1.0$

$<1.0$

$<1.0$

$<1.0$
5.0
5.0

5.0
$<1.0$

$<1.0$

$<1.0$
$<1.0$
$<1.0$
$<1.0$

$<1.0$

$<3.0$

$<0.20$

$<4.0$

$<50$

$<50$

$<5.0$

$<2.0$

$<2.0$

1,290
1,290
$<1,000$

$<1,000$

$<1,000$

$<1.0$
$<1.0$

$<1.0$

$<1.0$

$<1.0$

$<50$

$<1.0$

$<1.0$

$<1.0$

$<1.0$

$<20$

8.2

J2V
J2V

$\mu g / L \quad G E$

$G E$
$g, h$ G

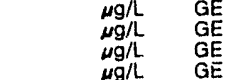

$\begin{array}{ll}\mu g / & G E \\ \mu g & G E \\ \mu g & G E \\ \mu g, h & G E\end{array}$

$\begin{array}{ll}\mu g / L & G E \\ \mu g / L & G E \\ \mu g / L & G E \\ g E & G / L\end{array}$

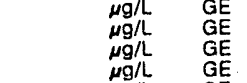

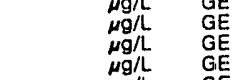

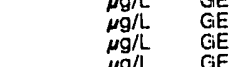

J1

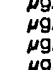

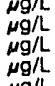

$\mu g / L \quad G E$

$\begin{array}{ll}\mu g / L & \mathrm{GE} \\ \mu \mathrm{g} / \mathrm{L} \\ \mu \mathrm{gE} / \mathrm{GE}\end{array}$

$\mu g, \quad G E$

LABORATORY ANALYSES

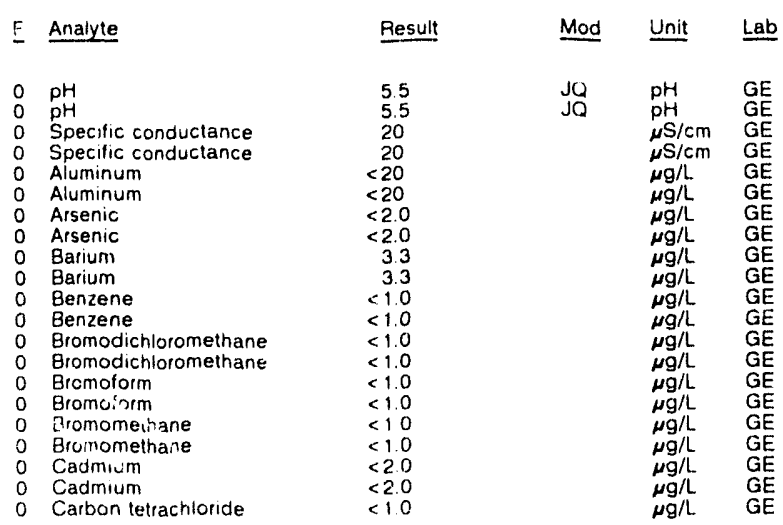

Time: 7:00

PH: 4.8

Water temperature: $150^{\circ} \mathrm{O}$
$G E$
$G E$
$G E$
$G E$
$G E$
$G E$
$G E$
$G E$
$G E$
$G E$
$G E$
$G E$
$G E$
$G E$
$G E$ 
ANALYTICAL RESULTS

WELL MSB 12TB collected on 10/09/91, laboratory analyses (r.ont)

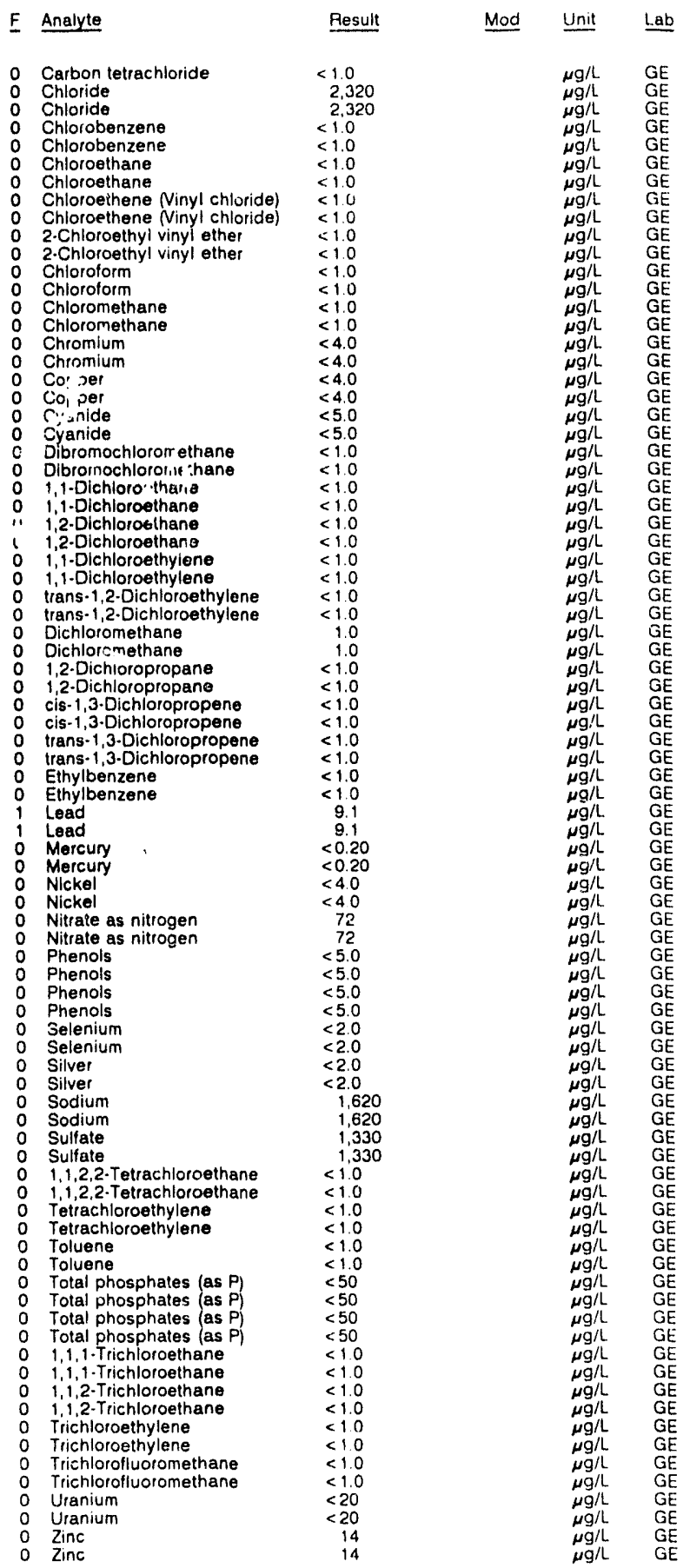

\section{WELL MSB 13A}

MEASUREMENTS CONDUCTEO IN THE FIELD

Sample date: $10 / 10 / 91$ H $(42.50 \mathrm{~m})$ below TOC Water elevation: $205.78 \mathrm{Ht}(62.72 \mathrm{~m}) \mathrm{ms}$

Sp. conductance: $21 \mu \mathrm{S} / \mathrm{cm}$ Water evacuated belore sampling $199 \mathrm{gal}$

LABORATOHY ANALYSES

E Analyte Pesult Mod Unit Lab

$\begin{array}{lll}0 & \mathrm{pH} \\ 0 & \text { Specific conductance }\end{array}$

0 Aluminum

0 Arsenic

O) Barium

Bromodichloromethane

Bromoform

Bromometh

Cadmium

Carbon tetrachloride

Chloride

Chlorobenzene

Chloroethane

2.Chloroethyl vinyl ethe

0 Chloromethane

Chromium

Copper

Cyanide

1,1-Dichloroethane

1,2-Dichloroethane

1,1 . Dichloroethylene
trans $1,2 \cdot$ Dichloroethylene

Dichloromethane

1,2.Dichloropropane
cis-1 3-Dichloropropen

cis-1,3-Dichloropropene

tra.ns-1,3-Dichl
Ethylbenzene

Lead

Mercury

Nickel

Phenols

Silver

Silver

Sodium

Suifate $1,1,2,2$-Tetrachloroethane

Tetrachloroethylene

Toluene

Total phosphates (as P)

1.1.1- Trichlorsethane

1,1,2-Trichloroethan

Trichloroethylene
Trichlorofluoromethane

Trichlorofluoromethane
Zinc
Uranium alpha activity

Uranium alpha activity
0 Uranium-233/234
0 Uranium-233/234

- Uranium-233/23

0 Uranium.238

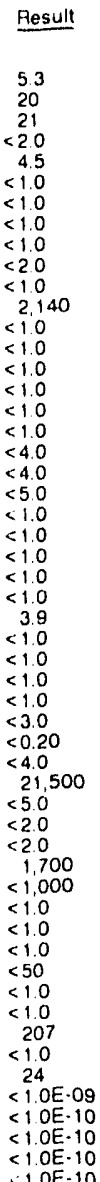

Time: $7: 05$

Alkalinity. $0 \mathrm{mg} / \mathrm{h}$

Water temperature: $19.6^{\circ} \mathrm{O}$

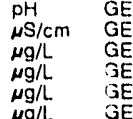

WELL MSB 13A Replicate

MEASUREMENTS CONDUCTED IN THE FIELD

Sample date $10 / 10 / 91$
Depth to water: $139.42 \mathrm{H}(42.50 \mathrm{~m})$ below TOC

Water elevation: $205.78 \mathrm{ft}(62.72 \mathrm{~m}) \mathrm{ms}$

Sp conductance: $21 \mu \mathrm{S} / \mathrm{cm}$

Water evacuated before sampling: $199 \mathrm{gal}$

LABORATORY ANALYSES

\begin{tabular}{|c|c|c|c|}
\hline Analyte & Result & Mod & Unit \\
\hline $\begin{array}{l}\text { pH } \\
\text { Specific conductance } \\
\text { Aluminum } \\
\text { Arsenic } \\
\text { Bariuin } \\
\text { Benzene } \\
\text { Bromodichloromethane } \\
\text { Bromoform } \\
\text { Bromomethane } \\
\text { Cadmium } \\
\text { Carbon tetrachloride } \\
\text { Chloride } \\
\text { Chiloobenzene } \\
\text { Chloroethane } \\
\text { Chloroethene Ninyl chloride; } \\
\text { 2. Chloroethyl vinyl ether } \\
\text { Chloroform }\end{array}$ & $\begin{aligned} & 5.3 \\
& 20 \\
&<20 \\
&<2.0 \\
& 4.5 \\
&<10 \\
&<1.0 \\
&<1.0 \\
&<1.0 \\
&<2.0 \\
&<10 \\
& 2.120 \\
&<10 \\
&<10 \\
&<10 \\
&<10 \\
&<10\end{aligned}$ & JO & $\begin{array}{l}\mathrm{pH} \\
\mu \mathrm{S} / \mathrm{cm} \\
\mu \mathrm{g} / \mathrm{L} \\
\mu \mathrm{g} / \mathrm{L} \\
\mu \mathrm{g} / \mathrm{L} \\
\mu \mathrm{g} / \mathrm{L} \\
\mu \mathrm{g} / \mathrm{L} \\
\mu \mathrm{g} / \mathrm{L} \\
\mu \mathrm{g} / \mathrm{L} \\
\mu \mathrm{g} / \mathrm{L} \\
\mu \mathrm{g} / \mathrm{L} \\
\mu \mathrm{g} / \mathrm{L} \\
\mu \mathrm{g} / \mathrm{L} \\
\mu \mathrm{g} / \mathrm{L} \\
\mu \mathrm{g} / \mathrm{L} \\
\mu \mathrm{g} / \mathrm{L} \\
\mu \mathrm{g} / \mathrm{L}\end{array}$ \\
\hline
\end{tabular}

Time 7.05

Alkalinity: $0 \mathrm{mg} /$

Water temper ature: $19.6^{\circ} \mathrm{C}$

ab

$G E$
$G E$
$G E$
$G E$
$G E$
$G E$
$G E$
$G E$
$G E$
$G E$
$G E$
$G E$
$G E$ 
ANALYTICAL RESULTS

WELL MSB 13A collected on 10/10/91, laboratory analyses (cont.)

\begin{tabular}{|c|c|c|c|}
\hline Analyte & Result & Mod & Unit \\
\hline $\begin{array}{l}\text { Chloromethane } \\
\text { Chromium } \\
\text { Copper } \\
\text { Cyanide } \\
\text { Oibromochloromethane } \\
1,1 \cdot \text { Dichloroethane } \\
1,2 \cdot \text { Dichloroethane } \\
1,1 \cdot \text { Dichloroethylene } \\
\text { trans-1,2.Dichloroethylene } \\
\text { Dichloromethane } \\
1,2-\text { Dichloropopane } \\
\text { cis-1,3-Dichloropropene } \\
\text { trans-1 3-Dichloropropene } \\
\text { Ethylbenzene } \\
\text { Lead } \\
\text { Mercury } \\
\text { Nickel } \\
\text { Nitrate as nitrogen } \\
\text { Phenols } \\
\text { Selenium } \\
\text { Silver } \\
\text { Sodium } \\
\text { Sulfate } \\
\text { 1,1,2.2. Tetrachloroethane } \\
\text { Tetrachloroethylene } \\
\text { Toluene } \\
\text { Total phosphates (as P) } \\
\text { 1,1,1.Trichloroethane } \\
\text { 1,1,2-Trichloroethane } \\
\text { Trichloroethylene } \\
\text { Trichlorofluoromethane } \\
\text { Zinc } \\
\text { Uranium alpha activity } \\
\text { Uranium-233/234 } \\
\text { Uranium-238 }\end{array}$ & $\begin{array}{l}<1.0 \\
<4.0 \\
<4.0 \\
<5.0 \\
<1.0 \\
<1.0 \\
<1.0 \\
<1.0 \\
<1.0 \\
1.6 \\
<1.0 \\
<1.0 \\
<1.0 \\
<1.0 \\
<3.0 \\
<0.20 \\
<40 \\
49,500 \\
<5.0 \\
<2.0 \\
<2.0 \\
11.690 \\
<1.000 \\
<1.0 \\
<1.0 \\
<1.0 \\
<50 \\
<1.0 \\
<1.0 \\
195 \\
<1.0 \\
24 \\
<1.0 E \cdot 09 \\
<1.0 E \cdot 10 \\
<10 E-10\end{array}$ & J2V & $\begin{array}{l}\mu g / L \\
\mu g / L \\
\mu g / L \\
\mu g / L \\
\mu g / L \\
\mu g / L \\
\mu g / L \\
\mu g / L \\
\mu g / L \\
\mu g / L \\
\mu g / L \\
\mu g / L \\
\mu g / L \\
\mu g / L \\
\mu g / L \\
\mu g / L \\
\mu g / L \\
\mu g / L \\
\mu g / L \\
\mu g / L \\
\mu g / L \\
\mu g / L \\
\mu g / L \\
\mu g / L \\
\mu g / L \\
\mu g / L \\
\mu g / L \\
\mu g / L \\
\mu g / L \\
\mu g / L \\
\mu g / L \\
\mu g / L \\
\mu C i / m L \\
\mu C i / m L \\
\mu C i / m L\end{array}$ \\
\hline
\end{tabular}

WELL MSB 13B

MEASUREMENTS CONDUCTEO IN THE FIELO

Sample date: $11 / 18 / 91$ (t) $14492 \mathrm{~m})$ below TOC

Water elevation: $19822 \mathrm{Ht} / 6042 \mathrm{~m}$
Sp conductance: $2242 \mu \mathrm{s} / \mathrm{cm}$

There was insutticient water to fill all or scme sample bottles.

LABORATOAY ANALYSES

\begin{tabular}{|c|c|c|c|c|c|}
\hline$F$ & Analyte & Fiesult & Mod & Unit & Lab \\
\hline 0 & 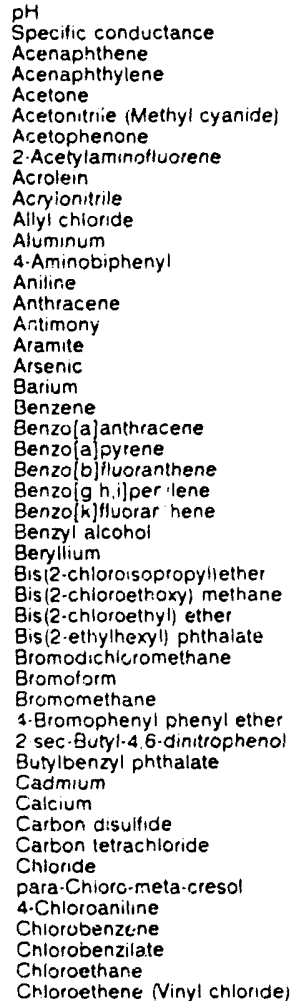 & 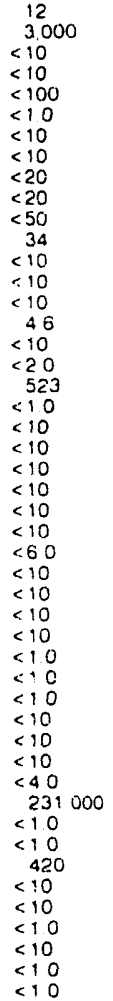 & JO & $\begin{array}{l}p H \\
\mu S / c m \\
\mu g / L \\
\mu g / L \\
\mu g / L \\
\mu g / L \\
\mu g / L \\
\mu g / L \\
\mu g / L \\
\mu g / L \\
\mu g / L \\
\mu g / L \\
\mu g / L \\
\mu g / L \\
\mu g / L \\
\mu g / L \\
\mu g / L \\
\mu g / L \\
\mu g / L \\
\mu g / L \\
\mu g / L \\
\mu g / L \\
\mu g / L \\
\mu g / L\end{array}$ & $\begin{array}{l}G E \\
G E \\
G E \\
G E \\
G E \\
G E \\
G E \\
G E \\
G E \\
G E \\
G E \\
G E \\
G E \\
G E \\
G E \\
G E \\
G E \\
G E \\
G E \\
G E \\
G E \\
G E \\
G E \\
G E \\
G E \\
G E \\
G E \\
G E \\
G E \\
G E \\
G E \\
G E \\
G E \\
G E \\
G E \\
G E \\
G E \\
G E \\
G E \\
G E \\
G E \\
G E \\
G E \\
G E \\
G E \\
G E \\
G E \\
G E\end{array}$ \\
\hline
\end{tabular}

WELL MSB 138 collected on 11/18/91, laboratory analyses (cont.)

E Analyte Result Mod Unit Lab

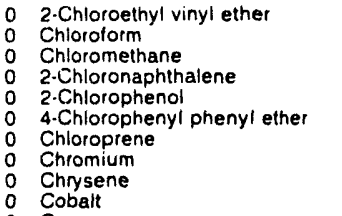

O-Ciesol (2-Methylphenol)

p-Cresol (4-Methylphenol)

P-Cresol

Di.n-butyl phthalate

Di.n.octyl

D Diallate

Dibenzofuran
1.2.Dibromo-3-chloropropa

1,2.Dibromo-3-chloropropar

1,2-Dibromoethane

Dibromomethane

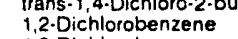

1.3. Dichloromzene

1,4-Dichlorobenzene

3,3'-Dichlorobenzidine

Dichlorodifluoromethan

1.1. Dichloroethane

1,1-Dichloroethylene

trans-1,2-Dichloroethylene

Dichloromethane

2,4.Dichiorophenol

1,2-Dichloropropane

cis-1,3-Dichloropropene

trans-1,3.Dichloropropene

Diethyl phthala

2,4-Dimethyl pheno

Dimethyl phthalate

p.Dimethylaminoazobenzene

3imethylbenzlajanthrace

a a-Dimethylphenethylamine

o a-Dimethylpheriethy

2,4-Dinitrophenol

2,4-Uinitrotoluene

1,4-Dioxane

Diphenylamine

$\begin{array}{ll}0 \text { Disulfoton } & <10 \\ 0 & <10\end{array}$

E.thyl methanesulfonate

Ethylbenzene

Famphur

Fivoranthen

Fluorene

Hexachlorobenzene

Hexachlobenzene

Hexachlorocyclopentadiene $<10$

Hexachloroethane $\quad<10$

Hexacnlotophene

Hexachloropiopene

2.Hexanone

indenol $1,2,3 \cdot 5$ djpyrene $<1.0$

lodomethane (Methyl iodide)

0 Iron

0 isobutyi alcohot

0 Isodrin

- Isophorone

0 Isosafrole

0 Kepone

$\begin{array}{ll}2 & \text { Lead } \\ 0 & \text { Magnesium } \\ & \text { Manganese }\end{array}$

Manganes

Methacrylonitrile

Methapyritene
Methyl ethyl ketone

Methyl isobutyl keton

Methyl methacrylate

Methyl methanesulfonare

2.Methyl.4,6-dinitrophen

3.Mechylcholanthrene

2.Methylnaphthalene

N.Nitrosodimethylamine

N.Nitrosodi-n-butylamine

N-Nitrosodipnenylamine

N-Nitrosodi-propylamine

N.Nittosometry'sth, lamina

N.Nitrosomur oline

N-Nitrosopiperidine

o N.N osopyrrolidine

$<10$

$\mu g / L \quad G E$

$<10$
$<10$

$<10$

$<10$
$<200$

$<10$
$<8.0$
16

$<10$
$<10$

$<5.0$

$<10$
$<10$

$<10$
$<10$

$<1.0$

$<1.0$

10

$<10$
$<10$

14

$<1.0$

$<1.0$
6.8

$<10$

$<1.0$

$<1.0$

$<10$

$<10$

$<10$
$<10$

$<10$
$<45$

$<10$

10

$<10$
$<1.0$

$<10$

$<10$
$<10$
139

$<10$
$<10$

$<15$
$<80$

$<8.0$
$<100$

$<10$
$<10$

$<10$
$<10$
87

87
27
$<4.0$

$<4.0$
$<0.20$
$<50$

$<50$
$<10$

$<1.0$
2.5

$<10$

$<10$

$<10$
$<10$

$<10$
$<10$

$<10$

$<10$

$<>0$
$<10$
$<10$

$<10$
$<10$

$<10$

$<10$
$<10$ 
ANALYTICAL RESULTS

WELL MSB 13B collected on 11/18/91, laboratory analyses (cont.)

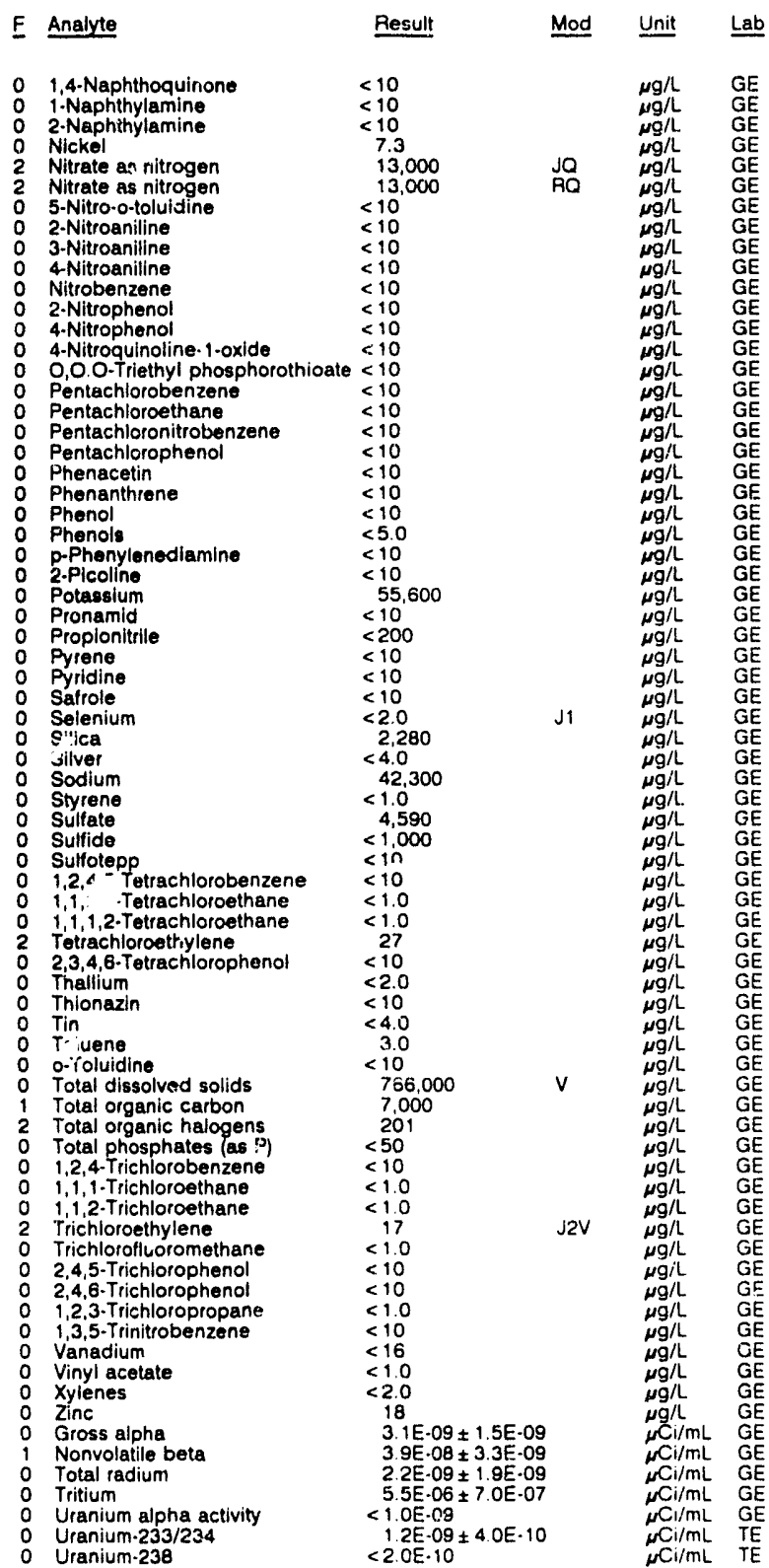

WELL MSB 13CC

MEASUREMENTS CONDUCTED IN THE FIELO

\begin{tabular}{|c|c|c|c|c|}
\hline \multicolumn{2}{|c|}{$\begin{array}{l}\text { Sample date: } 10 / 10 / 91 \\
\text { Depth to water: } 124.31 \mathrm{H}(37.89 \mathrm{~m}) \text { below TOC } \\
\text { Water elevation: } 222.59 \mathrm{ft}(67.85 \mathrm{~m}) \mathrm{ms} \\
\text { Sp. conductance: } 171 \text { \% } / \mathrm{cm} \\
\text { Water evacuated before sampling: } 16 \mathrm{gal} \\
\text { The well went dry during purging. }\end{array}$} & \multicolumn{3}{|c|}{$\begin{array}{l}\text { Time } 7.25 \\
\text { pH. } 54 \\
\text { Alkalinity } 6 \mathrm{mg} / \mathrm{L} \\
\text { Water temperature } 18.3^{\circ} \mathrm{C}\end{array}$} \\
\hline \multicolumn{5}{|l|}{ LABOAATORY ANALYSES } \\
\hline Analyte & Fesult & Mod & Unit & Lau \\
\hline $\begin{array}{l}\text { pH } \\
\text { Specific conductance } \\
\text { Aluminum } \\
\text { Arsenic } \\
\text { Barium } \\
\text { Benzene } \\
\text { Bromodichloromethane } \\
\text { Bromoform } \\
\text { Bromomethane } \\
\text { Cadmium }\end{array}$ & $\begin{array}{rl} & 5.7 \\
170 \\
<20 \\
<20 \\
3 & 20 \\
< & 10 \\
< & 10 \\
< & 10 \\
< & 10 \\
< & 20\end{array}$ & Jo & $\begin{array}{l}p H \\
\mu \mathrm{S} / \mathrm{cm} \\
\mu \mathrm{g} / \mathrm{h} \\
\mu \mathrm{g} / \mathrm{L} \\
\mu \mathrm{g} / \mathrm{h} \\
\mu \mathrm{g} / \mathrm{h} \\
\mu \mathrm{g} / \mathrm{h} \\
\mu \mathrm{g} / \mathrm{h} \\
\mu \mathrm{g} / \mathrm{h} \\
\mu \mathrm{g} / \mathrm{L}\end{array}$ & $\begin{array}{l}\mathrm{GE} \\
\mathrm{GE} \\
\mathrm{GE} \\
\mathrm{GE} \\
\mathrm{GE} \\
\mathrm{GE} \\
\mathrm{GE} \\
\mathrm{GE} \\
\mathrm{GE} \\
\mathrm{GE}\end{array}$ \\
\hline
\end{tabular}

WELL MSB 13CC collected on 10/10/91, laboratory analyses (cont.)

E Analyte Result Mod Unit Lab
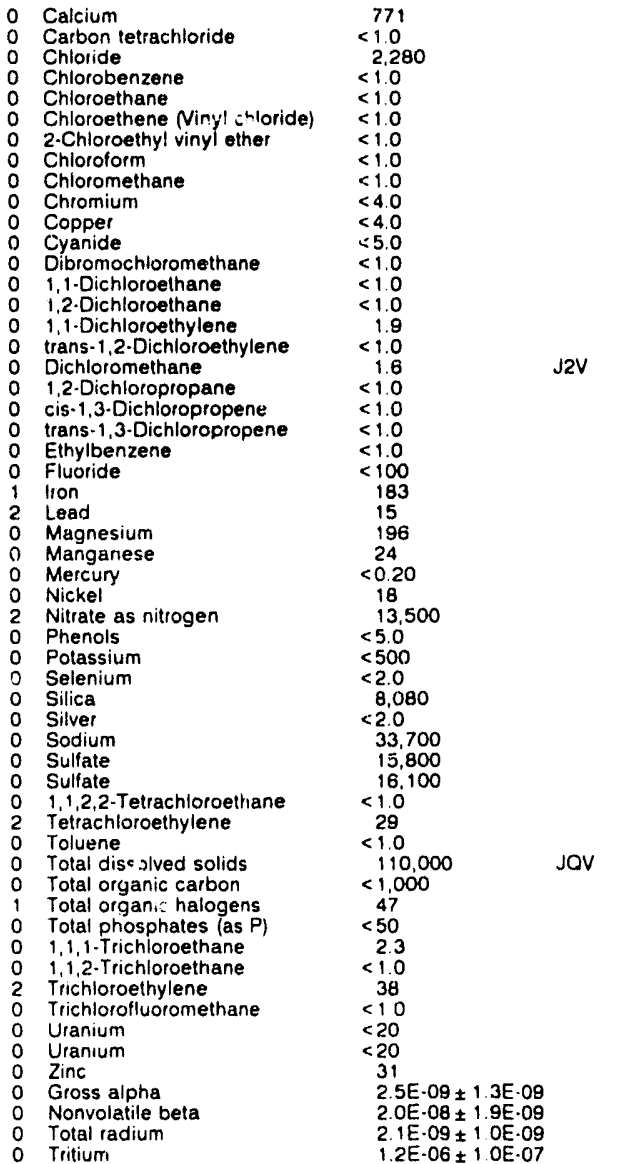

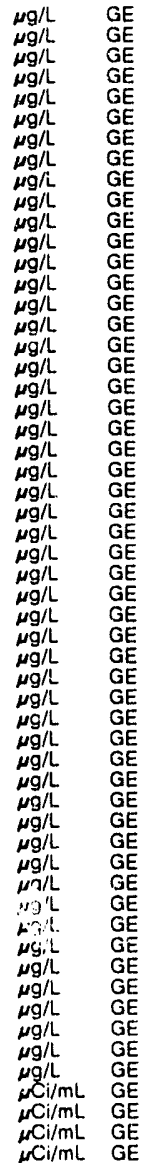

WELL MSB 130

MEASUREMENTS CONDUCTED IN THE FIELD

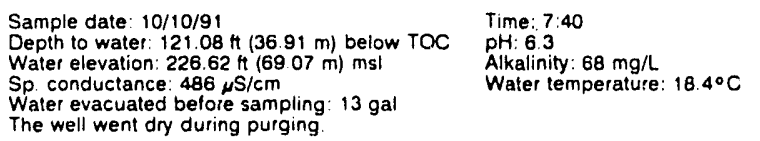

The well went dry during purging

LABORATORY ANALYSES

\begin{tabular}{|c|c|c|c|}
\hline Analyle & Result & Mod & Unit \\
\hline $\begin{array}{l}\text { pH } \\
\text { Specific conductance } \\
\text { Aluminum } \\
\text { Arsenic } \\
\text { Barium } \\
\text { Benzene } \\
\text { Bromodichloromethane } \\
\text { Bromoform } \\
\text { Bromomethane } \\
\text { Cadmium } \\
\text { Calcium } \\
\text { Carbon tetrachloride } \\
\text { Chloride } \\
\text { Chlorobenzene } \\
\text { Chloroethane } \\
\text { Chloroethene Ninyl chloride) } \\
\text { 2.Chloroethyl vinyl ether } \\
\text { Chloroform } \\
\text { Chloromethane } \\
\text { Chromium } \\
\text { Copper } \\
\text { Cyanide } \\
\text { Dibromochloromethane } \\
\text { 1.1.Dichloroethane } \\
\text { 1.2.Dichloroethane } \\
\text { 1. 1. Dichloroethylene } \\
\text { trans-1.2.Dichloroethylene }\end{array}$ & 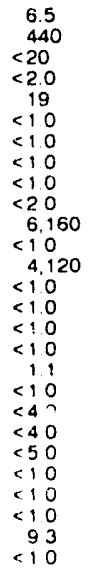 & $J Q$ & $\begin{array}{l}p H \\
\mu S / c m \\
\mu g / L \\
\mu g / L \\
\mu g / L \\
\mu g / L \\
\mu g / L \\
\mu g / L \\
\mu g / L \\
\mu g / L \\
\mu g / L \\
\mu g / L \\
\mu g / L \\
\mu g / L \\
\mu g / L \\
\mu g / L \\
\mu g / L \\
\mu g / L \\
\mu g / L \\
\mu g / L \\
\mu g / L \\
\mu g / L \\
\mu g / L \\
\mu g / L \\
\mu g / L \\
\mu g / L \\
\mu g / L\end{array}$ \\
\hline
\end{tabular}


ANALYTICAL RESULTS

WELL MSB ISD collected on 10/10/91, laboratory analyses (cont)

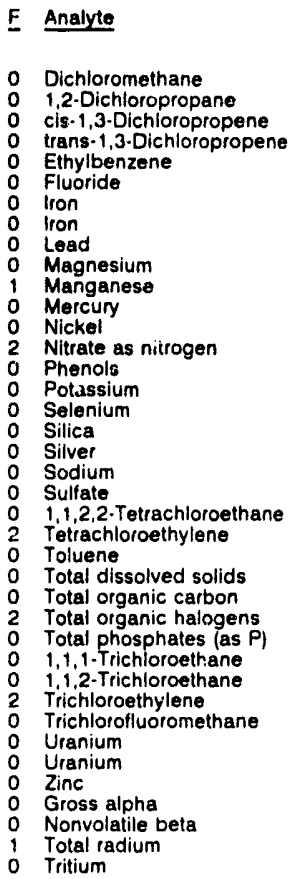

Result

1.8
$<1.0$
$<1.0$
$<1.0$
$<1.0$
$<100$
123
123
$<3.0$
998
34
$<0.20$
31
41,500
$<5.0$
3,730
$<2.0$
9,000
$<2.0$
79,900
9,600
$<1.0$
42
$<1.0$
302,000
2.000
58
1.230
11
$<1.0$
31
$<1.0$
$<20$
$<20$
90
$2.1 \mathrm{E} \cdot 09 \pm 1.4 \mathrm{E} \cdot 09$
$1.9 \mathrm{E} \cdot 08 \pm 1.9 \mathrm{E} \cdot 09$
$4.0 \mathrm{E} \cdot 09 \pm 1.3 \mathrm{E} \cdot 09$
$<7.0 \mathrm{E} \cdot 07$

WELL MSB 14A collected on 1/21/91, laboratory analyses (cont.)
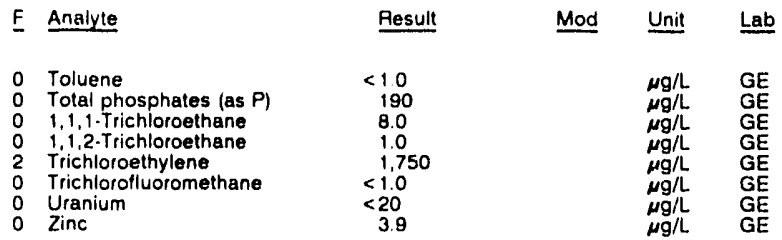

WELL MSB 14B

MEASUREMENTS CONDUCTED IN THE FIELD

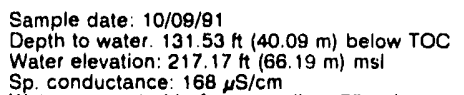

Time: 9:55

PH: 4.9

Water elevation: $217.17 \mathrm{ft}(66.19 \mathrm{~m}) \mathrm{msl}$ Sp. Conductance: $168 \mu \mathrm{s} / \mathrm{cm}$
Water evacuated before sampling: $75 \mathrm{gal}$

LABORATORY ANALYSES

E Analyte Besult Mod Unit Lab

$\begin{array}{ll}0 & \mathrm{pH} \\ 0 & \text { Specific conductance }\end{array}$

Aluminum

Arsenic

Barium

Bromodichloromethane

Bromolorm

Bromomethan

Cadmium

Carbon tetrachloride

Chloride

Chlorobenzen

Chloroethene (Vinyl chloride)

2.Chloroethyl vinyl ether
Chloroform

Chloromethane

Chromiun

Copper

Cyanide

Dibromochloromethan

1,1-Dichloroethane

1.1.Dichloroethylene

trans-1,2-Dichloroethylene

Dichloromethane

1,2-Dichloropropane

trans-1,3-Dichloropropene

Ethylbenzene

Lead

Mercury

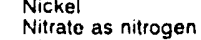

Nitrate as nitrogen

Phenols

Selenium

Silver

Sodium

1,1,2,2-Tetrachloroethane

Tetrachloroethylene

Toluene
Total phosphates (as

1.1.1. Trichloroethane

1.1,2. Trichloroethan

Trichloroethylene

Trichlorofluoromethane

Uranium

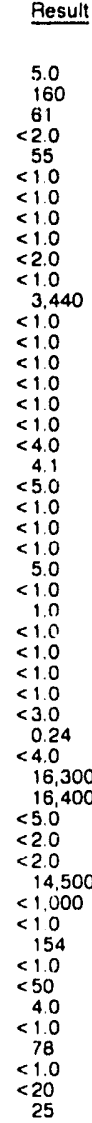

WELL MSB $14 C$

MEASUREMENTS CONDUCTED IN THE FIELD

Sampie date 10/09/91

Time: 10.00

Copper

Dibromochloromethane

1.2-Dichloroethane

1,1-Dichloroethylene

Dichloromethane

1,2-Dichloropropane

trans-1,3-Dichloropropen

Ethylbenzene

Lead

Mercury

Nickel

Nickate as nitrogen

Phenols

Selenium

Sodium

Sulfate

1,1,2.2. Tetrachloroethane

Tetrachloroethylene 


\section{ANALYTICAL RESULTS}

\section{WELL MSB 15A}

MEASUREMENTS CONDUCTED IN THE FIELD

Sample date: 12/10/91

Depth to water: $147.68 \mathrm{ft}(45.01 \mathrm{~m})$ belok TOC Weter elovation: $219.51 \mathrm{ft}(38.82 \mathrm{~m}) \mathrm{ms}$

Sp. conductance: $115 \mathrm{~s} / \mathrm{cm}$

No water was evacuated before sampling.

LABORATORY ANALYSES

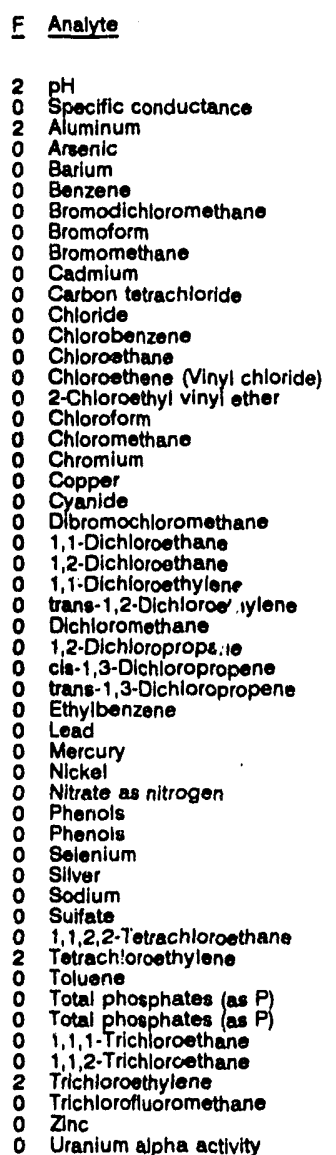

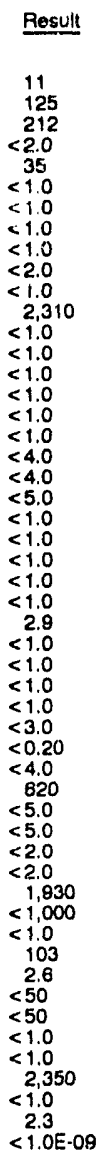

WELL MSB 15AA

MEASUREMENTS CONDUCTED IN THE FIELD

Sample date: 10/09/81

Dopth to water: $158.03 \mathrm{ft}(47.56 \mathrm{~m})$ below TOC Water elevation: $213.47 \mathrm{ft}(65.07 \mathrm{~m}) \mathrm{msl}$

Sp. conductance: $28 \mathrm{~s} / \mathrm{cm}$

Water evacuated before sampling: $186 \mathrm{gal}$

LABORATORY ANALYSES

\begin{tabular}{|c|c|c|c|c|}
\hline E & Analyte & Result & Mod & Unit \\
\hline $\begin{array}{l}0 \\
0 \\
0 \\
2 \\
0\end{array}$ & $\begin{array}{l}\text { Chloroform } \\
1,1-\text { Dichloroethylene } \\
\text { trans-1,2-Dichloroethylene } \\
\text { Totrachloroethylene } \\
1,1,1 \text {-Trichloroethane } \\
\text { Trichloroethylene }\end{array}$ & $\begin{array}{l}<2.0 \\
<2.0 \\
<2.0 \\
11 \\
<2.0 \\
116\end{array}$ & & $\begin{array}{l}\mu g / L \\
\mu g / L \\
\mu g / L \\
\mu g / L \\
\mu g / L \\
\mu g / L\end{array}$ \\
\hline
\end{tabular}

Tline: $16: 00$

Alkalinity: $24 \mathrm{mg} / \mathrm{L}$

Water temperature: $17.9^{\circ} \mathrm{C}$

jo

J2V

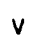

v
Time: $9: 30$
$\mathrm{pH}: 5.8$

Alkalinity: $15 \mathrm{mg} / \mathrm{L}$

Water temperature: $17.4^{\circ} \mathrm{C}$

WELL MSB 15C

MEASUREMENTS CONDUCTED IN THE FIELD

Sample date: $12 / 06 / 91$

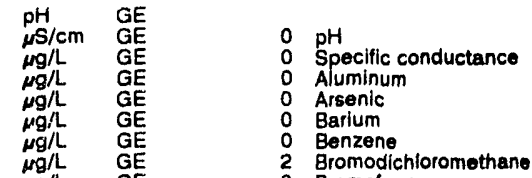

Bromodich

Bromomethan

Cadmium

Carbon tetrachloride

Chloride

Chlorobenzeno

Chloroethene Ninyl chloride

2-Chloroethyl vinyl ether

Chloroform

Chloromethane

Chromium

Copper

Dibromochloromethane

1,1-Dichloroethane

1,2-Dichloroethane

trans-1,2-Dichloroethylene

Dichloromethane

1,2-Dichloropropane

trans-1,3-Dichloropropene

Ethylbenzene

Lead

Me'zury
Nickel

Nitrate as nitrogen

Phenols

0 Selenium

Sodium

1,1,2,2-Tetrachloroethane

Tetrachloroethylene

Toluene

i. i, Trichlorothan

Trichloroethylene

Trichlorofluoromethane

Uranium alpha activity

WELL MSB 15D

MEASUREMENTS CONDUCTED IN THE FIELD

Sample date: 12/08/81

Depth to water: $137.81 \mathrm{ft}(42.04 \mathrm{~m})$ below TOC

Water elevation: 230.89 h $(70.38 \mathrm{~m}) \mathrm{msl}$

Sp. conductance: $30 \mu \mathrm{S} / \mathrm{cm}$

Water evacuated before sampling: $3 \mathrm{gal}$

The well went dry during purging

LABORATORY ANALYSES

$\begin{array}{llll}\text { E Analyte } & \text { Result } & \text { Mod Unit } & \\ & & & \\ 0 & \text { Chloroform } & <250 & \\ 0 & \text { Chloroform } & 250 & \end{array}$

Time: 13:10

Alkalinity: 4 man

Water tempereture: $17.3{ }^{\circ} \mathrm{C}$

Result Mod Unk Lab

6.4

D PH GE

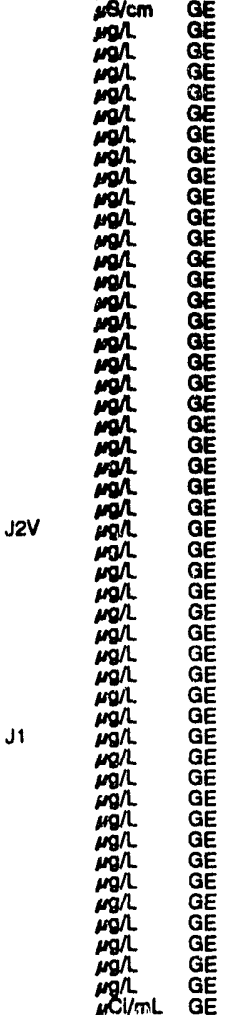

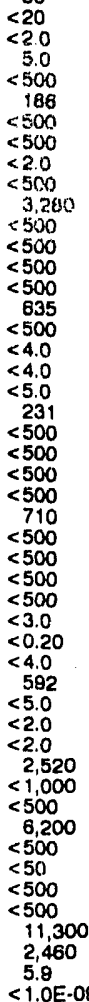


ANALYTICAL RESULTS

WELL MSB 16A

MEASUREMENTS CONDUCTED IN THE FIELD

Sample date: $11 / 18 / 91$

Depth to water: $148.69 \mathrm{ft}(45.32 \mathrm{~m})$ below TOC Sp conductance 34 S $/ \mathrm{cm}$ Water evacuated before sampling: $186 \mathrm{gal}$

LABORATORY ANALYSES

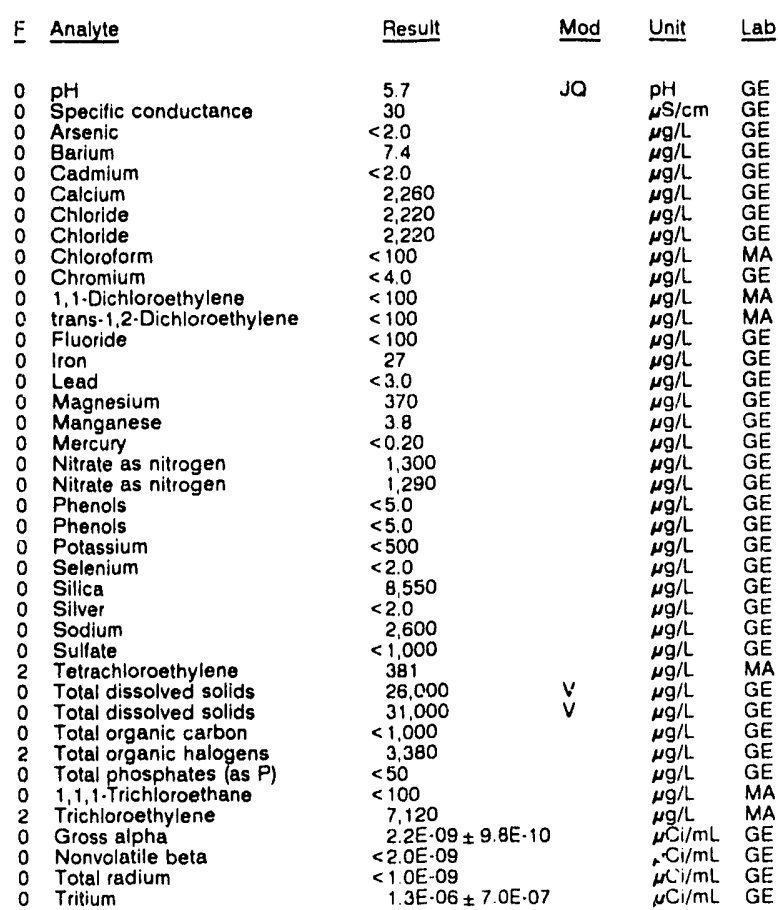

WELL MSB $16 C$

MEASUREMENTS CONDUCTED IN THE FIELD

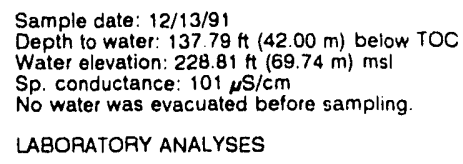

\begin{tabular}{|c|c|c|c|c|c|}
\hline E. & Analyte & Resuit & Mod & Unit & $\underline{\text { Lab }}$ \\
\hline 0 & $\mathrm{pH}$ & 7.0 & JO & $\rho \mathrm{H}$ & GE \\
\hline 0 & Specific conductance & 145 & & $\mu \mathrm{S} / \mathrm{cm}$ & GE \\
\hline $\begin{array}{l}0 \\
0\end{array}$ & $\begin{array}{l}\text { Aisenic } \\
\text { Barium }\end{array}$ & $<2.0$ & & $\mu \mathrm{g} / \mathrm{L}$ & $\begin{array}{l}\mathrm{GE} \\
\mathrm{GE}\end{array}$ \\
\hline 0 & $\begin{array}{l}\text { Garium } \\
\text { Cadmium }\end{array}$ & $\begin{array}{r}16 \\
<2.0\end{array}$ & & $\begin{array}{l}\mu g / L \\
\mu g / L\end{array}$ & GE \\
\hline 0 & Calcium & 7,110 & & $\mu \mathrm{g} / \mathrm{L}$ & $\mathrm{GE}$ \\
\hline $\begin{array}{l}0 \\
0\end{array}$ & Chloride & $\begin{array}{r}3,010 \\
50\end{array}$ & & $\mu g / L$ & GE \\
\hline 0 & $\begin{array}{l}\text { Chlorotorm } \\
\text { Chromium }\end{array}$ & $\begin{array}{l}<5.0 \\
<4.0\end{array}$ & & $\mu g / L$ & GE \\
\hline 0 & 1,1.Dichloroethylene & $<5.0$ & & $\mu \mathrm{g} / \mathrm{L}$ & MA \\
\hline 0 & trans-1,2-Dichloroethylene & $<5.0$ & & $\mu g / L$ & MA \\
\hline 0 & $\begin{array}{l}\text { Fluoride } \\
\text { Iron }\end{array}$ & $<100$ & & $\mu g / L$ & $\begin{array}{l}\mathrm{GE} \\
\mathrm{GE}\end{array}$ \\
\hline 0 & $\begin{array}{l}\text { lron } \\
\text { Lead }\end{array}$ & 124 & & $\mu \mathrm{g} / \mathrm{h}$ & GE \\
\hline $\begin{array}{l}0 \\
0\end{array}$ & $\begin{array}{l}\text { Lead } \\
\text { Magnesium }\end{array}$ & $\begin{array}{r}<3.0 \\
67\end{array}$ & & $\mu g / L$ & $\mathrm{GE}$ \\
\hline 0 & Manganese & 11 & & $\mu g / L$ & \\
\hline 0 & Mercury & $<0.20$ & & $\mu \mathrm{g} / \mathrm{L}$ & \\
\hline 0 & Nitrate as nitrogen & 370 & & $\mu \mathrm{g} / \mathrm{L}$ & \\
\hline 0 & Fhenols & $<5.0$ & & $\mu \mathrm{g} / \mathrm{L}$ & \\
\hline 0 & $\begin{array}{l}\text { Potassium } \\
\text { Selenium }\end{array}$ & 11,700 & & $\mu g / L$ & \\
\hline $\begin{array}{l}0 \\
0\end{array}$ & $\begin{array}{l}\text { Selenium } \\
\text { Silica }\end{array}$ & $\begin{array}{l}<2.0 \\
3.180\end{array}$ & J1 & $\begin{array}{l}\mu g / L \\
\mu g / L\end{array}$ & $G E$ \\
\hline 0 & Silver & $<2.0$ & & $\mu \mathrm{g} / \mathrm{L}$ & $\mathrm{GE}$ \\
\hline 0 & Sodium & 5,240 & & $\mu g / \mathrm{L}$ & \\
\hline $\begin{array}{l}0 \\
2\end{array}$ & $\begin{array}{l}\text { Sulfate } \\
\text { Tetrachloroethylene }\end{array}$ & $\begin{array}{l}3,500 \\
194\end{array}$ & & $\begin{array}{l}\mu \mathrm{g} / \mathrm{L} \\
\mu \mathrm{g} / \mathrm{L}\end{array}$ & $\begin{array}{l}\mathrm{GE} \\
\mathrm{MA}\end{array}$ \\
\hline 0 & Total dissolved solids & 92.000 & & $\mu g / L$ & \\
\hline 0 & Total organic carbon & 3.000 & & $\mu g / \mathrm{h}$ & \\
\hline 2 & Total organic halogens & 3.110 & Jo & $\mu g / \mathrm{L}$ & $\mathrm{E}$ \\
\hline 0 & Total phosphates (as P) & 7.100 & & $\mu g / \mathrm{L}$ & \\
\hline & 1,1,1-Trichloroethane & $<50$ & & $\mu g / L$ & MA \\
\hline
\end{tabular}

WELL MSB 16C collected on 12/13/91, laboratory analyses (cont.)

\begin{tabular}{|c|c|c|}
\hline F Analyte & Result & Unit \\
\hline $\begin{array}{ll}2 & \text { Trichloroethylene } \\
2 & \text { Gross alpha } \\
0 & \text { Nonvolatile beta } \\
0 & \text { Total activity } \\
2 & \text { Total radium } \\
0 & \text { Tritium }\end{array}$ & $\begin{array}{l}46 /, \\
1.6 \mathrm{E} \cdot 08 \pm 2.8 \mathrm{E} \cdot 09 \\
1.8 \mathrm{E} \cdot 08 \pm 2.8 \mathrm{E} \cdot 09 \\
2.0 \mathrm{E} \cdot 06 \pm 1.4 \mathrm{E} \cdot 06 \\
2.0 \mathrm{E} \cdot 08 \pm 2.4 \mathrm{E} \cdot 09 \\
4.1 \mathrm{E} \cdot 06 \pm 7.0 \mathrm{E} \cdot 07\end{array}$ & $\begin{array}{l}\mu g / \mathrm{L} \\
\mu \mathrm{Ci} / \mathrm{mL} \\
\mu \mathrm{Ci} / \mathrm{mL} \\
\mu \mathrm{Ci} / \mathrm{mL} \\
\mu \mathrm{Ci} / \mathrm{mL} \\
\mu \mathrm{Ci} / \mathrm{mL}\end{array}$ \\
\hline
\end{tabular}

\section{WELL MSB 17A}

MEASUREMENTS CONDUCTED IN THE FIELD

Sample date: 10/09/91 Water elevation: $213.64 \mathrm{ft}(65.12 \mathrm{ni}) \mathrm{ms}$ |

Sp. conductance: $184 \mu \mathrm{S} / \mathrm{cm}$

Water evacuated betore sampling: $155 \mathrm{gat}$

LABORATORY ANALYSES

E Analyte Result Mod Unit Lab

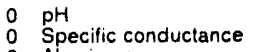

0 Aluminum

$\begin{array}{ll}0 & \text { Arsenic } \\ 0 & \text { Barium } \\ 0 & \text { Benzen }\end{array}$

Barium

Bromodichloromethane

Bromodich

Bromomethane

Cadmium

Carbon tetrachloride

Chloride

Chlorobenzene

Chloroethane

Chloroethene Ninyl chloride

2.Chloroethyl vinyl ether

Chloromethane

Chromium

Copper

Cyanide

o Dibromochloromethane

o 1,1-Dichloroethane

o 1,2-Dichloroethane

o 1,1-Dichloroethylene

Dichloromethane

1,2-Dichloropropane
0 cis-1.3.Dichloropropen

0 cis-1,3.Dichloropropene
0 trans-1,3-Dichloropropene

Ethyibenzene

0 Mercury

2 Nitrate as nitrogen

O Phenols

0 Selenium

Silver

0 Sodium

0 Sulfate

Tetrachloroethylene

0 Toluene

0 Total phosphates (as P)

0 1,1,1.Trichloroethane

1,1.2.Trichloroethan

2 Trichloroethylene

Trichlorofluoromethane

O Uranium

0 Zinc

Time: $11: 15$

Alkalinity: $0 \mathrm{mg} / \mathrm{L}$ Water temperature: $17.6^{\circ} \mathrm{C}$

WELL MSB 17B

MEASUREMENTS CONDUCTED IN THE FIELD

Sample date. 11/18/91

Depth to water $13456 \mathrm{H}(4101 \mathrm{~m})$ below TOC Water elevation $223.34 \mathrm{H}(68.07 \mathrm{mi}) \mathrm{msl}$

Sp. conductance $121 \mu \mathrm{S} / \mathrm{cm}$
Water evacuated before sampling $101 \mathrm{gat}$

4.9

66
$<2.0$

38
$<1.0$

$<1.0$

$<2.0$
$<1.0$

4.620

$<1.0$

$<1.0$
$<1.0$

$<1.0$
$<1.0$

$<40$

$<5.0$

$<1.0$

$<10$
13

$<1.0$
60

$<10$

$<1.0$
$<1.0$

$<1.0$

$<1.0$
3.3
0.33

4.0
17,900

$<5.0$
$<20$

$<2.0$
17.900

1.290
$<1.0$
110

$<1.0$
$<110$

$<1.0$
$<50$

10
10
$<10$

5.0

$<20$

$<20$
14

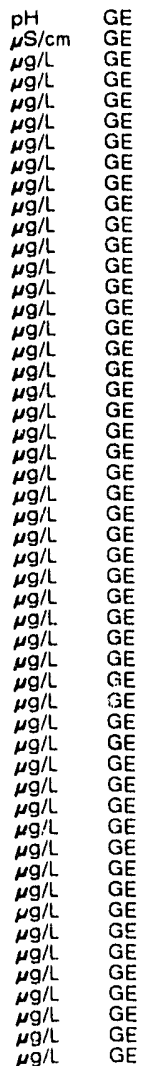

LABORATORY ANALYSES

\begin{tabular}{|c|c|c|c|}
\hline Analyte & Result & Mod & Unit \\
\hline $\begin{array}{l}\text { pH } \\
\text { Specific conductance } \\
\text { Aluminum } \\
\text { Arsenic } \\
\text { Barium } \\
\text { Benzene } \\
\text { Bromodichloromethane } \\
\text { Bromolorm } \\
\text { Bromomethane }\end{array}$ & $\begin{aligned} & 50 \\
& 110 \\
& 106 \\
&< 20 \\
& 14 \\
&< 10 \\
&< 10 \\
&< 10 \\
&< 10\end{aligned}$ & $\begin{array}{l}\text { JO } \\
\text { JQ } \\
\text { JQ } \\
\text { JO }\end{array}$ & $\begin{array}{l}\mathrm{pH} \\
\mu \mathrm{S} / \mathrm{cm} \\
\mu \mathrm{g} / \mathrm{L} \\
\mu \mathrm{g} / \mathrm{L} \\
\mu \mathrm{g} / \mathrm{L} \\
\mu \mathrm{g} / \mathrm{L} \\
\mu g / \mathrm{L} \\
\mu g / \mathrm{L} \\
\mu \mathrm{g} / \mathrm{L}\end{array}$ \\
\hline
\end{tabular}

Time 1115

Alkalinity $19 \mathrm{mg} / \mathrm{L}$

Water 
ANALYTICAL RESULTS

WELL MS8 178 collected on 11/18/91, laboratory analyses (cont)

\begin{tabular}{|c|c|}
\hline Analyte & Result \\
\hline $\begin{array}{l}\text { Cadmium } \\
\text { Carbon tetrachloride } \\
\text { Chloride } \\
\text { Chloride } \\
\text { Chlorobenzene } \\
\text { Chloroethare } \\
\text { Chloroethene Ninyl chloride) } \\
\text { 2.Chloroethyl vinyl ether } \\
\text { Chloroform } \\
\text { Chloromethane } \\
\text { Chromium } \\
\text { Copper } \\
\text { Cyanide } \\
\text { Dibromochloromethane } \\
1,1 \cdot \text { Dichloroethane } \\
1,2 \cdot \text { Dichloroethane } \\
1,1 \cdot \text { Dichloroethylene } \\
\text { trans-1,2-Dichloroethylene } \\
\text { Dichloromethane } \\
1,2 \cdot \text { Dichloropropane } \\
\text { cis-1,3-Dichloropropene } \\
\text { trans-1,3-Dichioropropene } \\
\text { Ethylbenzene } \\
\text { Lead } \\
\text { Mercury } \\
\text { Nickel } \\
\text { Nitrate as nitrogen } \\
\text { Phenols } \\
\text { Selenium } \\
\text { Silver } \\
\text { Sodium } \\
\text { Sulfate } \\
1,1,2,2-\text { Tetrachloroethane } \\
\text { Tetrachloroethylene } \\
\text { Toluene } \\
\text { Total phosphates (as P) } \\
1,1,1 \cdot \text { Trichloroethane } \\
1,1,2-\text { Trichloroethane } \\
\text { Trichloroethylene } \\
\text { Trichlorofluoromethane } \\
\text { Uranium } \\
\text { Zirc }\end{array}$ & $\begin{aligned}<2.0 \\
<1.0 \\
4,100 \\
4,100 \\
<1.0 \\
<1.0 \\
<1.0 \\
<1.0 \\
<1.0 \\
<1.0 \\
<4.0 \\
7.4 \\
<5.0 \\
<1.0 \\
<1.0 \\
<1.0 \\
<1.0 \\
<1.0 \\
240 \\
<1.0 \\
<1.0 \\
<1.0 \\
<1.0 \\
16 \\
<0.20 \\
7.0 \\
14.200 \\
<5.0 \\
2.1 \\
<20 \\
14.600 \\
<1.000 \\
<1.0 \\
1.200 \\
<1.0 \\
<50 \\
<1.0 \\
<1.0 \\
4.800 \\
<1.0 \\
<20 \\
14\end{aligned}$ \\
\hline
\end{tabular}

WELL MSB 17BB

MEASUREMENTS CONDUCTED IN THE FIELD

Sample date: $11 / 18 / 81$
Depth to water: $145.86 \mathrm{Ht}(44.46 \mathrm{~m})$ below TOC Water elevation: $213.44 \mathrm{ft}(65.06$
Sp conductance: $115 \mu \mathrm{S} / \mathrm{cm}$

Sp. conductance: $115 \mu \mathrm{\mu} / \mathrm{cm}$
Water evacuated before sampling: $211 \mathrm{gal}$

LABORATORY ANALYSES

\begin{tabular}{|c|c|c|c|}
\hline Analyte & fiesult & Mod & Unit \\
\hline $\begin{array}{l}\text { Chloroform } \\
1,1 \cdot \text { Dichloroethylene } \\
\text { trans. } 1,2 \cdot \text { Dichloroethylene } \\
\text { Tetrachloroethylene } \\
1,1.1 \text {. Trichloroethane } \\
\text { richloroethylene }\end{array}$ & $\begin{array}{l}<20 \\
<20 \\
<20 \\
288 \\
<20 \\
1.250\end{array}$ & & $\begin{array}{l}\mu \mathrm{g} / \mathrm{L} \\
\mu \mathrm{g} / \mathrm{L} \\
\mu \mathrm{g} / \mathrm{L} \\
\mu \mathrm{g} / \mathrm{L} \\
\mu \mathrm{g} / \mathrm{L} \\
\mu \mathrm{g} / \mathrm{L}\end{array}$ \\
\hline
\end{tabular}

WELL MSB 17C

MEASUREMENTS CONDUCTED IN THE FIELD

Sample date: 10/09/91

The well was $d r$

Time 1135

WELLL MSÉ 17D

MER̃CU'?EMENTS CONDUCTED IN THE FIELD

Sample date: $10 / 09 / 91$

Depth to water: $134.48 \mathrm{Ht}(40.99 \mathrm{~m})$ helow TOC

Water elevation: $225.72 \mathrm{Ht}(68.80 \mathrm{~m}) \mathrm{ms}$ !

Water evacuated before sampling 32 gat

LABORATORY ANALYSES

\begin{tabular}{|c|c|c|c|}
\hline Analyte & Fesult & Md & Unit \\
\hline $\begin{array}{l}\text { Chloroform } \\
1,1 \text {-Dichloroethylene } \\
\text { trans-1,2-Dichloroethylene } \\
\text { Tetrachloroethylene } \\
1,1,1 \text {-Trichloroethane } \\
\text { Trichloroethylene }\end{array}$ & 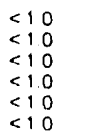 & & $\begin{array}{l}\mu C M / L \\
\mu g / L \\
\mu g / L \\
\mu g / L \\
\mu g / L \\
\mu g / L\end{array}$ \\
\hline
\end{tabular}

Time 1045

Alkalinity $2 \mathrm{mg} / \mathrm{L}$

Alkalinity $2 \mathrm{mg} / \mathrm{h}$
Water temperature. $176^{\circ} \mathrm{C}$
WELL MSB 18A

MEASUREMENTS CONDUCTED IN THE FIELD

Sample date $10 / 10 / 9$ Depth to water: $125.62 \mathrm{M}(38.28 \mathrm{~m})$ below TOC Water elevation: 214.58 \& $(65.40 \mathrm{~m}) \mathrm{msl}$

Water evacuated before sampling: $150 \mathrm{gal}$

LABORATORY ANALYSES

Ppecific conductance

Aluminum

Arsenic

Benzene

Bromodichloromethane

Bromoform

Bromomethane

Cadmium

Carbon tetrachloride

Chloride

Chlorobenzen

Chloroethene (Vir i chloride)

2.Chloroethyl vinyl ether

Chloroform

Chloromethane

Chromium

Copper

Cyanide

Cyanide
0 Dibromochloromethane

1,1.Dichloroethane

1,2-Dichloroethane

$1,1 \cdot$ Dichloroethylene
trans-1.2-Dichloroethylene

Dichloromethane

1,2-Dichloropropane

cis-1,3-Dichloropropene

trans-1,3-Dichloropropene

0 Lead

0 Mercury

Nitrate as nitrogen

Phenols

Selenium

0 Silver

Sodium

Sulfate

1,1,2,2-Tetrachloroethane

Tetrachloroethylene

Total phosphates (as $P$

1.1.1. Trichloroethane

2 Trichloroethylene

o Trichlorofluoromethane

o Jranium

$\begin{array}{ll}0 & \text { Uranium } \\ 0 & \text { Zinc }\end{array}$

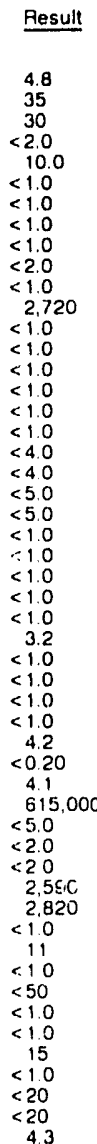

Time: $8: 30$

Alkalinity: $0 \mathrm{mg} / \mathrm{L}$

Water temperalure: $17.8^{\circ} \mathrm{C}$

WELL MSB 18B

MEASUREMENTS CONDUCTED IN THE FIELL

Sample date $10 / 10 / 91$

Depth to water 12254 (1 $(3735 \mathrm{~m})$ below TOC Water elevation $21776 \mathrm{ft}(66.37 \mathrm{~m}) \mathrm{msl}$

Sp conductance $106 \mu \mathrm{S} / \mathrm{cm}$

Water evacuated before sampling $68 \mathrm{gat}$

LABORATORY ANALYSES

$\begin{array}{ll}\text { F } & \text { Analyte } \\ 0 & \text { pH } \\ 0 & \text { Specific conductance } \\ 0 & \text { Aluminum } \\ 0 & \text { Arsenic } \\ 0 & \text { Barium } \\ 0 & \text { Benzene } \\ 0 & \text { Bromodichloromethane } \\ 0 & \text { Bromoform } \\ 0 & \text { Bromomethane } \\ 0 & \text { Cadmium } \\ 0 & \text { Carbon tetrachtoride } \\ 0 & \text { Chloride } \\ 0 & \text { Chlorobenzene } \\ 0 & \text { Chloroethane } \\ 0 & \text { Chloroethene (Vinyl chloride) } \\ 0 & 2 \cdot \text { Chlorvethyl vinyl ether } \\ 0 & \text { Chloroform } \\ 0 & \text { Chloromethane } \\ 0 & \text { Chromium } \\ \end{array}$

Result

5.5
120
28
$<20$
27
27.0
$<110$
$<1.0$
$<10$
$<2.0$
$<10$
5.050
$<1.0$
$<10$
$<10$
$<10$
$<110$
$<110$
$<40$

Time: 8.50

TH: 5

Water temperature $179^{\circ} \mathrm{C}$

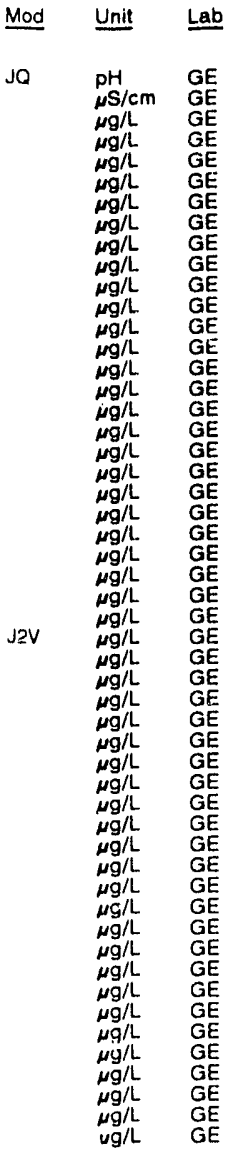

\begin{tabular}{|c|c|}
\hline Moo & Unit \\
\hline JO & $\begin{array}{l}\mathrm{pH} \\
\mu \mathrm{S} / \mathrm{sm} \\
\mu \mathrm{g} / \mathrm{L} \\
\mu \mathrm{g} / \mathrm{L} \\
\mu \mathrm{g} / \mathrm{L} \\
\mu \mathrm{g} / \mathrm{L} \\
\mu \mathrm{g} / \mathrm{L} \\
\mu \mathrm{g} / \mathrm{L} \\
\mu \mathrm{g} / \mathrm{L} \\
\mu \mathrm{g} / \mathrm{L} \\
\mu \mathrm{g} / \mathrm{L} \\
\mu \mathrm{g} / \mathrm{L} \\
\mu \mathrm{g} / \mathrm{L} \\
\mu \mathrm{g} / \mathrm{L} \\
\mu \mathrm{g} / \mathrm{L} \\
\mu \mathrm{g} / \mathrm{L} \\
\mu \mathrm{g} / \mathrm{L} \\
\mu \mathrm{g} / \mathrm{L}\end{array}$ \\
\hline
\end{tabular}


ANALYTICAL RESULTS

WELL MSB 188 collected on 10/10/91, laboratory analyses (cont.)

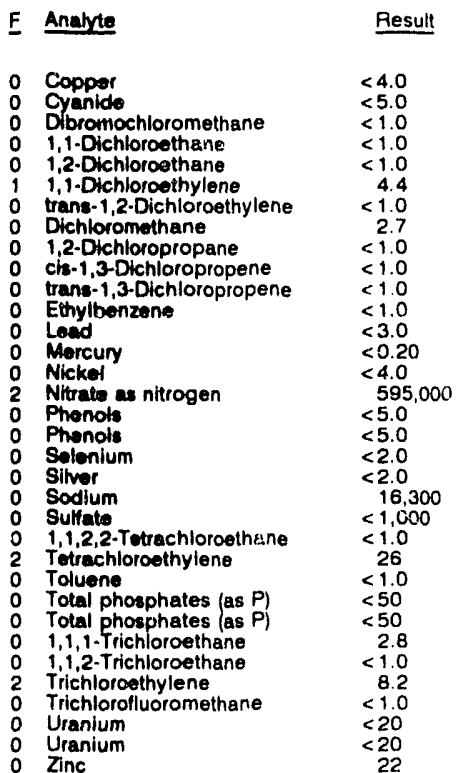

WELL MSB $18 \mathrm{C}$

MEASUREMENTS CONDUCTED IN THE FIELD

Semple date: 10/10/91 تrepth to water: $117.93 \mathrm{ft}(35.95 \mathrm{~m})$ below TOC Waler olevation: $222.87 \mathrm{Ht}(67.87 \mathrm{~m}) \mathrm{ms}$ l

Sp. conductance: $26 \mu \mathrm{S} / \mathrm{cm}$

$\underline{L a b}$

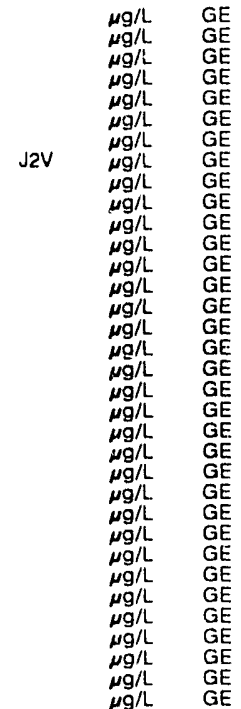

The well went dod belore sampling: 6 gal

LABORATORY ANALYYSES

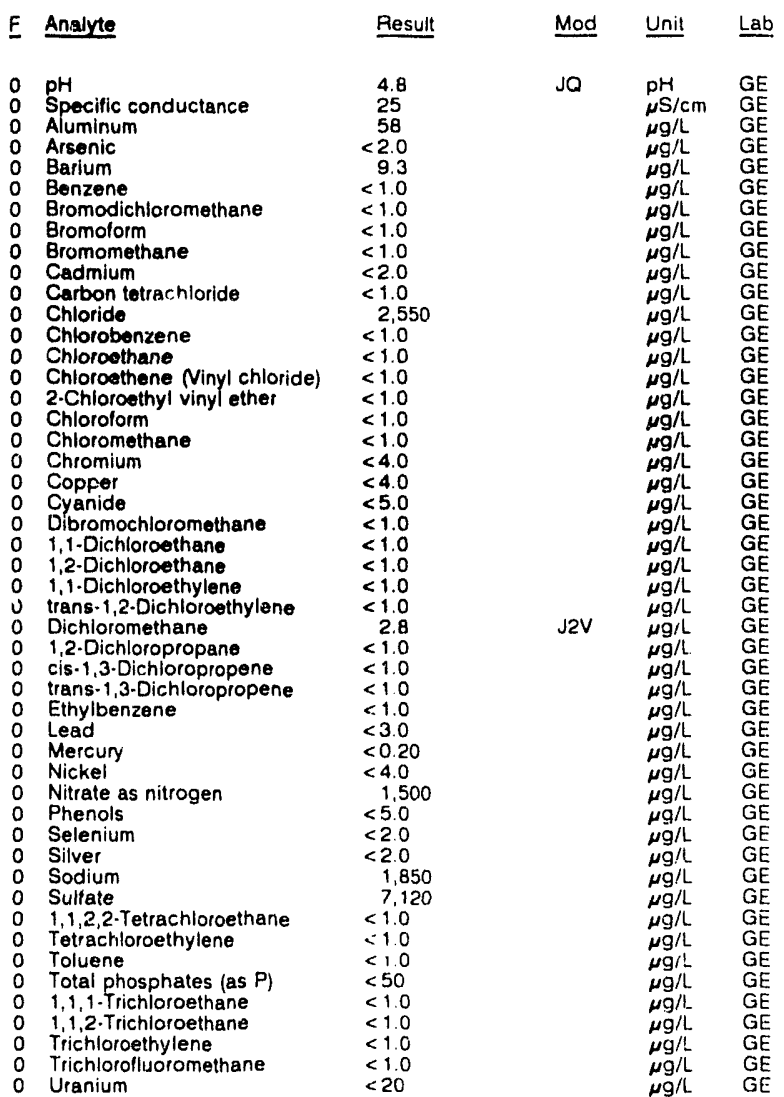

WELL MSB $18 \mathrm{C}$ collected on 10/10/91, laboratory analyses (cont.)

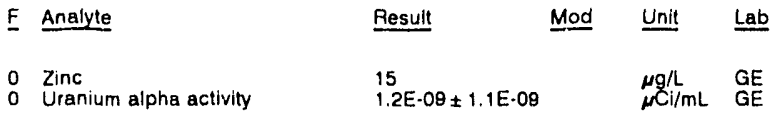

WELL MSB 19A

MEASUREMENTS CONDUCTED IN THE FIELD

Sample date: $11 / 01 / 91$

Depth to water: $86.23 \mathrm{ft}(26.28 \mathrm{~m})$ below TOC

Water elevation: $213.27 \mathrm{~h}(65.01 \mathrm{~m}) \mathrm{msl}$

Sp. conductance: $26 \mu \mathrm{S} / \mathrm{cm}$

sampling: $259 \mathrm{gal}$

Time: 13:25

pH: 5.4

Alkalinity: $2 \mathrm{mg} / \mathrm{L}$

LABDRATORY ANALYSES

$0_{0}^{0} \mathrm{pH}$ Specific conductance

Aluminum

Arsenic

Benzene

Bromodichloromethane

Bromolorm

Bromomethan

Cadmium

Carbon tetrachloride

Chloride

Chlorobenzene

Chloroethene Ninyl chloride

2-Chloroethyl vinyl ether

2.Chloroethyl

Chloromethane

Chromium

Copper

Dibromochloromethane

1,1.Dichloroethane

1,2-Dichloroethane

trans-1,2-Dichloroethylene

Dichloromethane

1,2-Dichloropropane
cis-1,3-Dichloropropen

trans-1,3-Dichloropropene

Lead

0 Mercury

Nitrate as nitrogen

Phenols

Selenium

Silver

Sodium

$1,1,2,2-$ Tetrachloroethane

Tetrachloroethylene

Total phosphates (as $P$ )

$1,1,1$ - Trichloroethane

Trich richloroethane

Trichloethylene

Zinc

Uranium sinha a tivity

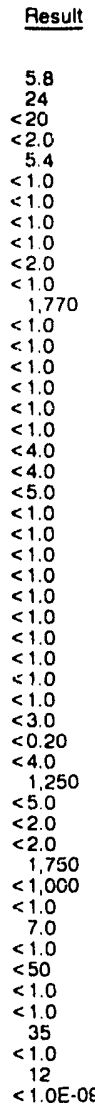

JO

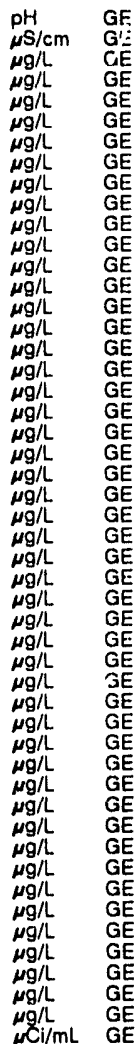

WELL MSB 193

MEASUREMENTS $S T, 2$, TED IN THE FIELO

Depth to water $83.94-59 \mathrm{~m})$ below TOC

Water elevation: $215.96 \mathrm{i}, \mathrm{i}(65.83 \mathrm{~m}) \mathrm{ms}$ |

Sp conductance 13 us

m

Time: 13:05

Alkalinity: $1 \mathrm{mg} / \mathrm{L}$

Water temperature: $18.5^{\circ} \mathrm{C}$

ABORATORY ANALYSES

\begin{tabular}{|c|c|c|c|}
\hline Analyte & Result & Mod & Unit \\
\hline 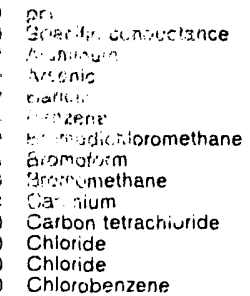 & $\begin{aligned} & 5.4 \\
& 1.9 \\
&<20 \\
&<2.0 \\
& 4.3 \\
&<1.0 \\
&<1.0 \\
&<1.0 \\
&<1.0 \\
&<2.0 \\
&<1.0 \\
& 1.800 \\
& 1.790 \\
&<1.0\end{aligned}$ & $J Q$ & $\begin{array}{l}\mathrm{pH} \\
\mu \mathrm{S} / \mathrm{cm} \\
\mu \mathrm{g} / \mathrm{L} \\
\mu \mathrm{g} / \mathrm{L} \\
\mu g / \mathrm{L} \\
\mu \mathrm{g} / \mathrm{L} \\
\mu g / \mathrm{L} \\
\mu \mathrm{g} / \mathrm{L} \\
\mu \mathrm{g} / \mathrm{L} \\
\mu g / \mathrm{L} \\
\mu \mathrm{g} / \mathrm{L} \\
\mu \mathrm{g} / \mathrm{L} \\
\mu \mathrm{g} / \mathrm{L} \\
\mu g / \mathrm{L}\end{array}$ \\
\hline
\end{tabular}




\section{ANALYTICAL RESULTS}

WELL MSB 198 collected on 11/01/91, laboratory analyses (cont)

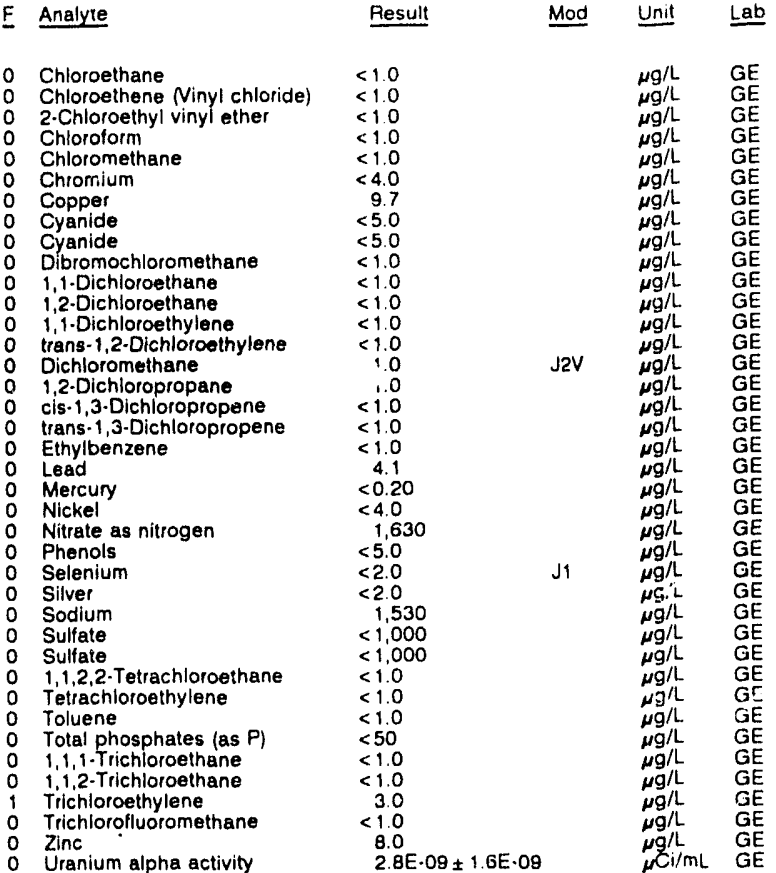

\section{WELL MSB $19 C$}

MEASUREMENTS CONDUCTED IN THE FIELD

$\begin{array}{ll}\text { Sample date: } 11 / 01 / 91 & \text { Time: } 13.40 \\ \text { Depth to water: } 61.33 \mathrm{ft}(18.69 \mathrm{~m}) \text { below TOC } & \text { pH: } 5: 1 \\ \text { Wate elevation: } 2.38 .87 \mathrm{ft}(72.81 \mathrm{~m}) \mathrm{ms} \text { l } & \text { Alkalinity. } 1 \mathrm{mg} / \mathrm{L} \\ \text { Sp. conductance: } 62 \mu \mathrm{\mu S} / \mathrm{cm} & \text { Water temperature: } 18.8^{\circ} \mathrm{C} \\ \text { Water evacuated before sampling: } 107 \mathrm{gal} & \end{array}$

\section{LABORATORY ANALYSES}

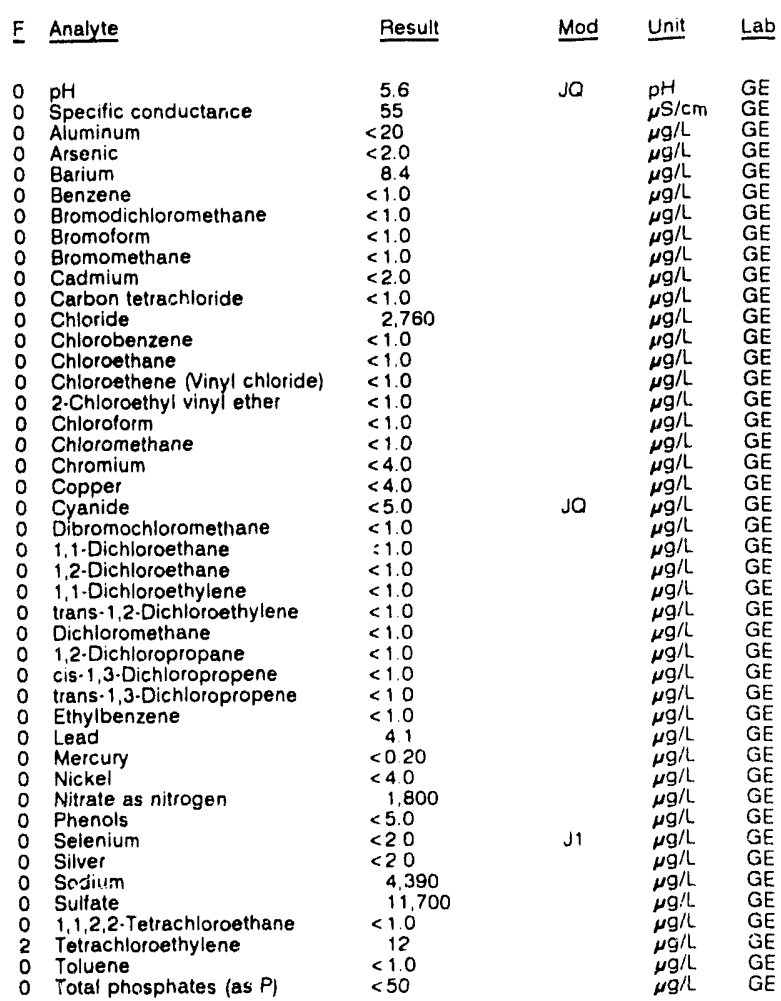

WELL MSB $19 \mathrm{C}$ collected on 11/01/91, laboratory analyses (cont.)

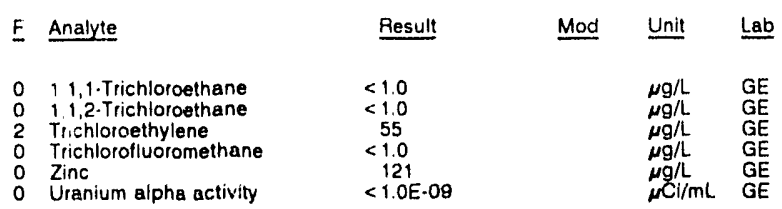

WELL MSB 20A

MEASUREMENTS CONDUCTED IN THE FIELD

Sample date: $11 / 21 / 91$ f $(42.67 \mathrm{~m})$ below TOC

Sp. conductance: $28 \mu \mathrm{s} / \mathrm{cm}$.

Water evacuated before sampling: $152 \mathrm{gal}$

LABORATORY ANALYSES

\begin{tabular}{|c|c|c|c|c|}
\hline & Analyte & Result & Mod & Unit \\
\hline $\begin{array}{l}0 \\
0 \\
0 \\
0\end{array}$ & $\begin{array}{l}\text { Chloroform } \\
1,1-\text { Dichloroethylene } \\
\text { trans } \cdot 1,2 \cdot \text { Dichloroethylene } \\
\text { Tetrachloroethylene } \\
1,1,1 \text {-Trichloroethane } \\
\text { Trichloroethylene }\end{array}$ & $\begin{array}{l}<20 \\
<20 \\
<20 \\
<20 \\
<20 \\
891\end{array}$ & & $\begin{array}{l}\mu g / L \\
\mu g / L \\
\mu g / L \\
\mu g / L \\
\mu g / L \\
\mu g / L\end{array}$ \\
\hline
\end{tabular}

WELL MSB 20C

MEASUREI IENTS CONDUCTED IN THE FIELD

Sample date 10/10/91

Depth to watt Not avallable

Sp conductance 203 avaliable

Water evacuated before sampling $7 \mathrm{gal}$

The well went dry during purging.

Time: $13: 45$

pH: 5.1

Water temperature: $19.0^{\circ} \mathrm{C}$

LABORATORY ANALYSES

\begin{tabular}{|c|c|c|c|c|}
\hline & Analyte & Result & Mod & Unit \\
\hline $\begin{array}{l}0 \\
0 \\
0\end{array}$ & $\begin{array}{l}\text { Chloroform } \\
1,1-\text { Dichloroethylene } \\
\text { trans }-1,2-\text { Dichloroethylene } \\
\text { Tettachloroethylene } \\
1,1,1-\text { Trichloroethane } \\
\text { Trichloroethylene }\end{array}$ & $\begin{array}{l}<1.0 \\
<1.0 \\
<1.0 \\
<1.0 \\
<1.0 \\
1.1\end{array}$ & & $\begin{array}{l}\mu g / L \\
\mu g / L \\
\mu g / L \\
\mu g / L \\
\mu g / L \\
\mu g / L\end{array}$ \\
\hline
\end{tabular}

\section{WE:LL MSB 21A}

MEASUREMENTS CONDUCTED IN THE FIELD

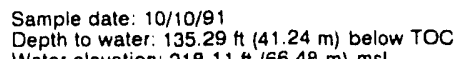
Water elevation: 218.11 t $(66.48 \mathrm{~m}) \mathrm{msl}$

$\mathrm{Sp}$ conductance: $22 \mu \mathrm{S} / \mathrm{cm}$

Water evacuated before sampling: $171 \mathrm{gai}$

LABORATORY ANALYSES

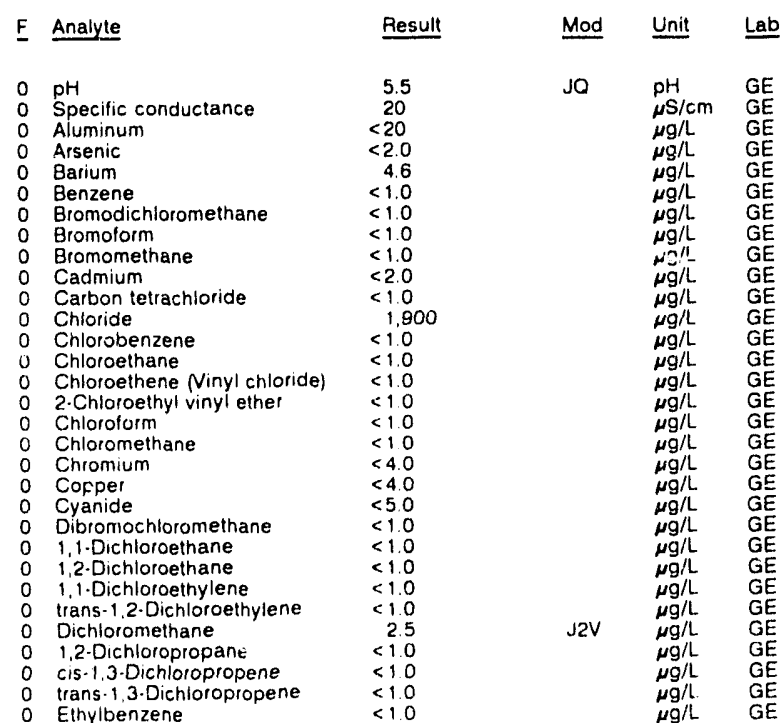

\section{Time: : $: 05$ \\ Alkalinity. $87 \mathrm{mg} / \mathrm{L}$ \\ Water temperature: $17.7^{\circ} \mathrm{C}$}

Alkalinity: $1 \mathrm{mg} / \mathrm{L}$ Water temperalure: $18.9^{\circ} \mathrm{C}$ 
ANALYTICAL RESULTS

WELL MSB 21A collected on 10/10/91, laboratory analyses (cont.)

\begin{tabular}{|c|c|c|c|}
\hline Analyte & Result & Mod & Unit \\
\hline $\begin{array}{l}\text { Lead } \\
\text { Mercury } \\
\text { Nickel } \\
\text { Nitrate as nitrogen } \\
\text { Nitrate as nitrogen } \\
\text { Phenols } \\
\text { Selenium } \\
\text { Silver } \\
\text { Sodium } \\
\text { Sulfate } \\
1,1,2,2 \text {-Tetrachloroethane } \\
\text { Tetrachloroethylene } \\
\text { Toluene } \\
\text { Total phosphates (as P) } \\
1,1,1 \text { - Trichloroethane } \\
1,1,2 \text { - Trichloroethane } \\
\text { Trichloroethylene } \\
\text { Trichlorofluoromethana } \\
\text { Zinc } \\
\text { Uranium aipha activity }\end{array}$ & $\begin{array}{l}3.6 \\
<0.20 \\
<4.0 \\
1.220 \\
1.220 \\
<5.0 \\
<2.0 \\
<2.0 \\
1.750 \\
<1.000 \\
<1.0 \\
<1.0 \\
<1.0 \\
<50 \\
<1.0 \\
<1.0 \\
3.0 \\
<1.0 \\
60 \\
<1.0 E-09\end{array}$ & & $\begin{array}{l}\mu g / L \\
\mu g / L \\
\mu g / L \\
\mu g / L \\
\mu g / L \\
\mu g / L \\
\mu g / L \\
\mu g / L \\
\mu g / L \\
\mu g / L \\
\mu g / L \\
\mu g / L \\
\mu g / L \\
\mu g / L \\
\mu g / L \\
\mu g / L \\
\mu g / L \\
\mu g / L \\
\mu g / L \\
\mu C \mathrm{i} / / \mathrm{mL}\end{array}$ \\
\hline
\end{tabular}

WELL MSB 218

MEASUREMENTS CONDUCTED IN THE FIELD

Sample date: $10 / 10 / 91$ Depth to water: $136.08 \mathrm{H}(41.48 \mathrm{~m})$ below TO
Water elevation: $219.22 \mathrm{Ht}(66.82 \mathrm{~m}) \mathrm{msl}$

Sp conductance $26 \mu \mathrm{S} / \mathrm{cm}$

Water evacuated before sampling: $201 \mathrm{gal}$

LABORATORY ANALYSES

\begin{tabular}{|c|c|c|c|}
\hline E Analyte & Result & Mod & Unit \\
\hline $\begin{array}{l}\text { Chloroform } \\
1,1-\text { Dichloroethylene } \\
\text { trans-1,2-Dichloroethylene } \\
\text { Tetrachloroethylene } \\
1,1,1 \cdot \text { Trichloroethane } \\
\text { Trichloroethylene }\end{array}$ & $\begin{array}{r}<5.0 \\
<5.0 \\
5.9 \\
<5.0 \\
<5.0 \\
227\end{array}$ & & $\begin{array}{l}\mu \mathrm{g} / \mathrm{L} \\
\mu \mathrm{g} / \mathrm{L} \\
\mu \mathrm{g} / \mathrm{L} \\
\mu \mathrm{g} / \mathrm{L} \\
\mu \mathrm{g} / \mathrm{L} \\
\mu \mathrm{g} / \mathrm{L}\end{array}$ \\
\hline
\end{tabular}

WELL MSB 21C

MEASUREMENTS CONDUCTED IN THE FIELD

Sample date: $10 / 10 / 91$

Depth to water: $126.63 \mathrm{ft}(38.60 \mathrm{~m})$ below TOC

Water elevation: $226.77 \mathrm{ft}(69.12 \mathrm{~m}) \mathrm{msl}$

conductance: $20 \mu \mathrm{s} / \mathrm{cm}$

Water evacuated before sampling: $39 \mathrm{gal}$

LABORATORY ANALYSES

\begin{tabular}{|c|c|c|c|}
\hline Analyte & Result & Mod & Unit \\
\hline $\begin{array}{l}\text { pH } \\
\text { Specific conductance } \\
\text { Aluminum } \\
\text { Arsenic } \\
\text { Barium } \\
\text { Benzene } \\
\text { Bromodichloromethane } \\
\text { Bromoform } \\
\text { Bromomethane } \\
\text { Cadmium } \\
\text { Carbon tetrachloride } \\
\text { Chloride } \\
\text { Chloride } \\
\text { Chlorobenzene } \\
\text { Chloroethane } \\
\text { Chloroethene Ninyl chloride) } \\
\text { 2-Chloroethyl vinyl ether } \\
\text { Chlorolorm } \\
\text { Chloromethane } \\
\text { Chromium } \\
\text { Copper } \\
\text { Cyanide } \\
\text { Dibromochloromsthane } \\
1,1 \cdot \text { Dichloroethane } \\
\text { 1,2-Dichlcroethane } \\
\text { 1,1-Dichloroethylene } \\
\text { trans } 1,2 \cdot \text { Dichloroethylene } \\
\text { Dichloromethane } \\
\text { 1,2-Dichloropropane } \\
\text { cis-1,3-Dichloropropene } \\
\text { trans-1,3.Dichloropropene } \\
\text { Ethylbenzene } \\
\text { Lead } \\
\text { Mercurv } \\
\text { Nickel } \\
\text { Nitrate as nitrogen } \\
\text { Phenols } \\
\text { Selenium } \\
\text { Silver } \\
\text { Sodium }\end{array}$ & $\begin{array}{l}5.4 \\
20 \\
<20 \\
<20 \\
6.2 \\
<1.0 \\
<1.0 \\
<1.0 \\
<1.0 \\
<2.0 \\
<1.0 \\
2.140 \\
2,190 \\
<1.0 \\
<1.0 \\
<1.0 \\
<1.0 \\
<1.0 \\
<1.0 \\
<40 \\
5.0 \\
<5.0 \\
<1.0 \\
<1.0 \\
<1.0 \\
<1.0 \\
<10 \\
3.0 \\
<1.0 \\
<1.0 \\
<1.0 \\
<1.0 \\
441 \\
<0.20 \\
<40 \\
520,000 \\
<5.0 \\
<2.0 \\
<2.0 \\
11.890\end{array}$ & $\mathrm{~J}_{2} \mathrm{~V}$ & $\begin{array}{l}p H \\
\mu \mathrm{S} / \mathrm{cm} \\
\mu g / L \\
\mu g / L \\
\mu g / L \\
\mu g / L \\
\mu g / L \\
\mu g / L \\
\mu g / L \\
\mu g / L \\
\mu g / L \\
\mu g / L \\
\mu g / L \\
\mu g / L \\
\mu g / L \\
\mu g / L \\
\mu g / L \\
\mu g / L \\
\mu g / L \\
\mu g / L \\
\mu g / L \\
\mu g / L \\
\mu g / L \\
\mu g / L \\
\mu g / L \\
\mu g / L \\
\mu g / L \\
\mu g / L \\
\mu g / L \\
\mu g / L \\
\mu g / L \\
\mu g / L \\
\mu g / L \\
\mu g / L \\
\mu g / L \\
\mu g / L \\
\mu g / L \\
\mu g / L \\
\mu g / L \\
\mu g / L\end{array}$ \\
\hline
\end{tabular}

Time: $9: 50$

Alkalinity: $5 \mathrm{mg} / \mathrm{L}$

Water tempersture: $18.3^{\circ} \mathrm{C}$

Time: 10:15

PH: 5.1 . $2 \mathrm{mg}$
WELL MSB 21C collected on 10/10/91, laboratory analyses (cont.)

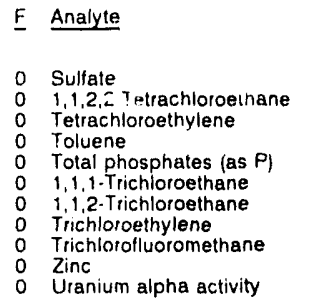

Result

$<1.000$
$<1.0$
$<1.0$
$<1.0$
$<50$
$<1.0$
$<1.0$
$<1.0$
$<1.0$
1.0
$2.0 E-09 \pm 1.2 E-09$

Mod Unit Lab

Uranium alpha activity

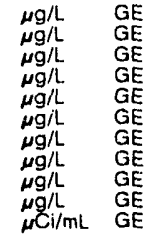

WELL MSB 21TA

MEASUAEMENTS CONDUCTED IN THE FIELD

Sample date: 10/10/91

Depth to water: $159.36 \mathrm{ft}(48.57 \mathrm{~m})$ below TOC

Water elevation: $195.34 \mathrm{H}(59.54 \mathrm{~m}) \mathrm{msl}$

Water evacuated belore sampling: $464 \mathrm{gal}$

LABORATORY ANALYSES

\begin{tabular}{|c|c|c|c|}
\hline Analyte & Result & Mod & Unit \\
\hline 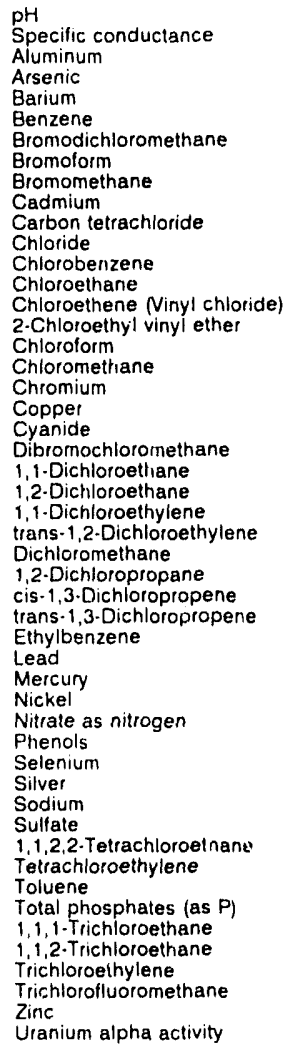 & $\begin{array}{l}5.9 \\
50 \\
77 \\
<2.0 \\
11 \\
<1.0 \\
<1.0 \\
<1.0 \\
<1.0 \\
<2.0 \\
<1.0 \\
2.080 \\
<1.0 \\
<1.0 \\
<1.0 \\
<1.0 \\
<1.0 \\
<1.0 \\
<4.0 \\
<4.0 \\
<5.0 \\
<1.0 \\
<1.0 \\
<1.0 \\
<1.0 \\
<1.0 \\
2.3 \\
<1.0 \\
<1.0 \\
<1.0 \\
<1.0 \\
<3.0 \\
<0.20 \\
5.1 \\
550.000 \\
<5.0 \\
<2.0 \\
<2.0 \\
<1.780 \\
9.430 \\
<1.0 \\
<1.0 \\
<1.0 \\
<50 \\
<1.0 \\
<1.0 \\
113 \\
<1.0 \\
6.8 \\
<1.0 \mathrm{E} .09\end{array}$ & J2V & 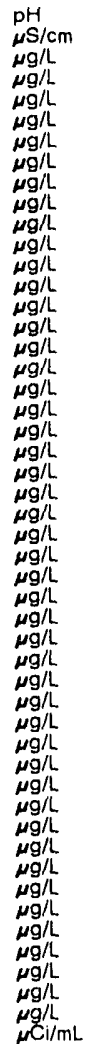 \\
\hline
\end{tabular}

Time: $11: 30$

Alkalinity: $12 \mathrm{mg} / \mathrm{L}$ Water temperature: $19.4^{\circ} \mathrm{C}$

Water temperature: $182^{\circ} \mathrm{C}$

Uranium alpha activity

WELL MSB 22

MEASUREMENTS CONDUCTED IN THE FIELD

Sample date: $11 / 13 / 91$

Time: $12: 30$

VIELL MSB 23

MEASUREMENTS CONDUCTED IN THE FIELD

Sample date: 12/02/91

Time: $10: 40$ 


\section{WELL MSB 23B}

MEASUAEMENTS CONOUCTED IN THE FIELD

Sample date: 12/02/91

Depth to water: $150.23 \mathrm{ft}(\mathbf{4 5 . 7 9} \mathrm{m})$ below TOC Water elevation: $221.37 \mathrm{ft}(67.4$
Sp. conductance: $28 \mu \mathrm{s} / \mathrm{cm}$ Water evacuated before sampling: $132 \mathrm{gal}$ LABORATORY ANALYSES

\begin{tabular}{|c|c|c|c|c|c|}
\hline$F$ & Analyte & Result & Mod & Unit & Lab \\
\hline $\begin{array}{l}0 \\
0 \\
0 \\
0 \\
0 \\
0 \\
0 \\
0 \\
0 \\
0 \\
0 \\
0\end{array}$ & $\begin{array}{l}\text { pH } \\
\text { Specific conductance } \\
\text { Arsenic } \\
\text { Barium } \\
\text { Cadmium } \\
\text { Calcium } \\
\text { Chloride } \\
\text { Chioride } \\
\text { Chloroform } \\
\text { Chromium } \\
1,1 \cdot \text { Dichloroethylene } \\
\text { trans-1.2.Dichloroethylene } \\
\text { Fluoride } \\
\text { Fluoride } \\
\text { Iron } \\
\text { Lead } \\
\text { Magnesium } \\
\text { Manganese } \\
\text { Mercury } \\
\text { Nittate as nitrogen } \\
\text { Phenols } \\
\text { Potassium } \\
\text { Selenium } \\
\text { Silica } \\
\text { Silver } \\
\text { Sodium } \\
\text { Sulfate } \\
\text { Sulfate } \\
\text { Tetrachloroethylene } \\
\text { Total dissolved solids } \\
\text { Total organic carbon } \\
\text { Total organic halogens } \\
\text { Total phosphates as P) } \\
\text { Total phosphates as P) } \\
1,1,1 \cdot \text { Trichloroethane } \\
\text { Trichloroethylene } \\
\text { Gross alpha } \\
\text { Nonvolatile beta } \\
\text { Total radium } \\
\text { Tritium }\end{array}$ & $\begin{array}{l}5.7 \\
30 \\
<2.0 \\
<3.0 \\
<2.0 \\
1,470 \\
2,260 \\
2,270 \\
<5.0 \\
<4.0 \\
<5.0 \\
<5.0 \\
<100 \\
<100 \\
<4.0 \\
<3.0 \\
133 \\
<2.0 \\
<0.20 \\
300 \\
<5.0 \\
<500 \\
<2.0 \\
8,820 \\
<2.0 \\
4.080 \\
1,370 \\
1,380 \\
263 \\
12,000 \\
<1.000 \\
469 \\
<50 \\
<50 \\
<5.0 \\
644 \\
2.2 E \cdot 09 \pm 9.3 E \cdot 10 \\
<2.0 E-09 \\
<1.0 E \cdot 09 \\
<7.0 E-07\end{array}$ & Jo & $\begin{array}{l}p H \\
\mu \mathrm{S} / \mathrm{cm} \\
\mu g / L \\
\mu g / L \\
\mu g / L \\
\mu g / L \\
\mu g / L \\
\mu g / L \\
\mu g / L \\
\mu g / L \\
\mu g / L \\
\mu g / L \\
\mu g / L \\
\mu g / L \\
\mu g / L \\
\mu g / L \\
\mu g / L \\
\mu g / L \\
\mu g / L \\
\mu g / L \\
\mu g / L \\
\mu g / L \\
\mu g / L \\
\mu g / L \\
\mu g / L \\
\mu g / L \\
\mu g / L \\
\mu g / L \\
\mu g / L \\
\mu g / L \\
\mu g / L \\
\mu g / L \\
\mu g / L \\
\mu g / L \\
\mu g / L \\
\mu g / L \\
\mu C \mathrm{i} / \mathrm{mL} \\
\mu C \mathrm{C} / \mathrm{mL} \\
\mu C \mathrm{i} / \mathrm{mL} \\
\mu C \mathrm{i} / \mathrm{mL}\end{array}$ & $\begin{array}{l}\mathrm{GE} \\
\mathrm{GE} \\
\mathrm{GE} \\
\mathrm{GE} \\
\mathrm{GE} \\
\mathrm{GE} \\
\mathrm{GE} \\
\mathrm{GE} \\
\mathrm{MA} \\
\mathrm{GE} \\
\mathrm{MA} \\
\mathrm{MA} \\
\mathrm{GE} \\
\mathrm{GE} \\
\mathrm{GE} \\
\mathrm{GE} \\
\mathrm{GE} \\
\mathrm{GE} \\
\mathrm{GE} \\
\mathrm{GE} \\
\mathrm{GE} \\
\mathrm{GE} \\
\mathrm{GE} \\
\mathrm{GE} \\
\mathrm{GE} \\
\mathrm{GE} \\
\mathrm{GE} \\
\mathrm{GE} \\
\mathrm{MA} \\
\mathrm{GE} \\
\mathrm{GE} \\
\mathrm{GE} \\
\mathrm{GE} \\
\mathrm{GE} \\
\mathrm{MA} \\
\mathrm{MA} \\
\mathrm{GE} \\
\mathrm{GE} \\
\mathrm{GE} \\
\mathrm{GE}\end{array}$ \\
\hline
\end{tabular}

\section{WELL MSB 23TA}

MEASUREMENTS CONDUCTED IN THE FIELD

\section{Sample date: 10/96/91}

Depth to water: $171.06 \mathrm{Ht}(52.14 \mathrm{~m})$ below TOC

Water elevation: $201.84 \mathrm{ft}(61.52 \mathrm{~m}) \mathrm{ms}$

Sp. conductance: $96 \mu \mathrm{S} / \mathrm{cm}$

Time: $11: 00$

$\mathrm{pH}: 5.4$

Alkalinity: $2 \mathrm{mg} / \mathrm{h}$

Water temperature: $20.4^{\circ} \mathrm{C}$

No water was evacuated before sampling

LABORATORY ANALYSES

\begin{tabular}{|c|c|c|c|}
\hline Analyte & Result & Mod & Unit \\
\hline $\begin{array}{l}\text { Chloroform } \\
\text { Chloroform } \\
\text { 1,1-Dichloroethylene } \\
1,1-\text { Dichloroethylene } \\
\text { trans-1,2-Dichloroethylene } \\
\text { trans } 1,2 \text {-Dichloroethylene } \\
\text { Tetrachloroethylene } \\
\text { Tetrachloroethylene } \\
1,1,1-\text { Trichloroethane } \\
1,1,1-\text { Trichloroethane } \\
\text { Trichloroelhylene } \\
\text { Trichloroethylene }\end{array}$ & $\begin{aligned}<2.0 \\
<2.0 \\
<2.0 \\
<2.0 \\
<2.0 \\
<2.0 \\
9.8 \\
9.4 \\
<2.0 \\
<2.0 \\
93 \\
86\end{aligned}$ & & $\begin{array}{l}\mu g / L \\
\mu g / L \\
\mu g / L \\
\mu g / L \\
\mu g / L \\
\mu g / L \\
\mu g / L \\
\mu g / L \\
\mu g / L \\
\mu g / L \\
\mu g / L \\
\mu g / L\end{array}$ \\
\hline
\end{tabular}

WELL MSB 23TA

MEASUREMENTS CONDUCTED IN THE FIELD

Sample date: 10/06/91

Depth to water: $171.06 \mathrm{ht}(52.14 \mathrm{~m})$ below TOC Water elevation: $201.84 \mathrm{ft}(61.52 \mathrm{~m}) \mathrm{msl}$ Sp. conductance: $52 \mu \mathrm{s} / \mathrm{cm}$
Water evacuated belore sampling: $92 \mathrm{gal}$

LABORATORY ANALYSES

$\begin{array}{lll}\text { F Analyte } & \text { Result } \\ & & \\ 0 & \text { Chloroform } & <5.0 \\ 0 & 1,1 \text {-Dichloroothylene } & <5.0 \\ 0 & \text { trans-1,2.Dichloroethylene } & <5.0 \\ 0 & \text { Tetrachloroethylene } & <5.0 \\ 0 & 1,1,1 \text { - Trichloroethane } & <5.0 \\ 2 & \text { Trichloroothylene } & 12\end{array}$

WELL MSB 23TA

MEASUAEMENTS CONDUCTED IN THE FIELD Sample date: 10/06/91 Depth to water: $171.06 \mathrm{Ht}(52.14 \mathrm{~m})$ below TOC Water elevalion: $201.84 \mathrm{tt}(81.52 \mathrm{~m}) \mathrm{msl}$

Water evacuated before sampling: $184 \mathrm{gal}$ LABORATORY ANALYSES
E Analyte
$\underline{\text { Result }}$
- Chlorolorm
0 1,1-Dichloroethylene
o trans-1,2-Dichloroethy
Tetrachloroethylene
0
0
0

$<1.0$
$<1.0$
$<1.0$
$<1.0$
$<1.0$
1.8

WELL MSB 23TA

MEASUREMENTS CONDUCTED IN THE FIELD

Sample date: 10/06/91

Depth to water: $171.06 \mathrm{ft}(52.14 \mathrm{~m})$ below TOC Water elevation: $201.84 \mathrm{H}(61.52 \mathrm{~m}) \mathrm{msl}$

Sp. conductance: $31 \mu \mathrm{S} / \mathrm{cm}$
Water evacuated before sampling: $276 \mathrm{gal}$

LABORATORY ANALYSES

\begin{tabular}{|c|c|c|c|c|}
\hline & Analyte & Result & Mod & Unit \\
\hline $\begin{array}{l}0 \\
0 \\
0 \\
0 \\
0\end{array}$ & $\begin{array}{l}\text { Chloroform } \\
1,1-\text { Dichloroethylene } \\
\text { rrans }-1,2 \cdot \text { Dichloroethylene } \\
\text { Tetrachloroethylene } \\
1,1,1-\text { Trichloroethane } \\
\text { Trichloroethylene }\end{array}$ & $\begin{aligned}<1.0 \\
<1.0 \\
<1.0 \\
<1.0 \\
<1.0 \\
4.0\end{aligned}$ & & $\begin{array}{l}\mu g / \mathrm{L} \\
\mu g / \mathrm{L} \\
\mu g / \mathrm{L} \\
\mu g / \mathrm{L} \\
\mu g / \mathrm{L} \\
\mu g / \mathrm{L}\end{array}$ \\
\hline
\end{tabular}

\section{WELL MSB 23TA}

MEASUREMENTS CONDUCTED IN THE FIELD

Sample date: 10/06/91

Depth to water: $171.06 \mathrm{ft}(52.14 \mathrm{~m})$ below TOC

Water elevation: $201.84 \mathrm{ft}(61.52 \mathrm{~m}) \mathrm{msl}$

Water evacuated before sampling: $368 \mathrm{gal}$

LUJORATORY ANALYSES

\begin{tabular}{|c|c|c|c|}
\hline Analyte & Result & Mod & $\underline{\text { Unit }}$ \\
\hline $\begin{array}{l}\text { Chloroform } \\
1,1 \cdot \text { Dichloroethylene } \\
\text { trans } 1,2 \cdot \text { Dichloroethylene } \\
\text { Tetrachloroethylene } \\
1,1,1 \cdot \text { Trichloroethane } \\
\text { Trichloroethylene }\end{array}$ & $\begin{array}{l}<1.0 \\
<1.0 \\
<1.0 \\
<1.0 \\
<1.0 \\
<10\end{array}$ & & $\begin{array}{l}\mu \mathrm{g} / \mathrm{L} \\
\mu \mathrm{g} / \mathrm{L} \\
\mu \mathrm{g} / \mathrm{L} \\
\mu \mathrm{g} / \mathrm{L} \\
\mu \mathrm{g} / \mathrm{L} \\
\mu \mathrm{g} / \mathrm{L}\end{array}$ \\
\hline
\end{tabular}

Time: $10: 20$

Alkalinity: $12 \mathrm{mg} / \mathrm{L}$

Water temperature: $19.6^{\circ} \mathrm{C}$

Alkalinity: $3 \mathrm{mg} / \mathrm{t}$

Water temperature: $20.9^{\circ} \mathrm{C}$

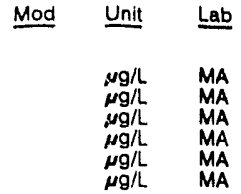

Time: $11: 10$

$\mathrm{pH}: 5.2$

Alinity: $2 \mathrm{mg} / \mathrm{l}$

Water temperature: $20.4^{\circ} \mathrm{C}$

$\mathrm{H}: 5.0$

Alkalinity: $1 \mathrm{mg} / \mathrm{L}$

Water temperature: $20.9^{\circ} \mathrm{C}$ $\begin{array}{ll}\text { Unit } & \text { Lab } \\ & \\ \mu g / L & M A \\ \mu g / L & M A \\ \mu g / L & M A \\ \mu g / L & M A \\ \mu g / L & M A\end{array}$ 
ANALYTICAL RESULTS

WELL MSB 23TA

MEASUREMENTS CONDUCIED IN THE FIELD

Sample date: $10 / 13 / 91$

Depth to water: $170.65 \mathrm{Ht}(52.01 \mathrm{~m})$ below TOC

Water elevation: $202.25 \mathrm{Ht}(61.65 \mathrm{~m}) \mathrm{ms}$ !

So. conductance. 28 ss/cm

LABORATORY ANALYSES

\begin{tabular}{|c|c|c|c|c|}
\hline$F$ & Analyte & Result & Mod & Unit \\
\hline $\begin{array}{l}0 \\
0 \\
0 \\
0 \\
0\end{array}$ & $\begin{array}{l}\text { Chloroform } \\
1,1-\text { Dichlootoethylene } \\
\text { trans-1,2-Dichloroethylene } \\
\text { Tetrachloroethylene } \\
1,1,1 \text {-Trichloroethane } \\
\text { Trichloroethylene }\end{array}$ & $\begin{aligned}<1.0 \\
<1.0 \\
<1.0 \\
<1.0 \\
<1.0 \\
6.4\end{aligned}$ & & $\begin{array}{l}\mu g / L \\
\mu g / L \\
\mu g / L \\
\mu g / L \\
\mu g / L \\
\mu g / L\end{array}$ \\
\hline
\end{tabular}

WELL MSB 23TA

MEASUREMENTS CONDUCTED IN THE FIELD

Sample clate: 10/13/91

(7t $152.01 \mathrm{~m})$ below TOC

Water elevation: $202.25 \mathrm{ft}(61.65 \mathrm{~m}) \mathrm{ms}$

evacuated before sampling: $93 \mathrm{gal}$

LABORATORY ANALYSES

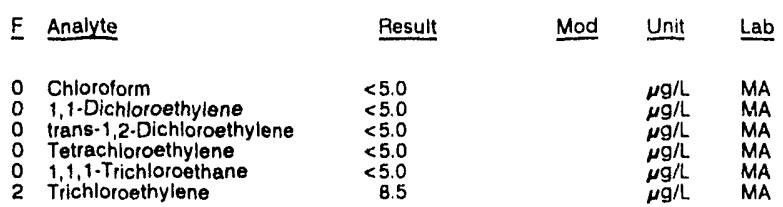

WELL MSB 23TA

MEASUREMENTS CONDUCTED IN THE FIELD

Sample date: 10/13/91

Depth to water: $170.85 \mathrm{ft}(52.01 \mathrm{~m})$ below TOC

Water elevation: $202.25 \mathrm{ft}(61.65 \mathrm{~m}) \mathrm{ms}$

Sp. conductance: 28 S $/ \mathrm{cm}$

Water evacuated betore sampling: $185 \mathrm{gal}$

LABORATORY ANALYSES

\begin{tabular}{|c|c|}
\hline E Analyte & Result \\
\hline $\begin{array}{l}\text { Chloroform } \\
1,1-\text { Dichloroethylene } \\
\text { trans-1,2.Dichloroethylene } \\
\text { Tetrachloroethylene } \\
1,1,1 \text {-Trichloroethane } \\
\text { Trichloroethylene }\end{array}$ & $\begin{array}{l}<1.0 \\
<1.0 \\
<1.0 \\
<1.0 \\
<1.0 \\
1.4\end{array}$ \\
\hline
\end{tabular}

WELL. MSB 23TA

MEASUREMENTS COINDUCTED IN THE FIELD

Sample date: 10/13/91

Depth to water: $170.65 \mathrm{ft}(52.01 \mathrm{~m})$ below TOC

Water elevation: $202.25 \mathrm{f}(61.65 \mathrm{~m}) \mathrm{ms}$

Sp. conductance: $27 \mu \mathrm{\mu S} / \mathrm{cm}$
Water evacuated betore sampling: $278 \mathrm{gal}$

LABORATORY ANALYSES

\begin{tabular}{|c|c|c|c|}
\hline F Analyte & Result & Mod & Unit \\
\hline $\begin{array}{l}\text { Chloroform } \\
1,1 \text {. Dichloroethylene } \\
\text { trans-1,2-Dichloroethylene } \\
\text { Tetrachloroethylene } \\
1,1,1 \cdot \text { Trichloroethane } \\
\text { Trichloroethylene }\end{array}$ & $\begin{array}{l}<1.0 \\
<1.0 \\
<1.0 \\
<1.0 \\
<1.0 \\
<1.0\end{array}$ & & $\begin{array}{l}\mu g / L \\
\mu g / L \\
\mu g / L \\
\mu g / L \\
\mu g / L \\
\mu g / L\end{array}$ \\
\hline
\end{tabular}

Time: 11:20

pH: 5.3

Water temperature: $20.5^{\circ} \mathrm{C}$
WELL MSB 23TA

MEASUREMENTS CONDUCTED IN THE FIELD

Sample date: $10 / 13 / 91$

Depth to water: $170.65 \mathrm{ft}(52.01 \mathrm{~m})$ below TOC Water elevation: $202.25 \mathrm{Ht}(61.65 \mathrm{~m}) \mathrm{msl}$

Water evacuated before $\mathrm{cm}$. 371

LABORATORY ANALYSES

\begin{tabular}{|c|c|c|}
\hline & Analyte & Resul \\
\hline & $\begin{array}{l}\text { Chloroform } \\
1,1 \cdot \text { Dichloroethylene } \\
\text { trans-1,2-Dichloroethylene } \\
\text { Tetrachioroethylene } \\
1,1,1 \text {-Trichloroethane } \\
\text { Trichloroethylene }\end{array}$ & $\begin{array}{l}<1.0 \\
<1.0 \\
<1.0 \\
<1.0 \\
<1.0 \\
<1.0\end{array}$ \\
\hline
\end{tabular}

\section{WELL MSB 23TA}

MEASUREMENTS CONDUCTED IN THE FIELO Sample date: $10 / 20 / 91$

Depth to water: $172.47 \mathrm{ft}(52.57 \mathrm{~m})$ below TOC Water olevation: $200.43 \mathrm{ft}(61.09 \mathrm{~m}) \mathrm{ms}$

Sp. conductance: $25 \mu \mathrm{S} / \mathrm{cm}$

No water was evacuated before sampling

LABORATORY ANALYSES

\begin{tabular}{|c|c|}
\hline Analyte & Result \\
\hline $\begin{array}{l}\text { Chloroform } \\
1,1 \cdot \text { Dichloroethylene } \\
\text { trans. } 1,2 \cdot \text {-Dichloroethylene } \\
\text { Tetrachloroethylene } \\
1,1,1 \cdot \text { Trichloroethane } \\
\text { Trichloroethylene }\end{array}$ & $\begin{aligned}<1.0 \\
<1.0 \\
<1.0 \\
<1.0 \\
<1.0 \\
2.5\end{aligned}$ \\
\hline
\end{tabular}

WELL MSB 23TA

MEASUREMENTS CONDUCTES IN THE FIELD

Sample date: $10 / 20 / 91$

Depth to water: 172.47 it $(52.57 \mathrm{~m})$ below TOC

Water elevation: $200.43 \mathrm{ft}(61.09 \mathrm{~m}) \mathrm{msl}$

Sp. conductance: $34, \mu \mathrm{S} / \mathrm{cm}$

Water evacuated before sampling: $81 \mathrm{gal}$

LABORATORY ANALYSES

E Analyte

Result

- Chloroform

1,1.Dichlorethylene

0 trans-1,2-Dichloroethylene

Tetrachloroethylen

$1,1,1$.Trichloroethane

$<5.0$
$<5.0$
$<5.0$
$<5.0$
$<5.0$
4.7

Time: 11:55

Alkalinity: $1 \mathrm{mg}$

Water temperature: $20.3^{\circ} \mathrm{C}$

Time: $12: 05$

pH: 5.0

Water temperature: $20.7^{\circ} \mathrm{C}$

VELL MSB 23TA

MEASUAEMENTS CONDUCTED IN THE FIELD

Sample date: $10 / 20 / 91 \mathrm{fop}(52.57 \mathrm{~m})$ below TOC

Water elevation: $200.43 \mathrm{ft}(61.09 \mathrm{~m}) \mathrm{ms}$ !

Sp. conductance: $27 \mathrm{~s} / \mathrm{cm}$

Water evacuated betore sampling: $183 \mathrm{gal}$

LABORATORY ANALYSES

E Analyte

Result

Time: $12: 40$

Alkelinity: $1 \mathrm{mg}$

Water temperature: $20.8^{\circ} \mathrm{C}$

Alkalinity: $5 \mathrm{mg} / \mathrm{L}$

Water temperature: $21.10 \mathrm{C}$

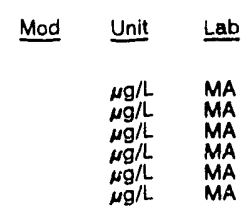

- Chloroform

1,1-Dichloroethylene

(n)

Tetrachloroethylene

Trichloroethylene
$<1.0$
$<1.0$
$<1.0$
$<1.0$
$<1.0$
$<1.0$ 
ANALYTICAL RESULTS

WELL MSB 23TA

MEASUREMENTS CONDUCTED IN THE FIELD

Sample date: 10/20/81 Depth to water: 172.47 h $(52.57 \mathrm{~m})$ below TOC Water olevation: $200.43 \mathrm{f}(61.09 \mathrm{~m}) \mathrm{ms}$ l p. conductance: $26 \mu \mathrm{s} / \mathrm{cm}$ Water ovacuated before sampling: $274 \mathrm{gal}$ LABORATORY ANALYSES

\begin{tabular}{|c|}
\hline Analyte \\
\hline $\begin{array}{l}\text { Chloroform } \\
1,1-\text { Dichloroethylene } \\
\text { trans-1,2-Dichloroethylene } \\
\text { Tetrachloroethylene } \\
1,1,1-\text { Trichloroethane } \\
\text { Trichloroethylene }\end{array}$ \\
\hline
\end{tabular}

WELL MSB 23TA

MEASUREMENTS CONDUCTED IN THE FIELO

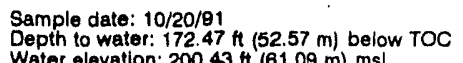
Water elevation: $200.43 \mathrm{ft}(61.09 \mathrm{~m}) \mathrm{msl}$ Water evacuated before sampling: $366 \mathrm{gal}$ LABORATORY ANALYSES

\begin{tabular}{|c|c|}
\hline E Analyte & Resuit \\
\hline $\begin{array}{l}\text { Chloroform } \\
\text { 1,1-Dichloroethylene } \\
\text { trans-1,2-Dichloroethylene } \\
\text { Tetrachloroothylene } \\
\text { 1,1,1-Trichloroethane } \\
\text { Trichloroethylene }\end{array}$ & $\begin{array}{l}<1.0 \\
<1.0 \\
<1.0 \\
<1.0 \\
<1.0 \\
<1.0\end{array}$ \\
\hline
\end{tabular}

WELL MSB 23TA

MEASUREMENTS CONDUCTED IN THE FIELD

Sample date: $10 / 27 / 91$

Depth to water: $172.37 \mathrm{ft}(52.54 \mathrm{~m})$ below TOC Water elevation: $200.53 \mathrm{ft}(61.12 \mathrm{~m}) \mathrm{ms}$ | No water was evacuated before sampling. LABOPATORY ANALYSES

\begin{tabular}{|c|c|c|}
\hline & Anajyte & Result \\
\hline & $\begin{array}{l}\text { Chloroform } \\
1,1-\text { Dichloroethylene } \\
\text { trans }-1,2 \text {-Dichloroethylene } \\
\text { Tetrachloroethylene } \\
1,1,1 \text {-Trichloroethane } \\
\text { Trichloroethylene }\end{array}$ & $\begin{array}{l}<1.0 \\
<1.0 \\
<1.0 \\
<1.0 \\
<1.0 \\
1.0\end{array}$ \\
\hline
\end{tabular}

WELL MSB 23TA

MEASUREMENTS CONDUCIED IN THE FIELD Sample date: 10/27/81 Depth to water: $172.37 \mathrm{ft}(52.54 \mathrm{~m})$ below TOC Water elevation: $200.53 \mathrm{~A}(61+2 \mathrm{~m}) \mathrm{msl}$ Sp. cunductance: $39 \mu \mathrm{s} / \mathrm{cm}$ Water evacuated before sampling: $92 \mathrm{gal}$ LABORATORY ANALYSES

\begin{tabular}{|c|c|c|c|c|}
\hline$\underline{F}$ & Analyte & Result & Mod & Unit \\
\hline $\begin{array}{l}0 \\
0 \\
0 \\
0 \\
0 \\
2\end{array}$ & $\begin{array}{l}\text { Chiofoform } \\
\text { 1,1-Dichloroethylene } \\
\text { trans-1,2-Dichloroethylene } \\
\text { Tetrachloroethylene } \\
1,1,1 \text {-Trichloroethene } \\
\text { Trichloroethylene }\end{array}$ & $\begin{aligned}<5.0 \\
<5.0 \\
<5.0 \\
<5.0 \\
<5.0 \\
\quad 7.2\end{aligned}$ & & $\begin{array}{l}\mu \mathrm{g} / \mathrm{L} \\
\mu \mathrm{g} / \mathrm{L} \\
\mu \mathrm{g} / \mathrm{L} \\
\mu \mathrm{g} / \mathrm{L} \\
\mu \mathrm{g} / \mathrm{L} \\
\mu \mathrm{g} / \mathrm{L}\end{array}$ \\
\hline
\end{tabular}

\author{
$\operatorname{Tim}_{\mathrm{pH}: 4.9} 13: 05$ \\ Alkalinity: $1 \mathrm{mg} /$ \\ Water temperature: $20.4^{\circ} \mathrm{C}$
}

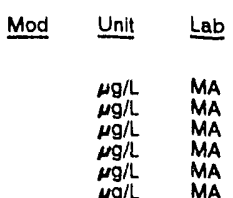

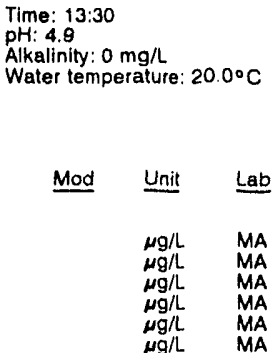

Time: 11:20

pH: 5.1

Water temperature: $21.4^{\circ} \mathrm{C}$

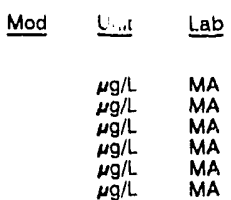

Time: $11: 40$

$\mathrm{pH}: 5.7$

Alkalinity: $6 \mathrm{mg}$

Water temperature: $20.5^{\circ} \mathrm{C}$

$\mu g / L \quad M A$

WELI. MSB 23TA

MEASUREMEN'S CONDUCTED IN THE FIELD

Sample date: 10/27/91

Depth to water: 172.37 it $(52.54 \mathrm{~m})$ below TOC Water elevation: $200.53 \mathrm{ft}(61.12 \mathrm{~m}) \mathrm{ms}$ !

Sp. conductance: $28, \mathrm{~S} / \mathrm{cm}$ Water evacuated belore sampling: $183 \mathrm{gal}$

LABORATORY ANALYSES

\begin{tabular}{|c|}
\hline Analyte \\
\hline $\begin{array}{l}\text { Chloroform } \\
1,1-\text { Dichloroethylene } \\
\text { trans } 1,2 \cdot \text { Dichloroethylene } \\
\text { Tetrachloroethylene } \\
\text { 1,1,1-Trichloroethane } \\
\text { Trichloroethylene }\end{array}$ \\
\hline
\end{tabular}

Time: 12:00

Alkalinity: $1 \mathrm{mg} / \mathrm{L}$

Water temperature: $21.0^{\circ} \mathrm{C}$

\section{WELL MSB 23TA}

MEASUREMENTS CONDUCTED IN THE FIELD

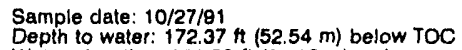
Water elevation: $200.53 \mathrm{ft}(61.12 \mathrm{~m}) \mathrm{ms}$

$\mathrm{Sp}$. conductance: $26 \mu \mathrm{S} / \mathrm{cm}$

Water evacuated before sampling: $275 \mathrm{gal}$

LABOFATORY ANALYSES

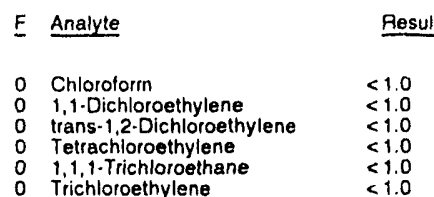

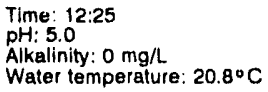

$\begin{array}{cc}\text { Mod Unit } & \text { Lab } \\ & \\ \mu g / L & M A \\ \mu g / L & M A \\ \mu g / L & M A \\ \mu g / L & M A \\ \mu g / L & M A \\ \mu g / L & M A\end{array}$

\section{WELL MSB 23TA}

MEASUREMENTS CONDUCTEO IN THE FIELD

Sample date: $10 / 27 / 81$

Depth to water: $172.37 \mathrm{Ht}(52.54 \mathrm{~m})$ below TOC

Water elevation: $200.53 \mathrm{ft}(61.12 \mathrm{~m}) \mathrm{ms}$ !

Sp. conductance: $25 \mu \mathrm{S} / \mathrm{cm}$
Water evacuated beiore sampling: $366 \mathrm{gal}$

LABORATORY ANALYSES

\begin{tabular}{|c|c|}
\hline$E$ Analyte & Result \\
\hline $\begin{array}{l}\text { Chloroform } \\
1,1-\text { Dichloroethylene } \\
\text { trans-1,2-Dichloroethylene } \\
\text { Tetrachloroethylene } \\
1,1,1-\text { Trichloroethane } \\
\text { Trichloroethylene }\end{array}$ & $\begin{array}{l}<1.0 \\
<1.0 \\
<1.0 \\
<1.0 \\
<1.0 \\
<1.0\end{array}$ \\
\hline
\end{tabular}

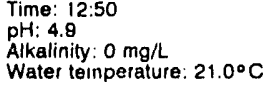

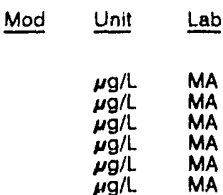

\section{WELL MSB 24}

MEASUAEMENTS CONDUCTED IN THE FIELD

Sample date: 12/02/91

Depth to water: $145.05 \mathrm{ft}(44.21 \mathrm{~m})$ below TOC Water elevation: $235.15 \mathrm{ft}(71.67 \mathrm{~m}) \mathrm{ms}$ |

Water evacuated before sampling: 6 gal The well went dry during purging.

LABORATORY ANALYSES

$\begin{array}{lll}\text { E Analyte } & \text { Result } \\ & & \\ 0 & \text { Chloroform } & <200 \\ 0 & 1,1 \cdot \text { Dichloroethylene } & <200 \\ 0 & \text { trans } 1,2 \cdot \text { Dichloroethylene } & <200 \\ 2 & \text { Tetrachloroethylene } & 1,890 \\ 0 & 1,1,1 \cdot \text { Trichloroethane } & <200 \\ 2 & \text { Trichloroethylene } & 8,270\end{array}$


ANALYTICAL RESULTS

WELL MSB 24A

MEASUREMENTS CONDUCTED IN THE FIELD Sample date: $12 / 13 / 91$
Depth to water: $157.70 \mathrm{ft}(48.07 \mathrm{~m})$ below TOC
Water elevation: $223.90 \mathrm{ft}(68.25 \mathrm{~m}) \mathrm{msl}$

Sp. conductance: $67 \mu \mathrm{S} / \mathrm{cm}$

No water was evacuated before sampling

LABORATORY ANALYSES

\begin{tabular}{|c|c|c|c|c|}
\hline$F$ & Analyte & Result & Mod & Unit \\
\hline $\begin{array}{l}0 \\
0 \\
0 \\
2 \\
0 \\
2\end{array}$ & $\begin{array}{l}\text { Chloroform } \\
1,1-\text { Dichloroethylene } \\
\text { trans-1,2-Dichloroethylene } \\
\text { Tetrachloroethylene } \\
1,1,1-\text { Trichloroethane } \\
\text { Trichloroethylene }\end{array}$ & $\begin{array}{l}<500 \\
<500 \\
<500 \\
2,030 \\
<500 \\
12,700\end{array}$ & & $\begin{array}{l}\mu g / L \\
\mu g / L \\
\mu g / L \\
\mu g / L \\
\mu g / L \\
\mu g / L\end{array}$ \\
\hline
\end{tabular}

WELL MSB 25

MEASUREMENTS CONDUCTED IN THE FIELD

Sample date: $11 / 13 / 91$
The well was dry.

Time: 11:45

WELL MSB 25A

MEASUREMENTS CONDUCTED IN THE FIELD

Sample date: $12 / 02 / 91$

Depth to water: $151.68 \mathrm{Ht}(46.23 \mathrm{~m})$ below TOC Water elevation: $214.72 \mathrm{tt}(65.45 \mathrm{~m}) \mathrm{msl}$

Water evacuated before sampling: $180 \mathrm{gal}$

LABORATORY ANALYSES

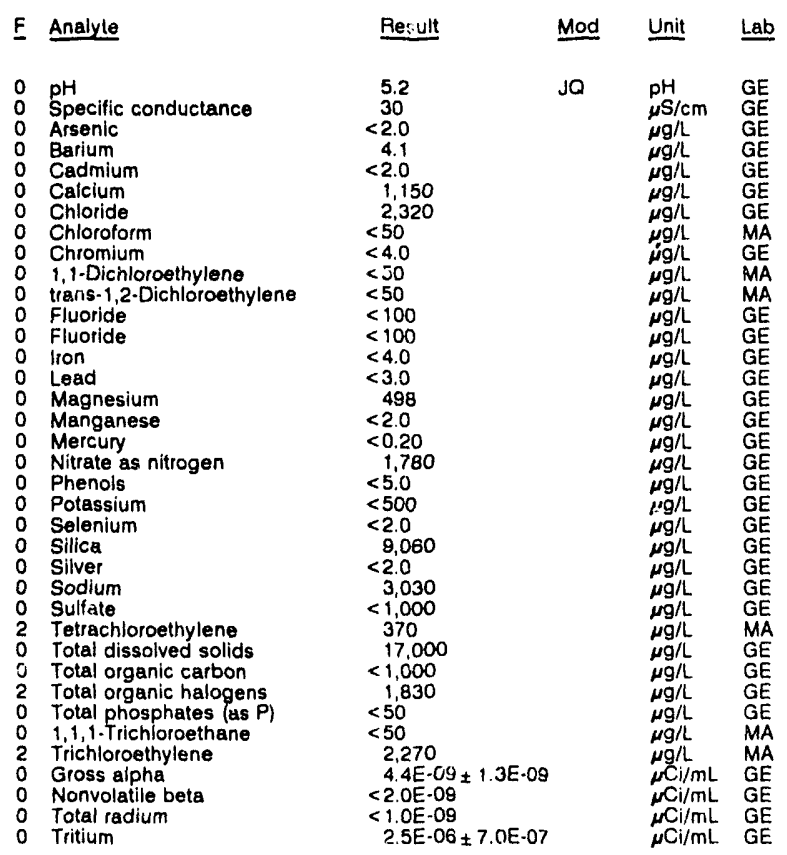

Whalinity: $15 \mathrm{mg}$
WELL MSB 26

MEASUREMENTS CONDUCTED IN THE FIELD

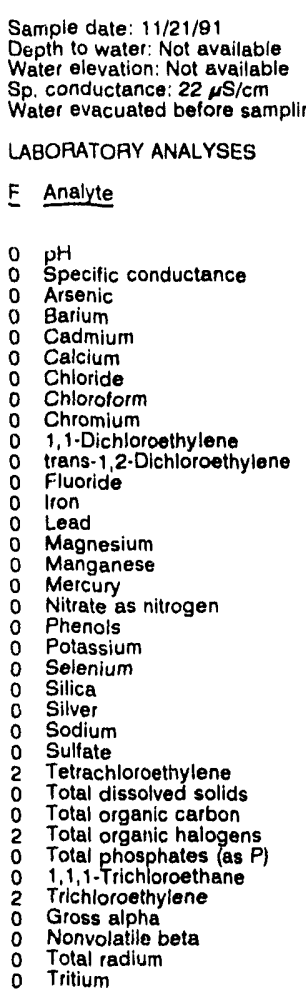

Time: $10: 20$

pH: 4.8

Water temperature: $20.3^{\circ} \mathrm{C}$

Alkalinity: $15 \mathrm{mg} / \mathrm{L}$
Water temperature: $20.8 \circ \mathrm{C}$

Water elevation: Not available

Sp. conductance: $22 \mu \mathrm{N} / \mathrm{cm}$
Water evacuated before sampling: $47 \mathrm{gg}$

LABORATORY ANALYSES

\begin{tabular}{l} 
Result \\
\hline 5.4 \\
20 \\
20 \\
$<2.0$ \\
$<3.0$ \\
$<2.0$ \\
440 \\
2,510 \\
$<2.0$ \\
$<4.0$ \\
$<2.0$ \\
$<2.0$ \\
$<100$ \\
17 \\
$<3.0$ \\
225 \\
3.0 \\
$<0.20$ \\
220 \\
$<5.0$ \\
$<500$ \\
$<2.0$ \\
8,280 \\
$<2.0$ \\
2,420 \\
1,100 \\
31 \\
28,000 \\
$<1,000$ \\
240 \\
$<50$ \\
$<2.0$ \\
117 \\
$2.2 \mathrm{E} \cdot 09 \pm 8.8 \mathrm{E}-10$ \\
$<2.0 \mathrm{E} \cdot 09$ \\
$1.1 \mathrm{E} \cdot 09 \pm 1.5 \mathrm{E} \cdot 09$ \\
$<7.0 \mathrm{E} \cdot 07$ \\
\end{tabular}

Mod Unit Lab

WELL MSB 26A

MEASUREMENTS CONDUCTED IN THE FIELD

Sample date: 11/21/81

Depth to water: $138.53 \mathrm{ft}(42.22 \mathrm{~m})$ below TOC

Water elevation: $222.37 \mathrm{Ht}(67.78 \mathrm{~m}) \mathrm{msl}$

Sp conductance $25 \mathrm{~s} / \mathrm{cm}$

Water evacuated before samplirig: $140 \mathrm{gal}$

LABORATORY ANALYSES

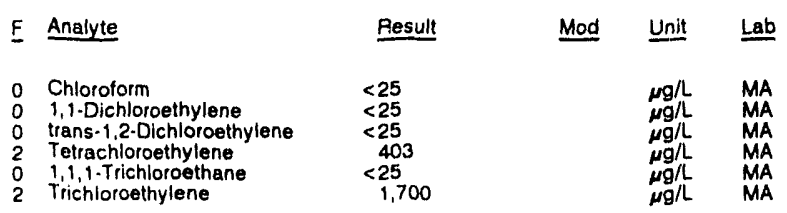

\section{WELL MSB 26B}

MEASUREMENTS CONDUCTED IN THE FIELD

Sample date: 11/05/81

Depth to water: $146.30 \mathrm{H}(44.59 \mathrm{~m})$ below TOC

Water elevation: $216.90 \mathrm{ft}(66.11 \mathrm{~m}) \mathrm{msl}$

Water evacuated before sampling: $222 \mathrm{gal}$

LABORATOPY ANALYSES

\begin{tabular}{|c|c|c|c|c|}
\hline$\underline{F}$ & Analyte & Result & Mod & Unit \\
\hline $\begin{array}{l}0 \\
0 \\
0 \\
0 \\
0\end{array}$ & $\begin{array}{l}\text { Chloroform } \\
1,1-\text { Dichloroethylene } \\
\text { trans } 1,2 \cdot \text { Dichloroethylene } \\
\text { Tetrachloroethylene } \\
1,1,1 \text {. Trichloroethane } \\
\text { Trichloroethylene }\end{array}$ & $\begin{array}{l}<2.0 \\
<2.0 \\
<2.0 \\
<2.0 \\
<2.0 \\
\quad 199\end{array}$ & & $\begin{array}{l}\mu g / L \\
\mu g / L \\
\mu g / L \\
\mu g / L \\
\mu g / L \\
\mu g, L\end{array}$ \\
\hline
\end{tabular}


WELL MSB 27

MEASUREMENTS CONDUCTED IN THE FIELL

Sample date: $11 / 13 / 91$

Depth to water: $138.09 \mathrm{ft}(42.09 \mathrm{~m})$ below TOC Water elevation: $237.41 \mathrm{Ht}(72.36 \mathrm{~m}) \mathrm{msl}$ Sp. Conductance: $54 \mu \mathrm{S} / \mathrm{cm}$
Water evacuated before sampling: $9 \mathrm{gal}$ LABORATORY ANALYSES

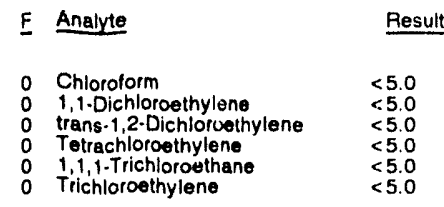

\section{WELL MSB 27A}

MEASUREMENTS CONDUCTED IN THE FIELD Sample date: $12 / 13 / 81$ Water to water: $146.89 \mathrm{~A}(44.80 \mathrm{~m})$ below Sp. conductance: $45 \mu \mathrm{s} / \mathrm{cm}$
No water was evacuated before sampling LABOPATORY ANALYSES

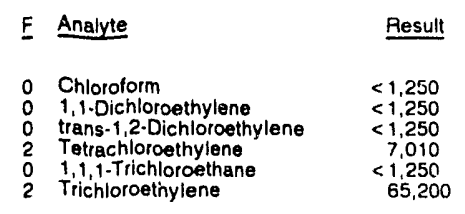

WELL MSB 27B

MEASUREMENTS CONDUCTED IN THE FIELD Sample date: $11 / 13 / 81$ fepth to water: $153.42 \mathrm{ft}(46.76 \mathrm{~m})$ below TOC Depth to water: $153.42 \mathrm{ft}(46.76 \mathrm{~m})$ below Sp. conductance: $24, \mathrm{NS} / \mathrm{cm}$
Water evacuated belore sampling: $155 \mathrm{gal}$ LABORATORY ANALYSES

\begin{tabular}{|c|c|}
\hline Enalyte & Pesult \\
\hline $\begin{array}{l}\text { Chloroform } \\
1,1-\text { Dichloroethylene } \\
\text { trans }-1,2 \text {-Dichloroethylene } \\
\text { Tetrachloroethylene } \\
1,1,1 \text {-Trichloroethane } \\
\text { Trichloroethylene }\end{array}$ & $\begin{array}{l}<20 \\
<20 \\
<20 \\
<20 \\
<20 \\
1,050\end{array}$ \\
\hline
\end{tabular}

WELL MSB 27TA

MEASUREMENTS CONDUCTED IN THE FIELD Sample date: 11/13/91 Depth to water: $177.41 \mathrm{ft}(54.08 \mathrm{~m})$ below TOC Water elevation: $199.19 \mathrm{ft}(60.71 \mathrm{~m}) \mathrm{ms}$ Water evacuated before sampling: $390 \mathrm{gal}$ LABORATORY ANALYSES

\begin{tabular}{|c|c|c|c|}
\hline Analyte & Resulf & Mod & Unit \\
\hline $\begin{array}{l}\text { Chloroform } \\
\text { 1,1-Dichloroethylene } \\
\text { trans-1,2-Dichloroethylene } \\
\text { Tetrachloroethylene } \\
1,1,1-\text { Trichloroethane } \\
\text { Trichloroethylene }\end{array}$ & $\begin{array}{l}<5.0 \\
<5.0 \\
<5.0 \\
<5.0 \\
<5.0 \\
<5.0\end{array}$ & & $\begin{array}{l}\mu \mathrm{g} / \mathrm{L} \\
\mu \mathrm{g} / \mathrm{L} \\
\mu \mathrm{g} / \mathrm{L} \\
\mu \mathrm{g} / \mathrm{L} \\
\mu \mathrm{g} / \mathrm{L} \\
\mu \mathrm{g} / \mathrm{L}\end{array}$ \\
\hline
\end{tabular}

Mod $\quad \begin{array}{cc}\text { Unit } & \text { Lab } \\ \mu g / L & M A \\ \mu g / L & M A \\ \mu g / L & M A \\ \mu g / L & M A \\ \mu g / L & M A \\ \mu g / L & M A\end{array}$

Time: $13: 25$

Alkalinity: $3 \mathrm{mg} / \mathrm{L}$
Water temperature. $19.1^{\circ} \mathrm{C}$
WELL MSB 28

MEASUREMENTS CONDUCTED IN THE FIELD

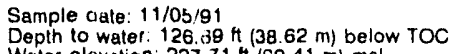

Water elevation: $227.71 \mathrm{H}(69.41 \mathrm{~m}) \mathrm{ms}$

Sp. conductance: $86 \mu \mathrm{S} / \mathrm{cm}$

Water evacuated before sampling: $45 \mathrm{gal}$

LABOFATORY ANALYSES
E Analyte
0 Chlorolorm
1,1-Dichloroethylene
0 trans-1,2-Dichloroethy
Tetrachloroethylene
$1,1,1-$ Trichloroethan
Trichloroethylene

$\underline{\text { Result }}$

$\begin{aligned} & \\ & \text { Result } \\ & <5.0 \\ \text { ne } & <5.0 \\ \text { ethylene } & <5.0 \\ & <5.0 \\ & <5.0 \\ & <5.0\end{aligned}$

Time: $7: 20$

Alkalinity $34 \mathrm{mg} / \mathrm{L}$

Water temperature: $15.6^{\circ} \mathrm{C}$

WELL MSB 28A

MEASUREMENTS CONDUCTED IN THE FIELD

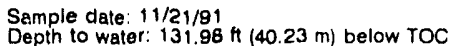

Water elevation: $222.22 \mathrm{ft}(67.73 \mathrm{~m}) \mathrm{msl}$

Sp. conductance: $2 \% \mu \mathrm{S} / \mathrm{cm}$

$\mathrm{pH}: 46$

Water evacuated before sampling: $183 \mathrm{gal}$

LABORATORY ANALYSES

\begin{tabular}{|c|c|}
\hline Analyte & Result \\
\hline $\begin{array}{l}\text { Chlorolorm } \\
1,1 \cdot \text { Dichloroethylene } \\
\text { trans } 1,2 \text {-Dichloroethylere } \\
\text { Tetrachloroethylene } \\
1,1,1 \cdot \text { Trichloroethane } \\
\text { Trichloroethylene }\end{array}$ & $\begin{aligned}<5.0 \\
<5.0 \\
<5.0 \\
<5.0 \\
<5.0 \\
275\end{aligned}$ \\
\hline
\end{tabular}

$\begin{array}{ll}\text { Mod Unit } & \text { Lab } \\ & \\ \mu g / L & M A \\ \mu g / L & M A \\ \mu g / L & M A \\ \mu g / L & M A \\ \mu g / L & M A \\ \mu g / L & M A\end{array}$

\section{WELL MSB 29A}

MEASUREMENTS CONDUCTED IN THE FIELO

Sample date: $10 / 04 / 91$

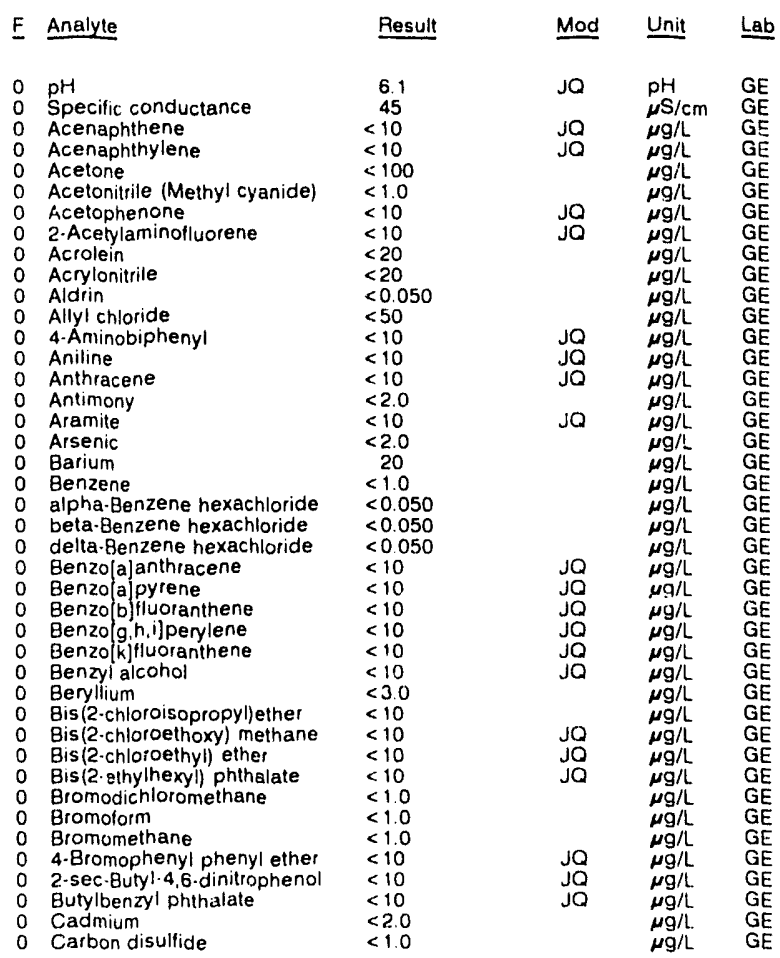

Time: $10: 40$

PH: 5.4

Water temperature $17.5^{\circ} \mathrm{C}$

(4) 1453 H (44.39 m) below TOC Water elevation: $219.77 \mathrm{Ht}(66.99 \mathrm{~m}) \mathrm{ms}$

Sp. conductance: $42 \mu \mathrm{S} / \mathrm{cm}$
Water evacuated before sampling: $265 \mathrm{gal}$

LABORATOAY ANALYSES

Time: $8: 40$

Alkalinity: $8 \mathrm{mg} / \mathrm{L}$ Water temperature: $188^{\circ} \mathrm{C}$

Time: $11: 20$

$\mathrm{pH}: 5.0$

Akalinity: $0 \mathrm{mg} / \mathrm{L}$

Water temperature $175^{\circ} \mathrm{C}$
Alkalinity: $2 \mathrm{mg} /$

$\begin{array}{cc}\text { Mod Unit } & \text { Lab } \\ & \\ \mu g / L & M A \\ \mu g / L & M A \\ \mu g / L & M A \\ \mu g / L & M A \\ \mu g / L & M A \\ \mu g / L & M A\end{array}$
Water temperature: $19.4^{\circ} \mathrm{C}$ 
ANALYTICAL RESULTS

WELL MS8 29A collecter on 10/04/91, laboratory analyses (cont.)

E Analyte

Carbon tetrachloride

$\begin{array}{lll}0 & 2,3,7,8-T C D F \\ 0 & 2,3,7,8-T C D F\end{array}$

o $2,3,7,8 . T C D F$

2,3,7,8.TCDF

0 Chlordane

para-Chloro-meta-cresol

4-Chloroaniline

o Chiorobenzilate

- Chloroethane

Chloroethane
Chilooethene Ninyl chloride)
2.Chioroethyl vinyl ether

Chloroform

2.Chloronaphthalene

4-Chlorophenyl phenyl ether

Chloroprene

O Chromium

Chrysene

Cobalt

O-Cresol (2-Methylphenal)

O m-Cresol (3-Methylphenol)

Cyanide

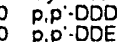

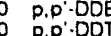

D,p.-DDT

Di.n-onl phalare

Dialiate

Dibenz[a,h]anthracere

1.2-Dibromo-3-chloropropane

Dibromochloromethan

1.2. Dibromoethane

Dibromomethane
trans-1,4-Dichloro-2.butene

1.2.Dichlorobenzene

1.3-Dichlorobenzene

1,3-Dichlorobenzene

Dichlorodifluoromethan

1, 1 .Dichloroethane

1,2.Dichloroethane

trans $:\{, 2$-Dichloroethylene

vichloromethane

2.4-Dichlorophenol

or

1,2-Dichloropropane

cis-1,3-Dichloropropene

trans-1,3-Dichloropropene

Dieldrin

Diethyl phthalate

2,4-Dimethyl phenol

p.Dimethylaminoazobenzene

Dimethylbenz(a)anthracene

3,3'-Dimethyibenzidine

a,a-Dimethyiphenethylamine

1.3.Dinitrobenzene

2.4.Dinitrotoluene

2,6. Dinitrotol

Diphenylamine

Disulfoton

Endosulfan I

Endosulfan sulfate

Endrin aldehyde

Ethyl methacrylate

Ethylbenzene

0 Famphur

Fluoranthene

Fivolene

Heplachlor epoxide

1,2.3.4.6,7,8.HPCDD

1,2,3,4,6,7,8-HPCDO

0
0
0

Heptachlorodibenzo-p-dioxins

Heplachlorodibenzo-p-dioxins

o Heptachlorodibenzo-p.dioxins

Heptachlorodibenzo-p.d

- $1,2,3,4,7,8 \cdot \mathrm{HPCDF}$

$\quad 1,2,3,4,6,7,8 . \mathrm{HPCDF}$

Heptachiorodibenzo-p.furans

0 Heptachlorodibenzo-p.furans
Result

$<1.0$

$<0.00040$

$<0.00040$

$<0.50$

1,690

$<10$
$<10$

$<1.0$
$<10$

$<10$

$<1.0$

$<10$

$<1.0$

$<10$

$<10$

$<40$
$<10$

$<10$

$<4.0$
$<4.0$

$<10$
$<10$
$<5$

$<5.0$
$<0.10$
$<0.10$
$<0.10$

0.10

$<10$

$<10$

10

$<10$

$<10$

$<20$

10

$<10$

$<10$

$<10$
$<10$

$<10$

$<10$

10

$<1.0$

$<10$
$<10$

$<0.30$

$<1.0$
$<1.0$

$<1.0$

$<0.50$

$<10$

$<10$
$<10$

$<10$

$<10$

$<<10$

$<10$

$<45$

$<40$

$<10$
$<10$

$<10$
$<10$

$<010$

$<0.10$

$<0.10$
$<0.0060$

$<0.10$

$<10$
$<10$

$<10$

$<10$

$<10$

$<10$
$<0050$

$<0.050$

$<000065$

$<0.00065$

$<0.00065$

$<0.00065$

$<000065$

$<0.00065$

$<00004$

0.0004

$<0.00045$

$<0.00045$
$<000045$

$<000045$

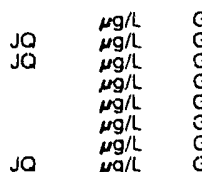

JO $\mu g / L$ GE

JO $\begin{array}{ll}\mu g / \mathrm{L} & \mathrm{GE} \\ \mu \mathrm{g} / \mathrm{L} & \mathrm{GE}\end{array}$

Jo $\begin{array}{ll}\mu g / L & G E \\ \mu g / h & G E\end{array}$

jo $\mu g / \mu \quad G E$

JO

Jo

Jo
Jo

-1
$j Q$
$j Q$
$j Q$
$j Q$

Jo
Jo
JO
JO

ja

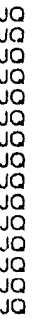

J

Jo

jo

jo

ja

ง

ja

jo
Lab

GE $\quad 0$ Heptachlorosinenzo-p-furans

Hexachlorobenzene

Hexachlorocyclopentadiene

$1,2,3,4,7,8-\mathrm{HXCOD}$
0

$1,2,3,4,7,8 \cdot H X C D D$

$1,2,3,4,7,8 \cdot+1 \times C D D$
$1,2,3,4,7,8.4 \times C D D$

Hexachlorodibenzo-p-dioxins

Hexachlorodibenzo-p-dioxins

Hexachlorodibenzo-p-dioxins

O Hexachlorodibenzo

$1,2,3,4,7,8+\mathrm{HXCO}$

$0 \quad 1,2,3,4,7,8-H X C D F$

o Hexachlorodibenzo-p.furans

Hexachlorodibenzo-p.furans

Hexactilorodibenzo-p.furans

Hexachlorodibenzo-p-furans

Hexachioroethane

Hexachlorophene

2.tiexanone

Indeno[1,2,3.c.d]pyrene

lodomethane (Methy

isobutyl alcohol

Isophorone

Kepone

Lead

Lindane

Miercury

Meihacryionitrilo

Methapyrilen

Methyl ethyl ketone

Methyl isobutyl ketone

Methyl methacrylate

Methyl methanesulfonate

2-Methyl-4,6-dinitroph
3-Methylcholanthrene

2-Methylnaphthalene

N.Nitrosodiethylamine

N-Nitrosodi-n-butylamine

$N-N i t r o s o d i-n-b u t y l a m i n e$
$N$-Nitrosodiphenylamine

N.Nitrosodi-propylamine

N.Nitrosomethylethylamine

N.Nitrosomorpholine

N-Nitrosopyrrolidine

Naphthalene

1.4-Naphthoquinone

1-Naphthylamine
2. Naphthylamine

Nitrate as nitrogen

5. Nitro.0-tuluidider

2.Nitroaniline

4.Nitroaniline

Nitrobenzene

2.Nitrophenal

4. Nitrophenol

4.Nitroquinoline-1-oxide

0,0,0-Triethyl phosphorothio

Octachlorodibenzo.p.oioxins

Octachlorodibenzo-p-dioxins

Octachlorodibenzo-p-dioxins

Octachlorodibenzo-p.furans

Octachlorodibenzo-p-furans

Octachlorodibenzo-p.furans

Oclachlorodibenzo-p.furans

Parathion

- PCB 1016

O PCB 1221

PCB 1242

C PCB 1248

0 PCB 1254

O Pentachlorobenzene

1,2,3,7.8.PCDF

$1,2,3,7,8 \cdot P C D F$

$1,2,3,7,8 \cdot P C D$

1,2,3,7,8.PCD

- Pentachlorodibenzo-p-dioxin

entachlorodibenzo-p-dioxin

- entachlorodibenzo-p.doxins

- Pentachlorodibenzo-p-dioxins

Pentacnlorodibenzo-p furans

- Pentachlorodibenzo-p.tufans

O Pentachlorodibenzo-p.furans

0 1,2,3.7.8.PCDF

Result Mod Unit Lab

$<0.00045$

$<<<0$

$<10$

$<0.00045$

$<0,00045$

$<0.00045$

$<0.00045$

$<0.00045$

$<0.00045$

$<0.00040$

$<0.00040$

$<0.0040$

$<0.00040$

$<0.00040$

$<0.00040$

$<10$

$<10$
$<10$
$<10$

$<10$
$<1.0$
$<10$
$<15$

$<15$
$<100$

$<10$

$<10$

$<10$

$<0.0050$

$<0.20$

$<50$

$<05$ 
ANALYTICAL RESULTS

WELL MSB 29A collerted on 10/04/91, laboratory analyses (cont)

\begin{tabular}{|c|c|c|c|c|c|}
\hline$F$ & Analyte & Result & Mod & Unit & Lat \\
\hline $\begin{array}{l}0 \\
0 \\
0 \\
0 \\
0 \\
0 \\
0 \\
0 \\
0 \\
0 \\
0 \\
0 \\
0 \\
0 \\
0 \\
0 \\
0 \\
0 \\
0 \\
0 \\
0 \\
0 \\
0 \\
0 \\
0 \\
0 \\
0 \\
0 \\
0 \\
0 \\
0 \\
0 \\
0 \\
0 \\
0 \\
0 \\
0 \\
0\end{array}$ & 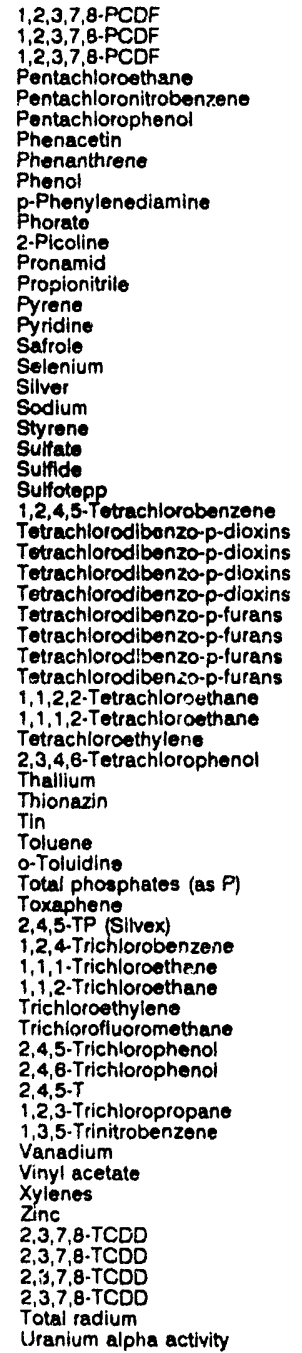 & $\begin{array}{l}<0.00055 \\
<0.00055 \\
<0.00055 \\
<10 \\
<10 \\
<10 \\
<10 \\
<10 \\
<10 \\
<10 \\
<0.10 \\
<10 \\
<10 \\
<200 \\
<10 \\
<10 \\
<10 \\
<2.0 \\
<2.0 \\
<1.680 \\
<1.0 \\
4,880 \\
<1,000 \\
<10 \\
<10 \\
<0.00045 \\
<0.00045 \\
<0.00045 \\
<0.00045 \\
<0.00040 \\
<0.00040 \\
<0.00040 \\
<0.00040 \\
<1.0 \\
<1.0 \\
<1.0 \\
<10 \\
<2.0 \\
<10 \\
<2.0 \\
<1.0 \\
<10 \\
<50 \\
<0.24 \\
<0.090 \\
<10 \\
<1.0 \\
<1.0 \\
<1.0 \\
<1.0 \\
<10 \\
<10 \\
<0.090 \\
<1.0 \\
<10 \\
<8.0 \\
<1.0 \\
<2.0 \\
<11 \\
<0.00045 \\
<0.00045 \\
<0.00045 \\
<0.00045 \\
<1.0 E \cdot 09 \\
<1.0 E \cdot 09\end{array}$ & $\begin{array}{l}\text { JO } \\
\text { JO } \\
\text { JO } \\
\text { JO } \\
\text { JO } \\
\text { JO } \\
\text { JQ } \\
\text { JO } \\
\text { JO } \\
\text { JQ } \\
\text { JQ } \\
\text { JO }\end{array}$ & 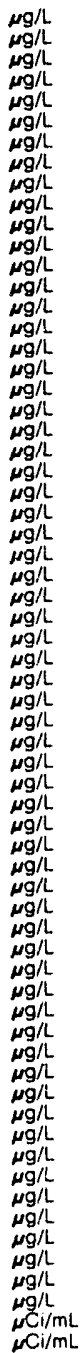 & $\begin{array}{l}\text { GE } \\
G E \\
G E \\
G E \\
G E \\
G E \\
G E \\
G E \\
G E \\
G E \\
G E \\
G E \\
G E \\
G E \\
G E \\
G E \\
G E \\
G E \\
G E \\
G E \\
G E \\
G E \\
G E \\
G E \\
G E \\
G E \\
G E \\
G E \\
G E \\
G E \\
G E \\
G E \\
G E \\
G E \\
G E \\
G E \\
G E \\
G E \\
G E \\
G E \\
G E \\
G E \\
G E \\
G E \\
G E \\
G E \\
G E \\
G E \\
G E \\
G E \\
G E \\
G E \\
G E \\
G E \\
G E \\
G E \\
G E \\
G E \\
G E \\
G E \\
G E \\
G E \\
G E \\
G E \\
G E\end{array}$ \\
\hline
\end{tabular}

WELL MSB 29B

MEASUREMENTS CONDUCTED IN THE FIELO

Sample cate: 10/04/81

Depth to wator: $142.06 \mathrm{H}(43.30 \mathrm{~m})$ below TOC

Water elevation: $223.14 \mathrm{t}(68.01$

Sp. conductance: $24 \mathrm{\mu s} / \mathrm{cm}$
Water evacuated before sampling: $198 \mathrm{gai}$

LABORATORY ANALYSES

\begin{tabular}{|c|c|c|c|}
\hline Analyte & Result & Mod & Urill \\
\hline $\begin{array}{l}\text { pH } \\
\text { Specific conductance } \\
\text { Acenaphthene } \\
\text { Acenaphthylene } \\
\text { Acetone } \\
\text { Acetonitrile (Methyl cyanide) } \\
\text { Acetophenone } \\
\text { 2-Acety!aminofluorene } \\
\text { Acrolein } \\
\text { Acrylonitrile } \\
\text { Aldrin } \\
\text { Allyl chloride } \\
\text { 4-Aminobiphenyl } \\
\text { Aniline } \\
\text { Anthracene } \\
\text { Antimony } \\
\text { Aramite } \\
\text { Arsenic }\end{array}$ & $\begin{array}{l}4.6 \\
30 \\
<10 \\
<10 \\
<100 \\
<1.0 \\
<10 \\
<10 \\
<20 \\
<20 \\
<0050 \\
<50 \\
<10 \\
<10 \\
<10 \\
<2.0 \\
<10 \\
<2.0\end{array}$ & Jo & $\begin{array}{l}p H \\
\mu S / c m \\
\mu g / L \\
\mu g / L \\
\mu g / L \\
\mu g / L \\
\mu g / L \\
\mu g / L \\
\mu g / L \\
\mu g / L \\
\mu g / L \\
\mu g / L \\
\mu g / L \\
\mu g / L \\
\mu g / L \\
\mu g / L \\
\mu g / L \\
\mu g / L\end{array}$ \\
\hline
\end{tabular}

WELL MSB 298 collected on 10/04/91, laboratory analyses (cont.)

E Analyte Result Mod Unit Lab

0 Barium

0 alpha-Benzene hexachloride $\quad<0.050$

0 beta-Benzene hexachloride $<0.050$

delta-Benzene hexachloride $\quad<0.050$

$\begin{array}{ll}\text { Benzola|anthracene } & <10 \\ \text { Benzolajpyrene } & <10\end{array}$

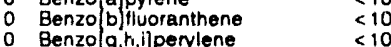

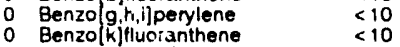

$\begin{array}{ll}0 & \text { Benzolkfluoianthene } \\ 0 & <10 \\ 0 & <10\end{array}$

$\begin{array}{ll}0 & \text { Beryllium } \\ 0 & <3.0 \\ & <10\end{array}$

0 Bis(2-chloroethoxy) methane $<10$

Bis(2-Chloroethyl) ether $\quad<10$

$\begin{array}{ll}0 & \text { Bromodir,hloromethane } \\ 0 & <1.0 \\ 0 & <1.0\end{array}$

$\begin{array}{ll}0 & \text { Bromomethane } \\ 0 & <1.0 \\ 0 & <1.0\end{array}$

2.sec Butyl.4,6-dinitrophenol $<10$

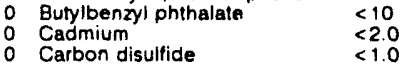

0 Carbon disulfide $\quad<1.0$

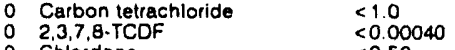

$\begin{array}{lll}0 & \text { Chlordane } & <0.50 \\ 0 & \text { Chloride } & 2,600\end{array}$

0 para-Chloro-meta-cresol $\quad<10$

4.Chloroaniline

Chlobenzene

Chlorothane

Chloroethene (Vinyl chloride) $<1.0$

0 2-Chloroethyl vinyl ether $<10$

0 Chloroform $\quad<1.0$

Chloromethane $\quad<1.0$

2-Chilorophienol

0 4-Chiorophenyl phenyl ether $<10$

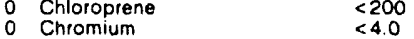

0 Chrysene $\quad<10$

0 Cobalt $\quad<40$

0 Copper (2.Methylphenol) $<40$

0 o-Cresol (2-Methylphenol) $<10$

0 p.Cresol (4.Methylphenol) $\quad<10$

0 Cyanide

0 o

$\begin{array}{ll}< & <0.10 \\ 0 & <0.10\end{array}$

o Di-n-butyl phthalate $<0.10$

$\begin{array}{ll}0 \text { Di-n-octyl phthalate } & <10\end{array}$

$\begin{array}{ll}0 & <10 \\ 0 & \text { Dibenz[a,h]anthracene }\end{array}$

- Dibenzolutan

0 Dizprome $<1.0$

12. $<1.0$

0 Dibromomethane $<20$

0 trans-1,4-Dichloro-2-butene $<30$

$0 \quad 1,2$-Dichlorobenzene $<10$

$0 \quad 1,3$.Dichlorobenzene $<10$

1,4.Dichlorobenzene $\quad<10$

0 Dichlarodifluoromethane < 10

o 1,1-Dichloroethane

- 1.2.Dichloroethane $<10$

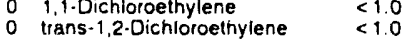

trans:1,2-Dichloroethylene $<1.0$

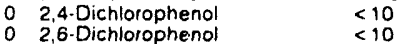

o 2,4-Dichlorophenoxyacetic acid $<0.30$

1.2.Dichloropropane $<1.0$

cis-1.3-Dichloropropene

trans-1.3-Dichloropropene

Dielárin

Diethyi phthalate

2.4.Dimethyl phenoi

Dimethyl phthalate

p-Dimethylaminoazobenzene

Dimethylbenz(a)anthracene

3,3. Dimethylbenzidine

a,a-Dimethylphenethylarnine $\quad<10$

, Dinitrophenol

2,4-Dinitrotoluene

2,6-Dinitrotoluene

1,4-Dioxane

Diphenylamin
Disulfotori

Endosulfan

Endosulfan II

Endrin

Endrin aldehyde

a

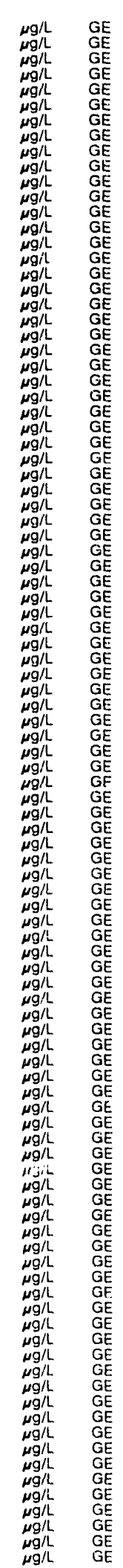


ANALYTICAL RESULTS

WELL MSB $29 B$ collected on 10/04/91, laboratory analyses (cont.)

E Analyte

- Ethyl methanesulfonate

0 Famphur

0 Fluoranthene

F Fuortane

Heptachlor epoxide

Heptachlorodibenzo-p-dioxins

$1,2,3,4,6,7,8 \cdot H P C D F$
Heptachiorodibenzo-p.furans

Hexachlorobenzene

Hexachlorocyclopentadiene

$1,2,3,4,7,8-H \times C D D$
Hexachiorodibenzo-p-dioxins

Hexachlorodibenzo

$1,2,3,4,7,8 \cdot H X C D F$
Hexachloradibenzo-p.furans

Hexachloroethane

Hexachtorophene

2.Hexanone

indeno $[1,2,3 \cdot c, d] p y r e n e$
lodomethane (Methyl iodide)

lodomethane (Methy
Isobutyl alcohol

Isodrin

Isosafrole

Kepone

Lead

Lindane

Methacrylonitrile

Methapyrilene

Methoxychlor

Methyl ethyl ketone

Methyl isobutyl keton

Methyl methanesulfonate

2.Methyl-4.6-dinitrophenol

3-Methyicholanthrene

2.Methylnaphthalene

N.Nitrosodimethylamine

N-Nitrosodi-n.butylamine

$\mathrm{N}$-Nitrosodiphenylamine

N.Nitrosodi-propylanine

N-Nitrosomethylethylamin

N.Nitrosomorpholine

N.Nitrosopyrrolidine

Naphthalene

2-Naphthylamine

Nicke

Nitrate as nitrogen

5-Nitro-O-tolvidine
2-Nitroaniline

3. Nitroaniline

4-Nitroaniline

Nitrobenzene

4.-Nitrophenol

4-Nitroquinoline-1-oxide

$0,0,0$-Triethyl phosphorothio

Octachlorodibenzo-p-dinxinis

Parathion

Parathion methy!

PCB 1016

PCB 1221

PCB 1232

PCB 1248

PCB 1254

Pentachlorobenzene

1,2,3,7,8.PCDF

Pentachlorodibenzo-p-dioxins

Pentachlorodibenzo-p-turans

$1,2,3,7,8$-PCDF

Pentachloroethane

Pentachloronitrobenzene $\quad<10$

Phenacetin $<10$

Phenanthrene $<10$

p.Phenylenediamine $\quad<10$

2.Picoline 10

0 Pronamid $<10$

$\begin{array}{ll}0 & \text { Pyrene } \\ 0 \text { Pyridine } & <10 \\ 0 & <10\end{array}$

- Safrole

Selenium

- Silver

o Sodium
$<10$

$<10$

$<0.050$

0.00065

$<0.00065$

0.00045

$<10$

$<0.00045$

$<0.00045$

0.00040

$<10$

$<10$

$<10$

$<15$
$<100$

$<10$
$<10$

$<10$
$<10$

$<3.0$

$<0.20$

$<10$

$<0.50$

$<1.0$

$<10$
$<10$

$<10$

$<10$

$<10$

$<10$
$<10$

$<10$

$<10$
$<10$

$<10$
$<10$

$<10$
$<10$

$<10$
$<10$

$<4.0$

$<10$
$<10$

$<10$
$<10$

$<10$
$<10$

$<10$

$<10$

$<0.0010$
$<0.0010$

$<0.050$

$<0.50$

$<0.50$

$<0.50$
$<0.50$
$<0.50$

$<0.50$
$<0.50$
$<0.50$

0.00055

0.00055

0.00055

$<10$
$<10$
$<2.0$

$<2.0$
$<2.0$
2.100
Mod

\begin{tabular}{|c|c|c|c|}
\hline $\begin{array}{l}\mu g / L \\
\mu g / L \\
\mu g / L \\
\mu g / L \\
\mu g / L \\
\mu g / L \\
\mu g / L \\
\mu g / L \\
\mu g / L \\
\mu g / L \\
\mu g / L \\
\mu g / L \\
\mu g / L \\
\mu g / L \\
\mu g / L \\
\mu g / L \\
\mu g / L \\
\mu g / L \\
\mu g / L \\
\mu g / L \\
\mu g / L \\
\mu g / L \\
\mu g / L \\
\mu g / L \\
\mu g / L \\
\mu g / L \\
\mu g / L \\
\mu g / L \\
\mu g / L \\
\mu g / L \\
\mu g / L \\
\mu g / L \\
\mu g / L \\
\mu g / L \\
\mu g / L\end{array}$ & $\begin{array}{l}\mathrm{GE} \\
\mathrm{GE} \\
\mathrm{GE} \\
\mathrm{GE} \\
\mathrm{GE} \\
\mathrm{GE} \\
\mathrm{GE} \\
\mathrm{GE} \\
\mathrm{GE} \\
\mathrm{GE} \\
\mathrm{GE} \\
\mathrm{GE} \\
\mathrm{GE} \\
\mathrm{GE} \\
\mathrm{GE} \\
\mathrm{GE} \\
\mathrm{GE} \\
\mathrm{GE} \\
\mathrm{GE} \\
\mathrm{GE} \\
\mathrm{GE} \\
\mathrm{GE} \\
\mathrm{GE} \\
\mathrm{GE} \\
\mathrm{GE} \\
\mathrm{GE} \\
\mathrm{GE} \\
\mathrm{GE} \\
\mathrm{GE} \\
\mathrm{GE} \\
\mathrm{GE}\end{array}$ & $\begin{array}{l}0 \\
0 \\
0 \\
0 \\
0 \\
0 \\
0 \\
0 \\
0 \\
0 \\
0 \\
0 \\
0 \\
0 \\
0 \\
0 \\
0 \\
0 \\
0 \\
0 \\
0 \\
0 \\
0 \\
0 \\
0 \\
0 \\
0 \\
0 \\
0 \\
0 \\
0 \\
0 \\
0 \\
0 \\
0\end{array}$ & 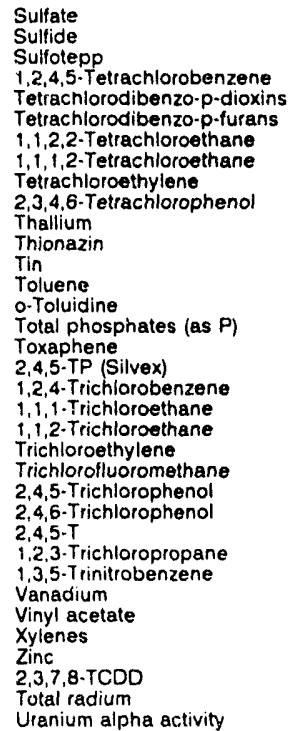 \\
\hline
\end{tabular}

WELL MSB $29 \mathrm{C}$

MEASUREMENTS CONDUCTEO IN THE FIELD

Sample date: 10/04/91

Depl' to water: $135.26 \mathrm{ft}(41.23 \mathrm{~m})$ below TOC

Water elevation: $229.94 \mathrm{th}(70.09 \mathrm{~m}) \mathrm{ms}$ |

Sp. conductance: $27 \mu \mathrm{s} / \mathrm{cm}$

ampling: $143 \mathrm{gal}$

LABORATORY ANALYSES

F Analyte

0 pH

$\begin{array}{lll}0 & \text { pH } \\ 0 & \text { Specif } & \\ 0 & \text { Acena } & \end{array}$

Acenaic conductance

Acenaphthylene

Acetonitrile (Methyl cyanide)

Acetophenone
2-Acetylaminofluorene

2.Acetylamir

Acrylonitrile

Aliyl chioride

4-Aminobiphenyl

Aniline

Aramite

Arsenic

Barium

alpha.Benzene hexachloride

bela.Benzene hexachloride

delta-Benzene hexachlorid

Benzo a anthrace

Benzo a pyrene
Benzo b ffluoranthene

Benzolg, h,ijperylene

Benzo[k]fluoranthen

Benzyl alcohol

Bis (2-chloroisopropyl)ether

Bis(2-chloroethoxy) methane

Bis (2.chloroethyli) ether

Bis(2-ethylhexyl) phthala

Bromodichior

Bromoform

4-Bromophenyl phenyl ether

2.-Bromophenyl phenyl ether

Butylbenzyl phthalate

Cadmium

Carbon disulfide

Carbon tetrachloride

Chlordane

para-Chioro-meta-cresol

4.Chloroaniline
Result

2,660
$<1,000$

$<10$

$<0.00045$

$<1.0$

$<1.0$

$<2.0$

$<2.0$

$<10$
$<50$

$<0.24$

$<10$

$<1.0$

$<1.0$

$<10$
$<10$

$<0.090$

$<1.0$

$<1.0$

$<2.0$
2.7

$<1.0 \mathrm{E}-09$
$<1.0 \mathrm{E} \cdot 09$

Time: $8: 20$

PH: 4.7 : $0 \mathrm{mg} / \mathrm{L}$

Alkalinity: $0 \mathrm{mg} / \mathrm{L}$

Result $\quad$ Mod Un:: Lab

$5.1 \quad \mathrm{~J}$

$<10$
$<10$

$<100$

$<1.0$

$<10$
$<20$

$<0.050$

$<50$

$<10$

$<2.0$

$<2.0$

5.4
$<1.0$

$<0.050$

$<0.050$

$<10$

$<10$

$<10$

$<10$

$<10$

$<10$

$<10$

$<10$

$<1.0$

$<1.0$

$<10$
$<10$

$<10$
$<2.0$

$<1.0$

$<0.00040$

$<0.50$

2,150

$<10$
$<10$
Jo

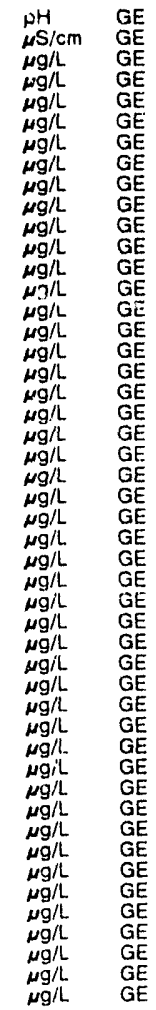


ANALYTICAL RESULTS

WELL MSB 29 C collected on 10/04/91, laboratory analyses (c

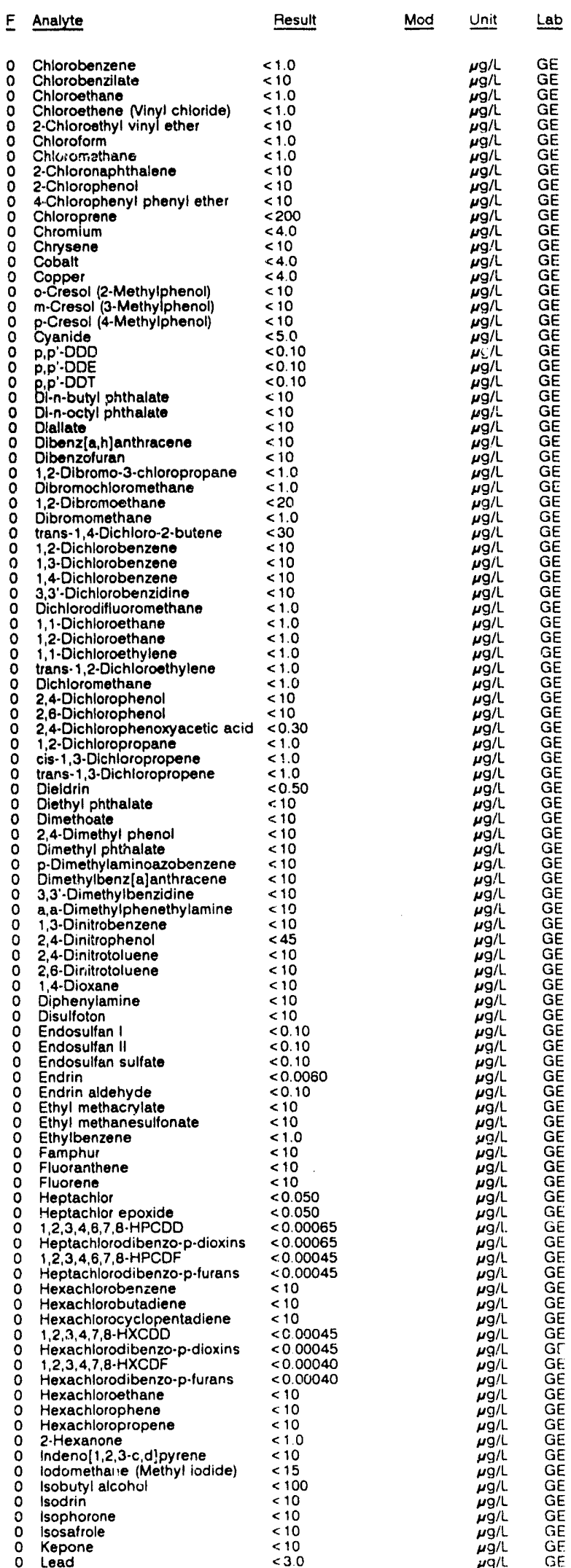

WELL MSB 29C collected on 10/04/91, labotatory analyses (cont.)

E Analyte Result Mod Unit Lab

Mercury $\quad<0.20$

Methapyrilene $\quad<10$

Methoxychlor $<0.50$

Methyl ethyl ketone $\quad<1.0$

Methyl methacry ate

Methyl methanesulfonate $\quad<10$

2-Methyl-4,6-dinitrophenol $\quad<10$

$\begin{array}{ll}\text { 3-Methylcholanthrene } & <10 \\ \text { 2-Methylnaphthalene } & <10\end{array}$

N-Nitrosodiethylamine $<10$

N-Nitrosodi-n-butylamine $\quad<10$

N-Nitrosodiphenylamine $<10$

N-Nitrosomethylethylamine $<10$

o N-Nitrosomorpholine $\quad<10$

N-Nitrosopiperidine $\quad<10$

0 N.Nitrosopyrrolidine $\quad<10$

0 1.4-Naphthoquinone $<10$

1-Naphthylamine $\quad<10$

$<4.0$

$\begin{array}{lll} & \text { Nitrate as nitrogen } & 1,600 \\ 0 & 5 \text {-Nitro-0-toluidine } & <10\end{array}$

2-Nitroaniline $<10$

4-Nitroaniline $<10$

Nitrobenzene $<10$

2-Nitrophenol $1<1$

0 4-Nitroquinoline-1-oxide $<10$

0 0,0-Triethyl phosphorothioate $<10$

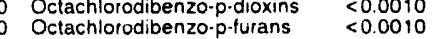

$<0.050$

Parathion methyl $<0.050$

$\begin{array}{ll}\text { PCB } 1016 & <0.50 \\ \text { PCB } 1221 & <0.50\end{array}$

PCB 1232

O $\mathrm{PCB} 1242$

0 PCE 1254

PCB 1260

$<10$

Pentachlorodibenzo-p-dioxins $<0.00055$

$\begin{array}{ll}\text { Pentachlorodibenzo-p.furans } & <0.00055 \\ 1,2,3,7,8 \cdot P C D F & <0.00055\end{array}$

$\begin{array}{lll}\mu \mathrm{g} / \mathrm{L} & \mathrm{GE} \\ \mathrm{g} / \mathrm{h} & \mathrm{GE}\end{array}$

$<10$

Pentachloronitrobenzene $<10$

$\begin{array}{ll}\text { Pentachlorophenol } & <10 \\ \text { Phenacetin } & <10\end{array}$

Phenanthre

p-Phenylenediamine

Phorale

2.Picoline

Propionitrile

Pyrene

Pyridine

Safrole

Selenium

Silver

Sodium

Styrene

Sulfate

Sulfide

$1,2,4,5$-Tetrachiorobenzene

Tetrachlorodibenzo.p.dioxiris

1,1,2,2. Tetrachloroethane

Tetrachloroethylene

2,3,4,6-Tetrachlorophenol

Thallium

Thionazin

Tin

o-Toluidine

Total phosphates (as P)

Toxaphene

2.4.5.TP (Silvex)

1,2,4-Trichlorobenzene

i. 1.1. Trichloroethane

1,1,2-Trichloroethane

Trichlorofluoromethane

2,4,5. Trichlorophenol

2,4,6.T

1,2,3-Trichloropropane

1,5 . Trinitoropropan

Vanadium

Vinyl acetate

$<10$
$<10$

$<0.10$

$<10$
$<10$

$<200$

$<10$

$<10$

$<10$

$<2.0$
$<2.0$
2,140
$<1.0$

$<1,000$

$<1,000$

$<10$

$<0.00045$

$<1.0$

$<1.0$

$\because 1.0$

$<10$

$<2.0$

$<10$
+2.0

$<1.0$

$<50$

$<0.24$
$<0.090$

$<10$

$<1.0$

$<10$

$<1.0$

$<10$

$<0.090$

$<1.0$

$<8.0$ 
ANALYTICAL RESULTS

WELL MSB $29 \mathrm{C}$ collected on 10/04/91, laboratory analyses (conc.)

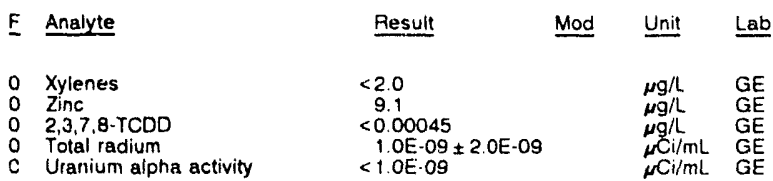

WELL MSB 29D

MEASUREMENTS CONDUCTED IN THE FIELD

Sample date: 10/04/91

Depth to water: $133.60 \mathrm{Ht}(40.72 \mathrm{~m})$ below TOC

Water elevation: $231.50 \mathrm{Ht}$ (70.

Water evacuated before sampling: $59 \mathrm{gal}$

Time: 9:05

pH: 4.4 : 0 malinity:

Water temperature: $18.5^{\circ} \mathrm{C}$

LABORATORY ANALYSES

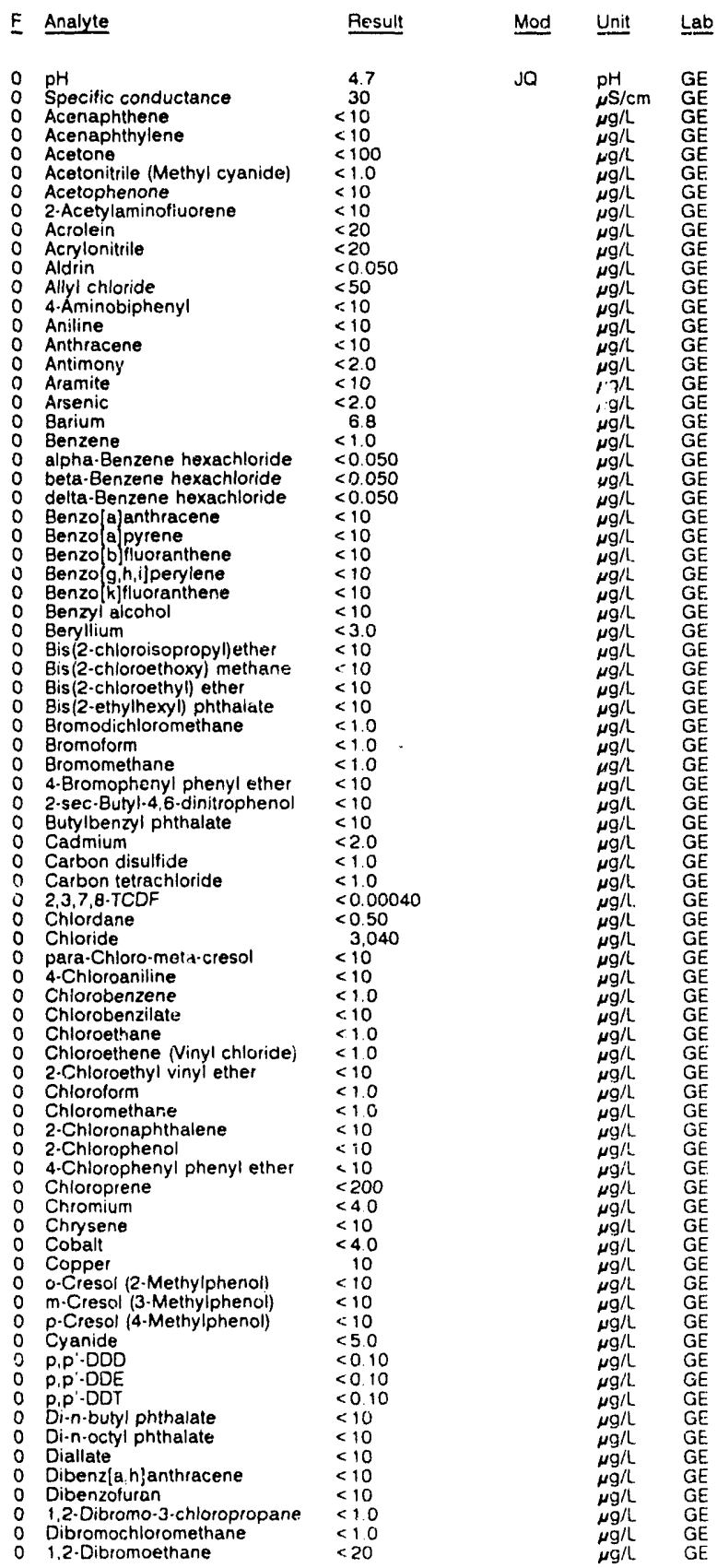

WELL MSB $29 D$ collected on 10/04/91, laboratory analyses (cont.)

\begin{tabular}{|c|c|c|c|c|c|}
\hline$F$ & Analyte & Result & Mod & $\underline{\text { Unit }}$ & Lab \\
\hline 0 & Dibromomethane & $<1,0$ & & $0 \mathrm{O} / \mathrm{L}$ & $\mathrm{GE}$ \\
\hline 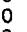 & trans- 1,4 -Dichloro-2-buterie & $<30$ & & $\mu g / L$ & $G E$ \\
\hline 0 & 1,2-Dichlorobenzene & $<10$ & & $\mu \mathrm{g} / \mathrm{h}$ & $G E$ \\
\hline & 1.3-Dichlorobenzene & $<10$ & & $\mu g / h$ & \\
\hline & 1.4-Dichlorobenzene & $<10$ & & $\mu g / L$ & $\mathrm{GE}$ \\
\hline U & 3,3'-Dichlorobenzidine & $<10$ & & $\mu g / \mathrm{h}$ & $\mathrm{GE}$ \\
\hline U & Dichlorodifluoromethane & $<10$ & & $\mu g / L$ & $\mathrm{GE}$ \\
\hline 0 & 1,1-Dichloroethane & $<1.0$ & & $\mu g / h$ & \\
\hline & 1,2-Dichloroethane & $<1.0$ & & $\mu \mathrm{g} / \mathrm{h}$ & $\mathrm{GE}$ \\
\hline U & $\begin{array}{l}\text { 1,1-Dichloroethylene } \\
\text { trans.1,2-Dichloroethylene }\end{array}$ & $<1.0$ & & $\mu g / \mathrm{h}$ & $\begin{array}{l}\mathrm{GE} \\
\mathrm{GE}\end{array}$ \\
\hline 0 & Dichloromethane & 1.5 & & $\mu \mathrm{g} / \mathrm{L}$ & $\mathrm{GE}$ \\
\hline & $\begin{array}{l}\text { 2,4-Dichlorophenol } \\
\text { 2.6-Dichlorophenol }\end{array}$ & $<10$ & & $\mu \mathrm{g} / \mathrm{h}$ & $\begin{array}{l}\mathrm{GE} \\
\mathrm{GE}\end{array}$ \\
\hline & 2,4-Dichlorophenoxyacetic acid & $<0.30$ & & $\mu g / L$ & $G E$ \\
\hline & 1,2-Dichloropropane & $<1.0$ & & $\mu \mathrm{g} / \mathrm{h}$ & $G E$ \\
\hline 0 & cis-1,3-Dichloropropene & $<1.0$ & & $\mu g / \mathrm{h}$ & \\
\hline 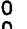 & trans-1,3-Dichloropropene & $<1.0$ & & $\mu \mathrm{g} / \mathrm{L}$ & \\
\hline & Dieldrin & $<0.50$ & & $\mu g / L$ & $\begin{array}{l}G E \\
G E\end{array}$ \\
\hline 0 & Dimethoate & $<10$ & & $\begin{array}{l}\mu g / L \\
\mu g / L\end{array}$ & \\
\hline & 2,4-Dimethyl phenol & $<10$ & & $\mu \mathrm{g} / \mathrm{L}$ & \\
\hline & Dimethyl phthalate & $<10$ & & $\mu \mathrm{g} / \mathrm{L}$ & \\
\hline & p-Dimeihylaminoazobenzene & $<10$ & & $\mu \mathrm{g} / \mathrm{L}$ & $\begin{array}{l}G E \\
G E\end{array}$ \\
\hline & 3,3'-Dimethylbenzidine & $\begin{array}{l}<10 \\
<10\end{array}$ & & $\underset{\mu g / L}{\mu g / L}$ & \\
\hline 0 & a,a-Dimethylphenethylamine & $<10$ & & $\mu g / L$ & 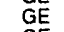 \\
\hline & 1.3-Dinitrobenzene & $<10$ & & $\mu \mathrm{g} / \mathrm{L}$ & $\mathrm{GE}$ \\
\hline & $\begin{array}{l}\text { 2,4-Dinitrophenol } \\
\text { 2,4-Dinitrotoluene }\end{array}$ & $<45$ & & $\mu \mathrm{g} / \mathrm{L}$ & $\begin{array}{l}\mathrm{GE} \\
\mathrm{GE}\end{array}$ \\
\hline & $\begin{array}{l}\text { 2.4-Dinitrotoluene } \\
\text { 2.6. Dinitrotoluene }\end{array}$ & $\begin{array}{l}<10 \\
<10\end{array}$ & & $\mu \mathrm{g} / \mathrm{h}$ & $\begin{array}{l}\mathrm{GE} \\
\mathrm{GE}\end{array}$ \\
\hline 0 & 1.4.Dioxane & $<10$ & & $\mu \mathrm{g} / \mathrm{L}$ & $\mathrm{GE}$ \\
\hline & Diphenylamine & $<10$ & & $\mu \mathrm{g} / \mathrm{L}$ & \\
\hline 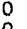 & Disulfoton & $<10$ & & $\mu g / L$ & c \\
\hline U & $\begin{array}{l}\text { Endosultan I } \\
\text { Endosulfan if }\end{array}$ & $<0.10$ & & $\mu g / L$ & \\
\hline & $\begin{array}{l}\text { Endosulfan if } \\
\text { Endosulfan sulfate }\end{array}$ & $\begin{array}{l}<0.10 \\
<0.10\end{array}$ & & 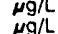 & \\
\hline & Endrin & $<0.0060$ & & $\mu \mathrm{g} / \mathrm{L}$ & \\
\hline & Endrin aldehyde & $<0.10$ & & $\mu \mathrm{g} / \mathrm{h}$ & \\
\hline & Ethyl methacrylate & $<10$ & & $\mu \mathrm{g} / \mathrm{L}$ & \\
\hline & Ethyl methanesulfonate & $<10$ & & $\mu \mathrm{g} / \mathrm{L}$ & \\
\hline & Ethylbenzene & $<1.0$ & & $\mu g / L$ & $\begin{array}{l}\mathrm{GE} \\
\mathrm{GE}\end{array}$ \\
\hline & $\begin{array}{l}\text { Famphur } \\
\text { Fluoranthene }\end{array}$ & $\begin{array}{l}<10 \\
<10\end{array}$ & & $\underset{\mu \mathrm{g} / \mathrm{L}}{\mu \mathrm{g} / \mathrm{L}}$ & $\mathrm{GE}$ \\
\hline 0 & Fluorene & $<10$ & & $\mu g / \mathrm{L}$ & \\
\hline & Heptachlor & $<0.050$ & & $\mu \mathrm{g} / \mathrm{L}$ & \\
\hline & $\begin{array}{l}\text { Heptachlor epoxide } \\
123,467.8 \cdot \mathrm{HPCDO}\end{array}$ & $<0.050$ & & $\mu \mathrm{g} / \mathrm{L}$ & $\begin{array}{l}\mathrm{GE} \\
\mathrm{GE}\end{array}$ \\
\hline 0 & $\begin{array}{l}1,2,3,4,6,7,8 \cdot H P C O U \\
\text { Heptachlorodibenzo-p-dioxins }\end{array}$ & $\begin{array}{l}<0.00065 \\
<0.00065\end{array}$ & & $\underset{\mu g / L}{\mu g / L}$ & $\mathrm{GE}$ \\
\hline 0 & $1,2,3,4,6,7,8-\mathrm{HPCOF}$ & $<0.00045$ & & $\mu \mathrm{g} / \mathrm{L}$ & \\
\hline 0 & Heptachlorodibenzo-p-furans & $<0.00045$ & & $\mu g / L$ & $\mathrm{GE}$ \\
\hline 0 & Hexachlorobenzene & $<10$ & & $\mu \mathrm{g} / \mathrm{L}$ & \\
\hline 0 & Hexachlorobutadiene & $<10$ & & $\mu g / L$ & \\
\hline 0 & Hexachiorocyclopentadiene & $<10$ & & $\mu \mathrm{g} / \mathrm{L}$ & c \\
\hline 0 & $1,2,3,4,7,8 \cdot+x \times C 0$ & $<0.00045$ & & $\mu \mathrm{g} / \mathrm{h}$ & \\
\hline 0 & Hexachlorodibenzo-p.dioxins & $<0.00045$ & & $\mu \mathrm{g} / \mathrm{L}$ & \\
\hline 0 & $1,2,3,4,7,8 \cdot H \times C D F$ & $<0.00040$ & & $\mu 9 / \mathrm{L}$ & $\mathrm{GE}$ \\
\hline 0 & Hexachlorodibenzo-p-turans & $<0.00040$ & & $\mu g / L$ & \\
\hline 0 & Hexachloroethane & $<10$ & & $\mu g / L$ & \\
\hline 0 & Hexachlorophene & $<10$ & & $\mu \mathrm{g} / \mathrm{L}$ & \\
\hline 0 & Hexachloropropene & $<10$ & & $\mu \mathrm{g} / \mathrm{L}$ & \\
\hline 0 & 2. Hexanone & $<10$ & & $\mu \mathrm{g} / \mathrm{h}$ & \\
\hline 0 & Indeno $(1,2,3 \cdot c, d]$ pyrene & $<10$ & & $\mu \mathrm{g} / \mathrm{L}$ & \\
\hline 0 & lodomethane (Methyl iodıde) & $<15$ & & $\mu g / L$ & \\
\hline 0 & Isobutyl alcohol & $<100$ & & $\mu \mathrm{g} / \mathrm{L}$ & \\
\hline 0 & Isodrin & $<10$ & & $\mu \mathrm{g} / \mathrm{L}$ & \\
\hline 0 & Isophorone & $<10$ & & $\mu g / L$ & \\
\hline 0 & Isosafrole & $<10$ & & $\mu g / \mathrm{L}$ & \\
\hline 0 & Kepone & $<10$ & & $\mu \mathrm{g} / \mathrm{L}$ & \\
\hline 0 & Lead & 4.0 & & $\mu \mathrm{g} / \mathrm{L}$ & \\
\hline 0 & Lindane & $<0.0050$ & & $\mu \mathrm{g} / \mathrm{L}$ & \\
\hline 0 & Mercury & $<0.20$ & & $\mu g / L$ & \\
\hline 0 & Methacry,onitrile & $<50$ & & $\mu g / L$ & \\
\hline 0 & Methapyrilene & $<10$ & & $\mu \mathrm{g} / \mathrm{L}$ & \\
\hline 0 & Methoxychlor & $<050$ & & $\mu \mathrm{g} / \mathrm{L}$ & \\
\hline 0 & Methyl ethyl ketone & $<10$ & & $\mu g / \mathrm{L}$ & \\
\hline 0 & Methyl isobutyl ketone & $<10$ & & $\mu g / L$ & \\
\hline 0 & Methy! methacrylate & $=10$ & & $\mu g / \mathrm{L}$ & \\
\hline 0 & Methyl methanesulfonate & $<10$ & & $\mu \mathrm{g} / \mathrm{h}$ & \\
\hline 0 & 2. Methy $1 \cdot 4,6 \cdot$ dinitrophenol & $<10$ & & $\mu g / L$ & \\
\hline 0 & 3-Methylcholanthrene & $<10$ & & $\mu \mathrm{g} / \mathrm{L}$ & \\
\hline 0 & 2-Methylnaphthalerie & $<10$ & & $\mu g / L$ & \\
\hline 0 & N-Nitrosodiethylamine & $<10$ & & $\mathrm{~g} / \mathrm{g} / \mathrm{L}$ & \\
\hline 0 & $N \cdot$ Nitrosodimethylamine & $<10$ & & $\mu \mathrm{g} / \mathrm{L}$ & \\
\hline 0 & N-Nitrosodi-n-butylamine & $<10$ & & $\mu g / L$ & \\
\hline 0 & N-Nitrosodiphenylamine & $<10$ & & $\mu \mathrm{g} / \mathrm{L}$ & \\
\hline 0 & N.Nitrosodi-propylamine & $<10$ & & $\mu g / L$ & \\
\hline 0 & N-Nitrosomethylethylanine & $<10$ & & $\mu \mathrm{g} / \mathrm{L}$ & \\
\hline 0 & N-Nitrosomorpholine & $<10$ & & $\mu g / L$ & $G$ \\
\hline 0 & N.Nitrosopiperidine & $<10$ & & $\mu g / \mathrm{L}$ & \\
\hline 0 & N.Nitrosopyrrolidine & $\div 10$ & & $\mu \mathrm{g} / \mathrm{L}$ & \\
\hline 0 & Naphthalene & $<10$ & & $\mu \mathrm{g} / \mathrm{L}$ & \\
\hline 0 & 1.4. Naphthoquinone & $<10$ & & $\mu \mathrm{g} / \mathrm{L}$ & \\
\hline 0 & 1. Naphthylamine & $<10$ & & $\mu \mathrm{g} / \mathrm{L}$ & \\
\hline 0 & 2. Naphthylamine & $<10$ & & $\mu g / L$ & \\
\hline 0 & Nickel & $<4.0$ & & $\mu \mathrm{g} / \mathrm{h}$ & \\
\hline 0 & Nitrate as nitrogen & 1,890 & & $\mu g / L$ & \\
\hline 0 & 5. Nitro.0-toluidine & $<10$ & & $\mu \mathrm{g} / \mathrm{L}$ & \\
\hline 0 & 2-Nitroandine & $<10$ & & $\mu g / L$ & \\
\hline 0 & 3-Nitcoaniline & $<10$ & & $\mu g / L$ & \\
\hline
\end{tabular}


ANALYTICAL RESULTS

WELL MSB 290 collected on 10/04/91, laboratory analyses (cont)

\begin{tabular}{|c|c|c|c|c|c|}
\hline$\underline{\mathbf{F}}$ & Analyte & Result & Mod & Unit & Lab \\
\hline 0 & 4-Nitroaniline & $<10$ & & $\mu g / \mathrm{L}$ & GE \\
\hline 0 & Nitrobenzene & $<10$ & & $\mu g / L$ & $\mathrm{GE}$ \\
\hline & 2. Nitrophenol & $<10$ & & $\mu g / L$ & $\mathrm{GE}$ \\
\hline & 4-Nitrophenol & $<10$ & & $\mu g / L$ & $\mathrm{GE}$ \\
\hline & 4-Nitroquinoline-1-oxide & $<10$ & & $\mu g / L$ & GE \\
\hline & O, 0,O- Triethyl phosphorothioate & & & $\mu g / L$ & GF \\
\hline 0 & $\begin{array}{l}\text { Octachlorodibenzo-p-dioxins } \\
\text { Octachlorodibenzo-p-furans }\end{array}$ & $\begin{array}{l}<0.0010 \\
<0.0010\end{array}$ & & $\begin{array}{l}\mu \mathrm{g} / \mathrm{L} \\
\mu \mathrm{q} / \mathrm{h}\end{array}$ & GE \\
\hline & Parathion & $<0.050$ & & $\mu g / L$ & $\mathrm{GE}$ \\
\hline $\begin{array}{l}0 \\
0\end{array}$ & $\begin{array}{l}\text { Parathion methyl } \\
\text { PCB } 1016\end{array}$ & $\begin{array}{l}<0.050 \\
<0.50\end{array}$ & & $\mu g / \mathrm{L}$ & $\mathrm{GE}$ \\
\hline 0 & PCB 1221 & $<0.50$ & & $\mu \mathrm{g} / \mathrm{L}$ & $\mathrm{GE}$ \\
\hline & PCB 1232 & $<0.50$ & & $\mu \mathrm{g} / \mathrm{L}$ & $\mathrm{GE}$ \\
\hline 0 & $\begin{array}{l}\text { PCB } 1242 \\
\text { PCB } 1248\end{array}$ & $\begin{array}{l}<0.50 \\
<0.50\end{array}$ & & $\mu g / L$ & $\begin{array}{l}\mathrm{GE} \\
\mathrm{GE}\end{array}$ \\
\hline 0 & PCB 1254 & $<0.50$ & & +2 & GE \\
\hline & PCB 1260 & $<0.50$ & & $\mu g / L$ & $\mathrm{GE}$ \\
\hline $\begin{array}{l}0 \\
0\end{array}$ & $\begin{array}{l}\text { Pentachlorobenzene } \\
1,3,78 . \mathrm{PCDF}\end{array}$ & $\begin{array}{l}<10 \\
<0.00055\end{array}$ & & $\mu g / L$ & GE \\
\hline 0 & $\begin{array}{l}, 2,3, a, 8-P C D F \\
\text { Pentachlorodibenzo-p-dioxins }\end{array}$ & $<0.00055$ & & $\begin{array}{l}\mu g / \mathrm{L} \\
\mu \mathrm{g} / \mathrm{L}\end{array}$ & $\begin{array}{l}\mathrm{GE} \\
\mathrm{GE}\end{array}$ \\
\hline & Pentachlorodibenzo-p-furans & $<0.00055$ & & $\mu g / L$ & $\mathrm{GE}$ \\
\hline $\begin{array}{l}0 \\
0\end{array}$ & $\begin{array}{l}1,2,3,7,8-P C D F \\
\text { Pentachloroethane }\end{array}$ & $\begin{array}{l}<0.00055 \\
<10\end{array}$ & & $\mu g / L$ & $\mathrm{GE}$ \\
\hline 0 & Pentachloronitrobenzene & $<10$ & & $\mu \mathrm{g} / \mathrm{L}$ & $\begin{array}{l}\text { GE } \\
\text { GE }\end{array}$ \\
\hline & Pentachlorophenol & $<10$ & & $\mu g / L$ & $\mathrm{GE}$ \\
\hline 0 & $\begin{array}{l}\text { Phenacetin } \\
\text { Phenanthrene }\end{array}$ & $<10$ & & $\mu g / L$ & $\mathrm{GE}$ \\
\hline $\begin{array}{l}0 \\
0\end{array}$ & $\begin{array}{l}\text { Phenanthrene } \\
\text { Phenol }\end{array}$ & $<10$ & & $\mu g / L$ & GE \\
\hline & $\begin{array}{l}\text { Phenol } \\
\text { p-Phenylenediamine }\end{array}$ & $<10$ & & $\mu g / L$ & \\
\hline $\begin{array}{l}0 \\
0\end{array}$ & $\begin{array}{l}\text { p.Phenylenediamine } \\
\text { Phorate }\end{array}$ & $\begin{array}{l}<10 \\
<0.10\end{array}$ & & $\mu \mathrm{g} / \mathrm{L}$ & $\begin{array}{l}\mathrm{GE} \\
\mathrm{GE}\end{array}$ \\
\hline & 2-Picoline & $<10$ & & $\mu g / \mathrm{L}$ & $\mathrm{GE}$ \\
\hline & Pronamid & $\begin{array}{l}<10 \\
<20 c\end{array}$ & & $\mu g / L$ & $\overline{G E}$ \\
\hline $\begin{array}{l}0 \\
0\end{array}$ & $\begin{array}{l}\text { Propionitrile } \\
\text { Pyrene }\end{array}$ & $\begin{array}{l}<200 \\
<10\end{array}$ & & $\begin{array}{l}\mu \mathrm{g} / \mathrm{L} \\
\mu \mathrm{g} / \mathrm{L}\end{array}$ & $\begin{array}{l}\mathrm{GE} \\
\mathrm{GE}\end{array}$ \\
\hline & Pyridine & $<10$ & & $\mu g / L$ & $\mathrm{GE}$ \\
\hline & Safrole & $<10$ & & $\mu \mathrm{g} / \mathrm{L}$ & GE \\
\hline $\begin{array}{l}0 \\
0\end{array}$ & $\begin{array}{l}\text { Selenium } \\
\text { Silver }\end{array}$ & $\begin{array}{l}<2.0 \\
<2.0\end{array}$ & & & $\begin{array}{l}\mathrm{GE} \\
\mathrm{GE}\end{array}$ \\
\hline & Sodium & 3,650 & & $\mu g / L$ & $\mathrm{GE}$ \\
\hline & Styrene & $<1.0$ & & $\mu g / L$ & $\overline{G E}$ \\
\hline & Sulfate & 7,310 & & $\mu g / L$ & \\
\hline & Sulfide & $\begin{array}{l}<1.000 \\
<10\end{array}$ & & $\mu \mathrm{g} / \mathrm{L}$ & GE \\
\hline & $\begin{array}{l}\text { Sulfotepp } \\
1,2,5 \text {-Tetrachlorobenzene }\end{array}$ & $<10$ & & $\mu g / L$ & GE \\
\hline & $\begin{array}{l}\text { 1,2,4,5-Tetrachlorobenzene } \\
\text { Tetrachlorodibenzo-p-dioxins }\end{array}$ & $\begin{array}{l}<10 \\
<000045\end{array}$ & & $\mu g / L$ & \\
\hline $\begin{array}{l}0 \\
0\end{array}$ & & $\begin{array}{l}<0.00045 \\
<000040\end{array}$ & & 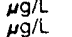 & $\begin{array}{l}\mathrm{GE} \\
\mathrm{GE}\end{array}$ \\
\hline & i, 1,2,2-Tetrachloroethane & $<10$ & & $\mu \mathrm{g} / \mathrm{L}$ & $\mathrm{GE}$ \\
\hline & 1.1,1,2-Tetrachloroethane & $<1.0$ & & $\mu g / \mathrm{h}$ & $\mathrm{GE}$ \\
\hline 0 & Tetrachloroethylene & $<1.0$ & & $\mu \mathrm{g} / \mathrm{L}$ & $\mathrm{GE}$ \\
\hline 0 & 2,3,4,6-Tetrachlorophenol & $<10$ & & $\mu \mathrm{g} / \mathrm{L}$ & GE \\
\hline & Thallium & $<2.0$ & & $\mu g / L$ & $\mathrm{GE}$ \\
\hline & Thionazin & $<10$ & & $\mu \mathrm{g} / \mathrm{L}$ & GE \\
\hline 0 & $\operatorname{Tin}$ & $<2.0$ & & $\mu \mathrm{g} / \mathrm{L}$ & \\
\hline 0 & Toluene & $<1.0$ & & $\mu g / L$ & $\mathrm{E}$ \\
\hline & O-Toluidine & $<10$ & & $\mu \mathrm{g} / \mathrm{L}$ & \\
\hline & Total phosphates (as, P) & $<50$ & & $\mu \mathrm{g} / \mathrm{L}$ & \\
\hline 0 & Toxaphene & $<0.24$ & & $\mu \mathrm{g} / \mathrm{L}$ & \\
\hline 0 & 2,4,5-TP (Silvex) & $<0.090$ & & $\mu \mathrm{g} / \mathrm{L}$ & \\
\hline 0 & 1,2,4-Trichiorobenzene & $<10$ & & $\mu g / L$ & E \\
\hline 0 & $1,1,1$. Trichloroethane & $<1.0$ & & $\mu \mathrm{g} / \mathrm{L}$ & $\mathrm{GE}$ \\
\hline 0 & 1,1,2-Trichloroethane & $<1.0$ & & $\mu \mathrm{g} / \mathrm{L}$ & \\
\hline 0 & Trichloroethylene & $<1.0$ & & $\mu \mathrm{g} / \mathrm{L}$ & GE \\
\hline 0 & Trichiorolluoromethane & $<10$ & & $\mu 9 / \mathrm{L}$ & $G E$ \\
\hline 0 & $\begin{array}{l}\text { 2,4,5-Trichlorophenol } \\
\text { 2,4,6. Trichlorophenol }\end{array}$ & $\begin{array}{l}<10 \\
<10\end{array}$ & & $\mu g / L$ & $\begin{array}{l}G E \\
G E\end{array}$ \\
\hline $\begin{array}{l}0 \\
0\end{array}$ & $\begin{array}{l}\text { 2.4,6-Trichlorophenol } \\
2,4,5 \cdot T\end{array}$ & $\begin{array}{l}<10 \\
<0.090\end{array}$ & & $\begin{array}{l}\mu g / L \\
\mu g / L\end{array}$ & $\mathrm{GE}$ \\
\hline 0 & 1,2,3-Trichloropropane & $<1.0$ & & $\mu \mathrm{g} / \mathrm{h}$ & $\mathrm{GE}$ \\
\hline 0 & 1.3,5-Trinitrobenzene & $<10$ & & $\mu \mathrm{g} / \mathrm{L}$ & $G E$ \\
\hline 0 & Vanadium & $<8.0$ & & $\mu g / L$ & GE \\
\hline 0 & Vinyl acetate & $<1.0$ & & $\mu \mathrm{g} / \mathrm{L}$ & $\mathrm{GE}$ \\
\hline 0 & Xylenes & $<2.0$ & & $\mu \mathrm{g} / \mathrm{L}$ & $\mathrm{GE}$ \\
\hline 0 & Zínc & 2.1 & & $\mu g / L$ & $\mathrm{GE}$ \\
\hline 0 & $2,3,7,8 \cdot T C D O$ & $<0.00045$ & & $\mu \mathrm{g} / \mathrm{L}$ & GE \\
\hline 1 & Total radium & $4.8 E \cdot 09 \pm 1.7 E \cdot 09$ & & ; & \\
\hline 0 & Uranium alpha activity & $<1.0 E-09$ & & $\mu \mathrm{Ci} / \mathrm{mL}$ & DE \\
\hline
\end{tabular}

WELL MSB 29TA

MEASUREMENTS CONDUCTED IN THE FIELD

Sample date: 10/04/9

Depth to water: $15321 \mathrm{ft}(46.70 \mathrm{~m})$ below TOC

Water elevation: $211.99 \mathrm{ft}(64.62 \mathrm{~m}) \mathrm{ms}$

Water evacuated before sampling: $398 \mathrm{gal}$

LABORATORY ANALYSES

\begin{tabular}{|c|c|c|c|}
\hline Analyte & Result & Mod & Unit \\
\hline $\begin{array}{l}\text { pH } \\
\text { Specific conductance } \\
\text { Acenaphthene } \\
\text { Acenaphthylene } \\
\text { Acetone } \\
\text { Acetonitrile (Methyl cyanide) } \\
\text { Acetophenone } \\
\text { 2-Acetylaminofluorene }\end{array}$ & $\begin{aligned} & 4.9 \\
& 20 \\
< & 10 \\
< & 10 \\
< & 100 \\
< & 10 \\
< & 10 \\
< & 10\end{aligned}$ & JO & $\begin{array}{l}\mathrm{pH} \\
\mu \mathrm{S} / \mathrm{cm} \\
\mu \mathrm{g} / \mathrm{L} \\
\mu \mathrm{g} / \mathrm{L} \\
\mu g / \mathrm{L} \\
\mu g / \mathrm{L} \\
\mu g / \mathrm{L}\end{array}$ \\
\hline
\end{tabular}

WELL MSB 29TA collected on 10/04/9! laboratony analyses (cont)

F Analyte Result Mod Unit Lab

0 Acrolein

0 Aldrin $\quad<0.050$

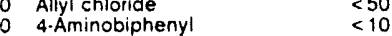

Aniline

o Anthracene

Antimony

- Aramite

O Arsenic

Barium

Benzene

alpha Benzene hexachloride

$\begin{array}{ll}\text { beta-Benzene hexachloride } & <0.050 \\ \text { delta.Benzene hexachloride } & <0.050\end{array}$

$<10$

Benzo[b]fluoranthene $<10$

Benzo $(g, h, i)$ perylene $\quad<10$

Benzo\{k\}fluoranthene $<10$

$\begin{array}{ll}\text { Benzyl alcohol } & <10 \\ & <30\end{array}$

Bis(2-chloroisopropyl)ether $<10$

Bis (2.chloroethoxy) methane $<10$

Bis (2-chloroethyl) ether

Bis (2-ethylhexyl) phthalate $<10$

$\begin{array}{ll} & <1.0 \\ 0 & <1.0\end{array}$

Bromomethane $<1.0$

4-Bromophenyl phenyl ether $<10$

$\begin{array}{ll}\text { 2-sec-Butyl-4.6.dinitrophenol } & <10 \\ \text { Butylbenzyl phthalate } & <10\end{array}$

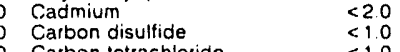

0 Carbon tetrachloride $\quad<1.0$

$\begin{array}{ll}0,3,7,8 \cdot T C D F & <0.00040 \\ 2,3,7,8 \cdot T C D F & <0.00040\end{array}$

Chlordane

Chloride

para-Chloro-meta-cresol

4.Chloroaniline

Chlorobenzere

Chlorobenzilate

Chloroethene (Vinyl chloride)

2-Chloroethyl vinyl ether

Chlorolorm

2.Chloronaphthalerie

4.Chlorophenyl phenyl ether

Chioroprene

Chromium

Chrysene
Cobalt

Cobalt

o-Cresol (2-Methylphenol)

m.Cresol (3-Methylphenol)
p-Cresol (4-Methylphenol)

P.Cresol $14-M$

p.p'-DDD

p.p'-DDE

Di-n-butyl phthalate

Di-n-octyl phthalate

Diallate

Dibenz[a,h]anthracene

Dibenzofuran

1,2-Dibromo-3-chloropropane

Dibromochloromethane

1,2-Dibromoethane

0 trans-1.4-Dichloro.2.butene

1,2-Dichlorobenzene

1,3-Dichlorobenzene

3,3'-Dichlorobenzidine

Dichlorodifluoromethan

1.2.Dichlcroethane

1,2-Oichlcroethane

trans.12. Dichlorothylene

Dichloromethane

2,6-Dichlorophenol

2.4. Dichlorophenoxyacetic acid

- 1,2-Dichloropropane

cis-1,3-Dichloroprupene
0 trans-1,3-Dichloropropene

0 Dieldrin

Dithyl phinalate

0 2,4-Dimethyl phenol $<10$

Dimethyl phthalate $<10$

p Dimethylaminoazobenzene

Dimethybenzla]anthracen

a a-Dimethylphenethylamine

a.a. Dimethylphenethyl

1,3-Dinitrobenzen
$<0.50$

1,890
$<10$

10

$<1.0$
$<10$

$<1.0$

$<1.0$

$<10$

$<1.0$

$<10$

$<10$
$<200$

4.0

$<10$

$<40$

$<10$

$<10$

$<10$
$<5.0$
$<0.10$
$<0.10$

$<0.10$

$<10$

$<10$

$<10$

$<10$

Mod Unit

b

$<0$

10

$<10$

$<10$

$<1.0$
$<10$

i

$<10$

10

$<10$

10

50

$<10$
$<10$
$\therefore 10$

$\because 10$
$<10$

$<10$
$<10$

$<10$
$<45$

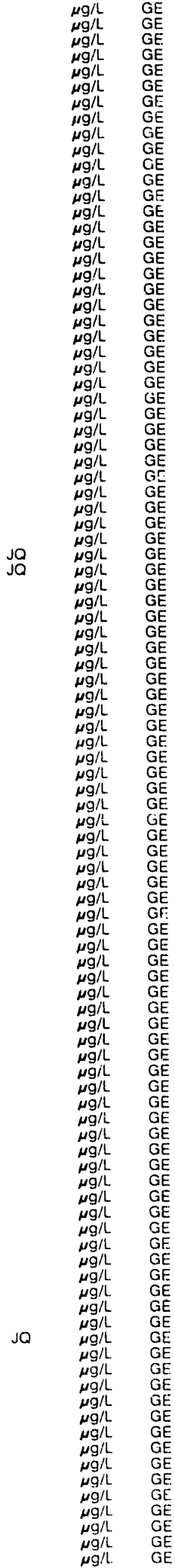


ANALYTICAL RESULTS

WELL MSE IJTA collected on 10/04/91, laboratory analyses (cont)

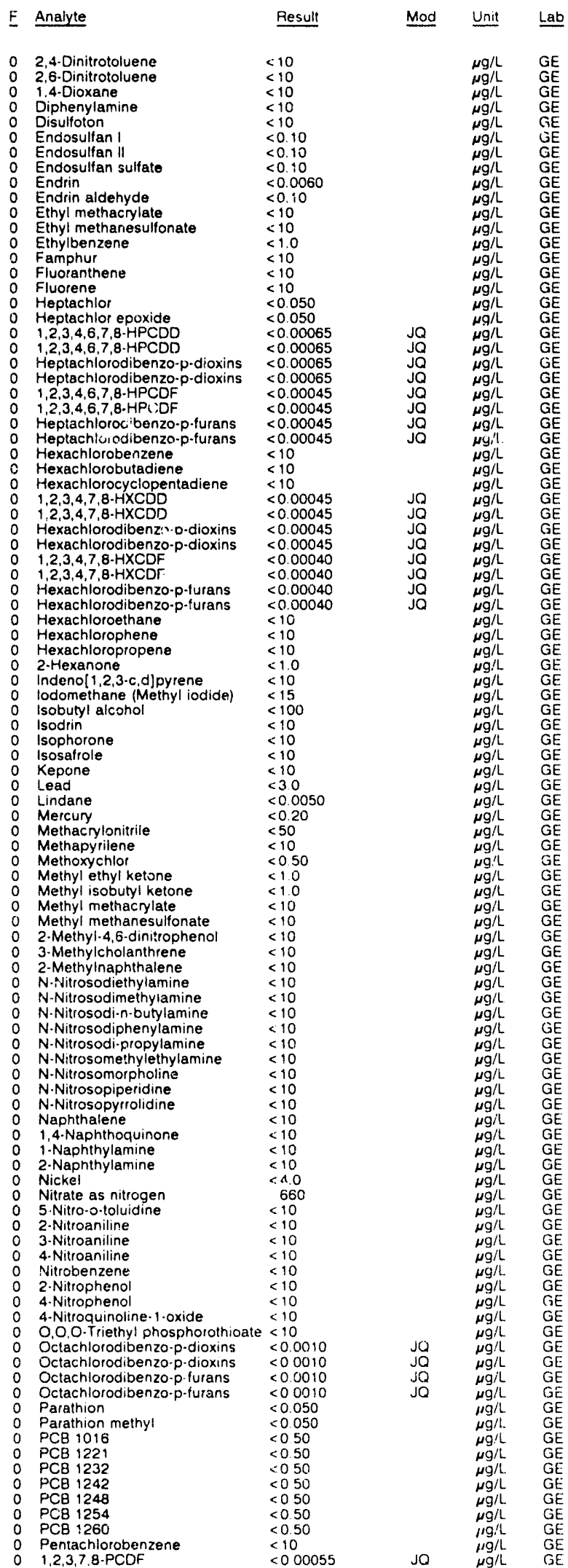

WELL i.1SB 29TA collected on 10/04/91, laboratory analyses (cont)

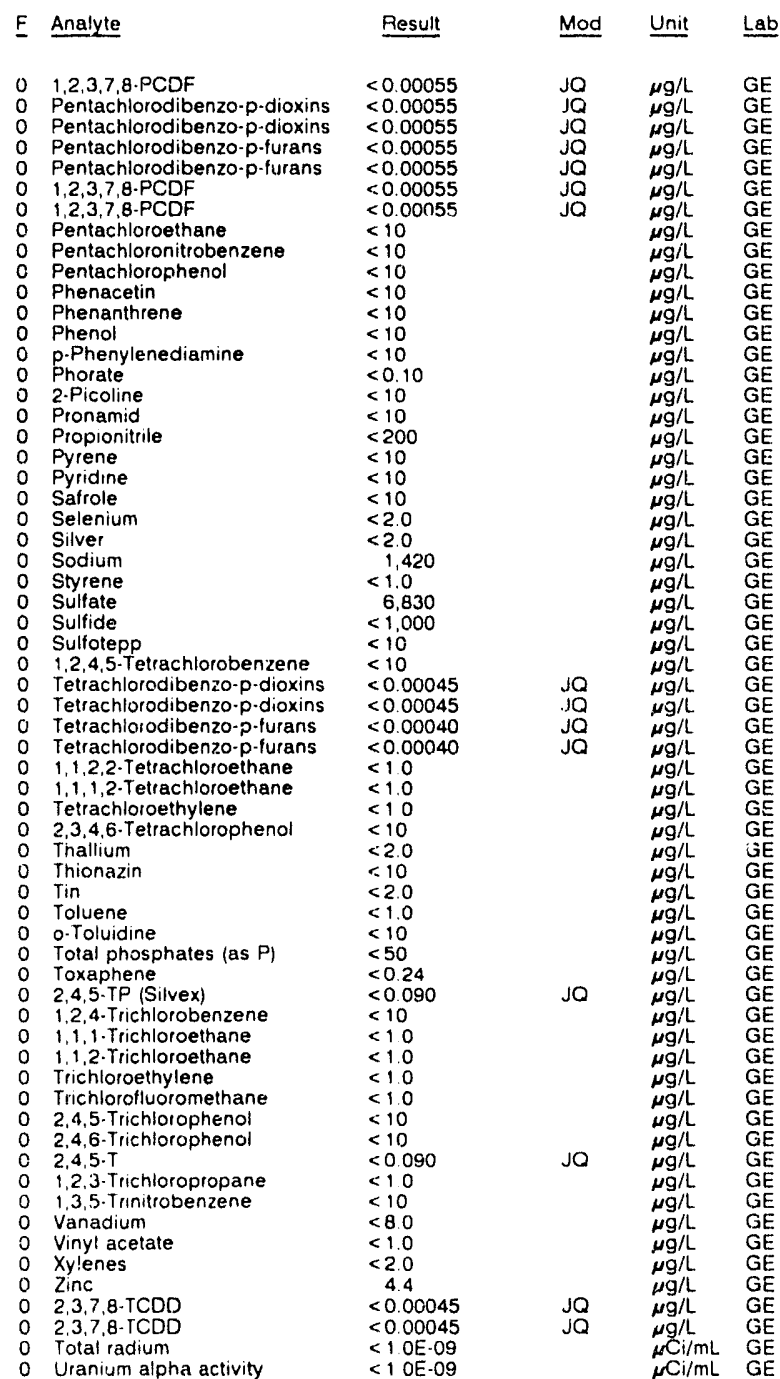

\section{WELL MSB 30A}

MEASUREMENTS CONDUCTEO IN THE FIELD

Sample date $11 / 05 / 91$

Depth to water $158.33 \mathrm{ft}(48.26 \mathrm{~m})$ below TOC

Water elevation. $196.27 \mathrm{H}(5982 \mathrm{~m}) \mathrm{msl}$

Sp. conductance : $63 \mu \mathrm{S} / \mathrm{cm}$
Water evacuated betore sampling: $445 \mathrm{gal}$

LABORATORY ANALYSES

\begin{tabular}{|c|c|c|c|}
\hline Analyte & Result & Mod & Unit \\
\hline $\begin{array}{l}\text { Chloroform } \\
1,1 \text {-Dichloroethylene } \\
\text { trans-1,2-Dichloroethylene } \\
\text { Tetrachloroethylene } \\
1,1,1 \text {-Trichloroethane } \\
\text { Trichloroethylene }\end{array}$ & $\begin{array}{l}<50 \\
<50 \\
<50 \\
<50 \\
<50 \\
<50\end{array}$ & & $\begin{array}{l}\mu g / \mathrm{L} \\
\mu \mathrm{g} / \mathrm{L} \\
\mu \mathrm{g} / \mathrm{L} \\
\mu \mathrm{g} / \mathrm{h} \\
\mu \mathrm{g} / \mathrm{L} \\
\mu \mathrm{g} / \mathrm{L}\end{array}$ \\
\hline
\end{tabular}

Time: 7.00

Alkalinity. $21 \mathrm{mg} / \mathrm{L}$ Water temperature: $16.2^{\circ} \mathrm{C}$ 
WELL MSB 30AA

MEASUREMENTS CONDUCTED IN THE FIELD

Sample date: 11/05/91

Wepth lowaler. (30.85 $\mathrm{Al}(39.88 \mathrm{~m})$ below TOC

Sp. conductance $87 \mu \mathrm{S} / \mathrm{cm}$

Water evacuated belore sampling: $77 \mathrm{gal}$

The well went dry during purging.

LABORATOPYY ANALYSES

\begin{tabular}{|c|c|c|c|}
\hline Analyte & Result & Mod & Unit \\
\hline 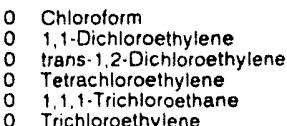 & $\begin{array}{l}<5.0 \\
<50 \\
55.0 \\
<5.0 \\
<50 \\
<50\end{array}$ & & $\begin{array}{l}\mu \mathrm{g} / \mathrm{L} \\
\mu \mathrm{g} / \mathrm{L} \\
\mu \mathrm{g} / \mathrm{L} \\
\mu \mathrm{g} / \mathrm{L} \\
\mu \mathrm{g} / \mathrm{L}\end{array}$ \\
\hline
\end{tabular}

WELL MSB 30B

MEASUREMENTS CONOUCTED IN THE FIELD

Sample date: 11/05/91

Depth to water: $129.25 \mathrm{ft}(39.40 \mathrm{~m})$ below TOC Water elevation: $223.85 \mathrm{Ht}(66$
$\mathrm{Sp}$ conductance. $31 \mu \mathrm{S} / \mathrm{cm}$

$\mathrm{Sp}$ conductance. $31 \mu \mathrm{\mu S} / \mathrm{cm}$
Water evacuated betcre sampling $261 \mathrm{gal}$

LABORATORY ANALYSES

\begin{tabular}{|c|c|c|c|c|}
\hline$F$ & Analyte & Result & Mod & Unit \\
\hline & $\begin{array}{l}\text { Chloroform } \\
1,1 \text {-Dichloroethylene } \\
\text { trans-1.2-Dichloroethylene } \\
\text { Tetrachloroethylene } \\
1,1,1, \text { Trichloroethane } \\
\text { Trichlornethylene }\end{array}$ & $\begin{array}{l}<50 \\
<50 \\
<50 \\
<50 \\
<50 \\
<50\end{array}$ & & $\begin{array}{l}\mu g / L \\
\mu g / L \\
\mu g / L \\
\mu g / L \\
\mu g / L \\
\mu g / L\end{array}$ \\
\hline
\end{tabular}

WELL MSB 30C

MEASUREMENTS CONDUCTED IN THE FIELD

Sample date $11 / 05 / 91$

Depth to water: 12478 \& $(38.03 \mathrm{~m})$ below TOC Water elevation: $230.12 \mathrm{H}(70.14 \mathrm{~m}) \mathrm{msl}$ Sp. conductance $16 \mu \mathrm{\mu S} / \mathrm{cm}$
Water evacuated betore sampling $34 \mathrm{gal}$

LABORATORY ANALYSES

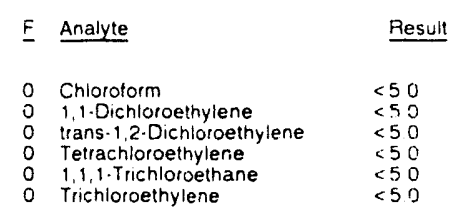

WELL MSB $30 C C$

MEASUREM NTS CONOUCTEO IN THE FIELD Sample date: $1 / 05 / 91$
Depth to water: $29.91 \mathrm{ft}(39.60 \mathrm{~m})$ below TOC Depth to water: '29.91 $\mathrm{ft}(39.60 \mathrm{~m})$ below
Water elevation: $2379 \mathrm{t} /(6821 \mathrm{~m}) \mathrm{msl}$ Water elevation: $2379 \mathrm{H} / \mathrm{k} 2$
Sp. conduclance $20, \mathrm{~S} / \mathrm{cm}$

Water evacuated 6 , tore sampling $168 \mathrm{gal}$

LABORATORY ANAL.'SES

\begin{tabular}{|c|c|c|c|}
\hline Analyte & Result & Mod & Unit \\
\hline $\begin{array}{l}\text { Chlorolorm } \\
\text { i.1.10ichioroethylene } \\
\text { trans } \cdot 1,2 \text { - Dichloroethylene } \\
\text { Tetrachioroethylerie } \\
1,1,1 . \text { Trichloroethane } \\
\text { Trichloroethylene }\end{array}$ & $\begin{array}{l}<5.0 \\
<50 \\
<5.0 \\
550 \\
550 \\
<50\end{array}$ & & $\begin{array}{l}\mu \mathrm{g} / \mathrm{L} \\
\mu \mathrm{g} / \mathrm{L} \\
\mu \mathrm{g} / \mathrm{L} \\
\mu \mathrm{g} / \mathrm{L} \\
\mu \mathrm{g} / \mathrm{L} \\
\mu \mathrm{g} / \mathrm{L}\end{array}$ \\
\hline
\end{tabular}

WELL MSB $31 \mathrm{~A}$

MEASUREMENTS CONDUCTED IN THE FIELO

Sample date $10 / 31 / 91$ is (46 $10 \mathrm{~m}$ ) below TOC Water elevation $195.96 \mathrm{ft}(59.73 \mathrm{~m}) \mathrm{msl}$

Inaccessibility or pump failure prevented sample collection

Time: 6.50

Alkalinity $0 \mathrm{mg} / \mathrm{l}$

Water temperature $16.3 \circ \mathrm{C}$

Time: 520

PH: 52

Alkalinity $2 \mathrm{mg} / \mathrm{L}$
Water temperature $153^{\circ} \mathrm{C}$

$\begin{array}{ll}\text { Mod Unit } & \text { Lab } \\ & \\ \mu g / L & M A \\ \mu g / L & M A \\ \mu g / L & M A \\ \mu g / L & M A \\ \mu g / L & M A \\ \mu g / L & M A\end{array}$

Time 605

prt 51

Alkalinity $0 \mathrm{mg} / \mathrm{L}$
Water temperature $1570 \mathrm{O}$
WELL MSB 31B

MEASUREMENTS CONDUCTED IN THE FIE!.D

Sample date 10/31/91

Depth to water: $136.18 \mathrm{Ht}(41.51 \mathrm{~m})$ below TOC

Water elevation: $211.32 \mathrm{Ht} / \mathrm{s}$

Sp conductance $34 \mu \mathrm{S} / \mathrm{cm}$

Water evacuated before sampling: $155 \mathrm{gal}$

LABORATORY ANALYSES

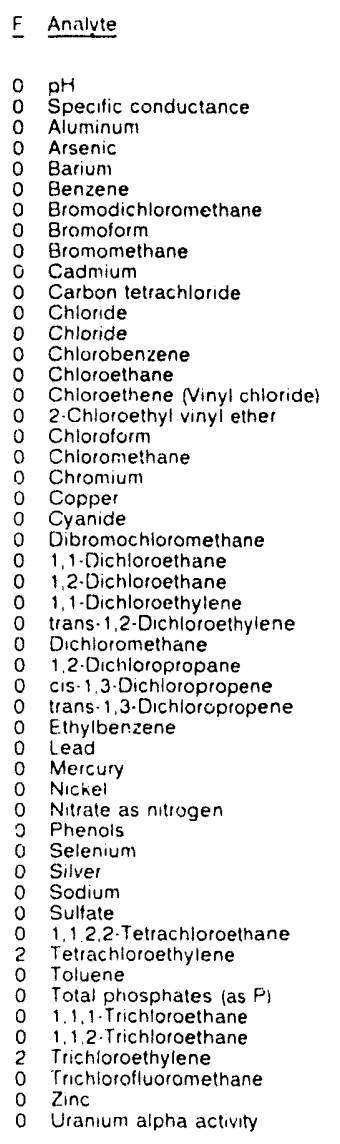

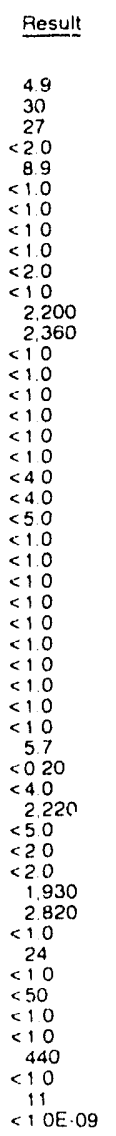

Time 640

PH. 4.7 .

Alkalinity: $0 \mathrm{mg} / \mathrm{L}$
Water temperature: 18.30 .

WELL MSB $31 \mathrm{C}$

MEASUREMENTS CONDUCTED IN THE FIELD

Sample date $12 / 13 / 91$
Depth to water $11344 \mathrm{Ht}(3458 \mathrm{~m})$ below TOC

Water elevation $23386 \mathrm{ft}(71.28 \mathrm{~m}) \mathrm{ms}$

Sp conductance $309 \mu \mathrm{S} / \mathrm{cm}$

LABOAATORY ANALYSES

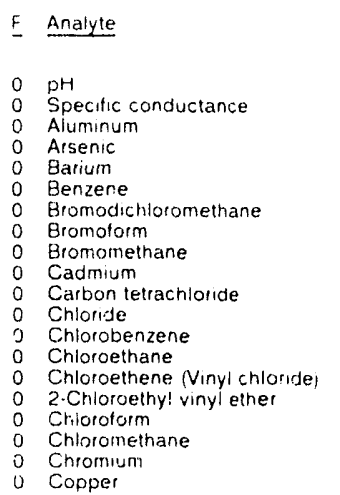

$\quad$ Result

66
115
$<20$
$<20$
40
410
$<10$
$<10$
$<10$
$<20$
$<10$
3420
$<10$
$<10$
$<10$
$<10$
23
210
$<40$
$<40$
$<40$

Time 1245

pH 61

Alkalinity: $20 \mathrm{mg} / \mathrm{L}$ Water temperature $19.2^{\circ} \mathrm{C}$

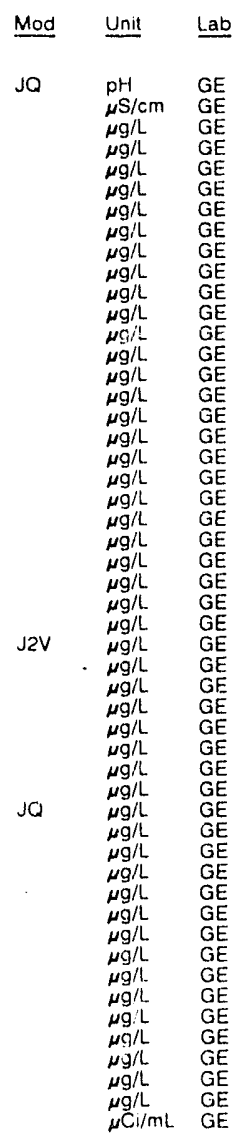


ANALYTICAL RESULTS

WELL MSB 31 C collected on 12/13/91, laboratory analyses (cont)

\begin{tabular}{|c|c|c|c|c|c|}
\hline$\underline{F}$ & Analyte & Result & Mod & Unit & Lab \\
\hline $\begin{array}{l}0 \\
0 \\
0 \\
0 \\
0 \\
0 \\
0 \\
0 \\
0 \\
0 \\
0 \\
2 \\
0 \\
0 \\
0 \\
0 \\
2 \\
1 \\
2 \\
0 \\
0\end{array}$ & 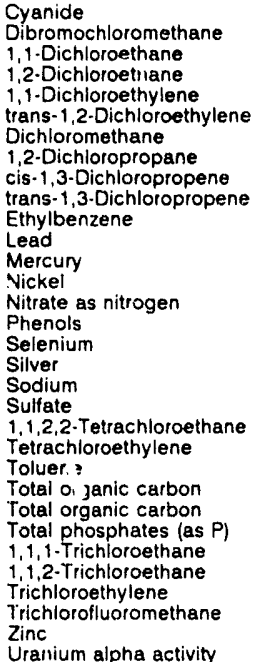 & $\begin{array}{l}<5.0 \\
<1.0 \\
2.0 \\
<1.0 \\
87 \\
<1.0 \\
1.1 \\
<1.0 \\
<1.0 \\
<1.0 \\
<1.0 \\
<3.0 \\
<0.20 \\
<4.0 \\
2.940 \\
<5.0 \\
<2.0 \\
<2.0 \\
6.790 \\
5.840 \\
<1.0 \\
387.000 \\
1.3 \\
1.300 \\
1.400 \\
50 \\
241 \\
5.0 \\
212,000 \\
<1.0 \\
73 \\
<1.0 \mathrm{E} \cdot 09\end{array}$ & JQ & $\begin{array}{l}\mu g / L \\
\mu g / L \\
\mu g / L \\
\mu g / L \\
\mu g / L \\
\mu g / L \\
\mu g / L \\
\mu g / L \\
\mu g / L \\
\mu g / L \\
\mu g / L \\
\mu g / L \\
\mu g / L \\
\mu g / L \\
\mu g / L \\
\mu g / L \\
\mu g / L \\
\mu g / L \\
\mu g / L \\
\mu g / L \\
\mu g / L \\
\mu g / L \\
\mu g / L \\
\mu g / L \\
\mu g / L \\
\mu g / L \\
\mu g / L \\
\mu g / L \\
\mu g / L \\
\mu g / L \\
\mu g / L \\
\mu C i / m L\end{array}$ & $\begin{array}{l}\mathrm{GE} \\
\mathrm{GE} \\
\mathrm{GE} \\
\mathrm{GE} \\
\mathrm{GE} \\
\mathrm{GE} \\
\mathrm{GE} \\
\mathrm{GE} \\
\mathrm{GE} \\
\mathrm{GE} \\
\mathrm{GE} \\
\mathrm{GE} \\
\mathrm{GE} \\
\mathrm{GE} \\
\mathrm{GE} \\
\mathrm{GE} \\
\mathrm{GE} \\
\mathrm{GE} \\
\mathrm{GE} \\
\mathrm{GE} \\
\mathrm{GE} \\
\mathrm{GE} \\
\mathrm{GE} \\
\mathrm{GE} \\
\mathrm{GE} \\
\mathrm{GE} \\
\mathrm{GE} \\
\mathrm{GE} \\
\mathrm{GE} \\
\mathrm{GE} \\
\mathrm{GE}\end{array}$ \\
\hline
\end{tabular}

WELL MSB 31 CC

MEASUREMENTS CONDUCTED IN THE FIELD

Sample date: 10/31/81

Depth to water: $136.58 \mathrm{ft}(41.63 \mathrm{~m})$ below TOC

Water elevation: $212.22 \mathrm{ft}(64.69 \mathrm{~m}) \mathrm{msl}$

Sp. conduciance: $53 \mu \mathrm{S} / \mathrm{cm}$

Water evacuated before sampling: $93 \mathrm{gal}$

LABORATORY ANALYSES

\begin{tabular}{|c|c|c|c|c|}
\hline$E$ & Analyte & Result & Mod & Unit \\
\hline & $\begin{array}{l}\text { Chloroform } \\
1,1-\text { Dichloroethylene } \\
\text { trans-1,2-Dichloroethylene } \\
\text { Tetrachloroethylene } \\
1,1,1-\text { Trichloroethane } \\
\text { Trichioroethylene }\end{array}$ & $\begin{aligned} &<5.0 \\
&<5.0 \\
&<5.0 \\
&<5.0 \\
&<5.0 \\
& 245\end{aligned}$ & & $\begin{array}{l}\mu \mathrm{g} / \mathrm{L} \\
\mu \mathrm{g} / \mathrm{L} \\
\mu \mathrm{g} / \mathrm{L} \\
\mu \mathrm{g} / \mathrm{L} \\
\mu \mathrm{g} / \mathrm{L} \\
\mu \mathrm{g} / \mathrm{L}\end{array}$ \\
\hline
\end{tabular}

WELL MSB 32

MEASUREMENTS CONDUCTED IN THE FIELD

\begin{tabular}{|c|c|}
\hline \multicolumn{2}{|r|}{$\begin{array}{l}\text { Sample date: } 11 / 01 / 91 \\
\text { Depth to water: } 29.87 \mathrm{Ht}(9.10 \mathrm{~m}) \\
\text { Water elevation: } 225.43 \mathrm{ft}(68.71 \\
\text { Sp. conductance: } 23 \mu \mathrm{H} / \mathrm{cm} \\
\text { Water evacuated betore sampling }\end{array}$} \\
\hline & BORATORY ANALYSES \\
\hline & Analyte \\
\hline & $\begin{array}{l}\text { pH } \\
\text { Specific conductance } \\
\text { Arsenic } \\
\text { Barium } \\
\text { Cadmium } \\
\text { Calcium } \\
\text { Chloride } \\
\text { Chloroform } \\
\text { Chromium } \\
\text { 1,1-Dichloroethylene } \\
\text { trans:1,2-Dichloroethylene } \\
\text { Fluoride } \\
\text { lron } \\
\text { Lead } \\
\text { Magnesium } \\
\text { Manganese } \\
\text { Mercury } \\
\text { Nitrate as nitrogen } \\
\text { Phenols } \\
\text { Potassium } \\
\text { Selenium } \\
\text { Silica } \\
\text { Silver } \\
\text { Sodium } \\
\text { Sulfate } \\
\text { Tetrachloroethylene } \\
\text { Total dissolved solids } \\
\text { Total organic carbon }\end{array}$ \\
\hline
\end{tabular}

Time: $6: 30$

pH: 5.8

Alkalinity: $10 \mathrm{mg} / \mathrm{L}$

Water temperature $18.3^{\circ} \mathrm{C}$

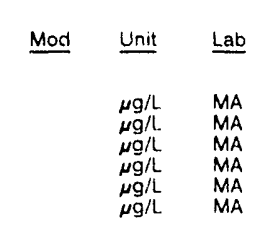

WELL MSB 32 collected on 11/01/91, laboratory analyses (cont)

\begin{tabular}{|c|c|c|c|}
\hline Analyte & Result & Mod & Unit \\
\hline $\begin{array}{l}\text { Total organic halogens } \\
\text { Total phosphates (as P) } \\
1,1,1 \text {. Trichloroethane } \\
\text { Trichloroethylene } \\
\text { Gross alpha } \\
\text { Nonvolatile beta } \\
\text { Total radium } \\
\text { Tritium }\end{array}$ & $\begin{array}{l}31 \\
<50 \\
<1.0 \\
<1.0 \\
<2.0 \mathrm{E} \cdot 09 \\
<2.0 \mathrm{E} \cdot 09 \\
<1.0 \mathrm{E} \cdot 09 \\
<7.0 \mathrm{E} \cdot 07\end{array}$ & & $\begin{array}{l}\mu \mathrm{g} / \mathrm{L} \\
\mu \mathrm{g} / \mathrm{L} \\
\mu \mathrm{g} / \mathrm{L} \\
\mu \mathrm{g} / \mathrm{L} \\
\mu \mathrm{Ci} / \mathrm{mL} \\
\mu \mathrm{Ci} / \mathrm{mL} \\
\mu \mathrm{Ci} / \mathrm{mL} \\
\mu \mathrm{Ci} / \mathrm{mL}\end{array}$ \\
\hline
\end{tabular}

\section{WELL MSB 33}

MEASUREMENTS CONDUCTED IN THE FIELD

Sample date: $10 / 29 / 91$
Depth to water: $37.29 \mathrm{Ht}(11.37 \mathrm{~m})$ below TOC
Water elevation: $219.31 \mathrm{Ht}(66.85 \mathrm{~m}) \mathrm{ms}$ l

Water elevation: $219.31 \mathrm{Ht}(66.85 \mathrm{~m}) \mathrm{msl}$
Sp. conductance: $63 \mu \mathrm{s} / \mathrm{cm}$
Water evacuated before sampling: $26 \mathrm{gal}$

LABORATORY ANALYSES

\begin{tabular}{|c|c|c|c|}
\hline Analyte & Pesult & Mod & Unit \\
\hline $\begin{array}{l}\text { Chloroform } \\
1,1-\text { Dichloroethylene } \\
\text { trans-1,2-Dichloroethylene } \\
\text { Tetrachloroethylene } \\
1,1,1 \text {-Trichloroothane } \\
\text { Trichloroethylene }\end{array}$ & $\begin{aligned}<1.0 \\
<1.0 \\
<1.0 \\
3.3 \\
<1.0 \\
6.5\end{aligned}$ & & $\begin{array}{l}\mu \mathrm{g} / \mathrm{L} \\
\mu \mathrm{g} / \mathrm{L} \\
\mu \mathrm{g} / \mathrm{L} \\
\mu \mathrm{g} / \mathrm{L} \\
\mu \mathrm{g} / \mathrm{L} \\
\mu \mathrm{g} / \mathrm{L}\end{array}$ \\
\hline
\end{tabular}

\section{WELL MSB 33A}

MEASUREMENTS CONDUCTED IN THE FIELO

Sample date: $10 / 29 / 91$

Depth to water: $51.54 \mathrm{Ht}(15.71 \mathrm{~m})$ below TOC

Sp conductance $23.86 \mathrm{ft}(62$.

Water evacuated before sampling: $314 \mathrm{gal}$

Time: $10: 30$

PH: 4.8 Alkalinity: $0 \mathrm{mg}$

Water temperature: $17.5^{\circ} \mathrm{C}$

LABORATORY ANALYSES

\begin{tabular}{|c|c|c|c|}
\hline Analyte & Result & Mod & Unit \\
\hline $\begin{array}{l}\text { pH } \\
\text { Specific conductance } \\
\text { Arsenic } \\
\text { Barium } \\
\text { Cadmium } \\
\text { Calcium } \\
\text { Chloride } \\
\text { Chioroform } \\
\text { Chromium } \\
1,1 \cdot \text { Dichloroethylene } \\
\text { trans-1,2-Dichloroethylene } \\
\text { Fluoride } \\
\text { lron } \\
\text { Lead } \\
\text { Magnesium } \\
\text { Manganese } \\
\text { Mercury } \\
\text { Nitrate as nitrogen } \\
\text { Phenols } \\
\text { Potassium } \\
\text { Selenium } \\
\text { Silica } \\
\text { Silvet } \\
\text { Sodium } \\
\text { Sulfate } \\
\text { Tetrachloroethylene } \\
\text { Total dissolved solids } \\
\text { Total organic carbon } \\
\text { Total organic halogens } \\
\text { Total phosphates (as P) } \\
\text { 1,1,1.Trichloroethane } \\
\text { Trichlorothylene } \\
\text { Gross alpha } \\
\text { Nonvolatile beta } \\
\text { Total radium } \\
\text { Trtium }\end{array}$ & $\begin{array}{l}5.2 \\
20 \\
<2.0 \\
3.9 \\
<2.0 \\
890 \\
1.900 \\
<1.0 \\
<4.0 \\
<1.0 \\
<1.0 \\
<100 \\
4.1 \\
<3.0 \\
308 \\
<2.0 \\
<0.20 \\
860 \\
<5.0 \\
<500 \\
<2.0 \\
10,100 \\
<2.0 \\
1.610 \\
2.900 \\
<1.0 \\
23,000 \\
<1,000 \\
5.9 \\
<50 \\
<1.0 \\
8.4 \\
2.2 E \cdot 09 \pm 1.2 E-09 \\
<2.0 E-09 \\
13 E \cdot 09 \pm 1.2 E-09 \\
<7.0 E-07\end{array}$ & JOV & $\begin{array}{l}\mathrm{pH} \\
\mu \mathrm{S} / \mathrm{cm} \\
\mu g / L \\
\mu g / L \\
\mu g / L \\
\mu g / L \\
\mu g / L \\
\mu g / L \\
\mu g / L \\
\mu g / L \\
\mu g / L \\
\mu g / L \\
\mu g / L \\
\mu g / L \\
\mu g / L \\
\mu g / L \\
\mu g / L \\
\mu g / L \\
\mu g / L \\
\mu g / L \\
\mu g / L \\
\mu g / L \\
\mu g / L \\
\mu g / L \\
\mu g / L \\
\mu g / L \\
\mu g / L \\
\mu g / L \\
\mu g / L \\
\mu g / L \\
\mu g / L \\
\mu g / L \\
\mu C i / m L \\
\mu C i / m L \\
\mu C i / m L \\
\mu C i / m L\end{array}$ \\
\hline
\end{tabular}




\section{WELL MSB 33B}

MEASUREMENTS CONDUCTED IN THE FIELD Sample date: $10 / 29 / 9$ Depth to water: 47.84 it $(14.58 \mathrm{~m})$ below TOC Water elevation: $207.36 \mathrm{H}(63.2$ Water evacuated before sampling: $223 \mathrm{gal}$ LABOPATORY ANALYSES

\begin{tabular}{|c|c|}
\hline Analyte & Result \\
\hline $\begin{array}{l}\text { pH } \\
\text { Specific conductance } \\
\text { Arsenic } \\
\text { Barium } \\
\text { Cadmium } \\
\text { Calcium } \\
\text { Chloride } \\
\text { Chloroform } \\
\text { Chromium } \\
1,1-\text { Dichloroethylene } \\
\text { trans-1,2-Dichloroethylene } \\
\text { Fluoride } \\
\text { Iron } \\
\text { Lead } \\
\text { Magnesium } \\
\text { Manganese } \\
\text { Mercury } \\
\text { Nitrate as nitrogen } \\
\text { Phenols } \\
\text { Potassium } \\
\text { Selenium } \\
\text { Silica } \\
\text { Silver } \\
\text { Sodium } \\
\text { Sulfate } \\
\text { Tetrachlorcethylene } \\
\text { Total dissolved solids } \\
\text { Total organic carbon } \\
\text { Total organic halogens } \\
\text { Total phosphates (as F) } \\
\text { 1,1.1. Trichloroethane } \\
\text { Trichloroethylene } \\
\text { Gross alpha } \\
\text { Nonvolatile beta } \\
\text { Total radium } \\
\text { Tritium }\end{array}$ & $\begin{array}{c}5.3 \\
30 \\
<2.0 \\
<3.0 \\
<2.0 \\
598 \\
3,200 \\
<1.0 \\
<4.0 \\
<1.0 \\
6.0 \\
<100 \\
4.9 \\
<30 \\
27.3 \\
<2.0 \\
<0.20 \\
880 \\
<5.0 \\
<500 \\
<2.0 \\
10,800 \\
<2.0 \\
3,960 \\
1,310 \\
22 \\
20,000 \\
<1,000 \\
24 \\
<50 \\
<1.0 \\
19 \\
<2.0 E-09 \\
<2.0 E-09 \\
<10 E-09 \\
<7,0 E-07\end{array}$ \\
\hline
\end{tabular}

\section{WELL MSB 33C}

MEASUREMENTS CONDUCTED IN THE FIEL]

Sample date: $10 / 29 / 91$

Depth to water 44.71 t $(13.63 \mathrm{~m})$ below TOC Water elevation: $210.59 \mathrm{~h}(64.19 \mathrm{~m}) \mathrm{ms}$ Sp. conductance: $38, \mathrm{~s} / \mathrm{cm}$ Water evacuated before sampling: $114 \mathrm{gal}$ LABORATORY ANALYSES

\begin{tabular}{|c|c|}
\hline Analyte & Result \\
\hline $\begin{array}{l}\text { Chloroform } \\
\text { 1,1-Dichloroethylene } \\
\text { trans-1,2-Dichloroethylene } \\
\text { Tetrachloroethylene } \\
\text { 1,1,1-Trichloroethane } \\
\text { Trichloroethylene }\end{array}$ & $\begin{array}{l}<10 \\
<10 \\
<10 \\
12 \\
<10 \\
15\end{array}$ \\
\hline
\end{tabular}

\section{WELL MSB $23 T A$}

MEASUREMENTS CC VDUCTED IN THE FIELD

Sample date: 10/29/81

Depth to water: $61.66 \mathrm{ft}(10.9 \mathrm{~m})$ below TOC Water elevation: $193.84 \mathrm{ft}(59.08 \mathrm{~m}) \mathrm{ms}$ ) Water evacuated before samping: $457 \mathrm{gal}$ LABORATORY ANALYSES

\begin{tabular}{|c|c|c|c|c|c|}
\hline$E$ & Analyze & Pesult & Mod & Unit & $\underline{\text { Lab }}$ \\
\hline $\begin{array}{l}{ }_{0}^{0} \\
0\end{array}$ & $\begin{array}{l}\text { pH } \\
\text { Specific conductance } \\
\text { Arsenic } \\
\text { Barium } \\
\text { Cadmium } \\
\text { Calcium } \\
\text { Chloride } \\
\text { Chlorolorm } \\
\text { Chromium } \\
1,1 \cdot \text { Dichloroethylene } \\
\text { trans-1,2-Dichloroethylene } \\
\text { Fluoride }\end{array}$ & $\begin{aligned} 5.1 \\
20 \\
<20 \\
54 \\
<20 \\
1040 \\
1.840 \\
<10 \\
<40 \\
<1.0 \\
<10 \\
<100\end{aligned}$ & JO & $\begin{array}{l}\mathrm{pH} \\
\mu \mathrm{S} / \mathrm{cm} \\
\mu \mathrm{g} / \mathrm{L} \\
\mu \mathrm{g} / \mathrm{L} \\
\mu \mathrm{g} / \mathrm{L} \\
\mu \mathrm{g} / \mathrm{L} \\
\mu \mathrm{g} / \mathrm{L} \\
\mu \mathrm{g} / \mathrm{L} \\
\mu \mathrm{g} / \mathrm{L} \\
\mu \mathrm{g} / \mathrm{L} \\
\mu \mathrm{g} / \mathrm{L} \\
\mu \mathrm{g} / \mathrm{L}\end{array}$ & $\begin{array}{l}\mathrm{GE} \\
\mathrm{GE} \\
\mathrm{GE} \\
\mathrm{GE} \\
\mathrm{GE} \\
\mathrm{GE} \\
\mathrm{GE} \\
\mathrm{MA} \\
\mathrm{GE} \\
\mathrm{MA} \\
\mathrm{MA} \\
\mathrm{GE}\end{array}$ \\
\hline
\end{tabular}

WELL MSB 33TA collected on 10/29/91, laboratory analyses 1:0nit.)

\begin{tabular}{|c|c|c|c|}
\hline Analyte & Result & Mod & Unit \\
\hline $\begin{array}{l}\text { Iron } \\
\text { Lead } \\
\text { Magnesium } \\
\text { Manganese } \\
\text { Mercury } \\
\text { Nitrate as nitrogen } \\
\text { Phenols } \\
\text { Potassium } \\
\text { Selenium } \\
\text { Silica } \\
\text { Silver } \\
\text { Sodium } \\
\text { Sulfate } \\
\text { Tetrachloroethylene } \\
\text { Total dissolved sofids } \\
\text { Total organic carbon } \\
\text { Total organic halogens } \\
\text { Total phosphates (as P) } \\
\text { 1,1,1. Trichloroethane } \\
\text { Trichloroethylene } \\
\text { Gross alpha } \\
\text { Nonvolatile beta } \\
\text { Tolal radium } \\
\text { Tritium }\end{array}$ & $\begin{array}{l}180 \\
7.6 \\
249 \\
62 \\
<0.20 \\
300 \\
<5.0 \\
<500 \\
<2.0 \\
9.230 \\
<2.0 \\
1.370 \\
3.460 \\
<1.0 \\
18.000 \\
<1.000 \\
<5.0 \\
<50 \\
<1.0 \\
<1.0 \\
<2.0 E \cdot 09 \\
<2.0 E \cdot 09 \\
2.0 E \cdot 09 \pm 1.3 E-09 \\
<7.0 E \cdot 07\end{array}$ & JQV & $\begin{array}{l}\mu g / L \\
\mu g / L \\
\mu g / L \\
\mu g / L \\
\mu g / L \\
\mu g / L \\
\mu g / L \\
\mu g / L \\
\mu g / L \\
\mu g / L \\
\mu g / L \\
\mu g / L \\
\mu g / L \\
\mu g / L \\
\mu g / L \\
\mu g / L \\
\mu g / L \\
\mu g / L \\
\mu g / L \\
\mu g / L \\
\mu C i / m L \\
\mu C / / m L \\
\mu C i / m L \\
\mu C i / m L\end{array}$ \\
\hline
\end{tabular}

WELL MSB 34A

MEASUREMENTS CONDUCTED IN THE FIELD

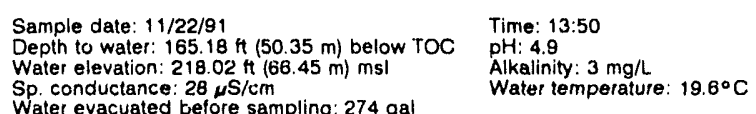

Sp. conductance: $28 \mu \mathrm{S} / \mathrm{cm}$

Water evacuated before sampling: 274 gal

LABORATORY ANALYSES

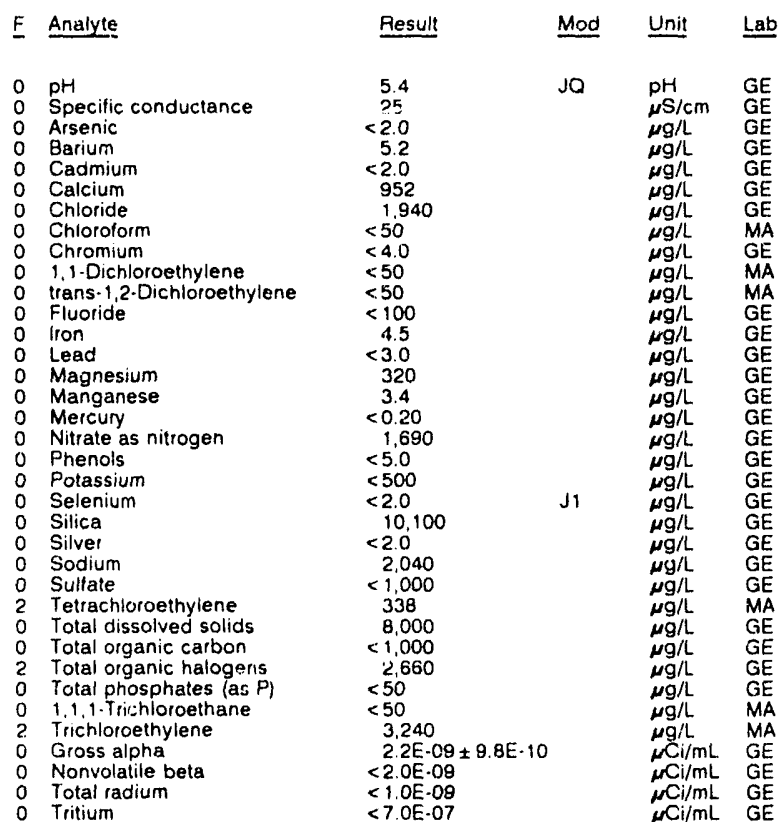

Time: 10:00

Alkalinity. $1 \mathrm{mg} / \mathrm{L}$

Water temperature: $18.0^{\circ} \mathrm{C}$

$G E$
$G E$
$G E$
$G E$
$G E$
$G E$
$G E$
$M A$
$G E$
$M A$
$M A$
$G E$

\section{rime: $9: 40$
pH: 4.6 \\ Alkalinity: $0 \mathrm{mg} / \mathrm{s}$ \\ Water temperature: $16.9^{\circ} \mathrm{C}$

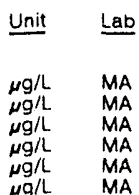

\section{WELL MSB 34B}

MEASUREMENTS CONDUCTED IN THE FIELD

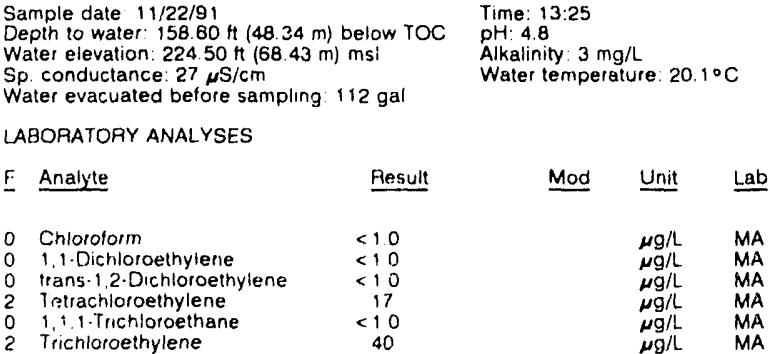


ANALYTICAL RESULTS

WELL MSB 34C

MEASUREMENTS CONDUCTEO IN THE FIELD

Sample date: 10/25/91

Depth to water: Not available

Water elevation. Not available

Water evacuated before samplirig: $35 \mathrm{gal}$

LABORATORY ANALYSES

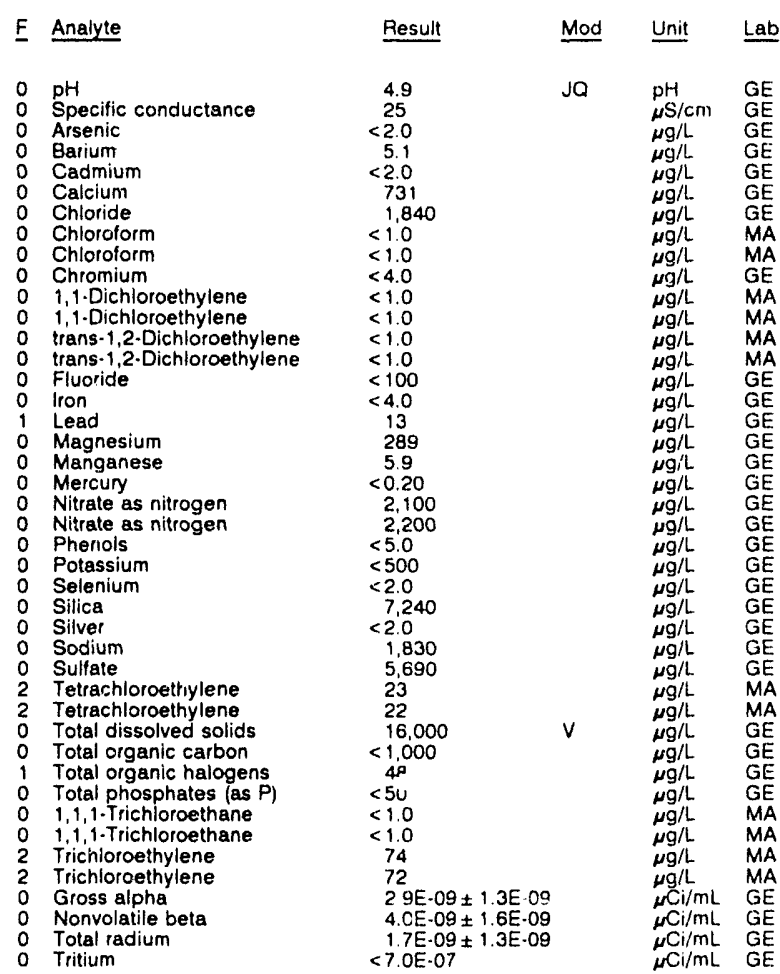

\section{WELL MSB 34TA}

MEASUREMENTS CONDUCTED IN THE FIELD

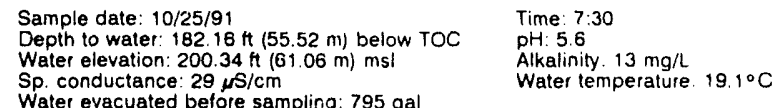

Water evacuated before sampling: $795 \mathrm{gal}$

LABORATORY ANALYSES

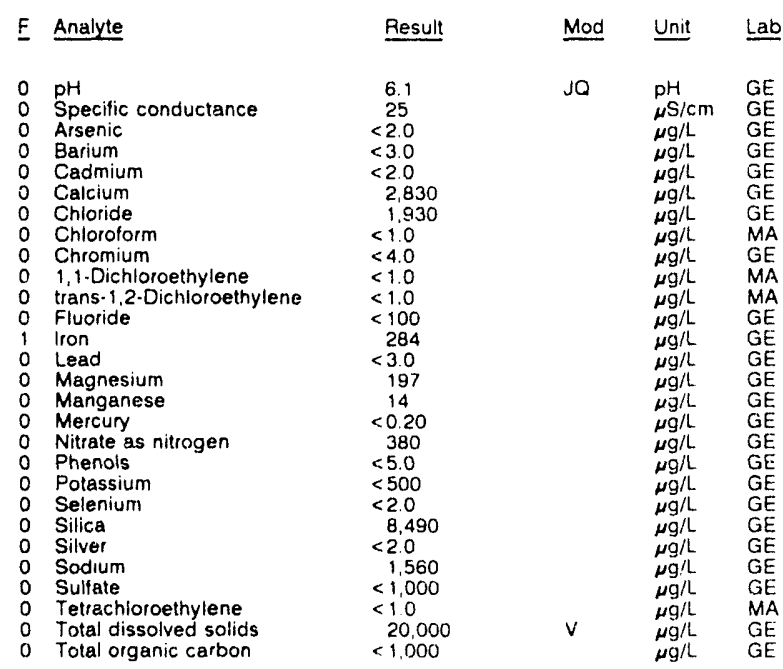

WELL MSB 34TA collected on 10/25/91, laboratory analyses (cont.)

\begin{tabular}{|c|c|c|c|c|}
\hline E & Analyte & Result & Mod & Unit \\
\hline $\begin{array}{l}0 \\
0 \\
0 \\
0 \\
0\end{array}$ & $\begin{array}{l}\text { Total organic halogens } \\
\text { Total organic halogens } \\
\text { Total phosphates (as P) } \\
1,1,1 \text {-Trichloroethane } \\
\text { Trichloroethylene } \\
\text { Gross alpha } \\
\text { Nonvolatile beta } \\
\text { Total radium } \\
\text { Tritium }\end{array}$ & $\begin{array}{l}<50 \\
<5.0 \\
<50 \\
<1.0 \\
<1.0 \\
<2.0 E-09 \\
<2.0 E-09 \\
<1.0 E-09 \\
<7.0 E-07\end{array}$ & & $\begin{array}{l}\mu \mathrm{g} / \mathrm{L} \\
\mu \mathrm{g} / \mathrm{L} \\
\mu \mathrm{g} / \mathrm{L} \\
\mu \mathrm{g} / \mathrm{L} \\
\mu \mathrm{g} / \mathrm{L} \\
\mu \mathrm{Ci} / \mathrm{mL} \\
\mu \mathrm{Ci} / \mathrm{mL} \\
\mu \mathrm{Ci} / \mathrm{mL} \\
\mu \mathrm{Ci} / \mathrm{mL}\end{array}$ \\
\hline
\end{tabular}

\section{WELL MSB 34TB}

MEASUREMENTS CONDUCTED IN THE FIELD

Sample date: 10/25/91

Depth to water: $181.47 \mathrm{ft}(55.31 \mathrm{~m})$ below TOC

Water elevation: $201.33 \mathrm{Ht}(61.37 \mathrm{~m}) \mathrm{msl}$

Water evacuated belore sampling: $356 \mathrm{gal}$

LABCRATORY ANALYSES

\begin{tabular}{|c|c|c|c|c|}
\hline Analyte & Result & Mod & Unit & Lab \\
\hline $\begin{array}{l}\text { pH } \\
\text { Specific conductance } \\
\text { Arsenic } \\
\text { Barium } \\
\text { Cadmium } \\
\text { Calcium } \\
\text { Chloride } \\
\text { Chloroform } \\
\text { Chromium } \\
1,1 \cdot \text { Dichloroethylene } \\
\text { trans-1,2-Dichloroethylene } \\
\text { Fluoride } \\
\text { lron } \\
\text { Lead } \\
\text { Magnesium } \\
\text { Manganese } \\
\text { Mercury } \\
\text { Nitrate as nitrogen } \\
\text { Phenols } \\
\text { Potassium } \\
\text { Selenium } \\
\text { Silica } \\
\text { Silver } \\
\text { Sodium } \\
\text { Sulfate } \\
\text { Tetrachloroethylene } \\
\text { Total dissolved solids } \\
\text { Total organic carbon } \\
\text { Total organic halogens } \\
\text { Total phosphates (as P) } \\
\text { 1,1.1. Trichloroethane } \\
\text { Trichloroethylene } \\
\text { Gross alpha } \\
\text { Nonvolatile beta } \\
\text { Total radium } \\
\text { Tritium }\end{array}$ & $\begin{aligned} & 5.3 \\
& 30 \\
&<2.0 \\
& 3.5 \\
&<2.0 \\
& 1.420 \\
& 1.970 \\
&<1.0 \\
&<4.0 \\
&<1.0 \\
&<1.0 \\
&<100 \\
& 643 \\
& 12 \\
& 224 \\
& 17 \\
& 0.32 \\
& 280 \\
&<5.0 \\
&<500 \\
&<2.0 \\
& 7,720 \\
&<2.0 \\
& 2,900 \\
& 5,410 \\
&<1.0 \\
& 21,000 \\
&<1,000 \\
& 32 \\
&<50 \\
&<1.0 \\
&<1.0 \\
&<2.0 \mathrm{E}-09 \\
&<2.0 \mathrm{E}-09 \\
& 1.1 \mathrm{E}-09 \pm 1.2 \mathrm{E}-09 \\
&<7.0 \mathrm{E}-07\end{aligned}$ & JQ & 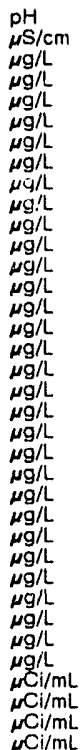 & $\begin{array}{l}G E \\
G E \\
G E \\
G E \\
G E \\
G E \\
G E \\
M A \\
G E \\
M A \\
M A \\
G E \\
G E \\
G E \\
G E \\
G E \\
G E \\
G E \\
G E \\
G E \\
G E \\
G E \\
G E \\
G E \\
G E \\
M A \\
G E \\
G E \\
G E \\
G E \\
M A \\
M A \\
G E \\
G E \\
G E \\
G E\end{array}$ \\
\hline
\end{tabular}

\section{WELL MSB 35A}

MEASUREMENTS CONDUCTED IN THE FIELD

Sample date: $10 / 25 / 91$

Depth to water: $135.76 \mathrm{ft}(41.38 \mathrm{~m})$ below TOC Water elevation: $215.34 \mathrm{ft}(65.64 \mathrm{~m}) \mathrm{msl}$ Water evacuated before sampling: $237 \mathrm{gal}$

Time: $7: 00$

Alkalinity: $4 \mathrm{mg} / \mathrm{L}$ Water temperature: $19.3^{\circ} \mathrm{C}$ ABORATORY ANALYSES

$\begin{array}{ll}\text { E } & \text { Analyte } \\ 0 & \text { pH } \\ 0 & \text { Specific conductance } \\ 0 & \text { Arsenic } \\ 0 & \text { Barium } \\ 0 & \text { Cadmium } \\ 0 & \text { Calcium } \\ 0 & \text { Chloride } \\ 0 & \text { Chloroform } \\ 0 & \text { Chromium } \\ 0 & 1,1 \cdot \text { Dichloroethylene } \\ 0 & \text { trans-1,2-Dichloroethylene } \\ 0 & \text { Fluoride } \\ 0 & \text { Iron } \\ 0 & \text { Lead } \\ 0 & \text { Magnesium } \\ 0 & \text { Manganese } \\ 0 & \text { Mercury } \\ 0 & \text { Nitrate as nitrogen } \\ 0 & \text { Phenols } \\ 0 & \text { Potassium } \\ 0 & \text { Selenium }\end{array}$

\begin{tabular}{l} 
Pesult \\
\multicolumn{1}{r}{} \\
5.2 \\
25 \\
$<2.0$ \\
5.8 \\
$<20$ \\
9.96 \\
2.600 \\
$<1.0$ \\
$<4.0$ \\
$<1.0$ \\
$<1.0$ \\
$<100$ \\
$<4.0$ \\
$<3.0$ \\
520 \\
2.1 \\
$<0.20$ \\
1.180 \\
$<5.0$ \\
$<500$ \\
$<2.0$
\end{tabular}

\begin{tabular}{|c|c|}
\hline Mod & Unit \\
\hline JQ & $\begin{array}{l}p \mathrm{pH} \\
\mu \mathrm{S} / \mathrm{cm} \\
\mu \mathrm{g} / \mathrm{L} \\
\mu \mathrm{g} / \mathrm{L} \\
\mu \mathrm{g} / \mathrm{L} \\
\mu \mathrm{g} / \mathrm{L} \\
\mu \mathrm{g} / \mathrm{L} \\
\mu \mathrm{g} / \mathrm{L} \\
\mu \mathrm{g} / \mathrm{L} \\
\mu \mathrm{g} / \mathrm{L} \\
\mu \mathrm{g} / \mathrm{L} \\
\mu \mathrm{g} / \mathrm{L} \\
\mu \mathrm{g} / \mathrm{L} \\
\mu \mathrm{g} / \mathrm{L} \\
\mu \mathrm{g} / \mathrm{L} \\
\mu \mathrm{g} / \mathrm{L} \\
\mu \mathrm{g} / \mathrm{L} \\
\mu \mathrm{g} / \mathrm{L} \\
\mu \mathrm{g} / \mathrm{L} \\
\mu \mathrm{g} / \mathrm{L} \\
\mu \mathrm{g} / \mathrm{L}\end{array}$ \\
\hline
\end{tabular}




\section{ANALYTICAL RESULTS}

WELL MSB 35A collected on 10/25/91, laboratory analyses (cont.)

\begin{tabular}{|c|c|c|c|c|}
\hline Analyte & Result & Mod & Unit & Lab \\
\hline $\begin{array}{l}\text { Silica } \\
\text { Silvet } \\
\text { Sodium } \\
\text { Sulfate } \\
\text { Tetrachloroethylene } \\
\text { Total dissolved solids } \\
\text { Total organic carbon } \\
\text { Total organic halogens } \\
\text { Total phosphates (as P) } \\
\text { Total phosphates (as P) } \\
1,1,1 \text {-Trichloroethane } \\
\text { Trichloroethylene } \\
\text { Gross alpha } \\
\text { Nonvolatile beta } \\
\text { Total radium } \\
\text { Tritium }\end{array}$ & $\begin{aligned} & 15,800 \\
&< 2.0 \\
& 2,110 \\
&< 1,000 \\
&< 1.0 \\
& 35,000 \\
&< 1,000 \\
&<5.0 \\
&<50 \\
&<50 \\
&<1.0 \\
& 1.4 \\
&<2.0 E-09 \\
&<2.0 E-09 \\
& 1.5 E-09 \pm 1.2 E \cdot 09 \\
&<1.0 E 07\end{aligned}$ & v & $\begin{array}{l}\mu g / \mathrm{L} \\
\mu \mathrm{g} / \mathrm{L} \\
\mu \mathrm{g} / \mathrm{L} \\
\mu \mathrm{g} / \mathrm{L} \\
\mu \mathrm{g} / \mathrm{L} \\
\mu \mathrm{g} / \mathrm{L} \\
\mu \mathrm{g} / \mathrm{L} \\
\mu \mathrm{g} / \mathrm{L} \\
\mu \mathrm{g} / \mathrm{L} \\
\mu \mathrm{g} / \mathrm{L} \\
\mu \mathrm{g} / \mathrm{L} \\
\mu \mathrm{g} / \mathrm{L} \\
\mu \mathrm{C} / \mathrm{mL} \\
\mu \mathrm{Ci} / \mathrm{mL} \\
\mu \mathrm{Ci} / \mathrm{mL} \\
\mu \mathrm{Ci} / \mathrm{mL}\end{array}$ & $\begin{array}{l}\mathrm{GE} \\
\mathrm{GE} \\
\mathrm{GE} \\
\mathrm{GE} \\
\mathrm{MA} \\
\mathrm{GE} \\
\mathrm{GE} \\
\mathrm{GE} \\
\mathrm{GE} \\
\mathrm{GE} \\
\mathrm{MA} \\
\mathrm{MA} \\
\mathrm{GE} \\
\mathrm{GE} \\
\mathrm{GE} \\
\mathrm{GE}\end{array}$ \\
\hline
\end{tabular}

WELL MSB 35B

MEASUREMENTS CONDUCTED IN THE FIELD

Sample date: 10/25/91

Depth to water: 135.52 . ft $(41.31 \mathrm{~m})$ below TOC

Water elevation: $216.28 \mathrm{Ht} / 65$

Sp. conductance. $39 \mu \mathrm{S} / \mathrm{cm}$.

LABORATORY ANALYYSES

\begin{tabular}{|c|c|c|c|}
\hline Analyte & Besult & Nisd & Unit \\
\hline $\begin{array}{l}\text { pH } \\
\text { Specific conductance } \\
\text { Arsenic } \\
\text { Barium } \\
\text { Cadmium } \\
\text { Calcium } \\
\text { Chloride } \\
\text { Chloroform } \\
\text { Chromium } \\
\text { 1,1-Dichloroethylene } \\
\text { trans-1,2-Dichloroethylene } \\
\text { Fluoride } \\
\text { ron } \\
\text { Lead } \\
\text { Magnesium } \\
\text { Manganese } \\
\text { Mercury } \\
\text { Nitrate as nitrogen } \\
\text { Phenols } \\
\text { Potassium } \\
\text { Selenium } \\
\text { Silica } \\
\text { Silver } \\
\text { Sodium } \\
\text { Sulfate } \\
\text { Tetrachloroethylene } \\
\text { Total dissolved solids } \\
\text { Total organic carbon } \\
\text { Total organic halogens } \\
\text { Total phosphates (as P) } \\
\text { 1,1,1-Trichloroethane } \\
\text { Trichloroethylene } \\
\text { Gross alpha } \\
\text { Nonvolatile beta } \\
\text { Total radium } \\
\text { Tritium }\end{array}$ & $\begin{aligned} & 5.8 \\
& 30 \\
&<2.0 \\
& 5.0 \\
&<2.0 \\
& 2.520 \\
& 3,280 \\
&<1.0 \\
&<4.0 \\
&<1.0 \\
&<1.0 \\
&<100 \\
&<4.0 \\
&<3.0 \\
& 150 \\
&<2.0 \\
& 0.93 \\
& 240 \\
&<5.0 \\
&<500 \\
&<2.0 \\
& 8,310 \\
&<2.0 \\
& 3,660 \\
& 1.170 \\
&<1.0 \\
& 32,000 \\
&<1.000 \\
&<5.0 \\
&<50 \\
&<1.0 \\
&<1.0 \\
&<2.0 \mathrm{E}-09 \\
&<2.0 \mathrm{E}-09 \\
& 2.0 \mathrm{E}-09 \pm 1.3 \mathrm{E} \cdot 09 \\
&<7.0 \mathrm{E}-07\end{aligned}$ & JQ & 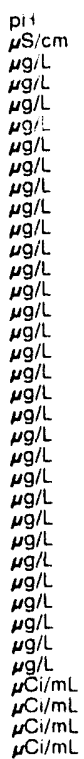 \\
\hline
\end{tabular}

WELL MSB 35D

MEASUREMENTS CONDUCTED IN THE FIELD

Sample date: 10/25/91

The well was dry.

Time: 9:15

WELL MSB 35TA

MEASUREMENTS CONDUCTED IN THE FIELD

Sample date: $10 / 25 / 91$

Depth to waler: $158.62 \pi(48.35 \mathrm{~m})$ below TOC

Water elevation: $191.78 \mathrm{ft}(58$.

Water evacuated before sampling: $412 \mathrm{gal}$

Time: $8: 45$

AH: 5.5 . $17 \mathrm{mg}$

Alkalinity: $17 \mathrm{mg} / \mathrm{L}$ : $190^{\circ} \mathrm{C}$

$\mathrm{ab}$

LABORATORY ANALYSES

\begin{tabular}{|c|c|c|c|}
\hline F Analyte & Result & Mod & Unit \\
\hline $\begin{array}{ll}0 & \text { pH } \\
0 & \text { Specific conductance } \\
0 & \text { Arsenic } \\
0 & \text { Barium }\end{array}$ & $\begin{aligned} & j 3 \\
& 15 \\
&<2.0 \\
&<3.0\end{aligned}$ & $\mathrm{JQ}$ & $\begin{array}{l}\rho H \\
\mu \mathrm{S} / \mathrm{cm} \\
\mu g / \mathrm{L} \\
\mu g / \mathrm{L}\end{array}$ \\
\hline
\end{tabular}

WELL MSB 35TA collected on 10/25/91, laboratory analyses (cont.)

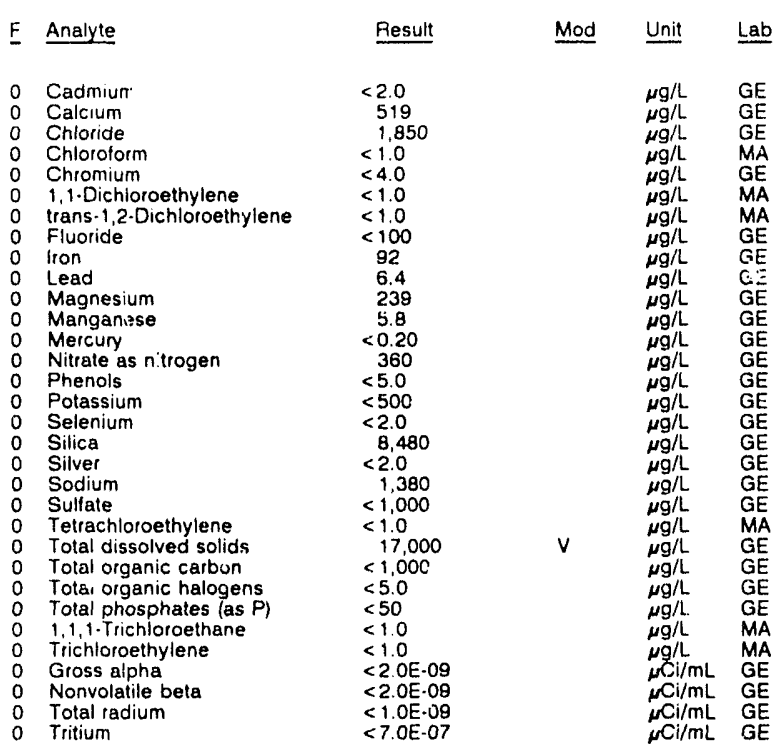

\section{WELL MSB 36A}

MEASUREMENTS CONOUCTEO IN THE FIELD

Sample date: $10 / 29 / 91$

Depth to water: $132.38 \mathrm{H}(40.35 \mathrm{~m})$ below TOC

Water elevation: $208.22 \mathrm{f}(63.47 \mathrm{~m}) \mathrm{ms}$

Water evacuated before sampling: $294 \mathrm{gal}$

Time: $7: 30$

PH: 4.3

Alkalinity: $0 \mathrm{mg} / \mathrm{h}$ : $190^{\circ} \mathrm{C}$

LABORATORY ANALYSES

\begin{tabular}{|c|c|c|c|c|c|}
\hline$\underline{F}$ & Analyte & Result & Mod & Unit & Lab \\
\hline $\begin{array}{l}0 \\
0\end{array}$ & $\begin{array}{l}\text { pH } \\
\text { Specific conductance }\end{array}$ & $\begin{array}{l}4.6 \\
35\end{array}$ & JQ & $\mathrm{pH}$ & $\begin{array}{l}\mathrm{GE} \\
\mathrm{GE}\end{array}$ \\
\hline 0 & Aluminum & 37 & & $\mu g / L$ & $\mathrm{GE}$ \\
\hline $\begin{array}{l}0 \\
0\end{array}$ & $\begin{array}{l}\text { Arsenic } \\
\text { Arsenic }\end{array}$ & $\begin{array}{l}<2.0 \\
<2.0\end{array}$ & & $\underset{\mu \mathrm{g} / \mathrm{L}}{\mu}$ & $\begin{array}{l}\mathrm{GE} \\
\mathrm{GE}\end{array}$ \\
\hline 0 & Barium & 10 & & $\mu$ & $\mathrm{GE}$ \\
\hline 0 & Benzene & $<1.0$ & & $\mu \mathrm{g} / \mathrm{h}$ & $\mathrm{GE}$ \\
\hline $\begin{array}{l}0 \\
0\end{array}$ & Bromodichloromethane & $<1.0$ & & $\mu g / L$ & $G E$ \\
\hline 0 & $\begin{array}{l}\text { Bromolorm } \\
\text { Bromomethane }\end{array}$ & $\begin{array}{l}<1.0 \\
<1.0\end{array}$ & & $\mu g / L$ & $\begin{array}{l}\mathrm{GE} \\
\mathrm{GE}\end{array}$ \\
\hline 0 & Cüunium & $<2.0$ & & $\mu g / L$ & $\mathrm{GE}$ \\
\hline $\begin{array}{l}0 \\
0\end{array}$ & Carbon tetrachioride & $<1.4$ & & $\mu g / \mathrm{L}$ & \\
\hline $\begin{array}{l}0 \\
0\end{array}$ & $\begin{array}{l}\text { Chloride } \\
\text { Chlorobenzene }\end{array}$ & $\begin{aligned} 2,400 \\
<10\end{aligned}$ & & $\mu g / L$ & GE \\
\hline 0 & Chloroethane & $<1.0$ & & $\mu g / L$ & $\begin{array}{l}\mathrm{GE} \\
\mathrm{GE}\end{array}$ \\
\hline 0 & Chloroethene (Ninyl chloride) & $<1.0$ & & $\mu g / \mathrm{L}$ & \\
\hline 0 & 2. Chloroethyi vinyl ether & $<1.0$ & & $\mu \mathrm{g} / \mathrm{L}$ & \\
\hline $\begin{array}{l}0 \\
0\end{array}$ & $\begin{array}{l}\text { Chlorolorin } \\
\text { Chloromethane }\end{array}$ & $<\begin{array}{ll}1 & 0 \\
<1 & 0\end{array}$ & & $\mu g / L$ & \\
\hline 0 & $\begin{array}{l}\text { Chloromethane } \\
\text { Chromium }\end{array}$ & $\begin{array}{l}<1.0 \\
<4.0\end{array}$ & & $\mu g / L$ & $\begin{array}{l}\mathrm{GE} \\
\mathrm{GE}\end{array}$ \\
\hline 0 & Copper & 5.7 & & $\mu \mathrm{g} / \mathrm{L}$ & $\mathrm{GE}$ \\
\hline c & Cyanide & $<5.0$ & JQ & $\mu \mathrm{g} / \mathrm{L}$ & $\mathrm{GE}$ \\
\hline 0 & Cyanide & $<5.0$ & JQ & $\mu g / L$ & $\mathrm{GE}$ \\
\hline 0 & Dibromochloromethane & $<1.0$ & & $\mu \mathrm{g} / \mathrm{L}$ & GE \\
\hline 0 & 1.1.Dichioroethiane & $<1.0$ & & $\mu g / L$ & \\
\hline 0 & 1,2-Dichloroethane & $<1.0$ & & $\mu \mathrm{g} / \mathrm{L}$ & \\
\hline 0 & 1,1.Dichloroethylene & $<1.0$ & & $\mu \mathrm{g} / \mathrm{L}$ & $E$ \\
\hline 0 & trans-1,2-Dichloroethylene & $<1.0$ & & $\mu g / L$ & \\
\hline 0 & Dichloromethane & 2.0 & $\mathrm{~J} 2 \mathrm{~V}$ & $\mu g / \mathrm{L}$ & $\bar{E}$ \\
\hline 0 & 1,2-Dichloropropane & $<1.0$ & & $\mu \mathrm{g} / \mathrm{L}$ & \\
\hline 0 & cis-1,3-Dichloropropene & $<1.0$ & & $\mu g / L$ & $G E$ \\
\hline $\begin{array}{l}0 \\
0\end{array}$ & $\begin{array}{l}\text { trans-1,3-Dichloropropene } \\
\text { Ethyibenzene }\end{array}$ & $\begin{array}{l}<1.0 \\
<10\end{array}$ & & $\mu g / L$ & \\
\hline $\begin{array}{l}0 \\
0\end{array}$ & $\begin{array}{l}\text { Ethylbenzene } \\
\text { Lead }\end{array}$ & $\begin{array}{l}<10 \\
<3.0\end{array}$ & & $\mu g / L$ & \\
\hline 0 & Lead & $<3.0$ & & $\mu \mathrm{g} / \mathrm{L}$ & $\mathrm{GE}$ \\
\hline 0 & Mercury & $<0.20$ & & $\mu \mathrm{g} / \mathrm{L}$ & \\
\hline$n$ & Nicke: & 6.8 & & $\mu \mathrm{g} / \mathrm{L}$ & \\
\hline c: & Nitrate as nitrogen & 190 & & $\mu g / L$ & $E$ \\
\hline 0 & Phenols & $<5.0$ & & $\mu g / L$ & \\
\hline 0 & Selenium & $<2.0$ & & $\mu \mathrm{g} / \mathrm{L}$ & \\
\hline 0 & Selenium & $<2.0$ & & $\mu \mathrm{g} / \mathrm{L}$ & \\
\hline 0 & Silver & $<2.0$ & & $\mu \mathrm{g} / \mathrm{L}$ & $\mathrm{GE}$ \\
\hline 0 & Sodium & 1,710 & & $\mu \mathrm{g} / \mathrm{L}$ & \\
\hline 0 & Sulfate & 24,000 & & $\mu \mathrm{g} / \mathrm{L}$ & \\
\hline 0 & $1,1,2,2$. Tetrachloroethane & $<10$ & & $\mu \mathrm{g} / \mathrm{L}$ & \\
\hline 0 & Tetrachloroethylene & $<10$ & & $\mu g / L$ & \\
\hline 0 & Toluene & $<1.0$ & & $\mu g / L$ & \\
\hline 0 & Total phosphates (as $P$ ) & $<50$ & & $\mu g / L$ & \\
\hline 0 & 1,1,1-Trichloroethane & $<1.0$ & & $\mu \mathrm{g} / \mathrm{L}$ & \\
\hline 0 & 1, 1,2. Trichloroethane & $<1.0$ & & $\mu g / L$ & E \\
\hline 2 & Trichloroethylene & 46 & & $\mu g / L$ & \\
\hline
\end{tabular}


ANALYTICAL RESULTS

WELL MSB 36A collected on 10/28/91, laboratory analyses (cont)

\begin{tabular}{|c|c|c|c|c|}
\hline$F$ & Analyte & Result & Mod & Unit \\
\hline ) & $\begin{array}{l}\text { Trichlorofluoromethane } \\
\text { Zinc } \\
\text { Uranium alpha activity }\end{array}$ & $\begin{array}{l}<1.0 \\
15 \\
2.3 E-08\end{array}$ & & $\underset{\mu \mathrm{m} h \mathrm{~h}}{\operatorname{mim} / \mathrm{mL}}$ \\
\hline
\end{tabular}

WELL MSB 36B

MEASUREMENTS CONDUCTED IN THE FIELD

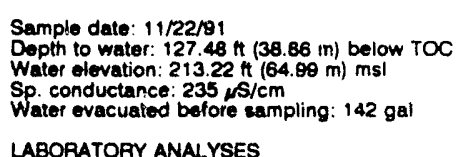

Time: $12: 40$

PH: 4.5

Water temperature: $18.7^{\circ} \mathrm{C}$

LABORATOAY ANALYYSES

\begin{tabular}{|c|c|c|c|c|c|}
\hline$F$ & Analyte & Result & Mod & Unit & Lab \\
\hline $\begin{array}{l}0 \\
0 \\
1 \\
0 \\
0 \\
0 \\
0 \\
0 \\
0 \\
0 \\
0 \\
0 \\
0 \\
0 \\
0 \\
0 \\
0 \\
0 \\
0 \\
0 \\
0 \\
0 \\
0 \\
0 \\
0 \\
0 \\
0 \\
0 \\
0 \\
0 \\
0 \\
0 \\
0 \\
0 \\
2 \\
0 \\
0 \\
0 \\
0 \\
0 \\
0 \\
0 \\
0 \\
0 \\
0 \\
0 \\
2 \\
0 \\
0 \\
0\end{array}$ & 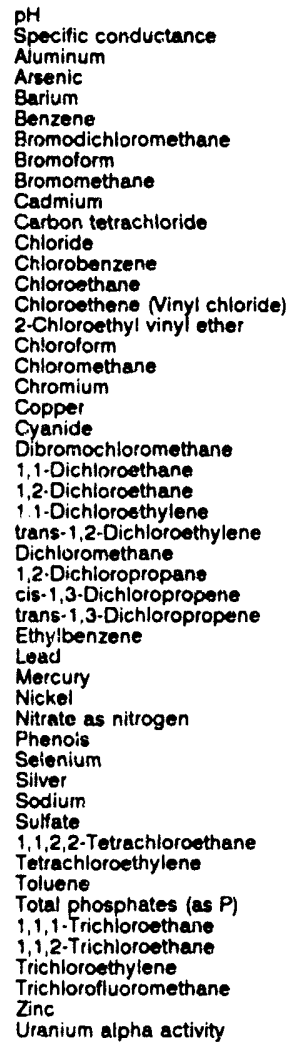 & $\begin{array}{l}4.9 \\
220 \\
11.0 \\
<2.0 \\
73 \\
<1.0 \\
<1.0 \\
<1.0 \\
<1.0 \\
<2.0 \\
<1.0 \\
2.770 \\
<1.0 \\
<1.0 \\
<1.0 \\
<1.0 \\
<1.0 \\
<1.0 \\
<4.0 \\
<4.0 \\
<5.0 \\
<1.0 \\
<1.0 \\
<1.0 \\
<1.0 \\
<1.0 \\
1.8 \\
<1.0 \\
<1.0 \\
<1.0 \\
<1.0 \\
<3.0 \\
<0.20 \\
<4.0 \\
30,000 \\
<5.0 \\
<2.0 \\
<2.0 \\
10,600 \\
<1.000 \\
<1.0 \\
<1.0 \\
<1.0 \\
<50 \\
<1.0 \\
<1.0 \\
<1.800 \\
<1.0 \\
27 \\
<1.0 E-09\end{array}$ & J2V & 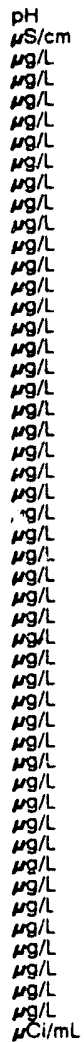 & $\begin{array}{l}G E \\
G E \\
G E \\
G E \\
G E \\
G E \\
G E \\
G E \\
G E \\
G E \\
G E \\
G E \\
G E \\
G E \\
G E \\
G E \\
G E \\
G E \\
G E \\
G E \\
G E \\
G E \\
G E \\
G E \\
G E \\
G E \\
G E \\
G E \\
G E \\
G E \\
G E \\
G E \\
G E \\
G E \\
G E \\
G E \\
G E \\
G E \\
G E \\
G E \\
G E \\
G E \\
G E \\
G E \\
G E \\
G E \\
G E \\
G E \\
G E \\
G E\end{array}$ \\
\hline
\end{tabular}

WELL MSB 36C

MEASUREMENTS CONDUCTED IN THE FIELD

Sample date: $10 / 29 / 81$

Depth to water: 127.18 i $(38.78 \mathrm{~m})$ below TOC Water elevation: $213.62 \mathrm{H}(65.11 \mathrm{~m}) \mathrm{ms}$

Sp. conductance: $28 \mathrm{~s} / \mathrm{cm}$

Water evacuated before sampling: $64 \mathrm{gal}$

LABORATORY ANALYSES

\begin{tabular}{|c|c|c|c|c|}
\hline Analyte & Result & Mod & Unit & $\underline{L a b}$ \\
\hline $\begin{array}{ll}0 & \text { pH } \\
0 & \text { Specific conductance } \\
0 & \text { Aluminum } \\
0 & \text { Arsenic } \\
0 & \text { Arsenic } \\
0 & \text { Barium } \\
0 & \text { Benzene } \\
0 & \text { Bromodichloromethane } \\
0 & \text { Bromolorm } \\
0 & \text { Bromomothane } \\
0 & \text { Cadmium } \\
0 & \text { Carbon tetrachloride } \\
0 & \text { Chloride }\end{array}$ & $\begin{array}{r}5.2 \\
25 \\
20 \\
<2.0 \\
<2.0 \\
5.9 \\
<1.0 \\
<1.0 \\
<1.0 \\
<1.0 \\
<2.0 \\
<1.0 \\
1.750\end{array}$ & a & $\begin{array}{l}p H \\
\mu S / c m \\
\mu g / L \\
\mu g / L \\
\mu g / L \\
\mu g / L \\
\mu g / L \\
\mu g / L \\
\mu g / L \\
\mu g / L \\
\mu g / h \\
\mu g / L \\
\mu g / L\end{array}$ & $\begin{array}{l}\mathrm{GE} \\
\mathrm{GE} \\
\mathrm{GE} \\
\mathrm{GE} \\
\mathrm{GE} \\
\mathrm{GE} \\
\mathrm{GE} \\
\mathrm{GE} \\
\mathrm{GE} \\
\mathrm{GE} \\
\mathrm{GE} \\
\mathrm{GE} \\
\mathrm{GE}\end{array}$ \\
\hline
\end{tabular}

Alkatinity: $0 \mathrm{mg} / \mathrm{h}$
Water temperature 17.700
WELL MSB 36C collected on 10/29/91, laboratory analyses (cont.)

\begin{tabular}{|c|c|c|c|}
\hline Analyte & Result & Mod & Unit \\
\hline $\begin{array}{l}\text { Chloride } \\
\text { Chlorobenzene } \\
\text { Chloroethane } \\
\text { Chloroethene Ninyl chloride) } \\
\text { 2-Chloroethyl vinyl ether } \\
\text { Chloroform } \\
\text { Chloromethane } \\
\text { Chromium } \\
\text { Copper } \\
\text { Cyanide } \\
\text { Dibromochloromethane } \\
1,1-\text { Dichloroethane } \\
1,2-\text { Dichloroothane } \\
1,1-\text { Dichloroethylene } \\
\text { trans-1,2-Dichloroethylene } \\
\text { Dichioromethane } \\
1,2 \cdot \text { Dichloropropane } \\
\text { cis-1,3-Dichloropropene } \\
\text { trans-1,3-Dichloropropene } \\
\text { Ethylbenzene } \\
\text { Lead } \\
\text { Lead } \\
\text { Mercury } \\
\text { Nickel } \\
\text { Nittrate as nitrogen } \\
\text { Nitrate as nitrogen } \\
\text { Phenols } \\
\text { Selenium } \\
\text { Selenium } \\
\text { Silvet } \\
\text { Sodium } \\
\text { Sulfate } \\
1,1,2,2 \cdot \text { Tetrachloroethane } \\
\text { Tetrachloroethylene } \\
\text { Toluene } \\
\text { Total phosphates (as P) } \\
1,1,1 \cdot \text { Trichloroethane } \\
1,1,2-\text { Trichloroethane } \\
\text { Trichloroothylene } \\
\text { Trichlorofluoromethane } \\
\text { Zinc } \\
\text { Uranium alpha activity }\end{array}$ & $\begin{array}{l}1,780 \\
<1.0 \\
<1.0 \\
<1.0 \\
<1.0 \\
<1.0 \\
<1.0 \\
<4.0 \\
<4.0 \\
<5.0 \\
<1.0 \\
<1.0 \\
<1.0 \\
<1.0 \\
<1.0 \\
2.0 \\
<1.0 \\
<1.0 \\
<1.0 \\
<1.0 \\
<3.0 \\
<3.0 \\
<0.20 \\
<4.0 \\
11330 \\
1,330 \\
<5.0 \\
<2.0 \\
<2.0 \\
<2.0 \\
2.000 \\
<1.000 \\
<1.0 \\
4.0 \\
<1.0 \\
<50 \\
<1.0 \\
<1.0 \\
48 \\
<1.0 \\
61.2 \\
<1.06-09\end{array}$ & $\mathrm{~J} 2 \mathrm{~V}$ & 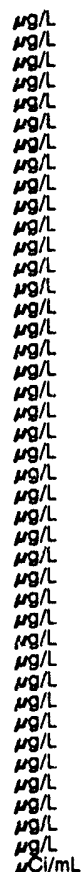 \\
\hline
\end{tabular}

\section{I“'ELL MSB 36D}

MEASUREMENTS CONDUCTED IN THE FIELD

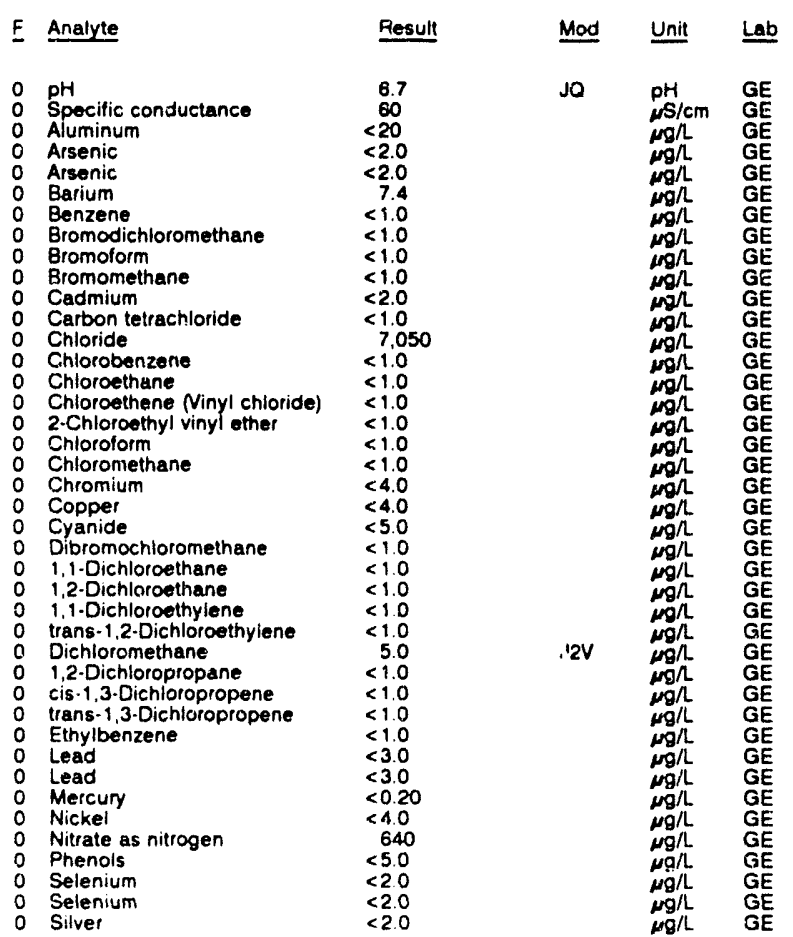

Time: :00
Lab

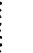

Sample date: 10/29/91

Depth to water: Not available

Water elevation: Not available

Water evacuated bolore sampling: $5 \mathrm{gal}$

The well went dry during purging.

LABORATORY ANALYSES

Alkalinity: $7 \mathrm{mg} /$

Alkalinity: $7 \mathrm{mg} / \mathrm{h}$
Water temperature: $17,0^{\circ} \mathrm{C}$

Time: 7:45

Alkalinity. $0 \mathrm{mg} / \mathrm{l}$

Lab

$\mathrm{GE}$
$\mathrm{GE}$
$\mathrm{GE}$
$\mathrm{GE}$
$\mathrm{GE}$
$\mathrm{GE}$
$\mathrm{GE}$
$\mathrm{GE}$
$\mathrm{GE}$
$\mathrm{GE}$
$\mathrm{GE}$
$\mathrm{GE}$
$\mathrm{GE}$

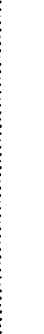




\section{ANALYTICAL RESULTS}

WELL MSB 36D collected on 10/29/91, laboratory analyses (cont.)

\begin{tabular}{|c|c|c|c|}
\hline Analyte & Result & Mod & Unit \\
\hline $\begin{array}{l}\text { Sodium } \\
\text { Sulfate } \\
1,1,2,2 \cdot \text { Tetrachloroethane } \\
\text { Tetrachloroethylene } \\
\text { Toluene } \\
\text { Total organic carbon } \\
\text { Total phosphates (as P) } \\
\text { Total phosphates (as P) } \\
1,1,1-\text { Trichloroethane } \\
1,1,2-\text { Trichloroethane } \\
\text { Trichlorothylene } \\
\text { Trichlorofluoromethane } \\
\text { Zinc } \\
\text { Uranlum alpha activity }\end{array}$ & $\begin{aligned} & 5.540 \\
&< 1.000 \\
&< 1.0 \\
&<1.0 \\
&<1.0 \\
&<1.000 \\
& 50 \\
&<50 \\
&<1.0 \\
&<1.0 \\
&<1.0 \\
&<1.0 \\
& 6.4 \\
&<1.0 \mathrm{E}-09\end{aligned}$ & & $\begin{array}{l}\mu g / L \\
\mu g / L \\
\mu g / L \\
\mu g / L \\
\mu g / L \\
\mu g / L \\
\mu g / L \\
\mu g / h \\
\mu g / L \\
\mu g / L \\
\mu g / L \\
\mu g / L \\
\mu g / L \\
\mu C i / m\end{array}$ \\
\hline
\end{tabular}

WELL MSB 36TA

MEASUREMENTS CONOUCTER IN THE FIELD

Sample rate: 10/29/81

Dopth to water: $147.85 \mathrm{H}(45.10 \mathrm{~m})$ below TOC Water elab tion: $192.65 \mathrm{ft}(58.72 \mathrm{~m}) \mathrm{ms}$ i

Wator evacuatod bofore sampling: $374 \mathrm{gal}$

LABORATORY ANALYSES

\begin{tabular}{|c|c|c|c|c|c|}
\hline$F$ & Analyte & Result & Mod & Unit & Lab \\
\hline $\begin{array}{l}0 \\
0 \\
0 \\
0 \\
0 \\
0 \\
0 \\
0 \\
0 \\
0 \\
0 \\
0 \\
0 \\
0 \\
0 \\
0 \\
0 \\
0 \\
0 \\
0 \\
0 \\
0 \\
0 \\
0 \\
0 \\
0 \\
0 \\
0 \\
0 \\
0 \\
0 \\
0 \\
0 \\
0\end{array}$ & 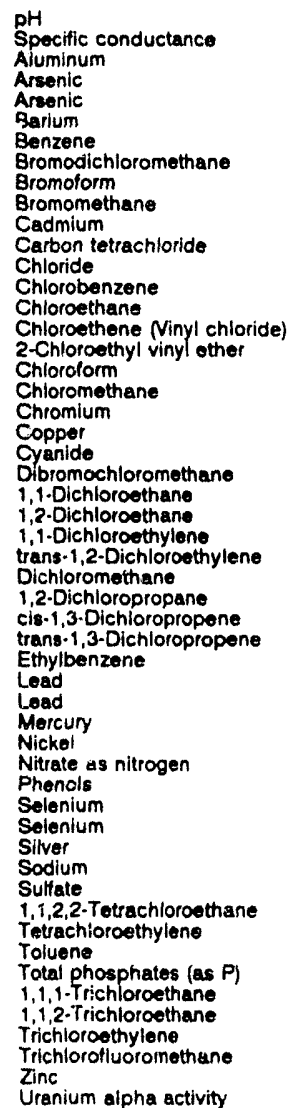 & $\begin{aligned} & 5.4 \\
& 25 \\
&<20 \\
&<2.0 \\
&<2.0 \\
& 5.9 \\
&<1.0 \\
&<1.0 \\
&<1.0 \\
&<1.0 \\
&<2.0 \\
&<1.0 \\
& 2.140 \\
&<1.0 \\
&<1.0 \\
&<1.0 \\
&<1.0 \\
&<1.0 \\
&<1.0 \\
&<4.0 \\
& 6.5 \\
&<5.0 \\
&<1.0 \\
&<1.0 \\
&<1.0 \\
&<1.0 \\
&<1.0 \\
& 4.0 \\
&<1.0 \\
&<1.0 \\
&<1.0 \\
&<1.0 \\
& 8.6 \\
& 6.6 \\
&<0.20 \\
&<4.0 \\
&<50 \\
&<5.0 \\
&<2.0 \\
&<2.0 \\
&<2.0 \\
& 1.470 \\
& 3.510 \\
&<1.0 \\
&<1.9 \\
&<10 \\
&<6 \% 3 \\
&<10 \\
&<1.0 \\
&<1.0 \\
&<1.0 \\
& 331 \\
&<1.0 E-09\end{aligned}$ & $\mathrm{~J}_{2} \mathrm{~V}$ & $\begin{array}{l}\mathrm{pH} \\
\mu \mathrm{S} / \mathrm{cm} \\
\mu g / L \\
\mu g / L \\
\mu g / L \\
\mu g / L \\
\mu g / L \\
\mu g / L \\
\mu g / L \\
\mu g / L \\
\mu g / L \\
\mu g / L \\
\mu g / L \\
\mu g / L \\
\mu g / L \\
\mu g / L \\
\mu g / L \\
\mu g / L \\
\mu g / L \\
\mu g / L \\
\mu g / L \\
\mu g / L \\
\mu g / L \\
\mu g / L \\
\mu g / L \\
\mu g / L \\
\mu g / L \\
\mu g / L \\
\mu g / L \\
\mu g / L \\
\mu g / L \\
\mu g / L \\
\mu g / L \\
\mu g / L \\
\mu g / L \\
\mu g / L \\
\mu g / L \\
\mu g / L \\
\mu g / L \\
\mu g / L \\
\mu g / L \\
\mu g / L \\
\mu g / L \\
\mu g / L \\
\mu g / L \\
\mu g / L \\
\mu g / L \\
\mu g / L \\
\mu g / L \\
\mu g / L \\
\mu g / L \\
\mu g / L \\
\mu C / / m L\end{array}$ & $\begin{array}{l}G E \\
G E \\
G E \\
G E \\
G E \\
G E \\
G E \\
G E \\
G E \\
G E \\
G E \\
G E \\
G E \\
G E \\
G E \\
G E \\
G E \\
G E \\
G E \\
G E \\
G E \\
G E \\
G E \\
G E \\
G E \\
G E \\
G E \\
G E \\
G E \\
G E \\
G E \\
G E \\
G E \\
G E \\
G E \\
G E \\
G E \\
G E \\
G E \\
G E \\
G E \\
G E \\
G E \\
G E \\
G E \\
G E \\
G E \\
G E \\
G E \\
G E \\
G E \\
G E \\
G E\end{array}$ \\
\hline
\end{tabular}

WELL MSB 37A

MEASUREMENTS CONDUCTED IN THE FIELD

Sariple date: 11/06/91 Depth to water: $175.75 \mathrm{ft}(53.57 \mathrm{~m})$ below Sp. conductance: $54 \mathrm{~s} / \mathrm{cm}$ Water evacuated before sampling: $80 \mathrm{gal}$ The well went dry during purging.

LABORATORY ANALYSES

\begin{tabular}{|c|c|c|c|}
\hline Al 10 & Result & Mod & Unit \\
\hline $\begin{array}{l}\text { pH } \\
\text { Specific conductance } \\
\text { Arsenic } \\
\text { Barium } \\
\text { Cadmium } \\
\text { Calcium } \\
\text { Chloride } \\
\text { Chlorotorm } \\
\text { Chromium } \\
1,1 \text {-Dichloroethylene } \\
\text { trans-1,2-Dichloroethylene } \\
\text { Fluoride } \\
\text { lron } \\
\text { Lead } \\
\text { Magnesium } \\
\text { Manganese } \\
\text { Mercury } \\
\text { Nitrate as nitrogen } \\
\text { Phenols } \\
\text { Potassium } \\
\text { Selenium } \\
\text { Silica } \\
\text { Silver } \\
\text { Sodium } \\
\text { Sulfate } \\
\text { Totrachloroethylene } \\
\text { Total dissolved solids } \\
\text { Total organic carbon } \\
\text { Total organic halogens } \\
\text { Total phosphates (as P) } \\
\text { 1,1,1-Trichloroethane } \\
\text { Trichloroethylene } \\
\text { Gross alpha } \\
\text { Nonvolatile beta } \\
\text { Total radium } \\
\text { Tritium }\end{array}$ & $\begin{array}{l}6.4 \\
55 \\
<2.0 \\
17 \\
8.6 \\
6,600 \\
1,600 \\
<2.0 \\
<4.0 \\
<2.0 \\
<2.0 \\
<100 \\
22 \\
3.7 \\
479 \\
4.7 \\
<0.20 \\
660 \\
<5.0 \\
1,670 \\
<2.0 \\
7,890 \\
<2.0 \\
2,290 \\
6,850 \\
24 \\
30,000 \\
<1,000 \\
141 \\
<50 \\
<2.0 \\
109 \\
<2.0 \mathrm{E}-09 \\
<2.0 \mathrm{E} \cdot 09 \\
<1.0 \mathrm{E}-09 \\
<7.0 \mathrm{E}-07\end{array}$ & JO & $\begin{array}{l}p H \\
\mu S / c m \\
\mu g / L \\
\mu g / L \\
g / L \\
\mu g / L \\
\mu g / L \\
\mu g / L \\
\mu g / L \\
\mu g / L \\
\mu g / L \\
\mu g / L \\
\mu g / L \\
\mu g / L \\
\mu g / L \\
\mu g / L \\
\mu g / L \\
\mu g / L \\
\mu g / L \\
\mu g / L \\
\mu g / L \\
\mu g / L \\
\mu g / L \\
\mu g / L \\
\mu g / L \\
\mu g / L \\
\mu g / L \\
\mu g / L \\
\mu g / L \\
\mu g / L \\
\mu g / L \\
\mu g / L \\
\mu L i / m L \\
\mu C i / m L \\
\mu C i / m L \\
\mu C i / m L\end{array}$ \\
\hline
\end{tabular}

WELL MSB 37B

MEASUREMENTS CONDUCTED IN THE FIELD

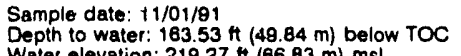
Water elevation: $219.27 \mathrm{H}(66.83 \mathrm{~m}) \mathrm{msl}$ Alkalinity: $14 \mathrm{mg} / \mathrm{L}$ Water temperature: $18.0^{\circ} \mathrm{C}$ LABORATORY ANALYSES

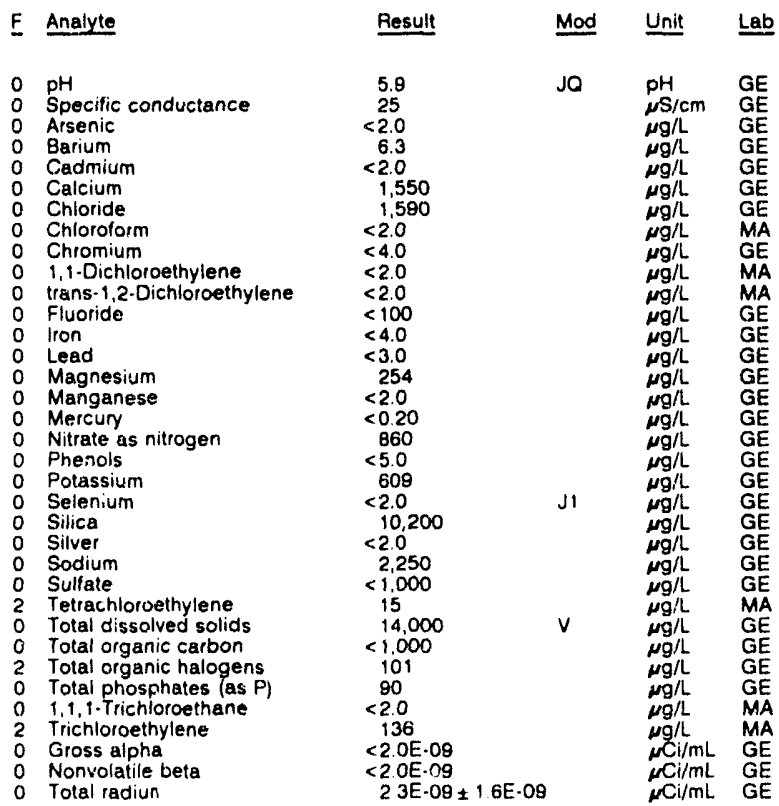


ANALYTICAL RESULTS

WELL MSB $37 \mathrm{~B}$ collected a 11/01/91, laboratory analyses (cont.)

$\begin{array}{lllll}\text { E Analyte } & \text { Result } & \text { Mod Unit Lab } & \text { La } \\ 0 \text { Tritium } & <7.0 E-07 & \mathrm{mCl} / \mathrm{mL} \text { GE }\end{array}$

\section{WELL MSB 37C}

MEASUREMENTS CONDUCTED IN THE FIELD

\begin{tabular}{|c|c|c|c|c|c|}
\hline \multicolumn{3}{|c|}{$\begin{array}{l}\text { Sample date: } 11 / 01 / 91 \\
\text { Depth to water: } 155.69 \mathrm{H}(47.55 \mathrm{~m}) \text { below TOC } \\
\text { Water olevation: } 227.11 \mathrm{ft}(68.22 \mathrm{~m}) \mathrm{msl} \\
\text { Sp. conductance: } 32 \mathrm{\mu s} / \mathrm{cm} \\
\text { Water evacuated before sampling: } 134 \mathrm{gal}\end{array}$} & \multicolumn{3}{|c|}{$\begin{array}{l}\text { Time: } 7: 15 \\
\text { pH: } 4.2 \\
\text { Alkalinity: } 8 \mathrm{mg} / \mathrm{h} \\
\text { Water temperature: } 17.7^{\circ} \mathrm{C}\end{array}$} \\
\hline \multicolumn{6}{|c|}{ LABORATORY ANALYSES } \\
\hline & Analyte & Result & Mod & Unit & Lab \\
\hline & $\begin{array}{l}\text { Chloroform } \\
\text { Chloroform } \\
\text { 1,1-Dichloroethyiene } \\
1,1 \text {-Dichloroethylene } \\
\text { trans-1,2-Dichloroethylene } \\
\text { trans-1,2-Dichloroethylene } \\
\text { Tetrachloroethylene } \\
\text { Tetrachloroethylene } \\
\text { i, } 1,1 \text {-Trichloroethane } \\
1,1,1 \text {-Trichloroethane } \\
\text { Trichloroethylene } \\
\text { Trichloroethylene }\end{array}$ & $\begin{aligned}<5.0 \\
<5.0 \\
<5.0 \\
<5.0 \\
<5.0 \\
<5.0 \\
65 \\
57 \\
<5.0 \\
<5.0 \\
15 \\
12\end{aligned}$ & & $\begin{array}{l}\mu g / L \\
\mu g / L \\
\mu g / L \\
\mu g / L \\
\mu g / L \\
\mu g / L \\
\mu g / L \\
\mu g / L \\
\mu g / L \\
\mu g / L \\
\mu g / L \\
\mu g / L\end{array}$ & $\begin{array}{l}\text { MA } \\
\text { MA } \\
\text { MA } \\
\text { MA } \\
\text { MA } \\
\text { MA } \\
\text { MA } \\
\text { MA } \\
\text { MA } \\
\text { MA } \\
\text { MA } \\
\text { MA }\end{array}$ \\
\hline
\end{tabular}

WELL MSB 37D

MEASUREMENTS CONDUCTED IN THE FIELD

Sample date: $11 / 01 / 91$ ft $(46.59 \mathrm{~m})$ below TOC

Depth to water: $152.85 \mathrm{ft}(46.59 \mathrm{~m})$ below

Inaccessibility or pump failure prevented sample collection.

\section{WELL MSB 37TA}

MEASUREMENTS CONDUCTED IN THE FIELD

Sample date: 11/22/91

Depth to water: $178.28 \mathrm{ft}(54.34 \mathrm{~m})$ below TOC Water clevation: $204.12 \mathrm{Ht}(62.22 \mathrm{~m}) \mathrm{ms}$

W. conductance: $26 \mu \mathrm{s} / \mathrm{cm}$

\section{Time: $15: 55$}

$\mathrm{pH}: 5.1$

Alkalinity: $4 \mathrm{mg} / \mathrm{L}$

Water temperature: $19.2^{\circ} \mathrm{C}$

LABORATORY ANIALYSES

\begin{tabular}{|c|c|c|c|}
\hline Analyte & Result & Mod & Unit \\
\hline $\begin{array}{l}\text { pH } \\
\text { Specific conductance } \\
\text { Arsenic } \\
\text { Barium } \\
\text { Cadmium } \\
\text { Calcium } \\
\text { Chloride } \\
\text { Chloroform } \\
\text { Chromium } \\
1,1 \text {-Dichloroethylene } \\
\text { trans-1,2-Dichloroethylene } \\
\text { Fluoride } \\
\text { lron } \\
\text { Lead } \\
\text { Magnesium } \\
\text { Manganese } \\
\text { Mercury } \\
\text { Nitrate as nitrogen } \\
\text { Phenols } \\
\text { Potassium } \\
\text { Selenium } \\
\text { Silica } \\
\text { Silver } \\
\text { Sodium } \\
\text { Sulfate } \\
\text { Tetrachloroethylene } \\
\text { Total dissolved solids } \\
\text { Total organic carbon } \\
\text { Total organic halogens } \\
\text { Total phosphates (as P) } \\
\text { 1,1,1-Trichloroethane } \\
\text { Trichloroethylene } \\
\text { Gross alpha } \\
\text { Nonvolatile beta } \\
\text { Total radium } \\
\text { Tritium }\end{array}$ & $\begin{array}{l}5.4 \\
25 \\
<2.0 \\
11 \\
<2.0 \\
1,200 \\
1,930 \\
<20 \\
<4.0 \\
<20 \\
<20 \\
<100 \\
123 \\
7.2 \\
341 \\
18 \\
<0.20 \\
1,480 \\
<5.0 \\
<500 \\
<2.0 \\
8,470 \\
<2.0 \\
1,850 \\
<1,000 \\
77 \\
13,000 \\
<1.000 \\
1,220 \\
<50 \\
<20 \\
1,420 \\
<2.0 \mathrm{E}-099 \\
<2.0 \mathrm{E} \cdot 09 \\
<1.0 \mathrm{E}-09 \\
2.6 \mathrm{E} \cdot 06 \pm 7.0 \mathrm{E}-07\end{array}$ & JO & 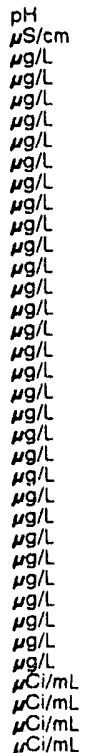 \\
\hline
\end{tabular}

WELL MSB 38B

MEASUREMENTS CONOUCTED IN TI :E FIELD

Sample date: 12/02/91

Depth to water: $145.19 \mathrm{ft}(44.25 \mathrm{~m})$ below TOC

Water elevation: $211.41 \mathrm{ft}$ (B.

Wp. conductance. $44 \mu \mathrm{s} / \mathrm{cm}$

Water evacuated before sampling: $189 \mathrm{gal}$

LABORATORY ANALYSES

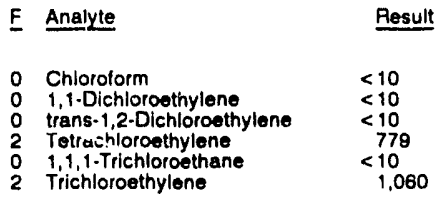

Time: 15:45

pH. 6.2

Water temperature: $20.1^{\circ} \mathrm{C}$

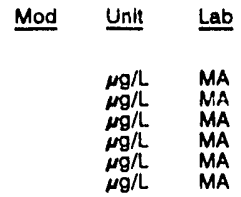

WELL MSB 38C

MEASUREMENTS CONDUCTED IN THE FIELD

Sample dute: 12/02/81

Depth to water: $142.11 \mathrm{H}(43.32 \mathrm{~m})$ below TOC

Water elevation: $214.19 \mathrm{At}$ (65)

Sp. conductanco: $55 \mathrm{sS} / \mathrm{cm}$.

LABORATORY ANALYSES

E Analyte

Pesult

o Chlorotorm

0 1,1-Dichloroethylene

o 1,1-Dichloroethylene

o trans-1,2-Dichloroethylene

0 trans-1,2-Dichloroethylen

2 Tetrachloroethylene

2 Tetrachloroethylene

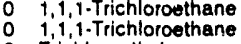

2 Trichloroethylene

$<5.0$
$<5.0$
$<5.0$
$<5.0$
$<5.0$
$<5.0$
363
302
$<5.0$
$<5.0$
651
563

Time: 15:55

pH: 6.1 : $8 \mathrm{mg} / \mathrm{L}$

Alkalinity: $8 \mathrm{mg} / \mathrm{L}$ : $20.4^{\circ} \mathrm{C}$

WELL MSB 38D

MEASUREMENTS CONDUCTED IN THE FIELD

Sample date: $11 / 01 / 9$

Time: 5:20

The well was dry.

\section{WELL MSB 38TA}

MEASUREMENTS CONDUCTED IN THE FIELD

Sample date: $11 / 01 / 91$

Depth to water: $162.78 \mathrm{H}(49.62 \mathrm{~m})$ below TOC

Water elevation: $193.92 \mathrm{ft}(59.11 \mathrm{~m}) \mathrm{msl}$

Water evacuated before sampling: $442 \mathrm{gal}$

LABORATORY ANALYSES

$\begin{array}{ll}\text { F } & \text { Analyte } \\ & \\ 0 & \text { pH } \\ 0 & \text { Specific conductance } \\ 0 & \text { Arsenic } \\ 0 & \text { Barium } \\ 0 & \text { Cadmium } \\ 0 & \text { Calcium } \\ 0 & \text { Carbon tetrachloride } \\ 0 & \text { Chloride } \\ 0 & \text { Chlorolorm } \\ 0 & \text { Chlorolorm } \\ 0 & \text { Chromium } \\ 0 & 1,1 \text {-Dichloloethylene } \\ 0 & \text { trans-1,2-Dichloroethylene } \\ 0 & \text { Fluoride } \\ 2 & \text { lron } \\ 1 & \text { Lead } \\ 0 & \text { Magnesium } \\ 0 & \text { Manganese } \\ 0 & \text { Mercury } \\ 0 & \text { Nitrate as nitrogen } \\ 0 & \text { Phenols } \\ 0 & \text { Potassium } \\ 0 & \text { Selenium } \\ 0 & \text { Silica } \\ 0 & \text { Silver } \\ 0 & \text { Suti im }\end{array}$

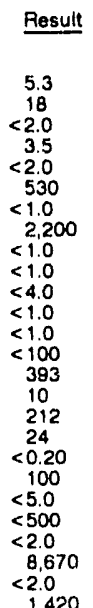

Time: 6:v0

pH: 4.6

Water temperature: $16.6^{\circ} \mathrm{C}$

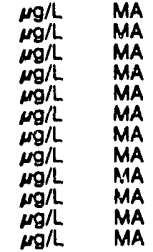


ANALYTICAL RESULTS

WELL MSB 38TA collected on 11/01/91, laboratory analyses (cont.)

\begin{tabular}{|c|c|c|c|}
\hline Analyte & Result & Mod & Unit \\
\hline $\begin{array}{l}\text { Sulfate } \\
\text { Tetrachioroethylene } \\
\text { Tetrachloroethyiene } \\
\text { Total dissolved solids } \\
\text { Total organic carton } \\
\text { Total organic halogens } \\
\text { Total phosphatos (as P) } \\
1,1,9 \text {. Trichloroethane } \\
1,1,1 \text { - Trichloroethane } \\
\text { Trichloroethylene } \\
\text { Trichloroethylene } \\
\text { Gross alpha } \\
\text { Nonvoletile beta } \\
\text { Total radium } \\
\text { Tritium }\end{array}$ & $\begin{array}{l}1,220 \\
<1.0 \\
<1.0 \\
12,000 \\
<1,000 \\
17 \\
<50 \\
<1.0 \\
<1.0 \\
<1.0 \\
<1.0 \\
<2.0 E-09 \\
<2.0 E-09 \\
1.9 E-09 \pm 1.5 E-09 \\
<7.0 E-07\end{array}$ & v & $\begin{array}{l}\mu g / L \\
\mu g / L \\
\mu m / L \\
\mu g / L \\
\mu g / L \\
\mu g / L \\
\mu g / L \\
\mu g / L \\
\mu g / L \\
\mu g / L \\
\mu g / L \\
\mu \mathrm{Li} / \mathrm{mL} \\
\mu \mathrm{Ci} / \mathrm{mL} \\
\mu \mathrm{Ci} / \mathrm{mL} \\
\mu \mathrm{Ci} / \mathrm{mL}\end{array}$ \\
\hline
\end{tabular}

WELL MSB 38TA Replicat!

MEASUREMENTS CONDUCTED IN THE FII:LD

Sample date: 11/01/81

Depth to water: $162.78 \mathrm{Ht}(49.62 \mathrm{~m})$ below TOC

Water olevation: $193.82 \mathrm{At}(5.1$

W. conductance: $19 \mathrm{~s} / \mathrm{cm}$.

LABORATORY ANALYSES

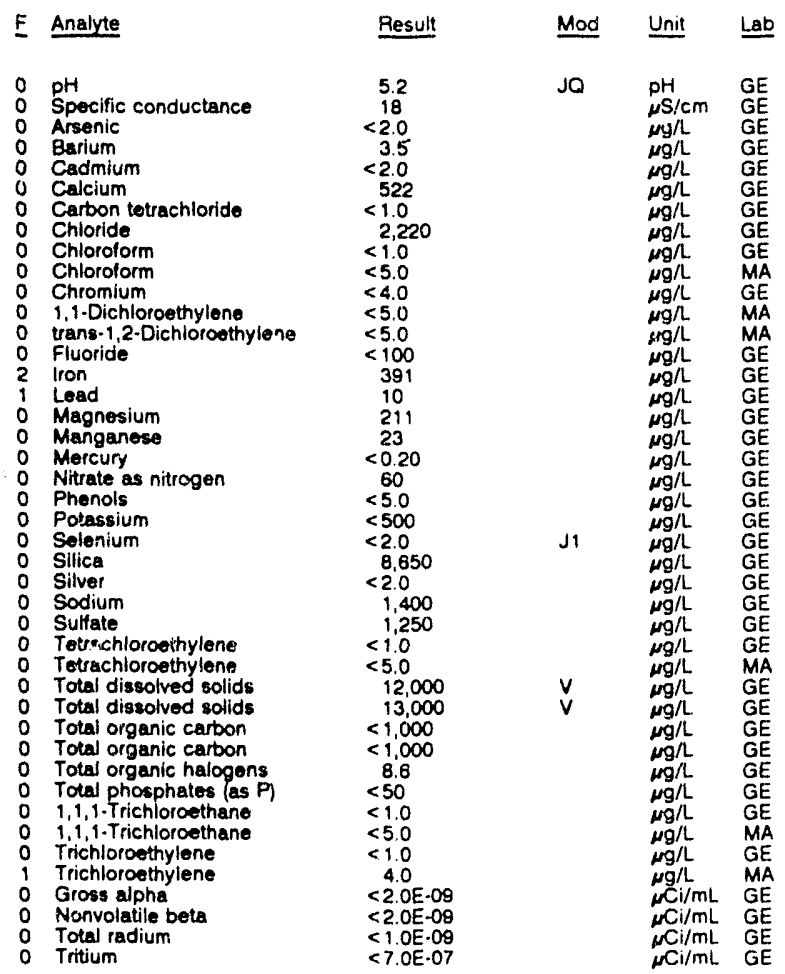

\section{WELL MSB 39A}

MEASUREMENTS CONDUCTED IN THE FIELD

Sample date: 10/08/8

Depth to walor: 133.88 H $(40.75 \mathrm{~m})$ below TOC

Water elevation: $207.92 \mathrm{ft}(63.37 \mathrm{~m}) \mathrm{msl}$

Sp. conductance: $38, \mathrm{~S} / \mathrm{cm}$

Water evacuated before sampling: 83 gal

The well went dry during purging

LABORATORY ANALYSES

\begin{tabular}{|c|c|c|c|c|c|}
\hline$\underline{F}$ & Analyte & Resu: & Mod & Unit & Lab \\
\hline $\begin{array}{l}0 \\
0 \\
0\end{array}$ & $\begin{array}{l}\text { pH } \\
\text { Specific conductance } \\
\text { Aluminum } \\
\text { Arsenic } \\
\text { Barium } \\
\text { Benzene } \\
\text { Bromodichloromethane } \\
\text { Bromoform }\end{array}$ & $\begin{array}{r}5.6 \\
30 \\
<20 \\
<2.0 \\
<11 \\
<1.0 \\
<10 \\
<1.0\end{array}$ & $J O$ & $\begin{array}{l}\mathrm{pH} \\
\mu \mathrm{sicm} \\
\mu g / L \\
\mu g / L \\
\mu g / L \\
\mu g / L \\
\mu g / L \\
\mu g / L\end{array}$ & $\begin{array}{l}G E \\
G E \\
G E \\
G E \\
G E \\
G E \\
G E \\
G E\end{array}$ \\
\hline
\end{tabular}

WELL MSB 39A collected on 10/08/91, laboratory analyses (cont.)

\begin{tabular}{|c|c|c|c|}
\hline Ans.lyte & P.isult & Mod & Unit \\
\hline 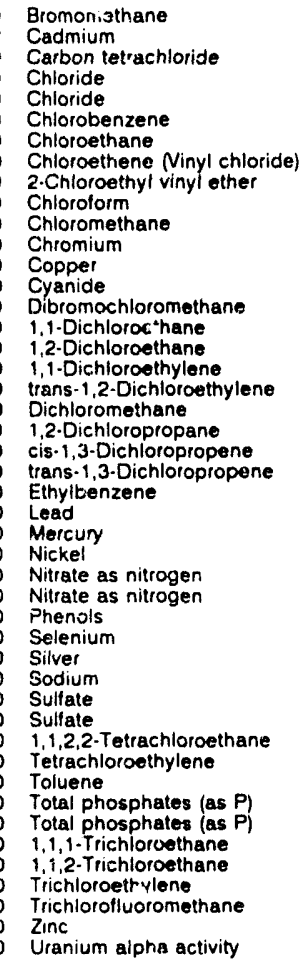 & $\begin{array}{l}<1.0 \\
8.7 \\
<1.0 \\
2.390 \\
2,410 \\
<1.0 \\
<1.0 \\
<1.0 \\
<1.0 \\
<1.0 \\
<1.0 \\
<4.0 \\
4.6 \\
<5.0 \\
<1.0 \\
<1.0 \\
<1.0 \\
<1.0 \\
<1.0 \\
<1.0 \\
<1.0 \\
<1.0 \\
<1.0 \\
<1.0 \\
3.4 \\
<0.20 \\
7.8 \\
180 \\
1180 \\
<5.0 \\
<2.0 \\
<2.0 \\
1.840 \\
8.000 \\
5,730 \\
<1.0 \\
<1.0 \\
<1.0 \\
<50 \\
<50 \\
<1.0 \\
<10 \\
200 \\
<1.0 \\
960 \\
<1.0 E \cdot 00\end{array}$ & & 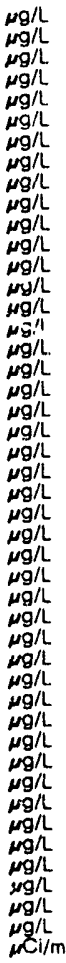 \\
\hline
\end{tabular}

\section{WELL MSB 39B}

MEASUREMENTS CONDUCTED IN THE FIE'D

Sample date: $10 / 08191$

Depth to water: $131.07 \mathrm{ft}(39.85 \mathrm{~m})$ below TOC

Water elevation: $210.73 \mathrm{H}(64.23 \mathrm{~m}) \mathrm{msl}$

Water evacuated betore sampling: 172 gal

Alkalinity: $0 \mathrm{mg}$

Water temperature $16.20 \mathrm{C}$

LABORATORY ANALYSES

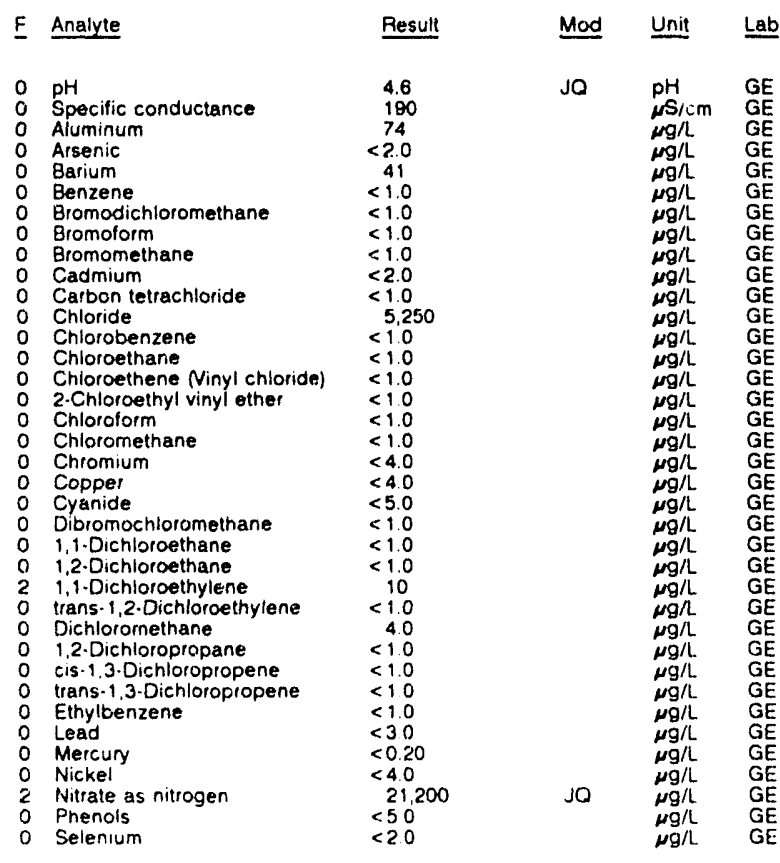




\section{ANALYTICAL RESULTS}

WELL MSB 398 collected on 10/08/91, laboratory analyses (cont.)

\begin{tabular}{|c|c|c|c|c|c|}
\hline$\underline{E}$ & Analyte & Result & Mod & Unit & Lab \\
\hline $\begin{array}{l}0 \\
0 \\
0 \\
0 \\
2 \\
0 \\
0 \\
0 \\
0 \\
2 \\
0 \\
0\end{array}$ & $\begin{array}{l}\text { Silver } \\
\text { Sodium } \\
\text { Sulfate } \\
\text { i,1,2,2-Tetrachloroethane } \\
\text { Tetrachloroethylene } \\
\text { Toluene } \\
\text { Total phosphates (as P) } \\
1,1,1 \text { - Trichloroethane } \\
1,1,2 \text {-Trichloroethane } \\
\text { Trichloroethylene } \\
\text { Trichlorofluoromethane } \\
\text { Zinc } \\
\text { Uranium alpha activity }\end{array}$ & $\begin{aligned}<2.0 \\
23,400 \\
3.040 \\
<1.0 \\
154 \\
<1.0 \\
<50 \\
8.0 \\
<1.0 \\
158 \\
<1.0 \\
4.7 \\
<1.0 E-09\end{aligned}$ & & $\begin{array}{l}\mu g / L \\
\mu g / L \\
\mu g / L \\
\mu g / L \\
\mu g / L \\
\mu g / L \\
\mu g / L \\
\mu g / L \\
\mu g / L \\
\mu g / L \\
\mu g / L \\
\mu g / L \\
\mu C i / m L\end{array}$ & $\begin{array}{l}\mathrm{GE} \\
\mathrm{GE} \\
\mathrm{GE} \\
\mathrm{GE} \\
\mathrm{GE} \\
\mathrm{GE} \\
\mathrm{GE} \\
\mathrm{GE} \\
\mathrm{GE} \\
\mathrm{GE} \\
\mathrm{GE} \\
\mathrm{GE} \\
\mathrm{GE}\end{array}$ \\
\hline
\end{tabular}

WELL MSB 39C

MEASUREMENTS CONDUCTED IN THE FIELD

Sample date: 10/08/9

Depth to water: $127.15 \mathrm{Ht}(38.76 \mathrm{~m})$ below TOC Water elevation: $214.35 \mathrm{tt}(65.33 \mathrm{~m}) \mathrm{ms}$

Water evacuated before sampling: $52 \mathrm{gal}$

LABORATORY ANALYSES

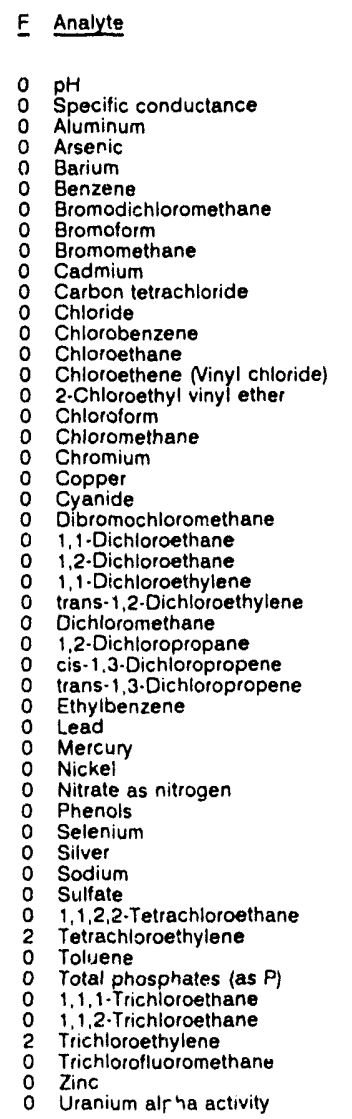

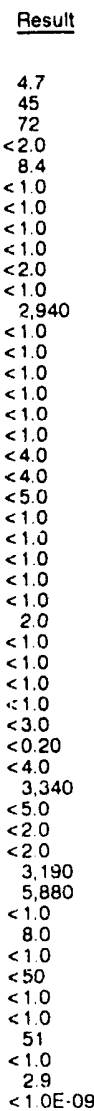

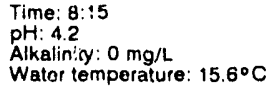

Wator temperature: $15.6^{\circ} \mathrm{C}$

Mod Unit Lab

jo

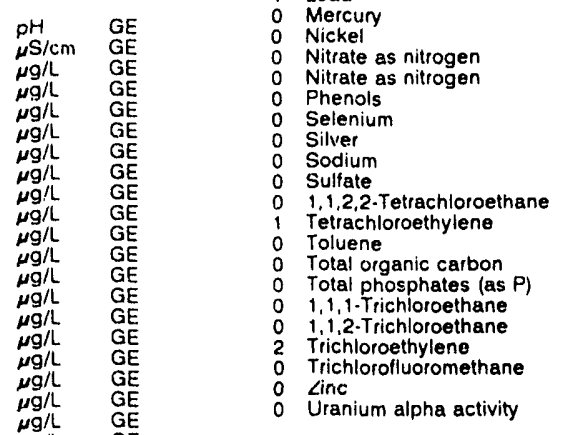

WELL MSB 39D collected on 10/08/91, laboratory analyses (cont.)

\begin{tabular}{|c|c|c|c|}
\hline Analyte & Result & Mod & Unit \\
\hline 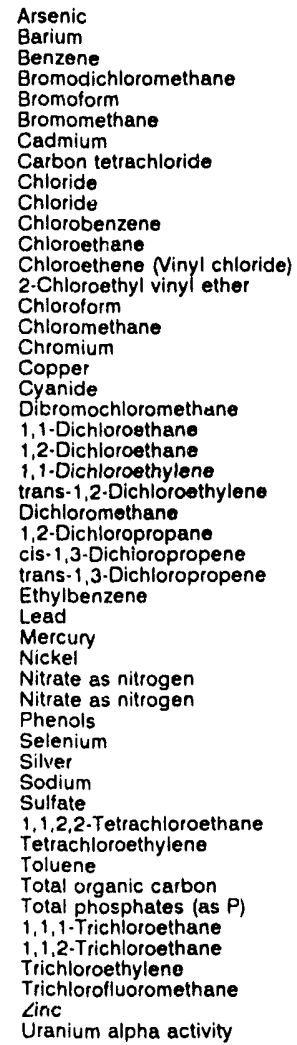 & $\begin{array}{l}<2.0 \\
5.7 \\
<1.0 \\
<1.0 \\
<1.0 \\
<1.0 \\
<2.0 \\
<1.0 \\
4,600 \\
4.620 \\
<1.0 \\
<1.0 \\
<1.0 \\
<1.0 \\
<1.0 \\
<1.0 \\
<4.0 \\
78 \\
<5.0 \\
<1.0 \\
<1.0 \\
<1.0 \\
<1.0 \\
<1.0 \\
4.7 \\
<1.0 \\
<1.0 \\
<1.0 \\
<1.0 \\
7.9 \\
<0.20 \\
<4.11 \\
2,2.20 \\
2.280 \\
<5.0 \\
<2.0 \\
<2.0 \\
51330 \\
<1.000 \\
<1.0 \\
2.7 \\
<1.0 \\
<1.000 \\
510 \\
<1.0 \\
<1.0 \\
7.7 \\
<1.0 \\
15 \\
<1.0 E \cdot 09\end{array}$ & $\begin{array}{l}\mathrm{JO} \\
\mathrm{J} Q\end{array}$ & $\begin{array}{l}\mu g / L \\
\mu g / L \\
\mu g / L \\
\mu g / L \\
\mu g / L \\
\mu g / L \\
\mu g / L \\
\mu g / L \\
\mu g / L \\
\mu g / L \\
\mu g / L \\
\mu g / L \\
\mu g / L \\
\mu g / L \\
\mu g / L \\
\mu g / L \\
\mu g / L \\
\mu g / L \\
\mu g / L \\
\mu g / L \\
\mu g / L \\
\mu g / L \\
\mu g / L \\
\mu g / L \\
\mu g / L \\
\mu g / L \\
\mu g / L \\
\mu g / L \\
\mu g / L \\
\mu g / L \\
\mu g / L \\
\mu g / L \\
\mu g / L \\
\mu g / L \\
\mu g / L \\
\mu g / L \\
\mu g / L \\
\mu g / L \\
\mu g / L \\
\mu g / L \\
\mu g / L \\
\mu g / L \\
\mu g / L \\
\mu g / L \\
\mu g / L \\
\mu g / L \\
\mu g / L \\
\mu g / L \\
\mu c / / m L\end{array}$ \\
\hline
\end{tabular}

WELL MSB 39TA

MEASUREMENTS CONDUCTED IN THE FIELD

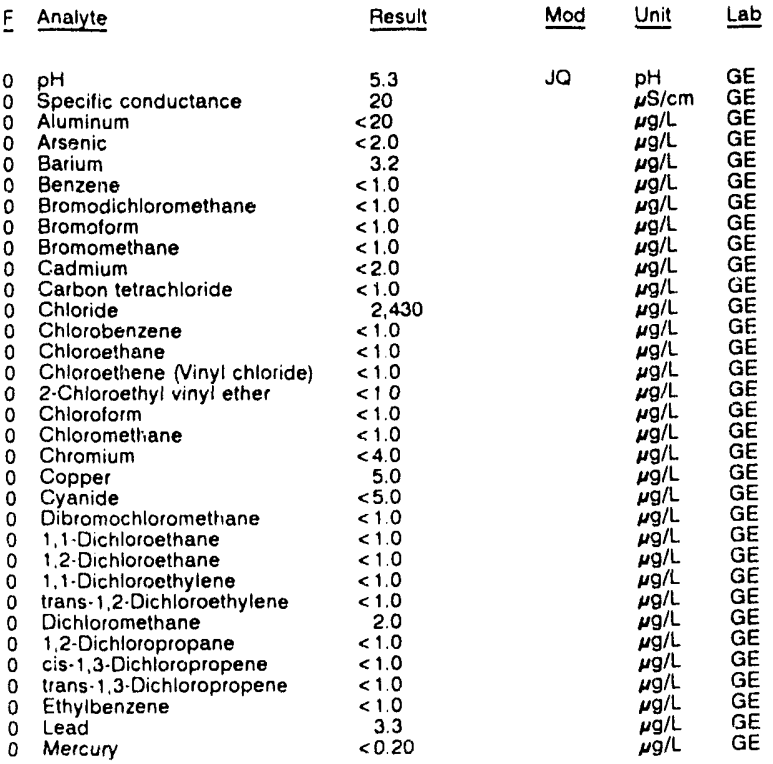

$\therefore$ imple date $10 / 08 / 91$

Depth to water: $150.30 \mathrm{Ht}(45.81 \mathrm{~m})$ below TOC Water elevation: $191.50 \mathrm{ft}(58.37 \mathrm{~m}) \mathrm{ms}$

Water evacuated before sampling: $383 \mathrm{gal}$

LABORATORY ANALYSES

Time: $7: 35$

PH: 5.0 . 0.0

Water temperatur $16.70^{\circ}$

Jo

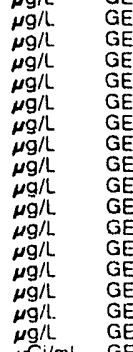

WELL MSB 39D

MEASUREMENTS CONDUCTED IN THE FIELD

Sample date: 10/08/9 1 Depth to water: $110.87 \mathrm{Ht}(33.79 \mathrm{~m})$ below TOC
Water elevation: $230.83 \mathrm{H}(70.36 \mathrm{~m}) \mathrm{ms}$ Water elevation: $230.83 \mathrm{~h}(70.36 \mathrm{~m}) \mathrm{ms}$
Sp.conductance: $73 \mu \mathrm{S} / \mathrm{cm}$
Water evacuated before sampling: $29 \mathrm{gat}$

LABORATORY ANALYSES

\begin{tabular}{|c|c|c|c|}
\hline Analyte & Result & Mod & Unit \\
\hline $\begin{array}{ll}0 & \mathrm{pH} \\
0 & \text { Specific conductance } \\
0 & \text { Aluminum }\end{array}$ & $\begin{array}{r}57 \\
45 \\
<20\end{array}$ & JQ & $\begin{array}{l}\mathrm{pH} \\
\mu \mathrm{S} / \mathrm{cm} \\
\mu \mathrm{g} / \mathrm{L}\end{array}$ \\
\hline
\end{tabular}

Time: $8 \cdot 30$

Alkalinity $10 \mathrm{mg} / \mathrm{L}$

Water temperature $146^{\circ} \mathrm{C}$
$<0.20$ 
WELL MSB 39TA collected on 10/08/91, laboratory analyses (cont.)

\begin{tabular}{|c|c|c|c|c|}
\hline$\underline{F}$ & Analyte & Result & Mod & Unit \\
\hline $\begin{array}{l}0 \\
0 \\
0 \\
0 \\
0 \\
0 \\
0 \\
0 \\
0 \\
0 \\
0 \\
0 \\
0 \\
0 \\
0 \\
0 \\
0\end{array}$ & $\begin{array}{l}\text { Nickel } \\
\text { Nitrate as nitrogen } \\
\text { Phenols } \\
\text { Selenium } \\
\text { Silver } \\
\text { Sodlum } \\
\text { Sultate } \\
1,1,2,2 \text {-Tetrachloroethane } \\
\text { Tetrachloroethylene } \\
\text { Toluene } \\
\text { Total phosphates (as P) } \\
1,1,1 \text {. Trichloroethane } \\
1,1,2 \text {-Trichloroethane } \\
\text { Trichloroethylene } \\
\text { Trichlorofluoromethane } \\
\text { Zinc } \\
\text { Uranium alpha }\end{array}$ & $\begin{array}{l}<4.0 \\
<50 \\
<5.0 \\
<2.0 \\
<2.0 \\
1.450 \\
3.770 \\
<1.0 \\
<1.0 \\
<1.0 \\
<50 \\
<1.0 \\
<1.0 \\
<1.0 \\
<1.0 \\
<2.0 \\
<1.0 E-09\end{array}$ & & $\begin{array}{l}\mu g / L \\
\mu g / L \\
\mu g / L \\
\mu g / L \\
\mu g / L \\
\mu g / L \\
\mu g / L \\
\mu g / L \\
\mu g / L \\
\mu g / L \\
\mu g / L \\
\mu g / L \\
\mu g / L \\
\mu g / L \\
\mu g / L \\
\mu g / L \\
\mu C i / m L\end{array}$ \\
\hline
\end{tabular}

WELL MSB 40A

MEASUREMENTS CONDUCTED IN THE FIELD

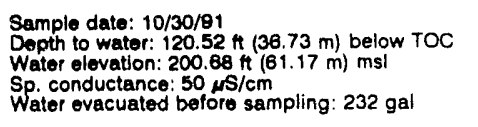

Time: 6:15

Alkalinity: $0 \mathrm{mg} / \mathrm{h}$

Water temperature: $17.9^{\circ} \mathrm{C}$

LABOFATORY ANALYSES

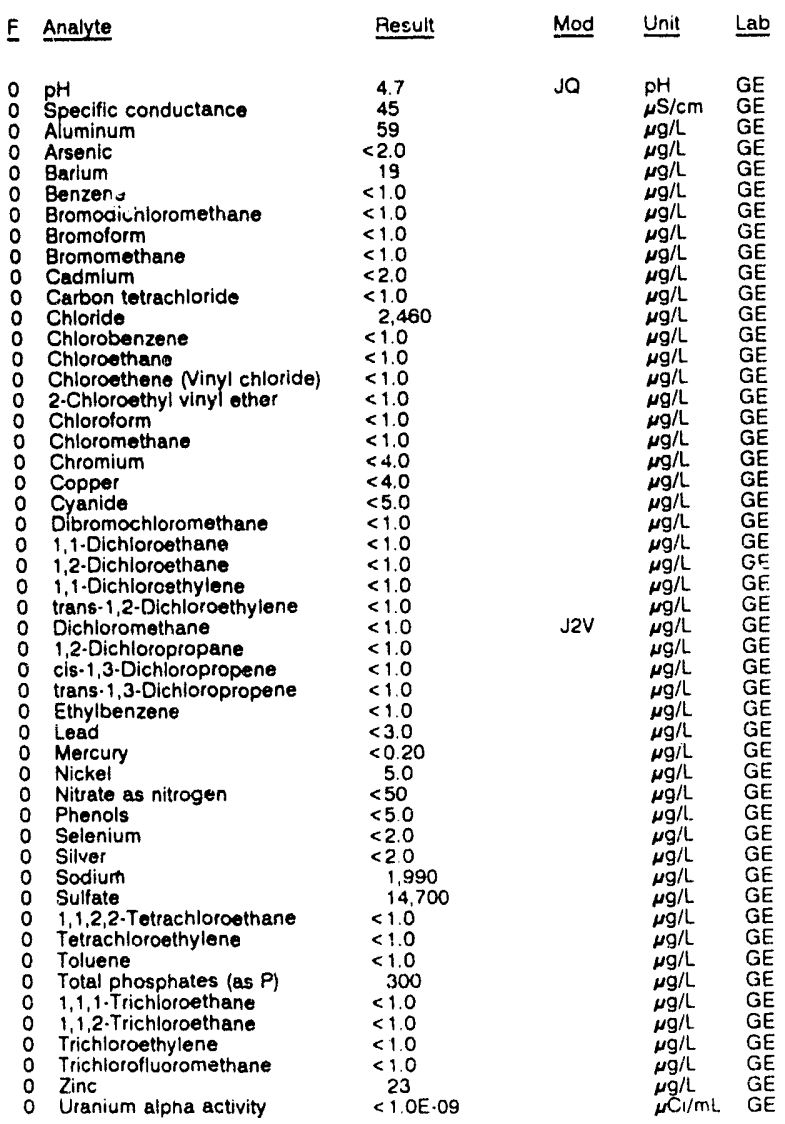

WELL MSB 40B

MEASUREMENTS CONDUCTED IN THE FIELD

$\begin{array}{ll}\text { Sample date: } 12 / 02 / 91 & \text { Time: } 15: 00 \\ \text { Depth to water: } 117.15 \mathrm{ft}(35.71 \mathrm{~m}) \text { below TOC } & \text { pH: } 4.9 \\ \text { Water elevation: } 204.55 \mathrm{ft}(62.35 \mathrm{~m}) \mathrm{msl} & \text { Alkalinity: } 1 \mathrm{mg} / \mathrm{h} \\ \text { Sp. conductance: } 28 \mu \mathrm{sm} / \mathrm{cm} & \text { Water temperature: } 20.7^{\circ} \mathrm{C} \\ \text { Water e /acuated before sampling: } 143 \mathrm{gal} & \end{array}$

Water e Jacuated before sampling: $143 \mathrm{gal}$

LABORATORY ANALYSES

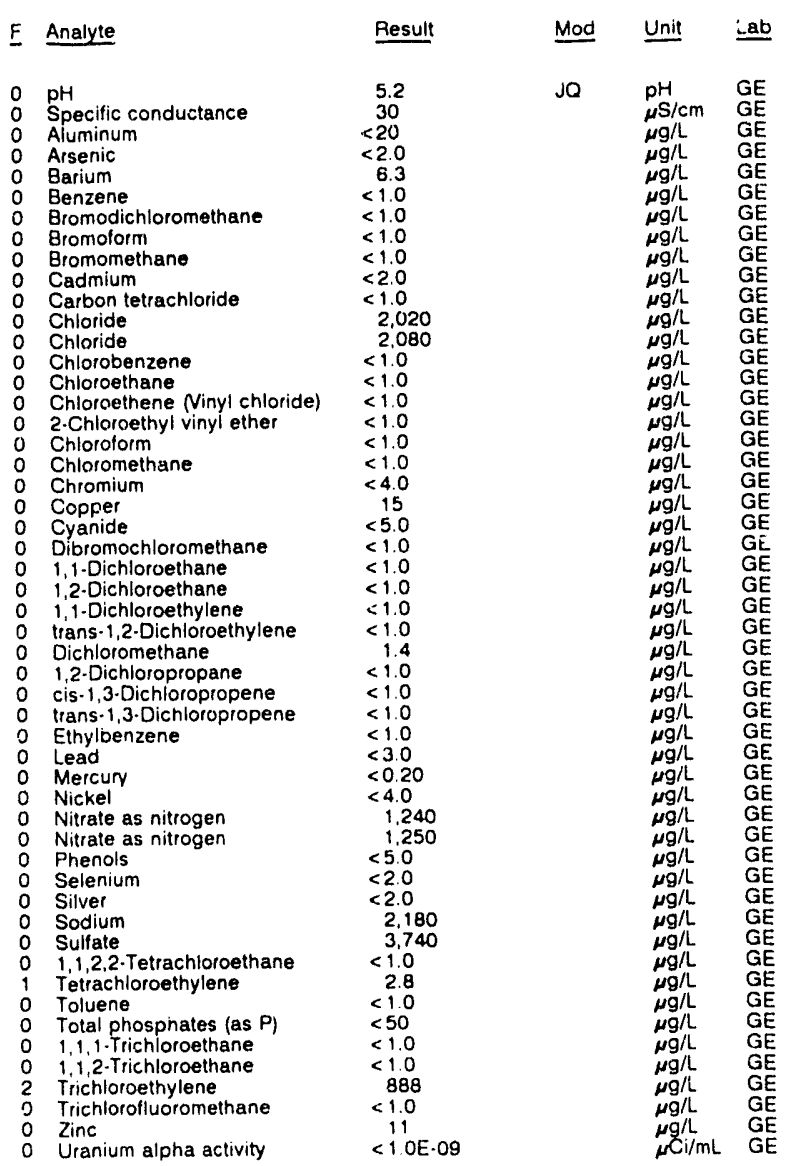

\section{WELL MSB 40C}

MEASUREMENTS CONDUCTED IN THE FIELD

Sample date: 10/30/91

Depth to water: Not avallable

Water elevation: Not available

Water evacuated before sampling: $40 \mathrm{gal}$

LABORATORY ANALYSES

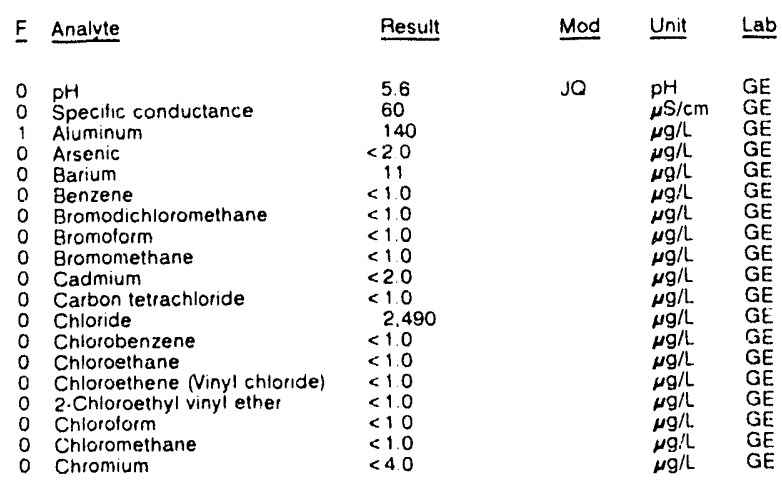


ANALYTICAL RESULTS

WELL MSB 4OC collected on 10/30/91, laboratory analyses (cont.)

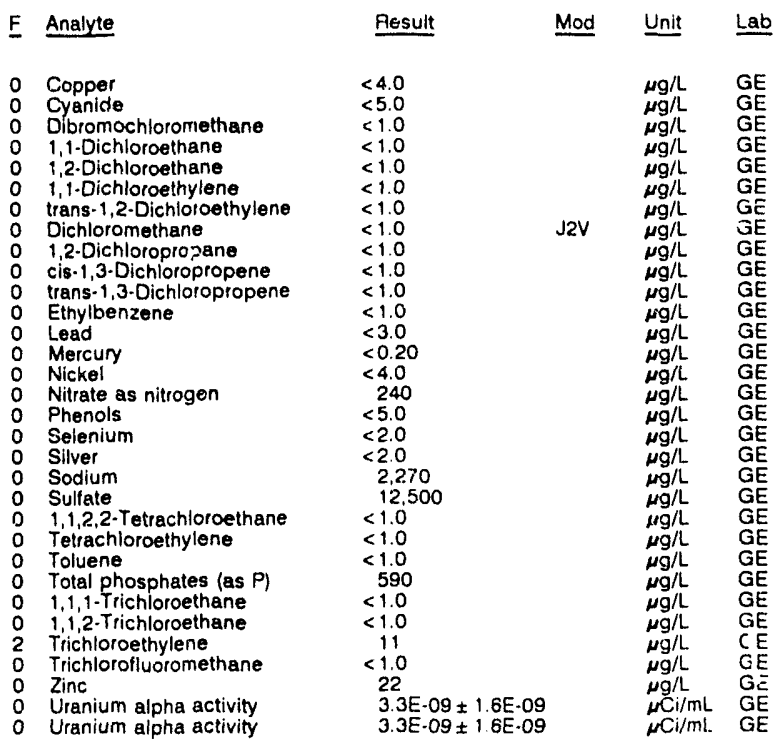

WELL MSB 40D

MEASUREMENTS CONDUCTED IN THE FIELD

Sample date: $10 / 30 / 91$
The well was $d r y$.

Time: 7.05

\section{WELL MSB 40TA}

MEASUREMENTS CONDUCTED IN THE FIELD

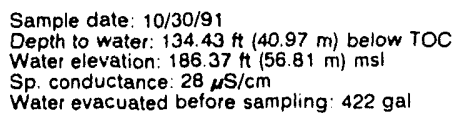

Time: $7: 00$

Alkalinity: $4 \mathrm{mg} / \mathrm{L}$

Water temperature $18.0^{\circ} \mathrm{C}$

LABORATORY ANALYSES

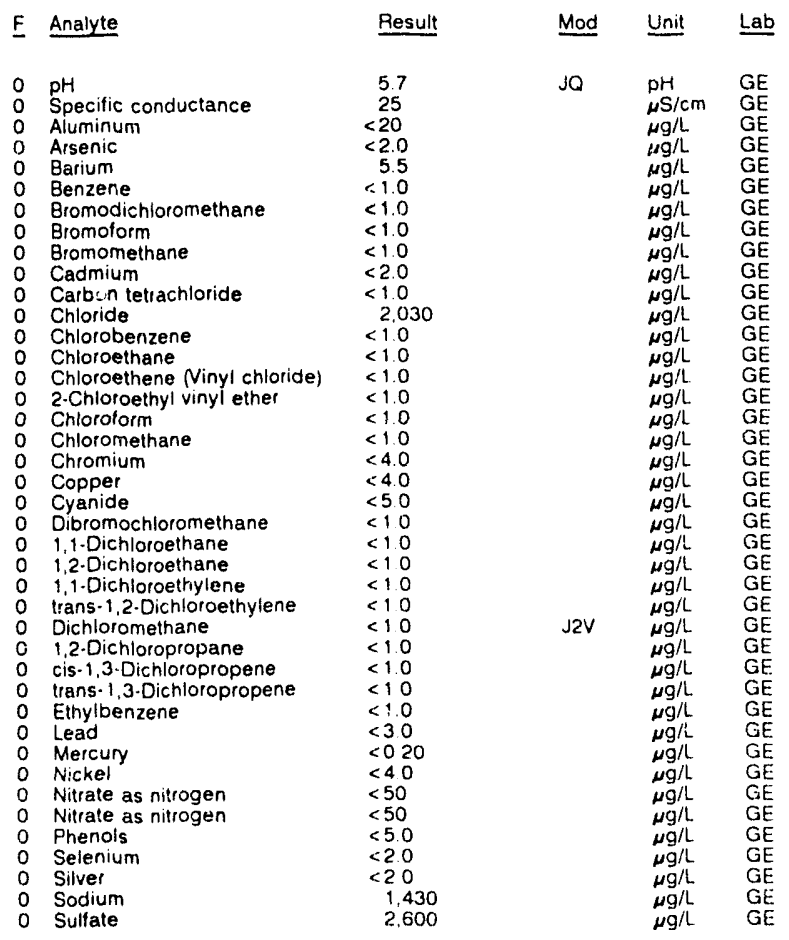

WELL MSB 4OTA collected on 10/30/91, laboratory analyses (cont.)

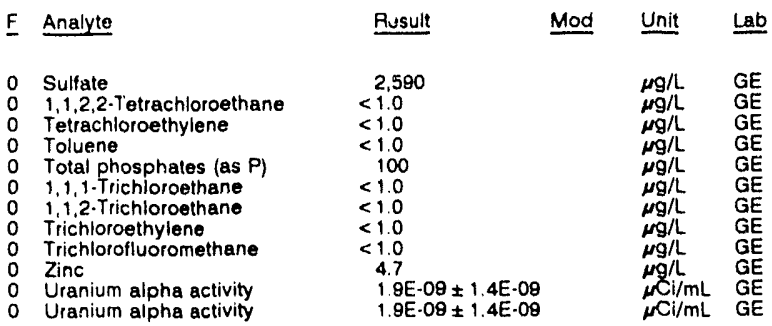

\section{WELL MSB 41A}

MEASUREMENTS CONDUCTED IN THE FIELD

$\begin{array}{ll}\text { Sample date: } 10 / 25 / 91 & \text { Time: } 10.05 \\ \text { Depth to water: } 109.00 \mathrm{ft}(33.22 \mathrm{~m}) \text { beiow TOC } & \text { pH: } 5.7 \\ \text { Water elevation: } 214.80 \mathrm{ft}(65.47 \mathrm{~m}) \mathrm{ms} & \text { Alkalinity: } 13 \mathrm{mg} / \mathrm{L} \\ \text { Sp. conductance: } 36 \mu \mathrm{S} / \mathrm{cm} & \text { Water temperature: } 19.0^{\circ} \mathrm{C} \\ \text { Water evacuated before sampling: } 345 \mathrm{gal} & \end{array}$

LABORATORY ANALYSES

\begin{tabular}{|c|c|c|c|c|}
\hline Analyte & Fesult & Mod & Unit & Lab \\
\hline $\begin{array}{l}\text { pH } \\
\text { Specific conductance } \\
\text { Arsenic } \\
\text { Barium } \\
\text { Cadmium } \\
\text { Calcium } \\
\text { Chloride } \\
\text { Chloroform } \\
\text { Chromium } \\
1,1-\text { Dichloroethylene } \\
\text { trans } 1,2 \text { - - Dichloroethylene } \\
\text { Fluoride } \\
\text { lron } \\
\text { Lead } \\
\text { Magnesium } \\
\text { Manganese } \\
\text { Mercury } \\
\text { Nitrate as nitrogen } \\
\text { Phenols } \\
\text { Potassium } \\
\text { Selenium } \\
\text { Silica } \\
\text { Silver } \\
\text { Sodium } \\
\text { Sulfate } \\
\text { Tetrachloroethylene } \\
\text { Total dissolved solids } \\
\text { Total organic carbon } \\
\text { Total organic halogens } \\
\text { Total phosphates (as P) } \\
1,11 \text { - Trichlsroethane } \\
\text { richloroethylene } \\
\text { Gross alpha } \\
\text { Nonvolatile beta } \\
\text { Total radium } \\
\text { Tritium }\end{array}$ & $\begin{aligned} & 6.0 \\
& 30 \\
&<2.0 \\
& 5.8 \\
&<2.0 \\
& 3,420 \\
& 1,710 \\
&<1.0 \\
&<4.0 \\
&<1.0 \\
&<1.0 \\
&<100 \\
&<4.0 \\
&<3.0 \\
& 370 \\
& 3.1 \\
&<0.20 \\
& 1.310 \\
&<5.0 \\
&<500 \\
&<2.0 \\
& 8,340 \\
&<2.0 \\
& 1,400 \\
&<1,000 \\
& 1.5 \\
& 421.000 \\
&<1,000 \\
&<5.0 \\
&<50 \\
&<1.0 \\
&<1.0 \\
&<2.0 \mathrm{E}-09 \\
&<2.0 \mathrm{E}-09 \\
&<1.0 \mathrm{E} \cdot 09 \\
&<7.0 \mathrm{E}-07\end{aligned}$ & JQ & $\begin{array}{l}\mathrm{pH} \\
\mu \mathrm{S} / \mathrm{cm} \\
\mu g / L \\
\mu g / L \\
\mu g / L \\
\mu g / L \\
\mu g / L \\
\mu g / L \\
\mu g / L \\
\mu g / L \\
\mu g / L \\
\mu g / L \\
\mu g / L \\
\mu g / L \\
\mu g / L \\
\mu g / L \\
\mu g / L \\
\mu g / L \\
\mu g / L \\
\mu g / L \\
\mu g / L \\
\mu g / L \\
\mu g / L \\
\mu g / L \\
\mu g / L \\
\mu g / L \\
\mu g / L \\
\mu g / L \\
\mu g / L \\
\mu g / L \\
\mu g / L \\
\mu g / L \\
\mu C i / m L \\
\mu C \mathrm{i} / \mathrm{mL} \\
\mu C \mathrm{i} / \mathrm{mL} \\
\mu C \mathrm{C} / \mathrm{mL}\end{array}$ & $\begin{array}{l}\mathrm{GE} \\
\mathrm{GE} \\
\mathrm{GE} \\
\mathrm{GE} \\
\mathrm{GE} \\
\mathrm{GE} \\
\mathrm{MA} \\
\mathrm{GE} \\
\mathrm{MA} \\
\mathrm{MA} \\
\mathrm{GE} \\
\mathrm{GE} \\
\mathrm{GE} \\
\mathrm{GE} \\
\mathrm{GE} \\
\mathrm{GE} \\
\mathrm{GE} \\
\mathrm{GE} \\
\mathrm{GE} \\
\mathrm{GE} \\
\mathrm{GE} \\
\mathrm{MA} \\
\mathrm{GE} \\
\mathrm{GE} \\
\mathrm{GE} \\
\mathrm{ME} \\
\mathrm{MA} \\
\mathrm{GE} \\
\mathrm{GE} \\
\mathrm{GE} \\
\mathrm{GE}\end{array}$ \\
\hline
\end{tabular}

WELL MSB 41B

MEASUREMENTS CONOUCTED IN THE FIELD

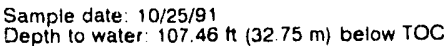
Water elevation. $216.54 \mathrm{t}(66.00 \mathrm{~m}) \mathrm{ms}$

$\mathrm{Sp}$ conductance $23 \mathrm{\mu S} / \mathrm{cm}$

sampling: $281 \mathrm{gal}$

LABORATORY ANALYSES

$\begin{array}{ll}\text { F } & \text { Analyte } \\ 0 & \text { pH } \\ 0 & \text { Specific conductance } \\ 0 & \text { Arsenic } \\ 0 & \text { Barium } \\ 0 & \text { Cadmium } \\ 0 & \text { Calcium } \\ 0 & \text { Chioride } \\ 0 & \text { Chloride } \\ 0 & \text { Chloroform } \\ 0 & \text { Chromium } \\ 0 & 1,1 \cdot \text { Dichloroethylene } \\ 0 & \text { trans-1.2-Dichloroethylene } \\ 0 & \text { Fluoride } \\ 0 & \text { Ftuoride } \\ 0 & \text { Iron } \\ 0 & \text { Lead } \\ 0 & \text { Magnesium } \\ 0 & \text { Manganese }\end{array}$

Result

5.6
20
$<2.0$
7.2
$<2.0$
1,250
1.460
1.470
$<1.0$
$<4.0$
$<1.0$
$<10$
$<100$
$<100$
$<4.0$
$<3.0$
362
$<2.0$

Time: $10: 50$

Alkalinity: $3 \mathrm{mg} /$ Water temperature: $18.7^{\circ} \mathrm{C}$

\begin{tabular}{|c|c|}
\hline Mod & Unit \\
\hline JQ & 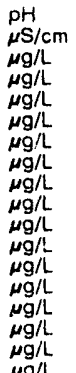 \\
\hline
\end{tabular}


WELL MSB 418 collected on 10/25/91, laboratory analyses (cont.)

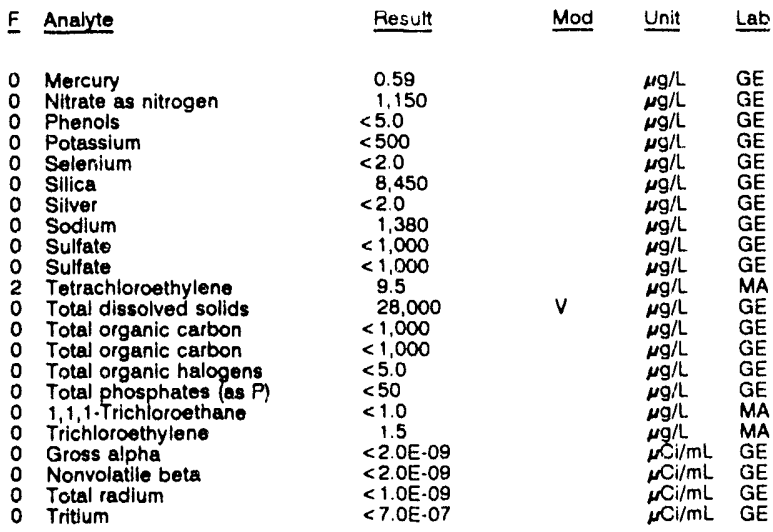

\section{WELL MSB 41C}

MEASUREMENTS CONDUCTED IN THE FIELD

Sample date: 10/25/91

$(33.64 \mathrm{~m})$ below TOC

Water olevation: $214.23 \mathrm{ft}(65.30 \mathrm{~m}) \mathrm{ms}$ !

Sp conductance 21 isicm

Water evacuated before sampling: $176 \mathrm{gal}$

LABORATORY ANALYSES

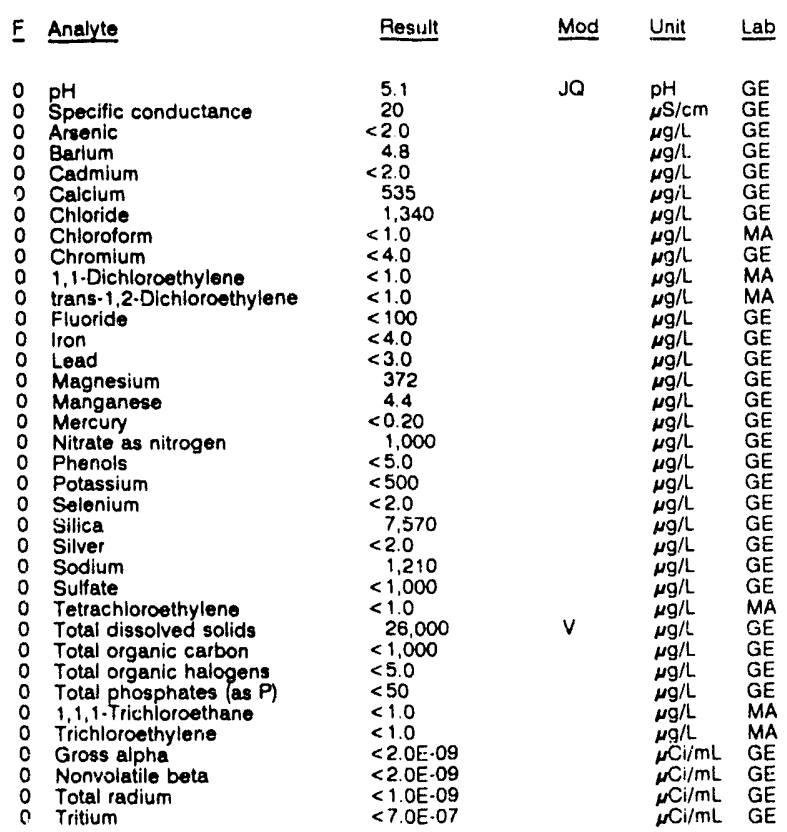

WELL MSB 41D

MEASUREMENTS CONDUCTED IN THE FIELO

Sample date: $10 / 25 / 9$

The well was dry.

Time: 11:15

Alkalinity: $2 \mathrm{mg} / \mathrm{L}$

Wate: temperature: $19.2^{\circ} \mathrm{C}$
WELL MSB 41TA

MEASUREMENTS CONDUCTED IN THE FIELD

Sample date: $10 / 25 / 91$

Depth to water: $119.84 \mathrm{ft}(36.53 \mathrm{~m})$ below TOC

Water elevation: $203.88 \mathrm{Ht}(62.14 \mathrm{~m}) \mathrm{ms}$ )

Water evacuated before sampling: $475 \mathrm{gal}$

LABORATORY ANALYSES

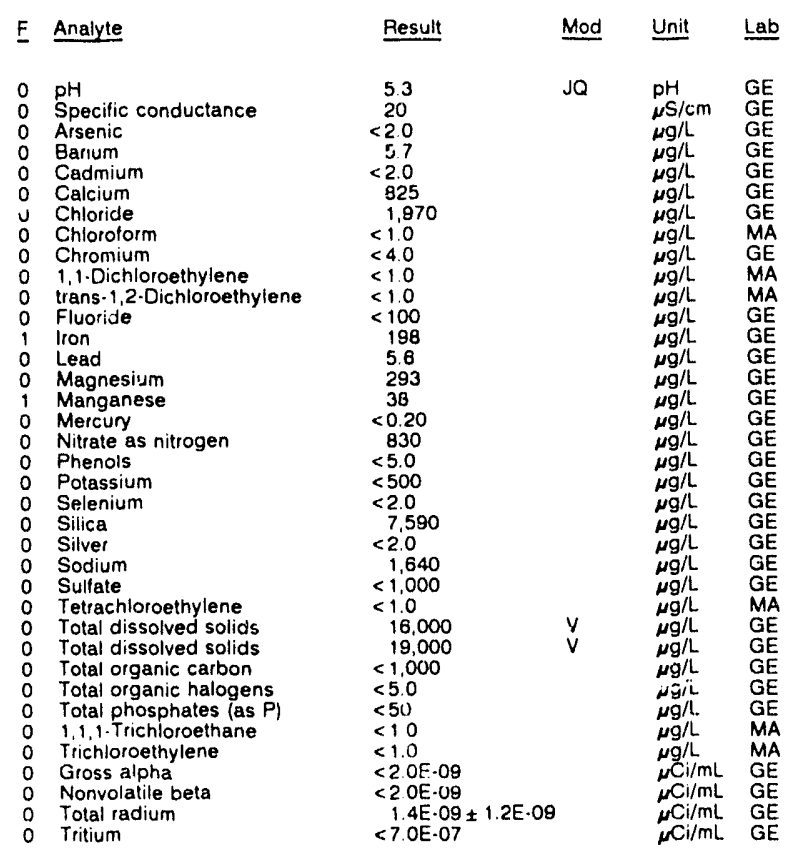

WELL MSB 42A

MEASUREMENTS CONDUCTED IN THE FIELD

Sample date: $11 / 26 / 91$

Depth to water: $157.81 \mathrm{Ht}(48.10 \mathrm{~m})$ below TOC

Water elevation: $218.79 \mathrm{ft}(66.69 \mathrm{~m}) \mathrm{msl}$ Water evacuated before sampling: $246 \mathrm{gal}$

Time: $11: 05$

Alkalinity: $4 \mathrm{mg}$

Water temperature: $19.2^{\circ} \mathrm{C}$

Water evacuated before

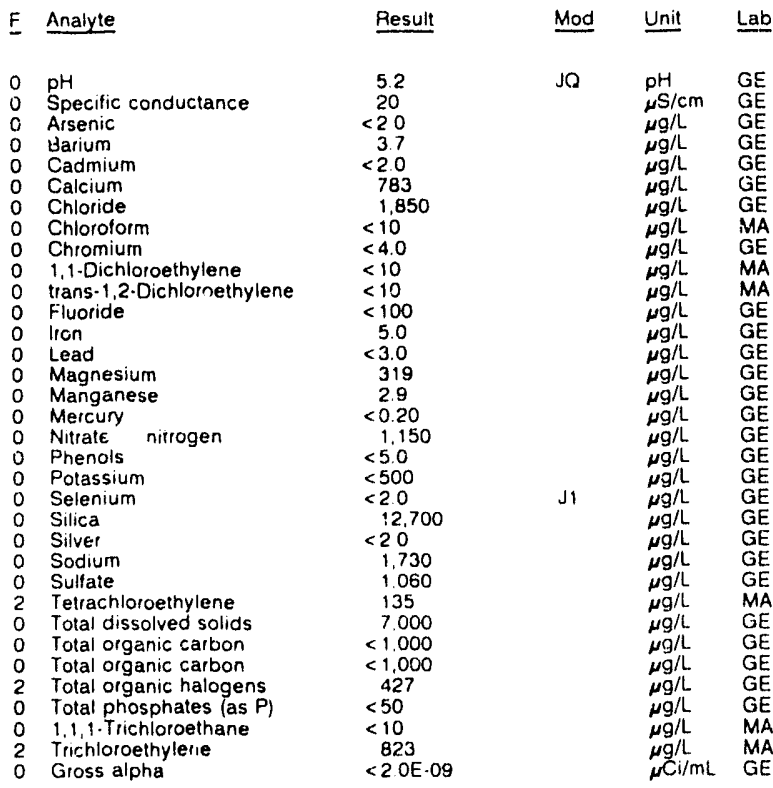

Time: $9: 30$

pH: 5.2

Alkalinity: $1 \mathrm{mg} / \mathrm{L}$. $18.1^{\circ} \mathrm{C}$

ab

\begin{abstract}
Gross alpha
\end{abstract}

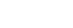




\section{ANALYTICAL RESULTS}

WELL MSA 42A collected on 11/26/91, laboratory analyses (cont.)

\begin{tabular}{|c|c|c|c|c|c|}
\hline E & Analyte & Result & Mod & Unit & $\underline{\text { Lab }}$ \\
\hline & $\begin{array}{l}\text { Nonvolatile beta } \\
\text { Total radium } \\
\text { Tritium }\end{array}$ & \multicolumn{2}{|c|}{$\begin{array}{l}<2.0 \mathrm{E}-09 \\
2.9 \mathrm{E}-09 \pm 1.9 \mathrm{E}-09 \\
<7.0 \mathrm{O}-07\end{array}$} & 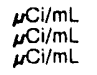 & $\begin{array}{l}\mathrm{GE} \\
\mathrm{GE} \\
\mathrm{GE}\end{array}$ \\
\hline \multicolumn{6}{|c|}{ WELL MSB $42 B$} \\
\hline \multicolumn{6}{|c|}{ MEASUREMENTS CONDUCTED IN THE FIELD } \\
\hline \multicolumn{3}{|c|}{$\begin{array}{l}\text { Sample date: } 11 / 04 / 91 \\
\text { Depth to water: } 151.54 \mathrm{tt}(46.19 \mathrm{~m}) \text { below } \text { TOC } \\
\text { Water elevation: } 224.96 \mathrm{ft}(68.57 \mathrm{~m}) \mathrm{ms} \\
\text { Sp. conductance: } 26 \mu \mathrm{S} / \mathrm{cm} \\
\text { Water evacuated before sampling: } 165 \mathrm{gal}\end{array}$} & \multicolumn{3}{|c|}{$\begin{array}{l}\text { Time: } 10: 10 \\
\text { pH: } 4.9 \\
\text { Alkalinity: } 0 \mathrm{mg} / \mathrm{h} \\
\text { Water temperature: } 17.2 \circ \mathrm{C}\end{array}$} \\
\hline \multicolumn{6}{|c|}{ LABORATORY ANALYSES } \\
\hline$\underline{\mathbf{E}}$ & Analyte & Result & Mod & Unit & $\underline{\text { Lab }}$ \\
\hline $\begin{array}{l}0 \\
0 \\
0 \\
0 \\
0 \\
0 \\
0 \\
0 \\
0 \\
0 \\
0 \\
0 \\
0 \\
0 \\
0 \\
0 \\
0 \\
0 \\
0 \\
0 \\
0 \\
0 \\
0 \\
0 \\
0 \\
0 \\
0 \\
0 \\
2 \\
0 \\
0 \\
2 \\
0 \\
0 \\
0\end{array}$ & $\begin{array}{l}\text { pH } \\
\text { Specific conductance } \\
\text { Arsenic } \\
\text { Barium } \\
\text { Cadmium } \\
\text { Calivium } \\
\text { Chloride } \\
\text { Chlorolorm } \\
\text { Chromium } \\
1,1-\text { Dichloroethylene } \\
\text { trans-1,2-Dichloroethylene } \\
\text { Fluoride } \\
\text { lron } \\
\text { Lead } \\
\text { Magnesium } \\
\text { Manganese } \\
\text { Mercury } \\
\text { Nitrate as nitrogen } \\
\text { Phenols } \\
\text { Potassium } \\
\text { Selenium } \\
\text { Silica } \\
\text { Silver } \\
\text { Sodium } \\
\text { Sulfate } \\
\text { Tetrachloroethylene } \\
\text { Total dissolved solids } \\
\text { Total organic carbon } \\
\text { Total organic halogens } \\
\text { Total phosphates (as P) } \\
1,1,1 \text {-Trichloroethane } \\
\text { Trichloroethylene } \\
\text { Gross alpha } \\
\text { Nonvolatile beta } \\
\text { Total radiurn } \\
\text { Tritium }\end{array}$ & $\begin{array}{l}5.0 \\
21 \\
<2.0 \\
3.3 \\
<2.0 \\
437 \\
2.700 \\
<2.0 \\
<4.0 \\
<2.0 \\
<2.0 \\
<100 \\
<4.0 \\
<3.0 \\
230 \\
<2.0 \\
<0.20 \\
900 \\
<5.0 \\
<500 \\
<2.0 \\
8,000 \\
<2.0 \\
2,210 \\
6.180 \\
<2.0 \\
16.000 \\
<1.000 \\
69 \\
<50 \\
<2.0 \\
128 \\
<2.0 E \cdot 09 \\
<2.0 E \cdot 09 \\
<1.0 \mathrm{E} \cdot 09 \\
<7.0 \mathrm{E} \cdot 07\end{array}$ & JO & 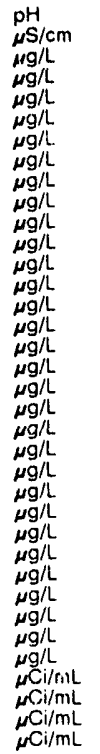 & $\begin{array}{l}\mathrm{GE} \\
\mathrm{GE} \\
\mathrm{GE} \\
\mathrm{GE} \\
\mathrm{GE} \\
\mathrm{GE} \\
\mathrm{MA} \\
\mathrm{GE} \\
\mathrm{MA} \\
\mathrm{MA} \\
\mathrm{GE} \\
\mathrm{GE} \\
\mathrm{GF} \\
\mathrm{GE} \\
\mathrm{GE} \\
\mathrm{GE} \\
\mathrm{GE} \\
\mathrm{GE} \\
\mathrm{GE} \\
\mathrm{GE} \\
\mathrm{GE} \\
\mathrm{GE} \\
\mathrm{GE} \\
\mathrm{MA} \\
\mathrm{GE} \\
\mathrm{GE} \\
\mathrm{GE} \\
\mathrm{GE} \\
\mathrm{MA} \\
\mathrm{MA} \\
\mathrm{GE} \\
\mathrm{GE} \\
\mathrm{GE} \\
\mathrm{GE}\end{array}$ \\
\hline
\end{tabular}

\section{WELL MSB 42C}

MEASUREMENTS CONDUCTED IN THE FIELD Sample date: $11 / 04 / 91$ Depth to water: $146.86 \mathrm{ft}(44.76 \mathrm{~m})$ below TOC Water elevation: $229.64 \mathrm{Ht}(70.0$

Sp. conduclance. $28 \mathrm{sS} / \mathrm{cm}$

LABOPATORY ANALYSES

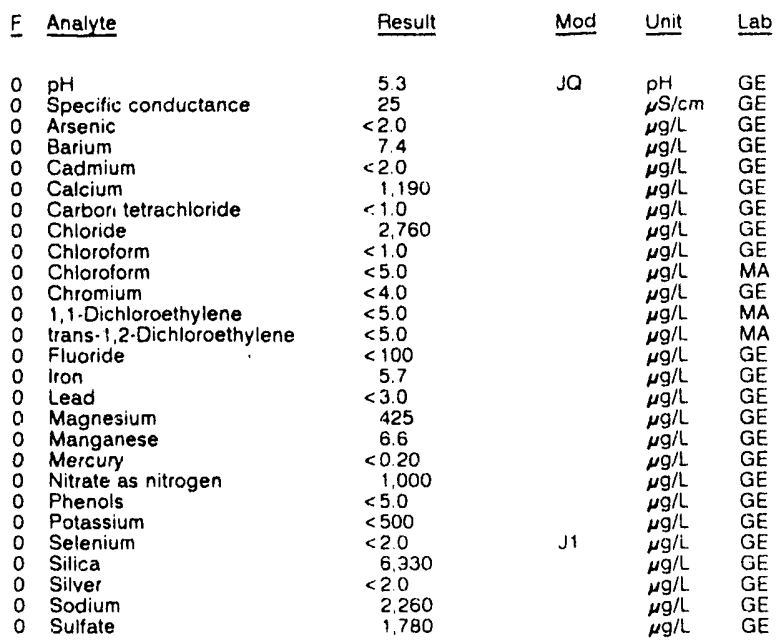

WELL MSB 42C collecied on 11/04/91, laboratory anulyses (cont.)

\begin{tabular}{|c|c|c|c|}
\hline Analyte & Result & Mod & Unit \\
\hline $\begin{array}{l}\text { Tetrachloroethylene } \\
\text { Tetrachloroethylene } \\
\text { Total dissolved solids } \\
\text { Total organic carbon } \\
\text { Total organic halogens } \\
\text { Total organic halogens } \\
\text { Total phosphates (as } P \text { ) } \\
\text { 1,1,1. Trichloroethane } \\
\text { 1,1, 1. Trichloroethane } \\
\text { Trichlor:ethylene } \\
\text { Trichloroethylene } \\
\text { Gross alpha } \\
\text { Nonvolatile beta } \\
\text { Total radium } \\
\text { Tritium }\end{array}$ & $\begin{array}{c}3.9 \\
2.6 \\
28.000 \\
<1.000 \\
9.1 \\
11 \\
<50 \\
<1.0 \\
<5.0 \\
9.8 \\
7.3 \\
<2.0 \mathrm{E}-00 \\
<2.0 \mathrm{E}-09 \\
<1.0 \mathrm{E}-09 \\
<7.0 \mathrm{E}-07\end{array}$ & V & $\begin{array}{l}\mu g / L \\
\mu g / L \\
\mu g / L \\
\mu g / L \\
\mu g / L \\
\mu g / L \\
\mu g / L \\
\mu g / L \\
\mu g / L \\
\mu g / L \\
\mu g / L \\
\mu C L / m L \\
\mu \mathrm{Cl} / \mathrm{mL} \\
\mu \mathrm{Ci} / \mathrm{mL} \\
\mu \mathrm{Ci} / \mathrm{mL}\end{array}$ \\
\hline
\end{tabular}

WELL MSB 42C Replicate

MEASUREMENTS CONDUCTED IN THE FIELD

Sample date: $11 / 04 / 91$

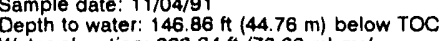
Water elevation: $229.64 \mathrm{Ht}(70 . \mathrm{C}$ Sp. conductance: $28 \mu \mathrm{S} / \mathrm{cm}$
Water evacuated betore sampling: $77 \mathrm{gal}$

LABORATORY ANALYSES

E Analyte Result Mod Unit Lab

${ }_{0}^{0} \mathrm{pH}_{\mathrm{S}}^{\mathrm{pH}}$ :eific conductance

0 Ar, enic

0 Barium

0 Cadmium

0 Calcium

Chloride

Chloride

Chloroform

Chloroform

$\begin{array}{ll}0 & \text { Chromium } \\ 0 & 1,1 \text {.Dichloroethylene }\end{array}$

trans-1,2-Dichloroethylene

0 Fluoride

0 Iron

0 Lead

- Magnesium

- Manganese

0 Mercun

Nitrate as nitrogen

0 Phenols

- Potassium

Selenium

Silica

Sodium

$\begin{array}{ll}0 & \text { Sodium } \\ 0 & \text { Sulfate }\end{array}$

Tetrachloroethylene

Tetrachloroethylene

Total dissolved solids

Total organic carbon

Total organic halogens

Total phosphates (as

1.1. Trichloroethane

T Tichloroethylene

Trichloroethylene

- Gross alpha

Nonvolatile beta

$\begin{array}{ll}0 & \text { Total radiun } \\ 0 & \text { Tritium } \\ & \end{array}$

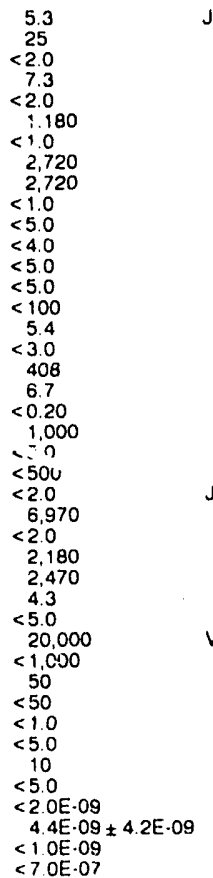

$J Q$

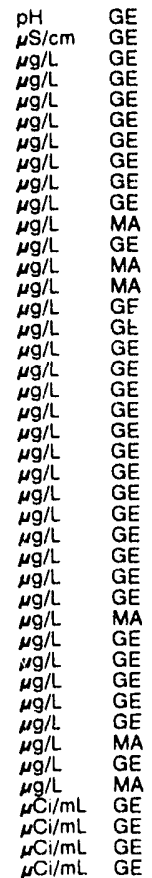

WELL MSB 42D

MEASUREMENTS CONDUCTED IN THE FIELD

Sample date: $11 / 04 / 9$

Time: 10:35 


\section{ANALYTICAL RESULTS}

WELL MSB 42TA

MEASUREMENTS CONDUCTED IN THE FIELO

Sample date: 11/04/91

Depth to water: $171.36 \mathrm{H}(52.23 \mathrm{~m})$ below TOC Water elevation: $205.34 \mathrm{ft}(62.59 \mathrm{~m}) \mathrm{msl}$

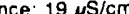

Water evacuated before sampling: $428 \mathrm{gal}$

LABORATORY ANALYSES

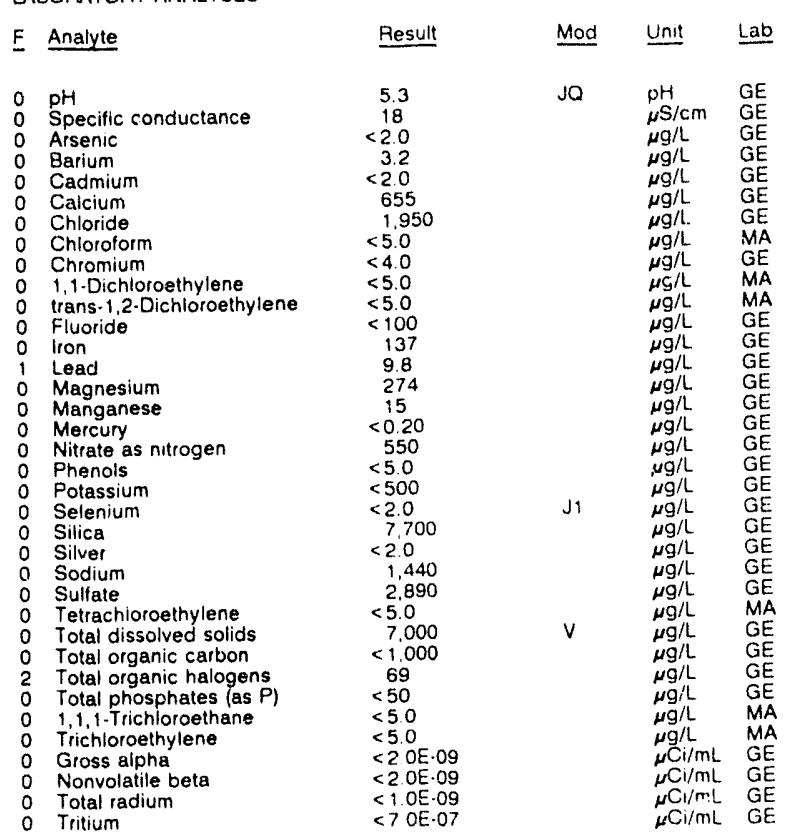

WEL.L MSB 43A

MEASUREMENTS CONDUCTED IN THE FIELD

Sample date: $10 / 07 / 91$ H $(\because 8.48 \mathrm{~m})$ bels $w$ TOC Depth to water: $129.53 \mathrm{H}(.29 .48 \mathrm{~m})$ bel $\mathrm{w}$ TOC
Water elevation: $228.37 \mathrm{~A}(39.61 \mathrm{~m}) \mathrm{ms}$

Water evacuated before sampling: $242 \mathrm{gal}$

LABORATORY ANALYSES

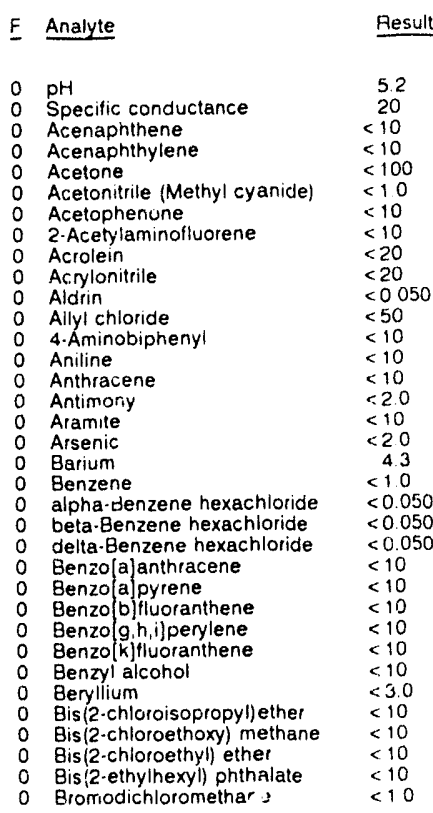

Time: 10.50

Alkalinity. $4 \mathrm{mg}$

Water temperature $182^{\circ} \mathrm{C}$

WELL MSB 43A collected on 10/07/91, laboratory analyses (cont)

E Analyte Result Mod Unit Laa

0 Bromotorm

4. Bromophenyl phenyl ether

2-sec-Butyl-4,6-dinitrophenol

Butylbenzyl phthalate

Cadmium

Carbon disulfide $<10$

$\begin{array}{ll}\text { Carbon tetrachloride } & <1.0 \\ 2,3,7,8 \cdot T C D F & <00040\end{array}$

Chiordane

0 Chloride

$\begin{array}{ll}0 & \text { Chloride } \\ 0 & \text { para.Chioro-meta-cresol }\end{array}$

4.Chloroaniline

Chlorobenzene

Chiorobenzilate

Chloroethene (Vinyl chloride)

2.Chloroethyl vinyl ether

Chloroform

Chlorornethane

2.Chloronaphthalen

2.Chlorophenol

4.Chlorophenyl phenyl ether

Chloroprene

Chromium

Cobalt

Copper

O.Cresol (2-Methylphenoi)

m-Cresol (3.Methylphenol)

p.Cresol

P.P.DDD

p.P.DOE

P.P.DDI

Di-n-octyi phthalate

Diallate

Dibenz $\{a, h] a n t h r a c e n e$

1.2.Dibromo-3-chloropropane

Dibrornochloromethane

1.2.Dibromoethane

Dibromomethane

trans-1,4-Dichloro-2-butene

1.2. Dichlorobenzene
1.3. Dichlorobenzene

1.3. Dichlorobenzene

3.3. Dichlorobenzidine
Dichloroditluoromethane

Dichlorodifluoromethe
1.1.Dichloroethane

1.2-Dichloroethane

$1,1 \cdot$ Dichloroethylene
0
0
tians $1.2 \cdot$ Dichioroethylene

0 Dichloromethane

2.4.Dichlorophenol

2.6.Dichlorophenol

$<10$
$<10$
$<10$

i. Dichlorophenoxyacetic acid $<0.30$

1,2-Dichloropropane
cis-1,3-Dichloropropen

- trans-1,3.Dichloropropene

0 Dieldrin

Diethyl phthalate

24.Dimethyi phenol

2,4.Dimethyl pheno

p.Dimethylaminoazobenzen

Dimethylbenziajanthracene

3.3'-Dimethylbenzidine

a,a.Dimethylphenethylamine

1.3.Dinitrobenzene

2,4.Dinitrophenol

2,4-Dinitrololuene

2.6-Dinitrotoluene

1.4-Dioxane

Diphenylam

Endosulfan I

Endosulian II

Endosulfan sulfate

Endrin

Endrin aldehyde

Ethyl methanesulfonate

Ethylbenzene

Famphur

Fluoranthene

Fluorene

Heptachlor

$1,2,3,4,6,7,8 \cdot \mathrm{HPCDD}$

Heptachlorodibenzo-0.dioxin

$1,3,4678$. HPCDF

Heptachlorodibenzo-p.furans

Hexachlorobenzene

Hexachlorobutadiene

Fiexachlorocyclopentadiene

$1,2,3,4,7,8 \cdot+\times C D O$
$<10$

$<10$

$<10$

0.5004

1.340
1.360

$<10$

$<1.0$

$<1.0$

$<10$

$<1.0$

$<10$

$<10$

$<10$
$<200$
$<4.0$

$<10$

$<4.0$

$<10$

$<10$

$<5.10$
$<0.10$
$<0.10$

$<10$

$<10$

$<10$
$<10$

$<1.0$

$<1.0$
$<20$

$<1.0$

$<30$
$<10$

$<10$

件

$<10$

$<10$
$<10$
$<10$

$<1.0$

10

$<1.0$
$<1.0$
$<1.0$

$<1.0$
$<0.50$

$<10$

$<10$
$<10$

<10

$<10$

$<10$

$<10$

$<45$

$<10$

$<10$

$<10$

$<010$

$<0.10$

$<0.0060$

$<0.10$
$<10$

$<10$

$<1.0$

$<10$

$<0050$

$<0.050$

$<0.00065$

$<0.00065$

$<0.00045$

$<10$

$<10$

$<000045$
$<0.00045$

$\mu \mathrm{g} / \mathrm{L} \quad \mathrm{GE}$

$\mu g / L \quad G E$ 
ANALYTICAL RESULTS

WELL MSB 43A collected on 10/07/91, laboratory analyses (cont)

\begin{tabular}{|c|c|c|c|c|c|}
\hline Analyte & Result & Unit & Lab & $\underline{E}$ & Analyte \\
\hline $\begin{array}{l}1,2,3,4,7,8 \cdot H X C D F \\
\text { Hexachlorodibenzo-p.furans } \\
\text { Hexachloroethane } \\
\text { Hexachlorophene } \\
\text { Hexachloropropene } \\
2 \cdot \text { Hexanone } \\
\text { Indeno[1,2,3.c, d]pyrene } \\
\text { lodomethane (Methyl lodide) } \\
\text { Isobutyl alcohol } \\
\text { Isocrin } \\
\text { Isophorone } \\
\text { Isosafrole } \\
\text { Kepone } \\
\text { Lead } \\
\text { Lindane } \\
\text { Mercury } \\
\text { Methacrylonitrile } \\
\text { Methapyrilene } \\
\text { Meihoxychlor } \\
\text { Methyl ethyl ketone } \\
\text { Methyl isobutyl ketone } \\
\text { Methy! methacrylate }\end{array}$ & $\begin{array}{l}<0.00040 \\
<0.00040 \\
<10 \\
<10 \\
<10 \\
<1.0 \\
<10 \\
<15 \\
<100 \\
<10 \\
<10 \\
<10 \\
<10 \\
<3.0 \\
<0.0050 \\
<0.20 \\
<50 \\
<10 \\
<0.50 \\
<1.0 \\
<1.0 \\
<10\end{array}$ & $\begin{array}{l}\mu g / L \\
\mu g / L \\
\mu g / L \\
\mu g / L \\
\mu g / L \\
\mu g / L \\
\mu g / L \\
\mu g / L \\
\mu g / L \\
\mu g / L \\
\mu g / L \\
\mu g / L \\
\mu g / L \\
\mu g / L \\
\mu g / L \\
\mu g / L \\
\mu g / L \\
\mu g / L \\
\mu g / L \\
\mu g / L \\
\mu g / L \\
\mu g / L\end{array}$ & $\begin{array}{l}\mathrm{GE} \\
\mathrm{GE} \\
\mathrm{GE} \\
\mathrm{GE} \\
\mathrm{GE} \\
\mathrm{GE} \\
\mathrm{GE} \\
\mathrm{GE} \\
\mathrm{GE} \\
\mathrm{GE} \\
\mathrm{GE} \\
\mathrm{GE} \\
\mathrm{GE} \\
\mathrm{GE} \\
\mathrm{GE} \\
\mathrm{GE} \\
\mathrm{GE} \\
\mathrm{GE} \\
\mathrm{GE} \\
\mathrm{GE} \\
\mathrm{GE} \\
\mathrm{GE}\end{array}$ & $\begin{array}{l}0 \\
0 \\
0 \\
0 \\
0 \\
0 \\
0 \\
0 \\
0 \\
0 \\
0 \\
0 \\
0 \\
0 \\
0 \\
0 \\
0 \\
0 \\
0 \\
0 \\
0\end{array}$ & 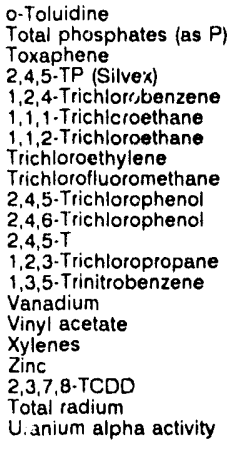 \\
\hline
\end{tabular}

WELL MSB 43B

MEASUREMENTS CONDUCTED IN THE FIELD

Sample date: $10 / 07 / 91 \mathrm{f}(39.31 \mathrm{~m})$ below TOC Water elevation: $229.04 \mathrm{tt}(69.81 \mathrm{~m}) \mathrm{ms}$

Water evacuated belore sampling: $152 \mathrm{gal}$

LABORATOBY ANALYSES

E Analyte

$\mathrm{pH}$

Specific conductance

Acenaphthene

Acetone

Acetonitrile (Methyl cyanide)

Acetophenone
2.Acetylaminofluorene

Acrolein

Acrylonitrile

Allyl chloride

4.Aminobiphenyl

0 Anthracene

0 Antimony

0 Aramite

Arsenic

Barium

alpha-Benzene hexachloride

beta-Benzene hexachloride

delta-Benzene hexachlorid

0 Benzola anthracene

o Benzolapyrene

- Benzo(b) fluoranthene

Benzolg, $h$,ijperylene

Benzyl alcohol

O Benzyl alcoh

Bis(2-chloroisopropyl)ether

Bis(2-chloroethoxy) methane

Bis(2-chloroethyl) ether

O Bis(2-ethylhexyl) phthalate

Bromoform

Bromomethane

4-Bromophenyl phenyl ether

2-sec-Butyl-4,6-dinitrophenol

Rutylbenzyl phthalale

- Carbon disulfide

- Carbon tetrachloride

2,3,7,8.TCDF

Chlordane

para-Chloro-meta-cresol

4-Chloroaniline

C Chlorobenzilate

Chloroethane

o Chloroethene Ninyl chloride)

2.Chloroethyl vinyl ether

Chloroform

Chloromethare

2.Chloronaphthaiene

o 4.Chlorophenyl phenyl ether

0 Chloropiene

0 Chromium

Chrysene
Cobalt

Pesult
$<10$
$<50$
$<0.24$
$<0.090$
$<10$
$<1.0$
$<1.0$
$<1.0$
$<1.0$
$<10$
$<10$
$<0.090$
$<1.0$
$<10$
$<8.0$
$<1.0$
$<2.0$
21
$<0.00045$
$<1.0 E \cdot 09$
$<1.0 E-09$

<10

Thallium $<2.0$

Tin

$<2.0$
$<1.0$

$\mu g / L$

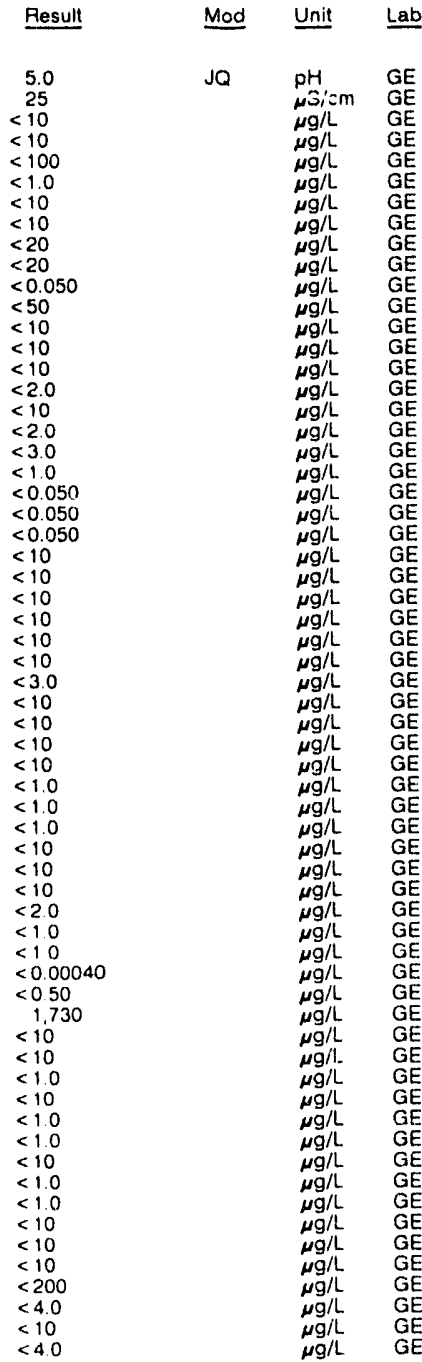

Mod Unit Lab

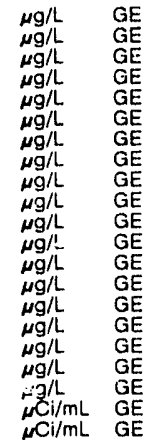

\section{Time: $7: 55$}

Alkalinity: $0 \mathrm{mg} / \mathrm{L}$

Water temperature: $14.1^{\circ} \mathrm{C}$ 
ANALYTICAL RESULTS

WELL MSB 438 collected on 10/07/91, laboratory analyses (cont)

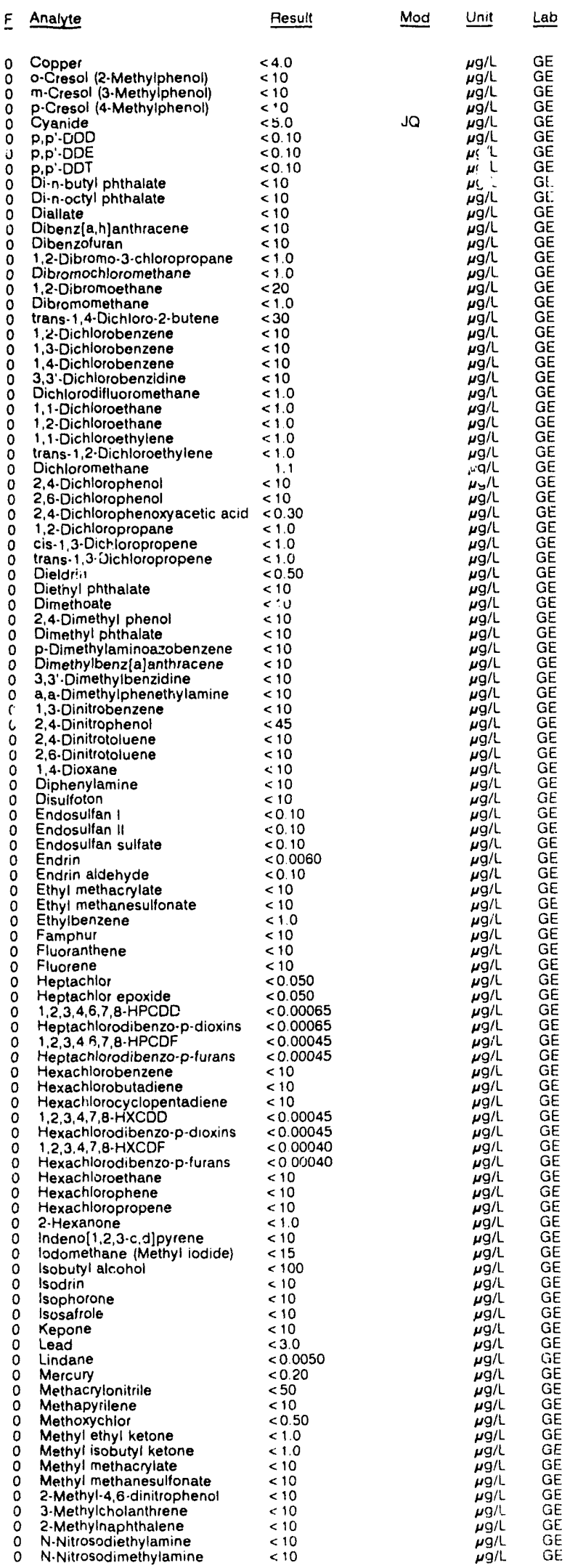

WELL MSB 43B collected on 10/07/91, lat oratory analyses (cont)

E Analyte Result Mod Unit Lab

$<10$
$<10$
$<10$
$<10$
$<10$
$<10$
$<10$
$<10$
$<10$
$<10$
$<10$
$<40$

$\begin{array}{lll}0 & \text { N-Nitrosodiphenylamine } & <10 \\ 0 & \text { N-Nitrosodi-propylamine } & <10 \\ 0 & \text { N-Nitrosomethylethylamine } & <10\end{array}$

N-Nitrosomorpholine

N.Nitrosopyrrolidine

1,4-Naphthoquinone

2.Naphthylamin

Nickel

Nittate as nitrogen

5.Nitro-o-toluidin

2.Nitroaniline

Jitro-niline

4. Nitroaniline

Nitrophenol

2. Nitrophenol

4-Nitroquinoline-1-oxide

作 $<10$

Octachlorodibenzo-p-dioxins $<0.0010$

Octachlorodibenzo-piox

Parathion

PCB 1016

PCB 1221

PCB 1242

PCB 1248

PCB 1254

Pentachlorobenzene

$1,2,3,7,8-P C D F$

Pentachlodibenzo-p-dioxins

1, $2,3,8$-PCDF

Pentachloroethane

Pentachloronitrobenzene

Pentachlorophenol

Phenacetin

Phenant

Phenol
p.Phenylenediamine

Phorate

2.Picoline

Propionitrile

Pyrene

Pyridine

Selenium

Sodium

Sodium

Sulfate

Sulfide

Sulfotepp

1,245. Tetrachlorobenzene

Tetrachlorodibenzo.p.dioxins

Tetrachlorodibenzo-p.furans

1, 1, 2-Tetrachloroethane

Tetrachioroethylene

2,3,4,6-Tetrachloropheno

Thallium

Tin

Tolvene

O.Toluidine

Toxaphene

2,4.5-TP (Silvex)

1.2.4. Trichloubenzene

1,1,1-Trichloroethane

Trichloroethylene

Trichlorofluoromethane

2.4.5. Trichlorophenol

2,4,6-Trichloropheno

o 1,2,3. Trichloropropane

robenzene

V Vanadium

- Vylenes

0 Zinc

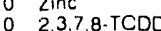

Total radium

Uranium alpha activity

$<10$
$<10$

$<10$

$<10$

$<10$

$<10$

$<0.050$

$<0.50$

$<0.50$

$<0.50$

$<0.50$

$<0.50$

$<10$

$<10$
$<10$
$<10$

$<10$

$<10$

$<10$
$<0.10$

$=0.10$

$<10$
$<10$

$<200$

$<10$
$<10$

$<10$
$<10$

$<2.0$

$<10$

$<1.0$

$<10$

$<10$
$<2.0$

$<10$

$<10$

$<10$

$<1.0$

$<1.0$

$<1.0$

$<10$

$<1.0$

$<10$

$<8.0$
$<10$

20
$7 \%$

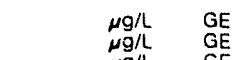

$<4.0$

$<0.0010$

$<0.050$

$<<0.00055$

$<0.0005$

2,000

$<1.00$

$<1,000$

$<0.00045$

$<0.00040$

$<0.24$

$<10$
$<0.090$

$<0.00045$

$<1.0 E-09$

$\mu g / L \quad G E$

$\begin{array}{ll}\mu g / L & G E \\ \mu g / L & G E\end{array}$

$\begin{array}{ll}\mu g / L & G E \\ \mu g / L & G E \\ \mu g / L & G E\end{array}$

$\mu g / L \quad G E$

$\mu g / L \quad G E$

$\mu g / L \quad G E$

$\mu g /$ GE

$\mu g / L$ GE

$\mu g / L \quad G E$

$\mu g / 2$ GE

$\mu \mathrm{g} / \mathrm{L} \quad \mathrm{GE}$

$\mu g / L$ GE

$\mu \quad \mu g / L \quad G E$

$\mu g / L \quad G E$ 
ANALYTICAL RESULTS

WELL MSB 43D

MEASUREMENTS CONDUCTED IN THE FIELD

Sample date: $10 / 04 / 91$ Hepth to water: $127.53 \mathrm{Ht}(38.87 \mathrm{~m})$ below TOS

Depth to water: $127.53 \mathrm{Ht}(38.87 \mathrm{~m})$ below
Water elevation: $229.97 \mathrm{ft}(70.10 \mathrm{~m}) \mathrm{ms}$

LABORATORY ANALYSES

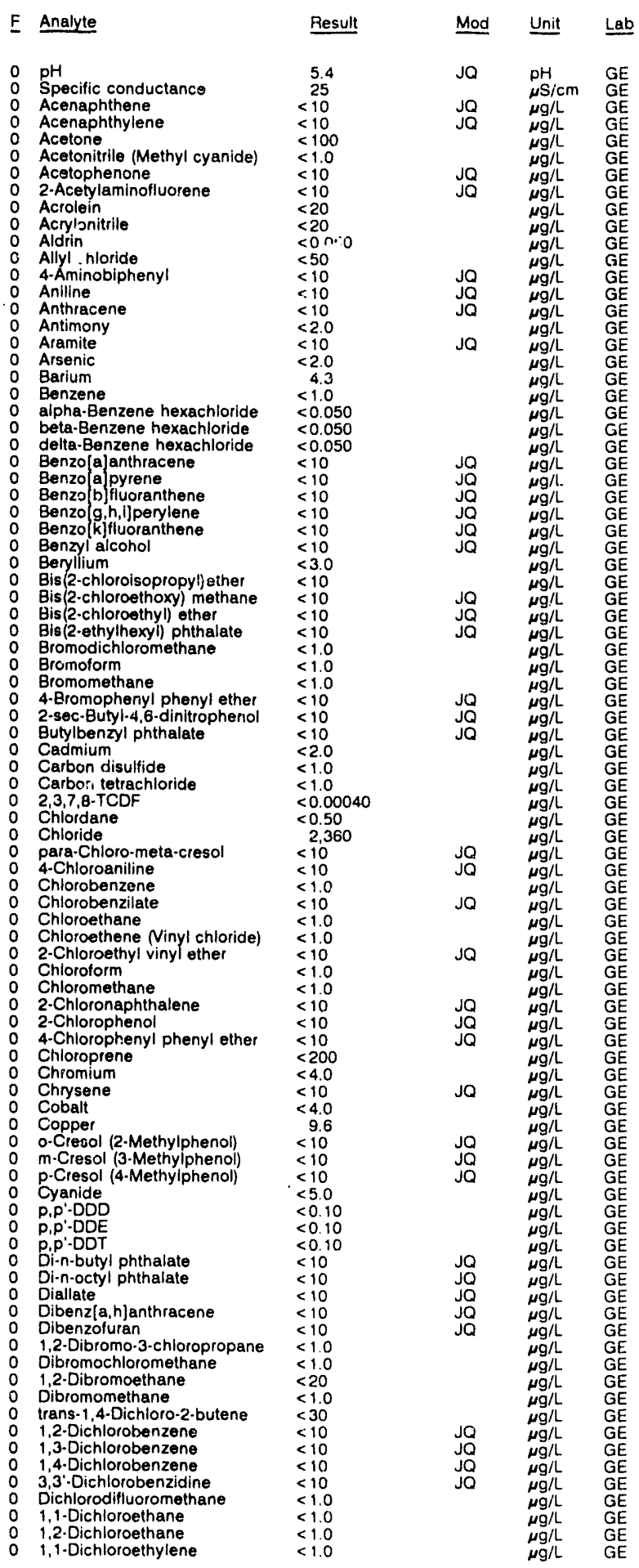

WELL MSB 43D collected on 10/04/91, laboratory analyses (cont.)

E Analyte Result Mod Unit Lab

Time: $10: 00$

Alkalinity: $0 \mathrm{mg} / \mathrm{L}$

Water temperature: $19.5^{\circ} \mathrm{C}$

0 trans-1,2-Dichloroethylene

$\begin{array}{lll}0 & <1.0 \\ 0 & \text { Dichloromethane } & <1.0 \\ 0 & 2,4 \cdot \text { Dichlorophenol } & <10 \\ 0 & 2,6 \cdot \text { Dichlorophenol } & <10 \\ 0 & 2,4 \text {. Dichlorophenoxyacetic acid } & <0.30\end{array}$

$\begin{array}{lll}0 & 1.2 \cdot \text { Dichloropropane } & <1.0 \\ 0 & \text { cis 3-Dichloropropene } & <1.0\end{array}$

$\begin{array}{lll}0 & \text { cis 3-Dichioropropene } & <1.0 \\ 0 & \text { trans-1,3-Dichloropropene } & <1.0\end{array}$

0 Diethyl phthalate $\quad<10$

0 Dimethoate $\quad<10$

$\begin{array}{ll}2,4 \cdot \text { Dimethyl phenol } & <10 \\ 0 \text { Dimethyl phthalate } & <10\end{array}$

0 p-Dimethylaminoazobenzene $<10$

0 Dimethylbenz(a)anthracene $<10$

a,a-Dimethylphenethylamine $<10$

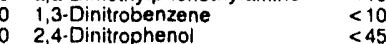

2,4.Dinitrotoluene

2,6-Dinitrotoluene
1,4-Dioxane

0 Diphenylamine

Disulfoton

${ }_{0}^{0}$ Endosulfan I

- Endosulfan sulfate

Endrin

Endrin aldehyde

E Ethy! methanesulfonate

0 Ethylbenzene

0 Famphur

0 Fluoranthen

Heptachlo

Heptachlor epoxide

o Heptachlorodibenzo-p-dioxins

Heptachlorodibenzo-p.furans

Heplachlorodibenzo-p

Hexachlorobenzene

Hexachlorocyclopentadiene
$1,2,3,4,7,8-\mathrm{HXCDD}$

Hexachlorodibenzo-p-dioxins

$1,2,3,4,7,8-H X C D F$

Hexachlorodibenzo-p-furans

Hexachloroethane

Hexachlorophene

Hexachloroprop

Indeno[ $1,2,3-c, d] p y r e n e$

lodomethane (Methyl iodide)

Isobutyl alcohol

isodrin

Isophorone
isosafrole

Kepone

Lead

Lindane

Mercury

Methacrylonitrile

Methoxychlo

Methyl ethyl ketone

Methyl isobutyl ketone

Methyl methacrylate

Methyl methanesulfonate

3.Methylcholanthrene

2-Methylnaphthalene

N-Nitresodiethylamine

N-Nitrosodimethylamine

N-Nitrosodiphenylamine

N-Nitrosodi-propylamint

$\mathrm{N}$-Nitrosomethylethylamine

N-Nitrosomorpholine

N-Nitrosopiperidine

$\mathrm{N}$-Nitrosopyrrolidine

- Naphthalene

o 1,4-Naphthoquinone

1. Naphthylamine

2.Naph

Nickel

Nitrate as nitrogen
5-Nitro-o-toluidine

2.Nitroaniline

4. Nitroaniline

4.Nitroaniline

2. Nitrophenol

2.Nitropheno

4-Nitroquinoline-1-oxide

0,00 -Triethyl phosphorothiogte

Octachloroditenzo-p-dioxins

Octactiorodibenzo-p turans

0 Parathion

- Parathion methy
$<10$
$<10$
$<10$
$<10$
$<10$
$<10$

$<45$
$<10$

$<10$
$<10$

$<10$
$<10$

$<0.10$

$<0.10$

$<0.0060$

$<0.10$

$<10$

$<1.0$

$<10$

$<10$

$<0.050$
$<0.050$

$<0.00065$

$<0.00065$

$<0.00045$

$<10$

$<10$

$<0.00045$

$<0.00040$

$<0.00040$

$<0.000$
$<10$
$<10$

$<10$

$<1.0$

$<10$
$<15$

$<15$
$<100$

$<10$
$<10$

$<10$
$<10$
$<10$

$<10$

$<0.0050$

$<0.20$

$<50$

$<0.50$

$<1.0$

$<10$

$<10$
$<10$

$<10$

$<10$

$<10$

$<10$
$<10$

$<10$

$<10$

$<10$

$<10$

$<10$
$<10$

$<10$

$<10$

$<10$
$<40$

$<4.0$
1.070

$<10$

$<10$
$<10$

$<10$

$<10$
$<10$

$<10$

$<10$
$<10$

$<0.0010$

$<0.0010$
$<0.0010$

$<0.050$

ja
$j a$
$j a$
$j a$
$j a$
$j a$
$j a$
$j a$
$j a$
$j a$
$j a$
$j a$
$j a$
$j a$
$j a$
$j a$
$j a$

$\mu \mathrm{\mu g} / \mathrm{GE}$

$\begin{array}{ll}\mu \mathrm{g} / & \mathrm{GE} \\ \mu \mathrm{g} / \mathrm{GE} & \mathrm{GE}\end{array}$

$\mu \mathrm{g} / \mathrm{L} \quad \mathrm{GE}$

$\mu g / L \quad G E$

$\mu g / L$ GE

$\mu g / L \quad G \quad G$

$\mu g / \mathrm{GE}$

$\mu g / L \quad G E$

$\mu \mathrm{g} / \mathrm{G} \quad \mathrm{GE}$

$\mu g /$ GE

$\mu \mathrm{g} / \mathrm{L} \quad \mathrm{GE}$

$\mu g / \mathrm{GE}$

$\mu g / L \quad G E$

$\mu g$ GE

JO \begin{tabular}{ll}
$\mu g / L$ & $G E$ \\
\hline$g g / L$ & $G E$
\end{tabular}

JO $\mu \mu_{g}, L$ GE

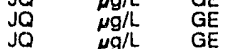

$\begin{array}{ll}\mu \mathrm{g} / & \mathrm{GE} \\ \mu \mathrm{g} / & \mathrm{GE} \\ \mu \mathrm{g} / \mathrm{GE} & \mathrm{GE} \\ \mu g h & \mathrm{GE}\end{array}$

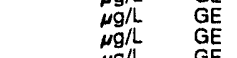

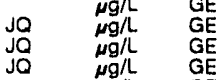

Jo
Ja
Jo
Jo
JQ
JO
JO

$\mu g, \quad G E$

$\mu g / L \quad G E$

$\mu g / L$ GE

GE

$\mu g / L \quad G E$

$\mu g / L \quad G E$

$\mu \mathrm{g} / \mathrm{GE}$

$G E$
$g / 2$

$g / 2 \quad G E$

$\begin{array}{ll}g / \mathrm{G} & \mathrm{GE} \\ \mathrm{g} / \mathrm{G} & \mathrm{GE}\end{array}$

$\mathrm{g} / \mathrm{L} \quad \mathrm{GE}$

$\mu g$ GE

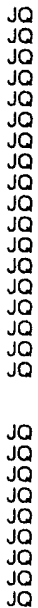

$\mu g / L$

$\mu g / L \quad G$

$\mu g / L \quad G E$

$\mu \mathrm{g} / \mathrm{L} \quad \mathrm{GE}$

$\mu g / 2$

$\mu g / L$

$\mu g / L$

$\mu g /$ L

$\mu g / h$

$\underset{\mu g / \Lambda}{\mu}$

$\mu g / L$

$\mu g$ GE

$\begin{array}{ll}\mu g / L & G E \\ \mu g / L & G E\end{array}$

$\mu g /$ GE

$\mu \mathrm{g} / \mathrm{GE}$

$\mu \mathrm{g} / \mathrm{GE}$

$\mu g / \mathrm{GE}$

$\begin{array}{ll}\mu g / \Lambda & G E \\ \mu g / L & G E\end{array}$

$\mu g / L$

$\begin{array}{ll}\mu \mathrm{g} / \mathrm{L} & \mathrm{GE} \\ \mu \mathrm{g} / \mathrm{L} & \mathrm{GE}\end{array}$ 
ANALYTICAL RESULTS

WELL MSB 43D collected on 10/04/91, laboratory analyses (cont.)

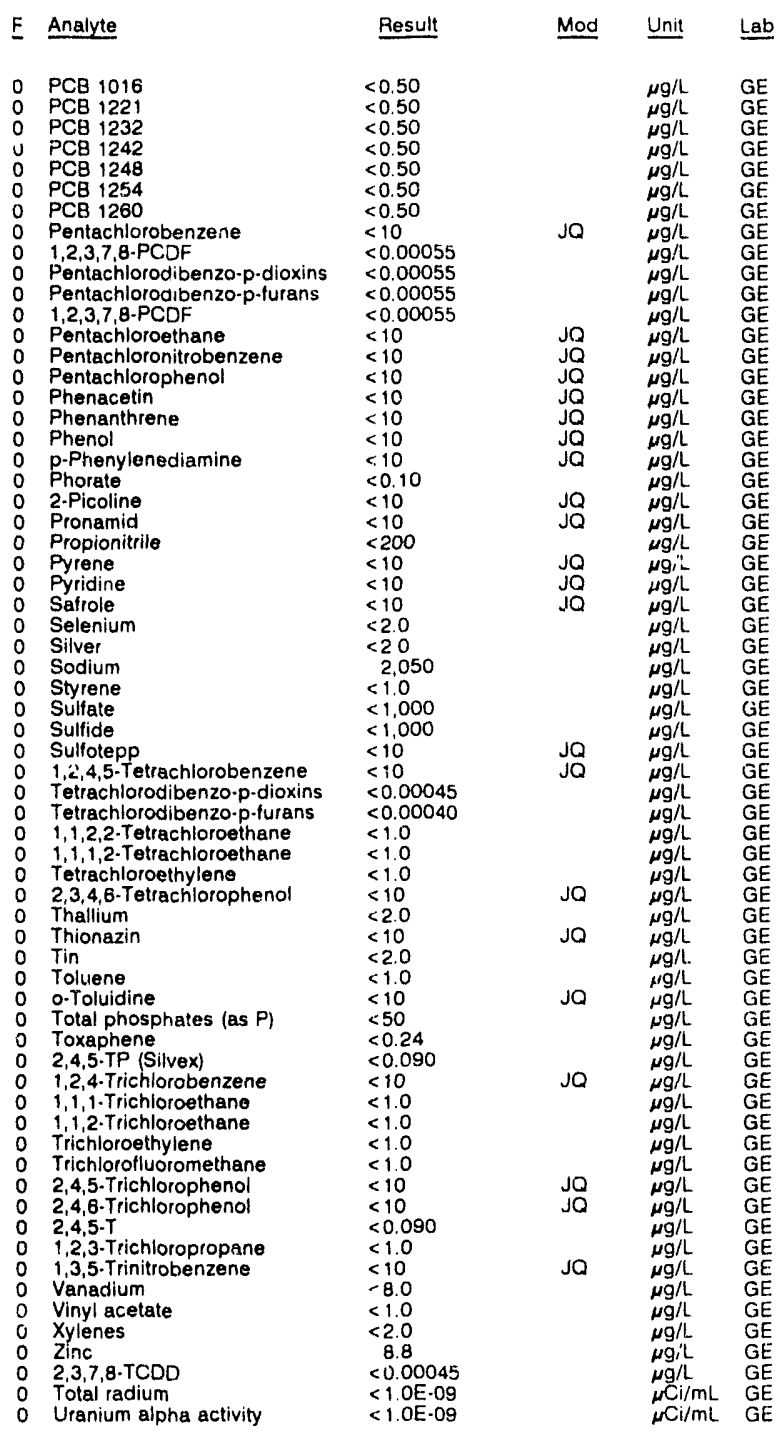

WELL MSB 43D Replicate

MEASUREMENTS CONDUCTED IN THE FIELD

Sample date: $10 / 04 / 91$

Depth to water: $127.53 \mathrm{H}(3887 \mathrm{~m})$ below TOC Water elevation: $229.97 \mathrm{H}$ (7)

Water evacuated before $\mathrm{cm}$

LABORATORY ANALYSES

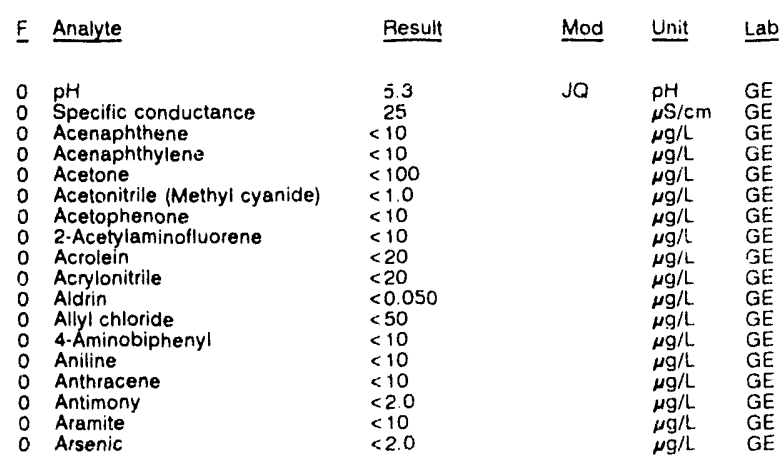

WELLL MSB 43D collected on 10/04/91, laboratory analyses (cont.)

E Analyte Besult Mod Unit Lab

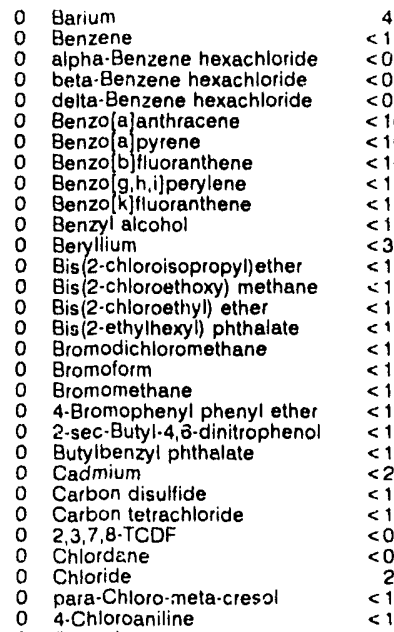

o Chlorobenzene

Chlorobenzilate

Chloroethene (Vinyl chloride)

2.Chloroethyl vinyl ether

vinyl ether $<10$

0 Chloromethan

o 2-Chloronaphthalen

0 2.Chlorophenol

o 4.Chlorophenyl phenyl ether

- Chloroprene

o Chromium

0 Chrysene

0 Cobalt

$\begin{array}{ll}0 & \text { Copper } \\ 0 & \text { o.Cresol (2.Methylphenol) }\end{array}$

m-Cresol (3-Methylphenol)

p-Cl, sol (4-Methylphenol)

Cyanide

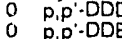

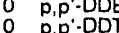

Di-n-butyl phthalate

Di-n-octyl phthalate

Diallate

Dibenz[a,h]anthracene

0 Dibenzofuran

- 1,2-Dibromo-3-chloropropane

- Dibromochioromethane

- 1,2-Dibromoethane

Dibromomethane

trans-1,4-Dichloro-2-butene

1,2-Dichlorobenzene

1,3-Dichlorobenzene

o 3,3 .Dichlorobenzidine

Dichlorodifluoromethane

1,1-Dichloroethane

1,2-Dichloroethane

1,1-Dichloroethylene

trans-1,2-Dichloroethylene

4.3

$<1.0$
$<0.050$

0.050

$<0.050$
$<10$

$<10$

$<10$

$<10$

$<3.0$
$<10$

10

$<10$

1.0

$<1.0$

$<10$

$<10$

2.0

$<1.0$

0.50

2,360
10

$<10$
$<1.0$

10

$<1.0$
$<10$

$<1.0$

$<1.0$

$<10$

$<10$

$<200$

$<4.0$
$<10$

$<4.0$

9.9
$<10$

$<10$

$<10$
$<5.0$

$<5.0$
$<0.10$
$<0.10$

$<0.10$

$<10$

$<10$

$<10$
$<10$

$<10$
$<10$

$<1.0$

$<20$
$<1.0$

$<30$

$<10$

$<10$
$<10$

$<10$
$<1.0$

$<1.0$
$<1.0$

$<1.0$

$<1.0$
$<1.0$

Dichloromethane

2,6-Dichlorophenol

$\begin{array}{ll}2,6 \text {.Dichlorophenol } & <10 \\ 2,4 \text {.Dichlorophenoxyacetic acid } & <0.30\end{array}$

1,2-Dichloropropane

cis-1,3-Dichloropropene

trans-1,3-Dichloropropene

Dieldrin

Diethyl phthalate $\quad<0.50$

Dimethoate $<10$

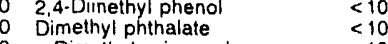

p-Dimethylaminoazobenzene

Dimethylbenz(a)anthracen

3,3'-Dimethylbenzidine
a, a. Dimethylphenethylamine

a,a.Dimethylphene

2,4-Dinitrophenol

2,4-Dinitrotoluene

2.6. Dinitrotoluen

1,4.Dioxane

Disulfoton

Endosulfan I

Endosulfan ll

Endrin

Endrin aldehyde

Endrin aldehyde
Ethyl methacrylate

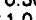

10
10
10

$<10$
$<10$

$<10$
$<10$
$<10$

$<40$

$<45$
$<10$

$<10$
$<10$

$<10$

$<10$
$<0.10$

$<0.10$

$<0.10$
$<0.0060$

$<0.10$
$<10$ 
ANALYTICAL RESULTS

WELL MSB 430 collected on 10/04/9 1, laboratory analyses (cont)

- Ethyl methanesulfonate

Ethylbenzene

Fluorarithene

Fluorene

Heptachlor epoxide

Heptachiorodibenzo-p-dioxins

, 2,3,4,6,7,8-HPCDF -furans

Hexachlorobenzene

Hexachlorobutadiene

$1,2,3,4,7,8-H X C D D$
0 Hexachiorodibenzo-p.dioxins

Hexachlorodibenzo-p-dioxins
$1,2,3,4,7,8-4 x C D F$
Hexachlorodibenzo-p-furens

Kexachloroethane
Hexachlorophene

Hexachloropropen

2-Hexanone

Indeno[1,2,3-c,d]pyrene

lodomethane (Moth

Isodrin

Isosafrole

Kepone

- Lindane

Methacrylonitrile

Methapyrilene

Methoxychlor

Methyl ethyl ketone

Methyl isobutyl ketone

Methy methacrylate

2-Methyl-4,6-dinitrophenol

3.Methylcholanthrene

2-Methylnaphthalene

N-Nitrosodiethylamine

N-Nitrosodimethylamino
N-Nitrosodi-n-butylamine

N.Nitrosodiphenylamine

N-Nitrosomethylettiylamine

N-Nitrosomorpholine

N.Nitosopiperidine

Naphthalene

1,4-Naphthoquinnne

1-Naphthylamine

2.Naphth

Nitrate as nitrogen
5 -Nitro-0.toluidine

2.Nitroaniline

3-Nitroaniline

4-Nitroaniline

2-Nitropheno

4-Nitrophenol

4-Nitroquinoline-1-oxide

. Triethyl phosphorothioate

Cetachordibenzo-p-dioxins

Parathion

Parathion methyl

PCB 1016

PCB 1221

PCB 1242

PCB 1248

PCB 1254

Pentachlorobenzene

Pontachlorodibenzo-p-dioxins

Pentachlorodibenzo-p-furans

1,2,3,7,8.PCOF

Pentach

Pentachloroethane

Pentachlorophenol

Phenacetin

Phenanthien

Phenol

p.Phenylenediamine

Phorate

2.Picoline

Propionitrile

Pyrene

Pyridine
Satrole

Selenium

Silver

Soutium
Result Mod Unit

$<10$

$<10$

$<0.050$

$<0.050$

$<0.00065$

$<0.00045$

$<10$

$<0.00045$

$<0.00045$
$<0.00040$

$<0.00040$

10

$<10$
$<10$
$<10$

$<1.0$

$<15$
$<100$

$<10$
$<10$
$<10$

$<10$

$<0.0050$

$<0.20$

$<10$

$<0.50$

$<1.0$

$<10$

$<10$

$<10$

$<10$
$<10$

$<10$

$<10$
$<10$
$<10$

$<10$

$<10$
$<10$

$<10$

$<10$
$<10$

$<10$

$<10$
$<10$

$<4.0$
1,200

$<10$
$<10$

10

$\$ 10$
$<10$

$<10$

$<10$

$<0.0010$

$<0.0010$

$<0.050$

$<0.50$

$<0.50$

$<0.50$
$<0.50$

$<0.50$
$<0.50$

$<0.50$

$<0.50$

$<0.00055$

$<0.00055$

$<0.00055$

$<10$

$<10$

$<10$

$<10$
$<10$

$<10$
$<10$
$<0.10$
$<10$

$<10$

$<10$

$<200$
$<10$

$<10$
$<16$

$<2.0$

$<<2.0$

2,080
$<1.0$
WELL MSB 430 collected on 10/04/91, laboratory analyses (cont.)

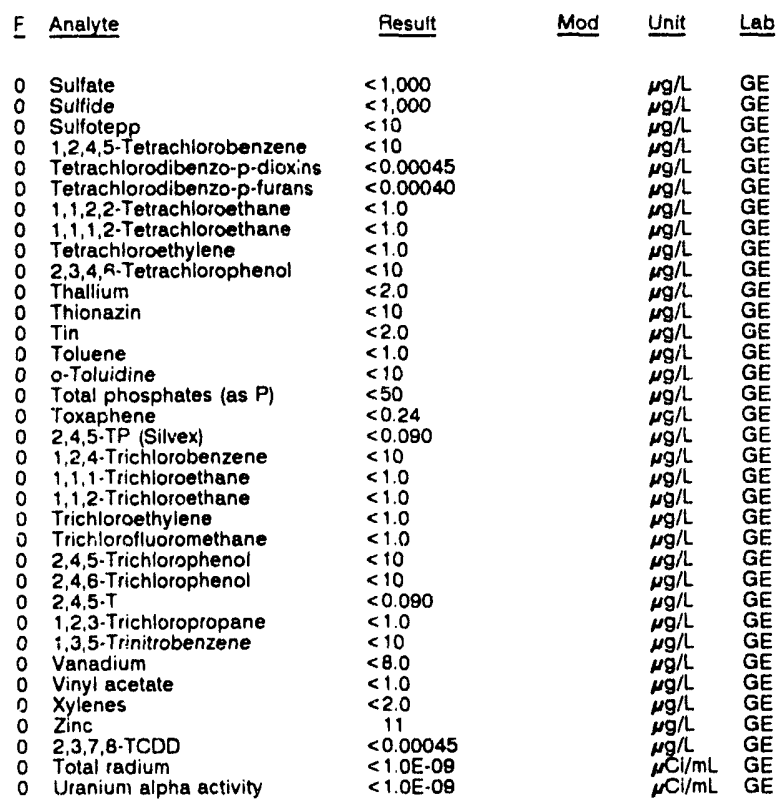

WELL MSB 43TA

MEASUREMENTS CONDUCTED IN THE FIELD

Sample date. 10/07/91

Depth to water: $15524 \mathrm{ft}(47.32 \mathrm{~m})$ below TOC Water elevation: $202.38 \mathrm{tt}(61.68 \mathrm{~m}) \mathrm{ms}$

Sp conductance: 18 Water evacuated before sampling: $434 \mathrm{gal}$

LABORATORY ANALYSES

E Analyte $\underline{\text { Result }} \underline{\text { Mod Unit Lab }}$

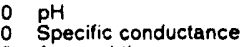

Acenaphthene

Acenaph

Acetonitrile (Methyl cyanide)

Acetophenone

2.Acetylaminofluorene

Acrolein

Acrylonitsite

Aldrin

Allyl chloride

Aniline

Anthracen

Antimony

Aramite

Arsenic

Barium

Benzene

beta-Benzene hexachloride

delta-Benzene hexachloride

Benzola)anthracene

Benzo a pyrene

Benzolb)fluoranthene

Benzo g, hil perylene

Benzo (k)fluoranther

Benzyl alcoho

Bis (2-chloroisoprop yl)ether

Bis (2-chloroethoxy) methan

Bis (2-chloroethyl) ether

Bis (2. elhylhexyl) ph

Bromoform

Bromomethane

4. Bromophenyl phenyl ether

2-sec-Butyl-4,6-dinitropheno

Butyibenzyl

Cadmium

Carbon disulfide

$2,3,7,8 \cdot$ TCDF
$2,3,7,8 \cdot$ TCDF

Chiordane

0 Chloride

para.Chloro-meta-cresol
Time: $7: 10$

Alkalinity: $0 \mathrm{mg} / \mathrm{L}$ Water temperature: $14.2^{\circ} \mathrm{C}$

JO

$\begin{array}{ll}\mathrm{pH} & \mathrm{GE} \\ \mu \mathrm{S} / \mathrm{cm} & \mathrm{GE} \\ \mu \mathrm{g} / \mathrm{L} & \mathrm{GE} \\ \omega \mathrm{g} / \mathrm{L} & \mathrm{GE} \\ \mu \mathrm{L} / \mathrm{L} & \mathrm{GE} \\ \mu \mathrm{g} / \mathrm{L} & \mathrm{GE}\end{array}$

$<1.0$

$\div 10$

$<20$

$<0.050$

$<10$

$<10$

$<2.0$

$<2.0$

$<1.0$

$<0.050$

$<0.050$

$<10$

$<10$

$<10$

$<10$

$<10$

$<10$
$<10$

$<10$

$<1.0$

$<1.0$
$<10$

$<10$
$<10$
$<10$
$<2.0$

$<1.0$
$<1.0$

$<0.00040$

2,310
$<10$ 


\section{ANALYTICAL RESULTS}

WELL MSB 43TA collected on 10/07/91, laboratory analyses (cont.)

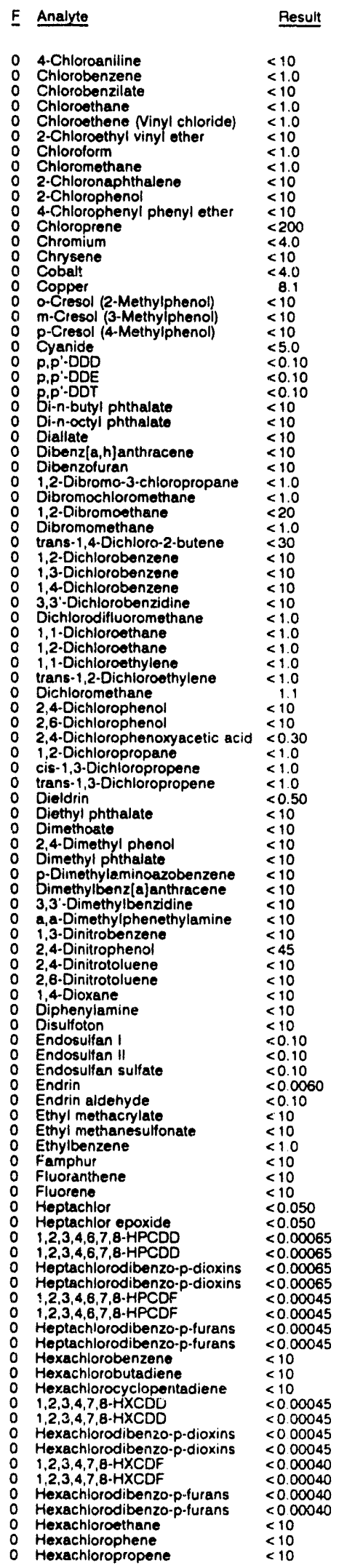

WELL MSB 43TA collected on 10/07/91, laboratory analyses (cont.)

E Analyte Result Mod Unit Lab

2.Hexanone

Indenol $1,2,3-c$, d]pyrene

Isobutyl alcohol $<100$

isoophoron

Isosafrole

Kepone

Lindane

Mercury

Methapyrilene

Methoxychler

Methyl ethyl ketone
Methyl isobutyl ketone

Methyl methacryl:tio

Methyl methanes ulionate

3-Methylcholanthrene

2-Methyinarhthalene

N-Nitrosodiethylamine

$\mathrm{N}$-Nitrosodimethylamine

N-Nitrosodi-n-butylamine

N-Nitrosodiphenylamine

- N.Nitrosomethylethylamine

N-Nitrosomorpholine

N-Nittosopiperidine

N-Nitrosopyrrolidine

1,4-Naphthoquinone

1.Naphthylamine

2-Naphthylamine

Nicke

5.Nitio-0. nitrogen

2.Nitroaniline

3-Nitroaniline

4-Nitroaniline

Nitrobenzene

2-Nitrophenol

4-Nitroquinoline-1.oxide $<10$

$0,0,0$ minathyl phosphorothioale

Octachlorodibenzo-p-dioxins

Octach

Parathion

Parathion methyl

PCB 1221

PCB 1232

PCB 1242

PCB 1254

0 PCB 1260

Pentachiorobenzen

$\begin{array}{ll}1 & 1,2,3,7,8 . P C D F \\ 0 & 1,2.3,7.8 . P C D F\end{array}$

Pentachlorodibenzo-p-dioxins <0.0005

Penlachlorodibenzo-p-dioxins

Pentachiorodibenzo-p-furans

Pentachiorodibe

$1,2,3,7,8 \cdot P C D F$

Pentachloroethane $<10$

Pentachlorophenol $<10$

Phenacetin $<10$

Phenanthrene

Phenol

p.Phenylenediamine

Phorate

2.Picoline

Propionitrile

Pyrene

Pyridine

Selenium

Sodium

Syltate

Sulfide

Sulfide

1,2,4,5.Tetrzchlorobenzene Tetrachlorodibenzo-p.dioxins

Tetrachlorodibenzo-p-dioxins

0 Telrachlorodibenzo-p.furans

Tetrachlorodibenzo-p.furans

1,1,2,2-Tetrachloroethane

1,1,1,2-Tetrachloroethan

Tetrachloroethylene
2,3,4,6-Tetrachlorophenol 2,3,4,6-retro

0 Thionazin

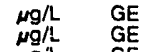

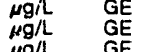

Mg/ $\mathrm{gE}$

H.

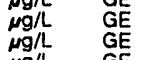

10

$<1.0$

$<\leq 10$

$<10$

$<10$

$<<10$

$<10$

$<10$

$<10$
$<10$

$<10$

4.0

$<10$

$<10$

$<10$
10

$<0.0010$
$<0.0010$

$<0.050$

$<0.050$

$<0.50$

$<0.50$
$<0.50$
$<0.50$

$<0.50$

$<0.50$

$<0.00055$

.00055

.00055

10
0

$<10$

$<10$

$<0.10$

$<10$
$<10$

$<200$

$<10$

$<10$
$<10$

$<2.0$

$<2.0$
1,370

1,370
$<1.0$

3,160
$<1,000$
$<1,000$

$<1,000$

$<10$
$<10$

$<000045$

$<0.00040$

$<0.00040$

$<1.0$

$<1.0$

$<10$

$<2.0$
$<10$

. GE

$G E$

GE

GE

E E 
ANALYTICAL RESULTS

WELL MSB 43TA collected on 10/07/91, laboratory analyses (cont.)

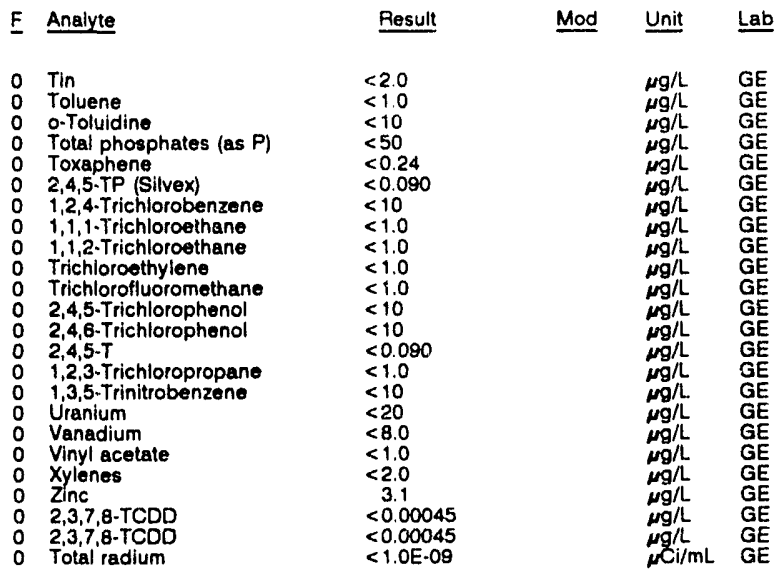

WELL MSB 44A

MEASUREMENTS CONDUCTED IN THE FIELD

Sample date: $11 / 06 / 91$

Depth to water: $160.63 \mathrm{ft}(48.96 \mathrm{~m})$ below TOC Water elevation: 218.27 tt (85.82 m) msi

Water evacuated bofore sampling: $242 \mathrm{gal}$

LABORATORY ANALYSES

\begin{tabular}{|c|c|c|c|c|c|}
\hline & Analyte & Result & Mod & Unit & Lab \\
\hline $\begin{array}{l}0 \\
0 \\
0 \\
0 \\
0 \\
0 \\
0 \\
0 \\
0 \\
0 \\
0 \\
0 \\
0\end{array}$ & $\begin{array}{l}\text { pH } \\
\text { Specific conductance } \\
\text { Arsenic } \\
\text { Barium } \\
\text { Cadmium } \\
\text { Calcium } \\
\text { Carbon tetrachloride } \\
\text { Chloride } \\
\text { Chloroform } \\
\text { Chloroform } \\
\text { Chromium } \\
1,1 \text {-Dichloroethylene } \\
\text { trans-1,2-Dichloroethylere } \\
\text { Fluoride } \\
\text { lron } \\
\text { Lead } \\
\text { Magnesium } \\
\text { Manganese } \\
\text { Mercury } \\
\text { Nitrate as nitrogen } \\
\text { Phenols } \\
\text { Potassium } \\
\text { Selenium } \\
\text { Silica } \\
\text { Silver } \\
\text { Sodium } \\
\text { Sulfate } \\
\text { Tetrachloroethylene } \\
\text { Tetrachlorothylene } \\
\text { Total dissolved solids } \\
\text { Total dissolved solids } \\
\text { Total organic carbon } \\
\text { Total organic halogens } \\
\text { Total phosphates (as P) } \\
\text { 1,1,1-Trichloroethane } \\
\text { t,1,1-Trichloroethane } \\
\text { Trichloroethylene } \\
\text { richloroethylene } \\
\text { Gross alpha } \\
\text { Nonvolatile beta } \\
\text { Total radium } \\
\text { Tritium }\end{array}$ & $\begin{array}{l}5.4 \\
20 \\
<2.0 \\
<3.0 \\
<2.0 \\
485 \\
<1.0 \\
1,990 \\
<1.0 \\
<5.0 \\
<4.0 \\
<5.0 \\
<5.0 \\
<100 \\
36 \\
3.4 \\
207 \\
7.8 \\
<0.20 \\
350 \\
<5.0 \\
<500 \\
<2.0 \\
12.300 \\
<2.0 \\
2.350 \\
5.300 \\
<1.0 \\
<5.0 \\
14.000 \\
19,000 \\
<1.000 \\
40 \\
60 \\
<1.0 \\
<5.0 \\
3.6 \\
<5.0 \\
<2.0 \mathrm{E}-09 \\
<2.0 \mathrm{E} \cdot 09 \\
2.3 \mathrm{E}-09 \times 1.6 \mathrm{E} \cdot 09 \\
<7.0 \mathrm{E}-07\end{array}$ & JQ & $\begin{array}{l}p H \\
\mu S / c m \\
\mu g / L \\
\mu g / L \\
\mu g / L \\
\mu g / L \\
\mu g / L \\
\mu g / L \\
\mu g / L \\
\mu g / L \\
\mu g / L \\
\mu g / L \\
\mu g / L \\
\mu g / L \\
\mu g / L \\
\mu g / L \\
\mu g / L \\
\mu g / L \\
\mu g / L \\
\mu g / L \\
\mu g / L \\
\mu g / L \\
\mu g / L \\
\mu g / L \\
\mu g / L \\
\mu g / L \\
\mu g / L \\
\mu g / L \\
\mu g / L \\
\mu g / L \\
\mu g / L \\
\mu g / L \\
\mu g / L \\
\mu g / L \\
\mu g / L \\
\mu g / L \\
\mu g / L \\
\mu g / L \\
\mu C i / m L \\
\mu C i / m L \\
\mu C i / m L \\
\mu C i / m L\end{array}$ & $\begin{array}{l}G E \\
G E \\
G E \\
G E \\
G E \\
G E \\
G E \\
G E \\
G E \\
M A \\
G E \\
M A \\
M A \\
G E \\
G E \\
G E \\
G E \\
G E \\
G E \\
G E \\
G E \\
G E \\
G E \\
G E \\
G E \\
G E \\
G E \\
G E \\
M A \\
G E \\
G E \\
G E \\
G E \\
G E \\
G E \\
M A \\
G E \\
M A \\
G E \\
G E \\
G E \\
G E\end{array}$ \\
\hline
\end{tabular}

Time: $5: 55$

Alkalinity: $2 \mathrm{mg} / \mathrm{L}$

Water temperature: $15.4^{\circ} \mathrm{C}$

.

WELL MSB 44A Replicate

MEASUREMENTS CONDUCTED IN THE FIELD

Depth to water: $160.63 \mathrm{Ht}(48.96 \mathrm{~m})$ below TOC Water elevation: $216.27 \mathrm{~h}(65.92 \mathrm{~m}) \mathrm{ms}$

Sp. conductance: $21 \mu \mathrm{s} / \mathrm{cm}$

Water evacuated before sampling: $242 \mathrm{gal}$

LABORATORY ANALYSES

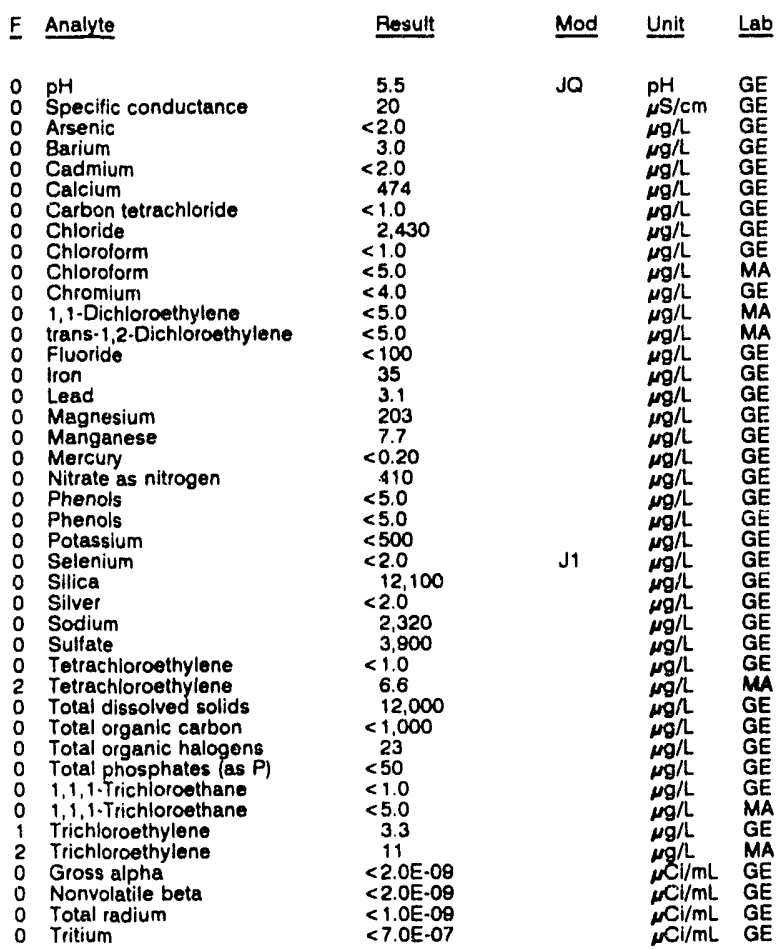

\section{WELL MSB 44B}

MEASUREMENTS CONDUCTED IN THE FIELD

Sample date: $11 / 06 / 91$

Depth to water: $155.78 \mathrm{ft}(47.48 \mathrm{~m})$ below TOC Water elevation: $221.32 \mathrm{Ht}(87.46 \mathrm{~m}) \mathrm{ms}$ Water evacuated before sampling: $124 \mathrm{gat}$

LABORATORY ANALYSES

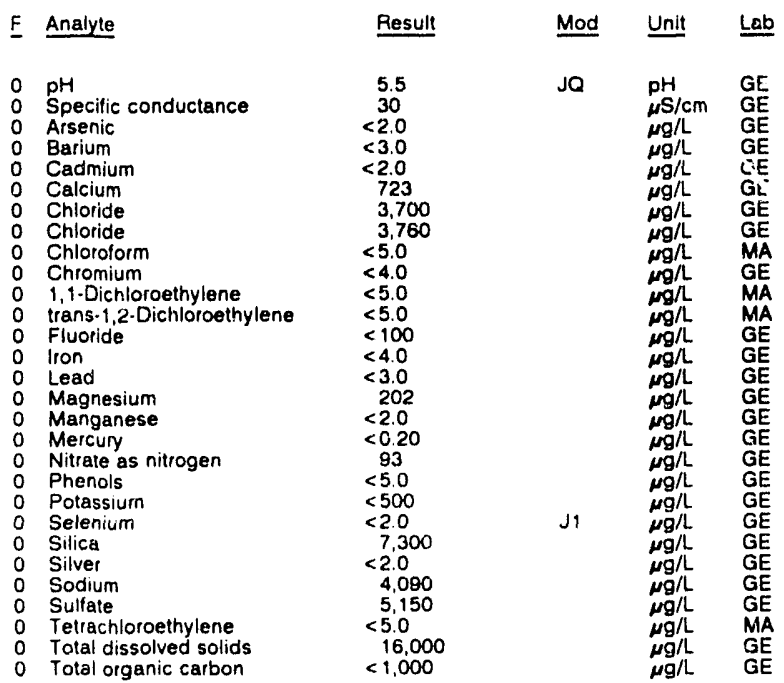

Time: 5:30

pH: 5.3

Water temperature: $16.3^{\circ} \mathrm{C}$

Time: 5:55

Alkalinity: $2 \mathrm{mg} / \mathrm{h}$

ater temperature: $15.4^{\circ} \mathrm{C}$

(1)




\section{ANALYTICAL RESULTS}

WELL. MSB 44B collected on 11/06/91, laboratory analyses (cont.)

\begin{tabular}{|c|c|c|c|c|}
\hline $\mathbf{F}$ & Analyte & Result & Mod & Unit \\
\hline & $\begin{array}{l}\text { Total organic halogens } \\
\text { Total phosphates (as P) } \\
1,1,1 \text { - Trichloroethane } \\
\text { Trichloroethylene } \\
\text { Gross alpha } \\
\text { Nonvolatile beta } \\
\text { Total radium } \\
\text { Tritium }\end{array}$ & $\begin{aligned} & 28 \\
&<50 \\
&<5.0 \\
&<5.0 \\
&<2.0 \mathrm{E}-09 \\
&<2.0 \mathrm{E}-09 \\
&<1.0 \mathrm{E}-09 \\
&<7.0 \mathrm{E}-07\end{aligned}$ & & $\begin{array}{l}\mu \mathrm{g} / \mathrm{L} \\
\mu \mathrm{g} / \mathrm{L} \\
\mu \mathrm{g} / \mathrm{L} \\
\mu \mathrm{g} / \mathrm{L} \\
\mu \mathrm{C} \mathrm{L} / \mathrm{mL} \\
\mu \mathrm{Ci} / \mathrm{mL} \\
\mu \mathrm{Ci} / \mathrm{mL} \\
\mu \mathrm{Ci} / \mathrm{mL}\end{array}$ \\
\hline
\end{tabular}

\section{WELL MSB 44C}

MEASUREMENTS CONDUCTED IN THE FIELD

$\begin{array}{ll}\text { Sample date: } 11 / 06 / 81 & \text { Time: } 7: 05 \\ \text { Dapth to water: } 144.79 \mathrm{nt}(44.13 \mathrm{~m}) \text { below TOC } & \text { pH: } 6.7 \\ \text { Water olovation: } 233.11 \mathrm{H}(71.05 \mathrm{~m}) \mathrm{ms} & \text { Alkalinity: } 70 \mathrm{mg} / \mathrm{h} \\ \text { Sp. Conductanco: } 193 \mu \mathrm{s} / \mathrm{cm} & \text { Water temperature: } 16.2^{\circ} \mathrm{C} \\ \text { Water evacuated before sampling: } 2 \mathrm{gal} & \end{array}$

LABORATORY ANALYSES

\begin{tabular}{|c|c|c|c|c|c|}
\hline $\mathrm{E}$ & Analyte & Result & Mod & Unit & Lab \\
\hline & 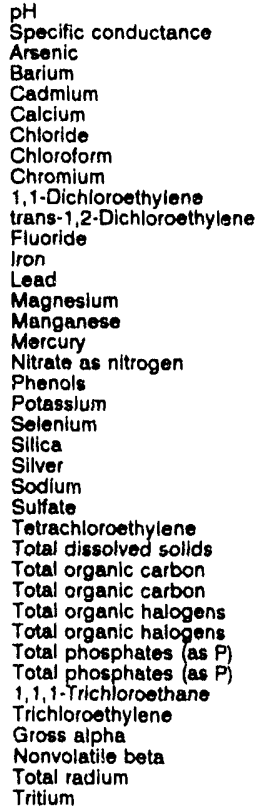 & $\begin{array}{l}6.8 \\
175 \\
<2.0 \\
17 \\
<2.0 \\
20,500 \\
2.470 \\
<5.0 \\
<4.0 \\
<5.0 \\
<5.0 \\
<100 \\
22 \\
<3.0 \\
2,050 \\
27 \\
<0.20 \\
550 \\
<5.0 \\
572 \\
<2.0 \\
15,400 \\
<2.0 \\
10,400 \\
8,660 \\
<5.0 \\
111,000 \\
2,000 \\
2,000 \\
34 \\
37 \\
4.920 \\
5.020 \\
<5.0 \\
<5.0 \\
4.3 \mathrm{E} \cdot 08 \pm 8.2 \mathrm{E} \cdot 09 \\
2.1 \mathrm{E}-09 \pm 5.2 \mathrm{E} \cdot 09 \\
4.0 \mathrm{E}-08 \pm 4.2 \mathrm{E} \cdot 09 \\
<7.0 \mathrm{E}-07\end{array}$ & Jo & $\begin{array}{l}p H \\
\mu \mathrm{S} / \mathrm{cm} \\
\mu g / L \\
\mu g / L \\
\mu g / L \\
\mu g / L \\
\mu g / L \\
\mu g / L \\
\mu g / L \\
\mu g / L \\
\mu g / L \\
\mu g / L \\
\mu g / L \\
\mu g / L \\
\mu g / L \\
\mu g / L \\
\mu g / L \\
\mu g / L \\
\mu g / L \\
\mu g / L \\
\mu g / L \\
\mu g / L \\
\mu g / L \\
\mu g / L \\
\mu g / L \\
\mu g / L \\
\mu g / L \\
\mu g / L \\
\mu g / L \\
\mu g / L \\
\mu g / L \\
\mu g / L \\
\mu g / L \\
\mu g / L \\
\mu g / L \\
\mu C i / m L \\
\mu C i / m L \\
\mu C i / m L \\
\mu C i / m L\end{array}$ & $\begin{array}{l}\mathrm{GE} \\
\mathrm{GE} \\
\mathrm{GE} \\
\mathrm{GE} \\
\mathrm{GE} \\
\mathrm{GE} \\
\mathrm{MA} \\
\mathrm{GE} \\
\mathrm{MA} \\
\mathrm{MA} \\
\mathrm{GE} \\
\mathrm{GE} \\
\mathrm{GE} \\
\mathrm{GE} \\
\mathrm{GE} \\
\mathrm{GE} \\
\mathrm{GE} \\
\mathrm{GE} \\
\mathrm{GE} \\
\mathrm{GE} \\
\mathrm{GE} \\
\mathrm{GE} \\
\mathrm{GE} \\
\mathrm{MA} \\
\mathrm{GE} \\
\mathrm{GE} \\
\mathrm{GE} \\
\mathrm{GE} \\
\mathrm{GE} \\
\mathrm{GE} \\
\mathrm{MA} \\
\mathrm{MA} \\
\mathrm{GE} \\
\mathrm{GE} \\
\mathrm{GE} \\
\mathrm{GE}\end{array}$ \\
\hline
\end{tabular}

WELL MSB 45A

MEASUREMENTS CONDUCTED IN THE FIELD

Semple date: $11 / 26 / 91$

Depth to water: $165.71 \mathrm{Ht}(50.51 \mathrm{~m})$ below TOC Water elovation: $215.39 \mathrm{ft}(65.85 \mathrm{~m}) \mathrm{ms}$

Sp. conductance: $38 \mu \mathrm{s} / \mathrm{cm}$

$$
\text { mpling: } 227 \mathrm{gal}
$$

LABORATORY ANALYSES

$\begin{array}{ll}\text { F } & \text { Analyte } \\ 0 & \text { pH } \\ 0 & \text { Specific conductance } \\ 0 & \text { Arsenic } \\ 0 & \text { Barium } \\ 0 & \text { Cadmium } \\ 0 & \text { Calciurn } \\ 0 & \text { Chiorice } \\ 0 & \text { Chloroform } \\ 0 & \text { Chromium } \\ 0 & 1,1-\text { Dichloroethylene } \\ 0 & \text { trans-1,2-Dichloroethylene } \\ 0 & \text { Fluoride } \\ 0 & \text { Iron } \\ 0 & \text { Load } \\ 0 & \text { Magnesium } \\ 0 & \text { Manganese } \\ 0 & \text { Mercury } \\ 0 & \text { Nitrate as nitrogen } \\ 0 & \text { Phenols }\end{array}$

Result

5.7
35
$<2.0$
10
$<2.0$
2,970
3,120
$<10$
$<4.0$
$<10$
$<10$
$<100$
$<4.0$
$<3.0$
243
2.6
$<0.20$
1.390
$<50$

Time: $13: 50$

pH: 5.5 Alkalinity: $5 \mathrm{mg} / \mathrm{L}$

Water temperature: $18.6^{\circ} \mathrm{C}$

Mod Unit Lab

JO

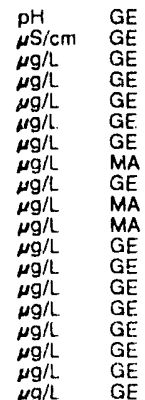

WELLL MSB 45A collected on 11/26/91, laboratory analyses (cont.)

\begin{tabular}{|c|c|c|c|}
\hline Analyte & Result & Mod & Unit \\
\hline $\begin{array}{l}\text { Potassium } \\
\text { Selenium } \\
\text { Silica } \\
\text { Silver } \\
\text { Sodium } \\
\text { Sulfate } \\
\text { Telrachloroethylene } \\
\text { Total dissolved solids } \\
\text { Total organic carbon } \\
\text { Total organic halogens } \\
\text { Total phosphates (as P) } \\
\text { 1,1,1-Trichloroethane } \\
\text { Trichloroethylene } \\
\text { Gross alpha } \\
\text { Nonvolatile beta } \\
\text { Total radium } \\
\text { Tritium }\end{array}$ & $\begin{array}{l}<500 \\
<2.0 \\
8,310 \\
<2.0 \\
2,860 \\
<1,000 \\
163 \\
17,000 \\
<1,000 \\
850 \\
<50 \\
<10 \\
824 \\
4.5 \mathrm{E} \cdot 09 \pm 1.4 \mathrm{E} \cdot 09 \\
<2.0 \mathrm{E} \cdot 09 \\
2.3 \mathrm{E} \cdot 09 \pm 2.0 \mathrm{E} \cdot 09 \\
<7.0 \mathrm{E} \cdot 07\end{array}$ & J1 & $\begin{array}{l}\mu g / L \\
\mu g / L \\
\mu g / L \\
\mu g / L \\
\mu g / L \\
\mu g / L \\
\mu g / L \\
\mu g / L \\
\mu g / L \\
\mu g / L \\
\mu g / L \\
\mu g / L \\
\mu g / L \\
\mu C I / m L \\
\mu C l / m L \\
\mu C i / m L \\
\mu C I / m L\end{array}$ \\
\hline
\end{tabular}

\section{WELL MSB 45B}

MEASUREMENTS CONDUCTED IN THE FIELD

Sample date: $11 / 01 / 91 \mathrm{H}(47.79 \mathrm{~m})$ below TOC Water elevation: $224.30 \mathrm{ft}(68.37 \mathrm{~m}) \mathrm{ms}$ Water evacuated before sampling: $117 \mathrm{gal}$

Time: 6:35

PH: 4.6

LABORATORY ANALYSES

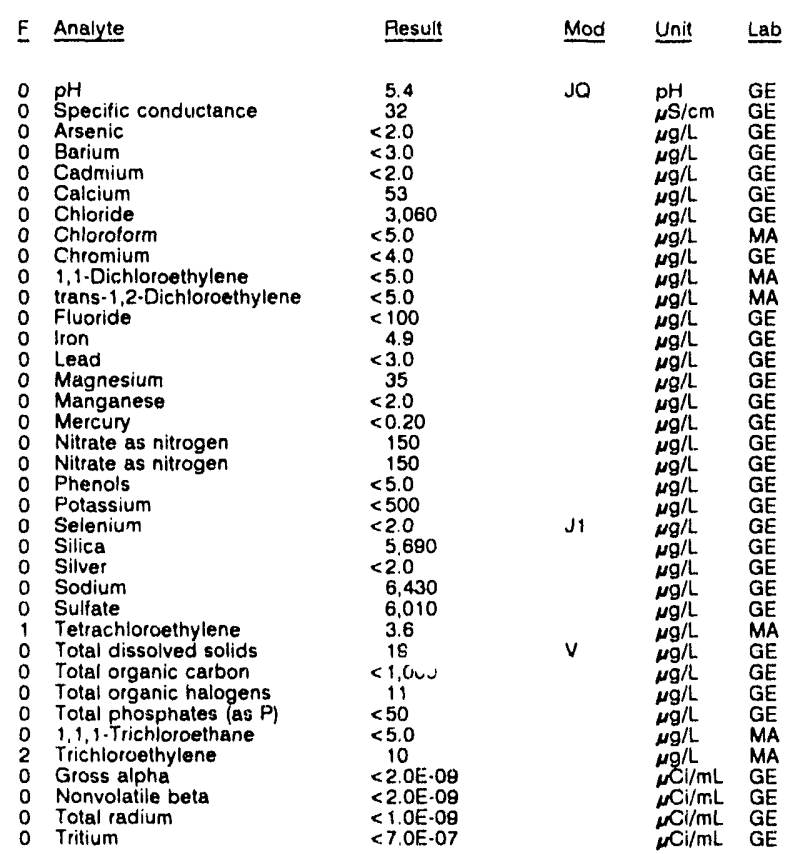

\section{WELL MSB 45C}

MEASUREMENTS CONDUCTED IN THE FIELD

Sample date: 11/01/91

Time 6:20 
ANALYTICAL RESULTS

WELL MSB 46A

MEASUREMENTS CONDU TED IN THE FIELL

Sample date: 10/31/81 Depth to water: $158.66 \mathrm{ft}(48.36 \mathrm{~m})$ below TOC Water elevation: $214.04 \mathrm{Ht}(65.24 \mathrm{~m}$

Sp. conductance: $128 \mu \mathrm{s} / \mathrm{cm}$

Whe well went dry during purging.
The

LABORATORY ANALYSES

\begin{tabular}{|c|c|c|c|}
\hline Analyte & Result & Mod & Unit \\
\hline 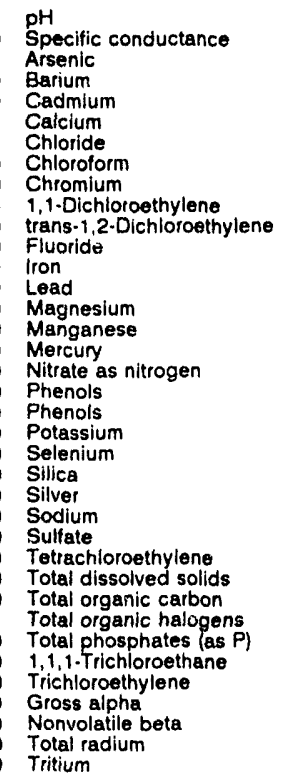 & $\begin{array}{l}9.4 \\
115 \\
2.4 \\
8.8 \\
<2.0 \\
<2.0 \\
8,250 \\
1,620 \\
<1.0 \\
<4.0 \\
<1.0 \\
<1.0 \\
282 \\
<4.0 \\
<3.0 \\
251 \\
<2.0 \\
<0.20 \\
<50 \\
<5.0 \\
<5.0 \\
9,600 \\
<2.0 \\
26,000 \\
<2.0 \\
8,190 \\
15,000 \\
<1.0 \\
88,000 \\
<1,000 \\
37 \\
<50 \\
<1.0 \\
<1.0 \\
<2.06-09 \\
8.8 E-09 \pm 1.9 \mathrm{E} \cdot 09 \\
<1.0 \mathrm{E} .09 \\
<7.0 \mathrm{E}-07\end{array}$ & JO & 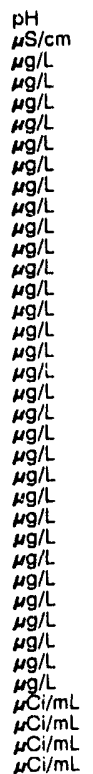 \\
\hline
\end{tabular}

\section{WELL MSB 46B}

MEASUREMENTS CONDUCTED IN THE FIELD

Sample date: $10 / 31 / 91$

Water elevation: Not available

Water elevation. Not avaliable

Water evacuated before sampling: $120 \mathrm{gal}$

LABORATORY ANALYSES

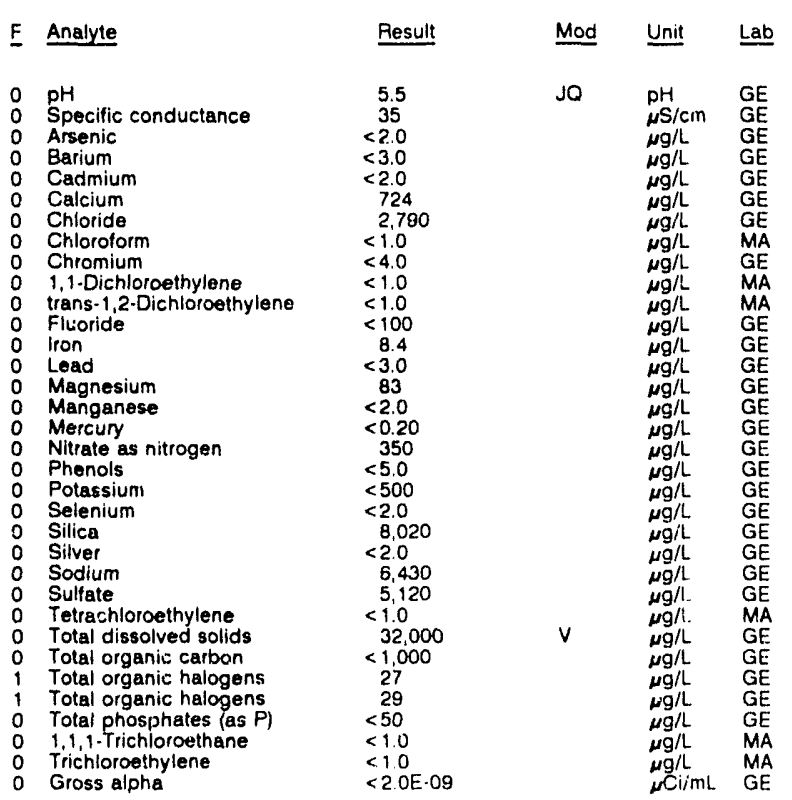

WELL MSB 46B collected on 10/31/91, laboratory analyses (cont.)

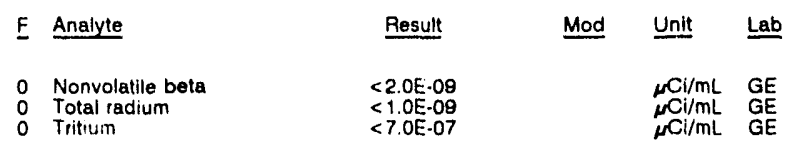

WELL MSB 46C

MEASUREMENTS CONDUCTED IN THE FIELD

Sample date: $10 / 31 / 91$
The well was $d \gamma$. Time: $5: 30$

WELL MSB 47B

MEASUREMENTS CONDUCTED IN THE FIELD

Sample date: 11/26/91

Depth to water: $141.26 \mathrm{Ht}(43.06 \mathrm{~m})$ below TOC

TIme: 10:35

Water elevation: $227.74 \mathrm{ft}(68.42$

Water evacuated before sampling: $163 \mathrm{gal}$

LABORATOAY ANALYSES

E Analyte Pesult Mod Unit Lab

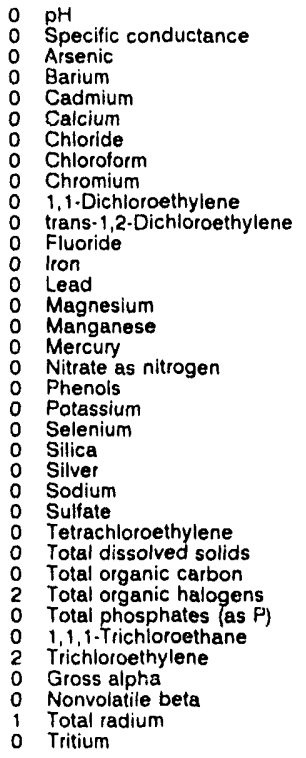

\begin{tabular}{|c|c|c|}
\hline $\begin{array}{l}6.3 \\
95 \\
<2.0 \\
34 \\
<2.0 \\
7,860 \\
4,460 \\
<25 \\
<4.0 \\
<25 \\
<25 \\
<100 \\
4.2 \\
<3.0 \\
896 \\
7.3 \\
<0.20 \\
3,720 \\
<5.0 \\
874 \\
<2.0 \\
8.160 \\
<2.0 \\
6,060 \\
<1,000 \\
<25 \\
52,000 \\
<1,000 \\
6,010 \\
<50 \\
<25 \\
2,290 \\
6.9 \mathrm{E} \cdot 09 \pm 1.9 \mathrm{E}-09 \\
8.9 \mathrm{E} \cdot 09 \pm 2.4 \mathrm{E}-09 \\
4.1 \mathrm{E}-09 \pm 2.1 \mathrm{E}-09 \\
4.4 \mathrm{E} \cdot 06 \pm 7.0 \mathrm{E}-07\end{array}$ & J1 & $\begin{array}{l}p H \\
\mu S / c m \\
\mu g / L \\
\mu g / L \\
\mu g / L \\
\mu g / L \\
\mu g / L \\
\mu g / L \\
\mu g / L \\
\mu g / L \\
\mu g / L \\
\mu g / L \\
\mu g / L \\
\mu g / L \\
\mu g / L \\
\mu g / L \\
\mu g / L \\
\mu g / L \\
\mu g / L \\
\mu g / L \\
\mu g / L \\
\mu g / L \\
\mu g / L \\
\mu g / L \\
\mu g / L \\
\mu g / L \\
\mu g / L \\
\mu g / L \\
\mu g / L \\
\mu g / L \\
\mu g / L \\
\mu g / L \\
\mu C i / m L \\
\mu C l / m L \\
\mu C L / m L \\
\mu C i / m L\end{array}$ \\
\hline
\end{tabular}

\section{WELL MSB 47BB}

MEASUREMENTS CONDUCTED IN THE FIELD

Sample date: $10 / 31 / 91$

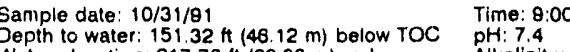

Sp conductance: $65.78 \mathrm{H}(66.38$

PH: 7.4 Alkalinity: $40 \mathrm{mg} / \mathrm{L}$

Sp. conductance: $65 \mu \mathrm{S} / \mathrm{cm}$
Water evacuated betore sampling: $267 \mathrm{gal}$

Alkalinity: $\mathbf{4 0} \mathrm{mg}$

LABORATORY ANALYSES

$\begin{array}{ll}\text { F } & \text { Analyte } \\ 0 & \text { pH } \\ 0 & \text { Specific conductance } \\ 0 & \text { Arsenic } \\ 0 & \text { Barium } \\ 0 & \text { Benzene } \\ 0 & \text { Bromodichloromethane } \\ 0 & \text { Bromolorm } \\ 0 & \text { Bromniethane } \\ 0 & \text { Cadtuum } \\ 0 & \text { Calcium } \\ 0 & \text { Carbon tetrachloride } \\ 0 & \text { Chloride } \\ 0 & \text { Chlorobenzene } \\ 0 & \text { Chloroethane } \\ 0 & \text { Chloroethene Ninyl chioride) } \\ 0 & 2 \text {-Chiorothyl vinyl ether } \\ 0 & \text { Chloroform }\end{array}$

\begin{tabular}{l} 
Resuit \\
\hline \\
7.3 \\
55 \\
$<2.0$ \\
32 \\
$<1.0$ \\
$<1.0$ \\
$<1.0$ \\
$<1.0$ \\
$<2.0$ \\
6.770 \\
$<1.0$ \\
1,870 \\
$<1.0$ \\
$<1.0$ \\
$<1.0$ \\
$<1.0$ \\
$<1.0$
\end{tabular}

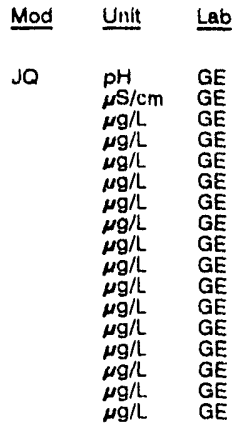


ANALYTICAL RESULTS

WELL MSB $478 B$ collected on 10/31/91, faboratory analyses (cont.)

\begin{tabular}{|c|c|c|c|}
\hline Analyte & Resuit & Mod & Unit \\
\hline 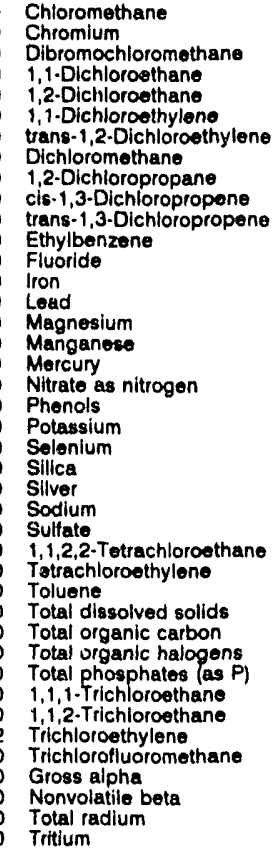 & $\begin{array}{l}<1.0 \\
<4.0 \\
<1.0 \\
<1.0 \\
<1.0 \\
<1.0 \\
<1.0 \\
<1.0 \\
<1.0 \\
<1.0 \\
<1.0 \\
<1.0 \\
<100 \\
10 \\
<3.0 \\
201 \\
4.0 \\
<0.20 \\
990 \\
<5.0 \\
1.900 \\
<2.0 \\
12,800 \\
<2.0 \\
3.710 \\
<1.000 \\
<1.0 \\
<1.0 \\
<1.0 \\
46.000 \\
<1.000 \\
23 \\
80 \\
<1.0 \\
<1.0 \\
21 \\
<1.0 \\
<2.0 \mathrm{E} \cdot 09 \\
<2.0 \mathrm{E}-09 \\
<1.0 \mathrm{E} \cdot 09 \\
<7.0 \mathrm{E} \cdot 07\end{array}$ & $\mathrm{~J} 2 \mathrm{~V}$ & $\begin{array}{l}\mu g / L \\
\mu g / L \\
\mu g / L \\
\mu g / L \\
\mu g / L \\
\mu g / L \\
\mu g / L \\
\mu g / L \\
\mu g / L \\
\mu g / L \\
\mu g / L \\
\mu g / L \\
\mu g / L \\
\mu g / L \\
\mu g / L \\
\mu g / L \\
\mu g / L \\
\mu g / L \\
\mu g / L \\
\mu g / L \\
\mu g / L \\
\mu g / L \\
\mu g / L \\
\mu g / L \\
\mu g / L \\
\mu g / L \\
\mu g / L \\
\mu g / L \\
\mu g / L \\
\mu g / L \\
\mu g / L \\
\mu g / L \\
\mu g / L \\
\mu g / L \\
\mu g / L \\
\mu g / L \\
\mu g / L \\
\mu C i / m L \\
\mu \mathrm{C} / / m L \\
\mu C i / m L \\
\mu C i / m L\end{array}$ \\
\hline
\end{tabular}

WELL MSB 47C

MEASUREMENTS CONDUCTED IN THE FIELD

Sample date: 11/26/91

Depth to water: $136.10 \mathrm{ft}(41.48 \mathrm{~m})$ below TOC Water olevation: $233.20 \mathrm{Ht}(71.08 \mathrm{~m}) \mathrm{ms}$ Water ovacuated before sampling: $96 \mathrm{gal}$

LABORATORY ANALYSES

\begin{tabular}{|c|c|c|c|c|c|}
\hline$F$ & Analyte & Presult & Mod & Unit & Lab \\
\hline $\begin{array}{l}0 \\
0 \\
0 \\
0 \\
0 \\
0 \\
0 \\
0 \\
0 \\
0 \\
0 \\
0 \\
0 \\
0 \\
0 \\
0 \\
0 \\
0 \\
0 \\
0 \\
0 \\
0 \\
0 \\
0 \\
0 \\
0 \\
0 \\
0\end{array}$ & $\begin{array}{l}\text { pH } \\
\text { Specific conductance } \\
\text { Arsenic } \\
\text { Earium } \\
\text { Cadmium } \\
\text { Calcium } \\
\text { Chloride } \\
\text { Chloride } \\
\text { Chloroform } \\
\text { Chromium } \\
\text { 1,1-Dichloroethylene } \\
\text { trans-1,2-Dichloroethylene } \\
\text { Fluoride } \\
\text { Iron } \\
\text { Lead } \\
\text { Magnesium } \\
\text { Manganese } \\
\text { Morcury } \\
\text { Nitrate as nitrogen } \\
\text { Phenols } \\
\text { Potassium } \\
\text { Selenium } \\
\text { Silica } \\
\text { Silver } \\
\text { Sodium } \\
\text { Sulfate } \\
\text { Totrachloroethylene } \\
\text { Total dissolved solids } \\
\text { Total organtc carbon } \\
\text { Total organic halogens } \\
\text { Total phosphates (as P) } \\
\text { 1,1, } 1 \text { - Trichloroethane } \\
\text { Trichloroethylene } \\
\text { Gross alpha } \\
\text { Nonvolatile beta } \\
\text { Total radium } \\
\text { Tritium }\end{array}$ & $\begin{array}{l}5.8 \\
55 \\
<2.0 \\
26 \\
<2.0 \\
2,840 \\
5,600 \\
5,450 \\
<200 \\
<4.0 \\
<200 \\
<200 \\
<100 \\
<4.0 \\
<3.0 \\
644 \\
24 \\
<0.20 \\
2,100 \\
<5.0 \\
531 \\
<2.0 \\
7,790 \\
<2.0 \\
5,220 \\
<1,000 \\
<200 \\
28.000 \\
<1,000 \\
6,630 \\
180 \\
<200 \\
8,150 \\
4.5 E-09 \pm 1.5 E-09 \\
<2.0 E-09 \\
3.0 E-09 \pm 1.6 E-09 \\
1.4 E-05 \pm 9.0 E-07\end{array}$ & JO & $\begin{array}{l}p H \\
\mu S / c m \\
\mu g / L \\
\mu g / L \\
\mu g / L \\
\mu g / L \\
\mu g / L \\
\mu g / L \\
\mu g / L \\
\mu g / L \\
\mu g / L \\
\mu g / L \\
\mu g / L \\
\mu g / L \\
\mu g / L \\
\mu g / L \\
\mu g / L \\
\mu g / L \\
\mu g / L \\
\mu g / L \\
\mu g / L \\
\mu g / L \\
\mu g / L \\
\mu g / L \\
\mu g / L \\
\mu g / L \\
\mu g / L \\
\mu g / L \\
\mu g / L \\
\mu g / L \\
\mu g / L \\
\mu g / L \\
\mu g / L \\
\mu C i / m L \\
\mu C i / m L \\
\mu C i / m L \\
\mu C i / m L\end{array}$ & $\begin{array}{l}G E \\
G E \\
G E \\
G E \\
G E \\
G E \\
G E \\
G E \\
M A \\
G E \\
M A \\
M A \\
G E \\
G E \\
G E \\
G E \\
G E \\
G E \\
G E \\
G E \\
G E \\
G E \\
G E \\
G E \\
G E \\
G E \\
M A \\
G E \\
G E \\
G E \\
G E \\
M A \\
M A \\
G E \\
G E \\
G E \\
G E\end{array}$ \\
\hline
\end{tabular}

\section{WELL MSB 47D}

MEASUREMENTS CONDUCTED IN THE FIELD

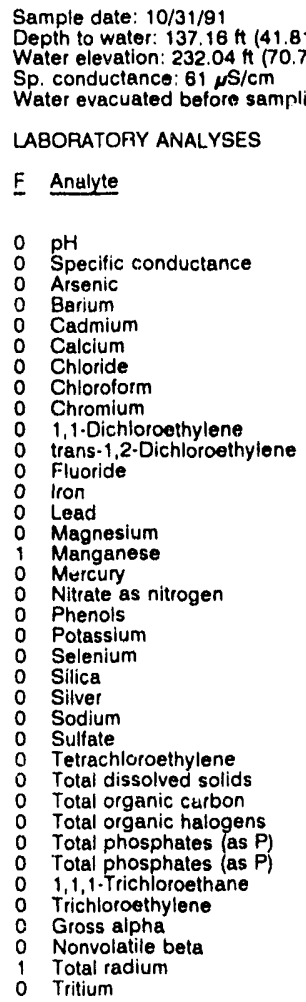

Alkalinity: $0 \mathrm{mg} / \mathrm{L}$

Viator temperature: $17.2^{\circ} \mathrm{C}$

Water evacuated before sampling: $15 \mathrm{gal}$

LABORATORY ANALYSES

\begin{tabular}{|c|c|c|}
\hline Result & Mod & Unit \\
\hline $\begin{aligned} 5.1 \\
50 \\
<2.0 \\
36 \\
<2.0 \\
1.810 \\
5.750 \\
<1.0 \\
<4.0 \\
<1.0 \\
<1.0 \\
<100 \\
17 \\
<3.0 \\
1,280 \\
33 \\
0.23 \\
3.050 \\
<5.0 \\
<500 \\
<2.0 \\
8.830 \\
<2.0 \\
4,470 \\
<1.000 \\
<1.0 \\
31.000 \\
<1.000 \\
9.3 \\
<50 \\
<50 \\
<1.0 \\
1.3 \\
7.4 \mathrm{E} \cdot 09 \pm 1.9 \mathrm{E} \cdot 09 \\
<2.0 \mathrm{E} \cdot 09 \\
2.6 \mathrm{E} \cdot 09 \pm 1.4 \mathrm{E} \cdot 09 \\
<7.0 \mathrm{E} \cdot 07\end{aligned}$ & JQ & 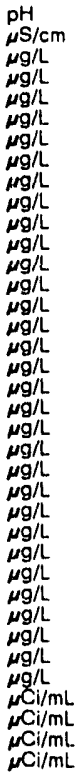 \\
\hline
\end{tabular}

WELL MSB 47TA

MEASUREMENTS CONDUCTED IN THE FIELD

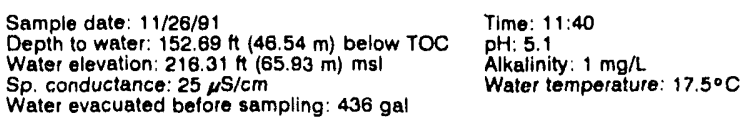

Water evacuated before sampling: $\mathbf{4 3 6} \mathrm{gal}$

LABORATORY ANALYSES

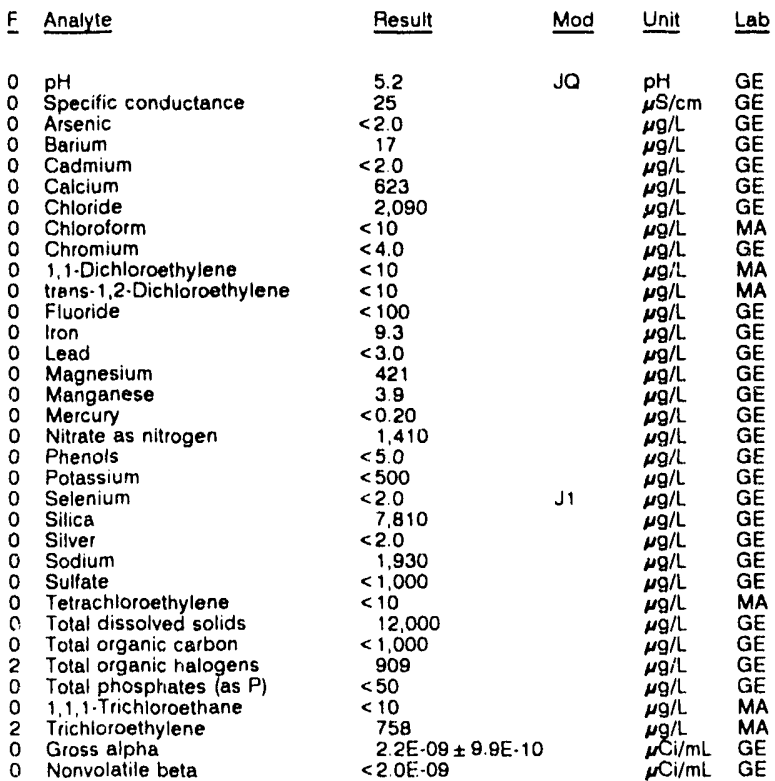


ANALYTICAL RESULTS

WELL MSB 47TA collected on 11/26/91, laboratory analyses (cont.)

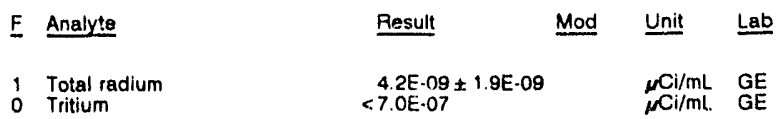

WELL MSB 48A

MEASUREMENTS CONDUCTED IN THE FIELD

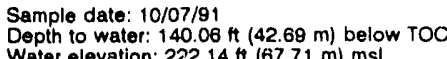
Water elevation: $222.14 \mathrm{f}(67.71 \mathrm{~m}) \mathrm{msl}$

Water ovacuated before sampling: $254 \mathrm{gal}$

LABORATORY ANALYSES

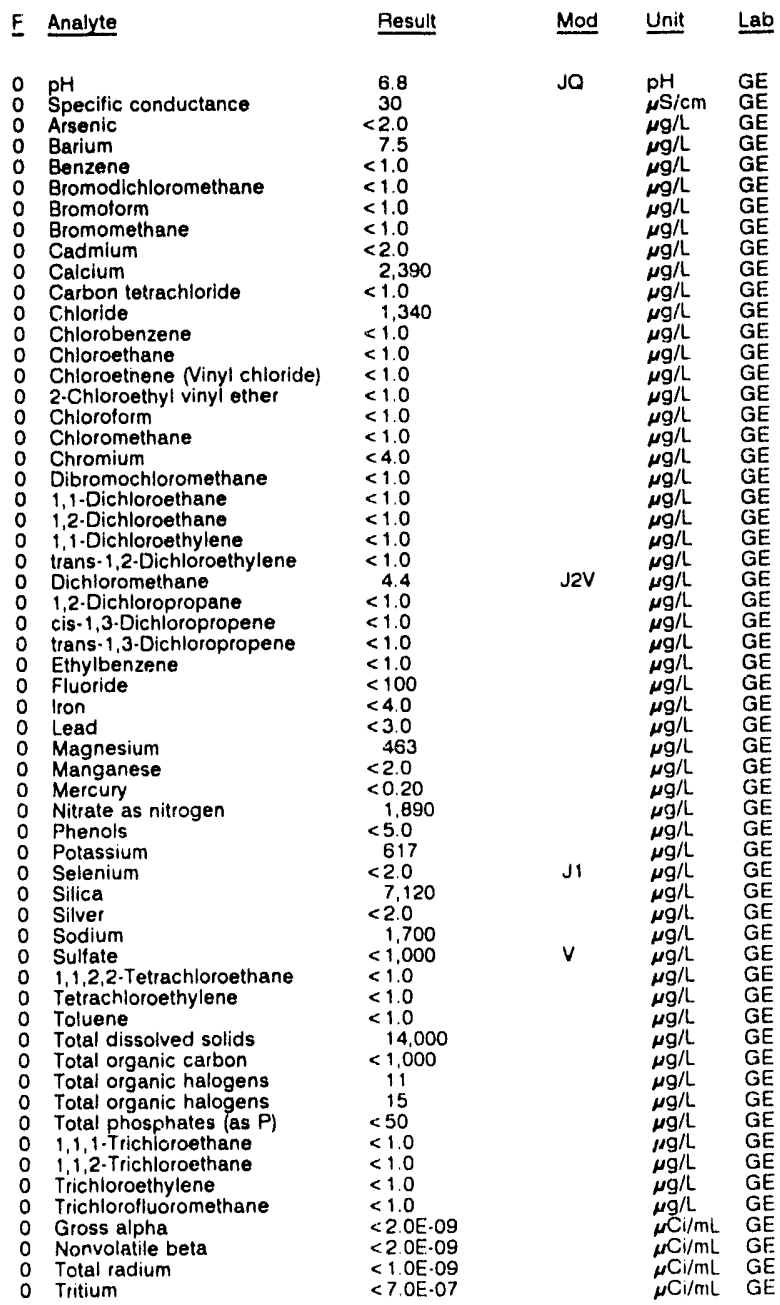

\section{WELL MSB 48B}

MEASUREMENTS CONDUCTED IN THE FIELD

Sample date: $11 / 26 / 91$

Depth to water: $137.69 \mathrm{ft}(41.97 \mathrm{~m})$ below TOC Water elevation: $224.21 \mathrm{tt}(68.0$

Water evacunced before sampling: 184 al

LABORATORY ANALYSES

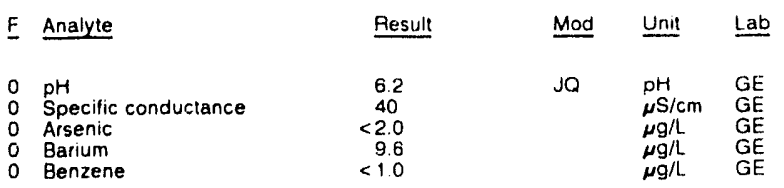

Time: 12:35

PH: 6.1 .

Waler temperature $18.1^{\circ} \mathrm{C}$

b
pH: 5.8
Alkalinity: $3 \mathrm{mg} / \mathrm{h}$
Water temperature: $16.7^{\circ} \mathrm{C}$
WELL MSB $48 \mathrm{~B}$ collected on $11 / 26 / 94$, laboratory analyses (cont.)

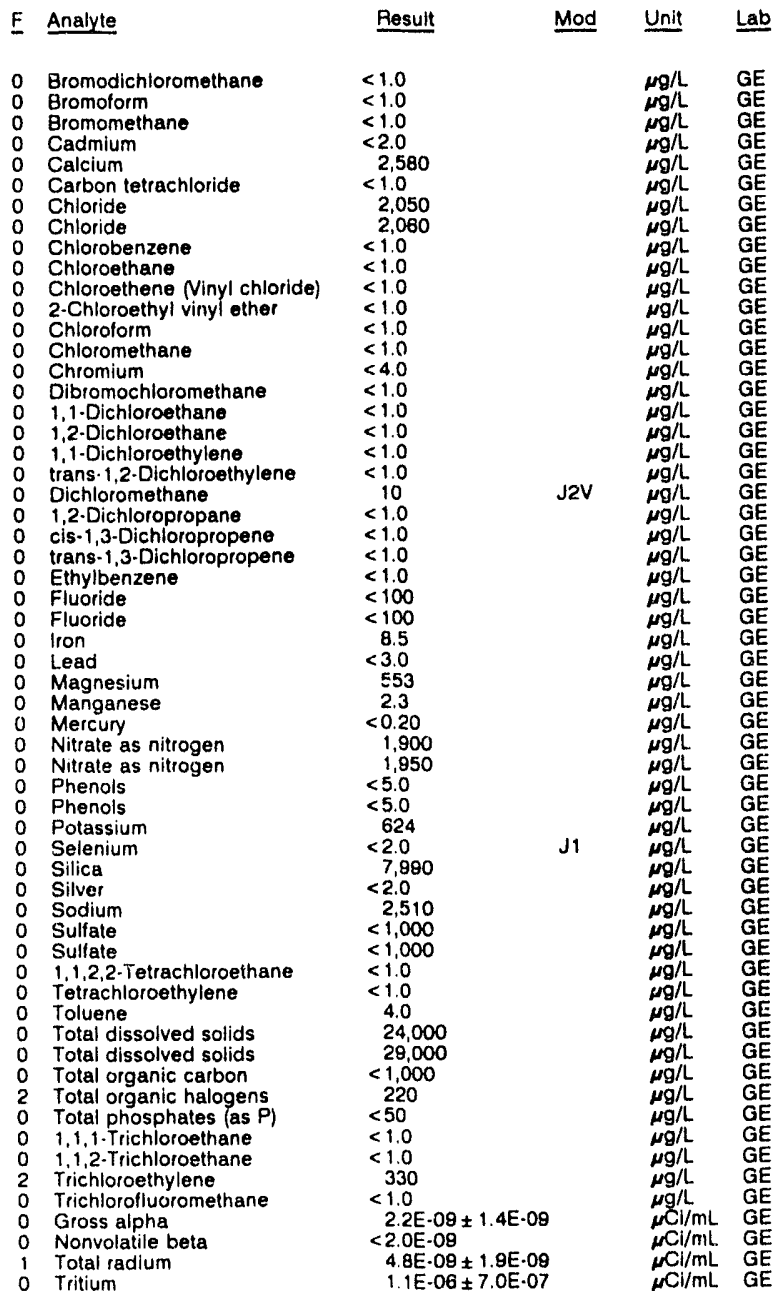

WELL MSB 48C

MEASUREMENTS CONDUCTED IN THE FIELD

$$
\begin{array}{ll}
\text { Sample date: } 10 / 07 / 91 & \text { Time: } 12 \\
\text { Depth to water: } 138.32 \mathrm{Ht}(42.16 \mathrm{~m}) \text { below rOC } & \text { pH: } 6.2 \\
\text { Water elevation: } 224.58 \mathrm{ft}(68.45 \mathrm{~m}) \mathrm{msl} & \text { Alkalinity: } \\
\text { Sp. conductance: } 50 \mu \mathrm{S} / \mathrm{cm} & \text { Water le } \\
\text { Water evacuated before sampling: } 127 \mathrm{gal} &
\end{array}
$$

\begin{tabular}{|c|c|c|}
\hline Result & Mod & Unit \\
\hline $\begin{array}{c}6.3 \\
45 \\
<2.0 \\
12 \\
<2.0 \\
3,890 \\
2.160 \\
<2.0 \\
<4.0 \\
<2.0 \\
<2.0 \\
<100 \\
<4.0 \\
<3.0 \\
571 \\
7.4 \\
<0.20 \\
2,040 \\
2,050 \\
<5.0 \\
969 \\
<2.0 \\
7.420 \\
<2.0\end{array}$ & Ja & $\begin{array}{l}\mathrm{pH} \\
\mu \mathrm{S} / \mathrm{cm} \\
\mu g / \mathrm{L} \\
\mu g / \mathrm{L} \\
\mu \mathrm{g} / \mathrm{L} \\
\mu \mathrm{g} / \mathrm{L} \\
\mu \mathrm{g} / \mathrm{L} \\
\mu \mathrm{g} / \mathrm{L} \\
\mu \mathrm{g} / \mathrm{L} \\
\mu \mathrm{g} / \mathrm{L} \\
\mu \mathrm{g} / \mathrm{L} \\
\mu \mathrm{g} / \mathrm{L} \\
\mu \mathrm{g} / \mathrm{L} \\
\mu \mathrm{g} / \mathrm{L} \\
\mu \mathrm{g} / \mathrm{L} \\
\mu \mathrm{g} / \mathrm{L} \\
\mu \mathrm{g} / \mathrm{L} \\
\mu \mathrm{g} / \mathrm{L} \\
\mu \mathrm{g} / \mathrm{L} \\
\mu \mathrm{g} / \mathrm{L} \\
\mu \mathrm{g} / \mathrm{L} \\
\mu \mathrm{g} / \mathrm{L} \\
\mu \mathrm{g} / \mathrm{L} \\
\mu \mathrm{g} / \mathrm{L}\end{array}$ \\
\hline
\end{tabular}$$
\text { LABORATORY ANALYSES }
$$

$\begin{array}{ll}\text { E } & \text { Analyte } \\ 0 & \text { pH } \\ 0 & \text { Specific conductance } \\ 0 & \text { Arsenic } \\ 0 & \text { Barium } \\ 0 & \text { Cadmium } \\ 0 & \text { Calcium } \\ 0 & \text { Chloride } \\ 0 & \text { Chlorotorm } \\ 0 & \text { Chromium } \\ 0 & 1,1 \cdot \text { Dichloroethylene } \\ 0 & \text { trans } 1.2 \cdot \text { Dichloroethylene } \\ 0 & \text { Fluoride } \\ 0 & \text { lron } \\ 0 & \text { Lead } \\ 0 & \text { Magnesium } \\ 0 & \text { Manganese } \\ 0 & \text { Mercury } \\ 0 & \text { Nitrate as nittogen } \\ 0 & \text { Nitrate as nitrogen } \\ 0 & \text { Phenols } \\ 0 & \text { Potassium } \\ 0 & \text { Selenium } \\ 0 & \text { Sitica } \\ 0 & \text { Silvet }\end{array}$

E




\begin{tabular}{|c|c|c|c|c|}
\hline$\underline{F}$ & Analyte & Result & Mod & Unit \\
\hline $\begin{array}{l}0 \\
0 \\
0 \\
0 \\
0 \\
1 \\
0 \\
0 \\
2 \\
0 \\
0 \\
0 \\
0\end{array}$ & $\begin{array}{l}\text { Sodium } \\
\text { Sulfate } \\
\text { Tetrachloroethylene } \\
\text { Total dissolved solids } \\
\text { Total organic carbon } \\
\text { Total organic halogens } \\
\text { Total phosphates (as P) } \\
\text { 1,1,1-Trichloroethane } \\
\text { Trichloroethylene } \\
\text { Gross alpha } \\
\text { Nonvolatile beta } \\
\text { Total radium } \\
\text { Tritium }\end{array}$ & $\begin{aligned} & 2,900 \\
&< 1,000 \\
&< 2.0 \\
& 25,000 \\
&<1,000 \\
& 44 \\
&<50 \\
&<2.0 \\
& 85 \\
& 2.6 E \cdot 09 \pm 9.0 E-10 \\
& 2.3 E-09 \pm 1.1 E \cdot 09 \\
& 1.0 E-09 \pm 1.0 E \cdot 09 \\
&<7.0 E-07\end{aligned}$ & - & $\begin{array}{l}\mu g / \mathrm{L} \\
\mu g / \mathrm{L} \\
\mu g / \mathrm{L} \\
\mu g / \mathrm{L} \\
\mu g / \mathrm{L} \\
\mu g / \mathrm{L} \\
\mu g / \mathrm{L} \\
\mu g / \mathrm{L} \\
\mu g / L \\
\mu \mathrm{Ci} / \mathrm{mL} \\
\mu \mathrm{Ci} / \mathrm{mL} \\
\mu \mathrm{Ci} / \mathrm{mL} \\
\mu \mathrm{Ci} / \mathrm{mL}\end{array}$ \\
\hline
\end{tabular}

\section{WELL MSB 48D}

MEASUREMENTS CONDUCTED IN THE FIELD

Sample date: $10 / 07 / 91$

Water olovallon: 232.07 it 7

well pumped dry before all field parameters were collected.

\section{WELL MSB 48TA}

MEASUREMENTS CONDUCTED IN THE FIELD

\section{Sample date: $10 / 07 / 91$}

Depth to water: 140.28 it $(4276 \mathrm{~m})$ below TOC Water elevation: $222.12 \mathrm{ft}(67.70 \mathrm{~m}) \mathrm{ms}$

Sp. conductance: $62 \mu \mathrm{S} / \mathrm{cm}$

Water evacuated before sampling: $312 \mathrm{gal}$

LABORATORY ANALYSES

E Analyte Pesult Mod Unit

$\begin{array}{ll}0 & \text { pH } \\ 0 & \text { Specific conductance } \\ 0 & \text { Arsenic }\end{array}$

Arsenic
Barlum

Benzene

Bromodich

Bromomethane

Cadmium

Carbon tetrachlorlde

Carion tera

Chlorobenzene

Chioroethane

2-Chiorothene

Chloroform

Chloromethane

Chromium

Dibromochloromethane

1,1-Dichloroethane

1,2-Dichloroethane

trans-1,2-Dichloroethylene

Dichloromethane

1,2-Dichloropropane

cis-1,3-Dichloropropene
trans-1,3-Dichloropropene

Ethylbenzene

Fluoride

0 Iron

Magnesium

Manganese

Nitrate as nitrogen

Nitrate as nitrogen

Phenols

Sotassium

Selenium

Silice

Sodium

Sodium

1,1,2,2-Tetrachloroethane

Tetrachloroethylene

Toluene

Total dissolved solids

Total organic carbon

Total organic carbon

Total organic halogens

Total phosphates (as P)

$1,1,1$-Trichloroethane

1,1,2-Trichloroethan

Trichloroethylene

Trichlorofluoromethane

Gross alpha
Time: $11: 50$

Alkalinity, $17 \mathrm{mg} / \mathrm{L}$

Water temperature: $18.0^{\circ} \mathrm{C}$

7.8
60
$<2.0$
8.0

$<2.0$
8.0

$<1.0$
$<1.0$

$<1.0$
$<1.0$

$<2.0$

$\begin{aligned} & 8,360 \\ < & 1.0\end{aligned}$

$<1.0$

$<1.0$

$<1.0$

$<1.0$

$<1.0$

$<1.0$

$<1.0$

$<1.0$

$<1.0$
$<1.0$

$<1.0$
4.2

$<1.0$

$<1.0$
$<1.0$
$<1.0$
$<100$

$<10$
$<100$
4.5
$<30$

$<.01$
8.0

$<0.20$
700

690

$<5.0$
$<500$
$<2.0$
8.150

$\begin{array}{r}8.150 \\ <2.0 \\ \hline\end{array}$

2,170
$<1,000$

$<1,0$

$<1.0$
$<1.0$

11.000

$<1,000$

$<1,000$

6.8
50

$<50$

$<10$
$<10$

$<10$
$<10$

$<10$

$<2$ OE.09
WELL MSB 48TA collected on 10/07/91, laboratory analyses (cont.)

\begin{tabular}{|c|c|c|c|}
\hline Analyte & hisult & Mod & Unit \\
\hline $\begin{array}{l}\text { Nonvolatile beta } \\
\text { Total radium } \\
\text { Tritium }\end{array}$ & $\begin{array}{l}<2.0 E-09 \\
<1.0 E-09 \\
<7.0 E-07\end{array}$ & & ${ }_{\mu \mathrm{Cl} / \mathrm{ml}}$ \\
\hline
\end{tabular}

WELL MSB 49A

MEASUREMENTS CONDUCTED IN THE FIELD

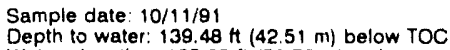

Water elevation: $195.82 \mathrm{ft}(59.72 \mathrm{~m}) \mathrm{ms}$.

Sp. conductance: 28 s $/ \mathrm{cm}$

Water evacuated before sampling: $323 \mathrm{gal}$

LABORATORY ANALYSES

\begin{tabular}{|c|c|c|c|c|}
\hline F & Analyte & Result & Mod & Unit \\
\hline & $\begin{array}{l}\text { Chloroform } \\
1,1 \text {-Dichloroethylene } \\
\text { trans. } 1,2 \cdot \text {-Dichloroethylene } \\
\text { Tetrachloroethylene } \\
1,1,1-\text { Trichloroethane } \\
\text { Trichloroethylene }\end{array}$ & $\begin{array}{l}<1.0 \\
<1.0 \\
<1.0 \\
<1.0 \\
<1.0 \\
<1.0\end{array}$ & & $\begin{array}{l}\mu \mathrm{g} / \mathrm{L} \\
\mu \mathrm{g} / \mathrm{L} \\
\mu \mathrm{g} / \mathrm{L} \\
\mu \mathrm{g} / \mathrm{L} \\
\mu \mathrm{g} / \mathrm{L} \\
\mu \mathrm{g} / \mathrm{L}\end{array}$ \\
\hline
\end{tabular}

\section{WELL MSB 49B}

MEASUREMENTS CONDUCTED IN THE FIELD

Sample date: 10/11/91

Depth to water: $134.30 \mathrm{H}(40.94 \mathrm{~m})$ below TOC

Water elevation: $200.50 \mathrm{Ht}$

Sp. conductance: $82 \mu \mathrm{S} / \mathrm{cm}$

Water evacuated before sampling: $236 \mathrm{gal}$

LABORATORY ANALYSES

E Analyte

Pesult

Time: $8: 00$

pH: 6.5 . $37 \mathrm{mgl}$

Water temperature: $17.1^{\circ} \mathrm{C}$

$\begin{array}{ll}0 & \mathrm{pH} \\ 0 & \text { Specific conductance }\end{array}$

0 Arsenic

Barium

Cadmium
Calcium

Calcium

Chloride

Chromium

trans-1.2-Dichloroethylene

Fluoride

0 Fluoride

0 Iron

M Magnesium

Manganes

Mercury

Nitrate as nitrogen

Nitrate as nitrogen

Phenols

Selassium

Silica

Silver

Sodium

Sulfate

Tetrachloroethylene

Total dissolved solids

Tolal organic carbon

Total organic halogens

Total phosphates (as

1,1,1-Trichloroethan

Grichloroethyle

Nonvolatile beta

0 Total radium

0 Tritium
Time: $7: 40$
pH: 4.7

Alkalinity: $1 \mathrm{mg} / \mathrm{L}$

ater temperature: $16.5^{\circ} \mathrm{C}$
7.0
80
$<2.0$

$<5$
$<2.0$

1,940

$<2.0$

$<<2.0$

$<<100$

$<100$
$<100$

$<4.0$
$<3.0$

503
7.4

$<0.20$

2.400

$<5.0$

$<2.010$

$<2.0$

$<.0$
3,700
1,400

1,480

3.3
115,000

$<1,000$

58
$<50$

$<2.0$

$<\begin{aligned} 99 \\ <20 \mathrm{E} .09\end{aligned}$

$<2.0 E \cdot 09$

$14 E \cdot 09+8.0 E-10$

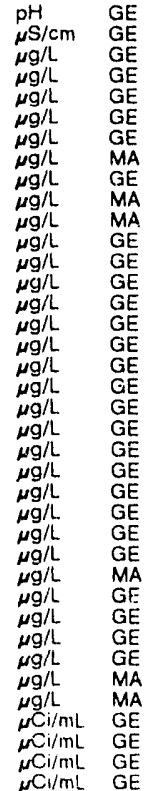


ANALYTICAL RESULTS

WELL MSB 49D

MEASUREMENTS CONDUCTED IN THE FIELD

Sample date: $10 / 11 / 91$

Depth to water: $107.62 \mathrm{H}(32.80 \mathrm{~m})$ below TOC

Sp. conductance: $33 \mu \mathrm{S} / \mathrm{cm}$

Sp. conduclance. $33 \mu \mathrm{s} / \mathrm{cm}$.

The well went dy during purging: $21 \mathrm{gal}$

LABORATORY ANALYSES

\begin{tabular}{|c|c|c|c|c|c|}
\hline & Analyte & Result & Mod & Unit & Lab \\
\hline & $\begin{array}{l}\text { pH } \\
\text { Specific conductance } \\
\text { Arsenic } \\
\text { Barium } \\
\text { Cadmium } \\
\text { Calcium } \\
\text { Chloride } \\
\text { Chloroform } \\
\text { Chromium } \\
\text { Cobalt } \\
1,1 \cdot \text { Dichloroethylene } \\
\text { trans-1,2-Dichloroethylene } \\
\text { Fluoride } \\
\text { lron } \\
\text { Lead } \\
\text { Magnesium } \\
\text { Manganese } \\
\text { Mercury } \\
\text { Nitrate as nitrogen } \\
\text { Phenols } \\
\text { Potassium } \\
\text { Selenium } \\
\text { Silica } \\
\text { Silver } \\
\text { Sodium } \\
\text { Sulfate } \\
\text { Tetrachloroethylene } \\
\text { Total dissolved solids } \\
\text { Total organic carbon } \\
\text { Total organic halogens } \\
\text { Total organic halogens } \\
\text { Total phosphates (as P) } \\
\text { 1,1,1-Trichloroethane } \\
\text { Trichloroethylene } \\
\text { Gross alphy } \\
\text { Nonvolatile beta } \\
\text { Total radium } \\
\text { Tritium }\end{array}$ & $\begin{array}{l}6.3 \\
40 \\
<2.0 \\
12 \\
<1, \\
1, y \cdot n \\
2,300 \\
<1.0 \\
<4.0 \\
<4.0 \\
<1.0 \\
<1.0 \\
<100 \\
15 \\
<3.0 \\
574 \\
9.2 \\
<0.20 \\
1,140 \\
<5.0 \\
688 \\
<2.0 \\
6.760 \\
<2.0 \\
2.230 \\
<1,000 \\
<1.0 \\
<1.000 \\
<1.000 \\
<5.0 \\
<5.0 \\
50 \\
<1.0 \\
<1.0 \\
2.9 E \cdot 09 \pm 1.2 E \cdot 09 \\
3.6 E \cdot 09 \pm 12 E-09 \\
419 E-09 \pm 1.6 E \cdot 09 \\
118 E \cdot 06 \pm 1.0 E-07\end{array}$ & JQ & 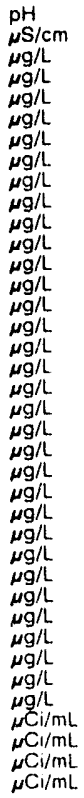 & $\begin{array}{l}\mathrm{GE} \\
\mathrm{GE} \\
\mathrm{GE} \\
\mathrm{GE} \\
\mathrm{GE} \\
\mathrm{GE} \\
\mathrm{GE} \\
\mathrm{MA} \\
\mathrm{GE} \\
\mathrm{GE} \\
\mathrm{MA} \\
\mathrm{MA} \\
\mathrm{GE} \\
\mathrm{GE} \\
\mathrm{GE} \\
\mathrm{GE} \\
\mathrm{GE} \\
\mathrm{GE} \\
\mathrm{GE} \\
\mathrm{GE} \\
\mathrm{GE} \\
\mathrm{GE} \\
\mathrm{GE} \\
\mathrm{GE} \\
\mathrm{GE} \\
\mathrm{GE} \\
\mathrm{MA} \\
\mathrm{GE} \\
\mathrm{GE} \\
\mathrm{GE} \\
\mathrm{GE} \\
\mathrm{GE} \\
\mathrm{MA} \\
\mathrm{MA} \\
\mathrm{GE} \\
\mathrm{GE} \\
\mathrm{GE} \\
\mathrm{GE}\end{array}$ \\
\hline
\end{tabular}

\section{WELL MSB 50B}

MEASUREMENTS CONDUCTED IN THE FIELD

Sample date: 10/30/91

Depth to water: $21.48 \mathrm{H}(6.55 \mathrm{~m})$ below rOC

Water elevation. $202.51 \mathrm{ft} / 61$

Water evacuated before sampling: $140 \mathrm{gal}$

LABORATORY ANALYSES

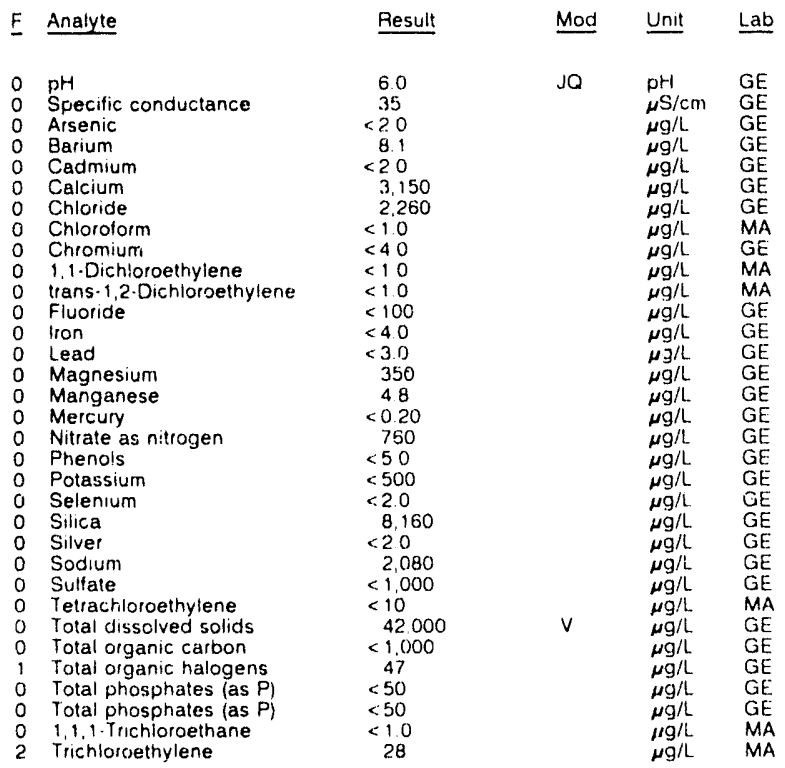

WELL MSB 50B collected on 10/30/91, laboratony analyses (cont.)

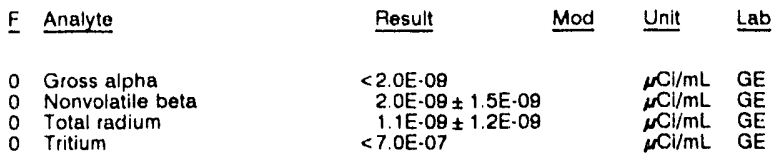

WELL MSB 50D

MEASUREMENTS CONDUCTED IN THE FIELD

Sample date: 10/30/91

Depth to water: $20.91 \mathrm{Ht}(6.37 \mathrm{~m})$ below TOC

Water elevation: $202.58 \mathrm{ft}(61.75 \mathrm{~m}) \mathrm{msl}$

Water evacuated before sampling: $31 \mathrm{gal}$

pH: 5.9

Alkalinity: $15 \mathrm{mg}$

LABORATORY ANALYSES

F Analyte

Result Mod Unit Lab

${ }_{0}^{\circ} \mathrm{pH}^{\mathrm{PH}}$

0 Arsenic

0 Barium

0 Calcium

Chloride

C Chloride

C Chlorolorm

1,1-Dichloroethylene

0 trans-1,2-Dichloroethylene

0 Fluoride

0 lion

0 Magnesium

1 Manganese

Mercury
Nitrate as nitrogen

Phenols

0 Potassium

0 Selenium

o Silica

Silver

${ }_{0}$ Sodium

0
0 Tetrachloroethylene

Total dissolved solids

Total organic carbon

Total organic halogens
Total phosphates (as P)

1,1,1-Trichloroethane

Trichloroethylen

Gross alpha

Total radium

Tritium

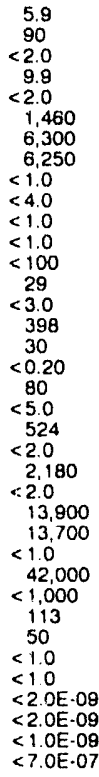

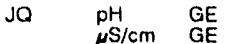

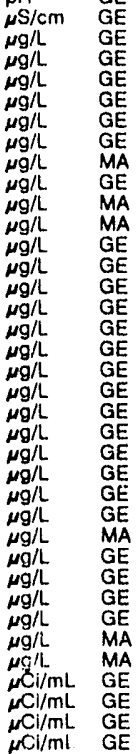

WELL MSB 51B

MEASUREMENTS CONDUCTED IN : EFIELD

Sample date: $10 / 30 / 91$

Depth to water: $58.65 \mathrm{Ht}(17.88 \mathrm{~m})$ below TOC

Water elevation: $204.85 \mathrm{ft}(62.44 \mathrm{~m}) \mathrm{msl}$

Sp conductance: $42 \mu \mathrm{S} / \mathrm{cm}$

Water evacuated before sampling: $133 \mathrm{gal}$

LABORATOAY ANALYSES

$\begin{array}{ll}\text { F } & \text { Analyte } \\ & \\ 0 & \text { pH } \\ 0 & \text { Specific conductance } \\ 0 & \text { Arsenic } \\ 0 & \text { Barium } \\ 0 & \text { Cadmium } \\ 0 & \text { Calcium } \\ 0 & \text { Chloride } \\ 0 & \text { Chloroform } \\ 0 & \text { Chromium } \\ 0 & 1,1 \text {-Dichioroethylene } \\ 0 & \text { trans } 1,2-\text { Dichloroethylene } \\ 0 & \text { Fluoride } \\ 0 & \text { tron } \\ 0 & \text { Lead } \\ 0 & \text { Magnesium } \\ 0 & \text { Manganese } \\ 0 & \text { Mercury } \\ 0 & \text { Nittate as nitrogen } \\ 0 & \text { Phenols } \\ 0 & \text { Potassium } \\ 0 & \text { Selenium } \\ 0 & \text { Silica } \\ 0 & \text { Silvet } \\ 0 & \text { Sodium } \\ 0 & \text { Sultate } \\ & \end{array}$

\begin{tabular}{c} 
Result \\
\hline \\
6.2 \\
35 \\
$<2.0$ \\
19 \\
$<2.0$ \\
4,080 \\
2,370 \\
$<1.0$ \\
$<4.0$ \\
$<1.0$ \\
$<1.0$ \\
$<100$ \\
$<4.0$ \\
$<3.0$ \\
296 \\
3.1 \\
$<020$ \\
260 \\
$<5.0$ \\
557 \\
$<2.0$ \\
7.700 \\
$<2.0$ \\
1,700 \\
$<1.000$
\end{tabular}

Time: $10: 15$

pH: 6.3

Alkalinity: $17 \mathrm{mg} /$

Water temperature: $17.0^{\circ} \mathrm{C}$

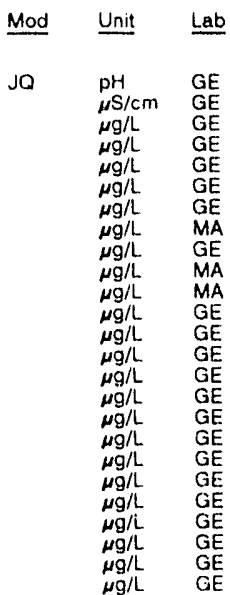


ANALYTICAL RESULTS

WELL. MSB 518 collected on 10/30/91, laboratory analyses (cont.)

\begin{tabular}{|c|c|c|c|}
\hline E Analyte & Result & Mod & Unit \\
\hline $\begin{array}{ll}0 & \text { Totrachloroothylene } \\
0 & \text { Total dissolved solids } \\
0 & \text { Total organic carbon } \\
0 & \text { Total organic carbon } \\
1 & \text { Total organic halogens } \\
0 & \text { Total phosphates (as P) } \\
0 & 1,1,1 . \text { Trichloroothane } \\
0 & \text { Trichloroethylene } \\
0 & \text { Gross alpha } \\
0 & \text { Nonvolatile beta } \\
0 & \text { Total radium } \\
0 & \text { Tritium }\end{array}$ & $\begin{array}{l}<1.0 \\
24,000 \\
<1.000 \\
<1.000 \\
29 \\
<50 \\
<1.0 \\
<1.0 \\
<2.0 E-09 \\
<2.0 \mathrm{E}-09 \\
<1.0 \mathrm{E}-09 \\
<7.0 \mathrm{E}-07\end{array}$ & V & $\begin{array}{l}\mu \mathrm{g} / \mathrm{L} \\
\mu \mathrm{g} / \mathrm{L} \\
\mu \mathrm{g} / \mathrm{L} \\
\mu \mathrm{g} / \mathrm{L} \\
\mu \mathrm{g} / \mathrm{L} \\
\mu g / \mathrm{L} \\
\mu g / \mathrm{L} \\
\mu \mathrm{g} / \mathrm{L} \\
\mu \mathrm{i} / \mathrm{mL} \\
\mu \mathrm{Ci} / \mathrm{mL} \\
\mu \mathrm{Ci} / \mathrm{mL} \\
\mu \mathrm{Ci} / \mathrm{mL}\end{array}$ \\
\hline
\end{tabular}

WELL MSB 51D

MEASUREMENTS CONDUCTED IN THE FIELD

\begin{tabular}{|c|c|c|c|c|c|}
\hline & 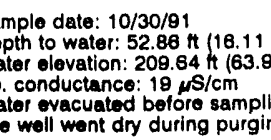 & $\begin{array}{l}\text { Ow TOC } \\
\text { isl } \\
\text { gal }\end{array}$ & $\begin{array}{l}\text { Time: } 9: 45 \\
\text { pH: } 5,1 \\
\text { Alkalinity: } \\
\text { Water temp }\end{array}$ & $\begin{array}{l}g / L \\
\text { ature: } 16.7\end{array}$ & \\
\hline & BORATORY ANALYSES & & & & \\
\hline $\mathbf{E}$ & Analyte & Result & Mod & Unit & Lab \\
\hline $\begin{array}{l}0 \\
0 \\
0 \\
0 \\
0 \\
0 \\
0 \\
0 \\
0 \\
0 \\
0 \\
0 \\
0 \\
0 \\
0 \\
0 \\
0 \\
0 \\
0 \\
0 \\
0 \\
0 \\
0 \\
0 \\
0 \\
0 \\
0 \\
0 \\
0 \\
1 \\
0 \\
0 \\
0 \\
0 \\
0 \\
0 \\
0\end{array}$ & $\begin{array}{l}\text { pH } \\
\text { Specific conductance } \\
\text { Arsenic } \\
\text { Barium } \\
\text { Cedmium } \\
\text { Calcium } \\
\text { Chloride } \\
\text { Chloroform } \\
\text { Chromium } \\
1,1-\text { Dichloroethylene } \\
\text { trans-1,2-Dichloroethylene } \\
\text { Fluoride } \\
\text { ron } \\
\text { Lead } \\
\text { Magnesium } \\
\text { Manganese } \\
\text { Mercury } \\
\text { Nitrate as nitrogen } \\
\text { Phenols } \\
\text { Potassium } \\
\text { Selenium } \\
\text { Silica } \\
\text { Silver } \\
\text { Sodium } \\
\text { Sulfate } \\
\text { Tetrachloroethylene } \\
\text { Total dissolved solids } \\
\text { Total dissolved solids } \\
\text { Total organic carbon } \\
\text { Total organic halogens } \\
\text { Total phosphates (as P) } \\
\text { 1,1,1. Trichloroethane } \\
\text { Trichiorothylene } \\
\text { Gross alpha } \\
\text { Nonvolatile beta } \\
\text { Total radium } \\
\text { Tritium }\end{array}$ & $\begin{array}{c}5.5 \\
20 \\
<2.0 \\
<3.0 \\
<2.0 \\
608 \\
1,900 \\
<1.0 \\
<4.0 \\
<1.0 \\
<1.0 \\
<100 \\
29 \\
<3.0 \\
221 \\
4.1 \\
<0.20 \\
<50 \\
<5.0 \\
743 \\
<2.0 \\
6,900 \\
<2.0 \\
1,600 \\
1.560 \\
<1.0 \\
15,000 \\
17,000 \\
<1,000 \\
26 \\
530 \\
<1.0 \\
<1.0 \\
<2.0 \mathrm{E} \cdot 09 \\
<2.0 \mathrm{E}-09 \\
<1.0 \mathrm{E}-09 \\
<7.0 \mathrm{E}-07\end{array}$ & $\begin{array}{l}v \\
v\end{array}$ & $\begin{array}{l}\mu \mathrm{pH} \\
\mu \mathrm{S} / \mathrm{cm} \\
\mu \mathrm{g} / \mathrm{L} \\
\mu \mathrm{g} / \mathrm{L} \\
\mu \mathrm{g} / \mathrm{L} \\
\mu \mathrm{g} / \mathrm{L} \\
\mu \mathrm{g} / \mathrm{L} \\
\mu \mathrm{g} / \mathrm{L} \\
\mu \mathrm{g} / \mathrm{L} \\
\mu \mathrm{g} / \mathrm{L} \\
\mu \mathrm{g} / \mathrm{L} \\
\mu \mathrm{g} / \mathrm{L} \\
\mu \mathrm{g} / \mathrm{L} \\
\mu \mathrm{g} / \mathrm{L} \\
\mu \mathrm{g} / \mathrm{L} \\
\mu \mathrm{g} / \mathrm{L} \\
\mu \mathrm{g} / \mathrm{L} \\
\mu \mathrm{g} / \mathrm{L} \\
\mu \mathrm{g} / \mathrm{L} \\
\mu \mathrm{g} / \mathrm{L} \\
\mu \mathrm{g} / \mathrm{L} \\
\mu \mathrm{g} / \mathrm{L} \\
\mu \mathrm{g} / \mathrm{L} \\
\mu \mathrm{g} / \mathrm{L} \\
\mu \mathrm{g} / \mathrm{L} \\
\mu \mathrm{g} / \mathrm{L} \\
\mu \mathrm{g} / \mathrm{L} \\
\mu \mathrm{g} / \mathrm{L} \\
\mu \mathrm{g} / \mathrm{L} \\
\mu \mathrm{g} / \mathrm{L} \\
\mu \mathrm{g} / \mathrm{L} \\
\mu \mathrm{g} / \mathrm{L} \\
\mu \mathrm{g} / \mathrm{L} \\
\mu \mathrm{Ci} / \mathrm{mL} \\
\mu \mathrm{Ci} / \mathrm{mL} \\
\mu C \mathrm{i} / \mathrm{mL} \\
\mu \mathrm{Ci} / \mathrm{mL}\end{array}$ & $\begin{array}{l}\mathrm{GE} \\
\mathrm{GE} \\
\mathrm{GE} \\
\mathrm{GE} \\
\mathrm{GE} \\
\mathrm{GE} \\
\mathrm{GE} \\
\mathrm{MA} \\
\mathrm{GE} \\
\mathrm{MA} \\
\mathrm{MA} \\
\mathrm{GE} \\
\mathrm{GE} \\
\mathrm{GE} \\
\mathrm{GE} \\
\mathrm{GE} \\
\mathrm{GE} \\
\mathrm{GE} \\
\mathrm{GE} \\
\mathrm{GE} \\
\mathrm{GE} \\
\mathrm{GE} \\
\mathrm{GE} \\
\mathrm{GE} \\
\mathrm{GE} \\
\mathrm{MA} \\
\mathrm{GE} \\
\mathrm{GE} \\
\mathrm{GE} \\
\mathrm{GE} \\
\mathrm{GE} \\
\mathrm{MA} \\
\mathrm{MA} \\
\mathrm{GE} \\
\mathrm{GE} \\
\mathrm{GE} \\
\mathrm{GE}\end{array}$ \\
\hline
\end{tabular}

\section{WELL. MSB 52B}

MEASUREMENTS CONDUCTED IN THE FIELD

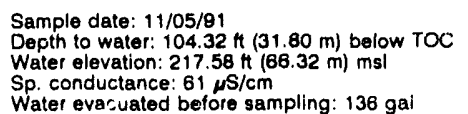

Sp. conductance: $61 \mathrm{\mu S} / \mathrm{cm}$

LABORATORY ANALYSES

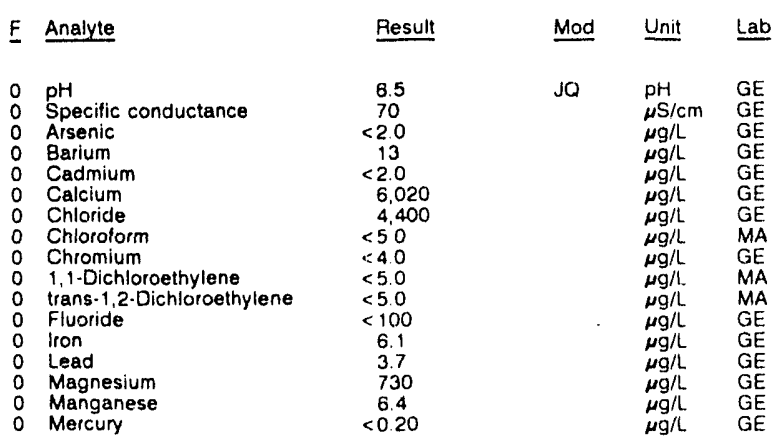

WELL MSB 52B collected on 11/05/91, laboratory analyses (cont.)

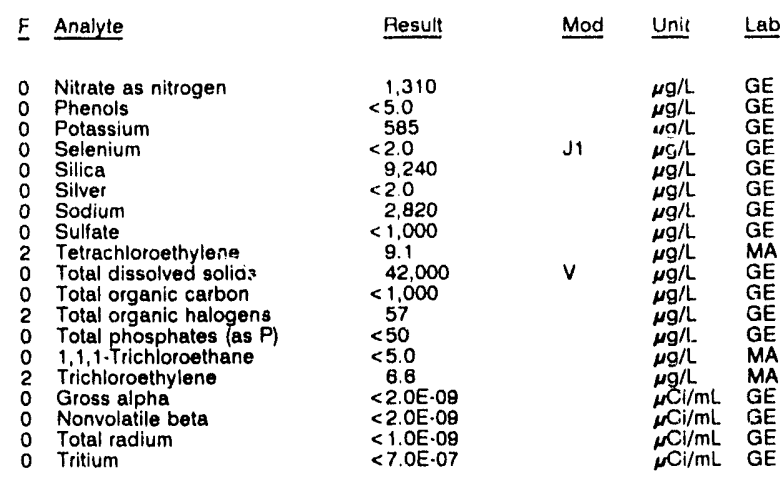

\section{WELL MSB 52D}

MEASUREMENTS CONDUCTED IN THE FIELD

Sample date: $11 / 05 / 91$

Depth to water $84.27 \mathrm{Ht}(25.69 \mathrm{~m})$ below TOC

Water elevation: $237.53 \mathrm{ft}(72.40 \mathrm{~m}) \mathrm{msl}$

Sp. conductance: $20 \mu \mathrm{S} / \mathrm{cm}$

PH: 5.6

Alkalinity: $2 \mathrm{mg} / \mathrm{L}$ : $15.4^{\circ} \mathrm{C}$

Water evacualed before sampling: $5 \mathrm{gal}$

The well went dry during purging

LABORATORY ANALYSES

\begin{tabular}{|c|c|c|c|}
\hline Analyte & Pesult & Mod & Unit \\
\hline $\begin{array}{l}\text { pH } \\
\text { Specific conductance } \\
\text { Arsenic } \\
\text { Barium } \\
\text { Cadmium } \\
\text { Calcium } \\
\text { Chloride } \\
\text { Chloroform } \\
\text { Chromium } \\
1,1 \text {-Dichloroethylene } \\
\text { trans-1,2-Dichloroethylene } \\
\text { Fluoride } \\
\text { tron } \\
\text { Lead } \\
\text { Magnesium } \\
\text { Manganese } \\
\text { Mercury } \\
\text { Nitrate as nitrogen } \\
\text { Phenols } \\
\text { Potassium } \\
\text { Selenium } \\
\text { Silica } \\
\text { Silver } \\
\text { Sodium } \\
\text { Sulfate } \\
\text { Tetrachloroethylene } \\
\text { Total dissolved solids } \\
\text { Total dissolved solids } \\
\text { Total organic carbon } \\
\text { Total organic halogens } \\
\text { Total phosphates (as P) } \\
\text { 1,1,1. Trichloroethane } \\
\text { Trichloroethylene } \\
\text { Gross alpha } \\
\text { Nonvolatile beta } \\
\text { Total radium } \\
\text { Tritium }\end{array}$ & $\begin{array}{l}6.0 \\
20 \\
<2.0 \\
9.2 \\
<2.0 \\
1.350 \\
2.420 \\
<5.0 \\
<4.0 \\
<5.0 \\
<5.0 \\
<100 \\
19 \\
3.7 \\
327 \\
3.4 \\
<0.20 \\
210 \\
<5.0 \\
<500 \\
<2.0 \\
5.720 \\
<2.0 \\
1.500 \\
<1.000 \\
<5.0 \\
15.000 \\
18.000 \\
<1.000 \\
20 \\
<50 \\
<5.0 \\
<5.0 \\
<2.0 E \cdot 09 \\
<2.0 E \cdot 09 \\
<1.0 E \cdot 09 \\
<7.0 \mathrm{E} \cdot 07\end{array}$ & $\begin{array}{l}V \\
v\end{array}$ & $\begin{array}{l}p H \\
\mu \mathrm{S} / \mathrm{cm} \\
\mu g / L \\
\mu g / L \\
\mu g / L \\
\mu g / L \\
\mu g / L \\
\mu g / L \\
\mu g / L \\
\mu g / L \\
\mu g / L \\
\mu g / L \\
\mu g / L \\
\mu g / L \\
\mu g / L \\
\mu g / L \\
\mu g / L \\
\mu g / L \\
\mu g / L \\
\mu g / L \\
\mu g / L \\
\mu g / L \\
\mu g / L \\
\mu g / L \\
\mu g / L \\
\mu g / L \\
\mu g / L \\
\mu g / L \\
\mu g / L \\
\mu g / L \\
\mu g / L \\
\mu g / L \\
\mu g / L \\
\mu C \mathrm{i} / \mathrm{mL} \\
\mu C \mathrm{Ci} / \mathrm{mL} \\
\mu \mathrm{Ci} / \mathrm{mL} \\
\mu \mathrm{Ci} / \mathrm{mL}\end{array}$ \\
\hline
\end{tabular}

Time: $8: 15$

pH: 8.0 Alkalinity. $10 \mathrm{mg}$

Water temperature: $16.1^{\circ} \mathrm{C}$

WELL MSB 53B

MEASUREMENTS CONDUCTED IN THE FIELD

Sample date: $10 / 28 / 91$

Depth to water: $123.17 \mathrm{Ht}(37.54 \mathrm{~m})$ below TOC

Water elevation: $221.43 \mathrm{ft}(67.49 \mathrm{~m}) \mathrm{msl}$

Sp. conductance: $19 \mu \mathrm{S} / \mathrm{cm}$
Water evacuated before sampling: $193 \mathrm{gal}$

LABORATORY ANALYSES

\begin{tabular}{|c|c|c|c|}
\hline Analyte & Result & Mod & $\underline{\text { Unit }}$ \\
\hline $\begin{array}{l}\text { Chlorotorm } \\
1,1 \cdot \text { Dichloroethylene } \\
\text { trans } 1,2 \cdot \text { Dichloroethylene } \\
\text { Tetrachloroethylene } \\
1,1.1 \cdot \text { Trichloroethane } \\
\text { Trichloroethylene }\end{array}$ & $\begin{array}{l}<1.0 \\
<1.0 \\
<10 \\
<1.0 \\
<1.0 \\
<10\end{array}$ & & $\begin{array}{l}\mu g / L \\
\mu g / L \\
\mu g / L \\
\mu g / L \\
\mu g / L\end{array}$ \\
\hline
\end{tabular}

Time: $8: 15$

Alkalinity: $4 \mathrm{mg}$

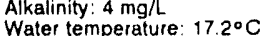

MA 
ANALYTICAL RESULTS

WELL MSB 53C

MEASUREMENTS CONDUCTED IN THE FIELL

Sample date: 10/28/91

Depth to water: $123.96 \mathrm{ft}(37.78 \mathrm{~m})$ below TOC

Water elevation: $221.54 \mathrm{ft}(67$.

Water evecunce. $22 \mu \mathrm{S} / \mathrm{cm}$.

LABORATORY ANALYSES

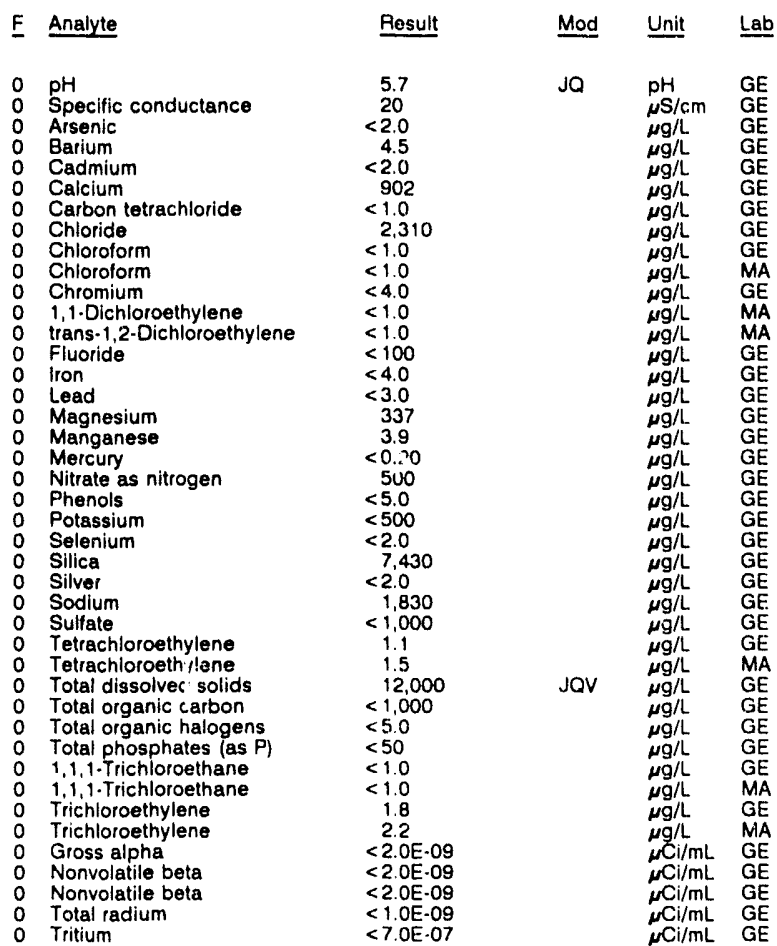

\section{WELL MSB 53C Replicate}

MEASUREMENTS CONDUCTED IN THE FIELD

Sample date: 10/28/91

Depth to water: $123.96 \mathrm{ft}(37.78 \mathrm{~m})$ below TOC

Water elevation: $221.54 \mathrm{ft}(67.53 \mathrm{~m}) \mathrm{msl}$

Water evacuated belore sampling: $88 \mathrm{gal}$

LABORATORY ANALYSES

$\begin{array}{ll}\text { F } & \text { Analyte } \\ & \\ 0 & \text { pH } \\ 0 & \text { Specific conductance } \\ 0 & \text { Arsenic } \\ 0 & \text { Barium } \\ 0 & \text { Cadmium } \\ 0 & \text { Calcium } \\ 0 & \text { Carbon tetrachloride } \\ 0 & \text { Chloride } \\ 0 & \text { Chloroform } \\ 0 & \text { Chloroform } \\ 0 & \text { Chromium } \\ 0 & 1,1 \cdot \text { Dichloroethylene } \\ 0 & \text { trans-1,2-Dichloroethylene } \\ 0 & \text { Fluoride } \\ 0 & \text { lron } \\ 0 & \text { Lead } \\ 0 & \text { Magnesium } \\ 0 & \text { Manganese } \\ 0 & \text { Mercury } \\ 0 & \text { Nitrate as nitrogen } \\ 0 & \text { Fhenols } \\ 0 & \text { Potassium } \\ 0 & \text { Selenium } \\ 0 & \text { Silica } \\ 0 & \text { Silver } \\ 0 & \text { Sodium } \\ 0 & \text { Sulfate } \\ 0 & \text { Tetrachloroethylene } \\ 0 & \text { Tetrachloroethylene } \\ & \end{array}$

\begin{tabular}{l} 
Result \\
\hline \\
5.6 \\
20 \\
$<2.0$ \\
4.5 \\
$<2.0$ \\
883 \\
$<1.0$ \\
21320 \\
$<1.0$ \\
$<1.0$ \\
$<4.0$ \\
$<1.0$ \\
$<1.0$ \\
$<100$ \\
$<4.0$ \\
$<3.0$ \\
330 \\
3.8 \\
$<0.20$ \\
500 \\
$<50$ \\
$<500$ \\
$<2.0$ \\
7.450 \\
$<2.0$ \\
1.830 \\
$<1.000$ \\
13 \\
1.2
\end{tabular}

Time: $8: 30$

PH: 5.1

Water temperature: $170^{\circ} \mathrm{O}$

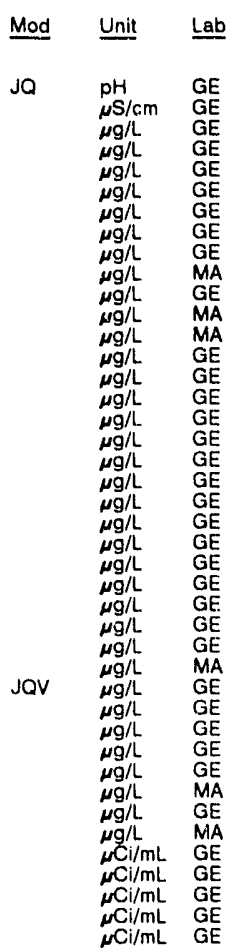

Time: $8: 30$

PH: 5.1 Alkalinity: $2 \mathrm{mg} / \mathrm{l}$

Alkaler temperature: $17.0^{\circ} \mathrm{C}$

Mod Unit Lab $\quad \begin{array}{lll}0 & 0 & \text { Nonvolatile beta } \\ & 0 & \text { Total radium } \\ \text { Tritium }\end{array}$

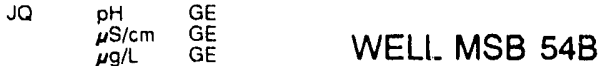

MEASUREMENTS CONDUCTED IN THE FIELD

Sample date: $10 / 07 / 91$

Depth to water: $151.83 \mathrm{ft}(46.28 \mathrm{~m})$ below TOC Water elevation: $221.87 \mathrm{H}(67.6$

LABORATOGY ANALYSES

\begin{tabular}{|c|c|c|c|}
\hline Analyte & Result & Mod & Unit \\
\hline $\begin{array}{l}\mathrm{pH} \\
\text { Specific conductance } \\
\text { Alsenic } \\
\text { Barium } \\
\text { Cadmium } \\
\text { Calclum } \\
\text { Chioride } \\
\text { Chloroforin } \\
\text { Chromium } \\
1,1-\text { Dichloroethylene } \\
\text { trans-1,2-Dichloroethylene } \\
\text { Fluoride } \\
\text { lron } \\
\text { Lead }\end{array}$ & $\begin{aligned} & 5.9 \\
& 30 \\
&< 2.0 \\
& 7.5 \\
&<2.0 \\
& 2.350 \\
& 1.590 \\
&<1.0 \\
&<4.0 \\
&<1.0 \\
&<1.0 \\
&<100 \\
&<4.0 \\
&<3.0\end{aligned}$ & JQ & $\begin{array}{l}p H \\
\mu S / c m \\
\mu g / L \\
\mu g / L \\
\mu g / L \\
\mu g / L \\
\mu g / L \\
\mu g / L \\
\mu g / L \\
\mu g / L \\
\mu g / L \\
\mu g / L \\
\mu g / L \\
\mu g / L\end{array}$ \\
\hline
\end{tabular}

\section{Time: 7:50 \\ Alkalinity: $1 \mathrm{mg}$ \\ Water temperature: $17.2^{\circ} \mathrm{C}$}

Time: $9: 50$

Alkalinity: $5 \mathrm{mg}$

Water lemperatur: $10.0^{\circ}$

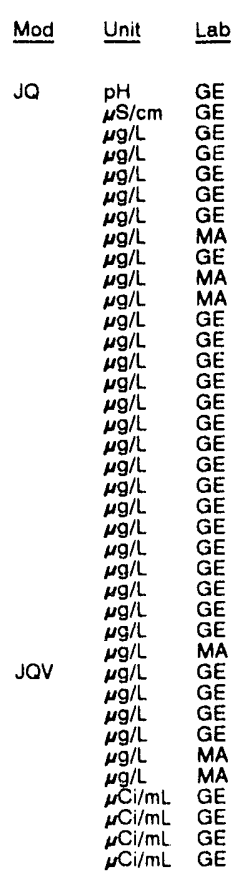

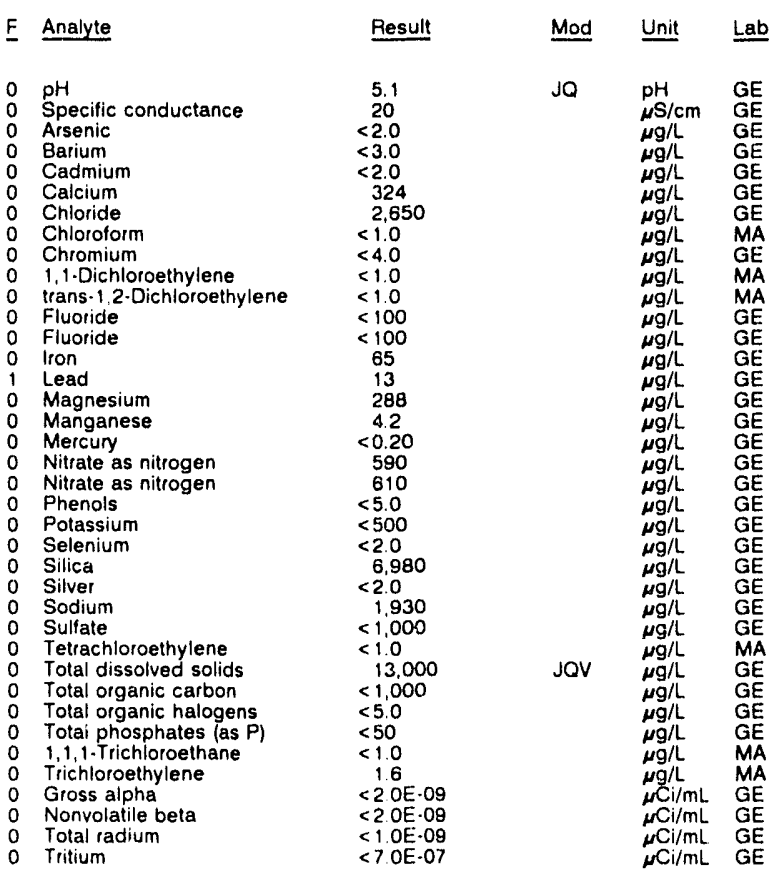


ANALYTICAL RESULTS

\begin{tabular}{|c|c|c|c|}
\hline Analyte & Result & Mad & Unit \\
\hline $\begin{array}{ll}0 & \text { Magnesium } \\
0 & \text { Manganese } \\
0 & \text { Mercury } \\
0 & \text { Nitrate as nitrogen } \\
0 & \text { Phenols } \\
0 & \text { Potassium } \\
0 & \text { Selenium } \\
0 & \text { Silica } \\
0 & \text { Silver } \\
0 & \text { Sodium } \\
0 & \text { Sulfate } \\
0 & \text { Tetrachloroethylene } \\
0 & \text { Total dissolved solids } \\
0 & \text { Total organic carbon } \\
0 & \text { Total organic halogens } \\
0 & \text { Total phosphates (as P) } \\
0 & 1,1,1 \text { Trichloroethane } \\
0 & \text { Trichloroethylene } \\
0 & \text { Gross alphia } \\
0 & \text { Nonvolatile beta } \\
0 & \text { Total radium } \\
0 & \text { Tritium }\end{array}$ & $\begin{array}{l}272 \\
4.3 \\
<020 \\
1,070 \\
<5.0 \\
<500 \\
<2.0 \\
9.190 \\
<2.0 \\
1,520 \\
<1.000 \\
<1.0 \\
11,000 \\
<1.000 \\
22 \\
<50 \\
<1.0 \\
<1.0 \\
<2.0 E \cdot 09 \\
<2.0 E \cdot 09 \\
1.0 E \cdot 09 \pm 9.0 E \cdot 10 \\
<7.0 E \cdot 07\end{array}$ & J1 & $\begin{array}{l}\mu g / L \\
\mu g / L \\
\mu g / L \\
\mu g / L \\
\mu g / L \\
\mu g / L \\
\mu g / L \\
\mu g / L \\
\mu g / L \\
\mu g / L \\
\mu g / L \\
\mu g / L \\
\mu g / L \\
\mu g / L \\
\mu g / L \\
\mu g / L \\
\mu g / L \\
\mu g / L \\
\mu C i / m L \\
\mu C i / m L \\
\mu C i / m L \\
\mu C i / m L\end{array}$ \\
\hline
\end{tabular}

WELL MSB 54C

MEASUREMENTS CONDUCTED IN THE FIELD

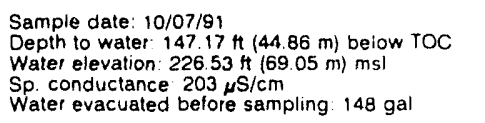

LABORATORY ANALYSES

\begin{tabular}{|c|c|c|c|c|}
\hline Analyte & Result & Mod & Unt & Lab \\
\hline $\begin{array}{l}\text { pH } \\
\text { Specific conductance } \\
\text { Arsenic } \\
\text { Barium } \\
\text { Cadmium } \\
\text { Calitium } \\
\text { Chloride } \\
\text { Chloroform } \\
\text { Chromium } \\
1,1 \text {. Dichloroethylene } \\
\text { trans-1,2.Dichloroethylene } \\
\text { Fluoride } \\
\text { lron } \\
\text { Lead } \\
\text { Magnesium } \\
\text { Manganese } \\
\text { Mercury } \\
\text { Nitrate as nitrogen } \\
\text { Phenols } \\
\text { Potassium } \\
\text { Selenium } \\
\text { Silica } \\
\text { Sitver } \\
\text { Sodium } \\
\text { Sulfate } \\
\text { Tetrachioroethylene } \\
\text { Total dissolved solids } \\
\text { Total organic carbon } \\
\text { Total organic halogens } \\
\text { Total phosphates las P } \\
\text { 1,1.1. Trichloroethane } \\
\text { Trichloroethylene } \\
\text { Gross alpha } \\
\text { Nonvolatile beta } \\
\text { Total radium } \\
\text { Tritium }\end{array}$ & $\begin{aligned} & 11 \\
& 180 \\
&<2.0 \\
& 61 \\
&<20 \\
& 24.700 \\
& 1.270 \\
&<10 \\
&<40 \\
&<10 \\
&<10 \\
&<100 \\
&<40 \\
&<30 \\
& 403 \\
&<2.0 \\
&<0.20 \\
& 1.340 \\
&<50 \\
& 1.300 \\
&<20 \\
& 8.770 \\
&<20 \\
& 2.620 \\
&<1.000 \\
&<1.0 \\
& 49.000 \\
&<1.000 \\
& 23 \\
&<50 \\
&<1.0 \\
&<1.0 \\
&<20 E \cdot 09 \\
&<2.0 E \cdot 09 \\
&<10 E \cdot 09 \\
&<70 E \cdot 07\end{aligned}$ & JQ & 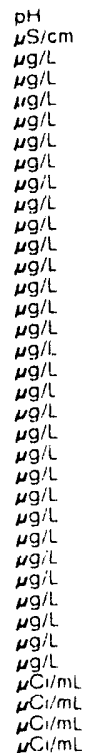 & $\begin{array}{l}G E \\
G E \\
G E \\
G E \\
G E \\
G E \\
G E \\
M A \\
G E \\
M A \\
M A \\
G E \\
G E \\
G E \\
G E \\
G E \\
G E \\
G E \\
G E \\
G E \\
G E \\
G E \\
G E \\
G E \\
G E \\
M A \\
G E \\
G E \\
G E \\
G E \\
M A \\
M A \\
G E \\
G E \\
G E \\
G E\end{array}$ \\
\hline
\end{tabular}

WELL MSB 54D

MEASUREMENTS CONDUCTED IN THE FIELD

Sample date: 10/07/91

Depth to water $14123 \mathrm{Ht}(4305 \mathrm{~m})$ below TOC

Water elevation: $232.77 \mathrm{ft}(7095 \mathrm{~m}) \mathrm{msl}$

Sp. conductance $25 \mathrm{yS} / \mathrm{cm}$

mpling $24 \mathrm{gal}$

LABORATORY ANALYSES

\begin{tabular}{|c|c|c|c|c|}
\hline Analyte & Besult & Mod & Unit & Lab \\
\hline $\begin{array}{l}\text { pH } \\
\text { Specitic conductance } \\
\text { Arsenic } \\
\text { Barium } \\
\text { Cadmium } \\
\text { Calcium } \\
\text { Chlofide } \\
\text { Chioride }\end{array}$ & $\begin{aligned} 53 \\
25 \\
<20 \\
41 \\
<20 \\
500 \\
1.020 \\
1.030\end{aligned}$ & $\mathrm{JO}$ & $\begin{array}{l}p H \\
\mu \operatorname{Sicm} \\
\mu \mathrm{g} / \mathrm{L} \\
\mu g / L \\
\mu \mathrm{g} / \mathrm{L} \\
\mu \mathrm{g} / \mathrm{L} \\
\mu g / \mathrm{L} \\
\mu \mathrm{g} / \mathrm{L}\end{array}$ & $\begin{array}{l}G E \\
G E \\
G E \\
G E \\
G E \\
G E \\
G E \\
G E\end{array}$ \\
\hline
\end{tabular}

WELL MSB 540 collected on 10/07/91, laboratory analyses (cont.)

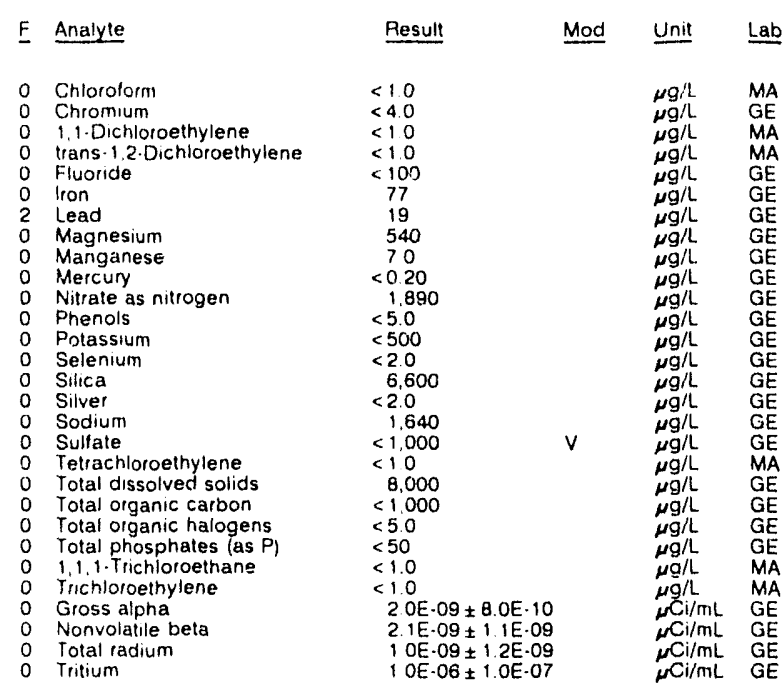

WELL MSB 54TA

MEASUREMENTS CONDUCTED IN THE FIELD

Sample date $10 / 07 / 91$

Deplt to wa $10 / 07 / 91$

$\begin{array}{ll}\text { Sample date } 10 / 07 / 91 & \text { Time: } 10.05 \\ \text { Depth to water } 15493 \mathrm{H}(4722 \mathrm{~m}) \text { below TOC } & \text { pH: } 70 \\ \text { Water elevation. } 218.87 \mathrm{H}(6671 \mathrm{~m}) \mathrm{msl} & \text { Alkalinity. } 36 \mathrm{mg} / \mathrm{h}\end{array}$

Water evacuated betore sampling. $376 \mathrm{gal}$

LABORATORY ANALYSES

\begin{tabular}{|c|c|c|c|c|c|}
\hline F & Analyte & Result & Mod & Unit & Lab \\
\hline 0 & $\mathrm{pH}$ & 70 & Jo & $\mathrm{pH}$ & $\mathrm{GE}$ \\
\hline 0 & Specific conductance & 45 & & $\mu \mathrm{S} / \mathrm{cm}$ & $\mathrm{GE}$ \\
\hline 0 & Arsenic & $<20$ & & $\mu \mathrm{g} / \mathrm{L}$ & $\mathrm{GE}$ \\
\hline 0 & Barium & 72 & & $\mu \mathrm{g} / \mathrm{L}$ & $G E$ \\
\hline $\begin{array}{l}0 \\
0\end{array}$ & $\begin{array}{l}\text { Cadmium } \\
\text { Calcium }\end{array}$ & $<2.0$ & & $\mu g / L$ & $\mathrm{GE}$ \\
\hline 0 & $\begin{array}{l}\text { Calcium } \\
\text { Chloride }\end{array}$ & $\begin{array}{l}6,000 \\
1,230\end{array}$ & & $\underset{\mu g / L}{\mu g / L}$ & $\begin{array}{l}\mathrm{GE} \\
\mathrm{GE}\end{array}$ \\
\hline 0 & Chloroform & $<10$ & & $\mu \mathrm{g} / \mathrm{L}$ & $M A$ \\
\hline 0 & Chromium & $<4.0$ & & $\mu \mathrm{g} / \mathrm{h}$ & $\mathrm{GE}$ \\
\hline 0 & 1,1-Dichioroethylene & $<1.0$ & & $\mu \mathrm{g} / \mathrm{h}$ & $M A$ \\
\hline 0 & trans 1 , 2 Drchloroethylene & $<1.0$ & & $\mu g / L$ & MA \\
\hline $\begin{array}{l}0 \\
0\end{array}$ & $\begin{array}{l}\text { Fluoride } \\
\text { Fluoridee }\end{array}$ & $\begin{array}{l}<100 \\
<100\end{array}$ & & $\underset{\mu g / L}{\mu g}$ & $\begin{array}{l}\mathrm{GE} \\
\mathrm{GE}\end{array}$ \\
\hline 0 & Iron & $<4.0$ & & $\mu \mathrm{g} / \mathrm{L}$ & $G E$ \\
\hline 0 & lead & $<30$ & & $\mu \mathrm{g} / \mathrm{L}$ & $\mathrm{GE}$ \\
\hline 0 & Magnesium & 255 & & $\mu \mathrm{g} / \mathrm{L}$ & $\mathrm{GE}$ \\
\hline 0 & Manganese & 33 & & $\mu \mathrm{g} / \mathrm{h}$ & $\mathrm{GE}$ \\
\hline 0 & Mercury & $<020$ & & $\mu \mathrm{g} / \mathrm{L}$ & $\mathrm{GE}$ \\
\hline 0 & Nitrate as nitrogen & 990 & & $\mu \mathrm{g} / \mathrm{L}$ & $\mathrm{GE}$ \\
\hline 0 & Nitrate as nitrogen & 1,090 & & $\mu \mathrm{g} / \mathrm{L}$ & $\mathrm{GE}$ \\
\hline 0 & Phienols & $<50$ & & $\mu \mathrm{g} / \mathrm{L}$ & $G E$ \\
\hline 0 & Potassium & $<500$ & & $\mu \mathrm{g} / \mathrm{h}$ & $\mathrm{GE}$ \\
\hline 0 & Selenium & $<2.0$ & & $\mu \mathrm{g} / \mathrm{L}$ & $\mathrm{GE}$ \\
\hline 0 & Silica & 8,500 & & $\mu g / L$ & $\mathrm{GE}$ \\
\hline 0 & Silver & $<20$ & & $\mu \mathrm{g} / \mathrm{L}$ & $\mathrm{GE}$ \\
\hline 0 & Sodium & 1.740 & & $\mu \mathrm{g} / \mathrm{L}$ & $\mathrm{GE}$ \\
\hline 0 & Sulfale & $<1.000$ & $v$ & $\mu g / \mathrm{L}$ & $\mathrm{GE}$ \\
\hline 0 & Tetrachloroethyiene & $<10$ & & $\mu \mathrm{g} / \mathrm{L}$ & $M A$ \\
\hline 0 & Total dissolved solids & 22.000 & & $\mu \mathrm{g} / \mathrm{L}$ & G \\
\hline 0 & Total organic carbon & $<1,000$ & & $\mu g / L$. & $\mathrm{GE}$ \\
\hline 0 & Total organic halogens & $<50$ & & $\mu \mathrm{g} / \mathrm{L}$ & $\mathrm{GE}$ \\
\hline 0 & Total organic halogens & $<5.0$ & & $\mu \mathrm{g} / \mathrm{L}$ & $\mathrm{GE}$ \\
\hline 0 & Total phosphates (as $\mathrm{P}$ ) & $<50$ & & $\mu \mathrm{g} / \mathrm{L}$ & $G \bar{E}$ \\
\hline 0 & 1.1.1-Trichloroethane & $<10$ & & $\mu g / L$ & $M A$ \\
\hline 0 & Trichloroethylene & $<10$ & & $\mu \mathrm{g} / \mathrm{L}$ & MA \\
\hline 0 & Gross alpha & $<2$ OE.09 & & $\mu \mathrm{Cl} / \mathrm{mL}$ & $\mathrm{GE}$ \\
\hline 0 & Nonvulatile beta & $\angle 2 O E .09$ & & $\mu \mathrm{Si} / \mathrm{mL}$ & $G E$ \\
\hline & Total radium & IOE. $09 \pm 13 \mathrm{E}-09$ & & $\mu \mathrm{Ci} / \mathrm{mL}$ & $G E$ \\
\hline 0 & Tritium & $\Leftrightarrow 7 \mathrm{OE}-07$ & & $\mu \mathrm{CimL}$ & E \\
\hline
\end{tabular}

Time 830

PH. 43 alinity o nigit

Water temperature $129^{\circ} \mathrm{C}$

Teitium
Alkalinity: $36 \mathrm{mg} / \mathrm{L}$

Alkalinity: $36 \mathrm{mg} / \mathrm{L}$. $174^{\circ} \mathrm{C}$ 


\section{ANALYTICAL RESULTS}

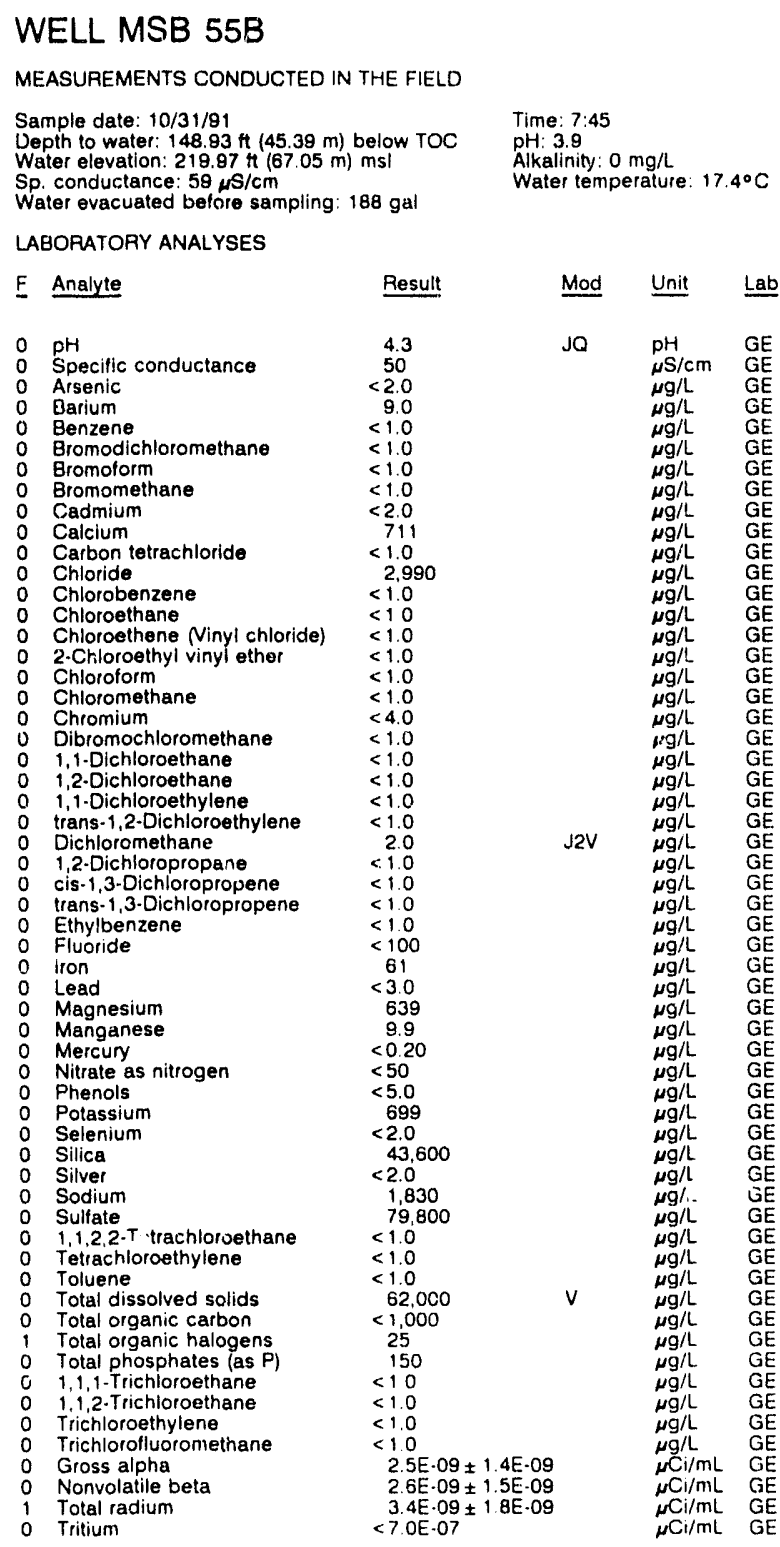

\section{WELL MSB 55C}

MEASUREMENTS CONOUCTED IN THE FIELD

Sample date: 10/31/91

Depth to water: $140.92 \mathrm{ft}(42.95 \mathrm{~m}$ ) below TOC Water elevation: 228.58 it

Sp. conductance: $27 \mu \mathrm{s} / \mathrm{cm}$
Water evacuated before sampling: $115 \mathrm{gat}$

LABORATORY ANALYSES

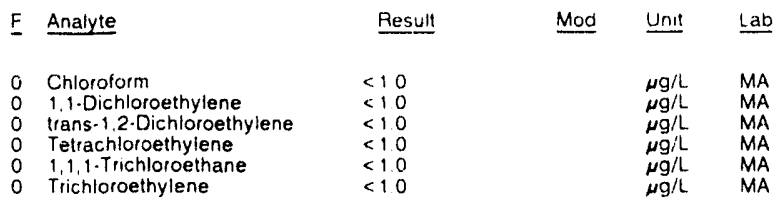

\section{WELL MSB 55D}

MEASUREMENTS CONDUCTED IN THE FIELD

Sample date: 10/31/91

Depth to water: Not available

Water elevation: Not available

Sp. Conductance: $33 \mu \mathrm{S} / \mathrm{cm}$
Water evacuated before sampling: $30 \mathrm{gal}$

LABORATORY ANALYSES

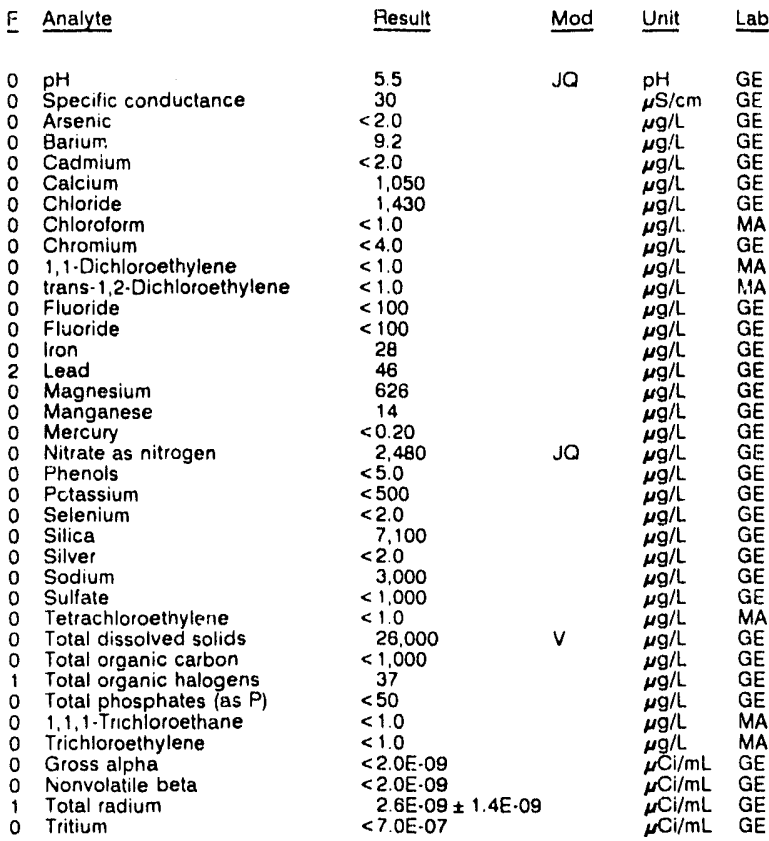

\section{WELL MSB 55HC}

MEASUREMENTS CONDUCTED IN THE FIELD

Sample date: 12/06/91

Depth to water: $136.27 \mathrm{ft}(41.54 \mathrm{~m})$ below TOC

Water elevation: $232.53 \mathrm{Ht}(70$

Water evacuated before sampling: $9 \mathrm{gal}$

The well went dry during purging

LABORATORY ANALYSES

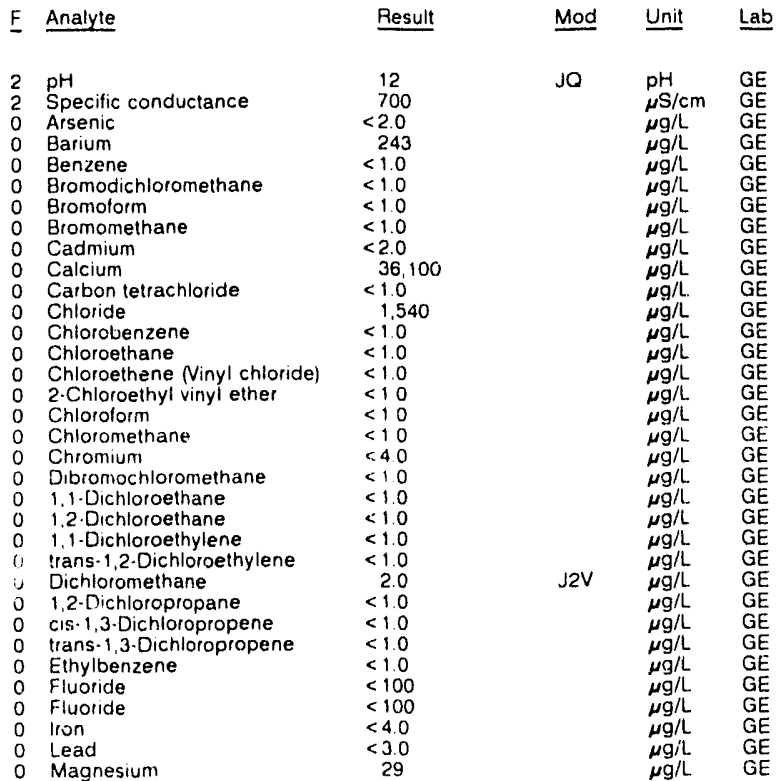

Time: $8: 20$

Alkalinity: $0 \mathrm{mg} / \mathrm{L}$

Water temperalure: $17.1^{\circ} \mathrm{C}$

\section{Mod Unit Lab}

E




\section{ANALYTICAL RESULTS}

WELL MSB 55HC collected on 12/06/91, laboratory analyses (cont.)

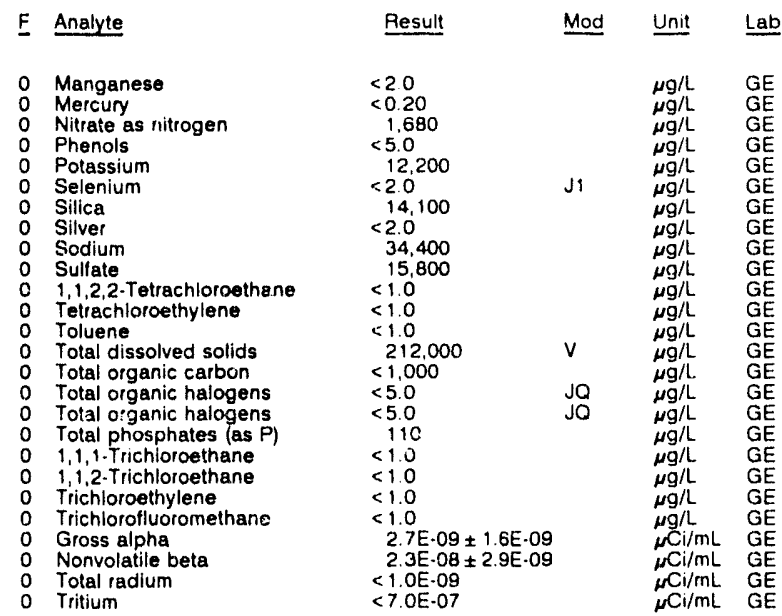

\section{WELL MSB 55TA}

MEASUAEMENTS CONDUCTED IN THE FIELD

Sample date: 10/31/91

$(47.05 \mathrm{~m})$ below TOC

Water elevation: $214.43 \mathrm{ft} / 65.36$

Water evacuated before sampling: $336 \mathrm{gal}$

LABORATORY ANALYSES

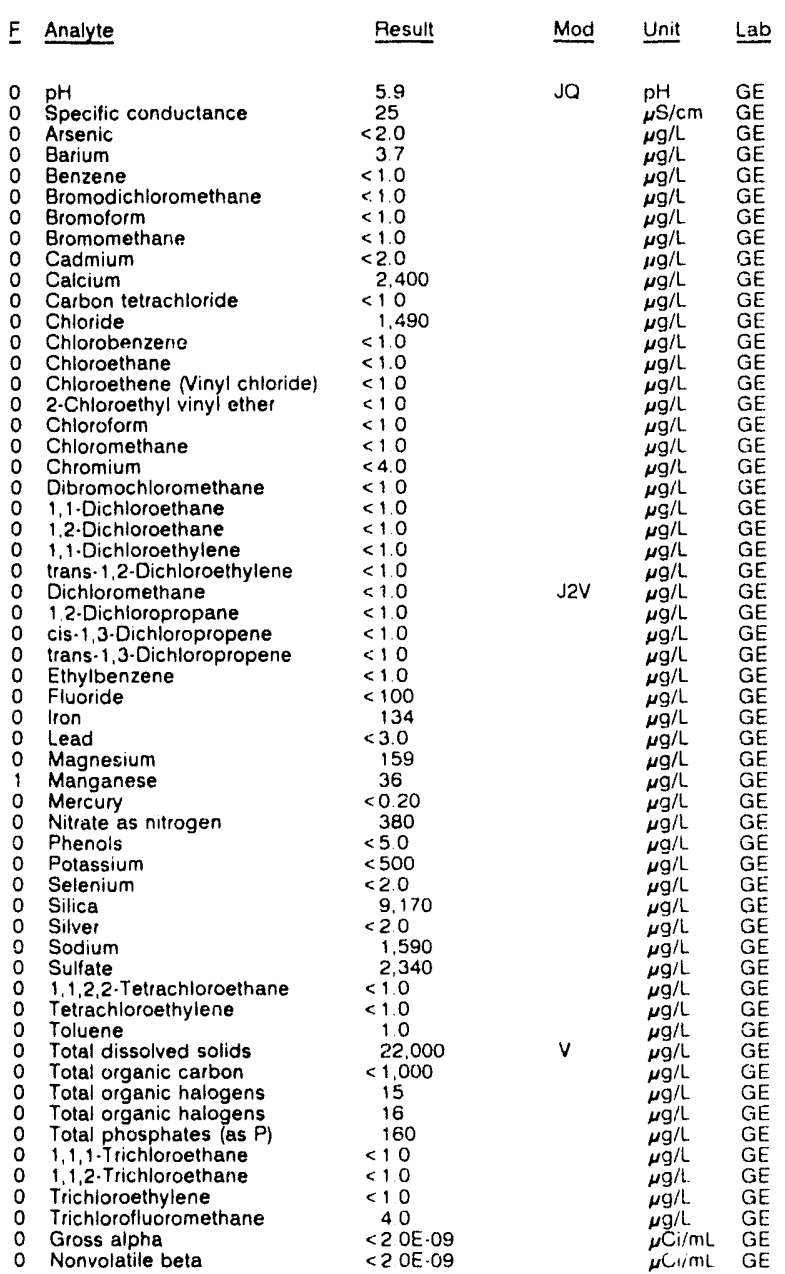

WELL MSB 55TA collected on 10/31/91, laboratory analyses (cont.)

$\begin{array}{lllll}E \text { Analyte } & \text { Result } & \text { Mod } & \text { Unit } & \text { Lab } \\ 0 \text { Total radium } & <1.0 \mathrm{OE} \cdot 09 & & & \\ 0 \text { Tritium } & <7.0 \mathrm{Cl}-07 & & \mu \mathrm{Cl} / \mathrm{mL} & \mathrm{GE} \\ \mu \mathrm{Cl} / \mathrm{mL} . & \mathrm{GE}\end{array}$

WELL MSB 56D

MEASUREMENTS CONDUCTED IN THE FIELD

Sample date: $10 / 13 / 91$

Depth to water: $58.49 \mathrm{ft}(17.83 \mathrm{~m})$ below TOC Waier elevation: $221.31 \mathrm{Ht}(67.46 \mathrm{~m}) \mathrm{ms}$ Water evacuated before sampling: $27 \mathrm{gal}$

pH: 4.9 . 0

Water temperature $18,1 \circ \mathrm{C}$

LABORATORY ANALYSES

\begin{tabular}{|c|c|c|c|c|}
\hline Analyte & Result & Mod & Unit & Lab \\
\hline $\mathrm{pH}$ & 5.1 & JQ & $\mathrm{pH}$ & $\mathrm{GE}$ \\
\hline Specific conductance & 20 & & $\mu \mathrm{S} / \mathrm{cm}$ & $\mathrm{GE}$ \\
\hline Arsenic & $<2.0$ & & $11 \mathrm{~g} / \mathrm{L}$ & $\mathrm{GE}$ \\
\hline Barium & 42 & & $+\mathrm{g} / \mathrm{L}$ & $\overline{G E}$ \\
\hline $\begin{array}{l}\text { Cadmium } \\
\text { Calcium }\end{array}$ & $\begin{array}{r}<2.0 \\
314\end{array}$ & & $\mu g / L$ & $\mathrm{GE}$ \\
\hline $\begin{array}{l}\text { Calcium } \\
\text { Carbon tetrachloride }\end{array}$ & $\begin{array}{r}314 \\
<10\end{array}$ & & $\mu g / L$ & $\begin{array}{l}\mathrm{GE} \\
\mathrm{GE}\end{array}$ \\
\hline Chloride & 3,280 & & $\mu \mathrm{g} / \mathrm{L}$ & $\mathrm{GE}$ \\
\hline Chloroform & $<10$ & & $\mu g / L$ & $\mathrm{GE}$ \\
\hline Chloroform & $<1.0$ & & $\mu \mathrm{g} / \mathrm{L}$ & $M \bar{A}$ \\
\hline Chromium & $<4.0$ & & $\mu g / \mathrm{L}$ & \\
\hline 1,1-Dichloroethylene & $<1.0$ & & $\mu g / L$ & \\
\hline $\operatorname{trans}-1,2 \cdot$ Dichloroethylene & $<1.0$ & & $\mu \mathrm{g} / \mathrm{L}$ & MA \\
\hline Fluoride & $<100$ & & $\mu \mathrm{g} / \mathrm{L}$ & \\
\hline Iron & 19 & & $\mu g / L$ & \\
\hline $\begin{array}{l}\text { Lead } \\
\text { Magnesium }\end{array}$ & $\begin{array}{l}4.8 \\
282\end{array}$ & & $\mu \mathrm{g} / \mathrm{L}$ & $\mathrm{GE}$ \\
\hline Manganese & $\begin{array}{l}282 \\
5.9\end{array}$ & & $\mu g / L$ & GE \\
\hline Mercury & $<0.20$ & & $\mu g / L$ & $\mathrm{GE}$ \\
\hline Nitrate as nitrogen & 350 & & $\mu g / L$ & \\
\hline $\begin{array}{l}\text { Phenols } \\
\text { Phenols }\end{array}$ & $\begin{array}{l}<5.0 \\
<5.0\end{array}$ & & $\mu g / L$ & \\
\hline Potassiun & $<500$ & & $\underset{\mu \mathrm{g} / \mathrm{L}}{\mu \mathrm{g} / \mathrm{h}}$ & $\mathrm{GE}$ \\
\hline Selenium & $<2.0$ & & $\mu \mathrm{g} / \mathrm{L}$ & $\mathrm{GE}$ \\
\hline Sitica & 8,890 & & $\mu g / L$ & \\
\hline Silver & $<20$ & & $\mu \mathrm{g} / \mathrm{L}$ & $G E$ \\
\hline Sodium & 1,600 & & $\mu g / L$ & \\
\hline Sulfate & $<1,000$ & & $\mu \mathrm{g} / \mathrm{L}$ & \\
\hline Tetrachloroethylene & $<10$ & & $\mu \mathrm{g} / \mathrm{L}$ & \\
\hline Tetrachloroethylene & $<1.0$ & & $\mu \mathrm{g} / \mathrm{L}$ & $M A$ \\
\hline Total dissolved solicis & $<1,000$ & & $\mu g / \mathrm{L}$ & \\
\hline Total organic carbon & $<1,000$ & & $\mu \mathrm{g} / \mathrm{L}$ & \\
\hline Total organic carbon & $<1,000$ & & $\mu \mathrm{g} / \mathrm{L}$ & \\
\hline Total organic halcy..s & $<5.0$ & & $\mu g / L$ & $\mathrm{GE}$ \\
\hline Total organic halogens & $<5.0$ & & $\mu \mathrm{g} / \mathrm{L}$ & \\
\hline Total phosphates (as $P$ \} & $<50$ & & $\mu \mathrm{g} / \mathrm{L}$ & \\
\hline 1,1,1-Trichloroethane & $<1.0$ & & $\mu g / L$ & \\
\hline 1.1,1-Trichloroethane & $<1.0$ & & $\mu \mathrm{g} / \mathrm{L}$ & \\
\hline Trichlorsethylene & $<1.0$ & & $\mu \mathrm{g} / \mathrm{L}$ & \\
\hline Trichloroethylene & $<1.0$ & & $\mu \mathrm{g} / \mathrm{h}$ & \\
\hline Gross alphá & $2.9 \mathrm{E}-09 \pm 1.1 \mathrm{E} \cdot 09$ & & $\mu \mathrm{C} \mathrm{i} / \mathrm{mL}$ & $\mathrm{GE}$ \\
\hline Nonvolatile beta & $<2.0 E-09$ & & $\mu \mathrm{Ci} / \mathrm{mL}$ & \\
\hline Total radium & $2.3 \mathrm{E}-09 \pm 1.0 \mathrm{E} \cdot 09$ & & $\mu \mathrm{Ci} / \mathrm{mL}$ & \\
\hline Tritium & $1.6 \mathrm{E} \cdot 06 \pm 1.0 \mathrm{E} \cdot 07$ & & $\mu \mathrm{Ci} / \mathrm{mL}$ & \\
\hline
\end{tabular}

WELL 1. 3R 56D Replicate

MEASUREMEN IS CONOUCTED IN THE FIELD

Sample date: $10 / 13 / 91$

Depth to water: $58.49 \mathrm{ft}(17.83 \mathrm{~m})$ below TOC Water elevation: $221.31 \mathrm{Ht}$

pH: 4.9

Watertempergluis $18.1^{\circ} \mathrm{C}$

LABORATOAY ANALYSES

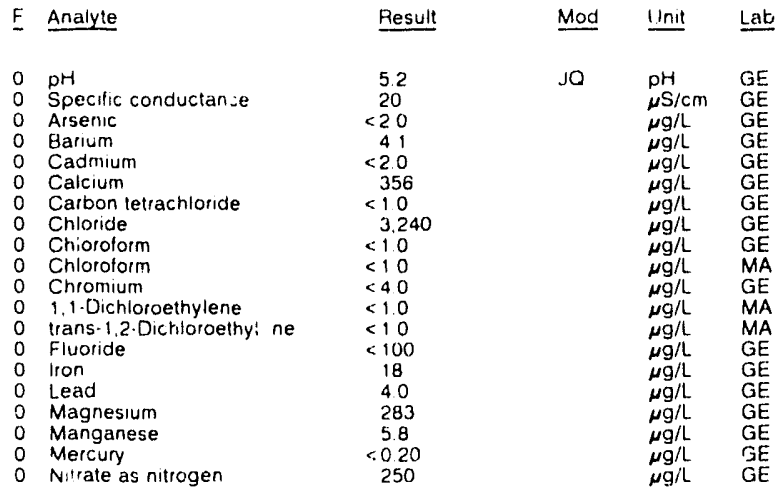


ANALYTICAL RESULTS

WELL MSB 56D collected on 10/13/81, laboratory analyses (cont.)

\begin{tabular}{|c|c|c|}
\hline Analyte & Result & Unit \\
\hline $\begin{array}{l}\text { Phenols } \\
\text { Potassium } \\
\text { Selenium } \\
\text { Silica } \\
\text { Silver } \\
\text { Sodium } \\
\text { Sulfate } \\
\text { Totrachloroethylene } \\
\text { Tetrachloroethylenc } \\
\text { Total dissolved solids } \\
\text { Total organic carbon } \\
\text { Total organic helogens } \\
\text { Total organic halogens } \\
\text { Total phosphates (as P) } \\
\text { 1,1.1.Trichloroethane } \\
\text { 1,1,1-Trichloroethane } \\
\text { Trichloroethylene } \\
\text { Trichloroe" lene } \\
\text { Gross alpha } \\
\text { Nonvolatile beta } \\
\text { Total radium } \\
\text { Trtium }\end{array}$ & 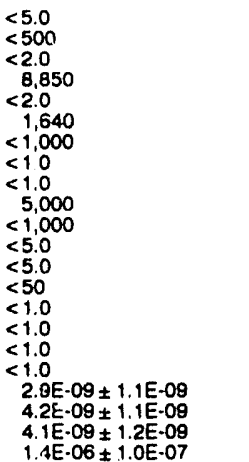 & $\begin{array}{l}\mu g / L \\
\mu g / L \\
\mu g / L \\
\mu g / L \\
\mu g / L \\
\mu g / L \\
\mu g / L \\
\mu g / L \\
\mu g / L \\
\mu g / L \\
\mu g / L \\
\mu g / L \\
\mu g / L \\
\mu g / L \\
\mu g / L \\
\mu g / L \\
\mu g / L \\
\mu g / L \\
\mu C i / m L \\
\mu C i / m L \\
\mu C i / m L \\
\mu C i / m L\end{array}$ \\
\hline
\end{tabular}

WELL MSB 57D

MEASUREMENTS CONDUCTED IN THE FIELD

Sample date: $10 / 08 / 91$
Depth to water: $125.96 \mathrm{ft}(38.39 \mathrm{~m})$ below TOC Water olevation: $230.24 \mathrm{ft}(70.18 \mathrm{~m}) \mathrm{ms}$

conductaince: 47 stcm

The well went diy during purging: $18 \mathrm{gal}$

LABORATORY ANALYSES

\begin{tabular}{|c|c|c|c|c|c|}
\hline & Analyte & Result & Mod & Unit & Lab \\
\hline & 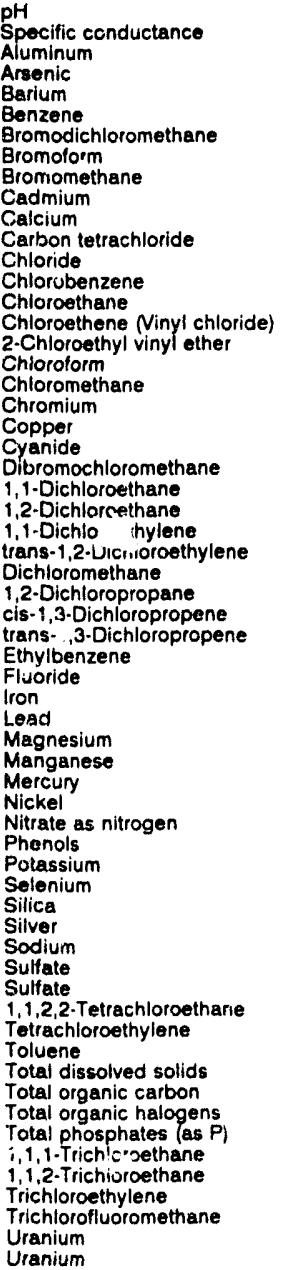 & 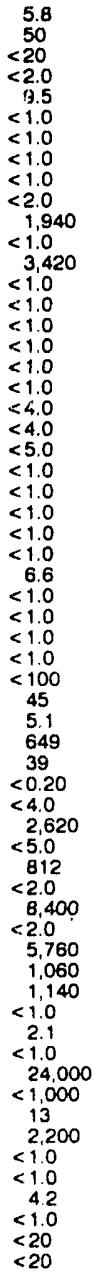 & $J 2 \mathrm{~V}$ & $\begin{array}{l}p H \\
\mu S / c m \\
\mu g / L \\
\mu g / L \\
\mu g / L \\
\mu g / L \\
\mu g / L \\
\mu g / L \\
\mu g / L \\
\mu g / L \\
\mu g / L \\
\mu g / L \\
\mu g / L \\
\mu g / L \\
\mu g / L \\
\mu g / L \\
\mu g / L \\
\mu g / L \\
\mu g / L \\
\mu g / L \\
\mu g / L \\
\mu g / L \\
\mu g / L \\
\mu g / L \\
\mu g / L \\
\mu g / L \\
\mu g / L \\
\mu g / L \\
\mu g / L \\
\mu g / L \\
\mu g / L \\
\mu g / L \\
\mu g / L \\
\mu g / L \\
\mu g / L \\
\mu g / L \\
\mu g / L \\
\mu g / L\end{array}$ & 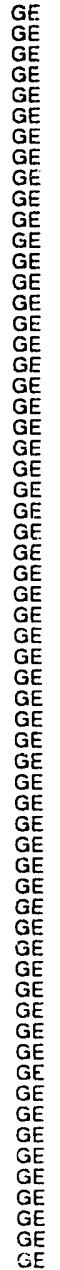 \\
\hline
\end{tabular}

Time: $12: 35$

Alkalinity: $8 \mathrm{mg} / \mathrm{L}$

Water tempeisture: $18.3^{\circ} \mathrm{C}$
WELL MSB 57D collected on 10/08/91, laboratory analyses (cont.)

\begin{tabular}{|c|c|c|c|c|}
\hline$\underline{F}$ & Analyte & Resul! & Mod & Unit \\
\hline $\begin{array}{l}0 \\
0 \\
0 \\
0 \\
0\end{array}$ & $\begin{array}{l}\text { Zinc } \\
\text { Gross alpha } \\
\text { Nonvolatile beta } \\
\text { Total radium } \\
\text { Tritium }\end{array}$ & $\begin{array}{l}16 \\
3.7 \mathrm{E}-00 \pm 1.2 \mathrm{E}-09 \\
<2.0 \mathrm{E}-09 \\
2.0 \mathrm{E}-00 \pm 1.4 \mathrm{E}-09 \\
9.7 \mathrm{E}-07 \pm 1.0 \mathrm{E}-07\end{array}$ & & $\begin{array}{l}\mu \mathrm{g} / \mathrm{L} \\
\mu \mathrm{LL} / \mathrm{mL} \\
\mu \mathrm{Cl} / \mathrm{mL} \\
\mu \mathrm{Cl} / \mathrm{mL} \\
\mu \mathrm{Cl} / \mathrm{mL}\end{array}$ \\
\hline
\end{tabular}

WELL MSB 58D

MEASUREMENTS CONDUCTED IN THE FIELD

Sample date: 11/22/91

Depth to water: $131.88 \mathrm{ft}(40.20 \mathrm{~m})$ below TOC

Water elevation: $226.02 \mathrm{~A}(68.89 \mathrm{~m}) \mathrm{msl}$

Water evacuated before sampling: $11 \mathrm{gal}$

Time: $8: 45$

pH: 5.0

$6 \mathrm{mg} / \mathrm{h}$

The well went dry during purging. 11 gal

LABORATORY ANALYSES

E Analyte Result Mod Unit Lab

0 pH

0 Acenaphthene

Acenaphthylen

Acetonitrile (Methyl cyanide)

Acetopl

2.Acetylaminofluorene

Acrolein

Acrylon

Allyl chloride

Aluminum

4-Aminobiphenyl

Aniline

Antimony

Are ite

Arsenic

Earium

Benzene

beta.Benzene hexachloride

delta.Benzene hexachlor te

Binzolajanthracane

Berzolalpyrene

Benzo b fluoranthene

Ben nolghilpen'lene

$\mathrm{Be} . . j \mathrm{kj}$ jlluoranthene

denzyl alcohol

Beryllium

Bis (2-chloroisoproryl)ether

Bis (2-chloroethoxy) methan

B-a -chloroethyl) ether

Bis(2-ethylhexyl) phthalate

Bromodichlor

Bromoform

4. Bromophenyl phenyl ether

2-sec.Butyl.4,6.dinitrophenol

Butylbenzyl phthalate

Cadmium

Calcium

Carbon disulfide

Carten tetrachloride

$2,3, i$;.TCDF

Chlorida

para.Chloro-meta-cresol

4-Chloroaniline

Chlorobenzene

Chlorobenzilate

Chloroethene Ninyl chloride

2-Chloroethyl vinyl ether

Chloroform

2.Chloronaphthalene

2.Chlorophenol

Chloroprene

Chromium

Chrysene

Cobali

o-Cresol (2-Melhyiphenol)

m-Cresol (3.Melnol

p-Cresol (4-Methylphenol)

Cyanide

Cyanide

P.P.'DOD

$p, p^{\prime} \cdot D D E$

Di-n.butyl phthalate

Di-n.butyl phthalate

Dialtate

Dibenz $[a, h]$ anthracene

Dibenzofuran

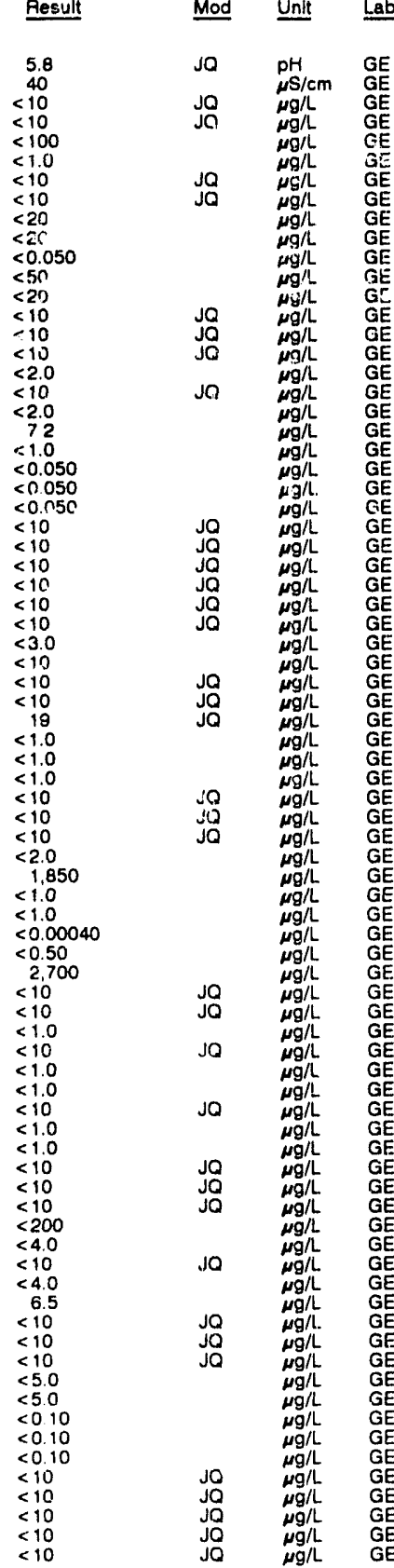




\section{ANALYTICAL RESULTS}

WELL MSB 58D collected on 11/22/91, laboratory analyses (cont.)

E Analyte

- 1,2-Dibromo-3-chloropropane

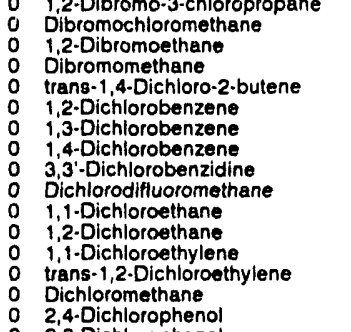

Dichloromethane
0 2,4-Dichlofopheno

,

2,4-Dichlorophenoxyacetic acid $<0.30$

cis-1,3-Dichloropropeno

trans-1,3-Dichloropropene

Diethyl phthalate

2,4-Dimethyl phenol

Dimethyl phthalat

p-Dimethylaminoazoberzene

3,3'-Dimetnylbenzidine

a,a.Dimethylphenethylamine

1,3.Dinitrobenzene

2,4.Dinitrophenol

2,4-Dinitrotoluene

2,6-Dinitrotoluen

D Diphenylam

Endosulfan I

O Endosulfan II

Endosulta

Endrin

Ethyl methacrylate

Ethylbenzene

Famphur

Fluoranthene

Fluorene

Fluoride

Heptachlor

$1,2,3,4,6,7,8-H P C: D D$
Heptachlorodiberizo-p-dioxins

Heptachlorodiberizo-p-dioxin
$1,2,4,8,7, z \cdot H P C D F$

Hepuachloresibenzo-p-fura
Hoxachlorobenzene

Hexachiorobutadiene

Hexachiorocyclopentar. sne

$1,2,3,4,7,8-H\rangle$. 200

Hexachiorodibenzo-p-dioxins

$1,2,3,4,7,8-H X C D F$
Hexachiorodibenzo-p-furans

Hexachloroethan

Hexachlorophene

2.Hexanone

Indenonone $1,2,3 \cdot c$, d) pyrene

lodomethane (Methyl iodide)

Iron

Isobutyl alcohol

isodrin

Isosafrole

Kepone

Lead

Lindane

Manganese

Mercury

Methacrylonitrile
Methapyrilene

Methoxychlor

Methyl ethyl ketone

Methyl isobutyl ketone

Methyl methacrylate

Methyl methanesulfonate

2-Methy|-4,6-dinitrophenol

3-Methylcholanthrene

2-Methylnaphthalene

N-Nitrosodiethylamine

N-Nitrosodimethylamine

N-Nitrosodi-n-butylamine

N-Nitrosodiphenylamine

N-Nitrosodi-propylamine

N-Nitrosomorpholine

N-Nitrosopiperidine

N-Nitrosopiperidine

Naphthaiene

1.4.Naphthoquinone
Resuit

$<1.0$

$<1.0$
$<20$
$<1.0$

$<1.0$

$<10$

$<10$

$<10$

$<1.0$

$<1.0$

$<1.0$

$<1.0$

$<0.50$

$<10$

$<10$

$<10$
$<10$

$<10$

$<10$

$<10$

$<45$

$<10$

$<10$

$<10$
$<10$

$<0.10$

$<0.10$
$<0.10$

$<0.0060$

$<10$

$<10$

$<1.0$

$<10$

$<10$

$<0.050$

$<0.050$
$<00065$

$<0.00045$

$<10$

$<10$
$<10$
$<10$

$<0.00045$

$<0.00045$

$<0.00040$
$<0.00040$

$<10$

$<10$
$<10$

$<1.0$

$<10$
$<15$

64
$<100$

$<100$
$<10$
$<10$

$<10$
$<10$
$<3.0$

$<3.0$
$<0.0050$

246
23

$<0.20$

$<50$
$<10$

$<0.50$

$<1.0$

$<10$

$<10$
$<10$

$<10$
$<10$

$<10$
$<10$

$<10$
$<10$

$<10$

$<10$
$<10$

$<10$

$<10$
$<10$

$<10$
$<10$

$<10$
$<10$

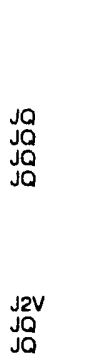

$\mu g / L \quad G E \quad 0 \quad 1 \cdot$ Naphthylamine

2-Naphthylamine
Nickel

Nitrate as nitrogen
5.Nitro-0.toluidine

2-Nitroaniline

3-Nitroaniline

4-Nitroaniline

Nitrobenzene

4-Nitrophenol

4-Nitroquinoline-1-oxide

,O,O-Triethyl phosphorothioate

Octachlorodicenzo-p-dioxin

$\begin{array}{ll} & <0.0010 \\ & <0.0010\end{array}$

Parathion

Parathion methyl

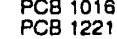

PCB 1232

PCB 1248

PCB 1254

Pentachlorobenzene

1,2,3,7,8-PCDF

Penlach odibenzo-p-dioxins

-p-furans

P,2,3,7,8.PCDF

Pentachloronitrobenzene

Pentachlorophenol

Phenacetin

Phenol

Phenols

p-Phenylenediamine

2.Picoline

Potassium

Propionitrile

Pyrene

Pyridine

Selenium

Silica

Sodium

Styrene

Sulfate

Sulfide

$1,2,4,5$-Tetrachlorobenzene

Tetrachlorodibenzo-p-dioxins

1,1,2,2-Tetrachloroethane

$1,1,1,2$-Tetrachloroeth

2,3,4,6.Tetrachloropheno

Thallium

0 Thionazin

0 Toluene

o.Toluidine

Total dissolved soliós

Total organic carbon

Tol phaspens

- Toxaphene

2,4,5-TP (Silvex)

1,2,4-Trichlorobenzene

1,1,1-Trichloroethane

1,i,2-Trichloroethane

Trichlorofluoromethane

2,4,5. Trichloropheno

2,4,6-Trichiorof

1,2,3-Trichloropropane

1,3,5-Trinitrobenzene

0 Uranium

- Vinyl acetate

0 Xylenes

Zinc

Gross alpha

Nonvolatile beta

Total radium

Tritium

$<0.0010$

$<0.050$

$<0.50$

$<0.50$

$<0.50$

$<0.50$

$<0.50$
$<10$

$<0.00055$

$<0.00055$

0.00055

$<10$

$<10$

$<10$
$<10$

$<10$
$<10$

$<10$
$<5.0$
$<10$
$<0.10$

$<10$
$<0.10$
$<10$
743

$<43$
$<10$
$<200$

$<200$

$<10$

$<10$

$<$ <.120

$<2.0$
3,850

$<1.0$

$<1,000$
$<1,000$

$\because 1,000$

$<10$

$<0.00045$

$<1.0$

$<1.0$
$<1.300$

$<10$

$<2.0$
$<10$
$<2.0$
$<10$

$<1.0$
$<10$

$<10$

$<1,000$
7,540

50

$<0.24$
$<0.080$

$<10$

2.9
$<1.0$

3,000

$<1.0$
$<10$

$<10$
$<10$

$<0.090$

$<1.0$

$<10$

$<80$

$<1.0$

$<2.0$
28

$<2.0 E .09$

Result Mod Unit Lab

$\begin{array}{ll}<10 & \text { JQ } \\ <10 & \text { JQ } \\ <4.0 & \\ 1,590 & \text { JQ } \\ <10 & \text { JO } \\ <10 & \text { JQ } \\ <10 & \text { JO } \\ <10 & \text { JO } \\ <10 & \text { JQ } \\ <10 & \text { JO } \\ <10 & \text { JO } \\ <10 & \text { JO }\end{array}$

$<0.00045=1.3 \mathrm{E} \cdot 09$

$4.1 \mathrm{E} \cdot 09 \pm 2.2 \mathrm{E} \cdot 09$
$2 . \mathrm{EE} \cdot 06 \pm 7.0 \mathrm{E} \cdot 07$

O $\mu g / L \quad G E$

$\begin{array}{ll}\mu \mathrm{g} / \mathrm{L} & \mathrm{GE} \\ \mu \mathrm{g} / \mathrm{L} & \mathrm{GE} \\ \mu \mathrm{g} / \mathrm{L} & \mathrm{GE} \\ \mu \mathrm{g} / \mathrm{L} & \mathrm{GE} \\ \mu \mathrm{g} / \mathrm{L} & \mathrm{GE} \\ \mu \mathrm{g} / \mathrm{L} & \mathrm{GE} \\ \mu \mathrm{g} / \mathrm{L} & \mathrm{GE} \\ \mu \mathrm{g} / \mathrm{L} & \mathrm{GE} \\ \mu \mathrm{g} / \mathrm{L} & \mathrm{GE} \\ \mu \mathrm{g} / \mathrm{L} & \mathrm{GE} \\ \mu \mathrm{g} / \mathrm{L} & \mathrm{GE}\end{array}$

跣

GE 
ANALYTICAL RESULTS

WELL MSB 59D

MEASUREMENTS CONOUCTED IN THE FIELD

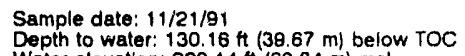
Depth to water: $130.16 \mathrm{ft}(38.67 \mathrm{~m})$ berlow
Water elevation: $229.14 \mathrm{ft}(69.84 \mathrm{~m}) \mathrm{msl}$

Water evacuated before sampling: 50 gal

LABORATOAY ANALYSEFS

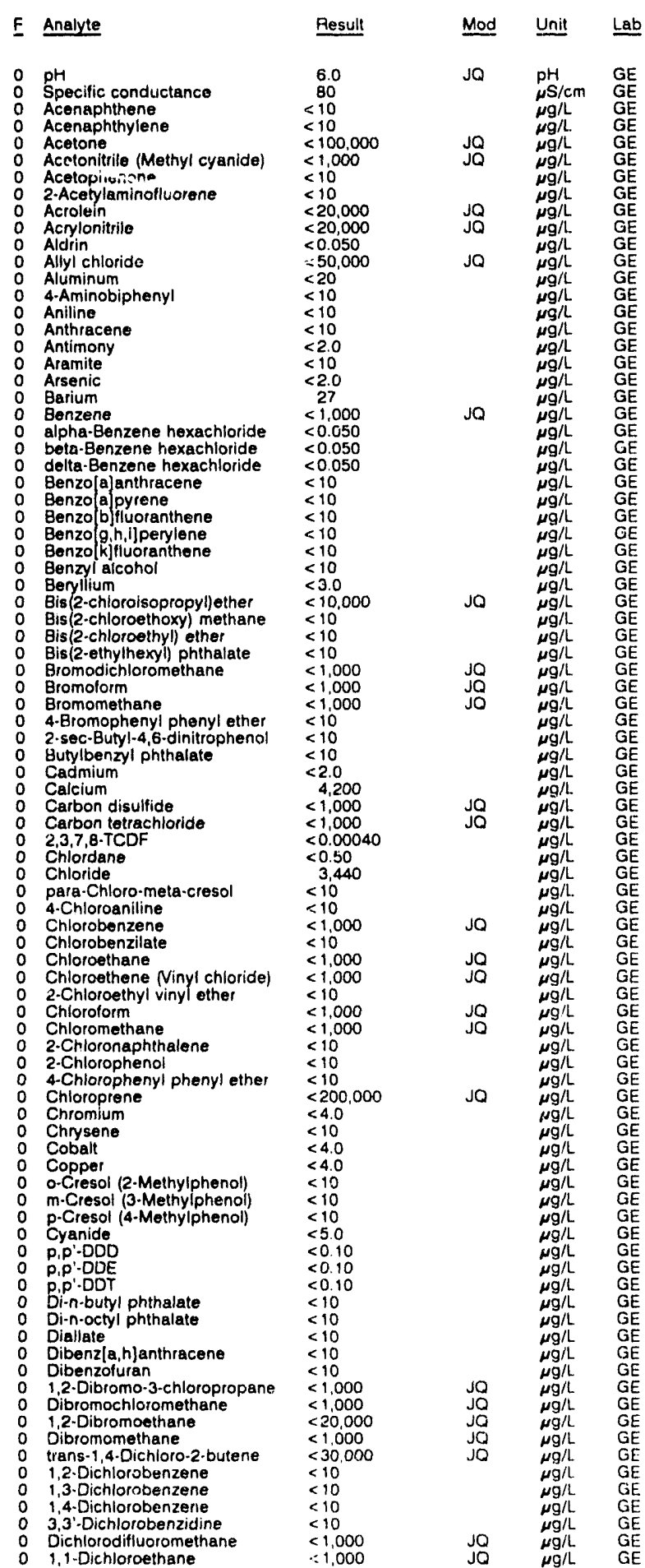

WELL MSB 590 collected on 11/21/91, laboratory analyses (cont.)

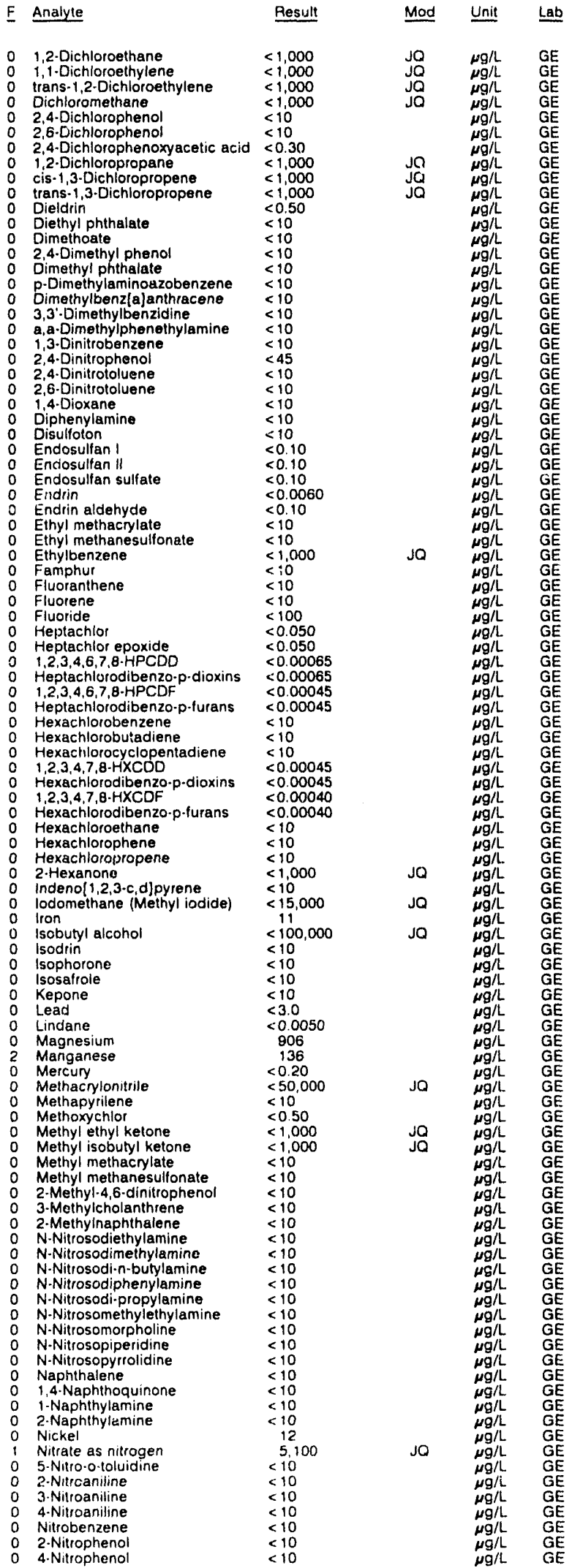


WELL MSB 590 collected on 11/21/91, laboratory analyses (cont.)

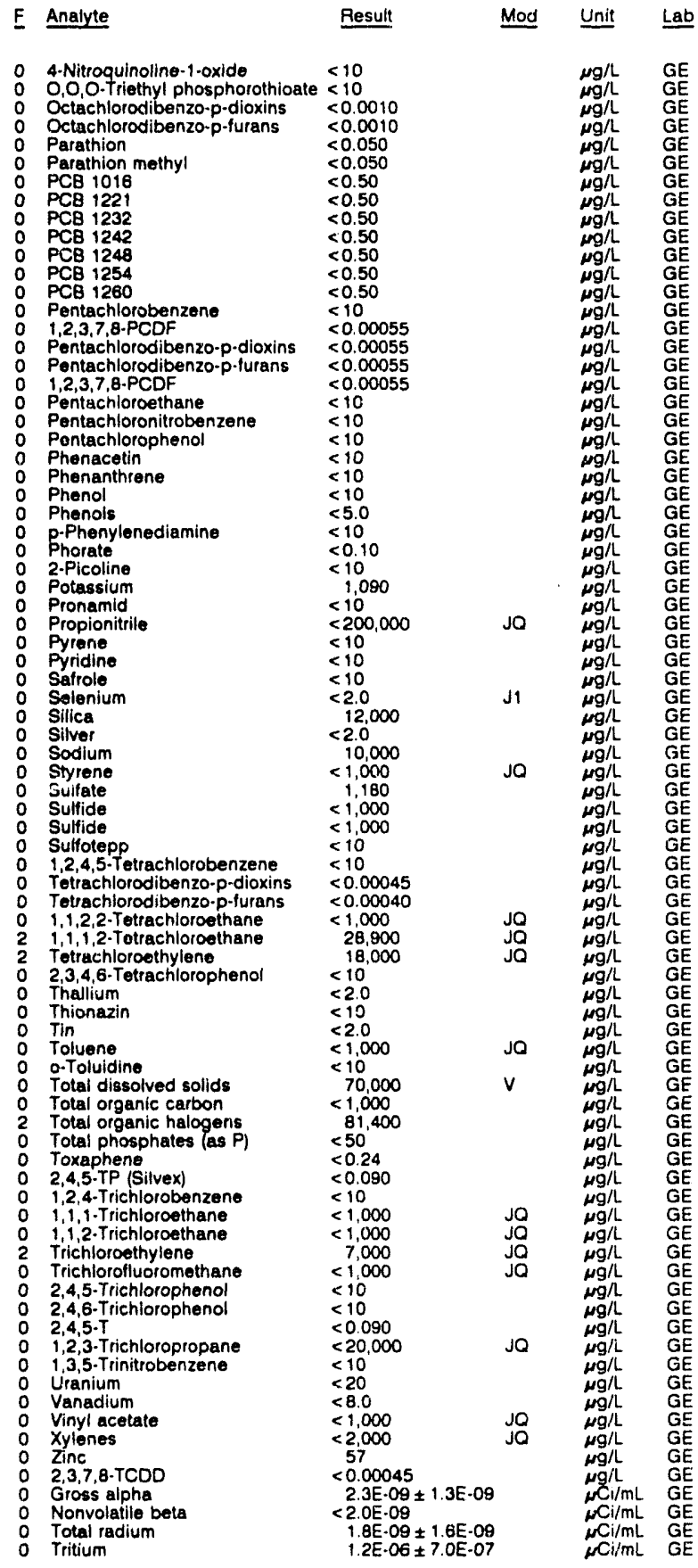

WELL MSB 60D

MEASUREMENTS CONDUCTED IN THE FIELD

Sample date: 10/08/91

Depth to water: $125.85 \mathrm{Ht}(38.36 \mathrm{~m})$ below TOC Water elevation: $228.65 \mathrm{At}(88.69 \mathrm{~m}) \mathrm{ms}$ ) Water evacuated before sampling: $52 \mathrm{gal}$

LABORATORY ANALYSES

E Analyte Result Mod Unit Lab

${ }_{0} \mathrm{pH}_{0}^{\mathrm{pH}}$ Specific conductance

0 Aluminum

0 Arsenic

O Barium

Bromodichloromethane

B Bromolorm

o Bromomethane

Cadmium

- Carbon tetrachlorido

0 Chloride

0 Chlorobenzene

Chloroethane

2.Chloroethyl vinyl ether

Chloroform

Chloromethane

Chromium

Copper

o Dibromochloromethane

1.1-Oichloroethane

o 1,2-Dichioroethane

1,1 -Dichloroethylene
0

o Dichloromethane

1,2-Dichloropropane

0
0
0 trans-1,3-Dichloropropene

Ethylbenzene

o Iron

o Iron

o Lagnesium

Manganese

Mercury

Nitrate as nitrogen

O Phenols

0 Potassium

O Selenium

$\begin{array}{ll}0 & \text { Silica } \\ 0 & \text { Silver }\end{array}$

0 Sodium

Sulfate

2 Tettachloroethylene

0 Toluene

Toluene

Total organic carbon

Total organic carbon

2 Total organic halogens

0 Total phosphates (as P)

$0 \quad 1,1,1$. Trichloroethane

o 1,1,2-Trichloroethane

2 Trichloroethylene

Trichlorofluoromethane

Uranium

Uranium

- Gross alpha

$\begin{array}{ll}\text { Nonvolatile beta } & <2.0 \mathrm{E}-09 \\ & <2.0 \mathrm{E}-08\end{array}$

Total radium $<1.0 \mathrm{E}-09$

Time: $9: 00$

PH: 5.6 . $9 \mathrm{mg}$

Alkalinity: $8 \mathrm{mg} / \mathrm{L}: 14.7^{\circ} \mathrm{C}$

$7.8 \mathrm{E} \cdot 07 \pm 1.0 \mathrm{E}-07$

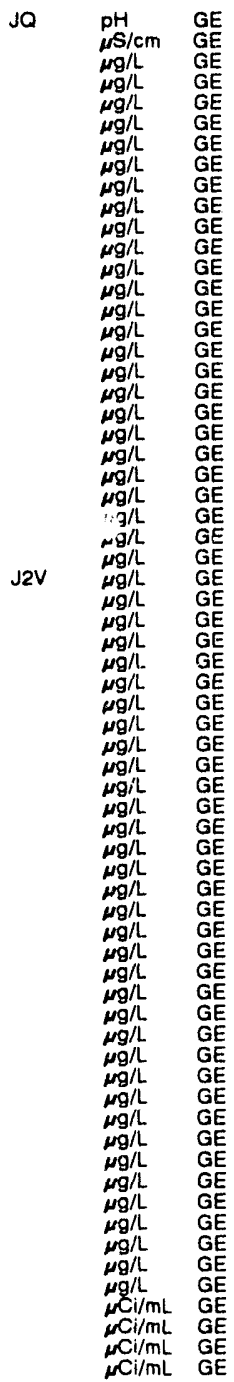

WELL MSB 61C

MEASUREMENTS CONDUCTED IN THE FIELD

Sample date: 10/28/81

Depth to water: $95.20 \mathrm{H}(29.02 \mathrm{~m})$ below TOC

Water elevation: $222.40 \mathrm{Ht}(67)$

5.8

Water evacuated botore sampling: 126 gal

Time: $7: 20$

Alkalinity: $1 \mathrm{mg} / \mathrm{h}$

LABORATORY ANALYSES

\begin{tabular}{|c|c|c|c|c|}
\hline Analyte & Result & Mod & Unit & Lab \\
\hline $\begin{array}{ll}0 & \mathrm{pH} \\
0 & \text { Specific conductance } \\
0 & \text { Arsenic } \\
0 & \text { Barium } \\
0 & \text { Cadmium }\end{array}$ & $\begin{array}{r}5.5 \\
25 \\
<2.0 \\
8.4 \\
<2.0\end{array}$ & JO & $\begin{array}{l}\mathrm{pH} \\
\mu \mathrm{S} / \mathrm{cm} \\
\mu \mathrm{g} / \mathrm{L} \\
\mu \mathrm{g} / \mathrm{L}\end{array}$ & $\begin{array}{l}\mathrm{GE} \\
\mathrm{GE} \\
\mathrm{GE} \\
\mathrm{GE} \\
\mathrm{GE}\end{array}$ \\
\hline
\end{tabular}


WELL MSB 61C collected on 10/28/91, laboratory analyses (cont.)

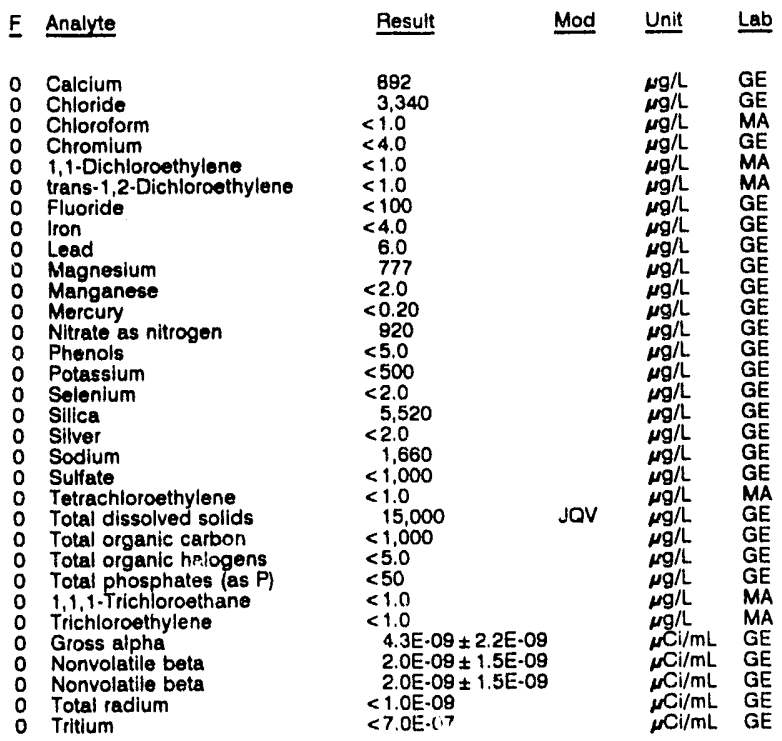

\section{WELL MSB 61D}

MEASUREMENTS CONDUCTED IN THE FIELD

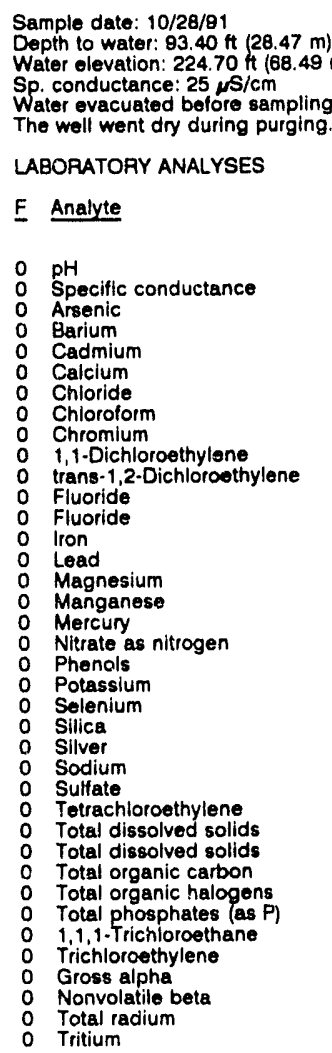

Time: $7: 35$

PH: 5.2

Water temperature: $16.7^{\circ} \mathrm{C}$

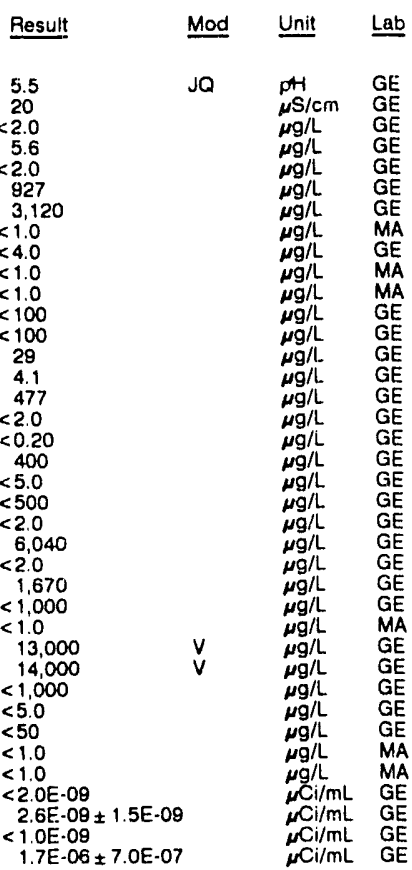

WELL MSB 62B

MEASUREMENTS CONDUCTED IN THE FIELD

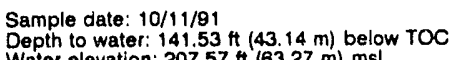
Water elevation: $207.57 \mathrm{ft}(63.27 \mathrm{~m}) \mathrm{ms}$ Water evacuated before sampling: $182 \mathrm{gal}$

LABORATORY ANALYSES

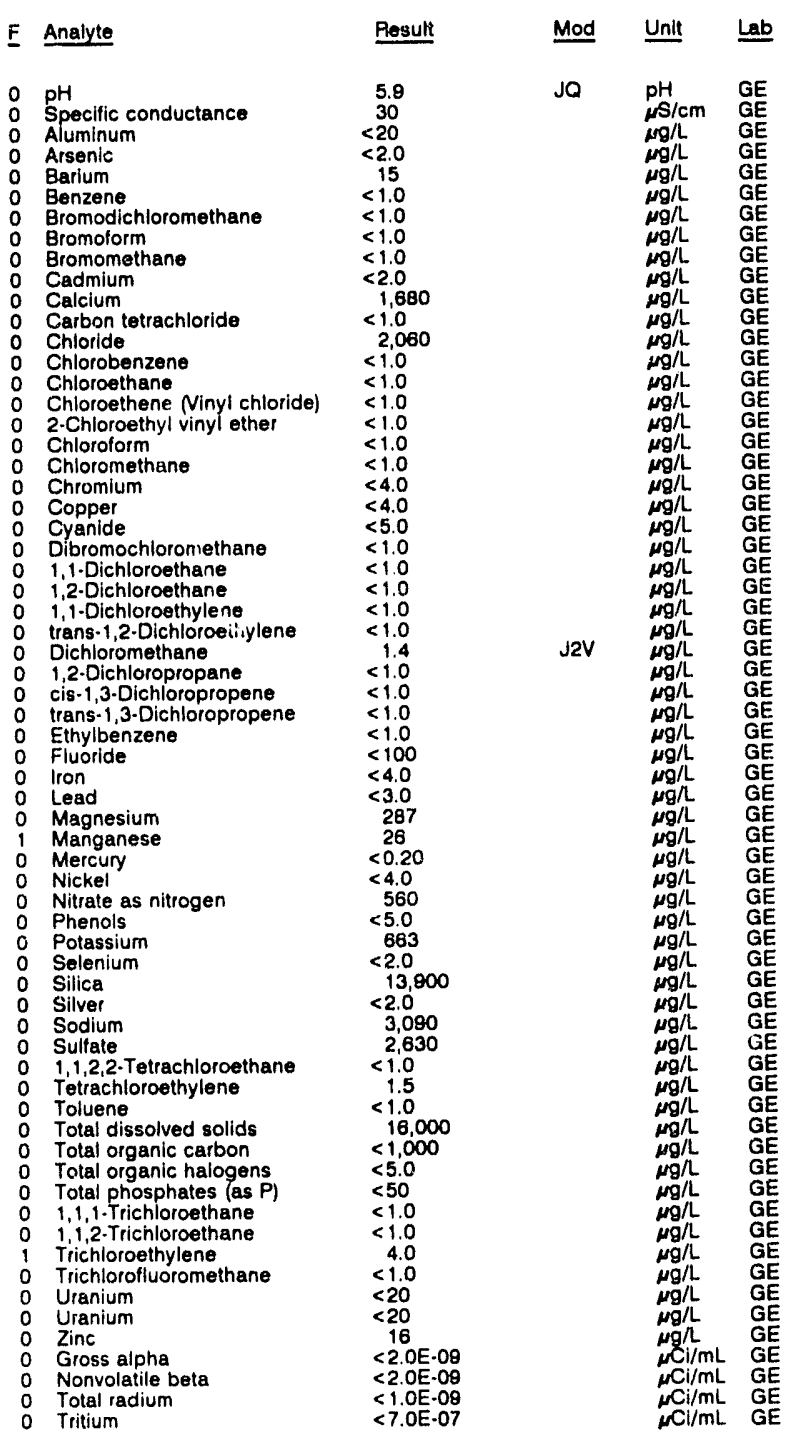

WELL MSB 62B Replicate

MEASUREMENTS CONDUCTED IN THE FIELD

Sample date: 10/11/91

Depth to water: $141.53 \mathrm{ft}(43.14 \mathrm{~m})$ below TOC Water elevation: $207.57 \mathrm{ht}(63.27 \mathrm{~m}) \mathrm{msl}$ Sp. conductance: $37 \mu \mathrm{s} / \mathrm{cm}$ Water evacuated before sampling: $182 \mathrm{gal}$

Time: $\theta: 55$

Alkalinity: $5 \mathrm{mg} / \mathrm{L}$

Water temperature: $18.1^{\circ} \mathrm{C}$

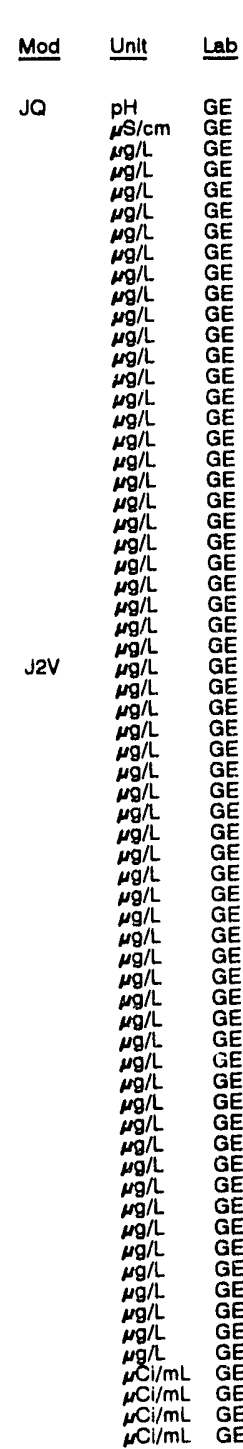

LABORATORY ANALYSES

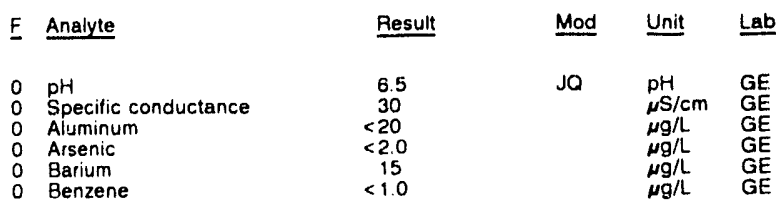

Alkalinity: $5 \mathrm{mg} /$

Water temperature: $18.1^{\circ} \mathrm{C}$
Time: $9: 55$ 


\section{ANALYTICAL RESULTS}

WELL MSB $62 B$ collected on 10/11/91, laboratory analyses (cont.)

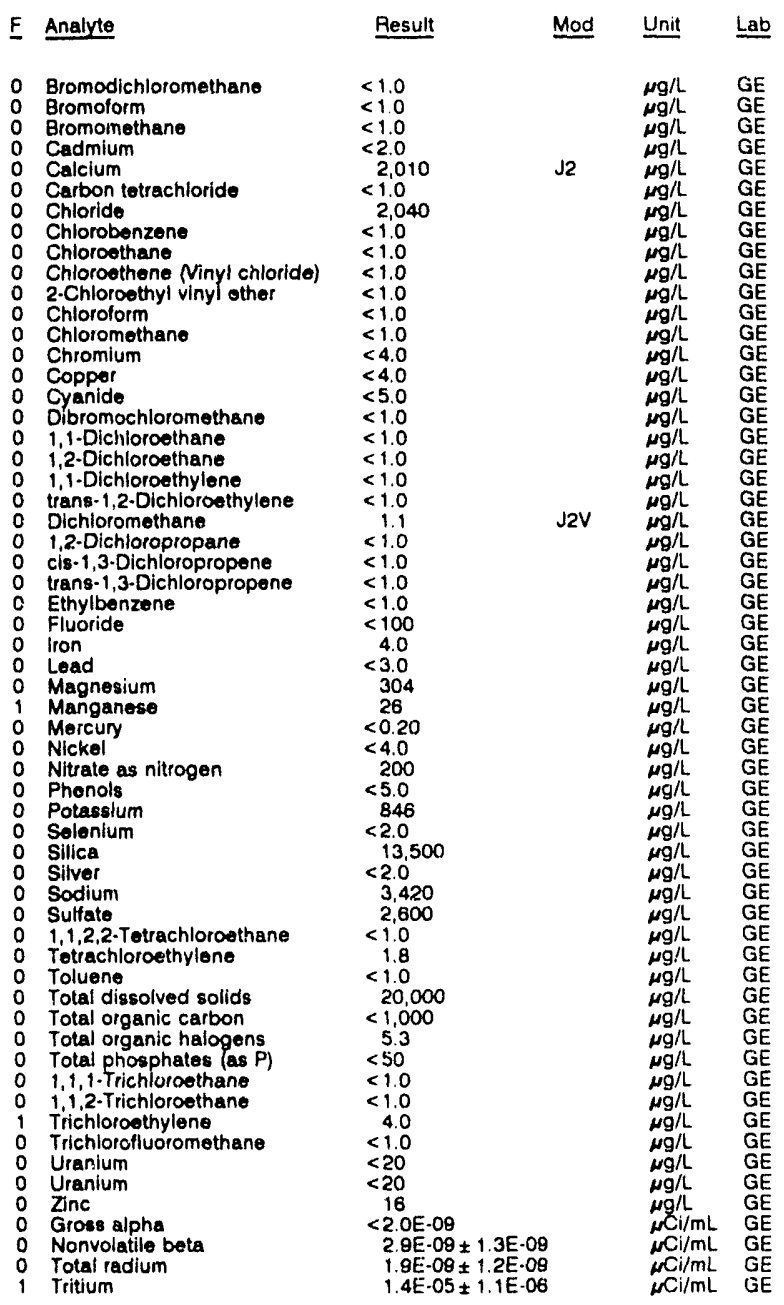

\section{WELL MSB 62C}

MEASUREMENTS CONDUCTED IN THE FIELD

Sample date: 10/11/91

Depth to water: $127.86 \mathrm{ft}(38.97 \mathrm{~m})$ below TOC

Water elevation: $221.24 \mathrm{ft}(67.43$

Sp. conduclance. $222 \mu \mathrm{s} / \mathrm{cm}$.

LABOFATORY ANALYSES

\begin{tabular}{|c|c|c|c|c|c|}
\hline$\underline{F}$ & Analyte & Result & Mod & Unit & Lab \\
\hline $\begin{array}{l}0 \\
0 \\
0 \\
0 \\
0 \\
0 \\
0 \\
0\end{array}$ & $\begin{array}{l}\text { pH } \\
\text { Specific conductance } \\
\text { Aluminum } \\
\text { Arsenic } \\
\text { Barium } \\
\text { Benzene } \\
\text { Bromodichloromethane } \\
\text { Bromolorm } \\
\text { Bromomethane } \\
\text { Cadmium } \\
\text { Calcium } \\
\text { Carbon tetrachloride } \\
\text { Chloride } \\
\text { Chlorobenzene } \\
\text { Chioroethane } \\
\text { Chiorothene Ninyl chloride) } \\
\text { 2. Chloroethyl vinyl ether } \\
\text { Chloroform } \\
\text { Chloromethane } \\
\text { Chromium } \\
\text { Copper } \\
\text { Cyanide } \\
\text { Dibromochloromethane } \\
\text { 1,1-Dichiloroethane }\end{array}$ & $\begin{aligned} & 5.6 \\
& 235 \\
&<20 \\
&<2.0 \\
& 41 . \\
&<1.0 \\
&<1.0 \\
&<1.0 \\
&<1.0 \\
&<2.0 \\
& 7.520 \\
&<1.0 \\
& 4.480 \\
&<1.0 \\
&<1.0 \\
&<1.0 \\
&<1.0 \\
&<1.0 \\
&<1.0 \\
&<4.0 \\
&<4.0 \\
&<5.0 \\
&<1.0 \\
& 1.2\end{aligned}$ & JO & $\begin{array}{l}\mathrm{pH} \\
\mu S / \mathrm{cm} \\
\mu g / L \\
\mu g / L \\
\mu g / L \\
\mu g / L \\
\mu g / L \\
\mu g / L \\
\mu g / L \\
\mu g / L \\
\mu g / L \\
\mu g / L \\
\mu g / L \\
\mu g / L \\
\mu g / L \\
\mu g / L \\
\mu g / L \\
\mu g / L \\
\mu g / L \\
\mu g / L \\
\mu g / L \\
\mu g / L \\
\mu g / L \\
\mu g / L\end{array}$ & $\begin{array}{l}G E \\
G E \\
G E \\
G E \\
G E \\
G E \\
G E \\
G E \\
G E \\
G E \\
G E \\
G E \\
G E \\
G E \\
G E \\
G E \\
G E \\
G E \\
G E \\
G E \\
G E \\
G E \\
G E \\
G E\end{array}$ \\
\hline
\end{tabular}

WELL MSB 62C collected on 10/11/91, laboratory analyses (cont)

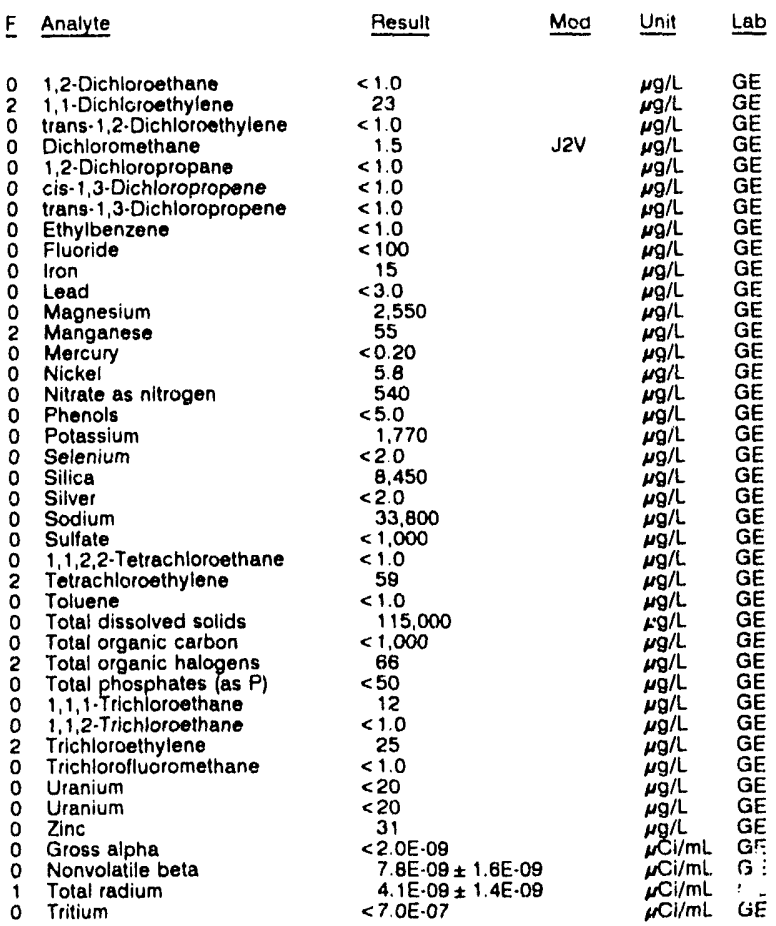

WELL MSB 62D

MEASUREMENTS CONDUCTED IN THE FIELD

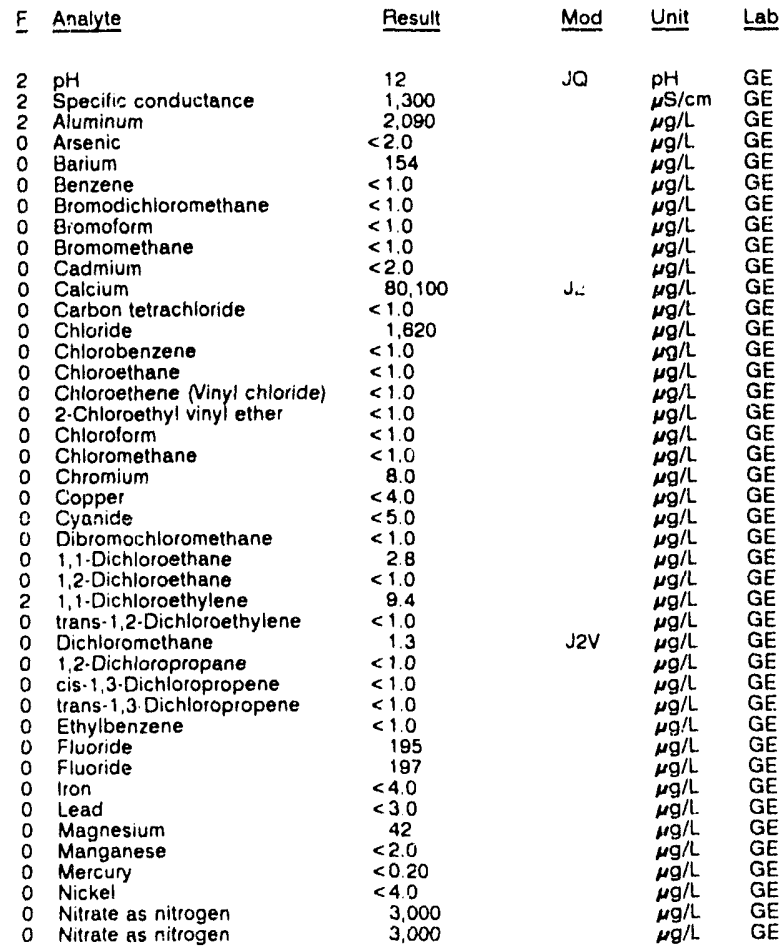
Sample date: $10 / 11 / 91$ (t) $(37.25 \mathrm{~m})$ below TOC Water elevation: $227.28 \mathrm{H}(68.28 \mathrm{~m}$

Sp. Conductance: $1772 \mu \mathrm{s} / \mathrm{cm}$ Water evacuated bolore sampling: 6 g The well went dry during purging

LABORATORY ANALYSES

Time: 9:35

Alkalinity: $510 \mathrm{mg}$ Water temperature: $17.6^{\circ} \mathrm{C}$

Time: 10:20

pH: 5.4

Water temperature: $18.5^{\circ} \mathrm{C}$

Lab 
ANALYTICAL RESULTS

WELL MSB $62 D$ collected on 10/11/91, laboratory analyses (cont.)

\begin{tabular}{|c|c|c|}
\hline Analyte & Result: & Unit \\
\hline $\begin{array}{l}\text { Phenols } \\
\text { Phenols } \\
\text { Potassium } \\
\text { Selenium } \\
\text { Silica } \\
\text { Silver } \\
\text { Sodlum } \\
\text { Sulfate } \\
1,1,2,2 \cdot \text { Tetrachloroethane } \\
\text { Totrachloroethylene } \\
\text { Toluene } \\
\text { Total dissolved solids } \\
\text { Total organic carbon } \\
\text { Total organic halogens } \\
\text { Total phosphates (as P) } \\
1,1,1 \text { - Trichloroethane } \\
\text { 1,1,2-Trichloroethane } \\
\text { Trichlorcothylene } \\
\text { Trichlorofluoromethane } \\
\text { Uranium } \\
\text { Uranlum } \\
\text { Zinc } \\
\text { Gross alpha } \\
\text { Nonvolatile beta } \\
\text { Total radium } \\
\text { Trtium }\end{array}$ & $\begin{array}{l}<5.0 \\
<5.0 \\
8,920 \\
<2.0 \\
15,200 \\
<2.0 \\
59,800 \\
17,500 \\
<1.0 \\
80 \\
5.8 \\
332,000 \\
<1,000 \\
141 \\
<50 \\
17 \\
<1.0 \\
51 \\
<1.0 \\
<20 \\
<20 \\
3.1 \\
6.6 E-09 \pm 3.3 E-09 \\
2.0 E-08 \pm 6.1 E-09 \\
3.4 E-09 \pm 1.4 E-09 \\
1.2 E-06 \pm 1.0 E-07\end{array}$ & $\begin{array}{l}\mu g / L \\
\mu g / L \\
\mu g / L \\
\mu g / L \\
\mu g / L \\
\mu g / L \\
\mu g / L \\
\mu g / L \\
\mu g / L \\
\mu g / L \\
\mu g / L \\
\mu g / L \\
\mu g / L \\
\mu g / L \\
\mu g / L \\
\mu g / L \\
\mu g / L \\
\mu g / L \\
\mu g / L \\
\mu g / L \\
\mu g / L \\
\mu g / L \\
\mu C \mathrm{i} / \mathrm{mL} \\
\mu C \mathrm{i} / \mathrm{mL} \\
\mu C \mathrm{i} / \mathrm{mL} \\
\mu C \mathrm{i} / \mathrm{mL}\end{array}$ \\
\hline
\end{tabular}

\section{WELL MSB 63B}

MEASUREMENTS CONDUCTED IN THE FIELD

Sample date: $10 / 11 / 91$
Depth to water: $137.89 \mathrm{ft}(42.03 \mathrm{~m})$ below TOC
Water elevation: $209.11 \mathrm{ft}(63.74 \mathrm{~m}) \mathrm{msl}$
Sp. conductance: $25 \mu \mathrm{s} / \mathrm{cm}$
Water evacuated before sampling. $191 \mathrm{gal}$
LABORATORY ANALYSES

Time: $9: 00$

Alkalinity: $5 \mathrm{mg} / \mathrm{h}$

Water temperature: $17.3^{\circ} \mathrm{C}$

LABORATORY ANALYSES

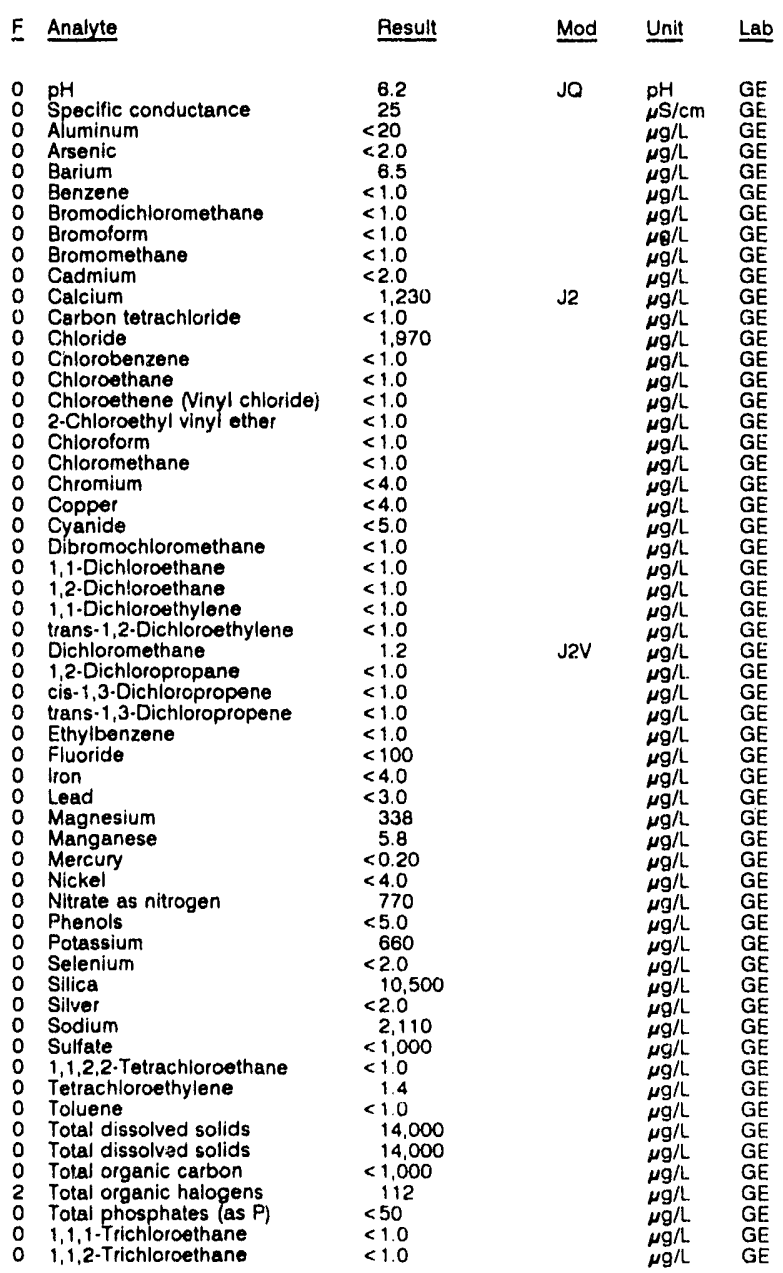

WELL MSB 63B collected on 10/11/81, laboratory analyses (cont.)

\begin{tabular}{|c|c|c|c|c|}
\hline Analyte & Result & Mod & Unit & Lab \\
\hline $\begin{array}{l}\text { Trichloroethylene } \\
\text { Trichlorofluoromethane } \\
\text { Uranium } \\
\text { Uranium } \\
\text { Zinc } \\
\text { Gross alpha } \\
\text { Nonvolatile beta } \\
\text { Total radium } \\
\text { Tritium }\end{array}$ & $\begin{aligned} & 163 \\
&< 1.0 \\
&<20 \\
&<20 \\
& 9.9 \\
&<2.0 E-09 \\
&<2.0 \mathrm{E}-00 \\
&<1.0 \mathrm{E}-09 \\
&<7.0 \mathrm{E}-07\end{aligned}$ & . & 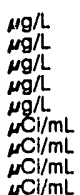 & $\begin{array}{l}\mathrm{GE} \\
\mathrm{GE} \\
\mathrm{GE} \\
\mathrm{GE} \\
\mathrm{GE} \\
\mathrm{GE} \\
\mathrm{GE} \\
\mathrm{GE} \\
\mathrm{GE}\end{array}$ \\
\hline
\end{tabular}

WELL MSB 63C

MEASUREMENTS CONDUCTED IN THE FIELD

Depth to water: $128.16 \mathrm{ft}(39.06 \mathrm{~m})$ below TOC Water elevation: $218.94 \mathrm{ft}(68.73 \mathrm{~m}) \mathrm{ms}$

Sp. conductance: $50 \mu \mathrm{S} / \mathrm{cm}$
Watei evacuated botore sampling: $73 \mathrm{gal}$

Tim: 0.15

Alkalinity: $6 \mathrm{mg}$

Water temperature: $17.0^{\circ} \mathrm{C}$

LABORATORY ANALYSES

Result

$\begin{array}{ll}0 & \mathrm{pH} \\ 0 & \text { Specific conductance }\end{array}$

0 Aluminum

0 Arsenic

Barium

Bromodichloromethane

Bromodich

Bromotorm

- Cadmium

Calcium

Carbon tetrachloride

Chloride

Chlorobenzene

Chioroethane

Chlcroethene Ninyl chloride
2-Chloroethyl vinyl ether

Chloroform

Chloromethane

Chromium

Copper

Cyanide

1,1-Dichloroethane

1,2-Dichloroethane

1,1-Dichloroethylene

trans-1,2-Dichloroethylene

Dichloromethane

1,2-Dichloropropane

cis-1,3-Dichloropropene

trans-1,3-Dichloropropene

Ethylbenzene

Fluoride

Iron

C Lead

Magnesium

Mercury

Nickel

Nitrate as

o Potassium

Selenium

Silica

- Silver

S Sulfate

1,1,2,2-Tetrachloroethane

Tetrachloroethylene

Toluene

Total dissolved solids

Total organic carbon

Total organic halogens

1,1,1-Trichloroethane

1,1,2-Trichloroetha

Trichloroethylene

- Trichlorofluoromethane

0 Uranium

Zinc

- Gross aiph

Nonvolatile bete

Total radium

Tritium

Mod Unit Lab

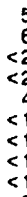

60
$<20$
$<2.0$
4.6
$<1.0$
$<1.0$
$<1.0$
$<1.0$
$<2.0$

$<2.0$

$<1.0$
2.150

$<1.0$

$<1.0$

$<1.0$
$<1.0$

$<1.0$

$<1.0$
$<4.0$
$<4.0$
$<5.0$

$<5.0$

$<1.0$

$<1.0$

$<1.0$

$<1.0$
$<1.0$

$<1.0$

$<1.0$

$<1.0$

$<100$
6.2

$<3.0$

13
$<0.20$

44.000

4,000
$<5.0$

2.170
$<2.0$

9,460
$<2.0$

8,270
$<1,000$

$<1,000$
$<1.0$
8.6

8.6
$<1.0$

41,000
$<1,000$

$<5.0$

$<50$

$<1.0$

$<.0$
3.5

$<20$
$<20$
16

16
$<2.0 E-09$

$<2.0 E-09$
$<2.0 E-09$
$<1.0 E$

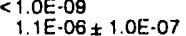

${ }_{\mu \mathrm{S} / \mathrm{cm}}^{\mathrm{pH}} \mathrm{GE}$

E


ANALYTICAL RESULTS

\section{WELL MSB 63D}

MEASUAEMENTS CONDUCTED IN THE FIELD

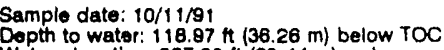

Water olovation: $227.83 \mathrm{ft}(69.44 \mathrm{~m}) \mathrm{msl}$

Sp. conductance: $109 \mu \mathrm{S} / \mathrm{cm}$

Water ovacuated betore sampling: $10 \mathrm{gal}$

The well went dry during purging.

LABORATORY ANALYSES

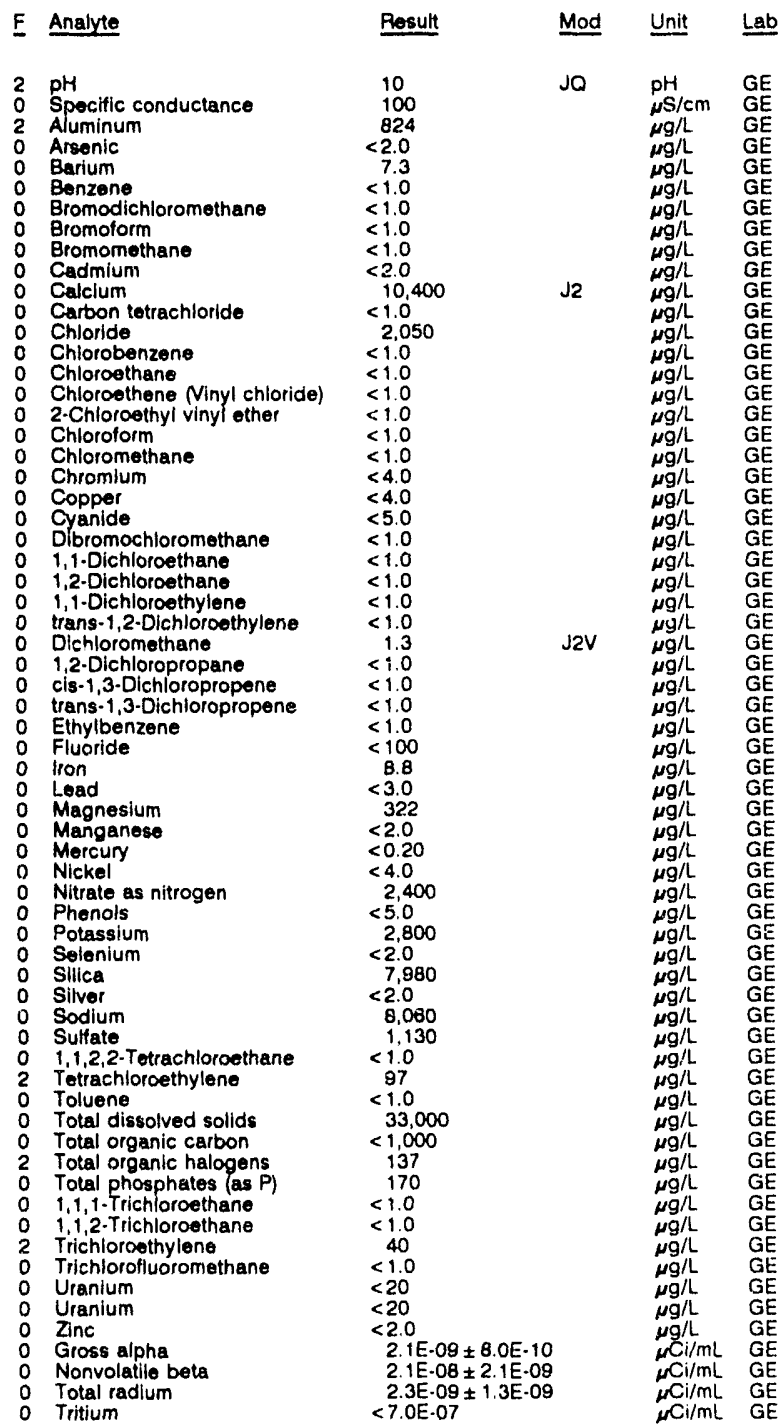

\section{WELL MSB 64B}

MEASUREMENTS CONDUCTED IN THE FIELD

Sample date: $11 / 21 / 9$

Depth to water: $14273 \mathrm{H}(43.50 \mathrm{~m})$ below TOC

Water elevation: $205.97 \mathrm{ft}(62.78 \mathrm{~m}) \mathrm{msl}$

Water evacuated betore sampling: $226 \mathrm{gal}$

Time: $8: 30$

PH: 10.0

Water temperature: $17.0^{\circ} \mathrm{C}$

LABORATORY ANALYSES

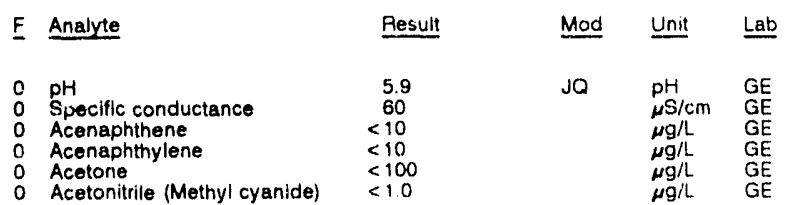

WELL MSB 648 coliected on 11/21/91, laboratory analyses (cont.)

$E$ Analyte

- Acetophenone

2-Acetylaminofluorene

Acrylo

0 Aldrin

Allyl chloride

4.Aminobiphenyl

Aniline

Anthracene

Antimony

Aramite

Barium

Benzene

beta-Benzene hexachloride

delta-Benzene hexachloride

Benzola anthraceno

Benzola)pyrene

Benzo b f fluoranthene

Benzo $g, h, i]$ perylene

Benzolx fluoranthen

Benzyl alcoho

Bis(2-chloroisopropyl)ether

Bis (2.chloroethox

Bis(2-chloroethyl) ether

Bis(2-ethylhexyl) phthalate

Bromodichloromethan

Bromoform

Bromomethane

4-Bromopheryl phenyl ether

2-sec-Butyl-4,6-dinitrophenol

Butylbenzy' phthalate

Cadmium

Carbon disulfide

Carbon telrachloride

2,3,7,8-TCDF

Chlordane

0 Chloride

o para-Chloro-meta-cresol

4-Chloroaniline

Chlorobenzene

Chlorobenzilat

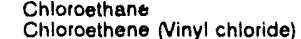

2-Chloroethyl vinyl ether

2-Chloroeth

Chloromethan

2-Chloronaphthalene <

2.Chlorophenol $<10$

4-Chlorophenyl phenyl ether

Chloroprene

Chryserie

Cobalt

O Copper

o-Cresol (2-Methylphenol)

m-Cresol (3-Methylpheno)

p-Cresol (4-Methylphenol)

Cyanide

P.P.DOD

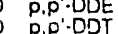

Di-n-butyl phthalate

Di-n-octyl phthalate

Diallate

Dibenz[a,h]anthracene

Dibenzofuran

1,2-Dibromo-3-chloropropane

Dibromochloromethane

1,2-Dibromoethane

Dibromomethane
trans-1,4-Dichloro-2-buten

trans-1,4-Dichloro-2-buten

1,3-Dichlorobenzene

1,4-Dichlorobenzene

3,3.Dichlorobenzidine

D Dichlorodifluoromethane

1,1-Dichloroethane

o 1.2.Dichloroethane

0
0
trans.1,2-Dichloroethylene

- Dichloromethane

2.4.Dichlorophenol

2,6-Dichiorophenol

2,4.Dichlorophenoxyacetic acio $<10$

1,2-Dichloropropane

cis-1,3-Dichloropropene

0
0
0

Diethyl phthalate

o Dimethoate

2,4-Dimethyl pheno

Dimethyl phthalate

p-Dimethylaminoazobenzene

Dimethylbenz[a]anthracene

0 3,3'-Dimethylbenzidine

$<10$

$<20$

$<>10$

$<10$
Result

Mod Unit Lab

$<0.050$

149

$<10$
$<2.0$

$<10$

14
$<1.0$

$<0.050$

$<0.050$

$<10$

$<10$

$<3.0$

$<10$

$<10$

$<1.0$

$<1.0$

$<10$
$<10$

$<10$
$<2.0$

2,830
$<1.0$

$<0.0004$

$<0.00040$
$<0.50$

$<10$

$<10$

$<10$

$<1.0$

1.0

$<10$
$<1.0$

$<10$
$<10$

$<10$
$<200$

$<200$
$<4.0$

$<10$
$<4.0$

$<4.0$

$<10$

$<10$
$<10$

$<5.0$
$<0.10$
$<0.10$
$<0.10$

10

$<10$
$<10$

$<10$

$<10$

$<1.0$

$<20$

$<1.0$

$<30$
$<10$

$<10$

$<10$

$<10$
$<1.0$

$<1.0$

$<1.0$

$<1.0$

6.6
$<10$

$<10$
$<0.30$

$<1.0$

$<1.0$

$<10$

$<10$
$<10$

$<10$
$<10$

$<10$
$<10$ 
ANALYTICAL RESULTS

WELL MSB 64B collected on 11/21/91, laboratory analyses (cont.)

\section{E Analyte}

$\begin{array}{ll}1,3 \cdot \text { Dinitrobenzene } \\ 0 & 2,4 \text {-Dinitropherol } \\ 0 & 2,4 \text {-Dinitrololuene } \\ 0 & 2,6 \cdot \text { Dinitrotoivene } \\ 0 & 1,4 \text {-Dioxane } \\ 0 & \text { Diphenylamine }\end{array}$

Disulfoton

Endosulfan I

Endosulfan sulfate

Endrin

Endrin aldehyde

Ethyl methanesulfonate

Ethyibenzene

0 Fluoranthene

Fluorene

0 Heptachlor

Heptachlor epoxide

Heptachlorodibenzo.p.dioxins

$1,2,3,4,6,7,8$.HPCD

Heptachlorodibenzo-p-furans

Hexachlorobenzene

Hexachlorobutadiene

Hexachlorocyclopent
$1,2,3,4,7,8-H \times C D D$

Hexachlorodibenzo-p-dioxins

$1,2,3,4,7,8 \cdot H X C D F$
Hexachlorodibenzo-p-furans

Hexachloroethane

Hexachlorophene

2-Hexanone

Indeno $[1,2,3-c, d] p y r e n e$

lodon

Isobutyl alcohol

Isodin

Isophorone
isosafrole

Kepone

Lead

Magnesium

Manganese

Mercury

Methacrylonitrile

Methapyrilene

Methoxychior

Methyl isobutyl ketone

Methyl methacrylate.

Methyl methanesulfonate

2-Methyl-4,6-dinitrophen

3-Methylcholanthrene

2-Methylnaphthalene

N-Nitrosodiethylamine

N.Nitrosodimethylamine

$\mathrm{N}$-Nitrosodiphenylamine

N.Nitrosodiphenylamine

N.Nitrosodi-propylamine
N-Nitrosomethylethylamine

N-Nitrosomerpholine

N-Nitrosopiperidine

N-Nitrosopyrrolidin

Naphthalene

1.4-Naphthoquinone

1.Naphthylamine

Nicke

Nitrate as nitrogen

5. Nitro-0-toluidin

2.Nitroaniline

4-Nitroaniline

4.Nitroaniline

2. Nitrophenol

4-Nitrophenol

4-Nittoquinoline-1.oxide

$0,0,0$ - Triethyl phosphorothioate

Octachlorodibenzo-p-dioxins

Octachlor

Parathion

Parathion me

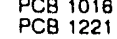

PCE 1232

PCE 1242

PCB 1248

PCB 1254

Pentachlorobenzene

Pentachlorodibenzo-p-dioxins

1,2,3,7,8.PCDF
Result Mod

$<10$

$<10$

$<45$
$<10$
$<10$

$<10$

$<10$
$<10$

$<0.10$

$<0.10$
$<0.0060$

$<0.10$

$<10$

$<10$
$<1.0$

210

$<10$

$<100$

$<0.050$

$<0.00065$

$<0.00065$

$<0.00045$

$<10$

$<10$
$<0.00045$

$<0.00045$

$<0.00040$
$<0.00040$

$<10$

$<10$

$<1.0$

$<15$
71

$<100$

$<10$

$<10$
$<10$
$<10$

$<3.0$
$<0.0050$

$<0.0050$
7.7

$<0.20$

$<0.20$
$<50$

$<0.50$

$<1.0$

$<10$

$<10$
$<10$

$<10$

$<10$

$<10$

$<10$

$<10$

$<10$
$<10$

$<10$
$<10$

$<10$

$<10$
$<10$

$<10$

$<10$
$<10$

$<4.0$
2.720
$<10$
$<10$

$<10$

$<10$

$<10$

$<10$
$<10$

$<10$

$<10$

$<0.0010$

$<0.0010$

$<0.050$
$<0.50$
$<0.50$

$<0.50$

$<0.50$

$<050$

$<0.50$

$<050$

$<0.00055$

$<0.00055$

$<0.00055$
Mod Unit Lab

\begin{tabular}{|c|c|c|c|}
\hline $\begin{array}{l}\mu \mathrm{g} / \mathrm{L} \\
\mu \mathrm{g} / \mathrm{L} \\
\mu \mathrm{g} / \mathrm{L} \\
\mu \mathrm{g} / \mathrm{L} \\
\mu \mathrm{g} / \mathrm{L} \\
\mu \mathrm{g} / \mathrm{L} \\
\mu \mathrm{g} / \mathrm{L} \\
\mu \mathrm{g} / \mathrm{L} \\
\mu \mathrm{g} / \mathrm{L} \\
\mu \mathrm{g} / \mathrm{L} \\
\mu \mathrm{g} / \mathrm{L} \\
\mu \mathrm{g} / \mathrm{L} \\
\mu \mathrm{g} / \mathrm{L} \\
\mu \mathrm{g} / \mathrm{L} \\
\mu \mathrm{g} / \mathrm{L} \\
\mu \mathrm{g} / \mathrm{L} \\
\mu \mathrm{g} / \mathrm{L} \\
\mu \mathrm{g} / \mathrm{L} \\
\mu \mathrm{g} / \mathrm{L} \\
\mu \mathrm{g} / \mathrm{L} \\
\mu \mathrm{g} / \mathrm{L} \\
\mu \mathrm{g} / \mathrm{L} \\
\mu \mathrm{g} / \mathrm{L} \\
\mu \mathrm{g} / \mathrm{L} \\
\mu \mathrm{g} / \mathrm{L} \\
\mu \mathrm{g} / \mathrm{L} \\
\mu \mathrm{g} / \mathrm{L} \\
\mu \mathrm{g} / \mathrm{L} \\
\mu \mathrm{g} / \mathrm{L} \\
\mu \mathrm{g} / \mathrm{L} \\
\mu \mathrm{g} / \mathrm{L} \\
\mu \mathrm{g} / \mathrm{L} \\
\mu \mathrm{g} / \mathrm{L} \\
\mu \mathrm{g} / \mathrm{L} \\
\mu \mathrm{g} / \mathrm{L} \\
\mu \mathrm{g} / \mathrm{L} \\
\mu \mathrm{g} / \mathrm{L} \\
\mu \mathrm{g} / \mathrm{L} \\
\mu \mathrm{g} / \mathrm{L} \\
\mu \mathrm{g} / \mathrm{L} \\
\mu \mathrm{g} / \mathrm{L} \\
\mu \mathrm{g} / \mathrm{L} \\
\mu \mathrm{g} / \mathrm{L} \\
\mu \mathrm{g} / \mathrm{L} \\
\mu \mathrm{g} / \mathrm{L} \\
\mu \mathrm{g} / \mathrm{L} \\
\mu \mathrm{g} / \mathrm{L} \\
\mu \mathrm{g} / \mathrm{L} \\
\mu \mathrm{g} / \mathrm{L} \\
\mu \mathrm{g} / \mathrm{L} \\
\mu \mathrm{g} / \mathrm{L} \\
\mu \mathrm{g} / \mathrm{L} \\
\mu \mathrm{g} / \mathrm{L} \\
\mu \mathrm{g} / \mathrm{L} \\
\mu \mathrm{g} / \mathrm{L} \\
\mu \mathrm{g} / \mathrm{L} \\
\mu \mathrm{g} / \mathrm{L} \\
\mu \mathrm{g} / \mathrm{L} \\
\mu \mathrm{g} / \mathrm{L} \\
\mu \mathrm{g} / \mathrm{L} \\
\mu \mathrm{g} / \mathrm{L} \\
\mu \mathrm{g} / \mathrm{L}\end{array}$ & $\begin{array}{l}\mathrm{GE} \\
\mathrm{GE} \\
\mathrm{GE} \\
\mathrm{GE} \\
\mathrm{GE} \\
\mathrm{GE} \\
\mathrm{GE} \\
\mathrm{GE} \\
\mathrm{GE} \\
\mathrm{GE} \\
\mathrm{GE} \\
\mathrm{GE} \\
\mathrm{GE} \\
\mathrm{GE} \\
\mathrm{GE} \\
\mathrm{GE} \\
\mathrm{GE} \\
\mathrm{GE} \\
\mathrm{GE} \\
\mathrm{GE} \\
\mathrm{GE} \\
\mathrm{GE} \\
\mathrm{GE} \\
\mathrm{GE} \\
\mathrm{GE} \\
\mathrm{GE} \\
\mathrm{GE} \\
\mathrm{GE} \\
\mathrm{GE} \\
\mathrm{GE} \\
\mathrm{GE} \\
\mathrm{GE} \\
\mathrm{GE} \\
\mathrm{GE} \\
\mathrm{GE} \\
\mathrm{GE} \\
\mathrm{GE} \\
\mathrm{GE} \\
\mathrm{GE} \\
\mathrm{GE} \\
\mathrm{GE} \\
\mathrm{GE} \\
\mathrm{GE} \\
\mathrm{GE} \\
\mathrm{GE} \\
\mathrm{GE} \\
\mathrm{GE} \\
\mathrm{GE} \\
\mathrm{GE} \\
\mathrm{GE} \\
\mathrm{GE} \\
\mathrm{GE} \\
\mathrm{GE} \\
\mathrm{GE} \\
\mathrm{GE} \\
\mathrm{GE} \\
\mathrm{GE} \\
\mathrm{GE} \\
\mathrm{GE} \\
\mathrm{GE} \\
\mathrm{GE} \\
\mathrm{GE} \\
\mathrm{GE}\end{array}$ & $\begin{array}{l}0 \\
0\end{array}$ & 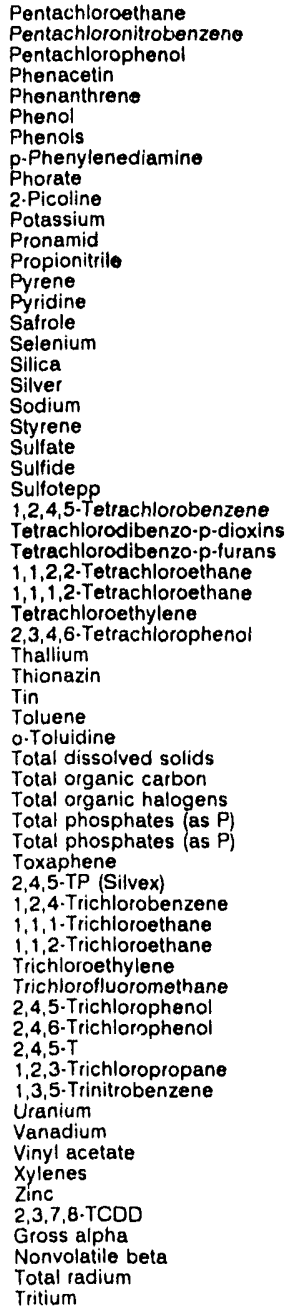 \\
\hline
\end{tabular}

WELL MSB 648 collected on 11/21/91, laboratory analyses (cont.)

F Analyte Result Mod Unit Lab

$<10$
$<10$
$<10$
$<10$
$<10$
$<10$
$<5$

$<0.10$

$<10$
869

$<200$

$<10$
$<10$
$<10$

$<2.0$

$<2.700$
$<2.0$

6,390

$<1.0$

1,420
$<1,000$

$<10$
$<10$

$<0.00045$

$<0.00040$

$<1.0$

$<.0$
39

$<10$

$<2.0$

$<2.0$
1.9

$<\begin{aligned} & 10 \\ & 59,000\end{aligned}$

$<1,000$

$<50$

$<50$

$<0.24$
$<0.090$

$<10$

$<1.0$
1.3

1.3
2.300

$<1.0$

$<10$

$<0.090$

$<1.0$

$<20$

$<8.0$
$<1.0$

$<2.0$
10

$<0.00045$

$<2.0 E-09$

$<1.0 E .09$

$<7.0 \mathrm{E}-07$

\section{WELL MSB 64C}

MEASUREMENTS CONDUCTED IN THE FIELD

Sample date: $10 / 08 / 91$

Depth to water: $127.50 \mathrm{ft}(38.86 \mathrm{~m})$ below roC Water elevation: $221.20 \mathrm{ft}(67.42$

Water evacuated before sampling: $117 \mathrm{gal}$

pH: 5.8

PH: 5.8 : $18 \mathrm{mg} / \mathrm{L}$

Water temperature: $19.0^{\circ} \mathrm{C}$

LABORATORY ANALYSES

\begin{tabular}{|c|c|c|c|}
\hline Analyte & Result & Mod & Unit \\
\hline $\begin{array}{l}\text { pH } \\
\text { Specific conductance } \\
\text { Aluminum } \\
\text { Arsenic } \\
\text { Barium } \\
\text { Benzene } \\
\text { Bromodichloromethane } \\
\text { Bromoform } \\
\text { Bromomethane } \\
\text { Cadmium } \\
\text { Calcium } \\
\text { Carbon tetrachloride } \\
\text { Chloride } \\
\text { Chlorobenzene } \\
\text { Chloroethane } \\
\text { Chloroethene (Vinyl chloride) } \\
\text { 2.Chloroethyl vinyl ether } \\
\text { Chlorolorm } \\
\text { Chloromethane } \\
\text { Chromium }\end{array}$ & $\begin{array}{r}5.5 \\
130 \\
104 \\
<2.0 \\
20 \\
<1.0 \\
<1.0 \\
<1.0 \\
<1.0 \\
<2.0 \\
6,000 \\
<1.0 \\
4,280 \\
<1.0 \\
<1.0 \\
<1.0 \\
<1.0 \\
<1.0 \\
<1.0 \\
<4.0\end{array}$ & JO & $\begin{array}{l}\mathrm{pH} \\
\mu \mathrm{S} / \mathrm{cm} \\
\mu \mathrm{g} / \mathrm{L} \\
\mu g / \mathrm{L} \\
\mu g / \mathrm{L} \\
\mu \mathrm{g} / \mathrm{L} \\
\mu \mathrm{g} / \mathrm{L} \\
\mu \mathrm{g} / \mathrm{L} \\
\mu \mathrm{h} / \mathrm{L} \\
\mu g / \mathrm{L} \\
\mu g / \mathrm{L} \\
\mu g / \mathrm{L} \\
\mu g / L \\
\mu g / L \\
\mu g / L \\
\mu g / L \\
\mu g / L \\
\mu g / L \\
\mu g / L \\
\mu g / L\end{array}$ \\
\hline
\end{tabular}


WELL MSB 64 C collected on 10/08/91, laboratory analyses (cont.)

\begin{tabular}{|c|c|c|c|c|}
\hline$\underline{F}$ & Analyte & Pesult & Mod & Unit \\
\hline $\begin{array}{l}\text { 0 } \\
0 \\
0 \\
0\end{array}$ & 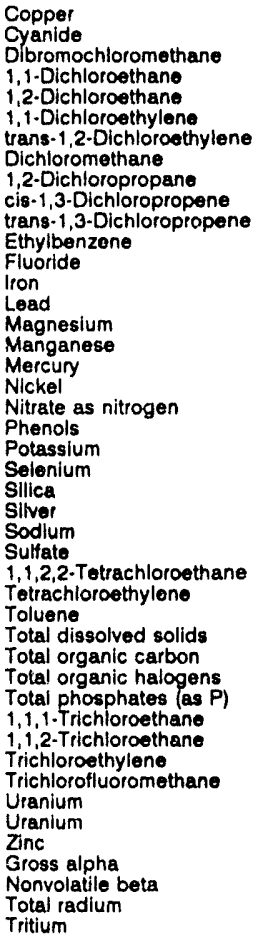 & $\begin{array}{l}<4.0 \\
<5.0 \\
<1.0 \\
<1.0 \\
<1.0 \\
4.1 \\
<1.0 \\
3.9 \\
<1.0 \\
<1.0 \\
<1.0 \\
<1.0 \\
<100 \\
8.3 \\
<3.0 \\
2,700 \\
8.2 \\
<0.20 \\
<4.0 \\
13,200 \\
<5.0 \\
931 \\
<2.0 \\
9,830 \\
<2.0 \\
12,500 \\
<1.000 \\
<1.0 \\
270 \\
<1.0 \\
55,000 \\
<1,000 \\
385 \\
<50 \\
2.4 \\
<1.0 \\
123 \\
<1.0 \\
<20 \\
<20 \\
6.0 \\
7.6 E \cdot 09 \pm 1.8 E-09 \\
8.3 E \cdot 09 \pm 1.5 E-09 \\
1.9 E-09 \pm 1.3 E-09 \\
<7.0 E \cdot 07\end{array}$ & J2V & $\begin{array}{l}\mu g / L \\
\mu g / L \\
\mu g / L \\
\mu g / L \\
\mu g / L \\
\mu g / L \\
\mu g / L \\
\mu g / L \\
\mu g / L \\
\mu g / L \\
\mu g / L \\
\mu g / L \\
\mu g / L \\
\mu g / L \\
\mu g / L \\
\mu g / L \\
\mu g / L \\
\mu g / L \\
\mu g / L \\
\mu g / L \\
\mu g / L \\
\mu g / L \\
\mu g / L \\
\mu g / L \\
\mu g / L \\
\mu g / L \\
\mu g / L \\
\mu g / L \\
\mu g / L \\
\mu g / L \\
\mu g / L \\
\mu g / L \\
\mu g / L \\
\mu g / L \\
\mu g / L \\
\mu g / L \\
\mu g / L \\
\mu g / L \\
\mu g / L \\
\mu g / L \\
\mu g / L \\
\mu C i / m L \\
\mu C i / m L \\
\mu C i / m L \\
\mu C i / m L\end{array}$ \\
\hline
\end{tabular}

\section{WELL MSB 64D}

MEASUREMENTS CONDUCTED IN THE FIELO

Sample date: 10/08/81

Depth to water: $123.48 \mathrm{ft}(37.64 \mathrm{~m})$ below TOC

Water elevation: 225.52 it $(68.74$

Wp. conductance: $267 \mu \mathrm{S} / \mathrm{cm}$.

LABOPATORY ANALYSES

\begin{tabular}{|c|c|c|c|}
\hline Anajyte & Result & Mod & Unit \\
\hline $\begin{array}{l}\text { pH } \\
\text { Specific conductance } \\
\text { Aluminum } \\
\text { Arsenic } \\
\text { Barium } \\
\text { Benzene } \\
\text { Bromodichloromethane } \\
\text { Bromoform } \\
\text { Bromomethane } \\
\text { Cadmium } \\
\text { Calcium } \\
\text { Carbon tetrachloride } \\
\text { Chloride } \\
\text { Chiorobenzene } \\
\text { Chloroethane } \\
\text { Chloroethene Ninyl chloride) } \\
\text { 2.Chloroethyl vinyl ether } \\
\text { Chloroform } \\
\text { Chloromethane } \\
\text { Chromium } \\
\text { Copper } \\
\text { Cyanide } \\
\text { Dibromochloromethane } \\
\text { 1,1-Dichloroethane } \\
1,2-\text { Dichloroethane } \\
\text { 1, -Dichloroethylene } \\
\text { trans-1,2-Dichloroethylene } \\
\text { Dichloromethane } \\
1,2-\text { Dichloropropane } \\
\text { cis-1,3-Dichloropropene } \\
\text { trans-1,3-Dichloropropene } \\
\text { Ethylbenzene } \\
\text { Flooride } \\
\text { 1ron } \\
\text { Lead } \\
\text { Magnesium } \\
\text { Manganese } \\
\text { Mercury }\end{array}$ & $\begin{aligned} & 6.2 \\
& 200 \\
&<20 \\
&<2.0 \\
& 19 \\
&<1.0 \\
&<1.0 \\
&<1.0 \\
&<1.0 \\
&<20 \\
& 4.990 \\
&<1.0 \\
& 3.880 \\
&<1.0 \\
&<1.0 \\
&<1.0 \\
&<1.0 \\
&<1.0 \\
&<1.0 \\
&<4.0 \\
&<4.0 \\
&<5.0 \\
&<1.0 \\
& 1.4 \\
&<1.0 \\
& 28 \\
&<1.0 \\
& 4.1 \\
&<1.0 \\
&<1.0 \\
&<1.0 \\
&<1.0 \\
&<100 \\
& 5.6 \\
&<3.0 \\
& 949 \\
& 23 \\
&<0.20\end{aligned}$ & $\mathrm{~J} 2 \mathrm{~V}$ & $\begin{array}{l}p H \\
\mu \mathrm{S} / \mathrm{cm} \\
\mu g / L \\
\mu g / L \\
\mu g / L \\
\mu g / L \\
\mu g / L \\
\mu g / L \\
\mu g / L \\
\mu g / L \\
\mu g / L \\
\mu g / L \\
\mu g / L \\
\mu g / L \\
\mu g / L \\
\mu g / L \\
\mu g / L \\
\mu g / L \\
\mu g / L \\
\mu g / L \\
\mu g / L \\
\mu g / L \\
\mu g / L \\
\mu g / L \\
\mu g / L \\
\mu g / L \\
\mu g / L \\
\mu g / L \\
\mu g / L \\
\mu g / L \\
\mu g / L \\
\mu g / L \\
\mu g / L \\
\mu g / L \\
\mu g / L \\
\mu g / L \\
\mu g / L \\
\mu g / L\end{array}$ \\
\hline
\end{tabular}

WELL MSB 64D collected on 10/08/91, laboratory analyses fcont.

\begin{tabular}{|c|c|c|c|}
\hline Analyte & Result & Mod & Unit \\
\hline $\begin{array}{l}\text { Nickel } \\
\text { Nitrate as nitrogen } \\
\text { Phenols } \\
\text { Potassium } \\
\text { Selenium } \\
\text { Silica } \\
\text { Silver } \\
\text { Sodium } \\
\text { Sulfate } \\
1,1,2,2 \text {-Tetrachloroethane } \\
\text { Tetrachloroethylene } \\
\text { Toluene } \\
\text { Total dissolved solids } \\
\text { Total organic carbon } \\
\text { Total organic halogens } \\
\text { Total phosphates (as P) } \\
1,1,1 \text {. Trichloroethane } \\
1,1,2-\text { Trichloroethane } \\
\text { Trichloroethylene } \\
\text { Trichlorofluoromethane } \\
\text { Uranium } \\
\text { Uranium } \\
\text { Zinc } \\
\text { Gross alpha } \\
\text { Nonvolatile beta } \\
\text { Total radium } \\
\text { Tritium }\end{array}$ & $\begin{array}{l}<4.0 \\
17,100 \\
<5.0 \\
1.210 \\
<2.0 \\
7.670 \\
<2.0 \\
38,300 \\
4,850 \\
<1.0 \\
58 \\
<1.0 \\
136,000 \\
<1.000 \\
55 \\
60 \\
18 \\
<1.0 \\
19 \\
<1.0 \\
<20 \\
<20 \\
14 \\
3.1 E \cdot 09 \pm 1.4 E \cdot 09 \\
1.8 E-08 \pm 1.0 E-09 \\
1.5 E \cdot 09 \pm 1.3 E-09 \\
<7.0 E-07\end{array}$ & JQ & $\begin{array}{l}\mu g / L \\
\mu g / L \\
\mu g / L \\
\mu g / L \\
\mu g / L \\
\mu g / L \\
\mu g / L \\
\mu g / L \\
\mu g / L \\
\mu g / L \\
\mu g / L \\
\mu g / L \\
\mu g / L \\
\mu g / L \\
\mu g / L \\
\mu g / L \\
\mu g / L \\
\mu g / L \\
\mu g / L \\
\mu g / L \\
\mu g / L \\
\mu g / L \\
\mu g / L \\
\mu C i / m L \\
\mu C \mathrm{Ci} / \mathrm{mL} \\
\mu C \mathrm{~L} / \mathrm{mL} \\
\mu C \mathrm{C} / \mathrm{mL}\end{array}$ \\
\hline
\end{tabular}

\section{WELL MSB 65D}

\section{MEASUREMENTS CONDUCTED IN THE FIELD}

Sample date: 11/05/91

Depth to water: $116.49 \mathrm{ft}(35.51 \mathrm{~m})$ below TOC

Water elevation: $233.01 \mathrm{ft}(71.02 \mathrm{~m}) \mathrm{msl}$

Sp. conductance: $30 \mu \mathrm{S} / \mathrm{cm}$

Water evacuated betore sampling: $11 \mathrm{gal}$

The well went dry during purging

LABORATORY ANALYSES

\begin{tabular}{|c|c|c|c|}
\hline Analyte & Result & Mod & Unit \\
\hline $\begin{array}{l}\text { Chloroform } \\
\text { 1.1-Dichloroethylene } \\
\text { trans-1,2-Dichloroethylene } \\
\text { Tetrachloroethylene } \\
1,1,1 \text {-Trichloroethane } \\
\text { Trichloroethylene }\end{array}$ & $\begin{aligned}<50 \\
<5.0 \\
<5.0 \\
3.9 \\
<5.0 \\
<5.0\end{aligned}$ & & $\begin{array}{l}\mu \mathrm{g} / \mathrm{h} \\
\mu \mathrm{g} / \mathrm{L} \\
\mu \mathrm{g} / \mathrm{h} \\
\mu \mathrm{g} / \mathrm{h} \\
\mu \mathrm{g} / \mathrm{h} \\
\mu \mathrm{g} / \mathrm{L}\end{array}$ \\
\hline
\end{tabular}

WELL MSB 66B

MEASUREMENTS CONDUCTED IN THE FIELD

Sample date: $11 / 04 / 91$

Depth to water: $164.90 \mathrm{H}(50.26 \mathrm{~m})$ below TOC

Wate, elevation: $218.60 \mathrm{ft}(66.63 \mathrm{~m}) \mathrm{msl}$

Water evacuated before sampling: $208 \mathrm{gal}$

LABORATORY ANALYSES

\begin{tabular}{|c|c|c|c|}
\hline Analyte & Result & Mod & Unit \\
\hline $\begin{array}{l}\text { Chlorolorm } \\
1,1 \text {-Dichloroethylene } \\
\text { trans } 1,2 \cdot \text { Dichloroethylene } \\
\text { Tetrachloroethylene } \\
1,1,1 \cdot \text { Trichloroethane } \\
\text { Trichloroethylene }\end{array}$ & $\begin{aligned}<5.0 \\
<5.0 \\
<5.0 \\
2.2 \\
<5.0 \\
<5.0\end{aligned}$ & & $\begin{array}{l}\mu \mathrm{g} / \mathrm{h} \\
\mu \mathrm{g} / \mathrm{L} \\
\mu \mathrm{g} / \mathrm{L} \\
\mu \mathrm{g} / \mathrm{L} \\
\mu \mathrm{g} / \mathrm{L} \\
\mu \mathrm{g} / \mathrm{L}\end{array}$ \\
\hline
\end{tabular}

WELL MSB 66C

MEASUAEMENTS CONDUCTED IN THE FIELD

Sample date: $11 / 04 / 91$ it $(47.43 \mathrm{~m})$ below TOC

Water elevation: $227.88 \mathrm{Ht}(69.46 \mathrm{~m}) \mathrm{ms}$ )

Sp. conductance: $26 \mu \mathrm{S} / \mathrm{cm}$

Water evacuated before sampling $162 \mathrm{gal}$

Time: 7:40

Alkalinity: $0 \mathrm{mg}$

Water tempera:ure: $15.1^{\circ} \mathrm{C}$

LABORATORY ANALYSES

\begin{tabular}{|c|c|c|c|}
\hline Analyte & Result & Mod & Unit \\
\hline $\begin{array}{l}\text { Chloroform } \\
1,1 \text {-Dichioroethylene } \\
\text { trans } \cdot 1,2 \cdot \text { Dichloroethylene } \\
\text { Tetrachloroethylene } \\
1,1,1 \cdot \text { Trichloroethane } \\
\text { Trichioroethylene }\end{array}$ & $\begin{array}{rl}<1 & 0 \\
<1.0 \\
<1.0 \\
79 \\
<1.0 \\
98\end{array}$ & & $\begin{array}{l}\mu g / L \\
\mu g / L \\
\mu g / L \\
\mu g / L \\
\mu g / L \\
\mu g / L\end{array}$ \\
\hline
\end{tabular}

Time: $6: 30$

Alkalinity: $80 \mathrm{mg} / \mathrm{t}$

Water temperature: $16.8^{\circ} \mathrm{C}$

Alkalinity: $8 \mathrm{mg} / \mathrm{L}$ Water temperature $169^{\circ} \mathrm{C}$ 
ANALYTICAL RESULTS

WELL MSB 66D

MEASUREMENTS CONDUCTED IN THE FIELD

Sample date: $11 / 04 / 91$
Depth to water: $152.54 \mathrm{ft}(46.49 \mathrm{~m})$ below TOC Time: $7: 35$
Water elevation: $230.78 \mathrm{ft}$ (70.34 m) msl
Inaccessibility or pump failure prevented sample collection.

WELL MSB 66TA

MEASUREMENTS CONDUCTED IN THE FIELD

\section{Sample date: 11/04/91}

Depth to water: 177.97 it $(54.25 \mathrm{~m})$ below TOC

Water elevation: $204.83 \mathrm{ft}(62.43 \mathrm{~m}) \mathrm{msl}$

Sater evacuated betore sampling: $456 \mathrm{gal}$

LABORATORY ANALYSES

\begin{tabular}{|c|c|c|c|c|}
\hline & Analyte & I 业 & Mod & Unit \\
\hline $\begin{array}{l}0 \\
0 \\
2 \\
0\end{array}$ & $\begin{array}{l}\text { Chloroform } \\
1,1-\text { Dichloroethylene } \\
\text { trans } 1,2 \text {-Dichloroethylene } \\
\text { Tetrachloroethylene } \\
1,1,1-\text { Trichloroethane } \\
\text { Trichloroethylene }\end{array}$ & $\begin{array}{r}<5.0 \\
<5.0 \\
<5.0 \\
6.8 \\
<5.0 \\
12\end{array}$ & & $\begin{array}{l}\mu g / h \\
\mu g / L \\
\mu g / L \\
\mu g / L \\
\mu g / L \\
\mu g / h\end{array}$ \\
\hline
\end{tabular}

\section{WELL MSB 67B}

MEASUREMENTS CONDUCTED IN THE FIELD

\begin{tabular}{|c|c|c|}
\hline & $\begin{array}{l}\text { ple date: } 11 / 01 / 91 \\
\text { th to water: } 146.58 \mathrm{ft}(44.68 \\
\text { er elevation: } 218.52 \mathrm{ft}(66.6 \\
\text { conductance: } 59 \mathrm{\mu S} / \mathrm{cm} \\
\text { er evacuated before sampli }\end{array}$ & $\begin{array}{l}\text { below } \mathrm{T} \\
\text { ) } \mathrm{msl} \\
290 \mathrm{gal}\end{array}$ \\
\hline & BORATORY ANALYSES & \\
\hline & Analyte & Resul \\
\hline & $\begin{array}{l}\text { Chloroform } \\
1,1-\text { Dichloroethylene } \\
\text { trans } 1,2 \text {-Dichloroethylene } \\
\text { Tetrachloroethylene } \\
1,1,1 \text {-Trichloroethane } \\
\text { Trichloroethylene }\end{array}$ & $\begin{aligned} & 4.1 \\
&< 10 \\
&<10 \\
&<10 \\
&<10 \\
& 413\end{aligned}$ \\
\hline
\end{tabular}

WELL MSB 67C

MEASUREMENTS CONDUCTED IN THE FIELD Sample date: $11 / 01 / 81$
Depth to water: $136.74 \mathrm{ft}(41.68 \mathrm{~m})$ below TOC
Water elevation. $228.06 \mathrm{tt}(69.51 \mathrm{~m}) \mathrm{msl}$ Sp. conductance: $48 \mu \mathrm{S} / \mathrm{cm}$

Water evacuated betore sampling: $152 \mathrm{gal}$

LABORATORY ANALYSES

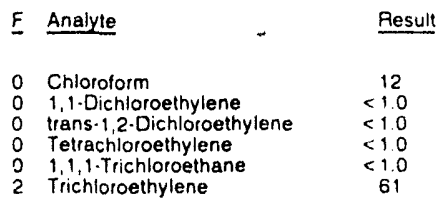

WELL MSB 67D

MEASUAEMENTS CONDUCTED IN THE FIELD

Sample date: $12 / 05 / 91$ f $(4056 \mathrm{~m})$ below TOC Water elevation: $231.93 \mathrm{H}(70.69 \mathrm{~m}) \mathrm{msl}$ Sp. conductance: $75 \mu \mathrm{S} / \mathrm{cm}$

Water evacuated before sampling: $27 \mathrm{gal}$

LABORATORY ANALYSES

\begin{tabular}{|c|c|}
\hline$=$ Analyte & Pesult \\
\hline $\begin{array}{l}\text { Chloroform } \\
1,1 \cdot \text { Dichloroethylene } \\
\text { trans }-1,2 \text {-Dichloroethyiene } \\
\text { Tetrachloroethylene } \\
1,1,1 . \text { Trichloroethane } \\
\text { Trichloroethylene }\end{array}$ & $\begin{array}{l}<100 \\
<100 \\
<100 \\
<100 \\
=100 \\
=5.040\end{array}$ \\
\hline
\end{tabular}

Time: $9: 15$

$\mathrm{pH}: 7.3$

Alkalinity: $19 \mathrm{mg} / \mathrm{L}$

Water temperature: $18.2^{\circ} \mathrm{C}$

Mod Unit Lab

$\begin{array}{ll}\mu g / L & M A \\ \mu g / L & M A \\ \mu g / L & M A \\ \mu g / L & M A \\ \mu g / L & M A \\ \mu g / L & M A\end{array}$

Time: 900

$\mathrm{pH}: 6.2$

Alkalinity: $9 \mathrm{mg} / \mathrm{L}$

Water temperature: $18.5^{\circ} \mathrm{C}$

Mod Unit

$\begin{array}{ll}\mu g / L & M A \\ \mu g / L & M A \\ \mu g / L & M A \\ \mu g / L & M A \\ \mu g / L & M A \\ \mu g / L & M A\end{array}$

Time: $10: 45$

pH: 6.1

Mod Unit Lab

$\begin{array}{ll}\mu g / L & M A \\ \mu g / L & M A \\ \mu g / L & M A \\ \mu g / L & M A \\ \mu g / L & M A \\ \mu g / L & M A\end{array}$

\section{WELL MSB 68B}

MEASUREMENTS CONDUCTED IN THE FIELD

Sample date: 11/01/91

Depth to water: $137.78 \mathrm{H}(41.99 \mathrm{~m})$ below TOC

Water elevation: 219.14 it $(66.78$

Water evacuated before sampling: $238 \mathrm{gal}$

LABORY, I JRY ANALYSES

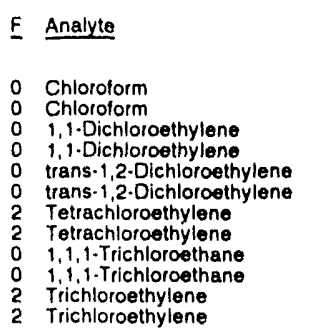

\begin{tabular}{|c|}
\hline Result \\
\hline $\begin{array}{c}<2.0 \\
<2.0 \\
<2.0 \\
<2.0 \\
<2.0 \\
<2.0 \\
19 \\
19 \\
<2.0 \\
<2.0 \\
118 \\
120\end{array}$ \\
\hline
\end{tabular}

WELL MSB 68C

MEASUREMENTS CONOUCTED IN THE FIELD Sample date: 12/05/91

Depth to water: $130.59 \mathrm{Ht}(39.80 \mathrm{~m})$ below TOC Water elevation: $226.11 \mathrm{ft}(68.92 \mathrm{~m}) \mathrm{ms})$

Sp. conductance: $29 \mu \mathrm{S} / \mathrm{cm}$

LABORATORY A.NALYSES

E Analyte

$\underline{\text { Result }}$

o Chloroform

1,1.Dichioroethylene

o Tetrachloroethylent

o 1.1.1-Trichloroethane

WELL MSB 68D

MEASUREMENTS CONDUCTED IN THE FIELD

Sample date: 12/05/91

Depth to water: $124.10 \mathrm{ft}(37.83 \mathrm{~m})$ below TOC Water elevation: $232.90 \mathrm{ft}(70.99 \mathrm{~m}) \mathrm{msl}$

Sp conductance: $37 \mu \mathrm{s} / \mathrm{cm}$

LABORATORY ANALYSES

E Analyte

$<10$
$<10$
$<10$
$<10$
$<10$
887

Time: $9: 50$

pH: 5.3

Alkalinity: $1 \mathrm{mg} / \mathrm{h}$

Water temperature: $17.2^{\circ} \mathrm{C}$

\begin{tabular}{|c|c|}
\hline Mod & Unit \\
\hline & $\begin{array}{c}\mu g / \\
\mu g / \\
\mu g / L \\
\mu g / L \\
\mu g / L \\
\mu g / L\end{array}$ \\
\hline
\end{tabular}

Time: 10:05

pH: $\mathbf{5 . 6}$

Alkalinity: $3 \mathrm{mg} / \mathrm{L}$

Water temperature: $17.8^{\circ} \mathrm{C}$

$\begin{array}{ll}0 & \text { Chlorolorm } \\ 0 & 1,1-\text { Dichloroethylene }\end{array}$

o trans-1,2-Dichloroethylene

Tetrachloroethylene

1,1,1-Trichloroethane
2 Trichloroethylene

WELL MSB 69B

MEASUREMENTS CONDUCTED IN THE FIELD

Sample date: 11/01/91

Depth to water: $160.44 \mathrm{H}(48.90 \mathrm{~m})$ below TOC

Water elevation: $221.26 \mathrm{ft}(67.44 \mathrm{~m}) \mathrm{msl}$

Sp conductance: $34 \mu \mathrm{S} / \mathrm{cm}$

Alkalinity $11 \mathrm{mg} / \mathrm{L}$

LABORATORY ANALYSES

E Analyte

Result

- Chloroform

0 trans-1,2-Dichloroethylen

Tetrachloroethylene

O $1,1,1$. Trichloroetnan
Trichloroethylene
Time: $10: 50$

$\mathrm{pH} 6.0$

Alkalinity: $9 \mathrm{mg} / \mathrm{h}$
Water temperature $188^{\circ} \mathrm{C}$

$\begin{array}{ccc}\text { Mod Unit } & \text { Lab } \\ & & \\ \mu g / L & M A \\ \mu g / L & M A \\ \mu g / L & M A \\ \mu g / L & M A \\ \mu g / L & M A \\ \mu g / L & M A\end{array}$




\section{WELL MSB 69C}

MEASUREMENTS CONOUCTEO IN THE FIELD

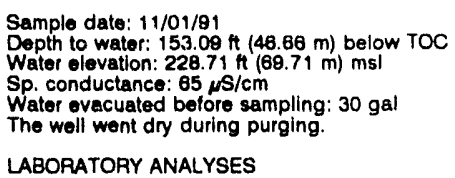

LABORATORY ANALYSES

\begin{tabular}{|c|c|}
\hline Analyte & Result \\
\hline $\begin{array}{l}\text { Chloroform } \\
1,1-\text { Dichloroethylene } \\
\text { trans-1,2-Dichloroethylone } \\
\text { Totrachloroethylene } \\
1,1,1 \text {-Trichloroethane } \\
\text { Trichloroethylene }\end{array}$ & $\begin{array}{l}<2.0 \\
<2.0 \\
<2.0 \\
<2.0 \\
<2.0 \\
167\end{array}$ \\
\hline
\end{tabular}

WELL MSB 69D

MEASUREMENTS CONDUCTED IN THE FIELD

Sample dato: 11/01/91

Dopth to water: $148.02 \mathrm{ft}(45.12 \mathrm{~m})$ below TOC Water olevation: $234.18 \mathrm{ft}(71.38 \mathrm{~m}) \mathrm{msl}$

Sp. conductance: $24 \mu \mathrm{S} / \mathrm{cm}$

Water evacuated before tismpling: $36 \mathrm{gal}$

LABORATORY ANALYSES

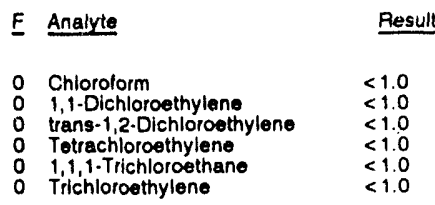

WELL MSB 69TA

MEASUREMENTS CONDUCTED IN THE FIELD

Sample date: 11/01/91

Depth to walor: $166.38 \mathrm{ft}(50.71 \mathrm{~m})$ below TOC Water elevation: $215.12 \mathrm{tt}(65.57 \mathrm{~m}) \mathrm{msl}$ Sp. conductance: $36 \mu \mathrm{S} / \mathrm{cm}$

Water ovacuatod before sampling: $368 \mathrm{gal}$

LABORATORY ANALYSES

\begin{tabular}{|c|c|c|c|c|}
\hline$F$ & Analyte & Result & Mod & Unit \\
\hline $\begin{array}{l}0 \\
0 \\
0 \\
0 \\
0\end{array}$ & $\begin{array}{l}\text { Chloroform } \\
1,1-\text { Dichloroethylene } \\
\text { trans-1,2-Oichloroethylene } \\
\text { Tetrachloroethylene } \\
1,1,1 \text {-Trichloroethane } \\
\text { Trichloroethylene }\end{array}$ & $\begin{array}{l}<1.0 \\
<1.0 \\
<1.0 \\
<1.0 \\
<1.0 \\
<1.0\end{array}$ & & $\begin{array}{l}\mu g / L \\
\mu g / L \\
\mu g / L \\
\mu g / L \\
\mu g / L \\
\mu g / L\end{array}$ \\
\hline
\end{tabular}

WELL MSB 70C

MEASUREMENTS CONOUCTED IN THE FIELD

Sample date: 11/05/91

Depth to water: $146.82 \mathrm{At}(44.75 \mathrm{~m})$ below TOC

Water elevation: $215.38 \mathrm{ft}(85$.

Sp. conductance: $181 \mu \mathrm{s} / \mathrm{cm}$
Water evacuated before sampling: $107 \mathrm{gal}$

LABORATORY ANALYSES

\begin{tabular}{|c|c|c|}
\hline & Analyte & Result \\
\hline$\frac{0}{2}$ & $\begin{array}{l}\text { Chlorofoim } \\
1,1-\text { Dichlorcethylene } \\
\text { trans } 1,2 \cdot \text { Dichloroethylene } \\
\text { Tetrachloroethylene } \\
1,1,1 \text {. Trichloroethane } \\
\text { Trichloroethylene }\end{array}$ & $\begin{array}{l}<5.0 \\
57 \\
<5.0 \\
412 \\
35 \\
54\end{array}$ \\
\hline
\end{tabular}

Time: 15:10

pH: 6.1

Akalinity: $13 \mathrm{mg} / \mathrm{L}$

Water temperature: $18.8^{\circ} \mathrm{C}$

Mod Unit Lab

$\begin{array}{ll}\mu g / L & M A \\ \mu g / L & M A \\ \mu g / L & M A \\ \mu g / L & M A \\ \mu g / L & M A \\ \mu g / L & M A\end{array}$

Time: 11:25

pH: 4.4

Alkalinity: $0 \mathrm{mg} / \mathrm{h}$

Water temperature: $18.8^{\circ} \mathrm{C}$

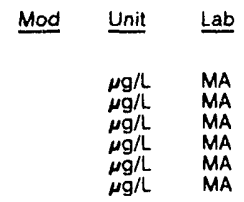

Time: $11: 10$

pH: 6.1

Alkalinity: $8 \mathrm{mg} / \mathrm{L}$

Water temperature: $19.0^{\circ} \mathrm{C}$

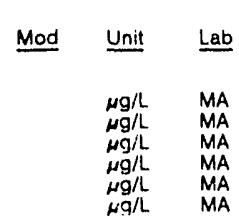

Time: $9: 30$

pH: 6.0

Alkalinity. $16 \mathrm{mg} / \mathrm{L}$

$\begin{array}{ll}\mu g / L & M A \\ \mu g / L & M A \\ \mu g / L & M A \\ \mu g / L & M A \\ \mu g / L & M A \\ \mu g / L & M A\end{array}$
Water temperature: $16.2^{\circ} \mathrm{C}$
WELL MSB 70D

MEASUREMENTS CONDUCTED IN THE FIELD

Sample date: $11 / 08 / 91$

Depth to water: $143.80 \mathrm{Ht}(43.83 \mathrm{~m})$ below TOC

Water elevation: $218.70 \mathrm{H}(66.66 \mathrm{~m}) \mathrm{ms}$ !

Sp. conductance: $72 \mu \mathrm{S} / \mathrm{cm}$

Water evacuated before sampling: $7 \mathrm{gal}$

The well went dry during purging.

LABORATORY ANALYSES

F Analyte Result Mod Unit Lab

$\begin{array}{ll}0 & \mathrm{pH} \\ 0 & \text { Specific conductance } \\ 0 & \text { Arsenic }\end{array}$

0 Barium

$\begin{array}{ll}0 & \text { Benzene } \\ 0 & \text { Bromodichloromothane }\end{array}$

Bromoform

Bromomethane

Cadmium

Calcium

Chloride

Chloroethane

Chloroethene (Vinyl chloride

2.Chloroethyl vinyl ether

Chloroform

Chloromethane

Chromium

Dibromochloromethane

1,1-Dichloroethane

1,2-Dichloroethane
1,1-Dichloroethylene

1,1-Dichloroethylene
trans-1,2-Dichloroethylene

trans-1,2-Dichloroe
Dichloromethane

1,2-Dichloropropane

cis-1,3-Dichloropropene
cisto

trans-1,3-Dichloropropene

Ethylbenzene

Fiuoride

lion

Magnesium

Manganes

Mercury

Nitrate as nitrogen

Nitrate as nitrogen

Phenols

Potassium

Selenium

Silica

Silver

Sodium

1,1,2,2-Tetrachloroethane

Tetrachloroethylene

Total dissolved solids

Total organic carbon

Total organic halogens

Total phosphates (as $P$

1,1.1. Trichloroethane

Trichlorothylene

- Trichlorofluoromethane

Gross alpha

Nonvolatile beta

2 Total radium

\section{WELL MSB 71B}

MEASUREMENTS CONDUCTED IN THE FIELD

Sample date: 11/06/91

Depth to water $129.17 \mathrm{H}(39.37 \mathrm{~m})$ below TOC

Water elevation: $215.93 \mathrm{tt}(65.82 \mathrm{~m}) \mathrm{ms}$ l

Sp. conductance: $2239 \mu \mathrm{S} / \mathrm{cm}$

5.8

pH: 5.5

alinity: $5 \mathrm{mg} / \mathrm{L}$

政

列

LABORATORY ANALYSES

\begin{tabular}{|c|c|c|c|}
\hline Analyte & Resull & Mod & Unit \\
\hline $\begin{array}{l}\text { Chloroform } \\
\text { 1.1.Dichloroethylene } \\
\text { trans-1,2-Dichloroethylene } \\
\text { Tetrachloroethylene } \\
\text { 1,1.1. Trichioroethane } \\
\text { Trichloroethylene }\end{array}$ & $\begin{array}{l}<5.0 \\
<50 \\
<5.0 \\
<5.0 \\
<50 \\
<5.0\end{array}$ & & $\begin{array}{l}\mu \mathrm{g} / \mathrm{L} \\
\mu \mathrm{g} / \mathrm{L} \\
\mu \mathrm{g} / \mathrm{L} \\
\mu \mathrm{g} / \mathrm{L} \\
\mu \mathrm{g} / \mathrm{L} \\
\mu \mathrm{g} / \mathrm{L}\end{array}$ \\
\hline
\end{tabular}


ANALYTICAL RESULTS

WELL MSB 72B

MEASUREMENTS CONDUCTED IN THE FIELD

Sample date: $10 / 30 / 91$
Oepth to water: $129.46 \mathrm{ht}(39.48 \mathrm{~m})$ below TOC

Water elevation: $198.74 \mathrm{th}(60.58 \mathrm{~m}) \mathrm{msl}$

Sp. conductance: $24 \mu \mathrm{S} / \mathrm{cm}$
Water evacuated before sampling: $123 \mathrm{gal}$

LABORATORY ANALYSES

\begin{tabular}{|c|c|}
\hline Anaiyte & Resul \\
\hline $\begin{array}{l}\text { Chloroform } \\
1,1-\text { Dichloroethylene } \\
\text { trans } 1,2 \text {-Dichloroethylene } \\
\text { Tetrachloroethylene } \\
1,1,1 . \text { Trichloroethane } \\
\text { Trichloroethylene }\end{array}$ & $\begin{array}{l}<1.0 \\
<1.0 \\
<1.0 \\
<1.0 \\
<1.0 \\
<1.0\end{array}$ \\
\hline
\end{tabular}

WELL MS3 338

MEASUREMENTS CONDUCTED IN THE FIELD

Sample date: $10 / 30 / 91 \mathrm{H}(42.63 \mathrm{~m})$ below TOC

Depth to water: $139.67 \mathrm{Ht}(42.63 \mathrm{~m})$ below
Water olevation: $200.53 \mathrm{ft}(61.12 \mathrm{~m}) \mathrm{msl}$

Sp. conductance: $36 \mu \mathrm{S} / \mathrm{cm}$

Water evacuated before sampling: $181 \mathrm{gal}$

LABORATORY ANAL.YSES

\begin{tabular}{|c|c|c|c|c|}
\hline$F$ & Analyte & Result & Mod & Unit \\
\hline & $\begin{array}{l}\text { Chloroform } \\
1,1-\text { Dichloroethylene } \\
\text { trans } \cdot 1,2 \cdot \text { Dichloroethylene } \\
\text { Tetrachioroethylene } \\
1,1,1 \cdot \text { Trichloroethane } \\
\text { Trichloroethylene }\end{array}$ & $\begin{array}{r}1.8 \\
<2.0 \\
<2.0 \\
1.4 \\
<2.0 \\
35\end{array}$ & & $\begin{array}{l}\mu \mathrm{g} / \mathrm{L} \\
\mu g / \mathrm{L} \\
\mu g / \mathrm{L} \\
\mu g / \mathrm{L} \\
\mu \mathrm{g} / \mathrm{L} \\
\mu \mathrm{g} / \mathrm{L}\end{array}$ \\
\hline
\end{tabular}

WELL MSB 74B

MEASUREMENTS CONDUCTED IN THE FIELD

Sample date: $12 / 02 / 91$

Depth to water: $103.86 \mathrm{ft}(31.66 \mathrm{~m})$ below TOC Water elevation: $210.64 \mathrm{ft}(64.20 \mathrm{~m}) \mathrm{msl}$

Water evacuated before sampling: $267 \mathrm{gal}$

LABORATORY ANALYSES

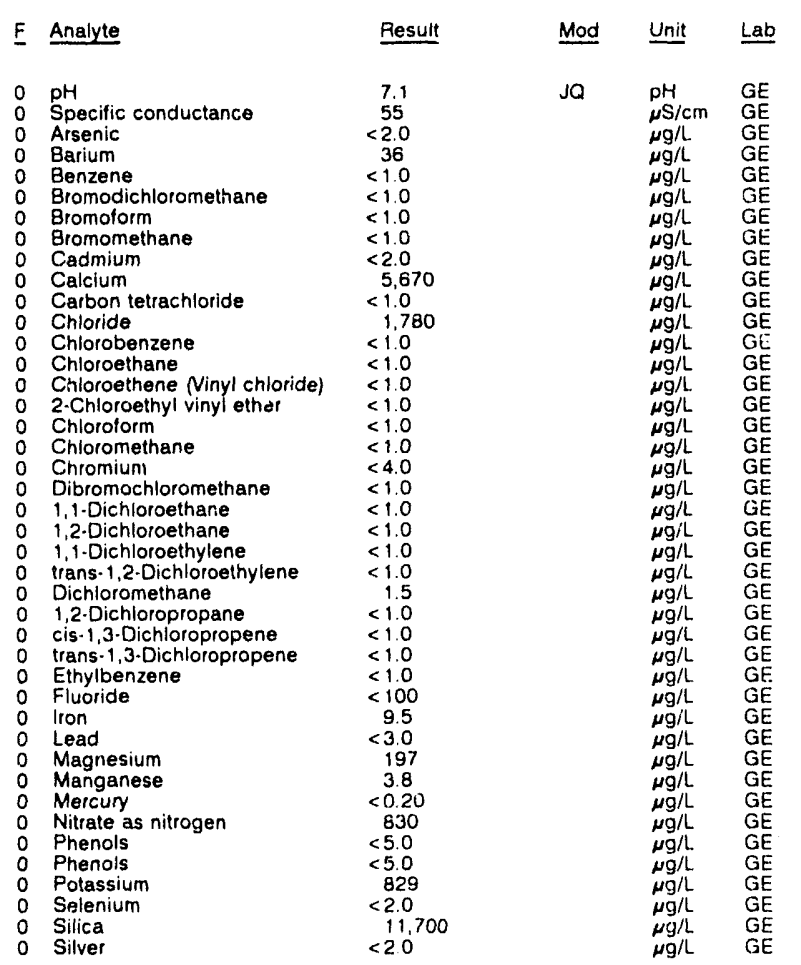

Time: 13:20

PH: 7.0 Alkalinity: $16 \mathrm{mg}$

Alkalinity: $16 \mathrm{mg} / \mathrm{L}, 19.1^{\circ} \mathrm{C}$
WELL. MSB 748 collected on 12/02/91, laboratory analyses (cont.)

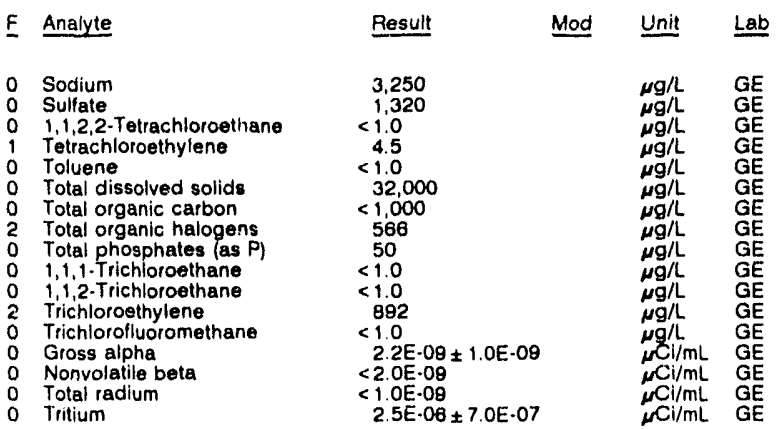

\section{WELL MSB 74C}

MEASUREMENTS CONDUCTED IN THE FIELD

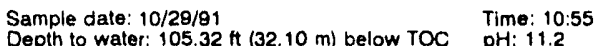

Water elevation: $209.68 \mathrm{ft}(63.91 \mathrm{~m})$ mst $\mathrm{TOC}$ pH: 11.2

Water evacuated before sampling: $18 \mathrm{gal}$

Water temperature: $17.6^{\circ} \mathrm{C}$

LABORATORY ANALYSES

E Analyte Result Mod Unit

$2 \mathrm{pH}$

Specific conductance

Arsenic

Benzene

Bromodichloromethane

Bromoform

Bromomethan

Cadmium

Carbon tetrachloride

Carbon

Chloride

Chlorobenzene

Chloroethene Ninyl chloride

2.Chloroethyl vinyl ether

Chloroform

Chloromethane

Chromium

Dibromochloromethane

1.1. Dichloroethane

o 1.1.Dichloroethylene

0 trans-1.2-Dichloroethylene

Dichloromethane

cis-13-Dichloropropene

trans-1,3-Dichloropropene

0 Ethylbenzene

0 Fluoride

0 iron

Magnesium

o Manganes

0 Mercury

Nitrate as nitrogen

Nitrate as nitrogen

Phenols

o Potassium

Selenium

Silica

Silver

Sodium

1,1,2,2-Tetrachloroethane

Tetrachloroethylene

Toluene

- Total dissolved solids

- Total organic carbon

Total organic halogens

Total phosphates (as $P$

i1, irichloroethane

- 1,1,2- irichloroethane

o Trichlorofluoromethane

o Grues alpha

o Nonvolatile beta

Total ratium

iritium

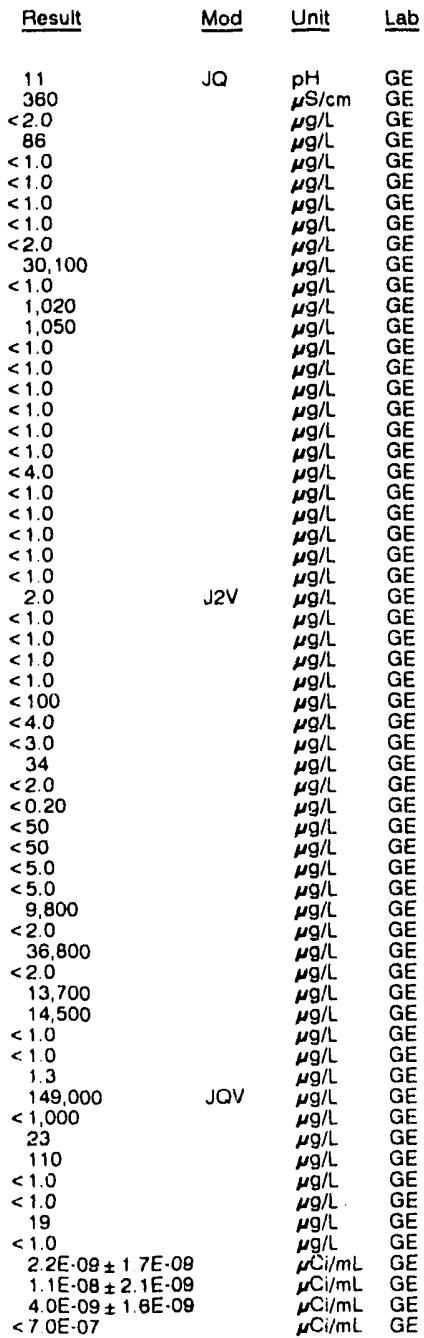


WELL MSB 74D

MEASUREMENTS CONOUCTED IN THE FIELD

Sample date: 10/29/91

Depth to water: $81.93 \mathrm{ft}(24.97 \mathrm{~m})$ below TOC

Sp. conductance: $37 \mu \mathrm{S} / \mathrm{cm}$

Water evacuated betore sampling: $14 \mathrm{gal}$

The well went dry during purging.

LABORATORY ANALYSES

\begin{tabular}{|c|c|c|c|c|c|}
\hline E & Analyte & Result & Mod & Unit & $\underline{\text { Lab }}$ \\
\hline & $\begin{array}{l}\mathrm{pH} \\
\text { Specific conductance }\end{array}$ & $\begin{array}{l}6.0 \\
40\end{array}$ & Jo & $\mathrm{pH}$ & GE \\
\hline & $\begin{array}{l}\text { Specific conductance } \\
\text { Arsenic }\end{array}$ & $\begin{array}{r}40 \\
<2.0\end{array}$ & & $\begin{array}{l}\mu \mathrm{S} / \mathrm{cm} \\
\mu \mathrm{g} / \mathrm{L}\end{array}$ & $\begin{array}{l}\mathrm{GE} \\
\mathrm{GE}\end{array}$ \\
\hline & Barium & $<3.0$ & & $\mu \mathrm{g} / \mathrm{L}$ & $\mathrm{GE}$ \\
\hline & $\begin{array}{l}\text { Benzene } \\
\text { Bromodichloromethane }\end{array}$ & $<1.0$ & & $\mu \mathrm{g} / \mathrm{L}$ & $\mathrm{GE}$ \\
\hline & $\begin{array}{l}\text { Bromodichloromethane } \\
\text { Bromoform }\end{array}$ & $\begin{array}{l}<1.0 \\
<1.0\end{array}$ & & $\underset{\mu g / L}{\mu g / L}$ & $\mathrm{GE}$ \\
\hline & Bromomethane & $<1.0$ & & $\mu \mathrm{g} / \mathrm{L}$ & $\mathrm{GE}$ \\
\hline & $\begin{array}{l}\text { Cadmium } \\
\text { Calcium }\end{array}$ & $\begin{aligned}<2.0 \\
280\end{aligned}$ & & $\underset{\mu g / h}{\mu g / L}$ & $\begin{array}{l}\mathrm{GE} \\
\mathrm{GE}\end{array}$ \\
\hline & Carbon tetrachloride & $<1.0$ & & $\mu \mathrm{g} / \mathrm{L}$ & $G E$ \\
\hline & Chloride & 1,920 & & $\mu \bar{g} / \mathrm{L}$ & $\mathrm{GE}$ \\
\hline & $\begin{array}{l}\text { Chlorobenzene } \\
\text { Chloroethane }\end{array}$ & $\begin{array}{l}<1.0 \\
<1.0\end{array}$ & & $\mu \mathrm{g} / \mathrm{L}$ & $\begin{array}{l}\mathrm{GE} \\
\mathrm{GE}\end{array}$ \\
\hline & $\begin{array}{l}\text { Chloroethane } \\
\text { Chloroethene (Vinyl chloride) }\end{array}$ & $\begin{array}{l}<1.0 \\
<1.0\end{array}$ & & $\underset{\mu g / L}{\mu g / L}$ & $\mathrm{GE}$ \\
\hline & 2. Chloroethyl vinyl ether & $<1.0$ & & $\mu \mathrm{g} / \mathrm{L}$ & $\overrightarrow{G E}$ \\
\hline & Chloroform & $<1.0$ & & $\mu g / L$ & GE \\
\hline & $\begin{array}{l}\text { Chloromethane } \\
\text { Chromium }\end{array}$ & $<1.0$ & & $\mu \mathrm{g} / \mathrm{L}$ & $\mathrm{GE}$ \\
\hline & $\begin{array}{l}\text { Chromium } \\
\text { Dibromochioromethane }\end{array}$ & $\begin{array}{l}<4.0 \\
<1.0\end{array}$ & & $\mu g / L$ & $\begin{array}{l}\text { GE } \\
\text { GE }\end{array}$ \\
\hline & $\begin{array}{l}\text { Dibromochloromethane } \\
\text { 1,1-Dichloroethane }\end{array}$ & $\begin{array}{l}<1.0 \\
<10\end{array}$ & & $\begin{array}{l}\mu g / L \\
\mu g / L\end{array}$ & $G E$ \\
\hline & 1,2 -Dichloroethane & $<10$ & & $\mu g / L$ & $\mathrm{GE}$ \\
\hline & 1.1-Dichloroethylene & $<10$ & & $\mu \mathrm{g} / \mathrm{L}$ & GE \\
\hline & trans-1,2-Dichloroethylene & $<10$ & & $\mu g / L$ & GE \\
\hline & Dichloromethane & 2.0 & $\mathrm{~J} 2 \mathrm{~V}$ & $\mu g / L$ & \\
\hline & 1,2-Dichloropropane & $<10$ & & $\mu g / L$ & E \\
\hline & cis-1,3-Dichloropropene & $<10$ & & $\mu \mathrm{g} / \mathrm{h}$ & $\mathrm{GE}$ \\
\hline & trans-1,3-Dichloropropene & $<10$ & & $\mu g / L$ & $\mathrm{E}$ \\
\hline & Ethylbenzene & $<10$ & & $\mu g / L$ & $\mathrm{GE}$ \\
\hline & Fluoride & $<100$ & & $\mu g / L$ & E \\
\hline & Fluoride & $<100$ & & $\mu g / L$ & $\mathrm{GE}$ \\
\hline & Iron & 6.4 & & $\mu \mathrm{g} / \mathrm{L}$ & GE \\
\hline & Lead & $<3.0$ & & $\mu \mathrm{g} / \mathrm{L}$ & \\
\hline & Magnesium & 87 & & $\mu \mathrm{g} / \mathrm{L}$ & E \\
\hline & Manganese & 9.7 & & $\mu \mathrm{g} / \mathrm{L}$ & GE \\
\hline & Mercury & $<0.20$ & & $\mu g / L$ & $\mathrm{GE}$ \\
\hline & Nitrate as nitrogen & 800 & & $\mu g / L$ & \\
\hline & $\begin{array}{l}\text { Phenols } \\
\text { Potassium }\end{array}$ & $\begin{array}{l}<50 \\
<500\end{array}$ & & $\mu g / \mathrm{L}$ & $\mathrm{GE}$ \\
\hline & $\begin{array}{l}\text { Potassium } \\
\text { Selenium }\end{array}$ & $\begin{array}{l}<500 \\
<2.0\end{array}$ & & $\mu \mathrm{g} / \mathrm{L}$ & GE \\
\hline & Silica & 8,330 & & $\mu \mathrm{g} / \mathrm{L}$ & $\mathrm{GE}$ \\
\hline & Silver & $<2.0$ & & $\mu g / \mathrm{L}$ & $\mathrm{GE}$ \\
\hline & Sodium & 6.280 & & $\mu \mathrm{g} / \mathrm{L}$ & GE \\
\hline & Sulfate & 3,430 & & $\mu \mathrm{g} / \mathrm{h}$ & $\mathrm{GE}$ \\
\hline & 1,1,2,2-Tetrachloroethane & $<10$ & & $\mu g / L$ & $\mathrm{GE}$ \\
\hline & Tetrachloroethylene & $<10$ & & $\mu g / L$ & GE \\
\hline & Tolvene & $<1.0$ & & $\mu \mathrm{g} / \mathrm{L}$ & GE \\
\hline & Total dissolved solids & 27,000 & JQV & $\mu \mathrm{g} / \mathrm{L}$ & GE \\
\hline & Total organic carbon & $<1.000$ & & $\mu \mathrm{g} L$ & \\
\hline 0 & Total organic halogens & 54 & & $\mu \mathrm{g} / \mathrm{L}$ & $\mathrm{GE}$ \\
\hline 0 & Total phosphates (as P) & 310 & & $\mu g / L$ & $G E$ \\
\hline 0 & 1,1,1-Trichloroethane & $<10$ & & $\mu g / L$ & GE \\
\hline 0 & 1.1,2-Trichloroethane & $<10$ & & $\mu g / h$ & GE \\
\hline 0 & Trichloroethylene & 2.0 & & $\mu \mathrm{g} / \mathrm{L}$ & $G E$ \\
\hline 0 & Trichlorofluoromethane & $<1.0$ & & $\mu g / \mathrm{L}$ & GE \\
\hline & Gross alpha & $<20 E \cdot 09$ & & $\mu \mathrm{Ci} / \mathrm{mL}$ & GE \\
\hline 0 & Nonvolatile beta & $<20 E-09$ & & $\mu \mathrm{Ci} / \mathrm{mL}$ & $\mathrm{GE}$ \\
\hline 0 & Total radium & $<1$ OE.09 & & $\mu \mathrm{Ci} / \mathrm{mL}$ & $E$ \\
\hline & Tritium & $<7.0 E-07$ & & $\mu \mathrm{Cl}_{1}^{\prime} / \mathrm{nIL}$ & GE \\
\hline
\end{tabular}

WELL MSB 75B

MEASUREMENTS CONDUCTED IN THE FIELD

Sample date. 12/02/91

Depth to water: $117.10 \mathrm{ft}(35.69 \mathrm{~m})$ below TOC Water elevation: $20960 \mathrm{ft}(63.89 \mathrm{~m}) \mathrm{ms} /$

$\mathrm{Sp}$. conductance $62 \mu \mathrm{S} / \mathrm{cm}$

Water evacuated before samping $139 \mathrm{gal}$

LABORATORY ANALYSES

\begin{tabular}{lc} 
F Analyte & Result \\
\cline { 2 - 2 } & \\
0 pH & 6.6 \\
0 Specific conductance & 70 \\
0 Arsenic & $<2.0$ \\
0 Barium & 30 \\
0 Benzene & 1.0 \\
0 Bromodichloromethane & $<10$ \\
0 Bromotorm & $<10$ \\
0 Bromomethane & 110 \\
0 Cadmium & $<20$ \\
0 Calcium & 7.430 \\
0 Carbon tetrachloride & $<10$ \\
0 Chloride & 2,140
\end{tabular}

Time: 10.45

Alkalinity $14 \mathrm{mg} / \mathrm{L}$

Water temperature $176^{\circ} \mathrm{C}$

.

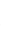

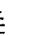

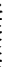

\section{WELL MSB 75C}

MEASUREMENTS CONDUCTED IN THE FIELD

Sample date $10 / 30 / 91$

Depth to water: $118.32 \mathrm{ft}(36.06 \mathrm{~m})$ below TOC

Water elevation $209.18 \mathrm{H}(63.76 \mathrm{~m}) \mathrm{msl}$

Sp conductance $92 \mu \mathrm{S} / \mathrm{cm}$

Water evacuated belore sampling $4 \mathrm{gal}$

uring purging

LABORATORY ANALYSES

\begin{tabular}{|c|c|c|c|c|c|}
\hline F & Analyte & Result & Mod & Unit & $\underline{L a b}$ \\
\hline 0 & $\mathrm{pH}$ & 6.2 & JO & $\mathrm{pH}$ & $\mathrm{GE}$ \\
\hline 0 & Specific conductance & 90 & & $\mu \mathrm{S} / \mathrm{cm}$ & $\mathrm{GE}$ \\
\hline 0 & Arsenic & $<2.0$ & & $\mu \mathrm{g} / \mathrm{h}$ & $\overrightarrow{G E}$ \\
\hline 0 & Barium & 16 & & $\mu \mathrm{g} / \mathrm{L}$ & GE \\
\hline 0 & Benzene & $<10$ & & $\mu \mathrm{g} / \mathrm{L}$ & GE \\
\hline 0 & Bromodichloromethane & $<1.0$ & & $\mu \mathrm{g} / \mathrm{h}$ & $\mathrm{GE}$ \\
\hline 0 & Bromoform & $<10$ & & $\mu \mathrm{g} / \mathrm{L}$ & $\mathrm{GE}$ \\
\hline 0 & Bromomethane & $<1.0$ & & $\mu \mathrm{g} / \mathrm{L}$ & GE \\
\hline 0 & Cadmium & $<20$ & & $\mu \mathrm{g} / \mathrm{L}$ & $\mathrm{GE}$ \\
\hline 0 & Calcium & 2,070 & & $\mu \mathrm{g} / \mathrm{L}$ & $\mathrm{GE}$ \\
\hline 0 & Carbon tellachloride & $<10$ & & $\mu g / L$ & \\
\hline 0 & Chloride & 2.170 & & $\mu \mathrm{g} / \mathrm{L}$ & $\mathrm{GE}$ \\
\hline 0 & Chlorobenzene & $<10$ & & $\mu \mathrm{g} / \mathrm{L}$ & $\mathrm{GE}$ \\
\hline 0 & Chloroethane & $<10$ & & $\mu g / \mathrm{L}$ & $\mathrm{GE}$ \\
\hline 0 & Chloroethene (Vinyl chloride) & $<10$ & & $\mu g / \mathrm{L}$ & \\
\hline 0 & 2-Chloroethyl vinyl ether & $<10$ & & $\mu \mathrm{g} / \mathrm{L}$ & $\mathrm{GE}$ \\
\hline 0 & Chloroform & $<10$ & & $\mu \mathrm{g} / \mathrm{L}$ & \\
\hline 0 & Chloromethane & $<10$ & & $\mu g / h$ & \\
\hline 0 & Chromium & $<40$ & & $\mu g / L$ & \\
\hline 0 & Dibromochloromethane & $<10$ & & $\mu g / L$ & $\mathrm{GE}$ \\
\hline 0 & 1.1. Dichloroethane & $<10$ & & $\mu g / L$ & \\
\hline 0 & 1.2-Dichloroethane & $<10$ & & $\mu \mathrm{g} / \mathrm{L}$ & \\
\hline 0 & 1,1. Dichloroethylene & $<1.0$ & & $\mu g / t$ & \\
\hline 0 & trans-1,2.Dichloroethylene & .10 & & $\mu \mathrm{g} / \mathrm{L}$ & \\
\hline 0 & Dichloromethane & $<10$ & $\mathrm{~J} 2 \mathrm{~V}$ & $\mu g / L$ & \\
\hline 0 & 1,2.Dichloropropane & $<10$ & & $\mu \mathrm{g} / \mathrm{L}$ & \\
\hline 0 & cis-1,3-Dichloropropene & $<10$ & & $\mu \mathrm{g} / \mathrm{L}$ & \\
\hline 0 & trans-1,3-Dichloropropene & $<10$ & & $\mu g / L$ & \\
\hline 0 & Etrylbenzene & $<10$ & & $\mu \mathrm{g} / \mathrm{l}$ & \\
\hline 0 & Fluoride & $<100$ & & $\mu g / L$ & \\
\hline 0 & Iron & $<40$ & & $\mu g / L$ & \\
\hline 0 & Lead & $<30$ & & $\mu g / L$ & \\
\hline 0 & Magnesium & 620 & & $\mu \mathrm{g} / \mathrm{L}$ & \\
\hline 1 & Manganese & 28 & & $\mu g / L$ & \\
\hline 0 & Mercury & $<020$ & & $\mu \mathrm{g} / \mathrm{L}$ & \\
\hline 0 & Nitrate as nitrogen & .50 & & $\mu g / \mathrm{L}$ & \\
\hline
\end{tabular}


ANALYTICAL RESULTS

WELL MSB 75C collected on 10/30/91, laboratory analyses (cont.)

\begin{tabular}{|c|c|c|c|c|}
\hline$F$ & Analyte & Result & Mod & Unit \\
\hline $\begin{array}{l}0 \\
0 \\
0 \\
0 \\
0 \\
0 \\
0 \\
0\end{array}$ & $\begin{array}{l}\text { Phenols } \\
\text { Potassium } \\
\text { Selenium } \\
\text { Silica } \\
\text { Silver } \\
\text { Sodium } \\
\text { Sulfate } \\
1,1,2,2 \text {-Tetrachloroethane } \\
\text { Tetrachloroethylene } \\
\text { Toluene } \\
\text { Total dissolved solids } \\
\text { Total organic carbon } \\
\text { Total organic halogens } \\
\text { Total phosphates (es P) } \\
1,1, \text { - Trichloroethane } \\
1,1,2 \text {-Trichloroethane } \\
\text { Trichloroethylene } \\
\text { Trichlorofluoromothane } \\
\text { Gross alpha } \\
\text { Nonvolatile beta } \\
\text { Total radium } \\
\text { Tritium }\end{array}$ & $\begin{array}{l}<5,0 \\
4,100 \\
<2,0 \\
50,600 \\
<2.0 \\
10,800 \\
16,300 \\
<1.0 \\
<1.0 \\
<1.0 \\
<1,000 \\
<1,000 \\
33 \\
80 \\
<1.0 \\
<1.0 \\
<1.0 \\
<1.0 \\
=2.0 \mathrm{E}-09 \\
41.0 \mathrm{E}-09 \pm 1.6 \mathrm{E}-09 \\
1.1 \mathrm{E} \cdot 09 \pm 1.2 \mathrm{E}-09 \\
<7.0 \mathrm{E}-07\end{array}$ & $v$ & $\begin{array}{l}\mu g / L \\
\mu g / L \\
\mu g / L \\
\mu g / L \\
\mu g / L \\
\mu g / L \\
\mu g / L \\
\mu g / L \\
\mu g / L \\
\mu g / L \\
\mu g / L \\
\mu g / L \\
\mu g / L \\
\mu g / L \\
\mu g / L \\
\mu g / L \\
\mu g / L \\
\mu g / L \\
\mu C \mathrm{~L} / \mathrm{mL} \\
\mu \mathrm{Ci} / \mathrm{mL} \\
\mu \mathrm{Ci} / \mathrm{mL} \\
\mu \mathrm{Ci} / \mathrm{mL}\end{array}$ \\
\hline
\end{tabular}

WELL MSB 76C

MEASUREMENTS CONDUCTED IN THE FIELD

Sample date: $11 / 21 / 91 \mathrm{ft}(40.62 \mathrm{~m})$ below TOC

Water elevation: $218.54 \mathrm{ft}(88.82 \mathrm{~m}) \mathrm{ms}$

Water evacuated before sampling: $98 \mathrm{gal}$

LABORATORY ANALYSES

E Analyte

0 pH

0 Apecific

0 Barium

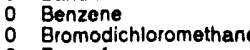

Bromoform

Bromomethan

Calcium

Carbon

Chloride
Chlorobenzene
Chloroethane

Chloroethene Ninyl chloride)

2.Chloroethyl vinyl ether

Chlorotorm

Chromium

Dibromochloromethane

1,1.Dichloroethane

1,1-Dichloroethylene

trans-1,2-Dichloro

1,2-Dichloropropane

cis-1,3-Dichioropropene

cis-1,3-Dichioropropene
trans-1,3-Dichloropropene

Ethylbenzene

Fluoride

Iron

Magnesium

Manganese

Mercury

Phenols

Potassium
Selenium

Selenı

Silver

Sodium

Sulfate

1,1,2.2.Tetrachloroethane

Tetrachloroethylene

Toluene

Total dissolved sclids

Total organic haloon

Total phosphates las P

$1,1,1$-Trichloroethane

i, 1,2 -Trichioroeth

Trichloroethylene

Gross alpha

Gross alpha
Nonvolatile beta

Total radium

Tritium
Time: 15:15

pH: 6.8

Alkalinity: $34 \mathrm{mg} / \mathrm{L}$

Water temperature: $1900^{\circ} \mathrm{C}$

Mod Unit Lab

Resuit

7.1
80
$<2.0$

$<2.0$
8.4
$<1.0$

$<1.0$

$<1.0$
$<1.0$

$<2.0$

$<1.0$

$<1.0$

$<1.0$

$<1.0$

$<1.0$

$<1.0$

$<1.6$

$<1.0$

$<1.0$
$<1.0$

$<1.0$

3.0
$<1.0$

$<1.0$

$<1.0$

$<100$

27
$<3.0$

138
3.0

$<0.20$

1,800
$<5.0$

3,230
$<2.0$

$<2.0$
$\mathbf{9}, 800$

$<2.0$
13,100

13,100
3,120

$<1.830$

1.830
$<1.0$
92.000

$<1,000$
25,300

25,300
150

$<1.0$

3.0
1.580

$<1.0$
$<2.0 E-09$

$<2.0 \mathrm{E}-09$

$<1$ OE-09
$<7.0 E-07$

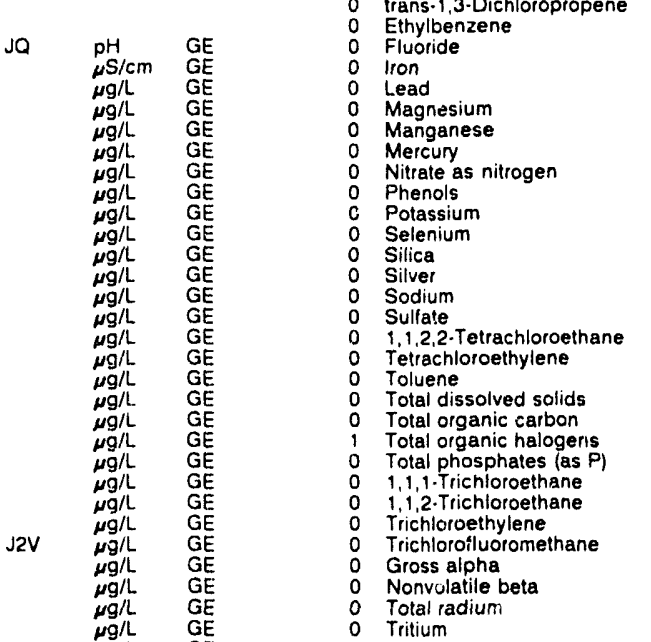

Ethylbenzene

Magnesium

Manganes

Nitrate as nitroge

oluene

Total dissolved solids

Torganic halogers

phosphates (as

1,1,2-Trichloroethane

atile be
WELL MSB 778

MEASUREMENTS CONDUCTED IN THE FIELO

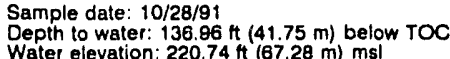

Water elevation: $220.74 \mathrm{ft}(67.28 \mathrm{~m}) \mathrm{msl}$

Water evacuated before sampling: $210 \mathrm{gal}$

LABORATORY ANALYSES

$\mathrm{pH}$
Specific
Arsenic

Barium

Bromodichloromethane

Bromolorm

Bromomethan

Cadmium

Carbon tetrachioride

Chloride

Chlorobenzen

Chloroethene (Vinyl chloride)

2.Chloroethyl vinyl ether

Chloroform

Chloromethane

Dibromochloromethane

1,1-Dichloroethane

1,2.Dichloroethane

trans-1,2-Dichloroethylene

Dichloromethane

cis.13-Dichloropropente

cisans-13-Dichloropropene

\section{WELL MSB 7TC}

MEASUREMENTS CONDUCTED IN THE FIELD

Sample date: 10/28/91

Depth to water: $134.86 \mathrm{Ht}(41.11 \mathrm{~m})$ below TOC

Water elevation: 222.84 ft $(97.92 \mathrm{~m}) \mathrm{ms}$

Sp conductance: $48 \mu \mathrm{S} / \mathrm{cm}$

Result $\quad$ Mod Unit Lab

ime: $9: 45$

Alkalinity: $64 \mathrm{mg} / \mathrm{L}$

Water temperature: $18.3^{\circ} \mathrm{C}$

作

LABORATORY ANALYSES

E Analyte

Result Mod Unit Lab

0 pH

Specific

Arsenic

Benzene

Bromodichloromethane

0 Bromoform

o Bromomethane

- Cadmium

O Carbon tetrachloride

Chloride

o Chlorobenzene

9.7
100
$<2.0$

$<1.0$

$<1.0$

$<2.0$

$<.0$
2,100

$<1.0$

$<1.0$

$<10$

$<4.0$

$<1.0$

$<1.6$

$<1.0$

$<1.0$

$<1.0$

$<.9$
$<3.0$

243
4.3

$<0.20$
390

$<5.0$
$7,09 \mathrm{C}$

$<2.00$

$<2.0$

$<1,000$

$<1.0$

49,000
$<1,000$

50

$<1.0$

2.0

$<2.0 E \cdot 09$

$7.8 \mathrm{E}-09 \pm 1.8 \mathrm{E}-09$

$1.3 E \cdot 09 \pm 1.4 E \cdot 09$
$<7.0 E .07$

$\begin{array}{ll}\mathrm{pH} & \mathrm{GE} \\ \mu \mathrm{S} / \mathrm{cm} & \mathrm{GE}\end{array}$
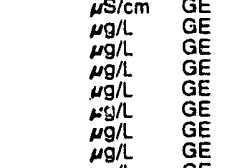

$\mu$

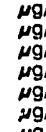

$\mu \mathrm{g} / \mathrm{L} \quad \mathrm{GE}$

$\mu g / L \quad G E$

$\mu g / L \quad G E$

$\mu g /$
$\mu g /$
$\mu g /$
$\mu g / L$
$\mu g / h$
$\mu g / h$
$\mu g /$
$\mu g /$
$\mu g /$
$\mu c /$
$\mu C i / m$
$\mu C i / m$

GE 


\section{ANALYTICAL RESULTS}

WELL MSB 77 C collected on 10/28/91, laboratory analyses (cont.)

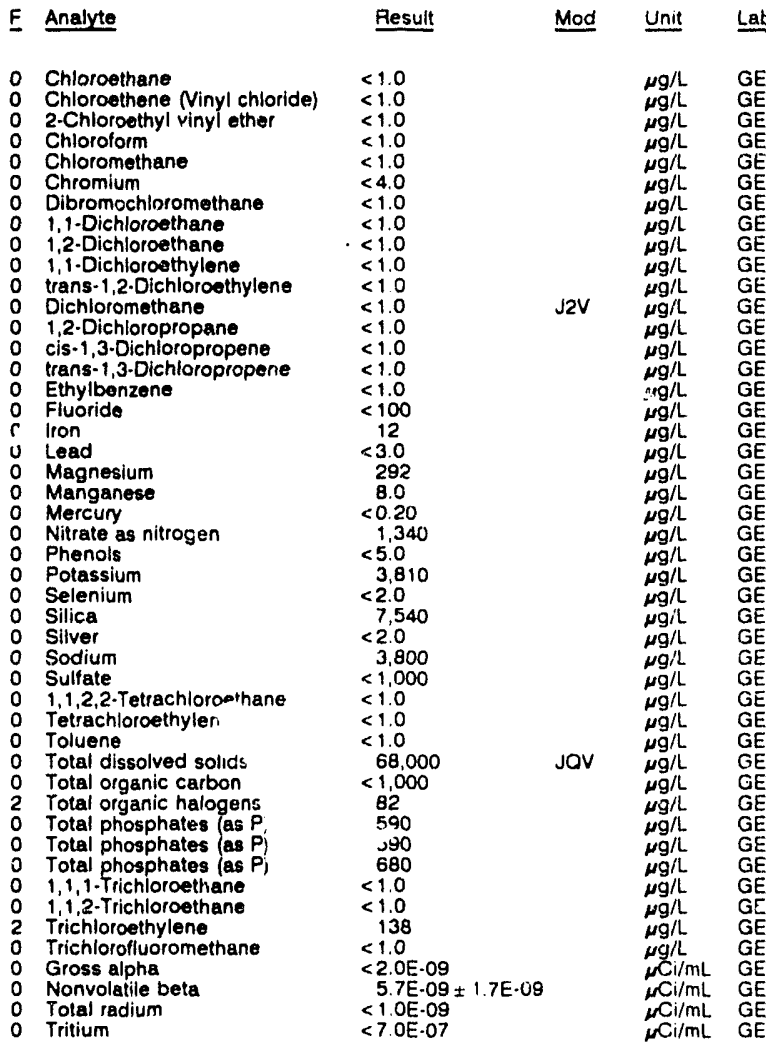

WELL MSB 77D

MEASUREMENTS CONDUCTED IN THE FIELD

Sample date. 10/28/81

Depth to water: $124.51 \mathrm{ft}(37.95 \mathrm{~m})$ below TOC

Water elevation: $233.29 \mathrm{H}(71.11$

Sp. conductance: $1369 \mu \mathrm{s} / \mathrm{cm}$

The well went dry during purging. $14 \mathrm{gal}$

LABORATORY ANALYSES

\begin{tabular}{|c|c|c|c|}
\hline Analyte & Pesult & Mod & Unit \\
\hline $\begin{array}{l}\text { pH } \\
\text { Specific conductance } \\
\text { Arsenic } \\
\text { Barium } \\
\text { Benzene } \\
\text { Bromodichloromethane } \\
\text { Gromoform } \\
\text { Bromomethane } \\
\text { Cadmium } \\
\text { Calcium } \\
\text { Carbon tetrachloride } \\
\text { Chioride } \\
\text { Chlorobenzene } \\
\text { Chloroethane } \\
\text { Chloroethene Ninyl chloride) } \\
\text { 2.Chloroethyl vinyl ether } \\
\text { Chloroform } \\
\text { Chloromethane } \\
\text { Chromium } \\
\text { Dibromochloromethane } \\
\text { 1,1-Dichloroethiane } \\
\text { 1,2-Dichloroethane } \\
\text { 1,1.Dichloroethylene } \\
\text { trans-1,2-Dichloroethylene } \\
\text { Dichloromethane } \\
1,2 \cdot \text { Dichloropropane } \\
\text { cis-1,3.Dichloropropene } \\
\text { trans-1,3-Dichloropropene } \\
\text { Ethylbenzene } \\
\text { Fluoride } \\
\text { tron } \\
\text { Lead } \\
\text { Magnesium } \\
\text { Manganese } \\
\text { Mercuny } \\
\text { Nitrate as nitrogen }\end{array}$ & $\begin{array}{l}6.4 \\
1,250 \\
3.5 \\
69 \\
<1.0 \\
<1.0 \\
<10 \\
<1.0 \\
<2.0 \\
11,400 \\
<1.0 \\
880 \\
<1.0 \\
<10 \\
<10 \\
<10 \\
<1.0 \\
<1.0 \\
111 \\
<1.0 \\
<1.0 \\
<1.0 \\
<1.0 \\
<1.0 \\
<1.0 \\
<10 \\
<1.0 \\
<1.0 \\
<1.0 \\
398 \\
18 \\
64 \\
8.4 \\
<2.0 \\
<020 \\
390\end{array}$ & $\mathrm{~J} 2 \mathrm{~V}$ & $\begin{array}{l}p H \\
\mu S / c m \\
\mu g / L \\
\mu g / L \\
\mu g / L \\
\mu g / L \\
\mu g / L \\
\mu g / L \\
\mu g / L \\
\mu g / L \\
\mu g / L \\
\mu g / L \\
\mu g / L \\
\mu g / L \\
\mu g / L \\
\mu g / L \\
\mu g / L \\
\mu g / L \\
\mu g / L \\
\mu g / L \\
\mu g / L \\
\mu g / L \\
\mu g / L \\
\mu g / L \\
\mu g / L \\
\mu g / L \\
\mu g / L \\
\mu g / L \\
\mu g / L \\
\mu g / L \\
\mu g / L \\
\mu g / L \\
\mu g / L \\
\mu g / L \\
\mu g / L \\
\mu g / L\end{array}$ \\
\hline
\end{tabular}

WELL MSB 77D collected on 10/28/91, laboratory analyses (cont.)

\begin{tabular}{|c|c|c|c|}
\hline Analyte & Result & Mod & Unit \\
\hline $\begin{array}{l}\text { Phenols } \\
\text { Potassium } \\
\text { Selenium } \\
\text { Silica } \\
\text { Silver } \\
\text { Sodium } \\
\text { Sulfate } \\
1,1,2,2 \cdot \text { Tetrachloroethane } \\
\text { Tetrachloroethylene } \\
\text { Toluene } \\
\text { Total dissolved solids } \\
\text { Total organic carbon } \\
\text { Total organic halogens } \\
\text { Total phosphates (as P) } \\
\text { 1,1,1. Trichloroethane } \\
1,1,2 . \text { Trichloroethane } \\
\text { Trichloroethylene } \\
\text { Trichlorofluoromethane } \\
\text { Gross alpha } \\
\text { Nonvolatile beta } \\
\text { Total radium } \\
\text { Tritium }\end{array}$ & $\begin{array}{l}<5.0 \\
81,800 \\
2.0 \\
14,000 \\
<2.0 \\
73,400 \\
15,300 \\
<1.0 \\
<1.0 \\
<1.0 \\
36,000 \\
2,000 \\
12 \\
120 \\
<1.0 \\
<1.0 \\
<1.0 \\
<1.0 \\
6.7 E \cdot 09 \pm 6.9 E \cdot 08 \\
6.2 E \cdot 08 \pm 12 E \cdot 08 \\
<1.0 E \cdot 09 \\
<7.0 E \cdot 07\end{array}$ & JQV & $\begin{array}{l}\mu g / L \\
\mu g / L \\
\mu g / L \\
\mu g / L \\
\mu g / L \\
\mu g / L \\
\mu g / L \\
\mu g / L \\
\mu g / L \\
\mu g / L \\
\mu g / L \\
\mu g / L \\
\mu g / L \\
\mu g / L \\
\mu g / L \\
\mu g / L \\
\mu g / L \\
\mu g / L \\
\mu C i / m L \\
\mu C i / m L \\
\mu C i / m L \\
\mu C i / m L\end{array}$ \\
\hline
\end{tabular}

WELL MSB 7TTA

MEASUREMENTS CONDUCTED IN THE FIELD

Sample date: i $0 / 28 / 91$

Depth to water: $136.88 \mathrm{Ht}(41.72 \mathrm{~m})$ below TOC

Water elevation: $220.52 \mathrm{Ht}$

Time: $9: 55$

Wherance. $269 \mu \mathrm{S} / \mathrm{cm}$

Tne well went dry during purging: 73 gal

LABORATORY ANALYSES

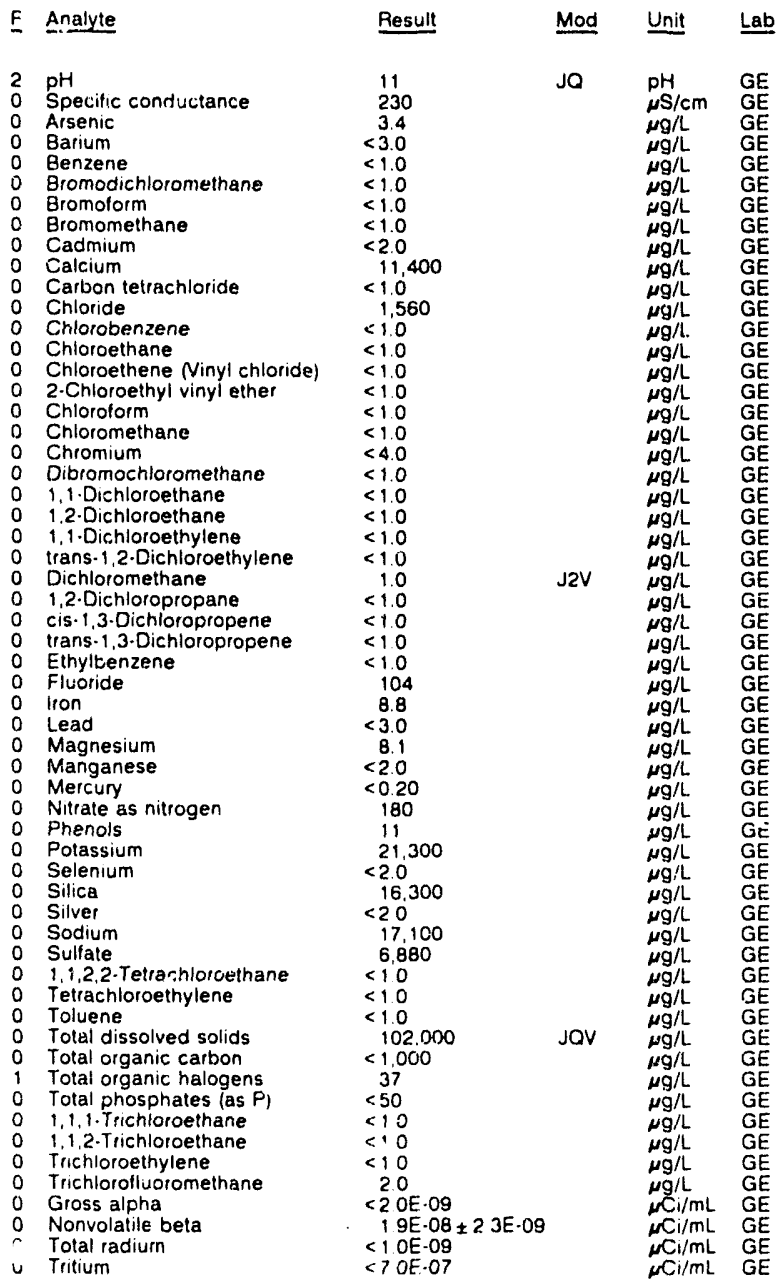


ANALYTICAL RESULTS

WELL MSB 78D

MEASUREMENTS CONDUCTED IN THE FIELD

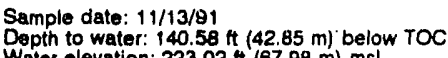

$223.02 \mathrm{ft}(67.98 \mathrm{~m}) \mathrm{ms}$

Inaccessibility or pump failure prevented sample collection

WELL MSB 79B

MEASUREMENTS CONDUCTED IN THE FIELD

Sample date: 10/02/81 Depth to water: $140.88 \mathrm{ft}(42.97 \mathrm{~m})$ below TOC Water olevation: $207.02 \mathrm{n}(63.10 \mathrm{~m}) \mathrm{msl}$

Sp, conductance: $2375 \mu \mathrm{s} / \mathrm{cm}$

Sp, conductance: 2375 ss/cm
Water evacuated before sampling: $43 \mathrm{gal}$
The well went dy during purging.

LABORATORY ANALYSES

F Analyte

2 pH 2 Specific conductance

Arsenic

Barium

Bromodichloromethane

Bromolorm

Bromomethane

Cadmium

Carbon tetrachloride

Chioride

Chlorobenzene

Chloroethane Ninyl chloridel

2.Chloroethyl vinyl ether

Chlorolorm

Chloromethane

Chromium

Dibromochloromethene

i, - Dichloroethane

1, -Dichloroethylens

trans-1,2-Dichloroethylene

Dichloromethane

1,2-Dichloropropane

cis-1,3-Dichloropropene

Ethylbenzene

Fluoride

lron

Magnesium

Manganese

Mercury

Nitrate as nitrogen

Nitrate as nitrogen

Phenols

Potassium

Selica

Silver

Silver

Sodium

Sulfate

1,1,2,2-Tetrachloroethane

Tetrachloroethylene

Toluene

Total dissolved solids

Total organic carbon

Total phosphates las P

1,1,1. Trichloroethane

1,1,2-Trichioroethe

Trichloroethylene

Gross alpha

Nonvolatile bete

Total radium
Time: 10:15

pH: 12.3

Alkalinity: $930 \mathrm{mg} / \mathrm{L}$

Water temperature: $18.4^{\circ} \mathrm{C}$

\section{Result}

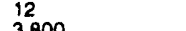

3,800
$<2,0$

898
$<1.0$

$<1.0$

$<1.0$

$<1.0$

254,000

$<1.0$

$<1.0$

$<1.0$

$<1.0$

$<1.0$

$<.7$
$<1.0$

$<1.0$

$<1.0$
$<1.0$
$<1.0$
1.0

1.0
$<1.0$

$<1.0$

$<1.0$

$<1.0$

7.6
15
5.6
$<4.0$

$<<.0$

340

360
5.3
76,200

$<2.0$
2.560

$\begin{aligned} & 2,560 \\ < & 4.0\end{aligned}$

$<4.07,200$

4,760
4,820

4,820
$<1.0$

$<1.0$
4.0

$905,000 v$

2,000

16

$<50$

$<50$
$<1.0$
$<1.0$

$<1.0$
$5.8 \mathrm{E}-09 \pm 5.0 \mathrm{E} \cdot 09$
$5.6 \mathrm{E}-08 \pm 7.4 \mathrm{E} \cdot 09$

$5.2 \mathrm{E}-09 \pm 4.2 \mathrm{E}-09$
$2.2 \mathrm{E}-06 \pm 2.0 \mathrm{E}-07$
WELL MSB 79C

MEASUREMENTS CONDUCTED IN THE FIELD

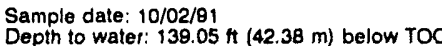

Water elevation: $208.75 \mathrm{ft}(63.63 \mathrm{~m}) \mathrm{ms}$ )

Sp. conductance: $2217 \mu \mathrm{s} / \mathrm{cm}$

Water evacuated before sampling: $6 \mathrm{gal}$

The well went dry during purging.

LABORATORY ANALYSES

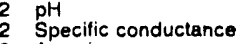

Arsenic

0 Barium

Bromodichloromethane

Bramoform

Bromomethane

Cadmium

Carbon tetrachioride

Chloride

Chlorobenzene

Chloroethane

2.Chloroethyl vinyl ether

Chloroform

Chloromethane

Chromium

Dibromochloromethane

1,1-Dichloroethane

1,2 . Dichloroethane

1,1 -Dichloroethylene

trans-1,2-Dichloroethylene

Dichloromethane

cis-1,3-Dichloropropene

trans-1,3-Dichloropropene

Ethylbenzene

Fluorid

Lead

Magnesium

Manganese

Mercury

Nitrate as nitrogen

Phenols

Potassium

Selenium

Silica

Silver

$1,1,2,2 \cdot$ Tetrachloroethane

Tetrachloroethylen

Toluene

Total dissolved solids

Total organic carbon

Total organic halogens

Total phosphates as P

1.1.1. Trichloroethane

Trichloroethylene

Trichlorofiuoromethane

Gross alpha

Nonvolatile bet

Total radium

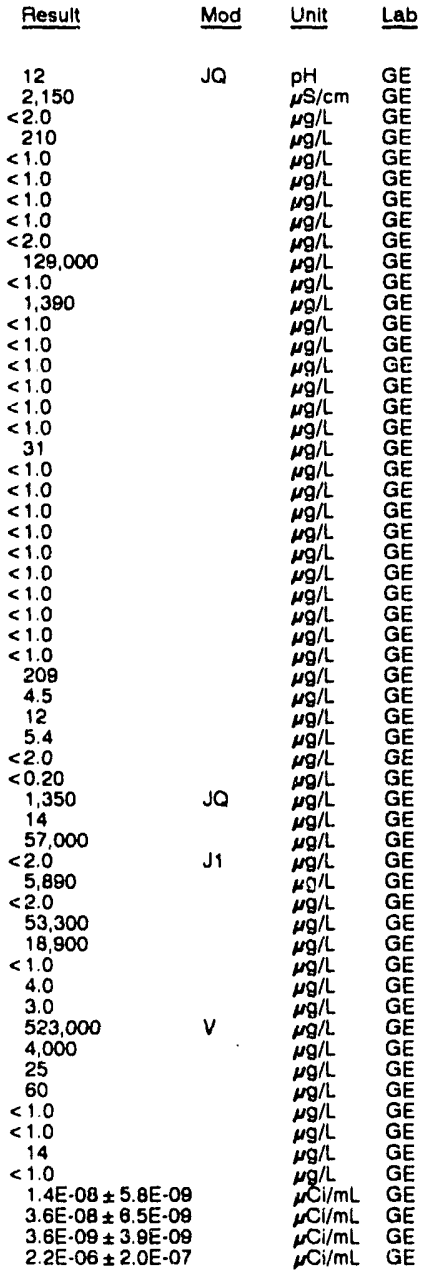

WELL MSB 81B

MEASUREMENTS CONDUCTED IN THE, "IELD

Sample date: 10/03/81

Depth to water: $48.35 \mathrm{ft}(14.74 \mathrm{~m})$ below TOC

Water elevation: $218.85 \mathrm{ft}(64.7$

Water evacuated before sampling: $204 \mathrm{gal}$

LABOPATOPY ANALYSES

\begin{tabular}{|c|c|c|c|}
\hline Analyte & Result & Mod & Unit \\
\hline $\begin{array}{ll}0 & \text { pH } \\
0 & \text { Specitic conductance } \\
0 & \text { Arsenic } \\
0 & \text { Barium } \\
0 & \text { Benzene } \\
0 & \text { Bromodichloromethane } \\
0 & \text { firomolorm } \\
0 & \text { Gromomethane } \\
0 & \text { Cadmium } \\
0 & \text { Calcium } \\
0 & \text { Carbon tetrachloride } \\
0 & \text { Chloride } \\
0 & \text { Chloride }\end{array}$ & $\begin{aligned} 6.1 \\
40 \\
<2.0 \\
27 \\
<1.0 \\
<1.0 \\
<1.0 \\
<1.0 \\
<2.0 \\
2.670 \\
<1.0 \\
3.060 \\
3.140\end{aligned}$ & JO & $\begin{array}{l}\mathrm{pH} \\
\mu \mathrm{S} / \mathrm{cm} \\
\mu g / L \\
\mu g / L \\
\mu g / L \\
\mu g / L \\
\mu g / L \\
\mu g / L \\
\mu g / L \\
\mu g / L \\
\mu g / L \\
\mu g / L \\
\mu g / L\end{array}$ \\
\hline
\end{tabular}




\section{ANALYTICAL RESULTS}

WELL MSB 81 B collected on 10/03/91, laboratory analyses (cont.)

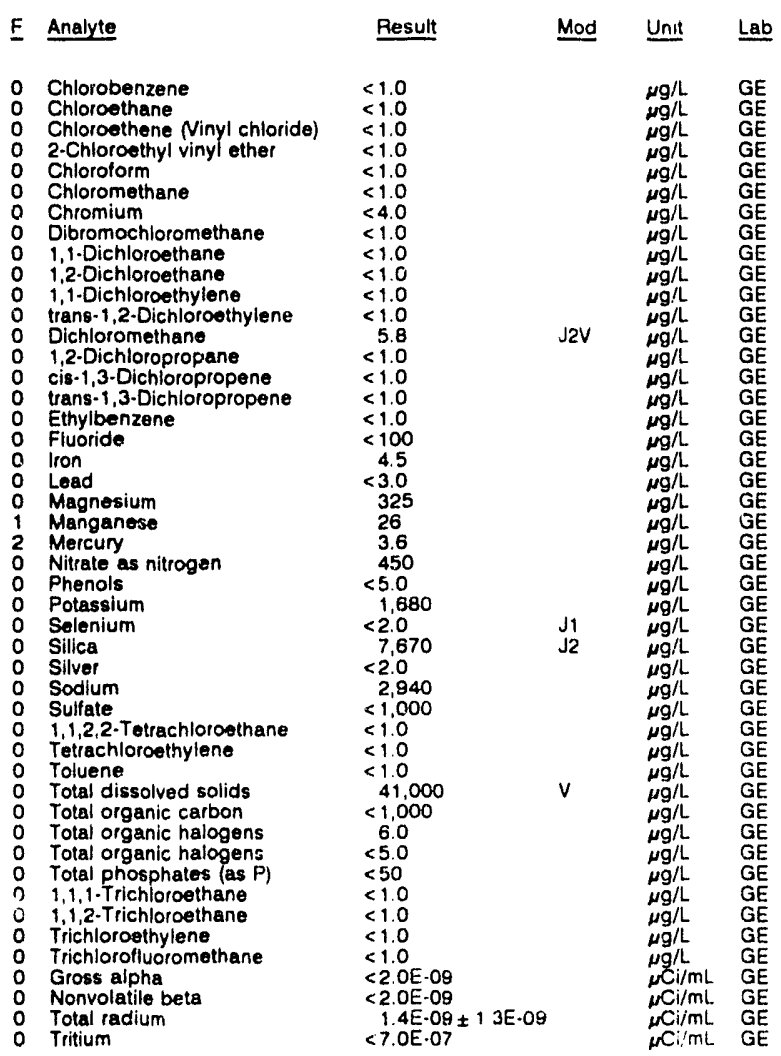

WELL MSB 82A

MEASUREMENTS CONDUCTED IN THE FIELD

Sample date: $10 / 02 / 91$ f $(45.08 \mathrm{~m})$ below TOC

Water olevation: $226.59 \mathrm{Ht}(69.07 \mathrm{~m}) \mathrm{msl}$

Sp. conductance: $2225 \mu \mathrm{s} / \mathrm{cm}$

Water evacuated before sampling. $30 \mathrm{ga}$

The well went dry during purging.

LABORATORY ANALYSES

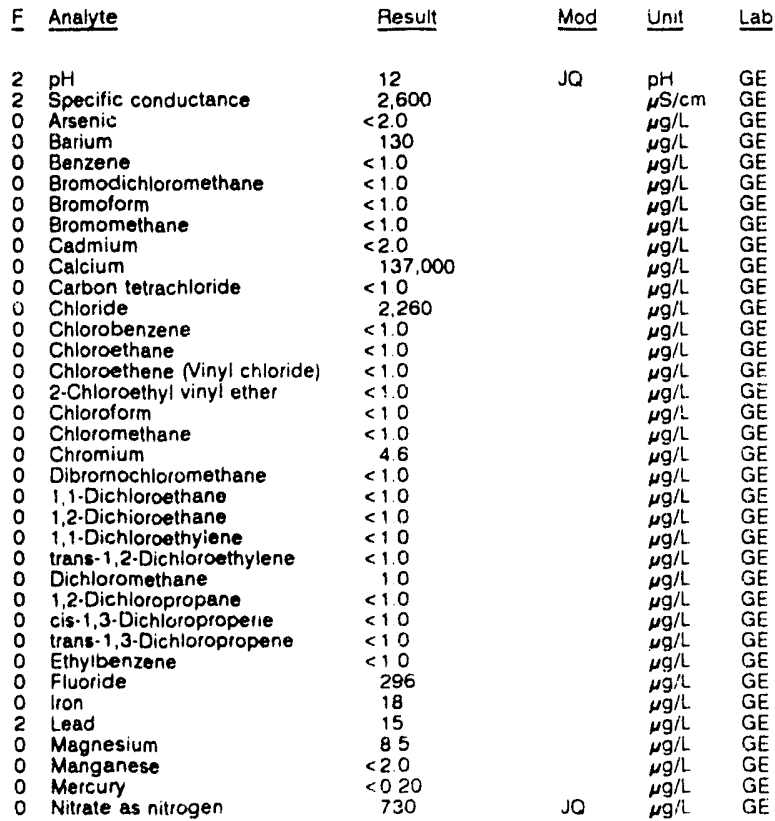

WELL MSB 82A collected on 10/02/91, laboratory analyses (cont.)

\begin{tabular}{|c|c|c|c|c|c|}
\hline$F$ & Analyte & Result & Mod & Unit & $\underline{L a b}$ \\
\hline $\begin{array}{l}0 \\
0 \\
0 \\
0 \\
0 \\
0 \\
0 \\
0 \\
0 \\
0 \\
0 \\
0 \\
1 \\
2 \\
0 \\
0 \\
0 \\
2 \\
0 \\
0 \\
1 \\
0 \\
0\end{array}$ & $\begin{array}{l}\text { Phenols } \\
\text { Potassium } \\
\text { Selenium } \\
\text { Silica } \\
\text { Silver } \\
\text { Sodium } \\
\text { Sulfate } \\
1,1,2,2-\text { Tetrachloroethane } \\
\text { Tetrachloroethylene } \\
\text { Toluene } \\
\text { Total dissolved solids } \\
\text { Total dissolved solids } \\
\text { Total organic carbon } \\
\text { Total organic halogens } \\
\text { Total phosphates (as P) } \\
\text { 1,1,1-Trichloroethane } \\
\text { 1,1,2.Trichloroethane } \\
\text { Trichloroethyiene } \\
\text { Trichlorofluoromethane } \\
\text { Gross alpha } \\
\text { Nonvolatile beta } \\
\text { Total radium } \\
\text { Tritium }\end{array}$ & $\begin{array}{l}19 \\
77,000 \\
<2.0 \\
4,270 \\
<2.0 \\
80,400 \\
21,100 \\
<1.0 \\
<1.0 \\
26 \\
626,000 \\
646,000 \\
5,000 \\
55 \\
<50 \\
<1.0 \\
<1.0 \\
40 \\
<1.0 \\
4.6 \mathrm{E} \cdot 09 \pm 5.1 \mathrm{E} \cdot 09 \\
4.4 \mathrm{E} \cdot 08 \pm 7.0 \mathrm{E} \cdot 09 \\
<1.0 \mathrm{E} \cdot 09 \\
1.6 \mathrm{E} \cdot 06 \pm 2.0 \mathrm{E} \cdot 07\end{array}$ & $\begin{array}{l}J 1 \\
\mathrm{~J} 2\end{array}$ & $\begin{array}{l}\mu g / L \\
\mu g / L \\
\mu g / L \\
\mu g / L \\
\mu g / L \\
\mu g / L \\
\mu g / L \\
\mu g / L \\
\mu g / L \\
\mu g / L \\
\mu g / L \\
\mu g / L \\
\mu g / L \\
\mu g / L \\
\mu g / L \\
\mu g / L \\
\mu g / L \\
\mu g / L \\
\mu g / L \\
\mu C i / m L \\
\mu C i / m L \\
\mu C l / m L \\
\mu C l / m L\end{array}$ & $\begin{array}{l}\mathrm{GE} \\
\mathrm{GE} \\
\mathrm{GE} \\
\mathrm{GE} \\
\mathrm{GE} \\
\mathrm{GE} \\
\mathrm{GE} \\
\mathrm{GE} \\
\mathrm{GE} \\
\mathrm{GE} \\
\mathrm{GE} \\
\mathrm{GE} \\
\mathrm{GE} \\
\mathrm{GE} \\
\mathrm{GE} \\
\mathrm{GE} \\
\mathrm{GE} \\
\mathrm{GE} \\
\mathrm{GE} \\
\mathrm{GE} \\
\mathrm{GE} \\
\mathrm{GE}\end{array}$ \\
\hline
\end{tabular}

\section{WELL MSB 82B}

MEASUREMENTS CONDUCTED IN THE FIELD

$\begin{array}{ll}\text { Sample date: } 10 / 02 / 91 & \text { Time: } 9: 00 \\ \text { Depth to water: } 154.26 \mathrm{H}(47.02 \mathrm{~m}) \text { below TOC } & \text { pH: } 4.1 \\ \text { Water elevation: } 220.14 \mathrm{H}(67.10 \mathrm{~m}) \mathrm{msl} & \text { Alkatinity: } 0 \mathrm{mg} / \mathrm{h} \\ \text { Sp. conductance: } 41 \mu \mathrm{cm} / \mathrm{cm} & \text { Water temperature: } 18.1^{\circ} \mathrm{C} \\ \text { Water evacuated betore sampling: } 200 \mathrm{gal} & \end{array}$

Water evacuated betore sampling: $200 \mathrm{gal}$

LABORATOAY ANALYSES

$\begin{array}{ll}\mathrm{pH} \\ 0 & \text { Specific conductance }\end{array}$

Arsenic

Barium

Benzene
Bromodichloromethane

Bromotorm

Bromotorm

Cadmium

Calcium

Carbon tetrachloride

Chloride

Chlorobenzene

Chloroethane

Chloroethene Ninyl chloride

2.Chloroethyl vinyl ethet

Chlorolorm

Chloromethan

Dibromochloromethane

1,i.Dichloroethane

1.2-Dichloroethane

1,1-Dichloroethylene

trans-1,2-Dichloroethylene

Dichloromethane

cis-1 3-Dichlopane

trans-13-Dichloropropene

Ethylbenzene

Fluorid

0 Iron

Magnesium

Manganese

Mercun

Nitrate as nitrogen

Phenols

Selenium

Silica

Silica

Sodium

Sullate

Sulfate

Tetrachloroethylene

Tolvene

Total dissolved soltds

Total organic carbon

Total organic halogens

Total phosphates (as P)

Total phosphates (as $P$

1, 1. Trichloroethane

1,1,2 Trichloroethane

Trichlorofluoromethane

Gross alpha

Nonvolatie beta

Tritium

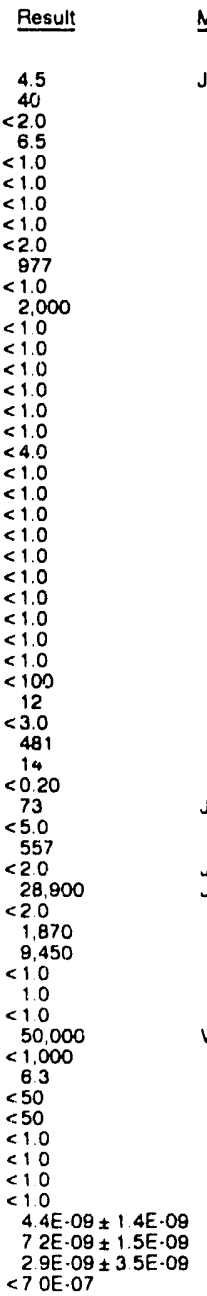

Mod Unit Lab

Jo

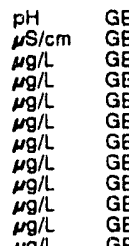

$\begin{array}{cc}\mathrm{gH} & \mathrm{GE} \\ \mathrm{S} / \mathrm{cm} & \mathrm{GE} \\ \mathrm{g} / \mathrm{L} & \mathrm{GE} \\ \mathrm{g} / \mathrm{L} & \mathrm{GE} \\ \mathrm{g} / \mathrm{L} & \mathrm{GE} \\ \mathrm{g} / \mathrm{L} & \mathrm{GE} \\ \mathrm{g} / \mathrm{L} & \mathrm{GE} \\ \mathrm{g} / \mathrm{L} & \mathrm{GE} \\ \mathrm{g} / \mathrm{L} & \mathrm{GE} \\ \mathrm{g} / \mathrm{L} & \mathrm{GE} \\ \mathrm{g} / \mathrm{L} & \mathrm{GE}\end{array}$

$g / L \quad G E$

$\mu g / L \quad G E$

$\mu g / L \quad G E$

$\mu g / L \quad G E$

$\mu g / L \quad G E$

$\mu g / 2$
$\mu g$

$\mu g / 2$
$\mu g i L$
$\mu G E$

$\begin{array}{ll}\mu g / L & G E \\ \mu g h & G E\end{array}$

$\begin{array}{ll}\mu g / L & G E \\ \mu g / L & G E \\ \mu g / L & G E\end{array}$

o

$\mu 9$ GE

$\sqrt{31}$

$\mu g h$ GE

$\begin{array}{ll}\mu g / \lambda & G E \\ \mu g / \lambda & G E \\ \mu g / \lambda & G E\end{array}$

$\begin{array}{ll}\mu, \mu / L & G E \\ \mu g / L & G E \\ \mu g / L & G E\end{array}$

GE

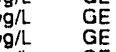

$\mu g / L$
$\mu g h$ GE

gh GE

Hgh GE

CilmL GE

NCI/mL GE 
ANALYTICAL RESULTS

WELL MSB 82C

MEASUREMENTS CONDUCTED IN THE FIELD

Sample date: 10/02/91 Depth to water: $150.64 \mathrm{ft}(45.82 \mathrm{~m})$ below TOC Water elevation: $223.38 \mathrm{Ht}(68.08 \mathrm{~m}) \mathrm{msl}$

Water evacuated before sampling: 132 gal

LABORATORY ANALYSES

\begin{tabular}{|c|c|c|c|c|}
\hline $\mathbf{F}$ & Analyte & Result & Mod & Unit \\
\hline $\begin{array}{l}0 \\
0 \\
0 \\
0\end{array}$ & $\begin{array}{l}\text { Chlorolorm } \\
1,1 \text {-Dichloroethylene } \\
\text { trans-1,2-Dichloroethylene } \\
\text { Tetrachloroethylene } \\
1,1,1 \text {. Trichloroethane } \\
\text { Trichloroethylene }\end{array}$ & $\begin{array}{l}<1.0 \\
<1.0 \\
<1.0 \\
<1.0 \\
<1.0 \\
<1.0\end{array}$ & & $\begin{array}{l}\mu g / L \\
\mu g / L \\
\mu g / L \\
\mu g / L \\
\mu g / L \\
\mu g / L\end{array}$ \\
\hline
\end{tabular}

WELL MSB 82D

MEASUREMENTS CONDUCTED IN THE FIELD

Sample dite: 100219

Depth to water: $141.62 \mathrm{Ht}(43.17 \mathrm{~m})$ below TOC Water olevation: $232.08 \mathrm{ft}(70.74 \mathrm{~m}) \mathrm{msl}$

Water evacuated before sampling: $40 \mathrm{gal}$

LABORATORY ANALYSES

\begin{tabular}{|c|c|c|c|c|}
\hline Analyte & Resull & Mod & Uni & Lab \\
\hline 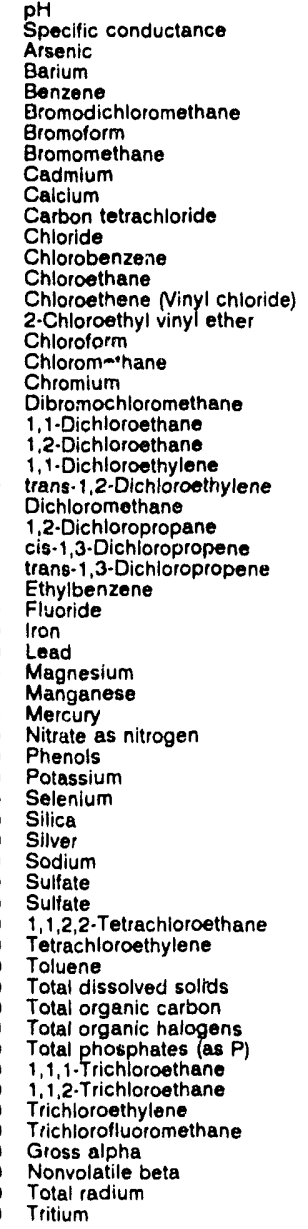 & 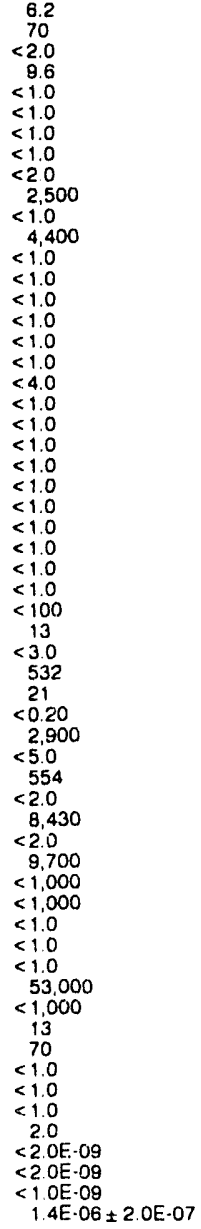 & $\begin{array}{l}\mathrm{J} 1 \\
\mathrm{~J} 2\end{array}$ & 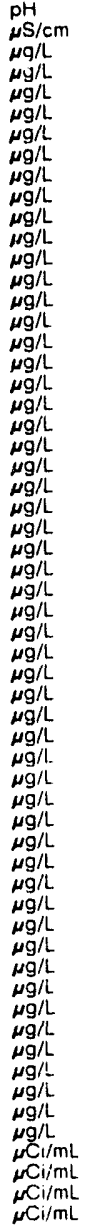 & $\begin{array}{l}G E \\
G E \\
G E \\
G E \\
G E \\
G E \\
G E \\
G E \\
G E \\
G E \\
G E \\
G E \\
G E \\
G E \\
G E \\
G E \\
G E \\
G E \\
G E \\
G E \\
G E \\
G E \\
G E \\
G E \\
G E \\
G E \\
G E \\
G E \\
G E \\
G E \\
G E \\
G E \\
G E \\
G E \\
G E \\
G E \\
G E \\
G E \\
G E \\
G E \\
G E \\
G E \\
G E \\
G E \\
G E \\
G E \\
G E \\
G E \\
G E \\
G E \\
G E \\
G E \\
G E \\
G E \\
G E \\
G E \\
G E \\
G E \\
G E \\
\end{array}$ \\
\hline
\end{tabular}

WELL MSB 82TA

MEASUREMENTS CONDUCTED IN THE FIELD

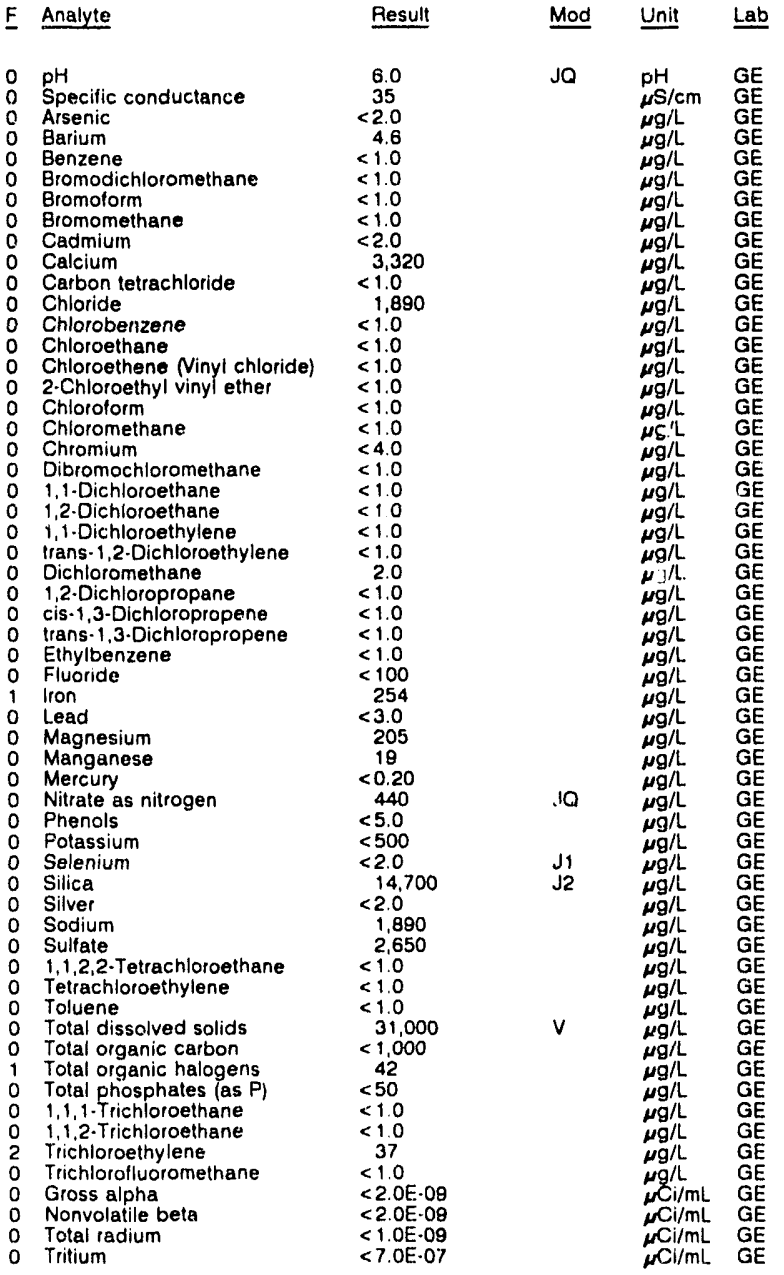

WELL MSB 83B

MEASUREMENTS CONDUCTED IN THE FIELD

Sample date: 10/01/91

Depth to water: $150.53 \mathrm{H}(45.88 \mathrm{~m})$ below TOC

Water elevation: $221.47 \pi(67.50 \mathrm{~m}) \mathrm{ms}$

Sp. conductance. $18 \mu \mathrm{S} / \mathrm{cm}$

mpling: 204 gal

LABORATORY ANALYSES

\begin{tabular}{|c|c|c|c|}
\hline Analyie & Result & Mod & Unit \\
\hline $\begin{array}{l}\text { PH } \\
\text { Specific conductance } \\
\text { Alsenic } \\
\text { Barlum } \\
\text { Benzene } \\
\text { Bromodichloromethane } \\
\text { Bromoform } \\
\text { Bromomethane } \\
\text { Cadmium } \\
\text { Calcium } \\
\text { Carbon letrachloride } \\
\text { Chloride } \\
\text { Chlorobenzene }\end{array}$ & $\begin{array}{l}5.3 \\
20 \\
<2.0 \\
<3.0 \\
<1.0 \\
<10 \\
<1.0 \\
<1.0 \\
<2.0 \\
614 \\
<1.0 \\
11.820 \\
<10\end{array}$ & JO & $\begin{array}{l}\mathrm{pH} \\
\mu \mathrm{S} / \mathrm{cm} \\
\mu \mathrm{g} / \\
\mu \mathrm{g} / \\
\mu \mathrm{g} / \mathrm{h} \\
\mu \mathrm{g} / \mathrm{h} \\
\mu \mathrm{g} / \mathrm{h} \\
\mu \mathrm{g} / \mathrm{h} \\
\mu \mathrm{g} / \mathrm{h} \\
\mu \mathrm{g} / \mathrm{h} \\
\mu \mathrm{g} / \mathrm{h} \\
\mu \mathrm{g} / \mathrm{h} \\
\mu \mathrm{g} / \mathrm{L}\end{array}$ \\
\hline
\end{tabular}

Time:

pH. 5.2 . $3 \mathrm{mgiL}$

Alkalinity: $3 \mathrm{mg} / \mathrm{L}$
Water temperature: $20.3^{\circ} \mathrm{C}$
Sample date: 10/02/91

Depth to waler: 159.68 \# $(48.67 \mathrm{~m})$ below TOC

Water elevation: $214.12 \mathrm{H}(65.26 \mathrm{~m}) \mathrm{msl}$

Water evacuated before sampling: $\mathbf{3 3 0} \mathrm{gal}$

LABORATORY ANALYSES

Time: $8: 00$

Alkalinity: $6 \mathrm{mgh}$

Alkalinity: $6 \mathrm{mg} / \mathrm{h}$

Time: $7: 20$

Alkalinity: $17 \mathrm{mg} / \mathrm{L}$

Water trinperature: $20.5^{\circ} \mathrm{C}$ 
WELL MSB 83B collected on 10/01/91, laboratory analyses (cont.)

\begin{tabular}{|c|c|c|c|}
\hline Analyte & Result & Mod & Unit \\
\hline $\begin{array}{l}\text { Chloroethane } \\
\text { Chloroethene Ninyl chloride) } \\
\text { 2-Chloroethyl vinyl ether } \\
\text { Chloroform } \\
\text { Chloromethane } \\
\text { Chromium } \\
\text { Dibromochloromethane } \\
\text { 1,1-Dichloroethane } \\
\text { 1,2-Dichloroethane } \\
1,1 \cdot \text { Dichloroethylene } \\
\text { trans-1,2-Dichloroethylene } \\
\text { Dichloromethane } \\
\text { 1,2-Dichloropropane } \\
\text { cis-1,3-Dichloropropene } \\
\text { trans-1,3-Dichloropropene } \\
\text { Ethylbenzene } \\
\text { Fluoride } \\
\text { lron } \\
\text { Lead } \\
\text { Magnesium } \\
\text { Manganese } \\
\text { Mercury } \\
\text { Nitrate as nitrogen } \\
\text { Phenols } \\
\text { Potasslum } \\
\text { Selenium } \\
\text { Silica } \\
\text { Silver } \\
\text { Sodium } \\
\text { Sulfate } \\
\text { 1,1,2,2-Totrachloroethane } \\
\text { Tetrachloroethylene } \\
\text { Toluene } \\
\text { Total dissolved solids } \\
\text { Total organic carbon } \\
\text { Total organic halogens } \\
\text { Total phosphates (as P) } \\
\text { Total phosphates as P) } \\
1,1,1-\text { Trichloroethane } \\
\text { 1,1,2-Trichloroethane } \\
\text { Trichloroethylene } \\
\text { Trictilorofluoromethane } \\
\text { Gross alpha } \\
\text { Nonvolatile beta } \\
\text { Total radium } \\
\text { Tritium }\end{array}$ & $\begin{array}{l}<1.0 \\
<1.0 \\
<1.0 \\
<1.0 \\
<1.0 \\
<4.0 \\
<1.0 \\
<1.0 \\
<1.0 \\
<1.0 \\
<1.0 \\
1.0 \\
<1.0 \\
<1.0 \\
<1.0 \\
<1.0 \\
<100 \\
5.6 \\
<3.0 \\
21.8 \\
8.9 \\
<0.20 \\
340 \\
<5.0 \\
<500 \\
<2.0 \\
10,600 \\
<2.0 \\
2.170 \\
2,030 \\
<1.0 \\
<1.0 \\
<1.0 \\
27.000 \\
<1.000 \\
<5.0 \\
<50 \\
<50 \\
<1.0 \\
<1.0 \\
<1.0 \\
<1.0 \\
<2.0 E \cdot 09 \\
9.9 E-09 \\
<1.0 E-09 \\
<7.0 E \cdot 07\end{array}$ & JOV & $\begin{array}{l}\mu g / L \\
\mu g / L \\
\mu g / L \\
\mu g / L \\
\mu g / L \\
\mu g / L \\
\mu g / L \\
\mu g / L \\
\mu g / L \\
\mu g / L \\
\mu g / L \\
\mu g / L \\
\mu g / L \\
\mu g / L \\
\mu g / L \\
\mu g / L \\
\mu g / L \\
\mu g / L \\
\mu g / L \\
\mu g / L \\
\mu g / L \\
\mu g / L \\
\mu g / L \\
\mu g / L \\
\mu g / L \\
\mu g / L \\
\mu g / L \\
\mu g / L \\
\mu g / L \\
\mu g / L \\
\mu g / L \\
\mu g / L \\
\mu g / L \\
\mu g / L \\
\mu g / L \\
\mu g / L \\
\mu g / L \\
\mu g / L \\
\mu g / L \\
\mu g / L \\
\mu g / L \\
\mu g / L \\
\mu C i / m L \\
\mu C i / m L \\
\mu C i / m L \\
\mu C i / m L\end{array}$ \\
\hline
\end{tabular}

\section{WELL MSB 83C}

MEASUREMENTS CONDUCTED IN THE FIELD Sample date: $10 / 01 / 91$
Depth to water: $144.18 \mathrm{H}(43.95 \mathrm{~m})$ below TOC
Water elevation: $227.92 \mathrm{ft}(89.47 \mathrm{~m}) \mathrm{ms}$
Sp. conductance: 75 f $\mathrm{s} / \mathrm{cm}$
Water evacuated betore sampling: $130 \mathrm{gal}$ LABORATORY ANALYSES

\begin{tabular}{|c|c|c|c|c|}
\hline$\underline{F}$ & Anaiyte & Result & Mod & Unit \\
\hline $\begin{array}{l}0 \\
0\end{array}$ & $\begin{array}{l}\text { Chlorolorm } \\
1,1-\text { Dichloroethylene } \\
\text { trans- } 1,2 \text {-Dichloroethylene } \\
\text { Tetracnloroethylene } \\
1,1,1-\text { Trichloroethane } \\
\text { Trichloroethylene }\end{array}$ & $\begin{array}{l}<1.0 \\
<1.0 \\
<1.0 \\
<1.0 \\
<1.0 \\
<1.0\end{array}$ & & $\begin{array}{l}\mu g / L \\
\mu g / L \\
\mu g / L \\
\mu g / L \\
\mu g / L \\
\mu g / L\end{array}$ \\
\hline
\end{tabular}

\section{WELL MSB 83D}

MEASUREMENTS CONOUCTED IN THE FIELD

Sample date: 10/01/91

Depth to water: $138.88 \mathrm{ft}(42.33 \mathrm{~m})$ below TOC

Water elevation: $232.84 \mathrm{ft}$ (70.

Water evacuated before sampling: 8 gal

The well went dry during purging.

LABOAATORY ANALYYSES

\begin{tabular}{|c|c|c|c|}
\hline Analyte & Result & Mod & Unit \\
\hline $\begin{array}{ll}1 & \text { pH } \\
0 & \text { Specific conductance } \\
0 & \text { Arsenic } \\
0 & \text { Barium } \\
0 & \text { Benzene } \\
0 & \text { Bromodichloromethane } \\
0 & \text { Eromoform } \\
0 & \text { Bromomethane } \\
0 & \text { Cadmium } \\
0 & \text { Caicium } \\
0 & \text { Carbon tetrachloride } \\
0 & \text { Chloride } \\
0 & \text { Chlorobenzene } \\
0 & \text { Chloroethane }\end{array}$ & $\begin{aligned} 9.0 \\
140 \\
<2.0 \\
9.1 \\
<1.0 \\
<1.0 \\
<1.0 \\
<1.0 \\
<2.0 \\
2.400 \\
<1.0 \\
2.000 \\
<1.0 \\
<1.0\end{aligned}$ & JO & $\begin{array}{l}p H \\
\mu S / c m \\
\mu g / L \\
\mu g / L \\
\mu g / L \\
\mu g / L \\
\mu g / L \\
\mu g / L \\
\mu g / L \\
\mu g / L \\
\mu g / L \\
\mu g / L \\
\mu g / L \\
\mu g / L\end{array}$ \\
\hline
\end{tabular}

WELL MSB 83D collected on 10/01/91, laboratory analyses (cont.)

\begin{tabular}{|c|c|c|c|}
\hline Analyte & Result & Mod & Unit \\
\hline 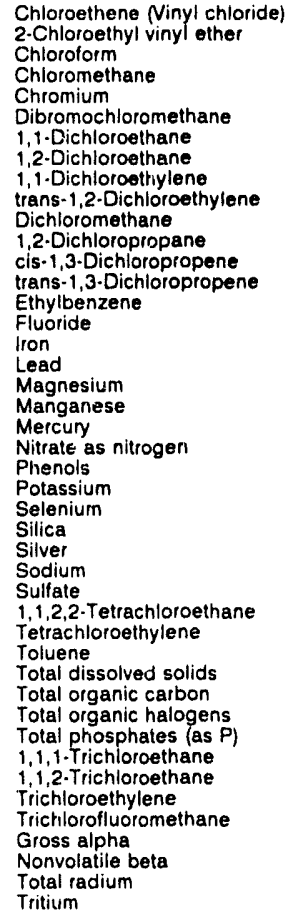 & 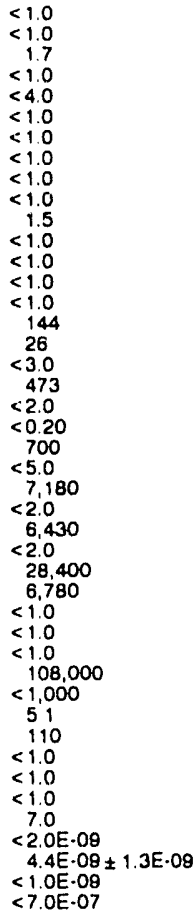 & JOV & $\begin{array}{l}\mu g / L \\
\mu g / L \\
\mu g / L \\
\mu g / L \\
\mu g / L \\
\mu g / L \\
\mu g / L \\
\mu g / L \\
\mu g / L \\
\mu g / L \\
\mu g / L \\
\mu g / L \\
\mu g / L \\
\mu g / L \\
\mu g / L \\
\mu g / L \\
\mu g / L \\
\mu g / L \\
\mu g / L \\
\mu g / L \\
\mu g / L \\
\mu g / L \\
\mu g / L \\
\mu g / L \\
\mu g / L \\
\mu g / L \\
\mu g / L \\
\mu g / L \\
\mu g / L \\
\mu g / L \\
\mu g g \\
\mu g / L \\
\mu g / L \\
\mu g / L \\
\mu g / L \\
\mu g / L \\
\mu g / L \\
\mu g / L \\
\mu g / L \\
\mu g / L \\
\mu C i / m L \\
\mu C i / m L \\
\mu C i / m L \\
\mu C i / m L\end{array}$ \\
\hline
\end{tabular}

\section{WELL MSB 83TA}

MEASUREMENTS CONDUCTED IN THE FIELO

Sample date: 10/01/91

Depth to water: 156.83 it $(47.83 \mathrm{~m})$ below TOC

Water elevation: $214.87 \mathrm{ft}(65.49 \mathrm{~m}) \mathrm{ms}$

Water evacuated before sampling: $374 \mathrm{gal}$

LABORATORY ANALYSES

E Analyte Result Mod Unit Lab

$0 \mathrm{pH}$

Specific conductance

A Arsenic

Barium

Benzene
0 Bromodichloromethane

Bromoform

Bromomethane

Cadmium

Calcium

Carbon tetrachloride

Chloride

Chlorobenzene

Chloroethane

Chloroethene Ninyl chloride

2-Chloroethyl vinyl ether

Chioroform

Chloromethan

Dibromochloromethane

1.1-Dichloroethane

1.1-Dichloroethane
1,2-Dichloroethane

1,1-Dichloroethylene

trans-1,2-Dichloroethylene

Dichloromethane

1,2.Dichloropropane

trans-1,3-Dichloropropene

0 Ethylbenzene

0 Fluoride

0 Iron

$\begin{array}{ll}0 & \text { Lead } \\ 0 & \text { Magnesium }\end{array}$

- Mariganese

Mercury

livtrate as nitrogen

Phenols

O Polassium

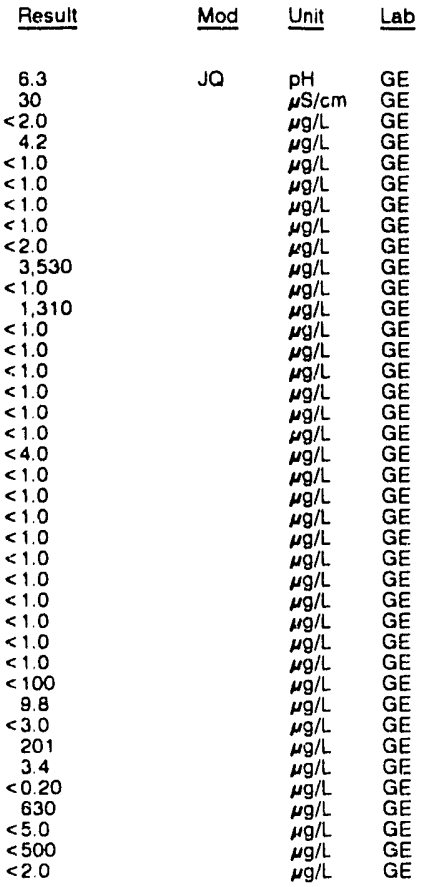


ANALYTICAL RESULTS

WELL. MSB 83TA collected on 10/01/91, laboratory analyses (cont.)

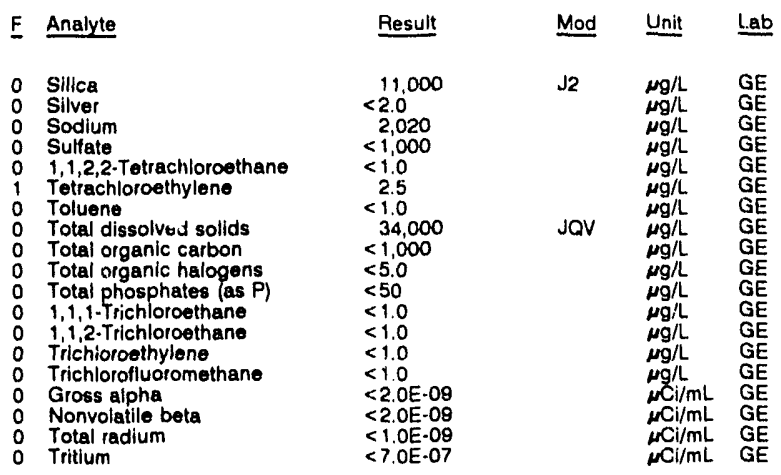

WELL MSB 84C

MEASUREMENTS CONDUCTED IN THE FIELD

Sample date: 10/02/91

Depth to water: $132.41 \mathrm{ft}(40.36 \mathrm{~m})$ below TOC

Water elevation: $229.59 \mathrm{H}(69.88 \mathrm{~m}) \mathrm{msl}$

Water evacuated before sampling: $104 \mathrm{gal}$

LABORATORY ANALYSES

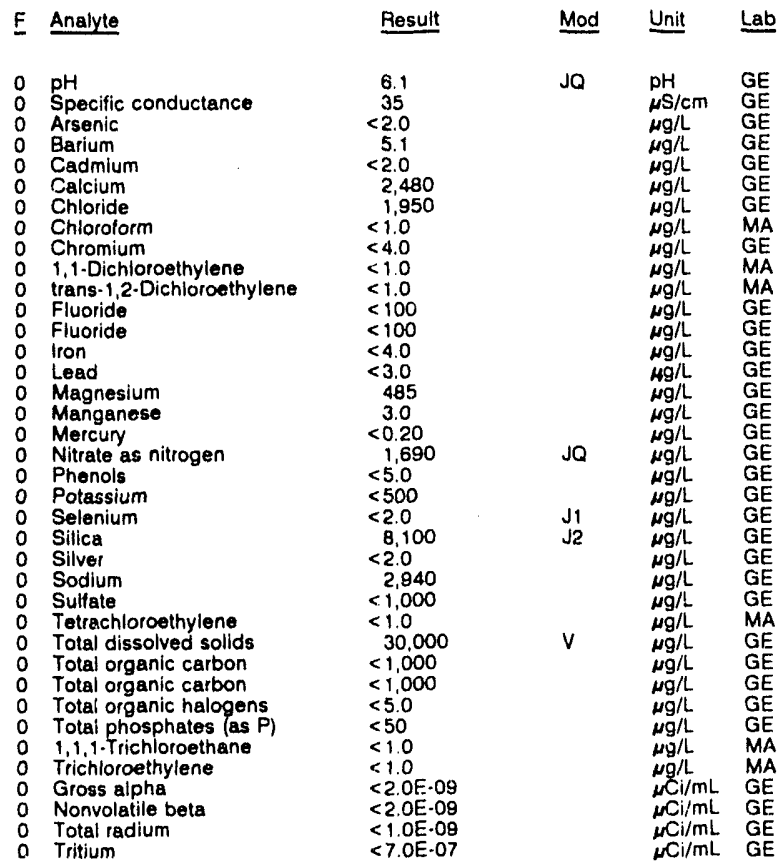

\section{WELL MSB 85B}

MEASUREMENTS CONDUCTED IN THE FIEL.D

Sample date: 10/01/91 Depth to water: $158.27 \mathrm{~h}(48.55 \mathrm{~m})$ below Waler elevalion. $221.53 \mathrm{t}(67.5$ Water evacuated before sampling: $232 \mathrm{gal}$

LABORATORY ANALYSES

\begin{tabular}{|c|c|c|c|c|}
\hline E Analyte & Result & Mod & Unit & Lab \\
\hline $\begin{array}{l}\text { pH } \\
\text { Specific conductance } \\
\text { Arsenic } \\
\text { Barium } \\
\text { Benzene } \\
\text { Bromodichloromethane } \\
\text { Bromotorm } \\
\text { Bromomethane } \\
\text { Cadmium }\end{array}$ & $\begin{array}{r}6.0 \\
30 \\
<2.0 \\
6.4 \\
<1.0 \\
<1.0 \\
<1.0 \\
<1.0 \\
<2.0\end{array}$ & JO & $\begin{array}{l}\mathrm{pH} \\
\mu \mathrm{S} / \mathrm{cm} \\
\mu \mathrm{g} / \mathrm{L} \\
\mu \mathrm{g} / \mathrm{L} \\
\mu \mathrm{g} / \mathrm{L} \\
\mu \mathrm{g} / \mathrm{L} \\
\mu \mathrm{g} / \mathrm{L} \\
\mu \mathrm{g} / \mathrm{L} \\
\mu \mathrm{g} / \mathrm{L}\end{array}$ & $\begin{array}{l}\mathrm{GE} \\
\mathrm{GE} \\
\mathrm{GE} \\
\mathrm{GE} \\
\mathrm{GE} \\
\mathrm{GE} \\
\mathrm{GE} \\
\mathrm{GE} \\
\mathrm{GE}\end{array}$ \\
\hline
\end{tabular}

WELL MSB 85B collected on 10/01/91, laboratory analyses (cont)

\begin{tabular}{|c|c|c|c|}
\hline Analyte & Result & Mod & Unit \\
\hline 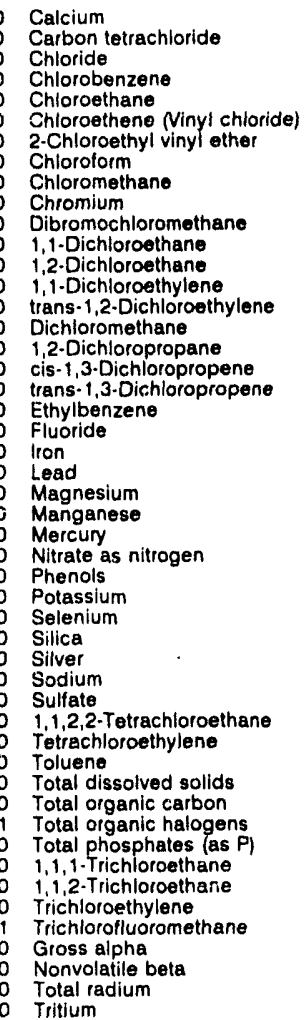 & $\begin{array}{l}879 \\
<1.0 \\
1.890 \\
<1.0 \\
<1.0 \\
<1.0 \\
<1.0 \\
<1.0 \\
<1.0 \\
<4.0 \\
<1.0 \\
<1.0 \\
<1.0 \\
<1.0 \\
<1.0 \\
1.0 \\
<1.0 \\
<1.0 \\
<1.0 \\
<1.0 \\
<100 \\
19 \\
<3.0 \\
253 \\
3.7 \\
<0.20 \\
1.290 \\
<5.0 \\
657 \\
<2.0 \\
8.160 \\
<2.0 \\
4,020 \\
<1,000 \\
<1.0 \\
<1.0 \\
<1.0 \\
31,000 \\
<1.000 \\
44 \\
80 \\
<1.0 \\
<1.0 \\
<1.0 \\
7.0 \\
<2.0 E-09 \\
<2.0 E-09 \\
<1.0 E \cdot 09 \\
<7.0 E \cdot 07\end{array}$ & JOV & $\begin{array}{l}\mu g / L \\
\mu g / L \\
\mu g / L \\
\mu g / L \\
\mu g / L \\
\mu g / L \\
\mu g / L \\
\mu g / L \\
\mu g / L \\
\mu g / L \\
\mu g / L \\
\mu g / L \\
\mu g / L \\
\mu g / L \\
\mu g / L \\
\mu g / L \\
\mu g / L \\
\mu g / L \\
\mu g / L \\
\mu g / L \\
\mu g / L \\
\mu g / L \\
\mu g / L \\
\mu g / L \\
\mu g / L \\
\mu g / L \\
\mu g / L \\
\mu g / L \\
\mu g / L \\
\mu g / L \\
\mu g / L \\
\mu g / L \\
\mu g / L \\
\mu g / L \\
\mu g / L \\
\mu g / L \\
\mu g / L \\
\mu g / L \\
\mu g / L \\
\mu g / L \\
\mu g / L \\
\mu g / L \\
\mu g / L \\
\mu g / L \\
\mu g / L \\
\mu K i / m L \\
\mu C i / m L \\
\mu C / / m L \\
\mu C / / m L\end{array}$ \\
\hline
\end{tabular}

\section{WELL MSB 85C}

MEASUREMENTS CONDUCTED IN THE FIELD

Sample date: $10 / 01 / 01$

Depth to water: $156.83 \mathrm{ft}(47.80 \mathrm{~m})$ below TOC Water elevation: $224.57 \mathrm{ft}(88.45 \mathrm{~m}) \mathrm{msl}$

wance $22.57 \mathrm{~cm}$

msl PH: 5.8

Alkalinity: $4 \mathrm{mg} / \mathrm{L}$. $18.1^{\circ} \mathrm{C}$ Were sampling: 145 gal

LABORATORY ANALYSES

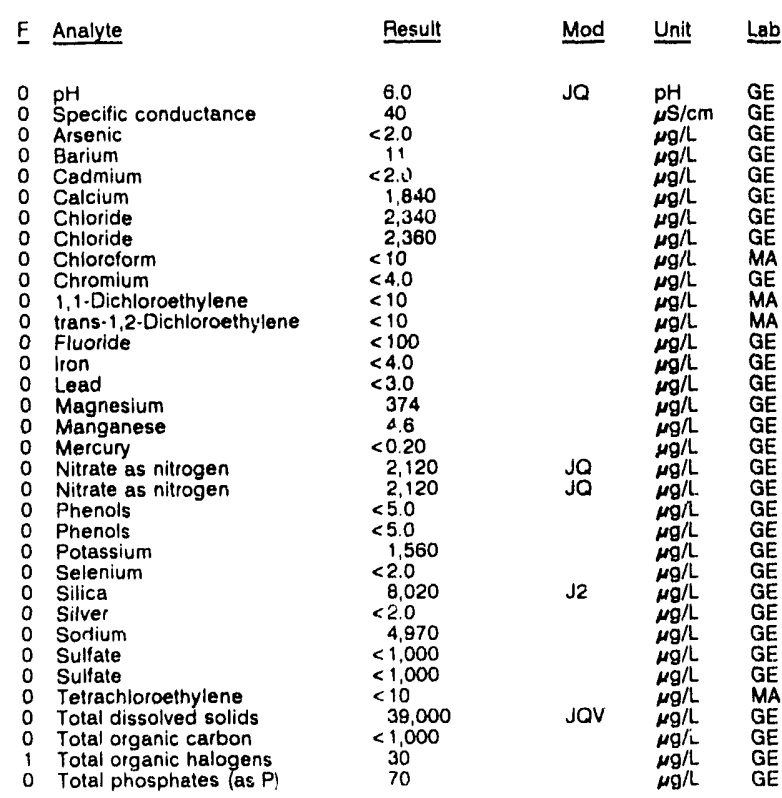


ANALYTICAL RESULTS

\begin{tabular}{|c|c|c|c|c|}
\hline Analyte & Result & Mod & Unit & Lab \\
\hline $\begin{array}{ll}0 & 1,1,1-\text { Trichloroethane } \\
2 & \text { Trichloroethylene } \\
0 & \text { Gross alpha } \\
0 & \text { Nonvolatlle beta } \\
0 & \text { Total radlum } \\
0 & \text { Tritium }\end{array}$ & $\begin{array}{l}<10 \\
31 \\
<2.0 E \cdot 09 \\
<2.0 E \cdot 09 \\
<1.0 E \cdot 09 \\
<7.0 E \cdot 07\end{array}$ & & $\begin{array}{l}\mu \mathrm{g} / \mathrm{L} \\
\mu \mathrm{g} / \mathrm{L} \\
\mu \mathrm{Ci} / \mathrm{mL} \\
\mu \mathrm{Ci} / \mathrm{mL} \\
\mu \mathrm{Ci} / \mathrm{mL} \\
\mu \mathrm{Ci} / \mathrm{mL}\end{array}$ & $\begin{array}{l}\text { MA } \\
M A \\
G E \\
G E \\
G E \\
G E\end{array}$ \\
\hline
\end{tabular}

WELL MSB 85D

MEASUREMENTS CONDUCTED IN THE FIELD

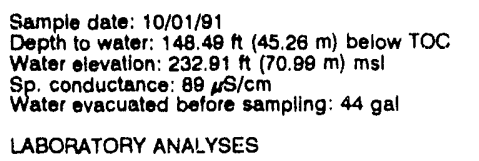

Time: 7:05

PH: 5.9

Water temperature: $18.6^{\circ} \mathrm{C}$

LABORATORY ANALYSES
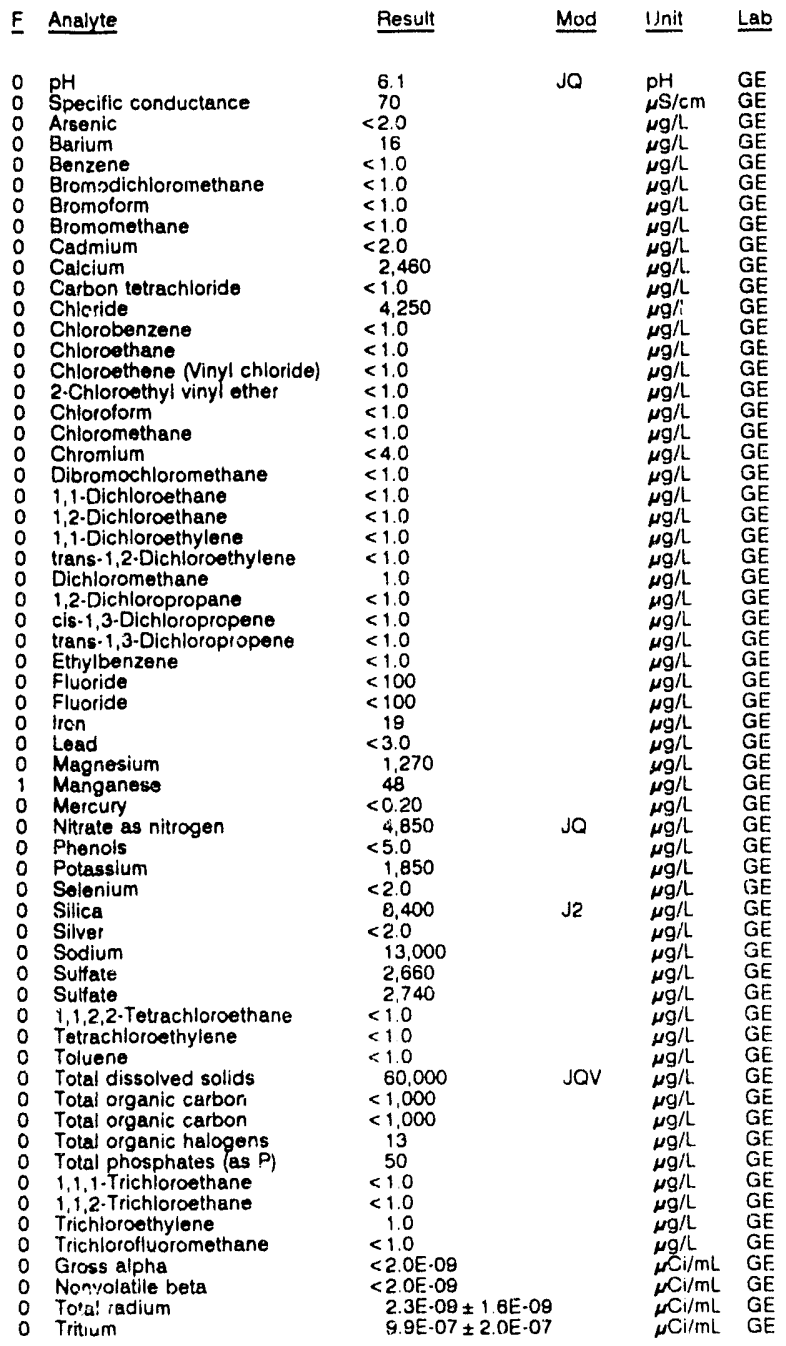

WELL MSB 85TA

MEASUREMENTS CONDUCTED IN THE FIELD

Sample date $10 / 01 / 91$
Depth to water: $158.83 \mathrm{H}(48.72 \mathrm{~m})$ below TOC Depth to water: $158.83 \mathrm{H}(48.72 \mathrm{~m})$ below TOC PH: 9.6 .

Waler elevalion. $221.17 \mathrm{~h}(07.41 \mathrm{~m}) \mathrm{ms}$ Alkalinity: $76 \mathrm{mg} / \mathrm{l}$

Water evacuated beforesampling: $29 \mathrm{gal}$

The well went dry during purging

LABORATORY ANALYSES

\begin{tabular}{|c|c|c|c|c|}
\hline Analyte & Result & Mod & Unit & Lab \\
\hline 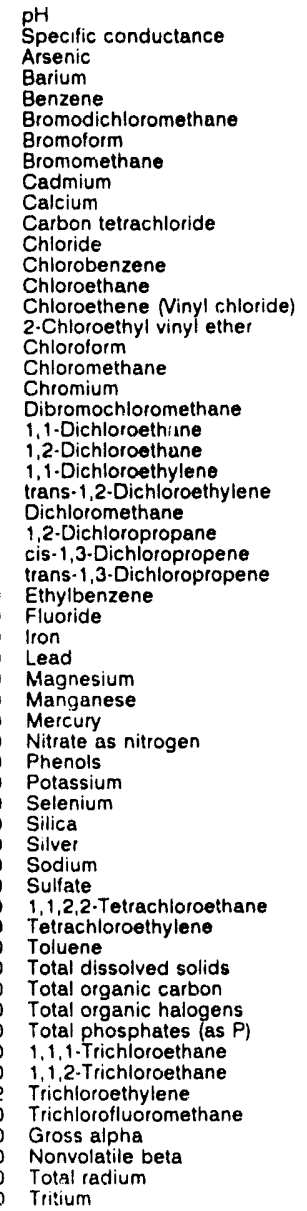 & $\begin{array}{l}9.4 \\
160 \\
<2.0 \\
11 \\
<1.0 \\
<1.0 \\
<1.0 \\
<1.0 \\
<2.0 \\
1.790 \\
<1.0 \\
2.090 \\
<1.0 \\
<1.0 \\
<1.0 \\
<1.0 \\
<1.0 \\
<1.0 \\
<4.0 \\
<1.0 \\
<1.0 \\
<1.0 \\
<1.0 \\
<1.0 \\
<1.0 \\
<1.0 \\
<1.0 \\
<1.0 \\
<1.0 \\
140 \\
105 \\
<3.0 \\
108 \\
<2.0 \\
<0.20 \\
<50 \\
11 \\
14,600 \\
<2.0 \\
2.180 \\
<2.0 \\
28,600 \\
3.420 \\
<1.0 \\
<1.0 \\
15 \\
221.000 \\
3.000 \\
22 \\
110 \\
<1.0 \\
<1.0 \\
14 \\
<1.0 \\
2.5 \mathrm{E} \cdot 09 \pm 3.6 \mathrm{E} \cdot 09 \\
1.4 \mathrm{E} \cdot 08 \pm 4.9 \mathrm{E} \cdot 09 \\
<1.0 \mathrm{E} \cdot 09 \\
<7.0 \mathrm{E} \cdot 07 \\
\end{array}$ & JOV & $\begin{array}{l}p H \\
\mu \mathrm{S} / \mathrm{cm} \\
\mu g / L \\
\mu g / L \\
\mu g / L \\
\mu g / L \\
\mu g / L \\
\mu g / L \\
\mu g / L \\
\mu g / L \\
\mu g / L \\
\mu g / L \\
\mu g / L \\
\mu g / L \\
\mu g / L \\
\mu g / L \\
\mu g / L \\
\mu g / L \\
\mu g / L \\
\mu g / L \\
\mu g / L \\
\mu g / L \\
\mu g / L \\
\mu g / L \\
\mu g / L \\
\mu g / L \\
\mu g / L \\
\mu g / L \\
\mu g / L \\
\mu g / L \\
\mu g / L \\
\mu g / L \\
\mu g / L \\
\mu g / L \\
\mu g / L \\
\mu g / L \\
\mu g / L \\
\mu g / L \\
\mu g / L \\
\mu g / L \\
\mu g / L \\
\mu g / L \\
\mu g / L \\
\mu g / L \\
\mu g / L \\
\mu g / L \\
\mu g / L \\
\mu g / L \\
\mu g / L \\
\mu g / L \\
\mu g / L \\
\mu g / L \\
\mu g / L \\
\mu / L \\
\mu c i / m L \\
\mu C i / m L \\
\mu C i / m L \\
\mu C i / m L\end{array}$ & $\begin{array}{l}G E \\
G E \\
G E \\
G E \\
G E \\
G E \\
G E \\
G E \\
G E \\
G E \\
G E \\
G E \\
G E \\
G E \\
G E \\
G E \\
G E \\
G E \\
G E \\
G E \\
G E \\
G E \\
G E \\
G E \\
G E \\
G E \\
G E \\
G E \\
G E \\
G E \\
G E \\
G E \\
G E \\
G E \\
G E \\
G E \\
G E \\
G E \\
G E \\
G E \\
G E \\
G E \\
G E \\
G E \\
G E \\
G E \\
G E \\
G E \\
G E \\
G E \\
G E \\
G E \\
G E \\
G E \\
G E \\
G E \\
G E \\
G E\end{array}$ \\
\hline
\end{tabular}

\section{WELL MSB 86C}

MEASUREMENTS CONDUCTED IN THE FIELD

Sample date: 10/01/91

Depth to water: $133.00 \#(40.54 \mathrm{~m})$ below TOC

Water elevation: $224.40 \mathrm{H}(68.40 \mathrm{~m}) \mathrm{ms}$

Sp. conductance : $44 \mu \mathrm{s} / \mathrm{cm}$

sampling: $168 \mathrm{gal}$

LABORATORY ANALYSES

\begin{tabular}{|c|c|c|c|}
\hline Anatyte & Result & Mod & Unit \\
\hline $\begin{array}{ll}\text { pH } \\
\text { Specilic conductance } \\
0 \text { Arsenic } \\
0 \text { Barium } \\
0 \text { Benzene } \\
0 \text { Bromodichloromethane } \\
0 \text { Bromulorm } \\
0 \text { Bromumethane } \\
0 \text { Cadmium } \\
0 \text { Calclum } \\
0 \text { Carbon tetrachloride } \\
0 \text { Chloride } \\
0\end{array}$ & $\begin{array}{r}6.1 \\
40 \\
<2.0 \\
7.2 \\
<1.0 \\
<1.0 \\
<10 \\
<1.0 \\
<2.0 \\
1.570 \\
<10 \\
2.220\end{array}$ & JO & $\begin{array}{l}\mathrm{pH} \\
\mu \mathrm{S} / \mathrm{cm} \\
\mu g / L \\
\mu g / L \\
\mu g / L \\
\mu g / L \\
\mu g / L \\
\mu g / L \\
\mu g / L \\
\mu g / L \\
\mu g / L \\
\mu g / L\end{array}$ \\
\hline
\end{tabular}


ANALYTICAL RESULTS

WELL MSB 86C collected on 10/01/91, laboratory analyses (cont.)

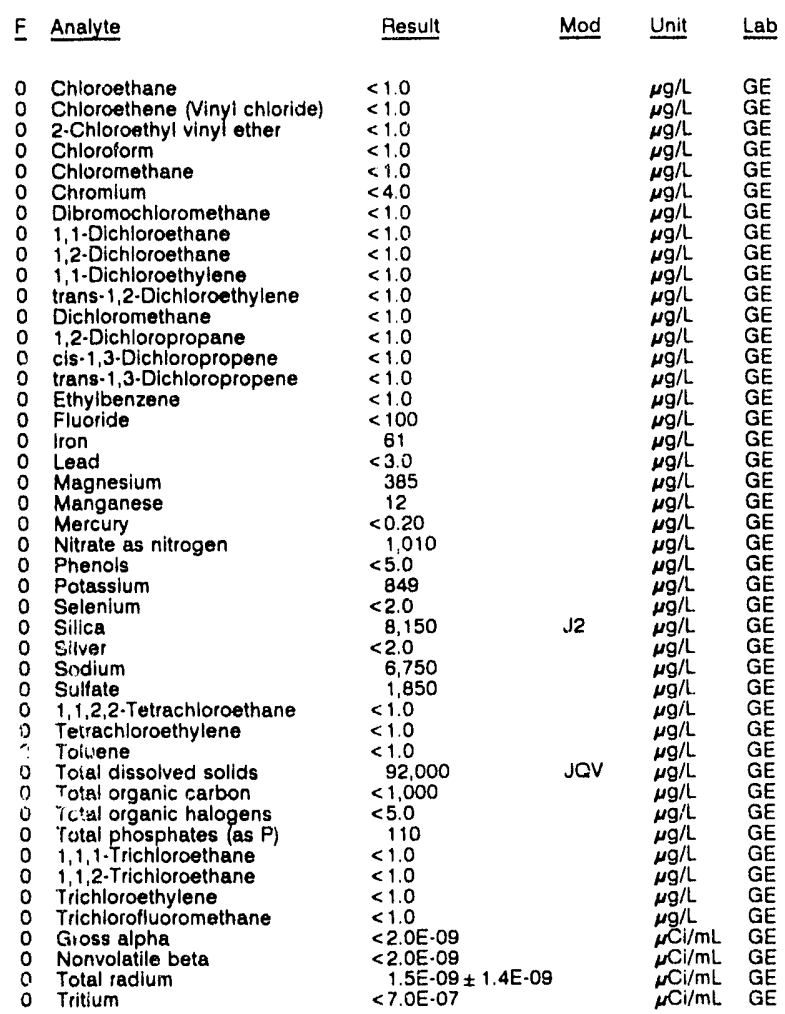

WELL MVID $1 \mathrm{~A}$

MEASUREMENTS CONDUCTED IN THE FIELD Sample date: $12 / 30 / 91$
Depth to water: $139.08 \mathrm{Ht}(42.39 \mathrm{~m})$ below TOC Time: $13: 50$
Water elevation: $190.42 \mathrm{ft}(\mathrm{S8.04} \mathrm{m}) \mathrm{ms}$

Inaccessibility or pump failure prevented sample collection.

WELL MWD 1B

MEASUREMENTS CONDUCTED IN THE FIELD

Sample date: $12 / 30 / 91$
Depth to water: $69.13 \mathrm{ft}(21.07 \mathrm{~m})$ below TOC Time: $14: 00$
Water elevation: $260.47 \mathrm{~h}(79.39 \mathrm{~m}) \mathrm{msl}$
Inaccessibility or pump failure prevented sample collection.

WELL MWD $1 \mathrm{C}$

MEASUREMENTS CONDUCTED IN THE FIELD

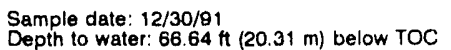

Depth to water: $66.64 \mathrm{ht}(20.31 \mathrm{~m})$ below

inaccessibility or pump fallure prevented sample collection.

WELL MWD 1D

MEASUREMENTS CONDUCTED IN THE FIELD

Sample date: $12 / 30 / 91$
Depth to water: $57.58 \mathrm{ft}(17.55 \mathrm{~m})$ below TOC

Depth to water: $57.58 \mathrm{ft}(17.55 \mathrm{~m})$ below
Water elevation: $272.42 \mathrm{ft}(83.03 \mathrm{~m}) \mathrm{ms}$ l

Water elevation: $272.42 \mathrm{ft}(83.03 \mathrm{~m}) \mathrm{ms}$ l
inaccessibility or pump failure prevented sample collection
WELL MWD 2A

MEASUREMENTS CONDUCTED IN THE FIELD

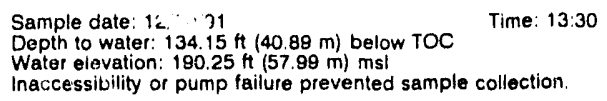

WELL MWD 2C

MEASUREMENTS CONDUCTED IN THE FIELD

Sample date: $12 / 30 / 81$ Time: 13:35

Depth to water: $61.00 \mathrm{H}(18.87 \mathrm{~m})$ below TOC

Water elevation: $262.40 \mathrm{ft}(79.98 \mathrm{~m}) \mathrm{ms}$ I
Inaccessibility or pump failure prevented sample collection

\section{WELL MWD 2D}

MEASUREMENTS CONDUCTED IN THE FIELD Sample date: $12 / 30 / 81$ Time: $13: 40$

Inaccessibility of pump tailure prevented sample collection.

\section{WELL MWD $3 A$}

MEASUREMENTS CONDUCTED IN THE FIELD

Sample date: $12 / 30 / 91 \quad$ Time: $14: 45$ Water evation: $189.74 \mathrm{t}(57.83 \mathrm{~m}) \mathrm{mst}$

inaccessibility or pump failure prevented sample collection

\section{WELL MWD 5A}

MEASUREMENTS CONDUCTED IN THE FIELD

Sample date: $12 / 30 / 91$ Timo: $14: 20$ Water elevation: $191.01 \mathrm{ft}(58.22 \mathrm{~m}) \mathrm{ms}$ ! inaccessibility or pump failure prevented sample collection.

\section{WELL MWD 5C}

MEASUREMENTS CONDUCTED IN THE FIELD

Sample date: $12 / 30 / 91$

Depth to water: $65.97 \mathrm{tt}(20.11 \mathrm{~m})$ below TOC Inaccessibility or pump lailure prevented sample collection.

\section{WELL MWD 5D}

MEASUREMENTS CONDUCTED IN THE FIELD

Sample date: $12 / 30 / 91$

Depth to water: $53.85 \mathrm{ht}(16.44 \mathrm{~m})$ below TOC

Water elevation: $270.85 \mathrm{th}(82.58 \mathrm{~m}) \mathrm{msl}$
Inaccessibility or pump failure prevented sample collection.

\section{WELL MWD 8D}

MEASUREMENTS CONDUCTED IN THE FIELD

Sample date: $12 / 30 / 91$ Time: $13: 25$ Depth to water: $53.45 \mathrm{ft}(16.29 \mathrm{~m})$ below TOC Inaccessibility or pump failure prevented sample collection. 
ANALYTICAL RESULTS

\section{WELL MWD 9}

MEASUREMENTS CONDUCTED IN THE FIELD

Sample date: $12 / 30 / 91$
Depth to water: $51.53 \mathrm{ft}(15.71 \mathrm{~m})$ below TOC Time: $14: 35$
Water

Inaccessibility or pump failure prevented sample collection.

WELL MWD 10

MEASUREMENTS CONDUCTED IN THE FIELD

Sample date: $12 / 30 / 91$ Time: $14: 10$

Water elevation: $263.91 \mathrm{~h}(80.44 \mathrm{~m}) \mathrm{ms}$.

inaccessibility or pump fallure prevented sample collection.

WELL MWD 11

MEASUREMENTS CONDUCTED IN THE FIELD

Sample date: $12 / 30 / 91$
Depth to water: $137.56 \mathrm{ft}(41.93 \mathrm{~m})$ below TOC Time: $14: 15$
Water elovation: $193.24 \mathrm{ft}(58.90 \mathrm{~m}) \mathrm{msl}$
Inaccessibllity or pump failure prevented sample collection.

WELL NBG 1

MEASUAEMENTS CONDUCTED IN THE FIELD

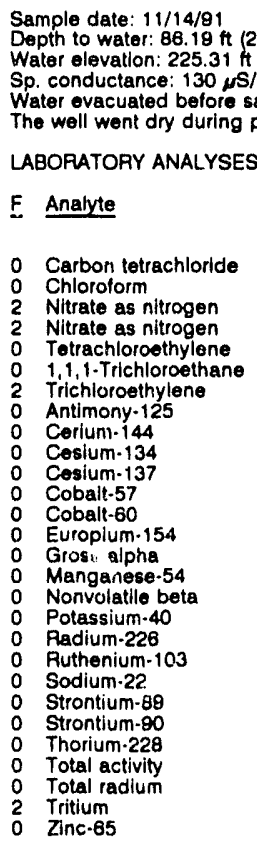

\begin{tabular}{ll} 
& Time: $10: 35$ \\
pH: 5.1 \\
Alow TOC & Alkalinity: $4 \mathrm{mg} / \mathrm{L}$ \\
\hline gal & Water temperature: $20.2^{\circ} \mathrm{C}$
\end{tabular}

Alkalinity: $4 \mathrm{mg} / \mathrm{h}$ ater temperature: $20.2^{\circ} \mathrm{C}$ The well went dry during purging.

LABRATORY ANALYSES

\begin{tabular}{|c|c|c|}
\hline Analyte & Result & Unit \\
\hline $\begin{array}{l}\text { Carbon tetrachloride } \\
\text { Chloroform } \\
\text { Nitrate as nitrogen } \\
\text { Nitrate as nitrogen } \\
\text { Totrachloroethylene } \\
1,1,1-\text { Trichloroethane } \\
\text { Trichloroethylene } \\
\text { Antimony-125 } \\
\text { Cerluni-144 } \\
\text { Coslum.134 } \\
\text { Cosium-137 } \\
\text { Cobalt-57 } \\
\text { Cobalt-60 } \\
\text { Europlum.154 } \\
\text { Gros: alpha } \\
\text { Manganese-54 } \\
\text { Nonvolatlle beta } \\
\text { Potassium-40 } \\
\text { Padium-226 } \\
\text { Ruthenium-103 } \\
\text { Sodium-22. } \\
\text { Strontium } 89 \\
\text { Strontium-90 } \\
\text { Thorium-228 } \\
\text { Total activity } \\
\text { Total radium } \\
\text { Tritium } \\
\text { Zinc- } 65\end{array}$ & 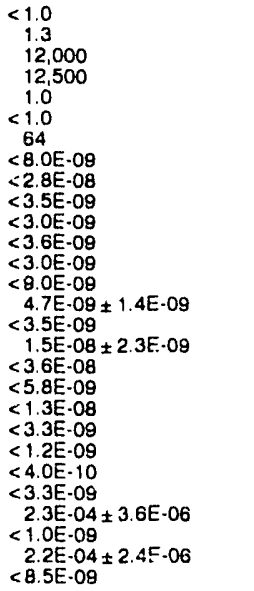 & $\begin{array}{l}\mu \mathrm{g} / \mathrm{L} \\
\mu \mathrm{g} / \mathrm{L} \\
\mu \mathrm{g} / \mathrm{L} \\
\mu \mathrm{g} / \mathrm{L} \\
\mu \mathrm{g} / \mathrm{L} \\
\mu \mathrm{g} / \mathrm{L} \\
\mu \mathrm{g} / \mathrm{L} \\
\mu \mathrm{CL} / \mathrm{mL} \\
\mu \mathrm{Ci} / \mathrm{mL} \\
\mu \mathrm{Ci} / \mathrm{mL} \\
\mu \mathrm{Ci} / \mathrm{mL} \\
\mu \mathrm{Ci} / \mathrm{mL} \\
\mu \mathrm{Ci} / \mathrm{mL} \\
\mu \mathrm{Ci} / \mathrm{mL} \\
\mu \mathrm{Ci} / \mathrm{mL} \\
\mu \mathrm{Ci} / \mathrm{mL} \\
\mu \mathrm{Ci} / \mathrm{mL} \\
\mu \mathrm{Ci} / \mathrm{mL} \\
\mu \mathrm{Ci} / \mathrm{mL} \\
\mu \mathrm{Ci} / \mathrm{mL} \\
\mu \mathrm{Ci} / \mathrm{mL} \\
\mu \mathrm{Ci} / \mathrm{mL} \\
\mu \mathrm{Ci} / \mathrm{mL} \\
\mu \mathrm{Ci} / \mathrm{mL} \\
\mu \mathrm{Ci} / \mathrm{mL} \\
\mu \mathrm{Ci} / \mathrm{mL} \\
\mu \mathrm{Ci} / \mathrm{mL} \\
\mu \mathrm{Ci} / \mathrm{mL}\end{array}$ \\
\hline
\end{tabular}

\section{WELL NBG 2}

\section{MEASUREMENTS CONOUCTED IN THE FIELD}

Sample date: $11 / 14 / 91$

Depth to water: $87.01 \mathrm{ft}(26.52 \mathrm{~m})$ below TOC

Water elevation: $225.68 \mathrm{ht}(68.78$

po. conductance: $478 \mu \mathrm{s} / \mathrm{cm}$

The evacuated belore sampling: $16 \mathrm{ga}$

LABORATORY ANALYSES

\begin{tabular}{|c|c|c|c|c|}
\hline Analyte & Result & Mod & Unit & $\underline{\text { Lab }}$ \\
\hline $\begin{array}{l}\text { Carbon totrachloride } \\
\text { Chloroform } \\
\text { Nitrate as nitrogen } \\
\text { Tetrachloroethylene } \\
1,1,1 . \text { Trichloroethane } \\
\text { Trichloroethylene } \\
\text { Antimony-125 }\end{array}$ & $\begin{array}{l}<1.0 \\
<1.0 \\
50,500 \\
3.2 \\
<1.0 \\
30 \\
<6.1 E-09\end{array}$ & & $\begin{array}{l}\mu g / L \\
\mu g / L \\
\mu g / L \\
\mu g / L \\
\mu g / L \\
\mu g / L \\
\mu C \mathrm{i} / \mathrm{mL}\end{array}$ & $\begin{array}{l}\mathrm{GE} \\
\mathrm{GE} \\
\mathrm{GE} \\
\mathrm{GE} \\
\mathrm{GE} \\
\mathrm{GE} \\
\mathrm{TE}\end{array}$ \\
\hline
\end{tabular}

WELL NBG 2 collected on 11/14/91, laboratory analyses (cont.)

$\begin{array}{ll}\text { E } & \text { Analyte } \\ & \\ 0 & \text { Cerium-144 } \\ 0 & \text { Cesium-134 } \\ 0 & \text { Cesium-137 } \\ 0 & \text { Cobalt-57 } \\ 0 & \text { Cobalt-60 } \\ 0 & \text { Europium-154 } \\ 0 & \text { Gross alpha } \\ 0 & \text { Manganese-54 } \\ 1 & \text { Nonvolatile beta } \\ 0 & \text { Potassium-40 } \\ 0 & \text { Radium-226 } \\ 0 & \text { Ruthenium-103 } \\ 0 & \text { Sodium-22 } \\ 0 & \text { Strontium-89 } \\ 0 & \text { Strontium- } 90 \\ 0 & \text { Thorium-228 } \\ 0 & \text { Total activity } \\ 2 & \text { Total radium } \\ 2 & \text { Tritium } \\ 0 & \text { Zinc- } 85\end{array}$

Result

$<2.3 E-08$
$<2.6 \mathrm{E}-09$
$<1.8 \mathrm{E}-09$
$<3.0 \mathrm{E}-09$
$<1.9 \mathrm{E}-09$
$<4.6 \mathrm{E}-09$
$5.4 \mathrm{E}-09 \pm 1.9 \mathrm{E}-09$
$<2.1 \mathrm{E} .09$
$4.1 \mathrm{E}-08 \pm 3.4 \mathrm{E}-09$
$<3.6 \mathrm{E}-08$
$<5.1 \mathrm{E}-09$
$<7.3 \mathrm{E}-09$
$<1.7 \mathrm{E}-09$
$<9.0 \mathrm{E}-10$
$<4.0 \mathrm{E}-10$
$<2.4 \mathrm{E}-09$
$1.2 \mathrm{E}-03 \pm 2.7 \mathrm{E}-05$
$5.5 \mathrm{E}-09 \pm 2.2 \mathrm{E}-09$
$1.1 \mathrm{E}-03 \pm 5.2 \mathrm{E}-08$
$<4.9 \mathrm{E}-09$

Mod Unit Lab

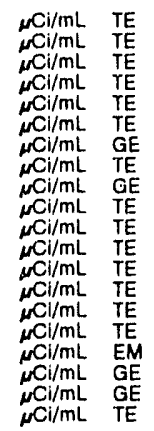

WELL NBG 3

MEASUREMENTS CONDUCTED IN THE FIELD

Sample date: $11 / 14 / 91$
Depth to water: $92.29 \mathrm{ft}(28.13 \mathrm{~m})$ below TOC

Water elevation: $220.11 \mathrm{t}(67.09 \mathrm{~m}) \mathrm{msl}$

Sp. conductance: $70 \mu \mathrm{S} / \mathrm{cm}$

Ther evacuated before sampling: 11 gal

LABORATORY ANALYSES

$\begin{array}{ll}\text { F } & \text { Analyte } \\ & \\ 0 & \text { Carbon tetrachloride } \\ 0 & \text { Chloroform } \\ 0 & \text { Nitrate as nitrogen } \\ 0 & \text { Nitrate as nitrogen } \\ 0 & \text { Tetrachloroethylene } \\ 0 & 1,1,- \text { Trichloroethane } \\ 2 & \text { Trichloroethylene } \\ 0 & \text { Antimony-125 } \\ 0 & \text { Cerium-144 } \\ 0 & \text { Cesium-134 } \\ 0 & \text { Cesium-137 } \\ 0 & \text { Cobalt-57 } \\ 0 & \text { Cobalt-60 } \\ 0 & \text { Europium-154 } \\ 0 & \text { Gross alpha } \\ 0 & \text { Manganese }-54 \\ 0 & \text { Nonvolatile beta } \\ 0 & \text { Potassium- } 40 \\ 0 & \text { Fadium-226 } \\ 0 & \text { Puthenium- } 103 \\ 0 & \text { Sodium-22 } \\ 0 & \text { Strontium- } 89 \\ 0 & \text { Strontium-90 } \\ 0 & \text { Thorium-228 } \\ 0 & \text { Total radium } \\ 2 & \text { Tritium } \\ 0 & \text { Zinc-65 }\end{array}$

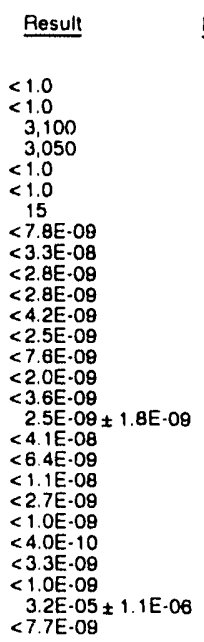

Mod Unit Lab

WELL NBG 4

MEASUREMENTS CONDUCTED IN THE FIELD

Sample date: 11/14/01

Depth to water: $86.95 \mathrm{tt}(26.50 \mathrm{~m})$ below TOC

Water elevation: $219.55 \mathrm{t}(66.92 \mathrm{~m}) \mathrm{ms}$ |

Sp conductance 28 S $/ \mathrm{cm}$

Water evacuated betore sampling: $12 \mathrm{gal}$

Time: 10:05

Alkalinity: $15 \mathrm{mg}$

Alkalinity: $15 \mathrm{mg} / \mathrm{L}: 19.0 \mathrm{C}$

The well went dry during purging.

LABORATORY ANALYSES

\begin{tabular}{|c|c|c|c|c|c|}
\hline$\underline{F}$ & Analyte & Fesult & Mod & Unif & Lab \\
\hline $\begin{array}{l}0 \\
0 \\
0 \\
0 \\
0 \\
1 \\
0 \\
0 \\
0 \\
0 \\
0 \\
0 \\
0 \\
0 \\
0 \\
0 \\
0 \\
0 \\
0\end{array}$ & $\begin{array}{l}\text { Carbon tetrachloride } \\
\text { Chloroform } \\
\text { Nitrate as nitrogen } \\
\text { Tetrachloroethylene } \\
1,1,1-\text { Trichloroethane } \\
\text { Trichlorothylene } \\
\text { Antimony-125 } \\
\text { Cerium-144 } \\
\text { Cesium- } 134 \\
\text { Cesium-137 } \\
\text { Cobalt-57 } \\
\text { Cobalt-60 } \\
\text { Europium.154 } \\
\text { Gross alpha } \\
\text { Manganese-54 } \\
\text { Nonvolatile beta } \\
\text { Potassium-40 } \\
\text { Radium-226 } \\
\text { Ruthenium-103 }\end{array}$ & $\begin{array}{l}<1.0 \\
<1.0 \\
1.640 \\
<1.0 \\
<1.0 \\
3.6 \\
<7.3 \mathrm{E} \cdot 09 \\
<3.0 \mathrm{E} \cdot 08 \\
<4.4 \mathrm{E} \cdot 09 \\
<2.2 \mathrm{E} \cdot 09 \\
<3.9 \mathrm{E} \cdot 09 \\
<2.4 \mathrm{E} \cdot 09 \\
<8.4 \mathrm{E} \cdot 09 \\
<2.0 \mathrm{E} \cdot 09 \\
<4.4 \mathrm{E} \cdot 09 \\
<2.0 \mathrm{E} \cdot 09 \\
<3.3 \mathrm{E} \cdot 08 \\
<6.3 \mathrm{E} \cdot 09 \\
<9.8 \mathrm{E} \cdot 09\end{array}$ & & $\begin{array}{l}\mu \mathrm{g} / \mathrm{L} \\
\mu \mathrm{g} / \mathrm{L} \\
\mu \mathrm{g} / \mathrm{L} \\
\mu \mathrm{g} / \mathrm{L} \\
\mu \mathrm{g} / \mathrm{L} \\
\mu \mathrm{g} / \mathrm{L} \\
\mu \mathrm{CL} / \mathrm{mL} \\
\mu \mathrm{Ci} / \mathrm{mL} \\
\mu \mathrm{Ci} / \mathrm{mL} \\
\mu \mathrm{Ci} / \mathrm{mL} \\
\mu \mathrm{Ci} / \mathrm{mL} \\
\mu \mathrm{Ci} / \mathrm{mL} \\
\mu \mathrm{Ci} / \mathrm{mL} \\
\mu \mathrm{Cit} / \mathrm{mL} \\
\mu \mathrm{Ci} / \mathrm{mL} \\
\mu \mathrm{Ci} / \mathrm{mL} \\
\mu \mathrm{Ci} / \mathrm{mL} \\
\mu \mathrm{Ci} / \mathrm{mL} \\
\mu \mathrm{Ci} / \mathrm{mL}\end{array}$ & $\begin{array}{l}\mathrm{GE} \\
\mathrm{GE} \\
\mathrm{GE} \\
\mathrm{GE} \\
\mathrm{GE} \\
\mathrm{GE} \\
\mathrm{TE} \\
\mathrm{TE} \\
\mathrm{TE} \\
\mathrm{TE} \\
\mathrm{TE} \\
\mathrm{TE} \\
\mathrm{TE} \\
\mathrm{GE} \\
\mathrm{TE} \\
\mathrm{GE} \\
\mathrm{TE} \\
\mathrm{TE} \\
\mathrm{TE}\end{array}$ \\
\hline
\end{tabular}


ANALYTICAL RESULTS

WELL NBG 4 collected or 11/14/91, laboratory analyses (cont.)

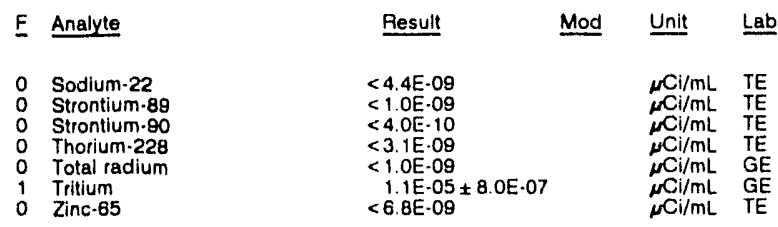

WELL NBG 5

MEASUREMENTS CONDUCTED IN THE FIELD

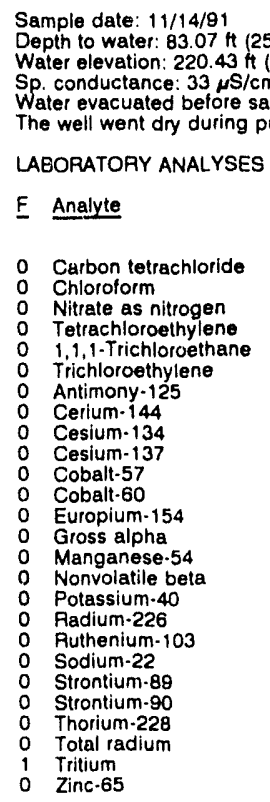

Time: $8: 30$

Alkalinity: $3 \mathrm{mg} / \mathrm{L}$

Water temperature: $19.3^{\circ} \mathrm{C}$

pling: $16 \mathrm{gal}$

LAEORATORY ANALYSES
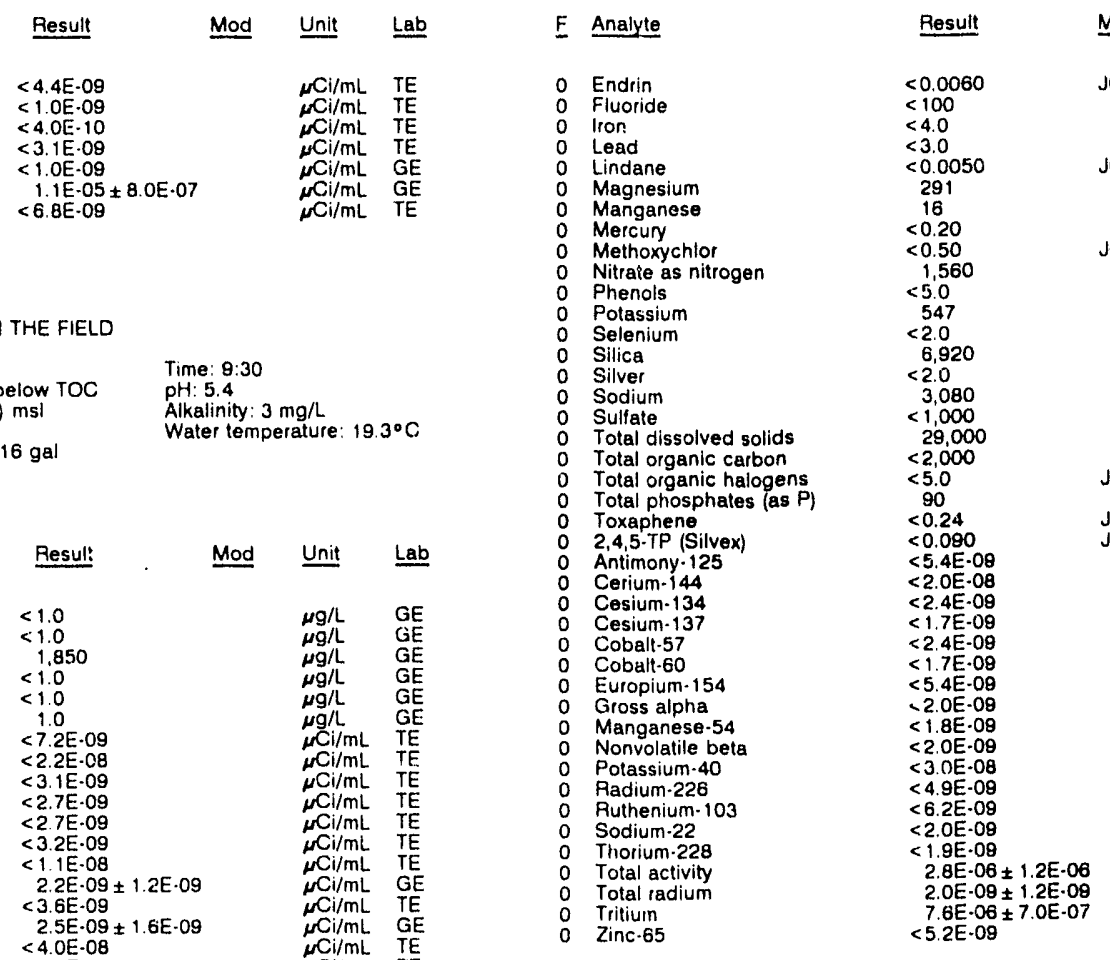

Mod Unit Lab

WELL NPM 3

MEASUREMENTS CONDUCTED IN THE FIELD

$<8.9 \mathrm{E}-09$

$<1.2 \mathrm{E}-09$

$<5.0 \mathrm{E} \cdot 10$
$<2.8 \mathrm{E}-09$

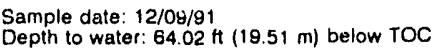
Water elevation: $272.28 \mathrm{ft}(82.99 \mathrm{~m}) \mathrm{msl}$ Wa

$<1.0 \mathrm{E} \cdot 09$

$\begin{aligned} & 1.2 \mathrm{E} \cdot 05 \\ &<98 \mathrm{E}-09\end{aligned}$

Time: $12: 10$

Alkalinity: $7 \mathrm{mg} / \mathrm{L}$ Water lemperature: $18.5^{\circ} \mathrm{C}$

WELL NPM 1

MEASUREMENTS CONDUCTED IN THE FIELD

Sample date: $12 / 10 / 91$ Time: 1005

Depth to water, $16.68 \mathrm{ft}(5.08 \mathrm{~m})$ below TOC

Watel elevation: $289.42 \mathrm{ft}(88.22 \mathrm{~m}) \mathrm{ms}$ |
Inaccessibility or pump failure prevented sample collection

WELL NPM $1 \mathrm{~A}$

MEASUREMENTS CONOUCTED IN THE FIELLD

Sample date: $12 / 10 / 91$ Time: 1000

Depth to water: $86.93 \mathrm{At}(26.50 \mathrm{~m})$ below TOC

Inaccessibility or pump failure prevented sample collection.

\section{WELL NPM 2}

MEASUREMENTS CONDUCTED IN THE FIELD

Sample date: $12 / 10 / 91$

Depth to water: $6198 \mathrm{ft}$ (18.89 m) below TOC

Water elevation. $275.12 \mathrm{H}(83.86 \mathrm{~m}) \mathrm{ms}$

Whe conduclance

ling $30 \mathrm{gal}$

LABORATORY ANALYSES

\begin{tabular}{|c|c|c|c|}
\hline Analyte & Result & Mod & Unit \\
\hline $\begin{array}{l}\mathrm{pH} \\
\text { Specilic conductance } \\
\text { Arsenic } \\
\text { Barium } \\
\text { Cadmium } \\
\text { Calcium } \\
\text { Chloride } \\
\text { Chromium } \\
\text { 2,4-Dichlorophenoxyacetic acird }\end{array}$ & $\begin{aligned} & 6.9 \\
& 55 \\
&<2.0 \\
& 8.5 \\
&<2.0 \\
& 5,900 \\
& 1.960 \\
&<4.0 \\
&<0.30\end{aligned}$ & JO & $\begin{array}{l}\mathrm{pH} \\
\mu \mathrm{S} / \mathrm{cm} \\
\mu \mathrm{g} / \mathrm{h} \\
\mu \mathrm{g} / \mathrm{L} \\
\mu \mathrm{g} / \mathrm{L} \\
\mu \mathrm{g} / \mathrm{L} \\
\mu \mathrm{g} / \mathrm{L} \\
\mu \mathrm{g} / \mathrm{h} \\
\mu \mathrm{g} / \mathrm{L}\end{array}$ \\
\hline
\end{tabular}

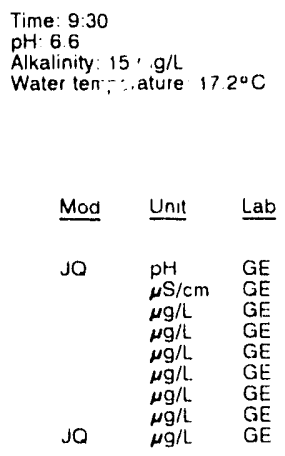

compling: 66 gal

LABORATORY ANALYSES

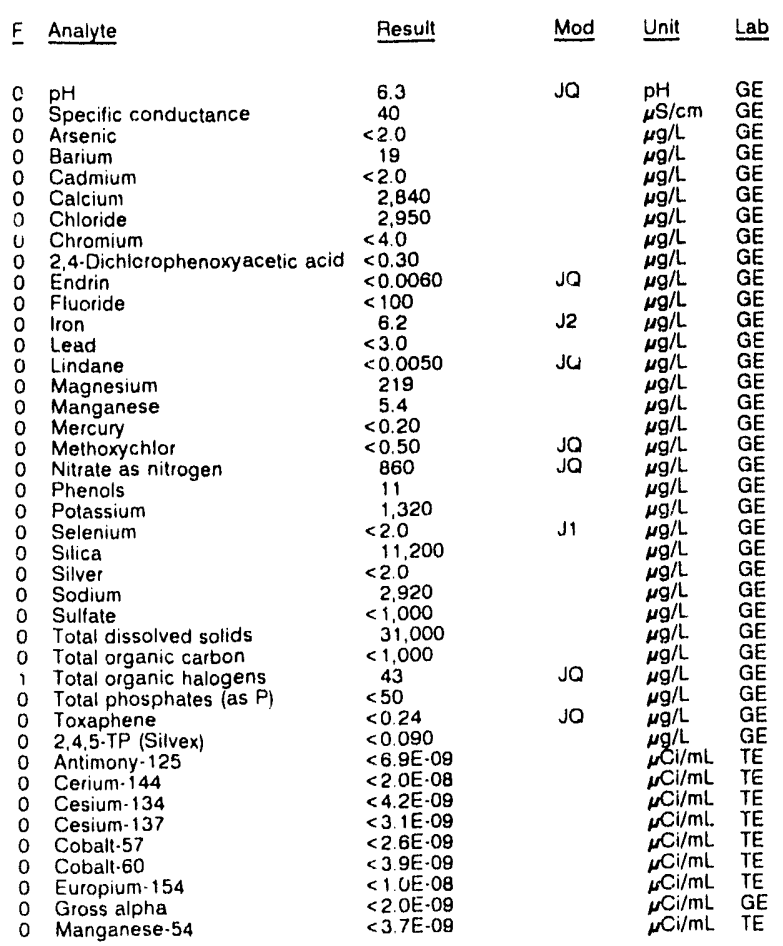


ANALYTICAL RESULTS

WELL NPM 3 collected on 12/09/91, laboratory analyses (cont.)

\begin{tabular}{|c|c|c|c|c|}
\hline$\underline{F}$ & Analyte & Result & Mod & Unit \\
\hline $\begin{array}{l}0 \\
0 \\
0 \\
0 \\
0 \\
0 \\
0 \\
0 \\
0 \\
0\end{array}$ & $\begin{array}{l}\text { Nonvolatile beta } \\
\text { Potasslum-40 } \\
\text { Radium-226 } \\
\text { Ruthenium-103 } \\
\text { Sodium-22 } \\
\text { Thorium-228 } \\
\text { Total activity } \\
\text { Total radium } \\
\text { Tritium } \\
\text { Zinc- } 65\end{array}$ & $\begin{array}{l}<2.0 \mathrm{E}-09 \\
<4.3 \mathrm{E} \cdot 08 \\
<4.7 \mathrm{E} \cdot 09 \\
<3.2 \mathrm{E}-09 \\
<3.8 \mathrm{E} \cdot 09 \\
<3.0 \mathrm{E} \cdot 09 \\
4.1 \mathrm{E} \cdot 06 \pm 1.2 \mathrm{E}-06 \\
<1.0 \mathrm{E} \cdot 09 \\
5.4 \mathrm{E} \cdot 06 \pm 7.0 \mathrm{E}-07 \\
<7.2 \mathrm{E} \cdot 09\end{array}$ & & $\begin{array}{l}\mu \mathrm{Ci} / \mathrm{mL} \\
\mu \mathrm{Ci} / \mathrm{mL} \\
\mu \mathrm{Ci} / \mathrm{mL} \\
\mu \mathrm{Ci} / \mathrm{mL} \\
\mu \mathrm{Ci} / \mathrm{mL} \\
\mu \mathrm{Ci} / \mathrm{mL} \\
\mu \mathrm{Ci} / \mathrm{mL} \\
\mu \mathrm{Ci} / \mathrm{mL} \\
\mu \mathrm{Ci} / \mathrm{mL} \\
\mu \mathrm{Ci} / \mathrm{mL}\end{array}$ \\
\hline
\end{tabular}

\section{WELL NPM 4}

MEASUREMENTS CONDUCTED IN THE FIELD

Sample date: 12/09/91

Depth to water: $26.55 \mathrm{Ht}(8.09 \mathrm{~m})$ below TOC

Water elevation: $287.25 \mathrm{Ht}(87$

Water evacuated belore sampling: $80 \mathrm{gal}$

LABORATORY ANALYSES

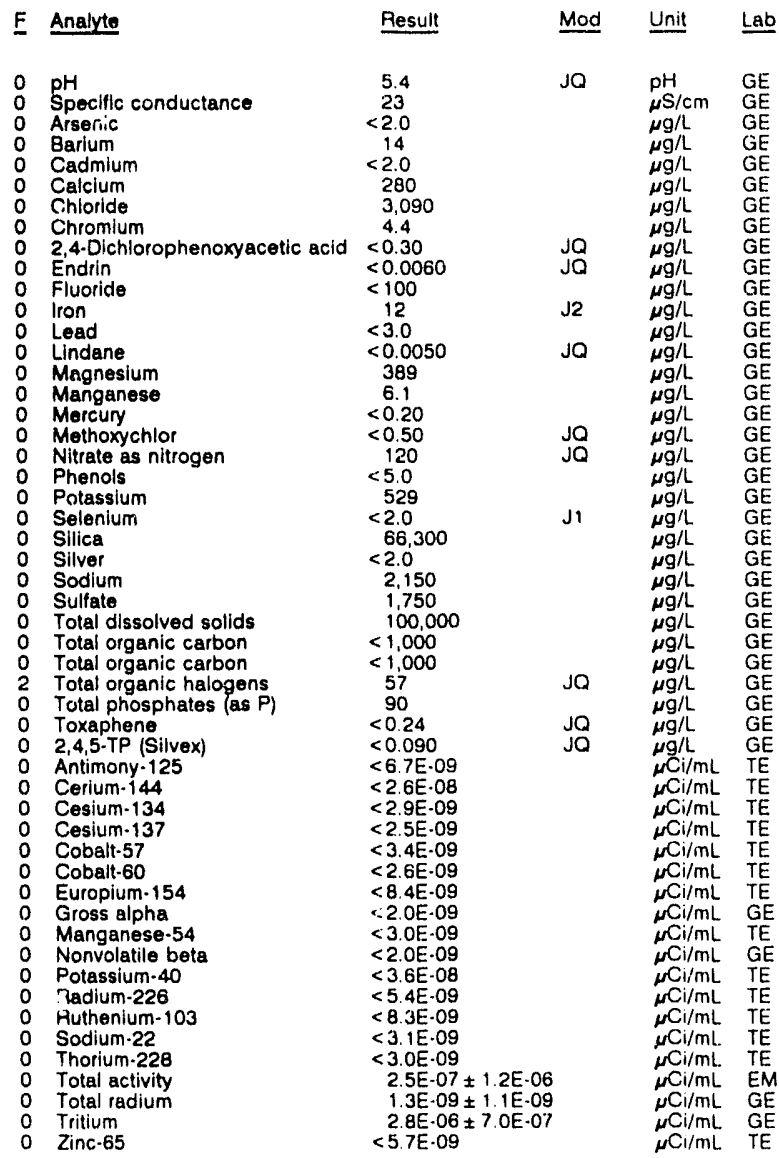

WELL NPM 4DD

MEASUREMENTS CONDUCTED IN THE FIELO

\begin{tabular}{|c|c|c|c|c|c|}
\hline & $\begin{array}{l}\text { nple date: } 12 / 10 / 81 \\
\text { th to water: } 16.03 \mathrm{ft} \\
\text { ter elevation: } 297.57 \\
\text { conductance: } 70 \mu \mathrm{S} / \\
\text { ter evacuated befcre } \\
\text { re was insufficient wa }\end{array}$ & $\begin{array}{l}\text { w TOC } \\
\text { msl } \\
\text { gal } \\
\text { or some }\end{array}$ & $\begin{array}{l}\text { Time: } 9.50 \\
\text { pH: } 6.4 \\
\text { Alkalinity: } \\
\text { Water temp } \\
\text { e bottles. }\end{array}$ & $\begin{array}{l}\mathrm{mg} / \mathrm{h} \\
\text { ature }\end{array}$ & $6.0^{\circ} \mathrm{C}$ \\
\hline & BORATUIYY ANALYSE & & & & \\
\hline E & Analyte & Result & Mod & Unit & Lab \\
\hline $\begin{array}{l}0 \\
0\end{array}$ & $\begin{array}{l}\text { Total organic carbon } \\
\text { Total activity }\end{array}$ & $\begin{array}{l}<2,000 \\
\quad 1.1 \mathrm{E} \cdot 0 \mathrm{~S}\end{array}$ & E.06 & $\mu \mathrm{g} / \mathrm{L}$ & $\begin{array}{l}G E \\
E M\end{array}$ \\
\hline
\end{tabular}

Alkalinity: $2 \mathrm{mg} / \mathrm{h}$

Alkalinity: $2 \mathrm{mg} / \mathrm{h}$. $20.2^{\circ} \mathrm{C}$
WELL NPM 19A

MEASUREMENTS CONDUCTED IN THE FIELD

Sample date: $12 / 08 / 91$

Depth to water: $53.38 \mathrm{Ht}(16.27 \mathrm{~m})$ below TOC

Water elevation: $273.92 \mathrm{ft}(83.49 \mathrm{~m}) \mathrm{ms}$

Sp. conductance: $52 \mu \mathrm{s} / \mathrm{cm}$

Water evacuated before sampling: $81 \mathrm{gal}$

LABORATORY ANAL.YSES

E Analyte Result Mod Unit Lab

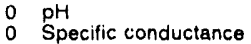

Arsenic

Barium

Cadmium

Calcium

Chromium

$\begin{array}{ll}0 & 2,4-D i c h l o r \\ 0 & \text { Endrin }\end{array}$

Fluoride

0 Iron

Lead

Magnesium

Manganes

Mercury

Nitrate as nitrogen

Phenols

Potassium
Selenium

Selenium

Silica

Sodium

Sulfate

Tolal dissolved solids

Total organic carbon
Total organic halogens

Total phosphates (as P)

Toxaphene

2,4,5.TP (Silvex)

Antimony-125

Cerium-144

Cesium-137

Cobalt- 57

Europium.154

Gross alpha

Manganese.54
Nonvolatile beta

Potassium.40

Radium-226

Ruthenium-103

Sodium-22

Thorium-228

0 Total radium

$\begin{array}{ll}0 & \text { Tritium } \\ 0 & \text { Zinc.65 }\end{array}$

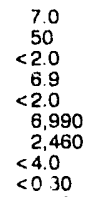

$<030$
$<00060$

$<000$
$<100$
6.3

$\begin{array}{r}6.3 \\ <3.0 \\ \hline\end{array}$

$<0.0050$

$\begin{aligned} & 163 \\ & 21 \\ &<0.20 \\ &<0.50\end{aligned}$

$<0.50$
471
$<5.0$

$<5.0$
1,130

$<2.0$
7.750

7.750
$<2.0$

2,710
$<1,000$

$<1,000$
35,000

$<1,000$

200
$<50$

$<0.24$

$<0.090$
$<7.4 \mathrm{E}-09$

$<2.3 \mathrm{E}-08$

$<3.6 E .09$

$<3.2 \mathrm{E} .09$

$<3.0 \mathrm{E} .09$

$<3.5 \mathrm{E}-09$
$<9.0 \mathrm{E} .09$

$<9.0 E .09$
$<2.0 E .09$

$<2.0 E .09$
$<3.6 \mathrm{E} .09$

$<3.6 \mathrm{E} \cdot 09$
$<2.0 \mathrm{E} .09$

$<4.5 \mathrm{E}-08$

<6.1E.09

$\angle 8.2 E .09$

$<3.1 \mathrm{E}-09$

$<3.1 E .09$
$<2.9 E .09$

$1.6 \mathrm{E} \cdot 06 \pm 1.2 \mathrm{E} \cdot 06$

$<1.0 \mathrm{E} .09$

Time: 15:30

pH: 7.0

Water temperature: $19.5^{\circ} \mathrm{C}$

$1.2 \mathrm{E}-06 \pm 7.0 \mathrm{E}-07$
$<76 \mathrm{E}-08$

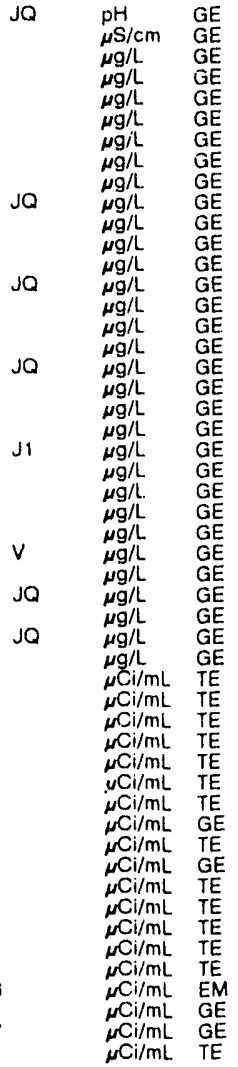

\section{WELL NPM 19B}

MEASUREMENTS CONDUCTED IN THE FIELLD

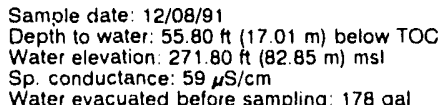

Time: $14: 50$

$\mathrm{pH}: 6.6$

Alkalinity: $19 \mathrm{mg} / \mathrm{L}$

Water temperature: $19.8^{\circ} \mathrm{C}$

Water evacuated before sampling: $178 \mathrm{gal}$

LABORATORY ANALYSES

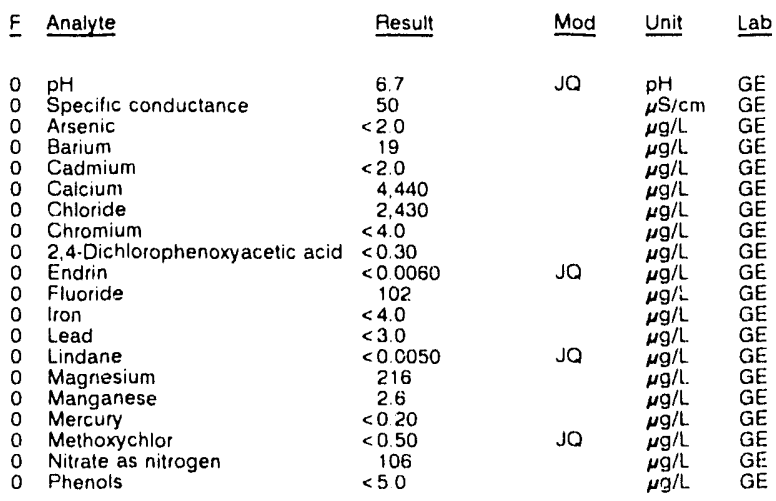


ANALYTICAL RESULTS

WELL NPM 198 coliected on 12/08/91, laboratory analyses (cont)

\begin{tabular}{|c|c|c|c|}
\hline Analyte & Result & Mod & Unit \\
\hline $\begin{array}{l}\text { Potassium } \\
\text { Selenium } \\
\text { Silica } \\
\text { Silver } \\
\text { Sodium } \\
\text { Sulfate } \\
\text { Total dissolved solids } \\
\text { Total organic carbon } \\
\text { Total organic halogens } \\
\text { Total phosphates (as P) } \\
\text { Toxaphene } \\
2,4,5 \cdot \text { TP (Silvex) } \\
\text { Antimony-125 } \\
\text { Cerium-144 } \\
\text { Cesium-134 } \\
\text { Cesium-137 } \\
\text { Cobalt-57 } \\
\text { Cobalt-60 } \\
\text { Europium-154 } \\
\text { Gross alpha } \\
\text { Manganese-54 } \\
\text { Nonvolatile beta } \\
\text { Totassium-40 } \\
\text { Radium-226 } \\
\text { Sodium-22 } \\
\text { Thorium-228 } \\
\text { Total activity } \\
\text { Total radium } \\
\text { Tritium } \\
\text { Zinc-65 }\end{array}$ & $\begin{array}{l}4.160 \\
<2.0 \\
11,900 \\
<2.0 \\
4,540 \\
3,260 \\
39,000 \\
<1.000 \\
7.5 \\
<50 \\
<0.24 \\
<0.090 \\
<6.4 \mathrm{E} \cdot 09 \\
<1.9 \mathrm{E} \cdot 08 \\
<3.6 \mathrm{E} \cdot 09 \\
<2.9 \mathrm{E} \cdot 09 \\
<2.6 \mathrm{E} \cdot 09 \\
<3.8 \mathrm{E} \cdot 09 \\
<8.7 \mathrm{E} \cdot 09 \\
<2.0 \mathrm{E} \cdot 09 \\
<3.8 \mathrm{E} \cdot 09 \\
2.2 \mathrm{E} \cdot 09 \pm 2.4 \mathrm{E} \cdot 09 \\
<4.5 \mathrm{E} \cdot 08 \\
<5.3 \mathrm{E} \cdot 09 \\
<3.2 \mathrm{E} \cdot 09 \\
<3.3 \mathrm{E} \cdot 09 \\
2.8 \mathrm{E} \cdot 06 \pm 1.2 \mathrm{E} \cdot 06 \\
1.6 \mathrm{E} \cdot 09 \pm 1.5 \mathrm{E} \cdot 09 \\
<7.0 \mathrm{E} \cdot 07 \\
<8.7 \mathrm{E} \cdot 09\end{array}$ & $\begin{array}{l}V \\
\mathrm{JQ} \\
\mathrm{JO}\end{array}$ & $\begin{array}{l}\mu g / L \\
\mu g / L \\
\mu g / L \\
\mu g / L \\
\mu g / L \\
\mu g / L \\
\mu g / L \\
\mu g / L \\
\mu g / L \\
\mu g i L \\
\mu g / L \\
\mu g / L \\
\mu C \mathrm{i} / \mathrm{mL} \\
\mu \mathrm{Ci} / \mathrm{mL} \\
\mu \mathrm{Ci} / \mathrm{mL} \\
\mu \mathrm{Ci} / \mathrm{mL} \\
\mu \mathrm{Ci} / \mathrm{mL} \\
\mu \mathrm{Ci} / \mathrm{mL} \\
\mu \mathrm{C} / \mathrm{mL} \\
\mu \mathrm{Ci} / \mathrm{mL} \\
\mu \mathrm{Ci} / \mathrm{mL} \\
\mu \mathrm{Ci} / \mathrm{mL} \\
\mu \mathrm{Ci} / \mathrm{mL} \\
\mu \mathrm{Ci} / \mathrm{mL} \\
\mu \mathrm{C} / \mathrm{mL} \\
\mu \mathrm{Ci} / \mathrm{mL} \\
\mu \mathrm{Ci} / \mathrm{mL} \\
\mu \mathrm{Ci} / \mathrm{mL} \\
\mu \mathrm{Ci} / \mathrm{mL} \\
\mu \mathrm{Ci} / \mathrm{mL}\end{array}$ \\
\hline
\end{tabular}

WELL NPM $19 C$

MEASUREMENTS CONDUCTED IN THE FIELD

Sample date: $12 / 08 / 91$

Depth to water: $57.50 \mathrm{ft}(17.53 \mathrm{~m})$ below TOC Water elevation: $271.40 \mathrm{ft}(82.72 \mathrm{~m}) \mathrm{msl}$ Water evacuated before sampling: $201 \mathrm{gal}$

Time: $14: 25$

pH: 6.3 : 9 mol

Water temperature $19.9^{\circ} \mathrm{C}$

LABORATORY ANALYSES

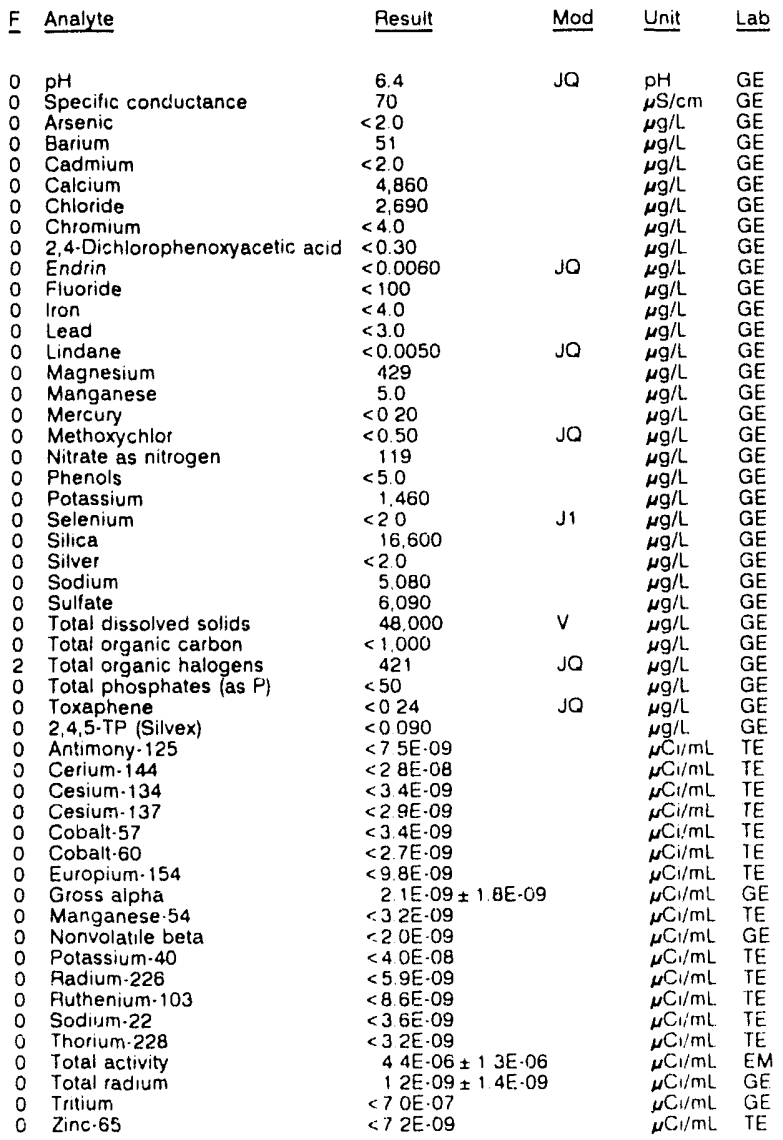

\section{WELL NPM 19D}

MEASUREMENTS CONDUCTED IN THE FIEL.D

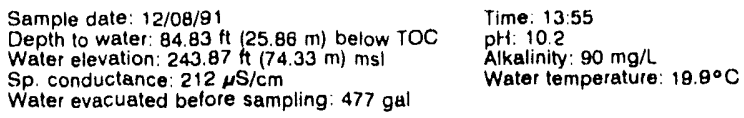

Water evacuated belore sampling: $477 \mathrm{gu}$

LABORATORY ANALYSES

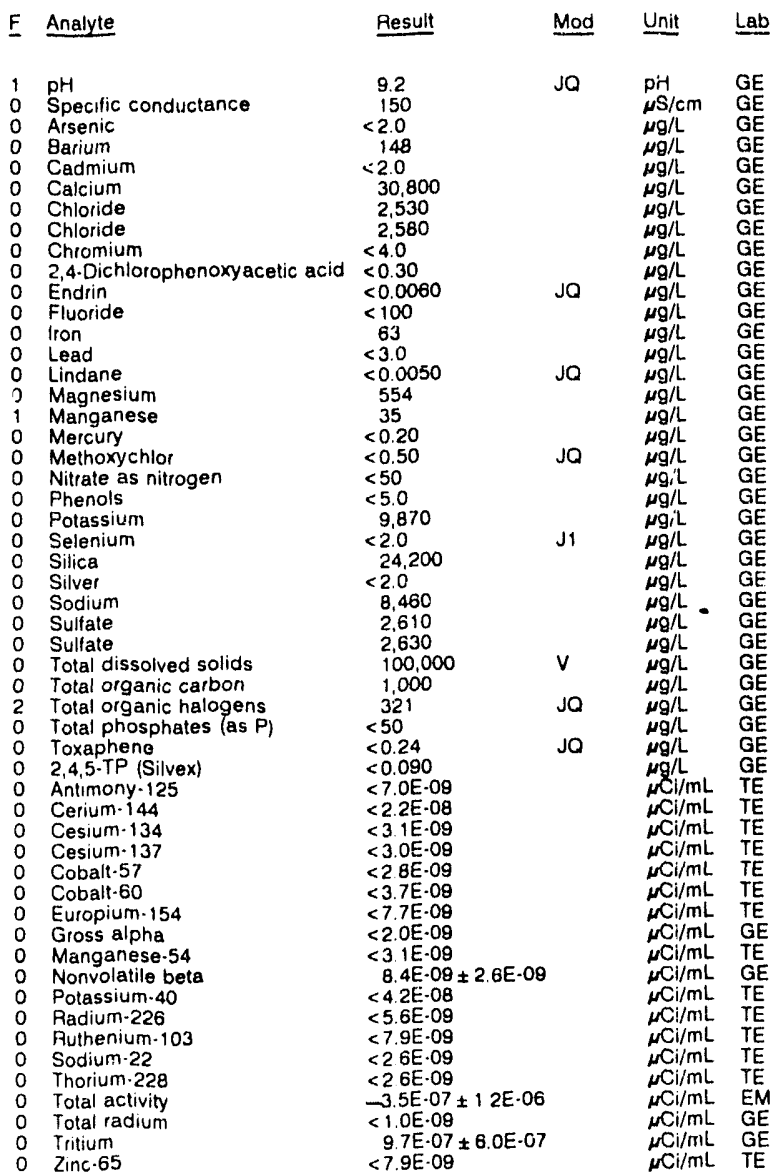

WELL NPM $19 E$

MEASUREMENTS CONOUCTED IN THE FIELD

Sample date: $12 / 08 / 91$

Depth to water: $143.18 \mathrm{ft}(43.64 \mathrm{~m})$ below TOC

Water elevation: $188.52 \mathrm{tt}(57.46 \mathrm{~m}) \mathrm{msl}$

Sp. conductance: $710 \mu \mathrm{S} / \mathrm{cm}$

Water evacuated before sampling: $35 \mathrm{gal}$

$\mathrm{pH}: 12.1$

Water temperature: $19.5^{\circ} \mathrm{C}$

LABORATORY ANALYSES

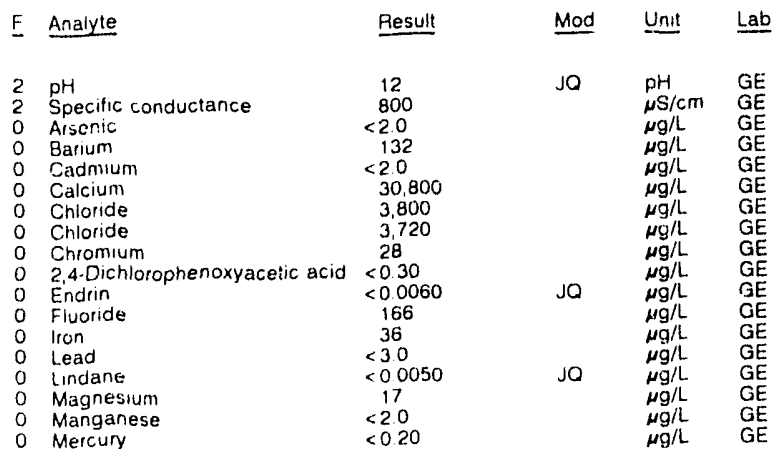


ANALYTICAL RESULTS

WELL NPM 19E collected on 12/08/91, laboratory analyses (cont.)

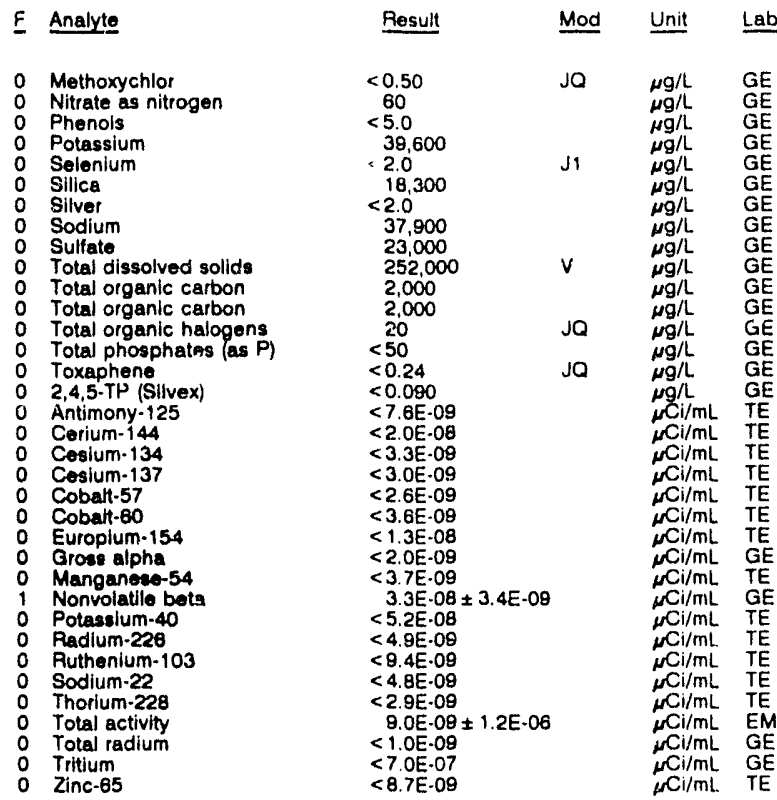

WELL NPM 34A

MEASUAEMENTS CONDUCTED IN THE FIELD

$\begin{array}{ll}\text { Sample date: } 12 / 08 / 91 & \text { Time: } 10: 40 \\ \text { Depth to water: } 28.24 \mathrm{ft}(8.81 \mathrm{~m}) \text { below TOC } & \text { pH: } 5.9 \\ \text { Water elevation: } 293.46 \mathrm{ft}(89.45 \mathrm{~m}) \mathrm{msl} & \text { Alkalinity: } 2 \mathrm{mg} / \mathrm{h} \\ \text { Sp. conductance: } 23 \mu \mathrm{s} / \mathrm{cm} & \text { Water temperature: } 19.5^{\circ} \mathrm{C} \\ \text { Water evacuated betore sampling: } 54 \mathrm{gal} & \\ \text { LABORATORY ANALYSES } & \end{array}$

E Analyte Result Mod Unit Lab

$\begin{array}{ll}0 & \mathrm{pH} \\ 0 & \text { Specific conductance } \\ 0 & \text { Arsenic }\end{array}$

0 Arsenic

Barium

Cadcium

Chloride

Chromium

$\begin{array}{ll}0 & 2,4-D i c h \\ 0 & \text { Endrin }\end{array}$

0 Fluoride

0 lion

0 Lead

o Lindane

- Manganese

Mercury

Methoxychlor
Nitrate as nitrogen

Phenols

Potassium

0 Selenium

Silice

S Silver

Sulfate

Total dissolved solids

Total dissolved solids

Total organic carbon

Total organic halogens

xaphene

2,4,5.TP (Silvex)

Antimony-125

Cerium 144

Cesium-134

Cesium-137

Coball. 57

Europium-154

Gross alpha

Nonvolatile beta

Potassium-40

Padium-226

Ruthenium-103

Thorium-228

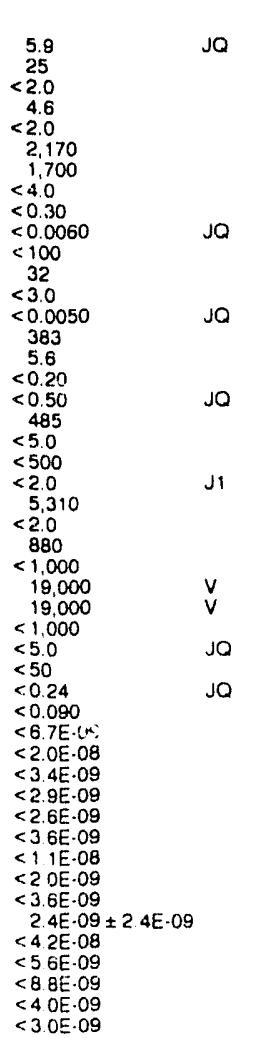

WELL NPM 34A collected on 12/08/91, laboratory analyses (cont.)

\begin{tabular}{|c|c|c|c|}
\hline Analyte & Result & Mod & Unit \\
\hline $\begin{array}{l}\text { Total activity } \\
\text { Total radium } \\
\text { Tritium } \\
\text { Zinc- } 65\end{array}$ & $\begin{array}{r}7.0 \mathrm{OE} \cdot 06 \pm 1.3 \mathrm{E} \cdot 06 \\
1.2 \mathrm{E} \cdot 09 \pm 1.4 \mathrm{E} \cdot 09 \\
5.2 \mathrm{E} \cdot 06 \pm 7.0 \mathrm{E} \cdot 07 \\
<7.2 \mathrm{E} \cdot 09\end{array}$ & & $\begin{array}{l}\mu \mathrm{Ci} / \mathrm{mL} \\
\mu \mathrm{Ci} / \mathrm{mL} \\
\mu \mathrm{Ci} / \mathrm{mL} \\
\mu \mathrm{Ci} / \mathrm{mL}\end{array}$ \\
\hline
\end{tabular}

WELL NPM 34B

MEASUREMENTS CONDUCTED IN THE FIELD

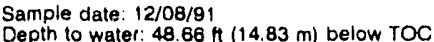

Water elevation: $273.14 \mathrm{ft}(83.25 \mathrm{~m}) \mathrm{ms}$ l

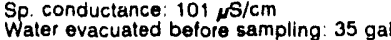

The well went dry during purging

LABORATORY ANALYSES

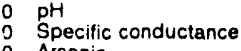

0 Arsenic

$\begin{array}{ll}0 & \text { Arsenic } \\ 0 & \text { Barium } \\ 0 & \text { Cadmium } \\ & \end{array}$

Calcium

$\begin{array}{ll}0 & \text { Chloride } \\ 0 & \text { Chromium }\end{array}$

2,4-Dichlorophenoxyacetic acid

0 Endrir

0 Fluoride

0 Fluoride

0 Lead

Lindane

Magnesium

Manganes

Methoxychlor

Nitrate as nitrogen

Nitrate as nitrogen

Phenols

Potassium

Silica

Silver

Sodium

Total dissolved solids

Total organic carbon

Total organic halogens

Total phosphates (as P)

Total phospha

2,4,5.TP (Silvex)

Antimony-125

Cerium-144

Cesium-134

Cobalt- 57

Cobalt-60

Europium.154

Gross alpha

Nonvolatile beta

Potassium. 40

Ruthenium-103

Sodium-22

Thorium-228

Total activity

Total radium

0 Zinc-65

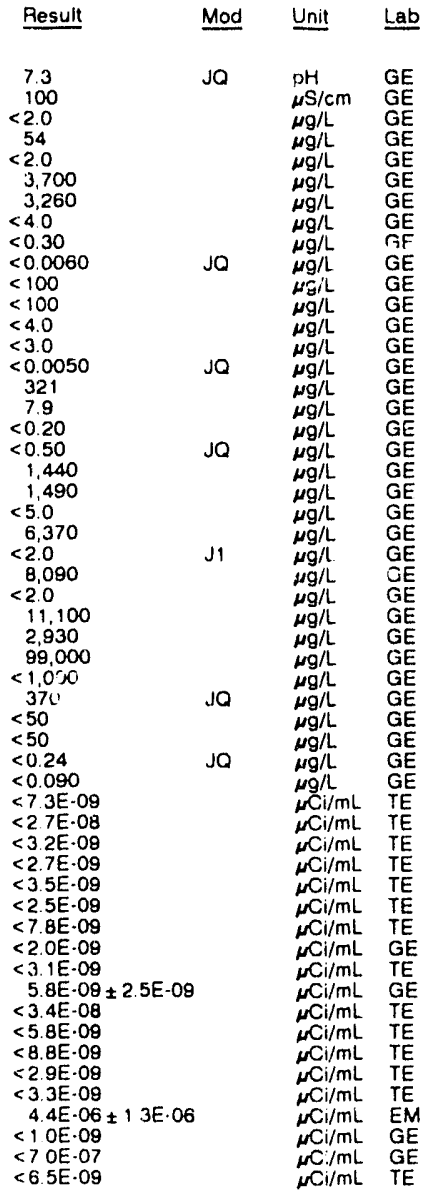

WELL NPM 340

MEASUREMENTS CONDUCTED IN THE FIELD

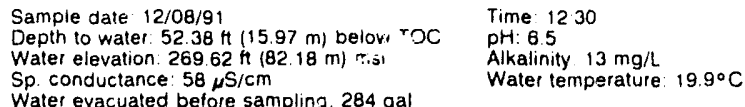

Water evacuated before sampling. $284 \mathrm{gal}$

Time: $16: 15$

Alkalinity: $30 \mathrm{mg} / \mathrm{L}$

Water temperature: $19.4^{\circ} \mathrm{C}$

LABORATORY ANALYSES

$\begin{array}{ll}\text { F } & \text { Analyte } \\ 0 & \text { pH } \\ 0 & \text { Specific conductance } \\ 0 & \text { Arsenic } \\ 0 & \text { Bariumi } \\ 0 & \text { Cadmium } \\ 0 & \text { Calcium } \\ 0 & \text { Chloride } \\ 0 & \text { Chromium }\end{array}$
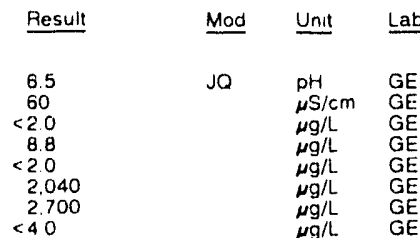
ANALYTICAL RESULTS

WELL NPM 34C collected on 12/08/91, laboratory analyses (cont)

\begin{tabular}{|c|c|c|c|c|c|}
\hline & Analyte & Result & Mod & Unit & $a b$ \\
\hline $\begin{array}{l}0 \\
0 \\
0 \\
0\end{array}$ & 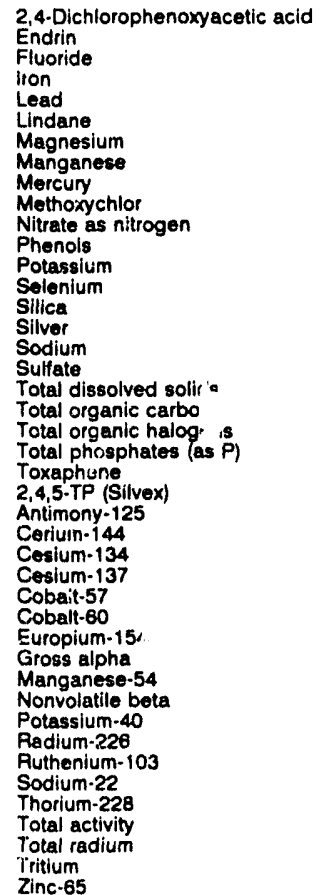 & 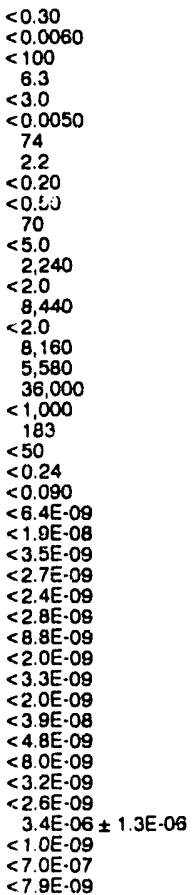 & $\begin{array}{l}\text { JO } \\
\text { J }\end{array}$ & 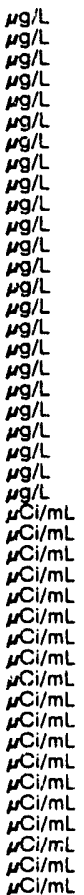 & $\begin{array}{l}\mathrm{GE} \\
\mathrm{GE} \\
\mathrm{GE} \\
\mathrm{GE} \\
\mathrm{GE} \\
\mathrm{GE} \\
\mathrm{GE} \\
\mathrm{GE} \\
\mathrm{GE} \\
\mathrm{GE} \\
\mathrm{GE} \\
\mathrm{GE} \\
\mathrm{GE} \\
\mathrm{GE} \\
\mathrm{GE} \\
\mathrm{GE} \\
\mathrm{GE} \\
\mathrm{GE} \\
\mathrm{GE} \\
\mathrm{GE} \\
\mathrm{GE} \\
\mathrm{GE} \\
\mathrm{GE} \\
\mathrm{GE} \\
\mathrm{TE} \\
\mathrm{TE} \\
\mathrm{TE} \\
\mathrm{TE} \\
\mathrm{rE} \\
\mathrm{TE} \\
\mathrm{TE} \\
\mathrm{GE} \\
\mathrm{TE} \\
\mathrm{GE} \\
\mathrm{TE} \\
\mathrm{TE} \\
\mathrm{TE} \\
\mathrm{TE} \\
\mathrm{TE} \\
\mathrm{EM} \\
\mathrm{GE} \\
\mathrm{GE} \\
\mathrm{TE}\end{array}$ \\
\hline
\end{tabular}

\section{WELL NPM 34D}

MEASUREMENTS CONDUCTED IN THE FIELD

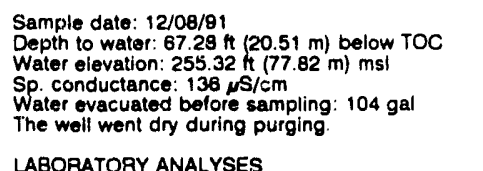

LABORATORY ANALYSES

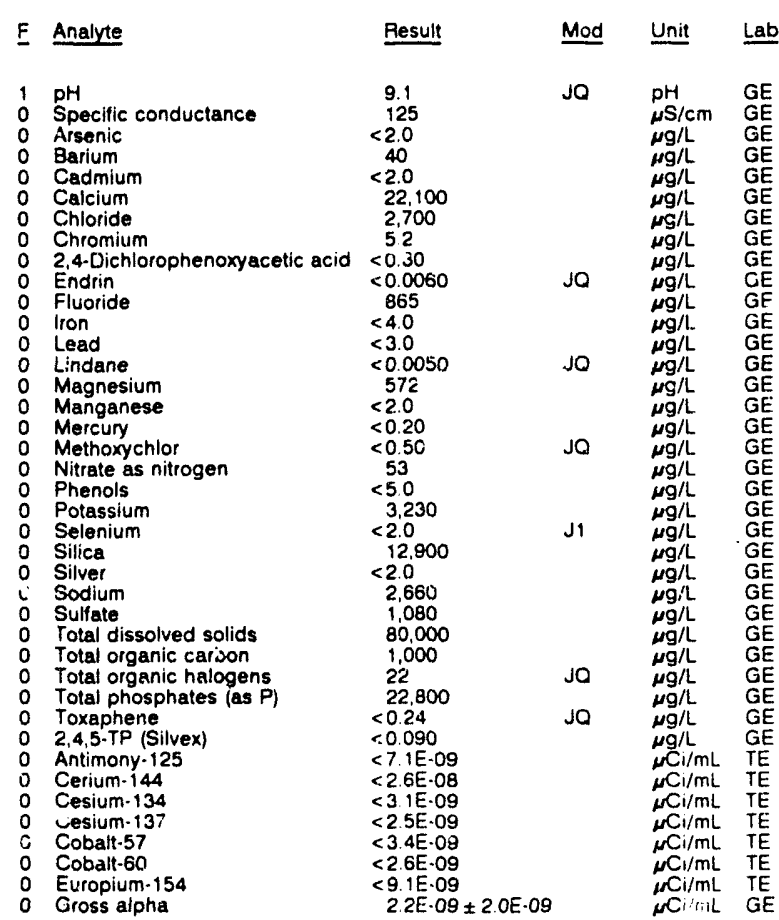

WELL NPM 34D collected on 12/08/81, laboratory analyses (cont.)

$$
\begin{array}{ll}
\text { F } & \text { Analyte } \\
0 & \text { Manganese-54 } \\
0 & \text { Nonvolatile beta } \\
0 & \text { Potassium-40 } \\
0 & \text { Radium-226 } \\
0 & \text { Ruthenium-103 } \\
0 & \text { Sodium-22 } \\
0 & \text { Thorium-228 } \\
0 & \text { Total activity } \\
1 & \text { Total radium } \\
0 & \text { Tritium } \\
0 & \text { Zinc-65 }
\end{array}
$$

\section{WELL NPM 34E}

MEASUREMENTS CONDUCTED IN THE FIELD

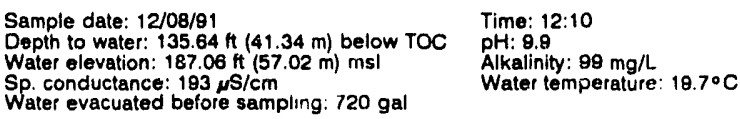

Water evacuated before sampling: $720 \mathrm{gal}$

LABOPATORY ANALYSES

E Analyte Result Mod Unit Lab

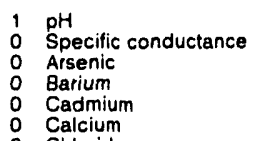

0 Arsenic

Cadmium

Chloride

Chloride

2.4-Dichlor

o Endrin

F Fluoride

Iron

0 Lead

O Lindane

Manganes

Mercury

Nitrate as nitrogen

Nitrate as nitrogen

Phenols

Potassium

Polassium

Silica

Silver

Sodium

0 Sulfate

Sulfate

Total organic carbon

Total crganic carbon

2 Total organic halogens

Total phosphates
0 Toxaphene
$2,4,5$.TP (Silvex)

$2,4,5 \cdot T P$ (Silvex)
0 Antimony-125

Antimony- 125

Cesium-134

Cobalt-57

Cobalt-57

Europium-154

Gross alpha

D Manganese.54

Nonvolatile beta

Potassium-40

Radium-226
Ruthenium-10

Ruthenium-10

S Scdium-22

Total activity

Total radivity

0 Tritium

$\begin{array}{ll}9.4 & \text { JO } \\ 190 & \\ 21 & \\ 44 & \\ <2.0 & \\ 31,100 & \\ 2,870 & 2,910 \\ <4.0 & \\ <0.30 & \end{array}$

$<0.0060$

113
$<100$

$<100$
15
$<30$

$<0.0050$

$\begin{aligned} & 355 \\ < & 2.0 \\ < & 0.20 \\ < & 0.50\end{aligned}$

$<0.20$
$<0.50$
$<50$
$<50$
$<5.0$

$<5.0$

$<5.00$

$<2.0$

\begin{tabular}{l}
14,400 \\
$<2.0$ \\
\hline
\end{tabular}

13,700
3,770

3,770
3,780

107,000

$<1,000$
$<1,000$

$<1,000$
158
$<50$

$<50$
$<0.24$

$<0.24$

$<8.0 \mathrm{E}-09$

$<2.9 \mathrm{E}-08$

$<<.2 \mathrm{E} .09$

$<3.7 \mathrm{E} .09$

$<2.7 \mathrm{E} .09$

$<8.1$ E-09

$<2.0 \mathrm{E} .09$

$<3.2 E .09$

$<4.3 \mathrm{E} \cdot 0 \mathrm{~B}$

$<6.1 \mathrm{E} .09$

$<9.0 E-09$

$<3.0 \mathrm{E} .09$

$<3.5 \mathrm{E} \cdot 09$
$6.2 \mathrm{E} \cdot 07 \pm 1.2 \mathrm{E} \cdot 06$

$6.2 \mathrm{E} \cdot 07 \pm 1.2 \mathrm{E} \cdot 06$
$1.1 \mathrm{E} \cdot 09 \pm 1.3 \mathrm{E} \cdot 09$

$<7.0 E .07$

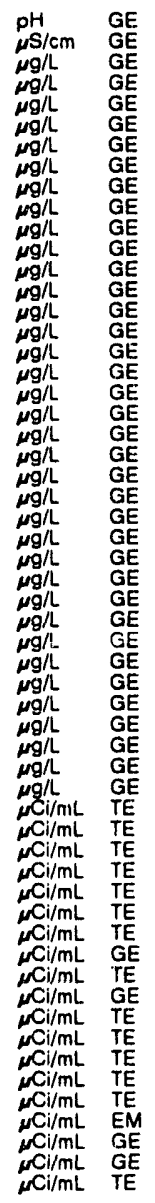

WELL P 14C

MEASUREMENTS CONDUCTED IN THE FIELO

Sample date: $12 / 09 / 91$ Time: 12.50 Wepth to water. $51.14 \mathrm{~h}(15.59 \mathrm{~m})$ below

Inaccessibility of pump failure prevented sample collection 
WELL P 14C

MEASUREMENTS CONDUCTED IN THE FIELD

Sample date: $12 / 30 / 91$

Depth to water: $51.61 \mathrm{Ht}(15.73 \mathrm{~m})$ below TOC

Water elevation: $245.39 \mathrm{tt}(74 \mathrm{gm}$

Sp. conductance: $160 \mu \mathrm{S} / \mathrm{cm}$
Water evacuated belore sampling: $271 \mathrm{gal}$

LABORATOAY ANALYSES

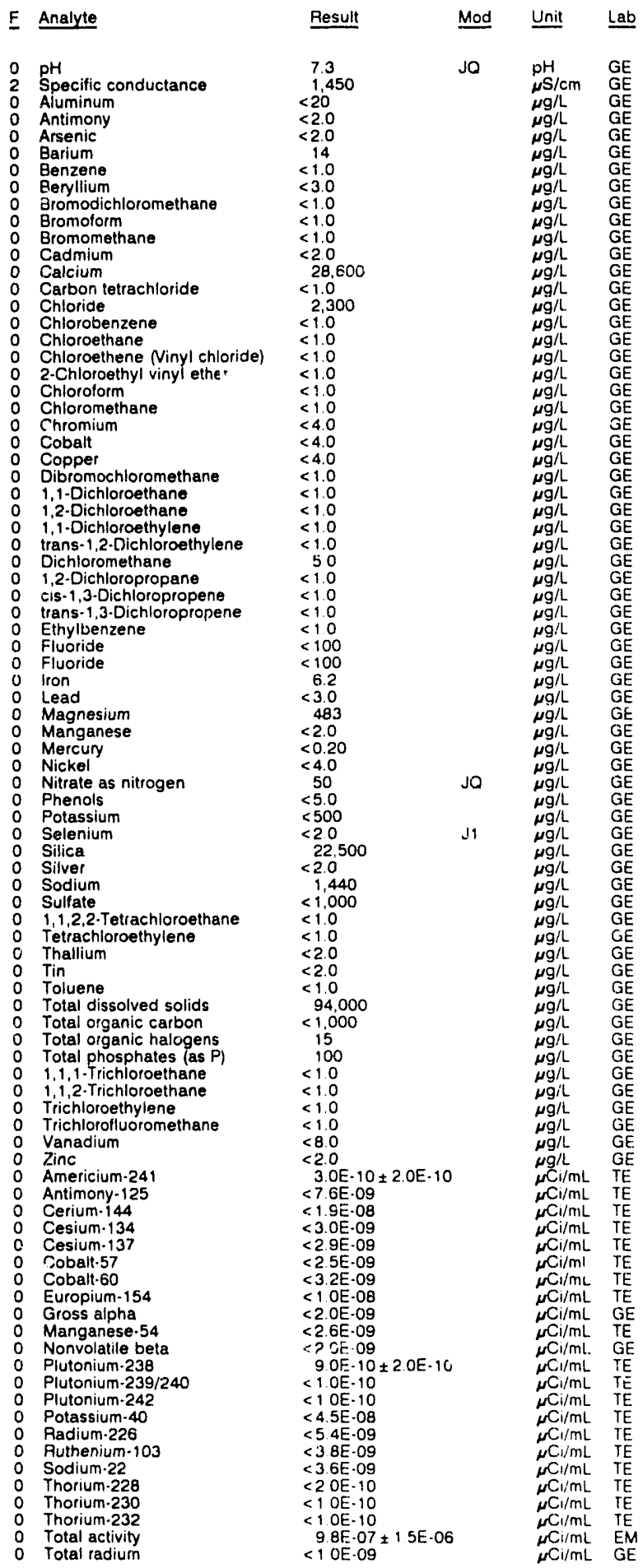

WELL P 14C collected on 12/30/91, laboratory analyses (cont.)

\begin{tabular}{|c|c|c|c|}
\hline Analyte & Result & Mad & Unit \\
\hline $\begin{array}{ll}0 & \text { Tritium } \\
0 & \text { Uranium.233/234 } \\
0 & \text { Uraniuun-238 } \\
0 & \text { Zinc-65 }\end{array}$ & $\begin{array}{l}<7.0 E \cdot 07 \\
<1.0 E \cdot 10 \\
<1.0 E-10 \\
<7.8 E \cdot 09\end{array}$ & & 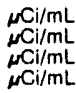 \\
\hline
\end{tabular}

WELL P 14TB

MEASUREMENTS CONDUCTED IN THE FIELD

Sample date: $12 / 00 / 91 \mathrm{Ht}(32.04 \mathrm{~m})$ below TOC

Denth to water: $105.13 \mathrm{ft}(32.04 \mathrm{~m})$ below
Water televation: $191.17 \mathrm{ft}(58.27 \mathrm{~m}) \mathrm{msl}$

Wa. conductarice: $43 \mu \mathrm{s} / \mathrm{cm}$ mpling: $1207 \mathrm{gal}$

LABORATORY ANALYSES

E Analyte Result Mod Unit Lab

$0_{0}^{0} \quad$ Specitic conductance

2 Aluminum

Arsenic

O Barium

0 Benzene

Bromodichloromethane

Bromoform

oromometh

Caamium

Carbon tetrachloride

0 Chloride

Chlorobenzene

Chlorvethene (Vinyl chloride)

2.Chloroethyl vinyl ether

0 Chloroform

Chloromethane

0 Chromiun

: Cobalt

Dibromochloromethane

1.1-Dichloroethane

- 1.2. Dichloroethane

1,1.Dichloroethylene

o trans-1,2-Dichloro

0 1,2-Oichloropiopane

trans-1,3-Dichloropropene

0 Ethylbenzene

0 Fluoride

2 lion

O Magnesium

Manganese

- Mercury

Nitrate as nitrogen

O Phenols

Phenols

Selenium

0 Silica

Silver

0 Sodium

0 Sulfate

S 1.1.2.2. Tetrachloroethane

Tetrachloroethylene

0 Tnallium

$0 \quad$ Tin

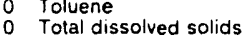

${ }_{0}$ Total dissolved solids

1 Total organic halogens

Total phosphates (as P)

0 1,1,1-Trichloroethane

o 1,1,2-Trichloroethan

T Trichloroethylene

- Trichlorofluciomethane

o Vanadium

0 Zinc

Americium-241

Antimony 125

Cerium-144

Cesium-134

Cobalt-57

Cobalt-60

Europium-154
Gross alpha

Manganese. 54

Plutonium.238

o Plutonium-238
pH: 5.8 : $1 \mathrm{mg} / \mathrm{L}$

Water temperature: $20.3^{\circ} \mathrm{C}$ 
ANALYTICAL RESULTS

WELL P 14TB collected on 12/09/91, laboratory analyses (cont.)

\begin{tabular}{|c|c|c|c|c|}
\hline$\underline{E}$ & Analyte & Result & Unit & Lab \\
\hline $\begin{array}{l}0 \\
0 \\
0 \\
0 \\
0 \\
0 \\
0 \\
0 \\
0 \\
0 \\
1 \\
0 \\
0 \\
0 \\
0\end{array}$ & $\begin{array}{l}\text { Plutonlum-242 } \\
\text { Potassium-40 } \\
\text { Radium-226 } \\
\text { Ruthenium-103 } \\
\text { Sodium-22 } \\
\text { Thorium-228 } \\
\text { Thorium-228 } \\
\text { Thorium-230 } \\
\text { Thorium-232 } \\
\text { Total activity } \\
\text { Total radium } \\
\text { Tritium } \\
\text { Uranium-233/234 } \\
\text { Uranium-238 } \\
\text { Zinc-65 }\end{array}$ & 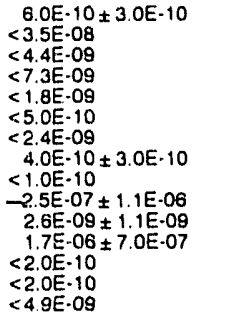 & 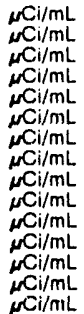 & $\begin{array}{l}\mathrm{TE} \\
\mathrm{TE} \\
\mathrm{TE} \\
\mathrm{TE} \\
\mathrm{TE} \\
\mathrm{TE} \\
\mathrm{TE} \\
\mathrm{TE} \\
\mathrm{TE} \\
\mathrm{EM} \\
\mathrm{GE} \\
\mathrm{GE} \\
\mathrm{TE} \\
\mathrm{TE} \\
\mathrm{TE}\end{array}$ \\
\hline
\end{tabular}

WELL. P 26A

MEASURI MENTS CONDUCTED IN THE FIELD

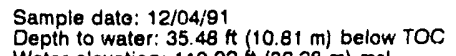

Time: $14: 45$

No water was evacuated before sampling

\section{WELL P 26B}

MEASUREMENTS CONDUCTED IN THE FIELD

Sample date: $12 / 04 / 91$

Depth to water: $42.85 \mathrm{ft}(13.06 \mathrm{~m})$ below TOC

Water elevation: $111.65 \mathrm{ft}(34.03 \mathrm{~m}) \mathrm{ms}$

Water evacuated before samplıng: $105 \mathrm{gal}$

LABORATORY ANALYSES

E Analyte Result Mod Unit Lab

0 pH

0 Benzene

Bromodichloromethane

Cadmium

Carbon tetrachloride

Chloride

Chlorobenzene

Chloroethane

2-Chloroethyl vinyl ether

Chloroform

Chromium $<4.0$

$\begin{array}{ll}\text { Dibromochloromethane } & <1.0 \\ 1,1 \cdot \text { Dichloroethane } & <1.0\end{array}$

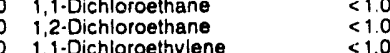

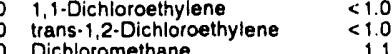

Dichloromethane
2.4.-Dichlorophenoxyacetic acid $<0.30$
1,2-Dichloropropane

cis-1,3-Dichloropropene

Endrin

Ethylbenzene

Fluoride
Iron

Lead

Lindane

Magnesium

Mercury

Methoxychlor

Phenols

Potassium

Selenium

Silica

Silver

Sodium

Sulfate

1,1,2,2-Tetrachloroethan
Tetrachloroethylene

Tolvene

Total dissolved solids

Total organic carbon

Total organic halogens
0 Total phosphates (as $\mathrm{P}$ )
Time: $9: 50$

Alkalinity: $18 \mathrm{mg} / \mathrm{L}$

Water temperature $153^{\circ} \mathrm{C}$

6.4
55

Jo

$\begin{array}{ll}\mu \mathrm{H} & \mathrm{GE} \\ \mu \mathrm{S} / \mathrm{cm} & \mathrm{GE} \\ \mu \mathrm{g} / \mathrm{L} & \mathrm{GE} \\ \mu \mathrm{g} / \mathrm{L} & \mathrm{GE} \\ \mu \mathrm{g} / \mathrm{L} & \mathrm{GE} \\ \mu \mathrm{g} / \mathrm{L} & \mathrm{GE} \\ \mu \mathrm{g} / \mathrm{L} & \mathrm{GE}\end{array}$

$<1.000$

$<1.0$

$<1.0$
$<1.0$
$<2.0$

7.530
$<1.0$

$<1.0$
2,390

$<1.0$

$<1.0$

1.0

1.0

0

0

1.0
1.1
0.30

$<1.0$
$<1.0$
$<1.0$

$<1.00060$

$<1.0$

$<100$

$<3.00050$

40.0050

403
$<2.0$
$<$

$<0.20$
$<0.50$

$<.50$
550

$\begin{array}{r}550 \\ <5.0 \\ \hline\end{array}$

679
$<2.0$
10.500

10,500
$<2.0$
1,900

1.900
1.740

$\begin{array}{r}1.900 \\ 1.740 \\ <1.0 \\ \hline\end{array}$

$<1.0$
$<1.0$

$<1.0$
27,000
$<1,000$
$<50$
$<50$
WELL P 268 collected on 12/04/91, laboratory analyses (cont.)

\begin{tabular}{|c|c|c|c|}
\hline Analyte & Resuit & Mod & Unit \\
\hline $\begin{array}{l}\text { Total phosphates (as P) } \\
\text { Toxaphene } \\
2,4,5-T P \text { (Silvex) } \\
1,1,1 \cdot \text { Trichloroethane } \\
1,1,2-\text { Trichloroethane } \\
\text { Trichloroethylene } \\
\text { Trichlorofluoromethane } \\
\text { Americium-241 } \\
\text { Antimony-125 } \\
\text { Cerium-144 } \\
\text { Cesium-134 } \\
\text { Cesium-137 } \\
\text { Cobalt-57 } \\
\text { Cobalt-60 } \\
\text { Europium-154 } \\
\text { Gross alpha } \\
\text { Manganese-54 } \\
\text { Nonvolatile beta } \\
\text { Plutonium-238 } \\
\text { Plutonium-239/240 } \\
\text { Plutonium-242 } \\
\text { Potassium-40 } \\
\text { Radium-226 } \\
\text { Radium-226 } \\
\text { Radium-226 } \\
\text { Padium-228 } \\
\text { Ruthenium-103 } \\
\text { Sodium-22 } \\
\text { Strontium-89 } \\
\text { Strontium-90 } \\
\text { Thoriumm-228 } \\
\text { Thoriumm-230 } \\
\text { Thorium-232 } \\
\text { Total radium } \\
\text { Tritium } \\
\text { Uranium-233/234 } \\
\text { Uranium-238 } \\
\text { Zinc-65 }\end{array}$ & 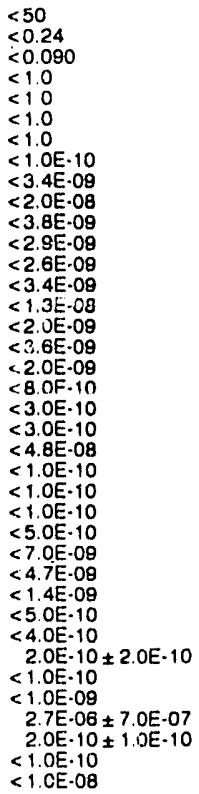 & JO & 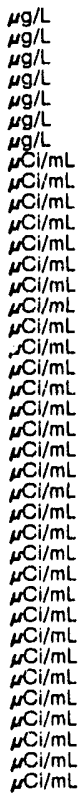 \\
\hline
\end{tabular}

WELL P 260

MEASUREMENTS CONDUCTED IN THE FIELD

Sample date: $12 / 04 / 91$

Depth to water: $33.31 \mathrm{ft}(10.15 \mathrm{~m})$ below
Water elevation: $121.19 \mathrm{ft}(36.94 \mathrm{~m}) \mathrm{ms}$

Sp. conductance: $33 \mathrm{\mu S} / \mathrm{cm}$.
Water evacuated before sampling: $52 \mathrm{gal}$

pH: 6.2

Plkalinity: $13 \mathrm{mg} / \mathrm{L}$

LABORATORY ANALYSES

E Analyte ㅁesult Mod Unit Lab

${ }_{0}^{0} \mathrm{pH}^{\mathrm{pH}} \mathrm{Specific}$ conductanse

0 A.rsenic

0 Barium

O Benzene

0 Bromodichloromethane

0 Bromoform

- Bromomethane

- Cadmium

0 Calcium

$\begin{array}{ll}0 & \text { Chloride } \\ 0 & \text { Chlorobenzene }\end{array}$

Chloroethane

$\begin{array}{ll}0 & \text { Chloroethene Ninyl chlorid } \\ 0 & \text { 2.Chloroethyl vinyl ether }\end{array}$

o 2 Chloroethyl

Chlorolorm

Chromium

Dibromochloromethane

1.1.Dichloroethane

o 1,2-Dichloroethane

1.1.Dichloroethylene
0
trans-1,2-Dichloroethylen

trans-1,2.Dichloroethylene
0 Dichloromethane
0 2,4.Dichlorophenoxyacetic acid $<0$

1,2-Dichloropropane

o cis-1,3-Dichloropropene

u uns-13-Dichloroprope

o Endrin

o Ethylbenzene

0 Fluoride

0 Lead

0 Lead

D Magnesium

o Manganes

O Mercury

0 Nitrate as nitrogen

0 Phenols

$\begin{array}{ll}0 & \text { Potassium } \\ 0 & \text { Selenium }\end{array}$

0 Selenium

Result

JQ $\quad \mathrm{pH} \quad \mathrm{GE}$

6.1
35
$<2.0$
7.0

$<1.0$

$<1,000$

$<1.0$
$<1.0$

$<1.0$
$<1.0$

$<2.0$

\begin{tabular}{l}
3,160 \\
$<1.0$ \\
\hline
\end{tabular}

$<1.0$

$<1.0$

$<1.0$

$<1.0$

$<10$

$\div 4.0$

$<1.0$

$<1.0$

$<0$
1.5

$<0.30$

$<10$
$<10$

$<10$

$<0.0060$
$<1.0$

$<10$
$<100$

5.7

$<0.0050$

292
$<20$

$<2.0$
$<0.20$

$<0.50$

530
$<50$

616
$<2.0$

$<.0$
8.710

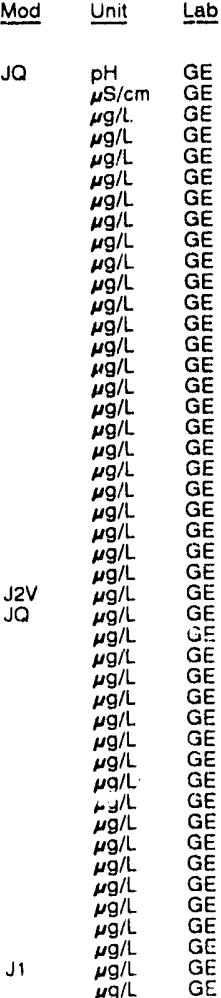


ANALYTICAL RESULTS

WELL P 26D collected on 12/04/91, laboratory analyses (cont.)

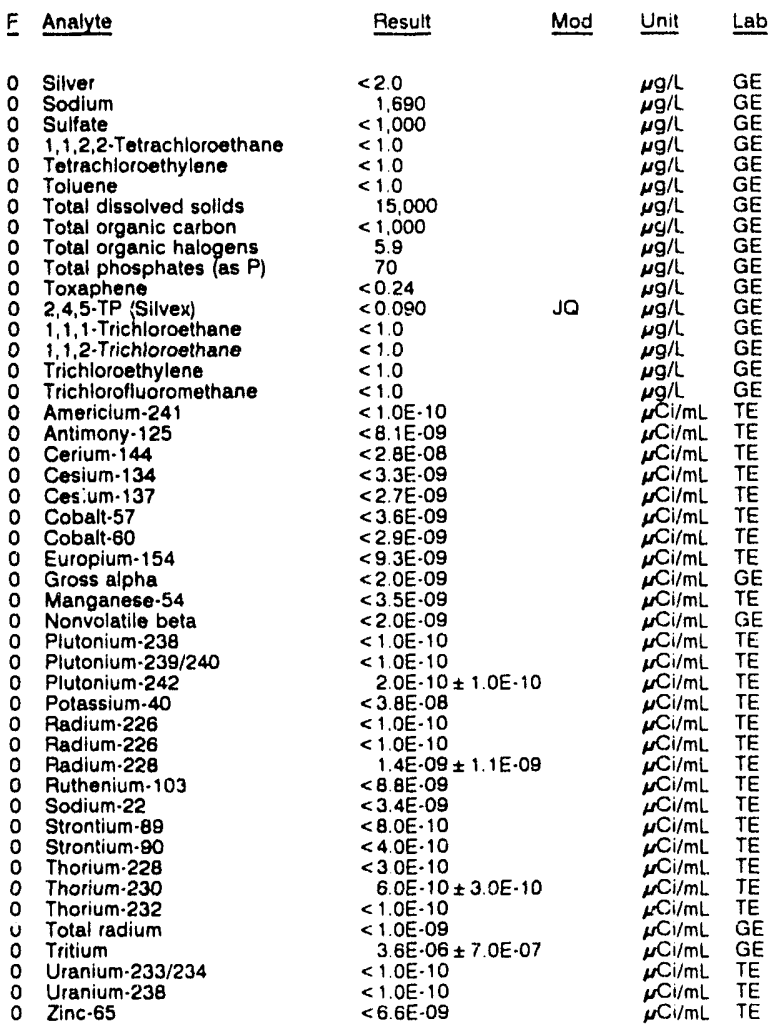

WELL P 26D Replicate

MEASUREMENTS CONDUCTED IN THE FIELD

Sample date: $12 / 04 / 91$

Depth to water: $33.31 \mathrm{ft}(10.15 \mathrm{~m})$ below TOC

Water elevation: $121.19 \mathrm{ft}$ (36

Sp. conductance: $33 \mu \mathrm{s} / \mathrm{cm}$
Water evacuated before sampling 52 gal

LABORATORY ANALYSES

\begin{tabular}{|c|c|c|c|}
\hline Analyte & Resull & Mod & Unit \\
\hline $\begin{array}{l}\text { pH } \\
\text { Specific conductance } \\
\text { Arsenic } \\
\text { Barium } \\
\text { Benzene } \\
\text { Bromide } \\
\text { Bromodichloromethane } \\
\text { Bromoform } \\
\text { Gromomethane } \\
\text { Cadmium } \\
\text { Catcium } \\
\text { Carbon tetrachloride } \\
\text { Chloride } \\
\text { Chlorobenzene } \\
\text { Chloroethane } \\
\text { Chloroethene Ninyl chloride) } \\
\text { 2.Chloroethyl vinyl ether } \\
\text { Chloroform } \\
\text { Chloromethane } \\
\text { Chromium } \\
\text { Dibromochloromethane } \\
1,1 \cdot \text { Dichloroethane } \\
1,2 \text {-Dichloroethane } \\
1,1 \cdot \text { Dichloroethylene } \\
\text { trans-1,2-Dichloroethylene } \\
\text { Dichloromethane } \\
2,4 \text {-Dichlorophenoxyacetic acid } \\
\text { 1,2-Dichloropropane } \\
\text { cis-1,3-Dichloroplopene } \\
\text { trans-1,3-Dichloropropene } \\
\text { Endrin } \\
\text { Ethylbenzene } \\
\text { Fluoride } \\
\text { Fluoride } \\
\text { lon } \\
\text { Lead } \\
\text { Lindane }\end{array}$ & $\begin{aligned} 6.0 \\
30 \\
<2.0 \\
7.4 \\
<1.0 \\
<1.000 \\
<10 \\
<1.0 \\
<10 \\
<2.0 \\
3,320 \\
<10 \\
2.480 \\
<1.0 \\
<1.0 \\
<1.0 \\
<1.0 \\
<1.0 \\
<1.0 \\
<4.0 \\
<1.0 \\
<1.0 \\
<1.0 \\
<10 \\
<1.0 \\
<1.7 \\
<0.30 \\
<1.0 \\
<1.0 \\
<1.0 \\
<0.0060 \\
<10 \\
<100 \\
<100 \\
53.4 \\
<3.0 \\
<0.0050\end{aligned}$ & $\begin{array}{l}\mathrm{J} 2 \mathrm{~V} \\
\mathrm{JO}\end{array}$ & $\begin{array}{l}p H \\
\mu S / c m \\
\mu g / L \\
\mu g / L \\
\mu g / L \\
\mu g / L \\
\mu g / L \\
\mu g / L \\
\mu g / L \\
\mu g / L \\
\mu g / L \\
\mu g / L \\
\mu g / L \\
\mu g / L \\
\mu g / L \\
\mu g / L \\
\mu g / L \\
\mu g / L \\
\mu g / L \\
\mu g / L \\
\mu g / L \\
\mu g / L \\
\mu g / L \\
\mu g / L \\
\mu g / L \\
\mu g / L \\
\mu g / L \\
\mu g / L \\
\mu g / L \\
\mu g / L \\
\mu g / L \\
\mu g / L \\
\mu g / L \\
\mu g / L \\
\mu g / L \\
\mu g / L \\
\mu g / L\end{array}$ \\
\hline
\end{tabular}

WELL P $26 \mathrm{D}$ collected on 12/04/91, laboratory analyses (cont.)

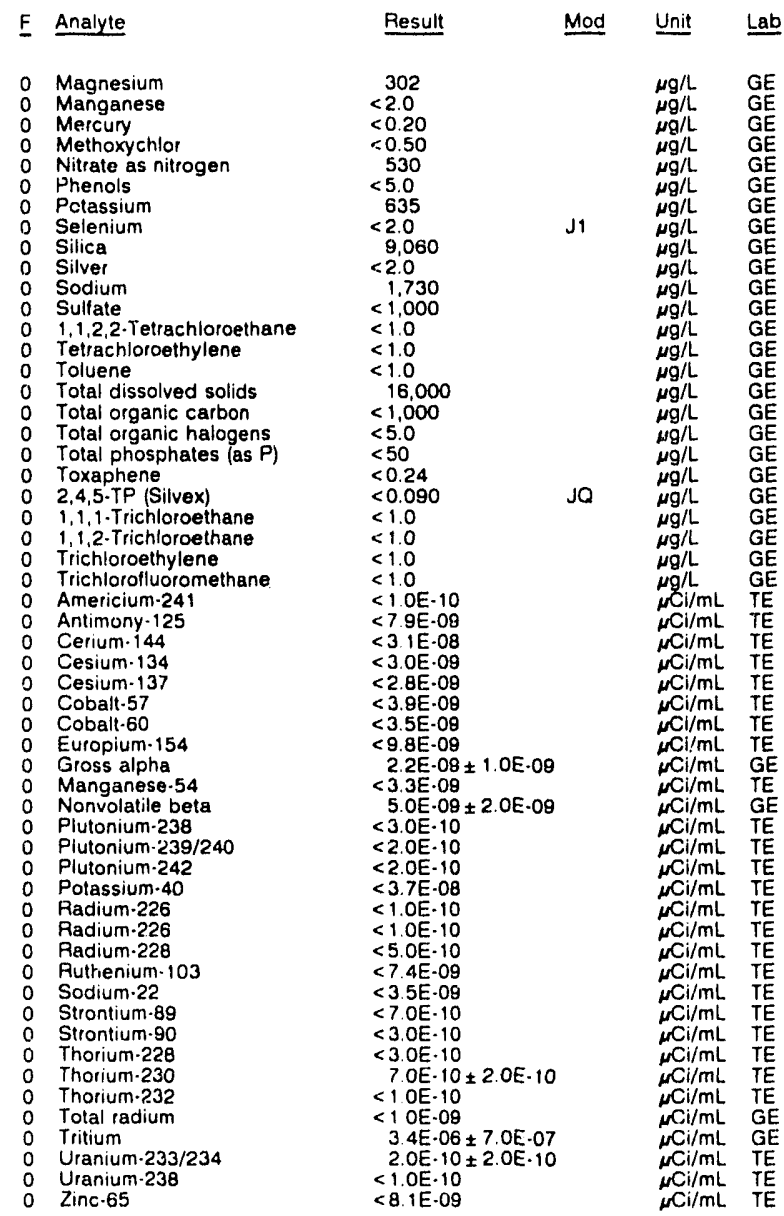

WELL P 28A

MEASIJREMENTS CONDUCTED IN THE FIELD

$\begin{array}{ll}\text { Sample date: } 11 / 08 / 91 & \text { Time: } 9: 20 \\ \text { Depth to water: } 108.50 \mathrm{Ht}(33.07 \mathrm{~m}) \text { below TOC } & \text { pH: } 6.2 \\ \text { Water elevation. } 17 / 20 \mathrm{ft}(54.01 \mathrm{~m}) \mathrm{ms} & \text { Alkalinity: } 21 \mathrm{mg} / \mathrm{L} \\ \text { Sp. conductance: } 72 \mu \mathrm{cS} / \mathrm{cm} & \text { Water temperature } 18.3^{\circ} \mathrm{C} \\ \text { Water evacuated before sampling: } 618 \mathrm{gal} & \end{array}$

Water evacuated before sampling: $618 \mathrm{gal}$

LABORATORY ANALYSES

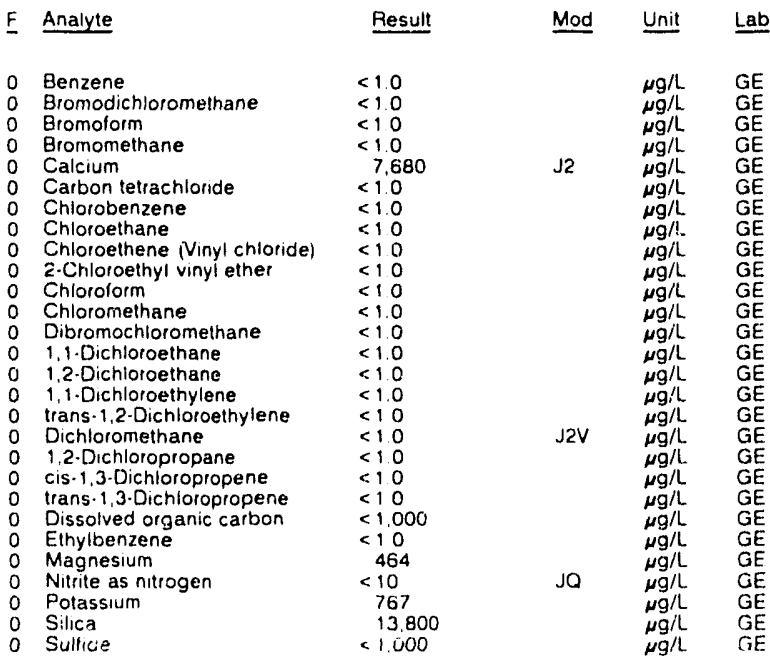


ANALYTICAL RESULTS

WELL P 2BA collected on 11/08/91, laboratory analyses (cont.)

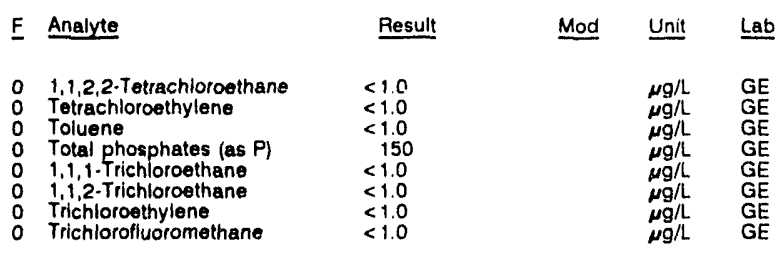

WELLP 28TB

MEASUREMENTS CONDUCTED IN THE FIELD

Sample date: 11/08/91

Depth to water: $109.96 \mathrm{ft}(33.52 \mathrm{~m})$ below TOC Water elevation: $175.44 \mathrm{ft} /(53.47$
Sp. conductance: $43 \mu \mathrm{s} / \mathrm{cm}$

Sater evacuated before sampling: $1400 \mathrm{gal}$

LABORATORY ANALYSES

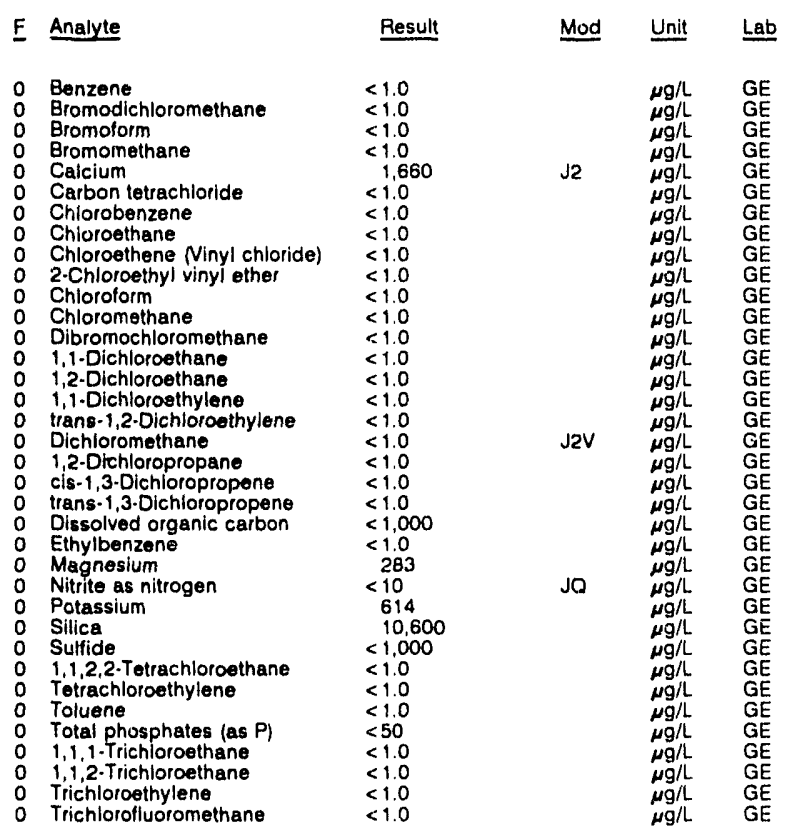

WELL P 28TB Replicate

MEASUREMENTS CONDUCTED IN THE FIELD

Sample date: $11 / 08 / 91$

Depth to water: $109.98 \mathrm{H}(33.52 \mathrm{~m})$ below TOC

Water olevation: $175.44 \mathrm{H}$

Water evacuated before sampling: $1400 \mathrm{gal}$

LABORATORY ANALYSES

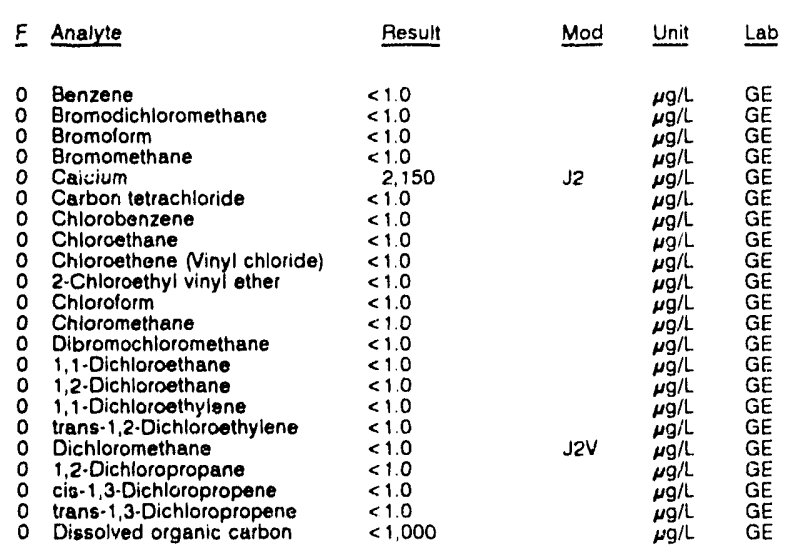

WELL P 28TB collected on 11/08/91, laboratory analyses (cont.)

\begin{tabular}{|c|c|c|c|}
\hline Analyte & Result & Mod & Unit \\
\hline $\begin{array}{l}\text { Ethylbenzene } \\
\text { Magnesium } \\
\text { Nitrite as nitrogen } \\
\text { Potassium } \\
\text { Silica } \\
\text { Sulfide } \\
1,1,2,2 \text {-Tetrachloroethane } \\
\text { Tetrachloroethylene } \\
\text { Toluene } \\
\text { Total phosphates (as P) } \\
\text { Total phosphates (as Pf } \\
1,1,1 \text {-Trichloroethane } \\
1,1,2 \text {-Trichloroethane } \\
\text { Trichloroethylene } \\
\text { Trichlorofluofomethane }\end{array}$ & $\begin{array}{l}<1.0 \\
290 \\
<10 \\
644 \\
10,600 \\
<1,000 \\
<1.0 \\
<1.0 \\
<1.0 \\
50 \\
<50 \\
<1.0 \\
<1.0 \\
<1.0 \\
<1.0\end{array}$ & $\mathrm{JO}$ & $\begin{array}{l}\mu g / L \\
\mu g / L \\
\mu g / L \\
\mu g / L \\
\mu g / L \\
\mu g / L \\
\mu g / L \\
\mu g / L \\
\mu g / L \\
\mu g / L \\
\mu g / L \\
\mu g / L \\
\mu g / L \\
\mu g / L \\
\mu g / L\end{array}$ \\
\hline
\end{tabular}

WELL P 29C

MEASUREMENTS CONDUCTED IN THE FIELD

Sample date: $11 / 18 / 91$ H $(31.43 \mathrm{~m})$ below TOC Water elevation: $166.19 \mathrm{f}(50.86 \mathrm{~m}) \mathrm{ms}$.

Sp. conductance: $47 \mathrm{\mu S} / \mathrm{cm}$
Water evacuated betore sampling: $105 \mathrm{gal}$

LABORATORY ANALYSES

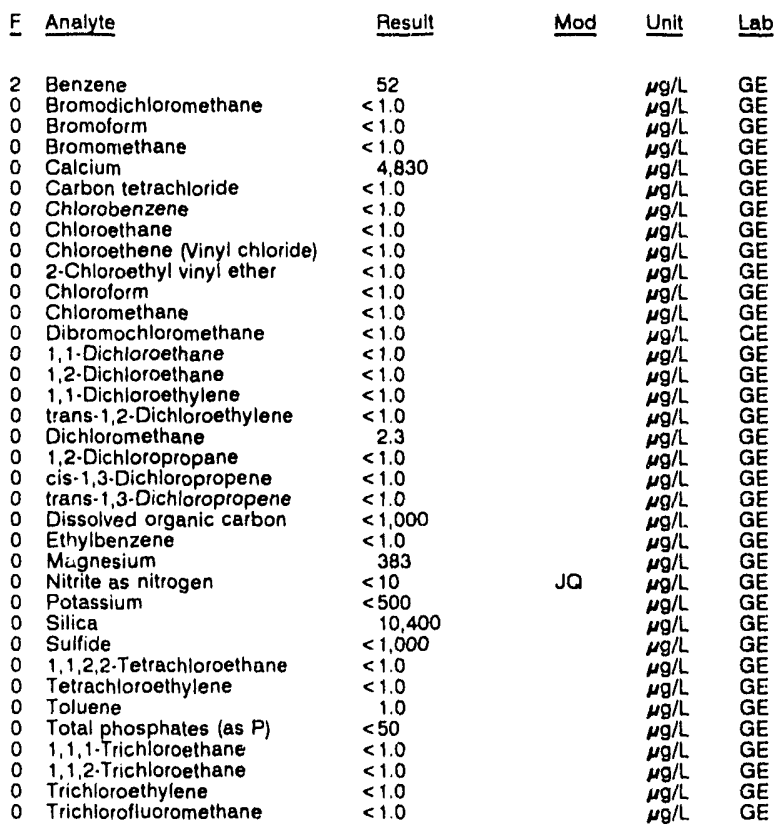

WELL P 29C Replicate

MEASUREMENTS CONDUCTED IN THE FIELD

Sample date: 11/18/91

Depth to water: $103.11 \mathrm{H}(31.43 \mathrm{~m})$ below TOC Water elevation: $166.19 \mathrm{ft}(50.66 \mathrm{~m}) \mathrm{ms}$

o. conductance: $47 \mu \mathrm{S} / \mathrm{cm}$

Water evacuated before sampling: $105 \mathrm{gal}$

Time: 7:00

Alkalinity: $27 \mathrm{mgl}$

Water temperature: $17.0^{\circ} \mathrm{C}$

LABORATORY ANALYSES

\begin{tabular}{|c|c|c|c|c|c|}
\hline & $\begin{array}{l}\text { ple date: } 11 / 18 / 91 \\
\text { th to water: } 103.11 \mathrm{~h}(31.43 \mathrm{~m} \\
\text { er elevation: } 166.19 \mathrm{ft}(50.66 \\
\text { conductance: } 47 \mathrm{\mu S} / \mathrm{cm} \\
\text { et evacuated before sampling }\end{array}$ & $\begin{array}{l}\text { below TOC } \\
\mathrm{msl} \\
05 \mathrm{gal}\end{array}$ & $\begin{array}{l}\text { Time: } 7: 00 \\
\text { pH: } 5.5 \\
\text { Alkalinity: } 27 \\
\text { Water temper }\end{array}$ & ure: 17.0 & \\
\hline & 3ORATORY ANALYSES & & & & \\
\hline$F$ & Analyte & Result & Mod & Unit & \\
\hline & $\begin{array}{l}\text { Benzene } \\
\text { Bromodichloromethane } \\
\text { Bromotorm } \\
\text { Bromomethane } \\
\text { Calcium } \\
\text { Carbon tetrachloride } \\
\text { Chlorobenzene } \\
\text { Chloroethane } \\
\text { Chloroethene Ninyl chloride) } \\
\text { 2.Chloroethyl vinyl ether } \\
\text { Chloroform } \\
\text { Chloromethane } \\
\text { Dibromochloromethane } \\
\text { 1.1.Dichloroethane } \\
\text { 1.2-Dichloroethane }\end{array}$ & $\begin{array}{l}53 \\
<1.0 \\
<1.0 \\
<1.0 \\
4.820 \\
<1.0 \\
<1.0 \\
<1.0 \\
<1.0 \\
<1.0 \\
<1.0 \\
<1.0 \\
<1.0 \\
<1.0 \\
<1.0\end{array}$ & & $\begin{array}{l}\mu g / L \\
\mu g / L \\
\mu g / L \\
\mu g / L \\
\mu g / L \\
\mu g / L \\
\mu g / L \\
\mu g / L \\
\mu g / L \\
\mu g / L \\
\mu g / L \\
\mu g / L \\
\mu g / L \\
\mu g / L \\
\mu g / L\end{array}$ & \\
\hline
\end{tabular}




\section{ANALYTICAL RESULTS}

WELL P 29 collected on 11/18/91, laboratory analyses (cont.)

\begin{tabular}{|c|c|}
\hline Analyte & Result \\
\hline $\begin{array}{l}\text { 1,1-Dichloroethylene } \\
\text { trans-1,2-Dichloroethylene } \\
\text { Dichloromethane } \\
1,2 \cdot \text { Dichloropropane } \\
\text { cis-1,3-Dichloropropene } \\
\text { trans-1,3-Dichloropropene } \\
\text { Dissolved organic carbon } \\
\text { Ethylbenzene } \\
\text { Magnesium } \\
\text { Nitrite as nitrogen } \\
\text { Potassium } \\
\text { Silica } \\
\text { Sulfide } \\
\text { Sulfide } \\
1,1,2,2 \cdot \text {-Tetrachloroethane } \\
\text { rotrachloroethylene } \\
\text { Toluene } \\
\text { Total phosphates (as P) } \\
1,1,1 \text {-Trichloroethane } \\
1,1,2 \cdot \text { Trichloroethane } \\
\text { Trichloroethylene } \\
\text { Trichlorofluoromethane }\end{array}$ & $\begin{array}{l}<1.0 \\
<1.0 \\
1.9 \\
<1.0 \\
<1.0 \\
<1.0 \\
<1.000 \\
<1.0 \\
383 \\
<10 \\
<500 \\
<10,400 \\
<1.000 \\
<1.000 \\
<1.0 \\
<1.0 \\
<1.0 \\
<50 \\
<1.0 \\
<1.0 \\
<1.0 \\
<1.0\end{array}$ \\
\hline
\end{tabular}

WELL P 29TA

MEASUREMENTS CONDUCTED IN THE FIELD

Sample date: $11 / 18 / 91$

Depth to water: 97.16 it $(29.61 \mathrm{~m})$ below TOC Water elevation: $171.44 \mathrm{H}(52.26 \mathrm{~m}) \mathrm{ms}$ )

Water evacuated before sampling: $1563 \mathrm{gal}$

LABORATORY ANALYSES

\begin{tabular}{|c|c|}
\hline Analyte & Pesult \\
\hline 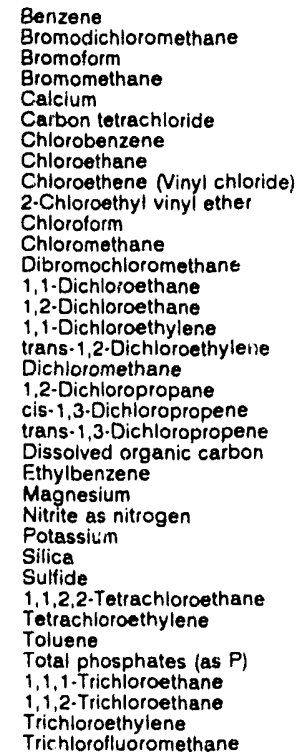 & $\begin{array}{l}<1.0 \\
<1.0 \\
<1.0 \\
<1.0 \\
457 \\
<1.0 \\
<1.0 \\
<1.0 \\
<1.0 \\
<1.0 \\
<1.0 \\
<1.0 \\
<1.0 \\
<1.0 \\
<1.0 \\
<1.0 \\
<1.0 \\
1.4 \\
<1.0 \\
<1.0 \\
<1.0 \\
<1.000 \\
<1.0 \\
257 \\
<10 \\
<500 \\
10,000 \\
<1.000 \\
<1.0 \\
<1.0 \\
<1.0 \\
<50 \\
<1.0 \\
<1.0 \\
<1.0 \\
<1.0\end{array}$ \\
\hline
\end{tabular}

WELL P 29TC

MEASUREMENTS CONDUCTED IN THE FIELD

Sample date: $11 / 18 / 9$

Depth to water: $9795 \mathrm{H}(29.86 \mathrm{~m})$ below TOC

Water elevation: $170.95 \mathrm{ft}(52.11 \mathrm{~m}) \mathrm{ms}$

Sp. conductance: $35 \mu \mathrm{s} / \mathrm{cm}$

Water evacuated before sampling $1089 \mathrm{ga}$

LABORATORY ANALYSES

\begin{tabular}{|c|c|c|c|}
\hline Analyte & Result & Mod & Unit \\
\hline $\begin{array}{l}\text { Benzene } \\
\text { Bromodichloromethane } \\
\text { Bromoform } \\
\text { Bromomethane } \\
\text { Calcium } \\
\text { Carbon tetrachloride } \\
\text { Chlorobenzene } \\
\text { Chloroethane }\end{array}$ & $\begin{array}{l}<10 \\
<10 \\
<1.0 \\
<1.0 \\
2,770 \\
<1.0 \\
<1.0 \\
<10\end{array}$ & & $\begin{array}{l}\mu g / L \\
\mu g / L \\
\mu g / L \\
\mu g / L \\
\mu g / L \\
\mu g / L \\
\mu g / L \\
\mu g / L\end{array}$ \\
\hline
\end{tabular}

Time: $6: 30$

Alkalinity: $8 \mathrm{mg} / \mathrm{L}$

Water temperature: $195^{\circ} \mathrm{C}$

Mod Unit Lab

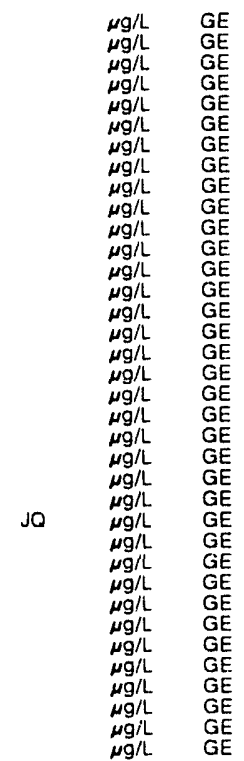

Time: 6.05

Time: 6.05

Alkalinity. $13 \mathrm{mg} / \mathrm{L}$

Water temperature $182 \circ \mathrm{C}$

$G E$
$G E$
$G E$
$G E$
$G E$
$G E$
$G E$
$G E$

WELL. P 29TC collected on 11/18/91, laboratory analyses (cont.)

\begin{tabular}{|c|c|c|c|}
\hline Analyte & Pesult & Mod & Unit \\
\hline $\begin{array}{l}\text { Chloroethene (Ninyl chloride) } \\
2 \cdot \text { Chloroethyl vinyl ethet } \\
\text { Chloroform } \\
\text { Chloromethane } \\
\text { Dibromochloromethane } \\
1,1-\text { Dichloroethane } \\
1,2 \cdot \text { Dichloroethane } \\
1,1-\text { Dichloroethylene } \\
\text { trans-1,2-Dichloroethylene } \\
\text { Dichloromethane } \\
1,2 \cdot \text { Dichloropropane } \\
\text { cis-1,3-Dichloropropene } \\
\text { trans-1,3-Dichloropropene } \\
\text { Dissolved organic carbon } \\
\text { Ethylbenzene } \\
\text { Megnesium } \\
\text { Nitrite as nitrogen } \\
\text { Potassiun } \\
\text { Silica } \\
\text { Sulfide } \\
\text { 1,1,2,2.Tetrachloroethane } \\
\text { Tetrachlorostinylene } \\
\text { Toluene } \\
\text { Total phosphates (as P) } \\
1,1,1 \text {. Trichloroethane } \\
1,1,2 \cdot \text { Trichloroethane } \\
\text { Trichloroethylene } \\
\text { Trichlorofluoromethane }\end{array}$ & $\begin{array}{l}<1.0 \\
<1.0 \\
<1.0 \\
<1.0 \\
<1.0 \\
<1.0 \\
<1.0 \\
<1.0 \\
<1.0 \\
2.4 \\
<1.0 \\
<1.0 \\
<1.0 \\
<1.000 \\
<1.0 \\
186 \\
<10 \\
<500 \\
9.190 \\
<1.000 \\
<1.0 \\
<1.0 \\
<1.0 \\
<50 \\
<1.0 \\
<1.0 \\
<1.0 \\
<1.0\end{array}$ & JQ & $\begin{array}{l}\mu g / L \\
\mu g / L \\
\mu g / L \\
\mu g / L \\
\mu g / L \\
\mu g / L \\
\mu g / L \\
\mu g / L \\
\mu g / L \\
\mu g / L \\
\mu g / L \\
\mu g / L \\
\mu g / L \\
\mu g / L \\
\mu g / L \\
\mu g / L \\
\mu g / L \\
\mu g / L \\
\mu g / L \\
\mu g / L \\
\mu g / L \\
\mu g / L \\
\mu g / L \\
\mu g / L \\
\mu g / L \\
\mu g / L \\
\mu g / L \\
\mu g / L\end{array}$ \\
\hline
\end{tabular}

WELL PAC 1

MEASUREMENTS CONDUCTED IN THE FIELD

Sample date: $11 / 19 / 91$

Depth to water: $11.38 \mathrm{ht}(3.47 \mathrm{~m})$ below TOC

Water elevation: $284.52 \mathrm{Ht}(6.4)$

Water evacuated before sampling: $80 \mathrm{gal}$

LABORATORY ANALYSES

E Analyte Result Mod Unit Lab

$0 \mathrm{pH}$

0 pH

$0 \mathrm{pH}$

Specific conductance

Specific conductance

Specific conductance

Turbidity

Arsenic

Barium

Cadmium

$\begin{array}{ll}\text { Chloride } & 3520 \\ \text { Chromium } & <4.0\end{array}$

2,4-Dichlorophenoxyacetic acid $<4.0$

Endrin

0 Fluoric

Lead

Lindare

Magnesium

Manganese

Mercury

Nitrale as nitrogen

Phenols

Potassium

Selenium

Silica

Silver

Sulfate

Total dissolved solids

Total organic carbon

Total organic carbon

Yotal organic carbon

Total organic halogens

Total orgaric halogens

Total organic halogens

Total organic halogens

Total phosphates (as P

Toxaphene

2,4,5.TP (Silvex)

Nonvolatile beta

Total radium

Tritium
Time: 15:25

PH: 5.1 . $2 \mathrm{mg}$

.lkalinity: $2 \mathrm{mg} / \mathrm{L}$ : $20.10 \mathrm{C}$

$<0.0060$

$<100$

4.9
$<0.0050$

197

$\begin{aligned} & 5.0 \\ < & 0.20\end{aligned}$

$<0.50$

780
$<5.0$

$<5.0$
$<500$

$<2.0$
5.930

$<2.0$

5,980
$<1,000$

25.000

$<1,000$

$<1,000$

$<1,000$
$<1,000$

$<5.0$

$<5.0$

$<5.0$

$<50$

$<0.24$

$<0.090$

$<2.0 E .09$

$<1.0 E-09$

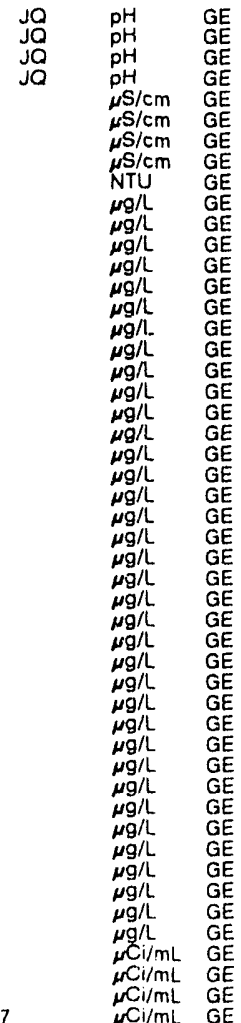


ANALYTICAL RESULTS

WELL PAC 2

MEASUREMENTS CONDUCTED IN THE FIELD
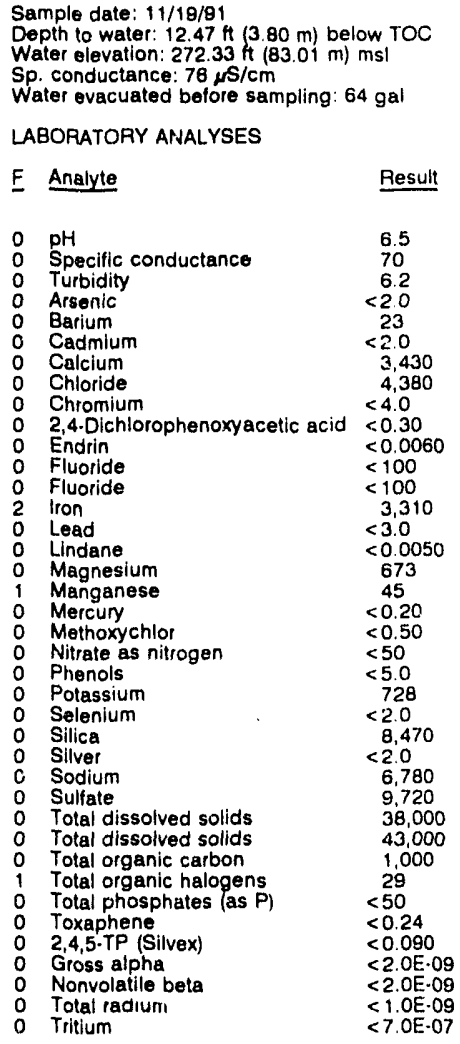

WELL PAC 3

MEASUREMENTS CONDUCTED IN THE FIELD

Sample date: $11 / 20 / 91$

Depth to water: $17.39 \mathrm{ft}(5.30 \mathrm{~m})$ below TOC

Water elevation: $272.51 \mathrm{~h}(83.06$

Sp. conductance: $403 \mu \mathrm{S} / \mathrm{cm}$
Water evacuated before sanipling: $51 \mathrm{gal}$

LABORATORY ANALYSES

\begin{tabular}{|c|c|c|c|}
\hline Analyie & Result & Mod & Unit \\
\hline $\begin{array}{l}\text { HH } \\
\text { Specific conductance } \\
\text { rurbidity } \\
\text { Arsenic } \\
\text { Barium } \\
\text { Cadmium } \\
\text { Calcium } \\
\text { Chloride } \\
\text { Chromium } \\
\text { 2,4-Dichlorophenoxyacetic acid } \\
\text { Endrin } \\
\text { Fluoride } \\
\text { lon } \\
\text { Lead } \\
\text { Lindane } \\
\text { Magnesium } \\
\text { Manganese } \\
\text { Mercury } \\
\text { Methoxychlor } \\
\text { Nitrate as nitrogen } \\
\text { Phenols } \\
\text { Potassium } \\
\text { Selenium } \\
\text { Silica } \\
\text { Silvel } \\
\text { Sodium } \\
\text { Sulfate } \\
\text { Total dissolved solids } \\
\text { Total organic carbon } \\
\text { Total organic halogens } \\
\text { Total organic halogens } \\
\text { Total phosphates (as P) }\end{array}$ & $\begin{array}{l}6.5 \\
395 \\
12 \\
<2.0 \\
141 \\
<2.0 \\
16,800 \\
15,000 \\
<4.0 \\
<0.30 \\
<0.0060 \\
<100 \\
5,360 \\
<3.0 \\
<0.0050 \\
4,950 \\
441 \\
<0.20 \\
<0.50 \\
160 \\
<5.0 \\
1.350 \\
<2.0 \\
19,700 \\
<2.0 \\
51,300 \\
94,000 \\
266,000 \\
2.000 \\
<5.0 \\
<5.0 \\
<50\end{array}$ & Jo & $\begin{array}{l}p H \\
\mu S / c m \\
N T U \\
\mu g / L \\
\mu g / L \\
\mu g / L \\
\mu g / L \\
\mu g / L \\
\mu g / L \\
\mu g / L \\
\mu g / L \\
\mu g / L \\
\mu g / L \\
\mu g / L \\
\mu g / L \\
\mu g / L \\
\mu g / L \\
\mu g / L \\
\mu g / L \\
\mu g / L \\
\mu g / L \\
\mu g / L \\
\mu g / L \\
\mu g / L \\
\mu g / L \\
\mu g / L \\
\mu g / L \\
\mu g / L \\
\mu g / L \\
\mu g / L \\
\mu g / L \\
\mu g / L\end{array}$ \\
\hline
\end{tabular}

Time: $12: 10$

pH: 6.1

$50 \mathrm{mg} / \mathrm{L}$

Water temperature: $20.10 \mathrm{C}$
WELL PAC 3 collected on 11/20/91. laboratory analyses (cont.)

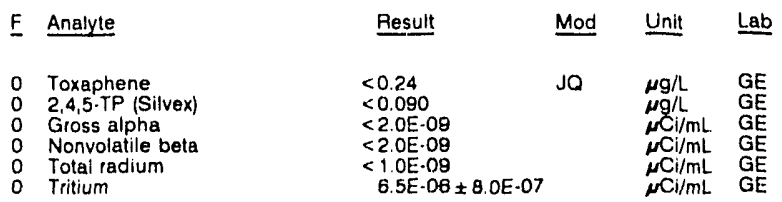

WELL PAC 4

MEASUREMENTS CONDUCTED IN THE FIELD

Sample date: $11 / 20 / 91$

Depth to water: $7.29 \mathrm{ft}(2.22 \mathrm{~m})$ below TOC

Water elevation: $284.31 \mathrm{ft}(86.66 \mathrm{~m}) \mathrm{msl}$

Sp. conductance: $118 \mu \mathrm{s} / \mathrm{cm}$
Water evacuated before sampling: $88 \mathrm{gal}$

Time: $13: 00$
pH: 5.2

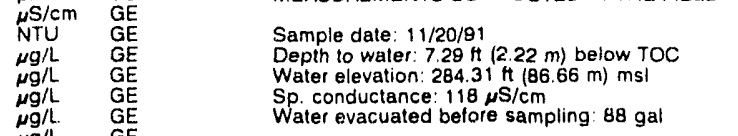

Alkalinity: $3 \mathrm{mg} / \mathrm{L}$

Water temperature: $20.8^{\circ} \mathrm{C}$

LABORATORY ANALYSES

F Analyte Result Mod Unit Lab

$\mathrm{O} \mathrm{pH}$

$\begin{array}{lll}0 & \mathrm{pH} \\ 0 & \mathrm{pH} \\ 0 & \mathrm{pH}\end{array}$

0 pH

Specific conductance

Specific conductance

Specific conductance

Turbidity

Acenaphthene

Acenaphthylene

Aldrin

Antimony

Antimony

Arsenic

Benzene

alpha.Benzene hexachloride

beta.Benzene hexachloride

delta-Benzene hexachloride

Benzo[a]anthracene

Benzola) pyrene

Benzo (b) fluoranthene

Benzo $\left., g_{i}, i\right] p e r y l e n e$

Benzokk

Gis (2.chloroethoxyl methane

Bis (2.chloroethoxyl methane

(2.chlor

Bis (2-ethylhexyll phthe

Bromide

$\begin{array}{ll} & <1,000 \\ \text { Gromodichloromethane } & <1,000\end{array}$

$<1.0$

Bromomethane $<1.0$

4.Bromophenyl phenyl ether

Butylbenzyl phthalate

Cadnium

Carbon tetrachloride

Carbon tetrac

Chlordane

para.Chloro-meta-cresol

para.Chloro-me

Chlorothane

Chloroethene Ninyl chloride

2.Chlorethyl vinyl chlor

Chloroform

Chloromethane

2.Chloronaphthalene
2.Chlorophencl
4.Chlorophenyl phenyl ethe

Chromium

Chrysene

Cobult

Cyanide

p.p'DOD
p.p.DDE

p.p.DDE

Di-n-butyl phthalate

Dibenzí phantale

Dibromochlorornethan

3,5'-Dichlorobenzidine

1,1.Dichloroethane

1,2-Dichloroethane

0
0
0
trans-1,2-Dichloroethylene

o Dichloromethane

$\begin{array}{ll}2,4 \text {-Dichlorophenol } & 30 \\ \text { 2.,4-Dichlorophenoxyacetic acid } & <0.30\end{array}$

1,2.Dichlaropropane

- cis-1,3.Dichloropropene

5.5
5.5
5.7
5.5


WELL PAC 4 collected on 11/20/91, laboratory analyses (cont.)

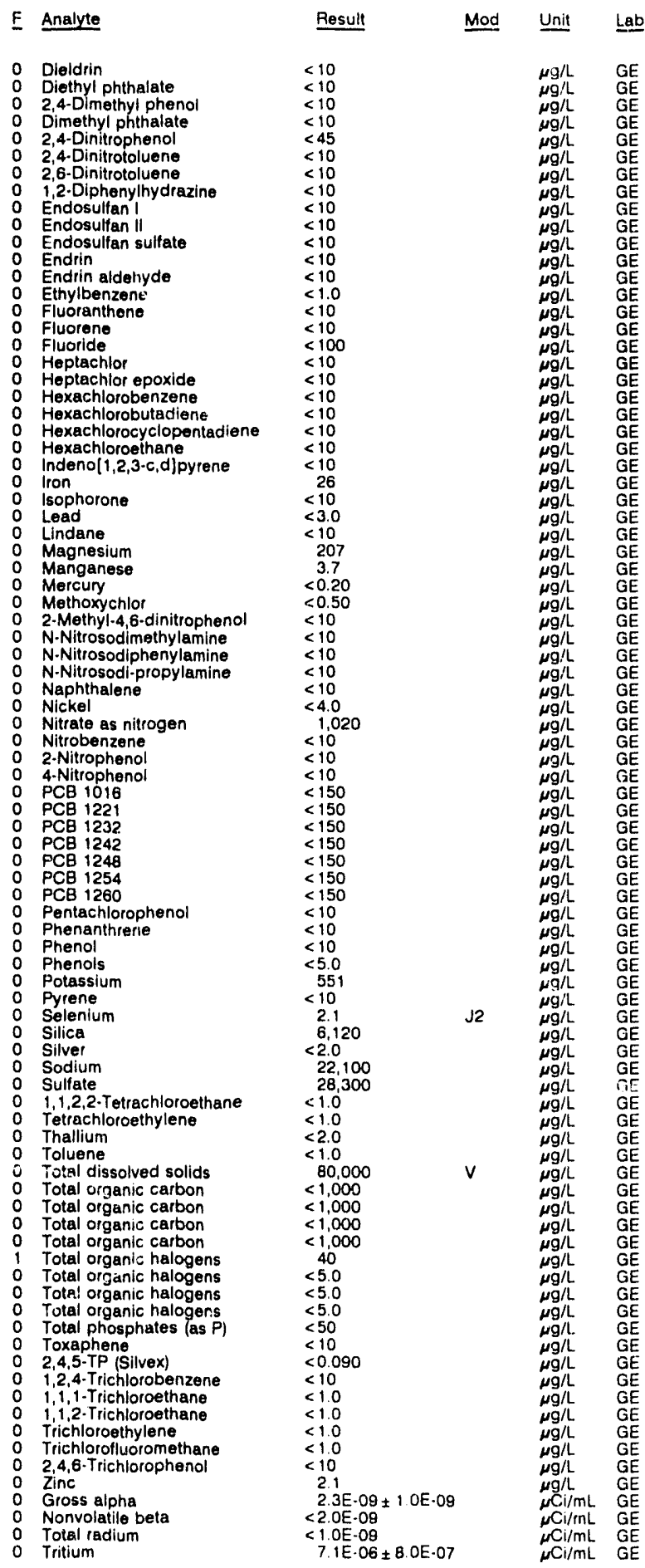

WELL PAC 4 Replicate

MEASUREMENTS CONDUCTED IN THE FIELD

Saniple date: $11 / 20 / 91$

Depth to water: $7.29 \mathrm{Ht}(2.22 \mathrm{~m})$ below TOC

Sp. conductance: $118 \mathrm{HS} / \mathrm{cm}$.

Water evacuated before sampling: $88 \mathrm{gal}$

LABORATORY ANALYSES

E Analyte Result Mod Unit Lab

$\begin{array}{ll}\text { pH } \\ 0 & \text { Speitic conductance } \\ 0 & \text { Turbidity } \\ 0 & \text { Acenaphthen }\end{array}$

Acenaphthene

$\begin{array}{lll}0 & \text { Acenaphit } \\ 0 & \text { Aldrin } \\ 0 & \text { Aluminum } & \\ 0 & \text { Anthracen } & \end{array}$

A Aldrin

0 Anthracene

Antimony

Arsenic

Barlum

alpha-Benzene hexachloride

beta-Benzene hexachloride

delta-Benzene hexachlorice

Benzidine

Benzo(a)anthracene

Benzo a pyrene

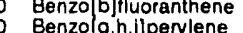

Benzo $9, h, i)$ perylene

Berllium

0 Bis(2-chloroethoxy) meth:sti:

Bis (2-chloroethyl) ether

Bis (2-chloroisopropyl) ether

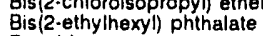

Bromide

Bromodichloromethane

Bromotorm

Bromomethane

4-Bromophenyl phenyl ether

Butylbenzyl phthalate

Cadmium

Carbon tetrachloride

Chlordane

para-Chloro-meta-cresol

Chlorobenzene

Chloroethane

Chloroethene (Ninyl chloride) 2.Chloroethyl vinyl ethe

Chloroform

Chloromethane

- 2.Chloronaphthalene

o 2-Chlorophenol

o 4-Chlorophenyl phenyl ether

Chromium

Chrysen
Cobalt
Coppert

0 Copper

0 Cyanide

$\begin{array}{ll}0 & \text { p.p'-DDD } \\ 0 & \text { p.p'-DDE }\end{array}$

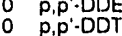

o Di-n.tuutyl phthalate

Di-n-octyl phthalate

Dibromochloromethane

3,3'.Dichlorobenzidine

1,1-Dichloroethane

1,2-Dichloroethane

1,1-Dichloroethylene
0 trans-1,2-Dichloroethylene

Dichloromethane

2,4.Dichlorophenol

-

0 cis-1,3-Dichioropropene $<1.0$

trans-1,3-Dichioropropene $<1.0$

0 Diethyl phthalate $<10$

0 2,4-Dimethyl phenol $\quad<10$

0 Dimethyl phthalate $<10$

2,4-Dinitrophenol

4.Dinitrotoluen

2,6.Dinitrotoluene

1,2.Diphenylhydrazine

Endosulfan I

Endosulfan II

Endrin

Endrin aldehyde

Ethylbenzen

Fluoranthe

Fluorene

Fluoride

55

JQ $\mathrm{PH} G$

$\begin{array}{ll}\mu S / \mathrm{cm} & \mathrm{GE} \\ \mathrm{NTU} & \mathrm{GE} \\ \mu \mathrm{GL} & \mathrm{GE}\end{array}$

10

$<10$
$<3$
53

$<2.0$
$<2.0$

$<\begin{gathered}<1.0 \\ <10\end{gathered}$

$<10$
$<10$

$<10$

$<10$

$<10$

$<10$
$<10$

$<10$
$<10$

$<1,000$

$<1.0$

$<10$

$<2.0$
182

$<1.0$

$<10$
3,500

$<1.0$

$<1.0$

$<1.0$

$<1.0$

$<10$

$<10$

$<10$

$<4.0$

$<10$

$<10$

$<10$
$<10$

$<1.0$

$<10$

1.0

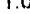

Time: 13.00

AH: 5.2200

Water temperature: $20.9^{\circ} \mathrm{C}$

Ja


ANALYTICAL RESULTS

WELL PAC 4 collected on 11/20/91, laboratory analyses (cont.)

\begin{tabular}{|c|c|c|c|}
\hline Analyte & Result & Mod & Unit \\
\hline 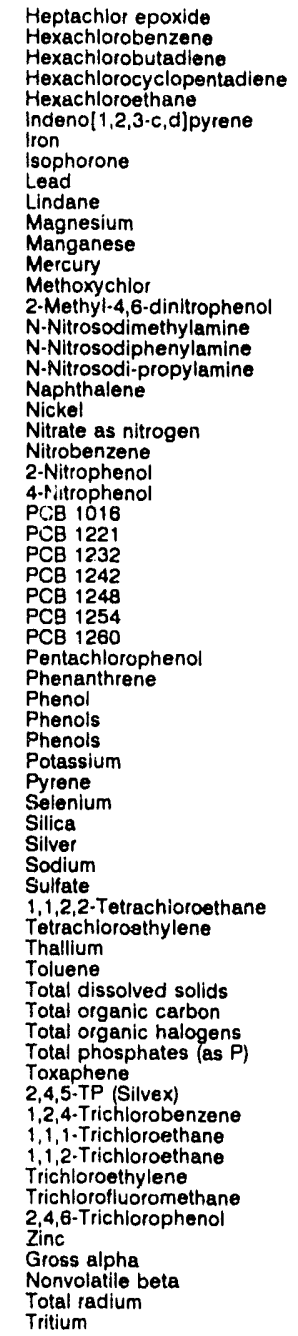 & $\begin{array}{l}<10 \\
<10 \\
<10 \\
<10 \\
<10 \\
<10 \\
27 \\
<10 \\
<3.0 \\
<10 \\
211 \\
3.3 \\
<0.20 \\
<0.50 \\
<10 \\
<10 \\
<10 \\
<10 \\
<10 \\
<4.0 \\
1.030 \\
<10 \\
<10 \\
<10 \\
<150 \\
<150 \\
<150 \\
<150 \\
<150 \\
<150 \\
<150 \\
<10 \\
<10 \\
<10 \\
<5.0 \\
<5.0 \\
596 \\
<10 \\
<2.0 \\
6,240 \\
<2.0 \\
21.900 \\
29.400 \\
<1.0 \\
3.0 \\
<2.0 \\
<1.0 \\
82,000 \\
<1.000 \\
7.8 \\
<50 \\
<10 \\
<0.090 \\
<10 \\
<1.0 \\
<1.0 \\
<1.0 \\
<1.0 \\
<10 \\
<2.0 \\
<2.0 \mathrm{E} \cdot 09 \\
<2.0 \mathrm{E} \cdot 09 \\
<1.0 \mathrm{E} \cdot 09 \\
7.3 \mathrm{E} \cdot 06 \pm 8.0 \mathrm{E} \cdot 07\end{array}$ & J1 & 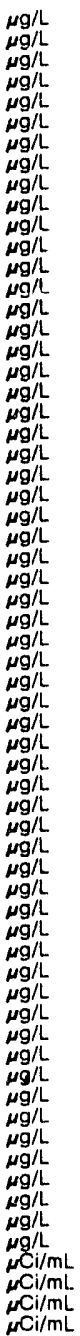 \\
\hline
\end{tabular}

\section{WELL PAC 5}

MEASUREMENTS CONDUCTED IN THE FIELD

$\begin{array}{ll}\text { Sample date: } 11 / 20 / 91 & \text { Time: } 11: 30 \\ \text { Depth to water: } 12.13 \mathrm{H}(3.70 \mathrm{~m}) \text { below TOC } & \text { pH: } 6.9 \\ \text { Water elevation: } 277.17 \mathrm{ft}(84.48 \mathrm{~m}) \mathrm{msl} & \text { Alkalinity: } 131 \mathrm{mg} / \mathrm{L} \\ \text { Sp. conductance: } 407 \mu \mathrm{cm} / \mathrm{cm} & \text { Water temperature: } 19.9^{\circ} \mathrm{C} \\ \text { Water t'vacuated before sampling: } 14 \mathrm{gal} & \end{array}$
Sp. conductance: $407 \mu \mathrm{s} / \mathrm{cm}$ The well went dry during purging.

LABORATORY ANALYSES

\begin{tabular}{|c|c|c|c|c|}
\hline Analyte & Result & Mod & Unit & Lab \\
\hline $\begin{array}{l}\text { pH } \\
\text { Specific conductance } \\
\text { Turbidity } \\
\text { Acenaphthene } \\
\text { Acenaphthylene } \\
\text { Aldrin } \\
\text { Aluminum } \\
\text { Anthracene } \\
\text { Antimony } \\
\text { Arsenic } \\
\text { Barium } \\
\text { Benzene } \\
\text { alpha-Benzene hexachloride } \\
\text { beta-Benzene hexachloride } \\
\text { delta-Benzene hexachloride } \\
\text { Benzidine } \\
\text { Benzo|ajanthracene } \\
\text { Benzo|a|pyrene } \\
\text { Benzolb]fluoranthene }\end{array}$ & $\begin{aligned} & 7.3 \\
& 390 \\
& 2.4 \\
&<10 \\
&<10 \\
&<10 \\
&<20 \\
&<10 \\
&<2.0 \\
&<2.0 \\
& 51 \\
&<1.0 \\
&<10 \\
&<10 \\
&<10 \\
&<10 \\
&<10 \\
&<10 \\
&<10\end{aligned}$ & JO & $\begin{array}{l}\mathrm{pH} \\
\mu \mathrm{S} / \mathrm{cm} \\
\mathrm{NTU} \\
\mu g / \mathrm{L} \\
\mu \mathrm{g} / \mathrm{L} \\
\mu \mathrm{g} / \mathrm{L} \\
\mu \mathrm{g} / \mathrm{L} \\
\mu \mathrm{g} / \mathrm{L} \\
\mu \mathrm{g} / \mathrm{L} \\
\mu \mathrm{g} / \mathrm{L} \\
\mu \mathrm{g} / \mathrm{L} \\
\mu \mathrm{g} / \mathrm{L} \\
\mu \mathrm{g} / \mathrm{L} \\
\mu \mathrm{g} / \mathrm{L} \\
\mu \mathrm{g} / \mathrm{L} \\
\mu \mathrm{g} / \mathrm{L} \\
\mu \mathrm{g} / \mathrm{L} \\
\mu \mathrm{g} / \mathrm{L} \\
\mu g / \mathrm{L}\end{array}$ & $\begin{array}{l}\mathrm{GE} \\
\mathrm{GE} \\
\mathrm{GE} \\
\mathrm{GE} \\
\mathrm{GE} \\
\mathrm{GE} \\
\mathrm{GE} \\
\mathrm{GE} \\
\mathrm{GE} \\
\mathrm{GE} \\
\mathrm{GE} \\
\mathrm{GE} \\
\mathrm{GE} \\
\mathrm{GE} \\
\mathrm{GE} \\
\mathrm{GE} \\
\mathrm{GE} \\
\mathrm{GE} \\
\mathrm{GE}\end{array}$ \\
\hline
\end{tabular}

WELL PAC 5 collected on 11/20/81, laboratory analyses (cont.)

F Analyte Besult

Mod Unit Lab

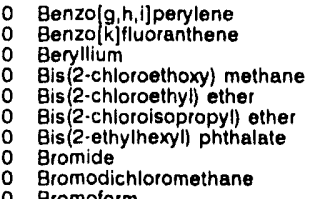

$<10$
$<10$

$<10$
$<3.0$
$<10$
$<10$

$<10$

$<1,000$

Bromodichloromethane $<1.0$
Bromoform

Bromomethane $<1.0$

4-Bromophenyl phenyl ether $<10$

$\begin{array}{ll}\text { Cadmium } & <2.0 \\ \text { Calcium } & 30,900\end{array}$

Carbon tetrachloride

Chlordane

para-Chloro-meta-cresol

Chlorobenzene

Chloroethene Ninyl chloride) 2-Chloroethyl vinyl ether Chloroform

Chioromethane

2.Chloronaphthalene

2.Chlorophenol

4.Chlorophenyl phenyl ether

Chromiun

Cobalt

Copper

Cyanide

p,p'-DDE

Bi-n-butyl phthalate

Dibenz $[a, h]$ anth

Dibromochloromethane

3,3'-Dichlo obenzidine

1,1-Dichlo: oethane

1,1-Dichloroetivlene

trans-1,2-Dichlora:
Dichloromethane

2,4-Dichlorophenol

2,4-Dichlorophenol
2,4-Dichlorophenoxyacetic acid $<10$

1,2.Dichioropropane

trans-1,3.Dichloropropene

0 Dieldrin

Diethyl phthalate

2,4-Dimethyl phenol

Dimethyl phthalate

2,4-Dinitrophenol

2,4-Dinitrololuene

1,2-Diphenylhydrazine

Endosulfan

Endosulfan sulfate

Endrin

Endrin aldehyde

Ethylbenzene

Fluoranthen

Fluoride

Heptachlor

Heptachlor epoxide

Hexachlorobenzene

Hexachlorobutadiene

Hexachlorocyclopentadiene

Hexachloroetharie

Indeno $(1,2,3-c, d] p y r e n e$

Iron
Isophorone

Lead

o Lindane

2 Manganese

o Manganese

Methoxychlor
$2 \cdot$ Methyl-4,6-dinitrophenol

N-Nitrosodimethylopheno

N-Nitrosodiphenylamine

N-Nitrosodi-propylamine

o Naphthal

Nickel
0 Nitrate as nitrogen

Nitrobenzene

2.Nitrophenol

4-Nitrophenol

PCB 1016

O PCB 1232

O PCB 1248

O PCB 1254

$<1.0$
$<10$

$<\begin{aligned} & \mathbf{5}, 350 \\ & <10\end{aligned}$

$<10$
$<1.0$
$<1.0$

$<1.0$

$<1.0$

$<1.0$
$<10$
$<10$

7.4
$<10$

$<4.0$

$<4.0$

$<10$

$<10$

$<10$
$<10$

$<10$

$<1.0$

$<10$

$<1.0$

$<1.0$

3.0

$<0.30$
$<1.0$

$<1,0$

$<1.0$

$<10$

$<10$

$<45$
$<10$

$<10$

$<10$

$<10$
$<10$

$<10$
$<10$

$<10$

$<1.0$

$<10$
$<10$
$<100$

$<10$

$<10$
$<10$

$<10$

$<10$
$<10$

$<10$
$<10$

143
$<10$
$<3.0$

$<10$

7,430
$<0.20$
$<0.50$

$<10$

$<10$
$<10$
$<10$

$<10$
$<10$

$<10$
8.6

$<50$

$<10$
$<10$

$<10$

$<150$
$<150$
$<150$

$<150$

$<150$

$<150$
$<150$

$\mu g / L \quad G E$

$\mathrm{GE}$

PCB $1260<150$ 
ANALYTICAL RESULTS

WELL PAC 5 collected on 11/20/91, laboratory analyses (cont.)

\begin{tabular}{|c|c|c|c|}
\hline Analyte & Result & Mod & Unit \\
\hline $\begin{array}{l}\text { Pentachlorophenol } \\
\text { Phenanthrene } \\
\text { Phenol } \\
\text { Phenols } \\
\text { Potassium } \\
\text { Pyrene } \\
\text { Seleniurn } \\
\text { Silica } \\
\text { Silver } \\
\text { Sodium } \\
\text { Sulfate } \\
1,1,2,2 \text {-Totrachloroethane } \\
\text { Tetrachloroethylene } \\
\text { Thallium } \\
\text { Toluene } \\
\text { Total dissolved sollds } \\
\text { Total organic carbon } \\
\text { Total organic halogens } \\
\text { Total phosphates gas P) } \\
\text { Total phosphates las P) } \\
\text { Toxaphenne } \\
2,4,5-T P \text { (Silvex) } \\
\text { 1,2,4-Trichlorobenzene } \\
\text { 1,1,1-Trichloruethano } \\
\text { 1,1,2-Trichloroethane } \\
\text { Trichloroethylene } \\
\text { Trichlorofluoromethane } \\
\text { 2,4,6-Trichlorophenol } \\
\text { Zinc } \\
\text { Gross alpha } \\
\text { Nonvolatile beta } \\
\text { Total radlum } \\
\text { Tritium }\end{array}$ & $\begin{array}{l}<10 \\
<10 \\
<10 \\
<5.0 \\
1,460 \\
<10 \\
<2.0 \\
15,800 \\
<2.0 \\
44,700 \\
58,600 \\
<1.0 \\
<1.0 \\
<2.0 \\
<1.0 \\
295,000 \\
2,000 \\
19 \\
<50 \\
<50 \\
<10 \\
<0.090 \\
<10 \\
<1.0 \\
<1.0 \\
<1.0 \\
<1.0 \\
<10 \\
7.5 \\
2.7 E-09 \pm 1.5 E-09 \\
5.3 E-09 \pm 2.3 E-09 \\
1.7 E-09 \pm 1.8 E \cdot 09 \\
6.2 E-06 \pm 8.0 E \cdot 07\end{array}$ & J1 & $\begin{array}{l}\mu g / L \\
\mu g / L \\
\mu g / L \\
\mu g / L \\
\mu g / L \\
\mu g / L \\
\mu g / L \\
\mu g / L \\
\mu g / L \\
\mu g / L \\
\mu g / L \\
\mu g / L \\
\mu g / L \\
\mu g / L \\
\mu g / L \\
\mu g / L \\
\mu g / L \\
\mu g / L \\
\mu g / L \\
\mu g / L \\
\mu g / L \\
\mu g / L \\
\mu g / L \\
\mu g / L \\
\mu g / L \\
\mu g / L \\
\mu g / L \\
\mu g / L \\
\mu g / L \\
\mu C i / m L \\
\mu C i / m L \\
\mu C i / m L \\
\mu C \mathrm{i} / \mathrm{mL}\end{array}$ \\
\hline
\end{tabular}

\section{WELL PAC 6}

MEASUREMENTS CONDUCTED IN THE FIELD

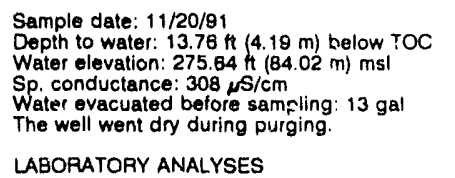

Time: $11: 45$

PH: 6.5 Alkalinity: $87 \mathrm{mg} / \mathrm{h}$

Water temperature: $19.0^{\circ} \mathrm{C}$

LABORATORY ANALYSES

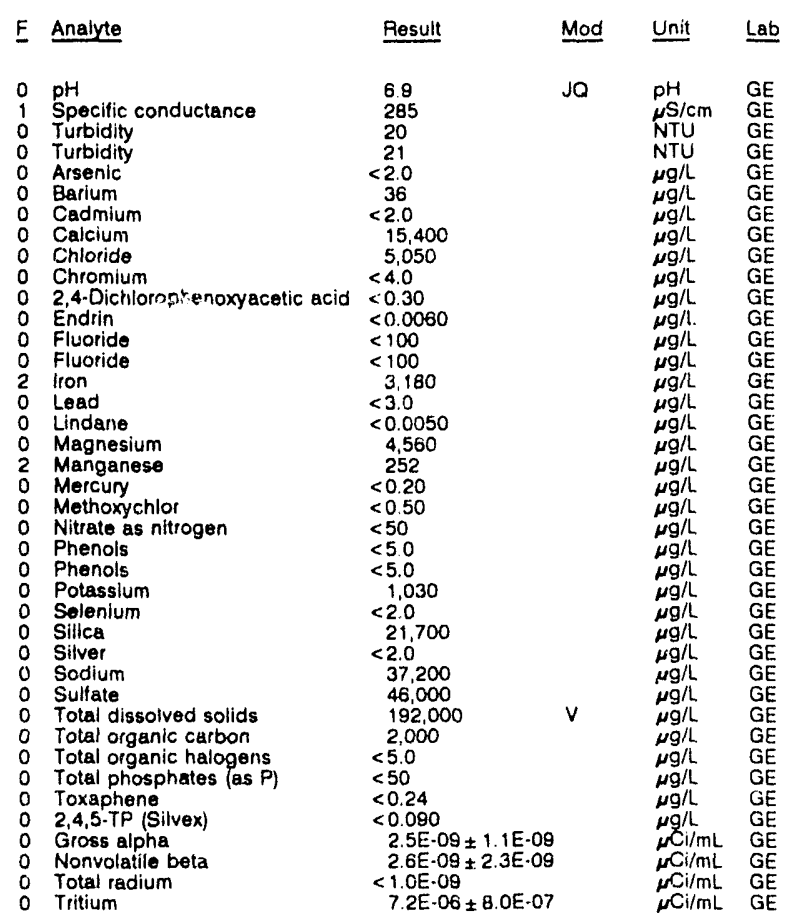

WELL PCB $1 \mathrm{~A}$

MEASUREMENTS CONDUCTED IN THE FIELD

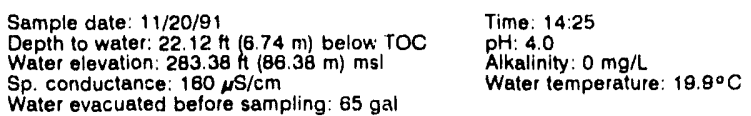

Water evacuated before sampling: $65 \mathrm{gal}$

LABORATORY ANALYSES

$\begin{array}{lllll}E \text { Analyte } & \text { Result } & \text { Mod Unit } & \text { Lab } \\ 0 \text { Lead } & <3.0 & \mu g / L & \text { GE }\end{array}$

WELL PCB $2 A$

MEASUREMENTS CONOUCTED IN THE FIELD

Sample date: $11 / 20 / 91$

Depth to water: $22.47 \mathrm{H}(6.85 \mathrm{~m})$ below TOC

Wp. conductance: $85.43 \mathrm{H}$ (85.

Water evacuated before sampling: $65 \mathrm{gal}$

LABORATORY ANALYSES

$\begin{array}{lllll}\text { E Analyte } & \text { Result } & \text { Mod } & \underline{\text { Lnit }} & \underline{\text { Lab }} \\ 0 \text { Lead } & <3.0 & \mathrm{\mu g} / \mathrm{L} & \mathrm{GE}\end{array}$

WELL PCB $3 A$

MEASUREMENTS CONDUCTED IN THE FIELD

Sample date: $11 / 20 / 91$

Depth to water: $21.83 n\left(6.65 m_{1}\right)$ below TOC

Waler elevation: $282.77 \mathrm{Ht}(86.19 \mathrm{~m}) \mathrm{msl}$

Sp. conductance: $451 \mu \mathrm{s} / \mathrm{cm}$
Water evacuated before sampling: $53 \mathrm{gal}$

LABORATORY ANALYSES

\begin{tabular}{|c|c|c|c|}
\hline F Analyte & Result & Mod & Unit \\
\hline 2 Lead & 23 & & $\mu g / L$ \\
\hline
\end{tabular}

WELL PCB 4A

MEASUREMENTS CONDUCTED IN THE FIELD

Sample date: $11 / 20 / 91$

Depth to water: $26.61 \mathrm{ft}(8.11 \mathrm{~m})$ below TOC

Water elevation: $282.99 \mathrm{th}(86.26 \mathrm{~m}) \mathrm{ms}$

Water evacuated before sampling: $53 \mathrm{gal}$

LABORATORY ANALYSES

F Analyte

Result

0 Lead

7.3

Time: $13: 55$

PH: 3.6 Alkalinity: $0 \mathrm{mg} / \mathrm{L}$

Alkalinity: $0 \mathrm{mg} / \mathrm{L}$ : $23.0^{\circ} \mathrm{C}$

Time: $14: 45$

Alkalinity: $0 \mathrm{mg}$

Water temperature: $20.1^{\circ} \mathrm{C}$

WELL PCB 2

MEASUREMENTS CONDUCTED IN THE FIELD

Sample date: 10/21/91

Depth to water: $37.95 \mathrm{ft}(11.57 \mathrm{~m})$ below TOC

Water elevation: $281.55 \mathrm{H}(85.82 \mathrm{~m}) \mathrm{msl}$

Water evacuated before sampling: $89 \mathrm{gal}$

LABORATORY ANALYSES

\begin{tabular}{|c|c|c|c|c|}
\hline Analyte & Result & Mod & Unit & $\underline{L a b}$ \\
\hline $\begin{array}{ll}0 & \text { Aluminum } \\
0 & \text { Carbon tetrachloride } \\
0 & \text { Chloroform } \\
1 & \text { Lead } \\
0 & \text { Tetrachloroethylene } \\
0 & 1,1,1 \text {-Trichloroethane } \\
0 & \text { Trichloroethylene } \\
0 & \text { Antimony-125 } \\
0 & \text { Cerium }-144 \\
0 & \text { Cesium } 134 \\
0 & \text { Cesium-137 } \\
0 & \text { Chromium.51 } \\
0 & \text { Cobalt } 60 \\
0 & \text { lodine-131 } \\
0 & \text { Niobium.95 } \\
0 & \text { Ruthenium-103 }\end{array}$ & $\begin{array}{l}47 \\
<1.0 \\
<1.0 \\
13 \\
<1.0 \\
<1.0 \\
<1.0 \\
<3.6 \mathrm{E} \cdot 08 \\
<7.7 \mathrm{E} \cdot 08 \\
<1.1 \mathrm{E} \cdot 08 \\
<1.2 \mathrm{E} \cdot 08 \\
<1.1 \mathrm{E} \cdot 07 \\
<1.6 \mathrm{E}-08 \\
<1.4 \mathrm{E} \cdot 08 \\
<1.5 \mathrm{E} \cdot 08 \\
<1.2 \mathrm{E} \cdot 08\end{array}$ & J2 & $\begin{array}{l}\mu \mathrm{g} / \mathrm{L} \\
\mu \mathrm{g} / \mathrm{L} \\
\mu \mathrm{g} / \mathrm{L} \\
\mu \mathrm{g} / \mathrm{L} \\
\mu \mathrm{g} / \mathrm{L} \\
\mu \mathrm{g} / \mathrm{L} \\
\mu \mathrm{g} / \mathrm{L} \\
\mu \mathrm{Ci} / \mathrm{mL} \\
\mu \mathrm{Ci} / \mathrm{mL} \\
\mu \mathrm{Ci} / \mathrm{mL} \\
\mu \mathrm{Ci} / \mathrm{mL} \\
\mu \mathrm{Ci} / \mathrm{mL} \\
\mu \mathrm{Ci} / \mathrm{mL} \\
\mu \mathrm{Ci} / \mathrm{mL} \\
\mu C \mathrm{i} / \mathrm{mL} \\
\mu \mathrm{Ci} / \mathrm{mL}\end{array}$ & $\begin{array}{l}G E \\
G E \\
G E \\
G E \\
G E \\
G E \\
G E \\
E M \\
E M \\
E M \\
E M \\
E M \\
E M \\
E M \\
E M \\
E M\end{array}$ \\
\hline
\end{tabular}

Alkalinity: $0 \mathrm{mg} / \mathrm{h}$

Water temperature: $20.5^{\circ} \mathrm{C}$

Mod Unit Lab
$\mu g / L \quad G E$

Time: $11: 50$

PH: 5.4 Alkalinity: 6 mg/L

Water temperature: $21.1^{\circ} \mathrm{C}$

b 
ANALYTICAL RESULTS

WELL PDB 2 collected on 10/21/91, laboratory analyses (cont.)

\begin{tabular}{|c|c|c|c|c|c|}
\hline$F$ & Analyte & Result & Mod & Unit & Lab \\
\hline $\begin{array}{l}0 \\
0 \\
0 \\
2 \\
2\end{array}$ & $\begin{array}{l}\text { Ruthenium-106 } \\
\text { Strontium-89/90 } \\
\text { Total activity } \\
\text { Tritium } \\
\text { Tritium } \\
\text { Zirconium-85 }\end{array}$ & $\begin{array}{l}<1.2 \mathrm{E} \cdot 07 \\
1.4 \mathrm{E} \cdot 09 \pm 1.8 \mathrm{E} \cdot 09 \\
1.4 \mathrm{E} \cdot 03 \pm 2.9 \mathrm{E} \cdot 05 \\
1.3 \mathrm{E} \cdot 03 \pm 5.7 \mathrm{E} \cdot 06 \\
1.3 \mathrm{E} \cdot 03 \pm 2.7 \mathrm{E} \cdot 05 \\
<2.5 \mathrm{E} \cdot 08\end{array}$ & & 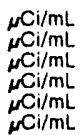 & $\begin{array}{l}E M \\
E M \\
E M \\
G E \\
E M \\
E M\end{array}$ \\
\hline
\end{tabular}

\section{WELL PDB 2 Replicate}

MEASUREMENTS CONDUCTED IN THE FIELO

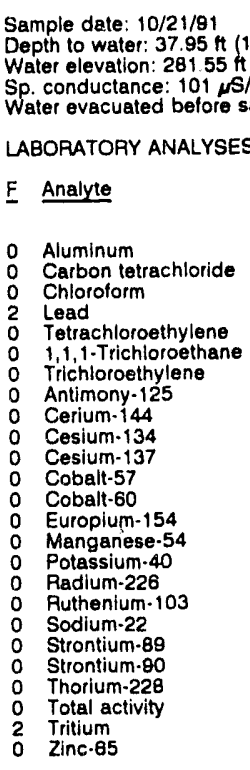

\section{Time: $11: 50$}

PH: 5.4

Alkalinity: $6 \mathrm{mg} / \mathrm{L}$

Water temperature: $21.1^{\circ} \mathrm{C}$

Water evacuated before sampling: $89 \mathrm{gal}$

LABORATORY ANALYSES
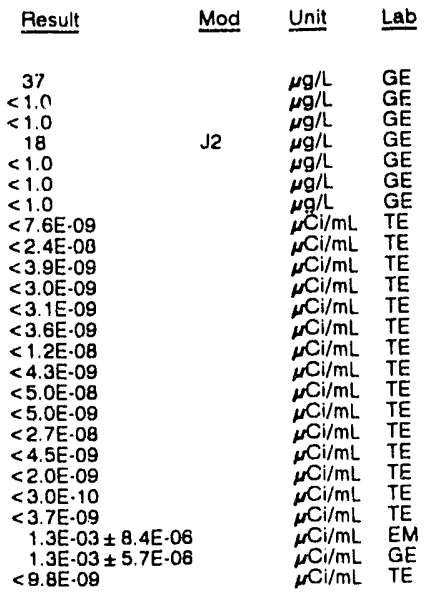

WELL PDB 2

MEASUREMENTS CONDUCTED IN THE FIELD

Sample date: $11 / 18 / 91$

Depth to water: $38.18 \mathrm{Ht}(11.64 \mathrm{~m})$ below TOC

Water elevation: $281.32 \mathrm{ft} / 85.75$

Sp. conductance: $100 \mu \mathrm{S} / \mathrm{cm}$
Water evacuated before sampling: $88 \mathrm{gal}$

LABORATORY ANALYSES

\begin{tabular}{|c|c|c|c|c|}
\hline$F$ & Analyte & Pesult & Mod & Unit \\
\hline 0 & $\begin{array}{l}\text { Aluminum } \\
\text { Gross alpha } \\
\text { Nonvolatile beta } \\
\text { Tritium } \\
\text { Tritium }\end{array}$ & $\begin{array}{l}35 \\
3.0 \mathrm{E} \cdot 09 \pm 8.9 \mathrm{E} \cdot 10 \\
3.0 \mathrm{E} \cdot 09 \pm 1.1 \mathrm{E} \cdot 09 \\
1.1 \mathrm{E} \cdot 03 \pm 5 \cdot 2 \mathrm{E} \cdot 06 \\
1.2 \mathrm{E} \cdot 03 \pm 2.6 \mathrm{E} \cdot 05\end{array}$ & & $\begin{array}{l}\mu \mathrm{g} / \mathrm{L} \\
\mu^{c} \mathrm{Ci} / \mathrm{mL} \\
\mu \mathrm{Ci} / \mathrm{mL} \\
\mu^{\mathrm{C}} \mathrm{Ci} / \mathrm{mL} \\
\mu \mathrm{Ci} / \mathrm{mL}\end{array}$ \\
\hline
\end{tabular}

WELL PDB 2

MEASUREMENTS CONDUCTED IN THE FIELD

Sample date: $12 / 16 / 81$ Depth to water: $38.96 \mathrm{ft}(11.88 \mathrm{~m})$ below TOC Water elevation: $280.54 \mathrm{ft}(85.51 \mathrm{~m}) \mathrm{msl}$ Sp. conductance: $88 \mu \mathrm{s} / \mathrm{cm}$ Water evacuated before sampling: $86 \mathrm{gal}$ LABORATORY ANAI.YSES

$\begin{array}{llllll}\text { E Analyte } & \text { Fiesult } & \text { Mod } & & \text { Unit } & \text { Lab } \\ & & & & \\ 0 & \text { Aluminum } & 38 & \mu \mathrm{g} / \mathrm{L} & \mathrm{GE} \\ 0 & \text { Gross alpha } & 3.8 \mathrm{E} \cdot 09 \pm 1.6 \mathrm{E}-09 & & \mu \mathrm{Ci} / \mathrm{mL} & \mathrm{EM} \\ 0 & \text { ivonvolatile beta } & 3.8 \mathrm{E} \cdot 09 \pm 1.3 \mathrm{E} \cdot 09 & & \mu \mathrm{Ci} / \mathrm{mL} & \mathrm{EM} \\ 2 & \text { Tritium } & 9.5 \mathrm{E} \cdot 04 \pm 4.8 \mathrm{E} \cdot 06 & & \mu \mathrm{Ci} / \mathrm{mL} & \mathrm{GE} \\ 2 & \text { Triticm } & 1.1 \mathrm{E} \cdot 03 \pm 2.4 \mathrm{E} \cdot 05 & & \mu \mathrm{Ci} / \mathrm{mL} & \mathrm{EM}\end{array}$

WELL PDB 3

MEASUREMENTS CONDUCTED IN THE FIELD

$\begin{array}{ll}\text { Sample date: } 10 / 21 / 91 & \text { Time: } 11: 20 \\ \text { Depth to water: } 38.01 \mathrm{Ht}(11.59 \mathrm{~m}) \text { below TOC } & \text { pH: } 5.2 \\ \text { Water elevation: } 281.49 \mathrm{Ht}(85.80 \mathrm{~m}) \mathrm{ms} & \text { Alkalinity: } 1 \mathrm{mg} / \mathrm{h} \\ \text { Sp. conductance: } 55 \mu \mathrm{S} / \mathrm{cm} & \text { Water temperature: } 21.5^{\circ} \mathrm{C} \\ \text { Water evacuated before sampling: } 88 \mathrm{gal} & \end{array}$
Sp. conductance: $55 \mu \mathrm{S} / \mathrm{cm}$
Water evacuated before sampling: $88 \mathrm{gal}$ LABORATORY ANALYSES

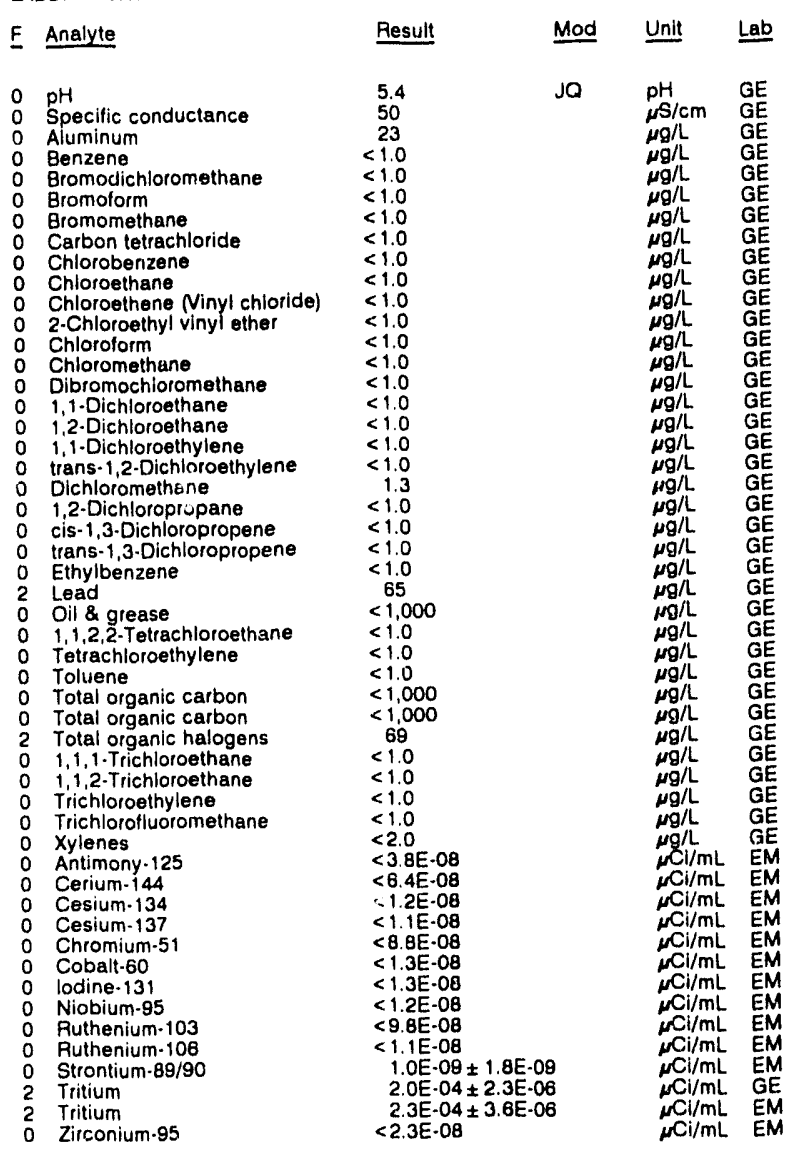

WELL PDB 3

MEASUREMENTS CONDUCTED IN THE FIELD

Sample date: 11/19/91

Depth to water: $38.30 \mathrm{ft}(: 1.67 \mathrm{~m})$ below TOC Water elevation: $281.20 \mathrm{ft}(85.71 \mathrm{~m}) \mathrm{ms}$ Sp. conductance: $56 \mu \mathrm{s} / \mathrm{cm}$

$\mathrm{pH}: 5.0$

Alkallnity: $0 \mathrm{mg} / \mathrm{h}$
Water temperaturs $23.0^{\circ} \mathrm{C}$

Water evacuated before sampling: $87 \mathrm{gal}$

LABORATORY ANALYSES

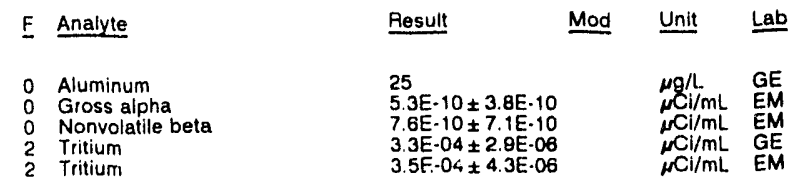


ANALYTICAL RESULTS

WELL PDB 3

MEASUREMENTS CONDUCTED IN THE FIELD

Sample date: $12 / 18 / 91$

Depth to water: $39.05 \mathrm{ft}(11.90 \mathrm{~m})$ below TOC

Water elevation: $280.45 \mathrm{~h}(85.48$

Sp. conductance: $57 \mu \mathrm{s} / \mathrm{cm}$

Water evacuated before sampling: $85 \mathrm{gal}$

LABORATORY ANALYSES

\begin{tabular}{|c|c|c|}
\hline Analyte & Result & Unit \\
\hline $\begin{array}{l}\text { Aluminum } \\
\text { Antimony-125 } \\
\text { Cerium-144 } \\
\text { Cesium-134 } \\
\text { Cesium-137 } \\
\text { Chromium-51 } \\
\text { Cobalt-60 } \\
\text { lodine-131 } \\
\text { Nioblum- } 95 \\
\text { Ruthenlum-103 } \\
\text { Ruthenium-106 } \\
\text { Strontium-88/90 } \\
\text { Tritium } \\
\text { Tritium } \\
\text { Zirconlum-95 }\end{array}$ & $\begin{aligned} & 26 \\
&<5.4 \mathrm{E}-08 \\
&<1.1 \mathrm{E}-07 \\
&<1.8 \mathrm{E} \cdot 08 \\
&<2.3 \mathrm{E}-08 \\
&<1.3 \mathrm{E}-06 \\
&<2.4 \mathrm{E}-08 \\
&<7.3 \mathrm{E} \cdot 05 \\
&<1.5 \mathrm{E}-07 \\
&<8.1 \mathrm{E}-08 \\
&<2.1 \mathrm{E} \cdot 07 \\
&-4.5 \mathrm{E}-11 \pm 1.8 \mathrm{E}-09 \\
& 3.5 \mathrm{E}-04 \pm 2.9 \mathrm{E} \cdot 06 \\
& 3.6 \mathrm{E} \cdot 04 \pm 4.3 \mathrm{E}-06 \\
&<8.7 \mathrm{E} \cdot 08\end{aligned}$ & 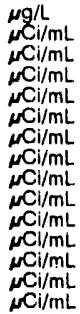 \\
\hline
\end{tabular}

\section{WELL PRP $1 A$}

MEASUREMENTS CONDUCTED IN THE FIELD

\begin{tabular}{|c|c|c|c|c|c|}
\hline & $\begin{array}{l}\text { nple date: } 11 / 20 / 91 \\
\text { pth to water: } 34.25 \mathrm{Ht} \\
\text { ter elevation: } 250.35 \mathrm{ft} \\
\text { conductance: } 52 \mathrm{\mu s} / \mathrm{c} \\
\text { ter evacuated before s }\end{array}$ & $\begin{array}{l}\text { elow TOC } \\
\mathrm{msl} \\
6 \mathrm{gal}\end{array}$ & $\begin{array}{l}\text { Time: } 9: 55 \\
\text { pH: } 4.7 \\
\text { Alkalinity: } \\
\text { Water temp }\end{array}$ & gature: & \\
\hline & BORATORY ANAL.YSES & & & & \\
\hline$\underline{F}$ & Analyte & Result & Mod & Unit & $\underline{L a b}$ \\
\hline $\begin{array}{l}0 \\
0 \\
0 \\
2 \\
0 \\
0 \\
0 \\
2\end{array}$ & $\begin{array}{l}\text { Carbon tetrachloride } \\
\text { Chloroform } \\
\text { Chromium } \\
\text { Lead } \\
\text { Totrachloroethylene } \\
1,1,1-\text { Trichloroethane } \\
\text { Trichloroethylene } \\
\text { Tritium }\end{array}$ & $\begin{array}{l}<1.0 \\
<1.0 \\
<4.0 \\
17 \\
1.0 \\
<1.0 \\
1.2 \\
2.8 E-05\end{array}$ & OE-06 $V$ & $\begin{array}{l}\mu g / L \\
\mu g / L \\
\mu g / L \\
\mu g / L \\
\mu g / L \\
\mu g / L \\
\mu g / L \\
\mu C i / n\end{array}$ & $\begin{array}{l}\mathrm{GE} \\
\mathrm{GE} \\
\mathrm{GE} \\
\mathrm{GE} \\
\mathrm{GE} \\
\mathrm{GE} \\
\mathrm{GE} \\
\mathrm{GE}\end{array}$ \\
\hline
\end{tabular}

WELL PRP 2

MEASUREMENTS CONDUCTED IN THE FIELD

\begin{tabular}{|c|c|c|c|c|c|}
\hline \multicolumn{3}{|c|}{$\begin{array}{l}\text { Sample date: } 11 / 19 / 91 \\
\text { Depth to water: } 31.20 \mathrm{ft}(9.51 \mathrm{~m}) \text { below TOC } \\
\text { Water elevation: } 255.20 \mathrm{ft}(77.79 \mathrm{~m}) \mathrm{msl} \\
\text { Sp. conductance: } 29 \mu \mathrm{s} / \mathrm{cm} \\
\text { Water evacuated before sampling: } 55 \mathrm{gal}\end{array}$} & \multicolumn{3}{|c|}{$\begin{array}{l}\text { Time: } 16: 00 \\
\text { pH: } 4.7 \\
\text { Alkalinity: } 0 \mathrm{mg} / \mathrm{L} \\
\text { Water temperature: } 20.2^{\circ} \mathrm{C}\end{array}$} \\
\hline \multicolumn{6}{|c|}{ LABORATORY ANALYSES } \\
\hline$\underline{F}$ & Analyte & Result & Mod & Unit & $\underline{\text { Lab }}$ \\
\hline $\begin{array}{l}0 \\
0 \\
0 \\
0 \\
0 \\
0 \\
0 \\
0\end{array}$ & $\begin{array}{l}\text { Carbon tetrachloride } \\
\text { Chloroform } \\
\text { Chromlum } \\
\text { Lead } \\
\text { Tetrachloroethylene } \\
1,1,1 \cdot \text { Trichloroethane } \\
\text { Trichloroethylene } \\
\text { Tritium }\end{array}$ & $\begin{array}{l}<1.0 \\
<1.0 \\
<4.0 \\
5.8 \\
<1.0 \\
<1.0 \\
<1.0 \\
5.1 E-0\end{array}$ & OE-07 $\mathrm{V}$ & $\begin{array}{l}\mu \mathrm{g} / \mathrm{L} \\
\mu \mathrm{g} / \mathrm{L} \\
\mu \mathrm{g} / \mathrm{L} \\
\mu \mathrm{g} / \mathrm{L} \\
\mu \mathrm{g} / \mathrm{L} \\
\mu \mathrm{g} / \mathrm{L} \\
\mu \mathrm{g} / \mathrm{L} \\
\mu \mathrm{C} / \mathrm{i}\end{array}$ & $\begin{array}{l}\mathrm{GE} \\
\mathrm{GE} \\
\mathrm{GE} \\
\mathrm{GE} \\
\mathrm{GE} \\
\mathrm{GE} \\
\mathrm{GE} \\
\mathrm{GE}\end{array}$ \\
\hline
\end{tabular}

\section{WELL PRP 3}

MEASUREMENTS CONDUCTED IN THE FIELD

\begin{tabular}{|c|c|c|c|c|c|}
\hline \multicolumn{3}{|c|}{$\begin{array}{l}\text { Sample date: } 11 / 20 / 91 \\
\text { Depth to water: } 25.89 \mathrm{ft}(7.89 \mathrm{~m}) \text { below TOC } \\
\text { Water olevation: } 254.81 \mathrm{ft}(77.67 \mathrm{~m}) \mathrm{msl} \\
\text { Sp. conductance: } 93 \mu \mathrm{s} / \mathrm{cm} \\
\text { Water evacuated before sampling: } 69 \mathrm{gal}\end{array}$} & \multicolumn{3}{|c|}{$\begin{array}{l}\text { Time: } 10: 40 \\
\text { pH: } 43 \\
\text { Alkalinity, } 0 \mathrm{mg} / \mathrm{h} \\
\text { Water temperature: } 21.5^{\circ} \mathrm{C}\end{array}$} \\
\hline \multicolumn{6}{|c|}{ LABOAATORY ANALYSES } \\
\hline & Analyte & Result & Mod & Unit & $\underline{\text { Lab }}$ \\
\hline & $\begin{array}{l}\text { Carbon tetrachloride } \\
\text { Chloroform } \\
\text { Chromium } \\
\text { Lead } \\
\text { Tetrachloroethylene } \\
1,1,1 \text {. Trichloroethane }\end{array}$ & $\begin{array}{l}<1.0 \\
<1.0 \\
<4.0 \\
78 \\
26 \\
174\end{array}$ & & $\begin{array}{l}\mu \mathrm{g} / \mathrm{L} \\
\mu \mathrm{g} / \mathrm{L} \\
\mu \mathrm{g} / \mathrm{L} \\
\mu \mathrm{g} / \mathrm{L} \\
\mu \mathrm{g} / \mathrm{L} \\
\mu \mathrm{g} / \mathrm{L}\end{array}$ & $\begin{array}{l}\mathrm{GE} \\
\mathrm{GE} \\
\mathrm{GE} \\
\mathrm{GE} \\
\mathrm{GE} \\
\mathrm{GE}\end{array}$ \\
\hline
\end{tabular}

WELL PRP 3 collected on 11/20/91, laboratory analyses (cont.)

$\begin{array}{llllll}E & \text { Analyte } & \text { Pesult } & \text { Mod } & \text { Unit } & \text { Lab } \\ 2 & \text { Trichloroethylene } & 43 & & \\ 1 & \text { Tritium } & 1.1 E .05 \pm 8.0 E .07 & \mu \mathrm{g} / \mathrm{h} & \mathrm{GE} \\ \mu \mathrm{C} i / \mathrm{mL} & \mathrm{GE}\end{array}$

\section{WELL PRP 4}

MEASUREMENTS CONDUCTED IN THE FIELD

$\begin{array}{ll}\text { Sample date: } 11 / 20 / 91 & \text { Time: } 11: 05 \\ \text { Depth to water: } 26.05 \mathrm{ft}(7.94 \mathrm{~m}) \text { below TOC } & \text { pH: } 4.5 \\ \text { Water elevation: } 258.65 \mathrm{H}(78.84 \mathrm{~m}) \mathrm{msl} & \text { Alkalinity: } 0 \mathrm{mg} / \mathrm{h} \\ \text { Sp. conductance: } 34 \mu \mathrm{S} / \mathrm{cm} & \text { Water temperalure: } 20.5^{\circ} \mathrm{C} \\ \text { Water evacuated before sampling: } 68 \mathrm{gal} & \end{array}$

Water evacuated before sampling: $68 \mathrm{gal}$

LABORATORY ANALYSES

\begin{tabular}{|c|c|c|c|c|}
\hline$F$ & Analyte & Result & Mod & Unit \\
\hline $\begin{array}{l}0 \\
0 \\
0 \\
0 \\
0 \\
0 \\
0 \\
0\end{array}$ & $\begin{array}{l}\text { Carbon tetrachloride } \\
\text { Chloroform } \\
\text { Chromium } \\
\text { Lead } \\
\text { Tetrachloroethylene } \\
1,1,1 \text {-Trichloroethane } \\
\text { Trichloroethylene } \\
\text { Tritium }\end{array}$ & $\begin{aligned} &< 1.0 \\
& 1.7 \\
&<4.0 \\
&<3.0 \\
&<1.0 \\
&<1.0 \\
&<1.0 \\
& 5.6 \mathrm{E} .06\end{aligned}$ & v & $\begin{array}{l}\mu g / L \\
\mu g / L \\
\mu g / L \\
\mu g / L \\
\mu g / L \\
\mu g / L \\
\mu g / L \\
\mu C i / m L\end{array}$ \\
\hline
\end{tabular}

\section{WELL PRP 4 Replicate}

MEASUREMENTS CONDUCTED IN THE FIELD

$\begin{array}{ll}\text { Sample date: } 11 / 20 / 91 & \text { Time: } 11: 05 \\ \text { Depth to water: } 26.05 \mathrm{ft}(7.94 \mathrm{~m}) \text { below TOC } & \text { pH: } 4.5 \\ \text { Water elevation: } 258.65 \mathrm{H}(78.84 \mathrm{~m}) \mathrm{msl} & \text { Alkalinity: } 0 \mathrm{mg} / \mathrm{L} \\ \text { Sp. conductance: } 34 \mu \mathrm{s} / \mathrm{cm} & \text { Water temperature: } 20.5^{\circ} \mathrm{C} \\ \text { Water evacuated belore sampling: } 68 \mathrm{gal} & \end{array}$

Water evacuated before sampling: $68 \mathrm{gal}$

LABORATORY ANALYSES

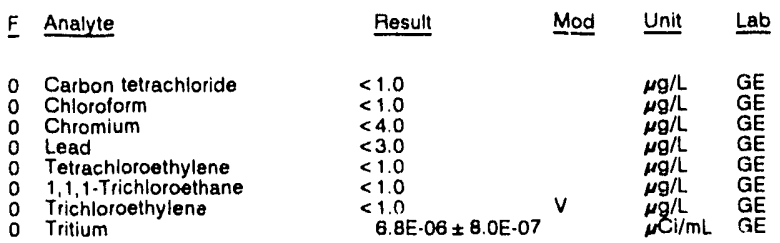

WELL PSB $1 A$

MEASUREMENTS CONDUCTED IN THE FIELD

$\begin{array}{ll}\text { Sample date: } 10 / 23 / 91 & \text { Time: } 12: 25 \\ \text { Depth to water: } 49.00 \mathrm{Ht}(14.94 \mathrm{~m}) \text { below TOC } & \text { pH: } 6.1 \\ \text { Water elevation: } 280.10 \mathrm{H}(85.38 \mathrm{~m}) \mathrm{msl} & \text { Alknlinity: } 5 \mathrm{mg} / \mathrm{h} \\ \text { Sp. conductance: } 44 \mu \mathrm{HS} / \mathrm{cm} & \text { Wa:er temperature: } 20.6^{\circ} \mathrm{C} \\ \text { Water evacuated before sampling: } 60 \mathrm{gal} & \end{array}$

LABORATOFY ANALYSES

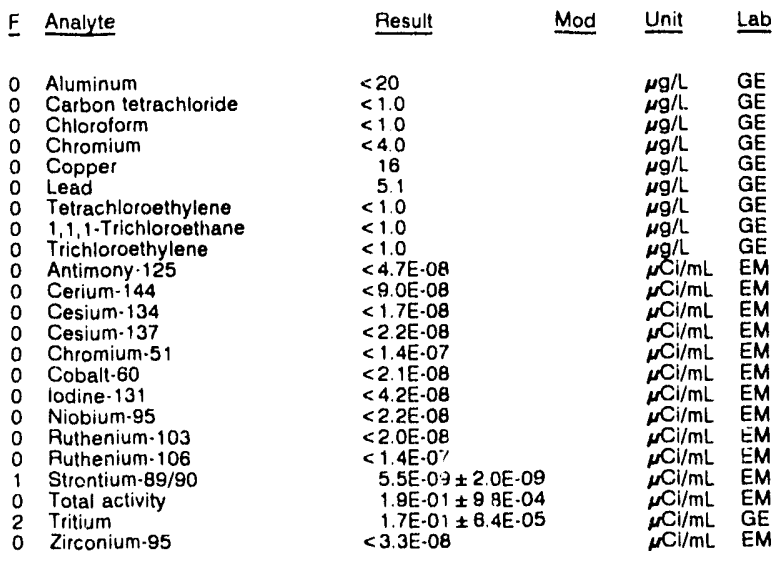


ANALYTICAL RESULTS

WELL PSB 1A

MEASUREMENTS CONDUCTED IN THE FIELD

Sample d

Depth to water: $49.45 \mathrm{ft}(15.07 \mathrm{~m})$ below TOC Water elevation: $279.65 \mathrm{Ht}(65.24 \mathrm{~m}) \mathrm{ms}$ l

Sp conductance $48 \mathrm{~s} / \mathrm{cm}$

Water evacuated before sampling: $58 \mathrm{gal}$

LABORATORY ANALYSES

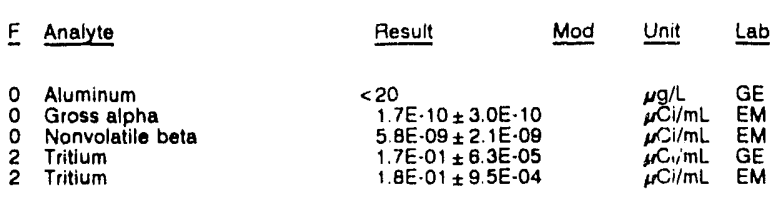

WELL PSB $1 \mathrm{~A}$

MEASUREMENTS CONDUCTED IN THE FIELD

Sample date: $12 / 16 / 91$

Depth to water: $50.19 \mathrm{ft}(15.30 \mathrm{~m})$ below TOC

Water elevation: $278.91 \mathrm{tt}$ (日5.

Alkalinity: $6 \mathrm{mg} / \mathrm{h}$

Water temperature: $18.50^{\circ} \mathrm{C}$

Water evacuated before sampling: $56 \mathrm{gal}$

Time: $12: 10$

Alkalinity: $7 \mathrm{mg}$

Water temperalure: $201^{\circ} \mathrm{C}$

LABORATORY ANALYSES

$\begin{array}{llclll}\text { E Analyle } & \text { Result } & \text { Mod } & \text { Unit } & \text { Lab } \\ 0 & \text { Aluminum } & & \\ 0 & \text { Gross alpha } & <20 & & \\ 0 & \text { Nonvolatile beta } & 9.3 \mathrm{E} \cdot 10 \pm 1.1 \mathrm{E}-09 & & \mu \mathrm{g} / \mathrm{L} & \mathrm{GE} \\ 2 & \text { Tritium } & 8.4 \mathrm{E} \cdot 09 \pm 2.1 \mathrm{E} \cdot 09 & & \mu \mathrm{Ci} / \mathrm{mL} & \mathrm{EM} \\ 2 & \text { Tritium } & 1.6 \mathrm{E} \cdot 01 \pm 6.1 \mathrm{E} \cdot 05 & & \mu \mathrm{Ci} / \mathrm{mL} & \mathrm{EM} \\ & 17 \mathrm{E} \cdot 01 \pm 9.3 \mathrm{E}-04 & & \mu \mathrm{Ci} / \mathrm{mL} & \mathrm{EM}\end{array}$

\section{WELL PSB 2A}

MEASUREMENTS CONDUCTED IN THE FIELD

Sample date: $10 / 23191$

Depth to water: $43.83 \mathrm{ft}(13.36 \mathrm{~m})$ below TOC Water elevation: $279.87 \mathrm{H}(8531 \mathrm{~m}) \mathrm{msl}$

Waler elevalion. 279.87 .

Alkalinity: $0 \mathrm{mg} / \mathrm{L}$

Water temperature $198^{\circ} \mathrm{C}$

Water evacuated before sampling: $59 \mathrm{gal}$

LABCRATORY ANALYSES

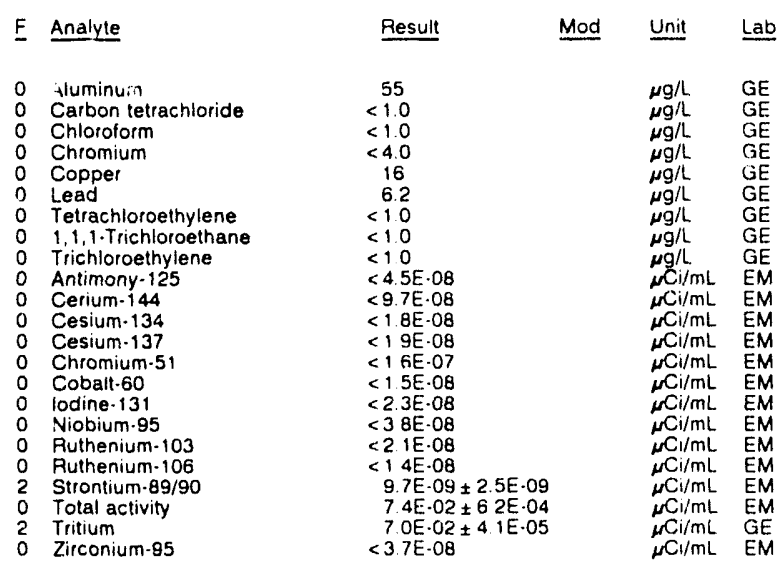

WELL PSB 2A

MEASUREMENTS CONDUCTED IN THE FIELD

Sample date: 11,

Depth to water: $4438 \mathrm{ft}(13.53 \mathrm{~m})$ below TOC

Water elevation: $279.32 \mathrm{H}(85.14 \mathrm{~m}) \mathrm{ms}$

Sp conductance $114 \mu \mathrm{s} / \mathrm{cm}$

aling 56 al

Time 11,40

Akalinity $0 \mathrm{mg}$

Water temperature $195^{\circ} \mathrm{C}$

LABORATORY ANALYSES

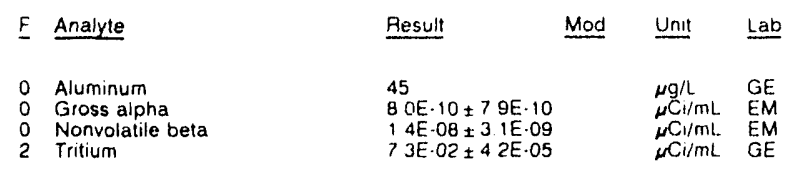

WELL. PSB $2 A$ collected on 11/19/91, laboratory analyses (cont.)

$\begin{array}{lllll}E & \text { Analyte } & \text { Pesult } & \text { Mod Unit } & \text { Lab } \\ 2 \text { Tritium } & 7.7 \mathrm{E} \cdot 02 \pm 6.3 \mathrm{E} \cdot 04 & & \\ \mu \mathrm{Cl} / \mathrm{mL} & \mathrm{EM}\end{array}$

WELL PSB 2A

MEASUREMENTS CONDUCTED IN THE FIELD

Sample date: $12 / 10 /$

Depth to water: $45.16 \mathrm{ft}(13.78 \mathrm{~m})$ below TOC

Water elevation: $278.54 \mathrm{Ht}(84.90 \mathrm{~m}) \mathrm{msl}$

Sp. conductance: $117 \mathrm{\mu S} / \mathrm{cm}$

Water evacuated before sampling: $56 \mathrm{ga}$

LABORATORY ANALYSES

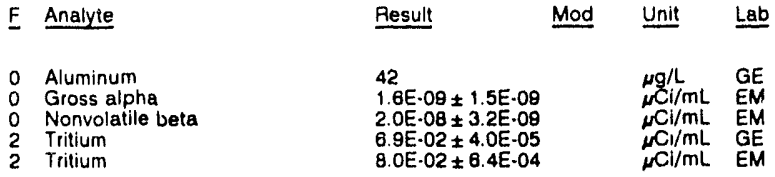

WELL PSB $3 A$

MEASUREMENTS CONDUCTED IN THE FIELD

Sample date: 10/23/91

Depth to water: $39.76 \mathrm{ft}(12.12 \mathrm{~m})$ below TOC

Water elevation: $278.84 \mathrm{H}(84.99 \mathrm{~m}) \mathrm{ms}$ l

Sp. conductance: $38 \mu \mathrm{S} / \mathrm{cm}$
Water evacuated before sampling: $59 \mathrm{ga}$

Time: 11:15

pH: 5.1

Alkalinity: $0 \mathrm{mg} /$

Water temperature: $18.2^{\circ} \mathrm{C}$

LABORATORY ANALYSES

E Analyte Result Mod Unit La

0 Aluminum

Chloroform

0 Chromium

O Copper

2 Tetrachloroethylene

1,1,1-Trichloroethane

Trichloroethylen

Cerium-144

Cesium-134

Cesium-137

Chromium-51

Cobalt-60

lodine-1.31

Ruthenium-103

Ruthenium-106

Strontium.89/90

0 Tolal activity

$\begin{array}{ll}2 & \text { Tritium } \\ 0 & \text { Zirconium-95 }\end{array}$

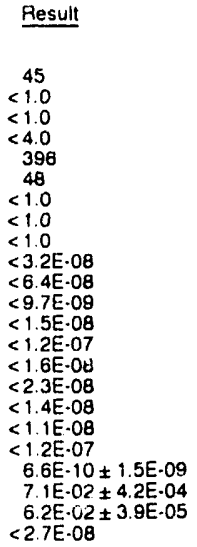

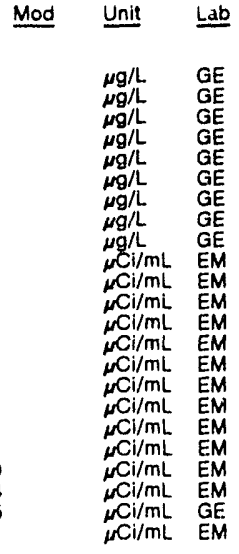

WELL PSB 3A Replicate

MEASUREMENTS CONDUCTED IN THE FIELD

Sample rite: 10/23/91

Depith to water: $39.76 \mathrm{ft}(12.12 \mathrm{~m})$ below TOC

Water elevation: 278.84 Ht 184.

Sp. conductance: $38 \mu \mathrm{S} / \mathrm{cm}$
Water evacuated before sampling: $59 \mathrm{ga}$

$\mathrm{pH}: 4.6$

Ikalinity: $0 \mathrm{mg} /$

$18.4^{\circ} \mathrm{C}$

LABORATORY ANALYSES

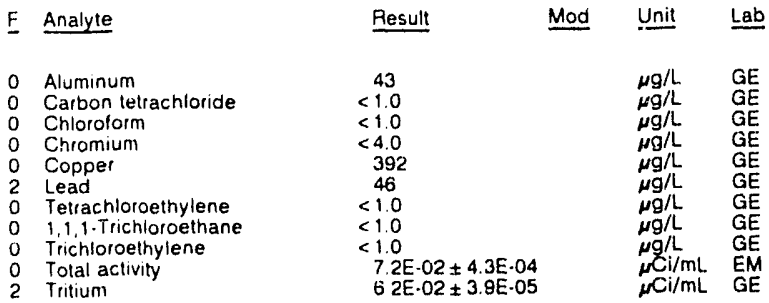

Time: : 1:25

pH: 4.8

Alkalinity: $0 \mathrm{mg} / \mathrm{h}, 19.4^{\circ} \mathrm{C}$ 
WELL PSB $3 A$

MEASUREMENTS CONOUCTED IN THE FIELD

Sample date: $11 / 19 / 91$
Dopth to water: 40.31 th $(12.29 \mathrm{~m})$ below TOC
Water olevation: $278.29 \mathrm{ft}(84.82 \mathrm{~m}) \mathrm{ms}$
Sp. conductance: 39 s

Water evacuated betore sampling: $57 \mathrm{gal}$

LABORATORY ANALYSES

\begin{tabular}{|c|c|c|c|}
\hline F Analyte & Result & Mod & Unit \\
\hline $\begin{array}{ll}0 & \text { Aluminum } \\
0 & \text { Gross alpha } \\
0 & \text { Nonvolatilo beta } \\
2 & \text { Tritium } \\
2 & \text { Tritium }\end{array}$ & $\begin{array}{l}30 \\
1.4 \mathrm{E} \cdot 09 \pm 8.9 \mathrm{E} \cdot 10 \\
1.9 \mathrm{E} \cdot 09 \pm 1.5 \mathrm{E} \cdot 09 \\
5.8 \mathrm{BE} \cdot 02 \div 3.7 \mathrm{E} \cdot 05 \\
6.8 \mathrm{E} \cdot 02 \pm 4.2 \mathrm{E} \cdot 04\end{array}$ & & $\begin{array}{l}\mu g / \mathrm{L} \\
\mu \mathrm{L} i / \mathrm{mL} \\
\mu \mathrm{Ci} / \mathrm{mL} \\
\mu \mathrm{Ci} / \mathrm{mL} \\
\mu \mathrm{Ci} / \mathrm{mL}\end{array}$ \\
\hline
\end{tabular}

WELL PSB $3 A$

MEASUREMENTS CONDUCTED IN THE FIELD

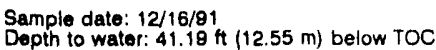

Water elevation: $277.41 \mathrm{~h}(84.56 \mathrm{~m}) \mathrm{ms}$ i

Sp. conductance: $40 \mu \mathrm{s} / \mathrm{cm}$

Water ovacuated before sampling: $55 \mathrm{gal}$

LABORATORY ANALYSES

\begin{tabular}{|c|c|c|c|}
\hline Analyte & Result & Mod & Unit \\
\hline $\begin{array}{l}\text { Aluminum } \\
\text { Gross alpha } \\
\text { Nonvolatile beta } \\
\text { Tritlum } \\
\text { Tritium }\end{array}$ & $\begin{array}{l}33 \\
1.5 E \cdot 09 \pm 1.3 E \cdot 09 \\
6.6 \mathrm{E} \cdot 10 \pm 1.2 \mathrm{E}-09 \\
5.3 \mathrm{E} \cdot 02 \pm 3.5 \mathrm{E} \cdot 05 \\
5.8 \mathrm{E} \cdot 02 \pm 3.8 \mathrm{~B} \cdot 04\end{array}$ & & $\begin{array}{l}\mu \mathrm{g} / \mathrm{L} \\
\mu \mathrm{Ci} / \mathrm{mL} \\
\mu \mathrm{Ci} / \mathrm{mL} \\
\mu \mathrm{Ci} / \mathrm{mL} \\
\mu \mathrm{Ci} / \mathrm{mL}\end{array}$ \\
\hline
\end{tabular}

WELL PSB 4A

MEASUREMENTS CONDUCTED IN THE FIELO

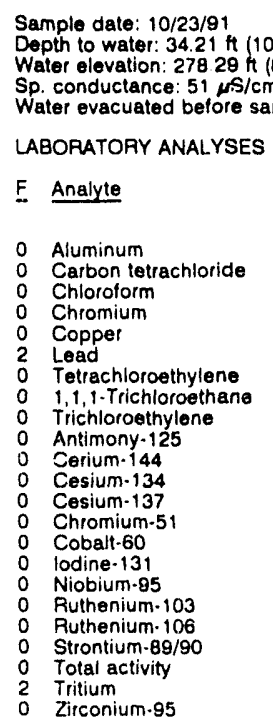

Time: $11: 10$

Alkalinity: $0 \mathrm{mg} / \mathrm{L}$

Water temperature: $19.4^{\circ} \mathrm{C}$
Time: $11: 00$

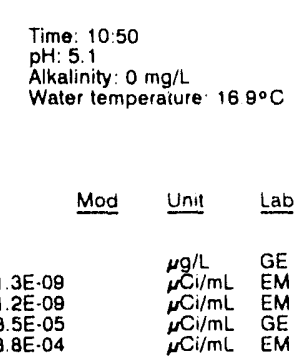

Alkalinity: $0 \mathrm{mg} / \mathrm{L}$

Water temperature $19.2^{\circ} \mathrm{C}$ mpling: $60 \mathrm{gal}$

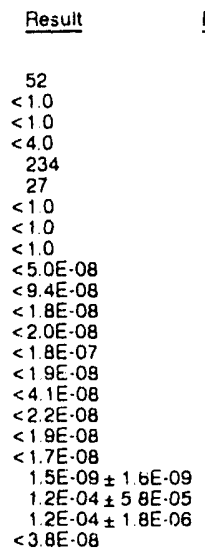

WELL PSB $4 A$ collected on $11 / 19 / 9,1$, laboratory analyses (cont.)

\begin{tabular}{|c|c|c|c|}
\hline E Analyte & Besult & Mod & Unit \\
\hline Tritium & 1.1E.04 & & $\mu \mathrm{Ci} / \mathrm{mL}$ \\
\hline
\end{tabular}

WELL PSB $4 A$

MEASUREMENTS CONDUCTED IN THE FIELD

Depth to water: $35.64 \mathrm{ft}(10.86 \mathrm{~m})$ below TOC

Water elevation: $276.96 \mathrm{ht}(84.39 \mathrm{~m}) \mathrm{ms} /$

Sp conductance $54.96 \mathrm{sm}$

ph. 48

Water temperature: $17.9^{\circ} \mathrm{C}$

Water evacuated before sampling: $56 \mathrm{ga}$

LABORATORY ANALYSES

\begin{tabular}{|c|c|c|c|}
\hline $\bar{E}$ Analyte & Pesult & Mod & Unit \\
\hline $\begin{array}{ll}0 & \text { Aluminum } \\
2 & \text { Tritiunii } \\
2 & \text { Tritium } \\
2 & \text { Tritium }\end{array}$ & $\begin{array}{l}56 \\
9.6 \mathrm{E} \cdot 05 \pm 1.6 \mathrm{E} \cdot 06 \\
1.0 \mathrm{E} \cdot 04 \pm 2.4 \mathrm{E} \cdot 06 \\
9.8 \mathrm{E} \cdot 05 \pm 8.0 \mathrm{E} \cdot 07\end{array}$ & & $\begin{array}{l}\mu \mathrm{g} / \mathrm{L} \\
\mu \mathrm{Ci} / \mathrm{mL} \\
\mu \mathrm{Ci} / \mathrm{mL} \\
\mu \mathrm{Ci} / \mathrm{mL}\end{array}$ \\
\hline
\end{tabular}

WELL PSB 5A

MEASUREMENTS CONDUCTED IN THE FIELD

Depth 10 Time. 13:10

Water elevation $279.87 \mathrm{ft}(85.31 \mathrm{~m}) \mathrm{msl}$ Alkalinity $0 \mathrm{mg} / \mathrm{L}$

Sp. conductance: $46 \mu / \mathrm{sm}$

Water temperature $19.4^{\circ} \mathrm{C}$

Water evacuated before sampling: $24 \mathrm{gal}$

The well went dry during purging

LABORATORY ANALYSES

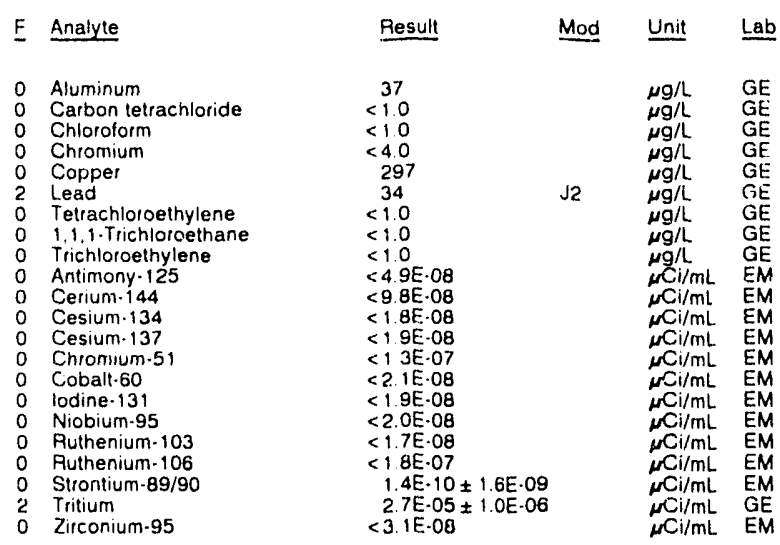

\section{WELL PSB 5A}

MEASUREMENTS CONDUCTED IN THE FIELD

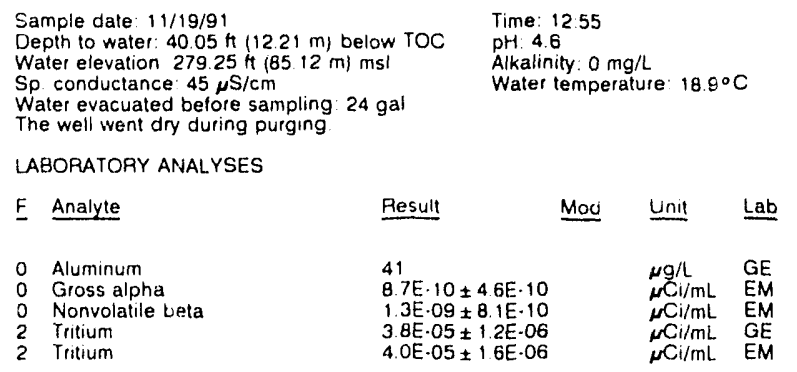

\section{WELL PSB 4A}

MEASUAEMENTS CONDUCTED IN THE FIELD

\section{Sample date: $11 / 19 / 91$}

Depth to water: $34.82 \mathrm{~A}(10.61 \mathrm{~m})$ below TOC

Water elevation: $277.68 \mathrm{ft}(84.64 \mathrm{~m}) \mathrm{ms}$

LABORATORY ANALYSES

\begin{tabular}{|c|c|c|c|}
\hline Analyte & Resulf & Mod & Unit \\
\hline $\begin{array}{ll}0 & \text { Aluminum } \\
0 & \text { Gross aipha } \\
0 & \text { Nonvolatile beta } \\
2 & \text { Tritium }\end{array}$ & $\begin{array}{l}53 \\
1.1 E \cdot 09 \pm 5.2 E \cdot 10 \\
12 E \cdot 09 \pm 0.0 E-10 \\
1.1 E \cdot 04 \pm 17 E \cdot 06\end{array}$ & & $\begin{array}{l}\mu \mathrm{g} / \mathrm{L} \\
\mu \mathrm{Ci} / \mathrm{mL} \\
\mu \mathrm{C}_{\mathrm{l}} / \mathrm{mL} \\
\mu \mathrm{Ci} / \mathrm{mL}\end{array}$ \\
\hline
\end{tabular}

$$
\begin{aligned}
& \text { Time } 10.50 \\
& \mathrm{pH}: 4.5 \\
& \text { Alkalinity: } 0 \mathrm{mg} / \mathrm{h} \\
& \text { Water temperature. } 190^{\circ} \mathrm{C}
\end{aligned}
$$$$
2 \text { Tritium }
$$ 
ANALYTICAL RESULTS

WELL PSB 5A

MEASUREMENTS CONDUCTED IN THE FIELD

Sample date: $12 / 18 / 91$

Depth to water: $40.93 \mathrm{ft}(12.48 \mathrm{~m})$ below TOC

Water elevation: $278.37 \mathrm{ft}$

S. conductance: $44 \mu \mathrm{S} / \mathrm{cm}$

The well went dry duing pupling: 23 gal

pH: 5.0

Alkalinity: $0 \mathrm{mg} / \mathrm{L}, 7.00 \mathrm{C}$

LABORATORY ANALYSES

\begin{tabular}{|c|c|c|c|}
\hline F Analyte & Result & Mod & Unit \\
\hline $\begin{array}{l}\text { Aluminum } \\
\text { Gross alpha } \\
\text { Nonvolatile beta } \\
\text { Tritium } \\
\text { Tritium }\end{array}$ & $\begin{array}{l}41 \\
1.7 E-09 \pm 1.1 E-09 \\
2.1 E-09 \pm 1.0 \mathrm{E}-09 \\
4.3 \mathrm{E}-05 \pm 1.2 \mathrm{0}-06 \\
4.3 \mathrm{E}-05 \pm 7.8 \mathrm{E}-06\end{array}$ & & $\begin{array}{l}\mu \mathrm{g} / \mathrm{L} \\
\mu \mathrm{Ci} / \mathrm{mL} \\
\mathrm{m} \mathrm{Cl} / \mathrm{mL} \\
\mu \mathrm{Ci} / \mathrm{mL} \\
\mu \mathrm{Cl} / \mathrm{mL}\end{array}$ \\
\hline
\end{tabular}

WELL PSB 6A

MEASUREMENTS CONDUCTED IN THE FIELD

Sample date: 10/23/91

Depth to water: $43.15 \mathrm{ft}(13.15 \mathrm{~m}$; below TOC

Water elevation: $281.05 \mathrm{Ht}$ (85.

Water evacuated before sampling: 50 gal

LABORATORY ANALYSES

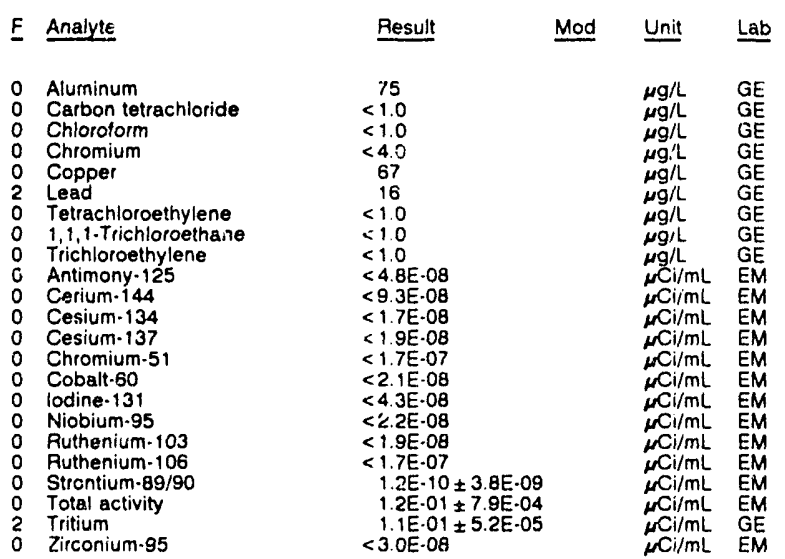

WELL PSB 6A

MEASUREMENTS CONDUCTED IN THE FIEL.D

Sample date: 11/19/91

Depth to water: $43.65 \mathrm{ft}(13.30 \mathrm{~m})$ below roC

Water elevation: $280.55 \mathrm{H}(85.51 \mathrm{~m}) \mathrm{ms}$

Sp. conductance: $62 \mathrm{~s} / \mathrm{cm}$

(a) 48 gal

Time: 10:40

PH: 4.7 : $0 \mathrm{mg}$

Water temperature: $19.4^{\circ} \mathrm{C}$

LABORATORY ANALYSES

E Analyte

Result Mod Unit Lab

Aluminum

Gross alpha

2 Tritium

$715 \mathrm{E}-10 \pm 4.9 \mathrm{E} \cdot 10 \quad \mu \mathrm{g} / \mathrm{L} \quad \mathrm{GE}$

$1.5 E-10 \pm 4.9 E \cdot 10$

2. $6 E \cdot 09 \pm 1.6 E \cdot 09$

$2.2 E-03 \pm 1.0 E \cdot 05$

Time: 10:25

Alkalinity: $0 \mathrm{mg}$

íater temperature: $19.1^{\circ} \mathrm{C}$

WELL PSB 6A

MLASUREMENTS CONDUCTED IN THE FIELD

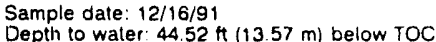

Water elevation: $279.68 \mathrm{ft}$

Sp. conductance: $59 \mu \mathrm{S} / \mathrm{cm}$
Water evacuated bctore sampling $46 \mathrm{gal}$

(8.25 m) ms!

$\mathrm{CCi} / \mathrm{mL}$ EM

$\mu \mathrm{Ci} / \mathrm{m}$ GE

LABORATORY ANALYSES

\begin{tabular}{|c|c|c|c|}
\hline E Analyte & Resuli & Mod & Unit \\
\hline $\begin{array}{ll}0 & \text { Aluminum } \\
0 & \text { Gross alpha } \\
0 & \text { Nonvolatile beta } \\
2 & \text { Tritium }\end{array}$ & $\begin{array}{l}50 \\
5.7 E \cdot 10 \pm 9.5 \mathrm{E} \cdot 10 \\
2.9 \mathrm{E} \cdot 09 \pm 1.5 \mathrm{E} \cdot 09 \\
9.7 \mathrm{E} \cdot 02 \pm 4.7 \mathrm{E} \cdot 05\end{array}$ & & 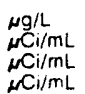 \\
\hline
\end{tabular}

WELL PSB 6A collected on 12/16/91, laboratory analyses (cont.)

$\begin{array}{llll}E \text { Analyte } & \text { Result } & \text { Mod Unit Lab } & \text { Lab } \\ 2 \text { Tritium } & 1.0 E-01 \pm 5.1 E .04 & N \mathrm{Cl} / \mathrm{mL} \text { EM }\end{array}$

WELL PSB 7A

MEASUREMENTS CONDUCTED IN THE FIELD

Sample date: $10 / 23 / 91$.

Water elevation: $280.64 \mathrm{Ht}(\mathbf{8 5 . 5 4} \mathrm{m}) \mathrm{ms}$

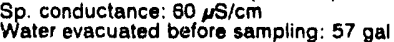

LABORATORY ANALYSES

\begin{tabular}{|c|c|c|c|}
\hline Analyte & Result & Unit & Lab \\
\hline $\begin{array}{l}\text { Aluminum } \\
\text { Carbon tetrachioride } \\
\text { Chloroform } \\
\text { Chromium } \\
\text { Copper } \\
\text { Lead } \\
\text { Tetrachloroethylene } \\
1,1,1 \text {-Trichloroethane } \\
\text { Trichloroethylene } \\
\text { Antimony-125 } \\
\text { Cerium- } 144 \\
\text { Cesium-134 } \\
\text { Cesium- } 137 \\
\text { Chromium-51 } \\
\text { Cobalt-60 } \\
\text { lodine-131 } \\
\text { Niobium-95 } \\
\text { Ruthenium-103 } \\
\text { Ruthenium-106 } \\
\text { Strontium-89/90 } \\
\text { Total activity } \\
\text { Tritic.n } \\
\text { Zirconium-95 }\end{array}$ & 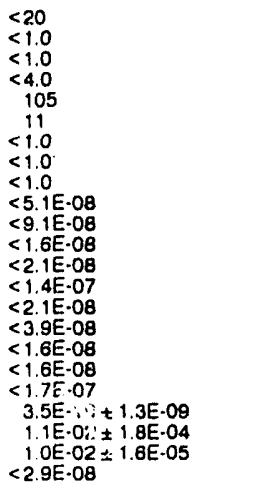 & 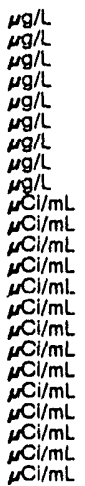 & $\begin{array}{l}G E \\
G E \\
G E \\
G E \\
G E \\
G E \\
G E \\
G E \\
G E \\
E M \\
E M \\
E M \\
E M \\
E M \\
E M \\
E M \\
E M \\
E M \\
E M \\
E M \\
E M \\
G E \\
E M\end{array}$ \\
\hline
\end{tabular}

WELL PSB 7A

MEASUREMENTS CONDUCTED IN I HE FIELD

Sample date: $11 / 19 / 91$

Depth to water: $50.41 \mathrm{ft}(15.37 \mathrm{~m})$ below TOC

Water elevation: $280.29 \mathrm{ft}$

S. conductance: $57 \mu \mathrm{s} / \mathrm{cm}$.

Time: $12: 50$

Alkalinity: $7 \mathrm{mg}$

Water temperature: $20.2^{\circ} \mathrm{C}$

Water evacuated before sampling: $70 \mathrm{gal}$

LABORATORY ANALYSES

\begin{tabular}{|c|c|c|c|}
\hline Analyte & Result & Mod & Unit \\
\hline $\begin{array}{ll}0 & \text { Aluminum } \\
0 & \text { Gross alpha } \\
0 & \text { Nonvolatile beta } \\
2 & \text { Tritium } \\
2 & \text { Tritium }\end{array}$ & $\begin{array}{l}<20 \\
4.4 \mathrm{E}-12 \pm 4.0 \mathrm{E} \cdot 10 \\
5.5 \mathrm{E}-10 \pm 1.3 \mathrm{E}-09 \\
1.0 \mathrm{E}-02 \pm 1.6 \mathrm{E}-05 \\
1.1 \mathrm{E}-02 \pm 7.4 \mathrm{E} \cdot 05\end{array}$ & & 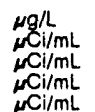 \\
\hline
\end{tabular}

WELL PSB 7A

MEASUREMENTS CONDUCTED IN THE FIELD

Sample date: 12/16/91

Depth to water: $51.27 \mathrm{H}(15.63 \mathrm{~m})$ below TOC

Water elevation: $279.43 \mathrm{tt}$ (85.

Sp. cunductance: $58 \mu \mathrm{S} / \mathrm{cm}$.

pH: 5.8

$5 \mathrm{mg} / \mathrm{L}$

Water evacuated belore sampling: $54 \mathrm{gal}$

LABORATORY ANALYSES

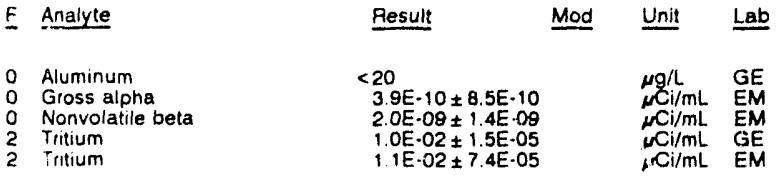


WELL PSS 1D

\section{MEASUREMENTS CONDUCTEU IN THE FIELD}

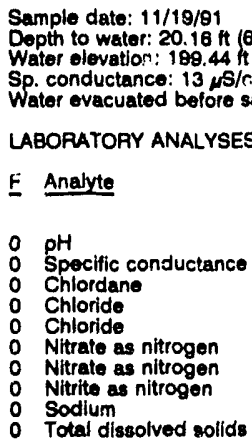

WELL PSS 1D Replicate

MEASUREMENTS CONDUCTED IN THE FIELD

Sample date: 11/19/91

Depth to water: $20.16 \mathrm{ft}(6.14 \mathrm{~m})$ below TOC

Water elovation: $198.44 \mathrm{tt}$ (14.

(1)

LABORATORY ANALYSES

\begin{tabular}{|c|c|}
\hline Analyte & Result \\
\hline $\begin{array}{l}\text { pH } \\
\text { Specific conductance } \\
\text { Chlordane } \\
\text { Chloride } \\
\text { Chloride } \\
\text { Nitrate as nitrugen } \\
\text { Nitrate as nitrogen } \\
\text { Nitrite as nitrogen } \\
\text { Nitrite as nitrogen } \\
\text { Sodium } \\
\text { Total dissolved solids } \\
\text { Total dissolved solids }\end{array}$ & $\begin{aligned} & 5.6 \\
& 15 \\
&< \\
&<.50 \\
& 1,300 \\
& 1,360 \\
& 3,50 \\
& 370 \\
&<10 \\
&<10 \\
& 744 \\
& 8,000 \\
& 8,000\end{aligned}$ \\
\hline
\end{tabular}

WELL PSS 2D

MEASUREMENTS CONDUCTED IN THE FIELD

Sample date: $11 / 19 / 91$

Depth to water: $30.62 \mathrm{ft}(9.33 \mathrm{~m})$ below TOC

Water olevation: $198.08 \mathrm{At}(60.38 \mathrm{~m}) \mathrm{msl}$

Water evacuated before sampling: $55 \mathrm{gal}$

LABORATORY ANALYSES

F Analyte

0 pH

Specific conductance

Chlordane

Nitrate as nitrogen

Nitrite as nitrogen

Sotal dissolved solids

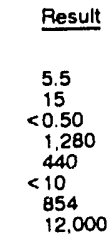

WELL PSS 3D

MEASUREMENTS CONDUCTED IN THE FIELD

Sample date: 11/19/91

Depth to water: $35.95 \mathrm{~h}(10.08 \mathrm{~m})$ below TOC

Water elevation: $198.05 \mathrm{ht}$

Sp. conductance: $10 \mu \mathrm{s} / \mathrm{cm}$

Water evacuated belore sampling: $10 \mathrm{gat}$

The well went dry during purging

LABORATORY ANALYSES

\begin{tabular}{|c|c|c|}
\hline & Analyte & Result \\
\hline $\begin{array}{l}0 \\
0 \\
0 \\
0 \\
0 \\
0 \\
0\end{array}$ & $\begin{array}{l}\text { pH } \\
\text { Specific conductance } \\
\text { Chlordane } \\
\text { Chloride } \\
\text { Nitrate as nitrogen } \\
\text { Nitrite as nitrogen } \\
\text { Sodium }\end{array}$ & $\begin{aligned} & 5.4 \\
& 10 \\
&< 0.50 \\
& 1.040 \\
& 140 \\
&< \\
& 600 \\
& 609\end{aligned}$ \\
\hline
\end{tabular}

Time: 13:55

PH: 4.8

Water temperature: $19.7^{\circ} \mathrm{C}$

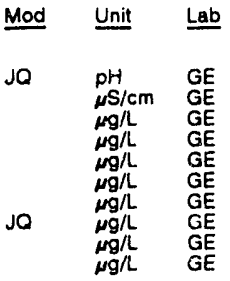

Time: $13: 55$

Alkalinity: $1 \mathrm{mg} / \mathrm{L}$

Water temperature: $19.7^{\circ} \mathrm{C}$

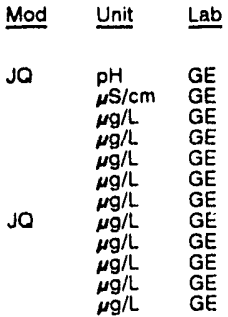

Time: $13: 20$

PH: 4.9

Water temperature: $19.1^{\circ} \mathrm{C}$

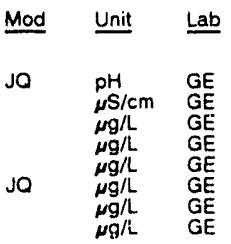

Time: $14: 15$

PH: 4.4 . 4 ilkalinity. o mg/t

Water temperature: $19.2^{\circ} \mathrm{C}$

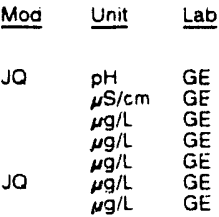

WELL PSS JD collected on 11/19/81, laboratory analyses (cont.)

$\begin{array}{lllll}E \text { Analyte } & \text { Result } & \text { Mod } & \text { Unit } & \text { Lab } \\ 0 \text { Total dissolved solids } & 4,000 & \mu \mathrm{g} / \mathrm{L} & \mathrm{GE}\end{array}$

WELL RAC 1

MEASUREMENTS CONDUCTED IN THE FIELD

Sample date: $12 / 15 / 91$

Time: 12:00

Water elevation: $273.00 \mathrm{ft}(83.21 \mathrm{~m}) \mathrm{msl} \quad$ Alkalinity: $0 \mathrm{mg} / \mathrm{l}$

Water temperature: $17.4^{\circ} \mathrm{C}$

Water evacuated betore sampling: $67 \mathrm{gal}$

LABORATORY ANALYSES

\begin{tabular}{|c|c|c|c|}
\hline Analyte & Result & Mod & Unit \\
\hline $\begin{array}{l}\text { Arsenic } \\
\text { Barium } \\
\text { Cadmium } \\
\text { Chromium } \\
2,4 \text {-Dichlorophenoxyacetic acid } \\
\text { Endrin } \\
\text { lron } \\
\text { Lead } \\
\text { Lindane } \\
\text { Manganese } \\
\text { Mercury } \\
\text { Methoxychior } \\
\text { Selenium } \\
\text { Silver } \\
\text { Toxaphene } \\
\text { 2,45-TP (Silvex) } \\
\text { Gross alpha } \\
\text { Nonvolatile beta } \\
\text { Total radium } \\
\text { Tritium }\end{array}$ & $\begin{array}{l}<2.0 \\
16 \\
<2.0 \\
<4.0 \\
<0.30 \\
<0.0060 \\
28 \\
4.2 \\
<0.0050 \\
13 \\
0.35 \\
<0.50 \\
<2.0 \\
<2.0 \\
<0.24 \\
<0.090 \\
<2.0 E-09 \\
<2.0 E \cdot 09 \\
1.3 E \cdot 09 \pm 1.2 E \cdot 09 \\
68 E \cdot 08 \pm 7.0 E-07\end{array}$ & $\mathrm{JQ}$ & $\begin{array}{l}\mu g / L \\
\mu g / L \\
\mu g / L \\
\mu g / L \\
\mu g / L \\
\mu g / L \\
\mu g / L \\
\mu g / L \\
\mu g / L \\
\mu g / L \\
\mu g / L \\
\mu g / L \\
\mu g / L \\
\mu g / L \\
\mu g / L \\
\mu g / L \\
\mu C L / m L \\
\mu C i / m L \\
\mu C i / m L\end{array}$ \\
\hline
\end{tabular}

WELL RAC 2

MEASUREMENTS CONDUCTED IN THE FIELD

Sample date: $12 / 15 / 91$ Depth to water: $8.48 \mathrm{ft}(2.58 \mathrm{~m})$ below TOC

Water elevation: $271.92 \mathrm{ft}(82.88 \mathrm{~m}) \mathrm{ms}$

Sp. conductance: $47 \mu \mathrm{S} / \mathrm{cm}$

Water evacuated before sampling: $75 \mathrm{gal}$

LABORATORY ANALYSES

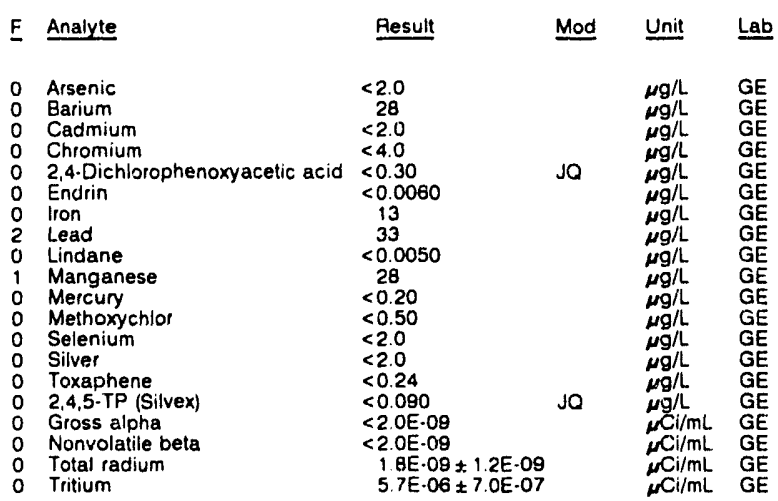

WELL RAC 3

MEASUREMENTS CONOUCTED IN THE FIELO

Sample date: 12/15/91

Water elevation: $271.77 \mathrm{Ht}(82.94 \mathrm{~m}) \mathrm{ms}$ !

Sp. conductance: $35 \mu \mathrm{S} / \mathrm{cm}$

Water evacuated before sampling: $77 \mathrm{gal}$

Time: $11: 30$

Alkalinity: $0 \mathrm{mg} / \mathrm{L}$

Water temperature: $18.0^{\circ} \mathrm{C}$

LABORATORY ANALYSES

\begin{tabular}{|c|c|c|c|c|}
\hline$F$ & Analyte & Result & Mod & Unit \\
\hline & $\begin{array}{l}\text { Arsenic } \\
\text { Barium } \\
\text { Cadmium } \\
\text { Chromium } \\
\text { 2.4-Dichlorophenoxyacelic acid } \\
\text { Endrin } \\
\text { iron } \\
\text { Lead }\end{array}$ & $\begin{array}{l}<2.0 \\
43 \\
<2.0 \\
<4.0 \\
<0.30 \\
<0.0060 \\
649 \\
58\end{array}$ & JO & $\begin{array}{l}\mu g / h \\
\mu g / / \\
\mu g / h \\
\mu g / L \\
\mu g / h \\
\mu g / h \\
\mu g / h \\
\mu g / h\end{array}$ \\
\hline
\end{tabular}


WELL RAC 3 collected on 12/15/81, laboratory analyses (cont.)

\begin{tabular}{|c|c|c|c|}
\hline Analyte & Result & Mod & Unit \\
\hline $\begin{array}{ll}0 & \text { Lindane } \\
1 & \text { Manganese } \\
0 & \text { Mercury } \\
0 & \text { Methoxychlor } \\
0 & \text { Selenium } \\
0 & \text { Silver } \\
0 & \text { Toxaphene } \\
0 & 2,4,5 \cdot T ? \text { (Silvex) } \\
0 & \text { Gross alpha } \\
0 & \text { Nonvolatile beta } \\
0 & \text { Total radium } \\
0 & \text { Tritium }\end{array}$ & $\begin{array}{l}<0.0050 \\
34 \\
<0.20 \\
<0.50 \\
<2.0 \\
<2.0 \\
<0.24 \\
<0.090 \\
5.9 E-09 \pm 2.1 \mathrm{E} \cdot 09 \\
<2.0 \mathrm{E}-09 \\
2.0 \mathrm{E} \cdot 09 \pm 1.2 \mathrm{E}-09 \\
7.1 \mathrm{E}-06 \pm 8.0 \mathrm{E} \cdot 07\end{array}$ & Jo & $\begin{array}{l}\mu g / L \\
\mu g / L \\
\mu g / L \\
\mu g / L \\
\mu g / L \\
\mu g / L \\
\mu g / L \\
\mu g / L \\
\mu C i / m L \\
\mu C i / m L \\
\mu C i / m L \\
\mu C i / m L\end{array}$ \\
\hline
\end{tabular}

\section{WELL RAC 4}

MEASUREMENTS CONDUCTED IN THE FIELD

\begin{tabular}{|c|c|c|c|c|c|}
\hline & $\begin{array}{l}\text { ple date: } 12 / 15 / 91 \\
\text { th to water: } 7.42 \mathrm{ft}(2.26 \mathrm{~m}) \text { belo } \\
\text { or elevation: } 271.58 \mathrm{ft}(82.78 \mathrm{~m}) \\
\text { conductance: } 37 \mu \mathrm{\mu S} / \mathrm{cm} \\
\text { or evacuated before sampling: } 8\end{array}$ & $\begin{array}{l}\text { w TOC } \\
\text { ms! } \\
\text { gal }\end{array}$ & $\begin{array}{l}\text { Time: } 11: 10 \\
\text { pH: } 4.7 \\
\text { Alkalinity: } 0 \\
\text { Water temp }\end{array}$ & $\begin{array}{l}\text { Ig/L } \\
\text { ature: } 17.2\end{array}$ & \\
\hline & BORATORY ANALYSES & & & & \\
\hline$\underline{\mathbf{E}}$ & Analyte & Result & Mod & Unit & Lab \\
\hline & $\begin{array}{l}\text { Arsenic } \\
\text { Barium } \\
\text { Cadmium } \\
\text { Chromium } \\
2,4 \text {-Dichlorophenoxyacetic acid } \\
\text { Endrin } \\
\text { Iron } \\
\text { Lead } \\
\text { Lindane } \\
\text { Manganese } \\
\text { Mercury } \\
\text { Methoxychlor } \\
\text { Selenium } \\
\text { Silver } \\
\text { Toxaphene } \\
\text { 2,4,5-TP (Silvex) } \\
\text { Gross alpha } \\
\text { Nonvolatile beta } \\
\text { Total radium } \\
\text { Tritium }\end{array}$ & $\begin{array}{l}<2.0 \\
23 \\
<2.0 \\
<4.0 \\
<0.30 \\
<0.0060 \\
10 \\
<3.0 \\
<0.0050 \\
8.0 \\
<0.20 \\
<0.50 \\
<2.0 \\
<2.0 \\
<0.24 \\
<0.090 \\
<2.0 \mathrm{E}-09 \\
<2.0 \mathrm{E}-09 \\
1.5 \mathrm{E} .09 \pm 1 . \\
5.9 \mathrm{E} \cdot 06 \pm 7 .\end{array}$ & JO & $\begin{array}{l}\mu g / L \\
\mu g / L \\
\mu g / L \\
\mu g / L \\
\mu g / L \\
\mu g / L \\
\mu g / L \\
\mu g / L \\
\mu g / L \\
\mu g / L \\
\mu g / L \\
\mu g / L \\
\mu g / L \\
\mu g / L \\
\mu g / L \\
\mu g / L \\
\mu C i / m L \\
\mu C i / m L \\
\mu C i / m L \\
\mu C i / m L\end{array}$ & $\begin{array}{l}\mathrm{GE} \\
\mathrm{GE} \\
\mathrm{GE} \\
\mathrm{GE} \\
\mathrm{GE} \\
\mathrm{GE} \\
\mathrm{GE} \\
\mathrm{GE} \\
\mathrm{GE} \\
\mathrm{GE} \\
\mathrm{GE} \\
\mathrm{GE} \\
\mathrm{GE} \\
\mathrm{GE} \\
\mathrm{GE} \\
\mathrm{GE} \\
\mathrm{GE} \\
\mathrm{GE} \\
\mathrm{GE} \\
\mathrm{GE}\end{array}$ \\
\hline
\end{tabular}

WELL RDB 1D

MEASUREMENTS CONDUCTED IN THE FIELD

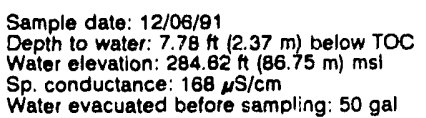

Time: $12: 15$

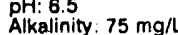

Water temperature: $18.1^{\circ} \mathrm{C}$

WELL RDB 2D

MEASUREMENTS CONDLICTED IN THE FIELO

Sample date: 12106181

Depth to water: $7.37 \mathrm{ft}(2.25 \mathrm{~m})$ below TOC

Water elevation: $285.23 \mathrm{Ht}(86.84 \mathrm{~m}) \mathrm{msl}$

( 237

Water evacuated before sampling: $64 \mathrm{gal}$

WELL RDB 3D

MEASUREMENTS CONOUCTED IN THE FIELD

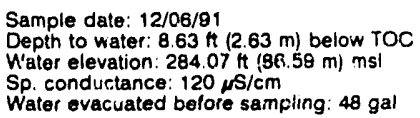

Time: 12:45

Alkalinity: $101 \mathrm{mg} / \mathrm{l}$

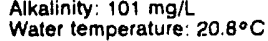

Time: 13:25

pH: 6.2

Water temperature: $20.0^{\circ} \mathrm{C}$
WELL RRP 1

MEASUREMENTS CONDUCTED IN THE FIELD

Sample date: 12/15/91

t $32.28 \mathrm{~m})$ below TOC

(elevation: $287.08 \mathrm{H} / 8 \mathrm{~m}$

Sp. conductance: $18 \mathrm{\mu S} / \mathrm{cm}$
Water evacuated before sampling: $65 \mathrm{gal}$

Time: $12: 40$

PH: 5.22 : $1 \mathrm{malinity:} \mathrm{mg} / \mathrm{L}$

Water temperature: $18.0^{\circ} \mathrm{C}$

WELL RRP 2

MEASUREMENTS CONDUCTED IN THE FIELD

Sample date: 12/15/91

Depth to water: $18.46 \mathrm{ht}(5.63 \mathrm{~m})$ below TOC

$09 \mathrm{ml} \mathrm{msl}$

Water evacuated before sampling: $62 \mathrm{gal}$

Time: $12: 55$

PH: 4.7

Water temperature: $19.5^{\circ} \mathrm{C}$

WELL RRP 3

MEASUREMENTS CONDUCTED IN THE FIELD

Sample date: $12 / 15 / 91$
Depth to water: $14.88 \mathrm{ft}(4.54 \mathrm{~m})$ below TOC

Water elevation: $265.22 \mathrm{~h}(80.84 \mathrm{~m}) \mathrm{msl}$

Water evacuated before sampling: $71 \mathrm{gal}$

Time: 13:25

Alkalinity: $1 \mathrm{mg} /$

Water temperature: $19.2^{\circ} \mathrm{C}$

WELL RRP 4

MEASUREMENTS CONDUCTED IN THE FIELD

Sample date: $12 / 15 / 81$

Depth to water: $15.42 \mathrm{H}(4.70 \mathrm{~m})$ below TOC

Water elovalion: $264.78 \mathrm{ft}(80.7$

Water evacuated before sampling: $69 \mathrm{gal}$

Time: $13: 10$

Alkalinity: $3 \mathrm{mg} / \mathrm{L}$

Water temperature $18.2^{\circ} \mathrm{C}$

WELL RSA 7

MEASUREMENTS CONDUCTED IN THE FIELD

Sample date: $12 / 18 / 91$

Depth to water: $26.30 \mathrm{it}(8.02 \mathrm{~m})$ below TOC

Water elevation: $288.10 \mathrm{~h}(87.20 \mathrm{~m}) \mathrm{ms} /$

No water was evacuated before sampling.

Time: $14: 35$
pH: 6.6

Water temperature: $18.8^{\circ} \mathrm{C}$

\section{WELL RSA 8}

MEASUREMENTS CONOUCTED IN THE FIELD

Sample date: $12 / 18 / 91$

Water elevation: $284.80 \mathrm{tt}(86.81 \mathrm{~m}) \mathrm{ms}$

Sp. conluctance: $35 \mu \mathrm{S} / \mathrm{cm}$
No water was evacuated before sampling.

Time: $14: 20$

Water temperature: $17.8^{\circ} \mathrm{C}$

WELL RSA 9

MEASUREMENTS CONDUCTED IN THE FIELO

Sample date: $12 / 18 / 91$

Depth to water: $27.80 \mathrm{ft}(8.47 \mathrm{~m})$ below TOC

Water elevalion. $283.80 \mathrm{~h}(88.53 \mathrm{ml} \mathrm{msl}$

. conduclance: $28 \mu \mathrm{S} / \mathrm{cm}$

pH: 6.5

Water temperature: $18.4^{\circ} \mathrm{C}$

\section{WELL RSA 10}

MEASUREMENTS CONDUCTED IN THE FIELD

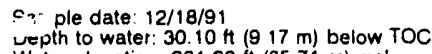

Water elevation: $281.20 \mathrm{ft}(85.71 \mathrm{~m}) \mathrm{msl}$

Sp. conductance: $31 \mu \mathrm{s} / \mathrm{cm}$

efore sampling
Time: $14: 30$

Water temperature: $18.3 \circ \mathrm{C}$ 
WELL RSB 7

MEASUREMENTS CONDUCTED IN THE FIELLD

Sample date: $12 / 18 / 91$

Depth to water: $24.20 \mathrm{ft}(7.38 \mathrm{~m})$ below TOC

Water elevation: $284.80 \mathrm{tt}$

rs/cm

No water was evacuated before sampling.

\section{WELL RSB 8}

MEASUREMENTS CONDUCTED IN THE FIELD

Sample date: 12/18/91

Depth to water: $18.00 \mathrm{H}(5.49 \mathrm{~m})$ below TOC

Water elevation: $287.80 \mathrm{ft} / 87$

酸

WELL RSB 9

MEASUREMENTS CONDUCTED IN THE FIELD

Sample date: 12/18/91

Depth to water: $18.30 \mathrm{H}(5.58 \mathrm{~m})$ below TOC

Water elevation: 287.30 \& 187.5

tance: $61 \mu \mathrm{S} / \mathrm{cm}$

WELL RSC 2

MEASUREMENTS CONDUCTED IN THE FIELD

Sample date: 12/16/91

Depth to water: $21,10 \mathrm{ft}(6.43 \mathrm{~m})$ below TOC

Water elevation: $280.90 \mathrm{Ht}(85$.

No water was evacuated before sampling

\section{WELL RSC 3}

MEASUREMENTS CONDUCTED IN THE FIELD

Sample date: $12 / 18 / 91$

Depth to water: $21.70 \mathrm{ft}(6.61 \mathrm{~m})$ below TOC

Water elevation: $279.60 \mathrm{ft}$

Sp. conductance: $45 \mu \mathrm{S} / \mathrm{cm}$

No water was evacuated before sampling.

WELL RSC 4

MEASUREMENTS CONOUCTED IN THE FIELD

Sample date: 12/16/91

Depth to water: $19.80 \mathrm{ft}(6.04 \mathrm{~m})$ below TOC

Water elevation: $280.50 \mathrm{ft}(85.50 \mathrm{~m}) \mathrm{ms}$ !

No water was evacuated before sampling

WELL RSC 5

MEASUREMENTS CONDUCTED IN THE FIELD

Sample date: $12 / 16 / 91$ Depth to water: $29.30 \mathrm{At}(8.93 \mathrm{~m})$ below TOC

Water elevation: $275.60 \mathrm{ft}(84.00 \mathrm{~m}) \mathrm{msl}$

Sp. conductance: $157 \mu \mathrm{S} / \mathrm{cm}$

No water was evacuated before sampling.

\section{$\operatorname{Tim}_{\mathrm{pH}:}: \mathbf{6 . 7}$}

Water temperature: $19.9^{\circ} \mathrm{C}$

Time: $10: 05$

$\mathrm{pH}: 6.3$

Water temperature: $18.2^{\circ} \mathrm{C}$

Time: $10: 00$

$\mathrm{pH}: 6.4$

Water temperature: $15.4^{\circ} \mathrm{C}$

Time: $10: 30$

Water temperature: $14.7^{\circ} \mathrm{C}$

Time: $14: 00$

$\mathrm{pH}: 6.2$

Water temperature: $18.2^{\circ} \mathrm{C}$

Time: 10.05

Water temperature: $15.3^{\circ} \mathrm{C}$

Time: $9: 50$
$\mathrm{pH}: 6.3$

Water temperature: $15.9^{\circ} \mathrm{C}$
WELL RSC 6

MEASUREMENTS CONDUCTED IN THE FIELD

Sample date: $12 / 18 / 91$

Depth to water: $13.90 \mathrm{Ht}(4.24 \mathrm{~m})$ below TOC

Water elevation: $290.20 \mathrm{ft}(88.45 \mathrm{~m}) \mathrm{msl}$

$\mathrm{Sp}$. conductance: $53 \mu \mathrm{S} / \mathrm{cm}$

$\mathrm{pH}: 6.2$

Water temperature: $18.0^{\circ} \mathrm{C}$

WVELL RSC 7

MEASUREMENTS CONDUCTED IN THE FIELD

Sample dale: $1218 / 81$

Depth to water: $24.70 \mathrm{ft}(7.53 \mathrm{~m})$ below TOC

Water elevation: $283.10 \mathrm{ft}(86.29 \mathrm{~m}) \mathrm{ms}$

Sp. conductance: $40 \mu \mathrm{S} / \mathrm{cm}$
No water was evacuated before sampling

Time: $14: 10$

$\mathrm{pH}: 6.2$

Water temperature: $17.7^{\circ} \mathrm{C}$

\section{WELL RSC 8}

MEASUREMENTS CONDUCTED IN THE FIELD

Sample date: $12 / 18 / 91$

Depth to water: $15.00 \mathrm{Ht}(4.57 \mathrm{~m})$ below TOC

(8) $293.80 \mathrm{Ht}(89.55 \mathrm{mi}) \mathrm{ms}$

$\mathrm{Sp}$ conductance: $28 \mu \mathrm{S} / \mathrm{cm}$
No water was evacuated before sampling

Time: is 15

$\mathrm{pH}: 6 . \mathrm{H}$

Water temperature: $17.6^{\circ} \mathrm{C}$

\section{WELL RSC 9}

MEASUREMENTS CONDUCTED IN THE FIELD

Sample date: 12/16/91

Depth to water: $27.00 \mathrm{ft}(8.23 \mathrm{~m})$ below TOC

Water elevation: $274.80 \mathrm{ft}(83.76 \mathrm{~m}) \mathrm{ms}$

Sp. conductance: $46 \mu \mathrm{S} / \mathrm{cm}$

No water was evacuated before sampling

$\operatorname{Time:~}_{\mathrm{pH}: 7.1}{ }^{10: 40}$

Water temperature: $15.2^{\circ} \mathrm{C}$

\section{WELL RSC 10}

MEASUREMENTS CON'JUCTED IN THE FIELO

Sample date $12 / 16 / 91$
Depth to water: $25.10 \mathrm{ft}(7.65 \mathrm{~m})$ below TOC
Water elevation: $272.30 \mathrm{ft}(83.00 \mathrm{~m}) \mathrm{msl}$
Sp. conductance: $31 \mu \mathrm{cm}$

No water was evacuated before sampling

Time: $10: 15$

Water temperature: $14.9^{\circ} \mathrm{C}$

\section{WELL RSD 1}

MEASUREMENTS CONDUCTED IN THE FIELD

Sample date: $12 / 17 / 91$
Depth to water: $15.50 \mathrm{ft}(4.72 \mathrm{~m})$ below TOC
Wa ?r elevation: $285.00 \mathrm{ft}(86.87 \mathrm{~m}) \mathrm{msl}$

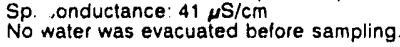

LABORATORY ANALYSES

\begin{tabular}{|c|c|c|c|}
\hline F Analyte & Result & Mod & $\underline{\text { Unit }}$ \\
\hline $\begin{array}{ll}0 & \text { Antimony-125 } \\
0 & \text { Cerium-144 } \\
0 & \text { Cesium-134 } \\
0 & \text { Cesium-137 } \\
0 & \text { Cobalt-57 } \\
0 & \text { Cobalt-60 } \\
0 & \text { Europium-154 } \\
0 & \text { Manganese-54 } \\
0 & \text { Potassium }-40 \\
0 & \text { Radium-226 } \\
0 & \text { Ruthenium-103 } \\
0 & \text { Sodium }-22 \\
0 & \text { Thorium-228 } \\
0 & \text { Zinc.65 }\end{array}$ & $\begin{array}{l}<5.4 \mathrm{E} \cdot 09 \\
<2.1 \mathrm{E} \cdot 08 \\
<2.4 \mathrm{E} \cdot 09 \\
<2.2 \mathrm{E} \cdot 09 \\
<2.7 \mathrm{E} \cdot 09 \\
<2.0 \mathrm{E} \cdot 09 \\
<6.1 \mathrm{E} \cdot 09 \\
<2.3 \mathrm{E} \cdot 09 \\
<3.5 \mathrm{E} \cdot 08 \\
<4.8 \mathrm{E} \cdot 09 \\
<6.6 \mathrm{E} \cdot 09 \\
<2.2 \mathrm{E} \cdot 09 \\
<2.1 \mathrm{E} \cdot 09 \\
<5.2 \mathrm{E} \cdot 09\end{array}$ & & $\begin{array}{l}\mu \mathrm{Ci} / \mathrm{mL} \\
\mu \mathrm{Ci} / \mathrm{mL} \\
\mu \mathrm{Ci} / \mathrm{mL} \\
\mu \mathrm{Ci} / \mathrm{mL} \\
\mu \mathrm{Ci} / \mathrm{mL} \\
\mu \mathrm{Ci} / \mathrm{mL} \\
\mu \mathrm{Ci} / \mathrm{mL} \\
\mu \mathrm{Ci} / \mathrm{mL} \\
\mu \mathrm{Ci} / \mathrm{mL} \\
\mu \mathrm{Ci} / \mathrm{mL} \\
\mu \mathrm{Ci} / \mathrm{mL} \\
\mu \mathrm{Ci} / \mathrm{mL} \\
\mu \mathrm{Ci} / \mathrm{mL} \\
\mu \mathrm{Ci} / \mathrm{mL}\end{array}$ \\
\hline
\end{tabular}

Time: $14: 15$

Water 'emperature: $18.0^{\circ} \mathrm{C}$

E 
WELL RSD 2A

MEASUREMENTS CONDUCTED IN THE FIELD

Sample date: $12 / 17 / 91$ Depth to water: $14.40 \mathrm{ft}\langle 4.39 \mathrm{~m})$ below TOC Water olevation: $286.80 \mathrm{ft}(87$

Sp. conductance: $33 \mu \mathrm{s} / \mathrm{cm}$
No water was evacuated before sampling.

LABORATORY ANALYSES

$\begin{array}{ll}\text { F } & \text { Analyte } \\ & \\ 0 & \text { Antimony-125 } \\ 0 & \text { Cerium-144 } \\ 0 & \text { Cesiumn-134 } \\ 0 & \text { Cesium } 137 \\ 0 & \text { Cobail. } 57 \\ 0 & \text { Cobalt.60 } \\ 0 & \text { Europium-154 } \\ 0 & \text { Manganese-54 } \\ 0 & \text { Potassium-40 } \\ 0 & \text { Radium-226 } \\ 0 & \text { Rutherium-103 } \\ 0 & \text { Sodium-22 } \\ 0 & \text { Thorium-228 } \\ 0 & \text { Zinc. } 85\end{array}$

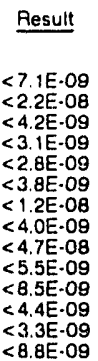

WELL RSD $2 B$

MEASUREMENTS CONDUCTED IN THE FIELD Sample date: $12 / 18 / 91$
The well was $d r y$.

WELL RSD $2 \mathrm{C}$

MEASUREMENTS CONDUCTED IN THE FIELD

Sample date: 12/17/91

Depth to water: $14.70 \mathrm{ft}(4.48 \mathrm{~m})$ below TOC

Water elevation: $287.00 \mathrm{ft}(87.48 \mathrm{~m}) \mathrm{msl}$

Sp. conductance: $80 \mu \mathrm{S} / \mathrm{cm}$

To water was evacuated before sampling.

LABORATORY ANALYSES

\begin{tabular}{|c|c|c|c|}
\hline Analyte & Result & Mod & Unit \\
\hline $\begin{array}{l}\text { Antimony-125 } \\
\text { Cerium-144 } \\
\text { Cesium-134 } \\
\text { Cesium-137 } \\
\text { Cobalt-57 } \\
\text { Cobalt-60 } \\
\text { Europium-154 } \\
\text { Manganese-54 } \\
\text { Potassium-40 } \\
\text { Radium-226 } \\
\text { Ruthenium-103 } \\
\text { Sodium-22 } \\
\text { Thorium.228 } \\
\text { Zinc-65 }\end{array}$ & $\begin{array}{l}<7.8 \mathrm{E}-09 \\
<3.1 \mathrm{E}-08 \\
<3.2 \mathrm{E}-09 \\
<3.2 \mathrm{E} \cdot 09 \\
<4.1 \mathrm{E}-09 \\
<3.3 \mathrm{E}-09 \\
<7.9 \mathrm{E}-09 \\
<3.3 \mathrm{E} \cdot 09 \\
<4.4 \mathrm{E} \cdot 08 \\
<6.5 \mathrm{E} \cdot 09 \\
<1.0 \mathrm{E} \cdot 08 \\
<2.9 \mathrm{E}-09 \\
<3.6 \mathrm{E}-09 \\
<7.6 \mathrm{E} \cdot 09\end{array}$ & & $\begin{array}{l}\mu \mathrm{Ci} / \mathrm{mL} \\
\mu \mathrm{Ci} / \mathrm{mL} \\
\mu \mathrm{Ci} / \mathrm{mL} \\
\mu \mathrm{Ci} / \mathrm{mL} \\
\mu \mathrm{Ci} / \mathrm{mL} \\
\mu \mathrm{Ci} / \mathrm{mL} \\
\mu \mathrm{Ci} / \mathrm{mL} \\
\mu \mathrm{Ci} / \mathrm{mL} \\
\mu \mathrm{Ci} / \mathrm{mL} \\
\mu \mathrm{Ci} / \mathrm{mL} \\
\mu \mathrm{Ci} / \mathrm{mL} \\
\mu \mathrm{Ci} / \mathrm{mL} \\
\mu \mathrm{Ci} / \mathrm{mL} \\
\mu \mathrm{Ci} / \mathrm{mL}\end{array}$ \\
\hline
\end{tabular}

WELL RSD 3

MEASUREMENTS CONDUCTED IN THE FIELD

Sample date: $12 / 18 / 91$
Depth to water: $13.20 \mathrm{ft}(4.02 \mathrm{~m})$ below TOC
Watet elevation: $287.60 \mathrm{ft}(87.66 \mathrm{~m}) \mathrm{msl}$

No water was evacuated before sampling
Time: $14: 25$
pH: 6.9

Water temperature: $18.1^{\circ} \mathrm{C}$

Mod Unit Lab

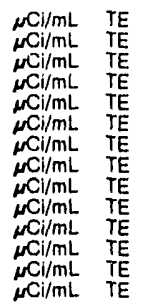

Time: $10: 35$

Time: $14: 30$

Water temperature: $19.0^{\circ} \mathrm{C}$

Time: $10: 40$

Water temperature: $17.5^{\circ} \mathrm{C}$
WELL RSD 4

MEASUREMENTS CONDUCTED IN THE FIELD

Sample date: $12 / 17 / 91$

Depth to water: $14.20 \mathrm{ft}(4.33 \mathrm{~m})$ below TOC

Wa

$\mathrm{Sp}$. conductance: $28 \mu \mathrm{S} / \mathrm{cm}$
No water was evacualed before sampling.

LABORATORY ANALYSES

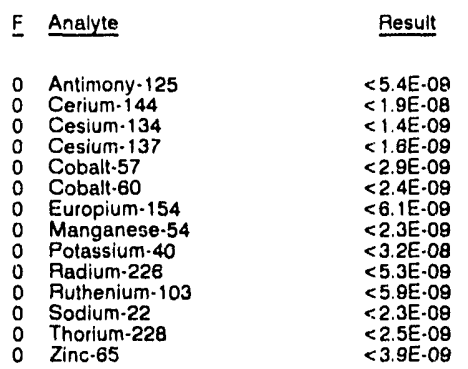

\section{Time: 1330 \\ $\mathrm{pH}: 6.6$}

Water temperature: $19.3^{\circ} \mathrm{C}$

WELL RSD 5

MEASUREMENTS CONDUCTED IN THE FIELD

Sample date: $12 / 17 / 91$

Cepth to water: $16.00 \mathrm{Ht}(4.88 \mathrm{~m})$ below TOC

Water elevation: $285.70 \mathrm{Ht}$

Sp. conduclance: $39 \mu \mathrm{S} / \mathrm{cm}$.

LABORATORY ANALYSES

E Analyte

Result

0 Antimony-125

0 Cerium-144

$\begin{array}{lll}0 & \text { Cesium-134 } \\ 0 & \text { Cesium-137 }\end{array}$

Cosium-137

Cobalt-60

Europium-154

Manganese.54

Radium.226

Ruthenium-103

Sodium-22

0 Zinc. 65

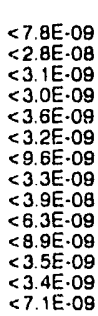

WELL RSD 6

MEASUREMENTS CONDUCTED IN THE FIELD

Sample date: 12/17/81

Depth to water: $16.30 \mathrm{ft}(4.97 \mathrm{~m})$ below TOC

Water elevation: $285.80 \mathrm{ft}(87.11 \mathrm{~m}) \mathrm{msl}$

$\mathrm{Sp}$. conductance: $50 \mu \mathrm{S} / \mathrm{cm}$
No water was evacuated before sampling.

LABORATORY ANALYSES

F Analyte

Fesult

0 Antimony-125

0 Cerium-144

Cesium-134

Cesium.137

Cobalt-57

Europium-154

Manganese.54

Potassium-40

Radium 226
Ruthenium 103

Ruthenium.103

Thorium-228

Zinc.65
Time: $13: 45$
$\mathrm{pH}: 6.5$

Water temperature: $17.7^{\circ} \mathrm{C}$

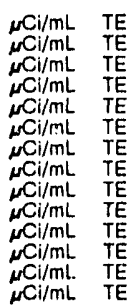

Time: $13: 40$
$\mathrm{pH}: 6.0$

Water temperature: $18.6^{\circ} \mathrm{C}$

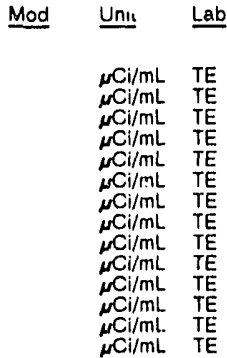

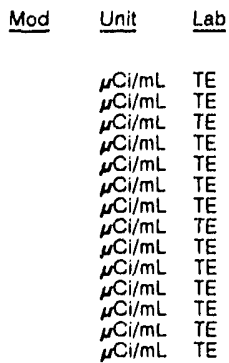




\section{ANALYTICAL RESULTS}

WELL RSD 7

MEASUREMENTS CONOUCTED IN THE FIELD

Sample date: $12 / 17 / 91$

Sample date: $12 / 17 / 91$
Depth to water: $9.80 \mathrm{ft}(2.89 \mathrm{~m})$ below TOC
Water elevation: $283.60 \mathrm{ft}(86.44 \mathrm{~m}) \mathrm{msl}$

Sp. conductance: $27 \mu \mathrm{s} / \mathrm{cm}$

LABORATORY ANALYSES

E Analyte

\begin{tabular}{l} 
Result \\
\multicolumn{1}{c}{} \\
$<7.0 \mathrm{E}-09$ \\
$<1.9 \mathrm{E} \cdot 08$ \\
$<3.4 \mathrm{E}-09$ \\
$<2.8 \mathrm{E}-09$ \\
$<2.6 \mathrm{E} \cdot 09$ \\
$<3.0 \mathrm{E} \cdot 09$ \\
$<1.0 \mathrm{E} \cdot 08$ \\
$<3.3 \mathrm{E}-08$ \\
$<5.0 \mathrm{E}-08$ \\
$<5.2 \mathrm{E}-09$ \\
$<7.7 \mathrm{E} \cdot 09$ \\
$<3.8 \mathrm{E}-09$ \\
$<2.9 \mathrm{E}-09$ \\
$<1.0 \mathrm{E} \cdot 08$
\end{tabular}

WELL RSD 8

MEASUREMENTS CONOUCTED IN THE FIELD

Sample date: $12 / 17 / 91$

$87 \mathrm{~m})$ below TOC

Water elevation: $283.60 \mathrm{ft}(86.44 \mathrm{~m}) \mathrm{msl}$

Sp. conductance: $35 \mu \mathrm{S} / \mathrm{cm}$

No water was evacuated before sampling.

LABORATORY ANALYSES

F Analyte

Pesult

Antimony -125

Cerium $\cdot 144$

Cesium-134

Cobalt-57

Cobalt-60

Europium-154

Mariganese-54

Potassium-40

Radium-226

Sodium-22

Thorium-228

Zine. 65

$<8.6 \mathrm{E} \cdot 09$

$<2.9 \mathrm{E} \cdot 00$

$<2.9 \mathrm{E} .09$

$<3.8 E .09$

$<3.0 E \cdot 09$

$<7.6 \mathrm{E} .09$

$<3.6 \mathrm{E} .09$

$<4.2 \mathrm{E} .08$
$<6.4 \mathrm{E} .0 \mathrm{~S}$

<. $3 \mathrm{E} .09$

$<2.8 \mathrm{E} .09$

$<3.6 \mathrm{E} .09$

WELL RSD 9

MEASUREMENTS CCNDUCTED IN THE FIELD

Sample date: 12/16/81

Depth to water: $10.10 \mathrm{H}(3.08 \mathrm{~m})$ below TOC

Water elevation: $282.50 \mathrm{ft}(86.11 \mathrm{~m}) \mathrm{ms}$ i

Sp. conductance: $30 \mu \mathrm{S} / \mathrm{cm}$

No water was evacuated before sampling

LABORATORY ANALYSES

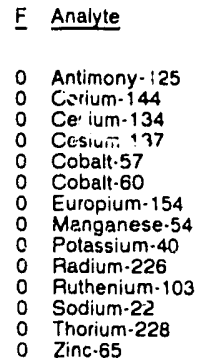

Result

$5.8 \tilde{c} \cdot 09$

$<1.8 \mathrm{E} .08$

$<2.4 E-09$

$<2.2 E-09$

$<2.4 E-09$
$<2.1 E-09$

$<4.7 \mathrm{E} \cdot 09$

$<2.4 E \cdot 09$

$<2.9 E .08$

$<4.9 E-09$

$<6.6 E \cdot 09$

$<2.2 E \cdot 09$

$<2.2 \mathrm{E} \cdot 09$
$<5.6 \mathrm{E}-09$
Time: $13: 55$

$\mathrm{pH}: 6.4$

Water temperature: $18.00 \mathrm{C}$

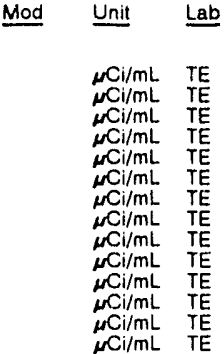

me: 1405

Time: 140

Wate erature $17.8^{\circ} \mathrm{C}$

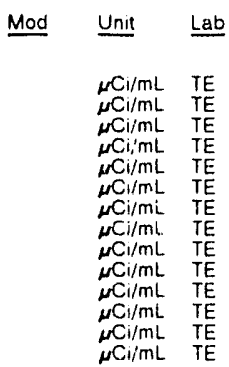

Time: 13.00
$\mathrm{pH}: 6.5$

Water temperature $179^{\circ} \mathrm{C}$

Mod Unit Lab

$\mu \mathrm{Ci} / \mathrm{mL} \quad \mathrm{TE}$

$\mu \mathrm{Ci} / \mathrm{mL}$ TE

$\mu \mathrm{Ci} / \mathrm{mL}$ TE

$\mu \mathrm{Ci} / \mathrm{mL}$.

$\mu \mathrm{Ci} / \mathrm{mL}$

$\mu \mathrm{Ci} / \mathrm{mL}$ TE

$\mu \mathrm{Ci} / \mathrm{mL}$ TE

$\mu \mathrm{Ci} / \mathrm{mL}$ TE

$\mu \mathrm{N} / / \mathrm{mL}$ TE

$\mathrm{MC} / \mathrm{mL}$ TE
WELL RSD 10

MEASUREMENTS CONDUCTED IN THE FIELD

Sample date: 12/16/91

Depth to water: $10.10 \mathrm{Ht}(3.08 \mathrm{~m})$ below TOC

ater elevation: $282.40 \mathrm{ft}(86.08 \mathrm{~m}) \mathrm{ms}$

p. conductance: $25 \mu \mathrm{S} / \mathrm{cm}$

ph': 5.5

Water temperature: $18.8^{\circ} \mathrm{C}$

\section{WELL RSD 11}

MEASUREMENTS CONDUCTED IN THE FIELD

Sample date: $12 / 16 / 91$

Depth to water: 10.10 it $(3.08 \mathrm{~m})$ below TOC

Water elevation: $282.20 \mathrm{ft}(88.02 \mathrm{~m}) \mathrm{msl}$

No water was evacuated before sampling.

Time: $12: 45$

Water temperature: $17.2^{\circ} \mathrm{C}$

\section{WELL RSE $1 \mathrm{~A}$}

MEASUREMENTS CONDUCTED IN THE FIELD

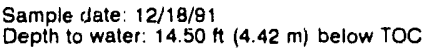

Water elevation: $289.70 \mathrm{ft}(88.30 \mathrm{n} / \mathrm{ms}$

Sp. conductance: $37 \mu \mathrm{S} / \mathrm{cm}$

No water was evacuated before sampling.

Time: $10: 50$

Water temperature $19.2^{\circ} \mathrm{C}$

\section{WELL RSE 1B}

MEASUREMENTS CONDUCTED IN THE FIELD

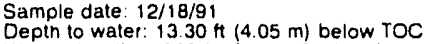

Water elevation: $290.00 \mathrm{Ht}(88.39 \mathrm{~m}) \mathrm{ms}$

Sp conductance: $38 \mu \mathrm{S} / \mathrm{cm}$

No water was evacuated before sampling.

Time: 10:55

Time: $10: 5$

Water temperature: $19.8^{\circ} \mathrm{C}$

WELL RSE $1 \mathrm{C}$

MEASUREMENTS CONDUCTED IN THE FIELD

Sample date: $12 / 18 / 91$

Depth to water: 13.10 \# $(3.99 \mathrm{~m})$ below TOC

Water elevation: $290.20 \mathrm{ft}(88.45 \mathrm{~m}) \mathrm{msl}$

Sp. conductance: $39 \mu \mathrm{S} / \mathrm{cm}$

No water was evacuated before sampling

WELL RSE 2

MEASUREMENTS CONDUCTED IN THE FIELD

Sample date: $12: 18 / 91$ Depth to water: $13.90 \mathrm{ft}(4.24 \mathrm{~m})$ below TOC

Water elevation $288.60 \mathrm{ft}(87.97 \mathrm{~m}) \mathrm{ms}$ |

No water was evacuated before sampling

$\mathrm{pH}: 6.1$

Water temperature: $18.3^{\circ} \mathrm{C}$

WELL RSE $3 A$

MEASUREMENTS CONDUCTED IN THE FIELD

Sample date: $12 / 18 / 91$

Depth to water: $16.10 \mathrm{ft}(491 \mathrm{~m})$ betow TOC

Wa: I levation: $28490 \mathrm{Ht}(8684 \mathrm{~m}) \mathrm{ms}$

Sp. conduclance $54 \mathrm{\mu S} / \mathrm{cm}$

Time: 10.30
pH: 6.2

Water temperature: $173^{\circ} \mathrm{C}$ 
ANALYTICAL RESULTS

\section{WELL RSE 4A}

MEASUREMENTS CONDUCTED IN THE FIELD

Samplo date: 12/18/81

Depth to water: $17.50 \mathrm{ft}(5.33 \mathrm{~m})$ below TOC

Water elevation: $287.10 \mathrm{ft}(87.51 \mathrm{~m}) \mathrm{msl}$

Sp. conductance: $55 \mu \mathrm{s} / \mathrm{cm}$

No water was evacuated before sampling.

\section{WELL RSE 4B}

MEASUREMENTS CONDUCTED IN THE FIELO

Sample date: $12 / 18 / 9$

The well was dry.

Time: 10:20

WELL RSE 4C

MEASUREMENTS CONDUCTED IN THE FIELO

Sample date: $12 / 18 / 91$

Depth to water: 17.00 tt $(5.18 \mathrm{~m})$ below $7.3 \mathrm{C}$

Water elevation: $287.70 \mathrm{ft}(87.69 \mathrm{~m}) \mathrm{msi}$

Sp. conductance: $37 \mu \mathrm{s} / \mathrm{cm}$

No water was evacuated before sampling.

\section{WELL RSE 5}

MEASUREMENTS CONDUCTED IN THE FIELD

Sample date: $12 / 18 / 91$

Depth to water: $19.00 \mathrm{Ht}(5.79 \mathrm{~m})$ below TOC

Water elevation: $287.00 \mathrm{ft}(87.48 \mathrm{~m}) \mathrm{ms}$ |

No water was evacuated bo

\section{WELL RSE 6}

MEASUREMENTS CONDUCTED IN THE FIELD

Sample date: $12 / 18 / 9$

The well was dry

Time: $10: 15$
$\mathrm{pH}: 6.2$

Water temperature: $18.3^{\circ} \mathrm{C}$

pH: 6.7

Water temperature: $18.0^{\circ} \mathrm{C}$

$\mathrm{pH}: 6.6$

Water temperature: $19.7^{\circ} \mathrm{C}$

Time: 10:45

\section{WELLL RSE 7}

MEASUREMENTS CONDUCTED IN THE FIELD

Sample date: $12 / 18 / 91$

Depth to water: 20.00 it $(6.10 \mathrm{~m})$ below TOC

Water elevation: $282.40 \mathrm{ft}(86.08 \mathrm{~m}) \mathrm{msl}$

ce: $47 \mu \mathrm{S} / \mathrm{cm}$

sampling

\section{WELL RSE 8}

MEASUREMENTS CONDUCTED IN THE FIELD

Sample date: $12 / 18 / 91$

Depth to water: $13.10 \mathrm{H}(3.89 \mathrm{~m})$ below TOC

Water elevation: $28910 \mathrm{ft}(88.12 \mathrm{~m}) \mathrm{ms}$

Sp. conductance: $70 \mu \mathrm{s} / \mathrm{cm}$

No water was evacuated before sampling.

\section{WELL RSE 9}

MEASUREMENTS CONDUCTED IN THE FIELD

Sample date: $12 / 18 / 91$

below TOC

Water elevation: $281.60 \mathrm{ft}(85.83 \mathrm{~m}) \mathrm{ms}$

Sp. conductance: $35 \mu \mathrm{S} / \mathrm{cm}$

No water was evacuated before sampling.

Time: 13:55

Water temperature: $20.1^{\circ} \mathrm{C}$

Time: $13: 50$
pH: 5.7
Water temperature: $21.1^{\circ} \mathrm{C}$

Time: 13:45

Time: 13.4

Water temperature: $21.5^{\circ} \mathrm{C}$

\section{WELL RSE 10}

MEASUREMENTS CONDUCTED IN THE FIELD

Sample date: $12 / 18 / \theta 1$

Depth to water: $19.80 \mathrm{Ht}(6.07 \mathrm{~m})$ below TOC

Water elevation: $284.80 \mathrm{ft}(86.81 \mathrm{~m}) \mathrm{ms}$ !

Sp. conductance: $47 \mu \mathrm{S} / \mathrm{cm}$

No water was evacuated before sampling.

Time: $13: 40$
pH: 5.8

Water temperature: $21.0^{\circ} \mathrm{C}$

WELL RSE 11

MEASUREMENTS CONDUCTED IN THE FIELD

Sample date: $12 / 18 / 91$

Depth to water: $17.00 \mathrm{ft}(5.18 \mathrm{~m})$ below TOC

Water elevation: $286.80 \mathrm{ft}(87.42 \mathrm{~m}) \mathrm{msl}$

Sp. conductance: $72 \mu \mathrm{S} / \mathrm{cm}$

$\mathrm{pH}: 6.0$

Water temperature: $18.8^{\circ} \mathrm{C}$

\section{WELL RSE 12}

MEASUREMENTS CONDUCTED IN THE FIELLD

Time: 11:10
Sample date: 12/18/91 ailure prevented sample collection.

\section{WELL. RSE 13}

MEASUREMENTS CONDUCTED IN THE FIELD

Sample dale: $12 / 10191$

Depth to water: $12.90 \mathrm{ft}(3.93 \mathrm{~m})$ below TOC

Water elevation: $288.30 \mathrm{ft}(87.87 \mathrm{~m}) \mathrm{msl}$

$\mathrm{Sp}$. conductance $32 \mu \mathrm{S} / \mathrm{cm}$

Water temperature: $18.1^{\circ} \mathrm{C}$

\section{WELL RSE 18}

MEASUREMENTS CONDUCTED IN THE FIELD

Sample date: $12 / 18 / 91$

Depth to water: $24.90 \mathrm{ft}(7.59 \mathrm{~m})$ below TOC

$\mathrm{Sp}$. conductance: $83.20 \mathrm{ft}$

No wal i was evacuated before sampling

Time: 11:05

pH: 6.1

Water temperature: $18.3^{\circ} \mathrm{C}$

\section{WELL RSE 19}

MEASUREMENTS CONDUCTED IN THE FIELD

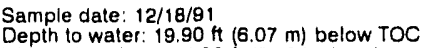
Water elevation: $284.90 \mathrm{ft}(86.84 \mathrm{~m}) \mathrm{ms}$ |

Sp. conductance: $63 \mu \mathrm{s} / \mathrm{cm}$

No water was evacuated before sampling.

Time: $11: 15$

Water temperature: $158^{\circ} \mathrm{C}$

\section{WELL RSE 24}

MEASUREMENTS CONDUCTED IN THE FIELD

Sample date: $12 / 06 / 91$ Depth to water: $10.62 \mathrm{ft}(3.24 \mathrm{ml}$ let $\mathrm{low}$ TOC Water elevation: $283.48 \mathrm{ft}(8641 \mathrm{~m}$ ingl

Sp. conductance: $32 \mu \mathrm{s} / \mathrm{cm}$

Time: 15

Alkalinity: $3 \mathrm{mg} / \mathrm{L}$

Water evacuated before sampling : $3:$, 


\section{WELLL RSE 25}

MEASUREMENTS CONDUCTED IN THE FIELD

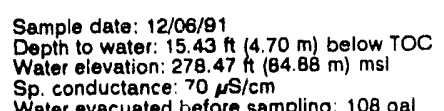

Water evacuated before sampling: $108 \mathrm{gal}$

\section{WELL RSF 1}

MEASUREMENTS CONDUCTED IN THE FILD

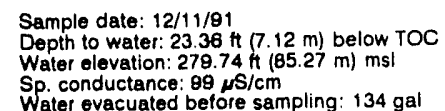

\section{WELL RSF 2}

MEASUREMENTS CONDUCTED IN THE FIELD Sample date: $12 / 11 / 91$
Depth to water: $21.31 \mathrm{ft}(6.50 \mathrm{~m})$ beiow TOC
Water elevation: $281.49 \mathrm{Ht}(85.80 \mathrm{~m}) \mathrm{ms}$
Sp. conductance: $43 \mathrm{~s} / \mathrm{cm}$
Water evacuated before sampling: $170 \mathrm{gal}$

WELL RSF 3

MEASUREMENTS CONDUCTED IN THE FIELD Sample date: $12 / 11 / 91$
Depth to water: $25.84 \mathrm{ft}(7.88 \mathrm{~m})$ below TOC
Water elevation: $281.26 \mathrm{H}(85.73 \mathrm{~m}) \mathrm{ms} /$
Sp. conductance: $33 \mu \mathrm{s} / \mathrm{cm}$

Sp. conductance: $33 \mu \mathrm{S} / \mathrm{cm}$
Water evacuated before sampling: $135 \mathrm{gal}$

WELL RWM 1

MEASUREMENTS CONDUCTED IN THE FIELD

Sample date: 10/11/91

Depth to water: $179.70 \mathrm{Ht}(54.77 \mathrm{~m})$ below TOC Water elevation: $185.00 \mathrm{ft}$ (56.38

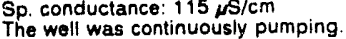

LABORATORY ANALYSES

\begin{tabular}{|c|c|}
\hline Enalyte & Result \\
\hline $\begin{array}{l}\text { Chloroform } \\
1,1-\text { Dichloroethylene } \\
\text { trans-1,2-Dichloroethylene } \\
\text { Tetrachloroethylene } \\
1,1,1 \cdot \text { Trichloroethane } \\
\text { Trichloroethylene }\end{array}$ & $\begin{array}{l}<500 \\
<500 \\
<500 \\
12,000 \\
<500 \\
30,700\end{array}$ \\
\hline
\end{tabular}

WELL RWM 1

MEASUREMENTS CONDUCTEO IN THE FIELO

\begin{tabular}{|c|c|c|}
\hline \multicolumn{3}{|c|}{$\begin{array}{l}\text { Sample date: } 11 / 07 / 91 \\
\text { Depth to water. Not available } \\
\text { Water elevatirn: Not available } \\
\text { Sp. conduct/nce: } 113 \text { sS/cm } \\
\text { The well wris continuously pumping. }\end{array}$} \\
\hline \multicolumn{3}{|c|}{ LABORA' ORY ANALYSES } \\
\hline & Ana'yte & Result \\
\hline & $\begin{array}{l}\text { pH } \\
\text { Specific conductance } \\
\text { Aluminum } \\
\text { Arsenic } \\
\text { Barium } \\
\text { Benzene } \\
\text { Bromodichloromethane } \\
\text { Bromolorm } \\
\text { Bromomathane } \\
\text { Cadmium } \\
\text { Carbon tetrachloride } \\
\text { Chloride } \\
\text { Chlorobenzene } \\
\text { Chloroethane } \\
\text { Chloroethere (Vinyl chloride) } \\
\text { 2-Chloroethyl vinyl ethel }\end{array}$ & $\begin{aligned} & 4.6 \\
& 120 \\
& 172 \\
&<2.0 \\
& 51 \\
& 2.5 \\
&<1.0 \\
&<1.0 \\
&<1.0 \\
&<20 \\
& 1.3 \\
& 3.060 \\
& 2.0 \\
&<1.0 \\
&<1.0 \\
&<1.0\end{aligned}$ \\
\hline
\end{tabular}

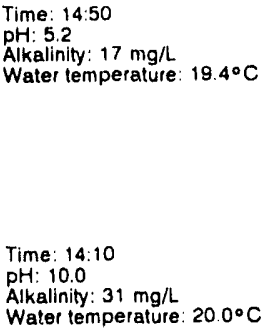

Time: $12: 35$
pH: 6.7

AH: 6.7

Alkalinity: $8 \mathrm{mg} / \mathrm{L}$
Water temperalure $21.5^{\circ} \mathrm{C}$

Time: $13 \cdot 30$

PH: 4.6 Alkalinity $0 \mathrm{mg} / \mathrm{L}$

Water temperature : $20.0^{\circ} \mathrm{C}$

$\begin{array}{cc}\text { Mad Unit } & \text { Lab } \\ & \\ \mu g / L & M A \\ \mu g / L & M A \\ \mu g / L & M A \\ \mu g / L & M A \\ \mu g / L & M A \\ \mu g / L & M A\end{array}$

\section{Time: 15:35}

$\mathrm{pH}: 4.6$

Alkalinity: $0 \mathrm{mg} / \mathrm{L}$
Water temperature: $20.4^{\circ} \mathrm{C}$

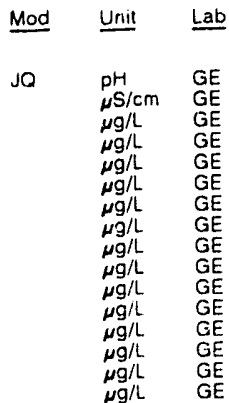

WELL RWM 1 collected on 11/07/91, laboratory analyses (cont.)

F Analyte

Chlorofor.n

Chloromethane

Copromium

Copper

Dibromochloromethane

1,1.Dichloroethane

1,2-Dichloroethane

1,1-Dichloroethylene
trans-1,2-Dichloroethylene

Dichloromethane

1,2-Dichloropropane

cis-1,3-Dichloropropene
trans-1,3-Dichloropropene

Ethylbenzene

Lead

Mercury

Nickel

Nitrate as mitrogen

Phenols

Selenium

0 Sodium

0 Sulfate

1 1,1,2,2.Tetrachloroethane

Tetrachloroethylene

Toluene

Total phosphates (as P)

0 Total phosphates (as $P$ )

1,i, Trichlorothane

rich

Trichlorofluoromethane

Unc
Unium alpha a 'ivity

WELL RWM ।

MEASUREMENTS CONOUCTED IN THE FIELD

Sample date: $11 / 11 / 91$

Depth to water: Not available

Sp conductance: $114 \mu$ S/cm

The weli was continuously pumping

LABORATORY ANALYSES

$\begin{array}{lll}\text { E Analyte } & \text { Result } \\ & & \\ 0 & \text { Chloroform } & <500 \\ 0 & 1,1 \cdot \text { Dichloroethylene } & <500 \\ 0 & \text { trans-1,2-Dichloroethylene } & <500 \\ 2 & \text { Tetrachloroethylene } & 9,770 \\ 0 & 1,1,1-\text { Trichloroethane } & <500 \\ 2 & \text { Trichloroethylene } & 19,700\end{array}$

Time: $14: 10$

$\mathrm{pH}: 4.7$

Alkalinity: $0 \mathrm{mg} / \mathrm{L}$

Water temperalure: $19.5^{\circ} \mathrm{C}$

WELL RWM 1

MEASUREMENTS CONDUCTED IN THE FIELD

Sample date: $12 / 12 / \theta 1$

Depth to water: Not available

Water elevation. Not available

The well was continuously pumping

LABORATORY ANALYSES

$\begin{array}{lll}\text { F } & \text { Analyte } & \text { Result } \\ & & \\ 0 & \text { Chlorolorm } & <500 \\ 0 & 1,1 \text {-Dichloroethylene } & <500 \\ 0 & \text { trans-1,2-Dichloroethylene } & <500 \\ 2 & \text { Tetrachloroethylene } & 12,800 \\ 0 & 1,1,1 \cdot \text { Trichloroethane } & <500 \\ 2 & \text { Trichloroethylene } & 25,600\end{array}$

Timt: 10:10

PH: 4.6 Alkalinity: $0 \mathrm{mg}$

Water temperature: $17.0^{\circ} \mathrm{C}$

\section{WELL RWM 2}

MEASUREMENTS CONDUCTED IN THE FIELח

Sample date: $10 / 11 / 91$

Depth to water: $208.05 \mathrm{ft}(63.41 \mathrm{~m})$ below TOC

Water elevation: $163.25 \mathrm{H}$ (49.

$\mathrm{sp}$. conductance: $56 \mu \mathrm{S} / \mathrm{cm}$

LABORATORY ANALYSES

\begin{tabular}{|c|c|}
\hline & Unit \\
\hline & $\begin{array}{l}\mu \mathrm{g} / \mathrm{L} \\
\mu \mathrm{g} / \mathrm{L} \\
\mu \mathrm{g} / \mathrm{L}\end{array}$ \\
\hline
\end{tabular}

Time: 14:45

PH: 4.8

Water temperature $213^{\circ} \mathrm{C}$

$\begin{array}{ll}\mu g / L & M A \\ \mu g / L & M A \\ \mu g / L & M A \\ \mu g / L & M A \\ \mu g / L & M A \\ \mu g / L & M A\end{array}$

$\mu g / L \quad M A$ 
ANALYTICAL RESULTS

WELL RWM 2 collected on 10/11/91, laboratory analyses (cont.)

$\begin{array}{llcccc}\text { E Analyte } & \text { Result } & \text { Mod } & \text { Unit } & \text { Lab } \\ 2 & \text { Tetrachloroethylene } & 5,870 & & \\ 0 & <1,1, \text { Trichloroethane } & <500 & & \mu \mathrm{g} / \mathrm{L} & \mathrm{MA} \\ 2 & \text { Trichloroethylene } & 18,800 & & \mu \mathrm{g} / \mathrm{L} & \mathrm{MA} \\ \mu \mathrm{g} / \mathrm{L} & \mathrm{MA}\end{array}$

WELL RWM 2

MEASUREMENTS CONDUCTED IN THE FIELD

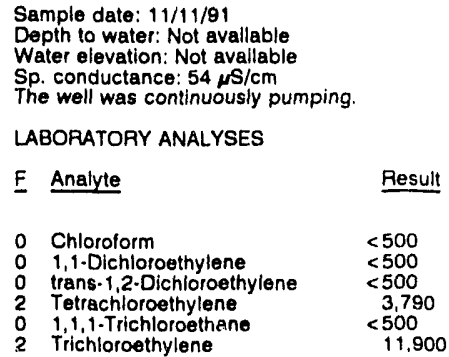

WELL RWM 2

MEASUREMENTS CONDUCTED IN THE FIELO

Sample date: 12/11/91

Depth to water: Not available

Water elevation: Not available

Sp. conductance: $61 \mu \mathrm{S} / \mathrm{cm}$

The well was continuously pumping.

LABORATORY ANALYSES

E Analyte

Chlorotorm

o Chloroform

0 1,1-Dichloroethylene

1,1-Dichloroethylene

trans-1,2-Dichloroethylene

2 Tetrachloroethylene

2 Tetrachloroethylene

1,1.1.Trichloroethane

2 Trichloroethylene

Trichloroethylene

Pesult

$<500$
$<500$
$<500$
$<500$
$<500$
$<500$
6,230
6,130
$<500$
$<500$
16,400
15,000

WELL RWM 3

MEASUREMENTS CONDUCTED IN THE FIELD Sample date: $10 / 11 / 91$ \# $(51.31 \mathrm{~m})$ below TOC Sp. conductance 63 . $1 / \mathrm{cm}$

The well was continuously pumping

LABORATORY ANALYSES

\begin{tabular}{|c|c|c|}
\hline & Analyte & Result \\
\hline & $\begin{array}{l}\text { Chloroform } \\
1,1-\text { Dichloroethylene } \\
\text { trans } 1,2 \text {-Dichloroethylene } \\
\text { Telrachloroethylene } \\
1,1,1 \text {-Trichloroethane } \\
\text { Trichloroethylerie }\end{array}$ & $\begin{array}{l}<500 \\
<500 \\
<500 \\
2,860 \\
<500 \\
14,900\end{array}$ \\
\hline
\end{tabular}

\section{WELL RWM 3}

MEASUREMENTS CONDUCTED IN THE FIELO

Sample date: $11 / 11 / 81$
Depth to water: $170.25 \mathrm{Ht}(51.89 \mathrm{~m})$ below TOC

Sp. conductance: $59 \mu \mathrm{s} / \mathrm{cm}$

The well was continuously pumping

LABORATORY ANALYSES

\begin{tabular}{|c|c|c|c|c|}
\hline$\underline{F}$ & Analyte & Result & Mod & Unit \\
\hline & $\begin{array}{l}\text { Chloroform } \\
1,1 \cdot \text { Dichloroethylene } \\
\text { trans-1,2-Dichloroethylene } \\
\text { Tetrachloroethylene } \\
1,1,1 \text {-Trichloroethane } \\
\text { Trichloroethylene }\end{array}$ & $\begin{array}{l}<500 \\
<500 \\
<500 \\
11.700 \\
<500 \\
5,280\end{array}$ & & $\begin{array}{l}\mu g / L \\
\mu g / L \\
\mu g / L \\
\mu g / L \\
\mu g / L \\
\mu g / L\end{array}$ \\
\hline
\end{tabular}

WELL RWM 3

MEASUREMENTS CONDUCTED IN THE FIELD

Sample date: $12 / 11 / 9$

Depth to water: $169.64 \mathrm{Ht}(51.71 \mathrm{~m})$ below TOC

Sp. conductance: $66 \mu \mathrm{S} / \mathrm{cm}$

The well was continuously pumping

LABORATORY ANALYSES

Time: $15: 20$

PH: 4.5

Water temperature: $19.6^{\circ} \mathrm{C}$

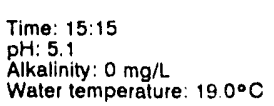

Mod Unit

$\begin{array}{ll}\mu g / L & M A \\ \mu g / L & M A \\ \mu g / L & M A \\ \mu g / L & M A \\ \mu g / L & M A \\ \mu g / L & M A\end{array}$

Time: $15: 30$

PH: 4.7 : $0 \mathrm{mg} / \mathrm{L}$

Water temperature: $19.3^{\circ} \mathrm{C}$

$\begin{array}{ccc}\text { Mod } & \text { Unit } & \text { Lab } \\ & \\ \mu g / L & M A \\ \mu g / L & M A \\ \mu g / L & M A \\ \mu g / L & M A \\ \mu g / L & M A \\ \mu g / L & M A \\ \mu g / L & M A \\ \mu g / L & M A \\ \mu g / L & M A \\ \mu g / L & M A \\ \mu g / L & M A \\ \mu g / L & M A\end{array}$

Time. 14:40

Alkalinity: $0 \mathrm{mg} / \mathrm{L}$

Water temperature: $21.1^{\circ} \mathrm{C}$

\begin{tabular}{|c|c|}
\hline Mod & Unit \\
\hline & $\begin{array}{l}\mu g / L \\
\mu g / L \\
\mu g / L \\
\mu g / L \\
\mu g / L \\
\mu g / L\end{array}$ \\
\hline
\end{tabular}

Time: 15:05

$\mathrm{pH}: 4.8$

: $0 \mathrm{mg} / \mathrm{L}$

Water temperature $19.0^{\circ} \mathrm{C}$

$a b$

MA
MA
MA
MA
MA

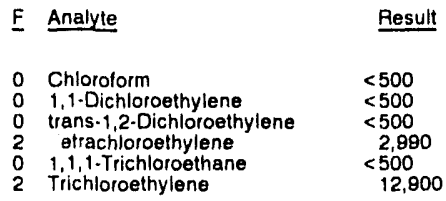

WELL RWM 4

MEASUREMENTS CONDUCTED IN THE FIELO

Sample date: $10 / 11 / 91$ Water elevation: $208.65 \mathrm{ft}(83.60 \mathrm{~m}) \mathrm{ms}$ | The well was continuously pumping.

LABORATORY ANALYSES

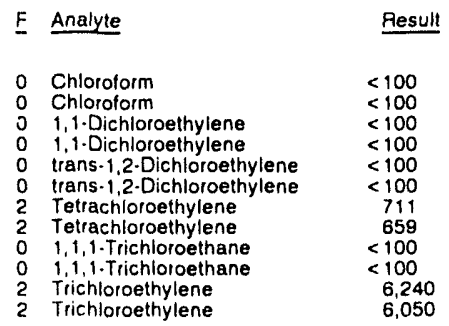

WELL RWM 4

MEASUREMENTS CONDUCTED IN THE FIELD

Sample date. 11/11/91

Depth to water: 158.46 \# $(48.30 \mathrm{~m})$ below TOC

Sp. conduclance: $23 \mu \mathrm{S} / \mathrm{cm}$

The well was continuously pumping

LABORATORY ANALYSES

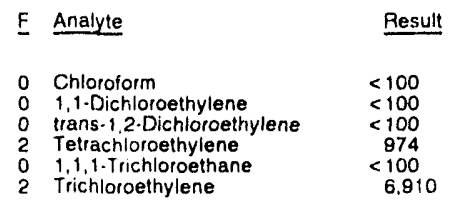

Time: $13: 40$

PH: 4.9 . $0 \mathrm{mg}$

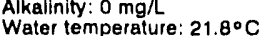

$\begin{array}{ll}\text { Mod Unit } & \text { Lab } \\ & \\ \mu g / L & M A \\ \mu g / L & M A \\ \mu g / L & M A \\ \mu g / L & M A \\ \mu g / L & M A \\ \mu g / L & M A\end{array}$

\begin{tabular}{|c|c|}
\hline Mod & Unit \\
\hline & $\begin{array}{l}\mu g / L \\
\mu g / L \\
\mu g / L \\
\mu g / L \\
\mu g / L \\
\mu g / L \\
\mu g / L \\
\mu g / L \\
\mu g / L \\
\mu g / L \\
\mu g / L\end{array}$ \\
\hline
\end{tabular}

Depth to water: $157.85 \mathrm{ft}(48.11 \mathrm{~m})$ below TOC

\section{WELL RWM 4}

MEASUREMENTS CONDUCTED IN THE FIELD

$$
\text { Sample date: } 12 / 12 / 91
$$

Depth to water: $159.26 \mathrm{ft}(48.54 \mathrm{~m})$ below TOC

Sp. conductance: $21 \mu \mathrm{s} / \mathrm{cm}$

The well was continuously pumping

LABORATORY ANALYSES

\begin{tabular}{|c|c|c|c|c|}
\hline $\mathrm{F}$ & Analyte & Result & Mod & Unit \\
\hline & $\begin{array}{l}\text { Chloroform } \\
1,1-\text { Dichloroethyl ene } \\
\text { trans-1,2-Dichlor sethylene } \\
\text { Tetrachloroethylene } \\
1,1,1-\text { Trichloroethane } \\
\text { Trichloroethylene }\end{array}$ & $\begin{array}{l}<100 \\
<100 \\
<100 \\
790 \\
<100 \\
5,800\end{array}$ & & $\begin{array}{l}\mu g / L \\
\mu g / L \\
\mu g / L \\
\mu g / L \\
\mu g / L \\
\mu g / L\end{array}$ \\
\hline
\end{tabular}

\begin{tabular}{|c|c|c|}
\hline \multicolumn{3}{|c|}{$\begin{array}{l}\text { Time: } 10: 20 \\
\text { pH: } 5.0 \\
\text { Alkalinity: } 0 \mathrm{mg} / \mathrm{L} \\
\text { Water temperature: } 17.4^{\circ} \mathrm{C}\end{array}$} \\
\hline \multirow[t]{2}{*}{ Mod } & Unit & Lab \\
\hline & $\begin{array}{l}\mu g / L \\
\mu g / L \\
\mu g / L \\
\mu g / L \\
\mu g / L \\
\mu g / L\end{array}$ & $\begin{array}{l}\text { MA } \\
M A \\
M A \\
M A \\
M A \\
M A\end{array}$ \\
\hline
\end{tabular}


WELL RWM 5

MEASUREMENTS CONDUCTED IN THE FIELD

Sample date: 10/11/91

Depth to water: $160.17 \mathrm{ft}(48.82 \mathrm{~m})$ below TOC Water elevation: $206.73 \mathrm{ft}(63.01 \mathrm{~m}) \mathrm{misl}$

Sp. conductance: $30 \mu \mathrm{s} / \mathrm{cm}$

The well was continuously pumping.

LABORATORY ANALYSES

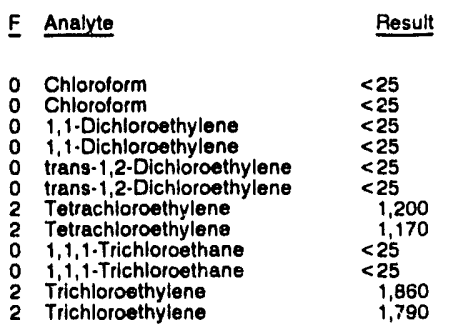

\section{WELL RWM 5}

MEASUREMENTS CONDUCTED IN THE FIELD

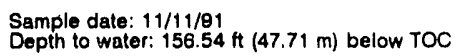

Sp. conductance: $20 \mu \mathrm{S} / \mathrm{cm}$

Sp. conductance: $20 \mu \mathrm{S} / \mathrm{cm}$
The well was continuously pumping.

LABORATORY ANALYSES

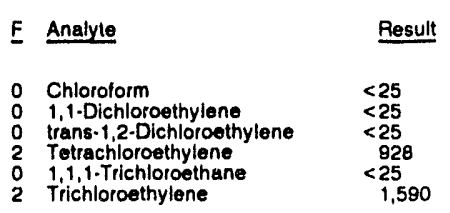

\section{WELL RWM 5}

MEASUREMENTS CONDUCTED IN THE FIELO Sample date: $12 / 11 / 91$
Depth to water: $155.84 \mathrm{ft}(47.50 \mathrm{~m})$ below TOC

Septh to water: $155.84 \mathrm{ft} / 47.50$

Sp. conductance: $30 \mu \mathrm{s} / \mathrm{cm}$
The well was continuously pumping

LABORATORY ANALYSES

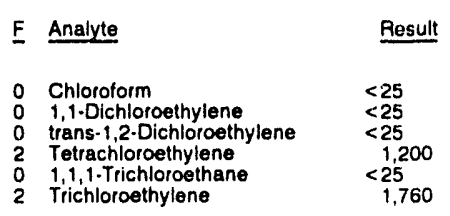

WELL RWM 6

MEASUREMENTS CONDUCTED IN THE FIELD

Sample date: $10 / 11 / 91$

Depth to water: $173.17 \mathrm{ft}(52.78 \mathrm{~m})$ below TOC Water elevation: $175.93 \mathrm{Ht}(53.62 \mathrm{~m}) \mathrm{msl}$

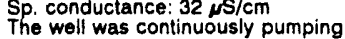

LABORATORY ANALYSES

\begin{tabular}{|c|c|c|c|c|}
\hline$F$ & Analyte & Result & Mod & $\underline{\text { Unit }}$ \\
\hline $\begin{array}{l}0 \\
0 \\
0 \\
2 \\
0 \\
2\end{array}$ & $\begin{array}{l}\text { Chloroform } \\
1,1-\text { Dichloroethylene } \\
\text { trans-1,2-Dichloroethylene } \\
\text { Tetrachloroethylene } \\
1,1,1-\text { Trichloroethane } \\
\text { Trichloroethylene }\end{array}$ & $\begin{aligned}<250 \\
<250 \\
<250 \\
5,850 \\
<250 \\
8,370\end{aligned}$ & & $\begin{array}{l}\mu g / L \\
\mu g / L \\
\mu g / L \\
\mu g / L \\
\mu g / L \\
\mu g / L\end{array}$ \\
\hline
\end{tabular}

Time: 14:50

PH: 4.9

Alkalinity: $0 \mathrm{mg} / \mathrm{h}$

Water temperature: $21.0^{\circ} \mathrm{C}$

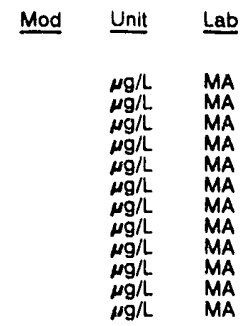

Time: $15: 20$

Alkalinity: $0 \mathrm{mg} / \mathrm{L}$

Water temperature: $18.6^{\circ} \mathrm{C}$

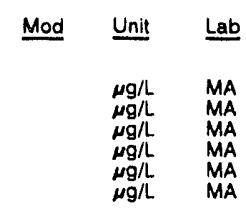

Time: $15: 50$

AH: 4.8

Water temperature: $19.0^{\circ} \mathrm{C}$

$\begin{array}{cc}\text { Mod Unit } & \text { Lab } \\ & \\ \mu g / L & M A \\ \mu g / L & M A \\ \mu g / L & M A \\ \mu g / L & M A \\ \mu g / L & M A \\ \mu g / L & M A\end{array}$

Time: 14:00

$\mathrm{pH}: 4.9$

Alkalinity: $0 \mathrm{mg} / \mathrm{L}$

Water temperature: $20.4^{\circ} \mathrm{C}$
WELL RWM 6

MEASUREMENTS CONDUCTED IN THE FIELD

Sample date: $11 / 11 / 91$
Depth to water: $173.7 \mathrm{e} \mathrm{H}(52.97 \mathrm{~m})$ below TOC

Sp. conductance: $33 \mu \mathrm{S} / \mathrm{cm}$

The well was continuously pumping

LABORATOAY ANALYSES

F Analyte

- Chloroform

o 1,1-Dichloroethylene

0 trans-1,2.Dichloroethylene

2 Tetrachioroethylene

1,1,1-Trichioroethane

Trichloroethylene

ylene

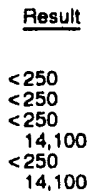

WELL RWM 6

MEASUREMENTS CONOUCTED IN THE FIELD

Sample date: $12 / 12 / 91$
Depth to water: $176.90 \mathrm{Ht}(53.82 \mathrm{~m})$ below TOC

Sp. conductance: $30 \mu \mathrm{S} / \mathrm{cm}$

The well was continuousiy pumping.

LABORATORY ANALYSES

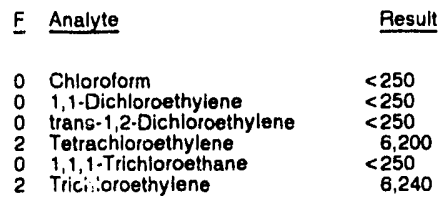

Time: 11:30

pH: 4.8

Alkalinity: $1 \mathrm{mg} / \mathrm{L}$ : $18.6^{\circ} \mathrm{C}$

Water temperalure:

Time: 14:30

PH: 5.1 : $0 \mathrm{mg} /$

A $19.2^{\circ} \mathrm{C}$

\begin{tabular}{|c|c|}
\hline Mod & Unit \\
\hline & $\begin{array}{l}\mu g / L \\
\mu g / L \\
\mu g / L \\
\mu g / L \\
\mu g / L \\
\mu g / L\end{array}$ \\
\hline
\end{tabular}

WELL RWM 7

MEASUREMENTS CONDUCTED IN THE FIELD

Sample date: $10 / 11 / 91$

Depth to water: $152.21 \mathrm{ft}(46.39 \mathrm{~m})$ below TOC

Water elevation: $196.79 \mathrm{ft}(59.98 \mathrm{~m}) \mathrm{msl}$

Sp. conductance: $76 \mu \mathrm{S} / \mathrm{cm}$

The well was continuously pumping

LABORATORY ANALYSES

\begin{tabular}{|c|c|c|c|c|}
\hline$F$ & Analyte & Result & Mod & Unit \\
\hline $\begin{array}{l}2 \\
0\end{array}$ & $\begin{array}{l}\text { Chloroform } \\
1,1 \text {-Dichloroethylene } \\
\text { trans-1,2-Dichloroethylene } \\
\text { Tetrachloroethylene } \\
1,1,1 \text {. Trichloroethane } \\
\text { Trichloroethylene }\end{array}$ & $\begin{array}{l}<100 \\
<100 \\
<100 \\
5,420 \\
<100 \\
5,410\end{array}$ & & $\begin{array}{l}\mu g / L \\
\mu g / L \\
\mu g / L \\
\mu g / L \\
\mu g / L \\
\mu g / L\end{array}$ \\
\hline
\end{tabular}

WELL RWM 7

MEASUREMENTS CONDUCTED IN THE FIELD

Sample date: $11 / 11 / 91$

Depth to water: $154.93 \mathrm{ft}(4 i .22 \mathrm{~m})$ below TOC

Sp. conductance: $74 \mu \mathrm{S} / \mathrm{cm}$

$\mathrm{pH}: 4.7$

Alkalinity: $0 \mathrm{mg} / \mathrm{L}$

Water temperature: $20.7^{\circ} \mathrm{C}$

Time: $14: 40$

pH: 4.8

Alkalinity: $0 \mathrm{mg} / \mathrm{L}$

LABORATORY ANALYSES

\begin{tabular}{|c|c|c|c|c|}
\hline$\underline{F}$ & Analyte & Result & Mod & Unit \\
\hline $\begin{array}{l}0 \\
0 \\
0 \\
0 \\
0 \\
2\end{array}$ & $\begin{array}{l}\text { Ch,loroform } \\
1,1 \text {-Dichlo:oethylene } \\
\text { trans-1,2-Dichloroethylene } \\
\text { Tetrachloroethylene } \\
1,1,1 \text {-Trichloroethane } \\
\text { Trichloroethylene }\end{array}$ & $\begin{array}{l}<100 \\
<100 \\
<100 \\
<100 \\
<100 \\
\quad 4,710\end{array}$ & & $\begin{array}{l}\mu g / L \\
\mu g / L \\
\mu g / L \\
\mu g / L \\
\mu g / L \\
\mu g / L\end{array}$ \\
\hline
\end{tabular}


WELL RWM 7

MEASUREMENTS CONOUCTED IN THE FIELD

Sample date: $12 / 12 / 91$
Depth to water: $155.03 \mathrm{Ht}(47.25 \mathrm{~m})$ below TOC

Sp. conductance: $74 \mu \mathrm{s} / \mathrm{cm}$

The well was continuously pumping

LABORATORY ANALYSES

$\begin{array}{lll}\text { E Analyte } & \text { Result } \\ & \\ 0 & \text { Chloroform } & <100 \\ 0 & 1,1 \text {-Dichloroethylene } & <100 \\ 0 & \text { trans-1,2-Dichloroethylene } & <100 \\ 2 & \text { Tetrachloroethylene } & 5,690 \\ 0 & 1,1,1 \text {-Trichloroethane } & <100 \\ 2 & \text { Trichlorothylene } & 5,150\end{array}$

WELL. RWM 8

MEASUREMENTS CONDUCTED IN THE FIELD

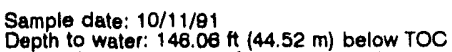

Water elevation: $202.24 \mathrm{ft}(61.64 \mathrm{~m}) \mathrm{ms}$

Sp. conductance: $112 \mu \mathrm{S} / \mathrm{cm}$

The well was continuously pumping

LABORATOHY ANAL.YSES

\begin{tabular}{|c|c|}
\hline Analyte & Result \\
\hline $\begin{array}{l}\text { Chloroform } \\
1,1-\text { Dichloroethylene } \\
\text { trans-1,2-Dichloroethylene } \\
\text { Tetrachloroethylene } \\
1,1,1-\text { Trichloroethane } \\
\text { Trichloroethylene }\end{array}$ & $\begin{aligned} &< 10 \\
&<10 \\
&<10 \\
& 310 \\
&<10 \\
& 730\end{aligned}$ \\
\hline
\end{tabular}

WELL RWM 8

MEASUREMENTS CONDUCTED IN THE FIELD

Sample date: $11 / 11 / 91$

Depth to water: $144.85 \mathrm{Ht}(44.15 \mathrm{~m})$ below TOC

Sp. conductance: $116 \mu \mathrm{S} / \mathrm{cm}$

The well was continuously pumping

LABORATORY ANALYSES

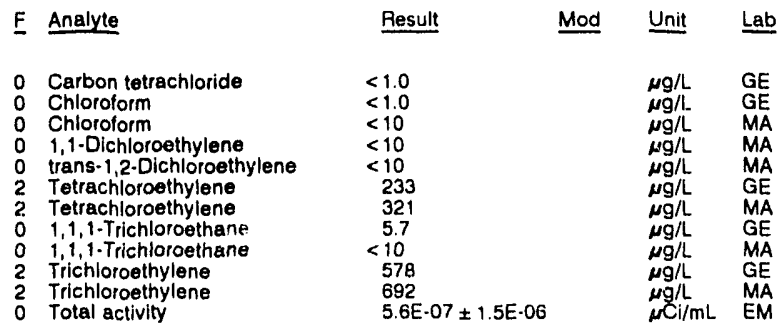

WELL RWM 8 Replicate

.AEASUREMENTS CONDUCTED IN THE FIELD

Sample date: $11 / 11 / 8$

Depth to water: $144.85 \mathrm{Ht}(44,15 \mathrm{~m})$ below TOC

Sp conductance: $116 \mu \mathrm{s} / \mathrm{cm}$

The well was continuously pumping.

LABORATORY ANALYSES

\begin{tabular}{|c|c|c|c|c|}
\hline F & Analyte & Result & Mod & Unit \\
\hline $\begin{array}{l}0 \\
2 \\
2 \\
0\end{array}$ & $\begin{array}{l}\text { Chloroform } \\
1,1 \cdot \text { Dichloroethylene } \\
\text { trans-1,2-Dichloroethylene } \\
\text { Tetrach horoethylene } \\
1,1,1-\text { lrichloroethane } \\
\text { Trichloroethylene }\end{array}$ & $\begin{array}{l}<20 \\
<20 \\
<20 \\
360 \\
<20 \\
825\end{array}$ & & $\begin{array}{l}\mu g / L \\
\mu g / L \\
\mu g / L \\
\mu g / L \\
\mu g / L \\
\mu g / L\end{array}$ \\
\hline
\end{tabular}

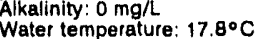

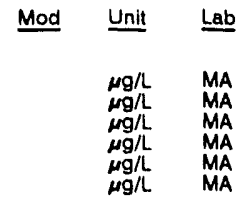

Time: 13:00

PH: 4.9

Alkalinity: $0 \mathrm{mg} / \mathrm{L}$

Mod Unit Lab

$\begin{array}{cc}\mu g / L & M A \\ \mu g / L & M A \\ \mu g / L & M A \\ \mu g / L & M A \\ \mu g / L & M A \\ \mu g / L & M A\end{array}$

Time: 13:45

pH: 5 .

Alkalinity: $0 \mathrm{mg} / \mathrm{l}$

Water temperature: $18.6^{\circ} \mathrm{C}$
WELL RWM 8

MEASUREMENTS CONDUCTED IN THE FIELD

Sample date: $12 / 12 / 91$

Depth to water: $144.65 \mathrm{ft}(44.09 \mathrm{~m})$ below TOC

Sp. conductance: $120 \mu \mathrm{s} / \mathrm{cm}$

The well was continuously pumping

LABORATORY ANALYSES

$\begin{array}{lll}\text { E Analyte } & \text { Result } \\ & & \\ 0 & \text { Chloroform } & <10 \\ 0 & 1,1-\text { Dichloroethylene } & <10 \\ 0 & \text { trans-1,2-Dichloroethylene } & <10 \\ 2 & \text { Tetrachloroethylene } & 302 \\ 0 & 1,1-1 \text {-Trichlorothane } & <10 \\ 2 & \text { Trichloroethylene } & 633\end{array}$

Time: $9: 50$

pH: 5.0

Alkalinity: $0 \mathrm{mg} / \mathrm{t}$

Water temperature: $17.0^{\circ} \mathrm{C}$

\section{WELL RWM 9}

MEASUREMENTS CONDUCTED IN THE FIELD

Sample date: $10 / 11 / 81$

Depth to water: $157.75 \mathrm{Ht}(48.08 \mathrm{~m})$ below TOC Water elevation: $222.85 \mathrm{ft}(87.83 \mathrm{~m}) \mathrm{msl}$

The well was continuously pumping.

LABORATORY ANALYSES

\begin{tabular}{|c|c|c|}
\hline & Analyte & Pesult \\
\hline & $\begin{array}{l}\text { Chloroform } \\
1,1-\text { Dichloroethylene } \\
\text { trans-1,2-Dichloroethylene } \\
\text { Tetrachloroethylene } \\
\text { 1,1,1-Trichloroethane } \\
\text { Trichloroethylene }\end{array}$ & $\begin{aligned}<2.0 \\
<2.0 \\
<2.0 \\
6.8 \\
<2.0 \\
136\end{aligned}$ \\
\hline
\end{tabular}

Time: $14: 20$

PH: 5.1 : 1 mallinity: $0 \mathrm{mg}$

Water temperature: $21.6^{\circ} \mathrm{C}$

Mod Unit Lab

$\begin{array}{cc}\mu g / L & M A \\ \mu g / L & M A \\ \mu g / L & M A \\ \mu g / L & M A \\ \mu g / L & M A \\ \mu g / L & M A\end{array}$

\section{WELL RWM 9}

MEASUREMENTS CONDUCTED IN THE FIELD

Sample date: $11 / 11 / 91$
Depth to water: $158.36 \mathrm{ft}(48.27 \mathrm{~m})$ below roc

Sp. conductance: $43 \mu \mathrm{S} / \mathrm{cm}$

The well was continuously pumping.

LABORATORY ANALYSES

E Analyte

Pesult
$<2.0$
$<2.0$
$<2.0$
11
$<2.0$
80

Time: 14:45

PH: 5.2

Water temperafure: $18.8^{\circ} \mathrm{C}$

Mod Unit Lab

O Chloroform

o 1,1-Dichloroethylene

0 trans-1,2-Dichloroethylene

2 Tetrachloroethylene

$\begin{array}{ll}1,1,1 \cdot T r i c h l o r o e t h a n \\ 2 & \text { Trichlorcethylene }\end{array}$

ne
ne
nene

Result

$\begin{array}{cc}\mu g / L & M A \\ \mu g / L & M A \\ \mu g / L & M A \\ \mu g / L & M A \\ \mu g / L & M A \\ \mu g / L & M A\end{array}$

WELL RWM 9

MEASUREMENTS CONDUCTED IN THE FIELD

Sample date: $12 / 1: / 91$ Depth to water: $158.26 \mathrm{ft}(48.24 \mathrm{~m})$ below TOC

Sp. conductance: $42 \mu \mathrm{S} / \mathrm{cm}$

The well was continuously pumping

Time: $11: 15$
pH: 5.1
Alkalinity: $1 \mathrm{mg} / \mathrm{L}$

Water temperature: $18.2^{\circ} \mathrm{C}$

LABORATORY ANALYSES

\begin{tabular}{|c|c|c|c|}
\hline Analyte & Result & Mod & Unit \\
\hline $\begin{array}{l}\text { Chloroform } \\
1,1-\text { Dichloroethylene } \\
\text { trans-1,2-Dichloroethylene } \\
\text { Tetrachloroethylene } \\
1,1,1 \cdot \text { Trichloroethane } \\
\text { Trichloroethylene }\end{array}$ & $\begin{aligned}<2.0 \\
<2.0 \\
<2.0 \\
15 \\
<2.0 \\
227\end{aligned}$ & & $\begin{array}{c}\mu g / \mathrm{L} \\
\mu g / \mathrm{L} \\
\mu g / \mathrm{h} \\
\mu g / \mathrm{L} \\
\mu g / \mathrm{L} \\
\mu g / \mathrm{L}\end{array}$ \\
\hline
\end{tabular}


ANALYTICAL RESULTS

\section{WELL RWM 10}

MEASUREMENTS CONDUCTED IN THE FIELD

Sample date: 10/11/91

Depth to water: $167.33 \mathrm{ft}(51.00 \mathrm{~m})$ below TOC

Water olevation: $188.17 \mathrm{Ht}(57.35 \mathrm{~m}) \mathrm{msl}$

The well was continuously pumping

LABORATORY ANALYSES

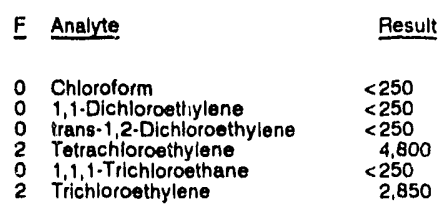

\section{WELL RWM 10}

MEASUREMENTS CONDUCTED IN THE FIELD

Sample date: 11/11/81

Depth to water: $168.24 \mathrm{ft}(51.58 \mathrm{~m})$ below TOC

$\mathrm{Sp}$ conductance: $81 \mu \mathrm{s} / \mathrm{cm}$

The well was continuously pumping.

LABORATORY ANALYSES

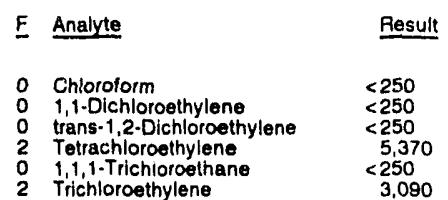

WELL RWM 10

MEASUREMENTS CONDUCTED IN THE FIELD Sample date: $12 / 12 / 91$
Depth to water: $171.76 \mathrm{ft}(52.35 \mathrm{~m})$ below TOC

Sp. conductance: $78 \mu \mathrm{S} / \mathrm{cm}$

The well was continuously pumping

LABORATORY ANALYSES

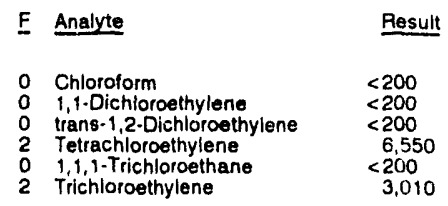

WELL RWM 11

MEASUREMENTS CONDUCTED IN THE FIELD

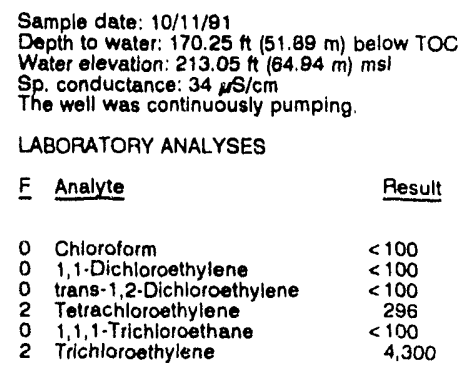

\section{WELL RWM 11}

MEASUREMENTS CONDUCTED IN THE FIELD

\begin{tabular}{|c|c|c|}
\hline \multicolumn{3}{|c|}{$\begin{array}{l}\text { Time: } 13: 10 \\
\text { pH: } 4.9 \\
\text { Alkalinity: } 0 \mathrm{mg} / \mathrm{h} \\
\text { Water temperature: } 21.9^{\circ} \mathrm{C}\end{array}$} \\
\hline \multirow[t]{2}{*}{ Mod } & Unit & Lab \\
\hline & $\begin{array}{l}\mu g / L \\
\mu g / L \\
\mu g / L \\
\mu g / L \\
\mu g / L \\
\mu g / L\end{array}$ & $\begin{array}{l}\text { MA } \\
M A \\
M A \\
M A \\
M A \\
M A\end{array}$ \\
\hline
\end{tabular}

Sample date: $11 / 11 / 91$
Depth to water: $171.46 \mathrm{H}(52.28 \mathrm{~m})$ below TOC

Sp. conductance: $33 \mu \mathrm{S} / \mathrm{cm}$

The viell was continuously pumping.

LABORATORY ANALYSES

E Analyte

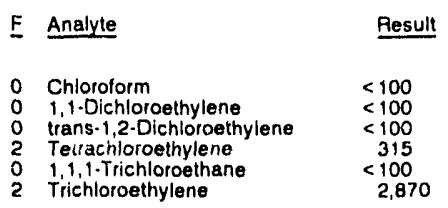

Time: $14: 55$

PH: 4.8 A

Water temperature: $19.4^{\circ} \mathrm{C}$

\section{WELL RWM 11}

\section{Time: $14: 00$ \\ Alkalinity: $0 \mathrm{mg} / \mathrm{L}$ \\ Water temperalure: $19.3{ }^{\circ} \mathrm{C}$}

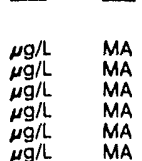

Time: 10:00

$\mathrm{pH}: 4.8$

Alkalinity: $0 \mathrm{mg} / \mathrm{L}$

Water temperature. $16.9^{\circ} \mathrm{C}$

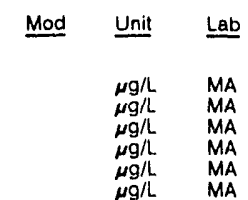

\section{Time: 14:30}

$\mathrm{pH}: 4.6$

Alkalinity: $0 \mathrm{mg} / \mathrm{h}$

Water temperature: $21.4^{\circ} \mathrm{C}$

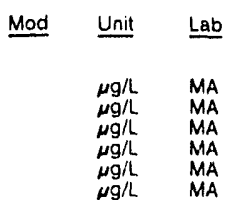

MEASUREMENTS CONDUCTED IN THE FIELD

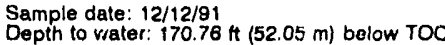

Sp. conductance: $31 \mu \mathrm{s} / \mathrm{cm}$

The well was continuously pumping

LABORATORY ANALYSES

F Analyte

Result

- Chloroform

1,1-Dichloroethylene

1,1-Dichloroethylene

trans-1,2-Dirhloivethylene

Tetrachloroethylene

Tetrachloroethylene

1,1,1-Trichloroethane

$1,1,1$. Trichloroethan

2 Trichloroethylene

$<100$

$<100$
$<100$

$<100$
$<100$

$<100$
$<00$

500
484

484
$<100$
$<100$

$<\begin{aligned} & 100 \\ & 3,350\end{aligned}$

WELL RWM 16

MEASUREMENTS CONDUCTED IN THE FIELD

Sample date: $12 / 31 / 91$

Depth to water: 117.93 t $(35.95 \mathrm{~m})$ below TOC Water elevation: $201.47 \mathrm{~h}(61.41 \mathrm{~m}) \mathrm{msl}$

Water evacuated before sampling: $329 \mathrm{gal}$

Time: $9: 10$
pH: 6.0

Alkalinity: $4 \mathrm{mg} / \mathrm{L}$

LABORATORY ANALYSES

E Analyte

Result

o Chloroform

0 Chloroform

o 1,1-Dichloroethylene

o 1,1-Dichloroethylene

0 trans-1,2-Dichloroethylene

0 trans-1,2-Dichloroethylen

o Tetrachloroethylene

0 Tetrachioroethylene

o 1,1,1.Trichloroethane

2 Trichloroethylene

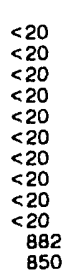

WELL SBG 1

MEASUREMENTS CONDUCTED IN THE FIELD

Sample date: $12 / 17 / 8$

Deplh

Sp conductanc $236.13 \mathrm{Ht}$

Water evacuated before sampling: $127 \mathrm{gat}$

Time: 15:25

$\mathrm{PH}: 4.7$

Water temperature: $185^{\circ} \mathrm{C}$

WELL SBG 2

MEASUREMENTS CONDUCTED IN THE FIELD

Sample date: $12 / 17 / 9$

Depth to water: $50.30 \mathrm{H}(15.33 \mathrm{~m})$ below TOC Water elevation: $239.70 \mathrm{ft}(73.06 \mathrm{~m}) \mathrm{ms}$

Sp conductance: $17 \mu \mathrm{S} / \mathrm{cm}$

Water evacuated before sampling: $89 \mathrm{gal}$
Alkalinity: $0 \mathrm{mg} / \mathrm{l}$

Water temperature: $18.6^{\circ} \mathrm{C}$

\begin{tabular}{|c|c|}
\hline Mod & Unit \\
\hline & $\begin{array}{l}\mu g / L \\
\mu g / L \\
\mu g / L \\
\mu g / L \\
\mu g / L \\
\mu g / L \\
\mu g / L \\
\mu g / L \\
\mu g / L \\
\mu g / L \\
\mu g / L \\
\mu g / L\end{array}$ \\
\hline
\end{tabular}

Time: $11: 05$
Time: $13: 05$

pH. 5.0

Water temperature: $18 \mathrm{C}$ 
WELLL SBG 3

MEASUAEMENTS CONDUCTED IN THE FIELD

Sample date: 12/17/81

Depth to water: $47.30 \mathrm{ft}(14.42 \mathrm{~m})$ below TOC

Water elevation: $238.30 \mathrm{tt}(72.84 \mathrm{~m}) \mathrm{msl}$

Sp. conductance: $18 \mathrm{mS} / \mathrm{cm}$

Water evacuated before sampling: $86 \mathrm{gal}$

WELL SBG 4

MEASUREMENTS CONOUCTED IN THE FIELD

Sample date: 12/17/91

Depth to water: 31.82 it $(9.70 \mathrm{~m})$ below TOC

Water elevation: $241.28 \mathrm{Ht}(73.54 \mathrm{~m}) \mathrm{msl}$

Water evacuated before sampling: $146 \mathrm{gal}$

WELL SBG 5

MEASUREMENTS CONDUCTED IN THE FIELD

Sample date: $12 / 17 / 91$

Depth to water: $34.21 \mathrm{tt}(10.43 \mathrm{~m})$ below TOC

Water elevation: 250.29 it $(76.29 \mathrm{~m}) \mathrm{ms}$

conductance: $49 \mathrm{\mu S} / \mathrm{cm}$

Water evacuated before sampling: $134 \mathrm{gal}$

WELLL SBG 6

MEASUREMENTS CONDUCTEO IN THE FIELD

Sample date: $12 / 17 / 91$

.

Water elevation: $245.86 \mathrm{ht}(74.8$

Water evacuated before sampling: 95 gal

WELL SCA 1

MEASUREMENTS CONOUCTED IN THE FIELD

Sample date: $12 / 17 / 9$

Depth to water: $45.45 \mathrm{H}(13.85 \mathrm{~m})$ below TOC

$\mathrm{Sp}$. conductance: $26 \mathrm{\mu S} / \mathrm{cm}$

Water evacuated before sampling: $91 \mathrm{ga}$

WELL SCA $1 A$

MEASUREMENTS CONDUCTED IN THE FIELD

Sample date: 12/17/91

The well was dry.

WELL SCA 2

MEASUREMENTS CONDUCTED IN THE FIELD

Sample date: $12 / 17 / 91$

Dupth to water: $45.37 \mathrm{ft}(13.83 \mathrm{~m})$ below TOC

Water elevatiun: $243.53 \mathrm{ft}(74.23 \mathrm{~m}) \mathrm{msl}$

Sp. conductance: $27 \mu \mathrm{S} / \mathrm{cm}$

Water evacuated before sampling: $73 \mathrm{gal}$

WELL SCA $2 A$

MEASUREMENTS CONDUCTED IN THE FIELD

Sample date: $12 / 17 / 91$

The well was dry.

WELL SCA 3

MEASUREMENTS CONDUCTED IN THE FIELD

PH: 4.8 : 0 mal

Water temperature: $17.7^{\circ} \mathrm{C}$

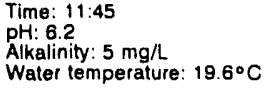

Water temperature: $19.6^{\circ} \mathrm{C}$

Time: $12: 00$
PH: 6.2
Alkalinity: $8 \mathrm{mg} / \mathrm{h}$
Water temperatur: $18.9^{\circ} \mathrm{C}$

Sample date: $11 / 22 / 9$

Depth to water: $44.65 \mathrm{Ht}(13.61 \mathrm{~m})$ below TOC

Water elevation: $242.85 \mathrm{ft}(73$

Sp. conductance. $28 \mu \mathrm{s} / \mathrm{cm}$

The ellocualed sampling: $18 \mathrm{gal}$

The well went dry during purging.

LABOPATORY ANALYSES

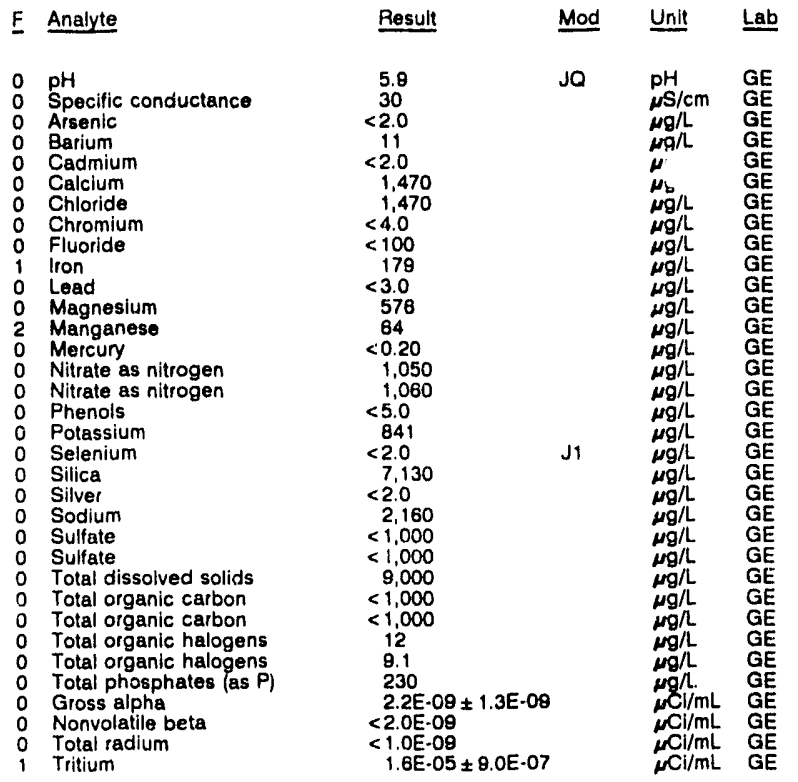

\section{WELL SCA $3 A$}

MEASUREMENTS CONDUCTED IN THE FIELLD

Time: $9: 45$

pH: 5.6 : $7 \mathrm{mg}$

Water temperature: $18.1^{\circ} \mathrm{C}$
Sample date: 11/21/81

Time: $14: 55$

WELL SCA 4

MEASUREMENTS CONDUCTED IN THE FIELD

Sample date: 11/22/81

Depth to water: $43.28 \mathrm{f}(13.19 \mathrm{~m})$ below TOC

Water elevation: $242.92 \mathrm{ft}(74.04 \mathrm{~m}) \mathrm{ms}$ |

Sp. conductance: $36 \mu \mathrm{s} / \mathrm{cm}$

Water evacuated before sampling: $13 \mathrm{gal}$

The well went dry during purging

LABORATORY ANAL.YSES

E Analyte

Specific

Arsenic

Barium

Cadmium

Chloride

Chromium

Fluoride

lion

Magnesium

Magnesium

Mercur;

Mercuri

Pheriols

Putassium

Selenium

Silica

Silver

Sodium

Sulfate

Total dissclved solids

Total organic carbon

Toti organic halogens

Total phosphates (as P)
Total phosphates (as P)

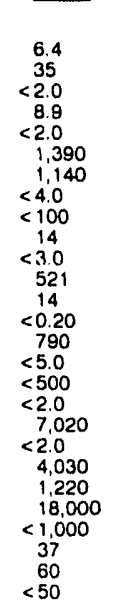

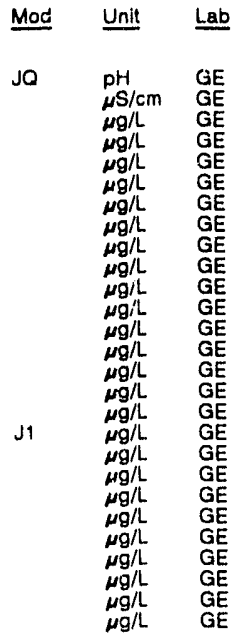

Time: 10:05

Alkalinity: $11 \mathrm{mg} / \mathrm{h}$

Water temperature: $18.0^{\circ} \mathrm{C}$

photes (as P) $<50$

$\frac{}{a}$
$G E$
$G E$
$G E$
$G E$
$G E$
$G E$
$G E$
$G E$
$G E$
$G E$
$G E$
$G E$
$G E$
$G E$
$G E$
$G E$
$G E$
$G E$
$G E$
$G E$
$G E$
$G E$
$G E$
$G E$
$G E$
$G E$
$G E$
$G E$
$G E$
$G E$
$G E$
$G E$
$G E$


WELL SCA 4 collected on 11/22/91, laboratory analyses (cont.)

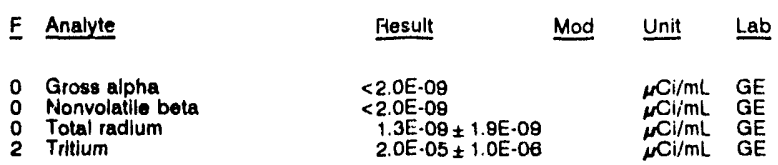

WELL SCA 4A

MEASUREMENTS CONDUCTED IN THE FIELO

Sample date: $11 / 21 / 91$
The well was dry.

Time: 14:25

WELL SCA 5

MEASUREMENTS CONDUCTED IN THE FIELD

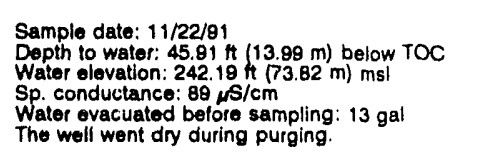

Time: 10:45

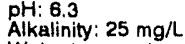

Water temperature: $19.8 \circ \mathrm{C}$ LABORATORY ANALYSES

\begin{tabular}{|c|c|c|c|}
\hline Analyte & Result & Mod & Unit \\
\hline $\begin{array}{l}\text { pH } \\
\text { Specifle conductance } \\
\text { Arrenic } \\
\text { Barium } \\
\text { Cadmium } \\
\text { Calclum } \\
\text { Chloride } \\
\text { Chloride } \\
\text { Chromium } \\
\text { Fluoride } \\
\text { Fluoride } \\
\text { lron } \\
\text { Lead } \\
\text { Magneslum } \\
\text { Manganese } \\
\text { Mercury } \\
\text { Nitrate as nitrogen } \\
\text { Phenols } \\
\text { Potassium } \\
\text { Solenium } \\
\text { Sillica } \\
\text { Silvot } \\
\text { Sodium } \\
\text { Sultate } \\
\text { Total diasolved collds } \\
\text { Total dissolved sollds } \\
\text { Total organic carbon } \\
\text { Total organic halogens } \\
\text { Total phosphates (as P) } \\
\text { Gross alpha } \\
\text { Nonvolatile bota } \\
\text { Total radlum } \\
\text { Trittum }\end{array}$ & $\begin{array}{l}6.4 \\
85 \\
<2.0 \\
14 \\
<2.0 \\
4,020 \\
2,700 \\
2,690 \\
<4.0 \\
<100 \\
<100 \\
7.7 \\
<3.0 \\
337 \\
26 \\
<0.20 \\
410 \\
<5.0 \\
3,260 \\
<2.0 \\
7,030 \\
<2.0 \\
11,800 \\
1,240 \\
43,00 C \\
47,000 \\
<1,000 \\
21 \\
280 \\
2.3 \mathrm{E}-09 \pm 1.3 \mathrm{E}-09 \\
3.8 \mathrm{E} \cdot 09 \pm 2.1 \mathrm{E} \cdot 09 \\
<1.0 \mathrm{E} \cdot 09 \\
1.3 \mathrm{E} \cdot 05 \pm 9.0 \mathrm{E} \cdot 07\end{array}$ & JQ & $\begin{array}{l}p H \\
\mu \mathrm{S} / \mathrm{cm} \\
\mu \mathrm{g} / \mathrm{L} \\
\mu g / L \\
\mu g / L \\
\mu g / L \\
\mu g / L \\
\mu g / L \\
\mu g / L \\
\mu g / L \\
\mu g / L \\
\mu g / L \\
\mu g / L \\
\mu g / L \\
\mu g / L \\
\mu g / L \\
\mu g / L \\
\mu g / L \\
\mu g / L \\
\mu g / L \\
\mu g / L \\
\mu g / L \\
\mu g / L \\
\mu g / L \\
\mu g / L \\
\mu g / L \\
\mu g / L \\
\mu g / L \\
\mu g / L \\
\mu C i / m L \\
\mu C i / m L \\
\mu C i / m L \\
\mu C i / m L\end{array}$ \\
\hline
\end{tabular}

\section{WELL SCA 6}

MEASUAEMENTS CONDUCTED IN THE FIELD

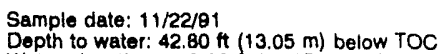

Water elevation: $243.00 \mathrm{ft}(74.07 \mathrm{~m}) \mathrm{ms}$ l

Sp. conductance: $145 \mathrm{\mu S} / \mathrm{cm}$

Water ovacuated before sampling: $15 \mathrm{gal}$

LABORATORY ANALYSES

\begin{tabular}{|c|c|c|c|c|}
\hline Anaiyte & Result & Mod & Unit & Lab \\
\hline $\begin{array}{l}\text { pH } \\
\text { Specific conductance } \\
\text { Arsenic } \\
\text { Barium } \\
\text { Cadmlum } \\
\text { Calcium } \\
\text { Chloride } \\
\text { Chromium } \\
\text { Fluoride } \\
\text { lron } \\
\text { Load } \\
\text { Magnesium } \\
\text { Manganese } \\
\text { Mercury } \\
\text { Nitrate as nitrogen } \\
\text { Phenols } \\
\text { Potassium } \\
\text { Selenium } \\
\text { Sllica }\end{array}$ & $\begin{array}{c}9.3 \\
135 \\
<2.0 \\
11 \\
<2.0 \\
11,700 \\
2,880 \\
<4.0 \\
144 \\
18 \\
<3.0 \\
604 \\
<2.0 \\
<0.20 \\
830 \\
<5.0 \\
805 \\
<2.0 \\
12,600\end{array}$ & JO & $\begin{array}{l}p H \\
\mu \mathrm{S} / \mathrm{cm} \\
\mu \mathrm{g} / \mathrm{h} \\
\mu \mathrm{g} / \mathrm{h} \\
\mu \mathrm{g} / \mathrm{h} \\
\mu \mathrm{g} / \mathrm{h} \\
\mu \mathrm{g} / \mathrm{h} \\
\mu \mathrm{g} / \mathrm{L} \\
\mu \mathrm{g} / \mathrm{h} \\
\mu \mathrm{g} / \mathrm{h} \\
\mu \mathrm{g} / \mathrm{L} \\
\mu \mathrm{g} / \\
\mu \mathrm{g} / \mathrm{h} \\
\mu \mathrm{g} / \mathrm{L} \\
\mu \mathrm{g} / \mathrm{L} \\
\mu \mathrm{g} / \mathrm{L} \\
\mu \mathrm{g} / \mathrm{L} \\
\mu \mathrm{g} / \mathrm{L} \\
\mu \mathrm{g} / \mathrm{L}\end{array}$ & $\begin{array}{l}\mathrm{GE} \\
\mathrm{GE} \\
\mathrm{GE} \\
\mathrm{GE} \\
\mathrm{GE} \\
\mathrm{GE} \\
\mathrm{GE} \\
\mathrm{GE} \\
\mathrm{GE} \\
\mathrm{GE} \\
\mathrm{GE} \\
\mathrm{GE} \\
\mathrm{GE} \\
\mathrm{GE} \\
\mathrm{GE} \\
\mathrm{GE} \\
\mathrm{GE} \\
\mathrm{GE} \\
\mathrm{GE}\end{array}$ \\
\hline
\end{tabular}

WELL SCA 6 collected on 11/22/91, laboratory analyses (cont.)

\begin{tabular}{|c|c|c|c|c|}
\hline$E$ inalyte & Result & Mod & Unit & Lab \\
\hline $\begin{array}{l}\text { Silver } \\
\text { Sodium } \\
\text { Sulfate } \\
\text { Total dissolved solids } \\
\text { Total organic carbon } \\
\text { Total organic halugens } \\
\text { Total phosphates (as P) } \\
\text { Gross alpha } \\
\text { Nonvolatile beta } \\
\text { Total radium } \\
\text { Tritium }\end{array}$ & $\begin{array}{l}<2,0 \\
16,200 \\
13,800 \\
60,000 \\
<1,000 \\
110 \\
<50 \\
<2.0 E-09 \\
<2.0 E-09 \\
<1.0 E-09 \\
2.6 E-05 \pm 1.0 E-06\end{array}$ & & $\begin{array}{l}\mu g / L \\
\mu g / L \\
\mu g / L \\
\mu g / L \\
\mu g / L \\
\mu g / L \\
\mu g / L \\
\mu C / / m L \\
\mu C i / m L \\
\mu C i / m L \\
\mu C i / m L\end{array}$ & $\begin{array}{l}\mathrm{GE} \\
\mathrm{GE} \\
\mathrm{GE} \\
\mathrm{GE} \\
\mathrm{GE} \\
\mathrm{GE} \\
\mathrm{GE} \\
\mathrm{GE} \\
\mathrm{GE} \\
\mathrm{GE} \\
\mathrm{GE}\end{array}$ \\
\hline
\end{tabular}

\section{WELL SLP 1}

MEASUREMENTS CONDUCTED IN THE FIELD

\begin{tabular}{|c|c|}
\hline $\begin{array}{l}\text { Sample date: } 12 / 17 / 91 \\
\text { Depth to water: } 38.37 \mathrm{tt}(11.70 \mathrm{~m}) \text { below TOC } \\
\text { Water elevation: } 246.43 \mathrm{ft}(75.11 \mathrm{~m}) \mathrm{msl} \\
\text { Sp. conductance: } 26, \mu \mathrm{S} / \mathrm{cm} \\
\text { Water evacuated before sampling: } 7 \mathrm{gal} \\
\text { The well went dry during purging. }\end{array}$ & $\begin{array}{l}\text { Time: } 13: 30 \\
\text { pH: } 5.2 \\
\text { Alkalinity: } 1 \mathrm{mg} / \mathrm{L} \\
\text { Water temperature: } 17.0^{\circ} \mathrm{C}\end{array}$ \\
\hline \multicolumn{2}{|l|}{ WELL SLP 2} \\
\hline \multicolumn{2}{|l|}{ MEASUREMENTS CONDUCTED IN THE FIELD } \\
\hline $\begin{array}{l}\text { Sample date: } 12 / 17 / 91 \\
\text { Depth to water: } 37.89 \mathrm{ft}(11.55 \mathrm{~m}) \text { below TOC } \\
\text { Water elevation: } 245.91 \mathrm{Ht}(74.95 \mathrm{~m}) \mathrm{msl} \\
\text { Sp conductance: } 34 \mu \mathrm{s} / \mathrm{cm} \\
\text { Water evacuated before sampling: } 74 \mathrm{gal}\end{array}$ & $\begin{array}{l}\text { Time: } 12: 40 \\
\text { pH: } 8.1 \\
\text { Alkalinity: } 7 \mathrm{mg} / \mathrm{h} \\
\text { Water temperature: } 18.3^{\circ} \mathrm{C}\end{array}$ \\
\hline
\end{tabular}

WELL SRW 1

MEASUREMENTS CONDUCTED IN THE FIELD

Sample date: $10 / 09 / 91$
Depth to water: $103.47 \mathrm{H}(31.54 \mathrm{~m})$ beiow TOC Time: $9: 20$

Water elevation: $211.73 \mathrm{H}(64.54 \mathrm{~m}) \mathrm{ms})$

inaccessibility or pump failure prevented sample rollection.

WELL SRW 2

MEASURFMENTS CONDUCTED IN THE FIELD

Sample date: 10/06/81

Depth to water: $106.61 \mathrm{ft}(32.50 \mathrm{~m})$ below TOC

Water elevation: $213.99 \mathrm{Ht}(65.22 \mathrm{~m}) \mathrm{ms}$ )

Water evacuated before sampling: $40 \mathrm{gal}$

LABORATORY ANALYSES

\begin{tabular}{|c|c|c|c|}
\hline Analyte & Result & Mod & Unit \\
\hline $\begin{array}{l}\text { Chloroform } \\
1,1 \text {-Dichloroethylene } \\
\text { trans-1,2-Dichloroethylene } \\
\text { Tetrachloroethylene } \\
1,1,1 \text {-Trichloroethane } \\
\text { Trichloroethylene }\end{array}$ & $\begin{array}{l}16 \\
<10 \\
<10 \\
<10 \\
<10 \\
<10\end{array}$ & & $\begin{array}{c}\mu g / L \\
\mu g / L \\
\mu g / d \\
\mu g / L \\
\mu g / L \\
\mu g / L\end{array}$ \\
\hline
\end{tabular}

WELL SRW $2 A$

MEASUREMENTS CONDUCTED IN THE FIELO

Sample date: 10/06/91

Dime: $14: 00$

$\begin{array}{ll}\text { Depth to water: } 113.85 \mathrm{H}(34.70 \mathrm{~m}) \text { below TOC } & \text { pH: } 4.7 \\ \text { Water elevation: } 208.75 \mathrm{H}(63.02 \mathrm{~m}) \mathrm{msl} & \text { Alkalinity: } 0 \mathrm{mg} / \mathrm{L}\end{array}$

$\begin{array}{ll}\text { Water elevation: } 206.75 \mathrm{H}(63.02 \mathrm{~m}) \mathrm{ms} & \text { Alkalinity: } 0 \mathrm{mg} / \mathrm{L} \\ \mathrm{Sp} \text {. conductance: } 19 \mu \mathrm{s} / \mathrm{cm} & \text { Water temperature: } 20.3^{\circ} \mathrm{C}\end{array}$

Water evacuated before sampling: $310 \mathrm{gal}$

LABORATORY ANALYSES

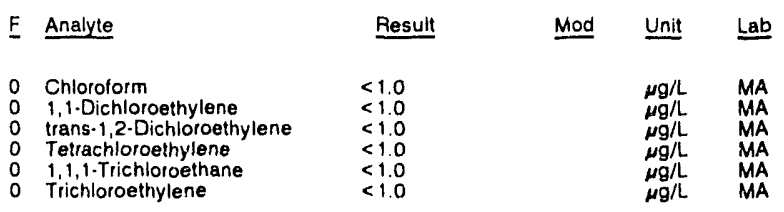




\section{ANALYTICAL RESULTS}

\section{WELL SRW 2B}

MEASUREMENTS CONDUCTED IN THE FIELD

Sample date: 10/06/91 Wepth to water: $113.09 \mathrm{At}(34.47 \mathrm{~m})$ below TOC Sp. conductance $18.510 \mathrm{~cm}$ Water evacuated before sampling: $144 \mathrm{gal}$

LABOPATORY ANALYSES

\begin{tabular}{|c|c|}
\hline Anainge & Result \\
\hline $\begin{array}{l}\text { Carbon tetrachloride } \\
\text { Chloroform } \\
\text { Chloroform } \\
\text { trana-1,2-Oichloroethylene } \\
\text { Tetrachloroethylene } \\
\text { Tetrachloroethylene } \\
1,1,1 \text {-Trichloroethane } \\
1,1,1 \text { - Trichloroethene } \\
\text { Trichloroethylene } \\
\text { Trichloroethylene }\end{array}$ & $\begin{array}{l}<1.0 \\
<1.0 \\
<1.0 \\
<1.0 \\
<1.0 \\
<1.0 \\
<1.0 \\
<1.0 \\
<1.0 \\
<1.0\end{array}$ \\
\hline
\end{tabular}

WELL SRW 2B Replicate

MEASUREMENTS CONOUCTED IN THE FIELD Sample date: $10 / 06 / 91$
Depth to water: $113.09 \mathrm{ft}(34.47 \mathrm{~m})$ below TOC
Water elevation: $207.51 \mathrm{ft}(63.25 \mathrm{~m}) \mathrm{ms}$ ! Wa $18 \mu \mathrm{S} / \mathrm{cm}$

Water evacuated before sampling: $144 \mathrm{gal}$

LABORATORY ANALYSES

\begin{tabular}{|c|c|c|}
\hline & Analyte & Result \\
\hline & $\begin{array}{l}\text { Chloroform } \\
\text { 1,1-Dichloroethylene } \\
\text { trans-1,2-Dichloroethylene } \\
\text { Tetrachloroethylene } \\
1,1,1 \text {-Trichloroethane } \\
\text { Trichloroethylene }\end{array}$ & $\begin{array}{l}<1.0 \\
<1.0 \\
<1.0 \\
<1.0 \\
<1.0 \\
<1.0\end{array}$ \\
\hline
\end{tabular}

WELL SRW $3 A$

MEASUREMENTS CONOUCTED IN THE FIELO

Sample date: 10/06/91

Depth to water: $120.20 \mathrm{H}(36.64 \mathrm{~m})$ below TOC Water elevation: $211.90 \mathrm{n}(64.59 \mathrm{~m}) \mathrm{msl}$

Sp. conductance: $18 \mu \mathrm{s} / \mathrm{cm}$

Water evacuated before sampling: $128 \mathrm{gal}$

LASORATOFIY ANALYSES

\begin{tabular}{|c|c|}
\hline Analyte & Result \\
\hline $\begin{array}{l}\text { Chloroform } \\
1,1 \cdot \text { Dichloroethylene } \\
\text { trans.1,2.Dichloroethylene } \\
\text { Tetrachloroethylene } \\
1.1,1 \text { - Trichloroethane } \\
\text { Trichloroethylene }\end{array}$ & $\begin{array}{l}<1.0 \\
<1.0 \\
<1.0 \\
<1.0 \\
<1.0 \\
<1.0\end{array}$ \\
\hline
\end{tabular}

WELL SRW 4

MEASUREMENTS CONOUCTED IN THE FIELD

Sample date: 10/08/9

Depth to water: $108.40 \mathrm{ft}(33.04 \mathrm{~m})$ below TOC

Water elevation: $211.70 \mathrm{H}(64.53 \mathrm{~m}) \mathrm{msl}$

Sp. conductance: $69 \mu \mathrm{S} / \mathrm{cm}$

Water evacuated before sampling: $32 \mathrm{gal}$

LABORATORY ANALYSES

\begin{tabular}{|c|c|c|}
\hline & Analyte & Result \\
\hline & $\begin{array}{l}\text { Chloroform } \\
\text { 1,1-Dichloroethylene } \\
\text { trans-1,2-Dichloroethylene } \\
\text { Tetrachloroethylene } \\
1,1,1 \text {-Trichloroethane } \\
\text { Trichloroethylene }\end{array}$ & $\begin{aligned} & 8.0 \\
&<1.0 \\
&<1.0 \\
&<1.0 \\
&<10 \\
&<10\end{aligned}$ \\
\hline
\end{tabular}

Time: 13:35

pH: 4.9

Water temperalurs: $20.7^{\circ} \mathrm{C}$

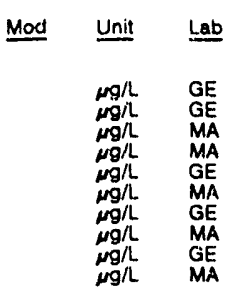

Time: 13:35

pH: 4.9

Alkalinity: $1 \mathrm{mg} / \mathrm{h}$

Water temperature: $20.7^{\circ} \mathrm{C}$

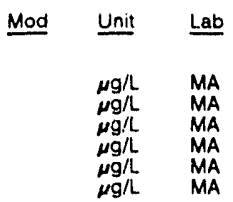

Time: 13:05

pH: 4.9

Alkalinity: $1 \mathrm{mg} / \mathrm{L}$
Water temperature $191^{\circ} \mathrm{C}$

Mod Unit Lab

$\begin{array}{ll}\mu g / L & M A \\ \mu g / L & M A \\ \mu g / L & M A \\ \mu g / L & M A \\ \mu g / L & M A \\ \mu g / L & M A\end{array}$

Time: $13: 30$

pH: 4.9

Alkalinity $0 \mathrm{mg} /$

Water temperature: $20.4^{\circ} \mathrm{C}$

$\begin{array}{cc}\text { Mod Unit } & \text { Lab } \\ & \\ \mu g / L & M A \\ \mu g / L & M A \\ \mu g / L & M A \\ \mu g / L & M A \\ \mu g / L & M A \\ \mu g / L & M A\end{array}$

WELL SRW 5

MEASUREMENTS CONDUCTED IN THE FIELD

Sample date: 10/08/91

(09.10 10.23 mil below TOC

Depth to water: $89.19 \mathrm{At}(30.23 \mathrm{~m})$ below

Sp. conductance: $55.5 / \mathrm{cm}$

Water evacuated before sampling: $41 \mathrm{gal}$

LABORATORY ANALYSES

E Analyte

Result

- Chloroform

1,1-Dichlorothylene

- trans-1,2-Dichloroethylene

Totrachloroethylene

Trichloroethylene

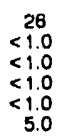

WELL SRW 6

MEASUREMENTS CONOUCTED IN THE FIELD

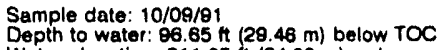
Water elevation: $211.05 \mathrm{tt}(64.33 \mathrm{~m}) \mathrm{ms}$

Sp. conductance: $37 \mu \mathrm{S} / \mathrm{cm}$

Water evacuated belore sampling: $48 \mathrm{gal}$

LABORATORY ANALYSES

E Analyte

Result

- Chloroform

0 1,1-Dichloroethylene

0 trans-1,2-Dichloroethylene

Tetrachloroethylene

Trichloroethylene

37
$<10$
$<10$
$<10$
$<10$
$<10$

WELL SRW 7

MEASUREMENTS CONDUCTED IN THE FIELLO

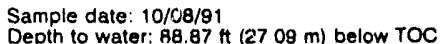
Water elevation: $21023 \mathrm{H}(64.08 \mathrm{~m}) \mathrm{msl}$

Sp. conductance: $24 \mathrm{~s} / \mathrm{cm}$

Water evacuated before sampling: $33 \mathrm{gal}$

LABORATORY ANALYSES

F Analyte

Result

o Chloroform

D 1,1-Dichloroethylene

trans.12-Dichloroethylen

Tetrachloroethylene

Trichloroeshylene

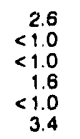

WELL SRW 8

MEASUREMENTS CONDUCTED IN THE FIELO

Sample date: 10/07/81

Depth to water: $79.75 \mathrm{ft}(24.31 \mathrm{~m})$ below TOC

Water elevation: $208.35 \mathrm{ht}(63.51 \mathrm{~m}) \mathrm{msl}$

Sp. conductance $23 \mu \mathrm{S} / \mathrm{cm}$

Water evacuated belore sampling: $33 \mathrm{gal}$

LABORATORY ANALYSES

E Analyte

Result

Time: $15: 10$
pH: 5.2

Alkalinity: $1 \mathrm{mg} / \mathrm{h}$

Water temperature: $20.0^{\circ} \mathrm{C}$

Time: $9: 40$

Alkalinity: $1 \mathrm{mg} / \mathrm{h}$

Water temperature: $18.2^{\circ} \mathrm{C}$

\begin{tabular}{|c|c|}
\hline Mod & Unit \\
\hline & $\begin{array}{c}\mu g / h \\
\mu g / h \\
\sim g / h \\
\mu g / h \\
\mu g / h \\
\mu g / h\end{array}$ \\
\hline
\end{tabular}

- Chlorotorm

1,1-Dichloroethylene

trans. 12. Dichloroethyien

Tetrachloroethylene

2 Trichloroethylene

$<1.0$
$<1.0$

$<1.0$
1.8
$<1.0$

$<1.0$
6.3

Time: $11: 45$

Alk: 5.4 . $3 \mathrm{mg}$

Water temperature: $17.0^{\circ} \mathrm{C}$

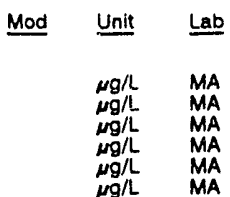

$\begin{array}{cc}\text { Mod Unit } & \text { Lab } \\ & \\ \mu g / L & M A \\ \mu g / L & M A \\ \mu g / L & M A \\ \mu g / L & M A \\ \mu g / L & M A \\ \mu g / L & M A\end{array}$


WELL SRW 9

MEASUREMENTS CONDUCTED IN THE FIELD

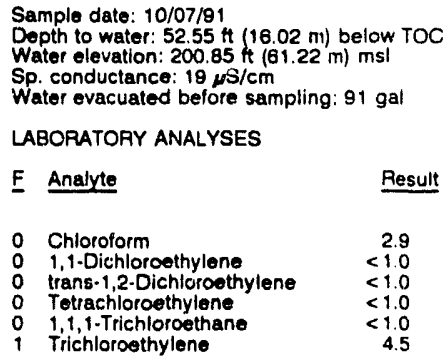

WELL SRW 9A

MEASUREMENTS CONDUCTED IN THE FIELD

Sample dato: 10/07/91

Dopth to water: $54.00 \mathrm{~N}(18.46 \mathrm{~m})$ below TOC Water olevation: $189.30 \mathrm{ht}(60.75 \mathrm{~m}) \mathrm{ms}$

Wator evacuatod betore sampling: 223 gal

LABORATORY ANALYSES

\begin{tabular}{|c|c|}
\hline Analyte & Result \\
\hline 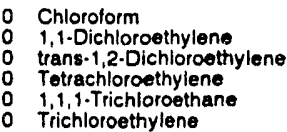 & $\begin{array}{l}<1.0 \\
<1.0 \\
<1.0 \\
<1.0 \\
<1.0 \\
<1.0\end{array}$ \\
\hline
\end{tabular}

WELL SRW SSB

MEASUREMENTS CONDUCTED IN THE FIELD

Sample date: 10/07/91

Depth to water: $52.49 \mathrm{ft}(18.00 \mathrm{~m})$ below TOC

Wator slevation: $200.91 \mathrm{ft}(61.24 \mathrm{~m}) \mathrm{msl}$

Water ovacuated before sampling: $127 \mathrm{gal}$

LABORATORY ANALYSES

$\begin{array}{llc}E & \text { Analyte } & \text { Result } \\ & & \\ 0 & \text { Chloroform } & <1.0 \\ 0 & 1,1-0 \text { - ichloroethylene } & <1.0 \\ 0 & \text { trans } 1,2 \text {-Dichloroethylene } & <1.0 \\ 0 & \text { Tetrachloroethylene } & <1.0 \\ 0 & 1,1,1 \text {-Trichloroethane } & <1.0 \\ 0 & \text { Trichloroethylene } & <1.0\end{array}$

WELL SRW 10

MEASUAEMENTS CONOUCTED IN THE FIELD

\section{Sample date: 10/08/91}

Depth to water: Not available

Water elevation: Not avallable

Sp. conductance: $18 \mathrm{\mu s} / \mathrm{cm}$

Water evacuated before sampling: $36 \mathrm{gal}$

LABORATORY ANALYSES

\begin{tabular}{|c|c|}
\hline F Analyte & Result \\
\hline $\begin{array}{ll}0 & \text { Chloroform } \\
0 & 1,1 \cdot \text { Dichloroethylene } \\
0 & \text { trans. } 1,2-\text { Dichloroethylene } \\
0 & \text { Tetrachloroethylene } \\
0 & 1,1,1 \text { - Trichloroethane } \\
0 & \text { Trichloroethylene }\end{array}$ & $\begin{array}{l}<1.0 \\
<1.0 \\
<1.0 \\
<1.0 \\
<10 \\
<1.0\end{array}$ \\
\hline
\end{tabular}

WELL SRW 11

Time: $14: 55$

PH: 5.2 Alkalinity: $1 \mathrm{mg} / \mathrm{L}$

Water temperature: $18.3^{\circ} \mathrm{C}$

$\begin{array}{cc}\text { Mod Unit } & \text { Lab } \\ \mu g / L & M A \\ \mu g / L & M A \\ \mu g / L & M A \\ \mu g / L & M A \\ \mu g / L & M A \\ \mu g / L & M A\end{array}$

Time: 15:05

pH: 5.1 Alkalinity: $1 \mathrm{mg} / \mathrm{L}$

Water temperature: $18.6^{\circ} \mathrm{C}$

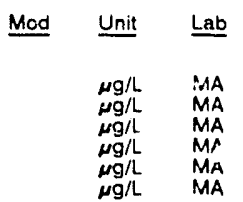

Time: $14: 45$

PH: 5.3
Alkalinity: $1 \mathrm{mg} / \mathrm{h}$

Water temperature: $18.4^{\circ} \mathrm{C}$

Mod Unit Lab

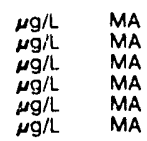

$\therefore$

MEASUREMENTS CONDUCTED IN THE FIELD

Sample date: 10/08/91

Depth to water: $85.64 \mathrm{Ht}(26.10 \mathrm{~m})$, elow TOC

Water elevation: $210.16 \mathrm{ft}(64.06 \mathrm{~m}) \mathrm{ms}$

Sp. conductance: $21 \mu \mathrm{s} / \mathrm{cm}$
Water evacuated betore sampling: $51 \mathrm{gal}$

LABORATORY ANALYSES

F Analyte

Result

Chloroform

1,1-Dichloroethylene

trans-1,2-Dichloroethylen

1 Tetrachioroethyiene

i Trichloroethylene

2.2
$<1.0$
$<1.0$
2.8
$<1.0$
4.2

Time: $14: 40$

pH: 4.9

Alkalinity: $0 \mathrm{mg} / \mathrm{L}$

Water temperature: $20.1^{\circ} \mathrm{C}$

WELL SRW 12A

MEASUREMENTS CONDUCTED IN THE FIELD

Sample date: 10/07/81

Depth to water: $41.06 \mathrm{ft}(12.52 \mathrm{~m})$ below TOC

Water elevation: $185.4 \mathrm{ft}(59.51 \mathrm{~m}) \mathrm{ms}$

P. conductance: $19 \mu \mathrm{S} / \mathrm{cm}$

Water evacuated before sampling: $240 \mathrm{gal}$

LABORATORY ANALYYSES

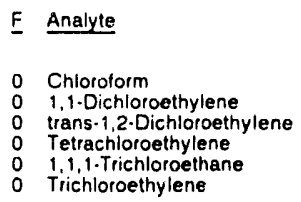

Result

$<1.0$
$<1.0$
$<1.0$
$<1.0$
$<1.0$
$<1.0$

Time: $14: 20$

pH: 4.8

Alkalinity: $0 \mathrm{mg} / \mathrm{L}$

Water temperature: $18.1^{\circ} \mathrm{C}$

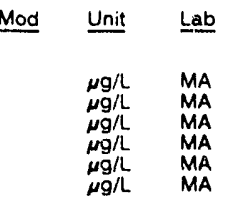

WELL SRW 12B

MEASUREMENTS CONDUCTED IN THE FIELD

Sample date: $10 / 07 / 91$
Depth to water: $45.02 \mathrm{Ht}(13.72 \mathrm{~m})$ below TOC
Water elevation: $191.28 \mathrm{th}(58.30 \mathrm{~m}) \mathrm{msl}$
Sp. conductance: $13 \mu \mathrm{S} / \mathrm{cm}$

Water evacuated betore sampling: $118 \mathrm{gal}$

LABORATORY ANALYSES

\begin{tabular}{|c|c|}
\hline Analyte & Resul \\
\hline $\begin{array}{l}\text { Chloroform } \\
\text { 1,1-Dichloroethylene } \\
\text { trans } 1,2 \cdot \text { Dichloroethylene } \\
\text { Tetrachloroethylene } \\
1,1,1-\text { Trichloroethane } \\
\text { Trichloroethylene }\end{array}$ & 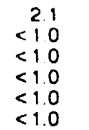 \\
\hline
\end{tabular}

Time: $14: 05$

pH: 5.5

Alkalinity: $2 \mathrm{mg} / \mathrm{h}$

Water temperature: $17.8^{\circ} \mathrm{C}$

$\begin{array}{cc}\text { Mod Unit } & \text { Lab } \\ & \\ \mu \mathrm{g} / \mathrm{L} & \mathrm{MA} \\ \mu \mathrm{g} / \mathrm{L} & \mathrm{MA} \\ \mu \mathrm{g} / \mathrm{L} & \mathrm{MA} \\ \mu \mathrm{g} / \mathrm{L} & \mathrm{MA} \\ \mu \mathrm{g} / \mathrm{L} & \mathrm{MA} \\ \mu \mathrm{g} / \mathrm{L} & \mathrm{MA}\end{array}$

WELL SRW $12 \mathrm{C}$

MEASUREMENTS CONDUCTED IN THE FIELD

Sample date: 10/07/91

Depth to water: $36.78 \mathrm{ft}(11.21 \mathrm{~m})$ below TOC

Water elevation: $199.52 \mathrm{ft}(60.81 \mathrm{~m}) \mathrm{ms}$ !

Sp. conductance: $16 \mu \mathrm{\mu} / \mathrm{cm}$
Water evacuated before sampling: $54 \mathrm{gA!}$

LABORATORY ANALYSES

\begin{tabular}{|c|c|c|c|}
\hline Analyte & Result & Mod & Unit \\
\hline $\begin{array}{l}\text { Chloroform } \\
\text { 1.1.Dichloroethylene } \\
\text { trans } 1,2 \cdot \text { Dichloroethylene } \\
\text { Tetrachloroethylene } \\
\text { 1,1,1.Trichioroethane } \\
\text { Trichloroethylene }\end{array}$ & $\begin{array}{l}1.4 \\
<1.0 \\
<1.0 \\
<1.0 \\
<1.0 \\
<1.0\end{array}$ & & $\begin{array}{l}\mu g / \mathrm{L} \\
\mu \mathrm{g} / \mathrm{L} \\
\mu \mathrm{g} / \mathrm{L} \\
\mu \mathrm{g} / \mathrm{L} \\
\mu \mathrm{g} / \mathrm{L} \\
\mu \mathrm{g} / \mathrm{L}\end{array}$ \\
\hline
\end{tabular}


ANALYTICAL RESULTS

WELL SRW 13A

MEASUREMENTS CONDUCTED IN THE FIELD

Sample date: 10/07/91

Depth to water: 96.21 it $(29.33 \mathrm{~m})$ below TOC

Water elevation: $201.49 \mathrm{H}(61$.

Water evacuated before sampling: $283 \mathrm{gal}$

LABORATORY ANALYSES

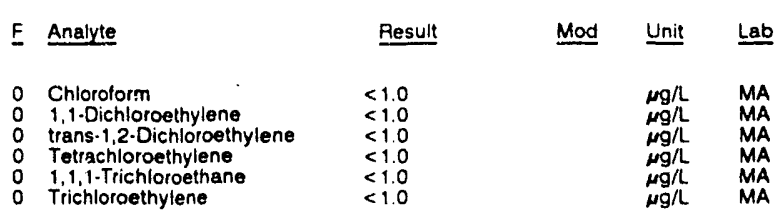

\section{WELL SRW $13 B$}

MEASUREMENTS CONDUCTED IN THE FIELD

Sample date: $10 / 07 / 91$

Weph to water: 84.32 ft $(28.75 \mathrm{~m})$ below TOC

Water elevation: $203.38 \mathrm{ft}(61.99 \mathrm{~m}) \mathrm{ms}$ |

Water evacuated before sampling: $131 \mathrm{gal}$

LABORATORY ANALYSES

\begin{tabular}{|c|c|}
\hline Analyte & Result \\
\hline $\begin{array}{l}\text { Chloroform } \\
1,1-\text { Dichloroelhylene } \\
\text { trans-1,2-Dichloroethylene } \\
\text { Tetrachloroethylene } \\
1,1,1-\text { Trichloroethane } \\
\text { Trichloroethylene }\end{array}$ & $\begin{array}{l}<1.0 \\
<1.0 \\
<1.0 \\
<1.0 \\
<1.0 \\
<1.0\end{array}$ \\
\hline
\end{tabular}

\section{WELL SRW $13 C$}

MEASUREMENTS CONDUCTED IN THE FIELO

Sample date: 10/07/91

89.16 it $(27.18 \mathrm{~m})$ below TOC

Water elevation: $208.54 \mathrm{ft}(63.56 \mathrm{~m}) \mathrm{ms}$

Water evacuated before sampling: $52 \mathrm{gal}$

LABORATORY ANALYSES

\begin{tabular}{|c|c|c|c|c|}
\hline$F$ & Analyte & Result & Mod & Unit \\
\hline $\begin{array}{l}0 \\
0 \\
0\end{array}$ & $\begin{array}{l}\text { Chloroform } \\
1,1 \cdot \text {-Dichloroethylene } \\
\text { trans } \cdot 1,2 \text {-Dichloroethylene } \\
\text { Tettachloroethylene } \\
1,1,1-\text { Trichloroethane } \\
\text { Trichloroethylene }\end{array}$ & $\begin{array}{l}<1.0 \\
<1.0 \\
<1.0 \\
<1.0 \\
<1.0 \\
<1.0\end{array}$ & & $\begin{array}{l}\mu g / L \\
\mu g / L \\
\mu g / L \\
\mu g / L \\
\mu g / L \\
\mu g / L\end{array}$ \\
\hline
\end{tabular}

\section{WELL SRW 14A}

MEASUREMENTS CONDUCTED IN THE FIELD

Sample date: 10/07/91

Depth to water: $123.72 \pi(37.71 \mathrm{~m})$ below TOC Water elevation: $203.28 \mathrm{ft}$

Time: $11: 30$

pH: 4.7

Water temperature: $17.7^{\circ} \mathrm{C}$

(a)

Water evacuated before sampling. $235 \mathrm{gal}$

LABORATORY ANALYSES

\begin{tabular}{|c|c|c|c|c|}
\hline & Analyte & Result & Mod & Unit \\
\hline & $\begin{array}{l}\text { Chloroform } \\
1,1 \cdot \text { Dichloroethylene } \\
\text { trans } 1,2 \cdot \text { Dichloroethylene } \\
\text { Tetrachloroethylene } \\
1,1,1-\text { Trichloroethane } \\
\text { Trichloroethylene }\end{array}$ & $\begin{array}{l}<2.0 \\
<2.0 \\
<2.0 \\
<20 \\
<2.0 \\
15\end{array}$ & & $\begin{array}{l}\mu g / L \\
\mu g / L \\
\mu g / L \\
\mu g / L \\
\mu g / h \\
\mu g / h\end{array}$ \\
\hline
\end{tabular}

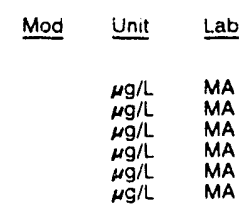

Time. $11: 15$

pH: 5.1 : 20

Water temperature $17.6^{\circ} \mathrm{C}$
WELL SRW 14B

MEASUREMENTS CONDUCTED IN THE FIELD

Sample date: 10/07/91

Depth to water: $121.96 \mathrm{ft}(37.17 \mathrm{~m})$ below TOC

Water elevation: $204.94 \mathrm{ft}(62$

Water evacuated before sampling: $136 \mathrm{gal}$

LABORATORY ANALYSES

\begin{tabular}{|c|c|c|c|c|}
\hline$E$ & Analyte & Result & Mod & Unit \\
\hline $\begin{array}{l}0 \\
0 \\
0 \\
0 \\
0\end{array}$ & $\begin{array}{l}\text { Chloroform } \\
1,1-\text { Dichloroethylene } \\
\text { trans } \cdot 1,2 \cdot \text { Dichloroethylene } \\
\text { Tetrachloroethylene } \\
\text { t, } 1,1 \text {-Trichloroethane } \\
\text { Trichloroethylene }\end{array}$ & $\begin{aligned}<1.0 \\
<1.0 \\
<1.0 \\
<1.0 \\
<1.0 \\
4.2\end{aligned}$ & & 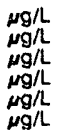 \\
\hline
\end{tabular}

\section{WELL SRW $14 \mathrm{C}$}

MEASUAEMENTS CONDUCTED IN THE FIELD

Sample date: 10/07/81

Depth to water: Not available

Sater elevation: Not availab

Water evacuated belore sampling: $75 \mathrm{gal}$

LABORATORY ANALYSES

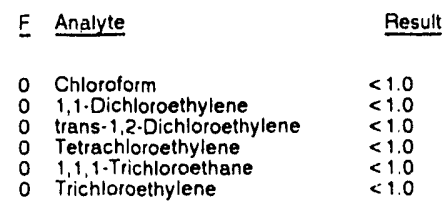

Time: $10: 30$

Alkalinity: $1 \mathrm{mg} / \mathrm{h}$

Water temperature: $18.0^{\circ} \mathrm{C}$

\section{WELL SRW 15A}

MEASUREMENTS CONDUCTED IN THE FIELD

Sample date: $10 / 06 / 91$

Depth to water: $109.77 \mathrm{~h}(33.46 \mathrm{~m})$ below TOC.

Water elevation: $209.33 \mathrm{Ht}$

Water evacuated before sampling: $293 \mathrm{gal}$

LABORATORY ANALYSES

\begin{tabular}{|c|c|c|c|}
\hline Analyte & Result & Mod & Unit \\
\hline $\begin{array}{l}\text { Chloroform } \\
1,1 \text { Dichloroethylene } \\
\text { trans-1,2-Dichloroethylene } \\
\text { Tetrachloroethylene } \\
1,1,1 \cdot \text { Trichloroethane } \\
\text { Trichloroethylene }\end{array}$ & $\begin{array}{l}<1.0 \\
<1.0 \\
<1.0 \\
<1.0 \\
<1.0 \\
<1.0\end{array}$ & & $\begin{array}{l}\mu g / \mathrm{L} \\
\mu g / \mathrm{L} \\
\mu g / \mathrm{L} \\
\mu g / \mathrm{L} \\
\mu g / \mathrm{L} \\
\mu g / \mathrm{L}\end{array}$ \\
\hline
\end{tabular}

\section{WELL SRW 15B}

MEASUREMENTS CONDUCTED IN THE FIELD

Sample date $10 / 06 / 91$

Depth to water: $109.53 \mathrm{Ht}(33.39 \mathrm{~m})$ below TOC Water elevation: $209.57 \mathrm{ft}(63.88 \mathrm{~m}) \mathrm{ms}$

Sp. conductance: $16 \mu \mathrm{s} / \mathrm{cm}$
Water evacuated before sampling: $152 \mathrm{gal}$

LABORATOAY ANALYSES

\begin{tabular}{|c|c|c|c|}
\hline F Analyte & Result & Mod & $\underline{\text { Unit }}$ \\
\hline $\begin{array}{ll}0 & \text { Chloroform } \\
0 & 1,1-\text { Dichloroethylene } \\
0 & \text { trans- } 1,2 \text {. Dichloroethylene } \\
0 & \text { Tetrachloroethylene } \\
0 & 1,1,1 \cdot \text { Trichloroethane } \\
0 & \text { Tfichloroethylene }\end{array}$ & $\begin{array}{l}<1.0 \\
<1.0 \\
<1.0 \\
<1.0 \\
<1.0 \\
<1.0\end{array}$ & & $\begin{array}{l}\mu g / L \\
\mu g / L \\
\mu g / L \\
\mu g / L \\
\mu g / L \\
\mu g / L\end{array}$ \\
\hline
\end{tabular}




\section{ANALYTICAL RESULTS}

\section{WELL SRW 15C}

MEASUREMENTS CONDUCTED IN THE FIELD

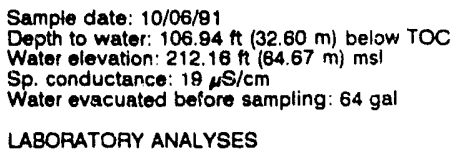

LABORATOAY ANALYSES

\begin{tabular}{|c|c|c|c|}
\hline Anaiyte & Result & Mod & Unit \\
\hline $\begin{array}{l}\text { Chloroform } \\
1,1-\text { Dichloroethylene } \\
\text { trans-1,2-Dichloroethylene } \\
\text { Tetrachloroethylene } \\
1,1,1-\text { Trichloroethane } \\
\text { Trichloroethylene }\end{array}$ & $\begin{array}{l}<1.0 \\
<1.0 \\
<1.0 \\
<1.0 \\
<1.0 \\
<1.0\end{array}$ & & $\begin{array}{l}\mu g / L \\
\mu g / L \\
\mu g / L \\
\mu g / L \\
\mu g / L \\
\mu g / L\end{array}$ \\
\hline
\end{tabular}

\section{WELL SRW 16A}

MEASUREMENTS CONDUCTED IN THE FIELD

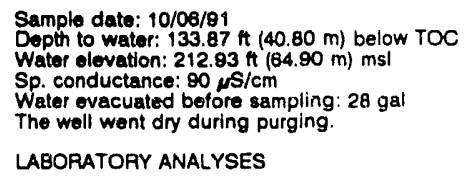

\begin{tabular}{|c|c|c|c|}
\hline E Analyte & Result & Mod & Unit \\
\hline $\begin{array}{l}\text { Chioroform } \\
1,1-\text { Dichloroethylene } \\
\text { trans-1,2-Dichloroethylene } \\
\text { Totrachloroethyiene } \\
1,1,1-\text { Trichloroethane } \\
\text { Trichloroethylene }\end{array}$ & $\begin{aligned}<1.0 \\
<1.0 \\
<1.0 \\
<1.0 \\
<1.0 \\
2.8\end{aligned}$ & & $\begin{array}{l}\mu g / \mathrm{L} \\
\mu g / \mathrm{L} \\
\mu g / \mathrm{L} \\
\mu g / \mathrm{L} \\
\mu g / L \\
\mu g / L\end{array}$ \\
\hline
\end{tabular}

\section{WELL SRW 16B}

MEASUREMENTS CONDUCTED IN THE FIELD Sample date: $10 / 06 / 81$
Depth to water: $133.32 \mathrm{Ht}(40.64 \mathrm{~m})$ below TOC
Water elevation: $213.48 \mathrm{H}(65.07 \mathrm{~m}) \mathrm{msl}$

Sp. conductance: $19 \mu \mathrm{S} / \mathrm{cm}$

Water evacuated before sampling: $140 \mathrm{gal}$

LABORATORY ANALYSES

\begin{tabular}{|c|c|}
\hline Analyte & Resul \\
\hline $\begin{array}{l}\text { Chloroform } \\
1,1-\text { Dichloroethylene } \\
\text { trans-1,2-Dichloroethylene } \\
\text { Tetrachloroethylene } \\
1,1,1-\text { Trichloroethane } \\
\text { Trichloroethylene }\end{array}$ & $\begin{array}{l}<1.0 \\
<1.0 \\
<1.0 \\
<1.0 \\
<1.0 \\
1.8\end{array}$ \\
\hline
\end{tabular}

WELL SRW $16 C$

MEASUREMENTS CONDUCTED IN THE FIELD

Sample date: $10 / 06 / 81$

Depth to water: $132.4 \mathrm{ft}(40.43 \mathrm{~m})$ beiow TOC

Water elevation: $213.96 \mathrm{ft}(65.22 \mathrm{~m}) \mathrm{msl}$

Sp. conductance: $16 \mu \mathrm{s} / \mathrm{cm}$

Water evacuated betore sampling: $22 \mathrm{gal}$

LABORATORY ANALYSES

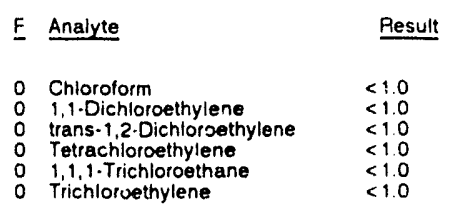

Time: 14:35

$\mathrm{pH}: 5.3$

Water temperature: $19.7^{\circ} \mathrm{C}$

Time: 15:00

pH: 6.9

Alkalinity: $42 \mathrm{mg} / \mathrm{L}$

Water temperature: $19.8^{\circ} \mathrm{C}$

Time: 12

Alkalinity: $1 \mathrm{mg} / \mathrm{L}$

Water temperature: $19.3^{\circ} \mathrm{C}$

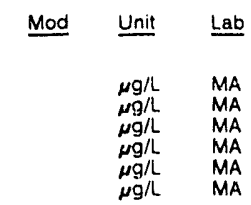

Time: $12: 25$

pH: 5 .

Alkalinity: $1 \mathrm{mg} / \mathrm{L}$

Water temperature: $19.0^{\circ} \mathrm{C}$

$\begin{array}{cc}\text { Mod Unit } & \text { lab } \\ & \\ \mu g / L & M A \\ \mu g / L & M A \\ \mu g / L & M A \\ \mu g / L & M A \\ \mu g / L & M A \\ \mu g / L & M A\end{array}$

\section{WELL SSS 1}

MEASUREMENTS CONDUCTED IN THE FIELD

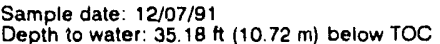
Water elevation: $159.72 \mathrm{ft}(48.68 \mathrm{~m}) \mathrm{msl}$

Sp. conductance: $25 \mu \mathrm{S} / \mathrm{cm}$ Water evacuated before sampling: $4 \mathrm{gal}$

Time: $13: 00$

Alkalinity: $1 \mathrm{mg} / \mathrm{L}$ Water temperature $17.5^{\circ} \mathrm{C}$

LABORATORY ANALYSES

\begin{tabular}{|c|c|c|c|}
\hline Analyte & Resuit & Mod & Unit \\
\hline $\begin{array}{l}\text { pH } \\
\text { Specific conductance } \\
\text { Arsenic } \\
\text { Barium } \\
\text { Cadmium } \\
\text { Calcium } \\
\text { Chloride } \\
\text { Chromium } \\
\text { 2,4-Dichlorophenoxyacetic acid } \\
\text { Endrin } \\
\text { Fluoride } \\
\text { lron } \\
\text { Lead } \\
\text { Lindane } \\
\text { Magnesium } \\
\text { Manganese } \\
\text { Mercury } \\
\text { Methoxychlor } \\
\text { Nitrate as nitrogen } \\
\text { Phenols } \\
\text { Potassium } \\
\text { Selenium } \\
\text { Silica } \\
\text { Silver } \\
\text { Sodium } \\
\text { Sulfate } \\
\text { Total dissolved solids } \\
\text { Total organic carbon } \\
\text { Total organic carbon } \\
\text { Total organic halogens } \\
\text { Total phosphates (as P) } \\
\text { Toxaphene } \\
\text { 2,4,5-TP (Silvex) } \\
\text { Gross alpha } \\
\text { Nonvolatile beta } \\
\text { Total radium } \\
\text { Tritium }\end{array}$ & $\begin{array}{l}5.4 \\
20 \\
<2.0 \\
<3.0 \\
<2.0 \\
1,440 \\
2,660 \\
<4.0 \\
<0.30 \\
<0.0060 \\
<100 \\
73 \\
<3.0 \\
<0.0050 \\
392 \\
4.6 \\
<0.20 \\
<0.50 \\
1,550 \\
6.9 \\
<500 \\
<2.0 \\
7.960 \\
<2.0 \\
3.090 \\
1,400 \\
33.000 \\
22,000 \\
23.000 \\
5.4 \\
1.220 \\
<0.24 \\
<0.090 \\
7.0 \mathrm{E}-09 \pm 1.7 \mathrm{E}-09 \\
7.6 \mathrm{E} \cdot 09 \pm 2.1 \mathrm{E}-09 \\
<1.0 \mathrm{E}-09 \\
3.1 \mathrm{E}-06 \pm 7.0 \mathrm{E}-07\end{array}$ & $\mathrm{JO}$ & $\begin{array}{l}p H \\
\mu \mathrm{S} / \mathrm{cm} \\
\mu g / L \\
\mu g / L \\
\mu g / L \\
\mu g / L \\
\mu g / L \\
\mu g / L \\
\mu g / L \\
\mu g / L \\
\mu g / L \\
\mu g / L \\
\mu g / L \\
\mu g / L \\
\mu g / L \\
\mu g / L \\
\mu g / L \\
\mu g / L \\
\mu g / L \\
\mu g / L \\
\mu g / L \\
\mu g / L \\
\mu g / L \\
\mu g / L \\
\mu g / L \\
\mu g / L \\
\mu g / L \\
\mu g / L \\
\mu g / L \\
\mu g / L \\
\mu g / L \\
\mu g / L \\
\mu g / L \\
\mu C i / m L \\
\mu C i / m L \\
\mu C i / m L \\
\omega C i / m L\end{array}$ \\
\hline
\end{tabular}

\section{WELL SSS 2}

MEASUREMENTS CONDUCTED IN THE FIELD

Sample date: $12 / 07 / 91$

Depth to water: 12.17 it $(3.71 \mathrm{~m})$ below TOC

Water elevation: $152.93 \mathrm{ft}(46.61 \mathrm{~m}) \mathrm{ms}$.

p. conductance: $28 \mu \mathrm{S} / \mathrm{cm}$

sampling: $8 \mathrm{gal}$

Time: 14:30

PH: 4.9

Water temperature: $20.3^{\circ} \mathrm{C}$

LABORATORY ANALYSES

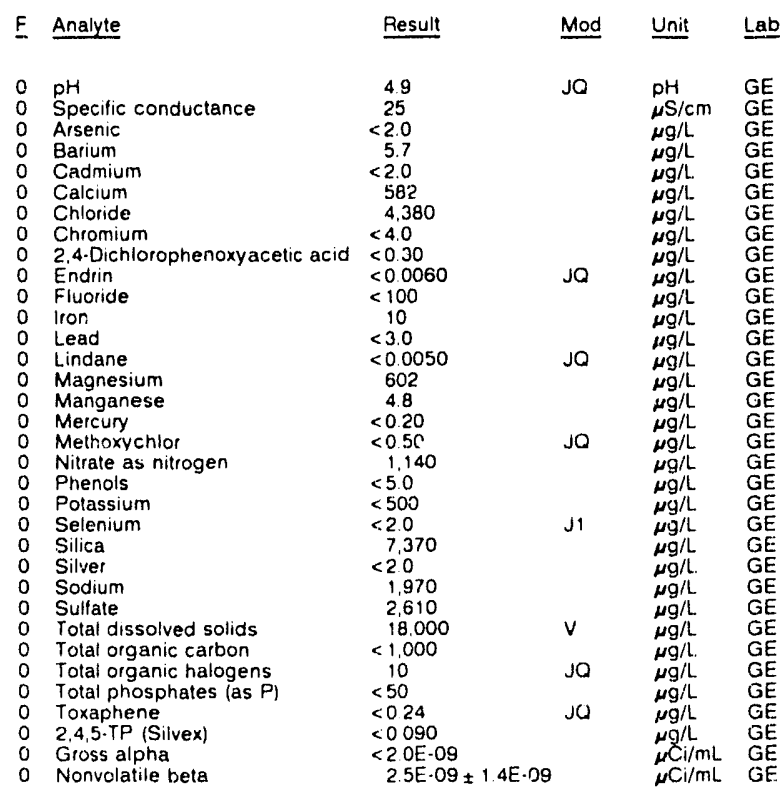


ANALYTICAL RESULTS

WELL SSS 2 collecied on 12/07/91, laboratory analyses (cont)

$\begin{array}{lllll}\text { F Anaiyte } & \text { Result } & \text { Mod } & \text { Unit } & \text { Lab } \\ 0 & \text { Total radium } & 1.0 \mathrm{E} \cdot 09 \pm 1.2 \mathrm{E} \cdot 09 & & \\ 0 & \text { Tritium } & 4.5 \mathrm{E}-06 \pm \mathrm{mL} & \mathrm{GE} \\ \mu \mathrm{Ci} / \mathrm{mL} & \mathrm{GE}\end{array}$

WELL SSS 3

MEASUREMENTS CONDUCTED IN THE FIELO

Sample date: $12 / 07 / 91$

(11.71 $(3.57 \mathrm{~m})$ below TOC

Water elevation: $151.89 \mathrm{ft}(46.3$

Alkalinity: $1 \mathrm{mg} /$

Water temperature: $18.8^{\circ} \mathrm{C}$

Water ovacuated before sampling: $5 \mathrm{gal}$

LABORATORY ANALYSES

\begin{tabular}{|c|c|c|c|}
\hline Analyte & Result & Mod & Unit \\
\hline $\begin{array}{l}\text { pH } \\
\text { Specific conductance } \\
\text { Arsenic } \\
\text { Barlum } \\
\text { Cadmium } \\
\text { Calcium } \\
\text { Chloride } \\
\text { Chromium } \\
\text { 2,4-Dichlorophenoxyacetic acid } \\
\text { Endrin } \\
\text { Fluoride } \\
\text { Iron } \\
\text { Lead } \\
\text { Lindane } \\
\text { Magnesium } \\
\text { Manganese } \\
\text { Mercury } \\
\text { Methoxychlor } \\
\text { Nitrate as nitrogen } \\
\text { Phenols } \\
\text { Potassium } \\
\text { Selenium } \\
\text { Silica } \\
\text { Silver } \\
\text { Sodium } \\
\text { Sulfate } \\
\text { Total dissolved solids } \\
\text { Total organic carbon } \\
\text { Total organic halogens } \\
\text { Total organic halogens } \\
\text { Total phosphates las P) } \\
\text { Toxaphene } \\
\text { 2,4,5-TP (Silvex) } \\
\text { Gross alpha } \\
\text { Nonvolatile bela } \\
\text { Total radium } \\
\text { Tritium }\end{array}$ & $\begin{array}{l}5.3 \\
20 \\
<2.0 \\
<3.0 \\
<2.0 \\
805 \\
1.590 \\
<4.0 \\
<0.30 \\
<0.0060 \\
<100 \\
45 \\
<3.0 \\
<0.0050 \\
293 \\
17 \\
<0.20 \\
<0.50 \\
2.42 \\
<5.0 \\
500 \\
<2.0 \\
6,430 \\
<2.0 \\
1,080 \\
3,820 \\
22,000 \\
4,000 \\
<5.0 \\
<5.0 \\
870 \\
<0.24 \\
<0.090 \\
2.2 L \cdot 09 \pm 1.2 E \cdot 09 \\
<2.0 E \cdot 09 \\
<1.0 E \cdot 09 \\
1.0 E-06 \pm 7.0 E-07\end{array}$ & $\begin{array}{l}\mathrm{V} \\
\text { JQ } \\
\text { JQ }\end{array}$ & 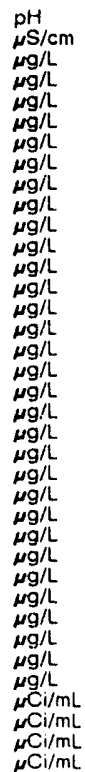 \\
\hline
\end{tabular}

WELL SSS 4

MEASUREMENTS CONDUCTED IN THE FIELD

Sample date: $11 / 21 / 91$

Depth to water: $63.90 \mathrm{H}(19.48 \mathrm{~m})$ below TOC

Water elevation: 202.90 i: 161.84

Sp. conductance: $54 \mu \mathrm{s} / \mathrm{cm}$
Water evacuated before sampling: $6 \mathrm{gal}$

Water evacuated belore sam

LABORATORY AN,ILISES

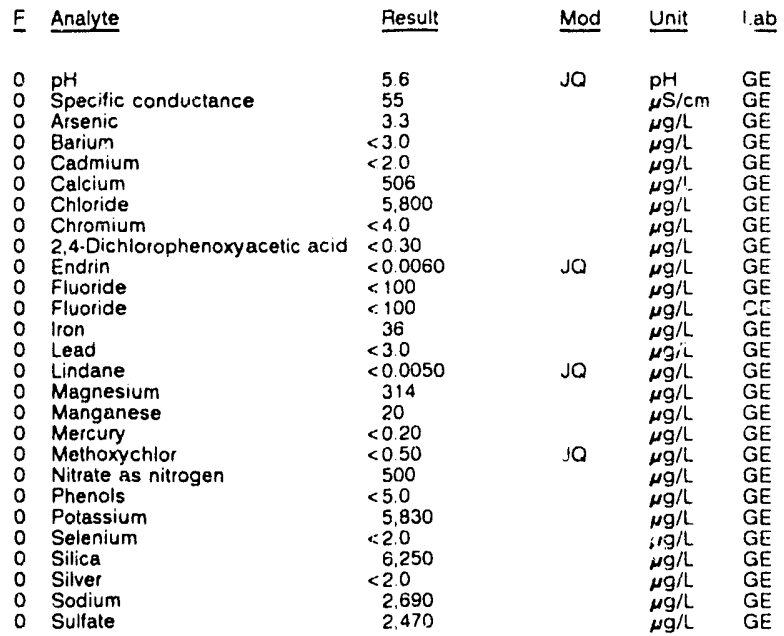

WELL SSS 4 collected on 11/21/91, laboratory analyses (cont)

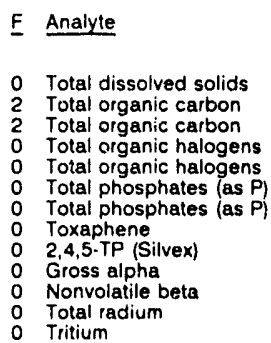

$\begin{array}{ll}\text { Result } & \text { Mod } \\ & \\ 98,000 & V \\ 29.000 & \\ 29.000 & \\ 7.5 & \\ 8.4 & \\ 7.900 & \\ 8.120 & \\ <0.24 & \\ <0.090 & \\ <2.0 \mathrm{E} \cdot 09 & \\ 6.3 \mathrm{E} \cdot 09 \pm 2.3 \mathrm{E}-09 & \\ 1.1 \mathrm{E}-09 \pm 1.6 \mathrm{E}-09 & \\ 3.9 \mathrm{E} \cdot 08 \pm 8.0 \mathrm{E}-07 & \end{array}$

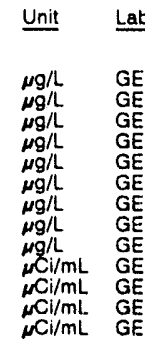

\section{WELL SSS 5}

MEASUREMENTS CONDUCTED IN THE FIELD

Sample date: $11 / 21 / 91$

Depth to water: $46.18 \mathrm{Ht}(14.08 \mathrm{~m})$ below TOC

Water elevation: 193.81 it $(58.0$

Water evacuated before sampling: $6 \mathrm{gal}$

PH: $5: 13.20$

Alkalinity: $2 \mathrm{mg} / \mathrm{L}$

Water temperature: $19.7^{\circ} \mathrm{C}$

LABORATORY ANALYSES

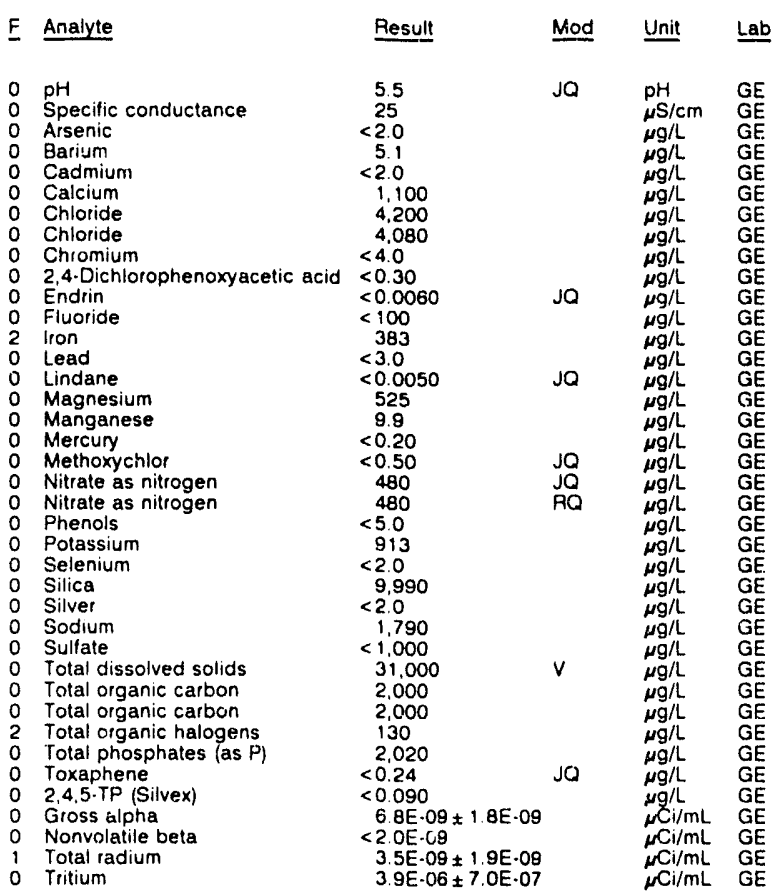

WELL SSS 6

MEASUREMENTS CONDUCTEO IN THE FIELD

Sample date: 11/15/91

Depth to water. $30.32 \mathrm{ft}(9.24 \mathrm{~m})$ below TOC

Water elevation $183.08 \mathrm{Ht}(55.80 \mathrm{~m}) \mathrm{ms}$

Water evacuated before sampling. $6 \mathrm{gal}$

LABORATOAY ANALYSES

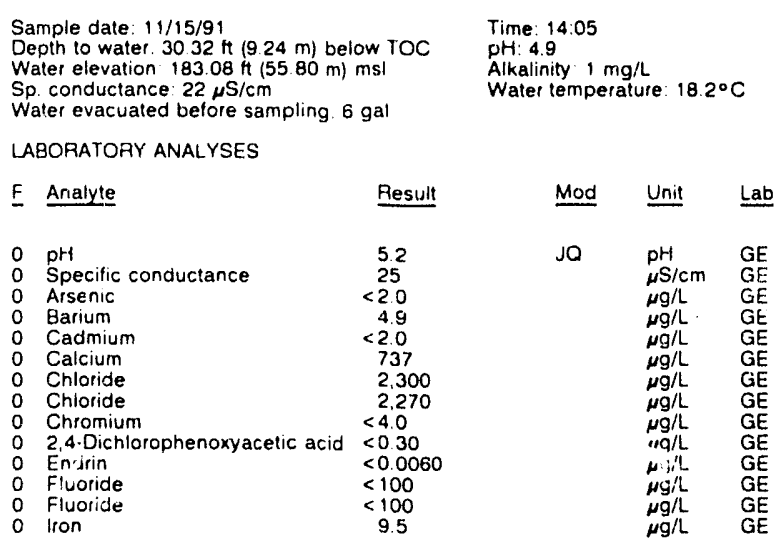




\section{ANALYTICAL RESULTS}

WELL SSS 6 collected on 11/15/91, laboratory analyses (cont)

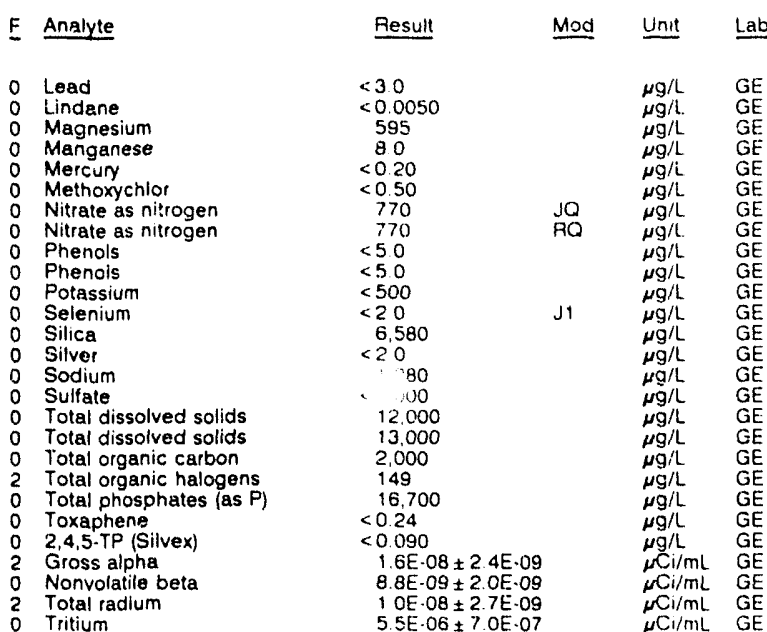

\section{WELL SSS 7}

MEASUREMENTS CONOUCTED IN THE FIELO

Sample date: $11 / 13 / 91$
Inaccessibility or pump failure prevented sample collection

\section{WELL SSS 8}

MEASUREMENTS CONDUCTED IN THE FIELD

Time: 1530
inaccessibility or pump failure prevented sample collection.

WELL SSS 9

MEASUREMENTS CONDUCTED IN THE FIELDD

Sample date: $11 / 13 / 91$
Inaccessibulity or pump tailure prevented sample collection 1530

WELL SSS 10

MEASUREMENTS CONDUCTED IN THE FIELD

Sample date: 12/04/91

Depth to water: $71.30 \mathrm{ft}(21.73 \mathrm{~m})$ below TOC

Water elevation: $240.30 \mathrm{Ht}(7324 \mathrm{~m}) \mathrm{msl}$

Sp. conductance $47 \mu \mathrm{S} / \mathrm{cm}$
Water evacuated before sampling $5 \mathrm{gal}$

Alkalinity $1 \mathrm{mglt}$

Water temperature $168^{\circ} \mathrm{C}$

LABORATORY ANALYSES

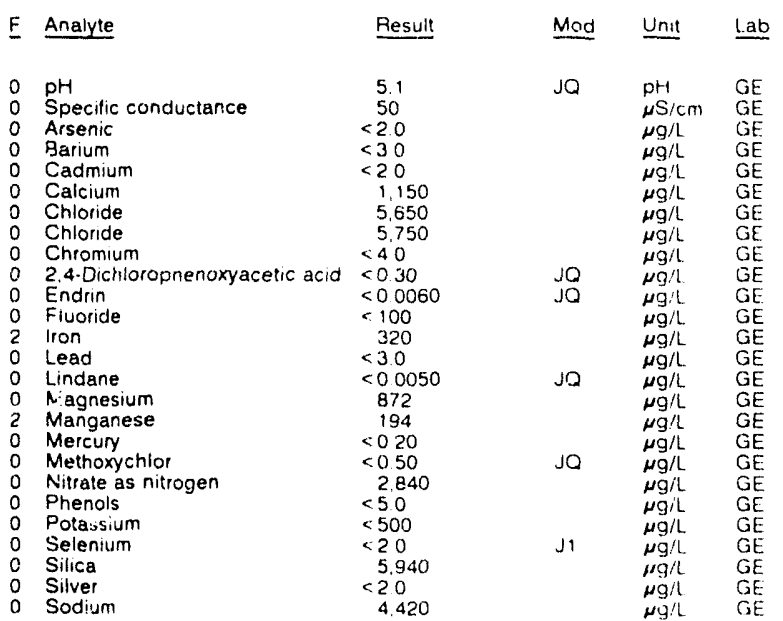

WELL SSS 10 collected on 12/04/91, laboratory analyses (cont.)

\begin{tabular}{|c|c|c|c|}
\hline Analyte & Result & Mod & Unit \\
\hline $\begin{array}{l}\text { Sulfate } \\
\text { Total dissolved solids } \\
\text { Total organic carbon } \\
\text { Total ogganic halogens } \\
\text { Total phosphates las P) } \\
\text { Toxaphene } \\
2,4,5 \cdot \text { TP (Silvex) } \\
\text { Gioss alpha } \\
\text { Nonvolatile beta } \\
\text { Total radium } \\
\text { Tritlum }\end{array}$ & $\begin{array}{l}<1,000 \\
32,000 \\
46.000 \\
<5.0 \\
10.900 \\
<0.24 \\
<0.090 \\
4.8 E \cdot 09 \pm 16 E \cdot 09 \\
5.2 E \cdot 09 \pm 1.8 E \cdot 09 \\
<1.0 E \cdot 09 \\
2.1 E \cdot 06 \pm 7.0 E-07\end{array}$ & $\begin{array}{l}\text { JO } \\
\text { JO }\end{array}$ & $\begin{array}{l}\mu g / L \\
\mu g / L \\
\mu g / L \\
\mu g / L \\
\mu g / L \\
\mu g / L \\
\mu g / L \\
\mu C i / m L \\
\mu C i / m L \\
\mu C i / m L \\
\mu C I / m L\end{array}$ \\
\hline
\end{tabular}

WELL SSS 11

MEASUREMENTS CONDUCTED IN THE FIELD

Sample date: $12 / 04 / 9$

Depth to da: $72 / 951$ Water elevater: $72.85 \mathrm{ft}(22.20 \mathrm{~m})$ below $\mathrm{rOC}$

Water elevation. $231.25 \mathrm{ft}(70.49 \mathrm{~m}) \mathrm{msl}$

Water evacuated before sampling. $1 \mathrm{gal}$

LABORATORY ANALYSES

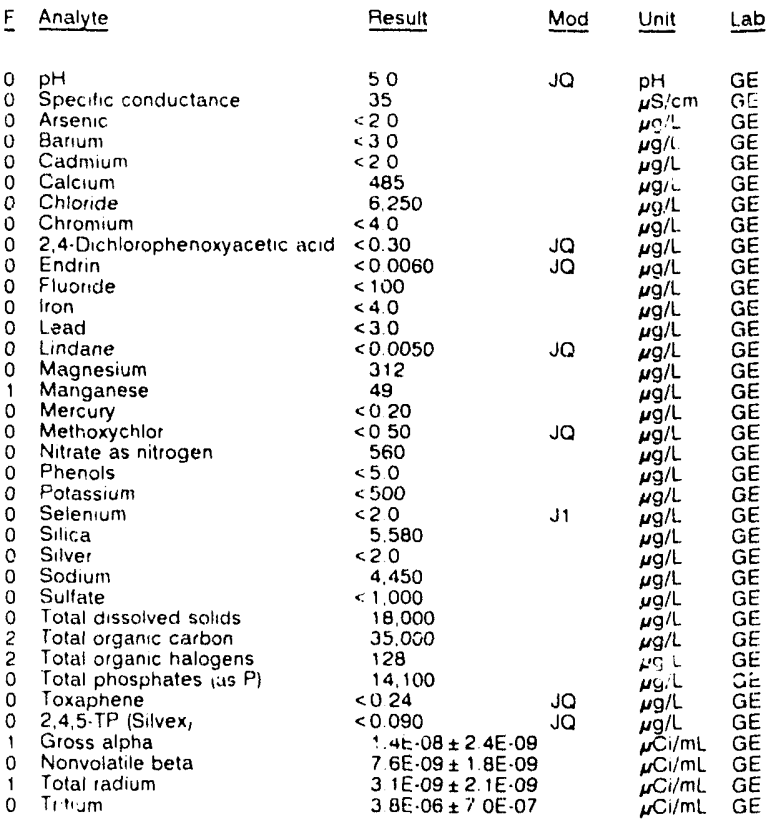

\section{WELL SSS 12}

MEASUREMENTS CONDUCTED IN THE FIELD

Sample date $12 / 04 / 91$
Depth to water $6883 \mathrm{H}(2098 \mathrm{~m})$ below TOC Time 1420
Water elevation $23347 \mathrm{ht}(71 \mathrm{16} \mathrm{m}) \mathrm{ms}$
inaccessibitity or pump farlure prevented sample collection

WELL SSS 17

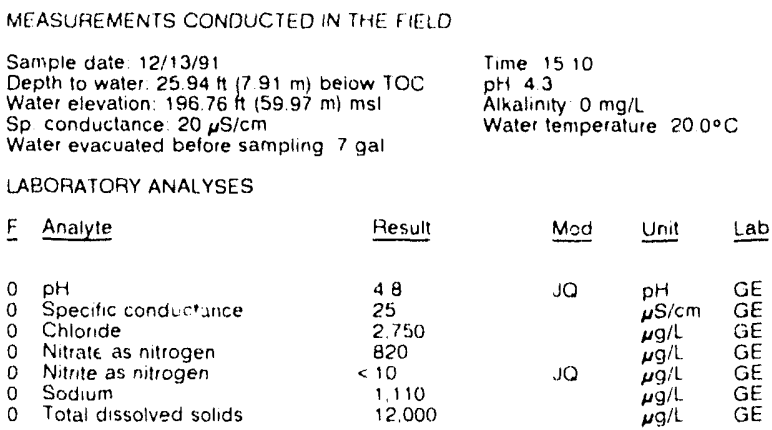


ANALYTICAL RESULTS

\section{WELL SSS 19}

MEASUREMENTS CONDUCTED IN THE FIELL

Sample date: $12 / 04 / 91$

Water elevation: $183.93 \mathrm{~h}(56.0$

Water evacuated before sampling: 4 gal

LABORATORY ANALYSES

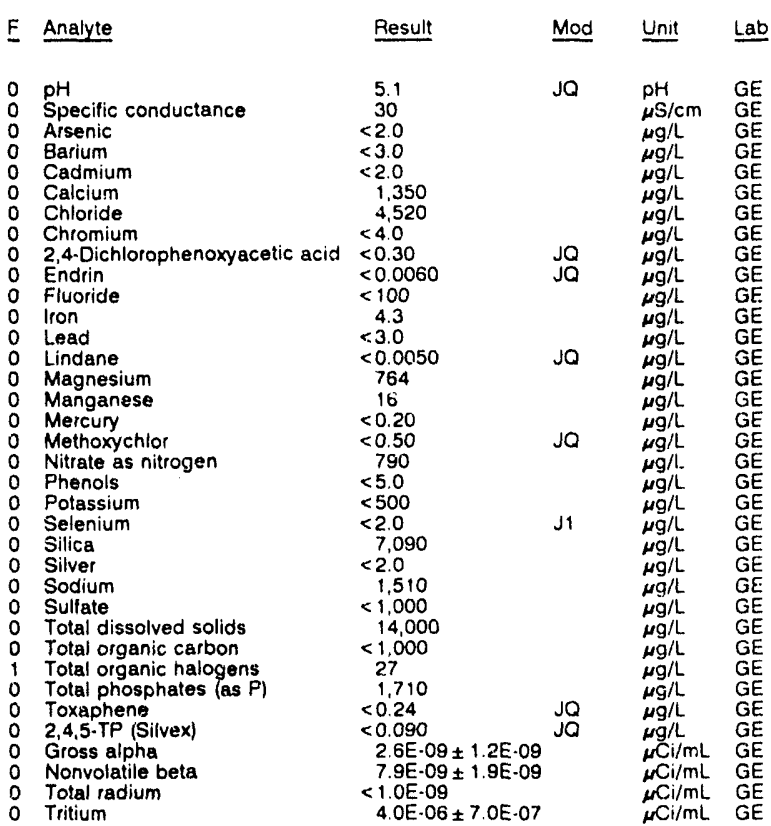

WELL SSS 20

MEASUREMENTS CONDUCTED IN THE FIELO

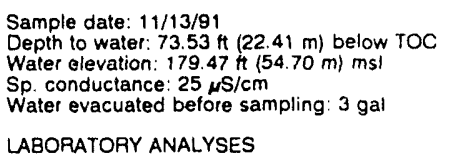

$$
\begin{aligned}
& \text { Time: } 14: 55 \\
& \text { pH: } 5.0 \\
& \text { Alkalinity: } 3 \mathrm{mg} / \mathrm{L} \\
& \text { Water temperature: } 17.5^{\circ} \mathrm{C}
\end{aligned}
$$

LABORATORY ANALYSES

\begin{tabular}{|c|c|c|c|}
\hline Analyte & Result & Mod & Unit \\
\hline Tritium & $E \cdot 0$ & & $\mathrm{Ci} / \mathrm{mL}$ \\
\hline
\end{tabular}

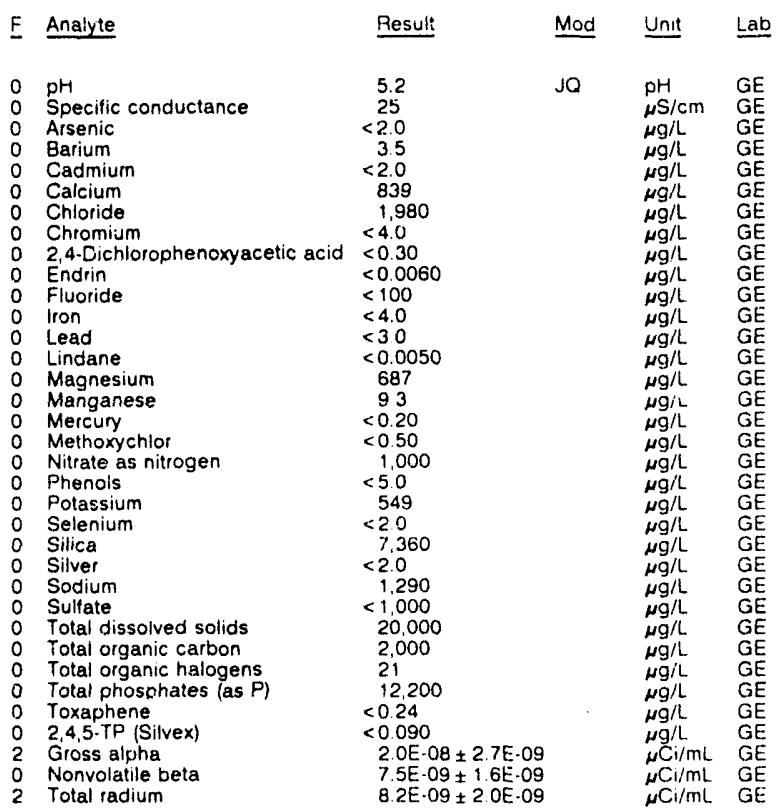

WELL SSS 20 collected on 11/13/91, laboratory analyses (cont.)

WELL SSS 21

MEASUREMENTS CONDUCTED IN THE FIELD

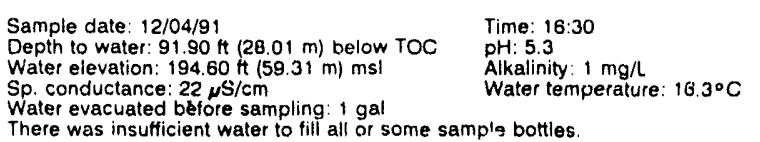

\begin{tabular}{|c|c|c|c|}
\hline Analyte & Result & Mod & Unit \\
\hline $\begin{array}{l}\text { pH } \\
\text { Specific conductance } \\
\text { Arsenic } \\
\text { Barium } \\
\text { Cadmium } \\
\text { Calcium } \\
\text { Chloride } \\
\text { Chromium } \\
\text { Fluoride } \\
\text { lron } \\
\text { Lead } \\
\text { Magnesium } \\
\text { Manganese } \\
\text { Mercury } \\
\text { Nitrate as nitrogen } \\
\text { Phenols } \\
\text { Potassium } \\
\text { Selenium } \\
\text { Silica } \\
\text { Silver } \\
\text { Sodium } \\
\text { Sulfate } \\
\text { Total dissolved solids } \\
\text { Total organic carbon } \\
\text { Total organic halogens } \\
\text { Total phosphates (as P) } \\
\text { Gross alpha } \\
\text { Nonvolatile beta } \\
\text { Total radium } \\
\text { Tritium }\end{array}$ & $\begin{aligned} & 5.2 \\
& 30 \\
&<2.0 \\
&<3.0 \\
&<2.0 \\
& 923 \\
& 6.250 \\
&<4.0 \\
&<100 \\
&<4.0 \\
&<3.0 \\
& 396 \\
& 13 \\
&<0.20 \\
& 92 \\
&<5.0 \\
&<500 \\
&<2.0 \\
& 11.100 \\
&<2.0 \\
& 2.240 \\
&<1.000 \\
& 16.000 \\
&<1.000 \\
& 18 \\
& 9.900 \\
& 1.2 E-08 \pm 2.3 E-09 \\
& 6.4 E-09 \pm 2.0 E-09 \\
& 2.0 E-09 \pm 1.8 E-09 \\
& 2.2 E \cdot 06 \pm 7.0 E \cdot 07\end{aligned}$ & Jo & $\begin{array}{l}\mathrm{pH} \\
\mu \mathrm{S} / \mathrm{cm} \\
\mu \mathrm{g} / \mathrm{L} \\
\mu \mathrm{g} / \mathrm{L} \\
\mu \mathrm{g} / \mathrm{L} \\
\mu \mathrm{g} / \mathrm{L} \\
\mu \mathrm{g} / \mathrm{L} \\
\mu \mathrm{g} / \mathrm{L} \\
\mu \mathrm{g} / \mathrm{L} \\
\mu \mathrm{g} / \mathrm{L} \\
\mu \mathrm{g} / \mathrm{L} \\
\mu \mathrm{g} / \mathrm{L} \\
\mu \mathrm{g} / \mathrm{L} \\
\mu \mathrm{g} / \mathrm{L} \\
\mu \mathrm{g} / \mathrm{L} \\
\mu \mathrm{g} / \mathrm{L} \\
\mu \mathrm{g} / \mathrm{L} \\
\mu \mathrm{g} / \mathrm{L} \\
\mu \mathrm{g} / \mathrm{L} \\
\mu \mathrm{g} / \mathrm{L} \\
\mu \mathrm{g} / \mathrm{L} \\
\mu \mathrm{g} / \mathrm{L} \\
\mu \mathrm{g} / \mathrm{L} \\
\mu \mathrm{g} / \mathrm{L} \\
\mu \mathrm{g} / \mathrm{L} \\
\mu \mathrm{g} / \mathrm{L} \\
\mu \mathrm{Ci} / \mathrm{mL} \\
\mu \mathrm{Ci} / \mathrm{mL} \\
\mu \mathrm{Ci} / \mathrm{mL} \\
\mu \mathrm{Ci} / \mathrm{mL}\end{array}$ \\
\hline
\end{tabular}

There was insufficient water to fill all or some samplo bottles.

LABORATORY ANALYSES

WELL SSS 22

MEASUREMENTS CONDUCTED IN THE FIELO

Sample date: 12/07/91 Depth to water: $46.76 \mathrm{Ht}(14.25 \mathrm{~m})$ below TOC Water elevation $244.14 \mathrm{ft}(74.41 \mathrm{~m}) \mathrm{ms}$ Sp. conductance: $23 \mu \mathrm{S} / \mathrm{cm}$

$\mathrm{pH}: 5.1$

Water evacuated before sampling: $15 \mathrm{gal}$

LABORATORY ANALYSES

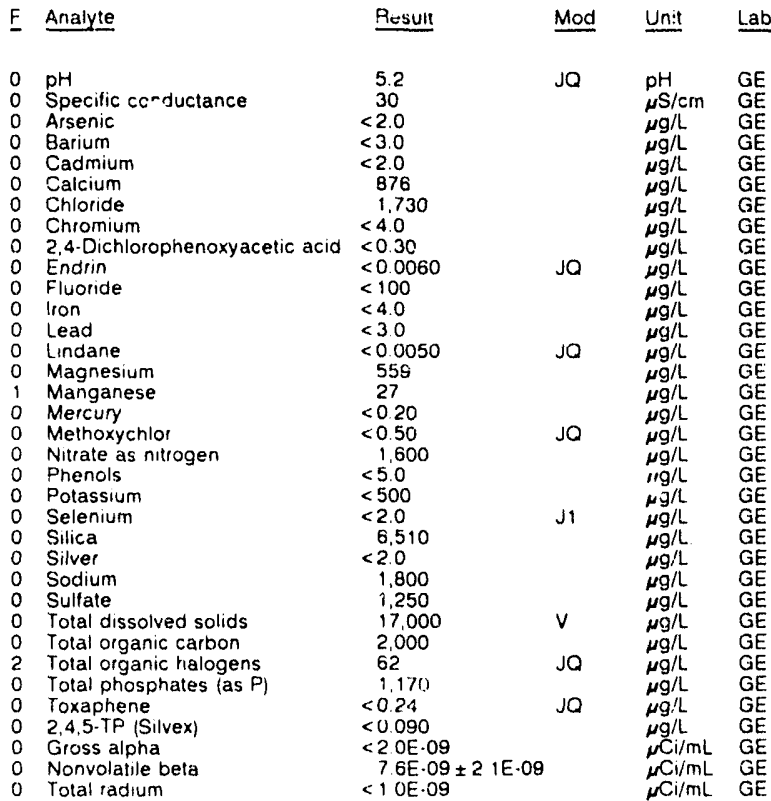




\section{ANALYTICAL RESULTS}

WELL SSS 22 collected on 12/07/91, laboratory analyses (cont)

$\begin{array}{lllll}\text { F Analyte } & \text { Result } & \text { Mod Unit } & \text { Lab } \\ 0 \text { Tritium } & 3.0 \mathrm{E} \cdot 06 \pm 7.0 \mathrm{E} \cdot 07 & \mu \mathrm{Ci} / \mathrm{mL}\end{array}$

WELL SSS 23

MEASUREMENTS CONDUCTED IN THE FIELD

Sample date: $12 / 07 / 91$ Depth to water: $49.11 \mathrm{ft}$ (14.97 m) below TOC Water elevation: $251.89 \mathrm{~h}(76.78 \mathrm{~m}) \mathrm{msl}$

LABORATORY ANALYSES

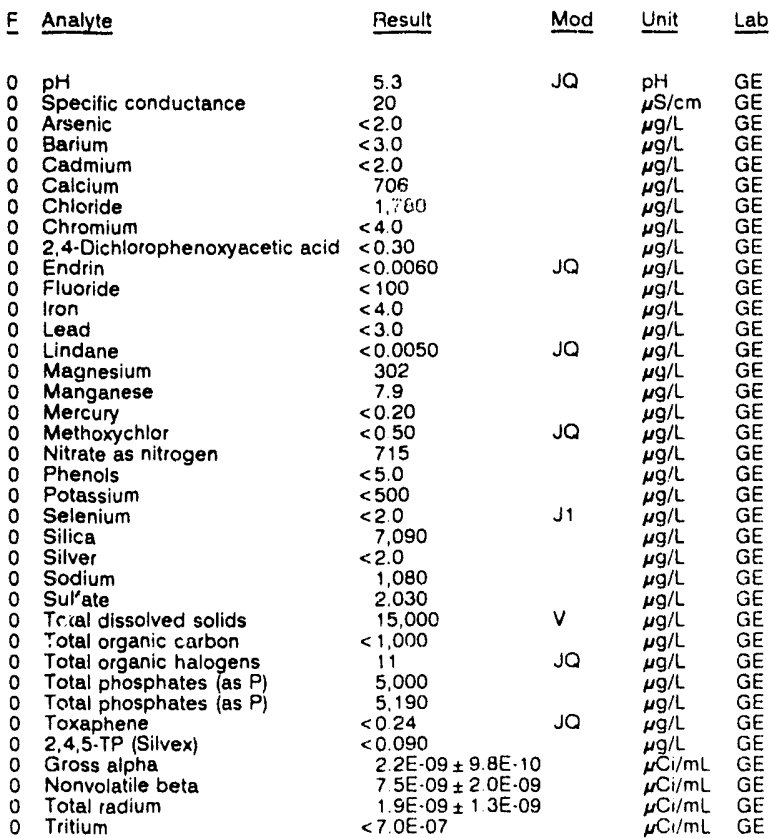

\section{WELL SSJ 24}

MEASUREMENTS CONDUCTED IN THE FIELD

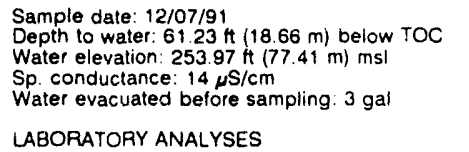

Time: $10: 10$
pH: 5.4

$1 \mathrm{mg} /$

Water temperature $170^{\circ} \mathrm{C}$

LABORATORY ANALYSES

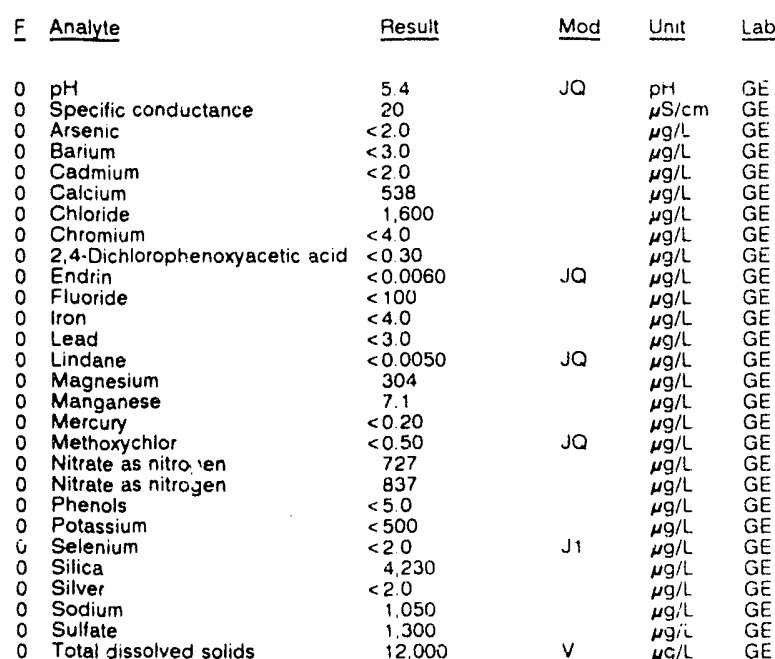

WELL SSS 24 collected on 12/07/91, laboratory enalyses (cont.)

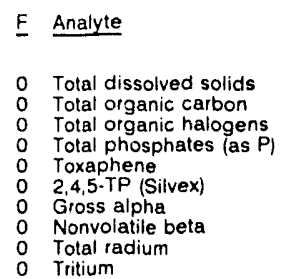

\begin{tabular}{|c|c|c|}
\hline Result & Mod & Unit \\
\hline $\begin{aligned} & 18,000 \\
&< 1.000 \\
& 8.0 \\
& 590 \\
&<0.24 \\
&<0.090 \\
& 2.2 \mathrm{E} \cdot 09 \pm 1.3 \mathrm{E} \cdot 09 \\
& 2.5 \mathrm{E}-09 \pm 1.6 \mathrm{E} \cdot 09 \\
&<1.0 \mathrm{E} \cdot 09 \\
& 2.7 \mathrm{E} \cdot 08 \pm 7.0 \mathrm{E} \cdot 07\end{aligned}$ & $\begin{array}{l}\mathrm{v} \\
\text { jo } \\
\text { jo }\end{array}$ & $\begin{array}{l}\mu \mathrm{g} / \mathrm{L} \\
\mu \mathrm{g} / \mathrm{L} \\
\mu \mathrm{g} / \mathrm{L} \\
\mu \mathrm{g} / \mathrm{L} \\
\mu \mathrm{g} / \mathrm{L} \\
\mu \mathrm{g} / \mathrm{L} \\
\mu \mathrm{Ci} / \mathrm{mL} \\
\mu \mathrm{Ci} / \mathrm{mL} \\
\mu \mathrm{Ci} / \mathrm{mL} \\
\mu \mathrm{Ci} / \mathrm{mL}\end{array}$ \\
\hline
\end{tabular}

\section{WELL SSS 25}

MEASUREMENTS CONDUCTED IN THE FIELD

Sample date. $12 / 13 / 91$

Water elevation: $185.12 \mathrm{ft}(56.43 \mathrm{~m}) \mathrm{msl}$

(a)

Water evacuated before sampling: $11 \mathrm{gal}$

Time: $16: 10$

Alkalinity: $16 \mathrm{mg} / \mathrm{L}$

Water temperature $20.4^{\circ} \mathrm{C}$

LABORATORY ANALYSES

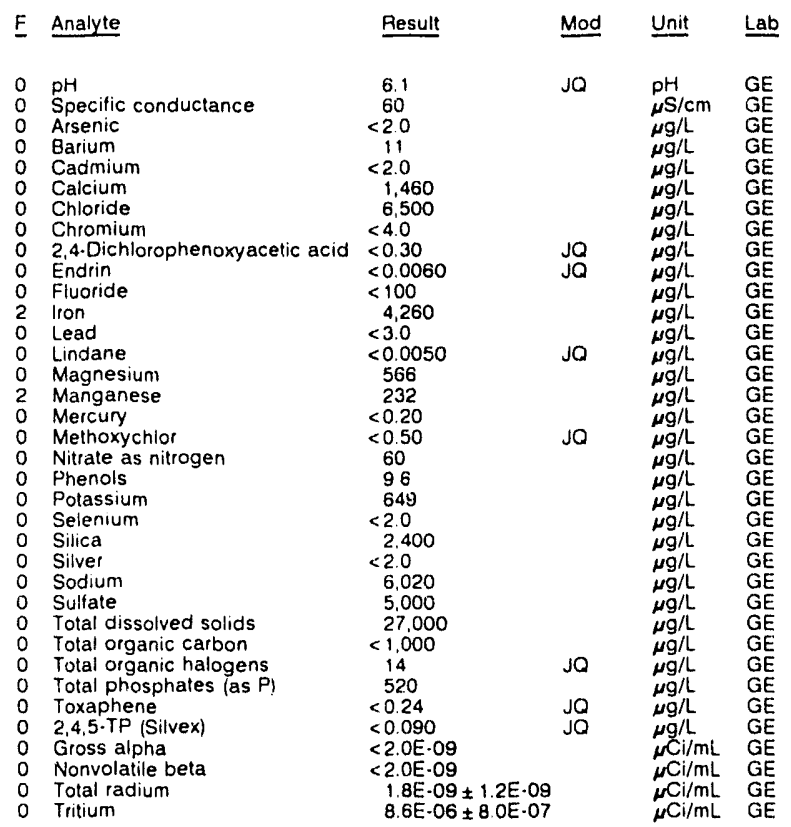

\section{WELL SSS 26}

MEASUREMENTS CONDUCTED IN THE FIELD

Sample date: $12 / 13 / 91$

Depth to wate $28.44 \mathrm{Ht}(8.67 \mathrm{~m})$ below TOC

Water elevation: $18616 \mathrm{ft} / 56$

Sp. conductance $40 \mu \mathrm{S} / \mathrm{cm}$

Water evacuated belore sampling 6 ga

LABORATORY ANALYSES

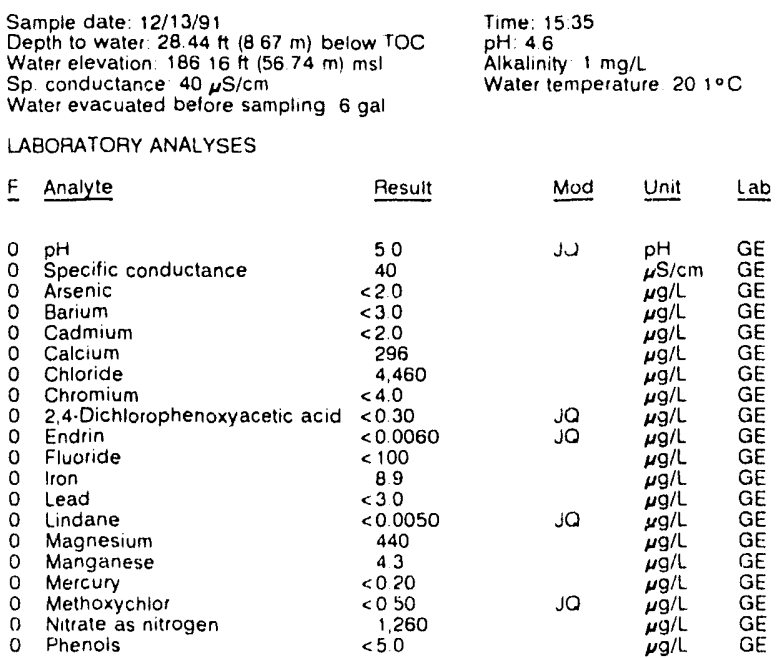


ANALYTICAL RESULTS

WELL SSS 26 collected on 12/13/91, laboratory analyses (cont.)

\begin{tabular}{|c|c|c|c|}
\hline Analyte & Result & Mod & Unit \\
\hline $\begin{array}{l}\text { Potassium } \\
\text { Selenium } \\
\text { Silica } \\
\text { Silver } \\
\text { Sodium } \\
\text { Sulfate } \\
\text { Total dissolved solids } \\
\text { Total organic carbon } \\
\text { Total organic halogens }\end{array}$ & $\begin{array}{l}<500 \\
<2.0 \\
4,310 \\
<2.0 \\
4,530 \\
3,200 \\
10,000 \\
<1,000 \\
38 \\
430\end{array}$ & JQ & 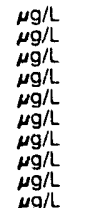 \\
\hline $\begin{array}{l}\text { Total phosphates (as P) } \\
\text { Toxaphene } \\
2,4,5-\mathrm{TP} \text { (Silvex) } \\
\text { Gross alpha } \\
\text { Nonvolatile beta } \\
\text { Total radium } \\
\text { Tritium }\end{array}$ & $\begin{array}{l}430 \\
<0.24 \\
<0.090 \\
<2.0 \mathrm{E} \cdot 09 \\
<2.0 \mathrm{E} \cdot 09 \\
2.1 \mathrm{E} \cdot 09 \pm 1.3 \mathrm{E} \cdot 09 \\
7.6 \mathrm{E}-06+7.0 \mathrm{E}-07\end{array}$ & $\begin{array}{l}\text { JO } \\
\text { Jo }\end{array}$ & $\begin{array}{l}\mu \mathrm{g} / \mathrm{L} \\
\mu \mathrm{g} / \mathrm{L} \\
\mu \mathrm{g} / \mathrm{L} \\
\mu \mathrm{C} / \mathrm{mL} \\
\mu \mathrm{Ni} / \mathrm{mL} \\
\mu \mathrm{Ci} / \mathrm{mL} \\
\mu \mathrm{Ci} / \mathrm{mL}\end{array}$ \\
\hline
\end{tabular}

\section{WELL SSS 27}

MEASUREMENTS CONOUCTED IN THE FIELD

\begin{tabular}{|c|c|c|c|c|c|c|}
\hline \multicolumn{3}{|c|}{$\begin{array}{l}\text { Sample date: } 12 / 13 / 91 \\
\text { Depth to water: } 38.89 \mathrm{H}(11.85 \mathrm{~m}) \text { below TOC } \\
\text { Water olevation } 174.91 \mathrm{ft}(53.31 \mathrm{~m}) \mathrm{ms} \\
\text { Sp. conductance: } 28 \mu \mathrm{s} / \mathrm{cm} \\
\text { Water evacuated betore sampling: } 10 \mathrm{gal}\end{array}$} & \multicolumn{4}{|c|}{$\begin{array}{l}\text { Time: } 16: 40 \\
\text { pH: } 4.4 \\
\text { Alkalinity: } 0 \mathrm{mg} / \mathrm{h} \\
\text { Water temperature: } 19.3^{\circ} \mathrm{C}\end{array}$} \\
\hline \multicolumn{7}{|c|}{ LABORATORY ANALYSES } \\
\hline$F$ & Analyte & Result & & Mod & Unit & $\underline{\text { Lab }}$ \\
\hline & $\begin{array}{l}\text { pH } \\
\text { Specific conductance } \\
\text { Arsenic } \\
\text { Barium } \\
\text { Cadmium } \\
\text { Calcium } \\
\text { Chloride } \\
\text { Chromium } \\
\text { 2,4-Dichlorophenoxyacetic acid } \\
\text { Endrin } \\
\text { Fluoride } \\
\text { ron } \\
\text { Lead } \\
\text { Lindane } \\
\text { Magnesium } \\
\text { Manganese } \\
\text { Mercury } \\
\text { Methoxychlor } \\
\text { Nitrate as nitrogen } \\
\text { Phenols } \\
\text { Potassium } \\
\text { Selenium } \\
\text { Silica } \\
\text { Silver } \\
\text { Sodium } \\
\text { Sulfate } \\
\text { Total dissolved solids } \\
\text { Total organic carbon } \\
\text { Total organic halogens } \\
\text { Total phosphates (as P) } \\
\text { Toxaphene } \\
\text { 2,4,5-TP (Silvex) } \\
\text { Gross alpha } \\
\text { Nonvolatile beta } \\
\text { Total radium } \\
\text { Tritium }\end{array}$ & $\begin{aligned} & 4.8 \\
& 30 \\
&<2.0 \\
&<3.0 \\
&<2.0 \\
& 212 \\
& 3,420 \\
&<4.0 \\
&<0.30 \\
&<0.0060 \\
&<100 \\
& 7.6 \\
&<3.0 \\
&<0.0050 \\
& 447 \\
& 4.2 \\
& 0.27 \\
&<0.50 \\
& 980 \\
&<5.0 \\
&<500 \\
&<2.0 \\
& 5,860 \\
&<2.0 \\
& 2.090 \\
& 1,330 \\
& 23.000 \\
& 2.000 \\
&<5.0 \\
& 4,325 \\
&<0.54 \\
&<C .090 \\
& 2.9 E \cdot 09 \pm \\
& 2.4 E \cdot 09 \pm \\
&<1.0 E \cdot 09 \\
& 6.8 E \cdot 06 \pm\end{aligned}$ & & $\begin{array}{l}\mathrm{JQ} \\
\mathrm{JQ}\end{array}$ & 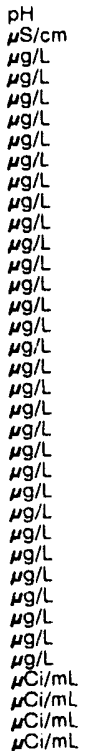 & $\begin{array}{l}\mathrm{GE} \\
\mathrm{GE} \\
\mathrm{GE} \\
\mathrm{GE} \\
\mathrm{GE} \\
\mathrm{GE} \\
\mathrm{GE} \\
\mathrm{GE} \\
\mathrm{GE} \\
\mathrm{GE} \\
\mathrm{GE} \\
\mathrm{GE} \\
\mathrm{GE} \\
\mathrm{GE} \\
\mathrm{GE} \\
\mathrm{GE} \\
\mathrm{GE} \\
\mathrm{GE} \\
\mathrm{GE} \\
\mathrm{GE} \\
\mathrm{GE} \\
\mathrm{GE} \\
\mathrm{GE} \\
\mathrm{GE} \\
\mathrm{GE} \\
\mathrm{GE} \\
\mathrm{GE} \\
\mathrm{GE} \\
\mathrm{GE} \\
\mathrm{GE} \\
\mathrm{GE} \\
\mathrm{GE} \\
\mathrm{GE} \\
\mathrm{GE} \\
\mathrm{GE} \\
\mathrm{GE}\end{array}$ \\
\hline
\end{tabular}

WELL TBG 1

MEASUREMENTS CONDUCTED IN THE FIELLD

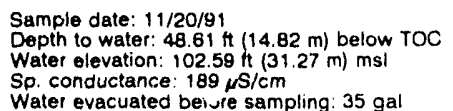

LABORATORY ANALYSES

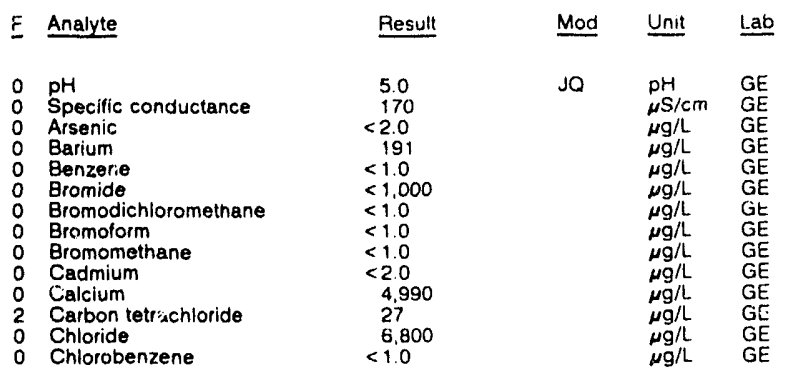

WELL TBG 1 collected on 11/20/91, laboratory analyses (cont.)

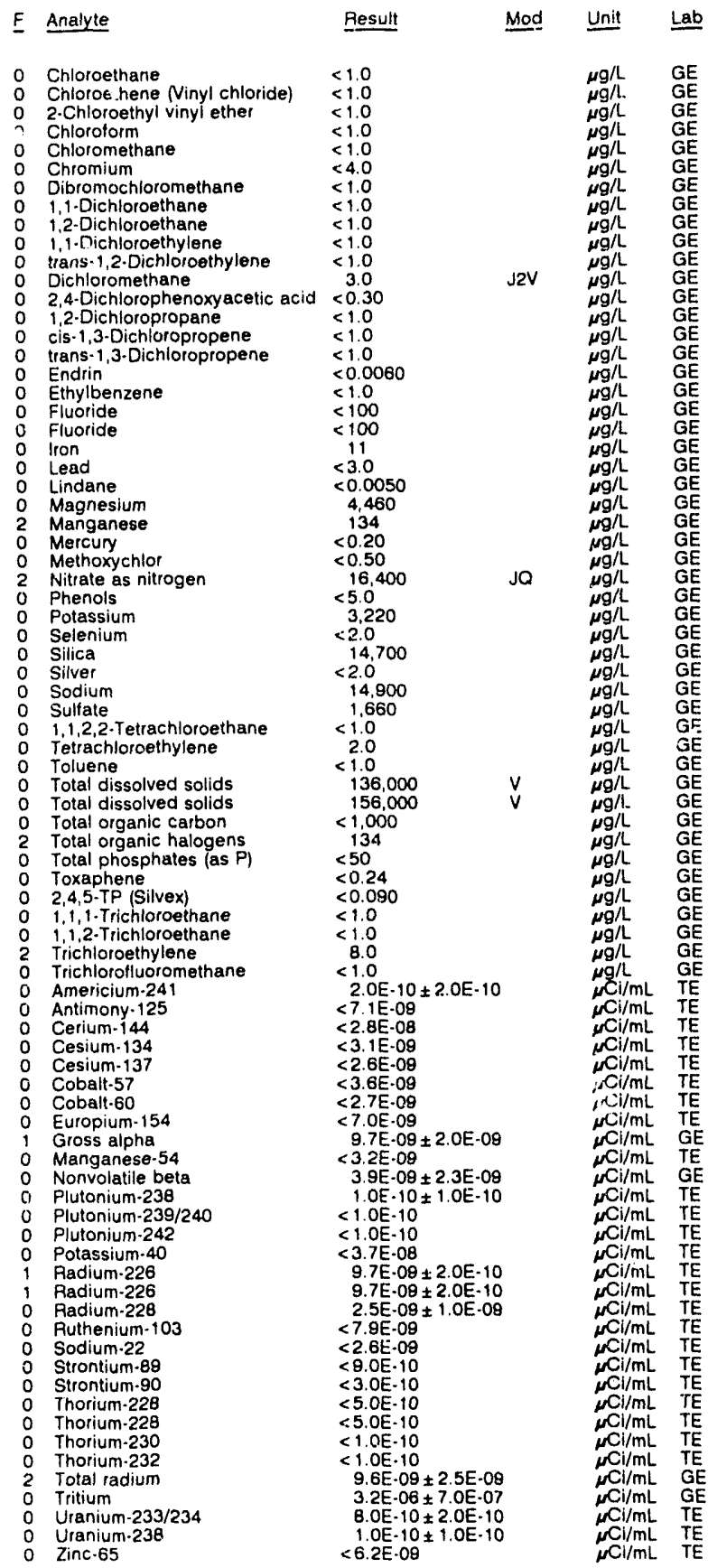

WELL TBG $5 A$

MEASUREMENTS CONDUCTED IN THE FIELD

Sample date: $11 / 20 / 91$

Depui ki water: 45.26 th $(13.80 \mathrm{~m})$ below TOC

LABORATORY ANALYSES

\begin{tabular}{|c|c|c|c|}
\hline F Analyte & Pesult & Mod & Unit \\
\hline $\begin{array}{ll}0 & \mathrm{pH} \\
0 & \text { Specific conductance } \\
0 & \text { Arsenic }\end{array}$ & $\begin{array}{r}5.4 \\
30 \\
<20\end{array}$ & Ja & $\begin{array}{l}\mathrm{pH} \\
\mu \mathrm{S} / \mathrm{cm} \\
\mu \mathrm{g} / \mathrm{h}\end{array}$ \\
\hline
\end{tabular}

Water elevation: $104.14 \mathrm{tt}(31.74 \mathrm{~m}) \mathrm{msl}$

Wi. cunductance: $37 \mu \mathrm{S} / \mathrm{cm}$

Water evacuated before sampling: $152 \mathrm{gal}$

Time: $6: 50$

pH: 4.8

Alkalinity: $2 \mathrm{mg} / \mathrm{L}$

Arsenic $\mu \mathrm{g} / \mathrm{L} \quad \mathrm{GE}$ 
ANALYTICAL RESULTS

WELL TBG $5 A$ collected on 11/20/91, lajoratory analyses (cont.)

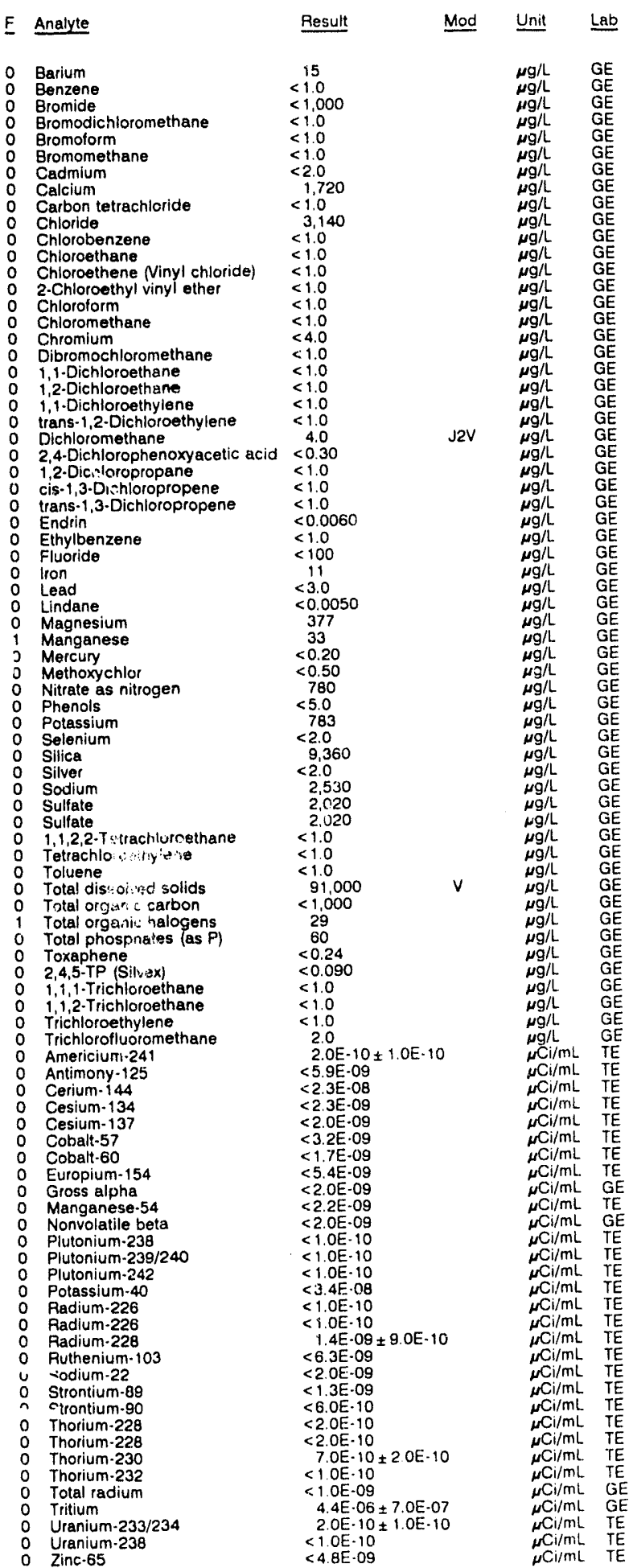

WELL TBG 5A Replicate

MEASUREMENTS CONDUCTEC IN THE FIELD

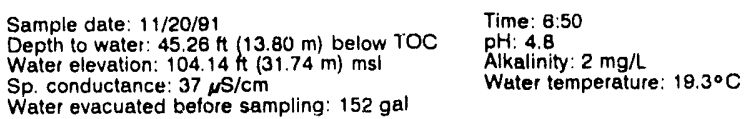

Water evacuated before sampling: $152 \mathrm{gal}$

LABORATORY ANALYSES

E Analyte Result Niod Unit

$0 \mathrm{pH}$

Specific conductance

0 Arsenic

o Benzene

Bromodichloromethane

Bromotorm

Bromomethane

0 Cadmium

Calcium

Carbon te

0 Chlorobenzene

Chloroethane

2-Chloroethyl vinyl ether

Chioroform

Chloromethane

Chromium

Result Niod Unit Lab

O Dibromochloromethane

1,1-Dichloroethane

1,2-Dichloroethane

1,1-Dichloroethylene
0 trans-1,2-Dichloroethylene

0 Dichloromethane

0 2,4-Dichlorophenoxyacetic acid

1,2-Dichloropropane

cis-1,3-Dichloropropene
trans-1,3-Dichloropropene

trans.

0 Ethylbenzene

Fluorid

lion

Lindane

Magnesium

Mercury

Methoxychlor
Nitrate as nitrogen

Phenols

Potassium

Silica

Silver

S Sulfate

- Tetrachloroethylene

Toluene

Total dissolved solids

Total organic carbon

Total organic halogens

Toxaphene

2,4,5-TP (Silvex)

1,1.1-Trichloroethane

1,1,2-Trichloroethan

- Trichloroethylene

0 Americium-24

O Antimony-125

Cesium-134

Cesium-137

Cobalt-57

Cobalt.60 154

Gross alpha

Manganese-54

Nonvolatile beta

Plutonium-238
Plutonium-239/240

Plutonium-242

Potassium-40

Radium-226

Radium-226
Radium-228

Radium-228
Ruthenium-103

Sodium-22

Strontium. 89

Strontium-90

Thorium.228

Thorium -230

Thorium-232

- Total radium $\begin{aligned} & 5.6 \\ & 30 \\ &<2.0 \\ & 15 \\ &<1.0 \\ &<1.000 \\ &<1.0 \\ &<1.0 \\ &<1.0 \\ &<2.0 \\ & 1.680 \\ &<1.0 \\ & 3.200 \\ &<1.0 \\ &<1.0 \\ &<1.0 \\ &<1.0 \\ &<1.0 \\ &<1.0 \\ &<4.0 \\ &<1.0 \\ &<1.0 \\ &<1.0 \\ &<1.0 \\ &<1.0 \\ & 4.0 \\ &<0.30 \\ &<1.0 \\ &<1.0 \\ &<1.0\end{aligned}$

$<<<0.0060$

$<1.0$

$<100$
11
$<3.0$

$<0.0050$

373

$<0.20$
$<0.50$
770

$<5.0$
755

$<2.0$

$<<2.00$

2,520
2,260

2,260
$<1.0$
1.0

$\begin{aligned} & 1.0 \\ <1.0 & \end{aligned}$

$<1,000$

15
$<50$

$<0.24$

$<0.090$

$<1.0$

$<1.0$

$<1.0 \mathrm{E} \cdot 10$

$<8.2 E \cdot 09$

$<3.2 \mathrm{E}-08$

$<3.2 E-09$

$<1.9 E-00$

$<1.0 \mathrm{E}-00$

$<2.0 E-09$

$<3.0 E .09$

$<3.0 \mathrm{E}-10$

$<1.0 \mathrm{E} \cdot 10$

2. OE-10 $2.0 \mathrm{E}-10$

$<7.3 \mathrm{E} .08$

$<1.0 E \cdot 10$

$<1.0 E \cdot 10+1.0 \mathrm{C}-09$

$\begin{array}{r}1.6 \mathrm{E}-09 \\ <1.1 \mathrm{E}-08 \\ \hline\end{array}$

$<3.8 \mathrm{E} \cdot 0$

$<8.06 \cdot 10$

$<3.0 E-10$
$<2.0 E-10$

$<2.0 \mathrm{E}-10$

$<1.0 E-10$

$<1.0 E-10$
JQ $\quad \underset{\mu H}{\mathrm{pH} / \mathrm{cm}} \quad \mathrm{GE}$

$\mu \mathrm{s} / \mathrm{cm}$ GE

$\begin{array}{ll}\mu g / L & G E \\ \mu g / \mu & G E\end{array}$

$\mu g / L \quad G E$ 
ANALYTICAL RESULTS

WELL TBG 5A collected on 11/20/91. laboratory analyses (cont.)

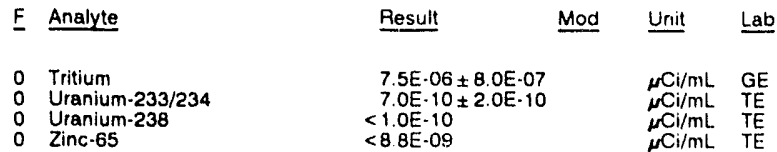

WELL TBG 5B

MEASUREMENTS CONDUCTED IN THE FIELD

Sample date: 11/20/91

Depth to water: $34.83 \mathrm{ft}(10.62 \mathrm{~m})$ below TOC

Water elevation: $115.17 \mathrm{tt}$ ( 35

Water evacuated before sampling: $119 \mathrm{gal}$

LABORATORY ANALYSES

F Analyte Result Mod Unit Lab

$\begin{array}{ll}\mathrm{pH} \\ 0 & \text { Specific conductance }\end{array}$

0 Arsenic

Barium

Bromide

Bromodichloromethane

Bromoform

Cadmium

Carbon tetrachloride

Chlorobenzene

Chloroethane

Chloroethene Ninyl chloride!

2.Chloroethyl vinyl ether

Chloroform

o Chrornium

$\begin{array}{ll} & <1.0 \\ \text { nyl vinyl ether } & <1.0 \\ \text { ane } & <1.0\end{array}$

Dibromochloromethane $<4.0$

1,1-Dichloroethane $<1.0$

1,2-Dichl rethane

0
0
0 trans-1,2-Dichloroethylene

Dichloromethane

2,4-Dichlorophennxvacetic acid

1,2-Dichloropropane

cis-1,3-Dichloropropenr
trans-1,3-Dichloropropent

Endrin

O Ethylbenzene

Fluoride

2 Lead

0 Lindane

Magnesium

Manganese

Methoxychlo

Nitrate as nitrogen

Phenols

Selenium

Silica

Silver

Sodium

${ }_{0}$ Sulfate $1,1,2,2$-Tetrachloroethane

Tetrachloroethylene

Toluene

Total dissolved solioss

Total organic carbon

- Total organic carbon

${ }_{0}$ Total organic halogens

- Toxaphene

2,4,5-TP (Silvex)

1,1,1-Trichloroethane

1,1,2-Trichloroethan

Trichlorethylene
Trichlorofluoromethane

Americium-241

Cerium- 144

Cesium-134

Cesium-10r

Cobalt -57

Europium-154

Gross alpha

Manganese.54

Plutonium -238

Plutonium-239/240

Plutonium-242

Potassium-40

Radium-226

\section{Time: 6:20}

Alkalinity: $2 \mathrm{mg}$

5.5
30
$<2.0$
17

$<1.0$

$<1.0$
$<1.0$

$<1.0$
$<2.0$

$<2.0$
1.990

1.0
1,820

$<1.0$

$<1.0$

$<: 0$
$<1.0$

$<1.0$
$<1.0$

$<1.0$

3.0
$<0.30$

$<1.0$
$<1.0$

$<1.0$

$<0.006$

$<1.0$
$<100$

426

$<3.0$
$<0.0050$

$\begin{aligned} & 634 \\ & 14 \\ &<0.20\end{aligned}$

$<0.20$

$\begin{array}{rl} & 77 \\ <5 & 5.0\end{array}$

$<5.0$
1.080

1,080
$<2.0$

24.000

$<2.0$

7,650

$<1.0$

$<1.0$

64,000

$<1,000$
$<1,000$

13
$<50$

$<0.24$

$<0.090$

$<1.0$

$<10$

$<1.0$

$<4.0 E-10$

$<6.8 E .09$

$<3.4 E-09$

$<3.4 E-09$
$<3.0 E-09$

$<2.6 \mathrm{E}-09$

$<3.3 \mathrm{E}-09$

$<3.3 E-09$
$<1.0 E-08$

2.2E.09 $01.0 \mathrm{OE} \cdot 09$

$<3.2 \mathrm{E}-09$

$<2.0 \mathrm{E} \cdot 09$
$<1.0 \mathrm{E} \cdot 10$

$<1.0 E \cdot 10$

$1.0 E-10 \pm 1.0 E-10$

$<4.8 E-08$

$<1.0 E \cdot 10$
$<1.0 E \cdot 10$
Water temperature: $19.3^{\circ} \mathrm{C}$
JQ $\mathrm{pH} \quad \mathrm{GE}$

$\begin{array}{ll}\mu \mathrm{S} / \mathrm{cm} & \mathrm{GE} \\ \mu \mathrm{g} / \mathrm{L} & \mathrm{GE} \\ \mu \mathrm{g} / \mathrm{L} & \mathrm{GE}\end{array}$

$\mu \mathrm{g} / \mathrm{L} \quad \mathrm{GE}$

$\mu g / L \quad G E$

$\mu g / L \quad G E$

$\mu g / L \quad G E$

$\mu g / L \quad G E$

$\mu \mathrm{g} / \mathrm{L} \quad \mathrm{GE}$

$\mu g / L \quad G E$

$\mu g / L \quad G E$

$\mu g / L \quad G E$

$\mu g / L \quad G E$

$\mu g / L \quad G E$

$\mu g / L \quad G E$

J2V

$\mu g / L \quad G E$

$\mu g / L \quad G E$

$\mu g / L \quad G E$

$\mu \mathrm{g} / \mathrm{L} \quad \mathrm{GE}$

$\mu g / L \quad G E$

$\mu g / L \quad G E$

$\mu \mathrm{g} / \mathrm{h} \quad \mathrm{GE}$

$\mu \mathrm{g} / \mathrm{L} \quad \mathrm{GE}$

$\mu g / \mathrm{h} \quad \mathrm{GE}$

$\mu g / L \quad G E$

$\mu \mathrm{g} / \mathrm{L} \quad \mathrm{GE}$

$g / L \quad G E$

$g / L \quad G E$

$\begin{array}{ll}\mathrm{g} / \mathrm{L} & \mathrm{GE} \\ \mathrm{g} / \mathrm{L} & \mathrm{GE} \\ \mathrm{g} / \mathrm{L} & \mathrm{GE}\end{array}$

$\mathrm{g} / \mathrm{L} / \mathrm{G} \quad \mathrm{GE}$

$g / L \quad G E$

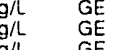

$\begin{array}{ll}G / L & G E \\ g / L & G E\end{array}$

$\mu \mathrm{Ci} / \mathrm{mL}$ TE

$\mathrm{Ci} / \mathrm{mL}$ TE

$\mathrm{Ci} / \mathrm{mL}$ TE

Ci/mL TE

TE

$\mathrm{Ci} / \mathrm{mL}$ GE

$\mathrm{Ci} / \mathrm{mL}$ TE

$\mathrm{Ci} / \mathrm{mL}$ TE

$\mathrm{Ci} / \mathrm{mL}$ T

$\begin{array}{ll}\mathrm{Ci} / \mathrm{mL} & T E \\ \mathrm{Ci} i / \mathrm{mL} & T E \\ & \end{array}$ $\mathrm{g} / \mathrm{L}$ GE

Ci/mL TE
WELL TBG 5 B collected on 11/20/91, laboratory analyses (cont.)

$\begin{array}{ll}\text { E } & \text { Analyte } \\ 0 & \text { Radium-228 } \\ 0 & \text { Ruthenium-103 } \\ 0 & \text { Sodium-22 } \\ 0 & \text { Strontium-89 } \\ 0 & \text { Strontium-90 } \\ 0 & \text { Thorium-228 } \\ 0 & \text { Thorium-228 } \\ 0 & \text { Thorium-230 } \\ 0 & \text { Thorium-232 } \\ 0 & \text { Total radium } \\ 0 & \text { Tritium } \\ 0 & \text { Uranium-233/234 } \\ 0 & \text { Uranium-238 } \\ 0 & \text { Zinc-65 }\end{array}$

Result
$1.1 \mathrm{E}-09 \pm 1.0 \mathrm{E} \cdot 10$
$<9.6 \mathrm{E} \cdot 09$
$<3.8 \mathrm{E} \cdot 09$
$<9.0 \mathrm{E} \cdot 10$
$<4.0 \mathrm{E} \cdot 10$
$2.0 \mathrm{E} \cdot 10 \pm 2.0 \mathrm{E} \cdot 10$
$2.0 \mathrm{E} \cdot 10 \pm 2.0 \mathrm{E} \cdot 10$
$2.0 \mathrm{E} \cdot 10 \pm 1.0 \mathrm{E} \cdot 10$
$<1.0 \mathrm{E} \cdot 10$
$<1.0 \mathrm{E} \cdot 09$
$6.8 \mathrm{E}-06 \pm 8.0 \mathrm{E} \cdot 07$
$<1.0 \mathrm{E} \cdot 10$
$<1.0 \mathrm{E} \cdot 10$
$<9.2 \mathrm{E}-09$

Mod Unit Lab

WELL TBG 7

MEASUREMENTS CONDUCTED IN THE FIELD

Sample date: $11 / 20 / 91$

Depth to water: $39.16 \mathrm{ft}(11.94 \mathrm{~m})$ below TOC

Water elevation: $107.64 \mathrm{ft}(32.81 \mathrm{~m}) \mathrm{ms}$

Water evacuated before sampling: $60 \mathrm{gal}$

Alkalinity: $10 \mathrm{mg} / \mathrm{L}$

Water temperature: $20.5^{\circ} \mathrm{C}$

LABORATORY ANALYSES

E Analyte Result

$0 \mathrm{pH}$

Specific conductance

0 Arsenic

0 Barium

Benzene

Bromide

Bromoform

Bromomethane

Cadmium

Carbon tetrachlorid

Carbon

Chlorobenzene

Chloroethane

Chloroethene Ninyl chloride
0

2-Chloroethy

Chlorotorm

- Chlorometh

- Dibromochloromethane

1,1.Dichloroethane

1,2. Dichlornethane

trans-1,2-Dichloroethylene

Dichloromethane

2.4-Dichlorophenoxy

1,2-Dichloropropane

o cis-1,3-Dichloropropene

0 Endrin

Ethylbenzene

Fluoride

Iron

Lead

Magnesium

Manganese

Mercury

Nitrate as nitrogen

Phenols

Potassium

Selenium

Sitica

Silver

Sodium

1,1,2,2-Tetrachloroethane

Tetrachloroethylene

Toluene

Total dissolved solids

Total organic carbon

Total organic halogens

Total phosphates (as P)

Toxaphene
$2,4.5-$ TP (Silvex)

2,4,5-TP (Silvex)
$1,1,1$-Trichloroethane

1,1,2-Trichloroethane

Trichloroethylene

Trichlorofluoromethane

Americium-241

Antimony-125

Cerium-144

Cesium-134
Cesium-137

Cobalt-57

Coball-60

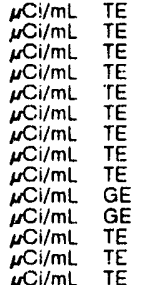


ANALYTICAL RESULTS

WELL TBG 7 collected on 11/20/9 1, laboratory analyses (cont.)

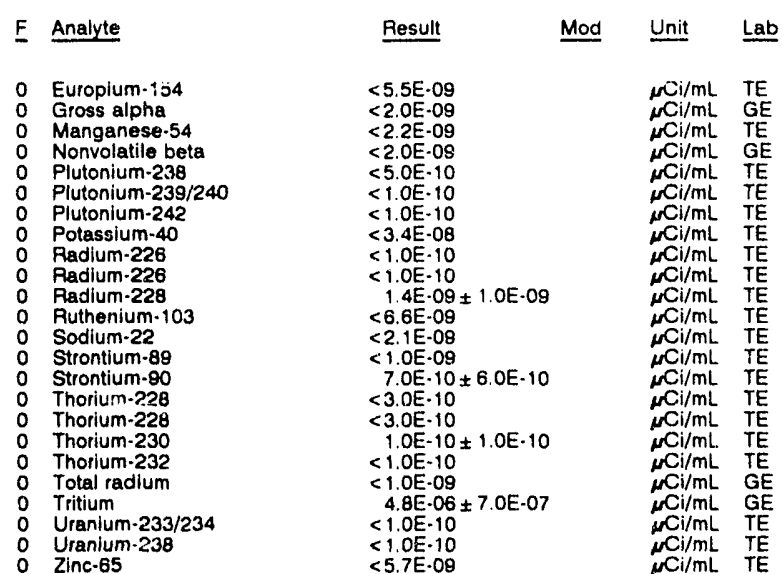

WELL. TNX 1D

MEASUREMENTS CONOUCTED IN THE FIELD

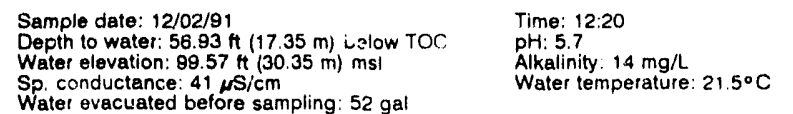

Water evacuated before sampling: 52 gal

LABORATORY ANALYSES

E Analyte Result Mod Unit Lab

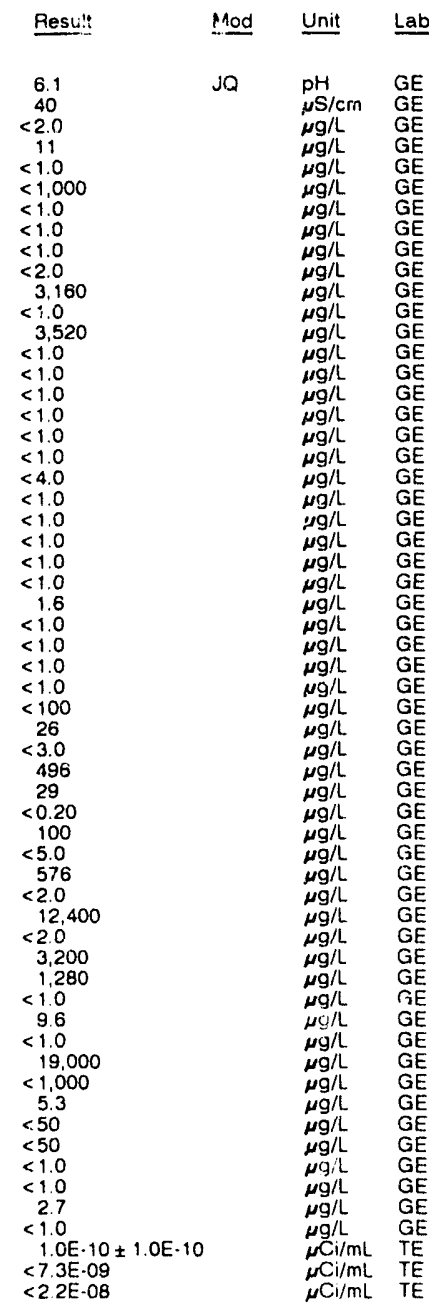

WELL TNX 10 collected on 12/02/81, laboratory analyses (cont)

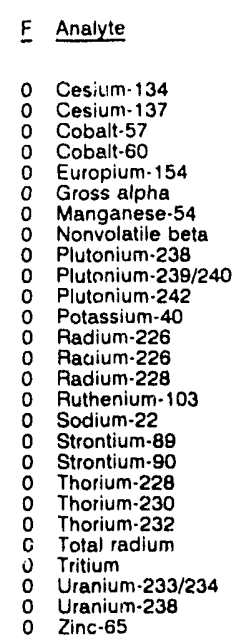

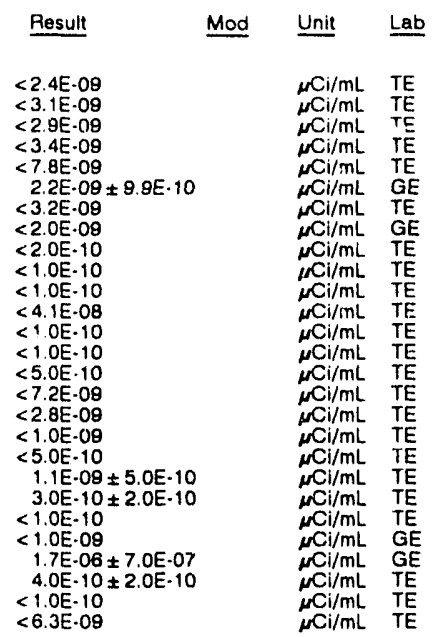

WELL TNX 2D

MEASUREMENTS CONDUCTED IN THE FIELD

Sample date: $12 / 02 / 91$

Depth to water: $55.63 \mathrm{H}(16.96 \mathrm{~m})$ below TOC

Water elevation: $99.47 \mathrm{tt}(30.32 \mathrm{~m}) \mathrm{msl}$

Sp. conductance: $65 \mu \mathrm{S} / \mathrm{cm}$
Water evacuated before sampling: $44 \mathrm{gal}$

LABORATORY ANALYSES

E Analyte Result Mod I'nit Lab

$\stackrel{\mathrm{pH}}{\mathrm{pH}} \mathrm{Specific} \mathrm{conductance}$

Arsenic

0 Barium

Benzene

Bromide
0 Bromodichloromethane

Bromoform

Bromomethane

Cadmium

Calcium

Chloride

Chloride
Chleride

o Chlorobenzene

Chloroethane

Chloroethen:- Ninyl chloride

2-Chloroethyl viny, ethe

Chlororm

Chloromethane

Chromium

Dibromochloromethane

1,1-Dichloroethane

1,2-Dichloroethane

0
0
0
trans-1,2-Dichloroethylene

0
0
0

0 1,2-Dichloropropane

$\begin{array}{ll}0 & \text { cis-1,3.Dichloropropene } \\ 0 & \text { trans-1,3-Dichloropropene }\end{array}$

0 Ethylbenzene

0 Fluoride

0 Iron

0 Lead

2 Magnesium

2 Mangan

Nitrate as nitrogen

Nitrate as nitrogen

0 Phenols

0 Potassium

Selenium

Silica

Silver

O Sodium

Sulfate

Sulfate

Tetrachloroethyiene

0 Toluene

Toluene
Tutal dissolved sclids

T Total organic carbon

Total organic halogens

o Total phosphates las $P$
Time: $11: 30$

pH: 5.5

Alkalinity: $13 \mathrm{mg}$

Water temperature: $21.7^{\circ} \mathrm{C}$

Mesult Lod L'nit Lab

5.9 JO

60
$<2.0$
22

$<1.0$

$<1.0$

$<1.0$

4,0
4,600

4,600
$<1.0$
4,620

4,620
4,780

$<1.0$

$<1.0$

$<1.0$

$<4.0$

$<1.0$

$<1.0$

$<1.0$
$<1.0$

5.7
$<1.0$

$\div 1.0$

$<1.0$
$<1.0$
$<100$

$<100$

20
$<3.0$
708
85

85
$<0.20$
1.620

1,620
1,620

$<5.0$
995

995
$<2.0$
13.500

13,500
$<2.0$
5,980

5,980
3,360
3,510

$<10$

$<1.0$

37,000

$<1,000$
$<5.0$

$<50$
$<10$ 
ANALYTICAL RESULTS

WELL TNX 20 collocted on 12/02/91, laboratory analyses (cont.)

\begin{tabular}{|c|c|c|}
\hline Analyte & Result & Unit \\
\hline $\begin{array}{l}\text { 1,1,2-Trichloroethane } \\
\text { Trichloroethylene } \\
\text { Trichlorofluoromethane } \\
\text { Americium-24: } \\
\text { Antimony-125 } \\
\text { Corium-144 } \\
\text { Cesium-134 } \\
\text { Cosium-137 } \\
\text { Cobalt-57 } \\
\text { Cobalt-60 } \\
\text { Europium-154 } \\
\text { Gross alpha } \\
\text { Manganese-54 } \\
\text { Nonvolatile beta } \\
\text { Plutonium-236 } \\
\text { Plutonium-239/240 } \\
\text { Plutonium-242 } \\
\text { Potasslum-40 } \\
\text { Radium-226 } \\
\text { Radium-226 } \\
\text { Radium-2263 } \\
\text { Ruthenium-103 } \\
\text { Sodium-22 } \\
\text { Stritium-89 } \\
\text { Strontium- } 90 \\
\text { Thorium-228 } \\
\text { Thorium-228 } \\
\text { Thorium-230 } \\
\text { Thorium-232 } \\
\text { Total radium } \\
\text { Tritium } \\
\text { Uranium-233/234 } \\
\text { Uranium-238 } \\
\text { Zinc-65 }\end{array}$ & $\begin{array}{l}<1.0 \\
3.1 \\
<1.0 \\
<1.0 E \cdot 10 \\
<1.2 E-08 \\
<4.7 E \cdot 08 \\
<5.6 E \cdot 09 \\
<3.6 E \cdot 09 \\
<5.7 E \cdot 09 \\
<4.1 E \cdot 09 \\
<1.4 E \cdot 08 \\
<2.0 E \cdot 09 \\
<5.5 E \cdot 09 \\
<2.0 E-09 \\
<5.0 E \cdot 10 \\
<1.0 E \cdot 10 \\
<1.0 E \cdot 10 \\
<6.7 E \cdot 08 \\
<1.0 E \cdot 10 \\
<1.2 E-08 \\
<5.0 E \cdot 10 \\
<1.3 E \cdot 08 \\
<5.0 E-09 \\
<8.0 E \cdot 10 \\
<4.0 E \cdot 10 \\
<2.0 E \cdot 10 \\
<7.01 .09 \\
2.0 E \cdot 10 \pm 2.0 E \cdot 10 \\
<1.0 E \cdot 10 \\
<1.0 E \cdot 09 \\
4.2 E \cdot 06 \pm 7.0 E-07 \\
2.0 E \cdot 10 \pm 1.0 E \cdot 10 \\
<1.0 E \cdot 10 \\
<1.2 E-08\end{array}$ & 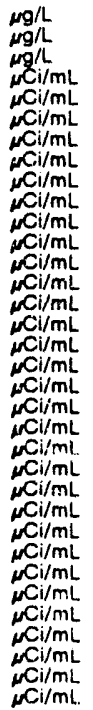 \\
\hline
\end{tabular}

\section{WELL TNX 2D Replicate}

MEASUAREMENTS CONDUCTED IN THE FIELD

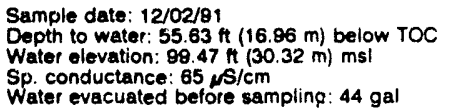

Time: $11: 30$

pH: 5.5

Water temperature: $21.7^{\circ} \mathrm{C}$

LABORATORY ANALYSES

\begin{tabular}{|c|c|}
\hline Analyte & Result \\
\hline 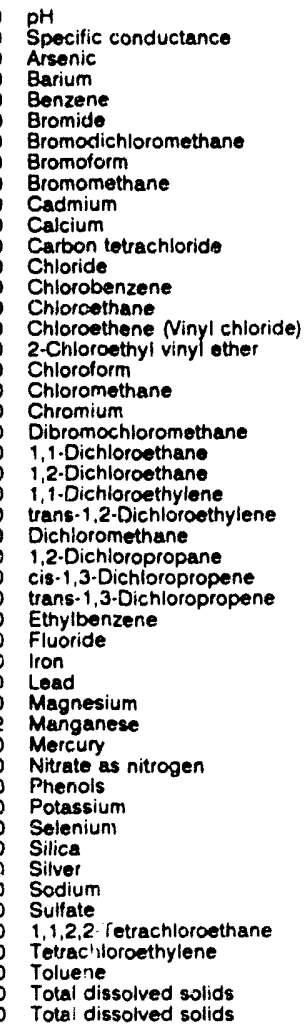 & $\begin{array}{l}6.0 \\
65 \\
<2.0 \\
23 \\
<1.0 \\
<1.000 \\
<1.0 \\
<1.0 \\
<1.0 \\
<2.0 \\
4.800 \\
<1.0 \\
51.040 \\
<1.0 \\
<1.0 \\
<1.0 \\
<1.0 \\
<1.0 \\
<1.0 \\
<4.0 \\
<1.0 \\
<1.0 \\
<1.0 \\
<1.0 \\
<1.0 \\
3.5 \\
<1.0 \\
<1.0 \\
<1.0 \\
<1.0 \\
<100 \\
20 \\
<3.0 \\
713 \\
88 \\
<0.20 \\
1.760 \\
<5.0 \\
899 \\
<2.0 \\
13.700 \\
<20 \\
6.000 \\
2.720 \\
<1.0 \\
<1.0 \\
<1.0 \\
35.000 \\
39.000\end{array}$ \\
\hline
\end{tabular}

Mod Unit Lab

JO ph GE
WELL TNX 20 collected on 12/02/9\%, laboratory analyses (cont.)
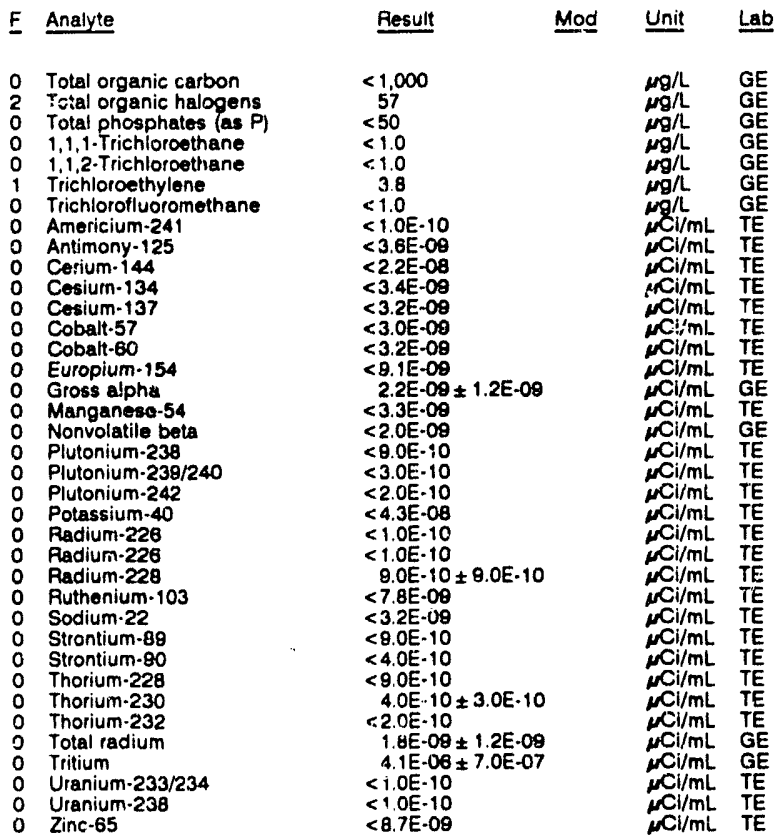

WELL TNX 3D

MEASUREMENTS CONDUCTED IN THE FIELD

Sample date: $12 / 03 / 91$ Depth to water: $54.06 \mathrm{Ht}(16.48 \mathrm{~m})$ below TOC Water elevation: $100.24 \mathrm{ft}(30.55 \mathrm{~m}) \mathrm{ms}$

Sp. conductance: $141 \mathrm{\mu S} / \mathrm{cm}$

Water evacuated before sampling: $12 \mathrm{gal}$

LABORATORY ANALYSES

E Analyte Result Mod Unit Lab

0 Ppecific conductance

Arsenic

Barium

Benzene

Bromide

Bromodichloromethane

Bromolorm

Bromometh

Cadmium

Carbon tetrachioride

Carbon

Chlorobenzen

Chloroethane

Chioroethene Ninyl chloride)

2-Chloroethyl vinyl ether

Chloroform

Chloromethane

Chromium

Dibromochloromethane

1,1-Dichloroethane

1,2-Dichloroethane

$1,1-D i c h i o r o e t h y l e n e$
0
trans-1,2-Dichloroethylene

trans-1,2-Dichloroeth

- 1,2-Dichloropropane

0
0
0

Ethylbenzene

0 Fluoride

o Iron

Lead

Manganese

Mercury

2 Nitrate as

o Phenols

0 Selenium

Silica

Silver

0 Sodium

1,1,2,2-Tetrachtorcethane

Tetrachloroethylene
Timn: $8: 15$

Alkalinity: $4 \mathrm{mg} /$

Water temperature: $21.0^{\circ} \mathrm{C}$ b

E

E

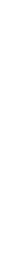

(n)


WELL TNX 3D collectod on 12/03/91, laboratory analyses (cont.)

\begin{tabular}{|c|c|c|c|c|}
\hline$\underline{\mathbf{F}}$ & Analyte & Result & Unit & Lab \\
\hline $\begin{array}{l}0 \\
0 \\
0 \\
2 \\
0 \\
0 \\
0 \\
2 \\
0 \\
0 \\
0 \\
0 \\
0 \\
0 \\
0 \\
0 \\
0 \\
1 \\
0 \\
n\end{array}$ & 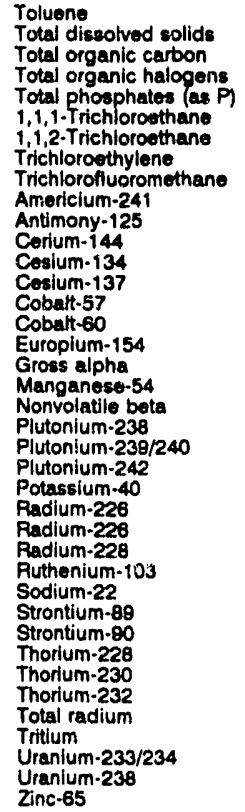 & 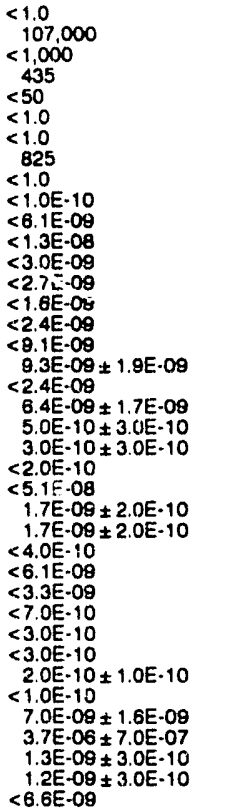 & 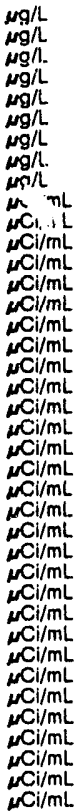 & $\begin{array}{l}G E \\
G E \\
G E \\
G E \\
G E \\
G E \\
G E \\
G E \\
G E \\
T E \\
T E \\
T E \\
T E \\
T E \\
T E \\
T E \\
T E \\
G E \\
T E \\
G E \\
T E \\
T E \\
T E \\
T E \\
T E \\
T E \\
T E \\
T E \\
T E \\
T E \\
T E \\
T E \\
T E \\
T E \\
G E \\
G E \\
T E \\
T E \\
T E\end{array}$ \\
\hline
\end{tabular}

\section{WELL TNX 4D}

MEASUREMENTS CONDUCTED IN THE FIELD

Sample date: 12/03/91 Dopth to water: $45.47 \mathrm{tt}(13.86 \mathrm{~m})$ below TOC Water elevation: $104.33 \mathrm{ft}(3 i .80 \mathrm{~m}) \mathrm{msl}$ Sp. conductance: $48 \mathrm{\mu s} / \mathrm{cm}$ The well went dy during purging: $14 \mathrm{gal}$

LABORATORY ANALYSES

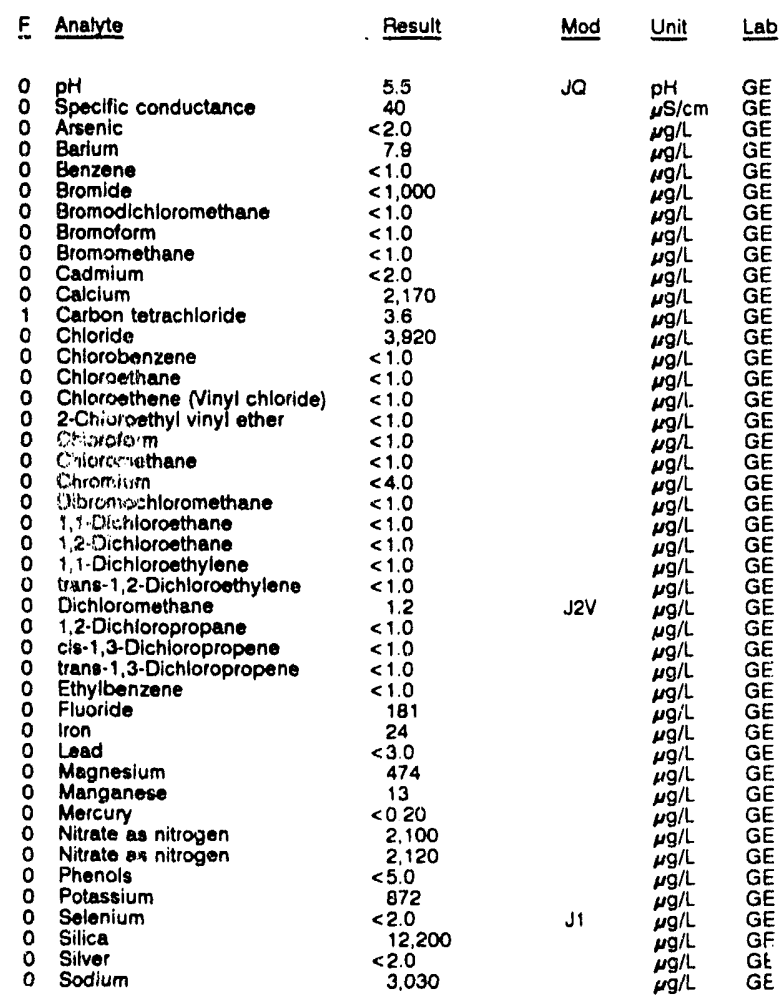

Time: $9: 35$

PH: 4.8 : $5 \mathrm{mg}$

Water temperature: $20.5 \circ \mathrm{C}$

ab

E

GE

WELL TNX 4D collected on 12/03/91, laboratory analyses (cont.)

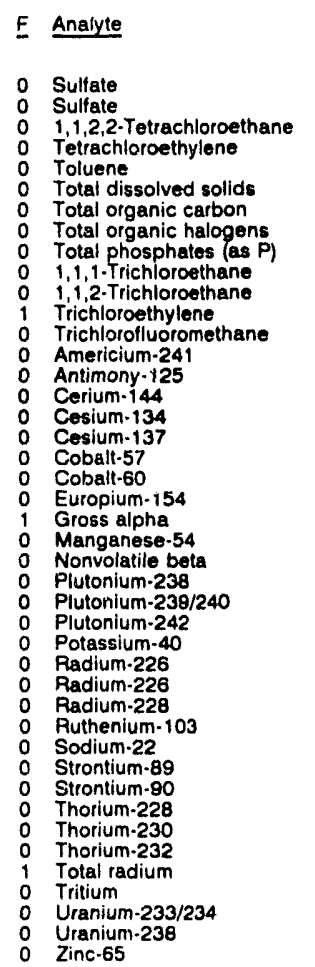

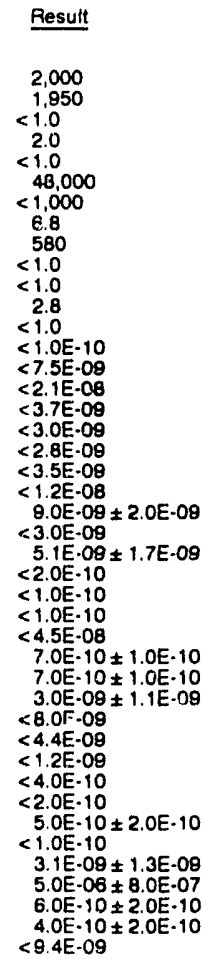

Mod Unit Lab

\section{WELL TNX 5D}

MEASUREMENTS CONDUCTEO IN THE FIELO

$\begin{array}{ll}\text { Sample date: } 12 / 03 / 91 & \text { Time: } 10: 00 \\ \text { Depth to water: } 42.52 \mathrm{~h}(12.96 \mathrm{~m}) \text { below TOC } & \text { pH: } 4.9 \\ \text { Water elevation: } 108.78 \mathrm{Ht}(32.55 \mathrm{~m}) \mathrm{ms} & \text { Alkalinity: } 3 \mathrm{mg} / \mathrm{h} \\ \text { Sp. conductance: } 136 \mathrm{HS} / \mathrm{cm} & \text { Water temperature: } 20.8^{\circ} \mathrm{C} \\ \text { Water evacuated before sampling: } 9 \mathrm{gal} & \\ \text { The well went dry during purging. } & \end{array}$

The well went dry during purging. $9 \mathrm{ga}$

LABORATORY ANALYSES

\begin{tabular}{|c|c|c|c|c|c|}
\hline$\underline{F}$ & Analyte & Result & Mod & Unit & Lab \\
\hline $\begin{array}{l}0 \\
0 \\
0 \\
0 \\
0 \\
0 \\
0 \\
0 \\
0 \\
0 \\
0 \\
0 \\
0 \\
0 \\
0 \\
0 \\
0 \\
0 \\
0 \\
0 \\
0 \\
0 \\
0 \\
0 \\
0 \\
0 \\
0 \\
0 \\
0 \\
0 \\
0 \\
0 \\
0 \\
0 \\
0 \\
0 \\
0 \\
0 \\
0 \\
1 \\
0 \\
0\end{array}$ & $\begin{array}{l}\text { pH } \\
\text { Specific conductance } \\
\text { Arsenic } \\
\text { Barium } \\
\text { Benzene } \\
\text { Bromide } \\
\text { Bromide } \\
\text { Bromodichloromethane } \\
\text { Bromoform } \\
\text { Bromomethane } \\
\text { Cadmium } \\
\text { Calcium } \\
\text { Carbon tetrachloride } \\
\text { Chloride } \\
\text { Chlorobenzene } \\
\text { Chloroethane } \\
\text { Chloroethene Ninyl chloride) } \\
\text { 2-Chloroethyl vinyl ether } \\
\text { Chloroform } \\
\text { Chloromethane } \\
\text { Chromium } \\
\text { Dibromochloromethane } \\
1,1 \text {-Dichloroethane } \\
1,2 \cdot \text {-Dichloroethane } \\
1,1 \cdot \text { Dichloroethylene } \\
\text { trans-1,2-Dichloroethylene } \\
\text { Dichloromethane } \\
\text { 1,2-Dichloropropane } \\
\text { cis-1,3-Dichloropropene } \\
\text { trans-1,3-Dichloropropene } \\
\text { Ethylbenzene } \\
\text { Fluoride } \\
\text { Iron } \\
\text { Lead } \\
\text { Magnesium } \\
\text { Manganese } \\
\text { Mercury } \\
\text { Nitrate as nitrogen } \\
\text { Phenols } \\
\text { Phenols }\end{array}$ & $\begin{aligned} & 5.4 \\
& 130 \\
&<2.0 \\
& 27 \\
&<1.0 \\
& 1.670 \\
& 1.920 \\
&<1.0 \\
&<1.0 \\
&<1.0 \\
&<2.0 \\
& 6.330 \\
&<1.0 \\
& 11.500 \\
&<1.0 \\
&<1.0 \\
&<1.0 \\
&<1.0 \\
& 41.3 \\
&<1.0 \\
&<4.0 \\
&<1.0 \\
&<1.0 \\
&<1.0 \\
&<1.0 \\
&<1.0 \\
&<1.0 \\
&<1.0 \\
&<1.0 \\
&<1.0 \\
&<1.0 \\
& 124 \\
& 43 \\
&<3.0 \\
& 1.150 \\
& 24 \\
&<0.20 \\
& 55.500 \\
&<5.0 \\
&<5.0\end{aligned}$ & $\mathrm{~J} 2 \mathrm{~V}$ & $\begin{array}{l}p H \\
\mu S / c m \\
\mu g / L \\
\mu g / L \\
\mu g / L \\
\mu g / L \\
\mu g / L \\
\mu g / L \\
\mu g / L \\
\mu g / L \\
\mu g / L \\
\mu g / L \\
\mu g / L \\
\mu g / L \\
\mu g / L \\
\mu g / L \\
\mu g / L \\
\mu g / L \\
\mu g / L \\
\mu g / L \\
\mu g / L \\
\mu g / L \\
\mu g / L \\
\mu g / L \\
\mu g / L \\
\mu g / L \\
\mu g / L \\
\mu g / L \\
\mu g / L \\
\mu g / L \\
\mu g / L \\
\mu g / L \\
\mu g / L\end{array}$ & $\begin{array}{l}\mathrm{GE} \\
\mathrm{GE} \\
\mathrm{GE} \\
\mathrm{GE} \\
\mathrm{GE} \\
\mathrm{GE} \\
\mathrm{GE} \\
\mathrm{GE} \\
\mathrm{GE} \\
\mathrm{GE} \\
\mathrm{GE} \\
\mathrm{GE} \\
\mathrm{GE} \\
\mathrm{GE} \\
\mathrm{GE} \\
\mathrm{GE} \\
\mathrm{GE} \\
\mathrm{GE} \\
\mathrm{GE} \\
\mathrm{GE} \\
\mathrm{GE} \\
\mathrm{GE} \\
\mathrm{GE} \\
\mathrm{GE} \\
\mathrm{GE} \\
\mathrm{GE} \\
\mathrm{GE} \\
\mathrm{GE} \\
\mathrm{GE} \\
\mathrm{GE} \\
\mathrm{GE} \\
\mathrm{GE} \\
\mathrm{GE} \\
\mathrm{GE} \\
\mathrm{GE} \\
\mathrm{GE} \\
\mathrm{GE} \\
\mathrm{GE} \\
\mathrm{GE} \\
\mathrm{GE}\end{array}$ \\
\hline
\end{tabular}


ANALYTICAL RESULTS

WELL TNX 5D collected on 12/03/91, laboratory analyses (cont.)

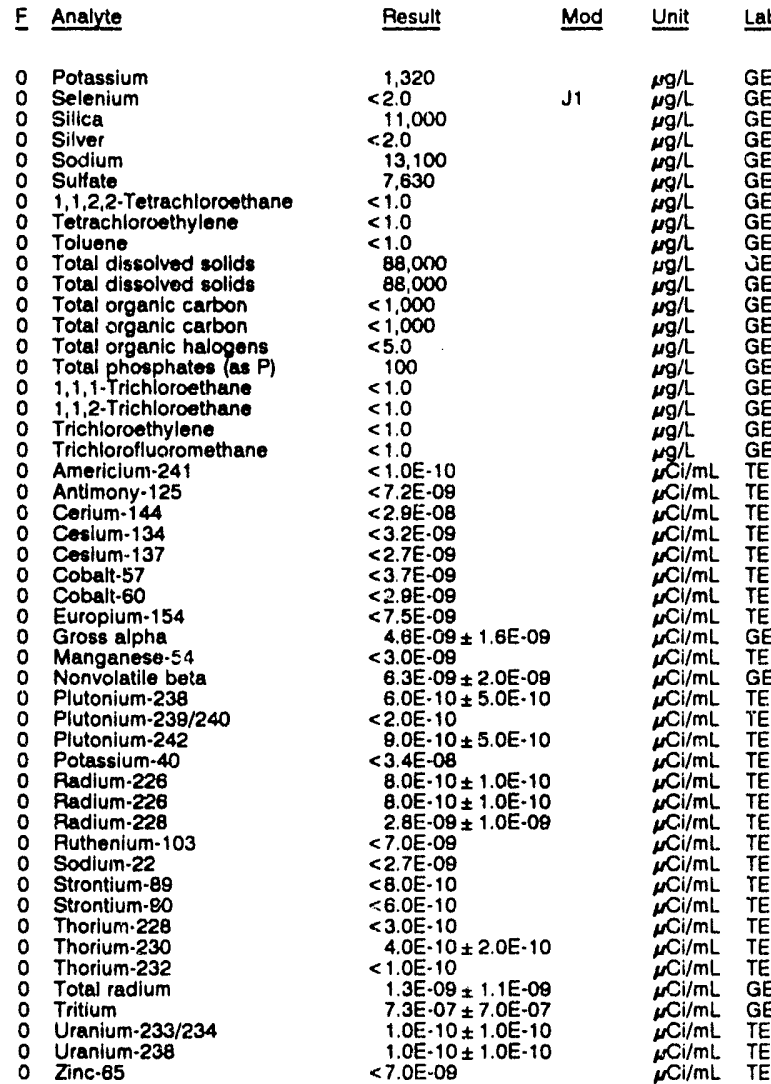

WELL TNX 6D

MEASUREMENTS CONDUCTED IN THE FIEL.D
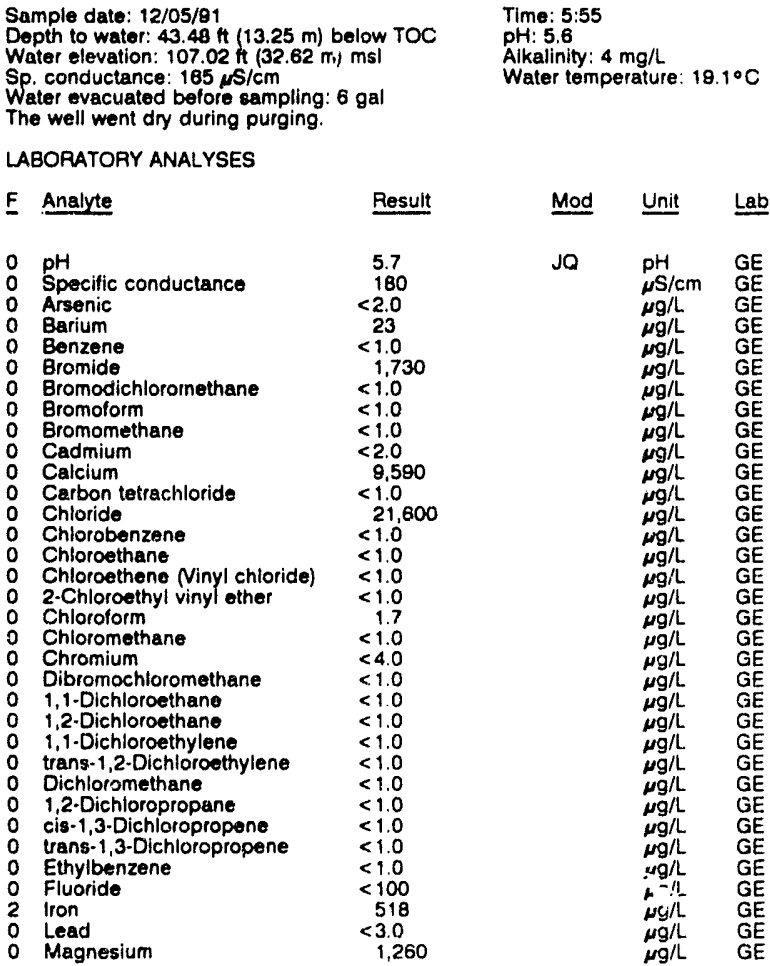

Alkalinity: $4 \mathrm{mg} / \mathrm{L}$
WELL TNX 6D collected on 12/05/91, laboratory analyses (cont.)
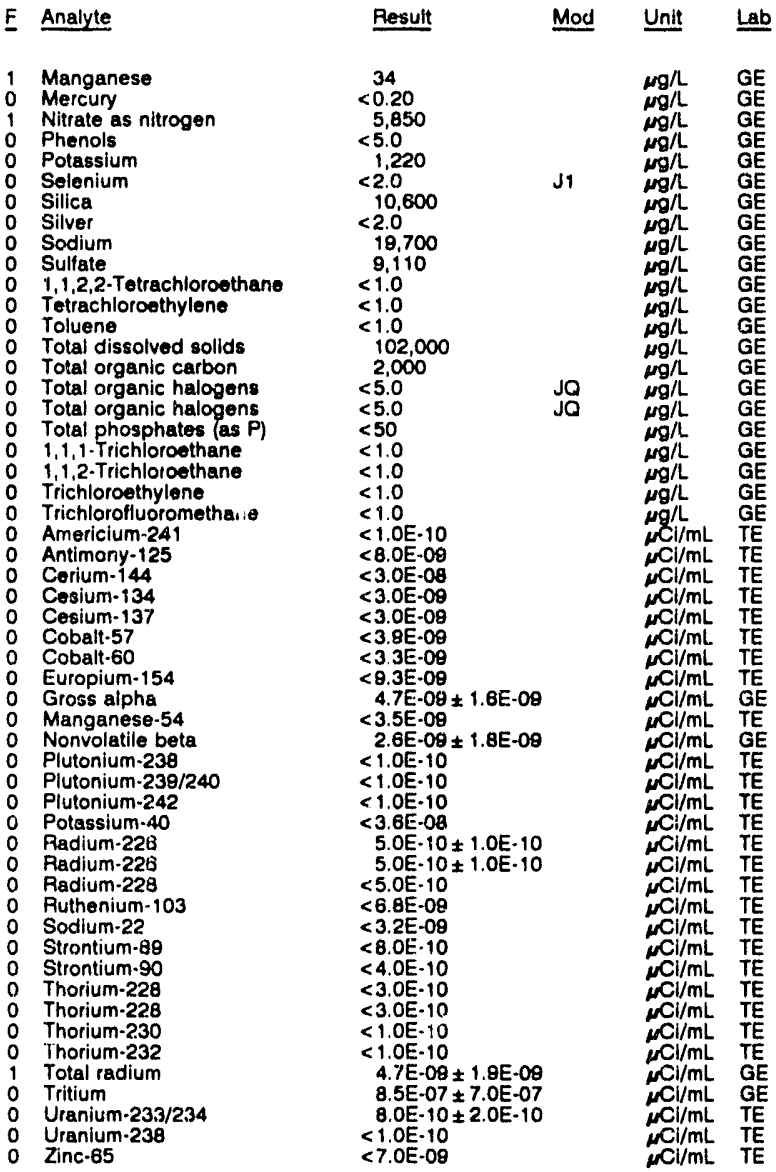

WELL TNX 7D

MEASUREMENTS CONDUCTED IN THE FIELD

Sample date: 12/02/81

Depth to water: $49.68 \mathrm{ft} / 15.14 \mathrm{~m})$ below TOC Water elevation: $101.22 \mathrm{tt}(30.85 \mathrm{~m}) \mathrm{msl}$ Sp. conductance: $57 \mu \mathrm{s} / \mathrm{cm}$ Water evacuated before sampling: $46 \mathrm{ga}$ LABORATORY ANALYSES

\begin{tabular}{|c|c|c|c|}
\hline Analyte & Result & Mod & Unit \\
\hline $\begin{array}{l}\text { pH } \\
\text { Specific conductance } \\
\text { Arsenic } \\
\text { Barlum } \\
\text { Benzene } \\
\text { Bromide } \\
\text { Bromide } \\
\text { Bromodichloromethane } \\
\text { Bromoform } \\
\text { Bromomethane } \\
\text { Cadmium } \\
\text { Caicium } \\
\text { Carbon tetrachloride } \\
\text { Chloride } \\
\text { Chlorobenzene } \\
\text { Chloroethane } \\
\text { Chloroethene Ninyl chloride) } \\
\text { 2-Chloroethyl vinylether } \\
\text { Chloroform } \\
\text { Chloromethane } \\
\text { Chromium } \\
\text { Dibromochloromethane } \\
\text { 1,1-Dichloroethane } \\
\text { 1,2-Dichloroethane } \\
\text { 1,1-Dichloroethylene } \\
\text { trans } 1,2-\text { Dichloreethylene } \\
\text { Dichloromethane } \\
\text { 1,2-Dichloropropane } \\
\text { cis-1,3-Dichloropropene } \\
\text { trans-1,3-Dichloropropene }\end{array}$ & $\begin{aligned} & 5.9 \\
& 55 \\
&<2.0 \\
& 15 \\
& 1.1 \\
&<1.000 \\
&<1.000 \\
&<1.0 \\
&<1.0 \\
&<1.0 \\
&<2.0 \\
& 2,580 \\
&<1.0 \\
& 2.540 \\
&<1.0 \\
&<1.0 \\
&<1.0 \\
&<1.0 \\
&<1.0 \\
&<1.0 \\
&<4.0 \\
&<1.0 \\
&<1.0 \\
&<1.0 \\
&<1.0 \\
&<1.0 \\
& 2.1 \\
&<1.0 \\
&<1.0 \\
&<1.0\end{aligned}$ & JQ & 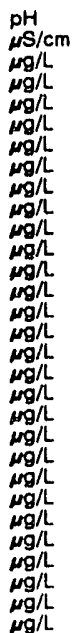 \\
\hline
\end{tabular}


WELL TNX 7D collectod on 12/02/91, laboratory aralyses (cont.)

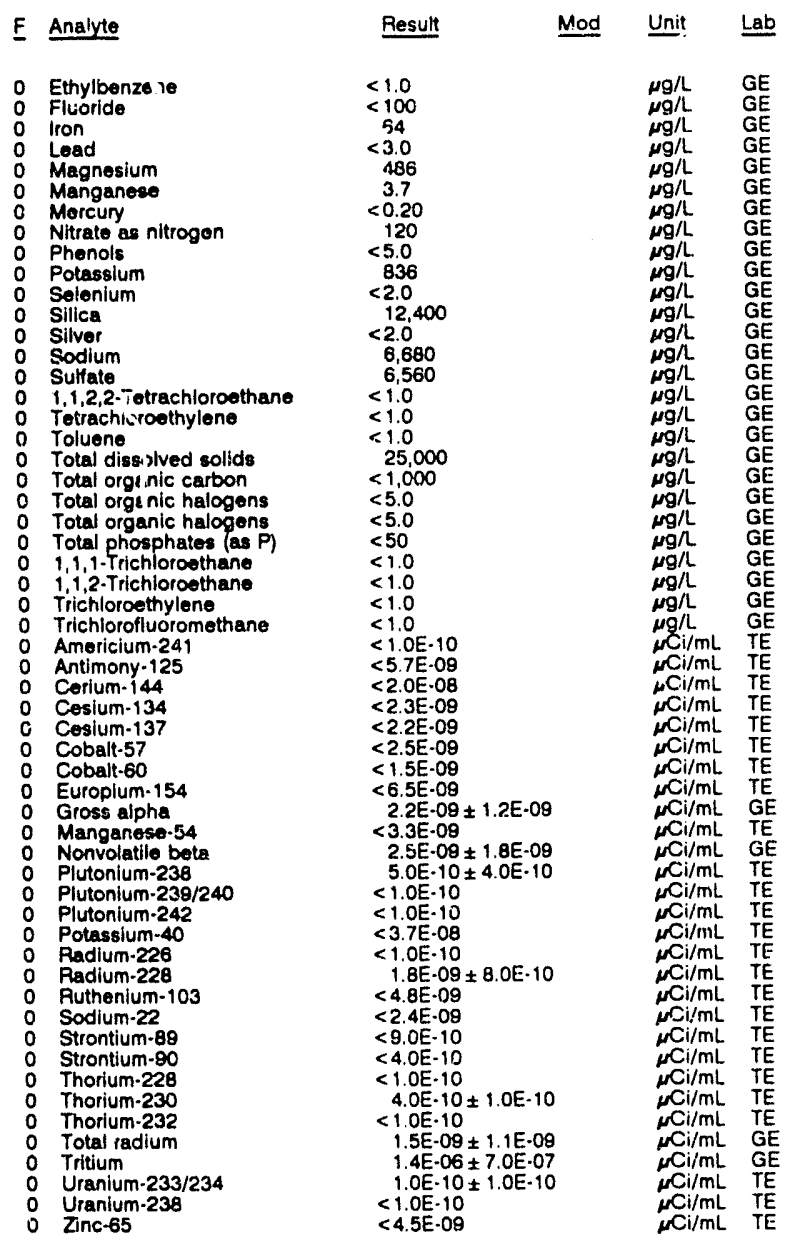

WELL TNX 8D

MEASUREMENTS CONDUCTED IN THE FIELD

Sample date: 12/02/81

Depth to water: $6.40 \mathrm{ft}(1.95 \mathrm{~m})$ below TOC

Wator olevation: $83.00 \mathrm{tt}(28$.

Sp. conductance: $108 \mu \mathrm{s} / \mathrm{cm}$.

LABOPATORY ANALYSES

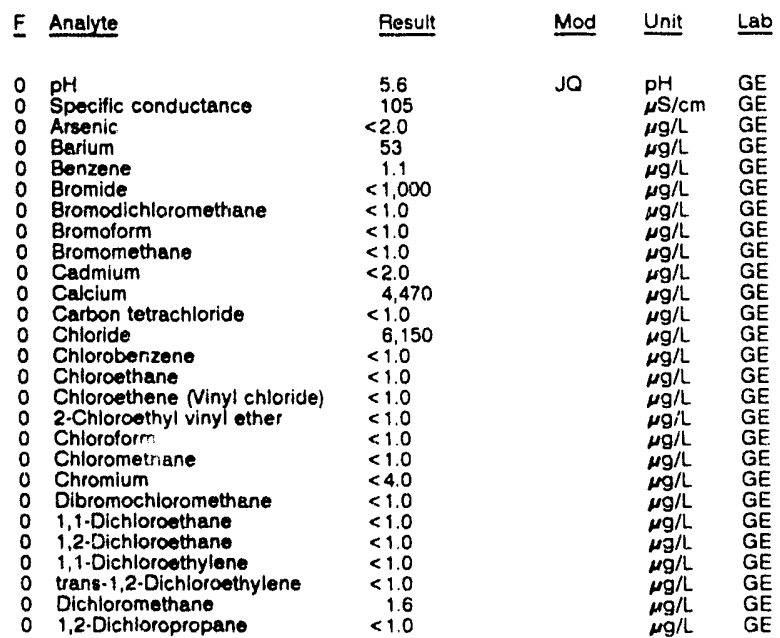

WELL TNX BD collected on 12/02/91, laboratory analyses (cont.)

E Analyte Fesult Mod Unit Lab

$\begin{array}{ll}0 & \text { cis-1,3-Dichloropropene } \\ 0 & \text { trans-1,3-Dichloropropene } \\ 0 & \text { Ethylbenzene } \\ 0 & \text { Fluoride } \\ 0 & \text { Iron } \\ 0 & \text { Lead } \\ 0 & \text { Magnesium } \\ 0 & \text { Manganese } \\ 0 & \text { Mercury }\end{array}$

$<1.0$

$<1.0$

$<100$
18
$<3.0$

$<3.0$

$<0.20$

$\begin{array}{ll}\text { Nitrate as nitrogen } & 4,950 \\ \text { Phenols } & <5.0\end{array}$

0 Phenols

- Polassium

0 Selenium

0 Silver

0 Sodium

0 Sulfate

Tetrachloroethylene

Toluene

Total dissolved solids

Total organic carbon

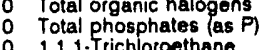

o $1,1,2$. Trichloroethane

0 Trichloroethylene

o Trichlorofluoromethane

0 Americium-241

0 Antimony.125

0 Cerlum. 144

o Cesium-136

Cosium-137

Cobalt-60

Europium-154

- Gross alpha

Nonvolatile beta

Ponvolatile beta

Plutonium-239/240

Plutonium-242

Potassium. 40

Radium-226

Radium.226

Ruthenium:103

Sodium-22

Strontium-89

Strontium-90

Thorium-225

Thorium-232

Total radium

Uranium-233/234

Uranium-238

$<5.0$

-2.0
12,000

$<2.0$
12,800

7,780

$<1.0$
$<1.0$

$<\begin{aligned} & 1.0 \\ & 59,000\end{aligned}$

$<1,000$

$<5$

$<50$
$<1.0$
$<1.0$
1.9

1.9
$<1.0$

$<1.0 \mathrm{E} \cdot 10$

$<7.6 \mathrm{E} .09$

$<2.9 \mathrm{E} .08$

$<3.7 E .08$

$<2.9 \mathrm{E}-09$
$<3.7 \mathrm{E}-09$

$<2.9 \mathrm{E} .09$

2.3E.08 $01.0 \mathrm{E} \cdot 08$

$<.42 .08+1.0 \mathrm{E} .09$

$\angle 6.0 \mathrm{OE} \cdot 10$

$<2.0 \mathrm{E} \cdot 10$

$<1.0 \mathrm{E}-10$

$<4.2 \bar{E}-00$

$<1.0 \mathrm{E} \cdot 10$

$<1.0 \mathrm{E}-100+7.0 \mathrm{E}-10$

$<9.0 E-09$

$<3.7 \mathrm{E}-09$

$<9.0 \varepsilon-10$

$7.0 \mathrm{E}-10 \pm 8.0 \mathrm{E}-10$

$7.0 E-10 \pm 6.0 E-10$

$2.0 E \cdot 10 \pm$

$<1.0 E \cdot 10$

$3.0 \mathrm{E}-06 \pm 7.0 \mathrm{E}-07$

2.0E-10ะ1.0E-10

$<1.0 \mathrm{E} \cdot 10$
$<8.0 \mathrm{E}-00$

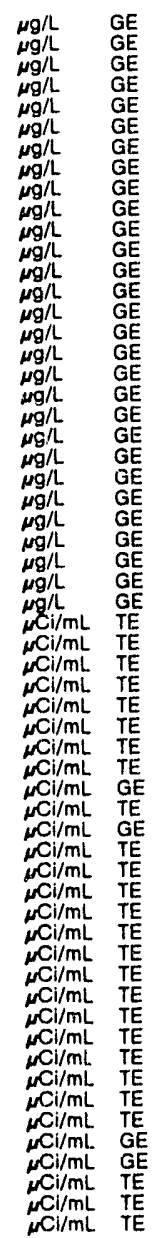

\section{WELL TNX 9D}

MEASUREMENTS CONDUCTED IN THE FIELD

Sample date: $12 / 02 / 91$

epth to water: $8.14 \mathrm{~h}(2.48 \mathrm{~m})$ below TOC

Water elevation: $93.56 \mathrm{tt}(28.52 \mathrm{~m}) \mathrm{ms}$

Water evacuated before sampling: $48 \mathrm{gal}$

LABORATORY ANALYSES

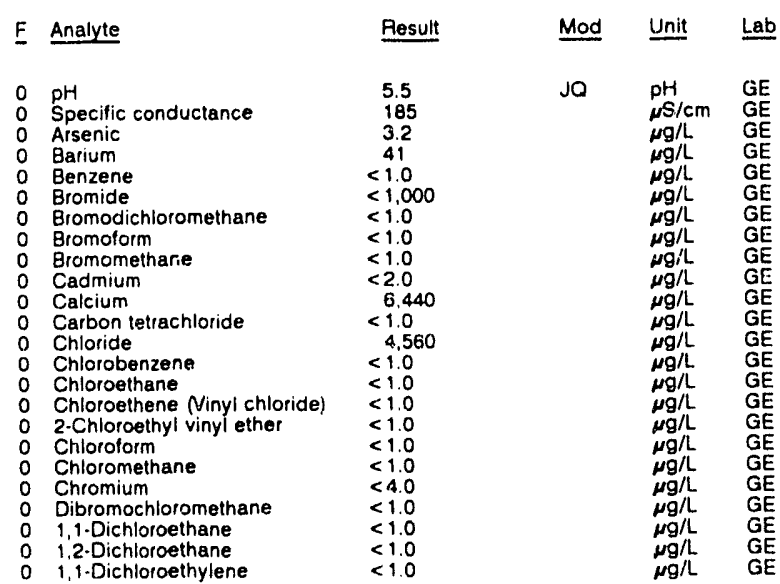


ANALYTICAL RESULTS

WELL TNX 9D collectes on 12/02/91, laboratory analyses (cont.)

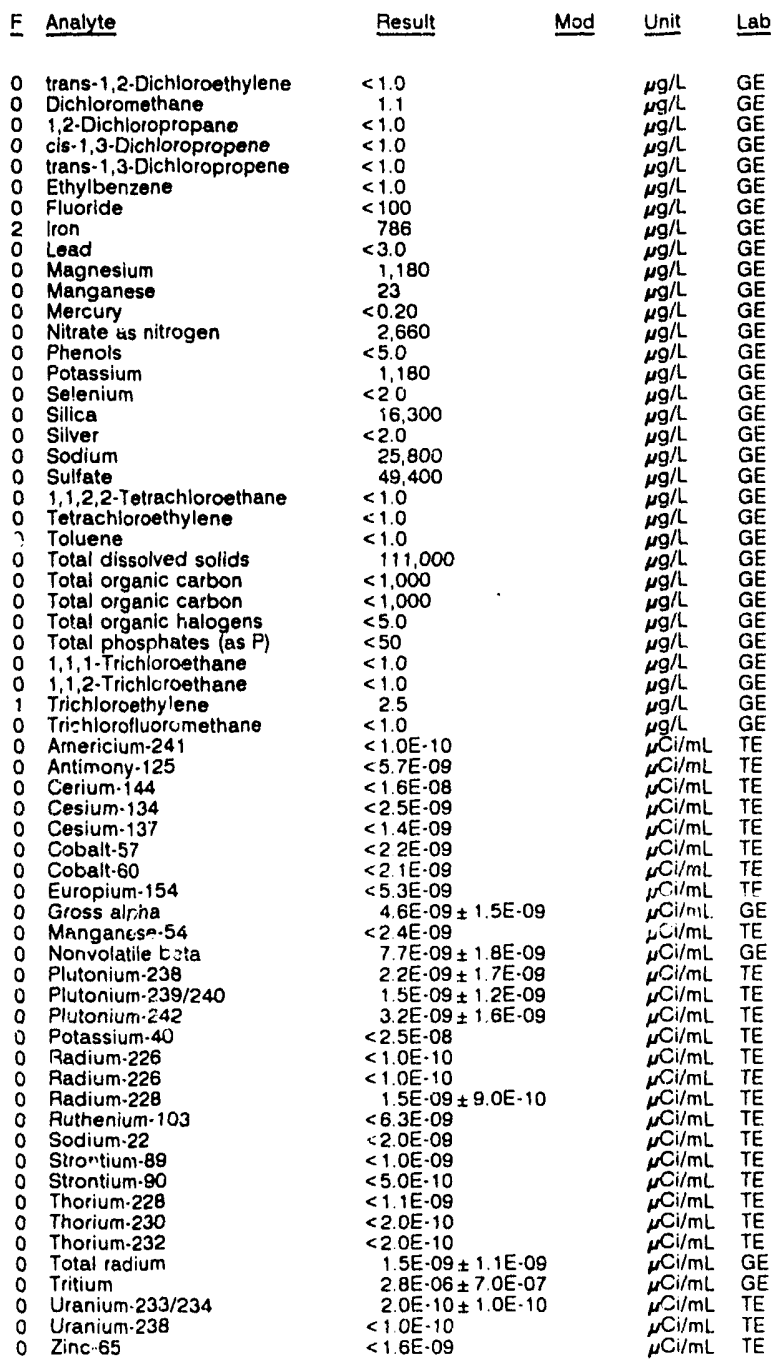

\section{WELL TNX 10D}

MEASUREMENTS CONDUCTED IN THE FIELO

Sample date $12 / 02 / 9$

Depth to water: $8.57 \mathrm{ft}(2.61 \mathrm{~m})$ below TOC

Water elevation: $93.73 \mathrm{ft}(28.57$

Sp. Conductance: $175 \mu \mathrm{S} / \mathrm{cm}$
Water evacuated before sampling: $44 \mathrm{gal}$

LABORATORY ANALYSES

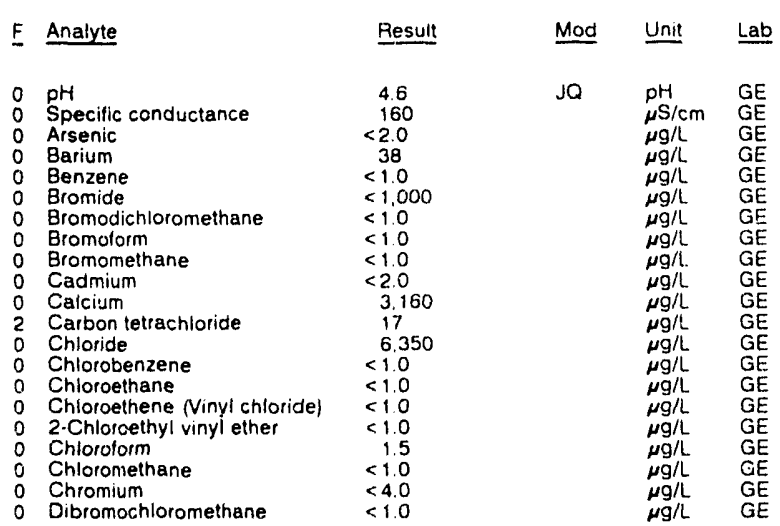

WELL TNX 100 collected on 12/02/91, laboratory analyses (cont.)

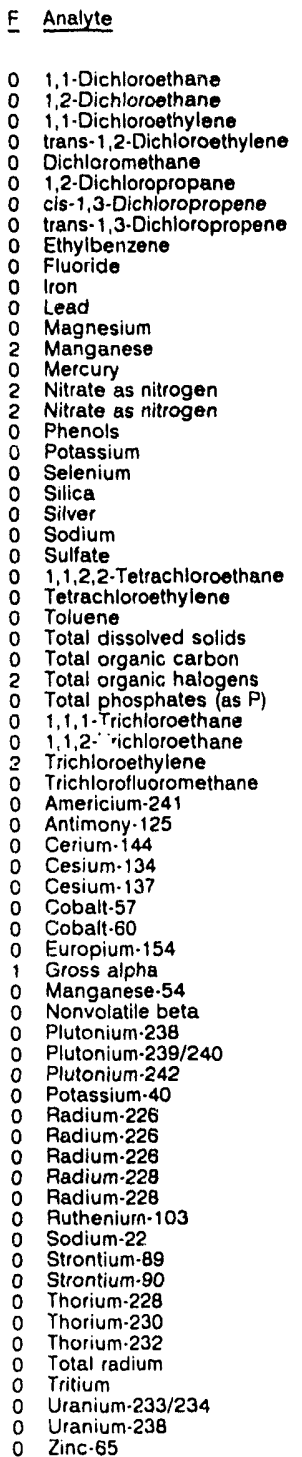

Result Mod Unit Lab

$<1.0$

$<1.0$

2.0

$<1.0$

$<1.0$

$<100$

$<31$

1,140
85
$<0.20$

$<0.20$
13,200

13,600
$<5.0$

1.090
$<2.0$

$<2.0$

$<2.0$
23.800

23,800

$<1.0$
$<1.0$
$<1.0$

$<1.00000$

1,000

$<50$

$<1.0$
$<1.0$

101

$1.0 \mathrm{E} \cdot 10 \pm 1.0 \mathrm{E} \cdot 10$

$<6.3 E .09$

$<3.3 \mathrm{E} .09$

$<2.9 \mathrm{E} .09$

$<2.7 \mathrm{E}-09$

$<1.8 \mathrm{E}-09$

$<8.5 \mathrm{E}-09$

1. $4 \mathrm{E}-08 \pm 2.5 \mathrm{E}-09$

$<3.3 \mathrm{E} \cdot 09$

$5.1 \mathrm{E}-09 \pm 1.7 \mathrm{E}-09$

$<6.0 E-10$

$<2.0 E \cdot 10$

$<2.6 \mathrm{E}-08$

$2.0 \mathrm{E}-10 \pm 1.0 \mathrm{E}-10$

$2.0 E \cdot 10 \pm 1.0 \mathrm{E}-10$

$1.2 \mathrm{E} \cdot 09 \pm 0.0 \mathrm{E} \cdot 10$

$<6.7 \mathrm{E} .09$

$<3.2 E-09$

$<9.0 E-10$

$<5.0 \mathrm{OE}-10$

$<1.0 E \cdot 10$

$<1.0 E-10$

$4.8 E \cdot 06 \pm 7.0 E \cdot 07$

$4.8 E-09 \pm 5.0 \mathrm{E}-10$

$5.6 \mathrm{E}-09 \pm 5.0 \mathrm{E}-10$

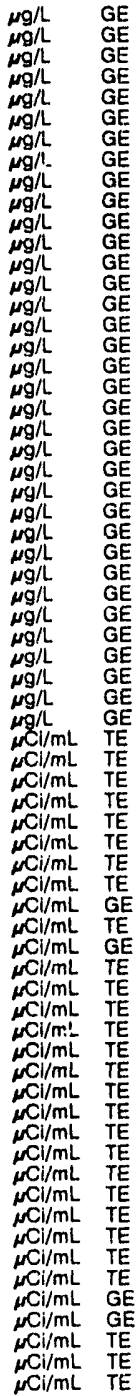

\section{WELL TNX 11D}

MEASUREMENTS CONDUCTED IN THE FIELO

Sample date: 12/02/81

Depth to water: $6.11 \mathrm{H}(1.86 \mathrm{~m})$ below TOC

Water elevation: $93.69 \mathrm{ft}(28.56 \mathrm{~m}) \mathrm{msl}$

Sp. conductance: $54 \mu \mathrm{S} / \mathrm{cm}$
Water evacuated before sampling: $54 \mathrm{gal}$

LABORATORY ANALYSES

\begin{tabular}{|c|c|c|c|}
\hline Analyte & Result & Mod & Unit \\
\hline $\begin{array}{ll}0 & \text { pH } \\
0 & \text { SFecific conductance } \\
0 & \text { Arsenic } \\
0 & \text { Barium } \\
0 & \text { Benzene } \\
0 & \text { Bromide } \\
0 & \text { Bromide } \\
0 & \text { Bromodichloromethane } \\
0 & \text { Bromoform } \\
0 & \text { Bromomethane } \\
0 & \text { Cadmium } \\
0 & \text { Calcium } \\
0 & \text { Carbon tetrachloride } \\
0 & \text { Chloride } \\
0 & \text { Chlorobenzene } \\
0 & \text { Chloroethane }\end{array}$ & $\begin{aligned} & 5.2 \\
& 50 \\
& 2.9 \\
& 25 \\
&<1.0 \\
&<1.000 \\
&<1.000 \\
&<1.0 \\
&<1.0 \\
&<1.0 \\
&<2.0 \\
& 3,120 \\
&<1.0 \\
& 2,900 \\
&<1.0 \\
&<1.0\end{aligned}$ & JO & $\begin{array}{l}\mathrm{pH} \\
\mu \mathrm{S} / \mathrm{cm} \\
\mu g / L \\
\mu g / L \\
\mu g / L \\
\mu g / L \\
\mu g / L \\
\mu g / L \\
\mu g / L \\
\mu g / L \\
\mu g / L \\
\mu g / L \\
\mu g / L \\
\mu g / L \\
\mu g / L \\
\mu g / L\end{array}$ \\
\hline
\end{tabular}


ANALYTICAL RESULTS

WELL TNX 110 collected on 12/02/91, laboratory analyses (cont.)

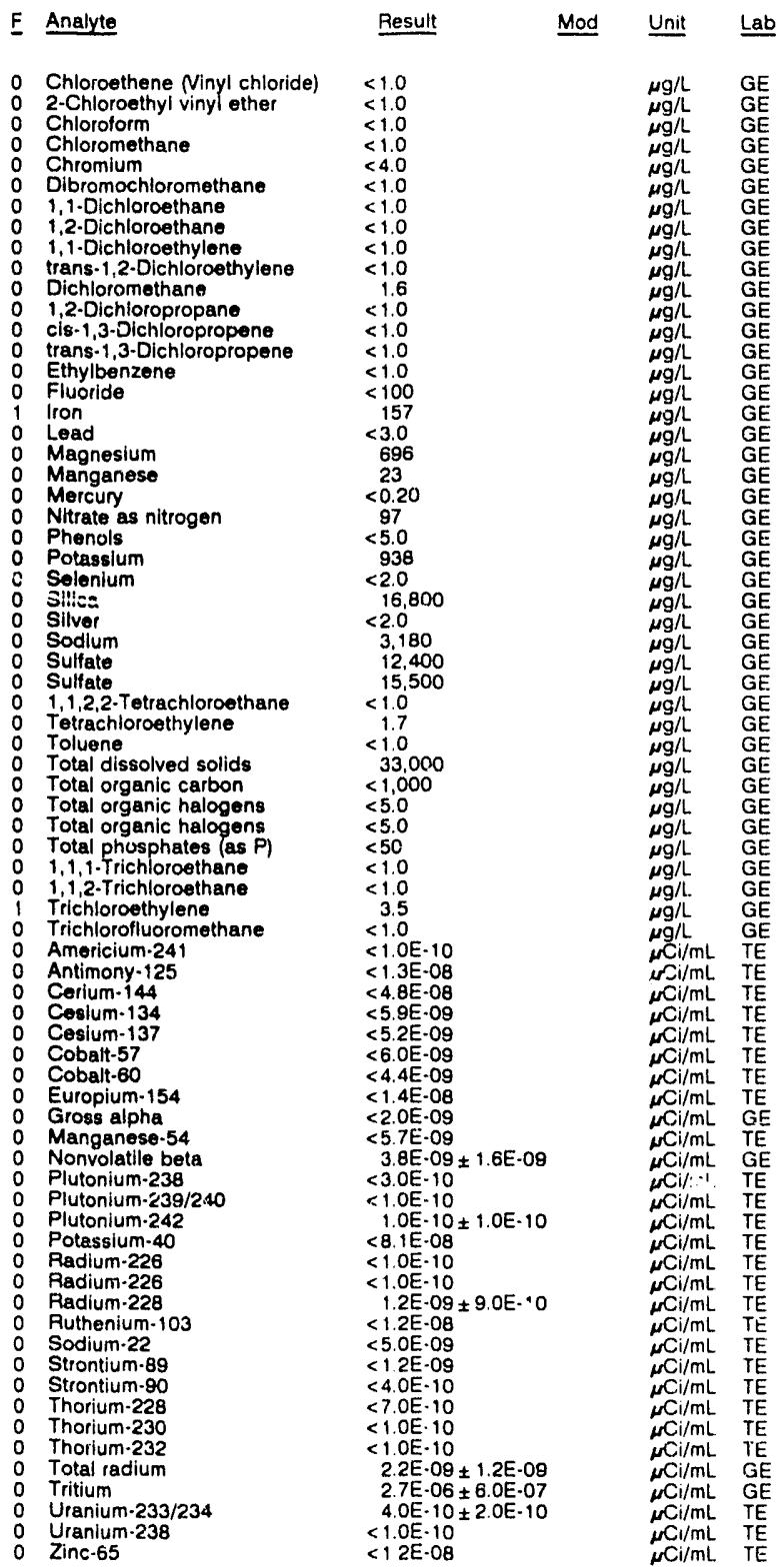

\section{WELL TNX 12D}

MEASUREMENTS CONDUCTED IN THE FIELD

Sampie date: $12 / 02 / 91$

Depth to water: 4.38 tt $(1.34 \mathrm{~m})$ below TOC

Water elevation: $94.82 \mathrm{ft}(28.90 \mathrm{~m}) \mathrm{ms}$

Sp. conductance: $77 \mathrm{mS} / \mathrm{cm}$

Water evacuated betore sampling: $57 \mathrm{gat}$

LABORATORY ANALYYSES

\begin{tabular}{|c|c|c|c|}
\hline Analyte & Result & Mod & Unit \\
\hline $\begin{array}{l}\mathrm{pH} \\
\text { Specific conductance } \\
\text { Arsenic } \\
\text { Barium } \\
\text { Benzene } \\
\text { Bromide } \\
\text { Bromodichloromethene } \\
\text { Bromoform } \\
\text { Bromomethane } \\
\text { Cadmium } \\
\text { Calcium }\end{array}$ & $\begin{aligned} & 6.3 \\
& 75 \\
&<2.0 \\
& 29 \\
&<1.0 \\
&<1.000 \\
&<1.0 \\
&<1.0 \\
&<1.0 \\
&<2.0 \\
& 6.260\end{aligned}$ & JO & $\begin{array}{l}\mathrm{pH} \\
\mu \mathrm{S} / \mathrm{cm} \\
\mu g / L \\
\mu g / L \\
\mu g / L \\
\mu g / L \\
\mu g / L \\
\mu g / L \\
\mu g / L \\
\mu g / L \\
\mu g / L\end{array}$ \\
\hline
\end{tabular}

WELL TNX 120 collected on 12/02/91, laboratory analyses (cont.)

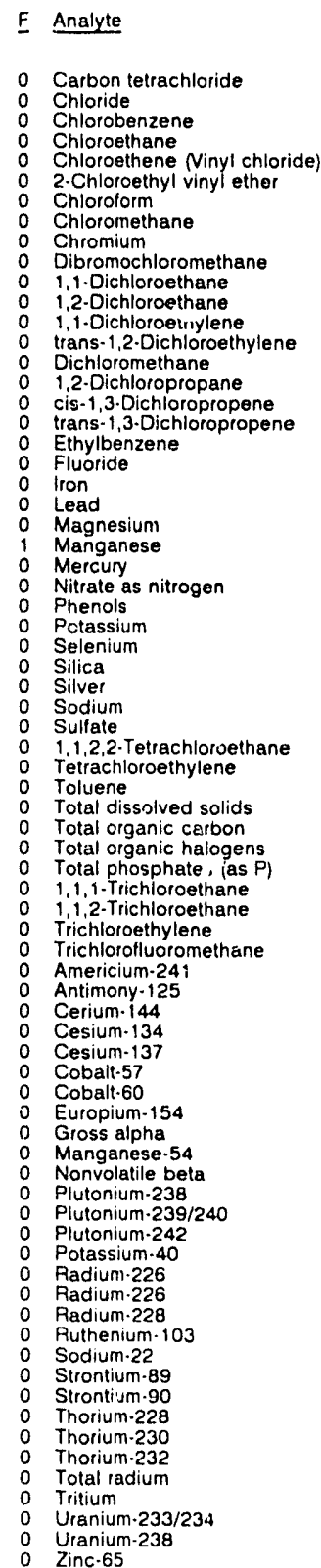

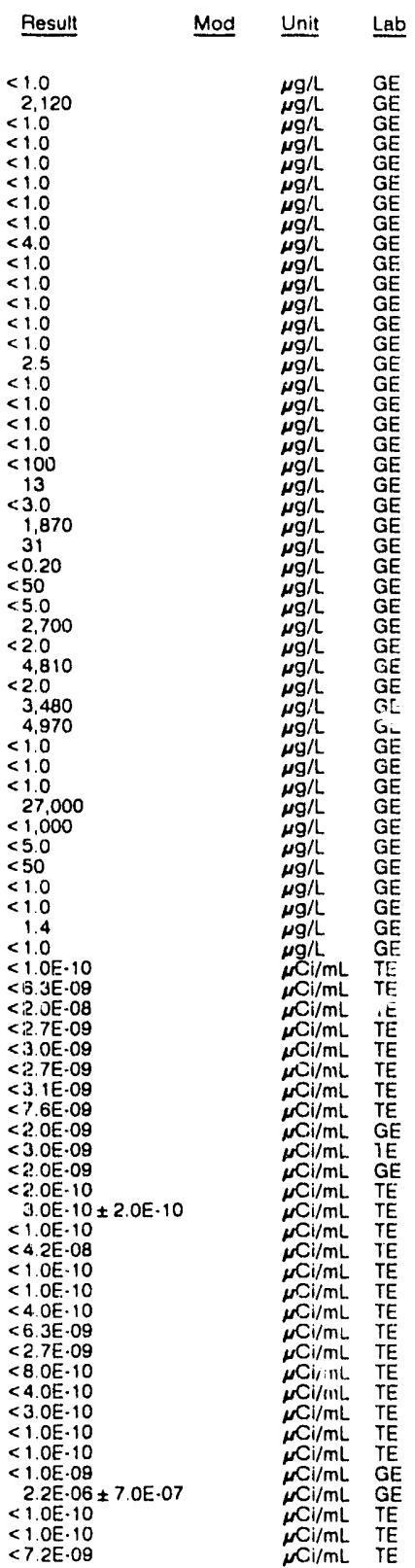

\section{WELL XSB $1 \mathrm{~A}$}

MEASUREMENTS CONDUCTED IN THE FIELD Sample date: $12 / 04 / 91$
Oepth to water: $56.83 \mathrm{Ht}(17.32 \mathrm{~m})$ below TOC
Water elevation: $99.17 \mathrm{ft}(30.23 \mathrm{~m}) \mathrm{msl}$ Sp conductance: $120 \mu \mathrm{S} / \mathrm{cm}$ Water evacuated before sampling. $146 \mathrm{gal}$

Alkalinity: $3 \mathrm{mg} / \mathrm{h}$

Water temperature $18.2^{\circ} \mathrm{C}$

LABORATORY ANALYSES

\begin{tabular}{|c|c|c|c|}
\hline Analyte & Pesult & Mod & Unit \\
\hline $\begin{array}{l}\text { pH } \\
\text { Specific conductance } \\
\text { Arsenic } \\
\text { Barium } \\
\text { Benzene } \\
\text { Bromide } \\
\text { Bromodichloromethane } \\
\text { Bromolorm } \\
\text { Bromomethane }\end{array}$ & $\begin{aligned} & 5.6 \\
& 110 \\
&<2.0 \\
& 12 \\
&<1.0 \\
&<1.000 \\
&<1.0 \\
&<1.0 \\
&<1.0\end{aligned}$ & JO & $\begin{array}{l}\mathrm{pH} \\
\mu \mathrm{S} / \mathrm{cm} \\
\mu \mathrm{g} / \mathrm{L} \\
\mu \mathrm{g} / \mathrm{L} \\
\mu \mathrm{g} / \mathrm{L} \\
\mu \mathrm{g} / \mathrm{L} \\
\mu \mathrm{g} / \mathrm{L} \\
\mu \mathrm{g} / \mathrm{L} \\
\mu \mathrm{g} / \mathrm{L}\end{array}$ \\
\hline
\end{tabular}


ANALYTICAL RESULTS

WELL XSB IA collected on 12/04/91, laboratory analyses (cont.)

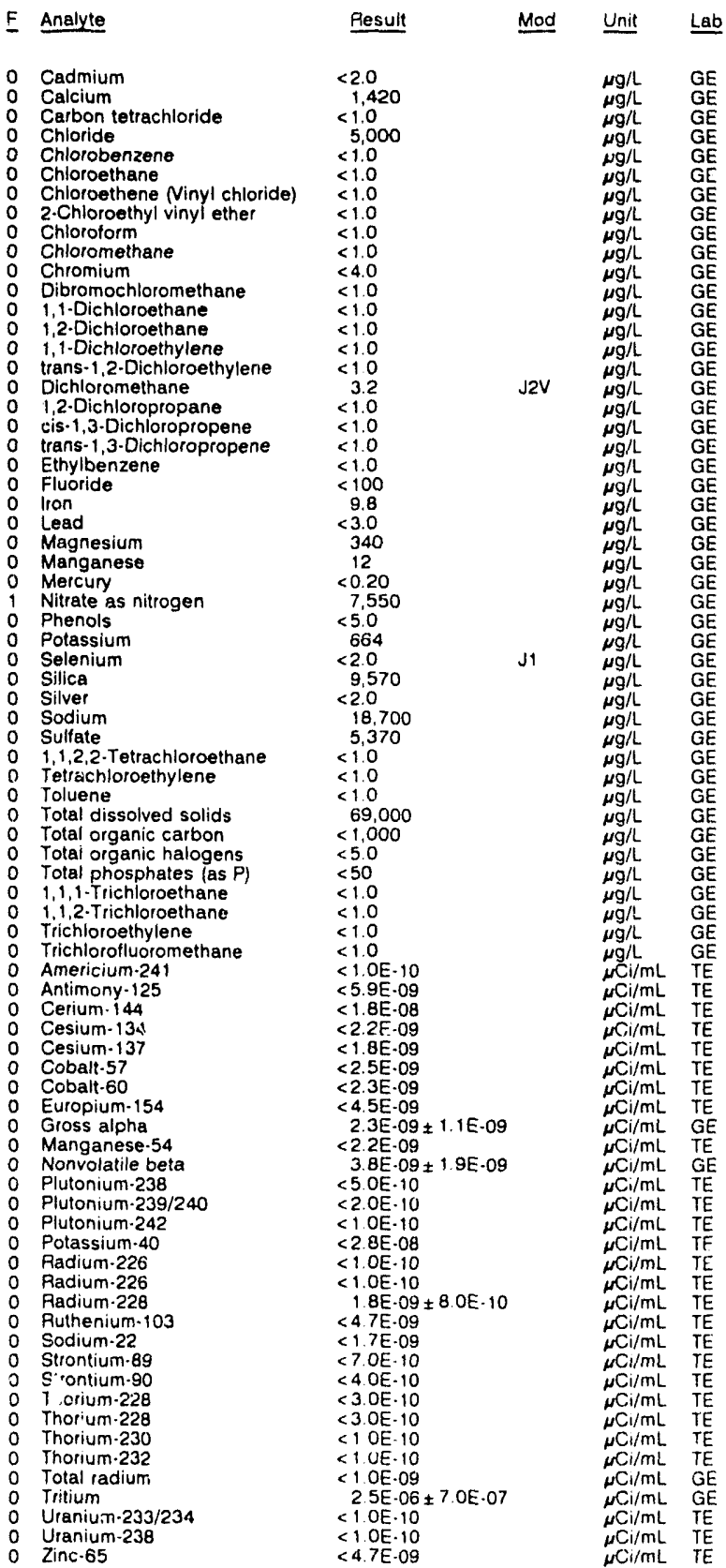

WELL XSB 1B

MEASUREMENTS CONDUCTED IN THE FIELD

Sample date: $12 / 04 / 91$

Depth to water 5193 tt $15.83 \mathrm{~m})$ below $\mathrm{rOC}$

Water elevation $103.97 \mathrm{ft}(3169 \mathrm{~m}) \mathrm{mis}$

Sp conductance $43 \mu \mathrm{S} / \mathrm{cm}$

Water evacuated before sampling 103 gal

LABORATORY ANALYSES

\begin{tabular}{|c|c|c|c|}
\hline$E$ Analyte & Resul! & Mod & Unit \\
\hline $\begin{array}{ll}0 & \text { pH } \\
0 & \text { Specific conductance } \\
0 & \text { Arsenic } \\
0 & \text { Barium } \\
0 & \text { Benzene } \\
0 & \text { Bromide }\end{array}$ & $\begin{aligned} & 5.7 \\
& 40 \\
&<20 \\
& 20 \\
&<10 \\
&<1000\end{aligned}$ & JO & $\begin{array}{l}\mathrm{pH} \\
\mu \mathrm{S} / \mathrm{cm} \\
\mu \mathrm{g} / \mathrm{L} \\
\mu \mathrm{g} / \mathrm{L} \\
\mu \mathrm{g} / \mathrm{L}\end{array}$ \\
\hline
\end{tabular}

WELL XSB 18 collected on 12/04/91, laboratony analyses (cont.)

E Analyte Result Mod Unit Lab

$\begin{array}{ll}0 & \text { Bromodichloromethane } \\ 0 & \text { Bromoform } \\ 0 & \text { Bromomethane } \\ 0 & \text { Cadmium } \\ 0 & \text { Calcium } \\ 0 & \text { Carbon tetrachloride } \\ 0 & \text { Chloride } \\ 0 & \text { Chloride } \\ 0 & \text { Chlorobenzene } \\ 0 & \text { Chloroethane } \\ 0 & \text { Chloroethene Ninyl chloride) } \\ 0 & 2 \cdot \text { Chloroethyl vinyl ether } \\ 0 & \text { Chloroform }\end{array}$

Chloromethane

Chromium

D Dibromochloromethane

1,1.Dichloroethane

1, -Dichloroethylene

trans-1,2-Dichloroethylene

Dichlormethane

1,2-Oicinloropropane
cis- 1,3 -Oichloropropene

trans-1,3.Dichloropropen

Ethylbenzene

2 Iron

0 Lead

O Magnesium

0 Mercury

Nitrate as nitrogen

Nitrate as nitrogen

Phenols

0 Potassium

Selenium

Silica

0 Sodium

Sulfate

0 Sulfate

1,1,2,2-Tetrachloroethane

Tetrachloroethylene

Tolvene
Total dissolved solids

Total dissolved solids

- Total organic carbon

- Total organic carbon

- Total organic halogens

- Total organic halogens

0 Total phosphates las P

- Total phosphates (as P)

1,1,1. Trichloroethane

o Trichloroethylene

Trichlorofluoromethane

Americium-241

o Antimony-125

0 Cerium 144

o Cesium-134

o Cesium-137

o Cobalt-57

0 Europium-154

o Gross alpha

O Manganese-54

Plutonium-238

P Plutonium-238

D Plutonium-239/240

0 Plutonium 242

0 Plutonium $\cdot 242$

0 Potassium.40

o Radium-226

- Radium-226

- Radium-226

- Radium-228

o Radium.228

R Ruthenium.

0 Sodium.22

Strontium-89

Strontium-90

Thorium-228

- Thorium.230

Thorium-230

Thorium-232

Thorium-232

Total radium

- Tritium

Uranium-233/234

Uranium-233/234

0 Uranium.238

$\begin{array}{ll}0 & \text { Uranium } \\ 0 & \text { Zinc. } 65\end{array}$

$\begin{array}{lll}<1.0 & \mu g / / & G E \\ <10 & \mu g / \mu & G E \\ <1.0 & G / L & G E\end{array}$

$<2.0$

$<\begin{gathered}2,830 \\ <1,0\end{gathered}$

1,860
1,870

$<1.0$

$<1.0$

$<1.0$

$<1.0$

$<4.0$
$<1.0$

$<1.0$

4.1 .0

$<1.0$
$<1.0$

$<1.1$

$<1.0$

$<1.0$.

$<100$

676
$<3.0$
626

16
$<0.20$

$<50$

$<50$
$<5.0$

$<5.00$

$<.350$
$<25$
25.400

$<25.400$

1,450
6,900

6,870

$<1.870$
$<1.0$

$<1.0$
$<1.0$

37,000

40,000
$<1,000$

$<1,000$

11
17

$<50$

$<1.0$

$<1.0$

$<1.70$

$<1.0 \mathrm{E}-10$
$<1.0 \mathrm{E}-10$

$<1.0 \mathrm{E}-10$
$<5.6 \mathrm{E}-09$

$<2.4 \mathrm{E} \cdot 0$

$<2$ E 09

$<31 \mathrm{E} .09$

$<1.7 E .09$

$<5.9 \mathrm{E} .09$

$2.2 \mathrm{E}-09 \pm 9.1 \mathrm{E}-10$

$<2.3 E \cdot 09$

$5.0 E .09$

$<2.0 \mathrm{E} \cdot 10$

$<1.0 \mathrm{E} \cdot 10$

$<1.0 E-10$
$<1.0 \mathrm{C}-10$

<1.0E-10

$<4.4 \mathrm{E}-08$

$<1.05 \cdot 10$

$<5.0 E \cdot 10$

$<5.0 E \cdot 10$

<2.1E.09

$<7.0 \mathrm{E} \cdot 10$

$<3.0 E \cdot 10$

$<3.0 E-10$

$<2.0 E-10$
$2.0 E-10 \pm 1.0 E-10$

$2.0 E-10 \pm 1.0 E-10$
$1.0 E \cdot 10 \pm 1$ OE- 10

<1.0E-10

$<$ L.OE-10

$<1.0 E \cdot 08$
$<7.0 E .07$

$2.0 E \cdot 10 \pm 1$ JE- 10
$5.0 E \cdot 10 \pm 3.0 E-10$

$<1.0 E-10$

$<1.0 E \cdot 10$

$<4.6 \mathrm{E} .09$ 
WELL XSB 10

MEASUREMENTS CONDUCTED IN THE FIELD

Sample date: 12/04/91

Depth to water: 56.53 ft $(17.23 \mathrm{~m})$ below TOC
Water elevation: $99.47 \mathrm{Ht}(30.32 \mathrm{~m}) \mathrm{ms}$ Sp. conductance: $91 \mu \mathrm{S} / \mathrm{cm}$

mpling: $30 \mathrm{gal}$

LABORATORY ANALYSES

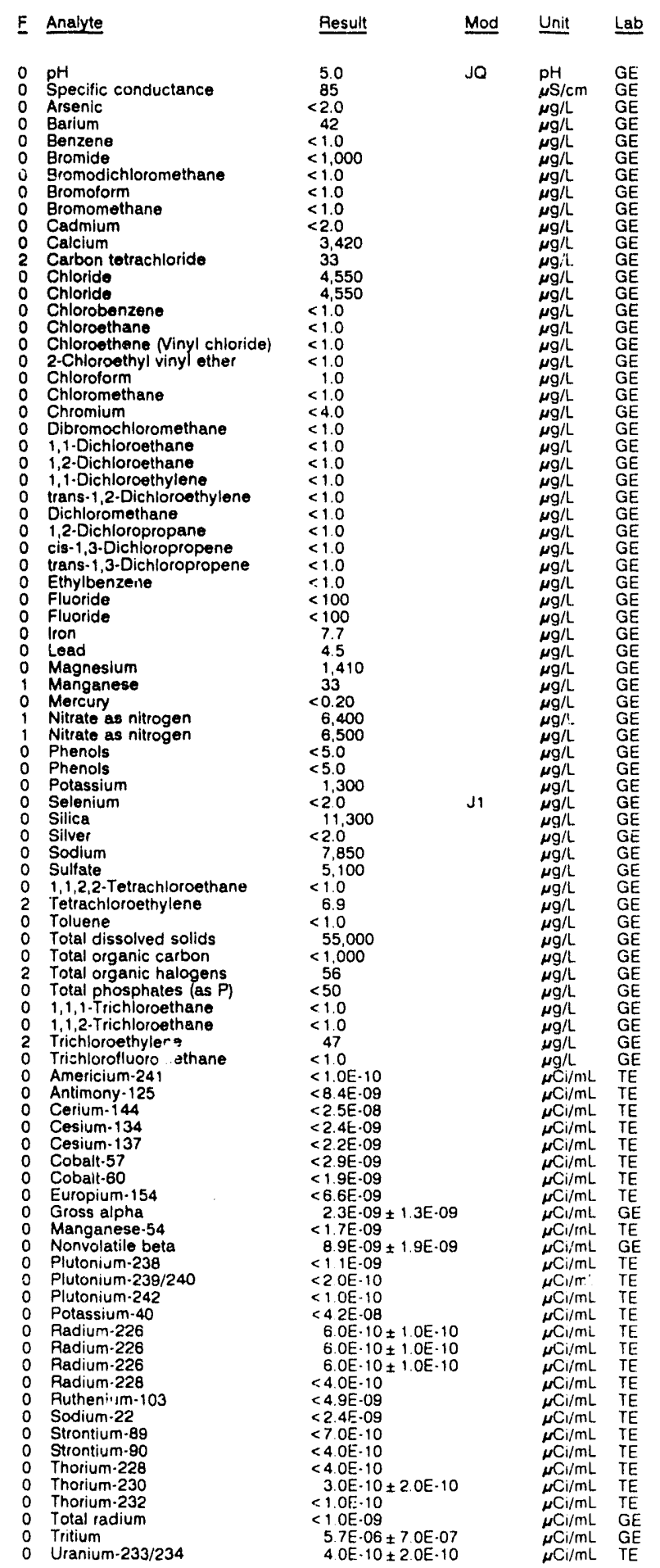

WELL XSB 10 coilected on 12/04/91, laboratory analyses (cont.)

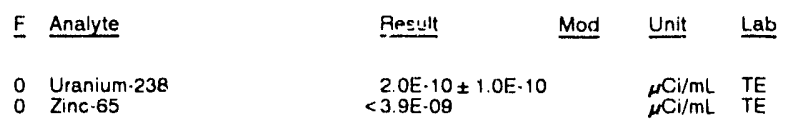

WELL XSB 2D

MLASUREMENTS CONDUCTED IN THE FIELD

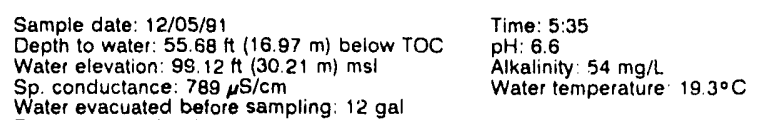

Water evacuated betore sampling: $12 \mathrm{gal}$

LABORATORY ANALYSES

E Analyte Result Mod Unit Lab

$\stackrel{\mathrm{pH}}{2} \mathrm{Specific}$ conductance

$\begin{array}{lll}0 & \text { Arsenic } \\ 0 & \text { Barium } \\ 0 & \text { anzing }\end{array}$

0 Benzene

1 Bromide

Bromodichloromethane

B Bromotorm

Bromomethan

Cadcium

2 Carbon tetrachloride

0 Chloride

0 Chlorobenzene

0 Chloroethane

0 Chloroethene Ninyl chloride)

2.Chloroethyl vinyl ether

0 Chloroform

Dibromochloromethane

$\begin{array}{ll}0 & 1,1 \cdot \text { Dichloroethane } \\ 0 & \end{array}$

o 1,2-Dichloroethane

1,1-Dichloroethylene

o trans-1,2-Dichloroethylene

0 Dichloriumethane

$\begin{array}{ll}0 & 1,2-D i c h l o r o p r o p a n e \\ 0 & \text { cis. } 1,3 . \text { D.chloropropen }\end{array}$

trans $-1,3$-Dichloropropene

$\begin{array}{ll}0 & \text { Ethylbenzene } \\ 0 & \text { Fluoride }\end{array}$

$\begin{array}{ll}0 & \text { Fluoride } \\ 0 & \text { lion }\end{array}$

0 Iron

\begin{tabular}{lll}
0 & Lead \\
0 & Magnesium \\
\hline & Magnesum
\end{tabular}

Magnesium

Manganese

Manganese

Nitrate as nitrogen

Phenols

0 Potassium

o Selenium

$\begin{array}{ll}0 & \text { Sllica } \\ 0 & \text { Silver }\end{array}$

Sodium

Sulfate

$1,1,2,2 \cdot$ Tetrachloroetha
Tetrachloroethylene

6.5
950

Total dissolved solids

Total organic carbon

Total phosphates (as P)

1,1,1.Trichloroethane

1,1.2-Trichloroethane

Trichlorofluoromethane

Americium-241

Antimony-125
Cerium-144

Cerium.144

Cesium-137

Cooall. 57

Europium-154

Gross alpha

Manganese-54

Nonvolatile beta

Plutonium-239/240

Plutonium-242

Potassium 40
Radiun1-226

Radiun -226
Radium -226

Radium-228

Ruthenium-103

Sodium-22

Strontium-89
Strontium-90

Strontium.90
$<2.0$
$<2.0$
199
$<1.0$
5.800
$<20.000$
$<1.0$
$<1.0$
$<1.0$
$<2.0$
48.700
15
7.000
$<1.0$
$<1.0$
$<1.0$
$<1.0$
4.0
$<1.0$
$<4.0$
$<1.0$
$<1.0$
$<1.0$
$<1.0$
$<1.0$
1.0
$<1.0$
$<1.0$
$<1.0$
$<1.0$
104
16
5.4
9.800
10.200
352
376
0.54
150.000

48,700

150,000
$<5.0$

4,610

$<2,000$

$<2.0$
109000

109,000
1.070

1.070
$<1.0$

$<.0$
4.1

687,000

$<1,000$

292

$<50$

$<1.0$

248
$<1.0$

$2.0 \mathrm{E} \cdot 10 \pm 1.0 \mathrm{E} \cdot 10$

$<7.5 \mathrm{E} .09$

$\begin{array}{rl}<2 & \mathrm{OE} \cdot 08 \\ <3 & \mathrm{O} .09\end{array}$

$<3$ BE.09
$<2.9 E \cdot 09$

$<2.96 .09$
$<2.71 .09$

<3. $1 \mathrm{E} .09$

1.1E.08 $+2.7 \mathrm{E} \cdot 09$

$<3.55 .09$

2. $0 E \cdot 08+2.7 E \cdot 09$

$<1.0 E-10$

$<1.0 E-10$

$<4.7 \mathrm{E} .08$

$4.6 E \cdot 09 \pm 3.0 E \cdot 10$

$4.6 E \cdot 09 \pm 3.0 E \cdot 10$
$1.4 E \cdot 09 \pm 1.0 E \cdot 09$

$1.4 \mathrm{E} \cdot 09 \pm$
$<6.4 \mathrm{E} .09$

$<6.4 \mathrm{E} \cdot 09$
$<4.0 \mathrm{E} \cdot 09$

$<4.0 E .09$
$<5$ OE. 10

6 OE-10 $4.0 E \cdot 10$

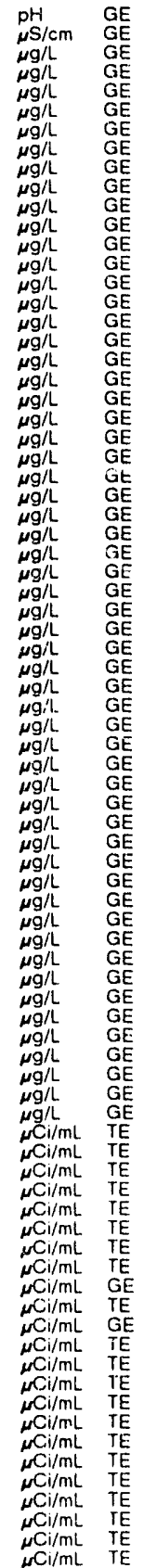


ANALYTICAL RESULTS

WELL XSB 2D collected on 12/05/91, laboratory analyses (cont.)

\begin{tabular}{|c|c|c|}
\hline Analyte & Result & Unit \\
\hline $\begin{array}{l}\text { Thorium-228 } \\
\text { Thorium-230 } \\
\text { Thorium.232 } \\
\text { Total radium } \\
\text { Tritium } \\
\text { Uranium-233/234 } \\
\text { Uranium-238 } \\
\text { Zinc-65 }\end{array}$ & $\begin{aligned}<3.0 \mathrm{E}-10 \\
<1.0 \mathrm{E}-10 \\
<1.0 \mathrm{E}-10 \\
7.4 \mathrm{E}-09 \pm 2.2 \mathrm{E}-09 \\
3.4 \mathrm{E}-06 \pm 7.0 \mathrm{E}-07 \\
9.0 \mathrm{E}-10 \pm 2.0 \mathrm{E}-10 \\
<1.0 \mathrm{E}-10 \\
<9.5 \mathrm{E} \cdot 09\end{aligned}$ & $\begin{array}{l}\mu \mathrm{Cl} / \mathrm{mL} \\
\mu \mathrm{Ci} / \mathrm{mL} \\
\mu \mathrm{Ci} / \mathrm{mL} \\
\mu \mathrm{Ci} / \mathrm{mL} \\
\mu \mathrm{Ci} / \mathrm{mL} \\
\mu \mathrm{Ci} / \mathrm{mL} \\
\mu \mathrm{Ci} / \mathrm{mL} \\
\mu \mathrm{Ci} / \mathrm{mL}\end{array}$ \\
\hline
\end{tabular}

\section{WELL XSB $3 A$}

MEASUREMENTS CONDUCTED IN THE FIELD

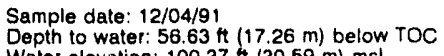

Depth to water: $56.63 \mathrm{H}(17.26 \mathrm{~m})$ below
Water elevation: $100.37 \mathrm{th}(30.59 \mathrm{~m}) \mathrm{msl}$

Water evacuated before sampling: $100 \mathrm{gal}$

Time: $11: 40$

pH: 5.9 Alkalinity: $8 \mathrm{mg} / \mathrm{L}$

Water temperature: $19.5^{\circ} \mathrm{C}$

LABORATORY ANALYSES

E Analyte Result $\underline{\text { Mod Unit Lab }}$

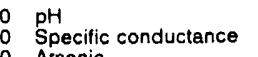

Arsenic

Barium

Bromide

Bromodichloromethane

Bromolorm

Cadmium

Calcium

Carbon tetrachioride

Chiloride

Chlorobenzene

Chloroethene Ninyl chloride)

2 Chloroethyl vinyl ether

Chloroform

Chloromethan

Dibromochloromethane

1,1-Dichloroethane

1,2-Dichloroethane

trans-1,2-Dichloroethylene

Dichloromethane

o cis-1,3-Dichioropropene

trans-1,3-Dichloropropene

Etrylbenzene

Iron

Lead

Magnesium

Manganese

Meicury

Nitrate as nitrogen

Phenols

Potassium

Seleniu

Silica

Sodium

Sulfate

Tetrachloroethylene

0 Toluene

Total dissolyed solids

Total organic carbon

2 Total organic halogens

Total phosphates as

1,1. Trichloroethane

Trichloroethylene

Trichlorofluoromethane

Americium-241

Antimony-125

Cerium-144

Cesium-137

Cobalt-57

Europium-154

Gross alpha

Manganese-54

Nonvolatile beta

Plutonium-238

Plutonium-239/240

Plutonium-242

Potassium-40
Radium-226

Radium.226

Radium-228

$\begin{aligned} & 5.8 \\ & 105 \\ &<2.0 \\ & 16 \\ &<1.0 \\ &<1.000 \\ &<1.0 \\ &<1.0 \\ &<1.0 \\ &<2.0 \\ & 55820 \\ &<1.0 \\ & 3.400 \\ &<1.0 \\ &<1.0 \\ &<10 \\ &<1.0 \\ &<1.0 \\ &<1.0 \\ &<4.0 \\ &<1.0 \\ &<1.0 \\ &<1.7 \\ &<1.0 \\ &<1.0 \\ & 1.1 \\ &<1.0 \\ &<1.0 \\ &<1.0 \\ &<1.0 \\ &<100 \\ & 26 \\ &<3.0 \\ & 11.290 \\ & 41\end{aligned}$

1,290
47
0.50

0.50
9,100
8,200

8,200
$<5.0$

1.120
$<2.0$

$<2.0$
10,100

$<2.0$
9.540

9,540
2,810

$<1.0$

$<1.0$

74,000

$<1,000$

104
$<50$

$<1.0$
$<1.0$

118

$<1.00$

$<5.5 E-09$

$<2.06 .00$

$<1.2 E .09$

$<2.5 \mathrm{E} .09$

$<1.8 E .09$

$<5.5 \mathrm{E} .09$

2.3E.09 $\pm 1.2 \mathrm{E}-09$

$<2.2 E-09$

3. $0 \mathrm{E} \cdot 10$

$7.0 E \cdot 10 \pm 4.0 E-10$

3. OE- $10 \pm 3.0 \mathrm{E}-10$

<3. $4 \mathrm{E}-08$

6. $0 E-10 \pm 1.0 E-10$

$6.0 E \cdot 10 \pm 1.0 E-10$
$<4.0 E \cdot 10$

JQ

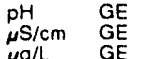

$\begin{array}{ll}\mu \mathrm{S} / \mathrm{cm} & \mathrm{GE} \\ \mu \mathrm{g} / \mathrm{L} & \mathrm{GE} \\ \mu \mathrm{g} / \mathrm{L} & \mathrm{GE}\end{array}$

$\mu g / L \quad G E$

$\mu g / L \quad G E$

$\mu g / L \quad G E$

$\mu g / L \quad G E$

$\mu g / L \quad G E$

$\mu \mathrm{g} / \mathrm{L} \quad \mathrm{GE}$

$<5.4 E-09$
WELL XSB $3 A$ collected on 12/04/91, laboratory analyses (cont.)

\begin{tabular}{|c|c|c|}
\hline Analyte & Result & Unit \\
\hline $\begin{array}{l}\text { Sodium-22 } \\
\text { Strontium-89 } \\
\text { Strontium-90 } \\
\text { Thorium-228 } \\
\text { Thorium-230 } \\
\text { Thorium-232 } \\
\text { Total radium } \\
\text { Tritium } \\
\text { Uranium-233/234 } \\
\text { Uranium-238 } \\
\text { Zinc. } 65 \text {. }\end{array}$ & $\begin{array}{l}<2.0 \mathrm{E}-09 \\
<8.0 \mathrm{O}-10 \\
<4.0 \mathrm{E}-10 \\
1.5 \mathrm{E}-09 \pm 1.1 \mathrm{E} \cdot 09 \\
<3.0 \mathrm{E}-10 \\
<1.0 \mathrm{E}-10 \\
<1.0 \mathrm{E}-09 \\
2.4 \mathrm{E} \cdot 05 \pm 1.0 \mathrm{E} \cdot \mathrm{r} \cdot 3 \\
6.0 \mathrm{E}-10 \pm 1.0 \mathrm{E} \cdot 00 \\
4.0 \mathrm{E}-10 \pm 1.0 \mathrm{E} \cdot 1 \mathrm{C} \\
<5.6 \mathrm{E} \cdot 09\end{array}$ & 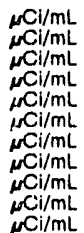 \\
\hline
\end{tabular}

WELL XSB 4D

MEASUREMENTS CONDUCTED IN THE FIELD

$\begin{array}{ll}\text { Sample date: } 12 / 04 / 91 & \text { Time: } 12: 20 \\ \text { Depth to water: } 55.64 \mathrm{Ht}(16.96 \mathrm{~m}) \text { below TOC } & \mathrm{pH}: 5.7 \\ \text { Water elevation: } 99.26 \mathrm{ft}(30.25 \mathrm{~m}) \mathrm{msl} & \text { Alkalinity: } 6 \mathrm{mg} / \mathrm{h} \\ \text { Sp. conductance: } 79 \mu \mathrm{S} / \mathrm{cm} & \text { Water temperature: } 19.5^{\circ} \mathrm{C} \\ \text { Water evacuated before sampling: } 40 \mathrm{gal} & \end{array}$

LABORATORY ANALYSES

E Analyte Result Mod Unit Lab

${ }_{0}^{0} \mathrm{pH}^{\mathrm{H}} \mathrm{\text {Specific }}$ conductance

$\begin{array}{ll}0 & \text { Arsenic } \\ 0 & \text { Barium } \\ 0 & \text { Benim }\end{array}$

Benzene

Bromide

Bromide

Brumoform

Bromemethane

Cadritum

Carbon tetrachloride

Chloride

Chloride

Chlorobenzene

Chloroethane

2.Chloroethyl vinyl ethe

Chloroform

Chloromethane

Dibromochloromethane

1.1.Dichloroethane

1. Q Uichloroethane

trans-1,2-Dichioroethylene

Dichloromethane

1,2-Dichloropropane

trans-1,3-Dichloropropene

Ethylbenzene

Fluoride

Iron

Lead

Mangesium

Mercury

Nitrate as nitrogen

Phenols

Selassium

Silica

Silver

Sodium

Sulfate

$1,1,2,2$-Tetrachioroethane

Tetrachlorvethylene

Toluene

Total dissolved solids

Total organic carbon

Total organic halogens

1,1,1-Trichloroethane

1,1,2-Trichloroethan

Trichlorolus o

Americium-ist 1 methan

Americium-e -1

Cerium. 144

Cesium-134

Cesium.137

Cobalt -57

- Cobalt.60 15

- Europium-154

Manganese. 54

Nonvolatile beta

Plutonium.238

Plutonium.239/240

Potassium 40

5.5

$\begin{aligned} & 8-15 \\ &<2.0< \\ &<23\end{aligned}$

$<1.0$

$<1,000$

$<1.0$

$<1.0$

$<1.0$
$<2.0$

$<\begin{gathered}2,860 \\ <1.0\end{gathered}$

5,800

$\begin{aligned} & 5,550 \\ < & 1.0 \\ < & 1.0\end{aligned}$

$<1.0$

$<1.0$

$<1.0$

$<4.0$
$<1.0$
$<1.0$
$<1.0$

$<1.0$

$<1.0$

$<1.0$
$<1.0$
$<1.0$
$<1.0$

$<1.0$

$<1.0$

$<3.0$
731

17
$<0.20$
4.100

4.100
$<5.0$

1,030

$<2.00$

$<2.0$

4,820

4,140
$<10$

$<1.0$

48,000
$<1,000$

86

$<1.0$
$<1.0$
3.3

3.3

$<1.0 E \cdot 10$
$<7.6 E-09$

$<2.1 E-08$

$<3.0 \mathrm{E} .00$

$<2.8 \mathrm{E} \cdot 09$

$<3.5 \mathrm{E}-09$

2.3E-09 $+1.4 \mathrm{E}-09$

$<2.9 \mathrm{E}-09+1.4 \mathrm{E}-09$

$<3$ OE. -10

$<1$ OE. 10

$<1.0 E \cdot 10$
$<4.2 E \cdot 08$ 
ANALYTICAL RESULTS

WELL XSB 40 collested on 12/04/91, laboratory analyses (cont)

\begin{tabular}{|c|c|c|}
\hline Analyte & Result & Unit \\
\hline $\begin{array}{l}\text { Radium-226 } \\
\text { Radium-226 } \\
\text { Radium-228 } \\
\text { Ruthenium-103 } \\
\text { Sodium-22 } \\
\text { Strontium-89 } \\
\text { Strontium-90 } \\
\text { Thorium-228 } \\
\text { Thorium-230 } \\
\text { Thorium-232 } \\
\text { Total radium } \\
\text { Tritium } \\
\text { Uranium-233/234 } \\
\text { Uranium-238 } \\
\text { Zinc-65 }\end{array}$ & 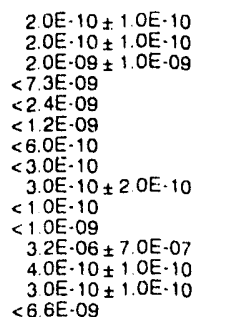 & $\begin{array}{l}\mu \mathrm{Ci} / \mathrm{mL} \\
\mu \mathrm{Ci} / \mathrm{mL} \\
\mu \mathrm{Ci} / \mathrm{mL} \\
\mu \mathrm{Ci} / \mathrm{mL} \\
\mu \mathrm{Ci} / \mathrm{mL} \\
\mu \mathrm{Ci} / \mathrm{mL} \\
\mu \mathrm{Cl} / \mathrm{mL} \\
\mu \mathrm{Ci} / \mathrm{mL} \\
\mu \mathrm{Ci} / \mathrm{mL} \\
\mu \mathrm{Ci} / \mathrm{mL} \\
\mu \mathrm{Ci} / \mathrm{mL} \\
\omega \mathrm{Ci} / \mathrm{mL} \\
\mu \mathrm{Ci} / \mathrm{mL} \\
\mu \mathrm{Ci} / \mathrm{mL} \\
\omega \mathrm{Ci} / \mathrm{mL}\end{array}$ \\
\hline
\end{tabular}

\section{WELL XSB 4D Replicate}

MEASUREMENTS CONOUCTED IN THE FIELD

Sample dale: $12 / 0491$

Depth to water: 55.64 it $(16.96 \mathrm{~m})$ below TOC Water elevation: $99.26 \mathrm{H}(30.25 \mathrm{~m}) \mathrm{ms}$

Wates evacuated before sampling: $40 \mathrm{gal}$

Time: $12: 20$

pH: 5.7

Water temperature $195^{\circ} \mathrm{C}$

LABORATORY ANALYSES

\begin{tabular}{|c|c|c|c|c|c|}
\hline$E$ & Analyte & Result & Mod & Unit & Lab \\
\hline 0 & $\mathrm{pH}$ & 5.6 & JO & $\mathrm{pH}$ & GE \\
\hline $\begin{array}{l}0 \\
0 \\
0\end{array}$ & $\begin{array}{l}\text { Specific conductance } \\
\text { Arsenic }\end{array}$ & $\begin{array}{r}85 \\
<2.0\end{array}$ & & $\begin{array}{l}\mu \mathrm{S} / \mathrm{cm} \\
\mu \mathrm{g} / \mathrm{L}\end{array}$ & $\begin{array}{ll}G E \\
G E\end{array}$ \\
\hline 0 & Barium & 23 & & $\mu g / L$ & $G E$ \\
\hline 0 & Benzene & $<1.0$ & & $\mu g / \mathrm{h}$ & $\mathrm{GE}$ \\
\hline 0 & Bromide & $<1.000$ & & $\mu \mathrm{g} / \mathrm{L}$ & $\overline{G E}$ \\
\hline 0 & Bromodichloromethane & $<1.0$ & & $\mu \mathrm{g} / \mathrm{L}$ & \\
\hline 0 & Bromotorm & $<1.0$ & & $\mu \mathrm{g} / \mathrm{L}$ & $\mathrm{GE}$ \\
\hline 0 & Bromomethane & $<1.0$ & & $\mu \mathrm{g} / \mathrm{L}$ & $\mathrm{GE}$ \\
\hline 0 & Cadmium & $<2.0$ & & $\mu g / \mathrm{L}$ & \\
\hline 0 & $\begin{array}{l}\text { Calcium } \\
\text { Carbon tetrachloride }\end{array}$ & $\begin{aligned} & 2,860 \\
&<1.0\end{aligned}$ & & $\underset{\mu \mathrm{g} / \mathrm{L}}{\mu \mathrm{g} / \mathrm{L}}$ & $\begin{array}{l}\mathrm{GE} \\
\mathrm{GE}\end{array}$ \\
\hline 0 & Chloride & 5.500 & & $\mu \mathrm{g} / \mathrm{h}$ & $\mathrm{GE}$ \\
\hline 0 & Chlorobenzene & $<1.0$ & & $\mu g / L$ & $\mathrm{GE}$ \\
\hline 0 & $\begin{array}{l}\text { Chloroethane } \\
\text { Chloroethene (Vinyl chloride) }\end{array}$ & $\begin{array}{l}<1.0 \\
<10\end{array}$ & & $\begin{array}{l}\mu g / L \\
\mu g / L\end{array}$ & $\begin{array}{ll}\mathrm{GE} \\
\mathrm{GE}\end{array}$ \\
\hline & 2-Chloroethyl vinyl ether & $<1.0$ & & $\mu \mathrm{g} / \mathrm{L}$ & $\mathrm{GE}$ \\
\hline 0 & Chloroform & $<1.0$ & & $\mu \mathrm{g} / \mathrm{L}$ & \\
\hline 0 & Chloromethane & $\begin{array}{l}<1.0 \\
<4.0\end{array}$ & & $\mu \mathrm{g} / \mathrm{L}$ & \\
\hline $\begin{array}{l}0 \\
0 \\
0\end{array}$ & $\begin{array}{l}\text { Chromium } \\
\text { Dibromochloromethane }\end{array}$ & $\begin{array}{l}<4.0 \\
<1.0\end{array}$ & & $\begin{array}{l}\mu g / \mathrm{L} \\
\mu \mathrm{g} / \mathrm{L}\end{array}$ & $\begin{array}{ll}\mathrm{GE} \\
\mathrm{GE}\end{array}$ \\
\hline 0 & 1,1-Dic nloroethane & $<1.0$ & & $\mu g / \mathrm{L}$ & $\mathrm{GE}$ \\
\hline 0 & 1.2-Dit ulorcethane & $<1.0$ & & $\mu \mathrm{g} / \mathrm{L}$ & \\
\hline 0 & 1.1.Dicnloroethylene & $\begin{array}{ll}<1 & 0 \\
<10\end{array}$ & & $\mu g / L$ & \\
\hline 0 & $\begin{array}{l}\text { trans-1,2-Dichloroethylene } \\
\text { Dichloromethane }\end{array}$ & $<100$ & & $\mu \mathrm{g} / \mathrm{L}$ & GE \\
\hline 0 & 1,2-Dichloropropane & $<10$ & & $\mu \mathrm{g} / \mathrm{h}$ & $\mathrm{GE}$ \\
\hline 0 & cis-1,3-Dichloropropene & $<1.0$ & & $\mu g / \mathrm{L}$ & \\
\hline & trans-1,3-Dichloropropene & $\begin{array}{l}<10 \\
10\end{array}$ & & $\mu g / L$ & \\
\hline 0 & Ethylbenzene & $\begin{array}{l}<10 \\
<100\end{array}$ & & $\mu g i L$ & \\
\hline $\begin{array}{l}0 \\
0\end{array}$ & Fluoride & $\begin{aligned}<100 \\
4.4\end{aligned}$ & & $\mu g / L$ & $G E$ \\
\hline 0 & $\begin{array}{l}\text { Iron } \\
\text { Lead }\end{array}$ & $\begin{array}{r}4.4 \\
<3.0\end{array}$ & & $\mu g / L$ & GE \\
\hline 0 & Magnesium & 718 & & $\mu g / \mathrm{L}$ & \\
\hline & Manganese & 17 & & $\mu \mathrm{g} / \mathrm{L}$ & \\
\hline 0 & Mercury & $<0.20$ & & $\mu g / \mathrm{h}$ & \\
\hline 0 & Nitrate as nitrogen & 4,000 & & $\mu \mathrm{g} / \mathrm{L}$ & \\
\hline 0 & $\begin{array}{l}\text { Fhenols } \\
\text { Potassium }\end{array}$ & $\begin{array}{l}<50 \\
962\end{array}$ & & $\mu g / L$ & $\mathrm{GE}$ \\
\hline 0 & Selenium & $<2.0$ & J1 & $\mu \mathrm{g} / \mathrm{h}$ & GE \\
\hline 0 & Silica & 9.920 & & $\mu 9 / \mathrm{L}$ & \\
\hline 0 & $\begin{array}{l}\text { Silver } \\
\text { Sodjum }\end{array}$ & $\begin{array}{l}<20 \\
9620\end{array}$ & & $\mu 9 / \mathrm{L}$ & GE \\
\hline 0 & Sulfate & 4,190 & & $\mu g / L$ & $\mathrm{GE}$ \\
\hline 0 & 1, 1,2,2. Tetrachloroethane & $<1.0$ & & $\mu g / \mathrm{h}$ & \\
\hline & $\begin{array}{l}\text { Tetrachloroethylene } \\
\text { Toluene }\end{array}$ & $<1.0$ & & $\mu g / \mathrm{h}$ & \\
\hline 0 & $\begin{array}{l}\text { Toluene } \\
\text { Total dissolved solids }\end{array}$ & $\begin{array}{l}<1.0 \\
54000\end{array}$ & & $\mu \mathrm{g} / \mathrm{L}$ & GE \\
\hline $\begin{array}{l}0 \\
0\end{array}$ & $\begin{array}{l}\text { Total dissolved solids } \\
\text { Total organic carbon }\end{array}$ & $\begin{aligned} & 54.000 \\
< & 1.000\end{aligned}$ & & $\begin{array}{l}\mu \mathrm{g} / \mathrm{L} \\
\mu \mathrm{g} / \mathrm{L}\end{array}$ & GE \\
\hline 2 & Total organic halogens & 150 & & $\mu \mathrm{g} / \mathrm{L}$ & \\
\hline & Total phosphates (as P) & $<50$ & & $\mu \mathrm{g} / \mathrm{L}$ & \\
\hline & 1, 1,1-Trichloroethane & $<10$ & & $\mu g / L$ & \\
\hline 0 & 1,1,2-Trichloroethane & $<10$ & & $\mu g / \mathrm{h}$ & \\
\hline 1 & Trichloroethylene & 26 & & $\mu g / L$ & \\
\hline 0 & Trichlorofluoromethane & $<1.0$ & & $\mu g / L$ & \\
\hline 0 & $\begin{array}{l}\text { Americium-241 } \\
\text { Antimany-125 }\end{array}$ & $<1 O E \cdot 10$ & & $\mu \mathrm{C}, 1 / \mathrm{mL}$ & \\
\hline & $\begin{array}{l}\text { Antimony } \cdot 125 \\
\text { Cerium } 144\end{array}$ & $\begin{array}{l}<8.4 E \cdot 09 \\
<2.9 E-08\end{array}$ & & ${ }_{\mu \mathrm{C} / / \mathrm{mL}}^{\mu \mathrm{Cl}}$ & TE \\
\hline 0 & Cesium-134 & $<3.6 \mathrm{E} .09$ & & $\mu \mathrm{Cl} / \mathrm{mL}$ & \\
\hline $\begin{array}{l}0 \\
0\end{array}$ & $\begin{array}{l}\text { Cesium. } 137 \\
\text { Cobalt-57 }\end{array}$ & $<2.7 \mathrm{E} .09$ & & $\mu \mathrm{Ci} / \mathrm{mL}$ & 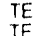 \\
\hline & $\begin{array}{l}\text { Cobalt.57 } \\
\text { Cobalt. } 60\end{array}$ & $\begin{array}{l}<3.9 \mathrm{E} \cdot 09 \\
<2.8 \mathrm{E} \cdot 09\end{array}$ & & $\begin{array}{l}\mu \mathrm{Cl} / \mathrm{mL} \\
\mu \mathrm{Cl} / \mathrm{mL}\end{array}$ & TE \\
\hline & Europium-154 & $<7.8 \mathrm{E}-09$ & & $\mu \mathrm{C}_{1} / \mathrm{mL}$ & TE \\
\hline & Gross aipha & $22 E-09 \pm 9.9 E-10$ & & $\mu \mathrm{C}_{1} / \mathrm{mL}$ & \\
\hline & $\begin{array}{l}\text { Manganese- } 54 \\
\text { Nonvolatile beta }\end{array}$ & $<3.6 \mathrm{E}-09$ & & $\mu \mathrm{Cl}_{1} / \mathrm{mL}$ & \\
\hline $\begin{array}{l}0 \\
0\end{array}$ & $\begin{array}{l}\text { Nonvolatile beta } \\
\text { Plutonium.238 }\end{array}$ & $\begin{array}{l}3.8 \mathrm{E}-09 \pm 19 \mathrm{E}-09 \\
6 \mathrm{OE}-10+3 \mathrm{OE} \cdot 10\end{array}$ & & $\mu \mathrm{Cl} / \mathrm{mL}$ & \\
\hline & Plutonium-239/240 & $\begin{array}{l}\text { C. } \\
<1.0 E-10 \pm 0 \text { - } 10 \text { UE } 10\end{array}$ & & $10 \mathrm{Cl} / \mathrm{mL}$ & \\
\hline
\end{tabular}

WE.LL. XSB AD collected on 12/04/91, laboratory analyses (cont.)

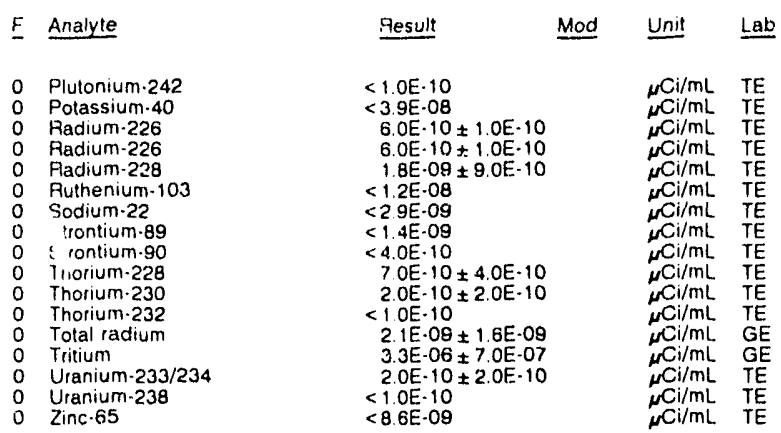

\section{WELL XSB 5A}

MEASUTEMENTS CONDUCT' : D IN THE FIELD

Depth to water: $19.86 \mathrm{n}(6.05 \mathrm{~m})$ below TOC

Water elevation. $92.14 \mathrm{ft}(28.08 \mathrm{~m}) \mathrm{msl}$

Water evacuated before sampling: $37 \mathrm{gal}$

LABORATORY ANALYYSES

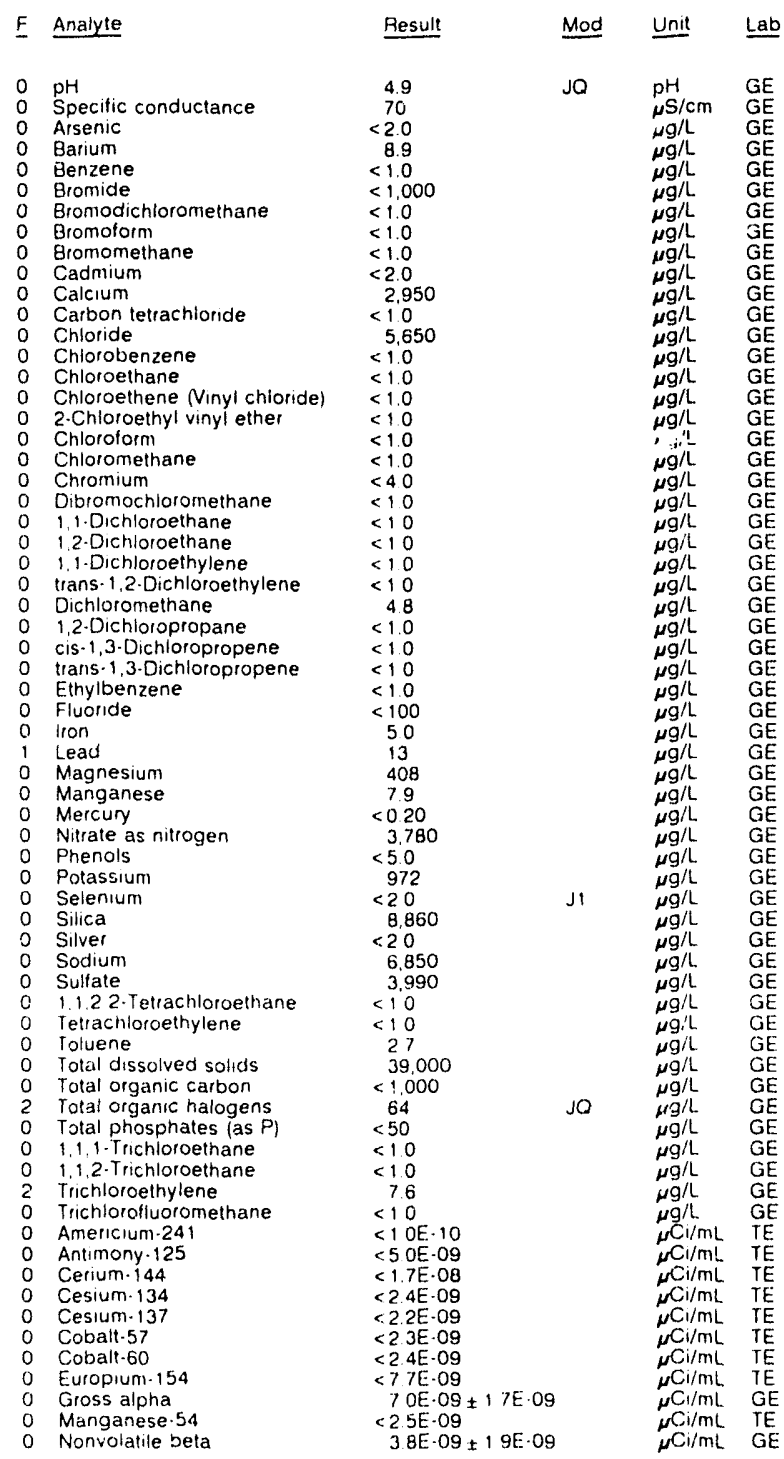


ANALYTICAL RESULTS

WELL XSB $5 A$ collected on 12/04/91, laboratory analyses (cont.)

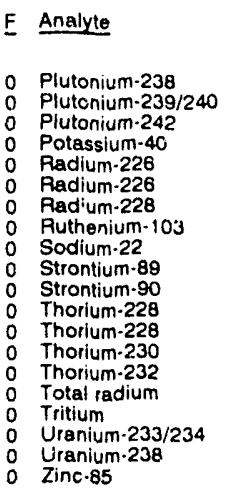

Result

Mod

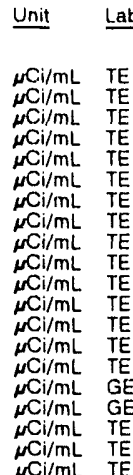

WELL YSB $1 \mathrm{~A}$

MEASUREMENTS CONOUCTED IN THE FIELD

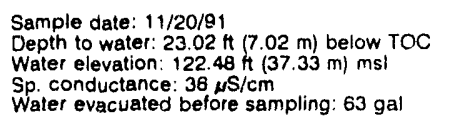

Time $9: 20$

Alkati, ity: $4 \mathrm{mg} / \mathrm{L}$

Wats; temperature: $21.8^{\circ} \mathrm{C}$

LABORATORY ANALYSES

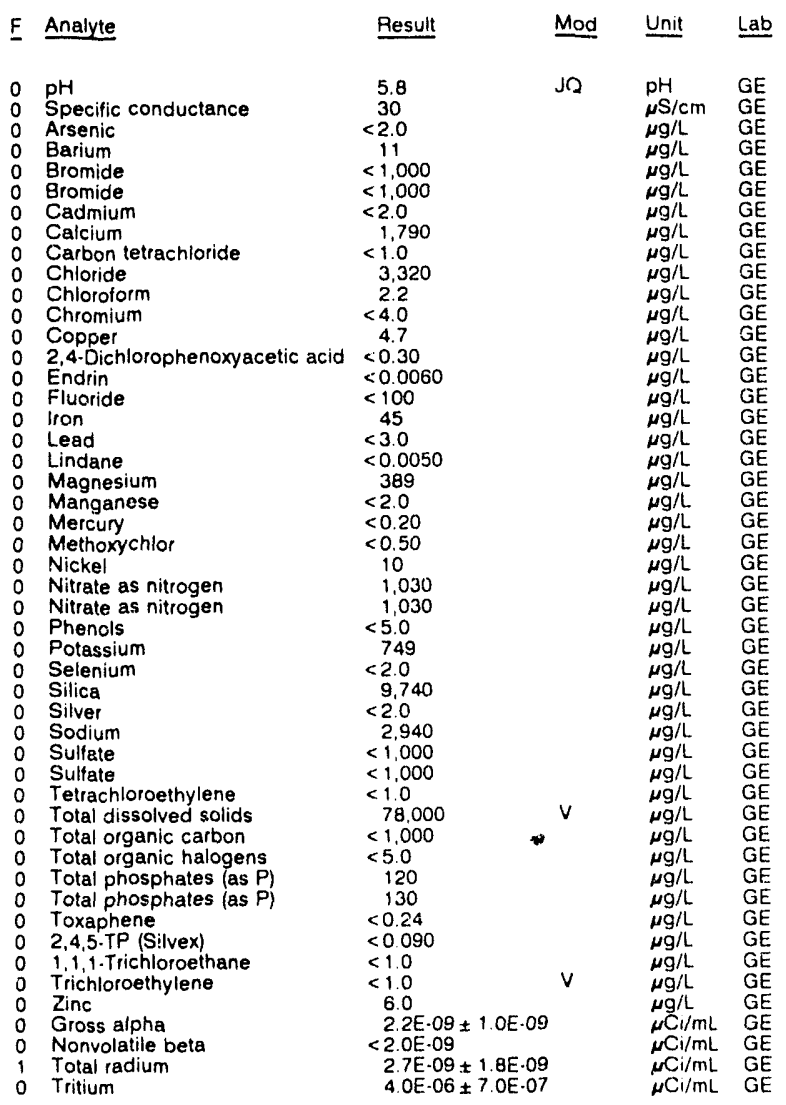

VVELL YSB $2 A$

MEASUREMENTS CONDUCTED IN THE FIELD

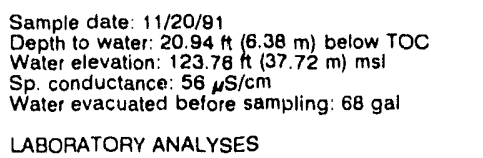

Time: 8:40

PH: 5.3 Alkalinity: $3 \mathrm{mgh}$ Water temperature: $19.5^{\circ} \mathrm{C}$

LABORATORY ANALYSES

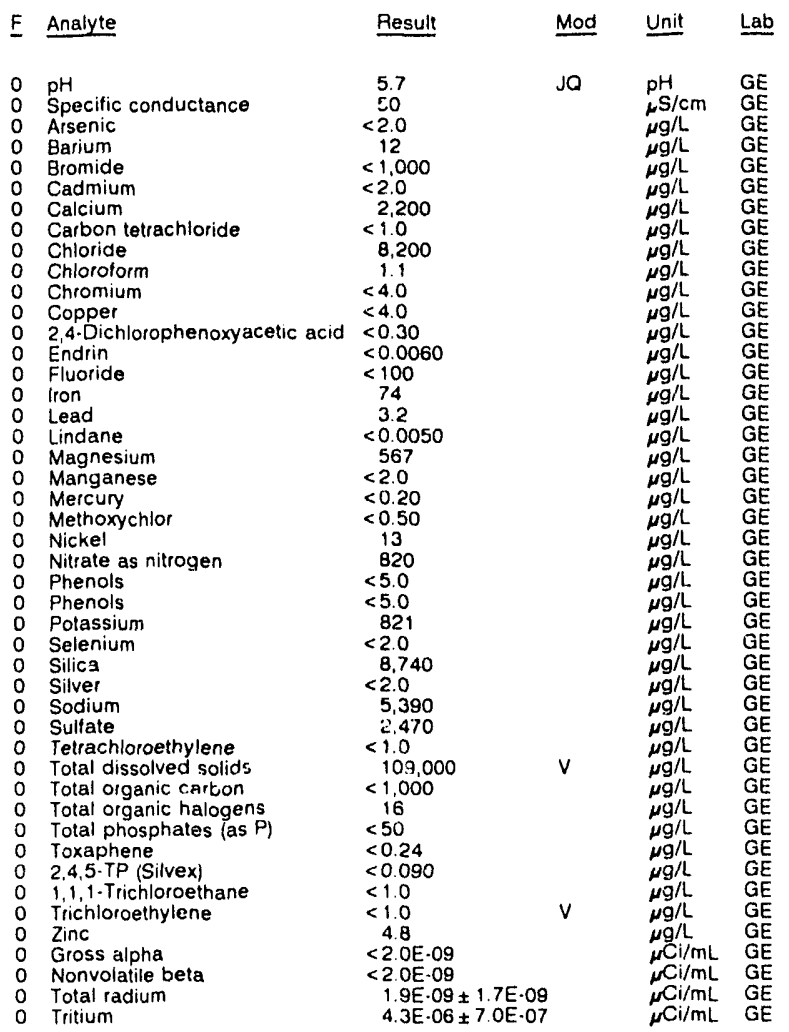

WELL YSB $3 A$

MEASUREMENTS CONDUCTED IN THE FIELD

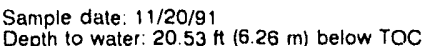

Water elevation: $123.37 \mathrm{H}(37.60 \mathrm{~m}) \mathrm{ms}$

Sp conductance: $327 \mu \mathrm{S} / \mathrm{cm}$

Water evacuated before sampling: $88 \mathrm{gal}$

LABORATORY ANALYSES

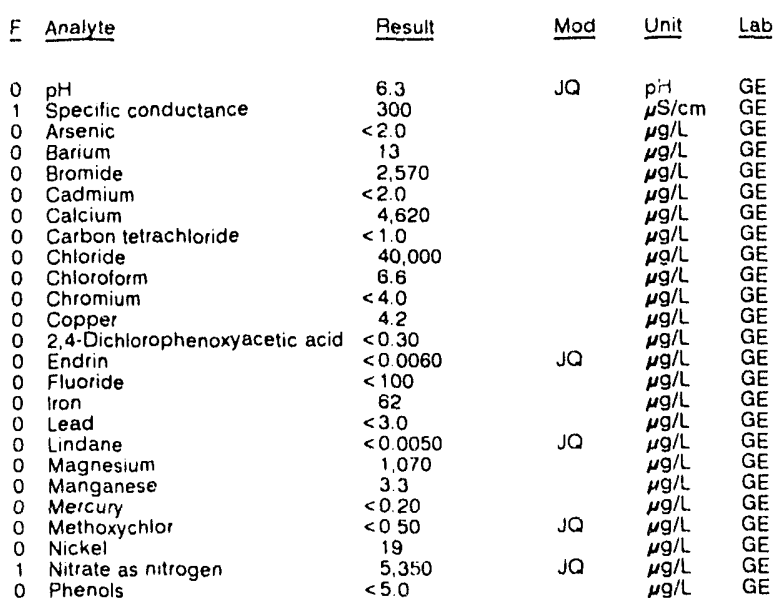

Time: $8: 15$
pH: 5.8
Alkalinity: $69 \mathrm{mg} / \mathrm{L}$
viva'er temperature: $20.4^{\circ} \mathrm{C}$

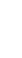


WELL YSB 3A collected on 11/20/91, laboratory analyses (cont)

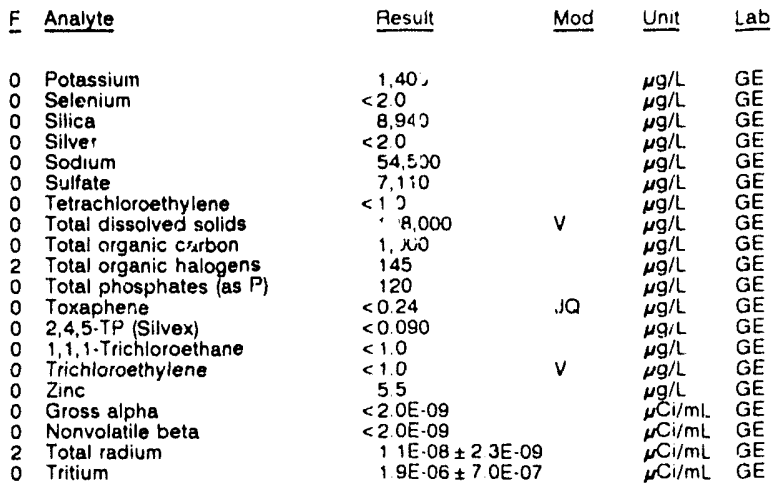

WELL YSB 4A

MEASUREMENTS CONDUCTED IN THE FIELD

Sample date: $11 / 20 / 91$

Depth to water: 22.36 it $(6.82 \mathrm{~m})$ below, TOC

Water elevation. $122.24 \mathrm{ft}(37$
Sp conductance : $94 \mu \mathrm{S} / \mathrm{cm}$

Sp. conductance: $94 \mu \mathrm{S} / \mathrm{cm}$
Water evacuated belore sampling: $65 \mathrm{gal}$

LABORATORY ANALYSES

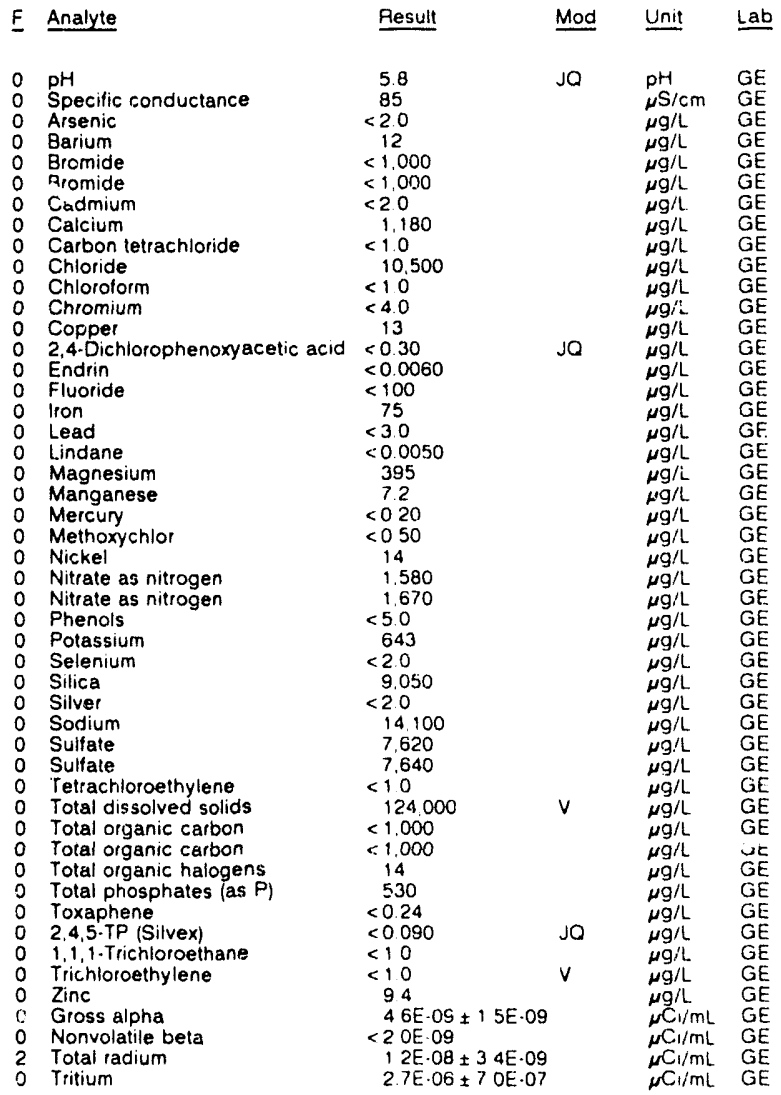

WELL YSC $1 \mathrm{~A}$

MEASUREMENTS CONDUCTED IN THE FIELD

Sample date: 11/21/91 Time 1250
WELL YSC $1 \mathrm{C}$

MEASUREMENTS CONDUCTED IN THE FIELD

Sample date $11 / 21 / 91$

Depth to water: $53.90 \mathrm{H}(16.43 \mathrm{~m})$ below TOC

Water elevation: $220.50 \mathrm{Ht}$

Timo: 13:15

pH: 6.5

$17 \mathrm{mg}$

Water temperature: $104^{\circ} \mathrm{C}$

LABORATORY ANALYSES

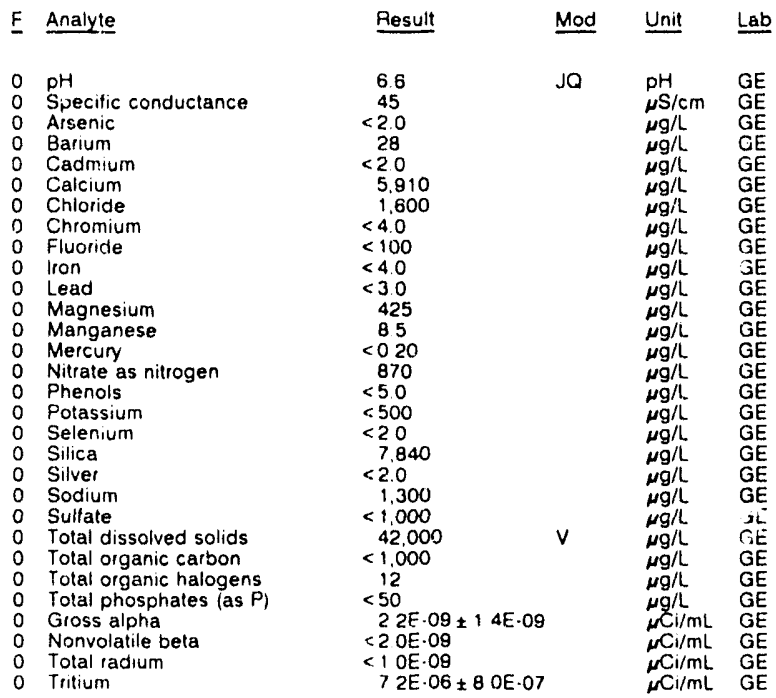

\section{WELL YSC $2 A$}

MEASUREMENTS CONDUCTED IN THE FIELD

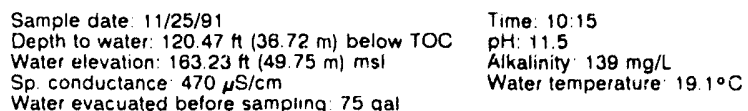
Water evacuated belore sampling: $75 \mathrm{gal}$

LABORATORY ANALYYSES

\begin{tabular}{|c|c|c|c|c|c|}
\hline E & Analyte & Pesult & Mod & Unit & Lab \\
\hline & pH & 11 & JQ & $\mathrm{pH}$ & GE \\
\hline & Specific conduclance & 355 & & $\mu \mathrm{S} / \mathrm{cm}$ & GE \\
\hline & Aisenic & $<20$ & & $\mu \mathrm{g} / \mathrm{L}$ & $G E$ \\
\hline & $\begin{array}{l}\text { Barium } \\
\text { Cadmium }\end{array}$ & $<20$ & & $\mu g / L$ & GE \\
\hline & Calcium & 42.700 & & $\mu g / h$ & $\begin{array}{l}G E \\
G E\end{array}$ \\
\hline & Chloride & 1,450 & & $\mu g / L$ & $\mathrm{GE}$ \\
\hline 0 & Chromium & $<40$ & & $\mu g / L$ & \\
\hline 0 & $\begin{array}{l}\text { Fluoride } \\
\text { Iron }\end{array}$ & $<100$ & & $\mu g / h$ & $G E$ \\
\hline 0 & $\begin{array}{l}\text { Iron } \\
\text { Lead }\end{array}$ & $\begin{array}{r}53 \\
<30\end{array}$ & & $\mu g / L$ & GE \\
\hline 0 & Magnesium & 331 & & $\mu g / \mathrm{h}$ & $\mathrm{GE}$ \\
\hline 0 & Manganese & 37 & & $\mu g / L$ & $\mathrm{GE}$ \\
\hline 0 & Mercury & $<020$ & & $\mu g / L$ & \\
\hline 0 & Nitrate as nitrogen & $<50$ & & $\mu g / \mathrm{L}$ & \\
\hline 0 & Phenois & $<50$ & & $\mu \mathrm{g} / \mathrm{L}$ & \\
\hline 0 & Potassium & 9.010 & & $\mu \mathrm{g} / \mathrm{L}$ & GE \\
\hline 0 & Selenium & $<20$ & JI & $\mu g / L$ & \\
\hline 0 & Sllica & 15.000 & & $\mu g / L$ & \\
\hline 0 & Silvet & -20 & & $\mu g / L$ & \\
\hline 0 & Sodium & 4.680 & & $\mu g / h$. & $\mathrm{GE}$ \\
\hline 0 & Sulfate & 8.340 & & $\mu g / L$ & \\
\hline : & Total dissolved solids & 142,000 & & $\mu \mathrm{g} / \mathrm{h}$ & \\
\hline & Total organic carbon & $<1,000$ & & $\mu \mathrm{g} / \mathrm{L}$ & \\
\hline 0 & Total organic halogens & $<50$ & & $\mu g / L$ & \\
\hline 0 & Total organic halogens & $<5.0$ & & $\mu g / h$ & \\
\hline 0 & Total phosphates (as P) & $<50$ & & $\mu g / \mathrm{h}$ & \\
\hline 0 & Gross alpha & $26 \mathrm{E} \cdot 09 \pm 14 \mathrm{E} \cdot 09$ & & $\mu \mathrm{C}_{\mathrm{I}} / \mathrm{mL}$ & \\
\hline 0 & Nonvolatile beta & $<20 E \cdot 09$ & & $\mathrm{mCl}_{\mathrm{C}} / \mathrm{mL}$ & \\
\hline 0 & Total - _tium & $<1$ OE 09 & & $\mathrm{mCl} / \mathrm{mL}$ & \\
\hline 0 & Tritium & $<70 E .07$ & & $\mu \mathrm{Cl} / \mathrm{mL}$ & $\mathrm{GE}$ \\
\hline
\end{tabular}


ANALYTICAL RESULTS

WELL YSC 2A Replicate

MEASUREMENTS CONDUCTED IN THE FIELD
Sample date: 11/25/91

Depth to water: $12 \mathrm{C} .47 \mathrm{Ht}(36.72 \mathrm{~m})$ below TOC

Water elevation: 183.23 \& (49.7

Sp. conductance: $470 \mu \mathrm{S} / \mathrm{cm}$

Water evacuated before sampling: $75 \mathrm{ga}$

LABORATORY ANALYSES

\begin{tabular}{|c|c|c|c|}
\hline Analyte & Result & Mod & Unit \\
\hline $\begin{array}{l}\text { pH } \\
\text { Specific conductance } \\
\text { Arsenic } \\
\text { Barium } \\
\text { Cadmium } \\
\text { Calcium } \\
\text { Chloride } \\
\text { Chromium } \\
\text { Fluoride } \\
\text { Fluoride } \\
\text { Iron } \\
\text { Lead } \\
\text { Magnesium } \\
\text { Manganese } \\
\text { Mercury } \\
\text { Nitrate as nitrogen } \\
\text { Nitrate as nitrogen } \\
\text { Phenols } \\
\text { Potassium } \\
\text { Selenium } \\
\text { Silica } \\
\text { Silver } \\
\text { Sodium } \\
\text { Sulfate } \\
\text { Sulfate } \\
\text { Total dissolved solids } \\
\text { Total organic carbon } \\
\text { Total organic halogens } \\
\text { Total organic halogens } \\
\text { Tutal phosphates (as P) } \\
\text { Gross alpha } \\
\text { Nonvolatile beta } \\
\text { Total radium } \\
\text { Tritium }\end{array}$ & $\begin{array}{l}11 \\
350 \\
<2.0 \\
122 \\
<2.0 \\
41,700 \\
1,380 \\
<4.0 \\
<100 \\
<100 \\
12 \\
<3.0 \\
325 \\
3.6 \\
<0.20 \\
<50 \\
<50 \\
<5.0 \\
8,670 \\
<2.0 \\
14,700 \\
<2.0 \\
4.560 \\
8.200 \\
8.110 \\
142,000 \\
<1.000 \\
8.5 \\
9.3 \\
<50 \\
2.6 \mathrm{E} \cdot 09 \pm 1.2 \mathrm{E} \cdot 09 \\
3.9 \mathrm{E} \cdot 09 \pm 2.3 \mathrm{E}-09 \\
<1.0 \mathrm{E} \cdot 09 \\
<7.0 \mathrm{E}-07\end{array}$ & $J O$ & $\begin{array}{l}p H \\
\mu \mathrm{S} / \mathrm{cm} \\
\mu g / L \\
\mu g / L \\
\mu g / L \\
\mu g / L \\
\mu g / L \\
\mu g / L \\
\mu g / L \\
\mu g / L \\
\mu g / L \\
\mu g / L \\
\mu g / L \\
\mu g / L \\
\mu g / L \\
\mu g / L \\
\mu g / L \\
\mu g / L \\
\mu g / L \\
\mu g / L \\
\mu g / L \\
\mu g / L \\
\mu g / L \\
\mu g / L \\
\mu g / L \\
\mu g / L \\
\mu g / L \\
\mu g / L \\
\mu g / L \\
\mu g / L \\
\mu C i / m L \\
\mu C i / m L \\
\mu C \mathrm{C} / \mathrm{mL} \\
\mu C \mathrm{i} / \mathrm{mL}\end{array}$ \\
\hline
\end{tabular}

\section{WELL YSC 2D}

MEASUREMENTS CONDUCTED IN THE FIELD

Sample date: 11/22/91 Depth to water: $63.54 \mathrm{ft}(19.37 \mathrm{~m})$ below TOC Water elevation: $220.46 \mathrm{~h}(67$.

Water evacuated before sampling: $16 \mathrm{gal}$ Whe well went dry during jurging.
The

Time: 10:15

Alkalinity: $139 \mathrm{mg}$ Water temperature $19.1^{\circ} \mathrm{C}$

ab

LABORATORY ANALYSES

\begin{tabular}{|c|c|c|c|c|c|}
\hline $\mathbf{F}$ & Analyte & Result & Mod & Unit & $\underline{\text { Lab }}$ \\
\hline & $\begin{array}{l}\text { pH } \\
\text { Specific conductance } \\
\text { Arsenic } \\
\text { Barium } \\
\text { Cadmium } \\
\text { Calcium } \\
\text { Chloride } \\
\text { Chromium } \\
\text { Fluoride } \\
\text { Iron } \\
\text { Lead } \\
\text { Magnesium } \\
\text { Manganese } \\
\text { Merzury } \\
\text { Nitrate as nitrogen } \\
\text { Phenols } \\
\text { Phenols } \\
\text { Potassium } \\
\text { Selenium } \\
\text { Silica } \\
\text { Silver } \\
\text { Sodium } \\
\text { Sulfate } \\
\text { Total dissolved solids } \\
\text { Total organic carbon } \\
\text { Total organic halogens } \\
\text { Total phosphates (as P) } \\
\text { Gross alpha } \\
\text { Nonvolatile beta } \\
\text { Total racium } \\
\text { Tritium }\end{array}$ & $\begin{array}{l}6.8 \\
305 \\
<2.0 \\
22 \\
<2.0 \\
13.400 \\
2.190 \\
<4.0 \\
<100 \\
149 \\
<3.0 \\
602 \\
32 \\
<0.20 \\
2,360 \\
<5.0 \\
<5.0 \\
2.180 \\
3.1 \\
9,880 \\
<2.0 \\
43.000 \\
82,200 \\
183.000 \\
<1,000 \\
39 \\
240 \\
9.9 E \cdot 09 \pm 2.1 E \cdot 09 \\
6.5 E \cdot 09 \pm 2.4 E \cdot 09 \\
4.0 E \cdot 09 \pm 2.2 E \cdot 09 \\
9.3 E \cdot 06 \pm 8.0 E \cdot 07\end{array}$ & $\mathrm{JQ}$ & $\begin{array}{l}p H \\
\mu \mathrm{S} / \mathrm{cm} \\
\mu g / L \\
\mu g / L \\
\mu g / L \\
\mu g / L \\
\mu g / L \\
\mu g / L \\
\mu g / L \\
\mu g / L \\
\mu g / L \\
\mu g / L \\
\mu g / L \\
\mu g / L \\
\mu g / L \\
\mu g / L \\
\mu g / L \\
\mu g / L \\
\mu g / L \\
\mu g / L \\
\mu g / L \\
\mu g / L \\
\mu g / L \\
\mu g / L \\
\mu g / L \\
\mu g / L \\
\mu g / L \\
\mu C / / m L \\
\mu C i / m L \\
\mu C I / m L \\
\mu C i / m L\end{array}$ & $\begin{array}{l}\mathrm{GE} \\
\mathrm{GE} \\
\mathrm{GE} \\
\mathrm{GE} \\
\mathrm{GE} \\
\mathrm{GE} \\
\mathrm{GE} \\
\mathrm{GE} \\
\mathrm{GE} \\
\mathrm{GE} \\
\mathrm{GE} \\
\mathrm{GE} \\
\mathrm{GE} \\
\mathrm{GE} \\
\mathrm{GE} \\
\mathrm{GE} \\
\mathrm{GE} \\
\mathrm{GE} \\
\mathrm{GE} \\
\mathrm{GE} \\
\mathrm{GE} \\
\mathrm{GE} \\
\mathrm{GE} \\
\mathrm{GE} \\
\mathrm{GE} \\
\mathrm{GE} \\
\mathrm{GE} \\
\mathrm{GE} \\
\mathrm{GE} \\
\mathrm{GE} \\
\mathrm{GE}\end{array}$ \\
\hline
\end{tabular}

WELL YSC $4 C$

MEASUAEMENTS CONOUCTED IN THE FIELD

Sample date: $11 / 21 / 91$

Depth to water: $58.80 \mathrm{ft}(17.92 \mathrm{~m})$ below TOC

Water elevation: $230.80 \mathrm{ft}$ (70.3

Sp. conductance: $26 \mu \mathrm{S} / \mathrm{cm}$
Water evacuated belore sampling: $92 \mathrm{gal}$

LABORATORY ANALYSES
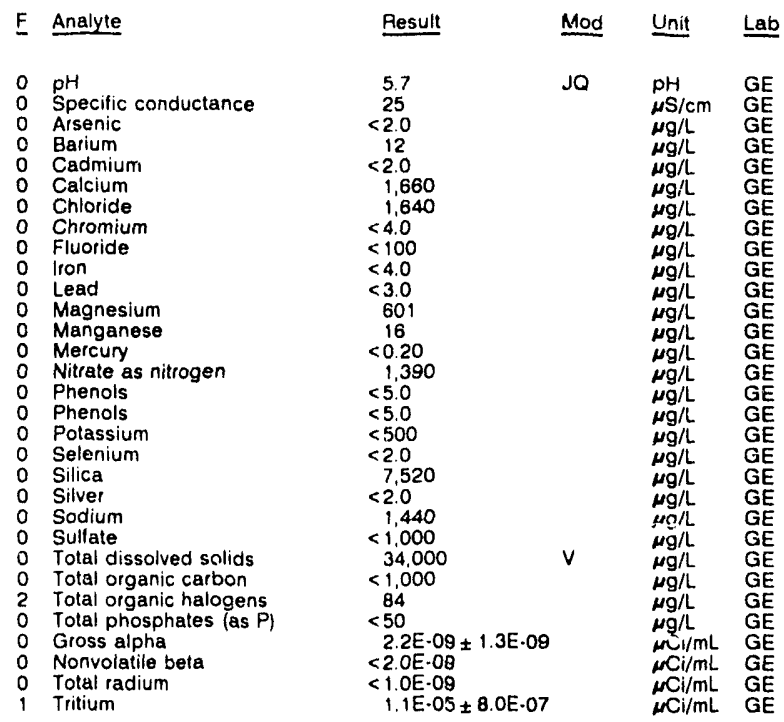

WELL YSC $5 A$

MEASUREMENTS CONDUCTED IN THE FIELD

Sample date: 11/21/91 Depth to water: $84.51 \mathrm{ft}(25.76 \mathrm{~m})$ below TOC Water elevation: $190.39 \mathrm{ft}(58.03 \mathrm{~m}) \mathrm{ms} \mid$

Sp. conductance: $213 \mu \mathrm{S} / \mathrm{cm}$

Water evacuated before sampling: $293 \mathrm{gal}$

Time: $12: 40$

PH: 5.3 Water temperature: $19.6^{\circ} \mathrm{C}$ LABORATORY ANALYSES
F Analyte

0 pH

0 Arsenic

o Barium

- Cadmium

Chloride

Chromium

0 Fluoride

0 Iron

- Magnesium

Manganes

Nitrate as nitrogen

o Phenols

- Potassium

o Selenium

- Silica

- Silver

0 Sulfate

Total dissolved solids

Total organic carbon

Total organic halogens

Total phosphat

- Nonvolatile beta

Total radium

Tritium

\section{Time: $12: 00$}

Alkalinity: $88 \mathrm{mg} / \mathrm{L}$ Water temperature: $19.2^{\circ} \mathrm{C}$ Tritum $9.3 \mathrm{E} .06 \pm \mathrm{B} .0 \mathrm{E} \cdot 07$ 


\section{ANALYTICAL RESULTS}

WELL $Z 2$

MEASUREMENTS CONDUCTED IN THE FIELD

Sample date: $12 / 18 / 81$ Time: Not avariable

Inaccessibility or pump failure prevented sample collection.

\section{WELL $Z$ 3}

MEASUREMENTS CONDUCTED IN THE FIELD

Sample dale: $12 / 10 / 91$

Time 1020

Depth to water: $44.00 \mathrm{ft}(13.41 \mathrm{~m})$ below TOC

or pump failure prevented sample collection

\section{WELL Z 8}

MEASUREMENTS CONDUCTED IN THE FIELD

Sample date: 12/10/81

Depth to water: $58.50 \mathrm{ft}(17.83 \mathrm{~m})$ below TOC

Water elevation: $221.50 \mathrm{t}(67.51 \mathrm{~m}) \mathrm{ms}$

Sp. conductance: 63 is $\$ \mathrm{~cm}$

Time: $10: 15$

No water was ovacuated before samp!:ing

Water temperature: $18.4^{\circ} \mathrm{C}$

\section{WELL Z 9}

MEASUREMENTS CONDUCTED IN THE FIELD

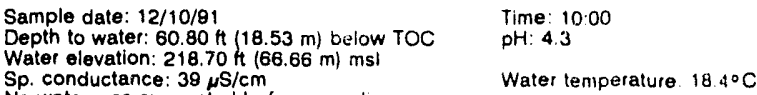

WELL Z 11

MEASUREMENTS CONDUCTED IN THE FIELD

Sample date: $12 / 10 / 9$ Time: Not available

\section{WELL Z 13}

MEASUREMENTS CONDUCTEO IN THE FIELD

Sample date: 12/10/91 Time. Not available

Inaccessibility or pump failure prevented sample collection.

WELL Z 15

MEASUREMENTS CONDUCTED IN THE FIELD

Sample date: $12 / 10 / 9$

Inaccessibility or pump failure prevented sample collection.

WELL $Z \quad 17$

MEASUREMENTS CONDUCTED IN THE FIELO

Sample date: $12 / 10 / 91$

Depth to water: $9.60 \mathrm{~h}(2.93 \mathrm{~m})$ below TOC

Water elevation: $169.20 \mathrm{ft}(51$.

Time: $9: 40$

No water was evacuated before sampling
WELL Z 18

MEASUREMENTS LONDUCTED IN THE FIELD

Sample date: 12/10/81

Depth to water: $16.00 \mathrm{Ht}(4.88 \mathrm{~m})$ below TOC

$10 \mathrm{ft}(56.72 \mathrm{~m}) \mathrm{msl}$

o water was evacuated before sampling

Time: $\mathbf{\theta : 3 0}$

Water temperature: $18.8^{\circ} \mathrm{C}$

WEL.L Z 19A

MEASUREMENTS CONDUCTED IN THE FIELD

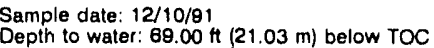

Water elevation: $193.00 \mathrm{it}(58.83 \mathrm{~m}) \mathrm{ms}$

Sp. conductance: $22, \mathrm{st}$

No water was evacuated before sampling

Time: $8: 20$

$\mathrm{pH}: 4.4$

Water temperature: $18.1^{\circ} \mathrm{C}$

\section{WELL $Z$ 20B}

MEASUREMENTS CONDUCTED IN THE FIELD

Sample date: 12/10/91

Depth to water: $48.50 \mathrm{ft}(14.78 \mathrm{~m})$ below TOC

Weter elevation: $195.10 \mathrm{tt}(59.47 \mathrm{~m}) \mathrm{ms}$ ।

Sp. conductance: $18 \mu \mathrm{S} / \mathrm{cm}$

No water was evacuated before sampling.

Time: $9: 15$

$\mathrm{pH}: 4.5$

Water temperature: $18.6^{\circ} \mathrm{C}$

WELL ZBG 1

MEASUREMENTS CONDUCTED IN THE FIELD

Sample date: $11 / 21 / 91$
Depth to water: $53.99 \mathrm{ft}(16.46 \mathrm{~m})$ below TOC

Water elevation: $237.11 \mathrm{Ht}(72.27 \mathrm{~m}) \mathrm{msl}$

Water evacuated before sampling: $45 \mathrm{gal}$

LABORATORY ANALYSES

Result

Antimony

Arsenic

Barium

Bromocichloromethane

Bromotorm

Bromomethan

Cadmium

Carbon tetrachloride

Chlorobenzene

Chloroethane

2-Chloroethy! vinyl ether

2-Chloroethy

Chloromethane

Chromium

Dibromochloromethane

1.1-Dichloroethane

1.2.Dichloroethane

1.1-Dichloroethylene

trans-1,2-Dichloroethylene

Dichloromethane

1.2-Dichloropropane

cis-i,3-Dichloropropene

trans-1,3-Dichloropropene

Ethylbenzene

Lead

Mercury

Nitrate as nitrogen

Nitrite as nitrogen

Nitrite as nitroge
Selenium

$1,1,2,2$-Tetrachloroethane

Tetrachloroethylene

Toluene

1,1,1-Trichloroethane

$1,1,2$-Trichloroethan

Trichloroethylene

Antimony-125

Cerium-144

Cesium-134

Cesium-137

Cobalt 57
$<2.0$
$<2.0$
12
$<1.0$

$<1.0$

$<1.0$

$<2.0$

$<1.0$

$<1.0$

$<1.0$

$<1.0$

$<1.0$

$<1.0$

$<4.0$
$<1.0$
$<1.0$

si.

$<1.0$

$<1.0$

$<1.0$

$<1.0$

$<1.0$
$<1.0$
$<1.0$

4.3

$<0.20$

$<10$

$<10$
$<2.0$

$<2.0$

$<1.0$

$<10$

$<1,0$

$<1.0$

$<6.9 \mathrm{E}-\mathrm{OO}$

$<2.1 \mathrm{E} \cdot 0 \mathrm{0}$

$<2.9 \mathrm{E} \cdot 09$

$<2.8 \mathrm{E} .09$

$<2.7 \mathrm{E} \cdot 00$
Time: 13:55

$\mathrm{pH}: 5.3$

Alkalinity' $1 \mathrm{mg} / \mathrm{h}$

Water ten.perature: $19.4^{\circ} \mathrm{C}$

\begin{tabular}{|c|c|}
\hline Mod & Unit \\
\hline $\begin{array}{l}\mathrm{JQ} \\
\mathrm{J} Q \\
\mathrm{~J} Q \\
\mathrm{~J} Q\end{array}$ & $\begin{array}{l}\mu g / L \\
\mu g / L \\
\mu g / L \\
m g / L \\
\mu g / L \\
\mu g / L \\
\mu g / L\end{array}$ \\
\hline $\begin{array}{l}\mathrm{JQ} \\
\mathrm{J} Q \\
\mathrm{~J} Q \\
\mathrm{~J} Q \\
\mathrm{JO} \\
\mathrm{J} Q \\
\mathrm{JO}\end{array}$ & $\begin{array}{l}\mu g / L \\
\mu g / L \\
\mu g / L \\
\mu g / L \\
\mu g / L \\
\mu g / L \\
\mu g / L\end{array}$ \\
\hline $\begin{array}{l}\mathrm{J} Q \\
\mathrm{~J} Q \\
\mathrm{~J} Q \\
\mathrm{~J} O \\
\mathrm{~J} Q \\
\mathrm{~J} Q \\
\mathrm{~J} Q \\
\mathrm{~J} Q \\
\mathrm{~J} Q \\
\mathrm{~J} Q\end{array}$ & $\begin{array}{l}\mu g / L \\
\mu g / L \\
\mu g / h \\
\mu g / h \\
\mu g / L \\
\mu g / L \\
\mu g / L \\
\mu g / L \\
\mu g / L \\
\mu g / L \\
\mu g / L \\
\mu g / L\end{array}$ \\
\hline $\begin{array}{l}\mathrm{JQ} \\
\mathrm{J} Q \\
\mathrm{~J} Q \\
\mathrm{~J} 1\end{array}$ & $\begin{array}{c}\mu g / L \\
\mu g / L \\
\mu g / L \\
\mu g / L \\
\mu g / L\end{array}$ \\
\hline $\begin{array}{l}J Q \\
J Q \\
J Q \\
J Q \\
J Q \\
J Q \\
J Q\end{array}$ & $\begin{array}{l}\mu g / \mathrm{L} \\
\mu g / \mathrm{L} \\
\mu \mathrm{g} / \mathrm{L} \\
\mu \mathrm{g} / \mathrm{L} \\
\mu \mathrm{g} / \mathrm{L} \\
\mu \mathrm{g} / \mathrm{L} \\
\mu \mathrm{g} / \mathrm{L} \\
\mu \mathrm{Ci} / \mathrm{mL} \\
\mu \mathrm{Ci} / \mathrm{mL} \\
\mu \mathrm{Ci} / \mathrm{mL} \\
\mu \mathrm{Cl} / \mathrm{mL} \\
\mu \mathrm{Ci} / \mathrm{mL} \\
\mu \mathrm{Ci} / \mathrm{mL}\end{array}$ \\
\hline
\end{tabular}


WELL ZBG 1 collected on 11/21/91, laboratory analyses (cont.)

\begin{tabular}{|c|c|c|c|}
\hline Analyte & Result & Mod & Unit \\
\hline $\begin{array}{l}\text { Europium-154 } \\
\text { Gross alpha } \\
\text { Manganese-54 } \\
\text { Potassium-40 } \\
\text { Radium-226 } \\
\text { Ruthenium-103 } \\
\text { Sodium-22 } \\
\text { Tochnetium-89 } \\
\text { Thorium-228 } \\
\text { Total radium } \\
\text { Tritium } \\
\text { Zinc-65 }\end{array}$ & $\begin{array}{l}<1.2 \mathrm{E} \cdot 08 \\
2.2 \mathrm{E} \cdot 09 \pm 8.0 \mathrm{E} \cdot 10 \\
<3.6 \mathrm{E} \cdot 09 \\
<4.6 \mathrm{E} \cdot 08 \\
<5.3 \mathrm{E} \cdot 09 \\
<8.5 \mathrm{E} \cdot 09 \\
<4.4 \mathrm{E} \cdot 09 \\
<1.5 \mathrm{E} \cdot 08 \\
<2.8 \mathrm{E} \cdot 09 \\
<1.0 \mathrm{E} \cdot 09 \\
1.1 \mathrm{E} \cdot 05 \pm 8.0 \mathrm{E}-07 \\
<8.7 \mathrm{E} \cdot 09\end{array}$ & & $\begin{array}{l}\mu_{\mathrm{Ci} / \mathrm{mL}} \\
\mu \mathrm{Ci} / \mathrm{mL} \\
\mu \mathrm{Ci} / \mathrm{mL} \\
\mu \mathrm{Ci} / \mathrm{mL} \\
\mu \mathrm{Ci} / \mathrm{mL} \\
\mu \mathrm{Ci} / \mathrm{mL} \\
\mu \mathrm{Ci} / \mathrm{mL} \\
\mu \mathrm{Ci} / \mathrm{mL} \\
\mu \mathrm{Ci} / \mathrm{mL} \\
\mu \mathrm{CC} / \mathrm{mL} \\
\mu \mathrm{Ci} / \mathrm{mL} \\
\mu \mathrm{Ci} / \mathrm{mL}\end{array}$ \\
\hline
\end{tabular}

WELL ZBG $1 A$

MEASUREMENTS CONDUCTED IN THE FIELD

Sample date: $11 / 21 / 91$
The well was dry.

Time: 13:45

WELL. ZBG 2

MEASUREMENTS CONDUCTED IN THE FIELD

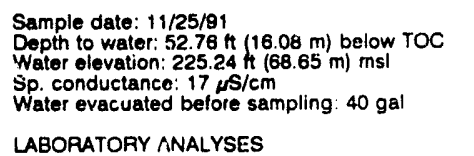

Time: $9: 35$

$\mathrm{pH}: 5.2$

Alkalinity: $1 \mathrm{mg} / \mathrm{L}$
Water temperature: $18.5^{\circ} \mathrm{C}$

Water evacuated before sampling: $40 \mathrm{gal}$

DOPATORY ANALYSES

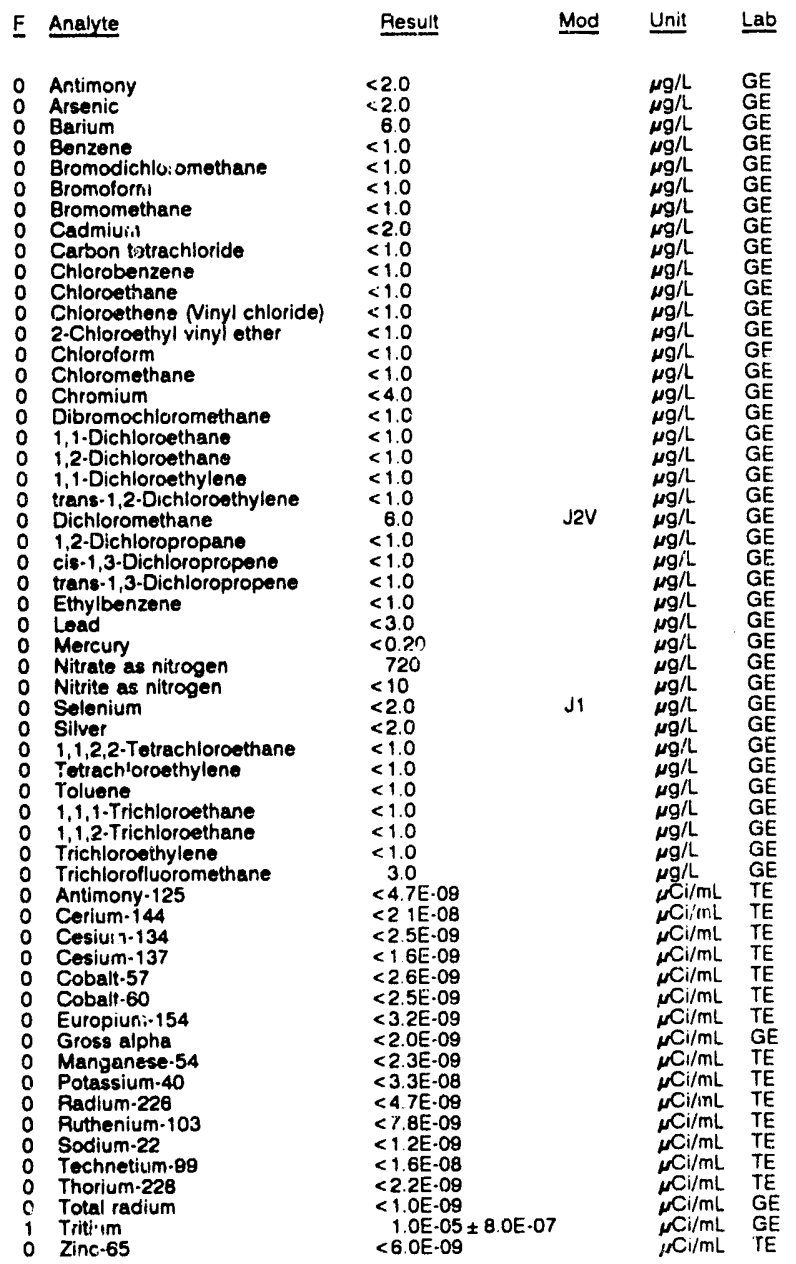

WELL ZBG 2 Replicate

MEASUREMENTS CONDUCTED IN THE FIELO

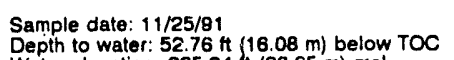

Water elevation: $225.24 \mathrm{ft}(68.65 \mathrm{~m}) \mathrm{ms}$ A

Sp. conductance: $17 \mu \mathrm{s} / \mathrm{cm}$
Water evacuated betore sampling: $40 \mathrm{gal}$

LABORATORY ANALYSES

E Analyte $\underline{\text { Result }}$ Mod Unit Lab

- Antimony

Barium

o Bromodichloromethane

Bromoform

Bromomethane

Carbon tetrachloride

Chlorobenzene

Chloroethene Ninyl chloride)

2-Chloroethyl vinyl ether

Chloroform

Chloromethane

Chromium

200

Water temperature: $18.5^{\circ} \mathrm{C}$

- Dibromochloromethane

o 1,1-Dichloroethane

1,2-Dichloroethane

$1,1-$ Dichloroethylene
0 trans-1,2-Dichloroethylene

Dichloromethane

1,2-Dichloropropane
cis-1,3-Dichloropropen

cis-1,3-Dichloropropene
0
trans-1,3-Dichloropropene

O trans-1,3-Dichlor

0 Lead

- Mercury

Nitrate as nitrogen

Selenium

0 Silve

1,1,2,2-Tetrachloroethane

Tetrachloroethylene

Toluene

1,1,2. Trichloroethan

Trichloroethylene

O Trichlorofluorom

Antimony $\cdot 125$

0 Cerium-144

$\begin{array}{ll}0 & \text { Cesium-134 } \\ 0 & \text { Cesium-137 }\end{array}$

Cobalt-57

Cobalt-57

0 Europium-154

Gross alpha

Manganese-54

Potassium-40

0 Ruthenium-103

0 Sodium-22

Technetium-98

Thorium-228

Total radium

0 Zinc-65

$<2.0$
$<2.0$
6.0

6.0
$<1.0$

$<1.0$

$<1.0$

$<1.0$
$<2.0$

$<1.0$

$<1.0$

$<1.0$

$<1.0$

$<1.0$

$<4.0$

$<10$

$<1.0$

1.0

$<1.0$
4.0

4.0
$<1.0$

$<1.0$

$<1.0$

$<1.0$
$<0.20$
720
$<10$

$<10$
$<2.0$
$<2.0$
$<1.0$

$<1.0$

$<1.0$
$<1.0$
$<1.0$
$<1.0$

$<1.0$
$<1.0$
$<1.0$

$<1.0$

$<8.3 E-09$

$<2.0 \mathrm{E}-08$
$<3.0 \mathrm{E}-09$

$<3.0$ E-09
$<2.9 \mathrm{E}-09$

$<2.6 \mathrm{E}-09$

$<3.5 \mathrm{E} .09$

$<8.7 \mathrm{E} .09$

$<2.0 \mathrm{E} \cdot 09$

$<3.5 \mathrm{E} .09$
$<4.3 \mathrm{E} .08$

$<4.1 \mathrm{E}-00$

$<8.0 \mathrm{E} .09$

$<3.2 \mathrm{E}-00$

$<1.5 E-08$

$<3.0 E-09$

$<1.0 E \cdot 09$

$1.0 \mathrm{E}-05 \pm 8.0 \mathrm{E} \cdot 07$
$<\theta .0 \mathrm{O}-09$

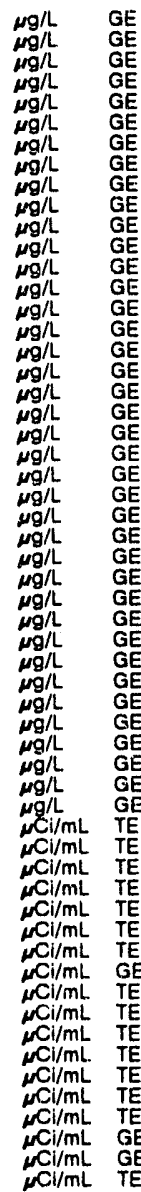

WELL ZDT 1

MEASUREMENTS CONDUCTED IN THE FIELD

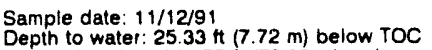

Water elevation: $239.77 \mathrm{ft}(73.08 \mathrm{~m}) \mathrm{msl}$

p. conductance: $130 \mathrm{~s} / \mathrm{cm}$

Water evacuated before sampling: $66 \mathrm{gal}$

Time: $13: 50$

PH: 6.3 : $47 \mathrm{mg} / \mathrm{l}$

Water temperature : $21.0^{\circ} \mathrm{C}$

WELL ZDT 2

MEASUREMENTS CONDUCTED IN THE FIELD

Sample date: $11 / 12 / 91$

Depth to water: 23.68 it $(7.22 \mathrm{~m})$ below TOC

Water elevation: $241.32 \mathrm{ft}(73.5$

$\mathrm{Sp}$. conductance: $43 \mu \mathrm{s} / \mathrm{cm}$
Water evacuated before sampling: $56 \mathrm{gal}$

Time: 13:40

$\mathrm{pH}: 5.3$

hity: $0 \mathrm{mg} / \mathrm{L}$

Water temperature: $19.6^{\circ} \mathrm{C}$ 
WELL ZW IA

MEASUREMENTS CONDUCTED IN THE FIELD

Sumple date: $12 / 10 / 91$ Depth to water: $133.50 \mathrm{ft}(40.69 \mathrm{~m})$ below TOC Water elevation: $143.20 \mathrm{f}(43.65 \mathrm{~m}) \mathrm{ms}$

Sp. conductance: $73 \mathrm{~s} / \mathrm{cm}$

No water was evacuated before sampling.

WELL ZW 2

MEASUREMENTS CONDUCTED IN THE FIELD

Sample date: 12/10/81

(2) below TOC

Water elevation: $210.50 \mathrm{th}(64.16 \mathrm{~m}) \mathrm{ms}$

No water was evacuated before sampling.

\section{WELL ZW 3}

MEASUREMENTS CONDUCTED IN THE FIELD

Sample date: $12 / 10 / 81$

Depth to water: $55.00 \mathrm{ft}$ (16.76 m) below TOC

Water elevation: $204.40 \mathrm{H}(62.30 \mathrm{~m}) \mathrm{ms}$

p. conductance: $38 \mu \mathrm{s} / \mathrm{cm}$

No water was ovacuated bofore sampling.

\section{WELL ZW 4}

MEASUREMFNIS CONDUCTED IN THE FIELD

Sample date: 12/10/91

Dopth to water: $39.00 \mathrm{~h}(11.89 \mathrm{~m})$ below TOC

Water elevation: $235.80 \mathrm{ft}(71.87 \mathrm{~m}) \mathrm{ms}$

po. conducte

Time: $14: 30$

pH: 8.4

Water temperature: $18.4^{\circ} \mathrm{C}$

Time: $10: 40$

Water temperature: $17.7^{\circ} \mathrm{C}$

Time: $10: 50$
pH: 5.7

Water temperature: $18.3^{\circ} \mathrm{C}$

Time: $12: 50$
pH: 6.2

Water temperature: $18.6^{\circ} \mathrm{C}$

\section{WELL ZW 5}

MEASUREMENTS CONDUCTED IN THE FIELO

Sample date: 12/10/81

Depth to wator: $47.50 \mathrm{ft}(14.48 \mathrm{~m})$ below TOC

$(70.20 \mathrm{~m}) \mathrm{ms}$

No water was ovacuated before sampling

\section{WELL ZW 6}

MEASUREMENTS CONDUCTED IN THE FIELD

Sample date: $12 / 10 / 91$

Depth to water: $45.00 \mathrm{ht}(13.72 \mathrm{~m})$ below TOC

Water olevation: $223.10 \mathrm{ht}(68.00 \mathrm{~m}) \mathrm{msl}$

Sp. conductance: $115 \mu \mathrm{s} / \mathrm{cm}$
No water was evacuated before sampling.

WELL ZW 7

MEASUREMENTS CONDUCTED IN THE FIELD

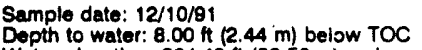

Water olevation: $264.40 \mathrm{ft}(80.50 \mathrm{~m}) \mathrm{mst}$

Sp. conductance: 154 is/cm

Time: 14:15

Time: $13: 00$

Water temperature: $19.7^{\circ} \mathrm{C}$

No water was evacuated before sampling

\section{WELL ZW 8}

MEASUREMENTS CONDUCTED IN THE FIELD

Sample date: $12 / 10 / 81$

Depth to water: $4.50 \mathrm{ft}(1.37 \mathrm{~m})$ below TOC

Water elevation: $268.80 \mathrm{ft}(81.96 \mathrm{~m}) \mathrm{ms}$

Sp. conductance: $143 \mathrm{~ms} / \mathrm{cm}$

No water was evacuated before sampling

\section{WELL ZW 9}

MEASUREMENTS CONDUCTED IN THE FIELD

Sample date: $12 / 10 / 91$

Depth to water: $39.00 \mathrm{ft}(11.89 \mathrm{~m}$ ) below TOC

Water elevation: $249.70 \mathrm{ht}(76.11 \mathrm{~m}) \mathrm{ms}$

Wo. conductance: $61 \mathrm{~s} / \mathrm{cm}$

No water was evacuated before sampling
$\mathrm{pH}: \mathrm{B}$

Water temperature: $18.0^{\circ} \mathrm{C}$

Water temperature: $17.7^{\circ} \mathrm{C}$

\section{Time: $13: 30$}

$\mathrm{pH}: 5.8$

Water temperature: $20.6^{\circ} \mathrm{C}$

\section{Time: $14: 00$}

WELL ZW 10

MEASUREMENTS CONDUCTED IN THE FIELD

$\begin{array}{ll}\text { Sample date: } 12 / 10 / 91 & \text { Time: } 13: 45 \\ \text { Depth to water: } 47.50 \mathrm{ft}(14.48 \mathrm{~m}) \text { below TOC } & \mathrm{pH}: 4.8 \\ \text { Water elavation: } 252.00 \mathrm{ft}(77.08 \mathrm{~m}) \mathrm{msl} & \text { Water temperature: } 20.6^{\circ} \mathrm{C} \\ \text { Sp. conductance: } 52 \mu \$ / \mathrm{cm} & \end{array}$




\section{APPENDIX B. Second Quarter Radionuclide Analyses}

This section presents the radionuclide results for samples collected during second quarter 1991 and analyzed by EcoTek Laboratory Services (ET). These results were not available for publication in the second or third quarter reports.

\section{EXECUTIVE SUMMARY}

One or more radionuclides exceeded Flag 2 during second quarter 1991 in 12 monitoring well series. Analytes exceeded the current Flag
2 criteria for the first time since 1987 in 10 of these 12 monitoring well series.

A detailed explanation of the current flagging criteria is presented in the Flagging Criteria section of this document.

Those groundwater monitoring sites with radionuclide constituents above Flag 2 during second quarter 1991 are listed in Table B-1, organized by location and well series.

Table B-1. Radionuclides Above Flag 2 Criteria, Second Quarter 1991

Site

Well Radionuclides Above Flag 2 Criteria

100 AREAS

Series Second Quarter 1991

P Area

P-Area Disassembly Basin

PDB

Potassium.40

200 AREAS

Burial Grounds (E Area) See 600 Areas.

F Area

F-Area Canyon Building

FCA

Radium-226, uranium-235

Between the F-Area Canyon Building and

NBG

Potassium-40

the Naval Fuel Material Facility

Note: Analytes in bold were detected above the current Flag 2 criteria for the first time since 1987. 


\section{SECOND QUARTER RADIONUCLIDE ANALYSES}

Table B-1. Radionuclides Above Flag 2 Criteria, Second Quarter 1991 (cont.)

$\underline{\text { Site }}$

Well Radionuclides Above Flag 2 Criteria

300/700 AREAS

Savannah River Laboratory (SRL)

ASB

Iodine-131, radium-226, radium-228, uranium-235

Seepage Basins

Series Second Quarter 1991

600 AREAS

Burial Grounds (E Area)

Burial Grounds

BG

Uranium-235

Burial Grounds Perimeter

BGO

Uranium-235

\section{General Areas}

Interim Waste Technology Site B: Characterization Wells

IDB Uranium-235

Interim Waste Technology Site P: Characterization Wells

IDP Uranium-235

Interim Waste Technology Site Q: Characterization Wells

IDQ

Potassium-40, uranium-235

TNX

Old TNX Seepage Basin

XSB Radium-9?6, radium-228

TNX Area: Assessment Wells

TNX

Radium-228

TNX Burying Grounds

IBG Radium-226, radium-228

Note: Analytes in bold were detecled above the current Flag 2 criteria for the first time since 1987.

Table B-2 combines the Executive Summary table originally printed in the second quarter 1991 report with the radionuclide data presented in Table B-1 above, and comprises all sites having any constituents detected above
Flag 2 levels during second quarter. The analysis incorrectly referred to as total radium in the second quarter report has been corrected here to total alpha-emitting radium. 
Table B-2. Analytes Above Flag 2 Criteria, Second Quarter 1991

$\underline{\text { Site }}$

Well Analytes Above Flag 2 Criteria

Series Second Quarter 1991

\section{AREAS}

C Area

C-Area Reactor Seepage Basins

CSB $\quad \mathrm{pH}$, trichloroethylene

C-Area Disassembly Basin

CDB 'Tritium

\section{K Area}

K-Area Acid/Caustic Basin

KAC Iron, lead, specific conductance, total organic halogens

K-Area Ash Basin

$\mathrm{KAB}$

Specific conductance

K-Area Coal Pile Runoff Containment Basin

$\mathrm{KCB}$

Specific conductance

K-Area Disassembly Basin

KDB

Tritium

K-Area Reactor Seepage Basin

KSB 'Tritium

\section{Area}

L-Area Oil and Chemical Basin

$\mathrm{LCO}$

Specific conductance, tetrachloroethylene, tritium

L-Area Reactor Seepage Basin

LSB

Gross alpha, lead, nonvolatile beta, tritium

\section{P Area}

P-Area Acid/Caustic Basin

PAC Iron, manganese, total organic carbon

P-Area Burning/Rubble Pit

PRP

Lead, tetrachloroethylene, trichloroethylene, trilium

P-Area Coal Pile Runoff Containment Basin

PCB

Lead, specific conductance

P-Area Disassembly Basin

PDB

Lead, potassium -40

P-Area Reactor Seepage Basins

PSB

Lead

R Area

Series F, R-Area Reactor Seepage Basins

RSF

$\mathrm{pH}$ 


\section{SECOND QUARTER RADIONUCLIDE ANALYSES}

Table B-2. Analytes Above Flag 2 Criteria, Second Quarter 1991 (cont.)

$\underline{\text { Site }}$

200 AREAS

F Area

Burma Road Rubble Pit

F-Area Acid/Caustic Basin

F-Area A Line

F-Area Canyon Building

F-Area Coal Pile Runoff Containment Basin

F-Area Microbiology Wells (P 28 cluster)

F-Area Sludge Land Application Site

F-Area Seepage Basins

F-Area Tank Farm

Old F-Area Seepage Basin

Between the F-Area Canyon Building and the Naval Fuel Material Facility \begin{tabular}{ll} 
Well & Analytes Above Flag 2 Criteria \\
Series & Second Quarter 1991 \\
\hline
\end{tabular}

FAC Manganese, total organic halogens, lolal alphaemitting radium

FAl 'Trichloroethylene

FCA Gross alpha, nonvolatile beta, nitrate as nitrogen, total alpha-emitting radium, trichloroethylene, tritium, radium-226, uranium-235

FCB Lead, total organic halogens

$\mathrm{P} \quad \mathrm{pH}$, specific conductance

FSS Iron, lead, manganese, tritium

FSB Antimony, aluminum, barium, cadmium, cobalt, Muoride, gross alpha, iron, lead, manganese, mercury, nickel, nitrate as nitrogen, nonvolatile bela, $\mathrm{pH}$, specific conductance, sulfate, tetrachloroethylene, total organic halogens, total alphaemilling radium, total silica, trichloroethylene, trichlorofluoromethane, trilium, uranium

F'lF $\quad$ Specific conductance, $\mathrm{pH}$

FNB Nonvolatile beta, manganese, nitrate as nitrogen, total alpha-emitting radium

NBG Nitrate as nitrogen, nonvolatile bela, specific conductance, total alpha-emitling radium, trichloroethylene, tritium, potassium-40

\section{H Area}

H-Area Acid/Caustic Basin

HAC Iron, tritium

H-Area Canyon Building

HCA

'Tritium

H-Area Coal Pile Runoff Containment Basin

$\mathrm{HCB}$

Specific conductance

Note: Analytes in bold were detected above the current Flag 2 cliteria for the first time since 1987. 
SECOND QUARTER RADIONUCLIDE ANALYSES

Table B-2. Analytes Above Flag 2 Criteria, Second Quarter 1991 (cont.)

Site

200 AREAS (cont.)

H Area (cont.)

H-Area Seepage Basins

H-Area Tank Farm

\section{S Area}

S-Area Vitrification Building

SCA

H'TF

Well

$\underline{\text { Series }}$

HSB

YSC

Y-Area Waste Solidification and

Disposal Facility

\section{0/700 AREAS}

A-Area Burning/Rubble Pits

ARP

A/M Areas: Cluster Perimeter Wells and Plume Definition Wells

A-Area Metals Burning Pit

M-Area Hazardous Waste

Management Facility (HWMF)

M Area: Recovery Wells talso used for plume definition!

$\mathrm{ABP}$

MSB
Analytes Above Flag 2 Critoria Second Quarter 1991
Aluminum, antimony, arsenic, cadmium, cobalt, gross alpha, iron, lead, manganese, mercury, nickel, nitrate as nitrogen, nonvolatile beta, $\mathrm{pH}$, silver, specific conductance, sulfate, tetrachloroethylene, total organic halogens, total alpha-emitting radium, tritium, total silica, vanadium

Lead, lotal alpha-emitting radium

Iron, manganese, specific conductance, total alpha-emitting radium, tritium

$\mathrm{pH}$, tritium

'T'richloroethylene

AC Total alpha-emitting radium

Antimony, nonvolatile beta, lithium, manganese, $\mathrm{pH}$, specific conduclance

Aluminum, barium, cadmium, carbon tetrachloride, chlorobenzene, 1,1-dichloroethylene, iron, lead, manganese, mercury, nitrate as nitrogen, nonvolatile beta, $\mathrm{pH}$, specific conductance, tetrachloroethylene, total organic carbon, total organic halogens, tota! alpha-emitling radium,

1,1,1-trichloroethane, 1,1,2-trichloroethane, 2,4,5-trichlorophenoxyacetic acid, trichloroethylene, trichlorofluoromethane, tritium, zinc

RWM Aluminum, carbon tetrachloride, iron, manganese, nitrate as nitrogen, tetrachloroethylene, total organic halogens, trichloroethylene,

trichlorofluoromethane

Note: Analytes in bold were detected above the current. Flag 2 criteria for the lirst time since 1987. 
Table B-2. Analytes Above Flag 2 Criteria, Second Q:tarter 1991 (cont.)

$\underline{\text { Site }}$

300/700 AREAS (cont.)

Metallurgical Laboratory Seepage Basin

Miscellaneous Chemical Basin

Motor Shop Oil Basin

Savannah River Laboratory (SRL)

Seepage Basins

Silverton Road Waste Site

400 AREA

\section{Area}

D-Area Coal Pile Runoff Containment Basin and Ash Basins

\section{AREAS}

\section{Burial Grounds (E Area)}

Burial Grounds

Burial Grounds Perimeter

E-Area Vaults Near the Burial Grounds

Hazardous Waste/Mixed Waste Disposal

Facility
BG

BGO

Well

$\underline{\text { Series }}$

AMB

MCB

AOB

ASB

SRW

DCB

BGX

HMD
Analytes Above Flag 2 Criteria

Second Quarter 1991

Iron, lead, manganese, tetrachloroethylene, trichloroethylene, total organic halogens, total alphaemitting radium

Lead, lithium, manganese, nonvolatile beta, $\mathrm{pH}$, specific conductance, tetrachloroethylene, total organic halogens, trichloroethylene, $\mathbf{2 , 4 , 5}$ trichlorophenoxyacetic acid

'Tetrachloroethylene, trichloroethylene

Chromium, lead, $\mathrm{pH}$, specific conductance, tetrachloroethylene, trichloroethylene, total organic halogens, tritium, iodine-131, radium-226, radium228 , uranium-235

Trichloroethylene
Aluminum, gross alpha, iron, lead, manganese, mercury, total carbon, lotal inorganic carbon, lotal alpha-emitting radium, tritium, uranium-235

Aluminum, cadmium, chloroethene (vinyl chloride), 1,1-dichloroethylene, 1,1-dichloroethane, dichloromethane (methylene chloride), iron, lead, manganese, nitrate as nitrogen, $\mathrm{pH}$, specific conductance, tetrachloroethylene, tin, total organic halogens, trichloroethylene, tritium, uranium-235

Manganese, trichloroethylene, tritium

Manganese, total alpha-emitting radium, trichlorofluoromethane

Note: Analytes in bold were detected above the current Flag 2 criteria for the first time since 1987. 


\section{SECOND QUARTER RADIONUCLIDE ANALYSES}

Table B-2. Analytes Above Flag 2 Criteria, Second Quarter 1991 (cont.)

\begin{tabular}{|c|c|c|}
\hline Site & $\begin{array}{l}\text { Well } \\
\text { Series }\end{array}$ & $\begin{array}{l}\text { Analytes Above Flag } 2 \text { Criteria } \\
\text { Second Quarter } 1991\end{array}$ \\
\hline \multicolumn{3}{|l|}{600 AREAS (cont.) } \\
\hline \multicolumn{3}{|l|}{ Central Shops Area } \\
\hline $\begin{array}{l}\text { Central Shops Burning/Rubble Pit south of } \\
\text { the Ford Building Seepage Basin }\end{array}$ & CBR & $\begin{array}{l}\text { Tetrachloroethylene, total organic halogens, } \\
\text { total alpha-emitting radium, trichloro- } \\
\text { ethylene }\end{array}$ \\
\hline $\begin{array}{l}\text { Central Shops Diesel Spill: Characterization } \\
\text { and Remediation Wells }\end{array}$ & CSD & $\mathrm{pH}$ \\
\hline Ford Building Seepage Basin & $\mathrm{HXB}$ & Manganese, trilium \\
\hline
\end{tabular}

\section{General Areas}

Chemicals, Metals, and Pesticides (CMP) Pits

CMP

Interim Waste Technology Site B: Characterization Wells

IDB Aluminum, antimony, specific conductance, iron, lead, $\mathrm{pH}$, total carbon, total inorganic carbon, uranium-235

Interim Waste Technology Site P:

IDP

Characterization Wells

Interim Waste Technology Site $Q$ :

Characterization Wells

IDQ

Road A Chemical Basin (Baxley Road)

BRD

Sanitary Landfill

Aluminum, iron, $\mathrm{pH}$, total carbon, total inorganic carbon, uranium-235

Aluminum, iron, manganese, $\mathrm{pH}$, total carbon, total inorganic carbon, potassium-40, uranium-235

Lead, specific conductance, total organic halogens

Acetone, antimony, benzene, chlorobenzene, chloroethene (vinyl chloride), chloromethane (methyl chloride), 1,1-dichloroethylene, 1,1dichloroethane, 1,2-dichloroethane, 1,2-dichlorobenzene, dichlorodifluoromethane, lead, manganese, specific conductance, tetrachloroethylene, lotal organic carbon, total organic halogens, lotal alpha-emitting radium, trichlorofluoromethane, trichloroethylene, 1,1,2-trichloroethane, tritium, xylenes

B-Area Microbiology Wells (P 29 cluster)

$\mathrm{P}$

Benzene

TNX

New T'NX Seepage Basin

YSB

'otal organic halogens

Note: Analytes in bold were detected above the current Flag 2 criteria for the first time since 1987. 


\section{SECOND QUARTER RADIONUCLIDE ANALYSES}

Table B-2. Analytes Above Flag 2 Criteria, Second Quarter 1991 (cont.)

Site

600 AREAS (cont.)

TNX (cont.)

Old TNX Seepage Basin

TNX Area: Background Wells (P 26 cluster)

TNX Area: Assessment Wells

TNX Burying Ground
Well Analytes Above Flag 2 Criteria

Series $\quad$ Second Quarter 1991
XSB

$P$

TNX

TBG
Carbon tetrachloride, iron, mercury, manganese, nitrate as nitrogen, total organic halogens, trichloroethylene, radium-226, radium-228

Iron, total organic halogens

Carbon tetrachloride, gross alpha, iron, manganese, nitrate as nitrogen, nonvolatile beta, tetrachlorcethylene, total alpha-emitting radium, total organic halogens, trichloroethylene, radium-228

Iron, manganese, nitrate as nitrogen, tetrachloroethylene, total organic halogens, total alphaemitting radium, trichloroethylene, radium-226, radium -228

Note: Analytes in bold were detected above the current Flag 2 criteria for the first time since 1987.

\section{REVIEW OF THE ANALYTICAL DATA}

A technical review of the quarter's analytical data identified the results of the radium-226 analyses for well IDQ 12 and its replicate as low in comparison to historical data. A review of the laboratory records did not reveal any problems with the analyses.
A technical review of the quarter's analytical data identified at least one reported result for the analyses in Table B-3 as high in comparison to historical data. A review of the laboratory records did not reveal any problems with the analyses.

Table B-3. Second Quarter Radionuclide Samples With High Analytical Results as Compared to Historical Data

Analyte

Potassium-40

Manganese-54

Radium-226

Radium-228

Uranium-235 $\underline{\text { Wells }}$

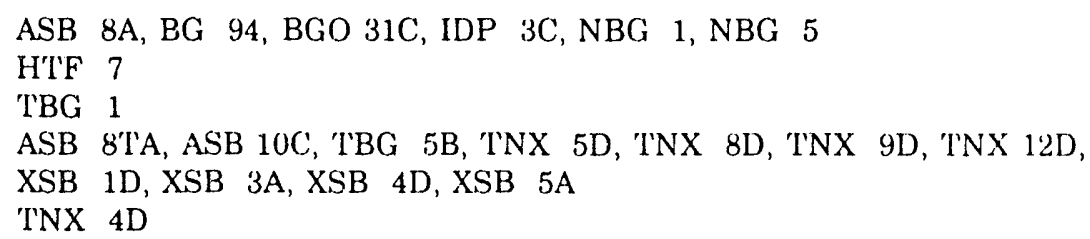

Table B-4 lists the methods and 90th percentile detection limits that were used by EcoTek

Laboratory Services for radionuclide analyses during second quarter 1991. 
Table B-4. Methods and Detection Limits Used by EcoTek for Radionuclide Analyses

$\begin{array}{lll}\text { Analyte } & \text { Method } & \text { Detection Limit } \\ \text { Antimony-125 } & \text { RL-4303-A } & 1.2 \mathrm{E}-08 \mu \mathrm{Ci} / \mathrm{mL} \\ \text { Cerium-144 } & \text { RL-4303-A } & 2.3 \mathrm{E}-08 \mu \mathrm{Ci} / \mathrm{mL} \\ \text { Cesium-134 } & \text { RL-4303-A } & 4.3 \mathrm{E}-09 \mu \mathrm{Ci} / \mathrm{mL} \\ \text { Cesium-137 } & \text { RL-4303-A } & 4.9 \mathrm{E}-09 \mu \mathrm{Ci} / \mathrm{mL} \\ \text { Chromium-51 } & \text { RL-4303-A } & 3.3 \mathrm{E}-08 \mu \mathrm{Ci} / \mathrm{mL} \\ \text { Cobalt-57 } & \text { RL-4303-A } & 2.9 \mathrm{E}-09 \mu \mathrm{Ci} / \mathrm{mL} \\ \text { Cobalt-60 } & \text { RL-4303-A } & 4.8 \mathrm{E}-09 \mu \mathrm{Ci} / \mathrm{mL} \\ \text { Europium-154 } & \text { RL-4303-A } & 6.0 \mathrm{E}-09 \mu \mathrm{Ci} / \mathrm{mL} \\ \text { Europium-155 } & \text { RL-4303-A } & 1.2 \mathrm{E}-08 \mu \mathrm{Ci} / \mathrm{mL} \\ \text { Iodine-131 } & \text { RL-4303-A } & 4.4 \mathrm{E}-09 \mu \mathrm{Ci} / \mathrm{mL} \\ \text { Manganese-54 } & \text { RL-4303-A } & 4.7 \mathrm{E}-09 \mu \mathrm{Ci} / \mathrm{mL} \\ \text { Plutonium-238 } & \text { RL-2325-A } & 2.0 \mathrm{E}-10 \mu \mathrm{Ci} / \mathrm{mL} \\ \text { Plutonium-239/240 } & \text { RL-2325-A } & 1.9 \mathrm{E}-10 \mu \mathrm{Ci} / \mathrm{mL} \\ \text { Plutonium-242 } & \text { RL-2325-A } & 1.9 \mathrm{E}-10 \mu \mathrm{Ci} / \mathrm{mL} \\ \text { Potassium-40 } & \text { RL-4303-A } & 1.1 \mathrm{E}-07 \mu \mathrm{Ci} / \mathrm{mL} \\ \text { Radium-226 } & \text { RL-2313 } & 1.1 \mathrm{E}-08 \mu \mathrm{Ci} / \mathrm{mL} \\ \text { Radium-228 } & \text { RL-2313 } & 3.5 \mathrm{E}-08 \mu \mathrm{Ci} / \mathrm{mL} \\ \text { Ruthenium-103 } & \text { RL-4303-A } & 4.3 \mathrm{E}-09 \mu \mathrm{Ci} / \mathrm{mL} \\ \text { Sodium-22 } & \text { RL-4303-A } & 4.8 E-09 \mu \mathrm{Ci} / \mathrm{mL} \\ \text { Uranium-235 } & \text { RL-2322-B } & 2.5 \mathrm{E}-08 \mu \mathrm{Ci} / \mathrm{mL} \\ \text { Zinc-65 } & \text { RL-4303-A } & 9.7 \mathrm{E}-09 \mu \mathrm{Ci} / \mathrm{mL} \\ \text { Zirconium-95 } & \text { RL-4303-A } & 8.0 \mathrm{E}-09 \mu \mathrm{Ci} / \mathrm{mL}\end{array}$

\section{ANALYTICAL RESULTS}

The tabular data beginning on page B-10 contain only the radionuclide results for samples collected during second quarter 1991 and their associated EPD/EMS blanks.

The following abbreviations may appear in the tabular data.

$\mathrm{E}=$ exponential notation (e.g., $1.1 \mathrm{E}-09=1.1 \times 10^{-9}=0.0000000011$ )

$\mathrm{ET}=$ EcoTek Laboratory Services

$\mathrm{F}=$ Flag

$\mathrm{mg} / \mathrm{L}=$ milligrams per milliliter

$\mathrm{msl}=$ mean sea level

TOC $=$ top of casing

$\mu \mathrm{Ci} / \mathrm{mL}=$ microcuries per milliliter

$\mu \mathrm{S} / \mathrm{cm}=$ microsiemens per centimeter 
ANALYTICAL RESULTS

WELL ASB $1 \mathrm{~A}$

MEASUREMENTS CONDUCTED IN THE FIELD

Sample date: 05/03/9

Depth to water: Not available

Water elevation: Not available

Sp. conductance: $74 \mu \mathrm{S} / \mathrm{cm}$

ater evacuated before sampling: $50 \mathrm{gal}$

LABORATORY ANALYSES

E Analyte

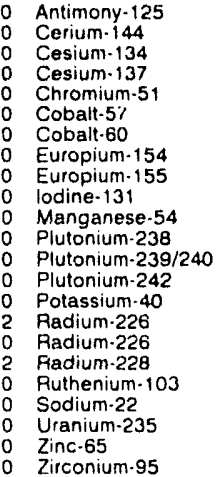

Result Unit Lab

\section{WELL ASB $2 A$}

MEASUREMENTS CONDUCTED IN THE FIELD

Sample date $05 / 03 / 91$

Depth to water $112.63 \mathrm{ft}(34.33 \mathrm{~m})$ below TOC

Water elevation: $236.37 \mathrm{ft}(72.05 \mathrm{~m}) \mathrm{msl}$

Water elevation: $236.37 \mathrm{Ht}(72.0$

Water evacuated before sampling $5: \mathrm{gal}$

LABORATORY ANALYSES

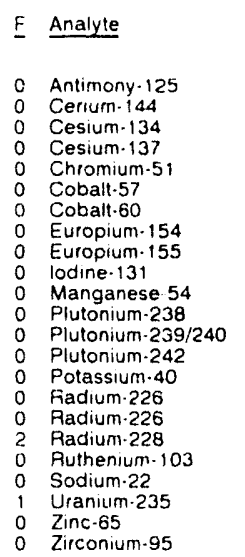

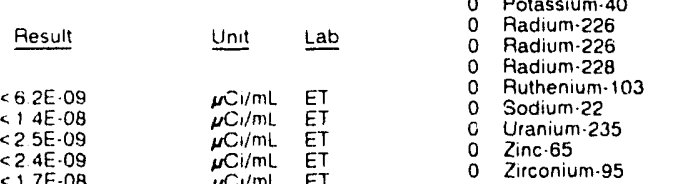

Time: 13:15

Alkalinity: $15 \mathrm{mg}$

Water temperature $208^{\circ} \mathrm{C}$

Time: 1430

Alkalinity: $3 \mathrm{mg} / \mathrm{l}$

Water temperature $212^{\circ} \mathrm{C}$

1. $2 \mathrm{E}-08 \pm 1.7 \mathrm{E} \cdot 08$

$<4.4 E .09$
$<4.7 E .09$

$<3.4 \mathrm{E} \cdot 08$

$<4.8 \mathrm{E} \cdot 09$

$<6.2 E \cdot 09$

$<4.2 E \cdot 09$

$<1.0 \mathrm{E}-10$

$<1.0 E-10$

$<1.1 E \cdot 07$

9. $9 \mathrm{E} \cdot 09$

9.6E. $09 \pm 2.4 \mathrm{E} \cdot 09$

C4.2E.09

$<8.7 E .09$
$<7.2 E .09$

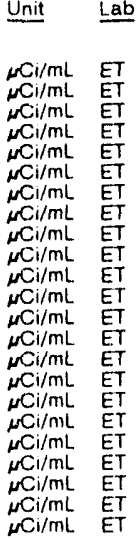

\section{WELL ASB 2A Replicate}

MEASUREMENTS CONOUCTED IN THE FIELD

Sample date 05/03/91

Depth to water: $112.63 \mathrm{Ht}(34.33 \mathrm{~m})$ below TOC

Water elevation: $236.37 \mathrm{H}(72.05 \mathrm{~m}) \mathrm{ms}$

Sp. conductance: $75 \mu \mathrm{S} /=\mathrm{m}$

Water evacuated before sa!npling: $51 \mathrm{gal}$

LABORATORY ANALYSES

\begin{tabular}{|c|c|c|}
\hline E Analyte & Result & Unit \\
\hline 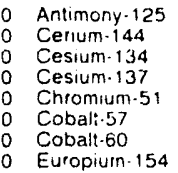 & 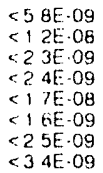 & $\begin{array}{l}\mu \mathrm{Cl} / \mathrm{mL} \\
\mu \mathrm{Ci} / \mathrm{mL} \\
\mu \mathrm{Cl} / \mathrm{mL} \\
\mu \mathrm{Cl} / \mathrm{mL} \\
\mu \mathrm{Cl} / \mathrm{mL} \\
\mu \mathrm{Ci} / \mathrm{mL} \\
\mu \mathrm{Cl} / \mathrm{mL} \\
\mu \mathrm{Ci} / \mathrm{mL}\end{array}$ \\
\hline
\end{tabular}

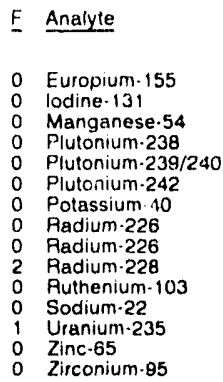

Sample date: $05 / 03 / 9$

Sample date: 05/03/9

$67 E \cdot 09 \pm 2.2 E \cdot 09$

$14 E \cdot 08+4.0 E \cdot 09$

$<2$ 4E.09
$<2$ 8E.09

1 IE. $08+12 E \cdot 08$

$<52 E \cdot 09$
$<39 E \cdot 09$

Cesium.137

Time: 1.3 .15

$\mathrm{pH}: 56.15$

Water temperature $208^{\circ} \mathrm{C}$
WELL. ASB 2A collected on 05/03/91, laboratory analyses (cont.)

Result:

Unit Lab

WELL ASB 3A

MEASUREMENTS CONDUCTED IN THE FIELD

Depth to water: $107.63 \mathrm{ft}(32.81 \mathrm{~m})$ below TOC

Water elevation: $237.37 \mathrm{ft}(72.35 \mathrm{~m}) \mathrm{msl}$

Sp. conductance: $54 \mu \mathrm{\mu} / \mathrm{cm}$
Water evacuated before sampling: $51 \mathrm{gal}$

$<6.5 E .09$
$<2.2 E .09$

<2. $3 E \cdot 09$

$<1.1 \mathrm{E}-10$

$<1$ E -10

7. $.5 \mathrm{E}-08 \pm 2.8 \mathrm{E}-06$
5. $9 \mathrm{E} \cdot 09 \pm 2.2 \mathrm{E}-09$

$<5.9 E .09$

$9.7 \mathrm{E} \cdot 09 \pm 2.4 \mathrm{E} \cdot 09$

$<2.2 \mathrm{E} .09$

1 . $3 \mathrm{E}-08 \pm 1.0 \mathrm{E} \cdot 08$

$<4.0 \mathrm{E} .08$
$<3.0 \mathrm{E} \cdot 08$

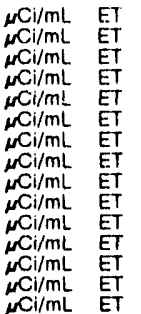

LABORATORY ANALYSES

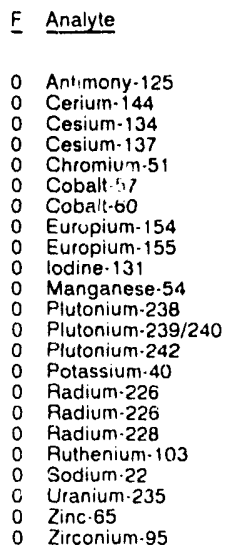

$\underline{\text { Unit }} \underline{\text { Lab }}$

WELL ASB 30

MEASUREMENTS CONDUCTED IN THE FIELD

Depth to water: $124.83 \mathrm{Ht}(38.05 \mathrm{~m})$ below TOC

Water elevation: $221.17 \mathrm{Ht}(67.4$

Water evacuated before sampling: $172 \mathrm{gal}$

LABORATORY ANALYSES

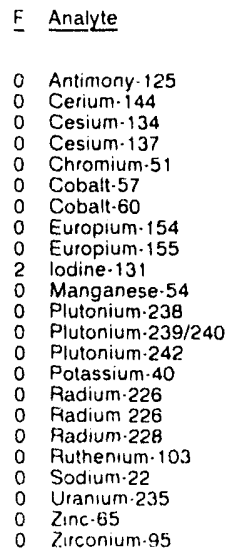

Result

Time: $12: 40$

$\mathrm{pH}: 9.5$

Alkalınity: $122 \mathrm{mg} / \mathrm{h}$ Water temperature: $18.6^{\circ} \mathrm{C}$

$<8.8 E \cdot 09$
$<1.7 \mathrm{E} \cdot 08$
$<3.2 \mathrm{E} \cdot 09$
$<3.6 \mathrm{E} \cdot 09$
$<2.4 \mathrm{E} \cdot 08$
$<2.0 \mathrm{E} \cdot 09$
$<3.5 \mathrm{E} \cdot 09$
$<4.3 \mathrm{E} \cdot 09$
$<8.5 \mathrm{E} \cdot 09$
$<3.2 \mathrm{E} \cdot 09$
$<3.4 \mathrm{E} \cdot 09$
$<1.3 \mathrm{E} \cdot 10$
$<1.3 \mathrm{E} \cdot 10$
$<1.3 \mathrm{E} \cdot 10$
$<8.1 \mathrm{E} \cdot 08$
$<7.2 \mathrm{E} \cdot 09$
$<7.8 \mathrm{E} \cdot 09$
$<2.0 \mathrm{E} \cdot 08$
$<3.09$
$<3.8 \mathrm{E} \cdot 09$
$4.3 \mathrm{~B} \cdot 09$
$<7.6 \mathrm{E} \cdot 09$
$<5.8 \mathrm{E} \cdot 09$

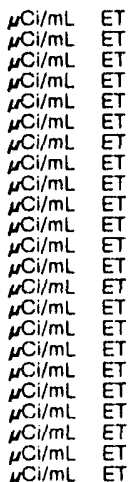


ANALYTICAL RESULTS

WELL ASB 5A

MEASUREMENTS CONDUCTED IN THE FIELD

Sample date: $05 / 03 / 91$

Depth to water: $109.73 \mathrm{Ht}(33.45 \mathrm{~m})$ below TOC

Water elevation: $235.27 \mathrm{ft}$

Water evacuated before sampling: 40 al

LABORATORY ANALYSES

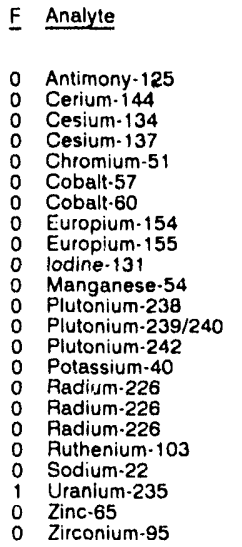

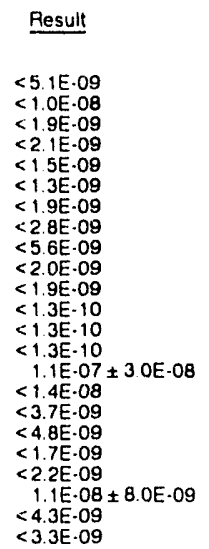

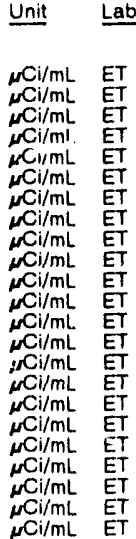

WELL ASB $6 A$

MEASUREMENTS CONDUCTED IN THE FIELD

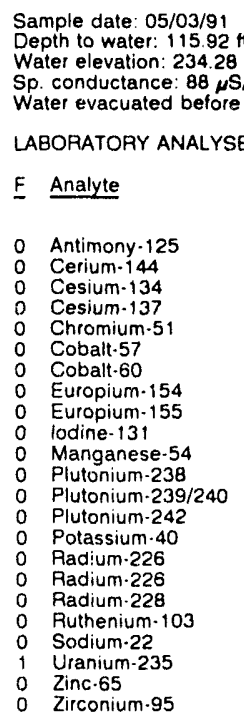

Time: $15: 10$

Alkalinity: $1 \mathrm{mg} /$

Water temperature: $21.0^{\circ} \mathrm{C}$

Water evacuated before sampling: 42 gal

ABORATORY ANALYSES

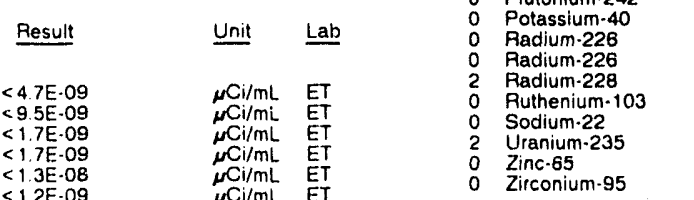

WELL ASB 7

MEASUREMENTS CONDUCTED IN THE FIELD

Sample date: 05/03/91

Depth to water: $120.21 \mathrm{ft}(36.64 \mathrm{~m})$ below TOC Water elevation: $233.19 \mathrm{ft}(71.08 \mathrm{~m}) \mathrm{msl}$ Sp. conductance: $92 \mu \mathrm{S} / \mathrm{cm}$ Water evacuated before sampling: $57 \mathrm{gal}$ LABORATORY ANALYSES

$\begin{array}{ll}\text { F } & \text { Analyte } \\ & \\ 0 & \text { Antimony-125 } \\ 0 & \text { Cerium-144 } \\ 0 & \text { Cesium-134 } \\ 0 & \text { Cesium-137 } \\ 0 & \text { Chiomium-51 } \\ 0 & \text { Cobalt-57 } \\ 0 & \text { Cobalt-60 } \\ 0 & \text { Europium-154 } \\ 0 & \text { Europium-155 } \\ 0 & \text { lodine-131 } \\ 0 & \text { Manganese-54 } \\ 0 & \text { Plutonium-238 } \\ 0 & \text { Flutonium-239/240 } \\ 0 & \text { Plutonium-242 } \\ 0 & \text { Potassium-40 } \\ 0 & \text { Radium-226 } \\ 0 & \text { Radium-226 } \\ 2 & \text { Radium-228 } \\ 0 & \text { Ruthenium-103 } \\ 0 & \text { Sodium-22 } \\ 0 & \text { Uranium-235 } \\ 0 & \text { Zinc-65 } \\ 0 & \text { Zirconium-95 } \\ & \end{array}$

E Analyte

LL ASB 6TA

Sample date: 05/04/y Depth to water: $140.36 \mathrm{At}(42.78 \mathrm{~m})$ below TOC clevation: $212.54 \mathrm{ft}(64.78$

The well wated before sampling: $37 \mathrm{ga}$

LABORATORY ANALYSES

F Analyte

0 Antimony-125

0 Cesium-134

C Chromium-51

0 Cobalt-60

Europium-154

lodine. 131

Manganese-54

Plutonium-239/240

BE.09

$<<.2 \mathrm{E} .09$

$<1.8 E .09$

$<1.2 \mathrm{E}-10$
$<1.2 \mathrm{E}-10$

$<1.2 \mathrm{E} \cdot 10$

$3.1 \mathrm{E} \cdot 08 \pm 2.5 \mathrm{E} \cdot 08$

$7.6 \mathrm{E} \cdot 09 \pm 3.8 \mathrm{E} \cdot 09$

>5.1E.09

<1. $6 \mathrm{E} .09$

$1.9 \mathrm{E} .08+8.0 \mathrm{E} .00$

$<3.5 \mathrm{E} .09$
$<28 \mathrm{E} .09$

$<>$

WELL ASB 6C

MEASUREMENTS CONDUCTED IN THE FIELD

Sample date: 05/03/91

Depth to water: $131.15 \mathrm{ft}(39.98 \mathrm{~m})$ below TOC

Water elevation: $222.45 \mathrm{H}(67.80 \mathrm{~m}) \mathrm{mst}$

.

Alkalinity: $9 \mathrm{mg} / \mathrm{L}$

Water temperature $209^{\circ} \mathrm{C}$

LABORATORY ANALYSES

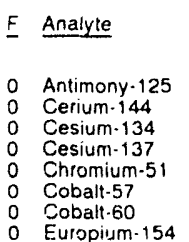

Result
< $1.2 \mathrm{E} \cdot 08$
$<2.0 \mathrm{0} \cdot 08$
$<4.4 \mathrm{E} \cdot 09$
$<5.0 \mathrm{0} \cdot 09$
$<31 \mathrm{E} \cdot 08$
$<2.7 \mathrm{E} \cdot 09$
$<4.9 \mathrm{E} \cdot 09$

$\underline{\text { Unit }} \underline{\underline{L a b}}$

$\mu \mathrm{Ci} / \mathrm{mL}$ ET

$\begin{array}{ll}\mu \mathrm{Ci} / \mathrm{mL} & \mathrm{ET} \\ \mu \mathrm{Ci} / \mathrm{mL} & \mathrm{ET}\end{array}$

$\mu \mathrm{Cli} / \mathrm{mL}$

\begin{tabular}{|c|c|}
\hline Result & Unit \\
\hline $\begin{array}{l}1.1 \mathrm{E} \cdot 08 \\
=4.2 \mathrm{E} \cdot 09 \\
5.0 \mathrm{E} \cdot 09 \\
=1.1 \mathrm{E} \cdot 10 \\
=1.1 \mathrm{E} \cdot 10 \\
=1.1 \mathrm{E} \cdot 10 \\
1.6 \mathrm{E} \cdot 08 \pm 9.9 \mathrm{E} \cdot 08 \\
=1.0 \mathrm{E} \cdot 08 \\
=4.2 \mathrm{E} \cdot 09 \\
9.1 \mathrm{E} \cdot 09 \pm 2.3 \mathrm{E} \cdot 09 \\
=4.3 \mathrm{E} \cdot 09 \\
=4.8 \mathrm{E} \cdot 09 \\
=2.3 \mathrm{E} \cdot 08 \\
=1.0 \mathrm{E} \cdot 08 \\
=7.8 \mathrm{E} \cdot 09\end{array}$ & 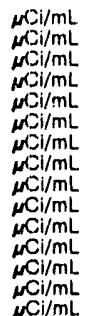 \\
\hline
\end{tabular}

$\mu \mathrm{Ci} / \mathrm{mL}$ ET

Time: $12: 00$

Alkalinity: $186 \mathrm{mg} / \mathrm{L}$

Water temperature: $19.8^{\circ} \mathrm{C}$

Result Unit Lab

6.1E-09 $\mu \mathrm{Cl} / \mathrm{mL} \quad \mathrm{ET}$

$<1.2 E-08$

$<2.4 \mathrm{E} \cdot 0$

$<1.6 E .00$

(1.5E.09

3.2E.09

$6.6 \mathrm{E}-09$

$<2.3 E-09$

$<1.0 E-10$

$<1.0 E-10$

$1.0 E-07 \pm 3.0 E-0 B$

$<4.2 E .09$

5.6E.09

$<2.2 \mathrm{E}-09$

. $5 \mathrm{E}-08 \pm 9.0 \mathrm{E}-09$

$4.5 \mathrm{E} .09$

$<4.5 E .09$
$<3.6 \mathrm{E}-09$
Result

$<1.2 E-08$
$<2.4 E-08$

$<4.2 E .09$

3.00

2. 9 E-09

4.3E-09

$<1.2 \mathrm{E} \cdot 0 \mathrm{O}$

<4. $4 \mathrm{E} \cdot 09$

$<14 \mathrm{E} .10$

<1. $4 \mathrm{E}-10$

<1.1E-08

1.3E.08 $03.0 E \cdot 09$

$1.0 \mathrm{E}-09 \pm 2.0 \mathrm{E}-0$

$2.5 \mathrm{E}-08$

$<9.1 E-09$
$<8.3 E-09$

\section{me: $15: 40$}

inity: $1 \mathrm{mg} / \mathrm{L}$

ater lemperature: $21.0^{\circ} \mathrm{C}$

Unit Lab

$\mu \mathrm{CL} / \mathrm{mL}$ ET

$\mu \mathrm{Ci}^{\prime} / \mathrm{mL}$ ET

$\mathrm{m} \mathrm{Ci} / \mathrm{mL}$

$\mathrm{NCi/mL}$

$\mathrm{Ci} / \mathrm{mL}$ ET

$\mu C \mathrm{C} / \mathrm{mL}$

$\mu \mathrm{Ci} / \mathrm{mL}$

$\mu \mathrm{Ni} / \mathrm{mL}$

$\mu \mathrm{Ci} / \mathrm{mL}$

$\mu \mathrm{Ci} / \mathrm{mL}$

$\mu \mathrm{Ci} / m L$ ET

$\mu \mathrm{Cl} / \mathrm{mL}$

${ }_{n, C N} \mathrm{C} / \mathrm{mL}$

$\mu \mathrm{Ci} / \mathrm{mL}$

${ }_{\mu \mathrm{NC} / / \mathrm{mL}}$ ET

$\mu \mathrm{Ci} / \mathrm{mL}$ ET 
WELL ASB 8

MEASUREMENTS CONDJCTED IN THE FIELD

Sample date: 05/04/91

Depth to water: $117.64 \mathrm{H}(35.86 \mathrm{~m})$ below TOC

Water elevation: $231.36(t)(.0 .52 \mathrm{~m}) \mathrm{msl}$

Water evacuated before sampling: 64 gal

LABORATOAY ANALYSES

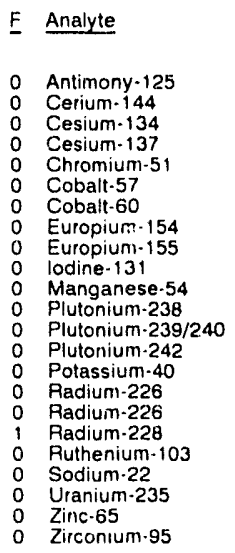

Result

Time: $14: 15$

$\mathrm{pH}: 4.3$

Akalinity: $0 \mathrm{mg} / \mathrm{h}$

Water temperature: $19.4^{\circ} \mathrm{C}$

$E$ Analyte

Cobalt-60

Europium-154

lodine-131

Plutonium-238

Plutonium-239/240

Potassium-40

Radium-226

Radium-228

Uranium.22

0 Zirconium.95

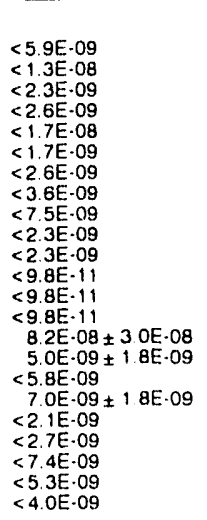

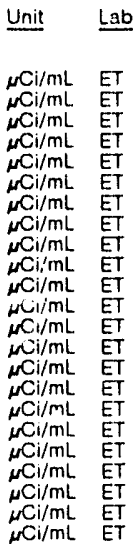

WELL ASB 8A

MEASUREMENTS CONOUCTEO IN THE FIELO

Sample date: $05 / 04 / 91$

Depth to water: $132.45 \mathrm{ft}(40.37 \mathrm{~m})$ below TOC

Water elevation: $216.85 \mathrm{ft}(66.1$
Sp. conductance: $26 \mu \mathrm{s} / \mathrm{cm}$

Sp. conduclance: $26 \mu \mathrm{S} / \mathrm{cm}$

pH: 4.8 . $1 \mathrm{mg}$

Water temperature $20.1{ }^{\circ} \mathrm{C}$

LABORATORY ANALYSES

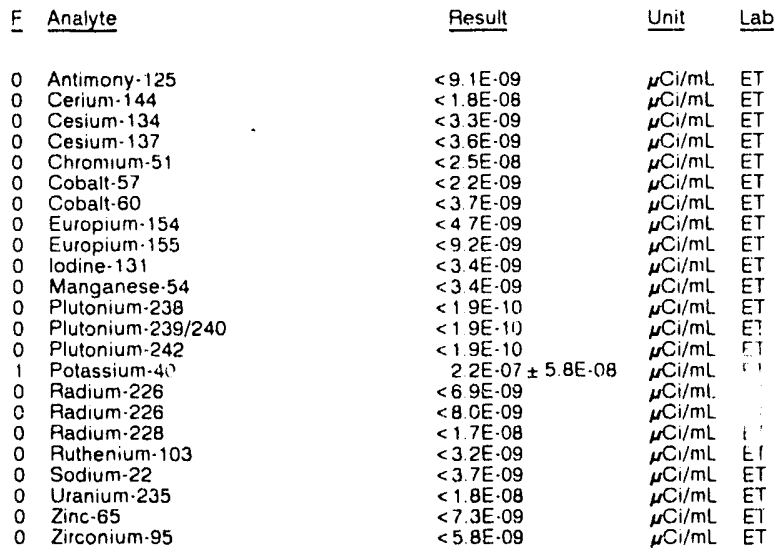

WELL ASB 8TA

MEASUREMENTS CONDUCTED IN THE FIELD

Sample date: 05/04/91

Depth to water $135.78 \mathrm{H}(41.39 \mathrm{~m})$ below TOC

Water elevation: $213.82 \mathrm{Ht}(65$

Sp. conductance: $22 \mu \mathrm{S} / \mathrm{cm}$
Water evacuated before sampling $510 \mathrm{gal}$

LABORATORY ANALYSES

\begin{tabular}{|c|c|c|}
\hline Analyte & Result & Unit \\
\hline $\begin{array}{ll}0 & \text { Antimony-125 } \\
0 & \text { Cerium-144 } \\
0 & \text { Cesium } 134 \\
0 & \text { Cesium. } 137 \\
0 & \text { Chromium } \cdot 51 \\
0 & \text { Cobalt }-57 \\
0 & \text { Cobalt } 60 \\
0 & \text { Europium } 154\end{array}$ & $\begin{array}{l}<8.9 E-09 \\
<1.7 E-08 \\
<3.2 E .09 \\
<3 \quad 0 E-09 \\
<2.5 E \cdot 08 \\
<2.2 E \cdot 09 \\
<35 E .09 \\
<4.6 E \cdot 09\end{array}$ & $\begin{array}{l}\mu \mathrm{Ci} / \mathrm{mL} \\
\mu \mathrm{Ci} / \mathrm{mL} \\
\mu \mathrm{Ci} / \mathrm{mL} \\
\mu \mathrm{Ci} / \mathrm{mL} \\
\mu \mathrm{Ci} / \mathrm{mL} \\
\mu \mathrm{Ci} / \mathrm{mL} \\
\mu \mathrm{Cl} / \mathrm{mL} \\
\mu \mathrm{Cl} / \mathrm{mL}\end{array}$ \\
\hline
\end{tabular}

WELL ASB GTA collected on 05/04/91, laboratory analyses (cont)

F Analyte

- Europium-155

0 Plutonium-238

Plutonium.239/240

0 Plutonium -242

0 Potassium-40

Radium-226
Radium-226

Radium-226
Radium-228

Radium-228
Ruthenium-103

Sodium-22

Zinc. 65

Zirconium-95
0 Manganese.54

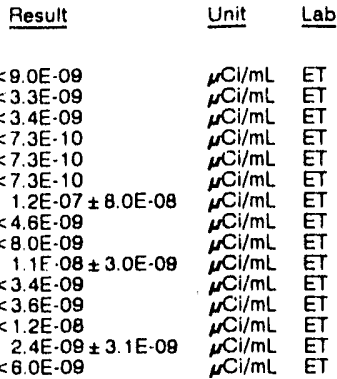

WELL ASB 9

MEASUREMENTS CONDUCTED IN THE FIELD

Sample date: $05 / 04 / 91$

Depth to water: $68.55 \mathrm{ft}(20.89 \mathrm{~m})$ below TOC

Water elevation: $24045 \mathrm{ft}(73$

Sp. conductance $43 \mu \mathrm{s} / \mathrm{cm} .29 \mathrm{~m}$ ) wisl

sumpling: $74 \mathrm{nal}$

pH: 48

Alkalinity: $1 \mathrm{mg} / \mathrm{L}$

Wister temperature: $18.6^{\circ} \mathrm{C}$

LABORATORY ANALYSES

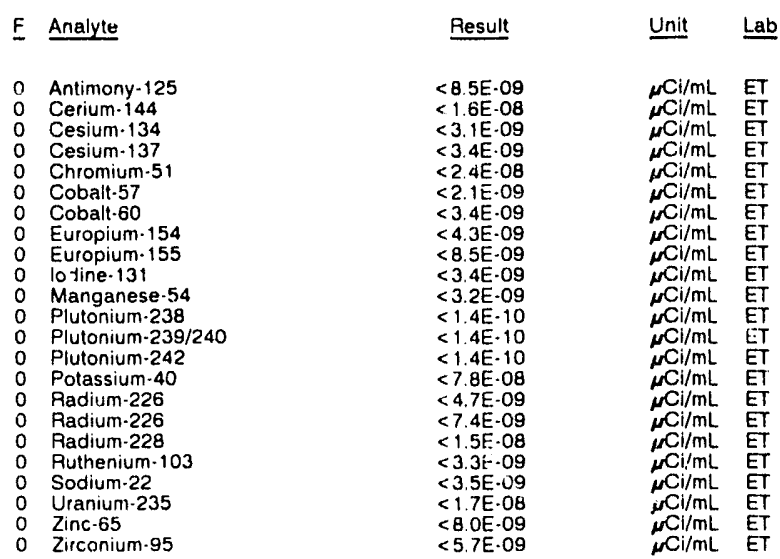

WELL ASB 9B

MEASUREMENTS CONDUCTED IN THE FIELO

Sample date $05 / 04 / 91$

Depth to water $91.22 \mathrm{ft}(27.80 \mathrm{~m})$ below TOC

Water elevation $2.17 .78 \mathrm{ft}(66.38 \mathrm{~m}) \mathrm{msl}$

Sp conductance $97 \mu \mathrm{s} / \mathrm{cm}$

Water evacuated betore sampling: $380 \mathrm{gal}$

LABORATORY ANALYSES

\begin{tabular}{|c|c|c|}
\hline Analyte & Result & Unit \\
\hline $\begin{array}{l}\text { Antimony-125 } \\
\text { Cerium-144 } \\
\text { Cesium-134 } \\
\text { Cesium-137 } \\
\text { Chromium-51 } \\
\text { Cobalt-57 } \\
\text { Cobalt-60 } \\
\text { Europium-154 } \\
\text { Europium-155 } \\
\text { lodine-131 } \\
\text { Manganese-54 } \\
\text { Plutonium-238 } \\
\text { Plutonium-239/240 } \\
\text { Plutonium-242 } \\
\text { Potassium-40 } \\
\text { Padium-226 } \\
\text { Radium-226 } \\
\text { Radium-228 } \\
\text { Ruthenium-103 } \\
\text { Sodium-22 } \\
\text { Uranium-235 } \\
\text { Zinc-65 } \\
\text { Zirconium-95 }\end{array}$ & $\begin{aligned}<4.8 E-09 \\
<1.2 \mathrm{E} \cdot 08 \\
<1.9 \mathrm{E} \cdot 09 \\
<2.2 \mathrm{E} \cdot 09 \\
<1.5 \mathrm{E} \cdot 08 \\
<1.5 \mathrm{E} \cdot 09 \\
<2.3 \mathrm{E} \cdot 09 \\
<32 \mathrm{E} \cdot 09 \\
<6.4 \mathrm{E} \cdot 09 \\
<1.9 \mathrm{E} \cdot 09 \\
<2 \mathrm{E} \cdot 09 \\
<1.8 \mathrm{E} \cdot 10 \\
<1.8 \mathrm{E} \cdot 10 \\
5.9 \mathrm{E} \cdot 10 \pm 2.3 \mathrm{E} \cdot 10 \\
8.4 \mathrm{E} \cdot 08 \pm 26 \mathrm{E} \cdot 08 \\
<47 \mathrm{E} \cdot 09 \\
<7.4 \mathrm{E} \cdot 09 \\
<1.7 \mathrm{E} \cdot 08 \\
<1.9 \mathrm{E} \cdot 09 \\
<2.3 \mathrm{E} \cdot 09 \\
<1.3 \mathrm{E} \cdot 08 \\
<4.5 \mathrm{E} \cdot 09 \\
<3.6 \mathrm{E} \cdot 09\end{aligned}$ & $\begin{array}{l}\mu \mathrm{Ci} / \mathrm{mL} \\
\mu \mathrm{Ci} / \mathrm{mL} \\
\mu \mathrm{Ci} / \mathrm{mL} \\
\mu \mathrm{Ci} / \mathrm{mL} \\
\mu \mathrm{Ci} / \mathrm{mL} \\
\mu \mathrm{Ci} / \mathrm{mL} \\
\mu \mathrm{Ci} / \mathrm{mL} \\
\mu \mathrm{Ci} / \mathrm{mL} \\
\mu \mathrm{Ci} / \mathrm{mL} \\
\mu \mathrm{Ci} / \mathrm{mL} \\
\mu \mathrm{Ci} / \mathrm{mL} \\
\mu \mathrm{Ci} / \mathrm{mL} \\
\mu \mathrm{Ci} / \mathrm{mL} \\
\mu \mathrm{Ci} / \mathrm{mL} \\
\mu \mathrm{Ci} / \mathrm{mL} \\
\mu \mathrm{Ci} / \mathrm{mL} \\
\mu \mathrm{Ci} / \mathrm{mL} \\
\mu \mathrm{Ci} / \mathrm{mL} \\
\mu \mathrm{Ci} / \mathrm{mL} \\
\mu \mathrm{Ci} / \mathrm{mL} \\
\mu \mathrm{Ci} / \mathrm{mL} \\
\mu \mathrm{Ci} / \mathrm{mL} \\
\mu \mathrm{Ci} / \mathrm{mL}\end{array}$ \\
\hline
\end{tabular}




\section{ANALYTICAL RESULTS}

\section{WELL ASB 9C}

MEASUREMENTS CONDUCTED IN THE FIELD

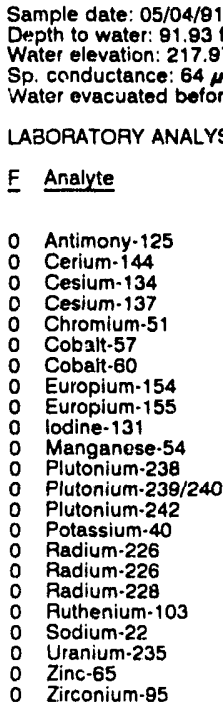

Time: 15:05

Alkalinity: $48 \mathrm{mg} / \mathrm{L}$

Water temperature: $19.8^{\circ} \mathrm{C}$ $(66.44 \mathrm{~m}) \mathrm{msl}$

gal

Result Unit Lab

WELL ASB $10 C$

MEASUREMENTS CONDUCTED IN THE FIELD

Sample date: 05/03/91

Depth to water: $127.45 \mathrm{ft}(38.85 \mathrm{~m})$ below TOC

Water elevation: $221.45 \mathrm{tt}(67.50 \mathrm{~m}) \mathrm{msl}$

Sp. conductance: $79 \mu \mathrm{s} / \mathrm{cm}$

Water evacuated before sampling: $131 \mathrm{gal}$

LABORATORY ANAL.YSES

\begin{tabular}{|c|c|c|}
\hline Analyte & Result & Unit \\
\hline $\begin{array}{l}\text { Antimony-125 } \\
\text { Cerium-144 } \\
\text { Cesium-134 } \\
\text { Cesium-137 } \\
\text { Chromium-51 } \\
\text { Cobalt-57 } \\
\text { Cobalt-60 } \\
\text { Europium-154 } \\
\text { Europilm-155 } \\
\text { lodine-131 } \\
\text { Mailganese-54 } \\
\text { Plutonium-238 } \\
\text { Plutonium-239/240 } \\
\text { Plutonium-242 } \\
\text { Potassium-40 } \\
\text { Radium-226 } \\
\text { Radium-228 } \\
\text { Ruthenium-103 } \\
\text { Sodium-22 } \\
\text { Uranium-235 } \\
\text { Zinc-65 } \\
\text { Zirconium-95 }\end{array}$ & $\begin{aligned}<5.6 \mathrm{E}-09 \\
<1.2 \mathrm{E} \cdot 08 \\
<2.2 \mathrm{E} \cdot 09 \\
<2.2 \mathrm{E} \cdot 09 \\
<1.7 \mathrm{E} \cdot 08 \\
<1.5 \mathrm{E} \cdot 09 \\
<2.4 \mathrm{E} \cdot 09 \\
<3.2 \mathrm{E} \cdot 09 \\
<6.5 \mathrm{E} \cdot 09 \\
<2.3 \mathrm{E} \cdot 09 \\
<2.2 \mathrm{E} \cdot 09 \\
<1.3 \mathrm{E} \cdot 10 \\
<1.3 \mathrm{E}-10 \\
<1.3 \mathrm{E}-10 \\
8.6 \mathrm{E} \cdot 08 \pm 2.7 \mathrm{E}-08 \\
<4.5 \mathrm{E} \cdot 09 \\
6.2 \mathrm{E}-09 \pm 1.6 \mathrm{E} \cdot 09 \\
<2.1 \mathrm{E} \cdot 09 \\
<2.3 \mathrm{E} \cdot 09 \\
<7.3 \mathrm{E}-09 \\
<4.7 \mathrm{E}-09 \\
<3.7 \mathrm{E}-09\end{aligned}$ & 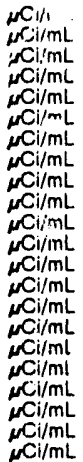 \\
\hline
\end{tabular}

WELL BG 91

MEASUREMENTS CONDUCTED IN THE FIELO

Sample date: 05/02/91

Depth to water: $53.33 \mathrm{ft}(16.26 \mathrm{~m})$ below TOC

Water elevation: $220.07 \mathrm{ft}(67.08 \mathrm{~m}) \mathrm{ms}$ l

Sp. conductance: $51 \mu \mathrm{S} / \mathrm{cm}$

Water evacuated before sampling: $16 \mathrm{gal}$

The well went dry during purging.

LABORATORY ANALYSES

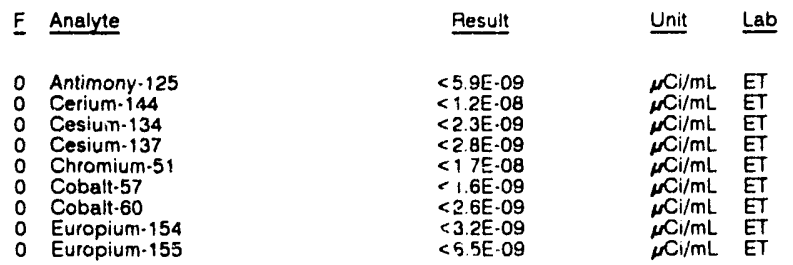

$<2.6 \mathrm{E}-09$

$<1.7 \mathrm{E} .09$

$<1.7 \mathrm{E} .09$

$<1.6 \mathrm{E}-10$

Q.

$<4.2 \mathrm{E} .09$

$<4.2 \mathrm{E} .09$
$<8.0 \mathrm{E}-09$

$<1.8 \mathrm{E} \cdot 08$

$<1.7 .09$

$<6.0 \mathrm{E} \cdot 09$

$<3.8 \mathrm{E} \cdot 09$

$<3.0 E \cdot 09$

WELL BG 91 collected on 05/02/91, laboratory analyses (cont.)

F Analyte

0 lodine-131

0 Manganese-54

0 Potassium-40

Radlum-226

- Ruthenium-103

2 Sodium-22

2 Uranium-2

0 Zirconium-95

\begin{tabular}{|c|c|}
\hline Result & Unit \\
\hline 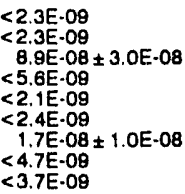 & 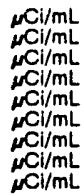 \\
\hline
\end{tabular}

WELL BG 92

MEASUREMENTS CONDUCTED IN THE FIELD

Sample date: 05/02/91

Depth to water: $45.00 \mathrm{ft}$ ( $13.72 \mathrm{~m}$ ) below TOC

Water elevation: $210.20 \mathrm{Ht}(64.07 \mathrm{~m}) \mathrm{mb}$ !

Sp. conductance: $188 \mu \mathrm{S} / \mathrm{cm}$

Water evacuated before sampling: $17 \mathrm{gal}$
The well went dry during purging.

pH: 6.8

LABORATOAY ANALYSES

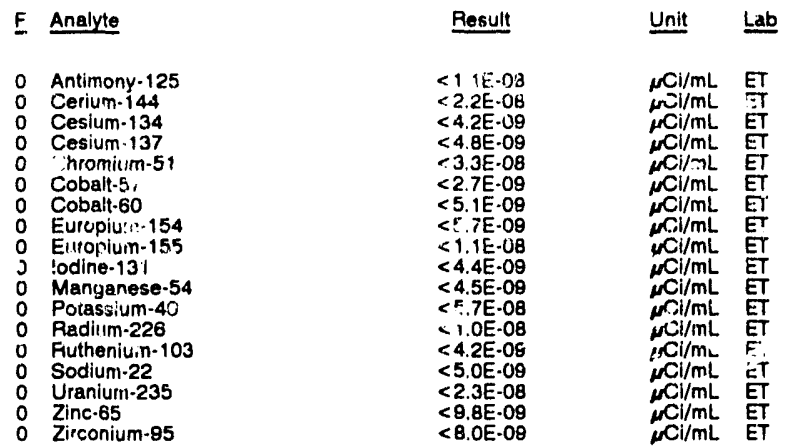

WELL BG 93

MEASUREMFNTS CONDUCTED IN THE FIELD

Sample date: $05 / 01 / 91$

Depth to water: $58.12 \mathrm{~A}(17.13 \mathrm{~m})$ below TOC

Water elevation: $202,3^{\prime \prime} "(61.66 \mathrm{~m}) \mathrm{ms}$

Water evacuated brafo; ; sampling: 71 gal

LABORATORY ANALYSES

- Antimony-125

Cerium-144

Cesium-137

Chromium-5

Ccbalt-57

Europium-15

Europium-15

lodine-131

Manganese.54

Potassium-40

Rathenium-103

Sodium-22

Uranium-235

Zinc.65

Zirconium-95

Time: $12: 25$

PH: 5.7

Alkalinity: $\theta \mathrm{mg} / \mathrm{h}, 185^{\circ} \mathrm{C}$

WELL BG 944

MEASUREMENTS CONDUCTED IN THE FIELD

Sample date: $05 / 01 / 91$

Depth to water: $58.46 \mathrm{At}(17.82 \mathrm{~m})$ below TOC

Water elevation: $182.34 \mathrm{ft}(58.63 \mathrm{~m}) \mathrm{ms}$

conductance. 102 is/cm

Water evacuated before sampling: $103 \mathrm{gal}$

LABORATORY ANALYSES

\begin{tabular}{|c|c|c|}
\hline Analyte & Result & Unit \\
\hline $\begin{array}{ll}0 & \text { Antimony-125 } \\
0 & \text { Cerium-144 } \\
0 & \text { Cesium-134 } \\
0 & \text { Cesium-137 }\end{array}$ & $\begin{array}{l}<9.3 \mathrm{E}-09 \\
<1.7 \mathrm{E} .08 \\
<3.4 \mathrm{E} .09 \\
<3.0 \mathrm{E} .09\end{array}$ & $\begin{array}{l}\mu \mathrm{Ci} / \mathrm{mL} \\
\mu \mathrm{Ci} / \mathrm{mL} \\
\mu \mathrm{Cl} / \mathrm{mL} \\
\mu \mathrm{Cl} / \mathrm{mL}\end{array}$ \\
\hline
\end{tabular}


ANALYTICAL RESULTS

WELL 8694 collected on 05/01/91, laboratory analyses (cont.)

\begin{tabular}{|c|c|c|}
\hline Ana'yte & Result & Unit \\
\hline $\begin{array}{l}\text { Chromium-51 } \\
\text { Cobalt-57 } \\
\text { Cobat-60 } \\
\text { Europium-154 } \\
\text { Europium-155 } \\
\text { lodine-131 } \\
\text { Manganese-54 } \\
\text { Potassium-40 } \\
\text { Radium-228 } \\
\text { Ruthenium-103 } \\
\text { Sodium-22 } \\
\text { Uranium-235 } \\
\text { Zinc-65 } \\
\text { Zirconium-85 }\end{array}$ & $\begin{aligned}<2.4 \mathrm{E} \cdot 09 \\
<2.1 \mathrm{E} \cdot 09 \\
<3.7 \mathrm{E} \cdot 09 \\
<4.4 \mathrm{E} \cdot 09 \\
<8.7 \mathrm{E} \cdot 09 \\
<3.3 \mathrm{E} \cdot 09 \\
<3.6 \mathrm{E} \cdot 09 \\
4.9 \mathrm{E} \cdot 08 \pm 1.8 \mathrm{E} \cdot 08 \\
<8.0 \mathrm{E} \cdot 09 \\
<3.4 \mathrm{E} \cdot 09 \\
<3.5 \mathrm{E} \cdot 09 \\
<1.8 \mathrm{E} \cdot 08 \\
<7.2 \mathrm{E} \cdot 00 \\
<6.0 \mathrm{E} \cdot 09\end{aligned}$ & 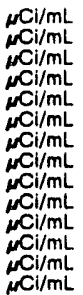 \\
\hline
\end{tabular}

WELL BG 95

MEASUREMENTS CONDUCTED IN THE FIELD

Sample date: 05/02/91

Depth to water: $28.36 \mathrm{Ht}(8.64 \mathrm{~m})$ below TOC

Water elevation: $194.14 \mathrm{ft}(59.17 \mathrm{~m}) \mathrm{msl}$

Sp. conductance: $52 \mu \mathrm{s} / \mathrm{cm}$

sampling: $109 \mathrm{gal}$

LABORATORY ANALYSES

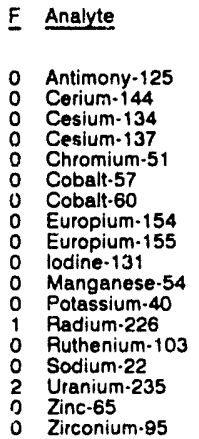

\begin{tabular}{|c|c|}
\hline Result & Unit \\
\hline 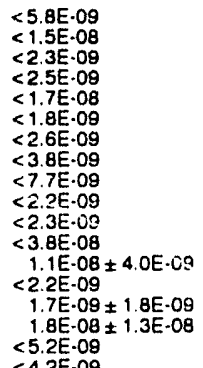 & 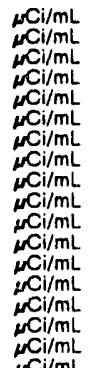 \\
\hline
\end{tabular}

WELL BG 95 Replicate

MEASUREMENTS CCNDUCTED IN THE FIELD

Sample tate: 05/02/81 Jepth to water: 28.36 H (B.64 m) below TOC Water elevation: $194.14 \mathrm{Ht}(50 \mathrm{H}$

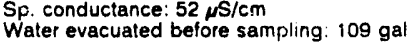
LABORATORY ANALYSES

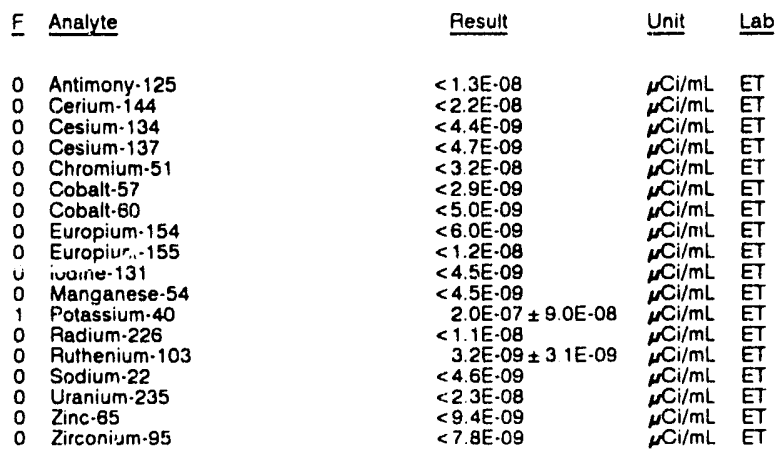

WELL BG 96

MEASUREMENTS CONDUCTED IN THE FIELD

$\begin{array}{ll}\text { Sample date: } 05 / 01 / 91 & \text { Time: } 10: 30 \\ \text { Depth to water: } 45,68 \mathrm{ft}(13.82 \mathrm{~m}) \text { below TOC } & \text { pH: } 5.3 \\ \text { Water elevation: } 199.52 \mathrm{Ht}(60.81 \mathrm{~m}) \mathrm{ms} & \text { Alkalinity: } 3 \mathrm{mg} / \mathrm{L} \\ \text { Sp. conductance: } 28 \mu \mathrm{s} / \mathrm{cm} & \text { Water temperature: } 19.8^{\circ} \mathrm{C} . \\ \text { Water evacuated before sampling: } 59 \mathrm{gal} & \end{array}$

LABORATORY ANALYSES

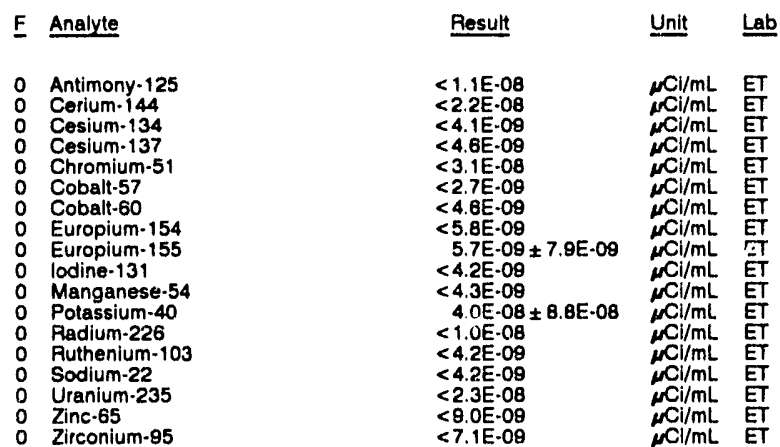

\section{WELLL BG 101}

MEASUREMENTS CONDUCTED IN THE FIELD

$\begin{array}{ll}\text { Sample date: } 05 / 01 / 91 & \text { Time: } 14: 50 \\ \text { Depth to water: } 34.56 \mathrm{Ht}(10.53 \mathrm{~m}) \text { below TOC } & \text { pH: } 5.1 \\ \text { Water elevation: } 196.84 \mathrm{H}(60.00 \mathrm{~m}) \mathrm{msl} & \text { Alkalinity: } 1 \mathrm{mg} / \mathrm{h} \\ \text { Sp. conductance: } 20 \mu \mathrm{cm} & \text { Water temperature: } 19.8^{\circ} \mathrm{C} \\ \text { Water evacuated before sampling: } 93 \mathrm{gal} & \end{array}$

Water evacuated before sampling: $93 \mathrm{gal}$

LABORATORY ANALYSES

\begin{tabular}{|c|c|c|}
\hline Analyte & Result & Unit \\
\hline $\begin{array}{l}\text { Antimony-125 } \\
\text { Cerium-1444 } \\
\text { Cesium-134 } \\
\text { Cesium-137 } \\
\text { Chromium-51 } \\
\text { Cobalt-57 } \\
\text { Cot - } 1 \cdot 60 \\
\text { Europium-154 } \\
\text { Europium-155 } \\
\text { lodine-131 } \\
\text { Manganese-54 } \\
\text { Potassium-40 } \\
\text { Radium-226 } \\
\text { Puthenium-103 } \\
\text { Sodium-22 } \\
\text { Uranium-235 } \\
\text { Zinc-65 } \\
\text { Zirconium-95 }\end{array}$ & $\begin{array}{l}<6.4 E-09 \\
<1.2 \mathrm{E}-080 \\
<2.3 \mathrm{E}-09 \\
<2.2 \mathrm{E} \cdot 09 \\
<1.7 \mathrm{E}-08 \\
<1.5 \mathrm{E} \cdot 09 \\
<2.4 \mathrm{E} \cdot 09 \\
<3.1 \mathrm{E}-09 \\
<6.5 \mathrm{E}-09 \\
<2.3 \mathrm{E}-09 \\
<2.2 \mathrm{E} \cdot 09 \\
7.5 \mathrm{E} \cdot 08 \pm 2.7 \mathrm{E} \cdot 08 \\
<5.2 \mathrm{E}-09 \\
<2.0 \mathrm{E} \cdot 09 \\
<2.3 \mathrm{E}-09 \\
8.8 \mathrm{E} \cdot 09 \pm 1.0 \mathrm{E} \cdot 08 \\
<4.5 \mathrm{E} \cdot 09 \\
<3.7 \mathrm{C} \cdot 09\end{array}$ & 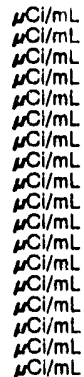 \\
\hline
\end{tabular}

\section{WELL BG 104}

MEASUREMENTS CONDUCTED IN THE FIELD

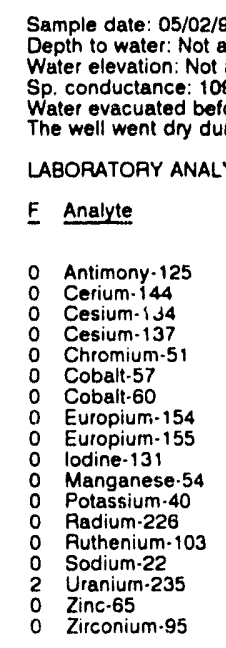

Time: 13:35

PH: 6.9

Water temperature: $19.0 \circ \mathrm{C}$

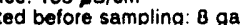

LABORATORY ANALYSES

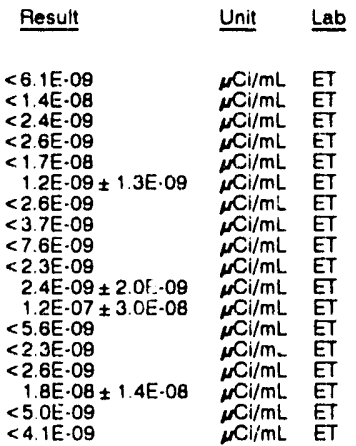


ANALYTICAL RESULTS

WELL BG 107

MEASUREMENTS CONDUCTED IN THE FIELD

Sample date: $05 / 02 / 91$
Depth to water: $12.27 \mathrm{ht}(3.74 \mathrm{~m})$ bolow TOC
Water elevation: $236.03 \mathrm{Ht}(71.94 \mathrm{~m}) \mathrm{msl}$
Sp. conductance: $32 \mu$ s/cm
Water ovacuated before sampling: $73 \mathrm{gal}$
LABORATORY ANALYSES

Time: $15: 10$

Alk: 4.8 : $3 \mathrm{mg} / \mathrm{h}$

Water temperature: $19.1^{\circ} \mathrm{C}$

LABORATORY ANALYSES
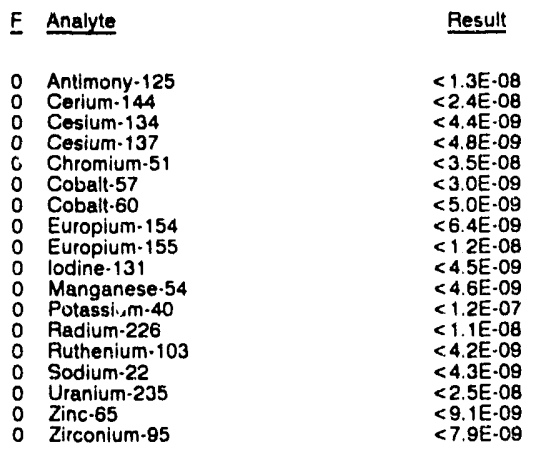

\begin{tabular}{|c|c|}
\hline Unit & \\
\hline 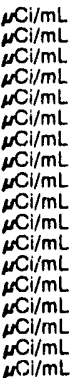 & $\begin{array}{l}\mathrm{E} \\
\mathrm{E} \\
\mathrm{E} \\
\mathrm{E} \\
\mathrm{E} \\
\mathrm{E} \\
\mathrm{E} \\
\mathrm{E} \\
\mathrm{E} \\
\mathrm{E} \\
\mathrm{E} \\
\mathrm{E} \\
\mathrm{E}\end{array}$ \\
\hline
\end{tabular}

WELL BG 108

MEASUREMENTS CONDUCTED IN THE FIELD

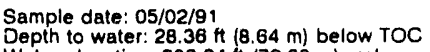

Water elevation: $238.94 \mathrm{H} / 72$

Sp. conductance: $40 \mu \mathrm{s} / \mathrm{cm}$

Water evacuated before sampling: $57 \mathrm{gal}$

LABORATORY ANALYSES
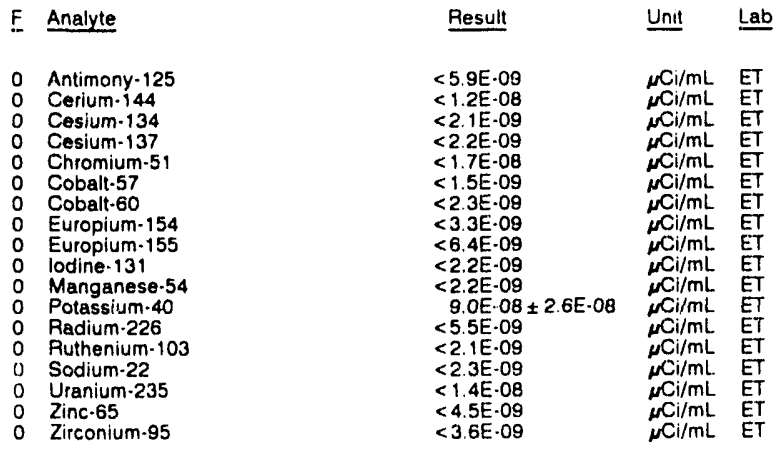

WELL BG 110

MEASUREMENTS CONDUCTED IN THE FIELD

Sample date: 05/02/81

Depth to water: $53.80 \mathrm{ft}(16.40 \mathrm{~m})$ below TOC

Water elevation: $240.50 \mathrm{H}(73.31 \mathrm{~m}) \mathrm{msl}$

Sp conductance: $101 \mu \mathrm{s} / \mathrm{cm}$

Water evacuated before sampling: $34 \mathrm{ga}$

The well went dry during purging

LABORATORY ANALYSES

\begin{tabular}{|c|c|c|}
\hline Analyte & Result & Unit \\
\hline $\begin{array}{ll}0 & \text { Antimony-125 } \\
0 & \text { Cerium-144 } \\
0 & \text { Cesium-134 } \\
0 & \text { Cesium-137 } \\
0 & \text { Chromium-51 } \\
0 & \text { Cobalt-57 } \\
0 & \text { Cobalt-60 } \\
0 & \text { Europium-154 } \\
0 & \text { Europium-155 } \\
0 & \text { lodine-131 } \\
0 & \text { Manganese-54 } \\
0 & \text { Potassium.40 } \\
0 & \text { Radium-226 } \\
0 & \text { Ruthenium-103 } \\
0 & \text { Sodium-22 } \\
1 & \text { Uranium. } 235 \\
0 & \text { Zinc.65 } \\
0 & \text { Zirconium.95 }\end{array}$ & $\begin{array}{l}<6.3 E \cdot 09 \\
<1.4 \mathrm{E} \cdot 08 \\
<2.4 \mathrm{E} \cdot 09 \\
<2.6 \mathrm{E} \cdot 09 \\
<1.7 \mathrm{E} \cdot 08 \\
<1.8 \mathrm{E} \cdot 09 \\
<2.8 \mathrm{E} \cdot 09 \\
<3.7 \mathrm{E} \cdot 09 \\
<7.6 \mathrm{E} \cdot 09 \\
<2.3 \mathrm{E} \cdot 09 \\
<2.5 \mathrm{E} \cdot 09 \\
7.6 \mathrm{E} \cdot 08 \pm 3.1 \mathrm{E} \cdot 08 \\
<5.8 \mathrm{BE}-09 \\
<2.2 \mathrm{E} \cdot 09 \\
<2.7 \mathrm{E} \cdot 09 \\
1.2 \mathrm{E}-08 \pm 1.3 \mathrm{E} \cdot 08 \\
<5.1 \mathrm{E} \cdot 09 \\
<3.9 \mathrm{E} \cdot 09\end{array}$ & 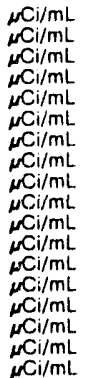 \\
\hline
\end{tabular}

WELL BG 121

MEASUREMENTS CONDUCTED IN THE FIELD

$\begin{array}{ll}\text { Sample date: } 05 / 02 / 91 & \text { Time: } 11: 40 \\ \text { Depth to water: } 68.06 \mathrm{ft}(21.05 \mathrm{~m}) \text { below TOC } & \text { pH: } 5.8 \\ \text { Water elevation: } 208.84 \mathrm{ft}(63.66 \mathrm{~m}) \mathrm{ms} & \text { Alkglinity: } 7 \mathrm{mg} / \mathrm{h} \\ \text { Sp. conductance: } 32 \mu \mathrm{\mu S} / \mathrm{cm} & \text { Water temperature: } 18.6^{\circ} \mathrm{C} \\ \text { Water evacuated before sampling: } 8 \mathrm{gal} & \end{array}$

Sp. conductance: $32 \mu \mathrm{s} / \mathrm{cm}$.

The well went dry during purging.

LABORATORY ANALYSES

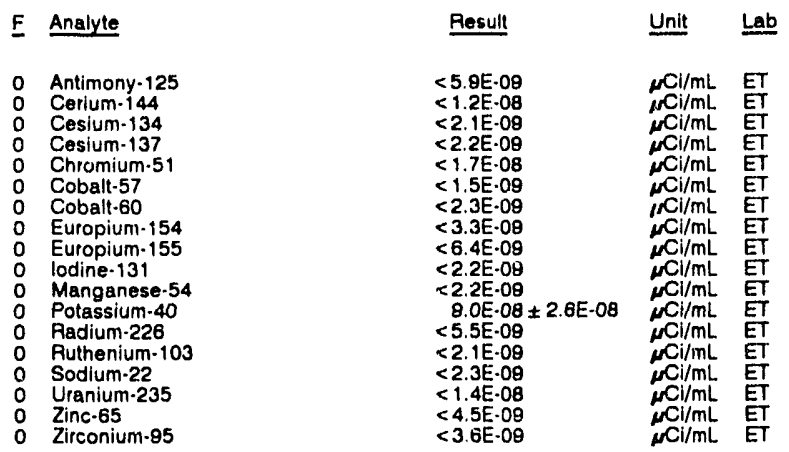

WELL BG 122

MEASUREMENTS CONDUCTED IN THE FIELD

Depth to water: $35.97 \mathrm{ft}(10.96 \mathrm{~m})$ below TOC Water elevation: $211.93 \mathrm{t}(64.60 \mathrm{~m}) \mathrm{msl}$ Water evacuated before sampling: $58 \mathrm{gal}$

pH: 5.6

Alkalinity: $10 \mathrm{mg} / \mathrm{L}$

LAEORATORY ANALYSES

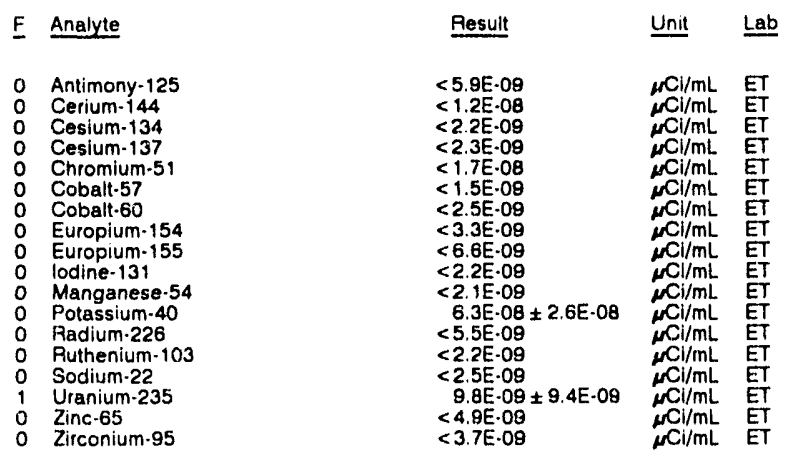

WELL BGO 26A

MEASUREMENTS CONDUC ILD IN THE FIELD

Sample date: 05/08/91

Time: $9: 35$

Water waler: $126.35 \mathrm{n}(38.52 \mathrm{~m})$ below TOC

Sp. conductance: $1509 \mu \mathrm{S} / \mathrm{cm}$

Water evacuated before sampling. $45 \mathrm{gal}$
The well went dry during purging.

$\mathrm{pH}: 12.0$

Alkalinity: $352 \mathrm{mg} / \mathrm{h}$

LABORATORY ANALYSES

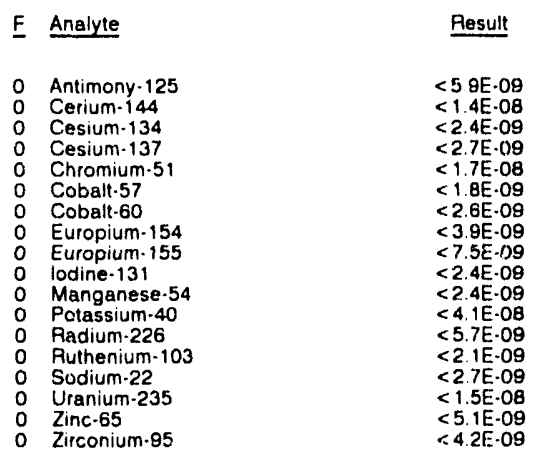

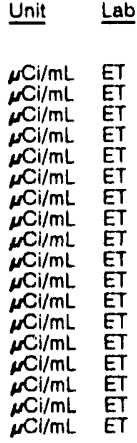


ANALYTICAL RESULTS

\section{WELL BGO 26D}

MEASUREMENTS CONDUCTED IN THE FIELD

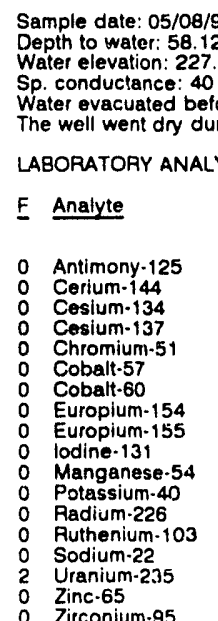

(69.31 m) ms
Time: $9: 20$

pH: 5.6

Alkalinity: $8 \mathrm{mg} / \mathrm{L}$

Water temperature: $18.8^{\circ} \mathrm{C}$

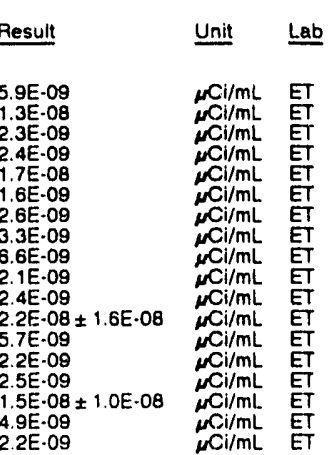

WELL BGO 27C

MEASUREMENTS CONDUCTED IN THE FIELD

Sample date: 05/03/81

Depth to water: $55.65 \mathrm{At}(16.96 \mathrm{~m})$ below TOC

Water elevation: $220.35 \mathrm{t}(67.1$

Water evacuated before sampling: $172 \mathrm{gal}$

LABORATORY ANALYSES

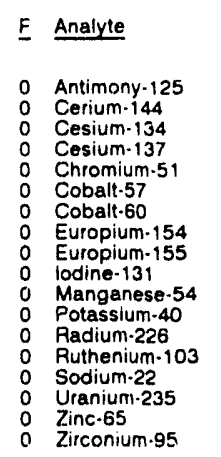

Result

Time: 13:10

pH: 6.9 : $38 \mathrm{mg}$

Water temperature: $20.6^{\circ} \mathrm{C}$

\begin{abstract}
(n)
\end{abstract}
WELL BGO 27D

MEASUREMENTS CONDUCTED IN THE FIELD

Sample date: 05/08/91

Depth to water: $48.87 \mathrm{ft}(14.90 \mathrm{~m})$ below TOC

Water elevation: $227.43 \mathrm{~h}(69.32 \mathrm{~m}) \mathrm{msl}$

Sp. conductance: $38 \mu \mathrm{s} / \mathrm{cm}$

Water evacuated before sampling: 12 gal

LABORATORY ANALYSES

\begin{tabular}{|c|c|c|}
\hline Analyte & Resuit & Unit \\
\hline $\begin{array}{l}\text { Antimony-125 } \\
\text { Cerium-144 } \\
\text { Cesium-134 } \\
\text { Cesium-137 } \\
\text { Chromium-51 } \\
\text { Cobalt-57 } \\
\text { Cobalt-60 } \\
\text { Europium } 154 \\
\text { Europium-155 } \\
\text { lodine- } 131 \\
\text { Manganese-54 } \\
\text { Potassium-40 } \\
\text { Radium-226 } \\
\text { Ruthenium-103 } \\
\text { Sodium-22 } \\
\text { Uranium-235 } \\
\text { Zinc-65 } \\
\text { Zirconium-95 }\end{array}$ & $\begin{aligned}<1.2 \mathrm{E} \cdot 08 \\
<2.2 \mathrm{E} \cdot 08 \\
<+3 \mathrm{E} \cdot 09 \\
<5.2 \mathrm{E} \cdot 09 \\
<3.2 \mathrm{E} \cdot 08 \\
<2.7 \mathrm{E} \cdot 09 \\
<4.7 \mathrm{E} \cdot 09 \\
<5.7 \mathrm{E} \cdot 09 \\
<1.1 \mathrm{E} \cdot 08 \\
<4.3 \mathrm{E} \cdot 09 \\
<4.7 \mathrm{E} \cdot 09 \\
9.6 \mathrm{E} \cdot 08 \pm 9.1 \mathrm{E} \cdot 08 \\
<1.0 \mathrm{E} \cdot 08 \\
<4.3 \mathrm{E} \cdot 09 \\
<5.0 \mathrm{E} \cdot 09 \\
<2.3 \mathrm{E} \cdot 08 \\
<1.0 \mathrm{E} \cdot 08 \\
<7.9 \mathrm{E} \cdot 09\end{aligned}$ & 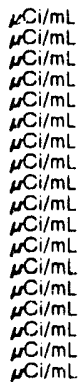 \\
\hline
\end{tabular}

\section{WELL BGO 28D}

MEASUREMENTS CONDUCTED IN THE FIELD

$\begin{array}{ll}\text { Sample date: } 05 / 08 / 91 & \text { Time: } 10: 35 \\ \text { Depth to water: } 51.06 \mathrm{ft}(15.56 \mathrm{~m}) \text { below TOC } & \text { pH: } 5.5 \\ \text { Water elevation: } 226.34 \mathrm{ft}(68.99 \mathrm{~m}) \mathrm{ms} & \text { Alkalinity: } 8 \mathrm{mg} / \mathrm{L} \\ \text { Sp. conductance: } 80 \mu \mathrm{\mu S} / \mathrm{cm} & \text { Water temperature: } 18.8^{\circ} \mathrm{C} \\ \text { Water evacuated before sampling: } 8 \mathrm{gal} & \\ \text { The well went dry during purging. } & \end{array}$

LABORATORY ANALYSES

\begin{tabular}{|c|c|c|}
\hline Analyte & Result & Unit \\
\hline $\begin{array}{l}\text { Antimiony- } 125 \\
\text { Cerium-144 } \\
\text { Cesium-134 } \\
\text { Cesium-137 } \\
\text { Chromium-51 } \\
\text { Cobalt-57 } \\
\text { Cobalt-60 } \\
\text { Europium-154 } \\
\text { Europium-155 } \\
\text { lodine-131 } \\
\text { Manganese-54 } \\
\text { Potassium-40 } \\
\text { Radium-228 } \\
\text { Ruthenium-103 } \\
\text { Sodium-22 } \\
\text { Uranium-235 } \\
\text { Zinc-65 } \\
\text { Zirconium-95 }\end{array}$ & $\begin{array}{l}<1.2 \mathrm{E}-08 \\
<2.4 \mathrm{E} \cdot 08 \\
<4.3 \mathrm{E} \cdot 09 \\
<5.1 \mathrm{E} \cdot 09 \\
<3.3 \mathrm{E} \cdot 08 \\
<3.0 \mathrm{E} \cdot 09 \\
<4.3 \mathrm{E} \cdot 09 \\
<8.4 \mathrm{E} \cdot 09 \\
<1.2 \mathrm{E} \cdot 08 \\
<4.3 \mathrm{E} \cdot 09 \\
<4.7 \mathrm{E} \cdot 09 \\
<1.1 \mathrm{E} \cdot 07 \\
<1.0 \mathrm{E} \cdot 08 \\
<4.2 \mathrm{E} \cdot 09 \\
<4.6 \mathrm{E} \cdot 09 \\
<2.5 \mathrm{E} \cdot 08 \\
<8.9 \mathrm{E} \cdot 09 \\
<7.3 \mathrm{E} \cdot 09\end{array}$ & 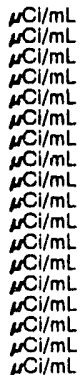 \\
\hline
\end{tabular}

WELLL BGO 29A

MEASUREMENTS CONDUCTED IN HE FIELD

Sample date: 05/08/91

Time: $8: 00$

Depth to water: $104.67 \mathrm{tt}(31.90 \mathrm{~m})$ below TOC

$\mathrm{Sp}$. conductance: $120 \mu \mathrm{S} / \mathrm{cm}$

Alkalinity: $39 \mathrm{mg} / \mathrm{L}$

Water temperature: $18.8^{\circ} \mathrm{C}$

Water evacuated before sampling: $44 \mathrm{gal}$

LABORATORY ANALYSES

\begin{tabular}{|c|c|c|}
\hline Analyte & Result & Unis \\
\hline $\begin{array}{l}\text { Antimony-125 } \\
\text { Cerium-144 } \\
\text { Cesium-134 } \\
\text { Cesium-137 } \\
\text { Chromium-51 } \\
\text { Cobalt-57 } \\
\text { Cobalt-60 } \\
\text { Europium-154 } \\
\text { Europium-155 } \\
\text { lodine-131 } \\
\text { Manganese-54 } \\
\text { Potassium-40 } \\
\text { Radium-226 } \\
\text { Ruthenium-103 } \\
\text { Sodium-22 } \\
\text { Uranium-235 } \\
\text { Zinc-65 } \\
\text { Zirconium-95 }\end{array}$ & $\begin{array}{l}<5.9 \mathrm{E} \cdot 09 \\
<1.4 \mathrm{E} \cdot 08 \\
<2.3 \mathrm{E} \cdot 09 \\
<2.5 \mathrm{E} \cdot 09 \\
<1.7 \mathrm{E} \cdot 09 \\
<1.8 \mathrm{E} \cdot 09 \\
<2.5 \mathrm{E} \cdot 09 \\
<3.7 \mathrm{E} \cdot 09 \\
<7.5 \mathrm{E} \cdot 09 \\
<2.3 \mathrm{E} \cdot 09 \\
<2.4 \mathrm{E} \cdot 09 \\
1.2 \mathrm{E} \cdot 09 \pm 3.0 \mathrm{E}-10 \\
<5.4 \mathrm{E} \cdot 09 \\
<2.1 \mathrm{E} \cdot 09 \\
<2.5 \mathrm{E} \cdot 09 \\
0.0 \mathrm{E}+00 \pm 7.3 \mathrm{E}-09 \\
<5.1 \mathrm{E} \cdot 09 \\
<4.0 \mathrm{E} \cdot 09\end{array}$ & $\begin{array}{l}\mu \mathrm{Ci} / \mathrm{mL} \\
\mu \mathrm{Cl} / \mathrm{mL} \\
\mu \mathrm{Ci} / \mathrm{mL} \\
\mu \mathrm{Cl} / \mathrm{mL} \\
\mu \mathrm{Ci} / \mathrm{mL} \\
\mu \mathrm{Cl} / \mathrm{mL} \\
\mu \mathrm{CC} / \mathrm{mL} \\
\mu \mathrm{Cl} / \mathrm{mL} \\
\mu \mathrm{Ci} / \mathrm{mL} \\
\mu \mathrm{Cl} / \mathrm{mL} \\
\mu \mathrm{Cl} / \mathrm{mL} \\
\mu \mathrm{Ci} / \mathrm{mL} \\
\mu \mathrm{Cl} / \mathrm{mL} \\
\mu \mathrm{Cl} / \mathrm{mL} \\
\mu \mathrm{Cl} / \mathrm{mL} \\
\mu \mathrm{Cl} / \mathrm{mL} \\
\mu \mathrm{Cl} / \mathrm{mL} \\
\mu \mathrm{Ci} / \mathrm{mL}\end{array}$ \\
\hline
\end{tabular}

WELL BGO $30 \mathrm{C}$

MEASUAEMENTS CONDUCTED IN THE FIELD

Sample date: 05/08/91

Depth to water: 55.18 H $(16.82 \mathrm{~m})$ below TOC

Water elevation: $218.31 \mathrm{ft}$

Water evaculat

The well went dry during purging: $24 \mathrm{gal}$

pH: 6.4

in: $19 \mathrm{mgll}$

Water temperature: $20.4^{\circ} \mathrm{C}$

LABORATORY ANALYSES

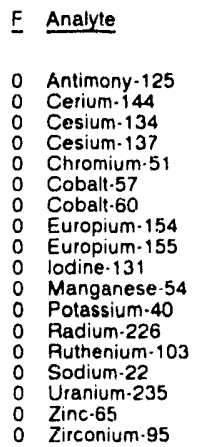

$\begin{aligned} & \text { Result } \\ & \\ &<1.1 E \cdot 08 \\ &<2.2 E \cdot 09 \\ &<1.0 \mathrm{E} \cdot 07 \\ &<4.8 \mathrm{E} \cdot 09 \\ &<3.1 \mathrm{E} \cdot 08 \\ &<3.0 \mathrm{E} \cdot 09 \\ &<4.1 \mathrm{E} \cdot 09 \\ &<5.8 \mathrm{E} \cdot 09 \\ &<1.2 \mathrm{E} \cdot 08 \\ &<4.1 \mathrm{E} \cdot 09 \\ &<4.4 \mathrm{E} \cdot 09 \\ & 1.1 \mathrm{E} \cdot 07 \pm 9.0 \mathrm{0} \cdot 08 \\ &<1.0 \mathrm{E} \cdot 08 \\ &<4.2 \mathrm{E} .09 \\ &<4.8 \mathrm{E} \cdot 09 \\ &<2.3 \mathrm{E} \cdot 08 \\ &<9.1 \mathrm{E} .09 \\ &<7.8 \mathrm{E} \cdot 09\end{aligned}$

Unit Lab

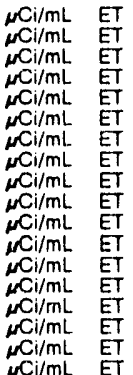


ANALYTICAL RESULTS

WELL BGO 30D

MEASUREMENTS CONDUCTED IN THE FIELD

Sample date: $05 / 08 / 91$ Depth to water: $48.73 \mathrm{Ht}(14.85 \mathrm{~m})$ below TOC Sp. conductance: $95 \mu \mathrm{s} / \mathrm{cm}$ Water evacuated betore sampling: 12 gal The well went dry during purging

LABORATORY ANALYSES

\begin{tabular}{|c|c|c|c|}
\hline Analyte & Result & Unit & Lab \\
\hline $\begin{array}{l}\text { Antimony-125 } \\
\text { Cerium-144 } \\
\text { Cesium-134 } \\
\text { Cesium-137 } \\
\text { Chromium-51 } \\
\text { Cobalt-57 } \\
\text { Cobalt-60 } \\
\text { Europium-154 } \\
\text { Europium-155 } \\
\text { lodine-131 } \\
\text { Manganese-54 } \\
\text { Potassium-40 } \\
\text { Radium-226 } \\
\text { Ruthenium-103 } \\
\text { Sodium-22 } \\
\text { Uranium-2.35 } \\
\text { Zinc-65 } \\
\text { Zirconium-95 }\end{array}$ & $\begin{array}{l}<6.2 \mathrm{E}-09 \\
<1.4 \mathrm{E}-08 \\
<2.2 \mathrm{E}-09 \\
<2.4 \mathrm{E}-09 \\
<1.7 \mathrm{E}-08 \\
<1.8 \mathrm{E}-09 \\
<2.5 \mathrm{E}-09 \\
<3.7 \mathrm{E} \cdot 09 \\
<7.7 \mathrm{E} \cdot 09 \\
<2.2 \mathrm{E} \cdot 09 \\
<2.3 \mathrm{E}-09 \\
1.0 \mathrm{E} \cdot 07 \pm 3.0 \mathrm{E} \cdot 08 \\
<5.7 \mathrm{E} \cdot 09 \\
<2.1 \mathrm{E} \cdot 09 \\
<2.8 \mathrm{E}-09 \\
5.9 \mathrm{E}-09 \pm 1.1 \mathrm{E}-00 \\
<5.4 \mathrm{E}-09 \\
<4.4 \mathrm{E} \cdot 09\end{array}$ & $\begin{array}{c}\mu \mathrm{Cl} / \mathrm{mL} \\
\mu \mathrm{Cl} / \mathrm{mL} \\
\mu \mathrm{Cl} / \mathrm{mL} \\
\mu \mathrm{Ci} / \mathrm{mL} \\
\mu \mathrm{Cl} / \mathrm{mL} \\
\mu \mathrm{Cl} / \mathrm{mL} \\
\mu \mathrm{Cl} / \mathrm{mL} \\
\mu \mathrm{Cl} / \mathrm{mL} \\
\mu \mathrm{Ci} / \mathrm{mL} \\
\mu \mathrm{Ci} / \mathrm{mL} \\
\mu \mathrm{Ci} / \mathrm{mL} \\
\mu \mathrm{Cl} / \mathrm{mL} \\
\mu \mathrm{Cl} / \mathrm{mL} \\
\mu \mathrm{Cl} / \mathrm{mL} \\
\mu \mathrm{Cl} / \mathrm{mL} \\
\mu \mathrm{Ci} / \mathrm{mL} \\
\mu \mathrm{Ci} / \mathrm{mL} \\
\mu \mathrm{Cl} / \mathrm{mL}\end{array}$ & $\begin{array}{l}\text { ET } \\
\text { ET } \\
\text { ET } \\
\text { ET } \\
\text { ET } \\
\text { ET } \\
\text { ET } \\
\text { ET } \\
\text { ET } \\
\text { ET } \\
\text { ET } \\
\text { ET } \\
\text { ET } \\
\text { ET } \\
\text { ET } \\
\text { ET } \\
\text { ET }\end{array}$ \\
\hline
\end{tabular}

\section{WELL BGO $31 \mathrm{C}$}

MEASUREMENTS CONDUCTED IN THE FIELD

Sample date: 05/08/91 below TOC Water elevation: 226.04 tt LABORATORY ANALYSES
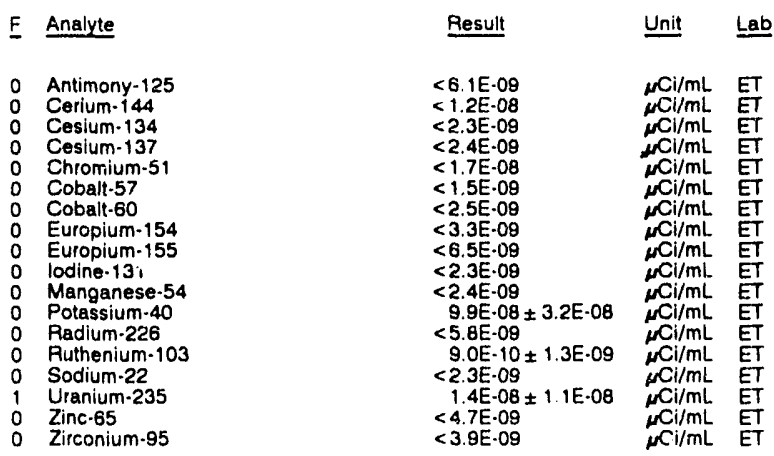

WELL BGO 31D

MEASUREMENTS CONDUCTED IN THE FIELD

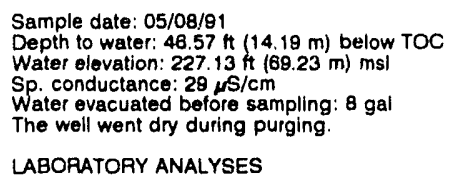

Tirne: $12: 15$

$\mathrm{pH}: 4.8$

Alkalinity: $0 \mathrm{mg} / \mathrm{L}$

Water temperature: $21.2^{\circ} \mathrm{C}$

LABORATORY ANALYSES
E Analyte
0 Antimony-125
Cerium-144
Cesium-134
Chromium-51
Cobalt-5
Eubalt-60
Europium-155
lodine-131
Manganese. 54
Potassium.40
Radium-226
Ruthenium-103
Sodium-22
Uranium-23
Zinc.65
- Zirconium-95

Time: $11: 5$

Alkalinity: $5 \mathrm{mg} / \mathrm{L}$

Water temperature: $21.8^{\circ} \mathrm{C}$
WELL BGO 32D

MEASUREMENTS CONDUCTED IN THE FIELD

Sample date: 05/08/8

Depth to water: $53.71 \mathrm{ft}(16.37 \mathrm{~m})$ below TOC

ater elevation: $227.99 \mathrm{H}(69.49 \mathrm{~m}) \mathrm{ms}$

Water evacuated bofore sampli

The well went dry during purging: $7 \mathrm{gal}$

LABORATORY ANALYSES

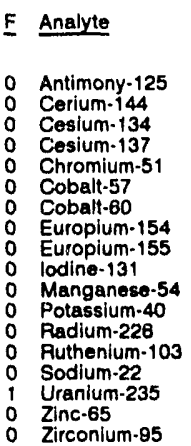

\begin{tabular}{|c|}
\hline Result \\
\hline 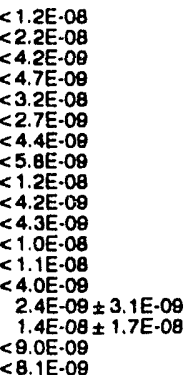 \\
\hline
\end{tabular}

Unit L Lab

WELL BGO 33C

MEASUREMENTS CONDUCTED IN THE FIELD

$\begin{array}{ll}\text { Sample date: } 05 / 08 / 91 & \text { Time: } 12: 00 \\ \text { Depth to water: } 53.86 \mathrm{ft}(16.42 \mathrm{~m}) \text { below TOC } & \text { pH: } 5.9 \\ \text { Water elevation: } 225.54 \mathrm{ft}(68.75 \mathrm{~m}) \mathrm{msl} & \text { Alkalinity: } 12 \mathrm{mg} / \mathrm{L} \\ \text { Sp. conductance: } 64 \mu \mathrm{S} / \mathrm{cm} & \text { Water temperature: } 20.1^{\circ} \mathrm{C} \\ \text { Water evacuated before sampling: } 125 \mathrm{gal} & \end{array}$
LABORATORY ANALYSES

\begin{tabular}{|c|c|c|}
\hline Analyte & Result & Unit \\
\hline $\begin{array}{ll}0 & \text { Antimony-125 } \\
0 & \text { Cerium-144 } \\
0 & \text { Cesium-134 } \\
0 & \text { Ceslum-137 } \\
0 & \text { Chromium-51 } \\
0 & \text { Cobalt-57 } \\
0 & \text { Cobalt-60 } \\
0 & \text { Europium-154 } \\
0 & \text { Europium-155 } \\
1 & \text { lodine-131 } \\
0 & \text { Manganese-54 } \\
0 & \text { Potassium-40 } \\
0 & \text { Radium-226 } \\
0 & \text { Ruthenium-103 } \\
0 & \text { Sodium-22 } \\
0 & \text { Uranium-235 } \\
0 & \text { Zinc-65 } \\
0 & \text { Zirconium-85 }\end{array}$ & $\begin{aligned}<5.6 \mathrm{E}-09 \\
<1.2 \mathrm{E}-08 \\
<2.3 \mathrm{E}-09 \\
<2.4 \mathrm{E}-09 \\
<1.7 \mathrm{E}-08 \\
<1.5 \mathrm{E}-09 \\
<2.3 \mathrm{E} \cdot 09 \\
<3.2 \mathrm{E}-09 \\
<6.7 \mathrm{E}-09 \\
1.5 \mathrm{E}-09 \pm 1.2 \mathrm{E}-09 \\
<2.3 \mathrm{E}-09 \\
6.0 \mathrm{E}-08 \pm 2.7 \mathrm{E}-08 \\
<5.2 \mathrm{E}-09 \\
<2.0 \mathrm{E}-09 \\
<2.4 \mathrm{E} \cdot 09 \\
<6.1 \mathrm{E}-09 \\
<4.7 \mathrm{E}-09 \\
<3.8 \mathrm{E}-09\end{aligned}$ & 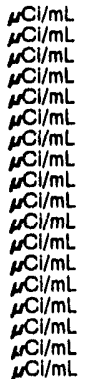 \\
\hline
\end{tabular}

WELL BGO 33D

MEASUREMENTS CONDUCTED IN THE FIELD

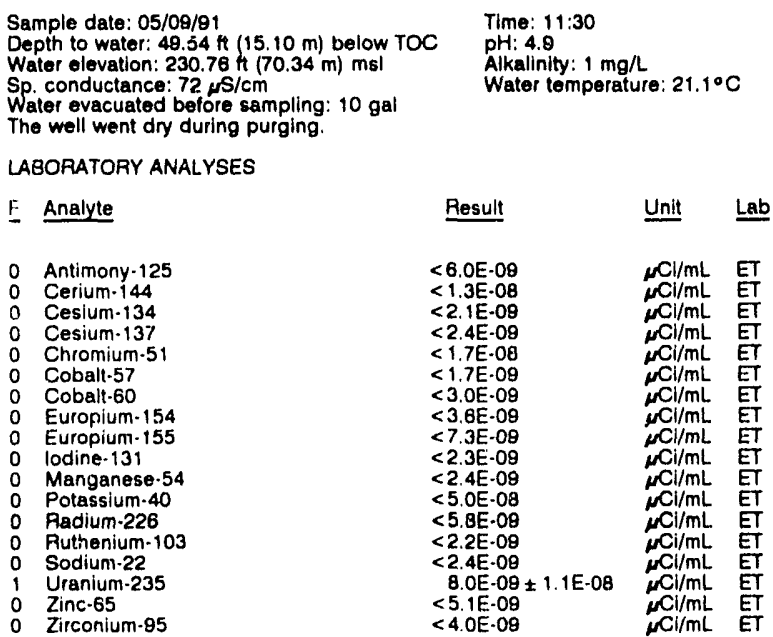




\section{WELL BGO 34D}

MEASUREMENTS CONDUCTED IN THE FIELD

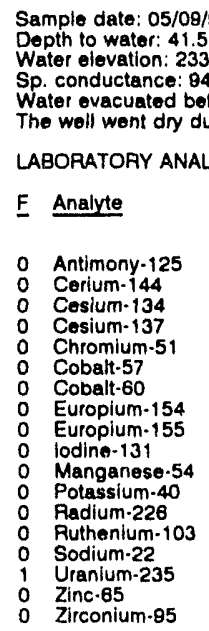

Time: $11: 05$

PH: 7.4 : $130 \mathrm{mg} / \mathrm{L}$

Water temperature: $20.3^{\circ} \mathrm{C}$

$(12.65 \mathrm{~m})$ below TOC
$(71.14 \mathrm{~m}) \mathrm{ms} !$

$14 \mathrm{gal}$

Result Unit Lab

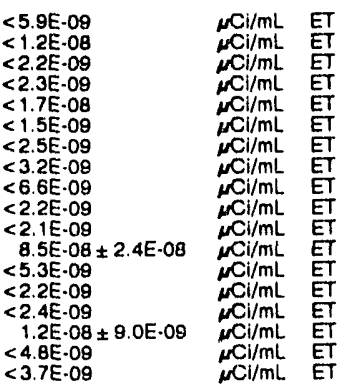

WELL BGO 35C

MEASUREMENTS CONDUCTED IN THE FIELD

Sample date: 05/03/81

Depth to water: $44.45 \mathrm{Ht}(13.55 \mathrm{~m})$ below TOC Water elevation: $228.95 \mathrm{H}(69.78 \mathrm{~m}) \mathrm{ms}$ Sp. conductance: $113 \mu \mathrm{S} / \mathrm{cm}$

Water evacuated belore sampling: $264 \mathrm{gal}$

LABORATOAY ANALYSES

\begin{tabular}{|c|c|c|}
\hline Analyte & Result & Unit \\
\hline $\begin{array}{ll}\text { Antimony-125 } \\
\text { Cerium-144 } \\
\text { Cesium-134 } \\
\text { Cesium-137 } \\
\text { Chromlum-51 } \\
\text { Cobalt-57 } \\
\text { Cobalt-60 } \\
\text { Europlum-154 } \\
\text { Europlum-155 } \\
\text { lodine-131 } \\
0 \text { Manganese-54 } \\
0 \text { Potasslum-40 } \\
0 \text { Radium-226 } \\
0 \text { Ruthenlum-103 } \\
0 \text { Sodium-22 } \\
0 \text { Uranium-235 } \\
0 \text { Zinc-65 } \\
0 \text { Zirconium-95 }\end{array}$ & $\begin{aligned}<1.2 \mathrm{E}-08 \\
<2.3 \mathrm{E} \cdot 08 \\
<4.0 \mathrm{E}-09 \\
<4.7 \mathrm{E}-09 \\
<3.2 \mathrm{E}-08 \\
<2.8 \mathrm{E}-09 \\
<4.3 \mathrm{E}-09 \\
<5.8 \mathrm{E}-09 \\
<1.2 \mathrm{E}-08 \\
<4.3 \mathrm{E}-09 \\
<4.3 \mathrm{E}-09 \\
5.0 \mathrm{E}-08 \pm 9.6 \mathrm{E}-08 \\
<9.7 \mathrm{E}-09 \\
<4.2 \mathrm{E}-09 \\
<4.7 \mathrm{E}-09 \\
<2.3 \mathrm{E} \cdot 08 \\
<9.1 \mathrm{E}-09 \\
<7.4 \mathrm{E}-09\end{aligned}$ & 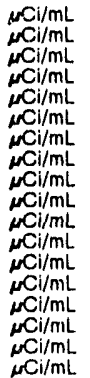 \\
\hline
\end{tabular}

WELL BGO 35D

MEASUREMENTS CONDUCTED IN THE FIELD

Sampln date: 05/09/91

Depth to water: $39.09 \mathrm{At}(11.91 \mathrm{~m})$ below TOC Water elevation: $234.41 \mathrm{~h}(71.45 \mathrm{~m}) \mathrm{ms}$ Water evacuated before sampling: $10 \mathrm{gal}$ The well went dry during purging.

LABORATORY ANALYSES

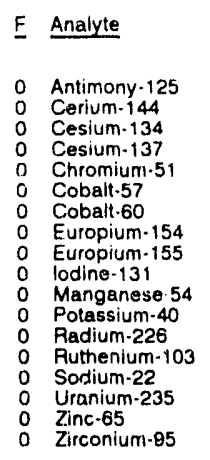

Result
$<6.0 E \cdot 09$
$<1.4 \mathrm{E} \cdot 08$
$<2.3 \mathrm{E} \cdot 09$
$<2.0 \mathrm{E} \cdot 09$
$<1.7 \mathrm{E} \cdot 08$
$<1.8 \mathrm{E} \cdot 09$
$<2.9 \mathrm{E} \cdot 09$
$<3.7 \mathrm{E} \cdot 09$
$<7.0 \mathrm{E} \cdot 09$
$<2.3 \mathrm{E} \cdot 09$
$<2.4 \mathrm{E} \cdot 09$
$<4.0 \mathrm{E} 00$
$<5.9 \mathrm{E} \cdot 09$
$<2.1 \mathrm{E} .09$
$<2.0 \mathrm{E} \cdot 08$
$<1.5 \mathrm{E} \cdot 08$
$<5.6 \mathrm{E} \cdot 09$
$<4.1 \mathrm{E} \cdot 09$

WELL BGO 36D

MEASUREMENTS CONDUCTED IN THE FIELD

Sample date: 05/09/91

Depth to water: $38.13 \mathrm{H}(11.93 \mathrm{~m})$ below TOC

Water elevation: 236.27 H 172

$\mathrm{Sp}$. conductance: $26 \mu \mathrm{s} / \mathrm{cm}$.

Water evacuated before sampling: 9 ga

The well went dry during purging.

LABORATORY ANALYSES

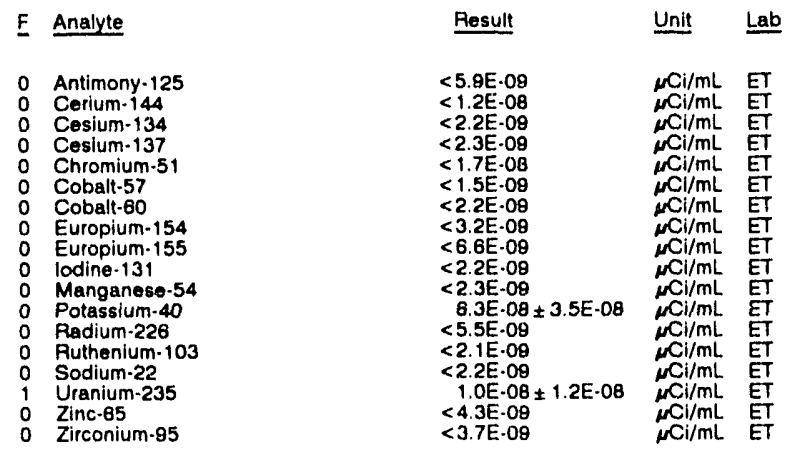

\section{WELL BGO 37D}

MEASUREMENTS CONDUCTED IN THE FIELD Time: 10:15 PH: 5.1 : $1 \mathrm{mg}$ Water temperature: $20.5^{\circ} \mathrm{C}$

Sample date: 05/08/91 15.20 m) below TOC Wepth to water: $49.88 \mathrm{ft}(15.20 \mathrm{~m})$ below TOC Water elevation: $237.42 \mathrm{H}(72.37 \mathrm{~m}) \mathrm{ms}$ l Water evacuated before sampling: $6 \mathrm{gal}$ The well went dry during purging.

Time: $9: 50$
pH: 5.5

PH: 5.5 Water temperature: $20.0^{\circ} \mathrm{C}$

Alkalinity: $37 \mathrm{mg} / \mathrm{L}$ Alkalinity: $37 \mathrm{mg} / \mathrm{L}$ : $19.5^{\circ} \mathrm{C}$

\begin{tabular}{|c|c|c|}
\hline Analyte & Result & Unit \\
\hline $\begin{array}{l}\text { Antimony-125 } \\
\text { Cerium-144 } \\
\text { Ceslum-134 } \\
\text { Ceslum-137 } \\
\text { Chromium-51 } \\
\text { Cobalt-57 } \\
\text { Cobalt-60 } \\
\text { Europium-154 } \\
\text { Europium-155 } \\
\text { lodine-131 } \\
\text { Manganese-54 } \\
\text { Potassium-40 } \\
\text { Radium-226 } \\
\text { Puthenium-103 } \\
\text { Sodium-22 } \\
\text { Uranium-235 } \\
\text { Zinc-65 } \\
\text { Zirconium-95 }\end{array}$ & $\begin{array}{l}<6.0 \mathrm{E} \cdot 09 \\
<1.2 \mathrm{E} \cdot 08 \\
<2.1 \mathrm{E} \cdot 09 \\
<2.4 \mathrm{E} \cdot 09 \\
<1.7 \mathrm{E} \cdot 08 \\
<1.5 \mathrm{E} \cdot 09 \\
<2.4 \mathrm{E}-09 \\
<3.2 \mathrm{E} \cdot 09 \\
<6.6 \mathrm{E}-09 \\
<2.2 \mathrm{E}-09 \\
<2.2 \mathrm{E} \cdot 09 \\
<1.8 \mathrm{E} \cdot 08 \\
<5.5 \mathrm{E}-09 \\
<2.2 \mathrm{E} \cdot 09 \\
<2.5 \mathrm{E}-09 \\
9.3 \mathrm{E}-09 \pm 6.1 \mathrm{E}-09 \\
<5.1 \mathrm{E} \cdot 09 \\
<3.9 \mathrm{E} \cdot 09\end{array}$ & $\begin{array}{l}\mu \mathrm{Ci} / \mathrm{mL} \\
\mu \mathrm{Ci} / \mathrm{mL} \\
\mu \mathrm{Cl} / \mathrm{mL} \\
\mu \mathrm{Ci} / \mathrm{mL} \\
\mu \mathrm{Cl} / \mathrm{mL} \\
\mu \mathrm{Cl} / \mathrm{mL} \\
\mu \mathrm{Ci} / \mathrm{mL} \\
\mu \mathrm{Cl} / \mathrm{mL} \\
\mu \mathrm{Cl} / \mathrm{mL} \\
\mu \mathrm{Ci} / \mathrm{mL} \\
\mu \mathrm{Cl} / \mathrm{mL} \\
\mu \mathrm{Ci} / \mathrm{mL} \\
\mu \mathrm{Ci} / \mathrm{mL} \\
\mu \mathrm{Ci} / \mathrm{mL} \\
\mu \mathrm{Ci} / \mathrm{mL} \\
\mu \mathrm{Cl} / \mathrm{mL} \\
\mu \mathrm{Cl} / \mathrm{mL} \\
\mu \mathrm{Ci} / \mathrm{mL}\end{array}$ \\
\hline
\end{tabular}

WELL BGO 38D

MEASUREMENTS CONDUCTED IN THE FIELD

Sample date: 05/09191

Depth to water: $58.39 \mathrm{th}(17.19 \mathrm{~m})$ below TOC Water elevation: $235.21 \mathrm{H}(71.69 \mathrm{~m}) \mathrm{ms}$ ( Sp. conductance: $31 \mu \mathrm{s} / \mathrm{cm}$ Water evacuated before sampling: $8 \mathrm{gal}$ $\mathrm{pH}: 4.7$ Water temperature: $20.7^{\circ} \mathrm{C}$ The well wented belore sampling: 8 ga

LABORATORY ANALYSES

\begin{tabular}{|c|c|c|}
\hline Analyte & Result & Unit \\
\hline $\begin{array}{ll}0 & \text { Antimony-125 } \\
0 & \text { Cerium-144 } \\
0 & \text { Cesium-134 } \\
0 & \text { Cesium-137 } \\
0 & \text { Chromium-51 } \\
0 & \text { Cobalt-57 } \\
0 & \text { Cobalt-60 } \\
0 & \text { Europium-154 } \\
0 & \text { Europium-155 } \\
0 & \text { lodine-131 } \\
0 & \text { Manganese-54 } \\
0 & \text { Potassium-40 } \\
0 & \text { Radium-226 } \\
0 & \text { Ruthenium-103 } \\
0 & \text { Sodium-22 } \\
0 & \text { Uranium-235 } \\
0 & \text { Zinc-65 } \\
0 & \text { Zirconium-95 }\end{array}$ & $\begin{aligned}<5.8 \mathrm{E} \cdot 09 \\
<1.2 \mathrm{E} \cdot 08 \\
<2.2 \mathrm{E} \cdot 09 \\
<2.6 \mathrm{E} \cdot 08 \\
<1.7 \mathrm{E} \cdot 08 \\
<1.5 \mathrm{E} \cdot 09 \\
<2.5 \mathrm{E} \cdot 09 \\
<3.2 \mathrm{E} \cdot 09 \\
<6.6 \mathrm{E} \cdot 09 \\
<2.0 \mathrm{E} \cdot 09 \\
<2.4 \mathrm{E} \cdot 09 \\
7.0 \mathrm{E} \cdot 08 \pm 3.2 \mathrm{E} \cdot 08 \\
<5.5 \mathrm{E} \cdot 09 \\
<2.1 \mathrm{E} \cdot 09 \\
<2.3 \mathrm{E} \cdot 09 \\
<1.3 \mathrm{E} \cdot 08 \\
<4.7 \mathrm{E} \cdot 09 \\
<3.7 \mathrm{E} \cdot 09\end{aligned}$ & $\begin{array}{l}\mu \mathrm{Ci} / \mathrm{mL} \\
\mu \mathrm{Ci} / \mathrm{mL} \\
\mu \mathrm{Ci} / \mathrm{mL} \\
\mu \mathrm{Ci} / \mathrm{mL} \\
\mu \mathrm{Ci} / \mathrm{mL} \\
\mu \mathrm{Ci} / \mathrm{mL} \\
\mu \mathrm{Ci} / \mathrm{mL} \\
\mu \mathrm{Ci} / \mathrm{mL} \\
\mu \mathrm{Ci} / \mathrm{mL} \\
\mu \mathrm{Ci} / \mathrm{mL} \\
\mu \mathrm{Ci} / \mathrm{mL} \\
\mu \mathrm{Ci} / \mathrm{mL} \\
\mu \mathrm{Ci} / \mathrm{mL} \\
\mu \mathrm{Ci} / \mathrm{mL} \\
\mu \mathrm{Ci} / \mathrm{mL} \\
\mu \mathrm{Ci} / \mathrm{mL} \\
\mu \mathrm{Ci} / \mathrm{mL} \\
\mu \mathrm{Ci} / \mathrm{mL}\end{array}$ \\
\hline
\end{tabular}


ANALYTICAL RESULTS

WELL BGO 39D

MEASUREMENTS CONDUCTED IN THE FIELD

Sample date: 05/09/91

Depth to water: $61.16 \mathrm{ft}(18.64 \mathrm{~m})$ below TOC

$\mathrm{Sp}$. conductance: $31, \mathrm{~s} / \mathrm{cm}$

Water evacuated before sampling: $6 \mathrm{gal}$

The well went dry during purging

LABORATORY ANALYSES

$\begin{array}{ll}\text { F } & \text { Analyte } \\ 0 & \text { Antimony-125 } \\ 0 & \text { Cerium-144 } \\ 0 & \text { Cesium } 134 \\ 0 & \text { Cesium-137 } \\ 0 & \text { Chromium-51 } \\ 0 & \text { Cobalt-57 } \\ 0 & \text { Cobalt-60 } \\ 0 & \text { Europium-154 } \\ 0 & \text { Europium-155 } \\ 0 & \text { lodine- } 131 \\ 0 & \text { Manganese-54 } \\ 0 & \text { Potassium-40 } \\ 0 & \text { Radium }-226 \\ 0 & \text { Ruthenium-103 } \\ 0 & \text { Sodium-22 } \\ 0 & \text { Uranium-235 } \\ 0 & \text { Zinc-65 } \\ 0 & \text { Zirconium-95 }\end{array}$

Result

Time: $9: 10$

Alk: 4.7

Water temperature: $20.5^{\circ} \mathrm{C}$

Zirconium-95

\section{WELL BLANK}

MEASUREMENTS CONIUCTED IN THE FIELD

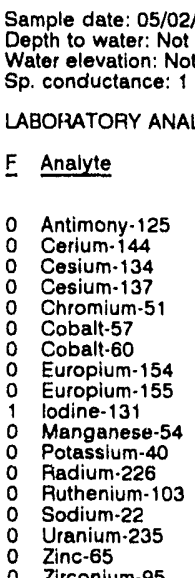

$<1.2 E-08$

$<4.1 E \cdot 09$

$<3.3 \mathrm{E}-08$

$<2.9 \mathrm{E}-09$

$<4.6 \mathrm{E}-09$
$<5.6 \mathrm{E}-09$

$<1.1 E-08$

$<4.6 \mathrm{E}-09$

$<1.1 \mathrm{E}-07$

$4.0 E-09 \pm 1.1 E-08$

$<4.2 \mathrm{E}-09$

$\triangle 2.3 E-08$

$<8.8 \mathrm{E}-09$

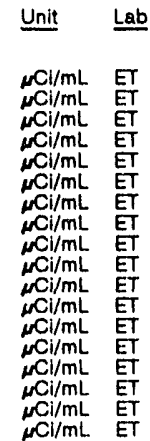

$\mathrm{NCl} / \mathrm{mL}$ ET

\section{Time: $7: 30$
pH: 4.7
Alkalinity: \\ Time: $7: 30$
pH: 4.7
Alkalinity: $1 \mathrm{mg} / \mathrm{L}$ \\ Water temperature: $21.8^{\circ} \mathrm{C}$}

Result Unit Lab

$<1.2 \mathrm{E}-08$

$<2.2 \mathrm{E}-08$

$<4.1 E-09$

$<4.5 E-09$

$<3.1 \mathrm{E} \cdot 08$

$<2.8 \mathrm{E}-09$
$<4.7 \mathrm{E}-09$

$<5.8 \mathrm{E} .09$

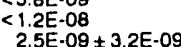

$2.5 \mathrm{E}-09$
$<4.3 \mathrm{E}-09$

$8.6 \mathrm{E} \cdot 09 \pm 8.2 \mathrm{E} \cdot 08$

$<9.9 \mathrm{E} \cdot 09$

$<4.3 \mathrm{E} .09$

$<4.6 \mathrm{E} \cdot 09$

$<\begin{aligned} & <2.4 E \cdot 08 \\ & <8.4 E \cdot 09\end{aligned}$

$<7.8 \mathrm{E}-09$

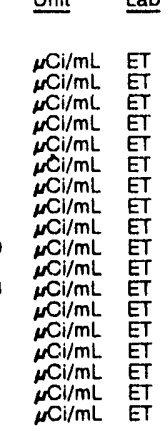

WELL BLANK

MEASUREMENTS CONDUCTED IN THE FIEI.D

Sample date: 05/03/81

Depth to water: Not available

Water elevation: Not available

Sp. conductance: $1 \mu \mathrm{S} / \mathrm{cm}$

LABORATORY ANALYSES

E Analyte

0 Antimony-125

Antimony-125

Cerium 144

Cerium-144

Cesium-134

Cesium-137

Cesium-137

Chromium-51

Chromium-5

Cobalt -57

Cobalt.57

Cobalt-60

Europium.154

Europium-154

Europium-155

Europium-155

lodine-13

Manganese-54

Manganese-54
Time: $7: 20$

pH: 5.0

Water temperalure: $19.4^{\circ} \mathrm{C}$

Result Unit Lab

$<9.1 \mathrm{E} \cdot 09 \quad \mu \mathrm{Ci} / \mathrm{mL} \quad \mathrm{ET}$

$<5.8 \mathrm{E} .09 \quad \mu \mathrm{Ci} / \mathrm{mL}$ ET

$<1.7 E-08$

$<3.3 \mathrm{E}-09$

$<2.3 E-09$

$1.9 \mathrm{E}-09$
$<2.6 \mathrm{E} \cdot 09$

$<2.5 \mathrm{E}-08$

$<1.6 \mathrm{E}-08$

$<2.1 \mathrm{E}-09$

$<1.7 \mathrm{E}-09$

$<3.8 \mathrm{E}-09$

$<2.7 \mathrm{E}-09$
$<4.5 \mathrm{E}-09$

$<4.5 \mathrm{E}-09$
$<3.7 \mathrm{E}-09$

$<3.7 \mathrm{E}-09$
$<8.7 \mathrm{E}-09$

$<8.7 E-09$
$<73 E .09$

$<7.3 E \cdot 09$
$<3.4 E-09$

$<3.4 E-09$

$<3.8 E-09$
WELL BLANK collected on 05/03/91, laboratory analyses (cont.)

E Analyte

Result

Unit Lab

0 Plutonium-238

Plutonium-236

Plutonium-238/240

Plutonium-238

Plutonium-242

Potassium-40

Potasslum-40

Radium-226

Radium-226

Radium-226

Radium-228

Ruthenium-103

Riuthenium-103

Sodium-22

Uranlum-22

Uranium-235

Zinc-65

Zinc. 65

Zirconium-95

$<2.0 E \cdot 10 \quad \mu \mathrm{CL} / \mathrm{mL}$ ET

$<1.1 E-10$
$<2.0 E-10$

$<1.1 \mathrm{E}-10$

$<2.0 \mathrm{E}-10$

$1.3 \mathrm{E} \cdot 08 \pm 6.4 \mathrm{E} \cdot 0 \mathrm{0}$

$6.6 \mathrm{E}-08 \pm 2.7 \mathrm{E} \cdot 08$

$<3.5 \mathrm{E} .00$

$<8.4 \mathrm{E}-00$

$<3.6 \mathrm{E}-09$

$<5.9 E-008$

$4 . \mathrm{BE}-09 \pm 1.2 \mathrm{E}-08$

$<3.4 \mathrm{E}-09$

$<2.2 \mathrm{E}-09$

$<4.0 E .09$

<2.5E-09 $3.4 \mathrm{E}-10 \pm 1.3 \mathrm{E}-10$

9.3E- $-00 \pm 2.3 \mathrm{E}-08$

$<7.4 \mathrm{E} .00$

$<7.4 E .09$
$<5.1 E-00$

$<6.1 \mathrm{E} .09$

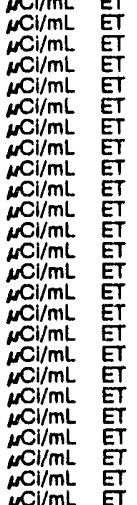

WELL BLANK

MEASUREMENTS CONDUCTED IN THE FIELD

Sample date: 05/07/81

Depth to water: Not available

Water elevation: Not available

LABORATORY ANALYSES

F Analyte

0 Antimony-125

0 Cerium-144

0 Cerium-144

0 Cesiurn-134

o Cesium-134

$\begin{array}{ll}0 & \text { Cesium-137 } \\ 0 & \text { Cesium-137 }\end{array}$

Chromium-51

Chromium.51

O Cobalt.57

0 Cobalt.57

Cobalt.60

Europium-154

Europium-154

Europium-155

lodine-131

Manganese-54

Manganese-54

Plutonium-238
Plutonium-239/240

Plutonium-239/240
Plutonium-242

Plutonium-242
Potassium-40

Potassium-40

Rudium-226

Radium-226

Radium.226

Radium-228

Ruthenium-103

0 Sodium-22

Sodium-22

Uranium-235

Uranium-235

Zinc-65

Zirconium-85

Time: 7:55

Alkalinity: $1 \mathrm{mg}$

Water temperature: $18.8^{\circ} \mathrm{C}$

Zirconium-05

Result

$<5.9 \mathrm{E}-09$

$<5.9 \mathrm{E}-09$
$<6.0 \mathrm{E}-09$

$<1.2 \mathrm{E}-08$

$<1.3 \mathrm{E}-08$

$<2.2 E .09$
$<2.2 \mathrm{E}-09$

$9.0 \mathrm{E}-10 \pm 2.6 \mathrm{E}-09$

$<2.6 E-09$

$<1.7 E \cdot 08$

$<1.6 E-08$

$<1.5 \mathrm{E}-09$
$<1.5 \mathrm{E}-09$

$<2.3 E-09$

$<2.2 \mathrm{E} .09$
$<3.2 \mathrm{E}-09$

$<3.2 E-09$

$<6.7 \mathrm{E} .09$

$<6.4 \mathrm{E}-09$

$<2.2 \mathrm{E}-09$

$<2.5 E .09$

$<2.2 \mathrm{E}-09$

$<1.1 \mathrm{E}-10$

$<1.1 \mathrm{E}-10$

1.1E-10
$9.2 \mathrm{E} \cdot 08+3.1 \mathrm{E} \cdot 08$

$9.2 E-08$
$<3.7 \mathrm{E}-08$

$<3.7 \mathrm{E}-08$
$<5.8 \mathrm{E}-00$

$<5.8 \mathrm{E}-09$

$<5.0 \mathrm{E} \cdot 09$

1. $2 \mathrm{E}-09$.08 $+3.0 \mathrm{E}-09$

$1.2 E-08$
$<2.1 E-09$
$<2.1 E-09$

$<2.3 \mathrm{E}-09$

<2.3E-09 $5 \mathrm{E} \cdot 08+1.3 \mathrm{E}-08$

$<1.4 \mathrm{E} .00$

$<4.9 \mathrm{E}-09$

$<4.1 \mathrm{E}-09$

$<3.9 \mathrm{E}-09$
$<3.8 \mathrm{E}-09$

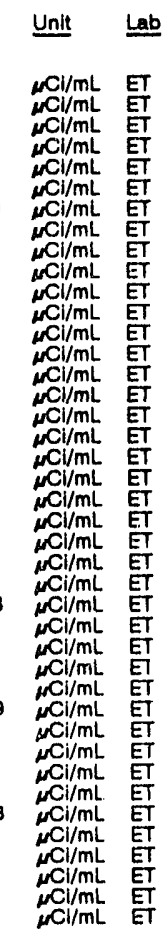

WELL BLANK

MEASUREMENTS CONDUCTED IN THE FIELD

Sample date: 05/16/91

Depth to water: Not available

Water elevation: Not availab

LABORATORY ANALYSES

E Analyte

Result

Time: $8: 25$

Alkalinity: $1 \mathrm{mg} / \mathrm{h}$

Water temperature: $23.4^{\circ} \mathrm{C}$

$<5.9 E \cdot 09$
$<1.3 \mathrm{E} \cdot 08$

$<2.3 \mathrm{E} .08$

$<2.3 E \cdot 09$
$<2.5 \mathrm{E} \cdot 09$ $\begin{array}{ll}0 & \text { Cesium-134 } \\ 0 & \text { Cesium-137 }\end{array}$
O Cerium-144 


\section{ANALYTICAL RESULTS}

WELL BLANK collected on 05/16/91, laboratory analyses (cont.)

$\begin{array}{ll}\text { F } & \text { Analyte } \\ 0 & \text { Chromium-51 } \\ 0 & \text { Cobalt-57 } \\ 0 & \text { Cobalt-60 } \\ 0 & \text { Europium-154 } \\ 0 & \text { Europium-155 } \\ 0 & \text { lodine-131 } \\ 0 & \text { Manganese-54 } \\ 0 & \text { Potassium-40 } \\ 0 & \text { Radium-226 } \\ 0 & \text { Ruthenium-103 } \\ 0 & \text { Sodium-22 } \\ 1 & \text { Uranium-235 } \\ 0 & \text { Zinc-65 } \\ 0 & \text { Zirconium-85 }\end{array}$

Result

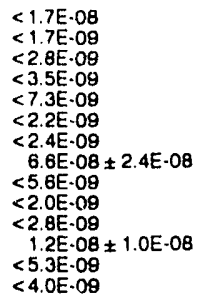

Unit Lab

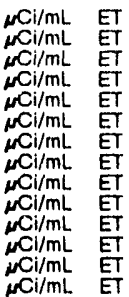

\section{WELL BLANK}

MEASUREMENTS CONDUCTED IN THE FIELD

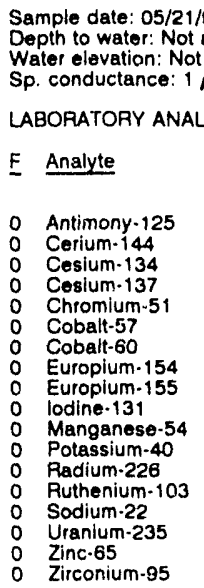

Time: : 8:25

Alkalinity: $1 \mathrm{mg} / \mathrm{L}$ Water temperature: $18.4^{\circ} \mathrm{C}$

LABORATORY ANALYSES

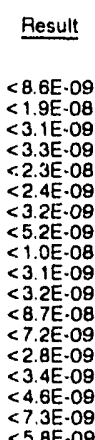

\begin{tabular}{|c|c|}
\hline Unit & Lab \\
\hline 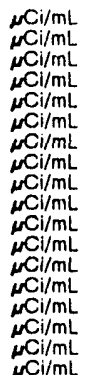 & $\begin{array}{l}E T \\
E T \\
E T \\
E T \\
E T \\
E T \\
E T \\
E T \\
E T \\
E T \\
E T \\
E T \\
E T \\
E T \\
E T \\
E T \\
E T \\
E T \\
E T \\
E T\end{array}$ \\
\hline
\end{tabular}

\section{WELL BLANK}

MEASUREMENTS CONDUCTED IN THE FIELD

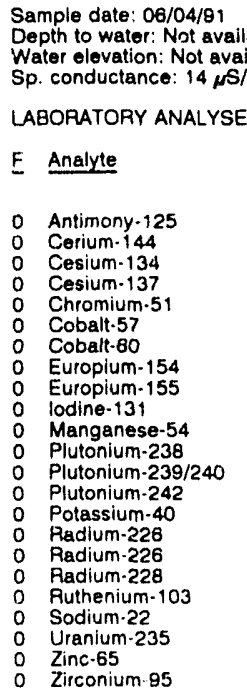

\section{Time: $8: 05$ \\ Alkalinity: $0 \mathrm{mg} / \mathrm{L}$ \\ Water temperature: $26.3^{\circ} \mathrm{C}$}

Resul: Unit Lab

$<1.1 E-09$
$<2.2 E .08$

$<2.2 \mathrm{E} .08$
$<4.1 \mathrm{E}-09$

$<4.7 E-09$

$<3.1 \mathrm{E}-08$

$<2.7 \mathrm{E}-09$

$<4.3 \mathrm{E} .08$
$<5.7 \mathrm{E} .09$

$<1.1 \mathrm{E}-08$

$<4.1 \mathrm{E}-09$

$<4.2 E-09$

$<1.8 \mathrm{E}-10$
$<1.2 \mathrm{E}-10$

$<1.2 \mathrm{E}-10$
$<1.2 \mathrm{E}-10$

$<1.2 \mathrm{E}-10$
$<1.1 \mathrm{E}-07$

$<9.6 E-09$

$<1.3 \mathrm{E}-08$

$<1.3 \mathrm{E}-08$
$<4.0 \mathrm{E} .09$

$<4.7 \mathrm{E} .09$

<2. $3 \mathrm{E}-08$

$<8.9 \mathrm{E}-09$
$<7.5 \mathrm{E}-09$
WELL FAL 1

MEASUREMENTS CONDUCTED IN THE FIELD

\begin{tabular}{|c|c|c|c|c|}
\hline \multicolumn{2}{|c|}{$\begin{array}{l}\text { Sample date: } 05 / 15 / 91 \\
\text { Depth to water: } 84.10 \mathrm{H}(28.68 \mathrm{~m}) \text { below TOC } \\
\text { Water elevation: } 218.80 \mathrm{ft}(86.89 \mathrm{~m}) \mathrm{msl} \\
\text { Sp. conductance: } 196 \mathrm{\mu S} / \mathrm{cm} \\
\text { Water evacuated before sampling: } 8 \mathrm{gal} \\
\text { The well went dry during purging. }\end{array}$} & \multicolumn{3}{|c|}{$\begin{array}{l}\text { Time: } 10: 10 \\
\text { pH: } 7.0 \\
\text { Alkalinity: } 75 \mathrm{mg} / \mathrm{h} \\
\text { Waler temperature: } 24.0^{\circ} \mathrm{C}\end{array}$} \\
\hline \multicolumn{5}{|c|}{ LABORATORY ANALYSES } \\
\hline$E$ & Analyte & Result & $\underline{\text { Unit }}$ & Lab \\
\hline $\begin{array}{l}0 \\
0 \\
0 \\
0 \\
0 \\
0 \\
0 \\
0 \\
0 \\
0 \\
0 \\
0 \\
0 \\
0 \\
0 \\
0 \\
0 \\
0\end{array}$ & $\begin{array}{l}\text { Antimony-125 } \\
\text { Cerium-144 } \\
\text { Cosium-134 } \\
\text { Cesium-137 } \\
\text { Chromium-51 } \\
\text { Cobalt-57 } \\
\text { Cobalt-60 } \\
\text { Europium-154 } \\
\text { Europium-155 } \\
\text { lodine-131 } \\
\text { Manganese-54 } \\
\text { Potassium-40 } \\
\text { Radium-226 } \\
\text { Ruthenium-103 } \\
\text { Sodium-22 } \\
\text { Uranium-235 } \\
\text { Zinc-65 } \\
\text { Zirconium-95 }\end{array}$ & $\begin{array}{l}<9.1 \mathrm{E}-09 \\
<1.7 \mathrm{E}-08 \\
<3.3 \mathrm{E} \cdot 09 \\
<3.7 \mathrm{E} \cdot 09 \\
<2.4 \mathrm{E} \cdot 08 \\
<2.1 \mathrm{E} \cdot 09 \\
<3.7 \mathrm{E} \cdot 09 \\
<4.3 \mathrm{E} \cdot 09 \\
<8.6 \mathrm{E} \cdot 09 \\
<3.4 \mathrm{E} \cdot 09 \\
<3.7 \mathrm{E}-09 \\
<8.6 \mathrm{E}-08 \\
<7.8 \mathrm{E} \cdot 09 \\
<3.3 \mathrm{E} \cdot 09 \\
<3.9 \mathrm{E} \cdot 09 \\
<1.7 \mathrm{E} \cdot 08 \\
<7.1 \mathrm{E} \cdot 09 \\
<6.2 \mathrm{E} \cdot 09\end{array}$ & 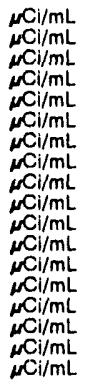 & $\begin{array}{l}E T \\
E T \\
E T \\
E T \\
E T \\
E T \\
E T \\
E T \\
E T \\
E T \\
E T \\
E T \\
E T \\
E T \\
E T \\
E T \\
E T \\
E T\end{array}$ \\
\hline
\end{tabular}

WELL FAL 2

MEASUREMENTS CONDUCTED IN THE FIELD

Sample date: 05/15/91

Depth to water: $85.02 \mathrm{Ht}(28.96 \mathrm{~m})$ below TOC

Water elevation: $217.08 \mathrm{H}$

Patenductance: $52 \mu \mathrm{s} / \mathrm{cm}$

The well went dry during purging: 2 gal

Time: $10: 25$
$\mathrm{pH}: 5.6$

pH: 5.6

Water temperature: $24.3^{\circ} \mathrm{C}$

LABORATORY ANALYSES

\begin{tabular}{|c|c|c|c|}
\hline Analyte & Result & Unit & Lab \\
\hline $\begin{array}{ll}0 & \text { Antimony-125 } \\
0 & \text { Cerium-144 } \\
0 & \text { Cesiumm-134 } \\
0 & \text { Cesium-137 } \\
0 & \text { Chromium-51 } \\
0 & \text { Cobalt-57 } \\
0 & \text { Cobalt-60 } \\
0 & \text { Europium-154 } \\
0 & \text { Europium-155 } \\
0 & \text { lodine-131 } \\
0 & \text { Manganese.54 } \\
0 & \text { Potassium-40 } \\
0 & \text { Radium-226 } \\
0 & \text { Ruthenium-103 } \\
0 & \text { Sodium-22 } \\
0 & \text { Uranium-235 } \\
0 & \text { Zinc.65 } \\
0 & \text { Zirconium-95 }\end{array}$ & $\begin{array}{l}<9.4 \mathrm{E} \cdot 09 \\
<1.6 \mathrm{E} \cdot 08 \\
<3.3 \mathrm{E} \cdot 09 \\
<3.6 \mathrm{E} \cdot 09 \\
<2.4 \mathrm{E} \cdot 08 \\
<2.1 \mathrm{E} \cdot 08 \\
<3.8 \mathrm{E} \cdot 08 \\
<4.3 \mathrm{E} \cdot 09 \\
<8.4 \mathrm{E} \cdot 09 \\
<3.3 \mathrm{E} \cdot 09 \\
<3.4 \mathrm{E} \cdot 09 \\
<7.2 \mathrm{E} \cdot 08 \\
<7.7 \mathrm{E} \cdot 08 \\
<3.2 \mathrm{E} \cdot 09 \\
<3.8 \mathrm{E}-09 \\
<1.1 \mathrm{E} \cdot 08 \\
<8.1 \mathrm{E} \cdot 09 \\
<6.0 \mathrm{E} \cdot 09\end{array}$ & 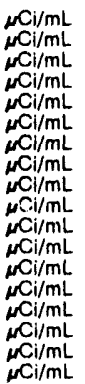 & $\begin{array}{l}E T \\
E T \\
E T \\
E T \\
E T \\
E T \\
E T \\
E T \\
E T \\
E T \\
E T \\
E T \\
E T \\
E T \\
E T \\
E T \\
E T \\
E T\end{array}$ \\
\hline
\end{tabular}

WELL FCA 2D

MEASUREMENTS CONDUCTED IN THE FIELO

Sample date: 05/15/91 Time: 11:05

Depth to water: $87.81 \mathrm{tt}(26.76 \mathrm{~m})$ below TOC pH: 4.1

Water elevation: $224.39 \mathrm{th}(68.39 \mathrm{~m}) \mathrm{ms} / \quad$ Alkalinity: $0 \mathrm{mg} / \mathrm{L}$

Sp. conductance: $240 \mu \mathrm{S} / \mathrm{cm} \quad$ Water temperature: $24.70 \mathrm{C}$

There evacuated before sampling: $4 \mathrm{gal}$

LABORATORY ANALYSES

\begin{tabular}{|c|c|c|}
\hline Analyte & Hesult & Unit \\
\hline $\begin{array}{l}\text { Antimony-125 } \\
\text { Cerium-144 } \\
\text { Cesium-134 } \\
\text { Cesium-137 } \\
\text { Chromium.51 } \\
\text { Cobalt-57 } \\
\text { Cobalt-60 } \\
\text { Europium-154 } \\
\text { Europium-155 } \\
\text { lodine-131 } \\
\text { Manganese-54 } \\
\text { Potassium-40 } \\
\text { Radium-226 } \\
\text { Puthenium-103 } \\
\text { Sodium-22 } \\
\text { Uranium-235 } \\
\text { Zinc-65 }\end{array}$ & $\begin{array}{l}<6.2 \mathrm{E} \cdot 09 \\
<1.2 \mathrm{~L} \cdot 08 \\
<22 \mathrm{E} \cdot 09 \\
<2.3 \mathrm{E} \cdot 09 \\
5.6 \mathrm{E} \cdot 08 \pm 1.2 \mathrm{C} \cdot 08 \\
<1.6 \mathrm{E} \cdot 09 \\
<2.4 \mathrm{E} \cdot 09 \\
<3.4 \mathrm{E} \cdot 09 \\
<6.5 \mathrm{E} \cdot 09 \\
<2.3 \mathrm{E} \cdot 09 \\
<2.3 \mathrm{E} \cdot 09 \\
<4.1 \mathrm{E} \cdot 08 \\
<5.8 \mathrm{E} \cdot 09 \\
<2.1 \mathrm{E} \cdot 09 \\
<2.5 \mathrm{E} \cdot 09 \\
1.7 \mathrm{E} \cdot 08 \pm 1.3 \mathrm{E} \cdot 08 \\
<4.9 \mathrm{E} \cdot 09\end{array}$ & 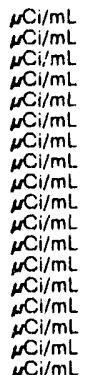 \\
\hline
\end{tabular}


ANALYTICAL RESULTS

WELL FCA 9D

MEASUREMENTS CONOUCTED IN THE FIELLO

Sample date: 05/15/91 Depth to water: $87.20 \mathrm{ht}(26.58 \mathrm{~m})$ below TOC Water elevation: $224.70 \mathrm{Ht} 68 \mathrm{~g}$

$\mathrm{Sp}$. conductance: $253 \mathrm{\mu S} / \mathrm{cm}$ Waler evacualed bo

LABORATORY ANALYSES

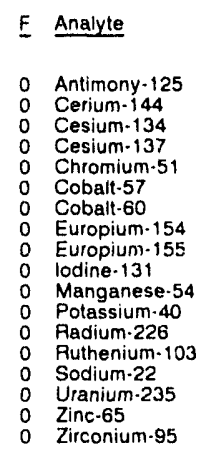

Pesult
<1.6E.08
$<2.8 \mathrm{E} .08$
$<6.1 \mathrm{E} .09$
$<7.0 \mathrm{E} .09$
$<4.5 \mathrm{E} .08$
$<3.5 \mathrm{E} .08$
$<6.1 \mathrm{E} .09$
$<7.4 \mathrm{E} .09$
$<1.5 \mathrm{E} .08$
$<5.5 \mathrm{E} .09$
$<6.5 \mathrm{E} .09$
$<1.5 \mathrm{E} .07$
$<1.6 \mathrm{E} .08$
$<5.7 \mathrm{E} .09$
$<6.6 \mathrm{E}-09$
$<3.1 \mathrm{E} .08$
$<1.5 \mathrm{E}-08$
$<1.2 \mathrm{E} .08$

Time: $12: 20$

AH: 3.8.

Alkalinity: $0 \mathrm{mg} / \mathrm{L}$ : $28.9^{\circ} \mathrm{C}$

\section{WELL FCA $10 A$}

MEASUREMENTS CONDUCTED IN THE FIELD

Sample date: $06 / 06 / 91$

Depth to water: $87.31 \mathrm{ft}(26.61 \mathrm{~m})$ beluw TOC

Sp. conductance $56.49 \mathrm{Ht}(68.48$

Water evacuated before sampling: $1 \mathrm{gal}$

the well went dry during purging.

LABORATORY ANALYSES

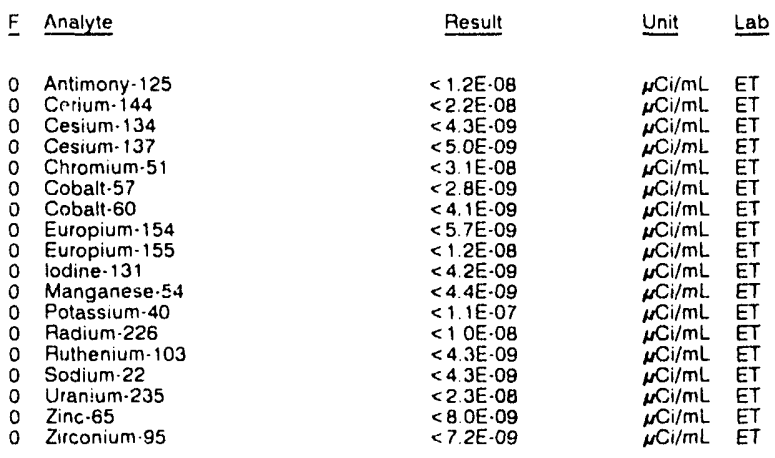

WELL FCA 16A

MEASUREMENTS CONDUCTED IN THE FIELD

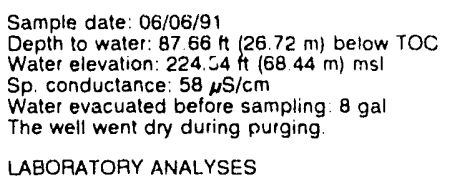

$$
\begin{aligned}
& \text { Time. } 9: 40 \\
& \text { pH: } 5.6 \\
& \text { Alkalinity, } \mathrm{mg} / \mathrm{h} \\
& \text { Water temperature }: 21.6^{\circ} \mathrm{C}
\end{aligned}
$$

LABORATORY ANALYSES

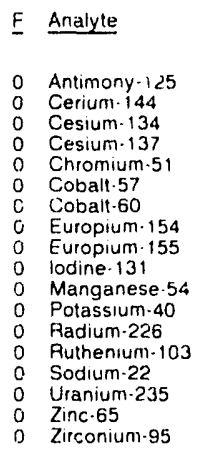

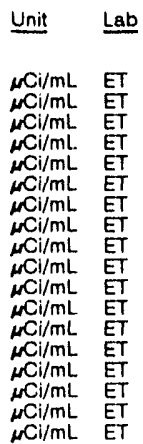

Time: $9: 10$

pH: 5.8

Water temperature: $21.3^{\circ} \mathrm{C}$
$<8.3 \mathrm{E} \cdot 09$

$<3.9 E \cdot 08$
$<3.0 E \cdot 09$

$<33 \mathrm{E} \cdot 09$

$<2.3 \mathrm{E} .08$
$<25 \mathrm{E} .09$

$<34 \mathrm{E} .09$

$<10 \mathrm{OE} .08$

$<3$ OE-09

$<3$ IE.09

< 75.09

$<28 \mathrm{E} .09$
$<3 \mathrm{OE}-09$

$<2.0 \mathrm{E}-08$

$<68 \mathrm{E} .09$
$<5.6 \mathrm{E} .09$
WELL FCA 16B

MEASUREMENTS CONDUCTED IN THE FIELD

Sample date: 00 (0691

Depth dawe 06/06/91 $40.25 \mathrm{~m}$ below TOC 10:05

Water elevation: $298.17 \mathrm{tt}(90.88 \mathrm{~m}) \mathrm{msl} \quad$ Alkalinity: $58 \mathrm{mg} / \mathrm{l}$

$\mathrm{Sp}$. conductance 178 (

Water evacuated betore sampling: 2 gal

Alkalinity: $56 \mathrm{mg} / \mathrm{h}$ : $25.2^{\circ} \mathrm{C}$

\begin{tabular}{|c|c|c|}
\hline Analyte & Result & Unit \\
\hline 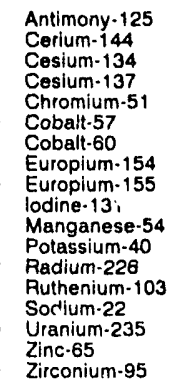 & 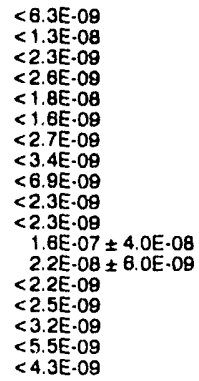 & 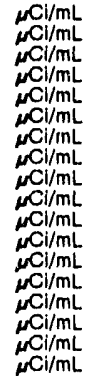 \\
\hline
\end{tabular}

There was insufficient water to fill all or some sample bottles.

LABORATORY ANALYSES

\section{WELL FCA 19D}

MEASUREMENTS CONOUCTED IN THE FIELD

Sample date: 05/15/91

Depth to water: $94.56 \mathrm{ft}(28.82 \mathrm{~m})$ below TOC

Water elevation: $217.04 \mathrm{Ht}(66.15 \mathrm{~m}) \mathrm{msl}$

Sp. conductance: $318 \mu \mathrm{S} / \mathrm{cm}$

Water evacuated before sampling: $5 \mathrm{gal}$
The well went dry during purging

$\mathrm{pH}: 6.9$

Alkalinity: $125 \mathrm{mg} / \mathrm{L}$ Water temperature: $24.5^{\circ} \mathrm{C}$

LABORATORY ANALYSES
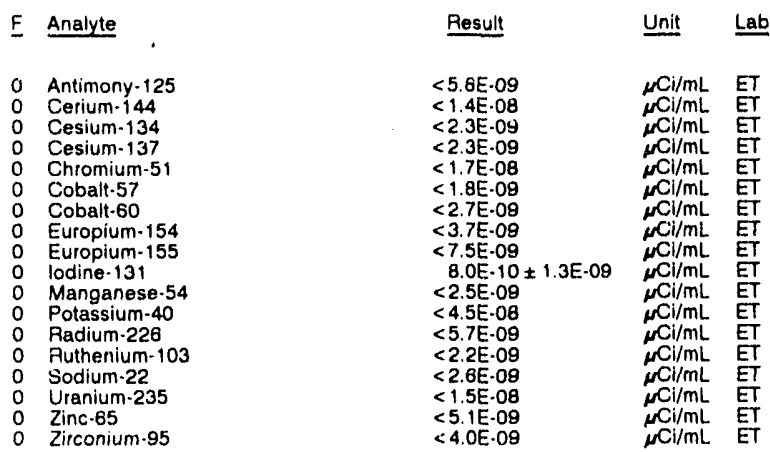

WELL HCA 1

MEASUREMENTS CONDUCTED IN THE FIELD

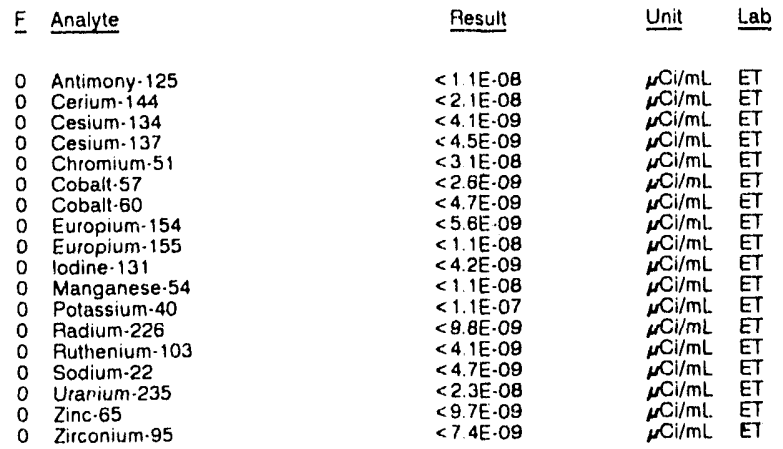

0 Zirconium.95
Sample date: 05/28/91

Depth to water: $39.89 \mathrm{ft}(12.16 \mathrm{~m})$ below TOC

Water elevation: $270.11 \mathrm{Ht}(82.33 \mathrm{~m}) \mathrm{msl}$

Water evacuated before sampling: $15 \mathrm{gal}$

The well went dry during purging.

LABORATORY ANALYSES

rime: $11: 20$

Aikalinity: $4 \mathrm{mg} / \mathrm{L}$

Water tomperature: $25.2^{\circ} \mathrm{C}$

Unit Lab

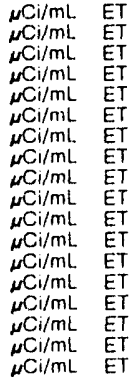


WELL HCA 2

MEASUREMENTS CONDUCTED IN THE FIELD

Sample date: $05 / 28 / 91$
Depth to water: $39.42 \mathrm{H}(12.02 \mathrm{~m})$ below TOC
Water elevation: $271.38 \mathrm{Ht}(82.72 \mathrm{~m}) \mathrm{msl}$
Sp. conductance: $198 \mu \mathrm{cm} / \mathrm{cm}$
Water evacuated before sampling: $77 \mathrm{gal}$

Time: 10.55

Alkalinity: $25 \mathrm{mg} / \mathrm{L}$

Water temperature: $26.1^{\circ} \mathrm{C}$

LABORATORY ANALYSES

\begin{tabular}{|c|c|c|}
\hline Analyte & Result & Unit \\
\hline $\begin{array}{l}\text { Antimony-125 } \\
\text { Cerium-144 } \\
\text { Cesium-134 } \\
\text { Coslum-137 } \\
\text { Chromium-51 } \\
\text { Cobalt-57 } \\
\text { Cobalt-60 } \\
\text { Europlum-154 } \\
\text { Europium-155 } \\
\text { lodine-131 } \\
\text { Manganese-54 } \\
\text { Potassium-40 } \\
\text { Radium-226 } \\
\text { Ruthenium-103 } \\
\text { Sodium-22 } \\
\text { Uranlum-235 } \\
\text { Zinc-65 } \\
\text { Zirconlum-85 }\end{array}$ & $\begin{array}{l}<5.9 E-09 \\
<1.3 \mathrm{E} \cdot 08 \\
<2.2 \mathrm{E}-09 \\
<2.6 \mathrm{E} \cdot 08 \\
<1.7 \mathrm{E}-08 \\
<1.7 \mathrm{E}-09 \\
<2.6 \mathrm{E}-09 \\
<3.7 \mathrm{E} \cdot 09 \\
<7.4 \mathrm{E}-09 \\
<2.3 \mathrm{E}-09 \\
<2.5 \mathrm{E}-09 \\
8.1 \mathrm{E}-08 \pm 3.0 \mathrm{E} \cdot 08 \\
<6.2 \mathrm{E} \cdot 09 \\
<2.1 \mathrm{E} \cdot 09 \\
<2.8 \mathrm{E}-09 \\
<1.6 \mathrm{E}-08 \\
<5.3 \mathrm{E} \cdot 09 \\
<4.4 \mathrm{E}-09\end{array}$ & $\begin{array}{l}\mu \mathrm{Ci} / \mathrm{mL} \\
\mu \mathrm{Ci} / \mathrm{mL} \\
\mu \mathrm{Ci} / \mathrm{mL} \\
\mu \mathrm{Ci} / \mathrm{mL} \\
\mu \mathrm{Ci} / \mathrm{mL} \\
\mu \mathrm{Ci} / \mathrm{mL} \\
\mu \mathrm{Ci} / \mathrm{mL} \\
\mu \mathrm{Ci} / \mathrm{mL} \\
\mu \mathrm{Ci} / \mathrm{mL} \\
\mu \mathrm{Ci} / \mathrm{mL} \\
\mu \mathrm{Ci} / \mathrm{mL} \\
\mu \mathrm{Ci} / \mathrm{mL} \\
\mu \mathrm{Ci} / \mathrm{mL} \\
\mu \mathrm{Ci} / \mathrm{mL} \\
\mu \mathrm{Cl} / \mathrm{mL} \\
\mu \mathrm{Ci} / \mathrm{mL} \\
\mu \mathrm{Ci} / \mathrm{mL} \\
\mu \mathrm{Ci} / \mathrm{mL}\end{array}$ \\
\hline
\end{tabular}

WELL HCA 3

MEASUREMENTS CONDUCTED IN THE FIELD

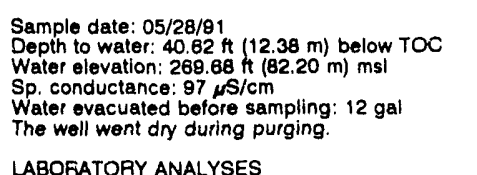

Time: 11:35

pH: 6.2

Water temperature: $24.5^{\circ} \mathrm{C}$

LABOFATORY ANALYSES

\begin{tabular}{|c|c|c|c|}
\hline Analyte & Result & Unit & $\angle a b$ \\
\hline $\begin{array}{ll}0 & \text { Antimony-125 } \\
0 & \text { Cerium-144 } \\
0 & \text { Cesium-134 } \\
0 & \text { Cesium-137 } \\
0 & \text { Chromium-51 } \\
0 & \text { Cobalt-57 } \\
0 & \text { Cobalt-60 } \\
0 & \text { Europium-154 } \\
0 & \text { Europlum-155 } \\
0 & \text { lodine-131 } \\
0 & \text { Manganese-54 } \\
0 & \text { Potassium-40 } \\
0 & \text { Radium-226 } \\
0 & \text { Ruthenium-103 } \\
0 & \text { Sodium-22 } \\
0 & \text { Uranium-235 } \\
0 & \text { Zinc-65 } \\
0 & \text { Zirconium-95 }\end{array}$ & $\begin{array}{l}<8.1 E \cdot 09 \\
<1.9 \mathrm{E} \cdot 08 \\
<3.0 \mathrm{E} \cdot 09 \\
<3.3 \mathrm{E} \cdot 09 \\
<2.3 \mathrm{E} \cdot 08 \\
<2.5 \mathrm{E} \cdot 09 \\
<3.3 \mathrm{E} \cdot 09 \\
<5.2 \mathrm{E} \cdot 09 \\
<1.0 \mathrm{E}-08 \\
<3.0 \mathrm{E}-09 \\
<3.1 \mathrm{E} \cdot 09 \\
<8.0 \mathrm{E} \cdot 08 \\
<7.1 \mathrm{E} \cdot 09 \\
<2.7 \mathrm{E}-09 \\
<3.4 \mathrm{E} \cdot 09 \\
<2.0 \mathrm{E} \cdot 08 \\
<7.0 \mathrm{E} \cdot 09 \\
<5.4 \mathrm{E} \cdot 09\end{array}$ & $\begin{array}{l}\mu \mathrm{Ci} / \mathrm{mL} \\
\mu \mathrm{Ci} / \mathrm{mL} \\
\mu \mathrm{Ci} / \mathrm{mL} \\
\mu \mathrm{Ci} / \mathrm{mL} \\
\mu \mathrm{Ci} / \mathrm{mL} \\
\mu \mathrm{Ci} / \mathrm{mL} \\
\mu \mathrm{Ci} / \mathrm{mL} \\
\mu \mathrm{Ci} / \mathrm{mL} \\
\mu \mathrm{Ci} / \mathrm{mL} \\
\mu \mathrm{Ci} / \mathrm{mL} \\
\mu \mathrm{Ci} / \mathrm{mL} \\
\mu \mathrm{CL} / \mathrm{mL} \\
\mu \mathrm{Ci} / \mathrm{mL} \\
\mu \mathrm{Ci} / \mathrm{mL} \\
\mu \mathrm{Ci} / \mathrm{mL} \\
\mu \mathrm{Ci} / \mathrm{mL} \\
\mu \mathrm{Ci} / \mathrm{mL} \\
\mu \mathrm{Ci} / \mathrm{mL}\end{array}$ & $\begin{array}{l}\text { ET } \\
\text { ET } \\
\text { ET } \\
\text { ET } \\
\text { ET } \\
\text { ET } \\
\text { ET } \\
E T \\
\text { ET } \\
\text { ET } \\
\text { ET } \\
\text { ET } \\
\text { ET } \\
\text { ET } \\
\text { ET } \\
\text { ET } \\
\text { ET } \\
\text { ET }\end{array}$ \\
\hline
\end{tabular}

WELL HCA 4

MEASUREMENTS CONDUCTED IN THE FIELD

Sample date: 05/28/91

Depth to water: $40.61 \mathrm{Ht}(12.38 \mathrm{~m})$ below TOC

Water elevation: $270.09 \mathrm{Ht}(82.32$

Sp. conductance: $95 \mu \mathrm{S} / \mathrm{cm}$.

Tater evacuated before sampling: 19 gal

The well went dry durirg purging.

LABORATORY ANALYSES

\begin{tabular}{|c|c|c|}
\hline Analyte & Result & Unit \\
\hline $\begin{array}{ll}0 & \text { Antimony-125 } \\
0 & \text { Cerium-144 } \\
0 & \text { Cesium-134 } \\
0 & \text { Cesium-137 } \\
0 & \text { Chromium-51 } \\
0 & \text { Cobalt-57 } \\
0 & \text { Cobalt-60 } \\
0 & \text { Europium-154 } \\
0 & \text { Europium-155 } \\
0 & \text { lodine-131 } \\
0 & \text { Manganese-54 } \\
0 & \text { Potassium-40 } \\
0 & \text { Radium-226 } \\
0 & \text { Authenium-103 } \\
0 & \text { Sodium-22 } \\
0 & \text { Uranium-235 } \\
0 & \text { Zinc-65 } \\
0 & \text { Zirconium-95 }\end{array}$ & $\begin{array}{l}<13 E \cdot 08 \\
<2.2 E \cdot 08 \\
<4.2 E .09 \\
54 E .09 \pm 5.0 E \cdot 09 \\
<3.2 E \cdot 08 \\
<2.6 E \cdot 09 \\
<46 E \cdot 09 \\
<5.7 E \cdot 09 \\
<1.1 E \cdot 08 \\
<4.1 E \cdot 09 \\
<4.4 E \cdot 09 \\
<1.2 E \cdot 07 \\
<1.1 E \cdot 08 \\
<4.2 E \cdot 09 \\
<4.7 E \cdot 09 \\
<2.4 E \cdot 08 \\
<9.2 E \cdot 09 \\
<7.6 E \cdot 09\end{array}$ & 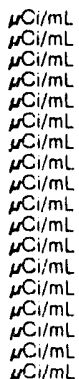 \\
\hline
\end{tabular}

WELL HTF 7

MEASUREMENTS CONDUCTED IN THE FIELD

Sample date: 04/24/91

Time: $9: 50$

Depth to water: $28.80 \mathrm{Ht}(8.78 \mathrm{~m})$ below TOC

Water elevation: $276.50 \mathrm{ft}(84.28 \mathrm{ml}) \mathrm{msl}$

No water was evacuated before sampling.

Water temperature: $22.8^{\circ} \mathrm{C}$

LABORATORY ANALYSES

\begin{tabular}{|c|c|c|}
\hline Analyte & Result & Unit \\
\hline $\begin{array}{ll}0 & \text { Antimony-125 } \\
0 & \text { Cerium-144 } \\
0 & \text { Cesium-134 } \\
0 & \text { Cesium-137 } \\
0 & \text { Chromium-51 } \\
0 & \text { Cobalt-57 } \\
0 & \text { Cobalt-60 } \\
0 & \text { Europium-154 } \\
0 & \text { Europium-155 } \\
0 & \text { lodine-131 } \\
0 & \text { Manganese-54 } \\
0 & \text { Potassium-40 } \\
0 & \text { Padium-226 } \\
0 & \text { Radium } 226 \\
0 & \text { Ruthenium-103 } \\
0 & \text { Sodium-22 } \\
0 & \text { Uranium-235 } \\
0 & \text { Zinc.65 } \\
0 & \text { Zirconium.95 }\end{array}$ & $\begin{aligned}<1.1 \mathrm{E} \cdot 08 \\
<2.1 \mathrm{E} \cdot 08 \\
<4.1 \mathrm{E} \cdot 09 \\
<4.8 \mathrm{E} \cdot 09 \\
<3.1 \mathrm{E} \cdot 08 \\
<2.6 \mathrm{E} \cdot 09 \\
<4.1 \mathrm{E} \cdot 09 \\
<5.6 \mathrm{E} \cdot 09 \\
<1.1 \mathrm{E} \cdot 08 \\
<4.2 \mathrm{E} \cdot 09 \\
7.6 \mathrm{E} \cdot 09 \pm 5.4 \mathrm{E} \cdot 09 \\
<8.9 \mathrm{E} \cdot 08 \\
<9.9 \mathrm{E} \cdot 09 \\
<4.1 \mathrm{E} \cdot 09 \\
<4.5 \mathrm{E} \cdot 00 \\
<2.2 \mathrm{E} \cdot 09 \\
<1.0 \mathrm{E} \cdot 08 \\
<1.0 \mathrm{E} \cdot 10\end{aligned}$ & 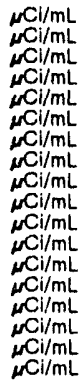 \\
\hline
\end{tabular}

WELL IDB 1A

MEASUREMENTS CONDUCTED IN THE FIELD

Sample date: $05 / 21 / 91$

Time: $9: 25$

Depth to water $107.75 \mathrm{ft}(32.84 \mathrm{~m})$ below TOC

Water elevation. $189.05 \mathrm{ft}(57.62 \mathrm{~m}) \mathrm{mst}$

Sp. conductance: $1123 \mu \mathrm{\mu S} / \mathrm{cm}$
Water evacuated betore sampling: $22 \mathrm{gal}$

Alkalinity: $262 \mathrm{mg} / \mathrm{L}$

Water temperature: $19.1^{\circ} \mathrm{C}$

The well went dry during purging

LABORATORY ANALYSES

\begin{tabular}{|c|c|c|}
\hline Analyte & Pesult & Unit \\
\hline $\begin{array}{ll}0 & \text { Antimony-125 } \\
0 & \text { Cerium-144 } \\
0 & \text { Cesium-134 } \\
0 & \text { Cesium-137 } \\
0 & \text { Chromium-51 } \\
0 & \text { Cobalt-57 } \\
0 & \text { Cobalt-60 } \\
0 & \text { Europium-154 } \\
0 & \text { Europium-155 } \\
0 & \text { lodine-131 } \\
0 & \text { Manganese-54 } \\
0 & \text { Potassium-40 } \\
0 & \text { Radium-226 } \\
0 & \text { Ruthenium-103 } \\
0 & \text { Sodium-22 } \\
2 & \text { Uranium-235 } \\
0 & \text { Zinc-65 } \\
0 & \text { Zirconium- } 95\end{array}$ & $\begin{array}{l}<6.1 \mathrm{E} \cdot 09 \\
<1.2 \mathrm{E} \cdot 08 \\
<2.4 \mathrm{E} \cdot 09 \\
<2.4 \mathrm{E} \cdot 09 \\
<1.7 \mathrm{E} \cdot 08 \\
<1.5 \mathrm{E} \cdot 09 \\
<2.6 \mathrm{E} \cdot 09 \\
<3.2 \mathrm{E} \cdot 09 \\
<6.2 \mathrm{E} \cdot 09 \\
<2.3 \mathrm{E} \cdot 09 \\
<2.4 \mathrm{E} \cdot 09 \\
<4.1 \mathrm{E} \cdot 08 \\
<5.6 \mathrm{E} \cdot 09 \\
<2.3 \mathrm{E} \cdot 09 \\
<2.2 \mathrm{E} \cdot 09 \\
1.8 \mathrm{E} \cdot 08 \pm 1.0 \mathrm{E}-08 \\
<5.4 \mathrm{E} \cdot 09 \\
<4.1 \mathrm{E}-09\end{array}$ & 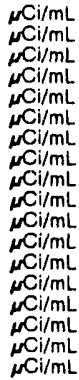 \\
\hline
\end{tabular}

WELL IDB 1B

MEASUREMENTS CONDUCTED IN THE FIELD

Sample dale: $05 / 21 / 91$

Depth to water: $112.00 \mathrm{Ht}(34.14 \mathrm{~m})$ below TOC

The well went dry during purging. 8 gal

LABORATORY ANALYSES

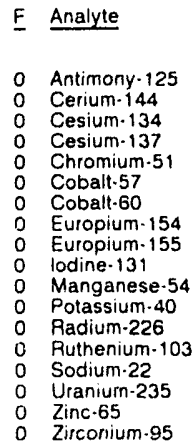

\begin{tabular}{|c|c|}
\hline Result & Unit \\
\hline $\begin{aligned}<6.0 \mathrm{E} \cdot 09 \\
<1.2 \mathrm{E} \cdot 08 \\
<2.3 \mathrm{E} \cdot 09 \\
<2.6 \mathrm{E} \cdot 09 \\
<1.7 \mathrm{E} \cdot 08 \\
<1.5 \mathrm{E} \cdot 09 \\
<2.4 \mathrm{E} \cdot 09 \\
<3.2 \mathrm{E} \cdot 09 \\
<6.6 \mathrm{E} \cdot 09 \\
<2.4 \mathrm{E} \cdot 04 \\
<2.3 \mathrm{E} \cdot 09 \\
8.5 \mathrm{E} \cdot 08 \pm 2.5 \mathrm{E} \cdot 08 \\
<5.4 \mathrm{E} \cdot 09 \\
<2.2 \mathrm{E} \cdot 09 \\
<2.5 \mathrm{E} \cdot 09 \\
<7.2 \mathrm{E} \cdot 09 \\
<4.9 \mathrm{E} \cdot 09\end{aligned}$ & 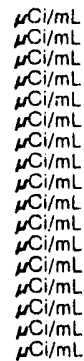 \\
\hline
\end{tabular}


ANALYTICAL RESULTS

WELL IDB $1 \mathrm{C}$

MEASUREMENTS CONDUCTED IN THE FIELD

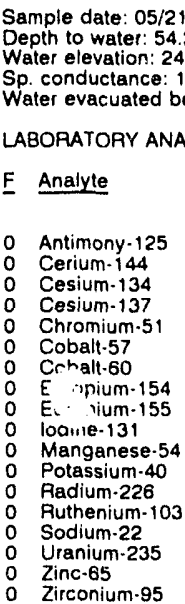

Time: $10: 00$

Alkalinity: $1 \mathrm{mg} / \mathrm{L}$

Water temperature: $18.7^{\circ} \mathrm{C}$ (74.04 m) msl pling: $123 \mathrm{gal}$

Result

WELL IDB $2 A$

MEASUREMENTS CONDUCTED IN THE FIELD

Sample date: $05 / 21 / 91$
Depth to water: $115.75 \mathrm{H}(35.28 \mathrm{~m})$ below TOC
Water elevation: $188.55 \mathrm{ft}(57.47 \mathrm{~m}) \mathrm{msl}$
Sp. conductance: $54 \mu \mathrm{cm} / \mathrm{cm}$
Water evacuated before sampling. $568 \mathrm{gal}$
LABORATORY ANALYSES

Time: $15: 45$

Alkalinity: $6 \mathrm{mg} / \mathrm{h}$ Water temperature: $20.3^{\circ} \mathrm{C}$ LABORATORY ANALYSES

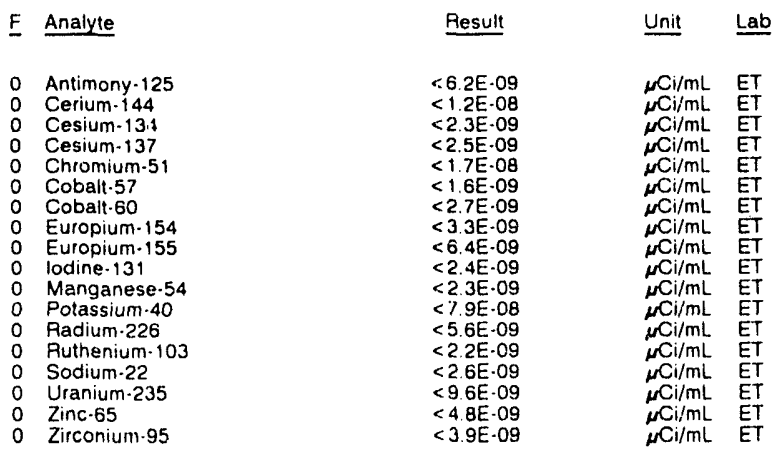

WELL IDB 2B

MEASUREMENTS CONDUCTED IN THE FIELD

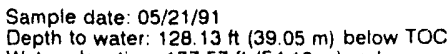
Depth to water: $128.13 \mathrm{Ht}(39.05 \mathrm{~m})$ below TOC
Water elevation: $177.57 \mathrm{ft}(54.12 \mathrm{~m}) \mathrm{msl}$ Water evacuated before sampling: $162 \mathrm{gal}$ LABORATORY ANALYSES

\begin{tabular}{|c|c|}
\hline Analyte & Result \\
\hline $\begin{array}{l}\text { Antimony-125 } \\
\text { Cerium-144 } \\
\text { Cesium- } 134 \\
\text { Cesium- } 137 \\
\text { Chromium-51 } \\
\text { Cobalt }-57 \\
\text { Cobalt-60 } \\
\text { Europium-154 } \\
\text { Europium-155 } \\
\text { lodine-131 } \\
\text { Manganese-54 } \\
\text { Potassium-40 } \\
\text { Radium-226 } \\
\text { Ruthenium-103 } \\
\text { Sodium-22 } \\
\text { Uranium-235 } \\
\text { Zinc. } 65 \\
\text { Zirconium } 95\end{array}$ & $\begin{array}{l}<8.2 \mathrm{E} \cdot 09 \\
<1.9 \mathrm{E} \cdot 08 \\
<2.9 \mathrm{E} \cdot 09 \\
<3.5 \mathrm{E} \cdot 09 \\
<23 \mathrm{2} \cdot 08 \\
<2.4 \mathrm{E} \cdot 09 \\
<3.3 \mathrm{E} \cdot 09 \\
<5.0 \mathrm{E} \cdot 09 \\
<1.0 \mathrm{E} \cdot 08 \\
<3.1 \mathrm{E} \cdot 09 \\
<3.1 \mathrm{E} \cdot 09 \\
<8.2 \mathrm{E} \cdot 08 \\
<7.3 \mathrm{E} \cdot 09 \\
<2.9 \mathrm{E} \cdot 09 \\
<3.4 \mathrm{E} \cdot 09 \\
<2.0 \mathrm{E} \cdot 08 \\
<6.7 \mathrm{E} \cdot 09 \\
<5.7 \mathrm{E} \cdot 09\end{array}$ \\
\hline
\end{tabular}

Time: 15:30

$\mathrm{pH}: 11.2$

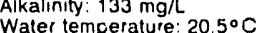

Unit Lab

\begin{tabular}{|c|c|}
\hline Unit & Lab \\
\hline 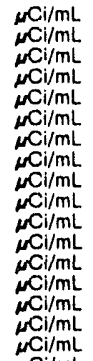 & $\begin{array}{l}E T \\
E T \\
E T \\
E T \\
E T \\
E T \\
E T \\
E T \\
E T \\
E T \\
E T \\
E T \\
E T \\
E T \\
E T \\
E T \\
E T \\
E T \\
E T\end{array}$ \\
\hline
\end{tabular}

WELL IDB 2C

MEASUREMENTS CONDUCTED IN THE FIELD

Sample date: 05/21/81

Depth to water: 70.09 it $(21.36 \mathrm{~m})$ below TOC

Water elevation: $238.31 \mathrm{H}(72.03 \mathrm{~m}) \mathrm{ms}$ l

Sp. conductance: $171 \mu \mathrm{S} / \mathrm{cm}$
Water evacuated belore sampling: $101 \mathrm{gal}$

LABORATORY ANALYSES

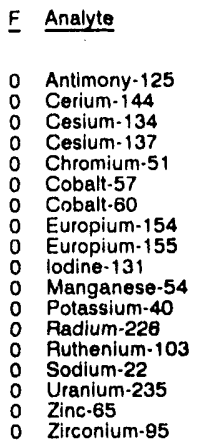

\begin{tabular}{|c|c|}
\hline Result & Unit \\
\hline 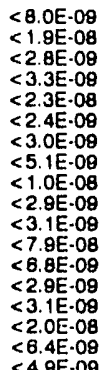 & $\begin{array}{l}\mu \mathrm{Ci} / \mathrm{mL} \\
\mu \mathrm{Ci} / \mathrm{mL} \\
\mu \mathrm{Cl} / \mathrm{mL} \\
\mu \mathrm{Cl} / \mathrm{mL} \\
\mu \mathrm{Ci} / \mathrm{mL} \\
\mu \mathrm{Cl} / \mathrm{mL} \\
\mu \mathrm{Ci} / \mathrm{mL} \\
\mu \mathrm{Cl} / \mathrm{mL} \\
\mu \mathrm{Cl} / \mathrm{mL} \\
\mu \mathrm{Cl} / \mathrm{mL} \\
\mu \mathrm{Cl} / \mathrm{mL} \\
\mu \mathrm{Cl} / \mathrm{mL} \\
\mu \mathrm{Cl} / \mathrm{mL} \\
\mu \mathrm{Cl} / \mathrm{mL} \\
\mu \mathrm{Cl} / \mathrm{mL} \\
\mu \mathrm{Ci} / \mathrm{mL} \\
\mu \mathrm{Ci} / \mathrm{mL}\end{array}$ \\
\hline
\end{tabular}

WELL IDB 3

MEASUREMENTS CONDUCTED IN THE FIELD

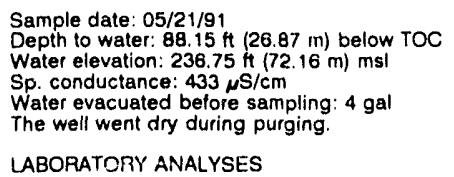

Time: $18: 20$

pH: 11.0

Water temperature: $22.2^{\circ} \mathrm{C}$

LABORATORY ANALYSES
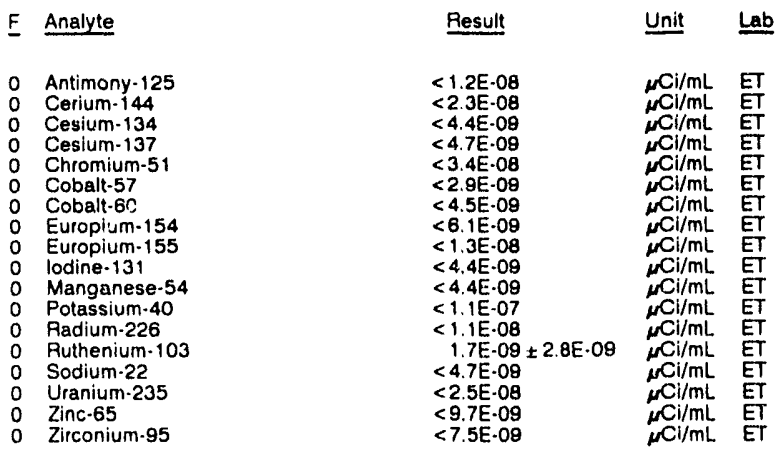

WELL IDB 4

MEASUREMENTS CONDUCTED IN THE FIELD

Sample date: $05 / 21 / 91$

Water elevation: $250.15 \mathrm{Ht}(76.25 \mathrm{~m}) \mathrm{msl}$

Sp. conductance: $24 \mu \mathrm{S} / \mathrm{cm}$

Water evacuated before sampling: $28 \mathrm{gal}$

LABORATORY ANALYSES

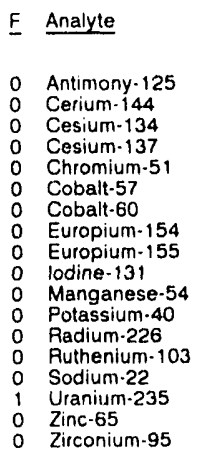

\begin{tabular}{|c|c|c|c|}
\hline $\begin{array}{l}\mu \mathrm{Cl} / \mathrm{mL} \\
\mu \mathrm{Ci} / \mathrm{mL} \\
\mu \mathrm{Ci} / \mathrm{mL} \\
\mu \mathrm{Ci} / \mathrm{mL} \\
\mu \mathrm{Ci} / \mathrm{mL} \\
\mu \mathrm{Ci} / \mathrm{mL} \\
\mu \mathrm{Ci} / \mathrm{mL} \\
\mu \mathrm{Ci} / \mathrm{mL} \\
\mu \mathrm{Cl} / \mathrm{mL} \\
\mu \mathrm{Ci} / \mathrm{mL} \\
\mu \mathrm{Ci} / \mathrm{mL} \\
\mu \mathrm{Ci} / \mathrm{mL} \\
\mu \mathrm{Ci} / \mathrm{mL} \\
\mu \mathrm{C} / \mathrm{i} L \\
\mu \mathrm{Ci} / \mathrm{mL} \\
\mu \mathrm{Ci} / \mathrm{mL} \\
\mu \mathrm{Ci} / \mathrm{mL} \\
\mu \mathrm{Ci} / \mathrm{mL}\end{array}$ & $\begin{array}{l}E T \\
E T \\
E T \\
E T \\
E T \\
E T \\
E T \\
E T \\
E T \\
E T \\
E T \\
E T \\
E T \\
E T \\
\text { ET } \\
\text { ET } \\
\text { ET } \\
\text { ET }\end{array}$ & $\begin{array}{l}0 \\
0 \\
0 \\
0 \\
0 \\
0 \\
0 \\
0 \\
0 \\
0 \\
0 \\
0 \\
0 \\
0 \\
0 \\
1 \\
0\end{array}$ & $\begin{array}{l}\text { Antimony-125 } \\
\text { Cerium-144 } \\
\text { Cesium-134 } \\
\text { Cesium-137 } \\
\text { Chromium-51 } \\
\text { Cobalt-57 } \\
\text { Cobalt-60 } \\
\text { Europium-154 } \\
\text { Europium-155 } \\
\text { lodine-131 } \\
\text { Manganese-54 } \\
\text { Potassium-40 } \\
\text { Radium-226 } \\
\text { Ruthenium-103 } \\
\text { Sodium-22 } \\
\text { Uranium-235 } \\
\text { Zinc-65 }\end{array}$ \\
\hline
\end{tabular}


WELL IDB 5

MEASUREMENTS CONDUCTEO IN THE FIELD

Sample date: 05/21/81

LABORATORY ANALYSES Depth to water: 74.32 it $(22.65 \mathrm{~m})$ below TOC Water elevation: $247.58 \mathrm{ft}(75.46 \mathrm{~m}) \mathrm{ms}$

The well went $d n^{\prime}$ during purging: $6 \mathrm{gal}$

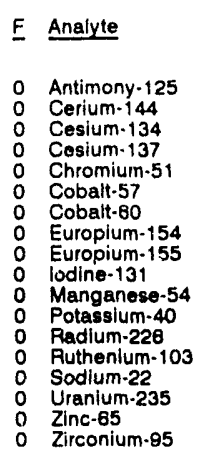

Result
<
$<1.1 \mathrm{E} \cdot 09$
$<1.9 \mathrm{E} \cdot 08$
$<2.9 \mathrm{E} \cdot 09$
$<3.2 \mathrm{E} \cdot 09$
$<2.2 \mathrm{E} \cdot 08$
$<2.4 \mathrm{E} \cdot 09$
$<3.1 \mathrm{E} \cdot 09$
$<5.1 \mathrm{E} \cdot 09$
$<1.0 \mathrm{E} \cdot 00$
$<3.0 \mathrm{E} \cdot 09$
$<3.0 \mathrm{E} \cdot 09$
$<7.8 \mathrm{E} \cdot 08$
$<6.8 \mathrm{E} \cdot 09$
$<2.9 \mathrm{E} \cdot 09$
$<3.3 \mathrm{E} \cdot 09$
$<2.0 \mathrm{E} \cdot 08$
$<6.1 \mathrm{E} \cdot 09$
$<5.3 \mathrm{E} \cdot 09$

Time: 13:05

Alkalinity: $10 \mathrm{mg} / \mathrm{h}$

Water temperature: $19.6^{\circ} \mathrm{C}$

WELLL IDB 6

MEASUREMENTS CONDUCTED IN THE FIELO

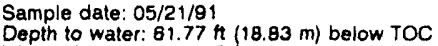
Water elevation: $257.23 \mathrm{~h}(78.40 \mathrm{~m}) \mathrm{msl}$

Water evacuated before sampling: $43 \mathrm{gal}$

LABORATORY ANALYSES

E Analyte

0 Antimony -125

Cerium-144

Cesium-134

Chromium-51

Cobalt-57

Europium.154

Europiur:-155
lodine.131

Manganese. 54

Potassium-20

Radium-226

Sodium-22

Uranium-235

Zinc-65

\section{WELL IDB 7}

MEASUREMENTS CONDUCTED IN THE FIELD Water elevation: $260.73 \mathrm{H}$

LABORATORY ANALYSES
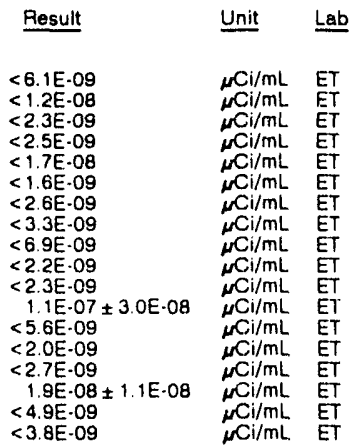

Time: 17:05

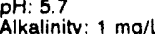

Alkalinity: $1 \mathrm{mg} / \mathrm{L}$ : $19.3^{\circ} \mathrm{C}$

$\begin{array}{ll}\text { Unit } & \text { Lab } \\ & \\ \mu \mathrm{Ci} / \mathrm{mL} & \text { ET } \\ \mu \mathrm{Ci} / \mathrm{mL} & \text { ET } \\ \mu \mathrm{Ci} / \mathrm{mL} & \text { ET } \\ \mu \mathrm{Ci} / \mathrm{mL} & \text { ET } \\ \mu \mathrm{Ci} / \mathrm{mL} & \mathrm{ET} \\ \mu \mathrm{Ci} / \mathrm{mL} & \mathrm{ET} \\ \mu \mathrm{Ci} / \mathrm{mL} & \text { ET } \\ \mu \mathrm{Ci} / \mathrm{mL} & \text { ET } \\ \mu \mathrm{Ci} / \mathrm{mL} & \text { ET } \\ \mu \mathrm{Ci} / \mathrm{mL} & \text { ET } \\ \mu \mathrm{Ci} / \mathrm{mL} & \text { ET } \\ \mu \mathrm{Ci} / \mathrm{mL} & \text { ET } \\ \mu \mathrm{Ci} / \mathrm{mL} & \text { ET } \\ \mu \mathrm{Ci} / \mathrm{mL} & \text { ET } \\ \mu \mathrm{Ci} / \mathrm{mL} & \text { ET } \\ \mu \mathrm{Ci} / \mathrm{mL} & \text { ET } \\ \mu \mathrm{Ci} / \mathrm{mL} & \text { ET } \\ \mu \mathrm{Ci} / \mathrm{mL} & \text { ET }\end{array}$

Pesult

Time: $11: 30$

Alkatinity: $0 \mathrm{mg} / \mathrm{L}$

Water temperature: $19.1{ }^{\circ} \mathrm{C}$

Pesult

$<6.2 \mathrm{E} \cdot 09$

<. $3 \mathrm{E} \cdot 0 \mathrm{0}$

$<2.3 \mathrm{E}-09$

$<1.6 \mathrm{E}-08$

$<1.7 \mathrm{E} .09$

$<2.7 E-09$

$<3.7 \mathrm{E}-09$
$<7.6 \mathrm{E}-09$

$<2.2 E-09$

$<2.4 E .09$
$<2.2 E-0 B$

$<2.2 \mathrm{E}-\mathrm{OB}$

$<2.1 E-09$

$<3.0 E \cdot 09$

$<23 \mathrm{E} .09$

$<5.6 E-09$
$<42 E .09$
Sample date: 05/21/91

Depth to water: $52.67 \mathrm{ft}(16.05 \mathrm{~m})$ below TOC
WELL IDB 8

MEASUREMENTS CONDUCTED IN THE FIELD

Sample date: 05/21/91

Water elevation: $241.07 \mathrm{t}(73.48 \mathrm{~m}) \mathrm{ms}$

Sp. conductance: $16 \mu \mathrm{S} / \mathrm{cm}$

PH: 4.0

PH: 4.8 Alkalinity: $1 \mathrm{mg} / \mathrm{L}$

Water temperature: $20.0 \circ \mathrm{C}$
Depth to water: 52.03 th $(15.06 \mathrm{~m})$ below $T 0 \mathrm{C}$

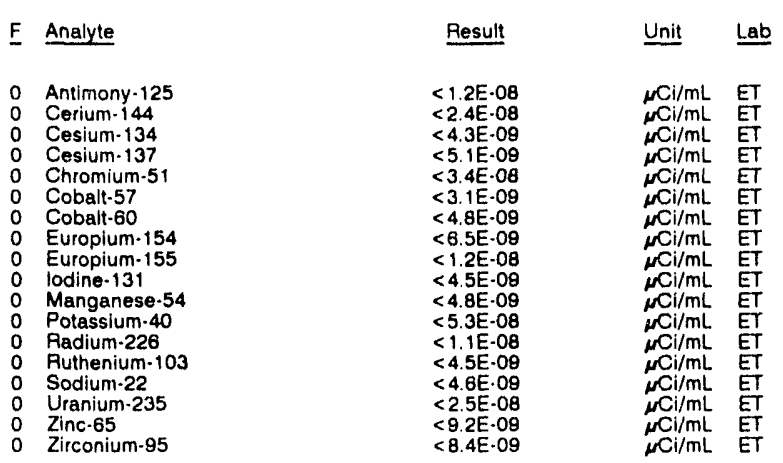

WELL IDB 9

MEASUREMENTS CONDUCTED IN THE FIELD

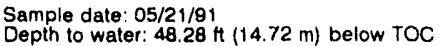

Water elevation: $240.02 \mathrm{ft}(73.16 \mathrm{~m}) \mathrm{msl}$

Water evacuated before sampling: $101 \mathrm{gal}$

Time: $12: 50$

pH: 8.9

Alkalinity: $57 \mathrm{mg} / \mathrm{L}: 19.10 \mathrm{C}$

LABORATORY ANALYSES

\begin{tabular}{|c|c|c|}
\hline Analyte & Result & Unit \\
\hline $\begin{array}{ll}0 & \text { Antimony-125 } \\
0 & \text { Cerium-144 } \\
0 & \text { Cesium-134 } \\
0 & \text { Cesium-137 } \\
0 & \text { Chromium-51 } \\
0 & \text { Cobalt-57 } \\
0 & \text { Cobalt-60 } \\
0 & \text { Europium-154 } \\
0 & \text { Europium-155 } \\
0 & \text { lodine-131 } \\
0 & \text { Manganese-54 } \\
0 & \text { Potassium-40 } \\
0 & \text { Hartium-226 } \\
0 & \text { Ithenium-103 } \\
0 & \text { Sodium-22 } \\
0 & \text { Uranium-235 } \\
0 & \text { Zinc-65 } \\
0 & \text { Zirconium-95 }\end{array}$ & $\begin{array}{l}<8.4 \mathrm{E} \cdot 09 \\
<1.9 \mathrm{E} \cdot 08 \\
<2.9 \mathrm{E} \cdot 09 \\
<3.3 \mathrm{E} \cdot 09 \\
<2.3 \mathrm{E} \cdot 08 \\
<2.5 \mathrm{E}-09 \\
<3.4 \mathrm{E} \cdot 09 \\
<5.2 \mathrm{E} \cdot 09 \\
<1.0 \mathrm{E} \cdot 08 \\
<3.0 \mathrm{E} \cdot 09 \\
<3.2 \mathrm{E} \cdot 09 \\
<9.1 \mathrm{E} \cdot 08 \\
<7.3 \mathrm{E} \cdot 09 \\
<3.0 \mathrm{E} \cdot 09 \\
<3.4 \mathrm{E} \cdot 09 \\
<2.0 \mathrm{E} \cdot 08 \\
<7.1 \mathrm{E} \cdot 09 \\
<5.6 \mathrm{E} \cdot 09\end{array}$ & $\begin{array}{l}\mu \mathrm{Ci} / \mathrm{mL} \\
\mu \mathrm{Ci} / \mathrm{mL} \\
\mu \mathrm{Ci} / \mathrm{mL} \\
\mu \mathrm{Ci} / \mathrm{mL} \\
\mu \mathrm{Ci} / \mathrm{mL} \\
\mu \mathrm{Ci} / \mathrm{mL} \\
\mu \mathrm{Ci} / \mathrm{mL} \\
\mu \mathrm{Ci} / \mathrm{mL} \\
\mu \mathrm{Ci} / \mathrm{mL} \\
\mu \mathrm{Ci} / \mathrm{mL} \\
\mu \mathrm{Ci} / \mathrm{mL} \\
\mu \mathrm{Ci} / \mathrm{mL} \\
\mu \mathrm{CL} / \mathrm{mL} \\
\mu \mathrm{Ci} / \mathrm{mL} \\
\mu \mathrm{Ci} / \mathrm{mL} \\
\mu \mathrm{Ci} / \mathrm{mL} \\
\mu \mathrm{Ci} / \mathrm{mL} \\
\mu \mathrm{Ci} / \mathrm{mL}\end{array}$ \\
\hline
\end{tabular}

\section{WELL IDB 10}

MEASUREMENTS CONDUCTED IN THE FIELD

Sample date: 05/21/91

Depth to water: $39.29 \mathrm{ft}(11.98 \mathrm{~m})$ below TOC

Water elevation: $256.51 \mathrm{ft}(78$

p. conductance. $33 \mu \mathrm{s} / \mathrm{cm}$.

Water evacuated before sampling: $107 \mathrm{gal}$

pH: 5.8

Alkalinity: $6 \mathrm{mg} / \mathrm{L}$

Water temperature: $18.4^{\circ} \mathrm{C}$

LABORATORY ANALYSES

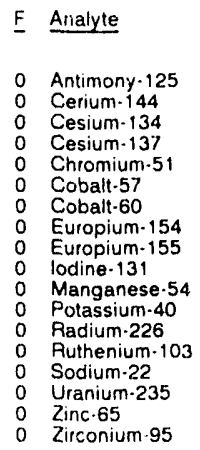

\begin{tabular}{|c|c|}
\hline Pesult & Unit \\
\hline $\begin{array}{l}<8.0 \mathrm{E} \cdot 09 \\
<1.9 \mathrm{E} \cdot 08 \\
<2.8 \mathrm{E} \cdot 09 \\
<3.3 \mathrm{E} \cdot 09 \\
<2.2 \mathrm{E} \cdot 08 \\
<2.3 \mathrm{E} \cdot 09 \\
<2.9 \mathrm{E} \cdot 09 \\
<4.9 \mathrm{E} \cdot 09 \\
<1.0 \mathrm{E} \cdot 08 \\
<2.9 \mathrm{E} \cdot 09 \\
<3.1 \mathrm{E} \cdot 09 \\
<7.7 \mathrm{E} \cdot 08 \\
<6.9 \mathrm{E} \cdot 09 \\
<2.8 \mathrm{E} \cdot 09 \\
<3.3 \mathrm{E} \cdot 09 \\
<1.9 \mathrm{E} \cdot 08 \\
<6.7 \mathrm{E} \cdot 09\end{array}$ & 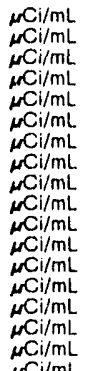 \\
\hline
\end{tabular}


WELL IDB 10 Feplicate

MEASUREMENTS CONDUCTED IN THE FIELD

Sample date: 05/21/81

Depth to water: $39.29 \mathrm{ft}(11.98 \mathrm{~m})$ below TOC

Water elevation: $256.51 \mathrm{ft}$

Sp. conduclance: $33 \mu \mathrm{S} / \mathrm{cm}$.

LABORATORY ANALYSES

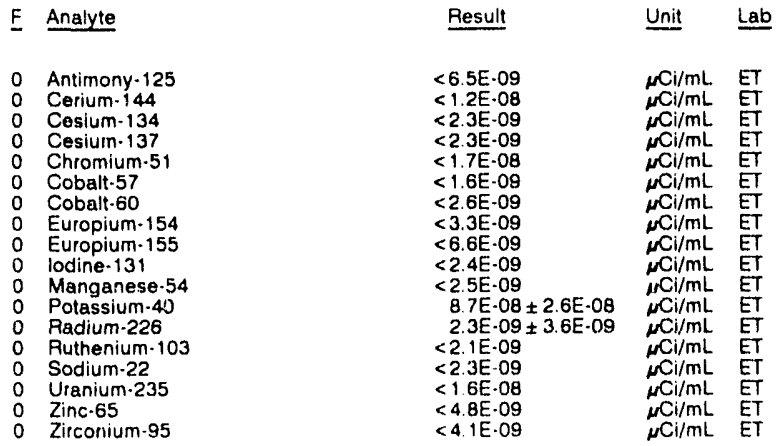

WELL IDP 1

MEASUREMENTS CONDUCTED IN THE FIELD

Sample date: 05/07/91

Depth to water: $78.86 \mathrm{ft}(24.04 \mathrm{~m})$ below TOC

Water elevation: $202.14 \mathrm{ft} / 6$

Sp. conductance: $55 \mu \mathrm{S} / \mathrm{cm}$

Waler evacuated belore sam

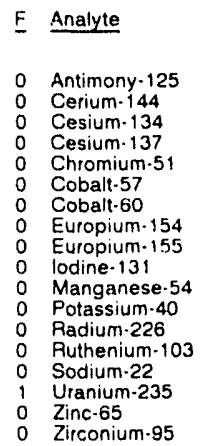

\begin{tabular}{|c|c|}
\hline Result & Unit \\
\hline $\begin{array}{l}<5.9 \mathrm{E}-09 \\
<1.2 \mathrm{E} \cdot 08 \\
<2.3 \mathrm{E} \cdot 0.99 \\
<2.4 \mathrm{E} \cdot 09 \\
<1.7 \mathrm{E} \cdot 08 \\
<1.6 \mathrm{E}-09 \\
<2.5 \mathrm{E} \cdot 09 \\
<3.4 \mathrm{E} \cdot 09 \\
<6.8 \mathrm{E} \cdot 09 \\
<2.2 \mathrm{E} \cdot 09 \\
<2.3 \mathrm{E} \cdot 09 \\
<8.5 \mathrm{E}-08 \\
<5.4 \mathrm{E} \cdot 09 \\
<2.0 \mathrm{O} \cdot 09 \\
<2.4 \mathrm{E} \cdot 09 \\
8.1 \mathrm{E} .09 \pm 9.4 \mathrm{E} \cdot 09 \\
<4.6 \mathrm{E}-09\end{array}$ & $\begin{array}{l}\mu \mathrm{Ci} / \mathrm{mL} \\
\mu \mathrm{Ci} / \mathrm{mL} \\
\mu \mathrm{Ci} / \mathrm{mL} \\
\mu \mathrm{Ci} / \mathrm{mL} \\
\mu \mathrm{Ci} / \mathrm{mL} \\
\mu \mathrm{Ci} / \mathrm{mL} \\
\mu \mathrm{Ci} / \mathrm{mL} \\
\mu \mathrm{Ci} / \mathrm{mL} \\
\mu \mathrm{Ci} / \mathrm{mL} \\
\mu \mathrm{Ci} / \mathrm{mL} \\
\mu \mathrm{Ci} / \mathrm{mL} \\
\mu \mathrm{Ci} / \mathrm{mL} \\
\mu \mathrm{Ci} / \mathrm{mL} \\
\mu \mathrm{Ci} / \mathrm{mL} \\
\mu \mathrm{Ci} / \mathrm{mL} \\
\mu \mathrm{Ci} / \mathrm{mL} \\
\mu \mathrm{Ci} / \mathrm{mL}\end{array}$ \\
\hline
\end{tabular}

WELL IDP 1 Replicate

MEASUREMENTS CONDUCTED IN THE FIELD

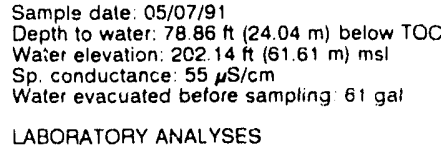

Sample dale 05/07/91 Depth to water: $78.86 \mathrm{H}(24.04 \mathrm{~m})$ below TOC Waier elevation: $202.14 \mathrm{ft}(61.61 \mathrm{~m}) \mathrm{ms}$

LABORATORY ANALYSES

ime: $10: 55$

H: 5.8

Alkalinity: $6 \mathrm{mg} / \mathrm{h}$

C. $1 \mathrm{E} \cdot 09$

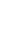

\section{Time: $15: 30$}

Alkalinity: $3 \mathrm{mg} / \mathrm{h}$

Water temperature: $21.5^{\circ} \mathrm{C}$

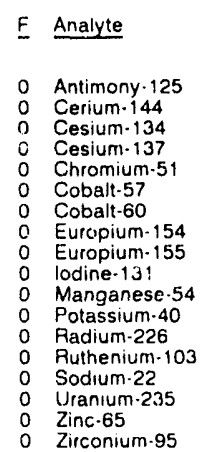

Result

Time: 15.30

Alkalinity $3 \mathrm{mg}$

Water temperature: $215^{\circ} \mathrm{C}$

$<9.0 E \cdot 09$

$<1,6 E .08$

$<3.3 E-09$
$<3$ BE-09

$<25 \mathrm{E}-08$

$<2.1 \mathrm{E}-09$

$<3.6 E-09$

$<4.4 \mathrm{E}-09$
$<8.4 \mathrm{E}-09$

$<8.4 \mathrm{E}-09$

$<3.2 \mathrm{E} \cdot 09$

$<36 \mathrm{E} \cdot 09$

$<76 \mathrm{E}-08$

$<8.1 \mathrm{E} \cdot 09$

$<3.2 \mathrm{E}-09$

7. $.0 \mathrm{EE} \cdot 09 \pm 1.4 \mathrm{E} \cdot 0 \mathrm{0B}$
$<\mathrm{B}$

$<81 \mathrm{E} \cdot 09$

$<81 \mathrm{E} \cdot 09$
$<5.9 \mathrm{E} .09$
WELL IDP 2

MEASUREMENTS CONDUCTED IN THE FIELLD

Sample date: 05/11/81

Depth to water: $62.24 \mathrm{Ht}(18.87 \mathrm{~m})$ below TOC

Water elevation: $195.66 \mathrm{ht}$

PH: 4.8 . $1 \mathrm{mal}$

Water temperature: $19.2^{\circ} \mathrm{C}$

LABORATORY ANALYSES

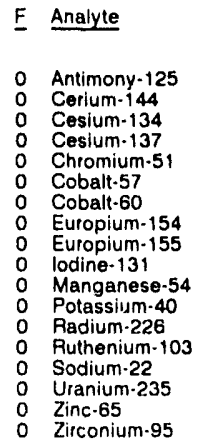

Result
$<1.2 \mathrm{E} \cdot 08$
$<2.2 \mathrm{E} \cdot 08$
$<4.1 \mathrm{E} \cdot 08$
$<4.8 \mathrm{E} \cdot 09$
$<3.1 \mathrm{E} \cdot 08$
$<2.8 \mathrm{E} \cdot 09$
$<4.5 \mathrm{E} \cdot 09$
$<5.9 \mathrm{E} \cdot 09$
$<1.2 \mathrm{E} \cdot 08$
$<4.3 \mathrm{E} \cdot 09$
$<4.4 \mathrm{E} \cdot 09$
$>17 \mathrm{E} \cdot 08 \pm 9.1 \mathrm{E} \cdot 08$
$<1.0 \mathrm{E} \cdot 08$
$<4.1 \mathrm{E} \cdot 09$
$<4.7 \mathrm{E} \cdot 09$
$<2.4 \mathrm{E} \cdot 08$
$<9.6 \mathrm{E} \cdot 09$
$<7.6 \mathrm{E} \cdot 09$

Unit Lab

WELL IDP $3 A$

MEASUREMENTS CONDUCTED IN THE FIELD

Sample date: $05 / 07 / 91$ it $(35.60 \mathrm{~m})$ below TOC Depth to water: $116.81 \mathrm{ft}(35.60 \mathrm{~m})$ below Water elevation: $167.19 \mathrm{ft}(50.96 \mathrm{~m}) \mathrm{ms}$ Water evacuated before sampling: $666 \mathrm{gal}$ pH: 5.0 Water temperature: $21.1^{\circ} \mathrm{C}$ Water evacuated belore sam BORATORY ANALYSES

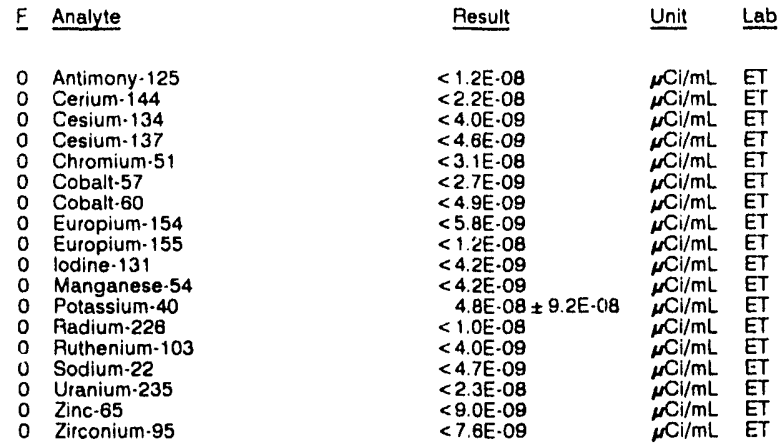

\section{WELL IDP 3B}

MEASUREMENTS CONOUCTED IN THE FIELD

$\begin{array}{ll}\text { Sample date: } 05 / 07 / 91 & \text { Time: } 15: 00 \\ \text { Depth to water: } 127.52 \mathrm{H}(38.87 \mathrm{~m}) \text { below TOC } & \text { pH: } 10.0 \\ \text { Water elevation: } 156.98 \mathrm{ft}(47.85 \mathrm{~m}) \mathrm{ms} & \text { Alkalinity: } 513 \mathrm{mg} / \mathrm{L} \\ \text { Sp conductance: } 160 \mu \mathrm{S} / \mathrm{cm} & \text { Water temperature: } 21.6^{\circ} \mathrm{C} \\ \text { Water evacuated before sampling: } 201 \mathrm{gal} & \end{array}$

Water evacuated before sampling: $201 \mathrm{gal}$

LABORATORY ANALYSES

\begin{tabular}{|c|c|c|}
\hline Analyte & Result & Unit \\
\hline $\begin{array}{l}\text { Antimony-125 } \\
\text { Cerium-144 } \\
\text { Cesium-134 } \\
\text { Cesium-137 } \\
\text { Chromium-51 } \\
\text { Cobalt-57 } \\
\text { Cobalt-60 } \\
\text { Europium-154 } \\
\text { Europium-155 } \\
\text { lodine-131 } \\
\text { Manganese-54 } \\
\text { Potassium-40 } \\
\text { Radium-226 } \\
\text { Ruthenium-103 } \\
\text { Sodium-22 } \\
\text { Uranium-235 } \\
\text { Zinc-65 } \\
\text { Zirconium-95 }\end{array}$ & $\begin{aligned}<5.9 E \cdot 09 \\
<1.2 \mathrm{E} \cdot 08 \\
<2.4 \mathrm{E} \cdot 09 \\
<2.4 \mathrm{E} \cdot 09 \\
<1.7 \mathrm{E} \cdot 08 \\
<1.5 \mathrm{E} \cdot 09 \\
<2.6 \mathrm{E} \cdot 09 \\
<3.1 \mathrm{E} \cdot 09 \\
<6.7 \mathrm{E} \cdot 09 \\
<2.3 \mathrm{E} \cdot 09 \\
<2.3 \mathrm{E} \cdot 09 \\
7.3 \mathrm{E} \cdot 08 \pm 2.8 \mathrm{E} \cdot 08 \\
<6.2 \mathrm{E} \cdot 09 \\
<2.2 \mathrm{E} \cdot 09 \\
<2.6 \mathrm{E} \cdot 09 \\
1.4 \mathrm{E} \cdot 08 \pm 1.1 \mathrm{E} \cdot 08 \\
<4.9 \mathrm{E} \cdot 09 \\
<3.9 \mathrm{E} \cdot 09\end{aligned}$ & 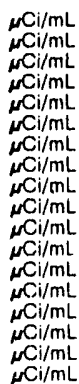 \\
\hline
\end{tabular}


WELL IDP $3 C$

MEASUREMENTS CONDUCTED IN THE FIELD

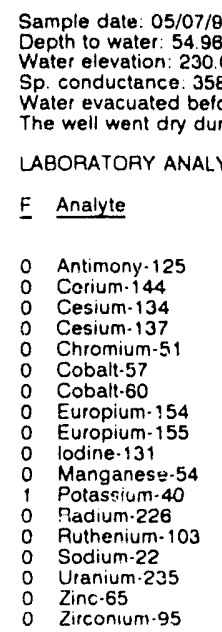

Time: 1545

Alkalinity. $110 \mathrm{mg} / \mathrm{L}$

Water temperature $218^{\circ} \mathrm{C}$ $6.75 \mathrm{~m})$ below TOC
$(70.12 \mathrm{~m}) \mathrm{msl}$ 170.12 purging $14 \mathrm{gal}$

Whe well went dry during purging

LABORATORY ANALYSES

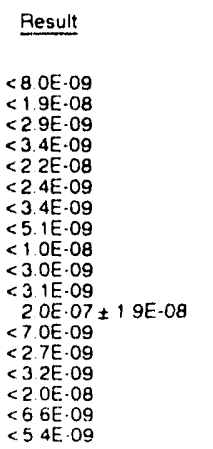

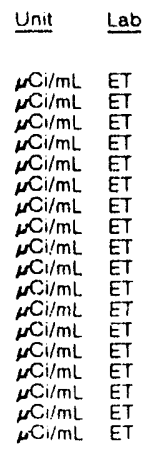

WELL IDP 5

MEASUREMENTS CONDUCTED IN THE FIELL

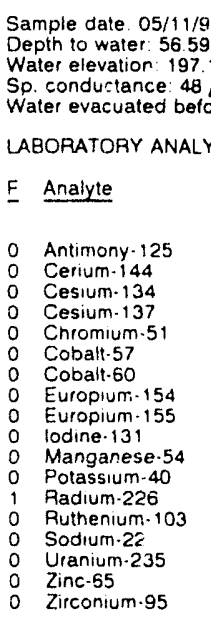

Time 9:45

Alkalinity: $8 \mathrm{mg} / \mathrm{L}$

Water temperature $198^{\circ} \mathrm{C}$ $7.25 \mathrm{~m})$ below
$(60.08 \mathrm{~m}) \mathrm{msl}$ mpling 28 gal

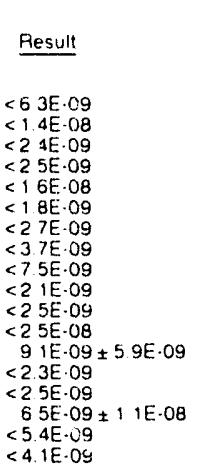

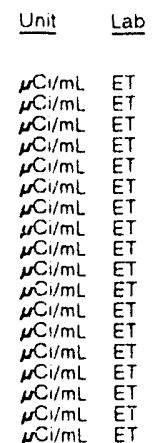

WELL IDP 6

MEASUREMENTS CONOUCTED IN THE FIE:D

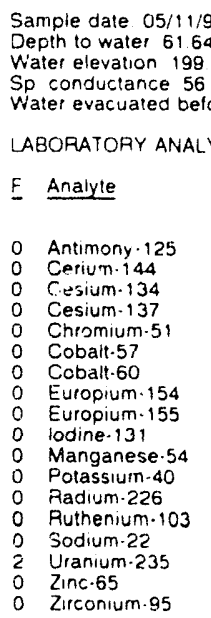

WELL IDP 7

MEASUREMENTS CONDUCTED IN THE FIELLD

Sample date: 05/11/91 Depth to water $48.83 \mathrm{H}(14.91 \mathrm{~m})$ below TOC Water elevation $199.57 \mathrm{tt}(60 \mathrm{~g}$ Sp conductance $58 \mu \mathrm{s} / \mathrm{cm}$ Water evacuated before sampling $29 \mathrm{gal}$ LABORATORY ANALYSES

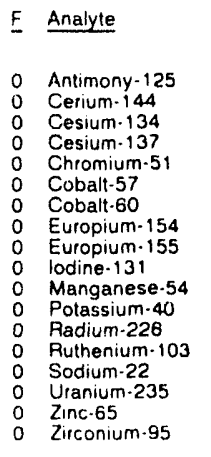

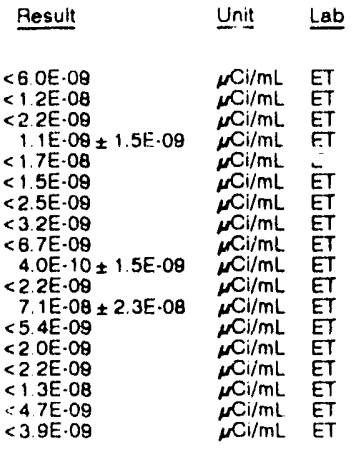

WELL IDP 8

MEASUREMENTS CONDUCTED IN THE FIELD

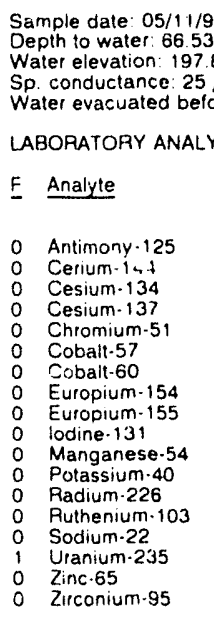

$$
\begin{aligned}
& \text { Time } 10: 45 \\
& \text { pH. } 5.3 \text {. } \\
& \text { Alkalinity: } 4 \mathrm{mg} / \mathrm{h} \\
& \text { Water temperature: } 21.5^{\circ} \mathrm{C}
\end{aligned}
$$

Time: $11: 30$

pH: 6.0

$\mu \mathrm{Cl} / \mathrm{mL}$

\section{WELL IDP 9}

MEASUREMENTS CONDUCTED IN THE FIELD

\begin{tabular}{|c|c|c|}
\hline Analyte & Result & Unit \\
\hline 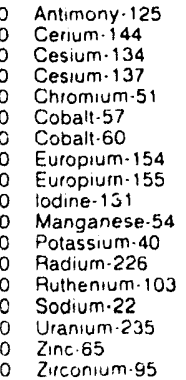 & 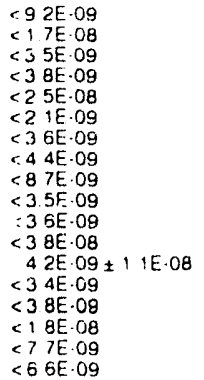 & 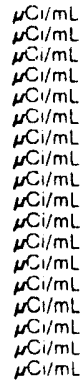 \\
\hline
\end{tabular}

$\begin{array}{ll}\text { Sample date } 05 / 07 / 91 & \text { Time } 1305 \\ \text { Depth to water } 70.19 \mathrm{Ht}(21.39 \mathrm{~m}) \text { below TOC } & \text { pH: } 5.3 \\ \text { Water elevation. } 201.71 \mathrm{Ht}(6148 \mathrm{~m}) \mathrm{msl} & \text { Alkalinity } 3 \mathrm{mg} / \mathrm{h} \\ \mathrm{Sp} \text { conductance } 29 \mu \mathrm{cm} & \text { Water temperature } 249^{\circ} \mathrm{C} \\ \text { Water evasuated before sampling. } 36 \mathrm{gal} & \end{array}$

LABORATOAY ANALYSES 
ANALYTICAL RESULTS

WELL IDQ 2

MEASUREIAENTS CONDUCTED IN THE FIELD

Sample date: 05/16/9

Depth to water: $88.86 \mathrm{H}(30.13 \mathrm{~m})$ below TOC

Water elevation: $164.34 \mathrm{ft}(50.08$
Sp. conductance: $19 \mu \mathrm{s} / \mathrm{cm}$

Water evacuated before sampling: $18 \mathrm{sal}$

The well went dry during purging

LABORATORY ANALYSES
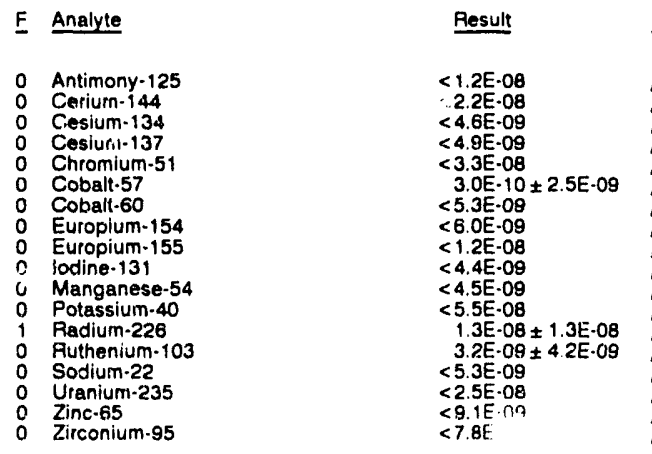

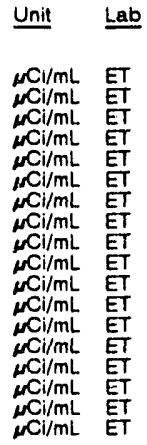

WELL IDQ $3 A$

MEASUREMENTS CONDUCTED IN THE FIELD

Sample date: 05/16/91

Depth to water: $39.36 \mathrm{ft}(12.00 \mathrm{~m})$ below TOC

Water elevation. $165.94 \mathrm{Ht}$ (50.

Sp. conductance: $46 \mu \mathrm{S} / \mathrm{cm}$.

Time: 10.55

pH: 5.7

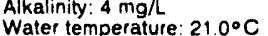

LABORATORY ANALYSES

\begin{tabular}{|c|c|c|}
\hline Analyte & Result: & Unit \\
\hline $\begin{array}{l}\text { Antimony-125 } \\
\text { Cerium-144 } \\
\text { Cesium-134 } \\
\text { Cesium-137 } \\
\text { Chromium-51 } \\
\text { Cobalt-57 } \\
\text { Cobalt-60 } \\
\text { Europium-154 } \\
\text { Europium-155 } \\
\text { lodine-131 } \\
\text { Manganese-54 } \\
\text { Potassium-40 } \\
\text { Radium-226 } \\
\text { Ruthenium-103 } \\
\text { Sodium-22 } \\
\text { Uranium-235 } \\
\text { Zinc-65 } \\
\text { Zirconium-95 }\end{array}$ & $\begin{array}{l}<1.1 \mathrm{E} \cdot 08 \\
<2.2 \mathrm{E} \cdot 08 \\
<4.1 \mathrm{E} \cdot 09 \\
<4.7 \mathrm{E} \cdot 09 \\
<3.2 \mathrm{E} \cdot 08 \\
<2.7 \mathrm{E} \cdot 09 \\
<5.0 \mathrm{E} \cdot 09 \\
<5.7 \mathrm{E}-09 \\
<1.1 \mathrm{E} \cdot 08 \\
<4.0 \mathrm{E} \cdot 09 \\
<4.6 \mathrm{E} \cdot 09 \\
<1.1 \mathrm{E} \cdot 07 \\
<1.0 \mathrm{E} \cdot 08 \\
1.9 \mathrm{E}-09 \pm 2.2 \mathrm{E} \cdot 09 \\
<5.0 \mathrm{E} \cdot 09 \\
<2.3 \mathrm{E} \cdot 08 \\
<9.7 \mathrm{E} \cdot 09 \\
<85 \mathrm{E} \cdot 09\end{array}$ & 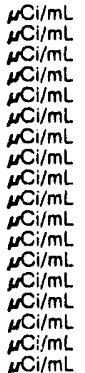 \\
\hline
\end{tabular}

WELL IDQ 3B

MEASUREMENTS CONOUCIED IN THE FIELO

Sample date: $05 / 16 / 91$

Depth to water: $65.57 \mathrm{H}(19.99 \mathrm{~m})$ below TOC Water elevation: $140.03 \mathrm{ft}(42.68 \mathrm{~m}) \mathrm{msl}$

Sp. conductance: $105 \mu \mathrm{s} / \mathrm{cm}$
Water evacuated betore sampling: $84 \mathrm{gal}$

LABORATORY ANALYSES

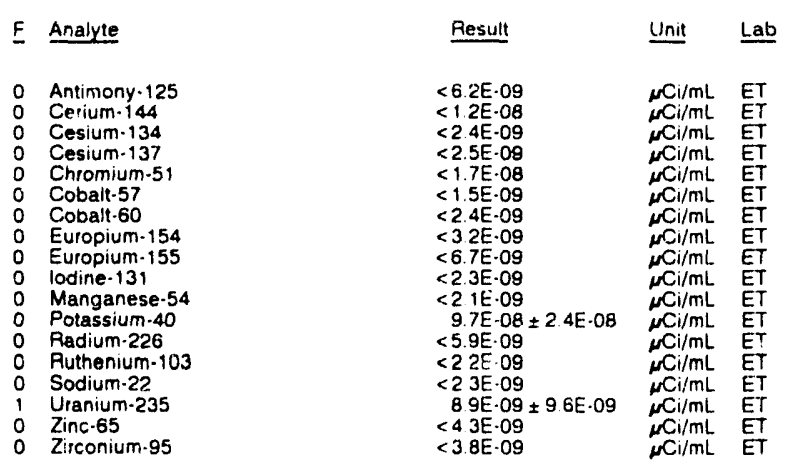

WELL IDQ 3C

MEASUREMENTS CONDUCTED IN THE FIELD

Sample date: $05 / 16 / 91$

Depth to water: $41.32 \mathrm{ft}(12.59 \mathrm{~m})$ below TOC

Water elevation: $165.18 \mathrm{tt}(50.38$

Sp. conductance: $23 \mu \mathrm{S} / \mathrm{cm}$

Water evacuated before sampling: $12 \mathrm{gal}$

The well went dry during purging.

LABORATORY ANALYSES

\begin{tabular}{|c|c|c|}
\hline Analyte & Result & Unit \\
\hline $\begin{array}{l}\text { Antimony-125 } \\
\text { Cerium-144 } \\
\text { Cesium-134 } \\
\text { Cesium-137 } \\
\text { Chromium-51 } \\
\text { Cobalt-57 } \\
\text { Cobalt-60 } \\
\text { Europium-154 } \\
\text { Europium-155 } \\
\text { lodine-131 } \\
\text { Manganese-54 } \\
\text { Potassium-40 } \\
\text { Radium-228 } \\
\text { Ruthenium-103 } \\
\text { Sodium-22 } \\
\text { Uranium-235 } \\
\text { Zinc-65 } \\
\text { Zirconium-95 }\end{array}$ & $\begin{array}{l}<1.2 \mathrm{E} \cdot 08 \\
<2.2 \mathrm{2E} \cdot 08 \\
<4.2 \mathrm{C} \cdot 09 \\
<4.0 \mathrm{E} \cdot 09 \\
<3.2 \mathrm{E} \cdot 08 \\
<2.7 \mathrm{E} \cdot 09 \\
<5.0 \mathrm{E} \cdot 09 \\
<5.5 \mathrm{E} \cdot 09 \\
<1.1 \mathrm{E} \cdot 08 \\
<4.4 \mathrm{E} \cdot 09 \\
<4.8 \mathrm{E} \cdot 09 \\
<5.4 \mathrm{E} \cdot 08 \\
<1.1 \mathrm{E} \cdot 08 \\
<4.4 \mathrm{E} \cdot 09 \\
<4.9 \mathrm{E} \cdot 09 \\
<2.4 \mathrm{E} \cdot 08 \\
<1.0 \mathrm{E} \cdot 08 \\
<7.7 \mathrm{E} \cdot 09\end{array}$ & 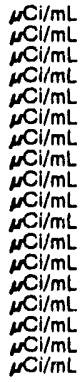 \\
\hline
\end{tabular}

WELL IDQ 4

MEASUREMENTS CONDUCTED IN THE FIELD

Sample date: 05/16/91

Depth to water: $67.84 \mathrm{ft}(20.68 \mathrm{~m})$ below TOC

Water elevation: $197.66 \mathrm{th}$

W. conduclance: $69 \mathrm{\mu s} / \mathrm{cm}$.

LABORATORY ANALYSES

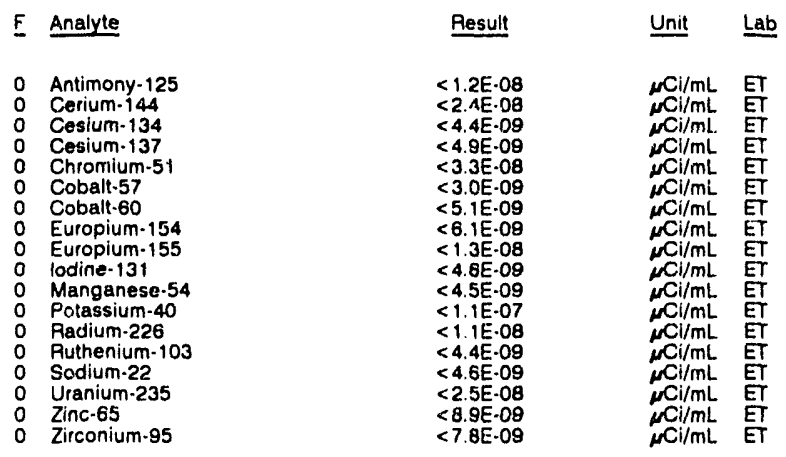

WELL IDQ 5

MEASUREMENTS CONDUCTED IN THE FIELD

Sample date: 05/16/91

Depth to water: $73.02 \mathrm{ft}(22.26 \mathrm{~m})$ below TOC

Water elevation: $194.18 \mathrm{ft}(59.19 \mathrm{~m}) \mathrm{msi}$

Sp. conductance: $32 \mu \mathrm{S} / \mathrm{cm}$

Time: $11: 00$

Alkalinity: $4 \mathrm{mg} / \mathrm{h}$

Water temperature: $21.1^{\circ} \mathrm{C}$

Water evacuated beiore sampling: 5 gal

LABORATORY ANALYSES

\begin{tabular}{|c|c|c|}
\hline Analyte & Result & Unit \\
\hline $\begin{array}{ll}0 & \text { Antimony-125 } \\
0 & \text { Cerium- } 144 \\
0 & \text { Cesium-134 } \\
0 & \text { Cesium-137 } \\
0 & \text { Chromium-51 } \\
0 & \text { Cobalt-57 } \\
0 & \text { Cobalt-60 } \\
0 & \text { Europium-154 } \\
0 & \text { Europium-155 } \\
0 & \text { lodine-131 } \\
0 & \text { Manganese-54 } \\
0 & \text { Potassium.40 } \\
0 & \text { Radium-226 } \\
0 & \text { Ruthenium-103 } \\
0 & \text { Sodiu } \cdot 2.2 \\
1 & \text { Uraniu.1.-235 } \\
0 & \text { Zinc.65 } \\
0 & \text { Zirconium-95 }\end{array}$ & $\begin{aligned}<5.7 \mathrm{E} \cdot 09 \\
<1.3 \mathrm{E} \cdot 08 \\
<2.3 \mathrm{E} \cdot 09 \\
<2.5 \mathrm{E} \cdot 09 \\
<1.7 \mathrm{E} \cdot 0 \mathrm{0r} \\
<1.7 \mathrm{E} \cdot 09 \\
<2.9 \mathrm{E} \cdot 09 \\
<3.5 \mathrm{E} \cdot 09 \\
<7.3 \mathrm{E} \cdot 09 \\
<2.2 \mathrm{E} \cdot 09 \\
<2.5 \mathrm{E} \cdot 09 \\
6.1 \mathrm{E} \cdot 08 \pm 2.9 \mathrm{E} \cdot 08 \\
5.0 \mathrm{E} \cdot 09 \pm 4.4 \mathrm{E} \cdot 09 \\
<2.2 \mathrm{E} \cdot 09 \\
<2.6 \mathrm{E} \cdot 09 \\
11.4 \mathrm{E} \cdot 08 \pm 3.0 \mathrm{E} \cdot 09 \\
<5.0 \mathrm{E} \cdot 09 \\
<3.8 \mathrm{E} \cdot 09\end{aligned}$ & 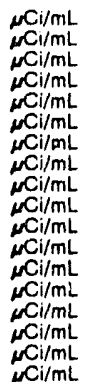 \\
\hline
\end{tabular}


WELL IDQ 6

MEASUREMENTS CONDUCTED IN THE FIELD

Sample date: 05/16/91 Depth to water: $65.37 \mathrm{ft}(19.93 \mathrm{~m})$ below TOC . Water evacuated before sampling: $6 \mathrm{gal}$ The well went dry during purging

LABCRATORY ANALYSES

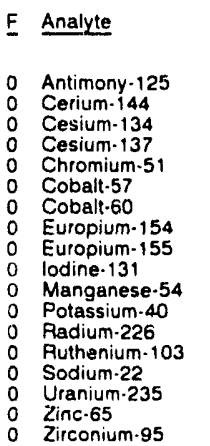

\begin{tabular}{|c|c|}
\hline Result & Unit \\
\hline 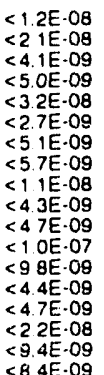 & 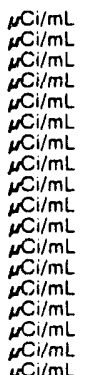 \\
\hline
\end{tabular}

WELL IDQ 7

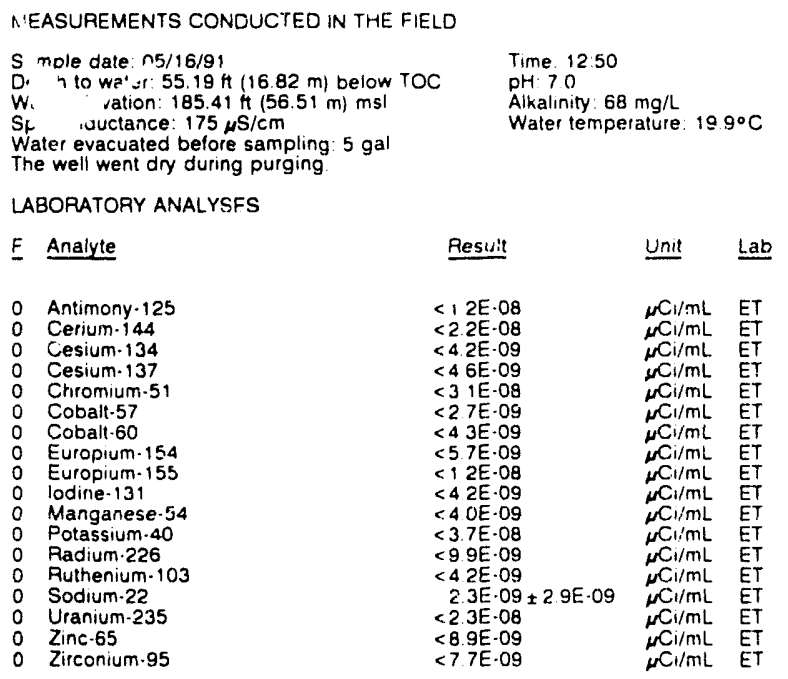

WELL IDQ 8

MEASUREMENTS CONDUCTED IN THE FIELD

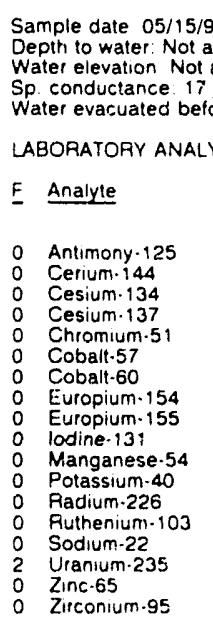

Time 1635

Plikalinity: $2 \mathrm{mg} / \mathrm{L}$

Water temperature: $204^{\circ} \mathrm{C}$

\begin{tabular}{|c|c|c|}
\hline Fesult & Unit & Lat \\
\hline 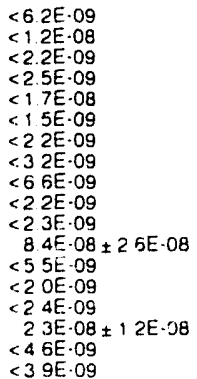 & 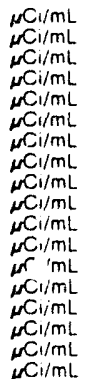 & $\begin{array}{l}E T \\
E T \\
E T \\
E T \\
E T \\
E T \\
E T \\
E T \\
E T \\
E T \\
E T \\
E T \\
E T \\
E T \\
E T \\
E T \\
E T \\
E T \\
E T \\
E T\end{array}$ \\
\hline
\end{tabular}

WELL IDQ 10

MEASUREMENTS CONDUCTED IN THE FIELD

Sample date: 05/16/91

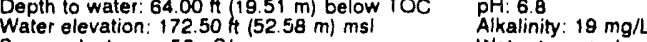

Sp. conductance: $58 \mu \mathrm{s} / \mathrm{cm} \quad$ Water temperature: $20.1^{\circ} \mathrm{C}$

Water evacuated before sampling: $8 \mathrm{gal}$

Well went dry during purging.

LABORATORY ANALYSES

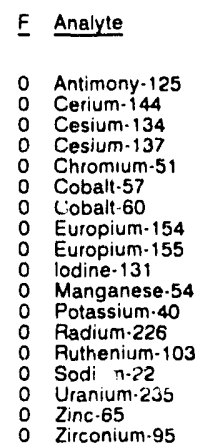

Result
$<1.2 \mathrm{E} \cdot 08$
$<2.4 \mathrm{E} \cdot 08$
$<4.3 \mathrm{E} \cdot 09$
$<4.9 \mathrm{E} \cdot 09$
$2.0 \mathrm{E} \cdot 08 \pm 2.0 \mathrm{E} \cdot 08$
$<2.9 \mathrm{E} \cdot 09$
$<4.4 \mathrm{E} \cdot 09$
$<6.2 \mathrm{E} \cdot 09$
$<1.2 \mathrm{E} \cdot 08$
$<4.3 \mathrm{E} \cdot 09$
$<4.3 \mathrm{E}-09$
$<1.2 \mathrm{E} \cdot 07$
$<1.0 \mathrm{E} \cdot 08$
$<4.4 \mathrm{E} \cdot 09$
$<4.6 \mathrm{E}-09$
$<2.5 \mathrm{E} \cdot 08$
$<9.1 \mathrm{E} \cdot 09$
$<8.3 \mathrm{E} \cdot 09$

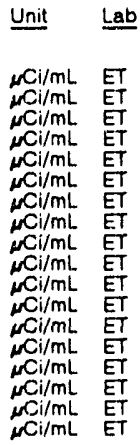

WELL IDQ 11

MEASUREMENTS CONDUCTED IN THE FIELD

Depth to water: $71.66 \mathrm{H}(21.84 \mathrm{~m})$ below TOC Water elevation: $137.14 \mathrm{ft}(41.80 \mathrm{~m}) \mathrm{ms}$ l

Water evacuated before sampling: $1 \mathrm{gal}$

The well went dry during purging.
The

Time: $9: 25$

Alkalinity $5 \mathrm{mg}$

Water temperature $19.7{ }^{\circ} \mathrm{C}$

LABOHATORY ANALYSES

$\underline{\text { Analyte }}$ Result Unit Lab

$\begin{array}{ll}0 & \text { Antimony } 125 \\ 0 & \text { Cerium } 144\end{array}$

0 Cesium-134

0 Cesium-137

0 Chromium.51
0 Cobalt -57

Cobalt 60

Europium-154

lodine-131

Manganese. 54

Potassium -40

Ruthenium-103

Sodium.22

Uranium.235

Zinc.65

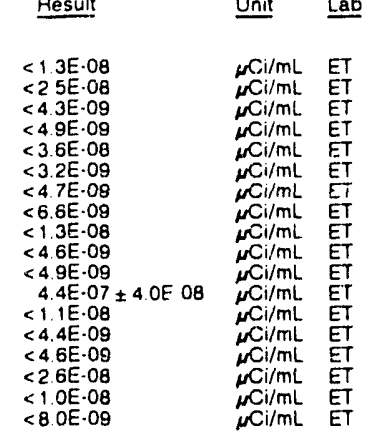

WELL IDQ 12

MEASUREMENTS CONDUCTED IN THE FIELD

Sample date 05/16/91

Depth to water $5650 \mathrm{H}(1722 \mathrm{~m})$ below TOC

Water elevation: $185.70 \mathrm{ft}(56.60 \mathrm{~m}) \mathrm{msl}$

Sp conductance. $15 \mu \mathrm{S} / \mathrm{cm}$

LABORATORY ANALYSES

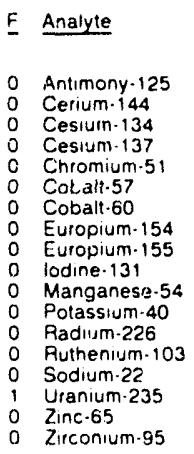

Time: $13: 30$

Alkalinity $1 \mathrm{mg} / \mathrm{L}$

Water temperature $20.1^{\circ} \mathrm{C}$

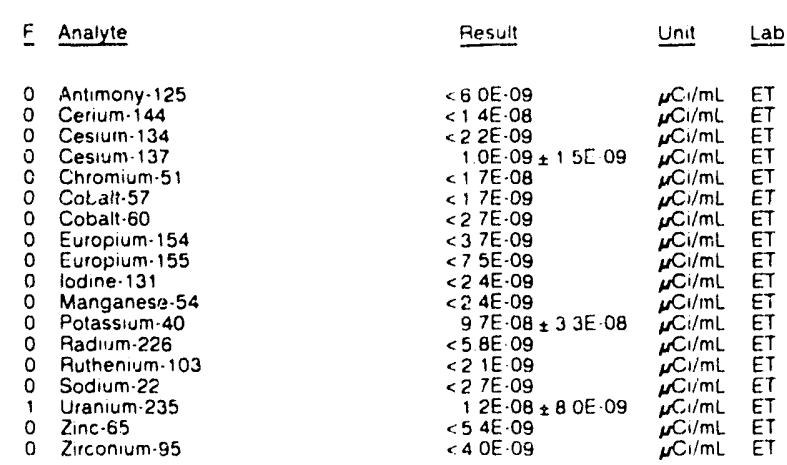


ANALYTICAL RESULTS

WELL IDQ 12 Replicate

MEASUREMENTS CONDUCTED IN THE FIELD

Sample date: $05 / 16 / 01$

Depth to water: $56.50 \mathrm{ht}(1722 \mathrm{~m})$ below TOC

Water elevation: $185.70 \mathrm{ft}(56.60 \mathrm{~m}) \mathrm{ms}$ i

Sp. conductance: $15 \mu \mathrm{s} / \mathrm{cm}$
Water evacuated before sampling: $57 \mathrm{gal}$

LABORATORY ANALYSES

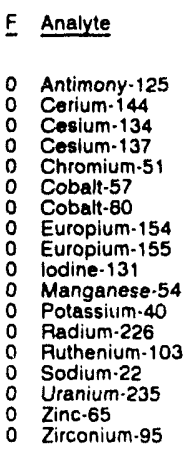

Result
<5.7E.09
$<1.2 \mathrm{E} \cdot 08$
$<2.2 \mathrm{E} \cdot 09$
$<2.4 \mathrm{E} \cdot 09$
$<1.6 \mathrm{E} \cdot 08$
$<1.6 \mathrm{E} \cdot 09$
$<2.5 \mathrm{E} \cdot 09$
$<3.3 \mathrm{E} \cdot 09$
$<6.4 \mathrm{E} \cdot 09$
$<2.2 \mathrm{E} .09$
$<2.2 \mathrm{E} \cdot 09$
$<2.7 \mathrm{E} \cdot 08$
$<5.4 \mathrm{E} \cdot 09$
$<2.0 \mathrm{E} \cdot 09$
$<2.5 \mathrm{E} \cdot 09$
$<1.4 \mathrm{E} \cdot 08$
$<4.0 \mathrm{E} \cdot 09$
$<3.9 \mathrm{E} \cdot 09$

Time: $13: 30$

pH: 5.4 .30

Water temperature: $20.1^{\circ} \mathrm{C}$

\section{WELL KDB 2}

MEASUREMENTS CONDUCTED IN THE FIELO

Sample date: 05/14/91 Wepth to water: $65.24 \mathrm{H}(19.89 \mathrm{~m})$ below TOC Water eievation: $208.26 \mathrm{Ht}$ $\mathrm{Sp}$. conductance: $40 \mathrm{\mu S} / \mathrm{cm}$
Water evacuated before sampling: $68 \mathrm{gal}$$$
\text { Time: } 15: 45
$$

PH: 4.7 : $1 \mathrm{mg}$

Alkalinity: $1 \mathrm{mg} / \mathrm{h}$ : $250^{\circ} \mathrm{C}$

LABORATORY ANALYSES
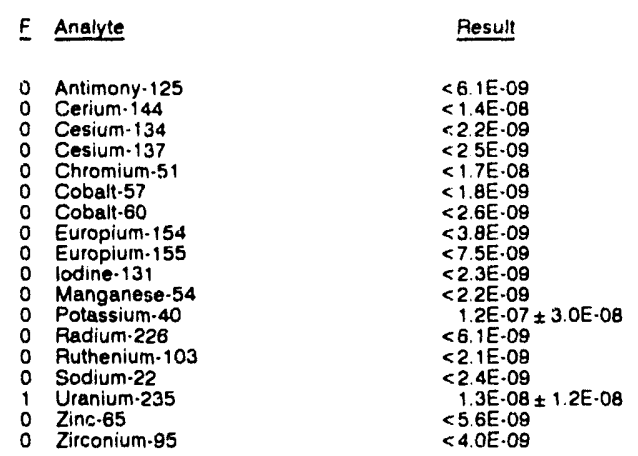

Unit Lab

WELL KDE 3

MEASUREMENTS CONDUCTED IN THE FIELD

Sample date: 05/14/91

Depth to water: 63.39 it $(1932 \mathrm{~m})$ below Water elevation: $21001 \mathrm{t}(64.01 \mathrm{~m}) \mathrm{msl}$

Sp. conductance' $264 \mathrm{H} / \mathrm{cm}$

Water evacuated before sampling: $21 \mathrm{ga}$

The well went dry during purging.

LABORATORY ANALYSES
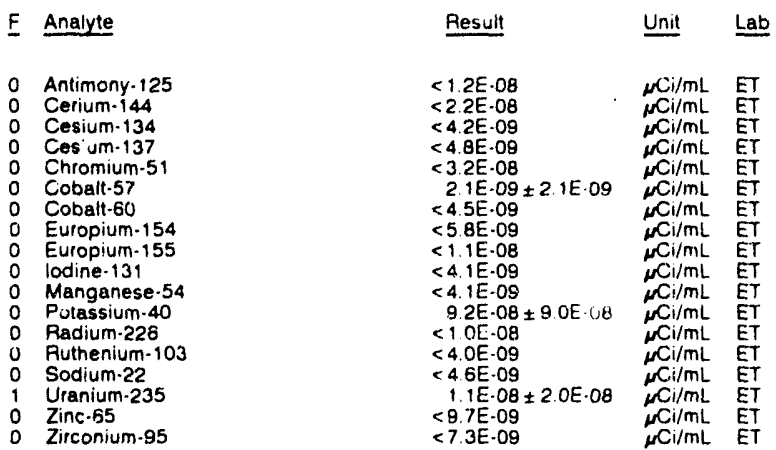

WELL LDB 1

MEASUREMENTS CONDUCTED IN THE FIELD

Sample date: $05 / 14 / 91$

Time: $14: 10$

Water elevation: $218.61 \mathrm{~h}(66.63 \mathrm{~m}) \mathrm{ms} 1 \quad$ Alkalinity: $0 \mathrm{mg} / \mathrm{h}$

Water temperature: $24.1^{\circ} \mathrm{C}$

Water evacuated before sampling: 22 gal
The well went dry during purging.

LABOFATOAY ANALYSES

\begin{tabular}{|c|c|c|}
\hline Analyte & Result & Unit \\
\hline $\begin{array}{l}\text { Antimony-125 } \\
\text { Cerium-144 } \\
\text { Cesium-134 } \\
\text { Cesium-137 } \\
\text { Chromium-51 } \\
\text { Cobalt }-57 \\
\text { Cobalt-60 } \\
\text { Europium-154 } \\
\text { Europium-155 } \\
\text { lodine-131 } \\
\text { Manganese-54 } \\
\text { Potassium-40 } \\
\text { Radium-226 } \\
\text { Ruthenium-103 } \\
\text { Sodium-22 } \\
\text { Uranium-235 } \\
\text { Zinc-65 } \\
\text { Zirconium-85 }\end{array}$ & $\begin{array}{l}<5.6 \mathrm{E} \cdot 08 \\
<1.2 \mathrm{E} \cdot 08 \\
<2.1 \mathrm{E} \cdot 09 \\
<2.4 \mathrm{E} \cdot 09 \\
<1.7 \mathrm{E} \cdot 08 \\
<1.5 \mathrm{E}-09 \\
<2.4 \mathrm{E} \cdot 09 \\
<3.1 \mathrm{E} \cdot 09 \\
<6.3 \mathrm{E} \cdot 09 \\
<2.2 \mathrm{E} \cdot 08 \\
<2.2 \mathrm{E}-09 \\
<3.9 \mathrm{E} \cdot 08 \\
<5.4 \mathrm{E} \cdot 09 \\
<2.2 \mathrm{E} \cdot 09 \\
<2.1 \mathrm{E} \cdot 09 \\
<1.3 \mathrm{E} \cdot 08 \\
<4.3 \mathrm{E} \cdot 09 \\
<3.7 \mathrm{E} \cdot 09\end{array}$ & 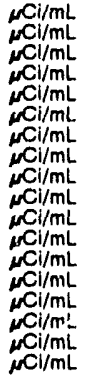 \\
\hline
\end{tabular}

WELL LDB 2

MEASUREMENTS CONDUCTED IN THE FIELD

Sample date: $05 / 14 / 91$ 1 000 m) below TOC Water elevation: $218.89 \mathrm{Ht}(66.75 \mathrm{~m}) \mathrm{msl}$

Sp. conductance: $64 \mu \mathrm{s} / \mathrm{cm}$

Water evacuated before sampling: $21 \mathrm{gal}$

Alkalinity. $1 \mathrm{mg}$

Alkalinity: $1 \mathrm{mg} / \mathrm{L}$ : $23.5^{\circ} \mathrm{C}$

LABORATORY ANALYSES

F Analyte

Result Unit Lab

0 Antimony-125

Cerium-144

Cesium-134
Cesium-137?

Chromium-51

0 Cobalt-6

O Europium-154

Europium-155

Manganese-54

Manganese.54

Radium-226

Ruthenium-103

Sodium-22

Zinc-65

Zirconium-95
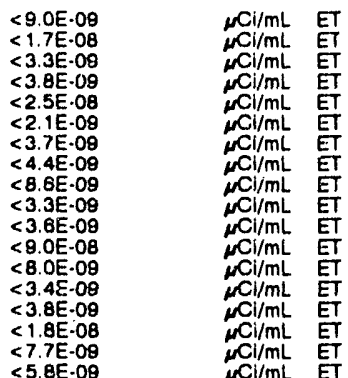

WELL NBG $\uparrow$

MEASUREMENTS CONDUCTED IN THE FIELD

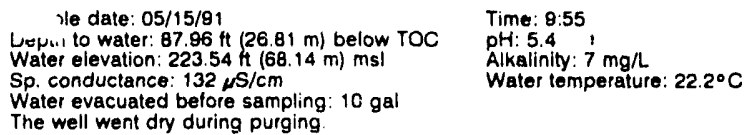

LABORATORY ANALYSES

\begin{tabular}{|c|c|c|}
\hline Analyte & Result & Unit \\
\hline $\begin{array}{l}\text { Antimony-125 } \\
\text { Cerium-144 } \\
\text { Cesium-134 } \\
\text { Cesium-137 } \\
\text { Chromium-51 } \\
\text { Cobalt-57 } \\
\text { Cobalt-60 } \\
\text { Europium-154 } \\
\text { Europium-155 } \\
\text { lodine-131 } \\
\text { Manganese-54 } \\
\text { Potassium- } 40 \\
\text { Radium-226 } \\
\text { Ruthenium-103 } \\
\text { Sodium-22 } \\
\text { Uranium-235 } \\
\text { Zinc-65 } \\
\text { Zirconium-95 }\end{array}$ & $\begin{aligned}<1.1 \mathrm{E} \cdot 08 \\
<2.2 \mathrm{E} \cdot 08 \\
<4.2 \mathrm{E} \cdot 09 \\
<4.9 \mathrm{E} \cdot 09 \\
<3.2 \mathrm{E} \cdot 08 \\
<2.7 \mathrm{E} \cdot 09 \\
<4.1 \mathrm{E} \cdot 09 \\
<5.7 \mathrm{E} \cdot 09 \\
<1.2 \mathrm{E} \cdot 08 \\
<4.0 \mathrm{E} \cdot 09 \\
<4.5 \mathrm{E} \cdot 09 \\
1.2 \mathrm{E} \cdot 07 \pm 9.0 \mathrm{E} \cdot 08 \\
<1.1 \mathrm{E} \cdot 08 \\
2.3 \mathrm{E} \cdot 09 \pm 4.5 \mathrm{E} \cdot 08 \\
<4.5 \mathrm{E} \cdot 09 \\
<2.3 \mathrm{E} \cdot 08 \\
<9.2 \mathrm{E} \cdot 09 \\
<7.0 \mathrm{E} \cdot 09\end{aligned}$ & 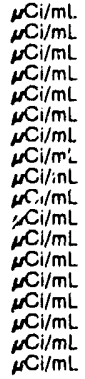 \\
\hline
\end{tabular}


WELLL NBG 2

MEASUREMENTS CONDUCTED IN THE FIELD

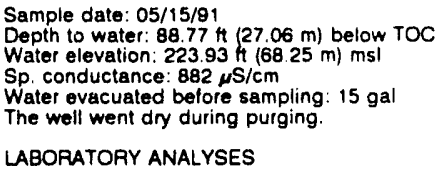

Sample date: 05/15/91 Depth to water: $88.77 \mathrm{H}(27.06 \mathrm{~m})$ below TOC Water elevation: $223.93 \mathrm{ht}(68.25 \mathrm{~m}) \mathrm{ms}$

Sp. conductance: $882 \mu \mathrm{S} / \mathrm{cm}$ Water evacuated belore sampling: $15 \mathrm{gal}$ The well went dry during purging

LABORATORY ANALYSES

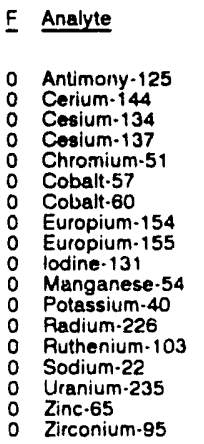

Result
<1.2E-08
$<2.2 \mathrm{E} \cdot 08$
$<3.0 \mathrm{E} \cdot 09$
$<4.6 \mathrm{E} \cdot 09$
$2.6 \mathrm{E}-08 \pm 2.4 \mathrm{E}-08$
$<2.7 \mathrm{E} \cdot 09$
$<4.6 \mathrm{E} \cdot 09$
$<5.8 \mathrm{E}-09$
$<1.1 \mathrm{E} \cdot 08$
$<4.1 \mathrm{E} \cdot 09$
$<4.1 \mathrm{E} \cdot 09$
$4.2 \mathrm{E} \cdot 08 \pm 8.7 \mathrm{E}-08$
$4.4 \mathrm{E} \cdot 09 \pm 1.0 \mathrm{E}-08$
$<4.0 \mathrm{E} \cdot 09$
$<4.7 \mathrm{E} \cdot 09$
$<2.3 \mathrm{E} \cdot 08$
$<9.0 \mathrm{E} \cdot 09$
$<7.2 \mathrm{E} \cdot 09$

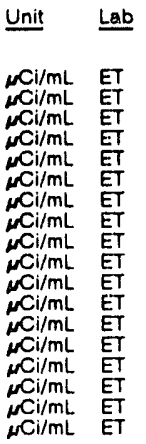

WELL NBG 3

MEASUREMENTS CONOUCTED IN THE FIELD
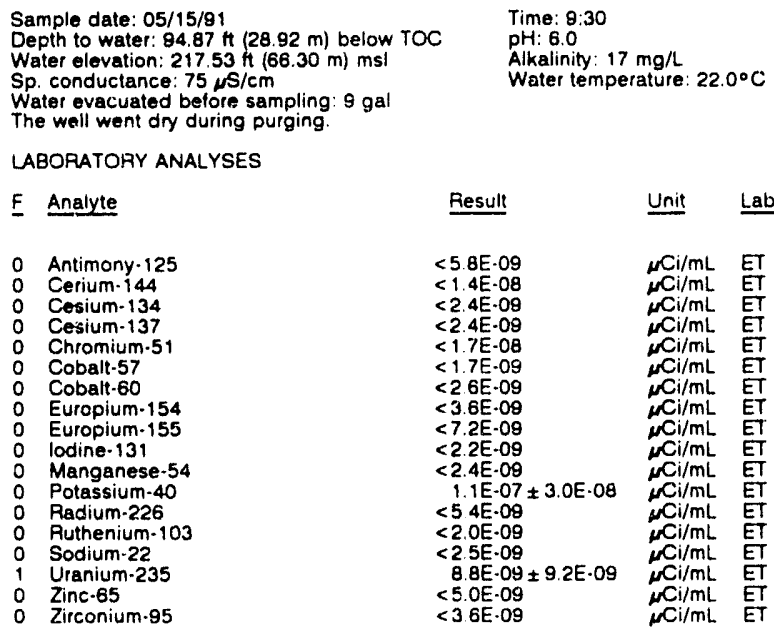

LABORATORY ANALYSES
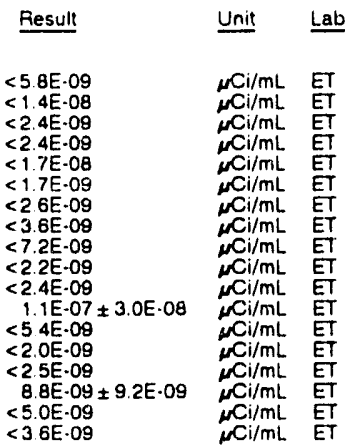

WELL NBG 4

MEASUAEMENTS CONDUCTED IN THE FIELD

Sample date: $05 / 15 / 91$
Depth to water: $89.45 \mathrm{Ht}(27.26 \mathrm{~m})$ below TOC
Water elevation: $217.05 \mathrm{~h}(66.16 \mathrm{~m}) \mathrm{ms}$ l
Sp. conductance: $27, \mathrm{~s} / \mathrm{cm}$
Water evacuated before sampling: $10 \mathrm{gal}$
The well went dry during purging.
LABORATORY ANALYSES

Time: 9:15

pH: 5.3

Water temperature $210^{\circ} \mathrm{C}$

LABORATORY ANALYSES

\begin{tabular}{|c|c|c|}
\hline Anaiyte & Result & Unit \\
\hline $\begin{array}{ll}0 & \text { Antimony-125 } \\
0 & \text { Cerium-144 } \\
0 & \text { Cesium-134 } \\
0 & \text { Cesium-137 } \\
0 & \text { Chromium-51 } \\
0 & \text { Cobalt-57 } \\
0 & \text { Cobalt-60 } \\
0 & \text { Europium-154 } \\
0 & \text { Europium-155 } \\
0 & \text { lodine } \cdot 131 \\
0 & \text { Manganese }-54 \\
0 & \text { Potassium-40 } \\
0 & \text { Radium-226 } \\
0 & \text { Ruthenium-103 } \\
0 & \text { Sodium-22 } \\
0 & \text { Uranium-235 } \\
0 & \text { Zinc-65 } \\
0 & \text { Zirconium-95 }\end{array}$ & $\begin{array}{l}<9.6 \mathrm{E} \cdot 09 \\
<1.8 \mathrm{E} \cdot 08 \\
<3.5 \mathrm{E} \cdot 09 \\
<4.0 \mathrm{E} \cdot 09 \\
<2.7 \mathrm{E} \cdot 08 \\
<2.3 \mathrm{E} \cdot 09 \\
<3.9 \mathrm{E} \cdot 09 \\
<4 \mathrm{BE} \cdot 09 \\
<9.5 \mathrm{E} \cdot 09 \\
<3.6 \mathrm{E} \cdot 09 \\
<37 \mathrm{E} \cdot 09 \\
<9.1 \mathrm{E} \cdot 08 \\
<8.6 \mathrm{E} \cdot 09 \\
<3.6 \mathrm{E} \cdot 09 \\
<4.3 \mathrm{E} \cdot 09 \\
<18 \mathrm{E} \cdot 08 \\
<8.1 \mathrm{E} \cdot 09 \\
<6.1 \mathrm{E} \cdot 09\end{array}$ & 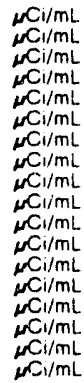 \\
\hline
\end{tabular}

WELL NBG 5

MEASUREMENTS CONDUCTED IN THE FIELD

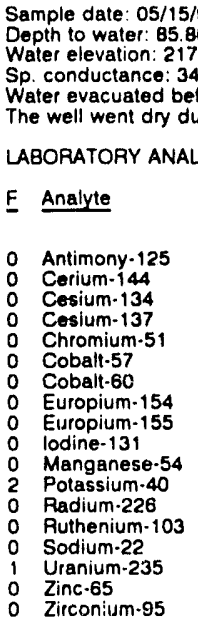

Time: $8: 05$

pH: 5.4

Alkalinity: $3 \mathrm{mg} / \mathrm{L}$ Water temperature: $21.4^{\circ} \mathrm{C}$

: $217.70 \mathrm{~h}(66$.

ed before sampling: $17 \mathrm{ga}$

RY ANALYSES

\section{WELL P 26A}

MEASUREMENTS CONDUCTED IN THE FIELD

$\begin{array}{ll}\text { Sample date: } 06 / 04 / 91 & \text { Time: } 12.05 \\ \text { Depth to water: } 33.88 \mathrm{H}(10.36 \mathrm{~m}) \text { below TOC } & \text { pH: } 5.4 \\ \text { Water elevation: } 120.52 \mathrm{ht}(36.73 \mathrm{~m}) \mathrm{msl} & \text { Alkalinity: } 3 \mathrm{mg} / \mathrm{L} \\ \text { Sp. conductance: } 40 \mu \mathrm{S} / \mathrm{cm} & \text { Water temperature: } 20.4^{\circ} \mathrm{C} \\ \text { Water evacuated before sampling: } 260 \mathrm{gal} & \end{array}$
LABORATORY ANALYSES

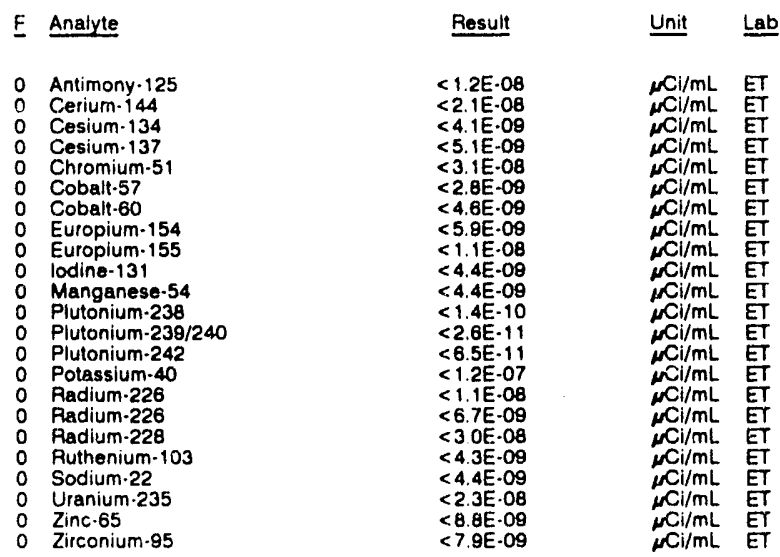

\section{WELL P 26B}

MEASUREMENTS CONDUCTED IN THE FIELD

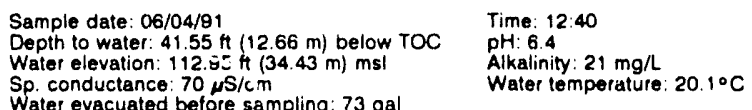

Water evacuated before sampling: $73 \mathrm{gal}$

LABORATORY ANALYSES

\begin{tabular}{|c|c|c|}
\hline Analyte & Result & Unit \\
\hline 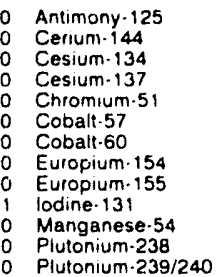 & $\begin{array}{l}<5.8 \mathrm{E} \cdot 09 \\
<1.2 \mathrm{E} \cdot 08 \\
<2.3 \mathrm{E} \cdot 09 \\
<2.4 \mathrm{E} \cdot 09 \\
<1.7 \mathrm{E} \cdot 08 \\
<1.5 \mathrm{E} \cdot 09 \\
<2.6 \mathrm{E} \cdot 09 \\
<3.3 \mathrm{E} \cdot 09 \\
<6.3 \mathrm{E} \cdot 09 \\
2.1 \mathrm{E} \cdot 09 \pm 1.9 \mathrm{E} \cdot 09 \\
<2.3 \mathrm{E} \cdot 09 \\
<1.2 \mathrm{E} \cdot 10 \\
<7.2 \mathrm{E} \cdot 11\end{array}$ & 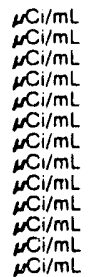 \\
\hline
\end{tabular}


ANALYTICAL RESULTS

WELL P 268 collected on 06/04/91, laboratory analyses (cont.)

\begin{tabular}{|c|c|c|c|}
\hline$E$ & Analyte & Pesult & Unit \\
\hline $\begin{array}{l}0 \\
0 \\
0 \\
0 \\
0 \\
0 \\
0 \\
0 \\
0 \\
0\end{array}$ & $\begin{array}{l}\text { Plutonium-242 } \\
\text { Potassium-40 } \\
\text { Radium-226 } \\
\text { Radium-226 } \\
\text { Radium-228 } \\
\text { Ruthenium-103 } \\
\text { Sodium-22 } \\
\text { Uranium-235 } \\
\text { Zinc-65 } \\
\text { Zirconium-95 }\end{array}$ & $\begin{array}{l}<7.2 \mathrm{E} \cdot 11 \\
9.4 \mathrm{E} \cdot 08 \pm 3.5 \mathrm{E} \cdot 08 \\
<5.6 \mathrm{E}-09 \\
<1.2 \mathrm{E} \cdot 08 \\
<1.4 \mathrm{E} \cdot 08 \\
<2.0 \mathrm{E} \cdot 09 \\
<2.3 \mathrm{E} \cdot 09 \\
<1.4 \mathrm{E} \cdot 08 \\
<4.9 \mathrm{E} \cdot 09 \\
<4.0 \mathrm{E}-09\end{array}$ & $\begin{array}{l}\mu \mathrm{Cl} / \mathrm{mL} \\
\mu \mathrm{Ci} / \mathrm{mL} \\
\mu \mathrm{Ci} / \mathrm{mL} \\
\mu \mathrm{Ci} / \mathrm{mL} \\
\mu \mathrm{Ci} / \mathrm{mL} \\
\mu \mathrm{Ci} / \mathrm{mL} \\
\mu \mathrm{Ci} / \mathrm{mL} \\
\mu \mathrm{Ci} / \mathrm{mL} \\
\mu \mathrm{Ci} / \mathrm{mL} \\
\mu \mathrm{Ci} / \mathrm{mL}\end{array}$ \\
\hline
\end{tabular}

WELL P 26D

MEASUREMENTS CONDUCTED IN THE FIELD

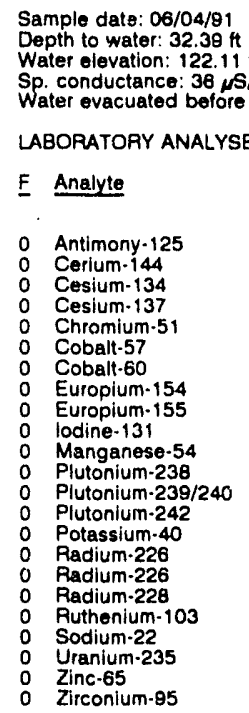

WELL PDB 2

MEASUREMENTS CONDUCTED IN THE FIELD

\section{Sample date: $05 / 14 / 91$}

Depth to water: $40.78 \mathrm{H}(12.43 \mathrm{~m})$ below TOC Water elevation: $278.72 \mathrm{Ht}(84.25)$
Sp. conductance: $110 \mu \mathrm{S} / \mathrm{cm}$

Sp. conductance: $110 \mu \mathrm{S} / \mathrm{cm}$
Water evacuated before sampling: $81 \mathrm{gal}$

LABORATORY ANALYSES

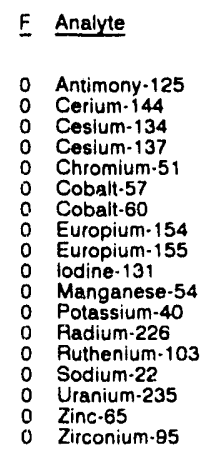

WELL PDB 3

\begin{tabular}{|c|c|c|c|c|}
\hline \multicolumn{5}{|c|}{ MEASUREMENTS CONDUCTED IN THE FIELD } \\
\hline \multicolumn{2}{|r|}{$\begin{array}{l}\text { Sample date: } 05 / 14 / 81 \\
\text { Depth to water: } 40.74 \mathrm{ft}(12.42 \mathrm{~m}) \text { below TOC } \\
\text { Water elevation: } 278.76 \mathrm{H}(84.87 \mathrm{~m}) \mathrm{msl} \\
\text { Sp. conductance: } 64 \mu \mathrm{\mu l} / \mathrm{cm} \\
\text { Water evacuated before sampling: } 80 \mathrm{gal}\end{array}$} & \multicolumn{3}{|c|}{$\begin{array}{l}\text { Time: } 11: 55 \\
\text { pH: } 4.8 \\
\text { Alkalinity: } 3 \mathrm{mg} / \mathrm{h} \\
\text { Water temperature: } 24.1^{\circ} \mathrm{C}\end{array}$} \\
\hline \multicolumn{5}{|c|}{ LABORATORY ANALYSES } \\
\hline$\underline{\mathbf{E}}$ & Analyte & Result & Unlt & $\underline{\text { Lab }}$ \\
\hline & $\begin{array}{l}\text { Antimony-125 } \\
\text { Cerium-144 } \\
\text { Cesium-134 } \\
\text { Ceslum-137 } \\
\text { Chromium-51 } \\
\text { Cobalt-57 } \\
\text { Cobalt-60 } \\
\text { Europium-154 } \\
\text { Europlum-155 } \\
\text { lodine-131 } \\
\text { Manganose-54 } \\
\text { Potassium-40 } \\
\text { Radium-226 } \\
\text { Ruthenium-103 } \\
\text { Sodium-22 } \\
\text { Uranium-235 } \\
\text { Zinc-65 } \\
\text { Zirconium-95 }\end{array}$ & $\begin{array}{l}<1.1 \mathrm{E} \cdot 08 \\
<2.1 \mathrm{E} \cdot 08 \\
<4.2 \mathrm{E} \cdot 09 \\
<4.5 \mathrm{E} \cdot 08 \\
<3.2 \mathrm{E} \cdot 08 \\
<2.7 \mathrm{E} \cdot 00 \\
<4.5 \mathrm{E} \cdot 09 \\
<5.8 \mathrm{E} \cdot 00 \\
<1.1 \mathrm{E} \cdot 08 \\
<4.1 \mathrm{E} \cdot 09 \\
<4.4 \mathrm{E} \cdot 09 \\
4.7 \mathrm{E} \cdot 07 \pm 8.0 \mathrm{E} \cdot 08 \\
<1.0 \mathrm{E} \cdot 08 \\
<4.1 \mathrm{E} \cdot 00 \\
<4.3 \mathrm{E} \cdot 09 \\
<2.3 \mathrm{E} \cdot 08 \\
<9.3 \mathrm{E} \cdot 00 \\
<7.9 \mathrm{E} \cdot 09\end{array}$ & 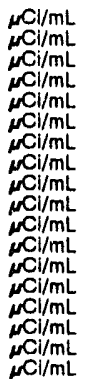 & $\begin{array}{l}E T \\
E T \\
E T \\
E T \\
E T \\
E T \\
E T \\
E T \\
E T \\
E T \\
E T \\
E T \\
E T \\
E T \\
E T \\
E T \\
E T \\
E T\end{array}$ \\
\hline
\end{tabular}

\section{WELL TBG 1}

MEASUREMENTS CONDUCTED IN THE FIELD

$\begin{array}{ll}\text { Sample date: } 06 / 03 / 91 & \text { Time: } 14: 55 \\ \text { Depth to water: } 49.76 \mathrm{ft}(15.17 \mathrm{~m}) \text { below TOC } & \text { pH: } 4.6 \\ \text { Water elevation: } 101.44 \mathrm{ft}(30.82 \mathrm{~m}) \mathrm{msl} & \text { Alkalinity: } 0 \mathrm{mg} / \mathrm{L} \\ \text { Sp. conductance: } 155 \mu \mathrm{s} / \mathrm{cm} & \text { Water temperature } 23.0^{\circ} \mathrm{C} \\ \text { Water evacuated before sampling: } 32 \mathrm{gal} & \end{array}$

LABORATORY ANALYSES

\begin{tabular}{|c|c|c|}
\hline Analyte & Result & $\underline{\text { Unit }}$ \\
\hline $\begin{array}{l}\text { Antimony-125 } \\
\text { Cerium-144 } \\
\text { Cesium-134 } \\
\text { Cesium-137 } \\
\text { Chromium-51 } \\
\text { Cobalt-57 } \\
\text { Cobaatt-60 } \\
\text { Europium-154 } \\
\text { Europium-155 } \\
\text { lodine-131 } \\
\text { Manganese-54 } \\
\text { Plutonium-238 } \\
\text { Plutonium-239/240 } \\
\text { Plutonium-242 } \\
\text { Potassium-40 } \\
\text { Radium-226 } \\
\text { Radium-226 } \\
\text { Radium-228 } \\
\text { Ruthentum-103 } \\
\text { Sodium-22 } \\
\text { Uranium-235 } \\
\text { Zinc-65 } \\
\text { Zirconium-95 }\end{array}$ & $\begin{array}{l}<1.2 \mathrm{E} \cdot 08 \\
<2.3 \mathrm{E} \cdot 08 \\
<4.2 \mathrm{2E} \cdot 09 \\
<4.8 \mathrm{E} \cdot 09 \\
1.4 \mathrm{E} \cdot 08 \pm 1.4 \mathrm{E} \cdot 08 \\
<2.6 \mathrm{E} \cdot 09 \\
<4.5 \mathrm{E} \cdot 09 \\
<5.6 \mathrm{E} \cdot 09 \\
<1.1 \mathrm{E} \cdot 08 \\
<4.3 \mathrm{E} \cdot 09 \\
<4.8 \mathrm{E} \cdot 09 \\
<2.2 \mathrm{E} \cdot 10 \\
<1.1 \mathrm{E} \cdot 10 \\
<1.1 \mathrm{E} \cdot 10 \\
<1.2 \mathrm{E} \cdot 07 \\
<9.8 \mathrm{E} \cdot 09 \\
2.9 \mathrm{E} \cdot 08 \pm 7.0 \mathrm{E} \cdot 09 \\
<3.5 \mathrm{E} \cdot 08 \\
<4.2 \mathrm{E} \cdot 09 \\
<4.5 \mathrm{E} \cdot 09 \\
<2.4 \mathrm{E} \cdot 08 \\
<9.9 \mathrm{E} \cdot 09 \\
<7.8 \mathrm{E} \cdot 09\end{array}$ & 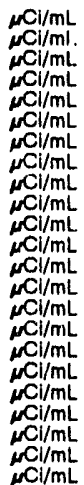 \\
\hline
\end{tabular}

WELL TBG 3

MEASUREMENTS CONDUCTED IN THE FIELO

$\begin{array}{ll}\text { Sample date: } 06 / 04 / 91 & \text { Time: }: 10: 10 \\ \text { Depth to water: } 46.56 \mathrm{H}(14.19 \mathrm{~m}) \text { below TOC } & \text { pH: } 4.4 \\ \text { Water elevation: } 104.64 \mathrm{ft}(31.89 \mathrm{~m}) \mathrm{msl} & \text { Alkalinity: } 0 \mathrm{mg} / \mathrm{h} \\ \text { Sp. conductance: } 213 \mu \mathrm{s} / \mathrm{cm} & \text { Water temperature: } 23.1 \circ \mathrm{C} \\ \text { Water evacuated before sampling: } 10 \mathrm{gal} & \\ \text { The well went dry during purging. } & \end{array}$

LABORATORY ANALYSES

\begin{tabular}{|c|c|c|}
\hline F Analyte & Result & Unit \\
\hline $\begin{array}{ll}0 & \text { Antimony-125 } \\
0 & \text { Cerium-144 } \\
0 & \text { Cesium-134 } \\
0 & \text { Cesium-137 } \\
0 & \text { Chromium-51 } \\
0 & \text { Cobalt-57 } \\
0 & \text { Cobalt-60 } \\
0 & \text { Europium-154 } \\
0 & \text { Europium-155 } \\
0 & \text { lodine-131 } \\
0 & \text { Manganese-54 } \\
0 & \text { Plutonium-238 } \\
0 & \text { Plutonium-239/240 }\end{array}$ & $\begin{array}{l}<1.2 \mathrm{E} \cdot 08 \\
<2.4 \mathrm{E} \cdot 08 \\
<4.3 \mathrm{E} \cdot 09 \\
<5.1 \mathrm{E} \cdot 09 \\
<3.4 \mathrm{E} \cdot 08 \\
<3.2 \mathrm{E} \cdot 09 \\
<4.9 \mathrm{E}-09 \\
<6.7 \mathrm{E} \cdot 09 \\
<1.3 \mathrm{E} \cdot 08 \\
<4.5 \mathrm{E} \cdot 09 \\
<4.8 \mathrm{E} \cdot 09 \\
<1.1 \mathrm{E}-10 \\
<1.1 \mathrm{E} \cdot 10\end{array}$ & 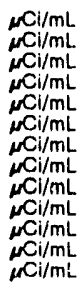 \\
\hline
\end{tabular}




\section{ANALYTICAL RESULTS}

WELL TBG 3 collected on 06/04/91, laboratory analyses (cont.)

\begin{tabular}{|c|c|c|c|c|}
\hline$\underline{F}$ & Analyte & Pesult & Unit & Lab \\
\hline $\begin{array}{l}0 \\
0\end{array}$ & $\begin{array}{l}\text { Plutonium-242 } \\
\text { Potassium-40 } \\
\text { Radium-226 } \\
\text { Radium-226 } \\
\text { Padium-228 } \\
\text { Puthenium-103 } \\
\text { Sodium-22 } \\
\text { Uranium-235 } \\
\text { Zinc-65 } \\
\text { Zirconium-85 }\end{array}$ & $\begin{array}{l}<1.1 E \cdot 10 \\
<5.2 E \cdot 08 \\
1.8 E \cdot 08 \pm 5.0 E \cdot 09 \\
<9.3 E-08 \\
1.5 E \cdot 08 \pm 4.0 E \cdot 09 \\
<4.6 E \cdot 09 \\
<4.7 E-09 \\
<2.6 E \cdot 08 \\
<9.2 E-09 \\
<8.1 E \cdot 09\end{array}$ & $\begin{array}{l}\mu \mathrm{Cl} / \mathrm{mL} \\
\mu \mathrm{Ci} / \mathrm{mL} \\
\mu \mathrm{Ci} / \mathrm{mL} \\
\mu \mathrm{Cl} / \mathrm{mL} \\
\mu \mathrm{Cl} / \mathrm{mL} \\
\mu \mathrm{Cl} / \mathrm{mL} \\
\mu \mathrm{Ci} / \mathrm{mL} \\
\mu \mathrm{Ci} / \mathrm{mL} \\
\mu \mathrm{Ci} / \mathrm{mL} \\
\mu \mathrm{Ci} / \mathrm{mL}\end{array}$ & $\begin{array}{l}\text { ET } \\
\text { ET } \\
\text { ET } \\
\text { ET } \\
\text { ET } \\
\text { ET } \\
\text { ET } \\
\text { ET } \\
\text { ET } \\
\text { ET }\end{array}$ \\
\hline
\end{tabular}

\section{WELL TBG $5 A$}

MEASUREMENTS CONDUCTED IN THE FIELD

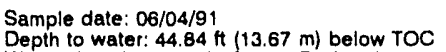

Water elevation: $104.56 \mathrm{H}(31.87 \mathrm{~m}) \mathrm{ms}$

Water evacuated before sampling: $153 \mathrm{gal}$

LABORATORY ANALYSES

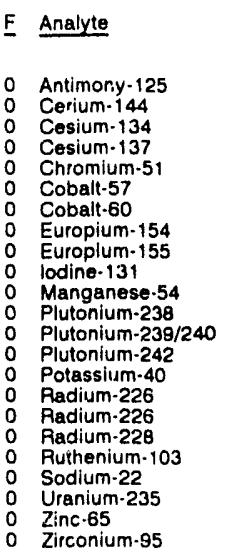

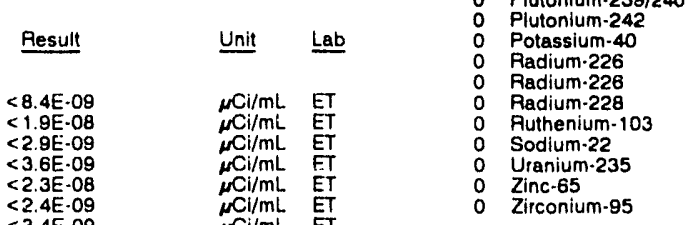

Time: 11:25

Alkalinity: $0 \mathrm{mg} / \mathrm{L}$

Water temperature: $213^{\circ} \mathrm{C}$

$<2.4 E \cdot 09$

$<3.4 \mathrm{E}-09$

$<1.0 \mathrm{E}-08$

$<3.0 \mathrm{E}-09$

$<3.1 \mathrm{E}-09$

$<1.9 \mathrm{E}-10$

$<1.9 \mathrm{E} \cdot 10$

$<1.9 \mathrm{E}-10$
$<8.2 \mathrm{E}-08$

$<8.2 E-08$

$<9.0 E-09$

$<1.7 \mathrm{E}-08$

$<3.0 \mathrm{E}-08$

$<3.5 \mathrm{E}-09$

$<2.0 \mathrm{E}-08$

$<6.9 \mathrm{E} .09$

Zirconil

Sp. conductance: $51 \mu \mathrm{s} / \mathrm{cm}$

LABORATORY ANALYSES
WELL TBG 7

MEASUREMENTS CONDUCTED IN THE FIELD

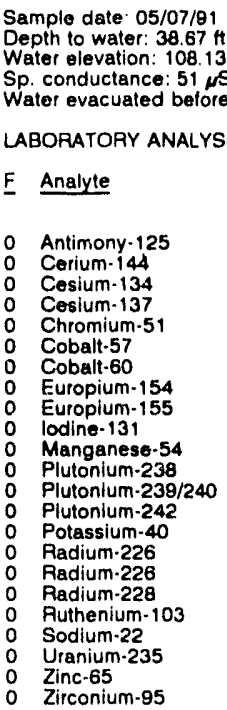

Time: 10:20

Alkalinity: $11 \mathrm{mg} / \mathrm{L}$

Water temperature: $220^{\circ} \mathrm{C}$

\section{WELL TBG 7 Replicate}

MEASUREMENTS CONOUCTED IN THE FIELD

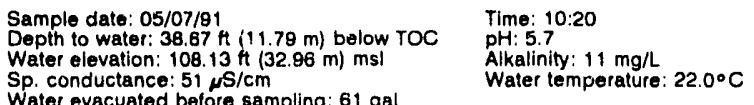

Water evacuated before sampling: $61 \mathrm{gal}$

\begin{tabular}{|c|c|c|}
\hline Analyte & Result & Unit \\
\hline $\begin{array}{l}\text { Antimony-125 } \\
\text { Cerium-144 } \\
\text { Cesium-134 } \\
\text { Cesium-137 } \\
\text { Chromium-51 } \\
\text { Cobalt-57 } \\
\text { Cobalt-60 } \\
\text { Europium-154 } \\
\text { Europium-155 } \\
\text { lodine-131 } \\
\text { Manganese-54 } \\
\text { Plutonium-238 } \\
\text { Plutonium-238/240 } \\
\text { Plutonium-242 } \\
\text { Potassium-40 } \\
\text { Radium-226 } \\
\text { Radium-226 } \\
\text { Radium-228 } \\
\text { Puthenium-103 } \\
\text { Sodium-22 } \\
\text { Uranium-235 } \\
\text { Zinc-65 } \\
\text { Zirconium-95 }\end{array}$ & 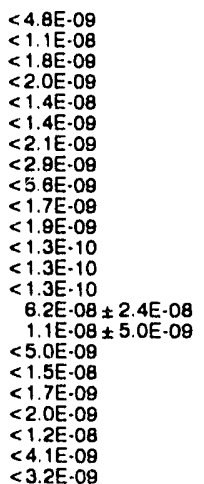 & 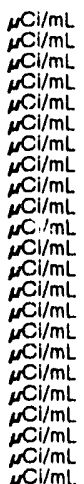 \\
\hline
\end{tabular}

WELL TNX 10

MEASUREMENTS CONDUCTED IN THE FIELD

Depth to water: $56.37 \mathrm{ft}(17.18 \mathrm{~m})$ below TOC

Water elevation: $100.13 \mathrm{ft}(30.52 \mathrm{~m}) \mathrm{ms}$

Sp conductance $45 \mathrm{~S} / \mathrm{cm}$

Pesult Unit Lab

WELL TBG 58

MEASUREMENTS CONDUCTED IN THE FIELD

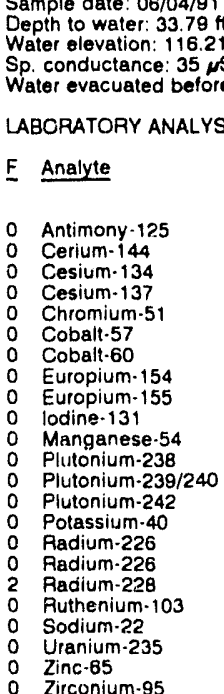

Unit Lab

$<1.2 \mathrm{E} \cdot 08$

(4.6E.

$<2,0.09$

$<5.3 \mathrm{E} .09$

$<4.0 \mathrm{E}-09$

$<3.3 \mathrm{E}-10$

$<1.7 E-10$

$<1.7 \mathrm{E}-10$
$<1.1 \mathrm{E}-07$

$<1.0 \mathrm{E} \cdot 08$

<. $3 \mathrm{E} \cdot 07 \pm 3.0 \mathrm{E} \cdot 0 \mathrm{~B}$

$<4.1 \mathrm{E} .09$

$<4.5 \mathrm{E} .09$

$<2.3 \mathrm{E}-08$

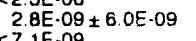

Water evacuated betore sampling: $54 \mathrm{ga}$

LABORATORY ANALYSES

\begin{tabular}{|c|c|c|}
\hline Analyte & Result & Unit \\
\hline $\begin{array}{l}\text { Antimony-125 } \\
\text { Cerium - } 144 \\
\text { Cesium-134 } \\
\text { Cesium-137 } \\
\text { Chromium-51 } \\
\text { Cobalt-57 } \\
\text { Cobalt-60 } \\
\text { Europium-154 }\end{array}$ & $\begin{array}{l}<8.0 \mathrm{E} \cdot 09 \\
<1.9 \mathrm{E} \cdot 08 \\
<3.0 \mathrm{E} \cdot 09 \\
<3.3 \mathrm{E} \cdot 08 \\
<2.3 \mathrm{E} \cdot 08 \\
<2.5 \mathrm{E} \cdot 08 \\
<3.2 \mathrm{E} \cdot 09 \\
<5.2 \mathrm{E} \cdot 08\end{array}$ & 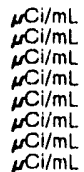 \\
\hline
\end{tabular}


ANALYTICAL RESULTS

WELL TNX 10 collected on 05/03/91, laboratory analyses (cont.)

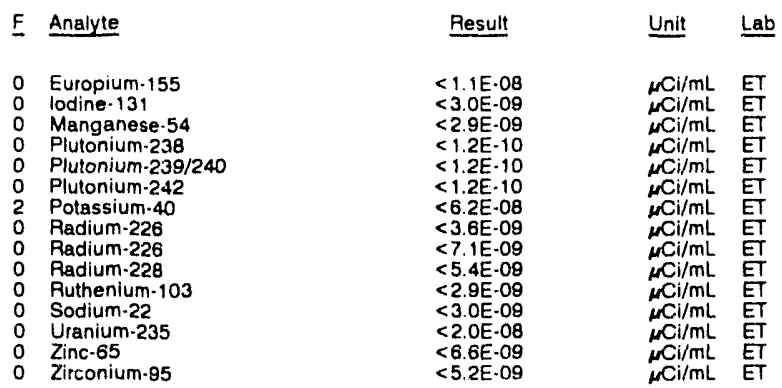

\section{WELL TNX 2D}

MEASUREMENTS CONDUCTED IN THE F!ELD

Sample date: 05/08/91

Depth to water: $55.12 \mathrm{Ht}(16.80 \mathrm{~m})$ below TOC

Water elevation: $98.98 \mathrm{th}(30.47 \mathrm{~m}) \mathrm{ms}$

Sp conductance 92 s/cm

LABORATORY ANALYSES

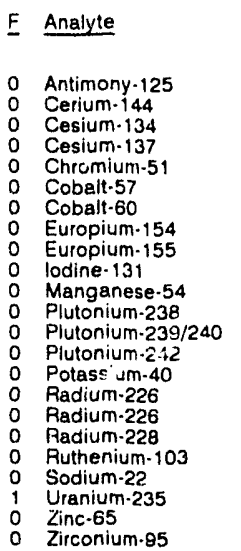

\begin{tabular}{|c|c|c|c|}
\hline Result & Unit & Lab & $\begin{array}{ll}0 & \text { Radium-228 } \\
0 & \text { Ruthenium-103 } \\
0 & \text { Sodium-22 } \\
1 & \text { Uranium-235 }\end{array}$ \\
\hline $\begin{array}{l}4.4 \mathrm{E}-09 \\
9.6 \mathrm{E}-09\end{array}$ & $\begin{array}{l}\mathrm{mCi}_{\mathrm{NCi} / \mathrm{mL}} \\
\mathrm{m}^{2}\end{array}$ & $\begin{array}{l}E T \\
E T\end{array}$ & $\begin{array}{l}0 \quad \text { Zinc-65 } \\
0\end{array}$ \\
\hline
\end{tabular}

WELL TNX 4D

MEASUREMENTS CONDUCTED IN THE FIELD

Sample date: 05/07/91

Depth to water: $44.88 \mathrm{ft}(13.68 \mathrm{~m})$ below TOC

Water elevation: $104.81 \mathrm{H}(31.98 \mathrm{~m}) \mathrm{ms}$

Sp. conductance: $46 \mu \mathrm{S} / \mathrm{cm}$

Waler evacuated bolore sampling: $10 \mathrm{gal}$

LABOPATORY ANALYSES

\begin{tabular}{|c|c|c|}
\hline Analyte & Result & Unit \\
\hline $\begin{array}{l}\text { Antimony-125 } \\
\text { Cerium-144 } \\
\text { Cesium-134 } \\
\text { Cesium-137 } \\
\text { Chromium-51 } \\
\text { Cobalt-57 } \\
\text { Cobalt-80 } \\
\text { Europium-154 } \\
\text { Europium-155 } \\
\text { lodine-131 } \\
\text { Manganese-54 } \\
\text { Plutonium-238 } \\
\text { Plutonium-239/240 } \\
\text { Plutonium-242 } \\
\text { Potassium-40 } \\
\text { Radium-226 } \\
\text { Radium-226 } \\
\text { Radium-228 } \\
\text { Ruthenium-103 } \\
\text { Sodium-22 } \\
\text { Uranium-235 } \\
\text { Zinc-65 } \\
\text { Zirconium-95 }\end{array}$ & 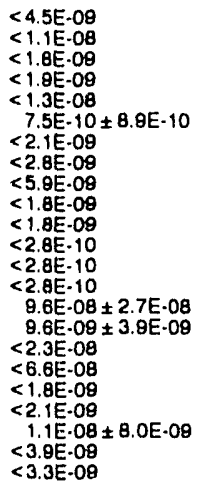 & 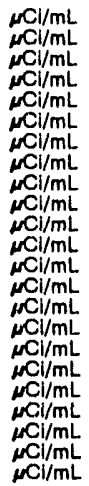 \\
\hline
\end{tabular}

WELL TNX 5D

MEASUREMENTS CONDUCTED IN THE FIELD

Sample dato: 05/0\%/日

Depth to water: 42.11 (t) $12.84 \mathrm{~m})$ below $T 0 C$

Water elevation: $107.19 \mathrm{H}(32.67 \mathrm{~m}) \mathrm{msl}$

Sp. conductence: 128 sicm

pH: 5.5 . $1 \mathrm{mg}$

Water temperature: $20.3^{\circ} \mathrm{C}$

(a) 9 gal

The well went dry during purging.

LABORATORY ANALYSES

\begin{tabular}{|c|c|c|}
\hline Analyte & Result & Unit \\
\hline $\begin{array}{l}\text { Antimony-125 } \\
\text { Cerium-144 } \\
\text { Cesium-134 } \\
\text { Cesium-137 } \\
\text { Chromlum-51 } \\
\text { Cobalt-57 } \\
\text { Cobatt-60 } \\
\text { Europium-154 } \\
\text { Europium-155 } \\
\text { lodine-131 } \\
\text { Manganese-54 } \\
\text { Plutonium-238 } \\
\text { Plutonium-238/240 } \\
\text { Plutonium-242 } \\
\text { Potassium-40 } \\
\text { Radium-226 } \\
\text { Radi-m-226 } \\
\text { Radium-228 } \\
\text { Ruthenium-103 } \\
\text { Sodium-22 } \\
\text { Uranium-235 } \\
\text { Zinc-65 } \\
\text { Zliconium-95 }\end{array}$ & 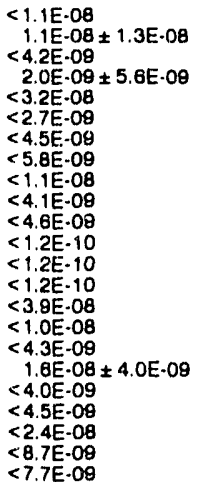 & 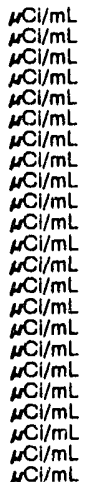 \\
\hline
\end{tabular}

\section{WELL TNX 6D}

MEASUREMENTS CONDUCTED IN THE FIELD

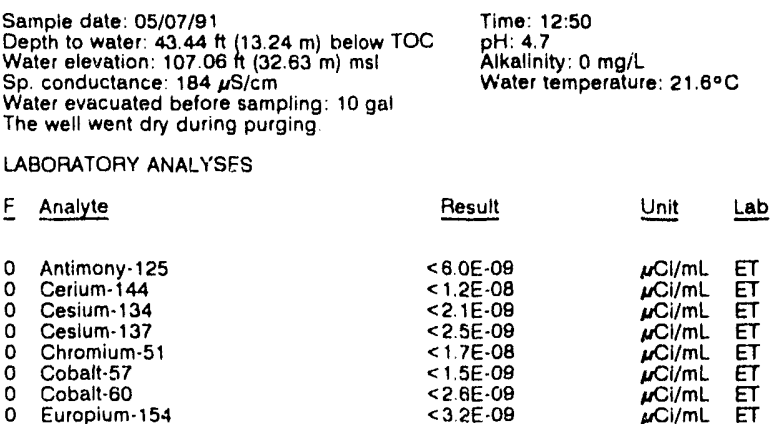


WELL TNX 60 collected on 05/07/91, laboratory analyses (cont.)

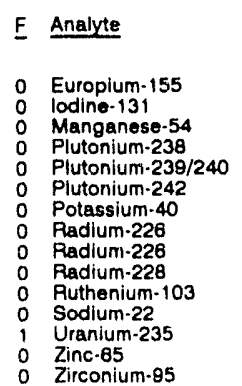

\begin{tabular}{|c|c|}
\hline Result & Unit \\
\hline $\begin{aligned} & 3.1 \mathrm{E} \cdot 09 \pm 4.3 \mathrm{E} \cdot 09 \\
&<2.3 \mathrm{E} \cdot 09 \\
&<2.4 \mathrm{E} \cdot 09 \\
&<1.2 \mathrm{E} \cdot 10 \\
&<1.2 \mathrm{E} \cdot 10 \\
&<1.2 \mathrm{E} \cdot 10 \\
& 8.9 \mathrm{E} \cdot 08 \pm 2.6 \mathrm{E}-08 \\
& 5.7 \mathrm{E} \cdot 09 \pm 2.1 \mathrm{E} \cdot 09 \\
&<6.3 \mathrm{E} \cdot 09 \\
&<1.1 \mathrm{E} \cdot 08 \\
&<2.1 \mathrm{E} \cdot 09 \\
&<2.5 \mathrm{E} \cdot 09 \\
& 7.8 \mathrm{E} \cdot 09 \pm 9.5 \mathrm{E} \cdot 09 \\
&<5.4 \mathrm{E} \cdot 09 \\
&<2.3 \mathrm{E} \cdot 09\end{aligned}$ & $\begin{array}{l}\mu \mathrm{Ci} / \mathrm{mL} \\
\mu \mathrm{Ci} / \mathrm{mL} \\
\mu \mathrm{Cl} / \mathrm{mL} \\
\mu \mathrm{Ci} / \mathrm{mL} \\
\mu \mathrm{Ci} / \mathrm{mL} \\
\mu \mathrm{Cl} / \mathrm{mL} \\
\mu \mathrm{Ci} / \mathrm{mL} \\
\mu \mathrm{Ci} / \mathrm{mL} \\
\mu \mathrm{Ci} / \mathrm{mL} \\
\mu \mathrm{Ci} / \mathrm{mL} \\
\mu \mathrm{Cl} / \mathrm{mL} \\
\mu \mathrm{Ci} / \mathrm{mL} \\
\mu \mathrm{Ci} / \mathrm{mL} \\
\mu \mathrm{Ci} / \mathrm{mL} \\
\mu \mathrm{Ci} / \mathrm{mL}\end{array}$ \\
\hline
\end{tabular}

\section{WELL TNX 7D}

MEASUREMENTS CONDUCTED IN THE FIELL

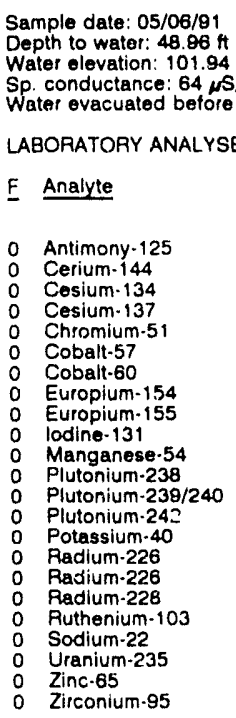

Time: $17: 40$

Time: $17: 4$

Alkalinity: $10 \mathrm{mg} / \mathrm{l}$ Water temperature: $21.3^{\circ} \mathrm{C}$ Water evacuated before sampling: $48 \mathrm{gal}$ LABORATORY ANALYSES

\begin{tabular}{|c|}
\hline Result \\
\hline 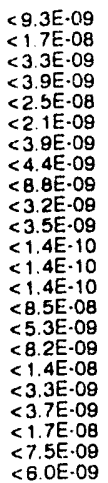 \\
\hline
\end{tabular}

WELL TNX 8D

MEASUREMENTS CONDUCTED IN THE FIELD

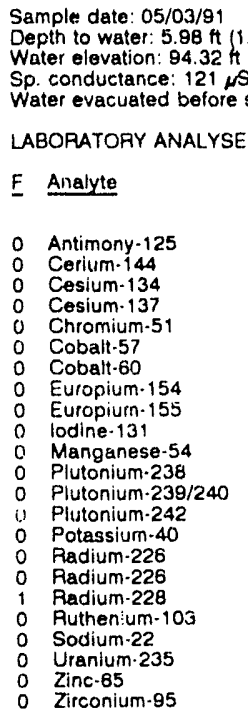

Alkalinity: $7 \mathrm{mg} /$ Nater temperature: $16.8^{\circ} \mathrm{C}$

Unit Lab

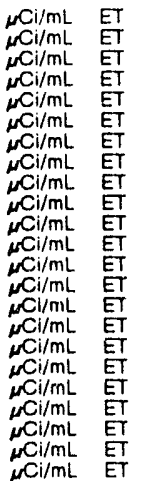

Depth to water: $5.98 \mathrm{ft}(1.82 \mathrm{~m})$ below TOC pling: $53 \mathrm{gal}$

LABORATORY ANALYSES

$<9.5 E \cdot 09$

$<3.4 \mathrm{E} .09$

$<3.8 \mathrm{E} .09$

$<2.5 \mathrm{E} \cdot 08$

$<3.7 \mathrm{E} \cdot 09$

$<4.5 \mathrm{E} \cdot 08$

$<8.6 E \cdot 09$

< 3. $4 \mathrm{E} \cdot 09$

< $3.6 \mathrm{E}-09$

< $1.2 \mathrm{2E} \cdot 10$

(.2E. 08 OE. 08

$2.0 E-08$
$<4.1 E-09$

$<.1 E .09$
$<8.6 E .09$

5. $3 E-09+1.3 \mathrm{E} \cdot 09$

$<3.4 \mathrm{E}-08$

$<3.7 \mathrm{E} .08$

$<1.8 \mathrm{E} \cdot 08$

$<B .2 \mathrm{E} \cdot 09$
$<6.6 \mathrm{E} \cdot 09$
WELL TNX 9D

MEASUREMENTS CONDUCTED IN THE FIELD

Sample date: 05/03/91

Depth to water: $7.48 \mathrm{Ht}(2.28 \mathrm{~m})$ below TOC

Water elevation: $84.21 \mathrm{ft}(28.72 \mathrm{~m}) \mathrm{ms}$

Water evacuated before sampling: $49 \mathrm{gal}$

Alkalinity: $1 \mathrm{mg} / \mathrm{L}$

Water temperature: $17.4^{\circ} \mathrm{C}$

LABORATORY ANALYSES

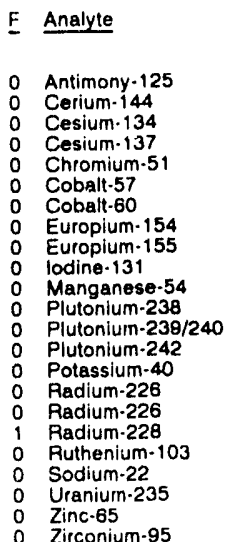

Result Unit Lab

$\begin{array}{lll}5.7 E .09 & \mu \mathrm{Cl} / \mathrm{mL} & \mathrm{ET} \\ <1.3 \mathrm{HE} .08 & \mathrm{\mu C} / \mathrm{mL} & \mathrm{ET}\end{array}$

$<2.2 \mathrm{E} .08$

$<2.4 \mathrm{E}-08$

$<1.5 \mathrm{E} \cdot 08$

$<2.2 E \cdot 08$

$<6.6 \mathrm{E}-00$

$<2.2 \mathrm{E}-09$
$<2.3 \mathrm{E}-09$
$<1.5 \mathrm{E}-10$

$<1.5 \mathrm{E}-10$

$<1.5 \mathrm{E} \cdot 10$

$7.6 \mathrm{E}-08 \pm 2.2 \mathrm{E} \cdot 0$

$4.0 \mathrm{E}-08 \pm 1.5 \mathrm{E}-00$

$<5.7 \mathrm{E}-0 \mathrm{O}$

$7.8 \mathrm{E} \cdot 09 \pm 2.0 \mathrm{E} \cdot 09$

$<2.2 \mathrm{E}-08$

$<2.4 \mathrm{E} \cdot 09$
$<1.3 \mathrm{E} \cdot 08$

$<4.3 E-08$

$<3.6 \mathrm{E} .09$

$\mathrm{NCl} / \mathrm{mL}$ ह

$\omega \mathrm{Ci} / \mathrm{mL}$

$\mu \mathrm{Cl} / \mathrm{mL}$

$\mathrm{MCl} / \mathrm{mL}$

$\mathrm{MCl} / \mathrm{mL}$

$\stackrel{\mathrm{C} i / \mathrm{mL}}{\mathrm{N}}$

$\mu \mathrm{Ci} / \mathrm{mL}$

$\mathrm{MCl} / \mathrm{mL}$

$\mu \mathrm{Ci} / \mathrm{mL}$

$\omega \mathrm{N} \mathrm{Ci} / \mathrm{mL}$

$\mu \mathrm{Ci} / \mathrm{mL}$

$\mathrm{Ci} / \mathrm{mL}$

$\omega \mathrm{Ci} / \mathrm{mL}$.

$\mathrm{rCi} / \mathrm{mL}$

WELL TNX 9D Replicate

MEASUREMENTS CONDUCTED IN THE FIELD

Sample date: $05 / 03 / 91$

Water elevation: $94.21 \mathrm{~h}(28.72 \mathrm{~m}) \mathrm{ms}$ |

Sp conductance: $192 \mu \mathrm{S} / \mathrm{cm}$

Water evacuated before sampling: $49 \mathrm{gal}$

Alkalinity: $1 \mathrm{mg} / \mathrm{h}$

Water temperature: $17.4^{\circ} \mathrm{C}$

LABORATORY ANALYSES

F Analyte

Result

Unit Lab

0 Antimony-125

Cerium-144

Cesium-134
0 Cesium.137

Chromium-51

Cobalt 57

Cobalt-60

Europium-154

lodine-131

Manganese-54

Plutonium-238

Plutonium-239/2

Plutonium-242

Potassium-40

Radium-226

Radium-228

Sodium-22

Uranium-235

Zinc-65

Zirconlum-95

$<5.5 E \cdot 09$
$<1.4 \mathrm{E} \cdot 08$
$<2.2 \mathrm{E} \cdot 09$
$<2.3 \mathrm{E} \cdot 09$
$<1.7 \mathrm{E} \cdot 08$
$<1.8 \mathrm{E} \cdot 09$
$<2.5 \mathrm{E} \cdot 09$
$<3.8 \mathrm{E} \cdot 09$
$<7.4 \mathrm{E} \cdot 09$
$<2.1 \mathrm{E} \cdot 09$
$<2.3 \mathrm{E} \cdot 09$
$<1.2 \mathrm{E} \cdot 10$
$<1.2 \mathrm{E}-10$
$<1.2 \mathrm{E}-10$
$<4.3 \mathrm{E} \cdot 09$
$<4.3 \mathrm{E} \cdot 09$
$<5.4 \mathrm{E} \cdot 09$
$1.1 \mathrm{E} \cdot 08 \pm 3.0 \mathrm{E} \cdot 09$
$<2.2 \mathrm{E} \cdot 09$
$<2.6 \mathrm{E} \cdot 09$
$<1.5 \mathrm{E} \cdot 08$
$<5.0 \mathrm{E} \cdot 09$
$<2.5 \mathrm{E} \cdot 09$

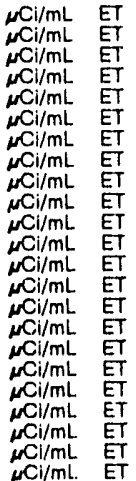

WELL TNX 10D

MEASUREMENTS CONDUCTED IN THE FIELD

Sample date: 05/03/91

Depth to water: $8.15 \mathrm{H}(2.48 \mathrm{~m})$ below TOC

Water elevation: $94.15 \mathrm{H}(28.70 \mathrm{~m}) \mathrm{ms}$ !

Sp. conductance: $165 \mu \mathrm{S} / \mathrm{cm}$

Water evacuated before sampling: $45 \mathrm{gal}$

LABORATORY ANALYSES

F Analyte

Result Unit Lab

0 Antimony-125

Cerium-144

Cesium.134

Chromium-5

Cobalt-57

Cobalt.60

\section{Time: $12: 20$}

Alkalinity: $1 \mathrm{mg}$

Water temperature: $18.0^{\circ} \mathrm{C}$

< $4.6 E .09$

$<1.1 E-08$

$<1.8 E \cdot 09$
$<1.9 \mathrm{E} \cdot 00$

$<1.4 \mathrm{E} .08$

$<1.4 \mathrm{E} .09$
$<1.8 \mathrm{E} .09$

$<3.1 E .09$
${ }_{\mu \mathrm{Ci} i / m \mathrm{~L}}$ ET

$\mu \mathrm{Ci} / \mathrm{ml}$ हT

$\mathrm{Ni} / \mathrm{mL}$ ET

$\mu \mathrm{Ci} / \mathrm{mL}$ EI
$\mu \mathrm{Ci} / \mathrm{mL}$ EI
$\mu \mathrm{CI} / \mathrm{mL}$ ET 
ANALYTICAL RESULTS

WELL TNX 100 collected on 05/03/91, laboratory analyses (cont.)

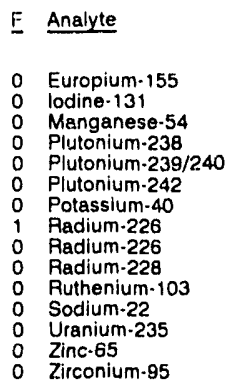

$\begin{aligned} & \text { Result } \\ & \\ &<5.9 E \cdot 09 \\ &<1.6 \mathrm{E} \cdot 09 \\ &<2.0 \mathrm{E} \cdot 09 \\ &<1.6 \mathrm{E} \cdot 10 \\ &<1.6 \mathrm{E} \cdot 10 \\ &<1.6 \mathrm{E} \cdot 10 \\ & 7.6 \mathrm{E} \cdot 08 \pm 2.6 \mathrm{E} \cdot 08 \\ & 9.6 \mathrm{E} \cdot 09 \pm 4.7 \mathrm{E}-09 \\ &<7.4 \mathrm{E} \cdot 09 \\ &<1.8 \mathrm{E} \cdot 08 \\ &<1.7 \mathrm{E} \cdot 09 \\ &<2.0 \mathrm{E} \cdot 09 \\ &<1.2 \mathrm{E}-08 \\ &<3.9 \mathrm{E} \cdot 09 \\ &<3.3 \mathrm{E} \cdot 09\end{aligned}$

\begin{tabular}{|c|c|}
\hline Unit & Lab \\
\hline 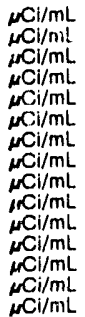 & $\begin{array}{l}E T \\
E T \\
E T \\
E T \\
E T \\
E T \\
E T \\
E T \\
E T \\
E T \\
E T \\
E T \\
E T \\
E T \\
E T\end{array}$ \\
\hline
\end{tabular}

WELL TNX 11D

MEASUREMENTS CONOUCTED IN THE FIELO

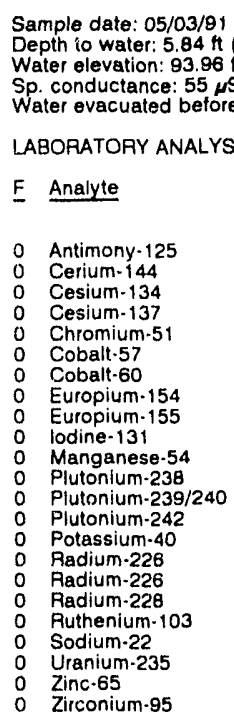

Time: 13:10

$\mathrm{pH}: 4.8$

Alkalinity: $1 \mathrm{mg} / \mathrm{h}$
Water temperature: $18.4^{\circ} \mathrm{C}$

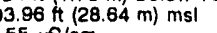

Water evacuated before sampling: $55 \mathrm{gal}$

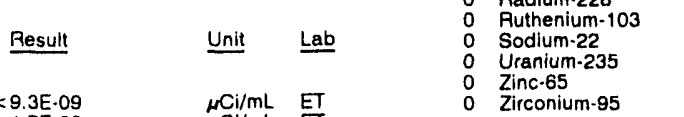

MEASUAEMENTS CONDUCTED IN THE FIELD

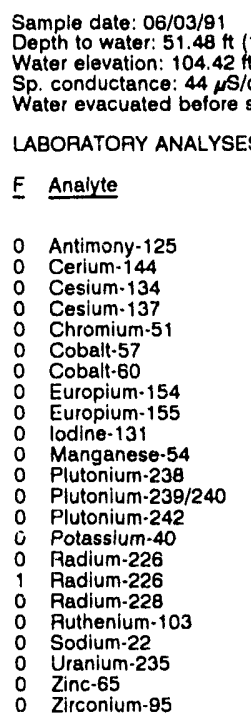

$<3.4 E .09$

$<4.1 \mathrm{E} \cdot 09$

$<2.6 \mathrm{E} .08$
$<2.1 \mathrm{E} .09$

$<3.6 \mathrm{E}-09$

$<4.5 E .09$

$<3.3 \mathrm{E}-09$

$<3.6 \mathrm{E} .09$

$<1.3 \mathrm{E}-10$

$<1.3 \mathrm{E} \cdot 10$

$<8.4 \mathrm{E} .08$

$<8.1 \mathrm{E} \cdot 09$

$<2.6 \mathrm{E}-08$

$<3.3 E-09$

$<1.8 \mathrm{E}-08$

$<7.5 \mathrm{E} \cdot 09$

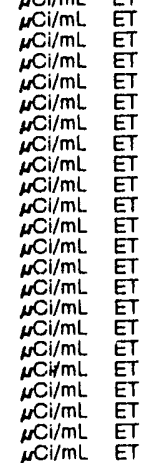

WELL TNX 12D

MEASUREMENTS CONDUCTED IN THE FIELD

Sample date: 05/03/91

Depth to water: $4.22 \mathrm{ft}(1.29 \mathrm{~m})$ below TOC

Sp conductance: $77 \mathrm{HS} / \mathrm{cm}$

Water evacuated before sampling: $57 \mathrm{gal}$

Time: $13: 40$

PH: 5.8

Water temperature: $18.4^{\circ} \mathrm{C}$

LABORATORY ANALYSES

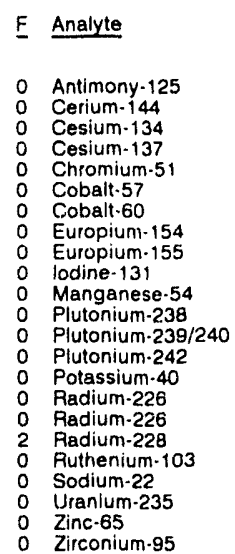

\begin{tabular}{|c|c|}
\hline Result & Unit \\
\hline $\begin{array}{l}<1.2 \mathrm{E} \cdot 08 \\
<2.1 \mathrm{E} \cdot 08 \\
<4.3 \mathrm{E} \cdot 09 \\
<4.8 \mathrm{E} \cdot 09 \\
<3.2 \mathrm{E} \cdot 08 \\
1.7 \mathrm{E}-09 \pm 1.9 \mathrm{E} \cdot 09 \\
<4.5 \mathrm{E} \cdot 09 \\
<5.9 \mathrm{E}-09 \\
<1.1 \mathrm{E} \cdot 08 \\
<4.3 \mathrm{E} \cdot 09 \\
<4.6 \mathrm{E} \cdot 09 \\
<9.6 \mathrm{E} \cdot 11 \\
<9.6 \mathrm{E} \cdot 11 \\
<9.6 \mathrm{E} \cdot 11 \\
<1.1 \mathrm{E} \cdot 07 \\
<1.0 \mathrm{E} \cdot 08 \\
<4.2 \mathrm{E} \cdot 09 \\
1.5 \mathrm{E} \cdot 08 \pm 4.0 \mathrm{E} \cdot 09 \\
<4.4 \mathrm{E}-08 \\
<5.4 \mathrm{E} \cdot 09 \\
<2.3 \mathrm{E} \cdot 08 \\
<1.1 \mathrm{E} \cdot 08 \\
<7.9 \mathrm{E} \cdot 09\end{array}$ & 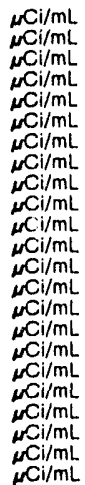 \\
\hline
\end{tabular}

WELL XSB 1B
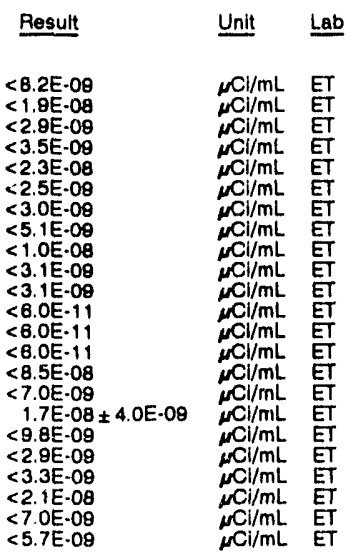

WELL XSB $1 \mathrm{~A}$

MEASUREMENTS CONDUCTED IN THE FIELO

\begin{tabular}{|c|c|c|c|}
\hline & \multicolumn{3}{|c|}{$\begin{array}{l}\text { Time: } 13: 50 \\
\text { pH: } 5.3 \\
\text { Alkalinity: } 2 \mathrm{mg} / \mathrm{L} \\
\text { Water temperature: } 21.8^{\circ} \mathrm{C}\end{array}$} \\
\hline \\
\hline $\begin{array}{l}\text { Sample date: } 08 / 03 / 91 \\
\text { Depth to water: } 56.64 \mathrm{Ht}(17.26 \mathrm{~m}) \text { below TO } \\
\text { Water elevation: } 99.36 \mathrm{tt}(30.29 \mathrm{~m}) \mathrm{msI} \\
\text { Sp. conductance: } 99 \mu \mathrm{s} / \mathrm{cm} \\
\text { Water evacuated betore sampling: } 146 \mathrm{gal} \\
\text { LABORATORY ANALYSES }\end{array}$ & Result & Unit & \multirow[b]{2}{*}{$\begin{array}{l}\text { Lab } \\
\text { ET } \\
\text { ET } \\
\text { EI } \\
E T \\
E T \\
E T \\
E T \\
E T \\
E T \\
E T \\
E T \\
E T \\
E T \\
E T \\
E T \\
E T \\
E T \\
E T \\
E T \\
E T \\
E T \\
E T \\
\text { ET }\end{array}$} \\
\hline $\begin{array}{l}\text { Antimony-125 } \\
\text { Cerium-144 } \\
\text { Cesium-134 } \\
\text { Cesium-137 } \\
\text { Chromium-51 } \\
\text { Cobalt-57 } \\
\text { Cobalt-60 } \\
\text { Europium-154 } \\
\text { Europium-155 } \\
\text { lodine-131 } \\
\text { Manganese-54 } \\
\text { Plutonium-238 } \\
\text { Plutonlum-239/ } \\
\text { Plutonlum-242 } \\
\text { Potassium-40 } \\
\text { Radlum-226 } \\
\text { Radium-228 } \\
\text { Radium-228 } \\
\text { Ruthenium-103 } \\
\text { Sodlum-22 } \\
\text { Uranium-235 } \\
\text { Zinc-65 } \\
\text { Zirconium-95 }\end{array}$ & $\begin{array}{l}<8.2 E-09 \\
<1.9 E-08 \\
<2.9 \mathrm{E}-09 \\
<3.5 \mathrm{E}-09 \\
<2.3 \mathrm{E}-08 \\
<2.5 \mathrm{E}-09 \\
<3.0 \mathrm{E}-09 \\
<5.1 \mathrm{E}-09 \\
<1.0 \mathrm{E}-08 \\
<3.1 \mathrm{E}-09 \\
<3.1 \mathrm{E}-09 \\
<6.0 \mathrm{E}-11 \\
<6.0 \mathrm{E}-11 \\
<8.0 \mathrm{E}-11 \\
<8.5 \mathrm{E}-08 \\
<7.0 \mathrm{E}-09 \\
1.7 \mathrm{E}-08 \pm 4.0 \mathrm{E}-09 \\
<9.8 \mathrm{\theta}-09 \\
<2.9 \mathrm{E}-09 \\
<3.3 \mathrm{E}-09 \\
<2.1 \mathrm{E}-00 \\
<7.0 \mathrm{E}-09 \\
<5.7 \mathrm{E}-09\end{array}$ & 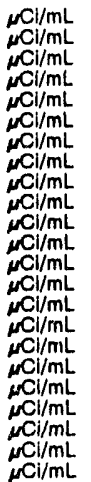 & \\
\hline
\end{tabular}

\section{Time: 13:35 \\ Alkalinity: $5 \mathrm{mg} /$ \\ Water temperature: $22.5^{\circ} \mathrm{C}$}

\begin{tabular}{|c|c|}
\hline Result & Unit \\
\hline $\begin{array}{l}5.9 \mathrm{E}-09 \\
1.4 \mathrm{E}-08 \\
2.1 \mathrm{E}-09 \\
2.4 \mathrm{E}-09 \\
1.7 \mathrm{E}-08 \\
1.8 \mathrm{E}-09 \\
2.8 \mathrm{E}-09 \\
3.7 \mathrm{E}-09 \\
7.6 \mathrm{E}-09 \\
2.2 \mathrm{E}-09 \\
2.3 \mathrm{E}-09 \\
8.3 \mathrm{E}-11 \\
5.8 \mathrm{E}-11 \\
5.8 \mathrm{E} \cdot 11 \\
8.8 \mathrm{E}-08 \pm 3.2 \mathrm{E}-08 \\
5.0 \mathrm{E} \cdot 09 \\
1.1 \mathrm{E}-08 \pm 3.0 \mathrm{E}-09 \\
1.5 \mathrm{E} \cdot 08 \\
2.1 \mathrm{E}-09 \\
2.7 \mathrm{E} \cdot 09 \\
7.0 \mathrm{E}-09 \\
5.5 \mathrm{E}-09 \\
3.9 \mathrm{E} \cdot 09\end{array}$ & 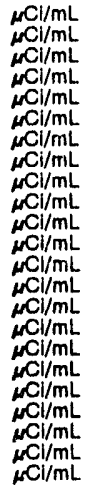 \\
\hline
\end{tabular}

WELL XSB 1D

MEASUREMENTS CONDUCTED IN THE FIELD

Sample date: 06/03/91

Depth to water: $56.14 \mathrm{ft}(17.11 \mathrm{~m})$ below TOC Water elevation: $99.86 \mathrm{ft}(30.44 \mathrm{~m}) \mathrm{ms}$

Sp conductance: $80 \mu \mathrm{S} / \mathrm{cm}$

Water evacuated before sampling: $31 \mathrm{gal}$

pH: 5.3 . 10

Water temperature: $22.8^{\circ} \mathrm{C}$

LABORATORY ANALYSES

\begin{tabular}{|c|c|c|}
\hline Analyte & Result & Unit \\
\hline $\begin{array}{ll}0 & \text { Antimony-125 } \\
0 & \text { Cerium-144 } \\
0 & \text { Cesium-134 } \\
0 & \text { Cesium-137 } \\
0 & \text { Chromium-51 } \\
0 & \text { Cobatt-57 } \\
0 & \text { Cobalt-60 } \\
0 & \text { Europium-154 }\end{array}$ & $\begin{array}{l}<1.2 \mathrm{E} \cdot 08 \\
<2.3 \mathrm{E} \cdot 08 \\
<4.4 \mathrm{E} \cdot 09 \\
<4.9 \mathrm{E} \cdot 09 \\
<3.4 \mathrm{E} \cdot 08 \\
<3.0 \mathrm{E} \cdot 09 \\
<5.3 \mathrm{E} \cdot 09 \\
<6.3 \mathrm{E} \cdot 09\end{array}$ & $\begin{array}{c}\mu \mathrm{Ci} / \mathrm{mL} \\
\mu \mathrm{Cl} / \mathrm{mL} \\
\mu \mathrm{Cl} / \mathrm{mL} \\
\mu \mathrm{Cl} / / \mathrm{mL} \\
\mu \mathrm{Cl} / \mathrm{mL} \\
\mu \mathrm{Cl} / \mathrm{mL} \\
\mu \mathrm{Cl} / \mathrm{mL} \\
\mu \mathrm{Cl} / \mathrm{mL}\end{array}$ \\
\hline
\end{tabular}


WELL XSB 1D collected on 06/03/91, laboratory analyses (cont.)
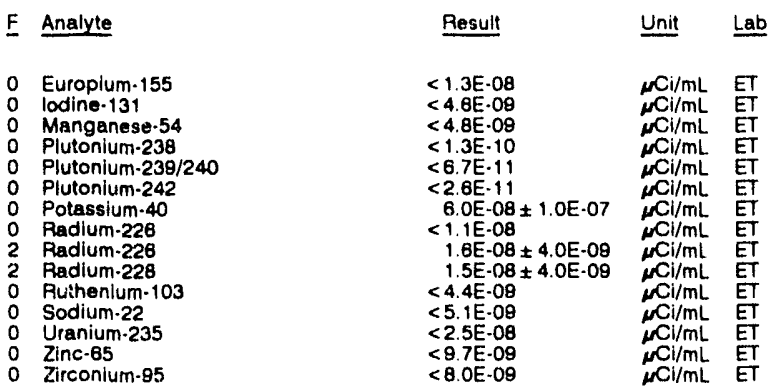

WELL XSB 2D

MEASUREMENTS CONDUCTED IN THE FIELD

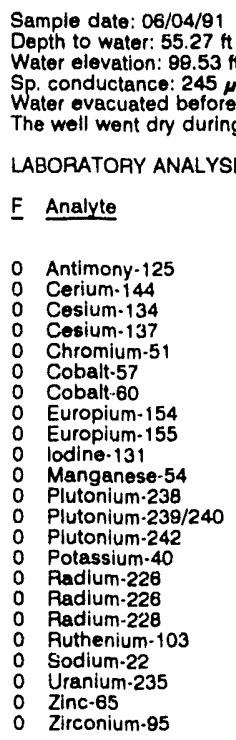

me: 8:30

pH: 8.6

Water temperature: $22.0^{\circ} \mathrm{C}$

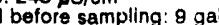

\section{LABORATORY ANALYSES}

$\begin{array}{lllll} & \text { Unit } & \text { Lab } & 0 & \text { Sodium-22 } \\ \text { Result } & 0 & \text { Uranium-235 } \\ & 0 & \text { Zinc-65 } \\ & 0 & \text { Zirconium-95 }\end{array}$

WELL XSB 4D

MEASUREMENTS CONDUCTED IN THE FIELD

Sample त ite: 06/04/91

$55.47 \mathrm{H}(16.81 \mathrm{~m})$ below TOC

Water elevation: $8 \theta .43 \mathrm{ft}(30.31 \mathrm{~m}) \mathrm{ms}$ )

Water evacuated before sampling: $41 \mathrm{gal}$

LABORATORY ANALYSES

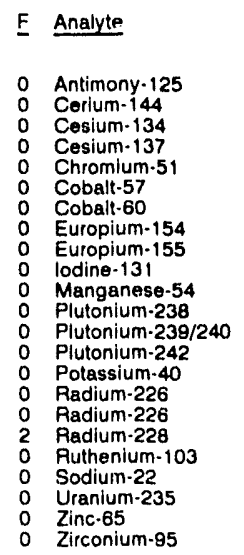

Result Unit Lab

WELL XSB 4D Replicate

MEASUREMENTS CONDUCTED IN THE FIELD

Sample date: $06 / 04 / 91 \mathrm{H}(16.91 \mathrm{~m})$ below TOC Water elevation: $88.43 \mathrm{tt}(30.31 \mathrm{~m}) \mathrm{msl}$ Water evacuated before sampling: $41 \mathrm{gal}$

LABORATORY ANALYSES

\begin{tabular}{|c|c|c|}
\hline Analyte & Result & Unit \\
\hline $\begin{array}{l}\text { Antimony-125 } \\
\text { Cerium-144 } \\
\text { Cesium-134 } \\
\text { Cesium-137 } \\
\text { Chromium-51 } \\
\text { Cobalt-57 } \\
\text { Cobalt-60 } \\
\text { Europium-154 } \\
\text { Europium-155 } \\
\text { lodine-131 } \\
\text { Manganese-54 } \\
\text { Plutonium-238 } \\
\text { Plutonium-239/240 } \\
\text { Plutonium-242 } \\
\text { Potassium-40 } \\
\text { Radium-226 } \\
\text { Radium-226 } \\
\text { Radium-228 } \\
\text { Ruthenlum-103 } \\
\text { Sodium-22 } \\
\text { Uranium-235 } \\
\text { Zinc-65 } \\
\text { Zirconium-95 }\end{array}$ & $\begin{aligned}<6.1 \mathrm{E} \cdot 09 \\
<1.4 \mathrm{E} \cdot 08 \\
<2.4 \mathrm{E}-09 \\
<2.5 \mathrm{E}-09 \\
<1.7 \mathrm{E} \cdot 08 \\
<1.8 \mathrm{E} \cdot 09 \\
<2.8 \mathrm{E} \cdot 09 \\
<3.7 \mathrm{E} \cdot 09 \\
<7.5 \mathrm{E} \cdot 09 \\
<2.4 \mathrm{E} \cdot 09 \\
<2.4 \mathrm{E} \cdot 09 \\
<1.0 \mathrm{E} \cdot 10 \\
<1.0 \mathrm{E} \cdot 10 \\
<1.0 \mathrm{E} \cdot 10 \\
9.3 \mathrm{E} \cdot 08 \pm 3.6 \mathrm{E} \cdot 08 \\
<5.6 \mathrm{E} \cdot 09 \\
7.7 \mathrm{E} \cdot 09 \pm 1.9 \mathrm{E} \cdot 09 \\
<1.9 \mathrm{E} \cdot 08 \\
<2.1 \mathrm{E}-09 \\
<2.4 \mathrm{E} \cdot 09 \\
<9.8 \mathrm{E} \cdot 09 \\
<5.3 \mathrm{E} \cdot 09 \\
<4.0 \mathrm{E} \cdot 09\end{aligned}$ & 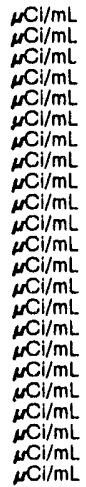 \\
\hline
\end{tabular}

WELL XSB $3 A$

MEASUREMENTS CONDUCTED IN THE FIELD

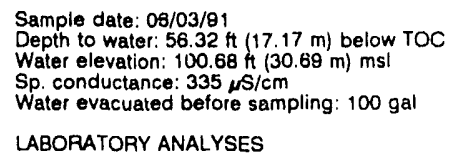

Time: 13:00

Alkalinity: $7 \mathrm{mg} / \mathrm{L}$

Water temperature: $21.3^{\circ} \mathrm{C}$

LLYSES

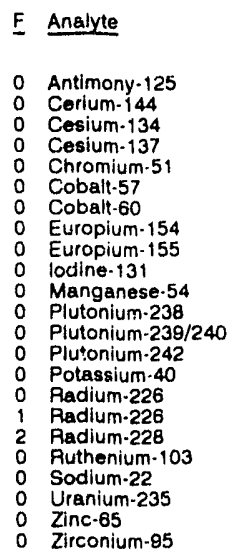

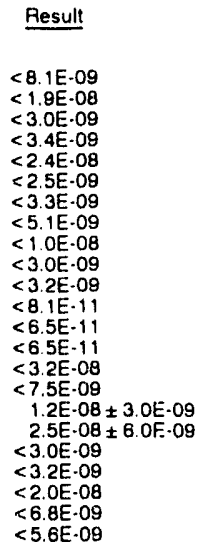

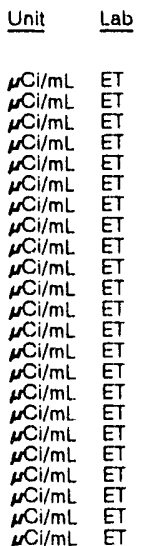

Time: $9 \cdot 55$

Alkalinity: $1 \mathrm{mg}$

Water temperature: $21.4^{\circ} \mathrm{C}$

$<1.9 E .08$

$<2.9 E .09$
$<3.4 E \cdot 09$

$<2.3 \mathrm{E} .08$

$<2.5 \mathrm{E}-09$
$<3.3 \mathrm{E}-09$

$<5.1 \mathrm{E} .09$

$<9.9 \mathrm{E}-09$

$<3.0 \mathrm{E} \cdot 00$

$<3.3 \mathrm{E} .00$

$<1.2 \mathrm{E} \cdot 10$
$<6.1 \mathrm{E} \cdot 11$

$<6.1 \mathrm{E}-11$

$<4.1 \mathrm{E} .08$

$<8.6 \mathrm{E} .09$

$4.3 \mathrm{E}-08 \pm 1.1 \mathrm{E}-08$

$<3.0 \mathrm{E} \cdot 09$

$<2.0 \mathrm{E}-08$

$<7.2 \mathrm{E}-09$
$<5.7 \mathrm{E}-09$

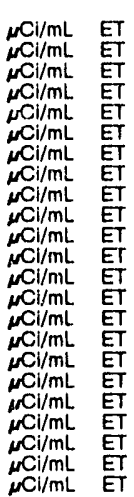

\section{Time: $9: 55$}

PH: 5.2 .2 Alkalinity: $1 \mathrm{mg} / \mathrm{L}$

$<9.2 E-11$

$<2.9 \mathrm{E}-11$
$<2.9 \mathrm{E}-11$

$<4.2 \mathrm{E}-08$

$<5.9 \mathrm{E}-09$

$<2.1 \mathrm{E} .08$

$<2.6 E-09$

$<5.3 \mathrm{E} .09$
$<4.2 \mathrm{E} .09$

$<1.4 \mathrm{E} .08$

$<2.5 \mathrm{E}-09$

$1.8 \mathrm{E} \cdot 0 \mathrm{0}$

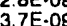

$7.5 \mathrm{E} \cdot 0 \mathrm{0}$

(2.4E.08

$1.0 \mathrm{E} \cdot$

$3 \mathrm{E} \cdot 08 \pm 3.6 \mathrm{E} \cdot 0 \mathrm{~B}$

$7.7 \mathrm{E} .09 \pm 1.9 \mathrm{E} \cdot 0$

$<1.9 \mathrm{E}-08$

$<2.4 \mathrm{E}-09$

$<5.3 \mathrm{E}-08$
$<4.0 \mathrm{E}-09$

$\omega \mathrm{CCl} / \mathrm{mL}$ ET

\section{WELL XSB 5A}

MEASUREMENTS CONDUCTED IN THE FIELD

\begin{tabular}{|c|c|c|c|c|}
\hline \multicolumn{2}{|r|}{$\begin{array}{l}\text { Sample date: } 06 / 05 / 91 \\
\text { Depth to water: } 13.02 \text { it }(4.15 \mathrm{~m}) \text { below TUC } \\
\text { Water elevation: } 98.38 \mathrm{Ht}(29.99 \mathrm{~m}) \mathrm{ms} \text { । } \\
\text { Sp. conductance: } 90 \mu \mathrm{s} / \mathrm{cm} \\
\text { Water eva }\end{array}$} & \multicolumn{3}{|c|}{$\begin{array}{l}\text { Time: } 9: 25 \\
\mathrm{pH}: 4.8 \\
\text { Alkalinity: } 0 \mathrm{mg} / \mathrm{L} \\
\text { Water temperature: } 19.4^{\circ} \mathrm{C}\end{array}$} \\
\hline \multicolumn{5}{|c|}{ LABORATORY ANALYSES } \\
\hline$\underline{E}$ & Analyte & Result & Unit & Lab \\
\hline $\begin{array}{l}0 \\
u \\
0 \\
0 \\
0 \\
0 \\
0 \\
0\end{array}$ & $\begin{array}{l}\text { Antimony-125 } \\
\text { Cerium- } 144 \\
\text { Cesium } 134 \\
\text { Cesium } 137 \\
\text { Chromium-51 } \\
\text { Cobalt }-57 \\
\text { Cobalt } 60 \\
\text { Europium } 154\end{array}$ & $\begin{array}{l}<7.8 \mathrm{E} \cdot 09 \\
<1.9 \mathrm{E} \cdot 08 \\
<3.1 \mathrm{E} \cdot 09 \\
<3.3 \mathrm{E} \cdot 09 \\
<2.3 \mathrm{E} \cdot 08 \\
<2.5 \mathrm{E} \cdot 09 \\
<3.1 \mathrm{E} \cdot 09 \\
<5.2 \mathrm{E} \cdot 09\end{array}$ & 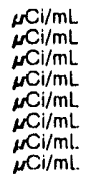 & $\begin{array}{l}E T \\
E T \\
E T \\
E T \\
E T \\
E T \\
E T \\
E T\end{array}$ \\
\hline
\end{tabular}


WELL XSB 5A collected on 06/05/91, laboratory analyses (cont.)

\begin{tabular}{|c|c|c|}
\hline Analyte & Result & Unit \\
\hline $\begin{array}{l}\text { Europium-155 } \\
\text { lodine-131 } \\
\text { Manganese-54 } \\
\text { Plutonium-238 } \\
\text { Plutonium-239/240 } \\
\text { Plutonium-242. } \\
\text { Potassium-40 } \\
\text { Radium-226 } \\
\text { Radium-228 } \\
\text { Radium-228 } \\
\text { Ruthenium-103 } \\
\text { Sodium.22 } \\
\text { Uranium-235 } \\
\text { Zinc-65 } \\
\text { Zirconium-95 }\end{array}$ & 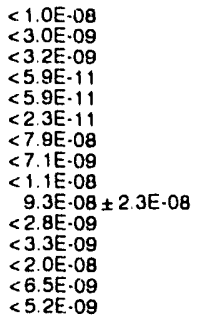 & 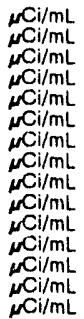 \\
\hline
\end{tabular}

WELL ZBG 1

MEASUREMENTS CONDUCTED IN THE FIELD

Sample date: 06/05/91

Depth to water: $56.65 \mathrm{ft}(17.27 \mathrm{~m})$ below TOC

Water elevation: $234.45 \mathrm{ft}(71.46 \mathrm{~m}) \mathrm{msl}$

Water evacuated betore sampling: $38 \mathrm{gal}$

Time: $12: 40$

pH: 5.7 Alkalinity: $2 \mathrm{mg} / \mathrm{L}$

Alkalinity: $2 \mathrm{mg} / \mathrm{L}$

LABORATORY ANALYSES

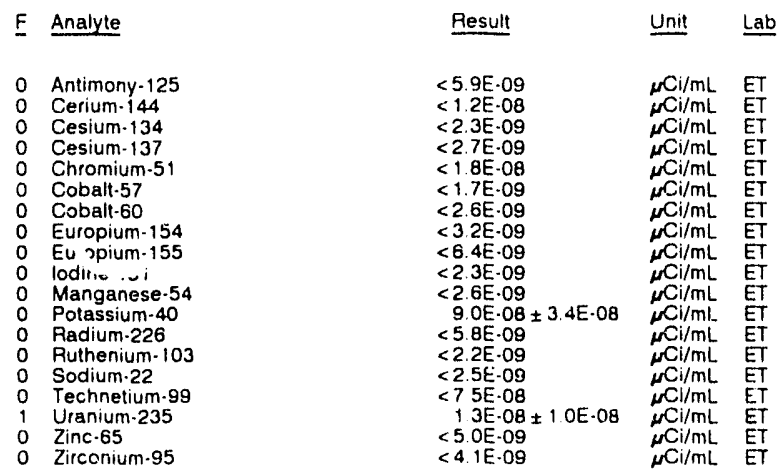

WELL ZBG 2

MEASUREMENTS CONDUCTED IN THE FIELD

Sample date: 06/05/91

Depth to water: $55.73 \mathrm{ft}(16.99 \mathrm{~m})$ below toC

Water elevation: $222.27 \mathrm{ht}(67.75 \mathrm{~m}) \mathrm{msl}$

Sp. conductance: $18 \mu \mathrm{S} / \mathrm{cm}$

Water evacuated before sampling: $30 \mathrm{gal}$

LABORATORY ANALYSES

F Analyte

Result

Time: 13:40

Alkalinity: $1 \mathrm{mg} / \mathrm{L}$

Water temperature: $20.5^{\circ} \mathrm{C}$

0 Antimony-125

Cerium-144

Cesium 134
Cesium 137

Chromium-51

Cobalt-57

Cobalt -57
Cobalt -60

Europium-154

Europium-155

Manganese-54

Potassium-40

Radiun-226

Rutnenium-103

Sodium-22

Technetium.99

Zinc.65

Zirconium-95

$<8.1 E .09$
$<2.0 E .08$

$<3.1 \mathrm{E} .09$
$<3.3 \mathrm{E} .09$

$<3.3 E .09$
$<23 E .08$

$<2$ 4E.09

$<3.3 E .09$

$<2 \mathrm{E} .09$
$<1 \mathrm{OE} .08$

$<1$ OE.08
$<30 E .09$

$<3.0 E \cdot 09$
$<33 \mathrm{E} .09$

$<8.6 E .08$

$<7.4 \mathrm{E} \cdot 09$

$<29 \mathrm{E} .09$
$<33 \mathrm{E} .09$

$<3$.

$<2.0 E-08$

$<2.0 \mathrm{E} \cdot 08$

$<7.2 \mathrm{E} .09$
$<5.5 \mathrm{E}-09$

Unit Lab

$\mu \mathrm{Ci} / \mathrm{mL}$ ET

$\mu \mathrm{Ci} / \mathrm{mL}$
$\mu \mathrm{CI} / \mathrm{mL}$

$\mu \mathrm{Ci} / \mathrm{mL}$ ET

$\mu \mathrm{Ci} / \mathrm{mL}$ ET

$\mu \mathrm{Cl} / \mathrm{mL}$ ET

$\mu \mathrm{Cl} / \mathrm{mL}$

$\mu \mathrm{Ci} / \mathrm{mL}$.

$\mu \mathrm{Cl} / \mathrm{mL}$ ET

$\mu \mathrm{Ci} / \mathrm{mL}$ ET

$\mu \mathrm{Ci} / \mathrm{mL}$ E

${ }_{\mu \mathrm{Ci} i / \mathrm{mL}} \mathrm{ET}$

Ci/mL ET

$\mu \mathrm{Ci} / \mathrm{mL}$ ET 


\section{APPENDIX C. Third Quarter Radionuclide Analyses}

\section{EXECUTIVE SUMMARY}

This section presents the radionuclide results for samples collected during third quarter 1991 and analyzed by Teledyne Isotopes. These results were not available for publication in the third quarter report.
One or more radionuclides exceeded Flag 2 during third quarter in four monitoring well series. Those groundwater monitoring sites with radionuclide constituents above Flag 2 during third quarter 1991 are listed in Table C1 , organized by location and well series.

Table C-1. Radionuclides Above Flag 2 Criteria During Third Quarter 1991

$\underline{\text { Site }}$

Well Analytes Above Flag 2 Criteria

Series Third Quarter 1991

200 Areas

F Area

F-Area Canyon Building

FCA

Strontium-90

F-Area Seepage Basins

FSB

Americium-241, radium-226, radium-228, strontium-89, strontium-90, uranium-233/234, uranium-238

\section{Area}

H-Area Seepage Basins

HSB

Cobalt-60, radium-226, radium-228, strontium-89, strontium-90

600 Areas

$T N X$

Old TNX Seepage Basin

Strontium-90

Table C-2 combines the Executive Summary table originally printed in the third quarter 1991 report with the radionuclide data

presented in 'Table C-1 above, and comprises all sites having any constituents detected above Flag 2 levels during third quarter. 


\section{THIRD QUARTER RADIONUCLIDE ANALYSES}

\section{Table C-2. Analytes Above Flag 2 Criteria During Third Quarter 1991}

$\underline{\text { Site }}$

Well

Analytes Above Flag 2 Criteria

Series

Third Quarter 1991

100 AREAS

C Area

C-Area Burning/Rubble Pit

CRP

'Total organic halogens, trichloroethylene, tritium

C-Area Disassembly Basin

$\mathrm{CDB} \quad$ Iron, lead, manganese, tritium

C-Area Reactor Seepage Basins

CSB

1,2-Dichloroethane, total organic halogens, tritium

K Area

K-Area Acid/Caustic Basin

KAC Iron, total organic halogens

K-Area Ash Basin

$\mathrm{KAB}$ Iron, manganese, specific conductance, total organic halogens, total radium

K-Area Burning/Rubble Pit

KRP

Iron, manganese, tetrachloroethylene, trichloroethylene

K-Area Coal Pile Runoff Containment Basin

$\mathrm{KCB}$

Manganese, specific conductance, total radium, tritium

K-Area Diesel Tank

$\mathrm{KDT}$

Manganese, tritium

K-Area Disassembly Basin

$\mathrm{KDB}$

Lead, Inanganese, tetrachloroethylene, total organic halogens, total radium, trichloroethylene, tritium

K-Area Reactor Seepage Basin

KSB

Tritium

\section{Area}

L-Area Acid/Caustic Basin

LAC Lead, tetrachloroethylene, trichloroethylene

L-Area Burning/Rubble Pit

LRP Lead

L-Area Disassembly Basin

LDB Lead, trichlorofluoromethane

L-Area Oil and Chemical Basin

LCO

Manganese, specific conductance, tetrachloroethylene, tritium

L-Area Reactor Seepage Basin

LSB

Lead, tritium 


\section{THIRD QUARTER RADIONUCLIDE ANALYSES}

Table C-2. Analytes Above Flag 2 Criteria During Third Quarter 1991 (cont.)

$\underline{\text { Site }}$

Well Analytes Above Flag 2 Criteria

Series l'hird Quarter 1991

100 AREAS (cont.)

\section{P Area}

P-Area Acid/Caustic Basin

PAC Iron, manganese, total organic halogens

P-Area Burning/Rubble Pit

PRP

Carbon tetrachloride, 1,1-dichloroethane, 1,2-dichloroethane, 1,1-dichloroethylene, lead, manganese, telrachloroethylene, total organic halogens, trichlorouthylene, tritium

P-Area Coal Pile Runoff Containment Basin

PCB

Iron, lead, manganese, nickel, specific conductance, sulfate, total radium

P-Area Disassembly Basin

PDB

Lead, tritium

P-Area Reactor Seepage Basins

PSB

Lead, tritium

\section{R Area}

R-Area Acid/Causıic Basin

RAC Lead

R-Area Burning/Rubble Pits

RRP

Chloroethene (vinyl chloride), 1,1-dichloroethane, iron

R-Area Disassembly Basin

RDB Iron, manganese

Series A, R-Area Reactor Seepage Basins

RSA Cadmium

Series B, R-Area Reactor Seepage Basins

RSB Cadmium

Series D, between R-Area Reactor Seepage Basins and R-Area Disassembly Basin

RSD Cadmium, gross alpha, nonvolatile beta

Series E, R-Area Reactor Seepage Basins

RSE

Cadmium, gross alpha, nonvolatile beta, tritium

Series F, R-Area Reactor Seepage Basins

RSF

'Tritium

Note: Analytes in bold were detected at levels above the current Flag 2 criteria for the first tine since 1984. 


\section{THIRD QUARTER RADIONUCLIDE ANALYSES}

Table C-2. Analytes Above Flag \& Criteria During Third Quarter 1991 (cont.)

$\underline{\text { Site }}$

Well Analytes Above Flag 2 Criteria

Series

200 AREAS

Burial Grounds (E Area)

Burial Grounds

BG

Aluminum, iron, lead, manganese, total carbon, total inorganic carbon, total radium, tritium

B rial Grounds Perimeter

BGO

Aluminum, antimony, chloroethene (vinyl chloride), 1,1-dichloroethane, iron, manganese, $\mathrm{pH}$, specific conductance, tetrachloroethylene, total organic halogens, lotal radium, trichlornethylene, tritium

E-Area Vaults Near the Burial Grounds BGX

Gross alpha, lead, manganese, nonvolatile beta, pH, specific conductance, total organic carbon, total radium, trichloroethylene, trichlorofluoromethane, tritium

Series C, Monitoring Grid Wells for Burial

MGC

Gross alpha, tritium Grounds

Series E, Monitoring Grid Wells for Burial

MGE

Nonvolatile beta, tritium

Grounds

Series G, Monitoring Grid Wells for Burial Grounds

MGG

Gross alpha, tritium

\section{F Area}

Burma Road Rubble Pit

BRR

Lead, manganese, total organic halogens, total radium, tritium

F Area and $\mathrm{H}$ Area

ZW

Tritium

F.Area Acid/Caustic Basin

FAC

Manganese, lotal organic halogens, total radium

F-Area A Line

FAL

1,2-Dichloroethane, lead, manganese, total organic halogens, total radium, trichloroethylene, trichlorofluoromethane

F-Area Burning/Rubble Pits

FBP

F-Area Canyon Building

FCA

Carbon tetrachloride, tetrachloroethylene, total organic halogens, trichloroethylene

1,1-Dichloroethane, gross alpha, lead, manganese, nitrate as nitrogen, nonvolatile beta, strontium-90, total organic halogens, total radium, trichloroethylene, trichlorofluoromethane

Note: Analytes in bold were detected above the current Flag 2 criteria for the first time since 1987. 


\section{Table C-2. Analytes Above Flag 2 Criteria During Third Quarter 1991 (cont.)}

Site

Well Analytes Above Flag 2 Criteria

200 AREAS (cont.)

F Area (cont.)

F-Area Coal Pile Runoff Containment Basin FCB

Iron, total organic carbon, total organic halogens, total radium

F-Area Seepage Basins

F

Gross alpha, nonvolatile beta, tritium

F-Area Seepage Basins

FSB

F-Area Sludge Land Application Site

FSS Iron, lead, manganese, total organic halogens, total radium, tritium

Between the F-Area Canyon Building and

Iron, lead, nitrate as nitrogen, specific conductance, trichloroethylene, tritium

F-Area Tank Farm

F'TF

Gross alpha, nonvolatile beta, $\mathrm{pH}$, total radium, tritium

Old F-Area Seepage Basin

FNB Manganese, nonvolatile beta, nitrate as nitrogen, total radium, trichloroethylene, tritium

\section{H Area}

H-Area Acid/Caustic Basin

HAC

Iron, total organic halogens, total radium, tritium

H-Area Canyon Building

HCA

H-Area Coal Pile Runorf Containment Basin

Iron, lear, manganese, tetrachloroethylene, total radium, trichlo oethylene, tritium

Gross alpha, iron, lead, manganese, specific conductance, sulfate, total radium, tritium

H-Area Effluent Treatment Cooling Water Basin

HET Iron, tritium

Note: Analytes in bold were detected at levels above the current Flag 2 criteria for the first time since 1984. 


\section{THIRD QUARTER RADIONUCLIDE ANALYSES}

Table C-2. Analytes Above Flag 2 Criteria During Third Quarter 1991 (cont.)

$\underline{\text { Site }}$

Well Analyles Above Flag 2 Criteria

Series $\quad$ Third Quarter 1991

200 AREAS (cont.)

H Area (cont.)

H-Area Seepage Basins

H-Area Seepage Basins

H-Area Sludge Land Application Site

H.Area Tank Farm

F Area and $\mathrm{H}$ Area

H-Area Retention Basin

Old H-Area Retention Basin

\section{S Area}

S-Area Defense Waste Processing Facility Background Wells

S.Area Vitrification Building

\section{Y Area}

Y-Area Waste Solidification and Disposal Facility

\section{Z Area}

Z-Area Low Point Drain Tank
$\mathrm{H}$

HSB

HSS

H'IF

ZW

HR8

HR3

$S B G$

SCA

YSC

$\mathrm{pH}$, specific conductance, total radium

Aluminum, antimony, arsenic, cadmium, cobalt, cobalt-60, gross alpha, iron, lead, manganese, mercury, nickel, nitrate as nitrogen, nonvolatile beta, $\mathrm{pH}$, radium-226, radium-228, specific conductance, strontium-89, strontium-90, tetrachloroethylene, total organic halogens, total radium, lotal silica, trichloroethylene, tritium, vanadium

Lead, lotal radium

Cadmium, lead, nitrate as nitrogen, nonvolatile beta, total radium, tritium

Tritium

Total radium, tritium

'Tritium

'Tetrachloroethylene, total radium, trichloroethylene, Iritium

Manganese, specific conductance, total radium, tritium

ZD'T' 'I'ritium 


\section{THIRD QUARTER RADIONUCLIDE ANALYSES}

\section{Table C-2. Analytes Above Flag 2 Criteria During Third Quarter 1991 (cont.)}

$\underline{\text { Site }}$

\section{0/700 AREAS}

A-Area Background Well near Firing Range

A-Area Burning/Rubble Pits

A/M Areas: Cluster Perimeter Wells and Plume Definition Wells

A-Area Coal Pile Runoff Conıainment Basin

A-Area Metals Burning Pit

M-Area Hazardous Waste Management Facility (HWMF)

M Area: Recovery Wells (also used for plume definition)

Metallurgical Laboratory Seepage Basin

Miscellaneous Chemical Basin

Motor Shop Oil Basin

Savannah River Laboratory (SRL)

Seepage Basins
Well Analytes Above Flag 2 Criteria

Series Third Quarter 1991

$\mathrm{ABW}$

1,1-Dichloroethylene, tetrachloroethylene, irichloroethylene

ARP

Trichloroethylene

$\mathrm{AC}$

1,1-Dichloroethylene, tetrachloroethylene, trichloroethylene

1,1-Dichloroethylene, manganese, tetrachloroethylene, total radium, trichloroethylene

ABP Lithium, manganese, $\mathrm{pH}$, phenols, specific conductance, tetrachloroethylene, total organic halogens, total radium, trichloroethylene

MSB Acetone, aluminum, dichlorodifluoromethane, 1,1-dichloroethylene, iron, lead, manganese, mercury, nitrate as nitrogen, nonvolatile beta, $\mathrm{pH}$, specific conductance, tetrachloroethylene, thallium, tin, total organic carbon, total organic halogens, total radium, 1,1,2-trichloroethane, trichloroethylene, tritium

RWM Chloroform, 1,1-dichloroethylene, trans-1,2dichloroethylene, nitrate as nitrogen, tetrachloroethylene, total organic halogens, total radium, 1,1,1-trichloroethane, trichloroethylene

AMB Iron, manganese, $\mathbf{p H}$, tetrachloroethylene, total organic halogens, total radium, trichloroethylene

MCB Lithium, manganese, $\mathrm{pH}$, specific conductance, tetrachloroethylene, total organic halogens, total radium, trichloroethylene

AOB Tetrachloroethylene, total organic halogens, total radium, trichloroethylene

ASB Chromium, lead, $\mathrm{pH}$, specific conductance, tetrachloroethylene, total organic halogens, total radium, irichloroethylene, tritium

Note: Analytes in bold were detected at levels above the current Flag 2 criteria for the first time since 1984. 


\section{THIRD QUARTER RADIONUCLIDE ANALYSES}

Table C-2. Analytes Above Flag 2 Criteria During Third Quarter 1991 (cont.)

$\underline{\text { Site }}$

Well Analytes Above Flag 2 Criteria

300/700 AREAS (cont.)

Silverton Road Waste Site

SRW

Carbon tetrachloride, 1,1-dichloroethylene, lead, tetrachloroethylene, total organic halogens, trichloroethylene

\section{AREA}

D Area

D-Area Burning/Rubble Pits

DBP

Iron, manganese

D-Area Coal Pile Runoff Containment Basin

DCB and Ash Basins

D-Area Oil Disposal Basin

DOB

Aluminum, beryllium, chromium, cobalt, gross alpha, iron, lead, lithium, manganese, nickel, nonvolatile beta, $\mathrm{pH}$, specific conductance, sulfate, tetrachloroethylene, total organic halogens, total radium, trichloroethylene, tritium

Iron, tetrachloroethylene, total organic halogens, trichloroethylene

\section{AREAS}

\section{Central Shops Area}

Central Shops Burning/Rubble Pit south of the Ford Building Seepage Basin

Central Shops Diesel Spill Characterization and Remediation Wells

Ford Building Seepage Basin

CBR

Total radium

CSD

$\mathrm{pH}$, total radium

HXB

Manganese, total organic halogens, total radium, tritium

\section{General Areas}

B-Area Microbiolo:sy Wells

$\mathrm{P}$

Benzene

Chemicals, Metals, and Pesticides

(CMP) Pits

CMP

1,2-Dichloroethane, iron, manganese, tetrachloroethylene, total organic carbon, total organic halogens, trichloroethylene, trichlor ? methane

Hazardous Waste/Mixed Waste Disposal

HMD

Manganese, tetrachloroethylene, $\ldots$ InroFacility

Note: Analytes in bold were delected at levels above the current Flag 2 criteria for the first time since 1984. 


\section{THIRD QUARTER RADIONUCLIDE ANALYSES}

\section{Table C-2. Analytes Above Flag 2 Criteria During Third Quarter 1991 (cont.)}

$\underline{\text { Site }}$

Well Analytes Above Flag 2 Criteria

600 AREAS (cont.)

General Areas (cont.)

Interim Waste Technology Site B:

IDB

Aluminum, iron, lead, $\mathrm{pH}$, specific conductance

Characterization Wells

Interim Waste Technology Site P:

IDP

Third Quarter 1991

Characterization Wells

Interim Waste Technology Site Q:

Characterization Wells

IDQ

Road A Chemical Basin (Baxley Road)

BRD

Sanitary Landfill

LFW

Sewage Sludge Application Sites

SSS

Aluminum, iron, $\mathrm{pH}$

Aluminum, iron, manganese, $\mathrm{pH}$

Lead, phenols, total organic halogens, total radium

Cadmium, chlorobenzene, chloroethane, chloroethene (vinyl chloride), chloromethane (methyl chloride), 1,4-dichlorobenzene, dichlorodifluoromethane, 1,1-dichloroethane, 1,2-dichloroethane, 1,1-dichloroethylene, iron, manganese, specific conductance, tetrachloroethylene, total organic carbon, total organic halogens, total radium, 1,1, 1 -trichloroethane, trichloroethylene, trichlorofluoromethane, tritium

\section{TNX}

New TNX Seepage Basin

Total organic halogens

Old TNX Seepage Basin

TNX Area: Assessment Wells

'TNX

INX Area: Background Wells

Iron, manganese, total radium

TNX Burying Grounds

'TBG

Carbon tetrachloride, iron, total organic halogens, strontium-90, trichloroethylene

Carbon tetrachloride, chloroethene (vinyl chloride), iron, manganese, nitrate as nitrogen, total organic carbon, total organic halogens, tetrachloroethylene, trichloroethylene

Iron, total organic halogens, total radium

Carbon tetrachloride, iron, manganese, nitrate as nitrogen, total organic halogens, total radium, trichloroethylene, trichlorofluoromethane

Note: Analytes in bold were detected above the current Flag 2 criteria for the first time since 1987. 


\section{THIRD QUARTER RADIONUCLIDE ANALYSES}

Table C-2. Analytes Above Flag 2 Criteria During Third Quarter 1991 (cont.)

Site

Well Analytes Above Flag 2 Criteria

Series Third Quarter 1991

Miscellaneous Well

F-Area Production Well

905103F Aluminum, iron

Note: Analytes in bold were detected at levels above the current Flag 2 criteria for the first time since 1984.

\section{REVIEW OF THE ANALYTICAL DATA}

A technical review of the quarter's analytical data identified at least one reported result for the analyses in Table C-3 as high in comparison to historical data. A review of the laboratory records did not reveal any problems with the analyses.

\section{Table C-3. Samples With High Ana- lytical Results Compared to Historical Data}

Analyte
Americium-241
Plutonium-238
Plutonium-
$239 / 240$

Plutonium-242

Radium-228

Strontium-89

Strontium-90

Thorium-228

Thorium-230

Uranium-238

\section{Wells}

FSB 79, FSB 79C, FSB 89D, FSB 92D

FSB 89D, FSB 91D, FSB106C

BGO $8 \mathrm{C}, \mathrm{BGO} 10 \mathrm{C}$,

BGO 15D, BGO 33C,

FBP 3A, FBP 4, FSB 78, FSB 78A, FSB 79, FSB 87A, FSB106C, HSB114D, TBG 7, TNX 2D, XSB 1B, XSB 2D, XSB 3A

ASB 8A, ASB 9, BGO 8C, BGO 9D, FSB 87A, FSB103C, FSB106C, HSB 85A,

HSB 86B, HSB105D, XSB 2D FSB 87B

HSB114D, TNX 9D, XSB 4D FSB 87A, FSB 88C, HSB 85A, HSB 86C, HSB101D, XSB 1D

XSB 4D

$\mathrm{XSB} \quad 1 \mathrm{~A}$

BGO 6C, FSB 78A

A technical review of the quarter's analytical data identified at least one reported result for the analyses in Table C-4 as low in comparison to historical data. A review of the laboratory records did not reveal any problems with the analyses.

Table C-4. Samples With Low Analytical Results Compared to Historical Data

$\begin{array}{ll}\text { Analyte } & \text { Wells } \\ \text { Americium-241 } & \text { ASB 3C, ASB 8TA, ASB 9B, } \\ & \text { ASB 10C, BGO 6C, BGO 9D, } \\ \text { Cesium-137 } & \text { FSB102C } \\ \text { Plutonium- } & \text { FBB 78 1A } \\ \text { 239/240 } & \\ \text { Radium-228 } & \text { FSB 78, FSB 79, FSB 79C, } \\ & \text { FSB 89D, HSB 84A, } \\ & \text { iSB 84A, HSB107D, } \\ \text { Strontium-90 } & \text { HSB111E, HSB116D } \\ \text { Thorium-228 } & \text { XSB 1B } \\ \text { Thorium-230 } & \text { BGB 129D } \\ & \text { FSB 87B, FSB 76B, FSB 79, } \\ & \text { FSB 90D, FSB 92D, FSB102C, } \\ & \text { FSB104D, FSB110D, } \\ \text { ThG 5A, TBG 5B, XSB 1B } \\ \text { Thorium-232 } & \text { BGO 6A, BGO 15D, } \\ & \text { FSB 87B, FSB 89D, FSB 92D, } \\ & \text { HSB137D } \\ \text { Uranium-235 } & \text { ASB 6TA, BGO 26D, } \\ & \text { BGO 30D, BGO 31C, } \\ & \text { BGO 31D, BGO 32D, } \\ & \text { BGO 33D, BGO 34D, } \\ & \text { BGO 36D, BGO 37D, FSB 78, } \\ & \text { FSB 91D, FSB 92D, FSB104D } \\ \text { Uranium-238 } & \text { ASB 3C, FSB 78, FSB 91D, } \\ & \text { TBG 5A, TBG 5B } \\ \text { Uranium- } & \text { BGO 10C, FSB 76C, FSB 78, } \\ 233 / 234 & \text { FSB 87B, FSB 91D, FSB 92D, } \\ & \text { FSB104D, FSB110D, XSB 3A } \\ & \end{array}$




\section{THIRD QUARTER RADIONUCLIDE ANALYSES}

Table C-5 lists analyses not performed by Teledyne Isotopes on wells that were not dry.

Table C-5. Analyses Not Performed by Teledyne Isotopes

Wells

$\underline{\text { Analytes }}$

Reason

BGO 40D

All scheduled radionuclides

Well pumped dry before samples could be collected

FCA 2C, FCA 10C, FCA 10D All scheduled radionuclides

Well bailed dry before samples could be collected

MSB 3D

All scheduled radionuclides

Well bailed dry of DNAPL before radionuclide samples could be collected

Table C-6 lists the methods and 90th percentile detection limits used by Teledyne Isotopes for radionuclide analyses.

Table C-6. Methods and Detection Limits Used by Teledyne for Radionuclides

Analyte
Americium-241
Antimony-125
Cerium-144
Cesium-134
Cesium-137
Cobalt-57
Cobalt-60
Europium-154
Manganese-54
Potassium-40
Plutonium-238
Plutonium-239/240
Plutonium-241
Plutonium-242
Radium-226
Radium-228
Ruthenium-103
Sodium-22
Strontium-89
Strontium-90
Technitium-99
Thorium-228
Thorium-230
Thorium-232
Uranium-233/234
Uranium-235
Uranium-238
Zinc-65

Method
PROO5232
TIMLGS01
TIMLGS01
'TIMLGS01
TIMLGS01
'TIMLGS01
'TIMLGS01
'TIMLGS01
TIMLGS01
'TIMLGS0'
'TIMLPU01
TIMLPU01
TIMLPU01
'TIMLPU01
'TIMLRA94
'TIMLRA94
'TIMLGS01
'TIMLGS01
'TIMLSR02
'TIMLSR02
PROO3278
TIMLGS01
PROO5232
PROO5232
PROO5232
PROO5232
PROO5232
TIMLGS01

Potection Limit

$2.0 \mathrm{E}-10 \mu \mathrm{Ci} / \mathrm{mL}$ 3.6E-08 $\mu \mathrm{Ci} / \mathrm{mL}$

$1.4 \mathrm{E}-07 \mu \mathrm{Ci} / \mathrm{mL}$ $1.5 \mathrm{E}-08 \mu \mathrm{Ci} / \mathrm{mL}$ $1.4 \mathrm{E}-08 \mu \mathrm{Ci} / \mathrm{mL}$ $1.9 \mathrm{E}-08 \mu \mathrm{Ci} / \mathrm{mL}$ $1.4 \mathrm{E}-08 \mu \mathrm{Ci} / \mathrm{mL}$ 4.0E-08 $\mu \mathrm{Ci} / \mathrm{mL}$ $1.5 \mathrm{E}-08 \mu \mathrm{Ci} / \mathrm{mL}$ $1.5 \mathrm{E}-07 \mu \mathrm{Ci} / \mathrm{mL}$ $4.0 \mathrm{E}-10 \mu \mathrm{Ci} / \mathrm{mL}$ 5.0E-10 $\mu \mathrm{Ci} / \mathrm{mL}$ $1.0 \mathrm{E}-10 \mu \mathrm{Ci} / \mathrm{mL}$ $3.0 \mathrm{E}-10 \mu \mathrm{Ci} / \mathrm{mL}$ $2.6 \mathrm{E}-08 \mu \mathrm{Ci} / \mathrm{mL}$ 1.0E-09 $\mu \mathrm{Ci} / \mathrm{mL}$ $6.5 \mathrm{E}-08 \mu \mathrm{Ci} / \mathrm{mL}$ $1.4 \mathrm{E}-08 \mu \mathrm{Ci} / \mathrm{mL}$ 8.3E-09 $\mu \mathrm{Ci} / \mathrm{mL}$ $1.5 \mathrm{E}-09 \mu \mathrm{Ci} / \mathrm{mL}$ 7.3E-09 $\mu \mathrm{Ci} / \mathrm{mL}$ 8.6E-09 $\mu \mathrm{Ci} / \mathrm{mL}$ $6.0 \mathrm{E} \cdot 10 \mu \mathrm{Ci} / \mathrm{mL}$ 4.0E- $10 \mu \mathrm{Ci} / \mathrm{mL}$ 1.1E-09 $\mu \mathrm{Ci} / \mathrm{mL}$ $5.0 \mathrm{E}-10 \mu \mathrm{Ci} / \mathrm{mL}$ $5.0 \mathrm{E}-10 \mu \mathrm{Ci} / \mathrm{mL}$ $3.5 \mathrm{E}-08 \mu \mathrm{Ci} / \mathrm{mL}$

\section{ANALYTICAL RESULTS}

The following tabular data contain only the radionuclicle results for samples collected during third quarter 1991 and their associated EPD/EMS blanks. 
The following abbreviations may appear in the tabular data.

$\mathrm{E}=$ exponential notation (e.g., $1.1 \mathrm{E}-09=1.1 \times 10^{-9}=0.0000000011$ )

$\mathrm{TE}=$ Teledyne Isotopes

$\mathrm{F}=$ Flag

$\mathrm{mg} / \mathrm{L}=$ milligrams per milliliter

$\mathrm{msl}=$ mean sea level

TOC $=$ top of casing

$\mu \mathrm{Ci} / \mathrm{mL}=$ microcuries per milliliter

$\mu \mathrm{S} / \mathrm{cm}=$ microsiemens per centimeter 
ANALYTICAL RESULTS

WELL ASB $1 A$

MEASUREMENTS CONDUCTED IN THE FIELD

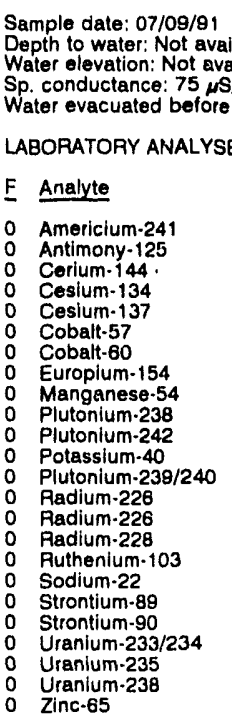

Time: 1r:40

PH: 5. .

Water temperature: $19.8^{\circ} \mathrm{C}$

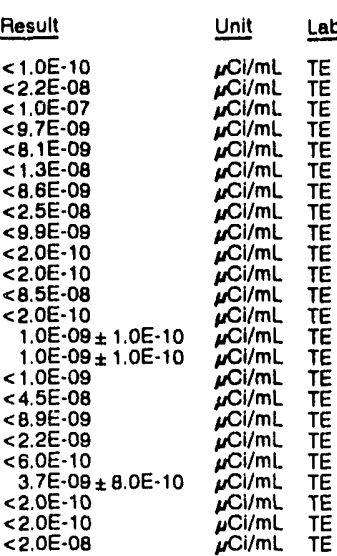

WELL ASB $2 A$

MEASUREMENTS CONDUCTED IN THE FIELD

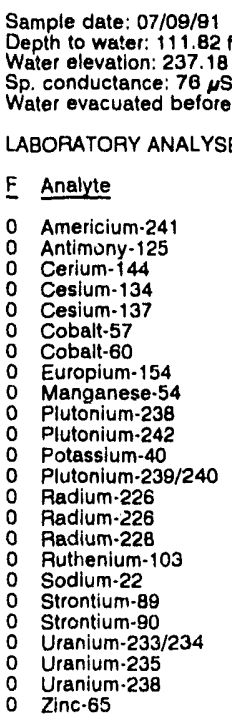

Ime: $11: 15$

PH: 5.8 . $5 \mathrm{mal}$

Water temperature: $19.8^{\circ} \mathrm{C}$

$2.0 \mathrm{E}-10 \pm 1.0 \mathrm{E}-10$
$<2.3 \mathrm{E}-08$
Result

$<2.0 \mathrm{E}-10$

$<2.9 \mathrm{E}-08$

$<1.1 \mathrm{E}-\mathrm{OB}$

$<1.1 \mathrm{E} \cdot 08$

$<1.6 \mathrm{E}-\mathrm{OB}$

$<1.1 E-08$
$<3.0 E-08$

$<1.2 \mathrm{E}-08$

$<1$. EE -10

$<1.0 \mathrm{E} \cdot 10$

$<1.2 E-07$

$1.2 \mathrm{E}-09 \pm 1.0 \mathrm{E}-10$

$1.2 \mathrm{E}-09 \pm 1.0 \mathrm{E}-10$

$1.2 E \cdot 09 \pm 7.0 E-10$

$<4.2 \mathrm{E}-08$

$<2.4 \mathrm{E}-09$

$<7.0 \mathrm{E} \cdot 10$

$2.0 \mathrm{E}-10 \pm 1.0 \mathrm{E}-10$

$<1.0 E-10$

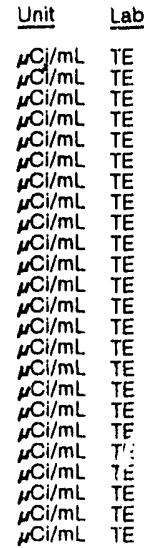

\section{WELL ASB 2C}

MEASUREMENTS CONDUCTED IN THE FIEL.D

Sample date: 09/19/91

Depth to water: $126.20 \mathrm{Ht}(38.47 \mathrm{~m})$ below TOC

Water elevation: $223.20 \%$

. conductance: $61 \mu \mathrm{s} / \mathrm{cm}$.

LABORATORY ANALYSES
E Analyte
0 Americium-241
Antimony-125
Cesium-134
$\begin{array}{ll}0 & \text { Cesium-137 } \\ 0 & \text { Cobalt }-57\end{array}$

Time: 10:20

$\mathrm{HH}: 5.8$

kalinity: $11 \mathrm{mg} / \mathrm{L}$

Water temperature: $19.4^{\circ} \mathrm{C}$

$1.0 E-10 \pm 1.0 E \cdot 10$

$<7.4 \mathrm{E}-09$

$<2.9 \mathrm{E} \cdot 0 \mathrm{0B}$

$<3.0 \mathrm{C}-09$
$<2.7 E \cdot 09$
$<3.9 E-09$
WELL ASB 2C collected on 09/19/81, laboratory analyses (cont)
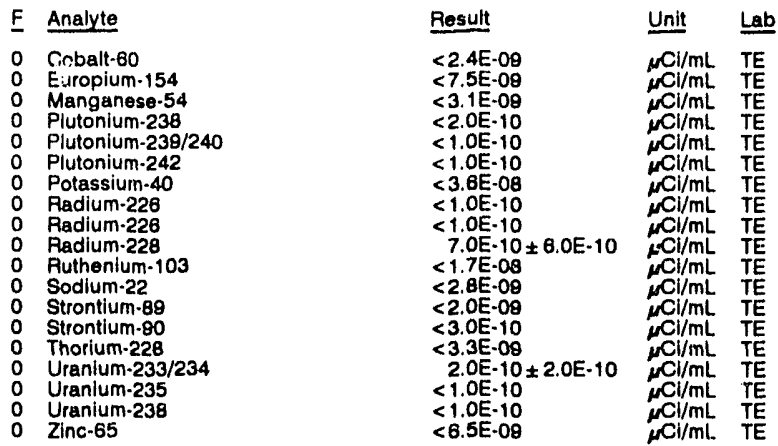

WELL ASB 3A

MEASUREMENTS CONDUCTED IN THE FIELD

$\begin{array}{ll}\text { Sample date: } 07 / 08 / 91 & \text { Time: } 12: 25 \\ \text { Depth to water: } 106.80 \mathrm{ft}(32.55 \mathrm{~m}) \text { below TOC } & \text { pH: } 5.6 \\ \text { Water elevation: } 238.20 \mathrm{ft}(72.60 \mathrm{~m}) \mathrm{ms} & \text { Alkalinity: } 8 \mathrm{mg} / \mathrm{h} \\ \text { Sp. conductance: } 52 \mu \mathrm{s} / \mathrm{cm} & \text { Water temperature: } 18.1^{\circ} \mathrm{C} \\ \text { Water evacuated before sampling: } 53 \mathrm{gal} & \end{array}$

Water evacuated before sampling: $53 \mathrm{gal}$

LABORATORY ANALYSES

\begin{tabular}{|c|c|c|c|}
\hline Analyte & Rosult & Unit & Lab \\
\hline $\begin{array}{ll}0 & \text { Americium-241 } \\
0 & \text { Antimony-125 } \\
0 & \text { Cerium-144 } \\
0 & \text { Cesium-134 } \\
0 & \text { Cesium-1377 } \\
0 & \text { Cobalt-57 } \\
0 & \text { Cobalt-80 } \\
0 & \text { Europium-154 } \\
0 & \text { Manganese-54 } \\
0 & \text { Plutonium-238 } \\
0 & \text { Plutonium-242 } \\
0 & \text { Potassium-40 } \\
0 & \text { Plutonium-238/240 } \\
0 & \text { Radium-226 } \\
0 & \text { Radium-226 } \\
0 & \text { Radium-228 } \\
0 & \text { Ruthenium-103 } \\
0 & \text { Sodium-22 } \\
0 & \text { Strontium-89 } \\
0 & \text { Strontium-90 } \\
0 & \text { Uranium-233/234 } \\
0 & \text { Uranium-235 } \\
0 & \text { Uranium-238 } \\
0 & \text { Zinc-65 }\end{array}$ & 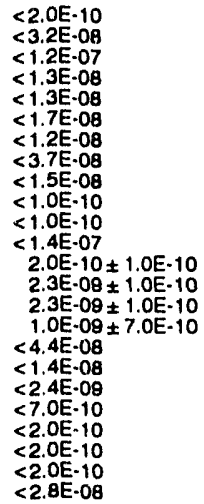 & 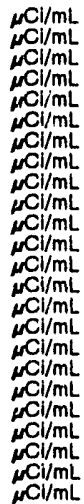 & $\begin{array}{l}\text { TE } \\
\text { TE } \\
\text { TE } \\
\text { TE } \\
\text { TE } \\
\text { TE } \\
\text { TE } \\
\text { TE } \\
\text { TE } \\
\text { TE } \\
\text { TE } \\
\text { TE } \\
\text { TE } \\
\text { TE } \\
\text { TE } \\
\text { TE } \\
\text { TE } \\
\text { TE } \\
\text { TE } \\
\text { TE } \\
\text { TE } \\
\text { TE }\end{array}$ \\
\hline
\end{tabular}

WELL ASB $3 C$

MEASUREMENTS CONDUCTED IN THE FIELD

\begin{tabular}{|c|c|c|c|c|c|}
\hline \multirow{2}{*}{\multicolumn{3}{|c|}{$\begin{array}{l}\text { Sample date: } 07 / 09 / 91 \\
\text { Depth to water: } 124.34 \mathrm{ft}(37.90 \mathrm{~m}) \text { below TOC } \\
\text { Water elevation: } 221.68 \mathrm{Ht}(67.58 \mathrm{~m}) \mathrm{msl} \\
\text { Sp. conductance: } 102 \mathrm{\mu S} / \mathrm{cm} \\
\text { Water evacuated before sampling: } 244 \mathrm{gal} \\
\text { LABORATORY ANALYSES }\end{array}$}} & \multicolumn{3}{|c|}{$\begin{array}{l}\text { Time: } 12: 40 \\
\text { pH: } 6.2 \\
\text { Alkalinity: } 27 \mathrm{mg} / \mathrm{h} \\
\text { Water temperature: } 19.3^{\circ} \mathrm{C}\end{array}$} \\
\hline & & & & & \\
\hline & Analyte & \multicolumn{2}{|c|}{ Result } & Unit & Lab \\
\hline & $\begin{array}{l}\text { Americium-241 } \\
\text { Antimony-125 } \\
\text { Cerium-144 } \\
\text { Cesium-134 } \\
\text { Ceslum-137 } \\
\text { Cobalt-57 } \\
\text { Cobalt-60 } \\
\text { Europium-154 } \\
\text { Manganese-54 } \\
\text { Plutonium-238 } \\
\text { Plutonium-242 } \\
\text { Potasslum-40 } \\
\text { Plutonium-239/240 } \\
\text { Padium-226 } \\
\text { Padium-226 } \\
\text { Padium-228 } \\
\text { Ruthenium-103 } \\
\text { Sodium-22 } \\
\text { Strontium-89 } \\
\text { Strontium-90 } \\
\text { Uranium-233/234 } \\
\text { Uranium-235 } \\
\text { Uranium-238 }\end{array}$ & \multicolumn{2}{|c|}{ 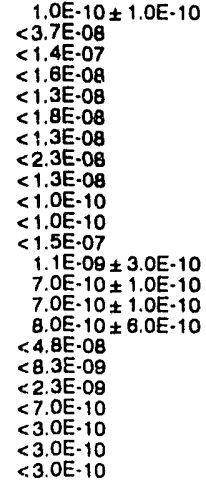 } & 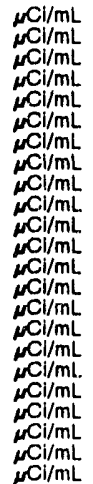 & $\begin{array}{l}\text { TE } \\
\text { TE } \\
\text { TE } \\
\text { TE } \\
\text { TE } \\
\text { TE } \\
\text { TE } \\
\text { TE } \\
\text { TE } \\
\text { TE } \\
\text { TE } \\
\text { TE } \\
\text { TE } \\
\text { TE } \\
\text { TE } \\
\text { TE } \\
\text { TE } \\
\text { TE } \\
\text { TE } \\
\text { TE } \\
T E \\
T E \\
T E\end{array}$ \\
\hline
\end{tabular}




\section{ANALYTICAL RESULTS}

WELL ASB 3C collected on 07/09/91, laboratory analyses (cont.)

\begin{tabular}{|c|c|c|}
\hline F Analyte & Result & Unit \\
\hline $0 \quad$ Zinc.65 & $<3.4 E-08$ & $\mu \mathrm{Cl} / \mathrm{mL}$ \\
\hline
\end{tabular}

WELL ASB 5A

MEASUREMENTS CONDUCTED IN THE FIELD

Sample date: $07 / 09 / 91$

Depth to water: $108.87 \mathrm{nt}(33.18 \mathrm{~m})$ below TOC

Water elevation: $236.13 \mathrm{ft}$ (7)

Sp. conductance: $47 \mu \mathrm{s} / \mathrm{cm}$

LABORATORY ANALYSES

\begin{tabular}{|c|c|c|c|c|}
\hline$\underline{F}$ & Analyte & Result & Unit & Lab \\
\hline $\begin{array}{l}0 \\
0 \\
0 \\
0 \\
0 \\
0 \\
0 \\
0 \\
0 \\
0 \\
0 \\
0 \\
0 \\
0 \\
0 \\
0 \\
0 \\
0 \\
0 \\
0 \\
0 \\
0 \\
0 \\
0\end{array}$ & $\begin{array}{l}\text { Americium-241 } \\
\text { Antimony-125 } \\
\text { Cerium-144 } \\
\text { Cesium-134 } \\
\text { Cesium-137 } \\
\text { Cobalt-57 } \\
\text { Cobalt-60 } \\
\text { Europium-154 } \\
\text { Manganese-54 } \\
\text { Plutoniurn-238 } \\
\text { Plutonium-242 } \\
\text { Potassium-40 } \\
\text { Plutonium-239/240 } \\
\text { Radium-226 } \\
\text { Radium-226 } \\
\text { Radium-228 } \\
\text { Authenium-103 } \\
\text { Sodium-22 } \\
\text { Strontium-89 } \\
\text { Strontium-90 } \\
\text { Uranium-233/234 } \\
\text { Uranium-235 } \\
\text { Uranium-238 } \\
\text { Zinc-65 }\end{array}$ & $\begin{aligned}<1.0 \mathrm{E} \cdot 10 \\
<3.3 \mathrm{E}-08 \\
<1.4 \mathrm{E} \cdot 07 \\
<1.6 \mathrm{E}-08 \\
<1.5 \mathrm{E}-08 \\
<1.7 \mathrm{E} \cdot 08 \\
<9.9 \mathrm{E} \cdot 09 \\
<4.8 \mathrm{E} \cdot 08 \\
<1.4 \mathrm{E} \cdot 08 \\
<1.0 \mathrm{E}-10 \\
<1.0 \mathrm{E} \cdot 10 \\
<1.4 \mathrm{E}-07 \\
<1.0 \mathrm{E} \cdot 10 \\
1.5 \mathrm{E} \cdot 09 \pm 1.0 \mathrm{E} \cdot 10 \\
1.5 \mathrm{E}-09 \pm 1.0 \mathrm{E}-10 \\
1.0 \mathrm{E}-09 \pm 8.0 \mathrm{E} \cdot 10 \\
<4.5 \mathrm{E}-08 \\
<1.7 \mathrm{E}-08 \\
<2.4 \mathrm{E} \cdot 09 \\
<7.0 \mathrm{E}-10 \\
3.0 \mathrm{E}-10 \pm 3.0 \mathrm{E}-10 \\
<2.0 \mathrm{E}-10 \\
<2.0 \mathrm{E}-10 \\
<3.1 \mathrm{E}-08\end{aligned}$ & 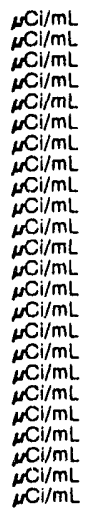 & $\begin{array}{l}\text { TE } \\
T E \\
T E \\
T E \\
T E \\
T E \\
T E \\
T E \\
T E \\
T E \\
T E \\
T E \\
T E \\
T E \\
T E \\
T E \\
T E \\
T E \\
T E \\
T E \\
T E \\
T E \\
T E \\
T E\end{array}$ \\
\hline
\end{tabular}

WELL ASB $6 A$

MEASUREMENTS CONDUCTED IN THE FIELD

\begin{tabular}{|c|c|c|c|c|c|}
\hline \multicolumn{3}{|c|}{$\begin{array}{l}\text { Sample date: } 07 / 09 / 91 \\
\text { Depth to water: } 114.85 \mathrm{H}(35.01 \mathrm{~m}) \text { below TOC } \\
\text { Water elevation: } 235.35 \mathrm{Ht}(71.74 \mathrm{~m}) \mathrm{msl} \\
\text { Sp. conductance: } 89 \mu \mathrm{si} / \mathrm{cm} \\
\text { Water evacuated before sampling: } 45 \mathrm{gal}\end{array}$} & \multicolumn{3}{|c|}{$\begin{array}{l}\text { Time: } 10: 15 \\
\text { pH: } 4.9 \\
\text { Alkalinity: } 0 \mathrm{mg} / \mathrm{h} \\
\text { Water temperature: } 19.6 \circ \mathrm{C}\end{array}$} \\
\hline \multicolumn{6}{|c|}{ LABORATORY ANALYSES } \\
\hline$\underline{E}$ & Analyte & Result & & Unit & Lab \\
\hline $\begin{array}{l}0 \\
0 \\
0 \\
0 \\
0 \\
0 \\
0 \\
0 \\
0 \\
0 \\
0 \\
0 \\
0 \\
0 \\
0 \\
0 \\
0 \\
0 \\
0 \\
0 \\
0 \\
0 \\
0 \\
0 \\
0\end{array}$ & $\begin{array}{l}\text { Americium-241 } \\
\text { Antimony-125 } \\
\text { Cerium-144 } \\
\text { Cesium-134 } \\
\text { Cesium-137 } \\
\text { Cobalt-57 } \\
\text { Cobalt-60 } \\
\text { Europium-154 } \\
\text { Manganese-54 } \\
\text { Plutonium-238 } \\
\text { Plutonium-242 } \\
\text { Potassium-40 } \\
\text { Plutonium-238/240 } \\
\text { Radium-226 } \\
\text { Radium-226 } \\
\text { Radium-228 } \\
\text { Ruthenium-103 } \\
\text { Sodium-22 } \\
\text { Strontiurn-89 } \\
\text { Strontium-90 } \\
\text { Uranium-233/234 } \\
\text { Uranium-235 } \\
\text { Uranium-238 } \\
\text { Zinc-65 }\end{array}$ & $\begin{aligned}<1.0 \mathrm{E} \\
<3.0 \mathrm{E} \\
<1.1 \mathrm{E} \\
<1.3 \mathrm{E} \\
<1.1 \mathrm{E} \\
<1.4 \mathrm{E} \\
<7.0 \mathrm{E} \\
<3.2 \mathrm{E} \\
<1.2 \mathrm{E} \\
<1.0 \mathrm{E} \\
<1.0 \mathrm{E} \\
<1.1 \mathrm{E} \\
4.0 \mathrm{E} \\
1.9 \mathrm{E} \\
1.9 \mathrm{E} \\
<9.0 \mathrm{E} \\
<3.7 \mathrm{E} \\
<1.1 \mathrm{E} \\
<2.2 \mathrm{E} \\
<7.0 \mathrm{E} \\
4.6 \mathrm{E} \\
<7.0 \mathrm{E} \\
5.3 \mathrm{E} \\
<2.2 \mathrm{E}\end{aligned}$ & $\begin{array}{l}-10 \\
.08 \\
.07 \\
.08 \\
.08 \\
.08 \\
.09 \\
-08 \\
.08 \\
.10 \\
.10 \\
.07 \\
-10 \pm 2.0 E-10 \\
.09 \pm 6.0 E-10 \\
.09 \pm 6.0 E-10 \\
.10 \\
.08 \\
.08 \\
.09 \\
-10 \\
09 \pm 1.4 E-09 \\
10 \\
09 \pm 7.0 E-10 \\
.08\end{array}$ & 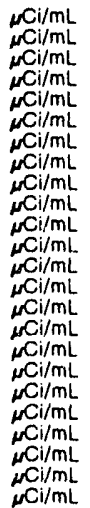 & $\begin{array}{l}\text { TE } \\
T E \\
T E \\
T E \\
T E \\
T E \\
T E \\
T E \\
T E \\
T E \\
T E \\
T E \\
T E \\
T E \\
T E \\
T E \\
T E \\
T E \\
T E \\
T E \\
T E \\
T E \\
T E \\
T E \\
T E\end{array}$ \\
\hline
\end{tabular}

WELL ASB 6C

MEASUREMENTS CONDUCTED IN THE FIELD

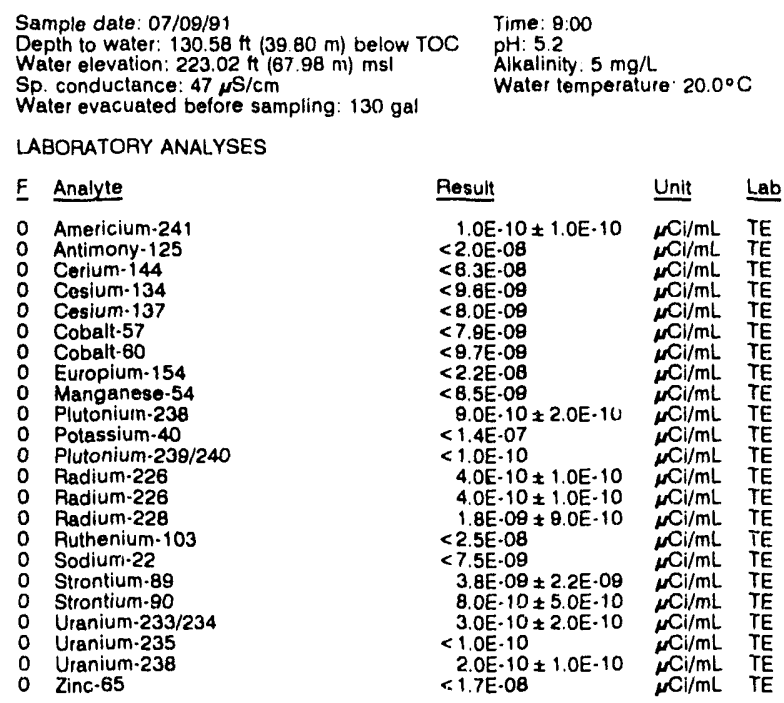

\section{WELL ASB 6TA}

MEASUREMENTS CONOUCTED IN THE FIELD

\begin{tabular}{|c|c|c|c|c|c|}
\hline & $\begin{array}{l}\text { nple date: } 07 / 09 / 91 \\
\text { pth to water: } 140.70 \mathrm{H}(42.89 \mathrm{~m}) \text { below } \\
\text { ter elevation: } 212.20 \mathrm{H} / 64.68 \mathrm{~m}) \mathrm{msl} \\
\text { conductance: } 767 \mu \mathrm{S} / \mathrm{cm} \\
\text { ler evacuated before sampling: } 37 \mathrm{gal} \\
\text { well went dry during purging. }\end{array}$ & & $\begin{array}{l}\text { Time: } 13: 15 \\
\text { pH: } 11.4 \\
\text { Alkalinity: } 164 \\
\text { Water tempera }\end{array}$ & ng/h: $21.0^{\circ}$ & \\
\hline & BORATORY ANALYSES & & & & \\
\hline$\underline{\mathbf{F}}$ & Analyte & Result & & Unit & $\underline{L a b}$ \\
\hline $\begin{array}{l}0 \\
0 \\
0 \\
0 \\
0 \\
0 \\
0 \\
0 \\
0 \\
0 \\
0 \\
0 \\
0 \\
0 \\
0 \\
0 \\
0 \\
0 \\
0 \\
0 \\
0 \\
0 \\
0 \\
0\end{array}$ & $\begin{array}{l}\text { Americiuin-241 } \\
\text { Antimony-125 } \\
\text { Cerium- } 144 \\
\text { Cesium-134 } \\
\text { Cesium-137 } \\
\text { Cobait-57 } \\
\text { Cobalt-60 } \\
\text { Europium-154 } \\
\text { Manganese-54 } \\
\text { Plutonium-238 } \\
\text { Plutonium-242 } \\
\text { Potassium-40 } \\
\text { Plutonium-238/240 } \\
\text { Radium-226 } \\
\text { Padium-226 } \\
\text { Padium-228 } \\
\text { Ruthenium-103 } \\
\text { Sodium-22 } \\
\text { Strontium- } 89 \\
\text { Strontium- } 90 \\
\text { Uranium-233/234 } \\
\text { Uranium-235 } \\
\text { Uranium-238 } \\
\text { Zinc- } 65\end{array}$ & $\begin{array}{l}<1.0 E \\
<3.2 E \\
<1.3 E \\
<1.5 E \\
<1.3 E \\
<1.8 E \\
<1.3 E \\
<3.9 E \\
<1.4 E \\
<2.0 E \\
<2.0 E \\
<1.3 E \\
5.0 E \\
4.0 E \\
<2.7 E \\
2.2 E \\
<4.6 E \\
<1.4 E \\
<1.6 E \\
<5.0 E \\
2.6 E \\
<3.0 E \\
<3.0 E \\
<40 E\end{array}$ & $\begin{array}{l}E \cdot 10 \\
E \cdot 08 \\
E \cdot 07 \\
E \cdot 08 \\
E \cdot 08 \\
E \cdot 08 \\
E \cdot 08 \\
E \cdot 08 \\
E \cdot 08 \\
E \cdot 10 \\
E \cdot 10 \\
E \cdot 07 \\
E \cdot 10 \pm 3.0 E-10 \\
E-10 \pm 1.0 E-10 \\
E \cdot 08 \\
E-09 \pm 1.0 E-09 \\
E \cdot 08 \\
E \cdot 08 \\
E-09 \\
E-10 \\
E-09 \pm 8.0 E-10 \\
E-10 \\
E \cdot 10 \\
E-08\end{array}$ & 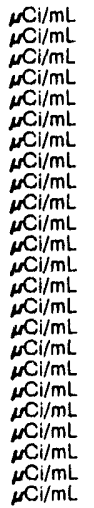 & $\begin{array}{l}\text { TE } \\
\text { TE } \\
\text { TE } \\
\text { TE } \\
\text { TE } \\
\text { TE } \\
\text { TE } \\
\text { TE } \\
\text { TE } \\
\text { TE } \\
\text { TE } \\
\text { TE } \\
\text { TE } \\
\text { TE } \\
\text { TE } \\
\text { TE } \\
\text { TE } \\
\text { TE } \\
\text { JE } \\
\text { TE } \\
\text { TE } \\
\text { TE } \\
\text { TE }\end{array}$ \\
\hline
\end{tabular}

WELL ASB 7

MEASUREMENTS CONDUCTED IN THE FIELD

\begin{tabular}{|c|c|c|c|c|c|}
\hline \multirow{2}{*}{\multicolumn{3}{|c|}{$\begin{array}{l}\text { Sample date: } 07 / 09 / 91 \\
\text { Depth to water: } 119.44 \mathrm{Ht}(36.41 \mathrm{~m}) \text { below TOC } \\
\text { Water elevation: } 233.96 \mathrm{H}(71.31 \mathrm{~m}) \mathrm{ms} \\
\text { Sp. conductance: } 87 \mathrm{HS} / \mathrm{cm} \\
\text { Water evacuated before sampling: } 59 \mathrm{gal} \\
\text { LABORATORY ANALYSES }\end{array}$}} & \multicolumn{3}{|c|}{$\begin{array}{l}\text { Time: } \mathbf{9}: 45 \\
\text { pH: } 4.7 \\
\text { Alkalinity: } 0 \mathrm{mg} / \mathrm{L} \\
\text { Water temperature: } 19.9^{\circ} \mathrm{C}\end{array}$} \\
\hline & & & & & \\
\hline & Analyte & \multicolumn{2}{|c|}{ Result } & Unit & $\underline{\text { Lab }}$ \\
\hline & $\begin{array}{l}\text { Americium-241 } \\
\text { Antimony- } 125 \\
\text { Cerium-144 } \\
\text { Cesium-134 } \\
\text { Cesium-137 } \\
\text { Cobalt-57 } \\
\text { Cobalt } 60\end{array}$ & \multicolumn{2}{|c|}{$\begin{array}{l}<1.0 \mathrm{E} \cdot 10 \\
<3.0 \mathrm{E} \cdot 08 \\
<1.4 \mathrm{E}-07 \\
<1.4 \mathrm{E} \cdot 08 \\
<1.3 \mathrm{E} \cdot 08 \\
<1.8 \mathrm{E}-08 \\
<1.1 \mathrm{E}-08\end{array}$} & 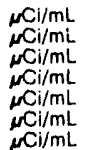 & $\begin{array}{l}\text { TE } \\
\text { TE } \\
\text { TE } \\
\text { TE } \\
\text { TE } \\
\text { TE } \\
\text { TE }\end{array}$ \\
\hline
\end{tabular}


ANALYTICAL RESULTS

WELL ASB 7 collected on 07/09/91, laboratory analyses (cont.)

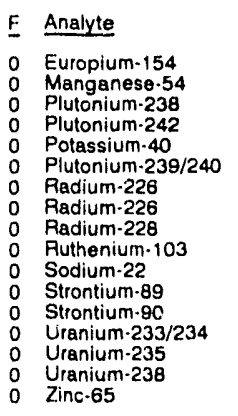

\begin{tabular}{|c|c|}
\hline Unit & Lab \\
\hline 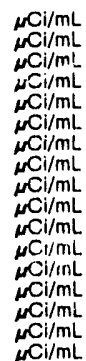 & $\begin{array}{l}\text { TE } \\
T E \\
T E \\
T E \\
T E \\
T E \\
T E \\
T E \\
T E \\
T E \\
T E \\
T E \\
T E \\
T E \\
T E \\
T E \\
T E \\
T E \\
T E\end{array}$ \\
\hline
\end{tabular}

\section{WELL ASB 7}

MEASUREMENTS CONDUCTED IN THE FIELO

Sample date: 07/09/91

Depth to water: $119.44 \mathrm{Ht}(36,41 \mathrm{~m})$ below TOC Water elevation: $233.96 \mathrm{ft}(71.31 \mathrm{~m}) \mathrm{ms}$ Sp. conductance: $97 \mu \mathrm{s} / \mathrm{cm}$
Water evacuated before sampling: $59 \mathrm{gal}$

LABORATORY ANALYSES

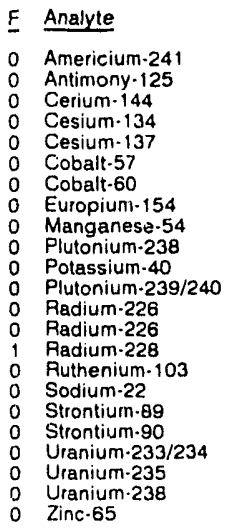

\begin{tabular}{|c|c|}
\hline Aesult & Unit \\
\hline $\begin{array}{rl} & 1.0 \mathrm{E} \cdot 10 \pm 1.0 \mathrm{E} \cdot 10 \\
<2 & 2.1 \mathrm{E} \cdot 08 \\
< & 7.8 \mathrm{E} \cdot 08 \\
< & 8.2 \mathrm{E} \cdot 09 \\
<6.9 \mathrm{E}-09 \\
<9.9 \mathrm{E} \cdot 09 \\
<6.1 \mathrm{E} \cdot 09 \\
<1.5 \mathrm{E} \cdot 08 \\
<7.9 \mathrm{E} \cdot 09 \\
<1.0 \mathrm{E}-10 \\
7.8 \mathrm{E} \cdot 08 \pm 6.3 \mathrm{E} \cdot 08 \\
<1.0 \mathrm{E} \cdot 10 \\
1.9 \mathrm{E}-09 \pm 2.0 \mathrm{E}-10 \\
1.9 \mathrm{E} \cdot 09 \pm 2.0 \mathrm{E}-10 \\
4.8 \mathrm{E}-09 \pm 1.2 \mathrm{E} \cdot 09 \\
<2.5 \mathrm{E} \cdot 08 \\
<5.5 \mathrm{E} \cdot 09 \\
<2.5 \mathrm{E} \cdot 09 \\
7.0 \mathrm{E} \cdot 10 \pm 6.0 \mathrm{E} \cdot 10 \\
7.0 \mathrm{E}-10 \pm 3.0 \mathrm{E} \cdot 10 \\
<1.0 \mathrm{E} \cdot 10 \\
<1.0 \mathrm{E}-10 \\
<1.2 \mathrm{E} \cdot 08\end{array}$ & 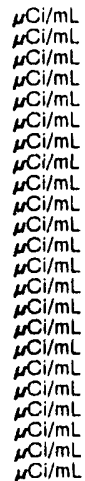 \\
\hline
\end{tabular}

\section{WELL ASB 8}

MEASUREMENTS CONDUCTED IN THE FIELD

Sample date: 07/09/91

Depth to water: $115.87 \mathrm{ft}(35.32 \mathrm{~m})$ below TOC

Water elevation: $233.13 \mathrm{ft}(71.06 \mathrm{~m}) \mathrm{ms}$

Sp. conductance: $31 \mu \mathrm{S} / \mathrm{cm}$

Water evacuated before sampling: $70 \mathrm{gal}$

LABORATORY ANALYSES

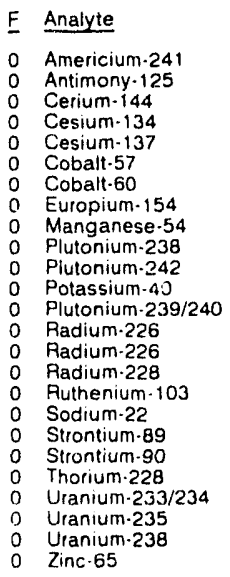

\begin{tabular}{|c|c|}
\hline Result & Unit \\
\hline $4.0 E \cdot 10 \pm 3.0 E \cdot 10$ & $\mu \mathrm{Ci} / \mathrm{mL}$ \\
\hline $\begin{array}{l}<3.2 E \cdot 08 \\
<1.3 E \cdot 07\end{array}$ & $\mathrm{Ci} / \mathrm{mL}$ \\
\hline$<1.5 \mathrm{E} \cdot 08$ & $\mu \mathrm{Ci} / \mathrm{mL}$ \\
\hline$<12 \mathrm{E} \cdot 08$ & $\mu \mathrm{Ci} / \mathrm{mL}$ \\
\hline$<1.7 E \cdot 08$ & $\mu \mathrm{Ci} / \mathrm{mL}$ \\
\hline$<1,4 \mathrm{E} \cdot 08$ & $\mu \mathrm{Ci} / \mathrm{mL}$ \\
\hline$\angle 4.0 E \cdot 08$ & $\mu \mathrm{Ci} / \mathrm{mL}$ \\
\hline $\begin{array}{l}<1.5 \mathrm{E}-08 \\
<4.0 \mathrm{E} \cdot 10\end{array}$ & $\underset{\mu \mathrm{Cl} / \mathrm{mL}}{\mu \mathrm{Ci}}$ \\
\hline$<2.0 \mathrm{E}-10$ & $\mu \mathrm{Ci} / \mathrm{mL}$ \\
\hline$<1.5 E-07$ & $\mu \mathrm{Ci} / \mathrm{mL}$ \\
\hline $\begin{array}{r}<2.0 \mathrm{E}-10 \\
8.0 \mathrm{E}-10\end{array}$ & $\underset{\mathrm{mi} / / \mathrm{mL}}{\mu \mathrm{Ci} / \mathrm{mL}}$ \\
\hline $8.0 E-10 \pm 1.0 E$ & $\mu \mathrm{Ci} / \mathrm{mL}$ \\
\hline$<8.0 E-10$ & $\omega \mathrm{CO} / \mathrm{mL}$. \\
\hline $\begin{array}{l}<3.5 \mathrm{E} \cdot 08 \\
<1.4 \mathrm{E}-08\end{array}$ & $\mu \mathrm{Ci} / \mathrm{mL}$ \\
\hline$<2.5 \mathrm{E} .09$ & $\mu \mathrm{Ci} / \mathrm{mL}$ \\
\hline$<7.0 \mathrm{E} \cdot 10$ & $\mathrm{NCi} / \mathrm{mL}$ \\
\hline$<1.5 E \cdot 08$ & $\mu \mathrm{Ci} / \mathrm{mL}$ \\
\hline$<1.0 E-10$ & $\mu \mathrm{Ci} / \mathrm{mL}$ \\
\hline$<1.0 E \cdot 1$ & $\mu \mathrm{Ci} / \mathrm{mL}$ \\
\hline$<1.0 E-1$ & $\mathrm{Ci} / \mathrm{mL}$ \\
\hline$<3.0 \mathrm{E} \cdot \mathrm{C}$ & \\
\hline
\end{tabular}

Time: $\mathbf{\theta : 4 5}$

pH: 4.7 . Alkalinity: $0 \mathrm{mg} / \mathrm{L}$. $19.9^{\circ} \mathrm{C}$

\section{WELL ASB 8A}

MEASUREMENTS CONDUCTED IN THE FIELD

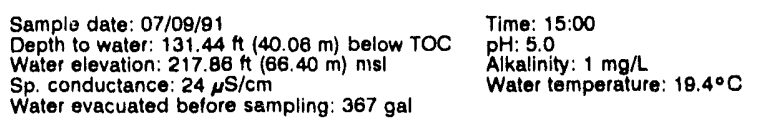

Water evacuated before sampling: $367 \mathrm{gal}$

LABORATORY ANALYSES
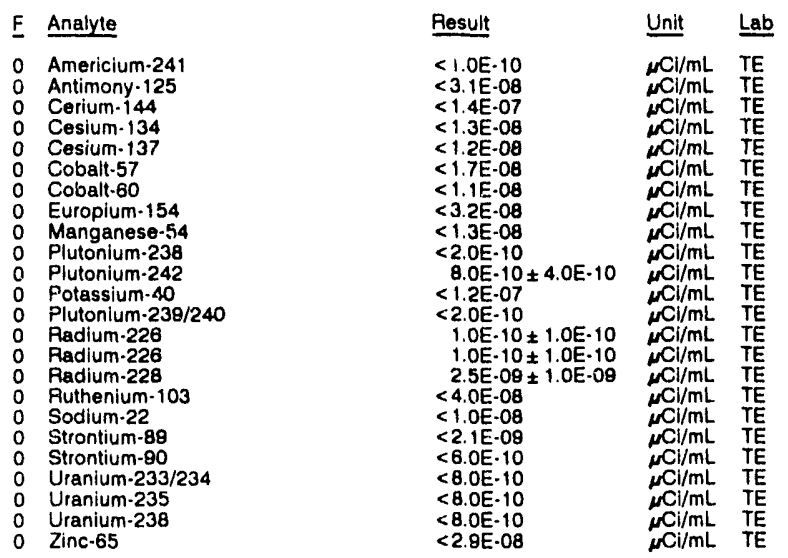

WELL ASB 8TA

MEASUREMENTS CONDUCTED IN THE FIELD

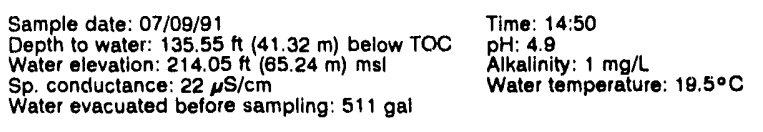

LABORATORY ANALYSES
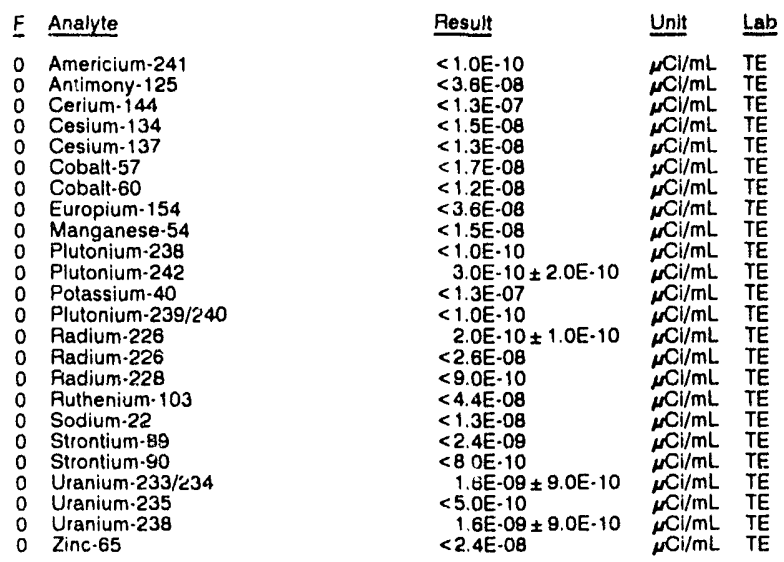

WELL ASB 9

MEASUREMENTS CONDUCTED IN THE FIELD

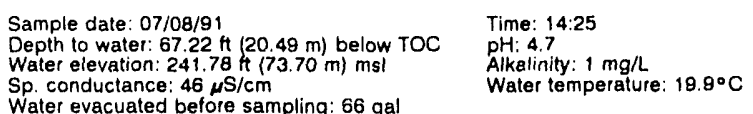

Water evacuated before sampling: $66 \mathrm{gal}$

LAECRATORY ANALYSES

\begin{tabular}{|c|c|c|c|}
\hline Analyte & Result & Unit & Lab \\
\hline $\begin{array}{l}\text { Americium-241 } \\
\text { Antimony-125 } \\
\text { Cerium } \cdot 144 \\
\text { Cesium } 134 \\
\text { Cesium-137 } \\
\text { Cobalt-57 }\end{array}$ & $\begin{array}{l}<2.0 \mathrm{E}-10 \\
<3.5 \mathrm{E}-08 \\
<1.5 \mathrm{E}-07 \\
<1.5 \mathrm{E}-08 \\
<1.4 \mathrm{E}-08 \\
<1.9 \mathrm{E} \cdot 08\end{array}$ & 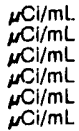 & $\begin{array}{l}\text { TE } \\
\text { TE } \\
\text { TE } \\
\text { TE } \\
\text { TE } \\
\text { TE }\end{array}$ \\
\hline
\end{tabular}


ANALYTICAL RESULTS

\begin{tabular}{|c|c|c|c|}
\hline Analyte & Result & Unit & Lab \\
\hline $\begin{array}{ll}0 & \text { Cobalt-60 } \\
0 & \text { Europlum-154 } \\
0 & \text { Manganese-54 } \\
0 & \text { Plutonlum-238 } \\
0 & \text { Plutonium-242 } \\
0 & \text { Potassium-40 } \\
0 & \text { Plutonium-239/240 } \\
0 & \text { Radium-226 } \\
0 & \text { Radium-226 } \\
0 & \text { Radium-228 } \\
0 & \text { Ruthenium-103 } \\
0 & \text { Sodlum-22 } \\
0 & \text { Strontium-89 } \\
0 & \text { Strontium-90 } \\
0 & \text { Uranium-233/234 } \\
0 & \text { Uranium-235 } \\
0 & \text { Uranium-238 } \\
0 & \text { Zinc-65 }\end{array}$ & $\begin{aligned}<1.1 \mathrm{E} \cdot 08 \\
<3.5 \mathrm{E} \cdot 08 \\
<1.5 \mathrm{E} \cdot 08 \\
<3.0 \mathrm{E}-10 \\
1.4 \mathrm{E}-09 \pm 5.0 \mathrm{E} \cdot 10 \\
<1.4 \mathrm{E} \cdot 07 \\
<2.0 \mathrm{E} \cdot 10 \\
8.0 \mathrm{E} \cdot 10 \pm 2.0 \mathrm{E} \cdot 10 \\
8.0 \mathrm{E}-10 \pm 2.0 \mathrm{E} \cdot 10 \\
2.4 \mathrm{E} \cdot 09 \pm 1.1 \mathrm{E} \cdot 09 \\
<6.5 \mathrm{E}-08 \\
<1.1 \mathrm{E} \cdot 08 \\
<7.6 \mathrm{E} \cdot 09 \\
<1.6 \mathrm{E} \cdot 09 \\
6.0 \mathrm{E} \cdot 10 \pm 4.0 \mathrm{E} \cdot 10 \\
<3.0 \mathrm{E} \cdot 10 \\
<20 \mathrm{0E} \cdot 10 \\
<3.5 \mathrm{E} \cdot 08\end{aligned}$ & 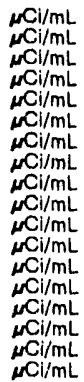 & $\begin{array}{l}\text { TE } \\
\text { TE } \\
\text { TE } \\
\text { TE } \\
\text { TE } \\
\text { TE } \\
\text { TE } \\
\text { TE } \\
\text { TE } \\
\text { TE } \\
\text { TE } \\
\text { TE } \\
\text { TE } \\
\text { TE } \\
\text { TE } \\
\text { TE } \\
\text { TE } \\
\text { TE }\end{array}$ \\
\hline
\end{tabular}

WELL ASB $10 \mathrm{C}$

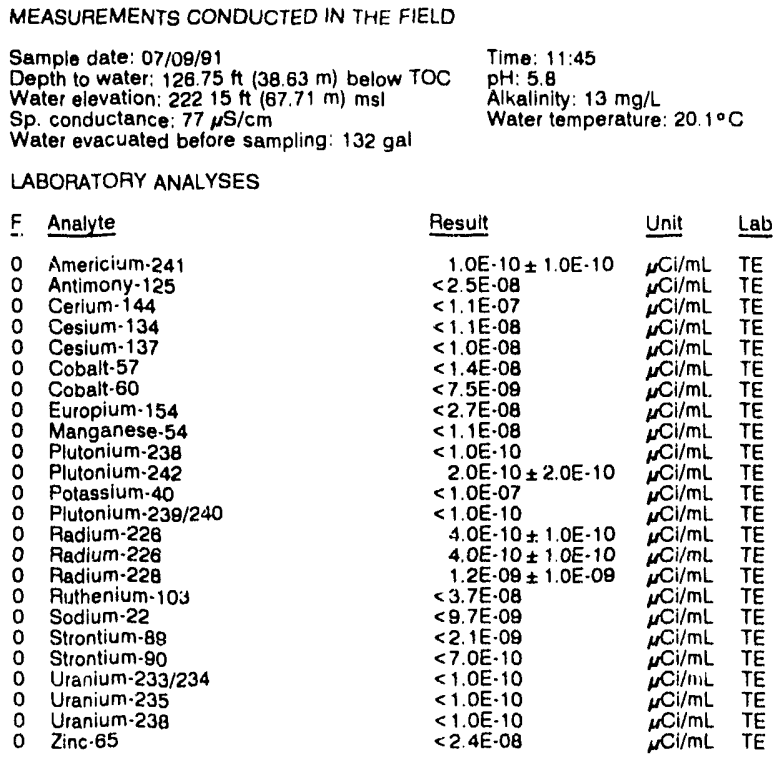

WELL ASB 9B

MEASUREMENTS CONDUCTED IN THE FIELD

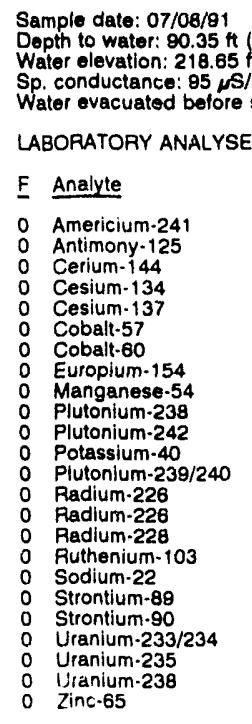

Time: $15: 00$

pH: 6.7 Alkalinity: $31 \mathrm{mg} / \mathrm{L}$

Water temperature: $18.8^{\circ} \mathrm{C}$ .

(a)

LABORATORY ANALYSES

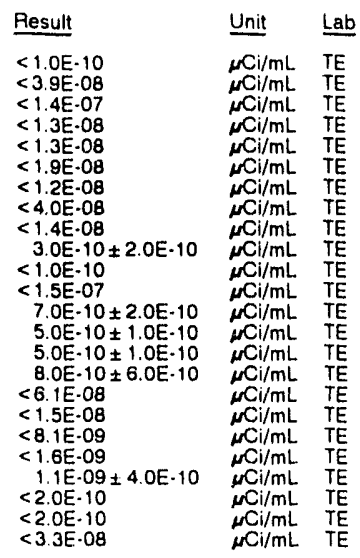

\section{WELL ASB $9 \mathrm{C}$}

MEASUREMENTS CONDUCTED IN THE FIELD

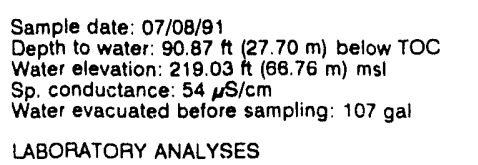

Time: $14: 50$

pH: 5.8

Water temperature: $19.0^{\circ} \mathrm{C}$

Water evacuated before sampling: $107 \mathrm{ga}$

LABORATORY ANALYSES
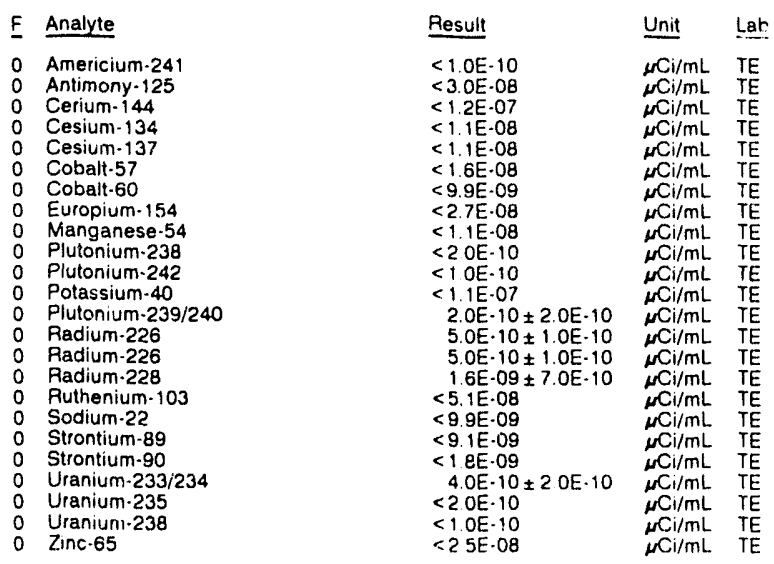

WELL BG 52

MEASUREMENTS CONDUCTED IN THE FIELD

$\begin{array}{ll}\text { Sample date: } 08 / 19 / 91 & \text { Time: } 14: 30 \\ \text { Depth to water: } 60.00 \mathrm{ft}(18.29 \mathrm{~m}) \text { below TOC } & \mathrm{pH}: 7.6 \\ \text { Water elevation: } 229.80 \mathrm{ft}(70.04 \mathrm{~m}) \mathrm{msl} & \text { Water temperature: } 23.3^{\circ} \mathrm{C} \\ \text { Sp. conductance: } 63 \mu \mathrm{s} / \mathrm{cm} & \end{array}$

No water was evacuated before sampling.

LABORATORY AN,ALYSES

\begin{tabular}{|c|c|c|c|c|}
\hline$\underline{E}$ & Analyte & Result & Unit & Lab \\
\hline $\begin{array}{l}0 \\
0 \\
0 \\
0\end{array}$ & $\begin{array}{l}\text { Antimony-125 } \\
\text { Cerium-144 } \\
\text { Cesium-134 } \\
\text { Cesium-137 } \\
\text { Cobalt-57 } \\
\text { Cobalt- } 60 \\
\text { Europiunt } 154 \\
\text { Manganese-54 } \\
\text { Potassium-40 } \\
\text { Radium }-226 \\
\text { Ruthenium-103 } \\
\text { Sodium-22 } \\
\text { Zinc- } 65\end{array}$ & $\begin{array}{l}<1.4 \mathrm{E} \cdot 08 \\
<5.5 \mathrm{E} \cdot 08 \\
<8.9 \mathrm{E} \cdot 09 \\
<6.2 \mathrm{E} \cdot 09 \\
<5.3 \mathrm{E} .09 \\
<5.1 \mathrm{E} .09 \\
<1.2 \mathrm{E} \cdot 08 \\
<6.5 \mathrm{E} \cdot 09 \\
<8.9 \mathrm{E} .08 \\
<3.2 \mathrm{E} .08 \\
<1.1 \mathrm{E} \cdot 08 \\
<4.2 \mathrm{E} \cdot 09 \\
<5.6 \mathrm{E} \cdot 09\end{array}$ & 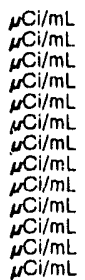 & $\begin{array}{l}\text { TE } \\
\text { TE } \\
\text { TE } \\
\text { TE } \\
\text { TE } \\
\text { TE } \\
\text { TE } \\
\text { TE } \\
\text { TE } \\
\text { TE } \\
\text { TE } \\
\text { TE } \\
\text { TE }\end{array}$ \\
\hline
\end{tabular}

WELL BG 54

MEASUREMENTS CONDUCTED IN THE FIELD

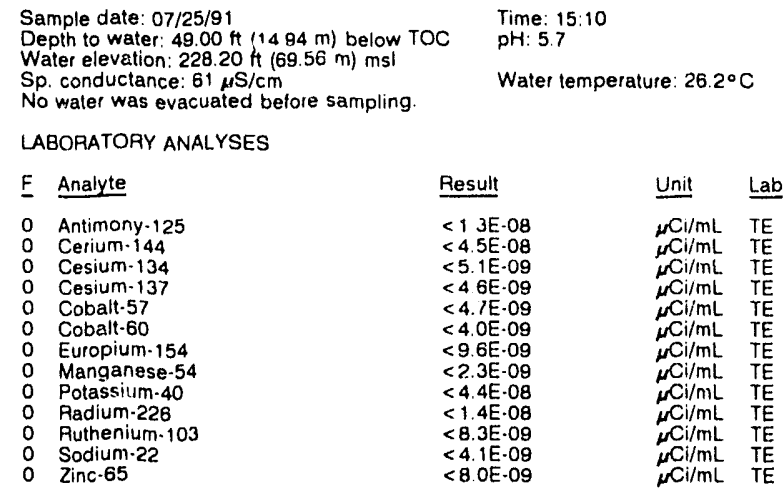


ANALYTICAL RESULTS

WELL BG 55

MEASUREMENTS CONDUCTED IN THE FIELD

Sample date: $07 / 25 / 91$
Oepth to water: $49.70 \mathrm{Ht}(15.15 \mathrm{~m}\rangle$ below TOC
Water elevation: $227.20 \mathrm{H}(69.25 \mathrm{~m}) \mathrm{ms}$
Sp. conductance: $36 \mu \mathrm{cm}$

No water was evacuated betore sampling

Time: $14: 50$

Water temperature: $25.6^{\circ} \mathrm{C}$

LABORATOAY ANALYSES

E Analyte

0 Antimony-125

Antimany 125

Cerium-144

Cesium-134

Cesium.134

Cesium-137

Cobalt-57

Cobalt-57

Cobalt-60

Europium-154

Europium-154

Manganese. 54

Potassium-40

Potassium. 40

Radium.226

Radium-226

Ruthenium-103
Ruthenium-103

Sodium-22

Zinc. 65

Zinc. 65

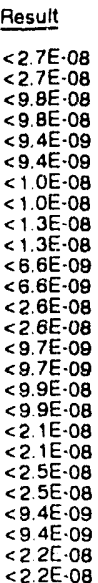

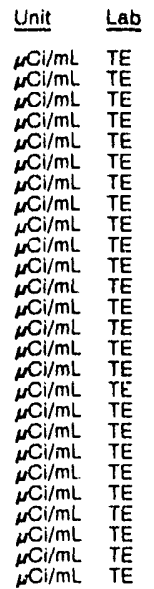

\section{WELL BG 59}

MEASUAEMENTS CONDUCTED IN THE FIELL

Sample date: 07/25/91

Depth to water: $52.00 \mathrm{Ht}(15.85 \mathrm{~m})$ beiow TC:

Water elevation: $230.70 \mathrm{ft}$ (70.

No water was evacuated before sampling

Time: $13: 30$

$\mathrm{\rho H}: 8.0$

Water temperature: $26.0^{\circ} \mathrm{C}$

LABCRATORY ANALYSES

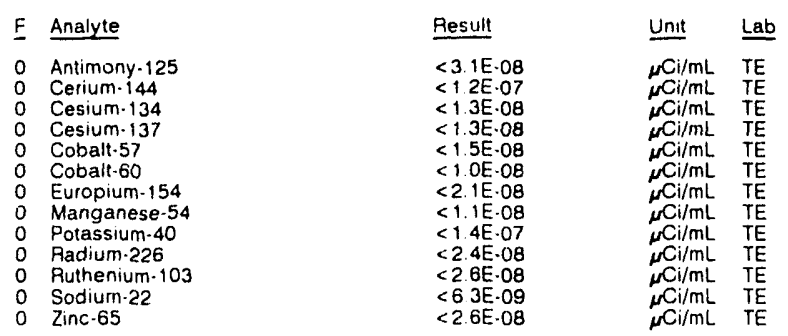

WELL BG 60

MEASUREMENTS CONDUCTED IN IHE FIELD

Sample date: $07 / 25 / 91$

Depth to water: $43.50 \mathrm{ft}(13.26 \mathrm{~m})$ below TOC

Water elevation $232.00 \mathrm{ft}$

$\mathrm{pH}: 7.6$

Water temperature: $23.3^{\circ} \mathrm{C}$

No water was evacuated before sampling

LABORATORY ANALYSES

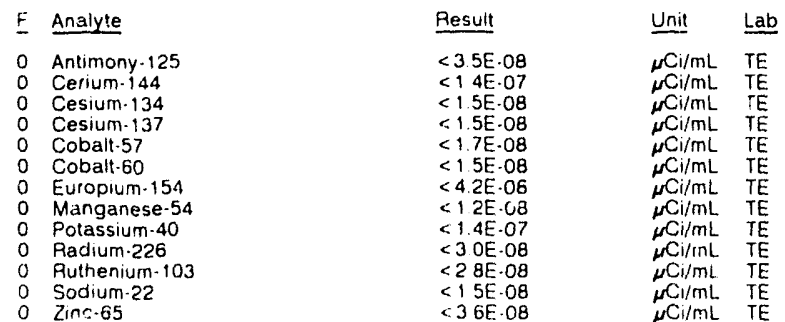

\section{WELL BG 61}

MEASUREMENTS CONDUCTED IN TIFF FIELD

$\begin{array}{ll}\text { Sample date: } 07 / 25 / 81 & T ! m 6: 14: 10 \\ \text { Depth to water: } 40.80 \mathrm{ft}(12.44 \mathrm{~m}) \text { below TOC } & \text { pH: } 8.1^{-1} \\ \text { Water elevation: } 234.20 \mathrm{ft}(71.38 \mathrm{~m}) \mathrm{ms} / & \text { Water temperature: } 24.6^{\circ} \mathrm{C} \\ \text { Sp. conductance: } 51 \mu / \mathrm{cm} & \\ \text { No water was evacuated before sampling. } & \end{array}$

LABORATORY ANALYSES

\begin{tabular}{|c|c|c|}
\hline Analyte & Pesult & Unit \\
\hline $\begin{array}{l}\text { Antimony-125 } \\
\text { Cerium-144 } \\
\text { Cesium-134 } \\
\text { Cesium-137 } \\
\text { Cobalt-57 } \\
\text { Cobalt-60 } \\
\text { Europium-154 } \\
\text { Manganese-54 } \\
\text { Potassium-40 } \\
\text { Radium-226 } \\
\text { Ruthenium-103 } \\
\text { Sodium-22 } \\
\text { Zinc-65 }\end{array}$ & 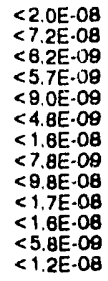 & 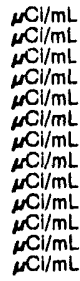 \\
\hline
\end{tabular}

\section{WELL BG 67}

MEASUREMENTS CONDUCTED IN THE FIELD

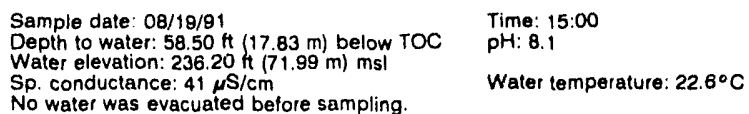

No water was evacuated before sampling

Water temperature: $22.6^{\circ} \mathrm{C}$

LABORATOAY ANALYSES

\begin{tabular}{|c|c|c|c|}
\hline Analyte & Result & $\underline{\text { Unit }}$ & Lab \\
\hline $\begin{array}{ll}0 & \text { Antimony-125 } \\
0 & \text { Cerium-144 } \\
0 & \text { Cesium-134 } \\
0 & \text { Cesium-137 } \\
0 & \text { Coball-57 } \\
0 & \text { Cobalt-60 } \\
0 & \text { Europium-154 } \\
0 & \text { Manganese-54 } \\
0 & \text { Potassium-40 } \\
0 & \text { Radium-226 } \\
0 & \text { Ruthenium-103 } \\
0 & \text { Sodium-22 } \\
0 & \text { Zinc-65 }\end{array}$ & 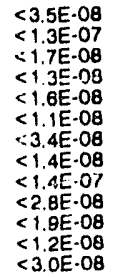 & 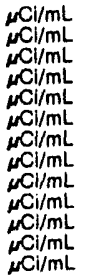 & $\begin{array}{l}\text { TE } \\
\text { TE } \\
\text { TE } \\
\text { TE } \\
\text { TE } \\
\text { TE } \\
\text { TE } \\
\text { TE } \\
\text { TE } \\
\text { TE } \\
\text { TE } \\
\text { TE } \\
\text { TE }\end{array}$ \\
\hline
\end{tabular}

WELL BG 91

MEASUREMENTS CONDUCTED IN THE FIELD

Sample date: 08106/91

Depth to water: $53.56 \mathrm{ft}(16.33 \mathrm{~m})$ below TOC Water elevation: $219.84 \mathrm{ft}(67.01 \mathrm{~m}) \mathrm{msl}$

Sp. conductance: $58 \mu \mathrm{S} / \mathrm{cm}$

Water evacuated before sampling: $13 \mathrm{gal}$

Time: 8:2

PH: 5.4 .

Water temperature: $19.4^{\circ} \mathrm{C}$

LABORATORY ANALYSES

\begin{tabular}{|c|c|c|}
\hline Analyte & Result & Unit \\
\hline $\begin{array}{l}\text { Antimony- } 125 \\
\text { Cerium- } 144 \\
\text { Cesium-134 } \\
\text { Cesium-137 } \\
\text { Cobalt-57 } \\
\text { Cobalt-60 } \\
\text { Europium-154 } \\
\text { Manganese-54 } \\
\text { Potassium-40 } \\
\text { Radium-226 } \\
\text { Ruthenium-103 } \\
\text { Sodium-22 } \\
\text { Zinc-65 }\end{array}$ & $\begin{array}{l}<1.5 \mathrm{E}-08 \\
<4.6 \mathrm{E} \cdot 08 \\
<5.7 \mathrm{E}-09 \\
<5.5 \mathrm{E}-09 \\
<6.1 \mathrm{E}-09 \\
<4.3 \mathrm{E}-09 \\
<1.3 \mathrm{E}-08 \\
<5.6 \mathrm{E}-09 \\
<8.4 \mathrm{E}-08 \\
<1.2 \mathrm{E}-08 \\
<1.1 \mathrm{E}-08 \\
<4.7 \mathrm{E}-09 \\
<1.3 \mathrm{E} \cdot 08\end{array}$ & $\begin{array}{l}\mu \mathrm{ci} / \mathrm{mL} \\
\mu \mathrm{Ci} / \mathrm{mL} \\
\mu \mathrm{Ci} / \mathrm{mL} \\
\mu \mathrm{Ci} / \mathrm{mL} \\
\mu \mathrm{Ci} / \mathrm{mL} \\
\mu \mathrm{Ci} / \mathrm{mL} \\
\mu \mathrm{Ci} / \mathrm{mL} \\
\mu \mathrm{Cl} / \mathrm{mL} \\
\mu \mathrm{Ci} / \mathrm{mL} \\
\mu \mathrm{Ci} / \mathrm{mL} \\
\mu \mathrm{Cl} / \mathrm{mL} \\
\mu \mathrm{Ci} / \mathrm{mL} \\
\mu \mathrm{CL} / \mathrm{mL}\end{array}$ \\
\hline
\end{tabular}


WELL BG 92

MEASUREMENTS CONDUCTED IN THE FIELD

Sample date: 08/06/91 Depth to water: $43.87 \mathrm{ft}(13.40 \mathrm{~m})$ below TOC Water elevation: $211.23 \mathrm{ft}(64.38 \mathrm{~m}) \mathrm{ms} /$ . Whe rell went dry during purging.

ABORATORY ANALYSES

\begin{tabular}{|c|c|c|}
\hline Analyte & Result & Unit \\
\hline $\begin{array}{l}\text { Antimony-125 } \\
\text { Cerium-144 } \\
\text { Cesium-134 } \\
\text { Cesium-137 } \\
\text { Cobalt-57 } \\
\text { Cobalt-60 } \\
\text { Europlum-154 } \\
\text { Manganese-54 } \\
\text { Potassium-40 } \\
\text { Radium-226 } \\
\text { Ruthenium-103 } \\
\text { Sodium-22 } \\
\text { Zlnc-65 }\end{array}$ & $\begin{array}{l}<2.1 \mathrm{E}-08 \\
<1.1 \mathrm{E}-07 \\
<1.3 \mathrm{E}-08 \\
<1.1 \mathrm{E}-08 \\
<1.4 \mathrm{E}-08 \\
<1.0 \mathrm{E}-08 \\
<3.2 \mathrm{E}-08 \\
<1.1 \mathrm{E}-08 \\
<8.9 \mathrm{E} \cdot 08 \\
<2.3 \mathrm{E}-08 \\
<2.1 \mathrm{E}-08 \\
<1.1 \mathrm{E}-08 \\
<1.7 \mathrm{E} .08\end{array}$ & 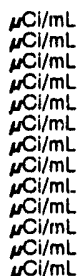 \\
\hline
\end{tabular}

\section{WELL BG 93}

MEASUREMENTS CONDUCTED IN THE FIELD

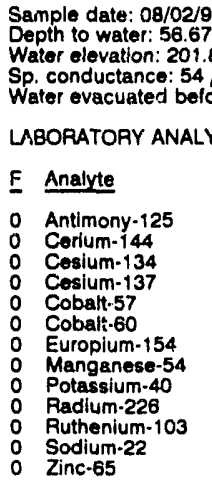

Water temperature: $19.70^{\circ} \mathrm{C}$

\begin{tabular}{|c|c|c|c|}
\hline E Analyte & Result & Unit & Lab \\
\hline $\begin{array}{ll}0 & \text { Antimony-125 } \\
0 & \text { Corium-144 } \\
0 & \text { Cosium-134 } \\
0 & \text { Cesium-137 } \\
0 & \text { Cobalt-57 } \\
0 & \text { Cobali-60 } \\
0 & \text { Europium-154 } \\
0 & \text { Mangenese-54 } \\
0 & \text { Potassium-40 } \\
0 & \text { Radlum-226 } \\
0 & \text { Ruthenium-103 } \\
0 & \text { Sodium-22 } \\
0 & \text { Zinc-65 }\end{array}$ & $\begin{array}{l}<3.2 \mathrm{E}-08 \\
<1.2 \mathrm{E}-07 \\
<1.3 \mathrm{E}-08 \\
<1.2 \mathrm{E}-08 \\
<1.5 \mathrm{E}-08 \\
<1.2 \mathrm{E}-08 \\
<3.6 \mathrm{E}-08 \\
<1.3 \mathrm{E}-08 \\
<1.5 \mathrm{E}-07 \\
<2.4 \mathrm{E}-08 \\
<2.6 \mathrm{E}-08 \\
<1.3 \mathrm{E}-08 \\
<2.5 \mathrm{E}-08\end{array}$ & $\begin{array}{l}\mu \mathrm{Cl} / \mathrm{mL} \\
\mu \mathrm{Ci} / \mathrm{mL} \\
\mu \mathrm{Ci} / \mathrm{mL} \\
\mu \mathrm{Ci} / \mathrm{mL} \\
\mu \mathrm{Ci} / \mathrm{mL} \\
\mu \mathrm{Ci} / \mathrm{mL} \\
\mu \mathrm{Ci} / \mathrm{mL} \\
\mu \mathrm{Ci} / \mathrm{mL} \\
\mu \mathrm{Cl} / \mathrm{mL} \\
\mu \mathrm{Ci} / \mathrm{mL} \\
\mu \mathrm{Cl} / \mathrm{mL} \\
\mu \mathrm{Ci} / \mathrm{mL} \\
\mu \mathrm{Cl} / \mathrm{mL}\end{array}$ & $\begin{array}{l}\text { TE } \\
\text { TE } \\
T E \\
T E \\
T E \\
T E \\
T E \\
T E \\
T E \\
T E \\
T E \\
T E \\
T E \\
T E\end{array}$ \\
\hline
\end{tabular}

\section{WELL BG 93}

MEASUREMENTS CONDUCTED IN THE FIELD

Sample date: $08102 / 91$

Depth to water: 56.67 it $(17.27 \mathrm{~m})$ below TOC

Water elevation: $201.83 \mathrm{ft}(61.52 \mathrm{~m}) \mathrm{ms}$ !

Wp. conductance: $54 \mu 5 / \mathrm{cm}$.

Water evacuated before sampling: $56 \mathrm{gal}$

pH: 5.8

Water temperature: $9.0^{\circ} \mathrm{C}$

F Analyte

0 . Intimony-125

Cerium- 144

Cesium-134

Cesium-137

Cobalt-57

Europium-154

Manganese-54

Pot ssium-40

Rac um-226

Sos um-22

Zinc. 65

Result Unit Lab

$<3.0 E-08$

$<1.1 \mathrm{E} \cdot 0$

Ci. $1.2 \mathrm{E}-08$

$<1.3 \mathrm{E}-0 \mathrm{0B}$

$<1.0 E-08$

$<2.9 E \cdot 08$

$<1.2 \mathrm{E} \cdot 08$

$<1.2 E \cdot 07$

$<2.2 \mathrm{E} \cdot \mathrm{O}$

$<1.0 \mathrm{E} .08$

$<2.3 \mathrm{E}-08$
WELL BG 94

MEASUREMENTS CONOUCTED IN THE FIELD

Sample date: 08/02/81

Depth to water: $58.70 \mathrm{ft}(17.89 \mathrm{~m})$ below TOC

Water elevation: $192.10 \mathrm{ft}(58.55 \mathrm{~m}) \mathrm{ms}$ |

Water evacuated before sampling: $103 \mathrm{gal}$

Time: $11: 25$

Water temperg/ $1000^{\circ}$

LABORATORY ANALYSES

$E$ Analyte

0 Antimony-125

0 Cerium-144

Cesium-134

Cobalt.57

Cobalt.60

Manganese-54

Potassium-40

Radium-226

Ruthenium-103

Sodium-22

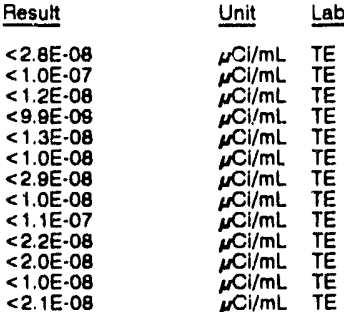

WELL BG 95

MEASUREMENTS CONDUCTED IN THE FIELD

$\begin{array}{ll}\text { Sample date: } 08 / 02 / 91 & \text { Time: } 10: 45 \\ \text { Depth to water } 28.73 \mathrm{ft}(8.76 \mathrm{~m}) \text { below TOC } & \text { PH: } 5.2 \\ \text { Water elevation: } 193.77 \mathrm{Ht}(59.06 \mathrm{~m}) \mathrm{msl} & \text { Alkalinity: } 1 \mathrm{mg} / \mathrm{h} \\ \text { Sp. conductance: } 43 \mu \mathrm{s} / \mathrm{cm} & \text { Water temperature: } 18.8^{\circ} \mathrm{C} \\ \text { Water evacuated before sampling: } 108 \mathrm{gal} & \end{array}$

LABORATOPY ANALYSES

\begin{tabular}{|c|c|c|}
\hline Analyte & Result & Unit \\
\hline $\begin{array}{ll}0 & \text { Antimony-12:i } \\
0 & \text { Cerium-144 } \\
0 & \text { Cesium-134 } \\
0 & \text { Cesium-137 } \\
0 & \text { Cobalt-57 } \\
0 & \text { Cobalt-60 } \\
0 & \text { Europium-154 } \\
0 & \text { Mariganese-54 } \\
0 & \text { Potassium-40 } \\
0 & \text { Radium-226 } \\
0 & \text { Ruthenium-103 } \\
0 & \text { Sodium-22 } \\
0 & \text { Zinc-65 }\end{array}$ & $\begin{array}{l}<1.0 \mathrm{E}-08 \\
<5.6 \mathrm{E}-08 \\
<8.0 \mathrm{E} \cdot 09 \\
<8.0 \mathrm{E}-09 \\
<5.9 \mathrm{E}-09 \\
<3.3 \mathrm{E}-09 \\
<2.3 \mathrm{E} \cdot 08 \\
<5.4 \mathrm{E}-09 \\
<1.1 \mathrm{E} \cdot 07 \\
<1.7 \mathrm{E}-08 \\
<8.1 \mathrm{E}-09 \\
<8.2 \mathrm{E} \cdot 09 \\
<1.7 \mathrm{E} \cdot 08\end{array}$ & 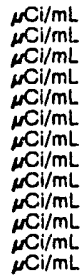 \\
\hline
\end{tabular}

WELL BG 96

MEASUREMENTS CONDUCTED IN THE FIELD

Sample date: 08/02/81 4 Time: 10:20

列

Sp. conductance: $32 \mu \mathrm{S} / \mathrm{cm}$

Alkalinity: $4 \mathrm{mgll}$

Water evacuated before sampling: $58 \mathrm{gal}$

Water temperature: $19.5^{\circ} \mathrm{C}$

LABORATORY ANALYSES

\begin{tabular}{|c|c|c|c|}
\hline F Analyte & Result & Unit & Lab \\
\hline $\begin{array}{ll}0 & \text { Antirnony-125 } \\
0 & \text { Cerium-144 } \\
0 & \text { Cesium-134 } \\
0 & \text { Cesium-137 } \\
0 & \text { Coball-57 } \\
0 & \text { Coball-60 } \\
0 & \text { Europiurn-154 } \\
0 & \text { Manganese-54 } \\
0 & \text { Potassium-40 } \\
0 & \text { Radium-226 } \\
0 & \text { Ruthenium-103 } \\
0 & \text { Sodium }-22 \\
0 & \text { Zinc. } 65\end{array}$ & $\begin{array}{l}<1.8 \mathrm{E} \cdot 08 \\
<5.6 \mathrm{E} \cdot 08 \\
<7.1 \mathrm{E} \cdot 09 \\
<7.4 \mathrm{E}-09 \\
<7.4 \mathrm{E} \cdot 09 \\
<8.1 \mathrm{E} .09 \\
<2.0 \mathrm{E} \cdot 08 \\
<8.0 \mathrm{E}-09 \\
<1.2 \mathrm{E}-07 \\
<1.6 \mathrm{E} \cdot 08 \\
<1.3 \mathrm{E}-08 \\
<7.4 \mathrm{E} .09 \\
<1.8 \mathrm{E} \cdot 08\end{array}$ & 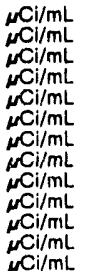 & $\begin{array}{l}\text { TE } \\
\text { TE } \\
\text { TE } \\
\text { TE } \\
\text { TE } \\
\text { TE } \\
\text { TE } \\
\text { TE } \\
\text { TE } \\
\text { TE } \\
\text { TE } \\
\text { TE } \\
\text { TE }\end{array}$ \\
\hline
\end{tabular}


ANALYTICAL RESULTS

WELL BG 101

MEASUREMENTS CONDUCTEO IN THE FIELD

Sample date: 08/05/91

Depth to water: $35.04 \mathrm{At}(10.68 \mathrm{~m})$ below TOC

Water e'evation: $196.36 \mathrm{ft}$

(2)

Water evacuated before sampling: $92 \mathrm{gal}$

PH: 5.2 : 1 malinity: $1 \mathrm{mg} /$

Water temperature: $19.1^{\circ} \mathrm{C}$

LABORATORY ANALYSES

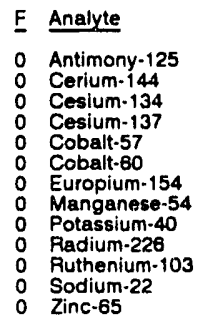

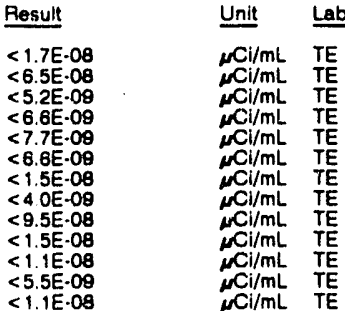

\section{WELL BG 103}

MEASUREMENTS CONDUCTED IN THE FIELD

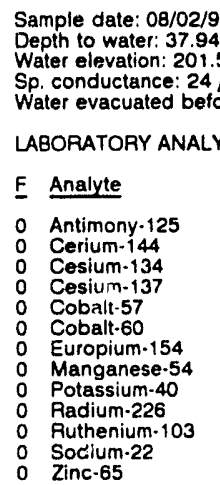

Time: 9:40

Alkalinity: $1 \mathrm{mg} / \mathrm{L}$

Water temperature: $19.0^{\circ} \mathrm{C}$

Water evacuated before sampling: 84 gal

ABORATORY ANALYSES

$\begin{array}{ll}\text { F } & \text { Analyte } \\ 0 & \text { Antimony-125 } \\ 0 & \text { Cerium-144 } \\ 0 & \text { Cesium-134 } \\ 0 & \text { Cesium-137 } \\ 0 & \text { Cobalt-57 } \\ 0 & \text { Cobalt-60 } \\ 0 & \text { Europium-154 } \\ 0 & \text { Manganese-54 } \\ 0 & \text { Potassium-40 } \\ 0 & \text { Radium-226 } \\ 0 & \text { Ruthenium-103 } \\ 0 & \text { Soctium-22 } \\ 0 & \text { Zinc-65 }\end{array}$

\section{WELL BG 107}

MEASUREMENTS CONDUCTED IN THE FIEI.D

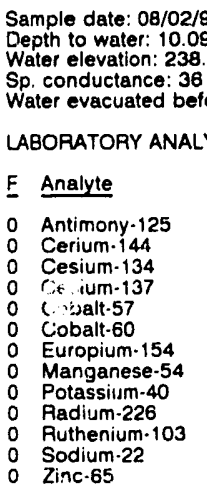

\begin{tabular}{|c|c|}
\hline Result & Unit \\
\hline $\begin{array}{l}<2.1 \mathrm{E} \cdot 08 \\
<\mathrm{B} .0 \mathrm{E} \cdot 08 \\
<9.6 \mathrm{E}-09 \\
<7.5 \mathrm{E} \cdot 09 \\
<7.6 \mathrm{E}-09 \\
<1.1 \mathrm{E} .08 \\
<2.5 \mathrm{E} \cdot 08 \\
<9.0 \mathrm{E} \cdot 09 \\
<1.3 \mathrm{E} \cdot 07 \\
<1.7 \mathrm{E}-08 \\
<1.4 \mathrm{E}-08 \\
<9.1 \mathrm{E} \cdot 09 \\
<1.9 \mathrm{E} \cdot 08\end{array}$ & 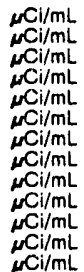 \\
\hline
\end{tabular}

Sample date: $08 / 02 / 81$
Depth to water: $10.09 \mathrm{it}(3.08 \mathrm{~m})$ below TOC
Water elevation: $238.21 \mathrm{ft}(72.61 \mathrm{~m}) \mathrm{msl}$
Sp. conductance: $36 \mu 5 \mathrm{~cm}$
Water evacuated before sampling: $78 \mathrm{gal}$
LABORATORY ANALYSES

$$
\text { Time: 13:35 }
$$

PH: 5.4 : $13 \mathrm{mg} / \mathrm{L}$

Water temperature: $20.2^{\circ} \mathrm{C}$

\section{Result}

$<2.6 \mathrm{E}-08$

$<6.5 E \cdot 08$

$<1.2 E .08$
$<9.8 E .09$

$<7.7 \mathrm{E}-09$

$<8.1 E .09$

$<2.4 E-08$

$<9.7 \mathrm{E} .09$
$<1.5 \mathrm{E} .07$

$<1.5 \mathrm{E}-07$

$<1.9 \mathrm{E}-08$

$<1.8 E-08$
$<7.7 E-09$

$<7.7 \mathrm{E}-09$
$<2.8 \mathrm{E}-08$
WELL BG 110

MEASUREMENTS CONDUCTED IN THE FIELD

$\begin{array}{ll}\text { Sample date: } 08 / 08 / 91 & \text { Time: } 11: 35 \\ \text { Depth to water: } 52.22 \mathrm{ft}(15.92 \mathrm{~m}) \text { below TOC } & \text { pH: } 4.8 \\ \text { Wate olevation: } 242.08 \mathrm{ft}(73.79 \mathrm{~m}) \mathrm{msl} & \text { Alkalinity: } 0 \mathrm{mg} / \mathrm{h} \\ \text { Sp. conductance: } 81 \mu \mathrm{s} / \mathrm{cm} & \text { Water temperature: } 19.8^{\circ} \mathrm{C} \\ \text { Water evacuated before sampling: } 38 \mathrm{gal} & \end{array}$
Water evacuated before sampling: $38 \mathrm{ga}$

LABORATORY ANALYYSES

\begin{tabular}{|c|c|c|}
\hline Analyte & Result & Unit \\
\hline $\begin{array}{ll}0 & \text { Antimony-125 } \\
0 & \text { Cerium-144 } \\
0 & \text { Cesium-134 } \\
0 & \text { Ceslum-137 } \\
0 & \text { Cobalt-57 } \\
0 & \text { Cobalt-60 } \\
0 & \text { Europium-154 } \\
0 & \text { Manganese-54 } \\
0 & \text { Potassium-40 } \\
0 & \text { Radium-226 } \\
0 & \text { Ruthenium-103 } \\
0 & \text { Sodium-22 } \\
0 & \text { Zinc-65 }\end{array}$ & 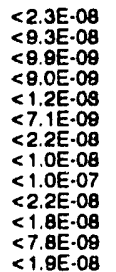 & $\begin{array}{l}\mu \mathrm{Cl} / \mathrm{mL} \\
\mu \mathrm{Ci} / \mathrm{mL} \\
\mu \mathrm{Cl} / \mathrm{mL} \\
\mu \mathrm{Cl} / \mathrm{mL} \\
\mu \mathrm{Cl} / \mathrm{mL} \\
\mu \mathrm{Cl} / \mathrm{mL} \\
\mu \mathrm{Ci} / \mathrm{mL} \\
\mu \mathrm{Ci} / \mathrm{mL} \\
\mu \mathrm{Ci} / \mathrm{mL} \\
\mu \mathrm{Ci} / \mathrm{mL} \\
\mu \mathrm{Ci} / \mathrm{mL} \\
\mu \mathrm{Ci} / \mathrm{mL} \\
\mu \mathrm{Ci} / \mathrm{mL}\end{array}$ \\
\hline
\end{tabular}

\section{WELL BG 121}

MEASUREMENTS CONDUCTED IN THE FIELD

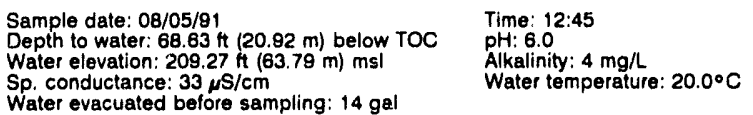
Water evacuated before sampling: $14 \mathrm{gal}$ LABORATORY ANALYSES

\begin{tabular}{|c|c|c|c|}
\hline Analyte & Result & Unit & $\underline{L a b}$ \\
\hline 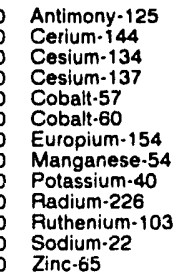 & $\begin{array}{l}<4.0 E-08 \\
<1.5 \Gamma \cdot 07 \\
<1.4 E \cdot 08 \\
<1.6 \mathrm{E} .09 \\
<2.0 \mathrm{E} \cdot 08 \\
<1.3 \mathrm{E} \cdot 08 \\
<5.0 \mathrm{E} \cdot 08 \\
<1.6 \mathrm{E} \cdot 08 \\
<1.7 \mathrm{E} \cdot 07 \\
<3.3 \mathrm{E} \cdot 08 \\
<3.1 \mathrm{E} \cdot 08 \\
<1.7 \mathrm{E}-08 \\
<3.3 \mathrm{E} \cdot 08\end{array}$ & 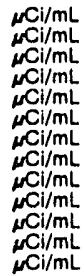 & $\begin{array}{l}\text { TE } \\
\text { TE } \\
\text { TE } \\
\text { TE } \\
\text { TE } \\
\text { TE } \\
\text { TE } \\
\text { TE } \\
\text { TE } \\
\text { TE } \\
\text { TE } \\
\text { TE } \\
\text { TE }\end{array}$ \\
\hline
\end{tabular}

WELL BG 122

MEASUREMENTS CONDUCTED IN THE FIELD

$\begin{array}{ll}\text { Sample date: } 08 / 02 / 91 & \text { Time: } 12.25 \\ \text { Depth to water: } 35.15 \mathrm{tt}(10.71 \mathrm{~m}) \text { below TOC } & \text { pH: } 5.7 \\ \text { Water elevation: } 212.75 \mathrm{ft}(64.85 \mathrm{~m}) \mathrm{msl} & \text { Alkalinity: } 12 \mathrm{mg} / \mathrm{h} \\ \text { Sp. conductance: } 65 \mu \mathrm{\mu S} / \mathrm{cm} & \text { Water temperature: } 18.2^{\circ} \mathrm{C} \\ \text { Water evacuated before sampling: } 60 \mathrm{gal} & \end{array}$

Water evacuated before sampling: $60 \mathrm{gal}$

LABORATOAY ANALYSES

\begin{tabular}{|c|c|c|}
\hline Analyte & Result & Unit \\
\hline $\begin{array}{ll}0 & \text { Antimony-125 } \\
0 & \text { Cerium-144 } \\
0 & \text { Cesium-134 } \\
0 & \text { Cesium-137 } \\
0 & \text { Cobalt-57 } \\
0 & \text { Cobalt-60 } \\
0 & \text { Europium-154 } \\
0 & \text { Manganese-54 } \\
0 & \text { Potassium-40 } \\
0 & \text { Radium-226 } \\
0 & \text { Ruthenium-103 } \\
0 & \text { Sodium-22 } \\
0 & \text { Zinc-65 }\end{array}$ & $\begin{array}{l}<2.7 \mathrm{E} \cdot 08 \\
<9.6 \mathrm{E} \cdot 08 \\
<1.1 \mathrm{E} \cdot 08 \\
<1.0 \mathrm{E} \cdot 08 \\
<1.3 \mathrm{E} \cdot 08 \\
<8.4 \mathrm{E} \cdot 09 \\
<2.5 \mathrm{E} \cdot 08 \\
<9.6 \mathrm{E} \cdot 09 \\
<1.0 \mathrm{E} \cdot 07 \\
<2.1 \mathrm{E} \cdot 08 \\
<2.1 \mathrm{E} \cdot 08 \\
<9.5 \mathrm{E} \cdot 09 \\
<2.1 \mathrm{E} \cdot 08\end{array}$ & $\begin{array}{l}\mu \mathrm{Ci} / \mathrm{mL} \\
\mu \mathrm{Ci} / \mathrm{mL} \\
\mu \mathrm{Ci} / \mathrm{mL} \\
\mu \mathrm{Ci} / \mathrm{mL} \\
\mu \mathrm{Ci} / \mathrm{mL} \\
\mu \mathrm{Ci} / \mathrm{mL} \\
\mu \mathrm{Cl} / \mathrm{mL} \\
\mu \mathrm{Ci} / \mathrm{mL} \\
\mu \mathrm{Ci} / \mathrm{mL} \\
\mu \mathrm{Cl} / \mathrm{mL} \\
\mu \mathrm{Cl} / \mathrm{mL} \\
\mu \mathrm{Cl} / \mathrm{mL} \\
\mu \mathrm{Cl} / \mathrm{mL}\end{array}$ \\
\hline
\end{tabular}




\section{WELL BGO 1D}

MEASUREMENTS CONOUCTED IN THE FIELD

\begin{tabular}{|c|c|c|c|c|c|}
\hline \multicolumn{2}{|r|}{$\begin{array}{l}\text { Sample date: } 07 / 02 / 91 \\
\text { Depth to water: } 56.24 \mathrm{Ht}(17.14 \mathrm{~m}) \text { below TOC } \\
\text { Water elevation: } 238.86 \mathrm{ft}(72.81 \mathrm{~m}) \mathrm{msl} \\
\text { Sp. conductance: } 41 \mathrm{\mu S} / \mathrm{cm} \\
\text { Water evacuated before sampling: } 7 \mathrm{gal} \\
\text { The well went dry during purging. }\end{array}$} & & \multicolumn{3}{|c|}{$\begin{array}{l}\text { Time: } 11.50 \\
\text { pHl } 5.5 \\
\text { Alkalinity: } 1 \mathrm{mg} / \mathrm{L} \\
\text { Water temperature: } 22.3^{\circ} \mathrm{C}\end{array}$} \\
\hline \multicolumn{6}{|c|}{ LABOPATORY ANALYSES } \\
\hline$\underline{E}$ & Analyte & Result & & Unit & Lab \\
\hline & $\begin{array}{l}\text { Uranium-233/234 } \\
\text { Uranium-235 } \\
\text { Uranium-238 }\end{array}$ & $\begin{aligned} & 5.0 \mathrm{E} . \\
< & 1.0 \mathrm{E} . \\
< & 1.0 \mathrm{E} .\end{aligned}$ & & $\underset{\mu \mathrm{Cl} / \mathrm{mL}}{\underset{\mu \mathrm{Ci} / \mathrm{mL}}{\mathrm{NCl} / \mathrm{mL}}}$ & $\begin{array}{l}\text { TE } \\
\text { TE } \\
\text { TE }\end{array}$ \\
\hline
\end{tabular}

\section{WELL BGO 2D}

MEASUREMENTS CONDUCTED IN THE FIELO

Depth to water: $59.03 \mathrm{H}(17.99 \mathrm{~m})$ below TOC

Water elevation: $237.87 \mathrm{th}(72.50 \mathrm{~m}) \mathrm{msl}$
Sp. conductance: $44 \mu \mathrm{s} / \mathrm{cm}$

Water evacuated before sampling: $50 \mathrm{gal}$

LABORATORY ANALYSES

F Analyte

0 Uranium.233/234

0 Uranium-235

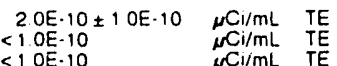

WELL BGO 6A

MEASUREMENTS CONDUCTED IN THE FIELD

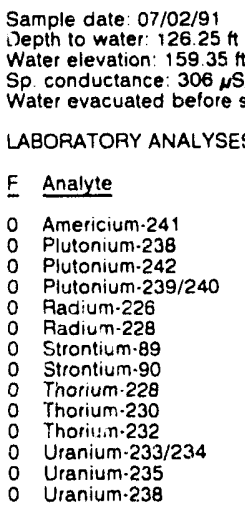

Time: $9: 10$

Alkalinity: $0 \mathrm{mg} / \mathrm{l}$

Water temperature: $21.2^{\circ} \mathrm{C}$

WEI L BGO 6C

MEASUREMENTS CONOUCTED IN THE FIELO

Sample date: $07 / 02 / 91$
Depth to water: $64.81 \mathrm{~h}(19.75 \mathrm{~m})$ below TOC
Water elevation: $220.79 \mathrm{Ht}(67.30 \mathrm{~m}) \mathrm{msl}$
Sp conductance: $141 \mu \mathrm{HS} / \mathrm{cm}$
Water evacuated betore sampling: $172 \mathrm{gal}$
LABORATORY ANALYSES

Pesult Unit Lab

$<1.0 E \cdot 10 \quad \mu \mathrm{Ci} / \mathrm{mL}$ TE

$<2.0 E-10 \quad \mathrm{MCi} / \mathrm{mL}$ TE

$<2.0 E \cdot 10$

$<2.0 \mathrm{E} \cdot 10$

$<1.0 E \cdot 10$

$<1.0 \mathrm{E} .08$

$<1.0 E \cdot 08$
$<2.0 E \cdot 09$

$3.0 E \cdot 10 \pm 3.0 E \cdot 10 \quad \mathrm{NCi} / \mathrm{mL}$ TE

3 OE-10 $+1.0 E-10$

$<1.0 \mathrm{E} \cdot 10$

$1.0 E \cdot 10 \pm 1.0 E \cdot 10$

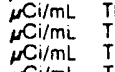

$\mu \mathrm{Ci} / \mathrm{mL}$ TE

$\mathrm{Ci} / \mathrm{mL}$ TE

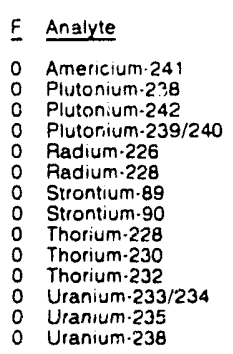

Tinie: 12:45

Alk 7.1 . 50.0

Water temperature $207^{\circ} \mathrm{C}$

Pesult

$<1$ OE. 10

$<1$ OE. 10

$<1.0 E \cdot 10$

$<1.0 E \cdot 10$

$1.6 E \cdot 09 \pm 8.0 E \cdot 10$

$<1.6 E \cdot 09$
$6.0 E \cdot 10 \pm 4.0 E \cdot 10$

$<1$ OE. 09

$<2.0 E \cdot 10$

$19 E .09 \pm 40 E \cdot 10$

$20 E \cdot 10 \pm 10 E \cdot 10$

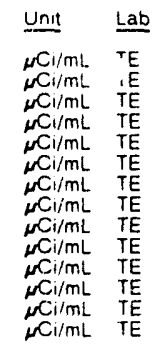

WELL BGO 6D

MEASUREMENTS CONDUCTED IN THE FIELD

\section{Sample date: $07 / 02 / 91$}

Depth to water: $54.36 \mathrm{ft}(16.57 \mathrm{~m})$ below TOC

Water elevation: 231.14 \& $(70.45 \mathrm{~m}) \mathrm{msl}$

Sp. conductance: $103 \mu \mathrm{S} / \mathrm{cm}$

Water evacualed before sampling: $7 \mathrm{gal}$

Time: $12: 40$
pH: 6.2

Water temperature: $20.4^{\circ} \mathrm{C}$

LABORATORY ANALYSES

\begin{tabular}{|c|c|c|c|}
\hline Analyte & Result & Unit & Lab \\
\hline $\begin{array}{ll}0 & \text { Uranium.233/234 } \\
0 & \text { Uranium.235 } \\
0 & \text { Uranium.238 }\end{array}$ & $\begin{array}{r}5.9 \mathrm{E}-09 \pm 1.3 \mathrm{E} \cdot 09 \\
<5.0 \mathrm{E}-10 \\
2.3 \mathrm{E} \cdot 09 \pm 9.0 \mathrm{E} \cdot 10\end{array}$ & $\underset{\substack{\mathrm{MCi} / \\
\mathrm{NCi} / \mathrm{mL}}}{\mathrm{mL} / \mathrm{mL}}$ & $\begin{array}{l}\text { TE } \\
\text { TE } \\
\text { TE }\end{array}$ \\
\hline
\end{tabular}

WELL BGO 8AR

MEASUREMENTS CONDUCTED IN THE FIELD

Sample date: $07 / 03 / 91$ Water elevation: $159.08 \mathrm{Ht}(48.49 \mathrm{~m}) \mathrm{ms}$

Sp. Conductance: $232 \mu \mathrm{r} / \mathrm{cm}$
Water evacuated before sampling: $171 \mathrm{gal}$

Alkalinity: $102 \mathrm{mg} / \mathrm{L}$

LAEORATORY ANALYSES

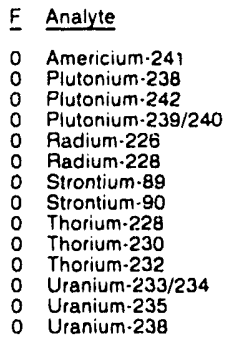

\begin{tabular}{|c|c|}
\hline Result & Unit \\
\hline $\begin{aligned} &< 2.0 \mathrm{E}-10 \\
&<2.0 \mathrm{E} \cdot 10 \\
&<1.0 \mathrm{E}-10 \\
&<1.0 \mathrm{E}-10 \\
& 1.0 \mathrm{E}-10 \pm 1.0 \mathrm{E} \cdot 10 \\
& 2.4 \mathrm{E} \cdot 09 \pm 1.1 \mathrm{E}-09 \\
&<1.7 \mathrm{E} \cdot 09 \\
&<5.0 \mathrm{E}-10 \\
&<1.0 \mathrm{E} \cdot 09 \\
& 8.0 \mathrm{E} \cdot 10 \pm 4.0 \mathrm{E} \cdot 10 \\
&<2.0 \mathrm{E} \cdot 10 \\
& 3.1 \mathrm{E} \cdot 09 \pm 7.0 \mathrm{E} \cdot 10 \\
&<2.0 \mathrm{E} \cdot 10 \\
&<2.0 \mathrm{E} \cdot 10\end{aligned}$ & 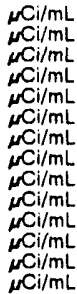 \\
\hline
\end{tabular}

WELL BGO $8 \mathrm{C}$

MEASUREMENTS CONOUCTED IN THE FIELD

Sample date: $07 / 02 / 91$ 1 $52 \mathrm{~m}$ ) below TOC

Depth to water: $64.04 \mathrm{ft}(19.52 \mathrm{~m})$ below TOC

Water elevation: $219.26 \mathrm{Ht}(66.83 \mathrm{~m}) \mathrm{ms} /$

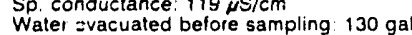

Time: $15: 50$
pH: 7.1

Water temperature $21.5^{\circ} \mathrm{C}$

LABORATORY ANALYSES

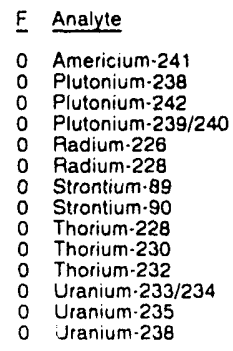

Result
$<1.0 \mathrm{E} \cdot 10$
$<8.0 \mathrm{E} \cdot 10$
$2.6 \mathrm{E} \cdot 09 \pm 1.2 \mathrm{E}-09$
$8.0 \mathrm{E} \cdot 10 \pm 7.0 \mathrm{E} \cdot 10$
$<2.0 \mathrm{E} \cdot 10$
$2.0 \mathrm{E} \cdot 09 \pm 1.0 \mathrm{E} \cdot 09$
$<5.6 \mathrm{E} \cdot 09$
$<1.1 \mathrm{E} \cdot 09$
$<1.3 \mathrm{E} \cdot 09$
$<2.0 \mathrm{E} \cdot 10$
$<2.0 \mathrm{E} \cdot 10$
$<2.0 \mathrm{E} \cdot 10$
$<2.0 \mathrm{E} \cdot 10$
$<2.0 \mathrm{E} \cdot 10$

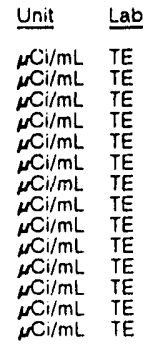

WELLL BGO 8D

MEASUREMENTS CONDUCTED IN THE FIELL

Sample date: $07 / 02 / 91$ Time 15.25

$\begin{array}{ll}\text { Depth to water: } 56.10 \mathrm{H}(17.10 \mathrm{~m}) \text { below TOC } & \text { PH } 49 \\ \text { Water elevation: } 227.10 \mathrm{ft}(69.22 \mathrm{~m}) \mathrm{msl} & \text { Alkalinity. } 0 \mathrm{mg} / \mathrm{l}\end{array}$

$\begin{array}{ll}\text { Wp. conductance } 27 \mu \mathrm{s} / \mathrm{cm} & \text { Watin temperature. } 22.1{ }^{\circ} \mathrm{C} \\ \text { Water evacuated before sampling: } 32 \mathrm{gal} & \end{array}$

LABORATORY ANALYSES

F Analyte

O Uranium-233/234

U Uranium.2.35 
ANALYTICAL RESULTS

WELL BGO 9D

MEASUREMENTS CONDUCTED IN THE FIELD

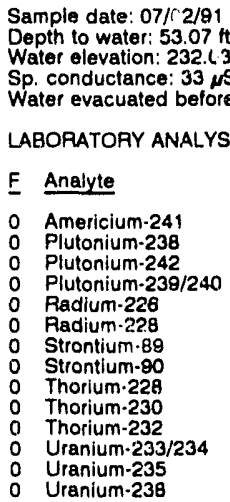

Time: $17: 00$

pH: 4.8 :

Water temperature: $23.3^{\circ} \mathrm{C}$

Water evacuated before sampting: $60 \mathrm{gal}$

LABORATORY ANALYSES

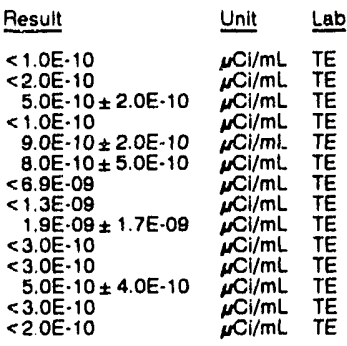

\section{WELL BGO 10AR}

MEASUREMENTS CONDUCTED IN THE FIELD

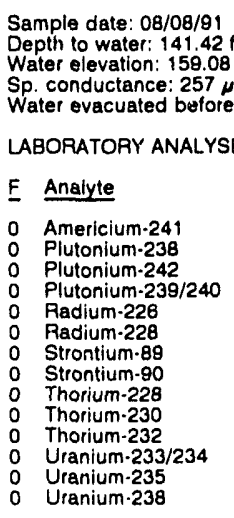

Time: 10:40

Alkalinity: $108 \mathrm{mg} / \mathrm{L}$ Water temperature: $20.5^{\circ} \mathrm{C}$ Water ovecuated bufore sampling: $207 \mathrm{gal}$

LABORATORY ANALYSES

\begin{tabular}{|c|c|}
\hline Result & Unit \\
\hline 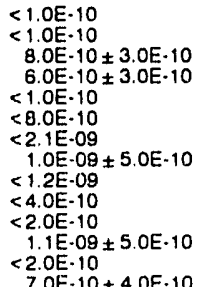 & 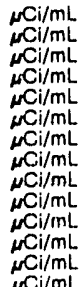 \\
\hline
\end{tabular}

WELL BGO $10 \mathrm{C}$

MEASUREMENTS CONDUCTED IN THE FIELD

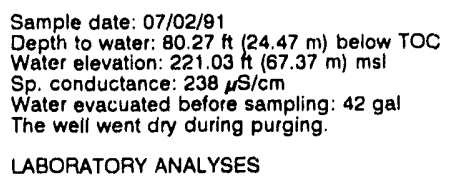

$$
\begin{aligned}
& \text { Time: }\{3: 05 \\
& \text { pH: } 7.7 \\
& \text { Alkalinity: } 90 \mathrm{mg} / \mathrm{L} \\
& \text { Water temperature: } 21.5^{\circ} \mathrm{C}
\end{aligned}
$$

LABORATORY ANALYSES
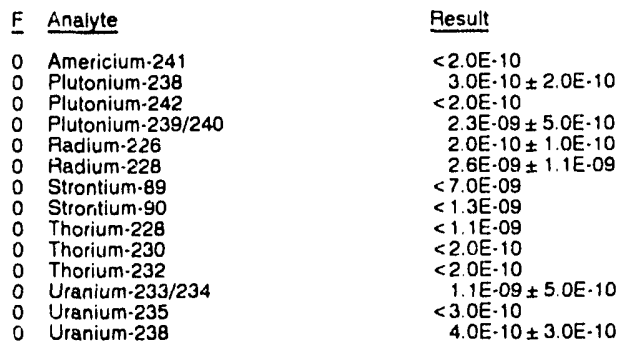

\begin{tabular}{ll} 
Unit & Lab \\
\hline$\mu \mathrm{Ci} / \mathrm{mL}$ & TE \\
$\mu \mathrm{Ci} / \mathrm{mL}$ & $T E$ \\
$\mu \mathrm{Ci} / \mathrm{mL}$ & $T E$ \\
$\mu \mathrm{Ci} / \mathrm{mL}$ & TE \\
$\mu \mathrm{Ci} / \mathrm{mL}$ & TE \\
$\mu \mathrm{Ci} / \mathrm{mL}$ & $T E$ \\
$\mu \mathrm{Ci} / \mathrm{mL}$ & $T E$ \\
$\mu \mathrm{Ci} / \mathrm{mL}$ & $T E$ \\
$\mu \mathrm{Ci} / \mathrm{LL}$ & $T E$ \\
$\mu \mathrm{Ci} / \mathrm{mL}$ & $T E$ \\
$\mu \mathrm{Ci} / \mathrm{mL}$ & $T E$ \\
$\mu \mathrm{Ci} / m L$ & $T E$ \\
$\mu \mathrm{Ci} / \mathrm{mL}$ & TE \\
$\mu \mathrm{Ci} / \mathrm{mL}$ & TE
\end{tabular}

WELL BGO 110

MEASUREMENTS CONDUCTED IN THE FIELD

$\begin{array}{ll}\text { Sample date: } 07 / 02 / 91 & \text { Time: } 14: 30 \\ \text { Depth to water: } 73.83 \mathrm{H}(22.53 \mathrm{~m}) \text { below TOC } & \text { pH: } 4.6 \\ \text { Water elevation: } 231.37 \mathrm{Ht}(70.52 \mathrm{~m}) \mathrm{ms} & \text { Alkalinity: } 0 \mathrm{mg} / \mathrm{L} \\ \text { Sp. conductance: } 31 \mu \mathrm{S} / \mathrm{cm} & \text { Water temperature: } 25.4^{\circ} \mathrm{C} \\ \text { Water evacuated before sampling: } 40 \mathrm{gal} & \end{array}$
LABORATORY ANALYSES

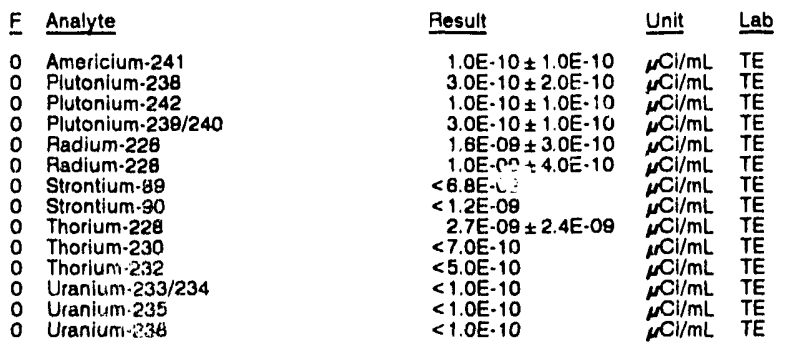

\section{WELL BGO 12AR}

MEASUREMENTS CONDUCTED IN THE FIELD

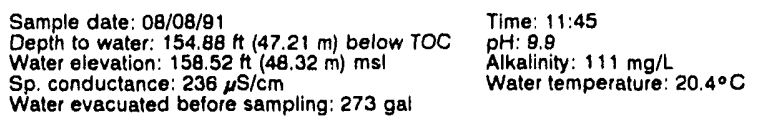

Water evacuated before sampling: $273 \mathrm{gal}$

\section{LABORATORY ANALYSES}

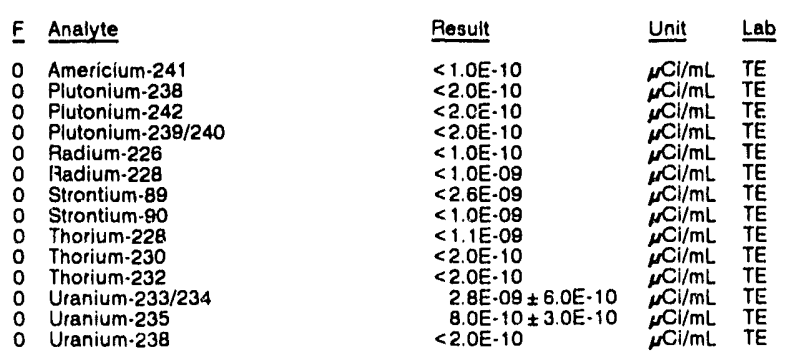

\section{WELL BGO 12CR}

MEASUREMENTS CONDUCTED IN THE FIELD

\section{Semple date: 08/CJ/91 Depth to water: $92.24 \mathrm{H}(28.12 \mathrm{~m})$ below TOC Water elevation: $221.76 \mathrm{ft}(67$ \\ Sp. conductance: $447 \mu \mathrm{s} / \mathrm{cm}$ \\ Water evacuated before sampling: 46 gal The well went dry during purging. \\ LABORATORY ANALYSES}
F Analyte
0 Americium-241
0 Plutonium-238
0 Plutonium-242
0 Radium-22
O Radium-228
0 Strontium-89
0 Strontium-90
O Thorium-228
Thorium-230
$\begin{array}{ll}0 & \text { Thorium-232 } \\ 0 & \text { Uranium-233/234 }\end{array}$
0 Uranium-235

\section{Yime: $9: 25$}

Alkalinity: $145 \mathrm{mg} / \mathrm{L}$ Water temperature: $21.3^{\circ} \mathrm{C}$
Result $\quad$ Unit Lab

$1.0 \mathrm{E} \cdot 10 \pm 1.0 \mathrm{E} \cdot 10$

$<4.0 \mathrm{E}-10$ - $2 \mathrm{E}-10$

$5.0 E \cdot 10 \pm 3.0 E \cdot 10$

$<1.0 \mathrm{E}-10=0.0 \mathrm{E} \cdot 10$

$<2.5 \mathrm{E}-09$

$1.0 \mathrm{E}-09 \pm 6.0 \mathrm{E}-10$

$<1.1 E \cdot 08$

$<2.0 \mathrm{E}-10$

$<2.0 E \cdot 10$

$1.8 \mathrm{E}-09 \pm 4.0 \mathrm{E}-10$
$<1.0 \mathrm{E}-10$

$1.0 \mathrm{E} \cdot 10 \pm 1.0 \mathrm{E} \cdot \mathrm{O}$ 
ANALYTICAL RESULTS

\section{WELL BGO 12D}

MEASUREMENTS CONDUCTED IN THE FIELD

Sample date: $07 / 02 / 91$
Depth to water: $82.58 \mathrm{H}(25.17 \mathrm{~m})$ below TOC
Water elevation: $231.12 \mathrm{H}(70.45 \mathrm{~m}) \mathrm{ms}$
Sp. conductance: $170 \mu \mathrm{S} / \mathrm{cm}$
Water evacuated before sampling: $8 \mathrm{gal}$
The well went dry during purging.
LABORATORY ANALYSES

Time: 13:25

$\mathrm{pH}: 6.9$

Alkalinity: $56 \mathrm{mg} / \mathrm{h}$

Water temperature: $23.2^{\circ} \mathrm{C}$

Pesult

F Analyte

o Uranium-233/234

0 Uranium-238

$<1.0 E-10$

$<1.0 \mathrm{E} \cdot 10$

\section{WELL BGO 14AR}

MEASUREMENTS CONDUCTED IN THE FIELD

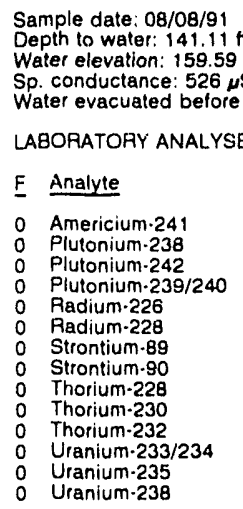

Time: $13 \cdot 20$

Alkalinity: $174 \mathrm{mg} /$

Water temperature: $20.2^{\circ} \mathrm{C}$

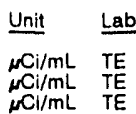

\section{WELL BGO 14CR}

MEASUREMENTS CONDUCTED IN THE FIELD

Sample date: 08/09/91

Depth to water: $76.57 \mathrm{ft}(23.34 \mathrm{~m})$ below TOC Water elevation: $223.93 \mathrm{ft}(68.25 \mathrm{~m}) \mathrm{ms}$ Sp. conductance: $134 \mu \mathrm{S} / \mathrm{cm}$

The well went dry during sampling: $17 \mathrm{gal}$

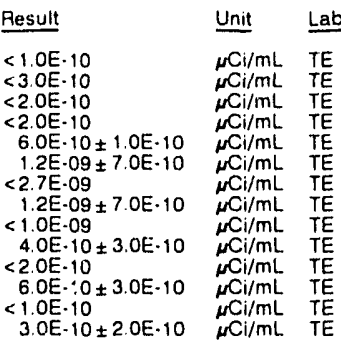

LABORATOAY ANALYSES

\begin{tabular}{|c|c|c|c|c|}
\hline$\underline{F}$ & Analyte & Result & Unit & Lab \\
\hline $\begin{array}{l}0 \\
0 \\
0 \\
0 \\
0 \\
0 \\
0 \\
0 \\
0 \\
0 \\
0\end{array}$ & $\begin{array}{l}\text { Americium-241 } \\
\text { Plutonium-238 } \\
\text { Plutonium-242 } \\
\text { Plutonium-239/240 } \\
\text { Radium-226 } \\
\text { Radium-228 } \\
\text { Strontium-89 } \\
\text { Strontium-90 } \\
\text { Thorium-228 } \\
\text { Thorium-230 } \\
\text { Thorium-232 } \\
\text { Uranium-233/234 } \\
\text { Uranium-235 } \\
\text { Uranium-238 }\end{array}$ & 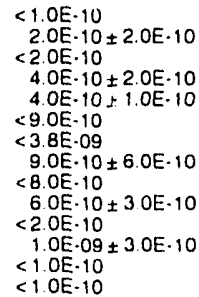 & $\begin{array}{l}\mu \mathrm{Ci} / \mathrm{mL} \\
\mu \mathrm{Ci} / \mathrm{mL} \\
\mu \mathrm{Ci} / \mathrm{mL} \\
\mu \mathrm{Ci} / \mathrm{mL} \\
\mu \mathrm{Ci} / \mathrm{mL} \\
\mu \mathrm{Ci} / \mathrm{mL} \\
\mu \mathrm{Ci} / \mathrm{mL} \\
\mu \mathrm{Ci} / \mathrm{mL} \\
\mu \mathrm{Ci} / \mathrm{mL} \\
\mu \mathrm{Ci} / \mathrm{mL} \\
\mu \mathrm{Ci} / \mathrm{mL} \\
\mu \mathrm{Ci} / \mathrm{mL} \\
\mu \mathrm{Ci} / \mathrm{mL} \\
\mu \mathrm{Ci} / \mathrm{mL}\end{array}$ & $\begin{array}{l}\text { TE } \\
\text { TE } \\
\text { TE } \\
\text { TE } \\
\text { TE } \\
\text { TE } \\
\text { TE } \\
\text { TE } \\
\text { TE } \\
\text { TE } \\
\text { TE } \\
\text { TE } \\
\text { TE } \\
\text { TE }\end{array}$ \\
\hline
\end{tabular}

\section{WELL BGO 14DR}

MEASUREMENTS CONDUCTED IN THE FIELL

Sample date: 07/03/91

(t) $2131 \mathrm{~m})$ below TOC

Water elevation: $230.39 \mathrm{ft}(70$.

ance $68 \mathrm{\mu S} / \mathrm{cm}$

Water evacuated before sampling: $33 \mathrm{gal}$

\section{Time: $9: 50$}

pH: 7.3 Alkalinity: $39 \mathrm{mg} / \mathrm{L}$

Water temperature: $20.7^{\circ} \mathrm{C}$

LABORATORY ANALYSES

\begin{tabular}{|c|c|c|c|}
\hline Analyte & Resuit & Unit & $\underline{L a b}$ \\
\hline $\begin{array}{ll}0 & \text { Americium-241 } \\
0 & \text { Plutonium-238 } \\
0 & \text { Plutonium-241 } \\
0 & \text { Plutonium-239/240 } \\
0 & \text { Radium-226 } \\
0 & \text { Padium-228 }\end{array}$ & $\begin{array}{l}<1.0 E \cdot 10 \\
<1.0 E \cdot 10 \\
<1.0 E \cdot 10 \\
<10 E \cdot 10 \\
1.0 E \cdot 10 \pm 1 \cdot C E \cdot 10 \\
12 E \cdot 09 \pm 80 E \cdot 10\end{array}$ & $\begin{array}{l}\mu \mathrm{Cl} / \mathrm{mL} \\
\mu \mathrm{Ci} / \mathrm{mL} \\
\mu \mathrm{C}, / \mathrm{mL} \\
\mu \mathrm{Cl} / \mathrm{mL} \\
\mu \mathrm{Cl} / \mathrm{mL} \\
\mu \mathrm{Ci} / \mathrm{mL}\end{array}$ & $\begin{array}{l}T E \\
T E \\
T E \\
T E \\
T E \\
T E \\
T E\end{array}$ \\
\hline
\end{tabular}

WELL BGO 14DR collected on 07/03/81, laboratory analyses (cont.)

\begin{tabular}{|c|c|c|}
\hline Analyte & Result & Unit \\
\hline $\begin{array}{ll}0 & \text { Strontium- } 89 \\
0 & \text { Strontium-90 } \\
0 & \text { Thorium-228 } \\
0 & \text { Thorium-230 } \\
0 & \text { Thorium-232 } \\
0 & \text { Uranium-233/234 } \\
0 & \text { Uranium }-235 \\
0 & \text { Uranium.238 }\end{array}$ & 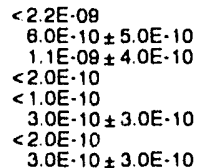 & $\begin{array}{l}\mu \mathrm{Cl} / \mathrm{mL} \\
\mu \mathrm{Ci} / \mathrm{mL} \\
\mu \mathrm{Ci} / \mathrm{mL} \\
\mu \mathrm{Cl} / \mathrm{mL} \\
\mu \mathrm{Ci} / \mathrm{mL} \\
\mu \mathrm{Cl} / \mathrm{mL} \\
\mu \mathrm{Cl} / \mathrm{mL} \\
\mu \mathrm{Ci} / \mathrm{mL}\end{array}$ \\
\hline
\end{tabular}

\section{WELL BGO 15D}

MEASUREMENTS CONDUCTED IN THE FIELD

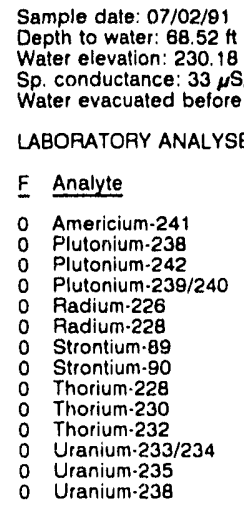

\section{Time: $14: 00$}

pH: 5.1 Water temperature: $25.3^{\circ} \mathrm{C}$

cm mpling: $30 \mathrm{gal}$

LABORATORY ANALYSES

E Analyte

0 Americium-241

Plutonium-238

Plutonium.239/240

Radium-226

Strontium-89

Strontium.90

Thorium.230

Uranium-233/234

Uranium-238

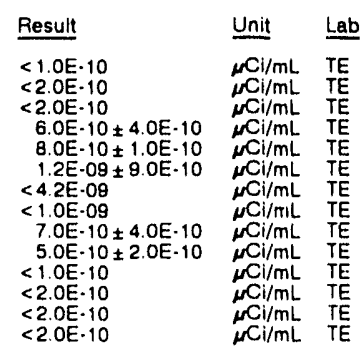

WELL. BGO 16A

MEASUREMENTS CONDUCTED IN THE FIELD

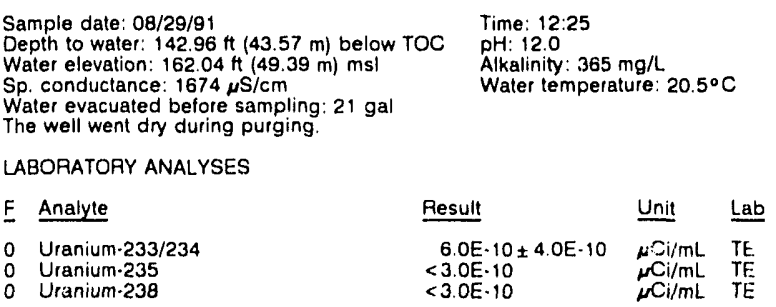

WELL BGO 18A

MEASUREMENTS CONDUCTED IN THE FIELD

Sample date: 08/29/91

Depth to water: $133.06 \mathrm{ft}\langle 40.56 \mathrm{~m}\rangle$ below TOC

Water elevation: $162.14 \mathrm{Ht}(49.42 \mathrm{~m}) \mathrm{msl}$

Sp. conductance: $199 \mu \mathrm{S} / \mathrm{cm}$

Water evacuated before sampling: $165 \mathrm{ga}$

LABORATORY ANALYSES

\begin{tabular}{|c|c|c|}
\hline Analyte & Result & Unit \\
\hline $\begin{array}{ll}0 & \text { Uranium-233/234 } \\
0 & \text { Uranium-235 } \\
0 & \text { Uranium-238 }\end{array}$ & $\begin{aligned} & 4.0 E-09 \pm 1.1 E \cdot 09 \\
< & 4.0 E-10 \\
< & 4.0 E \cdot 10\end{aligned}$ & $\begin{array}{l}\underset{\mu C i / m L}{ }{ }^{\mathrm{C} i} \mathrm{mi} / \mathrm{mL} \\
\mu \mathrm{Ci} / \mathrm{mL}\end{array}$ \\
\hline
\end{tabular}

\section{WELLL BGO 18D}

MEASUREMENTS CONDUCTED IN THE FIELD

$\begin{array}{ll}\text { Sample date: } 08 / 29 / 91 & \text { Time: } 11.35 \\ \text { Depth to water: } 62.57 \mathrm{H}(19.07 \mathrm{~m}) \text { below TOC } & \text { pH: } 4.7 \\ \text { Water elevation: } 232.33 \mathrm{Ht}(70.82 \mathrm{~m}) \mathrm{msl} & \text { Alkalinity: } 0 \mathrm{mg} / \mathrm{L} \\ \text { Sp. conductance: } 26 \mu \mathrm{S} / \mathrm{cm} & \text { Water temperature: } 20.0^{\circ} \mathrm{C} \\ \text { Water evacuated betore sampling: } 33 \mathrm{gat} & \end{array}$

LABORATORY ANALYSES

\begin{tabular}{|c|c|c|}
\hline F Analyte & Result & $\underline{\text { Unit }}$ \\
\hline $\begin{array}{ll}0 & \text { Uranium-233/234 } \\
0 & \text { Uranium-235 } \\
0 & \text { Uranium-238 }\end{array}$ & $\begin{aligned} & 3.0 E \cdot 10 \pm 2 O E \cdot 10 \\
&<2 . O E \cdot 10 \\
&<2.0 E \cdot 10\end{aligned}$ & $\begin{array}{l}\underset{\mu \mathrm{Ci} / \mathrm{mL}}{\mu \mathrm{Ci} / \mathrm{mL}} \\
\mu \mathrm{Ci} / \mathrm{mL}\end{array}$ \\
\hline
\end{tabular}


ANALYTICAL RESULTS

\section{WELL BGO 20D}

MEASUREMENTS CONDUCTED IN THE FIELD

\begin{tabular}{|c|c|c|c|c|c|}
\hline & $\begin{array}{l}\text { mple date: } 08 / 29 / 91 \\
\text { pth to water: } 49.19 \mathrm{H}(14.89 \mathrm{~m}) \text { below TOC } \\
\text { ter elevation: } 234.51 \mathrm{ft}(71.48 \mathrm{~m}) \mathrm{msl} \\
\text { conductance: } 75 \mu \mathrm{s} / \mathrm{cm} \\
\text { iter evacuated before sampling: } 8 \mathrm{gal} \\
\text { well went dry during purging. }\end{array}$ & & $\begin{array}{l}\text { Time: } 12: 10 \\
\text { pH: } 5.6 \\
\text { Alkalinity: } 15 \\
\text { Waler tempe }\end{array}$ & mg/L. & \\
\hline & BORATORY ANALYSES & & & & \\
\hline E & Analyte & Result & & Unit & Lab \\
\hline & $\begin{array}{l}\text { Uranium-233/234 } \\
\text { Uranium.235 } \\
\text { Uranium-238 }\end{array}$ & $\begin{array}{r}3.0 \mathrm{E} \\
<1.0 \mathrm{E} \\
1.0 \mathrm{E}\end{array}$ & $\begin{array}{l}-10 \pm 2.0 E \cdot 10 \\
10 \\
10 \pm 1 . n E-10\end{array}$ & 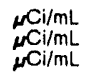 & $\begin{array}{l}\text { TE } \\
\text { TE } \\
\text { TE }\end{array}$ \\
\hline
\end{tabular}

\section{WELL BGO 21D}

MEASUREMENTS CONDUCTED IN THE FIELD

\begin{tabular}{|c|c|c|c|c|c|}
\hline & $\begin{array}{l}\text { mple date: } 08 / 29 / 91 \\
\text { pth to water: } 49.99 \mathrm{ft}(15.24 \mathrm{~m}) \text { below TOC } \\
\text { ter elevation: } 235.41 \mathrm{ft}(71.75 \mathrm{~m}) \mathrm{msl} \\
\text { conductance: } 189 \mu \mathrm{s} / \mathrm{cm} \\
\text { ter ovacuated before sampling: } 8 \mathrm{gal} \\
\text { o well went dry during purging. }\end{array}$ & & $\begin{array}{l}\text { Time: } 12: 50 \\
\text { pH: } 6.5 \\
\text { Alkalinity: } 39 \\
\text { Water tempe }\end{array}$ & $\begin{array}{l}\mathrm{mg} / \mathrm{L} \\
\text { ature: } 21 .\end{array}$ & \\
\hline & BORATORY ANALYSES & & & & \\
\hline$\underline{F}$ & Analyte & Result & & Unit & $\underline{L a b}$ \\
\hline & $\begin{array}{l}\text { Uranium-233/234 } \\
\text { Uranium-235 } \\
\text { Uranium-238 }\end{array}$ & $\begin{array}{r}7.0 E \\
<1.0 E \\
<1.0 E\end{array}$ & $\begin{array}{l}10 \pm 3.0 \mathrm{E} \cdot 10 \\
10 \\
10\end{array}$ & 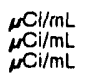 & $\begin{array}{l}\text { TE } \\
\text { TE } \\
\text { TE }\end{array}$ \\
\hline
\end{tabular}

\section{WELL BGO 22D}

MEASUREMENTS CONDUCTED IN THE FIELD

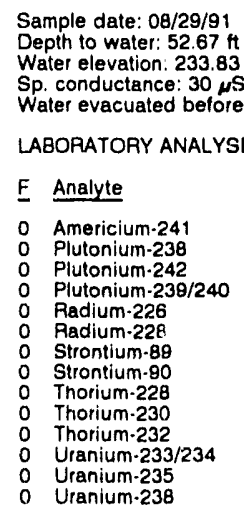

Time: 10:45

AH: 5.3

Water temperature: $20 . \epsilon=C$

Water evacuated $30 \mu \mathrm{S} / \mathrm{cm}$.

LABORATORY ANALYSES

\begin{tabular}{|c|c|c|}
\hline Analyte & Result & Unit \\
\hline $\begin{array}{l}\text { Americium-241 } \\
\text { Plutonium-238 } \\
\text { Plutonium-242 } \\
\text { Plutonium-239/240 } \\
\text { Radium-226 } \\
\text { Padium-228 } \\
\text { Strontium-89 } \\
\text { Strontium-90 } \\
\text { Thorium-228 } \\
\text { Thorium-230 } \\
\text { Thorium-232 } \\
\text { Uranium-233/234 } \\
\text { Uranium-235 } \\
\text { Uranium-238 }\end{array}$ & 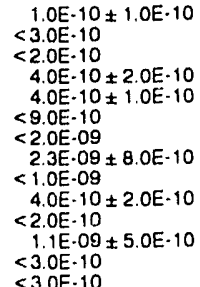 & $\begin{array}{l}\mu \mathrm{Cl} / \mathrm{mL} \\
\mu \mathrm{Ci} / \mathrm{mL} \\
\mu \mathrm{Cl} / \mathrm{mL} \\
\mu \mathrm{Ci} / \mathrm{mL} \\
\mu \mathrm{Ci} / \mathrm{mL} \\
\mu \mathrm{Ci} / \mathrm{mL} \\
\mu \mathrm{Cl} / \mathrm{mL} \\
\mu \mathrm{Ci} / \mathrm{mL} \\
\mu \mathrm{Ci} / \mathrm{mL} \\
\mu \mathrm{Ci} / \mathrm{mL} \\
\mu \mathrm{Ci} / \mathrm{mL} \\
\mu \mathrm{Ci} / \mathrm{mL} \\
\mu \mathrm{Ci} / \mathrm{mL} \\
\mu \mathrm{Ci} / \mathrm{mL}\end{array}$ \\
\hline
\end{tabular}

\section{WELL BGO 23D}

MEASUREMENTS CONDUCTED IN THE FIELD

\begin{tabular}{|c|c|c|c|c|}
\hline \multicolumn{3}{|c|}{$\begin{array}{l}\text { Sample date: } 08 / 29 / 91 \\
\text { Depth to water: } 52.77 \mathrm{ft}(16.08 \mathrm{~m}) \text { below TOC } \\
\text { Water elevation: } 236.43 \mathrm{H}(72.06 \mathrm{~m}) \mathrm{msl} \\
\text { Sp. cunductance: } 53 \mu \mathrm{\mu S} / \mathrm{cm} \\
\text { Water evacuated before sampling: } 38 \mathrm{gal}\end{array}$} & \multicolumn{2}{|c|}{$\begin{array}{l}\text { Time: } 9: 5 t \\
\text { pH: } 6.2 \\
\text { Alkalinity: } 12 \mathrm{mg} / \mathrm{L} \\
\text { Water temperature: } 21.5^{\circ} \mathrm{C}\end{array}$} \\
\hline \multicolumn{5}{|c|}{ LABORATORY ANALYSES } \\
\hline & Analyte & Result & $\underline{\text { Unit }}$ & $\underline{\text { Lab }}$ \\
\hline & $\begin{array}{l}\text { Uranium-233/234 } \\
\text { Uranium-235 } \\
\text { Uranium-238 }\end{array}$ & $\begin{array}{l}<1.0 E-10 \\
<1.0 E \cdot 10 \\
<1.0 E-10\end{array}$ & 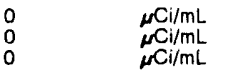 & $\begin{array}{l}\text { TE } \\
\text { TE } \\
\text { TE }\end{array}$ \\
\hline
\end{tabular}

\section{WELL BGO 25A}

MEASUREMENTS CONDUCTED IN THE FIELD

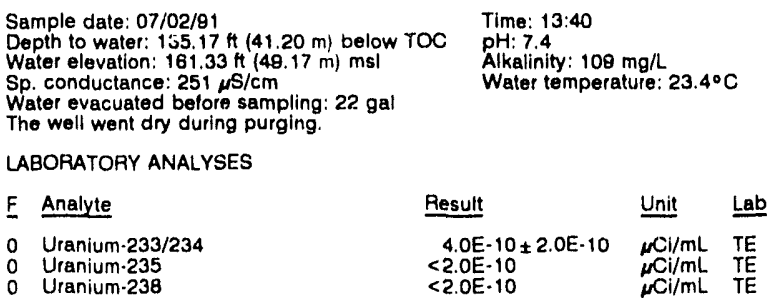

\section{WELL BGO 26D}

MEASUREMENTS CONDUCTED IN THE FIELD

$\begin{array}{ll}\text { Sample date: } 07 / 02 / 91 & \text { Time: } 7: 50 \\ \text { Depth to water: } 57.50 \mathrm{H}(17.53 \mathrm{~m}) \text { below TOC } & \text { pH: } 5.5 \\ \text { Water elevation: } 228.00 \mathrm{Ht}(89.50 \mathrm{~m}) \mathrm{ms} & \text { Alkalinity: } 8 \mathrm{mg} / \mathrm{L} \\ \text { Sp. conductarlce: } 39 \mu \mathrm{S} / \mathrm{cm} & \text { Water temperafure: } 20.5{ }^{\circ} \mathrm{C} \\ \text { Water ovacuated before sampling: } 9 \mathrm{gal} & \\ \text { ihe well went dry during purging. } & \end{array}$

LABORATORY ANALYSES

\begin{tabular}{|c|c|c|}
\hline F Analyte & Result & Unit \\
\hline $\begin{array}{ll}0 & \text { Antimony-125 } \\
0 & \text { Cerium-144 } \\
0 & \text { Cesium-134 } \\
0 & \text { Cesium.137 } \\
0 & \text { Cobalt-57 } \\
0 & \text { Cobalt-60 } \\
0 & \text { Europium-154 } \\
0 & \text { Manganese-54 } \\
0 & \text { Potasslum-40 } \\
0 & \text { Radium-226 } \\
0 & \text { Ruthenium-103 } \\
0 & \text { Sodium-22 } \\
0 & \text { Thorium-228 } \\
0 & \text { Thorium-230 } \\
0 & \text { Thorium-232 } \\
0 & \text { Uranium-233/234 } \\
0 & \text { Uranlum-235 } \\
0 & \text { Uranium-238 } \\
0 & \text { Zinc-65 }\end{array}$ & 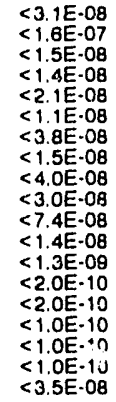 & 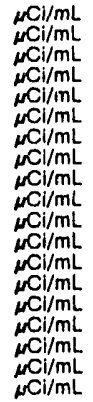 \\
\hline
\end{tabular}

\section{WELL BGO 27C}

MEASUREMENTS CONDUCTED IN THE FIELD

$\begin{array}{ll}\text { Sample date: } 07 / 01 / 91 & \text { Time: } 13: 50 \\ \text { Depth to water: } 5 \mathrm{5}, 16 \mathrm{H}(16.81 \mathrm{~m}) \text { below TOC } & \text { pH: } 7.0 \\ \text { Water elevation: } 220.84 \mathrm{ft}(67.31 \mathrm{~m}) \mathrm{ms} & \text { Alkalinity: } 34 \mathrm{mg} / \mathrm{L} \\ \text { Sp. conductance: } 116 \mu \mathrm{s} / \mathrm{sm} & \text { Water temperature: } 23.4^{\circ} \mathrm{C} \\ \text { Water evacuated telore sampling: } 173 \mathrm{gal} & \end{array}$

Water evacuated tefore sampling: $173 \mathrm{ga}$

LABORATORY ANALYSES

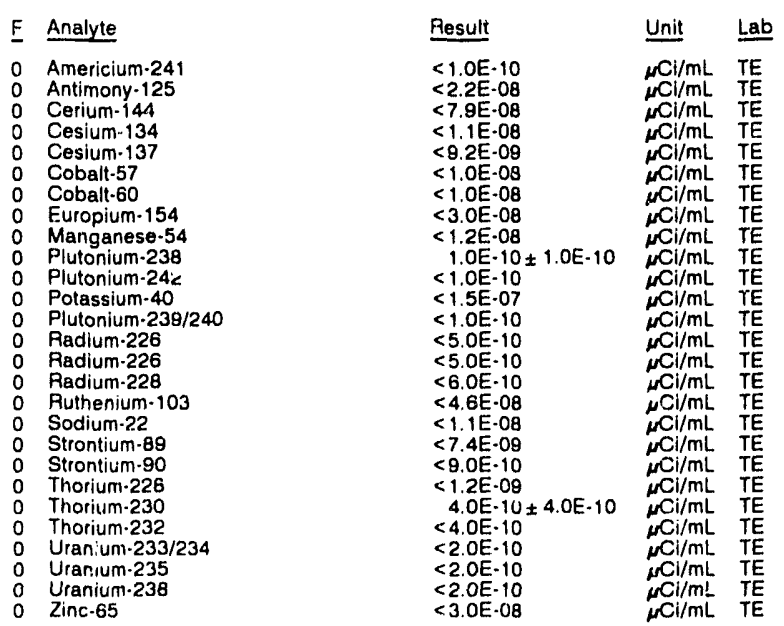




\section{ANALYTICAL RESULTS}

WELL BGO 27C

MEASUREMENTS CONDUCTED IN THE FIELD

Sample date: 07/01/91

Depth to water: $55.16 \pi(16.81 \mathrm{~m})$ below TDC

Sp conductance 104 (cm

Water evacuated hefore

LABORATORY ANALYSES

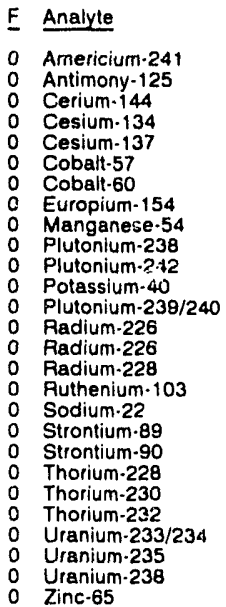

Resull

Time: 13:50

Alkalinity: $34 \mathrm{mgll}$

Water temperature: $23.4^{\circ} \mathrm{C}$

$1.0 \mathrm{E}$ -

$<1.0 \mathrm{E}-10$
$<3.2 \mathrm{E}-08$

$<1.4 \mathrm{E} \cdot 07$

$<1.1 \mathrm{E}-08$
$<1.3 \mathrm{E}-08$

$<1.8 E .08$

$<9.5 \mathrm{E}-09$

$<2.9 \mathrm{E}-08$

$<2.0 \mathrm{E}-10$

$<1.0 \mathrm{E} \cdot 10$

$<1.2 \mathrm{E} .07$

$<1.0 \mathrm{E}-10$

6. $0 \mathrm{E}-10 \pm 2.0 \mathrm{E}-10$

$6.0 E-10 \pm 2.0 E-10$

2.7E-09 $\pm 1.1 \mathrm{E} \cdot 09$

$<6.2 \mathrm{E} .08$

$<1.0 E .08$

2.3E-09 $090 \mathrm{E}-10$

$4.2 \mathrm{E}-09 \pm 1.8 \mathrm{E}-09$

$4.2 E-09$
$<5 \mathrm{OE}-10$

$<5.0 \mathrm{E}-10$
$<5.0 \mathrm{E}-10$

$<2.0 \mathrm{E}-10 \pm 4.0 \mathrm{E}-10$

$<1.0 E \cdot 10$

$<1.0 E-10$

$<3.4 \mathrm{E} \cdot 08$

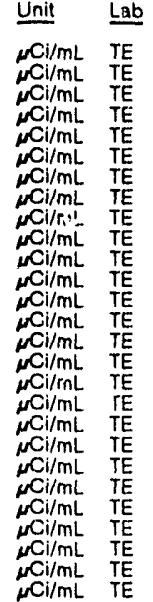

WELL BGO 27D

MEASUREMENTS CONDUCTED IN THE FIELD

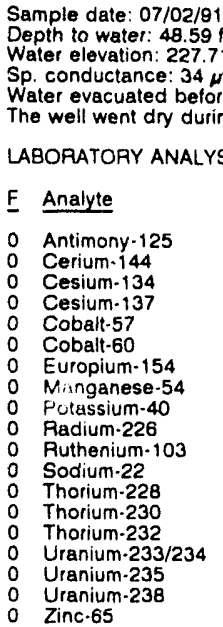

The well went dry during purging.

TORY ANALYSES

Result

$<2.3 \mathrm{E}-\mathrm{OB}$
$<7.7 \mathrm{E}-0 \mathrm{O}$

$<1.3 \mathrm{E} .00$

$<7.6 \mathrm{E}-09$

$<9.0 E-09$

$<4.4 \mathrm{E} .08$

$<1.3 \mathrm{E} .08$

$<1.3 \mathrm{E}-07$

$<1.7 \mathrm{E}-08$

$<3.6 \mathrm{E}-08$

$<1.6 \mathrm{E}-08$

$<3.0 E \cdot 10$

$<3$. 10

1. $1 \mathrm{E} \cdot 09+5.0 \mathrm{E} \cdot 10$

$<2.0 \mathrm{E}-10$ 10.

B. $0 E \cdot 10 \pm 4.0 E-10$

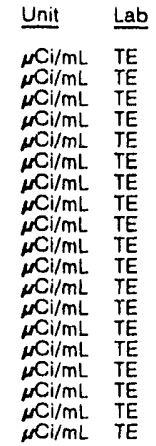

WELL BGO 28D

MEASUREMENTS CONDUCTED IN THE FIELD

Sample date: 07/02/91 Depth to water: $50.97 \mathrm{ft}(15.54 \mathrm{~m})$ below TOC Water elevation: $226.43 \mathrm{ft}(69.02 \mathrm{~m}) \mathrm{msl}$

Sp. conductance: $82,45 / c m$

Water evacuated before sampling: $9 \mathrm{gal}$

The well went dry during purging.

LABORATORY ANALYSES

F Analyte

0 Antimony-125

Cesium.134

Cesium-134

Cobalt. 57

Cobalt-60

Europium 154
Manganese. 54
Time: $8: 30$

$\mathrm{pH}: 5.3$

Water temperature: $: 3.70 \mathrm{C}$
Result

$<3.0 \mathrm{E}-\mathrm{OB}$

$<1.3 E-07$

$<1.1 \mathrm{E}-08$

$<1.6 \mathrm{E}-08$

$<1.0 E-08$

$<3.0 E \cdot 08$

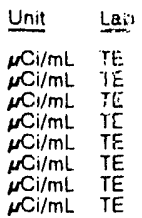

WELL BGO 28D collected on 07/02/91, laboratory analyses (cont)

F Analyte

Potassium-40

Ruthenium-103

0 Sodium-22

0 Thorium-228

0 Thorium-232

O Uranium-233/234

o Uranium-235

O Zinc-65

Result

$<1.1 E-07$

$<2.3 E-08$

$<1.1 \mathrm{E}-00$

$<1.2 E-09$

$<2.0 E-10$

$<4.0 E-10$

$<7.0 \mathrm{E}-10$

$<7.0 E-10$

\begin{tabular}{ll} 
Unit & Lab \\
\hline$\mu \mathrm{Cl} / \mathrm{mL}$ & TE \\
$\mu \mathrm{Ci} / \mathrm{mL}$ & $T E$ \\
$\mu \mathrm{Cl} / \mathrm{mL}$ & $T E$ \\
$\mu \mathrm{Cl} / \mathrm{mL}$ & $T E$ \\
$\mu \mathrm{Cl} / \mathrm{mL}$ & $T E$ \\
$\mu \mathrm{Cl} / \mathrm{mL}$ & $T E$ \\
$\mu \mathrm{Cl} / \mathrm{mL}$ & $T E$ \\
$\mu \mathrm{C} / \mathrm{mL}$ & $T E$ \\
$\mu \mathrm{Cl} / \mathrm{mL}$ & $T E$ \\
$\mu \mathrm{Cl} / \mathrm{mL}$ & $T E$ \\
$\mu \mathrm{Cl} / \mathrm{mL}$ & $T E$
\end{tabular}

WELL BGO 29A

MEASUREMENTS CONDUCTED IN THE FIELD

Sample dato: 07/02/81

Depth to water: $104.28 \mathrm{ft}(31.78 \mathrm{~m})$ below TOC

Water elevation: $159.82 \mathrm{n}(48.74 \mathrm{~m}) \mathrm{msl}$

ling: $40 \mathrm{gal}$

pH: 73

Alkalinity: $33 \mathrm{mg} / \mathrm{l}$ Water temperature: $19.8^{\circ} \mathrm{C}$

The well went dry during purging.

LABOAATORY ANALYSES

E Analyte

o Antimony-125

Cerium-144

O Cesium-134

O Cesium-137

0 Cobalt-60

O Europium-154

Manganese-54

Potassium-40

Pladium-226

Sodium-22

Thorium-228

Thorium-230

Uhorium-232

Uranium-233/234

Uranium-23

0 Zinc.65

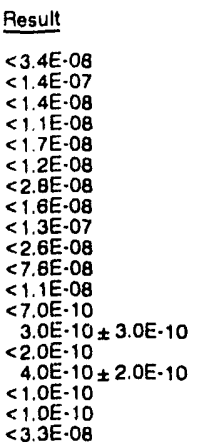

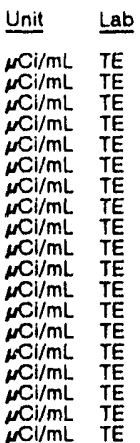

WELL BGO $30 \mathrm{C}$

MEASUREMENTS CONDUCTED IN THE FIELD

Sample date: 07/02/91

Depth to water: $55.08 \mathrm{At}(16.79 \mathrm{~m})$ below TOC

Water elevation: $218.42 \mathrm{ft}(66.88 \mathrm{~m}) \mathrm{msl}$

Water evacuated before sampling: $24 \mathrm{gal}$

The well went dry during purging.

LABORATORY ANALYSES

E Analyte

- Antimony-125

C Cerium.144

Cosium-134

Cesivint-137

Cobat a

Eurowite $15 \mathrm{~A}$

o Mangei $=4$

Potessis 3 a $^{2}$

Radisn :

Sodiun: ' 4 '

Thorium 7 ?

Thorium 2 iso

Uhoriuin. 232

Uranium.233/234

Uranium 23
Time: $8: 50$

Alkalinity: $15 \mathrm{mg} / \mathrm{h}$ Water tomperature: $20.3^{\circ} \mathrm{C}$
Result

$<3.3 E-08$

$<1.4 \mathrm{E}-07$

$<1.6 E .08$
$<1.1 E .08$

$<1.8 \mathrm{E} .08$

$<1.1 \mathrm{E} \cdot 08$

$<3.0 E \cdot 08$

$<1.7 E-08$

$<2.6 \mathrm{E}-08$

$<5.0 \mathrm{E}-08$

\.

$3.0 \mathrm{E} \cdot 10 \pm 2.0 \mathrm{E} \cdot 10$

$2.0 \mathrm{E} \cdot 10$
$7.0 \mathrm{E} \cdot 10 \pm 2.0 \mathrm{E} \cdot 10$

$<1.0 \mathrm{E}-10$

$<1.0 E-10$
$<3.0 E-08$

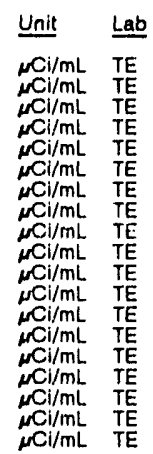


ANALYTICAL RESULTS

WELL BGO 30D

MEASUREMENTS CONDUCTED IN THE FIELD

Sample date: $07 / 02 / 91$

Depth to water: $48.72 \mathrm{ft}(14.85 \mathrm{~m})$ below TOC

Water elevation: $226.00 \mathrm{H}(68.91 \mathrm{~m}) \mathrm{ms}$

Pp. conductance: $116 \mu \mathrm{S} / \mathrm{cm}$

Water evacuated before sampling. $11 \mathrm{gal}$

The well went dry during purging.

LABORATORY ANALYSES

\begin{tabular}{|c|c|c|}
\hline Analyte & Result & Unit \\
\hline $\begin{array}{l}\text { ihorium-228 } \\
\text { Ti. rium-230 } \\
\text { Tr. um-232 } \\
\text { Uraniumm-233/234 } \\
\text { Uranium-235 }\end{array}$ & $\begin{aligned} & 6.0 \mathrm{OE} \cdot 10 \pm 1.0 \mathrm{E} \cdot 10 \\
&<4.0 \mathrm{E}-10 \\
&<4.0 \mathrm{E}-10 \\
&<3.0 \mathrm{E} \cdot 10 \\
&<3.0 \mathrm{E} \cdot 10 \\
&\end{aligned}$ & 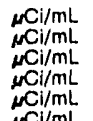 \\
\hline
\end{tabular}

\section{WELL BGO 31C}

MEASUREMENTS CONDUCTED IN THE FIELD

Sample date: 07/02/91

Depth to water: $47.13 \mathrm{ft}(14.37 \mathrm{~m})$ below TOC

Water elevation: $225.97 \mathrm{Ht}(6 \mathrm{~B} .0 \mathrm{H}$

Water evacuated before sampling $32 \mathrm{gal}$

The well went dry during purging.

LABORATORY ANALYSES
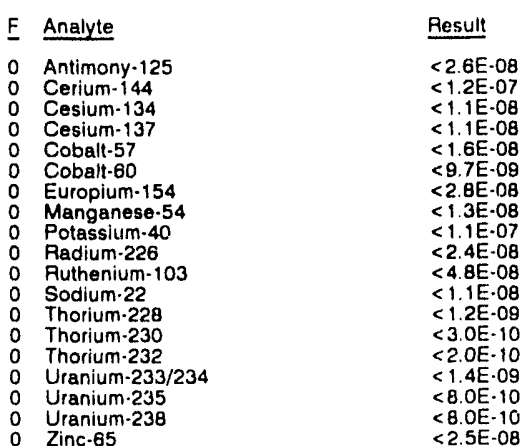

Time: $8: 05$

Alkalinity: $3 \mathrm{mg} / \mathrm{l}$

Water temperature: $206^{\circ} \mathrm{C}$

$\mathrm{pH}: 5.8$

Alkalinity: $24 \mathrm{mg} / \mathrm{L}$

Water temperature: $21.6^{\circ} \mathrm{C}$

\section{WELL BGO 31D}

MEASUREMENTS CONDUCTED IN THE FIELD

Sample date: $07 / 02 / 91$
Depth to water: $46.58 \mathrm{ft}(14.20 \mathrm{~m})$ below TOC
Water elevation: $227.12 \mathrm{ft}(69.23 \mathrm{~m}) \mathrm{msl}$
Sp. conductarice: $32, \mu \mathrm{S} / \mathrm{cm}$
Water evacuated betore sampling: $9 \mathrm{gal}$
The well went dry during purging.
LABORATORY ANALYSES

Time: 9:15

Alkalinity: $0 \mathrm{mg}$

Water temperature: $21.0^{\circ} \mathrm{C}$

LABORATORY ANALYSES

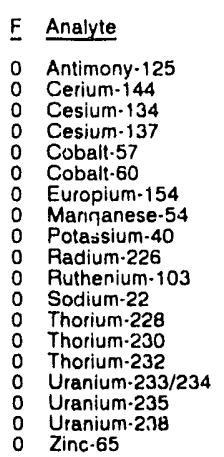

Result

$<2.3 \mathrm{E} \cdot 08$

$<7.3 \mathrm{E} \cdot 08$

$<1.3 \mathrm{E} \cdot 08$

$<8.5 \mathrm{E}-09$

$<1.0 \mathrm{E} \cdot 08$

$<3.1 \mathrm{E} \cdot 08$

$<1.1 \mathrm{E} \cdot 08$

$<1.2 E-07$

$<1.6 E-08$

$<4.0 E-08$

$<1.1 \mathrm{E}-08$

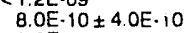

$<3.0 \mathrm{E}-10$

$2.5 \mathrm{E} \cdot 09 \pm 1.7 \mathrm{E}-09$

$<1.4 \mathrm{E}-09$

$<1.4 \mathrm{E}-09$

$<3.4 \mathrm{E} .08$
WELL BGO 32D

MEASUREMENTS CONDUICTED IN THE FIELD

$\begin{array}{ll}\text { Sample date: } 07 / 02 / 91 & \text { Time: } 8: 30 \\ \text { Depth to water: } 53.56 \mathrm{H}(16.33 \mathrm{~m}) \text { below roC } & \text { pH: } 4.5 \\ \text { Water elevation: } 228.14 \mathrm{ft}(69.54 \mathrm{~m}) \mathrm{ms} & \text { Alkalinity: } 0 \mathrm{mg} / \mathrm{L} \\ \text { Sp. conductance: } 60 \mu \mathrm{s} / \mathrm{cm} & \text { Water temperature: } 21.2^{\circ} \mathrm{C} \\ \text { Water evacuated before sampling: } 9 \mathrm{gal} & \\ \text { The well went dry during purging. } & \end{array}$

LABORATOPY ANALYSES

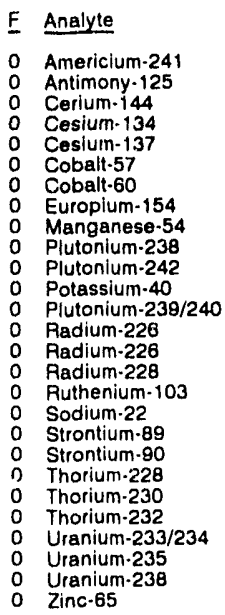

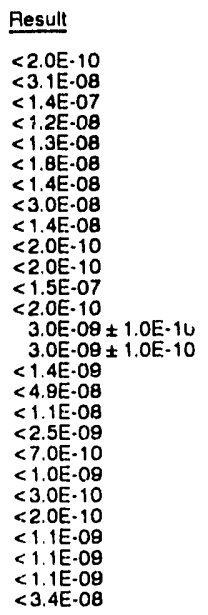

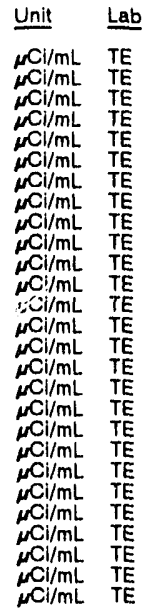

WELL BGO 33C

MEASUREMENTS CONDUCTED IN THE FIELD

Sample date: 07/01/91

Depth to water: $53.92 \mathrm{ft}(16.44 \mathrm{~m})$ below TOC

Water elevation: $225.48 \mathrm{Ht}(68.7$

Sp. conduclance: $66 \mu \mathrm{s} / \mathrm{cm}$

Time: $15: 35$
pH: 5.9

Alkalinity: $10 \mathrm{mgl}$

Water temperature: $22.8^{\circ} \mathrm{C}$

LABORATORY ANALYSES

$\begin{array}{ll}\text { F } & \text { Analyte } \\ 0 & \text { Americium-241 } \\ 0 & \text { Antimony-125 } \\ 0 & \text { Cerium }-144 \\ 0 & \text { Cesium }-134 \\ 0 & \text { Cesium-137 } \\ 0 & \text { Cobalt-57 } \\ 0 & \text { Cobalt-60 } \\ 0 & \text { Europium-154 } \\ 0 & \text { Manganese-54 } \\ 0 & \text { Plutonium-238 } \\ 0 & \text { Plutonium-242 } \\ 0 & \text { Potassium-40 } \\ 0 & \text { Plutonium-238/240 } \\ 0 & \text { Padium-228 } \\ 0 & \text { Radium-226 } \\ 0 & \text { Radium-228 } \\ 0 & \text { Ruthenium-103 } \\ 0 & \text { Sodium-22 } \\ 0 & \text { Strontium-89 } \\ 0 & \text { Strontium-90 } \\ 0 & \text { Thorium-228 } \\ 0 & \text { Thorium-230 } \\ 0 & \text { Thorium-232 } \\ 0 & \text { Uranium }-233 / 234 \\ 0 & \text { Uranium-235 } \\ 0 & \text { Uranium-238 } \\ 0 & \text { Zinc- } 65 \\ & \end{array}$

Result

Unit Lab

$<1.0 E-10$

$<3.7 \mathrm{E} .08$

$<1.5 \mathrm{E}-00$

$<1.5 \mathrm{E}-0 \mathrm{0}$

$<1.9 \mathrm{E}-08$

$<1.1 \mathrm{E}-08$

$<3.8 \mathrm{EE}-08$

$<1.7 \mathrm{E}-08$

$<2.0 \mathrm{E}-10$

$4.0 \mathrm{E}-10 \pm 2.0 \mathrm{E}-10$

$2.0 \mathrm{E}-10 \pm 1.0 \mathrm{E}-10$

$2.0 \mathrm{E} \cdot 10 \pm 1.0 \mathrm{E}-10$

$<7.6 \mathrm{E} \cdot 08$

$<5.8 \mathrm{E}-08$

$<1.1 \mathrm{E}-09$

$<1.1 E-09$

$<2.0 \mathrm{E} \cdot 10$

$<4.0 \mathrm{E}-10$

$<5.0 \mathrm{E}-10$

$<5.0 \mathrm{E}-10$

$<5.0 \mathrm{E}-10$
$<3.2 \mathrm{E} \cdot 08$

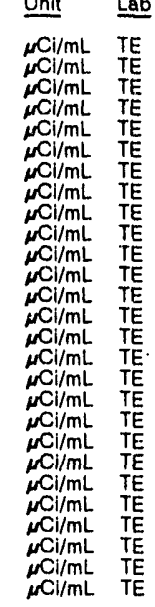




\section{WELL BGO 33D}

MEASUREMENTS CONDUCTED IN THE FIELD

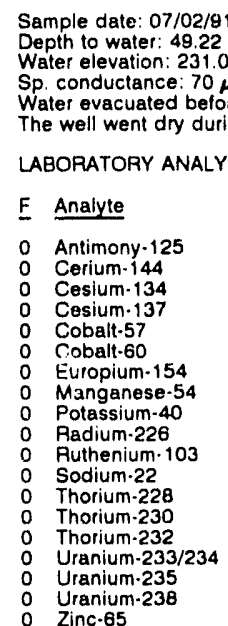

Time: $9: 55$

Alkalinity. $1 \mathrm{mg} / \mathrm{L}$

Water temperature: $21.3^{\circ} \mathrm{C}$

sampling: $12 \mathrm{gal}$

LABORATORY ANALYSES

E Analyte

Antimony -125

Cesium.137

Cobalt-60

Europium.154

Potassium-40

Ruthenium.103

Sodium-22

Thorium-230

Uranium-233/234

Uranium-238

\section{WELL BGO 34D}

MEASUREMENTS CONDUCTED IN THE FIELD

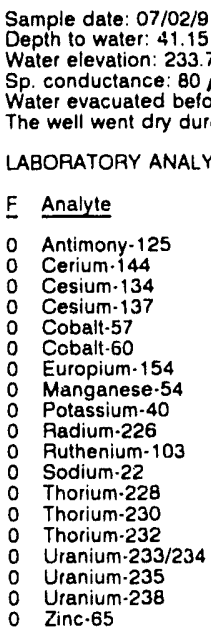

Result

$<3.3 \mathrm{E} \cdot 08$
$<1.4 \mathrm{E} .07$

$<1.5 \mathrm{E}-08$

$<1.7 \mathrm{E} \cdot 08$

$<1.2 \mathrm{E} \cdot 08$
$<4.0 \mathrm{E} \cdot 08$

$<1.4 \mathrm{E} .08$

$<1.2 \mathrm{E} .07$

$<6.8 \mathrm{E} \cdot 08$

$<1.4 E-08$

$<2.0 \mathrm{E}-10$

$1.8 \mathrm{E} \cdot 09 \pm 6.0 \mathrm{E} \cdot 10$

$<2.0 \mathrm{E} \cdot 10$

$<\begin{aligned} & 3.0 \mathrm{E}-10 \\ & <3.2 \mathrm{E}-0 \mathrm{0B}\end{aligned}$

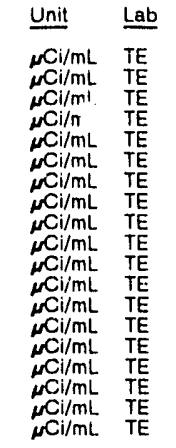

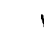

\begin{tabular}{|c|c|c|c|}
\hline$\underline{F}$ & Analyte & Result & Unit \\
\hline $\begin{array}{l}0 \\
0 \\
0\end{array}$ & $\begin{array}{l}\text { Uranium-23j } \\
\text { Uranium-238 } \\
\text { Zinc-65 }\end{array}$ & $\begin{array}{l}<1.0 \mathrm{E} \cdot 10 \\
<1.0 \mathrm{E} \cdot 10 \\
<1.8 \mathrm{E} \cdot 08\end{array}$ & 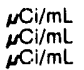 \\
\hline
\end{tabular}

\section{WELL BGO 35C}

MEASUREMENTS CONDUCTED IN THE FIELO

$\begin{array}{ll}\text { Sample date: } 07 / 02 / 91 & \text { Time: } 10: 40 \\ \text { Depth to water: } 44.62 \mathrm{ft}(13.60 \mathrm{~m}) \text { below TOC } & \text { pH: } 8.7 \\ \text { Water elevation: } 228.78 \mathrm{tt}(69.73 \mathrm{~m}) \mathrm{msl} & \text { Alkalinity: } 34 \mathrm{mg} / \mathrm{L} \\ \text { Sp. conductance: } 94 \mu \mathrm{NS} / \mathrm{cm} & \text { Water temperature: } 20.70 \mathrm{C} \\ \text { Water evacuated before sampling: } 175 \mathrm{gal} & \end{array}$

Water evacuated before sampling: $175 \mathrm{gal}$

LABORATORY ANALYSES

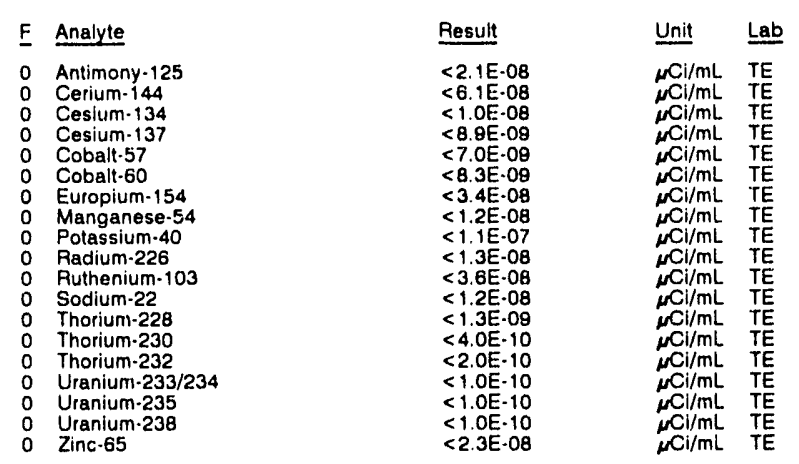

\section{WELL BGO 35D}

MEASUREMENTS CONDUCTED IN THE FIELD

\begin{tabular}{|c|c|c|c|c|c|}
\hline \multicolumn{2}{|c|}{$\begin{array}{l}\text { Sample date: } 07 / 02 / 91 \\
\text { Depth to water: } 38.50 \mathrm{Ht}(11.73 \mathrm{~m}) \text { below TOC } \\
\text { Water elevation: } 235.00 \mathrm{Ht}(71.63 \mathrm{~m}) \mathrm{ms} \\
\text { Sp. conductance: } 40 \mu \mathrm{s} / \mathrm{cm} \\
\text { Water evacuated before sampling: } 10 \mathrm{gal} \\
\text { The well went dry during purging. }\end{array}$} & \multicolumn{4}{|c|}{$\begin{array}{l}\text { Time: } 10: 25 \\
\text { pH: } 4.8 \\
\text { Alkalinity: } 0 \mathrm{mg} / \mathrm{L} \\
\text { Water temperature: } 20.8^{\circ} \mathrm{C}\end{array}$} \\
\hline \multicolumn{6}{|c|}{ LABORATORY ANALYSES } \\
\hline & Analyte & Result & & Unit & $\underline{\text { Lab }}$ \\
\hline $\begin{array}{l}0 \\
0 \\
0 \\
0 \\
0 \\
0 \\
0 \\
0 \\
0 \\
0 \\
0 \\
0 \\
0 \\
0 \\
0 \\
0\end{array}$ & $\begin{array}{l}\text { Antimony-125 } \\
\text { Cerium-144 } \\
\text { Cesium-134 } \\
\text { Cesium-137 } \\
\text { Cobalt-57 } \\
\text { Cobalt-60 } \\
\text { Europium-154 } \\
\text { Manganese-54 } \\
\text { Potassium-40 } \\
\text { Radium-226 } \\
\text { Ruthenium-103 } \\
\text { Sodium-22 } \\
\text { Thorium-228 } \\
\text { Thorium-230 } \\
\text { Thorium-232 } \\
\text { Uranium-233/234 } \\
\text { Uranium-235 } \\
\text { Uranium-238 } \\
\text { Zinc-65 }\end{array}$ & $\begin{array}{l}<3.4 \mathrm{E} \\
<1.3 \mathrm{E} \\
<1.3 \mathrm{E} \\
<1.2 \mathrm{E} \\
<1.7 \mathrm{E} \\
<1.3 \mathrm{E} \\
<2.6 \mathrm{E} \\
<1.5 \mathrm{E} \\
<1.2 \mathrm{E} \\
<3.0 \mathrm{E} \\
<5.2 \mathrm{E} \\
<0.6 \mathrm{E} \\
<1.0 \mathrm{E} \\
5.0 \mathrm{E} \\
<2.0 \mathrm{E} \\
8.0 \mathrm{E} \\
<1.0 \mathrm{E} \\
5.0 \mathrm{E} \\
<3.4 \mathrm{E}\end{array}$ & $\begin{array}{l}E-08 \\
E-07 \\
E-08 \\
E-08 \\
E \cdot 08 \\
E-08 \\
E \cdot 08 \\
E \cdot 08 \\
E \cdot 07 \\
E \cdot 08 \\
E \cdot 08 \\
E \cdot 09 \\
E \cdot 09 \\
E \cdot 10 \pm 30 E \cdot 10 \\
E \cdot 10 \\
E \cdot 10 \pm 2.0 E-10 \\
E \cdot 10 \\
E-08 \pm 2.0 E-10\end{array}$ & 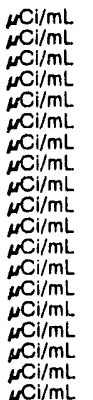 & $\begin{array}{l}\text { TE } \\
\text { TE } \\
\text { TE } \\
\text { TE } \\
\text { TE } \\
\text { TE } \\
\text { TE } \\
\text { TE } \\
\text { TE } \\
\text { TE } \\
\text { TE } \\
\text { TE } \\
\text { TE } \\
\text { TE } \\
\text { TE } \\
\text { TE } \\
\text { TE } \\
\text { TE } \\
\text { TE }\end{array}$ \\
\hline
\end{tabular}

\section{WELL BGO 36D}

MEASUREMENTS CONDUCTED IN THE FIELD

\begin{tabular}{|c|c|c|c|c|c|}
\hline \multicolumn{3}{|c|}{$\begin{array}{l}\text { Sample date: } 07 / 02 / 91 \\
\text { Depth to water: } 38.64 \mathrm{Ht}(11.78 \mathrm{~m}) \text { below TOC } \\
\text { Water elevation: } 236.76 \mathrm{ft}(72.17 \mathrm{~m}) \mathrm{msl} \\
\text { Sp. conductance: } 29 \mu \mathrm{s} / \mathrm{cm} \\
\text { Water evacuated before sampling: } 9 \mathrm{gal} \\
\text { The well went dry during purging. }\end{array}$} & \multicolumn{3}{|c|}{$\begin{array}{l}\text { Time: } 11: 05 \\
\text { pH: } 5.2 \\
\text { Alkalinity: } 1 \mathrm{mg} / \mathrm{L} \\
\text { Water temperature: } 21.0^{\circ} \mathrm{C}\end{array}$} \\
\hline \multicolumn{6}{|c|}{ LABORATORY ANALYSES } \\
\hline$\underline{F}$ & Analyte & Result & & Unit & Lab \\
\hline & $\begin{array}{l}\text { Antimony-125 } \\
\text { Cerium-144 } \\
\text { Cesium-134 } \\
\text { Cesium } 137 \\
\text { Cobalt-57 } \\
\text { Cobalt-60 } \\
\text { Europium-154 } \\
\text { Manganese-54 }\end{array}$ & $\begin{array}{l}<1.8 E \\
<6.4 E \\
<7.5 E \\
<8.3 E \\
<8.0 E \\
<7.7 E \\
<1.9 E \\
<8.2 E\end{array}$ & $\begin{array}{l}E-08 \\
E-08 \\
E-09 \\
E-09 \\
E .09 \\
E .09 \\
E .08 \\
E-08\end{array}$ & $\begin{array}{l}\mu \mathrm{Cl} / \mathrm{mL} \\
\mu \mathrm{Ci} / \mathrm{mL} \\
\mu \mathrm{Ci} / \mathrm{mL} \\
\mu \mathrm{Ci} / \mathrm{mL} \\
\mu \mathrm{Ci} / \mathrm{mL} \\
\mu \mathrm{Ci} / \mathrm{mL} \\
\mu \mathrm{Ci} / \mathrm{mL} \\
\mu \mathrm{Ci} / \mathrm{mL}\end{array}$ & $\begin{array}{l}\text { TE } \\
\text { TE } \\
\text { TE } \\
\text { TE } \\
\text { TE } \\
\text { TE } \\
\text { TE } \\
\text { TE }\end{array}$ \\
\hline
\end{tabular}


ANALYTICAL RESIILTS

WELL BGO 36D collected on 07/02/91, laboratory analyses (cont.)

\begin{tabular}{|c|c|c|c|}
\hline Analyte & Result & Unit & Lab \\
\hline $\begin{array}{ll}0 & \text { Potassium-40 } \\
0 & \text { Radium-226 } \\
0 & \text { Ruthenium-103 } \\
0 & \text { Sodium-22 } \\
0 & \text { Thorium-228 } \\
0 & \text { Thorium-230 } \\
0 & \text { Thorlum-232 } \\
0 & \text { Uranium-233/234 } \\
0 & \text { Uranium-235 } \\
0 & \text { Uranium-238 } \\
0 & \text { Zinc-65-238 }\end{array}$ & $\begin{array}{l}<1.1 \mathrm{E} \cdot 07 \\
<1.5 \mathrm{E} \cdot 08 \\
<3.5 \mathrm{E} \cdot 08 \\
<7.0 \mathrm{E} \cdot 08 \\
<1.3 \mathrm{E} \cdot 09 \\
<3.0 \mathrm{E} \cdot 10 \\
<2.0 \mathrm{E}-10 \\
9.0 \mathrm{E} \cdot 10 \pm 4.0 \mathrm{E} \cdot 10 \\
<2.0 \mathrm{E} \cdot 10 \\
<2.0 \mathrm{E} \cdot 10 \\
<1.9 \mathrm{E} \cdot 08\end{array}$ & 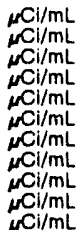 & $\begin{array}{l}\text { TE } \\
\text { TE } \\
T E \\
T E \\
T E \\
T E \\
T E \\
T E \\
T E \\
T E \\
T E \\
T E\end{array}$ \\
\hline
\end{tabular}

WELL BGO 37D

MEASUREMENTS CONDUCTED IN THE FIELD

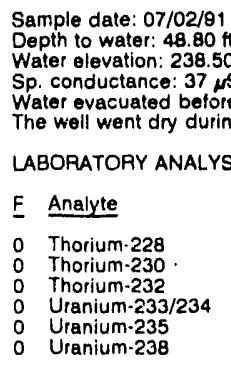

\section{LABORATORY ANALYSES}

\begin{tabular}{|c|c|c|}
\hline Analyte & Result & Unit \\
\hline $\begin{array}{ll}0 & \text { Thorium-228 } \\
0 & \text { Thorium-230 } \\
0 & \text { Thorium-232 } \\
0 & \text { Uranium-233/234 } \\
0 & \text { Uranium-235 } \\
0 & \text { Uranium-238 }\end{array}$ & $\begin{array}{l}<4.0 E \cdot 10 \\
2.0 E \cdot 10 \pm 1.0 E \cdot 10 \\
<1.0 E \cdot 10 \\
6.0 E-10 \pm 2.0 E \cdot 10 \\
<1.0 E \cdot 10 \\
<1.0 E \cdot 10\end{array}$ & 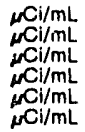 \\
\hline
\end{tabular}

\section{WELL BGO 38D}

MEASUREMENTS CONDUCTED IN THE FIELD

Sample date: $07 / 02 / 91$

Depth to water: $55.62 \mathrm{~h}(16.95 \mathrm{~m})$ below TOC

Water elevation: $235.98 \mathrm{tt}(71.93 \mathrm{~m}) \mathrm{ms}$

Sp. conductance: $31 \mu \mathrm{s} / \mathrm{cm}$

Water evacuated before sampling: $6 \mathrm{ga}$
The well went dry during purging.

Time: $11: 30$
$\mathrm{pH}: 4.3$

PH: 4.3

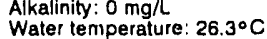

LABORATORY ANALYSES

\begin{tabular}{|c|c|c|}
\hline F Analyte & Pesult & Unit \\
\hline $\begin{array}{ll}0 & \text { Thorium-228 } \\
0 & \text { Thorium-230 } \\
0 & \text { Thorium -232 } \\
0 & \text { Uranium.233/234 } \\
0 & \text { Uranium-235 } \\
0 & \text { Uranium-238 }\end{array}$ & 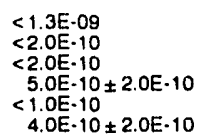 & 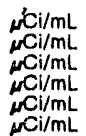 \\
\hline
\end{tabular}

\section{WELL BGO 39D}

MEASUREMENTS CONDUCTED IN THE FIELD

Sample date: $07 / 02 / 81$ 1 $18.46 \mathrm{~m}$. Tw TOC

Water to water: $60.55 \mathrm{ft}(18.46 \mathrm{~m}$, ow TOC

Sp. conductance: $32 \mu \mathrm{S} / \mathrm{cm}$

Water evacuated before samplir.

The well went dry during purging 3

LABORATORY ANLI.YSES

\begin{tabular}{|c|c|c|}
\hline E Analyte & Result & Unit \\
\hline $\begin{array}{ll}0 & \text { Thorium-228 } \\
0 & \text { Thorium-230 } \\
0 & \text { Thorium-232 } \\
0 & \text { Uranium-233/234 } \\
0 & \text { Uranium-235 } \\
0 & \text { Uranium-238 }\end{array}$ & $\begin{array}{l}5.0 \mathrm{OE}-10 \pm 5.0 \mathrm{E} \cdot 10 \\
<2.0 \mathrm{E}-10 \\
<2.0 \mathrm{E}-10 \\
5.0 \mathrm{E} \cdot 10 \pm 2.0 \mathrm{E} \cdot 10 \\
<1.0 \mathrm{E} \cdot 10 \\
2.0 \mathrm{E} \cdot 10 \pm 1.0 \mathrm{E}-10\end{array}$ & 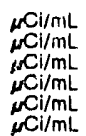 \\
\hline
\end{tabular}

\section{WELL BGO 45A}

MEASUREMENTS CONDUCTED IN THE FIELD

Sample date: 07/03/91

Depth to water $118.38 \mathrm{ft}(36.08 \mathrm{~m})$ below TOC

Water elevation: $160.52 \mathrm{ft}(48.93 \mathrm{~m}) \mathrm{msl}$

Water evacuated before sampling: $116 \mathrm{gai}$

Time: $11: 40$

pH: 4.5 . $0.9 \mathrm{mglt}$

Water temperature: $22.0^{\circ} \mathrm{C}$

LABORATORY ANALYSES

F Analyte

0 Americium-241

0
0 Plutonium-238
Time: $12: 10$

Alkalinity: $79 \mathrm{mg} / \mathrm{h}$

Water temperature: $21.0^{\circ} \mathrm{C}$

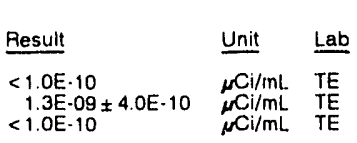

WELL BGO $45 \mathrm{~A}$ collected on 07/0J/91, laboratory analyses (cont.)

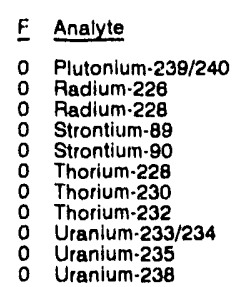

WELL BGO 45B

MEASUAEMENTS CONDUCTED IN THE FIELD

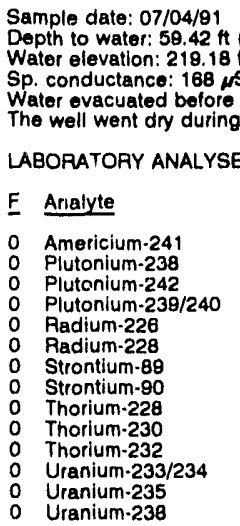

\begin{tabular}{|c|c|}
\hline Pesult & Unit \\
\hline $\begin{array}{l}<1.0 \mathrm{D}-10 \\
1.0 \mathrm{E}-10 \pm 1.0 \mathrm{E}-10 \\
8.0 \mathrm{E}-10 \pm 2.0 \mathrm{E}-10 \\
<1.1 \mathrm{E}-09 \\
<4.0 \mathrm{E}-10 \\
8.0 \mathrm{E}-10 \pm 4.0 \mathrm{E}-10 \\
<2.0 \mathrm{E}-10 \\
<1.0 \mathrm{E}-10 \\
2.0 \mathrm{E}-10 \pm 2.0 \mathrm{E}-10 \\
<1.0 \mathrm{E}-10 \\
<1.0 \mathrm{E}-10\end{array}$ & $\begin{array}{l}\mu \mathrm{NL} / \mathrm{mL} \\
\mu \mathrm{Cl} / \mathrm{mL} \\
\mu \mathrm{Cl} / \mathrm{mL} \\
\mu \mathrm{Ci} / \mathrm{LL} \\
\mu \mathrm{Cl} / \mathrm{mL} \\
\mu \mathrm{Cl} / \mathrm{mL} \\
\mu \mathrm{Cl} / \mathrm{mL} \\
\mu \mathrm{Cl} / \mathrm{mL} \\
\mu \mathrm{Cl} / \mathrm{LL} \\
\mu \mathrm{Cl} / \mathrm{mL} \\
\mathrm{C} / \mathrm{mL}\end{array}$ \\
\hline
\end{tabular}

Time: $8: 40$

Alkalinity: $28 \mathrm{mg} / \mathrm{l}$

Water temperature: $23.0^{\circ} \mathrm{C}$

cm

(1)

ing: 43 gal

\section{WELL BGO $45 C$}

MEASUREMENTS CONDUCTED IN THE FIELD
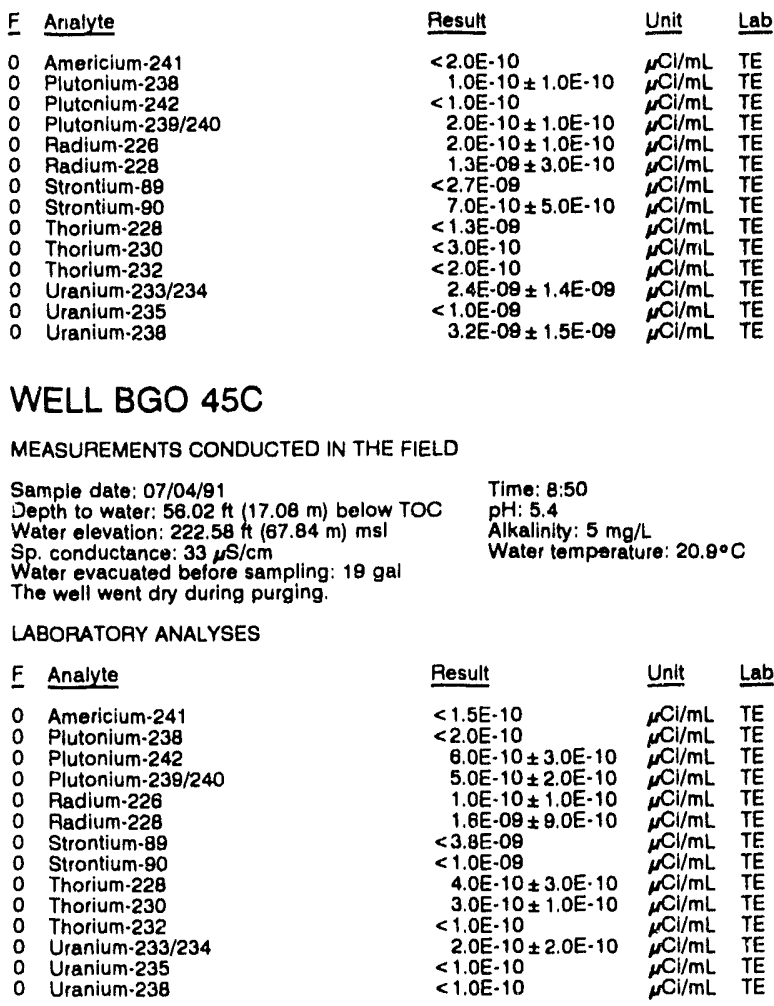

LABORATORY ANALYSES

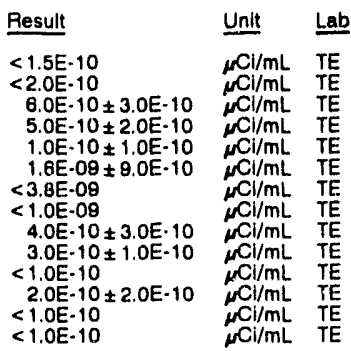

\section{V'ELL BGO 45D}

MEASUAEMENTS CONDUCTED IN THE FIELD

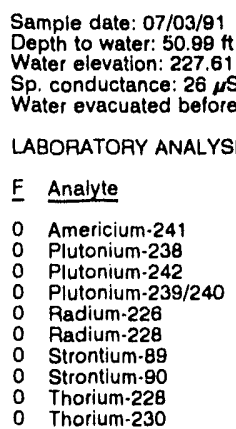

Time: $11: 30$

Alkalinity: $1 \mathrm{mg}$

Water tomperature: $21.4^{\circ} \mathrm{C}$

Water evacuated belore sampling: $48 \mathrm{gal}$

LABORATORY ANALYSES

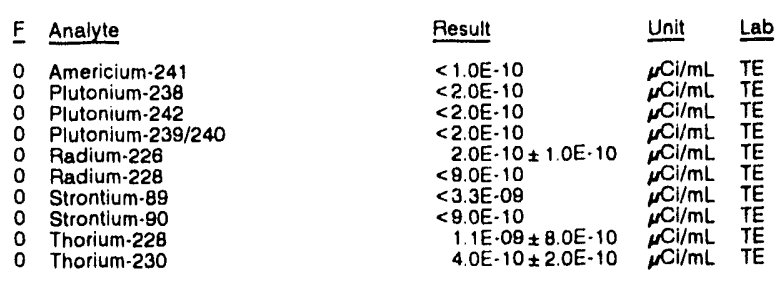


ANALYTICAL RESULTS

WELL BGO 45D collected on 07/03/91, laboratory analyses (cont.)

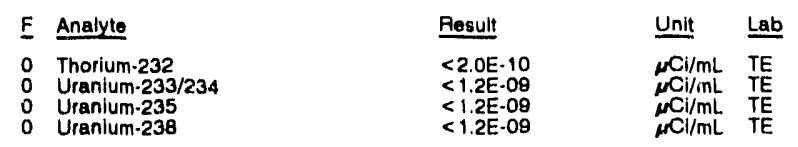

\section{WELL BLANK}

MEASUREMENTS CONDUCTED IN THE FIELD

Sample date: $07 / 01 / 81$
No water was evacuated before sampling.

Time: Not available

LABORATORY ANALYYSES

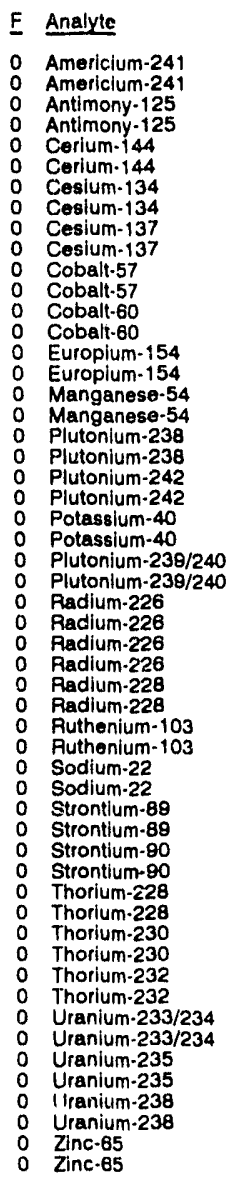

Pesult

$1.0 E \cdot 10 \pm 1.0 E \cdot 10$

$<1.0 \mathrm{E} \cdot 10$
$<1.7 \mathrm{E}-\mathrm{OB}$

$<2.8 \mathrm{E}-08$

$<7.0 \mathrm{E}-08$

$<1.1 \mathrm{E}-07$
$<7.5 \mathrm{E}-09$

$<7.5 \mathrm{E}-09$
$<1.0 \mathrm{E}-08$

$<5.8 \mathrm{E}-09$

$<9.4 \mathrm{E}-09$

$<6.6 \mathrm{E}-09$

$<1.4 \mathrm{E} .08$

$<6.0 \mathrm{OE}-09$
$<1.0 \mathrm{E}-08$

$<1.0 \mathrm{E}-08$

$<1.4 \mathrm{E}-08$
$<3.0 \mathrm{E}-08$

$<7.7 \mathrm{E}-09$

$<1.1 \mathrm{E}-08$

$<1.0 \mathrm{E}-10$

$2.0 \mathrm{E}-10 \pm 1.0 \mathrm{E}-10$

$<1.0 \mathrm{E}-10$

$<8.3 \mathrm{E}-08$

$<.0 E-10 \pm 2.0 E-10$
8.

$<1.0 E \cdot 10$

$<1.0 \mathrm{E}-10$

$<1.0 E-10$
$<1.0 \mathrm{E}-10$

$<1.0 E-10$
$<1.0 E-10$

$<8.0 \mathrm{E}-10$

B. $-10 \pm 4.0 E-10$

$<3.5 \mathrm{E}-08$

$<5.5 \mathrm{E}-08$

$<6.2 \mathrm{E}-09$

$<\begin{aligned} & <1.1 \mathrm{E}-08 \\ & <7.2 \mathrm{E}-09\end{aligned}$

$<7.2 \mathrm{E}-09$

$<7.7 E-09$
$<1.3 \mathrm{E}-00$

$<1.5 \mathrm{E}-09$

$<1.0 \mathrm{E}-09$

$4.0 E-10 \pm 2.0 E-10$

$<2.0 \mathrm{E}-10 \pm$

$<2.0 \mathrm{E}-10$

1. $4 \mathrm{E}-09 \pm 4.0 \mathrm{E}-10$

$8.7 E-09+12 E-09$

$2 \mathrm{OE}-10+20 \mathrm{E} \cdot 10$

$<2.0 E-10$.

$1.8 \mathrm{E}-\mathrm{O}$

$<2.0 \mathrm{E}-10$

$<1.8 \mathrm{E}-08$
$<2.3 \mathrm{E}-08$

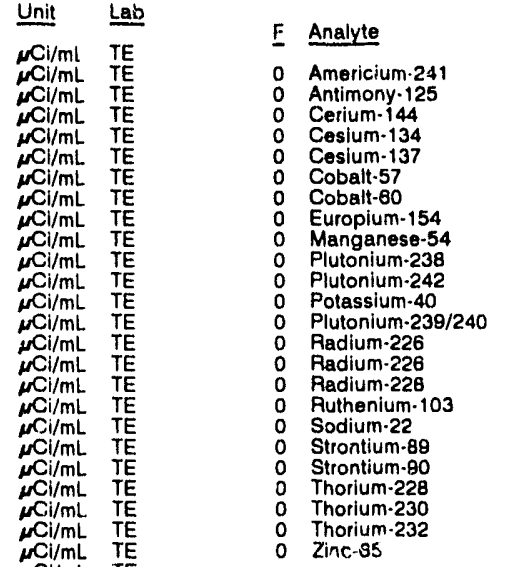

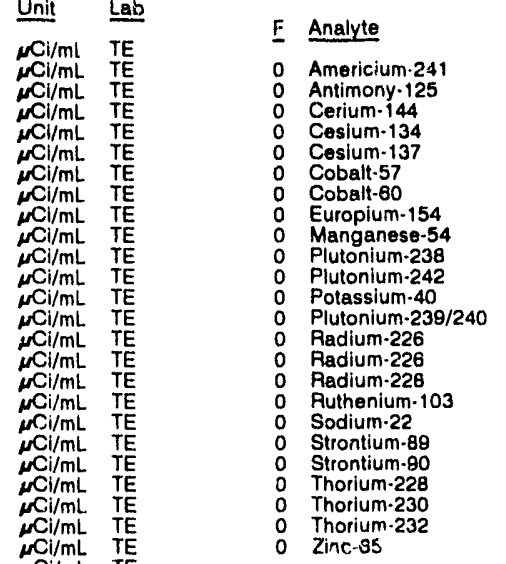

\section{WEILL BLANK}

MEASUREMENTS CONDUCTED IN THE FIELD

Sample date: $07 / 08 / 91$
No water was ovacuated before sampling.

Time: Not available

LABORATORY ANALYSES

\begin{tabular}{ll} 
F & Analyte \\
\hline 0 & Americlum-241 \\
0 & Americium-241 \\
0 & Antimony-125 \\
0 & Antimony-125 \\
0 & Cerium-144 \\
0 & Cerium-144 \\
0 & Cesium-134 \\
0 & Cesium-134 \\
0 & Cesium-137 \\
0 & Cesium-137 \\
0 & Cobalt-57 \\
0 & Cobalt-57 \\
0 & Cobalt-60 \\
0 & Cobalt-60 \\
0 & Europium-154 \\
0 & Europium-154 \\
0 & Manganese-54 \\
0 & Manganese-54 \\
0 & Plutonlum-238 \\
0 & Plutonium-238 \\
0 & Plutonium-242 \\
0 & Plutonium-242 \\
0 & Potassium-40 \\
0 & Potassium-40 \\
0 & Plutonium-239/240 \\
0 & Plutonium-239/240 \\
0 & Radium-226 \\
0 & Radium-226 \\
0 & Radium-226 \\
0 & Padium-226 \\
0 & Radium-228 \\
0 & Radium-228 \\
0 & Ruthenium-103 \\
0 & Puthenium-103 \\
0 & Sodium-222 \\
0 & Sodium-22 \\
0 & Strontium-89 \\
0 & Strontium-89 \\
0 & Strontium-90 \\
0 & Strontium- 90 \\
0 & Thorlum-228 \\
0 & Thorium-228 \\
0 & Thorium-230 \\
&
\end{tabular}

$1.0 \mathrm{E} \cdot 10 \pm 1.0 \mathrm{E} \cdot 10$

$<3.8 \mathrm{E} .08$

$<1.5 \mathrm{E}-08$

$<1.3 \mathrm{E} .08$

$<1.2 \mathrm{E}-08$

$<4.0 \mathrm{E} \cdot 08$

$5.0 \mathrm{E}-10 \pm 2.0 \mathrm{E} \cdot 10$

$<1.0 \mathrm{E}-10$

$7.0 \mathrm{E} \cdot 10 \pm 2.0 \mathrm{E} \cdot 10$

$2.0 \mathrm{E} \cdot 10 \pm 1.0 \mathrm{E} \cdot 10$

$<7.0 \mathrm{E}-08$

$<1.4 \mathrm{E} .08$

$<7.5 \mathrm{E}-09$

$<1.4 \mathrm{E} \cdot 09$

$<1.0 \mathrm{E} \cdot 08$

$<2.0 \mathrm{E} \cdot 10$

$<3.0 \mathrm{E}-10$
$<3.0 \mathrm{E}-08$

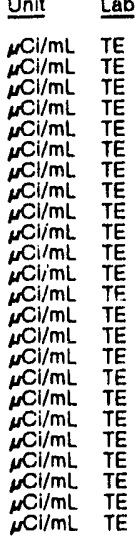

WELL BLANK

MEASUREMENTS CONDUCTED IN THE FIELD

Sample date: 07/02/9

No water was evacuated before sampling.

Time: Not available

LABORATORY ANALYSES

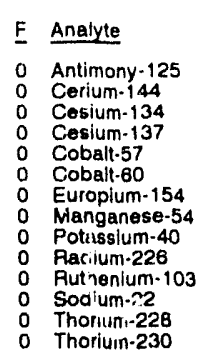

Result

$<2.4 E-08$

$<3.7 E .08$

$<1.3 \mathrm{E}-08$

$<8.9 E-09$

$<1.1 \mathrm{E}-08$

$<3.1 \mathrm{E}-08$
$<1.3 \mathrm{E}-08$

$<1.3 \mathrm{E}-08$
$<1.4 \mathrm{E}-07$

$<1.7 E-08$
$<4.8 E-08$

$<1.1 \mathrm{E}-08$

$7.0 \mathrm{E} \cdot 10 \pm 6.0 \mathrm{E}-10$
$<2.0 \mathrm{E}-10$

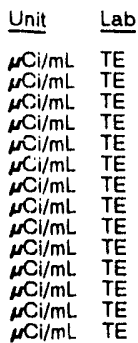

Result

$<1.0 E-10$

$<1.0 \mathrm{E}-10$

$<3.8 \mathrm{E} .08$

$<7.9 \mathrm{E} .08$

$<1.3 \mathrm{E} \cdot 07$

$<1.1 \mathrm{E} .08$

$<1.4 \mathrm{E}-0 \mathrm{~B}$

$<1.0 \mathrm{E} \cdot 08$

$<1.1 \mathrm{E}-08$
$<1.0 \mathrm{E}-08$

$<1.0 \mathrm{E}-08$
$<1.7 \mathrm{E} \cdot 08$

$<9.3 \mathrm{E}-09$

$<1.3 \mathrm{E} .08$

$<3.4 \mathrm{E} .08$

$<1.1 \mathrm{E} .08$

$<1.1 \mathrm{E}-08$

$3.0 E \cdot 10 \pm 2.0 E-10$

$<3.0 \mathrm{E} \cdot 10$

$2.0 \mathrm{E}-10 \pm 1.0 \mathrm{E}-10$
$3.0 \mathrm{E}-10 \pm 3.0 \mathrm{E}-10$

$<1.5 \mathrm{E}-07$

$<1.4 \mathrm{E} \cdot 07$

$8.0 \mathrm{E} \cdot 10 \pm 2.0 \mathrm{E}-10$

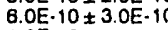

$<1.0 \mathrm{E} \cdot 10$

$<3.0 E \cdot 10$

2.3E-09 $01.3 \mathrm{E} \cdot 09$

$<4.1 E-08$

$<5.08$

$<1.1 \mathrm{E}-08$

$<1.2 \mathrm{E} \cdot 08$
$<6.3 \mathrm{E} \cdot 08$

$<6.8 \mathrm{E} .09$

$<1.3 \mathrm{E} .09$

$<1.4 \mathrm{E}-09$

$1.2 E \cdot 09$
$6.0 E \cdot 10 \pm 4.0 E-10$
7.0E.10

$1.8 \mathrm{E}-09 \pm 1.4 \mathrm{E}-09$

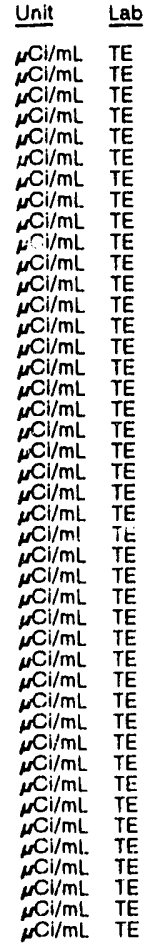


ANALYTICAL RESULTS

WELL. BLANK collected on $07 / 08 / 91$, laboratory analyses (cont.)

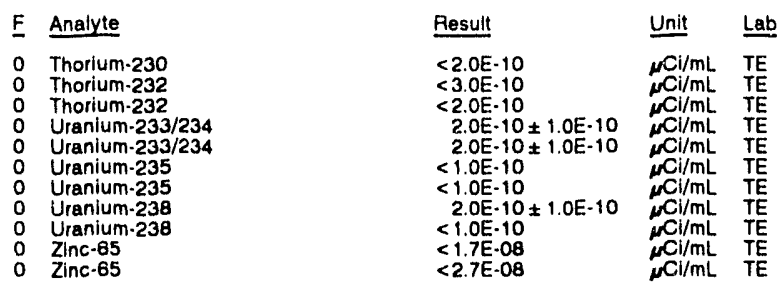

\section{WELL BLANK}

MEASUREMENTS CONDUCTED IN THE FIELD

Sample date: 07/09/91

No water was evacuated before sampling.

Time: Not available

LABORATORY ANALYSES

\begin{tabular}{ll} 
F & Analyte \\
\hline 0 & Americium-241 \\
0 & Americium-241 \\
0 & Antimony-125 \\
0 & Antimony-125 \\
0 & Cerium-144 \\
0 & Cerium-144 \\
0 & Cesium-134 \\
0 & Cesium-134 \\
0 & Cesium-137 \\
0 & Cesium-137 \\
0 & Cobalt-57 \\
0 & Cobalt-57 \\
0 & Cobalt-60 \\
0 & Cobalt-60 \\
0 & Europlum-154 \\
0 & Europium-154 \\
0 & Manganese-54 \\
0 & Aanganese-54 \\
0 & Plutonium-238 \\
0 & Plutonium-238 \\
0 & Plutonium-242 \\
0 & Plutonium-242 \\
0 & Potassium-40 \\
0 & Potassium-40 \\
0 & Plutonium-239/240 \\
0 & Plutonium-239/240 \\
0 & Radium-226 \\
0 & Radium-226 \\
0 & Padium-226 \\
0 & Padium-226 \\
0 & Padium-228 \\
0 & Padium-228 \\
0 & Puthenium-103 \\
0 & Ruthenium-103 \\
0 & Sodium-22 \\
0 & Sodium-22 \\
0 & Strontium-89 \\
0 & Strontium-89 \\
0 & Strontium-90 \\
0 & Strontium-90 \\
0 & Thorium-228 \\
0 & Thoilum-230 \\
0 & Thorium-232 \\
0 & Uranium-233/234 \\
0 & Uranium-233/234 \\
0 & Uranium-235 \\
0 & Uranium-235 \\
0 & Uranium-238 \\
0 & Uranium-238 \\
0 & Zinc-65 \\
0 & Zinc-65 \\
&
\end{tabular}

Result

9.0E-10 $\pm 3.0 E-10$

$<1.0 \mathrm{E}-10$
$<2,3 \mathrm{E}-\mathrm{OB}$

$<2.3 \mathrm{E} \cdot 08$

$<6.7 \mathrm{E} .08$

$<7.0 \mathrm{E}-08$

$<1.1 \mathrm{E}-08$
$<9.4 \mathrm{E}-09$

$<9.2 \mathrm{E} .09$

$<1.1 \mathrm{E}-08$
$<7.6 \mathrm{E}-09$

$<7.6 \mathrm{E}-09$
$<8.8 \mathrm{E}-09$

$<1.4 \mathrm{E}-08$

$<1.4 \mathrm{E}-08$
$<1.2 \mathrm{E}-08$

$<2.8 E-08$

$<3.2 \mathrm{E} .08$

$<1.3 \mathrm{E}-08$

$<1.3 \mathrm{E}-08$

$<1.0 \mathrm{E}-10$

$<1.0 \mathrm{E}-10$

$<1.0 \mathrm{E}-10$

$1.2 \mathrm{E}-09 \pm 5.0 \mathrm{E}-10$

$<1.4 \mathrm{E}-07$

$<1.4 \mathrm{E} \cdot 07$

$<1.0 \mathrm{E}-10$
$>1.0 \mathrm{E}-10 \pm 4.0 \mathrm{E}-10$

$<1.0 \mathrm{E}-10$

$<1.0 \mathrm{E}-10$
$<1.0 \mathrm{E}-10$

$<1.0 \mathrm{E}-10$
$<1.0 \mathrm{E}-10$

1.3E-09 : tت-10

$<8.0 \mathrm{E}-10$

$<3.3 \mathrm{E}-08$

$<1.0 \mathrm{E} \cdot 08$

$<1.1 \mathrm{E}-08$

$<2.4 \mathrm{E} .09$

$<2.2 E-09$

$<$ B. OE-10

$<6.0 \mathrm{E}-10$

$<\begin{aligned} & <3.2 E-09 \\ & <3.0 E-10\end{aligned}$

$<2.0 E \cdot 10$
$<2.0 E \cdot 10$

$6.6 \mathrm{E} \cdot 09+1.4 \mathrm{E} \cdot 09$

$<2.0 \mathrm{E} \cdot 10$

$<4.0 \mathrm{E}-10$

6. $0 \mathrm{E}-10 \pm 4.0 \mathrm{E}-10$

$3.4 \mathrm{E}-09 \pm 1.0 \mathrm{E}-09$

$<3.4 E-08$
$<3.8 E-08$

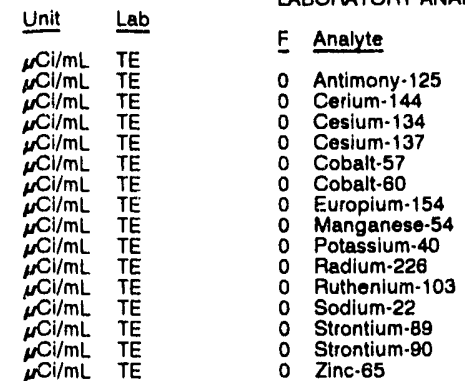

Reoult

Reryit

$<7.8 E-09$
$<1.2 \mathrm{E}-07$

$<1.7 \mathrm{E} .08$

$<8.1 \mathrm{E}-09$

$<8.2 E-09$

$<2.6 \mathrm{E}-09$

$3.8 \mathrm{E}-09$
$<2.0 \mathrm{E} \cdot 08$

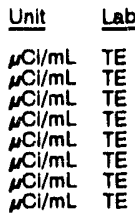

WELL FAL 2

MEASUREMENTS CONDUCTED IN THE FIELD

Sample date: 08/27/91

$90 \mathrm{ft}(28.62 \mathrm{~m})$ below TOC

Water elevation: $218.20 \mathrm{Ht}(66.51 \mathrm{~m}) \mathrm{ms}$

Wher evacuated betore sampl

sampling: 3 gal

The well went dry during purging.

LABORATORY ANALYSES

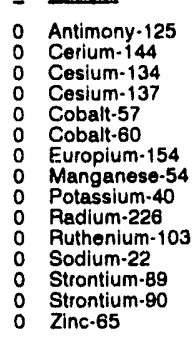

$<1.6 \mathrm{E}-08$

$<5.4 \mathrm{E} .08$

$<6.8 \mathrm{E} \cdot 09$

$<6.9 \mathrm{E}-09$
$<7.1 \mathrm{E}-09$

$<7.1 \mathrm{E}-09$
$<7.7 \mathrm{E} \cdot 00$

$<2.2 \mathrm{E} \cdot 08$

$<6.6 \mathrm{E} .09$

$<1.1 \mathrm{E} .07$

$<1.4 \mathrm{E}-08$

$<8.1 E .08$

$<8.0 \mathrm{E}-10$

$<6.0 \mathrm{E}-10$

Time: $9: 40$

Alkalinity: $14 \mathrm{mg} / \mathrm{L}$

Water temperature: $22.9^{\circ} \mathrm{C}$

WELL FBP $1 \mathrm{~A}$

MEASUREMENTS CONDUCTED IN THE FIELD

\begin{tabular}{|c|c|c|c|}
\hline $\begin{array}{l}\text { Sample date: } 07 / 09 / 91 \\
\text { Depth to water: } 81.61 \mathrm{Ht}(24.88 \mathrm{~m}) \text { below TOC } \\
\text { Water elevation: } 206.29 \mathrm{Ht}(62.88 \mathrm{~m}) \mathrm{ms} \\
\text { Sp. conductance: } 78 \text { \%s/cm } \\
\text { Water evacuated before sampling: } 116 \mathrm{gal}\end{array}$ & \multicolumn{3}{|c|}{$\begin{array}{l}\text { Time: } 15: 55 \\
\text { pH: } 4.6 \\
\text { Alkalinity: } 0 \mathrm{mg} / \mathrm{h} \\
\text { Water temperature: } 22.0^{\circ} \mathrm{C}\end{array}$} \\
\hline \multicolumn{4}{|l|}{ LABORATORY ANALYSES } \\
\hline Analyte & Result & Unit & Lab \\
\hline $\begin{array}{ll}0 & \text { Plutonium-238 } \\
0 & \text { Plutonium-239/240 } \\
0 & \text { Plutonium-242 }\end{array}$ & $\begin{array}{l}1.0 \mathrm{E}-10 \pm 1.0 \mathrm{E}-10 \\
1.0 \mathrm{E}-10 \pm 1.0 \mathrm{E}-10 \\
4.0 \mathrm{E}-10 \pm 1.0 \mathrm{E}-10\end{array}$ & $\begin{array}{l}\mu \mathrm{Cl} / \mathrm{mL} \\
\mu \mathrm{Cl} / \mathrm{mL} \\
\mu \mathrm{Cl} / \mathrm{mL}\end{array}$ & $\begin{array}{l}\text { TE } \\
\text { TE } \\
\text { TE }\end{array}$ \\
\hline
\end{tabular}

WELL FBP $2 A$

MEASUREMENTS CONDUCTED IN THE FIELL

Sample date: $07 / 09 / 91$

Depth to water: $98.60 \mathrm{Ht}(30.05 \mathrm{~m})$ below TOC

Water elevation: $190.50 \mathrm{ht}(58.07 \mathrm{~m}) \mathrm{msl}$

Water evacuated before sampling: $140 \mathrm{gal}$

LABORATORY ANALYSES

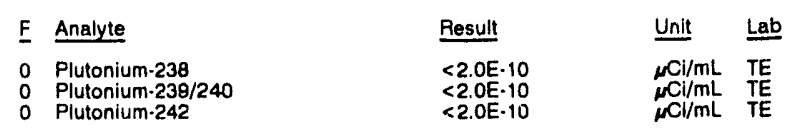

WELL FBP $3 A$

MEASUREMENTS CONDUCTED IN THE FIELD

Depth to water: $88.96 \mathrm{ft}(30.16 \mathrm{~m})$ below TOC

$<1.8 \mathrm{E} \cdot 08$

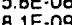

$<B .1 \mathrm{E}-09$

$<7.4 \mathrm{E}-09$

$<6.7 \mathrm{E} .09$

$<2.3 \mathrm{E} .08$
$<2.09$
Sample date: 07/09/91

Water elevation: $193.94 \mathrm{ft}(59.11 \mathrm{~m}) \mathrm{ms}$

Water evacuated before sampling: $140 \mathrm{gal}$

LABORATORY ANALYSES

E Analyte

Time: $13: 50$

pH: 5.0

0 Plutonium-238
Alkalinity: $6 \pi \mathrm{g} / \mathrm{h}$

Water temperature: $21.4^{\circ} \mathrm{C}$

0 Plutonium-242
Result

$2.0 \mathrm{E}-10 \pm 2.0 \mathrm{E}-10$ $\begin{array}{lll}2.0 \mathrm{E} \cdot 10 \pm 2.0 \mathrm{E}-10 & \mu \mathrm{Cl} / \mathrm{mL} & \mathrm{TE} \\ 5.0 \mathrm{E}-10 \pm 2.0 \mathrm{E} \cdot 10 & \mu \mathrm{Cl} / \mathrm{mL} & \mathrm{TE} \\ 4.0 \mathrm{E}-10 \pm 2.0 \mathrm{E}-10 & \mu \mathrm{Ci} / \mathrm{mL} & \mathrm{TE}\end{array}$ 
WELL FBP 4

MEASUREMENTS CONDUCTED IN THE FIELD

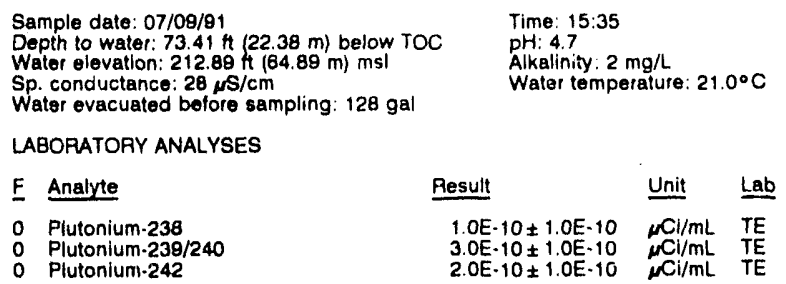

\section{WELL FCA $1 \mathrm{~N}$}

MEASUREMENTS CONDUCTED IN THE FIELD
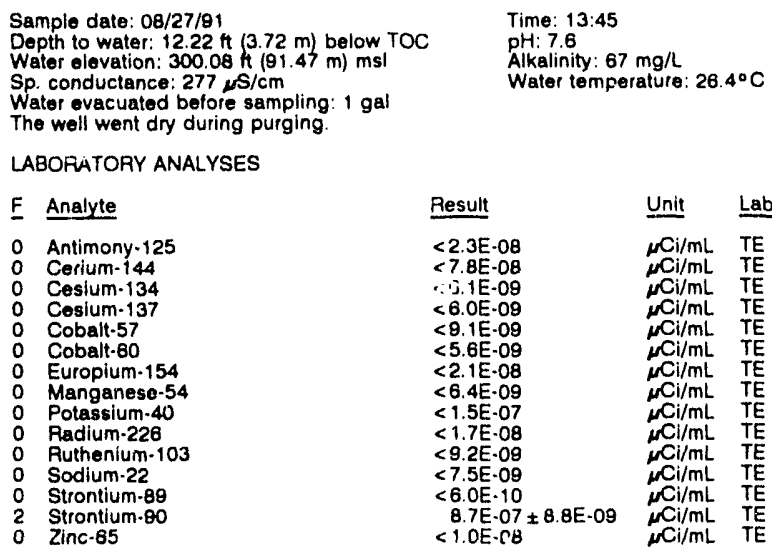

LABOFMTORY ANALYSES

Result

$<2.3 \mathrm{E}-00$

$<7.8 E-08$

ㄱ.

$<9.1 \mathrm{E}-09$

$<<.1 E .08$

$<6.4 \mathrm{E} .09$

$<1.5 \mathrm{E}-07$

$<1.7 E .08$

$<9.2 E .08$

$<7.5 \mathrm{E} \cdot 09$

$<6.0 .10$

$\begin{array}{r}\text { 8.7E- } 07 \\ <1.0 \mathrm{E} \cdot \mathrm{CB} \\ \hline\end{array}$

WELL FCA $2 D$

MEASUREMENTS SONDUCTED IN THE FIELD

Sample date: $08 / 27 / 81$
Depth to water: $86.18 \mathrm{At}(26.27 \mathrm{~m})$ below TOC

Water elevation: $226.02 \mathrm{Ht}(68.89 \mathrm{~m}) \mathrm{msl}$

Wall sal 5 ga

ABOPATOR, ANALYSES

\begin{tabular}{|c|c|c|}
\hline Analyte & Result & Unit \\
\hline $\begin{array}{l}\text { Antimony-125 } \\
\text { Cerium-144 } \\
\text { Cesium-134 } \\
\text { Cesium- } 9 ., 7 \\
\text { Cobalt-57 } \\
\text { Cobalt-60 } \\
\text { Europium-154 } \\
\text { Manganese-54 } \\
\text { Potassium-40 } \\
\text { Radium-226 } \\
\text { Ruthenium-103 } \\
\text { Sodium-22 } \\
\text { Strontium-89 } \\
\text { Strontium-90 }\end{array}$ & $\begin{array}{l}<2.9 \mathrm{E} \cdot 08 \\
<9.3 \mathrm{E} \cdot 08 \\
<9.6 \mathrm{E} \cdot 09 \\
<1.1 \mathrm{E} \cdot 08 \\
<1.2 \mathrm{E} \cdot 08 \\
<8.1 \mathrm{E} .09 \\
<2.9 \mathrm{E} .08 \\
<9.7 \mathrm{E} \cdot 09 \\
<1.0 \mathrm{E} \cdot 07 \\
<2.2 \mathrm{E} \cdot 08 \\
<1.2 \mathrm{E} \cdot 08 \\
<9.9 \mathrm{E} \cdot 09 \\
5.6 \mathrm{E}-09 \pm 1.3 \mathrm{E}-09 \\
<6.0 \mathrm{E} \cdot 00 \\
<2.2 \mathrm{E} \cdot 08\end{array}$ & $\begin{array}{l}\mu \mathrm{Ci} / \mathrm{mL} \\
\mu \mathrm{Ci} / \mathrm{mL} \\
\mu \mathrm{Ci} / \mathrm{mL} \\
\mu \mathrm{Ci} / \mathrm{mL} \\
\mu \mathrm{Ci} / \mathrm{mL} \\
\mu \mathrm{Ci} / \mathrm{mL} \\
\mu \mathrm{Ci} / \mathrm{mL} \\
\mu \mathrm{Ci} / \mathrm{mL} \\
\mu \mathrm{Ci} / \mathrm{mL} \\
\mu \mathrm{Ci} / \mathrm{mL} \\
\mu \mathrm{Ci} / \mathrm{mL} \\
\mu \mathrm{Ci} / \mathrm{mL} \\
\mu \mathrm{Ci} / \mathrm{mL} \\
\mu \mathrm{Ci} / \mathrm{mL} \\
\mu \mathrm{Ci} / \mathrm{mL}\end{array}$ \\
\hline
\end{tabular}

WELL FCA 9D

MEASUREMENTS CONDUCTED IN THE FIELD

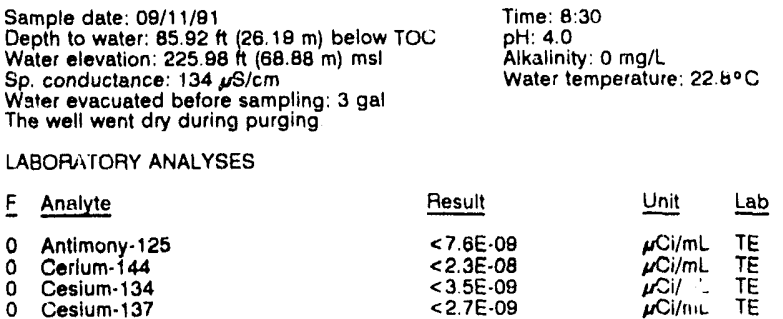

WELL FCA 9D collected on 09/11/91, laboratory analyses (cont.)

\begin{tabular}{|c|c|c|}
\hline Analyte & Plesult & Unit \\
\hline $\begin{array}{ll}0 & \text { Cobalt }-57 \\
0 & \text { Cobalt }-60 \\
0 & \text { Europium-154 } \\
0 & \text { Manganese-54 } \\
0 & \text { Polassium-40 } \\
0 & \text { Radium-226 } \\
0 & \text { Ruthenium-103 } \\
0 & \text { Sodium-22 } \\
0 & \text { Strontium-89 } \\
2 & \text { Strontium-90 } \\
0 & \text { Thorium-228 } \\
0 & \text { Zinc-65 }\end{array}$ & $\begin{array}{l}<3.1 E \cdot 08 \\
<3.7 E \cdot 08 \\
<8.8 \mathrm{E}-09 \\
<3.6 \mathrm{E} \cdot 09 \\
<3.6 \mathrm{E}-08 \\
<5.1 \mathrm{E} \cdot 09 \\
<2.4 \mathrm{E} \cdot 08 \\
<3.3 \mathrm{E} \cdot 09 \\
<2.1 \mathrm{E}-09 \\
4.1 \mathrm{E} \cdot 08 \pm 2.5 \mathrm{E} \cdot 09 \\
<3.7 \mathrm{E} \cdot 09 \\
<1.1 \mathrm{E} \cdot 08\end{array}$ & $\begin{array}{l}\mu \mathrm{Ci} / \mathrm{mL} \\
\mu \mathrm{Cl} / \mathrm{mL} \\
\mu \mathrm{Ci} / \mathrm{mL} \\
\mu \mathrm{Ci} / \mathrm{mL} \\
\mu \mathrm{Ci} / \mathrm{mL} \\
\mu \mathrm{Cl} / \mathrm{mL} \\
\mu \mathrm{Ci} / \mathrm{mL} \\
\mu \mathrm{Cl} / \mathrm{mL} \\
\mu \mathrm{Ci} / \mathrm{mL} \\
\mu \mathrm{Ci} / \mathrm{mL} \\
\mu \mathrm{Ci} / \mathrm{mL} \\
\mu \mathrm{Ci} / \mathrm{mL}\end{array}$ \\
\hline
\end{tabular}

\section{WELL FCA 10A}

MEASUREMENTS CONDUCTED IN THE FIELD

Sample date: 08/27/91

Depth to water: $86.30 \mathrm{ft}(26.30 \mathrm{~m})$ below Tur

Water elevation: $225.50 \mathrm{tt}(38.73 \mathrm{~m}) \mathrm{ms}$

Sp. conductance. $88 \mu \mathrm{s} / \mathrm{cm}$

The well went dry during purging: $4 \mathrm{ga}$

Time: $14: 20$

H: 5.7

Alkalinity: $2 \mathrm{mg} / \mathrm{L}$

LABORATORY ANALYSES

\begin{tabular}{|c|c|c|}
\hline Analyte & Pesult & Unit \\
\hline $\begin{array}{ll}0 & \text { Antimony-125 } \\
0 & \text { Cerium-144 } \\
0 & \text { Cesium-134 } \\
0 & \text { Ceslum-137 } \\
0 & \text { Cobalt-57 } \\
0 & \text { Cobalt-60 } \\
0 & \text { Europium-154 } \\
0 & \text { Manganese-54 } \\
0 & \text { Potassium-40 } \\
0 & \text { Radium-226 } \\
0 & \text { Radiun-226 } \\
0 & \text { Puthenium-103 } \\
0 & \text { Sodium-22 } \\
0 & \text { Strontium-69 } \\
0 & \text { Strontium-90 } \\
0 & \text { Zinc-65 }\end{array}$ & $\begin{array}{l}<3.0 E-08 \\
<1.0 \mathrm{r} \cdot 07 \\
<1.1 \mathrm{E} \cdot 08 \\
<1.1 \mathrm{E} \cdot 08 \\
<1.2 \mathrm{E} .08 \\
<1.2 \mathrm{E} \cdot 08 \\
<2.7 \mathrm{E} \cdot 08 \\
<1.1 \mathrm{E}-08 \\
<1.3 \mathrm{E} \cdot 07 \\
<2.4 \mathrm{E}-08 \\
<1.2 \mathrm{E}-08 \\
<9.2 \mathrm{E}-09 \\
<9.0 \mathrm{E} \cdot 10 \\
1.8 \mathrm{E}-09 \pm 6.0 \mathrm{E} \cdot 10 \\
<2.3 \mathrm{E} \cdot 08\end{array}$ & $\begin{array}{l}\mu \mathrm{Cl} / \mathrm{mL} \\
\mu \mathrm{Ci} / \mathrm{mL} \\
\mu \mathrm{Ci} / \mathrm{mL} \\
\mu \mathrm{Ci} / \mathrm{mL} \\
\mu \mathrm{Ci} / \mathrm{mL} \\
\mu \mathrm{Ci} / \mathrm{mL} \\
\mu \mathrm{Ci} / \mathrm{mL} \\
\mu \mathrm{Ci} / \mathrm{mL} \\
\mu \mathrm{Ci} / \mathrm{mL} \\
\mu \mathrm{Ci} / \mathrm{mL} \\
\mu \mathrm{Ci} / \mathrm{mL} \\
\mu \mathrm{Ci} / \mathrm{mL} \\
\mu \mathrm{Ci} / \mathrm{mL} \\
\mu \mathrm{Cl} / \mathrm{mL} \\
\mu \mathrm{Ci} / \mathrm{mL}\end{array}$ \\
\hline
\end{tabular}

\section{WELL FCA 16A}

MEASUREMENTS CONDUCTED IN THE FIELD

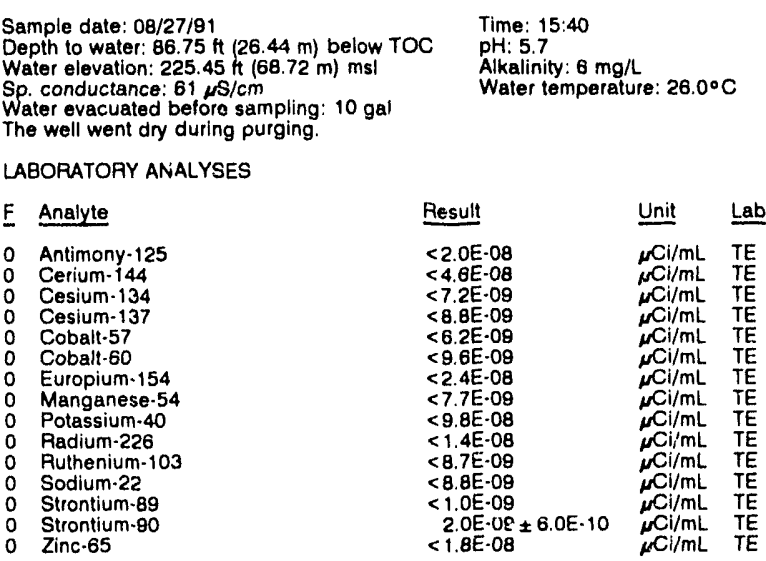

\section{WELL FCA 16B}

MEASUREMENTS CONDUCTED IN THE FIELD

\begin{tabular}{|c|c|c|c|}
\hline $\begin{array}{l}\text { Sample date: } 08 / 27 / 91 \\
\text { Depth to water: } 13.70 \mathrm{Ht}(4.18 \mathrm{~m}) \text { below TOC } \\
\text { Water elevation: } 298.40 \mathrm{Ht}(90.85 \mathrm{~m}) \mathrm{msl} \\
\text { Sp. conductance: } 195 \mu \mathrm{s} \text { 'cm } \\
\text { Water evacuated before sampling: } 2 \text { gal } \\
\text { The well went dry during purging }\end{array}$ & $\begin{array}{l}\text { Time } \\
\text { pH: } \\
\text { Alka } \\
\text { Wate }\end{array}$ & IL $: 28.8^{\circ}$ & \\
\hline LABORATORY ANALYSES & & & \\
\hline E Arralyte & Result & Unit & Lab \\
\hline $\begin{array}{ll}0 & \text { Antimony-125 } \\
0 & \text { Cerium-144 } \\
0 & \text { Cesium-134 } \\
0 & \text { Cesium }-137 \\
0 & \text { Coball. }-57 \\
0 & \text { Cobalt-60 } \\
0 & \text { Europium-154 }\end{array}$ & $\begin{array}{l}<2.1 \mathrm{E} \cdot 08 \\
<6.4 \mathrm{E} \cdot 08 \\
<6.6 \mathrm{E} \cdot 09 \\
<4.5 \mathrm{E} \cdot 09 \\
<8.0 \mathrm{E} \cdot 09 \\
<4.9 \mathrm{E} \cdot 09 \\
<1.4 \mathrm{E} \cdot 00\end{array}$ & 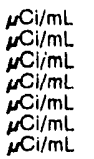 & $\begin{array}{l}\text { TE } \\
\text { TE } \\
\text { TE } \\
\text { TE } \\
\text { TE } \\
\text { TE } \\
\text { TE }\end{array}$ \\
\hline
\end{tabular}


WELL. FCA 168 collected on 08/27/91, laboratory analyses (cont.)

\begin{tabular}{|c|c|c|}
\hline Analyte & Result & Unit \\
\hline $\begin{array}{l}\text { Manganese-54 } \\
\text { Potassium-40 } \\
\text { Radium-226 } \\
\text { Ruthenium }-103 \\
\text { Sodium-22 } \\
\text { Strontium }-89 \\
\text { Strontium-90 } \\
\text { Zinc-65 }\end{array}$ & $\begin{array}{l}<5.9 E \cdot 08 \\
<9.7 E \cdot 08 \\
<1.8 \mathrm{E} \cdot 08 \\
<8.9 \mathrm{E} \cdot 09 \\
<5.0 \mathrm{E} \cdot 09 \\
<6.0 \mathrm{E} \cdot 10 \\
2.7 \mathrm{E} \cdot 09 \pm 5.0 \mathrm{E} \cdot 10 \\
<8.1 \mathrm{E} \cdot 09\end{array}$ & 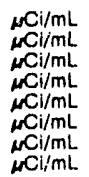 \\
\hline
\end{tabular}

\section{WELL FCA 19D}

MEASUREMENTS CONDUCTED IN THE FIELD

Sample date: 08/27/91

Depth to water: $93.43 \mathrm{ft}(28.48 \mathrm{~m})$ below TOC

Sp. conductance $293.17 \mathrm{ft} 166.50$

Alkalinity: $118 \mathrm{mg} / \mathrm{h}$

Water temperature: $23.9^{\circ} \mathrm{C}$

Water evacuated before sampling: 6 gal
The well went dry during purging.

LABORATORY ANALYSES

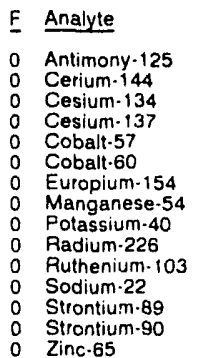

\begin{tabular}{|c|c|}
\hline Result & Unit \\
\hline $\begin{array}{l}<2.5 \mathrm{E} \cdot 08 \\
<8.7 \mathrm{E} \cdot 08 \\
<9.2 \mathrm{E} \cdot 09 \\
<9.9 \mathrm{E} \cdot 09 \\
<1.1 \mathrm{E} \cdot 08 \\
<7.8 \mathrm{E} \cdot 09 \\
<2.2 \mathrm{~F} \cdot 08 \\
<7.6 \mathrm{c} \cdot 09 \\
<9.7 \mathrm{E} \cdot 08 \\
<2.0 \mathrm{E} \cdot 08 \\
<1.3 \mathrm{E} \cdot 08 \\
<7.6 \mathrm{E} \cdot 09 \\
<7.0 \mathrm{E} \cdot 10 \\
1.4 \mathrm{E} \cdot 09 \pm 4.0 \mathrm{E} \cdot 10 \\
<19 \mathrm{E} \cdot 08\end{array}$ & $\begin{array}{l}\omega \mathrm{Ci} / \mathrm{mL} \\
\omega \mathrm{Ci} / \mathrm{mL} \\
\omega \mathrm{Ci} / \mathrm{mL} \\
\omega \mathrm{Ci} / \mathrm{mL} \\
\omega \mathrm{CLi} / \mathrm{mL} \\
\omega \mathrm{CLi} / \mathrm{mL} \\
\omega \mathrm{Ci} / \mathrm{mL} \\
\omega \mathrm{Ci} / \mathrm{mL} \\
\omega \mathrm{Ci} / \mathrm{mL} \\
\omega \mathrm{Ci} / \mathrm{mL} \\
\omega \mathrm{Ci} / \mathrm{mL} \\
\omega \mathrm{Ci} / \mathrm{mL} \\
\omega \mathrm{Ci} / \mathrm{mL} \\
\omega \mathrm{Ci} / \mathrm{mL}\end{array}$ \\
\hline
\end{tabular}

\section{WELL FSB 76}

MEASUREMENTS CONDUCTED IN THE FIELD

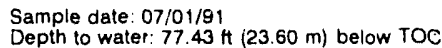

Water elevation: $216.77 \mathrm{~h}(66.07 \mathrm{~m}) \mathrm{ms}$ )

Sp. conductance: $70 \mu \mathrm{s} / \mathrm{cm}$
Water evacuated before sampling: $52 \mathrm{gal}$

Time: $15: 30$

Alkalinity: $0 \mathrm{mg} / \mathrm{h}$

Water temperature: $22.7^{\circ} \mathrm{C}$

LABORATORY ANALYSES

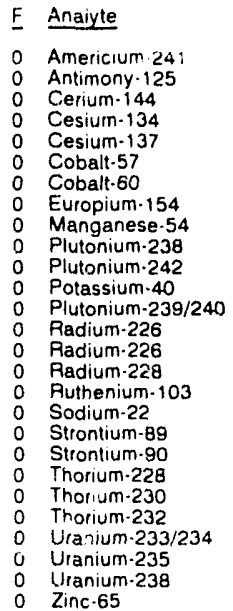

Result

$1.0 \mathrm{E} \cdot 10 \pm 1.0 \mathrm{E} \cdot 10$

$<3.4 \mathrm{E} \cdot 08$
$<1$ bE.07

$<1$ SE. 07
$<15 \mathrm{E} .08$

$<1.4 E .08$

$<2.0 E .08$

$<15 E .08$

$<32 \mathrm{CO} 08$

OE. $10 \pm 2$ OE. 10

$<2$ OE. 10

$70 \mathrm{E} \cdot 10 \pm 3.0 \mathrm{OE} \cdot 10$

3 OE. $09 \pm 3.0 E \cdot 10$

$8.0 \mathrm{E} \cdot 10$

$<8.3 \mathrm{E} \cdot 08$

$<13 \mathrm{E} \cdot 08$

$<5.2 E .09$
$<10 E .09$

$<1$
$<11 E .09$

$\begin{array}{ll}<1 & 1 E-09 \\ <1 & \text { OE- } 10\end{array}$

$1, O E \cdot 10$

$<2.0 \mathrm{E} \cdot 10$

$<2.0 E-10$
$<22 E-08$

WELL FSB 7.08

MEASUREMENTS CONDUCTED IN THE FIELD

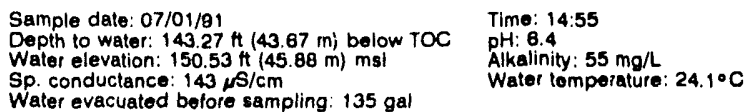

Sp. conductance: $143 \mu \mathrm{s} / \mathrm{cm}$

LABORATORY ANALYSES
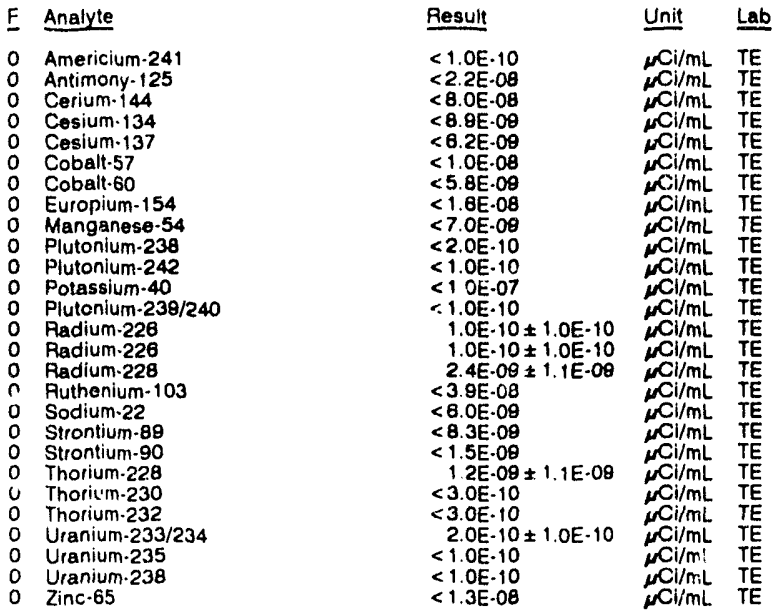

WELL FSB 76B

MEASUREMENTS CONDUCTED IN THE FIELD

Sample date: 07/01/91

Depth to water: $143.27 \mathrm{ft}(43.67 \mathrm{~m})$ below TOC

Sp. conductance: $143 \mu \mathrm{s} / \mathrm{cm}$

Water evacuated before sampling: 135 gal

pH: 8.4 :

Alkalinity: $55 \mathrm{mg} / \mathrm{L}$

Water temperature: $24.1^{\circ} \mathrm{C}$

LABORATORY ANALYSES

E Analyte

0 Americium-241

Antimony $\cdot 125$

Cesium-134

Cesium-137

Cobalt.57

Cobalt-60

Maropium-154

Plutonium-238

Plutonium-242

Potassium.40

Plutonium-239/240

Radium-226

Radium.226

Radium-228
Rutherium-103

Ruther.jum-102

Strontium- 89

Strontium-90

Thorium-228

Thorium-230

Thorium 232

Uranium-233/234

Uranium.235

Uranium-

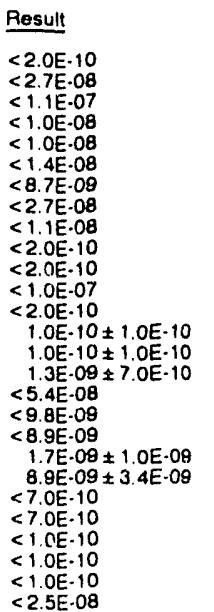

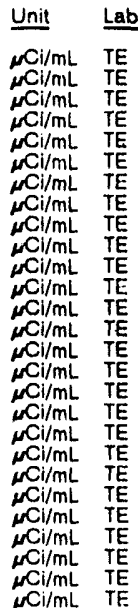




\section{WELL FSB 76C}

MEASUREMENTS CONDUCTED IN THE FIELD

Sample date: $07 / 02 / 81$
Depth to water: $81.11 \mathrm{H}(24.72 \mathrm{~m})$ below TOC
Water elevation: $212.49 \mathrm{ft}(64.77 \mathrm{~m}) \mathrm{ms}$
Sp. conductance: $53 \mu 5 / \mathrm{cm}$
Water evecuated belore sampling: $149 \mathrm{gal}$
LABOPATORY ANALYSES
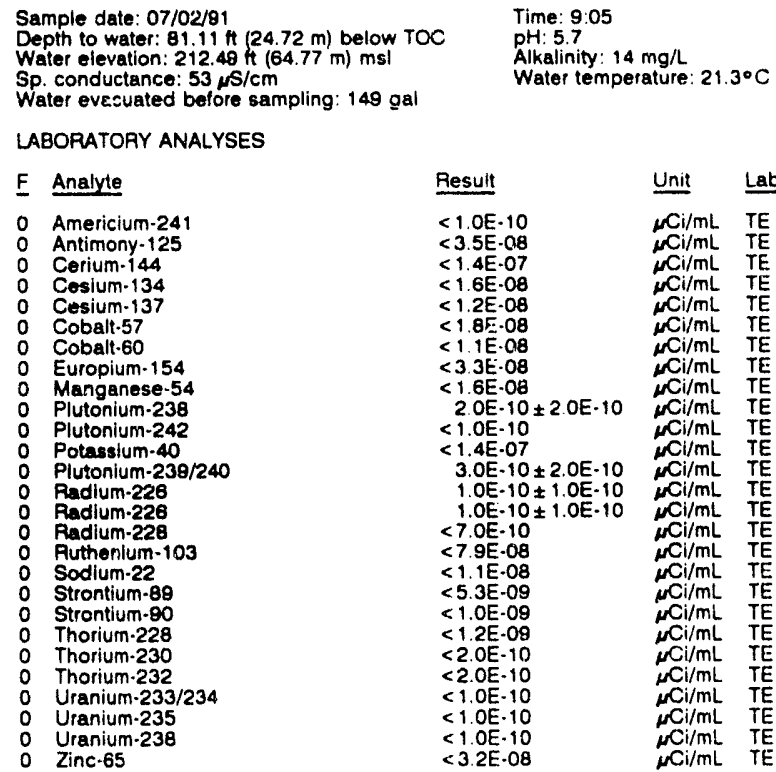

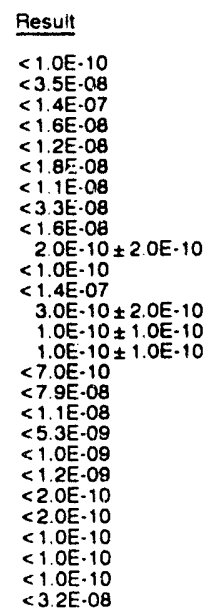

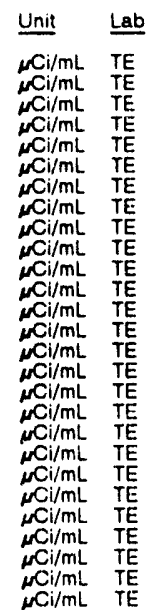

WELL FSB 78

MEASUREMENTS CONDUCTED IN THE FIELD

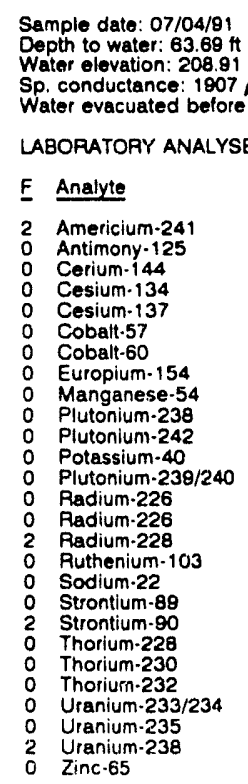

Time: 8:40

Alkalinity: $0 \mathrm{mg} / \mathrm{l}$

Water temperature $22,1 \circ \mathrm{C}$

LABORATORY ANALYSES

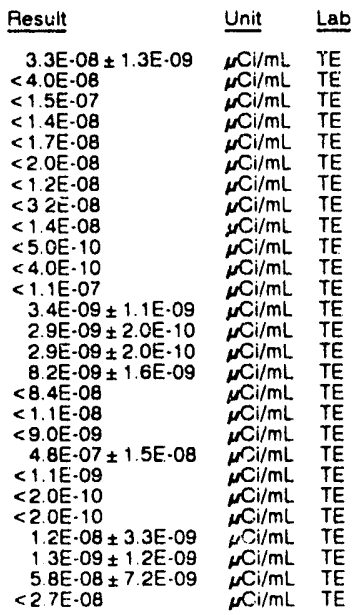

\section{WELL. FSB 78A}

MEASUREMENTS CONDUCTED IN THE FIELD

$\begin{array}{ll}\text { Sample date: } 07 / 04 / 81 & \text { Time: } 9: 55 \\ \text { Depth to water: } 117.60 \mathrm{Ht}(35.84 \mathrm{~m}) \text { below TOC } & \text { pH: } 6.2 \\ \text { Water elevation: } 155.00 \mathrm{ft}(47.24 \mathrm{~m}) \mathrm{msl} & \text { Alkalinity: } 43 \mathrm{mg} / \mathrm{h} \\ \text { Sp. conductance: } 112 \mu \mathrm{cm} / \mathrm{cm} & \text { Water temperature: } 21.8^{\circ} \mathrm{C} \\ \text { Water evacuated before sampling: } 336 \mathrm{gai} & \end{array}$

LABORATORY ANALYSES

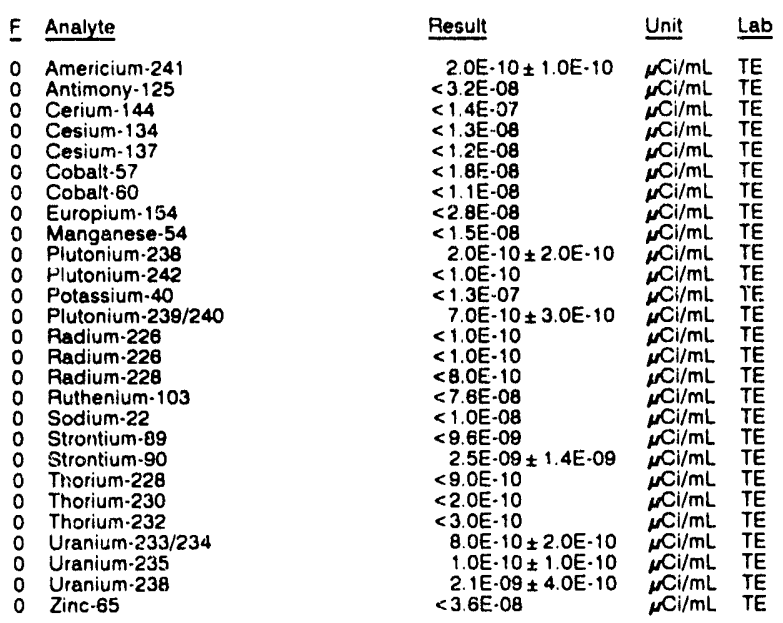

\section{WELL FSB 78B}

MEASUREMENTS CONDUCTED IN THE FIELD

\section{Sample date: $07 / 04 / 91$ \\ Depth to water: $119.63 \mathrm{H}(36.46 \mathrm{~m})$ below TOC \\ Water elevation: $153.17 \mathrm{ft}(46.69 \mathrm{~m}) \mathrm{msl}$ \\ Sp. conductance: $246 \mu \mathrm{S} / \mathrm{cm}$ \\ Water evacuated before sampling: $188 \mathrm{gal}$ \\ LABORATORY ANALYSES}

$\begin{array}{ll}\text { F } & \text { Analyte } \\ 0 & \text { Americium-241 } \\ 0 & \text { Antimony-125 } \\ 0 & \text { Cerium-144 } \\ 0 & \text { Cesium-134 } \\ 0 & \text { Cesium-137 } \\ 0 & \text { Cobalt-57 } \\ 0 & \text { Cobalt-60 } \\ 0 & \text { Europium-154 } \\ 0 & \text { Manganese-54 } \\ 0 & \text { Plutonium-238 } \\ 0 & \text { Plutonium-242 } \\ 0 & \text { Potassium-40 } \\ 0 & \text { Plutonium-239/240 } \\ 0 & \text { Radium-226 } \\ 0 & \text { Radium-226 } \\ 0 & \text { Radium-228 } \\ 0 & \text { Authenium-103 } \\ 0 & \text { Sodium-22 } \\ 0 & \text { Strontium-89 } \\ 0 & \text { Strontium-90 } \\ 0 & \text { Thorium-228 } \\ 0 & \text { Thorium-230 } \\ 0 & \text { Thorium-232 } \\ 0 & \text { Uranium-233/234 } \\ 0 & \text { Uranium-235 } \\ 0 & \text { Uranium-238 } \\ 0 & \text { Zinc-65 } \\ 0 & \end{array}$

\begin{tabular}{|c|c|}
\hline esult & Unit \\
\hline$<1.0 E \cdot 10$ & $\mathrm{Ci} / \mathrm{mL}$ \\
\hline$<3.1 E .08$ & $\mu \mathrm{Ci} / \mathrm{mL}$ \\
\hline$<1.3 \mathrm{E}-07$ & $\mathrm{milir}$ \\
\hline $\begin{array}{l}<1.2 \mathrm{E}-08 \\
<1.4 \mathrm{E}-08\end{array}$ & $m \mathrm{Ci} / \mathrm{mL}$ \\
\hline$<1.6 \mathrm{E} \cdot 0$ & $\mu \mathrm{Ci} / \mathrm{mL}$ \\
\hline$<1.2 E-0$ & $\mathrm{~m} \mathrm{Ci} / \mathrm{mL}$ \\
\hline $\begin{array}{l}<2.9 \mathrm{E} .08 \\
<1.4 \mathrm{E} \cdot 08\end{array}$ & $\mathrm{mi} / \mathrm{mL}$ \\
\hline$<6.0 E$. & $\mathrm{mCi} / \mathrm{mL}$ \\
\hline$<3.0 \mathrm{E} \cdot 10$ & $\mathrm{mCl} / \mathrm{mL}$ \\
\hline $\begin{array}{l}<1.3 \mathrm{E}-07 \\
4.0 \mathrm{E} \cdot 10 \pm 4.0 \mathrm{E}-10\end{array}$ & $\begin{array}{l}\mu \mathrm{Ci} / \mathrm{mL} \\
\mathrm{mCl} / \mathrm{mL}\end{array}$ \\
\hline $\begin{array}{l}3.0 \mathrm{E} \cdot 10 \pm 1.0 \mathrm{E} \cdot 10 \\
3.0 \mathrm{E}-10 \pm 1.0 \mathrm{E}-10\end{array}$ & ${ }^{m C i / m L}$ \\
\hline$<1.0 \mathrm{E}-09$ & $\mathrm{NCl} / \mathrm{mL}$ \\
\hline $\begin{array}{l}<4.9 E \\
<1.1 E\end{array}$ & $\mu \mathrm{Ci} / \mathrm{mL}$. \\
\hline$<3.8 \mathrm{E}$ & \\
\hline$<\begin{array}{l}<.0 \mathrm{E}- \\
1.4 \mathrm{E}\end{array}$ & $\mathrm{m} \mathrm{Cl} / \mathrm{mL}$ \\
\hline $\pm 3.0 \mathrm{E}-10$ & \\
\hline $\begin{array}{l}<2.0 \mathrm{E} . \\
<3.0 \mathrm{E} .\end{array}$ & \\
\hline$<3.0 \mathrm{E}$ & \\
\hline & \\
\hline & \\
\hline
\end{tabular}


WELL FSB 79

MEASUREMENTS CONDUCTED IN THE FIELD

Sample date: 07/04/91 Depth to water: $15.39 \mathrm{Ht}(4.69 \mathrm{~m})$ below TOC Water elevation: 202.41 Ht 61.7

Water evacuated before sampling: $76 \mathrm{gal}$

LABORATORY ANALYSES

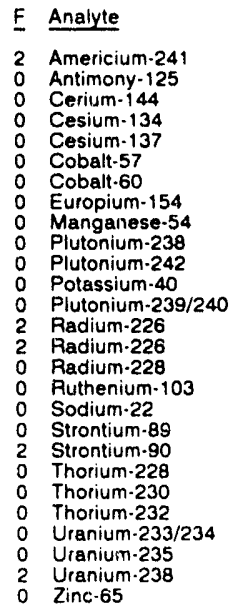

\begin{tabular}{|c|c|}
\hline esult & Unit \\
\hline 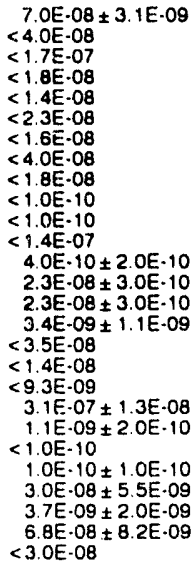 & 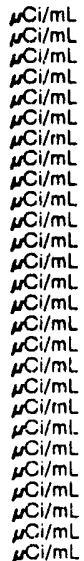 \\
\hline
\end{tabular}

\section{WELL FSB 79C}

MEASUREMENTS CONDUCTED IN THE FIELO

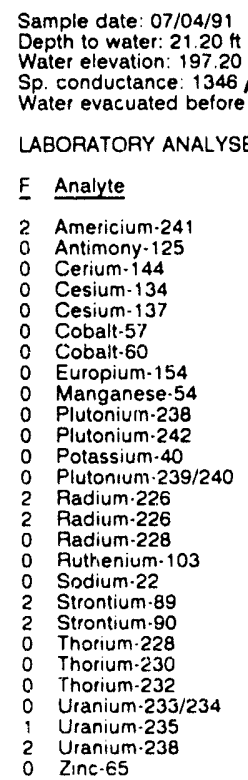

Tims: $15: 15$

PH: 3.5 : $0 \mathrm{mg} / \mathrm{L}$

Water temperature: $22.1^{\circ} \mathrm{C}$

Time: $14: 10$

PH: 3.2

Water temperature: $21.6^{\circ} \mathrm{C}$

\section{WELL FSB 87A}

MEASUREMENTS CONDUCTED IN THE FIELD

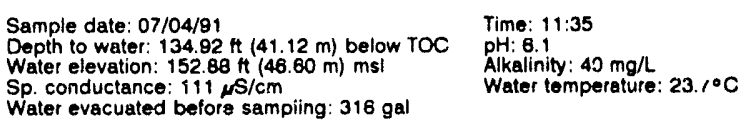

Water evacuated before samping: $316 \mathrm{gal}$

LABORATORY ANALYSES
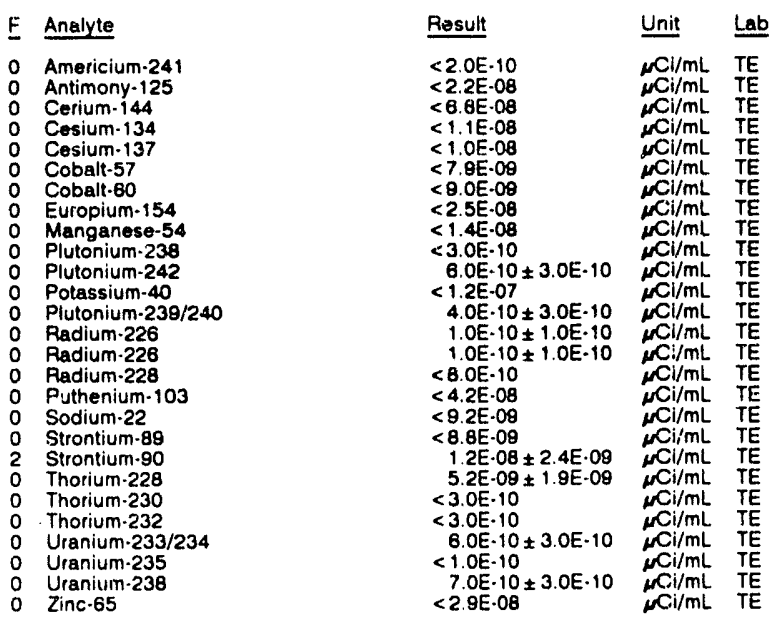

\section{WELL FSB 873}

MEASUREMENTS CONDUCTED IN THE FIELO

$\begin{array}{ll}\text { Sample date: } 07 / 04 / 91 & \text { Time: } 12: 00 \\ \text { Depth to water: } 137.76 \mathrm{ft}(41.89 \mathrm{~m}) \text { below TOC } & \text { pH: } 5.8 \\ \text { Water elevation: } 149.74 \mathrm{ft}(45.64 \mathrm{~m}) \mathrm{msl} & \text { Alkalinity: } 9 \mathrm{mg} / \mathrm{L} \\ \text { Sp. conductance: } 71 \mu \mathrm{S} / \mathrm{cm} & \text { Water temperature: } 23.5^{\circ} \mathrm{C} \\ \text { Water evacuated before sampling: } 157 \mathrm{gal} & \end{array}$

列

LABORATORY ANALYSES

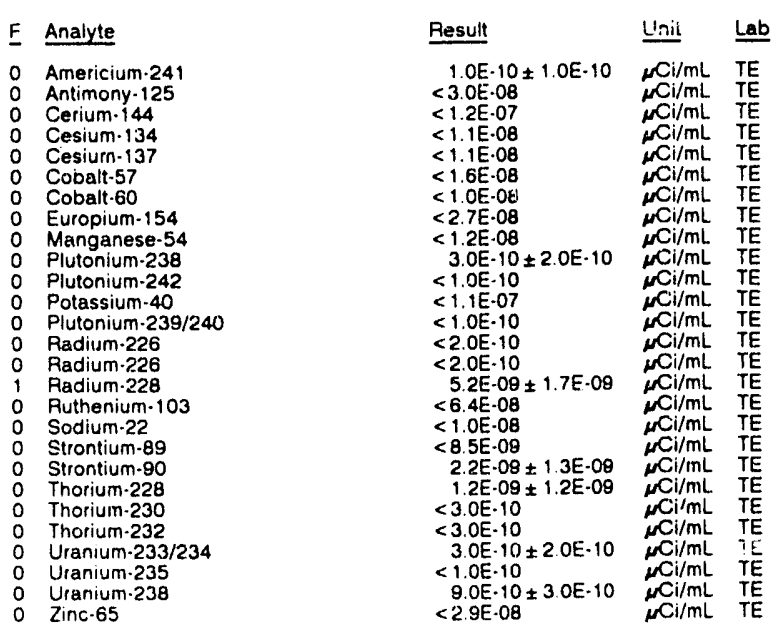


WELL FSB 87C

MEASUREMENTS CONDUCTED IN THE FIELD

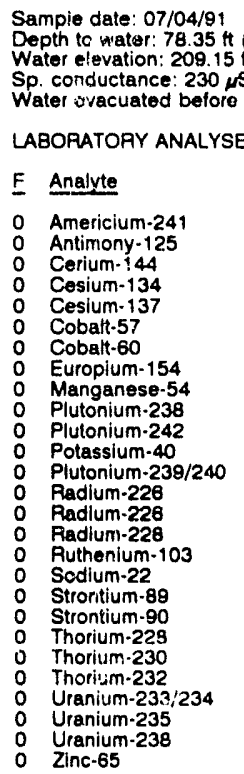

Time: $12: 35$

Alkalinity: $6 \mathrm{mg} / \mathrm{h}$

Water temperature: $25.7^{\circ} \mathrm{C}$

Water uvacuated bof $\mu \mathrm{S} / \mathrm{cm}$. $160 \mathrm{ge}$

\section{LABORATORY ANALYSES}

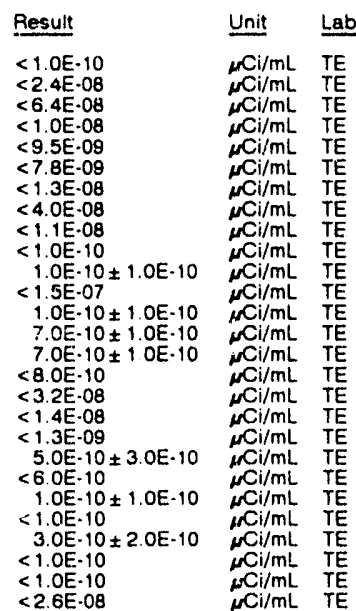

\section{WELL FSB 88C}

MEASUREMENTS CONDUCTED IN THE FIELD

\begin{tabular}{|c|c|c|c|c|c|}
\hline \multicolumn{2}{|r|}{$\begin{array}{l}\text { Sample date: } 07 / 02 / 91 \\
\text { Depth to water: } 70.65 \mathrm{tt}(21.53 \mathrm{~m}) \text { below TOC } \\
\text { Water elevation: } 212.35 \mathrm{ft}(64.73 \mathrm{~m}) \mathrm{ms} \text { l } \\
\text { Sp. conductance: } 55 \mu \mathrm{S} / \mathrm{cm} \\
\text { Water evacuated belore sampling: } 141 \mathrm{gal}\end{array}$} & & \multicolumn{3}{|c|}{$\begin{array}{l}\text { Time: } 11: 00 \\
\text { pH: } 5.3^{-1} \\
\text { Alkalinity: } 8 \mathrm{mg} / \mathrm{L} \\
\text { Water temperature: } 22.3^{\circ} \mathrm{C}\end{array}$} \\
\hline \multicolumn{6}{|c|}{ LABOPATORY ANALYSES } \\
\hline$\underline{F}$ & Analyte & Result & & Unit & $\underline{L a b}$ \\
\hline & $\begin{array}{l}\text { Strontium-69 } \\
\text { Strontium-90 }\end{array}$ & $\begin{array}{r}<8.4 E \\
3.4 E\end{array}$ & $\begin{array}{l}09 \\
08 \pm 4.2 E \cdot 09\end{array}$ & $\underset{\mu \mathrm{Ci} / \mathrm{mL}}{\mu \mathrm{Ci} / \mathrm{mL}}$ & TE \\
\hline
\end{tabular}

\section{WELL FSB 88D}

MEASUREMENTS CONDUCTED IN THE FIELD

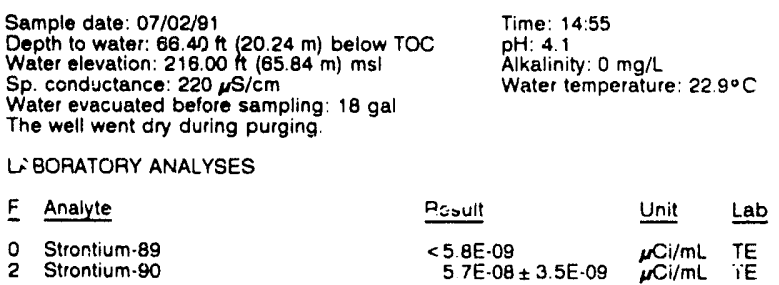

\section{WELL FSB 89D}

\begin{tabular}{|c|c|c|c|}
\hline \multirow{2}{*}{$\begin{array}{l}\text { Sample date: } C 7 / 02 / 91 \\
\text { Depth to water: } 65.70 \mathrm{Ht}(20.03 \mathrm{~m}) \text { below TOC } \\
\text { Water elevation: } 215.50 \mathrm{ft}(65.69 \mathrm{~m}) \mathrm{ms} \\
\text { SF. conductarice: } 453 \mu \mathrm{s} / \mathrm{cm} \\
\text { Watel evacuated before sampling: } 36 \mathrm{gal} \\
\text { LABORATORY ANALYSES }\end{array}$} & \multirow{2}{*}{\multicolumn{3}{|c|}{$\begin{array}{l}\text { Time: } 12.05 \\
\mathrm{pH}: 3.7 \\
\text { Alkalinity: } 0 \mathrm{mg} / \mathrm{h} \\
\text { Water temperature: } 233^{\circ} \mathrm{C}\end{array}$}} \\
\hline & & & \\
\hline F Analyte & Result & Unit & Lab \\
\hline $\begin{array}{ll}2 & \text { Americium-241 } \\
0 & \text { Antimony-125 } \\
0 & \text { Cerium-144 } \\
0 & \text { Cesium-134 } \\
0 & \text { Cesium-137 } \\
0 & \text { Cobalt } 57\end{array}$ & $\begin{aligned} & 1.6 \mathrm{E} \cdot 08 \pm 1.2 \mathrm{E} \cdot 08 \\
< & 3.0 \mathrm{E} \cdot 08 \\
< & 1.4 \mathrm{E} \cdot 07 \\
< & 1.4 \mathrm{E} \cdot 08 \\
< & 1.1 \mathrm{E} .08 \\
< & 1.7 \mathrm{E} \cdot 08\end{aligned}$ & $\begin{array}{l}\mu \mathrm{Ci} / \mathrm{mL} \\
\mu \mathrm{Ci} / \mathrm{mL} \\
\mu \mathrm{Ci} / \mathrm{mL} \\
\mu \mathrm{Ci} / \mathrm{mL} \\
\mu \mathrm{Ci} / \mathrm{mL} \\
\mu \mathrm{Ci} / \mathrm{mL}\end{array}$ & $\begin{array}{l}\text { TE } \\
\text { TE } \\
\text { TE } \\
\text { TE } \\
\text { TE } \\
\text { TE }\end{array}$ \\
\hline
\end{tabular}

WELL FSB 890 collected on $07 / 02 / 91$, laboratory analyses (cont.)

\begin{tabular}{|c|c|c|c|}
\hline Analyte & Result & Unit & $\underline{\text { Lab }}$ \\
\hline $\begin{array}{l}\text { Cobalt-60 } \\
\text { Europium-154 } \\
\text { Manganese-54 } \\
\text { Plutonium-23日 } \\
\text { Plutonium-242 } \\
\text { Potassium-40 } \\
\text { Plutonium-239/240 } \\
\text { Padium-226 } \\
\text { Padium-226 } \\
\text { Radium-228 } \\
\text { Puthenium-103 } \\
\text { Sodium-22 } \\
\text { Strontium-89 } \\
\text { Strontium-90 } \\
\text { Thorium-228 } \\
\text { Thorium-230 } \\
\text { Thorium-232 } \\
\text { Uranium-233/234 } \\
\text { Uranium-235 } \\
\text { Uranium-238 } \\
\text { Zinc-65 }\end{array}$ & 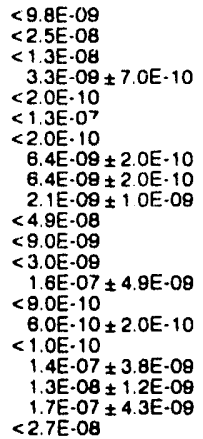 & 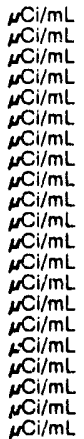 & $\begin{array}{l}\text { TE } \\
\text { TE } \\
\text { TE } \\
\text { TE } \\
\text { TE } \\
\text { TE } \\
\text { TE } \\
\text { TE } \\
\text { TE } \\
\text { TE } \\
\text { TE } \\
\text { TE } \\
\text { TE } \\
\text { TE } \\
\text { TE } \\
\text { TE } \\
\text { TE } \\
\text { TE } \\
\text { TE } \\
\text { TE } \\
\text { TE }\end{array}$ \\
\hline
\end{tabular}

WELL FSB 90D

MEASUREMENTS CONDUCTED IN THE FIELD

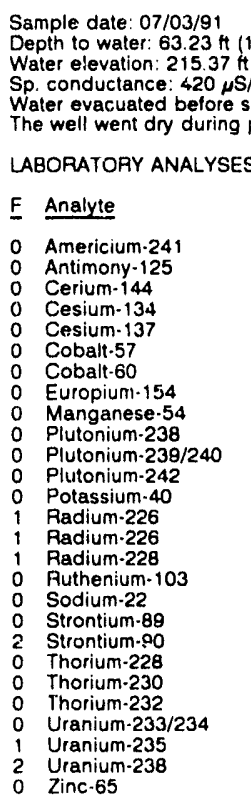

Time: 8:20

pH: 4.4

Alkalinity: $4 \mathrm{mg} / \mathrm{L}$
Water temperature: $22.3^{\circ} \mathrm{C}$ $(65.65 \mathrm{~m}) \mathrm{mst}$ mpling: $7 \mathrm{gal}$ lemperature: $22.3^{\circ} \mathrm{C}$ The well went dry during purging

\begin{tabular}{|c|c|c|c|c|}
\hline$E$ & Analyte & Result & Unit & Lab \\
\hline $\begin{array}{l}0 \\
0 \\
0 \\
0 \\
0 \\
0 \\
0\end{array}$ & $\begin{array}{l}\text { Americium-241 } \\
\text { Antimony-125 } \\
\text { Cerium-144 } \\
\text { Cesium-134 } \\
\text { Cesium-137 } \\
\text { Cobalt-57 } \\
\text { Cobalt-60 } \\
\text { Europium-154 } \\
\text { Manganese-54 } \\
\text { Plutonium-238 } \\
\text { Plutonium-239/240 } \\
\text { Plutonium-242 } \\
\text { Potassium-40 } \\
\text { Radium-226 } \\
\text { Radium-226 } \\
\text { Radium-228 } \\
\text { Puthenium-103 } \\
\text { Sodium-22 } \\
\text { Strontiumm-89 } \\
\text { Strontium-90 } \\
\text { Thorium-228 } \\
\text { Thorium-230 } \\
\text { Thorium-232 } \\
\text { Uranium-233/234 } \\
\text { Uranium-235 } \\
\text { Uranium-238 } \\
\text { Zinc-65 }\end{array}$ & $\begin{aligned} & 1.4 \mathrm{E} \cdot 09 \pm 3.0 \mathrm{E}-10 \\
&< 1.8 \mathrm{E} \cdot 08 \\
&<6.3 \mathrm{E} \cdot 08 \\
&<6.4 \mathrm{E} \cdot 09 \\
&<6.6 \mathrm{E}-09 \\
&<8.5 \mathrm{E} \cdot 09 \\
&<6.9 \mathrm{E}-09 \\
&<1.7 \mathrm{E} \cdot 08 \\
&<6.8 \mathrm{E}-09 \\
&<2.0 \mathrm{E} \cdot 10 \\
&<2.0 \mathrm{E}-10 \\
&<2.0 \mathrm{E} \cdot 10 \\
&<1.0 \mathrm{E}-07 \\
& 1.4 \mathrm{E} \cdot 08 \pm 6.0 \mathrm{E} \cdot 10 \\
& 1.4 \mathrm{E}-08 \pm 6.0 \mathrm{E} \cdot 10 \\
& 6.8 \mathrm{E}-09 \pm 1.5 \mathrm{E} \cdot 09 \\
&<2.3 \mathrm{E} \cdot 08 \\
&<6.4 \mathrm{E}-09 \\
&<1.8 \mathrm{E}-09 \\
& 3.1 \mathrm{E} \cdot 07 \pm 6.6 \mathrm{E}-09 \\
&<6.0 \mathrm{E} \cdot 10 \\
& 1.0 \mathrm{E}-10 \pm 1.0 \mathrm{E}-10 \\
&<1.0 \mathrm{E}-10 \\
& 1.9 \mathrm{E} \cdot 07 \pm 4.5 \mathrm{E} \cdot 08 \\
& 8.1 \mathrm{E} \cdot 09 \pm 1.2 \mathrm{E} \cdot 09 \\
& 1.6 \mathrm{E}-07 \pm 4.2 \mathrm{E} \cdot 08 \\
&<1.8 \mathrm{E} \cdot 08\end{aligned}$ & 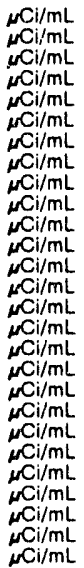 & $\begin{array}{l}\text { TE } \\
T E \\
T E \\
T E \\
T E \\
T E \\
T E \\
T E \\
T E \\
T E \\
T E \\
T E \\
T E \\
T E \\
T E \\
T E \\
T E \\
T E \\
T E \\
T E \\
T E \\
T E \\
T E \\
T E \\
T E \\
T E \\
T E\end{array}$ \\
\hline
\end{tabular}

\section{WELL FSB 91D}

MEASUREMENTS CONDUCTED IN THE FIELD

$\begin{array}{ll}\text { Sample date: } 07 / 02 / 91 & \text { Time: } 13: 45 \\ \text { Depth to water: } 65.84 \mathrm{ft}(20.07 \mathrm{~m}) \text { below TOC } & \text { pH: } 34.4 \\ \text { Water elevation: } 213.36 \mathrm{ft}(65.03 \mathrm{~m}) \mathrm{msl} & \text { Alkalinity: } 0 \mathrm{mg} / \mathrm{L} \\ \text { Sp. conductance: } 962 \mu \mathrm{S} / \mathrm{cm} & \text { Water temperature: } 24.3^{\circ} \mathrm{C} \\ \text { Water evacuated before sampling: } 33 \mathrm{gal} & \end{array}$

Water evacuated before sampling: $33 \mathrm{gal}$

LABORATORY ANALYSES

\begin{tabular}{|c|c|c|c|}
\hline Analyte & Result & Unit & $\mathrm{Lab}$ \\
\hline $\begin{array}{l}\text { Americium-241 } \\
\text { Antimony-125 } \\
\text { Cerium-144 } \\
\text { Cesium-134 } \\
\text { Cesium-137 } \\
\text { Cobalt-57 } \\
\text { Cobalt-60 } \\
\text { Europium-154 } \\
\text { Manganese-54 } \\
\text { Plutonium-238 } \\
\text { Plutonium-242 } \\
\text { Potassium-40 } \\
\text { Plutonium-239/240 } \\
\text { Radium-226 } \\
\text { Padium-226 } \\
\text { Radium-228 } \\
\text { Ruthenium-103 } \\
\text { Sodium-22 }\end{array}$ & $\begin{aligned} & 1.6 \mathrm{EE} \cdot 08 \pm 2.4 \mathrm{E} \cdot 09 \\
&< 2.4 \mathrm{E} \cdot 08 \\
&<1.1 \mathrm{E} \cdot 07 \\
&<9.9 \mathrm{E} \cdot 09 \\
&<9.7 \mathrm{E} \cdot 09 \\
&<1.4 \mathrm{E} \cdot 08 \\
&<7.8 \mathrm{E} \cdot 09 \\
&<2.2 \mathrm{E} \cdot 08 \\
&<1.1 \mathrm{E} \cdot 08 \\
& 4.0 \mathrm{E} \cdot 10 \pm 3.0 \mathrm{E} \cdot 10 \\
&<3.0 \mathrm{E} \cdot 10 \\
&<1.0 \mathrm{E} \cdot 07 \\
& 6.0 \mathrm{E} \cdot 10 \pm 4.0 \mathrm{E} \cdot 10 \\
& 3.1 \mathrm{E} \cdot 08 \pm 1.1 \mathrm{E} \cdot 09 \\
& 3.1 \mathrm{E} \cdot 08 \pm 1.1 \mathrm{E} \cdot 09 \\
& 2.3 \mathrm{E} \cdot 08 \pm 2.3 \mathrm{E} \cdot 09 \\
&<5.6 \mathrm{E} \cdot 08 \\
&<\mathrm{B} \cdot 1 \mathrm{E} \cdot 09\end{aligned}$ & $\begin{array}{l}\mu \mathrm{Ci} / \mathrm{mL} \\
\mu \mathrm{Ci} / \mathrm{mL} \\
\mu \mathrm{Ci} / \mathrm{mL} \\
\mu \mathrm{Ci} / \mathrm{mL} \\
\mu \mathrm{Ci} / \mathrm{mL} \\
\mu \mathrm{Ci} / \mathrm{mL} \\
\mu_{\mathrm{Cl}} / \mathrm{mL} \\
\mu \mathrm{Ci} / \mathrm{mL} \\
\mu \mathrm{Ci} / \mathrm{mL} \\
\mu \mathrm{Ci} / \mathrm{mL} \\
\mu \mathrm{Ci} / \mathrm{mL} \\
\mu \mathrm{Ci} / \mathrm{mL} \\
\mu \mathrm{Ci} / \mathrm{mL} \\
\mu \mathrm{Ci} / \mathrm{mL} \\
\mu \mathrm{Ci} / \mathrm{mL} \\
\mu \mathrm{Ci} / \mathrm{mL} \\
\mu \mathrm{Ci} / \mathrm{mL} \\
\mu \mathrm{Ci} / \mathrm{mL}\end{array}$ & $\begin{array}{l}\text { TE } \\
\text { TE } \\
\text { TE } \\
\text { TE } \\
\text { TE } \\
\text { TE } \\
\text { TE } \\
\text { TE } \\
T E \\
\text { TE } \\
\text { TE } \\
\text { TE } \\
\text { TE } \\
\text { TE } \\
\text { TE } \\
\text { TE } \\
\text { TE } \\
\text { TE }\end{array}$ \\
\hline
\end{tabular}


ANALYTICAL RESULTS

WELL FSB 910 collected on 07/02/91, laboratory analyses (con

\begin{tabular}{|c|c|c|}
\hline Analyte & Result & writ \\
\hline $\begin{array}{ll}0 & \text { Strontium-89 } \\
2 & \text { Strontium-90 } \\
0 & \text { Thorium-228 } \\
0 & \text { Thorium-230 } \\
0 & \text { Thorium-232 } \\
0 & \text { Uranium-233/234 } \\
0 & \text { Uranium-235 } \\
2 & \text { Uranium-238 } \\
0 & \text { Zinc-65 }\end{array}$ & $\begin{array}{r}<7.8 \mathrm{E}-09 \\
4.8 \mathrm{BE}-07 \pm 1.5 \mathrm{E}-08 \\
1.1 \mathrm{E}-09 \pm 3.0 \mathrm{E}-10 \\
7.0 \mathrm{E}-10 \pm 2.0 \mathrm{E}-10 \\
<1.0 \mathrm{E}-10 \\
1.5 \mathrm{E}-08 \pm 4.0 \mathrm{E}-09 \\
<1.1 \mathrm{E} \cdot 09 \\
1.7 \mathrm{E}-08 \pm 4.1 \mathrm{E}-09 \\
<2.4 \mathrm{E}-08\end{array}$ & $\begin{array}{l}\mu \mathrm{Ci} / \mathrm{mL} \\
\mu \mathrm{Ci} / \mathrm{mL} \\
\mu \mathrm{Ci} / \mathrm{mL} \\
\mu \mathrm{Ci} / \mathrm{mL} \\
\mu \mathrm{Cl} / \mathrm{mL} \\
\mu \mathrm{Ci} / \mathrm{mL} \\
\mu \mathrm{Ci} / \mathrm{mL} \\
\mu \mathrm{Ci} / \mathrm{mL} \\
\mu \mathrm{Ci} / \mathrm{mL}\end{array}$ \\
\hline
\end{tabular}

\section{WELL FSB 92D}

MEASUREMENTS CONDUCTED IN THE FIELD

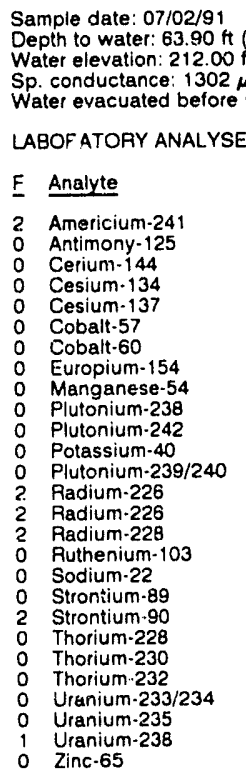

Time: $14: 15$

$\mathrm{pH}: 3.4$

Alkalinity: $0 \mathrm{mg} / \mathrm{L}$

Water temperature: $22.7^{\circ} \mathrm{C}$

Water evacuated before sampling: $27 \mathrm{gal}$

LABOFATORY ANALYSES

Result

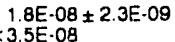

$<3.5 \mathrm{E} \cdot 08$

$<1.5 \mathrm{E}-07$

$<1.4 \mathrm{E} \cdot 08$

$<1.9 \mathrm{E}-08$

$<9.5 \mathrm{E}-09$

$<3.5 \mathrm{E} \cdot 08$

$<8.0 \mathrm{E} \cdot 10$

$<8.0 \mathrm{E}-10$

$<1.2 E \cdot 07$

$3.2 E \cdot 08 \pm 1.1 E \cdot 09$

$3.2 E \cdot 08 \pm 1.1 E \cdot 09$
$3.2 E \cdot 08 \pm 1.1 E \cdot 09$

1. $4 \mathrm{E} \cdot 08 \pm 2.3 \mathrm{E} \cdot 09$

$<8.0 \mathrm{E} \cdot 08$

$<1.3 \mathrm{E} \cdot 0 \mathrm{0B}$

$<8.5 \mathrm{E} .09$

$7.9 \mathrm{E}-07 \pm 1.9 \mathrm{E}-08$

$<7.0 \mathrm{E} \cdot 10$

$<1.0 \mathrm{E}-10$

$<1.0 \mathrm{E} \cdot 10$

$1.6 \mathrm{E} \cdot 08 \pm 3.8 \mathrm{E} \cdot 09$

$<1.0 E .09+3.8 E .09 .09$

$1.4 \mathrm{E} \cdot 08 \pm 3.5 \mathrm{E} \cdot 09$
$<3.7 \mathrm{E} \cdot 08$

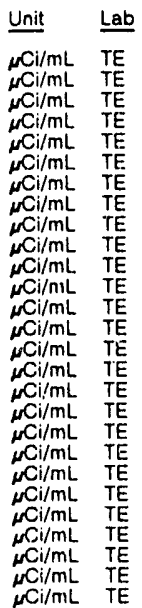

WELL FSB102C

MEASUREMENTS CONDUCTED IN THE FIELD

Sample date: 07/03/91

Depth to water: $5.91 \mathrm{ft}(1.80 \mathrm{~m})$ below TOC Water elevation: $195.19 \mathrm{ft}(59.49$

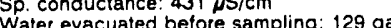

Time: 9.20

PH: 4.3 Alkalinity: $0 \mathrm{mg} / \mathrm{L}$

Water temperature: $19.8^{\circ} \mathrm{C}$

LABORATORY ANALYSES

$\begin{array}{ll}\text { F } & \text { Analyte } \\ 0 & \text { Anericium-241 } \\ 0 & \text { Antimony-125 } \\ 0 & \text { Cerium-144 } \\ 0 & \text { Cesium }-134 \\ 0 & \text { Cesium-137 } \\ 0 & \text { Cobalt-57 } \\ 0 & \text { Cobalt-60 } \\ 0 & \text { Europium-154 } \\ 0 & \text { Manganese-54 } \\ 0 & \text { Plutonium-238 } \\ 0 & \text { Plutonium-242 } \\ 0 & \text { Potassium-40 } \\ 0 & \text { Plutonium-239/240 } \\ 0 & \text { Padium-226 } \\ 0 & \text { Radium-226 } \\ 0 & \text { Radium-228 } \\ 0 & \text { Puthenium-103 } \\ 0 & \text { Sodium-22 } \\ 2 & \text { Strontium- } 89 \\ 2 & \text { Strontium- } 90 \\ 0 & \text { Thorium-228 } \\ 0 & \text { Thorium-230 } \\ 0 & \text { Thorium-232 } \\ 0 & \text { Uranium-233/234 } \\ 0 & \text { Uranium-235 } \\ 0 & \text { Uranium-238 } \\ 0 & \text { Zinc-65 }\end{array}$

Result

$1.0 \mathrm{E} \cdot 10 \pm 1.0 \mathrm{E} \cdot 10$

$<1.9 \mathrm{E}-08$

$<6.4 \mathrm{E} .08$
$<9.0 \mathrm{E} .09$

$<9.0 \mathrm{E} .09$

$<7.5 \mathrm{E}-09$
$<8.2 \mathrm{E}-09$

$<8.2 E-09$
$<9.9 E-09$

$<2.7 \mathrm{E} .08$

$<8.2 E-09$

$<1.0 \mathrm{E} \cdot 10$

$<1.0 \mathrm{E}-10$
$<1.3 \mathrm{E}-07$

2.0E-10ะ1.0E-10

$4.2 \mathrm{E} \cdot 09 \pm 1.0 \mathrm{E}-10$

. $2 E \cdot 09 \pm 1.0 \mathrm{E}-10$

1.5E-09 $\pm 9.0 \mathrm{E}-10$

$<2.9 E \cdot 08$

$9.9 E \cdot 09$

6. 3E.08 $01.9 \mathrm{E} \cdot 0$

1.8E- $07 \pm 4.4 \mathrm{E} \cdot 0$

$<B .0 E \cdot 10$

$<1.0 E \cdot 10$

$1.4 \mathrm{E} \cdot 09 \pm 4.0 \mathrm{E}-10$

$1.0 \mathrm{E} \cdot 10 \pm 1.0 \mathrm{E} \cdot 10$

$1.0 \mathrm{E} \cdot 09 \pm 3.0 \mathrm{E} \cdot 10$

$<2.9 \mathrm{E} .08$

WELL. FSB103C

MEASUREMENTS CONDUCTED IN THE FIELD

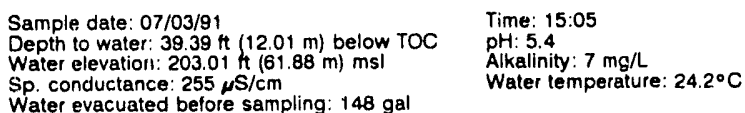

Water evacuated before sampling: $148 \mathrm{gal}$

LABORATORY ANALYSES

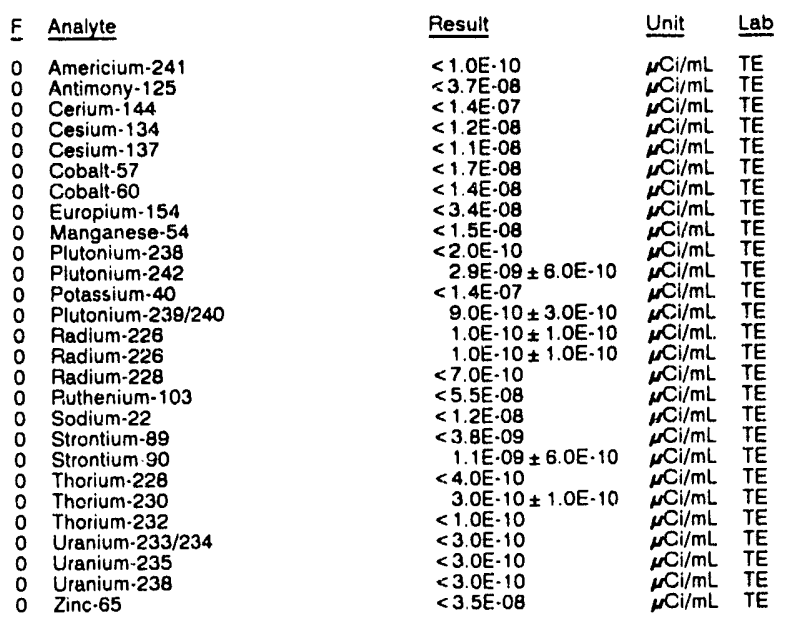

WELL FSB104D

MEASUREMENTS CONDUCTED IN THE FIELD

Depth is water: 14.39 it $(4.39 \mathrm{~m})$ below TOC

Water elevation: $204.81 \mathrm{ft}(62.43 \mathrm{~m}) \mathrm{ms}$

Water evacuated before sampling: $50 \mathrm{gal}$

LABORATORY ANALYSES

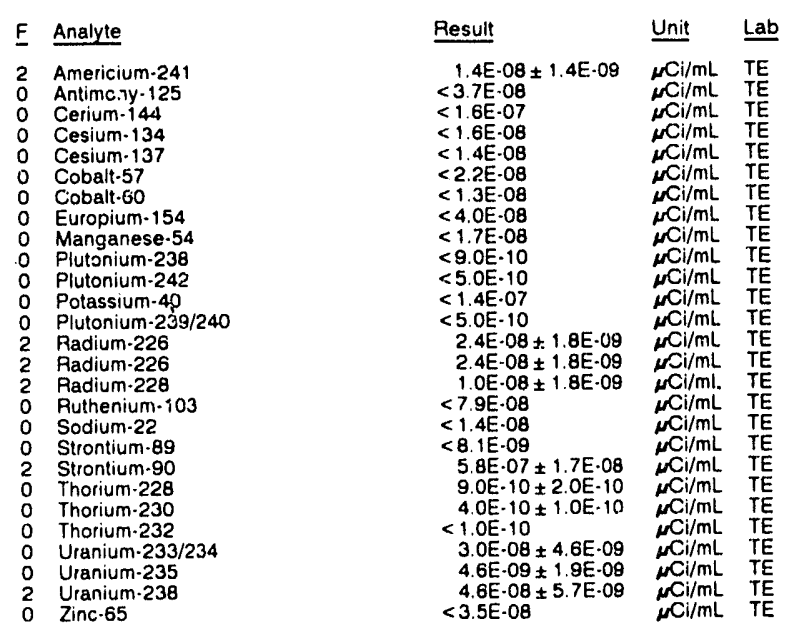


WELL FSB106C

MEASUREMENTS CONDUCTED IN THE FIELD

Sample date: $07 / 03 / 91$
Depth to water: $33.84 \mathrm{Ht}(10.31 \mathrm{~m})$ below TOC
Water elevation: $201.26 \mathrm{ft}(61.34 \mathrm{~m}) \mathrm{ms}$
Sp. conductance: $716 \mu \mathrm{s} / \mathrm{cm}$
Waler evacuated betore sampling: $119 \mathrm{gal}$
LABORATORY ANALYSES

Time: 10:15

pH: 4.8 ,

Water temperature: $209^{\circ} \mathrm{C}$

\section{LABORATORY ANALYSES}

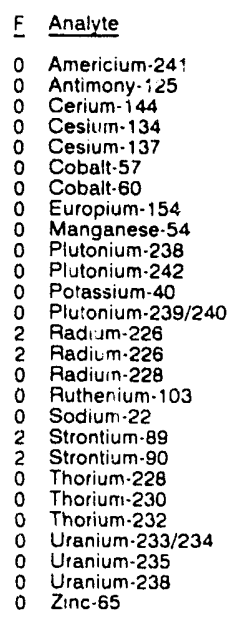

\begin{tabular}{|c|c|}
\hline Result & Unit \\
\hline 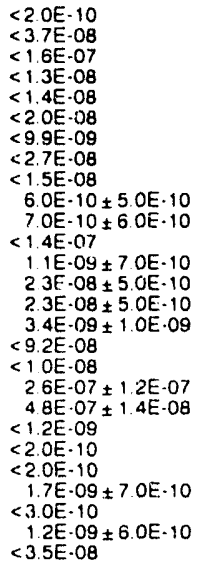 & 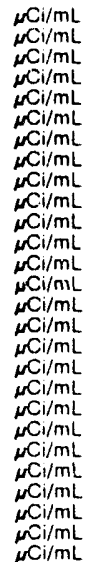 \\
\hline
\end{tabular}

\section{WELL FSB110D}

MEASUREMENTS CONDUCTEO IN THE FIELD

Sample date $07 / 03 / 91$

Depth to water: $28.89 \mathrm{H}(8.81 \mathrm{~m})$ below TOC

Water elevation: $205.61 \mathrm{ht}(62.67 \mathrm{r}$
Sp. conductance. $1735 \mu \mathrm{S} / \mathrm{cm}$

Sp. conductance $1735 \mathrm{\mu S} / \mathrm{cm}$
Water evacuated before sampling: $40 \mathrm{gal}$

LAEORATORY ANALYSES

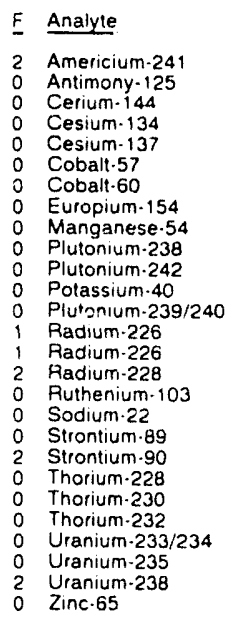

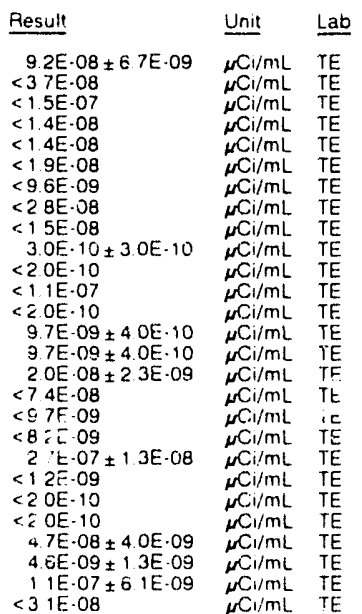

Time 11.40

PH: 3.2

Water temperature $229^{\circ} \mathrm{C}$
< TE.08
WELL HCA 1

MEASUREMENTS CONDUCTED IN THE FIELD

Sample date: 08/21/91

Depth to water: $38.56 \mathrm{ft}(11.75 \mathrm{~m})$ below TOC

Water elevation: $271.44 \mathrm{ft}(8274 \mathrm{~m}) \mathrm{msl}$

Water evacuated before sampling: $15 \mathrm{gal}$

The well went dry during purging.

LABORATORY ANALYSES

\begin{tabular}{|c|c|c|}
\hline$E$ Analyte & Result & Unit \\
\hline 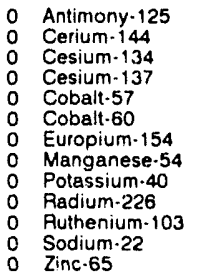 & $\begin{array}{l}<3.3 E-08 \\
<1.2 E-07 \\
<1.6 E .08 \\
<1.3 E-08 \\
<1.5 E-08 \\
<8.0 E .09 \\
<3.2 E .08 \\
<1.3 E .08 \\
<1.3 E .07 \\
<2.7 E .08 \\
<2.05 .08 \\
<1.1 E .08 \\
<2.9 E .08\end{array}$ & 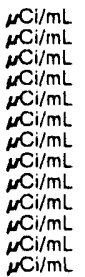 \\
\hline
\end{tabular}

WELL HCA 2

MEASUREMENTS CONDUCTED IN THE FIELLD

Sample date: $08 / 21 / 91$

Depth to water: $37.82 \pi(11.53 \mathrm{~m})$ below TOC

Water elevation: $272.98 \mathrm{ft}(83.21 \mathrm{~m}) \mathrm{ms}$ )

Sp conductance: $206 \mu \mathrm{S} / \mathrm{cm}$
Water evacuated before sampling: $81 \mathrm{gal}$

PH: 5.1 . 1 malinity. $4 \mathrm{mg}$

Water tentiperature: $24.5 \circ \mathrm{C}$

Water evacuated before sam

\begin{tabular}{|c|c|c|}
\hline Analyte & Result & Unit \\
\hline 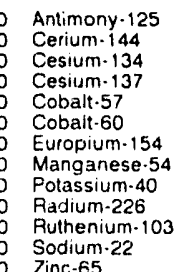 & $\begin{array}{l}<3.0 \mathrm{E} \cdot 08 \\
<1.1 \mathrm{E} \cdot 07 \\
<1.3 \mathrm{E} \cdot 08 \\
<1.2 \mathrm{E} \cdot 08 \\
<1.4 \mathrm{E} \cdot 08 \\
<8.7 \mathrm{E} \cdot 09 \\
<2.6 \mathrm{E} \cdot 08 \\
<1.2 \mathrm{E} \cdot 08 \\
<1.2 \mathrm{E} \cdot 07 \\
<2.6 \mathrm{E} \cdot 08 \\
<1.8 \mathrm{E} \cdot 08 \\
<8.5 \mathrm{E} \cdot 09\end{array}$ & 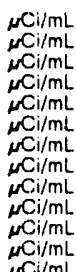 \\
\hline
\end{tabular}

WELL HCA 2

MEASUREMENTS CONDUCTED IN THE FIELD

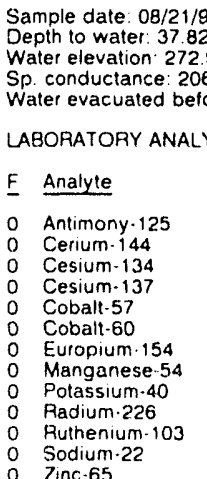

Time: 11.35

pH: 6.0

Water temperature: $26.2^{\circ} \mathrm{C}$
Time: $11: 35$

Alkalinity $37 \mathrm{mg} / \mathrm{h}$

Water temperature $26.2^{\circ} \mathrm{C}$

Result

$<3.0 E-08$

$<1.0 E \cdot 07$

$<1$
$<90 \mathrm{E} \cdot 08$

$<13 \mathrm{E} \cdot 0 \mathrm{0}$

$<9.0 E \cdot 09$
$<3.3 E \cdot 08$

$<1.0 \mathrm{E} .08$

$<12 \mathrm{E} .07$

$<23 \mathrm{E} .0 \mathrm{OB}$

$<16 \mathrm{E} .08$

$<1$ 1 $\mathrm{E} \cdot 08$
$<2.4 \mathrm{E} \cdot 08$

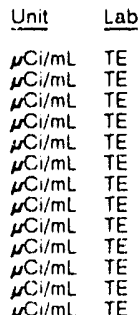


ANALYTICAL RESULTS

\section{WELL HCA 3}

MEASUREMENTS CONDUCTED IN THE FIELD

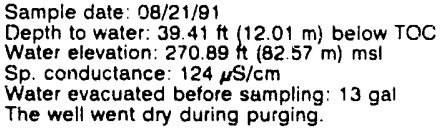

F Analyte

0 Antimony-125

Cerium-144

Cesium-137

Cobalt-57

Cobalt-60

Europium.154

Manganese-54

Potassium-40

Radium-226

Ruthenium-103

Sodium -2

\section{WELL HCA 4}

MEASUREMENTS CONDUCTED IN THE FIELD

Sample date: $08 / 21 / 91$

Depth to water: $39.14 \mathrm{ft}(11.93 \mathrm{~m})$ below TOC

Water elevation: $271.56 \mathrm{Ht}(82.77$
$\mathrm{Sp}$. conductance. $190 \mu \mathrm{S} / \mathrm{cm}$

Water evacuated

The well went dry during purging:

LABORATORY ANALYSES

\begin{tabular}{|c|c|c|}
\hline Analyte & Result & Unit \\
\hline $\begin{array}{ll}0 & \text { Antimony-125 } \\
0 & \text { Cerium-144 } \\
0 & \text { Cesium-134 } \\
0 & \text { Cesium-137 } \\
0 & \text { Cobalt-57 } \\
0 & \text { Cobalt-60 } \\
0 & \text { Europium-154 } \\
0 & \text { Manganese-54 } \\
0 & \text { Potassium-40 } \\
0 & \text { Padium-226 } \\
0 & \text { Ruthenium-103 } \\
0 & \text { Sodium-22 } \\
0 & \text { Zinc-65 }\end{array}$ & $\begin{array}{l}<3.4 \mathrm{E} \cdot 08 \\
<1.2 \mathrm{E} \cdot 07 \\
<1.4 \mathrm{E} \cdot 08 \\
<1.2 \mathrm{E} \cdot 08 \\
<1.5 \mathrm{E} \cdot 08 \\
<1.0 \mathrm{E} \cdot 08 \\
<3.0 \mathrm{E} \cdot 08 \\
<1.2 \mathrm{E} \cdot 08 \\
<1.4 \mathrm{E} \cdot 07 \\
<2.5 \mathrm{E} \cdot 08 \\
<1.7 \mathrm{E} \cdot 08 \\
<1.1 \mathrm{E} \cdot 08 \\
<2.7 \mathrm{E} \cdot 08\end{array}$ & $\begin{array}{l}\mu \mathrm{Ci} / \mathrm{mL} \\
\mu \mathrm{Ci} / \mathrm{mL} \\
\mu \mathrm{Ci} / \mathrm{mL} \\
\mu \mathrm{Ci} / \mathrm{mL} \\
\mu \mathrm{Ci} / \mathrm{mL} \\
\mu \mathrm{Ci} / \mathrm{mL} \\
\mu \mathrm{Ci} / \mathrm{mL} \\
\mu \mathrm{Ci} / \mathrm{mL} \\
\mu \mathrm{Ci} / \mathrm{mL} \\
\mu \mathrm{Ci} / \mathrm{mL} \\
\mu \mathrm{Ci} / \mathrm{mL} \\
\mu \mathrm{Ci} / \mathrm{mL} \\
\mu \mathrm{Ci} / \mathrm{mL}\end{array}$ \\
\hline
\end{tabular}

\section{WELL HSB 66}

MEASUREMENTS CONDUCTED IN THE FIELD

Sar.,pie date: $07 / 05 / 91$

Delow TOC

Water elevation: $225.36 \mathrm{ft} 168 \mathrm{6}$

Water evacuated before sampling: 72 gal

Time: $12: 15$

Alkalinity: $48 \mathrm{mg} / \mathrm{h}$

Water temperature: $23.4^{\circ} \mathrm{C}$

Result

$<1.9 E-08$

$<6.9 E .09$

$<8.4 \mathrm{E}-09$

$<5.6 E .09$

$<2.2 \mathrm{E} \cdot 0 \mathrm{a}$

$<8.2 E .09$

$<1.0 E \cdot 07$

$<1.4 E-08$

$<8.7 \mathrm{E}-09$

$<7.8 \mathrm{E}-09$
$<1.9 \mathrm{E}-08$

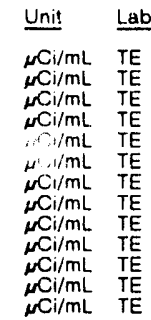

Time: $13: 05$

pH: 6.5 . $71 \mathrm{mg}$

Alkalinity: $71 \mathrm{mg} / \mathrm{h}$

LABORATORY ANALYSES

Time 1000

Alkalinity: $1 \mathrm{mg}$

Water temperature: $20.1^{\circ} \mathrm{C}$
F Analyte

- Americium-241

Antimony -125

Cerium-144

Cesium-137

Cobait-57

Europium.154

Manganese.54

Plutonium-238

Piutonium-242

Potassium 40

Plutonium-239/240

Radiuin-226

- Radium.226

Ruthenium.103

Sodium-22

Strontium. 89

Strontium-90

Thorium-228

Thorium.232

Zinc. 65

\begin{tabular}{|c|c|c|}
\hline sult & Unit & \\
\hline $0 E \cdot 10$ & $\mu \mathrm{Ci} / \mathrm{mL}$ & \\
\hline $3 \mathrm{E} .08$ & $\mu \mathrm{Ci} / \mathrm{mL}$ & \\
\hline $.0 \mathrm{E} \cdot 07$ & $\mu \mathrm{Ci} / \mathrm{mL}$ & \\
\hline $9.5 \mathrm{E} .09$ & $\mu \mathrm{Ci} / \mathrm{mL}$ & \\
\hline $8.6 \mathrm{E} .09$ & $\mu \mathrm{Ci} / \mathrm{mL}$ & \\
\hline $4 \mathrm{E} \cdot 08$ & $\mathrm{NCi} / \mathrm{mL}$ & \\
\hline $1 \mathrm{E}-09$ & $\mu \mathrm{Ci} / \mathrm{mL}$ & \\
\hline $4 \mathrm{E} \cdot 08$ & $\mathrm{mCi} / \mathrm{mL}$ & \\
\hline $1 \mathrm{E}-08$ & $\mathrm{mCi} / \mathrm{mL}$ & \\
\hline $2.0 E \cdot 10$ & $\mathrm{~m} \mathrm{Ci} / \mathrm{mL}$ & \\
\hline$O E \cdot 10$ & $\mathrm{mCi} / \mathrm{mL}$ & \\
\hline $6 \mathrm{E} \cdot 09$ & $\mathrm{Ni} / \mathrm{mL}$ & \\
\hline $1 \mathrm{OE} \cdot 10$ & $m \mathrm{i} / \mathrm{mL}$ & \\
\hline $3 . O E-10 \pm 1 . O E-10$ & $\mathrm{NCl} / \mathrm{mL}$ & \\
\hline $\begin{array}{l}O E \cdot 10 \pm 1.0 E \cdot 10 \\
O E \cdot 10\end{array}$ & $\begin{array}{l}\mu \mathrm{Cl} / \mathrm{mL} \\
\mathrm{NCl} / \mathrm{mL}\end{array}$ & \\
\hline $4 E-08$ & $\mu \mathrm{Ci} / \mathrm{mL}$ & \\
\hline$O E \cdot 09$ & $\mu \mathrm{Ci} / \mathrm{mL}$ & \\
\hline 8E-09 & $\mu \mathrm{Cl} / \mathrm{mL}$ & \\
\hline 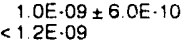 & $\mathrm{m} \mathrm{Ci} / \mathrm{mL}$ & \\
\hline$D E-10$ & $\mu \mathrm{Ci} / \mathrm{mL}$ & \\
\hline $\mathrm{DE} \cdot 10$ & $\mathrm{mCl} / \mathrm{mL}$ & \\
\hline
\end{tabular}

\section{WELL HSB 67}

MEASUREMENTS CONDUCTED IN THE FIELD

$\begin{array}{ll}\text { Sample datc: } 07,05 / 81 & \text { Time: } 12.20 \\ \text { Depth to water: } 13.70 \mathrm{ft}(4.18 \mathrm{~m}) \text { below TOC } & \text { pH: } 4.0 \\ \text { Water elevation: } 224.10 \mathrm{ft}(68.31 \mathrm{~m}) \mathrm{ms} \text { l } & \text { Alkalinity: } 0 \mathrm{mg} / \mathrm{h} \\ \text { Sp. conductance: } 131 \mu \mathrm{sS} / \mathrm{cm} & \text { Water temperature: } 22.3^{\circ} \mathrm{C} \\ \text { Water evacuated before sampling: } 61 \mathrm{gal} & \end{array}$

Water evacuated before sampling: $61 \mathrm{gal}$

LABORATORY ANALYSES

\begin{tabular}{|c|c|c|}
\hline Analyte & Result & Unit \\
\hline $\begin{array}{ll}0 & \text { Strontium-89 } \\
2 & \text { Strontium-90 }\end{array}$ & $\begin{array}{l}<5.4 \mathrm{E} \cdot 09 \\
2.8 \mathrm{E} \cdot 07=7.4 \mathrm{E} \cdot 09\end{array}$ & $\underset{\mu \mathrm{Ci} / \mathrm{mL}}{\mu \mathrm{Cl}}$ \\
\hline
\end{tabular}

\section{WELL HSB 69}

MEASUREMENTS CONDUCTED IN THE FIELD

Sample date: $07 / 04 / 91$

Time: 10:25

Water elevation $219.35 \mathrm{ft}(66.86 \mathrm{~m} / \mathrm{msl}$

Sp conductance: $241 \mathrm{~s} / \mathrm{cm}$

Alkalinity: $0 \mathrm{mg} / \mathrm{L}$

Water temperalure: $20.4^{\circ} \mathrm{C}$

Water evacuated before sampling: $63 \mathrm{gal}$

\section{LABORATORY ANALYSES}

$\begin{array}{ll}\text { E } & \text { Analyte } \\ 0 & \text { Americium-241 } \\ 0 & \text { Antimony-125 } \\ 0 & \text { Cerium-144 } \\ 0 & \text { Cesium-134 } \\ 0 & \text { Cesium-137 } \\ 0 & \text { Cobalt-57 } \\ 2 & \text { Cobalt-60 } \\ 0 & \text { Europium-154 } \\ 0 & \text { Manganese-54 } \\ 0 & \text { Plutonium-238 } \\ 0 & \text { Plutonium-242 } \\ 0 & \text { Potassium-40 } \\ 0 & \text { Plutonium-239/240 } \\ 1 & \text { Radium-226 } \\ 1 & \text { Padium-226 } \\ 0 & \text { Padium-228 } \\ 0 & \text { Puthenium-103 } \\ 0 & \text { Sodium-22 } \\ 0 & \text { Strontium-89 } \\ 2 & \text { Strontium-90 } \\ 0 & \text { Thorium-228 } \\ 0 & \text { Thorium-230 } \\ 0 & \text { Thorium-232 } \\ 0 & \text { Zinc-65 }\end{array}$

Result
$<1.0 \mathrm{E} \cdot 10$
$<3.3 \mathrm{E} \cdot 08$
$<1.4 \mathrm{E} \cdot 07$
$<1.7 \mathrm{E} \cdot 08$
$<1.4 \mathrm{E} \cdot 08$
$<1.8 \mathrm{E} \cdot 08$
$1.7 \mathrm{E} \cdot 07 \pm 1.8 \mathrm{E} \cdot 08$
$<3.1 \mathrm{E} \cdot 08$
$<1.7 \mathrm{E} \cdot 08$
$<4.0 \mathrm{E} \cdot 10$
$51.0 \mathrm{E} \cdot 10 \pm 5.0 \mathrm{E} \cdot 10$
$<1.1 \mathrm{E} \cdot 07$
$<4.0 \mathrm{E} \cdot 10$
$8.5 \mathrm{E} \cdot 09 \pm 4.0 \mathrm{E} \cdot 10$
$8.5 \mathrm{E} \cdot 09 \pm 4.0 \mathrm{E} \cdot 10$
$3.2 \mathrm{E} \cdot 09 \pm 1.1 \mathrm{E} \cdot 09$
$<5.3 \mathrm{E} \cdot 08$
$<1.1 \mathrm{E} \cdot 08$
$<5.4 \mathrm{E} \cdot 09$
$2.1 \mathrm{E} \cdot 06 \pm 2.1 \mathrm{E} \cdot 08$
$<9.0 \mathrm{E} \cdot 10$
$3.0 \mathrm{E} \cdot 10 \pm 2.0 \mathrm{E} \cdot 10$
$<1.0 \mathrm{E} \cdot 10$
$<3.7 \mathrm{E} \cdot 08$

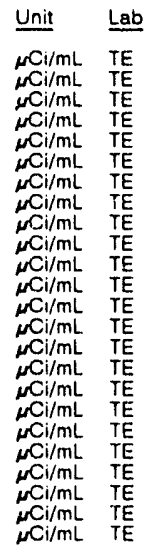

\section{WELL HSB 84A}

MEASUREMENTS CONDUCTED IN THE FIELD

Sample date: 07/04/91

Depth to water: $56.94 \mathrm{H}(17.36 \mathrm{~m})$ below TOC

Water elevation. $171.76 \mathrm{ft} / 52.3$

Water evacuated betore sampling: 281 ga

Time: 10.05

Alkalinity: $37 \mathrm{mg} / \mathrm{L}$

Water temperature $205^{\circ} \mathrm{C}$

LABORATORY ANALYSES

\begin{tabular}{|c|c|c|c|}
\hline Analyte & Result & $\underline{\text { Unit }}$ & $\underline{\text { Lab }}$ \\
\hline Americium-241 & $<1.0 E \cdot 10$ & $\mu \mathrm{Ci} / \mathrm{mL}$ & TE \\
\hline Antimony-125 & $<2.6 \mathrm{E} .08$ & $\mathrm{mCl} / \mathrm{mL}$ & $T E$ \\
\hline Cerium-144 & $<1.1 \mathrm{E} .07$ & $\mathrm{mCl} / \mathrm{mL}$ & TE \\
\hline Cesium-134 & $<1.2 \mathrm{E}-08$ & $m \mathrm{Ci} / \mathrm{mL}$ & TE \\
\hline Cesium-137 & $<1.1 \mathrm{E}-08$ & $\mathrm{mCl} / \mathrm{mL}$ & TE \\
\hline Cobalt-57 & $<1.5 \mathrm{E}-08$ & $\mu \mathrm{Ci} / \mathrm{mL}$ & $T E$ \\
\hline Cobalt-60 & $<8.8 \mathrm{E} \cdot 09$ & $m \mathrm{Ci} / m \mathrm{~L}$ & TE \\
\hline $\begin{array}{l}\text { Europium } 154 \\
\text { Manganese-54 }\end{array}$ & $\begin{array}{l}<3.3 \mathrm{E} \cdot 08 \\
<1.2 \mathrm{E} \cdot 08\end{array}$ & $\underset{\mu \mathrm{Ci} / \mathrm{mL}}{\mu \mathrm{mL}}$ & TE \\
\hline Plutonium-238 & $<2.0 \mathrm{E}-10$ & $\mu \mathrm{Ci} / \mathrm{mL}$ & TE \\
\hline Plutonium-242 & $<2.0 E-10$ & $\mathrm{NCi} / \mathrm{mL}$ & $T E$ \\
\hline Potassium -40 & $<1.2 \mathrm{E} \cdot 07$ & $\mathrm{mCi} / \mathrm{mL}$ & TE \\
\hline $\begin{array}{l}\text { Plutonium-239/240 } \\
\text { Radium-226 }\end{array}$ & $\begin{array}{l}<2.0 E \cdot 10 \\
1.0 E \cdot 09 \pm 1.0 E-10\end{array}$ & $\mu \mathrm{Ci} / \mathrm{mL}$ & TE \\
\hline Radium-226 & $1.0 E-09 \pm 1.0 E-10$ & $\mu \mathrm{Ci} / \mathrm{mL}$ & TE \\
\hline Radium-228 & $1.5 \mathrm{E} \cdot 09 \pm 8.0 \mathrm{E} \cdot 10$ & $\mu \mathrm{Ci} / \mathrm{mL}$ & TE \\
\hline Ruthenium-103 & $<4.4 \mathrm{E} \cdot 08$ & $\mu \mathrm{Ci} / \mathrm{mL}$ & \\
\hline Sodium-22 & $<12 \mathrm{E}-08$ & $\mu \mathrm{Ci} / \mathrm{mL}$ & TE \\
\hline Strontium 89 & $<5.1 \mathrm{E} \cdot 09$ & $\mu \mathrm{Ci} / \mathrm{mL}$ & TE \\
\hline Strontium-90 & $1.5 E \cdot 07 \pm 5.3 E \cdot 09$ & $\mu \mathrm{Ci} / \mathrm{mL}$ & $T E$ \\
\hline Thorium.228 & $<1.3 E \cdot 09$ & $\mathrm{mCl} / \mathrm{mL}$ & $T E$ \\
\hline Thorium-230 & $<2.0 E-10$ & $\mu \mathrm{Cl} / \mathrm{mL}$ & \\
\hline Thorium-232 & $<2.0 E-10$ & $\mu \mathrm{Ci} / \mathrm{mL}$ & TE \\
\hline Zinc-65 & $<2.6 \mathrm{E} \cdot 08$ & $\mathrm{mCi} / \mathrm{mL}$ & \\
\hline
\end{tabular}




\section{ANALYTICAL RESULTS}

WELL HSB 84A

MEASUREMENTS CONDUCTED IN THE FIELD

Sample date: 07/04/91

Depth to water: $56.94 \mathrm{ft}(17.36 \mathrm{~m})$ below TOC

Water elevation: $171.78 \mathrm{ft}$ (52.38

Sp. conductance: $107 \mu \mathrm{S} / \mathrm{cm}$

LABORATORY ANALYSES

\begin{tabular}{|c|c|c|}
\hline Analyte & Result & Unit \\
\hline Americium-241 & $=1.0 E \cdot 10$ & $\mathrm{MCi} / \mathrm{mL}$ \\
\hline Antimony-125 & $<3.6 \mathrm{E} \cdot 08$ & $\mathrm{moi} / \mathrm{mL}$ \\
\hline Cerium-144 & $<1.4 \mathrm{E} \cdot 07$ & $\mathrm{MCi} / \mathrm{mL}$ \\
\hline Cesium 134 & $<1.5 \mathrm{E} .08$ & $\mu \mathrm{Ci} / \mathrm{mL}$ \\
\hline Cesium.137 & $<1.3 \mathrm{E}-08$ & $\mathrm{mCi} / \mathrm{mL}$ \\
\hline Cobalt. 57 & $<1.8 \mathrm{E} .08$ & $\mathrm{~m} \mathrm{Ci} / \mathrm{mL}$ \\
\hline Cobalt-6C & $<1.3 E \cdot 08$ & $\mathrm{mi} / \mathrm{mL}$ \\
\hline $\begin{array}{l}\text { Europium. } 154 \\
\text { Manganese-54 }\end{array}$ & $\begin{array}{l}<3.0 E \cdot 08 \\
<15 E .08\end{array}$ & $\underset{\mathrm{Cl} / \mathrm{mL}}{\mathrm{Cl} / \mathrm{mL}}$ \\
\hline Plutonium-238 & 2. $0 \mathrm{E} \cdot 10 \pm 2.0 \mathrm{E}-10$ & $\mathrm{mCl} / \mathrm{mL}$ \\
\hline Plutonium-242 & $<2.0 \mathrm{E}-10 \pm 10 \mathrm{E}-10$ & NClimL \\
\hline Potassium -40 & $<1.1 \mathrm{E}-07$ & $\mathrm{mC} / \mathrm{mL}$ \\
\hline Plutonium-239/240 & $<2.0 \mathrm{E}-10 \pm 3.0 \mathrm{E} \cdot 10$ & $\mathrm{mCl} / \mathrm{mL}$ \\
\hline Radium-226 & 9.0E-10 $\pm 1.0 \mathrm{E}-10$ & $\mathrm{mCi} / \mathrm{mL}$ \\
\hline $\begin{array}{l}\text { Radium-226 } \\
\text { Radium.228 }\end{array}$ & $9.0 E \cdot 10 \pm 1.0 E \cdot 10$ & $\mathrm{mCl} / \mathrm{mL}$ \\
\hline $\begin{array}{l}\text { Radium-228 } \\
\text { Ruthenium-103 }\end{array}$ & $\begin{aligned} & 2.6 \mathrm{E} \cdot 09 \pm 1.3 \mathrm{E}-09 \\
< & 6.2 \mathrm{E} .08\end{aligned}$ & $\underset{\mu \mathrm{Ci} / \mathrm{mL}}{\mu \mathrm{Cl}}$ \\
\hline Sodium 22 & $<1.0 \mathrm{E}-08$ & $\mathrm{mCi} / \mathrm{mL}$ \\
\hline Strontium-89 & $<7.6 \mathrm{E}-09$ & $\mu \mathrm{Ci} / \mathrm{mL}$ \\
\hline Strontium-90 & $11 \mathrm{E}-07 \pm 82 \mathrm{E} \cdot 09$ & $\mathrm{mCi} / \mathrm{ml}$ \\
\hline Thorium-228 & $<13 \mathrm{E} \cdot 09$ & $\mathrm{mCl} / \mathrm{mL}$ \\
\hline Thorium-230 & $<3$ OE -10 & $\mu \mathrm{Cl} / \mathrm{mL}$ \\
\hline Thorium-232 & $<3.0 E \cdot 10$ & $\omega \mathrm{Cl}_{1} / \mathrm{mL}$ \\
\hline Zinc- 65 & $<23 E \cdot 08$ & mCliml. \\
\hline
\end{tabular}

\section{WELL HSB 85A}

MEASUREMENTS CONDUCTED IN THE FIELD

Sample date: $07 / 04 / 91$

Depth to water: $125.52 \mathrm{Ht}(38.26 \mathrm{~m})$ below TOC

ion: $168.88 \mathrm{ft}(51.48 \mathrm{~m}) \mathrm{msi}$

Sp. conductance: $182 \mu \mathrm{S} / \mathrm{cm}$
Water evacuated before sampling. $283 \mathrm{gal}$

Time: 10.05

pH: 6.3

Alkalinity: $37 \mathrm{mg} / \mathrm{h}$

Water temperature $20.5^{\circ} \mathrm{C}$

LABORATORY AN!ALYSES

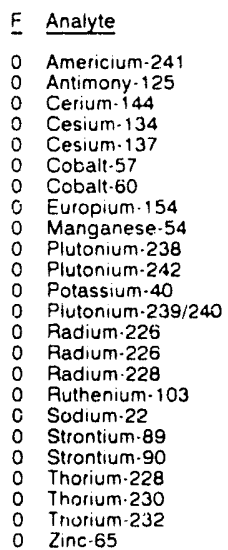

Fiesult

Time: $15: 55$

Alkalinity. $73 \mathrm{mg} / \mathrm{L}$

Water temperature $213^{\circ} \mathrm{C}$

$<4.7 \mathrm{E} .08$

$<45 \mathrm{E} .09$

2 CE. $09 \pm 7.0 E \cdot 10$

$15 \mathrm{E} \cdot 09 \pm 13 \mathrm{E} \cdot 09$

$=4.0 E \cdot 10$

$<4$ OE. 10

WELL HS8 858 collected on 07/05/91, laboratory arialyses (cont.)

$\begin{array}{ll}\text { E } & \text { Analyte } \\ 0 & \text { Cobait-60 } \\ 0 & \text { Europium-154 } \\ 0 & \text { Manganese-54 } \\ 0 & \text { Plutonium-238 } \\ 0 & \text { Plutonium-242 } \\ 0 & \text { Potassium-40 } \\ 0 & \text { Plutonium-239/240 } \\ 0 & \text { Radium-226 } \\ 0 & \text { Padium-226 } \\ 0 & \text { Padium-228 } \\ 0 & \text { Ruthenium-103 } \\ 0 & \text { Sodium-22 } \\ 0 & \text { Strontium-69 } \\ 0 & \text { Strontium-90 } \\ 0 & \text { Thorium-228 } \\ 0 & \text { Thorium-230 } \\ 0 & \text { Thorium-232 } \\ 0 & \text { Zinc-65 }\end{array}$

Result

$<1.3 E \cdot 08$
$<3.78 .08$

$<1.0 E \cdot 10$

$<1.0 E \cdot 10$

$<1.7 \mathrm{E}-07$

2. $0 \mathrm{E}-10 \pm 2.0 \mathrm{E} \cdot 10$

2. $. \mathrm{OE} \cdot 10 \pm 1.0 \mathrm{E} \cdot 10$

$2.0 \mathrm{OE} \cdot 10 \pm 1.0 \mathrm{E} \cdot 10$

$<7.0 E-10$

$<5.9 \mathrm{E} .08$

$<1.1 \mathrm{E}-08$

$2.02-09+8.0 E-10$

1.8E-09 $\pm 1.5 \mathrm{E} \cdot 09$

$<7.0 \mathrm{E}-10$

$<3.2 E-08$

WELL HSB 85C

MEASUREMENTS CONDUCTED IN THE FIELD

$\begin{array}{ll}\text { Sample date: } 07 / 04 / 91 & \text { Time: } 15: 25 \\ \text { Depth to water: } 54.90 \mathrm{Ht}(16.73 \mathrm{~m}) \text { below TOC } & \text { pH: } 4.6 \\ \text { Water elevation: } 239.20 \mathrm{ft}(72.91 \mathrm{~m}) \mathrm{msl} & \text { Alkalinity: } 0 \mathrm{mg} / \mathrm{L} \\ \text { Sp. conductance: } 30 \mu \mathrm{S} / \mathrm{cm} & \text { Water temperature: } 23.2^{\circ} \mathrm{C} \\ \text { Water evacuated before sampling: } 56 \mathrm{gal} & \end{array}$

LAHORATORY ANALYSES

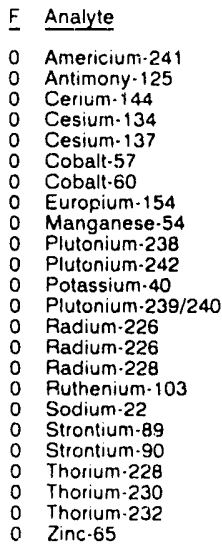

Result

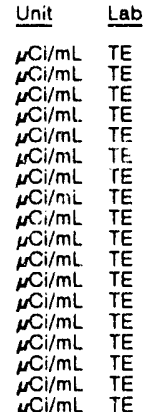

\section{WELL HSB 86A}

\section{MEASUREMENTS CONDUCTED IN THE FIELD}

Sample date: $07 / 04 / 9$

Depth to water: $93.93 \mathrm{ft}(28.63 \mathrm{~m})$ below TOC

Water elevation: $168.47 \mathrm{ft}(51.35 \mathrm{~m}) \mathrm{ms}$ l

Sp. conductance: $130 \mu \mathrm{S} / \mathrm{cm}$
Water evacuated before sampling: $296 \mathrm{gal}$

Time: 13.00
$\mathrm{pH}: 6.4$

Alkalinity: $43 \mathrm{mg} / \mathrm{L}$

LABORATORY ANALYSES

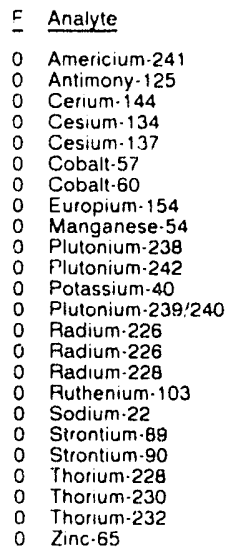

Result

$<2.0 \mathrm{OE} \cdot 10$

$<3.6 E .08$
$<14 \mathrm{E} .07$

$<1.4 \mathrm{E} .08$

$<12 E .08$

$\therefore 13 \mathrm{E} .08$

$<35 \mathrm{E}-08$

$<16 E \cdot 08$

$<3.0 \mathrm{E}-10$

$<30 E-10$

$<1$ 1E.07

5 OE-10 $10 E \cdot 10$

$5.0 E \cdot 10 \pm 1.0 E \cdot 10$

9 OE. $10 \pm 8$ OE. 10

$<5.9 \mathrm{E} .08$

$<1.3 \mathrm{E} .0 \mathrm{~B}$

$<5.2 E .08$

$<11 \mathrm{E} .09$

C) $3 \mathrm{E} \cdot 09$

$<2.0 E-10$

$<2 \mathrm{OE} \cdot 10$
$<34 \mathrm{E} \cdot 08$

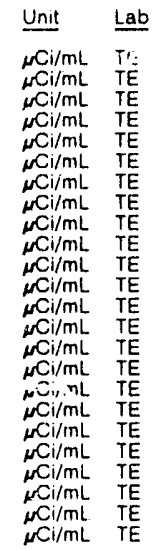

E

\begin{tabular}{|c|c|c|}
\hline Analyte & Result & Unit \\
\hline $\begin{array}{ll}0 & \text { Americium }-241 \\
0 & \text { Antimony-125 } \\
0 & \text { Cerium }-144 \\
0 & \text { Cesium }-134 \\
0 & \text { Cesium. } 137 \\
0 & \text { Cobalt. } 57\end{array}$ & $\begin{array}{l}<2 \text { OE. } 10 \\
<3 \text { GE.08 } \\
<1 \quad 4 \mathrm{E} \cdot 07 \\
<13 \mathrm{E} \cdot 08 \\
<15 \mathrm{E} \cdot 08 \\
<1 \quad 8 \mathrm{E} \cdot 08\end{array}$ & $\begin{array}{l}\mu \mathrm{Ci} / \mathrm{mL} \\
\mu \mathrm{Ci} / \mathrm{mL} \\
\mu \mathrm{Ci} / \mathrm{mL} \\
\mu \mathrm{Ci} / \mathrm{mL} \\
\mu \mathrm{Ci} / \mathrm{mL} \\
\mu \mathrm{Ci} / \mathrm{mL}\end{array}$ \\
\hline
\end{tabular}


ANALYTICAL RESULTS

WELL HSB 86B

MEASUREMENTS CONDUCTED IN THE FIELD

Depth to water: $39.10 \mathrm{Ht}(11.92 \mathrm{~m})$ below TOC

Water Elevation: 223.80 H 68
Sample date: 07/04/91 Depth to water: $40.12 \mathrm{H}(12.23 \mathrm{~m})$ below TOC Water elevation. $221.78 \mathrm{H}(67$. Sp. conductance: $212 \mu \mathrm{s} / \mathrm{cm}$. LABORATORY ANALYSES

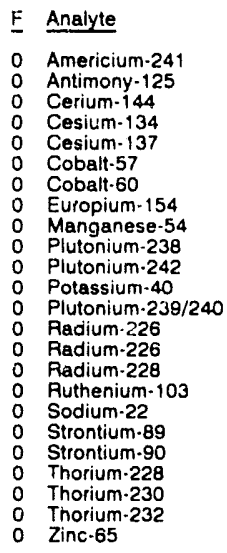

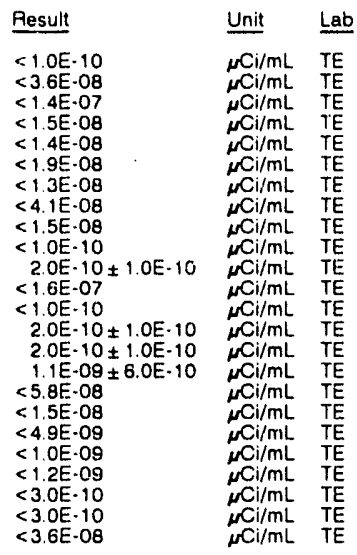

\section{WELL HSB 86C}

MEASUREMENTS CONDUCTED IN THE FIELD

Sample date: $07 / 04 / 91$

Sp. conductance: $334 \mu \mathrm{S} / \mathrm{cm}$
Water evacuated before sampling: $91 \mathrm{~g} A l$

Time: $13: 40$

pH: 7.2

Alkalinity: $98 \mathrm{mg} / \mathrm{l}$

Water temperature: $21.3^{\circ} \mathrm{C}$

LABURATORY ANALYSES

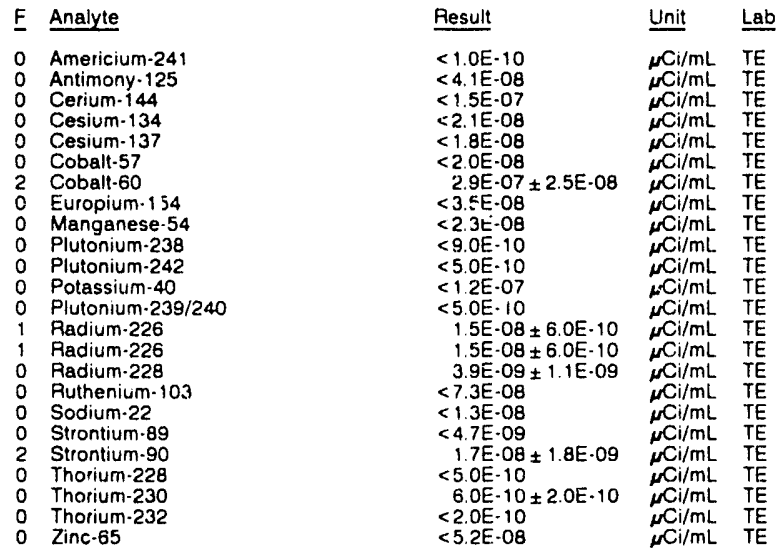

\section{WELL HSB101D}

MEASUREMENTS CONDUCTED IN THE FIELD

Depth to water: $28.20 \mathrm{ft}(8.60 \mathrm{~m})$ below TOC

Water elevation: $230.50 \mathrm{ft}(70$

Sp. conductance: $729 \mu \mathrm{S} / \mathrm{cm}$
Water evacuated before sampling: $38 \mathrm{gal}$

LABORATORY ANALYSES

\begin{tabular}{|c|c|c|}
\hline Analyte & Result & Unit \\
\hline $\begin{array}{ll}0 & \text { Americium-241 } \\
0 & \text { Antimony-125 } \\
0 & \text { Cerium }-144 \\
0 & \text { Cesium-134 } \\
0 & \text { Cesium-137 } \\
0 & \text { Cobalt-57 }\end{array}$ & $\begin{array}{l}<2.0 \mathrm{E} \cdot 10 \\
<2.6 \mathrm{E} \cdot 1.8 \\
<7.0 \mathrm{E} \cdot 09 \\
<1.2 \mathrm{E} \cdot 08 \\
<8.6 \mathrm{E} \cdot 09 \\
<8.8 \mathrm{E} \cdot 09\end{array}$ & $\begin{array}{l}\mu \mathrm{Ci} / \mathrm{mL} \\
\mu \mathrm{Ci} / \mathrm{mL} \\
\mu \mathrm{Ci} / \mathrm{mL} \\
\mu \mathrm{Ci} / \mathrm{mL} \\
\mu \mathrm{Ci} / \mathrm{mL} \\
\mu \mathrm{Ci} / \mathrm{mL}\end{array}$ \\
\hline
\end{tabular}

Tirne: 13:15

Alk: $4.2: 15: 0 \mathrm{mg}$

Water temperature $21.8 \circ \mathrm{C}$
Sam, le date: 07/03/91
WELL HSB 101D collected on 07/03/91, laboratory analyses (cont.)

$\begin{array}{ll}\text { F } & \text { Analyte } \\ 0 & \text { Cobalt-60 } \\ 0 & \text { Europium-154 } \\ 0 & \text { Manganese-54 } \\ 0 & \text { Plutonium-238 } \\ 0 & \text { Plutonium-242 } \\ 0 & \text { Potassium-40 } \\ 0 & \text { Plutonium-238/240 } \\ 0 & \text { Radium-226 } \\ 0 & \text { Radium-226 } \\ 0 & \text { Radium-228 } \\ 0 & \text { Ruthenium-103 } \\ 0 & \text { Sodium-22 } \\ 0 & \text { Strontium-89 } \\ 2 & \text { Strontium-90 } \\ 0 & \text { Thorium-228 } \\ 0 & \text { Thorium-230 } \\ 0 & \text { Thorium-232 } \\ 0 & \text { Zinc-65 }\end{array}$

Result
$<9.4 E-09$
$<3.5 \mathrm{E}-08$
$<1.2 \mathrm{E}-08$
$<2.0 \mathrm{E}-10$
$<2.0 \mathrm{E}-10$
$<1.4 \mathrm{E}-07$
$<2.0 \mathrm{E}-10$
$<1.0 \mathrm{E}-10$
$<1.0 \mathrm{E}-10$
$1.0 \mathrm{E}-09 \pm 1.1 \mathrm{E} \cdot 09$
$<4.6 \mathrm{E}-08$
$<1.2 \mathrm{E}-08$
$<4.7 \mathrm{E}-08$
$3.9 \mathrm{E}-08 \pm 2.8 \mathrm{E}-09$
$5.0 \mathrm{E}-10 \pm 1.0 \mathrm{E}-10$
$<3.0 \mathrm{E}-10$
$<3.0 \mathrm{C}-10$
$<2.6 \mathrm{E}-08$

\begin{tabular}{|c|c|}
\hline Unit & Lab \\
\hline 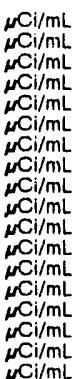 & $\begin{array}{l}\text { TE } \\
\text { TE } \\
T E \\
T E \\
T E \\
T E \\
T E \\
T E \\
T E \\
T E \\
T E \\
T E \\
T E \\
T E \\
T E \\
T E \\
T E \\
T E \\
T E\end{array}$ \\
\hline
\end{tabular}

\section{WELL HSB103D}

MEASUREMENTS CONDUCTED IN THE FIELD

$\begin{array}{ll}\text { Sample date: } 07 / 03 / 91 & \text { Time: } 14: 15 \\ \text { Depth to water: } 22.42 \mathrm{ft}(6.83 \mathrm{~m}) \text { below TOC } & \text { pH: } 4.2 \\ \text { Water elevation: } 225.18 \mathrm{H}(68.64 \mathrm{~m}) \mathrm{msl} & \text { Alkalinity: } 0 \mathrm{mg} / \mathrm{h} \\ \text { Sp. conductance }: 215 \mu \mathrm{s} / \mathrm{cm} & \text { Water temperature: } 22.2^{\circ} \mathrm{C} \\ \text { Water evacuated before sampling: } 30 \mathrm{gal} & \end{array}$

Water evacuated before sampling: $30 \mathrm{gal}$

LABORATORY ANALYSES

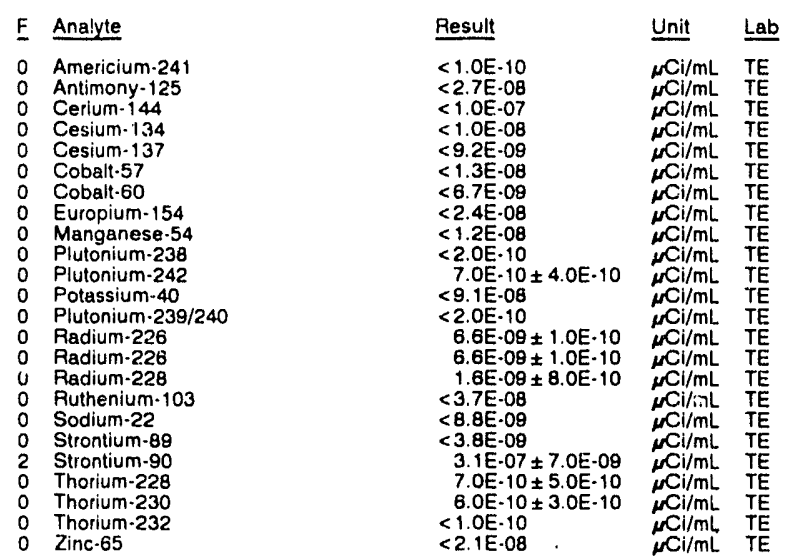

\section{WELL HSB105D}

MEASUREMENTS CONDUCTED IN THE FIELD

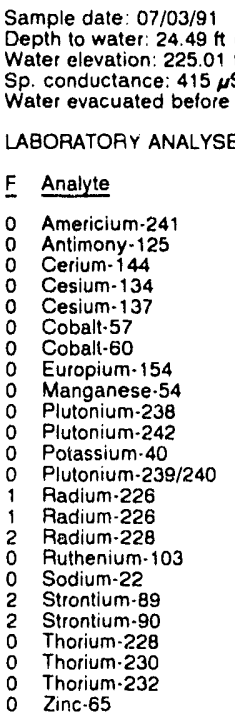

Time: $14: 45$
pH: 3.7

Alkalinity: $0 \mathrm{mg}$

Water temperature: $21.6^{\circ} \mathrm{C}$
Time: $13 \cdot 15$

oH: 9.4

Alkalinity. $157 \mathrm{mg} / \mathrm{h}$
Water temperature: $22.8^{\circ} \mathrm{C}$

$<8.8 \mathrm{E} .09$ 


\section{ANALYTICAL RESULTS}

WELL HSB107D

MEASUREMENTS CONDUCTED IN THE FIELD

Sample date: 07/05/91

Depth to water: $37.62 \mathrm{ft}(11.47 \mathrm{~m})$ below TOC

Sp conductance: 307 (6).

Water evacuated before sampling: $27 \mathrm{gal}$

LABORATORY ANALYSES

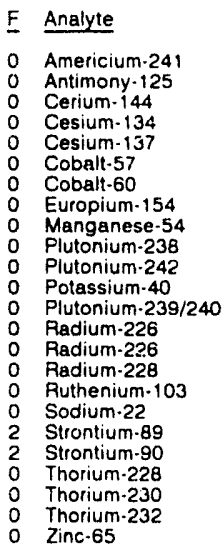

Result

Time: $11: 10$

PH: 4.8 :

Water temperature: $220^{\circ} \mathrm{C}$

$<1.0 \mathrm{E} \cdot 10$
$<1.0 \mathrm{E}-08$

$<7.3 \mathrm{E} .08$

$<9.2 \mathrm{E}-09$

<7.1E-09

$<3.5 \mathrm{E} \cdot 09$

$<1.7 E .08$

$<8.1 \mathrm{E}-09$

$5.0 E \cdot 10 \pm 4$
$<1.0 E-07$

$<3.0 E-10$

$3.5 \mathrm{E}-09 \pm 2.0 \mathrm{E}-10$

3.5E-09 $\pm 2.0 \mathrm{E}-10$

3.0E- $09 \pm 1.0 \mathrm{E} \cdot 09$

$<2.8 \mathrm{E}-08$

$<6.2 \mathrm{E} .09$

$2.6 \mathrm{E}-07 \pm 9.9 \mathrm{E}-08$

$1.3 E \cdot 06 \pm 1.5 \mathrm{E} \cdot 0 \mathrm{OB}$

$8.0 \mathrm{E} \cdot 10 \pm 5.0 \mathrm{E} \cdot 10$
$7.0 \mathrm{E} \cdot 10 \pm 2.0 \mathrm{E} \cdot 10$

$7.0 \mathrm{E} \cdot 10 \pm 2.0 \mathrm{E} \cdot 10$
$<1.0 \mathrm{E} \cdot 10$

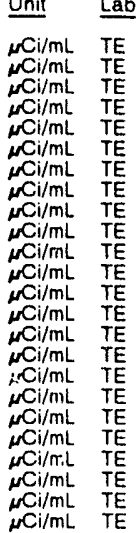

\section{WELL HSB111E}

MEASUREMENTS CONDUCTED IN THE FIELD

Sample date: $07 / 05 / 91$

Depth to water: $33.68 \mathrm{Ht}(10.27 \mathrm{~m})$ below TOC

Sp elevalion. $222.22 \mathrm{f}$ (67.73

Water evacuated before sampling: $31 \mathrm{gal}$

Time: 11.30

Alkalinity: $0 \mathrm{mg}$

A kater temperature: $212^{\circ} \mathrm{C}$

LABORATORY ANALYYSES

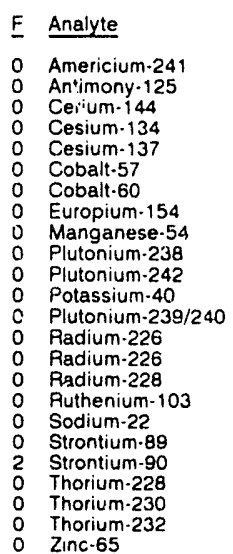

Resuit

$<1.0 E \cdot 10$

$<3.5 \mathrm{E} \cdot 08$
$<1.4 \mathrm{E} \cdot 07$

$<1.4 \mathrm{E} .08$

$<1.3 E \cdot 08$
$<18 E \cdot 08$

$<1.4 E-08$

$<3.7$ E.08

$<2.0 \mathrm{E} \cdot 10$

$<2.0 \mathrm{E} \cdot 10$

$<1.4 \mathrm{E} \cdot 07$

$7.0 E \cdot 10 \pm 3.0 E-10$

$2.9 \mathrm{E} \cdot 09 \pm 2.0 \mathrm{E} \cdot 10$

$2.9 \mathrm{E} \cdot 09 \pm 2.0 \mathrm{E} \cdot 10$

$1.2 \mathrm{E} \cdot 09 \pm 1.1 \mathrm{E} \cdot 09$

$<52 \mathrm{E} .0 \mathrm{~B}$

< $1.3 \mathrm{E}-0 \mathrm{O}$

$<3.8 E-09$

6. $9 E \cdot 07 \pm 1.1 \mathrm{E} \cdot 08$

5. $0 \mathrm{E}-10 \pm 2.0 \mathrm{E} \cdot 10$

$<1.0 E-10$
$<2.9 E-08$

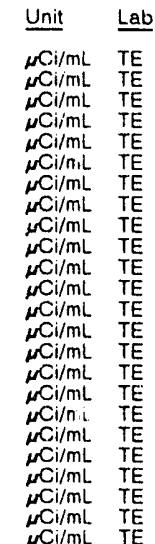

\section{W'ELL HSB114D}

MEASUREMENTS CONDUCTED IN THE FIELD

Sample date: 07/04/91

Depth to water: $40.39 \mathrm{ft}(12.31 \mathrm{~m})$ below TOC

Wp. conductance: $291 \mu \mathrm{S} / \mathrm{cm}$

Water evacuated before sampling: $28 \mathrm{gal}$

LABOPATOAY ANALYSES

\begin{tabular}{|c|c|c|}
\hline F Analyte & Result & Unit \\
\hline $\begin{array}{ll}0 & \text { Americium-241 } \\
0 & \text { Antimony-125 } \\
0 & \text { Cerium-144 } \\
0 & \text { Cesium-134 } \\
0 & \text { Cesium-137 } \\
0 & \text { Cobalt-57 }\end{array}$ & $\begin{array}{l}<2.0 \mathrm{E} \cdot 10 \\
<2.8 \mathrm{E} \cdot 08 \\
<8.0 \mathrm{E} \cdot 08 \\
<1.5 \mathrm{E} \cdot 08 \\
<1.1 \mathrm{E} \cdot 08 \\
<1.0 \mathrm{E} \cdot 08\end{array}$ & 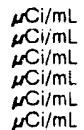 \\
\hline
\end{tabular}

WELL HSB114D collected on 07/04/91, laboratory analyses (cont.)
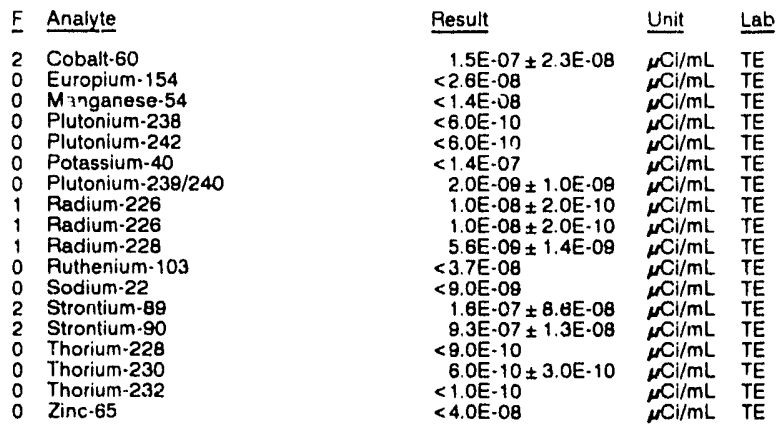

WELL HSB116D

MEASUREMENTS CONOUCTED IN THE FJELO

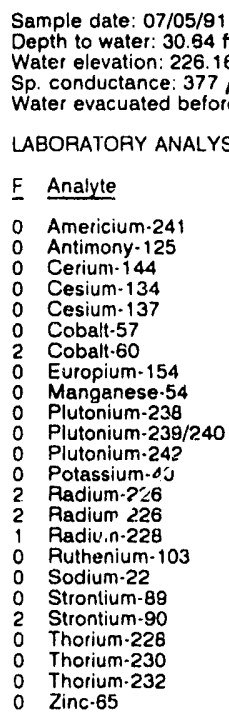

Alkalinity: $0 \mathrm{mg} / \mathrm{L}$

Water temperature: $22.5^{\circ} \mathrm{C}$

Water evacuated before sampling: $31 \mathrm{gal}$

ABORATORY ANALYSES

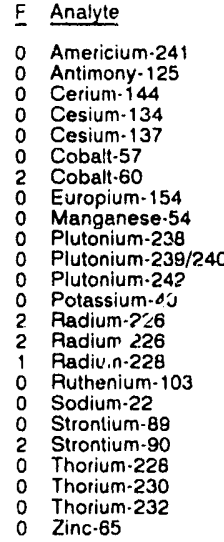

Result

$<1.0 E \cdot 10$

$<3.4 \mathrm{E} \cdot \mathrm{OB}$
$<1.0 \mathrm{E} \cdot 07$

$<2.3 E .08$

$<2.3 \mathrm{E} \cdot 08$

$<1.3 \mathrm{E} .08$

3.3E- $07 \pm 3.6 \mathrm{E}-08$

$<4.0 \mathrm{E}-08$
$<2.1 \mathrm{E}-08$

$<3.0 \mathrm{E} \cdot 10$

$<2.0 E-10$

3.0E-10 $\pm 2.0 \mathrm{E}-10$

2. $6 \mathrm{E}-08 \pm 5.0 \mathrm{E} \cdot 10$

$2.6 \mathrm{E}-08 \pm 5.0 \mathrm{E} \cdot 10$

$7.7 E-09 \pm 1.4 E \cdot 00$
$<5.9 E-08$

$<1.4 \mathrm{E} .08$

$<3.9 \mathrm{E} .09$

$3.9 \mathrm{E}-06 \pm 2.5 \mathrm{E}-08$

1. $3 \mathrm{E} \cdot 09 \pm 5.0 \mathrm{E} \cdot 10$

$5.0 \mathrm{E}-10 \pm 2.0 \mathrm{E}-10$

$<1.0 \mathrm{E} \cdot 10$

WELL HSB129D

MEASUREMENTS CONDUCTED IN THE FIELD

Seinple date: 07/04/91

epth to water: $6.43 \mathrm{H}(1.96 \mathrm{~m})$ below TOC

Water elevation: $208.27 \mathrm{ft}(63.48 \mathrm{~m}) \mathrm{msl}$

Sp. conductance: $369 \mu \mathrm{S} / \mathrm{cm}$

Water evacuated before sampling: $61 \mathrm{gal}$

LABORATORY ANALYSES

E Analyte

Time: 11:00

oH: 4.4

Water temperature: $20.8^{\circ} \mathrm{C}$

0 inaricium-241

Antimu 125

C Cerium-144

0 Cesium-137

0 Cobalt-57

0 Cobalt-60

0 Europium 154

- Manganese-54

- Plutonium 238

Plutonium 242

Polassium-40

Radium-226

Radium-226

O Ruthenium-103

0 s- Jium-22

strontium-89

Strontium-90

Thorium-230

Thorium-232
Zinc-65
Pesult

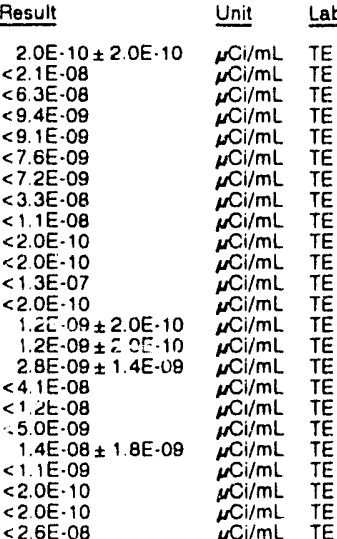


ANALYTICAL RESULTS

\section{WELL HSB133D}

MEASUREMENTS CONDUCTED IN THE FIELO

Sampis date: $07 / 05 / 91$
Depth to water: $19.92 \mathrm{Ht}(6.07 \mathrm{~m})$ below TOC
Water elevation: $235.38 \mathrm{ft}(71.74 \mathrm{~m}) \mathrm{msl}$
Sp. conductance: $88 \mu \mathrm{s} / \mathrm{cm}$
Water evacuated betore sampling: $80 \mathrm{gal}$
LABORATORY ANALYSES

Time: $13: 20$

pH: 5.4

Alkalinity: $9 \mathrm{mg} / \mathrm{L}$

Water temperature: $19.1^{\circ} \mathrm{C}$

LABORATORY ANALYSES

$E$ Analyte

0 Antimony-125

Corium-144

Cobalt-57

Europium-15

Manganese-54

Plutonium-23日

Plutonium-242

Potassium-40

Plutonium-239/2
Radium-226

Radium-226

Radium-228
Ruthenium-103

Ruthenium-103

Sodium-22

Strontium-89

Thorium-228

Thorium-228

Thorium-232

0 Zinc-65
- Americium-241

Cesium-137

\begin{tabular}{|c|c|}
\hline Result & Unit \\
\hline 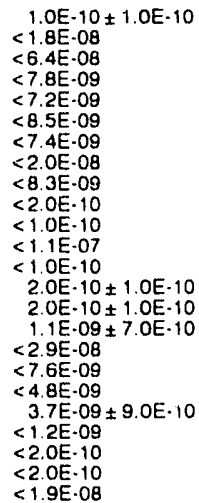 & 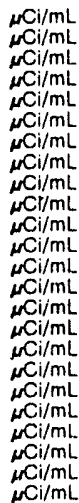 \\
\hline
\end{tabular}

WELL HSB134D

MEASUREMENTS CONDUCTED IN THE FIELD

\begin{tabular}{|c|c|c|c|}
\hline $\begin{array}{l}\text { Sample date: } 07 / 05 / 91 \\
\text { Depth to water: } 16.22 \mathrm{ft}(4.94 \mathrm{~m}) \text { below TOC } \\
\text { Water elevation: } 221.88 \mathrm{ft}(67.63 \mathrm{~m}) \mathrm{msl} \\
\text { Sp. conductance: } 99 \mu \mathrm{s} / \mathrm{cm} \\
\text { Water evacuated before sampling: } 42 \mathrm{gal}\end{array}$ & \multicolumn{3}{|c|}{$\begin{array}{l}\text { Time: } 12: 50 \\
\text { pH: } 4.3 \\
\text { Alkalinity: } 0 \mathrm{mg} / \mathrm{L} \\
\text { Water temperature: } 20.0^{\circ} \mathrm{C}\end{array}$} \\
\hline LABORATORY ANALYSES & & & \\
\hline F Analyte & Besult & Unit & Lab \\
\hline $\begin{array}{ll}0 & \text { Antimony-125 } \\
0 & \text { Cerium- }-144 \\
0 & \text { Cesium-134 } \\
0 & \text { Cesium-137 } \\
0 & \text { Cobalt-57 } \\
0 & \text { Cobalt-60 } \\
0 & \text { Europilim-154 } \\
0 & \text { Manganese.54 } \\
0 & \text { Potassium-40 } \\
0 & \text { Radium-226 } \\
0 & \text { Ruthenium-103 } \\
0 & \text { Sodium-22 } \\
0 & \text { Thorium-228 } \\
0 & \text { Zinc-65 }\end{array}$ & $\begin{array}{r}2.3 \mathrm{E} \cdot 08 \\
<2.2 \mathrm{E} \cdot 08 \\
<8.5 \mathrm{E}-09 \\
<\quad 7 \mathrm{E} \cdot 09 \\
<1.2 \mathrm{E} \cdot 08 \\
<6.8 \mathrm{E} \cdot 09 \\
<1.9 \mathrm{E} \cdot 08 \\
<9.6 \mathrm{E} \cdot 09 \\
<9.5 \mathrm{E} \cdot 08 \\
<1.9 \mathrm{E} \cdot 08 \\
<3.4 \mathrm{E} \cdot 08 \\
<6.7 \mathrm{E} \cdot 09 \\
<9.1 \mathrm{E} \cdot 09 \\
<1.9 \mathrm{E} \cdot 08\end{array}$ & 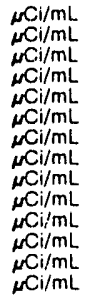 & $\begin{array}{l}\text { TE } \\
\text { TE } \\
\text { TE } \\
\text { TE } \\
\text { TE } \\
\text { TE } \\
\text { TE } \\
\text { TE } \\
\text { TE } \\
\text { TE } \\
\text { TE } \\
\text { TE } \\
\text { TE } \\
\text { TE }\end{array}$ \\
\hline
\end{tabular}

WELL HSB137D

MEASUREMENTS CONDUCTED IN THE FIELD

Sample date: 07/04/9i

Depth to water: $14.50 \mathrm{ft}(1.42 \mathrm{~m})$ below TOC

Water elevation: $222.10 \mathrm{ft} / 67$
Sp. conductance: $180 \mu \mathrm{S} / \mathrm{m}$

Sp. conductance: $180 \mu \mathrm{S} /=\mathrm{m}$

Water evacuated before s impling: $44 \mathrm{ga}$

LABORATORY ANALYSES

E Analyte

- Americium-241

0 Antimony-125

0 Cerium-144

0 Cesium-137

0 Cobalt-57

0 Europium-154

Manganese-54

Plutonium-242

Potassium -40

Plutonium.239/240

Radium-226

Radium-228

\section{Time: 11:25}

Alkalinity: $0 \mathrm{mg} / \mathrm{L}$

Water temperature: $19.5^{\circ} \mathrm{C}$
Result $<3.4 \mathrm{E}-08$

$<1.5 \mathrm{E}-07$

$<1.5 \mathrm{E}-08$

$<1.8 \mathrm{E} .08$

< $1.1 \mathrm{E} .08$

<2. $3 \mathrm{E}-08$

$<1.5 \mathrm{E} .08$

$<2.0 E \cdot 10$
$1.0 E \cdot 10 \pm 1.0 E \cdot 10$

$1.0 \mathrm{E} \cdot 10$
$<1.3 \mathrm{E} \cdot 07$

$<1.3 \mathrm{E} \cdot 07$

$<2.0 \mathrm{E}-10=1.0 \mathrm{E}-10$

$1.1 E-09 \pm 1.0 E \cdot 10$
$1.2 E-09 \pm 8.0 E \cdot 10$
$1.0 E \cdot 10 \pm 1.0 E \cdot 10$
Unit LLab

$\mu \mathrm{Ci} / \mathrm{mL}$ TE

$\mu \mathrm{Ci} / \mathrm{mL}$ TE

$\mathrm{NCi} / \mathrm{mL}$ TE

$\mu \mathrm{Ci} / \mathrm{mL}$ TE

$\mu \mathrm{Ci} / \mathrm{mL}$ TE

$\mu \mathrm{Ci} / \mathrm{mL}$ TE

$\omega \mathrm{Ci} / \mathrm{mL}$ TE

$\mathrm{Ci} / \mathrm{mL}$ TE

$\omega \mathrm{Ci} / \mathrm{mL}$ TE

$\mathrm{NCl} / \mathrm{mL}$ TE $\mu \mathrm{Ci} / \mathrm{mL}$ TE
$\mu \mathrm{Ci} / \mathrm{mL}$ TE

\begin{tabular}{|c|c|c|c|}
\hline Analyte & Result & Unit & Lab \\
\hline $\begin{array}{ll}0 & \text { Ruthenium-103 } \\
0 & \text { Sodium-22 } \\
0 & \text { Strontium-89 } \\
2 & \text { Strontium-90 } \\
0 & \text { Thorium-228 } \\
0 & \text { Thorium-230 } \\
0 & \text { Thorium-232 } \\
0 & \text { Zinc-65 }\end{array}$ & 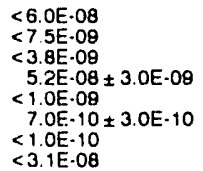 & 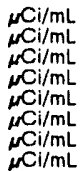 & $\begin{array}{l}\text { TE } \\
\text { TEE } \\
T E \\
T E \\
T E \\
T E \\
T E \\
T E \\
T E\end{array}$ \\
\hline
\end{tabular}

WELL HSB139D

MEASUREMENTS CONDUCTED IN THE FIELD

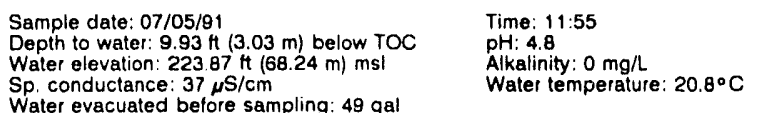

Water evacuated before sampling: $49 \mathrm{gal}$

Water temperature: $20.8^{\circ} \mathrm{C}$

LABOPATOFY ANALYSES
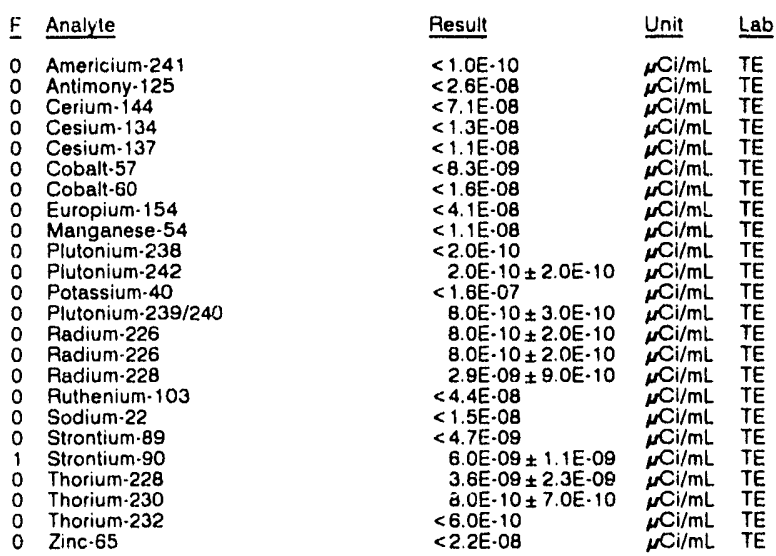

WELL HTF 7

MEASUREMENTS CONDUCTED IN THE FIELD

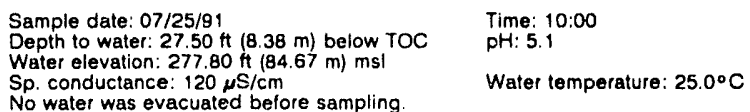

No water was evacuated before sampling.

LABORATORY ANALYSES

\begin{tabular}{|c|c|c|}
\hline Analyte & Result & Unit \\
\hline $\begin{array}{l}\text { Antimony-125 } \\
\text { Cerium-144 } \\
\text { Cesiurn-134 } \\
\text { Cesium-137 } \\
\text { Coball-57 } \\
\text { Cobalt-60 } \\
\text { Europium-154 } \\
\text { Manganese-54 } \\
\text { Potassium-40 } \\
\text { Radium-226 } \\
\text { Ruthenium-103 } \\
\text { Sodium-22. } \\
\text { Uranium-233/234 } \\
\text { Uranium-235 } \\
\text { Uranium-238 } \\
\text { Zinc-65 }\end{array}$ & $\begin{aligned}<2.4 \mathrm{E}-08 \\
<6.6 \mathrm{E} \cdot 08 \\
<9.9 \mathrm{E} \cdot 09 \\
<9.4 \mathrm{E} \cdot 09 \\
<8.6 \mathrm{E}-09 \\
<1.0 \mathrm{E}-08 \\
<2.2 \mathrm{E} \cdot 08 \\
<1.1 \mathrm{E}-08 \\
<1.5 \mathrm{E}-07 \\
<1.8 \mathrm{EE}-08 \\
<2.0 \mathrm{E}-08 \\
<1.1 \mathrm{E}-08 \\
5.7 \mathrm{E}-09 \pm 6.0 \mathrm{E}-10 \\
<1.0 \mathrm{E}-10 \\
1.0 \mathrm{E}-09 \pm 3.0 \mathrm{E}-10 \\
<2.6 \mathrm{E}-08\end{aligned}$ & $\begin{array}{l}\mu \mathrm{Ci} / \mathrm{mL} \\
\mu \mathrm{Ci} / \mathrm{mL} \\
\mu \mathrm{Ci} / \mathrm{mL} \\
\mu \mathrm{Ci} / \mathrm{mL} \\
\mu \mathrm{Ci} / \mathrm{mL} \\
\mu \mathrm{Ci} / \mathrm{mL} \\
\mu \mathrm{Ci} / \mathrm{mL} \\
\mu \mathrm{Cl} / \mathrm{mL} \\
\mu \mathrm{Ci} / \mathrm{mL} \\
\mu \mathrm{Ci} / \mathrm{mL} \\
\mu \mathrm{Ci} / \mathrm{mL} \\
\mu \mathrm{Ci} / \mathrm{mL} \\
\mu \mathrm{Ci} / \mathrm{mL} \\
\mu \mathrm{Ci} / \mathrm{mL} \\
\mu \mathrm{Ci} / \mathrm{mL} \\
\mu \mathrm{Ci} / \mathrm{mL}\end{array}$ \\
\hline
\end{tabular}


ANALYTICAL RESULTS

WELL. IDB $1 \mathrm{~A}$

MEASUREMENTS CONOUCTED IN THE FIELO

Sample date: 09/05/91

Depth to water: $106.79 \mathrm{Ht}(32.55 \mathrm{~m})$ below TOC

Water elevation: $190.01 \mathrm{ft}(57.82 \mathrm{~m}) \mathrm{msl}$

Sp. conductance: $1189 \mu \mathrm{S} / \mathrm{cm}$

Water evacuated before sampling: 21 gal

pH: 11.8 Alkalinity: $287 \mathrm{mg} / \mathrm{L}$

Water temperature: $18.4^{\circ} \mathrm{C}$

LABORATORY ANALYSES

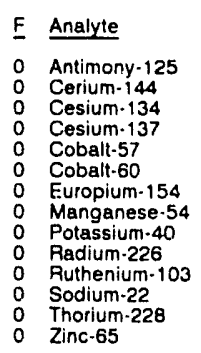

Result

$<1.6 \mathrm{E}-08$

$<5.0 E .08$

$<7.4 \mathrm{E} \cdot 09$
$<6.6 \mathrm{E} \cdot 09$

$<6.5 \mathrm{E} .09$

$<8.4 E .09$

$<2.2 E .08$

$<2.2 \mathrm{E} .08$
$<8.4 \mathrm{E} .00$

$<8.7 \mathrm{E}-08$

$<4.2 E-08$

$<8.4 \mathrm{E} \cdot 09$

$<7.9 E \cdot 09$
$<2.4 E \cdot 08$

\section{WELL IDB 18}

MEASUREMENTS CONDUCTED IN THE FIELD

\section{Sample date: 09/05/91}

Depth to water: $111.22 \mathrm{ft}(33.90 \mathrm{~m})$ below TOC

Water elevation: $186.08 \mathrm{ft} / 56$

Sp. conductarice: $136 \mu \mathrm{S} / \mathrm{cm}$

The well went dry during surging. $24 \mathrm{gal}$

Time: 11:15

pH: 10.3

Alkalinity: $40 \mathrm{mg} / \mathrm{L}$

Water temperature: $19.0^{\circ} \mathrm{C}$

LABORATORY ANALYSES
E Analyte
0 Antimony-125
C Cerium-144
Cesium-134
Cesium.137
Coball-60
Europium-154
Manganese-54
Potassium-40
0 Ruthenium-103
C Sodium-22
0 Thorium-22
Zinc.65

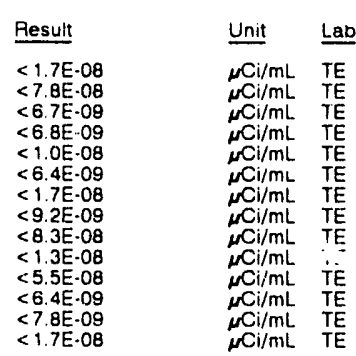

\section{WELL IDB $1 \mathrm{C}$}

MEASUREMENTS CONDUCTED IN THE FIELD

Sample date: 0910419

Depth to water: $49.65 \mathrm{ft}(15.13 \mathrm{~m})$ below TOC

Water elevation: $247.55 \mathrm{ft}(75.45 \mathrm{~m}) \mathrm{ms}$

Water evacuated before sampling: $135 \mathrm{gal}$

LABORATORY ANALYSES
F Analyte
- Antimony-125
Cerium-144
Cesium-134
Cobalt-57
Cobalt-60
Europium-154
Manganese.54
Radium-226
Ruthenium.103
Sndium -22
rhorium -228
0 Zinc 65

Time: $14: 50$

Alkalinity: $1 \mathrm{mg} / \mathrm{L}$

Water temperature: $18.8^{\circ} \mathrm{C}$

\section{WELL IDB 2A}

MEASUREMENTS CONDUCTED IN THE FIELD

Depth to water: $114.81 \mathrm{ft}(34.99 \mathrm{~m})$ below TOC Time: 15:15

Water elevation: $189.49 \mathrm{H}(57.76 \mathrm{~m}) \mathrm{msl}$ Alkalinity: $\mathrm{s} \mathrm{mg/t}$

Water temperature: $20.1^{\circ} \mathrm{C}$

Water evacuated before sampling: $6.31 \mathrm{gal}$

LABORATORY ANALYSES

\begin{tabular}{|c|c|c|}
\hline Analyte & Result & Unit \\
\hline $\begin{array}{l}\text { Antimony-125 } \\
\text { Cerium-1 } 144 \\
\text { Cesium-134 } \\
\text { Cesium-137 } \\
\text { Cobalt-57 } \\
\text { Cobalt-60 } \\
\text { Europium-154 } \\
\text { Manganese-54 } \\
\text { Potassium-40 } \\
\text { Radium-226 } \\
\text { Ruthenium-103 } \\
\text { Sodium-22 } \\
\text { Thorium-228 } \\
\text { Zinc-65 }\end{array}$ & $\begin{array}{l}<2.0 \mathrm{E} \cdot 08 \\
<5.6 \mathrm{E} \cdot 08 \\
<8.7 \mathrm{E} \cdot 08 \\
<7.4 \mathrm{E} \cdot 09 \\
<7.4 \mathrm{E} \cdot 09 \\
<7.0 \mathrm{E} \cdot 09 \\
<2.6 \mathrm{E} \cdot 08 \\
<1.0 \mathrm{E} \cdot 08 \\
<8.7 \mathrm{E} \cdot 08 \\
<1.2 \mathrm{E} \cdot 08 \\
<5.2 \mathrm{E} \cdot 08 \\
<1.0 \mathrm{E} \cdot 08 \\
<8.1 \mathrm{E} \cdot 09 \\
<2.3 \mathrm{E} \cdot 08\end{array}$ & $\begin{array}{l}\mu \mathrm{Cl} / \mathrm{mL} \\
\mu \mathrm{Cl} / \mathrm{mL} \\
\mu \mathrm{Ci} / \mathrm{mL} \\
\mu \mathrm{Ci} / \mathrm{mL} \\
\mu \mathrm{Ci} / \mathrm{mL} \\
\mu \mathrm{Ci} / \mathrm{mL} \\
\mu \mathrm{Cl} / \mathrm{mL} \\
\mu \mathrm{Ci} / \mathrm{mL} \\
\mu \mathrm{Ci} / \mathrm{mL} \\
\mu \mathrm{Ci} / \mathrm{mL} \\
\mu \mathrm{Ci} / \mathrm{mL} \\
\mu \mathrm{Ci} / \mathrm{mL} \\
\mu \mathrm{Ci} / \mathrm{mL} \\
\mu \mathrm{Cl} / \mathrm{mL}\end{array}$ \\
\hline
\end{tabular}

WELL IDB 2B

MEASUREMENTS CONDUCTED IN THE FIELD

Sample date: 09/05/81 Depth to water: $127.68 \mathrm{ft}(38.92 \mathrm{~m})$ below TOC Water elevation: $178.02 \mathrm{ft}(54.26 \mathrm{~m}) \mathrm{ms}$ Sp. conductance: $673 \mu \mathrm{S} / \mathrm{cm}$
Water evacuated before sampling: $163 \mathrm{gal}$ LABORATORY ANALYSES

$E$ Analyte

0 Antimony-125

Cerium-144

Cesium-137

Cobalt-57
0 Cobalt-60

0 Europium-154

Manganese-54

Potassium-40

Ruthenium-103

Sodium-22

0 Thorium-2

Time: $15: 00$

$\mathrm{pH}: 11.5$

Alkalinity: $159 \mathrm{mg} / \mathrm{L}$ Water temperature: $20.0^{\circ} \mathrm{C}$

WELLL IDB $2 \mathrm{C}$

MEASUREMENTS CONDUCTED IN THE FIELD

Sample date: 09/05/91

Depth to water: $65.07 \mathrm{ft}(19.83 \mathrm{~m})$ below TOC

Water elevation: $241.33 \mathrm{ft}(73.56 \mathrm{~m}) \mathrm{ms}$

Water

mpling: $111 \mathrm{gal}$

Time: $15: 2$

pH: 11.0

Nkalinity: $88 \mathrm{mg} / \mathrm{L}$

Water evacuated belore sam

F Analyte

0 Antimony-125

Cerium-144

Cesium-134

Cesium-137

Cobalt.57

Cobalt-60

Europium-154

Potassium-40

Radium-226

Ruthenium-103

Sodium.22

0 Zinc -65

\begin{tabular}{|c|c|}
\hline Result & Unit \\
\hline $\begin{array}{l}<1.8 \mathrm{EE}-08 \\
<5.4 \mathrm{E}-08 \\
<8.3 \mathrm{E}-09 \\
<6.5 \mathrm{E}-09 \\
<7.3 \mathrm{E}-09 \\
<7.7 \mathrm{E}-09 \\
<1.5 \mathrm{E}-08 \\
<9.5 \mathrm{E}-09 \\
<7.8 \mathrm{E}-08 \\
<1.2 \mathrm{E}-08 \\
<4.6 \mathrm{E}-08 \\
<5.5 \mathrm{E}-09 \\
<7.6 \mathrm{E}-09 \\
<1.7 \mathrm{E}-08\end{array}$ & $\begin{array}{l}\mu \mathrm{Cl} / \mathrm{mL} \\
\mu \mathrm{Cl} / \mathrm{mL} \\
\mu \mathrm{Cl} / \mathrm{mL} \\
\mu \mathrm{Cl} / \mathrm{mL} \\
\mu \mathrm{Ci} / \mathrm{mL} \\
\mu \mathrm{Ci} / m \mathrm{~mL} \\
\mu \mathrm{Cl} / \mathrm{mL} \\
\mu \mathrm{Ci} / \mathrm{mL} \\
\mu \mathrm{Ci} / \mathrm{mL} \\
\mu \mathrm{Ci} / \mathrm{mL} \\
\mu \mathrm{Ci} / \mathrm{mL} \\
\mu \mathrm{Ci} / \mathrm{mL} \\
\mu \mathrm{Ci} / \mathrm{mL} \\
\mu \mathrm{Cl} / \mathrm{mL}\end{array}$ \\
\hline
\end{tabular}

Result

$<1.9 E \cdot 08$

$<8.5 E-08$

$<7.7 E-09$

$<7.1 E .09$

$<7.1 \mathrm{E}-08$

$<2.1 \mathrm{E}-08$

$<8.3 \mathrm{E}-09$

$<9.7 E-08$

$<1.6 \mathrm{E}-08$

$<5.9 \mathrm{E} .08$

$<7.6 E-09$
$<9.1 E-09$

$<2$ E. 08 \begin{tabular}{ll} 
Unit & Lab \\
\hline$\mu \mathrm{Ci} / \mathrm{mL}$ & TE \\
$\mu \mathrm{Ci} / \mathrm{mL}$ & TE \\
$\mu \mathrm{Ci} / \mathrm{mL}$ & TE \\
$\mu \mathrm{Ci} / \mathrm{mL}$ & TE \\
$\mu \mathrm{Ci} / \mathrm{mL}$ & TE \\
$\mu \mathrm{Ci} / \mathrm{mL}$ & $\mathrm{TE}$ \\
$\mu \mathrm{Ci} / \mathrm{mL}$ & $\mathrm{TE}$ \\
$\mu \mathrm{Ci} / \mathrm{mL}$ & TE \\
$\mu \mathrm{Ci} / \mathrm{mL}$ & $\mathrm{TE}$ \\
$\mu \mathrm{Ci} / \mathrm{mL}$ & TE \\
$\mu \mathrm{Ci} / \mathrm{mL}$ & TE \\
$\mu \mathrm{Ci} / \mathrm{mL}$ & TE \\
$\mu \mathrm{Ci} / \mathrm{mL}$ & TE \\
$\mu \mathrm{Ci} / \mathrm{mL}$ & TE
\end{tabular} 
WELL IDB 3

MEASUREMENTS CONOUCTED IN THE FIELD

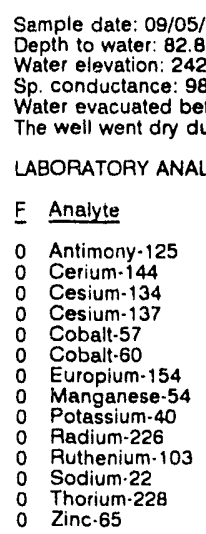

Time: 13:20

pH: 11.7

Water temperature: $20.7^{\circ} \mathrm{C}$

p. conductance: $981 \mu \mathrm{s} / \mathrm{cm}$

ofore sampling: 4 gal

LABORATORY ANALYSES

Result

$<1.8 \mathrm{E}-08$

$<5.6 \mathrm{E}-08$

$<7.8 \mathrm{E}-09$

$<7.3 \mathrm{E}-09$

$<2.2 \mathrm{E}-0 \mathrm{~B}$

$<1.0 \mathrm{E}-08$

$<1.0 \mathrm{E} \cdot 07$

$<1.3 \mathrm{E}-08$

$<5.7 E-08$

$<8.3 \mathrm{E}-09$
$<9.2 \mathrm{E}-09$

$<2.6 \mathrm{E} \cdot 08$

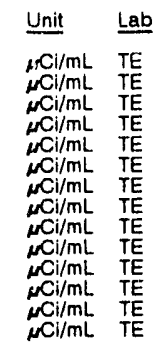

\section{WELL IDB 4}

MEASUREMENTS CONDUCTED IN THE FIELD

Sample date: $00104 / 91$

Depth to water: $61.18 \mathrm{ft}(18.65 \mathrm{~m})$ below tOC

Water elevation: $255.42 \mathrm{ft}(77.85 \mathrm{~m}) \mathrm{ms}$.

(a) $26.42 \mathrm{~cm}$

Water evacuated before sampling: $42 \mathrm{gal}$

LABORATORY ANALYSES

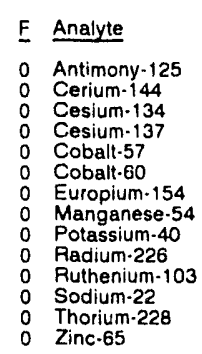

Time: $15: 40$

Alkalinity: $1 \mathrm{mg}$

Water temperature: $19.1^{\circ} \mathrm{C}$

WELL IDB 5

MEASUREMENTS CONDUCTED IN THE FIELD

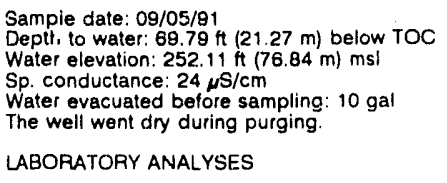

Sampie date: 09/05/9

Deptt, to water: $69.79 \mathrm{ft}(21.27 \mathrm{~m})$ below TOC

Water elevation: $252.11 \mathrm{ft}(76.84 \mathrm{~m}) \mathrm{ms}$

Sp. conductance: $24 \mu \mathrm{s} / \mathrm{cm}$

Water evacuated before sampling: $10 \mathrm{gal}$

The well went dry during purging

LABORATORY ANALYSES

$\begin{array}{ll}\text { E } & \text { Analyte } \\ 0 & \text { Antimony-125 } \\ 0 & \text { Cerium-144 } \\ 0 & \text { Cesium-134 } \\ 0 & \text { Cesium-137 } \\ 0 & \text { Cobalt.57 } \\ 0 & \text { Cobalt-60 } \\ 0 & \text { Europium-154 } \\ 0 & \text { Manganese-54 } \\ 0 & \text { Potassium-40 } \\ 0 & \text { Radium-226 } \\ 0 & \text { Ruthenium-103 } \\ 0 & \text { Sodium-22 } \\ 0 & \text { Thorium-228 } \\ 0 & \text { Zinc-65 }\end{array}$

\section{Time: 13:05}

Alkalinity: $3 \mathrm{mg} / \mathrm{L}$ Water temperature: $19.8^{\circ} \mathrm{C}$

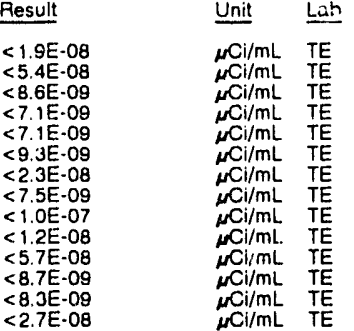

WELL IDB 6

MEASUREMENTS CONDUCTED IN THE FIELD

Sample date: 09/05/91

Depth to water: 57.78 it $(17.61 \mathrm{~m})$ below TOC

Water elevation: $261.22 \mathrm{tt}(79.62 \mathrm{~m}) \mathrm{ms}$

Water evacuated before sampling: $54 \mathrm{gal}$

Time: $10: 45$
pH: 5.8

PH: 5.8 : $4 \mathrm{~mol}$

Water temperature: $18.8^{\circ} \mathrm{C}$

LABORATORY ANALYSES
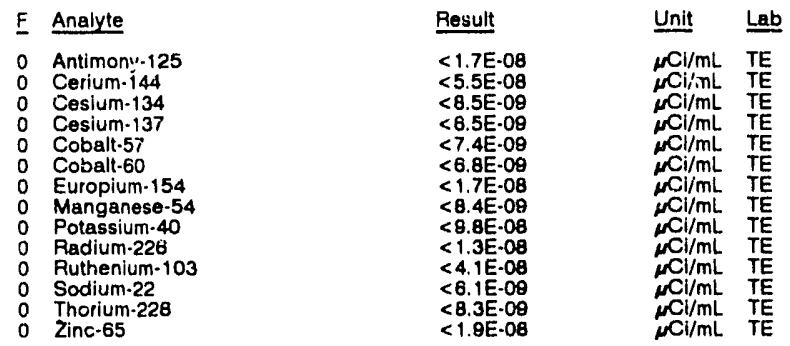

WELL IDB 6

MEASUREMENTS CONDUCTED IN THE FIELD

$\begin{array}{ll}\text { Sample date: } 09 / 05 / 91 & \text { Time: } 10: 45 \\ \text { Depth to water: } 57.78 \mathrm{Ht}(17.61 \mathrm{~m}) \text { below TOC } & \text { pH: } 5.8 \\ \text { Water elevation: } 261.22 \mathrm{ft}(79.62 \mathrm{~m}) \mathrm{msl} & \text { Alkalinity: } 4 \mathrm{rig} / \mathrm{h} \\ \text { Sp. conductance: } 24 \mu \mathrm{s} / \mathrm{cm} & \text { Water temperature: } 18.80 \mathrm{C} \\ \text { Water evacuated betore sampling: } 54 \mathrm{gal} & \end{array}$

Water evacuated betore sampling: $54 \mathrm{gal}$

LABORATORY ANALYSES

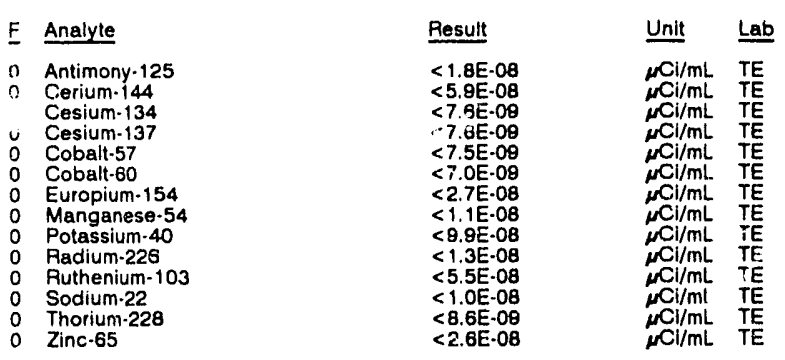

WELL IDB 7

MEASUREMENTS CONDUCTED IN THE FIELC

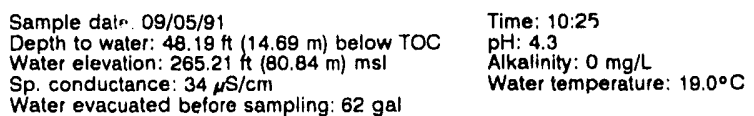

Water evacuated before sampling: 62 gal

LABORATORY ANALYSES

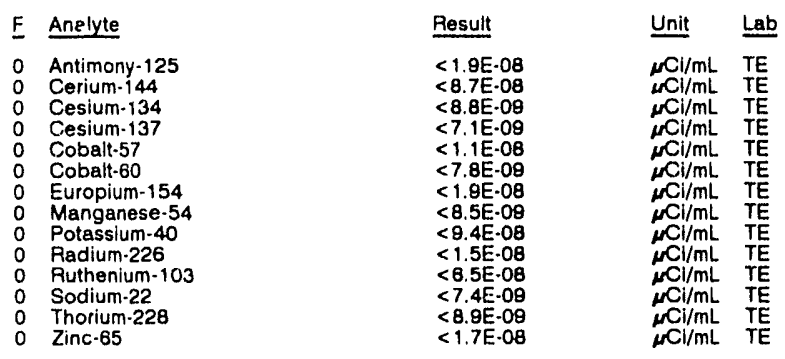




\section{WELL IDB 8}

MEASUREMENTS CONDUCTED IN THE FIELD

Sample date: $09 / 05 / 91$
Dopth to water: $47.75 \mathrm{~h}(14.55 \mathrm{~m})$ below TOC
Water elovation: $245.35 \mathrm{~h}(74.78 \mathrm{~m}) \mathrm{ms}$
Sp. conductance: $19 \mu \mathrm{s} / \mathrm{cm}$
Water evac uated before sampling: $42 \mathrm{gal}$
LQBOFATOQY ANALLYSES

Time: $11: 45$

PH: 4.8

Alkalinity: $1 \mathrm{mg} / \mathrm{L}$
Water temperature: $19.1^{\circ} \mathrm{C}$

LABORATOGY ANALYSES

\begin{tabular}{|c|c|c|}
\hline F Analyte & Result & Unit \\
\hline $\begin{array}{ll}0 & \text { Antimony-125 } \\
0 & \text { Cerium-144 } \\
r & \text { Cesium-134 } \\
0 & \text { Cesium-1377 } \\
0 & \text { Cobaht-57 } \\
0 & \text { Cobalt-60 } \\
0 & \text { Europium-154 } \\
0 & \text { Manganese-54 } \\
0 & \text { Potassium-40 } \\
0 & \text { Radium-226 } \\
0 & \text { Puthenium-103 } \\
0 & \text { Sodium-22 } \\
0 & \text { Thorium-228 } \\
0 & 7 \text { Tof }\end{array}$ & $\begin{array}{l}<1.8 E-08 \\
<5.3 E-08 \\
<7.3 E-09 \\
<6.8 E-09 \\
<6.6 E-09 \\
<7.6 E-09 \\
<2.4 E-08 \\
<8.5 E-09 \\
<8.8 E \cdot 08 \\
<1.1 E-08 \\
<5.2 E \cdot 08 \\
<\theta .2 E \cdot 09 \\
<6.9 E-09\end{array}$ & 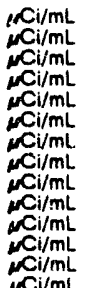 \\
\hline
\end{tabular}

WELL IDB 9

MEASUREMENTS CONDUCTED IN THE FIELD

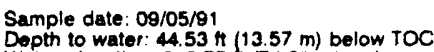

Water elevation: 243.77 h 774

Water evacuated before sampling: $111 \mathrm{gal}$

LABORATORY ANALYSES

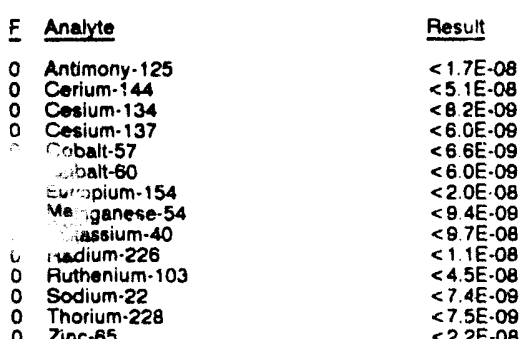

Time: $12: 50$

Alkalinity: $41 \mathrm{ing} /$

Water temperature: $19.10 \mathrm{C}$

\section{WELL IDB 10}

MEASUREMENTS CONOUCTED IN THE FIELD

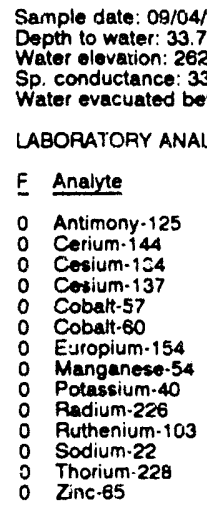

\begin{tabular}{|c|c|}
\hline nit & \\
\hline 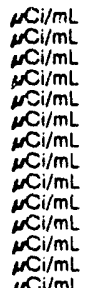 & \\
\hline
\end{tabular}


ANALYTICAL RESULTS

WELL IDP 3A collected on 09/05/81, laboratory analyses (cont.)

\begin{tabular}{|c|c|c|}
\hline Analyte & Result & Unit \\
\hline $\begin{array}{ll}0 & \text { Zinc-65 } \\
0 & \text { Zinc-65 }\end{array}$ & $\begin{array}{l}<2.5 E-08 \\
<1.8 E-08\end{array}$ & $\stackrel{\mathrm{cl} / \mathrm{mL}}{\mathrm{NCl} / \mathrm{mL}}$ \\
\hline
\end{tabular}

WELL IDP 3B

MEASUREMENTS CONDUCTED IN THE FIELD

Sample date: $09 / 05 / 91$

Depth to water: $127.58 \mathrm{ft}(38.89 \mathrm{~m})$ below TOC Water olevation: $156.82 \mathrm{ft}(47.83 \mathrm{~m}) \mathrm{ms}$

$\mathrm{Sp}$. conductance: $456 \mathrm{~s} / \mathrm{cm}$

Water evacuated bofore sampling: $160 \mathrm{gal}$

LABORATORY ANALYSES

\begin{tabular}{|c|c|c|}
\hline F Analyte & Result & Unit \\
\hline $\begin{array}{ll}0 & \text { Antimony-125 } \\
0 & \text { Cerium-144 } \\
0 & \text { Cesium-134 } \\
0 & \text { Cesium-137 } \\
0 & \text { Cobalt-57 } \\
0 & \text { Cobalt-60 } \\
0 & \text { Europium-1.4. } \\
0 & \text { Manganest. } \\
0 & \text { Potassium-40 } \\
0 & \text { Radium-226 } \\
0 & \text { Ruthenium-103 } \\
0 & \text { Sodium-22 } \\
0 & \text { Thorium-228 } \\
0 & \text { Zinc-65 }\end{array}$ & $\begin{array}{l}<1.6 E \cdot 08 \\
<8.1 E \cdot 08 \\
<8.5 E \cdot 09 \\
<7.3 E \cdot 09 \\
<1.0 E \cdot 08 \\
<5.9 E \cdot 09 \\
<2.0 E \cdot 08 \\
<8.2 E \cdot 09 \\
<9.8 E \cdot 08 \\
<1.4 E \cdot 08 \\
<5.7 E \cdot 08 \\
<7.4 E \cdot 09 \\
<8.3 E \cdot 09 \\
<2.1 E \cdot 08\end{array}$ & 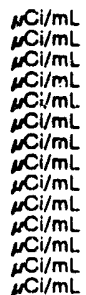 \\
\hline
\end{tabular}

\section{WELL IDP 3C}

MEASUREMENTS CONDUCTED IN THE FIELD

Sample date: 09/05/91

Depth to water: $55.12 \pi(16.80 \mathrm{~m})$ below TOC

Water elevation: $229.88 \mathrm{it}(70.07 \mathrm{~m}) \mathrm{msl}$

Sp. conductance: $380 \mu \mathrm{S} / \mathrm{ct}$

$\begin{array}{ll}<2.5 E .08 & \mathrm{NCl} / \mathrm{mL} \text { TE } \\ <1.8 \mathrm{CL} .08 & \mathrm{TE} / \mathrm{mL}\end{array}$

Water ovacuated before sampling: $14 \mathrm{gal}$

LABORATORY ANALYSES

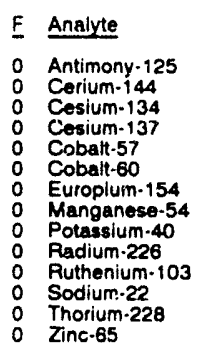

Result
$<1.9 \mathrm{E} \cdot 08$
$<5.5 \mathrm{E} \cdot 0 \mathrm{0B}$
$<8.7 \mathrm{E} \cdot 09$
$<6.9 \mathrm{E} \cdot 09$
$<7.1 \mathrm{E} \cdot 09$
$<9.6 \mathrm{E} \cdot 09$
$<2.5 \mathrm{E} \cdot 0.08$
$<9.2 \mathrm{E} \cdot 09$
$<9.7 \mathrm{E} \cdot 00$
$<1.1 \mathrm{E} \cdot 08$
$<5.1 \mathrm{E} \cdot 08$
$<9.6 \mathrm{E}-09$
$<6.0 \mathrm{E} \cdot 09$
$<2.0 \mathrm{E} \cdot 00$

Time: $8: 40$

pH: 11.4

Water temperature: $21.4^{\circ} \mathrm{O}$

Time: $8: 25$

Alkalinity: $125 \mathrm{mg} / \mathrm{h}$

\section{WELL IDP 4}

MEASUREMENTS CONDUCTED IN THE FIELO

Sample date: 09/06/91

Depth to water: $49.16 \mathrm{ft}(14.98 \mathrm{~m})$ below TOC

Water elevation: $191.64 \mathrm{~h}(58.41 \mathrm{~m}) \mathrm{msl}$

Sp. conductance: $36 \mu \mathrm{s} / \mathrm{cm}$

The well went dry during pumpling: $4 \mathrm{gal}$

LABORATOAY ANALYSES

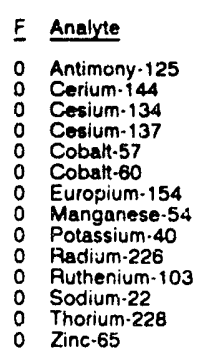

Rescist:

Time: $7: 50$

PH: 5.4 : $6 \mathrm{mgh}$

Water temperature: $18.4^{\circ} \mathrm{C}$

\begin{tabular}{|c|c|}
\hline Init & \\
\hline 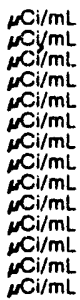 & \\
\hline
\end{tabular}

< 1 SE.08

C $5.8 \mathrm{EE}-08$
$<8.8 \mathrm{E}-09$

$<8.8 \mathrm{E}-09$
$<7.5 \mathrm{E} .00$

$<7.5 \mathrm{E} .08$

$<1.0 \mathrm{E} .08$

$<2.2 \mathrm{E}-08$

$<9.1 \mathrm{E}-09$

$<9.9 E \cdot 08$

$<12 E-08$

$<8.5 \mathrm{E} .09$

$<8.8 \mathrm{E}-\mathrm{co}$

$<2.4 \mathrm{E} \cdot 06$
WELL IDP 5

MEASUAEMENTS CONDUCTED IN THE FIELD

$\begin{array}{ll}\text { Sample date. } 09 / 05 / 91 & \text { Time: } 12: 15 \\ \text { Depth to v:aier: } 55.64 \mathrm{~h}(16.86 \mathrm{~m}) \text { bolow TOC } & \text { pH: } 5.9 \\ \text { Water olevation: } 186.06 \mathrm{~h}(60.37 \mathrm{~m}) \mathrm{msl} & \text { Alkalinity: } 17 \mathrm{mg} / \mathrm{h} \\ \text { Sp. conductance: } 60 \mathrm{NS} / \mathrm{cm} & \text { Water temperature: } 23.3^{\circ} \mathrm{C} \\ \text { Water evacuated before sampling: } 32 \mathrm{gal} & \end{array}$

LABORATORY ANALYSES

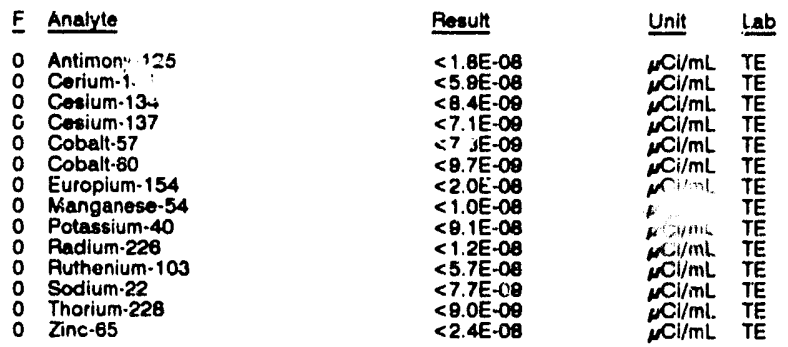

WELL IDP 6

MEASUAEMENTS CONDUCTED IN THE WIELD

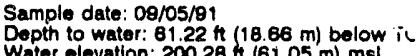
Water olevation: $200.28 \mathrm{~h}(61.05 \mathrm{~m}) \mathrm{mst}$

Sp. conductance: $69 \mu \mathrm{s} / \mathrm{cin}$

Water evacuated before sampling: $\mathbf{4 0}$ gal

LABORATORY ANALYSES

\begin{tabular}{|c|c|c|c|}
\hline Analyte & Result & Unit & Lab \\
\hline $\begin{array}{ll}0 & \text { Antimony-125 } \\
0 & \text { Cerium-144 } \\
0 & \text { Cesium-134 } \\
0 & \text { Cesium-137 } \\
0 & \text { Cobalt-57 } \\
0 & \text { Cobalt-60 } \\
0 & \text { Europium-154 } \\
0 & \text { Manganese-54 } \\
0 & \text { Potassium-40 } \\
0 & \text { Radium-226 } \\
0 & \text { Ruthenium-103 } \\
0 & \text { Sodium-22 } \\
0 & \text { Thorium-228 } \\
0 & \text { Zinc-65 }\end{array}$ & $\begin{array}{l}<1.8 E-08 \\
<8.1 \mathrm{E}-08 \\
<8.0 \mathrm{E}-09 \\
<7.2 \mathrm{E}-09 \\
<1.0 \mathrm{E}-08 \\
<6.0 \mathrm{E}-09 \\
<2.1 \mathrm{E}-08 \\
<8.8 \mathrm{E}-09 \\
<8.3 \mathrm{E}-08 \\
<1.4 \mathrm{E}-08 \\
<5.4 \mathrm{E}-08 \\
<7.7 \mathrm{E}-09 \\
<8.3 \mathrm{E}-09 \\
<2.1 \mathrm{E}-08\end{array}$ & 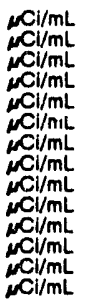 & $\begin{array}{l}\text { TE } \\
\text { TE } \\
\text { TE } \\
\text { TE } \\
\text { TE } \\
\text { TE } \\
\text { TE } \\
\text { TE } \\
\text { Tr. } \\
\text { TE } \\
\text { TE } \\
\text { TE } \\
\text { TE } \\
\text { TE }\end{array}$ \\
\hline
\end{tabular}

WELL IDP 7

MEASUREMENTS CONDUCTED IN THE FIELD

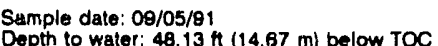

Wepth to water: $48.13 \mathrm{At}(14.67 \mathrm{~m})$ below TOC

$\mathrm{Sp}$. conductance: $54 \mathrm{sS} / \mathrm{cm}$

Water evacuated before sampling: $32 \mathrm{gal}$

Time: 10

Alkalinity: $6 \mathrm{~mol}$

Water temperature: $20.0^{\circ} \mathrm{C}$

LABORATOAY ANALYSES

\begin{tabular}{|c|c|c|c|}
\hline Analyte & Rosult & Unit & Lab \\
\hline $\begin{array}{l}\text { Antimony-125 } \\
\text { Cerium-144 } \\
\text { Cosium-134 } \\
\text { Cesium-137 } \\
\text { Cobalt-57 } \\
\text { Cobalt-60 } \\
\text { Europium-154 } \\
\text { Manganese-54 } \\
\text { Potassium-40 } \\
\text { Radium-228 } \\
\text { Ruthenium-103 } \\
\text { Sodium-22 } \\
\text { Thorium-226 } \\
\text { Zinc-65 }\end{array}$ & $\begin{array}{l}<1.9 \mathrm{E}-08 \\
<8.5 \mathrm{E}-08 \\
<6.5 \mathrm{E}-09 \\
<7.1 \mathrm{E}-09 \\
<1.1 \mathrm{E}-08 \\
<7.5 \mathrm{E}-09 \\
<2.3 \mathrm{E}-08 \\
<9.7 \mathrm{E}-09 \\
<9.5 \mathrm{E}-08 \\
<1.5 \mathrm{E}-08 \\
<5.7 \mathrm{E}-08 \\
<8.0 \mathrm{E}-09 \\
<9.0 \mathrm{E}-09 \\
<2.0 \mathrm{E}-08\end{array}$ & 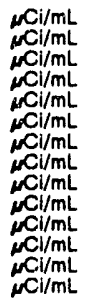 & $\begin{array}{l}\text { TE } \\
\text { TE } \\
\text { TE } \\
T E \\
T E \\
T E \\
T E \\
T E \\
T E \\
T E \\
T E \\
T E \\
T E \\
T E \\
T E\end{array}$ \\
\hline
\end{tabular}


WELL IDP 8

MEASUREMENTS CONDUCTED IN THE FIELD

Sample date: 00/05/91 Depth to water: $83.60 \mathrm{ft}(10.39 \mathrm{~m})$ below TOC Wator elevation: $200.80 \mathrm{~h}(61.20 \mathrm{~m}) \mathrm{ms}$

eampling: $40 \mathrm{gal}$

LABORATORY ANALYSES

\begin{tabular}{|c|c|c|}
\hline Analyte & Resuht & Unit \\
\hline $\begin{array}{ll}0 & \text { Antimony-125 } \\
0 & \text { Corium-144 } \\
0 & \text { Cesium-134 } \\
0 & \text { Cosium-137 } \\
0 & \text { Cobalt-57 } \\
0 & \text { Cobalt-60 } \\
0 & \text { Europium-154 } \\
0 & \text { Manganese-54 } \\
0 & \text { Potassium-40 } \\
0 & \text { Radium-226 } \\
0 & \text { Ruthenium-103 } \\
0 & \text { Sodium-22 } \\
0 & \text { Thorium-228 } \\
0 & \text { Zitic-65 }\end{array}$ & $\begin{array}{l}<1.4 \mathrm{E}-08 \\
<5.5 \mathrm{E} \cdot 08 \\
<4.6 \mathrm{E} \cdot 09 \\
<4.7 \mathrm{E} \cdot 09 \\
<6.2 \mathrm{E} \cdot 09 \\
<4.9 \mathrm{E} \cdot 09 \\
<1.2 \mathrm{E} \cdot 08 \\
<5.6 \mathrm{E}-09 \\
<8.6 \mathrm{E} \cdot 08 \\
<1.1 \mathrm{E} \cdot 08 \\
<3.5 \mathrm{E} \cdot 08 \\
<4.6 \mathrm{E} \cdot 09 \\
<5.5 \mathrm{E} \cdot 09 \\
<6.9 \mathrm{E} \cdot 09\end{array}$ & 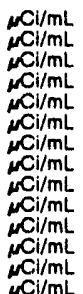 \\
\hline
\end{tabular}

WELL IDP 9

MEASUREMENTS CONOUCTED IN THE FIELD

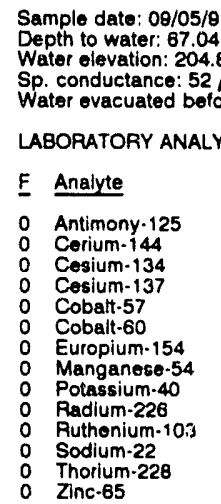

Time: $8: 40$

pH: 5.9

Alkalinity: $17 \mathrm{mg} / \mathrm{L}$ Water temperature: $21.7^{\circ} \mathrm{C}$

Time: 11:30

Alkalinity: $6 \mathrm{mg} / \mathrm{L}$

Water temperature: $23.4^{\circ} \mathrm{C}$

$6.9 \mathrm{E} \cdot 09$

\begin{tabular}{|c|c|}
\hline Result & Unit \\
\hline $\begin{array}{l}<1.7 \mathrm{E} \cdot 08 \\
<5.2 \mathrm{E}-08 \\
<8.3 \mathrm{E}-09 \\
<6.3 \mathrm{E} \cdot 09 \\
<7.2 \mathrm{E} \cdot 09 \\
<8.8 \mathrm{E} \cdot 09 \\
<2.6 \mathrm{E}-08 \\
<9.2 \mathrm{E} \cdot 09 \\
<1.0 \mathrm{E} \cdot 07 \\
<1.2 \mathrm{E}-08 \\
<5.1 \mathrm{E} \cdot 08 \\
<9.8 \mathrm{E} \cdot 09 \\
<8.1 \mathrm{E} \cdot 09 \\
<1.9 \mathrm{E} \cdot 08\end{array}$ & 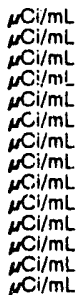 \\
\hline
\end{tabular}

\section{WELL IDQ 2}

MEASUREMENTS CONDUCTED IN THE FIELD

Sample date: 09/06/91 Depth to water: $97.53 \mathrm{ft}(29.73 \mathrm{~m})$ below TOC Water elevation: $165.67 \mathrm{ft}(50.50 \mathrm{~m}) \mathrm{ms}$ Sp. conductance: $19 \mu \mathrm{s} / \mathrm{cm}$

The well went dy during puing: 33 gal

LABORATORY ANALYSES

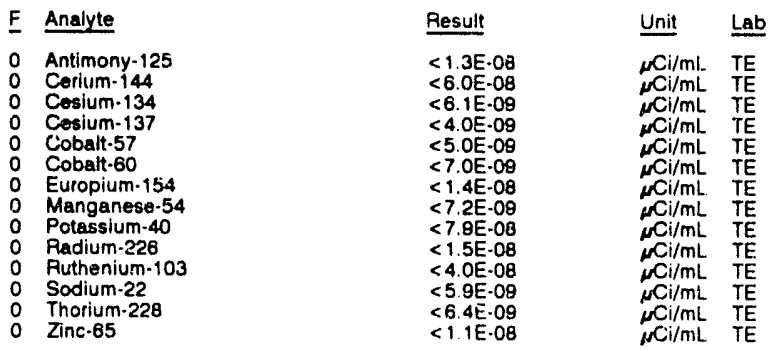

WELL IDQ 3A

MEASUREMENTS CONDUCTED IN THE FIELD

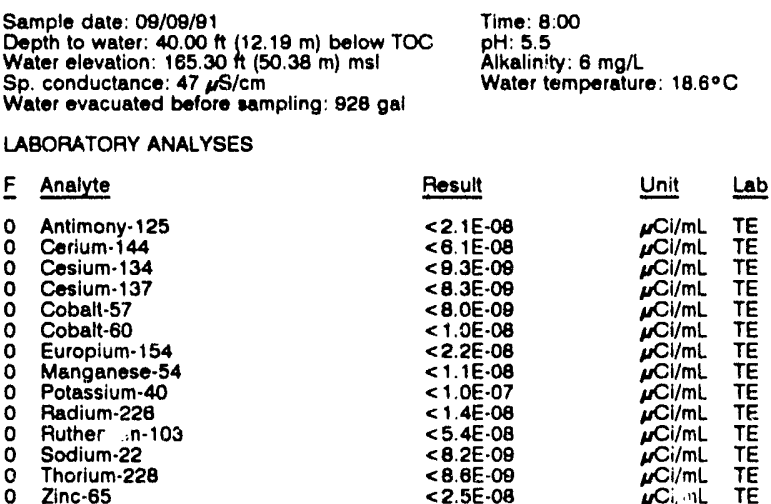

WELL IDQ 3B

MEASUREMENTS CONDUCTED IN THE FIELD

$\begin{array}{ll}\text { Sample date: } 09 / 08 / 91 & \text { Time: } 7: 45 \\ \text { Depth to water: } 65.13 \mathrm{H}(19.85 \mathrm{~m}) \text { below TOC } & \text { pH: } 10.1 \\ \text { Water elevation: } 140.47 \mathrm{Ht}(42.82 \mathrm{~m}) \mathrm{msl} & \text { Alkalinity: } 66 \mathrm{mg} / \mathrm{L} . \\ \text { Sp. conductance: } 177 \mu \mathrm{s} / \mathrm{cm} & \text { Water temperature: } 18.2^{\circ} \mathrm{C} \\ \text { Water evacuated before sampling: } 84 \mathrm{gal} & \end{array}$

LABORATORY ANALYSES

\begin{tabular}{|c|c|c|c|}
\hline Analyte & Result & Unit & Lab \\
\hline $\begin{array}{ll}0 & \text { Antimony-125 } \\
0 & \text { Antimony-125 } \\
0 & \text { Cerium-144 } \\
0 & \text { Cerium-144 } \\
0 & \text { Cesium-134 } \\
0 & \text { Cesium-134 } \\
0 & \text { Cesium-137 } \\
0 & \text { Cesium-137 } \\
0 & \text { Cobalt-57 } \\
0 & \text { Cobalt-57 } \\
0 & \text { Cobalt-60 } \\
0 & \text { Cobalt-60 } \\
0 & \text { Europium-154 } \\
0 & \text { Europium-154 } \\
0 & \text { Manganese-54 } \\
0 & \text { Manganese-54 } \\
0 & \text { Potassium-40 } \\
0 & \text { Potassium-40 } \\
0 & \text { Radium-226 } \\
0 & \text { Radium-226 } \\
0 & \text { Ruthenium-103 } \\
0 & \text { Ruthenium-103 } \\
0 & \text { Sodium-22 } \\
0 & \text { Sodium-22 } \\
0 & \text { Thorium-228 } \\
0 & \text { Thorium-228 } \\
0 & \text { Zinc-65 } \\
0 & \text { Zinc-65 }\end{array}$ & $\begin{array}{l}<2.1 \mathrm{E} \cdot 08 \\
<1.2 \mathrm{E} \cdot 08 \\
<9.4 \mathrm{E} \cdot 08 \\
<4.6 \mathrm{E} \cdot 08 \\
<8.2 \mathrm{E} \cdot 09 \\
<5.3 \mathrm{E} \cdot 08 \\
<7.6 \mathrm{E} \cdot 08 \\
<4.7 \mathrm{E} \cdot 09 \\
<1.2 \mathrm{E} \cdot 08 \\
<5.4 \mathrm{E} \cdot 09 \\
<7.3 \mathrm{E} \cdot 09 \\
<5.0 \mathrm{E} \cdot 09 \\
<2.6 \mathrm{E} \cdot 08 \\
<1.2 \mathrm{E} \cdot 08 \\
<1.0 \mathrm{E} \cdot 08 \\
<5.0 \mathrm{E} \cdot 09 \\
<1.1 \mathrm{E} \cdot 07 \\
<8.0 \mathrm{E} \cdot 08 \\
<1.6 \mathrm{E} \cdot 08 \\
<1.3 \mathrm{E} \cdot 08 \\
<6.1 \mathrm{E} \cdot 08 \\
<4.3 \mathrm{E} \cdot 08 \\
<9.1 \mathrm{E} \cdot 09 \\
<4.7 \mathrm{E} \cdot 09 \\
<1.0 \mathrm{E} \cdot 08 \\
<6.2 \mathrm{E} \cdot 09 \\
<2.3 \mathrm{E} \cdot 08 \\
<1.6 \mathrm{E} \cdot 08\end{array}$ & 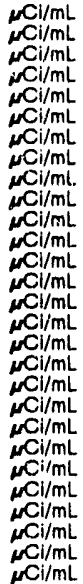 & $\begin{array}{l}\text { TE } \\
T E \\
T E \\
T E \\
T E \\
T E \\
T E \\
T E \\
T E \\
T E \\
T E \\
T E \\
T E \\
T E \\
T E \\
T E \\
T E \\
T E \\
T E \\
T E \\
T E \\
T E \\
\text { TE } \\
\text { TE } \\
\text { TE } \\
\text { TE } \\
\text { TE } \\
\text { TE }\end{array}$ \\
\hline
\end{tabular}

WELL IDQ 3C

MEASUREMENTS CONDUCTED IN THE FIELD

$\begin{array}{ll}\text { Sample date: } 09 / 09 / 91 & \text { Time: } 8: 20 \\ \text { Depth to water: } 41.58 \mathrm{Ht}(12.68 \mathrm{~m}) \text { below TOC } & \text { pH: } 5.5 \\ \text { Water elevation: } 164.91 \mathrm{H}(50.27 \mathrm{~m}) \mathrm{msl} & \text { Alkalinity: } 5 \mathrm{mg} / \mathrm{h} \\ \text { Sp. conductance: } 26 \mu \mathrm{s} / \mathrm{cm} & \text { Water temperatu }-: 18.8^{\circ} \mathrm{C} \\ \text { Water evacuated before sampling: } 12 \mathrm{gal} & \end{array}$

Water evacuated before sampling: $12 \mathrm{gal}$

The well went dry during purging.

LABORATORY ANALYSES

\begin{tabular}{|c|c|c|}
\hline Anaiyte & Result & Unit \\
\hline $\begin{array}{l}\text { Antimony-125 } \\
\text { Cerium-144 } \\
\text { Cesium- } 134 \\
\text { Cesium-137 } \\
\text { Cobalt-57 } \\
\text { Cobalt-60 } \\
\text { Europium-154 } \\
\text { Manganese-54 } \\
\text { Potassium-40 } \\
\text { Radium-226 } \\
\text { Ruthenium-103 } \\
\text { Sodium-22 }\end{array}$ & $\begin{array}{l}<1.9 \mathrm{E} \cdot 08 \\
<5.6 \mathrm{E} \cdot 08 \\
<8.6 \mathrm{E} \cdot 09 \\
<7.1 \mathrm{E} \cdot 09 \\
<7.4 \mathrm{E} \cdot 09 \\
<9.6 \mathrm{E} \cdot 09 \\
<2.5 \mathrm{E} \cdot 08 \\
<9.4 \mathrm{E} \cdot 09 \\
<9.1 \mathrm{E} \cdot 08 \\
<1.4 \mathrm{E} \cdot 08 \\
<4.0 \mathrm{E} \cdot 08 \\
<9.6 \mathrm{E} \cdot 09\end{array}$ & 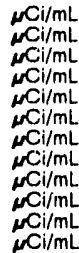 \\
\hline
\end{tabular}


ANALYTICAL RESULTS

WELL IDO 3C collected on 09/09/81, lavoratory analyses (cont.)

\begin{tabular}{|c|c|c|}
\hline F Analyte & Besult & Unit \\
\hline $\begin{array}{ll}0 & \text { Thorium-228 } \\
0 & \text { Zinc-65 }\end{array}$ & $\begin{array}{l}<8.0 \mathrm{E} \cdot 09 \\
<2.5 \mathrm{E}-08\end{array}$ & $\underset{\mu \mathrm{Ci} / \mathrm{mL}}{\mu \mathrm{Ci}}$ \\
\hline
\end{tabular}

WELL IDQ 4

MEASUREMENTS CONDUCTED IN THE FIELD

Sample date: 09/09/91

Depth to water: $69.73 \mathrm{~h}(21.25 \mathrm{~m})$ below TOC

Water olevation: $195.77 \mathrm{ht}(59.67 \mathrm{~m}) \mathrm{msl}$

Sp. conductance: $68 \mu \mathrm{S} / \mathrm{cm}$

Water evacuated before sampling: $28 \mathrm{gal}$

Time: $8: 35$

pH: 8.8 . $32 \mathrm{mg}$

Water temperature: $19.0^{\circ} \mathrm{C}$

LABORATORY ANALYSES

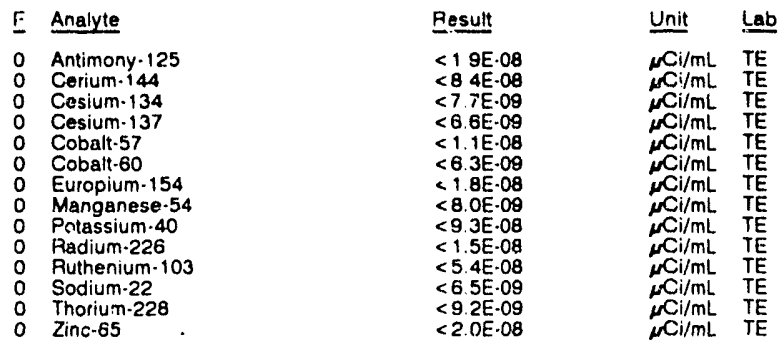

\section{WELL IDQ 5}

MEASUREMENTS CONDUCTED IN THE FIELD

\begin{tabular}{|c|c|c|c|c|c|c|}
\hline \multicolumn{4}{|c|}{$\begin{array}{l}\text { Sample date: } 09 / 06 / 91 \\
\text { Depth to water: } 73.29 \mathrm{Ht}(22.34 \mathrm{~m}) \text { below TOC } \\
\text { Water elevation: } 193.91 \mathrm{ft}(59.10 \mathrm{~m}) \mathrm{msl} \\
\text { Sp. conductance: } 71 \mu \mathrm{s} / \mathrm{cm} \\
\text { Water evacuated belore sampling: } 4 \mathrm{gal} \\
\text { The well went dry during purging. }\end{array}$} & \multicolumn{3}{|c|}{$\begin{array}{l}\text { Time: } 6: 40 \\
\text { pH: } 65 \\
\text { Alkalinity: } 40 \mathrm{mg} / \mathrm{h} \\
\text { Water temperature: } 19.1^{\circ} \mathrm{C}\end{array}$} \\
\hline \multicolumn{7}{|c|}{ LABORATORY ANALYSES } \\
\hline$\underline{F}$ & Analyte & & Result & & $\underline{\text { Unit }}$ & Lab \\
\hline $\begin{array}{l}0 \\
0 \\
0 \\
0 \\
0 \\
0 \\
0 \\
0 \\
0 \\
0 \\
0 \\
0 \\
0 \\
0\end{array}$ & $\begin{array}{l}\text { Antimony-125 } \\
\text { Cerium-144 } \\
\text { Cesium-134 } \\
\text { Cesium-137 } \\
\text { Cobalt-57 } \\
\text { Cobalt-60 } \\
\text { Europium-154 } \\
\text { Manganese-54 } \\
\text { Potassium-40 } \\
\text { Radium-226 } \\
\text { Ruthenium-103 } \\
\text { Sodium-22 } \\
\text { Thorium -28 } \\
\text { Zinc-65 }\end{array}$ & : & $\begin{array}{l}<1.8 \mathrm{E} \\
<5.9 \mathrm{E} \\
<8.8 \mathrm{E} \\
<7.1 \mathrm{E} \\
<7.6 \mathrm{E} \\
<9.8 \mathrm{E} \\
<1.7 \mathrm{E} \\
<1.0 \mathrm{E} \\
<9.4 \mathrm{E} \\
<1.3 \mathrm{E} \\
<6.1 \mathrm{E} \\
<6.5 \mathrm{E} \\
<8.1 \mathrm{E} \\
<2.5 \mathrm{E}\end{array}$ & $\begin{array}{l}08 \\
08 \\
09 \\
09 \\
09 \\
09 \\
08 \\
08 \\
08 \\
08 \\
08 \\
09 \\
09 \\
08\end{array}$ & $\begin{array}{c}\mu \mathrm{Ci} / \mathrm{mL} \\
\mu \mathrm{Ci} / \mathrm{mL} \\
\mu \mathrm{Ci} / \mathrm{mL} \\
\mu \mathrm{Ci} / \mathrm{mL} \\
\mu \mathrm{Ci} / \mathrm{mL} \\
\mu^{\mathrm{Cu} i / m L} \\
\mu \mathrm{Ci} / \mathrm{mL} \\
\mu \mathrm{Ci} / \mathrm{mL} \\
\mu \mathrm{Ci} / \mathrm{mL} \\
\mu \mathrm{Ci} / \mathrm{mL} \\
\mu \mathrm{Ci} / \mathrm{mL} \\
\mu \mathrm{Ci} / \mathrm{mL} \\
\mu \mathrm{Ci} / \mathrm{mL} \\
\mu \mathrm{Ci} / \mathrm{mL} .\end{array}$ & $\begin{array}{l}\text { TE } \\
\text { TE } \\
\text { TE } \\
\text { TE } \\
\text { TE } \\
\text { TE } \\
\text { TE } \\
\text { TE } \\
\text { TE } \\
\text { TE } \\
\text { TE } \\
\text { TE } \\
\text { TE } \\
\text { TE }\end{array}$ \\
\hline
\end{tabular}

\section{WELL IDQ 6}

MEASUREMENTS CONDUCTED IN THE FIELD

Sample date: 09/06/91

Depth to water: $65.85 \mathrm{ft}(20.07 \mathrm{~m})$ below TOC

Water elevation: $192.25 \mathrm{tt}(58.60 \mathrm{~m}) \mathrm{msl}$

Sp. conductance: $372 \mu \mathrm{S} / \mathrm{cm}$

Water evacuated before sampling $8 \mathrm{gal}$

The well went dry during purging.

LABORATORY ANALYSES

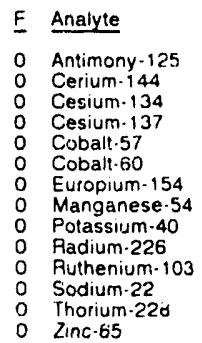

Result

$<1$ 8E.06

$<74 \mathrm{E} .08$

$<63 \mathrm{E} \cdot 09$

$<5$. 4 . 09
$<9.5 E \cdot 09$

$<6.2 E .09$

$<16 \mathrm{E} .08$

$<5.4 E .09$

$<1.0 E \cdot 07$

$<14 \mathrm{E} \cdot 08$

$<46 \mathrm{E} \cdot 08$

$<6$
$<6$
$<6.09$

$<14 \mathrm{E} \cdot 08$
WELL IDQ 7

MEASUREMENTS CONDUCTED IN THE FIELD

Sample dais: 09/06/91

Depth to wato: $54.86 \mathrm{ft}(16.72 \mathrm{~m})$ below TOC

Water elevation: $185.74 \mathrm{ft}(58.61 \mathrm{~m}) \mathrm{msl}$

The well went dy during purging: $7 \mathrm{ga}$

LABORATORY ANALYSES

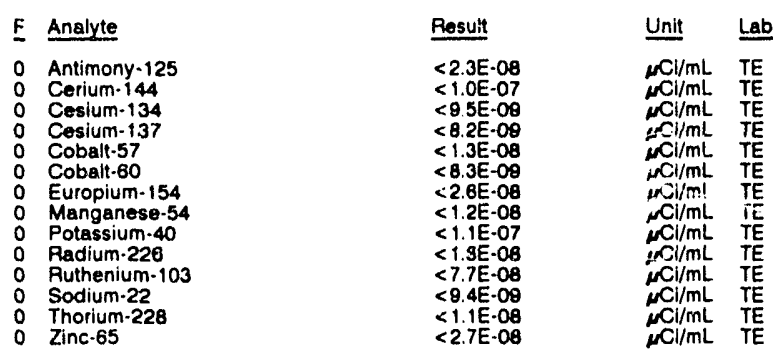

WELL IDQ 10

MEASUREMENTS CONDUCTED IN THE FIELD

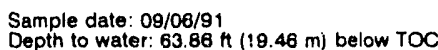

Water elevation: $172.64 \mathrm{~h}(52.62 \mathrm{~m}) \mathrm{ms}$ !

$\mathrm{Sp}$. conductance: $118 \mu \mathrm{S} / \mathrm{cm}$

Water evacuated betore sampling: $10 \mathrm{gal}$
The well went dry during purging.

Time: 7:20

Alkalinity: $103 \mathrm{mg} / \mathrm{h}$

Water temperature: $18.7 \circ \mathrm{C}$

LABORATORY ANALYSES

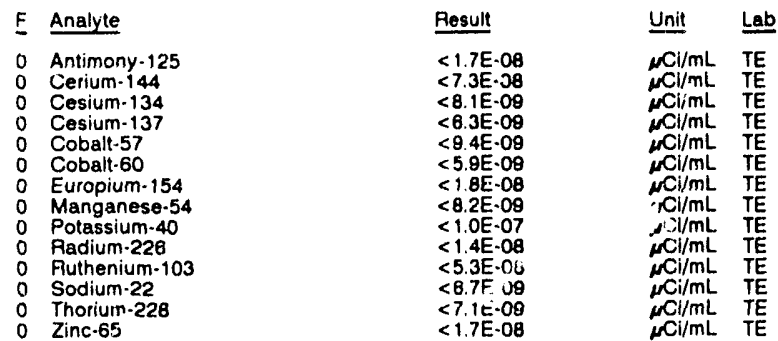

\section{WELL IDQ 12}

MEASUREMENTS CONDUCTED IN THE FIELD

Sample date: $09 / 09 / 91$

Depth to water: $56.26 \mathrm{ft}(17.15 \mathrm{~m})$ below TOC

Water elevation: $185.94 \mathrm{ft}(56.68 \mathrm{~m}) \mathrm{ms}$

Sp. conductance: $15 \mu \mathrm{s} / \mathrm{cm}$

Water evacuated before sampling: $56 \mathrm{gal}$

\section{Time: $8: 45$}

pH: 6.8

Alkalinity: $70 \mathrm{mg} / \mathrm{L}$
Water temperature: $18.5^{\circ} \mathrm{C}$

LABORATORY ANALYSES

\begin{tabular}{|c|c|c|}
\hline Analyte & Resuit & Unit \\
\hline $\begin{array}{ll}0 & \text { Antimony-125 } \\
0 & \text { Cerium-144 } \\
0 & \text { Cesium-134 } \\
0 & \text { Cesium-137 } \\
0 & \text { Cobalt-57 } \\
0 & \text { Cobalt-60 } \\
0 & \text { Europium-154 } \\
0 & \text { Manganese-54 } \\
0 & \text { Potassium-40 } \\
0 & \text { Radium-226 } \\
0 & \text { Ruthenium-103 } \\
0 & \text { Sodium-22 } \\
0 & \text { Thorium-228 } \\
0 & \text { Zinc.65 }\end{array}$ & $\begin{array}{l}<1.7 \mathrm{E}-08 \\
<5.7 \mathrm{E}-08 \\
<7.1 \mathrm{E}-09 \\
<7.6 \mathrm{E}-09 \\
<7.2 \mathrm{E}-09 \\
<9.0 \mathrm{E} \cdot 09 \\
<2.3 \mathrm{E}-08 \\
<9.7 \mathrm{E} \cdot 09 \\
<8.5 \mathrm{E}-08 \\
<1.1 \mathrm{E}-08 \\
<5.2 \mathrm{E} \cdot 08 \\
<8.6 \mathrm{E} \cdot 00 \\
<8.6 \mathrm{E}-09 \\
<2.6 \mathrm{E} \cdot 08\end{array}$ & 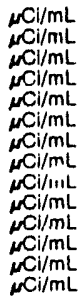 \\
\hline
\end{tabular}




\section{WELL KSB 1}

MEASUREMENTS CONDUCTED IN THE FIELD

Sample date: $08 / 20 / 91$ Jepth to water: $59.87 \mathrm{ft}(18.25 \mathrm{~m})$ below TOC Water elevation: $207.53 \mathrm{ft}(83.26 \mathrm{~m}) \mathrm{ms}$ Water evacuated before sampling: $84 \mathrm{gal}$

Time: $14: 00$

PH: 4.6 : $0 \mathrm{mg}$ Water temperature: $22.6^{\circ} \mathrm{C}$

LABORATORY ANALYSES

\begin{tabular}{|c|c|c|}
\hline Anaiyte & Pesult & Unit \\
\hline $\begin{array}{ll}0 & \text { Thorium-228 } \\
0 & \text { Thorium-228 } \\
0 & \text { Thorium-230 } \\
0 & \text { Thorium-230 } \\
0 & \text { Thorium.232 } \\
0 & \text { Thorium-232 }\end{array}$ & $\begin{array}{l}1.0 \mathrm{E} \cdot 10 \pm 1.0 \mathrm{E}-10 \\
1.0 \mathrm{E}-10 \pm 1.0 \mathrm{E} \cdot 10 \\
5.0 \mathrm{E}-10 \pm 2.0 \mathrm{E} \cdot 10 \\
5.0 \mathrm{E}-10 \pm 2.0 \mathrm{E} \cdot 10 \\
<1.0 \mathrm{E}-10 \\
<1.0 \mathrm{E} \cdot 10\end{array}$ & 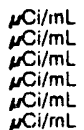 \\
\hline
\end{tabular}

WELL KSB 2

MEASUREMENTS CONDUCTED IN THE FIELD

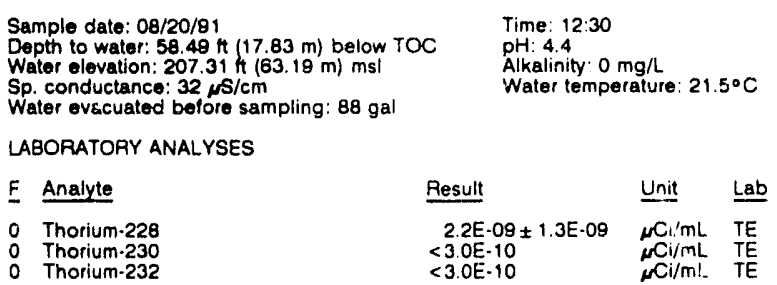

WELLL KSB 2

MEASUREMENTS CONDUCTED IN THE FIELD

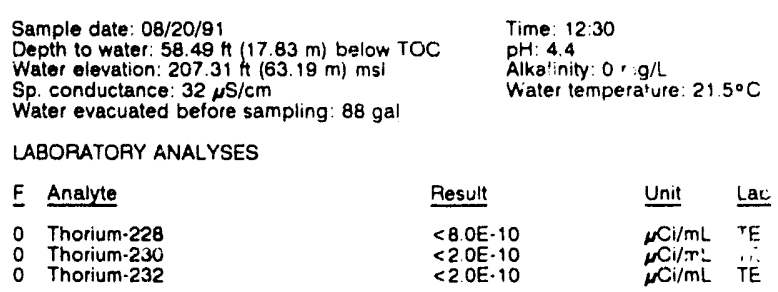

WELL KSB 3

MEASUREMENTS CONDUCTED IN THE FIELD

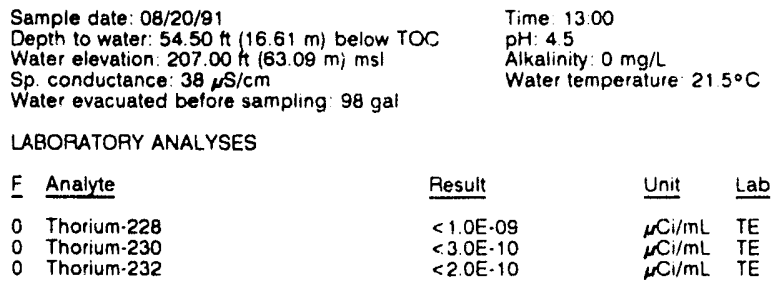

WELL KSB 4A

MEASUREMENTS CONDUCTED IN TRE FIELD

Sample dale: $08 / 20 / 91$

Depth to water: $56.53 \mathrm{ft}(17.23 \mathrm{~m})$ below TOC

evation: $207.57 \mathrm{th}(63$

PH. 4.5

Alkalinity. $0 \mathrm{mg} / \mathrm{h}$

Water evacuated before sampling: $100 \mathrm{gal}$

LABORATORY ANALYSES

\begin{tabular}{|c|c|c|}
\hline F Analyze & Resilt & Unit \\
\hline $\begin{array}{ll}0 & \text { Thorium-228 } \\
0 & \text { Thorium-230 } \\
0 & \text { Thorium-232 }\end{array}$ & $\begin{array}{l}<11 E \cdot 09 \\
3.0 E \cdot 10 \pm 2.0 E \cdot 10 \\
<2.0 E \cdot 10\end{array}$ & 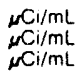 \\
\hline
\end{tabular}

WELL MSB 13A

MEASUREMENTS CONDUCTED IN THE FIELD

Depth to water: $140.92 \mathrm{ft}(42.95 \mathrm{~m})$ below TOC Water elevation: $204.28 \mathrm{ft}(62.27 \mathrm{~m}) \mathrm{msl}$

Sp conductance $23 \mu 5 / \mathrm{cm}$

Water evacuated before sampling: $195 \mathrm{gul}$

LABORATORY ANALYSES

\begin{tabular}{|c|c|c|c|}
\hline F Analyte & Result & Unit & Lab \\
\hline $\begin{array}{ll}0 & \text { Uranium-233/234 } \\
0 & \text { Uranium-235 } \\
0 & \text { Uranium-238 }\end{array}$ & $\begin{aligned} & 5.0 \mathrm{E} \cdot 10 \pm 4.0 \mathrm{E} \cdot 10 \\
< & 4.0 \mathrm{E} \cdot 10 \\
< & 4.0 \mathrm{E} \cdot 10\end{aligned}$ & $\underset{\substack{\mu \mathrm{Ci} / \mathrm{mL} \\
\mu \mathrm{Ci} / \mathrm{mL} \\
\mu \mathrm{Ci} / \mathrm{mL}}}{\mathrm{s}}$ & $\begin{array}{l}\text { TE } \\
\text { TE } \\
\text { TE }\end{array}$ \\
\hline
\end{tabular}

WELL NBG 1

MEASUREMENTS CONDUCTED IN THE FIELD

Depth to water: 87.22 it $(26.58 \mathrm{~m})$ below TOC

Water elevation: $224.28 \mathrm{ft}(68.36 \mathrm{~m}) \mathrm{msl}$

Sp. conductance: $133 \mu \mathrm{S} / \mathrm{cm}$

Water evacuated botore sampling: $11 \mathrm{gal}$
The well went dry during purging.

pH: 47

Alkelinity: $1 \mathrm{mg} / \mathrm{L}$

Water temperalure: $215^{\circ} \mathrm{C}$

LABORATORY ANALYSES

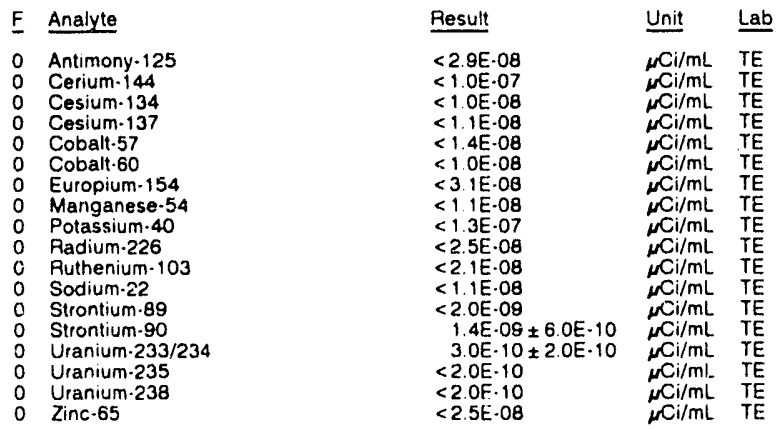

WELL NBG 2

MEASUREMENTS CONDUCTED IN THE FIELD

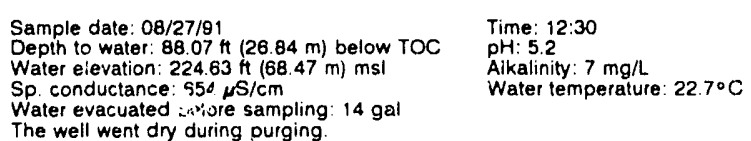

The well went dry during purging. 14 gal

LABORATORY ANALYSES

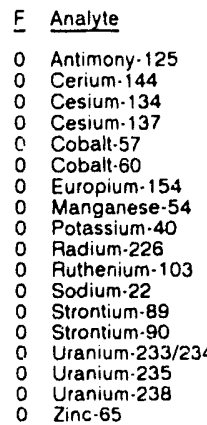

Result

Time: 12:55

Akalinity: $4 \mathrm{mg} / \mathrm{h}$

Water temperature: $23.0^{\circ} \mathrm{C}$

政


ANALYTICAL RESULTS

WELL NBG 3

MEASUREMENTS CONDUCTED IN THE FIELD

Sample date: $08 / 27 / 91$

Depth to water: $93.48 \mathrm{it}(28.49 \mathrm{~m})$ below TOC

Water elevation: $218.92 \mathrm{Ht}(66.7$
Sp. conductance: $75 \mu \mathrm{S} / \mathrm{cm}$

Sp. conductance: $75 \mu \mathrm{S} / \mathrm{cm}$.

Time: $12: 05$
pH: 5.8

PH: 5.8 Alkalinity: $16 \mathrm{mg}$

Water temperature: $22.0^{\circ} \mathrm{C}$

The well went dry during purging

LABORATORY ANALYSES

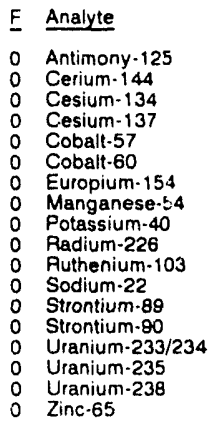

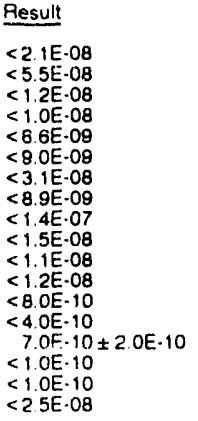

\begin{tabular}{ll} 
Unit & Lab \\
\hline$\mu \mathrm{Cl} / \mathrm{mL}$ & $T E$ \\
$\mu \mathrm{Ci} / \mathrm{mL}$ & $\mathrm{TE}$ \\
$\mu \mathrm{Ci} / \mathrm{mL}$ & $\mathrm{TE}$ \\
$\mu \mathrm{Ci} / \mathrm{mL}$ & $\mathrm{TE}$ \\
$\mu \mathrm{Ci} / \mathrm{mL}$ & $\mathrm{TE}$ \\
$\mu \mathrm{Ci} / \mathrm{mL}$ & $\mathrm{TE}$ \\
$\mu \mathrm{Ci} / \mathrm{mL}$ & $\mathrm{TE}$ \\
$\mu \mathrm{Ci} / \mathrm{mL}$ & $\mathrm{TE}$ \\
$\mu \mathrm{Ci} / \mathrm{mL}$ & $\mathrm{TE}$ \\
$\mu \mathrm{Ci} / \mathrm{mL}$ & $\mathrm{TE}$ \\
$\mu \mathrm{Ci} / \mathrm{mL}$ & $\mathrm{TE}$ \\
$\mu \mathrm{Ci} / \mathrm{mL}$ & $\mathrm{TE}$ \\
$\mu \mathrm{Ci} / \mathrm{mL}$ & $\mathrm{TE}$ \\
$\mu \mathrm{Ci} / \mathrm{mL}$ & $\mathrm{TE}$ \\
$\mu \mathrm{Ci} / \mathrm{mL}$ & $\mathrm{TE}$ \\
$\mu \mathrm{Ci} / \mathrm{mL}$ & $\mathrm{TE}$ \\
$\mu \mathrm{Ci} / \mathrm{mL}$ & $\mathrm{TE}$ \\
$\mu \mathrm{Ci} / \mathrm{mL}$ & $\mathrm{TE}$
\end{tabular}

WELL NBG 4

MEASUREMENTS CONDUCTED IN THE FIELD

Sample date: $08 / 27 / 91$

Depth to water: 88.19 ft $(26.88 \mathrm{~m})$ below TOC

Water elevation: $218.31 \mathrm{it} / 66$.

Time: $11: 50$

pH: 5.2

Water evacualed before sampling: 11 gai

Water temperature $21.2^{\circ} \mathrm{C}$

LABORATORY ANALYSES

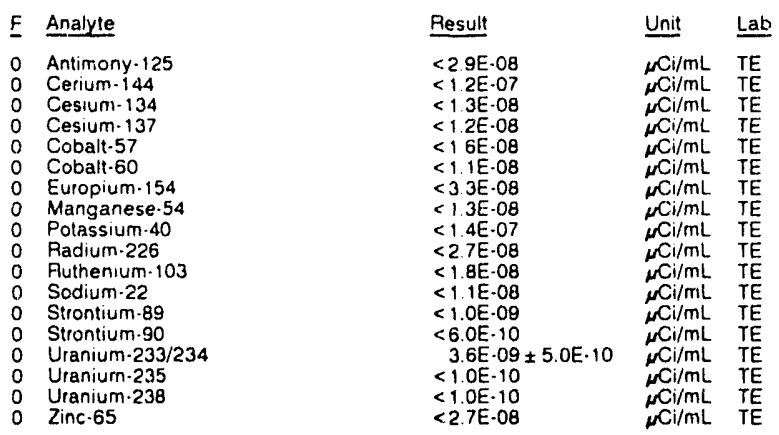

\section{WELL NBG 5}

MEASUREMENTS CONDUCTED IN THE FIELD

Sample date $08 / 27 / 9$ 1

Depth to water: $84.34 \mathrm{ft}(2571 \mathrm{~m})$ below TOC

Water elevatic n: $219.16 \mathrm{ft}(66.80 \mathrm{~m}) \mathrm{ms}$

Sp conduclance. $33 \mu \mathrm{s} / \mathrm{cm}$

The well went dry during purging 16 ga

LABOAATOAY ANALY'SES

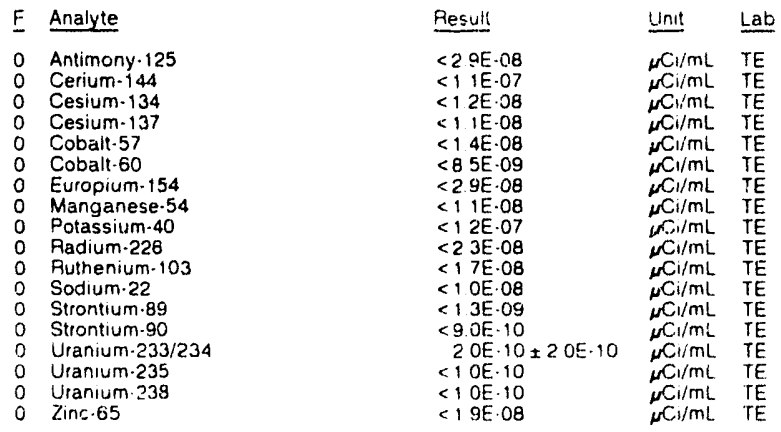

WELL P 26A

MEASUREMENTS CONDUCTED IN THE FIELD

Sample date: $07 / 08 / 91$

Depth to water: $35.24 \mathrm{ft}(10.74 \mathrm{~m})$ below TOC

Water elevation: $119.28 \mathrm{Ht}$

m) mal

LABORATORY ANALYSES

E Analyte

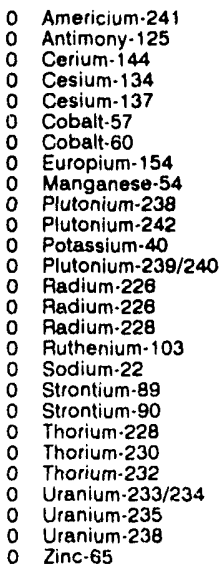

Result

Time: $11: 05$

Alkalinity: $7 \mathrm{mg} / \mathrm{t}$

Water tempergture: $22.2^{\circ} \mathrm{C}$

\section{WELL P 26B}

MEASUREMENTS CONDUCTED IN THE FIELLD

$\begin{array}{ll}\text { Sample date: } 07 / 09 / 91 & \text { Time: } 11: 30 \\ \text { Depth to water: } 42.94 \mathrm{ft}(13.09 \mathrm{~m}) \text { below TOC } & \text { pH: } 8.0 \\ \text { Water elevation: } 111.56 \mathrm{ft}(34.00 \mathrm{~m}) \mathrm{ms} / & \text { Alkalinity: } 20 \mathrm{mg} / \mathrm{L} \\ \text { Sp. conductance: } 70 \mu \mathrm{s} / \mathrm{cm} & \text { Water temperature: } 21.7^{\circ} \mathrm{C} \\ \text { Water evacuated before sampling: } 104 \mathrm{gal} & \end{array}$

LABORATORY ANALYSES

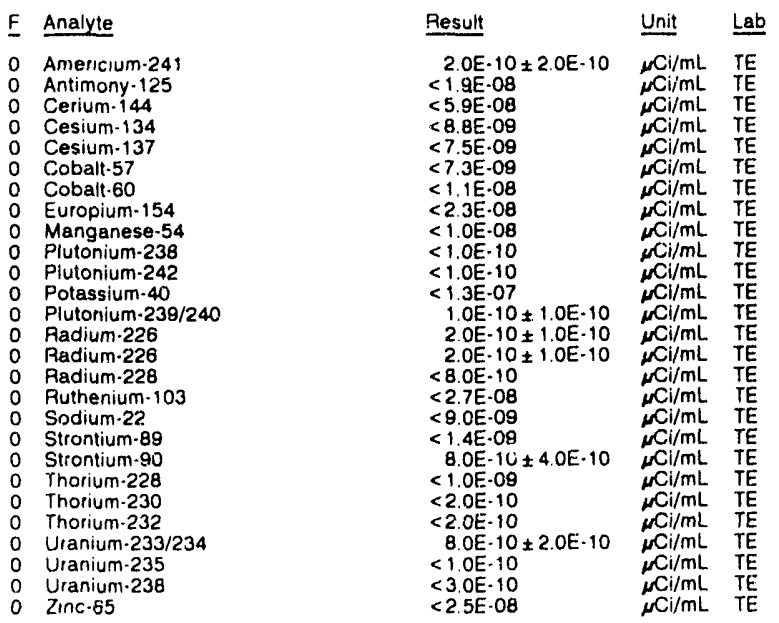


WELL P 26B

MEASUREMENTS CONDUCTED IN THE FIELD Sample date: $07 / 09 / 91$
Depth to water: $42.94 \mathrm{ft}(13.09 \mathrm{~m})$ below TOO Water elevation: $111.56 \mathrm{ft}(34.00 \mathrm{~m}) \mathrm{msl}$ Water evacuated before sampling: $104 \mathrm{gal}$

LABOFATORY ANALYSES

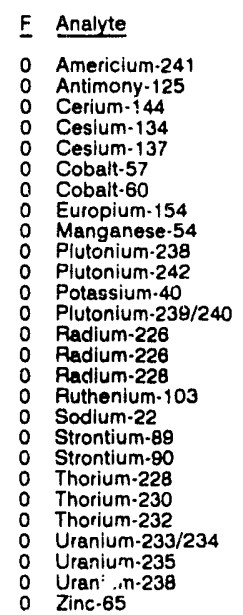

Result

$<1.0 \mathrm{E}-10$

$<3.3 \mathrm{E}-08$

$<1.4 \mathrm{E}-07$

$<1.3 \mathrm{E} \cdot 08$

$<1.4 \mathrm{E}-08$
$<1.8 \mathrm{E} \cdot 08$

$<\begin{aligned} & <1.8 E .08 \\ & <1.2 E-08\end{aligned}$

$<3.4 \mathrm{E}-08$

$<1.5 \mathrm{E} \cdot 08$

$1, \mathrm{EE}-09+3 \cdot 0 \mathrm{E}-10$

$<1.3 \mathrm{E} \cdot 07$
$<1.0 \mathrm{E} \cdot 10$

$2.0 \mathrm{E} \cdot 10 \pm 1.0 \mathrm{E} \cdot 10$

$2.0 \mathrm{E} \cdot 10 \pm 1.0 \mathrm{E} \cdot 10$

$<1.2 \mathrm{E}-09$

$<4.7 E-08$

$<1.2 E \cdot 08$

Q.

$1.0 E-09 \pm 6.0 E \cdot 10$

$9 \mathrm{EE} \cdot 10+4.0 \mathrm{E} \cdot 10$

$1.4 \mathrm{E} \cdot 09+5.0 \mathrm{E}-10$

$<1.8 \mathrm{E} \cdot 09$

$<5.0 E-10$

$<5.0 \mathrm{E}-10$
$<3.3 \mathrm{E}-0 \mathrm{~B}$
WELL TBG 1

MEASUREMENTS CONOUCTED IN THE FIELD

Sample date: $07 / 08 / 91$

Depth to water: $50.13 \mathrm{ft}(15.28 \mathrm{~m})$ below TOC

Water elevation: $101.07 \mathrm{ft}$ (30.

We

TH: 10.25

Alkalinity: $0 \mathrm{mg}$

Water temperature: $22.2^{\circ} \mathrm{C}$

LABORATOAY ANALYSES

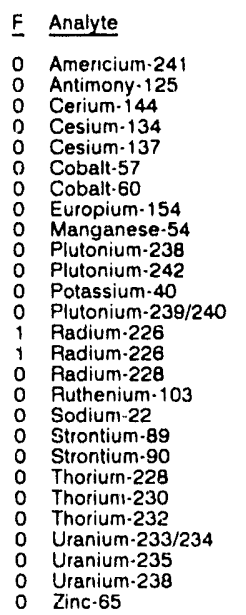

Resul

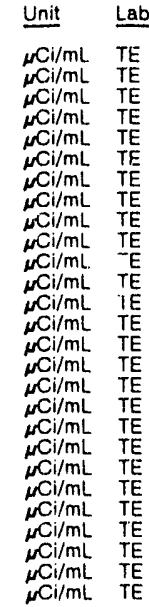

WELL P 26D

MEASUREMENTS CONDUCTED IN THE FIELD

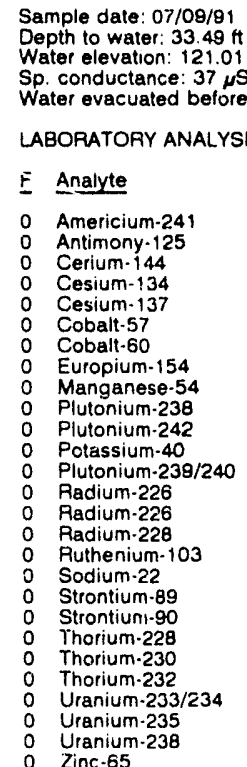

Time: $12: 20$

pH: 5.6

Water temperature: $21.2^{\circ} \mathrm{C}$

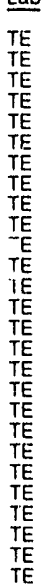

TE
$T E$
$T E$
$T E$
$T E$
$T E$
$T E$
$T E$
$T E$
$T E$
$T E$
$T E$
$T E$
$T E$
$T E$
$T E$
$T E$
$T E$
$T E$
$T E$
$T E$
$T E$

\section{WELL TBG 1}

MEASUREMENTS CONDUCTED IN THE FIELD

Sample date: 07/08/91

Depth to water: $50.13 \mathrm{H}(15.28 \mathrm{~m})$ below TOC

Water elevation: $101.07 \mathrm{ft}(30.81 \mathrm{~m}) \mathrm{msl}$

Sp. conductance: $166 \mu \mathrm{s} / \mathrm{cm}$

Water evacuated before sampling: $31 \mathrm{gal}$

LABORATORY ANALYSES

$\begin{array}{ll}\text { F } & \text { Analyte } \\ 0 & \text { Americium-241 } \\ 0 & \text { Antimony-125 } \\ 0 & \text { Cerium-1444 } \\ 0 & \text { Cesium-134 } \\ 0 & \text { Cesium-137 } \\ 0 & \text { Cobalt-57 } \\ 0 & \text { Cobalt-60 } \\ 0 & \text { Europium-154 } \\ 0 & \text { Manganese-54 } \\ 0 & \text { Plutonium-238 } \\ 0 & \text { Plutonium-242 } \\ 0 & \text { Potassium-40 } \\ 0 & \text { Plutonium-239/240 } \\ 0 & \text { Radium-226 } \\ 0 & \text { Padium-226 } \\ 0 & \text { Padium-228 } \\ 0 & \text { Puthenium-103 } \\ 0 & \text { Sodium-22 } \\ 0 & \text { Strontium- } 89 \\ 0 & \text { Strontium-90 } \\ 0 & \text { Thorium-228 } \\ 0 & \text { Thorium-230 } \\ 0 & \text { Thorium-232 } \\ 0 & \text { Uranium-233/234 } \\ 0 & \text { Uranium-235 } \\ 0 & \text { Uranium-238 } \\ 0 & \text { Zinc-65 } \\ & \end{array}$

Alkalinity: $0 \mathrm{mg}$

Water temperat re: $22.2^{\circ} \mathrm{C}$

$<1.0 \mathrm{E}-10$

$<3.6 \mathrm{E}-\mathrm{ng}$

$<1.5 \mathrm{E} \cdot 08$

$<1.92 .08$

$<1.4 E .08$

$<1.5 \mathrm{E} .08$

$2.0 \mathrm{E}-10 \pm 2.0 \mathrm{E}-10$

$<1.4 \mathrm{E}-07$

S. OE. $09 \pm 3.0 \mathrm{O}-10$

$9.0 \mathrm{E}-09 \pm 2.0 \mathrm{E}-10$

$<6.2 \mathrm{E} .08$

$<$ <. 5 .08

.2E-09 $02.0 E \cdot 10$

$7.0 \mathrm{E}-10$

$3.0 \mathrm{E} \cdot 10 \pm 2.0 \mathrm{E} \cdot 10$
$1.0 \mathrm{E}-10$

$2.8 \mathrm{E} \cdot 09 \pm 4 . \mathrm{OE} \cdot 10$

$1.0 \mathrm{E} \cdot 10 \pm 1 \mathrm{nE} \cdot 10$

$<3.3 \mathrm{E} \cdot 08$
Result Unit Lab

$1.0 \mathrm{E}-10 \pm 1.0 \mathrm{E} \cdot 10 \quad \mathrm{N \textrm {Ci } / \mathrm { mL }} \mathrm{TE}$

$<5.2 \mathrm{E}-08$

$<7.2 \mathrm{E} .09$

$<5.7 E .09$

$<6.2 E .09$

$<2.1 \mathrm{E} \cdot 08$

$<5.9 E \cdot 09$

$<1,0 E \cdot 10$

$<\rightarrow E$. 08

$<1.0 \mathrm{E} \cdot 10$

$<1.0 \mathrm{OE} \cdot 10$

$<1$ OE.10

$<1.5 \% 38$

<7.0द.09

<6.OE. 10

2.3E-09 $\pm 1.5 \mathrm{E} .09$

$1.0 E \cdot 09 \pm 5.0 E \cdot 10$

$<3.0 E \cdot 10$
$2.2 E \cdot 09 \pm 1.3 E \cdot 09$

$<8.0 \mathrm{E}-10$

$<8.0 E \cdot 10$
$<1.6 E-08$

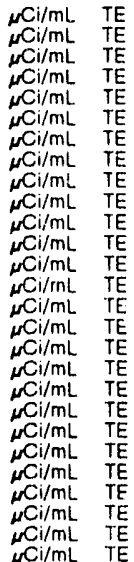

Result

$<1.0 E-10$
$<26 E-08$

$<1.0 \mathrm{E}-07$

$<1.1 \mathrm{E} \cdot 08$

$<1.0 E-00$

$<1.3 E \cdot 08$

$<8.3 \mathrm{E} .09$

$<2.8 E .08$
$<1.1 E .08$

$<1.0 E-10$

$<1$ OE-10

$6 \mathrm{E} \cdot 09 \pm 1 \mathrm{OE} \cdot 10$

$1.6 \mathrm{E}-09 \pm 1 \mathrm{OE}-10$

3. $8 \mathrm{E} \cdot 09 \pm 1.3 \mathrm{E}-09$

$<2.2 E .08$
$<9.5 E .09$

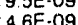

$<1.0 \mathrm{E} \cdot 09$

$4.0 E-10$

$<1.0 E-10$

$1.0 E \cdot 09 \pm 2.0 E \cdot 10$

$<1.0 E-10$

$6.0 E-10 \pm 2.0 E-10$

$<<2.5 E \cdot 08$ <.
2. $0 E \cdot 10 \pm 10 E \cdot 10$

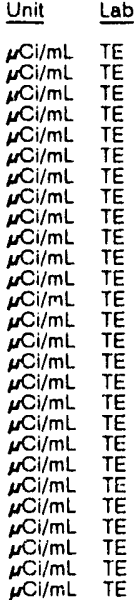


ANALYTICAL RESULTS

WELL TBG 3

MEASUREMENTS CONDUCTED IN THE FIELD

Sample date: 07/08/91 Depth to water: $46.91 \mathrm{ft}(14.30 \mathrm{~m})$ below: TOC

Sp. conductance: $243 \mu \mathrm{s} / \mathrm{cm}$

Water evacuated before saming: $10 \mathrm{gal}$

The well went dry during purging.

LABORATORY ANALYSES

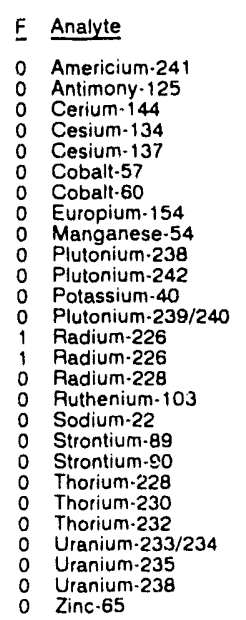

Fesult

Time $12: 30$

Alkalinity, $0 \mathrm{mg} / \mathrm{L}$

Water temperature: $23.1^{\circ} \mathrm{C}$

\section{WELL TBG 5B}

MEASUREMENTS CONOUCTED IN THE FIELD $\begin{array}{ll}\text { Sample date: } 07 / 08 / 91 & \text { Time: } 11: 10 \\ \text { Depth to water: } 34.88 \mathrm{Ht}(10.63 \mathrm{~m}) \text { below TOC } & \text { pH: } 4.8 \\ \text { Water elevation: } 115.12 \mathrm{ft}(35.09 \mathrm{~m}) \mathrm{ms} \text { ( } & \text { Alkalinity: } 1 \mathrm{mg} / \mathrm{L} \\ \text { Sp. conductance: } 34 \mu \mathrm{cm} / \mathrm{cm} & \text { Water temperature: } 22.0^{\circ} \mathrm{C} \\ \text { Water evacuated belore sampling: } 118 \mathrm{gal} & \end{array}$

LABORATOAY ANALYSES

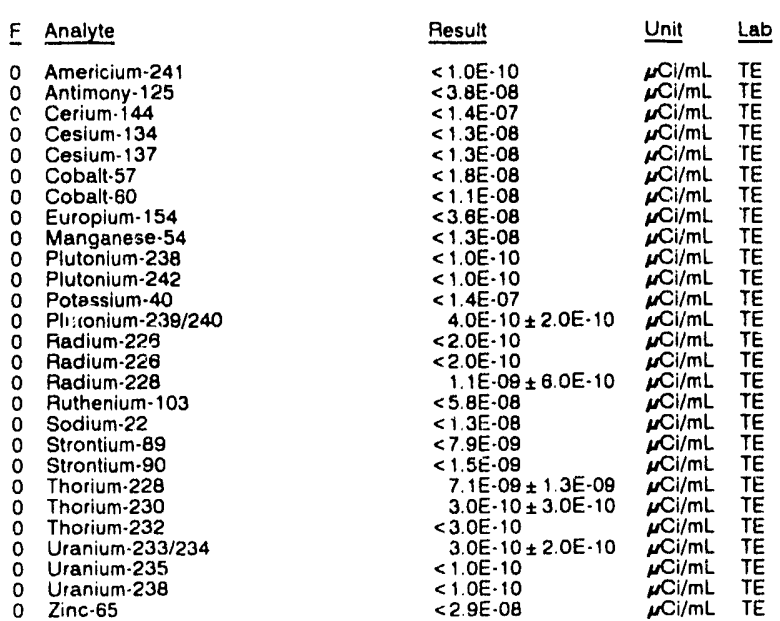

\section{WELL TBG 7}

MEASUREMENTS CONDUCTED IN THE FIELD

$\begin{array}{ll}\text { Sample date: } 07 / 08 / 91 & \text { Time: } 10: 40 \\ \text { Depth to water: } 39.30 \mathrm{ft}(11.98 \mathrm{~m}) \text { below TOC } & \text { pH: } 5.4 \\ \text { Water elevation: } 107.50 \mathrm{ft}(32.77 \mathrm{~m}) \mathrm{msl} & \text { Alkalinity: } 9 \mathrm{mg} / \mathrm{h} \\ \text { Sp. conductance: } 53 \mu \mathrm{S} / \mathrm{cm} & \text { Water temperature: } 22.4^{\circ} \mathrm{C} \\ \text { Water evacuated before sampling: } 60 \mathrm{gal} & \end{array}$

LABORATORY ANALYSES

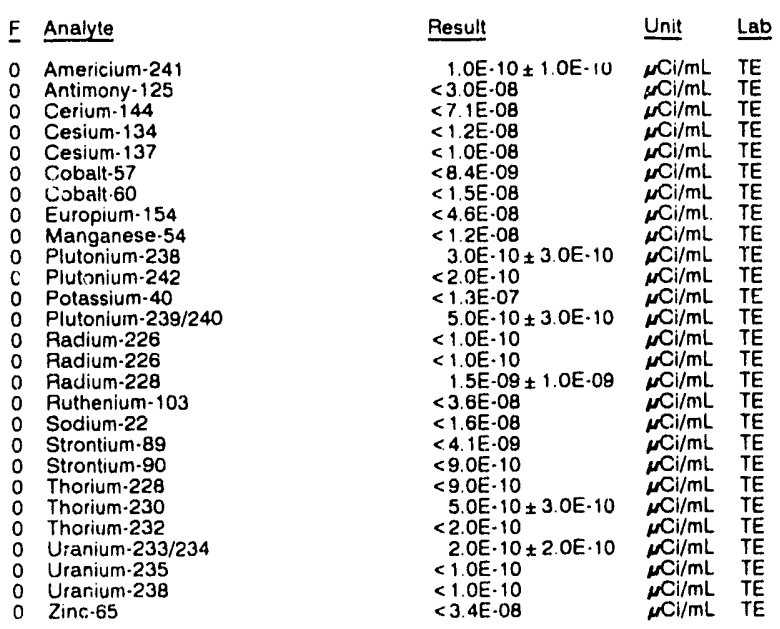


WELL TNX 1D

MEASUREMENTS CONDUCTELU IN THE FIELD

Sample date: $07 / 08 / 91$
Depth to water: $56.94 \mathrm{ft}(17.36 \mathrm{~m})$ veluw TOC
Water elevation. $99.56 \mathrm{ft}(30.35 \mathrm{~m}) \mathrm{msl}$
Sp. conductance: $43 \mu \mathrm{S} / \mathrm{cm}$
Water evacuated before sampling: $52 \mathrm{gal}$
LABORATORY ANALYSES

Time: 12:15

PH: 5.3 Alkalinity: $13 \mathrm{mg} / \mathrm{L}$

Water temperature: $23.1^{\circ} \mathrm{C}$

LABORATORY ANALYSES

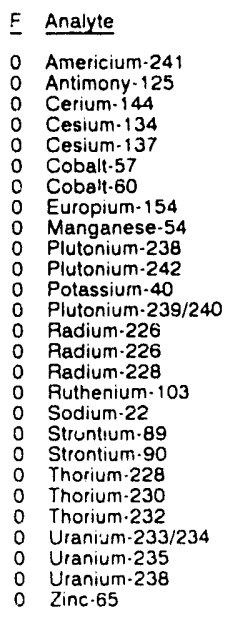

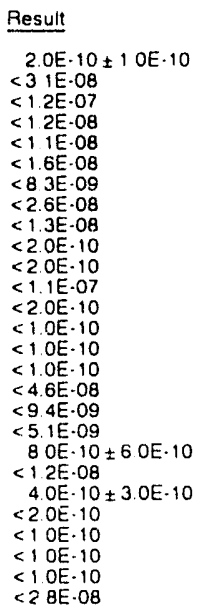

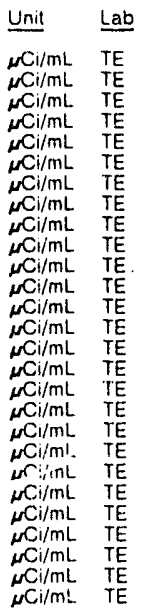

\section{WELL TNX 2D}

MEASUREMENTS CONDUCTED IN THE FIELD

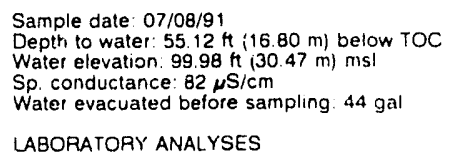

Time. 12:5'

Alkalinity: $11 \mathrm{mg} / \mathrm{h}$

Water temperature $245^{\circ} \circ^{\circ}$

LABORATORY ANALYSES

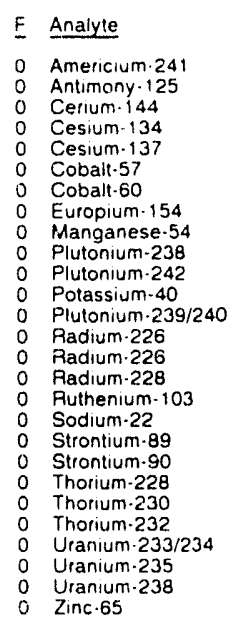

Resull

$<1 \mathrm{OE} \cdot 10$

$<27 \mathrm{E} \cdot 08$
$<1$ OE. 07

$<1$ OE.08

$<95 \mathrm{E} \cdot 09$

$<\begin{aligned}< & 4 E .08 \\ < & 4 \mathrm{E}-09\end{aligned}$

$<26 \mathrm{E} .08$

$<9.0 E \cdot 09$

$<4.0 E \cdot 10$

$<5.0 E-10$

$<1.1 \mathrm{E} \cdot 07$

1. $4 \mathrm{E} \cdot 09 \pm 7 \mathrm{OE}-10$

3. $0 E \cdot 10 \pm 1.0 E \cdot 10$

2. $2 \mathrm{OE} \cdot 09 \pm 9.0 \mathrm{OE} \cdot 10$

$<3.5 E \cdot 08$

$<6.8 E \cdot 09$

< $6 \mathrm{E} \cdot 09 \pm 60 \mathrm{OE} \cdot 10$

2.6E.09 09 OE.10

$4.0 E \cdot 10+3.0 E \cdot 10$

4 OE 10

$<2$ OE- 10

$<2.0 \mathrm{E} \cdot 10$

$<2$ OE. 10

$<2.1 \mathrm{E} \cdot 0 \mathrm{O}$

\section{WELL TNX 3D}

MEASUREMENTS CCNDUCTED IN THE FIELD

Sample date: $07 / 09 / 91$

Depth to water: $54.04 \mathrm{tt}(16.47 \mathrm{~m})$ below TOC

Water elevation: $100.26 \mathrm{ft}(30.56 \mathrm{~m}) \mathrm{msl}$

ance: $233 \mu \mathrm{S} / \mathrm{cm}$

The well went dry during purging: 9 gal

.H. 4.7

Alkalinity: $4 \mathrm{mg} / \mathrm{l}$

Water temperalure $22.6^{\circ} \mathrm{C}$

LABORATORY ANALYSES

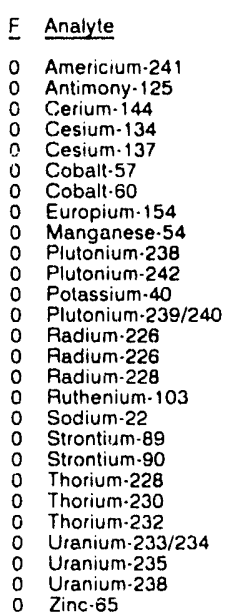

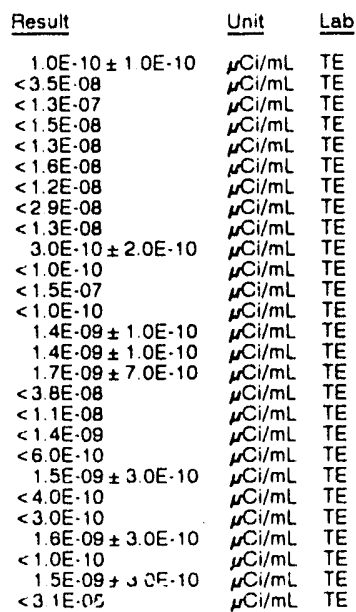

\section{WELL TNX 4D}

MEASUREMENTS CONDUCTED IN THE FIELD

$\begin{array}{ll}\text { Sample date: } 07 / 09 / 91 & \text { Time: } 9: 00 \\ \text { Depth to water: } 45.46 \mathrm{ft}(13.86 \mathrm{~m}) \text { below TOC } & \text { pH: } 5.0 \\ \text { Water elevation: } 104.34 \mathrm{ft}(31.80 \mathrm{~m}) \mathrm{msl} & \text { Alkalinity: } 3 \mathrm{mg} / \mathrm{L} \\ \text { Sp. conductance: } 38 \mu \mathrm{S} / \mathrm{cm} & \text { Water temperature: } 21.5^{\circ} \mathrm{C} \\ \text { Water evacuated before sampling: } 10 \mathrm{gal} & \\ \text { Tine well went dry during purging } & \end{array}$

LABORATORY ANALYSES

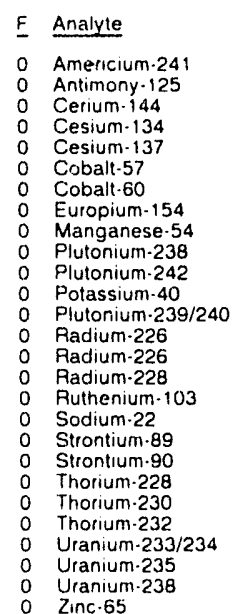

\begin{tabular}{|c|c|}
\hline Pesult & Unit \\
\hline $\begin{aligned} & 10 E \cdot 10 \pm 1.0 E \cdot 10 \\
&<2.6 E \cdot 08 \\
&<6.7 E \cdot 08 \\
&<8.8 E \cdot 09 \\
&<1.1 E \cdot 08 \\
&<6.7 E \cdot 09 \\
&<1.3 E \cdot 08 \\
&<39 E \cdot 08 \\
&<12 E \cdot 08 \\
&<1.0 E \cdot 10 \\
&<1.0 E \cdot 10 \\
&<111 E \cdot 07 \\
&<1.0 E \cdot 10 \\
& 110 E \cdot 09 \pm 2.0 E \cdot 10 \\
& 1.8 E \cdot 09 \pm 2.0 E \cdot 10 \\
& 3.4 E \cdot 09 \pm 1.1 E \cdot 09 \\
&<2.9 E \cdot 08 \\
&<1.3 E \cdot 08 \\
&<1.6 E \cdot 09 \\
&<6.0 E \cdot 10 \\
& 610 E \cdot 10 \pm 40 E \cdot 10 \\
&<10 E \cdot 10 \\
&<1.0 E \cdot 10 \\
& 20 E \cdot 10 \pm 10 E \cdot 10 \\
&<10 E \cdot 10 \\
& 20 E \cdot 10 \pm 10 E \cdot 10 \\
&<26 E \cdot 08\end{aligned}$ & 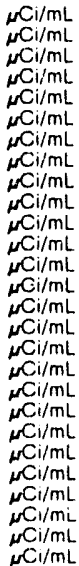 \\
\hline
\end{tabular}


ANALYTICAL RESULTS

WELL TNX 5D

MEASUREMENTS CONDUCTED IN THE FIEI.D

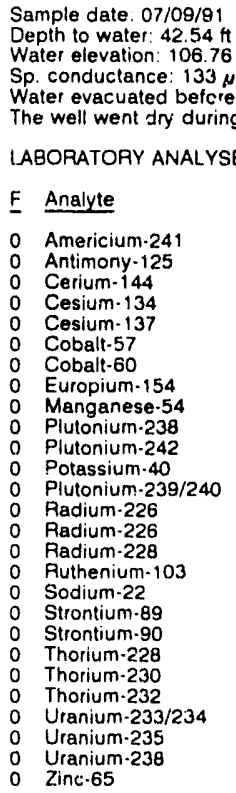

WELL TNX 6D

MEASUAEMENTS CONDUCTED IN THE FIELU

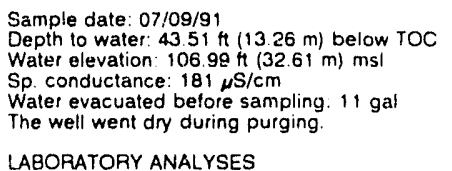

LABORATORY ANALYSES

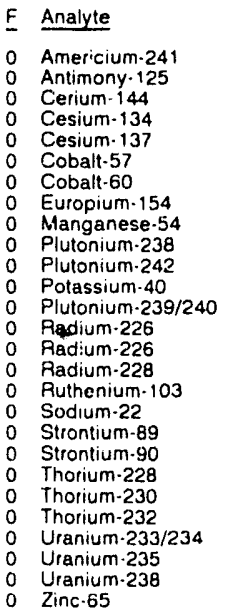

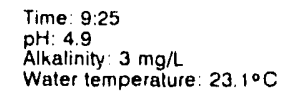

Water temperalure: $23.1^{\circ} \mathrm{C}$

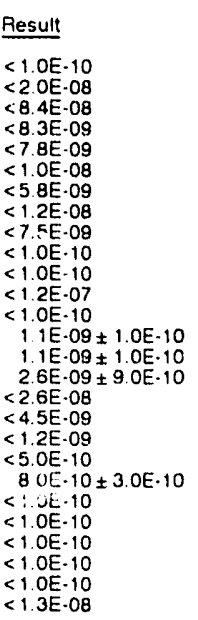

\section{WELL TNX 7D}

MEASUREMENTS CONDUCTED IN THE FIELD

Sample date. 07/08/91

(15.11 m) below TOC

$\mathrm{Sp}$. conductance $101.32 \mathrm{ft}$

Alkalinity: $12 \mathrm{mg} / \mathrm{h}$

Water temperature $25.4^{\circ} \mathrm{C}$
LABORATORY ANALYSES

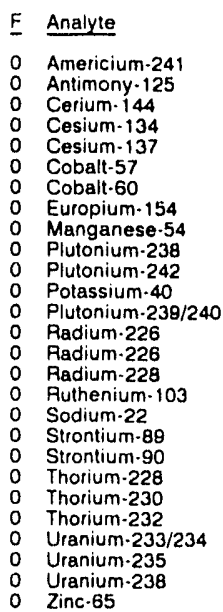

Pesult

<. OE-10

$<.7 E .08$
$<5.0 E \cdot 00$

$<8.3 E .00$

$<6.9 \mathrm{E} .09$

$<6.3 \mathrm{E} .09$

$<5.4 E .09$
$<2.4 \mathrm{E} .08$

$<8.9 \mathrm{E} .09$

$<3.0 \mathrm{E} \cdot 10$

$<2.0 E-10$

$<2.0 E \cdot 10$

2.0E-10 $1.0 E-10$

$2.0 \mathrm{E} \cdot 10 \pm 1.0 \mathrm{OE} \cdot 10$

$1.3 \mathrm{E} \cdot 09 \pm 8.0 \mathrm{E} \cdot 10$

$<2.6 \mathrm{E} \cdot 08$

$<8.5 E \cdot 09$

$<4.2 E \cdot 09$

1.1E.09 $09.0 \mathrm{E} \cdot 10$

$1.1 E \cdot 09 \pm 8.0 E-10$

$<2.0 \mathrm{E} \cdot 10$

$<1.0 \mathrm{E} \cdot 10$

$<1.0 \mathrm{E} \cdot 10$

$<1.0 E \cdot 10$

\section{WELL TNX 8D}

MEASUREMENTS CONDUCTED IN THE FIELO

$\begin{array}{ll}\text { Sample date: } 07 / 08 / 91 & \text { Time: } 9: 45 \\ \text { Depth to water: } 6.40 \mathrm{H}(1.95 \mathrm{~m}) \text { below TOC } & \text { pH: } 5.2 \\ \text { Water elevation: } 93.90 \mathrm{ft}(28.62 \mathrm{~m}) \mathrm{msl} & \text { Alkalinity: } 11 \mathrm{mg} / \mathrm{L} \\ \text { Sp. conductance: } 126 \mu \mathrm{S} / \mathrm{cm} & \text { Water temperature: } 215^{\circ} \mathrm{C} \\ \text { Water evacuated before sampling: } 52 \mathrm{gal} & \end{array}$

LABORATORY ANALYSES

\begin{tabular}{|c|c|c|c|}
\hline Analyte & Result & Unit & Lab \\
\hline Americium-241 & $<2.0 E \cdot 10$ & $\mu \mathrm{Ci} / \mathrm{mL}$ & TE \\
\hline $\begin{array}{l}\text { Antimony-125 } \\
\text { Cerium-144 }\end{array}$ & $<2.3 E \cdot 08$ & $\mathrm{mCi} / \mathrm{mL}$ & TE \\
\hline $\begin{array}{l}\text { Cerlum-144 } \\
\text { Cesium-134 }\end{array}$ & $\begin{array}{l}<7.2 E \cdot 08 \\
<1.1 E \cdot 08\end{array}$ & $\mu \mathrm{Cl} / \mathrm{mL}$ & TE \\
\hline Cesium.137 & $<9.1 E .09$ & $\mu \mathrm{Ci} / \mathrm{mL}$ & TE \\
\hline Cobalt-57 & $<8.9 \bar{E} \cdot 09$ & $\mathrm{mCl} / \mathrm{mL}$ & TE \\
\hline $\begin{array}{l}\text { Cobalt }-60 \\
\text { Europium-154 }\end{array}$ & $<8.9 E-09$ & $\mathrm{mil} / \mathrm{mL}$ & TE \\
\hline $\begin{array}{l}\text { Europium-154 } \\
\text { Manganese.54 }\end{array}$ & $<2.6 E \cdot 08$ & $m \mathrm{Ci} / \mathrm{mL}$ & TE \\
\hline Plutonium-238 & $<1.0 E \cdot 10$ & $\mu \mathrm{Ci} / \mathrm{mL}$ & TE \\
\hline Plutonium-242 & $<1.0 E \cdot 10$ & $\mu \mathrm{Ci} / \mathrm{mL}$ & TE \\
\hline Potassium-40 & $<1.5 \mathrm{E} .07$ & $\mathrm{mCi} / \mathrm{mL}$ & E \\
\hline Plutonium-239/240 & $<1.0 \bar{E}-10$ & $\mathrm{Ni} / \mathrm{mL}$ & $\vec{E}$ \\
\hline Radium-226 & $<1.0 E-10$ & $\mathrm{MCl} / \mathrm{mL}$ & \\
\hline Radium-226 & $<1.0 E \cdot 10$ & $\mu \mathrm{Ci} / \mathrm{mL}$ & $\mathrm{TE}$ \\
\hline Radium-228 & $<1.0 E .09$ & $\mu \mathrm{Ci} / \mathrm{mL}$ & \\
\hline $\begin{array}{l}\text { Ruthenium-103 } \\
\text { Sodium-22 }\end{array}$ & $<3.4 E .08$ & $\mathrm{~m} \mathrm{Ci} / \mathrm{mL}$ & TE \\
\hline $\begin{array}{l}\text { Sodium-22 } \\
\text { Strontium-89 }\end{array}$ & $\begin{array}{l}<9.6 \mathrm{E} .09 \\
<3.9 \mathrm{E} .09\end{array}$ & $\mu \mathrm{Ci} / \mathrm{mL}$ & TE \\
\hline Strontium.90 & $<9.0 \mathrm{E}-10$ & $\mu \mathrm{Ci} / \mathrm{mL}$ & TE \\
\hline Thorium-228 & $1.6 \mathrm{E} \cdot 09 \pm 1.1 \mathrm{E} \cdot 09$ & $\mu \mathrm{Ci} / \mathrm{mL}$ & \\
\hline Thorium-230 & $<4.0 \mathrm{E} \cdot 10$ & $10 \mathrm{Ci} / \mathrm{mL}$ & \\
\hline Thorium-232 & $<2.0 E \cdot 10$ & $\mu \mathrm{Ci} / \mathrm{mL}$ & TE \\
\hline Uranium-233/234 & $<1.0 \mathrm{E} \cdot 10$ & $\mu \mathrm{Ci} / \mathrm{mL}$ & TE \\
\hline Uranium-235 & $<1.0 \bar{E} \cdot 10$ & $\mu \mathrm{Ci} / \mathrm{mL}$ & \\
\hline Uranium-238 & $<1.0 E \cdot 10$ & $\mu \mathrm{Ci} / \mathrm{mL}$ & \\
\hline Zinc-65 & $<2.2 \mathrm{E}-08$ & $\mu \mathrm{Ci} / \mathrm{mL}$ & \\
\hline
\end{tabular}




\section{WELL TNX 9D}

MEASUREMENTS CONDUCTED IN THE FIELD

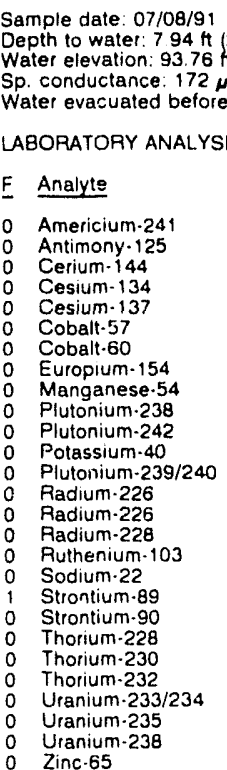

Time: 10:15

pH: 48 . 8 . $3 \mathrm{mg}$

Water temperature $204^{\circ} \mathrm{C}$

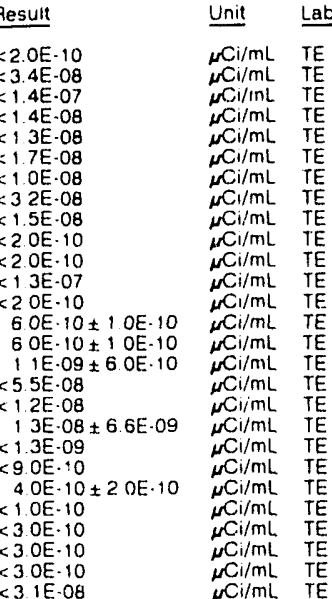

\section{WEL.L TNX 12D}

MFASUREMENTS CONOUCTED IN THE FIELD

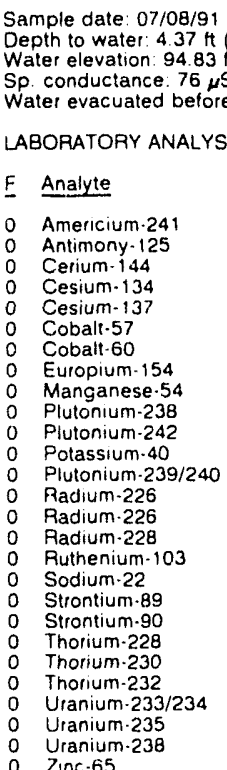

Time 1120

Alkalinity. $24 \mathrm{mg} / \mathrm{h}$

Water temperature $205^{\circ} \mathrm{C}$

Result

$<1.0 E+10$

$<3.6 \mathrm{E} .08$

$<1.5 \mathrm{E} .07$

$<1.4 E-08$

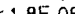

<1 $8 E .08$

$<3.4 \mathrm{E} \cdot \mathrm{GB}$

$<16 \mathrm{E} .08$

$<2 O E \cdot 10$

$<1$.

C1. $4 \mathrm{E} \cdot 07$

$<1 \mathrm{OE} \cdot 10$

4. $O E \cdot 10 \pm 1 \mathrm{OE} \cdot 10$

$4 \mathrm{OE} \cdot 10 \pm 1 \mathrm{OE} \cdot 10$

$<9$ OE. 10

$<57 E .08$

< $3 \mathrm{E}-08$

$<3.9 \mathrm{E} \cdot 09$

$\angle B, O E-10$

$<1$ OE.09

$<2.0 E \cdot 10$

<1

$<10 E-10$

$<1$ OE -10
$<1.0 E$

$<2.9 E \cdot 08$
WELL TNX 12D

MEASUREMENTS CONDUCTED IN THE FIELD

Sample date: 07/08/91

Depth to water: $4.37 \mathrm{ft}(1.33 \mathrm{~m})$ below TOC

Water elevalion. $34.83 \mathrm{Ht}(28 \mathrm{n}$

Sp. conduclance. $76 \mu \mathrm{S} / \mathrm{cm}$

mpling: $57 \mathrm{gal}$

Time: 11:20

pH. 5.7

LABORATORY ANALYSES
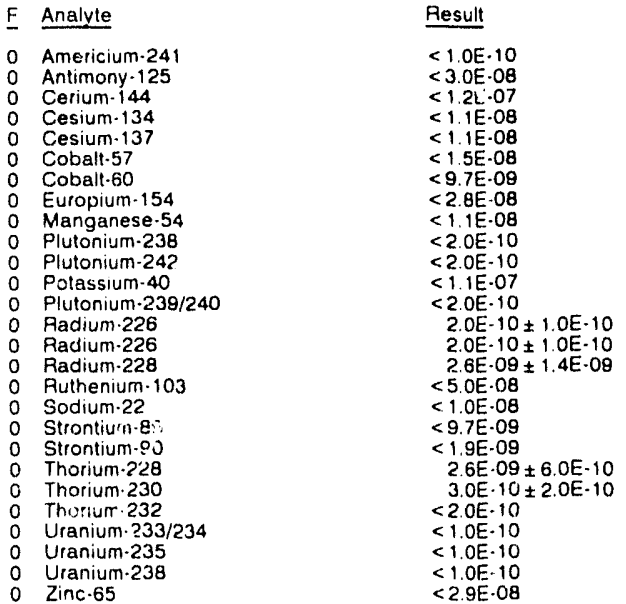

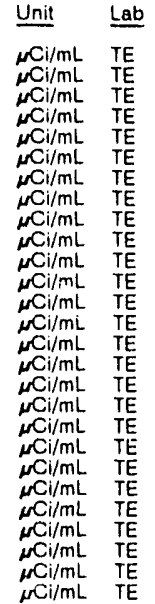

\section{WELL XSB 1A}

\section{MEASUREMENTS CONOUCTES IN THE FIELD}

Sample date: 07/08/91

Depth to water. $56.96 \mathrm{ft}\left(17.3^{\circ} \mathrm{m}\right)$ below TOC

Water elevalion: $99.04 \mathrm{Ht}(30$

Water evacuated before sampling $145 \mathrm{gal}$

LABORATORY ANALYSES

\begin{tabular}{|c|c|c|}
\hline Analyte & Pesuit & $\underline{\text { Unit }}$ \\
\hline Americium-241 & $<2.0 E \cdot 10$ & $\mu \mathrm{Ci} / \mathrm{mL}$ \\
\hline Antimony-125 & $<2.7 \mathrm{E}-08$ & $\mu \mathrm{Ci} / \mathrm{mL}$ \\
\hline Cerium. 144 & $<1.1 E-0\rangle$ & $\mu \mathrm{Ci} / \mathrm{mL}$. \\
\hline Cesium.134 & $<1.0 \mathrm{E}-08$ & $\mu \mathrm{Ci} / \mathrm{mL}$. \\
\hline Cesium-137 & $<1.0 E-08$ & $\mu \mathrm{Ci} / \mathrm{mL}$ \\
\hline Cobalt -57 & $<15 \mathrm{E} .08$ & $\mu \mathrm{Ci} / \mathrm{mL}$ \\
\hline Cobalt -60 & $<10 \mathrm{E}-08$ & $\mu \mathrm{Ci} / \mathrm{mL}$ \\
\hline Europium-154 & $<3.0 \mathrm{E} \cdot 08$ & $\mu \mathrm{Ci} / \mathrm{mL}$ \\
\hline Manganese. 54 & $<1.4 \mathrm{E}-08$ & $\mu \mathrm{Ci} / \mathrm{mL}$ \\
\hline Plutonium-238 & $3.0 \mathrm{E}-10 \pm 1 \mathrm{OE}-10$ & $\mathrm{NCl} / \mathrm{mL}$ \\
\hline Plutonium-242 & $<1.0 E \cdot 10$ & $\mathrm{mCi} / \mathrm{mL}$ \\
\hline Potassium -40 & $<1.1 E-07$ & $\mathrm{mi} / \mathrm{mL}$ \\
\hline Plutonium -239/240 & $<1.0 \mathrm{E}-10$ & $\mu \mathrm{Ci} / \mathrm{mL}$ \\
\hline Radium.226 & $4.0 E \cdot 10 \pm 1.0 E \cdot 10$ & $\mathrm{mCi} / \mathrm{m!}$ \\
\hline Radium-226 & $4.0 E \cdot 10 \pm 1.0 \mathrm{E} \cdot 10$ & $\mathrm{mCi} / \mathrm{mL}$ \\
\hline Radium-228 & $7.0 E \cdot 10 \pm 6 \mathrm{OE} \cdot 10$ & $\mathrm{mCi} / \mathrm{mL}$ \\
\hline $\begin{array}{l}\text { Ruthenium } 103 \\
\text { Sodium }-22\end{array}$ & $\begin{array}{l}<4.5 E \cdot 08 \\
<10 E .08\end{array}$ & $m \mathrm{Ci} / \mathrm{mL}$ \\
\hline Strontium-89 & $\begin{array}{l}<1.0 E \cdot 08 \\
<4.0 E \cdot 09\end{array}$ & $\mathrm{mCl} / \mathrm{mL}$ \\
\hline Strontium.90 & $<8.0 E \cdot 10$ & $\mu \mathrm{Ci} / \mathrm{mL}$ \\
\hline Thorium-228 & $1.1 \mathrm{E} \cdot 09 \pm 7 \mathrm{OE} \cdot 10$ & $\mu \mathrm{Ci} / \mathrm{mL}$ \\
\hline Thorium-230 & $4.0 E \cdot 10 \pm 30 E \cdot 10$ & $\mu \mathrm{Ci} / \mathrm{mL}$ \\
\hline Thorium-232 & $<2.0 \mathrm{E} \cdot 10$ & $\mu \mathrm{Ci} / \mathrm{mL}$ \\
\hline Uranium-233/234 & $<2.0 \mathrm{E} \cdot 10$ & $\mu \mathrm{Ci} / \mathrm{mL}$ \\
\hline Uranium-235 & $<2.0 \mathrm{E} \cdot 10$ & $\mu \mathrm{Ci} / \mathrm{mL}$ \\
\hline Uranium-238 & $<2 \cap E \cdot 10$ & $\mu \mathrm{Ci} / \mathrm{mL}$ \\
\hline Zinc.65 & $<24 \mathrm{E} \cdot 08$ & $\mu \mathrm{Ci} / \mathrm{mL}$ \\
\hline
\end{tabular}


ANALYTICAL RESULTS

WELL XSB 1B

MEASUREMENTS CONDUCTED IN THE FIELD

Sample date: $07 / 08 / 91$

Depth to water: $52.04 \mathrm{Ht}(15.86 \mathrm{~m})$ below TOC Water elevation. 103.86 tr $(31.66 \mathrm{~m}) \mathrm{mis}$

Sp. conductance: $42 \mu \mathrm{S} / \mathrm{cm}$

Water evacuated before sampling: $103 \mathrm{gal}$

Time: $12: 00$

Alkalinity: $4 \mathrm{mg} / \mathrm{L}$

Water temperature: $26.9^{\circ} \mathrm{C}$

LABORATORY ANALYSES

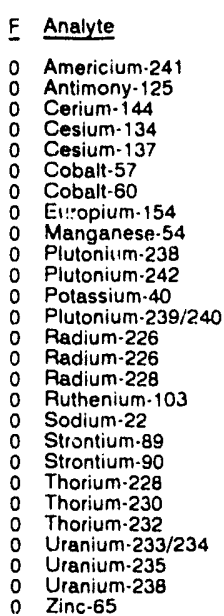

Result

$<1.0$. 10

$<\begin{aligned} & <3 \mathrm{E} \cdot 08 \\ & <1.4 \mathrm{E} \cdot 07\end{aligned}$

$<1.3 \mathrm{E} \cdot 08$

$<1.4 \mathrm{E} \cdot 08$

$<1.9 \mathrm{E} \cdot 08$

$<3.3 \mathrm{E} \cdot 08$

$<1.3 \mathrm{E} .08$

$<2.0 E \cdot 10$

$<1.4 \mathrm{E} \cdot 07$

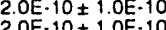

$2.0 \mathrm{E} \cdot 10 \pm 1.0 \mathrm{E} \cdot 10$
$1.4 \mathrm{E} \cdot 09 \pm 1.0 \mathrm{E} \cdot \mathrm{O}$

$1.4 \mathrm{E} \cdot 09$
$<5.5 \mathrm{E} .08$

$<5.5 \mathrm{E}-08$
$<1.2 \mathrm{E}-08$

$<4.3 \mathrm{E} .09$

$<1.0 \mathrm{E} \cdot 09$

$5.0 \mathrm{E}-10 \pm 3.0 \mathrm{E} \cdot 10$

$<2.0 E-10$ -

$2.0 \mathrm{E} \cdot 10 \pm 2.0 \mathrm{E} \cdot 10$

2.0E-10 $\pm 1.0 \mathrm{E}-10$

$<1.0 \mathrm{E} \cdot 10$
$<3.4 \mathrm{E} \cdot 08$
$4.0 E \cdot 10 \pm 3.0 E \cdot 10$

\begin{tabular}{|c|c|}
\hline Unit & \\
\hline$\mu \mathrm{Ci} / \mathrm{mL}$ & \\
\hline $\mathrm{Cl} / \mathrm{mL}$ & \\
\hline $\mathrm{NC \textrm {i } / \mathrm { mL }}$ & $\mathrm{TE}$ \\
\hline $\mathrm{Ci} / \mathrm{mL}$ & \\
\hline $\begin{aligned} \mu \mathrm{Ci} / \mathrm{mL} \\
\mu \mathrm{Ci} / \mathrm{mL}\end{aligned}$ & TE \\
\hline$\mu \mathrm{Ci} / \mathrm{mL}$ & \\
\hline$\mu \mathrm{Ci} / \mathrm{mL}$ & $T$ \\
\hline $\begin{array}{l}\mu \mathrm{Cl} / \mathrm{mL} \\
\mu \mathrm{Ci} / \mathrm{mL}\end{array}$ & TE \\
\hline$\underset{\mu \mathrm{Ci} / \mathrm{mL}}{\mathrm{Ni}}$ & ${ }_{T}^{T}$ \\
\hline $\mathrm{mCl} / \mathrm{mL}$ & $\mathrm{T}$ \\
\hline $\mathrm{NC \textrm {C } / \mathrm { mL }}$ & \\
\hline $\begin{array}{l}\mu C \mathrm{i} / \mathrm{mL} \\
\mu \mathrm{C}_{1}, \mathrm{~mL}\end{array}$ & $\mathrm{~T}$ \\
\hline $\begin{array}{l}\mu \mathrm{Ci} / \mathrm{mL} \\
\mu \mathrm{Ci} / \mathrm{mL}\end{array}$ & \\
\hline $\mathrm{Ci} / \mathrm{mL}$ & \\
\hline$\mu \mathrm{Cl} / \mathrm{mL}$ & \\
\hline$\omega^{m \mathrm{Ci} / \mathrm{mL}}$ & \\
\hline$\mu \mathrm{ci} / \mathrm{mL}$ & \\
\hline & \\
\hline
\end{tabular}

WELL XSB 1D

MEASUREMENTS CONDUCTED IN THE FIELLD

Sample date: $07 / 08 / 91$

Depth to water: $56.48 \mathrm{ft}(17.22 \mathrm{~m})$ below TOC

Water elevation: $99.52 \mathrm{tt}(30$

Sp. conductance: $82 \mu \mathrm{S} / \mathrm{cm}$
Water evacuated before sampling: $30 \mathrm{gal}$

LABORATOAY ANALYSES

F Analyte

0 Americium-241

Antimony $\cdot 125$

Cesium-134

Cesium-137

Cobalt-57

Cobalt-60

Europium-154

Manganese. 54

Plutonium-238

Plutonium-24

Potassium-40
Plutonium-239/240

Radium-226

Radium-226

Radium.228

Ruthenium-103

Sodium.22

Strontium-89

Strontium-90

Thorium-228

Thorium-230

Uranium-233/234

Uranium-235

Uranium-238
Time: 11:50

pH: 4.9

Alkalinity: $1 \mathrm{mg} / \mathrm{L}$

Water temperature: $23.7^{\circ} \mathrm{C}$

Result

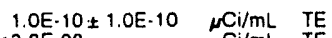

Unit Lab

$<3.8 \mathrm{E} \cdot 08$
$<1.4 \mathrm{E} \cdot 07$

$<1.4 \mathrm{E} .08$

$<1.4 \mathrm{E} .08$

$<1.4 \mathrm{E} \cdot 08$
$<1.8 \mathrm{E} \cdot 08$

$<1.1 \mathrm{E}-08$

$<1.7 E-08$

$<2.0 \mathrm{E}-10$

$<2.0 \mathrm{E}-10$

$<2.0 \mathrm{E}-10$
$<1.3 \mathrm{E} \cdot 07$

$3.0 E \cdot 10 \pm 2.0 E-10$

$6.0 \mathrm{E}-10 \pm 2.0 \mathrm{E}-10$

$\begin{array}{r}6.0 \mathrm{E}-10 \\ <2.7 \mathrm{E}-08 \\ \hline\end{array}$

$<9.0 E \cdot 10$

$<5.9 \mathrm{E}-08$

$<1.3 \mathrm{E} .08$

B. $8 \mathrm{E}-09 \pm 1.3 \mathrm{E} \cdot 09$

$1.4 \mathrm{E} \cdot 09 \pm 1.2 \mathrm{E} .09$

$<4.0 \mathrm{E}-10$

$<4.0 \mathrm{E}-10$

$<4.0 \mathrm{E}-10$

$<3.0 \mathrm{E}-10$

5. OE-10 $\pm 4.0 E \cdot 10$

$<3.3 \mathrm{E}-08$

\section{WELL XSB 2D}

MEASUREMENTS CONDUCTED IN THE FIELD

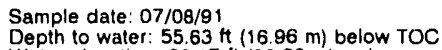

Water elevation: $99.17 \mathrm{ft}(30.23 \mathrm{~m}) \mathrm{ms}$

Sp. conductance: $197 \mu \mathrm{s} / \mathrm{cm}$

Water evacuated before sampling: $9 \mathrm{gal}$

The well went dry during purging.

LABORATORY ANALYSES

F Analyte

0 Aritericium-241

Antimony-125

0 Cesium.134

Cesium-137

Cobalt-57

0 Europium-154

0 Manganese-54

0 Plutonium 238

0 Plutonium-242

0 Potassium -40

O Plutonium-239/240

0 Radium.226

Radium-226

0 Ruthenium-103

Ruthenium-105

Sodium-22

1 Strontium-89

Thorium-228

Thorium.230

Thorium.232

Uranium-233/234

0 Uranium-235

0 Uranium-238

pH: 8.6

Alkalinity: $31 \mathrm{ng} / \mathrm{L}$

Water temperature: $22.2^{\circ} \mathrm{C}$

WELL XSB $3 A$

MEASUREMENTS CONDUCTED IN THE FIELD

Sample date: 07/08/91

Depth to water: $56.63 \mathrm{H}(17.26 \mathrm{~m})$ below TOC

Water elevation: $100.37 \mathrm{ft}(30.59 \mathrm{~m}) \mathrm{msl}$

Water evacuated before sampling: $100 \mathrm{gal}$

LABORATORY ANALYSES

E Analyte

0 Americium-241

Antimony-125

Cerium.144 134

o Cesium-137

0 Cobalt.57

o Coball-60

O Europium-154

Plutonium-238

Plutonium-242

Platonium. $239 / 240$

Plutonium-23

Padium.226

Padium.220

Ruthenium-103

0 Sodium-22

S Strontium-89

Strontium.90

Thorium-228

Thorium-230

Uranium-233/234

Uranium-235

Uranium-23
Result

$<1.0 \mathrm{E}-10$

$<2.8 E-08$

$<1.5 \mathrm{E} .08$

$<1,2 E-08$

$<1.08$

$<3.5 \mathrm{E} \cdot 08$

$<1.3 E-08$

$5.0 E-10 \pm 3.0 E-10$

$<1.25 .07$

$6.0 E \cdot 10 \pm 3.0 E \cdot 10$

$1.0 \mathrm{E} \cdot 09 \pm 2.0 \mathrm{E} \cdot 10$

. $8 \mathrm{E} \cdot 08$

1.3E- $09 \pm 6.0 \mathrm{E} \cdot 10$

$<4.1 E .08$

政

C.7E-09 $+1.0 \mathrm{E}-09$

$5.7 \mathrm{E}-09 \pm 1.0 \mathrm{E}-09$

$<9.0 E-10$

$<5.0 \mathrm{E} \cdot 10$

$<2.0 \mathrm{E} \cdot 10$

$<2.0 \mathrm{E}-10$

$<2.9 E-08$

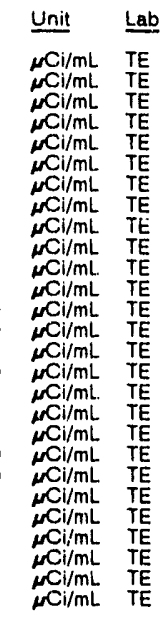


ANALYTICAL RESULTS

\section{WELL XSB $3 A$}

MEASUREMENTS CONDUCTED IN THE FIELD

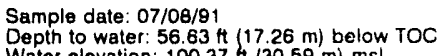

Warer elevation: $100.37 \mathrm{ft}$ (30.5

Water evacuated before sampling: $100 \mathrm{gal}$

Time. 10:05

Alkalinity: $8 \mathrm{mg} /$

Water temperature: $21.3^{\circ} \mathrm{C}$

LABORATORY ANALYSES

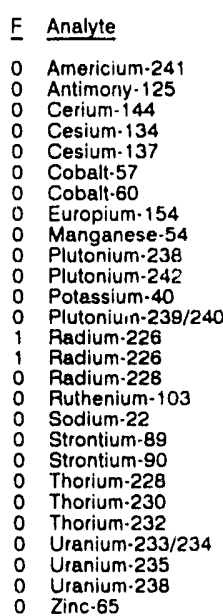

Result

$<1.0 E \cdot 10$

$<2.4 \mathrm{E}-08$

$<6.7 E .08$

$<9.8 E-09$
$<1.0 \mathrm{E} \cdot 08$

$<8.1 \mathrm{E} .09$

$<1.4 \mathrm{E} \cdot 08$

$<3.2 \mathrm{E} .08$

$<1.3 E-08$

$<4.0 E-10$

1. $6 \mathrm{E}-08 \pm 6 \mathrm{~nL} \cdot 10$

$8.4 \mathrm{E} \cdot 09 \pm 2.0 \mathrm{E} \cdot 10$

8. $4 \mathrm{E} \cdot 09 \pm 2.0 \mathrm{E}-10$
$2.1 \mathrm{E}-09 \pm 6.0 \mathrm{E}-10$

$2.1 \mathrm{E}-09$
$<3.7 \mathrm{E}-08$

$<1.1 \mathrm{E} \cdot 0 \mathrm{0B}$

$<4.3 \mathrm{E} \cdot 09$

$1.0 \mathrm{E} \cdot 10 \mathrm{E}$

$1.8 E-09$
$<3.0 E \cdot 10$

$<3.0 \mathrm{E} \cdot 10$
$<3.0 \mathrm{E} \cdot 10$

$1.0 E \cdot 10 \pm 1.0 E \cdot 10$

$<1.0 E \cdot 10$

$<3.0 E \cdot 08$

WELL XSB 4D

MEASUREMENTS CONDUCTED IN THE FIE!O

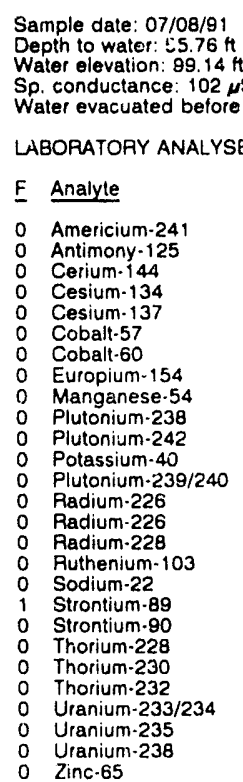

Time 9:20

PH: 5.2 Alkalinity: $2 \mathrm{mg}$

Water temperature: $22.0^{\circ} \mathrm{C}$

Resuli Unit

$1.0 \mathrm{E} \cdot 10 \pm 1.0 \mathrm{E} \cdot 10 \quad \mathrm{N \textrm {Ci } / \mathrm { mL }} \mathrm{TE}$

$<3.4 \mathrm{E}-08$
$<1.4 \mathrm{E}-07$

$<1.4 \mathrm{E} .07$

$<1.4 \mathrm{E}-08$

$<1.8 \mathrm{E} .08$

$<1.6 \mathrm{E}-08$

$<4.3 E \cdot 08$

$<1.7 \mathrm{E} .08$

$<2.0 E-10$

$3.0 \mathrm{E}-10 \times 1.0 \mathrm{E} \cdot 10$

1.3E-07

< $4.0 E \cdot 10=10 \pm 2.0 E \cdot 10$

$3.0 E-08$
$1.5 \mathrm{E}-09 \pm 8.0 \mathrm{E}-10$

$1.5 \mathrm{E} .09$
$<6.0 \mathrm{E}-08$

$<6.0 \mathrm{E}-08$
$<1.5 \mathrm{E}-08$

$1.5 \mathrm{E}-09 \pm 6.3 \mathrm{E}-09$

$1.6 \mathrm{E}-09 \pm 7.0 \mathrm{E}-10$

$2.4 \mathrm{E} \cdot 08 \pm 4.8 \mathrm{E} \cdot 09$

$<1.0 \mathrm{E}-09$

$<1.0 E-09$

$3.0 \mathrm{E}-10 \pm 2.0 \mathrm{E} \cdot 10$

$<1.0 \mathrm{E} \cdot 10$

$3.0 \mathrm{E} \cdot 10 \pm 2.0 \mathrm{E} \cdot 10$
$4.4 \mathrm{E} \cdot 08$

\section{WELL XSB 5A}

MEASUAEMENTS CONDUCTED IN THE FIELD

$\begin{array}{ll}\text { 3ample date: } 08 / 12 / 91 & \text { Time: } 9: 20 \\ \text { Depth to water: } 18.91 \mathrm{H}(6.07 \mathrm{~m}) \text { below TOC } & \text { pH: } 4.9 \\ \text { Water elevation: } 92.09 \mathrm{H}(28.07 \mathrm{~m}) \mathrm{msl} & \text { Alkkalinity: } 0 \mathrm{mg} / \mathrm{h} \\ \text { Sp. conductance: } 57 \mu \mathrm{s} / \mathrm{cm} & \text { Water temperature: } 21.8^{\circ} \mathrm{C} \\ \text { Water evacuated belore campling: } 37 \mathrm{gal} & \end{array}$

LABORATORY ANALYSES

$\begin{array}{ll}\text { E } & \text { Analyte } \\ 0 & \text { Americium-241 } \\ 0 & \text { Antimony-125 } \\ 0 & \text { Cerium-144 } \\ 0 & \text { Cesium-134 } \\ 0 & \text { Cesium-137 } \\ 0 & \text { Cobalt-57 } \\ 0 & \text { Cobalt-60 } \\ 0 & \text { Europium-154 } \\ 0 & \text { Manganese-54 } \\ 0 & \text { Plutonium-238 } \\ 0 & \text { Plutonium-239/240 } \\ 0 & \text { Plutonium-242 } \\ 0 & \text { Potassium-40 } \\ 0 & \text { Padium-228 } \\ 0 & \text { Radium-226 } \\ 0 & \text { Radium-228 } \\ 0 & \text { Ruthenium-103 } \\ 0 & \text { Sodium-22 } \\ 0 & \text { Strontium-89 } \\ 0 & \text { Strontium-90 } \\ 0 & \text { Thorium-228 } \\ 0 & \text { Thorium-228 } \\ 0 & \text { Thorium-230 } \\ 0 & \text { Thorium-232 } \\ 0 & \text { Uranium-233/234 } \\ 0 & \text { Uranium-235 } \\ 0 & \text { Uranium-238 } \\ 0 & \text { Zinc-65 }\end{array}$

\begin{tabular}{|c|c|}
\hline Result & Unit \\
\hline $\begin{aligned} & 1.0 \mathrm{E} \cdot 10 \pm 1.0 \mathrm{E} \cdot 10 \\
&< 1.6 \mathrm{E} \cdot 08 \\
&<5.0 \mathrm{O} \cdot 08 \\
&<6.2 \mathrm{E} \cdot 00 \\
&<7.3 \mathrm{E} \cdot 00 \\
&<6.3 \mathrm{E} \cdot 09 \\
&<8.4 \mathrm{E} \cdot 09 \\
&<1.7 \mathrm{E} \cdot 08 \\
&<8.5 \mathrm{E} \cdot 09 \\
&<1.0 \mathrm{E} \cdot 10 \\
&<1.0 \mathrm{E} \cdot 10 \\
& 5.0 \mathrm{E} \cdot 10 \pm 3.0 \mathrm{E} \cdot 10 \\
&<7.6 \mathrm{E} \cdot 08 \\
& 2.0 \mathrm{E} \cdot 10 \pm 1.0 \mathrm{E} \cdot 10 \\
& 2.0 \mathrm{E} \cdot 10 \pm 1.0 \mathrm{E} \cdot 10 \\
& 8.0 \mathrm{E} \cdot 10 \pm 8.0 \mathrm{E} \cdot 10 \\
&<4.6 \mathrm{E} \cdot 08 \\
&<6.6 \mathrm{E} \cdot 09 \\
&<2.2 \mathrm{E} \cdot 09 \\
&<3.0 \mathrm{E} \cdot 10 \\
&<6.0 \mathrm{E} \cdot 10 \\
&<6.0 \mathrm{E} \cdot 10 \\
&<1.0 \mathrm{E} \cdot 10 \\
&<1.0 \mathrm{E} \cdot 10 \\
& 2.1 \mathrm{E} \cdot 09 \pm 4.0 \mathrm{E} \cdot 10 \\
&<1.0 \mathrm{E} \cdot 10 \\
& 1.7 \mathrm{E}-09 \pm 4.0 \mathrm{E} \cdot 10 \\
&<2.0 \mathrm{E} \cdot 08\end{aligned}$ & 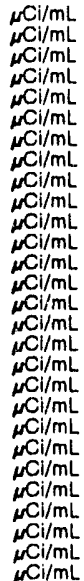 \\
\hline
\end{tabular}

WELL ZBG 1

MEASUAEMENTS CONDUCTED IN THE FIELD

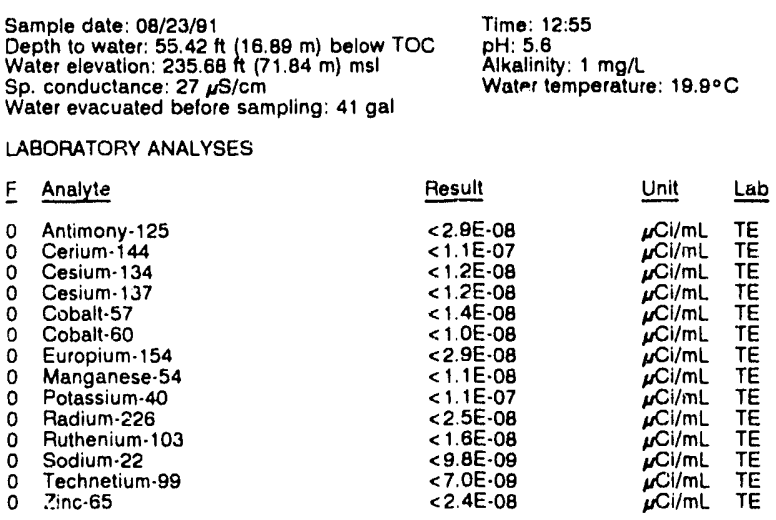

WELL ZBG 1

MEASUREMENTS CONDUCTED IN THE FIELD

Sample date: 08/23/91

Depth to water: $55.42 \mathrm{ft}(16.89 \mathrm{~m})$ below TOC

Water elevation: $235.68 \mathrm{ft}(71.84 \mathrm{~m}) \mathrm{ms}$

Water evacuated before sampling: $41 \mathrm{gal}$

PH: 5.6

Water temperature: $19.9^{\circ} \mathrm{C}$

LABORATORY ANALYSES

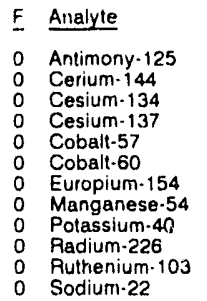

Result

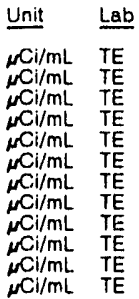


WELL ZBG 1 collected on 08/23/91, laboratory analyses (cont)

\begin{tabular}{|c|c|c|}
\hline E Analyte & Pesult & Unit \\
\hline $\begin{array}{ll}0 & \text { Technetium-99 } \\
0 & \text { Zinc.65 }\end{array}$ & $\begin{array}{l}<6.3 E-09 \\
<2.7 E-08\end{array}$ & $\underset{\mu \mathrm{Ci} / \mathrm{mL}}{\mu \mathrm{Ci} / \mathrm{mL}}$ \\
\hline
\end{tabular}

WELL ZBG $1 A$

MEASUREMENTS CONDUCTED IN THE FIELD

Sample date: 08/23/91

Depth to water: 11.87 \& $(3.62 \mathrm{~m})$ below TOC

Water elevation: $279.13 \mathrm{ft}(85.08 \mathrm{~m}) \mathrm{msl}$

Alkalinity: $1 \mathrm{mg} /$

Sp. conductance: $19 \mu \mathrm{S} / \mathrm{cm}$

Water temperature: $23.8 \circ \mathrm{C}$

Water evacuated before sampling: 3 gal

LABORATORY ANALYSES

\begin{tabular}{|c|c|c|}
\hline E Analyte & Result & Unit \\
\hline 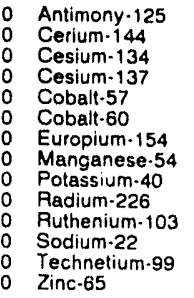 & $\begin{array}{l}<3.0 \mathrm{E} \cdot 08 \\
<1.1 \mathrm{E} \cdot 07 \\
<1.2 \mathrm{E} \cdot 08 \\
<1.3 \mathrm{E} \cdot 08 \\
<1.3 \mathrm{E} \cdot 08 \\
<7.5 \mathrm{E} \cdot 09 \\
<3.1 \mathrm{E} \cdot 08 \\
<1.1 \mathrm{E} \cdot 08 \\
<1.1 \mathrm{E} \cdot 07 \\
<2.4 \mathrm{E} \cdot 08 \\
<1.6 \mathrm{E} \cdot 08 \\
<1.1 \mathrm{E} \cdot 08 \\
<7.3 \mathrm{E} \cdot 09 \\
<2.3 \mathrm{E} \cdot 08\end{array}$ & $\begin{array}{l}{ }_{\mu} \mathrm{Ci} / \mathrm{mL} \\
\mu \mathrm{Ci} / m \mathrm{~mL} \\
\mu \mathrm{Ci} / m \mathrm{~mL} \\
\mu \mathrm{Ci} / m \mathrm{~mL} \\
\mu \mathrm{Ci} / \mathrm{mL} \\
\mu \mathrm{Ci} / m \mathrm{~mL} \\
\mu \mathrm{Ci} / \mathrm{mL} \\
\mu \mathrm{Ci} / \mathrm{mL} \\
\mu \mathrm{Ci} / \mathrm{mL} \\
\mu \mathrm{Ci} / \mathrm{mL} \\
\mu \mathrm{Ci} / \mathrm{mL} \\
\mu \mathrm{Ci} / \mathrm{mL} \\
\mu \mathrm{Ci} / \mathrm{mL} \\
\mu \mathrm{Ci} / \mathrm{mL}\end{array}$ \\
\hline
\end{tabular}

WELL ZBG 2

MEASUREMENTS CONDUCTEO IN THE FIELD

Sample date: $08 / 23 / 91$

Depth to water: $53.51 \mathrm{ft}(16.31 \mathrm{~m})$ below TOC

Water elevation: $224.49 \mathrm{ft}(68.43 \mathrm{~m}) \mathrm{ms}$ )

Sp. conductance: $18 \mu \mathrm{s} / \mathrm{cm}$

$\mathrm{pH}: 5.1$

Alkalinity: $1 \mathrm{mg} / \mathrm{h}$

Water temperature: $19.8^{\circ} \mathrm{C}$

LABORATORY ANALYSES

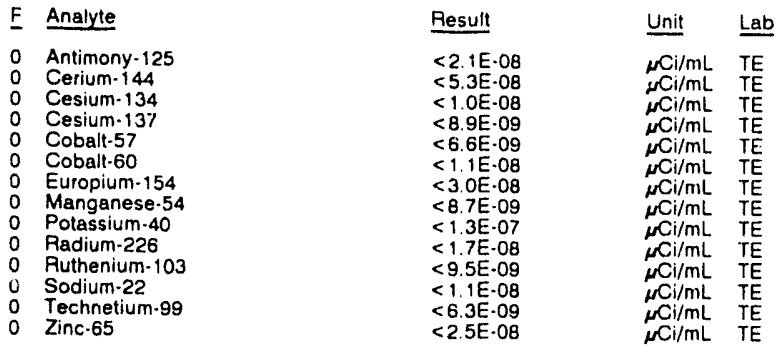

aU.S. GOVERnMENT PRINTING OfFICE: 1992-642-373-No Program 

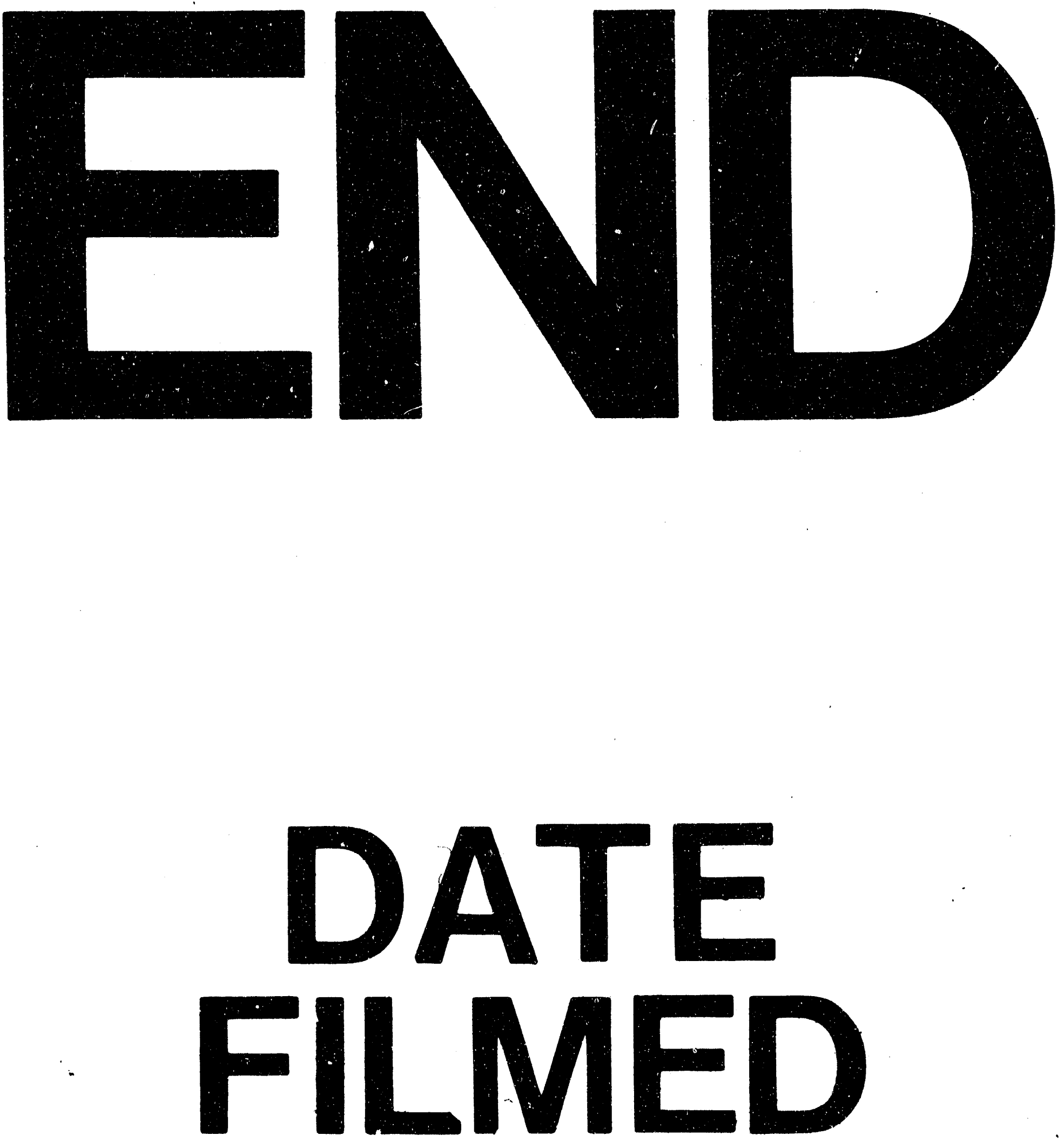

I

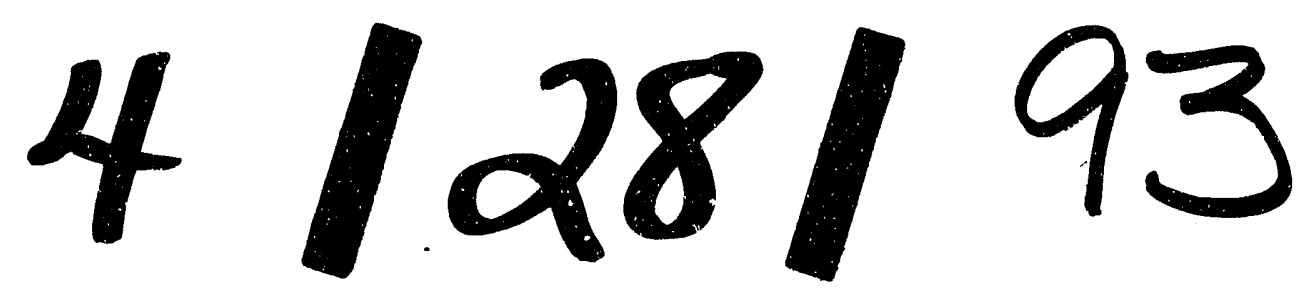


